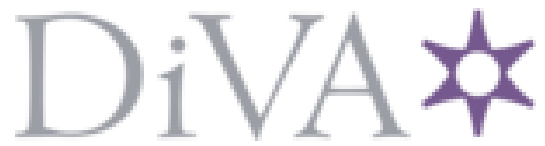

http://www.diva-portal.org

Preprint

This is the submitted version of a paper published in Fungal diversity.

Citation for the original published paper (version of record):

Wijayawardande, N., Prieto, M., Olariaga, I., Wedin, M. (2017)

Notes for genera - Ascomycota

Fungal diversity, 86: 1-594

https://doi.org/10.1007/s13225-017-0386-o

Access to the published version may require subscription.

N.B. When citing this work, cite the original published paper.

Permanent link to this version:

http://urn.kb.se/resolve?urn=urn:nbn:se:nrm:diva-2558 


\section{Notes for genera-Ascomycota}

Nalin N. Wijayawardene $\mathrm{e}^{1,2,3,4} \cdot$ Kevin D. Hyde ${ }^{1,2,3,4} \cdot$ Kunhiraman C. Rajeshkumar $^{5} \cdot$ David L. $^{2}$ Hawksworth $^{6,7} \cdot$ Hugo Madrid $^{8} \cdot$ Paul M. Kirk $^{9} \cdot$ Uwe Braun $^{10} \cdot$ Rajshree V. Singh ${ }^{5} \cdot$ Pedro W. Crous $^{11} \cdot$ Martin Kukwa $^{12} \cdot$ Robert Lücking $^{13} \cdot$ Cletus P. Kurtzman ${ }^{14}$ - Andrey Yurkov ${ }^{15}$ • Danny Haelewaters ${ }^{16,17}$ - André Aptroot ${ }^{18} \cdot$ H. Thorsten Lumbsch ${ }^{19}$ - Einar Timdal ${ }^{20}$ • Damien Ertz $^{21} \cdot$ Javier Etayo $^{22} \cdot$ Alan J.L. Phillips $^{23} \cdot$ Johannes Z. Groenewald $^{11} \cdot$ Moslem $^{2}$ Papizadeh $^{24}$ • Laura Selbmann ${ }^{25} \cdot$ Monika C. Dayarathne $^{1,2} \cdot$ Gothamie Weerakoon $^{26,27}$ E. B. Gareth Jones $^{28}$ - Satinee Suetrong ${ }^{29}$ • Qing Tian ${ }^{2,3} \cdot$ Rafael F. Castañeda-Ruiz ${ }^{30}$ - Paul Diederich $^{31} \cdot$ Ka-Lai Pang ${ }^{32} \cdot$ Kazuaki Tanaka $^{33}$ - Dong Qin Dai ${ }^{34}$ - Jariya Sakayaroj ${ }^{29}$ • Martina Hujslová ${ }^{35} \cdot$ Lorenzo Lombard $^{11}$ - Belle D. Shenoy ${ }^{36}$ - Ave Suija ${ }^{37}$ - Sajeewa S. N. Maharachchikumbura $^{38}$ - Kasun M. Thambugala ${ }^{2,4,39}$ - Dhanushka N. Wanasinghe ${ }^{2,3,4}$ • Bharati O. Sharma ${ }^{40}$ • Subhash Gaikwad ${ }^{40}$ - Gargee Pandit ${ }^{40}$ - Laura Zucconi ${ }^{24}$ - Silvano Onofri $^{24} \cdot$ Eleonora Egidi ${ }^{41} \cdot$ Huzefa A. Raja ${ }^{42} \cdot$ Rampai Kodsueb $^{43} \cdot$ Marcela E. S. Cáceres $^{44}$ - Sergio Pérez-Ortega ${ }^{45}$ - Patrícia O. Fiuza ${ }^{46}$ - Josiane Santana Monteiro ${ }^{46}$ - Larisa N. Vasilyeva $^{47} \cdot$ Roger G. Shivas ${ }^{48} \cdot$ Maria Prieto $^{49,50} \cdot$ Mats Wedin $^{50} \cdot$ Ibai Olariaga $^{50} \cdot$ Adebola $^{2}$ Azeez Lateef ${ }^{51} \cdot$ Yamini Agrawal $^{52} \cdot$ Seyed Abolhassan Shahzadeh Fazeli ${ }^{23,53} \cdot$ Mohammad $^{5}$ Ali Amoozegar ${ }^{54} \cdot$ Guo Zhu Zhao ${ }^{55} \cdot$ Walter P. Pfliegler ${ }^{56} \cdot$ Gunjan Sharma $^{57} \cdot$ Magdalena Oset $^{12}$ - Mohamed A. Abdel-Wahab ${ }^{58}$ - Susumu Takamatsu ${ }^{59}$ - Konstanze Bensch ${ }^{11,60}$ • Nimali Indeewari de Silva, 1,2,3,61 - André De Kesel ${ }^{21}$ - Anuruddha Karunarathna ${ }^{2,3,4,62}$ • Saranyaphat Boonmee ${ }^{2,3} \cdot$ Donald H. Pfister ${ }^{63} \cdot$ Yong-Zhong Lu $^{2,3} \cdot$ Zong-Long Luo $^{2,3,64}$ • Nattawut Boonyuen ${ }^{29} \cdot$ Dinushani A. Daranagama ${ }^{2,4} \cdot$ Indunil C. Senanayake ${ }^{1,2,3} \cdot$ Subashini C. Jayasiri ${ }^{2,3} \cdot$ Milan C. Samarakoon ${ }^{2,61} \cdot$ Xiang-Yu Zeng $^{2,3,65} \cdot$ Mingkwan Doilom $^{2} \cdot$ Luis Quijada $^{66} \cdot$ Sillma Rampadarath ${ }^{67} \cdot$ Gabriela Heredia $^{68} \cdot$ Asha J. Dissanayake $^{2,3} \cdot$ Ruvishika Jayawardana $^{2,3} \cdot$ Rekhani H. Perera ${ }^{2,4,39} \cdot$ Li Zhou Tang ${ }^{34} \cdot$ Chayanard Phukhamsakda $^{1,2,3}$ • Margarita Hernández-Restrepo ${ }^{11,69}$ - Xiaoya $\mathrm{Ma}^{2,3}$ - Saowaluck Tibpromma ${ }^{2,3,4}$ - Luis F. P. Gusmao $^{46} \cdot$ Ali H Bahkali ${ }^{70} \cdot$ Darshani Weerahewa $^{62} \cdot$ Samantha C. Karunarathna $^{1,2,3,4 *}$

${ }^{1}$ Key Laboratory for Plant Diversity and Biogeography of East Asia, Kunming Institute of Botany, Chinese Academy of Science, Kunming 650201, Yunnan, P.R. China

${ }^{2}$ Center of Excellence in Fungal Research, Mae Fah Luang University, Chiang Rai 57100, Thailand

${ }^{3}$ World Agroforestry Centre, East and Central Asia, Kunming 650201, Yunnan, P.R. China

${ }^{4}$ Mushroom Research Foundation, 128 M.3 Ban Pa Deng T. Pa Pae, A. Mae Taeng, Chiang Mai 50150, Thailand

${ }^{5}$ National Fungal Culture Collection of India (NFCCI), Biodiversity and Palaeobiology (Fungi) Group, Agharkar Research Institute, Pune 411 004, Maharashtra, India

${ }^{6}$ Comparative Plant and Fungal Biology, Royal Botanic Gardens, Kew, Richmond, TW9 3DS, UK

${ }^{7}$ Department of Life Sciences, The Natural History Museum, Cromwell Road, London SW7 $5 \mathrm{BD}, \mathrm{UK}$.

${ }^{8}$ Centro de Genómica y Bioinformática, Facultad de Ciencias, Universidad Mayor de Chile, Camino La Pirámide 5750, Huechuraba, Santiago, Chile.

${ }^{9}$ Royal Botanic Gardens, Kew, Richmond, Surrey TW9 3DS, UK

${ }^{10}$ Martin-Luther-Universität, Institut für Biologie, Bereich Geobotanik und Botanischer Garten, Herbarium, Neuwerk 21, 06099 Halle (Saale), Germany

${ }^{11}$ Westerdijk Fungal Biodiversity Institute, Uppsalalaan 8, 3584 CT Utrecht, The Netherlands 
${ }^{12}$ Department of Plant Taxonomy and Nature Conservation, University of Gdańsk, Wita Stwosza 59, PL-80-308 Gdańsk, Poland

${ }^{13}$ Botanic Garden and Botanical Museum, Konigin-Luise-Str. 6-8, 14195 Berlin, Germany

${ }^{14}$ Mycotoxin Prevention and Applied Microbiology Research Unit, National Center for Agricultural Utilization Research, Agricultural Research Service, U.S. Department of Agriculture, Peoria, Illinois 61604, USA

${ }^{15}$ Leibniz Institute DSMZ-German Collection of Microorganisms and Cell Cultures, Inhoffenstraße 7B, 38124 Braunschweig, Germany

${ }^{16}$ Farlow Reference Library and Herbarium of Cryptogamic Botany, Harvard University, 22 Divinity Avenue, Cambridge, Massachusetts 02138, USA

${ }^{17}$ Department of Organismic and Evolutionary Biology, Harvard University, 22 Divinity Avenue, Cambridge, Massachusetts 02138, USA

${ }^{18}$ ABL Herbarium, G.v.d. Veenstraat 107, NL-3762 XK Soest, The Netherlands

${ }^{19}$ Science \& Education, The Field Museum, 1400 S. Lake Shore Drive, Chicago, IL 60605, USA

${ }^{20}$ Natural History Museum, University of Oslo, P.O. Box 1172 Blindern, 0318 Oslo, Norway

${ }^{21}$ Botanic Garden Meise - Research Department, Nieuwelaan 38, BE-1860 Meise, Belgium

${ }^{22}$ Department of Biology, IES Zizur, Ronda S. Cristóbal 196, 31180 Zizur Mayor, Navarra, Spain

${ }^{23}$ University of Lisbon, Faculty of Sciences, Biosystems and Integrative Sciences Institute (BioISI), Campo Grande, 1749-016 Lisbon, Portugal

${ }^{24}$ Microorganisms Bank, Iranian Biological Resource Center (IBRC), Academic Center for Education, Culture and Research (ACECR), Tehran, Iran

${ }^{25}$ DEB, University of Tuscia, Largo dell'Università, Viterbo, Italy

${ }^{26}$ Scientific Affiliate, Integrative Research Center, Science \& Education, The Field Museum, Chicago, IL, USA

${ }^{27}$ Research Associate, National Institute of Fundamental Studies, Kandy- SriLanka

${ }^{28} 33$ B St. Edwards Road Southsea Hants. PO5 3DH. UK

${ }^{29}$ National Center for Genetic Engineering and Biotechnology (BIOTEC) 113 Thailand Science Park, Phahonyothin Road, Khlong Nueng, Khlong Luang, Pathum Thani 12120 Thailand

${ }^{30}$ Instituto de Investigaciones Fundamentales en Agricultura Tropical 'Alejandro de Humboldt' (INIFAT), Santiago de Las Vegas, Habana, Cuba

${ }^{31}$ Musée national d'histoire naturelle, 25 rue Munster, L-2160 Luxembourg

${ }^{32}$ Institute of Marine Biology and Center of Excellence for the Oceans, National Taiwan Ocean University, 2 Pei-Ning Road, Keelung 20224, Taiwan, Republic of China

${ }^{33}$ Faculty of Agriculture and Life Science, Hirosaki University, 3 Bunkyo-cho, Hirosaki, Aomori 036-8561, Japan

${ }^{34}$ Center for Yunnan Plateau Biological Resources Protection and Utilization, College of Biological Resource and Food Engineering, Qujing Normal University, Qujing, Yunnan 655011, China

${ }^{35}$ Institute of Microbiology ASCR, Videnska 1083, 14220 Prague 4, Czech Republic

${ }^{36}$ CSIR-National Institute of Oceanography Regional Centre, 176, Lawsons Bay Colony, Visakhapatnam - 17, Andhra Pradesh, India

${ }^{37}$ Institute of Ecology and Earth Sciences, University of Tartu, Tartu, Estonia

${ }^{38}$ Department of Crop Sciences, College of Agricultural and Marine Sciences, Sultan Qaboos University, PO Box 34, Alkhoud 123, Oman

${ }^{39}$ Guizhou Key Laboratory of Agricultural Biotechnology, Guizhou Academy of Agricultural Sciences, Guiyang, Guizhou 550006, P.R. China 
${ }^{40}$ Biodiversity and Palaeobiology (Lichens) Group, Agharkar Research Institute, Pune 411 004 Maharashtra, India

${ }^{41}$ Department of Physiology, Anatomy and Microbiology, La Trobe University, 3086 Bundoora, Victoria, Australia

${ }^{42}$ Department of Chemistry and Biochemistry, University of North Carolina at Greensboro, North Carolina 27402 USA

${ }^{43}$ Microbiology Program, Faculty of Science and Technology Pibulsongkram Rajabhat University, Phitsanulok 65000, Thailand

${ }^{44}$ Departamento de Biociências, Universidade Federal de Sergipe, CEP: 49500-000, Itabaiana, Sergipe, Brazil

${ }^{45}$ Real Jardín Botánico (CSIC), Plaza Murillo 2, E-28014 Madrid, Spain

${ }^{46}$ Universidade Estadual de Feira de Santana Departamento de Ciências Biológicas Laboratório de Micologia Av. Transnordestina, s/n - Bairro: Novo Horizonte CEP:44036-900 Feira de Santana - BA, Brazil

${ }^{47}$ Institute of Biology \& Soil Science, Far East Branch of the Russian Academy of Sciences, Vladivostok 690022, Russia

${ }^{48}$ Centre for Crop Health, Institute for Agriculture and the Environment, University of Southern Queensland, Toowoomba, Queensland 4350, Australia

${ }^{49}$ Universidad Rey Juan Carlos, Departamento de Biología y Geología, Física y Química Inorgánica, C/ Tulipan s/n, 28933 Mostoles, Madrid, Spain

${ }^{50}$ Swedish Museum of Natural History, Department of Botany, PO Box 50007, SE-10405 Stockholm, Sweden

${ }^{51}$ Department of Plant Biology, Faculty of Life Sciences, University of Ilorin, Nigeria

${ }^{52}$ Shahid Rajguru College of applied sciences for women Vasundhara Enclave, East Delhi, Pin - 110096, India

${ }^{53}$ Department of Molecular and Cellular Biology, Faculty of Basic Sciences and Advanced Technologies in Biology, University of Science and Culture, Tehran, Iran

${ }^{54}$ Extremophiles Laboratory, Department of Microbiology, Faculty of Biology and Center of Excellence in Phylogeny of Living Organisms, College of Science, University of Tehran, Tehran, Iran

${ }^{55}$ College of Biological Sciences and Biotechnology, Beijing Forestry University, Beijing 100083, P.R. China

${ }^{56}$ Department of Biotechnology and Microbiology, University of Debrecen, Debrecen, Hungary

${ }^{57}$ Regional Centre for Biotechnology, NCR Biotech Science Cluster, Faridabad, Pin-121001, Haryana, India.

${ }^{58}$ Department of Botany and Microbiology, Faculty of Science, Sohag University, Sohag, Egypt

${ }^{59}$ Graduate School of Bioresources, Mie University, 1577 Kurima-Machiya, Tsu 514-8507, Japan

${ }^{60}$ Botanische Staatssammlung München, Menzinger Straße 67, D-80638 München, Germany

${ }^{61}$ Department of Biology, Faculty of Science, Chiang Mai University, Chiang Mai, 50200 Thailand

${ }^{62}$ Department of Botany, The Open University of Sri Lanka, Nawala, Nugegoda, Sri Lanka

${ }^{63}$ Department of Organismic and Evolutionary Biology Harvard University, 22 Divinity Ave. Cambridge, MA 02138 USA

${ }^{64}$ College of Agriculture and Biological Sciences, Dali University, Dali, 671003, Yunnan, P.R. China

${ }^{65}$ Engineering Research Center of Southwest Bio-Pharmaceutical Resources, Ministry of Education, Guizhou University, Guiyang 550025, Guizhou, P.R. China 
${ }^{66}$ Departamento de Botánica, Ecología y Fisiología Vegetal. University of La Laguna, Pharmacy Faculty, 38200 apdo. 456 Avda. Francisco Sánchez s/n. Tenerife, Canary Islands, Spain

${ }^{67}$ Department of Agriculture and Food Science, Faculty of Agriculture, University of Mauritius, Réduit, Mauritius

${ }^{68}$ Instituto de Ecología A. C. Laboratory of Microfungi. Xalapa, Ver. México

${ }^{69}$ Department of Microbiology and Plant Pathology, Forestry and Agricultural Biotechnology Institute (FABI), University of Pretoria, Pretoria 0002, South Africa

${ }^{70}$ Department of Botany and Microbiology, College of Science, King Saud University, P.O. Box: 2455, Riyadh, 1145, Saudi Arabia

*Corresponding author: samanthakarunarathna@gmail.com

This paper is dedicated to the memory of Walter Gams, Hubertus Antonius van der Aa, Larisa N. Vasilyeva, E. Punithalingam and Vadim A. Mel'nik whose efforts contributed greatly to mycology.

\begin{abstract}
Knowledge of the relationships and thus the classification of fungi, has developed rapidly with increasingly widespread use of molecular techniques, over the last 10-15 years, and continues to accelerate. Genera have been found to be polyphyletic and their generic concepts narrowed. New names have thus been introduced for species which are phylogenetically distinct from the type species of particular genera. The ending of the separate naming of morphs of the same species in 2011, has also caused changes in fungal generic names. In order to facilitate access to all important changes, it was desirable to compile these in a single document. The present article provides a list of generic names of Ascomycota (approximately 6500 accepted names published to the end of 2016), including those which are lichen-forming. Notes and summaries of the changes since the last edition of 'Ainsworth \& Bisby's Dictionary of the Fungi' in 2008 are provided. The notes include the number of accepted species, classification, type species (with location of the type material), culture availability, life-styles, distribution, and selected publications that have appeared since 2008. This work is intended to provide the foundation for updating the ascomycete component of the "Without prejudice list of generic names of Fungi" published in 2013, which will be developed into a list of protected generic names. This is subject to the International Botanical Congress in Shenzhen in July 2017 agreeing to a modification in the rules relating to protected lists, and scrutiny by procedures determined by the Nomenclature Committee for Fungi (NCF). The previously invalidly published generic names Barriopsis, Collophora (as Collophorina), Cryomyces, Dematiopleospora, Heterospora (as Heterosporicola), Lithophila, and Saxomyces are validated, as are two previously invalid family names, Bartaliniaceae and Wiesneriomycetaceae. Catenomycopsis Tibell \& Constant. reduced under Chaenothecopsis Vain., while Dichomera Cooke is reduce under Botryosphaeria Ces. \& De Not. (Art. 59). Invalid and illegitimate generic names are also provided with nomenclature comments.
\end{abstract}

Keywords Article $59 \bullet$ Classification $\bullet$ One name $・$ Pleomorphic fungi $\bullet$ Taxonomy

\title{
Introduction
}

Knowledge of the taxonomy of fungi, has been changing rapidly since the last edition of Ainsworth \& Bisby's Dictionary of the Fungi (Kirk et al. 2008), as a consequence of new 
information from DNA and protein sequence studies, and the integration of asexual and asexual morphs into a unified system. Phylogenetic affiliations and taxonomic placements of a large number of genera are being clarified, and at the same time species complexes and generic circumscriptions are being resolved. Sequences are also increasingly being obtained from genera representing fungi with ecologies not previously well-represented in the system, such as rock-inhabiting and lichenicolous fungi, or which are uncultured or unculturable. In addition, neo- and epitypifications are enabling the application of historic species and genera to be accommodated into molecularly based systems. Major progress towards a natural classification system is being made.

The ending of dual nomenclature for pleomorphic non-lichenized ascomycetes and basidiomycetes in 2011 (McNeill et al. 2012) has also led to a need to select the name to be adopted for pleomorphic genera. Lists of names are now being proposed for protection or suppression by working groups established under the auspices of the International Commission on the Taxonomy of Fungi (ICTF). The proposals from the working groups are being published and will then be scrutinized by the Nomenclature Committee for Fungi (NCF) and the General Committee (Art. 14.13) established by the last International Botanical Congress.

The problem is especially acute in the phylum Ascomycota, the largest in kingdom Fungi, with some 15 classes, 68 orders, 327 families, c. 6300 genera, and over 64000 species (Kirk et al. 2008). However, 1000-1500 new taxa are introduced each year, and our understanding of the Ascomycota has been developing rapidly. Keeping track of all the changes and the incorporation of so much new knowledge is a major challenge, though some important compilations have been prepared, for example those of Hyde et al. (2013) and Wijayawardene et al. (2014c) for Dothideomycetes, and Maharachchikumbura et al. (2015, 2016) for Sordariomycetes, which considered both asexually and sexually typified genera. Molecular clock analyses has also provided addition evidence for the placement of genera at the family, order and class levels (Chay et al. 2016; Deepavir et al. 2017; Hongsanan et al. 2017; Hyde et al. 2017; Liu et al. 2017). There has also been a major attempt to produce an overall system for Ascomycota referring accepted genera down to family (Jaklitsch et al. 2016a).

The long-running series Notes on Ascomycete Systematics (1986-2010) aimed to provide a current awareness system of novel taxa and changes proposed, and provided 5113 notes. This has not, however, been continued to include asexually typified genera. Here we start to redress this problem, taking the last edition of the Dictionary (Kirk et al. 2008) as our starting point. In addition to recent nomenclature changes, we include typification details of the type species of genera (including lecto-, neo- and epitypifications), information on the availability of cultures, and references to accessible sequence data. References to recently established DNA barcodes for plant pathogenic genera are also included where available.

In addition to providing an overview of current knowledge on accepted genera of ascomycetes, this work is also intended to provide the foundation for updating the ascomycete component of the "Without prejudice list of generic names of Fungi" published in 2013 (Kirk et al. 2013), which is anticipated will be developed into a list of protected generic names. This will, however, be subject to the XIX ${ }^{\text {th }}$ International Botanical Congress in Shenzhen in July 2017 agreeing to a modification in the rules relating to protected lists of names supported by the $10^{\text {th }}$ International Mycological Congress in 2014 (Redhead et al. 2014; Hawksworth 2015), and scrutiny by procedures determined by the Nomenclature Committee for Fungi (NCF).

In this study, we list 6540 accepted genera of ascomycetes with an estimate of $* *$ species. They belong in $* * *$ families, $* * *$ orders and $* *$ classes. We have attempted to include all genera and place them in a natural classification using the most recent evidence 
and publications. We however, have surely missed some entries and may not have found all of the latest data. We therefore regard this as a working paper and will continually update it in are webpage www.fungalgenera.org. Suggestions for changes or omissions will be welcome and readers can contact the corresponding author.

\section{Materials and Methods Data collection}

Collecting data on existing names of taxa in use was based on Kirk et al. $(2008,2013)$ and Species Fungorum (2016). The works of Sutton $(1977,1980)$ and Seifert et al. (2011) were also used for further clarification of nomenclatural issues for asexually typified genera. Previous outlines of sexually typified genera (i.e. Lumbsch and Huhndorf 2010) and asexually typified genera (i.e. Hyde et al. 2011; Wijayawardene et al. 2012, 2017) have been used to extract taxonomic placements. For the taxonomic placement of lichen-forming genera, the compilation of Lücking et al. (2016b) was used. Synonyms of generic names (if less than 10) are also provided based on recent publications and Species Fungorum 2017.

\section{One fungus: one name}

Recent proposals on names to be selected for use in non-lichenized pleomorphic ascomycete genera were gathered from the reports of ICTF working groups (Table 1).

Table 1. ICTF working groups and reports

\begin{tabular}{ll}
\hline Taxonomic group & Reference \\
\hline Diaporthales & Rossman et al. 2015a \\
Dothideomycetes & Hyde et al. 2013; Wijayawardene et al. \\
& 2014c; Rossman et al. 2015b, 2016a \\
Hypocreales & Rossman et al. 2013b \\
Leotiomycetes & Johnston et al. 2014b \\
Magnaporthales & Zhang et al. 2016b \\
Miscellaneous genera & Rossman et al. 2016a \\
Pezizomycetes & Healy et al. 2016 \\
Sordariomycetes - (except Diaporthales, & Maharachchikumbura et al. 2015, 2016; \\
Hypocreales, and Magnaporthales) & Réblová et al. 2016c \\
Xylariales & Stadler et al. 2014; Daranagama et al. \\
& 2017; Wendt et al. 2017 \\
\hline
\end{tabular}

\section{Results}

\section{Validating of invalid families}

Bartaliniaceae Wijayaw., P.M. Kirk \& K.D. Hyde

Index Fungorum number: 551079

= Bartaliniaceae Wijayaw., Maharachch. \& K.D. Hyde, Fungal Diversity 73: 85. 2015, Nom. inval., Art. 42.1 (Melbourne)

Type: Bartalinia Tassi, Bulletin Labor. Orto Bot. de R. Univ. Siena 3: 4 (1900)

Description: see Senanayake et al. (2015)

Notes: Senanayake et al. (2015) introduced Bartaliniaceae but it is invalid (Art. 42.1) as the identifier cited in the protologue, (i.e. IF511183), was not issued for the name published (i.e. Bartaliniaceae). This identifier was issued for Boletellus exiguus T.W. Henkel 
\& Fulgenzi 2008. A new identifier was obtained (i.e. 551079) thus Bartaliniaceae validly published.

Wiesneriomycetaceae Wijayaw., P.M. Kirk, K.D. Hyde

Index Fungorum number: IF550306

$=$ Wiesneriomycetaceae Suetrong, Rungjindamai, Somrithipol. \& E.B.G. Jones, Phytotaxa 176(1): 288. 2014; Nom. inval., Art. 42.1 (Melbourne) IF 10438

Type: Wiesneriomyces Koord., Verh. K. Akad. Wet., tweede sect. 13(4): 246 (1907)

Description: see Suetrong et al. (2014)

Notes: Suetrong et al. (2014) introduced Wiesneriomycetaceae but it is invalid (Art. 42.1) as the identifier cited in the protologue, (i.e. MB809097), was not issued for the name published (i.e. Wiesneriomycetaceae). This identifier was issued for Hypogymnia papilliformis McCune, Tchabanenko \& X.L. Wei 2015. A new identifier was obtained (i.e. IF550306) thus Wiesneriomycetaceae is herein validly published.

\section{Notes for genera}

Aaosphaeria Aptroot 1995, Dacampiaceae, Pleosporales, Dothideomycetes, one species, type: A. arxii (van der Aa) Aptroot, asexual morph coelomycetous, saprobes, terrestrial, tropical, see Lumbsch and Huhndorf (2010; outline), Hyde et al. (2013; accepted as a genus in Dacampiaceae), Kirk et al. (2013; genus accepted), sequence available for the type: KU158145 (ITS) (unpublished).

Abropelta B. Sutton 1986, Ascomycota genera incertae sedis, one species, type: A. fusarioides B. Sutton, coelomycetous, sexual morph unknown, caulicolous, terrestrial, India, see Hyde et al. (2011; outline), Wijayawardene et al. (2012, 2017; outline), cultures and sequences are unavailable, holotype of the type: IMI 236263.

Abrothallus De Not. 1845 (= Abrothallomyces Cif. \& Tomas. 1953; = Phymatopsis Tul. ex Trevis. 1857; = Pseudolecidea Marchand 1896; = Vouauxiomyces Dyko \& D. Hawksw. 1979 fide Rossman et al. 2016a; Species Fungorum 2017), Abrothallaceae, Abrothallales, Dothideomycetes, c. 40 species, type: A. bertianus De Not., obligately lichenicolous, parasymbiontic or parasitic on macrolichens from several families of lichen-forming fungi, sexual morph with apothecioid ascomata, asexual morph coelomycetous, some species are known only either by their asexual or sexual morph, terrestrial, worldwide, see Pérez-Ortega et al. (2011b, 2014; anamorph-teleomorph connection, phylogeny), Suija et al. (2015a; phylogeny, key for species on Peltigerales), Rossman et al. (2016a; nomenclature), holotype of the type: likely in VER or RO. the species growing on Parmeliaceae are in urgent need of revision, preliminary molecular data suggest that current species delimitation, largely based on the host identity is inaccurate (Pérez-Ortega and Suija, data not published).

Absconditella Vězda 1965, Stictidaceae, Ostropales, Lecanoromycetes, twelve species, type: A. sphagnorum Vězda \& Poelt, lichenized, see Lumbsch and Huhndorf (2010; outline), Kirk et al. (2013; genus accepted), Lücking et al. (2016b; classification), sequences are available.

Abyssomyces Kohlm. 1970, Sordariales genera incertae sedis, Sordariomycetes, one species, type: A. hydrozoicus Kohlm., saprobes, asexual morph unknown, marine, Scotland, see Lumbsch and Huhndorf (2010; outline), Kirk et al. (2013; genus accepted), Jones et al. (2015; outline), Maharachchikumbura et al. (2015, 2016; outline), cultures and sequences are unavailable.

Acallomyces Thaxt. 1903, Laboulbeniaceae, Laboulbeniales, Laboulbeniomycetes, three species, type: A. homalotae Thaxt., asexual morph unknown, biotrophic on Coleoptera in decaying agarics (Staphylinidae), worldwide, see Lumbsch and Huhndorf (2010; outline), 
Kirk et al. (2013; genus accepted), morphologically related to Polyascomyces Thaxter, cultures and sequences are unavailable, needs generic revision.

Acanthogymnomyces Udagawa \& Uchiy. 2000, Eoterfeziaceae, Ascomycota family incertae sedis, one species, type: A. terrestris Udagawa \& Uchiy., asexual morph unknown, from soil, terrestrial, Japan, see Lumbsch and Huhndorf (2010; outline), sequences are unavailable, holotype of the type: CBM SUM3162.

Acanthohelicospora Boonmee \& K.D. Hyde 2014, Tubeufiaceae, Tubeufiales, Dothideomycetes, four species, type: A. pinicola Boonmee \& K.D. Hyde, saprobes, worldwide, asexual morph hyphomycetous, see Boonmee et al. (2014b; taxonomy, phylogeny), Rossman et al. (2016b; plant pathogens, new combinations), holotype and extype: MFLU 10-0049, MFLUCC 10-0116 = BCC 52036.

Acanthonitschkea Speg. 1908 (= Euacanthe Theiss. 1917; = Fitzpatrickia Cif. 1928; = Hystrix Alstrup \& Olech 1993; = Petelotia Pat. 1924; = Sydowinula Petr. 1923 fide Species Fungorum 2017), Nitschkiaceae, Coronophorales, Sordariomycetes, nine species, type: A. argentinensis Speg., asexual morph acremonium-like, saprobes and on lichens, terrestrial, worldwide, see Lumbsch and Huhndorf (2010; outline), Mugambi and Huhndorf (2010; DNA), Kirk et al. (2013; genus accepted), Maharachchikumbura et al. (2015, 2016; outline), Jaklitsch et al. (2016a; classification), cultures and sequences are available.

Acanthophiobolus Berl. 1893 (= Ophiobolus subgen. Ophiochaeta Sacc. 1883; = Ophiochaeta (Sacc.) Sacc. 1895; = Ophiosphaeria Kirschst. 1907 [1906]; = Ophiotrichia Berl. 1893 fide Species Fungorum 2017), Tubeufiaceae, Tubeufiales, Dothideomycetes, three species, type: A. helminthosporus (Rehm) Berl., asexual morph unknown, saprobes, widespread, see Lumbsch and Huhndorf (2010; outline), Boonmee et al. (2011, 2014b; accepted as a genus in Tubeufiaceae), Hyde et al. (2013; accepted as a genus in Tubeufiaceae), Kirk et al. (2013; genus accepted), Wijayawardene et al. (2014c; outline), cultures and sequences are unavailable.

Acanthorus Bat. \& Cavalc. 1967, Ascomycota genera incertae sedis, one species, type: A. maranhensis Bat. \& Cavalc., coelomycetous, sexual morph unknown, saprobes, terrestrial, Brazil, see Kirk et al. (2013; genus accepted), Wijayawardene et al. (2014c; accepted as a genus in Dothideomycetes), Wijayawardene et al. (2017) and in here we treat this genus as Ascomycota genera incertae sedis since cultures and sequences are unavailable.

Acanthosphaeria Kirschst. 1939, Trichosphaeriaceae, Trichosphaeriales, Sordariomycetes, two species, type: need typification, asexual morph unknown, saprobes, Europe, see Lumbsch and Huhndorf (2010; outline), Maharachchikumbura et al. (2015, 2016; outline), cultures and sequences are available.

Acanthostigma De Not., 1863, Tubeufiaceae, Tubeufiales, Dothideomycetes, 64 species, type: A. perpusillum de Not., saprobes on dead wood, widespread, asexual morph hyphomycetous, see Lumbsch and Huhndorf (2010; outline), Boonmee et al. (2011, 2014b; accepted as a genus in Tubeufiaceae), Hyde et al. (2013; accepted as a genus in Tubeufiaceae), Kirk et al. (2013; genus accepted), Wijayawardene et al. (2014c; outline), cultures and sequences are available for three species, strains available for type: UAMH 7237.

Acanthostigmella Höhn., 1905, Dothideomycetes genera incertae sedis, six species, type: A. genuflexa Höhn., asexual morph unknown, saprobes, widespread, see Lumbsch and Huhndorf (2010; outline, accepted as a genus in Tubeufiaceae), Boonmee et al. (2011; accepted as a genus in Tubeufiaceae), Hyde et al. (2013) and Boonmee et al. (2014b) did not accept as a genus in Tubeufiaceae, Kirk et al. (2013; genus accepted), Wijayawardene et al. (2014c; outline), cultures and sequences are unavailable.

Acanthostigmina Höhn. 1909, Tubeufiaceae, Tubeufiales, Dothideomycetes, three species, type: A. minuta (Fuckel) Clem. \& Shear, saprobes on decaying wood, cosmopolitan, see Hyde et al. (2013; accepted as a genus in Tubeufiaceae), Kirk et al. (2013; genus accepted), 
Boonmee et al. (2014b; taxonomy), Wijayawardene et al. (2014c; outline), cultures and sequences are available.

Acanthotheciella Höhn. 1911 (= Acanthotheca Clem. \& Shear 1931 fide Species Fungorum 2017), Sordariales genera incertae sedis, Sordariomycetes, one species, type: A. barbata (Pat.) Höhn., asexual morph unknown, on dead scale insects, terrestrial, Asia, North America, see Lumbsch and Huhndorf (2010; outline), Kirk et al. (2013; genus accepted), Maharachchikumbura et al. (2015, 2016; outline), cultures and sequences are unavailable, needs generic revision.

Acanthothecis Clem. 1909 (= Acanthographina (Vain.) Walt. Watson 1929; = Acanthographis (Vain.) Walt. Watson 1929; = Acanthotheciopsis Zahlbr. 1923 [1924]; = Acanthothecium Vain. 1890; = Acanthothecium sect. Acanthographina Vain. 1890; = Acanthothecium sect. Acanthographis Vain. 1890; Acanthothecomyces Cif. \& Tomas. 1953; = Psorographis Clem. 1909 fide Species Fungorum 2017), Graphidaceae, Ostropales, Lecanoromycetes, c. 56 species, type: A. hololeucoides (Nyl.) Staiger \& Kalb, all with ascomata, lichenized (Trenthepohlia), terrestrial (mainly corticolous), pantropical-subtropical, see Lumbsch and Huhndorf (2010; outline), Kirk et al. (2013; genus accepted), Rivas Plata et al. (2013; taxonomy), Lumbsch et al. (2014a, b; taxonomy), Lücking et al. (2016b; classification), sequences are available.

Acanthotrema Frisch 2006, Graphidaceae, Ostropales, Lecanoromycetes, five species, type: A. brasilianum (Hale) Frisch, lichenized, tropical, see Lumbsch and Huhndorf (2010; outline), Kirk et al. 2013 (genus accepted), Rivas Plata et al. (2010a, 2012a; key), Sipman et al. (2012; key), sequences are available.

Acarella Syd. 1927, Ascomycota genera incertae sedis, one species, type: A. costaricensis Syd., coelomycetous, sexual morph unknown, saprobes, terrestrial, Central America, see Kirk et al. (2013; genus accepted), Wijayawardene et al. (2017; outline), cultures and sequences are unavailable, needs generic revision.

Acarellina Bat. \& H. Maia 1960, Ascomycota genera incertae sedis, one species, type: A. psidii Bat. \& H. Maia, coelomycetous, sexual morph unknown, epiphytes, terrestrial, Brazil, see Wijayawardene et al. (2012, 2017; outline), Kirk et al. (2013; genus accepted), cultures and sequences are unavailable, needs generic revision.

Acaroconium Kocourk. \& D. Hawksw. 2008, Ascomycota genera incertae sedis, one species, type: A. punctiforme Kocourk. \& D. Hawksw., coelomycetous, sexual morph unknown, lichenicolous, terrestrial, Europe, North America, see Kocourková and Hawksworth (2008; taxonomy), Wijayawardene et al. (2016b, 2017; taxonomy, outline), holotype of the type: PRM 8926543, cultures and sequences are unavailable, some lichenicolous Microsphaeropsis species may belong to this genus.

Acarocybe Syd. 1937, Ascomycota genera incertae sedis, three species, type: A. hansfordii Syd., hyphomycetous, sexual morph unknown, saprobes, terrestrial, Central America, see Seifert et al. (2011; morphology), Wijayawardene et al. (2012, 2017; outline), Kirk et al. (2013; genus accepted), cultures and sequences are unavailable, needs generic revision.

Acarocybellina Subram. 1992, Ascomycota genera incertae sedis, one species, type: A. arengae (Matsush.) Subram., hyphomycetous, sexual morph unknown, saprobes, terrestrial, Brazil, see Seifert et al. (2011; morphology), Wijayawardene et al. (2012, 2017; outline), Kirk et al. (2013; genus accepted), cultures and sequences are unavailable.

Acarocybiopsis J. Mena, A. Hern.-Gut. \& Mercado 1999, Ascomycota genera incertae sedis, one species, type: A. cubitaensis J. Mena, A. Hern. Gut. \& Mercado, hyphomycetous, sexual morph unknown, saprobes, terrestrial, Cuba, see Seifert et al. (2011; morphology), Wijayawardene et al. (2012, 2017; outline), Kirk et al. (2013; genus accepted), cultures and sequences are unavailable. 
Acaropeltis Petr. 1937, Ascomycota genera incertae sedis, one species, type: A. costaricensis Petr., coelomycetous, sexual morph unknown, on living leaves, terrestrial, North America, see Wijayawardene et al. (2012, 2017; outline), Kirk et al. (2013; genus accepted), cultures and sequences are unavailable, needs generic revision.

Acarospora A. Massal. 1852 (= Myriospora Nägeli 1853; = Myriospora Nägeli ex Uloth 1861 fide Species Fungorum 2017), Acarosporaceae, Acarosporales, Lecanoromycetes, c. 200 species, type type: A. schleicheri (Ach.) A. Massal. all with ascomata, lichenized (green algae), terrestrial (mostly saxicolous or terricolous), cosmopolitan, see Lumbsch and Huhndorf (2010; outline), Kirk et al. (2013; genus accepted), Miądlikowska et al. (2014a; phylogeny), Westberg et al. (2015; phylogeny), Lücking et al. (2016b; classification), polyphyletic, sequences are available.

Acarosporina Sherwood 1977, Stictidaceae, Ostropales, Lecanoromycetes, five species, type: A. monilifera (Ellis \& Everh.) Sherwood, lichenized, see Lumbsch and Huhndorf (2010; outline), Kirk et al. (2013; genus accepted), Lücking et al. (2016b; classification), sequences are available.

Acaulium Sopp 1912 (= Acaulium Sopp 1912; = Masonia G. Sm. 1952; = Masoniella G. Sm. 1952; = Phaeoscopulariopsis M. Ota 1928 fide Species Fungorum 2017), Microascaceae, Microascales, Sordariomycetes, three species, type: A. albonigrescens Sopp, hyphomycetous, the genus was treated as a synonym of Scopulariopsis Bainier 1907 (fide Seifert et al. 2011), Sandoval-Denis et al. (2016b; phylogeny, reinstated the genus, new species), cultures and sequences are available.

Acephala Grünig \& T.N. Sieber 2005, Vibrisseaceae, Helotiales, Leotiomycetes, two species, type: A. applanata Grünig \& T.N. Sieber, hyphomycetous, sexual morph unknown, from fine roots of Pinus, terrestrial, Germany, Switzerland, see Munzenberger et al. (2009; morphology, new species), Seifert et al. (2011; morphology), Wijayawardene et al. (2017; outline), ex-type strain of the type: CBS 109321.

Acerbiella Sacc. \& D. Sacc. 1905, Sordariomycetes genera incertae sedis, two species, type: A. macrospora (Rick) Sacc. \& D. Sacc., asexual morph unknown, saprobes, terrestrial, South America, Java, see Lumbsch and Huhndorf (2010; outline), Kirk et al. (2013; genus accepted), Maharachchikumbura et al. (2015, 2016; outline), needs generic revision, cultures and sequences are unavailable.

Acerviclypeatus Hanlin 1990, Ascomycota genera incertae sedis, one species, type: $A$. poriformans Hanlin, coelomycetous, sexual morph unknown, on living leaves of Vaccinium, terrestrial, USA, see Wijayawardene et al. (2012, 2017; outline), Kirk et al. (2013; genus accepted), cultures and sequences are unavailable, needs generic revision.

Acervuloseptoria Crous \& Jol. Roux 2014, Mycosphaerellaceae, Capnodiales, Dothideomycetes, two species, type: A. ziziphicola Crous \& Jol. Roux, coelomycetous, sexual morph unknown, associated with leaf spots, terrestrial, South Africa, see Crous et al. (2014c, 2015c; morphology and phylogeny), holotype and ex-type culture of type: CBS H-21723, CPC 23707.

Acervus Kanouse 1938 (= Phaedropezia Le Gal 1953 fide Species Fungorum 2017), Otideaceae, Pezizales, Pezizomycetes, eight species, type: A. aurantiacus Kanouse, asexual morph unknown, saprobes, terrestrial, worldwide, see Lumbsch and Huhndorf (2010; outline), Zhuang et al. (2011; morphology, taxonomy), Kirk et al. (2013; genus accepted), Ekanayaka et al. (2016; new species, China), Jaklitsch et al. (2016a; classification), cultures and sequences are available but lacks for the type species.

Achaetobotrys Bat. \& Cif. 1963, Antennulariellaceae, Capnodiales, Dothideomycetes, three species, type: A. affinis (L.R. Fraser) Bat. \& Cif., asexual morph unknown, saprobes, terrestrial, worldwide, see Lumbsch and Huhndorf (2010; outline), Hyde et al. (2013; accepted as a genus in Antennulariellaceae), Kirk et al. (2013; genus accepted), 
Wijayawardene et al. (2014c; outline), cultures and sequences are unavailable, needs generic revision.

Achaetomium J.N. Rai, J.P. Tewari \& Mukerji 1964, Chaetomiaceae, Sordariales, Sordariomycetes, 13 species, asexual morph unknown, type: A. globosum J.N. Rai \& J.P. Tewari, saprobes, terrestrial, Asia, Africa, see Lumbsch and Huhndorf (2010; outline), Kirk et al. (2013; genus accepted), Maharachchikumbura et al. (2015, 2016; outline), sequence are available.

Achorella Theiss. \& Syd. 1915, Dothideomycetes genera incertae sedis, ten species, type: A. ametableta (Rehm) Theiss. \& Syd., asexual morph unknown, saprobes, terrestrial, worldwide, see Lumbsch and Huhndorf (2010; outline), Kirk et al. (2013; genus accepted), Wijayawardene et al. (2014c; outline), cultures and sequences are unavailable, needs generic revision.

Achorodothis Syd. 1926, Mycosphaerellaceae, Capnodiales, Dothideomycetes, two species, type: A. poasensis Syd., asexual morph unknown, saprobes, terrestrial, Costa Rica, see Lumbsch and Huhndorf (2010; outline), Hyde et al. (2013; accepted as a genus in Mycosphaerellaceae), Kirk et al. (2013; genus accepted), Wijayawardene et al. (2014c; outline), cultures and sequences are unavailable, needs generic revision.

Achoropeltis Syd. 1929, Ascomycota genera incertae sedis, one species, type: A. modesta Syd., coelomycetous, saprobes, USA, see Wijayawardene et al. (2012, 2017; outline), Kirk et al. (2013; genus accepted), cultures and sequences are unavailable, needs generic revision.

Achroceratosphaeria Réblová, J. Fourn., K.D. Hyde \& Ranghoo 2010, Pisorisporiaceae, Pisorisporiales, Sordariomycetes, two species, type: A. potamia Réblová, Fournier \& K.D. Hyde, asexual morph unknown, saprobes, aquatic, Europe, see Réblová et al. (2010; morphology, phylogeny), Maharachchikumbura et al. (2015, 2016; outline, phylogeny), holotype and ex-type strain of the type: PRM 915719, CBS 125414.

Achroiostachys L. Lombard \& Crous 2016, Stachybotriaceae, Hypocreales, Sordariomycetes, six species, type: A. humicola L. Lombard \& Crous, hyphomycetous, sexual morph unknown, saprobes, from soil, terrestrial, cosmopolitan, see Lombard et al. (2016; taxonomy, phylogeny), holotype and ex-type culture of the type: CBS H-22420, CBS 868.73.

Aciascus Doweld 2013, Gymnoascaceae, Onygenales, Eurotiomycetes, one species, type: A. purpureus (Thaxt. ex Currah) Doweld, asexual morph unknown, saprobes, USA, see Index Fungorum (2013; introduced to replace Acitheca Currah 1985), Wijayawardene et al. (2017; outline),.

Aciculoconidium D.S. King \& S.C. Jong 1976, Metschnikowiaceae, Saccharomycetales, Saccharomycetes, one species, type: A. aculeatum (Phaff, M.W. Mill. \& Shifrine) D.S. King \& S.C. Jong, asexual morph unknown (budding of cells and formation of true hyphae with blastoconidia), saprophytes, isolated from fruit flies (Drosophila spp.), terrestrial, California, USA, see Kirk et al. (2013; genus accepted), cultures and sequences are available.

Aciculopsora Aptroot \& Trest 2006, Ramalinaceae, Lecanorales, Lecanoromycetes, two species, type: A. salmonea Aptroot \& Trest, asexual morph unknown, lichenized, terrestrial, tropical, see Lumbsch and Huhndorf (2010; outline), Kirk et al. (2013; genus accepted), Lücking et al. (2016b; classification), holotype of the type: CR, Lücking 17543, cultures and sequences are unavailable.

Aciculosporium I. Miyake 1908 (= Albomyces I. Miyake ex I. Hino 1908; = Mitosporium Clem. \& Shear 1931 fide Species Fungorum 2017), Clavicipitaceae, Hypocreales, Sordariomycetes, seven species, type: A. take I. Miyake, asexual morph unknown, saprobes, terrestrial, Asia, see Tanaka (2009; in situ visualization), Lumbsch and Huhndorf (2010; outline), Kirk et al. (2013; genus accepted), Maharachchikumbura et al. (2015, 2016; outline), cultures and sequences are available. 
Acicuseptoria Quaedvl., Verkley \& Crous 2013, Leptosphaeriaceae, Pleosporales, Dothideomycetes, one species, type: A. rumicis Quaedvlieg, Verkley \& Crous, asexual morph coelomycetous, sexual morph unknown, saprobes, one species, France, see Quaedvlieg et al. (2013; morphology and phylogeny), holotype and ex-type culture of type: CBS H-18163, CPC 522.78 .

Acidea Hujslová \& M. Kolařík 2014, Helotiales genera incertae sedis, Leotiomycetes, one species, type: A. extrema Hujslová \& M. Kolařík, hyphomycetous, sexual morph unknown, saprobes, terrestrial, aquatic, Europe, Antarctica, see Hujslová et al. (2014; morphology, phylogeny), holotype and ex type of the type: PRM 922617, CBS 136258.

Acidiella Hujslová \& M. Kolař́k 2013, Teratosphaeriaceae, Capnodiales, Dothideomycetes, two species, type: A. bohemica Hujslová \& M. Kolarík, hyphomycetous, sexual morph unknown, saprobes, terrestrial and aquatic, Europe, Australia, see Hujslová et al. (2013; morphology, phylogeny), Kolařík et al. (2015a; new species), holotype and ex-type of cultures of the type: PRM 859933, CBS 132721.

Acidomelania E. Walsh \& N. Zhang 2014, Helotiales genera incertae sedis, Leotiomycetes, one species, type: A. panicicola E. Walsh \& N. Zhang, hyphomycetous, sexual morph unknown, saprobes, terrestrial, USA, see Walsh et al. (2014; taxonomy, phylogeny), Wijayawardene et al. (2017; outline), holotype: RUTPP 61R8

Acidomyces B.J. Baker, M.A. Lutz, S.C. Dawson, P.L. Bond \& Banfield ex Selbmann, de Hoog \& De Leo 2008 (= Acidomyces B.J. Baker, M.A. Lutz, S.C. Dawson, P.L. Bond \& Banfield, Appl. 2004 fide Species Fungorum 2017), Teratosphaeriaceae, Capnodiales, Dothideomycetes, hyphomycetous, two species, type: A. acidophilus (Sigler \& J.W. Carmich.) Selbmann, de Hoog \& De Leo, sexual morph unknown, from soil, terrestrial, Canada, see Selbmann et al. (2008; morphology; phylogeny), Seifert et al. (2011; morphology), Wijayawardene et al. (2012, 2014c, 2017; outline), holotype and ex-type strain of the type: UAMH 3460, CBS 270.74.

Acidothrix Hujslová \& M. Kolařík 2014, Amplistromataceae, Amplistromatales, Sordariomycetes, one species, type: A. acidophila Hujslová \& M. Kolařík, hyphomycetous, sexual morph unknown, in highly acidic soil, terrestrial, CzechRepublic, see Hujslová et al. (2014; taxonomy), Maharachchikumbura et al. (2015, 2016; outline, phylogeny), Wijayawardene et al. (2017; outline), ex-type culture available for the type: CBS 136259.

Acleistia Bayl. Ell. 1917, Ascomycota genera incertae sedis, one species, type: A. alniella Bayl. Ell., coelomycetous, sexual morph unknown, saprobes, terrestrial, Europe, see Wijayawardene et al. (2012, 2017; outline), Kirk et al. (2013; genus accepted), cultures and sequences are available but lacks for the type species.

Acolium (Ach.) Gray = Acolium Trevis. 1862; = Calicium subdiv. Acolium Ach. 1808; = Crateridium Trevis. 1862; = Cypheliomyces E.A. Thomas ex Cif. \& Tomas. 1953; = Mycacolium Reinke 1895; = Pseudacoliomyces Cif. \& Tomas. 1953; = Pseudacolium Stizenb. ex Clem. 1909 fide Species Fungorum 2017), Caliciaceae, Caliciales, Lecanoromycetes, five species, type:

Type species: Calicium tympanellum Ach. (lectotype, designated by Tibell 1984) = Acolium inquinans (Sm.) A. Massal., lichenized, see Gaya et al. (2012; taxonomy), Prieto et al. (2013; phylogeny), Lücking et al. (2016b; classification), Prieto and Wedin (2016; phylogeny), sequences are available.

Acompsomyces Thaxt. 1901, Laboulbeniaceae, Laboulbeniales, Laboulbeniomycetes, six species, type: A. corticariae Thaxt., asexual morph unknown, biotrophic on Coleoptera (Cryptophagidae and Lathridiidae), America, Europe, probably worldwide, see Lumbsch and Huhndorf (2010; outline), Kirk et al. (2013; genus accepted), cultures and sequences are unavailable, needs generic revision. 
Acontium Morgan 1902, Ascomycota genera incertae sedis, four species, type: A. album Morgan, see Seifert et al. (2011; mentioned as a doubtful genus), Kirk et al. (2013; genus accepted), cultures and sequences are unavailable, need generic revision.

Acremoniopsis Giraldo, Gené \& Guarro 2014, Hypocreales, genera incertae sedis, Sordariomycetes, one species, type: A. suttonii Giraldo, Gené \& Guarro, hyphomycetous, sexual morph unknown, from soil, terrestrial, see Crous et al. (2014d; taxonomy), Maharachchikumbura et al. (2015, 2016), holotype and ex-type: CBS H-21936, CBS 138708. Acremoniula G. Arnaud ex Cif. 1962 (= Acremoniula G. Arnaud 1954 [1953] nom. inval. fide Species Fungorum 2017), Ascomycota genera incertae sedis, five species, type: $A$. sarcinellae (Pat. \& Har.) G. Arnaud ex Deighton, hyphomycetous, sexual morph unknown, saprobes, terrestrial, cosmoploitan, see Seifert et al. (2011; morphology), Wijayawardene et al. (2012, 2017; outline), Kirk et al. (2013; genus accepted), cultures and sequences are unavailable, needs generic revision.

Acremonium Link 1809, Bionectriaceae, Hypocreales, Sordariomycetes, c. 150 species, type: A. alternatum Link, hyphomycetous, sexual morph unknown, saprobes, lichenicolous, cosmopolitan, see Weisenborn et al. (2010; new species), Gräfenhan et al. (2011; overview), Kiyuna et al. (2011; new species), Seifert et al. (2011; morphology), Summerbell et al. (2011; overview), Giraldo et al. (2012, 2014; new species, phylogeny), von Brackel et al. (2012; new species), Wijayawardene et al. (2012, 2017; outline), Kirk et al. (2013; genus accepted), Maharachchikumbura et al. (2015, 2016; outline), Lynch et al. (2016; new species), cultures and sequences are available, needs generic revision.

Acrocalymma Alcorn \& J.A.G. Irwin 1987, Acrocalymmaceae, Pleosporales, Dothideomycetes, six species, type: A. medicaginis Alcorn \& J.A.G. Irwin, coelomycetous, sexual morph unknown, saprobes, terrestrial, cosmopolitan, see Zhang et al. (2012a; new species, phylogeny), Kirk et al. (2013; genus accepted), Trakunyingcharoen et al. (2014; phylogeny, introduced Acrocalymmaceae), Wijayawardene et al. (2014c, 2017; outline), cultures and sequences are available for the type species.

Acroconidiella J.C. Lindq. \& Alippi 1964, Cladosporiaceae, Capnodiales, Dothideomycetes, five species, type: A. tropaeoli (T.E.T. Bond) J.C. Lindq. \& Alippi, hyphomycetous, sexual morph unknown, saprobes, worldwide, see Seifert et al. (2011; morphology), Wijayawardene et al. (2012, 2014, 2017; outline), Kirk et al. (2013; genus accepted), cultures and sequences are available.

Acroconidiellina M.B. Ellis 1971 (= Zeuctomorpha Sivan. et al. 1984 fide Rossman et al. 2016a), Sympoventuriaceae, Venturiales, Dothideomycetes, four species, type: A. loudetiae M.B. Ellis, hyphomycetous, sexual morph formerly known in Zeuctomorpha, widespread (especially in tropical regions), see Wijayawardene et al. (2012, 2017; outline), Kirk (2013; genus accepted), Rossman et al. (2016a; nomenclature), cultures and sequences are unavailable, needs generic revision.

Acrocordia A. Massal. 1854 (= Acrocordiomyces Cif. \& Tomas. 1953; = Amphididymella Petr. 1928 fide Species Fungorum 2017), Monoblastiaceae, Monoblastiales, Dothideomycetes, ten species, type: A. gemmata (Ach.) A. Massal., asexual morph unknown, lichenized, terrestrial, temperate, placement in Monoblastiaceae supported by molecular data, see Nelsen et al. (2009, 2011b; phylogeny), Lumbsch and Huhndorf (2010; outline), Kirk et al. (2013; genus accepted), cultures available but lacks for the type species.

Acrocordiella O.E. Erikss 1982, Pyrenulaceae, Pyrenulales, Eurotiomycetes, one species, type: A. occulta (Romell) O.E. Erikss, asexual morph unknown, saprobes, terrestrial, temperate, see Lumbsch and Huhndorf (2010; outline), Kirk et al. (2013; genus accepted), cultures and sequences are unavailable.

Acrocordiopsis Borse \& K.D. Hyde 1989, Salsugineaceae, Pleosporales, Dothideomycetes, two species, type: A. patilii Borse \& K.D. Hyde, asexual morph unknown, saprobes, marine, 
worldwide, see Lumbsch and Huhndorf (2010; outline, accepted as a genus in Melanommataceae), Suetrong et al. (2009; phylogeny, morphology), Jones et al. (2009b, 2015; classification), Alias and Jones (2009, monograph), Besitulo et al. (2010; diversity), Pang et al. (2010b; diversity, Malaysia), Zainuddin et al. (2010; antimicrobial activities), Sakayaroj et al. (2011b; diversity, Thailand), Lee et al. (2012; checklist, Malaysia), Zhang et al. (2012e; phylogeny, morphology), Hyde et al. (2013; phylogeny), Samón-Legrá et al. (2014; diversity), Tian et al. (2015; morphology, phylogeny), holotype of type: IMI 297769, available cultures of type: BCC 28167, BCC 28166.

Acrodictyella W.A. Baker \& Partr. 2001, Ascomycota genera incertae sedis, one species, type: A. obovata W.A. Baker \& Partr. 2001, hyphomycetous, sexual morph unknown, wood decaying, North America, see Seifert et al. (2011; morphology), Wijayawardene et al. (2012, 2017; outline), cultures and sequences are unavailable, needs generic revision.

Acrodictyopsis P.M. Kirk 1983, Ascomycota genera incertae sedis, one species, type: A. lauri P.M. Kirk, hyphomycetous, sexual morph unknown, saprobes, Europe, see Seifert et al. (2011; morphology), Wijayawardene et al. (2012, 2017; outline), Kirk et al. (2013; genus accepted), cultures and sequences are unavailable, need generic revision.

Acrodictys M.B. Ellis1961, Sordariomycetidae genera incertae sedis, 22 species, type: A. bambusicola M.B. Ellis, hyphomycetous, sexual morph unknown, saprobes, terrestrial, aquatic, see Seifert et al. (2011; morphology), Wijayawardene et al. (2012, 2017; outline), Zhao et al. (2011a; descriptions of Acrodictys and related genera from China), Hu (2011; key to aquatic Acrodictys spp.), Ma et al. (2014, 2016; new species), sequences are available.

Acrodontiella U. Braun \& Scheuer 1995, Ascomycota genera incertae sedis, one species, type: A. fallopiae U. Braun \& Scheuer, hyphomycetous, sexual morph unknown, terrestrial, foliicolous, associated with leaf-spots, Europe, see Seifert et al. (2011; morphology), Wijayawardene et al. (2012, 2017; outline), holotype of type: GZU 294903, cultures and sequences are unavailable, needs generic revision.

Acrodontium de Hoog 1972, Teratosphaeriaceae, Capnodiales, Dothideomycetes, 13 species, type: A. crateriforme (J.F.H. Beyma) de Hoog, hyphomycetous, sexual morph unknown, saprobes, cosmopolitan, see Seifert et al. (2011; morphology), Crous et al. (2014c; new species), Videira et al. (2016; phylogeny), Wijayawardene et al. (2017; outline), ex-type culture of the type: CBS $144.33=$ ATCC 15679.

Acrogenospora M.B. Ellis 1971 (= Farlowiella Sacc. 1891 fide Rossman et al. 2015b), Pleosporomycetidae, genera incertae sedis, Dothideomycetes, nine species, type: $A$. sphaerocephala (Berk. \& Broome) M.B. Ellis, hyphomycetous, sexual morph formerly known in Farlowiella, saprobes, cosmopolitan, see Hu et al. (2010b; new species), Seifert et al. (2011; morphology), Rossman et al. (2015b; nomenclature), Wijayawardene et al. (2017; outline), cultures and sequences are available.

Acrogenotheca Cif. \& Bat. 1963 (= Laterotheca Bat. 1963 fide Species Fungorum 2017), Trichopeltinaceae, Dothideomycetes families incertae sedis, two species, type: A. pulcherrima Bat. \& Cif., asexual morph unknown, saprobes, terrestrial, tropical, see Lumbsch and Huhndorf (2010; outline), Kirk et al. (2013; genus accepted), Wijayawardene et al. (2014c; outline), cultures and sequences are unavailable, needs generic revision.

Acrogynomyces Thaxt. 1931, Laboulbeniaceae, Laboulbeniales, Laboulbeniomycetes, six species, type specie: A. eumicri Thaxt, parasitic on African scydmaenid genus Eumicrus, see Lumbsch and Huhndorf (2010; outline), Kirk et al. (2013; genus accepted), cultures and sequences are unavailable, needs generic revision.

Acrophialophora Edward 1961 (= Taifanglania Z.Q. Liang, Y.F. Han, H.L. Chu \& R.T.V. Fox 2009 fide Zhang et al. 2015b), Chaetomiaceae, Sordariales, Sordariomycetes, six species, type: A. nainiana Edward, sexual morph unknown, pathogen, terrestrial, worldwide, thermotolerant, see Seifert et al. (2011; morphology), Hyde et al. (2011; outline), Wijayawardene et 
al. (2012, 2016b; outline), Kirk et al. (2013; genus accepted), Sandoval-Denis et al. (2015a; clinical), Zhang et al. (2015b; DNA), ex-isotype of type: CBS 100.60, ex-type sculture of type: ATCC 22555, IMI 076567.

Acrophragmis Kiffer \& Reisinger 1970, Ascomycota genera incertae sedis, three species, type: A. coronata Kiffer \& Reisinger, hyphomycetous, sexual morph unknown, saprobes, terrestrial, cosmoploitan, see Seifert et al. (2011; morphology), Wijayawardene et al. (2012, 2017; outline), Kirk et al. (2013; genus accepted), cultures and sequences are unavailable.

Acroscyphus Lév. 1846, Caliciaceae, Caliciales, Lecanoromycetes, one species, type: A. sphaerophoroides Lév., lichenized, terrestrial (saxicolous), Americas, Asia, Africa, see Gaya et al. (2012; phylogeny), Prieto et al. (2013; phylogeny), Lücking et al. (2016b; classification), Prieto and Wedin (2016; phylogeny), sequences are available.

Acrospeira Berk. \& Broome 1857 (= Spirospora L. Mangin \& Vincens 1920 fide Species Fungorum 2017), Ascomycota genera incertae sedis, one species, type: A. mirabilis Berk. \& Broome, hyphomycetous, sexual morph unknown, saprobes, terrestrial, Europe, see Seifert et al. (2011; morphology), Wijayawardene et al. (2012, 2017; outline), Kirk et al. (2013; genus accepted), cultures and sequences are unavailable.

Acrospermoides J.H. Mill. \& G.E. Thomps. 1940, Sordariomycetes genera incertae sedis, two species, type: A. subulata J.H. Mill. \& G.E. Thomps., asexual morph unknown, saprobes, terrestrial, Greece, see Lumbsch and Huhndorf (2010; outline), Kirk et al. (2013 genus accepted), Maharachchikumbura et al. (2015, 2016; outline), cultures and sequences are unavailable.

Acrospermoides J.H. Mill. \& G.E. Thomps. 1940, Sordariomycetes genera incertae sedis, two species, type: A. subulata J.H. Mill. \& G.E. Thomps., asexual morph unknown, saprobes, terrestrial, Greece, see Lumbsch and Huhndorf (2010; outline), Kirk et al. (2013 genus accepted), Maharachchikumbura et al. (2015, 2016; outline), sequences are unavailable.

Acrospermum Tode 1790 (= Scleroglossum Fr. 1874; = Xyloglossum Pers. 1818 fide Species Fungorum 2017), Acrospermaceae, Acrospermales, Dothideomycetes, eleven species, type: A. compressum Tode, asexual morph hyphomycetous, saprobes, terrestrial, worldwide, see Lumbsch and Huhndorf (2010; outline), Stenroos et al. (2010; phylogeny), Hyde et al. (2013; morphology, phylogeny), Kirk et al. (2013 genus accepted), Wijayawardene et al. (2014c; outline), cultures and sequences are available for type species.

Acrostalagmus Corda 1838, Plectosphaerellaceae, Glomerellales, Sordariomycetes, three species, type: A. cinnabarinus Corda, hyphomycetous, sexual morph unknown, widespread, see Wijayawardene et al. (2012, 2017; outline), Réblová et al. (2011; DNA, phylogeny), cultures and sequences are available, needs generic revision.

Acrostaurus Deighton \& Piroz. 1972, Ascomycota genera incertae sedis, one species, type: A. turneri Deighton \& Piroz. 1972, asexual morph unknown, fungicolous, saprobes, widespread especially in tropical regions, see Wijayawardene et al. (2012, 2017; outline), Kirk (2013; genus accepted), cultures and sequences are unavailable, needs generic revision.

Actidiographium Lar. N. Vassiljeva 2000, Hysteriaceae, Hysteriales, Dothideomycetes, one species, type: A. orientale Lar \& Vassiljeva, asexual morphs unknown, saprobes, terrestrial, north temperate, see Boehm et al. (2009a; accepted as in Hysteriaceae), Lumbsch and Huhndorf (2010; outline), ), Hyde et al. (2013; accepted as a genus in Mytilinidiaceae), Wijayawardene et al. (2014c; outline), holotype: VLA P-2938, cultures and sequences are unavailable.

Actidium Fr. 1815 (= Bulliardella (Sacc.) Paoli 1905; = Mytilinidion subgen. Bulliardella Sacc. 1883; = Ostreionella Seaver 1926 fide Species Fungorum 2017), Mytilinidiaceae, Mytilinidiales, Dothideomycetes, nine species, type: A. hysterioides Fr., asexual morphs unknown, saprobes, terrestrial, Europe, North America, see Boehm et al. (2009a, b; accepted as a genus in Mytilinidiaceae), Lumbsch and Huhndorf (2010; outline), Hyde et al. (2013; 
accepted as in Mytilinidiaceae), Kirk et al. (2013; genus accepted), Wijayawardene et al. (2014c; outline), cultures and sequences are unavailable, needs generic revision.

Actinocladium Ehrenberg 1819, Ascomycota genera incertae sedis, eight species, type: A. rhodosporum Ehrenb., hyphomycetous, sexual morph unknown, pathogen of wood and bark of fallen twigs and trunk, worldwide, mainly Europe, Asia, Africa, Carribean, see Manoharachary et al. (2010; two new species), Hyde et al. (2011; outline), Seifert et al. (2011; morphology), Wijayawardene et al. (2012, 2017; outline), Kirk et al. (2013; genus accepted), cultures and sequences are unavailable, needs generic revision.

Actinocymbe Höhn. 1911 (= Limaciniella J.M. Mend. 1925 fide Species Fungorum 2017), Chaetothyriaceae, Chaetothyriales, Eurotiomycetes, three species, type: A. separato-setosa (Henn.) Höhn., asexual morph unknown, parasitic, epiphyllous to hypophyllous, terrestrial, temperate to tropical, see Lumbsch and Huhndorf (2010; outline), Kirk et al. (2013; genus accepted), cultures and sequences are unavailable, needs generic revision.

Actinomyxa Syd. \& P. Syd. 1917, Dothideomycetes genera incertae sedis, one species, type: A. australiensis Syd. \& P. Syd., asexual morph unknown, saprobes, terrestrial, Australia, see Lumbsch and Huhndorf (2010; outline, accepted as a genus in Microthyriaceae), Hyde et al. (2013) did not accept as a genus in Microthyriaceae, Kirk et al. (2013; genus accepted), Wijayawardene et al. (2014c; outline, accepted as a genus in Dothideomycetes genera incertae sedis), cultures and sequences are unavailable, needs generic revision.

Actinoplaca Müll. Arg. 1891 (= Actinoplacomyces Cif. \& Tomas. 1953 fide Species Fungorum 2017), Gomphillaceae, Ostropales, Lecanoromycetes, two species, type: A. strigulacea Müll. Arg., lichenized, terrestrial (foliicolous), tropical, see Lumbsch and Huhndorf (2010; outline), Kirk et al. (2013; genus accepted), Lücking et al. (2016; classification), sequences are available.

Actinotexis Arx 1960, Ascomycota genera incertae sedis, one species, type: A. mirabilis Berk. \& Broome, coelomycetous, sexual morph unknown, saprobes, terrestrial, Europe, see Wijayawardene et al. (2012, 2017; outline), Kirk et al. (2013; genus accepted), cultures and sequences are unavailable, needs generic revision.

Actinothecium Flot. 1855 (see Species Fungorum 2017 for synonyms), Ascomycota genera incertae sedis, five species, type: A. caricicola Ces., coelomycetous, sexual morph unknown, widespread, see Wijayawardene et al. (2012, 2017; outline), cultures and sequences are unavailable, needs generic revision.

Actinothyrium Kunze 1823, Ascomycota genera incertae sedis, ten species, type: A. graminis Kunze ex Fr., coelomycetous, sexual morph unknown, saprobes, terrestrial, worldwide, see Wijayawardene et al. (2012, 2017; outline), Kirk et al. (2013; genus accepted), cultures and sequences are unavailable, needs generic revision.

Acumispora Matsush. 1980, Ascomycota genera incertae sedis, four species, type: A. uniseptata Matsush., hyphomycetous, sexual morph unknown, saprobes, terrestrial, Asia, Neotropics, see Seifert et al. (2011; morphology), Wijayawardene et al. (2012, 2017; outline), Kirk et al. (2013; genus accepted), cultures and sequences are unavailable, needs generic revision.

Adautomilanezia Gusmão, S.S. Silva, Fiuza, L.A. Costa, T.A.B. Santos 2016, Chaetosphaeriaceae, Chaetosphaeriales, Sordariomycetes, one species, type: A. caesalpiniae Gusmão, S.S. Silva, Fiuza, L.A. Costa, T.A.B. Santos, hyphomycetous, sexual morph unknown, saprobes, terrestrial, Brazil, see Crous et al. (2016a; taxonomy, phylogeny), holotype and ex-type: HUEFS216632, CCLAMIC 102/12.

Adelococcus Theiss. \& Syd. 1918, Adelococcaceae, Verrucariales, Eurotiomycetes, one species, type: A. alpestris (Zopf) Theiss. \& Syd., asexual morph unknown, lichenicolous, terrestrial, temperate, see Lumbsch and Huhndorf (2010; outline), Kirk et al. (2013; genus accepted), cultures and sequences are unavailable, needs generic revision. 
Adelodiscus Syd. 1931, Leotiomycetes genera incertae sedis, three species, type: A. philippinensis Syd., asexual morph unknown, saprobes, terrestrial, Philippines, see Lumbsch and Huhndorf (2010; outline), Kirk et al. (2013; genus accepted), Jaklitsch et al. (2016a; classification), cultures and sequences are unavailable, need generic revision.

Adelolecia Hertel \& Hafellner in Hafellner 1984 (= Lecideomyces E.A. Thomas ex Cif. \& Tomas. 1953 fide Species Fungorum 2017), Lecanoraceae, Lecanorales, Lecanoromycetes, four species, type: A. pilati (Hepp) Hertel \& Hafellner, all with ascomata, lichenized (green algae), terrestrial (saxicolous, rarely corticolous), temperate regions of both Hemispheres, Ekman et al. (2008; phylogeny), Lumbsch and Huhndorf (2010; outline), Kirk et al. (2013; genus accepted), Lücking et al. (2016; classification), cultures and sequences are available.

Adelosphaeria Réblová 2016 [2017], Pleurotheciaceae, Pleurotheciales, Sordariomycetes, one species, type: A. catenata Réblová, asexual morph hyphomycetous, saprobes, terrestrial, Czech Republic, see Maharachchikumbura et al. (2015, 2016; outline), Réblová et al. (2017; taxonomy), holotype and ex-type: PRM 933853, CBS 138679.

Aderkomyces Bat. 1961, Gomphillaceae, Ostropales, Lecanoromycetes, c. 30 species, type: A. couepiae Bat, currently accepted, with ascomata, lichenized (green algae), terrestrial (foliicolous or corticolous), tropical, Lumbsch and Huhndorf (2010; outline), Kirk et al. (2013; genus accepted), Lücking et al. (2016; classification), cultures and sequences are available but lacks for the type.

Adisciso Kaz. Tanaka, Okane \& Hosoya 2011, Sporocadaceae, Xylariales, Sordariomycetes, three species, type: A. yakushimense Kaz. Tanaka, Okane \& Hosoya, sexual morph unknown, saprobes, Asia, see Tanaka et al. (2011; taxonomy, phylogeny), Maharachchikumbura et al. (2015, 2016; outline), cultures and sequences are available.

Adomia S. Schatz 1985, Xylariales genera incertae sedis, Sordariomycetes, one species, type: A. avicenniae S. Schatz, saprobes, on mangrove wood, saprobe, Australia, Egypt, Red Sea, Thailand, New Zealand, see Lumbsch and Huhndorf (2010; outline), Kirk et al. (2013; genus accepted), Jones et al. (2015; morphology, outline), Maharachchikumbura et al. (2015, 2016; outline), cultures and sequences are unavailable.

Aegeritella Balazy \& J. Wisn. 1974, Trichosporonaceae, Trichosporonales, Tremellomycetes, five species, type: A. superficialis Bałazy \& J. Wiśn., Poland, hyphomycetous, sexual morph unknown, ectoparasite on ants, worldwide, mainly reported from Europe, Brazil, Spain, Morocco, Poland, Czech Republic, North America, Greece, see Hyde et al. (2011; outline), Seifert et al. (2011; morphology), Wijayawardene et al. (2012, 2017; outline), Kirk et al. (2013; genus accepted), Wrzosek et al. (2016; new insights on phylogeny and biology), reference strain of Aegeritella tuberculata $=$ CBS 141264 (Wrzosek et al. 2016), sequences are available from Wrzosek et al. (2016), needs generic revision.

Aequabiliella Crous 2015, Phaeomoniellaceae, Phaeomoniellales, Eurotiomycetes, coelomycetous, sexual morph unknown, one species, type: A. effusa Damm \& Crous, on living leaves, pathogens, terrestrial, South Africa, see Damm et al. (2010b as Phaeomoniella effuse Damm \& Crous, morphology), Crous et al. (2015d; phylogeny), holotype and ex-type culture of type: CBS H-19998, CBS 120883.

Aeruginoscyphus Dougoud 2012, Hyaloscyphaceae, Helotiales, Leotiomycetes, seven species, type: A. sericeus (Alb. \& Schwein.) Dougoud, asexual morph unknown, saprobes, terrestrial, Europe, see Dougoud (2012; taxonomy), cultures and sequences are unavailable.

Agaricodochium X.J. Liu 1981, Ascomycota genera incertae sedis, one species, type: A. camelliae X.J. Liu, A.J. Wei \& S.G. Fan, hyphomycetous, on leaves of Camellia oleosa, pathogen of Camellia oleiferra, terrestrial, Zhejiang, China, see Guang-yu et al. (2008; control), Hyde et al. (2011; outline), Seifert et al. (2011; morphology), Wijayawardene et al. (2012, 2017; outline), Fangyan et al. (2013; control), Kirk et al. (2013; genus accepted), cultures and sequences are unavailable, needs generic revision. 
Agarwalomyces R.K. Verma \& Kamal 1987, Ascomycota genera incertae sedis, one species, type: A. indicus R.K. Verma \& Kamal, hyphomycetous, on fruit of Lythraceae, terrestrial, India, see Hyde et al. (2011; outline), Seifert et al. (2011; morphology), Wijayawardene et al. (2012, 2017; outline), Kirk et al. (2013; genus accepted), cultures and sequences are unavailable, needs generic revision.

Aggregatorygma M.Cáceres, Aptroot \& Lücking 2014, Graphidaceae, Ostropales, Lecanoromycetes, one species, type: A. triseptatum M. Cáceres, Aptroot \& Lücking, lichenized, see Cáceres et al. (2014; taxonomy), Lücking et al. (2016b; classification), sequences are available.

Agonimia Zahlbr. 1909 (= Agonimiella H. Harada 1993 fide Species Fungorum 2017), Verrucariaceae, Verrucariales, Eurotiomycetes, c. 17 species, type: A. tristicula (Nyl.) Zahlbr., asexual morph unknown, lichenized, lichenicolous, terrestrial, worldwide, see Lumbsch and Huhndorf (2010; outline), Muggia et al. (2010; DNA), Dymytrova et al. (2011; new species), Guzow-Krzemińska et al. (2012; new species), Aptroot and Cáceres (2013; new species), Harada (2013; new species, Japan), Kirk et al. (2013; genus accepted), Kondratyuk (2015; new species), cultures available for the type: L469 (fide Muggia et al. 2010).

Agrabeeja Subram. 1995, Ascomycota genera incertae sedis, one species, type: A. kavakapriya Subram., hyphomycetous, sexual morph unknown, saprobes, terrestrial, Singapore, see Hyde et al. (2011; outline), Seifert et al. (2011; morphology), Wijayawardene et al. (2012, 2017; outline), Kirk et al. (2013; genus accepted), holotype MUBL 3140.

Agyriella Sacc. 1884, Ascomycota genera incertae sedis, two species, type: A. nitida (Lib.) Sacc., hyphomycetous, sexual morph unknown, saprobes, terrestrial, Africa, Europe, see Seifert et al. (2011; morphology), Wijayawardene et al. (2012, 2017; outline), Kirk et al. (2013; genus accepted), cultures and sequences are unavailable, needs generic revision.

Agyriellopsis Höhn. 1903, Ascomycota genera incertae sedis, three species, type: A. caeruleoatra Höhn., coelomycetous, sexual morph unknown, Europe see Wijayawardene et al. (2012, 2017; outline), Kirk et al. (2013; genus accepted), cultures and sequences are unavailable, need generic revision.

Agyrium Fr. 1822 (= Agyrium Fr. 1821; = Exogone Henn. 1908; = Myxomphalos Wallr. 1833 fide Species Fungorum 2017), Pertusariaceae, Pertusariales, Lecanoromycetes, three species, type: A. rufum (Pers.) Fr., asexual morph unknown, saprobes, terrestrial, temperate, see Lumbsch and Huhndorf (2010; outline), Hodkinson and Lendemer (2011b; taxonomy), Kirk et al. (2013; genus accepted), Resl et al. (2015; DNA), cultures and sequences are available, needs generic revision.

Ahmadia Syd. 1939, Ascomycota genera incertae sedis, one species, type: A. pentatropidis Syd., coelomycetous, sexual morph unknown, saprobes, terrestrial, Pakistan, see Wijayawardene et al. (2012, 2017; outline), Kirk et al. (2013; genus accepted), cultures and sequences are unavailable, needs generic revision.

Ahtiana Goward 1986, Parmeliaceae, Lecanorales, Lecanoromycetes, three species, type: A. sphaerosporella (Müll. Arg.) Goward, all with ascomata, lichenized (green algae), terrestrial (corticolous, epixylic), western North America, see Thell et al. (2009; phyogeny), Nelsen et al. (2011a; phyogeny), Miądlikowska et al. (2014a; phyogeny), Divakar et al. (2015; phyogeny), Lücking et al. (2016b; classification), sequences are available.

Aigialus Kohlm. \& S. Schatz 1986, Aigialaceae, Pleosporales, Dothideomycetes, asexual morph unknown, five species, type: A. grandis Kohlm. \& Schatz, saprobes, marine, worldwide, see Alias and Jones (2009, monograph), Jones et al. (2009b, 2012, 2015; classification, outline, review), Schoch et al. (2009; phylogeny), Suetrong et al. (2009, 2011a, b, 2014, 2016; phylogeny, morphology), Zhang et al. (2009a, 2012e; phylogeny), Isaka et al. (2009; secondary metabolites), Nambiar and Raveendran (2009a, b; diversity), Nambiar et al. 
(2009; diversity), Zainuddin et al. (2010; antimicrobial activities), Besitulo et al. (2010; diversity), Lumbsch and Huhndorf, (2010; outline), Pang et al. (2010b, 2011b, 2013a; diversity, phylogeny), Sakayaroj et al. (2011b; diversity), Josphine et al. (2011, diversity), Liu et al. (2011b, 2014, 2015; phylogeny, morphology), Boonmee et al. (2012; phylogeny), Dai et al. (2012; phylogeny), Lee et al. (2012; checklist), Pang and Jheng (2012a; checklist), Hyde et al. (2013; phylogeny, morphology, outline), Ariyawansa et al. (2014a, b; phylogeny), Ren et al. (2013b; phylogeny), Kocharin et al. (2013; optimization), Sivakumar (2013; review), Sarma and Raghukumar (2013; diversity), Gnavi et al. (2014, phylogeny), Phookamsak et al. (2014b, 2015a; phylogeny), Wijayawardene et al. (2014c; outline), Shearer et al. (2014; phylogeny), Pratibha and Prabhugaonkar (2015; phylogeny), Shen et al. (2015; secondary metabolites), Doilom et al. (2016; phylogeny), holotype: J.K. 4332a (IMS), exisotype strain J.K.4332b (NY).

Ainoa Lumbsch \& I. Schmitt 2001, Baeomycetaceae, Baeomycetales, Lecanoromycetes, three species, type: A. geochroa (Körb.) Lumbsch \& Schmitt, ascomata apotheciate, conidiomata pycnidial, lichen-forming, saxicolous or terrestrial, worldwide, see Lumbsch and Huhndorf, (2010; outline), Resl et al. (2015; phylogeny), Lücking et al. (2016b; classification), sequences are available.

Aithaloderma Syd. \& P. Syd. 1913 (= Asbolisia Bat. \& Cif. 1963; = Blastocapnias Cif. \& Bat. 1963; Chaetopotius Bat. 1951; = Hypocapnodium Speg. 1918; = Phaeochaetia Bat. \& Cif. 1962; = Vertixore V.A.M. Mill. \& Bonar 1941 fide Species Fungorum 2017), Capnodiaceae, Capnodiales, Dothideomycetes, 15 species, type: A. clavatisporum Syd. \& P. Syd., asexual morph unknown, saprobes, terrestrial, tropical, see Lumbsch and Huhndorf (2010; outline), other recent articles such as Chomnunti et al. (2011), Hyde et al. (2013) and Wijayawardene et al. (2014) did not accept as a genus in Capnodiaceae, Kirk et al. (2013; outline, genus accepted), cultures and sequences are unavailable, needs generic revision.

Aivenia Svrček 1977, Calloriaceae, Helotiales, Leotiomycetes, four species, type: A. tantula Svrček, asexual morph unknown, saprobes, terrestrial, former Czechoslovakia, see Lumbsch and Huhndorf (2010; outline), Kirk et al. (2013; genus accepted), cultures and sequences are unavailable, needs generic revision.

Ajrekarella Kamat \& Kalani 1964, Ascomycota genera incertae sedis, one species, type: A. polychaetriae Kamat \& Kalani, coelomycetous, sexual morph unknown, saprobes, terrestrial, India, see Wijayawardene et al. (2012, 2017; outline), Kirk et al. (2013; genus accepted), cultures and sequences are unavailable, needs generic revision.

Akanthomyces Lebert 1858, Cordycipitaceae, Hypocreales, Sordariomycetes, c. 13 species, type: A. aculeatus Lebert, hyphomycetous, sexual morph unknown, saprobes, on insects and spiders, cosmopolitan, see Seifert et al. (2011; morphology), Wijayawardene et al. (2012, 2017; outline), Kirk et al. (2013; did not list), cultures and sequences are available, needs generic revision.

Alanphillipsia Crous \& M.J. Wingf. 2013, Botryosphaeriaceae, Botryosphaeriales, Dothideomycetes, five species, type: A. aloes Crous \& M.J. Wingf., coelomycetous, sexual morph unknown, saprobes or possibly pathogenic, associated with leaf lesions, South Africa, see Crous et al. (2013b, 2014d; morphology), Wijayawardene et al. (2016b, 2017; outline, morphology, phylogeny), holotype and ex-type: CBS H-21418, CPC 21298.

Alascospora Raja, Violi \& Shearer 2010, Dothideomycetes, genera incertae sedis, one species, type: A. evergladensis Raja, Violi \& Shearer, asexual morph unknown, saprobes, aquatic, USA, see Raja et al. (2010c; morphology), Wijayawardene et al. (2014c; outline), holotype of the type: ILL 40789, cultures and sequences are unavailable.

Alatosessilispora K. Ando \& Tubaki 1984, Ascomycota genera incertae sedis, one species, type: A. bibrachiata K. Ando \& Tubaki, hyphomycetous, sexual morph unknown, Japan, see 
Seifert et al. (2011; morphology), Wijayawardene et al. (2012, 2017; outline), Kirk et al. (2013; genus accepted), sequences are available for the type, need generic revision.

Alatospora Ingold 1942, Leotiaceae, Helotiales, Leotiomycetes, four species, type: A. acuminata Ingold, hyphomycetous, sexual morph unknown, saprobes, aquatic, worldwide, see Seifert et al. (2011; morphology), Wijayawardene et al. (2012, 2017; outline), Baschien et al. (2013; DNA), Kirk et al. (2013; genus accepted), Duarte et al. (2015; DNA), neotype of type: IMI 222997, available cultures of the type: CCM Fl2186.

Albertiniella Kirschst. 1936, Cephalothecaceae, Sordariomycetes, families incertae sedis, one species, type: A. reticulata Kirschst., asexual morph acremonium-like, saprobes, terrestrial, Europe, Japan, see Lumbsch and Huhndorf (2010; outline), Kirk et al. (2013; genus accepted), Maharachchikumbura et al. (2015, 2016; outline, phylogeny), cultures available for the type: NBRC 9424.

Albifimbria L. Lombard \& Crous 2016, Stachybotriaceae, Hypocreales, Sordariomycetes, four species, type: A. verrucaria (Alb. \& Schwein.) L. Lombard \& Crous, hyphomycetous, sexual morph unknown, saprobes, from soil, terrestrial, cosmopolitan, see Lombard et al. (2016; taxonomy, phylogeny), cultures and sequences are available.

Albonectria Rossman \& Samuels 1999, Nectriaceae, Hypocreales, Sordariomycetes, type: A. rigidiuscula (Berk. \& Broome) Rossman \& Samuels, one species, asexual morph hyphomycetous, terrestrial, cosmopolitan, see Lumbsch and Huhndorf (2010; outline), Zhao et al. (2011b; phylogeny), Lombard et al. (2015b; phylogeny), Maharachchikumbura et al. (2015, 2016; outline), cultures and sequences are available.

Albosynnema E.F. Morris 1967, Bionectriaceae, Hypocreales, Sordariomycetes, two species, type: A. elegans E.F. Morris 1967, asexual morph hyphomycetous, America, Caribbean, see Seifert et al. (2011; morphology), Wijayawardene et al. (2012, 2017; outline), Kirk (2013; genus accepted), Lombard et al. (2016; phylogeny), cultures and sequence are available, needs generic revision.

Albotricha Raitv. 1970, Lachnaceae, Helotiales, Leotiomycetes, c. 19 species, type: A. acutipila (P. Karst.) Raitv., asexual morph unknown, saprobes, terrestrial, north temperate, see Lumbsch and Huhndorf (2010; outline), Kirk et al. (2013; genus accepted), Jaklitsch et al. (2016a; classification), cultures and sequences are available.

Alciphila Harmaja 2002, Ascomycota genera incertae sedis, one species, type: A. vulgaris Harmaja, hyphomycetous, sexual morph unknown, saprobes, terrestrial, Europe, see Seifert et al. (2011; morphology), Wijayawardene et al. (2012, 2017; outline), cultures and sequences are unavailable, needs generic revision.

Aldona Racib. 1900, Parmulariaceae, Dothideomycetes, families incertae sedis, three species, type: A. stella-nigra Racib., asexual morph unknown, saprobes, terrestrial, pantropical, see Lumbsch and Huhndorf (2010; outline), Hyde et al. (2013; accepted as a genus in Parmulariaceae), Wijayawardene et al. (2014c; outline), cultures and sequences are unavailable, needs generic revision.

Aldonata Sivan. \& A.R.P. Sinha 1989, Parmulariaceae, Dothideomycetes families incertae sedis, one species, type: A. pterocarpi Sivan. \& A.R.P. Sinha, asexual morph unknown, saprobes, terrestrial, India, see Lumbsch and Huhndorf (2010; outline), Hyde et al. (2013; accepted as a genus in Parmulariaceae), Wijayawardene et al. (2014c; outline), cultures and sequences are unavailable, needs generic revision.

Alectoria Ach. 1809 (= Alectoria sect. Eualectoria Th. Fr. 1880; = Alectoriomyces Cif. \& Tomas. 1953; = Bryopogon Link 1833; = Ceratocladia Schwend. 1860; = Cornicularia Schaer. 1850; = Eualectoria (Th. Fr.) Gyeln. fide Species Fungorum 2017), Parmeliaceae, Lecanorales, Lecanoromycetes, seven species, type: A. sarmentosa (Ach.) Ach., with ascomata, but often absent, lichenized (green algae), terrestrial (corticolous, terricolous), widespread, see Halonen et al. (2009; taxonomy, phylogeny), Lumbsch and Huhndorf (2010; 
outline), Kirk et al. (2013; genus accepted), Miądlikowska et al. (2014a; phylogeny), Divakar et al. (2015; phylogeny), Lücking et al. (2016b; classification), McMullin et al. (2016; phylogeny), sequences are available.

Aleuria Fuckel 1870 (= Peziza Fuckel 1870; = Peziza subgen. Aleuria (Fuckel) Quél. 1886 fide Species Fungorum 2017), Pyronemataceae, Pezizales, Pezizomycetes, 17 species, type: A. aurantia (Pers.) Fuckel, asexual morph unknown, on soil, terrestrial, worldwide, see Lumbsch and Huhndorf (2010; outline), Kirk et al. (2013; genus accepted), cultures and sequences are available for the type species.

Aleurina Massee 1898 (= Jafneadelphus Rifai 1968 fide Species Fungorum 2017), Pyronemataceae, Pezizales, Pezizomycetes, eleven species, type: A. tasmanica Massee, asexual morph unknown, on soil, terrestrial, worldwide, see Lumbsch and Huhndorf (2010; outline), Kirk et al. (2013; genus accepted), cultures and sequences are available but lacks for the type species.

Alfaria Crous, Montano-Mata \& Garcia-Jim. 2014, Hypocreales genera incertae sedis, Sordariomycetes, eight species, type: A. cyperi-esculenti Crous, N.J. Montaño-Mata \& García-Jim., asexual morph coelomycetous, pathogenic, terrestrial, Spain, Italy, see Crous et al. (2014c; morphology of sexual morph), Lombard et al. (2016; phylogeny, new species), Wijayawardene et al. (2016b, 2017; morphology of asexual morph, phylogeny), ex-type strains of type: CPC 23153; holotype CBS H-21703.

Alfariacladiella Crous \& R.K. Schumach. 2016, Stachybotriaceae, Hypocreales, Sordariomycetes, one species, type: A. spartii Crous \& R.K. Schumach., hyphomycetous, sexual morph unknown, saprobes, terrestrial, Spain, see Hernández-Restrepo et al. (2016a; taxonomy, phylogeny), Wijayawardene et al. (2017; outline), holotype and culture ex-type culture of the type: CBS H-22655, CPC 24966.

Algincola Velen. 1939, Helotiales genera incertae sedis, three species, type: A. quercina Velen., asexual morph unknown, saprobes, terrestrial, former Czechoslovakia, see Lumbsch and Huhndorf (2010; outline), Kirk et al. (2013; genus accepted), cultures and sequences are unavailable, need generic revision.

Algonquinia R.F. Castañeda \& W.B. Kendr. 1991, Ascomycota genera incertae sedis, one species, type: A. inflata R.F. Castañeda \& W.B. Kendr., hyphomycetous, sexual morph unknown, saprobes, terrestrial, Canada, see Seifert et al. (2011; morphology), Kirk et al. (2013; genus accepted), Wijayawardene et al. (2017; outline), holotype of the type: INIFAT C89/401, cultures and sequences are unavailable, compare with Catenocuneiphora, Hormomyces and Sphaerosporium.

Alina Racib. 1909, Perisporiopsidaceae, Dothideomycetes, families incertae sedis, one species species, type: A. jasmini Racib., asexual morph hyphomycetous, parasitic on living leaves of Jasminum spp., Buitenzorg, Indonesia, see Lumbsch and Huhndorf (2010; outline), Hyde et al. (2013; accepted as a genus in Perisporiopsidaceae), Kirk et al. (2013; genus accepted), Wijayawardene et al. (2014c; outline), cultures and sequences are unavailable, recollection and revision required.

Aliquandostipite Inderb. 2001, Aliquandostipitaceae, Jahnulales, Dothideomycetes, seven species, type: A. khaoyaiensis Inderb., asexual morph unknown, saprobes, freshwater, Australia, China, Costa Rica, Egypt, Panama, Thailand, Venesuela, USA, see Schoch et al. (2009; phylogeny), Shearer et al. (2009; phylogeny), Suetrong et al. (2010a, 2011a; outline, phylogeny), Raja et al. (2011b; phylogeny), Liu et al. (2015a; morphology), holotype and extype culture of the type: UBC F13875, CBS 118232.

Alisea Dupont \& E. B. G. Jones 2009, Halosphaeriaceae, Microascales, Sordariomycetes, one species (est. spp. five), type: A. longicolla Dupont \& Jones, asexual morph unknown, saprobes, marine, ascomata on deep sea sunken wood, south Pacific Ocean and South China 
Sea, see Dupont et al. (2009; taxonomy), Jones et al. (2015; outline), Maharachchikumbura et al. (2016; outline), holotype of type: PC 0115840.

Allantonectria Earle 1901 (see Species Fungorum 2017 for synnonyms), Nectriaceae, Hypocreales, Sordariomycetes, type: A. yuccae Earle, four species, asexual morph hyphomycetous, terrestrial, saprobes, cosmopolitan, see Hirooka et al. (2012; monograph), Lombard et al. (2015b; phylogeny), Maharachchikumbura et al. (2015, 2016; outline), cultures and sequences are available.

Allantoparmelia (Vain.) Essl. 1978 (= Parmelia subgen. Allantoparmelia Vain. 1909 fide Species Fungorum 2017), Parmeliaceae, Lecanorales, Lecanoromycetes, three species, type: A. alpicola (Th. Fr.) Essl., all with ascomata (but often absent), lichenized (green algae), terrestrial (saxicolous, rarely terricolous), boreal or arctic alpine in Northern Hemisphere, see Crespo et al. (2010b; phylogeny), Lumbsch and Huhndorf (2010; outline), Spribille et al. (2011; DNA, phylogeny), Kirk et al. (2013; genus accepted), Miądlikowska et al. (2014a; DNA, phylogeny), Divakar et al. (2015; DNA, phylogeny), Lücking et al. (2016b; classification), sequences are available.

Allantophomopsiella Crous 2014, Phacidiaceae, Phacidiales, Leotiomycetes, one species, type: A. pseudotsugae (M. Wilson) Crous, saprobes, Europe, see Crous et al. (2014b; morphology, phylogeny), reference specimen and culture of type: CBS H-15946, culture CBS 562.63.

Allantophomopsis Petr. 1925 (= Apostrasseria Nag Raj 1983 fide Jaklitsch et al. 2016a), Phacidiaceae, Phacidiales, Leotiomycetes, eight species, type: A. cytisporea (Fr.) Petr., asexual morph unknown, saprobes, terrestrial, worldwide, see Crous et al. (2014b, 2015a; phylogeny), Wijayawardene et al. (2017; outline), ex-epitype culture of the type: CPC 24977. Allantoporthe Petr. 1921 (= Allantoporthe Petr. 1921; = Aporhytisma Höhn. 1917; = Chorostate (Nitschke ex Sacc.) Traverso 1906; = Clypeorhynchus Kirschst. 1936; = Dialytes Nitschke 1867; = Diaporthe subgen. Chorostate Nitschke ex Sacc. 1882; = Melanoporthe Wehm. 1938; = Septomazzantia Theiss. \& Syd. 1915 fide Species Fungorum 2017), Diaporthaceae, Diaporthales, Sordariomycetes, one species, type: A. leucothoës Lar.N. Vassiljeva, asexual morph unknown, saprobes, terrestrial, North America, see Maharachchikumbura et al. (2015, 2016; outline), cultures and sequences are unavailable.

Alloanthostomella Daranag., Camporesi \& K.D. Hyde 2016, Xylariales genera incertae sedis, Sordariomycetes, one species, type: A. rubicola (Speg. ex Sacc. \& Trotter) Daranag., Camporesi \& K.D. Hyde, asexual morph unknown, terrestrial, saprobes, see Daranagama et al. (2016a; taxonomy), Wendt et al. (2017; placed in Xylariales), cultures and sequences are available.

Alloarthopyrenia Phukhamsakda, Lücking \& K.D. Hyde 2016, Trypetheliaceae, Trypetheliales, Dothideomycetes, one species, type: A. italica Phukhamsakda, Camporesi, Ariyawansa \& K.D. Hyde, asexual morph unknown, saprobes, terrestrial, Italy, see Hyde et al. (2016; taxonomy, phylogeny), holotype of the type: MFLU 15-0399.

Alloascoidea Kurtzman \& Robnett 2013, Alloascoideaceae, Saccharomycetales, Saccharomycetes, one species, type: A. africana (L.R. Batra \& Francke-Grosm.) C.P. Kurtzman \& C.J. Robnett, asexual morph unknown (budding of cells and formation of true hyphae), saprophytes, from trees and associated insects, terrestrial, Europe, Africa, see Kurtzman and Robnett (2013; taxonomy), cultures and sequences are available.

Allocalicium M.Prieto \& Wedin 2016, Caliciaceae, Caliciales, Lecanoromycetes, one species, type: A. adaequatum (Nyl.) M. Prieto and Wedin., lichenized, see Prieto and Wedin (2016; taxonomy, phylogeny), Lücking et al. (2016b; classification), sequences are available.

Allocetraria Kurok. \& M.Y.Lai 1991 (= Usnocetraria M.J. Lai \& J.C. Wei 2007 fide Species Fungorum 2017), Parmeliaceae, Lecanorales, Lecanoromycetes, nine species, type: A. stracheyi (C. Bab.) Kurok. \& M.J. Lai; lichenized; see Thell et al. (2009; DNA, phylogeny), 
Lumbsch and Huhndorf (2010; outline), Nelsen et al. (2011a; DNA, phylogeny), Miądlikowska et al. (2014a; DNA, phylogeny), Lücking et al. (2016b; classification), sequences are available.

Alloconiothyrium Verkley, Göker \& Stielow 2014, Didymosphaeriaceae, Pleosporales, Dothideomycetes, one species, type: A. aptrootii Verkley \& Stielow, coelomycetous, sexual morph unknown, from soil, Papua New Guinea, see Verkley et al. (2014; morphology, phylogeny); Wijayawardene et al. (2016b; morphology, phylogeny), holotype and ex-type culture of type species CBS H-21035, CBS 980.95.

Alloleptosphaeria Ariyawansa, Wanasinghe \& K.D. Hyde 2015, Leptosphaeriaceae, Pleosporales, Dothideomycetes, one species, type: A. italica Wanas., Camporesi, Ariyaw. \& K.D. Hyde, asexual morph unknown, terrestrial, Europe, see Ariyawansa et al. (2015b; taxonomy, phylogeny), holotype MFLU 15-1517, cultures and sequences are available.

Allonecte (Pat.) Syd. 1939, Dothideomycetes genera incertae sedis, one species, type: $A$. lagerheimii (Pat.) Syd. (=Broomella lagerheimii Pat. 1895), asexual morph coelomycetous, terrestrial, Ecuador, see Lumbsch and Huhndorf (2010; outline), Kirk et al. (2013; genus accepted), Wijayawardene et al. (2014c; outline), cultures and sequences are unavailable, needs generic revision.

Allonectella Petr. 1950, Nectriaceae, Hypocreales, Sordariomycetes, two species, type: A. rubescens Petr., sexual morph unknown, saprobes, terrestrial, cosmopolitan, see Lumbsch and Huhndorf (2010; outline), Kirk et al. (2013; genus accepted), Maharachchikumbura et al. $(2015,2016)$, needs generic revision, cultures and sequences are available.

Alloneottiosporina Nag Raj 1993, Ascomycota genera incertae sedis, two species, type: A. carolinensis Nag Raj, coelomycetous, sexual morph unknown, saprobes, terrestrial, Australia, USA, see Wijayawardene et al. (2012, 2017; outline), Kirk et al. (2013; genus accepted), holotype of the type: BPI 1110181.

Allophaeosphaeria Ariyaw., Camporesi \& K.D. Hyde 2015, Phaeosphaeriaceae, Pleosporales, Dothideomycetes, five species, type: A. muriformia Ariyawansa, Camporesi \& K.D. Hyde, asexual morph unknown, saprobes, terrestrial, Europe, see Ariyawansa et al. (2015a; taxonomy, pylogeny), Liu et al. (2015a; taxonomy, phylogeny), Wijayawardene et al. (2017; outline), holotype and ex-type cultures of the type: MFLU 15-0067, MFLUCC 130349 .

Allophoma Q. Chen \& L. Cai 2015, Didymellaceae, Pleosporales, Dothideomycetes, six species, type: A. tropica (R. Schneid. \& Boerema) Q. Chen \& L. Cai, coelomycetous, saprobes, ?pathogens, terrestrial, cosmopolitan, see Chen et al. (2015b; taxonomy, phylogeny), Wijayawardene et al. (2017; outline), isotype and ex-isotype culture of the type: CBS H-7629, CBS 436.75.

Allophoron Nádv. 1942, Ascomycota genera incertae sedis, one species, type: A. farinosum Nádv., asexual morph unknown, lichenized, terrestrial, Colombia, see Lumbsch and Huhndorf (2010; outline), Kirk et al. (2013; genus accepted), cultures and sequences are unavailable, needs generic revision.

Allophylaria (P. Karst.) P. Karst. 1870 (= Helotidium Sacc. 1884; = Peziza sect. Allophylaria P. Karst. 1869 fide Species Fungorum 2017), Pezizellaceae, Helotiales, Leotiomycetes, six species, type: X. sticticum (Fr.) Wallr., asexual morph unknown, saprobes, terrestrial, China, worldwide, see Lumbsch and Huhndorf (2010; outline), Kirk et al. (2013; genus accepted), cultures and sequences are unavailable, needs generic revision.

Allosoma Syd. 1926, Englerulaceae, Dothideomycetes family incertae sedis, four species, type: A. cestri Syd., asexual morph hyphomycetous, epiphytic on leaves or saprobes on dead stems, North and South America, India, see Lumbsch and Huhndorf (2010; outline), Kirk et al. (2013; genus accepted), Thambugala et al. (2014c), cultures and sequences are unavailable, needs generic revision, Holotype of type: GZU157-80. 
Allothyrina Bat. \& J.L. Bezerra 1964, Ascomycota genera incertae sedis, one species, type: A. serjaniae Bat. \& J.L. Bezerra, coelomycetous, sexual morph unknown, saprobes, terrestrial, Brazil, see Wijayawardene et al. (2012, 2017; outline), Kirk et al. (2013; genus accepted), cultures and sequences are unavailable, needs generic revision.

Allothyriopsis Bat., Cif. \& H. Maia 1959, Ascomycota genera incertae sedis, one species, type: A. landolphiae Bat., Cif. \& H. Maia, coelomycetous, sexual morph unknown, saprobes, terrestrial, Ghana, see Wijayawardene et al. (2012, 2017; outline), Kirk et al. (2013; genus accepted), cultures and sequences are unavailable, needs generic revision.

Alnecium Voglmayr \& Jaklitsch 2014, Gnomoniaceae, Diaporthales, Sordariomycetes, two species, type: A. auctum (Berk. \& Broome) Voglmayr \& Jaklitsch, asexual morph unknown, saprobes, terrestrial, Europe, see Voglmayr and Jaklitsch (2014; taxonomy, phyloeny), Maharachchikumbura et al. (2015, 2016; outline), cultures and sequences are available.

Alpakesa Subram. \& K. Ramakr. 1954, Ascomycota genera incertae sedis, four species, type: A. yuccifolia (J.G. Hall) Subram. \& K. Ramakr., coelomycetous, sexual morph unknown, saprobes, terrestrial, USA, Thiwan, see Wijayawardene et al. (2012, 2017; outline), Kirk et al. (2013; genus accepted), available specimens of type: IMI 177975, cultures are unavailable.

Alpakesiopsis Abbas, B. Sutton, Ghaffar \& A. Abbas 2003, Ascomycota genera incertae sedis, one species, type: A. ghaffarii Abbas, B. Sutton \& Al. Abbas, coelomycetous, sexual morph unknown, saprobes, terrestrial, Pakistan, see Wijayawardene et al. (2012, 2017; outline), holotype of the type: IMI 202284, cultures are unavailable.

Alpestrisphaeria Thambugala \& K.D. Hyde 2015, Lophiostomataceae, Pleosporales, Dothideomycetes, one species, type: A. terricola (G.S. Gong) Thambugala \& K.D. Hyde, asexual morph unknown, associated with soil, China, see Thambugala et al. (2015b; phylogeny), ex-type culture of type: SC-12.

Alternaria Nees 1817 (= Allewia E.G. Simmons 1990 fide Woudenberg et al. 2013; Wijayawardene et al. 2014c; Rossman et al. 2015b; see Woudenberg et al. 2013 for all synonyms), Pleosporaceae, Pleosporales, Dothideomycetes, 663 species, type: A. alternata (Fr.) Keissl., sexual morph Lewia, saprobes, plant and animal pathogens, terrestrial, worldwide, see Aly et al. (2008; cytotoxic metabolites), Andersen et al. (2008; metabolite profiling), Avenot et al. (2008; succinate dehydrogenase mutation), Azcarate et al. (2008; toxins), Bartra et al. (2008; respiratory allergy), Cota et al. (2008; Altenusin), Craven et al. (2008; Anastomosis), Flors et al. (2008; cell signalling), Grinn-Gofroń and Strzelczak (2008; meteorological factors), Harimoto et al. (2008; AMT2 gene), Kumar et al. (2008a, b; variability, India, host resistance), Lawrence et al. (2008; pathogenicity review), Miyamoto et al. (2008, 2009; ACT-toxin biosynthesis, phylogeny), Ostry (2008; Alternaria mycotoxins), Park et al. (2008; phylogeny), Parada et al. (2008; toxin from germinating spores), Pasche and Gudmestad (2008; F129L mutation), Pastor and Guarro (2008; infections), Perello et al. (2008; Argentina, black point of wheat), Rosenzweig et al. (2008; sensitivity to azoxystrobin), Sabirov et al. (2008; nasal polyposis), Saravanakumar et al. (2008; competition for host), Schmechel et al. (2008; environmental immunoassays), Tabar et al. (2008; immunotherapy), Vélëz et al. (2008; Mannitol biosynthesis), Wang et al. (2008c; biocontrol), Yuan et al. (2008; Tricycloalternarenes), Logrieco et al. (2009; pathogenicity review), Latha et al. (2009; host resistance induction), Lee et al. (2009b; protein disruption study), Pogány et al. (2009; biochemistry), Kjer et al. (2009; phenolic extrolites), Mishra et al. (2009; inhibition by Cinnamomum), Kobayashi et al. (2009; hypersensitivity), Hadizadeh et al. (2009; antifungal activity), Andrew et al. (2009; phylogeny), Lin et al. (2009; pathological mechanism), Tu (2009; keratitis), Avenot et al. (2009; protein mutation), Ali et al. (2009; malachite green degradation), Pedras et al. (2009; review), Siegel et al. (2009; HPLC, MS), Grinn-Gofroń and Rapiejko (2009; Poland), Aoki et al. (2009; mycovirus), Wight et al. (2009; biochemistry), Fawzi et al. (2009; antifungal effects), Wang et al. (2009c, 
d; cerebrosides, postharvest biocontrol), Gu (2009, Bioactive metabolites), Andersen et al. (2009; polyphasic taxonomy), Phuwapraisirisan et al. (2009; antitumour metabolites), Yang et al. (2009; AP1 pathway study), Cho et al. (2009; virulence factors), Fernandes et al. (2009; fermentation extract activity), Stępalska and Wołek (2009; Intradiurnal periodicity), Hedayati et al. (2009; IgE analysis), Nallathambi et al. (2009; Trichoderma effects), Gao et al. (2009; Perylene derivatives), Anand et al. (2009; host resistance), Pose et al. (2009; growth factors), Kim et al. (2009b; Alternaramide), Evidente et al. (2009; Alternethanoxins), Hipolito et al. (2009; brain abscess), Kasahara et al. (2010; Solanapyrone synthase), Mukherjee et al. (2010; infection proteomics), Wolf et al. (2010; $\mathrm{CO}_{2}$ effects), Imazaki et al. (2010; peroxisomes), Lin and Chung (2010; signaling pathways), Ntui et al. (2010; wasabi defensin gene), Horsfield et al. (2010; fungicides), Randriamanantany et al. (2010; allergic rhinitis), Siegel et al. (2010; tenuazonic acid), Boyce et al. (2010; Phaeohyphomycosis), Kilic et al. (2010; effect on children), Lin et al. (2010, 2011; FUS3 MAPK pathway, pathogenicity), Dellavalle et al. (2011; antifungal activity), Kuna et al. (2011; immunotherapy), Boitano et al. (2011; molecular pathogenesis), Dey et al. (2011; lipid profiling), Song et al. (2011; Abscisic acid resistance), Huang et al. (2011; bianthraquinone derivatives), Escuredo et al. (2011; meteorological factors), Joubert et al. (2011a, b; stress adaptation, pathogenicity), Sinha and Chattopadhyay (2011; host proteome profile), Yago et al. (2011; cell signalling), Noser et al. (2011; UPLC-MS/MS), Karaoglanidis et al. (2011; QoI fungicides resistance), Zheng et al. (2012; bioactive metabolites), Doherty et al. (2012; immunology), Fleck et al. (2012; toxins in mammals), Nowicki et al. (2012; crucifers host), Chruszcz et al. (2012; allergen), Pane et al. (2012; whey compost-tea control), Matsuwaki et al. (2012; immunological pathway), Recio et al. (2012; spore fluctuation), Skjøth et al. (2012; Copenhagen), Yang and Chung (2012; stress resistance), $\mathrm{Hu}$ et al. (2012d; Genomic characterization), Cho et al. (2012; Amr1), Fuiano et al. (2012; nasal IgE measurement), Asam et al. (2012; mycotoxin in food), Sarkar et al. (2012; Au nanoparticles), Twaroch et al. (2012; vaccine candidates), Chhikara et al. (2012; host resistance), Saha et al. (2012; biochemistry), Woudenberg et al. (2013, 2014; review), Tsuge et al. (2013; toxins), Lawrence et al. (2013; phylogeny), Lou et al. (2013; metabolites review), Jia et al. (2013; host pathogen interaction), Prelle et al. (2013; toxin detection in food), Müller and Korn (2013; mycotoxins in wheat), Chakraborty et al. (2013; congo red dye degradation), Mamgain et al. (2013; pathogenicity), Snelgrove et al. (2014; immunology), Wijayawardene et al. (2014c; nomenclature), Ouda (2014; nanoparticle effect), Ariyawansa et al. (2015a, c; new species, phylogeny), Rossman et al. (2015b; nomenclature), Templeton (2016, pathogenesis), Meena et al. (2016; mustard disease), Zhang et al. (2017; LAMP), Molecular data available for most of the species, including type species; GenBank Number NR_131316, epitype and ex-epitype of type: IMI 254138; CBS 916.96.

Alternariaster E.G. Simmons 2007, Leptosphaeriaceae, Pleosporales, Dothideomycetes, two species, type: A. helianthi (Hansf.) E.G. Simmons, hyphomycetous, sexual morph unknown, pathogens, Brazil, see Alves et al. (2013; new species, morphology, phylogeny), Hyde et al. (2013; accepted as a genus in Pleosporaceae), Wijayawardene et al. (2014c; outline), Woudenberg et al. (2014; phylogeny), cultures and sequences are available.

Alveariospora Meir. Silva, R.F. Castañeda, O.L. Pereira \& R.W. Barreto, Ascomycota genera incertae sedis, one species, type: A. distoseptata Meir. Silva, R.F. Castañeda, O.L. Pereira \& R.W. Barreto, hyphomycetous, sexual morph unknown, saprobes, terrestrial, Brazil, see Silva et al. (2012; taxonomy), Wijayawardene et al. (2017; outline), holotype of the type: VIC 31399, cultures and sequences are unavailable, compare with Annellophragmia, Annellosympodia and Spiropes.

Alveophoma Alcalde 1952, Ascomycota genera incertae sedis, one species, type: A. caballeroi Alcalde, coelomycetous, sexual morph unknown, saprobes, Spain, see 
Wijayawardene et al. (2012, 2017; outline), Kirk et al. (2013; genus accepted), cultures and sequences are unavailable, need further revisions.

Alysidiella Crous 2006, Dothideomycetes genera incertae sedis, four species, type: A. parasitica Crous, hyphomycetous, sexual morph unknown, pathogens, Cyprus, South Africa, Uruguay, see Seifert et al. (2011; morphology), Cheewangkoon et al. (2012; morphology, phylogeny), Wijayawardene et al. (2012, 2017; outline), holotype and ex-type culture of type: CBS H-19742, CPC 12835.

Alysidiopsis B. Sutton 1973, Ascomycota genera incertae sedis, five species, type: A. pipsissewae B. Sutton, hyphomycetous, sexual morph unknown, saprobes, terrestrial, worldwide, see Seifert et al. (2011; morphology), Wijayawardene et al. (2012, 2017; outline), Kirk et al. (2013; genus accepted), cultures and sequences are unavailable, need further revisions.

Alyxoria Ach. 1821, Lecanographaceae, Arthoniales, Arthoniomycetes, twelve species (many additional species in the tropics; revision needed), type: A. varia (Pers.) Ertz \& Tehler, lichenized, see Ertz and Tehler (2011; taxonomy, phylogeny), Diederich et al. (2012a; taxonomy, checklist), Lücking et al. (2016b; classification), sequences are available.

Amallospora Penz. 1897, Ascomycota genera incertae sedis, one species, type: A. dacrydion Penz., hyphomycetous, sexual morph unknown, saprobes, Java, see Seifert et al. (2011; morphology), Wijayawardene et al. (2012, 2017; outline), Kirk et al. (2013; genus accepted), cultures and sequences are unavailable, need further revisions.

Amandinea M.Choisy ex Scheid. \& M. Mayrhofer 1993 (= Amandinea M. Choisy, Bull. 1950 fide Species Fungorum 2017), Caliciaceae, Caliciales, Lecanoromycetes, 35 species, type: A. coniops (Wahlenb.) M. Choisy ex Scheid. \& H. Mayrhofer, lichenized, see Lumbsch and Huhndorf (2010; outline), Gaya et al. (2012; phylogeny), Kirk et al. (2013; outline, genus accepted), Kondratyuk et al. (2015d; notes), Prieto et al. (2013; phylogeny), Prieto and Wedin (2016; phylogeny), Lücking et al. (2016b; classification), sequences are available.

Amarenographium O.E. Erikss. 1982 (= Amarenomyces O.E. Erikss. 1981 fide Rossman et al. 2016a), ?Phaeosphaeriaceae, Pleosporales, Dothideomycetes, four species, type: A. metableticum (Trail) Erikss., asexual morph coelomycetous, sexual morph unknown, endophytic and saprobes, China, Saudi Arabia, Sweden, Italy, see Hodhod et al. (2012; morphology, phylogeny); Wijayawardene et al. (2016b; morphology, phylogeny), Rossman et al. (2016a; nomenclature), cultures and sequences are available but lacks for the type.

Amaurascopsis Guarro, Gené \& De Vroey 1992, Gymnoascaceae, Onygenales, Eurotiomycetes, asexual morph unknown, two species, type: A. perforata Guarro, Gené \& De Vroey, saprobes, from chicken yard soil, Burundi, see Lumbsch and Huhndorf (2010; outline), Kirk et al. (2013; genus accepted), cultures and sequenceas are available.

Amauroascus J. Schröt. 1893, Onygenaceae, Onygenales, Eurotiomycetes, 14 species, type: A. verrucosus (Eidam) J. Schröt., asexual morph unknown, saprobes, terrestrial, worldwide, see Lumbsch and Huhndorf (2010; outline), Kirk et al. (2013; genus accepted), Sigler et al. (2013; DNA), cultures and sequences are available but lacks for the type.

Amazonia Theiss. 1913 (= Actinodothis Syd. \& P. Syd. 1914; = Amazoniella Bat. \& H. Maia 1960; = Meliolaster Doidge 1920 fide Species Fungorum 2017), Meliolaceae, Meliolales, Sordariomycetes, more than 70 species, type specie: A. psychotriae (Henn.) Theiss., asexual morph unknown, pathogens causing black mildew disease, terrestrial, tropical and subtropical distribution, see Hosagoudar and Archana (2009; host distribution in India), Lumbsch and Huhndorf (2010; outline), Hosagoudar et al. (2010c; new species, morphology), Housagoudar and Robin (2011; new species, morphology), Hosagoudar (2013; new species, morphology), LSU sequence are available for A. acacia. 
Amazonomyces Bat. 1964, Arthoniaceae, Arthoniales, Arthoniomycetes, two species, type: A. palmae Bat. \& Cavalc., lichenized, see Lumbsch and Huhndorf (2010; outline), Kirk et al. (2013; genus accepted), Lücking et al. (2016b; classification), sequences are unavailable.

Amazonotheca Bat. \& H. Maia 1959, Schizothyriaceae, Dothideomycetes family incertae sedis, one species, type: A. santiriae Bat. \& H. Maia, asexual morph unknown, saprobes, terrestrial, Philippines, see Lumbsch and Huhndorf (2010; outline), Hyde et al. (2013; accepted as a genus in Schizothyriaceae), Kirk et al. (2013; genus accepted), Wijayawardene et al. (2014c; outline), cultures and sequences are unavailable, needs generic revision.

Amazonotrema Kalb \& Lücking 2009, Graphidaceae, Ostropales, Lecanoromycetes, one species, type: A. nigrum Kalb \& Lücking, asexual morph unknown, lichenized, terrestrial, tropical, see Kalb (2009; new records), Lumbsch and Huhndorf (2010; outline), Rivas Plata et al. (2012a; classification), Lücking et al. (2016b; classification), sequences unavailable.

Ambarignomonia Sogonov 2008, Gnomoniaceae, Diaporthales, Sordariomycetes, one species, type: A. petiolorum (Schwein.) Sogonov, asexual morph unknown, saprobes, USA, see Sogonov et al. (2008; taxonomy, phylogeny), Lumbsch and Huhndorf (2010; outline), Maharachchikumbura et al. (2015, 2016; outline), cultures and sequences are available.

Amblyosporium Fresen. 1863 (= Gueguenia Bainier 1907; = Searchomyces B.S. Mehrotra \& M.D. Mehrotra 1963 fide Seifert et al. 2011; Species Fungorum 2017), Ascomycota genera incertae sedis, four species, type: A. botrytis Fresen., hyphomycetous, sexual morph unknown, Europe, see Seifert et al. (2011; morphology), Wijayawardene et al. (2012, 2017; outline), Kirk et al. (2013; genus accepted), cultures and sequences are unavailable, need generic revision.

Ambrodiscus S.E. Carp. 1988, Hyaloscyphaceae, Helotiales, Leotiomycetes, one species, type: A. pseudotsugae S.E. Carp., asexual morph unknown, on bark beetle galleries, terrestrial, USA, see Lumbsch and Huhndorf (2010; outline), Kirk et al. (2013; genus accepted), cultures and sequences are unavailable, needs generic revision.

Ambrosiella Brader ex Arx \& Hennebert 1965, Ceratocystidaceae, Microascales, Sordariomycetes, seven species, type: A. xylebori Brader, hyphomycetous, obligate, mutualistic symbionts of ambrosia beetles, from bark beetle galleries/ mycangia in Ivory Coast, USA, Africa, Asia, Europe, USA, Japan, Taiwan, terrestrial, polyphyletic, some species belong to Ophiostomataceae, see Six et al. (2009; new species), Alamouti et al. (2009; phylogeny), Harrington et al. (2010, 2014; taxonomic revisions and new combinations), Hyde et al. (2011; outline), Seifert et al. (2011; morphology), Wijayawardene et al. (2012, 2017; outline), Mayers et al. (2015; phylogeny), Maharachchikumbura et al. (2016; outline), isotype: CBS 110.61, sequences are available at GenBank from Alamouti et al. (2009).

Ambrosiozyma Van der Walt 1972 (= Hormoascus Arx 1972 fide Species Fungorum 2017), Saccharomycopsidaceae, Saccharomycetales, Saccharomycetes, six species, type: A. monospora (Saito) Van der Walt, yeast or yeast-like, fungal symbionts of ambrosia beetles, widespread, see Endoh et al. (2008; phylogeny), Kirk (2013; genus accepted), Kurtzman and Robnett (2013a; phylogeny), ex-type strains of type: CBS 2554.

Ameghiniella Speg. 1887 (= Ionomidotis E.J. Durand ex Thaxt. 1923; = Poloniodiscus Svrček \& Kubička 1967 fide Species Fungorum 2017), Cordieritidaceae, Helotiales, Leotiomycetes, two species, type: A. australis Speg., asexual morph unknown, bark beetle galleries, terrestrial, North and South America, see Lumbsch and Huhndorf (2010; outline), Kirk et al. (2013; genus accepted), Pärtel et al. (2017; DNA, phylogeny), cultures and sequences are available.

Ameliella Fryday \& Coppins 2008, Lecanoraceae, Lecanorales, Lecanoromycetes, two species, type: A. andreaeicola Fryday \& Coppins, lichenized, see Coppins (2008; taxonomy), Fryday and Tønsberg (2015; taxonomy), Lücking et al. (2016b; classification), sequences are unavailable. 
Ameroconium U. Braun \& Zhurb. 2013, Ascomycota genera incertae sedis, one species, type: A. hansfordii Syd., hyphomycetous, sexual morph unknown, lichenicolous, terrestrial, cosmopolitan, see Zhurbenko and Braun (2013; taxonomy), Wijayawardene et al. (2017; outline), holotype: LE 260838, cultures and sequences are unavailable, needs generic revision. Amerodiscosiella Farr 1961, Ascomycota genera incertae sedis, one species, type: A. renispora M.L. Farr 1961, coelomycetous, sexual morph unavailable, saprobes, see Wijayawardene et al. (2012, 2017; outline), Kirk (2013; genus accepted), cultures and sequences are unavailable, needs generic revision.

Amerodiscosiellina Bat. \& Cavalc. 1966, Ascomycota genera incertae sedis, one species, type: A. annonacearum Bat. \& Cavalc., coelomycetous, sexual morph unavailable, saprobes, see Wijayawardene et al. (2012, 2017; outline), Kirk (2013; genus accepted), cultures and sequences are unavailable, needs generic revision.

Ameromassaria Hara 1918, Sordariomycetes genera incertae sedis, one species, type: A. japonica Hara, asexual morph unknown, pathogens, terrestrial, Japan, see Lumbsch and Huhndorf (2010; outline), Kirk et al. (2013 genus accepted), Maharachchikumbura et al. (2015, 2016; outline), cultures and sequences are unavailable.

Ameromassaria Hara 1918, Sordariomycetes genera incertae sedis, one species, type: A. japonica Hara, asexual morph unknown, pathogen, terrestrial, Japan, see Lumbsch and Huhndorf (2010), Kirk et al. (2013; genus accepted), Maharachchikumbura et al. (2015, 2016), cultures and sequences are unavailable, needs generic revision.

Amerosporiopsis Petr. 1941, Ascomycota genera incertae sedis, one species, type: A. gaubae Petr., coelomycetous, sexual morph unavailable, saprobes, Iran, see Wijayawardene et al. (2012, 2017; outline), Kirk (2013; genus accepted), cultures and sequences are unavailable, needs generic revision.

Amerosympodula Matsush. 1996, Ascomycota genera incertae sedis, one species, type: A. malaysiana Matsush., hyphomycetous, sexual morph unknown, saprobes, terrestrial, Asia, see Seifert et al. (2011; morphology), Wijayawardene et al. (2012, 2017; outline), Kirk et al. (2013; genus accepted), cultures and sequences are unavailable, needs generic revision.

Amicodisca Svrček 1987, Hyaloscyphaceae, Helotiales, Leotiomycetes, six species, type: A. brdensis (Velen.) Svrček, asexual morph unknown, saprobes, terrestrial, north temperate, see Lumbsch and Huhndorf (2010; outline), Han et al. (2012, 2014; new species, phylogeny), Kirk et al. (2013; genus accepted), cultures and sequences are available but lacks for the type species.

Amniculicola Y. Zhang ter \& K.D. Hyde 2008 (= Anguillospora Ingold 1942 fide Rossman et al. 2016a), Amniculicolaceae, Pleosporales, Dothideomycetes, four species, type: A. lignicola Y. Zhang ter \& K.D. Hyde, asexual morph hyphomycetous, saprobes in freshwater habitats, Europe, see Zhang et al. (2008b, 2009c, 2012e; taxonomy, phylogeny), Wijayawardene et al. (2012, 2014c), Wanasinghe et al. (2015; phylogeny), Rossman et al. (2016a; nomenclature), sequence are available for all species, holotype of type: PC 0092661.

Amoenodochium Peláez \& R.F. Castañeda 1996, Ascomycota genera incertae sedis, one species, type: A. humicola Peláez \& R.F. Castañeda, hyphomycetous, sexual morph unknown, saprobes, terrestrial, India, see Seifert et al. (2011; morphology), Wijayawardene et al. (2012, 2016; outline), Kirk et al. (2013; genus accepted), holotype of the type: MA-33881, cultures and sequences are unavailable, compare with Acanthodochium, Asperisporium, Megalodochium and Polythrincium.

Amoenomyces R.F. Castañeda, Saikawa \& Hennebert 1996, Ascomycota genera incertae sedis, one species, type: A. catenosporus R.F. Castañeda, Saikawa \& Hennebert, hyphomycetous, sexual morph unknown, saprobes, terrestrial, Cuba, see Seifert et al. (2011; morphology), Wijayawardene et al. (2012, 2017; outline), Kirk et al. (2013; genus accepted), 
holotype of the type: INIFAT C94/192, cultures and sequences are unavailable, compare with Alternaria, Embellisia and Parapithomyces.

Amorosia Mantle \& D. Hawksw. 2006, Amorosiaceae, Pleosporales, Dothideomycetes, one species, type: A. littoralis Mantle \& D. Hawksw., hyphomycetous, sexual morph unknown, recovered from intertidal sediments, The Bahamas, see Seifert et al. (2011; morphology), Wijayawardene et al. (2012, 2014c, 2017; outline), Jones et al. (2015; outline of marine genera), Thambugala et al. (2015b; phylogeny), holotype of the type: K(M) 139387, cultures and sequences are available, AM292047 (ITS).

Amorphomyces Thaxt. 1893, Laboulbeniaceae, Laboulbeniales, Laboulbeniomycetes, ten species, type: A. falagriae Thaxt., asexual morph unknown, dioecious, biotrophic on Coleoptera (Staphylinidae), terrestrial, marine, worldwide, see Lumbsch and Huhndorf (2010; outline), Kirk et al. (2013; genus accepted), cultures and sequences are unavailable, needs generic revision.

Amorphotheca Parbery 1969, Amorphothecaceae, Leotiomycetes, families incertae sedis, one species, type: A. resinae Parbery, asexual morph unknown, saprobes on resins, hydrocarbons, terrestrial, worldwide, see Lumbsch and Huhndorf (2010; outline), Kirk et al. (2013; genus accepted), Wang et al. (2015b; applications), cultures available for the type: CBS 184.54.

Ampelomyces Ces. ex Schltdl. 1852 (= Byssocystis Riess 1853; = Cicinobolus Ehrenb. 1853 fide Species Fungorum 2017), Phaeosphaeriaceae, Pleosporales, Dothideomycetes, five species, type: A. quisqualis Ces., coelomycetous, sexual morph unknown, fungicolous, terrestrial, worldwide, see de Gruyter et al. (2009; pylogeny), Park et al. (2010; genetic variability), Wijayawardene et al. (2012, 2014c, 2017; taxonomy, phylogeny, outline), Hyde et al. (2013; accepted as a genus in Phaeosphaeriaceae), Phookamsak et al. (2014b; accepted as a genus in Phaeosphaeriaceae), Verkley et al. (2014; phylogeny), cultures of the type: CBS 131.31, CBS 129.79.

Amphibambusa D.Q. Dai \& K.D. Hyde 2015, Cainiaceae, Xylariales, Sordariomycetes, one species, type: A. bambusicola Dai \& Hyde, asexual morph unknown, saprobes, terrestrial, Thailand, see Liu et al. (2015a; phylogeny, taxonomy), Senanayake et al. (2015; phylogeny), holotype and ex-type culture of type: MFLUCC 11-0617, MFLU 14-0825.

Amphichaetella Höhn. 1916 (= Amphichaete Kleb. 1914 fide Species Fungorum 2017), Ascomycota genera incertae sedis, one species, type: A. echinata (Kleb.) Höhn., hyphomycetous, sexual morph unknown, Europe, Australia, see Seifert et al. (2011; morphology), Wijayawardene et al. (2012, 2017; outline), Kirk et al. (2013; genus accepted), cultures and sequences are unavailable, need generic revision.

Amphilogia Gryzenh., H.F. Glen \& M.J. Wingf. 2005, Cryphonectriaceae, Diaporthales, Sordariomycetes, two species, type: A. gyrosa (Berk. \& Broome) Gryzenh., H.F. Glen \& M.J. Wingf., asexual morph coelomycetous, pathogenic, terrestrial, temperate, Sri Lanka, New Zealand, see Lumbsch and Huhndorf (2010; outline), Maharachchikumbura et al. (2015, 2016; outline), holotype and ex-epitype strain of the type: CBS H-20178, CMW 10470.

Amphimyces Thaxt. 1931, Laboulbeniaceae, Laboulbeniales, Laboulbeniomycetes, one species, type: A. cerylonis Thaxt., asexual morph unknown, biotrophic on Coleoptera from the genus Cerylon (Cerylonidae), West Africa, see Lumbsch and Huhndorf (2010; outline), Kirk et al. (2013; genus accepted), cultures and sequences are unavailable, needs generic revision.

Amphiporthe Petr. 1971 (= Amphicytostroma Petr. 1921 fide Rossman et al. 2015a), Gnomoniaceae, Diaporthales, Sordariomycetes, two species, type: A. tiliae (Sacc.) Petr., asexual morph hyphomycetous, saprobes, terrestrial, Europe, see Lumbsch and Huhndorf (2010; outline), Seifert et al. (2011; morphology), Wijayawardene et al. (2012, 2017; outline), Kirk et al. (2013; genus accepted), Maharachchikumbura et al. (2015, 2016), Rossman et al. (2015a; nomenclature), needs generic revision. 
Amphirosellinia Y.M. Ju, J.D. Rogers, H.M. Hsieh \& Lar.N. Vassiljeva 2004, Xylariaceae, Xylariales, Sordariomycetes, five species, type: A. nigrospora Y.M. Ju, J.D. Rogers \& H.M. Hsieh, asexual morph unknown, saprobes, terrestrial, north temperate, see Hsieh et al. (2010; DNA, phylogeny), Lumbsch and Huhndorf (2010; outline), Maharachchikumbura et al. (2015, 2016; outline), holotype: HAST Ju \& Hsieh 91092308, sequences are available for the type species.

Amphisphaerellula Gucevič 1952, Sordariomycetes, genera incertae sedis, two species, type: A. fagi Gucevič, sexual morph unknown, saprobes, errestrial, former USSR, see Lumbsch and Huhndorf (2010; outline), Kirk et al. (2013; genus accepted), Maharachchikumbura et al. (2015, 2016; outline), cultures and sequences are unavailable.

Amphisphaeria Ces. \& De Not. 1863 (= Macrothelia M. Choisy 1949; = Massariella Speg. 1880; = Massariopsis Niessl 1876; = Phorcys Niessl 1876; = Poikiloderma Füisting 1868; = Rhynchostomopsis Petr. \& Syd. 1923 fide Species Fungorum 2017), Amphisphaeriaceae, Xylariales, Sordariomycetes, 266 species, type: A. umbrina (Fr.) De Not., asexual morph coelomycetous, saprobes, widespread, see Lumbsch and Huhndorf (2010; outline), Kirk et al. (2013; genus accepted), Senanayake et al. (2015, morphology and phylogeny), Maharachchikumbura (2015, 2016; morphology, phylogeny), sequences are available.

Amphisphaerina (Cooke) Höhnel 1919, Sordariomycetes genera incertae sedis, one species, type: A. texensis (Cooke) Höhnel, asexual morph unknown, saprobes, terrestrial, USA, See Lumbsch and Huhndorf (2010; outline), Kirk et al. (2013; genus accepted), Maharachchikumbura et al. (2015, 2016; outline), cultures and sequences are unavailable.

Amphobotrys Hennebert 1973, Sclerotiniaceae, Helotiales, Leotiomycetes, one species, type: A. ricini (N.F. Buchw.) Hennebert, hyphomycetous, sexual morph unknown, North America, see Seifert et al. (2011; morphology), Wijayawardene et al. (2012, 2017; outline), Kirk et al. (2013; genus accepted), cultures and sequences are available, need generic revision.

Amphoropycnium Bat. 1963, Ascomycota genera incertae sedis, one species, type: A. philippinense Bat., coelomycetous, sexual morph unknown, saprobes, terrestrial, Brazil, Philippines, see Wijayawardene et al. (2012, 2017; outline), Kirk et al. (2013; genus accepted), cultures and sequences are unavailable, needs generic revision.

Amphorothecium P.M. McCarthy, Kantvilas \& Elix 2001, Ostropales genera incertae sedis, Lecanoromycetes, one species, type: A. occultum P.M. McCarthy, Kantvilas \& Elix, lichenized, terrestrial, Australia, see Lumbsch and Huhndorf (2010; outline), Lücking et al. (2016b; classification), sequences unavailable.

Amphorulopsis Petr. 1959, Sordariomycetes genera incertae sedis, one specie, type: A. polygonacearum Petr., asexual morph unknown, terrestrial, former Yugoslavia, see Lumbsch and Huhndorf (2010; outline), Kirk et al. (2013; genus accepted), Index Fungorum (2017) listed the type species as a synonym of Ceriospora polygonacearum, needs generic revision. Ampliotrema Kalb ex Kalb 2006 (= Ampliotrema Kalb 2004 fide Species Fungorum 2017), Graphidaceae, Ostropales, Lecanoromycetes, c. 20 species, type: A. amplius (Nyl.) Kalb, asexual morph unknown, lichenized fungi, terrestrial, tropical, see Lumbsch and Huhndorf (2010; outline), Sipman et al. (2012; key Costa Rica), Rivas Plata et al. (2012b; phylogeny), Cáceres et al. (2012b), Rivas Plata and Lücking (2012; classification), Mercado-Díaz et al. (2014; taxonomy), Lücking et al. (2016b; classification), sequences are available.

Amplistroma Huhndorf, A.N. Mill., Greif \& Samuels 2009, Amplistromataceae, Amplistromatales, Sordariomycetes, nine species, type: A. carolinianum Huhndorf, A.N. Mill., Greif \& Samuels, asexual morph hyphomycetous, acrodontium-like in culture, sexual morph ascomycetes, saprobes, French Guiana, Costa Rica, Spain, Singapore, USA, see Lumbsch and Huhndorf (2010; outline), Maharachchikumbura (2015, 2016; morphology, phylogeny), holotype: BPI 878925, sequences are available. 
Ampullicephala R.F. Castañeda, Minter \& M. Stadler 2009, Ascomycota genera incertae sedis, one species, type: A. setiformis (R.F. Castañeda) R.F. Castañeda, Minter \& M. Stadler, hyphomycetous, sexual morph unknown, saprobes, terrestrial, Cuba, see Castañeda-Ruiz et al. (2009b; txonomy), Seifert et al. (2011; morphology), Wijayawardene et al. (2012, 2017; outline), holotype of the type: INIFAT C85/79, cultures and sequences are unavailable, compare with Gonatobotryum and Gonatobotrys.

Ampulliferina B. Sutton 1969, Ascomycota genera incertae sedis, three species, type: A. persimplex B. Sutton, hyphomycetous, sexual morph unknown, saprobes, terrestrial, worldwide, see Seifert et al. (2011; morphology), Wijayawardene et al. (2012, 2017; outline), holotype of the type: IMI 134269.

Amundsenia Søchting, Garrido-Benavent, Arup \& Frödén 2014, Teloschistaceae, Teloschistales, Lecanoromycetes, two species, type: A. austrocontinentalis Garrido-Benavent, Søchting, Pérez-Ortega \& Seppelt, lichenized, see Søchting et al. (2014b; taxonomy), Lücking et al. (2016b; classification), sequences are available.

Amycosphaerella Quaedvl. \& Crous 2014, Mycosphaerellaceae, Capnodiales, Dothideomycetes, one species, type: A. africana (Crous \& M.J. Wingf.) Quaedvlieg \& Crous, asexual morph unknown, pathogens, terrestrial, Australia, South Africa, see Quaedvlieg et al. (2014; morphology, phylogeny), holotype and ex-type culture of the type: PERTH 05849543 , CBS 110500.

Amygdalaria Norman 1853, Lecideaceae, Lecideales, Lecanoromycetes, 14 species, type: A. pelobotryon (Wahlenb.) Norman, lichenized, see Lumbsch and Huhndorf (2010; outline), Schmull et al. (2011; taxonomy), Lücking et al. (2016b; classification), sequences are available.

Amylascus Trappe 1971, Pezizaceae, Pezizales, Pezizomycetes, five species, type: A. herbertianus (J.W. Cribb) Trappe, mycorrhizal, Australia, the Americas, see Lumbsch and Huhndorf (2010; outline), Healy et al. (2013; phylogeny), Kirk et al. (2013; genus accepted), cultures and sequences are for several undescribed species.

Amylis Speg. 1922, Sordariomycetes genera incertae sedis, one specie, type: A. memorabilis Speg., asexual morph unknown, saprobes, terrestrial, South America, see Lumbsch and Huhndorf (2010; outline), Kirk et al. (2013; genus accepted), cultures and sequences are unavailable, needs generic revision.

Amylocarpus Cur. 1859 (= Plectolitus Kohlm. 1960 fide Species Fungorum 2017), Helotiaceae, Helotiales, Leotiomycetes, one species, type: A. encephaloides Curr., asexual morph unknown, drift wood, temperate marine waters, saprobe, sequence are available, see Lumbsch and Huhndorf (2010; outline), Kirk et al. (2013; genus accepted), Rämä et al. (2014; DNA, records in Norway), Jones et al. (2015; outline), cultures and sequences are available.

Amylora Rambold 1994, Trapeliaceae, Trapeliales, Lecanoromycetes, one species, type: A. cervinocuprea (Arnold) Rambold, lichenized, see Lumbsch and Huhndorf (2010; outline), Hodkinson and Lendemer (2011b; taxonomy), Kirk et al. (2013; genus accepted), Lücking et al. (2016b; classification), cultures and sequences are unavailable, needs generic revision.

Anabahusakala Carmo, J.S. Monteiro, Gusmão \& R.F. Castañeda 2014, Ascomycota genera incertae sedis, one species, type: A. amapensis L.T. Carmo, J.S. Monteiro, Gusmão \& R.F. Castañeda, hyphomycetous, sexual morph unknown, saprobes, Brazil, Carmo et al. (2014; taxonomy), Wijayawardene et al. (2017; outline), cultures and sequences are unavailable.

Anacraspedodidymum C.R. Silva, R.F. Castañeda \& Gusmão 2014, Ascomycota genera incertae sedis, two species, type: A. aquaticum C.R. Silva, R.F. Castañeda \& Gusmão, hyphomycetous, sexual morph unknown, saprobes, terrestrial, Brazil, see Silva et al. (2014; taxonomy), Wijayawardene et al. (2017; outline), cultures and sequences are unavailable, needs generic revision. 
Anaexserticlava T.S. Santa Izabel, R.F. Castañeda \& Gusmão 2015, Ascomycota genera incertae sedis, one species, type: A. caatingae T.S. Santa Izabel, R.F. Castañeda \& Gusmão, hyphomycetous, sexual morph unknown, saprobes, terrestrial, Brazil, see Santa Izabel et al. (2015; taxonomy), Wijayawardene et al. (2017; outline), cultures and sequences are unavailable, needs generic revision.

Anamylopsora Timdal 1991, Baeomycetaceae, Baeomycetales, Lecanoromycetes, one species, type: A. pulcherrima (Vain.) Timdal (Lecidea pulcherrima Vain.), lichenized, saxicolous, terricolous, temperate northern hemisphere, see Lumbsch and Huhndorf (2010; outline), Kirk et al. (2013; genus accepted), Resl et al. (2015; phylogeny), holotype: TUR-V22644 (holotype), sequences are available.

Anaphysmene Bubák 1906 (= Wakefieldia G. Arnaud, Bull 1954 [1953] fide Species Fungorum 2017), Ascomycota genera incertae sedis, two species, type: A. heraclei (Lib.) Bubák, coelomycetous, sexual morph unknown, Europe, Gautamala see Wijayawardene et al. (2012, 2017; outline), Kirk et al. (2013; genus accepted), cultures and sequences are unavailable, need generic revision.

Anaptychia Körb. 1848 (= Anaptychiomyces E.A. Thomas 1939; = Hagenia Eschw. 1824; = Imbricaria (Schreb.) Michx. 1803; = Lichen sect. Imbricaria Schreb. 1791; Lichenoides Hoffm. 1789 [1790]; = Parmelia sect. Imbricaria (Schreb.) Fr. 1825; = Tornabenia A. Massal. 1853 fide Species Fungorum 2017), Physciaceae, Caliciales, Lecanoromycetes, 15 species, type: A. ciliaris (L.) Körb. ex A. Massal., lichenized, see Gaya et al. (2012; phylogeny), Prieto et al. (2013; phylogeny), Miądlikowska et al. (2014a; phylogeny), Prieto and Wedin (2016; classification), Lücking et al. (2016b; classification), sequences are available.

Anarhyma M.H. Pei \& Z.W. Yuan 1986, Ascomycota genera incertae sedis, one species, type: A. rhododendri M.H. Pei \& Z.W. Yuan, coelomycetous, sexual morph unknown, saprobes, terrestrial, China, see Wijayawardene et al. (2012, 2017; outline), Kirk et al. (2013; genus accepted), cultures and sequences are unavailable, needs generic revision.

Anariste Syd. 1927, Micropeltidaceae, Microthyriales, Dothideomycetes, one species, type: A. poliothea Syd., asexual morph unknown, epiphytes, terrestrial, Costa Rica, see Hofmann (2009; review, accepted as a genus in Asterinaceae), Lumbsch and Huhndorf (2010; outline, accepted as a genus in Asterinaceae), Hongsanan et al. (2014c; taxonomy, keys, transferred to Micropeltidaceae), Wijayawardene et al. (2014c; outline, accepted as a genus in Micropeltidaceae), placement in Micropeltidaceae supported by morphology, syntype of type: BPI 690985, cultures and sequences are unavailable.

Anaselenosporella Heredia, R.F. Castañeda \& R.M. Arias 2010, Ascomycota genera incertae sedis, two species, type: A. sylvatica Heredia, Castañeda \& Arias, hyphomycetous, sexual morph unknown, saprobes, terrestrial, Mexico, see Castañeda-Ruiz et al. (2010a; morphology), Pratibha et al. (2011; new species), Wijayawardene et al. (2012, 2017; outline), holotype of the type: MUCL 45630, cultures and sequences are unavailable, compare with Selenosporella and Selenosporopsis.

Anaseptoidium R.F. Castañeda, Heredia \& R.M. Arias 2012, Ascomycota genera incertae sedis, hyphomycetous, sexual morph unknown, one species, type: A. mycophilum Castañeda, Heredia \& Arias, mycophilous, on synnemata of Phaeoisaria clavulata, terrestrial, Mexico, see Castañeda-Ruiz et al. (2012a; taxonomy), Wijayawardene et al. (2017; outline), holotype of type: XAL CB1696, cultures and sequences are unavailable, compare with Septoidium.

Ancistrosporella G. Thor. 1995 (= Ancistrospora G. Thor 1991 fide Species Fungorum 2017), Roccellaceae, Arthoniales, Arthoniomycetes, three species, type: A. australiensis (G. Thor) G. Thor, lichenized, see Lumbsch and Huhndorf (2010; outline), Kirk et al. (2013; genus accepted), Ertz et al. (2015c; taxonomy), Lücking et al. (2016b; classification), sequences are unavailable. 
Ancoraspora Mig. Rodr. 1982, Ascomycota genera incertae sedis, one species, type: A. cubensis Mig. Rodr., hyphomycetous, sexual morph unknown, saprobes, Cuba, see Seifert et al. (2011; morphology), Wijayawardene et al. (2012, 2017; outline), Kirk (2013; genus accepted), cultures and sequences are unavailable, needs generic revision.

Andamanomyces Hosag. 2014, Asterinales genera incertae sedis, Dothideomycetes, one species, type: A. fragariae Hosag., S.P. Mathew \& D. Babu, asexual morph unknown, epiphytes, biotrophic, terrestrial, India, see Hosagoudar et al. (2014; morphology, accepted as a genus in Asterinales), placement in Asterinales supported by morphology, holotype: TBGT 6666, cultures and sequences are unavailable.

Andreiomyces B.P. Hodk. \& Lendemer 2013, Andreiomycetaceae, Arthoniales, Arthoniomycetes, two species, type: A. morozianus (Lendemer) B.P. Hodk. \& Lendemer, lichenized, see Hodkinson and Lendemer (2013; taxonomy), Lücking et al. (2016b; classification), cultures available for the type: NY1377.

Anema Nyl. ex Forssell 1885 (= Omphalaria A. Massal. 1855 fide Species Fungorum 2017), Lichinaceae, Lichinales, Lichinomycetes, ten species, type: A. decipiens (A. Massal.) Forssell, with ascomata, lichenized (cyanobacteria), terrestrial (saxicolous), arid, semiarid to warm temperate regions, see Lumbsch and Huhndorf (2010; outline), Kirk et al. (2013; genus accepted), Lücking et al. (2016b; classification), see sequences are available.

Angatia Syd. \& P. Syd. 1914, Saccardiaceae, Ascomycota families incertae sedis, five species, type: A. eugeniae Syd. \& P. Syd., asexual morph unknown, saprobes, tropical, see Lumbsch and Huhndorf (2010; outline), Kirk et al. (2013; genus accepted), cultures and sequences are unavailable, needs generic revision.

Angelina Fr. 1849, Helotiales genera incertae sedis, Leotiomycetes, one species, type: A. rufescens (Schwein.) Duby, asexual morph unknown, saprobes, terrestrial, North America, see Lumbsch and Huhndorf (2010; outline, accepted as a genus in Dermateaceae), Kirk et al. (2013; genus accepted), Karakehian et al. (2014; DNA, phylogeny), Jaklitsch et al. (2016a; classification), culture available for the type: JK 12040101.

Angiactis Aptroot \& Sparrius 2008, Arthoniales genus incertae sedis, Arthoniomycetes, three species, type: A. littoralis (Kantvilas) Aptroot \& Sparrius, lichenized, terrestrial, tropical, see Aptroot et al. (2008; taxonomy), Lumbsch and Huhndorf (2010; outline), Kirk et al. (2013; genus accepted), Lücking et al. (2016b; classification), cultures and sequences are unavailable.

Angiopomopsis Höhn. 1912, Ascomycota genera incertae sedis, one species, type: $A$. lophostoma Höhn., coelomycetous, sexual morph unknown, saprobes, terrestrial, Java, see Wijayawardene et al. (2012, 2017; outline), Kirk et al. (2013; genus accepted), cultures and sequences are unavailable, needs generic revision.

Anguillosporella U. Braun 1995, Ascomycota genera incertae sedis, two species, type: A. vermiformis (Davis) U. Braun., hyphomycetous, terrestrial, foliicolous, leaf-spotting, North America, see Seifert et al. (2011; morphology), Wijayawardene et al. (2012, 2017; outline), Kirk et al. (2013; genus accepted), lectotype of type: BPI 442755, cultures and sequences are unavailable, needs generic revision.

Angulimaya Subram. \& Lodha 1964, Ascomycota genera incertae sedis, one species, type: A. sundara Subram. \& Lodha, hyphomycetous, sexual morph unknown, on dung, terrestrial, Asia, see Seifert et al. (2011; morphology, accepted as a genus in Lasiosphaeriaceae), Kirk et al. (2013; genus accepted), Wijayawardene et al. (2017; outline, treated as Ascomycota genera incertae sedis), cultures and sequences are unavailable, needs generic revision.

Angulospora Sv. Nilsson., 1962, Ascomycota genera incertae sedis, one species, type: A. aquatica Sv. Nilsson, hyphomycetous, sexual morph unknown, aquatic, on submerged decaying wood, see Seifert et al. (2011; morphology), Wijayawardene et al. (2012), Kirk et al. (2013; genus accepted), cultures and sequences are unavailable. 
Angustimassarina Thambugala, Kaz. Tanaka \& K.D. Hyde 2015, Amorosiaceae, Pleosporales, Dothideomycetes, three species, type: A. populi Thambugala \& K.D. Hyde, asexual morph hyphomycetous, fungicolous or saprobes, terrestrial, Germany and Italy, three species, see Thambugala et al. (2015b; morphology, phylogeny), holotype and ex-type strain of type: MFLU 14-0588, MFLUCC 13-0034.

Angustospora Abdel-Aziz 2016, Testudinaceae, Pleosporales, Dothideomycetes, one species, type: A. nilensis Abdel-Aziz, asexual morph unknown, saprobes, aquatic, Egypt, see Li et al. (2016a; taxonomy, phylogeny), holotype and ex-isotype culture of the type: MFLU 15-1511, MF804.

Anhellia Racib. 1900 (= Agostaea (Sacc.) Theiss. \& Syd. 1915; = Ramosiella Syd. \& P. Syd. 1917; = Trabutia subgen. Agostaea Sacc. 1895; = Whetzeliomyces Viégas 1945 fide Species Fungorum 2017), Myriangiaceae, Myriangiales, Dothideomycetes, nine species, type: A. tristis Racib., asexual morph unknown, parasitic on leaves, terrestrial, tropical, see Lumbsch and Huhndorf (2010; outline), Pinho et al. (2012; morphology, phylogeny), Kirk et al. (2013; genus accepted), Dissanayake et al. (2014; morphology), holotype of the type: F47931.

Aniptodera Shearer \& M. A. Mill. 1977, Halosphaeriaceae, Microascales, Sordariomycetes, c. 16 species, type: A. chesapeakensis Shearer \& Mill., asexual morph unknown, saprobes, freshwater, marine, worldwide, see Lumbsch and Huhndorf (2010; outline), Kirk et al. (2013; genus accepted), Jones et al. (2015; outline), Maharachchikumbura et al. (2015, 2016; outline), ex-type strains of type: CS-97-26 = ATCC 32818, holotype: ILLS 36523.

Anisogramma Theiss. \& Syd. 1917 (= Apioporthe Höhn. 1917 fide Species Fungorum 2017), Diaporthales genera incertae sedis, Sordariomycetes, three species, type: A. virgultorum (Fr.) Theiss. \& Syd., asexual morph unknown, terrestrial, saprobes, Europe, North America, see Lumbsch and Huhndorf (2010; outline), Kirk et al. (2013; genus accepted), Maharachchikumbura et al. (2015, 2016; outline), cultures and sequences are available.

Anisomeridium (Müll. Arg.) M. Choisy 1928 (= Arthopyrenia sect. Anisomeridium Müll. Arg., Flora 1883; = Compsosporiella Sankaran \& B. Sutton 1991; = Ditremis Clem. 1909; = Lembidium Körb. 1855; = Microthelia Körb. 1855; = Sarcinulella B. Sutton \& Alcorn 1983 fide Species Fungorum 2017), Monoblastiaceae, Monoblastiales, Dothideomycetes, c. 200 species, type: A. xylogena Müll. Arg., asexual morph unknown, lichenized, terrestrial, mostly tropical, see Nelsen et al. (2009, 2011b; phylogeny), Lumbsch and Huhndorf (2010; outline), Kirk et al. (2013; genus accepted), sequences are available.

Anisomyces Theiss. \& Syd. 1914 (= Apiospora subgen. Phaeoapiospora Sacc. \& P. Syd. 1902; Phaeoapiospora (Sacc. \& P. Syd.) Theiss. \& Syd. 1915; = Stegastroma Syd. \& P. Syd. 1916 fide Species Fungorum 2017), Gnomoniaceae, Diaporthales, Sordariomycetes, seven species, type: A. papilloideoseptatus (Henn.) Theiss. \& Syd., asexual morph unknown, saprobes?, terrestrial, tropical America, see Lumbsch and Huhndorf (2010; outline), Kirk et al. (2013; genus accepted), sequences are unavailable, needs generic revision.

Anisomycopsis I. Hino \& Katum. 1964, Diaporthales, genera incertae sedis, Sordariomycetes, one species, type: A. rosae I. Hino \& Katum., asexual morph unknown, saprobes, terrestrial, Japan, see Lumbsch and Huhndorf (2010; outline), Maharachchikumbura et al. (2015, 2016; outline), cultures and sequences are unavailable, needs generic revision.

Anisostagma K.R.L. Petersen \& Jørg. Koch 1996, Halosphaeriaceae, Microascales, Sordariomycetes, one species, type: A. rotundatum K.R.L. Petersen \& Jørg. Koch, asexual morph unknown, saprobes, marine, Denmark, see Lumbsch and Huhndorf (2010; outline), Kirk et al. (2013; genus accepted), Jones et al. (2015; outline), Maharachchikumbura et al. (2015, 2016; outline), holotype: K. R. L. Petersen 9 slides numbered 1-9, Herbarium C, Copenhagen, cultures and sequences are unavailable, needs generic revision. 
Annellodentimyces Matsush. 1985, Ascomycota genera incertae sedis, one species, type: A. antennatuloideus Matsush., hyphomycetous, sexual morph unknown, saprobes, terrestrial, Asia, see Seifert et al. (2011; morphology), Wijayawardene et al. (2012, 2017; outline), Kirk et al. (2013; genus accepted), cultures and sequences are unavailable, needs generic revision. Annellodochium Deighton 1969, Ascomycota genera incertae sedis, one species, type: A. ramulisporum Deighton, hyphomycetous, sexual morph unknown, saprobes, terrestrial, Africa, South America, see Seifert et al. (2011; morphology), Wijayawardene et al. (2012, 2017; outline), Kirk et al. (2013; genus accepted), cultures and sequences are unavailable, needs generic revision.

Annellolacinia B. Sutton 1964, Discosiaceae, Xylariales, Sordariomycetes, two species, type: A. dinemasporioides B. Sutton, coelomycetous, sexual morph unknown, pathogens, Ghana, Sierra Leone, Trinidad, India, Australia, cultures and sequences are unavailable, see Wijayawardene et al. (2012, 2016, 2017; taxonomy, outline), Kirk et al. (2013; genus accepted), holotype: IMI37897c.

Annellophora S. Hughes 1952 (= Chaetotrichum Syd. 1927 fide Species Fungorum 2017), Ascomycota genera incertae sedis, 13 species, type: A. solani (Syd.) S. Hughes, hyphomycetous, sexual morph unknown, Cuba, see Seifert et al. (2011; morphology), Wijayawardene et al. (2012, 2017; outline), cultures and sequences are unavailable, needs generic revision.

Annellophorella Subram. 1962, Ascomycota genera incertae sedis, five species, type: A. densa (Syd. \& P. Syd.) Subram., hyphomycetous, sexual morph unknown, see Seifert et al. (2011; morphology), Wijayawardene et al. (2012, 2017; outline), cultures and sequence are unavailable, needs generic revision.

Annellophragmia Subram. 1963, Ascomycota genera incertae sedis, one species, type: A. coonoorensis (Subram.) Subram., hyphomycetous, sexual morph unknown, saprobes, terrestrial, Asia, see Seifert et al. (2011; morphology), Wijayawardene et al. (2012, 2017; outline), Kirk et al. (2013; genus accepted), cultures and sequences are unavailable, needs generic revision.

Annellospermosporella P.R. Johnst. 1999, Ascomycota genera incertae sedis, one species, type: A. meliolinae P.R. Johnst., hyphomycetous, sexual morph unknown, saprobes, terrestrial, Australasia, see Seifert et al. (2011; morphology), Wijayawardene et al. (2012, 2017; outline), Kirk et al. (2013; genus accepted), cultures and sequences are unavailable, needs generic revision.

Annellosympodia McTaggart, R.G. Shivas \& U. Braun 2007, Ascomycota genera incertae sedis, one species, type: A. orbiculata McTaggart, Shivas \& Braun, hyphomycetous, sexual morph unknown, pathogens, terrestrial, Australia, see Seifert et al. (2011; morphology), Wijayawardene et al. (2012, 2017; outline), holotype of the type: PERTH 03270173, isotype BRIP 49805, paratype BRIP 19908, living cultures unavailable.

Annellosympodiella Crous \& Assefa 2014, Mycosphaerellaceae, Capnodiales, Dothideomycetes, one species, type: A. juniperi Crous \& Assefa, hyphomycetous, sexual morph unknown, saprobes, terrestrial, Ethiopia, see Crous et al. (2014c; morphology, phylogeny), Wijayawardene et al. (2014c; outline), holotype of the type: CBS H-21706, extype strain of type: CPC 23276.

Annulatascus Ces. \& De Not. 1863, Annulatascaceae, Annulatascales, Sordariomycetes, c. 19 species, type: A. velatispora K.D. Hyde, asexual morph coelomycetous, saprobes, terrestrial, aquatic, worldwide, see Lumbsch and Huhndorf (2010; outline), Boonyuen et al. (2012; new species; phylogeny), Kirk et al. (2013; genus accepted), Maharachchikumbura et al. (2015, 2016; outline), Luo et al. (2015; taxonomy), holotype of type: BRIP 17373; epitype MFLU 16-2204. 
Annulohypoxylon Y.M. Ju, J.D. Rogers \& H.M. Hsieh 2005, Hypoxylaceae, Xylariales, Sordariomycetes, three species, type: A. truncatum (Schwein.) Y.M. Ju, J.D. Rogers \& H.M. Hsieh, four species, asexual morph hyphomycetous, terrestrial, saprobes, Europe, North America, see Marincowitz et al. (2008; new species, South Africa), Hladki and Romero (2009; new species), Lumbsch and Huhndorf (2010; outline), Pereira et al. (2010; new species, Brazil), Liu et al. (2015a; new species), Li et al. (2016a; new species, Thailand), Maharachchikumbura et al. (2015, 2016; outline), Vasilyeva et al. (2016; new species), Kuhnert et al. (2017; new species, revision), Wendt et al. (2017; phylogeny), cultures and sequences are available.

Annulusmagnus J. Campb. \& Shearer 2004, Annulatascaceae, Annulatascales, Sordariomycetes, one species, type: A. triseptatus (Wong, Hyde \& Jones) Campb. \& Shearer, asexual morph unknown, saprobes, aquatic, Australia, Canada, USA, see Réblová et al. (2012; DNA, phylogeny), Maharachchikumbura et al. (2015, 2016; outline, phylogeny), neotype of the type: HKU889, cultures available CBS 128831.

Anomalographis Kalb 1992, Graphidaceae, Ostropales, Lecanoromycetes, two species, type: A. madeirensis (Tav.) Kalb, asexual morph unknown, lichenized, terrestrial, tropical, see Lumbsch and Huhndorf (2010; outline), Rivas Plata et al. (2012a; phylogeny), Kirk et al. (2013; genus accepted), Lücking et al. (2016b; classification), sequences are unavailable.

Anomomorpha Nyl. ex Hue 1891 (= Anomomorpha Nyl. ex Hue, Nouv 1891; = Anomomorpha Nyl. 1889; = Aulacographa Leight. 1854; = Ctesium Pers. 1827 [1826-1830]; = Digraphis Clem. 1909; = Diplographis Kremp. ex A. Massal. 1860 [1859-1860]; = Dyplolabia A. Massal. 1854; = Graphidomyces E.A. Thomas ex Cif. \& Tomas. 1953; = Opegrapha Humb. 1793; = Oxystoma Eschw. 1824; = Scaphis Eschw. 1824; = Thelographis Nyl. 1857 fide Species Fungorum 2017), Graphidaceae, Ostropales, Lecanoromycetes, eight species, type: A. turbulenta ( $\mathrm{Nyl})$ Hue, asexual morph unknown, lichenized, terrestrial, tropical, see Lumbsch and Huhndorf (2010; outline), Rivas Plata et al. (2012a; phylogeny), Lücking et al. (2016b; classification), sequences are unavailable.

Anopeltis Bat. \& Peres 1960, Dothideomycetes genera incertae sedis, one species, type: A. venezuelensis Bat. \& Peres, asexual morph unknown, saprobes, terrestrial, Venezuela, see Lumbsch and Huhndorf (2010; outline, accepted as a genus in Capnodiaceae), Hyde et al. (2013) did not accept as a genus in Capnodiaceae, Kirk et al. (2013; genus accepted), Wijayawardene et al. (2014c; outline, accepted as a genus in Dothideomycetes, genera incertae sedis), cultures and sequences are unavailable, needs generic revision.

Anopodium N. Lundq. 1964, Lasiosphaeriaceae, Sordariales, Sordariomycetes, two species, type: A. ampullaceum N. Lundq., asexual morph unknown, saprobes, terrestrial, Europe, see Lumbsch and Huhndorf (2010; outline), Kirk et al. (2013; genus accepted), Kruys et al. (2015; DNA, phylogeny), Maharachchikumbura et al. (2015, 2016; outline), cultures and sequences are available.

Antarctomyces Stchigel \& Guarro 2001, Thelebolaceae, Thelebolales, Leotiomycetes, one species, type: A. psychrotrophicus Stchigel \& Guarro, asexual morph sporothrix-like, saprobes, terrestrial, Antarctica, see Lumbsch and Huhndorf (2010; outline), Kirk et al. (2013; genus accepted), Bansal et al. (2014; antifreeze proteins), cultures and sequences are available.

Anteaglonium Mugambi \& Huhndorf 2009, Anteagloniaceae, Pleosporales, Dothideomycetes, six species, type: A. abbreviatum (Schwein.) Mugambi \& Huhndorf, asexual morph unknown, saprobes, terrestrial, aquatic, worldwide, see Mugambi and Huhndorf (2009a, 2010, taxonomy), Almeida et al. (2014b, new species), Jayasiri et al. (2016, new species, asexual morph of this genus and reference specimens), Hyde et al. (2013, included in to new family, Anteagloniaceae), Wijayawardene et al. (2014c; outline), cultures available for the type: ANM 925aT. 
Antennatula Fr. ex F. Strauss 1850 (= Hormisciella Bat. 1956 fide Species Fungorum 2017), Ascomycota genera incertae sedis, ten species, type: A. pinophila Fr., hyphomycetous, sexual morph unknown, saprobes, terrestrial, cosmopolitan, see Seifert et al. (2011; morphology), Wijayawardene et al. (2012, 2017; outline), Kirk et al. (2013; genus accepted), cultures and sequences are unavailable.

Antennopsis R. Heim 1952, Ascomycota genera incertae sedis, three species, type: A. gallica R. Heim \& Buchli ex R. Heim, hyphomycetous, sexual morph unknown, see Seifert et al. (2011; morphology), Wijayawardene et al. (2012, 2017; outline), cultures and sequences are unavailable, needs generic revision.

Antennospora Meyers 1957, Halosphaeriaceae, Microascales, Sordariomycetes, one species, type: A. caribbea Meyers, asexual morph unknown, saprobes, marine, worldwide, see Pang et al. (2008b; taxonomy), Lumbsch and Huhndorf (2010; outline), Kirk et al. (2013; genus accepted), Jones et al. (2015; outline), Maharachchikumbura et al. (2015, 2016; outline), cultures and sequences are available, needs generic revision.

Antennulariella Woron. 1915 (= ?Antennariella Bat. \& Cif.;= Capnodendron S. Hughes 1963; = Capnociferria Bat. 1963; = Capnocrinum Bat. \& Cif. 1963; = Capnodina (Sacc.) Sacc. 1926; = Capnodium subgen. Capnodina Sacc. 1913 fide Wijayawardene et al. 2014c; Species Fungorum 2017), Antennulariellaceae, Capnodiales, Dothideomycetes, three species, type: A. fuliginosa Woron., asexual morph unknown, saprobes, terrestrial, worldwide, see Lumbsch and Huhndorf (2010; outline), Hyde et al. (2013; accepted as a genus in Antennulariellaceae), Kirk et al. (2013; genus accepted), Wijayawardene et al. (2014c; outline, treated Antennariella Bat. \& Cif. and Capnodendron S. Hughes as synonyms), Rossman et al. (2015b) did not agree with Wijayawadene et al. (2014c), cultures and sequences are unavailable, needs generic revision.

Anthocanalis Daranagama, Camporesi \& K.D. Hyde 2015, Hypoxylaceae, Xylariales, Sordariomycetes, one species, type: A. sparti Daranag., Camporesi \& K.D. Hyde, asexual morph nodulisporium-like, saprobes, terrestrial, Europe, see Daranagama et al. (2015a), Maharachchikumbura et al. (2015, 2016), Wendt et al. (2017; phylogeny), holotype and extype strains of type: MFLU 14-0225, MFLUCC 14-0010.

Anthonectria Döbbeler 2010, Bionectriaceae, Hypocreales, Sordariomycetes, eight species, type: A. mammispora Döbbeler, asexual morph unknown, saprobes, epiphytes, terrestrial, cosmopolitan, see Döbbeler (2010; taxonomy), Lumbsch and Huhndorf (2010; outline), Maharachchikumbura et al. (2015, 2016; outline), cultures and sequences are unavailable.

Anthopsis Fil. March., A. Fontana \& Luppi Mosca 1977, Ascomycota genera incertae sedis, three species, type: A. deltoidea Fil. March., A. Fontana \& Luppi Mosca, asexual morph hyphomycetous, Europe, Japan, see Seifert et al. (2011; morphology), Wijayawardene et al. (2012, 2017; outline), Kirk (2013; genus accepted), cultures and sequence are unavailable, needs generic revision.

Anthostoma Nitschke 1867, Diatrypaceae, Xylariales, Sordariomycetes, one species, type: $N$. stictarum Nannf. \& R. Sant., asexual morph unknown, saprobes, see Kirk et al. (2008; treated as a synonym of Cryptosphaeria Ces. \& De Not.), Lumbsch and Huhndorf (2010; outline), Maharachchikumbura et al. (2015, 2016; outline, accepted as a distinct genus), cultures and sequences are available.

Anthostomaria (Sacc.) Theiss. \& Syd. 1918 (= Anthostomella subgen. Anthostomaria Sacc. 1905 fide Species Fungorum 2017), Sordariomycetes genera incertae sedis, one species, type: A. apogyra (Nyl.) Theiss. \& Syd., asexual morph unknown, lichenicolous, terrestrial, former USSR, see Lumbsch and Huhndorf (2010; outline), Kirk et al. (2013; genus accepted), Maharachchikumbura et al. $(2015,2016)$, needs generic revision.

Anthostomella Sacc. 1875 (= Cryptosordaria De Not. ex Sacc. 1891; = Entosordaria Speg. 1910, nom. Inval.; = Maurinia Niessl 1876; = Myconeesia Kirschst. 1936; $\equiv$ Neesiella 
Kirschst. 1935; = Paranthostomella Speg. 1910; = Phaeophomatospora Speg. 1909 fide Wendt et al. 2017), Xylariaceae, Xylariales, Sordariomycetes, more than 100 species, type: A. tomicoides Sacc., asexual morph hyphomycetous, terrestrial, saprobes, worldwide, see Lumbsch and Huhndorf (2010; outline), Kirk et al. (2013; genus accepted), Daranagama et al. (2015a; phylogeny), Maharachchikumbura et al. (2015, 2016; outline), cultures and sequences are available.

Anthostomellina L.A. Kantsch. 1928, Sordariomycetes genera incertae sedis, two species, type: A. carpinea L.A. Kantsch., asexual morph unknown, saprobes, terrestrial, former USSR, see Lumbsch and Huhndorf (2010; outline), Kirk et al. (2013; genus accepted), Maharachchikumbura et al. $(2015,2016)$, needs generic revision.

Anthostomelloides Tibpromma \& K.D. Hyde 2016, Xylariaceae, Xylariales, Sordariomycetes, five species, type: A. krabiensis Tibpromma \& K.D. Hyde, asexual morph unknown, terrestrial, saprobes, Asia, see Tibpromma et al. (2017a; taxonomy), Wendt et al. (2017; placed in Hypoxylaceae), cultures and sequences are available.

Anthracobia Boud. 1885, Pyronemataceae, Pezizales, Pezizomycetes, 20 species, type: A. melaloma (Alb. \& Schwein.) Boud., scytalidium-like asexual morph has been reported, saprobes, terrestrial, on burnt soil, worldwide, see Lumbsch and Huhndorf (2010; outline), Kirk et al. (2013; genus accepted), Hansen et al. (2013; phylogeny), cultures and sequences are available.

Anthracocarpon Breuss 1996, Verrucariaceae, Verrucariales, Eurotiomycetes, three species, type: A. virescens (Zahlbr.) Breuss, lichenized, see Lumbsch and Huhndorf (2010; outline), Prieto et al. (2012; phylogeny), Kirk et al. (2013; genus accepted), Lücking et al. (2016b; classification), sequences are available.

Anthracoderma Speg. 1888, Ascomycota genera incertae sedis, three species, type: A. hookeri Speg., coelomycetous, sexual morph unknown, South America see Wijayawardene et al. (2012, 2017; outline), Kirk et al. (2013; genus accepted), cultures and sequences are unavailable, need generic revision.

Anthracothecium Hampe ex A. Massal. 1860 (= Phaeodictyon M. Choisy 1929 fide Species Fungorum 2017), Pyrenulaceae, Pyrenulales, Eurotiomycetes, five species, type: $A$. doleschallii A. Massal., asexual morph unknown, lichenized, terrestrial, tropical, see Lumbsch and Huhndorf (2010; outline), Aptroot (2012; key), Weerakoon et al. (2012a; phylogeny), Kirk et al. (2013; genus accepted), Gueidan et al. (2016; taxonomy), Lücking et al. (2016b; classification), cultures and sequences are available but lacks for the type species. Antimanoa Syd. 1930, Ascomycota genera incertae sedis, one species, type: A. grisleae Syd., asexual morph unknown, saprobes, terrestrial, South America, see Lumbsch and Huhndorf (2010; outline), Kirk et al. (2013; genus accepted), cultures and sequences are unavailable, needs generic revision.

Antoniomyces Inácio 2012, Parmulariaceae, Dothideomycetes families incertae sedis, Dothideomycetes, one species, type: A. loranthicola Inácio, Araúz \& M. Piepenbr., asexual morph unknown, epiphytes, terrestrial, Panama, see Inácio et al. (2012; morphology, accepted as a genus in Parmulariaceae), Hyde et al. (2013; review, keys), Wijayawardene et al. (2014c; outline), placement in Parmulariaceae supported by morphology, holotype of type: PMA, cultures and sequences are unavailable, needs generic revision.

Antromyces Fresen. 1850, Ascomycota genera incertae sedis, four species, type: Antromyces copridis Fresen., hyphomycetous, sexual morph unknown, Europe, South America, see Seifert et al. (2011; morphology), Wijayawardene et al. (2012, 2017; outline), Kirk et al. (2013; genus accepted), cultures and sequences are unavailable, need generic revision.

Anulohypha Cif. 1962, Ascomycota genera incertae sedis, one species, type: A. serpens Cif., hyphomycetous, sexual morph unknown, Dominican Republic, see Seifert et al. (2011; did 
not accept), Kirk et al. (2013; genus accepted), cultures and sequences are unavailable, need generic revision.

Anungitea B. Sutton 1973, Xylariales genera incertae sedis, Sordariomycetes, 17 species, type: A. fragilis B. Sutton, asexual morph unknown, saprobes, terrestrial, cosmopolitan, see Seifert et al. (2011; morphology), Wijayawardene et al. (2012, 2017; outline), Kirk et al. (2013; genus accepted), Crous et al. (2014c, 2016a; new species), Xia et al. (2015b; new species), cultures and sequences are available but lacks for the type species, needs generic revision.

Anungitopsis R.F. Castañeda \& W.B. Kendr. 1990, Ascomycota genera incertae sedis, type: A. speciosa R.F. Castañeda \& W.B. Kendr., hyphomycetous, sexual morph unknown, saprobes, terrestrial, Cuba, see Seifert et al. (2011; taxonomy), Wijayawardene et al. (2012, 2017; outline), Kirk et al. (2013; genus accepted), holotype of type: INIFAT C88/275, sequences are available, compare with Anungitea and Iyengarina.

Anzia Stizenb. 1861 (= Chondrospora A. Massal. 1860 [1859-1860] fide Species Fungorum 2017), Parmeliaceae, Lecanorales, Lecanoromycetes, c. 25 species, type: A. colpodes (Ach.) Stizenb., with ascomata, lichenized (green algae), terrestrial, tropical to subtropical, see Crespo et al. (2010b; phylogeny), Lumbsch and Huhndorf (2010; outline), Jayalal et al. (2012b; new species), Kirk et al. (2013; genus accepted), Miądlikowska et al. (2014a; phylogeny), Divakar et al. (2015; phylogeny), Wang et al. (2015d; new species), Lücking et al. (2016b; classification), sequences are available.

Anzina Scheid. 1982, Ostropales genera incertae sedis, Lecanoromycetes, one species, type: A. carneonivea (Anzi) Scheid., lichenized, terrestrial, Eurasia, see Lumbsch and Huhndorf (2010; outline), Yu-liang et al. (2012; China), Kirk et al. (2013; genus accepted), Resl et al. (2015; phylogeny), Lücking et al. (2016b; classification), sequences are available.

Aoria Cif. 1962, Ascomycota genera incertae sedis, one species, type: A. amphistroma Cif., coelomycetous, sexual morph unknown, Dominican Republic, see Wijayawardene et al. (2012, 2017; outline), Kirk et al. (2013; genus accepted), cultures and sequences are unavailable, need generic revision.

Aparaphysaria Speg. 1922, Pezizales genera incertae sedis, Pezizomycetes, two species, type: A. doelloi Speg., asexual morph unknown, terrestrial, South America, Tierra del Fuego, see Lumbsch and Huhndorf (2010; outline), Kirk et al. (2013; genus accepted), Jaklitsch et al. (2016a; classification), cultures and sequences are unavailable, needs generic revision.

Apatelomyces Thaxt. 1931, Laboulbeniaceae, Laboulbeniales, Laboulbeniomycetes, one species, type: A. ogmoceri Thaxt., asexual morph unknown, biotrophic only host known is Ogmocerus sp. (Coleoptera, Pselaphidae), Afrotropical, Liberia, see Lumbsch and Huhndorf (2010; outline), Kirk et al. (2013; genus accepted), cultures and sequences are unavailable, needs generic revision.

Apatomyces Thaxt. 1931, Laboulbeniaceae, Laboulbeniales, Laboulbeniomycetes, one species, type: A. laboulbenioides Thaxt., asexual morph unknown, dioecious, biotrophic only host known is Tachys ceylonicus Nietn. (Coleoptera, Carabidae), Philippines, see Lumbsch and Huhndorf (2010; outline), Kirk et al. (2013; genus accepted), cultures and sequences are unavailable, needs generic revision.

Apatoplaca Poelt \& Hafellner 1980 (see Species Fungorum 2017 for synonyms), Teloschistaceae, Teloschistales, Lecanoromycetes, one species, type: A. oblongula (H. Magn.) Poelt \& Hafellner, lichenized, see Vondrák et al. (2012; taxonomy), Lücking et al. (2016b; classification), sequences are unavailable.

Apenidiella Quaedvl. \& Crous 2014, Teratosphaeriaceae, Capnodiales, Dothideomycetes, one species, type: A. strumelloidea (Milko \& Dunaev) Quaedvlieg \& Crous, hyphomycetous, sexual morph unknown, pathogens, terrestrial, Russia, see Quaedvlieg et al. (2014; 
morphology, phylogeny), Wijayawardene et al. (2014c; outline), holotype of the type: BKMF-2534, ex-type strain of type: CBS 114484.

Aphanandromyces W. Rossi 1982, Laboulbeniaceae, Laboulbeniales, Laboulbeniomycetes, one species, type: A. audisioi W. Rossi, asexual morph unknown, biotrophic only host known is Brachypterus urticae (Coleoptera, Kateretidae), Europe, temperate to cool, see Lumbsch and Huhndorf (2010; outline), Kirk et al. (2013; genus accepted), cultures and sequences are unavailable, needs generic revision.

Aphanoascus Zukal 1890, Onygenaceae, Onygenales, Eurotiomycetes, c. 10 species, type: A. cinnabarinus Zukal, asexual morph unknown, saprobes, worldwide, see Lumbsch and Huhndorf (2010; outline), Kirk et al. (2013; genus accepted), Jaklitsch et al. (2016a; classification), sequences and culture available.

Aphanocladium W. Gams 1971, Clavicipitaceae, Hypocreales, Sordariomycetes, one species, type: A. album (Preuss) W. Gams, asexual morphs unknown, on mycetozoans, terrestrial, cosmopolitan, see Seifert et al. (2011; morphology), Wijayawardene et al. (2012, 2017; outline), Kirk (2013; genus accepted), cultures and sequences are available.

Aphanofalx B. Sutton 1986, Ascomycota genera incertae sedis, two species, type: A. mali B. Sutton, coelomycetous, sexual morph unknown, saprobes, Pakistan, Zambia, see Wijayawardene et al. (2012, 2017; outline), Kirk et al. (2013; genus accepted), cultures and sequences are unavailable, needs generic revisions, holotype: IMI293036.

Aphanophora Réblová \& Unter. 2013, Chaetothyriaceae, Chaetothyriales, Eurotiomycetes, three species, type: A. eugeniae (Crous \& Alfenas) Réblová \& Unter., hyphomycetous, sexual morph unknown, from living leaves of Eugenia uniflora, terrestrial, Rio Grande do Sul, see Réblová et al. (2013; taxonomy), ex-type cultures of the type: CBS 124105.

Aphanopsis Nyl. ex Sydow 1882 (= Aphanopsis Nyl. ex P. Syd. 1887 fide Species Fungorum 2017), Aphanopsidaceae, Ascomycota family incertae sedis, two species, type: A. terrigena (Ach.) Nyl. ex P. Syd., lichenized, see Lumbsch and Huhndorf (2010; outline), Printzen et al. (2012; taxonomy), Kirk et al. (2013; genus accepted), Lücking et al. (2016b; classification), sequences are available.

Aphanostigme Syd. 1926 (= Gomezina Chardón \& Toro 1934; = Somatexis Toro, in Chardon \& Toro 1934 fide Species Fungorum 2017), Pseudoperisporiaceae, Dothideomycetes families incertae sedis, 21 species, type: A. solani Syd., asexual morph unknown, ascomata occurring as a saprophyte or a leaf hair parasite, see Lumbsch and Huhndorf (2010; outline), Hyde et al. (2013; accepted as a genus in Pseudoperisporiaceae), Kirk et al. (2013; genus accepted), Wijayawardene et al. (2014c; outline), cultures and sequences are unavailable, needs generic revision.

Aphanotria Döbbeler 2007, Bionectriaceae, Hypocreales, Sordariomycetes, one species, type: A. paradoxa Döbbeler, asexual morph unknown, saprobes, Colombia, see Lumbsch and Huhndorf (2010; outline), Maharachchikumbura et al. (2016; outline), Jaklitsch et al. (2016a; classification), cultures and sequences are unavailable, needs generic revision.

Apharia Bonord. 1864, Sordariomycetes genera incertae sedis, one specie, type: $H$. nigrescens Bonord., asexual morph unknown, saprobes, terrestrial, Europe, see Lumbsch and Huhndorf (2010; outline), Kirk et al. (2013; genus accepted), Maharachchikumbura et al. (2015, 2016; outline), needs generic revision

Aphidomyces Brain 1923, Saccharomycetales genera incertae sedis, Saccharomycetes, three species, type: no typification data, asexual morph unknown, in insects, terrestrial, worldwide, see Lumbsch and Huhndorf (2010) did not include, Kirk et al. (2013; genus accepted), needs generic revision.

Apiculospora Wijayaw., Camporesi, A.J.L. Phillips \& K.D. Hyde 2016, Helotiales genera incertae sedis, Leotiomycetes, one species, type: A. spartii Wijayaw., W.J. Li, Camporesi, A.J.L. Phillips \& K.D. Hyde, coelomycetous, sexual morph unknown, saprobes, terrestrial, 
Italy, see Wijayawardene et al. (2016b, 2017; taxonomy, phylogeny, outline), holotype and ex-type culture of the type: MFLU 15-3556, MFLUCC 13-0400.

Apinisia La Touche 1968, Onygenaceae, Onygenales, Eurotiomycetes, two species, type: A. graminicola La Touche, asexual morph unknown, saprobes, terrestrial, Europe, Australia, see Lumbsch and Huhndorf (2010; outline), Kirk et al. (2013; genus accepted), culture available for the type: CBS 721.68.

Apiocamarops Samuels \& J.D. Rogers 1987, Boliniaceae, Boliniales, Sordariomycetes, three species, type: A. alba Samuels \& J.D. Rogers, asexual morphs unknown, saprobes, terrestrial, Central and South America, see Lumbsch and Huhndorf (2010; outline), Kirk et al. (2013; genus accepted), Maharachchikumbura et al. (2015, 2016; outline, phylogeny), cultures and sequences are unavailable.

Apiocarpella Syd. \& P. Syd. 1919 (= Apiosporella Speg. 1910 fide Species Fungorum 2017), Ascomycota genera incertae sedis, eight species, type: A. macrospora (Speg.) Syd. \& P. Syd., coelomycetous, sexual morph unknown, saprobes, terrestrial, cosmopolitan, see Wijayawardene et al. (2012, 2017; outline), Kirk et al. (2013; genus accepted), cultures and sequences are available but unpublished, needs generic revision.

Apioclypea K.D. Hyde 1994, Clypeosphaeriaceae, Xylariales, Sordariomycetes, six species, type: A. livistonae K.D. Hyde, asexual morphs unknown, saprobes, terrestrial, cosmopolitan, see Lumbsch and Huhndorf (2010; outline), Kirk et al. (2013; genus accepted), Maharachchikumbura et al. (2015, 2016; outline), cultures and sequences are available for unidentified species.

Apiodiscus Petr. 1940, Rhytismatales genera incertae sedis, Leotiomycetes, one species, type: A. gillii Petr., asexual morph unknown, saprobes, terrestrial, Iran, see Lumbsch and Huhndorf (2010; outline), Kirk et al. (2013; genus accepted), cultures and sequences are unavailable, needs generic revision.

Apiognomonia Höhn. 1917, Gnomoniaceae, Diaporthales, Sordariomycetes, c. 15 species, type: A. veneta (Sacc. \& Speg.) Höhn., asexual morph unknown, saprobes, terrestrial, North America, Europe, see Lumbsch and Huhndorf (2010; outline), Vasilyeva and Stephenson (2010; new species), Kirk et al. (2013; genus accepted), Maharachchikumbura et al. (2015, 2016; outline), Crous et al. (2016a; new species), cultures and sequences are available.

Apioplagiostoma M.E. Barr 1978, Gnomoniaceae, Diaporthales, Sordariomycetes, three species, type: A. populi (E.K. Cash \& Waterman) M.E. Barr, asexual morph discula-like, weak pathogens, terrestrial, temperate, Europe, North America, see Lumbsch and Huhndorf (2010; outline, accepted genus in Valsaceae), Sogonov et al. (2008; taxonomy, phylogeny), Kirk et al. (2013; genus accepted), Maharachchikumbura et al. (2015, 2016; outline), cultures and sequences are available.

Apioporthella Petr. 1929 (= Apiothecium Lar.N. Vassiljeva 1987 fide Species Fungorum 2017), Diaporthaceae, Diaporthales, Sordariomycetes, one species, type: A. bavarica Petr., asexual morph unknown, saprobe, terrestrial, temperate, Europe, Japan, see Lumbsch and Huhndorf (2010; outline), Kirk et al. (2013; genus accepted), Maharachchikumbura et al. (2015, 2016; outline), cultures and sequences are unavailable.

Apiorhynchostoma Petr. 1923, Boliniaceae, Boliniales, Sordariomycetes, five species, type: A. apiculatum (Sacc.) Petr., asexual morphs unknown, saprobes, terrestrial, Europe, see Lumbsch and Huhndorf (2010; outline), Kirk et al. (2013; genus accepted), Maharachchikumbura et al. (2015, 2016; outline), cultures and sequences are available.

Apiosordaria Arx \& W. Gams. 1967 (= Cainea S. Hughes 1951; = Echinopodospora B.M. Robison 1970; = Echinospora Mirza 1963; = Lacunospora Cailleux 1969 [1968] fide Species Fungorum 2017), Lasiosphaeriaceae, Sordariales, Sordariomycetes, 23 species; type: A. verruculosa Arx \& W. Gams, asexual morph unknown, saprobes, endophytes, terrestrial, aquatic, worldwide, see Lumbsch and Huhndorf (2010; genus accepted), Kirk et al. (2013; 
genus accepted), Maharachchikumbura et al. (2015, 2016; outline), sequences are and culture are available for type: CBS 244.71.

Apiosphaeria (Spegazzini) Höhnel 1909 (= Anisochora Theiss. \& Syd. 1915; = Oswaldia Rangel 1921 fide Species Fungorum 2017), Phyllachoraceae, Phyllachorales, Sordariomycetes, four species, type: A. guaranitica (Speg.) Höhn, asexual morph unknown, terrestrial, South America, Lumbsch and Huhndorf (2010; genus accepted), Kirk et al. (2013; genus accepted), Maharachchikumbura et al. (2015, 2016; outline), culture are available for type: CCMF 766.

Apiosporina Höhn. 1910 (= Dibotryon Theiss. \& Syd. 1915 fide Zhang et al. 2011d), Venturiaceae, Venturiales, Dothideomycetes, c. two species, type: A. collinsii (Schwein.) Höhn., asexual morph unknown, saprobes, terrestrial, worldwide, see Lumbsch and Huhndorf (2010; outline), Raja et al. (2011a; DNA), Zhang et al. (2011d; morphology, phylogeny), Hyde et al. (2013; accepted as in Venturiaceae, phylogeny), Wijayawardene et al. (2014c; outline), cultures and sequences are available.

Apiosporopsis (Traverso) Mariani 1911 (= Guignardia subgen. Apiosporopsis Traverso 1907; = Sphaerognomonia Potebnia ex Höhn. 1917 fide Species Fungorum 2017), Diaporthales genera incertae sedis, Sordariomycetes, three species, type: A. saccardoana Mariani (as 'saccardiana'), asexual morph unknown, saprobes, endophytes, terrestrial, Dominican Republic, Europe, India, Japan, see Lumbsch and Huhndorf (2010; outline), Osono and Masuya (2012; diversity on Betulaceae), Kirk et al. (2013; genus accepted), Keča et al. (2015; diversity on Poplars), Maharachchikumbura et al. (2015, 2016; outline), sequences are available for Apiosporopsis carpinea.

Apiothyrium Petr. 1947, Hyponectriaceae, Xylariales, Sordariomycetes, two species, type: A. arcticum Petr., asexual morph unknown, saprobes, terrestrial, Finland, see Lumbsch and Huhndorf (2010; outline), Kirk et al. (2013; genus accepted), Maharachchikumbura et al. (2015, 2016; outline), cultures and sequences are unavailable, needs generic revision.

Apiotypa Petr. 1925, Ascomycota genera incertae sedis, one species, type: A. philippinensis Petr., asexual morph unknown, saprobes, terrestrial, Phillipines, see Lumbsch and Huhndorf (2010; outline), Kirk et al. (2013; genus accepted), cultures and sequences are unavailable, needs generic revision as Kirk et al. (2008) mentioned that type material is missing.

Aplanocalenia Lücking, Sérus. \& Vězda 2005, Gomphillaceae, Ostropales, Lecanoromycetes, one species, type: A. inconspicua (Müll. Arg.) Lücking, Sérus. \& Vězda, lichenized, see Lumbsch and Huhndorf (2010; outline), Lücking et al. (2016b; classification), sequences are unavailable.

Aplosporella Speg. 1880 (= Aplosporella subgen. Aplosporella Speg. 1880; = Aplosporella subgen. Euaplosporella Petr. \& Syd. 1926; = Aplosporella subgen. Pleosphaeropsis (Died.) Petr. \& Syd. 1880; = Epicyta Syd. 1926; = Microhaplosporella Sousa da Câmara 1949; = Pleosphaeropsis Died. 1916; = Podosporium Bonord. 1851; = Podosporium Sacc. \& Schulzer 1884 fide Species Fungorum 2017), Aplosporellaceae, Botryosphaeriales, Dothideomycetes, c. 70 species, type: A. chlorostroma Speg., asexual morph unknown coelomycetous, saprobes, terrestrial, worldwide, see Wijayawardene et al. (2012, 2014c, 2016b, 2017; outline, taxonomy, phylogeny), Hyde et al. (2013; accepted as a genus in Botryosphaeriaceae), Kirk et al. (2013; genus accepted), Slippers et al. (2013; phylogeny), Trakunyingcharoen et al. (2015; new species, phylogeny), Crous et al. (2016a; new species, phylogeny), cultures and sequences are available.

Apodospora Cain \& J.H. Mirza 1970, Lasiosphaeriaceae, Sordariales, Sordariomycetes, four species, type: A. simulans Cain \& J.H. Mirza, asexual morph unknown, coprophilous, North America, Europe, see Lumbsch and Huhndorf (2010; outline), Kirk et al. (2013; genus accepted), Maharachchikumbura et al. (2015, 2016; outline), culture and sequences are available. 
Apodothina Petr. 1970, Sordariomycetes genera incertae sedis, one species, type: A. pringlei (Peck) Petr., asexual morph unknown, saprobes, from living leaves, terrestrial, USA, see Lumbsch and Huhndorf (2010; outline), Kirk et al. (2013; genus accepted), Maharachchikumbura et al. (2015, 2016; outline), cultures and sequences are unavailable, needs generic revision.

Apodus Malloch \& Cain 1971, Lasiosphaeriaceae, Sordariales, Sordariomycetes, two species, type: A. deciduus Malloch \& Cain, asexual morph unknown, coprophilous, terrestrial, North America, see Lumbsch and Huhndorf (2010; outline), Kirk et al. (2013; genus accepted), Maharachchikumbura et al. (2015, 2016; outline), cultures available for the type: CBS 506.70.

Apogaeumannomyces Matsush. 2003, Sordariomycetes genera incertae sedis, one species, type: A. perplexus Matsush., asexual morph unknown, saprobes, from living leaves, terrestrial, Peru, see Lumbsch and Huhndorf (2010; outline), Maharachchikumbura et al. (2015, 2016; outline), holotype: MFC 1P446, cultures and sequences are unavailable, needs generic revision.

Apogloeum Petr. 1954, Ascomycota genera incertae sedis, one species, type: A. concinnum Petr., coelomycetous, sexual morph unknown, rarely reported and in case on leaves of Lomatia polymorpha in Tasmania, Australia, see Wijayawardene et al. (2012, 2017; outline), Kirk et al. (2013; genus accepted), cultures and sequences are unavailable, needs generic revision, holotype: BPI 1110296.

Apoharknessia Crous \& S.J. Lee 2004, Diaporthales genera incertae sedis, Sordariomycetes, one species, type: A. insueta (B. Sutton) Crous \& S.J. Lee, sexual morph unknown, pathogens, Mauritius, Brazil, Colombia, see Crous et al. (2012f; phylogeny), Wijayawardene et al. (2012, 2016b, 2017; taxonomy, phylogeny), epitype and ex-epitype culture of type: herb. CBS 9913, CBS 111377.

Apomelasmia Grove 1937 (= Cheilariopsis Petr. 1959 fide Species Fungorum 2017), Ascomycota genera incertae sedis, eight species, type: A.urticae (Fr.) Grove, coelomycetous, sexual morph unknown, saprobes, terrestrial, cosmopolitan, see Wijayawardene et al. (2012), Maharachchikumbura et al. $(2015,2016)$ treated as a genus in Diaporthales, Kirk et al. (2013; genus accepted), Wijayawardene et al. (2017; outline), cultures and sequences are unavailable, needs generic revision.

Aporellula B. Sutton 1986 [1985] (= Aporella Syd. 1939 fide Species Fungorum 2017), Ascomycota genera incertae sedis, two species, type: A. erigerontis (Syd.) B. Sutton, coelomycetous, sexual morph unknown, saprobes, Ecuador, see Wijayawardene et al. (2012, 2017; outline), Kirk et al. (2013; genus accepted), cultures and sequences are unavailable, needs generic revision, isotype: IMI 288252.

Aporomyces Thaxt. 1931, Laboulbeniaceae, Laboulbeniales, Laboulbeniomycetes, eleven species, type: A. uniflagellatus Thaxt., asexual morph unknown, parasitic on Limnichidae, Histeridae, and Staphylinidae beetles, terrestrial, Asia, Europe, North and South America, see Lumbsch and Huhndorf (2010; outline), Kirk et al. (2013; genus accepted), Rossi and Santamaria (2015; Ecuador), cultures and sequences are unavailable.

Aposphaeria Sacc. 1880, Melanommataceae, Pleosporales, Dothideomycetes, 189 species, type: A. pulviscula (Sacc.) Sacc., coelomycetous, sexual morph ?Melanomma Nitschke ex Fuckel, saprobes, terrestrial, temperate, see Wijayawardene et al. (2012, 2014c, 2017; outline), Kirk et al. (2013; genus accepted), Tian et al. (2015; morphology, phylogeny), Li et al. (2016a; new species), cultures and sequences are available, needs generic revision.

Aposporella Thaxt. 1920, Ascomycota genera incertae sedis, three species, type: A.elegans Thaxt., hyphomycetous, sexual morph unknown, on insects, terrestrial, Africa, see Seifert et al. (2011; taxonomy), Kirk et al. (2013; genus accepted), Wijayawardene et al. (2017; outline), cultures and sequences are unavailable, needs generic revision. 
Apostrasseria Nag Raj 1983, Ascomycota genera incertae sedis, two species, type: A. lunata (Shear) Nag Raj, coelomycetous, sexual morph unknown, saprobes, terrestrial, New Zealand, North America, see Wijayawardene et al. (2012) treated as a genus in Phacidiaceae, Kirk et al. (2013; genus accepted), Wijayawardene et al. (2017; outline), cultures and sequences are unavailable, needs generic revision.

Appendichordella R.G. Johnson, E.B.G. Jones \& S.T. Moss 1987, Halosphaeriaceae, Microascales, Sordariomycetes, one species, type: A. amicta (Kohlm.) R.G. Johnson, E.B.G. Jones \& S.T. Moss, asexual morph unknown, saprobes, marine, Denmark, France, Germany, Yogoslavia, USA, see Jones et al. (2009b, 2015; outline, phylogeny), Lumbsch and Huhndorf (2010; outline), Kirk et al. (2013; genus accepted), Maharachchikumbura et al. (2015, 2016; outline), cultures and sequences are unavailable, needs generic revision.

Appendicospora K.D. Hyde 1995, Apiosporaceae, Xylariales, Sordariomycetes, two species, type: A. coryphae (Rehm) K.D. Hyde, asexual morph unknown, saprobes, terrestrial, Asia, see Lumbsch and Huhndorf (2010; outline), Kirk et al. (2013; genus accepted), Maharachchikumbura et al. (2015, 2016; outline), sequences are available.

Appendicospora K.D. Hyde 1995, Apiosporaceae, Xylariales, Sordariomycetes, two species, asexual morph unknown, saprobes, terrestrial, Asia, type: A. coryphae (Rehm) K.D. Hyde, see Lumbsch and Huhndorf (2010; outline), in Kirk et al. (2013; genus accepted), Maharachchikumbura et al. (2015, 2016; outline), cultures and sequences are unavailable, needs generic revision.

Appendiculella Höhn. 1919 (= Irenina F. Stevens 1927; = Meliola subgen. Irenina (F. Stevens) Cif. 1938 fide Species Fungorum 2017), Meliolaceae, Meliolales, Sordariomycetes, c. 110 species, type: A. calostroma (Desm.) Höhn., asexual morph unknown, saprobes, terrestrial, tropical, see Lumbsch and Huhndorf (2010; outline), Kirk et al. (2013; genus accepted), Maharachchikumbura et al. (2015, 2016; outline), cultures and sequences are available but lacks for the type species, needs generic revision.

Appendispora K.D. Hyde 1994, Roussoellaceae, Pleosporales, Dothideomycetes, two species, type: A. frondicola K.D. Hyde, asexual morph unknown, saprobes, terrestrial, Brunei, see Lumbsch and Huhndorf (2010; outline, accepted as a genus in Didymosphaeriaceae), Hyde et al. (2013; accepted as a genus in Didymosphaeriaceae), Kirk et al. (2013; genus accepted), Ariyawansa et al. (2014a; transferred to Roussoellaceae), Wijayawardene et al. (2014c; outline), cultures and sequences are unavailable, needs generic revision.

Appendixia B.S. Lu \& K.D. Hyde 2000, Xylariales genera incertae sedis, Sordariomycetes, five species, type: A. closterium (Berk. \& M.A. Curtis) B.S. Lu \& K.D. Hyde, asexual morph unknown, saprobes, terrestrial, USA, see Lumbsch and Huhndorf (2010; outline), Maharachchikumbura et al. (2015, 2016; outline), Wendt et al. (2017; placed in Xylariales), cultures and sequences are unavailable, needs generic revision.

Apseudocercosporella Videira \& Crous 2016, Mycosphaerellaceae, Capnodiales, Dothideomycetes, one species, type: A. trigonotidis Videira, H.D. Shin \& Crous, hyphomycetous, sexual morph unknown, plant pathogenic, see Videira et al. (2016; morphology, phylogeny), Wijayawardene et al. (2017; outline), holotype and ex-type culture of the type: KUS-F20054, CBS $131890=$ CPC 10864.

Aptrootia Lücking \& Sipman 2007, Trypetheliaceae, Trypetheliales, Dothideomycetes, three species, type: A. terricola Lücking, Umaña \& Sipman, asexual morph unknown, lichenized fungi, terrestrial, tropical, see Lumbsch and Huhndorf (2010; outline), Hyde et al. (2013; accepted as a genus in Trypetheliaceae), Aptroot and Lücking (2016; monograph), Lücking et al. (2016b, c; classification), sequences are available.

Aquadiscula Shearer \& J.L. Crane 1985, Helotiales genera incertae sedis, Leotiomycetes, two species, type: A. appendiculata Shearer \& J.L. Crane, asexual morph unknown, saprobes 
on submerged leaf, USA, see Lumbsch and Huhndorf (2010; outline), Kirk et al. (2013; genus accepted), cultures and sequences are unavailable.

Aquadulciospora Fallah \& Shearer 2001, Sordariomycetes genera incertae sedis, one species, type: A. rhomboidia Fallah \& Shearer, asexual morph unknown, saprobes, aquatic, USA, see Lumbsch and Huhndorf (2010; outline), Maharachchikumbura et al. (2015, 2016; outline), holotype: ILLS 53999, cultures and sequences are unavailable, needs generic revision.

Aqualignicola Ranghoo, K.M. Tsui \& K.D. Hyde 2001, Annulatascaceae, Annulatascales, Sordariomycetes, two species, type: A. hyalina Ranghoo, K.M. Tsui \& K.D. Hyde, asexual morph unknown, saprobes, fresh water, terrestrial, China, Hong Kong, see Lumbsch and Huhndorf (2010; outline), Hu et al. (2012a; new species, China), Maharachchikumbura et al. (2015, 2016; outline), holotype: HKU (M) 12178, cultures and sequences are unavailable, needs generic revision.

Aquamarina Kohlm., Volkm.-Kohlm. \& O.E. Erikss. 1996, Sordariomycetes genera incerate sedis, one species, type: A. speciosa Kohlm., Volkm.-Kohlm. \& O.E. Erikss., asexual morph unknown, saprobes, marine, tropical, see Lumbsch and Huhndorf (2010; outline), Kirk et al. (2013; genus accepted), cultures and sequences are unavailable, needs generic revision.

Aquanectria L. Lombard \& Crous 2015, Nectriaceae, Hypocreales, Sordariomycetes, two species, type: A. penicillioides (Ingold) L. Lombard \& Crous, asexual morph hyphomycetous, saprobes, aquatic, Jamaica, USA, see Lombard et al. (2015b; morphology, phylogeny), Maharachchikumbura et al. (2015, 2016; outline), ex-epitype of type: CBS 257.54.

Aquapeziza D.M. Hu, L. Cai \& K.D. Hyde 2012, Pezizaceae, Pezizales, Pezizomycetes, one species, type: A. globispora D.M. Hu, L. Cai \& K.D. Hyde, asexual morph unknown, saprobes, aquatic, China, see $\mathrm{Hu}$ et al. (2012c; taxonomy, phylogeny), holotype and cultures available for the type: IFRD 8978, DMH-2010.

Aquaphila Goh, K.D. Hyde \& W.H. Ho 1998, Tubeufiaceae, Tubeufiales, Dothideomycetes, two species, type: A. albicans Goh, K.D. Hyde \& W.H. Ho, sexual morph tubeufia-like, saprobes, submerged wood in aquatic habitats, see Boonmee et al. (2011, 2014b), Seifert et al. (2011; morphology), Wijayawardene et al. (2014c; outline), Hyde et al. (2016; new species, sexual morph), cultures and sequences are available for authentic strains BCC 3520, BCC 3543 and reference strains MFLUCC16-0010, MFLUCC16-0020.

Aquapoterium Raja \& Shearer 2008, Helotiales genera incertae sedis, Leotiomycetes, one species, type: A. pinicola Raja \& Shearer, saprobes, aquatic, see Koukol and Kolárová (2010; demonstrated that Bactrodesmium gabretae Koukol \& Kolářová, which was isolated from spruce needles is closely related to A pinicola Raja \& Shearer, in the Helotiales), Lumbsch and Huhndorf (2010; outline), ex-type strain F47-1 = MYA 4213 (American Type Culture Collection), holotype: F47-1, ILL 40117

Aquapteridospora J. Yang, K.D. Hyde \& Maharachch. 2015, Sordariomycetidae genera incertae sedis, Sordariomycetes, one species, type: A. lignicola Yang Jing, K.D. Hyde \& Maharachch., hyphomycetous, sexual morph unknown, saprobes, aquatic, Thailand, see Yang et al. (2015a; taxonomy, phylogeny), Wijayawardene et al. (2017; outline), holotype: MFLU 15-1172.

Aquasphaeria K.D. Hyde 1995, Sordariomycetes, genera incertae sedis, one species, type: A. dimorphospora K.D. Hyde, asexual morph unknown, saprobes, aquatic, Australia, see Lumbsch and Huhndorf (2010; outline), Kirk et al. (2013; genus accepted), Maharachchikumbura et al. (2015, 2016; outline), holotype: BRIP 21482, cultures and sequences are unavailable, needs generic revision.

Aquastroma Kaz. Tanaka \& K. Hiray. 2015, Parabambusicolaceae, Pleosporales, Dothideomycetes, one species, type: A. magniostiolata Kaz. Tanaka \& K. Hiray., asexual morph unknown, saprobes, aquatic, Japan, see Tanaka et al. (2015; taxonomy, phylogeny), holotype and ex-type strain of the type: HHUF 30122, CBS 139680. 
Aquasubmersa K.D. Hyde \& Huang Zhang 2012, Pleosporales, Dothideomycetes, two species, type: A. mircensis Huang Zhang \& K.D. Hyde, coelomycetous, sexual morph unknown, saprobes, aquatic, Aisa, see Wijayawardene et al. (2012, 2017; outline), Zhang et al. (2012a; taxonomy, phylogeny), Ariyawansa et al. (2015a; new species), cultures and sequences are available.

Aquaticola W.H. Ho, K.M. Tsui, Hodgkiss \& K. D. Hyde 1999, Annulatascaceae, Incertae sedis, Sordariomycetes, six species, type: A. triseptata K.M. Tsui, Hodgkiss \& K.D. Hyde, asexual morph unknown, saprobes, aquatic, Hong Kong, Australia, China, see Lumbsch and Hunduf (2010; outline), Kirk et al. (2013; genus accepted), Maharachchikumbura et al. (2015, 2016; outline), holotype: HKU(M) 2969.

Aquilomyces D.G. Knapp, Kovács, J.Z. Groenew. \& Crous 2015, Morosphaeriaceae, Pleosporales, Dothideomycetes, one species, type: A. patris D.G. Knapp, Kovács, Groenewald \& Crous, endophytes, see Knapp et al. (2015; phylogeny), cultures and sequences are available.

Arachniotus J. Schröt. 1893 (= Disarticulatus G.F. Orr 1977; = Petalosporus G.R. Ghosh, G.F. Orr \& Kuehn 1963; = Plunkettomyces G.F. Orr 1977; = Rollandina Pat. 1905; = Waldemaria Bat., H. Maia \& Cavalc. 1960 fide Species Fungorum 2017), Gymnoascaceae, Onygenales, Eurotiomycetes, three species, type: A. ruber (Tiegh.) J. Schröt., asexual morph unknown, saprobes, from soil, Poland, see Lumbsch and Huhndorf (2010; outline), Ropars et al. (2012; DNA), Kirk et al. (2013; genus accepted), cultures available for the type: MUCL 39748, needs generic revision.

Arachnocrea Z. Moravec 1956, Hypocreaceae, Hypocreales, Sordariomycetes, three species, type: A. stipata (Fuckel) Z. Moravec, asexual morphs ?verticillium-like, saprobes, terrestrial, Japan, see Lumbsch and Huhndorf (2010; outline), Kirk et al. (2013; genus accepted), Maharachchikumbura et al. (2015, 2016; outline), Jaklitsch et al. (2016a; classification), cultures and sequences are available.

Arachnomyces Massee \& E.S. Salmon 1902, Arachnomycetaceae, Onygenales, Eurotiomycetes, ten species, type: A. nitidus Massee \& E.S. Salmon, asexual morph unknown, saprobes, Europe, see Gueidan et al. (2008; DNA), Lumbsch and Huhndorf (2010; outline), Kirk et al. (2013; genus accepted), sequence available for the type: AB075351, needs generic revision.

Arachnopeziza Fuckel 1870 (= Arachnopezizella Kirschst. 1938; = Arachnoscypha Boud. 1885 fide Species Fungorum 2017), Arachnopezizaceae, Helotiales, Leotiomycetes, c. 15 species, type: A. aurelia (Pers.) Fuckel., asexual morph hyphomycetous, saprobes worldwide, common in temperate and subtropical, see Lumbsch and Huhndorf (2010; outline), Kirk et al. (2013; genus accepted), Han et al. (2014; phylogeny), cultures and sequence are available but lacks for the type species.

Arachnophora Hennebert 1963 (= Cacahualia Mercado \& R.F. Castañeda 1984; = Sopagraha Subram. \& Sudha 1979 fide Species Fungorum 2017), Ascomycota genera incertae sedis, three species, type: A. fagicola Hennebert, hyphomycetous, sexual morph unknown, saprobes, terrestrial, cosmopolitan, see Pratibha et al. (2011; new species), Seifert et al. (2011; taxonomy), Wijayawardene et al. (2012, 2017; outline), Kirk et al. (2013; genus accepted), cultures and sequences are unavailable, needs generic revision.

Arachnoscypha Boud. 1885, Arachnopezizaceae, Helotiales, Leotiomycetes, three species, type: A. aranea (De Not.) Boud., sexual morph unknown, saprobes, UK, see Jaklitsch et al. (2016a; classification), Index Fungorum (2017; treated as a synonym of Arachnopeziza Fuckel), cultures and sequences are unavailable.

Arachnospora R.F. Castañeda, Minter \& Camino 2003, Ascomycota genera incertae sedis, one species, type: A. insolita R.F. Castañeda, Minter \& Camino, hyphomycetous, sexual morph unknown, saprobes, terrestrial, Cuba, see Seifert et al. (2011; morphology), 
Wijayawardene et al. (2012, 2017; outline), holotype: MUCL 42859, cultures and sequences are unavailable, compare with Arachnophora and Iyengarina.

Arachnotheca Arx 1971, Onygenaceae, Onygenales, Eurotiomycetes, three species, type: A. glomerata (E. Müll. \& Pacha-Aue) Arx, asexual morph unknown, saprobes, terrestrial, worldwide, see Lumbsch and Huhndorf (2010; outline), Kirk et al. (2013; genus accepted), Sigler et al. (2013; DNA), culture available for the type: UAMH 3551.

Araneomyces Höhn. 1909 (= Paranectriella (Henn. ex Sacc. \& D. Sacc.) Höhn. fide Wijayawardene et al. 2014c; Rossman et al. 2015b), Paranectriellaceae, Dothideomycetes families incertae sedis, two species, type: A. acarifer Höhn., sexual morph formerly known in Paranectriella, South America, see Seifert et al. (2011; taxonomy), Wijayawardene et al. (2012, 2014c, 2017; outline, nomenclature), Kirk et al. (2013; genus accepted), Rossman et al. (2015b; nomenclature), cultures and sequences are unavailable.

Arborillus Munt.-Cvetk. \& Gómez-Bolea 1998, Ascomycota genera incertae sedis, one species, type: A. llimonae Munt.-Cvetk. \& Gómez-Bolea, hyphomycetous, sexual morph unknown, lichenicolous, terrestrial, Europe, see Seifert et al. (2011; morphology), Wijayawardene et al. (2012, 2017; outline), Kirk et al. (2013; genus accepted), cultures and sequences are unavailable, needs generic revision.

Arborispora K. Ando., 1986, Ascomycota genera incertae sedis, four species, type: A. palma K. Ando, in rainwater draining from leaves of Quercus: Honshu, see Seifert et al. (2011; morphology), Wijayawardene et al. (2012, 2017; outline), Kirk et al. (2013; genus accepted), sexual morph unknown, cultures and sequences are unavailable.

Arbusculina Marvanová \& Descals 1987, Hyaloscyphaceae, Helotiales, Leotiomycetes, three species, type: A. irregularis (R.H. Petersen) Marvanová \& Descals, asexual morph unknown, saprobes, aquatic, Europe, North America, see Seifert et al. (2011; morphology), Wijayawardene et al. (2012, 2017; outline), Kirk et al. (2013; genus accepted), Funck et al. (2015; DNA), cultures and sequences are available but lacks for the type species.

Archaeorhizomyces Rosling \& T.Y. James 2011, Archaeorhizomycetaceae, Archaeorhizomycetales, Archaeorhizomycetes, two species (but many others are predicted from the analysis of environmental sequences), type: A. finlayi Rosling \& T.Y. James, asexual morph unknown, saprobes, from soil, terrestrial, Sweden, Lithuania, see Rosling et al. (2011; taxonomy, phylogeny), Menkis et al. (2014; new species, Lithuania, phylogeny), holotype and ex-type cultures: MICH 72671, CBS 128710.

Architrypethelium Aptroot 1991, Trypetheliaceae, Trypetheliales, Dothideomycetes, seven species, type: A. seminudum(Mont.) Aptroot, asexual morph unknown, lichenized, terrestrial, tropical, see Lumbsch and Huhndorf (2010; outline), Kirk et al. (2013; genus accepted), Aptroot and Lücking (2016; monograph), Lücking et al. (2016b; classification), sequences are available.

Arctocetraria Kärnefelt \& Thell 1993, Parmeliaceae, Lecanorales, Lecanoromycetes, three species, type: A. andrejevii (Oxner) Kärnefelt \& A. Thell, lichenized, terrestrial (corticolous or terricolous), Northern Hemisphere (arctic), see Thell et al. (2009; DNA, phylogeny), Lumbsch and Huhndorf (2010; outline), Nelsen et al. (2011a; DNA, phylogeny), Kirk et al. (2013; genus accepted), Miądlikowska et al. (2014a; DNA, phylogeny), Divakar et al. (2015; DNA, phylogeny), Lücking et al. (2016b; classification), sequences are available.

Arctomia Th. Fr. 1860, Arctomiaceae, Arctomiales, Lecanoromycetes, ten species, type: A. delicatula Th. Fr. lichenized (cyanobacteria), terrestrial (saxicolous, terricolous or corticolous), cosmopolitan, see Lumbsch and Huhndorf (2010; outline), Magain and Sérusiaux (2012; new species), Kirk et al. (2013; genus accepted), Otálora and Wedin (2013; DNA, phylogeny), Miądlikowska et al. (2014a; DNA, phylogeny), Lücking et al. (2016b; classification), sequences are available. 
Arctomollisia Raitv. 2008, Dermateaceae, Helotiales, Leotiomycetes, two species, type: A. oxyparaphysata (Rehm) Raitv., asexual morph unknown, saprobes, terrestrial, Magadan, see Raitviir (2008; taxonomy), cultures and sequences are unavailable, needs generic revision.

Arctoparmelia Hale 1986, Parmeliaceae, Lecanorales, Lecanoromycetes, five species, type: A. centrifuga (L.) Hale, lichenized (green algae), terrestrial (mainly saxicolous), arctic and alpine regions of Northern Hemisphere, see Lumbsch and Huhndorf (2010; outline), Kirk et al. (2013; genus accepted), Miądlikowska et al. (2014a; DNA, phylogeny), Divakar et al. (2015; DNA, phylogeny), Lücking et al. (2016b; classification), sequences are available.

Arcuadendron Sigler \& J.W. Carmich. 1976, Ascomycota genera incertae sedis, three species, type: A. ovatum Sigler \& J.W. Carmich, hyphomycetous, sexual morph unknown, soil, India, former Yugoslavia, see Hyde et al. (2011; outline), Seifert et al. (2011; morphology), Wijayawardene et al. (2012, 2017; outline), Kirk et al. (2013; genus accepted), ex-type strain of type: = ATCC 34519, CBS 122.77, sequences are unavailable, needs generic revision.

Arecacicola Joanne E. Taylor, J. Fröhl. \& K.D. Hyde 2001, Sordariomycetes genera incertae sedis, one species, type: A. calami Joanne E. Taylor, J. Fröhl. \& K.D. Hyde, asexual morph unknown, saprobes, terrestrial, Java, see Lumbsch and Huhndorf (2010; outline), Maharachchikumbura et al. (2015, 2016; outline), holotype: HKU (M) 1126a, cultures and sequences are unavailable, needs generic revision.

Arecomyces K.D. Hyde 1996, Hyponectriaceae, Xylariales, Sordariomycetes, eleven species, type: A. frondicola K.D. Hyde, ascomycetous, asexual morph unknown, saprobes, reported only from palms, terrestrial, widespread, see Lumbsch and Huhndorf (2010; outline), Vitoria et al. (2011, new species), Kirk et al. (2013; genus accepted), Maharachchikumbura et al. (2015, 2016; outline), cultures and sequences are unavailable, needs generic revision.

Arecophila K.D. Hyde 1996, Cainiaceae, Xylariales, Sordariomycetes, 15 species, type: A. gulubiicola K.D. Hyde, asexual morph unknown, saprobes, South East Asia and Papua New Guinea, see Lumbsch and Huhndorf (2010; outline), Kirk et al. (2013; genus accepted), Lee et al. (2013a; sesquiterpenes from A. saccharicola), Maharachchikumbura et al. (2015, 2016; outline), sequence data available for two species but lacks for the type, needs generic revision. Arenariomyces Höhnk 1954, Halosphaeriaceae, Microascales, Sordariomycetes, five species, type: A. trifurcatus Höhnk, aquatic, New Zealand, see Lumbsch and Huhndorf (2010; outline), Kirk et al. (2013; genus accepted), Maharachchikumbura et al. (2015, 2016; outline), sequences are available.

Areolospora S.C. Jong \& E.E. Davis 1974, Sordariomycetes genera incertae sedis, two species, type: A. terrophila S.C. Jong \& E.E. Davis, asexual morph unknown, saprobes, worldwide, see Lumbsch and Huhndorf (2010; outline), Kirk et al. (2013; genus accepted), Maharachchikumbura et al. (2015, 2016; outline), Wendt et al. (2017; accepted as a genus in Sordariomycetes genera incertae sedis), cultures and sequences are unavailable.

Argentinomyces N.I. Peña \& Aramb. 1997, Diaporthales genera incertae sedis, Sordariomycetes, one species, type: A. naviculisporus Peña \& Aramb., asexual morph unknown, saprobes, marine, Argentina, Lumbsch and Huhndorf (2010; outline, accepted as a genus in Ascomycota genera incertae sedis), Koch (2013, new species), Kirk et al. (2013; genus accepted), Maharachchikumbura et al. (2015, 2016; outline), holotype: LPS 45469.

Argopericonia B. Sutton \& Pascoe 1987, Ascomycota genera incertae sedis, two species, type: A. elegans B. Sutton \& Pascoe, hyphomycetous, sexual morph unknown, saprobes, saprophytes, Australia, India, see Seifert et al. (2011; morphology), Wijayawardene et al. (2012, 2017; outline), Kirk et al. (2013; genus accepted), cultures and sequences are unavailable, need further revisions, holotype: VPRI13846.

Argopsis Th.Fr. 1857, Lecanoromycetes genera incertae sedis, three species, type: A. megalospora Th. Fr., lichenized, see Lumbsch and Huhndorf (2010; outline, accepted as a 
genus in Brigantiaeaceae), Kirk et al. (2013; genus accepted), Lücking et al. (2016b; classification), sequences are unavailable.

Argynna Morgan 1895, Argynnaceae, Dothideomycetes families incertae sedis, two species, type: A. polyhedron (Schwein.) Morgan, asexual morph unknown, saprobes, terrestrial, North America, see Lumbsch and Huhndorf (2010; outline), Hyde et al. (2013; accepted as a genus in Argynnaceae, taxonomy), Kirk et al. (2013; genus accepted), Wijayawardene et al. (2014c; outline), cultures and sequences are unavailable, needs generic revision.

Aristastoma Tehon 1933, Ascomycota genera incertae sedis, one species, type: $A$. concentrica Tehon, coelomycetous, sexual morph unknown, saprobes, pathogens, terrestrial, worldwide, see Wijayawardene et al. (2012, 2017; outline), Zhu et al. (2012; DNA, pathogens), Kirk et al. (2013; genus accepted), cultures and sequences are unavailable, needs generic revision.

Arkoola J. Walker \& Stovold 1986, Dothideomycetes genera incertae sedis, one species, type: A. nigra J. Walker \& Stovold, asexual morph unknown, saprobes, terrestrial, Australia, see Lumbsch and Huhndorf (2010; outline, accepted as a genus in Venturiaceae), Zhang et al. (2011d; provisionally accepted as a genus in Venturiaceae), Hyde et al. (2013; did not accept as Venturiaceae), Kirk et al. (2013; genus accepted), Wijayawardene et al. (2014c; outline), cultures and sequences are unavailable, needs generic revision.

Armata W. Yamam. 1958, Dothideomycetes, genera incertae sedis, one species, type: A. macrospora (W. Yamam.) W. Yamam., asexual morph unknown, saprobes, terrestrial, Japan, see Lumbsch and Huhndorf (2010; outline, accepted as a genus in Micropeltidaceae), Hyde et al. (2013; did not accept as a genus in Micropeltidaceae), Kirk et al. (2013; genus accepted), Wijayawardene et al. (2014c; outline), cultures and sequences are unavailable, needs generic revision.

Armatella Theiss. \& Syd. 1915 (= Artallendea Bat. \& H. Maia 1960 fide Species Fungorum 2017), Armatellaceae, Meliolales, Sordariomycetes, 20 species, type: A. litseae (Henn.) Theiss. \& Syd., asexual morph unknown, epiphytes, terrestrial, worldwide distribution, see Hosagoudar and Archana (2009; distribution on Lauraceae), Lumbsch and Huhndorf (2010; outline), Kirk et al. (2013; genus accepted), Hosagoudar et al. (2013; new species), Hongsanan et al. (2015c; family placement), Maharachchikumbura et al. (2015, 2016; outline), cultures and sequences are unavailable.

Arnaudiella Petr. 1927 (= Seynesiola Speg. 1918 fide Wu et al. 2011), Microthyriaceae, Microthyriales, Dothideomycetes, 13 species, type: A. caronae (Pass.) Petr., asexual morph hyphomycetous, saprophyte, see Lumbsch and Huhndorf (2010; outline), Hyde et al. (2013; accepted as a genus in Microthyriaceae), Kirk et al. (2013; genus accepted), Wijayawardene et al. (2014c; outline), cultures and sequences are unavailable.

Arnium Nitschke ex G. Winter 1873, Lasiosphaeriaceae, Sordariales, Sordariomycetes, twelve species, type: A. lanuginosum Nitschke, asexual morph unknown, saprobes and coprophilous, worldwide, see Lumbsch and Huhndorf (2010; outline), Kirk et al. (2013; genus accepted), Maharachchikumbura et al. (2015, 2016; outline), cultures and sequences are available.

Aropsiclus Kohlm. \& Volkm.-Kohlm. 1994 (= Sulcospora Kohlm. \& Volkm.-Kohlm. 1993 fide Species Fungorum 2017), Sordariomycetes, genera incertae sedis, one species, type: A. junci (Kohlm. \& Volkm.-Kohlm.) Kohlm. \& Volkm.-Kohlm., asexual morph unknown, saprobes, terrestrial, USA, see Lumbsch and Huhndorf (2010; outline), Kirk et al. (2013; genus accepted), Maharachchikumbura et al. (2015, 2016; outline), cultures and sequences are unavailable, needs generic revision.

Arpinia Berthet 1974, Otideaceae, Pezizales, Pezizomycetes, four species, type: A. inops Berthet, saprobes, terrestrial, north temperate, see Lumbsch and Huhndorf (2010; outline), 
Kirk et al. (2013; genus accepted), Jaklitsch et al. (2016a; classification), cultures and sequences are available.

Arrhenosphaera Stejskal 1974, Ascosphaeraceae, Onygenales, Eurotiomycetes, two species, type: A. craneae Stejskal, asexual morph unknown, from bee hive, Venezuela, see Lumbsch and Huhndorf (2010; outline), Kirk et al. (2013; genus accepted), Jaklitsch et al. (2016a; classification), sequences and culture available.

Arthonia Ach. 1806 (see Species Fungorum 2017 for synonyms), Arthoniaceae, Arthoniales, Arthoniomycetes, c. 500 species, type: A.radiata (Pers.) Ach. 1808, sexual morph with mainly apothecioid ascomata, asexual morph coelomycetous, lichenized, lichenicolous, saprobes, terrestrial, worldwide, see Lumbsch and Huhndorf (2010; outline), Ertz and Tehler (2011; phylogeny), Kirk et al. (2013; genus accepted), Frisch et al. (2014; phylogeny), Lücking et al. (2016b; classification), cultures and sequences are available.

Arthophacopsis Hafellner 1998, Arthoniales genera incertae sedis, Arthoniomycetes, one species, type: A. parmeliarum Hafellner, lichenicolous, terrestrial, North America, Europe (including Canary Islands), see Lumbsch and Huhndorf (2010; outline), Kirk et al. (2013; genus accepted), holotype: Hafellner 41023 (GZU), cultures and sequences are unavailable.

Arthopyrenia A. Massal. [nom. cons.] 1852, Arthopyreniaceae, Pleosporales, Dothideomycetes, five species, type: A. cerasi (Schrad.) A. Massal., lichenized, see Lumbsch and Huhndorf (2010; outline), Hyde et al. (2013; accepted as a genus in Arthopyreniaceae), Kirk et al. (2013; genus accepted), Wijayawardene et al. (2014c; outline), Lücking et al. (2016b; classification), cultures and sequences are available.

Arthotheliopsis Vain. 1896, Gomphillaceae, Ostropales, Lecanoromycetes, five species, type: A. hymenocarpoides Vain., lichenized, see Lumbsch and Huhndorf (2010; outline), Lücking et al. (2016b; classification), sequences are available.

Arthothelium A. Massal. 1852, Arthoniaceae, Arthoniales, Arthoniomycetes, ten species, type: A. spectabile Flot. ex A. Massal., lichenized, see Lumbsch and Huhndorf (2010; outline), Kirk et al. (2013; genus accepted), Lücking et al. (2016b; classification), sequences are available.

Arthrinium Kunze 1817 (see Species Fungorum 2017 for synonyms), Apiosporaceae, Xylariales, Sordariomycetes, 64 species, type: A. caricicola Kunze \& J.C. Schmidt, saprobes, pathogenic, endophytic, terrestrial, widely distribute, see Seifert et al. (2011; morphology), Wijayawardene et al. (2012, 2017; outline), Crous and Groenewald (2013; phylogeny), Crous and Groenewald (2013; asexual morph, morphology, phylogeny), Kirk et al. (2013; genus accepted), Maharachchikumbura et al. (2015, 2016; outline), Senanayake et al. (2015; morphology, phylogeny), Dai et al. (2016; sexual and asexual morph, morphology, phylogeny), cultures and sequences are unavailable for type species.

Arthrobotrys Corda 1839 (= Dactylariopsis Mekht. 1967; = Dactylium Nees 1816 [1816-17]; = Didymozoophaga Soprunov \& Galiulina 1951; = Duddingtonia R.C. Cooke 1969; = Monacrosporium Oudem. 1885; = Woroninula Mekht. 1979 fide Species Fungorum 2017), Orbiliaceae, Orbiliales, Orbiliomycetes, 112 species, type: A. superba Corda, sexual morph unknown, nematophagous, terrestrial, marine, worldwide see Han et al. (2008; extrolite profiling), Li et al. (2008c, 2009a; taxonomic revision, new species), Swe et al. (2008; new species, marine), Wang et al. (2008b, 2013a, e; amino acid effect, mutant predatory activity, immunological effect of nanoparticles), Braga et al. (2009, 2010, 2014; predatory activity), Ranjbar-Bahadori et al. (2010; in vivo study), Silva et al. (2010; control sheep gastroenteritis), Zhang et al. (2011f, 2012b, 2013e; phylogeny, metabolites studyv, genetic diversity), Carvalho et al. (2011; predatory activity after freeze dry), Niu and Zhang (2011; review), Su et al. (2011a; new species), Wei et al. (2011, 2013; Arthrobotrisins, chitinase encoding gene analysis), Yang et al. (2011b, 2013a; genomics, proteomics), Freire et al. (2012; effect of Fusarium extrolites), Qiao et al. (2012; description), Singh et al. (2012, 
2013c; role in plant immunity, biocontrol potential), Wu et al. (2012a; 2013a; new species, metabolite profiling), Arias et al. (2013; developmental biology), Chen et al. (2013c; trap formation), Falbo et al. (2013; characterization), Jamshidnejad et al. (2013; biocontrol activity), Liang et al. (2013, 2015; cell signalling, proteomic and transcriptional analyses), Wang et al. (2013a; nematophagous), Yang et al. (2013; nematode trapping), Braga et al. (2014; predatory activity after preservation), Liu et al. (2014d; new species), Mostafanezhad et al. (2014; nematode control), Pandit et al. (2014; protease study), Zhao et al. (2014b; malate synthase gene), sequences are available for few species, including type: KT215210.

Arthrobotryum Ces. 1854 (= Arthrographium Ces. 1854; = Lindauomyces Koord. 1907; = Wettsteiniella Kuntze 1891 fide Species Fungorum 2017), Ascomycota genera incertae sedis, five species, type: A. stilboideum Ces., coelomycetous, sexual morph unknown, widespread, see Wijayawardene et al. (2012, 2017; outline), Kirk et al. (2013; genus accepted), cultures and sequences are unavailable, need generic revision.

Arthrocatena Egidi \& Selbmann 2014, Capnodiales genera incertae sedis, Dothideomycetes, one species, type: A. tenebrio E. Egidi \& L. Selbmann, rock-inhabiting fungus, conidia resulting from arthric secession, sexual morph unknown, see Egidi et al. (2014; taxonomy, phylogeny), Wijayawardene et al. (2017; outline), ex-type cultures available for the type: CBS $136100=$ CCFEE 5413.

Arthrocladiella Vassilkov 1960, Erysiphaceae, Erysiphales, Leotiomycetes, three species, type: A. lycii (Lasch) Vassilkov, asexual morph unknown, saprobes, terrestrial, worldwide, see Lumbsch and Huhndorf (2010; outline), Kirk et al. (2013; genus accepted), cultures and sequences are available.

Arthrocladium Papendorf 1969, Trichomeriaceae, Chaetothyriales, Eurotiomycetes, four species, type: A. caudatum Papendorf, asexual morph hyphomycetous, saprobes, terrestrial, Africa and Brazil, see Seifert et al. (2011; morphology), Wijayawardene et al. (2012, 2017; outline), Kirk (2013; genus accepted), Nascimento et al. (2016; phylogeny, human opportunist), ex-type strains of type: CBS 457.67.

Arthrocristula Sigler, M.T. Dunn \& J.W. Carmich. 1982, Ascomycota genera incertae sedis, one species, type: A. hyphenata Sigler, M.T. Dunn \& J.W. Carmich., hyphomycetous, sexual morph unknown, saprobes, terrestrial, North America, see Seifert et al. (2011; morphology), Wijayawardene et al. (2012, 2017; outline), Kirk et al. (2013; genus accepted), cultures and sequences are unavailable, needs generic revision.

Arthroderma Curr. 1860 (= Nannizzia Stockdale 1961 fide Species Fungorum 2017), Arthrodermataceae, Onygenales, Eurotiomycetes, 41 species, type: A. curreyi Berk, asexual morph unknown, see Lumbsch and Huhndorf (2010; outline), Kirk et al. (2013; genus not accepted), sequences and culture are available for type: NCPF 0797

Arthrographis G. Cochet ex Sigler \& J.W. Carmich. 1976, Eremomycetaceae, Dothideomycetes family incertae sedis, twelve species, type: A. kalrae (R.P. Tewari \& Macph.) Sigler \& J.W. Carmich., hyphomycetous, sexual morph unknown, saprobes, on human, terrestrial, cosmopolitan, see Seifert et al. (2011; morphology), Wijayawardene et al. (2012, 2017; outline), Giraldo et al. (2014a; phylogeny, new species), cultures available for type: CBS 693.77.

Arthrophiala W.S. Lisboa, Meir. Silva \& R.W. Barreto 2016, Chaetothyriaceae, Chaetothyriales, Eurotiomycetes, one species, type: A. arthrospora (D.J. Soares et al.) W.S. Lisboa, Meir. Silva \& R.W. Barreto, hyphomycetous, sexual morph unknown, saprobes, terrestrial, Brazil, see Crous et al. (2016a; taxonomy, phylogeny), holotype and ex-type culture of the type: VIC 30505, COAD 658.

Arthropsis Sigler, M.T. Dunn \& J.W. Carmich. 1982, Onygenales, Eurotiomycetes, four species, type: A. truncata Sigler, M.T. Dunn \& J.W. Carmich., hyphomycetous, sexual morph unknown, worldwide, see Seifert et al. (2011; morphology), Wijayawardene et al. (2012, 
2017; outline), Kirk et al. (2013; genus accepted), cultures and sequences are available, need generic revision.

Arthrorhaphis Th. Fr. [nom. cons.] 1860 (= Gongylia Körb. 1855; = Mycobacidia Rehm 1890 [1896]; = Parathalle Clem. 1909; = Raphiospora A. Massal. 1853 fide Species Fungorum 2017), Arthrorhaphidaceae, order incertae sedis, Lecanoromycetes, 13 species, type: A. flavovirescens (A. Massal.) Th. Fr.; lichenized, see Lumbsch and Huhndorf (2010; outline), Kirk et al. (2013; genus accepted), Miądlikowska et al. (2014a; phylogeny), Lücking et al. (2016b; classification), sequences are available.

Arthrorhynchus Kolen. 1857 (= Helminthophana Peyr. 1873 fide Species Fungorum 2017), Laboulbeniaceae, Laboulbeniales, Laboulbeniomycetes, three species, one additional species (A. acrandros Merola) is doubtful, type: A. nycteribiae (Peyr.) Thaxt., no asexual state, biotrophic, hosts are Nycteribiidae (Diptera: Hippoboscoidea), Eastern Hemisphere distribution, see Lumbsch and Huhndorf (2010; outline), Kirk et al. (2013; genus accepted), sequences are available for type species.

Arthrosporium Sacc. 1880 (= Phragmostilbe Subram. 1959 fide Seifert et al. 2011), Ascomycota genera incertae sedis, two species, type: A. albicans (Sacc.) Sacc., hyphomycetous, sexual morph unknown, Europe, North America, see Seifert et al. (2011; morphology), Wijayawardene et al. (2012, 2017; outline), Kirk et al. (2013; genus accepted), cultures and sequences are available, needs generic revision.

Arthrosporum A. Massal. 1853 (= Arthrospora Th. Fr. 1861 fide Species Fungorum 2017), Ramalinaceae, Lecanorales, Lecanoromycetes, one species, type: A. populorum Massal., with ascomata, lichenized (green algae), terrestrial (corticolous), Northern Hemisphere, see Lumbsch and Huhndorf (2010; outline), Kirk et al. (2013; genus accepted), Lücking et al. (2016b; classification), sequences are available.

Arthrowallemia R.F. Castañeda, Dania García \& Guarro 1998, Ascomycota genera incertae sedis, two species, type: A. formosa R.F. Castañeda, Dania García \& Guarro, hyphomycetous, sexual morph unknown, saprobes, terrestrial, Cuba, see Seifert et al. (2011; morphology), Wijayawardene et al. (2012, 2017; outline), Kirk et al. (2013; genus accepted), holotype of the type: INIFAT C95/88, sequences are unavailable, compare with Arthrocristala, Bahusakala and Parasympodiella.

Arthroxylaria Seifert \& W. Gams 2002, Xylariaceae, Xylariales, Sordariomycetes, one species, type: P. hunteri Lloyd, hyphomycetous, sexual morph unknown, terrestrial, saprobes, North America, see Seifert et al. (2011; morphology), Wendt et al. (2017; placed in Hypoxylaceae), Wijayawardene et al. (2017; outline), cultures and sequences are available.

Articulophora C.J.K. Wang \& B. Sutton 1982, Ascomycota genera incertae sedis, one species, type: A. variispora C.J.K. Wang \& B. Sutton, hyphomycetous, sexual morph unknown, saprobes, USA, see Seifert et al. (2011; morphology), Wijayawardene et al. (2012, 2017; outline), Kirk et al. (2013; genus accepted), sequences are unavailable, needs generic revision, holotype: Wang 11021.

Articulospora Ingold 1942, Helotiaceae, Helotiales, Leotiomycetes, six species, type: A. tetracladia Ingold, hyphomycetous, saprobes, endophytic, aquatic, worldwide, see Seifert et al. (2011; morphology), Seena et al. (2012; phylogeny), Wijayawardene et al. (2012, 2017; outline), Kirk et al. (2013; genus accepted), Baschien et al. (2013; phylogeny), compare with Geniculospora and Isthmotricladia.

Artocarpomyces Subram. 1996, Ascomycota genera incertae sedis, one species, type: A. paradoxa Subram., saprobes, terrestrial, Singapore, see Seifert et al. (2011; morphology), Wijayawardene et al. (2012, 2017; outline), Kirk et al. (2013; genus accepted), holotype of the type: MUBL 3147, cultures and sequences are unavailable, needs generic revision.

Arundellina Wanasinghe, E.B.G. Jones \& K.D. Hyde 2016, Lindgomycetaceae, Pleosporales, Dothideomycetes, one species, type: A. typhae Wanasinghe, E.B.G. Jones \& K.D. Hyde, 
asexual morph unknown, saprobes, terrestrial, UK, see Hyde et al. (2016; taxonomy, phylogeny), holotype and ex-type culture of the type: MFLU 16-1276, MFLUCC 16-0310.

Arwidssonia Arwidssonia B. Erikss. 1974, Hyponectriaceae, Xylariales, Sordariomycetes, two species, type: A. empetri (Rehm) B. Erikss., asexual morph unknown, plant pathogen, Europe, see Lumbsch and Huhndorf (2010; outline), Kirk et al. (2013; genus accepted), Maharachchikumbura et al. (2015, 2016; outline), cultures and sequences are unavailable, needs generic revision.

Arxiella Papendorf 1967, Dothideomycetes, genera incertae sedis, one species, type: A. terrestris Papendorf, hyphomycetous, sexual morph unknown, saprobes, terrestrial, Japan, see Seifert et al. (2011; morphology), Wijayawardene et al. (2012, 2017; outline), Kirk et al. (2013; genus accepted), Crous et al. (2014d; DNA, new species), cultures and sequences are available but lacks for the type, needs generic revision.

Arxiomyces P.F. Cannon \& D. Hawksw. 1983 (= Ceratostoma Pers. 1818; = Phaeostoma Arx \& E. Müll. 1954 fide Species Fungorum 2017), Ceratostomataceae, Melanosporales, Sordariomycetes, one species, type: A. vitis (Fuckel) P.F. Cannon \& D. Hawksw., asexual morph unknown, on bark, Europe, terrestrial, see Lumbsch and Huhndorf (2010; outline), Kirk et al. (2013; genus accepted), Maharachchikumbura et al. (2015, 2016; outline), cultures and sequences are unavailable.

Asahinea W.L.Culb. \& C.F.Culb. 1965, Parmeliaceae, Lecanorales, Lecanoromycetes, four species; type: A. chrysantha (Tuck.) W.L. Culb. \& C.F. Culb., lichenized, see Lumbsch and Huhndorf (2010; outline), Kirk et al. (2013; genus accepted), Miądlikowska et al. (2014a; DNA, phylogeny), Lücking et al. (2016b; classification), sequences are available.

Asaphomyces Thaxt. 1931 (= Barbariella Middelh. 1949 fide Species Fungorum 2017), Laboulbeniaceae, Laboulbeniales, Laboulbeniomycetes, four species, type: A. cholevae Thaxt., asexual morph unknown, parasitic on Leiodidae beetles, terrestrial, widespread, Lumbsch and Huhndorf (2010; outline), Kirk et al. (2013; genus accepted), cultures and sequences are unavailable.

Ascitendus J. Campb. \& Shearer 2004, Annulatascaceae, Annulatascales, Sordariomycetes, one species, type: A. austriacus (Réblová, Winka \& Jaklitsch) J. Campb. \& Shearer, asexual morph unknown, saprobes, fresh water, terrestrial, Austria, see Lumbsch and Huhndorf (2010; outline), Maharachchikumbura et al. (2015, 2016; outline), holotype: PRM 842991, cultures available for the type: CBS 131685.

Ascluella DiCosmo, Nag Raj \& W.B. Kendr. 1983, Helotiales genera incertae sedis, Leotiomycetes, one species, type: A. symplocina (P. Syd.) DiCosmo, Nag Raj \& W.B. Kendr., asexual morph unknown, saprobes, terrestrial, India, see Lumbsch and Huhndorf (2010; outline), Kirk et al. (2013; genus accepted), cultures and sequences are unavailable, needs generic revision.

Ascobolus Pers. 1792 (= Anserina Velen. 1934; = Ascobolus sect. Sphaeridiobolus (Boud.) Brumm. 1967; = Ascobolus subgen. Dasyobolus Sacc. 1889; = Crouaniella (Sacc.) Lambotte 1887 [1888]; = Dasyobolus (Sacc.) Sacc. 1895; = Phaeopezia subgen. Crouaniella Sacc. 1884; = Seliniella Arx \& E. Müll. 1955; = Sphaeridiobolus Boud. 1885 fide Species Fungorum 2017), Ascobolaceae, Pezizales, Pezizomycetes, c. 70 species, type: A. pezizoides Pers., asexual morph unknown, saprobes, terrestrial, worldwide, see Lumbsch and Huhndorf (2010; outline), Kirk et al. (2013; genus accepted), Doveri (2011, 2014; worldwide key), Mungai et al. (2012c; from dung), Aluoch et al. (2015; fungi on wildlife dung), cultures and sequences are available but lacks for the type species.

Ascocalathium Eidam ex J. Schröt. (1893) [1908], Pezizales, genera incertae sedis, Pezizomycetes, one species, type: A. stipitatum Eidam ex J. Schröt., asexual morph unknown, saprobes, terrestrial, Europe, see Lumbsch and Huhndorf (2010; outline, treated as 
Pyronemataceae), Jaklitsch et al. (2016a; classification), cultures and sequences are unavailable.

Ascocalvatia Malloch \& Cain 1971, Onygenaceae, Onygenales, Eurotiomycetes, one species, type: A. alveolata Malloch \& Cain, asexual morph unknown, saprobes, terrestrial, worldwide, see Lumbsch and Huhndorf (2010; outline), Kirk et al. (2013; genus accepted), culture available for the type: ATCC 22147.

Ascocalyx Naumov 1926 (= Bothrodiscus Shear 1907; = Lagerbergia J. Reid 1971 fide Johnston et al. 2014b; Species Fungorum 2017), Godroniaceae, Helotiales, Leotiomycetes, four species, type: A. abietis Naumov, asexual morph Bothrodiscus, saprobes, terrestrial, worldwide, see Lumbsch and Huhndorf (2010; outline), Kirk et al. (2013; genus accepted), Johnston et al. (2014b; nomenclature), cultures and sequences are available.

Ascocephalophora K. Matsush. \& Matsush. 1995, Ascomycota genera incertae sedis, one species, type: A. petasiformis K. Matsush. \& Matsush., needs generic revision, cultures and sequences are unavailable.

Ascocephalophora K. Matsush. \& Matsush. 1995, Saccharomycetales genera incertae sedis, Saccharomycetes, one species, type: A. petasiformis K. Matsush. \& Matsush., Japan, see Lumbsch and Huhndorf (2010; outline), Kirk et al. (2013; genus accepted), cultures and sequences are unavailable.

Ascochalara Réblová 1999, Chaetosphaeriaceae, Chaetosphaeriales, Sordariomycetes, one species, type: A. gabretae Réblová, asexual morph chalara-like, saprobes, Czech Republic, see Lumbsch and Huhndorf (2010; outline), Kirk et al. (2013; genus accepted), cultures and sequence available but lack for the type species, generic placement is based on non-type species, needs generic revision.

Ascochyta Lib. 1830 (= Ascochyta subgen. Ascochytula Potebnia 1907; = Ascochytella Tassi 1902; = Ascochytula (Potebnia) Died. 1912; = Macrodiplodina Petr. 1962 [1961]; = Stagonosporopsis Died. 1912 fide Species Fungorum 2017), Didymellaceae, Pleosporales, Dothideomycetes, c. 400 species, type: A. pisi Lib., coelomycetous, saprobes, pathogens, terrestrial, worldwide, see Chilvers et al. (2009; pathogens), Aveskamp et al. (2010; phylogeny), de Gruyter et al. (2009; phylogeny), Wijayawardene et al. (2012, 2014c, 2017; outline), Hyde et al. (2013; accepted as a genus in Didymellaceae), Kirk et al. (2013; genus accepted), Chen et al. (2015b; taxonomy, phylogeny), cultures and sequences are available, needs generic revision as more than 1000 records are available.

Ascochytopsis Henn. 1905 (= Cryptogene Syd. 1939; = Cryptogenella Syd. 1939; = Scleroparodia Petr. 1934 fide Species Fungorum 2017), Ascomycota genera incertae sedis, five species, type: A. vignae Henn., coelomycetous, saprobes, endophytic, pathogenic, terrestrial and aquatic, cosmopolitan, see Wijayawardene et al. (2012, 2017; outline, taxonomy), Kirk et al. (2013; genus accepted), cultures and sequences are unavailable, needs generic revision.

Ascochytulina Petr. 1922 (= Clypeodiplodina F. Stevens 1927 fide Species Fungorum 2017), Ascomycota genera incertae sedis, three species, type: A.deflectens (P. Karst.) Petr., coelomycetous, sexual morph unknown, saprobes, terrestrial, Europe, see Wijayawardene et al. (2012, 2017; outline, taxonomy), Kirk et al. (2013; genus accepted), cultures and sequences are unavailable, needs generic revision.

Ascoclavulina Otani 1974, Helotiales genera incertae sedis, Leotiomycetes, eight species, type: A. sakaii Y. Otani, asexual morph gliomastix-like, saprobes, terrestrial, Japan, see Lumbsch and Huhndorf (2010; outline), Kirk et al. (2013; genus accepted), cultures and sequences are unavailable, needs generic revision.

Ascocodinaea Samuels, Cand. \& Magni 1997, Glomerellales genera incertae sedis, Sordariomycetes, two species, type: A. stereicola Samuels, Cand. \& Magni, asexual morph dictyochaeta-like, saprobes, on old polypore, see Lumbsch and Huhndorf (2010; outline), 
Kirk et al. (2013; genus accepted), Maharachchikumbura et al. (2015, 2016; outline), cultures and sequences are available.

Ascoconidium Seaver 1942 (= Sageria A. Funk 1975 fide Johnston et al. 2014b), Helotiaceae, Helotiales, Leotiomycetes, three species, type: A. castaneae Seaver, hyphomycetous, sexual morph formerly known in Sageria, saprobes, Asia, North America, see Seifert et al. (2011; morphology), Johnston et aal. (2014b; nomenclature), Wijayawardene et al. (2012, 2017; outline), Kirk et al. (2013; genus accepted), cultures and sequences are unavailable.

Ascocorticiellum Jülich \& B. de Vries 1982, Ascocorticiaceae, Helotiales, Leotiomycetes, three species, type: A. vermisporum (Hauerslev) Jülich \& B. de Vries, asexual morph unknown, saprobes, terrestrial, Europe, see Lumbsch and Huhndorf (2010; outline), Kirk et al. (2013; genus accepted), Jaklitsch et al. (2016a; classification), cultures and sequences are unavailable, needs generic revision.

Ascocorticium Bref. 1891, Ascocorticiaceae, Helotiales, Leotiomycetes, eight species, type: A. albidum Bref. \& Tavel, asexual morph unknown, saprobes, terrestrial, temperate, see Lumbsch and Huhndorf (2010; outline), Kirk et al. (2013; genus accepted), Jaklitsch et al. (2016a; classification), cultures and sequences are unavailable, needs generic revision.

Ascocoryne J.W. Groves \& D.E. Wilson 1967 (= Coryne Nees 1816; = Pirobasidium Höhn. 1902; Pleurocolla Petr. 1924; = Endostilbum Malençon 1964 fide Johnston et al. 2014b), Gelatinodiscaceae, Helotiales, Leotiomycetes, eight species, type: A. sarcoides (Jacq.) J.W. Groves \& D.E. Wilson, asexual morph Monilia, saprobes, terrestrial, worldwide, see Lumbsch and Huhndorf (2010; outline), Johnston et al. (2014b; nomenclature), Zhu et al. (2016; pathogens, phylogeny), cultures and sequences are available.

Ascocratera Kohlm. 1986, Aigialaceae, Pleosporales, Dothideomycetes, one species, type: A. manglicola Kohlm., asexual morph unknown, saprobes, marine, worldwide, see Schoch et al. (2009; phylogeny), Suetrong et al. (2009; phylogeny, morphology), Besitulo et al. (2010; diversity), Zainuddin et al. (2010; antimicrobial activities), Pang et al. (2010b; diversity), Sakayaroj et al. (2011b; diversity), Zhang et al. (2012e, 2016a; phylogeny), Boonmee et al. (2012; phylogeny), Jones et al. (2012; phylogeny, review), Lee et al. (2012; checklist), Ariyawansa et al. (2014a; phylogeny), Wanasinghe et al. (2015; phylogeny), holotype and exisotype of type: J.K. 4812a (FH), J.K.4812b (IMS).

Ascocylindrica Abdel-Wahab, Bahkali \& E.B.G. Jones 2015, Ascocylindricaceae, Pleosporales, Dothideomycetes, one species, type: A. marina Abdel-Wahab, Bahkali \& E.B.G. Jones, asexual morph unknown, saprobes, marine, Saudi Arabia, see Ariyawansa et al. (2015a; taxonomy, phylogeny), holotype and ex-type culture of the type: MFLU 15-0750, MFLUCC 15-0750.

Ascodesmis Tiegh. 1876, Ascodesmidaceae, Pezizales, Pezizomycetes, six species, type: A. aurea Tiegh., asexual morph unknown, saprobes, terrestrial, worldwide, see Lumbsch and Huhndorf (2010; outline), Doveri (2011; new record from Italy), Hansen et al. (2013; DNA, phylogeny), Kirk et al. (2013; genus accepted), cultures and sequences are available but lacks for type species.

Ascodichaena Butin 1977 (= Polymorphum Chevall. 1822 fide Johnston et al. 2014b), Ascodichaenaceae, Rhytismatales, Leotiomycetes, two species, type: A. rugosa Butin, see Lumbsch and Huhndorf (2010; outline), Kirk et al. (2013; genus accepted), Johnston et al. (2014b; nomenclature), culture available for type: DSM 4703.

Ascofascicula Matsush. 2003, Ascomycota genera incertae sedis, six species, type: $A$. talaroluteoides Matsush., asexual morph unknown, saprobes, terrestrial, Japan, see Lumbsch and Huhndorf (2010; outline), cultures and sequences are available but lacks for type species.

Ascographa Velen. 1934, Lecanoromycetes genera incertae sedis, Leotiomycetes, one species, type: A. hederae Velen., asexual morph unknown, former Czechoslovakia, on decaying trunk 
of Hederae helicis, see Lumbsch and Huhndorf (2010; outline), Kirk et al. (2013; genus accepted), Jaklitsch et al. (2016a; classification), cultures and sequences are unavailable, needs generic revision.

Ascoidea Bref. 1891, Ascoideaceae, Saccharomycetales, Saccharomycetes, three species, type: A. rubescens Bref., asexual morph unknown (by budding of cells and formation of hyphae), saprophyte, terrestrial, Europe, South America, see Lumbsch and Huhndorf (2010; outline), Kirk et al. (2013; genus accepted), cultures and sequences are available, needs generic revision.

Ascolacicola Ranghoo \& K.D. Hyde 1998, Sordariales genera incertae sedis, Sordariomycetes, one species, type: A. aquatica Ranghoo \& K.D. Hyde, asexual morph trichocladium-like, saprobes, aquatic, Hong Kong, see Lumbsch and Huhndorf (2010; outline), Kirk et al. (2013; genus accepted), Maharachchikumbura et al. (2015, 2016; outline), sequences are available.

Ascolectus Samuels \& Rogerson 1990, Saccardiaceae, Ascomycota families incertae sedis, one species, type: A. albus Samuels \& Rogerson, asexual morph unknown, saprobes, Brazil, see Lumbsch and Huhndorf (2010; outline), Kirk et al. (2013; genus accepted), cultures and sequences are unavailable, needs generic revision.

Ascomauritiana Ranghoo \& K.D. Hyde 1999, Ascomycota genera incertae sedis, one species, type: A. lignicola Ranghoo \& K.D. Hyde, asexual morph unknown, saprobes, aquatic, Mauritius, see Kirk et al. (2013; genus accepted), holotype of type species HKU (M) 5255.

Ascominuta Ranghoo \& K.D. Hyde 2000, Dothideomycetes genera incertae sedis, two species, type: A. lignicola Ranghoo \& K.D. Hyde, asexual morph unknown, saprobes, aquatic, Thailand, Hong Kong, see Wijayawardene et al. (2014c; outline), holotype: HKU (M) 5246.

Ascophanus Boud. 1869, Thelebolaceae, Thelebolales, Leotiomycetes, one species, type: A. granuliformis (P. Crouan \& H. Crouan) Boud., asexual morph unknown, saprobes, terrestrial, Antarctica, see Lumbsch and Huhndorf (2010; outline), Kirk et al. (2013; genus accepted), Bansal et al. (2014; antifreeze proteins), cultures and sequences are available.

Ascopolyporus Möller 1901, Cordycipitaceae, Hypocreales, Sordariomycetes, five species, type: A. polychrous Möller, asexual morph unknown, saprobes, terrestrial, Central and South America, see Lumbsch and Huhndorf (2010; outline), Kirk et al. (2013; genus accepted), Maharachchikumbura et al. (2015, 2016; outline), cultures and sequences are available.

Ascoporia Samuels \& A.I. Romero 1993 (= Pseudosolidum Lloyd (as McGinty) 1923 fide Hyde et al. 2013), Ascoporiaceae, Dothideomycetes families incertae sedis, one species, type: A. lateritia Samuels \& A.I. Romero, asexual morph unknown, saprobes, terrestrial, Brazil, see Lumbsch and Huhndorf (2010; outline), Hyde et al. (2013; taxonomy), Kirk et al. (2013; genus accepted), Wijayawardene et al. (2014c; outline), cultures are unavailable.

Ascorhiza Lecht.-Trinka 1931, Sordariomycetes, genera incertae sedis, one species, type: A. leguminosarum Lecht.-Trinka, asexual morph unknown, saprobes, terrestrial, Europe, see Lumbsch and Huhndorf (2010; outline), Maharachchikumbura et al. (2015, 2016; outline), cultures and sequences are unavailable, needs generic revision.

Ascorhizoctonia Chin S. Yang \& Korf 1985, Pyronemataceae, Pezizales, Pezizomycetes, seven species, type: A. praecox Chin S. Yang \& Korf, hyphomycetous, sexual morph unknown, saprobes, terrestrial, Asia, Europe, North America, see Seifert et al. (2011; morphology), Wijayawardene et al. (2012, 2017; outline), Kirk et al. (2013; genus accepted), cultures and sequences are available for unidentified species.

Ascorhombispora L. Cai \& K.D. Hyde 2007, Pleosporales genera incertae sedis, Dothideomycetes, one species, type: A. aquatica L. Cai \& K.D. Hyde, asexual morph unknown, China, see Lumbsch and Huhndorf (2010; outline), Wijayawardene et al. (2014c; outline), holotype: HKU (M) 10859, cultures and sequences are available. 
Ascoronospora Matsush. 2003, Pleosporales genera incertae sedis, Dothideomycetes, one species, type: A. yakuensis Matsush., asexual morph coronospora-like, saprobes, terrestrial, Japan, see Wijayawardene et al. (2014c; outline), cultures and sequences are unavailable.

Ascosacculus J. Campb., J.L. Anderson \& Shearer 2003, Halosphaeriaceae, Microascales, Sordariomycetes, two species, type: A. aquaticus (K.D. Hyde) J. Campb., J.L. Anderson \& Shearer, saprobes, aquatic, cosmoplitan, see Lumbsch and Huhndorf (2010; outline), Maharachchikumbura et al. (2015, 2016; outline), cultures and sequences are available but lacks for the type, needs generic revision.

Ascosorus Henn. \& Ruhland 1900 (= Gymnoascopsis C. Moreau \& M. Moreau 1959 fide Species Fungorum 2017), Ascocorticiaceae, Helotiales, Leotiomycetes, one species, type: A. floridanus (Ellis \& G. Martin) Henn. \& Ruhland, asexual morph unknown, saprobes, North America, see Lumbsch and Huhndorf (2010; outline), Kirk et al. (2013; genus accepted), Jaklitsch et al. (2016a; classification), cultures and sequences are unavailable, needs generic revision.

Ascosparassis Kobayasi 1960, Otideaceae, Pezizales, Pezizomycetes, one species, type: A. shimizuensis Kobayasi, saprobes, terrestrial, tropics, see Lumbsch and Huhndorf (2010; outline), Kirk et al. (2013; genus accepted), Jaklitsch et al. (2016a; classification), cultures and sequences are unavailable.

Ascosphaera L.S.Olive \& Spiltoir 1955 (= Pericystis Betts 1912 fide Species Fungorum 2017), Ascosphaeraceae, Onygenales, Eurotiomycetes, c. 30 species, type: A. apis (Maasen ex Claussen) L.S. Olive \& Spiltoir, pathogens, worldwide, see Lumbsch and Huhndorf (2010; outline), Kirk et al. (2013; genus accepted), sequences and culture available for type: NBRC 31608.

Ascostratum Syd. \& P. Syd. 1912, Myriangiaceae, Myriangiales, Dothideomycetes, two species, type: A. insigne Syd. \& P. Syd., asexual morph unknown, saprobes, terrestrial, South Africa, Canada, see Lumbsch and Huhndorf (2010; outline), Kirk et al. (2013; genus accepted), Tian et al. (2014; morphology, nomenclature, phylogeny), Wijayawardene et al. (2014c; outline), cultures and sequences are unavailable, needs generic revision.

Ascotaiwania Sivan. \& H.S. Chang 1992, Savoryellaceae, Savoryellales, Sordariomycetes, 13 species, type: A. lignicola Sivan. \& H.S. Chang, asexual morph hyphomycetous, saprobes, terrestrial, aquatic, worldwide, see Lumbsch and Huhndorf (2010; outline), Kirk et al. (2013; genus accepted), Maharachchikumbura et al. (2015; 2016), holotype: IMI 348977.

Ascotremella Seaver 1930, Gelatinodiscaceae, Helotiales, Leotiomycetes, two species, type: A. faginea (Peck) Seaver, asexual morph unknown, saprobes, terrestrial, Japan, see Lumbsch and Huhndorf (2010; outline), Kirk et al. (2013; genus accepted), cultures and sequences are unavailable, needs generic revision.

Ascotricha Berk. 1838 (= Dicyma Boulanger 1897; = Gonytrichella Emoto \& Tubaki 1971; = Puciola De Bert. 1976 fide Wendt et al. 2017), Xylariaceae, Xylariales, Sordariomycetes, one species, type: A. chartarum Berk., asexual morph unknown, saprobes, terrestrial, Chile, see Lumbsch and Huhndorf (2010; outline), Kirk et al. (2013; genus accepted), Cheng et al. (2015; new species, phylogeny), Maharachchikumbura et al. (2015, 2016; outline), cultures and sequences are available.

Ascotrichella Valldos. \& Guarro 1988, Xylariales, genera incertae sedis, Sordariomycetes, one species, type: A. hawksworthii Valldos. \& Guarro, asexual morph hyphomycetous, saprobes, terrestrial, Chile, see Lumbsch and Huhndorf (2010; outline), Kirk et al. (2013; genus accepted), Maharachchikumbura et al. (2015, 2016; outline), cultures and sequences are unavailable.

Ascovaginospora Fallah, Shearer \& W.D. Chen 1997, Phyllachoraceae, Phyllachorales, Sordariomycetes, one species, type: A. stellipala Fallah, Shearer \& W.D. Chen, saprobes, aquatic, USA, see Lumbsch and Huhndorf (2010; outline, accepted as a genus in 
Sordariomycetidae, genera incertae sedis), Kirk et al. (2013; genus accepted), Maharachchikumbura et al. (2015, 2016; outline), holotype: ILLS 52319, sequences are available, needs generic revision.

Ascoyunnania L. Cai \& K.D. Hyde 2005, Sordariomycetes genera incertae sedis, two species, type: A. aquatica L. Cai \& K.D. Hyde, saprobes, aquatic, China, see Lumbsch and Huhndorf (2010; outline), Maharachchikumbura et al. (2015, 2016; outline), cultures and sequences are unavailable, needs generic revision.

Ascozonus (Renny) E.C. Hansen 1877 (= Ascobolus sect. Ascozonus Renny, Trans. 1873 [1871-1873]; = Gymnodiscus Zukal 1887; = Streptotheca Vuill. 1887; = Zukalina Kuntze 1891 fide Species Fungorum 2017), Thelebolaceae, Thelebolales, Leotiomycetes, c. six species, type: A. cunicularius (Boud.) Marchal, asexual morph unknown, saprobes, terrestrial, north temperate, see Lumbsch and Huhndorf (2010; outline), Kirk et al. (2013; genus accepted), cultures and sequences are available but acks for the type species.

Ashtaangam Subram. 1995, Ascomycota genera incertae sedis, one species, type: $A$. sundaram Subram., hyphomycete, sexual morph unknown, saprobe, terrestrial, Malaysia, see Seifert et al. (2011; morphology), Wijayawardene et al. (2012, 2017; outline), Kirk et al. (2013; genus accepted), holotype: MUBL 3127.

Aspergillus P. Micheli ex Haller 1768 (= Chaetosartorya Subram. 1972; = Cristaspora Fort \& Guarro 1984; = Dichotomomyces Saito ex D.B. Scott 1970; = Emericella Berk. 1857; = Eurotium Link 1809; = Fennellia B.J. Wiley \& E.G. Simmons 1973; = Neocarpenteles Udagawa \& Uchiy. 2002; = Neopetromyces Frisvad \& Samson 2000; = Neosartorya Malloch \& Cain 1973; = Petromyces Malloch \& Cain 1973; = Phialosimplex Sigler, Deanna A. Sutton, Gibas, Summerb. \& Iwen 2010; = Polypaecilum G. Sm. 1961), Aspergillaceae, Eurotiales, Eurotiomycetes, c. 360 species, type: A. glaucus (L.) Link, mostly terrestrial, but also reported from aquatic environments, mainly saprobes associated with soil, plant material and foodstuffs, but also including phytopathogenic and clinically-relevant fungi causing opportunistic mycoses (aspergillosis) and mycotoxicoses in various vertebrates including humans, cosmopolitan, monophyletic but morphologically diverse both in its sexual and asexual morphs, see Peterson (2008; phylogeny), Sigler et al. (2010b; morphology as "Phialosimplex"), Varga et al. (2010a, b, 2011; phylogeny, new species, mycotoxins), Houbraken and Samson (2011; phylogeny), Guarro et al. (2012; selected soilborne species), Hubka et al. (2013a, 2013b, 2015, 2016a, 2016b; phylogeny, new combinations, new species), Asgari et al. (2014; new species, sexual morph), Samson et al. (2014; polyphasic taxonomy, new species, outline), Sugui et al. (2014; new species), Crous et al. (2015e; new species), Guinea et al. (2015; new species), Jurjević et al. (2015; new section and new species), Arzanlou et al. (2016b; new species), Tsang et al. (2016; new species), Visagie et al. (2017; new species), ex-neotype: CBS 516.65, sequences are available.

Asperisporium Maubl. 1913, Mycosphaerellaceae, Capnodiales, Dothideomycetes, twelve species, type: A. caricae (Speg.) Maubl., hyphomycetous, saprobes, terrestrial, America, see Seifert et al. (2011; morphology), Minnis et al. (2011; phylogeny, typification), Wijayawardene et al. (2012, 2017; outline), Kirk (2013; genus accepted), ex-epitype strains of type: CBS 130298.

Asperopilum Spooner 1987, Hyaloscyphaceae, Helotiales, Leotiomycetes, one species, type: A. juncicola (Dennis) Spooner, asexual morph unknown, saprobes, terrestrial, Australasia, see Lumbsch and Huhndorf (2010; outline), Kirk et al. (2013; genus accepted), Jaklitsch et al. (2016a; classification), cultures and sequences are available.

Aspicilia A. Massal. [nom. cons.] 1852 (= Agrestia J.W. Thomson 1961; = Athecaria Nyl. 1897; = Chlorangium Link 1849; Manzonia Garov. 1866; Paraplacodium Motyka 1996; Sagedia Ach. 1809; Sphaerothallia Nees ex Eversm. 1831; = Urceolaria Hook. 1821 fide Species Fungorum 2017), Megasporaceae, Pertusariales, Lecanoromycetes, 200 species, 
type: A. cinerea (L.) Körb., lichenized, worldwide, see Lumbsch and Huhndorf (2010; outline), Nordin et al. (2010; phylogeny), Sohrabi et al. (2010; DNA), Raggio et al. (2011; survive exposure to space), Kirk et al. (2013; genus accepted), Lücking et al. (2016b; classification), sequences are available.

Aspiciliopsis (Müll. Arg.) M. Choisy 1929, Trapeliaceae, Trapeliales, Lecanoromycetes, one species; type: A. macrophthalma (Hook. f. \& Taylor) B. de Lesd., lichenized, see Hodkinson and Lendemer (2011b; taxonomy), Lücking et al. (2016b; classification), sequences are available.

Aspidothelium Vain. 1890 (= Aspidopyrenis Clem. \& Shear 1931; = Aspidopyrenium Vain. 1890; = Aspidotheliomyces Cif. \& Tomas. 1953; = Lecania sect. Secoligella Müll. Arg. 1919 [1918]; = Porinopsis Malme 1928; = Secoligella (Müll. Arg.) Vain. 1896 fide Species Fungorum 2017)), Thelenellaceae, Ostropales, Lecanoromycetes, 17 species, type: A. cinerascens Vain., lichenized, see Lumbsch and Huhndorf (2010; outline, accepted as a genus in Aspidotheliaceae), Kirk et al. (2013; genus accepted), Aptroot et al. (2014d; new species), Nelsen et al. (2016; phylogeny), Lücking et al. (2016b; classification), sequences are available.

Aspilaima Bat. \& H. Maia 1961, Ascomycota genera incertae sedis, one species, type: A. platoniae Bat. \& H. Maia, coelomycetous, sexual morph unknown, saprobes, terrestrial, Brazil, see Wijayawardene et al. (2012, 2017; outline), Kirk et al. (2013; genus accepted), cultures and sequences are unavailable, needs generic revision.

Aspilidea Hafellner 2001, Ostropomycetidae genera incertae sedis, Lecanoromycetes, one species, type: A. myrinii (Fr.) Hafellner, lichenized (green algae), terrestrial (saxicolous), restricted to the alpine zone, see Jørgensen and Nordin (2009, DNA), Lumbsch and Huhndorf (2010; outline), Nordin et al. (2010; taxonomy), Lücking et al. (2016b; classification), sequences unavailable.

Asteridiella McAlpine 1897 (= Irene Theiss. 1917; = Meliola subgen. Irene (Theiss., Syd. \& P. Syd.) 1938; = Parasteridiella H. Maia 1960 fide Species Fungorum 2017), Meliolaceae, Meliolales, Sordariomycetes, more than 300 species, type specie: A. solani McAlpine, asexual morph unknown, pathogens saprobes, terrestrial, worldwide, see Hosagoudar and Archana (2009; host distribution in India), Lumbsch and Huhndorf (2010; outline), Kirk et al. (2013 genus accepted), Maharachchikumbura et al. (2015, 2016; outline), cultures and sequences are available.

Asterina Lév. 1845 (see Hongsanan et al. 2014c for synonyms), Asterinaceae, Asterinales, Dothideomycetes, more than 700 species, type: A. melastomatis Lév., asexual morph coelomycetous or hyphomycetous (=asterostomella-like, clasterosporium-like and mahanteshomyces-like, fide Hofmann 2009). Epiphytes, biotrophic, terrestrial, worldwide, most species do not have molecular data, see Hofmann (2009; review, DNA), Hosagoudar et al. (2010a; morphology of Bheemamyces), Lumbsch and Huhndorf (2010; outline), Hyde et al. (2013; review, keys), Hongsanan et al. (2014c; taxonomy, DNA, keys, nomenclature), Wijayawardene et al. (2014c; outline), Guatimosim et al. (2015; phylogeny, taxonomy, DNA), neotype: PC 0084477, type sequence KP143739 (voucher VIC 42822).

Asterinella Theiss. 1912 (= Calothyrium Theiss. 1912; = Opasterinella Speg. 1919 [1918] fide Species Fungorum 2017), Asterinaceae, Asterinales, Dothideomycetes, c 40 species, type: A. puiggarii (Speg.) Theiss., asexual morph coelomycetous (= asterostomula-like), epiphytes, biotrophic, terrestrial, worldwide, no molecular data, see Hofmann (2009; review, accepted as a genus in Asterinaceae), Lumbsch and Huhndorf (2010; outline, accepted as a genus in Microthyriacae), Wijayawardene et al. (2014c; outline), Wu et al. (2014; review, transferred to Asterinaceae), holotype: LPS 1377, cultures and sequences unavailable.

Asterinema Bat. \& Gayão 1953, Dothideomycetes genera incertae sedis, one species, type: A. puiggarii (Speg.) Theiss., asexual morph unknown, foliar epiphytes, terrestrial, Brazil, see 
Lumbsch and Huhndorf (2010; outline, accepted as a genus in Microthyriaceae), Kirk et al. (2013; genus accepted), Hongsanan et al. (2014c; accepted as a genus in Dothideomycetes genera incertae sedis), Wu et al. (2014; accepted as a genus in Asterinaceae), Wijayawardene et al. (2014c; outline), cultures and sequences are unavailable, needs generic revision.

Asterinothyriella Bat. \& Cif. 1959, Ascomycota genera incertae sedis, three species, type: A. landolphiae Bat. \& Cif., coelomycetous, sexual morph unknown, saprobes, terrestrial, Uganda, see Wijayawardene et al. (2012, 2017; outline, taxonomy), Kirk et al. (2013; genus accepted), cultures and sequences are unavailable, needs generic revision.

Asterinothyrium Bat., Cif. \& H. Maia 1959, Ascomycota genera incertae sedis, one species, type: A. singulatum Bat. \& H. Maia, coelomycetous, sexual morph unknown, saprobes, terrestrial, Africa, see Wijayawardene et al. (2012, 2017; outline), Kirk et al. (2013 genus accepted), cultures and sequences are unavailable.

Asteristion Leight. 1870, Graphidaceae, Ostropales, Lecanoromycetes, five species, type: A. erumpens Leight., asexual morph unknown, lichenized fungi, terrestrial, tropical, placement in Graphidaceae supported by molecular data, new synonym Phaeotrema Müll.Arg., see Medeiros et al. (2016; taxonomy), Lücking et al. (2014, 2016b; classification), sequences are available.

Asteroconium Syd. \& P. Syd. 1903, Ascomycota genera incertae sedis, two species, type: A. saccardoi Syd. \& P. Syd., coelomycetous, sexual morph unknown, saprobes, terrestrial, Central America, China, India, see Wijayawardene et al. (2012, 2017; outline), Kirk et al. (2013 genus accepted), cultures and sequences are unavailable.

Asterodiscus Voglmayr, Gardiennet \& Jaklitsch 2016, Stigmatodiscaceae, Stigmatodiscales, Dothideomycetes, two speies, type: A. tamaricis Voglmayr, Gardiennet \& Jaklitsch, asexual morph coelomycetous, saprobes, Europe, see Voglmayr et al. (2016; taxonomy, phylogeny), Wijayawardene et al. (2017; outline), holotype: WU 35906, cultures and sequences are available.

Asterodothis Theiss. 1912, Dothideomycetes genera incertae sedis, one species, type: A. solaris (Kalchbr. \& Cooke) Theiss., asexual morph unknown, saprobes, terrestrial, USA, see Lumbsch and Huhndorf (2010; outline, accepted as a genus in Asterinaceae), Kirk et al. (2013; genus accepted), Hongsanan et al. (2014c; transferred this genus from Asterinaceae to Dothideomycetes genera incertae sedis), Wijayawardene et al. (2014c; outline), cultures and sequences are unavailable.

Asteroglobulus Brackel 2011, Ascomycota genera incertae sedis, one species, type: $A$. giselae Brackel, coelomycetous, sexual morph unknown, lichenicolous, terrestrial, Europe, see Brackel (2011a; taxonomy), Wijayawardene et al. (2017; outline), cultures and sequences are unavailable.

Asteroma DC. 1815 (= Actinonemella Höhn. 1916; = Cylindrosporella Höhn. 1916; = Depazea Fr. 1818; = Gloeosporina Höhn. 1916; = Ribaldia Cif. 1954; = Titaeosporina Luijk 1920 fide Sutton 1977; Species Fungorum 2017), Gnomoniaceae, Diaporthales, Sordariomycetes, more than 200 species, type specie: M. stellaris (Pers.) Theiss. \& Syd., sexual morph Gnomoniella, Plagiostoma, pathogens associated with leaf spots, saprobes, terrestrial, worldwide distribution, see Maharachchikumbura et al. (2015, 2016; outline), sequences are available for A. alneum.

Asteromassaria Höhn. 1917, Dothideomycetes genera incertae sedis, type: A. macrospora (Desm.) Höhn., twelve species but could be higher, asexual morph coelomycetous, saprobes, parasites, terrestrial, Europe, India, Japan, USA, see Lumbsch and Huhndorf (2010; outline), Zhang et al. (2012e; accepted as a genus in Morosphaeriaceae), Kirk et al. (2013; genus accepted), Wijayawardene et al. (2014c; outline), holotype of type: CBS H-15119, cultures and sequences are available but lacks for the type species. 
Asteromella Pass. \& Thüm. 1880 (= Apiosporella Speg. 1912; = Aplosporidium Speg. 1912; = Plectophoma Höhn. 1907; = Porterula Speg. 1920; = Stictochorella Höhn. 1917; = Stictochorellina Petr. 1922 fide Species Fungorum 2017), Dothideomycetes genera incertae sedis, c. 265 species, type: A. ovata Thüm., polyphyletic, coelomycetous, sexual morph unknown, widespread, see Hyde et al. (2011; outline), Wijayawardene et al. (2012, 2017; outline), Kirk et al. (2013; genus accepted), sequences are available, needs generic revision.

Asteromellopsis H.E. Hess \& E. Müll. 1951, Dothideaceae, Dothideales, Dothideomycetes, one species, type: A. insculpta H.E. Hess \& E. Müll., saprobes, Switzerland, see Kirk et al. (2013; genus accepted), cultures and sequences are unavailable, needs generic revision.

Asteromidium Speg. 1888 (= Asterostomidium Lindau 1900 fide Species Fungorum 2017), Ascomycota genera incertae sedis, three species, type: A. imperspicuum Speg., coelomycetous, sexual morph unknown, saprobes, terrestrial, Brazil, see Wijayawardene et al. (2012, 2017; outline), Kirk et al. (2013; genus accepted), cultures and sequences are unavailable, needs generic revision.

Asteromyces Moreau \& M. Moreau ex Hennebert 1962, Ascomycota genera incertae sedis, one species, type: A. cruciatus Moreau \& M. Moreau ex Hennebert, hyphomycetous, on seaweeds, sand grains, drift wood, saprobe, mostly marine temperate, see Seifert et al. (2011; morphology), Wijayawardene et al. (2012, 2017; outline), Kirk et al. (2013; genus accepted), Gulder et al. (2012; biochemistry), Jones et al. (2015; outline), cultures and sequences are unavailable.

Asteronectrioidea Cant. 1949, Ascomycota genera incertae sedis, one species, type: A. heveicola Cant., possibly hyphomycetous, sexual morph unknown, saprobes, Africa, see Kirk et al. (2013; genus accepted), cultures and sequences are unavailable, needs generic revision.

Asteronia (Sacc.) Henn. 1895 (= Asterina subgen. Asteronia Sacc. 1882 fide Species Fungorum 2017), Dothideomycetes genera incertae sedis, two species, type: A. sweetiae Henn., asexual morph unknown, saprobes, terrestrial, Brazil, see Lumbsch and Huhndorf (2010; outline, accepted as a genus in Microthyriaceae), Kirk et al. (2013; genus accepted), Wijayawardene et al. (2014c; outline), cultures and sequences are unavailable, needs generic revision.

Asteroporum Müll. Arg. 1884 (= Asteroporomyces Cif. \& Tomas. 1953 fide Species Fungorum 2017), Ascomycota genera incertae sedis, seven species, type: A. perminimum Müll. Arg., lichenized, see Lumbsch and Huhndorf (2010; outline), Kirk et al. (2013; genus accepted), Lücking et al. (2016b; classification), sequences are unavailable.

Asteroscutula Petr. 1948, Ascomycota genera incertae sedis, one species, type: A. sydowii Petr., coelomycetous, sexual morph unknown, saprobes, terrestrial, Ecuador, see Wijayawardene et al. (2012, 2017; outline), Kirk et al. (2013 genus accepted), cultures and sequences are unavailable.

Asterosporium Kunze 1819, Sordariales genera incertae sedis, seven species, type: A. asterospermum (Pers.) Hughes, coelomycetous, sexual morph unknown, saprobes, terrestrial, temperate, see Tanaka et al. (2010; taxonomy, phylogeny), Wijayawardene et al. (2012, 2016b, 2017; outline, taxonomy), Maharachchikumbura et al. (2015, 2016; outline), cultures available for the type: CBS 112404.

Asterostomopora Bat. \& H. Maia 1960, Ascomycota genera incertae sedis, one species, type: A. jamaicensis Bat. \& H. Maia, coelomycetous, Jamaica, see Wijayawardene et al. (2012, 2017; outline), Kirk (2013; genus accepted), cultures and sequences are unavailable, needs generic revision.

Asterostomopsis Bat., Cif. \& H. Maia 1959, Ascomycota genera incertae sedis, one species, A. ghanaensis Bat., Cif. \& H. Maia, coelomycetous, rarely reported and in case on leaves of Lawsonia inermis in Ghana and India, see Wijayawardene et al. (2012, 2017; outline), Kirk (2013; genus accepted), and sequences are unavailable, needs generic revision. 
Asterostomula Theiss. 1916, Ascomycota genera incertae sedis, four species, type: A. loranthi Theiss., coelomycetous, sexual morph unknown, saprobes, terrestrial, tropical, see Kirk et al. (2013; genus accepted), Wijayawardene et al. (2017; outline), cultures and sequences are unavailable, needs generic revision.

Asterostomulina Bat., J.L. Bezerra \& H. Maia 1964, Ascomycota genera incertae sedis, one species, type: A. phoebeicola Bat., J.L. Bezerra \& Cavalc., coelomycetous, sexual morph unknown, rarely reported and in case on Phoebe rivularis, Brazil, see Wijayawardene et al. (2012, 2017; outline), Kirk (2013; genus accepted), cultures and sequences are unavailable, needs generic revision.

Asterotexis Arx 1958, Asterotexaceae, Asterotexales, Dothideomycetes, two species, type: A. cucurbitacearum (Rehm) Arx 1958, asexual morph unknown, saprobes, South America, India, see Lumbsch and Huhndorf (2010; outline), Kirk et al. (2013; genus accepted), Hongsanan et al. (2014c; treated as a genus in Asterinaceae), Wijayawardene et al. (2014c; outline), Guatimosim et al. (2015; phylogeny, introdued Asterotexaceae), cultures and sequences are available.

Asterotexis Arx 1958, Asterotexaceae, Asterotexiales, Dothideomycetes, two species, type: A. cucurbitacearum (Rehm) Arx, asexual morph unknown epiphytes, pathogens, biotrophic, terrestrial, worldwide, see Hofmann (2009; review, accepted as a genus in Asteriaceae), Lumbsch and Huhndorf (2010; outline, accepted as a genus in Asterinaceae), Hyde et al. (2013; review, keys, accepted as a genus in Asterinaceae), Hongsanan et al. (2014c; taxonomy, keys, accepted as a genus in Asterinaceae), Wijayawardene et al. (2014c; outline, accepted as a genus in Asterinaceae), Guatimosim et al. (2015; phylogeny, DNA, transferred to a newly described family Asterotexaceae), placement in Asterotexaceae supported by morphology and phylogeny, syntype: S-F7565, type sequence KP143734 (voucher VIC 24814), HQ610510 (voucher PMA M-0141224).

Asterothyrium Müll. Arg. 1890 (= Actinoteichus Cavalc. \& Poroca 1971; = Asterothyriomyces Cif. \& Tomas. 1953; = Diplopeltopsis Henn. ex Höhn. 1911; = Psorotheciella Sacc. \& P. Syd. 1905 fide Species Fungorum 2017), Gomphillaceae, Ostropales, Lecanoromycetes, 33 species; type: A. argenteum Müll. Arg., lichenized, see Flakus and Lücking (2008; new species), Lücking et al. (2016b; classification), sequences are available.

Astomella Thirum. 1947, Ascomycota genera incertae sedis, one species, type: A. neolitseae Thirum., saprobes, India, see Lumbsch and Huhndorf (2010; outline), Kirk et al. (2013; genus accepted), cultures and sequences are unavailable, needs generic revision.

Astrochapsa Parnmen, Lücking \& Lumbsch 2012, Graphidaceae, Ostropales, Lecanoromycetes, 26 species, type: A. astroidea (Berk. \& Broome) Parnmen, Lücking \& Lumbsch, asexual morph unknown, ascomata apotheciate, conidiomata pycnidial, lichenforming, corticolous, pantropical, see Parnmen et al. (2012; taxonomy, phylogeny), Rivas Plata et al. (2013; phylogeny), Lumbsch et al. (2014a, b; classification).

Astrocystis Berk. \& Broome 1873, Xylariaceae, Xylariales, Sordariomycetes, c. 20 species, type: P. invocans Morgan, asexual morph unknown, saprobes, North America, Asia, see Lumbsch and Huhndorf (2010; outline), Pinnoi et al. (2010; new species), Kirk et al. (2013; genus accepted), Daranagama et al. (2015a; new species, DNA), Maharachchikumbura et al. (2015, 2016; outline), cultures and sequences are available.

Astronatelia Bat. \& H. Maia 1962, Ascomycota genera incertae sedis, one species, type: A. andromedae Bat. \& H. Maia, coelomycetous, sexual morph unknown, saprobes, terrestrial, USA, see Wijayawardene et al. (2012, 2017; outline), Kirk et al. (2013 genus accepted), cultures and sequences are unavailable.

Astrosphaeriella Syd. \& P. Syd. 1913 (= Asterella Hara 1936; = Asterotheca I. Hino 1938; = Astrosphaeria (Höhn.) Syd. 1913; = Astrotheca I. Hino 1938; = Leptosphaeria sect. 
Astrosphaeria Höhn. 1909 fide Species Fungorum 2017), Astrosphaeriellaceae, Pleosporales, Dothideomycetes, c. 10 species, type: A. fusispora Syd. \& P. Syd., asexual morph unknown, saprobes, terrestrial, widespread, see Tanaka et al. (2009; phylogeny), Lumbsch and Huhndorf (2010; outline), Liu et al. (2011b; phylogeny), Zhang et al. (2012e; morphology, phylogeny), Kirk et al. (2013; genus accepted), cultures available for type: MFLUCC 100555

Astrosphaeriellopsis Phookamsak, J.K. Liu \& K.D. Hyde 2015, Pleosporales genera incertae sedis, Dothideomycetes, one species, type: P. thailandensis Phookamsak, Z.L. Luo \& K.D. Hyde, asexual morph unknown, saprobes, Asia, see Phookamsak et al. (2015b; taxonomy, phylogeny), cultures and sequences are available.

Astrothelium Eschw. 1824, Trypetheliaceae, Trypetheliales, Dothideomycetes, c. 250 species, type: A. conicum Eschw., asexual morph unknown, lichenized, terrestrial, tropical, see Lumbsch and Huhndorf (2010; outline), Kirk et al. (2013; genus accepted), Nelsen et al. (2014a; phylogeny) Aptroot and Lücking (2016; monograph), Lücking et al. (2016b; classification).

Asymmetricospora J. Fröhl. \& K.D. Hyde 1998, Melanommataceae, Pleosporales, Dothideomycetes, one species, type: A. calamicola J. Fröhl. \& K.D. Hyde, asexual morph unknown, saprobes, terrestrial, Australia, see Lumbsch and Huhndorf (2010; outline), Kirk et al. (2013; genus accepted), Wijayawardene et al. (2014c; outline), Tian et al. (2015; morphology, phylogeny), cultures and sequences are unavailable, needs generic revision.

Athallia Arup, Frödén \& Søchting 2013, Teloschistaceae, Teloschistales, Lecanoromycetes, 13 species, type: A. holocarpa (Hoffm.) Arup, Frödén \& Søchting, with ascomata, lichenized ('Pseudotrebouxia'), (corticolous, epixylic, terricolous, saxicolous), cosmopolitan, see Arup et al. (2013, DNA), Lücking et al. (2016b, classification), Vondrák et al. (2016, geographical range), sequences are available for voucher JV14428 of the type: (fide Arup et al. 2013).

Atichia Flot. 1850 (= Actinomma Sacc. 1884; = Hyphodictyon Millardet 1866; = Myriophysa Fr. 1849; = Seuratia Pat. 1904 fide Rossman et al. 2016a; Species Fungorum 2017), Ascomycota family incertae sedis, four species, type: A. mosigii Flot., hyphomycetous, sexual morph formerly known in Seuratia Pat., widespread, see Seifert et al. (2011; morphology), Wijayawardene et al. (2012, 2017; outline), Kirk (2013; genus accepted), Rossman et al. (2016a; nomenclature), cultures and sequences are unavailable, needs generic revision.

Atkinsonella Diehl 1950, Clavicipitaceae, Hypocreales, Sordariomycetes, two species, type: A. hypoxylon (Peck) Diehl, asexual morph unknown, saprobes, terrestrial, worldwide, see Lumbsch and Huhndorf (2010; outline), Kirk et al. (2013; genus accepted), Maharachchikumbura et al. $(2015,2016)$, cultures and sequences are available.

Atla Savić \& Tibell 2008, Verrucariaceae, Verrucariales, Eurotiomycetes, nine species, type: A. alpina Savić \& Tibell, lichenized, terrestrial, Europe, see Savic and Tibell (2008; taxonomy), Lumbsch and Huhndorf (2010; outline), Tibell and Tibell (2015; new species, Alaska), Lücking et al. (2016b; classification), Pykälä and Myllys (2016; new species), holotype and culture of the type: UPS, Savić 3129, SS193.

Atopospora Petr. 1925, Venturiaceae, Venturiales, Dothideomycetes, two species, type: A. betulina (Fr.) Petr., asexual morph unknown, saprobes, terrestrial, north temperate, see Lumbsch and Huhndorf (2010; outline), Zhang et al. (2011d; accepted as a genus in Venturiaceae), Hyde et al. (2013; accepted as a genus in Venturiaceae), Wijayawardene et al. (2014c; outline), cultures and sequences are unavailable, needs generic revision.

Atractilina Dearn. \& Barthol. 1924, Ascomycota genera incertae sedis, two species, type: A. callicarpae Dearn. \& Barthol., hyphomycetous, sexual morph unknown, fungicolous, terrestrial, tropical, see Seifert et al. (2011; morphology), Wijayawardene et al. (2012, 2017; outline), Kirk et al. (2013; genus accepted), cultures and sequences are unavailable, needs generic revision. 
Atractium Link 1809, Nectriaceae, Hypocreales, Sordariomycetes, three species, type: A. stilbaster Link, hyphomycetous, sexual morph unknown, saprobes or isolated from drinking water, terrestrial, aquatic, worldwide, see Gräfenhan et al. (2011; phylogeny), Seifert et al. (2011; morphology), Wijayawardene et al. (2012, 2017; outline), Lombard et al. (2015b; phylogeny), Maharachchikumbura et al. (2015, 2016; outline), epitype and ex-epitype: CBS 410.67.

Atractobolus Tode 1790, Ascomycota genera incertae sedis, one species, type: A.ubiquitarius Tode, saprobes, Europe, see Lumbsch and Huhndorf (2010; outline), Kirk et al. (2013; genus accepted), cultures and sequences are unavailable, needs generic revision.

Atradidymella M.L. Davey \& Currah 2009, Pleosporales genera incertae sedis, Dothideomycetes, one species, type: A. muscivora M.L. Davey \& Currah, asexual morph unknown, saprobes, Canada, see Davey and Currah (2009; taxonomy), Lumbsch and Huhndorf (2010; outline), Wijayawardene et al. (2014c; outline), holotype: UAMH 10909, cultures and sequences are available.

Atrogeniculata J.S. Monteiro, Gusmão \& R.F. Castañeda 2014, Ascomycota genera incertae sedis, one species, type: A. submersa J.S. Monteiro, Gusmão \& R.F. Castañeda, hyphomycetous, sexual morph unknown, saprobes of submerged leaves, Brazil, see Santa Izabel et al. (2015; taxonomy), Wijayawardene et al. (2017; outline), cultures and sequences are unavailable, needs generic revision.

Atrokylindriopsis Y.R. Ma \& X.G. Zhang 2015, Chaetothyriales genera incertae sedis, Eurotiomycetes, one species, type: A. setulosa Y.R. Ma \& X.G. Zhang, hyphomycetous, sexual morph unknown, saprobes, terrestrial, Asia, see Ma et al. (2015; taxonomy, DNA), Wijayawardene et al. (2017; outline), holotype and ex-type strain of type: HSAUP H4560; HSAUPmyr4560, HMAS 245592.

Atronectria Etayo 2008, Niessliaceae, Hypocreales, Sordariomycetes, one species, type: A. magellanica Etayo, asexual morph unknown, parasymbion on macrolichens, aquatic, South America, see Etayo and Sancho (2008; morphology, distinction of similar lichenicolous genera), Lumbsch and Huhndorf (2010; outline), Maharachchikumbura et al. (2015, 2016; outline), need revision, holotype: MAF, Etayo 22938, cultures and sequences are unavailable. Atropellis Zeller \& Goodd. 1930, Godroniaceae, Helotiales, Leotiomycetes, four species, type: A. pinicola Zeller \& Goodd., asexual morph unknown, saprobes, terrestrial, North America, see Lumbsch and Huhndorf (2010; outline), Kirk et al. (2013; genus accepted), cultures and sequences are unavailable, needs generic revision.

Atrosetaphiale Matsush. 1995, Ascomycota genera incertae sedis, two species, type: A. flagelliformis Matsush., hyphomycetous, sexual morph unknown, saprobes, terrestrial, South America, see Seifert et al. (2011; morphology), Wijayawardene et al. (2012, 2017; outline), Kirk et al. (2013; genus accepted), cultures and sequences are unavailable, needs generic revision.

Atrotorquata Kohlm. \& Volkm.-Kohlm. 1993, Cainiaceae, Xylariales, Sordariomycetes, two species, type: Atrotorquata lineata Kohlm. \& Volkm.-Kohlm., asexual morph unknown, saprobes, Italy, USA, see Lumbsch and Huhndorf (2010; outline), Kirk et al. (2013; genus accepted), Liu et al. (2015a; new species, phylogeny), Maharachchikumbura et al. (2015, 2016; outline), only Atrotorquata spartii has sequence: MFLU 14-0738, MFLUCC 13-0444, further sequences are necessary for confirm its placement in Cainiaceae.

Auerswaldia Sacc. 1883, Dothideomycetes genera incertae sedis, c. 20 species, type: A. examinans (Mont. \& Berk.) Sacc., asexual morph coelomycetous, saprobes, terrestrial, widespread, see Lumbsch and Huhndorf (2010; outline), Liu et al. (2012; phylogeny, treated as a genus in Botryosphaeriaceae), Hyde et al. (2013; accepted as a genus in Botryosphaeriaceae), Kirk et al. (2013; genus accepted), Wijayawardene et al. (2014c; outline, accepted as a genus in Botryosphaeriaceae), Phillips et al. (2013; phylogeny, 
excluded from Botryosphaeriaceae), cultures and sequences are unavailable for type species, needs generic revision.

Auerswaldiella Theiss. \& Syd. 1914 (= Dimeriellina Chardón 1939; = Stichodothis Petr. 1927 fide Species Fungorum 2017), Botryosphaeriaceae, Botryosphaeriales, Dothideomycetes, four species, type: A. puccinioides (Speg.) Theiss. \& Syd., asexual morph unknown, saprobes, terrestrial, tropical, see Lumbsch and Huhndorf (2010; outline), Liu et al. (2012; accepted as a genus in Botryosphaeriaceae), Hyde et al. (2013; accepted as a genus in Botryosphaeriaceae), Wijayawardene et al. (2014c, 2016; outline), cultures and sequences are unavailable, needs generic revision.

Aulacostroma Syd. \& P. Syd. 1914, Parmulariaceae, Dothideomycetes families incertae sedis, Dothideomycetes, five species, type: A. palawanense Syd. \& P. Syd., asexual morph unknown, epiphytes, terrestrial, worldwide, see Hofmann (2009; review), Lumbsch and Huhndorf (2010; outline), Hyde et al. (2013; review, keys), Wijayawardene et al. (2014c; outline), cultures and sequences are unavailable.

Aulaxina Fée 1825, Graphidaceae, Ostropales, Lecanoromycetes, 13 species, type: A. opegraphina Fée, with ascomata, lichenized (Trebouxia), terrestrial (foliicolous and corticolous), tropical, see Lücking (2008; outline), Lumbsch and Huhndorf (2010; outline), Kirk et al. (2013; genus accepted), Lücking et al. (2016b, classification), Sanders and de los Ríos (2016; outline), sequences are available.

Aulographina Arx \& E. Müll. 1960, Teratosphaeriaceae, Capnodiales, Dothideomycetes, two species, type: A. pinorum (Desm.) Arx \& E. Müll., asexual morph unknown, epiphytes, terrestrial, worldwide, see Hofmann (2009; review, accepted as genus in Asterinaceae), Lumbsch and Huhndorf (2010; outline, accepted as genus in Asterinaceae), Hongsanan et al (2014c; taxonomy, transferred to Teratosphaeriaceae), Wijayawardene et al. (2014c; outline), holotype: PC 0084689.

Aulographum Lib. 1834, Aulographaceae, Dothideomycetes families incertae sedis, Dothideomycetes, c. 30, type: A. hederae Lib., asexual morph unknown, saprobes, terrestrial, widespread, see Lumbsch and Huhndorf (2010; outline), Hyde et al (2013; morphology, phylogeny), Kirk et al. (2013; genus accepted), Wijayawardene et al. (2014c; outline), cultures available for type species MFLUCC 13-0001, CPC21373.

Aulospora Speg. 1909, Sordariomycetes genera incertae sedis, one species, type: A. epimyces (Speg.) Speg., asexual morph unknown, saprobes, terrestrial, Argentina, see Lumbsch and Huhndorf (2010; outline), Kirk et al. (2013; genus accepted), Maharachchikumbura et al. (2015, 2016; outline), cultures and sequences are unavailable.

Aurantiosacculus Dyko \& B. Sutton 1979, Cryphonectriaceae, Diaporthales, Sordariomycetes, three species, type: A. eucalypti (Cooke \& Massee) Dyko \& B. Sutton, coelomycetous, sexual morph unknown, foliicolous, pathogens, saprobes, three species, Australia, see Crous et al. (2012d; morphology, phylogeny), Wijayawardene et al. (2012, 2017; outline), Kirk et al. (2013; genus accepted), sequences are unavailable, holotype of the type: Reader No. $24 \mathrm{~K}$.

Aurapex Gryzenh. \& M.J. Wingf. 2006, Cryphonectriaceae, Diaporthales, Sordariomycetes, one species, type: A. penicillata Gryzenh. \& M.J. Wingf., coelomycetous, sexual morph unknown, ?pathogens, saprobes, terrestrial, cosmopolitan, see Wijayawardene et al. (2012, 2017; outline), Maharachchikumbura et al. (2015, 2016; outline), holotype and ex-type cultures of type: PREM 57520, CMW $10030=$ CBS115740.

Auratiopycnidiella Crous \& Summerell 2012, Diaporthales genera incertae sedis, Sordariomycetes, one species, type: A. tristaniopsidis Crous \& Summerell, coelomycetous, sexual morph unknown, pathogens, terrestrial, Australia, see Crous et al. (2012d; morphology, phylogeny), Maharachchikumbura et al. (2015; classification, phylogeny), holotype and extype: CBS H-20932, CPC 16371. 
Aureobasidium Viala \& G. Boyer 1891 (= Aureobasis Clem. \& Shear 1931; = Dematoidium Stautz 1931; = Pachybasidiella Bubák \& Syd. 1915; = Polyspora Laff. 1921 [1920-22]; = Protocoronis Clem. \& Shear 1931; = Protocoronospora G.F. Atk. \& Edgerton 1907; = Pullularia Berkhout 1923 fide Speccies Fungorum 2017), Saccotheciaceae, Dothideales, Dothideomycetes, 36 species, type: A. vitis Viala \& G. Boyer, hyphomycetous, sexual morph unknown, saprobes, terrestrial, widespread, see Seifert et al. (2011; morphology), Wijayawardene et al. (2012, 2017; outline), Kirk et al. (2013; genus accepted), Peterson et al. (2013; phylogeny), Kirk (2013; genus accepted), Thambugala et al. (2014a; taxonomy), exepitype: CBS 130298.

Auriculora Kalb 1988, Ramalinaceae, Lecanorales, Lecanoromycetes, one species, type: A. byssomorpha (Nyl.) Kalb, lichenized, Neotropical, see Lumbsch and Huhndorf (2010; outline), Kirk et al. (2013; genus accepted), Jaklitsch et al. (2016a; classification), Lücking et al. (2016b; classification), sequences are unavailable.

Aurifilum Begoude, Gryzenh. \& Jol. Roux 2010, Cryphonectriaceae, Diaporthales, Sordariomycetes, one species, type: A. marmelostoma, asexual morph ceolomycetous, pathogens, terrestrial, Cameroon, Taiwan, see Begoude et al. (2010; taxonomy, phylogeny), Maharachchikumbura et al. (2015, 2016; outline), extype: CBS 124928 = CMW28290; exparatypes of type: CBS 124929, CBS 124930; holotype: PREM 60256.

Aurophora Rifai 1968, Sarcoscyphaceae, Pezizales, Pezizomycetes, one species, type: A. dochmia (Berk. \& M.A. Curtis) Rifai, asexual morph unknown, saprobes, terrestrial, pantropical, see Lumbsch and Huhndorf (2010; outline), Kirk et al. (2013; genus accepted), cultures and sequences are unavailable, needs generic revision.

Aurosphaeria Sun J. Lee, Strobel, Eisenman, Geary, Vargas \& S.A. Strobel 2009, Ascomycota genera incertae sedis, one species, type: A. flaviradians Sun J. Lee, Strobel, Eisenman, Geary, Vargas \& S.A. Strobel, coelomycetous, sexual morph unknown, saprobes, terrestrial, Bolivia, see Lee et al. (2009c; taxonomy), Wijayawardene et al. (2012, 2017; outline), holotype: MONT 2349, cultures and sequences are unavailable, needs generic revision.

Australiaena Matzer, H. Mayrhofer \& Elix 1997, Physciaceae, Caliciales, Lecanoromycetes, one species, type: A. streimannii Matzer, H. Mayrhofer \& Elix, with ascomata, lichenized (green algae), terrestrial (saxicolous), Australia, Papua-New Guinea see Lumbsch and Huhndorf (2010; outline), Gaya et al. (2012; phylogeny), Kirk et al. (2013; genus accepted), Prieto et al. (2013; phylogeny), Lücking et al. (2016b, classification), Prieto and Wedin (2016; phylogeny), sequences are available.

Austrella P.M. Jørg. 2004, Pannariaceae, Peltigerales, Lecanoromycetes, two species, type: A. arachnoidea P.M. Jørg., with ascomata, lichenized (Nostoc), terrestrial (corticolous), Australia, New Zealand, see Lumbsch and Huhndorf (2010; outline), Lücking et al. (2016b; classification), sequences are available for the type species.

Austroafricana Quaedvl. \& Crous 2014, Teratosphaeriaceae, Capnodiales, Dothideomycetes, hyphomycetous, three species, type: A. associata (Crous \& Carnegie) Quaedvl. \& Crous, asexual morph unknown, pathogens, terrestrial, Australia, South Africa, see Quaedvlieg et al. (2014; morphology, phylogeny), Wijayawardene et al. (2014c; outline), holotype: CBS-H 19833, ex-type: CPC 13119.

Austrocenangium Gamundí 1997, Cordieritidaceae, Helotiales, Leotiomycetes, two species, type: A. australe (Speg.) Gamundí, asexual morph unknown, saprobes, terrestrial, South America, see Lumbsch and Huhndorf (2010; outline), Kirk et al. (2013; genus accepted), Jaklitsch et al. (2016a; classification), cultures and sequences are unavailable, needs generic revision.

Austrographa Sparrius, Elix \& A.W.Archer 2010, Roccellaceae, Arthoniales, Arthoniomycetes, three species, type: A. kurriminensis Sparrius, Elix \& A.W. Archer, 
lichenized, see Sparrius et al. (2010, 2013; taxonomy), Lücking et al. (2016b; classification), sequences are unavailable.

Austrolecia Hertel 1984, Catillariaceae, Lecanorales, Lecanoromycetes, one species, type: A. antarctica Hertel, lichenized, see Lumbsch and Huhndorf (2010; outline), Kirk et al. (2013; genus accepted), Lücking et al. (2016b; classification), sequences are available.

Austroparmeliella (P.M. Jørg.) P.M. Jørg. 2014, Pannariaceae, Peltigerales, Lecanoromycetes, two species, type: A. arachnoidea P.M. Jørg., with ascomata, lichenized (Nostoc), terrestrial (corticolous), Australia, New Zealand, see Lücking et al. (2016b; classification), sequences are available.

Austroparmelina A. Crespo, Divakar \& Elix 2010, Parmeliaceae, Lecanorales, Lecanoromycetes, 15 species, type: A. endoleuca (Taylor) A. Crespo, Divakar \& Elix, with ascomata, lichenized (green algae), terrestrial (corticolous, saxicolous), Australasia, South Africa, see Crespo et al. (2010a, b; taxonomy), Kantvilas and Divakar (2013; phylogeny), Lücking et al. (2016b; classification), sequences are available.

Austropeltum Henssen, Döring \& Kantvilas 1992, Sphaerophoraceae, Lecanorales, Lecanoromycetes, one species, type: A. glareosum Henssen, Döring \& Kantvilas, with ascomata, lichenized (green algae), terrestrial (terricolous), Tasmania and New Zealand, see Lumbsch and Huhndorf (2010; outline), Kirk et al. (2013; genus accepted), Lücking et al. (2016b; classification).

Austropezia Spooner 1987, Arachnopezizaceae, Helotiales, Leotiomycetes, one species, type: A. samuelsii (Korf) Spooner, sexual morph unknown, saprobes, New Zealand, see Lumbsch and Huhndorf (2010; outline, accepted as a genus in Hyaloscyphaceae), Kirk et al. (2013; genus accepted), Jaklitsch et al. (2016a; classification), cultures and sequences are unavailable.

Austroplaca Søchting, Frödén \& Arup 2013, Teloschistaceae, Teloschistales, Lecanoromycetes, ten species, type: A. ambitiosa (Darb.) Søchting, Frödén \& Arup, lichenized, see Arup et al. (2013; taxonomy), Lücking et al. (2016b; classification); sequences are available.

Austropleospora R.G. Shivas \& L. Morin 2010, Didymosphaeriaceae, Pleosporales, Dothideomycetes, two species, type: A. osteospermi R.G. Shivas \& L. Morin, asexual morph coelomycetous, pathogens, terrestrial, Australia, South Africa, see Morin et al. (2010), Thambugala et al. (2014c; taxonomy), Ariyawansa et al. (2015a; phylogeny), holotype of the type: BRIP 52234, isotype BRIP 51628 (includes ex-isotype culture).

Austroroccella Tehler \& Ertz 2013, Roccellaceae, Arthoniales, Arthoniomycetes, one species, type: A. gayana (Mont.) Tehler \& Ertz, sexual morph with apothecioid ascomata, asexual morph coelomycetous, lichenized, terrestrial, Chile, see Tehler et al. (2013b; morphology, phylogeny), Lücking et al. (2016b; classification), cultures and sequences are available

Austrostigmidium Pérez-Ortega \& Garrido-Benavent 2015, Teratosphaeriaceae, Capnodiales, Dothideomycetes, one species, type: A. mastodiae Pérez-Ortega \& GarridoBenavent, lichenicolous, terrestrial, Artarctica, Tierra del Fuego, asexual morph coelomycetous, see Pérez-Ortega et al. (2015, phylogeny, taxonomy), closely related to the lichenicolous genus Xanthoriicola and the rock-inhabiting fungal genus Friedmanniomyces, holotype: MA-Lich 18215.

Austrotrema I. Medeiros, Lücking \& Lumbsch 2017, Graphidaceae, Ostropales, Lecanoromycetes, three species, type: A. bicinctulum (Nyl.) I. Medeiros, Lücking \& Lumbsch, lichenized, see Lücking et al. (2016b; classification), Medeiros et al. (2017; taxonomy), sequences are available.

Autoicomyces Thaxt. 1908, Ceratomycetaceae, Laboulbeniales, Laboulbeniomycetes, 28 species, type: A. acuminatus (Thaxt.) Thaxt., asexual morph unknown, parasitic on Hydrophilidae beetles, aquatic, Asia, Europe, North America, South America, see Lumbsch 
and Huhndorf (2010; outline), Kirk et al. (2013; genus accepted), cultures and sequences are unavailable.

Autophagomyces Thaxt. 1912 (= Bordea Maire 1916 fide Species Fungorum 2017), Laboulbeniaceae, Laboulbeniales, Laboulbeniomycetes, 20 species, type: A. platensis Thaxt., asexual morph unknown, parasitic on Anthicidae, Phalacridae, and Staphylinidae beetles, terrestrial, Africa, Asia, North America, South America, see Lumbsch and Huhndorf (2010; outline), Kirk et al. (2013; genus accepted), cultures and sequences are unavailable.

Auxarthron G.F. Orr \& Kuehn 1963, Onygenaceae, Onygenales, Eurotiomycetes, 17 species, type: A. californiense G.F. Orr \& Kuehn, asexual morph hyphomycetous, saprobes, terrestrial, worldwide, see Lumbsch and Huhndorf (2010; outline), Crous et al. (2013b; new species, Portugal), Hubka et al. (2013; new species), Kirk et al. (2013; genus accepted), cultures and sequences are available.

Auxarthronopsis Rahul Sharma, Gräser \& S.K. Singh 2011, Onygenaceae, Onygenales, Eurotiomycetes, 18 species, type: A. californiense G.F. Orr \& Kuehn, asexual morph hyphomycetous, saprobes, terrestrial, India, see Sharma et al. (2011; taxonomy), cultures and sequences are available.

Avesicladiella W.P. Wu, B. Sutton \& Gange 1997, Ascomycota genera incertae sedis, two species, type: A. britannica Wu, Sutton \& Gange, saprobes, hyphomycetous, sexual morph unknown, UK, China, see Seifert et al. (2011; morphology), Wijayawardene et al. (2012, 2017; outline), Kirk et al. (2013; genus accepted), holotype: IMI 372453, sequence are unavailable.

Avettaea Petr. \& Syd. 1927, Ascomycota genera incertae sedis, three species, type: A. philippinensis Petr. \& Syd., coelomycetous, sexual morph unknown, saprobes, terrestrial, cosmopolitan, see Wijayawardene et al. (2012, 2016b, 2017; outline, taxonomy), Kirk et al. (2013; genus accepted), cultures and sequences are unavailable, needs generic revision.

Awasthiella Kr. P. Singh 1980, Verrucariaceae, Verrucariales, Eurotiomycetes, one species, type: A. indica Kr. P. Singh, lichenized, terrestrial, India, see Lumbsch and Huhndorf (2010; outline), Kirk et al. (2013; genus accepted), Lücking et al. (2016b; classification), cultures and sequences are unavailable, needs generic revision.

Ayria Fryar \& K.D. Hyde 2004, Annulatascaceae, Annulatascales, Sordariomycetes, two species, type: A. appendiculata Fryar \& K.D. Hyde, saprobes, aquatic, Costa Rica, USA, Brunei, see Lumbsch and Huhndorf (2010; outline), Maharachchikumbura et al (2016), holotype: HKU (M) 15553.

Azbukinia Lar. N. Vassiljeva 1989, Sordariomycetes genera incertae sedis, one species, type: A. ferruginea (Fuckel) Lar.N. Vassiljeva, asexual morphs unknown, saprobes, terrestrial, north temperate, see Lumbsch and Huhndorf (2010; outline), Kirk et al. (2013; genus accepted), Maharachchikumbura et al. (2016; outline), cultures and sequences are unavailable. Azureothecium Matsush. 1989, Eurotiomycetidae genera incertae sedis, Eurotiomycetes, two species, type: A. australiense Matsush., asexual morph unknown, saprobes, from soil, terrestrial, Australia, see Lumbsch and Huhndorf (2010; outline), Kirk et al. (2013; genus accepted), cultures and sequences are unavailable, needs generic revision.

Babjeviella Kurtzman \& M. Suzuki 2010, Debaryomycetaceae, Saccharomycetales, Saccharomycetes, one species, type: B. inositovora (Golubev \& Blagod.) Kurtzman \& M. Suzuki, asexual reproduction by multilateral budding and cells are short-ellipsoid to elongate, saprophytes, known from peat, rotted balsam fir (Abies balsamea), insect frass, unidentified tree, Russia, Canada, USA, see Kurtzman and Suzuki (2010; taxonomy), Kurtzman and Robnett (2013; phylogeny), cultures and sequences are available.

Bachmanniomyces D. Hawksw. 1981, Ascomycota genera incerate sedis, type: B. uncialicola (Zopf) D. Hawksw. (syn. Phyllosticta uncialicola Zopf), three species, coelomycetous, sexual morph unknown, gall-forming on lichens, Europe, North and South America, see 
Wijayawardene et al. (2012, 2017; outline), Kirk et al. (2013; genus accepted), lectotype: E, cultures and sequences are unavailable.

Bacidia De Not. 1846 (= Bacidiomyces Cif. \& Tomas. 1953; = Byssopsora A. Massal. 1861; = Psorella Müll. Arg. 1894; = Sporacestra A. Massal. 1860 [1859-1860]; = Urophora Sommerf. ex Arnold 1899 fide Species Fungorum 2017), Ramalinaceae, Lecanorales, Lecanoromycetes, 230 species, type: B. rosella (Pers.) De Not., lichenized, worldwide, see Lumbsch and Huhndorf (2010; outline), Kirk et al. (2013; genus accepted), Lücking et al. (2016b; classification), sequences are available.

Bacidina Vězda [nom. cons.] 1991, Ramalinaceae, Lecanorales, Lecanoromycetes, twelve species, type: B. phacodes (Körb.) Vězda, lichenized, see Lumbsch and Huhndorf (2010; outline), Czarnota and Guzow-Krzeminska (2012; DNA), Kirk et al. (2013; genus accepted), Lücking et al. (2016b; classification), sequences are available.

Bacidiopsora Kalb 1988, Ramalinaceae, Lecanorales, Lecanoromycetes, five species, type: $B$. squamulosa (Nyl.) Kalb (Lecidea squamulosa Nyl.), lichenized, corticolous, tropical, see Lumbsch and Huhndorf (2010; outline), Kirk et al. (2013; genus accepted), Lücking et al. (2016b; classification), cultures and sequences are unavailable.

Bacillopeltis Bat. 1957, Ascomycota genera incertae sedis, one species, type: B. paypayrolae Bat., coelomycetous, sexual morph unknown, saprobes, on soil, terrestrial, Brazil, see Wijayawardene et al. (2012, 2017; outline), Kirk et al. (2013; genus accepted), cultures and sequences are unavailable, needs generic revision.

Bactridium Kunze 1817 (= Damnosporium Corda 1842; = Ericianella Brond. 1828 [18281830; = Podobactridium Penz. \& Sacc. ex Petch 1916 fide Species Fungorum 2017), Ascomycota genera incertae sedis, 15 species, type: B. flavum Kunze, hyphomycetous, sexual morph unknown, saprobes, terrestrial, cosmopolitan, see Seifert et al. (2011; morphology), Wijayawardene et al. (2012, 2017; outline), Kirk et al. (2013; genus accepted), cultures and sequences are unavailable, needs generic revision.

Bactrodesmiastrum Hol.-Jech. 1984, Sordariomycetes genera incertae sedis, two species, type: B. obscurum Hol.-Jech., asexual morph unknown, saprobes, terrestrial, cosmopolitan, see Seifert et al. (2011; morphology), Kirk et al. (2013; genus accepted), Hernández-Restrepo et al. (2015a; taxonomy, phylogeny), Maharachchikumbura et al. (2015, 2016; outline), needs generic revision, cultures and sequences are available.

Bactrodesmiella M.B. Ellis 1959, Ascomycota genera incertae sedis, two species, type: $B$. masonii (S. Hughes) M.B. Ellis, hyphomycetous, sexual morph unknown, saprobes, terrestrial, Australasia, Europe, see Seifert et al. (2011; morphology), Wijayawardene et al. (2012, 2017; outline), Kirk et al. (2013; genus accepted), cultures and sequences are unavailable, needs generic revision.

Bactrodesmium Cooke 1883, Dothideomycetes genera incertae sedis, more than 48 species, type: B. abruptum (Berk. \& Broome) Mason \& Hughes, sexual morph Stuartella spp., saprobes, terrestrial and aquatic, worldwide, see Zhao et al. (2009; outline, diversity), da Cruz and Gusmão (2009; diversity), Koukol and Kolářová (2010; morphology, phylogeny), Kalko (2011; diversity), Seephueak et al. (2011a, 2011b; diversity), Hernández-Restrepo et al. (2013; morphology), Tanaka et al. (2015; phylogeny), sequences are available.

Bactrosphaeria Penz. \& Sacc. 1897, Sordariomycetes genera incertae sedis, one specie, type: B. asterostoma Penz. \& Sacc, asexual morph unknown, saprobe, Java, see Lumbsch and Huhndorf (2010; outline), Kirk et al. (2013; genus accepted), cultures and sequences are unavailable, needs generic revision.

Bactrospora A. Massal. 1852 (= Bactrosporomyces Cif. \& Tomas. 1953; = Melampydiomyces Cif. \& Tomas. 1953; = Melampylidium Stirt. ex Müll. Arg. 1894; = Scolecactis Clem. 1909 fide Species Fungorum 2017), Arthoniales genera incertae sedis, Arthoniomycetes, 35 species, type: B. dryina (Ach.) A. Massal., lichenized, terrestrial, 
worldwide, see Lumbsch and Huhndorf (2010; outline), Knudsen et al. (2011; new species), Kirk et al. (2013; genus accepted), Sobreira et al. (2015; new species), Lücking et al. (2016b; classification), sequences are unavailable.

Bactrospora A. Massal. 1852, Arthoniales genera incertae sedis, Arthoniomycetes, 35 species; type: B. dryina (Ach.) A. Massal., lichenized, temperate, see Lumbsch and Huhndorf (2010; outline), Kirk et al. (2013; genus accepted), Lücking et al. (2016b; classification), sequences are unavailable.

Baculifera Marbach \& Kalb 2000, Caliciaceae, Caliciales, Lecanoromycetes, 14 species, type: B. orosa Marbach., with ascomata, lichenized (green algae), terrestrial (mostly corticolous and lignicolous), tropical, see Elix and Kantvilas (2014; new records), Elix and Mayrhofer (2016; outline), Lücking et al. (2016b; classification), Prieto and Wedin (2016; DNA, genus accepted), sequences are available but lacks for the type.

Baculospora Zukal 1887, Ascomycota genera incertae sedis, one species, type: B. pellucida Zukal, asexual morph unknown, saprobes, terrestrial, Europe, see Lumbsch and Huhndorf (2010; outline), Kirk et al. (2013; genus accepted), cultures and sequences are unavailable, needs generic revision.

Bacusphaeria Norlailatul, Alias \& Suetrong 2017, Tirisporellaceae, Tirisporellales, Sordariomycetes, one species, type: B. nypae Norlailatul, Alias \& Suetrong, asexual morph unknown, saprobes, marine, Malaysia, see Abdel-Wahab et al. (2017; phylogeny), holotype and ex-type: MFLU 13-0617, BCC51275

Badarisama Kunwar, J.B. Manandhar \& J.B. Sinclair 1986, Ascomycota genera incertae sedis, one species, type: B. sojae Kunwar, J.B. Manandhar \& J.B. Sinclair, hyphomycetous, sexual morph unknown, saprobes, terrestrial, North America, see Seifert et al. (2011; morphology), Wijayawardene et al. (2012, 2017; outline), Kirk et al. (2013; genus accepted), cultures and sequences are unavailable, needs generic revision.

Badimia Vězda [nom. cons.] 1986 (= Pseudogyalecta Vězda 1975 fide Species Fungorum 2017), Ramalinaceae, Lecanorales, Lecanoromycetes, 18 species, type: B. dimidiata (Bab. ex Leight.) Vězda, lichenized, tropical, see Lumbsch and Huhndorf (2010; outline), Kirk et al. (2013; genus accepted), Lücking et al. (2016b; classification), sequences are available.

Badimiella Malcolm \& Vězda 1994, Pilocarpaceae, Lecanorales, Lecanoromycetes, one species, type: B. serusiauxii Malcolm \& Vězda, lichenized, south temperate, see Lumbsch and Huhndorf (2010; outline), Kirk et al. (2013; genus accepted), Lücking et al. (2016b; classification), sequences unavailable.

Baeomyces Pers. 1794 (= Baeomycetomyces E.A. Thomas ex Cif. \& Tomas. 1953; = Cladoniopsis Zahlbr. 1941; = Cyanobaeis Clem. 1909; = Ludovicia Trevis. 1857; = Sphyridiomyces E.A. Thomas ex Cif. \& Tomas. 1953; = Sphyridium Flot. 1843 fide Species Fungorum 2017), Baeomycetaceae, Baeomycetales, Lecanoromycetes, nine species, type: B. byssoides (L.) P. Gaertn., G. Mey. \& Scherb., lichenized, terrestrial, worldwide, see Lumbsch and Huhndorf (2010; outline), Kirk et al. (2013; genus accepted), Lücking et al. (2016b; classification), sequences are available.

Baflavia Lücking 2008, Pilocarpaceae, Lecanorales, Lecanoromycetes, one species, type: B. flavescens (Lücking) Lücking, lichenized, see Lücking et al. (2016b; classification), sequences are unavailable.

Bagadiella Cheew. \& Crous 2009, Diaporthales genera incertae sedis, Sordariomycetes, two species, type: B. lunata Cheew. \& Crous, hyphomycetous, sexual morph unknown, saprobes, ?pathogens, terrestrial, Australasia, see Cheewangkoon et al. (2009; taxonomy, phylogeny), Crous et al. (2011a; new species), Seifert et al. (2011; morphology), Wijayawardene et al. (2012, 2017; outline), Maharachchikumbura et al. (2015, 2016; outline), holotype and ex-type: CBS H-20281, CBS 124762. 
Bagcheea E. Müll. \& R. Menon 1954, Gnomoniaceae, Diaporthales, Sordariomycetes, two species, type: B. albomaculans (Fukui) Hino \& Katumoto asexual morph unknown, mild pathogens, terrestrial, temperate and tropical, Asia, see Lumbsch and Huhndorf (2010; outline), Kirk et al. (2013; genus accepted), Maharachchikumbura et al. (2015, 2016; outline), cultures and sequences are unavailable.

Bagcheea E. Müll. \& R. Menon 1954, Gnomoniaceae, Diaporthales, Sordariomycetes, two species, type: B. albomaculans (Fukui) Hino \& Katumoto asexual morph unknown, mild pathogens, terrestrial, temperate and tropical, Asia, see Lumbsch and Huhndorf (2010; outline), Kirk et al. (2013; genus accepted), Maharachchikumbura et al. (2015, 2016; outline), cultures and sequences are unavailable.

Baggea Auersw. 1866, Patellariaceae, Patellariales, Dothideomycetes, one species, type: $B$. pachyascus Auersw., asexual morph unknown, saprobes, terrestrial, Germany, see Lumbsch and Huhndorf (2010; outline), Hyde et al. (2013; accepted as a genus in Patellariaceae), Kirk et al. (2013; genus accepted), Wijayawardene et al. (2014c; outline), Yacharoen et al. (2015; accepted as a genus in Patellariaceae), neotype: $\mathrm{K}$ herbarium.

Bagliettoa A. Massal. 1853, Verrucariaceae, Verrucariales, Eurotiomycetes, 20 species, type: B. limborioides A. Massal., lichenized, see Lumbsch and Huhndorf (2010; outline), Lücking et al. (2016b; classification), sequences are available.

Bagnisiella Speg. 1880 (= Robertomyces Starbäck 1880 fide Species Fungorum 2017), Aplosporellaceae, Botryosphaeriales, Dothideomycetes, c. 20 species, type: B. australis Speg., asexual morph unknown, saprobes, South America, India, see Lumbsch and Huhndorf (2010; outline), Kirk et al. (2013; genus accepted), Thambugala et al. (2014a; transferred to Aplosporellaceae), Wijayawardene et al. (2014c; outline), cultures and sequences are available.

Bagnisimitrula S. Imai 1942, Leotiomycetes genera incertae sedis, one species, type: $B$. saccardoa (Bagnis) S. Imai, asexual morph unknown, saprobes, terrestrial, Japan, see Lumbsch and Huhndorf (2010; outline), Kirk et al. (2013; genus accepted), cultures and sequences are unavailable, needs generic revision.

Bahianora Kalb 1984, Lecideaceae, Lecideales, Lecanoromycetes, one species, type: B. poeltii Kalb, lichenized, see Lumbsch and Huhndorf (2010; outline), Schmull et al. (2011; phylogeny), Kirk et al. (2013; genus accepted), Lücking et al. (2016b; classification), sequences unavailable.

Bahuchashaka Subram. 1978, Ascomycota genera incertae sedis, one species, type: B. graminis (Matsush.) Subram., hyphomycetous, sexual morph unknown, saprobes, terrestrial, Japan, see Seifert et al. (2011; morphology), Wijayawardene et al. (2012, 2017; outline), Kirk et al. (2013; genus accepted), cultures and sequences are unavailable, needs generic revision.

Bahukalasa Subram. \& Chandrash. 1979, Ascomycota genera incertae sedis, one species, type: B. samala Subram. \& Chandrash., hyphomycetous, sexual morph unknown, saprobes, terrestrial, Asia, see Seifert et al. (2011; morphology), Wijayawardene et al. (2012, 2017; outline), Kirk et al. (2013; genus accepted), cultures and sequences are unavailable, needs generic revision.

Bahusakala Subram. 1958, Dothideomycetes genera incertae sedis, four species, type: B. olivaceonigra (Berk. \& Broome) Subram., hyphomycetous, sexual morph unknown, saprobes, terrestrial, Asia, Australasia, Caribbean, North America, see Kang et al. (2010; DNA), Seifert et al. (2011; morphology), Wijayawardene et al. (2012, 2014c, 2017; outline), cultures and sequences are available, needs generic revision.

Bahusandhika Subram. 1956, Ascomycota genera incertae sedis, four species, type: B. indica (Subram.) Subram., hyphomycetous, sexual morph unknown, saprobes, terrestrial, Asia, see Seifert et al. (2011; morphology), Wijayawardene et al. (2012, 2017; outline), Kirk et al. (2013; genus accepted), cultures and sequences are unavailable, needs generic revision. 
Bahusutrabeeja Subram. \& Bhat 1977, Botryosphaeriales genera incertae sedis, Dothideomycetes, six species, type: B. dwaya Subram. \& Bhat, hyphomycetous, sexual morph unknown, saprobes, terrestrial, sometimes aquatic, cosmopolitan see Shenoy et al. (2010, phylogeny), Seifert et al. (2011; morphology), Wijayawardene et al. (2012, 2017; outline), Kirk et al. (2013; genus accepted), Li et al. (2013; new species, key), Gao et al. (2015a; new record for B. angularis from China), sequences are available.

Baipadisphaeria Pinruan 2011, Nectriaceae, Hypocreales, Sordariomycetes, one species, type: B. spathulospora Pinruan, asexual morph unknown, saprobes, aquatic, on decaying leaves of peat swamp palm Licuala longicalycata, Thailand, see Pinruan et al. (2010; taxonomy, phylogeny), Maharachchikumbura et al. (2015, 2016; outline), holotype and extype culture of type: BBH Pinruan Wah32A, BCC16119.

Bakerophoma Died. 1916, Ascomycota genera incertae sedis, three species, type: B. sacchari Died., lichenocolous, see Kirk (2013; genus accepted), cultures and sequences are unavailable, needs generic revision.

Balaniopsis P.M. Kirk 1985, Ascomycota genera incertae sedis, four species, type: $B$. africana (Kiffer) P.M. Kirk, hyphomycetous, sexual morph unknown, saprobes, on soil, terrestrial, Africa, Australasia, North America, see Seifert et al. (2011; morphology), Wijayawardene et al. (2012, 2017; outline), cultures and sequences are unavailable, needs generic revision.

Balanium Wallr. 1833, Ascomycota genera incertae sedis, one species, type: B. stygium Wallr., hyphomycetous, sexual morph unknown, saprobes, on soil, terrestrial, Europe, see Seifert et al. (2011; morphology), Wijayawardene et al. (2012, 2017; outline), cultures and sequences are unavailable, needs generic revision.

Balansia Speg. 1885 (= Dothichlö̈ G.F. Atk. 1894; = Ephelis Fr. 1849; = Ophiodothis Sacc. 1883 fide Rossman et al. 2016a; Species Fungorum 2017), Clavicipitaceae, Hypocreales, Sordariomycetes, 27 species, type: B. claviceps Speg., asexual morph unknown, saprobes, terrestrial, subtropical, see Lumbsch and Huhndorf (2010; outline), Kirk et al. (2013; genus accepted), Maharachchikumbura et al. (2015, 2016; outline), Rossman et al. (2016a; nomenclature), cultures and sequences are available.

Balazucia R.K. Benj. 1968, Laboulbeniaceae, Laboulbeniales, Laboulbeniomycetes, two species, type: B. bilateralis R.K. Benj., asexual morph unknown, parasitic on Staphylinoidea beetles, terrestrial, Central America and Japan, see Rossi and Weir (2008; treated as a synonym of Cucujomyces), Lumbsch and Huhndorf (2010; outline, misspelled as Balazusia), Kirk et al. (2013; genus accepted), cultures and sequences are unavailable.

Balladyna Racib. 1900 (= Wageria Stevens \& Dalbey. 1918), Perisporiopsidaceae, Dothideomycetes family incertae sedis, c. 17 species, type: B. gardeniae Racib., asexual morph unknown, see Lumbsch and Huhndorf (2010; outline), Kirk et al. (2013; genus accepted), Wijayawardene et al. (2014c; outline), cultures and sequences are unavailable, needs generic revision.

Balladynocallia Bat. 1965, Perisporiopsidaceae, Dothideomycetes family incertae sedis, three species, type: B. glabra (Hansf.) Bat., asexual morph unknown, saprophytes on leaves, see Lumbsch and Huhndorf (2010; outline), Kirk et al. (2013; genus accepted), Wijayawardene et al. (2014; outline), cultures and sequences are unavailable, needs generic revision.

Balladynopsis Theiss. \& Syd., 1917 (= Balladynastrum Hansf. 1941 [1940-41]; = Xenostigmella Petr. 1950 fide Species Fungorum 2017), Perisporiopsidaceae, Dothideomycetes family incertae sedis, 17 species, type: B. philippinensis Syd. \& P. Syd., asexual morph hyphomycetous, mostly saprophyte on leave, see Lumbsch and Huhndorf (2010; outline), Kirk et al. (2013; genus accepted), Wijayawardene et al. (2014c; outline), sequences unavailable. 
Balsamia Vittad. 1831 (= Pseudobalsamia E. Fisch. 1907 fide Species Fungorum 2017), Helvellaceae, Pezizales, Pezizomycetes, six species, type: B. vulgaris Vittad., asexual morph unknown, saprobes, ?from soil, terrestrial, worldwide, see Lumbsch and Huhndorf (2010; outline), Kirk et al. (2013; genus accepted), Crous et al. (2014d; DNA, phylogeny), sequences are available.

Bambusaria Jaklitsch, D.Q. Dai, K.D. Hyde \& Voglmayr 2015, Valsariaceae, Valsariales, Dothideomycetes, one species, type: B. bambusae (J.N. Kapoor \& H.S. Gill) Jaklitsch, D.Q. Dai, K.D. Hyde \& Voglmayr, asexual morph coelomycetous, saprobes, terrestrial, India and Thailand, see Jaklitsch et al. (2015; phylogeny, morphology, sexual and asexual morphs), reference specimen culture of type: MFLUCC 12-0851 = CBS $139763=$ MUCL 55880.

Bambusicola D.Q. Dai \& K.D. Hyde 2012, Bambusicolaceae, Pleosporales, Dothideomycetes, nine species, type: B. massarinia D.Q. Dai \& K.D. Hyde, asexual morph coelomycetous, saprobes, terrestrial, Thailand, see Dai et al. (2012, 2015, 2016; phylogeny, morphology, sexual morph, key), Wijayawardene et al. (2014c; outline), ex-type: MFLUCC $11-0389=$ CBS 139985 .

Bambusicularia Klaubauf, Lebrun \& Crous 2014, Pyriculariaceae, Magnaporthales, Sordariomycetes, one species, type: B. brunnea Klaubauf, Lebrun \& Crous, hyphomycetous, sexual morph unknown, pathogens, terrestrial, Japan, see Klaubauf et al. (2014; morphology, phylogeny), Maharachchikumbura et al. (2015, 2016; outline), holotype: CBS H-21839, extype strain of type: CBS 133599.

Bambusistroma D.Q. Dai \& K.D. Hyde 2015, Massarinaceae, Massarineae, Pleosporales, Dothideomycetes, one species, type: B. didymosporum D.Q. Dai \& K.D. Hyde, asexual morph unknown, saprobes, terrestrial, Thailand, see Adamčík et al. (2015; phylogeny, morphology, sexual morph), holotype and ex-type strain of type: MFLU 15-0057, MFLUCC 13-0862.

Banhegyia Zeller \& Tóth 1960, Dothideomycetes genera incertae sedis, two species, type: $B$. setispora L. Zeller \& Tóth, asexual morph unknown, saprobes, terrestrial, Europe, see Sanderson et al. (2009; excluded the genus Banhegyia due to differing morphology and phylogeny and synonymized Banhegiya with Mycoelaspilea), Lumbsch and Huhndorf (2010; outline), Kirk et al. (2013; genus accepted), Hyde et al. (2013; did not accept as a genus in Patellariaceae but included in key due to historical reasons), Wijayawardene et al. (2014c; outline), Yacharoen et al. (2015; did not accept as a genus in Patellariaceae), holotype: BP 2835.

Banksiamyces G.W. Beaton 1982, Helotiales genera incertae sedis, Leotiomycetes, four species, type: B. macrocarpus G.W. Beaton, asexual morph unknown, saprobes, terrestrial, Australia, see Lumbsch and Huhndorf (2010; outline), Kirk et al. (2013; genus accepted), sequence (ITS) is available for an unidentified species, needs generic revision.

Bapalmuia Sérus. 1993, Pilocarpaceae, Lecanorales, Lecanoromycetes, 23 species, type: B. palmularis (Müll. Arg.) Sérus., lichenized, tropical, see Lumbsch and Huhndorf (2010; outline), Kirk et al. (2013; genus accepted), van den Broeck et al. (2014; new species, Congo), Lücking et al. (2016b; classification), sequences are available.

Barbarosporina Kirulis 1942, Ascomycota genera incertae sedis, one species, type: $B$. rhytismatis Kirulis, coelomycetous, sexual morph unknown, former USSR see Wijayawardene et al. (2012, 2017; outline), Kirk et al. (2013; genus accepted), cultures and sequences are unavailable, need generic revision.

Barbatosphaeria Réblová 2008 (= Tectonidula Réblová 2009 fide Réblová et al. 2015c), Sordariomycetes genera incertae sedis, eight species, type: B. barbirostris (Dufour) Réblová, asexual morph unknown, saprobes, tropical, see Lumbsch and Huhndorf (2010; outline), Réblová et al. (2015c; new species), Maharachchikumbura et al. (2016; outline, phylogeny), cultures available for the type: CBS 121149. 
Barnettella D. Rao \& P. Rag. Rao 1964 (= Vinculum R.Y. Roy, R.S. Dwivedi \& P.K. Khanna 1965 fide Species Fungorum 2017), Ascomycota genera incertae sedis, one species, type: B. speciosa D. Rao \& P.Rag. Rao, coelomycetous, sexual morph unknown, saprobes, on soil, terrestrial, India, see Wijayawardene et al. (2012, 2016b, 2017; outline, taxonomy), cultures and sequences are unavailable, needs generic revision.

Barnettozyma Kurtzman, Robnett \& Bas.-Powers 2008, Phaffomycetaceae, Saccharomycetales, Saccharomycetes, ten species, type: B. populi (Phaff, Y. Yamada, Tredick \& M. Miranda) Kurtzman, Robnett \& Basehoar-Powers, asexual reproduction by budding, saprophytic, on soil, water, tree fluxes, insect frass in trees, animal dung, one clinical isolate, worldwide, see Kurtzman et al. (2008; taxonomy), Lumbsch and Huhndorf (2010; outline), cultures and sequences are available.

Barrenia E. Walsh \& N. Zhang 2015, Helotiales genera incertae sedis, Leotiomycetes, two species, type: B. panicia E. Walsh \& N. Zhang, hyphomycetous, sexual morph unknown, root endophytes, terrestrial, USA, see Walsh et al. (2015; taxonomy, phylogeny), Wijayawardene et al. (2017; outline), holotype: RUTPP WSF1R37.

Barretomyces Klaubauf, Lebrun \& Crous 2014, Pyriculariaceae, Magnaporthales, Sordariomycetes, hyphomycetous, one species, type: B. calatheae (Soares, Rocha \& Barreto) Klaubauf, Lebrun \& Crous, sexual morph unknown, pathogens, terrestrial, Brazil, see Klaubauf et al. (2014; morphology, phylogeny), Maharachchikumbura et al. (2015; outline), holotype of the type: VIC 30699, ex-type strain of type: CBMAI 1060.

Barria Z.Q. Yuan 1994, Didymosphaeriaceae, Pleosporales, Dothideomycetes, one species, type: B. piceae Z.Q. Yuan, asexual morph unknown, pathogens, terrestrial, China, see Lumbsch and Huhndorf (2010; outline), Kirk et al. (2013; genus accepted), Ariyawansa et al. (2014d; transferred the genus Barria from Phaeosphaeriaceae to Didymosphaeriaceae), Phookamsak et al. (2014b; accepted as a genus in Didymosphaeriaceae), Wijayawardene et al. (2014c; outline), sequences are unavailable, isotype of type species NY 00164027.

Barrina A.W. Ramaley 1997, Coniochaetaceae, Coniochaetales, Sordariomycetes, one specie (type): B. polyspora A.W. Ramaley, asexual morph Phialophora-like, saprobes, USA see Lumbsch and Huhndorf (2010; outline), Kirk et al. (2013; genus accepted), Maharachchikumbura et al. (2015; outline), sequences are available.

Barriopsis A.J.L. Phillips, A. Alves \& Crous, Persoonia 21: 39. 2008, Botryosphaeriaceae, Botryosphaeriales, Dothideomycetes, four species, type: $P$. fusca N.E. Stevens [三 Barriopsis fusca nom. illeg.; $\equiv$ Barriopsis stevensiana A.J.L. Phillips \& Pennycook], coelomycetous, saprobes, weak pathogens, terrestrial, distribution not known, see Abdollahzadeh et al. (2009; taxonomy), Lumbsch and Huhndorf (2010; outline), Liu et al. (2012; phylogeny), Hyde et al. (2013; accepted as a genus in Botryosphaeriaceae), Phillips et al. (2013; phylogeny), Wijayawardene et al. (2014c, 2016b; outline, taxonomy), ex-type: CBS 174.26, needs generic revision.

Barriopsis stevensiana A.J.L. Phillips \& Pennycook, nom. nov. MycoBank MB819573

三Barriopsis fusca (N.E. Stevens) A.J.L. Phillips, A. Alves \& Crous, Persoonia 21: 39. 2008, nom illeg. [ICN(Melbourne) Art. 52.1], replaced synonym.

$\equiv$ Phaeobotryosphaeria fusca (N.E. Stevens) Petr., Sydowia 6: 317. 1952.

$\equiv$ Physalospora fusca N.E. Stevens, Mycologia 18: 210. 1926.

Etymology: Named in honour of N.E. Stevens, the American mycologist and plant pathologist.

See Phillips et al. (2008) for illustrations, description and diagnosis.

Holotype: Cuba, Herradura, on twigs of Citrus sp., 15 Jan. 1925, N.E. Stevens, holotype BPI 599052, culture ex-type CBS 174.26. 
Notes: Phillips et al. (2008) introduced Barriopsis fusca as a new combination based on Physalospora fusca, but inadvertantly rendered it illegitimate (superfluous) by listing Botryosphaeria disrupta (Berk. \& M.A. Curtis) Arx \& E. Müll., as a synonym. However, this synonymy is erroneous; the dark brown, aseptate ascospores of B. stevensiana are distinct from the light brown ("hellbraun") ascospores of B. disrupta sensu von Arx and Müller (1954), and clearly distinct from the hyaline ascospores of Sphaeria disrupta, the basionym of B. disrupta (Berkeley 1876).

Barrmaelia Rappaz 1995, Xylariales genera incertae sedis, Sordariomycetes, three species, type: B. rhamnicola Rappaz, six species, asexual morph libertella-like, terrestrial, saprobes, Europe, North America, see Lumbsch and Huhndorf (2010; outline), Kirk et al. (2013; genus accepted), Maharachchikumbura et al. (2015, 2016; outline), Wendt et al. (2017; placed in Xylariales genera incertae sedis), cultures and sequences are available.

Barssia Gilkey 1925 (= Phymatomyces Kobayasi 1937 fide Species Fungorum 2017), Helvellaceae, Pezizales, Pezizomycetes, four species, type: B. oregonensis Gilkey, asexual morph unknown, saprobes, ?from soil, terrestrial, worldwide, see Lumbsch and Huhndorf (2010; outline), Kirk et al. (2013; genus accepted), Crous et al. (2014d; new species), sequences are available for the type species.

Bartalinia Tassi 1900 (= Hyalotia Guba 1961; = Pestalozzina P. Karst. \& Roum. 1890 fide Species Fungorum 2017), Bartaliniaceae, Xylariales, Sordariomycetes, 17 species, type: B. robillardoides Tassi, saprobes, associated with leaf spots, cosmopolitan, see Marincowitz et al. (2010; new species), Wijayawardene et al. (2012, 2016b, 2017; phylogeny, taxonomy, outline), Maharachchikumbura et al. (2015, 2016; phylogeny, outline), Senanayake et al. (2015; phylogeny, morphology), cultures and sequences are available.

Bartlettiella D.J. Galloway \& P.M. Jørg. 1990, Lecanoromycetes genus incertae sedis one species, type: B. fragilis D.J. Galloway \& P.M. Jørg., with ascomata, lichenized (green algae), lichenized, terrestrial (saxicolous), New Zealand, South America, see Lumbsch and Huhndorf (2010; outline), Kirk et al. (2013; genus accepted), Lücking et al. (2016b, classification), cultures and sequences are unavailable.

Barubria Vezda 1986, Pilocarpacae, Lecanorales, Lecanoromycetes, two species, type: B. fuscorubra (Vezda) Vezda with ascomata, lichenized (green algae), terrestrial (foliicolous), Neotropics and tropical Africa, rare see Lücking (2008; outline), Lumbsch and Huhndorf (2010; outline), Kirk et al. (2013; genus accepted), Farkas (2015; nomenclature), Lücking et al. (2016b, classification), cultures and sequences are unavailable.

Basauxia Subram. 1995 (= Basauxia Subram. 1992 fide Species Fungorum 2017), Ascomycota genera incertae sedis, one species, type: B. pulchra Subram., hyphomycetous, sexual morph unknown, saprobes, terrestrial, Asia, see Seifert et al. (2011; morphology), Wijayawardene et al. (2012, 2017; outline), Kirk et al. (2013; genus accepted), holotype: MUBL 3126, cultures and sequences are unavailable, needs generic revision.

Basavamyces Hosag. 2005, Meliolaceae, Meliolales, Sordariomycetes, two species, type: $B$. litseae Hosag., C.K. Biju \& T.K. Abraham, asexual morph unknown, obligate parasites, terrestrial, India, see Lumbsch and Huhndorf (2010; outline), Housagoudar and Archana (2009; key), holotype (HCIO 43453), cultures and sequences are unavailable, needs generic revision.

Basidiobotrys Höhn. 1909, Sordariomycetes genera incertae sedis, one species, type: B. clautriavii (Pat.) Höhn., hyphomycetous, sexual morph unknown, terrestrial, saprobes, see Wendt et al. (2017; resurrected the genus), cultures and sequences are available.

Basifimbria Subram. \& Lodha 1968, Ascomycota genera incertae sedis, three species, type: $B$. aurea Subram. \& Lodha, coelomycetous, sexual morph unknown, saprobes, terrestrial, worldwide, see Seifert et al. (2011; morphology, accepted as genus in Pyronemataceae), 
Wijayawardene et al. (2012, 2017; outline), Kirk et al. (2013; genus accepted), cultures and sequences are unavailable, needs generic revision.

Batcheloromyces Marasas, P.S. van Wyk \& Knox-Dav. 1975, Teratosphaeriaceae, Capnodiales, Dothideomycetes, five species, type: B. proteae Marasas, P.S. van Wyk \& Knox-Dav., hyphomycetous, sexual morph unknown, pathogens, saprobes, terrestrial, Australia, Thailand, see Crous et al. (2009e; phylogeny), Seifert et al. (2011; morphology), Wijayawardene et al. (2012, 2014c, 2017, phylogeny, outline), Kirk et al. (2013; genus accepted), Quaedvlieg et al. (2014; phylogeny), cultures available for type: CBS 110696.

Bathelium Ach. 1803, Trypetheliaceae, Trypetheliales, Dothideomycetes, 16 species, type: $B$. mastoideum Afzel. ex Ach., lichenized, see Nelsen et al. (2014a; phylogeny), Aptroot and Lücking (2016; monograph), Lücking et al. (2016b, c; phylogeny; classification), sequences are available.

Bathyascus Kohlm. 1977, Halosphaeriaceae, Microascales, Sordariomycetes, five species, type: B. vermisporus Kohlm., asexual morph unknown, saprobes, marine, worldwide, see Lumbsch and Huhndorf (2010; outline), Kirk et al. (2013; genus accepted), Jones et al. (2015; outline), Maharachchikumbura et al. (2015, 2016; outline), holotype: J.K. $1947=00966736$, NYBG.

Batistia Cif. 1958 (= Acrostroma Seifert 1987 fide Rossman et al. 2016a), Batistiaceae, Ascomycota families incertae sedis, one species, type: B. annulipes (Mont.) Cif., asexual morph formerly known in Acrostroma, Brazil, see Seifert et al. (2011; morphology), Wijayawardene et al. (2012, 2017; outline), Rossman et al. (2016a; nomenclature), cultures and sequences are unavailable, needs generic revision.

Batistina Peres 1961, Ascomycota genera incertae sedis, one species, type species $B$. splendida Peres, coelomycetous, sexual morph unknown, saprobes, terrestrial, Brazil, see Wijayawardene et al. (2012, 2017; outline), Kirk et al. (2013; genus accepted), cultures and sequences are unavailable, needs generic revision.

Batistinula Arx 1960, Asterinaceae, Asterinales, Dothideomycetes, one species, type: $B$. gallesiae Arx, asexual morph triposporium-like, epiphytes, biotrophic, terrestrial, worldwide, see Hofmann (2009; review), Lumbsch and Huhndorf (2010; outline), Hyde et al. (2013; review, keys), Hongsanan et al. (2014c; taxonomy, keys), Wijayawardene et al. (2014c; outline), Guatimosim et al. (2015; phylogeny, DNA), holotype: URM 19988, cultures and sequences are unavailable.

Batistospora J.L. Bezerra \& M.P. Herrera 1964, Ascomycota genera incertae sedis, one species, type: B. septentrionalis J.L. Bezerra \& M.P. Herrera, asexual morph unknown, saprobes, Neotropics, see Lumbsch and Huhndorf (2010; outline), Kirk et al. (2013; genus accepted), cultures and sequences are unavailable, needs generic revision.

Battarrina (Sacc.) Clem. \& Shear 1931 (= Hypocrea subgen. Battarrina Sacc. 1883 fide Species Fungorum 2017), Bionectriaceae, Hypocreales, Sordariomycetes, one species, type: B. inclusa (Berk. \& Broome) Clem. \& Shear, asexual morph unknown, parasitic (fungicolous), terrestrial, UK, see Lumbsch and Huhndorf (2010; outline), Kirk et al. (2013; genus accepted), Maharachchikumbura et al. (2015, 2016), holotype: K.

Baudoinia J.A. Scott \& Unter. 2007, Teratosphaeriaceae, Capnodiales, Dothideomycetes, five species, type: B. compniacensis (Richon) J.A. Scott \& Unter., hyphomycetous, sexual morph unknown, saprobes, terrestrial and aquatic, cosmopolitan, see Seifert et al. (2011; morphology), Wijayawardene et al. (2012, 2014c, 2017; outline), Scott et al. (2016; new species, phylogeny), epitype and ex-epitype: DAOM 238773, UAMH 10808.

Beauveria Vuill. 1912, Cordycipitaceae, Hypocreales, Sordariomycetes, five species, type: B. bassiana (Bals.-Criv.) Vuill., asexual morph unknown, saprobes, terrestrial, Central and South America, see Lumbsch and Huhndorf (2010; outline), Rehner et al. (2011; new species), Kirk et al. (2013; genus accepted), Maharachchikumbura et al. (2015, 2016; outline), 
Robène-Soustrade et al. (2015; new species), Imoulan et al. (2016; new species, entomopathogens), cultures and sequences are available.

Beauveriphora Matsush. 1975, Ascomycota genera incertae sedis, one species, type: $B$. sporotricis Matsush., hyphomycetous, sexual morph unknown, saprobes, Asia, see Seifert et al. (2011; morphology), Wijayawardene et al. (2012, 2017, outline), cultures and sequences are unavailable, needs generic revision.

Beccopycnidium F. Stevens 1930, Ascomycota genera incertae sedis, one species, type: $B$. palmicola F. Stevens, coelomycetous, sexual morph unknown, see Wijayawardene et al. (2012, 2017, outline), Kirk et al. (2013; genus accepted), cultures and sequences are unavailable, needs generic revision.

Beejadwaya Subram. 1977, Ascomycota genera incertae sedis, one species, type: B. bispora (Matsu.) Subram., hyphomycetous, sexual morph unknown, saprobe, terrestrial, Japan, see Seifert et al. (2011; morphology), Wijayawardene et al. (2012, 2017, outline), cultures and sequences are unavailable, needs generic revision, holotype: Matsushima herb. 4861.

Beelia F. Stevens \& R.W. Ryan 1925, Chaetothyriaceae, Chaetothyriales, Eurotiomycetes, one species, type: B. suttoniae F. Stevens \& R.W. Ryan, asexual morph unknown, saprobes, Hawaii, see Lumbsch and Huhndorf (2010; outline, accepted as a genus in Elsinoaceae), Kirk et al. (2013; genus accepted), Jayawardena et al. (2014; transferred to Chaetothyriaceae), Wijayawardene et al. (2014c, outline), cultures and sequences are unavailable, needs generic revision.

Belemnospora P.M. Kirk 1981, Ascomycota genera incertae sedis, seven species, type: $B$. epiphylla P.M. Kirk, hyphomycetous, sexual morph unknown, saprobes, Asia, Australasia, Europe, North America, see Seifert et al. (2011; morphology), Wijayawardene et al. (2012, 2017; outline), cultures and sequences are unavailable, needs generic revision.

Belizeana Kohlm. \& Volkm.-Kohlm. 1987, Dothideomycetes genera incertae sedis, one species, type: B. tuberculata Kohlm. \& Volkm.-Kohlm., asexual morph unknown, saprobes, marine, Belize, see Lumbsch and Huhndorf (2010; outline, accepted as a genus in Elsinoaceae), Kirk et al. (2013; genus accepted), Wijayawardene et al. (2014c: outline), Jones et al. (2015; outline, accepted as a genus in Dothideales genera incertae sedis), cultures and sequences are unavailable, needs generic revision.

Bellemerea Hafellner \& Cl. Roux 1984, Lecanoromycetes genus incertae sedis; nine species, type: B. alpina (Sommerf.) Clauzade \& Cl. Roux,, with ascomata, lichenized (green algae), terrestrial (saxicolous), Eurasia, North America, Australia, New Zealand and Antarctica, montane and boreal, arctic-alpine/antarctic regions, see Ekman et al. (2008, DNA), Lumbsch and Huhndorf (2010; outline), Schmull et al. (2011; phylogeny), Miądlikowska et al. (2014a; DNA, phylogeny), Lücking et al. (2016b; classification), cultures and sequences are available for the type:.

Bellemerella Nav.-Ros. \& Cl. Roux 1997, Verrucariaceae, Verrucariales, Eurotiomycetes, four species, type: B. trapeliae Nav.-Ros. \& Cl. Roux, lichenicolous, terrestrial, Europe, see Lumbsch and Huhndorf (2010; outline), Kirk et al. (2013; genus accepted), cultures and sequences are unavailable, needs generic revision.

Bellojisia Réblová 2008, Lasiosphaeriaceae, Sordariales, Sordariomycetes, one species, type: B. rhynchostoma (Höhn.) Réblová, asexual morph unknown, saprobes, terrestrial, Austria, see Réblová (2008; taxonomy, phylogeny), Maharachchikumbura et al. (2015, 2016; outline), culture of the type: CBS 118484.

Bellulicauda B. Sutton 1967, Ascomycota genera incertae sedis, two species, type: B. dialii (Syd.) B. Sutton, coelomycetous, sexual morph unknown, saprobes, Italy, Sierra Leone, Zambia, see Wijayawardene et al. (2012, 2016b, 2017; taxonomy, new species, outline), Kirk et al. (2013; genus accepted), sequences are unavailable, holotype of the type: IMI 21609. 
Belonioscyphella Höhn. 1918, Helotiales genera incertae sedis, Leotiomycetes, four species, type: B. hypnorum (Syd. \& P. Syd.) Höhn., asexual morph unknown, saprobes, terrestrial, Europe, see Huhtinen et al. (2010; new records), Lumbsch and Huhndorf (2010; outline), Kirk et al. (2013; genus accepted), cultures and sequence are available, needs generic revision. Beltramono Rashmi Dubey, A.K. Pandey bis \& Manohar. 2011, Ascomycota genera incertae sedis, one species, type: B. costi Dubey, Pandey \& Manohar., hyphomycetous, sexual morph unknown, pathogens, terrestrial, India, see Dubey et al. (2011; taxonomy), Wijayawardene et al. (2017; outline), cultures and sequences are unavailable, needs generic revision.

Beltrania Penz. 1882, Beltraniaceae, Xylariales, Sordariomycetes, 14 species, type: $B$. rhombica Penz., saprobes, worldwide, see Kirk et al. (2013; genus accepted), Crous et al. (2015e; emended the family), Maharachchikumbura et al. (2015, 2016; outline), Rajeshkumar et al (2016; taxonomy, phylogeny), cultures and sequences are available, needs generic revision.

Beltraniella Subram. 1952 (= Ellisiopsis Bat. 1956 fide Species Fungorum 2017), Beltraniaceae, Xylariales, Sordariomycetes, 21 species, type: B. odinae Subram., saprobes, worldwide, see Shirouzu et al. (2010; new species, phylogeny), Seifert et al. (2011; morphology), Wijayawardene et al. (2012, 2017; outline), Crous et al. (2014c, 2016a; new species, New South Wales), Maharachchikumbura et al. (2015, 2016; outline), Jaklitsch et al. (2016a; new species, phylogeny), cultures and sequences are available, needs generic revision. Beltraniomyces Manohar., D.K. Agarwal \& Rao 2003, Ascomycota genera incertae sedis, one species, type: B. lignicola Manohar., D.K. Agarwal \& Rao, hyphomycetous, sexual morph unknown, saprobes, terrestrial, Asia, see Seifert et al. (2011; morphology), Wijayawardene et al. (2012, 2017; outline), cultures and sequences are unavailable, needs generic revision.

Beltraniopsis Bat. \& J.L. Bezerra 1960, Beltraniaceae, Xylariales, Sordariomycetes, nine species, type: B. odinae Subram., saprobes, cosmopolitan, see Seifert et al. (2011; morphology), Wijayawardene et al. (2012, 2017; outline), Crous et al. (2014c; new species, New South Wales), Maharachchikumbura et al. (2015, 2016; outline), cultures and sequences are available, needs generic revision.

Benguetia Syd. \& P. Syd. 1917, Helotiales genera incertae sedis, one species, type: B. omphalodes Syd. \& P. Syd., asexual morph unknown, saprobes, terrestrial, Philipplnes, see Lumbsch and Huhndorf (2010; outline), Kirk et al. (2013; genus accepted), cultures and sequences are unavailable, need generic revision.

Beniowskia Racib. 1900 (= Clathrotrichum Pat. 1921 fide Species Fungorum 2017), Ascomycota genera incertae sedis, four species, type: B. graminis Racib., hyphomycetous, sexual morph unknown, pantropical, saprobes, see Seifert et al. (2011; morphology), Wijayawardene et al. (2012, 2017; outline), Kirk (2013; genus accepted), cultures and sequences are unavailable, needs generic revision.

Benjaminiomyces I.I. Tav. 2000 (= Benjaminella I.I. Tav. 1981 fide Species Fungorum 2017), Laboulbeniaceae, Laboulbeniales, Laboulbeniomycetes, four species, type: $B$. melanophthalmae (Thaxt.) I.I. Tav., asexual morph unknown, parasitic on Cryptophagidae, Latridiidae, Monotomidae, and Phalacridae beetles, terrestrial, North and South America, see Lumbsch and Huhndorf (2010; outline), cultures and sequences are unavailable.

Benjpalia Subram. \& Bhat 1989, Ascomycota genera incertae sedis, one species, type: $B$. sundara Subram. \& Bhat, hyphomycetous, sexual morph unknown, India, see Seifert et al. (2011; morphology), Wijayawardene et al. (2012, 2017; outline), Kirk (2013; genus accepted), cultures and sequences are unavailable, needs generic revision.

Berkelella (Sacc.) Sacc. 1891 (= Byssostilbe Petch 1912; = Hypomyces subgen. Berkelella Sacc. 1883 fide Species Fungorum 2017)), Hypocreales genera incertae sedis, Sordariomycetes, two species, type: B. caledonica (Pat.) Sacc., asexual morph unknown, on 
Myxomycetes, worldwide, see Kirk et al. (2013; genus accepted), Maharachchikumbura et al. (2015, 2016; outline), cultures and sequences are unavailable, needs generic revision.

Berkleasmium Zobel 1854, Pleosporales genera incertae sedis, Dothideomycetes, 36 species, type: B. concinnum (Berk.) S. Hughes, sexual morph unknown, saprobes, terrestrial and aquatic, see McKenzie (2008; new species), Zhang et al. (2009a; new species), Seifert et al. (2011; morphology), Wijayawardene et al. (2012, 2017; outline), Whitton et al. (2012a; key to 34 Berkleasmium species), Hüseyın et al. (2014; new species), Qu et al.(2014; new species), three species have sequences, needs generic revision.

Bertia De Not. 1844 (= Sphaeria a Bertiae (De Not.) Fr. 1849 fide Species Fungorum 2017), Bertiaceae, Coronophorales, Sordariomycetes, 30 species, type: B. moriformis., worldwide, see Lumbsch and Huhndorf (2010; outline), Mugambi and Huhndorf (2010; new species), Kirk et al. (2013; genus accepted), Maharachchikumbura et al. (2015, 2016; outline), sequences are available.

Bertiella (Sacc.) Sacc. \& P. Syd. 1899, Melanommataceae, Pleosporales, Dothideomycetes, two species, type: B. polyspora Kirschst., asexual morph unknown, saprobes, terrestrial, worldwide, see Lumbsch and Huhndorf (2010; outline), Hyde et al. (2013, 2016; accepted as a genus in Melanommataceae, new species), Wijayawardene et al. (2014c; outline), Tian et al. (2015; accepted as a genus in Melanommataceae), cultures and sequences are available.

Bettsia Skou 1972, Ascosphaeraceae, Onygenales, Eurotiomycetes, two species, type: B. alvei (Betts) Skou, asexual morph hyphomycetous, Europe, see Lumbsch and Huhndorf (2010; outline), Kirk et al. (2013; genus accepted), Pitt et al. (2013; new species), sequences and culture available.

Beverwykella Tubaki., 1975, Pleomassariaceae, Pleosporales, Dothideomycetes, three species, type: B. pulmonaria (Beverw.) Tubaki, sexual morph unknown, aquatic, see Seifert et al. (2011; morphology), Wijayawardene et al. (2012, 2014c; outline, accepted as a genus in Melanommataceae), Hyde et al. (2013; accepted as a genus in Melanommataceae), Kirk et al. (2013; genus accepted), Tian et al. (2015; phylogeny, transferred to Pleomassariaceae), Wijayawardene et al. (2017; outline), cultures and sequences are available for authentic strains CBS 283.53, MFUCC 15-0183, reference specimen MFLU 15-1398.

Bhadradriella Nagaraju, Kunwar \& Manohar. 2011, Ascomycota genera incertae sedis, one species, type: B. hyalina Nagaraju, Kunwar \& Manohar., hyphomycetous, sexual morph unknown, saprobes, terrestrial, India, see Nagaraju et al. (2011b; taxonomy), Wijayawardene et al. (2017; outline), holotype: HCIO 50143, cultures and sequences are unavailable, needs generic revision.

Bhadradriomyces Sureshk., Manohar. \& Kunwar 2009, Ascomycota genera incertae sedis, one species, type: B. elegans Sureshk., Manohar. \& Kunwar, hyphomycetous, sexual morph unknown, saprobes, terrestrial, India, see Suresh Kumar et al. (2009; taxonomy), Wijayawardene et al. (2017; outline), holotype: HCIO 43002, cultures and sequences are unavailable, needs generic revision.

Bharatheeya D'Souza \& Bhat 2002, Ascomycota genera incertae sedis, one species, type: $B$. goanensis (Bhat \& W.B. Kendr.) D'Souza \& Bhat, hyphomycetous, sexual morph unknown, saprobes, terrestrial, India, see Seifert et al. (2011; morphology), Wijayawardene et al. (2012, 2017; outline), holotype: DAOM 214612, cultures and sequences are unavailable, needs generic revision

Bhatia W.A. Baker \& Morgan-Jones 2009, Ascomycota genera incertae sedis, one species, type: B. malabarica (Subram. \& Bhat) W.A. Baker \& Morgan-Jones, hyphomycetous, sexual morph unknown, saprobes, terrestrial, India, see Seifert et al. (2011; morphology), Wijayawardene et al. (2012, 2017; outline), cultures and sequences are unavailable, needs generic revision. 
Biappendiculispora Thambugala, Kaz. Tanaka \& K.D. Hyde 2015, Lophiostomataceae, Pleosporales, Dothideomycetes, one species, type: B. japonica Thambug., Wanas., Kaz. Tanaka \& K.D. Hyde, asexual morph unknown, saprobes on Poaceae spp., terrestrial, river bank, Japan, see Thambugala et al. (2015b; taxonomy, phylogeny), holotype of type: HHUF 27313, ex-type living culture of type: MAFF 239452.

Biatora Fr. 1817, Ramalinaceae, Lecanorales, Lecanoromycetes, 42 species, type: $B$. vernalis (L.) Fr., usually with ascomata an often pycnidia, some species sorediate, lichenized (green algae), terrestrial (various substrata), probably cosmopolitan, see Lumbsch and Huhndorf (2010; outline), Printzen (2014; DNA), Rodriguez Flakus and Printzen (2014; DNA), sequences are available.

Biatorella De Not. 1846 (= Maronella M. Steiner 1959; = Myrioblastus Trevis. 1857; = Piccolia A. Massal. 1856 fide Species Fungorum 2017), Biatorellaceae, Lecanorales, Lecanoromycetes, 30 species, type: B. rousselii (Durieu \& Mont.) De Not., lichenized, see Lumbsch and Huhndorf (2010; outline), Kirk et al. (2013; genus accepted), Lücking et al. (2016b; classification), sequences are unavailable.

Biatoridium J. Lahm ex Körb. 1860 (= Chiliospora A. Massal. 1860 [1859-1860] fide Species Fungorum 2017), Lichinomycestes genera incerte sedis, two species, type: $B$. monasteriense J. Lahm ex Körb., with ascomata only, lichenized (green algae), terrestrial (corticolous), Northern Hemisphere, see Lumbsch and Huhndorf (2010; outline), Miądlikowska et al. (2014a; DNA, phylogeny), Lücking et al. (2016b; classification), sequences are available.

Biatriospora K.D. Hyde \& Borse 1986, Biatriosporaceae, Pleosporales, Dothideomycetes, two species, type: B. marina K.D. Hyde \& Borse, asexual morph coelomycetous, on mangroves, human mycetoma, Seychelles, Venezuela, see Lumbsch and Huhndorf (2010; outline), Hyde et al. (2013; introduced Biatriosporaceae), Kirk et al. (2013; genus accepted), Ahmed et al. (2014a; new species, asexual morph), Wijayawardene et al. (2014c; outline), sequences and culture are available.

Bibanasiella R.F. Castañeda \& W.B. Kendr. 1991, Ascomycota genera incertae sedis, one species, type: B. ramispora R.F. Castañeda \& W.B. Kendr., hyphomycetous, sexual morph unknown, saprobes, terrestrial, Cuba, see Seifert et al. (2011; morphology), Wijayawardene et al. (2012, 2017; outline), Kirk et al. (2013; genus accepted), holotype: INIFAT C91/137, cultures and sequences are unavailable, compare with Catenosynnema and Speiropsis.

Biciliopsis Diederich 1997, Dothideomycetes genera incertae sedis, one species, type: $B$. leptogiicola Diederich, asexual morph unknown, lichenicolous, non-lichenized, terrestrial, Papua New Guinea, see Lumbsch and Huhndorf (2010; outline), Kirk et al. (2013; genus accepted), sequences are unavailable.

Biciliospora Petr. 1952, Scortechiniaceae, Coronophorales, Sordariomycetes, one species, type: B. velutina Petr., asexual morph unknown, saprobes, see Kirk et al. (2008; treated as a synonym of Nitschkia), Mugambi and Huhndorf (2010; phylogeny), Maharachchikumbura et al. (2015, 2016; outline), Jaklitsch et al. (2016a; classification), cultures and sequences are available.

Biciliosporina Subram. \& Sekar 1993, Nitschkiaceae, Coronophorales, Sordariomycetes, one species, type: B. karwarensis Subram. \& Sekar, asexual unknown, saprobe, terrestrial, India, see Lumbsch and Huhndorf (2010; outline), Kirk et al. (2013; genus accepted), Maharachchikumbura et al. (2015, 2016; outline), holotype: herb. FSI [sic] 3189; isotype IMI 32468, cultures and sequences are unavailable.

Bicoloromyces Heuchert, U. Braun \& D. Hawksw. 2015, Ascomycota genera incertae sedis, one species, type: B. kyffinensis Heuchert, U. Braun \& D. Hawksw., sexual morph unknown, on sterile lichen on rock, Antarctica, see Heuchert et al. (2015; taxonomy), holotype: MAF 19121, cultures and sequences are unavailable. 
Biconiosporella Schaumann 1972, Sordariomycetes genera incertae sedis, one species, type: B. corniculata Schaumann, asexual morph unknown, saprobes, marine, Germany, see Jones et al. (2009b, 2015; classification), Lumbsch and Huhndorf (2010; outline), Kirk et al. (2013; genus accepted), Maharachchikumbura et al. (2015, 2016; outline), cultures and sequences are unavailable.

Bicornispora Checa, Barrasa, M.N. Blanco \& A.T. Martínez 1996, Rutstroemiaceae, Helotiales, Leotiomycetes, two species, type: B. exophiala Checa, Barrasa, M.N. Blanco \& A.T. Martínez, saprobes, terrestrial, Spain, see Lumbsch and Huhndorf (2010; outline, accepted as a genus in Coryneliaceae), Kirk et al. (2013; genus accepted), Galán et al. (2015; phylogeny, new species), cultures and sequences are available but lacks for the type:, needs generic revision.

Bicrouania Kohlm. \& Volkm.-Kohlm. 1990, Melanommataceae, Pleosporales, Dothideomycetes, one species, type: B. maritima (P. Crouan \& H. Crouan) Kohlm. \& Volkm.-Kohlm., asexual morph unknown, saprobes, marine aquatic, France, see Lumbsch and Huhndorf (2010; outline), Kirk et al. (2013; genus accepted), Wijayawardene et al. (2014c; outline), Tian et al. (2015; morphology, phylogeny), cultures and sequences are unavailable, needs generic revision.

Bifidocarpus Cano, Guarro \& R.F. Castañeda 1994, Onygenaceae, Onygenales, Eurotiomycetes, two species, type: B. cubensis Cano, Guarro \& R.F. Castañeda saprobes, terrestrial, Cuba, see Lumbsch and Huhndorf (2010; outline), Kirk et al. (2013; genus accepted), holotype: IMI 356298, cultures and sequences are unavailable, compare with Renispora and Onygena.

Biflagellospora Matsush. 1975, Ascomycota genera incertae sedis, one species, type: $B$. japonica Matsush., hyphomycetous, sexual morph unknown, saprobes, terrestrial, Japan, see Seifert et al. (2011; morphology), Wijayawardene et al. (2012, 2017; outline), Kirk et al. (2013; genus accepted), cultures and sequences are unavailable, needs generic revision.

Biflagellosporella Matsush. 1993, Ascomycota genera incertae sedis, one species, type: $B$. amazonensis Matsush., hyphomycetous, sexual morph unknown, saprobes, terrestrial, South America, see Seifert et al. (2011; morphology), Wijayawardene et al. (2012, 2017; outline), Kirk et al. (2013; genus accepted), cultures and sequences are unavailable, needs generic revision.

Biflua Jørgen Koch \& E.B.G. Jones 1989, Ascomycota genera incertae sedis, one species, type: B. physasca Jørg. Koch \& Jones, asexual morph unknown, on wood associated with sand, temperate, see Lumbsch and Huhndorf (2010; outline), Kirk et al. (2013; genus accepted), Jones et al. (2015; outline), cultures and sequences are unavailable, needs generic revision.

Bifrontia Norman 1872, Tubeufiaceae, Tubeufiales, Dothideomycetes, three species, type: $B$. compactior Norman, saprobes on decaying wood, Europe, see Kirk et al. (2013; genus accepted), Boonmee et al. (2014b; taxonomy), Wijayawardene et al. (2014c; outline), cultures and sequences are unavailable.

Bifusella Höhn. 1917, Rhytismataceae, Rhytismatales, Leotiomycetes, eleven species, type: B. linearis (Peck) Höhn., asexual morph unknown, saprobes, terrestrial, worldwide, see Lumbsch and Huhndorf (2010; outline), Kirk et al. (2013; genus accepted), Rossman et al. (2016b; new combination), cultures and sequences are available (unpublished).

Bifusepta Darker 1963, Rhytismataceae, Rhytismatales, Leotiomycetes, one species, type: $B$. tehonii Darker, asexual morph unknown, saprobes, terrestrial, North America, see Lumbsch and Huhndorf (2010; outline), Kirk et al. (2013; genus accepted), cultures and sequences are unavailable, needs generic revision.

Bilimbia De Not. 1846, Ramalinaceae, Lecanorales, Lecanoromycetes, six species, type: B. hexamera De Not., lichenized, see Ekman et al. (2008; taxonomy), Lumbsch and Huhndorf 
(2010; outline), Printzen (2014; taxonomy), Lücking et al. (2016b; classification), sequences are available.

Bimeris Petr. 1949, Ascomycota genera incertae sedis, one species, type: B. aperta Petr., coelomycetous, sexual morph unknown, saprobes, terrestrial, Ecuador, see Wijayawardene et al. (2012, 2017; outline), Kirk et al. (2013; genus accepted), cultures and sequences are unavailable, needs generic revision.

Bimuria D. Hawksw., Chea \& Sheridan 1979, Didymosphaeriaceae, Pleosporales, Dothideomycetes, type: B. novae-zelandiae D. Hawksw., Chea \& Sheridan, one species, asexual morph unknown, isolated from soil, see Lumbsch and Huhndorf (2010; outline), Kirk et al. (2013; genus accepted), Ariyawansa et al. (2014d; taxonomy), Wijayawardene et al. (2014c; outline), holotype: K(M)-IMI 229814, cultures and sequences are available.

Bioconiosporium Bat. \& J.L. Bezerra 1964, Ascomycota genera incertae sedis, two species, type: B. baccharidis Bat. \& J.L. Bezerra, hyphomycetous, sexual morph unknown, saprobes, terrestrial, Asia, South America, see Seifert et al. (2011; morphology), Wijayawardene et al. (2012, 2017; outline), Kirk et al. (2013; genus accepted), cultures and sequences are unavailable, needs generic revision.

Biophomopsis Petr. 1931, Ascomycota genera incertae sedis, three species, type: B. brenesii Petr., coelomycetous, sexual morph unknown, West Indies, see Wijayawardene et al. (2012, 2017; outline), Kirk et al. (2013; genus accepted), cultures and sequences are unavailable, need generic revision.

Bioscypha Syd. 1927, Helotiales genera incertae sedis, Leotiomycetes, two species, type: $B$. cyatheae Syd., asexual morph hyphomycetous, saprobes, terrestrial, Central America, see Lumbsch and Huhndorf (2010; outline), Kirk et al. (2013; genus accepted), cultures and sequence are unavailable, needs generic revision.

Biostictis Petr. 1950, Stictidaceae, Ostropales, Lecanoromycetes, five species, type: $B$. rubiacearum (Pat.) Petr., with ascomata only, terrestrial (parasitic on leaves), tropical America, see Lumbsch and Huhndorf (2010; outline), Kirk et al. (2013; genus accepted), sequences are unavailable.

Bipolaris Shoemaker 1959, Pleosporaceae, Pleosporales, Dothideomycetes, 121 species, type: B. maydis (Y. Nisik. \& C. Miyake) Shoemaker, sexual morph Cochliobolus, plant and animal pathogen, saprobes, terrestrial, worldwide, see Aggarwal et al. (2008, 2009, 2010, 2011a, b; intraspecific variations, DNA fingerprinting, pathogen histopathology), Antoniazzi et al. (2008; xanthan and allicin as elicitors), Chand et al. (2008, 2014; cell biology, disease resistance screening), de Moura Nascimento and Van Der Sand (2008; restriction analysis), Durkin et al. (2008; phaeohyphomycotic keratitis), Dyer et al. (2008; bronchopulmonary mycosis), Felle et al. (2008; host pathogen interaction), Geng et al. (2008; Echinochloa control), Ghazvini and Tekauz (2008; Host-pathogen interaction), Janni et al. (2008; resistance in wheat), Jiang and Zhang (2008; new species), Kihara et al. (2008, 2009; BMR1 gene characterization), Kobayashi et al. (2008; Disseminated infection), Motlagh and Kaviani (2008; Iran), Pandey et al. (2008; clonal variability), Persson et al. (2008, 2009; mutant host resistance), Shabana et al. (2008; pathogen control), Asad et al. (2009; Pakistan), Bashir et al. (2009; keratomycosis, endophthalmitis), El Mhadri et al. (2009; Citrullus lanatus host), Iftikhar et al. (2009a, b; synthetic host screening), Kamal and Mia (2009; DNA fingerprinting), Kumar et al. (2009; host resistance), Naumann et al. (2009; host enzyme modification), Poloni et al. (2009a, b; morphology, physiology, virulence, vegetative incompatibility), Zhang and Li (2009; new species), Bashyal et al. (2010, 2011; conidiogenesis study, host resistance components), Carissimi et al. (2010; Bacillus sp. E164 activity), Dong et al. (2010; TaPIEP1 study), Gomathinayagam et al. (2010; Trichoderma effect), Han et al. (2010b; cytology), Kleczewski and Flory (2010; Microstegium vimineum host), Knight et al. (2010; genetic variation), Kumar et al. (2010; host resistance), Lapmak et 
al. (2010; L-asparaginase production), Martinez et al. (2010; Tanzania), Matusinsky et al. (2010; species specific detection), Motlagh and Anvari (2010; genetic variation), Saha et al. (2010; Ag nanoparticle production), Shali et al. (2010; SG2 chitinases inhibition), TomasoPeterson and Balbalian (2010; Mississippi), Acharya et al. (2011; review), Ahmadpour et al. (2011, 2012; new species), Baturo-Ciesniewska (2011; Poland), Ben-Ze'ev et al. (2011; Israel), Chowdhary et al. (2011; bronchopulmonary mycosis), Dallagnol et al. (2011a, b, 2013; host pathogen interaction), Giri et al. (2011; phaeohyphomycosis in dog), Ishihara et al. (2011; defense response), Jiao et al. (2011; MYB73 analysis), Kawahigashi et al. (2011; resistance gene cloning), Kumar et al. (2011; molecular and pathological characterization), Moya-Elizondo et al. (2011; population dynamics), Rosow et al. (2011; Cerebral phaeohyphomycosis), Vu et al. (2011, 2015; on switchgrass), Arunpanichlert et al. (2012; metabolite profiling), Da Cunha et al. (2012; clinical diversity), Manamgoda et al. (2012; phylogeny), Mizuno et al. (2012; host pathogen interaction), Nizam et al. (2012; transformation), Zhang et al. (2012d, j; host resistance, from soil), Almaguer et al. (2013; conidial germination), Burgos et al. (2013; Philippines), Eisa et al. (2013; resistance screening), Gupta et al. (2013; fungicidal management), Rossman et al. (2013a; name conservation), Tarnowski et al. (2013; South Florida), Wang et al. (2013c; metabolite as drug), Yazawa et al. (2013; transcriptome analysis), Amaradasa and Amundsen (2014; Nebraska), Bencsik et al. (2014; Ophiobolin A), Manamgoda et al. (2014; review), Meena et al. (2014; genetic evaluation of host), Minckler et al. (2014; Bipolaris endophthalmitis), Mishra et al. (2014b; Ag nanoparticle fungicide), Small et al. (2014; endophthalmitis), Teran et al. (2014; fatal infection), Ariyawansa et al. (2015c; phylogeny), Eghtedari (2015; conjunctiva cyst), Fatima et al. (2015; nanoparticle synthesis), Kuan et al. (2015; phylogeny, genomics), Waxman and Bergstrom (2015; New York), Kekuda et al. (2016; antifungal activity), sequences are available, paratype and ex-paratype of type species CBS 136.29.

Biporispora J.D. Rogers, Y.M. Ju \& Cand. 1999, Xylariales genera incertae sedis, one species, type: B. europaea J.D. Rogers, Y.M. Ju \& Cand., asexual morph unknown, saprobes, terrestrial, France, see Lumbsch and Huhndorf (2010; outline), Kirk et al. (2013; genus accepted), Maharachchikumbura et al. (2015, 2016; outline), Wendt et al. (2017; placed in Xylariales genera incertae sedis), cultures and sequences are unavailable, needs generic revision.

Bisbyopeltis Bat. \& A.F. Vital 1957, Ascomycota genera incertae sedis, one species, type: $B$. phoebes Bat. \& A.F. Vital, coelomycetous, sexual morph unknown, saprobes, terrestrial, USA, Australia, see Wijayawardene et al. (2012, 2017; outline), Kirk et al. (2013; genus accepted), cultures and sequences are unavailable, needs generic revision.

Biscogniauxia Kuntze 1891 (= Albocrustum Lloyd 1925; = Kommamyce Nieuwl., Am. Midl. 1916; = Nummularia Tul. \& C. Tul 1863; = Nummulariella Eckblad \& Granmo 1978; = Numulariola House 1923 fide Wendt et al, 2017), Graphostromataceae, Xylariales, Sordariomycetes, 33 species, type: B. nummularia (Bull.) Kuntze, asexual morph unknown, saprobes, terrestrial, France, see Mugambi et al. (2009; new species, Kenya), Lumbsch and Huhndorf (2010; outline), Vasilyeva and Stephenson (2010; new species), Vasilyeva et al. (2012; new species, Thailand), Kirk et al. (2013; genus accepted), Liu et al. (2015a; new species), Maharachchikumbura et al. (2015, 2016; outline), Wendt et al. (2017; transferred to Graphostromataceae), cultures and sequences are available.

Bisifusarium L. Lombard, Crous \& W. Gams 2015, Nectriaceae, Hypocreales, Sordariomycetes, seven species, type: B. dimerum (Penz.) L. Lombard \& Crous, hyphomycetous, sexual morph unknown, saprobes, terrestrial, cosmopolitan, see Lombard et al. (2015b; taxonomy, phylogeny), Maharachchikumbura et al. (2015, 2016; outline), ex-type culture of the type: CBS 108944. 
Bispora Corda 1837, Ascomycota genera incertae sedis, 31 species, type: B. moniliodes Corda, hyphomycetous, phialophora-like synanamorph, sexual morph unknown, meristematic black fungi, saprobes on wood and leaves, widespread (temperate), producer of various enzymes possessing industrial applications, see Luo et al. (2009a, b; enzymes), Wang et al. (2010a; enzyme), Dubey and Pandey (2011; new species), Seifert et al. (2011; morphology), Kirk et al. (2013; genus accepted), Xu et al. (2013; enzymes), Hua et al. (2014; enzyme), Liu et al. (2015b; enzyme), molecular data not available from the type materials, needs generic revision.

Bisporella Sacc. 1884 (= Bispora Fuckel 1870 [1869-70]; = Calycella Quél. 1886 fide Species Fungorum 2017), Helotiaceae, Helotiales, Leotiomycetes, 19 species, type: B. monilifera (Fuckel) Sacc., asexual morph unknown, saprobes, terrestrial, worldwide, see Lumbsch and Huhndorf (2010; outline), Kirk et al. (2013; genus accepted), cultures and sequence are available but lacks for the type species, needs generic revision.

Bisporostilbella Brandsb. \& E.F. Morris 1971, Ascomycota genera incertae sedis, one species, type: B. fusca Brandsb. \& E.F. Morris, hyphomycetous, sexual morph unknown, saprobes, terrestrial, North America, see Seifert et al. (2011; morphology), Wijayawardene et al. (2012, 2017; outline), Kirk et al. (2013; genus accepted), cultures and sequences are unavailable, needs generic revision.

Bisseomyces R.F. Castañeda, 1985, Ascomycota genera incertae sedis, one species, type: $B$. havanensis R.F. Castañeda, hyphomycetous, sexual morph unknown, saprobes, terrestrial, Cuba, see Seifert et al. (2011; morphology), Wijayawardene et al. (2012, 2017; outline), Kirk et al. (2013; genus accepted), holotype of the type: C84/90-2, cultures and sequences are unavailable, compare with Neojohnstonia and Parapithomyces.

Bivallum P.R. Johnst. 1991, Rhytismataceae, Rhytismatales, Leotiomycetes, seven species, type: B. zelandicum P.R. Johnst., asexual morph unknown, saprobes, terrestrial, Australasia, Chile, Panama, see Hou and Piepenbring (2009a; new species, Panama), Lumbsch and Huhndorf (2010; outline), Kirk et al. (2013; genus accepted), cultures and sequences are unavailable, needs generic revision.

Blasdalea Sacc. \& P. Syd., 1902 (= Singeriella Petr. 1959; = Chrysogloeum Petr. 1959 fide Wijayawardene et al. 2014c; Species Fungorum 2017), Vizellaceae, Dothideomycetes family incertae sedis, one species, type: B. disciformis (Rehm) Sacc. \& P. Syd., asexual morph coelomycetous, ring-like or linear loculus arrangement, associated with leaf spots on leaves of Escallonia vaccinioidess, Brazil, see Lumbsch and Huhndorf (2010; outline), Hyde et al. (2013; morphology), Kirk et al. (2013; genus accepted), Wijayawardene et al. (2014c; outline, nomenclature), Rossman et al. (2016a; accept the genus status), cultures and sequences are unavailable, needs generic revision.

Blastacervulus H.J. Swart 1988, Asterinaceae, Asterinales, Dothideomycetes, one species, type: B. eucalypti H.J. Swart, coelomycetous, sexual morph unknown, pathogens, terrestrial, Australia, see Cheewangkoon et al. (2009; taxonomy, phylogeny), Wijayawardene et al. (2012, 2016b, 2017; outline, taxonomy, accepted as a genus in Planistromellaceae), Kirk et al. (2013; genus accepted), cultures available for the type: CBS124759.

Blastenia A. Massal. 1852, Teloschistaceae, Teloschistales, Lecanoromycetes, eleven species, type: B. ferruginea (Huds.) A. Massal., lichenized, see Arup et al. (2013; taxonomy), Lücking et al. (2016b; classification), sequences are available.

Blasticomyces I.I. Tav. 1985, Laboulbeniaceae, Laboulbeniales, Laboulbeniomycetes, three species, type: B. lispini (Thaxt.) I.I. Tav., asexual morph unknown, parasitic on Hydrophilidae, Sphaeridiinae and Staphylinidae beetles, asexual morph unknown, terrestrial, Asia, see Lumbsch and Huhndorf (2010; outline), Kirk et al. (2013; genus accepted), Haelewaters and Yaakop (2014; Borneo), cultures and sequences are unavailable. 
Blastobotrys Klopotek 1967 (= Sympodiomyces Fell \& Statzell 1971; = Trichomonascus H.S. Jackson emend Kurtzman \& Robnett 2007; = Stephanoascus M.T. Sm., Van der Walt \& Johannsen 1976 fide Species Fungorum 2017), Trichomonascaceae, Saccharomycetales, Saccharomycetes, 30 species, type: $B$. nivea Klopotek, asexual reproduction by budding (occasionally) or hyphomycetous, primarily saprophytic, some species cause human infections, insect frass from trees, growth on mushrooms, moss, ensiled maize, soil, air, sea water, bat liver, human infections, worldwide, Kirk et al. (2013; genus accepted), Crous et al. (2016b; new species), cultures and sequences are available.

Blastocatena Subram. \& Bhat 1989, Ascomycota genera incertae sedis, one species, type: $B$. pulneyensis Subram. \& Bhat, hyphomycetous, sexual morph unknown, saprobes, terrestrial, Asia, see Seifert et al. (2011; morphology), Wijayawardene et al. (2012, 2017; outline), Kirk et al. (2013; genus accepted), cultures and sequences are unavailable, needs generic revision.

Blastodesmia A. Massal. 1852, Pyrenulaceae, Pyrenulales, Eurotiomycetes, one species, type: B. nitida A. Massal., asexual morph unknown, lichenized, terrestrial, temperate, see Lumbsch and Huhndorf (2010; outline), Kirk et al. (2013; genus accepted), Lücking et al. (2016b; classification), holotype US National Herbarium barcode 01138889 - on bark of Fraxini, Austria (Schuler J), cultures and sequences are unavailable.

Blastodictys M.B. Ellis 1976, Ascomycota genera incertae sedis, one species, type: B. hibisci (Hansf.) M.B. Ellis, hyphomycetous, sexual morph unknown, saprobes, terrestrial, Africa, see Seifert et al. (2011; morphology), Wijayawardene et al. (2012, 2017; outline), Kirk et al. (2013; genus accepted), cultures and sequences are unavailable, needs generic revision.

Blastofusarioides Matsush. 1996, Ascomycota genera incertae sedis, one species, type: $B$. fusca Matsush., hyphomycetous, sexual morph unknown, saprobes, terrestrial, Asia, see Seifert et al. (2011; morphology), Wijayawardene et al. (2012, 2017; outline), Kirk et al. (2013; genus accepted), cultures and sequences are unavailable, needs generic revision.

Blastomyces Gilchrist \& W.R. Stokes 1898 (三 Gilchristia Cif. \& Redaelli 1934; = Ajellomyces McDonough \& A.L Lewis 1968; = Zymonema Beurm. \& Gougerot 1909) Ajellomycetaceae, Onygenales, Eurotiomycetes, two species, (but phylogenetic studies suggest the existence of more taxa fide de Hoog et al. 2016), type: B. dermatitidis Gilchrist \& W.R. Stokes, terrestrial, pathogenic to humans, canids, felines and other animals, also reported from soil, Africa, India, North America, Blastomyces Gilchrist \& W.R. Stokes is an illegitimate genus (Art. 53.1) but, due to its wide use in medical literature, most modern authors prefer this name instead of any of its synonyms (Seifert et al. 2011), and a proposal of conservation against an earlier homonym, Blastomyces Costantin \& Rolland, has been published (de Hoog et al. 2016), see Saccente and Woods (2010; clinical and laboratory aspects), Brown et al. (2013; phylogeny, new species), Kirk et al. (2013; genus accepted), exepitype strain of the type species $=$ CBS 674.68, sequences are available.

Blastophorella Boedijn 1937, Ascomycota genera incertae sedis, one species, type: B. smithii Boedijn, hyphomycetous, sexual morph unknown, saprobes, terrestrial, South East Asia, see Seifert et al. (2011; morphology), Wijayawardene et al. (2012, 2017; outline), Kirk et al. (2013; genus accepted), cultures and sequences are unavailable, needs generic revision.

Blastophorum Matsush. 1971, Reticulascaceae, Glomerellales, Sordariomycetes, five species, type: B. truncatum Matsush., hyphomycetous, sexual morph unknown, saprobes, terrestrial, Asia, China, Europe, see Seifert et al. (2011; morphology), Wijayawardene et al. (2012, 2017; outline), Kirk et al. (2013; genus accepted), Hyde et al. (2016; new species, China), cultures and sequences are unavailable, needs generic revision.

Blastophragma Subram. 1995, Ascomycota genera incertae sedis, four species, type: $B$. subulatum Subram., hyphomycetous, sexual morph unknown, saprobes, terrestrial, Asia, see Seifert et al. (2011; morphology), Wijayawardene et al. (2012, 2017; outline), Kirk et al. 
(2013; genus accepted), Gao et al. (2015a; new species), Xia et al. (2016; new species), holotype: MUBL 3128, cultures and sequences are unavailable, needs generic revision.

Blennoria Moug. \& Fr. 1825, Ascomycota genera incertae sedis, four species, type: B. buxi Fr., coelomycetous, sexual morph unknown, saprobes and plant endophytes, terrestrial, worldwide, see Wijayawardene et al. (2012, 2017; outline), Kirk (2013; genus accepted), cultures and sequences are unavailable, needs generic revision.

Blennoriopsis Petr. 1920, Ascomycota genera incertae sedis, one species, type: B. moravica Petr., coelomycetous, sexual morph unknown, rarely reported and in case as saprobes, Europe, see Wijayawardene et al. (2012, 2017; outline), Kirk (2013; genus accepted), cultures and sequences are unavailable, needs generic revision.

Blennothallia Trevis. 1853, Collemataceae, Peltigerales, Lecanoromycetes, four species, type: need typification, lichenized, see Otálora et al. (2013, 2014; taxonomy), Lücking et al. (2016b; classification), sequences are available.

Bleptosporium Steyaert 1961 (= Monochaetina Subram. 1961 fide Species Fungorum 2017), Ascomycota genera incertae sedis, four species, type: B. montteae Speg. ex Steyaert, coelomycetous, sexual morph unknown, saprobes, terrestrial, Argentina, see Wijayawardene et al. (2012, 2017; outline, taxonomy), Kirk et al. (2013; genus accepted), cultures and sequences are unavailable, needs generic revision.

Blodgettia Harv. 1858 (= Blodgettia E.P. Wright 1881; = Blodgettiomyces Feldmann 1939 fide Species Fungorum 2017), Ascomycota genera incertae sedis, two species, type: $B$. confervoides Harv., hyphomycetous, sexual morph unknown, saprobes, terrestrial, Asia, Europe, South America, see Seifert et al. (2011; morphology), Wijayawardene et al. (2012, 2017; outline), Kirk et al. (2013; genus accepted), cultures and sequences are unavailable, needs generic revision.

Bloxamia Berk. \& Broome 1854 (= Endosporostilbe Subram. 1958; = Thecostroma Clem. 1909; = Trichotheca P. Karst. 1887 fide Species Fungorum 2017), Pezizellaceae, Helotiales, Leotiomycetes, 19 species, type: B. truncata Berk. \& Broome, hyphomycetous, sexual morph unknown, saprobes, terrestrial, fresh water, cosmopolitan, see Seifert et al. (2011; morphology), Wijayawardene et al. (2012, 2017; outline), Kirk et al. (2013; genus accepted), Spooren (2014; new species), Guatimosim et al. (2016b; new species, DNA, phylogeny), cultures and sequences are available but lacks for the type species.

Blumeria Golovin ex Speer 1974 (= Oidium Link 1824 fide Braun and Cook 2012), Erysiphaceae, Erysiphales, Leotiomycetes, one species, type: B. graminis (DC.) Speer, asexual morphs hyphomycetous, biotrophic, obligate plant pathogens, terrestrial, worldwide, see Braun and Cook (2012; taxonomy), neotype: Germany, Bonn, Botanical garden Poppelsdorf, on Triticum aestivum, 25 June 1869, Körnicke, in herb. De Candolle (G 00122110), cultures and sequences are available.

Blumeriella Arx 1961 (= Higginsia Nannf. 1932; = Microgloeum Petr. 1922; = Phloeosporella Höhn. 1924 fide Johnston et al. 2014b; Species Fungorum 2017), Drepanopezizaceae, Helotiales, Leotiomycetes, seven species, type: B. jaapii (Rehm) Arx, asexual morphs Microgloeum, Phloeosporella, saprobes, terrestrial, Europe, see Lumbsch and Huhndorf (2010; outline), Kirk et al. (2013; genus accepted), Johnston et al. (2014b; nomenclature), cultures and sequences are available.

Boeremia Aveskamp, Gruyter \& Verkley 2010, Didymellaceae, Pleosporales, Dothideomycetes, eleven species, type: B. exigua (Desm.) Aveskamp, Gruyter \& Verkley, asexual morph coelomycetous, saprobes or plant pathogenic, widespread, see Aveskamp et al. (2010; taxonomy, phylogeny), Wijayawardene et al. (2012, 2017; outline), Kirk (2013; genus accepted), Chen et al. (2015b; phylogeny), ex-type: CBS 101207 (Boeremia exigua var. pseudolilacis), CBS 443.94 (Boeremia exigua var. heteromorpha), CBS 100167 (Boeremia exigua var. populi). 
Boerlagiomyces Butzin 1977 (= Boerlagella Penz. \& Sacc. 1897; = Garethjonesia K.D. Hyde 1992 fide Species Fungorum 2017), Tubeufiaceae, Tubeufiales, Dothideomycetes, c. 9 species, type: B. velutinus (Penz. \& Sacc.) Butzin, asexual morph coelomycetous, saprobes, aquatic, Australia, India, Indonesia, Philippines and USA, see Lumbsch and Huhndorf (2010; outline), Kirk et al. (2013; genus accepted), Boonmee et al. (2011, 2014b); Wijayawardene et al. (2014c; outline), sequences are available.

Bogoriella Zahlbr. 1928 (= Bogoriellomyces Cif. \& Tomas. 1954 fide Species Fungorum 2017), Trypetheliaceae, Trypetheliales, Dothideomycetes, 29 species, type: B. subpersicina Zahlbr., lichenized, see Lumbsch and Huhndorf (2010; outline), Kirk et al. (2013; genus accepted), Nelsen et al. (2014b; phylogeny), Aptroot and Lücking (2016; taxonomy), Lücking et al. (2016b, c; phylogeny), sequences are available.

Bolinia (Nitschke) Sacc. 1882 (= Naemaspora Willd. 1849 fide Species Fungorum 2017), Boliniaceae, Boliniales, Sordariomycetes, three species, type: B. tubulina (Alb. \& Schwein.) Sacc., asexual morph unknown, saprobes, cosmopolitan, see Kirk et al. (2008; treated as a synonym of Camarops P. Karst.), Lumbsch and Huhndorf (2010; did not list), Maharachchikumbura et al. (2015, 2016; outline, accepted as a distinct genus), cultures and sequences are unavailable.

Bombardia (Fr.) P. Karst. 1873, Lasiosphaeriaceae, Sordariales, Sordariomycetes, one species, type: B. bombarda (Batsch) J. Schröt., asexual morph unknown, saprobes, terrestrial, Europe, North America, see Lumbsch and Huhndorf (2010; outline, accepted as a genus in Sordariomycetes, genera incertae sedis), Kirk et al. (2013; genus accepted), Maharachchikumbura et al. (2015, 2016; outline), cultures and sequences are available.

Bombardiastrum Pat. 1893, Sordariomycetes genera incertae sedis, one species, type: $B$. andinum Pat., asexual morph unknown, saprobes, terrestrial, South America, see Lumbsch and Huhndorf (2010; outline), Kirk et al. (2013; genus accepted), Maharachchikumbura et al. (2015, 2016; outline), cultures and sequences are unavailable.

Bombardiella Höhn. 1909, Sordariales genera incertae sedis, Sordariomycetes, one species, type: B. caespitosa Höhn., asexual morph unknown, saprobes, terrestrial, Europe, North America, see Lumbsch and Huhndorf (2010; outline), Kirk et al. (2013; genus accepted), Maharachchikumbura et al. (2016; outline), cultures and sequences are unavailable, needs generic revision.

Bombardioidea C. Moreau ex N. Lundq. 1972 (= Bombardioidea C. Moreau 1954 fide Species Fungorum 2017), Lasiosphaeriaceae, Sordariales, Sordariomycetes, four species, type: B. bombardioides (Auersw.) C. Moreau ex C. Moreau, asexual morph unknown, coprophilous, terrestrial, worldwide, see Lumbsch and Huhndorf (2010; outline), Kirk et al. (2013; genus accepted), Maharachchikumbura et al. (2015, 2016; outline), cultures and sequences are available but lacks the type:.

Bommerella Marchal 1885, Chaetomiaceae, Sordariales, Sordariomycetes, one species, type: B. trigonospora Marchal, asexual morph scopulariopsis-like, saprobes, from soil, terrestrial, worlwide, see Lumbsch and Huhndorf (2010; outline), Kirk et al. (2013; genus accepted), Maharachchikumbura et al. (2015, 2016; outline), type species have been transferred to Chaetomium (fide Index Fungorum 2016).

Bonanseja Sacc. 1906, Rhytismatales genera incertae sedis, Leotiomycetes, one species, type: B. mexicana Sacc., asexual morph unknown, saprobes, terrestrial, Mexico, see Lumbsch and Huhndorf (2010; outline), Kirk et al. (2013; genus accepted), cultures and sequences are unavailable, needs generic revision.

Bonaria Bat. 1959, Dothideomycetes genera incertae sedis, one species, type: B. lithocarpi (V.A.M. Mill. \& Bonar) Bat., asexual morph unknown, saprobes, terrestrial, Mexico, see Lumbsch and Huhndorf (2010; outline, accepted as a genus in Micropeltidaceae), Hyde et al. (2013) did not accept as a genus in Micropeltidaceae, Kirk et al. (2013; genus accepted), 
Wijayawardene et al. (2014c; outline), cultures and sequences are unavailable, needs generic revision.

Bondiella Piroz. 1972, Mesnieraceae, Dothideomycetes families incertae sedis, one species, type: B. palmicola Piroz., asexual morph unknown, saprobes, terrestrial, Tanzania, see Lumbsch and Huhndorf (2010; outline), Hyde et al. (2013; taxonomy), Kirk et al. (2013; genus accepted), Wijayawardene et al. (2014c; outline), cultures and sequences are unavailable, needs generic revision.

Boothiella Lodhi \& Mirza 1962 (= Thielaviella Arx \& T. Mahmood 1968 fide Species Fungorum 2017), Chaetomiaceae, Sordariales, Sordariomycetes, one species, type: $B$. tetraspora Lodhi \& J.H. Mirza, asexual morph unknown, saprobes, from soil, terrestrial, Asia, see Lumbsch and Huhndorf (2010; outline), Kirk et al. (2013; genus accepted), Maharachchikumbura et al. (2015, 2016; outline), cultures and sequences are unavailable, needs generic revision.

Boreoplaca Timdal 1994, Ophioparmaceae, Umbilicariales, Lecanoromycetes, one species; type: B. ultrafrigida Timdal, lichenized, see Lumbsch and Huhndorf (2010; outline), Bendiksby and Timdal (2013; phylogeny), Kirk et al. (2013; genus accepted), Miądlikowska et al. (2014a; taxonomy), Lücking et al. (2016b; classification), holotype: O-L-127, sequences are available.

Borinquenotrema Mercado-Díaz, Lücking \& Parnmen 2014, Graphidaceae, Ostropales, Lecanoromycetes, one species, type: B. sorediocarpum Mercado-Díaz, Lücking \& Parnmen, lichenized, terrestrial, see Lumbsch et al. (2014a, b; taxonomy), Lücking et al. (2016b; classification), holotype: UPR, Mercado-Díaz 883, sequences are available.

Botryandromyces I.I. Tav. \& T. Majewski 1976, Laboulbeniaceae, Laboulbeniales, Laboulbeniomycetes, two species, type: B. heteroceri (Maire) I.I. Tav. \& T. Majewski, asexual morph unknown, parasitic on Heteroceridae beetles, semi-aquatic, widespread, see Lumbsch and Huhndorf (2010; outline), Kirk et al. (2013; genus accepted), sequence is available but lacks for the type species.

Botryobambusa Phook., J.K. Liu \& K.D. Hyde 2012, Botryosphaeriaceae, Botryosphaeriales, Dothideomycetes, one species, type: B. fusicoccum R. Phookamsak, J.K. Liu \& K.D. Hyde, asexual morph coelomycetous, saprobes, terrestrial, Thailand, see Liu et al. (2012; taxonomy, phylogeny), Hyde et al. (2013; accepted as a genus in Botryosphaeriaceae), Phillips et al. (2013; phylogeny), Wijayawardene et al. (2014c; outline), holotype and ex-type: MFLU 110179, MFLUCC 11-0143.

Botryochora Torrend 1914, Dothideomycetes genera incertae sedis, one species, type: $B$. nigra (Torrend) Torrend, asexual morph unknown, saprobes, terrestrial, Africa, see Lumbsch and Huhndorf (2010; outline, accepted as a genus in Dothioraceae), Kirk et al. (2013; genus accepted), Wijayawardene et al. (2014c; outline), cultures and sequences are unavailable.

Botryoderma Papendorf \& H.P. Upadhyay 1969, Ascomycota genera incertae sedis, four species, type: B. lateritium Papendorf \& H.P. Upadhyay, hyphomycetous, sexual morph unknown, saprobes, terrestrial, cosmopolitan, see Seifert et al. (2011; morphology), Wijayawardene et al. (2012, 2017; outline, taxonomy), Kirk et al. (2013; genus accepted), cultures and sequences are unavailable, needs generic revision.

Botryodiplodina Dias \& Sousa da Câmara 1954, Ascomycota genera incertae sedis, one species, type: B. mori Dias \& Sousa da Câmara, coelomycetous, sexual morph unknown, saprobes, terrestrial, Portugal, see Wijayawardene et al. (2012, 2017; outline, taxonomy), Kirk et al. (2013; genus accepted), cultures and sequences are unavailable, needs generic revision.

Botryohypoxylon Samuels \& J.D. Rogers 1986 (= Iledon Samuels \& J.D. Rogers 1986 fide Wijayawardene et al. 2014c), Dothideomycetes genera incertae sedis, one species, type: $B$. nigra (Torrend) Torrend, asexual morph coelomycetous, saprobes, terrestrial, Brazil, see 
Lumbsch and Huhndorf (2010; outline), Kirk et al. (2013; genus accepted), Wijayawardene et al. (2014c; outline, nomenclature), Rossman et al. (2015b; nomenclature), cultures and sequences are unavailable.

Botryola Bat. \& J.L. Bezerra 1964, Nitschkiaceae, Coronophorales, Sordariomycetes, six species, type: B. tetrasperma Bat. \& J.L. Bezerra, asexual morph unknown, saprobes, lichenicolous, terrestrial, saprobes, see Lumbsch and Huhndorf (2010; outline), Kirk et al. (2013; genus accepted), Maharachchikumbura et al. (2015, 2016; outline), cultures and sequences are unavailable, needs generic revision.

Botryolepraria Canals, Hern.-Mar., Gómez-Bolea \& Llimona 1997, Verrucariales genera incertae sedis, Eurotiomycetes, two species, type: B. lesdainii (Hue) Canals, Hern.-Mar., Gómez-Bolea \& Llimona, lichenized, see Kukwa and Pérez-Ortega (2010; taxonomy), Lumbsch and Huhndorf (2010; outline, accepted as a genus in Lecanoromycetes, genera incertae sedis), Kirk et al. (2013; genus accepted), Lücking et al. (2016b; classification), sequences are available.

Botryomonilia Goos \& Piroz. 1975, Ascomycota genera incertae sedis, four species, type: $B$. scheeleae Goos \& Piroz., hyphomycetous, sexual morph unknown, saprobes, terrestrial, Central America, see Seifert et al. (2011; morphology), Wijayawardene et al. (2012, 2017; outline, taxonomy), Kirk et al. (2013; genus accepted), cultures and sequences are unavailable, needs generic revision.

Botryosphaeria Ces. \& De Not. 1863 (= Fusicoccum Corda 1829; = Dichomera Cooke 1878 fide Wijayawardene et al. 2014c, 2016b; Rossman et al. 2015b; Art. 59), Botryosphaeriaceae, Botryosphaeriales, Dothideomycetes, eleven species, type: B. dothidea (Moug. Fr.) Ces. \& De Not., asexual morph coelomycetous, saprobes, pthogens, terrestrial, worldwide, see Lumbsch and Huhndorf (2010; outline), Liu et al. (2012; accepted as a genus in Botryosphaeriaceae), Abdollahzadeh et al. (2013; species in Iran), Hyde et al. (2013; accepted as a genus in Botryosphaeriaceae), Phillips et al. (2013; taxonomy, phylogeny), Slippers et al. (2013; phylogeny), Wijayawardene et al. (2014c, 2016b; outline, taxonomy), Dissanayake et al. (2016; taxonomy), cultures and sequences are available, needs generic revision.

Botryosporium Corda 1831 (= Peylia Opiz 1857; Radaisiella Bainier 1910 fide Species Fungorum 2017), Sordariomycetes genera incertae sedis, seven species, type: B. diffusum (Grev.) Corda, hyphomycetous, sexual morph unknown, saprobes, pathogens, terrestrial, cosmopolitan, see Seifert et al. (2011; morphology), Wijayawardene et al. (2012, 2017; outline), Kirk et al. (2013; genus accepted), Choi et al. (2014; pathogens, DNA), cultures and sequences are available but lacks for the type, needs generic revision.

Botryostroma Höhn. 1911 (= Parodiellina Viégas 1944; = Robledia Chardón 1929 fide Species Fungorum 2017)), Ascomycota genera incertae sedis, two species, type: B. inaequale (G. Winter) Höhn., coelomycetous, sexual morph unknown, saprobes, terrestrial, America (tropical) see Kirk et al. (2013; genus accepted), Wijayawardene et al. (2017; outline), cultures and sequences are unavailable, needs generic revision.

Botryozyma Shann \& M.Th. Smith emend. Lachance \& Kurtzman 2013, Trigonopsidaceae, Saccharomycetales, Saccharomycetes, four species, type: B. nematodophila Shann \& M.T. Smith, asexual reproduction by budding (multilateral), ?saprophytic, from Panagrellus nematodes or associated with Drosophila flies, Northwestern USA, Italy, see Kirk et al. (2013; genus accepted), Lachance and Kurtzman (2013; re-visited, generic revision), cultures and sequences are available.

Botrytis P. Micheli ex Pers. 1794 (= Botryotinia Whetzel 1945 fide Johnston et al. 2014b; see Species Fungorum 2017 for synonyms), Sclerotiniaceae, Helotiales, Leotiomycetes, three species, type: $B$. cinerea Pers., asexual morph hyphomycetous, saprobes, pathogens, 
terrestrial, worldwide, see Lumbsch and Huhndorf (2010; outline), Kirk et al. (2013; genus accepted), Johnston et al. (2014b; nomenclature), cultures and sequences are available.

Boubovia Svrček 1977, Ascodesmidaceae, Pezizales, Pezizomycetes, five species, type: B.luteola (Velen.) Svrček, asexual morph unknown, saprobes, terrestrial, temperte, see Lumbsch and Huhndorf (2010; outline), Kirk et al. (2013; genus accepted), cultures and sequences are available for unidentified species.

Boudiera Cooke 1877 (= Svrcekia Kubička 1960 fide Species Fungorum 2017), Pezizaceae, Pezizales, Pezizomycetes, ten species, type: B.areolata Cooke \& W. Phillips, asexual morph unknown, saprobes, terrestrial, Europe, North America, see Lumbsch and Huhndorf (2010; outline), Kirk et al. (2013; genus accepted), cultures and sequences are available but lacks for the type species.

Boudierella Sacc. 1895, Pezizales genera incertae sedis, Pezizomycetes, one species, type: $B$. cana Marchal \& É.J. Marchal, asexual morph unknown, saprobes, terrestrial, Europe, see Lumbsch and Huhndorf (2010; outline), Kirk et al. (2013; genus accepted), Jaklitsch et al. (2016a; classification), cultures and sequences are unavailable, needs generic revision.

Bouvetiella Øvstedal 1986, Lecanoromycetes genera incertae sedis, one species; type: $B$. pallida Øvstedal, lichenized, see Lumbsch and Huhndorf (2010; outline), Kirk et al. (2013; genus accepted), Lücking et al. (2016b; classification), sequences are unavailable.

Brachiosphaera Nawawi 1976, Aliquandostipitaceae, Jahnulales, Dothideomycetes, two species, type: B. tropicalis Nawawi, isolated from river foam: Peninsular Malaysia, see Seifert et al. (2011; morphology), Suetrong et al. (2011a; taxonomy), Wijayawardene et al. (2012, 2017; outline), Kirk et al. (2013; genus accepted), sexual morph unknown, cultures and sequences are available for authentic strains SS2523, E192-1.

Brachyalara Réblová \& W. Gams 2011, Helotiales, genera incertae sedis, Leotiomycetes, one species, type: B. straminea Réblová \& W. Gams, hyphomycetous, sexual morph unknown, saprobes, terrestrial, Europe, see Réblová and Gams (2011; morphology, phylogeny), Wijayawardene et al. (2012, 2017; outline), ex-type culture of the type: CBS 175.74 .

Brachycephala J.S. Monteiro, Gusmão \& R.F. Castañeda 2015, Ascomycota genera incertae sedis, one species, type: B. exotica J.S. Monteiro, Gusmaño \& Castañeda-Ruiz, hyphomycetous, sexual morph unknown, saprobes, terrestrial, Brazil, see Monteiro et al. (2015b; morphology), holotype of the type: HUEFS 210446, cultures and sequences are unavailable, compare with Acarocybellina, Brachysporiella and Kramabeeja.

Brachyconidiella R.F. Castañeda \& W.B. Kendr. 1990 Ascomycota genera incertae sedis, Dothidiomycetes, one species, type: B. monilispora R.F. Castañeda \& W.B. Kendr., sexual morph unknown, saprobes, terrestrial, Cuba, see Seifert et al. (2011; morphology), Wijayawardene et al. (2012, 2017; outline), holotype: INIFAT C88/300, sequences are available, compare with Brachyconidiellopsis and Matsushimaea.

Brachyconidiellopsis Decock, R.F. Castañeda \& Adhikari 2004, Microascaceae, Microascales, Sordariomycetes, two species, type: B. fimicola Decock, R.F. Castañeda \& Adhikari, hyphomycetous, sexual morph unknown, saprobes, terrestrial, worldwide, see Seifert et al. (2011; morphology), Wijayawardene et al. (2012, 2017; outline), Maharachchikumbura et al. (2015; outline, phylogeny), holotype: MUCL 44677, cultures and sequences are available.

Brachydesmiella G. Arnaud ex S. Hughes 1961, Ascomycota genera incertae sedis, eight species, type: B. biseptata G. Arnaud ex S. Hughes, hyphomycetous, sexual morph unknown, saprobes, terrestrial, Asia, Europe, North and South America, see Seifert et al. (2011; morphology), Wijayawardene et al. (2012, 2017; outline), Kirk et al. (2013; genus accepted), cultures and sequences are unavailable, needs generic revision. 
Brachyphoris Juan Chen, L.L. Xu, B. Liu \& Xing Z. Liu 2007, Orbiliaceae, Orbiliales, Orbiliomycetes, five species, type: B. oviparasitica (G.R. Stirling \& Mankau) Juan Chen, L.L. $\mathrm{Xu}$, B. Liu \& Xing Z. Liu, saprobes, on nematode eggs, on soil, terrestrial, Asia, Europe, North America, see Seifert et al. (2011; morphology), Wijayawardene et al. (2012, 2017; outline), cultures and sequences are available, needs generic revision.

Brachysporiella Bat. 1952 (= Edmundmasonia Subram. 1958; = Monosporella S. Hughes1953; = Monotosporella S. Hughes 1958; = Sporidesmiopsis Subram. \& Bhat 1989 [1987] fide Species Fungorum 2017), Pleurotheciaceae, Pleurotheciales, Sordariomycetes, 15 species, type: B. gayana Bat., hyphomycetous, sexual morph unknown, saprobes, widespread, see Hyde et al. (2011; outline), Seifert et al. (2011: morphology), Wijayawardene et al. (2012, 2017; outline), Kirk et al. (2013; genus accepted), sequences available, needs generic revision.

Brachysporiellina Subram. \& Bhat 1989, Ascomycota genera incertae sedis, two species, type: B. pulneyensis Subram. \& Bhat, hyphomycetous, sexual morph unknown, saprobes, terrestrial, Asia, South America, see Seifert et al. (2011; morphology), Wijayawardene et al. (2012, 2017; outline), Kirk et al. (2013; genus accepted), cultures and sequences are unavailable, needs generic revision.

Brachysporiopsis Yanna, W.H. Ho \& K.D. Hyde 2004, Ascomycota genera incertae sedis, one species, type: B. chinensis Yanna, W.H. Ho \& K.D. Hyde, coelomycetous, sexual morph unknown, saprobes, terrestrial, Asia, see Seifert et al. (2011; morphology), Wijayawardene et al. (2012, 2017; outline), cultures and sequences are unavailable, needs generic revision.

Brachysporium Sacc. 1886 (= Cryptadelphia Réblová \& seifert 2004 fide Réblová et al. 2016c), Trichosphaeriaceae, Trichosphaeriales, Sordariomycetes, twelve species, type: $B$. obovatum Keissl., hyphomycetous, sexual morph unknown, saprobes, terrestrial, Asia, Australasia, Europe, North America, see Seifert et al. (2011; morphology), Wijayawardene et al. (2012, 2017; outline), Kirk et al. (2013; genus accepted), Maharachchikumbura et al. (2015, 2016; outline), Réblová et al. (2016c; nomenclature), cultures and sequences are available.

Bradymyces Hubka, Réblová, Selbmann \& M. Kolař́k 2014, Trichomeriaceae, Chaetothyriales, Eurotiomycetes, three species, type: B. oncorhynchi Hubka, Řehulka Réblová, \& M. Kolařík, sexual morph unknown, cold-blooded, water vertebrates opportunist, rock-inhabiting, see Hubka et al. (2014b; taxonomy, phylogeny), Réblová et al. (2016b; new species), holotype and ex-type: PRM 861507 CBS $133066=$ CCF $4369=$ CCFEE 6134

Bramhamyces Hosag. 2009, Dothideomycetes genera incertae sedis, one species, type: $B$. ilicis Hosag. \& Chandrapr, sexual morph unknown, epiphytes, terrestrial, India, see Hosagoudar and Chandraprabha (2009a; protologue, accepted as an anamorphic genus in Asterinaceae), Wijayawardene et al. (2014c; outline, accepted as a genus in Dothideomycetes genera incertae sedis), holotype: HCIO 48300, cultures and sequences are unavailable.

Brasilicia Lücking, Kalb \& Sérus. 2008, Pilocarpaceae, Lecanorales, Lecanoromycetes, six species, type: B. brasiliensis (Müll. Arg.) Lücking, Kalb \& Sérus., lichenized, see Lumbsch and Huhndorf (2010; outline), Lücking et al. (2016b; classification), sequences unavailable.

Brasiliomyces Viégas 1944 (= Californiomyces U. Braun 1981; = Salmonia S. Blumer \& E. Müll. 1964 fide Species Fungorum 2017), Erysiphaceae, Erysiphales, Leotiomycetes, four species, type: B. malvastri Viégas, asexual morphs unknown, biotrophic, obligate plant pathogens, terrestrial, Africa, Asia, South America, Hawaii, see Lumbsch and Huhndorf (2010; outline), Braun and Cook (2012; taxonomy), Kirk et al. (2013; genus accepted), holotype: IACM 3719.

Braunomyces V.A. Melnik \& Crous 2014, Ascomycota genera incertae sedis, one species, type: B. dictyosporus V.A. Melnik \& Crous, hyphomycetous, sexual morph unknown, saprobes, terrestrial, Vietnam, see Mel'nik and Crous (2011; taxonomy), Wijayawardene et al. 
(2017; outline), holotype: HAL 2606 F, cultures and sequences are unavailable, needs generic revision.

Brefeldiella Speg. 1889, Trichopeltinaceae, Dothideomycetes family incertae sedis, four species, type: B. brasiliensis Speg., asexual morph unknown, epiphytes, appearance as thallus on leave, see Lumbsch and Huhndorf (2010; outline), Kirk et al. (2013; genus accepted), Hyde et al. (2013; morphology), Kirk et al. (2013; genus accepted), Hongsanan et al. (2014a; accepted as a genus in Trichopeltinaceae), Wijayawardene et al. (2014c; outline), need recollecting and sequencing to verify generic placement.

Brefeldiopycnis Petr. \& Cif. 1932, Ascomycota genera incertae sedis, one species, type: $B$. membranacea Petr. \& Cif., coelomycetous, sexual morph unknown, saprobes, terrestrial, West Indies, see Wijayawardene et al. (2012, 2017; outline, taxonomy), Kirk et al. (2013; genus accepted), cultures and sequences are unavailable, needs generic revision.

Brefeldochium Verkley 2005, Helotiales genera incertae sedis Leotiomycetes, one species, type: B. pruinosum Verkley, hyphomycetous, sexual morph unknown, saprobes, terrestrial, Europe, see Seifert et al. (2011; morphology), Wijayawardene et al. (2017; outline, taxonomy), cultures available for the type: CBS 160.92.

Brenesiella Syd. 1929, Sordariomycetes, genera incertae sedis, one species, type: $B$. erythroxyli Syd., asexual morph unknown, saprobes, terrestrial, Central America, see Lumbsch and Huhndorf (2010; outline), Maharachchikumbura et al. (2015, 2016; outline), cultures and sequences are unavailable, needs generic revision.

Brettanomyces Kufferath \& van Laer 1921, Pichiaceae, Saccharomycetales, Saccharomycetes, six species, type: B. bruxellensis Kufferath \& van Laer, asexual reproduction is either by multilateral budding or, rarely, by bipolar budding on a narrow base, saprophytes, terrestrial, worldwide, see Kirk et al. (2013; genus accepted), cultures and sequences are available.

Brevicatenospora R.F. Castañeda, Minter \& Saikawa 2006, Ascomycota genera incertae sedis, one species, type: $B$. enteroproliferata R.F. Castañeda, Minter \& Saikawa, hyphomycetous, sexual morph unknown, saprobes, aquatic (fresh water), Cuba, see Seifert et al. (2011; morphology), Wijayawardene et al. (2012, 2017; outline), holotype: INIFAT C04/111, cultures and sequences are unavailable, compare with Annellophora, Acrogenospora, Belemnospora, Sporidesmiella and Repetophragma.

Brevistachys L. Lombard \& Crous 2016, Stachybotriaceae, Hypocreales, Sordariomycetes, five species, type: B. variabilis L. Lombard \& Crous, hyphomycetous, sexual morph unknown, saprobes, terrestrial, cosmopolitan, see Lombard et al. (2016; taxonomy, phylogeny), holotype and ex-type culture of the type: CBS H-22431, CBS 141057.

Brianaria S. Ekman \& M. Svensson 2014, Psoraceae, Lecanorales, Lecanoromycetes, four species, type: B. sylvicola (Flot. ex Körb.) S. Ekman \& M. Svensson, lichenized, terrestrial, see Ekman and Svensson (2014; taxonomy), Lücking et al. (2016b; classification), type specimen UPS-L-133138 (lectotype), sequences are available.

Briancoppinsia Diederich, Ertz, Lawrey \& van den Boom 2012, Arthoniaceae, Arthoniales, Arthoniomycetes, one species, type: B. cytospora (Vouaux) Diederich, Ertz, Lawrey \& van den Boom, coelomycetous, sexual morph unknown, lichenicolous, non-lichenized, terrestrial, Europe, North America, see Diederich et al. (2012b; morphology, phylogeny), Wijayawardene et al. (2017; outline), sequences are available.

Briania D.R. Reynolds 1989, Meliolinaceae, Dothideomycetes, families incertae sedis, one species, type: B. fruticetum D.R. Reynolds, sexual morph unknown, saprobes, terrestrial, Hawaiian Island, see Wijayawardene et al. (2012, 2017; outline), Kirk et al. (2013; genus accepted), cultures and sequences are unavailable.

Bricookea M.E. Barr 1982, Phaeosphaeriaceae, Pleosporales, Dothideomycetes, two species, type: B. sepalorum (Vleugel) M.E. Barr, asexual morph unknown, saprobes, terrestrial, 
cosmopolitan, see Kirk et al. (2008; treated as a synonym of Lophiostoma), Lumbsch and Huhndorf (2010; outline), Hyde et al. (2013; accepted as a genus in Phaeosphaeriaceae), Phookamsak et al. (2014b; accepted as a genus in Phaeosphaeriaceae), Wijayawardene et al. (2014c; outline), cultures and sequences are unavailable.

Brigantiaea Trevis. 1853 (= Myxodictyon A. Massal. 1860 [1859-1860]; = Myxodictyonomyces Cif. \& Tomas. 1953 fide Species Fungorum 2017), Brigantieaceae, Teloschistales, Lecanoromycetes, 29 species; type: B. tricolor (Mont.) Trevis., lichenized, terrestrial, worldwide, see Lumbsch and Huhndorf (2010; outline), Gaya et al. (2012; phylogeny), Kirk et al. (2013; genus accepted), Lücking et al. (2016b; classification), sequences are available.

Briosia Cavara 1888, Ascomycota genera incertae sedis, six species, type: B. ampelophaga Cavara, hyphomycetous, plant pathogen, widespread, see Hyde et al. (2011; outline), Seifert et al. (2011; morphology), Wijayawardene et al. (2012, 2017; outline), Kirk (2013; genus accepted), cultures and sequences are unavailable, needs generic revision.

Brobdingnagia K.D. Hyde \& P.F. Cannon 1999, Phyllachoraceae, Phyllachorales, Sordariomycetes, two species, type: B. nigeriensis (Sivan. \& Okpala) Hyde \& Cannon, asexual morph unknown, pathogens, saprobes, terrestrial, Australia, Sierra Leone, see Lumbsch and Huhndorf (2010; outline), Kirk et al. (2013; genus accepted), Maharachchikumbura et al. (2015, 2016; outline), cultures and sequences are unavailable, holotype of Brobdingnagia nigeriensis subsp. corneri IMI 390a.

Brodoa Goward 1987, Parmeliaceae, Lecanorales, Lecanoromycetes, three species, type: $B$. oroarctica (Krog) Goward, lichenized, see Lumbsch and Huhndorf (2010; outline), Kirk et al. (2013; genus accepted), Lücking et al. (2016b; classification), sequences are available.

Brooksia Hansf. 1956 (= Capnogonium Bat. \& Peres 1961; = Hiospira R.T. Moore 1962; = Overeemia G. Arnaud 1954 [1953] fide Wijayawardene et al. 2014c; Rossman et al. 2015b; Species Fungorum 2017), Dothideomycetes genera incertae sedis, one species, three variety, type: B. tropicalis Hansf., hyphomycetous, on leaf as parasite, common in tropical regions, see Lumbsch and Huhndorf (2010; outline), Kirk et al. (2013; genus accepted), Wijayawardene et al. (2014c; nomenclature), Rossman et al. (2015b; nomenclature), sequences are unavailable, need recollecting to verify generic placement.

Broomella Sacc. 1883 (= Keissleria Höhn. 1918 fide Species Fungorum 2017), Bartaliniaceae, Xylariales, Sordariomycetes, two species, type: B. vitalbae (Berk. \& Broome) Sacc., asexual morph coelomycetous, saprobes, terrestrial, worldwide, see Wijayawardene et al. (2012, 2016b; outline, taxonomy), Li et al. (2015d; taxonomy), Senanayake et al. (2015; outline), Maharachchikumbura et al. (2015, 2016; outline), cultures available for the type: MFLUCC 15-0023 (fide Li et al. 2015).

Brownliella S.Y. Kondr., Kärnefelt, Elix, A. Thell \& Hur 2013, Teloschistaceae, Teloschistales, Lecanoromycetes, four species, type: need typification data, lichenized, terrestrial, see Kondratyuk et al. (2013a, 2015b; taxonomy), Lücking et al. (2016b; classification), sequences are available.

Bruceomyces Rikkinen 2012 (= Brucea Rikkinen 2003 fide Species Fungorum 2017), Lecanorales genera incertae sedis, Lecanoromycetes, four species, type: B. castoris (Rikkinen) Rikkinen, lichenized, terrestrial, see Tuovila et al. (2012; taxonomy), cultures and sequences are unavailable.

Brunneiapiospora K.D. Hyde, J. Fröhl. \& Joanne E. Taylor 1998, Clypeosphaeriaceae, Xylariales, Sordariomycetes, six species, type: B. javensis K.D. Hyde, J. Fröhl. \& Joanne E. Taylor, asexual morphs unknown, saprobes, terrestrial, cosmopolitan, see Lumbsch and Huhndorf (2010; outline), Vitoria et al. (2012; new species), Crous et al. (2012c; new species, New Zealand), Kirk et al. (2013; genus accepted), Maharachchikumbura et al. (2015, 2016; outline), cultures and sequences are available for unidentified species. 
Brunneiperidium Daranagama, Camporesi \& K.D. Hyde 2015, Xylariaceae, Xylariales, Sordariomycetes, asexual morph hyphomycetous, only known for B. gracilentum, saprobes, terrestrial, Italy, Europe, two species, all the species have molecular data, see Daranagama et al. (2015a; taxonomy, phylogeny), Maharachchikumbura et al. (2016; outline), ex-type: MFLUCC 14-0011; holotype MFLU 14-0229.

Brunneocarpos Giraldo \& Crous 2016, Mycocaliciaceae, Mycocaliciales, Eurotiomycetes, one species, type: B. banksiae Giraldo \& Crous, asexual morph unknown, saprobes, Australia, see Crous et al. (2016b; taxonomy, phylogeny), holotype and ex-type: CBS H-22633, CPC 29841.

Brunneoclavispora Phook. \& K.D. Hyde 2015, Halotthiaceae, Pleosporales, Dothideomycetes, one species, type: B. bambusae Phookamsak \& K.D. Hyde, asexual morph unknown, saprobes, terrestrial, Thailand, see Ariyawansa et al. (2015a; taxonomy, phylogeny), holotype and ex-type culture of the type: MFLU 11-0213, MFLUCC 11-0177.

Brunneodinemasporium Crous \& R.F. Castañeda 2012, Chaetosphaeriaceae, Chaetosphaeriales, Sordariomycetes, one species, type: B. brasiliense Crous \& Castañeda, coelomycetous, sexual morph unknown, saprobes, terrestrial, Brazil, see Crous et al. (2012g; morphology, phylogeny), Maharachchikumbura et al. (2015; classification, phylogeny), Wijayawardene et al. (2016b; morphology, phylogeny), ex-type: CPC 112007; holotype CBS H-20948.

Brunneomycosphaerella Dissan., J.K. Liu \& K.D. Hyde 2015, Capnodiales genera incertae sedis, one species, type: B. laburni Dissanayake., J. K. Liu \& K. D. Hyde, saprobes, terrestrial, Italy, see Liu et al. (2015a; taxonomy, phylogeny), holotype: MFLU 14-0808, sequences are available.

Brunneosphaerella Crous 2009, Mycosphaerellaceae, Capnodiales, Dothideomycetes, three species, type: B. protearum (Syd. \& P. Syd.) Crous., asexual morph coelomycetous, saprobes, terrestrial, South Africa, see Crous et al. (2009d, 2011d; morphology; phylogeny), Schoch et al. (2009; morphology, phylogeny), Hyde et al. (2013; accepted as in Mycosphaerellaceae), Wijayawardene et al. (2014c; accepted as in Mycosphaerellaceae), epitype: CBS H-20335, ex-epitype culture CBS $130597=$ CPC 16368.

Brunneosporella Ranghoo \& K.D. Hyde 2001, Papulosaceae, Diaportheomycetidae families incertae sedis, Sordariomycetes, one species, type: B. aquatica Ranghoo \& K.D. Hyde, one species, asexual morph unknown, saprobes, aquatic, Hong Kong, see Lumbsch and Huhndorf (2010; outline, as a genus in Annulatascaceae), Maharachchikumbura et al. (2015, 2016; outline, accepted as a genus in Papulosaceae), holotype: HKU (M) 5251.

Brunnipila Baral 1985, Lachnaceae, Helotiales, Leotiomycetes, two species, type: $B$. clandestina (Bull.) Baral, asexual morph unknown, saprobes, terrestrial, north temperate, see Lumbsch and Huhndorf (2010; outline), Kirk et al. (2013; genus accepted), Han et al. (2014; DNA, phylogeny), cultures and sequences are available but lacks for the type species.

Brycekendrickia Nag Raj 1973, Ascomycota genera incertae sedis, one species, type: B. indica Nag Raj., coelomycetous, sexual morph unknown, saprobes, terrestrial, India, see Nag Raj et al. (1973; morphology), Wijayawardene et al. (2012, 2017; outline), cultures and sequences are unavailable.

Brycekendrickomyces Crous \& M.J. Wingf. 2009, Herpotrichiellaceae, Chaetothyriales, Eurotiomycetes, one species, type: $B$. acaciae Crous \& Wingf, hyphomycetous, sexual morph unknown, saprobes, terrestrial, Indonesia, see Crous et al. (2009a; morphology, phylogeny), holotype and ex-type: CBS H-20198, CPC 15078 = CBS 124104.

Bryobilimbia Fryday, Printzen \& S. Ekman 2014, Lecideaceae, Lecideales, Lecanoromycetes, six species, type: B. hypnorum (Lib.) Fryday, Printzen \& S. Ekman, lichenized, see Fryday et al. (2014; taxonomy), Lücking et al. (2016b; classification), sequences are available. 
Bryocaulon Kärnefelt 1986, Parmeliaceae, Lecanorales, Lecanoromycetes, four species, type: B. divergens (Ach.) Kärnefelt, lichenized, terrestrial, north temperate, see Lumbsch and Huhndorf (2010; outline), Kirk et al. (2013; genus accepted), Lücking et al. (2016b; classification), sequences are available.

Bryocentria Döbbeler 2004, Bionectriaceae, Hypocreales, Sordariomycetes, eight species, type: B. brongniartii (P. Crouan \& H. Crouan) Döbbeler, sexual morph unknown, saprobes, epiphytes, terrestrial, cosmopolitan, see Döbbeler (2010; new species), Lumbsch and Huhndorf (2010; outline), Maharachchikumbura et al. (2015, 2016; outline), cultures and sequences are available.

Bryochiton Döbbeler \& Poelt 1978, Pseudoperisporiaceae, Dothideomycetes families incertae sedis, four species, type: B. monascus Döbbeler \& Poelt, asexual morph unknown, saprobes, terrestrial, Europe, see Lumbsch and Huhndorf (2010; outline), Hyde et al. (2013; accepted as a genus in Pseudoperisporiaceae), Kirk et al. (2013; genus accepted), Wijayawardene et al. (2014c; outline), cultures and sequences are available for unidentified species, needs generic revision.

Bryoclaviculus L. Ludw., P.R. Johnst. \& Steel 2013, Helotiales genera incertae sedis, Leotiomycetes, one species, type: B. campylopi P.R. Johnst., asexual morph unknown, saprobes, terrestrial, New Zealand, see Johnston et al. (2013; taxonomy, DNA), holotype of the type: OTA 062197, cultures and sequences are available.

Bryodina Hafellner 2001, Lecanoraceae, Lecanorales, Lecanoromycetes, two species, type: B. rhypariza (Nyl.) Hafellner, with ascomata, terrestrial (bryophilous), Northern Hemisphere, see Lumbsch and Huhndorf (2010; outline), Lücking et al. (2016b; classification), sequences unavailable.

Bryoglossum Redhead 1977, Helotiales genera incertae sedis, Leotiomycetes, two species, type: B. gracile (P. Karst.) Redhead, asexual morph unknown, saprobes, terrestrial, Europe, North America, see Lumbsch and Huhndorf (2010; outline), Kirk et al. (2013; genus accepted), cultures available for the type: DAOM178087.

Bryogomphus Lücking, W.R. Buck, Sérus. \& L.I. Ferraro 2005, Pilocarpaceae, Lecanorales, Lecanoromycetes, one species, type: B. caribaeus (W.R. Buck) Lücking, W.R. Buck, Sérus. \& L.I. Ferraro, lichenized, see Lumbsch and Huhndorf (2010; outline), Lücking et al. (2016b; classification), sequences are unavailable.

Bryonora Poelt 1983, Lecanoraceae, Lecanorales, Lecanoromycetes, eleven species, type: $B$. castanea (Hepp) Poelt, with ascomata, terrestrial (bryophilous), bipolar, see Lumbsch and Huhndorf (2010; outline), Lücking et al. (2016b; classification), sequences are available only for the type species.

Bryopelta Döbbeler \& Poelt 1978, Mycosphaerellaceae, Capnodiales, Dothideomycetes, one species, type: B. variabilis Döbbeler \& Poelt, asexual morph unknown, saprobes, terrestrial, Norway, Sweden, see Lumbsch and Huhndorf (2010; outline; accepted as a genus in Dothideomycetes), Kirk et al. (2013; genus accepted), Li et al. (2014b; accepted as a genus in Mycosphaerellaceae), Wijayawardene et al. (2014c; outline), cultures and sequences are unavailable, needs generic revision.

Bryoplaca Søchting, Frödén \& Arup 2013, Teloschistaceae, Teloschistales, Lecanoromycetes, three species, type: B. sinapisperma (DC.) Søchting, Frödén \& Arup, lichenized, Northern Hemisphere and Antarctica, see Arup et al. (2013; taxonomy), Lücking et al. (2016b; classification), sequences are available.

Bryorella Döbbeler 1978, Dothideomycetes genera incertae sedis, ten species, type: $B$. acrogena Döbbeler, asexual morph unknown, saprobes or parasitic, terrestrial, Europe (Italy, Austria, Poland, Sweden, Switzerland), see Lumbsch and Huhndorf (2010; outline), Kirk et al. (2013; genus accepted), Li et al. (2014b; taxonomy), Wijayawardene et al. (2014c; outline), sequences are available, needs generic revision. 
Bryoria Brodo \& D. Hawksw. 1977 (= Bryopogon Th. Fr. 1860; Setaria Ach. ex Michx. 1803 fide Species Fungorum 2017), Parmeliaceae, Lecanorales, Lecanoromycetes, c. 60 species, type: B. trichodes (Michx) Brodo \& D. Hawksw., widespread but mainly $\mathrm{N}$ Hemisphere, see Lumbsch and Huhndorf (2010; outline), Myllys et al. (2011, 2014; phylogeny), Kirk et al. (2013; genus accepted), Velmala et al. (2014; phylogeny), Jaklitsch et al. (2016a; position), Lücking et al. (2016b; classification), holotype: PC, sequences are available.

Bryoscyphus Spooner 1984 (= Calyptellopsis Svrček 1986 fide Jaklitsch et al. 2016a), Helotiaceae, Helotiales, Leotiomycetes, 19 species, type: B. conocephali (Boyd) Spooner, asexual morph unknown, saprobes, terrestrial, cosmopolitan, see Lumbsch and Huhndorf (2010; outline), Stenroos et al. (2010; DNA), Kirk et al. (2013; genus accepted), Jaklitsch et al. (2016a; classification), cultures and sequences are available but lacks for the type.

Bryosphaeria Döbbeler 1978, Trematosphaeriaceae, Pleosporales, Dothideomycetes, nine species, type: B. cinclidoti (Racov.) Döbbeler, asexual morph unknown, terrestrial, Europe, see Lumbsch and Huhndorf (2010; outline), Kirk et al. (2013; genus accepted), Li et al. (2014b; transferred to Trematosphaeriaceae), sequences are unavailable, needs generic revision.

Bryostigma Poelt \& Döbbeler 1979, Arthoniales genera incertae sedis, Arthoniomycetes, two species, type: B. leucodontis Poelt \& Döbbeler, lichenized, see Sundin et al. (2012; taxonomy), Frisch et al. (2014; taxonomy), Lücking et al. (2016b; classification), sequences are available.

Bryostroma Döbbeler 1978, Dothideomycetes genera incertae sedis, seven species, type: $B$. rhacomitrii Döbbeler, asexual morph unknown, saprobes, terrestrial, Europe, see Lumbsch and Huhndorf (2010; outline), Kirk et al. (2013; genus accepted), Wijayawardene et al. (2014c; outline), sequences are unavailable, needs generic revision.

Bryothele Döbbeler 1998, Dothideomycetes genera incertae sedis, one species, type: B. mira Döbbeler \& Melnik, asexual morph unknown, saprobes or parasitic, terrestrial, America and Africa, see Lumbsch and Huhndorf (2010; outline), Kirk et al. (2013; genus accepted), Wijayawardene et al. (2014c; outline), sequences are unavailable, needs generic revision.

Budhanggurabania P. Wong, Khemmuk \& R.G. Shivas 2015, Magnaporthaceae, Magnaporthales, Sordariomycetes, one species, type: B. cynodonticola P. Wong, Khemmuk \& R.G. Shivas, coelomycetous, saprobes, Australia, see Crous et al. (2015d; taxonomy, phylogeny), Wijayawardene et al. (2017; outline), epitype and ex-epitype: BRIP 59305.

Buellia De Not. [nom. cons.] 1846, Caliciaceae, Caliciales, Lecanoromycetes, 300 species, type: B. disciformis (Fr.) Mudd, lichenized, worldwide, see Lumbsch and Huhndorf (2010; outline), Gaya et al. (2012; phylogeny), Kirk et al. (2013; genus accepted), Prieto and Wedin (2016; taxonomy), Lücking et al. (2016b; classification), sequences are available.

Buelliastrum Zahlbr. 1930, family incertae sedis, order incertae sedis, subclass incertae sedis, Lecanoromycetes, two species, type: need typification data, lichenized, China, see Lumbsch and Huhndorf (2010; outline), Lücking et al. (2016b; classification), sequences are unavailable.

Buelliella Fink 1935, Asterinales genera incerte sedis, Dothideomycetes, eleven species, type: B. minimula (Tuck.) Fink, lichenicolous, Asia, see Hafellner et al. (2008; new species), Lumbsch and Huhndorf (2010; outline), Pérez-Ortega and Etayo (2010; new species), van den Boom (2010; new species), Kirk et al. (2013; genus accepted), Wijayawardene et al. (2014c; outline), Ertz and Diederich (2015; phylogeny, aceepted s Asterinales), sequences are available.

Buerenia M.S. Reddy \& C.L. Kramer 1975, Protomycetaceae, Taphrinales, Taphrinomycetes, three species, type: B. cicutae (Lindr.) M.S. Reddy \& C.L. Kramer, asexual morph unknown, ?saprobes or parasites, terrestrial, worldwide, see Lumbsch and Huhndorf 
(2010; outline), Kirk et al. (2013; genus accepted), cultures and sequences are unavailable, needs generic revision.

Buergenerula Syd. 1936 (= Yukonia R. Sprague 1962 fide Species Fungorum 2017), Magnaporthaceae, Magnaporthales, Sordariomycetes, six species, type: B. biseptata (Rostr.) Syd., asexual morph harpophora-like and pyricularia-like, pathogen, marine and freshwater habitats, worldwide, see Jones et al. (2009b, 2015; outline), Lumbsch and Huhndorf (2010; outline), Yuan et al. (2010; phylogeny), Al-Nasrawi and Hughes (2012; diversity), Kirk et al. (2013; genus accepted), Luo and Zhang (2013; phylogeny), Chen et al. (2014; mitoviruses), Hujslová et al. (2014; phylogeny), Klaubauf et al. (2014; phylogeny), Calado et al. (2015; diversity, ecology), Maharachchikumbura et al. (2015, 2016; outline, phylogeny), cultures and sequences are unavailable.

Bulbilopycnis Matsush. 1996, Ascomycota genera incertae sedis, one species, type: B. caffra Matsush., coelomycetous, sexual morph unknown, saprobes, terrestrial, Transvaal, see Wijayawardene et al. (2012, 2017; outline), Kirk et al. (2013; genus accepted), cultures and sequences are unavailable, needs generic revision.

Bulbithecium Udagawa \& T. Muroi 1990, Hypocreales genera incertae sedis, Sordariomycetes, one species, type: B. hyalosporum Udagawa \& T. Muroi, asexual morph acremonium-like, saprobes, India, see Lumbsch and Huhndorf (2010; outline), Giraldo et al. (2012; DNA, phylogeny), Kirk et al. (2013; genus accepted), Maharachchikumbura et al. (2015, 2016; outline), cultures available for the type: CBS 318.91.

Bulbocatenospora R.F. Castañeda \& Iturr. 2000, Ascomycota genera incertae sedis, one species, type: B. complanata R.F. Castañeda, Iturr. \& Decock, hyphomycetous, sexual morph unknown, saprobes, terrestrial, Venezuela, see Seifert et al. (2011; morphology), Wijayawardene et al. (2012, 2017; outline), holotype: MUCL 40705, cultures and sequences are unavailable, compare with Piricauda, Chuppia, Neoarbuscula and Peyronelia.

Bulbomollisia Graddon 1984, Mollisiaceae, Helotiales, Leotiomycetes, one species, type: $B$. radiata Graddon, sexual morph unknown, saprobes, UK, see Jaklitsch et al. (2016a; classification), cultures and sequences are unavailable.

Bulbothrix Hale 1974, Parmeliaceae, Lecanorales, Lecanoromycetes, 60 species, type: B. semilunata (Lynge) Hale, lichenized, terrestrial, tropical, see Lumbsch and Huhndorf (2010; outline), Kirk et al. (2013; genus accepted), Kirika et al. (2015; phylogeny), Lücking et al. (2016b; classification), sequences are available.

Bulgaria Fr. 1822, Phacidiaceae, Helotiales, Leotiomycetes, two species, type: B. inquinans (Pers.) Fr., asexual morph unknown, saprobes, terrestrial, northern and southern temperate, see Lumbsch and Huhndorf (2010; outline), Kirk et al. (2013; genus accepted), Crous et al. (2014b; phylogeny), cultures available for the type: CBS 315.71.

Bulgariella P. Karst. 1885, Helotiales genera incerate sedis, Leotiomycetes, four species, type: B. pulla (Fr.) P. Karst., asexual morph unknown, saprobes, terrestrial, Europe, South America, see Lumbsch and Huhndorf (2010; outline), Stenroos et al. (2010; DNA), Kirk et al. (2013; genus accepted), cultures and sequences are available (unpublished).

Bulgariopsis Henn. 1902, Helotiales genera incerate sedis, Leotiomycetes, two species, type: B. moelleriana Henn., asexual morph unknown, saprobes, terrestrial, Brazil, see Lumbsch and Huhndorf (2010; outline), Stenroos et al. (2010; DNA), Kirk et al. (2013; genus accepted), cultures and sequences are unavailable.

Bullanockia Crous 2016, Bionectriaceae, Hypocreales, Sordariomycetes, one species, type: B. australis Crous, hyphomycetous, sexual morph unknown, saprobes, terrestrial, Australia, see Crous et al. (2016a; new species, phylogeny), holotype and ex-type culture of the type: CBS H-22879, CPC 28976.

Bullaserpens Bat., J.L. Bezerra \& Cavalc. 1965, Ascomycota genera incertae sedis, one species, type: B. bignoniacearum Bat., J.L. Bezerra \& Cavalc., coelomycetous, sexual morph 
unknown, saprobes, terrestrial, Brazil, see Wijayawardene et al. (2012, 2017; outline), Kirk et al. (2013; genus accepted), cultures and sequences are unavailable, needs generic revision.

Bullimyces A. Ferrer, A.N. Mill., C. Sarmiento \& Shearer 2012, Sordariomycetidae incertae sedis, Sordariomycetes, three species, type: B. communis A. Ferrer, A.N. Mill., Sarmiento \& Shearer, Costa Rica, see Ferrer et al. (2012; taxonomy), Cai et al. (2014; phylogeny), Maharachchikumbura et al. (2015, 2016; outline), holotype: AF281-1, ILL, cultures and sequences are available.

Bunodophoron A. Massal. 1861, Sphaerophoraceae, Lecanorales, Lecanoromycetes, 24 species, type: B. australe (Laurer) A. Massal., , lichenized, terrestrial, mainly in the temperate rainforests of the Southern Hemispheres, rarely in oceanic areas of the Northern Hemisphere or in high-altitude rainforests in tropical or subtropical areas, see Lumbsch and Huhndorf (2010; outline), Kirk et al. (2013; genus accepted), Lücking et al. (2016b; classification), sequences are available.

Burenia M.S. Reddy \& C.L. Kramer 1975, Protomycetaceae, Taphrinales, Taphrinomycetes, three species, type: B. cicutae (Lindr.) M.S. Reddy \& C.L. Kramer, asexual reproduction is nknown, plant parasitic, parasitic on Apiaceae, Europe, see see Lumbsch and Huhndorf (2010; outline), cultures and sequences are unavailable.

Bussabanomyces Klaubauf, Lebrun \& Crous 2014, Magnaporthaceae, Magnaporthales, Sordariomycetes, one species, type: B. longisporus (Bussaban) Klaubauf, Lebrun \& Crous, hyphomycetous, sexual morph unknown, enodophyte, terrestrial, Thailand, see Klaubauf et al. (2014; morphology, phylogeny), Maharachchikumbura et al. (2015; outline), Wijayawardene et al. (2017; outline), holotype and ex-type: BCC11377, CBS 125232.

Butleria Sacc. 1914, Myriangiaceae, Myriangiales, Dothideomycetes, one species, type: B. inaghatahani Sacc., asexual morph unknown, parasitic, terrestrial, tropical, holotype of type: PAD 1677, see Lumbsch and Huhndorf (2010; outline), Li et al. (2011; morphology), Kirk et al. (2013; genus accepted), Dissanayake et al. (2014; morphology), Wijayawardene et al. (2014c; outline), cultures and sequences are unavailable.

Byrsomyces Cavalc. 1972, Sordariomycetes genera incertae sedis, one species, type: B. olivaceus Cavalc., asexual morph unknown, terrestrial, Brazil, see Lumbsch and Huhndorf (2010; outline), Kirk et al. (2013; genus accepted), Maharachchikumbura et al. (2015, 2016; outline), type material is not in good condition hence need to recollect and subject them to molecular analysis, holotype: URM 27661 /Exs. 20057.

Byssoascus Arx 1971, Myxotrichaceae, Leotiomycetes families incertae sedis, two species, type: B. striatosporus (G.L. Barron \& C. Booth) Arx, asexual morph unknown, saprobes, terrestrial, Canada, see Lumbsch and Huhndorf (2010; outline), Kirk et al. (2013; genus accepted), holotype: BF 24290, cultures available for type: UAMH 3572.

Byssocallis syd. 1927, Dothideomycetes genera incertae sedis, two species, type: B. phoebes Syd., asexual morph unknown, parasitic on living leaves (Phoebe tonduzii Mez. and Podocarpus elongate L'Herit.), see Lumbsch and Huhndorf (2010; outline, accepted as a genus in Tubeufiaceae), Hyde et al. (2013) and Boonmee et al. (2014b) did not accept as a genus in Tubeufiaceae, Kirk et al. (2013; genus accepted), Wijayawardene et al. (2014c; outline), cultures and sequences are unavailable, needs generic revision.

Byssocaulon Mont. 1835, Chrysotrichaceae, Arthoniales, Arthoniomycetes, six species, type: $B$. niveum Mont., lichenized, saxicolous or epiphytic, tropical, see Lumbsch and Huhndorf (2010; outline), Kirk et al. (2013; genus accepted), cultures and sequences are unavailable.

Byssogene Syd. 1922, Dothideomycetes genera incertae sedis, two species, type: $B$. amboinensis Syd., asexual morph unknown, saprobes, terrestrial, Brazil and Indonesia, see Lumbsch and Huhndorf (2010; outline), Kirk et al. (2013; genus accepted), Wijayawardene et al. (2014c; outline), da Silva (2016; taxonomy, phylogeny, accepted as a genus in Saccardiaceae), cultures and sequences are unavailable, needs generic revision. 
Byssolecania Vain. 1921 (= Dothiomyces Bat. \& J.L. Bezerra 1961; = Gonolecania Zahlbr. 1924; = Lecaniella Vain. 1896 fide Species Fungorum 2017), Pilocarpaceae, Lecanorales, Lecanoromycetes, seven species, type: B. fuscolivida Vain., lichenized, worldwide, see Lumbsch and Huhndorf (2010; outline), Kirk et al. (2013; genus accepted), Lücking et al. (2016b; classification), sequences are available.

Byssoloma Trevis. 1853 (= Calidia Stirt. 1876; = Limbalba Nieuwl. 1916; = Pilocarpon Vain. 1890; = Tricholechia A. Massal. 1853; = Wainioa Nieuwl. 1916 fide Species Fungorum 2017), Pilocarpaceae, Lecanorales, Lecanoromycetes, possibly heterogeneous, c. 50 spp., type: B. leprieurii Trevis., sexual morph with apothecioid ascomata usually having a byssoid margin, asexual morph coelomycetous, rarely campylidial, lichenized, terrestrial, mainly foliicolous in tropical rainforests, see Lücking (2008; morphology), Miądlikowska et al. (2014a; phylogeny), Lücking et al. (2016b; classification), van den Boom (2016; new species), holotype: Leprieur 1366 (PC), sequences are available but lacks for the type species. Byssonectria P. Karst. 1881 (= Inermisia Rifai 1968; = Pseudocollema Kanouse \& A.H. Sm. 1940 fide Species Fungorum 2017), Pyronemataceae, Pezizales, Pezizomycetes, eleven species, type: B. obducens P. Karst., asexual morph unknown, saprobes, terrestrial, worldwide, see Lumbsch and Huhndorf (2010; outline), Kirk et al. (2013; genus accepted), Lindemann et al. (2015; new species, DNA), cultures and sequences are available but lacks for the type, needs generic revision.

Byssoonygena Guarro, Punsola \& Cano 1987, Onygenaceae, Onygenales, Eurotiomycetes, one species, type: B. ceratinophila Guarro, Punsola \& Cano, asexual morph unknown, saprobes, terrestrial, Spain, see Lumbsch and Huhndorf (2010; outline), Kirk et al. (2013; genus accepted), culture available for the type: IMI 370021.

Byssophytum Mont. 1848, Ascomycota genera incertae sedis, one species, type: $B$. sulphureum Mont., asexual morph unknown, lichenized, terrestrial, Java, Tahiti, see Kirk et al. (2013; genus accepted), cultures and sequences are unavailable, needs generic revision.

Byssosphaeria Cooke 1879 (= Macbridella Seaver 1909; = Xenonectria Höhn. 1920 fide Species Fungorum 2017), Melanommataceae, Pleosporales, Dothideomycetes, 25 species, type: B. keithii (Berk. \& Broome) Cooke, chaetophoma-like, saprobes, terrestrial, widespread, see Lumbsch and Huhndorf (2010; outline), Kirk et al. (2013; genus accepted), Wijayawardene et al. (2014c; outline), Tian et al. (2015; morphology, phylogeny), cultures and sequences of type species are unavailable, needs generic revision.

Byssotheciella Petr. 1923, Sordariomycetes, genera incertae sedis, two species, type: B. tiliae Petr., asexual morph unknown, saprobes, terrestrial, Europe, South America, see Lumbsch and Huhndorf (2010; outline), Kirk et al. (2013; genus accepted), Maharachchikumbura et al. (2015, 2016; outline), cultures and sequences are unavailable, needs generic revision.

Byssothecium Fuckel 1861, Dothideomycetes genera incertae sedis, eight species, type: $B$. circinans Fuckel, asexual morph coelomycetous, saprobes or parasites, terrestrial, freshwater or marine, worldwide, see Zhang et al. (2009e) accepted as Massarinaceae but Zhang et al. (2012e) showed it distinct from Massarinaceae, Lumbsch and Huhndorf (2010; outline), Kirk et al. (2013; genus accepted), Wijayawardene et al. (2014c; outline), cultures and sequences are available.

Byssotrema M. Cáceres, Aptroot \& Lücking 2014, Graphidaceae, Ostropales, Lecanoromycetes, one species, type: B. mirabile M. Cáceres, Aptroot \& Lücking, lichenized, see Cáceres et al. (2014; taxonomy), Lücking et al. (2016b; classification), sequences are unavailable.

Caccobius Kimbr. 1967, Thelebolaceae, Thelebolales, Leotiomycetes, c. six species, type: $C$. minusculus Kimbr., asexual morph unknown, coprophilous, terrestrial, north temperate, see Lumbsch and Huhndorf (2010; outline), Kirk et al. (2013; genus accepted), cultures and sequences are unavailable, needs generic revision. 
Cacumisporium Preuss 1851, Ascomycota genera incertae sedis, seven species, type: $C$. tenebrosum Preuss, hyphomycetous, sexual morph unknown, saprobes, terrestrial, Asia, Caribbean, Europe, North America, see Wongsawas et al. (2009; new species), Seifert et al. (2011; morphology), Wijayawardene et al. (2012, 2017; outline), Kirk et al. (2013; genus accepted), cultures and sequences are unavailable, needs generic revision.

Cadophora Lagerb. \& Melin 1927, Ploettnerulaceae, Helotiales, Leotiomycetes, 15 species, type: C. fastigiata Lagerb. \& Melin, hyphomycetous, sexual morph unknown, saprobes, terrestrial, worldwide, see Navarrete et al. (2011; associated with grapevine trunk diseases), Seifert et al. (2011; morphology), Day et al. (2012; new species), Wijayawardene et al. (2012, 2017; outline), Kirk et al. (2013; genus accepted), Travadon et al. (2015; new species), cultures and sequences are available.

Caeruleum Arcadia 2012, Acarosporaceae, Acarosporales, Lecanoromycetes, two species; type: C. heppii (Nägeli ex Körb.) K. Knudsen \& Arcadia, lichenized, see Arcadia and Knudsen (2012; taxonomy), Lücking et al. (2016b; classification), sequences unavailable.

Caespitotheca S. Takam. \& U. Braun 2005, Erysiphaceae, Erysiphales, Leotiomycetes, one species, type: C. forestalis (Mena) S. Takam. \& U. Braun, asexual morphs hyphomycetous, biotrophic, obligate plant pathogens, terrestrial, South America (Argentina), see Lumbsch and Huhndorf (2010; outline), Braun and Cook (2012; taxonomy), cultures and sequences are available.

Cainia Arx \& E. Müll. 1955, Cainiaceae, Xylariales, Sordariomycetes, seven species, type: C. graminis (Niessl) Arx \& E. Müll., asexual morph coelomyctous, saprobes, pathogenic, terrestrial, temperate, see Kirk et al. (2008, 2013; genus accepted), Lumbsch \& Huhndorf (2010; outline), Senanayake et al. (2015; outline), Maharachchikumbura et al. (2015, 2016; outline), Jaklitsch et al. (2016a; phylogeny), cultures and sequences are available, reference specimens: CBS 136.62, MFLUCC 15-0540 = It 1462.

Cainiella E. Müll. 1957, Sydowiellaceae, Diaporthales, Sordariomycetes, four species, type: C. johansonii (Rehm) E. Müll., asexual morphs unknown, saprobes, terrestrial, Canada, Europe, see Lumbsch and Huhndorf (2010; outline), Kruys and Castlebury (2012; phylogeny), Kirk et al. (2013; genus accepted), Maharachchikumbura et al. (2015, 2016; outline, phylogeny), cultures and sequences are available.

Cainomyces Thaxt. 1901, Laboulbeniales genera incertae sedis, Laboulbeniomycetes, one species, type: $C$. isomali Thaxt., asexual morph unknown, saprobes, terrestrial, see Kirk et al. (2013; genus accepted), cultures and sequences are unavailable, needs generic revision.

Calathaspis I.M. Lamb \& W.A. Weber 1972, Cladoniaceae, Lecanorales, Lecanoromycetes, one species, type: $C$. devexa I.M. Lamb \& W.A. Weber, lichenized, see Lumbsch and Huhndorf (2010; outline), Kirk et al. (2013; genus accepted), Lücking et al. (2016b; classification), sequences are unavailable.

Calcarispora Marvanová \& Marvan 1963, Ascomycota genera incertae sedis, one species, type: $C$. hiemalis Marvanová \& Marvan, hyphomycetous, sexual morph unknown, aquatic, Europe and Canada, see Hyde et al. (2011; outline), Seifert et al. (2011; morphology), Wijayawardene et al. (2012, 2017; outline), Kirk et al. (2013; genus accepted), cultures and sequences are unavailable, needs generic revision.

Calcarisporium Preuss 1851, Hypocreales genera incertae sedis, Sordariomycetes, 15 species, type: $C$. arbuscula Preuss, hyphomycetous, sexual morph unknown, saprobes, widespread, see Hyde et al. (2011; outline), Seifert et al. (2011; morphology), Wijayawardene et al. (2012, 2017; outline), Kirk et al. (2013; genus accepted), Sun et al. (2016; new species), cultures and sequences are unavailable, needs generic revision.

Calceispora Matsush. 1975, Ascomycota genera incertae sedis, two species, type: $C$. hachijoensis Matsush., hyphomycetous, sexual morph unknown, saprobes, terrestrial, Asia, 
see Seifert et al. (2011; morphology), Wijayawardene et al. (2012, 2017; outline), Kirk et al. (2013; genus accepted), cultures and sequences are unavailable, needs generic revision.

Calceomyces Udagawa \& S. Ueda 1988, Xylariales genera incertae sedis, Sordariomycetes, one species, type: C. lacunosus Udagawa \& S. Ueda, asexual morph hyphomycetous, saprobes, terrestrial (collected from activated sludge), see Lumbsch and Huhndorf (2010; outline), Kirk et al. (2013; genus accepted), Maharachchikumbura et al. (2015, 2016; outline), Wendt et al. (2017; accepted as Xylariales genera incertae sedis), cultures and sequences are unavailable, type: CBS $633.88=$ NHL 2983.

Calenia Müll. Arg. 1890 (= Phlyctidium Müll. Arg. 1888 fide Species Fungorum 2017), Gomphillaceae, Ostropales, Lecanoromycetes, 30 species, type: C. depressa Müll. Arg., lichenized, tropical, see Lumbsch and Huhndorf (2010; outline), Kirk et al. (2013; genus accepted), Lücking et al. (2016b; classification), sequences are available.

Caleniopsis Vězda \& Poelt 1987 (= Caleniomyces Cif. \& Tomas. 1953 fide Species Fungorum 2017), Gomphillaceae, Ostropales, Lecanoromycetes, two species, type: $C$. laevigata (Müll. Arg.) Vězda \& Poelt, lichenized, tropical, see Lumbsch and Huhndorf (2010; outline), Kirk et al. (2013; genus accepted), Lücking et al. (2016b; classification), sequences are available.

Caleutypa Petr. 1934, Sordariomycetes, genera incertae sedis, two species, type: C. maculans Petr., saprobes, tropical, see Lumbsch and Huhndorf (2010; outline), Kirk et al. (2013; genus accepted), Maharachchikumbura et al. (2015, 2016; outline), cultures and sequences are unavailable, needs generic revision.

Caliciopsis Peck 1883 (= Capnodiella (Sacc.) Sacc. \& D. Sacc. 1905; = Capnodium subgen. Capnodiella Sacc. 1882; = Hypsotheca Ellis \& Everh. 1885; = Lagenula G. Arnaud 1930; = Sorica Giesenh. 1904 fide Species Fungorum 2017), Coryneliaceae, Coryneliales, Eurotiomycetes, 31 species, type: $C$. pinea Peck, asexual morph coelomycetous (phoma-like), parasites, pathogens, see Lumbsch and Huhndorf (2010; outline), Pratibha et al. (2010; new species), Garrido-Benavent and Pérez-Ortega (2015; new species), Crous et al. (2016a; new species, phylogeny), Wood et al. (2016; DNA, phylogeny), cultures available for the type: CBS 139.64.

Calicium Pers. 1794 (see Species Fungorum 2017 for synonyms; = Cyphelium Ach. 1815), Caliciaceae, Caliciales, Lecanoromycetes, 30 species, type: C. viride Pers., lichenized, see Lumbsch and Huhndorf (2010; outline), Kirk et al. (2013; genus accepted), Gaya et al. (2012; phylogeny), Prieto et al. (2013; phylogeny), Prieto and Wedin (2016; classification), Lücking et al. (2016b; classification), sequences are available.

Callebaea Bat. 1962, Dothideomycetes, genera incertae sedis, one species, type: C. rutideae (Hansf.) Bat., saprobes, terrestrial, Uganda, see Lumbsch and Huhndorf (2010; outline), Kirk et al. (2013; genus accepted), Wijayawardene et al. (2014c; outline), cultures and sequences are unavailable, needs generic revision.

Callerascus Whitton, K.D. Hyde \& McKenzie 2012, Leotiomycetes genera incertae sedis, one species, type: C. tunicaerulus Whitton, K.D. Hyde \& McKenzie, asexual morph unknown, saprobes, terrestrial, Australia, see Whitton et al. (2012b; taxonomy holotype of the type: IFRD 9021, cultures and sequences are unavailable, needs generic revision.

Callistospora Petr. 1955, Ascomycota genera incertae sedis, one species, type: C. gaubae Petr., coelomycetous, sexual morph unknown, saprobes, terrestrial, Australia, see Wijayawardene et al. (2012, 2016b, 2017; outline, taxonomy), Kirk et al. (2013; genus accepted), cultures and sequences are unavailable, needs generic revision.

Callome Otálora \& Wedin 2014, Collemataceae, Peltigerales, Lecanoromycetes, one species, type: C. multipartita (Sm.) Otálora, P.M. Jørg. \& Wedin, lichenized, see Otálora et al. (2013; 2014; taxonomy, phylogeny), Lücking et al. (2016b; classification), sequences are available. 
Calloria Fr. 1836 (= Beloniella Rehm 1892; = Belonopeziza Höhn. 1917; = Cylindrocolla Bonord. 1851; Callorina Korf 1971 fide Johnston et al. 2014b; Species Fungorum 2017), Calloriaceae, Helotiales, Leotiomycetes, five species, type: C. fusarioides (Berk.) Fr., asexual morph Cylindrocolla, saprobes, terrestrial, Europe, North America, see Lumbsch and Huhndorf (2010; outline), Seifert et al. (2011; morphology of asexual morph), Kirk et al. (2013; genus accepted), Wijayawardene et al. (2017; outline), cultures and sequences are available but lacks for the type species.

Calloriopsis Syd. \& P. Syd. 1917 (= Diplothrix Vain. 1921 fide Jaklitsch et al. 2016a), Helicogoniaceae, Phacidiales, Leotiomycetes, five species, type: C. gelatinosa (Sacc.) Syd. $\&$ P. Syd., asexual morph unknown, saprobes, terrestrial, tropical, see Lumbsch and Huhndorf (2010; outline), Kirk et al. (2013; genus accepted), cultures and sequences are unavailable, needs generic revision.

Calogaya Arup, Frödén \& Søchting 2013, Teloschistaceae, Teloschistales, Lecanoromycetes, 14 species, type: C. biatorina (A. Massal.) Arup, Frödén \& Søchting; lichenized, see Arup et al. (2013; taxonomy, phylogeny), Lücking et al. (2016b; classification), sequences are available.

Calonectria De Not. 1867 (= Cylindrocladium Morgan 1892; = Candelospora Rea \& Hawley 1912 fide Rossman et al. 2016a), Nectriaceae, Hypocreales, Sordariomycetes, type: pyrochroa (Desm.) Sacc., 248 species are listed in Index Fungorum (2016), type: $C$. daldiniana De Not., pathogenic to plants or isolated from soil, terrestrial, worldwide, see Lombard et al. (2010a, b, 2015a, b; taxonomy, phylogeny), Maharachchikumbura et al. (2015, 2016; outline), Rossman et al. (2016a; nomenclature), ex-epitype: CBS 749.70; epitype: of the type: CBS H-15110.

Calongea Healy, Bonito \& Trappe 2009, Pezizaceae, Pezizales, Pezizomycetes, one species, type: C. prieguensis (Mor.-Arr., J. Gómez \& Calonge) Healy, Bonito \& Trappe, asexual morph unknown, saprobes, from soil, terrestrial, Europe, see Healy et al. (2009b; taxonomy), holotype of the type: MA (Fungi) 33502, cultures and sequences are available.

Calongeomyces Hawksworth \& Etayo 2011 (= Calongia D. Hawksw. \& Etayo 2010 fide Species Fungorum 2017), Ascomycota genera incertae sedis, one species, type: $C$. gibelluloides (D. Hawksw. \& Etayo) D. Hawksw. \& Etayo, coelomycetous, sexual morph unknown, parasymbiont on Cladonia, Flavoparmelia, Pertusaria, terrestrial, southern Europe, see Hawksworth and Etayo (2011; morphology, distinction of similar lichenicolous genera), holotype: (K, (M) 164014, J. Etayo \& A. Etayo), cultures and sequences are unavailable.

Calopadia Vězda 1986 (= Crocicreomyces Bat. \& Peres 1964 [1963]; = Cyrta Bat. \& H. Maia 1961 fide Species Fungorum 2017), Pilocarpaceae, Lecanorales, Lecanoromycetes, 27 species, type: $C$. fusca (Müll. Arg.) Vězda, lichenized, tropical, see Lumbsch and Huhndorf (2010; outline), Kirk et al. (2013; genus accepted), Lücking et al. (2016b; classification), sequences are available.

Calopadiopsis Lücking \& R. Sant. 2002, Pilocarpaceae, Lecanorales, Lecanoromycetes, two species, type: C. tayabasensis (Vain.) Lücking \& R. Sant., lichenized, Argentina, see Lumbsch and Huhndorf (2010; outline), Lücking et al. (2016b; classification), sequences are unavailable.

Calophoma Q. Chen \& L. Cai 2015, Didymellaceae, Pleosporales, Dothideomycetes, six species, type: C. clematidina (Thüm.) Q. Chen \& L. Cai, coelomycetous, saprobes, ?pathogens, terrestrial, The Netherlands, New Zealand, Switzerland, see Chen et al. (2015b; taxonomy, phylogeny), Wijayawardene et al. (2017; outline), epitype and ex-epitype culture of the type: CBS H-16193, CBS 108.79.

Caloplaca Th. Fr. [nom. cons.] 1860 (see Species Fungorum 2017 for synonyms), Teloschistaceae, Teloschistales, Lecanoromycetes, 350 species, type: C. cerina (Hedw.) Th. Fr., lichenized, see Lumbsch and Huhndorf (2010; outline), Arup et al. (2013; taxonomy, 
phylogeny), Kirk et al. (2013; genus accepted), Lücking et al. (2016b; classification), sequences are available.

Caloscypha Boud. 1885 (= Geniculodendron G.A. Salt 1974; = Otidella Sacc. 1889 fide Healy et al. 2016; Species Fungorum 2017), Caloscyphaceae, Pezizales, Pezizomycetes, two species, type: $C$. fulgens (Pers.) Boud., asexual morph unknown, saprobes, terrestrial, Europe, see Lumbsch and Huhndorf (2010; outline), Hansen et al. (2013; DNA, phylogeny), Kirk et al. (2013; genus accepted), cultures available for the type: AFTOL-ID 152.

Calosphaeria Tul. \& C. Tul. 1863 (= Calosphaeriophora Réblová, L. Mostert, W. Gams \& Crous 2004 fide Réblová et al. 2016c), Calosphaeriaceae, Calosphaeriales, Sordariomycetes, c. 30 species, type: $C$. princeps Tul. \& C. Tul., asexual morph hyphomycetous, saprobes, terrestrial, worldwide, see Damm et al. (2008; new species), Lumbsch and Huhndorf (2010; outline), Kirk et al. (2013; genus accepted), Maharachchikumbura et al. (2015, 2016; outline), Réblová et al. (2015a, 2016c; phylogeny, nomenclature), cultures available but lacks for the type species.

Calosphaeriopsis Petr. 1941, Sordariomycetes, genera incertae sedis, one species, type: $C$. huberiana (Kirschst.) Petr., asexual morph unknown, saprobes, terrestrial, Europe, see Lumbsch and Huhndorf (2010; outline), Kirk et al. (2013; genus accepted), Maharachchikumbura et al. (2015, 2016; outline), cultures and sequences are unavailable, needs generic revision.

Calosporella J. Schröt. 1897, Sydowiellaceae, Diaporthales, Sordariomycetes, one species, type: $C$. innesii (Curr.) J. Schröt., asexual morph unknown, saprobes, terrestrial, Europe, see Voglmayr and Jaklitsch (2014; DNA, phylogeny), Maharachchikumbura et al. (2015, 2016; outline), cultures and sequences are unavailable, ex-type and epitype: CBS 123810, WU 32161.

Calostilbe Sacc. \& P. Syd. 1902 (= Calostilbella Höhn. 1919; = Nectria subgen. Phaeonectria Sacc. 1895; = Phaeonectria (Sacc.) Sacc. \& Trotter 1913; = Xenostilbum Petr. fide Rossman et al. 2016a; Species Fungorum 2017), Nectriaceae, Hypocreales, Sordariomycetes, two species, type: C. striispora (Ellis \& Everh.) Seaver, asexual morph hyphomycetous, saprobes on wood and bark, commonly in tropical regions, see Lumbsch and Huhndorf (2010; outline), Kirk et al. (2013; genus accepted), Lombard et al. (2015a; phylogeny); Maharachchikumbura et al. (2015, 2016; outline), Rossman et al. (2016a; nomenclature), lectotype: NY, iso-lectotypes BPI 553210, 553211.

Calothyriopsis Höhn. 1919 (= Ptychopeltis Syd. 1927 fide Species Fungorum 2017), Microthyriaceae, Microthyriales, Dothideomycetes, two species, type: C. conferta (Theiss.) Höhn., saprobes, terrestrial, tropical, see Lumbsch and Huhndorf (2010; outline), Wu et al. (2011; taxonomy), Kirk et al. (2013; genus accepted), Hyde et al. (2013; accepted as a genus in Microthyriaceae), Wijayawardene et al. (2014c; outline), cultures and sequences are unavailable, needs generic revision.

Calotrichopsis Vain. 1890, Lichinaceae, Lichinales, Lichinomycetes, three species, type: $C$. insignis Vain., lichenized, terrestrial, South America, see Lumbsch and Huhndorf (2010; outline), Kirk et al. (2013; genus accepted), Lücking et al. (2016b; classification), sequences are unavailable.

Calvitimela Hafellner 2001, Tephromelataceae, Lecanorales, Lecanoromycetes, ten species, type: C. armeniaca (DC.) Hafellner, lichenized, see Fryday (2011; taxonomy), Bendiksby et al. (2015; phylogeny), Lücking et al. (2016b; classification), sequences are available.

Calvolachnella Marinc., T.A. Duong \& M.J. Wingf. 2016, Chaetosphaeriales genera incertae sedis, Sordariomycetes, one species, type: C. guaviyuensis (Marinc. T.A. Duong, M.J. Wingf. \& C.A. Perez) Marinc., T.A. Duong \& M.J. Wingf., coelomycetous, sexual morph unknown, saprobes, terrestrial, Uruguay, see Hernández-Restrepo et al. (2016a; 
taxonomy, phylogeny), Wijayawardene et al. (2017; outline), holotype and ex-type: PREM 60964, CBS 134695 = CMW 39055.

Calycella (Sacc.) Sacc. 1899 (= Helotium subgen. Calycella Sacc. 1889 fide Species Fungorum 2017), Helotiaceae, Helotiales, Leotiomycetes, one species, type: C. gelatinosa (Sacc.) Syd. \& P. Syd., asexual morph unknown, saprobes, terrestrial, Europe, see Kirk et al. (2013; genus accepted), cultures and sequences are unavailable, needs generic revision.

Calycellina Höhn. 1918 (= Chaetochalara B. Sutton \& Piroz. 1965; Phialina Höhn. 1926; = Phialoscypha Raitv. 1977; = Scutoscypha Graddon 1980; = Setoscypha Velen. 1934 fide Johnston et al. 2014b; Species Fungorum 2017), Pezizellaceae, Helotiales, Leotiomycetes, c. 45 species, type: $C$. punctiformis (Grev.) Höhn., asexual morph hyphomycetous, saprobes, terrestrial, worldwide, see Lumbsch and Huhndorf (2010; outline), Seifert et al. (2011; morphology of asexual morph), Kirk et al. (2013; genus accepted), Johnston et al. (2014b; nomenclature), cultures and sequences are available but lacks for the type:.

Calycellinopsis W.Y. Zhuang 1990, Helotiales genera incertae sedis, Leotiomycetes, one species, type: C. xishuangbanna W.Y. Zhuang, asexual morph unknown, saprobes, terrestrial, China, see Lumbsch and Huhndorf (2010; outline), Kirk et al. (2013; genus accepted), cultures and sequences are available but lacks for the type.

Calycidium Stirt. 1877 (= Calycidiomyces Cif. \& Tomas. 1953; = Coniophyllum Müll. Arg. 1892 fide Species Fungorum 2017), Sphaerophoraceae, Lecanorales, Lecanoromycetes, two species, type: C. cuneatum Stirt., lichenized, see Lumbsch and Huhndorf (2010; outline, accepted as a genus in Calycidiaceae), Kirk et al. (2013; genus accepted), Prieto et al. (2013; phylogeny), Lücking et al. (2016b; classification), sequences are available.

Calycina Nees ex Gray 1821 (= Antinoa Velen. 1934; = Calycella (Fr.) Boud., 1885; = Cystopezizella Svrček 1983; Eubelonis Clem. 1909; = Gemmina Raitv. 2004; = Helotium subgen. Calycella Fr. 1849; = Malotium Velen. 1934; = Parthenope Velen. 1934; = Pezizella Fuckel 1870 [1869-70]; = Septopezizella Svrček 1987; = Weinmannioscyphus Svrček fide Jaklitsch et al. 2016a; Species Fungorum 2017), Pezizellaceae, Helotiales, Leotiomycetes, c. 30 species, type: $C$. herbarum (Pers.) Gray, asexual morph hyphomycetous, saprobes, cones scales, herbaceous stems and leaves, widespread, see Lumbsch and Huhndorf (2010; outline), Kirk et al. (2013; did not list), Baral et al. (2013; genus accepted), Han et al. (2014; genus accepted), Baral and Rämä (2015; genus accepted), type in S herbarium, cultures and sequences are unavailable for the type of the type species, needs generic revision.

Calyptra Theiss. \& Syd. 1918, Dothideomycetes genera incertae sedis, five species, type: $C$. cordobensis (Speg.) Theiss. \& Syd., asexual morph unknown, saprobes, terrestrial, see Lumbsch and Huhndorf (2010; outline), Kirk et al. (2013; genus accepted), Wijayawardene et al. (2014c; outline), cultures and sequences are unavailable, needs generic revision.

Calyptronectria Speg. 1909, Melanommataceae, Pleosporales, Dothideomycetes, three species, type: $C$. platensis Speg., asexual morph unknown, saprobes, terrestrial, Argentina, India, see Lumbsch and Huhndorf (2010; outline), Kirk et al. (2013; genus accepted), Wijayawardene et al. (2014c; outline), Tian et al. (2015; taxonomy, phylogeny), cultures and sequences of type species are unavailable, needs generic revision.

Calyptrozyma Boekhout \& Spaay 1995, Eurotiomycetidae, genera incertae sedis, one species, type: $C$. arxii Boekhout \& Spaay, asexual morph unknown, saprobes, terrestrial, USA, see Lumbsch and Huhndorf (2010; outline), Kirk et al. (2013; genus accepted), cultures available for the type: CBS 354.92.

Camaroglobulus Speer 1986, Ascomycota genera incertae sedis, one species, type: $M$. caespitosa Petr., coelomycetous, sexual morph unknown, saprobes, terrestrial, Brazil, see Kirk et al. (2013; genus accepted), Wijayawardene et al. (2017; outline), cultures and sequences are unavailable, needs generic revision. 
Camarographium Bubák 1916, Pleosporales genera incertae sedis, Dothideomycetes, seven species, type: C. stephensii (Berk. \& Broome) Bubák, coelomycetous, sexual morph unknown, saprobes, terrestrial, cosmopolitan, see Crous et al. (2011c; new species, key), Kirk et al. (2013; genus accepted), Wijayawardene et al. (2016b, 2017; outline, taxonomy, new species), cultures and sequences are available but lacks for the type species, needs generic revision.

Camaropella Lar. N. Vassilyeva 1997, Boliniaceae, Boliniales, Sordariomycetes, two species, type: $C$. pugillus (Schwein.) Lar.N. Vassiljeva, asexual morphs unknown, saprobes, terrestrial, North tempetrate zone, see Huhndorf and Miller (2008; DNA, phylogeny), Lumbsch and Huhndorf (2010; outline), Untereiner et al. (2013; phylogeny), Friebes and Wendelin (2014), Maharachchikumbura et al. (2015, 2016; outline), cultures and sequences are available.

Camarops P. Karst. 1873 (= Biscogniauxia sect. Camarops (P. Karst.) Lar.N. Vassiljeva et al. 1998; = Bolinia (Nitschke) Sacc. 1882; = Chromendothia Lar.N. Vassiljeva 1993; = Hypoxylon sect. Bolinia Nitschke 1867; = Peridoxylon Shear 1923; = Phaeosperma Nitschke ex Fuckel 1870 [1869-70]; = Sarcostromella Boedijn 1959; = Solenoplea Starbäck 1901 fide Species Fungorum 2017), Boliniaceae, Boliniales, Sordariomycetes, 20 species, type: $C$. hypoxyloides P. Karst., asexual morphs unknown, saprobes, terrestrial, worldwide, see Huhndorf and Miller (2008; new species), Lumbsch and Huhndorf (2010; outline), Kirk et al. (2013; genus accepted), Maharachchikumbura et al. (2015, 2016; outline), cultures and sequences are available.

Camaropycnis E.K. Cash 1945, Ascomycota genera incertae sedis, one species, type: C. libocedri E.K. Cash, coelomycetous, sexual morph unknown, saprobes, terrestrial, USA, see Wijayawardene et al. (2012, 2017; outline), Kirk et al. (2013; genus accepted), cultures and sequences are unavailable, needs generic revision.

Camarosporellum Tassi 1902, Ascomycota genera incertae sedis, one species, type: $C$. nervisequum (Tassi) Tassi, coelomycetous, sexual morph unknown, saprobes, terrestrial, USA, see Wijayawardene et al. (2012, 2016, 2017; taxonomy, outline), Kirk et al. (2013; genus accepted), cultures and sequences are unavailable, needs generic revision.

Camarosporioides W.J. Li \& K.D. Hyde 2016, Phaeosphaeriaceae, Pleosporales, Dothideomycetes, one species, type: C. phragmitis W.J. Li \& K.D. Hyde, coelomycetous, sexual morph unknown, saprobes, terrestrial, Germany, see Hyde et al. (2016; taxonomy, phylogeny), holotype and ex-type culture of the type: MFLU 16-1488, MFLUCC 13-0365.

Camarosporiopsis Abbas, B. Sutton \& Ghaffar 2000, Ascomycota genera incertae sedis, one species, type: C. capparis (S. Ahmad) Abbas, Sutton \& Ghaffar, coelomycetous, sexual morph unknown, one species, saprobes, Pakistan, see Wijayawardene et al. (2012, 2016b, 2017; taxonomy, outline), sequences are unavailable, needs generic revision.

Camarosporium Schulzer 1870 (= Piringa Speg. 1911; = Sclerotheca Bubák \& Vleugel 1917 fide Species Fungorum 2017), Pleosporineae genera incertae sedis, Pleosporales, Dothideomycetes, more than 100 spp., type: C. quaternatum Schulzer, coelomycetous, sexual morph cucurbitaria-like, terrestrial, worldwide, see Kirk et al. (2013; genus accepted), Wijayawardene et al. (2012, 2014a, c, 2016b, 2017; taxonomy, phylogeny, outline), Liu et al. (2015a, taxonomy, phylogeny), Tibpromma et al. (2016b; taxonomy, phylogeny), sequences are available for 11 species, needs generic revision.

Camarosporula Petr. 1954 (= Anthracostroma Petr. 1954 fide Rossman et al. 2015b), Teratosphaeriaceae, Capnodiales, Dothideomycetes, one species, type: C. persoonii (Henn.) Petr., asexual morph coelomycetous, saprobes, terrestrial, Australia, see Crous et al. (2011e; phylogeny), Wijayawardene et al. (2012, 2016b, 2017; outline, taxonomy), Kirk et al. (2013; genus accepted), Rossman et al. (2015b; nomenclature), cultures available for the type: CBS 116258. 
Camarosporulum Tassi 1902, Ascomycota genera incertae sedis, one species, type: $C$. ampelopsidis Tassi, coelomycetous, sexual morph unknown, saprobes, terrestrial, worldwide, see Wijayawardene et al. (2012, 2017; outline), Kirk et al. (2013; genus accepted), cultures and sequences are unavailable, needs generic revision.

Camarotella Theiss. \& Syd. 1915, Phyllachoraceae, Phyllachorales, Sordariomycetes, three species, type: $C$. astrocaryae (Rehm) Theiss. \& Syd., asexual morph unknown, saprobes, see Kirk et al. (2008; treated as a synonym of Coccodiella Hara), Lumbsch and Huhndorf (2010; did not list), Maharachchikumbura et al. (2015, 2016; outline, accepted as a distinct genus), cultures and sequences are unavailable.

Cameronia Kantvilas 2012, Cameroniaceae, Baeomycetales, Lecanoromycetes, two species, type: $C$. pertusarioides Kantvilas, lichenized, see Kantvilas (2012; taxonomy), Lumbsch et al. (2012; taxonomy), Lücking et al. (2016b; classification), sequences are available.

Camillea Fr. 1849 (= Bacillaria Mont. 1840; Diatrype subgen. Nummularoidea Cooke \& Massee 1892; = Diatrypeopsis Speg. 1884; = Nummularioidea (Cooke \& Massee) Lloyd 1924; = Xylocladium P. Syd. ex Lindau 1900; = Jongiella M. Morelet 1971; = Nummularioidea (Cooke \& Massee) Lloyd 1924 fide Species Fungorum 2017; Wendt et al. 2017), Graphostromataceae, Xylariales, Sordariomycetes, more than 41 species, type: $C$. leprieurii (Mont.) Mont., endophytes-saprobes, widespread and high in tropics, see Lumbsch and Huhndorf (2010; outline), Kirk et al. (2013; genus accepted), Stadler et al. (2013), Maharachchikumbura et al. (2015, 2016; outline), Wendt et al. (2017; transferred to Graphostromataceae), cultures and sequences are available.

Campoa Speg. 1921 (= Myxostomella Syd. 1931 fide Species Fungorum 2017), Parmulariaceae, Dothideomycetes families incertae sedis, two species, type: C. pulcherrima Speg., asexual morph unknown, saprobes, terrestrial, South America, Philipines, see Lumbsch and Huhndorf (2010; outline), Kirk et al. (2013; genus accepted), Hyde et al. (2013; accepted as a genus in Parmulariaceae), Wijayawardene et al. (2014c; outline), cultures and sequences are unavailable, needs generic revision.

Camporesia W.J. Li \& K.D. Hyde 2016, Xylariales genera incertae sedis, Sordariomycetes, two species, type: C. sambuci W.J. Li \& K.D. Hyde, coelomycetous, sexual morph unknown, saprobes, terrestrial, Italy, see Li et al. (2016a; taxonomy, phylogeny), Wendt et al. (2017; transferred to Xylariales genera incertae sedis), holotype and ex-type: MFLU 15-3905, MFLUCC 13-0203.

Camposporidium Nawawi \& Kuthub. 1988, Ascomycota genera incertae sedis, three species, type: $C$. cristatum Nawawi \& Kuthub., hyphomycetous, sexual morph unknown, saprobes, aquatic, terrestrial, Asia, Caribbean, see Seifert et al. (2011; morphology), Wijayawardene et al. (2012, 2017; outline), Kirk et al. (2013; genus accepted), cultures and sequences are unavailable, needs generic revision.

Camposporium Harkn. 1884, Leptosphaeriaceae, Pleosporales, Dothideomycetes, 18 species, type: $C$. antennatum Harkn., hyphomycetous, sexual morph unknown, saprobes, terrestrial, worldwide, see Seifert et al. (2011; morphology, accepted as a genus in Leptosphaeriaceae), Wijayawardene et al. (2012, 2017; outline), Adamčík et al. (2015; new species), cultures available for the type: ICMP15321.

Camptomeriphila Crous \& M.J. Wingf. 2016, Mycosphaerellaceae, Capnodiales, Dothideomycetes, one species, type: C. leucaenae Crous \& M.J. Wingf., hyphomycetous, sexual morph unknown, saprobes, terrestrial, Malaysia, see Crous et al. (2016a; new species, phylogeny), holotype and ex-type: CBS H-22884, CPC 27608.

Camptomeris Syd. 1927, Ascomycota genera incertae sedis, seven species, type: $C$. calliandrae Syd., hyphomycetous, sexual morph unknown, saprobes, terrestrial, pantropical, see Seifert et al. (2011; morphology), Wijayawardene et al. (2012, 2017; outline), Kirk et al. (2013; genus accepted), cultures and sequences are unavailable, needs generic revision. 
Camptomyces Thaxt. 1894, Laboulbeniaceae, Laboulbeniales, Laboulbeniomycetes, eight species, type: $C$. melanopus Thaxt., asexual morph unknown, parasitic on Staphylinidae beetles, terrestrial, widespread, see Lumbsch and Huhndorf (2010; outline), Kirk et al. (2013; genus accepted), cultures and sequences are unavailable.

Camptophora Réblová \& Unter. 2013, Chaetothyriaceae, Chaetothyriales, Eurotiomycetes, one species, type: C. hylomeconis (Crous, de Hoog \& H.D. Shin) Réblová \& Unter., asexual morph unknown, from living leaves of Hylomecon vernalis, terrestrial, South Korea, see Réblová et al. (2013; genus accepted), Madrid et al. (2016; phylogeny), holotype and ex-type culture of the type: CBS H-19907, CBS 113311.

Camptosphaeria Fuckel 1870, Lasiosphaeriaceae, Sordariales, Sordariomycetes, four species, type: $C$. sulphurea Fuckel, asexual morph unknown, saprobes, terrestrial, worldwide, see Lumbsch and Huhndorf (2010; outline), Kirk et al. (2013; genus accepted), Maharachchikumbura et al. (2015, 2016; outline), cultures and sequences are unavailable, need generic revision.

Campylocarpon Halleen, Schroers \& Crous 2004, Nectriaceae, Hypocreales, Sordariomycetes, two species, type: $C$. fasciculare Schroers, Halleen \& Crous, hyphomycetous, sexual morph unknown, pathogenic on Vitis vinifera, South Africa see Seifert et al. (2011; morphology), Wijayawardene et al. (2012, 2017; outline), Maharachchikumbura et al. (2015, 2016; outline), holotype and ex-type of the type: Holotype CBS 6590, CBS $112613=$ CPC 3970.

Campylospora Ranzoni. 1953, Hypocreomycetidae genera incertae sedis, five species, type: C. chaetocladia Ranzoni, hyphomycetous, sexual morph unknown, saprobes, endophytes, aquatic, Asia, Europe, North and South America, see Seifert et al. (2011; morphology), Wijayawardene et al. (2012, 2017; outline), Kirk et al. (2013; genus accepted), Marvanová and Laichmanová (2014; new species), cultures and sequences are available for authentic strains CCM F-17708, CCM F-10610, CCM F-10710, CCM F-10810.

Campylothelium Müll. Arg. 1883, Trypetheliaceae, Trypetheliales, Dothideomycetes, six species, type: C. puiggarii Müll. Arg., lichenized, terrestrial, cosmopolitan, see Lumbsch and Huhndorf (2010; outline), Kirk et al. (2013; genus accepted), Nelsen et al. (2014b; taxonomy), cultures available for the type: MPN268.

Canalisporium Nawawi \& Kuthub 1989 (= Ascothailandia Sri-indr. et al. 2010 fide Réblová et al. 2016c), Savoryellaceae, Savoryellales, Sordariomycetes, twelve species, type: $C$. caribense (Hol.-Jech. \& Mercado) Nawawi \& Kuthub., hyphomycetous, freshwater habitats except $C$. microsporum and C. nigrum, Africa, see Seifert et al. (2011; morphology), SriIndrasutdhi et al. (2010; new species), Kirk et al. (2013; genus accepted), Maharachchikumbura et al. (2015, 2016; outline), Wijayawardene et al. (2017; outline), Réblová et al. (2016c; nomenclatue).

Canariomyces Arx 1984, Microascaceae, Microascales, Sordariomycetes, one species, type: C. notabilis Arx, asexual morph unknown, saprobes, terrestrial, Canary Islands, see Lumbsch and Huhndorf (2010; outline), Kirk et al. (2013; genus accepted), Maharachchikumbura et al. (2015, 2016; outline, phylogeny), holotype of the type: MUCL 44677, a sequence available but unpublished.

Canavirgella W. Merr., N.G. Wenner \& Dreisbach 1996, Rhytismataceae, Rhytismatales, Leotiomycetes, one species, type: C. banfieldii W. Merr., N.G. Wenner \& Dreisbach, asexual morph unknown, saprobes, terrestrial, USA, see Lumbsch and Huhndorf (2010; outline), Kirk et al. (2013; genus accepted), cultures and sequences are unavailable, needs generic revision.

Cancellidium Tubaki 1975, Sordariales genera incertae sedis, two species, type: $C$. applanatum Tubaki, hyphomycetous, sexual morph unknown, saprobes, aquatic, Asia, Europe, see Seifert et al. (2011; morphology), Kirk et al. (2013; genus accepted), Zhao et al. (2013a; China), Pratibha et al. (2014; phylogeny), Maharachchikumbura et al. (2015, 2016; 
outline), Wijayawardene et al. (2017; outline), cultures and sequences are available, needs generic revision.

Candelabrum Beverw. 1951 (= Dionysia G. Arnaud fide Species Fungorum 2017), Ascomycota genera incertae sedis, seven species, type: C. spinulosum Beverw, hyphomycetous, sexual morph unknown, on decaying leaves in water, aquatic, cosmopolitan, see Seifert et al. (2011; morphology), Wijayawardene et al. (2012, 2017; outline), Kirk et al. (2013; genus accepted), cultures and sequences are unavailable.

Candelaria A. Massal. 1852, Candelariaceae, Candelariales, Lecanoromycetes, seven species, type: C. concolor (Dicks.) Arnold, lichenized, see Lumbsch and Huhndorf (2010; outline), Bendiksby and Timdal (2013; taxonomy), Kirk et al. (2013; genus accepted), Lücking et al. (2016b; classification), sequences are available.

Candelariella Müll. Arg. 1894 (= Caloplacopsis (Zahlbr.) B. de Lesd. 1932; = Candelariella sect. Caloplacopsis Zahlbr. 1926; = Candelariellomyces E.A. Thomas ex Cif. \& Tomas. 1953 [1952], = Candelariellopsis Werner 1936; =Eklundia C.W. Dodge 1968; = Pleochroma Clem. 1909 fide Species Fungorum 2017), Candelariaceae, Candelariales, Lecanoromycetes, 50 species; type: C. vitellina (Hoffm.) Müll. Arg., lichenized, terrestrial, worldwide, see Lumbsch and Huhndorf (2010; outline), Aptroot and Aslan (2012; new records), Bendiksby and Timdal (2013; taxonomy), Kirk et al. (2013; genus accepted), Lücking et al. (2016; classification), sequences are available.

Candelina Poelt 1974, Candelariaceae, Candelariales, Lecanoromycetes, three species, type: C. mexicana (B. de Lesd.) Poelt, lichenized, worldwide, see Lumbsch and Huhndorf (2010; outline), Bendiksby and Timdal (2013; taxonomy), Kirk et al. (2013; genus accepted), Lücking et al. (2016; classification), sequences are available.

Candelosynnema K.D. Hyde \& Seifert 1992, Ascomycota genera incertae sedis, one species, type: C. ranunculosporum K.D. Hyde \& Seifert, hyphomycetous, sexual morph unknown, saprobes, terrestrial, Australasia, see Seifert et al. (2011; morphology), Wijayawardene et al. (2012, 2017; outline), Kirk et al. (2013; genus accepted), cultures and sequences are unavailable, needs generic revision.

Candida Berkhout 1923 (= Lodderomyces Van der Walt 1966), Candidaceae, Saccharomycetales, Saccharomycetes, 40 species, type: C. tropicalis var. tropicalis (Castell.) Berkhout, asexual reproduction by multilateral budding and formation of pseudohyphae and true hyphae, saprophytic, others pathogens or opportunistic pathogens of humans and animals, terrestrial, worldwide, phylogenetic analysis of gene sequences shows that there are about 40 species in the Candida tropicalis clade, the type species of the genus Candida, which also includes $C$. albicans and Lodderomyces elongisporus. Prior to DNA sequence analysis and changes in the Code of nomenclature for fungi (Melbourne Code), approximately 400 described anamorphic species were included in the genus Candida

Cannonia Joanne E. Taylor \& K.D. Hyde 1999, Xylariales genera incertae sedis, Sordariomycetes, one species, type: C. australis (Speg.) Joanne E. Taylor \& K.D. Hyde, asexual morph unknown, saprobes, Argentina, Australia, see Lumbsch and Huhndorf (2010; outline), Kirk et al. (2013; genus accepted), Wendt et al. (2017; transferred to Xylariales genera incertae sedis), cultures and sequences are unavailable.

Canoparmelia Elix \& Hale 1986, Parmeliaceae, Lecanorales, Lecanoromycetes, 40 species; type: C. texana (Tuck.) Elix \& Hale, lichenized, worldwide, see Lumbsch and Huhndorf (2010; outline), Leonardo et al. (2011; indicator for environmental pollution), Kirk et al. (2013; genus accepted), Kirika et al. (2016; phylogeny and circumscription), Lücking et al. (2016b; classification), sequences are available.

Cantharomyces Thaxt. 1890, Laboulbeniaceae, Laboulbeniales, Laboulbeniomycetes, 29 species, type: $C$. bledii Thaxt., asexual morph unknown, biotrophic, hosts are Dryopidae, Hydrophilidae, Limnichidae, and Staphylinidae (Coleoptera), widespread, see Lumbsch and 
Huhndorf (2010; outline), Kirk et al. (2013; genus accepted), Haelewaters and De Kesel (2013; morphology),cultures and sequences are unavailable, needs generic revision.

Capillataspora K.D. Hyde 1989, Dothideomycetes genera incertae sedis, one species, type: $C$. corticola K.D. Hyde, asexual morph unknown, saprobes, collected from mangroves, see Lumbsch and Huhndorf (2010; outline), Kirk et al. (2013; genus accepted), cultures and sequences are unavailable, needs generic revision.

Capillipes R. Sant. 1956, Helotiales genera incertae sedis, Leotiomycetes, one species, type: C. cavorum R. Sant., asexual morph unknown, saprobes, terrestrial, Lapland, see Lumbsch and Huhndorf (2010; outline), Kirk et al. (2013; genus accepted), cultures and sequences are unavailable, needs generic revision.

Capillistichus Santam. 2004, Laboulbeniaceae, Laboulbeniales, Laboulbeniomycetes, one species, type: $C$. tenellus Santam., asexual morph unknown, parasitic on Hydrophilidae beetles, aquatic, Europe, see Lumbsch and Huhndorf (2010; outline), Kirk et al. (2013; genus accepted), cultures and sequences are unavailable.

Capitofimbria L. Lombard \& Crous 2016, Stachybotriaceae, Hypocreales, Sordariomycetes, one species, type: $C$. compacta (R.F. Castañeda et al.) L. Lombard \& Crous, hyphomycetous, sexual morph unknown, saprobes, terrestrial, Brazil, see Lombard et al. (2016; taxonomy, phylogeny), holotype and ex-type culture of the type: CBS-H6584a, CBS 111739.

Capitorostrum Bat. 1957, Ascomycota genera incertae sedis, one species, type: $C$. asteridiellae Bat., coelomycetous, sexual morph unknown, saprobes, terrestrial, Australia, Papua New Guinea, see Wijayawardene et al. (2012, 2016b, 2017; outline, taxonomy), Kirk et al. (2013; genus accepted), cultures and sequences are unavailable, needs generic revision.

Capitotricha (Raitv.) Baral 1985, Lachnaceae, Helotiales, Leotiomycetes, ten species, type: $C$. bicolor (Bull.) Baral, sexual morph unknown, saprobes, UK, see Lumbsch and Huhndorf (2010; outline, accepted as a genus in Hyaloscyphaceae), Kirk et al. (2013; genus accepted), Jaklitsch et al. (2016a; classification), Index Fungorum (2017; treated as a synonym of Lachnum Retz.), cultures and sequences are unavailable.

Capnobotryella Sugiy. 1987, Teratosphaeriaceae, Capnodiales, Dothideomycetes, five species, type: C. renispora Sugiy., hyphomycetous, sexual morph unknown, saprobes, Asia, Europe, North America, see Seifert et al. (2011; morphology), Sert et al. (2011, 2012; new species, Australia), Wijayawardene et al. (2012, 2014c, 2017; outline), Kirk et al. (2013; genus accepted), cultures available for the type: CBS 214.90.

Capnobotrys S. Hughes 1970, Metacapnodiaceae, Capnodiales, Dothideomycetes, c. 20 species, type: $C$. neesii S. Hughes, hyphomycetous, sexual morph unknown, sooty mould on living plants, terrestrial, Asia, Australasia, Europe, North America, South America, North America, see Seifert et al. (2011; morphology), Hughes and Seifert (2012; new species), Wijayawardene et al. (2012, 2017; outline), Hyde et al. (2013; accepted as a genus in Metacapnodiaceae), Kirk et al. (2013; genus accepted), cultures and sequences are unavailable, needs generic revision.

Capnocheirides J.L. Crane \& S. Hughes 1982, Ascomycota genera incertae sedis, one species, type: C. rhododendri (Kunze) J.L. Crane \& S. Hughes, hyphomycetous, sexual morph unknown, saprobes, terrestrial, Europe, see Seifert et al. (2011; morphology), Wijayawardene et al. (2012, 2017; outline), Kirk et al. (2013; genus accepted), cultures and sequences are available for unidentified species, needs generic revision.

Capnodiastrum Speg. 1886, Ascomycota genera incertae sedis, one species, type: $C$. guaraniticum Speg., coelomycetous, sexual morph unknown, saprobes, terrestrial, worldwide, see Wijayawardene et al. (2012, 2016, 2017; outline, taxonomy), Kirk et al. (2013; genus accepted), cultures and sequences are unavailable thus placed in Ascomycota incertae sedis in here, needs generic revision. 
Capnodium Mont. 1849 (= Polychaeton (Pers.) Lév. 1846; = Fumagospora G. Arnaud 1911 fide Chomnunti et al. 2011; Hyde et al. 2013; Wijayawardene et al. 2014c), Capnodiaceae, Capnodiales, Dothideomycetes, one species, type: C. citri Berk. \& Desm., asexual morph coelomycetous, sooty moulds, worldwide, see Lumbsch and Huhndorf (2010; outline), Chomnunti et al. (2011, 2014; taxonomy, nomenclature), Hyde et al. (2013; accepted as a genus in Capnodiaceae), Kirk et al. (2013; genus accepted), Wijayawardene et al. (2014c; outline, nomenclature), cultures and sequences are available.

Capnofrasera S. Hughes 2003, Antennulariellaceae, Capnodiales, Dothideomycetes, one species, type: $C$. dendryphioides S. Hughes, hyphomycetous, sexual morph unknown, saprobes, terrestrial, Australasia, North and South America, see Seifert et al. (2011; morphology), Wijayawardene et al. (2012, 2017; outline), cultures and sequences are unavailable, needs generic revision.

Capnokyma S. Hughes 1975, Euantennariaceae, Dothideomycetes families incertae sedis, two species, type: C. corticola S. Hughes, asexual morph unknown, saprobes, terrestrial, Australasia, South America, see Seifert et al. (2011; morphology), Wijayawardene et al. (2012, 2014c, 2017; outline), Hyde et al. (2013; accepted as a genus in Euantennariaceae), Kirk et al. (2013; genus accepted), cultures and sequences are unavailable.

Caprettia Bat. \& H. Maia 1965 (= Porinula Vězda 1975 fide Species Fungorum 2017), Monoblastiaceae, Monoblastiales, Dothideomycetes, eight species, type: C. amazonensis Bat. \& H. Maia, asexual morph coelomycetous, saprobes, thallus epiphyllous, worldwide, see Nelsen et al. (2009, 2011b; taxonomy), Yeshitela et al. (2009; taxonomy), Lumbsch and Huhndorf (2010; outline), Kirk et al. (2013; genus accepted), Wijayawardene et al. (2014c; outline), Lücking et al. (2016b; classification), sequences are unavailable, needs generic revision.

Capricola Velen. 1947, Helotiales genera incertae sedis, one species, type: C. fuscidula Velen., asexual morph unknown, saprobes, terrestrial, Europe, see Lumbsch and Huhndorf (2010; outline), Kirk et al. (2013; genus accepted), cultures and sequences are unavailable, need generic revision.

Capronia Sacc. 1883 (= Berlesiella Sacc. 1888; = Caproniella Berl. 1899; = Dictyotrichiella Munk 1953; = Didymotrichiella Munk 1953; = Herpotrichiella Petr. 1914; = Melanostigma Kirschst. 1939; = Polytrichiella M.E. Barr 1972 fide Species Fungorum 2017), Herpotrichiellaceae, Chaetothyriales, Eurotiomycetes, c. 60 species, type: C. sexdecimspora (Cooke) Sacc., asexual morphs hyphomycetous, parasitic (on fungi or lichens) or saprobes, terrestrial, worldwide, see Badali et al. (2008; taxonomy), Halici et al. (2010; new species), Lumbsch and Huhndorf (2010; outline), Untereiner et al. (2011; phylogeny), Friebes (2012; morpholgy), Diederich et al. (2013; phylogeny), Kirk et al. (2013; genus accepted), Gueidan et al. (2014a; phylogeny), sequences are available.

Caproniella Berl. 1896, Sordariomycetes, genera incertae sedis, two species, type: $C$. pleiospora (Mouton) Berl., asexual morph unknown, saprobes, terrestrial, Europe, see Lumbsch and Huhndorf (2010; outline), Kirk et al. (2013; genus accepted), Maharachchikumbura et al. (2015, 2016; outline), cultures and sequences are unavailable, needs generic revision.

Caproventuria U. Braun 1998, Venturiaceae, Venturiales, Dothideomycetes, two species, type: $C$. hanliniana (U. Braun \& Feiler) U. Braun, asexual morph hyphomycetous, saprobes, soil-borne, Africa, Asia, Europe, New Zealand, see Lumbsch and Huhndorf (2010; outline), Zhang et al. (2011d; phylogeny, accepted as a genus in Venturiaceae), Hyde et al. (2013; accepted as a genus in Venturiaceae), Wijayawardene et al. (2014c; outline), strains of the type: ATCC 9601, IFM 52023, holotype of type: Germany, ascomata formed in culture, dried culture on SNA, 1994, F. Feiler (HAL 7623 F). 
Capsicumyces Gamundí, Aramb. \& Giaiotti 1979, Ascomycota genera incertae sedis, one species, type: C. delicatus Gamundí, Aramb. \& Giaiotti, hyphomycetous, sexual morph unknown, saprobes, terrestrial, South America, see Seifert et al. (2011; morphology), Wijayawardene et al. (2012, 2017; outline), Kirk et al. (2013; genus accepted), cultures and sequences are unavailable, needs generic revision.

Capsulospora K.D. Hyde 1996, Xylariales genera incertae sedis, Sordariomycetes, nine species, type: C. frondicola K.D. Hyde, asexual morph unknown, sexual morph ascomycetes, saprobes on dead branches, Vanuatu, Brunei, Jawa, China, see Lumbsch and Huhndorf (2010; outline), Kirk et al. (2013; genus accepted), cultures and sequences are unavailable, needs generic revision.

Capulatispora Thambugala, Kaz. Tanaka \& K.D. Hyde 2015, Lophiostomataceae, Pleosporales, Dothideomycetes, one species, type: C. sagittiformis (Kaz. Tanaka \& Hosoya) Thambugala \& Hyde, asexual morph unknown, saprobes, terrestrial, Japan, see Thambugala et al. (2015b; morphology, phylogeny), holotype of type: TNS-F-12453, ex-type strains of type: JCM 15100.

Carassea S. Stenroos 2002, Cladoniaceae, Lecanorales, Lecanoromycetes, one species; type: C. connexa (Vain.) S. Stenroos, lichenized, terrestrial, Brazil, see Lumbsch and Huhndorf (2010; outline), Lücking et al. (2016b; classification), sequences are available.

Carbacanthographis Staiger \& Kalb in Staiger (2002), Graphidaceae, Ostropales, Lecanoromycetes, 28 species, type: C. chionophora (Redinger) Staiger \& Kalb, lichenized (Trenthepohlia), terrestrial (mainly corticolous), tropical, see Tripp et al. (2010; new species), Sharma et al. (2010; key), Rivas Plata et al. (2013; DNA, phylogeny), Lumbsch et al. (2014a, b; tribe Wirthiotremateae), Sharma and Khadilkar (2011; new species), Kukwa et al. (2013; new species), sequences are available.

Carbomyces Gilkey 1954, Pezizaceae, Pezizales, Pezizomycetes, three species; type: C. emergens Gilkey, saprobes, terrestrial, USA, see Lumbsch and Huhndorf (2010; outline), Moreno et al. (2012b; re-visited, DNA, phylogeny), Kirk et al. (2013; genus accepted), Jaklitsch et al. (2016a; classification, treated as a genus in Pezizaceae and Carbomycetaceae as a synonym of Pezizaceae), sequences are available for the voucher AH 39344 of the type species.

Carbonicola Bendiksby \& Timdal 2013, Carbonicolaceae, Lecanorales, Lecanoromycetes, Ascomycota; three species; type: C. anthracophila (Nyl.) Bendiksby \& Timdal; lichenized; temperate northern hemisphere, Australia, see Bendiksby and Timdal (2013; taxonomy), Lücking et al. (2016b; classification), holotype: H-NYL-20375 p.p. (lectotype by Timdal 1984), sequences are available.

Carbosphaerella I. Schmidt 1969, Halosphaeriaceae, Microascales, Sordariomycetes, two species, type: $C$. pleosporoides Schmidt, asexual morph unknown, saprobes, marine, Denmark, Germany, USA, see Lumbsch and Huhndorf (2010; outline), Kirk et al. (2013; genus accepted), Jones et al. (2015; outline), cultures and sequences are unavailable.

Carestiella Bres. 1897, Stictidaceae, Ostropales, Lecanoromycetes, one species, type: C. socia Bres., coelomycetous, sexual morph unknown, saprobes, cosmopolitan, see Baloch et al. (2010; phylogeny), Lumbsch and Huhndorf (2010; outline), Kirk et al. (2013; genus accepted), Jaklitsch et al. (2016a; classification), cultures and sequences are available.

Caribaeomyces Cif. 1962, Microthyriaceae, Microthyriales, Dothideomycetes, one species, type: C. tetrasporus (Toro) Cif., saprobes, terrestrial, Dominican Republic, see Lumbsch and Huhndorf (2010; outline), Wu et al. (2011; taxonomy), Kirk et al. (2013; genus accepted), Hyde et al. (2013; accepted as a genus in Microthyriaceae), Wijayawardene et al. (2014c; outline), cultures and sequences are unavailable, needs generic revision.

Carinispora K.D. Hyde 1992, Phaeosphaeriaceae, Pleosporales, Dothideomycetes, two species, type: C. nypae K.D. Hyde, saprobes, marine habitat (collected from palm Nypa 
fruticans), see Lumbsch and Huhndorf (2010; outline), Kirk et al. (2013; genus accepted), sequences are available, needs generic revision, holotype: BCC 36316.

Carnegieispora Etayo 2009, Ascomycota genera incertae sedis, one species, type: C. rimeliae Etayo \& Berger, coelomycetous, sexual morph unknown, parasymbiont on Parmotrema, terrestrial, Azores, see Etayo and Berger (2009; morphology, distinction of similar lichenicolous genera), Wijayawardene et al. (2016b; morphology), holotype: LI, F. Berger 18380 , cultures and sequences are unavailable.

Carnia Bat. 1960, Ascomycota genera incertae sedis, one species, type: C. tabebuiae Bat. \& Peres, asexual morph unknown, saprobes, terrestrial, Brazil, see Lumbsch and Huhndorf (2010; outline), Kirk et al. (2013; genus accepted), cultures and sequences are unavailable, needs generic revision.

Carpophoromyces Thaxt. 1931, Laboulbeniaceae, Laboulbeniales, Laboulbeniomycetes, one species, type: $C$. cybocephali Thaxt., asexual morph unknown, parasitic on Cybocephalidae beetles, terrestrial, Asia, Lumbsch and Huhndorf (2010; outline), Kirk et al. (2013; genus accepted), cultures and sequences are unavailable.

Carrismyces R.F. Castañeda \& Heredia 2000, Ascomycota genera incertae sedis, one species, type: C. proliferatus Castañeda \& Heredia, hyphomycetous, sexual morph unknown, saprobes, terrestrial, Mexico, see Seifert et al. (2011; morphology), Wijayawardene et al. (2012, 2017; outline), holotype: XAL CB736, cultures and sequences are unavailable, compare with Bioconosporium, Oncopodiella, Pseudopetrakia and Septosporium.

Caryophylloseptoria Verkley, Quaedvl. \& Crous 2013, Mycosphaerellaceae, Capnodiales, Dothideomycetes, four species, type: C. lychnidis (Desm.) Verkley, Quaedvlieg \& Crous, coelomycetous, sexual morph unknown, plant pathogenic, see Verkley et al. (2013; morphology, phylogeny), Wijayawardene et al. (2014c, 2017; outline), reference material CBS H-21161, living cultures CBS 109098, 109102.

Caryospora De Not. 1855, Caryosporaceae, Pleosporales, Dothideomycetes, six species, type: C. putaminum (Schwein.) De Not., saprobes, terrestrial, worldwide, see Lumbsch and Huhndorf (2010; outline, accepted as a genus in Zopfiaceae), Hyde et al. (2013; accepted as a genus in Zopfiaceae), Kirk et al. (2013; genus accepted), Wijayawardene et al. (2014c; accepted as a genus in Zopfiaceae), Zhao and Zhao (2012; new species, China), Ariyawansa et al. (2015a; new species, introduced Caryosporaceae), cultures and sequences are available but lacks for the type species, needs generic revision.

Caryosporella Kohlm. 1985, Dothideomycetes, genera incertae sedis, one species, type: $C$. rhizophorae Kohlm., asexual morph unknown, saprobes, marine aquatic, America, see Jones et al. (2009b, 2015; classification), Suetrong et al. (2009; phylogeny, morphology), Besitulo et al. (2010; diversity), Lumbsch and Huhndorf (2010; outline), Zainuddin et al. (2010; antimicrobial activities), Lee et al. (2012; checklist), Zhang et al. (2012e; morphology), Hyde et al. (2013; morphology, outline), Kirk et al. (2013; genus accepted), Wijayawardene et al. (2014c; outline), Samón-Legrá et al. (2014; diversity), Tian et al. (2015; morphology; nomenclature; phylogeny), cultures available for the type: JK 5302A.

Casaresia Gonz. Frag. 1920 (= Ankistrocladium Perrott 1960 fide Species Fungorum 2017), Ascomycota genera incertae sedis, one species, type: C. sphagnorum Gonz. Frag, hyphomycetous, sexual morph unknown, aquatic, see Wijayawardene et al. (2012, 2017; outline), Kirk et al. (2013; genus accepted), cultures and sequences are unavailable.

Cashiella Petr. 1951, Helotiales genera incertae sedis, Leotiomycetes, three species, type: $C$. atra Petr., asexual morph unknown, saprobes, terrestrial, North America, New Zealand, see Lumbsch and Huhndorf (2010; outline), Kirk et al. (2013; genus accepted), cultures and sequences are available but lacks for the type.

Castanedaea W.A. Baker \& Partr. 2001, Ascomycota genera incertae sedis, one species, type: C. minor (R.F. Castañeda) W.A. Baker \& Partr., hyphomycetous, sexual morph unknown, 
saprobes, terrestrial, Caribbean, see Seifert et al. (2011; morphology), Wijayawardene et al. (2012, 2017; outline), Kirk et al. (2013; genus accepted), cultures and sequences are unavailable, needs generic revision.

Castanediella M. Hern.-Restr., Crous \& M.J. Wingf. 2015, Xylariales genera incertae sedis, Sordariomycetes, nine species, type: C. acaciae Crous, M. Hern.-Restr. \& M.J. Wingf., hyphomycetous, sexual morph unknown, saprobes, terrestrial, Caribbean, see Crous et al. (2015d, 2016a, b; taxonomy), Hernández-Restrepo et al. (2016a; new species; phylogeny), holotype and ex-type: CBS H-22225, CPC 24869 = CBS 139896.

Castanedomyces Cano, L.B. Pitarch \& Guarro 2002, Onygenaceae, Onygenales, Eurotiomycetes, one species, type: C. australiensis Cano, L.B. Pitarch \& Guarro., asexual morph unknown, saprobes, terrestrial, Australia, see Liang et al. (2009a; phylogeny), cultures available for the type: IMI 370015.

Catabotrys Theiss. \& Syd. 1915 (= Pseudonectriella Petr. 1959 fide Species Fungorum 2017), Catabotrydaceae, Amplistromatales, Sordriomycetes, one species, type: C. palmarum (Pat.) Theiss. \& Syd., asexual morph unknown, saprobes, terrestrial, tropical, see Lumbsch and Huhndorf (2010; outline), Kirk et al. (2013; genus accepted), Maharachchikumbura et al. (2015, 2016; outline, phylogeny), cultures and sequences are available.

Catapyrenium Flot. 1850 (= Catapyrenium Flot. 1849; = Endopyrenium Flot. 1855; = Involucrocarpon Servít 1953 fide Species Fungorum 2017), Verrucariaceae, Verrucariales, Eurotiomycetes, six species, type: C. cinereum (Pers.) Körb., lichenized, see Lumbsch and Huhndorf (2010; outline), Prieto et al. (2010b; species in in the Iberian Peninsula and the Balearic Islands), Kirk et al. (2013; genus accepted), Lücking et al. (2016b; classification), sequences are available.

Cataractispora K.D. Hyde, S.W. Wong \& E.B.G. Jones 1999, Annulatascaceae, Annulatascales, Sordariomycetes, five species, type: C. aquatica K.D. Hyde, S.W. Wong \& E.B.G. Jones, saprobes, aquatic, Hong Kong, see Lumbsch and Huhndorf (2010; outline), Kirk et al. (2013; genus accepted), Maharachchikumbura et al. (2015, 2016; outline), holotype of type species HKU (M) 5239, cultures and sequences are available.

Catarraphia A. Massal. 1860 (= Cyclographa Vain. 1921 fide Species Fungorum 2017), Arthoniales genera incertae sedis, Arthoniomycetes, one species, type: $C$. dictyoplaca (Mont. \& Bosch) A. Massal., lichenized, see Lumbsch and Huhndorf (2010; outline), Kirk et al. (2013; genus accepted), Lücking et al. (2016b; classification), sequences are unavailable.

Catarrhospora Brusse 1994, Lecideaceae, Lecideales, Lecanoromycetes, two species, type: $C$. mira Brusse, lichenized, South Africa, see Lumbsch and Huhndorf (2010; outline), Schmull et al. (2011; taxonomy), Lücking et al. (2016b; classification), sequences are unavailable.

Catenarina Søchting, Søgaard, Arup, Elvebakk \& Elix 2014, Teloschistaceae, Teloschistales, Lecanoromycetes, three species, type: $C$. desolata Søchting, Søgaard \& Elvebakk, lichenized, see Søchting et al. (2014; taxonomy), Lücking et al. (2016b; classification), sequences are available.

Catenocuneiphora Matsush. 2003, Ascomycota genera incertae sedis, one species, type: $C$. mucosa Matsush., hyphomycetous, sexual morph unknown, saprobes, terrestrial, Asia, see Seifert et al. (2011; morphology), Wijayawardene et al. (2012, 2017; outline), cultures and sequences are unavailable, needs generic revision.

Catenophoropsis Nag Raj \& W.B. Kendr. 1988, Ascomycota genera incertae sedis, one species, type: C. eucalypticola Nag Raj \& W.B. Kendr., coelomycetous, sexual morph unknown, saprobes, terrestrial, Australasia, see Wijayawardene et al. (2012, 2017; outline), cultures and sequences are unavailable, needs generic revision.

Catenosubulispora Matsush. 1971, Ascomycota genera incertae sedis, one species, type: $C$. honiaraensis Matsush., hyphomycetous, sexual morph unknown, saprobes, terrestrial, South East Asia, see Seifert et al. (2011; morphology), Wijayawardene et al. (2012, 2017; outline), 
Kirk et al. (2013; genus accepted), cultures and sequences are unavailable, needs generic revision.

Catenosynnema Kodsueb, K.D. Hyde \& W.H. Ho 2007, Ascomycota genera incertae sedis, one species, type: C. micheliae Kodsueb, K.D. Hyde \& W.H. Ho, hyphomycetous, sexual morph unknown, saprobes, terrestrial, Thailand, see Seifert et al. (2011; morphology), Wijayawardene et al. (2012, 2017; outline), holotype: PDD 87914, cultures and sequences are unavailable.

Catenularia Grove 1886, Chaetosphaeriaceae, Chaetosphaeriales, Sordariomycetes, type: $C$. simplex Grove, hyphomycetous, sexual morph unknown, saprobes, terrestrial (wood), worlwide, see Seifert et al. (2011; morphology), Wijayawardene et al. (2012, 2017; outline), Maharachchikumbura et al. (2015, 2016; outline, phylogeny), cultures and sequences are available.

Catenulomyces Egidi \& de Hoog 2014, Capnodiales genera incertae sedis, Dothideomycetes, one species, type: C. convolutus Egidi \& Quaedvlieg, hyphomycetous, sexual morph unknown, rock-inhabiting, Spain, see Egidi et al. (2014; taxonomy, phylogeny), Wijayawardene et al. (2014c, 2017; outline, accepted as Capnodiales genera incerte sedis), ex-type cultures of the type species CBS $118609=$ TRN9

Catenulostroma Crous \& U. Braun 2007, Teratosphaeriaceae, Capnodiales, Dothideomycetes, five species, type: C. protearum (Crous \& M.E. Palm) Crous \& U. Braun, hyphomycetous, sexual morph ?teratosphaeria-like, saprobes, terrestrial, cosmopolitan, see Seifert et al. (2011; morphology), Wijayawardene et al. (2012, 2014c, 2017; outline), Hyde et al. (2013; accepted as a genus in Teratosphaeriaceae), Quaedvlieg et al. (2014; phylogeny, introduced new genus Neocatenulostroma), holotype and ex-type of the type: BPI 1107938, CPC 18276.

Catillaria A. Massal. 1852 (= Catillaria A. Massal. ex R. Sant. 1952; = Microlecia M. Choisy 1949; = Ulocodium A. Massal. 1855 fide Species Fungorum 2017), Catillariaceae, Lecanorales, Lecanoromycetes, 150 species, type: C. chalybeia (Borrer) A. Massal., lichenized, terrestrial, worldwide, see Lumbsch and Huhndorf (2010; outline), Kirk et al. (2013; genus accepted), Lücking et al. (2016b; classification), sequences are available.

Catillochroma Kalb 2007, Ramalinaceae, Lecanorales, Lecanoromycetes, seven species, type: C. endochroma (Fée) Kalb, lichenized, see Lendemer (2010; re-visit), Lumbsch and Huhndorf (2010; outline), Schmull et al. (2011; taxonomy), Miądlikowska et al. (2014a; taxonomy), Lücking et al. (2016b; classification), sequences are unavailable.

Catinaria Vain. [nom. cons.] 1922 (= Biatorina A. Massal. 1852 fide Species Fungorum 2017), Ramalinaceae, Lecanorales, Lecanoromycetes, two species, type: C. atropurpurea (Schaer.) Vězda \& Poelt, lichenized, temperate, see Lumbsch and Huhndorf (2010; outline), Kirk et al. (2013; genus accepted), Lücking et al. (2016b; classification), sequences are available.

Catinella Boud. 1907, Dothideomycetes genera incertae sedis, one or two species, type: $C$. olivacea (Batsch) Boud., asexual morph unknown, saprobes or parasitic, terrestrial, worldwide, see Lumbsch and Huhndorf (2010; outline), Kirk et al. (2013; genus accepted), Wijayawardene et al. (2014c; outline), sequence are available only for the type specie, needs generic revision.

Catinopeltis Bat. \& C.A.A. Costa 1957, Ascomycota genera incertae sedis, one species, type: C. recifensis Bat. \& C.A.A. Costa, coelomycetous, sexual morph unknown, saprobes, terrestrial, Brazil, see Wijayawardene et al. (2012, 2017; outline), Kirk et al. (2013; genus accepted), cultures and sequences are unavailable, needs generic revision.

Catolechia Flot. 1850 (= Dimaura Norman 1853 [1852]; = Xanthopsis Acloque 1893 fide Species Fungorum 2017), Rhizocarpaceae, Rhizocarpales, Lecanoromycetes, one species, type: C. wahlenbergii (Ach.) Flot., lichenized, Europe, see Lumbsch and Huhndorf (2010; 
outline), Kirk et al. (2013; genus accepted), Lücking et al. (2016b; classification), type specimen UPS-ACH-L-244 (isotype), sequences are available.

Catulus Malloch \& Rogerson 1978, Dothideomycetes genera incertae sedis, one species, type: C. aquilonius Malloch \& Rogerson, asexual morph unknown, saprobes, fungicolous, terrestrial, Canada, see Lumbsch and Huhndorf (2010; outline), Kirk et al. (2013; genus accepted), Wijayawardene et al. (2014c; outline), sequences are unavailable, needs generic revision.

Caudatispora J. Fröhl. \& K.D. Hyde 1995, Chaetosphaeriales genera incertae sedis, Sordariomycetes, two species, type: C. palmicola J. Fröhl. \& K.D. Hyde, asexual morph unknown, terrestrial, saprobes, America (tropical), see Lumbsch and Huhndorf (2010; outline, accepted as a genus in Sordariomycetidae, genera incertae sedis), Kirk et al. (2013; genus accepted), Maharachchikumbura et al. (2015, 2016; outline), cultures available but lacks for the type species.

Caudella Syd. \& P. Syd. 1916, Micropeltidaceae, Microthyriales, Dothideomycetes, two species, type: C. oligotricha Syd. \& P. Syd., asexual morph unknown, saprobes, terrestrial, America, see Lumbsch and Huhndorf (2010; outline, accepted as a genus in Microthyriaceae), Hyde et al. (2013; accepted as a genus in Micropeltidaceae), Kirk et al. (2013; genus accepted), Wijayawardene et al. (2014c; outline) cultures and sequences are unavailable.

Caudospora Starbäck 1889, Diaporthales genera incertae sedis, Sordariomycetes, one species, type: C. taleola (Fr.) Starbäck, asexual morph unknown, terrestrial, saprobes, see Lumbsch and Huhndorf (2010; outline), Kirk et al. (2013; genus accepted), Maharachchikumbura et al. (2015, 2016; outline), cultures and sequences are unavailable, needs generic revision.

Cavaraella Speg. 1921, Rhytismataceae, Rhytismatales, Leotiomycetes, one species, type: $C$. micraspis (Berk. \& M.A. Curtis) Speg., asexual morph unknown, saprobes, terrestrial, Cuba, see Lumbsch and Huhndorf (2010; outline), Kirk et al. (2013; genus accepted), cultures and sequences are unavailable, needs generic revision.

Cavimalum Yoshim. Doi, Dargan \& K.S. Thind 1977, Clavicipitaceae, Hypocreales, Sordariomycetes, two species, type: C. indicum Yoshim. Doi, Dargan \& K.S. Thind, asexual morph unknown, saprobes, terrestrial, Asia, see Lumbsch and Huhndorf (2010; outline), Kirk et al. (2013; genus accepted), Maharachchikumbura et al. (2015, 2016; outline), cultures and sequences are unavailable.

Cazia Trappe 1989, Pezizaceae, Pezizales, Pezizomycetes, one species, type: C. flexiascus Trappe, asexual morph unknown, from soil, terrestrial, USA, see Lumbsch and Huhndorf (2010; outline), Kirk et al. (2013; genus accepted), sequences are available for voucher SOC 469 of the type species.

Cecidiomyces U. Braun \& Zhurb. 2012, Ascomycota genera incertae sedis, one species, type: C. santessonii U. Braun \& Zhurb, hyphomycetous, sexual morph unknown, terrestrial, lichenicolous, Australia, see Zhurbenko and Braun (2012; taxonomy), Wijayawardene et al. (2017; outline), holotype of type: UPS F-552770, cultures and sequences are unavailable.

Cecidioskyttea Etayo 2004, ?Lecanoromycetes genera incertae sedis, one species, type: $C$. osorioi Etayo, asexual morph coelomycetous, sexual morph stromatic and hairy and spores simples, parasymbiont on macrolichens belonging to Parmeliaceae, South America, see Suija et al. (2015c; taxonomy), cultures and sequences are unavailable, holotype of the type: $\mathrm{Hb}$. Osorio, H,S. Osorio \& G. Geymonat 9639a.

Cecidonia Triebel \& Rambold 1988, Lecideaceae, Lecideales, Lecanoromycetes, two species, type: C. umbonella (Nyl.) Triebel \& Rambold, asexual morph unknown, lichenicolous, Europe, see Lumbsch and Huhndorf (2010; outline), Schmull et al. (2011; phylogeny), Kirk et al. (2013; genus accepted), Lücking et al. (2016b; classification), sequences are available. 
Ceeveesubramaniomyces Pratibha, K.D. Hyde \& Bhat 2005, Ascomycota genera incertae sedis, one species, type: C. litseae Pratibha, K.D. Hyde \& Bhat 2005, hyphomycetous, sexual morph unknown, saprobes, terrestrial, India, see Seifert et al. (2011; morphology), Wijayawardene et al. (2012, 2017; outline), holotype: GUBH P 198, cultures and sequences are unavailable.

Cejpia Velen. 1934, Helotiales genera incertae sedis, Leotiomycetes, three species, type: $C$. coerulea Velen., asexual morph unknown, saprobes, terrestrial, Europe, see Lumbsch and Huhndorf (2010; outline), Kirk et al. (2013; genus accepted), cultures and sequences are available but lacks for the type:.

Celerioriella Crous 2015, Phaeomoniellaceae, Phaeomoniellales, Eurotiomycetes, three species, type: C. dura (Damm \& Crous) Crous, coelomcetous, sexual morph unknown, on living leaves, pathogens, terrestrial, South Africa, see Damm et al. (2010b as Phaeomoniella dura Damm \& Crous, morphology), Crous et al. (2015d, 2016a; phylogeny), holotype and ex-type: CBS H-19999, CBS 120882.

Celoporthe Nakab., Gryzenh., Jol. Roux \& M.J. Wingf. 2006, Cryphonectriaceae, Diaporthales, Sordariomycetes, two species, type: C. dispersa Nakab., Gryzenh., Jol. Roux \& M.J. Wingf., asexual morph coelomycetous, pathogenic, terrestrial, cosmopolitan, see Lumbsch and Huhndorf (2010; outline), Chen et al. (2011; species from Eucalyptus and Syzygium trees in China and Indonesia), Crous et al. (2012d; phylogeny), Vermeulen et al. (2013; new species, phylogeny), Maharachchikumbura et al. (2015, 2016; outline), Wijayawardene et al. (2017; outline), holotype and ex-epitype strain of the type: PREM 58896, CMW 9976.

Celothelium A. Massal. 1860, Celotheliaceae, Phaeomoniellales, Eurotiomycetes, eight species, type: C. socialis (Zenker) A. Massal., lichenized, see Lumbsch and Huhndorf (2010; outline), Kirk et al. (2013; genus accepted), Gueidan et al. (2014b; taxonomy, DNA), Chen et al. (2015a; taxonomy), Lücking et al. (2016b; classification), sequences are available.

Celtidia J.D. Janse 1897, Zopfiaceae, Pleosporales, Dothideomycetes, one species, type: C. duplicispora J.D. Janse, asexual morph unnown, marine habitat (root nodules of Celtis in Java), see Lumbsch and Huhndorf (2010; outline), Hyde et al. (2013; accepted as a genus in Zopfiaceae), Kirk et al. (2013; genus accepted), cultures and sequences are unavailable, needs generic revision.

Cenangiopsis Rehm 1912 (= Pyrenopezizopsis Höhn. 1917 fide Species Fungorum 2017), Cenangiaceae, Helotiales, Leotiomycetes, two species, type: C. quercicola (Romell) Rehm, asexual morph unknown, saprobes, terrestrial, China, Europe, see Lumbsch and Huhndorf (2010; outline), Kirk et al. (2013; genus accepted), Pärtel et al. (2017; DNA, phylogeny), cultures available for the type: KL174, needs generic revision.

Cenangium Fr. 1818 (= Cenangina Höhn. 1909; = Cenangium trib. Clithris Fr. 1822; = Clithris (Fr.) Bonord. 1851 fide Species Fungorum 2017), Cenangiaceae, Helotiales, Leotiomycetes, c. 30 species, type: C. ferruginosum Fr., asexual morph unknown, saprobes, terrestrial, worldwide, see Lumbsch and Huhndorf (2010; outline), Kirk et al. (2013; genus accepted), Pärtel et al. (2017; DNA, phylogeny), cultures available for the type: KL390, needs generic revision.

Cenangiumella J. Fröhl. \& K.D. Hyde 2000, Helotiales genera incertae sedis, Leotiomycetes, one species, type: $C$. rattanicola J. Fröhl. \& K.D. Hyde, asexual morph unknown, saprobes, terrestrial, Brunei, see Lumbsch and Huhndorf (2010; outline), cultures and sequences are unavailable, needs generic revision.

Cenococcum Moug. \& Fr. 1829, Gloniaceae, Mytilinidiales, Dothideomycetes, nine species, type: C. geophilum Fr., coelomycetous, sexual morphs unknown, ectomycorrhizal, terrestrial, Europe, North America, see Wijayawardene et al. (2012, 2014c, 2017; outline), Hyde et al. 
(2013; accepted as in Gloniaceae), Kirk et al. (2013; genus accepted), Peter et al. (2016; DNA, ectomycorrhizal), cultures and sequences are available.

Cenozosia A.Massal. 1854, Ramalinaceae, Lecanorales, Lecanoromycetes, one species, type: C. inanis (Mont.) A. Massal., lichenized, see Lumbsch and Huhndorf (2010; outline), Lücking et al. (2016b; classification), sequences unavailable.

Cephaliophora Thaxt. 1903 (= Cephalomyces Bainier 1907 fide Species Fungorum 2017), Pezizales genera incertae sedis, four species, type: $C$. tropica Thaxt., hyphomycetous, sexual morph unknown, saprobes, on dung, soil, terrestrial, pantropical, temperate, see Seifert et al. (2011; morphology), Wijayawardene et al. (2012, 2017; outline), Kirk et al. (2013; genus accepted), cultures and sequences are available.

Cephaloascus Hanawa 1920 (= Ascocybe D.E. Wells 1954; = Aureomyces Ruokola \& Salonen 1970 fide Species Fungorum 2017), Cephaloascaceae, Saccharomycetales, Saccharomycetes, two species, type: C. dispersa Nakab., Gryzenh., Jol. Roux \& M.J. Wingf., asexual reproduction by budding and blastoconidia, saprophytic, although one strain of $C$. fragrans was isolated from a human ear, terrestrial, worldwide, see Lumbsch and Huhndorf (2010; outline), Kirk et al. (2013; genus accepted), Kurtzman and Robnett (2013b; DNA, phylogeny), cultures and sequences are available.

Cephalophysis (Hertel) H. Kilias 1985 (= Lecidea subgen. Cephalophysis Hertel 1967 fide Species Fungorum 2017), Teloschistaceae, Teloschistales, Lecanoromycetes, one species, type: C. leucospila (Anzi) H. Killas \& Scheid., asexual morph unknown, lichenized, terrestrial, Europe, see Lumbsch and Huhndorf (2010; outline), Arup et al. (taxonomy; 2013), Kirk et al. (2013; genus accepted), Lücking et al. (2016b; classification), cultures and sequences are unavailable.

Cephalotheca Fuckel 1871 (= Aposphaeriopsis Died. 1913; = Carothecis Clem. 1931; = Crepinula Kuntze 1891; Erythrosphaera Sorokīn 1871 fide Species Fungorum 2017), Cephalothecaceae, Sordariomycetes families incertae sedis, six species, type: C. sulfurea Fuckel, asexual morph unknown, saprobes, terrestrial, worldwide, see Lumbsch and Huhndorf (2010; outline), Kirk et al. (2013; genus accepted), Maharachchikumbura et al. (2015, 2016; outline, phylogeny), cultures and sequences are available.

Cephalotrichiella Crous 2014, Microascales, genera incertae sedis, Sordariomycetes, one species, type: $C$. penicillata Crous, hyphomycetous, sexual morph unknown, saprobes, terrestrial, Netherlands, see Crous et al. (2014c; outline, marine), Maharachchikumbura et al. (2015, 2016; outline), Wijayawardene et al. (2017; outline), holotype and ex-type: CBS H21725, CPC 23865.

Cephalotrichum Link 1809 (= Berkeleyna Kuntze 1898; = Capnostysanus Speg. 1918; = Doratomyces Corda 1829; = Stelechotrichum Ritgen 1831; = Stysanopsis Ferraris 1909; = Stysanus Corda 1837; = Synpenicillium Costantin 1888; = Trichurus Clem. 1896 fide Seifert et al. 2011; Species Fungorum 2017), Microascaceae, Microascales, Sordariomycetes, 31 species, type: C. stemonitis (Pers.) Nees, hyphomycetous, sexual morph unknown, saprobes, soil, dung terrestrial, worldwide, see Jiang et al. (2011; new species), Seifert et al. (2011; morphology), Wijayawardene et al. (2012, 2017; outline), de Beer et al. (2013; new species), Maharachchikumbura et al. (2015, 2016; outline, phylogeny), Sandoval-Denis et al. (2016a; new species), cultures and sequences are available.

Ceramoclasteropsis Bat. \& Cavalc. 1962, Dothideomycetes genera incertae sedis, one species, type: C. coumae Bat. \& Cavalc., asexual morph unknown, saprobes, terrestrial, Brazil, see Lumbsch and Huhndorf (2010; outline, accepted as a genus in Capnodiaceae), Kirk et al. (2013; genus accepted), Wijayawardene et al. (2014c; outline), cultures and sequences are unavailable.

Ceramothyrium Bat. \& H. Maia 1956, Chaetothyriaceae, Chaetothyriales, Eurotiomycetes, 34 species, type: C. paiveae Bat. \& H. Maia, asexual morph hyphomycetous, Stanhughesia 
Constant., epiphytic, epiphyllous, terrestrial, worldwide, see Lumbsch and Huhndorf (2010; outline), Chomnunti et al. (2012; 2014 morphology, phylogeny), Kirk et al. (2013; genus accepted), Zeng et al. (2016; morphology, phylogeny), cultures and sequences of type species are unavailable, needs generic revision.

Ceratocarpia Rolland 1896, Chaetothyriaceae, Chaetothyriales, Eurotiomycetes, two species, type: C. cactorum Rolland, asexual morph unknown, saprobes, terrestrial, America, France, see Lumbsch and Huhndorf (2010; outline), Kirk et al. (2013; genus accepted), Tian et al. (2014; morphology; nomenclature), cultures and sequences are unavailable, needs generic revision.

Ceratocladium Corda 1839, Ascomycota genera incertae sedis, two species, type: $C$. microspermum Corda, hyphomycetous, sexual morph unknown, saprobes, terrestrial, Asia, Europe, see Seifert et al. (2011; morphology), Wijayawardene et al. (2012, 2017; outline), Kirk et al. (2013; genus accepted), cultures and sequences are unavailable, needs generic revision.

Ceratocystiopsis H.P. Upadhyay \& W.B. Kendr. 1975, Ophiostomataceae, Ophiostomatales, Sordariomycetes, eleven species, type: C. minuta (Siemaszko) H.P. Upadhyay \& W.B. Kendr., sexual morph unknown, saprobes, terrestrial, worldwide, see Plattner et al. (2009; phylogeny), Lumbsch and Huhndorf (2010; outline), Maharachchikumbura et al. (2015, 2016; outline), Wijayawardene et al. (2017; outline), cultures and sequences are available.

Ceratocystis Ellis \& Halst. 1890 (= Chaetonaemosphaera Schwarzman 1968); = Milowia Massee 1884; = Mycorhynchella Höhn. 1918; = Rostrella Fabre 1879 [1878]; = Rostrella Zimm. 1900 fide Species Fungorum 2017), Ceratocystidaceae, Microascales, Sordariomycetes, c. 70 species, type: C. fimbriata Ellis \& Halst., asexual morph unknown, saprobes, pathogens, terrestrial, worldwide, see Lumbsch and Huhndorf (2010; outline), van Wyk et al. (2009, 2010, 2011; new species), Kajitani and Masuya (2011; new species, pathogens), Tarigan et al. (2011; new species, Indonesia), Nkuekam et al. (2012; new species), Chen et al. (2013a; species associated with Eucalyptus, China), Kirk et al. (2013; genus accepted), Maharachchikumbura et al. (2015, 2016; outline), Crous et al. (2015d; new species, phylogeny), cultures and sequences are available.

Ceratolenta Réblová 2013, Sordariomycetidae genera incertae sedis, Sordariomycetes, eight species, type: $C$. caudata Réblová, asexual morph unknown, saprobes, Europe, see Réblová et al. (2013; taxonomy, phylogeny), Maharachchikumbura et al. (2015, 2016; outline, phylogeny), holotype and ex-type cultures available for the type: PRM 899854, CBS 125234. Ceratomyces Thaxt., 1892, Ceratomycetaceae, Laboulbeniales, Laboulbeniomycetes, 32 species, type: C. mirabilis Thaxt., parasitic on Hydrophilidae and Staphylinidae beetles, terrestrial and aquatic, widespread, see Lumbsch and Huhndorf (2010; outline), Kirk et al. (2013; genus accepted), sequence is available for the type: AF431764 (SSU).

Ceratophacidium J. Reid \& Piroz. 1966, Rhytismataceae, Rhytismatales, Leotiomycetes, one species, type: $C$. aristosporum (Bonar) J. Reid \& Piroz., asexual morph unknown, saprobes, terrestrial, USA, see Lumbsch and Huhndorf (2010; outline), Kirk et al. (2013; genus accepted), cultures and sequences are unavailable, needs generic revision.

Ceratophoma Höhn. 1917, Ascomycota genera incertae sedis, one species, type: C. rostrata (Fuckel) Höhn., coelomycetous, sexual morph unknown, saprobes, terrestrial, Europe, see Wijayawardene et al. (2012, 2017; outline), Kirk et al. (2013; genus accepted), cultures and sequences are unavailable, needs generic revision.

Ceratophorum Sacc. 1880, Ascomycota genera incertae sedis, two species, type: $C$. helicosporium (Sacc.) Sacc., hyphomycetous, sexual morph unknown, saprobes, terrestrial, Europe, North America, see Wijayawardene et al. (2012, 2017; outline), Kirk et al. (2013; genus accepted), cultures and sequences are unavailable, needs generic revision. 
Ceratoporthe Petr. 1925, Melanconidaceae, Xylariales, Sordariomycetes, one species, type: $C$. didymospora Petr., asexual morph unknown, saprobes, Europe, see Lumbsch and Huhndorf (2010; outline), Kirk et al. (2013; genus accepted), Maharachchikumbura et al. (2015, 2016; outline), cultures and sequences are unavailable.

Ceratopycnis Höhn. 1915 (= Rhynchophorus Hollós 1926 fide Species Fungorum 2017), Ascomycota genera incertae sedis, two species, type: C. clematidis Höhn., coelomycetous, sexual morph unknown, saprobes, terrestrial, Europe, see Wijayawardene et al. (2012, 2016, 2017; outline, taxonomy, new species), Kirk et al. (2013; genus accepted), cultures and sequences are unavailable, needs generic revision.

Ceratospermopsis Bat. 1951, Ascomycota genera incertae sedis, two species, type: need typification data, asexual morph unknown, saprobes, terrestrial, Brazil, see Lumbsch and Huhndorf (2010; outline, accepted as a genus in Meliolaceae), Kirk et al. (2013; genus accepted), Hongsanan et al. (2015c; excluded from Meliolaceae), cultures and sequences are available but lacks for the type species, needs generic revision.

Ceratosphaerella Huhndorf, Greif, Mugambi \& A.N. Mill. 2008, Magnaporthaceae, Magnaporthales, Sordariomycetes, one species, type: C. castillensis (C.L. Sm.) Huhndorf, Greif, Mugambi \& A.N. Mill., asexual morph hyphomycetous, saprobes, terrestrial, Costa Rica, Nicaragua, Puerto Rico, see Huhndorf et al. (2008; taxonomy, phylogeny), Lumbsch and Huhndorf (2010; outline), Maharachchikumbura et al. (2015, 2016; outline), ex-type culture of type: SMH1865.

Ceratosphaeria Niessl 1876, Magnaporthaceae, Magnaporthaceae, Magnaporthales, Sordariomycetes, twelve species, type: C. lampadophora (Berk. \& Broome), asexual morph harpophora-like, saprobes, terrestrial, worldwide, see Huhndorf et al. (2008; taxonomy, phylogeny), Lumbsch and Huhndorf (2010; outline), Kirk et al. (2013; genus accepted), Maharachchikumbura et al. (2015, 2016; outline), culture available for type: CBS 117555.

Ceratosporella Höhn. 1923, Ascomycota genera incertae sedis, 20 species (14 valid taxa as per Monteiro and Gusmao 2014), type: C. bicornis Höhn., hyphomycetous, sexual morph unknown, saprobes, terrestrial, aquatic, worldwide, see Seifert et al. (2011; morphology), Wijayawardene et al. (2012, 2017; outline), Kirk et al. (2013; genus accepted), Monteiro and Gusmao (2014; key to species), sequence available but lacks for the type species.

Ceratosporium Schwein. 1832, Ascomycota genera incertae sedis, c. 14 species, type: $C$. fuscescens Schwein, widespread, see Seifert et al. (2011; morphology), Kirk et al. (2013; genus not accepted), Wijayawardene et al. (2017; outline), cultures and sequences are available, needs generic revision.

Ceratostomella Sacc. 1878 (= Cerastomis Clem. 1931; = Rhynchophoma P. Karst. 1884 fide Species Fungorum 2017), Sordariomycetidae genera incertae sedis, Sordariomycetes, 18 species, type: need typification, asexual morph unknown, saprobes, terrestrial, temperate, see Réblová and Štěpánek (2009; DNA, phylogeny), Lumbsch and Huhndorf (2010; outline), Kirk et al. (2013; genus accepted), Maharachchikumbura et al. (2015, 2016; outline), cultures and sequences are available, needs generic revision.

Cercidospora Körb. 1865 (= Neonorrlinia Syd. 1923; = Norrlinia Vain. 1921; = Pleosphaeropsis Vain. 1921; = Prolisea Clem. 1931; = Vainiona Werner 1943 fide Species Fungorum 2017), Dothideomycetes genera incertae sedis, more than 100 species, type: $C$. ulothii Körb., on lichens, temperate, see Lumbsch \& Huhndorf (2009; outline), Kirk et al. (2013; genus accepted), Wijayawardene et al. (2014c; outline), cultures and sequences are unavailable, needs generic revision.

Cercophora Fuckel 1870 (= Bovilla Sacc. 1883; = Heteronectria Penz. \& Sacc. 1898 [1897]; = Lasiosordaria Chenant. 1919; = Lasiosordariopsis Chenant. 1919 fide Species Fungorum 2017), Lasiosphaeriaceae, Sordariales, Sordariomycetes, 51 species, type: C. mirabilis Fuckel, asexual morph unknown, saprobes, terrestrial, Europe, see Chang et al. (2010; 
phylogeny), Lumbsch and Huhndorf (2010; outline), Catania et al. (2011; new species), Kirk et al. (2013; genus accepted), Kruys et al. (2015; DNA, phylogeny), Maharachchikumbura et al. (2015, 2016; outline), Crous et al. (2016a, b; new species), Dai et al. (2016; new species, phylogeny), cultures and sequences are available.

Cercosperma G. Arnaud ex B. Sutton \& Hodges 1983, Ascomycota genera incertae sedis, two species, type: $C$. arnaudii B. Sutton \& Hodges, hyphomycetous, sexual morph unknown, saprobes, Brazil, see Seifert et al. (2011; morphology), Wijayawardene et al. (2012, 2017; outline), Kirk et al. (2013; genus accepted), sequences are unavailable.

Cercospora Fresen. 1863 (= Cercosporina Speg. 1911; = Virgasporium Cooke 1875 fide Species Fungorum 2017), Mycosphaerellaceae, Capnodiales, Dothideomycetes, about 3000 described species (c. 700 accepted species), and 357 orthographic variants (Mycobank), type: C. apii Fresen., hyphomycetous, saprobes, plant pathogens, terrestrial, worldwide, see Groenewald et al. (2008, 2013; sexual reproduction, phylogeny), To-Anun et al. (2010, 2011; phylogeny, key), Hesami et al. (2011; phylogeny, new species), Seifert et al. (2011; morphology), Hyde et al. (2013; accepted as a genus in Mycosphaerellaceae), Wijayawardene et al. (2014c, 2017; outline), Bakhshi et al. (2015a, b; phylogeny), Nguanhom et al. (2015; phylogeny), Braun and Crous (2016; nomenclature), sequences are available for most of the species, holotype: Fungi rhen. 117.

Cercosporella Sacc. 1880, Mycosphaerellaceae, Capnodiales, Dothideomycetes, c. 251 species, type: C. cana (Sacc.) Sacc., hyphomyceteous, sexual morph of mycosphaerella-like, saprobes, plant pathogen, terrestrial, worldwide, see Kirschner (2009; differentiation from Ramularia), Seifert et al. (2011; morphology), Braun (2013a; taxonomy), Braun and Urtiaga (2013; new species), Braun et al. (2015; new species, key), Crous et al. (2014c; new species), Machado et al. (2012; pathology), Zhang et al. (2013b; secondary metabolites), Videira et al. (2016; morphology, phylogeny), lectotype K, non-European reference cultures CPC 19492, CPC 11461, CBS 113304, holotype of type: BPI 420584.

Cercosporidium Earle 1901, Mycosphaerellaceae, Capnodiales, Dothideomycetes, 70 species, of which five are confirmed based on DNA, type: C. euphorbiae Tracy \& Earle, hyphomycetous, sexual morph unknown, plant pathogenic, see Braun et al. (2013; morphology), Videira et al. (2017; morphology, phylogeny), resurrect the genus, and designate an epitype.

Cerillum Clem. 1931, Xylariales genera incertae sedis, Sordariomycetes, one species, type: $C$. paradoxa (Har. \& Pat.) Clem., terrestrial, saprobes, see Wendt et al. (2017; resurrected the genus in Xylariales), cultures and sequences are available.

Cerion Massee 1901, Rhytismataceae, Rhytismatales, Leotiomycetes, two species, type: $C$. coccineum Massee \& Rodway, asexual morph unknown, saprobes, terrestrial, Australia, America (tropical), see Lumbsch and Huhndorf (2010; outline), Kirk et al. (2013; genus accepted), cultures and sequences are unavailable, needs generic revision.

Ceriophora Höhn. 1919, Amphisphaeriaceae, Xylariales, Sordariomycetes, one species, type species: C. palustris (Sacc.) Höhn., Europe, doubtful genus, see Kirk et al. (2008; genus accepted), Lumbsch and Huhndorf (2010; outline), Senanayake et al. (2015; outline), Maharachchikumbura et al. (2015, 2016; outline), cultures and sequences are unavailable.

Ceriospora Niessl 1876 (= Ceriophora Höhn. 1919; = Hindersonia Moug. \& Nestl. ex J. Schröt. 1897 [1908] fide Species Fungorum 2017), Amphisphaeriaceae, Xylariales, Sordariomycetes, 18 species, type species: $C$. dubyi Niessl., doubtful genus, see Kirk et al. (2008; 2013), Lumbsch and Huhndorf (2010; outline), Senanayake et al. (2015; outline), Maharachchikumbura et al. (2015; outline), cultures and sequences are unavailable.

Ceriosporopsis Barghoon \& Linder 1944, Halosphaeriaceae, Microascales, Sordariomycetes, four species, type: $C$. halima Linder, asexual morph not unknown, saprobes, marine, worldwide, see Jones et al. (2009b, 2015; outline, phylogeny), Sakayaroj et al. (2011a; new 
species, phylogeny, however this species is invalid fide Index Fungorum 2017), sequence data available for C. halima (BCC15553).

Cerodothis Muthappa 1969, Dothideomycetes genera incertae sedis, one species, type: $C$. aurea Muthappa, asexual morph unknown, saprobes, terrestrial, India, see Lumbsch and Huhndorf (2010; outline), Kirk et al. (2013; genus accepted), cultures and sequences are unavailable, needs generic revision.

Cerothallia Arup, Frödén \& Søchting 2013, Teloschistaceae, Teloschistales, Lecanoromycetes, four species, type: C. luteoalba (Turner) Arup, Frödén \& Søchting, lichenized, see Arup et al. (2013; taxonomy), Lücking et al. (2016b; classification), sequences are available.

Cesariella W. Rossi \& Santam. 2008, Laboulbeniaceae, Laboulbeniales, Laboulbeniomycetes, one species, type: C. graeca W. Rossi \& Santam., asexual morph unknown, parasitic on Carabidae beetles, terrestrial, Europe, Rossi and Santamaría (2008; taxonomy, did not explicitly state family level placement, but suggested very close relationship to Laboulbenia), Lumbsch and Huhndorf (2010; outline, accepted as Laboulbeniales incertae sedis), cultures and sequences are unavailable.

Cesatiella Sacc. 1878, Hyponectriaceae, Xylariales, Sordariomycetes, four species, type species: C. australis Sacc. \& Speg., see Kirk et al. (2008, 2013; genus accepted), Lumbsch and Huhndorf (2010; outline), Senanayake et al. (2015; outline), Maharachchikumbura et al. (2015, 2016; outline), cultures and sequences are unavailable.

Cetradonia J.C. Wei \& Ahti. 2002, Cladoniaceae, Lecanorales, Lecanoromycetes, one species, type: C. linearis (A. Evans.) J.C. Wei \& Ahti., asexual morph unknown, lichenized, terrestrial, North America, see Lumbsch and Huhndorf (2010; outline), Lücking et al. (2016b; classification), sequences are available.

Cetraria Ach. 1803 nom. cons. (= Cetrariomyces E.A. Thomas 1939; = Coelocaulon Link 1833; = Geissodea Vent. 1799; = Platisma Hoffm. 1796 [1795]; = Platyphyllum Vent. 1799; = Pseudocornicularia Gyeln. 1933; = Squamaria Hoffm. 1789 [1790] fide Species Fungorum 2017), Parmeliaceae, Lecanorales, Lecanoromycetes, 21 species, type: C. islandica (L.) Ach., asexual morph unknown, epiphytic or saxicolous, widespread, see Thell et al. (2009; taxonomy), Lumbsch and Huhndorf (2010; outline), Kirk et al. (2013; genus accepted), Miądlikowska et al. (2014a; phylogeny), Lücking et al. (2016b; classification), sequences are available.

Cetrariella Kärnefelt \& A. Thell, 1993, Parmeliaceae, Lecanorales, Lecanoromycetes, four species, type: $C$. delisei (Bory ex Schaer.) Kärnefelt \& A. Thell, asexual morph unknown, lichenized, terrestrial temperate and artic regions of nothern hemisphere, see Thell et al. (2009; DNA, phylogeny), Lumbsch and Huhndorf (2010; outline), Kirk et al. (2013; genus accepted), Lücking et al. (2016b; classification), sequences are available.

Cetrelia W.L. Culb. \& C.F. Culb. 1968, Parmeliaceae, Lecanorales, Lecanoromycetes, c. 18 species, type: C. cetrarioides (Delise) W.L. Culb. \& C.F. Culb., asexual morph unknown, lichenized, terrestrial or on lignum, widespread, see Lumbsch and Huhndorf (2010; outline), Crespo et al. (2010b; phylogeny), Kirk et al. (2013; genus accepted), Lücking et al. (2016b; classification), sequences are available.

Cetreliopsis M.J. Lai. 1980, Parmeliaceae, Lecanorales, Lecanoromycetes, seven species, type: C. rhytidocarpa (Mont. \& Bosch) Lai, asexual morph unknown, lichenized, epiphytic, Australasia, see Lumbsch and Huhndorf (2010; outline), Kirk et al. (2013; genus accepted), Lücking et al. (2016b; classification), sequences are available.

Ceuthodiplospora Died. 1912, Ascomycota genera incertae sedis, one species, type: $C$. robiniae (Roberge) Died., asexual morph coelomycetous, terrestrial, Czech Republic, see Kirk et al. (2013; genus accepted), Wijayawardene et al. (2017; outline), cultures and sequences are unavailable, needs generic revision. 
Ceuthosira Petr. 1924, Ascomycota genera incertae sedis, one species, type: C. aesculicarpa Petr., coelomycetous, sexual morph unknown, saprobes, terrestrial, Europe, see Wijayawardene et al. (2012, 2017; outline), Kirk et al. (2013; genus accepted), cultures and sequences are unavailable, needs generic revision.

Ceuthosporella Petr. \& Syd. 1923 (= Microcyta Petr. \& Syd. 1927 fide Species Fungorum 2017), Ascomycota genera incertae sedis, one species, type: C. sambuci Höhn., coelomycetous, sexual morph unknown, saprobes, terrestrial, Japan, see Wijayawardene et al. (2012, 2017; outline), Kirk et al. (2013; genus accepted), cultures and sequences are unavailable, needs generic revision.

Chadefaudia Feldm.-Maz. 1957 (= Mycophycophila Cribb \& J.W. Cribb 1960 fide Species Fungorum 2017), Halosphaeriaceae, Microascales, Sordariomycetes, six species, type: C. marina Feldm.-Maz., saprobes, ?marine, worldwide, see Lumbsch and Huhndorf (2010; outline), Kirk et al. (2013; genus accepted), Jones et al. (2015; outline of marine genera), Maharachchikumbura et al. (2015, 2016; outline), cultures and sequences are unavailable, needs generic revision.

Chadefaudiella Faurel \& Schotter 1959, Chadefaudiellaceae, Microascales, Sordariomycetes, two species, type: C. quezelii Faurel \& Schotter, saprobes, coprophilous, terrestrial, North America, see Lumbsch and Huhndorf (2010; outline), Kirk et al. (2013; genus accepted), Maharachchikumbura et al. (2015, 2016; outline), cultures and sequences are unavailable, needs generic revision.

Chadefaudiomyces Kamat, V.G. Rao, A.S. Patil \& Ullasa 1974, Valsaceae, Diaporthales, Sordariomycetes, one species, type: C. indicus Kamat, V.G. Rao, A.S. Patil \& Ullasa, asexual morph unknown, saprobes, terrestrial, India, see Lumbsch and Huhndorf (2010; outline), Kirk et al. (2013; genus accepted), Maharachchikumbura et al. (2015, 2016; outline), cultures and sequences are unavailable, needs generic revision.

Chaenocarpus Rebent. 1804 (= Chaenocarpus Spreng. 1806; = Chaenocarpus Lév. 1843; = Coenocarpus Fr. 1825; = Cryptothamnium Wallr. 1842; = Simoninus Roum. 1879 fide Species Fungorum 2017; Wendt et al. 2017), Xylariales genera incertae sedis, Sordariomycetes, three species, type: C. setosus (Roth) Rebent., asexual morph unknown, Europe, see Lumbsch and Huhndorf (2010; outline), Kirk et al. (2013; genus accepted), Maharachchikumbura et al. (2016: outline), Wendt et al. (2017; accepted as Xylariales genera incertae sedis), cultures and sequences are unavailable, needs generic revision.

Chaenotheca (Th. Fr.) Th. Fr. 1860 (= Allodium Nyl. 1896 [1895]; = Calicium b Chaenotheca Th. Fr. 1856; = Chaenothecomyces Cif. \& Tomas. 1953; = Cybebe Tibell 1984; = Cyphelium Chevall. 1826; = Embolus Batsch 1786; = Eucyphelis Clem. 1909; = Heydeniopsis Naumov 1915 fide Species Fungorum 2017), Coniocybaceae, Coniocybales, Coniocybomycetes, c. 25 species, type: C. trichialis (Ach.) Th. Fr., asexual morph unknown, lichenized, epiphytic, widespread but mostly Northern Boreal, see Lumbsch and Huhndorf (2010, outline), Kirk et al. (2013; genus accepted), Prieto et al. (2013; phylogeny), Lücking et al. (2016b; classification), sequences are available.

Chaenothecopsis Vain. 1927 (= Catenomycopsis Tibell \& Constant. 1991 = Chaenotheciella Räsänen 1943; = Pseudocalicium Marchand 1896; = Strongyleuma Vain. 1927 fide Species Fungorum 2017; Art. 59), Mycocaliciaceae, Mycocaliciales, Eurotiomycetes, 27 species, type: C. rubescens Vain., lichenicolous, fungicolous, saprobes, terrestrial, Europe, see Lumbsch and Huhndorf (2010; outline), Seifert et al. (2011; morphology of Catenomycopsis), Tuovila et al. (2011; new species, Oregon), Kirk et al. (2013; genus accepted), Selva (2013; new species), Hawksworth et al. (2014; new species), Rikkinen et al. (2014; new species), cultures and sequences are available but lacks for the type.

Chaetarthriomyces Thaxt. 1931, Laboulbeniaceae, Laboulbeniales, Laboulbeniomycetes, three species, type: $C$. flexatus Thaxt., asexual morph unknown, parasitic on Hydrophilidae 
beetles, aquatic, widespread, Lumbsch and Huhndorf (2010; outline), Kirk et al. (2013; genus accepted), Haelewaters et al. (2014b; Netherlands), cultures and sequences are unavailable.

Chaetasbolisia Speg. 1918, Didymellaceae, Pleosporales, Dothideomycetes, seven species, type: C. erysiphoides Griffon \& Maubl., coelomycetous, sexual morph unknown, saprobes, terrestrial, worldwide, see de Gruyter et al. (2009; DNA, phylogeny, Wijayawardene et al. (2012, 2014c, 2017; outline), Hyde et al. (2013; accepted as a genus in Didymellaceae), Kirk et al. (2013; genus accepted), cultures available for the type: CBS 148.94.

Chaetendophragmia Matsush. 1971, Ascomycota genera incertae sedis, six species, type: $C$. triangularis Matsush., hyphomycetous, sexual morph unknown, saprobes, terrestrial, pantropical, see Seifert et al. (2011; morphology), Wijayawardene et al. (2012, 2017; outline), Kirk et al. (2013; genus accepted), cultures and sequences are unavailable, needs generic revision.

Chaetendophragmiopsis B. Sutton \& Hodges 1978, Ascomycota genera incertae sedis, two species, type: C. pulchra Sutton \& Hodges, hyphomycetous, sexual morph unknown, two species, saprobes, Brazil, see Seifert et al. (2011; morphology), Wijayawardene et al. (2012, 2017; outline), cultures and sequences are unavailable.

Chaetoamphisphaeria Hara 1918, Sordariomycetes, genera incertae sedis, two species, type: C. japonica Hara, asexual morph unknown, saprobes, terrestrial, Japan, see Lumbsch and Huhndorf (2010; outline), Kirk et al. (2013; genus accepted), Maharachchikumbura et al. (2015, 2016; outline), cultures and sequences are unavailable, needs generic revision.

Chaetoblastophorum Morgan-Jones 1977, Ascomycota genera incertae sedis, one species, type: $C$. ingramii Morgan-Jones, hyphomycetous, sexual morph unknown, saprobes, terrestrial, North America, see Seifert et al. (2011; morphology), Wijayawardene et al. (2012, 2017; outline), Kirk et al. (2013; genus accepted), cultures and sequences are unavailable, needs generic revision.

Chaetocapnodium Hongsanan \& K.D. Hyde 2015, Capnodiaceae, Capnodiales, Dothideomycetes, one species, type: C. siamensis Hongsanan \& K.D. Hyde, asexual morph unknown, saprobes, terrestrial, Thailand, see Liu et al. (2015a; taxonomy, phylogeny), holotype and ex-type: MFLU 14-0747, MFLUCC 13-0778.

Chaetoconis Clem. 1909 (= Amphorula Grove 1922 fide Species Fungorum 2017), Diaporthales genera incertae sedis, Sordariomycetes, one species, type: C. polygoni (Ellis \& Everh.) Clem., coelomycetous, sexual morph unknown, saprobes, terrestrial, north temperate, see de Gruyter et al. (2009; DNA, phylogeny), Kirk et al. (2013; genus accepted), Maharachchikumbura et al. (2015, 2016; outline), Wijayawardene et al. (2017; outline), cultures available for the type: CBS 405.95 .

Chaetocrea Syd. 1927, Dothideomycetes genera incertae sedis, one species, type: $C$. parasitica Syd., asexual morph unknown, fungicolous associated with black areas of fungi on leaves, see Lumbsch and Huhndorf (2010; outline, accepted as a genus in Tubeufiaceae), Kirk et al. (2013; genus accepted), Boonmee et al. (2014b; excluded from Tubeufiaceae), Wijayawardene et al. (2017; outline), cultures and sequences are unavailable.

Chaetocytostroma Petr. 1920, Ascomycota genera incertae sedis, one species, type: $C$. arundinacea Petr., coelomycetous, sexual morph unknown, saprobes, terrestrial, Europe, see Wijayawardene et al. (2012, 2017; outline), Kirk et al. (2013; genus accepted), cultures and sequences are unavailable, needs generic revision.

Chaetodiplis Clem. 1931, Ascomycota genera incertae sedis, one species, type: C. hirta (Sacc.) Clem., coelomycetous, sexual morph unknown, saprobes, terrestrial, Europe, see Wijayawardene et al. (2012, 2017; outline), Kirk et al. (2013; genus accepted), cultures and sequences are unavailable, needs generic revision.

Chaetodiplodia P. Karst. 1884, Ascomycota genera incertae sedis, nine species, type: $C$. caulina P. Karst., coelomycetous, sexual morph unknown, saprobes, terrestrial, tropical, see 
Wijayawardene et al. (2012, 2014c, 2017; outline), Kirk et al. (2013; genus accepted), cultures and sequences are available for unidentified species, needs generic revision.

Chaetodiplodina Speg. 1911, Ascomycota genera incertae sedis, two species, type: $C$. graminicola Speg., coelomycetous, sexual morph unknown, saprobes, terrestrial, South America, see Wijayawardene et al. (2012, 2017; outline), Kirk et al. (2013; genus accepted), cultures and sequences are unavailable, needs generic revision.

Chaetomastia (Sacc.) Berl. 1890 (= Herpothrix Clem. 1909; = Melanomma subgen. Chaetomastia Sacc. 1883 fide Species Fungorum 2017), Teichosporaceae, Pleosporales, Dothideomycetes, ten species, type: C. hirtula (P. Karst.) Berl., asexual morph unknown, terrestrial, saprobes, widespread, see Lumbsch and Huhndorf (2010; outline), Kirk et al. (2013; genus accepted), Hyde et al. (2013; accepted as a genus in Teichosporaceae), Wijayawardene et al. (2014c; outline), cultures and sequences are unavailable, needs generic revision.

Chaetomella Fuckel 1870 (= Harikrishnaella D.V. Singh \& A.K. Sarbhoy 1972 [1971]; = Volutellospora Thirum. \& P.N. Mathur 1965 [1964]; = Zoellneria Velen. 1934 fide Johnston et al. 2014b; Species Fungorum 2017), Chaetomellaceae, Helotiales, Leotiomycetes, six species, type: C. oblonga Fuckel, asexual morph coelomycetous, saprobes, in soil, terrestrial, worldwide, see Wijayawardene et al. (2012, 2017; outline), Kirk et al. (2013; genus accepted), Crous et al. (2014c; new species, Zambia), Johnston et al. (2014b; nomenclature), cultures available for the type: BPI 843552.

Chaetomidium (Zopf) Sacc. 1882 (= Chaetomium subgen. Chaetomidium Zopf 1881 fide Species Fungorum 2017), Chaetomiaceae, Sordariales, Sordariomycetes, 16 species, type: $C$. fimeti (Fuckel) Zopf, asexual morph phialophora-like, saprobes, in soil, coprophilous, worldwide, see Greif et al. (2009; DNA, phylogeny), Lumbsch and Huhndorf (2010; outline), Kirk et al. (2013; genus accepted), Maharachchikumbura et al. (2015, 2016; outline), cultures available for the type: CBS 168.71.

Chaetomiopsis Moustafa \& Abdul-Wahid 1990, Chaetomiaceae, Sordariales, Sordariomycetes, one species, type: $C$. dinae Moustafa \& Abdul-Wahid, asexual morph unknown, saprobes, Egypt, see Lumbsch and Huhndorf (2010; outline), Maharachchikumbura et al. (2015, 2016; outline, accepted as a distinct genus), cultures and sequences are unavailable.

Chaetomium Kunze, in Kunze \& Schmidt 1817 (= Achaetomiella Arx 1970; = Bolacotricha Berk. \& Broome 1851; = Bommerella Marchal, 1885; = Botryotrichum Sacc. \& Marchal 1885; Chaetomiotricha Peyronel 1914; = Cladochaete Sacc. 1912; = Trichocladium Harz 1871; = Vanhallia L. Marchand 1828 fide Réblová et al. 2016c; Species Fungorum 2017), Chaetomiaceae, Sordariales, Sordariomycetes, more than 150 species., type: C. globosum Kunze, in Kunze \& Schmidt (1817), asexual morph hyphomycetous, saprophytic fungus that primarily resides on plants, soil, straw, and dung, potential biological control agents, worldwide, see Ahmed et al. (2012; enzymes), Maharachchikumbura et al (2015, 2016; outline), Réblová et al. (2016c; nomenclature), Wang et al. (2016d; taxonomy), cultures and sequences are available.

Chaetomyces Thaxt. 1938, Laboulbeniaceae, Laboulbeniales, Laboulbeniomycetes, two species, type: $C$. pinophili Thaxt., asexual morph unknown, parasitic on Staphylinidae beetles, terrestrial, North and South America, Rossi and Bergonzo (2008; Brazil), Lumbsch and Huhndorf (2010; outline), Kirk et al. (2013; genus accepted), cultures and sequences are unavailable.

Chaetonaevia Arx 1951, Calloriaceae, Helotiales, Leotiomycetes, three species, type: C. nannfeldtii Arx, asexual morph unknown, saprobes, terrestrial, Europe, see Lumbsch and Huhndorf (2010; outline), Kirk et al. (2013; genus accepted), cultures and sequences are unavailable, needs generic revision. 
Chaetonectrioides Matsush. 1996, Nectriaceae, Hypocreales, Sordariomycetes, one species, type: C. malaysiana Matsush., saprobes, see Lumbsch and Huhndorf (2010; outline), Kirk et al. (2013; genus accepted), Maharachchikumbura et al. (2015, 2016), holotype: 5T121 (Matsushima Fungus Collection, Kobe), cultures and sequences are unavailable, needs generic revision.

Chaetopeltaster Katum. 1975, Ascomycota genera incertae sedis, one species, type: $C$. japonicus Katum., coelomycetous, sexual morph unknown, saprobes, terrestrial, Japan, see Wijayawardene et al. (2012, 2017; outline), Kirk et al. (2013; genus accepted), cultures and sequences are unavailable, needs generic revision.

Chaetophiophoma Speg. 1911, Ascomycota genera incertae sedis, one species, type: C. trematis Speg., coelomycetous, sexual morph unknown, saprobes, terrestrial, USA, see Wijayawardene et al. (2012, 2017; outline), Kirk et al. (2013; genus accepted), cultures and sequences are unavailable, needs generic revision.

Chaetophoma Cooke 1878, Ascomycota genera incertae sedis, c. 30 species, type: $C$. quercifolia Cooke, coelomycetous, sexual morph unknown, saprobes, terrestrial, worldwide, see Wijayawardene et al. (2012, 2017; outline), Kirk et al. (2013; genus accepted), cultures and sequences are unavailable, needs generic revision.

Chaetoplaca Syd. \& P. Syd. 1917, Ascomycota genera incertae sedis, one species, type: $C$. memecyli Syd. \& P. Syd., asexual morph unknown, saprobes, terrestrial, Philippines, see Lumbsch and Huhndorf (2010; outline, accepted as a genus in Schizothyriaceae), Kirk et al. (2013; genus accepted), Hyde et al. (2013, accepted as a genus in Schizothyriaceae), Wijayawardene et al. (2014c; outline, accepted as a genus in Schizothyriaceae), Phookamsak et al. (2016; taxonomy, transferred to Ascomycota genera incertae sedis), cultures and sequences are unavailable, needs generic revision.

Chaetoplea (Sacc.) Clem. 1931 (= Pyrenophora subgen. Chaetoplea Sacc. 1883 fide Species Fungorum 2017), Leptosphaeriaceae, Pleosporales, Dothideomycetes, c. 17 species, type: $C$. calvescens (Fr.) Clem., asexual morph coelomycetous, saprobes, terrestrial, worldwide, see Lumbsch and Huhndorf (2010; outline), Kirk et al. (2013; genus accepted), Hyde et al. (2013; accepted as Phaeosphaeriaceae), Phookamsak et al. (2014b; morphology, accepted as Leptosphaeriaceae), Wijayawardene et al. (2014c, 2016b; outline, morphology of asexual morph), sequence data and cultures are unavailable.

Chaetopreussia Locq.-Lin. 1977, Sporormiaceae, Pleosporales, Dothideomycetes, one species, type: $C$. chadefaudii Locq.-Lin., asexual morph unknown, saprobes, terrestrial, see Lumbsch and Huhndorf (2010; outline), Kirk et al. (2013; genus accepted), Hyde et al. (2013; accepted as Sporormiaceae), Wijayawardene et al. (2014c; outline), cultures and sequences are unavailable, needs generic revision.

Chaetopsina Rambelli 1956 (= Chaetopsinectria J. Luo \& W.Y. Zhuang 2010 fide Rossman et al. 2016a), Nectriaceae, Hypocreales, Sordariomycetes, 18 species, type: C. fulva Rambelli, hyphomycetous, asexual morph unknown, saprobes, terrestrial, worldwide, see Nagaraju et al. (2011a; new species), Crous et al. (2013b, 2014c, morphology, new species), Lombard et al. (2015b; DNA), Maharachchikumbura et al. (2016; outline), Rossman et al. (2016a; nomenclature), Wijayawardene et al. (2017; outline), available cultures of type: CBS 142.56. Chaetopsis Grev. 1825 (= Chaetopsella Höhn. 1930 fide Species Fungorum 2017), Ascomycota genera incertae sedis, seven species, type: $C$. wauchii Grev., hyphomycetous, sexual morph unknown, saprobes, terrestrial, worldwide, see Seifert et al. (2011; morphology), Wijayawardene et al. (2012, 2017; outline), Kirk et al. (2013; genus accepted), cultures and sequences are unavailable, needs generic revision.

Chaetopyrena Pass. 1881 (= Sclerochaeta Höhn. 1917 fide Species Fungorum 2017), Ascomycota genera incertae sedis, two species, type: C. poae (Niessl) Sacc., coelomycetous, sexual morph unknown, saprobes, terrestrial, Europe, see Seifert et al. (2011; morphology), 
Wijayawardene et al. (2012, 2017; outline), Kirk et al. (2013; genus accepted), cultures and sequences are unavailable, needs generic revision.

Chaetorostrum Zelski, Raja, A.N. Mill. \& Shearer 2011, Annulatascaceae, Annulatascales, Sordariomycetes, one species, type: C. quincemilense Zelski, Raja, A.N. Mill. \& Shearer, asexual morph unknown, saprobes, aquatic, Peru, see Zelski et al. (2011b; morohology), Maharachchikumbura et al. (2015, 2016; outline), holotype: ILL 40822, cultures and cultures and sequences are unavailable.

Chaetosclerophoma Petr. 1924, Ascomycota genera incertae sedis, two species, type: $C$. coluteae Petr., coelomycetous, sexual morph unknown, saprobes, terrestrial, Europe, Pakistan, see Wijayawardene et al. (2012, 2017; outline), Kirk et al. (2013; genus accepted), cultures and sequences are unavailable, needs generic revision.

Chaetoscutula E. Müll. 1958, Pseudoperisporiaceae, Dothideomycetes families incertae sedis, one species, type: C. juniperi E. Müll., asexual morph unknown, saprobes, terrestrial, France, see Lumbsch and Huhndorf (2010; outline), Kirk et al. (2013; genus accepted), Wijayawardene et al. (2014c; outline), cultures and sequences are unavailable, needs generic revision.

Chaetoseptoria Tehon 1937, Ascomycota genera incertae sedis, one species, type: C. vignae Tehon, coelomycetous, sexual morph unknown, saprobes, terrestrial, North America, see Wijayawardene et al. (2012, 2017; outline), Kirk et al. (2013; genus accepted), sequences and cultures are unavailable, needs generic revision.

Chaetosphaerella E. Müll. \& C. Booth 1972 (= Cladotrichum Corda 1831; = Dimera Fr. 1825; = Diplosporium Link 1824; = Gongylocladium Wallr. 1833; = Jacobaschella Kuntze 1891; = Oedemium Link 1824; = Sphinctrosporium Kunze 1849; = Veramyces Subram. 1994; = Veramycina Subram. 1995 fide Réblová et al. 2016c; Species Fungorum 2017), Chaetosphaerellaceae, Coronophorales, Sordariomycetes, 14 species, type: C. phaeostroma (Durieu \& Mont.) E. Müll. \& C. Booth, hyphomycetous, Chaetosphaerella sexual morph reported for E. didymium (=E. atrum) and E. minus, while Acrogenotheca sexual morph reported for E. robustum, saprobes, terrestrial, widespread, see Lumbsch and Huhndorf (2010; outline), Maharachchikumbura et al. (2015, 2016; outline, phylogeny), Réblová et al. (2016c; nomenclature).

Chaetosphaeria Tul. \& C. Tul. 1863 (= Aposphaeriella Died. 1912; = Chaetolentomita Maubl. 1915; = Didymopsamma Petr. 1925; = Lentomita Niessl 1876; = Melanopsammina Höhn. 1919; = Miyoshia Kawam. 1907; = Miyoshiella Kawam. 1929; = Montemartinia Curzi 1927; = Trichocollonema Höhn. 1902; = Urnularia P. Karst. 1866 fide Species Fungorum 2017), Chaetosphaeriaceae, Chaetosphaeriales, Sordariomycetes, more than 100 species, type: C. innumera Berk. \& Broome ex Tul. \& C. Tul., asexual morph complex, saprobes, worldwide, see Lumbsch and Huhndorf (2010; outline), Kirk et al. (2013; genus accepted), Maharachchikumbura et al. (2015, 2016; outline, phylogeny), cultures and sequences are available, needs generic revision.

Chaetosphaerides Matsush. 2003, Sordariomycetidae genera incertae sedis, one species, typ species: C. ramichloridifera Matsush., saprobes, terrestrial, Japan, see Maharachchikumbura et al. (2015, 2016; outline, accepted as Sordariomycetidae genera incertae sedis), holotype: MFC 210, sequences and cultures are unavailable.

Chaetosphaeronema Moesz 1915 (= Pseudophoma Höhn. 1916 fide Species Fungorum 2017), Phaeosphaeriaceae, Pleosporales, Dothideomycetes, eleven species, type: $C$. hispidulum (Corda) Moesz, asexual morph coelomycetous, saprobes or plant pathogenic, widespread, see de Gruyter et al. (2010; phylogeny), Hyde et al. (2013; accepted as a genus in Phaeosphaeriaceae), Quaedvlieg et al. (2013; phylogeny), Wijayawardene et al. (2012, 2017; outline), Kirk (2013; genus accepted), sequence are available. 
Chaetosphaerulina I. Hino 1938 (= Thaxteriellopsis Sivan. 1977 [1976] fide Species Fungorum 2017), ?Tubeufiaceae, Tubeufiales, Dothideomycete, six species, type: C. yasudai I. Hino, asexual morph hyphomycetous, saprobes on dead wood, see Lumbsch and Huhndorf (2010; outline), Kirk et al. (2013; genus accepted), Boonmee et al. (2011, 2014b; treated as a doubtful genus but listed under Tubeufiaceae), Wijayawardene et al. (2014c; outline),cultures and sequences are unavailable.

Chaetosticta Petr. \& Syd. 1925 (= Pyrenochaeta subgen. Trichocicinnus Sacc. 1906 [1905]; = Trichocicinnus (Sacc.) Höhn. 1919 fide Species Fungorum 2017), Pseudoperisporiaceae, Dothideomycetes families incertae sedis, three species, type: C. perforata (Ellis \& Everh.) Petr. \& Syd., asexual morph unknown, saprobes or parasitic, terrestrial, Europe, Japan, North America and South America, see, Kirk et al. (2013; genus accepted), Wijayawardene et al. (2014c; outline), no sequence data available, need adequate sequence data, needs generic revision.

Chaetotheca Zukal 1890, Trichocomaceae, Eurotiales, Eurotiomycetes, one species, type: $C$. fragilis Zukal, asexual morph unknown, terrestrial, on bile concretion, Austria, see Lumbsch and Huhndorf (2010; outline), Kirk et al. (2013; genus accepted), cultures and sequences are unavailable, needs phylogenetic assessment.

Chaetothiersia B.A. Perry \& Pfister 2008, Pyronemataceae, Pezizales, Pezizomycetes, one species, type: C. vernalis B.A. Perry \& Pfister, asexual morph unknown, saprobes, terrestrial, USA, see Lumbsch and Huhndorf (2010; outline), holotype of the type: FH, Perry 492, cultures and sequences are available but lacks for the type species, needs generic revision.

Chaetothyrina Theiss. 1913 (= Ceratochaetopsis F. Stevens \& Weedon 1927; = Chaetopeltopsis Theiss. 1913; = Plochmopeltidella J.M. Mend. 1925; = Setopeltis Bat. \& A.F. Vital 1959 fide Species Fungorum 2017), Micropeltidaceae, Microthyriales, Dothideomycetes, six species, type: C. musarum (Speg.) Theiss., asexual morph unknown, saprobes, terrestrial, tropical, see Lumbsch and Huhndorf (2010; outline, accepted as a genus in Microthyriaceae), Hyde et al. (2013; accepted as a genus in Micropeltidaceae), Kirk et al. (2013; genus accepted), Wijayawardene et al. (2014c; outline), Singtripop et al. (2016; new species, phylogeny), cultures available for the type: MFLUCC 15-0383.

Chaetothyriomyces Pereira-Carv., Inácio \& Dianese 2009, Chaetothyriaceae, Chaetothyriales, Eurotiomycetes, one species, type: C. brasiliensis Pereira-Carv., Inácio \& Dianese, asexual morph unknown, epiphytic, terrestrial, Brazil, see Pereira-Carvalho et al. (2009a; morphology), Lumbsch and Huhndorf (2010; outline), Kirk et al. (2013; genus accepted), cultures and sequences are unavailable, needs generic revision.

Chaetothyriothecium Hongsanan \& K.D. Hyde 2014, Microthyriaceae, Microthyriales, Dothideomycetes, one species, type: C. elegans Hongsanan \& K.D. Hyde, asexual morph unknown, epiphytes, Thailand, see Hongsanan et al. (2014b; taxonomy, phylogeny), Wijayawardene et al. (2014c; outline), cultures and sequences are available.

Chaetothyrium Speg. 1888 (= Almeidaea Cif. \& Bat. 1962; = Chaetasterina Bubák 1909; = Gilmania Bat. \& Cif. 1962; = Sphaerochaetia Bat. \& Cif. 1962; = Trotterula Speg. 1921; = Uloseia Bat. 1963; = Zukalia Sacc. 1891 fide Species Fungorum 2017), Chaetothyriaceae, Chaetothyriales, Eurotiomycetes, 66 species, type: C. guaraniticum Speg., asexual morph ceolomycetous, epiphytic, sooty moulds, terrestrial, worldwide, see Lumbsch and Huhndorf (2010; outline), Chomnunti et al. (2012; morphology; phylogeny), Wijayawardene et al. (2012; 2017; outline), Kirk et al. (2013; genus accepted), Liu et al. (2015a; morphology; phylogeny), cultures and sequences are available for some species, needs generic revision.

Chalara (Corda) Rabenh. 1844 (= Chaetochalara B. Sutton \& Piroz. 1965; = Cylindrocephalum Bonord. 1851; = Excioconidium Plunkett 1925; = Excioconis Clem. \& Shear 1931; = Hughesiella Bat. \& A.F. Vital 1956; = Stilbochalara Ferd. \& Winge 1910; = Torula subgen. Chalara Corda 1838 fide Species Fungorum 2017), Pezizellaceae, Helotiales, 
Leotiomycetes, c. 100 species, type: C. fusidioides (Corda) Rabenh., hyphomycetous, sexual morph unknown, saprobes, pthogens, terrestrial, cosmopolitan, see Kowalski and Holdenrieder (2009; pathogens), Koukol (2011; new species), Seifert et al. (2011; morphology), Wijayawardene et al. (2012, 2017; outline), Kirk et al. (2013; genus accepted), Crous et al. (2016a, b; taxonomy, phylogeny), cultures and sequences are available.

Chalarodendron C.J.K. Wang \& B. Sutton 1984, Ascomycota genera incertae sedis, one species, type: C. fuscum C.J.K. Wang \& B. Sutton, hyphomycetous, sexual morph unknown, saprobes, USA, see Seifert et al. (2011; morphology), Wijayawardene et al. (2012, 2017; outline), Kirk et al. (2013; genus accepted), cultures and sequences are unavailable.

Chalarodes McKenzie 1991, Ascomycota genera incertae sedis, two species, type: C. bisetis McKenzie, hyphomycetous, sexual morph unknown, saprobes, terrestrial, Australasia, see Seifert et al. (2011; morphology), Wijayawardene et al. (2012, 2017; outline), Kirk et al. (2013; genus accepted), cultures and sequences are unavailable, needs generic revision.

Chalaropsis Peyronel 1916, Ceratocystidaceae, Microascales, Sordariomycetes, c. five species, type: $C$. thielavioides Peyronel, hyphomycetous, sexual morph unknown, saprobes, pathogens, terrestrial, worldwide, see de Beer et al. (2014; revision, new species, phylogeny), Maharachchikumbura et al. (2015, 2016; outline), cultures are available.

Chalazion Dissing \& Sivertsen 1975, Pyronemataceae, Pezizales, Pezizomycetes, three species, type: C. sociabile Dissing \& Sivertsen, asexual morph unknown, saprobes, terrestrial, Europe, see Lumbsch and Huhndorf (2010; outline), Kirk et al. (2013; genus accepted), holotype: FH, Perry 492, cultures and sequences are available but lacks for the type, needs generic revision.

Chamaeascus L. Holm, K. Holm \& M.E. Barr 1993, Hyponectriaceae, Xylariales, Sordariomycetes, one species, type: C. arcticus L. Holm, K. Holm \& M.E. Barr, see Lumbsch and Huhndorf (2010; outline), Kirk et al. (2013; genus accepted), Senanayake et al. (2015), Maharachchikumbura et al. (2015, 2016: outline), cultures and sequences are unavailable.

Chamaeleomyces Sigler 2010, Clavicipitaceae, Hypocreales, Sordariomycetes, two species, type: $C$. granulomatis Sigler, asexual morph unknown, reptile pathogen, terrestrial, America, see Sigler et al. (2010a; taxonomy), Schmidt et al. (2012; outline), Schmidt (2015; reptile pathogens), Maharachchikumbura et al. (2015, 2016; outline), cultures and sequences are available.

Chantransiopsis Thaxt. 1914, Ascomycota genera incertae sedis, three species, type: $C$. decumbens Thaxt., coelomycetous, sexual morph unknown, entomogenous, terrestrial, Java, Europe, see Wijayawardene et al. (2012, 2017; outline), Kirk et al. (2013; genus accepted), cultures and sequences are unavailable, needs generic revision.

Chapeckia M.E. Barr 1978, Sydowiellaceae, Diaporthales, Sordariomycetes, four species, type: $C$. nigrospora (Peck) M.E. Barr, asexual morphs unknown, saprobes, terrestrial, North America, see Lumbsch and Huhndorf (2010; outline), Kruys and Castlebury (2012; DNA, phylogeny), Kirk et al. (2013; genus accepted), Maharachchikumbura et al. (2015, 2016; outline, phylogeny), cultures available for the type: CBS 125532.

Chapsa A. Massal. 1860, Graphidaceae, Ostropales, Lecanoromycetes, 62 species, type: C. indica A. Massal., asexual morph unknown, lichenized fungi, terrestrial, tropical, see Mangold et al. (2009; key Australia), Lumbsch and Huhndorf (2010; outline), Rivas Plata et al. (2010a, 2012a; key), Sipman et al. (2012; key, Costa Rica), Kirk et al. (2013; genus accepted), Lücking et al. (2016b; classification), sequences are available.

Characonidia Bat. \& Cavalc. 1965, Ascomycota genera incertae sedis, one species, type: $C$. ingae Bat. \& Cavalc., coelomycetous, sexual morph unknown, saprobes, terrestrial, Brazil, see Wijayawardene et al. (2012, 2017; outline), Kirk et al. (2013; genus accepted), cultures and sequences are unavailable, needs generic revision. 
Charcotiana Søchting, Garrido-Benavent \& Arup in Søchting et al. 2014, Teloschistaceae, Teloschistales, Lecanoromycetes, one species, type: C. antarctica Søchting et al., asexual morph unknown, lichenized, saxicolous, Anctartica, see Søchting et al. (2014b; phylogeny), Lücking et al. (2016b; classification), sequences are available.

Charomyces Seifert 1987, Ascomycota genera incertae sedis, one species, type: C. amphimelas Seifert, hyphomycetous, sexual morph unknown, saprobes, terrestrial, Hawaiian Island, Cuba, see Wijayawardene et al. (2012, 2017; outline), Kirk et al. (2013; genus accepted), sequences and cultures are unavailable, needs generic revision.

Charonectria Sacc. 1880, Hyponectriaceae, Xylariales, Sordariomycetes, two species, type: C. sceptri (P. Karst.) Lowen, temperate, dead leaves or lichenicolous, see Lumbsch and Huhndorf (2010; outline), Kirk et al. (2013), Maharachchikumbura et al. (2015, 2016: outline), sequences and cultures are unavailable, needs generic revision.

Chasakopama Manohar., Bagyanaryana, N.K. Rao \& Kunwar 2009, Ascomycota genera incertae sedis, one species, type: C. velgodensis Manohar., Bagyanaryana, N.K. Rao \& Kunwar, hyphomycetous, sexual morph unknown, saprobes, terrestrial, India, see Manoharachary et al. (2009; taxonomy), Seifert et al. (2011; morphology), Wijayawardene et al. (2012, 2017; outline), holotype: IMI 296874, sequences are unavailable.

Cheilaria Lib. 1830, Ascomycota genera incertae sedis, one species, type: C. agrostidis Lib., coelomycetous, sexual morph unknown, saprobes, terrestrial, worldwide, see Wijayawardene et al. (2012, 2017; outline), isotype: IMI 152241, cultures and sequences are unavailable, needs generic revision.

Cheilymenia Boud. 1885 (= Coprobia Boud. 1885 fide Species Fungorum 2017, Pyronemataceae, Pezizales, Pezizomycetes, c. 66 species, type: C. stercorea (Pers.) Boud., asexual morph unknown, saprobes, terrestrial, worldwide, see Lumbsch and Huhndorf (2010; outline), Kirk et al. (2013; genus accepted), Jaklitsch et al. (2016a; classification), cultures and sequences are unavailable.

Cheiroidea W.A. Baker \& Morgan-Jones 2009, Ascomycota genera incertae sedis, one species, type: C. triarmata (Whitton, McKenzie \& K.D. Hyde) W.A. Baker \& Morgan-Jones, hyphomycetous, sexual morph unknown, saprobes, terrestrial (on Pandunus), Mauritius, see Gams et al. (2009; morphology), Seifert et al. (2011; morphology), Wijayawardene et al. (2012, 2017; outline), holotyp: HKU(M) 13034, cultures and sequence unavailable, needs generic revision.

Cheiromycella Höhn. 1910, Ascomycota genera incertae sedis, three species, type: $C$. speiroidea (Höhn.) Höhn., hyphomycetous, sexual morph unknown, on cheese and fungi, terrestrial, Europe, North America, see Braun et al. (2009; new species), Seifert et al. (2011; morphology, treated as a genus in Hyaloscyphaceae), Wijayawardene et al. (2012, 2017; outline), Kirk et al. (2013; genus accepted), cultures and sequences are unavailable, needs generic revision.

Cheiromyceopsis Mercado \& J. Mena 1988, Ascomycota genera incertae sedis, one species, type: C. echinulata Mercado \& J. Mena, hyphomycetous, sexual morph unknown, saprobes, terrestrial, Cuba, see Seifert et al. (2011; morphology), Wijayawardene et al. (2012, 2017; outline), sequences and cultures are unavailable, needs generic revision.

Cheiromycina B. Sutton 1986, Ascomycota genera incertae sedis, type: C. flabelliformis B. Sutton, five species, hyphomycetous, sexual morph unknown, saprobes, lichenized, Austria, Russia, Sweden, see Diederich et al. (2008; treated C. ananas Aptroot \& Schiefelb. as a synonym of Dictyocatenulata alba Finley \& E.F. Morris), An et al. (2012; morphology), Lücking et al. (2016b; classification), cultures and sequences are unavailable, holotype: IMI288326.

Cheiropolyschema Matsush. 1980, Ascomycota genera incertae sedis, two species, type: $C$. formosana Matsush., hyphomycetous, sexual morph unknown, saprobes, terrestrial, India, 
Taiwan, see Seifert et al. (2011; morphology), Wijayawardene et al. (2012, 2017; outline), holotype: MFC-6717, sequences and cultures are unavailable, needs generic revision.

Cheirospora Moug. \& Fr. 1825 (= Hyperomyxa Corda 1839; = Moronopsis Delacr. 1891; = Myriocephalum De Not. ex Corda 1842; = Rabdosporium Chevall. 1826; = Thyrsidium Mont. 1848 [1846-49] fide Species Fungorum 2017), Helotiales genera incertae sedis, Leotiomycetes, two species, type: C. botryospora (Mont.) Berk. \& Broome, coelomycetous, sexual morph unknown, saprobes, terrestrial, worldwide, see Crous et al. (2015c; morphology, phylogeny, DNA), Wijayawarden et al. (2016b; morphology, phylogeny, outline), reference specimens available for type: MFLU 15-3550, cultures available: CPC 24603 = CBS 139999, CPC 24605, CPC 24607, CPC 24611.

Cheirosporium L. Cai \& K.D. Hyde 2008, Dictyosporiaceae, Pleosporales, Dothideomycetes, two species, type: $C$. triseriale L. Cai \& K.D. Hyde, hyphomycetous, sexual morph unknown, saprobes, Asia, Egypt, see Seifert et al. (2011; morphology), Wijayawardene et al. (2012, 2017; outline), Boonmee et al. (2016; phylogeny), cultures and sequences are available.

Chevalieropsis Arnaud. 1923 (= Chevalieria Arnaud 1920; = Parodiellinopsis Hansf. 1946 [1944-45] fide Species Fungorum 2017), Perisporiopsidaceae, Dothideomycetes genera incertae sedis, two species, type: C. ctenotricha (Pat. \& Har.) G. Arnaud, asexual morph hyphomycetous, see Lumbsch and Huhndorf (2010; outline), Kirk et al. (2013; genus accepted), Wijayawardene et al. (2014c; outline), sequences are unavailable, need recollecting to verify generic placement.

Chiastospora Riess 1852, Ascomycota genera incertae sedis, one species, type: $C$. parasitica Riess, coelomycetous, sexual morph unknown, saprobes, terrestrial, Europe, see Wijayawardene et al. (2012, 2017; outline), Kirk et al. (2013; genus accepted), cultures and sequences are unavailable, needs generic revision.

Chikaneea B. Sutton 1973, Ascomycota genera incertae sedis, one species, type: C. holleroniae B. Sutton, hyphomycetous, sexual morph unknown, saprobes, Canada, see Seifert et al. (2011; morphology), Kirk et al. (2013; genus accepted), sequences are unavailable.

Chiodecton Ach. 1814 (= Melanodecton A. Massal. 1860 [1859-1860] fide Species Fungorum 2017), Roccellaceae, Arthoniales, Arthoniomycetes, c. 24 species, type: $C$. sphaerale Ach., lichenized, corticolour or saxicolous, worldwide, see Ertz et al. (2009; phylogeny), Lumbsch and Huhndorf (2010; outline), Kirk et al. (2013; genus accepted), Lücking et al. (2016b; classification), sequences are available.

Chionomyces Deighton \& Piroz. 1972, Ascomycota genera incertae sedis, seven species, type: C. meliolicola (Cif.) Deighton \& Piroz., hyphomycetous, sexual morph unknown, saprobes, worldwide (tropical), see Seifert et al. (2011; morphology), Wijayawardene et al. (2012, 2017; outline), sequences and cultures are unavailable, needs generic revision.

Chirleja Lendemer \& B.P. Hodk. 2012, Icmadophilaceae, Pertusariales, Lecanoromycetes, one species, type: C. buckii Lendemer \& B.P. Hodk., asexual morph unknown, lichenized, terrestrial, South America, see Lendemer and Hodkinson (2012; taxonomy), Lücking et al. (2016b; classification), sequences are available.

Chithramia Nag Raj 1988, Ascomycota genera incertae sedis, one species, type: $C$. elegantissima Nag Raj, coelomycetous, sexual morph unknown, saprobes, terrestrial, India, see Wijayawardene et al. (2012, 2016b, 2017; morphology, outline), Kirk et al. (2013; genus accepted), holotype: BPI 71492, sequences and cultures are unavailable, needs generic revision.

Chitonomyces Peyr. 1873 (= Heimatomyces Peyr. 1873 fide Species Fungorum 2017), Laboulbeniaceae, Laboulbeniales, Laboulbeniomycetes, 98 species, type: C. melanurus Peyr., asexual morph unknown, biotrophic, worldwide, see Lumbsch and Huhndorf (2010; outline), Goldmann and Weir (2012; phylogeny), Kirk et al. (2013; genus accepted), sequences are available for type: (SSU, LSU). 
Chitonospora E. Bommer, M. Rousseau \& Sacc. 1891, Phlogicylindriaceae, Xylariales, Xylariomycetidae, Sordariomycetes, one species, type: C. ammophila E. Bommer, M. Rousseau \& Sacc., from dead grasses, Europe, see Lumbsch and Huhndorf (2010; outline), Kirk et al. (2013; genus accepted), Maharachchikumbura et al. (2015; outline), sequences and cultures are unavailable, needs generic revision.

Chlamydomyces Bainier 1907, Ascomycota genera incertae sedis, two species, type: C. diffusus Bainier, hyphomycetous, sexual morph unknown, saprobes, terrestrial, worldwide, see Seifert et al. (2011; morphology), Wijayawardene et al. (2012, 2017; outline), Kirk et al. (2013; genus accepted), sequences and cultures are unavailable, needs generic revision.

Chlamydopsis Hol.-Jech. \& R.F. Castañeda 1986, Ascomycota genera incertae sedis, one species, type: C. proliferans Hol.-Jech. \& R.F. Castañeda, hyphomycetous, sexual morph unknown, saprobes, terrestrial, Cuba, see Seifert et al. (2011; morphology), Wijayawardene et al. (2012, 2017; outline), Kirk et al. (2013; genus accepted), holotype: INIFAT C84/140, cultures and sequences are unavailable, compare with Acrodictys, Ashtaangam and Petrakia.

Chlamydorubra K.B. Deshp. \& K.S. Deshp. 1966, Ascomycota genera incertae sedis, one species, type: C. verrucosa K.B. Deshp. \& K.S. Deshp., hyphomycetous, sexual morph unknown, saprobes, terrestrial, India, see Seifert et al. (2011; morphology), Wijayawardene et al. (2012, 2017; outline), Kirk et al. (2013; genus accepted), sequences and cultures are unavailable, needs generic revision.

Chlamydosauromyces Sigler, Hambl. \& Paré 2002, Onygenaceae, Onygenales, Eurotiomycetes, one species, type: C. punctatus Sigler, Hambl. \& Paré, asexual morph unknown, from bee hive, USA, see Lumbsch and Huhndorf (2010; outline), Jaklitsch et al. (2016a; classification), sequences and culture available.

Chlamydotubeufia Boonmee \& K.D. Hyde. 2011, Tubeufiaceae, Tubeufiales, Dothideomycetes, five species, type: C. huaikangplaensis Boonmee \& K.D. Hyde, saprobes on decaying wood, Thailand, asexual morph hyphomycetous, see Boonmee et al. (2011, 2012; taxonomy), Hyde et al. (2013; accepted as a genus in Tubeufiaceae), Wijayawardene et al. (2014c; outline), cultures and sequences are available, holotype and ex-type strains of the type: MFLUCC 10-0926, MFLU 10-0972.

Chlorencoelia J.R. Dixon 1975, Cenangiaceae, Helotiales, Leotiomycetes, four species, type: C. versiformis (Pers.) J.R. Dixon, asexual morph unknown, saprobes, terrestrial, Europe, North America, see Lumbsch and Huhndorf (2010; outline), Kirk et al. (2013; genus accepted), Ren and Zhuang (2014; new species, China), Pärtel et al. (2017; DNA, phylogeny), cultures and sequences are available.

Chloridium Link 1809 (= Gonytrichum Nees \& T. Nees 1818; = Melanopsammella Höhn. 1920 fide Réblová et al. 2016c), Chaetosphaeriaceae, Chaetosphaeriales, Sordariomycetes, c. five new species, type: $C$. viride Link, hyphomycetous, sexual morph unknown, saprobes, terrestrial, widespread, Seifert et al. (2011; morphology), Wijayawardene et al. (2012, 2017; outline), Kirk et al. (2013; genus accepted), Maharachchikumbura et al. (2015, 2016; outline), cultures and sequences are unavailable for type species, needs generic revision.

Chlorociboria Seaver ex C.S. Ramamurthi, Korf \& L.R. Batra 1958, Chlorociboriaceae, Helotiales, Leotiomycetes, c. 22 species, saprobes, worldwide, see Huhtinen et al. (2010; new species), Lumbsch and Huhndorf (2010; outline), Kirk et al. (2013; genus accepted), Pärtel et al. (2016; new species, phylogeny), cultures and sequences are available.

Chloroepilichen Etayo 2010, Helotiales genera incertae sedis, Leotiomycetes, one species, type: $C$. rolfii Etayo, asexual morph unknown, lichenicolous, terrestrial, Southern America, see Etayo (2010; description and distinction of similar lichenicolous genera), cultures and sequences are unavailable, holotype: UPS, R. Santesson \& G. Thor P75:5.

Chloroscypha Seaver 1931 (= Parksia E.K. Cash 1945 fide Species Fungorum 2017), Gelatinodiscaceae, Helotiales, Leotiomycetes, 14 species type: C. seaveri Rehm ex Seaver, 
asexual morph sporodochia-like, endophytic, weak pathogen and saprobes, on leaves of Cupressaceae (rarely Taxodiaceae), widespread in temperate areas, see Lumbsch and Huhndorf (2010; outline), Kirk et al. (2013; genus accepted), holotype: NY herbarium (NY00915009), living cultures and sequences are unavailable for the type of the type species.

Chlorospleniella P. Karst. 1885, Helotiales genera incertae sedis, Leotiomycetes, one species, type: C. fennica (P. Karst.) Sacc. ex Clem. \& Shear, asexual morph unknown, saprobes, terrestrial, Brazil, see Lumbsch and Huhndorf (2010; outline), Kirk et al. (2013; genus accepted), cultures and sequences are unavailable.

Chlorosplenium Fr. 1849 (= Chrysosplenium Allesch. 1898 fide Species Fungorum 2017), Helotiales genera incertae sedis, Leotiomycetes, five species, type: C. chlora (Schwein.) M.A. Curtis, asexual morph unknown, saprobes, terrestrial, worldwide, see Lumbsch and Huhndorf (2010; outline), Kirk et al. (2013; genus accepted), cultures and sequences are unavailable.

Chlorostroma A.N. Mill., Lar. N. Vassiljeva \& J. D. Rogers. 2007, Hypoxylaceae, Xylariales, Sordariomycetes, three species, type: C. subcubisporum A.N. Mill., Lar.N. Vassiljeva \& J.D. Rogers, USA, see Lumbsch and Huhndorf (2010; outline), Maharachchikumbura et al. (2015, 2016: outline), Wendt et al. (2017; accepted as a genus in Hypoxylaceae), cultures and sequences are unavailable.

Chlorovibrissea L.M. Kohn 1989, ?Vibrisseaceae, Helotiales, Leotiomycetes, four species type: C. bicolor (G.W. Beaton \& Weste) L.M. Kohn, asexual morph phialophora-like, aquatic or semi-aquatic on wood and twigs, Australasia, South America, see Lumbsch and Huhndorf (2010; outline), Kirk et al. (2013; genus accepted), Sandoval-Leiva et al. (2014; DNA), holotype in MELU herbarium, cultures and sequences are available.

Choanatiara DiCosmo 1984, Ascomycota genera incertae sedis, two species, type: C. lunata DiCosmo \& Nag Raj, coelomycetous, sexual morph unknown, saprobes, terrestrial, India, Canada, see Wijayawardene et al. (2012, 2017; outline), Kirk et al. (2013; genus accepted), cultures and sequences are unavailable, needs generic revision.

Choiromyces Vittad. 1831 (= Choeromyces Tul. \& C. Tul. 1862; = Piersonia Harkn. 1899; = Tartufa (Gray) Kuntze 1898; = Tuber sect. Tartufa Gray 1821; = Zobelia Opiz 1855 fide Species Fungorum 2017), Tuberaceae, Pezizales, Pezizomycetes, type: C. meandriformis Vittad., asexual morph unknown, saprobes, hypogeous, terrestrial, worldwide, see Wedén et al. (2009; edible truffle Choiromyces venosus in Sweden), Bonito et al. (2013; phylogeny), Lumbsch and Huhndorf (2010; outline), Moreno et al. (2012b; phylogeny), Kirk et al. (2013; genus accepted), cultures and sequences are available.

Chondroderris Maire 1937, Helotiales, genera incertae sedis, Leotiomycetes, one species, type: $C$. nevadensis Maire, asexual morph unknown, saprobes, terrestrial, Spain, see Lumbsch and Huhndorf (2010; outline), Kirk et al. (2013; genus accepted), cultures and sequences are unavailable, needs generic revision.

Chordomyces Bilanenko, M.L. Georgieva \& Grum-Grzhimaylo 2016, Plectosphaerellaceae, Glomerellales, Sordariomycetes, one species, type: C. antarcticus E.N. Bilanenko, M.L. Georgieva, A.A. Grum-Grzhimaylo, saprobes, from soil, see Grum-Grzhimaylo et al. (2016; taxonomy), Maharachchikumbura et al. (2015, 2016; outline), cultures and sequences are available.

Choreospora Constant. \& R. Sant. 1987, Ascomycota genera incertae sedis, two species, type: C. tibellii Constant. \& R. Sant., hyphomycetous, sexual morph unknown, lichenicolous, terrestrial, Australia, see Seifert et al. (2011; morphology), Wijayawardene et al. (2012, 2017; outline), Kirk et al. (2013; genus accepted), cultures and sequences are unavailable, needs generic revision.

Chorioactis Kupfer ex Eckblad 1968 (= Chorioactis Kupfer 1902 nom. inval. Art. 38.5, Ex. 1 (Melbourne), Chorioactidaceae, Pezizales, Pezizomycetes, one species, type: C. geaster (Peck) Kupfer ex Eckblad, asexual morph unknown, saprobes, terrestrial, USA, China, see 
Lumbsch and Huhndorf (2010; outline), Jaklitsch et al. (2016a; classification), sequences are available.

Chrismofulvea Marbach 2000, Caliciaceae, Caliciales, Lecanoromycetes, four species, type: C. dialyta (Nyl.) Marbach, asexual morph unknown, lichenized, epiphytic, North and South America, see Lücking et al. (2016b; classification), sequences are available.

Chromatochlamys Trevis. 1860 (= Microglaenomyces Cif. \& Tomas. 1953; = Weitenwebera Körb. 1863 fide Species Fungorum 2017), Thelenellaceae, Ostropales, Lecanoromycetes, three species, type: C. muscicola (Ach.) Trevis., lichenized, see Lumbsch and Huhndorf (2010; outline), Nelsen et al. (2016; taxonomy), Lücking et al. (2016b; classification), sequences are available.

Chromendothia Lar.N. Vassiljeva 1993, Cryphonectriaceae, Diaporthales, Sordariomycetes, two species, type: $C$. appendiculata Lar.N. Vassiljeva, asexual morphs unknown, saprobes, terrestrial, temperate north-eastern Asia, see Lumbsch and Huhndorf (2010; outline), Maharachchikumbura et al. (2016; phylogeny, outline), holotype of type: VLA P-2939, sequences are available for $C$. citrina.

Chroodiscus (Müll. Arg.) Müll. Arg. 1890 (= Ocellularia sect. Chroodiscus Müll. Arg. 1883; = Phyllobrassia Vain. 1921 fide Species Fungorum 2017), Graphidaceae, Ostropales, Lecanoromycetes, 14 species, type: C. coccineus (Leight.) Müll. Arg., lichenized (Trenthepohlia or Phycopeltis), terrestrial (foliicolous), tropical, see Papong et al. (2009a, b; DNA), Parnmen et al. (2012; DNA), Sipman et al. (2012; key), Rivas Plata et al. (2013; DNA), Lumbsch et al. (2014a, b; phylogeny), Lücking et al. (2016b; classification), sequences are available.

Chrysachne Cif. 1938, Ascomycota genera incertae sedis, two species, type: C. hyphochoria Cif., hyphomycetous, sexual morph unknown, saprobes, terrestrial, West Indies, see Seifert et al. (2011; morphology), Wijayawardene et al. (2012, 2017; outline), Kirk et al. (2013; genus accepted), cultures and sequences are unavailable, needs generic revision.

Chrysocrypta Crous \& Summerell 2012, Cryphonectriaceae, Diaporthales, Sordariomycetes, one species, type: $C$. corymbiae Crous \& Summerell, coelomycetous, sexual morph unknown, terrestrial, Australia, see Crous et al. (2012e; taxonomy, phylogeny), Maharachchikumbura et al. (2015, 2016; outline), Wijayawardene et al. (2017; outline), holotype: CBS H-20963, cultures and sequences are available.

Chrysofolia Crous \& M.J. Wingf. 2015, Cryphonectriaceae, Diaporthales, Sordariomycetes, one species, type: C. colombiana Crous, Rodas \& M.J. Wingf., coelomycetous, saprobes, Colombia, see Crous et al. (2015d; taxonomy, phylogeny), Wijayawardene et al. (2017; outline, phylogeny), holotype and ex-type: CBS H-22238, CPC 24986.

Chrysoporthe Gryzenh. \& M.J. Wingf. 2004 (= Chrysoporthella Gryzenh. \& M.J. Wingf. 2004 fide Maharachchikumbura et al. 2015, 2016), Cryphonectriaceae, Diaporthales, Sordariomycetes, eight species, type: C. cubensis (Bruner) Gryzenh. \& M.J. Wingf., asexual morph coelomycetous, one species, saprobes, terrestrial, cosmopolitan, see Lumbsch and Huhndorf (2010; outline), Chungu et al. (2010; new species), Maharachchikumbura et al. (2015, 2016; outline), holotype of the type: BPI 631857, cultures and sequences are available. Chrysosporium Corda 1833 (= Aleurophora O. Magalh. 1916; = Atrichophyton Castell. \& Chalm. 1919; = Blastomyces Costantin \& Rolland 1889 [1888]; = Emmonsia Cif. \& Montemart. 1959; = Rhinocladiella Kamyschko 1960; = Rhinocladiopsis Kamyschko1961 fide Species Fungorum 2017), Onygenaceae, Onygenales, Eurotiomycetes, c. 70 species, type: $C$. corii Corda, hyphomycetous, terrestrial, saprobes on keratinous substrates, but also reported from other sources, including dung, soil and foodstuffs, several species are opportunistic pathogens of vertebrates including humans, cosmopolitan, highly polyphyletic, see Liang et al. (2009a; taxonomy), Pitt et al. (2013; reallocation of some xerophilic species, with comments on the polyphyly of the genus), Crous et al. (2016b; new species, phylogeny), 
cultures and sequences properly representing the type species are unavailable, needs phylogenetic assessment, Chrysosporium is tentatively considered herein as a member of Onygenaceae following de Hoog et al. (in press).

Chrysothrix Mont. 1852 (= Allarthonia (Nyl.) Zahlbr. 1902; = Plearthonis Clem. 1909 fide Jaklitsch et al. 2016a), Chrysotrichaceae, Arthoniales, Arthoniomycetes, 14 species, type: $C$. noli-tangere (Mont.) Mont., asexual morph unknown, lichenized, saxicolous or epiphytic, widespread, see Nelsen et al. (2009; phylogeny), Lumbsch and Huhndorf (2010; outline), Laundon (2012, conserved against Alysphaeria), Sundin et al. (2012; taxonomy), Kirk et al. (2013; genus accepted), Lücking et al. (2016b; classification), sequences are available.

Chuppia Deighton 1965, Ascomycota genera incertae sedis, one species, type: C. sarcinifera Deighton, hyphomycetous, sexual morph unknown, saprobes, terrestrial, West Indies, see Seifert et al. (2011; morphology), Wijayawardene et al. (2012, 2017; outline), sequences and cultures unavailable, needs generic revision.

Ciboria Fuckel 1870 (= Ciboriopsis Dennis 1962; = Moellerodiscus Henn. 1902 fide Species Fungorum 2017), Sclerotiniaceae, Helotiales, Leotiomycetes, c. 21 species, type: C. caucus (Rebent.) Fuckel, asexual morph unknown, saprobes, terrestrial, temperate, see Lumbsch and Huhndorf (2010; outline), Kirk et al. (2013; genus accepted), Pärtel et al. (2017; DNA, phylogeny), cultures and sequences are available.

Ciborinia Whetzel 1945, Sclerotiniaceae, Helotiales, Leotiomycetes, 16 species, type: C. bifrons (Whetzel) Whetzel, asexual morph unknown, saprobes, terrestrial, worldwide, see Lumbsch and Huhndorf (2010; outline), Kirk et al. (2013; genus accepted), cultures and sequences are available.

Cicadocola Brain 1923, Ascomycota genera incertae sedis, one species, type: C. cicadarum (Šulc) Bain, hyphomycetous, sexual morph unknown, saprobes, terrestrial, South Africa, see Seifert et al. (2011; morphology), Wijayawardene et al. (2012, 2017; outline), sequences and cultures unavailable, needs generic revision.

Cidaris Fr. 1849, Pezizales genera incertae sedis, Pezizomycetes, three species, type: $C$. caroliniana (Schwein.) Fr., asexual morph unknown, saprobes, terrestrial, North America, see Lumbsch and Huhndorf (2010; outline), Jaklitsch et al. (2016a; classification), cultures and sequences are unavailable, needs generic revision.

Cidaris Fr. 1849, Pezizales, genera incertae sedis, Pezizomycetes, one species, type: $C$. caroliniana (Schwein.) Fr., asexual morph unknown, saprobes, terrestrial, North America, see Lumbsch and Huhndorf (2010; outline, treated as Helvellaceae), Jaklitsch et al. (2016a; classification), cultures and sequences are unavailable.

Ciferria Gonz. Frag. 1925, Ascomycota genera incertae sedis, one species, type: $C$. coccothrinacis Gonz. Frag., coelomycetous, sexual morph unknown, saprobes, terrestrial, South Africa, see Wijayawardene et al. (2012, 2017; outline), Kirk et al. (2013; genus accepted), sequences and cultures unavailable, needs generic revision.

Ciferriascosea Senan., Bhat, Camporesi \& K.D. Hyde 2015, Phlogicylindriaceae, Xylariales, Sordariomycetes, one species, type: $C$. rectamurum Senanayake, Bhat, Camporesi \& K.D. Hyde, asexual morph unknown, saprobes, Italy, see Senanayake et al. (2015; taxonomy, phylogeny), Maharachchikumbura et al. (2015, 2016; outline), cultures and sequences are available.

Ciferrina Petr. 1932, Ascomycota genera incertae sedis, one species, type: $C$. pulchella Petr., coelomycetous, sexual morph unknown, saprobes, terrestrial, West Indies, see Wijayawardene et al. (2012, 2017; outline), Kirk et al. (2013; genus accepted), sequence data and cultures are unavailable, needs generic revision.

Ciferriopeltis Bat. \& H. Maia 1965, Ascomycota genera incertae sedis, one species, type: $C$. domingensis (Petr. \& Cif.) Bat. \& H. Maia, coelomycetous, sexual morph unknown, saprobes, 
terrestrial, West Indies, see Wijayawardene et al. (2012, 2017; outline), Kirk et al. (2013; genus accepted), cultures and sequences are unavailable, needs generic revision.

Ciliella Sacc. \& P. Syd. 1902, Helotiales genera incertae sedis, Leotiomycetes, one species, type: C. epidendri (Rehm) Sacc. \& P. Syd., asexual morph unknown, saprobes, terrestrial, Brazil, see Lumbsch and Huhndorf (2010; outline), Kirk et al. (2013; genus accepted), cultures and sequences are unavailable, needs generic revision.

Ciliochora Höhn. 1919 (= Petrakomyces Subram. \& K. Ramakr. 1953 fide Species Fungorum 2017), Ascomycota genera incertae sedis, two species, type: C. longiseta (Racib.) Höhn. coelomycetous, sexual morph unknown, saprobes, terrestrial, Dominican Republic, see Wijayawardene et al. (2012, 2017; outline), Kirk et al. (2013; genus accepted), cultures and sequences are unavailable, needs generic revision.

Ciliochorella Syd. 1935 (= Phaeociliospora Bat. \& Peres 1967; = Plagionema Subram. \& K. Ramakr. 1927 fide Species Fungorum 2017), Pestalotiopsidaceae, Xylariales, Sordariomycetes, four species, type: C. mangiferae Syd., coelomycetous, sexual morph unknown, saprobes, terrestrial, worldwide, see Allegrucci et al. (2011; morphology, new species), Wijayawardene et al. (2012, 2016b, 2017; morphology, phylogeny, outline), Kirk et al. (2013; genus accepted), Tangthirasunun et al. (2015; morphology, DNA, phylogeny), Hyde et al. (2016; new species, phylogeny), available specimens and cultures of type: MFLU 13-0264, MFLUCC 12-0310 = ICMP 20052.

Ciliofusospora Bat. \& J.L. Bezerra 1963, Sordariomycetes, genera incertae sedis, one species, type: C. oenocarpi Bat. \& J.L. Bezerra, asexual morph unknown, saprobes, terrestrial, Brazil, see Lumbsch and Huhndorf (2010; outline), Kirk et al. (2013; genus accepted), Maharachchikumbura et al. (2015, 2016; outline), cultures and sequences are unavailable.

Ciliolarina Svrček 1977, Pezizellaceae, Helotiales, Leotiomycetes, one species, type: C. laricina (Raitv.) Svrček, asexual morph hyphomycetous (septonema-like), saprobes, terrestrial, Europe, see Lumbsch and Huhndorf (2010; outline), Filippova (2012; records from west Siberia), Kirk et al. (2013; genus accepted), cultures and sequences are unavailable, needs generic revision.

Ciliophora Petr. 1929, Ascomycota genera incertae sedis, two species, type: C. cryptica Petr. coelomycetous, sexual morph unknown, saprobes, terrestrial, Central America, China, see Wijayawardene et al. (2012, 2017; outline), Kirk et al. (2013; genus accepted), cultures and sequences are unavailable, needs generic revision.

Ciliophorella Petr. 1940, Ascomycota genera incertae sedis, two species, type: C. insignis Petr. coelomycetous, sexual morph unknown, saprobes, terrestrial, Austria, see Wijayawardene et al. (2012, 2017; outline), Kirk et al. (2013; genus accepted), cultures and sequences are unavailable, needs generic revision.

Cilioplea Munk 1953, Dothideomycetes genera incertae sedis, one species, type: C. coronata (Niessl) Munk, asexual morph unknown, saprobes, terrestrial, worldwide, see Lumbsch and Huhndorf (2010; outline, accepted as a genus in Lophiostomataceae), Hyde et al. (2013) did not accept as a genus in Lophiostomataceae, Kirk et al. (2013; genus accepted), Wijayawardene et al. (2014; outline, accepted as a genus in Dothideomycetes, genera incertae sedis), cultures and sequences are unavailable, needs generic revision.

Ciliosporella Petr. 1927, Ascomycota genera incertae sedis, two species, type: C. selenospora Petr., coelomycetous, sexual morph unknown, saprobes, terrestrial, Austria, Australia, see Wijayawardene et al. (2012, 2017; outline), Kirk et al. (2013; genus accepted), cultures and sequences are unavailable, needs generic revision.

Ciposia Marbach 2000, Caliciaceae, Caliciales, Lecanoromycetes, one species, type: $C$. wheeleri (R.C. Harris) Marbach, asexual morph unknown, lichenized, epiphytic, North America, see Lücking et al. (2016b; classification), sequences are unavailable. 
Circinaria Link 1809, Megasporaceae, Pertusariales, Lecanoromycetes, 25 species, type: $C$. contorta (Hoffm.) A. Nordin, Savić \& Tibell, lichenized, see Nordin et al. (2010; phylogeny), Sohrabi et al. (2013a; phylogeny), Lücking et al. (2016b; classification), sequences are available.

Circinoconiopsis A. Hern.-Gut. 2013, Ascomycota genera incertae sedis, one species, type: $C$. amazonica A. Hern. Gut., coelomycetous, sexual morph unknown, saprobes, terrestrial, Brazil, see Hernández-Gutiérrez (2013; morphology), holotype: MG 203121, sequences and cultures unavailable.

Circinoconis Boedijn 1942, Ascomycota genera incertae sedis, one species, type: $C$. paradoxa Boedijn, hyphomycetous, sexual morph unknown, saprobes, terrestrial, East Indies, Australasia, see Seifert et al. (2011; morphology), Wijayawardene et al. (2012, 2017; outline), Kirk et al. (2013; genus accepted), cultures and sequences are unavailable, needs generic revision.

Circinoniesslia Samuels \& M.E. Ban 1997, Niessliaceae, Hypocreales, Sordariomycetes, one species, type: C. nectriae Samuels \& M.E. Barr, asexual morph unknown, saprobes or fungicolous, terrestrial, Puerto Rico, see Lumbsch and Huhndorf (2010; outline), Kirk et al. (2013; genus accepted), Maharachchikumbura et al. (2015, 2016; outline), holotype: BPI, Samuels 8028, cultures and sequences are unavailable, needs generic revision.

Circinotrichum Nees 1816 (= Dephilippia Rambelli 1959; = Gyrocerus Corda, Icon. fung. (Prague) 1: 9 1837; = Gyrotrichum Spreng. 1827 fide Species Fungorum 2017), Ascomycota genera incertae sedis, c. 20 species, type: $C$. maculiforme Nees, hyphomycetous, sexual morph unknown, saprobes, terrestrial, widespread, see Seifert et al. (2011; morphology), Wijayawardene et al. (2012, 2017; outline), Kirk et al. (2013; genus accepted), Crous et al. (2014c; morphology, cultures available for type: CBS 122758, CPC 24566.

Cirrenalia Meyers \& R.T. Moore 1960, Halosphaeriaceae, Microascales, Sordariomycetes, 14 species, type: C. macrocephala (Kohlm.) Meyers \& R.T. Moore, hyphomycetous, sexual morph unknown, saprobes, aquatic, terrestrial, worldwide, see Abdel-Wahab et al. (2010; phylogeny, key), Seifert et al. (2011; morphology), Kirk et al. (2013; genus accepted), Maharachchikumbura et al. (2015, 2016; outline), cultures available MUCL 15736.

Cirrosporium S. Hughes 1980, Eurotiomycetes, genera incertae sedis, one species, type: $C$. novae-zelandiae S. Hughes, coelomycetous, sexual morph unknown, saprobes, terrestrial, New Zealand, see Réblova and Seifert (2012; morphology, phylogeny), Wijayawardene et al. (2012, 2016b, 2017; morphology, phylogeny, outline), Kirk et al. (2013; genus accepted), holotype: PDD 36101, cultures available CBS 123236, ICMP 18891.

Cirsosia G. Arnaud 1918 (= Cirsosiella G. Arnaud 1918 [1917]; = Halbanina G. Arnaud 1918 [1917]; = Lembopodia Bat. 1960; = Morqueria Bat. \& H. Maia 1963 fide Species Fungorum 2017), Asterinaceae, Asterinales, Dothideomycetes, 15 species, type: $C$. manaosensis (Henn.) G. Arnaud, asexual morph coelomycetous (= homalopeltis-like fide Hofmann 2009), epiphytes, terrestrial, worldwide, see Hofmann (2009; review), Lumbsch and Huhndorf (2010; outline), Hyde et al. (2013; accepted as a genus in Asterinaceae), Kirk et al. (2013; genus accepted), Hongsanan et al. (2014c; taxonomy, keys), Wijayawardene et al. (2014c; outline), placement in Asterinaceae supported by morphology, isotype of type: $\mathrm{K}(\mathrm{M})$ 176510 , cultures and sequences are unavailable, needs generic revision.

Cirsosina Bat. \& J.L. Bezerra 1960, Dothideomycetes genera incertae sedis, two species, type: C. rhododendri Bat. \& J.L. Bezerra, asexual morph unknown, saprobes, terrestrial, Europe, Bomeo, see Lumbsch and Huhndorf (2010; outline, accepted as a genus in Microthyriaceae), Kirk et al. (2013; genus accepted), Wijayawardene et al. (2014c; outline), cultures and sequences are unavailable, needs generic revision.

Cirsosiopsis Butin \& Speer 1979, Parmulariaceae, Dothideomycetes families incertae sedis, Dothideomycetes, one species, type: $C$. violacescens Butin \& Speer, asexual morph unknown, 
epiphytes, terrestrial, Brazil, see Hofmann (2009; review, accepted as a genus in Microthyriaceae), Lumbsch and Huhndorf (2010; outline, accepted as a genus in Microthyriaceae), Hyde et al. (2013; did not accepted as a genus in Microthyriaceae), Wijayawardene et al. (2014c; outline, accepted as a genus in Dothideomycetes, genera incertae sedis), Wu et al. (2014; review, transferred to Parmulariaceae) placement in Parmulariaceae supported by morphology, holotype: ZT Myc 4325, cultures and sequences are unavailable, needs generic revision.

Cissococcomyces Brain 1923, Ascomycota genera incertae sedis, one species, type: $C$. natalensis Brain, hyphomycetous, sexual morph unknown, saprobes, terrestrial, South Africa, see Seifert et al. (2011; morphology), Wijayawardene et al. (2012, 2017; outline), cultures and sequences are unavailable, needs generic revision.

Cistella Quél. 1886 (= ?Chimaeroscypha Raitv. 2004; Clavidisculum Kirschst. 1938 fide Jaklitsch et al. 2016a), Hyaloscyphaceae, Helotiales, Leotiomycetes, c. 45 species, type: $C$. dentata (Pers.) Quél., asexual morph unknown, erroneously linked with Phialophora-like anamorph (Cistella rubescens = Hyphodiscus hymeniophilus, saprobes on wood, dead herbaceous stems, fallen leaves, needles and cones, widespread, mainly in temperate zones, see Lumbsch and Huhndorf (2010; outline), Kirk et al. (2013; genus accepted), Han et al. (2014; taxonomy), Baral et al. (2015; taxonomy), cultures and sequences are available, needs generic revision.

Citeromyces Santa María 1957, Saccharomycetaceae, Saccharomycetales, Saccharomycetes, five species, type: $C$. matritensis (Santa María) Santa María, saprobes, terrestrial, worldwide, see Kurtzman (2012; new species), Casaregola et al. (2013; new species), cultures and sequences are available.

Civisubramaniania Vittal \& Dorai 1986, Ascomycota genera incertae sedis, two species, type: C. eucalypti Vittal \& Dorai hyphomycetous, sexual morph unknown, saprobes, terrestrial, India, see Seifert et al. (2011; morphology), Wijayawardene et al. (2012, 2017; outline), holotype: IMI 298300, cultures and sequences are unavailable, needs generic revision.

Cladia Nyl. 1870 (= Clathrina Müll. Arg. 1883 fide Species Fungorum 2017), Cladoniaceae, Lecanorales, Lecanoromycetes, c. 25 species, type: Cladia aggregata (Sw.) Nyl., asexual morph unknown, lichenized, terrestrial, austral or widespred, see Parnmen et al. (2010; generic delimitation), Lumbsch and Huhndorf (2010; outline, accepted as a genus in Lecanoraceae), Lumbsch et al. (2010b; generic delimitation), Kirk et al. (2013; genus accepted), Lücking et al. (2016b; classification), sequences are available.

Cladidium Hafellner 1984 (= Cladodium (Tuck.) Gyeln. 1934; = Lecanora sect. Cladodium Tuck. 1882 fide Species Fungorum 2017), Lecanoraceae, Lecanorales, Lecanoromycetes, one species, type: $C$. thamnitis (Tuck.) Hafellner (= C. bolanderi (Tuck) B.D. Ryan), asexual morph unknown, lichenized, saxicolous, USA, see Lumbsch and Huhndorf (2010; outline), Kirk et al. (2013; genus accepted), Lücking et al. (2016b; classification), sequences are unavailable.

Cladochasiella Marvanová 1997, Hyaloscyphaceae, Helotiales, Leotiomycetes, one species, type: $C$. divergens Marvanová, hyphomycetous, sexual morph unknown, saprobes, aquatic, Czech Republic, see Seifert et al. (2011; morphology), Wijayawardene et al. (2012, 2017; outline), Baschien et al. (2013; phylogeny), Kirk et al. (2013; genus accepted), holotype and ex-type of the type: PRM 842967, CCM F-13489.

Cladoconidium Bandoni \& Tubaki 1985, Ascomycota genera incertae sedis, one species, type: $C$. articulatum Bandoni \& Tubaki, hyphomycetous, sexual morph unknown, saprobes, terrestrial, Japan, Canada, see Seifert et al. (2011; morphology), Wijayawardene et al. (2012, 2017; outline), Kirk et al. (2013; genus accepted), cultures and sequences are unavailable. 
Cladographium Peyronel 1918, Ascomycota genera incertae sedis, one species, type: $C$. rivulorum Peyronel, hyphomycetous, sexual morph unknown, saprobes, terrestrial, Europe, see Seifert et al. (2011; morphology), Wijayawardene et al. (2012, 2017; outline), cultures and sequences are unavailable.

Cladonia P. Browne 1756 (see Species Fugorum 2017 for synonyms), Cladoniaceae, Lecanorales, Lecanoromycetes, c. 550 species, type: C. subulata (L.) F.H. Wigg., asexual morph unknown, lichenized, terricolous or on lignum, worldwide, see Lumbsch and Huhndorf (2010; outline, accepted as a genus in Lecanoraceae), Pino-Bodas et al. (2012; polymorphic species), Ahti and Stenroos (2013; taxonomy), Kirk et al. (2013; genus accepted), Lücking et al. (2016b; classification), sequences are available.

Cladoniicola Diederich, van den Boom \& Aptroot 2001, Pezizomycotina, genera incertae sedis, one species, type: C. staurospora Diederich, van den Boom \& Aptroot, asexual morph unknown, lichenicolous, terrestrial, temperate, see Etayo (2010b; new species), Lumbsch and Huhndorf (2010; outline), Kirk et al. (2013; genus accepted), cultures and sequences are unavailable.

Cladophialophora Borelli 1980, Herpotrichiellaceae, Chaetothyriales, Eurotiomycetes, 35 species, type: C. carrionii (Trejos) de Hoog, Kwon-Chung \& McGinnis, hyphomycetous, mostly terrestrial, but also reported from mangrove environments, mainly saprobes associated with soil and plant material but a few species are lichenicolous, endophytic or plantpathogenic, several species cause infections in animals, including humans, cosmopolitan, although the type species belongs in Herpotrichiellaceae, some species are related to other families of Chaetothyriales, see Crous et al. (2011c, 2013a; new species, pathogenicity to plants), Badali et al. (2008, 2009, 2011; outline, new species), Diederich et al. (2013; lichenicolous species), Feng et al. (2013; new species), Seyedmousavi et al. (2013; pathogenicity to animals), Gueidan et al. (2014a; phylogeny), Madrid et al. (2016; new species, comments about the polyphyly of the genus), Usui et al (2016; new species), ex-type strain of the type: $=$ CBS 160.54 , sequences are available.

Cladoriella Crous 2006, Dothideomycetes genera incertae sedis, three species, type: $C$. eucalypti Crous, hyphomycetous, sexual morph unknown, saprobes or ?pathogens, terrestrial, Australia, South Africa, see Cheewangkoon et al. (2009; morphology, new species, phylogeny), Seifert et al. (2011; morphology), Wijayawardene et al. (2012, 2014c, 2017; outline), holotype and ex-type: CBS H-18043, CPC 10953-10955 = CBS 115898-115890.

Cladorrhinum Sacc. \& Marchal 1885 (= Bahupaathra Subram. \& Lodha 1964 fide Species Fungorum 2017), Lasiosphaeriaceae, Sordariales, Sordariomycetes, eight species, type: $C$. foecundissimum Sacc. \& Marchal, hyphomycetous, sexual morph unknown, saprobes, terrestrial, worldwide, see Madrid et al. (2011a; new species), Seifert et al. (2011; morphology), Wijayawardene et al. (2012, 2017; outline), Carmaran et al. (2015; phylogeny), Maharachchikumbura et al. (2015, 2016; phylogeny, outline), available cultures of type: BCCM 6980.

Cladosphaera Dumort. 1822, Ascomycota genera incertae sedis, one species, type: $C$. cespitosa (Tode) Dumort., asexual morph unknown, saprobes, terrestrial, Europe, see Lumbsch and Huhndorf (2010; outline), Kirk et al. (2013; genus accepted), cultures and sequences are unavailable, needs generic revision.

Cladosporiella Deighton 1965, Ascomycota genera incertae sedis, five species, type: $C$. cercosporicola Deighton, hyphomycetous, sexual morph unknown, saprobes, fungicolous, terrestrial, Africa, Asia, Caribbean, Europe, see Seifert et al. (2011; morphology), Wijayawardene et al. (2012, 2017; outline), Kirk et al. (2013; genus accepted), cultures and sequences are unavailable, needs generic revision.

Cladosporiopsis S.C. Ren \& X.G. Zhang 2012, Ascomycota genera incertae sedis, one species, type: C. ovata S.C. Ren \& X.G. Zhang, hyphomycetous, sexual morph unknown, 
saprobes, fungicolous, terrestrial, China, see Ren et al. (2012a; taxonomy), Wijayawardene et al. (2017; outline), cultures and sequences are unavailable, needs generic revision.

Cladosporium Link 1816 (= Acrosporella Riedl \& Ershad 1977 [1976]; = Azosma Corda 1831; = Davidiella Crous \& U. Braun 2003; = Didymotrichum Bonord. 1851; = Heterosporium Klotzsch ex Cooke 1877; = Hormodendrum Bonord. 1851; = Mydonosporium Corda 1833; = Myxocladium Corda 1837; = Polyrhizium Giard 1889; = Spadicesporium V.N. Boriss. \& Dvoïnos 1982; = Sporocladium Chevall. 1826 fide Wijayawardene et al. 2014c; Rossman et al. 2015b; Species Fungorum 2017), Cladosporiaceae, Capnodiales, Dothideomycetes, c. 300 species, type: C. herbarum (Pers.) Link, hyphomycetous, sexual morph formerly known in Davidiella, saprobes, endophytes, animal, human and plant pathogens, worldwiede, see Seifert et al. (2011; morphology), Bensch et al. (2012, 2015; phylogeny, taxonomy), Wijayawardene et al. (2012, 2014c, 2017; outline), Hyde et al. (2013; accepted as a genus in Cladosporiaceae), Sandoval-Denis et al. (2015b; clinical), lectotype of type: Sine loco, sine dato (L 910.225-733), epitype: CBS-H 19853; ex epitype culture, CBS 121621.

Clandestinotrema Rivas Plata, Lücking \& Lumbsch 2012, Graphidaceae, Ostropales, Lecanoromycetes, 17 species, type: C. clandestinum (Ach.) Rivas Plata, Lücking \& Lumbsch, lichenized, see Rivas Plata et al. (2012a; taxonomy), Lumbsch et al. (2014a, b; phylogeny), Lücking et al. (2016b; classification), sequences are available.

Clasteropycnis Bat. \& Cavalc. 1963, Ascomycota genera incertae sedis, one species, type: $C$. coumae Bat. \& Cavalc., sexual morph unknown, saprobes, terrestrial, Brazil, see Wijayawardene et al. (2012, 2017; outline), Kirk et al. (2013; genus accepted), cultures and sequences are unavailable, needs generic revision.

Clasterosphaeria Sivan. 1984, Magnaporthaceae, Magnaporthales, Sordariomycetes, two species, type: C. cyperi Sivan., asexual morph clasterosporium-like, saprobes, terrestrial, India, Malayasia, see Lumbsch and Huhndorf (2010; outline), Kirk et al. (2013; genus accepted), Maharachchikumbura et al. (2015, 2016; outline), holotype: IMI 56878, cultures and sequences are unavailable, needs generic revision.

Clasterosporium Schwein. 1832 (= Apotemnoum Corda 1833; = Brachydesmium (Sacc.) Costantin 1888; = Cheiropodium Syd. \& P. Syd. 1915; = Clasterosporium sect. Brachydesmium Sacc. 1886; = Cometella Schwein. ex Fr. 1849; = Hymenopodium Corda 1837; = Phanerocoryneum Höhn. 1923; = Sporhelminthium Speg. 1918 fide Species Fungorum 2017), Magnaporthaceae, Magnaporthales, Sordariomycetes, ten species, type: $C$. caricinum Schwein., sexual morph ?clasterosphaeria-like, saprobes, terrestrial, worldwide, see Maharachchikumbura et al. (2015, 2016; outline), cultures and sequences are unavailable, needs generic revision, sexual-asexual link was not confirmed.

Clathroconium Samson \& H.C. Evans 1982, Ascomycota genera incertae sedis, one species, type: C. arachnicola Samson \& H.C. Evans, hyphomycetous, sexual morph unknown, entemopathogens, terrestrial, Brazil, see Seifert et al. (2011; morphology), Wijayawardene et al. (2012, 2017; outline), cultures and sequences are unavailable, needs generic revision.

Clathroporina Müll. Arg. 1882, Porinaceae, Ostropales, Lecanoromycetes, 25 species, type: C. endochrysea (C. Bab.) Müll. Arg., lichenized, see Lumbsch and Huhndorf (2010; outline), Lücking et al. (2016b; classification), sequences are available.

Clathrosphaerina Beverw. 1951, Hyaloscyphaceae, Helotiales, Leotiomycetes, one species, type: C. zalewskii Beverw., sexual morph unknown, saprobes, terrestrial, Europe, see Seifert et al. (2011; morphology), Wijayawardene et al. (2012, 2017; outline), Kirk et al. (2013; genus accepted), cultures and sequences are unavailable, needs generic revision.

Clathrospora Rabenh. 1857, Pleosporaceae, Pleosporales, Dothideomycetes, more than 40 species, type: $C$. elynae Rabenh., asexual morph unknown, saprobes, worldwide, see Lumbsch and Huhndorf (2010; outline), Kirk et al. (2013; genus accepted), Ariyawansa et al. 
(2015c; morphology, accepted as Pleosporaceae), sequences are available, type sequence data are available: CBS 161.51; CBS 196.54, needs generic revision.

Clathrosporium Nawawi \& Kuthub. 1987, Helotiales genera incertae sedis, Leotiomycetes, one species, type: $C$. intricatum Nawawi \& Kuthub., sexual morph unknown, saprobes, aeroaquatic, Malaysia, see Seifert et al. (2011; morphology), Wijayawardene et al. (2012, 2017; outline), Kirk et al. (2013; genus accepted), cultures and sequences are available, needs generic revision.

Claurouxia D. Hawksw. 1988 (= Pseudolecidea Clauzade \& Cl. Roux 1984 [1983] fide Species Fungorum 2017), Lecanoraceae, Lecanorales, Lecanoromycetes, one species, type: C. chalybeioides (Nyl.) D. Hawksw., asexual morph unknown, lichenized, saxicolous, Europe, North America, see Gilbert and Hawksworth (2009; taxonomy), Lumbsch and Huhndorf (2010; outline), Kirk et al. (2013; genus accepted), Lücking et al. (2016b; classification), sequences are unavailable.

Claussenomyces Kirschst. 1923 (= Corynella Boud. 1885; = Dendrostilbella Höhn. 1905 fide Johnston et al. 2014b; Species Fungorum 2017), Tympanidaceae, Phacidiales, Leotiomycetes, 19 species, type: $C$. jahnianus Kirschst., asexual morph formerly known in Dendrostilbella, saprobes, worldwide, see Lumbsch and Huhndorf (2010; outline), Wijayawardene et al. (2012; outline and asexual morph), Kirk et al. (2013; genus accepted), Johnston et al. (2014b; nomenclature), sequence data are available for unidentified Claussenomyces species.

Clauzadea Hafellner \& Bellem. 1984, Lecideaceae, Lecideales, Lecanoromycetes, five species, type: C. monticola (Ach.) Hafellner \& Bellem., asexual morph unknown, lichenized, saxicolous, widespread, see Lumbsch and Huhndorf (2010; outline), Schmull et al. (2011; taxonomy), Kirk et al. (2013; genus accepted), Lücking et al. (2016b; classification), sequences are available.

Clauzadeana Cl. Roux 1984, Lecanoraceae, Lecanorales, Lecanoromycetes, one species, type: C. instratula (Nyl.) Cl. Roux, asexual morph unknown, lichenized, saxicolous, Asia, Europe, North America, see Lumbsch and Huhndorf (2010; outline), Kirk et al. (2013; genus accepted), Lücking et al. (2016b; classification), sequences are unavailable.

Clauzadella Nav.-Ros. \& Cl. Roux 1996, Verrucariaceae, Verrucariales, Eurotiomycetes, one species, type: C. gordensis Nav.-Ros. \& Cl. Roux, asexual morph unknown, terrestrial, lichenized, on Verrucaria viridula (Schrad.) Ach., France, see Lumbsch and Huhndorf (2010; outline), Kirk et al. (2013; genus accepted), Lücking et al. (2016b; classification), cultures and sequences are unavailable, needs generic revision.

Clauzadeomyces Diederich 1994, Ascomycota genera incertae sedis, one species, type: $C$. verrucosus Diederich, hyphomycetous, sexual morph unknown, lichenicolous, non-lichenized, terrestrial, Belgium (Ardennes), see Seifert et al. (2011; morphology), Wijayawardene et al. (2012, 2017; outline), holotype of the type: LG, Lambinon, 22 Aug. 1965, cultures and sequences are unavailable, needs generic revision.

Clavariana Nawawi 1976, Ascomycota genera incertae sedis, one species, type: C. aquatica Nawawi, hyphomycetous, sexual morph unknown, in river foam, Asia, see Seifert et al. (2011; morphology), Wijayawardene et al. (2012, 2017; outline), cultures and sequences are unavailable, needs generic revision.

Clavascidium Breuss 1996, Verrucariaceae, Verrucariales, Eurotiomycetes, eight species, type species: C. umbrinum (Breuss) Breuss, asexual morph coelomycetous, terrestrial, lichenized, occurring on soil, rocks and mosses, America, Asia, Europe, see Gueidan et al. (2009; phylogeny, proposal to synonymize Clavascidium with Placidium A. Massal.), Prieto et al. (2010b, 2012; morphology, reinstatement of Clavascidium as a distinct genus), sequences of the type material of the type species are unavailable, but sequences of non-type material are available. 
Clavatispora Boonmee \& K.D. Hyde 2014, Venturiales genera incertae sedis, Dothideomycetes, one species, type: $C$. thailandica Boonmee \& K.D. Hyde, asexual morph hyphomycetous, saprobes, terrestrial, Thailand, see Boonmee et al. (2014a; taxonomy), sequence data available, holotype and ex-type: MFLU 10-0038, MFLUCC 10-0107 = BCC $38863=$ IFRD 2170.

Clavatisporella K.D. Hyde 1995, Magnaporthaceae, Magnaporthales, Sordariomycetes, one species, type: C. musicola K.D. Hyde, asexual morph unknown, saprobes, Irian Jaya (Papua), see Lumbsch and Huhndorf (2010; outline), Kirk et al. (2013; genus accepted), Maharachchikumbura et al. (2016; outline), holotype: BRIP 22403, cultures and sequences are unavailable, needs generic revision.

Clavatospora Sv. Nilsson ex Marvanová \& Sv Nilsson 1971 (= Clavatospora Sv. Nilsson 1933 fide Species Fungorum 2017), Halosphaeriaceae, Microascales, Sordariomycetes, three species, type: C. longibrachiata (Ingold) Sv. Nilsson ex Marvanová \& Sv. Nilsson, hyphomycetous, sexual morph corollospora-like, saprobes, aquatic, worldwide, see Seifert et al. (2011; morphology), Wijayawardene et al. (2012, 2017; outline), Kirk et al. (2013; genus accepted), Maharachchikumbura et al. (2015, 2016; outline), needs revision since genus shown to be polyphyletic, reference cultures of type: UMB-1109.13.

Claviceps Tul. 1853 (= Sphacelia Lév. 1827; = Ustilagopsis Speg. 1880 fide Rossman et al. 2016a), Clavicipitaceae, Hypocreales, Sordariomycetes, 56 species, type: C. purpurea (Fr.) Tul., asexual morph unknown, saprobes, terrestrial, worldwide, see Lumbsch and Huhndorf (2010; outline), Pažoutová et al. (2008, 2011, 2015; new species), Kirk et al. (2013; genus accepted), Kolařík (2015; new species), Maharachchikumbura et al. (2015, 2016; outline), Rossman et al. (2016a; nomenclature), cultures and sequences are available.

Claviradulomyces P.R. Johnst., D.C. Park, H.C. Evans, R.W. Barreto \& D.J. Soares 2010, Odontotremataceae, Ostropales, Lecanoromycetes, two species, type: C. dabeicola P.R. Johnst., D.C. Park, H.C. Evans, R.W. Barreto \& D.J. Soares, asexual morph (putative) pycnidial on branches of vascular plants, Africa, South America, see Evans et al. (2010; taxonomy), Barreto et al. (2012; phylogeny), cultures and sequences are available.

Clavispora Rodrigues de Miranda 1979, Metschnikowiaceae, Saccharomycetales, Saccharomycetes, 20 species, type: C. lusitaniae Rodrigues de Miranda, asexual reproduction by budding, saprophytic, from cacti, agave, processed dates and other high osmotic environments, occasionally an opportunistic human pathogen, worldwide, see Lumbsch and Huhndorf (2010; outline), Kirk et al. (2013; genus accepted), cultures and sequences are available.

Cleistocystis Sousa da Câmara 1931, Ascomycota genera incertae sedis, one species, type: $C$. rosarum Sousa da Câmara, coelomycetous, sexual morph unknown, saprobes, terrestrial, Portugal, see Wijayawardene et al. (2012, 2017; outline), Kirk et al. (2013; genus accepted), cultures and sequences are unavailable, needs generic revision.

Cleistoiodophanus J.L. Bezerra \& Kimbr. 1976, Pezizaceae, Pezizales, Pezizomycetes, one species, type: C. conglutinatus J.L. Bezerra \& Kimbr., asexual morph unknown, saprobes, terrestrial, USA, see Lumbsch and Huhndorf (2010; outline), Kirk et al. (2013; genus accepted), Jaklitsch et al. (2016a; classification), cultures and sequences are unavailable.

Cleistonium Speer 1986, Ascomycota genera incertae sedis, one species, type: C. parasiticum Speer, coelomycetous, sexual morph unknown, saprobes, terrestrial, Brazil, see Wijayawardene et al. (2012, 2014c) accepted as a genus in Gloniaceae, Kirk et al. (2013; genus accepted), Wijayawardene et al. (2017; outline, accepted as Ascomycota genera incertae sedis), cultures and sequences are unavailable, needs generic revision.

Cleistophoma Petr. \& Syd. 1927, Ascomycota genera incertae sedis, two species, type: $C$. suberis (Prill. \& Delacr.) Petr. \& Syd., coelomycetous, sexual morph unknown, saprobes, 
terrestrial, North America, Europe, see Wijayawardene et al. (2012, 2017; outline), Kirk et al. (2013; genus accepted), cultures and sequences are unavailable, needs generic revision.

Cleistosphaera Syd. \& P. Syd. 1916, Perisporiopsidaceae, Dothideomycetes family incertae sedis, one species, type: C. macrostegia Syd. \& P. Syd., asexual morph unknown, saprobes, terrestrial, S. America, see Lumbsch and Huhndorf (2010; outline), Kirk et al. (2013; genus accepted), Hyde et al. (2013; accepted as in Perisporiopsidaceae, key), Wijayawardene et al. (2014c; outline), cultures and sequences are unavailable, needs generic revision.

Cleistothelebolus Malloch \& Cain 1971, Thelebolaceae, Thelebolales, Pezizomycetes, one species, type: $C$. nipigonensis Malloch \& Cain, asexual morph unknown, coprophilous, terrestrial, Canada, see Lumbsch and Huhndorf (2010; outline), Kirk et al. (2013; genus accepted), cultures and sequences are available.

Clematidis Tibpromma, Camporesi \& K.D. Hyde 2016, Pleosporales genera incertae sedis, Dothideomycetes, one species, type: C. italica Tibpromma, Camporesi \& K.D. Hyde, asexual morph unknown, saprobes, terrestrial, Italy, see Li et al. (2016a; taxonomy, phylogeny), holotype and ex-type: MFLU 14-0669, MFLUCC 15-0084.

Clematomyces Thaxt. 1900, Laboulbeniaceae, Laboulbeniales, Laboulbeniomycetes, five species, type: $C$. pinophili Thaxt., asexual morph unknown, biotrophic, Asia, West Africa, see Lumbsch and Huhndorf (2010; outline), Kirk et al. (2013; genus accepted), cultures and sequences are unavailable.

Clibanites (P. Karst.) P. Karst. 1871, Bionectriaceae, Hypocreales, Sordariomycetes, one species, type: C. paradoxa (P. Karst.) P. Karst., asexual morph unknown, saprobes on wood, Finland, see Lumbsch and Huhndorf (2010; outline), Kirk et al. (2013; genus accepted), Maharachchikumbura et al. (2015, 2016; outline), cultures and sequences are unavailable, needs generic revision, holotype in $\mathrm{H}$.

Cliostomum Fr. 1825, Ramalinaceae, Lecanorales, Lecanoromycetes, c. 25 species, type: $C$. corrugatum (Ach.) Fr., asexual morph unknown, lichenized, epiphytic, world-wide, see Lumbsch and Huhndorf (2010; outline), Kirk et al. (2013; genus accepted), Printzen (2014; phylogeny and relationships), Lücking et al. (2016b; classification), sequences are available.

Clohesyomyces K.D. Hyde 1993, Lindgomycetaceae, Pleosporales, Dothideomycetes, one species, type: C. aquaticus K.D. Hyde, coelomycetous, sexual morph unknown, saprobes, aquatic, Australia, see Zhang et al. (2012a; new species, phylogeny), Kirk et al. (2013; genus accepted), Wijayawardene et al. (2017; outline), holotype: BRIP 20092, cultures and sequences are available, needs generic revision.

Clohiesia K.D. Hyde 1995, Annulatascaceae, Annulatascales, Sordariomycetes, three species, type: C. corticola K.D. Hyde, sexual morph unknown, saprobes, terrestrial, China, Australia, see umbsch and Huhndorf (2010; outline), Kirk et al. (2013; genus accepted), Maharachchikumbura et al. (2015, 2016; outline), holotype: BRIP 21485, cultures available for Clohiesia corticola HKUCC 3712.

Clonophoromyces Thaxt. 1931, Laboulbeniaceae, Laboulbeniales, Laboulbeniomycetes, two species, type: $C$. grenadinus Thaxt., asexual morph unknown, biotrophic, West Indies, Japan, see Lumbsch and Huhndorf (2010; outline), Kirk et al. (2013; genus accepted), Haelewaters et al. (2015c; notes), cultures and sequences are unavailable.

Clonostachys Corda 1839 (= Bionectria Speg. 1919 fide Rossman et al. 2013b), Bionectriaceae, Hypocreales, Sordariomycetes, c. 50 species, type: C. araucaria Corda, hyphomycetous, sexual morph formerly known in Bionectria, on soil, saprobes, terrestrial, cosmopolitan, see Seifert et al. (2011; morphology), Wijayawardene et al. (2012, 2017; outline), Kirk et al. (2013; genus accepted), Lombard et al. (2015b; phylogeny, new species), Maharachchikumbura et al. $(2015,2016)$, cultures and sequences are available.

Clypeispora A.W. Ramaley 1991, Ascomycota genera incertae sedis, one species, type: $C$. angustifoliorum A.W. Ramaley, coelomycetous, sexual morph unknown, saprobes, terrestrial, 
USA, see Kirk et al. (2013; genus accepted),Wijayawardene et al. (2017; outline), holotype: BPI 1102631, cultures and sequences are unavailable, needs generic revision.

Clypeoceriospora Sousa da Câmara 1946, Sordariomycetes genera incertae sedis, one species, type: C. rubi Sousa da Câmara, asexual morph unknown, saprobes, terrestrial, Europe, see Lumbsch and Huhndorf (2010; outline), Kirk et al. (2013; genus accepted), Maharachchikumbura et al. (2015, 2016; outline), cultures and sequences are unavailable, needs generic revision.

Clypeochorella Petr. 1923, Ascomycota genera incertae sedis, one species, type: $C$. orientalis (Sacc. \& Penz.) Petr., coelomycetous, sexual morph unknown, saprobes, terrestrial, Europe, see Wijayawardene et al. (2012, 2017; outline), Kirk et al. (2013; genus accepted), cultures and sequences are unavailable, needs generic revision.

Clypeococcum D. Hawksw. 1977, Polycoccaceae, Trypetheliales, Dothideomycetes, eleven species, type: C. cladonema (Wedd.) D. Hawksw., on lichens, widespread, see Lumbsch and Huhndorf (2010; outline), Hyde et al. (2013; accepted as a genus in Dacampicaeae), Kirk et al. (2013; genus accepted), Wijayawardene et al. (2014c; outline), Ertz et al. (2015a; sequences two species, but not the type species), Jaklitsch et al. (2016a; accepted as a genus in Dacampicaeae), holotype of type: PC.

Clypeoloculus Kaz. Tanaka \& K. Hiray. 2015, Morosphaeriaceae, Pleosporales, Dothideomycetes, four species, type: $C$. akitaensis Kaz. Tanaka \& K. Hiray., asexual morph unknown, saprobes, aquatic, Japan, see Tanaka et al. (2015; morphology, phylogeny), holotype and ex-type: HHUF 27557, CBS 139681.

Clypeolum Speg. 1881, Ascomycota genera incertae sedis, eight species, type: $C$. atroareolatum Speg., asexual morph unknown, saprobes, terrestrial, tropical, see Lumbsch and Huhndorf (2010; outline), Kirk et al. (2013; genus accepted), cultures and sequences are unavailable, needs generic revision.

Clypeopatella Petr. 1942, Ascomycota genera incertae sedis, one species, type: $C$. cylindrospora Petr., coelomycetous, sexual morph unknown, saprobes, terrestrial, Rhodes, see Wijayawardene et al. (2012, 2017; outline), Kirk et al. (2013; genus accepted), cultures and sequences are unavailable, needs generic revision.

Clypeophialophora Bat. \& Peres 1962, Ascomycota genera incertae sedis, one species, type: C. erythroxyli Bat. \& Peres, coelomycetous, sexual morph unknown, saprobes, terrestrial, Brazil, see Wijayawardene et al. (2012, 2017; outline), Kirk et al. (2013; genus accepted), cultures and sequences are unavailable, needs generic revision.

Clypeoporthe Höhn. 1919, Gnomoniaceae, Diaporthales, Sordariomycetes, four species, type: C. monocarpa Höhn., asexual morphs unknown, saprobes, terrestrial, tropical, see Lumbsch and Huhndorf (2010; outline), Kirk et al. (2013; genus accepted), Maharachchikumbura et al. (2015, 2016; outline), cultures and sequences are unavailable, needs generic revision.

Clypeoporthella Petr. 1924, Diaporthaceae, Diaporthales, Sordariomycetes, four species, type: C. brencklei Petr., asexual morphs unknown, saprobes, terrestrial, Europe, North America, see Lumbsch and Huhndorf (2010; outline), Kirk et al. (2013; genus accepted), Maharachchikumbura et al. (2015, 2016; outline), cultures and sequences are unavailable, needs generic revision.

Clypeopycnis Petr. 1925, Ascomycota genera incertae sedis, three species, type: $C$. aeruginascens Petr., coelomycetous, sexual morph unknown, saprobes, terrestrial, worldwide, see Wijayawardene et al. (2012, 2017; outline), Kirk et al. (2013; genus accepted), cultures and sequences are unavailable, needs generic revision.

Clypeopyrenis Aptroot 1991, Pyrenulaceae, Pyrenulales, Eurotiomycetes, two species, type: C. microsperma (Müll. Arg.) Aptroot, asexual morph unknown, lichenized, terrestrial, tropical, see Lumbsch and Huhndorf (2010; outline), Kirk et al. (2013; genus accepted), Lücking et al. (2016b; classification), cultures and sequences are unavailable. 
Clypeoseptoria F. Stevens \& P.A. Young 1925, Ascomycota genera incertae sedis, three species, type: C. rockii F. Stevens \& P.A. Young, coelomycetous, sexual morph unknown, saprobes, terrestrial, Hawaii, Brazil, see Wijayawardene et al. (2012, 2017; outline), Kirk et al. (2013; genus accepted), cultures and sequences are unavailable, needs generic revision.

Clypeosphaerella Guatimosim, R.W. Barreto \& Crous 2016, Mycosphaerellaceae, Capnodiales, Dothideomycetes, two species, type: C. quasiparkii (Cheew., K.D. Hyde \& Crous) Guatimosim, R.W. Barreto \& Crous, asexual morph unknown, plant pathogenic, see Guatimosim et al. (2016a; morphology, phylogeny), holotype CBS H-22088, isotype VIC 42607, culture ex-type CPC 24705.

Clypeosphaeria Fuckel 1870, Xylariaceae, Xylariales, Sordariomycetes, c. 30 species, type: C. notarisii Fuckel, asexual morph unknown, saprobes (dead wood and bark), terrestrial, widespread, see Lumbsch and hunduf (2010; outline), Kirk et al. (2013; genus accepted), Maharachchikumbura et al. (2015, 2016; outline), cultures and sequences are unavailable for type species, needs generic revision.

Clypeosphaerulina Sousa da Câmara 1939, Sordariomycetes genera incertae sedis, one species, type: C. vincae (Sousa da Câmara) Sousa da Câmara, asexual morph unknown, saprobes, terrestrial, Portugal, see Lumbsch and Huhndorf (2010; outline), Kirk et al. (2013; genus accepted), Maharachchikumbura et al. (2015, 2016; outline), cultures and sequences are unavailable, needs generic revision.

Clypeostagonospora Punith. 1981, Ascomycota genera incertae sedis, one species, type: $C$. muhlenbergiae Punith., coelomycetous, sexual morph unknown, saprobes, terrestrial, USA, see Wijayawardene et al. (2012, 2017; outline), Kirk et al. (2013; genus accepted), cultures and sequences are unavailable, needs generic revision.

Clypeostroma Theiss. \& Syd. 1914, Dothideomycetes genera incertae sedis, two species, type: C. spilomeum (Berk.) Theiss. \& Syd., asexual morph unknown, saprobes, Australasia, see Kirk et al. (2013; genus accepted), Wijayawardene et al. (2014c; outline), cultures and sequences are unavailable, needs generic revision.

Coccidiascus Chatton emend. Lushbaugh, Rowton \& McGhee 1976, Saccharomycetales genera incertae sedis, Saccharomycetes, one species, type: C. legeri Chatton, asexual reproduction by budding, perhaps parasitic on Drosophila spp., found within the intestinal epithelial cells of Drosophila, possibly worldwide, see Lumbsch and Huhndorf (2010; outline), Kirk et al. (2013; genus accepted), cultures and sequences are unavailable, needs generic revision.

Coccidioides G.W. Stiles 1896, Onygenaceae, Onygenales, Eurotiomycetes, two species, type: C. immitis G.W. Stiles, sexual morph unknown, saprobes, terrestrial, southern USA, see Seifert et al. (2011; morphology), Wijayawardene et al. (2012, 2017; outline), Kirk et al. (2013; genus accepted), cultures and sequences are available.

Coccidomyces Buchner 1912, Saccharomycetidae genera incertae sedis, Saccharomycetes, one species, type: $C$. pierantonii Buchner, asexual morphs unknown, in insects, terrestrial, Germany, see Kirk et al. (2013; genus accepted), cultures and sequences are unavailable, needs generic revision.

Coccinonectria L. Lombard \& Crous 2015, Nectriaceae, Hypocreales, Sordariomycetes, two species, type: C. pachysandricola (B.O. Dodge) L. Lombard \& Crous, asexual morph hyphomyctous, saprobes, France, USA, see Lombard et al. (2015b; morphology, phylogeny), Maharachchikumbura et al. (2015, 2016; outline), available cultures of the type: CBS 501.63 476.92

Cocciscia Norman 1870, Dothideomycetes genera incertae sedis, two species, type: $C$. hammeri Norman, asexual morph unknown, saprobes, Scandinavia, see Lumbsch and Huhndorf (2010; outline, accepted as a genus in Dacampiaceae), Kirk et al. (2013; genus 
accepted), Wijayawardene et al. (2014c; outline), cultures and sequences are unavailable, needs generic revision.

Coccocarpia Pers. 1827, Coccocarpiaceae, Peltigerales, Lecanoromycetes, c. 25 species, type: C. molybdaea Pers., asexual morph unknown, lichenized, epiphytic or epiphyllous, worldwide tropical-subtropical, see Wedin et al. (2009b; systematics), Lumbsch and Huhndorf (2010; outline), Kirk et al. (2013; genus accepted), Lücking et al. (2016b; classification), sequences are available.

Coccochora Höhn. 1909, Dothideomycetes genera incertae sedis, one species, type: C. quercicola (Henn.) Höhn., asexual morph unknown, saprobes, Asia, see Lumbsch and Huhndorf (2010; outline), Kirk et al. (2013; genus accepted), Wijayawardene et al. (2014c; outline), cultures and sequences are unavailable, needs generic revision.

Coccochorina Hara 1927, Dothideomycetes genera incertae sedis, two species, type: need typification, asexual morph unknown, saprobes, terrestrial, see Kirk et al. (2008; treated as a synonym of Clypeosphaeria), Lumbsch and Huhndorf (2010; outline), Kirk et al. (2013; did not list), Wijayawardene et al. (2014c; outline), sequences are unavailable, needs generic revision.

Coccodiella Hara 1910, Phyllachoraceae, Phyllachorales, Sordariomycetes, 21 species, type: $C$. arundinariae Hara, asexual morph unknown, biotrophic, tropical, see Lumbsch and Huhndorf (2010; outline), Kirk et al. (2013; genus accepted), Maharachchikumbura et al. (2015, 2016; outline, phylogeny), cultures available for C. melastomatum CMU78543, $C$. miconiae ppMP 1342.

Coccodinium A. Massal. 1860, Coccodiniaceae, Chaetothyriales, Eurotiomycetes, two species, type: C. bartschii A. Massal., asexual morph unknown, saprobes, Europe, see Lumbsch and Huhndorf (2010; outline), Kirk et al. (2013; genus accepted), Hyde et al. (2013; accepted as a genus in Coccodiniaceae; excluded family from Dothideomycetes), Jaklitsch et al. (2016a; classification), cultures and sequences are unavailable, needs generic revision.

Coccodothis Theiss. \& Syd. 1914, Dothideomycetes genera incertae sedis, one species, type: C. sphaeroidea (Cooke) Theiss. \& Syd., asexual morph unknown. Epiphytes, terrestrial, Georgia, see Hofmann (2009; review, accepted as a genus in Parmulariaceae), Lumbsch and Huhndorf (2010; outline, accepted as a genus in Parmulariaceae), Hyde et al. (2013; excluded from Parmulariaceae), Wijayawardene et al. (2014c; outline, accepted as a genus in Dothideomycetes, genera incertae sedis), cultures and sequences are unavailable.

Coccogloeum Petr. 1955, Ascomycota genera incertae sedis, one species, type: $C$. microsporum Petr., coelomycetous, sexual morph unknown, saprobes, terrestrial, USA, see Wijayawardene et al. (2012, 2017; outline), Kirk et al. (2013; genus accepted), cultures and sequences are unavailable, needs generic revision.

Coccoidea Henn. 1900, Coccoideaceae, Dothideomycetes families incertae sedis, two species, type: C. quercicola Henn. \& Shirai, asexual morph unknown, saprobes, Japan, India, Central America, see Lumbsch and Huhndorf (2010; outline), Kirk et al. (2013; genus accepted), Hyde et al. (2013; accepted as a genus in Coccoideaceae, morphology), cultures and sequences are unavailable, needs generic revision.

Coccoidella Höhn. 1909, Coccoideaceae, Dothideomycetes families incertae sedis, seven species, type: C. scutula (Berk. \& M.A. Curtis) Höhn., asexual morph unknown, saprobes, America, Australia, see Lumbsch and Huhndorf (2010; outline), Kirk et al. (2013; genus accepted), Hyde et al. (2013; accepted as a genus in Coccoideaceae), cultures and sequences are unavailable, needs generic revision.

Coccomyces De Not. 1847, Rhytismataceae, Rhytismatales, Leotiomycetes, 118 species, type: C. coronatus (Schumach.) De Not., asexual morph unknown, pathogens, worldwide, see Marincowitz et al. (2008; new species, morphology), Jia et al. (2011; new species, morphology), Li et al. (2014c, 2015b; new species, morphology), Moreno-Rico et al. (2014; 
new species, morphology), Wang et al. (2014c; new species, morphology), sequences are available for $C$. dentatus and $C$. strob, needs generic revision.

Coccomycetella Höhn 1917, Odontotremataceae, Ostropales, Lecanoromycetes, one species, type: C. belonospora (Nyl.) Höhn, asexual morph unknown, epixylic, Europe, North America, see Lumbsch and Huhndorf (2010; outline), Baloch et al. (2013; systematics), Kirk et al. (2013; genus accepted), Jaklitsch et al. (2016a; classification), sequences are available.

Cocconia Sacc. 1889, Parmulariaceae, Dothideomycetes families incertae sedis, Dothideomycetes, c 25 species, type: C. placenta (Berk. \& Broome) Sacc., asexual morph unknown, epiphytes, terrestrial, worldwide, see Hofmann (2009; review), Lumbsch and Huhndorf (2010; outline), Hyde et al. (2013; accepted as a genus in Parmulariaceae), Wijayawardene et al. (2014c; outline), Jayasiri et al. (2015; re-visited), placement in Parmulariaceae supported by morphology, unknown, cultures are sequences unavailable.

Coccostromella Petr. 1968, Botryosphaeriaceae, Botryosphaeriales, Dothideomycetes, one species, type: C. puttemansii (Henn.) Petr., asexual morph unknown, saprobes, terrestrial, tropical, see Lumbsch and Huhndorf (2010; outline, accepted as Dothideaceae), Hyde et al. (2013; accepted as a genus in Dothideaceae), Thambugala et al. (2014a; excluded from Dothideaceae and placed Botryosphaeriaceae), Wijayawardene et al. (2014c; outline, taxonomy), cultures and sequences are unavailable, needs generic revision.

Coccotrema Müll. Arg. 1888, Coccotremataceae, Pertusariales, Lecanoromycetes, 16 species, type: C. antarcticum Müll.Arg., asexual morph unknown, lichenized, terricolous, saxicolous or epiphytic, world-wide in arctic and subantarctic areas, see Lumbsch and Huhndorf (2010), Kirk et al. (2013; genus accepted), Lücking et al. (2016b; classification), sequences are available

Cochliomyces Speg. 1912, Euceratomycetaceae, Laboulbeniales, Laboulbeniomycetes, two species, type: $C$. argentinensis Speg., asexual morph unknown, biotrophic, Central and South America, see Lumbsch and Huhndorf (2010; outline), Kirk et al. (2013; genus accepted), cultures and sequences are unavailable.

Cocoicola K.D. Hyde 1995, Phaeochoraceae, Phyllachorales, Sordariomycetes, five species, type: C. cylindrospora (C. Booth \& D.E. Shaw) K.D. Hyde, saprobes, worldwide, see Lumbsch and Huhndorf (2010), Kirk et al. (2013; genus accepted), cultures and sequences are unavailable, needs generic revision.

Codinaea Maire 1937, Chaetosphaeriaceae, Chaetosphaeriales, Sordariomycetes, c. 80 species, type: C. monocarpa Höhn., hyphomycetous, sexual morphs unknown, saprobes, terrestrial, tropical, see Seifert et al. (2011; morphology), Wijayawardene et al. (2012, 2017; outline), Kirk et al. (2013; genus accepted), Almeida et al. (2014c; new species, Brazil), Crous et al. (2014d, 2015d; new species), Granados et al. (2014; new species, Costa Rica), Maharachchikumbura et al. (2015, 2016; outline), Xia et al. (2015a; new species, China), Barbosa et al. (2016; new species, Brazil), Oliveira et al. (2016b; new species, Brazil, aquatic), cultures and sequences are available.

Codonmyces Calatayud \& Etayo 1999, Ascomycota genera incertae sedis, one species, type: C. lecanorae Calat. \& Etayo, hyphomycetous, sexual morph unknown, lichenicolous, terrestrial, Spain, see Seifert et al. (2011; morphology), Wijayawardene et al. (2012, 2017; outline), Kirk et al. (2013; genus accepted), holotype: VAB (lich.) 15404, cultures and sequences are unavailable, needs generic revision.

Coelodictyosporium Thambugala \& K.D. Hyde 2015, Lophiostomataceae, Pleosporales, Dothideomycetes, two species, type: $C$. pseudodictyosporium (Qing Tian, Camporesi \& K.D. Hyde) Thambugala \& K.D. Hyde, asexual morph coelomycetous, saprobes, terrestrial, Italy, all species has sequence data, see Thambugala et al. (2015b; phylogeny), Wijayawardene et al. (2016b; morphology, phylogeny), holotype: MFLU 14-0737, ex-type strains of type: MFLUCC 13-0451. 
Coelopogon Brusse \& Kärnefelt 1991, Parmeliaceae, Lecanorales, Lecanoromycetes, two species, type: $C$. abraxas Brusse, lichenized, south temperate, see Lumbsch and Huhndorf (2010; outline), Kirk et al. (2013; genus accepted), Lücking et al. (2016b; classification), sequences are available.

Coenogonium Ehrenb. ex Nees 1820, Coenogoniaceae, Ostropales, Lecanoromycetes, 90 species, type: $C$. linkii Ehrenb., lichenized, see Baloch et al. (2010; taxonomy), Lumbsch and Huhndorf (2010; outline), Schmull et al. (2011; DNA), Kirk et al. (2013; genus accepted), Lücking et al. (2016b; classification), sequences are available.

Colemaniella Agnihothr. 1974, Ascomycota genera incertae sedis, one species, type: C. ossoorii Agnihothr., hyphomycetous, sexual morph unknown, saprobes, terrestrial, India, see Seifert et al. (2011; morphology), Wijayawardene et al. (2012, 2017; outline), Kirk et al. (2013; genus accepted), cultures and sequences are unavailable, needs generic revision.

Colensoniella Hafellner 1979, Patellariaceae, Patellariales, Dothideomycetes, one species, type: C. torulispora (W. Phillips) Hafellner, asexual morph unknown, saprobes, terrestrial, New Zealand, see Lumbsch and Huhndorf (2010; outline), Kirk et al. (2013; genus accepted), Tian et al. (2014; morphology; nomenclature), cultures and sequences are unavailable, needs generic revision.

Coleodictyospora Charles 1929, Ascomycota genera incertae sedis, one species, type: C. cubensis Charles, hyphomycetous, sexual morph unknown, saprobes, terrestrial, West Indies, see Seifert et al. (2011; morphology), Wijayawardene et al. (2012, 2017; outline), Kirk et al. (2013; genus accepted), cultures and sequences are unavailable, needs generic revision.

Coleophoma Höhn. 1907, Dermateaceae, Helotiales, Leotiomycetes, more than 35 species, type: C. crateriformis (Durieu \& Mont.) Höhn., coelomycetous, sexual morph unknown, pathogenic, saprobes or endophytic on a wide host range, worldwide, see Wijayawardene et al. (2012, 2017; outline), Kirk et al. (2013; genus accepted), Crous et al. (2016a; new species), holotype of type: FH 00304449.

Coleoseptoria Petr. 1940, Ascomycota genera incertae sedis, one species, type: C. ephedrae (Auersw.) Petr., coelomycetous, sexual morph unknown, saprobes, terrestrial, Germany, see Wijayawardene et al. (2012, 2017; outline), Kirk et al. (2013; genus accepted), cultures and sequences are unavailable, needs generic revision.

Coleosperma Ingold 1954, Helotiales genera incertae sedis, Leotiomycetes, one species, type: C. lacustre Ingold, asexual morph unknown, saprobes, aquatic, British Isles, see Lumbsch and Huhndorf (2010; outline), Kirk et al. (2013; genus accepted), cultures and sequences are unavailable, needs generic revision.

Coleroa Rabenh. 1850, Venturiaceae, Venturiales, Dothideomycetes, eight species, type: $C$. chaetomium (Kunze) Rabenh., asexual morph unknown, saprobes, terrestrial, worldwide, see Lumbsch and Huhndorf (2010; outline), Zhang et al. (2011d; morphology, phylogeny), Hyde et al. (2013; accepted as in Venturiaceae, phylogeny), Kirk et al. (2013; genus accepted), Wijayawardene et al. (2014c; outline), sequence data available for Coleroa robertiani CBS 458.64.

Colipila Baral \& Guy García 2012, Helotiales genera incertae sedis, Leotiomycetes, two species, type: C. masduguana Baral \& Guy Garcia, asexual morph unknown, saprobes, cosmopolitan, see Baral et al. (2012; taxonomy, phylogeny), holotype: M-014088, cultures and sequences are available.

Colispora Marvan'Ová 1988, Sarcosomataceae, Pezizales, Pezizomycetes, three species, type: C. elongata Marvanová, hyphomycetous, sexual morph unknown, saprobes, aquatic, worldwide, see Seifert et al. (2011; morphology), Wijayawardene et al. (2012, 2017; outline), Kirk et al. (2013; genus accepted), sequences and cultures available for Colispora elongata (F-08382 fide Baschien et al. 2013), needs generic revision. 
Collarina Giraldo, Gené \& Guarro 2014, Clavicipitaceae, Hypocreales, Sordariomycetes, two species, type: $C$. aurantiaca Giraldo, Gené \& Guarro, hyphomycetous, sexual morph unknown, from water sediment, aquatic, Spain, see Crous et al. (2014d; taxonomy), Maharachchikumbura et al. (2015, 2016), Wijayawardene et al. (2017; outline), cultures and sequences are available.

Collema F.H. Wigg. [nom. cons.] 1780, Collemataceae, Peltigerales, Lecanoromycetes, 40 species, type: C. lactuca (Weber) Weber ex F.H. Wigg., lichenized, see Lumbsch and Huhndorf (2010; outline), Kirk et al. (2013; genus accepted), Lücking et al. (2016b; classification), sequences are available.

Collematospora Jeng \& Cain 1976, Trichosphaeriaceae, Trichosphaeriales, Sordariomycetes, one species, type: $C$. venezuelensis Jeng \& Cain, asexual morph unknown, saprobes, terrestrial, Venezuela, see Lumbsch and Huhndorf (2010; outline), Kirk et al. (2013; genus accepted), Maharachchikumbura et al. (2015, 2016; outline), cultures and sequences are unavailable, needs generic revision.

Collembolispora Marvanová \& Pascoal 2003, Helotiales genera incertae sedis, Leotiomycetes, two species, type: C. barbata Marvanová, Pascoal \& Cássio, hyphomycetous, sexual morph unknown, saprobes, aquatic, Portugal, see Seifert et al. (2011; morphology), Wijayawardene et al. (2012, 2017; outline), Crous et al. (2012c; new species, DNA, morphology), holotype and ex-type: IMI 389661, UMB-088.01.

Collemopsidium Nyl. 1881, Xanthopyreniaceae, Collemopsidiales, Dothiodeomycetes, c. 40 species (but the number could be higher), type: C. iocarpum (Nyl.) Nyl., molecular data suggest that the number of marine species has been largely underestimated (Pérez-Ortega et al. 2016), asexual morph coelomycetous, lichen-forming fungi, associated with cyanobacteria, terrestrial, aquatic, worldwide, see Lumbsch and Huhndorf (2010; outline), Kirk et al. (2013; genus accepted), Lücking et al. (2016b, classification), Pérez-Ortega et al. (2016, phylogeny), lectotype of type: H-NYL 42858.

Colletoconis de Hoog \& Aa 1978, Ascomycota genera incertae sedis, one species, type: $C$. aecidiophila (Speg.) de Hoog, Aa \& U.P. Singh, coelomycetous, sexual morph unknown, saprobes, fungicolous, Argentina, see Wijayawardene et al. (2012, 2017; outline), Kirk et al. (2013; genus accepted), cultures and sequences are unavailable, needs generic revision.

Colletogloeum Petr. 1953, Mycosphaerellaceae, Capnodiales, Dothideomycetes, one species, type: C. sissoo (Syd.) B. Sutton, coelomycetous, sexual morph unknown, saprobes, terrestrial, worldwide, see Crous et al. (2009f; taxonomy, phylogeny), Wijayawardene et al. (2012, 2016, 2017; outline), Zhao and Zhao (2012; new species, China), cultures and sequences are available for unidentified species, needs generic revision.

Colletotrichum Corda. 1831 (= Glomerella Spauld. \& H. Schrenk 1903 fide Réblová et al. 2016c), Glomerellaceae, Glomerellales, Sodariomycetes, more than 100 spp., type: C. lineola Corda, coelomycetous sexual morph Glomerella, pathogens, endophytes, saprobes, terrestrial and aquatic worldwide, many species have molecular data including the epitype or neotype, sequence data available for accepted species, see Hyde et al. (2009, 2014; phylogeny, species number), Cannon et al. (2012; phylogeny), O'Connell et al. (2012; pathogenic species), Damm et al. (2010a, 2012a,b, 2013, 2014; species complexes, phylogeny), Weir et al. (2012; phylogeny, species complex), Liu et al. (2015a), ex-epitype: CBS 125337, epitype of type: CBS H-20362.

Collodiscula I. Hino \& Katum. 1955 (= Acanthodochium Samuels et al. 1987 fide Réblová et al. 2016c), Xylariaceae, Xylariales, Sordariomycetes, one species, type: $C$. japonica I. Hino \& Katum., asexual morph hyphomycetous (Acanthodochium), saprobes, Japan, Taiwan, see Lumbsch and Huhndorf (2010; outline), Kirk et al. (2013; genus accepted), Jaklitsch and Voglmayr (2012; phylogeny), Wijayawardene et al. (2012, 2017; outline), Stadler et al. (2013; 
one name), Maharachchikumbura et al. (2015, 2016; outline, one name), Réblová et al. (2016c; nomenclature), cultures and sequences are available.

Collophorina Damm \& Crous, nom. nov. MycoBank MB821422

三 Collophora Damm \& Crous, Persoonia 24: 64. 2010. nom. illeg., [ICN (Melbourne)

Art. 53.1], non Collophora Mart. 1830 (Apocynaceae).

Leotiomycetes genera incertae sedis, five species, coelomycetous, sexual morph unknown, endophytes, saprobes, plant pathogens, Baleares, Pacific Northwest regions (USA), South Africa, Germany, Iran, see Damm et al. (2010; morphology, phylogeny), Gramaje et al. (2012; new species, phylogeny), Wijayawardene et al. (2012; outline), Xie et al. (2013; new species).

See Damm et al. (2010) for illustrations, description and diagnoses.

Holotype: South Africa, Western Cape Province, Paarl, from wood of Prunus persica, 10 Jun. 2004, U. Damm, holotype CBS H-19992, ex-type strain of the type species C. rubra: CBS 120873 = STE-U 6109.

Collophorina aceris (J. Xie, Strobel \& Geary) Damm \& Crous, comb. nov. MycoBank MB 821434

$\equiv$ Collophora aceris J. Xie, Strobel \& Geary, Microbial Ecology 66: 787. 2013.

Collophorina africana (Damm \& Crous) Damm \& Crous, comb. nov. MycoBank MB821423

$\equiv$ Collophora africana Damm \& Crous, Persoonia 24: 65. 2010.

三Collophora capensis Damm \& Crous, Persoonia 24: 67. 2010.

Collophorina hispanica (Gramaje, Armengol \& Damm) Damm \& Crous, comb. nov. MycoBank MB 821430

三Collophora hispanica Gramaje, Armengol \& Damm, Persoonia 28: 9. 2012.

Collophorina paarla (Damm \& Crous) Damm \& Crous, comb. nov. MycoBank MB821427

$\equiv$ Collophora paarla Damm \& Crous, Persoonia 24: 67. 2010.

三Collophora pallida Damm \& Crous, Persoonia 24: 69. 2010.

Collophorina rubra (Damm \& Crous) Damm \& Crous, comb. nov. MycoBank MB821428 三Collophora rubra Damm \& Crous, Persoonia 24: 69. 2010.

Notes: The genus Collophora Damm \& Crous 2010 is illegitimate, being a later homonym of the plant genus Collophora Mart. 1830. In order to replace this name, the new name Collophorina nom. nov. is provided for this genus. Species of the genus are associated with black spots and dark brown to black streaking of the xylem tissues of woody plant hosts, and can cause wood necroses (Gramaje et al. 2012; Arzanlou et al. 2016a); it was also collected from air samples (Fischer et al. 2017).

Collostroma Petr. 1947, Ascomycota genera incertae sedis, one species, type: C. gelatinosum Petr., coelomycetous, sexual morph unknown, saprobes, Austria, see Wijayawardene et al. (2012, 2017; outline), Kirk et al. (2013; genus accepted), cultures and sequences are unavailable, needs generic revision.

Colonomyces R.K. Benj. 1955, Euceratomycetaceae, Laboulbeniales, Laboulbeniomycetes, two species, type: C. appendiculatus R.K. Benj., asexual morph unknown, biotrophic, USA, Europe, see Lumbsch and Huhndorf (2010; outline), Kirk et al. (2013; genus accepted), cultures and sequences are unavailable.

Colpoma Wallr. 1833, Rhytismataceae, Rhytismatales, Leotiomycetes, 14 species, type: $C$. quercinum (Pers.) Wallr., asexual morph unknown, saprobes, worldwide, see Lumbsch and Huhndorf (2010; outline), Kirk et al. (2013; genus accepted), Lantz et al. (2011; phylogeny), Lee et al. (2016; antifungal properties), cultures and sequences are unavailable, available cultures for type: Lantz 368 (UPS).

Columnodomus Petr. 1941, Ascomycota genera incertae sedis, one species, type: $C$. microsporus Petr. coelomycetous, sexual morph unknown, saprobes, Europe, see 
Wijayawardene et al. (2012, 2017; outline), Kirk et al. (2013; genus accepted), cultures and sequences are unavailable, needs generic revision.

Columnomyces R.K. Benj. 1955, Laboulbeniaceae, Laboulbeniales, Laboulbeniomycetes, two species, type: $C$. grenadinus Thaxt, asexual morph unknown, biotrophic, USA, see Lumbsch and Huhndorf (2010; outline), Kirk et al. (2013; genus accepted), cultures and sequences are unavailable.

Columnothyrium Bubák 1916, Ascomycota genera incertae sedis, one species, type: $C$. myriospermum (C. Massal.) Bubák, coelomycetous, sexual morph unknown, saprobes, Europe, see Wijayawardene et al. (2012, 2017; outline), Kirk et al. (2013; genus accepted), cultures and sequences are unavailable, needs generic revision.

Coma Nag Raj \& W.B. Kendr. 1972 (= Ascocoma H.J. Swart 1987 fide Johnston et al. 2014b; Wijayawardene et al. 2016b), Phacidiales genera incertae sedis, Leotiomycetes, two species, type: C. circularis (Cooke \& Massee) Nag Raj \& W.B. Kendr., coelomycetous, sexual morph Ascocoma, saprobes, Australasia, see Lumbsch and Huhndorf (2010; outline), Kirk et al. (2013; genus accepted), Johnston et al. (2014b; nomenclature), Wijayawardene et al. (2016b; outline, one name, morphology), available specimens for type: BRIP 14753, cultures and sequences are unavailable, needs generic revision.

Comatospora Piroz. \& Shoemaker 1971, Ascomycota genera incertae sedis, one species, type: C. suttonii Piroz. \& Shoemaker, coelomycetous, sexual morph unknown, saprobes, Canada, see Wijayawardene et al. (2012, 2017; outline), Kirk et al. (2013; genus accepted), cultures and sequences are unavailable, needs generic revision.

Combea De Not. 1846, Opegraphaceae, Arthoniales, Arthoniomycetes, two species, type: $C$. mollusca (Ach.) Nyl., lichenized, see Lumbsch and Huhndorf (2010; outline, accepted as a genus in Roccellaceae), Kirk et al. (2013; genus accepted), Ertz and Tehler (2011; taxonomy, placed in Opegraphaceae), Lücking et al. (2016b; classification), sequences are available.

Comesella Speg. 1923, Dothideomycetes genera incertae sedis, one species, type: C. anomala (Berk. \& M.A. Curtis) Speg., asexual morph unknown, saprobes, Canada, see Lumbsch and Huhndorf (2010; outline), Kirk et al. (2013; genus accepted), Wijayawardene et al. (2014c; outline), cultures and sequences are unavailable, needs generic revision.

Comesia Sacc. 1884, Helotiales genera incertae sedis, three species, type: C. felicitatis (P. Crouan \& H. Crouan) Sacc., asexual morph unknown, saprobes, Europe, North America, see Lumbsch and Huhndorf (2010; outline), Kirk et al. (2013; genus accepted), cultures and sequences are unavailable, needs generic revision.

Comminutispora A.W. Ramaley 1996 (= Hyphospora A.W. Ramaley 1996 fide Wijayawardene et al. 2014c; Rossman et al. 2015b), Dothideomycetes genera incertae sedis, one species, type: $C$. agavacearum A.W. Ramaley, asexual morph hyphomycetous (Hyphospora), saprobes, USA, see Lumbsch and Huhndorf (2010; outline; accepted as Planistromellaceae), Hyde et al. (2013; did not accepta as Planistromellaceae); Wijayawardene et al. (2014c; outline, nomenclature), Rossman et al. (2015b; nomenclature), holotype: BPI 802958, cultures and sequences are unavailable, needs generic revision.

Comocephalum Syd. 1939, Ascomycota genera incertae sedis, one species, type: C. vismiae Syd., coelomycetous, sexual morph unknown, saprobes, Equador, see Wijayawardene et al. (2012, 2017; outline), Kirk et al. (2013; genus accepted), cultures and sequences are unavailable, needs generic revision.

Comoclathris Clem. 1909, Pleosporaceae, Pleosporales, Dothideomycetes, 26 species, type: $C$. lanata Clem., asexual morph unknown, saprobes, worldwide, see Lumbsch and Huhndorf (2010; outline; accepted as a genus in Diademaceae), Hyde et al. (2013; accepted as Diademaceae) Wijayawardene et al. (2014c; outline; accepted as as a genus in Diademaceae), Ariyawansa et al. (2015c; morphology, accepted as Pleosporaceae), Li et al. (2016a; new species, Russia), holotype of the type: COLO 62872, sequences are available. 
Complexipes C. Walker 1979, Ascomycota genera incertae sedis, two species, type: C. moniliformis C. Walker, hyphomycetous, sexual morph unknown, saprobes, terrestrial, Europe, North America, see Seifert et al. (2011; morphology, accepted as a genus in Otideaceae, Pezizales), Wijayawardene et al. (2012; outline, accepted as a genus in Pyronemataceae), Kirk et al. (2013; genus accepted), Wijayawardene et al. (2017; transferred to Ascomycota genera incertae sedis), cultures and sequences are unavailable, needs generic revision.

Compositrema Rivas Plata, Lücking \& Lumbsch 2012, Graphidaceae, Ostropales, Lecanoromycetes, four species, type: C. cerebriforme J.E. Hern. \& Lücking, lichenized, see Rivas Plata et al. (2012b), Kraichak et al. (2014; taxonomy), Lücking et al. (2016b; classification), sequences are available.

Compsocladium I.M. Lamb 1956, Ramalinaceae, Lecanorales, Lecanoromycetes, two species, type: C. archboldianum I.M. Lamb, lichenized, see Lumbsch and Huhndorf (2010; outline), Kirk et al. (2013; genus accepted), Lücking et al. (2016b; classification), sequences unavailable.

Compsomyces Thaxt. 1894, Laboulbeniaceae, Laboulbeniales, Laboulbeniomycetes, seven species, type: $C$. verticillatus (Thaxt.) Thaxt., asexual morph unknown, biotrophic, worldwide, see Lumbsch and Huhndorf (2010; outline), Kirk et al. (2013; genus accepted), cultures and sequences are unavailable.

Condylospora Nawawi 1976, Ascomycota genera incertae sedis, four species, type: $C$. spumigena Nawawi, hyphomycetous, saprobes, on decaying leaves, aquatic, Brazil, Malaysia, Poland, Puerto Rico, Republic of Cameroon, Venezuela, Vietnam, see Seifert et al. (2011; morphology), Wijayawardene et al. (2012, 2017; outline), Kirk et al. (2013; genus accepted), Fiuza et al. (2015c; first record from Amazon), sequence data available for one species, compare with Angulospora, isotype of type: IMI 193709.

Coniambigua Etayo \& Diederich 1995, Ascomycota genera incertae sedis, one species, type: C. phaeographidis Etayo \& Diederich, coelomycetous, sexual morph unknown, lichenicolous, non-lichenized, terrestrial, Europe, North America, see Wijayawardene et al. (2012, 2016b, 2017; morphology, outline), Kirk et al. (2013; genus accepted), holotype: MA (Lich.), Etayo 4215 , sequence data of type species is unavailable.

Coniangium Fr. 1821, Arthoniaceae, Arthoniales, Arthoniomycetes, four species, type: $C$. vulgare Fr., lichenized, see Lumbsch and Huhndorf (2010; outline), Sundin et al. (2012; taxonomy), Kirk et al. (2013; genus accepted), Lücking et al. (2016b; classification), sequences are unavailable.

Coniarthonia Grube 2001, Arthoniaceae, Arthoniales, Arthoniomycetes, seven species, type: C. pyrrhula (Nyl.) Grube, lichenized, see Lumbsch and Huhndorf (2010; outline), Aptroot et al. (2015a; phylogeny), Lücking et al. (2016b; classification), sequences are available but lacks for the type.

Conicomyces R.C. Sinclair, Eicker \& Morgan-Jones 1983, Chaetosphaeriaceae, Chaetosphaeriales, Sordariomycetes, four species, type: C. transvaalensis R.C. Sinclair, Eicker \& Morgan-Jones, hyphomycetous, worldwide, see Seifert et al. (2011; morphology), Wijayawardene et al. (2012, 2017; outline), Kirk et al. (2013; genus accepted), Liu et al. (2015a; new species, morphology, DNA), sequences are available for $C$. pseudotransvaalensis (HHUF 29956 fide Liu et al. 2015).

Conidiascus Holterm. 1898, Saccharomycetes genera incertae sedis, one species, type: $C$. paradoxus Holterm., asexual morphs unknown, terrestrial, Java, see Kirk et al. (2013; genus accepted), cultures and sequences are unavailable, needs generic revision.

Conidiotheca Réblová \& L. Mostert 2007, Togniniaceae, Togniniales, Sordariomycetes, one species, type: C. tympanoides (M.E. Barr) Réblová \& L. Mostert, asexual morph unknown, 
terrestrial, USA, see Lumbsch and Huhndorf (2010; outline), Maharachchikumbura et al. (2015, 2016; phylogeny, outline), holotype: holotype of Romellia tympanoides, NY.

Coniella Höhn. 1918 (= Schizoparme Shear 1923; Pilidiella Petr. \& Syd. 1927 fide Alvarez et al. 2016), Schizoparmeaceae, Diaporthales, Sordariomycetes, 29 species, type: $C$. pulchella Höhn., coelomycetous, sexual morph Schizoparme, saprobes, pathogens, terrestrial, widespread, see Crous et al. (2015c; new species, phylogeny), Maharachchikumbura et al. (2015, 2016; phylogeny, outline), Alvarez et al. (2016; revision, nomenclature, treated Schizoparme and Pilidiella as synonyms), Wijayawardene et al. (2016b; morphology, phylogeny), cultures and sequences are available.

Coniobrevicolla Réblová 1999, Trichosphaeriaceae, Trichosphaeriales, Sordariomycetes, one species, type: C. larsenii Réblová, asexual morph unknown, terrestrial, saprobes, Europe, see Lumbsch and Huhndorf (2010; outline), Kirk et al. (2013; genus accepted), Maharachchikumbura et al. (2015, 2016; outline), cultures and sequences are unavailable, needs generic revision.

Coniocarpon DC. 1805, Arthoniaceae, Arthoniales, Arthoniomycetes, five species, type: $C$. cinnabarinum DC., lichenized, see Sundin et al. (2012; taxonomy), Frisch et al. (2014; taxonomy), Lücking et al. (2016b; classification), sequences are available.

Coniocessia Dania García, Stchigel, D. Hawksw. \& Guarro 2006, Coniocessiaceae, Xylariales, Sordariomycetes, five species, type: C. nodulisporioides (D. Hawksw.) Dania García, Stchigel, D. Hawksw. \& Guarro, asexual morph hyphomycetous (nodulisporium-like), terrestrial, saprobes, coprophilous, from soil, Jordan, Iran, Spain, see Lumbsch and Huhndorf (2010; outline), Asgari and Zare (2011; new species, DNA), Senanayake et al. (2015; phylogeny), Maharachchikumbura et al. (2015, 2016; outline), holotype: IMI 204247 (as Coniochaeta nodulisporioides D. Hawksw.), sequence data and cultures available.

Coniochaeta (Sacc.) Cooke 1887 (= Lecythophora Nannf. 1934 fide Réblová et al. 2016c), Coniochaetaceae, Coniochaetales, Sordariomycetes, 78 species, type: C. ligniaria (Grev.) Cooke, asexual morph formerly known in Lecythophora, terrestrial, aquatic, saprobes, coprophilous, widespread, see Damm et al. (2010b; South Africa, phylogeny), Lumbsch and Huhndorf (2010; outline), Kirk et al. (2013; genus accepted), Maharachchikumbura et al. (2015, 2016; phylogeny), Réblová et al. (2016c; nomenclature), ex-type cultures are unavailable but none-type cultures are available.

Coniolariella Dania García, Stchigel \& Guarro 2006, Xylariaceae, Xylariales, Sordariomycetes, eight species, type: $C$. gamsii Asgari \& Zare, asexual morph rhinocladiellalike, saprobes, worldwide, see Checa et al. (2008; new species), Lumbsch and Huhndorf (2010; outline), Zare et al. (2010; new species, morphology), Maharachchikumbura et al. (2015, 2016; outline, phylogeny), holotype: IRAN 12363F (as Coniochaeta gamsii Asgari \& Zare), sequence data available.

Conioscypha Höhn. 1904 (= Conioscyphascus Réblová \& Seifert 2004 fide Maharachchikumbura et al. 2016; Réblová et al. 2016c), Conioscyphaceae, Conioscyphales, Sordariomycetes, twelve species, type: C. lignicola Höhn., sexual morph formerly known in Conioscyphascus, saprobes, terrestrial, worldwide, see Crous et al. (2014c; new species, DNA), Zelski et al. (2014; new species), Maharachchikumbura et al. (2015, 2016; outline, phylogeny), Réblová et al. (2016c; nomenclature), cultures and sequences are available.

Conioscyphopsis Goh \& K.D. Hyde 1998, Ascomycota genera incertae sedis, one species, type: C. australiensis Goh \& K.D. Hyde, hyphomycetous, sexual morph unknown, saprobes, Australia, see Seifert et al. (2011; morphology), Wijayawardene et al. (2012, 2017; outline), Kirk et al. (2013; genus accepted), cultures and sequences are unavailable, needs generic revision.

Coniosporium Link 1809, Hysteriaceae, Hysteriales, Dothideomycetes, c. 20 species, type: $C$. olivaceum (Link) Tubaki, hyphomycetous, sexual morph unknown, saprobes, cosmopolitan, 
see Li et al. (2008a; new species), Seifert et al. (2011; morphology), Tsuneda et al. (2011; phylogeny), Wijayawardene et al. (2012, 2014c, 2017; outline), cultures and sequences are available.

Coniothyrina Syd. \& P. Syd. 1912, Ascomycota genera incertae sedis, one species, type: $C$. agavicola (Speg.) Syd., coelomycetous, sexual morph unknown, saprobes, subtropical, see Wijayawardene et al. (2012, 2017; outline), Kirk et al. (2013; genus accepted), cultures and sequences are unavailable, needs generic revision.

Coniothyrium Corda 1840 (= Dactuliochaeta G.L. Hartm. \& J.B. Sinclair 1988 fide de Gruyter et al. 2012), Coniothyriaceae, Pleosporales, Dothideomycetes, c. 50 species, type: $C$. palmarum Corda, coelomycetous, terrestrial, pathogens, saprobes, worldwide, see de Gruyter et al. (2012; phylogeny, generic concept) Verkley \& Gruyter), Crous et al. (2013b, 2016a; new species), Hyde et al. (2013; morphology), Verkley et al. (2014; phylogeny), Wijayawardene et al. (2016b; morphology, phylogeny), cultures and sequences are available, reference culture for type: CBS 400.71.

Coniozyma Crous 2008, Dothideomycetes genera incertae sedis, one sprcies, type: $C$. leucospermi (Crous \& Denman) Crous, coelomycetous, terrestrial, pathogens, saprobes, South Africa, see Marincowitz et al. (2008; morphology), Wijayawardene et al. (2017; outline), holotype and ex-type: PREM 55348, CBS 114035 = STE-U 2852.

Conjunctospora Udagawa \& Uchiy. 1999, Ascomycota genera incertae sedis, one species, type: C. vesiculifera Udagawa, Uchiy. \& Kamiya, hyphomycetous, sexual morph unknown, saprobes, Japan, see Seifert et al. (2011; morphology), Wijayawardene et al. (2012, 2017; outline), Kirk et al. (2013; genus accepted), holotype: CBM, Uchiyama SUM3064, cultures and sequences are unavailable, needs generic revision.

Conlarium F. Liu \& L. Cai 2012, Sordariomycetes genera incertae sedis, one sprcies, type: $C$. dupliciascosporum F. Liu \& L. Cai, sexual morph unknown, terrestrial, pathogens, saprobes, China, see Liu et al. (2012a; morphology, phylogeny), Maharachchikumbura et al. (2015, 2016; outline), holotype and ex-type: HMAS243129, CGMCC3.14939 = GD34-5-2.

Connersia Malloch 1974, Pseudeurotiaceae, Leotiomycetes family incertae sedis, one species, type: C. rilstonei (C. Booth) Malloch, asexual morph unknown, saprobes, British Isles, Canada, see Lumbsch and Huhndorf (2010; outline), Kirk et al. (2013; genus accepted), available cultures of the type: CBS 537.74, AFTOL-ID 1264.

Conoideocrella D. Johnson, G.H. Sung, Hywel-Jones \& Spatafora 2009, Clavicipitaceae, Hypocreales, Sordariomycetes, type: C. luteorostrata (Zimm.) D. Johnson, G.H. Sung, Hywel-Jones \& Spatafora, two species, asexual morph unknown, saprobes, cosmopolitan, see Johnson et al. (2009; morphology, phylogeny), Lumbsch and Huhndorf (2010; outline), Maharachchikumbura et al. (2015, 2016; outline), cultures and sequences are available.

Conoplea Pers. 1797, Sarcosomataceae, Pezizales, Pezizomycetes, eleven species, type: C. sphaerica (Pers.) Pers., hyphomycetous, sexual morph unknown, saprobes, terrestrial, cosmopolitan, see Marincowitz et al. (2008; DNA), Rivera-Orduña et al. (2011; DNA), Seifert et al. (2011; morphology), Wijayawardene et al. (2012, 2017; outline), Kirk et al. (2013; genus accepted), cultures and sequences are available, needs generic revision.

Conostomatium Doweld 2013, Ascomycota genera incertae sedis, one species, type: $C$. oenocarpi (Bat. \& J.L. Bezerra) Doweld, asexual morph unknown, fossil Pteridospermae, see Index Fungorum (2017).

Conostroma Moesz 1921, Ascomycota genera incertae sedis, three species, type: C. didymum (Fautrey \& Roum.) Moesz (current name: Colpoma quercinum (Pers.) Wallr. fide Species Fungorum 2017), coelomycetous, sexual morph unknown, saprobes, Asia, see Wijayawardene et al. (2012, 2017; outline), Kirk et al. (2013; genus accepted), Zhao and Zhao (2012; new species, China), cultures and sequences are unavailable, needs generic revision. 
Conotremopsis Vězda 1977, Stictidaceae, Ostropales, Lecanoromycetes, one species, type: $C$. weberiana Vězda, lichenized, Australia, see Lumbsch and Huhndorf (2010; outline), Kirk et al. (2013; genus accepted), Lücking et al. (2016b; classification), sequences are unavailable.

Consetiella Hol.-Jech. \& Mercado 1982, Ascomycota genera incertae sedis, one species, type: C. solida (Berk. \& M.A. Curtis) Hol.-Jech. \& Mercado, hyphomycetous, sexual morph unknown, saprobes, Cuba, see Seifert et al. (2011; morphology), Wijayawardene et al. (2012, 2017; outline), Kirk et al. (2013; genus accepted), cultures and sequences are unavailable, needs generic revision.

Constantinomyces Egidi \& Onofri 2014, Teratosphaeriacae, Capnodiales, Dothideomycetes, four species, type: $C$. virgultus Egidi \& Onofri, hyphomycetous, sexual morph unknown, rock-inhabiting, Spain, see Egidi et al. (2014; taxonomy, phylogeny), Wijayawardene et al. (2017; outline), holotype: CBS $117930=$ TRN 79.

Constrictolumina Lücking, M.P.Nelsen \& Aptroot 2016, Trypetheliaceae, Trypetheliales, Dothideomycetes, nine species, type: C. cinchonae (Ach.) Lücking, M.P. Nelsen \& Aptroot, lichenized, see Nelsen et al. (2014a; taxonomy), Aptroot and Lücking (2016; taxonomy) Lücking et al. (2016b, c; taxonomy), sequences are available.

Cookeina Kuntze 1891, Sarcoscyphaceae, Pezizales, Pezizomycetes, 13 species, type: C. tricholoma (Mont.) Kuntze, asexual morph unknown, saprobes, terrestrial, worldwide, see Lumbsch and Huhndorf (2010; outline), Kirk et al. (2013; genus accepted), cultures and sequences are available.

Cookella Sacc. 1878, Cookellaceae, Dothideomycetes family incertae sedis, seven species, type: C. microscopica Sacc., asexual morph unknown, parasites, fungicolous, worldwide, see Lumbsch and Huhndorf (2010; outline), Hyde et al. (2013; taxonomy), Kirk et al. (2013; genus accepted), Wijayawardene et al. (2014c; outline), cultures and sequences are unavailable.

Cooksonomyces H.J. Swart \& D.A. Griffiths 1974, Ascomycota genera incertae sedis, one species, type: $C$. banksiae H.J. Swart \& D.A. Griffiths, coelomycetous, sexual morph unknown, saprobes, Australia, see Kirk et al. (2008), however Kirk et al. (2013) did not accept, cultures and sequences are unavailable.

Cophinforma Doilom, J.K. Liu \& K.D. Hyde 2012, Botryosphaeriaceae, Botryosphaeriales, Dothideomycetes, three species, type: C. eucalypti Doilom, J.K. Liu \& K.D. Hyde, asexual morph coelomycetous, saprobes, terrestrial, South Africa, USA, Thailand, see Liu et al. (2012b; taxonomy, phylogeny), Hyde et al. (2013; accepted as a genus in Botryosphaeriaceae), Phillips et al. (2013; taxonomy, new species, phylogeny), Slippers et al. (2013; phylogeny), Wijayawardene et al. (2014c; outline), holotype and ex-type culture of the type: MFLU 12-0752, MFLUCC 11-0425.

Coppinsia Lumbsch \& Heibel 1998, Trapeliaceae, Trapeliales, Lecanoromycetes, one species, type: C. minutissima Lumbsch \& Heibel, lichenized, see Lumbsch and Huhndorf (2010; outline), Kirk et al. (2013; genus accepted), Hodkinson and Lendemer (2011b; taxonomy), Lücking et al. (2016b; classification), sequences unavailable.

Coprobolus Cain \& Kimbr. 1970, Thelebolaceae, Thelebolales, Leotiomycetes, one species, type: C. poculiformis Cain \& Kimbr., asexual morph unknown, coprophilous, terrestrial, Canada, see Lumbsch and Huhndorf (2010; outline), Kirk et al. (2013; genus accepted), cultures and sequences are unavailable, needs generic revision.

Copromyces N. Lundq. 1967, Sordariaceae, Sordariales, Sordariomycetes, one species, type: C. bisporus N. Lundq., asexual morph unknown, coprophilous, terrestrial, Sweden, Canada, see Lumbsch and Huhndorf (2010; outline), Kirk et al. (2013; genus accepted), Maharachchikumbura et al. (2015, 2016; outline), cultures and sequences are unavailable, needs generic revision. 
Coprotiella Jeng \& J.C. Krug 1976, Ascodesmidaceae, Pezizales, Pezizomycetes, one species, type: C. gongylospora Jeng \& J.C. Krug, asexual morph unknown, coprophilous, terrestrial, South America, see Lumbsch and Huhndorf (2010; outline), Kirk et al. (2013; genus accepted), Jaklitsch et al. (2016a; classification), cultures and sequences are unavailable, needs generic revision.

Coprotus Korf \& Kimbr. 1967, Ascodesmidaceae, Pezizales, Pezizomycetes, 29 species, type: C. sexdecimsporus (P. Crouan \& H. Crouan) Kimbr. \& Korf, asexual morph unknown, cupfungus, saprobes or plant pathogenic, widespread, see Lumbsch and Huhndorf (2010; outline), Hansen et al. (2013; phylogeny), Kirk et al. (2013; genus accepted), Jaklitsch et al. (2016a; classification), cultures and sequences are available.

Corallicola Volkm.-Kohlm. \& Kohlm. 1992, Halosphaeriaceae, Microascales, Sordariomycetes, one species, type: C. nana Volkm.-Kohlm. \& Kohlm., asexual morph unknown, saprobes, marine, Belize, see Lumbsch and Huhndorf (2010; outline), Kirk et al. (2013; genus accepted), Maharachchikumbura et al. (2015, 2016; outline), ex-type cultures are unavailable, holotype of type: J.K. $5004=01594700$, NYBG.

Corallocytostroma Y.N. Yu \& Z.Y. Zhang 1980, Clavicipitaceae, Hypocreales, Sordariomycetes, two species, type: C. oryzae Y.N. Yu \& Z.Y. Zhang, coelomycetous, saprobes or plant pathogenic, widespread, sequence data available only for $C$. ornithocopreoides, see Hyde et al. (2011; outline), Wijayawardene et al. (2012, 2017; outline), Kirk (2013; genus accepted), Maharachchikumbura et al. (2015, 2016; outline).

Corallomycetella Henn. 1904 (= Rhizostilbella Wolk 1914 fide Rossman et al. 2016a), Nectriaceae, Hypocreales, Sordariomycetes, type: C. heinsenii Henn., three species, asexual morph hyphomycetous, terrestrial, saprobes, associated with diseased plants, cosmopolitan, see Lumbsch and Huhndorf (2010; outline), Herrera et al. (2013; new species, revision), Kirk et al. (2013; genus accepted), Lombard et al. (2015b; taxonomy, phylogeny), Maharachchikumbura et al. (2015, 2016; outline), Rossman et al. (2016a; nomenclature), cultures and sequences are available.

Corallonectria C. Herrera \& P. Chaverri 2013, Nectriaceae, Hypocreales, Sordariomycetes, one species, type: C. jatrophae (Möller) C. Herrera \& P. Chaverri, asexual morph hyphomycetous, terrestrial, saprobes, associated with diseased plants, cosmopolitan, see Herrera et al. (2013; new species, revision), Lombard et al. (2015b; taxonomy, phylogeny), Maharachchikumbura et al. (2015, 2016; outline), cultures and sequences are available.

Cordana Preuss 1851 (= Porosphaerella E. Müll. \& Samuels 1982; = Pseudobotrytis Krzemien. \& Badura 1954 fide Réblová et al. 2016c), Cordanaceae, Cordanales, Sordariomycetes, eight species, type: C. pauciseptata Preuss, hyphomycetous, saprobes or plant pathogenic, widespread, sequence data available for all species, see Kirk (2013; genus accepted), Hernández-Restrepo et al. (2015b; phylogeny), Zelski et al. (2014; phylogeny), Maharachchikumbura et al. (2015, 2016; outline), Réblová et al. (2016c; nomenclature), Wijayawardene et al. (2017; outline), ex-type: IMI 232041a; holotype of type: CBS H-21148. Cordierites Mont. 1840, Cordieritidaceae, Helotiales, Leotiomycetes, three species, type: $C$. guianensis Mont., asexual morph unknown, saprobes, worldwide, see Kirk (2013; genus accepted), Lumbsch and Huhndorf (2010; outline), Peterson and Pfister (2010; DNA, phylogeny), cultures and sequences are available.

Cordyceps Fr. 1818, Cordycipitaceae, Hypocreales, Sordariomycetes, c. 500 species, type: $C$. militaris (L.) Fr., asexual morph unknown, on insect, widespread, terrestrial, see Lumbsch and Huhndorf (2010; outline), Kirk et al. (2013; genus accepted), Maharachchikumbura et al. (2015, 2016; outline), Sanjuan et al. (2015; phylogeny), Tasanathai et al. (2016; new species), cultures and sequences are available.

Coremiella Bubák \& Krieg. 1912, Ascomycota genera incertae sedis, one species, type: $C$. cystopodoides Bubák \& Krieg., hyphomycetous, sexual morph unknown, saprobes, 
worldwide, see Seifert et al. (2011; morphology), Wijayawardene et al. (2012, 2017; outline), Kirk et al. (2013; genus accepted), sequence data available for unidentified species, needs generic revision.

Coreomyces Thaxt. 1903, Laboulbeniaceae, Laboulbeniales, Laboulbeniomycetes, 21 species, type: $C$. corisae Thaxt., asexual morph unknown, biotrophic, worldwide, see Lee and $\mathrm{Na}$ (2009; new species), Lumbsch and Huhndorf (2010; outline), Kirk et al. (2013; genus accepted), cultures and sequences are unavailable.

Coreomycetopsis Thaxt. 1920, Laboulbeniaceae, Laboulbeniales, Laboulbeniomycetes, one species, type: C. oedipus Thaxt., asexual morph unknown, biotrophic (on termites), West Indies, USA, see Kirk et al. (2013; genus accepted), cultures and sequences are unavailable.

Corethromyces Thaxt. 1892, Laboulbeniaceae, Laboulbeniales, Laboulbeniomycetes, 82 species, type: Corethromyces cryptobii Thaxt., asexual morph unknown, biotrophic, West Indies, USA, see Lumbsch and Huhndorf (2010; outline), Kirk et al. (2013; genus accepted), cultures and sequences are unavailable.

Corethrostroma Kleb. 1933, Ascomycota genera incertae sedis, one species, type: C. laricis Kleb., coelomycetous, sexual morph unknown, saprobes, Europe, see Kirk et al. (2013; genus accepted), sequence data available for unidentified species, needs generic revision.

Cornicularia (Schreb.) Ach. 1794, Parmeliaceae, Lecanorales, Lecanoromycetes, one species, type: $C$. tristis (Weber ex F.H. Wigg.) Hoffm., lichenized, see Lumbsch and Huhndorf (2010; outline), Kirk et al. (2013; genus accepted), Lücking et al. (2016b; classification), sequences are available.

Corniculariella P. Karst. 1884, Dermateaceae, Helotiales, Leotiomycetes, one species, type: C. abietis P. Karst., coelomycetous, sexual morph unknown, saprobes, worldwide, see Oliveira et al. (2010; new species, DNA), Wijayawardene et al. (2012, 2017; outline), Kirk et al. (2013; genus accepted), sequence data available for $C$. brasiliensis but type species lack sequences, needs generic revision.

Cornipulvina Huhndorf, A.N. Mill., F.A. Fernández \& Lodge 2005, Boliniaceae, Boliniales, Sordariomycetes, one species, type: C. ellipsoides Huhndorf, A.N. Mill., F.A. Fernández \& Lodge, asexual morphs unknown, saprobes, terrestrial, Puerto Rico, see Lumbsch and Huhndorf (2010; outline), Maharachchikumbura et al. (2015, 2016; outline), cultures and sequences are available.

Cornucopiella Höhn. 1915, Ascomycota genera incertae sedis, two species, type: C. mirabilis Höhn., coelomycetous, sexual morph unknown, saprobes, Europe, see Wijayawardene et al. (2012, 2017; outline), Kirk et al. (2013; genus accepted), cultures and sequences are unavailable, needs generic revision.

Cornuntum Velen. 1947, Helotiales genera incertae sedis, Leotiomycetes, one species, type: C. fagineum Velen., asexual morph unknown, saprobes, Europe, see Lumbsch and Huhndorf (2010; outline), Kirk et al. (2013; genus accepted), Jaklitsch et al. (2016a; treated as a synonym of Strossmayeria Schulzer), cultures and sequences are unavailable, needs generic revision.

Cornutispora Piroz. 1973, Ascomycota genera incertae sedis, five species, type: $C$. limaciformis Piroz., coelomycetous, sexual morph unknown, lichenicolous, worldwide, see Etayo (2010; new species), Wijayawardene et al. (2012, 2017; outline), Kirk et al. (2013; genus accepted), cultures and sequences are unavailable, needs generic revision.

Cornutostilbe Seifert 1990, Ascomycota genera incertae sedis, five species, type: C. medusa Seifert, hyphomycetous, sexual morph unknown, from soil, saprobes, Indonesia, see Seifert et al. (2011; morphology), Wijayawardene et al. (2012, 2017; outline), Kirk et al. (2013; genus accepted), holotype of the type: BO 14356.

Cornuvesica C.D. Viljoen, M.J. Wingf. \& K. Jacobs 2000, Ophiostomataceae, Ophiostomatales, Sordariomycetes, four species, type: C. falcata (E.F. Wright \& Cain) C.D. 
Viljoen, M.J. Wingf. \& K. Jacobs, hyphomycetous, asexual morph chalara-like, from soil, saprobes, Europe, N. America, South Africa, see Lumbsch and Huhndorf (2010; outline), Maharachchikumbura et al. (2015, 2016; outline), Marincowitz et al. (2015; new species, morphology, phylogeny), sequences are available for all species.

Corollospora Werderm. 1922 (= Varicosporina Meyers \& Kohlm. 1965; = Halosigmoidea Nakagiri et al. 2009 fide Réblová et al. 2016c), Halosphaeriaceae, Microascales, Sordariomycetes, 25 species, type: C. maritima Werderm., asexual morph hyphomycetous, saprobes, marine, worldwide, see Abdel-Wahab et al. (2009; new species, phylogeny), Lumbsch and Huhndorf (2010; outline), Sakayaroj et al. (2011a; diversity), Kirk et al. (2013; genus accepted), Maharachchikumbura et al. (2015, 2016; outline), Réblová et al. (2016c; nomenclature), cultures and sequences are available.

Coronatomyces Dania García, Stchigel \& Guarro 2004, Sordariales genera incertae sedis, Sordariomycetes, one species, type: C. cubensis Dania García, Stchigel \& Guarro, asexual morph unknown, saprobes, terrestrial, Cuba, see Lumbsch and Huhndorf (2010; outline), Maharachchikumbura et al. (2015, 2016; outline), holotype and ex-type: IMI 385316, FMR 7132.

Coronellaria (P. Karst.) P. Karst. 1870, Helotiales genera incertae sedis, Leotiomycetes, four species, type: $C$. delitschiana (Auersw.) P. Karst., asexual morph unknown, saprobes, terrestrial, Europe, see Lumbsch and Huhndorf (2010; outline), Kirk et al. (2013; genus accepted), cultures and sequences are unavailable, needs generic revision.

Coronopapilla Kohlm. \& Volkm.-Kohlm. 1990, Zopfiaceae, Pleosporales, Dothideomycetes, two species, type: C. avellina Kohlm. \& Volkm.-Kohlm., asexual morph unknown, saprobes, marine, worldwide, see Jones et al. (2009b, 2015; classification), Suetrong et al. (2009; morphology), Alias et al. (2010; diversity), Besitulo et al. (2010; diversity), Lee et al. (2012; checklist, Malaysia), Zhang et al. (2012e; morphology), Hyde et al. (2013; morphology, outline), Wijayawardene et al. (2014c; outline), holotype and ex-isotype: J.K. 5144a (IMS), J.K.5144b (IMS 330805).

Coronophora Fuckel 1864, Coronophoraceae, Coronophorales, Sordariomycetes, five species, type: C. gregaria Fuckel, asexual morph unknown, saprobes, terrestrial, Europe, see Mugambi and Huhndorf (2010; phylogeny), Kirk et al. (2013; genus accepted), Maharachchikumbura et al. (2015, 2016; outline; phylogeny), available cultures of type: ANM1555 (fide Mugambi and Huhndorf 2010).

Coronophorella Höhn. 1909, Scortechiniaceae, Coronophorales, Sordariomycetes, one species, type: $C$. chaetomioides (Penz. \& Sacc.) Höhn., asexual morph unknown, saprobes, Indonesia, see Kirk et al. (2008; treated as a synonym of Nitschkia), Mugambi and Huhndorf (2010; phylogeny), Maharachchikumbura et al. (2015, 2016; outline), available cultures of type: GKM1099.

Coronoplectrum Brusse 1987, Lecanorales genera incertae sedis, Lecanoromycetes, one species, type: C. namibicum Brusse, lichenized, see Thell et al. (2012; taxonomy), Lücking et al. (2016b; classification), sequences are unavailable.

Corticifraga D. Hawksw. \& R. Sant.1990, Helotiales genera incertae sedis, Leotiomycetes, seven species, type: C. peltigerae (Fuckel) D. Hawksw. \& R. Sant., lichenicolous, terrestrial, widespread, asexual morph unknown, see Zhurbenko (2009; new species, review), Etayo and Sancho (2008; new species), Spribille et al. (2010; new species), Kirk et al. (2013; genus accepted), Jaklitsch et al. (2016a; outline), cultures and sequences are unavailable, holotype: ?G and isotypes K(M)-IMI and S.

Corticiruptor Wedin \& Hafellner 1998, Lecanoromycetes genera incertae sedis, two species, type: C. abeloneae (P.M. Jørg.) Wedin \& Hafellner, asexual morphs unknown, lichenicolous, terrestrial, Europe, see Etayo and Sancho (2008; new species), Lumbsch and Huhndorf (2010; outline), cultures and sequences are unavailable. 
Corticorygma M. Cáceres, Feuerstein, Aptroot \& Lücking 2014, Graphidaceae, Ostropales, Lecanoromycetes, one species, type: C. stellatum M. Cáceres, Feuerst., Aptroot \& Lücking, lichenized, see Cáceres et al. (2014; taxonomy), Lücking et al. (2016b; classification), sequences are available.

Corylomyces Stchigel, M. Calduch \& Guarro 2006, Sordariales genera incertae sedis, Sordariomycetes, type: one species, C. selenosporus Stchigel, M. Calduch \& Guarro, asexual morph unknown, saprobes, see Lumbsch and Huhndorf (2010; outline), Maharachchikumbura et al. (2015, 2016; outline), holotype and ex-type culture of type: ILLS 57506, FMR 8279.

Corylophomyces R.K. Benj. 1994, Laboulbeniaceae, Laboulbeniales, Laboulbeniomycetes, 82 species, type: $C$. cryptobii Thaxt., asexual morph unknown, biotrophic, West Indies, USA, see Lumbsch and Huhndorf (2010; outline), Kirk et al. (2013; genus accepted), cultures and sequences are unavailable.

Corynascella Arx \& Hodges 1975, Chaetomiaceae, Sordariales, Sordariomycetes, seven species, type: $C$. humicola Arx \& Hodges, asexual morph unknown, saprobes, worldwide, see Lumbsch and Huhndorf (2010; outline), van den Brink et al. (2012; DNA), Maharachchikumbura et al. (2015, 2016; outline), Wang et al. (2016c; DNA), sequences are available.

Corynecercospora V.K. Pal, Akhtar, N. Ahmad, Kamal \& D.K. Agarwal 2006, Ascomycota genera incertae sedis, one species, type: C. teraiensis V.K. Pal, Akhtar, N. Ahmad, Kamal \& D.K. Agarwal, hyphomycetous, sexual morph unknown, saprobes, terrestrial, temperate regions, see Seifert et al. (2011; morphology), Wijayawardene et al. (2012, 2017; outline), cultures and sequences are unavailable, needs generic revision.

Corynecystis Brusse 1985, Lichinaceae, Lichinales, Lichinomycetes, one species, type: C. capensis Brusse, lichenized, South Africa, see Lumbsch and Huhndorf (2010; outline), Lücking et al. (2016b; classification), cultures and sequences are unavailable, needs generic revision.

Corynelia Ach. 1823, Coryneliaceae, Coryneliales, Eurotiomycetes, nine species, type species: C. uberata Fr., asexual morph unknown, but spermogonia often produced, terrestrial, parasitic on members of the plant family Podocarpaceae, Africa, Central and South America, Japan, Oceania, see Lumbsch and Huhndorf (2010; outline), Kirk et al. (2013; genus accepted), Wood et al. (2016; phylogeny, new species, proposal of the subclass Coryneliomycetidae), epitype: PREM 61207.

Coryneliella Har. \& P. Karst. 1890, Ascomycota genera incertae sedis, one species, type: $C$. consimilis Har. \& P. Karst., asexual morph unknown, saprobes, terrestrial, Mauritius, see Lumbsch and Huhndorf (2010; outline), Kirk et al. (2013; genus accepted), cultures and sequences are unavailable.

Coryneliopsis Butin 1972, Coryneliaceae, Coryneliales, Eurotiomycetes, two species, type species: C. cupulifera Butin, asexual morph unknown, terrestrial, always associated with members of Cyttaria Berk. which parasitize Nothofagus spp., Chile, see Lumbsch and Huhndorf (2010; outline), Kirk et al. (2013; genus accepted), Wood et al. (2016; morphotaxonomy), cultures and sequences are unavailable, needs generic revision.

Coryneliospora Fitzp. 1942, Coryneliaceae, Coryneliales, Eurotiomycetes, two species, type: C. fructicola (Pat.) Fitzp., asexual morph unknown, but spermogonia often produced, terrestrial, parasitic on fruits of Rapanea Aubl. and Myrsine L., China, India, New Guinea, South Africa, see Lumbsch and Huhndorf (2010; outline), Kirk et al. (2013; genus accepted), Wood et al. (2016; morphotaxonomy), cultures and sequences are unavailable, needs generic revision.

Corynespora Güssow 1906 (= Corynesporasca Sivan. 1996 fide Rossman et al. 2015b), Corynesporascaceae, Pleosporales, Dothideomycetes, more than 130 species, type: C. mazei 
Güssow, hyphomycetous, sexual morph formerly known in Corynesporasca, saprobes, widespread, see Lumbsch and Huhndorf (2009; outline, sexual morph), Zhang et al. (2009d; phylogeny), Ma et al. (2011c; new species), Kirk et al. (2013; genus accepted), Wijayawardene et al. (2014c; outline), Rossman et al. (2015b; nomenclature), sequences are available for two species, type sequence data are not available, needs generic revision.

Corynesporella Munjal \& H. S. Gill 1961, Ascomycota genera incertae sedis, ten species, type: C. urticae Munjal \& H.S. Gill, hyphomycetous, sexual morph unknown, saprobes, terrestrial, worldwide, see Seifert et al. (2011; morphology), Zhang et al. (2012f, g; new species), Ma et al. (2012g; new species), Xia et al. (2014a; new species; key to species), cultures and sequences are unavailable.

Corynesporina Subram. 2009, Ascomycota genera incertae sedis, one species, type: $C$. elegans Subram., hyphomycetous, sexual morph unknown, saprobes, terrestrial, Singapore, see Gams et al. (2009; taxonomy), Seifert et al. (2011; morphology), Wijayawardene et al. (2012, 2017; outline), holotype: MUBL 3523, cultures and sequences are unavailable.

Corynesporopsis P. M. Kirk 1981, Ascomycota genera incertae sedis, 15 species, type: $C$. quercicola (Borowska) P.M. Kirk, hyphomycetous, sexual morph unknown, saprobes, terrestrial, worldwide, see Castañeda-Ruiz et al. (2010c; new species), Seifert et al. (2011; morphology), Ma et al. (2010a, 2012b; new species, China), Wijayawardene et al. (2012, 2017; outline), Hernández-Restrepo et al. (2014b; new species), Xia et al. (2013a, 2014b; new species), Kirschner (2015; new species), and sequences are available but lacks for the type species.

Coryneum Nees 1816 (= Pseudovalsa Ces. \& De Not. 1863 fide Rossman et al. 2015a), Pseudovalsaceae, Diaporthales, Sordariomycetes, c. 30 species, type: C. umbonatum Nees, sexual morph Pseudovalsa, pathogens, saprobes, terrestrial, temperate regions, see Wijayawardene et al. (2012, 2016b, 2017; outline, morphology, new species), Kirk et al. (2013; genus accepted), Rossman et al. (2015a; nomenclature), cultures and sequences are unavailable.

Coscinocladium Kunze 1846, Physciaceae, Caliciales, Lecanoromycetes, two species, type: C. occidentale Kunze, lichenized, see Lumbsch and Huhndorf (2010; outline), Gaya et al. (2012; taxonomy), Kirk et al. (2013; genus accepted), Prieto et al. (2013; phylogeny), Lücking et al. (2016b; classification), Prieto and Wedin (2016; phylogeny), sequences are available.

Cosmariospora Sacc. 1880, Ascomycota genera incertae sedis, one species, type: $C$. bizzozeriana Sacc., hyphomycetous, sexual morph unknown, saprobes, terrestrial, Italy, see Seifert et al. (2011; morphology), Wijayawardene et al. (2012, 2017; outline), Kirk et al. (2013; genus accepted), cultures and sequences are unavailable, needs generic revision.

Cosmospora Rabenh. 1862, Nectriaceae, Hypocreales, Sordariomycetes, c. 50 species, type: C. coccinea Rabenh., asexual morph acremonium-like, on fruiting bodies and stromata of other fungi or isolated from soil, cosmopolitan, see Lumbsch and Huhndorf (2010; outline), Kirk et al. (2013; genus accepted), Lombard et al. (2015b; phylogeny), Maharachchikumbura et al. (2015, 2016; outline), lectotype of the generic type: BPI, designated by Rossman et al. (1999), cultures and sequences are available.

Costanetoa Bat. \& J.L. Bezerra 1963, Ascomycota genera incertae sedis, one species, type: $C$. caryotae Bat. \& J.L. Bezerra, coelomycetous, sexual morph unknown, saprobes, terrestrial, Brazil, see Wijayawardene et al. (2012, 2017; outline), Kirk et al. (2013; genus accepted), cultures and sequences are unavailable, needs generic revision.

Crandallia Ellis \& Sacc. 1897, Ascomycota genera incertae sedis, four species, type: $C$. juncicola Ellis \& Sacc., coelomycetous, sexual morph unknown, saprobes, pathogens, terrestrial, ?worldwide, see Marincowitz et al. (2008; new species), Wijayawardene et al. 
(2012, 2017; outline), Rossman et al. (2016b; new combinations for pathogens), cultures and sequences are unavailable, needs generic revision.

Craneomyces Morgan-Jones, R.C. Sinclair \& Eicker 1987, Ascomycota genera incertae sedis, one species, type: C. verrucosus Morgan-Jones, R.C. Sinclair \& Eicker, hyphomycetous, sexual morph unknown, saprobes, terrestrial, South Africa, see Seifert et al. (2011; morphology), Wijayawardene et al. (2012, 2017; outline), Kirk et al. (2013; genus accepted), cultures and sequences are unavailable, needs generic revision.

Craspedodidymum Hol.-Jech. 1972, Chaetosphaeriaceae, Chaetosphaeriales, Sordariomycetes, twelve species, type: C. elatum Hol.-Jech., hyphomycetous, sexual morph unknown, saprobes, terrestrial, worldwide, see Ma et al. (2011c; new species), Seifert et al. (2011; morphology), Wijayawardene et al. (2012, 2017; outline), Mel'nik et al. (2014; new species), Maharachchikumbura et al. (2015, 2016; outline), cultures and sequences are available, needs generic revision.

Crassicarpon Y. Marín, Stchigel, Guarro \& Cano 2015, Chaetomiaceae, Sordariales, Sordariomycetes, one species, type: C. thermophilum (Fergus \& Sinden) Y. Marín, Stchigel, Guarro \& Cano, asexual morph hyphomycetous, from soil, USA, see Maharachchikumbura et al. (2015, 2016; outline), Marin-Felix et al. (2015; taxonomy, phylogeny), cultures and sequences are available.

Crassiparies Matsumura, K. Hiray. \& Kaz. Tanaka 2016, Pleosporales incertae sedis, Dothideomycetes, one species, type: C. quadrisporus Matsumura, K. Hiray. \& Kaz. Tanaka, asexual morph unknown, saprobes, terrestrial, Japan, see Li et al. (2016a; morphology, phylogeny), holotype and ex-type: HHUF 30409, MAFF 245408.

Crassoascus Checa, Barrasa \& A.T. Martínez 1993, Clypeosphaeriaceae, Xylariales, Sordariomycetes, two species, type: C. fusisporus Checa, Barrasa \& A.T. Martínez asexual morph unknown, saprobes, terrestrial, Argentina, Spain, see Lumbsch and Huhndorf (2010; outline), Catania and Romero (2012; new species), Kirk et al. (2013; genus accepted), Maharachchikumbura et al. (2015, 2016; outline), holotype: MA-Fungi 26331, cultures and sequences are unavailable, needs generic revision.

Crassochaeta Réblová 1999, Chaetosphaerellaceae, Coronophorales, Sordariomycetes, two species, type: C. nigrita (Sacc.) Réblová, asexual morph unknown, saprobes, terrestrial, Argentina, Spain, see Lumbsch and Huhndorf (2010; outline), Kirk et al. (2013; genus accepted), Maharachchikumbura et al. (2015, 2016; outline, phylogeny), holotype: K37405, cultures and sequences are available, needs generic revision.

Cratiria Marbach 2000, Caliciaceae, Caliciales, Lecanoromycetes, 20 species, type: C. lauricassiae (Fée) Marbach, lichenized, see Lumbsch and Huhndorf (2010; outline), Gaya et al. (2012; taxonomy), Prieto et al. (2013; phylogeny), Lücking et al. (2016b; classification), Prieto and Wedin (2016; phylogeny), sequences are available.

Crauatamyces Viégas 1944, Dothideomycetes genera incertae sedis, one species, type: $C$. eupatorii Viégas, asexual morph unknown, saprobes, terrestrial, Brazil, see Lumbsch and Huhndorf (2010; outline), Kirk et al. (2013; genus accepted), Wijayawardene et al. (2014c; outline), cultures and sequences are unavailable, needs generic revision.

Creodiplodina Petr. 1957, Ascomycota genera incertae sedis, one species, type: C. fusispora Petr., coelomycetous, sexual morph unknown, saprobes, terrestrial, Australia, see Wijayawardene et al. (2012, 2017; outline), Kirk et al. (2013; genus accepted), cultures and sequences are unavailable, needs generic revision.

Creographa A. Massal. 1860, Graphidaceae, Ostropales, Lecanoromycetes, 30 species, type: C. brasiliensis A. Massal., lichenized, see Rivas Plata et al. (2013; taxonomy), Lücking et al. (2016b; classification), sequences are available.

Creonecte Petr. 1949, Ascomycota genera incertae sedis, one species, type: C. biparasitica Petr., coelomycetous, sexual morph unknown, fungicolous (on Uredo), terrestrial, South 
America, see Wijayawardene et al. (2012, 2017; outline), Kirk et al. (2013; genus accepted), cultures and sequences are unavailable, needs generic revision.

Creoseptoria Petr. 1937, Ascomycota genera incertae sedis, one species, type: C. watzlii Petr., coelomycetous, sexual morph unknown, saprobes, terrestrial, Caucasus, see Wijayawardene et al. (2012, 2017; outline), Kirk et al. (2013; genus accepted), cultures and sequences are unavailable, needs generic revision.

Creosphaeria Theiss. 1910, Lopadostomataceae, Xylariales, Sordariomycetes, two species, type: C. sassafras (Schwein.) Y.M. Ju, F. San Martín \& J.D. Rogers, asexual morph unknown, saprobes, terrestrial, Argentina, Spain, see Lumbsch and Huhndorf (2010; outline), Raja et al. (2011a; DNA, phylogeny), Maharachchikumbura et al. (2015, 2016; outline, phylogeny), Sir et al. (2016; DNA), Wendt et al. 2017; transferred to Lopadostomataceae), cultures and sequences are available.

Creothyriella Bat. \& C.A.A. Costa 1957, Ascomycota genera incertae sedis, one species, type: C. sideroxyfoliae Bat. \& C.A.A. Costa, coelomycetous, sexual morph unknown, saprobes, terrestrial, India, see Wijayawardene et al. (2012, 2017; outline), Kirk et al. (2013; genus accepted), cultures and sequences are unavailable, needs generic revision.

Cresponea Egea \& Torrente 1993, Roccellaceae, Arthoniales, Arthoniomycetes, 21 species; type: C. premnea (Ach.) Egea \& Torrente, lichenized, see Lumbsch and Huhndorf (2010; outline), Kirk et al. (2013; genus accepted), Ertz et al. (2015b, phylogeny), Lücking et al. (2016b; classification, accepted as a genus in Opegraphaceae), sequences re available.

Cresporhaphis M.B. Aguirre 1991, Trichosphaeriaceae, Trichosphaeriales, Sordariomycetes, two species, type: C. wienkampii (J. Lahm ex Hazsl.) M.B. Aguirre, asexual morph unknown, lichenized, terrestrial, worldwide, see Lumbsch and Huhndorf (2010; outline), Kirk et al. (2013; genus accepted), Harada (2014; new species), Maharachchikumbura et al. (2015, 2016; outline), cultures and sequences are unavailable, needs generic revision.

Cribropeltis Tehon 1933, Ascomycota genera incertae sedis, one species, type: C. citrullina Tehon, coelomycetous, sexual morph unknown, saprobes, terrestrial, USA, see Wijayawardene et al. (2012, 2017; outline), Kirk et al. (2013; genus accepted), cultures and sequences are unavailable, needs generic revision.

Criella (Sacc.) Henn. 1900, Rhytismataceae, Rhytismatales, Leotiomycetes, one species, type: C. austrocaledonica (Crié) Sacc. \& P. Syd., asexual morph unknown, saprobes, terrestrial, tropical, see Lumbsch and Huhndorf (2010; outline), Kirk et al. (2013; genus accepted), cultures and sequences are unavailable, needs generic revision.

Crinigera I. Scmidt 1985, Ascomycota genera incertae sedis, one species, type: C. maritima I. Schmidt, asexual morph unknown, marine, temperate, on wood, saprobes, see Lumbsch and Huhndorf (2010; outline), Kirk et al. (2013; genus accepted), cultures and sequences are unavailable, needs generic revision.

Crinitospora B. Sutton \& Alcorn 1985, Melanconidaceae, Diaporthales, Sordariomycetes, one species, type: C. pulchra B. Sutton \& Alcorn, coelomycetous, sexual morph unknown, saprobes, Australia, Thailand, see Kirk et al. (2013; genus accepted), Crous et al. (2014a; morphology, phylogeny), Maharachchikumbura et al. (2015, 2016; outline), epitype and exepitype culture of type: CBS H-21729, CBS 138014.

Criserosphaeria Speg. 1912, Helotiales genera incertae sedis, Leotiomycetes, one species, type: $C$. phyllostictoides Speg., asexual morph unknown, saprobes, terrestrial, Argentina, see Lumbsch and Huhndorf (2010; outline), Kirk et al. (2013; genus accepted), cultures and sequences are unavailable, needs generic revision.

Cristula Chenant. 1920, Ascomycota genera incertae sedis, one species, type: C. integra Chenant., hyphomycetous, sexual morph unknown, saprobes, terrestrial, Europe, see Seifert et al. (2011) did not accept the genus, Wijayawardene et al. (2012, 2017; outline), Kirk et al. (2013; genus accepted), cultures and sequences are unavailable, needs generic revision. 
Cristulariella Höhn. 1916 (= Nervostroma Narumi \& Y. Harada 2006 fide Johnston et al. 2014b), Sclerotiniaceae, Helotiales, Leotiomycetes, five species, type: C. depraedans (Cooke) Höhn., hyphomycetous, sexual morph Nervostroma, pathogens, terrestrial, worldwide, see Lumbsch and Huhndorf (2010; outline, sexual morph), Seifert et al. (2011; morphology), Wijayawardene et al. (2012, 2017; outline), Kirk et al. (2013; genus accepted), Johnston et al. (2014b; nomenclature), Cho et al. (2015; DNA, pathogens), cultures and sequences are available.

Crocellina Tehler \& Ertz 2014, Roccellaceae, Arthoniales, Arthoniomycetes, one species, type: C. cinerea (Müll. Arg.) Tehler \& Ertz, lichenized, see Ertz et al. (2015b, c; morphology, phylogeny), Lücking et al. (2016b; classification), sequences are available.

Crocicreas Fr. 1849, Helotiales genera incertae sedis, Leotiomycetes, five species, type: $C$. gramineum (Fr.) Fr., asexual morph unknown, saprobes, terrestrial, widespread (esp. north temperate), see Lumbsch and hunduf (2010; outline), Whitton et al. (2012b; new species), Kirk et al. (2013; genus accepted), cultures and sequences are available but lacks for type species, needs generic revision.

Crocodia Link 1833, Lobariaceae, Peltigerales, Lecanoromycetes, five species; type: C. aurata (Ach.) Link, lichenized, see Galloway and Elix (2013; taxonomy), Moncada et al. (2013a; taxonomy), Lücking et al. (2016b; classification), sequences are unavailable.

Crocynia (Ach.) A. Massal. [nom. cons.] 1860, Ramalinaceae, Lecanorales, Lecanoromycetes, three species, type: L. gossypina (Sw.) Ach., lichenized, tropical, see Ekman et al. (2008; taxonomy), Lumbsch and Huhndorf (2010; outline), Kirk et al. (2013; genus accepted), Lücking et al. (2016b; classification), sequences are available.

Crotone Theiss. \& Syd. 1915, Dothideomycetes genera incertae sedis, one species, type: $C$. drimydis (Lév.) Theiss. \& Syd., asexual morph unknown, saprobes, terrestrial, South America, see Lumbsch and Huhndorf (2010; outline, accepted as a genus in Venturiaceae), Kirk et al. (2013; genus accepted), Wijayawardene et al. (2014c; outline, as Dothideomycetes genera incertae sedis ), cultures and sequences are unavailable, needs generic revision.

Crucellisporiopsis Nag Raj 1983, Hyaloscyphaceae, Helotiales, Leotiomycetes, three species, type: C. gelatinosa Nag Raj, coelomycetous, sexual morph unknown, saprobes, terrestrial, Venezuela, New Zealand, Zambia, see Wijayawardene et al. (2012, 2017; outline), Kirk et al. (2013; genus accepted), Crous et al. (2014d; new species, morphology, DNA), holotype: PDD 41405, sequence data available for C. marquesiae P.W. Crous (holotype CBS H-21977, culture ex-type CPC $22539=$ CBS 138895 fide)

Crucellisporium M.L. Farr 1968, Helotiales genera incertae sedis, Leotiomycetes, three species, type: C. selaginellae M.L. Farr, coelomycetous, sexual morph unknown, saprobes, terrestrial, USA, Tanzania, see Marincowitz et al. (2010; new species, DNA), Wijayawardene et al. (2012, 2017; outline), Kirk et al. (2013; genus accepted), cultures and sequencea are available for $C$. umtamvunae Marinc. et al., needs generic revision.

Cruentotrema Rivas Plata, Papong, Lumbsch \& Lücking 2012, Graphidaceae, Ostropales, Lecanoromycetes, five species, type: $C$. cruentatum (Mont.) Rivas Plata, Lumbsch \& Lücking, asexual morph unknown, lichenized, terrestrial, tropical, placement in Graphidaceae supported by molecular data, see Sipman et al. 2012 (key), Rivas Plata et al. (2012a; taxonomy), Lumbsch et al. (2014a, b), Kalb et al. (2016; taxonomy), Lücking et al. (2016b; classification), sequences are available.

Crumenella P. Karst. 1890 (= Obscurodiscus Raitv. 2002 fide Species Fungorum 2017), Helotiales genera incertae sedis, Leotiomycetes, one species, type: C. myricae (P. Karst.) P. Karst., asexual morph unknown, saprobes, terrestrial, Europe, see Lumbsch and Huhndorf (2010; outline), Kirk et al. (2013; genus accepted), cultures and sequencea are unavailable, needs generic revision. 
Crumenulopsis J.W. Groves 1969 (= Digitosporium Gremmen 1953 fide Johnston et al. 2014b), Cenangiaceae, Helotiales, Leotiomycetes, one species, type: C. pinicola (Rebent.) J.W. Groves, asexual morph Digitosporium, saprobes, terrestrial, Europe, North America, see Johnston et al. (2014b; nomenclature) Pärtel et al. (2017; DNA), Wijayawardene et al. (2016b; morphology of Digitosporium).

Crustodiplodina Punith. 1988, Ascomycota genera incertae sedis, one species, type: $C$. integra Chenant., coelomycetous, sexual morph unknown, saprobes, terrestrial, Europe, see Wijayawardene et al. (2012, 2017; outline), Kirk et al. (2013; genus accepted), cultures and sequences are unavailable, needs generic revision.

Crustospathula Aptroot 1998, Ramalinaceae, Lecanorales, Lecanoromycetes, three species, type: C. cartilaginea Aptroot, lichenized, see Lumbsch and Huhndorf (2010; outline), Kirk et al. (2013; genus accepted), Lücking et al. (2016b; classification), sequences are unavailable.

Crustospathula Aptroot 1998, Ramalinaceae, Lecanorales, Lecanoromycetes, four species, type: $C$. cartilaginea Aptroot, asexual morph unknown, lichenized, terrestrial, tropical, see Lumbsch and Huhndorf (2010; outline), Kirk et al. (2013; genus accepted), Lücking et al. (2016b; classification), cultures and sequences are unavailable.

Crutarndina Parnmen, Lücking \& Lumbsch 2012, Graphidaceae, Ostropales, Lecanoromycetes, one species, type: $C$. petractoides (P.M. Jørg. \& Brodo) Parnmen, Lücking \& Lumbsch, lichenized, see Parnmen et al. (2012; taxonomy), Lücking et al. (2016b; classification), sequences are available.

Cryomyces Selbmann, de Hoog, Mazzaglia, Friedmann \& Onofri 2005, Dothideomycetes genera incertae sedis, type: C. antarcticus Selbmann, de Hoog, Mazzaglia, Friedmann \& Onofri, sexual morph unknown, rock-inhabiting, holotype CBS 116301. From sandstone, Linnaeus Terrace, McMurdo Dry Valleys, Southern Victoria Land, Antarctica; = CCFEE 534 (NCBI accession numbers: DQ028269 (ITS), DQ066713 (SSU)), taxonomic species delimitation supported by molecular data.

Additional species: C. minteri Selbmann, de Hoog, Mazzaglia, Friedmann \& Onofri, MB500194. For diagnosis see Studies in Mycology 51: 21 (2005); C. montanus Isola \& Zucconi, MB802901 and C. funiculosus Selbmann \& de Hoog, MB802893, described from the Alps (Selbmann et al., 2014). These last two taxa were invalidly published, since the holotypes are missing in the original publication [ICN (Melbourne) Art. 40]; the two species are here validated as follows:

Cryomyces montanus Isola \& Zucconi sp. nov., MB819850. For diagnosis see Fungal Diversity 65(1): 177 (2014). Holotype: CBS 135221. From rock, Val de la Mare, Passo dello Stelvio, Italy; =CCFEE 5476. Culture preserved in liquid nitrogen and in dried condition (NCBI accession numbers: KC315849 (ITS), GU250352 (SSU), GU250394 (LSU), GU250434 (mtSSU)), taxonomic species delimitation supported by molecular data.

Cryomyces funiculosus Selbmann \& de Hoog sp. nov., MB819849. For diagnosis see Fungal Diversity 65(1): 175 (2014). Holotype: CBS 134687. From rock, Colle delle Pisse, Monte Rosa, Italy; = CCFEE 5554. Culture preserved in liquid nitrogen and in dried condition (NCBI accession number: KC315848 (ITS)), taxonomic species delimitation supported by molecular data.

Cryphonectria (Sacc.) Sacc. \& D. Sacc. 1905, Cryphonectriaceae, Diaporthales, Sordariomycetes, one species, type: N. parasitica D. Sacc., asexual morph coelomycetous, saprobes, terrestrial, worldwide, see Gryzenhout et al. (2009; new species, revision),Lumbsch and Huhndorf (2010; outline), Braganca et al. (2011; new species), Maharachchikumbura et al. (2015, 2016; taxonomy, phylogeny, outline), cultures and sequences are available.

Cryptandromyces Thaxt. 1912, Laboulbeniaceae, Laboulbeniales, Laboulbeniomycetes, 13 species, type: $C$. geniculatus Thaxt., asexual morph unknown, biotrophic, worldwide, see 
Lumbsch and Huhndorf (2010; outline), Kirk et al. (2013; genus accepted), cultures and sequences are unavailable.

Cryptascoma Ananthap. 1988, Valsaceae, Diaporthales, Sordariomycetes, one species, type: C. bisetula Ananthap., asexual morph unknown, saprobes, terrestrial, India, see Lumbsch and Huhndorf (2010; outline), Maharachchikumbura et al. (2015, 2016; outline, phylogeny), cultures and sequences are unavailable, needs generic revision.

Cryptendoxyla Malloch \& Cain 1970, Cephalothecaceae, Sordariomycetes, families incertae sedis, one species, type: $C$. hypophloia Malloch \& Cain, asexual morph hyphomycetous (chalara-like), from soil, on human as pathogen, terrestrial, Canada, see Lumbsch and Huhndorf (2010; outline), Lysková et al. (2014; DNA, human pathogen), Maharachchikumbura et al. (2015, 2016; outline, phylogeny), living cultures and sequence data available CBS 796.84, CBS 508.70, CBS 138.78.

Crypthonia Frisch \& G. Thor 2010, Arthoniaceae, Arthoniales, Arthoniomycetes, c. 15 species, type: C. polillensis (Vain.) Frisch \& G. Thor, lichenized, widespread tropical, see Frisch and Thor (2010; taxonomy), Menezes et al. (2013; taxonomy, key), Kirk et al. (2013; genus accepted), Frisch et al. (2014; systematics), Lücking et al. (2016b; classification), sequences are available but lacks for the type.

Cryptoascus Petri 1909, Sordariomycetes genera incertae sedis, two species, type: $C$. oligosporus Petri, saprobes or pathogens, terrestrial, Europe, see Lumbsch and Huhndorf (2010; outline), Maharachchikumbura et al. (2015, 2016; outline), cultures and sequences are unavailable, needs generic revision.

Cryptoceuthospora Petr. 1921, Ascomycota genera incertae sedis, two species, type: $C$. moravica Petr., coelomycetous, sexual morph unknown, saprobes, terrestrial, Europe, see Wijayawardene et al. (2012, 2017; outline), Kirk et al. (2013; genus accepted), cultures and sequences are unavailable, needs generic revision.

Cryptocline Petr. 1924, Ascomycota genera incertae sedis, 15 species, type: C. effusa Petr., coelomycetous, sexual morph unknown, saprobes, pathogens, terrestrial, worldwide, see Wijayawardene et al. (2012, 2017; outline), Kirk et al. (2013; genus accepted), cultures and sequences are unavailable, needs generic revision.

Cryptocoryneopsis B. Sutton 1980, Ascomycota genera incertae sedis, one species, type: $C$. umbraculiformis B. Sutton, hyphomycetous, sexual morph unknown, saprobes, Australia, see Seifert et al. (2011; morphology), Wijayawardene et al. (2012, 2017; outline), Kirk et al. (2013; genus accepted), cultures and sequences are unavailable, needs generic revision, holotype of the type: IMI 234264a.

Cryptocoryneum Fuckel 1870, Pleosporales incertae sedis, Dothideomycetes, 20 species, type: $C$. fasciculatum Fuckel, hyphomycetous, dictyosporium-like, sexual morph unknown, saprobes, worldwide, see Seifert et al. (2011; morphology), Wijayawardene et al. (2012, 2017; outline), Kirk et al. (2013; genus accepted), da Silva et al. (2015; morphology), Hashimoto et al. (2016; morphology, phylogeny), holotype: PRM 155688, type species lacks cultures, seven species have sequence data.

Cryptodictyon A. Massal. 1860, Lecideaceae, Lecideales, Lecanoromycetes, two species, type: P. holleana Mont. \& Bosch, lichenized, see Lumbsch and Huhndorf (2010; outline), Schmull et al. (2011; taxonomy), Kirk et al. (2013; genus accepted), Lücking et al. (2016b; classification), sequences are unavailable.

Cryptodiscus Corda 1838, Stictidaceae, Ostropales, Lecanoromycetes, nine species; type: $C$. pallidus (Pers.) Corda, lichenized, see Baloch et al. (2009; taxonomy), Lumbsch and Huhndorf (2010; outline), Kirk et al. (2013; genus accepted), Lücking et al. (2016b; classification), sequences are available. 
Cryptohymenium Samuels \& L.M. Kohn 1987, Helotiales genera incertae sedis, Leotiomycetes, one species, type: C. pycnidiophorum Samuels \& L.M. Kohn, asexual morph unknown, saprobes, pathogens, terrestrial, worldwide, see Lumbsch and Huhndorf (2010; outline), Kirk et al. (2013; genus accepted), cultures and sequences are unavailable, needs generic revision.

Cryptolechia A. Massal. 1853, Gyalectaceae, Ostropales, Lecanoromycetes, 13 specie, type: C. carneolutea (Turner) A. Massal., with ascomata, lichenized (Trentepohlia), terrestrial (corticolous or rarely lignicolous), mainly tropical, rarely noted in the Northern Hemisphere see Mangold et al. (2008b; DNA), Lumbsch and Huhndorf (2010; outline), Kalb et al. (2012; new species), Kirk et al. (2013; genus accepted), Lücking et al. (2016b, classification), sequences are available.

Cryptoleptosphaeria Petr. 1923, Diaporthales genera incertae sedis, one species, type: $C$. moravica Petr., asexual morph unknown, saprobes, pathogens, terrestrial, worldwide, see Lumbsch and Huhndorf (2010; outline), Kirk et al. (2013; genus accepted), Maharachchikumbura et al. (2015, 2016; outline), cultures and sequences are unavailable, needs generic revision.

Cryptomeliola S. Hughes \& Piroz. 1997, Meliolaceae, Meliolales, Sordariomycetes, three species, type: C. orbicularis (Berk. \& M.A. Curtis) S. Hughes \& Piroz., asexual morph produced from the hyphae, saprobes, terrestrial, Cuba, Kenya, see Lumbsch and Huhndorf (2010; outline), Kirk et al. (2013; genus accepted), Hongsanan et al. (2015c; taxonomy), Maharachchikumbura et al. (2015, 2016; outline), cultures and sequences are unavailable, needs generic revision.

Cryptometrion Gryzenh. \& M.J. Wingf. 2010, Cryphonectriaceae, Diaporthales, Sordariomycetes, one species, type: C. aestuescens Gryzenh. \& M.J. Wingf., asexual morphs coelomycetous, pathogens, terrestrial, North Sumatra, Indonesia, see Gryzenhout et al. (2010; taxonomy, phylogeny), Maharachchikumbura et al. (2015, 2016; taxonomy, phylogeny, outline), holotype and culture ex-type: CMW 22535.

Cryptomycella Höhn. 1925, Ascomycota genera incertae sedis, one species, type: C. pteridis (Kalchbr.) Höhn., coelomycetous, sexual morph unknwon, saprobes, terrestrial, Europe, see Wijayawardene et al. (2012, 2017; outline), Kirk et al. (2013; genus accepted), cultures and sequences are unavailable, needs generic revision.

Cryptomyces Grev. 1825, Rhytismataceae, Rhytismatales, Leotiomycetes, one species, type: C. wauchii Grev., asexual morph unknown, saprobes, terrestrial, north temperate, see Lumbsch and Huhndorf (2010; outline, accepted as a genus in Cryptomycetaceae), Lantz et al. (2011; DNA, phylogeny), Kirk et al. (2013; genus accepted), Jaklitsch et al. (2016a; treated Cryptomycetaceae as a synonym of Rhytismataceae), cultures and sequences are available.

Cryptomycina Höhn. 1917, Sordariomycetes, genera incertae sedis, one species, type: C. pteridis (Rebent.) Höhn., asexual morph ? Cryptomycella, saprobes, terrestrial, North Temperate, see Kirk et al. (2013; genus accepted), Maharachchikumbura et al. (2015, 2016; outline), cultures and sequences are unavailable, needs generic revision.

Cryptonectriella (Höhn.) Weese 1919, Diaporthales genera incertae sedis, Sordariomycetes, one species, type: C. biparasitica (Höhn.) Weese, see Kirk et al. (2008; treated as a synonym of Nectriella Nitschke ex Fuckel), Lumbsch and Huhndorf (2010; outline), Kirk et al. (2013; did not list), Maharachchikumbura et al. (2015, 2016; outline), sequences are unavailable.

Cryptonectriopsis (Höhn.) Weese 1919, Diaporthales genera incertae sedis, Sordariomycetes, type: C. biparasitica (Höhn.) Höhn., see Kirk et al. (2008; treated as a synonym of Phomatospora Sacc.), Lumbsch and Huhndorf (2010; outline), Kirk et al. (2013; did not list), Maharachchikumbura et al. (2015, 2016; outline), sequences are unavailable.

Cryptoniesslia Scheuer 1993, Niessliaceae, Hypocreales, Sordariomycetes, one species, type: C. setulosa Scheuer, asexual morph unknown, saprobes, terrestrial, British Isles, see 
Lumbsch and Huhndorf (2010; outline), Kirk et al. (2013; genus accepted), Maharachchikumbura et al. (2015, 2016; outline), cultures and sequences are unavailable, needs generic revision.

Cryptopezia Höhn. 1919, Helotiales genera incertae sedis, one species, type: C. mirabilis Höhn., asexual morph unknown, saprobes, terrestrial, Samoa, see Lumbsch and Huhndorf (2010; outline), Kirk et al. (2013; genus accepted), cultures and sequences are unavailable, needs generic revision.

Cryptophaea Van den Broeck \& Ertz 2016, Arthoniaceae, Arthoniales, Arthoniomycetes, one species, type: $C$. phaeospora Van den Broeck \& Ertz, asexual morph unknown, lichenized, terrestrial, Democratic Republic of the Congo, see Van den Broeck and Ertz (2016; morphology, phylogeny), Lücking et al. (2016b; classification), holotype and ex-type: Van den Broeck 5964 (BR).

Cryptophiale Piroz. 1968, Ascomycota genera incertae sedis, 18 species, type: $C$. kakombensis Piroz., hyphomycetous, sexual morph unknown, saprobes, terrestrial, North America, see Seifert et al. (2011; morphology, accepted as a genus in Chaetosphaeriaceae, Chaetosphaeriales), Whitton et al. (2012a; new species), Wijayawardene et al. (2012, 2017; outline), Kirk et al. (2013; genus accepted), cultures and sequences are unavailable, needs generic revision.

Cryptophialoidea Kuthub. \& Nawawi 1987, Ascomycota genera incertae sedis, three species, type: C. secunda (Kuthub. \& B. Sutton) Kuthub. \& Nawawi, hyphomycetous, sexual morph unknown, saprobes, terrestrial, Cuba, Malaysia, see Wijayawardene et al. (2012, 2017; outline), Kirk et al. (2013; genus accepted), cultures and sequences are unavailable, needs generic revision.

Cryptosphaerella Sacc. 1882, Scortechiniaceae, Coronophorales, Sordariomycetes, c. 15 species, type: C. nitschkei (Auersw.) Sacc., asexual morph unknown, saprobes, terrestrial, Cuba, Malaysia, see Lumbsch and Huhndorf (2010; outline), Mugambi and Huhndorf (2010; DNA, phylogeny), Maharachchikumbura et al. (2016; outline, phylogeny), cultures and sequences are available.

Cryptosphaeria Ces. \& De Not. 1863, Diatrypaceae, Xylariales, Sordariomycetes, c. 13 species, type: $C$. millepunctata Grev., asexual morph unknown, saprobes, terrestrial, teperate, see Lumbsch and Huhndorf (2010; outline), Trouillas et al. (2015; new species, USA, DNA, Phylogeny), Maharachchikumbura et al. (2016; outline, phylogeny), cultures and sequences are available.

Cryptosporella Sacc. 1877 (= Disculina Höhn. 1916; = Cryptospora Tul. \& C. Tul. 1863; = Cryptospora subgen. Winterella Sacc. 1883; = Cryptosporina Höhn. 1905; = Hystricula Cooke 1884; = Ophiovalsa Petr. 1966; = Winterella (Sacc.) Kuntze 1891 fide Mejia et al. 2008; Rossman et al. 2015a; Species Fubgorum 2017), Gnomoniaceae, Diaporthales, Sordariomycetes, c. 26 species, type: C. hypodermia (Fr.) Sacc., asexual morph unknown, saprobes, terrestrial, temperate, see Lumbsch and Huhndorf (2010; outline), Mejía et al. (2008, 2011; new species, DNA, Phylogeny), Maharachchikumbura et al. (2016; outline, phylogeny), cultures and sequences are available.

Cryptosporium Kunze 1817, Ascomycota genera incertae sedis, 25 species, type: C. atrum Kunze, coelomycetous, sexual morph unknown, saprobes, terrestrial, temperate, see Wijayawardene et al. (2012, 2017; outline), Kirk et al. (2013; genus accepted), cultures and sequences are unavailable, needs generic revision.

Cryptostroma P.H. Greg. \& S. Waller 1952, Xylariaceae, Xylariales, Sordariomycetes, one species, type: C. corticale (Ellis \& Everh.) P.H. Greg. \& S. Waller, hyphomycetous, sexual morph unknown, saprobes, terrestrial, temperate, see Wijayawardene et al. (2012, 2017; outline), Kirk et al. (2013; genus accepted), cultures and sequences are unavailable, needs generic revision. 
Cryptothecia Stirt. 1877 nom. cons., Arthoniaceae, Arthoniales, Arthoniomyecetes, c. 65 species, type: $C$. subnidulans Stirt., asexual morph unknown, lichenized, epiphytic and foliicolous, widespread, pantropical to subtropical, see Ertz et al. (2009; phylogeny), Lumbsch and Huhndorf (2010; outline), Bungartz et al. (2013a; taxonomy), Kirk et al. (2013; genus accepted), Frisch et al. (2014; phylogeny: genus Myriostigma reinstated for the Cryptothecia candida group), Jagadeesh Ram and Sinha (2016; world key), Lücking et al. (2016b; classification), sequences are available.

Cryptothele Th. Fr. 1866, Lichinaceae, Lichinales, Lichinomycetes, six species, type: C. permiscens (Nyl.) Th. Fr., asexual morph unknown, lichenized, saxicolous, widespread, see Lumbsch and Huhndorf (2010; outline), Kirk et al. (2013; genus accepted), Lücking et al. (2016; classification), sequences are unavailable.

Cryptovalsa Ces. \& De Not. ex Fuckel 1870, Diatrypaceae, Xylariales, Sordariomycetes, 24 species, type: $C$. protracta (Pers.) De Not., asexual morph coelomycetous, saprobes, pathogens, worldwide, see Lumbsch and Huhndorf (2010; outline; as Sordariomycetes, genera incertae sedis), Trouillas et al. (2010; pathogens), Senanayake et al. (2015; outline), Li et al. (2016a; coelomycetous asexual morph), Maharachchikumbura et al. (2016; outline), cultures and sequences are available.

Cryptumbellata Udagawa \& Uchiy. 1999, Ascomycota genera incertae sedis, one species, type: $C$. terricola Udagawa \& Uchiy., hyphomycetous, sexual morph unknown, saprobes, terrestrial, China, see Seifert et al. (2011; morphology), Wijayawardene et al. (2012, 2017; outline), Kirk et al. (2013; genus accepted), cultures and sequences are unavailable, needs generic revision.

Ctenomyces Eidam 1880, Arthrodermataceae, Onygenales, Eurotiomycetes, one species, type: C. serratus Eidam, asexual morph hyphomycetous, saprobes, terrestrial, common on keratinous substrates, especially feathers, also occurring in soil and on dung, cosmopolitan, see Lumbsch and Huhndorf (2010; outline), Guarro et al. (2012; morphology), van den Brink et al. (2012; phylogeny), Kirk et al. (2013; genus accepted), de Hoog et al. (2016; phylogeny, outline), ex-neotype: CBS 187.61.

Ctenosporium R. Kirschner 2006, Ascomycota genera incertae sedis, one species, type: $C$. pectinatum R. Kirschner, hyphomycetous, sexual morph unknown, saprobes, terrestrial, Panama, see Seifert et al. (2011; morphology), Wijayawardene et al. (2012, 2017; outline), cultures and sequences are unavailable, needs generic revision.

Cubasina R.F. Castañeda 1986, Ascomycota genera incertae sedis, two species, type: $C$. albofusca R.F. Castañeda, hyphomycetous, sexual morph unknown, saprobes, terrestrial, Cuba, see see Seifert et al. (2011; morphology), Wijayawardene et al. (2012, 2017; outline), Kirk et al. (2013; genus accepted), holotype: INIFAT C85/154, cultures and sequences are unavailable, needs generic revision.

Cucujomyces Speg. 1917, Laboulbeniaceae, Laboulbeniales, Laboulbeniomycetes, 20 species, type: need typification, asexual morph unknown, biotrophic, worldwide, see Rossi and Weir (2008; new species), Lumbsch and Huhndorf (2010; outline), Kirk et al. (2013; genus accepted), cultures and sequences are unavailable.

Cucullosporella K.D. Hyde \& E.B.G. Jones 1986, Halosphaeriaceae, Microascales, Sordariomycetes, one species, type: C. mangrovei (K.D. Hyde \& E.B.G. Jones) K.D. Hyde \& E.B.G. Jones, asexual morph unknown, saprobes, marine, worldwide, see Lumbsch and Huhndorf (2010; outline), Sakayaroj et al. (2011a; DNA, phylogeny), Kirk et al. (2013; genus accepted), Jones et al. (2015; outline), cultures and sequences are available.

Cucurbidothis Petr. 1921, Cucurbitariaceae, Pleosporales, Dothideomycetes, one species, type: C. pityophila (J.C. Schmidt \& Kunze) Petr., asexual morph unknown, saprobes, terrestrial, worldwide, see Ariyawansa et al. (2014e; accepted as agenus in Cucurbitariaceae), 
Wijayawardene et al. (2014c; outline), cultures and sequences are available for Cucurbidothis but needs verification.

Cucurbitaria Gray 1821, Cucurbitariaceae, Pleosporales, Dothideomycetes, c. 40 species, type: C. berberidis (Pers.) Gray, asexual morph coelomycetous, with pyrenochaeta-like asexual morph, saprobes, terrestrial, worldwide, see Lumbsch and Huhndorf (2010; outline), Doilom et al. (2013; txonomy, typification), Hyde et al. (2013; phylogeny), Kirk et al. (2013; genus accepted), Wijayawardene et al. (2014c; outline), ex-epityp: CB1 = CBS $130007=$ MFLUCC11-0384; Epitype of type: MFLU 12-0111.

Cucurbitopsis Bat. \& Cif. 1957, Sordariomycetes genera incertae sedis, one species, type: $C$. ramulorum Bat., Nascim. \& Cif., asexual morph unknown, saprobes, pathogens, worldwide, see Lumbsch and Huhndorf (2010; outline), Maharachchikumbura et al. (2016; outline), cultures and sequences are unavailable.

Cudonia Fr. 1849, Cudoniaceae, Rhytismatales, Leotiomycetes, nine species, type: C. circinans (Pers.) Fr., asexual morph unknown, saprobes, temperate, see Lumbsch and Huhndorf (2010; outline), Kirk et al. (2013; genus accepted), cultures and sequences are available, cultures available for type: AFTOL-ID 353.

Cudoniella Sacc. 1889, Helotiaceae, Helotiales, Leotiomycetes, 31 species, type: C. queletii (Fr.) Sacc., asexual morph hyphomycetous (Tricladium?), saprobes, terrestrial, worldwide, see Lumbsch and Huhndorf (2010; outline), Hustad and Miller (2011b; DNA), Kirk et al. (2013; genus accepted), cultures and sequences are available available, type lacks sequence data.

Cudoniopsis Speg. 1925, Sclerotiniaceae, Helotiales, Leotiomycetes, one species, type: C. pusilla Speg., asexual morph unknown, saprobes, terrestrial, worldwide, see Lumbsch and Huhndorf (2010; outline), Kirk et al. (2013; genus accepted), cultures and cultures and sequences are unavailable.

Culbersonia Essl. 2000, Physciaceae, Caliciales, Lecanoromycetes, two species; type: $C$. americana Essl., lichenized, see Lumbsch and Huhndorf (2010; outline), Gaya et al. (2012; taxonomy), Prieto et al. (2013; phylogeny), Lücking et al. (2016b; classification), Prieto and Wedin (2016; phylogeny), sequences are unavailable.

Culicidospora R.H. Petersen 1960, Ascomycota genera incertae sedis, two species, type: $C$. aquatica R.H. Petersen, hyphomycetous, sexual morph unknown, saprobes, aquatic, Newfoundland, see Seifert et al. (2011; morphology), Wijayawardene et al. (2012, 2017; outline), Kirk et al. (2013; genus accepted), cultures and cultures and sequences are unavailable.

Culicinomyces Couch, Romney \& B. Rao 1974, Ascomycota genera incertae sedis, two species, type: C. clavisporus Couch, Romney \& B. Rao, hyphomycetous, sexual morph unknown, on mosquitos, aquatic, USA, see Seifert et al. (2011; morphology), Wijayawardene et al. (2012, 2017; outline), Kirk et al. (2013; genus accepted), sequence data available for Culicinomyces bisporalis Sigler, Frances \& C. Panter, type lacks sequence data.

Cumulospora I. Schmidt 1985, Lulworthiaceae, Lulworthiales, Sordariomycetes, one species, type: C. marina I. Schmidt, hyphomycetous, sexual morph unknown, saprobes, marine, worldwide, see Abdel-Wahab et al. (2010; phylogeny), Seifert et al. (2011; morphology), Wijayawardene et al. (2012, 2017; outline), Kirk et al. (2013; genus accepted), cultures and sequences are unavailable, needs generic revision.

Cupulina Dougoud, Van Vooren \& M. Vega 2015, Pyronemataceae, Pezizales, Pezizomycetes, one species, type: C. montana Dougoud, Van Vooren \& M. Vega, asexual morph unknown, saprobes, terrestrial, Europe, see Dougoud et al. (2015; morphology, taxonomy), holotype and isotype: G00262366 (herbarium Geneva), R. Dougoud RD32.43.544.13. 
Cupulomyces R.K. Benj. 1992, Laboulbeniaceae, Laboulbeniales, Laboulbeniomycetes, one species, type: C. lasiochili (Thaxt.) R.K. Benj., asexual morph unknown, biotrophic, Grenada, see Lumbsch and Huhndorf (2010; outline), Kirk et al. (2013; genus accepted), cultures and sequences are unavailable.

Curreya Sacc. 1883 Cucurbitariaceae, Pleosporales, Dothideomycetes, two species, type: $C$. conorum (Fuckel) Sacc., asexual morph coelomycetous, saprobes, terrestrial, cosmopolitan, see Lumbsch and Huhndorf (2010; outline), Doilom et al. (2013; acceptd as a genus in Cucurbitariaceae), Hyde et al. (2013; acceptd as a genus in Cucurbitariaceae), Kirk et al. (2013; genus accepted), Wijayawardene et al. (2014c; outline), ex-holotype: S F8461.

Curucispora Matsush. 1981, Ascomycota genera incertae sedis, three species, type: $C$. ponapensis Matsush., hyphomycetous, sexual morph unknown, saprobes, terrestrial, Asia, see Seifert et al. (2011; morphology), Wijayawardene et al. (2012, 2017; outline), Kirk et al. (2013; genus accepted), cultures and sequences are unavailable, needs generic revision.

Curvatispora V.V. Sarma \& K.D. Hyde 2001, Sordariomycetes genera incertae sedis, one species, type: C. singaporensis V.V. Sarma \& K.D. Hyde, asexual morph unknown, saprobes, terrestrial, Singapore, see Lumbsch and Huhndorf (2010; outline), Maharachchikumbura et al. (2016; outline), cultures and sequences are unavailable, needs generic revision.

Curvicladiella Decock \& Crous 2006 (= Curvicladium Decock \& Crous 1998 nom. inval. Art. 53), Nectriaceae, Hypocreales, Sordariomycetes, one species, type: C. cignea (Decock \& Crous) Decock \& Crous, asexual morph hyphomycetous, saprobes, terrestrial, French Guiana, see Wijayawardene et al. (2012, 2017; outline), Lombard et al. (2015b; taxonomy, DNA, phylogeny), Maharachchikumbura et al. (2016; outline), holotype and ex-type: MUCL 40269, CPC $1595=$ CBS 109167 .

Curvularia Boedijn 1933 (= Pseudocochliobolus Tsuda, Ueyama \& Nishih. 1978 fide Wijayawardene et al. 2014c; Rossman et al. 2015b), Pleosporaceae, Pleosporales, Dothideomycetes, more than 100 species, type: C. lunata (Wakker) Boedijn, asexual morph hyphomycetous, pathogenic or saprobes on plant or humans, terrestrial, worldwide, see Seifert et al. (2011; morphology), Manamgoda et al. (2012, 2014; taxonomy, phylogeny), Kirk et al. (2013; genus accepted), Wijayawardene et al. (2014c; outline, nomenclature), Ariyawansa et al. (2015c; taxonomy, phylogeny), Rossman et al. (2015b; nomenclature), sequence data available for more than 50 species, ex-neotype: CBS 730.96.

Curvulariopsis M.B. Ellis 1961, Ascomycota genera incertae sedis, one species, type: C. cymbisperma (Pat.) M.B. Ellis, hyphomycetous, sexual morph unknown, saprobes, Ecuador, see Seifert et al. (2011; morphology), Wijayawardene et al. (2012, 2017; outline), Kirk et al. (2013; genus accepted), cultures and sequences are unavailable, needs generic revision.

Cuspidatispora Shearer \& Bartolata 2006, Sordariales genera incertae sedis, Sordariomycetes, one species, type: C. xiphiago Shearer \& Bartolata, asexual morph unknown, saprobes, aquatic, USA, see Lumbsch and Huhndorf (2010; outline), Maharachchikumbura et al. (2015, 2016; outline), holotype: ILL, Shearer A184-1, cultures and sequences are available.

Custingophora Stolk, Hennebert \& Klopotek 1968, Gondwanamycetaceae, Microascales, Sordariomycetes, eight species, type: C. olivacea Stolk, Hennebert \& Klopotek, sexual morph unknown, saprobes, terrestrial, worldwide, see Kolarík and Hulcr (2009; new species), Nagaraju et al. (2011a; new species), Crous et al. (2013b; new species, DNA), Dubey and Moonambeth (2013; new species), Maharachchikumbura et al. (2015, 2016; outline), cultures available for type: CBS 335.68.

Cyanoannulus Raja, J. Campb. \& Shearer 2003, Annulatascaceae, Annulatascales, Sordariomycetes, one species, type: C. petersenii Raja, J. Campb. \& Shearer, see Boonyuen et al. (2012; phylogeny), Cai et al. (2014; phylogeny), Maharachchikumbura et al. (2015, 2016; outline), holotype: R044-1, ILL 86218, cultures and sequences are available. 
Cyanochyta Höhn. 1915, Nectriaceae, Hypocreales, Sordariomycetes, one species, type: C. cyanogena (Speg.) Höhn, coelomycetous, sexual morph unknown, saprobes, terrestrial, Italy, see Wijayawardene et al. (2012, 2017; outline), Kirk et al. (2013; genus accepted), Maharachchikumbura et al. (2015, 2016; outline), cultures and sequences are unavailable, needs generic revision.

Cyanodermella O.E. Erikss. 1981, Stictidaceae, Ostropales, Lecanoromycetes, four species, type: $C$. viridula (Berk. \& M.A. Curtis) O.E. Erikss., coelomycetous, sexual morph unknown, saprobes, cosmopolitan, see Jaklitsch et al. (2016a; classification), van Nieuwenhuijzen et al. (2016; DNA), Wijayawardene et al. (2017; outline), cultures and sequences are available.

Cyanodiscus E. Müll. \& M.L. Farr 1971, Saccardiaceae, Pezizomycotina families incertae sedis, two species, type: C. occidentalis E. Müll. \& M.L. Farr, asexual morph unknown, saprobes, terrestrial, sub tropical regions, see Lumbsch and Huhndorf (2010; outline), Kirk et al. (2013; genus accepted), cultures and sequences are unavailable, needs generic revision.

Cyanonectria Samuels \& P. Chaverri 2009, Nectriaceae, Hypocreales, Sordariomycetes, two species, type: C. cyanostoma (Sacc. \& Flageolet) Samuels \& P. Chaverri, asexual morph hyphomycetous, saprobes, terrestrial, French Guiana, see Samuels et al. (2009; morphology), Schroers et al. (2011; DNA, phylogeny), Lombard et al. (2015b; taxonomy, DNA, phylogeny), Maharachchikumbura et al. (2016; outline), cultures and sequences are available.

Cyanopatella Petr. 1949, Ascomycota genera incertae sedis, one species, type: C. iranica Petr., coelomycetous, sexual morph unknown, saprobes, terrestrial, Iran, see Wijayawardene et al. (2012, 2017; outline), Kirk et al. (2013; genus accepted), cultures and sequences are unavailable, needs generic revision.

Cyanophomella Höhn. 1918, Nectriaceae, Hypocreales, Sordariomycetes, one species, type: C. acervalis (Sacc.) Höhn, asexual morph coelomycetous, saprobes, Rhenogovia, see Kirk et al. (2013; genus accepted), Maharachchikumbura et al. (2015, 2016; outline), cultures and sequences are unavailable, needs generic revision.

Cyanoporina Groenh. 1951, Pezizomycotina genera incertae sedis, one species, type: $C$. granulosa Groenh., asexual morph unknown, saprobes, terrestrial, Java, see Lumbsch and Huhndorf (2010; outline), Hyde et al. (2013; accepted as in Pyrenotrichaceae), Kirk et al. (2013; genus accepted), Lücking et al. (2016b; classification), cultures and sequences unavailabe, needs a revision.

Cyanopulvis J. Fröhl. \& K.D. Hyde 2000, Xylariales genera incertae sedis, Sordariomycetes, one species, type: C. australiensis J. Fröhl. \& K.D. Hyde, asexual morph unknown, saprobes, terrestrial, Australia, see Lumbsch and Huhndorf (2010; outline), Maharachchikumbura et al. (2015, 2016; outline), Wendt et al. (2017; accepted as Xylariales genera incertae sedis), cultures and sequences unavailabe, needs a revision.

Cyanopyrenia H. Harada 1995, Ascomycota genera incertae sedis, one species, type: $C$. japonica $\mathrm{H}$. Harada, asexual morph unknown, saprobes, terrestrial, Japan, see Lumbsch and Huhndorf (2010; outline), Kirk et al. (2013; genus accepted), holotype: HIRO, Harada 3444, cultures and sequences unavailabe, needs a revision.

Cyathicula De Not. 1864 (= Conchatium Velen. 1934 fide Jaklitsch et al. 2016a), Helotiaceae, Helotiales, Leotiomycetes, c. 30 species, type: C. coronata (Bull.) De Not., asexual morph Glarea (fide Jaklitsch et al. 2016a), saprobes on leaves, culms, herbaceous stems and wood, widespread, Kirk et al. (2013; did not list), acceptd in Jaklitsch et al. (2016a), cultures and sequences are unavailable for the type.

Cyberlindnera Minter 2009, Phaffomycetaceae, Saccharomycetales, Saccharomycetes, 30 species, type: C. americana (Wickerham) Minter, asexual reproduction is by multilateral budding and formation of pseudohyphae and true hyphae, saprophytic, one species is an opportunistic human and animal pathogen, see Minter (2009; taxonomy), cultures and sequences are available. 
Cyclaneusma DiCosmo, Peredo \& Minter 1983, Marthamycetaceae, Rhytismatales, Leotiomycete, two species, type: C. minus (Butin) DiCosmo, Peredo \& Minter, asexual morph unknown, saprobes, terrestrial, worldwide, see Kirk et al. (2013; genus accepted), cultures and sequences are available.

Cyclodomus Höhn. 1909, Phyllachoraceae, Phyllachorales, Sordariomycetes, three species, type: C. umbellulariae Höhn., coelomycetous, sexual morph unknown, saprobes, terrestrial, North America, see Wijayawardene et al. (2012, 2017; outline), Kirk et al. (2013; genus accepted), cultures and sequences are unavailable, needs generic revision.

Cyclomarsonina Petr. 1965, Ascomycota genera incertae sedis, one species, type: C.cedrelae (T.S. Ramakr. \& K. Ramakr.) Petr., sexual morph unknown, saprobes, terrestrial, India, see coelomycetous, sexual morph unknown, saprobes, terrestrial, North America, see Wijayawardene et al. (2012, 2017; outline), Kirk et al. (2013; genus accepted), cultures and sequences are unavailable, needs generic revision.

Cyclopeltella Petr. 1953, Micropeltidaceae, Microthyriales, Dothideomycetes, one species, type: C. orbicularis Petr., saprobes, terrestrial, Phillipines, see Wijayawardene et al. (2012, 2014c; outline, reduced under Cyclopeltis), Hyde et al. (2013; accepted as Micropeltidaceae), Kirk et al. (2013; genus accepted), Rossman et al. (2015b; nomenclature), cultures and sequences are unavailable, needs generic revision.

Cycloschizon Henn. 1902, Parmulariaceae, Dothideomycetes families incertae sedis, Dothideomycetes, c. 13 species, type: C. brachylaenae (Rehm) Henn., asexual morph unknown, epiphytes, terrestrial, worldwide, see Hofmann (2009; review), Lumbsch and Huhndorf (2010; outline), Hyde et al. (2013; review, keys), Kirk et al. (2013; genus accepted), Wijayawardene et al. (2014c; outline), placement in Parmulariaceae supported by morphology, cultures and sequences are unavailable.

Cyclostomella Pat. 1896, Parmulariaceae, Dothideomycetes families incertae sedis, Dothideomycetes, four species, type: $C$. disciformis Pat., epiphytes, terrestrial, worldwide, see Hofmann (2009; review), Lumbsch and Huhndorf (2010; outline), Hyde et al. (2013; review, keys), Kirk et al. (2013; genus accepted), Wijayawardene et al. (2014c; outline), cultures and sequences are unavailable.

Cyclotheca Theiss. 1914 nom. cons. prop., Dothideomycetes, genera incertae sedis, nine species, type: C. miconiae (P. Syd.) Theiss., asexual morph unknown, saprobes, worldwide, Lumbsch and Huhndorf (2010; outline), Wu et al. (2011; nomenclature), Wijayawardene et al. (2014c; outline), cultures and sequences are unavailable.

Cyclothyrium Petr. 1923, Pleosporales genera incertae sedis, Dothideomycetes, two species, type: C. ulmigenum (Berk.) Petr., coelomycetous, ?sexual morph thyridaria-like, saprobes, terrestrial, worldwide, see Damm et al. (2008; phylogeny), de Gruyter et al. (2012; phylogeny), Wijayawardene et al. (2014c, 2016b; outline, morphology, phylogeny), cultures and sequences are available.

Cylindrium Bonord. 1851, Hypocreales genera incertae sedis, Sordariomycetes, c. 50 species, type: C. elongatum Bonord., hyphomycetous, sexual morph unknown, on soil, saprobes, terrestrial, cosmopolitan, see Seifert et al. (2011; morphology), Kirk et al. (2013; genus accepted), Lombard et al. (2015b; phylogeny, new species), Wijayawardene et al. (2017; outline), cultures and sequences are available.

Cylindrocarpostylus R. Kirschner \& Oberw. 1999, Nectriaceae, Hypocreales, Sordariomycetes, one species, type: C. gregarius (Bres.) R. Kirschner \& Oberw., hyphomycetous, sexual morph unknown, in bark beetle galleries, Europe, see see Seifert et al. (2011; morphology), Wijayawardene et al. (2012, 2017; outline), Kirk et al. (2013; genus accepted), cultures and sequences are unavailable, needs generic revision.

Cylindrocladiella Boesew. 1982 (= Nectricladiella Crous \& C. L. Schoch 2000 fide Rossman et al. 2013b), Nectriaceae, Hypocreales, Sordariomycetes, eight species, type: C. parva (P.J. 
Anderson) Boesew., soil-borne fungi, pathogenic and/or saprobes of various plant hosts and substrates, worldwide, see Seifert et al. (2011; morphology), Wijayawardene et al. (2012, 2017; outline), Kirk et al. (2013; genus accepted), Lombard et al. (2012, 2015b), Maharachchikumbura et al. (2015, 2016; outline), ex-epitype: CBS $114524=$ ATCC $28272=$ CPC 2370; holotype: ATCC 28272.

Cylindrodendrum Bonord. 1851, Nectriaceae, Hypocreales, Sordariomycetes, three species, type $C$. album Bonord., sexual morph unknown, saprobes, pathogenic or isolated from soil, marine, fresh-water and terrestrial, worldwide, Seifert et al. (2011; morphology), Wijayawardene et al. (2012, 2017; outline), Kirk et al. (2013; genus accepted), Lombard et al. (2012, 2015b), Maharachchikumbura et al. (2015, 2016; outline), ex-epitype: CBS $301.83=$ ATCC 46842 = IMI 255534; isotype: CBS H-3483A = CBS H-3483B = CBS H-3483C.

Cylindrogloeum Petr. 1941, Ascomycota genera incertae sedis, one species, type: C. arcticum Petr., coelomycetous, sexual morph unknown, saprobes, Lapland, see Wijayawardene et al. (2012, 2017; outline), Kirk et al. (2013; genus accepted), cultures and sequences are unavailable, needs generic revision.

Cylindromyces Manohar., D.K. Agarwal \& N.K. Rao 2004, Ascomycota genera incertae sedis, one species, type: C. striatus Manohar., D.K. Agarwal \& N.K. Rao, hyphomycetous, sexual morph unknown, saprobes, India, see Wijayawardene et al. (2012, 2017; outline), Kirk et al. (2013; genus accepted), cultures and sequences are unavailable, needs generic revision.

Cylindrophoma (Berl. \& Voglino) Höhn. 1978, Ascomycota genera incertae sedis, one species, type: C. smilacina (Desm.) Höhn., coelomycetous, sexual morph unknown, saprobes, Italy, see Kirk et al. (2013; genus accepted), cultures and sequences are unavailable, needs generic revision.

Cylindroseptoria Quaedvl., Verkley \& Crous 2013, Dothideaceae, Dothideales, Dothideomycetes, two species, type: C. ceratoniae Quaedvlieg, Verkley \& Crous, saprobes, terrestrial, Spain, see Quaedvlieg et al. (2013; morphology, DAN, phylogeny), Wijayawardene et al. (2014c; outline, phylogeny), holotype and ex-type: CBS H-21301, CBS 471.69.

Cylindrosporella Höhn. 1916, Gnomoniaceae, Diaporthales, Sordariomycetes, three species, type: C. carpini (Lib.) Höhn., saprobes, terrestrial, Spain, see Wijayawardene et al. (2012, 2017; outline), Maharachchikumbura et al. (2016; outline), cultures and sequences are unavailable, needs generic revision.

Cylindrosympodioides Crous \& M.J. Wingf. 2016, Venturiales genera incertae sedis, Dothideomycetes, one species, type: C. brabejum Crous \& M.J. Wingf., hyphomycetous, sexual morph unknown, saprobes, terrestrial, South Africa, see Crous et al. (2016b; new species, phylogeny), Wijayawardene et al. (2017; outline, phylogeny), holotype and ex-type culture of the type: CBS H-22594, CPC 25934.

Cylindrosympodium (de Hoog) W.B. Kendr. \& R.F. Castañeda 1990, Ascomycota genera incertae sedis, twelve species, type: C. variabile (de Hoog) W.B. Kendr. \& R.F. Castañeda, hyphomycetous, sexual morph unknown, saprobes, terrestrial, Netherlands, see Seifert et al. (2011; morphology), Castañeda-Ruiz et al. (2012a; new species), Wijayawardene et al. (2012, 2017; outline), Kirk et al. (2013; genus accepted), holotype: CBS-H 1634, sequence data, vailable, compare with Mirandina, Parasympodiella, Solosympodiella and Subulispora.

Cylindrothyrium Maire 1907, Ascomycota genera incertae sedis, one species, type: $C$. subericola Maire, coelomycetous, sexual morph unknown, saprobes, France, see Wijayawardene et al. (2012, 2017; outline), Kirk et al. (2013; genus accepted), cultures and sequences are unavailable, needs generic revision.

Cylindrotrichum Bonord. 1851 (= Reticulascus Réblová \& W. gams 2011 fide Maharachchikumbura et al. 2016; Réblová et al. 2016c), Reticulascaceae, Glomerellales, Sordariomycetes, 14 species, type: C. oligospermum (Corda) Bonord., hyphomycetous, 
sexual morph formerly known in Reticulascus, Europe, see Réblová et al. (2011, 2016c; sexual morph, DNA, morphology, phylogeny, nomenclature), Seifert et al. (2011; morphology), Maharachchikumbura et al. (2015, 2016; outline, nomenclature), cultures available for type: CBS 561.77, CBS 570.76, CBS 557.74.

Cylindroxyphium Bat. \& Cif. 1963, Ascomycota genera incertae sedis, one species, type: $C$. virginianum Bat. \& Cif., coelomycetous, sexual morph unknown, saprobes, USA, see Wijayawardene et al. (2012, 2017; outline), Kirk et al. (2013; genus accepted), cultures and sequences are unavailable, needs generic revision.

Cymostachys L. Lombard \& Crous 2016, Stachybotriaceae, Hypocreales, Sordariomycetes, two species, type: $C$. fabispora L. Lombard \& Crous, hyphomycetous, sexual morph unknown, saprobes, terrestrial, Cuba, see Lombard et al. (2016; taxonomy, phylogeny), Wijayawardene et al. (2017; outline), holotype and ex-type: CBS H-22433, CBS 136180.

Cyniclomyces van der Walt \& D.B. Scott 1971, Saccharomycetaceae, Saccharomycetales, pe Saccharomycetes, one species, type: C. guttulatus (C.P. Robin) van der Walt \& D.B. Scott, asexual reproduction is by multilateral budding, saprophyte, stomach and intestines of rabbits and certain other herbivores, worldwide, see Lumbsch and Huhndorf (2010; outline), Kurtzman and Robnett (2013b; DNA, phylogeny), Kirk et al. (2013; genus accepted), sequences are available.

Cyphelium Ach. 1815, Caliciaceae, Caliciales, Lecanoromycetes, seven species, type: C. tigillare (Ach.) Ach., lichenized, see Lumbsch and Huhndorf (2010; outline), Gaya et al. (2012; taxonomy), Kirk et al. (2013; genus accepted), Prieto et al. (2013; phylogeny), Lücking et al. (2016b; classification), Prieto and Wedin (2016; taxonomy, here Cyphelium is included in Calicium), sequences are available.

Cyphellophora G.A. de Vries 1962, Cyphellophoraceae, Chaetothyriales, Eurotiomycetes, 25 species, type: $C$. laciniata G.A. de Vries, hyphomycetous, sexual morph unknown, saprobes, terrestrial, southern USA, see Seifert et al. (2011; morphology), Wijayawardene et al. (2012, 2017; outline), Kirk et al. (2013; genus accepted), Réblová et al. (2013; new species), Feng et al. (2014; new species), Gao et al. (2015; new species), Crous et al. (2016b; new species), Madrid et al. (2016; new species), cultures and sequences are available.

Cyphellophoriella Crous \& A.J. Sm. 2015, Chaetothyriaceae, Chaetothyriales, Eurotiomycetes, one species, type: C. pruni Crous \& A.J. Sm., hyphomycetous, saprobes, USA, see Crous et al. (2015c; taxonomy, phylogeny), Wijayawardene et al. (2017; outline, phylogeny), holotype and ex-type: CBS H-22255, CPC 25120.

Cyrtidium Vain. 1921, Ascomycota genera incertae sedis, one species, type: C. naevium Vain., asexual morph unknown, saprobes, Europe, see Lumbsch and Huhndorf (2010; outline; accepted as Dothideomycetes genera incertae sedis), Kirk et al. (2013; genus accepted), Wijayawardene et al. (2014c) excluded from Dothideomycetes, cultures and sequences are unavailable, needs generic revision.

Cyrtidula Minks 1876, Ascomycota genera incertae sedis, one species, type: need typification, asexual morph unknown, saprobes, Italy, see Lumbsch and Huhndorf (2010; outline; accepted as Dothideomycetes genera incertae sedis), Kirk et al. (2013; genus accepted), Wijayawardene et al. (2014c) excluded from Dothideomycetes, cultures and sequences are unavailable, needs generic revision.

Cyrtopsis Vain. 1921, Ascomycota genera incertae sedis, one species, type: C. fumosa Vain., asexual morph unknown, saprobes, Italy, see Lumbsch and Huhndorf (2010; outline; accepted as Dothideomycetes genera incertae sedis), Kirk et al. (2013; genus accepted), Wijayawardene et al. (2014c) excluded from Dothideomycetes, cultures and sequences are unavailable, needs generic revision.

Cystocoleus A. Massal. 1849, Cystocoleaceae, Capnodiales, Dothideomycetes, one species; type: C. ebeneus (Dillwyn) Thwaites, lichenized, lichenicolous, terrestrial, see Muggia et al. 
(2008; taxonomy), Nelsen et al. (2009; taxonomy, phylogeny), Lumbsch and Huhndorf (2010; outline), Hawksworth et al. (2011b; typification), Kirk et al. (2013; genus accepted), Tian et al. (2014; morphology; nomenclature), Lücking et al. (2016b; classification), sequences are available.

Cystodendron Bubák 1914, Mollisiaceae, Helotiales, Leotiomycetes, two species, type: $C$. dryophilum (Pass.) Bubák, hyphomycetous, sexual morph unknown, saprobes, Europe, see Grunig et al. (2009; DNA), Seifert et al. (2011; morphology), Wijayawardene et al. (2012, 2017; outline), Selçuk et al. (2014; Turkey), cultures and sequences are available for unidentified species, needs generic revision.

Cystodium Fée 1837, Ascomycota genera incertae sedis, one species, type: need typification, asexual morph unknown, saprobes, Italy, see Lumbsch and Huhndorf (2010; outline; accepted as Dothideomycetes genera incertae sedis), Kirk et al. (2013; genus accepted), Wijayawardene et al. (2014c) excluded from Dothideomycetes, cultures and sequences are unavailable, needs generic revision.

Cystotheca Berk. \& M.A. Curtis 1860 (三Sphaerotheca sect. Cystotheca ; = Lanomyces Gäum. 1922 = Sphaerotheca auct. p.p. fide Braun and Cook 2012), Erysiphaceae, Erysiphales, Leotiomycetes, nine species, type: C. wrightii Berk. \& M.A. Curtis, sexual and hyphomycetous asexual morphs, biotrophic, obligate plant pathogens, terrestrial, Asia and North America, asexual morph: Setoidium (R.T.A. Cook, A.J. Inman \& C. Billings) R.T.A. Cook \& U. Braun, see Braun and Cook (2012; taxonomy), lectotype of C. wrightii: Japan, Ryukyu Island (Loo-Choo Islands), on Quercus cf. stenophylla, C. Wright coll., Herb. Of U.S. Pacific Expl. Exped. (K(M) 168934), sequences are available.

Notes: Setoidium was originally described as Oidium subgen. Setoidium R.T.A. Cook, A.J. Inman \& C. Billings, typified by Oidium japonicum Syd. (Cook et al. 1997), this subgenus was subsequently raised to genus status by Braun and Cook (2012), but no binomial in Setoidium was given to the type species. Oidium japonicum is the asexual morph of $C$. wrightii (Braun and Cook 2012) and under unitary nomenclature, the genus Setoidium should be considered as synonym of Cystotheca. In addition, two names in Setoidium which lack a Cystotheca sexual state are known. The generic affinity of $S$. castanopsidis Meeboon \& S. Takam. has been proven by means of molecular sequence data, justifying the reallocation of this species to Cystotheca. However, the combination S. murrayae (Hosag., U. Braun \& Rabindran) U. Braun \& R.T.A. Cook was only based on morphological similarity and has not yet been confirmed by sequence data, precluding a reallocation to Cystotheca in the current state. The respective synonymy and a new combination are introduced as follows:

\section{Cystotheca wrightii Berk. \& M.A. Curtis, Proc. Amer. Acad. Arts 4:130. 1860}

= Oidium japonicum Syd., Mém. Herb. Boissier 4:6. 1900.

Cystotheca castanopsidis (Meeboon \& S. Takam.) Meeboon \& S. Takam., comb.

nov.

IndexFungorum: IF553185

Basionym: Setoidium castanopsidis Meeboon \& S. Takam., Mycoscience 54:275. 2012.

Cystotrichiopsis Abbas, B. Sutton \& Ghaffar 2001, Ascomycota genera incertae sedis, coelomycetous, sexual morph unknown, one species, type: C. salvadorae Abbas, Sutton \& Ghaffar, saprobes, terrestrial, Pakistan, see Wijayawardene et al. (2012, 2017; outline), Kirk et al. (2013; genus accepted), holotype: UCMH 759 (IMI 322594), cultures and sequences are unavailable, genus need revision.

Cytodiscula Petr. 1931, Ascomycota genera incertae sedis, one species, type: C. carnea Petr., coelomycetous, sexual morph unknown, saprobes, Madeira, see Wijayawardene et al. (2012, 2017; outline), Kirk et al. (2013; genus accepted), cultures and sequences are unavailable, needs generic revision. 
Cytogloeum Petr. 1925, Ascomycota genera incertae sedis, one species, type: C. tiliae Petr., coelomycetous, sexual morph unknown, saprobes, Europe, see Wijayawardene et al. (2012, 2017; outline), Kirk et al. (2013; genus accepted), cultures and sequences are unavailable, needs generic revision.

Cytomelanconis Naumov 1951, Melanconidaceae, Diaporthales, Sordariomycetes, one species, type: C. systema-solare Naumov, asexual morph coelomycetous, saprobes, former USSR, see Lumbsch and Huhndorf (2010; outline), Kirk et al. (2013; genus accepted), Maharachchikumbura et al. (2015, 2016; outline), Fan et al. (2016; species associated wit Betula), cultures and sequences are unavailable, needs generic revision.

Cytonaema Höhn. 1914, Ascomycota genera incertae sedis, two species, type: C. spinella (Kalchbr.) Höhn., coelomycetous, asexual morph unknown, saprobes, Austria, South Africa, see Marincowitz et al. (2008; morphology, new species), Wijayawardene et al. (2012, 2017; outline), Kirk et al. (2013; genus accepted), cultures and sequences are unavailable, needs generic revision.

Cytoplacosphaeria Petr. 1920, Ascomycota genera incertae sedis, two species, type: C. rimosa Petr., coelomycetous, asexual morph unknown, saprobes, Europe, Hong Kong, see Wijayawardene et al. (2012, 2017; outline), Kirk et al. (2013; genus accepted), cultures and sequences are unavailable, needs generic revision.

Cytoplea Bizz. \& Sacc. 1885, Roussoellaceae, Pleosporales, Dothideomycetes, five species, type: C. arundinacea (Sacc.) Petr. \& Syd., coelomycetous, asexual morph roussoella-like, saprobes, Europe, Hong Kong, see, Wijayawardene et al. (2012, 2014c, 2016b; outline, morphology, nomenclature), Kirk et al. (2013; genus accepted), cultures and sequences are available, needs generic revision.

Cytosphaera Died. 1916, Ascomycota genera incertae sedis, two species, type: C. mangiferae Died., coelomycetous, asexual morph unknown, saprobes, Asia, Australia, see Wijayawardene et al. (2012, 2017; outline), Kirk et al. (2013; genus accepted), cultures and sequences are unavailable, needs generic revision.

Cytospora Ehrenb. 1818 (= Valsa Fr. 1825; = Valsella Fuckel 1870; = Leucostoma (Nitschke) Höhn. 1917; = Valseutypella Höhn. 1919; = Leucocytospora (Höhn.) Höhn. 1927 fide Rossman et al. 2015a), Valsaceae, Diaporthales, Sordariomycetes, c. 120 species, type: $C$. chrysosperma (Pers.) Fr., coelomycetous, sexual morph Valsa, saprobes, pathogens, worldwide, see Fotouhifar et al. (2010; phylogeny), Fan et al. (2014, 2015; morphology, pathogens, China), Liu et al. (2015a; new species), Rossman et al. (2015a; nomenclature), Yang et al. (2015b; pathogens, China), Crous et al. (2016b; new species), Maharachchikumbura et al. (2015, 2016; outline, phylogeny), cultures and sequences are available.

Cytosporella Sacc. 1884, Ascomycota genera incertae sedis, 32 species, type: C. sycina (Sacc.) Sacc., coelomycetous, sexual morph unknown, saprobes, temperate regions, see Wijayawardene et al. (2012, 2017; outline), Kirk et al. (2013; genus accepted), cultures and sequences are unavailable, needs generic revision.

Cytostagonospora Bubák 1916, Mycosphaerellaceae, Capnodiales, Dothideomycetes, three species, type: $C$. photiniicola Bubák, coelomycetous, sexual morph unknown, saprobes, temperate regions, see Wijayawardene et al. (2012, 2017; outline), Kirk et al. (2013; genus accepted), Quaedvlieg et al. (2013; DNA, phylogeny), cultures and sequences are available for C. martiniana (CBS 135102), type lacks sequence data, needs generic revision.

Cyttaria Berk. 1842, Cyttariaceae, Cyttariales, Leotiomycetes, type: C. darwinii Berk., asexual morph unknown, saprobes, south temperate regions, see Lumbsch and Huhndorf (2010; outline), Peterson and Pfister (2010; phylogeny), Kirk et al. (2013; genus accepted), cultures and sequences are available. 
Cyttariella skottsbergii Palm, Ascomycota genera incertae sedis, one species, type: $C$. skottsbergii Palm., coelomycetous, sexual morph unknown, saprobes, terrestrial, South America, cultures and sequences are unavailable, needs generic revision.

Dacampia A. Massal. 1853, Dacampiaceae, Dothideomycetes families incertae sedis, 14 species, type: D. hookeri (Borrer) A. Massal., lichenicolous, or saprobes, terrestrial, Europe, see Halici et al. (2008, 2009; new species), Brackel (2010a; new species), Hyde et al. (2013; phylogeny), Wijayawardene et al. (2014; outline), Ertz et al. (2015a; DNA, phylogeny), Lücking et al. (2016b; classification), cultures and sequences are available, available cultures for type: Hafellner 81840 (GZU), Hafellner 75980 (GZU), Hafellner 74269 (GZU), Hafellner 73897 (GZU).

Dacryoma Samuels 1988, Nectriaceae, Hypocreales, Sordariomycetes, two species, type D. album Samuels, sexual morph unknown, saprobes on palms, terrestrial, Indonesia Peru, see Lumbsch and Huhndorf (2010; outline), Kirk et al. (2013; genus accepted), Maharachchikumbura et al. (2015, 2016), holotype: BO, isotype NY.

Dactylaria Sacc. 1880, Helotiales genera incertae sedis, Leotiomycetes, c. 100 species, type: D. purpurella, hyphomycetous, saprobes, pathogens, parasites, terrestrial and aquatic, widespread, see Seifert et al. (2011; morphology), Wijayawardene et al. (2012, 2017; outline), Kirk et al. (2013; genus accepted), Magalhães et al. (2014), Mel'nik et al. (2013; new species), Crous et al. (2016a; new species, phylogeny), few sequence available for this genus but not available for the type, sexual morph hypomyces-like reported for D. mycophila, needs generic revision.

Dactylella Grove 1884, Orbiliaceae, Orbiliales, Orbiliomycetes, hetergenous, type: $D$. minuta Grove, c. 70 species, hyphomycetous, ?sexual morph Orbilia, saprobes, terrestrial, worldwide, see Zhang et al. (2010d; new species), Qin et al. (2011; new species), Seifert et al. (2011; morphology), Wijayawardene et al. (2012, 2017; outline), Kirk et al. (2013; genus accepted), cultures and sequences are available.

Dactylellina M. Morelet 1968, Orbiliaceae, Orbiliales, Orbiliomycetes, c. 23 species, type: D. leptospora (Drechsler) M. Morelet, hyphomycetous, sexual morph unknown, nematode trapping, in soil, terrestrial, aquatic, Asia, Europe, see Seifert et al. (2011; morphology), Hanying et al. (2012; development), Wijayawardene et al. (2012, 2017; outline), Wu et al. (2012b; first report of D. candidum in Korea), Yu et al. (2012; biology), Kirk et al. (2013; genus accepted), cultures and sequences are available, needs generic revision.

Dactylifera Alcorn 1927, Ascomycota genera incertae sedis, one species, type: $D$. australiensis Alcorn, hyphomycetous, sexual morph unknown, saprobes, terrestrial, Australia, see Seifert et al. (2011; morphology), Wijayawardene et al. (2012, 2017; outline), Kirk et al. (2013; genus accepted), cultures and sequences are unavailable, needs generic revision.

Dactylina Nyl. 1860, Parmeliaceae, Lecanorales, Lecanoromycetes, two species, type: D. arctica (Richardson) Nyl., asexual reproduction by small lateral lobules and sexual by apothecia (rarely developed), lichenized, terricolous, circumpolar, arctic-alpine Northern Hemisphere, see Lumbsch and Huhndorf (2010; outline), Kirk et al. (2013; genus accepted), Lücking et al. (2016b; classification), cultures available for the type: AFTOL 225.

Dactylonectria L. Lombard \& Crous 2014, Nectriaceae, Hypocreales, Sordariomycetes, ten species, type: D. macrodidyma (Halleen, Schroers \& Crous) L. Lombard, van der Merwe \& J.Z. Groenew. \& Crous, asexual morph unknown, saprobes, terrestrial, cosmopolitan, see Lombard et al. (2014, 2015b; phylogeny), Maharachchikumbura et al. (2015, 2016; outline), cultures and sequences are available.

Dactylospora Körb. 1855, Dactylosporaceae, Eurotiomycetes incertae sedis, c. 50 species, type: D. floerkei Körb., asexual morph unknown, on lichens, hepatics or saprobes, terrestrial or marine, worldwide, see Lumbsch and Huhndorf (2010; outline), Kirk et al. (2013; genus 
accepted), Diederich et al. (2013; phylogeny), Pang et al. (2014), sequence data available for for species, ex-type cultures and holotype unavailable.

Dactylosporium Harz 1871, Ascomycota genera incertae sedis, two species, type: $D$. macropus (Corda) Harz, hyphomycetous, sexual morph unknown, saprobes, terrestrial, Europe, Cuba, see Seifert et al. (2011; morphology), Wijayawardene et al. (2012, 2017; outline), Kirk et al. (2013; genus accepted), cultures and sequences are unavailable, needs generic revision.

Daldinia Ces. \& De Not. 1863 (= Annellosporium M.L. Davey 2010; = Hemisphaeria Klotzsch 1843; = Peripherostoma Gray 1821; = Stromatosphaeria Grev. 1824; = Versiomyces Whalley \& Watling 1989 fide Réblová et al. 2016c; Wendt et al. 2017), Hypoxylaceae, Xylariales, Sordariomycetes, c. 40 species, type: D. concentrica (Bolton) Ces. $\&$ De Not., asexual morph hyphomycetous, terrestrial, saprobes, worldwide, see Lumbsch and Huhndorf (2010; outline), Kirk et al. (2013; genus accepted), Stadler et al. (2014; new species), Maharachchikumbura et al. (2015, 2016; outline), Réblová et al. (2016c; nomenclature), Kuhnert et al. (2017; new species, revision), Wendt et al. (2017; accepted as a genus in Hypoxylaceae), cultures and sequences are available.

Dangeardiella Sacc. \& P. Syd. 1899, Pleosporales genera incertae sedis, Dothideomycetes, two species, type: D. macrospora (J. Schröt.) Sacc. \& P. Syd., asexual morph unknown, saprobes, Europe, see Lumbsch and Huhndorf (2010; outline), Kirk et al. (2013; genus accepted), Thambugala et al. (2014c; transferred to Pleosporales, genera incertae sedis), Wijayawardene et al. (2014c; outline), cultures and sequences are available.

Danielozyma Kurtzman \& Robnett 2014, Metschnikowiaceae, Saccharomycetales, Saccharomycetes, two species, type: D. ontarioensis (Kurtzman \& Robnett) Kurtzman \& Robnett, asexual reproduction by multilateral budding and from formation of pseudohyphae and true hyphae, saprophyte, in insect frass from various tree species, see Kurtzman and Robnett (2014; taxonomy), cultures and sequences are available.

Darkera H.S. Whitney, J. Reid \& Piroz. 1975, Phacidiaceae, Phacidiales, Leotiomycetes, five species, type: D. parca H.S. Whitney, J. Reid \& Piroz., asexual morph coelomycetous, pathogens, terrestrial, Europe, Cuba, see Kirk et al. (2013; genus accepted), Crous et al. (2015b; revision, morphology, DNA, phylogeny), cultures and sequences are available.

Darksidea D.G. Knapp, Kovács, J.Z. Groenew. \& Crous 2015, Lentitheciaceae, Pleosporales, Dothideomycetes, one species, type: D. alpha D.G. Knapp, Kovács, Groenewald \& Crous, endophytes, see Knapp et al. (2015; phylogeny), cultures and sequences are available.

Dasyscyphella Tranzschel 1898 (= Lachnaster Höhn. 1917 fide Jaklitsch et al. 2016a), Lachnaceae, Helotiales, Leotiomycetes, one species, type: D. cassandrae Tranzschel, asexual morph unknown, saprobes, terrestrial, Asia, North America, see Lumbsch and Huhndorf (2010; outline), Kirk et al. (2013; genus accepted), cultures and sequences are available.

Dasysphaeria Speg. 1912, Sordariomycetes genera incertae sedis, one species, type: D. andicola Speg., asexual morph unknown, saprobes, terrestrial, South America, see Lumbsch and Huhndorf (2010; outline), Kirk et al. (2013; genus accepted), Maharachchikumbura et al. (2015; outline), cultures and sequences are unavailable, needs generic revision.

Dasysticta Speg. 1912, Ascomycota genera incertae sedis, two species, type: D. sapindophila Speg., coelomycetous, sexual morph unknown, saprobes, terrestrial, South America, see Wijayawardene et al. (2012, 2017; outline), Kirk et al. (2013; genus accepted), cultures and sequences are unavailable, needs generic revision.

Davidgallowaya Aptroot 2007, Parmeliaceae, Lecanorales, Lecanoromycetidae, one species, type: D. cornutispora Aptroot, asexual morph, unknown, terrestrial, New Guinea, see Lumbsch and Huhndorf (2010; outline), Kirk et al. (2013; genus accepted), Lücking et al. (2016b; classification), cultures and sequences are unavailable, needs generic revision. 
Davidsoniella Z.W. de Beer, T.A. Duong \& M.J. Wingf. 2014, Ceratocystidaceae, Microascales, Sordariomycetes, one species, type: D. virescens (R.W. Davidson) Z.W. de Beer, T.A. Duong \& M.J. Wingf., asexual morph hyphomycetous, enodophyte, terrestrial, Thailand, have sequence data, see de Beer et al. (2014; phylogeny), Maharachchikumbura et al. (2015, 2016; outline), cultures and sequences are available.

Davisiella Petr. 1924, Ascomycota genera incertae sedis, two species, type: D. elymina (Davis) Petr., coelomycetous, sexual morph unknown, saprobes, terrestrial, USA, see Wijayawardene et al. (2012, 2017; outline), Kirk et al. (2013; genus accepted), cultures and sequences are unavailable, needs generic revision.

Davisomycella Darker 1967, Rhytismataceae, Rhytismatales, Leotiomycetes, ten species, type: D. ampla (Davis) Darker, asexual morph unknown, saprobes, endophytes, terrestrial, worldwide, see Lumbsch and Huhndorf (2010; outline), Kirk et al. (2013; genus accepted), cultures and sequence available for D. medusa (BPI842078).

Davisoniella H.J. Swart 1988, Teratosphaeriaceae, Capnodiales, Dothideomycetes, one species, type: D. eucalypti H.J. Swart, coelomycetous, sexual morph teratosphaeria-like, saprobes, terrestrial, North America, see Wijayawardene et al. (2012, 2014c, 2017), Kirk et al. (2013; genus accepted), cultures and sequences are unavailable, needs generic revision.

Dawsicola Döbbeler 1981, Helotiales genera incertae sedis, one species, type: D. neglecta Döbbeler, asexual morph unknown, saprobes, endophytes, terrestrial, worldwide, see Lumbsch and Huhndorf (2010; outline), Kirk et al. (2013; genus accepted), cultures and sequences are unavailable, needs generic revision.

Dawsomyces Döbbeler 1981, Dothideomycetes genera incertae sedis, two species, type: D. mirabilis Döbbeler, asexual morph unknown, saprobes, endophytes, terrestrial, worldwide, see Lumbsch and Huhndorf (2010; outline), Kirk et al. (2013; genus accepted), Wijayawardene et al. (2014c; outline), cultures and sequences are unavailable, needs generic revision.

Dawsophila Döbbeler 1981, Dothideomycetes genera incertae sedis, two species, type: D. pygmaea Döbbeler, asexual morph unknown, saprobes, endophytes, terrestrial, New Guinea, New Zealand, see Lumbsch and Huhndorf (2010; outline), Wijayawardene et al. (2014; outline), cultures and sequences are unavailable, needs generic revision.

Deakozyma Kurtzman \& Robnett 2014, Trichomonascaceae, Saccharomycetales, Saccharomycetes, one species, type: D. indianensis Kurtzman \& Robnett, asexual reproduction by multilateral budding and from formation of pseudohyphae and true hyphae, saprophyte, rotting wood, insect eggs, Indiana, Michigan, USA, see Kurtzman and Robnett (2014; taxonomy), cultures and sequences are unavailable.

Dearnessia Bubák 1916, Ascomycota genera incertae sedis, one species, type: D. apocyni Bubák, coelomycetous, sexual morph unknown, saprobes, terrestrial, Canada, see Wijayawardene et al. (2012, 2017; outline), Kirk et al. (2013; genus accepted), cultures and sequences are unavailable, needs generic revision.

Debaryomyces Lodder \& Kreger-van Rij 1952, Debaryomycetaceae, Saccharomycetales, Saccharomycetes, 15 species, type: D. indianensis Kurtzman \& Robnett, asexual reproduction by multilateral budding and some species may also form poorly developed pseudohyphae, saprophytic, but several of the species are opportunistic pathogens of humans, soil, sea and fresh water, high osmotic foods such as cheese and sausages, bees, tree exudates, spoiled sake, see Lumbsch and Huhndorf (2010; outline), Kirk et al. (2013; genus accepted), cultures and sequences are available.

Decaisnella Fabre, 1878, Pleosporales genera incertae sedis, Dothideomycetes, 13 species, type: D. spectabilis Fabre, asexual morph unknown, terrestrial and marine, worldwide, see Lumbsch and Huhndorf (2010; outline), Zhang et al. (2012e; morphology), Kirk et al. (2013; genus accepted), Wijayawardene et al. (2014c; outline, accepted as a genus in 
Dothideomycetes genera incertae sedis), sequences are available only one species, need recollection to verify generic placement.

Decorospora Inderb., Kohlm. \& Volkm.-Kohlm. 2002, Pleosporaceae, Pleosporales, Dothideomycetes, one species, type: D. gaudefroyi (Pat.) Inderb., Kohlm. \& Volkm.-Kohlm., asexual morph unknown, saprobes, marine, see Lumbsch and Huhndorf (2010; outline), Hyde et al. (2013; accepted as a genus in Pleosporaceae), Wijayawardene et al. (2014c; outline), Jones et al. (2015; outline), cultures and sequences are available.

Degelia Arv. \& D.J. Galloway 1981, Pannariaceae, Peltigerales, Lecanoromycetes, 22 species, type: D. gayana (Mont.) Arv. \& D.J. Galloway, , lichenized, epiphytic or on mossy rocks, Southern hemisphere, in humid regions, see Wedin et al. (2009b; phylogeny), Lumbsch and Huhndorf (2010; outline), Kirk et al. (2013; genus accepted), Spribille and Muggia (2013; phylogeny), Ekman et al. (2014; phylogeny, Degelia is heterogeneous and excluded the section Amphiloma as the genus Pectenia), Lücking et al. (2016b; classification), need generic revision.

Degeliella P. M. Jørg 2004, Pannariaceae, Peltigerales, Lecanoromycetes, two species, type: D. rosulata (P.M. Jørg. \& D.J. Galloway) P.M. Jørg., asexual morph unknown, lichenized, epiphytic or on mossy rocks, Gondwana distribution, Australia (Tasmania), southermost South America, See Lumbsch and Huhndorf (2010; outline), Ekman et al. (2014; phylogeny, non-monophyly of the genus), Jørgensen and Andersen (2015; showed that the name Degeliella was superfluous and that Psoromaria (type: $P$. versicolor) should be taken up for the genus, which is still likely to be non-monopyletic), Lücking et al. (2016b; classification), sequence available for voucher Galloway 840b (BG) of the type (unpublished).

Deichmannia Alstrup \& D. Hawksw. 1990, Ascomycota genera incertae sedis, one species, type: $M$. caespitosa Petr., coelomycetous, sexual morph unknown, saprobes, terrestrial, North America, see Seifert et al. (2011; morphology), Wijayawardene et al. (2012, 2017; outline), Kirk et al. (2013; genus accepted), cultures and sequences are unavailable, needs generic revision.

Deightoniella S. Hughes 1952, Pyriculariaceae, Magnaporthales, Sordariomycetes, 20 species, type: D. africana S. Hughes, hyphomycetous, sexual morph unknown, pathogens, terrestrial, worldwide, see Seifert et al. (2011; morphology), Wijayawardene et al. (2012, 2017; outline), Klaubauf et al. (2014; phylogeny), Maharachchikumbura et al. (2015, 2016; outline), Zhang et al. (2016b; nomenclature), cultures and sequences are available for Deightoniella roumeguerei (CBS 128780), needs generic revision.

Dekkera Van der Walt 1964, Pichiaceae, Saccharomycetales, Saccharomycetes, five species, type: D. bruxellensis Van der Walt, saprophytic, see Lumbsch and Huhndorf (2010; outline), Kirk et al. (2013; genus accepted), cultures and sequences are available.

Delastria Tul. \& C. Tul. 1843, Pezizaceae, Pezizales, Pezizomycetes, one species, type: D. rosea Tul. \& C. Tul., asexual morph unknown, hypogeous, Europe (southem), Northern America, see Lumbsch and Huhndorf (2010; outline), Alvarado et al. (2011a; DNA, phylogeny), Kirk et al. (2013; genus accepted), Jaklitsch et al. (2016a; classification), cultures and sequences are available.

Delitschia Auersw. 1866, Delitschiaceae, Pleosporales, Dothideomycetes, 52 species, type: D. didyma Auersw., asexual morph unknown, commonly occurs as coprophilous and saprobes, worldwide, see Lumbsch and Huhndorf (2010; outline), Zhang et al. (2012e; morphology and phylogeny), Kirk et al. (2013; genus accepted), Wijayawardene et al. (2014c; outline), holotype of the type: L 1950, cultures available for type: UME 31411,.

Delortia Pat. \& Gaillard 1888, Ascomycota genera incertae sedis, one species, type: D. palmicola Pat. \& Gaillard, hyphomycetous, sexual morph unknown, saprobes, terrestrial, Pantropical, see Seifert et al. (2011; morphology), Wijayawardene et al. (2012, 2017; outline), 
Kirk et al. (2013; genus accepted), cultures and sequences are unavailable, needs generic revision.

Delphinella (Sacc.) Kuntze 1898, Dothideaceae, Dothideales, Dothideomycetes, eight species, type: D. strobiligena (Desm.) Sacc. ex E. Müll. \& Arx, asexual morph unknown, saprobes or pathogens, terrestrial, worldwide, see Lumbsch and Huhndorf (2010; outline, accepted as a genus in Dothioraceae), Kirk et al. (2013; genus accepted), Thambugala et al. (2014a; accepted as a genus in Dothideaceae), Wijayawardene et al. (2014c; outline), holotype: PC 0084688.

Delpinoella Sacc. 1899, Sordariomycetes genera incertae sedis, one species, type: D. insignis Sacc. \& Trotter, asexual morph unknown, saprobes, terrestrial, Canada, see Kirk et al. (2013; genus accepted), Maharachchikumbura et al. (2016; outline), cultures and sequences are unavailable, needs generic revision.

Delpinoëlla Sacc. 1899, Sordariomycetes genera incertae sedis, one species, type: D. insignis Sacc. \& Trotter, asexual morph unknown, saprobes, terrestrial, Africa, see Lumbsch and Huhndorf (2010; outline), Kirk et al. (2013; genus accepted), Maharachchikumbura et al. (2015, 2016; outline), needs generic revision, cultures and sequences are available.

Delpinoina Kuntze 1891, Ascodichaenaceae, Rhytismatales, Leotiomycetes, two species, type: D. lusitanica (Pass. \& Thüm.) Kuntze, asexual morph unknown, saprobes, terrestrial, Canada, see Lumbsch and Huhndorf (2010; outline), Kirk et al. (2013; genus accepted), cultures and sequences are unavailable, needs generic revision.

Delpontia Penz. \& Sacc. 1901, ? Stictidaceae, Ostropales, Lecanoromycetes, one species, type: D. pulchella Penz. \& Sacc., asexual morph unknown, saprobes, on fern stalks, Java, see Lumbsch and Huhndorf (2010; outline: doubtful position), cultures and sequences are unavailable, needs generic revisión.

Deltopyxis Baral \& G. Marson 2012, Leotiomycetes genera incertae sedis, one species, type: D. triangulispora Baral \& G. Marson, saprobes, terrestrial, Luxembourg, see Baral and Marson (2012; taxonomy), Jaklitsch et al. (2016a; classification), a sequence is available.

Dematiocladium Allegr., Aramb., Cazau \& Crous 2005, Nectriaceae, Hypocreales, Sordariomycetes, two species, type D. celtidis Allegr., Aramb., Cazau \& Crous, saprobes, terrestrial, Argentina, China, see Wijayawardene et al. (2012, 2017; outline), Crous et al. (2014c; new species), ex-type: CBS 115994; holotype of the type: LPS 47255, isotype CBS 9921.

Dematiopleospora Wanas., Camporesi, E.B.G. Jones \& K.D. Hyde, gen. nov. 2017

Index Fugorum number: IF552175

Description: see Wanasinghe et al. (2014)

= Dematiopleospora Wanas., Camporesi, E.B.G. Jones \& K.D. Hyde, Cryptogamie, Mycologie 35(2): 110 (2014), Nom. inval., Art. 42.1 (Melbourne)

Type: Dematiopleospora mariae Wanas., Camporesi, E.B.G. Jones \& K.D. Hyde

Notes: Wanasinghe et al. (2014) introduced Dematiopleospora but it is invalid (Art. 42.1) as the genus and type species both have same identifier IF550536. Three other species are consequently not validly published. Thus, new identifiers have been obtained and species are validly published.

Dematiopleospora alliariae Thambugala, Camporesi \& K.D. Hyde

Index Fugorum: IF552256 
Description: see Hyde et al. (2016) = Dematiopleospora alliariae Thambugala, Camporesi \& K.D. Hyde, Fungal Diversity 80: 89 (2015); nom. inval., Art. 35.1

Dematiopleospora cirsii Wanas., Camporesi, E.B.G. Jones \& K.D. Hyde

Index Fugorum number: IF552282

Description: see Hyde et al. (2016)

= Dematiopleospora cirsii Wanas., Camporesi, E.B.G. Jones \& K.D. Hyde, Fungal Diversity 80: 89 (2015); nom. inval., Art. 35.1

Dematiopleospora luzulae Wanas., Camporesi, E.B.G. Jones \& K.D. Hyde

Index Fugorum number: IF552283

Description: see Hyde et al. (2016)

= Dematiopleospora luzulae Wanas., Camporesi, E.B.G. Jones \& K.D. Hyde, Fungal Diversity 75: 103 (2015); nom. inval., Art. 35.1

Dematiopleospora mariae Wanas., Camporesi, E.B.G. Jones \& K.D. Hyde

Index Fugorum number: IF552185

Description: see Wanasinghe et al. (2014)

= Dematiopleospora mariae Wanas., Camporesi, E.B.G. Jones \& K.D. Hyde, Cryptogamie, Mycologie 35 (2): 110 (2014); nom. inval., Art. 35.1

Dematioscypha Svrček 1977 (= Schizocephalum Preuss 1852; Haplographium Berk. \& Broome 1859 fide Johnston et al. 2014b), Hyaloscyphaceae, Helotiales, Leotiomycetes, four species, type: D. dematiicola (Berk. \& Broome) Svrček, asexual morph hyphomycetous, saprobes, Europe, New Zealand, see Lumbsch and Huhndorf (2010; outline), Kirk et al. (2013; genus accepted), Han et al. (2014; DNA, phylogeny), Johnston et al. (2014b; nomenclature), Wijayawardene et al. (2017; outline), cultures and sequence data available for Haplographium delicatum.

Dencoeliopsis Korf 1971, Rutstroemiaceae, Helotiales, Leotiomycetes, two species, type: D. johnstonii (Berk.) Korf, asexual morph unknown, saprobes, terrestrial, USA, Europe, see Lumbsch and Huhndorf (2010; outline), Kirk et al. (2013; genus accepted), cultures and sequences are unavailable, needs generic revision.

Dendriscosticta Moncada \& Lücking 2013, Lobariaceae, Peltigerales, Lecanoromycetes, five species, type: D. wrightii (Tuck.) Moncada \& Lücking, lichenized, see Moncada et al. (2013a; taxonomy), Lücking et al. (2016b; classification), sequences are available.

Dendroclathra Voglmayr \& G. Delgado 2001, Hypocreomycetidae genera incertae sedis, Sordariomycetes, one species, type: D. caeruleofusca Voglmayr \& G. Delgado, hyphomycetous, sexual morph unknown, saprobes, terrestrial, Caribbean, see Seifert et al. (2011; morphology), Wijayawardene et al. (2012, 2017; outline), Kirk et al. (2013; genus accepted), cultures and sequences are available, needs generic revision.

Dendrodomus Bubák 1915, Ascomycota genera incertae sedis, one species, type: D. annulatus Bubák, coelomycetous, sexual morph unknown, saprobes, terrestrial, Europe, see Wijayawardene et al. (2012, 2017; outline), Kirk et al. (2013; genus accepted), cultures and sequences are unavailable, needs generic revision.

Dendrographa Darb. 1895, Roccellaceae, Arthoniales, Arthoniomycetes, six species, type: D. leucophaea (Tuck.) Darb., lichenized, corticolous and saxicolous, worldwide, see Lumbsch 
and Huhndorf (2010; outline), Ertz and Tehler (2011; phylogeny and taxonomy), Kirk et al. (2013; genus accepted), Lücking et al. (2016b; classification), sequences are available.

Dendrophoma Sacc. 1880, Chaetosphaeriaceae, Chaetosphaeriales, Sordariomycetes, c. 100 species, type: D. cytisporoides Sacc., coelomycetous, sexual morph unknown, saprobes, terrestrial, worldwide, see Kirk et al. (2008; treated as a synonym of Dinemasporium), Crous et al. (2012g; reinstated the genus, DNA, phylogeny), Liu et al. (2015a; new species), Maharachchikumbura et al. (2016; outline), epitype and ex-epitype: CBS H-12004, CBS 223.95.

Dendrosphaera Pat. 1907, Trichocomaceae, Eurotiales, Eurotiomycetes, one species, type: D. eberhardtii Pat., asexual morph hyphomycetous, terrestrial, probably mycorrhizal, Asia, see Houbraken and Samson (2011; morphotaxonomy), Kirk et al. (2013; genus accepted), cultures and sequences are unavailable, needs phylogenetic assessment.

Dendrospora Ingold 1943, Ascomycota genera incertae sedis, ten species, type: D. erecta Ingold, hyphomycetous, sexual morph unknown, saprobes, terrestrial, North temperate, subtropical, see Seifert et al. (2011; morphology), Wijayawardene et al. (2012, 2017; outline), Kirk et al. (2013; genus accepted), Duarte et al. (2015; DNA), cultures and sequences are available, needs generic revision.

Dendrosporium Plakidas \& Edgerton ex J.L. Crane 1972, Ascomycota genera incertae sedis, three species, type: D. lobatum Plakidas \& Edgerton ex J.L. Crane, hyphomycetous, sexual morph unknown, saprobes, terrestrial, Asia, Caribbean, North and South America, see Seifert et al. (2011; morphology), Wijayawardene et al. (2012, 2017; outline), Kirk et al. (2013; genus accepted), cultures and sequences are available for unidentified species, needs generic revision.

Dendryphiella Bubák \& Ranoj. 1914, Dictyosporiaceae, Pleosporales, Dothideomycetes, nine species, type: D. interseminata (Berk. \& Ravenel) Bubák, hyphomycetous, sexual morph unknown, saprobes, terrestrial, cosmopolitan, see Seifert et al. (2011; morphology), Wijayawardene et al. (2012, 2017; outline), Crous et al. (2014c, 2016b; new species, phylogeny), cultures and sequences are available, needs generic revision.

Dendryphion Wallr. 1833, Torulaceae, Pleosporales, Dothideomycetes, 66 species, type: D. comosum Wallr., hyphomycetous, sexual morph unknown, saprobes, worldwide, see Kirk et al. (2013; genus accepted), Crous et al. (2015a; phylogeny), sequences are available for five species, needed generic placement.

Dendryphiosphaera Lunghini \& Rambelli 1978, Ascomycota genera incertae sedis, four species, type: D. taiensis Lunghini \& Rambelli, hyphomycetous, sexual morph unknown, Ivory coast, pantropical, see Hyde et al. (2011; outline), Wijayawardene et al. (2012, 2017; outline), Kirk et al. (2013; genus accepted), cultures and sequences are unavailable, needs generic revision.

Deniquelata Ariyaw. \& K.D. Hyde 2013, Didymosphaeriaceae, Pleosporales, Dothideomycetes, one species, type: D. barringtoniae Ariyawansa \& K.D. Hyde, asexual morph unknown, pathogens, terrestrial, Thailand, see Ariyawansa et al. (2013b, 2014c; morpholology, DNA, phylogeny), Hyde et al. (2013; phylogeny), Wijayawardene et al. (2014c; outline, phylogeny), holotype and ex-type of the type: MFLU 12-0303, MFLUCC 12-0257.

Dennisiella Bat. \& Cif. 1962, Coccodiniaceae, Chaetothyriales, Eurotiomycetes, seven species, type: D. babingtonii (Berk.) Bat. \& Cif., asexual morph microxyphium-like, saprobes, terrestrial, tropical regions, see Lumbsch and Huhndorf (2010; outline), Hyde et al. (2013; accepted as genera in Coccodiniaceae), Kirk et al. (2013; genus accepted), cultures and sequences are unavailable, needs generic revision.

Dennisiodiscus Svrcek 1976, Ploettnerulaceae, Helotiales, Leotiomycetes, ten species, type: D. prasinus (Quél.) Svrček, asexual morph unknown, saprobes, terrestrial, Europe, Papua 
New Guinea, see Lumbsch and Huhndorf (2010; outline), Jaklitsch et al. (2016a; classification), cultures and sequences are unavailable, needs generic revision.

Dennisiopsis Subram. \& Chandrash. 1977, Pezizales genera incertae sedis, Pezizomycetes, two species, type: D. octospora Subram. \& Chandrash., asexual morph unknown, saprobes, terrestrial, India, see Lumbsch and Huhndorf (2010; outline), Kirk et al. (2013; genus accepted), cultures and sequences are unavailable.

Dennisographium Rifai 1977, Ascomycota genera incertae sedis, two species, type: D. episphaeriae Rifai, hyphomycetous, sexual morph unknown, Java, see Hyde et al. (2011; outline), Seifert et al. (2011; morphology), Wijayawardene et al. (2012, 2017; outline), Kirk et al. (2013; genus accepted), cultures and sequences are unavailable, needs generic revision.

Denticularia Deighton 1972, Ascomycota genera incertae sedis, seven species, type: D. modesta (Syd.) Deighton, hyphomycetous, sexual morph unknown, saprobes, terrestrial, Africa, Europe, see Seifert et al. (2011; morphology), Wijayawardene et al. (2012, 2017; outline), Kirk et al. (2013; genus accepted), cultures and sequences are unavailable, needs generic revision.

Dentocircinomyces R.F. Castañeda \& W.B. Kendr. 1990, Ascomycota genera incertae sedis, one species, type: D. occidentalis R.F. Castañeda \& W.B. Kendr., hyphomycetous, sexual morph unknown, saprobes, terrestrial, Cuba, see Seifert et al. (2011; morphology), Wijayawardene et al. (2012, 2017; outline), Kirk et al. (2013; genus accepted), cultures and sequences are unavailable, needs generic revision, holotype of the type: INFAT C88/114, cultures and sequences are unavailable, compare with Cryptumbellata, Hansfordia and Redbia.

Derexia Naras. 1970, Ascomycota genera incertae sedis, one species, type: D. lecanii (Zimm.) Naras., hyphomycetous, sexual morph unknown, on Lecanium viride, India, Indonesia, Java, see Hyde et al. (2011; outline), Seifert et al. (2011; morphology), Wijayawardene et al. (2012, 2017; outline), cultures and sequences are unavailable, needs generic revision.

Dermapteromyces Thaxt. 1931, Laboulbeniaceae, Laboulbeniales, Laboulbeniomycetes, three species, type: D. ctenophorus Thaxt., asexual morph unknown, biotrophic, America (tropical), see Lumbsch and Huhndorf (2010; outline), Kirk et al. (2013; genus accepted), cultures and sequences are unavailable.

Dermateopsis Nannf. 1932, Helotiales genera incertae sedis, Leotiomycetes, two species, type: D. tabacina (Cooke) Nannf., asexual morph unknown, saprobes, terrestrial, temperate regions, see Lumbsch and Huhndorf (2010; outline), cultures and sequences are unavailable.

Dermatiscum Nyl. 1867, Caliciaceae, Caliciales, Lecanoromycetes, three species, type: D. thunbergii (Ach.) Nyl., asexual morph is coelomycetous, lichenized, saxicolous, South Africa, Madagascar, St. Helena, see Aptroot (2008; new species), Lumbsch and Huhndorf (2010; outline), Kirk et al. (2013; genus accepted), Prieto et al. (2013; phylogeny), Lücking et al. (2016b; classification), Prieto and Wedin (2016; phylogeny), sequences are available for the type: AF540507 (ITS).

Dermatocarpon Eschw. 1824, Verrucariaceae, Verrucariales, Eurotiomycetes, c. 20 species, type: D. miniatum (L.) W. Mann, asexual morph coelomycetous, terrestrial, lichenized, on rocks and soil, cosmopolitan, see Gueidan et al. (2009; phylogeny, outline), Prieto et al. (2012; phylogeny), Lücking et al. (2016b; classification), sequences of the type material of the type are unavailable, but sequences of non-type material are available.

Dermatodothella Viégas 1944, Polystomellaceae, Dothideomycetes families incertae sedis, one species, type: D. multiseptata Viégas, asexual morph unknown, saprobes, terrestrial, Brazil, see Lumbsch and Huhndorf (2010; outline, as Dothideomycetes, genera incertae sedis), Ariyawansa et al. (2013c; morphology, accepted as Polystomellaceae), Wijayawardene et al. (2014; outline), cultures and sequences are unavailable. 
Dermatodothis Racib. ex Theiss. \& Syd. 1914, Dothideomycetes genera incertae sedis, six species, type: D. javanica Racib., asexual morph unknown, saprobes, terrestrial, Asia, South America, see Lumbsch and Huhndorf (2010; outline), Kirk et al. (2013; genus accepted), Wijayawardene et al. (2014c; outline), cultures and sequences are unavailable.

Dermea Fr. 1825 (= Sphaeronaema Fr. 1815; = Foveostroma DiCosmo 1978 fide Johnston et al. 2014b), Dermateaceae, Helotiales, Leotiomycetes, c. 25 species, type: D. cerasi (Pers.) Fr., asexual morphs formerly known in Sphaeronaema and Foveostroma, saprobes, terrestrial, worldwide, see Lumbsch and Huhndorf (2010; outline), Johnston et al. (2014b; nomenclature, new comb.), cultures and sequences are available.

Dermiscellum Hafellner, Mayrhofer, \& Poelt 1979, Caliciaceae, Caliciales, Lecanoromycetes, one species, type: D. catawbense (Willey) Hafellner \& Poelt, asexual morph is coelomycetous, lichenized, saxicolous, North America, see Lumbsch and Huhndorf (2010; outline), Gaya et al. (2012; taxonomy), Kirk et al. (2013; genus accepted), Prieto et al. (2013; phylogeny), Lücking et al. (2016b; classification), Prieto and Wedin (2016; taxonomy), cultures and sequences are unavailable, needs generic revision.

Descalsia A. Roldán \& Honrubia 1989, Ascomycota genera incertae sedis, one species, type: D. cruciata A. Roldán \& Honrubia, hyphomycetous, sexual morph unknown, aquatic, isolated from Spanish streams, South western Europe, Spain, Northwest Portugal, see Hyde et al. (2011; outline), Seifert et al. (2011; morphology), Wijayawardene et al. (2012, 2017; outline), Kirk et al. (2013; genus accepted), holotype: IMI 328087, sequences are unavailable, needs generic revision.

Desertella Mouch. 1979, Ascomycota genera incertae sedis, two species, type: D. globulifera Mouch., hyphomycetous, sexual morph unknown, from soil, submerged wood in river, Egypt, USA, see Hyde et al. (2011; outline), Seifert et al. (2011; morphology), Wijayawardene et al. (2012, 2017; outline), Kirk et al. (2013; genus accepted), cultures are unavailable, unverified sequences are available (KR230020-KR230041), needs generic revision.

Deshpandiella Kamat \& Ullasa 1973, Phyllachoraceae, Phyllachorales, Sordariomycetes, one species, type: D. jambolana (T.S. Ramakr., Sriniv. \& Sundaram) Kamat \& Ullasa, asexual morph unknown, biotrophic, terrestrial, India, see Lumbsch and Huhndorf (2010; outline), Kirk et al. (2013; genus accepted), Maharachchikumbura et al. (2015, 2016; outline), cultures and sequences are unavailable.

Desmazierella Lib. 1829 (= Verticicladium Preuss 1851 fide Healy et al. 2016), Chorioactidaceae, Pezizales, Pezizomycetes, two species, type: D. acicola Lib., asexual morph Verticicladium, saprobes, terrestrial, India, see Pfister et al. (2008; taxonomy), Lumbsch and Huhndorf (2010; outline), Martinović et al. (2016; DNA, phylogeographic structure), cultures and sequences are available.

Desmidiospora Thaxt. 1891, Ascomycota genera incertae sedis, three species, type: $D$. myrmecophila Thaxt., hyphomycetous, sexual morph unknown, terrestrial, saprobes, North America, Canada, Northwest Territories, see Hyde et al. (2011; outline), Seifert et al. (2011; morphology), Wijayawardene et al. (2012, 2017; outline), Kirk et al. (2013; genus accepted), cultures and sequences are unavailable, needs generic revision.

Devriesia Seifert \& N.L. Nick. 2004, Teratosphaeriaceae, Capnodiales, Dothideomycetes, 24 species, type: D. staurophora (W.B. Kendr.) Seifert \& N.L. Nick., asexual morph hyphomycetous, saprobes, terrestrial, India, see Schoch et al. (2009; new species, phylogeny), Crous et al. (2011a, 2012c, e; new species, DNA), Frank et al. (2010; new species, DNA, phylogeny), Li et al. (2012a; new species, China), Egidi et al. (2014; new species, DNA, phylogeny), cultures and sequences are available.

Dexhowardia J.J. Taylor 1970, Ascomycota genera incertae sedis, one species, type: D. tetraspora J.J. Taylor, hyphomycetous, sexual morph unknown, see Hyde et al. (2011; 
outline), Seifert et al. (2011; morphology), Wijayawardene et al. (2012, 2017; outline), Kirk et al. (2013; genus accepted), sequences are available, needs generic revision.

Diaboliumbilicus I. Hino \& Katum. 1955, Ascomycota genera incertae sedis, one species, type: D. mirabilis I. Hino \& Katum., asexual morph unknown, saprobes, terrestrial, Japan, see Lumbsch and Huhndorf (2010; outline), Kirk et al. (2013; genus accepted), cultures and sequences are unavailable.

Diachora Jul. Müll. 1893 (= Diachorella Höhn. 1918 fide Maharachchikumbura et al. 2016; Réblová et al. 2016c), Phyllachoraceae, Phyllachorales, Sordariomycetes, six species, type: D. onobrychidis (DC.) Jul. Müll., asexual morph Diachorella, saprobes, terrestrial, Japan, see Lumbsch and Huhndorf (2010; outline), Kirk et al. (2013; genus accepted), Maharachchikumbura et al. (2015, 2016; outline), Réblová et al. (2016c; nomenclature), Wijayawardene et al. (2017; outline), cultures and sequences are unavailable.

Diacrochordon Petr. 1955, Sordariomycetes genera incertae sedis, six species, type: $D$. rehmii Petr. 1955, asexual morph unknown, saprobes, terrestrial, Germany, see Lumbsch and Huhndorf (2010; outline), Kirk et al. (2013; genus accepted), Maharachchikumbura et al. (2016; outline), cultures and sequences are unavailable.

Diadema Shoemaker \& C.E. Babc. 1989, Diademaceae, Pleosporales, Dothideomycetes, nine species, type: D. tetramerum Shoemaker \& C.E. Babc., asexual morph unknown, saprobes, terrestrial, worldwide, see Lumbsch and Huhndorf (2010; outline), Zhang et al. (2011b; taxonomy), Hyde et al. (2013; taxonomy), Ariyawansa et al. (2014c; taxonomy, phylogeny), Wijayawardene et al. (2014c; outline), cultures and sequences are available.

Diademosa Shoemaker \& C.E. Babc. 1992, Diademaceae, Pleosporales, Dothideomycetes, one species, type: D. californiana (M.E. Barr) Shoemaker \& C.E. Babc., asexual morph unknown, saprobes on herbaceous, USA, see Lumbsch and Huhndorf (2010; outline), Kirk et al. (2013; genus accepted), Ariyawansa et al. (2015c; generic placement), Wijayawardene et al. (2014c; outline), sequences unavailable, needed generic placement.

Diademospora B.E. Soderstr. \& Bååth 1979, Ascomycota genera incertae sedis, one species, type: D. ramigera B.E. Söderstr. \& Bååth, hyphomycetous, sexual morph unknown, from forest soil, coniferous, Sweden, see Hyde et al. (2011; outline), Seifert et al. (2011; morphology), Wijayawardene et al. (2012, 2017; outline), Kirk et al. (2013; genus accepted), ex- type: CBS 427.76, IMI 203569, ATCC 42210, needs generic revision.

Dialaceniopsis Bat. 1959, Ascomycota genera incertae sedis, one species, type: $D$. landolphiae Bat., coelomycetous, sexual morph unknown, from Landolphia ugandensis, Uganda, see Hyde et al. (2011; outline), Wijayawardene et al. (2012, 2017; outline), cultures and sequences are unavailable, needs generic revision.

Dialhypocrea Speg. 1919, Hypocreaceae, Hypocreales, Sordariomycetes, one species, type: D. puiggariana Speg., asexual morph unknown, saprobes, terrestrial, Brazil, see Lumbsch and Huhndorf (2010; outline), Kirk et al. (2013; genus accepted), Jaklitsch et al. (2014b; phylogeny), Maharachchikumbura et al. (2015, 2016; outline), cultures and sequences are unavailable.

Diamantinia A.N. Mill., Læssøe \& Huhndorf 2003, Xylariales, genera incertae sedis, Sordariomycetes, one species, type: D. citrina A.N. Mill., Læssøe \& Huhndorf, asexual morph unknown, saprobes, terrestrial, Brazil, see Lumbsch and Huhndorf (2010; outline), Maharachchikumbura et al. (2015, 2016; outline, accepted as a genus in Xylariales), holotype and extype: SP, Buck 26886.

Diandromyces Thaxt. 1918, Laboulbeniaceae, Laboulbeniales, Laboulbeniomycetes, two species, type: D. chilenus Thaxt, asexual morph unknown, biotrophic, Chile, Ecuador, see Lumbsch and Huhndorf (2010; outline), Rossi (2010; new species, Ecuador), Kirk et al. (2013; genus accepted), cultures and sequences are unavailable. 
Dianesea (F. Stevens) Inácio \& P.F. Cannon 2002, Dothideomycetes genera incertae sedis, one species, type: D. palmae (F. Stevens) Inácio \& P.F. Cannon, saprobes, terrestrial, Cost Rica, see Lumbsch and Huhndorf (2010; outline), Wijayawardene et al. (2014c; outline), Jayasiri et al. (2015; re-described type), sequences are unavailable, needs generic revision.

Diaphorographis A.W. Archer \& Kalb 2009, Graphidaceae, Ostropales, Lecanoromycetes, two species, type: D. queenslandica Kalb \& A.W. Archer, asexual morph unknown, lichenized, terrestrial, tropical, see Kalb et al. (2009; taxonomy), Lumbsch and Huhndorf (2010; outline), Rivas Plata et al. (2012a; taxonomy), Kirk et al. (2013; genus accepted), sequences are unavailable.

Diaphoromyces Thaxt. 1926, Laboulbeniaceae, Laboulbeniales, Laboulbeniomycetes, three species, type: D. marginatus (Thaxt.) Thaxt., asexual morph unknown, biotrophic, worldwide, see Lumbsch and Huhndorf (2010; outline), Kirk et al. (2013; genus accepted), cultures and sequences are unavailable.

Diaporthe Nitschke 1870 (= Phomopsis (Sacc.) Bubák 1905 fide Udayanga et al. 2012; Rossman et al. 2015a; Maharachchikumbura et al. 2016), Diaporthaceae, Diaporthales, Sordariomycetes, more than 125 species, type: D. eres Nitschke, asexual morph coelomycetous, endophytes, pathogens, saprobes, associate with wide host range, worldwide, see Udayanga et al. (2012, 2014a, b; review, nomenclature, phylogeny), Gomes et al. (2013; taxonomy), Kirk et al. (2013; genus accepted), Maharachchikumbura et al. (2015, 2016; outline), Rossman et al. (2015a; nomenclature), Crous et al. (2016a; taxonomy, phylogeny), holotype and culture ex-epitype: BPI 892912, AR5193,

Diaporthella Petr. 1924, Diaporthaceae, Diaporthales, Sordariomycetes, four species, type: D. aristata (Fr.) Petr., asexual morph unknown, saprobes, terrestrial, Europe, North America, Eastern Asia, see Lumbsch and Huhndorf (2010; outline), Gomes et al. (2013; DNA), Kirk et al. (2013; genus accepted), Maharachchikumbura et al. (2015, 2016; outline), cultures and sequences are available but lacks for the cultures.

Diarimella B. Sutton 1980, Ascomycota genera incertae sedis, three species, type: D. setulosa B. Sutton, coelomycetous, sexual morph unknown,saprobes, terrestrial, Argentina, Canada, India, see Wijayawardene et al. (2012, 2017; outline), Kirk et al. (2013; genus accepted), holotype: IMI 103785, cultures and sequences are unavailable, genus need revision. Diatractium Syd. \& P. Syd. 1921, Phyllachoraceae, Phyllachorales, Sordariomycetes, two species, type: D. cordiae (F. Stevens) Syd. \& P. Syd., asexual morph unknown, pathogens, terrestrial, Central and South America, see Palmateer et al. (2008; DNA, pathogens), Lumbsch and Huhndorf (2010; outline), Kirk et al. (2013; genus accepted), Maharachchikumbura et al. (2016; outline), cultures and sequences are available.

Diatrypasimilis J.J. Zhou \& Kohlm. 2016, Diatrypaceae, Xylariales, Sordariomycetes, one species, type: D. australiensis J.J. Zhou \& Kohlm., asexual morph unknown, saprobes, on mangroves, Central and South America, see Palmateer et al. (2008; DNA, pathogens), Lumbsch and Huhndorf (2010; outline), Maharachchikumbura et al. (2015, 2016; outline; taxonomy), Index Fungorum(2017; validate the genus), cultures and sequences are available.

Diatrype Fr. 1849 (= Libertella Desm. 1830 fide Réblová et al. 2016c), Diatrypaceae, Xylariales, Sordariomycetes, cf. 60 species, type: D. disciformis (Hoffm.) Fr., asexual morph Libertella, saprobes, terrestrial, worldwide, see Lumbsch and Huhndorf (2010; outline), Liu et al. (2015a; new species), Maharachchikumbura et al. (2015, 2016; outline; taxonomy), Senanayske et al. (2015; phylogeny, outline), Réblová et al. (2016c; nomenclature), cultures and sequences are available.

Diatrypella (Ces. \& De Not.) De Not. 1863, Diatrypaceae, Xylariales, Sordariomycetes, c. 35 species, type: D. verruciformis (Ehrh.) Nitschke, asexual morph unknown, saprobes, terrestrial, worldwide, see Lumbsch and Huhndorf (2010; outline), Maharachchikumbura et al. (2015, 2016; outline; taxonomy), Senanayske et al. (2015; phylogeny, outline), Crous et al. 
(2016a; new species, phylogeny), Almeida et al. (2016; new species, phylogeny), cultures and sequences are available.

Diatrypoidiella Manohar., Kunwar \& D.K. Agarwal 2005, Diaporthales genera incertae sedis, Sordariomycetes, one species, type: D. lignicola Manohar., Kunwar \& D.K. Agarwal, asexual morph unknown, saprobes, terrestrial, worldwide, see Lumbsch and Huhndorf (2010; outline), Maharachchikumbura et al. (2015, 2016; outline; taxonomy), holotype of the type: HCIO 43762, cultures and sequences are unavailable.

Dibaeis Clem. 1909, Icmadophilaceae, Pertusariales, Lecanoromycetes, 13 species, type: D. rosea (Pers.) Clem., lichenized, see Lumbsch and Huhndorf (2010; outline), Kirk et al. (2013; genus accepted), Kondratyuk et al. (2015a; phylogeny), Lücking et al. (2016b; classification), ), culture available for the type: AFTOL-ID 358.

Dicarpella Syd. \& P. Syd. 1921, Melanconidaceae, Diaporthales, Sordariomycetes, four species, type: D. lignicola Manohar., Kunwar \& D.K. Agarwal, asexual morph unknown, saprobes, terrestrial, North America, see Lumbsch and Huhndorf (2010; outline), Kirk et al. (2013; genus accepted), Maharachchikumbura et al. (2015, 2016; outline, taxonomy), cultures and sequences are available.

Dicephalospora Spooner 1987, Helotiaceae, Helotiales, Leotiomycetes, four species, type: D. calochroa (Syd.) Spooner, asexual morph unknown, saprobes, terrestrial, worldwide, see Lumbsch and Huhndorf (2010; outline), Kirk et al. (2013; genus accepted), cultures and sequences are available.

Dichelostroma Bat. \& Peres 1963, Ascomycota genera incertae sedis, one species, type: D. powellii Bat. \& Peres, coelomycetous, sexual morph unknown, saprobes, terrestrial, USA, see Wijayawardene et al. (2012, 2017; outline), Kirk et al. (2013; genus accepted), data inadequate, cultures and sequences are unavailable.

Dichlaena Durieu \& Mont. 1849, Aspergillaceae, Eurotiales, Eurotiomycetes, four species, type: D. lentisci Durieu \& Mont., asexual morph hyphomycetous, terrestrial, saprobes, occurring on decaying plant material, wood and dung, Algeria, Brazil, India, Italy, Mauritania, USA, see Houbraken and Samson (2011), cultures and sequences are unavailable, needs phylogenetic assessment.

Dicholobodigitus G.P. White \& Illman 1988, Ascomycota genera incertae sedis, one species, type: D. niger G.P. White \& Illman, hyphomycetous, sexual morph unknown, on rotten wood of Pinus contorta, Canada, see Hyde et al. (2011; outline), Seifert et al. (2011; morphology), Wijayawardene et al. (2012, 2017; outline), Kirk et al. (2013; genus accepted), cultures and sequences are unavailable, needs generic revision.

Dichosporidium Pat. 1903, Roccellaceae, Arthoniales, Arthoniomycetes, eight species, type: D. glomeratum (Pat.) Pat., asexual morph unknown, lichenized, widespread (tropical), corticolous (occasionally saxicolous), see Lumbsch and Huhndorf (2010; outline), Kirk et al. (2013; genus accepted), Ertz et al. (2015c; phylogeny), Lücking et al. (2016b; classification), sequences are available.

Dichotomophthora Mehrl. \& Fitzp. ex P.N. Rao 1966, Ascomycota genera incertae sedis, four species, type: D. portulacae Mehrl. \& Fitzp. ex P.N. Rao, hyphomycetous, sexual morph unknown, on living leaves and stems of Portulacca oleracea, Hawaii, USA, widespread (esp. tropical), see Hyde et al. (2011; outline), Seifert et al. (2011; morphology), Wijayawardene et al. (2012, 2017; outline), Kirk et al. (2013; genus accepted), cultures and sequences are available, needs generic revision.

Dichotomophthoropsis M.B. Ellis 1971, Ascomycota genera incertae sedis, two species, type: D. nymphaearum (F.V. Rand) M.B. Ellis, hyphomycetous, sexual morph unknown, plant pathogen, India, USA, see Hyde et al. (2011; outline), Seifert et al. (2011; morphology), Wijayawardene et al. (2012, 2017; outline), Kirk et al. (2013; genus accepted), reference 
strain of Di. nymphaearum $=$ ATCC 64770, ATCC 204261-204266, sequences are unavailable, needs generic revision.

Dichotophora Whitton, K.D. Hyde \& McKenzie 2012, Ascomycota genera incertae sedis, two species, type: D. setiramosa Whitton, McKenzie \& K.D. Hyde, hyphomycetous, sexual morph unknown, saprobes, terrestrial, Philippines, see Whitton et al. (2012a; outline), Wijayawardene et al. (2017; outline), holotype: IFRD 9016, cultures and sequences are unavailable, needs generic revision.

Diclonomyces Thaxt. 1931, Laboulbeniaceae, Laboulbeniales, Laboulbeniomycetes, three species, type: D. eumicrophilus Thaxt., asexual morph unknown, biotrophic, pantropical, see Lumbsch and Huhndorf (2010; outline), Kirk et al. (2013; genus accepted), cultures and sequences are unavailable.

Dicranidion Harkn. 1885, Orbiliaceae, Orbiliales, Orbiliomycetes, four species, type: D. fragile Harkn., asexual morph unknown, saprobes, terrestrial, USA, see Kirk et al. (2013; genus accepted), data inadequate, cultures and sequences are available.

Dictyoarthrinium S. Hughes 1952, Apiosporaceae, Xylariales, Sordariomycetes, six new species, type: D. quadratum S. Hughes, hyphomycetous, sexual morph unknown, saprobes, terrestrial, widespread (tropical), see Seifert et al. (2011; morphology), Hyde et al. (2011; outline), Kirk et al. (2013; genus accepted), Crous and Groenewald (2013; phylogeny), Maharachchikumbura et al. (2015, 2016; outline), cultures and sequences are unavailable for type species, needs generic revision.

Dictyoasterina Hansf. 1947, Dothideomycetes genera incertae sedis, one species, type: D. conopharyngiae Hansf., asexual morph unknown, saprobes, terrestrial, Africa, see Lumbsch and Huhndorf (2010; outline), Wu et al. (2011; accepted as genus in Venturiaceae), Wijayawardene et al. (2014; outline, accepted as Dothideomycetes, genera incertae sedis), Kirk et al. (2013; genus accepted), cultures and sequences are unavailable, needs generic revision.

Dictyocatenulata Finley \& E.F. Morris 1967, Ostropomycetidae genera incertae sedis, Lecanoromycetes, one species, type: D. alba Finley \& E.F. Morris, hyphomycetous, sexual morph unknown, saprobes, Karnataka, India, widespread, see Hyde et al. (2011; outline), Seifert et al. (2011; morphology), An et al. (2012; phylogenetic revision), Wijayawardene et al. (2012, 2017; outline), Kirk et al. (2013; genus accepted), Lücking et al. (2016b; classification), cultures and sequences are available, needs generic revision.

Dictyochaeta Speg. 1923 (= Codinaeopsis Morgan-Jones 1972; = Dictyochaetopsis Aramb. \& Cabello 1990; = Menisporella Agnihothr. 1962 fide Seifert et al. 2011; Species Fungorum 2017), Chaetosphaeriaceae, Chaetosphaeriales, Sordariomycetes, c. 80 species, type: $D$. fuegiana Speg., hyphomycetous, sexual morph unknown, saprobes, terrestrial/aquatic, widespread, see Seifert et al. (2011; morphology), Hyde et al. (2011; outline), Wijayawardene et al. (2012, 2017; outline), Kirk et al. (2013; genus accepted), Silva and Gusmão (2013; new species), Maharachchikumbura et al. (2015, 2016; outline), cultures and sequences are available but lacks for type species, needs generic revision.

Dictyocheirospora D'souza, Boonmee \& K.D. Hyde 2016, Dictyosporiaceae, Pleosporales, Dothideomycetes, one species, type: D. rotunda D'souza, Bhat \& K.D. Hyde, hyphomycetous, sexual morph unknown, saprobes, Thailand, see Boonmee et al. (2016; phylogeny), Wijayawardene et al. (2017; outline), holotype: MFLUCC 14-0293, cultures and sequences are available.

Dictyocoprotus J.C. Krug \& R.S. Khan 1991, Ascodesmidaceae, Pezizales, Pezizomycetes, one species, type: $C$. nipigonensis Malloch \& Cain, asexual morph unknown, coprophilous, terrestrial, Mexico, USA, see Lumbsch and Huhndorf (2010; outline), Kirk et al. (2013; genus accepted), cultures and sequences are unavailable. 
Dictyocyclus Sivan., W.H. Hsieh \& Chi Y. Chen 1998, Myriangiaceae, Myriangiales, Dothideomycetes, one species, type: D. hydrangeae Sivan., W.H. Hsieh \& Chi Y. Chen, asexual morph unknown. Epiphytes, terrestrial, Taiwan, no molecular data, see Hofmann (2009; review, accepted as a genus in Parmulariaceae), Lumbsch and Huhndorf (2010; outline, accepted as a genus in Parmulariaceae), Hyde et al. (2013; review, keys, accepted as a genus in Parmulariaceae), Dissanayake et al. (2014; taxonomy, accepted as a genus in Myriangiaceae), Wijayawardene et al. (2014c; outline, accepted as a genus in Myriangiaceae), placement in Myriangiaceae supported by morphology, holotype: IMI 371179 , cultures and sequences unavailable.

Dictyodesmium S. Hughes 1951, Ascomycota genera incertae sedis, four species, type: D. ulmicola (Ellis \& Kellerm.) S. Hughes, hyphomycetous, sexual morph unknown, on living leaves of Ulmus fulva, USA; France, see Hyde et al. (2011; outline), Seifert et al. (2011; morphology), Wijayawardene et al. (2012, 2017; outline), Kirk et al. (2013; genus accepted), cultures and sequences are unavailable, needs generic revision.

Dictyodochium Sivan. 1984, Dothideomycetes genera incertae sedis, one species, type: $D$. prinsepiae Sivan., asexual morph unknown, saprobes, terrestrial, Africa, see Kirk et al. (2013; genus accepted), Wijayawardene et al. (2014; outline, accepted as Dothideomycetes, genera incertae sedis), data inadequate, cultures and sequences are unavailable.

Dictyodothis Theiss. \& Syd. 1915, Dothideaceae, Dothideales, Dothideomycetes, two species, type: D. berberidis (Rehm) Theiss. \& Syd., asexual morph unknown, saprobes, terrestrial, America, Asia, see Lumbsch and Huhndorf (2010; outline), Kirk et al. (2013; genus accepted), Thambugala et al. (2014a; accepted as a genus in Dothideaceae), Wijayawardene et al. (2014c; outline), sequences are available.

Dictyographa Müll. Arg. 1893, Opegraphaceae, Arthoniales, Arthoniomycetes, two species, type: D. arabica Müll. Arg., lichenized, see Lumbsch and Huhndorf (2010; outline, treated as a synonym of Opegrapha), Ertz and Tehler (2011; taxonomy), Lücking et al. (2016b; classification), sequences are available.

Dictyomeridium Aptroot, M.P. Nelsen \& Lücking 2016, Trypetheliaceae, Trypetheliales, Dothideomycetes, seven species, type: D. proponens (Nyl.) Aptroot, M.P. Nelsen \& Lücking, asexual morph unknown, lichenized, terrestrial, tropical, see Aptroot and Lücking (2016; taxonomy), Lücking et al. (2016b; classification), sequences are available.

Dictyonella Höhn. 1909, Saccardiaceae, Ascomycota families incertae sedis, seven species, type: D. erysiphoides (Rehm) Höhn., asexual morph unknown, saprobes, terrestrial, worldwide, see Lumbsch and Huhndorf (2010; outline), Kirk et al. (2013; genus accepted), data inadequate, cultures and sequences are unavailable.

Dictyopalmispora Pinruan, Boonmee \& K.D. Hyde 2016, Dictyosporiaceae, Pleosporales, Dothideomycetes, one species, type: D. palmae Pinruan \& K.D. Hyde, hyphomycetous, sexual morph unknown, saprobes, Thailand, see Boonmee et al. (2016; phylogeny), Wijayawardene et al. (2017; outline), holotype: BBH 39848, cultures and sequences are available.

Dictyopeltella Bat. \& I.H. Lima 1959, Micropeltidaceae, Microthyriales, Dothideomycetes, two species, type: D. domingensis (Petr. \& Cif.) Bat. \& I.H. Lima, asexual morph unknown, saprobes, terrestrial, tropical see Lumbsch and Huhndorf (2010; outline), Hyde et al. (2013; accepted as a genus in Micropeltidaceae), Wijayawardene et al. (2014c; outline), cultures and sequences are unavailable.

Dictyopeltis Theiss. 1913, Dothideomycetes genera incertae sedis, six species, type: D. vulgaris (Racib.) Theiss., asexual morph unknown, saprobes, terrestrial, pantropical, see Lumbsch and Huhndorf (2010; outline, as a genus in Micropeltidaceae), Kirk et al. (2013; genus accepted), Wijayawardene et al. (2014c; outline, accepted as Dothideomycetes, genera incertae sedis), data inadequate, cultures and sequences are unavailable. 
Dictyophrynella Bat. \& Cavalc. 1964, Ascomycota genera incertae sedis, one species, type: D. bignoniacearum Bat. \& Cavalc., hyphomycetous, sexual morph unknown, lichenicolous, Brazil, see Hyde et al. (2011; outline), Seifert et al. (2011; morphology), Wijayawardene et al. (2012, 2017; outline), cultures and sequences are unavailable, needs generic revision.

Dictyopolyschema M.B. Ellis 1976, Ascomycota genera incertae sedis, one species, type: D. pirozynskii, hyphomycetous, sexual morph unknown, saprobes on dead twigs of Picea, Great Britain, see Hyde et al. (2011; outline), Seifert et al. (2011; morphology), Wijayawardene et al. (2012, 2017; outline), Kirk et al. (2013; genus accepted), ex-type: IMI 89652, sequences are unavailable, needs generic revision.

Dictyoporthe Petr. 1955, Melanconidaceae, Diaporthales, Sordariomycetes, three species, type: D. ahmadii Petr., asexual morph unknown, saprobes, terrestrial, Pakistan, Taiwan, see Voglmayr and Jaklitsch (2008; DNA, transferred Dictyoporthe acerophila M.E. Barr to Prosthecium), Lumbsch and Huhndorf (2010; outline), Kirk et al. (2013; genus accepted), Maharachchikumbura et al. (2015, 2016; outline), cultures and sequences are available.

Dictyorostrella U. Braun 1999, Ascomycota genera incertae sedis, one species, type: D. caricicola (U. Braun \& Melnik) U. Braun, asexual morph hyphomycetous, terrestrial, foliicolous, Asia (Far East of Russia), North America, see Seifert et al. (2011; morphology), Wijayawardene et al. (2012, 2017; outline), Kirk et al. (2013; genus accepted), holotype: (DAOM), isotype: HAL $1645 \mathrm{~F}$, cultures and sequences are unavailable.

Dictyospiropes M.B. Ellis 1976, Ascomycota genera incertae sedis, one species, type: D. ziziphi M.B. Ellis, hyphomycetous, sexual morph unknown, saprobes, terrestrial, Philippines, see Seifert et al. (2011; morphology), Wijayawardene et al. (2012, 2017; outline), Kirk et al. (2013; genus accepted), cultures and sequences are unavailable, needs generic revision.

Dictyosporella Abdel-Aziz 2015, Annulatascaceae, Annulatascales, Sordariomycetes, one species, type: D. aquatica Abdel-Aziz, asexual morph unknown, saprobes, aquatic, Egypt, see Ariyawansa et al. (2015a; taxonomy, phylogeny), holotype and ex-type: CBS H-22127, MD1302.

Dictyosporium Corda 1836, Dictyosporiaceae, Pleosporales, Dothideomycetes, c. 50 species, type: D. elegans Corda, hyphomycetous, saprobes, terrestrial, aquatic, widespread, see Crous et al. (2009a; new species), Hyde et al. (2011; outline), Seifert et al. (2011; morphology), Wijayawardene et al. (2012, 2017; outline), Kirk et al. (2013; genus accepted), Liu et al. (2015a; new species), Boonmee et al. (2016; new species), cultures available for type species NBRC 32502.

Dictyostomiopelta Viégas 1944, Dothideomycetes, genera incertae sedis, one species, type: D. manihoticola Viégas, asexual morph unknown, saprobes, terrestrial, Brazil, see Lumbsch and Huhndorf (2010; outline, as a genus in Micropeltidaceae), Kirk et al. (2013; genus accepted), Wijayawardene et al. (2014c; outline, accepted as a genus in Dothideomycetes, genera incertae sedis), cultures and sequences are unavailable.

Dictyothyriella Speg. 1924, Dothideomycetes genera incertae sedis, one species, type: D. bauhiniae (Rehm) Theiss. \& Syd., asexual morph unknown, saprobes, terrestrial, Cape Horn, see Lumbsch and Huhndorf (2010; outline, as a genus in Micropeltidaceae), Kirk et al. (2013; genus accepted), Wijayawardene et al. (2014c; outline, accepted as a genus in Dothideomycetes, genera incertae sedis), cultures and sequences are unavailable.

Dictyothyrina Theiss. 1913, Dothideomycetes genera incertae sedis, one species, type: D. fecunda (Sacc.) Theiss., asexual morph unknown, saprobes, terrestrial, USA, see Lumbsch and Huhndorf (2010; outline, accepted as a genus in Micropeltidaceae), Kirk et al. (2013; genus accepted), Wijayawardene et al. (2014c; outline, accepted as a genus in Dothideomycetes, genera incertae sedis), cultures and sequences are unavailable.

Dictyothyrium Theiss. 1912, Dothideomycetes genera incertae sedis, two species, type: D. chalybeum (Rehm) Theiss., asexual morph unknown, saprobes, terrestrial, tropical, see 
Lumbsch and Huhndorf (2010; outline, as a genus in Micropeltidaceae), Kirk et al. (2013; genus accepted), Wijayawardene et al. (2014c; outline, accepted as a genus in Dothideomycetes, genera incertae sedis), cultures and sequences are unavailable.

Diddensiella Péter, Dlauchy \& Kurtzman 2012, Trichomonascaceae, Saccharomycetales, Saccharomycetes, three species, type: D. caesifluorescens G. Péter, Dlauchy \& Kurtzman, asexual reproduction is by multilateral budding, saprophytic, rotten wood and forest litter, worldwide, see Péter et al. (2012; taxonomy), sequences are available.

Didonia Velen. 1934, Helotiales genera incertae sedis, Leotiomycetes, five species, type: needs typification, asexual morph unknown, saprobes, terrestrial, Europe, see Lumbsch and Huhndorf (2010; outline), Kirk et al. (2013; genus accepted), cultures and sequences are unavailable.

Didymascella Maire \& Sacc. 1903, Cenangiaceae, Helotiales, Leotiomycetes, five species, type: D. oxycedri Maire \& Sacc., asexual morph unknown, saprobes, terrestrial, Europe, North America, see Lumbsch and Huhndorf (2010; outline), Kirk et al. (2013; genus accepted), Jaklitsch et al. (2016a; classification), cultures and sequences are available for Didymascella thujina.

Didymascus Sacc. 1896, Rhytismatales genera incertae sedis, Leotiomycetes, one species, type: D. metkinoffi Sacc., asexual morph unknown, saprobes, terrestrial, Siberia, see Lumbsch and Huhndorf (2010; outline), Kirk et al. (2013; genus accepted), cultures and sequences are unavailable.

Didymella Sacc. 1880 (= Arcangelia Sacc.1890; = Haplotheciella Höhn. 1918; = Mycosphaerellopsis Höhn. 1918 fide Hyde et al. 2013), Didymellaceae, Pleosporales, Dothideomycetes, c. 100 species, type: D. exigua (Niessl) Sacc., asexual morph coelomycetous, saprobes, pathogens, terrestrial, worldwide, see de Gruyter et al. (2009; phylogeny), Aveskamp et al. (2010; taxonomy, phylogeny), Lumbsch and Huhndorf (2010; outline), Hyde et al. (2013; accepted as a genus in Didymellaceae, taxonomy), Wijayawardene et al. (2014c; outline), Chen et al. (2015b; phylogeny, new species, taxonomy), Liu et al. (2015a; new species), cultures and sequences are available.

Didymellocamarosporium Wijayaw., Camporesi, D.J. Bhat \& K.D. Hyde 2016, Didymellaceae, Pleosporales, Dothideomycetes, one species, type: D. tamaricis Wijayaw., Camporesi, D.J. Bhat \& K.D. Hyde, coelomycetous, sexual morph unknown, saprobes, terrestrial, Italy, see Wijayawardene et al. (2016b, 2017; taxonomy, phylogeny, outline), holotype and ex-type: MFLU 15-3548, MFLUCC 14-0241.

Didymellopsis (Sacc.) Clem. \& Shear 1931, Xanthopyreniaceae, Collemopsidiales, Dothideomycetes, five species, type: D. latitans (Nyl.) Sacc. ex Clem. \& Shear, asexual morph unknown, lichenicolous, terrestrial, Europe, see Lumbsch and Huhndorf (2010; outline, family placed as Ascomycota family incertae sedis), Kirk et al. (2013; genus accepted), Zhurbenko et al. (2015b; new species), holotype: H-NYL 42670.

Didymobotryum Sacc. 1886, Sordariomycetes genera incertae sedis, one species, type: D. rigidum (Berk. \& Broome) Sacc., hyphomycetous, sexual morph unknown, saprobes, terrestrial, North America, Asia, see Seifert et al. (2011; morphology), Wijayawardene et al. (2017; outline), cultures available for type: JCM 8837.

Didymochaetina Bat. \& J.L. Bezerra 1965, Ascomycota genera incertae sedis, one species, type: D. galactiae Bat. \& J.L. Bezerra, coelomycetous, sexual morph unknown, saprobes, terrestrial, Jamaica, see Wijayawardene et al. (2012, 2017; outline), Kirk et al. (2013; genus accepted), cultures and sequences are unavailable, needs generic revision.

Didymochora Höhn. 1918, Ascomycota genera incertae sedis, one species, type: D. betulina Höhn., coelomycetous, sexual morph unknown, saprobes, terrestrial, Jamaica, see Wijayawardene et al. (2012, 2014c; outline, listed under Mycosphaerellaceae and 
Dothideomycetes, genera incertae sedis respectively), cultures and sequences are unavailable, needs generic revision.

Didymocoryne Sacc. \& Trotter 1913, Gelatinodiscaceae, Helotiales, Leotiomycetes, type: D. striata (Ellis \& Everh.) Sacc. \& Trotter, asexual morph unknown, saprobes, terrestrial, north temperate, see Lumbsch and Huhndorf (2010; outline), Kirk et al. (2013; genus accepted), Johnston et al. (2014b; reduced D. solitaria (Rehm) Sacc. \& Trotter under Ascocoryne albida (Berk.) Seifert, cultures and sequences are unavailable, needs generic revision.

Didymocrea Kowalski 1965, Didymosphaeriaceae, Pleosporales, Dothideomycetes, one species, type: D. sadasivanii (T.K.R. Reddy) Kowalski, asexual morph unknown, saprobes, terrestrial, India, see Lumbsch and Huhndorf (2010; outline), Hyde et al. (2013; accepted as a genera in Didymosphaeriaceae), Ariyawansa et al. (2014d; accepted as a genera in Didymosphaeriaceae, phylogeny), Wijayawardene et al. (2014c; phylogeny, outline), cultures available for type: CBS 438.65.

Didymocyrtidium Vain. 1921, Dothideomycetes genera incertae sedis, two species, type: need typification, asexual morph unknown, saprobes, terrestrial, Europe, see Lumbsch and Huhndorf (2010; outline), Wijayawardene et al. (2014c; outline), cultures and sequences are unavailable, needs generic revision.

Didymocyrtis Vain. 1921, Dothideomycetes genera incertae sedis, two species, type: D. consimilis Vain., asexual morph unknown, saprobes, terrestrial, Europe, see Lumbsch and Huhndorf (2010; outline), Wijayawardene et al. (2014c; outline), cultures and sequences are unavailable, needs generic revision.

Didymolepta Munk 1953, Dothideomycetes genera incertae sedis, two species, type: $D$. winteriana (Sacc.) Munk, asexual morph unknown, saprobes, terrestrial, Europe, see Wijayawardene et al. (2014c; outline), cultures and sequences are unavailable, needs generic revision.

Didymopleella Munk 1953, Dothideomycetes genera incertae sedis, four species, type: Didymopleella cladii (P. Larsen \& Munk) Munk, asexual morph unknown, saprobes, terrestrial, Europe, see Lumbsch and Huhndorf (2010; outline), Kirk et al. (2013; genus accepted), Wijayawardene et al. (2014c; outline), cultures and sequences are unavailable, needs generic revision.

Didymosphaeria Fuckel (1870) [1869-70], Didymosphaeriaceae, Pleosporales, Dothideomycetes, 25 species, type: D. futilis (Berk. \& Broome) Rehm, asexual morph coelomycetous, saprobes, terrestrial, worldwide, see Lumbsch and Huhndorf (2010; outline), Zhang et al. (2012e; taxonomy, phylogeny), Kirk et al. (2013; genus accepted), Ariyawansa et al. (2014a, d; taxonomy, phylogeny), Wijayawardene et al. (2014c; outline), cultures and sequences are available but lacks for the type species, needs generic revision..

Didymosporiella Traverso \& Migliardi 1911, Ascomycota genera incertae sedis, type: D. aeluropodis Traverso \& Migliardi, Kirk et al. (2008; treated as nom. dub.), Kirk et al. (2013; genus accepted.

Didymosporina Höhn. 1916, Ascomycota genera incertae sedis, one species, type: D. aceris (Lib.) Höhn., coelomycetous, sexual morph unknown, saprobes, terrestrial, Europe, see Wijayawardene et al. (2012, 2016b, 2017; outline, morphology), Kirk et al. (2013; genus accepted), cultures and sequences are unavailable, needs generic revision.

Didymostilbe Henn. 1902, Stachybotriaceae, Hypocreales, Sordariomycetes, eight species, type: D. coffeae Henn., hyphomycetous, saprobes, terrestrial, Asia, see Kirk et al. (2013; did not list), Maharachchikumbura et al. (2015, 2016; outline, accepted as a genus in Bionectriaceae), Lombard et al. (2016; phylogeny), cultures and sequences are available, needs generic revision.

Didymothozetia Rangel 1915, Ascomycota genera incertae sedis, one species, type: $D$. mimosoensis Rangel, hyphomycetous, sexual morph unknown, saprobes, terrestrial, Brazil, 
see Seifert et al. (2011; morphology), Wijayawardene et al. (2012, 2017; outline), Kirk et al. (2013; genus accepted), cultures and sequences are unavailable, needs generic revision.

Diederimyces Etayo 1995, Verrucariaceae, Verrucariales, Eurotiomycetes, two species, type: D. fuscideae Etayo, asexual morph unknown, lichenicolous, Europe, see Lumbsch and Huhndorf (2010; outline), Kirk et al. (2013; genus accepted), cultures and sequences are unavailable.

Diedickea Syd. \& P. Syd. 1913, Ascomycota genera incertae sedis, three species, type: D. singularis Syd. \& P. Syd., coelomycetous, sexual morph unknown, saprobes, terrestrial, tropical, see Wijayawardene et al. (2012, 2017; outline), Kirk et al. (2013; genus accepted), cultures and sequences are unavailable, needs generic revision.

Diehliomyces Gilkey 1954, Otideaceae, Pezizales, Pezizomycetes, one species, type: D. microsporus (Diehl \& E.B. Lamb.) Gilkey, asexual morph unknown, fungicolous, terrestrial, worldwide, see Lumbsch and Huhndorf (2010; outline, treated as Ascomycota, genera incertae sedis), Kirk et al. (2013; genus accepted), Jaklitsch et al. (2016a; classification), cultures and sequences are available.

Diffractella Guarro, P.F. Cannon \& Aa 1991, Lasiosphaeriaceae, Sordariales, Sordariomycetes, one species, type: D. curvata (Fuckel) Guarro, P.F. Cannon \& Aa, asexual morph unknown, saprobes, terrestrial, Asia, see Lumbsch and Huhndorf (2010; outline), Kirk et al. (2013; genus accepted), Maharachchikumbura et al. (2015, 2016; outline), cultures and sequences are unavailable, needs generic revision.

Digicatenosporium S.M. Leão, Gusmão \& R.F. Castaneda 2015, Ascomycota genera incertae sedis, one species, type: D. polyramosum S.M. Leão, Gusmão \& R.F. Castaneda, hyphomycetous, sexual morph unknown, saprobes, Brazil, see Leão-Ferreira et al. (2015; taxonomy), Wijayawardene et al. (2017; outline), cultures and sequences are unavailable, needs generic revision.

Digitodesmium P.M. Kirk 1981, Dictyosporiaceae, Pleosporales, Dothideomycetes, six species, type: D. elegans P.M. Kirk, hyphomycetous, sexual morph unknown, saprobes, Europe, see Silvera-Simon et al. (2010; new species), Seifert et al. (2011; morphology), Boonmee et al. (2016; phylogeny), Wijayawardene et al. (2017; outline), holotype: BBH 39848 , cultures and sequences are available.

Digitodochium Tubaki \& Kubono 1989, Ascomycota genera incertae sedis, one species, type: D. rhodoleucum Tubaki \& Kubono, hyphomycetous, sexual morph unknown, saprobes, terrestrial, Asia, see Seifert et al. (2011; morphology), Wijayawardene et al. (2012, 2017; outline), Kirk et al. (2013; genus accepted), cultures and sequences are unavailable, needs generic revision.

Digitomyces Mercado, M. Calduch \& Gené 2003, Ascomycota genera incertae sedis, one species, type: D. verrucosus (Tzean \& J.L. Chen) Mercado, M. Calduch \& Gené, hyphomycetous, sexual morph unknown, saprobes, terrestrial, Asia, neotropics, see Seifert et al. (2011; morphology), Wijayawardene et al. (2012, 2017; outline), cultures and sequences are unavailable, needs generic revision.

Digitopodium U. Braun, Heuchert \& K. Schub. 2005, Ascomycota genera incertae sedis, one species, type: D. hemileiae (Steyaert) U. Braun, Heuchert \& K. Schub., hyphomycetous, sexual morph unknown, terrestrial, fungicolous, Africa, see Seifert et al. (2011; morphology), Wijayawardene et al. (2012, 2017; outline), cultures and sequences are unavailable, needs generic revision, holotype of the type: BPI 426854.

Digitoramispora R.F. Castañeda \& W.B. Kendr. 1990, Ascomycota genera incertae sedis, three species, type: D. caribensis R.F. Castaneda \& W.B. Kendr., hyphomycetous, sexual morph unknown, saprobes, terrestrial, Cuba, see Seifert et al. (2011; morphology), Wijayawardene et al. (2012, 2017; outline), Kirk et al. (2013; genus accepted), holotype: 
INIFAT C89/167, cultures and sequences are unavailable, compare with Acrodictys, Acrodictyopsis, Cheiroidea and Cryptocoryneopsis.

Digitosarcinella S. Hughes 1984, Englerulaceae, Dothideomycetes, families incertae sedis, three species, type: D. caseariae S. Hughes, hyphomycetous, sexual morph unknown, saprobes, terrestrial, Brazil, see Seifert et al. (2011; morphology), Wijayawardene et al. (2012, 2014c, 2017; outline), Kirk et al. (2013; genus accepted), cultures and sequences are unavailable, needs generic revision.

Digitothyrea P. P. Moreno \& Egea 1992, Lichinaceae, Lichinales, Lichinomycetes, three species, type: D. rotundata (Büdel, Henssen \& Wessels) P.P. Moreno \& Egea, asexual morph unknown, lichenized, Africa, Central America, saxicolous, see Lumbsch and Huhndorf (2010; outline), Kirk et al. (2013; genus accepted), Lücking et al. (2016b; classification), sequences are available.

Dilophospora Desm. 1840 (= Lidophia J. Walker \& B. Sutton 1974 fide Rossman et al. 2016a), Dothideomycetes genera incertae sedis, c. two species, type: D. graminis Desm., coelomycetous, sexual morph formerly named in Lidophia, saprobes, terrestrial, worldwide, see Wijayawardene et al. (2012, 2017; outline), Kirk et al. (2013; genus accepted), Rossman et al. (2016a; nomenclaturea), cultures and sequences are unavailable, needs generic revision. Diluviicola K.D. Hyde, S.W. Wong \& E.B.G. Jones 1998, Annulatascaceae, Annulatascales, Sordariomycetes, type: D. capensis K.D. Hyde, S.W. Wong \& E.B.G. Jones, asexual morph unknown, saprobes, fresh water, Brunei, see Lumbsch and Huhndorf (2010; outline, misspelled as Diluvicola), Kirk et al. (2013; genus accepted), Maharachchikumbura et al. (2015, 2016; accepted as a genus in Annulatascaceae, misspelled as Diluvicola), cultures and sequences are unavailable, needs generic revision.

Dimastigosporium Faurel \& Schotter 1965, Ascomycota genera incertae sedis, two species, type: D. musimonum Faurel \& Schotter, coelomycetous, sexual morph unknown, saprobes, terrestrial, Sahara, India, see Yadav and Bhat (2009a; new species, India), Wijayawardene et al. (2012, 2017; outline), Kirk et al. (2013; genus accepted), cultures and sequences are unavailable, needs generic revision.

Dimelaena Norman 1852, Caliciaceae, Caliciales, Lecanoromycetes, c. ten species, type: D. oreina (Ach.) Norman, asexual morph unknown, lichenized, lichenicolous, saxicolous, on siliceous or basaltic rocks, world-wide, see Lumbsch and Huhndorf (2010; outline), Kirk et al. (2013; genus accepted), Knudsen et al. (2013b; key), Prieto et al. (2013; phylogeny), Lücking et al. (2016b; classification), Prieto and Wedin (2016; phylogeny; showed that Dimelaena is non-monophyletic as currently circumscribed), sequences available.

Dimeriella Speg. 1908, Perisporiopsidaceae, Dothideomycetes families incertae sedis, one species, type: D. hirtula Speg., asexual morph unknown, saprobes, terrestrial, Asia, see Lumbsch and Huhndorf (2010; outline), Kirk et al. (2013; genus accepted), Wijayawardene et al. (2014; outline), cultures and sequences are unavailable, needs generic revision.

Dimerina Theiss. 1912, Ascomycota genera incertae sedis, c. ten species, type: D. strychni (Henn.) Theiss., asexual morph unknown, saprobes, terrestrial, Sahara, India, see Kirk et al. (2013; genus accepted), cultures and sequences are unavailable, needs generic revision.

Dimerium (Sacc. \& P. Syd.) McAlpine 1903, Perisporiopsidaceae, Dothideomycetes families incertae sedis, one species, type: D. pulveraceum (Speg.) Theiss., see Hyde et al. (2013; accepted as a genus in Perisporiopsidaceae), Kirk et al. (2013; did not include), data inadequate, needs generic revision.

Dimeromyces Thaxt. 1896, Laboulbeniaceae, Laboulbeniales, Laboulbeniomycetes, 114 species, type: D. africanus Thaxt., asexual morph unknown, biotrophic, worldwide, see Lumbsch and Huhndorf (2010; outline), Rossi (2010; new species, Ecuador), Kirk et al. (2013; genus accepted), Rossi et al. (2015; new species, Ecuador), cultures and sequences are unavailable. 
Dimerosporiella Speg. 1908, Bionectriaceae, Hypocreales, Sordariomycetes, seven species, type $D$. paulistana Speg, on living leaves, terrestrial, worldwide, see Lumbsch and Huhndorf (2010; outline), Kirk et al. (2013; genus accepted), Maharachchikumbura et al. (2015, 2016; outline), holotype: LPS, cultures and sequences are unavailable.

Dimidiographa Ertz \& Tehler 2011, Roccellographaceae, Arthoniales, Arthoniomycetes, three species, type: D. loandensis (Nyl.) Ertz, Bungartz \& Tehler, sexual morph with lirelliform ascomata, coelomycetous, lichenized, terrestrial, tropical, see Ertz and Tehler (2011; taxonomy, phylogeny), Lücking et al. (2016b; classification), sequences are available for three species.

Dimorphiopsis Crous 2013, Lophiostomataceae, Pleosporales, Dothideomycetes, one species, type: D. brachystegiae Crous, coelomycetous or hyphomycetous, sexual morph unknown, Zambia, see Crous et al. (2013b; morphology, DNA), Wijayawardene et al. (2014c, 2016b; outline, morphology, phylogeny), holotype and ex-type: CBS H-21430, CPC 22679, $22680=$ CB 136422 .

Dimorphiseta L. Lombard \& Crous 2016, Stachybotriaceae, Hypocreales, Sordariomycetes, one species, type: D. terrestris L. Lombard \& Crous, hyphomycetous, sexual morph unknown, saprobes, terrestrial, USA, see Lombard et al. (2016; taxonomy, phylogeny), holotype and ex-type: CBS H-22442, CBS 127345.

Dimorphomyces Thaxt. 1893, Laboulbeniaceae, Laboulbeniales, Laboulbeniomycetes, 27 species, type: Dimorphomyces denticulatus Thaxt., asexual morph unknown, parasites, saprobes, terrestrial, worldwide, see Lumbsch and Huhndorf (2010; outline), Rossi (2010; new species), cultures and sequences are unavailable, needs generic revision.

Dimorphospora Tubaki 1958, Helotiaceae, Helotiales, Leotiomycetes, one species, type: D. foliicola Tubaki, hyphomycetous, sexual morph unknown, saprobes, terrestrial, worldwide, see Seifert et al. (2011; morphology), Wijayawardene et al. (2012, 2017; outline), cultures and sequences are available, needs generic revision.

Dimorphotricha Spooner 1987, Hyaloscyphaceae, Helotiales, Leotiomycetes, one species, type: D. australis Spooner, asexual morph unknown, saprobes, terrestrial, Australia, see Lumbsch and Huhndorf (2010; outline), Kirk et al. (2013; genus accepted), cultures and sequences are unavailable, needs generic revision.

Dinemasporium Lév. 1846, Chaetosphaeriaceae, Chaetosphaeriales, Sordariomycetes, 35 species, type: D. graminum (Lib.) Lév., coelomycetous, sexual morph unknown, saprobes, worldwide, see Crous et al. (2012g, 2014c; new species, morphology, phylogeny), Hashimoto et al. (2015a; morphology, phylogeny), Liu et al. (2015a; morphology, phylogeny), Wijayawardene et al. (2016b, 2017; morphology, outline), isotype, epitype and ex-epitype: K(M) 175981, CBS H-20952, CBS 828.84.

Dingleya Trappe 1979, Tuberaceae, Pezizales, Pezizomycetes, six species, type: D. verrucosa Trappe, asexual morph unknown, pathogens, saprobes, terrestrial, Australia, see Lumbsch and Huhndorf (2010; outline), Kirk et al. (2013; genus accepted), cultures and sequences are available for unidentified species, needs generic revision.

Dioicomyces Thaxt. 1901, Laboulbeniaceae, Laboulbeniales, Laboulbeniomycetes, 32 species, type: D. anthici Thaxt., asexual morph unknown, patasites, terrestrial, worldwide, see Lumbsch and Huhndorf (2010; outline), Kirk et al. (2013; genus accepted), Bernardi et al. (2014; Ecuador), cultures and sequences are available for unidentified species, needs generic revision.

Diorygma Eschw. 1824, Graphidaceae, Ostropales, Lecanoromycetes, 71 species, type: D. hieroglyphica (Pers.) Staiger \& Kalb, asexual morph unknown, lichenized, terrestrial, tropical, see Archer (2009; key, Australia), Lumbsch and Huhndorf (2010; outline), Nelsen et al. (2012; DNA, phylogeny), Rivas Plata et al. (2012a; taxonomy), Kirk et al. 2013 (genus 
accepted), Feuerstein et al. (2014; key), Lumbsch et al. (2014a, b; phylogeny), Lücking et al. (2016b; classification), cultures and sequences are available but lacks for the type.

Diphymyces I.I. Tav. 1985, Laboulbeniaceae, Laboulbeniales, Laboulbeniomycetes, 32 species, type: D. appendiculatus (Thaxt.) I.I. Tav., asexual morph unknown, patasites, terrestrial, worldwide, see Lumbsch and Huhndorf (2010; outline), Rossi and Santamaria (2010; new species), Kirk et al. (2013; genus accepted), Haelewaters et al. (2014a; new species), cultures and sequences are available for unidentified species, needs generic revision.

Diplacella Syd. 1930, Gnomoniaceae, Diaporthales, Sordariomycetes, 32 species, type: D. paulliniae (Gonz. Frag. \& Cif.) Syd., asexual morph unknown, saprobes, terrestrial, tropical, see Lumbsch and Huhndorf (2010; outline), Kirk et al. (2013; genus accepted), Maharachchikumbura et al. (2015, 2016; outline), cultures and sequences are available for unidentified species, needs generic revision.

Diplocarpa Massee 1895, Cordieritidacea, Helotiales, Leotiomycetes, one species, type: D. curreyana Massee, asexual morph unknown, fungicolous, terrestrial, Europe, see Lumbsch and Huhndorf (2010; outline, accepted as a genus in Dermateaceae), Kirk et al. (2013; genus accepted), Pärtel et al. (2017; DNA, phylogeny, treated as a genus in Cordieritidacea), cultures and sequences are available, cultures available for type: KL317.

Diplocarpon F.A. Wolf 1912 (= Entomosporium Lév. 1857; = Bostrichonema Ces. 1867; = Marssonina Magnus 1906; = Entomopeziza Kleb. 1914 fide Johnston et al. 2014b), Drepanopezizaceae, Helotiales, Leotiomycetes, seven species, type: D. rosae F.A. Wolf, asexual morph Entomosporium; Marssonina, pathogens, saprobes, terrestrial, Europe, see Lumbsch and Huhndorf (2010; outline), Kirk et al. (2013; genus accepted), Johnston et al. (2014b; nomenclature), cultures and sequences are available.

Diplochorina Gutner 1933, Dothideomycetes genera incertae sedis, one species, type: D. naumovii Gutner, asexual morph unknown, saprobes, terrestrial, USSR, see Lumbsch and Huhndorf (2010; outline), Kirk et al. (2013; genus accepted), Wijayawardene et al. (2014c; outline), cultures and sequences are available for unidentified species, needs generic revision.

Diplocladiella G. Arnaud ex M.B. Ellis 1976, Ascomycota genera incertae sedis, one species, type: D. scalaroides G. Arnaud ex M.B. Ellis, hyphomycetous, sexual morph unknown, saprobes, terrestrial, Asia, Australasia, neotropics, see Seifert et al. (2011; morphology), Wijayawardene et al. (2012, 2017; outline), Kirk et al. (2013; genus accepted), cultures and sequences are unavailable, needs generic revision.

Diplococcium Grove 1885, Helminthosphaeriaceae, Sordariomycetidae, families incertae sedis, Sordariomycetes, c. 25 species, type: D. spicatum Grove, hyphomycetous, sexual morph unknown, saprobes, terrestrial, widespread, see Shenoy et al. (2010; phylogeny, polyphyletic), Hyde et al. (2011; outline), Seifert et al. (2011; morphology), HernándezRestrepo et al. (2012b; new species, key), Ma et al. (2012h, new species), Wijayawardene et al. (2012, 2017; outline), Kirk et al. (2013; genus accepted), Silva et al. (2014; new species), Almeida et al. (2015, new species), Maharachchikumbura et al. (2016; outline, accepted as a genus in Helminthosphaeriaceae), cultures available for type species CBS 162.47, CBS 852.73, needs generic revision.

Diplodia Fr. 1834, Botryosphaeriaceae, Botryosphaeriales, Dothideomycetes, 23 species, type: D. mutila (Fr.) Mont., holomorph, asexual morph coelomycetous, endophytes, pathogens, saprobes, associated with cankers, dieback and fruit rot, worldwide, see Phillips et al. (2008, 2013; morphology, phylogeny), Liu et al. (2012; morphology, phylogeny), Hyde et al. (2013; accepted as a genus in Botryosphaeriaceae), Alves et al. (2014; morphology, phylogeny), Wijayawardene et al. (2016b; morphology, phylogeny), holotype and ex-epitype: BPI 599153 and CBS 136014,

Diplodinis Clem. 1931, Ascomycota genera incertae sedis, one species, type: D. rostrupi (Vestergr.) Clem., coelomycetous, sexual morph unknown, saprobes, terrestrial, Scandinavia, 
see Wijayawardene et al. (2012, 2017; outline), Kirk et al. (2013; genus accepted), cultures and sequences are unavailable, needs generic revision.

Diplodinula Tassi 1902, Ascomycota genera incertae sedis, one species, type: need typification, coelomycetous, sexual morph unknown, saprobes, terrestrial, worldwide, see Wijayawardene et al. (2012, 2017; outline), Kirk et al. (2013; genus accepted), cultures and sequences are unavailable, needs generic revision.

Diplogelasinospora Cain 1961, Chaetomiaceae, Sordariales, Sordariomycetes, three species, type: D. princeps Cain, asexual morph unknown, saprobes, terrestrial, Asia, North America, see Lumbsch and Huhndorf (2010; outline, accepted as genus in Lasiosphaeriaceae), Kirk et al. (2013; genus accepted), Crous et al. (2014c; new species, DNA), Maharachchikumbura et al. (2016; outline, accepted as a genus in Chaetomiaceae), cultures and sequences are available.

Diplogramma Müll. Arg. 1891, Roccellaceae, Arthoniales, Arthoniomycetes, one species, type: D. australiensis Müll. Arg., lichenized, Australia, epiphytic, see Lumbsch and Huhndorf (2010; outline), Kirk et al. (2013; genus accepted), Lücking et al. (2016b; treated as a synonym of Opegrapha), sequences are unavailable

Diploicia A. Massal. 1852, Caliciaceae, Caliciales, Lecanoromycetes, four species, type: D. canescens (Dicks.) A. Massal., asexual morph unknown, lichenized, corticolous, worldwide, see Lumbsch and Huhndorf (2010; outline), Gaya et al. (2012; taxonomy), Kirk et al. (2013; genus accepted), Bungartz et al. (2016: generic concept, key to all species; discussed the distinction from Diplotomma, but showed both are distinct), Lücking et al. (2016b; classification), sequence are available for voucher MAF 8656 of the type.

Diplolaeviopsis Giralt \& D. Hawksw. 1991, Cordieritidaceae, Helotiales, Leotiomycetes, three species, type: D. ranula Giralt \& D. Hawksw., on lichens, sexual morph unknown, see Kirk et al. (2013; genus accepted), Suija et al. (2015b; position), Pärtel et al. (2017; phylogeny), Wijayawardene et al. (2017; outline), cultures and sequences are available, holotype of type: BCC-Lich 4120.

Diplomyces Thaxt. 1895, Laboulbeniaceae, Laboulbeniales, Laboulbeniomycetes, three species, type: D. actobianus Thaxt., asexual morph unknown, parasites, terrestrial, worldwide, see Lumbsch and Huhndorf (2010; outline), Kirk et al. (2013; genus accepted), cultures and sequences are available.

Diplonaevia Sacc. 1889, Calloriaceae, Helotiales, Leotiomycetes, 23 species, type: D. caricum (Auersw.) Sacc., asexual morph unknown, saprobes, terrestrial, worldwide, see Lumbsch and Huhndorf (2010; outline), Kirk et al. (2013; genus accepted), cultures and sequences are unavailable, needs generic revision.

Diploöspora Grove 1916, Clavicipitaceae, Hypocreales, Sordariomycetes, one species, type: D. rosea Grove, hyphomycetous, sexual morph unknown, saprobes, terrestrial, Asia, Caribbean, South America, see Seifert et al. (2011; morphology), Wijayawardene et al. (2012, 2017; outline), cultures and sequences are unavailable, needs generic revision.

Diploplenodomus Died. 1912, Ascomycota genera incertae sedis, two species, type: $D$. malvae Died. ex Died., coelomycetous, sexual morph unknown, saprobes, terrestrial, Europe, see Wijayawardene et al. (2012, 2017; outline), Kirk et al. (2013; genus accepted), cultures and sequences are unavailable, needs generic revision.

Diplopodomyces W. Rossi \& Balazuc 1977, Laboulbeniaceae, Laboulbeniales, Laboulbeniomycetes, three species, type: D. callipodos W. Rossi \& Balazuc, asexual morph unknown, parasites, terrestrial, worldwide, see Lumbsch and Huhndorf (2010; outline), Kirk et al. (2013; genus accepted), Santamaría et al. (2014; new species), cultures and sequences are unavailable. 
Diploschistella Vain. 1926, Gomphillaceae, Ostropales, Lecanoromycetes, four species, type: D. urceolata Vain., lichenized, pantropical, see Lumbsch and Huhndorf (2010; outline), Lücking et al. (2016b; classification), sequences are unavailable.

Diploschistes Norman 1852, Graphidaceae, Ostropales, Lecanoromycetes, c. 33 species, type: D. scruposus (Schreb.) Norman, asexual morph coelomycetous, lichenized (young states sometimes parasitic), on rocks, soil or over mosses and other lichens, worldwide, see Lumbsch and Huhndorf (2010; outline), Fermández-Brime et al. (2013; phylogeny), Mangold et al. (2009; key, Australia), Rivas Plata et al. (2010a, 2012a; key, taxonomy), Kirk et al. (2013; genus accepted), Wang et al. (2013b; new species), Lücking et al. (2016b; classification), cultures available for the type: AFTOL-ID 98.

Diplosporonema Höhn. 1917, Ascomycota genera incertae sedis, one species, type: $D$. delastrei (Lacroix) Höhn. ex Petr., coelomycetous, sexual morph unknown, saprobes, terrestrial, worldwide, see Wijayawardene et al. (2012, 2017; outline), Kirk et al. (2013; genus accepted), cultures and sequences are unavailable, needs generic revision.

Diplotomma Flot. 1849, Caliciaceae, Caliciales, Lecanoromycetes, 30 species, type: D. alboatrum (Hoffm.) Flot., lichenized, see Lumbsch and Huhndorf (2010; outline), Gaya et al. (2012; taxonomy), Kirk et al. (2013; genus accepted), Lücking et al. (2016b; classification), Prieto and Wedin (2016; phylogeny), sequences are available.

Diplozythiella Died. 1916, Ascomycota genera incertae sedis, one species, type: D. bambusina Died., coelomycetous, sexual morph unknown, saprobes, terrestrial, worldwide, see Wijayawardene et al. (2012, 2017; outline), Kirk et al. (2013; genus accepted), cultures and sequences are unavailable, needs generic revision.

Dipodascopsis Batra \& P. Millner emend. Kurtzman, Albertyn \& Basehoar-Powers 2007 (= Babjevia Van der Walt \& M.T. Sm. 1995 fide Kurtzman et al. 2007), Lipomycetaceae, Saccharomycetales, Saccharomycetes, three species, type: D. uninucleata (Biggs) L.R. Batra \& Millner, asexual reproduction by multilateral budding and pseudohyphae may be present, saprophytic, soil, wood, fruit fly, Canada, USA, Europe, see Lumbsch and Huhndorf (2010; outline), Kirk et al. (2013; genus accepted), Kurtzman and Robnett (2013b; DNA, phylogeny), sequences are available.

Dipodascus de Lagerheim 1892, Dipodascaceae, Saccharomycetales, Saccharomycetes, ten species, type: D. albidus Lagerh., asexual reproduction present (arthroconidia, chlamydospores may be formed), saprophytic, insects, insect galleries in pine trees, fluxes from trees, mushroom gills, cacti, worldwide, see Nagahama et al. (2008; DNA), Lumbsch and Huhndorf (2010; outline), Kirk et al. (2013; genus accepted), sequences are available.

Dipodomyces Thaxt. 1931, Laboulbeniaceae, Laboulbeniales, Laboulbeniomycetes, two species, type: D. monstruosus Thaxt., asexual morph unknown, parasites, terrestrial, worldwide, see Lumbsch and Huhndorf (2010; outline), Kirk et al. (2013; genus accepted), cultures and sequences are unavailable.

Diporotheca C.C. Gordon \& C.G. Shaw 1961, Diporothecaceae, Ascomycota families incertae sedis, two species, type: D. rhizophila C.C. Gordon \& C.G. Shaw, asexual morph unknown, saprobes, terrestrial, aquatic, USA, see Lumbsch and Huhndorf (2010; outline), Kirk et al. (2013; genus accepted), Hawksworth et al. (2016; Diporotheca palynomorph), holotype: WSP 48900, cultures and sequences are unavailable.

Dipyrgis Clem. 1909, Ascomycota genera incertae sedis, one species, type: data inadequate asexual morph unknown, saprobes, terrestrial, worldwide, see Lumbsch and Huhndorf (2010; outline), Kirk et al. (2013; genus accepted), cultures and sequences are unavailable, needs generic revision.

Dirina Fr. 1825, Roccellaceae, Arthoniales, Arthoniomycetes, 24 species, type: D. ceratoniae (Ach.) Fr., asexual morph unknown, lichenized, saxicolous and corticolous, worldwide (coastal regions of mediterranean and subtropical climates), see Lumbsch and Huhndorf 
(2010; outline), Kirk et al. (2013; genus accepted), Tehler et al. (2013a; phylogeny and taxonomy), Lücking et al. (2016b; classification, but recording only 13 species), sequences are available.

Dirinaria (Tuck.) Clem. 1909, Caliciaceae, Caliciales, Lecanoromycetes, 35 species; type: D. picta (Sw.) Clem. \& Shear, lichenized, see Lumbsch and Huhndorf (2010; outline), Gaya et al. (2012; taxonomy), Kirk et al. (2013; genus accepted), Lücking et al. (2016b; classification), Prieto and Wedin (2016; phylogeny), sequences are available.

Dirinastrum Müll.Arg. 1893, Caliciaceae, Teloschistales, Lecanoromycetes, three species; type: D. australiense Müll. Arg., lichenized, see Lumbsch and Huhndorf (2010; outline), Bungartz et al. (2011; phylogeny), Lücking et al. (2016b; classification, treated as a genus in Roccellaceae), sequences are unavailable.

Diromma Ertz \& Tehler 2014, Roccellaceae, Arthoniales, Arthoniomycetes, one species, type: D. dirinellum (Nyl.) Ertz \& Tehler, sexual morph with apothecioid ascomata, asexual morph unknown, lichenized, terrestrial, Mediterranean and Canary Islands, see Ertz et al. (2015c; morphology, phylogeny), Lücking et al. (2016b; classification), lectotype and ex-type strain of type: Dufour (H-NYL4756).

Discina (Fr.) Fr. 1849, Discinaceae, Pezizales, Pezizomycetes, 20 species, type: D. perlata (Fr.) Fr., asexual morph unknown, saprobes, terrestrial, worldwide, see Kirk et al. (2013; genus accepted), cultures and sequences are unavailable, needs generic revision.

Discinella Boud. 1885 (= Pachydisca Boud. 1885; Geocoryne Korf 1978 fide Species Fungorum 2017), Helotiales genera incertae sedis, Leotiomycetes, twelve species, type: D. boudieri (Quél.) Boud., asexual morph unknown, saprobes, terrestrial, worldwide, see Lumbsch and Huhndorf (2010; outline), Kirk et al. (2013; genus accepted), cultures and sequences are unavailable, needs generic revision.

Disciotis Boud. 1885, Morchellaceae, Pezizales, Pezizomycetes, four species, type: D. venosa (Pers.) Arnould, asexual morph unknown, saprobes, terrestrial, worldwide, see Lumbsch and Huhndorf (2010; outline), Kirk et al. (2013; genus accepted), Methven et al. (2013; DNA, phylogeny), Carris et al. (2016; mitosporic stage; DNA, phylogeny), cultures and sequences are available.

Discocainia J. Reid \& A. Funk 1966, Rhytismataceae, Rhytismatales, Leotiomycetes, type: D. treleasei (Sacc.) J. Reid \& A. Funk, asexual morph unknown, saprobes, terrestrial, worldwide, see Lumbsch and Huhndorf (2010; outline), Kirk et al. (2013; genus accepted), Li et al. (2014c; new species, Japan), cultures and sequences are available.

Discocolla Prill. \& Delacr. 1894, Ascomycota genera incertae sedis, one species, type: D. pyrina Prill. \& Delacr., hyphomycetous, sexual morph unknown, saprobes, terrestrial, north temperate, see Seifert et al. (2011), Wijayawardene et al. (2012, 2017; outline), Kirk et al. (2013; genus accepted), cultures and sequences are unavailable, needs generic revision.

Discocurtisia Nannf. 1983, Mollisiaceae, Helotiales, Leotiomycetes, twelve species, type: D. arundinariae (Berk. \& M.A. Curtis) Nannf., asexual morph unknown, saprobes, terrestrial, North America, see Lumbsch and Huhndorf (2010; outline), Kirk et al. (2013; genus accepted), cultures and sequences are unavailable, needs generic revision.

Discogloeum Petr. 1923, Ascomycota genera incertae sedis, one species, type: $D$. veronicarum (Ces.) Petr., coelomycetous, sexual morph unknown, saprobes, terrestrial, Europe, see Wijayawardene et al. (2012, 2017; outline), Kirk et al. (2013; genus accepted), cultures and sequences are unavailable, needs generic revision.

Discomycella Höhn. 1912, Helotiales genera incertae sedis, Leotiomycetes, one species, type: D. tjibodensis Höhn., asexual morph unknown, saprobes, terrestrial, Java, see Lumbsch and Huhndorf (2010; outline), Kirk et al. (2013; genus accepted), cultures and sequences are unavailable, needs generic revision. 
Discomycetoidea Matsush. 1993, Ascomycota genera incertae sedis, one species, type: D. aequatorialis Matsush., hyphomycetous, sexual morph unknown, saprobes, terrestrial, South America, see Seifert et al. (2011; morphology), Wijayawardene et al. (2012, 2017; outline), cultures and sequences are unavailable, needs generic revision.

Discorehmia Kirschst. 1936, Helotiaceae, Helotiales, Leotiomycetes, five species, type: D. eburnea Kirschst., asexual morph unknown, saprobes, terrestrial, North America, see Kirk et al. (2013; genus accepted), cultures and sequences are unavailable, needs generic revision.

Discosia Lib. ex Durieu \& Mont. 1849, Sporocadaceae, Xylariales, Sordariomycetes, six species, type: D. strobilina Lib., coelomycetous, sexual morphs unknown, saprobes, terrestrial, cosmopolitan, see Wijayawardene et al. (2012, 2016b, 2017; taxonomy, outline), Kirk et al. (2013; genus accepted), Maharachchikumbura et al. (2015, 2016; outline, phylogeny), Senanayake et al. (2015; new species, phylogeny), Jaklitsch et al. (2016a; phylogeny), cultures and sequences are available.

Discosiellina Subram. \& K.R.C. Reddy 1972, Ascomycota genera incertae sedis, one species, type: D. longiciliata (Agnihothr.) Subram. \& K.R.C. Reddy, coelomycetous, sexual morph unknown, saprobes, terrestrial, India, see Wijayawardene et al. (2012, 2017; outline), Kirk et al. (2013; genus accepted), cultures and sequences are unavailable, needs generic revision.

Discosphaerina Höhn. 1917, Hyponectriaceae, Xylariales, Sordariomycetes, eleven species, type: D. discophora Höhn., asexual morph unknown, saprobes, terrestrial, Europe, North America, see Lumbsch and Huhndorf (2010; outline), Kirk et al. (2013; genus accepted), Maharachchikumbura et al. (2015, 2016; outline), cultures and sequences are available.

Discosporina Höhn. 1927, Ascomycota genera incertae sedis, one species, type: D. deplanata (Höhn.) Höhn., coelomycetous, sexual morph unknown, saprobes, terrestrial, worldwide, see Wijayawardene et al. (2012, 2017; outline), Kirk et al. (2013; genus accepted), cultures and sequences are unavailable, needs generic revision.

Discotheciella Syd. \& P. Syd. 1917, Ascomycota genera incertae sedis, one species, type: D. bakeri (Syd. \& P. Syd.) Syd. \& P. Syd., coelomycetous, sexual morph unknown, saprobes, terrestrial, Philippines, see Wijayawardene et al. (2012, 2017; outline), Kirk et al. (2013; genus accepted), cultures and sequences are unavailable, needs generic revision.

Discozythia Petr. 1922, Ascomycota genera incertae sedis, one species, type: D. bakeri (Syd. \& P. Syd.) Syd. \& P. Syd., coelomycetous, sexual morph unknown, saprobes, terrestrial, Philippines, see Wijayawardene et al. (2012, 2017; outline), Kirk et al. (2013; genus accepted), cultures and sequences are unavailable, needs generic revision.

Disculoides Crous, Pascoe, I.J. Porter \& Jacq. Edwards 2012, Diaporthales genera incertae sedis, Sordariomycetes, two species, type: D. eucalypti Crous, Pascoe, I.J. Porter \& Jacq. Edwards, coelomycetous, sexual morph unknown, pathogens, terrestrial, Australia, see Crous et al. (2012d, 2016a; morphology, new species, phylogeny), Maharachchikumbura et al. (2015; classification, phylogeny), holotype and ex-type: CBS H-20935, CPC 17650.

Dissitimurus E.G. Simmons, McGinnis \& Rinaldi 1987, Ascomycota genera incertae sedis, one species, type: D. exedrus E.G. Simmons, McGinnis \& Rinaldi, hyphomycetous, sexual morph unknown, on human, terrestrial, North America, see Seifert et al. (2011; morphology), Wijayawardene et al. (2012, 2017; outline), Kirk et al. (2013; genus accepted), cultures and sequences are unavailable, needs generic revision.

Dissoconium de Hoog, Oorschot \& Hijwegen 1983, Dissoconiaceae, Capnodiales, Dothideomycetes, four species, type: D. aciculare de Hoog, Oorschot \& Hijwegen, hyphomycetous, sexual morph mycosphaerella-like, saprobes, pathogens, terrestrial, worldwide, see Crous et al. (2009d; taxonomy, phylogeny), Seifert et al. (2011; morphology), Hyde et al. (2013; taxonomy, phylogeny), Kirk et al. (2013; genus accepted), Quaedvlieg et al. (2014; phylogeny), Wijayawardene et al. (2014c; outline, phylogeny), cultures and sequences are available. 
Distocercospora N. Pons \& B. Sutton 1988, Mycosphaerellaceae, Capnodiales, Dothideomycetes, four species, type: D. pachyderma (Syd. \& P. Syd.) N. Pons \& B. Sutton, hyphomycetous, sexual morph unknown, saprobes, ?pathogens, terrestrial, South Africa, India, New Zealand, Philippines, see Seifert et al. (2011; morphology), Wijayawardene et al. (2012, 2017; outline), Kirk et al. (2013; genus accepted), Verma and Rai (2014; morphology, new species), Braun et al. (2014b; morphology and typification), neotype S-F37683, epitype MUMH11476, duplicate: CBS H-21733; ex-epitype cultures: MUCC1716, CBS 138247.

Distolomyces Thaxt. 1931, Laboulbeniaceae, Laboulbeniales, Laboulbeniomycetes, two species, type: D. fijianus Thaxt., asexual morph unknown, parasites, terrestrial, Asia, Europe, see Lumbsch and Huhndorf (2010; outline), Kirk et al. (2013; genus accepted), cultures and sequences are unavailable.

Distopyrenis Aptroot 1991, Pyrenulaceae, Pyrenulales, Eurotiomycetes, eight species, type: D. americana Aptroot, lichenized, terrestrial, tropical, see Lumbsch and Huhndorf (2010; outline), Kirk et al. (2013; genus accepted), Lücking et al. (2016b; classification), sequences unavailable.

Distorimula F. San Martín, P. Lavínn \& Esqueda 1999, Amphisphaeriaceae, Xylariales, Sordariomycetes, two species, type: D. mexicana F. San Martín, P. Lavín \& Esqueda, asexual morph unknown, saprobes, terrestrial, Mexico, see Lumbsch and Huhndorf (2010; outline), Kirk et al. (2013; genus accepted), Maharachchikumbura et al. (2015, 2016; outline), holotype: FSM, Esqueda 3693, cultures and sequences are unavailable.

Distoseptispora K.D. Hyde, McKenzie \& Maharachch. 2016, Distoseptisporaceae, Diaportheomycetidae, Sordariomycetes, six species, type: D. fluminicola McKenzie, H.Y. Su, Z.L. Luo \& K.D. Hyde, hyphomycetous, sexual morph unknown, saprobes, aquatic, China, Thailand, see Hyde et al. (2016; new species), Doilom et al. (2016; species on Tectonia), Su et al. (2016a; taxonomy, phylogeny), Wijayawardene et al. (2017; outline), holotype and extype: HKAS84006, MFLUCC 15-0417.

Distothelia Aptroot 2005, Trypetheliaceae, Trypetheliales, Dothideomycetes, three species; type: D. isthmospora Aptroot, lichenized, see Lumbsch and Huhndorf (2010; outline), Aptroot and Lücking (2016; taxonomy), Lücking et al. (2016b; classification), sequences are unavailable.

Ditopella De Not. 1863, Gnomoniaceae, Diaporthales, Sordariomycetes, two species, type: D. fusispora De Not., asexual morph unknown, saprobes, terrestrial, Europe, see Mejía et al. (2008, 2011; DNA, phylogeny), Sogonov et al. (2008; DNA, phylogeny), Lumbsch and Huhndorf (2010; outline), Kirk et al. (2013; genus accepted), Maharachchikumbura et al. (2015, 2016; outline), cultures and sequences are available for $D$. ditopa.

Ditopellina J. Reid \& C. Booth 1967, Valsaceae, Diaporthales, Sordariomycetes, one species, type: D. saccardoana (Traverso \& Spessa) J. Reid \& C. Booth, asexual morph unknown, saprobes, terrestrial, Europe, see Lumbsch and Huhndorf (2010; outline), Kirk et al. (2013; genus accepted), Maharachchikumbura et al. (2015, 2016; outline), cultures and sequences are unavailable.

Ditopellopsis J. Reid \& C. Booth 1967, Gnomoniaceae, Diaporthales, Sordariomycetes, four species, type: D. clethrae J. Reid \& C. Booth, asexual morph unknown, saprobes, terrestrial, North America, see Mejía et al. (2008, 2011; DNA, phylogeny), Sogonov et al. (2008; DNA, transferred Ditopellopsis racemula (Cooke \& Peck) M.E. Barr to Gnomoniopsis), Lumbsch and Huhndorf (2010; outline), Kirk et al. (2013; genus accepted), Maharachchikumbura et al. (2015, 2016; outline), cultures and sequences are available for unidentified Ditopellopsis sp.

Diutina Khunnamwong, Lertwattanasakul, Jindamorakot, Limtong \& Lachance 2015, Saccharomycetales genera incertae sedis, Saccharomycetes, eight species, type: D. rugosa (Anderson) Khunnamwong, Jindamorakot, Limtong \& Lachance, asexual reproduction by multilateral and pseudohyphae are produced, sexual reproduction unknown, saprophytic, but 
some species are common clinical isolates, rice leaf, bee, soil, soybean factory, clinical, worldwide, see Khunnamwong et al. (2015; taxonomy), sequences are available.

Diversimorbus S.F. Chen \& Jol. Roux 2013, Cryphonectriaceae, Diaporthales, Sordariomycetes, one species, type: D. metrosideri S.F. Chen bis \& Jol. Roux, with coelomycetous asexual morph, saprobes, terrestrial, South Africa, have sequence data, see Chen et al. (2013b; morphology, phylogeny), Maharachchikumbura et al. (2015; outline), holotype and ex-type: PREM 60741, CMW37322.

Divinia Cif. 1955, Ascomycota genera incertae sedis, one species, type: D. diatricha Cif., hyphomycetous, sexual morph unknown, saprobes, terrestrial, Dominican Republic, see Seifert et al. (2011; morphology), Kirk et al. (2013; genus accepted), cultures and sequences are unavailable, needs generic revision.

Dixomyces I.I. Tav. 1985, Laboulbeniaceae, Laboulbeniales, Laboulbeniomycetes, two species, type: D. perpendicularis (Thaxt.) I.I. Tav., asexual morph unknown, parasites, terrestrial, worldwide, see Lumbsch and Huhndorf (2010; outline), Kirk et al. (2013; genus accepted), cultures and sequences are unavailable.

Dolabra C. Booth \& W.P. Ting 1964, Chaetothyriomycetidae genera incertae sedis, Eurotiomycetes, one species, type: D. nepheliae C. Booth \& W.P. Ting, asexual morph coelomycetous (fide Rossman et al. 2010), saprobes, pathogens, terrestrial, Malaysia, see Lumbsch and Huhndorf (2010; outline, as Dothideomycetes, genera incertae sedis), Rossman et al. (2010, 2012; Eurotiomycetes genera incertae sedis, DNA, phylogeny, asexual morph), Kirk et al. (2013; genus accepted), Thambugala et al. (2014b; taxonomy), cultures and sequences are available.

Dolichocarpus R. Sant. 1949, Roccellaceae, Arthoniales, Arthoniomycetes, two species, type: D. chilensis R. Sant., asexual morph unknown, lichenized, saxicolous and epiphytic, Chile and Saint Helena, see Aptroot (2008; taxonomy), Ertz and Tehler (2011; phylogenetic position), Lumbsch and Huhndorf (2010; outline), Kirk et al. (2013; genus accepted), Lücking et al. (2016b; classification), sequences are available.

Doliomyces Steyaert 1961, Bartaliniaceae, Xylariales, Sordariomycetes, two species, type: D. senegalensis (Speg.) Steyaert, sexual morph unknown, saprobes, terrestrial, India, South America, see Kirk et al. (2013; genus accepted), Maharachchikumbura et al. (2015, 2016; outline, accepted as in Amphisphaeriaceae), Wijayawardene et al. (2016b; placed in Bartaliniaceae based on morphology), cultures and sequences are unavailable.

Domingoella Petr. \& Cif. 1932, Ascomycota genera incertae sedis, four species, type: D. asterinarum Petr. \& Cif., hyphomycetous, sexual morph unknown, on fungi, terrestrial, Pantropical, Australasia, Europe, see Seifert et al. (2011; morphology), Wijayawardene et al. (2012, 2017; outline), Kirk et al. (2013; genus accepted), cultures and sequences are unavailable, needs generic revision.

Donadinia Bellem. \& Mel.-Howell 1990, Sarcosomataceae, Pezizales, Pezizomycetes, four species, type: D. helvelloides (Donadini, Berthet \& Astier) Bellem. \& Mel.-Howell, sexual morph unknown, saprobes, terrestrial, Europe, Asia, see Lumbsch and Huhndorf (2010; outline), Carbone et al. (2013, 2014; new species; DNA), Kirk et al. (2013; genus accepted), cultures and sequences are available.

Doratomyces Corda 1829, Microascaceae, Microascales, Sordariomycetes, two species, type: D. neesii Corda, sexual morph unknown, saprobes, terrestrial, worldwide, see Kirk et al. (2013; genus accepted), Maharachchikumbura et al. (2015, 2016; outline, phylogeny), Sandoval-Denis et al. (2016b; phylogeny), cultures and sequences are available.

Dothichiza Lib. ex Roum. 1880, Dothideomycetes genera incertae sedis, 15 species, type: $D$. populea Sacc. \& Briard, sexual morph unknown, saprobes, terrestrial, worldwide, see Zalar et al. (2008; DNA, phylogeny), Wijayawardene et al. (2012, 2014c; outline, accepted as Dothioraceae, and Dothideomycetes, genera incertae sedis respectively), Kirk et al. (2013; 
genus accepted), Gonzalez-Menendez et al. (2016; DNA), Hyde et al. (2013) and Thambugala et al. (2014a) excluded from Dothioraceae, cultures and sequences are available. Dothidasteroma Höhn. 1909, Parmulariaceae, Dothideomycetes families incertae sedis, five species, type: D. pterygotae (Berk. \& Broome) Höhn., asexual morph unknown, epiphytes, terrestrial, worldwide, see Hofmann (2009; review, accepted as a genus in Parmulariaceae), Lumbsch and Huhndorf (2010; outline, accepted as a genus in Parmulariaceae), Hyde et al. (2013; review, keys, excluded from Parmulariaceae), Wijayawardene et al. (2014c; outline, accepted as a genus in Parmulariaceae), placement in Parmulariaceae supported by morphology, cultures and sequences are unavailable.

Dothidasteromella Höhn. 1910, Dothideomycetes genera incertae sedis, one species, type: D. sepulta (Berk. \& M.A. Curtis) Höhn., asexual morph unknown, saprobes, terrestrial, worldwide, see Lumbsch and Huhndorf (2010; outline, accepted as a genus in Asterinaceae), Hyde et al. (2013) did not accept as a genus in Asterinaceae, Kirk et al. (2013; genus accepted), Wijayawardene et al. (2014c; outline, accepted as a genus in Dothideomycetes, genera incertae sedis), cultures and sequences are unavailable, needs generic revision.

Dothidea Fr. 1818, Dothideaceae, Dothideales, Dothideomycetes, around 500 spp. (the actual number of species could be less than 100), type: D. sambuci (Pers.) Fr., asexual morph unknown, saprobes, terrestrial, aquatic, worldwide, see Lumbsch and Huhndorf (2010; outline), Hyde et al. (2013; morphology), Kirk et al. (2013; genus accepted), Thambugala et al. (2014a; morphology, phylogeny), Wijayawardene et al. (2014c; outline), ex-type strains of type: DAOM 231303, epitype of type: GZU 78-2002.

Dothidella Speg. 1880, Polystomellaceae, Dothideomycetes families incertae sedis, two species, type: D. australis Speg., sexual morph unknown, saprobes, terrestrial, tropical, see Lumbsch and Huhndorf (2010; outline), Hyde et al. (2013; outline), Kirk et al. (2013; genus accepted), cultures and sequences are available.

Dothideodiplodia Murashk. 1927, Ascomycota genera incertae sedis, one species, type: D. agropyri Murashk., coelomycetous, sexual morph unknown, saprobes, terrestrial, USSR, see Wijayawardene et al. (2012, 2017; outline, morphology), Kirk et al. (2013; genus accepted), cultures and sequences are unavailable, needs generic revision.

Dothideopsella Höhn. 1915, Dothideomycetes genera incertae sedis, one species, type: D. agminalis (Sacc. \& Morthier) Höhn., asexual morph unknown, saprobes, terrestrial, see Kirk et al. (2008; treated as a synonym of Leptosphaeria), Lumbsch and Huhndorf (2010; outline), Kirk et al. (2013; did not list), Wijayawardene et al. (2014c; outline), sequences are unavailable, needs generic revision.

Dothidotthia Höhn. 1918, Dothidotthiaceae, Pleosporales, Dothideomycetes, c. ten species, type: D. symphoricarpi (Rehm) Höhn., asexual morph unknown, saprobes, terrestrial, temperate, see Phillips et al. (2008; DNA, phylogeny), Lumbsch and Huhndorf (2010; outline), Hyde et al. (2013; outline, phylogeny), Kirk et al. (2013; genus accepted), Wijayawardene et al. (2014c; outline, phylogeny), epitype and ex-epitype: BPI 871823, CPC $12929=$ CBS 119687.

Dothiopeltis E. Müll. 1957, Leptopeltidaceae, Dothideomycetes families incertae sedis, cf. one species, type: D. arunci E. Müll., asexual morph idriella-like, saprobes, terrestrial, Switzerland, see Lumbsch and Huhndorf (2010; outline), Hyde et al. (2013; accepted as a genus in Leptopeltidaceae), Kirk et al. (2013; genus accepted), Wijayawardene et al. (2014c; outline), cultures and sequences are unavailable, needs generic revision.

Dothiora Fr. 1849, Dothideaceae, Dothideales, Dothideomycetes, more than 50 species, type: D. pyrenophora (Fr.) Fr., asexual morph coelomycetous, hormonema-like synasexual morph, dothichiza or hormonema-like, saprobes or pathogens, terrestrial, worldwide, see Lumbsch and Huhndorf (2010; outline, accepted as a genus in Dothioraceae), Hyde et al. (2013; 
accepted as a genus in Dothioraceae), Kirk et al. (2013; genus accepted), Thambugala et al. (2014a), cultures and sequences are available.

Dothiorella Sacc. 1880, Botryosphaeriaceae, Botryosphaeriales, Dothideomycetes, 24 species, type: D. pyrenophora Sacc., holomorph, asexual morph coelomycetous, endophytes, pathogens, saprobes, associated with wide range of woody hosts, worldwide distribution, See Phillips et al. (2008, 2013; morphology, phylogeny), Liu et al. (2012, phylogeny), Dissanayake et al. (2016, morphology, phylogeny), Crous et al. (2016b; new species, phylogeny), Wijayawardene et al. (2016b; morphology, phylogeny), holotype and culture exepitype: IMI 63581b, CBS 115038,

Dothioropsis Riedl 1974, Ascomycota genera incertae sedis, one species, type: D. corni Riedl, coelomycetous, sexual morph unknown, saprobes, terrestrial, Europe, see Wijayawardene et al. (2012, 2017; outline), Kirk et al. (2013; genus accepted), cultures and sequences are unavailable, needs generic revision.

Dothistroma Hulbary 1941, Mycosphaerellaceae, Capnodiales, Dothideomycetes, two species, type: D. pini Hulbary, coelomycetous, sexual morph mycoshaerella-like, plant pathogenic, see Wijayawardene et al. (2012, 2017; outline), Kirk et al. (2013; genus accepted), Barnes et al. (2014; neotypification of Dothistroma septosporum and epitypification of $D$. pini), Braun et al. (2014b; morphology and typification), epitype and exepitype: CBS H-12211, CMW 10951 = CBS 116487.

Dothivalsaria Petr. 1966, Dothideomycetes genera incertae sedis, one species, type: $D$. megalospora (Auersw.) Petr., asexual morph unknown, saprobes, terrestrial, Europe, see Lumbsch and Huhndorf (2010; outline, accepted as genus in Massariaceae), Hyde et al. (2013; did not include as a genus in Massariaceae), Kirk et al. (2013; genus accepted), Wijayawardene et al. (2014c; accepted as Dothideomycetes, genera incertae sedis), cultures and sequences are available.

Drechmeria W. Gams \& H.-B. Jansson 1985 (= Haptocillium W. Gams \& Zare fide Maharachchikumbura et al. 2015), Ophiocordycipitaceae, Hypocreales, Sordariomycetes, two species, type: D. coniospora (Drechsler) W. Gams \& H.-B. Jansson, sexual morph unknown, parasitic, terrestrial, worldwide, see Kirk et al. (2013; genus accepted), Maharachchikumbura et al. (2015, 2016; outline, phylogeny), Spatafora et al. (2015; new species), Zhang et al. (2016c; endoparasites of nematodes, DNA), cultures and sequences are available.

Drechslerella Subram. 1964, Orbiliaceae, Orbiliales, Orbiliomycetes, two species, type: D. acrochaeta (Drechsler) Subram., sexual morph unknown, parasitic, terrestrial, worldwide, see Castillo et al. (2010; biocontrol), Kirk et al. (2013; genus accepted), Liu et al. (2014c; genomic studies), cultures and sequences are available.

Drepanomyces Thaxt. 1931, Ceratomycetaceae, Laboulbeniales, Laboulbeniomycetes, one species, type: D. malayanus Thaxt., asexual morph unknown, parasitic, terrestrial, Sumatra, see Lumbsch and Huhndorf (2010; outline), Kirk et al. (2013; genus accepted), cultures and sequences are unavailable.

Drepanopeziza (Kleb.) Höhn. 1917 (= Gloeosporium Desm. \& Mont. 1849; = Gloeosporidiella Petr. 1921 fide Rossman et al. 2016a), Drepanopezizaceae, Helotiales, Leotiomycetes, five species, type: D. ribis (Rehm ex Kleb.) Höhn., asexual morph unknown, saprobes, terrestrial, temperate, see Lumbsch and Huhndorf (2010; outline), Kirk et al. (2013; genus accepted), Rossman et al. (2016a; nomenclature), cultures and sequences are unavailable, needs generic revision.

Drudeola Kuntze 1891, Ascomycota genera incertae sedis, one species, type: D. sarraceniae (Peck \& Cooke) Kuntze, coelomycetous, sexual morph unknown, saprobes, terrestrial, USA, see Wijayawardene et al. (2012, 2017; outline), Kirk et al. (2013; genus accepted), cultures and sequences are unavailable, needs generic revision. 
Drumopama Subram. 1957, Ascomycota genera incertae sedis, one species, type: D. girisa Subram., hyphomycetous, sexual morph unknown, saprobes, terrestrial, India, Cuba, see Wijayawardene et al. (2012, 2017; outline), Kirk et al. (2013; genus accepted), cultures and sequences are unavailable, needs generic revision.

Dryosphaera Jørgen Koch \& E.B.G. Jones 1989, Ascomycota genera incertae sedis, three species, type: D. navigans Jørg. Koch \& E.B.G. Jones asexual morph unknown, on wood associated with sand, marine, temperate and tropical, see Lumbsch and Huhndorf (2010; outline), Kirk et al. (2013; genus accepted), Jones et al. (2015; outline), cultures and sequences are unavailable.

Dualomyces Matsush. 1987, Ascomycota genera incertae sedis, two species, type: $D$. asterinarum Petr. \& Cif., hyphomycetous, sexual morph unknown, saprobes, terrestrial, Asia, see Seifert et al. (2011; morphology), Wijayawardene et al. (2012, 2017; outline), Kirk et al. (2013; genus accepted), cultures and sequences are unavailable, needs generic revision.

Dubitatio Speg. 1882, Dothideomycetes genera incertae sedis, one species, type: $D$. dubitationum Speg., asexual morph coelomycetous, saprobes, terrestrial, South America, see Lumbsch and Huhndorf (2010; outline, accepted as a genus in Massariaceae), Hyde et al. (2013) excluded from Massariaceae, Kirk et al. (2013; genus accepted), Wijayawardene et al. (2014c; outline), cultures and sequences are unavailable, needs generic revision.

Dubujiana D.R. Reynolds \& G.S. Gilbert 2005, Dothideomycetes genera incertae sedis, one species, type: D. glandulifera D.R. Reynolds \& G.S. Gilbert, asexual morph coelomycetous, saprobes, terrestrial, Australia, see Wijayawardene et al. (2014c; outline), cultures and sequences are unavailable, needs generic revision.

Duebenia Fr. 1849, Calloriaceae, Helotiales, Leotiomycetes, five species, type: D. rufa Fr., asexual morph unknown, saprobes, terrestrial, temperate, see Lumbsch and Huhndorf (2010; outline), Kirk et al. (2013; genus accepted), cultures and sequences are unavailable, needs generic revision.

Dufourea Ach. 1809, Teloschistaceae, Teloschistales, Lecanoromycetes, 23 species, type: D. flammea (L. f.) Ach., lichenized, see Arup et al. (2013; taxonomy), Kondratyuk et al. (2014b; taxonomy), Lücking et al. (2016b; classification), sequences are available.

Dumontinia L.M. Kohn 1979, Sclerotiniaceae, Helotiales, Leotiomycetes, five species, type: D. tuberosa (Bull.) L.M. Kohn, asexual morph unknown, saprobes, terrestrial, temperate, see Lumbsch and Huhndorf (2010; outline), Kirk et al. (2013; genus accepted), Pärtel et al. (2017; DNA, phylogeny), cultures and sequences are available.

Duosporium K.S. Thind \& Rawla 1961, Ascomycota genera incertae sedis, one species, type: D. cyperi K.S. Thind \& Rawla, hyphomycetous, sexual morph unknown, saprobes, terrestrial, India, China, see Seifert et al. (2011; morphology), Kirk et al. (2013; genus accepted), cultures and sequences are unavailable, needs generic revision.

Duplicaria Fuckel 1870, Rhytismataceae, Rhytismatales, Leotiomycetes, one species, type: D. empetri (Pers.) Fuckel, asexual morph unknown, saprobes, terrestrial, worldwide, see Lumbsch and Huhndorf (2010; outline), Zou et al. (2011; DNA, phylogeny), Kirk et al. (2013; genus accepted), cultures and sequences are available but type lacks DNA.

Duplicariella B. Erikss. 1970, Rhytismataceae, Rhytismatales, Leotiomycetes, one species, type: D. phyllodoces B. Erikss., asexual morph unknown, saprobes, terrestrial, worldwide, see Lumbsch and Huhndorf (2010; outline), Lantz et al. (2011; DNA, phylogeny), Kirk et al. (2013; genus accepted), cultures and sequences are available.

Duradens Samuels \& Rogerson 1990, Sordariomycetes genera incertae sedis, one species type: D. lignicola Samuels \& Rogerson, asexual morph unknown, saprobes, terrestrial, temperate, see Lumbsch and Huhndorf (2010; outline, accepted as a genus in Clypeosphaeriaceae), Kirk et al. (2013; genus accepted), Maharachchikumbura et al. (2015, 
2016; outline, excluded from Clypeosphaeriaceae and placed in Sordariomycetes, genera incertae sedis), cultures and sequences are unavailable, needs generic revision.

Durandiella Seaver 1932, Tympanidaceae, Phacidiales, Leotiomycetes, ten species, type: D. fraxini (Schwein.) Seaver, asexual morph unknown, saprobes, terrestrial, worldwide, see Lumbsch and Huhndorf (2010; outline), Kirk et al. (2013; genus accepted), cultures and sequences are unavailable.

Durispora K.D. Hyde 1994, Valsaceae, Diaporthales, Sordariomycetes, two species, type: D. elaeidicola K.D. Hyde, asexual morph unknown, saprobes, terrestrial, Malaysia, Hong Kong, see Lumbsch and Huhndorf (2010; outline), Kirk et al. (2013; genus accepted), Maharachchikumbura et al. (2015, 2016; outline), cultures and sequences are unavailable, needs generic revision.

Durotheca Læssøe, Srikitik., Luangsa-ard \& M. Stadler 2013, Xylariales genera incertae sedis, Sordariomycetes, four species, type: D. depressa Læssøe \& Srikitikulchai, asexual morph nodulisporium-like, saprobes, terrestrial, Thailand, see Læssøe et al. (2013; morphology, DNA, phylogeny), Maharachchikumbura et al. (2015, 2016; outline), Li et al. (2016a; new species, DNA), holotype and ex-type: BBH 18222, BBC 23016.

Dussiella Pat. 1890, Clavicipitaceae, Hypocreales, Sordariomycetes, one species, type: D. tuberiformis (Berk. \& Ravenel) Pat., asexual morph unknown, saprobes, terrestrial, USA, see Lumbsch and Huhndorf (2010; outline), Kirk et al. (2013; genus accepted), Maharachchikumbura et al. (2015, 2016; outline), cultures and sequences are available, needs generic revision.

Dwayaangam Subram. 1978, Orbiliaceae, Orbiliales, Orbiliomycetes, seven species, type: D. quadridens (Drechsler) Subram., sexual morph unknown, saprobes, terrestrial, USA, see Seifert et al. (2011; morphology), Wijayawardene et al. (2012, 2017; outline), Kirk et al. (2013; genus accepted), cultures and sequences are available, needs generic revision.

Dwayabeeja Subram. 1958, Ascomycota genera incertae sedis, three species, type: D. sundara Subram., hyphomycetous, sexual morph unknown, saprobes, terrestrial, Africa, Asia, Caribbean, see Seifert et al. (2011; morphology), Wijayawardene et al. (2012, 2017; outline), Kirk et al. (2013; genus accepted), cultures and sequences are unavailable, needs generic revision.

Dwayaloma Subram. 1957, Ascomycota genera incertae sedis, two species, type: D. trina Subram., hyphomycetous, sexual morph unknown, saprobes, terrestrial, Asia, see Seifert et al. (2011; morphology), Wijayawardene et al. (2012, 2017; outline), Kirk et al. (2013; genus accepted), cultures and sequences are unavailable, needs generic revision.

Dwayalomella Brisson, Piroz. \& Pauzé 1975, Ascomycota genera incertae sedis, one species, type: D. vaccinii Brisson, Piroz. \& Pauzé, hyphomycetous, sexual morph unknown, saprobes, terrestrial, North America, see Wijayawardene et al. (2012, 2017; outline), Kirk et al. (2013; genus accepted), cultures and sequences are unavailable, needs generic revision.

Dwibahubeeja N. Srivast., A.K. Srivast. \& Kamal 1995, Ascomycota genera incertae sedis, one species, type: D. indica N. Srivast., A.K. Srivast. \& Kamal, hyphomycetous, sexual morph unknown, saprobes, terrestrial, Asia, see Seifert et al. (2011; morphology), Wijayawardene et al. (2012, 2017; outline), Kirk et al. (2013; genus accepted), cultures and sequences are unavailable, needs generic revision.

Dwibeeja Subram. 1995, Ascomycota genera incertae sedis, one species, type: D. sundara Subram., hyphomycetous, sexual morph unknown, saprobes, terrestrial, Asia, see Seifert et al. (2011; morphology), Wijayawardene et al. (2012, 2017; outline), Kirk et al. (2013; genus accepted), cultures and sequences are unavailable, needs generic revision.

Dwiroopa Subram. \& Muthumary 1986, Diaporthales genera incertae sedis, Sordariomycetes, one species, type: D. ramya Subram. \& Muthumary, coelomycetous, sexual morph unknown, saprobes, terrestrial, Asia, see Wijayawardene et al. (2012, 2016b, 2017; outline, taxonomy), 
Kirk et al. (2013; genus accepted), Maharachchikumbura et al. (2015, 2016; outline), cultures and sequences are unavailable, needs generic revision.

Dwiroopella Subram. \& Muthumary 1986, Ascomycota genera incertae sedis, one species, type: D. sundara Subram. \& Muthumary, coelomycetous, sexual morph unknown, saprobes, terrestrial, Asia, see Wijayawardene et al. (2012, 2017; outline), Kirk et al. (2013; genus accepted), cultures and sequences are unavailable, needs generic revision.

Dyfrolomyces K.D. Hyde, K.L. Pang, Alias, Suetrong \& E.B.G. Jones 2013, Dyfrolomycetaceae, Dyfrolomycetales, Dothideomycetes, four species, type: D. tiomanensis K.L. Pang, S.A. Alias, K.D. Hyde, Suetrong \& E.B.G. Jones, asexual morph unknown, saprobes, on wood in aquatic or terrestrial environments, worldwide, see Hyde et al (2013; phylogeny, morphology, outline), Pang et al. (2013a; phylogeny, morphology), Shearer et al. (2014; review), Wijayawardene et al. (2014c; outline), Jones et al. (2015; classification, marine), holotype: MFLU 13-00063.

Dyplolabia A. Massal. 1854, Graphidaceae, Ostropales, Lecanoromycetes, four species, type: D. afzelii (Ach.) A. Massal., asexual morph unknown, lichenized, terrestrial, tropical, see Rivas Plata et al. (2012a; taxonomy), Lumbsch and Huhndorf (2010; outline), Kirk et al. (2013; genus accepted), Kalb et al. (2016; taxonomy), Lücking et al. (2016b; classification), sequences are available.

Dyrithiopsis L. Cai, Jeewon \& K.D. Hyde 2003 (= Monochaetiopsis L. cai et al. 2003 fide Maharachchikumbura et al. 2015; Réblová et al. 2016c), Bartaliniaceae, Xylariales, Sordariomycetes, one species, type: D. lakefuxianensis L. Cai, Jeewon \& K.D. Hyde, asexual morph formerly known in Monochaetiopsis, saprobes, terrestrial, China, see Lumbsch and Huhndorf (2010; outline), Kirk et al. (2013; genus accepted), Maharachchikumbura et al. (2015, 2016; outline, accepted as a genus in Bartaliniaceae), Réblová et al. (2016c; nomenclature), Wijayawardene et al. (2012, 2017; outline), holotype: HKU (M) 8280, cultures and sequences are available.

Dyrithium M.E. Barr 1994, Amphisphaeriaceae, Xylariales, Sordariomycetes, one species, type: D. lividum (Fr.) M.E. Barr, asexual morph unknown, saprobes, terrestrial, North America, see Lumbsch and Huhndorf (2010; outline), Kirk et al. (2013; genus accepted), Maharachchikumbura et al. (2015, 2016; outline), cultures and sequences are available.

Dysrhynchis Clem. 1909, Perisporiopsidaceae, Dothideomycetes families incertae sedis, Dothideomycetes, seven species, type: D. pulchella (Sacc.) Clem., asexual morph unknown, saprobes, terrestrial, worldwide, see Lumbsch and Huhndorf (2010; outline, accepted as a genus in Perisporiopsidaceae), Hyde et al. (2013; accepted as a genus in Perisporiopsidaceae), Kirk et al. (2013; genus accepted), Wijayawardene et al. (2014c; outline), cultures and sequences are available.

Ebollia Minter \& Caine 1980, Ascomycota genera incertae sedis, one species, type: E. valdiviensis (Speg.) Minter \& Caine, coelomycetous, sexual morph unknown, saprobes, terrestrial, Chile, see Wijayawardene et al. (2012, 2017; outline), Kirk et al. (2013; genus accepted), cultures and sequences are unavailable, needs generic revision.

Ebullia K.L. Pang 2015, Halosphaeriaceae, Microascales, Sordariomycetes, one species, type: E. octonae (Kohlm.) K.L. Pang, asexual morph unknown, saprobes, marine, Brunei, Hawaiian Islands, India, Taiwan, sequence data available, see Chu et al. (2015), Maharachchikumbura et al. (2016; outline), holotype: J.K. 4474a = 01271926, NYBG.

Echidnocymbium Brusse 1987, Ramalinaceae, Lecanorales, Lecanoromycetes, one species, type: E. speciosum Brusse, asexual morph coelomycetous, lichenized, saxicolous, South Africa, see Lumbsch and Huhndorf (2010; outline), Lücking et al. (2016b; classification), cultures and sequences are unavailable, needs generic revision.

Echidnodella Theiss. \& Syd. 1918, Asterinaceae, Asterinales, Dothideomycetes, 34 species, type: E. linearis (Syd. \& P. Syd.) Syd., asexual morph unknown. Epiphytes, terrestrial, 
worldwide, no molecular data, see Hofmann (2009; review), Lumbsch and Huhndorf (2010; outline), Hyde et al. (2013; review, keys), Hongsanan et al. (2014c; taxonomy), Wijayawardene et al. (2014c; outline), placement in Asterinaceae supported by morphology, cultures and sequences are unavailable, needs generic revision.

Echidnodes Theiss. \& Syd. 1918, Asterinaceae, Asterinales, Dothideomycetes, c. 17 species, type: E. liturae (Cooke) Theiss. \& Syd., asexual morph unknown, saprobes, terrestrial, widespread, see Lumbsch and hunduf (2010; outline), Kirk et al. (2013; genus accepted), Hyde et al. (2013; accepted as a genus in Echidnodes), Hongsanan et al. (2014c; phylogeny), cultures and sequences are unavailable for type species, needs generic revision.

Echinoascotheca Matsush. 1995, Phaeotrichaceae, Phaeotrichales, Dothideomycetes, one species, type: E. duplooformis Matsush., asexual morph unknown, saprobes, terrestrial, Pakistan, see Lumbsch and Huhndorf (2010; outline), Zhang et al. (2012e; accepted as genus in Phaeotrichaceae), Hyde et al. (2013; accepted as genus in Phaeotrichaceae), Kirk et al. (2013; genus accepted), Wijayawardene et al. (2014c; outline), cultures and sequences are available.

Echinobotryum Corda 1831, Microascaceae, Microascales, Sordariomycetes, one species, type: E. atrum Corda, hyphomycetous, sexual morph unknown, saprobes, terrestrial, worldwide, see Seifert et al. (2011; morphology), Wijayawardene et al. (2012, 2017; outline), Kirk et al. (2013; genus accepted), Maharachchikumbura et al. (2015, 2016; outline), cultures and sequences are unavailable.

Echinocatena R. Campb. \& B. Sutton 1977, Ascomycota genera incertae sedis, one species, type: E. arthrinioides R. Campb. \& B. Sutton, hyphomycetous, sexual morph unknown, saprobes, terrestrial, India, see Seifert et al. (2011; morphology), Wijayawardene et al. (2012, 2017; outline), Kirk et al. (2013; genus accepted), holotype: IMI 199279, cultures and sequences are unavailable, genus need revision.

Echinochondrium Samson \& Aa 1975, Ascomycota genera incertae sedis, one species, type: E. pulchrum Samson \& Aa, hyphomycetous, sexual morph unknown, saprobes, terrestrial, Asia, see Seifert et al. (2011; morphology), Wijayawardene et al. (2012, 2017; outline), Kirk et al. (2013; genus accepted), cultures and sequences are unavailable, needs generic revision.

Echinoconidiophorum Pereira-Carv. \& Dianese 2009, Ascomycota genera incertae sedis, one species, type: E. cerradense Pereira-Carv. \& Dianese, hyphomycetous, sexual morph unknown, saprobes, terrestrial, South America, see Seifert et al. (2011; morphology), Wijayawardene et al. (2012, 2017; outline), cultures and sequences are unavailable, needs generic revision.

Echinodiscus Etayo \& Diederich 2000, Helotiales genera incertae sedis, Leotiomycetes, two species, type: E. lesdainii (Vouaux) Etayo \& Diederich, asexual morph unknown, lichenicolous, non-lichenized, Eurasia, see Zhurbenko (2009; morphology, new species), Lumbsch and Huhndorf (2010; outline), cultures and sequences are unavailable but lacks for th type species.

Echinomyces Rappaz 1987, Diatrypaceae, Xylariales, Sordariomycetes, two species, type: E. obesa (Syd.) Rappaz, asexual morph unknown, saprobes, terrestrial, worldwide, see Lumbsch and Huhndorf (2010; outline), Kirk et al. (2013; genus accepted), Maharachchikumbura et al. (2015, 2016; outline), cultures and sequences are unavailable.

Echinoplaca Fée 1825, Gomphillaceae, Ostropales, Lecanoromycetes, c. 40 species, type: E. epiphylla Fée, asexual morph unknown, lichenized, widespread (tropical), foliicolous (but a few species are corticolous), see Lumbsch and Huhndorf (2010; outline), Kirk et al. (2013; genus accepted), Lücking et al. (2016b; classification), sequences are available.

Echinosphaeria A.N. Mill. \& Huhndorf 2004, Helminthosphaeriaceae, Sordariomycetidae, families incertae sedis, Sordariomycetes, seven species, type: E. canescens (Pers.) A.N. Mill. \& Huhndorf, asexual morph unknown, saprobes, terrestrial, worldwide, see Bell and 
Mahoney (2008, 2016; new species), Declercq (2009; new species), Dhargalkar and Bhat (2009; new species), Bell (2010; new species), Lumbsch and Huhndorf (2010; outline), Kirk et al. (2013; genus accepted), Miller et al. (2014; new species; DNA, phylogeny), Maharachchikumbura et al. (2015, 2016; outline), cultures and sequences are available for type: SMH4666, TL5730.

Echinula Graddon 1977, Hyaloscyphaceae, Helotiales, Leotiomycetes, one species, type: E. asteriadiformis Graddon, asexual morph unknown, saprobes, terrestrial, worldwide, see Lumbsch and Huhndorf (2010; outline), Kirk et al. (2013; genus accepted), cultures and sequences are unavailable, needs generic revision.

Echria (N. Lundq.) Kruys, Huhndorf \& A.N. Mill. 2015, Lasiosphaeriaceae, Sordariales Sordariomycetes, two species, type: E. macrotheca (P. Crouan \& H. Crouan) Kruys, Huhndorf \& A.N. Mill., saprobes, marine, USA, see Kruys et al. (2015; phylogeny), cultures and sequences are available.

Ecteinomyces Thaxt. 1903, Laboulbeniaceae, Laboulbeniales, Laboulbeniomycetes, one species, type: E. trichopterophilus Thaxt, asexual morph unknown, parasites, terrestrial, America, Europe, see Lumbsch and Huhndorf (2010; outline), Kirk et al. (2013; genus accepted), Haelewaters et al. (2014b; the Netherlands), cultures and sequences are unavailable.

Ectendomeliola Hosag. \& D.K. Agarwal 2006, Ascomycota genera incertae sedis, two species, type: E. walsurae Hosag. \& D.K. Agarwal, asexual morph produced from the hyphae, on living leaves, terrestrial, worldwide, see Hosagoudar and Archana (2010a; new species, India), Lumbsch and Huhndorf (2010; outline, accepted as a genus in Meliolaceae), Kirk et al. (2013; genus accepted), Hongsanan et al. (2015c; excluded from Meliolaceae), holotype: HCIO 45237, cultures and sequences are unavailable.

Edenia M.C. González, Anaya, Glenn, Saucedo \& Hanlin 2007, Phaeosphaeriaceae, Pleosporales, Dothideomycetes, two species, type: E. gomezpompae M.C. González, Anaya, Glenn, Saucedo \& Hanlin, asexual morph unknown, endophytes, human pathogens, terrestrial, Pakistan, Quintana Roo, see Crous et al. (2009a; DNA, phylogeny), Hyde et al. (2013; outline, accepted as a genus in Pleosporaceae), Cui et al. (2013; DNA, human pathogens), Sun et al. (2013; new species, endophytic), Wijayawardene et al. (2014c; outline, accepted as a genus in Pleosporaceae), Ariyawansa et al. (2015c; phylogeny, excluded from Pleosporaceae and placed in Phaeosphaeriaceae), Pili et al. (2015; endophytes, Kenya, DNA), Keilor Rojas-Jimenez et al. (2016; endophytes, DNA, Costa Rica), holotype: MEXU 25346, cultures and sequences are available.

Edrudia W. P. Jord. 1980, Lecanoraceae, Lecanorales, Lecanoromycetes, one species, type: E. constipans (Nyl.) W.P. Jord., asexual morph unknown, lichenized, saxicolous, California, see Lumbsch and Huhndorf (2010; outline), Kirk et al. (2013; genus accepted), Lücking et al. (2016b; classification), sequences are unavailable.

Edwardiella Henssen 1986, Lichinaceae, Lichinales, Lichinomycetes, one species, type: E. mirabilis Henssen, asexual morph unknown, lichenized, saxicolous, Marion Island, see Lumbsch and Huhndorf (2010; outline), Kirk et al. (2013; genus accepted), Lücking et al. (2016b; classification), sequences are unavailable.

Effetia Bartoli, Maggi \& Persiani 1984, Sordariaceae, Sordariales, Sordariomycetes, one species, type: E. craspedoconidica Bartoli, Maggi \& Persiani, asexual morph virgariella-like, from soil, terrestrial, Ivory Coast, see Lumbsch and Huhndorf (2010; outline), Kirk et al. (2013; genus accepted), Maharachchikumbura et al. (2015, 2016; outline), holotype: horto botanico Roma105S, cultures and sequences are unavailable.

Eiglera Hafellner 1984, Eigleraceae, Acarosporales, Lecanoromycetes, two species, type: E. flavida (Hepp) Hafellner, asexual morph unknown, lichenized, saxicolous, Europe, North America, see Lumbsch and Huhndorf (2010; accepted as a genus in Hymeneliaceae, 
Pertusariales), Kirk et al. (2013; genus accepted), Miądlikowska et al. (2014a; the phylogenetic placement of Eiglera outside of the Hymeneliaceae, sister to Acarosporaceae, needs to be confirmed, which would justify the reinstitution of the family Eigleraceae belonging to the Acarosporales), Lücking et al. (2016b; classification), sequences are available.

Eilifdahlia S. Y. Kondr., Kärnefelt, Elix, A. Thell et J.-S. Hur 2014, Teloschistaceae, Lecanorales, Lecanoromycetes, two species, type: E. dahlii (Elix, S.Y. Kondr. \& Kärnefelt) S.Y. Kondr., Kärnefelt, Elix, A. Thell, J. Kim, A.S. Kondr. \& Hur, asexual morph unknown, lichenized, epiphytic, Australia, South Africa, see Kondratyuk et al. (2014a; taxonomy), Lücking et al. (2016b; classification), sequences are available.

Eiona Kohlm. 1968, Ascomycota genera incertae sedis, asexual morph unknown, one species, type: E. tunicata Kohlm., on wood often associated with sand, temperate, no sequence data, see Lumbsch and Huhndorf (2010; outline), Kirk et al. (2013; genus accepted), Jones et al. (2015; outline, marine), cultures and sequences are unavailable, needs generic revision.

Elachopeltella Bat. \& Cavalc. 1964, Ascomycota genera incertae sedis, two species, type: E. sapindacearum Bat. \& Cavalc., coelomycetous, sexual morph unknown, saprobes, terrestrial, Brazil, see Wijayawardene et al. (2012, 2017; outline), Kirk et al. (2013; genus accepted), cultures and sequences are unavailable, needs generic revision.

Elaeodema Syd. 1922, Ascomycota genera incertae sedis, two species, type: E. cinnamomi Syd., coelomycetous, sexual morph unknown, saprobes, terrestrial, Brazil, see Sutton (1977; nomenclature), Wijayawardene et al. (2012, 2017; outline), Kirk et al. (2013; genus accepted), cultures and sequences are unavailable, needs generic revision.

Elaphomyces Nees 1820, Elaphomycetaceae, Elaphomycetales, Eurotiomycetes, apparently polyphyletic, c. 78 species, type: E. granulatus Fr., terrestrial, hypogeous, forming mycorrhizas with conifers and broad-leaved trees, cosmopolitan, see Zhang and Minter (2011; new species), Castellano et al. (2011, 2012a, 2012b, 2016; new species, phylogeny), Paz et al. (2012; new species), Buyck et al. (2016; phylogeny), cultures and sequences are available.

Elasticomyces Zucconi \& Selbmann 2008, Teratosphaeriaceae, Capnodiales, Dothideomycetes, one species, type: E. elasticus Zucconi \& Selbmann, hyphomycetous, sexual morph unknown, lichenicolous, terrestrial, Antarctica, see Selbmann et al. (2008; morphology, phylogeny), Quaedvlieg et al. (2014; phylogeny), Wijayawardene et al. (2012, 2014c, 2017; outline), holotype and ex-type: CBS H-20177, CBS 122538.

Elattopycnis Bat. \& Cavalc. 1964, Ascomycota genera incertae sedis, one species, type: E. protii Bat. \& Cavalc., coelomycetous, sexual morph unknown, saprobes, terrestrial, Brazil, see Wijayawardene et al. (2012, 2017; outline), Kirk et al. (2013; genus accepted), cultures and sequences are unavailable, needs generic revision.

Eleutherascus Arx 1971, Ascodesmidaceae, Pezizales, Pezizomycetes, four species, type: E. lectardii (Nicot) Arx, asexual morph unknown, saprobes, terrestrial, Europe, South America, see Lumbsch and Huhndorf (2010; outline), Kirk et al. (2013; genus accepted), cultures available for type: CBS 626.71.

Eleutheromycella Höhn. 1908, Helicogoniaceae, Phacidiales, Leotiomycetes, one species, type: E. mycophila Höhn., coelomycetous, sexual morph unknown, saprobes, terrestrial, Europe, see Wijayawardene et al. (2012, 2017; outline), Kirk et al. (2013; genus accepted), cultures and sequences are unavailable, needs generic revision.

Eleutheromyces Fuckel 1870, Helicogoniaceae, Phacidiales, Leotiomycetes, one species, type: E. subulatus (Tode) Fuckel, coelomycetous, sexual morph unknown, saprobes, terrestrial, temperate, see Wijayawardene et al. (2012, 2017; outline), Kirk et al. (2013; genus accepted), Crous et al. (2014a; DNA, phylogeny), epitype and ex-epitype: CBS H-12355, CBS113.86. 
Elixia Lumbsch 1997, Elixiaceae, Umbilicariales, Lecanoromycetes, two species; type: E. flexella (Ach.) Lumbsch, lichenized, see Lumbsch and Huhndorf (2010; outline), Bendiksby and Timdal (2013; taxonomy), Kirk et al. (2013; genus accepted), Miądlikowska et al. (2014a; taxonomy), Lücking et al. (2016b; classification), sequences are available, type specimen UPS-ACH-L-1286 (syntype).

Elletevera Deighton 1969, Ascomycota genera incertae sedis, one species, type: E. pulchrum Samson \& Aa, hyphomycetous, sexual morph unknown, saprobes, terrestrial, Asia, see Seifert et al. (2011; morphology), Wijayawardene et al. (2012, 2017; outline), Kirk et al. (2013; genus accepted), cultures and sequences are unavailable, needs generic revision.

Elliottinia L.M. Kohn 1979, Sclerotiniaceae, Helotiales, Leotiomycetes, one species, type: E. kerneri (Wettst.) L.M. Kohn, asexual morph unknown, saprobes, terrestrial, Europe, see Lumbsch and Huhndorf (2010; outline), Kirk et al. (2013; genus accepted), Pärtel et al. (2017; DNA, phylogeny), cultures available for the type: KL402, specimen voucher TU:104529.

Ellisembia Subram. 1992, Sordariomycetes genera incerte sedis, c. 61 species, type: E. coronata (Fuckel) Subram., sexual reported for E. adscendens (Berk.) Subram., saprobes, lichenicolous (e.g. E. lichenicola), terrestrial, aquatic, worldwide, see Ma et al. (2008, 2010b; new species), McKenzie (2010; new species), Seifert et al. (2011; phylogeny), Rajeshkumar et al. (2012; new species), Delgado (2013; new species), Rajeshkumar et al. (2013; new species), Ren et al. (2013c; new species), Xia et al. (2015b; new species), Santa Izabel et al. (2013; new combinations), cultures and sequences are available for few species (not from type material) but lacks for the type.

Ellisembiopsis T.S. Santa Izabel \& Gusmão 2013, Ascomycota genera incertae sedis, two species, type: E. brasiliensis T.S. Santa Izabel \& Gusmão, hyphomycetous, sexual morph unknown, saprobes, terrestrial, Brazil, China, see Santa Izabel et al. (2013; morphology), holotype of the type: HUEFS 155102, cultures and sequences are unavailable.

Elmerinula Syd. 1934, Dothideomycetes genera incertae sedis, one species, type: E. capnoides Syd., asexual morph unknown, saprobes, terrestrial, Phillipines, see Lumbsch and Huhndorf (2010; outline), Kirk et al. (2013; genus accepted), Wijayawardene et al. (2014c; outline), cultures and sequences are unavailable, needs generic revision.

Elongatopedicellata J.F. Zhang, J.K. Liu, K.D. Hyde \& Z.Y. Liu 2015, Roussoellaceae, Pleosporales, Dothideomycetes, one species, type: E. lignicola J.F. Zhang, J.K. Liu, K.D. Hyde \& Z.Y. Liu, asexual morph unknown, saprobes, terrestrial, Thailand, see Ariyawansa et al. (2015a; taxonomy, phylogeny), holotype and ex-type: MFLU 15-2717, MFLUCC 15-0642. Elotespora R.F. Castañeda \& Heredia 2010, Ascomycota genera incertae sedis, one species, type: E. mexicana R.F. Castaneda \& Heredia, hyphomycetous, sexual morph unknown, saprobes, terrestrial, Mexico, see Castañeda-Ruiz et al. (2010b; morphology), Seifert et al. (2011; morphology), Wijayawardene et al. (2012, 2017; outline), holotype: XAL CB883, cultures and sequences are unavailable, compare with Artocarpomyces, Colemaniella and Glomerobolus.

Elsino $\ddot{e}$ Racib. 1900 (= Sphaceloma de Bary 1874 fide Wijayawardene et al. 2014c; Rossman et al. 2015b), Elsinoaceae, Myriangiales, Dothideomycetes, c. 30 species (known by cultures), type: E. canavaliae Racib., asexual morph coelomycetous (Sphaceloma), pathogens, saprobes, terrestrial, Phillipines, see Lumbsch and Huhndorf (2010; outline), Chung (2011; pathogens), Hyde et al. (2013; taxonomy), Kirk et al. (2013; genus accepted), Wijayawardene et al. (2014c; outline, nomenclature), Rossman et al. (2015b, 2016a; nomenclature, new combinations), Crous et al. (2016a; new species, phylogeny), cultures and sequences are available.

Elytroderma Darker 1932, Rhytismataceae, Rhytismatales, Leotiomycetes, one species, type: E. deformans (Weir) Darker, asexual morph unknown, endophytes, saprobes, terrestrial, 
Europe, North America, see Lumbsch and Huhndorf (2010; outline), Kirk et al. (2013; genus accepted), sequences are available for unidentified species.

Emarcea Duong, Jeewon \& K.D. Hyde 2004, Xylariaceae, Xylariales, Sordariomycetes, three species, type: E. castanopsidicola Duong, Jeewon \& K.D. Hyde, asexual morph unknown, saprobes, terrestrial, Thailand, Taiwan, see Li et al. (2009b; new species, Taiwan), Lumbsch and Huhndorf (2010; outline), Kirk et al. (2013; genus accepted), Crous et al. (2015d; new species; DNA), Maharachchikumbura et al. (2015, 2016; outline), isotype: MRC DLA 008, HKUM 17498, CMU H224410, PDD 78748, ex-type: CBS and HKUCC 10344.

Emblemospora Jeng \& J.C. Krug 1976, Lasiosphaeriaceae, Sordariales, Sordariomycetes, one species, type: E. monotrema Jeng \& J.C. Krug, asexual morph unknown, from soil, terrestrial, Venezuela, see Lumbsch and Huhndorf (2010; outline), Kirk et al. (2013; genus accepted), Maharachchikumbura et al. (2015, 2016; outline), sequences are unavailable.

Embryonispora G.Z. Zhao 2014, Pezizomycotina, genera incertae sedis, one species, type: E. bambusicola, G.Z. Zhao, hyphomycetous, sexual morph unknown, saprobes, terrestrial, China, see Zhao et al. (2014a; taxonomy), cultures and sequences are unavailable.

Emericellopsis J.F.H. Beyma 1940, Hypocreales genera incertae sedis, Sordariomycetes, twelve species, type: E. terricola J.F.H. Beyma, asexual morph hyphomycetous, endophytes, saprobes, terrestrial, worldwide, see Lumbsch and Huhndorf (2010; outline), GrumGrzhimaylo et al. (2013b; new species), Kirk et al. (2013; genus accepted), Hyde et al. (2016; new species, hyphomycetous asexual morph), sequences are available.

Emilmuelleria Arx 1986, Chaetomiaceae, Sordariales, Sordariomycetes, one species, type: E. spirotricha (R.K. Benj.) Arx, asexual morph unknown, saprobes, terrestrial, Venezuela, see Lumbsch and Huhndorf (2010; outline), Kirk et al. (2013; genus accepted), Maharachchikumbura et al. (2015, 2016; outline), cultures and sequences are available.

Emodomelanelia Divakar \& A. Crespo 2010, Parmeliaceae, Lecanorales, Lecanoromycetes, one species, type: E. masonii (Essl. \& Poelt) Divakar \& A. Crespo, asexual morph unknown, lichenized, saxicolous, Asian endemic (mainland China, India, Nepal and Taiwan), see Crespo et al. (2010a; phylogeny and taxonomy), Lücking et al. (2016b; classification), sequences are available.

Enantioptera Descals 1983, Ascomycota genera incertae sedis, two species, type: E. tetraalata Descals, hyphomycetous, sexual morph unknown, in river foam, Europe, see Seifert et al. (2011; morphology), Wijayawardene et al. (2012, 2017; outline), Kirk et al. (2013; genus accepted), cultures and sequences are unavailable, needs generic revision.

Enarthromyces Thaxt. 1896, Laboulbeniaceae, Laboulbeniales, Laboulbeniomycetes, one species, type: E. indicus Thaxt., asexual morph unknown, parasites, saprobes, terrestrial, Asia, Africa, see Lumbsch and Huhndorf (2010; outline), Rossi (2010; new species), Kirk et al. (2013; genus accepted), cultures and sequences are unavailable, needs generic revision.

Encephalographa A. Massal. 1854, Melaspileaceae, Eremithallales, Dothideomycetes, one species, type: E. cerebrina (DC.) A. Massal., asexual morph unknown, lichenized, saxicolous, Europe (southern), see Lumbsch and Huhndorf (2010; outline, doubtful position in Arthoniomycetes), Kirk et al. (2013; genus accepted), Ertz and Diederich (2015; phylogenetic position), Lücking et al. (2016b; classification), sequences and cultures are available; the placement of all species but E. elisae in Encephalographa should be reassessed.

Enchnoa Fr. 1849, Calosphaeriales genera, incertae sedis, Sordariomycetes, one species, type: E. lanata (Fr.) Fr., asexual morph unknown, saprobes, terrestrial, Venezuela, see Lumbsch and Huhndorf (2010; outline, accepted as a genus in Nitschkiaceae), Kirk et al. (2013; genus accepted), Maharachchikumbura et al. (2015, 2016; outline, accepted as a genus in Calosphaeriales genera, incertae sedis), cultures and sequences are unavailable. 
Enchylium (Ach.) Gray 1821, Collemataceae, Peltigerales, Lecanoromycetidae, Lecanoromycetes, nine species, type: need typification, lichenized, see Otálora et al. (2013, 2014; taxonomy, phylogeny), Lücking et al. (2016b; classification), sequences are available.

Encoelia (Fr.) P. Karst. 1871, Cenangiaceae, Helotiales, Leotiomycetes, 40 species, type: E. furfuracea (Roth) P. Karst., asexual morph unknown, endophytes, saprobes, terrestrial, worldwide, see Lumbsch and Huhndorf (2010; outline), Kirk et al. (2013; genus accepted), Pärtel et al. (2017; morphology, ultrastructure, DNA, phylogeny), cultures and sequences are available.

Encoeliopsis Nannf. 1932, Helotiales genera incertae sedis, Leotiomycetes, four species, type: E. rhododendri (Ces. ex Rabenh.) Nannf., asexual morph unknown, endophytes, saprobes, terrestrial, Europe, North America, see Lumbsch and Huhndorf (2010; outline, accepted as a genus in Helotiaceae), Kirk et al. (2013; genus accepted), Pärtel et al. (2017; DNA, phylogeny), cultures available for type: KL118.

Endobotrya Berk. \& M.A. Curtis 1874, Ascomycota genera incertae sedis, one species, type: E. elegans Berk. \& M.A. Curtis, coelomycetous, sexual morph unknown, saprobes, terrestrial, North America, see Wijayawardene et al. (2012, 2017; outline, morphology), Kirk et al. (2013; genus accepted), cultures and sequences are unavailable, needs generic revision.

Endobotryella Höhn. 1909, Ascomycota genera incertae sedis, one species, type: E. oblonga (Fuckel) Höhn., coelomycetous, sexual morph unknown, saprobes, terrestrial, Europe, see Wijayawardene et al. (2012, 2017; outline), Kirk et al. (2013; genus accepted), cultures and sequences are unavailable, needs generic revision.

Endocalyx Berk. \& Broome 1876, Apiosporaceae, Xylariales, Sordariomycetes, one species, type: E. thwaitesii Berk. \& Broome, hyphomycetous, sexual morph unknown, saprobes, terrestrial, worldwide, see Capdet and Romero (2010; Argentina), Seifert et al. (2011; morphology), Wijayawardene et al. (2012; outline, accepted as Ascomycota genera incertae sedis), Kirk et al. (2013; genus accepted), Maharachchikumbura et al. (2015, 2016; outline), cultures and sequences are available.

Endocarpon Hedw. 1788, Verrucariaceae, Verrucariales, Eurotiomycetes, c. 70 species, type: E. pusillum Hedw., asexual morph coelomycetous, terrestrial and aquatic (maritime and freshwater), lichenized, occurring on rocks, soil and bark, cosmopolitan, see Gueidan et al. (2009; phylogeny, outline), Yang and Wei (2008; new species), Prieto et al. (2012; phylogeny), Joshi and Hur (2013a, b; new species), Lücking et al. (2016b; classification), sequences are available.

Endocena Cromb. 1877, Icmadophilaceae, Pertusariales, Lecanoromycetes, one species, type: E. informis Cromb., asexual morph unknown, lichenized, terricolous, South America, see Lumbsch and Huhndorf (2010; outline), Kirk et al. (2013; genus accepted), Lücking et al. (2016b; classification), sequences are available.

Endococcus Nyl. 1855, Dothideomycetes genera incertae sedis, 34 species, type: E. rugulosus (Borrer ex Leight.) Nyl., asexual morph unknown, lichenicolous, terrestrial, worldwide, see Lumbsch and Huhndorf (2010; outline), Kirk et al. (2013; outline, genus accepted), Kocourková and Knudsen (2011; new species), Zhurbenko et al. (2012; new species), Jayasiri et al. (2015; re-visited), a culture and sequence is available, needs generic revision.

Endocolium Syd. 1937, Ascomycota genera incertae sedis, one species, type: E. costaricanum Syd., asexual morph unknown, saprobes, terrestrial, Central America, see Lumbsch and Huhndorf (2010; outline), Kirk et al. (2013; genus accepted), cultures and sequences are unavailable, needs generic revision.

Endoconidioma Tsuneda, Hambl. \& Currah 2004, Dothideaceae, Dothideales, Dothideomycetes, one species, type: E. populi Tsuneda, Hambl. \& Currah, coelomycetous, 
sexual morph unknown, saprobes, terrestrial, worldwide, see Wijayawardene et al. (2012, 2017; outline), cultures and sequences are available, needs generic revision.

Endoconidiophora Münch 1907, Ceratocystidaceae, Microascales, Sordariomycetes, one species, type: E. coerulescens Münch, hyphomycetous, sexual morph unknown, saprobes, terrestrial, worldwide, see Wijayawardene et al. (2012; outline, accepted as Ascomycota genera incertae sedis), Kirk et al. (2013; genus accepted), Maharachchikumbura et al. (2015, 2016; outline), cultures and sequences are unavailable.

Endoconospora Gjaerum 1971, Ascomycota genera incertae sedis, two species, type: E. cerastii Gjaerum, hyphomycetous, sexual morph unknown, saprobes, terrestrial, Norway, India, see Wijayawardene et al. (2012; outline, accepted as Ascomycota genera incertae sedis), Kirk et al. (2013; genus accepted), cultures and sequences are unavailable, needs generic revision.

Endocoryneum Petr. 1922, ?Didymellaceae, Pleosporales, Dothideomycetes, two species, type: E. loculosum (Sacc.) Petr., coelomycetous, sexual morph unknown, saprobes, terrestrial, Norway, India, see Wijayawardene et al. (2012, 2016; outline, accepted as Ascomycota genera incertae sedis and Didymellaceae respectively), Kirk et al. (2013; genus accepted), cultures and sequences are available for E. festucae Wijayaw. et al. (MFLUCC 14-0461), needs generic revision.

Endodothiora Petr. 1929, Dothideaceae, Dothideales, Dothideomycetes, one species, type: E. sydowiana Petr., asexual morph unknown, saprobes, terrestrial, former USSR, see Lumbsch and Huhndorf (2010; outline), Kirk et al. (2013; genus accepted), Wijayawardene et al. (2014c; outline), cultures and sequences are available, needs generic revision.

Endogenospora R.F. Castañeda, O. Morillo \& Minter 2010, Ascomycota genera incertae sedis, type: E. aspectabilis R.F. Castaneda, O. Morillo \& Minter, hyphomycetous, sexual morph unknown, one species, saprobes, terrestrial, Venezuela, see Castañeda-Ruiz et al., (2010a; morphology), Seifert et al. (2011; morphology), Wijayawardene et al. (2012, 2017; outline), holotype of the type: INIFAT C09/74, cultures and sequences are unavailable, compare with Ascoconidium, Sporoschisma and Sporoschismopsis.

Endohyalina Marbach 2000. Physciaceae, Lecanorales, Lecanoromycetidae, type: E. rappii (Imshaug ex R.C. Harris) Marbach, ten species, three varieties, asexual morph unknown, lichenized, terrestrial, corticolous, lignicolous, sometimes obligately lichenicolous, Australia, tropical to subtropical, see Giralt et al. (2010; taxonomy, Elix and Kantvilas (2015; new records, new taxa), Lücking et al. (2016b; classification), cultures and sequences are unavailable.

Endomelanconiopsis E.I. Rojas \& Samuels 2008, Botryosphaeriaceae, Botryosphaeriales, Dothideomycetes, two species, type: E. endophytica E.I. Rojas \& Samuels, coelomycetous, saprobes, terrestrial, South America, see Liu et al. (2012; taxonomy, phylogeny), Hyde et al. (2013; accepted as a genus in Botryosphaeriaceae), Phillips et al. (2013; taxonomy, new species, phylogeny), Slippers et al. (2013; phylogeny), Wijayawardene et al. (2014c; outline), cultures and sequences are available.

Endomelanconium Petr. 1940, Ascomycota genera incertae sedis, four species, type: E. pini (Corda) Petr., coelomycetous, sexual morph unknown, endophytes, saprobes, terrestrial, worldwide, see Kirk et al. (2013; genus accepted), Wijayawardene et al. (2016b, 2017; morphology; outline), cultures and sequences are unavailable.

Endomeliola S. Hughes \& Piroz. 1994, Meliolaceae, Meliolales, Sordariomycetes, one species, type: E. dingleyae S. Hughes \& Piroz., asexual morph unknown, saprobes, terrestrial, New Zealand, see Lumbsch and Huhndorf (2010; outline), Kirk et al. (2013; genus accepted), Maharachchikumbura et al. (2015, 2016; outline), holotype of the type: DAOM 167533, cultures and sequences are available for PDD:98304 (unpublished). 
Endomyces Reess 1870, Saccharomycetales genera incertae sedis, Saccharomycetes, four species, type: E. decipiens (Tul. \& C. Tul.) Reess, asexual reproduction is by pseudohyphae or septate hyphae or blastoconidia, parasite of mushrooms, grow on various mushrooms, worldwide, Lumbsch and Huhndorf (2010; outline), Kirk et al. (2013; genus accepted), sequences are available.

Endophoma Tsuneda \& M.L. Davey 2011, Didymellaceae, Pleosporales, Dothideomycetes, two species, type: E. elongata Tsuneda \& M.L. Davey, coelomycetous, sexual morph unknown, saprobes (soil of bat cave), terrestrial, Canada, see Tsuneda et al. (2011a; taxonomy, DNA, phylogeny), Chen et al. (2015b; phoma-like taxa in Didymellaceae), holotype and ex-type: UAMH 11216.

Endophragmiella B. Sutton 1973, Helminthosphaeriaceae, Sordariales, Sordariomycetes, c. 70 species, type: E. pallescens B. Sutton, hyphomycetous, Manitoba, see Seifert et al. (2011; morphology), Ma et al. (2012c; new species), Wijayawardene et al. (2012, 2017; outline), Maharachchikumbura et al. (2015, 2016; outline), cultures and sequences are available.

Endophragmiopsis M.B. Ellis 1966, Ascomycota genera incertae sedis, one species, type: E. pirozynskii M.B. Ellis, hyphomycetous, sexual morph unknown, saprobes, terrestrial, India, see Wijayawardene et al. (2012, 2017; outline), Kirk et al. (2013; genus accepted), cultures and sequences are unavailable, needs generic revision.

Endoplacodium Petr. 1949, Ascomycota genera incertae sedis, one species, type: E. nigrescens Petr., coelomycetous, sexual morph unknown, saprobes, terrestrial, Iran, see Wijayawardene et al. (2012, 2017; outline), Kirk et al. (2013; genus accepted), cultures and sequences are unavailable, needs generic revision.

Endoramularia Petr. 1923, Ascomycota genera incertae sedis, one species, type: E. ulmi Petr., hyphomycetous, sexual morph unknown, saprobes, terrestrial, Europe, see Wijayawardene et al. (2012, 2017; outline), Kirk et al. (2013; genus accepted), cultures and sequences are unavailable, needs generic revision.

Endoscypha Syd. 1924, Hyaloscyphaceae, Helotiales, Leotiomycetes, one species, type: E. perforans Syd., asexual morph unknown, saprobes, terrestrial, New Zealand, see Lumbsch and Huhndorf (2010; outline), Kirk et al. (2013; genus accepted), cultures and sequences are available PDD:102231 (unpublished), needs generic revision.

Endosporoideus W.H. Ho, Yanna, K.D. Hyde \& Goh 2005, Ascomycota genera incertae sedis, one species, type: E. pedicellatus W.H. Ho, Yanna, K.D. Hyde \& Goh, hyphomycetous, sexual morph unknown, saprobes, terrestrial, Hong Kong, see Seifert et al. (2011; morphology), Wijayawardene et al. (2012, 2017; outline), Kirk et al. (2013; did not accept as a valid genus), cultures and sequences are unavailable, needs generic revision.

Endostilbum Malençon 1964, Ascomycota genera incertae sedis, one species, type: E. cerasi (Bourdot \& Galzin) Malençon, hyphomycetous, sexual morph unknown, saprobes, terrestrial, Europe, Morocco, see Seifert et al. (2011; morphology), Wijayawardene et al. (2012, 2017; outline), Kirk et al. (2013; did not accept as a valid genus), cultures and sequences are unavailable, needs generic revision.

Endothia Fr. 1849 (= Calopactis Syd. \& P. Syd. fide Rossman et al. 2015a), Cryphonectriaceae, Diaporthales, Sordariomycetes, two species, type: E. gyrosa (Schwein.) Fr., asexual morphs unknown, saprobes, terrestrial, worldwide, see Lumbsch and Huhndorf (2010; outline), Kirk et al. (2013; genus accepted), Rossman et al. (2015a; nomenclature), Maharachchikumbura et al. (2015, 2016; outline), cultures and sequences are available, needs generic revision.

Endotryblidium Petr. 1959, Patellariaceae, Patellariales, Dothideomycetes, one species, type: E. insculptum (Cooke) Petr., asexual morph unknown, saprobes, terrestrial, temperate, see Lumbsch and Huhndorf (2010; outline), Hyde et al. (2013; accepted as a genus in Patellariaceae), Kirk et al. (2013; genus accepted), Wijayawardene et al. (2014c; outline), 
Yacharoen et al. (2015; accepted as a genus in Patellariaceae), cultures and sequences are unavailable, needs generic revision.

Endoxyla Fuckel 1871, Boliniaceae, Boliniales, Sordariomycetes, ten species, type: E. operculata (Nitschke) Sacc., asexual morphs unknown, saprobes, terrestrial, Puerto Rico, see Lumbsch and Huhndorf (2010; outline), Kirk et al. (2013; genus accepted), Untereiner et al. (2013; new species), Maharachchikumbura et al. (2015, 2016; outline), cultures and sequences are available.

Endoxylina Romell 1892, Sordariomycetes genera incertae sedis, seven species, type: E. stellulata Romell, asexual morph unknown, saprobes, terrestrial, worldwide, see Lumbsch and Huhndorf (2010; outline), Vasilyeva (2010; new species; Russia), Kirk et al. (2013; genus accepted), Untereiner et al. (2013; new species), Maharachchikumbura et al. (2015, 2016; outline), cultures and sequences are unavailable.

Endozythia Petr. 1959, Ascomycota genera incertae sedis, one species, type: E. moravica Petr., coelomycetous, sexual morph unknown, saprobes, terrestrial, former Yugoslavia, see Wijayawardene et al. (2012, 2017; outline), Kirk et al. (2013; genus accepted), cultures and sequences are unavailable, needs generic revision.

Enerthidium Syd. 1939, Ascomycota genera incertae sedis, one species, type: E. canarii Syd., coelomycetous, sexual morph unknown, saprobes, terrestrial, Africa, see Wijayawardene et al. (2012, 2016; outline, morphology), Kirk et al. (2013; genus accepted), cultures and sequences are unavailable, needs generic revision.

Engelhardtiella A. Funk 1973, Ascomycota genera incertae sedis, one species, type: E. alba A. Funk, hyphomycetous, sexual morph unknown, saprobes, terrestrial, North America, see Seifert et al. (2011; morphology), Wijayawardene et al. (2012, 2017; outline), Kirk et al. (2013; genus accepted), cultures and sequences are unavailable, needs generic revision.

Englerodothis Theiss. \& Syd. 1915, Dothideomycetes genera incertae sedis, three species, type: E. kilimandscharica (Henn.) Theiss. \& Syd., asexual morph unknown, epiphytes, terrestrial, worldwide, see Hofmann (2009; review, accepted as a genus in Parmulariaceae), Lumbsch and Huhndorf (2010; outline, accepted as a genus in Parmulariaceae), Hyde et al. (2013; review, keys, excluded from Parmulariaceae), Wijayawardene et al. (2014c; outline, accepted as a genus in Dothideomycetes, genera incertae sedis), cultures and sequences unavailable.

Engleromyces Henn. 1900 (三 Stromne Clem. 1909; Colletomanginia Har. \& Pat. 1906 fide Wendt et al. 2017), Xylariales genera incertae sedis, Sordariomycetes, two species, type: E. goetzei Henn., asexual morph unknown, saprobes, terrestrial, Africa, Asia, see Lumbsch and Huhndorf (2010; outline), Whalley et al. (2010; new species. China), Kirk et al. (2013; genus accepted), Maharachchikumbura et al. (2015, 2016; outline), Wendt et al. (2017; accepted as genus in Xylariales genera incertae sedis), cultures and sequences are unavailable.

Englerula Henn. 1904, Englerulaceae, Dothideomycetes families incertae sedis, six species, type: E. macarangae Henn., asexual morph coelomyceteous, saprobes, epiphytic, terrestrial, Africa, India, see Lumbsch and Huhndorf (2010; outline), Hyde et al. (2013; accepted as a genus in Englerulaceae), Dai et al. (2014c; morphology), cultures and sequences are unavailable, needs generic revision.

Engyodontium de Hoog 1978, Cordycipitaceae, Hypocreales, Sordariomycetes, five species, type: E. parvisporum (Petch) de Hoog, hyphomycetous, sexual morph unknown, saprobes, on insects and spiders, cosmopolitan, see Seifert et al. (2011; morphology), Jaklitsch et al. (2016a; classification), Maharachchikumbura et al. (2016; outline), Wijayawardene et al. (2017; outline), cultures and sequences are available, needs generic revision.

Enigmotrema Lücking 2012, Graphidaceae, Ostropales, Lecanoromycetes, one species, type: E. rubrum Lücking, lichenized, see Sipman et al. (2012; taxonomy), Lücking et al. (2013, 2016b; phylogeny, classification), Lücking (2014; taxonomy), sequences are available. 
Enridescalsia R.F. Castañeda \& Guarro 1998, Ascomycota genera incertae sedis, one species, type: E. speciosa R.F. Castaneda \& Guarro, hyphomycetous, sexual morph unknown, saprobes, aquatic (fresh water), Cuba, see see Seifert et al. (2011; morphology), Wijayawardene et al. (2012, 2017; outline), Kirk et al. (2013; genus accepted), holotype: INIFAT C95/96, cultures and sequences are unavailable, compare with Xylomyces and Gonatobotrys.

Enterocarpus Locq.-Lin. 1977, Microascaceae, Microascales, Sordariomycetes, two species, type: E. uniporus Locq.-Lin., asexual morph unknown, coprophilous, terrestrial, Sahara, Italy, see Lumbsch and Huhndorf (2010; outline), Kirk et al. (2013; genus accepted), Maharachchikumbura et al. (2015, 2016; outline), cultures and sequences are available.

Enterodictyon Müll. Arg. 1892, Roccellaceae, Arthoniales, Arthoniomycetes, two species, type: E. indicum Müll. Arg., lichenized, see Lumbsch and Huhndorf (2010; outline), Kirk et al. (2013; genus accepted), Lücking et al. (2016b; classification), sequences are unavailable.

Enterographa Fée 1824, Roccellaceae, Arthoniales, Arthoniomycetes, \pm 60 species, type: E. crassa (DC.) Fée, sexual morph with punctiform or rounded to lirelliform ascomata, lichenized, rarely lichenicolous, terrestrial, world-wide with a preference for (sub)tropical regions, see Ertz and Tehler (2011; phylogeny), Lumbsch and Huhndorf (2010; outline), Aptroot et al. (2013a; new species), Kirk et al. (2013; genus accepted), Ertz et al. (2015c, phylogeny), Lücking et al. (2016b; classification), sequences are available.

Enthallopycnidium F. Stevens 1925, Ascomycota genera incertae sedis, one species, type: E. gouldiae F. Stevens, coelomycetous, sexual morph unknown, saprobes, terrestrial, pantropical, see Wijayawardene et al. (2012, 2017; outline), Kirk et al. (2013; genus accepted), cultures and sequences are unavailable, needs generic revision.

Entoderma Hanula, Andreadis \& M. Blackw. 1991, Ascomycota genera incertae sedis, one species, type: E. colletosporium Hanula, Andreadis \& M. Blackw., coelomycetous, sexual morph unknown, saprobes, terrestrial, USA, see Wijayawardene et al. (2012, 2017; outline), Kirk et al. (2013; genus accepted), cultures and sequences are unavailable, needs generic revision.

Entodesmium Riess 1854, Phaeosphaeriaceae, Pleosporales, Dothideomycetes, eight species, type: E. rude Riess, sexual morph unknown, saprobes, terrestrial, temperate, see Schoch et al. (2009; DNA, phylogeny), Hyde et al. (2013; outline, accepted as a genus in Phaeosphaeriaceae), Phookamsak et al. (2014b; accepted as a genus in Phaeosphaeriaceae, phylogeny), Wijayawardene et al. (2014c; outline), Ariyawansa et al. (2015a; new species, Russia, DNA, phylogeny), cultures available for the type: CBS 650.86.

Entoleuca Syd. 1922, Xylariaceae, Xylariales, Sordariomycetes, three species, type: E. callimorpha Syd., asexual morph unknown, saprobes, terrestrial, temperate, see Lumbsch and Huhndorf (2010; outline), Kirk et al. (2013; genus accepted), Maharachchikumbura et al. (2015, 2016; outline), cultures and sequences are available.

Entonaema Möller 1901, Hypoxylaceae, Xylariales, Sordariomycetes, six species, type: E. liquescens Möller, asexual morph unknown, terrestrial, saprobes, tropical, see Lumbsch and Huhndorf (2010; outline), Kirk et al. (2013; genus accepted), Maharachchikumbura et al. (2015, 2016; outline), Wendt et al. (2017; accepted as a genus in Hypoxylaceae), cultures and sequences are available.

Eoaleurina Korf \& W.Y. Zhuang 1986, Pyronemataceae, Pezizales, Pezizomycetes, one species, type: E. foliicola (Henn.) Korf \& W.Y. Zhuang, asexual morph unknown, saprobes, terrestrial, Central and South America, see Lumbsch and Huhndorf (2010; outline), Kirk et al. (2013; genus accepted), cultures and sequences are unavailable.

Eopyrenula R.C. Harris 1973, Ascomycota genera incertae sedis, three species, type: E. leucoplaca (Wallr.) R.C. Harris, sexual morph unknown, saprobes, terrestrial, north temperate, see Lumbsch and Huhndorf (2010; outline), Kirk et al. (2013; genus accepted), 
Hyde et al. (2013; outline, accepted as a genus in Dacampiaceae), Kirk et al. (2013; genus accepted), Wijayawardene et al. (2014c; accepted as a genus in Dacampiaceae), cultures and sequences are unavailable.

Eosphaeria Höhn. 1917, Lasiosphaeriaceae, Sordariales, Sordariomycetes, one species, type: E. uliginosa (Kunze) Höhn., asexual morph hyphomycetous, saprobes, terrestrial, Europe, North America, see Lumbsch and Huhndorf (2010; outline), Kirk et al. (2013; genus accepted), Maharachchikumbura et al. (2015, 2016; outline), cultures and sequences are unavailable.

Eoterfezia G.F. Atk. 1902, Eoterfeziaceae, Ascomycota families incertae sedis, type: E. parasitica G.F. Atk., six species, asexual morph unknown, terrestrial, saprobes, North America, see Lumbsch and Huhndorf (2010; outline), Kirk et al. (2013; genus accepted), cultures and sequences are unavailable, needs generic revision.

Epaphroconidia Calat. \& V. Atienza 1995, Ascomycota genera incertae sedis, one species, type: E. hawksworthii Calat. \& V. Atienza, coelomycetous, sexual morph unknown, lichenicolous, terrestrial, Spain, North America, see Wijayawardene et al. (2012, 2017; outline), Kirk et al. (2013; genus accepted), cultures and sequences are unavailable, needs generic revision.

Ephebe Fr., 1825. Lichinaceae, Lichinales, Lichinomycetidae, 13 species, type: E. lanata (L.) Vain., asexual morph unknown, lichenized, terrestrial, corticolous, see Lumbsch and Huhndorf (2010; outline). Kirk et al. (2013; genus accepted), Lücking et al. (2016b; classification), sequences are available.

Ephelidium C.W. Dodge \& E.D. Rudolph 1955, Ascomycota genera incertae sedis, one species, type: E. heardense C.W. Dodge \& E.D. Rudolph, coelomycetous, sexual morph unknown, saprobes, terrestrial, Antarctica, see Wijayawardene et al. (2012, 2017; outline), Kirk et al. (2013; genus accepted), cultures and sequences are unavailable, needs generic revision.

Epibelonium E. Müll. 1963, Saccardiaceae, Ascomycota families incertae sedis, one species, type: E. plagiochilae (Gonz. Frag.) Döbbeler, asexual morph unknown, saprobes, terrestrial, France, see Lumbsch and Huhndorf (2010; outline), Kirk et al. (2013; genus accepted), cultures and sequences are unavailable, needs generic revision.

Epibryon Döbbeler 1978, Epibryaceae, Chaetothyriales, Eurotiomycetes, c. 30 species, type: E. plagiochilae (Gonz. Frag.) Döbbeler, asexual morph unknown, saprobes, terrestrial, worldwide, see Lumbsch and Huhndorf (2010; outline), Stenroos et al. (2010; DNA, symbioses), Hyde et al. (2013; outline, accepted as a genus in Pseudoperisporiaceae), Kirk et al. (2013; genus accepted), Gueidan et al. (2014a; phylogeny), cultures and sequences are available.

Epichlö̈ (Fr.) Tul. \& C. Tul. 1865 (= Neotyphodium Glenn, C.W. Bacon \& Hanlin 1996 fide Rossman et al. 2016a), Clavicipitaceae, Hypocreales, Sordariomycetes, six species, type: E. typhina (Pers.) Tul. \& C. Tul., sexual morph unknown, saprobes, endophytes, terrestrial, worldwide, see Kirk et al. (2013; genus accepted), Young et al. (2014; endophytes), Hettiarachchige et al. (2015; endophytes), Maharachchikumbura et al. (2015, 2016; outline), Rossman et al. (2016a; nomenclature), cultures and sequences are available.

Epicladonia D. Hawksw. 1981, Ascomycota genera incertae sedis, four species, type: E. sandstedei (Zopf) D. Hawksw., on lichens, sexual morph unknown, see Kirk et al. (2013; genus accepted), cultures and sequences are unavailable, topotype material of type: B (Krypt. Exs. Vindob. No. 1330b).

Epiclinium Fr. 1849, Ascomycota genera incertae sedis, two species, type: E. pezizoideum (Schwein.) Fr., coelomycetous, sexual morph unknown, saprobes, terrestrial, Europe, USA, see Wijayawardene et al. (2012, 2017; outline), Kirk et al. (2013; genus accepted), cultures and sequences are unavailable, needs generic revision. 
Epicoccospora Budathoki \& S.K. Singh 1995, Ascomycota genera incertae sedis, two species, type: E. nepalensis Budathoki \& S.K. Singh, hyphomycetous, sexual morph unknown, saprobes, terrestrial, Nepal, see Wijayawardene et al. (2012, 2017; outline), Kirk et al. (2013; genus accepted), cultures and sequences are unavailable, needs generic revision.

Epicoccum Link 1816, Didymellaceae, Pleosporales, Dothideomycetes, c. ten species, type: E. nigrum Link, hyphomycetous, sexual morph unknown, saprobes, terrestrial, worldwide, see Aveskamp et al. (2009, 2010; DNA, new species, phylogeny), Seifert et al. (2011; morphology), Wijayawardene et al. (2012, 2014c; outline, accepted as a genus in Didymellaceae), Hyde et al. (2013; accepted as a genus in Didymellaceae), Kirk et al. (2013; genus accepted), Chen et al. (2015b; taxonomy, new species, DNA, phylogeny), ex-type cultures available for type: CBS 173.73.

Epicoleosporium Videira \& Crous 2016, Mycosphaerellaceae, Capnodiales, Dothideomycetes, one species, type: E. ramularioides Videira, H.D. Shin \& Crous, hyphomycetous, sexual morph unknown, plant pathogenic, see Videira et al. (2016; morphology, phylogeny), holotype KUS-F19603, isotype CBS H-22542, culture ex-type: CBS $141103=$ CPC 10672.

Epicrea Petr. 1950, Clavicipitaceae, Hypocreales, Sordariomycetes, six species, type: E. insignis Petr., asexual morph unknown, saprobes, terrestrial, Ecuador, see Lumbsch and Huhndorf (2010; outline), Kirk et al. (2013; genus accepted), Maharachchikumbura et al. (2015, 2016; outline), cultures and sequences are available.

Epidermophyton Sabour. 1907, Arthrodermataceae, Onygenales, Eurotiomycetes, one species: E. floccosum (Harz) Langeron \& Miloch., hyphomycetous, terrestrial, on human skin, one of the main etiological agents of dermatophytosis worldwide, see Seifert et al. (2011; morphology), Wijayawardene et al. (2012, 2017; outline), Kirk et al. (2013; genus accepted), neotype strain of the type: $=$ CBS 230.76, sequences are available from de Hoog et al. (in press).

Epigloea Zukal 1889, Epigloeaceae, Ascomycota families incertae sedis, 13 species, type: E. bactrospora Zukal, on algae, Europe, Antarctica, see Lumbsch and Huhndorf (2010; outline), Kirk et al. (2013; genus accepted), cultures and sequences are unavailable, needs generic revision.

Epilichen Clem. 1909, Rhizocarpaceae, Rhizocarpales, Lecanoromycetes, three species; type: E. scabrosus (Ach.) Clem., lichenized, see Lumbsch and Huhndorf (2010; outline), Kirk et al. (2013; genus accepted), Lücking et al. (2016b; classification), sequences unavailable. type specimen UPS-ACH-L-130 (isotype),

Epinephroma Zhurb. 2012, Ascomycota genera incertae sedis, two species, type: E. kamchatica Zhurb. \& Stepanch., coelomycetous, lichenicolous, terrestrial, Russia, see Zhurbenko et al. (2012; morphology), cultures and sequences are unavailable, needs generic revision.

Epiphloea Trevis 1880, Heppiaceae, Lecanorales, Lecanoromycetes, two species, type: E. terrena (Nyl.) Trevis., asexual morph unknown, lichenized, terrestrial, see Lumbsch and Huhndorf (2010; outline). Kirk et al. (2013; genus accepted), cultures and sequences are unavailable.

Episclerotium L.M. Kohn 1984, Helotiales genera incertae sedis, Leotiomycetes, two species, type: E. sclerotiorum (Rostr.) L.M. Kohn, asexual morph unknown, saprobes, terrestrial, Europe, see Lumbsch and Huhndorf (2010; outline), Kirk et al. (2013; genus accepted), cultures and sequences are unavailable, needs generic revision.

Episphaerella Petr. 1924, Pseudoperisporiaceae, Dothideomycetes, families incertae sedis, six species, type: E. manihotis (Henn.) Petr., asexual morph unknown, saprobes, terrestrial, USA, Africa, China, see Lumbsch and Huhndorf (2010; outline), Zhao and Zhao (2012; new species, China), Hyde et al. (2013; outline, accepted as a genus in Pseudoperisporiaceae), 
Kirk et al. (2013; genus accepted), Wijayawardene et al. (2014c; accepted as a genus in Pseudoperisporiaceae), cultures and sequences are available for Episphaerella dodonaeae PDD:104466 (unpublished).

Episporogoniella U. Braun 1994, Ascomycota genera incertae sedis, one species, type: E. muscigena (Speg.) U. Braun, hyphomycetous, sexual morph unknown, terrestrial, muscicolous, South America, see Seifert et al. (2011), Wijayawardene et al. (2012, 2017; outline), Kirk et al. (2013; genus accepted), holotype of type: LPS 12764, cultures and sequences are unavailable.

Epistigme Syd. 1924, Ascomycota genera incertae sedis, two species, type: E. nidulans Syd., coelomycetous, sexual morph unknown, saprobes, terrestrial, South Africa, see Wijayawardene et al. (2012, 2017; outline), Kirk et al. (2013; genus accepted), cultures and sequences are unavailable, needs generic revision.

Epithamnolia Zhurb. 2012, Ascomycota genera incertae sedis, two species, type: E. karatyginii Zhurb., asexual morph unknown, lichenicolous, terrestrial, South Africa, see Zhurbenko (2011; morphology, key), cultures and sequences are unavailable, needs generic revision.

Epithyrium (Sacc.) Trotter 1931, Ascomycota genera incertae sedis, two species, type: E. resinae (Sacc. \& Berl.) Trotter, coelomycetous, sexual morph unknown, saprobes, terrestrial, South Africa, see Wijayawardene et al. (2012, 2016, 2017; outline, morphology), Kirk et al. (2013; did not accept as a valid genus), cultures and sequences are unavailable, needs generic revision.

Eremascus Eidam 1877, Eremascaceae, Onygenales, Eurotiomycetes, two species, type: E. albus Eidam, asexual morph absent in the type species, but hyphomycetous in E. terrestris Asthana \& Mahmud (Asthana \& Mahmud 1944), terrestrial, saprobes, usually xerophilic, occurring on substrates with low water and high carbohydrate content, such as dried fruits, honey, jams, mustard and others, also reported from soil, Argentina, Australia, India, Western Europe, see Gueidan et al. (2008; phylogeny), Pitt and Hocking (2009; morphology, food spoilage), Wynns (2015; phylogeny, proposal of a segregate genus), material of the type species is lost (Harrold 1950) and neotypification is necessary.

Eremastrella S. Vogel, 1955 Psoraceae, Lecanorales, Lecanoromycetes, two species, type: E. tobleri S. Vogel, asexual morph unknown, lichenized, terrestrial, see Ekman, and Blaalid, (2011; molecular sequence), Lumbsch, and Huhndorf, (2011; list), Kirk et al. (2013; genus accepted), sequences are available.

Eremiomyces Trappe \& Kagan-Zur 2005, Pezizaceae, Pezizales, Pezizomycetes, two species, type: E. echinulatus (Trappe \& Marasas) Trappe \& Kagan-Zur, asexual morph unknown, saprobes, from soil, terrestrial, South Africa, Spain, see Lumbsch and Huhndorf (2010; outline, accepted as a genus in Pezizaceae), Alvarado et al. (2011b; new species, Spain, DNA, placed in Tuberaceae), cultures and sequences are available.

Eremithallus Lücking, Lumbsch \& Umaña, 2008, Melaspileaceae, Eremithallales, Dothideomycetes, two species, type: E. costaricensis Lücking, Lizano \& Chaves, asexual morph unknown, lichenized, terrestrial, corticolous, Costa Rica, see Lücking et al. (2008b; molecular), Ertz and Diederich (2015; taxonomy), Lumbsch et al. (2016; taxonomy), sequences are available.

Eremomyces Malloch \& Cain 1971, Eremomycetaceae, Dothideomycetes genera incertae sedis, two species, type: E. bilateralis Malloch \& Cain, asexual morph hyphomycetous, saprobes, terrestrial, North America, Netherlands, see Malloch and Sigler (1988; asexual morph, morphology), Lumbsch and Huhndorf (2010; outline), Hyde et al. (2013; morphlogy), Kirk et al. (2013; genus accepted), cultures and sequences are available but lacks for type, needs generic revision. 
Eremothecella Syd. \& P. Syd. 1917. Arthoniaceae, Arthoniales, Arthoniomycetidae, type: E. calamicola Syd. \& P. Syd., eleven species, asexual morph unknown, lichenized, terrestrial, Australia, Netherland, see Lumbsch and Huhndorf (2010; outline). Kirk et al. (2013; genus accepted), Cáceres and Aptroot (2014; taxonomy), Lücking et al. (2016b; classification), molecular and culture data unavailable.

Eremothecium Borzi emend. Kurtzman 1995, Saccharomycetaceae, Saccharomycetales, Saccharomycetes, six species, type: E. cymbalariae Borzí, asexual reproduction is by budding cells are absent or present, and when present, budding is multilateral on a narrow base, enteroarthric conidia are infrequently produced by one species, pseudohyphae and true hyphae are generally present, plant pathogens, cotton, hazel nuts, tomatoes, mustard, insects, worldwide, see Lumbsch and Huhndorf (2010; outline), Kirk et al. (2013; genus accepted), sequences are available.

Erikssonia Penz. \& Sacc. 1898, Phyllachoraceae, Phyllachorales, Sordariomycetes, five species, type: E. pulchella Penz. \& Sacc., sexual morph unknown, biotrophic, terrestrial, worldwide, see Lumbsch and Huhndorf (2010; outline), Kirk et al. (2013; genus accepted), Maharachchikumbura et al. (2015, 2016; outline), cultures and sequences are unavailable.

Erikssonopsis M. Morelet 1971, Helotiales genera incertae sedis, Leotiomycetes, one species, type: E. ericae (Fr.) M. Morelet, asexual morph unknown, saprobes, terrestrial, Europe, see Lumbsch and Huhndorf (2010; outline), Kirk et al. (2013; genus accepted), Jaklitsch et al. (2016a; classification), cultures and sequences are unavailable, needs generic revision.

Erinacellus T. Sprib., Muggia \& Tønsberg 2014, Peltigerales genera incertae sedis, Lecanoromycetes, two species, type: E. dendroides (Henssen) T. Sprib., Tønsberg \& Muggia, lichenized, see Spribille et al. (2014b; taxonomy), Lücking et al. (2016b; classification), sequences are available.

Eriocercospora Deighton 1969, Dothideomycetes genera incertae sedis, two species, type: E. balladynae (Hansf.) Deighton, hyphomycetous, sexual morph unknown, saprobes, mycoparasites, terrestrial, worldwide, see Wijayawardene et al. (2012, 2014c; outline), Kirk et al. (2013; genus accepted), cultures and sequences are unavailable, needs generic revision.

Eriocercosporella Rak. Kumar, A.N. Rai \& Kamal ex U. Braun 1998, Ascomycota genera incertae sedis, one species, type: E. indica Rak. Kumar, A.N. Rai \& Kamal ex U. Braun, hyphomycetous, sexual morph unknown, terrestrial, foliicolous, plant pathogenic, Asia, see Seifert et al. (2011), Wijayawardene et al. (2012, 2014c; outline), Kirk et al. (2013; genus accepted), cultures and sequences are unavailable, holotype of type: IMI 302747.

Erioderma Feé 1825, Pannariaceae, Peltigerales, Lecanoromycetes, 40 species, type: E. polycarpum Fée, lichenized, see Lumbsch and Huhndorf (2010; outline), Kirk et al. (2013; genus accepted), Lücking et al. (2016b; classification), sequences are available.

Eriomycopsis Speg. 1911, Ascomycota genera incertae sedis, 13 species, type: E. bomplandi Speg., hyphomycetous, sexual morph unknown, fungicolous, terrestrial, worldwide, see Seifert et al. (2011), Wijayawardene et al. (2012, 2017; outline), Kirk et al. (2013; genus accepted), cultures and sequences are unavailable, needs generic revision.

Eriopezia (Sacc.) Rehm 1892, Arachnopezizaceae, Helotiales, Leotiomycetes, 30 species, type: E. caesia (Pers.) Rehm, asexual morph unknown, saprobes, terrestrial, Europe, New Zealand, see Lumbsch and Huhndorf (2010; outline), Kirk et al. (2013; genus accepted), cultures and sequences are unavailable, needs generic revision.

Erioscyphella Kirschst. 1938, Lachnaceae, Helotiales, Leotiomycetes, c. ten species, type: . bicolor (Bull.) Baral, sexual morph unknown, saprobes, cosmopolitan, see Kirk et al. (2008; treated as a synonym of Lachnum Retz.), Jaklitsch et al. (2016a; classification), cultures and sequences are available. 
Eriosphaeria Sacc. 1875, Trichosphaeriaceae, Trichosphaeriales, Sordariomycetes, six species, type: E. vermicularia (Nees) Sacc., asexual morph unknown, biotrophic, terrestrial, worldwide, see Lumbsch and Huhndorf (2010; outline), Kirk et al. (2013; genus accepted), Maharachchikumbura et al. (2015, 2016; outline), cultures and sequences are unavailable.

Eriospora Berk. \& Broome 1850, Ascomycota genera incertae sedis, one species, type: E. leucostoma Berk. \& Broome, coelomycetous, sexual morph unknown, saprobes, terrestrial, Europe. South America, see Kirk et al. (2013; genus accepted), Wijayawardene et al. (2017; outline), cultures and sequences are unavailable, needs generic revision.

Eriosporella Höhn. 1916, Capnodiales genera incertae sedis, Dothideomycetes, two species, type: E. calami (Niessl) Höhn., coelomycetous, sexual morph unknown, saprobes, terrestrial, Europe, Thailand, see Wijayawardene et al. (2012, 2014c; outline), Kirk et al. (2013; genus accepted), Dai et al. (2014e; new species, DNA, phylogeny), cultures and sequences are available for Eriosporella bambusicola D.Q. Dai et al. (ex-type MFLUCC 11-0436), needs generic revision.

Eriosporopsis Petr. 1947, Ascomycota genera incertae sedis, one species, type: E. albida Petr., coelomycetous, sexual morph unknown, saprobes, terrestrial, Europe, see Wijayawardene et al. (2012, 2017; outline), Kirk et al. (2013; genus accepted), cultures and sequences are unavailable, needs generic revision.

Eriothyrium Speg. 1887, Ascomycota genera incertae sedis, one species, type: E. dubiosum Speg., coelomycetous, sexual morph unknown, saprobes, terrestrial, South America, see Wijayawardene et al. (2012, 2017; outline), Kirk et al. (2013; genus accepted), cultures and sequences are unavailable, needs generic revision.

Erispora Pat. 1922, Ascomycota genera incertae sedis, one species, type: E. parasitica Pat., coelomycetous, sexual morph unknown, saprobes, terrestrial, Philippines, holotype is lost.

Ernakulamia Subram. 1996, Ascomycota genera incertae sedis, one species, type: E. cochinensis (Subram.) Subram, hyphomycetous, sexual morph unknown, saprobes, terrestrial, South East Asia, see Capdet and Romero (2010; Argentina), Seifert et al. (2011; morphology), Wijayawardene et al. (2012, 2017; outline), Kirk et al. (2013; genus accepted), cultures and sequences are unavailable, needs generic revision.

Erysiphe R. Hedw. ex DC. 1805 Fr. 1829 emend. Braun \& Takamatsu 2000, Erysiphaceae, Erysiphales, Leotiomycetes, 378 species in Erysiphe and 72 species in Pseudoidium, type: E. polygoni DC., hyphomycetous asexual morphs, biotrophic, obligate plant pathogens, terrestrial, worldwide, see Braun and Cook (2012; taxonomy), Takamatsu et al. (2015a, b; phylogeny), lectotype of type: G 00122108.

Erythrocarpon Zukal 1886, Ceratostomataceae, Melanosporales, Sordariomycetes, six species, type: E. microstomum Zukal, asexual morph unknown, biotrophic, terrestrial, worldwide, see Lumbsch and Huhndorf (2010; outline), Kirk et al. (2013; genus accepted), Maharachchikumbura et al. (2015, 2016; outline), cultures and sequences are unavailable.

Erythrodecton G. Thor 1991, Roccellaceae, Arthoniales, Arthoniomycetes, three species; type: E. granulatum (Mont.) G. Thor, lichenized, see Lumbsch and Huhndorf (2010; outline), Ertz and Tehler (2011, phylogeny), Kirk et al. (2013; genus accepted), Lücking et al. (2016b; classification), sequences are available.

Erythrogloeum Petr. 1953, Diaporthales genera incertae sedis, Sordariomycetes, two species, type: E. hymenaeae Gonz. Frag. \& Cif. ex Petr., coelomycetous, sexual morph unknown, biotrophic, terrestrial, Costa Rica, South and Central America, see Crous et al. (2012d; DNA, phylogeny), Kirk et al. (2013; genus accepted), Maharachchikumbura et al. (2015, 2016; outline), Wijayawardene et al. (2017; outline), epitype and ex-epitype of the type: CBS H-20937, CPC $18819=$ CBS 132185.

Erythromada Huhndorf, A.N. Mill., F.A. Fernández \& Lodge 2005, Chaetosphaeriales genera incertae sedis, Sordariomycetes, one species, type: E. lanciospora Huhndorf, A.N. 
Mill., F.A. Fernández \& Lodge, asexual morphs unknown, saprobes, terrestrial, Puerto Rico, see Lumbsch and Huhndorf (2010; outline), Maharachchikumbura et al. (2015, 2016; outline), cultures and sequences are available.

Eschatogonia Trevis. 1853, Ramalinaceae, Lecanorales, Lecanoromycetes, seven species; type: E. montagnei Trevis., lichenized, see Lumbsch and Huhndorf (2010; outline), Kirk et al. (2013; genus accepted), Lücking et al. (2016b; classification), isotype of the type: UPS-L129880, sequences are unavailable.

Escovopsioides H.C. Evans \& J.O. Augustin 2012, Hypocreaceae, Hypocreales, Sordariomycetes, one species, type: E. nivea H.C. Evans \& J.O. Augustin, asexual morph hyphomycetous, on nest of leaf-cutting ants, terrestrial, Brazil, see Augustin et al. (2012; morphology, DNA, phylogeny), Maharachchikumbura et al. (2015, 2016; outline), Wijayawardene et al. (2017; outline), holotype IMI 501181; isotype DOA627-VIC 31754, cultures and sequences are available.

Escovopsis J.J. Muchovej \& Della Lucia 1990, Hypocreaceae, Hypocreales, Sordariomycetes, one species, type: E. weberi J.J. Muchovej \& Della Lucia, hyphomycetous, sexual morph unknown, on nest of attine ants, terrestrial, worldwide, see Augustin et al. (2012; morphology, DNA, phylogeny), Kirk et al. (2013; genus accepted), Maharachchikumbura et al. (2015, 2016; outline), Masiulionis et al. (2015; new species), Meirelles et al. (2015; new species), cultures and sequences are available.

Esdipatilia Phadke 1981, Ascomycota genera incertae sedis, one species, type: E. indica Phadke, hyphomycetous, sexual morph unknown, saprobes, terrestrial, India, see Wijayawardene et al. (2012, 2017; outline), Kirk et al. (2013; genus accepted), holotype of the type: AMH4616, cultures and sequences are unavailable, needs generic revision.

Esfandiariomyces Ershad 1985, Sordariomycetes, genera incertae sedis, one species, type: E. insignis (Petr.) Ershad, asexual morph unknown, saprobes, terrestrial, worldwide, see Lumbsch and Huhndorf (2010; outline), Kirk et al. (2013; genus accepted), Maharachchikumbura et al. (2015, 2016; outline), cultures and sequences are unavailable, needs generic revision.

Esslingeriana Hale \& M.J. Lai 1980, Parmeliaceae, Lecanorales, Lecanoromycetes, one species, type: E. idahoensis (Essl.) Hale \& M.J. Lai, lichenized, see Lumbsch and Huhndorf (2010; outline), Kirk et al. (2013; genus accepted), Lücking et al. (2016b; classification), sequences are available.

Esteya J.Y. Liou, J.Y. Shih \& Tzean 1999, Ascomycota genera incertae sedis, one species, type: E. vermicola J.Y. Liou, J.Y. Shih \& Tzean, hyphomycetous, sexual morph unknown, saprobes, terrestrial, Taiwan, Europe, see Seifert et al. (2011; morphology), Wijayawardene et al. (2012, 2017; outline), Kirk et al. (2013; genus accepted), cultures and sequences are unavailable, needs generic revision.

Etayoa Diederich \& Ertz 2014, Phaeococcomycetaceae, Lichenostigmatales, Arthoniomycetes, one species, type: E. trypethelii (Flakus \& Kukwa) Diederich \& Ertz, both sexual and asexual morphs stromatic, lichenicolous, non-lichenized, on corticolous lichens, worldwide, see Ertz et al. (2014b; morphology, phylogeny), cultures and sequences are available.

Etheirophora Kohlm. \& Volkm.-Kohlm. 1989, Etheirophoraceae, Torpedosporales, Sordariomycetes, three species, type: E. bijubata Kohlm. \& Volkm.-Kohlm., saprobes, marine, Atlantic Ocean, Pacific Ocean, see Lumbsch and Huhndorf (2010; outline), Kirk et al. (2013; genus accepted), Jones et al. (2015; phylogeny), Maharachchikumbura et al. (2015, 2016; outline), cultures and sequences are available but lacks for type.

Euacanthe Theiss. 1917, Scortechiniaceae, Coronophorales, Sordariomycetes, two species, type: E. usambarensis (Rehm) Theiss., asexual morph unknown, saprobes, terrestrial, 
worldwide, see Lumbsch and Huhndorf (2010; outline), Mugambi and and Huhndorf (2010; DNA), Kirk et al. (2013; genus accepted), Maharachchikumbura et al. (2015, 2016; outline), cultures and sequences are available for Euacanthe foveolata (GKM1221 fide Mugambi and and Huhndorf 2010), treated as a synonym of Acanthonitschkea Speg. in Species Fungorum (2016).

Euantennaria Speg. 1918, Euantennariaceae, Dothideomycetes families incertae sedis, six species, type: E. tropicicola Speg., saprobes, parasitic, terrestrial, worldwide, see Lumbsch and Huhndorf (2010; outline), Hyde et al. (2013; taxonomy), Kirk et al. (2013; genus accepted), Wijayawardene et al. (2014c; outline), cultures and sequences are unavailable.

Eubelonis Höhn. 1926, Helotiaceae, Helotiales, Leotiomycetes, two species, type: E. albosanguinea Höhn., asexual morph unknown, saprobes, terrestrial, Europe, see Lumbsch and Huhndorf (2010; outline), Kirk et al. (2013; genus accepted), cultures and sequences are unavailable, needs generic revision.

Eucalyptostroma Crous \& M.J. Wingf. 2016, Chaetosphaeriaceae, Chaetosphaeriales, Sordariomycetes, one species, type: E. eucalypti Crous \& M.J. Wingf., coelomycetous, sexual morph unknown, saprobes, terrestrial, Malaysia, see Crous et al. (2016a; new species, phylogeny), holotype and ex-type culture of the type: CBS H-22871, CPC 28764.

Eucantharomyces Thaxt. 1895, Laboulbeniaceae, Laboulbeniales, Laboulbeniomycetes, 26 species, type: E. atrani Thaxt., asexual morph unknown, parasites, saprobes, terrestrial, worldwide, see Rossi and Ponziani (2008; new species), Lumbsch and Huhndorf (2010; outline), cultures and sequences are unavailable, needs generic revision.

Eucasphaeria Crous 2007, Niessliaceae, Hypocreales, Sordariomycetes, one species, type: E. capensis Crous, asexual morph coelomycetous, saprobes, terrestrial, South Africa, see Lumbsch and Huhndorf (2010; outline), Kirk et al. (2013; genus accepted), Azeem et al. (2015; DNA), Crous et al. (2016a; new species, phylogeny), holotype and the ex-type strains of the type: CBS-H19764, CPC $12796=$ CBS 120028.

Euceramia Bat. \& Cif. 1962, Chaetothyriaceae, Chaetothyriales, Eurotiomycetes, one species, type: E. palmicola Bat. \& Cif., asexual morph unknown, epiphytic, epiphyllous, terrestrial, Brazil, see Lumbsch and Huhndorf (2010; outline), Kirk et al. (2013; genus accepted), cultures and sequences are unavailable, needs generic revision.

Euceratomyces Thaxt. 1931, Euceratomycetaceae, Laboulbeniales, Laboulbeniomycetes, one species, type: E. terrestris Thaxt., asexual morph unknown, parasites, terrestrial, North America, see Lumbsch and Huhndorf (2010; outline), Rossi (2010; new species), cultures and sequences are unavailable, needs generic revision.

Eudarluca Speg. 1908, Phaeosphaeriaceae, Pleosporales, Dothideomycetes, c. five species, type: E. australis Speg., asexual morph unknown, hyperparasitic associated with rust species (but not necessarily parasitic), terrestrial, worldwide, all species have sequence data, see Lumbsch and Huhndorf (2010; outline), Hyde et al. (2013; accepted as a genus in Phaeosphaeriaceae), Kirk et al. (2013; genus accepted), Phookamsak et al. (2014b; phylogeny), Wijayawardene et al. (2014c; outline), isotype of the type: S-F11420, cultures and sequences are available.

Eudimeriolum Speg. 1912, Pseudoperisporiaceae, Dothideomycetes families incertae sedis, eight species, type: E. elegans Speg., asexual morph unknown, saprobes, terrestrial, tropical, see Lumbsch and Huhndorf (2010; outline), Hyde et al. (2013; accepted as a genus in Pseudoperisporiaceae), Kirk et al. (2013; genus accepted), Wijayawardene et al. (2014c; outline), cultures and sequences are unavailable.

Euepixylon Füisting 1867, Xylariaceae, Xylariales, Sordariomycetes, two species, type: E. udum (Pers.) Læssøe \& Spooner, asexual morph unknown, saprobes, terrestrial, Europe, Eastern Russia, see Lumbsch and Huhndorf (2010; outline), Kirk et al. (2013; did not list), Maharachchikumbura et al. (2015, 2016; outline), cultures and sequences are unavailable. 
Eugeniella Lücking, Sérus. \& Kalb 2008, Pilocarpaceae, Lecanorales, Lecanoromycetes, nine species, type: E. psychotriae (Müll. Arg.) Lücking, Sérus. \& Kalb, lichenized, see Lücking (2008; taxonomy), Lücking et al. (2016b; classification), sequences are unavailable.

Euhaplomyces Thaxt. 1901, Laboulbeniaceae, Laboulbeniales, Laboulbeniomycetes, one species, type: E. ancyrophori Thaxt., asexual morph unknown, parasites, saprobes, terrestrial, worldwide, see Rossi and Ponziani (2008; new species), Lumbsch and Huhndorf (2010; outline), Kirk et al. (2013; genus accepted), cultures and sequences are unavailable, needs generic revision.

Eumela Syd. 1925, Pseudoperisporiaceae, Dothideomycetes, families incertae sedis, one species, type: E. chiococcae Syd., asexual morph unknown, saprobes, terrestrial, Central America, all species have sequence data, see Lumbsch and Huhndorf (2010; outline), Hyde et al. (2013; accepted as a genus in Pseudoperisporiaceae), Kirk et al. (2013; genus accepted), Wijayawardene et al. (2014c; outline), cultures and sequences are unavailable.

Eumonoicomyces Thaxt. 1901, Laboulbeniaceae, Laboulbeniales, Laboulbeniomycetes, two or three species, type: E. californicus Thaxt., asexual morph unknown, parasites, terrestrial, worldwide, see Rossi and Ponziani (2008; new species), Lumbsch and Huhndorf (2010; outline), cultures and sequences are unavailable, needs generic revision.

Euopsis Nyl. 1875, Lichinaceae, Lichinales, Lichinomycetes, two species, type: E. granatina (Sommerf.) Nyl., lichenized, see Lumbsch and Huhndorf (2010; outline), Kirk et al. (2013; genus accepted), Lücking et al. (2016b; classification), sequences are available.

Eupelte Syd. 1924 (= Maurodothina G. Arnaud ex Piroz. \& Shoemaker 1970; Pirozynskia Subram. 1972 fide Rossman et al. 2016a), Dothideomycetes genera incertae sedis, four species, type: E. amicta Syd., asexual morph (= sporidesmium-like, fide Sivanesan 1984), epiphytes, terrestrial, worldwide, see Hofmann (2009; review, accepted as a genus in Asterinaceae), Lumbsch and Huhndorf (2010; outline, accepted as a genus in Asterinaceae), Hongsanan et al. (2014c; taxonomy, treated as a doubtful genus in Asterinales), Wijayawardene et al. (2014c; outline, accepted as a genus in Dothideomycetes, genera incertae sedis), Rossman et al. (2016a; nomenclature), holotype of type: IMI 240625, cultures and sequences are unavailable, needs generic revision.

Eupenidiella Quaedvlieg \& Crous 2014, Teratosphaeriaceae, Capnodiales, Dothideomycetes, one species, type: E. venezuelensis (Crous \& U. Braun) Quaedvl. \& Crous, hyphomycetous, sexual morph unknown, saprobes, terrestrial, Venezuela, see Quaedvlieg et al. (2014; morphology, phylogeny), Wijayawardene et al. (phylogeny, nomenclature), holotype, ex-type strain of the type: CBS H-19934, CBS 106.75.

Euphoriomyces Thaxt. 1931, Laboulbeniaceae, Laboulbeniales, Laboulbeniomycetes, 14 species, type: E. bilateralis Thaxt., asexual morph unknown, parasites, terrestrial, worldwide, see Rossi and Ponziani (2008; new species), Lumbsch and Huhndorf (2010; outline), Lee and $\mathrm{Na}$ (2011; new species), cultures and sequences are unavailable.

Eupropolella Höhn. 1917, Calloriaceae, Helotiales, Leotiomycetes, seven species, type: E. vaccinii (Rehm) Höhn., asexual morph unknown, saprobes, terrestrial, Europe, see Lumbsch and Huhndorf (2010; outline), Kirk et al. (2013; genus accepted), cultures and sequences are unavailable, needs generic revision.

Euryachora Fuckel 1870, Mycosphaerellaceae, Capnodiales, Dothideomycetes, five species, type: E. sedi (Link) Fuckel, asexual morph placosphaeria-like, saprobes, terrestrial, temperate, see Lumbsch and Huhndorf (2010; outline), Kirk et al. (2013; genus accepted), Wijayawardene et al. (2014c; outline), cultures and sequences are unavailable, needs generic revision.

Eurytheca De Seynes 1878, Myriangiaceae, Myriangiales, Dothideomycetes, one species, type: E. monspeliensis De Seynes, asexual morph unknown, saprobes, terrestrial, Trinidad, see Lumbsch and Huhndorf (2010; outline), Kirk et al. (2013; genus accepted), Dissanayake 
et al. (2014; morphology), Wijayawardene et al. (2014c; outline), holotype of the type: F11411.

Eusynaptomyces Thaxt. 1931, Ceratomycetaceae, Laboulbeniales, Laboulbeniomycetes, five species, type: E. borealis Thaxt., asexual morph unknown, parasites, terrestrial, worldwide, see Rossi and Carolina Proaño Castro (2009; compare with Rhachomyces), Lumbsch and Huhndorf (2010; outline), Kirk et al. (2013; genus accepted), cultures and sequences are unavailable.

Euteratosphaeria Quaedvl. \& Crous 2014, Teratosphaeriaceae, Capnodiales, Dothideomycetes, one species, type: E. verrucosiafricana (Crous \& M.J. Wingf.) Quaedvlieg \& Crous, asexual morph unknown, pathogens, terrestrial, Indonesia, have sequence data, see Quaedvlieg et al. (2014; morphology, phylogeny), Wijayawardene et al. (2014c; outline), holotype of the type: CBS H-19705, ex-type strain of type: CBS 118496.

Eutiarosporella Crous 2015, Botryosphaeriaceae, Botryosphaeriales, Dothideomycetes, seven species, type: E. tritici (B. Sutton \& Marasas) Crous, coelomycetous, sexual morph unknown, saprobes, pathogens, terrestrial, cosmopolitan, see Crous et al. (2015b; taxonomy, phylogeny), Thynne et al. (2015; new species, pathogens), Li et al. (2016a; new species, phylogeny), Wijayawardene et al. (2017; outline), holotype and ex-type culture of the type: PREM 60866, CMW 38423.

Eutypa Tul. \& C. Tul. 1863, Diatrypaceae, Xylariales, Sordariomycetes, c. 35 epithets, type: E. lata (Pers.) Tul. \& C. Tul., asexual morph coelomycetous, saprobes, pathogenic, terrestrial, widely distribute, see Lumbsch and Huhndorf (2010; outline), Kirk et al. (2013; genus accepted), Maharachchikumbura et al. (2015, 2016; outline), Senanayake et al. (2015; morphology, phylogeny, new species), Dai et al. (2016; morphology, phylogeny, new species), Almeida et al. (2016; new species), cultures and sequence are available, but lacks for type materials, need generic revision.

Eutypella (Nitschke) Sacc. 1875, Diatrypaceae, Xylariales, Sordariomycetes, two species, type: E. cerviculata (Fr.) Sacc., asexual morph unknown, saprobes, pathology, terrestrial, worldwide, see Carmarán et nal. (2009; Argentina), Lumbsch and Huhndorf (2010; outline), Trouillas et al. (2010, 2011; new species, Australia), Fournier and Lechat (2011; new species), Isaka et al. (2011; endophytes, active compounds), Chacón et al. (2013; Panama, phylogeny), Kirk et al. (2013; genus accepted), Maharachchikumbura et al. (2015, 2016; outline), Almeida et al. (2016; new species, Brazil), Jurc et al. (2016; pathogens), cultures and sequences are available.

Euzodiomyces Thaxt. 1900, Euceratomycetaceae, Laboulbeniales, Laboulbeniomycetes, two species, type: E. lathrobii Thaxt., asexual morph unknown, parasites, terrestrial, worldwide, see Lumbsch and Huhndorf (2010; outline), Kirk et al. (2013; genus accepted), cultures and sequences are unavailable, needs generic revision.

Evanidomus Caball. 1941, Ascomycota genera incertae sedis, one species, type: E. valentinus Caball., coelomycetous, sexual morph unknown, saprobes, terrestrial, Spain, see Wijayawardene et al. (2012, 2017; outline), Kirk et al. (2013; genus accepted), cultures and sequences are unavailable, needs generic revision.

Everhartia Sacc. \& Ellis 1882, Ascomycota genera incertae sedis, three species, type: E. hymenuloides Sacc. \& Ellis, hyphomycetous, sexual morph unknown, saprobes, terrestrial, worldwide, see Wijayawardene et al. (2012, 2017; outline), Kirk et al. (2013; genus accepted), cultures and sequences are unavailable, needs generic revision.

Evernia Ach. 1809, Parmeliaceae, Lecanorales, Lecanoromycetes, ten species, type: E. prunastri (L.) Ach., lichenized, worldwide, see Lumbsch and Huhndorf (2010; outline), Kirk et al. (2013; genus accepted), Lücking et al. (2016b; classification), sequences are available.

Everniicola D. Hawksw. 1982, Ascomycota genera incertae sedis, one species, type: E. flexispora D. Hawksw., coelomycetous, sexual morph unknown, on lichens, terrestrial, 
Europe and North America, see Wijayawardene et al. (2012, 2017; outline), Kirk et al. (2013; genus accepted), cultures and sequences are unavailable, needs generic revision, holotype material of type: E.

Everniopsis Nyl. 1860, Parmeliaceae, Lecanorales, Lecanoromycetes, one species; type: E. trulla (Ach.) Nyl., lichenized, Central and South America, see Lumbsch and Huhndorf (2010; outline), Kirk et al. (2013; genus accepted), Lücking et al. (2016b; classification), sequences are available.

Eversia J.L. Crane \& Schokn. 1977, Ascomycota genera incertae sedis, one species, type: E. subopaca (Cooke \& Ellis) J.L. Crane \& Schokn., hyphomycetous, sexual morph unknown, saprobes, terrestrial, worldwide, see Wijayawardene et al. (2012, 2017; outline), Kirk et al. (2013; genus accepted), cultures and sequences are unavailable, needs generic revision.

Evlachovaea B.A. Borisov \& Tarasov 1999, Ascomycota genera incertae sedis, one species, type: E. kintrischica B.A. Borisov \& Tarasov, hyphomycetous, sexual morph unknown, saprobes, terrestrial, Russia, see Rocha and Luz (2009; fungicides), Wijayawardene et al. (2012, 2017; outline), Humber et al. (2013; DNA), Kirk et al. (2013; genus accepted), cultures and sequences are unavailable, needs generic revision.

Exarmidium P. Karst. 1873, Hyponectriaceae, Xylariales, Sordariomycetes, nine species, type: E. hysteriiforme P. Karst., asexual morph unknown, saprobes, terrestrial, worldwide, see Lumbsch and Huhndorf (2010; outline), Kirk et al. (2013; genus accepted), Maharachchikumbura et al. (2015, 2016; outline), cultures and sequences are unavailable.

Excipularia Sacc. 1884, Ascomycota genera incertae sedis, two species, type: E. fusispora (Berk. \& Broome) Sacc., hyphomycetous, sexual morph unknown, saprobes, terrestrial, Europe, Russia, see Seifert et al. (2011; morphology), Wijayawardene et al. (2012, 2017; outline), Kirk et al. (2013; genus accepted), cultures and sequences are unavailable, needs generic revision.

Excipulariopsis P.M. Kirk \& Spooner 1982 (= Kentingia Sivan. \& W.H. Hsieh 1989 fide Wijayawardene et al. 2014c; Rossman et al. 2015b), Dothideomycetes, genera incertae sedis, two species, type: E. narsapurensis (Subram.) Spooner \& P.M. Kirk, hyphomycetous, sexual morph formerly known in Kentingia, saprobes, terrestrial, India, see Lumbsch and Huhndorf (2010; outline; sexual morph), Seifert et al. (2011; morphology), Wijayawardene et al. (2012, 2014c, 2017; outline, nomenclature), Kirk et al. (2013; genus accepted), Rossman et al. (2015b; nomenclature), cultures and sequences are unavailable, needs generic revision.

Exiliseptum R.C. Harris 1986, Dothideomycetes, genera incertae sedis, two species, type: E. ocellatum (Müll. Arg.) R.C. Harris, asexual morph unknown, saprobes, terrestrial, Brazil, see Lumbsch and Huhndorf (2010; outline, accepted as a genus in Trypetheliaceae), Hyde et al. (2013; excluded from Trypetheliaceae), Kirk et al. (2013; genus accepted), Wijayawardene et al. (2014c; outline, accepted as a genus in Dothideomycetes, genera incertae sedis), cultures and sequences are unavailable, needs generic revision.

Exochalara W. Gams \& Hol.-Jech. 1976, Leotiomycetes genera incertae sedis, two species, type: E. longissima (Grove) W. Gams \& Hol.-Jech., hyphomycetous, sexual morph unknown, saprobes, terrestrial, India, Europe, see Réblová et al. (2011; DNA, phylogeny), Seifert et al. (2011; morphology), Wijayawardene et al. (2012, 2017; outline), Kirk et al. (2013; genus accepted), cultures and sequences are available: CBS 393.82 and CBS 980.73.

Exophiala J.W. Carmich. 1966, Herpotrichiellaceae, Chaetothyriales, Eurotiomycetes, polyphyletic, (the core of the genus belongs in Herpotrichiellaceae, but some species are related to other families of Chaetothyriales, such as Chaetothyriaceae and Trichomeriaceae), c. 41 species, type: E. salmonis J.W. Carmich., predominantly terrestrial, although some species occur in freshwater or sea environments, mostly saprobes associated with soil and plant material, but also occurring as endophytes or as opportunistic pathogens in a wide spectrum of animal hosts, including humans, certain species are common in harsh habitats 
such as rock surfaces or areas contaminated with aromatic hydrocarbons, cosmopolitan, see Zeng and de Hoog (2008; diagnostics of selected species), Crous and Groenewald (2011; new species), Gueidan et al. (2008, 2014a; phylogeny), de Hoog et al. (2011; DNA), Seyedmousavi et al. (2013; pathogenicity to various animals), Zupančič et al. (2016; species in indoor enviroments), Isola et al. (2013, 2016; species associated with polluted habitats and rock surfaces), Maciá-Vicente et al. (2016; new endophytic species), Madrid et al. (2016; phylogeny, some species from soil and river sediments). ex-type: CBS 157.67.

Exophoma Weedon 1926, Ascomycota genera incertae sedis, one species, type: E. magnoliae Weedon, coelomycetous, sexual morph unknown, saprobes, terrestrial, North America, see Sutton (1977; nomenclature), Wijayawardene et al. (2012, 2017; outline), Kirk et al. (2013; genus accepted), cultures and sequences are unavailable, needs generic revision.

Exormatostoma Gray 1821, Diaporthales genera incertae sedis, Sordariomycetes, type: E. nebulosa (Pers.) Gray, see Kirk et al. (2008; treated as nom. dub.), Lumbsch and Huhndorf (2010; outline), Kirk et al. (2013; did not list), Maharachchikumbura et al. (2015, 2016; outline), sequences are unavailable.

Exosporella Höhn. 1912, Ascomycota genera incertae sedis, one species, type: E. symploci Höhn., hyphomycetous, sexual morph unknown, saprobes, terrestrial, Java, see Seifert et al. (2011; morphology), Wijayawardene et al. (2012, 2017; outline), Kirk et al. (2013; did not accept as a valid genus), cultures and sequences are unavailable, needs generic revision.

Exosporiella P. Karst. 1892 (= Anomalemma sivan. 1983 fide Wijayawardene et al. 2014c; Rossman et al. 2015b), Melanommataceae, Pleosporales, Dothideomycetes, one species, type: E. fungorum (Fr.) P. Karst., sexual morph Anomalemma Sivan., saprobes or fungicolous, terrestrial, commonly occur on Corticium species in Europe, see Lumbsch and Huhndorf (2010; outline), Wijayawardene et al. (2012; 2014; 2016; outline, nomenclature), Kirk et al. (2013; genus accepted), Rossman et al. (2015b; nomenclature), Tian et al. (2015; morphology; nomenclature, phylogeny), cultures and sequences are unavailable for both sexual and asexual morphs, needs generic revision.

Exosporium Link 1809, Ascomycota genera incertae sedis, one species, type: E. tiliae Link, hyphomycetous, sexual morph unknown, saprobes, terrestrial, Java, see Seifert et al. (2011; morphology), Wijayawardene et al. (2012, 2017; outline), Kirk et al. (2013; did not accept as a valid genus), cultures and sequences are unavailable, needs generic revision.

Exosporodiella Ganie, Azam \& A.H. Wani 2012, Ascomycota genera incertae sedis, one species, type: Exosporodiella phoenicis Ganie, Azam \& A.H. Wani, coelomycetous, sexual morph unknown, saprobes, terrestrial, India, see Ganie et al. (2012; morphology), holotype of the type: HCIO 50058, cultures and sequences are unavailable, needs generic revision.

Exserohilum K.J. Leonard \& Suggs 1974 (= Setosphaeria K.J. Leonard \& Suggs 1974 fide Wijayawardene et al. 2014c), Pleosporaceae, Pleosporales, Dothideomycetes, c. 30 species, type: E. turcicum (Pass.) K.J. Leonard \& Suggs, hyphomycetous, sexual morph Setosphaeria, on grasses, terrestrial, cosmopolitan, see Seifert et al. (2011; morphology), Wijayawardene et al. (2012, 2014c, 2017; outline, nomenclature), Kirk et al. (2013; genus accepted), Ariyawansa et al. (2015c; phylogeny), Rossman et al. (2015b; nomenclature), cultures and sequences are available.

Exserticlava S. Hughes 1978, Chaetosphaeriaceae, Chaetosphaeriales, Sordariomycetes, seven species, type: E. vasiformis (Matsush.) S. Hughes, hyphomycetous, sexual morph chaetosphaeria-like, saprobes, terrestrial, pantropical, see Seifert et al. (2011; morphology), Wijayawardene et al. (2012, 2017; outline), Maharachchikumbura et al. (2015, 2016; outline, phylogeny), cultures and sequences are available.

Extrawettsteinina M.E. Barr 1972, Pleosporaceae, Pleosporales, Dothideomycetes, four species, type: E. minuta M.E. Barr, asexual morph unknown, saprobes, terrestrial, Europe, North America, see Lumbsch and Huhndorf (2010; outline), Hyde et al. (2013; outline, 
accepted as a genus in Pleosporaceae), Kirk et al. (2013; genus accepted), Wijayawardene et al. (2014c; outline), Ariyawansa et al. (2015c; morphology, taxonomy), cultures and sequences are unavailable.

Extremus Quaedvl. \& Crous 2014, Extremaceae, Capnodiales, Dothideomycetes, hyphomycetous, two species, sexual morph unknown, rock-inhabiting, terrestrial, Antarctica, Spain, have sequence data, see Quaedvlieg et al. (2014; morphology, phylogeny), Wijayawardene et al. (2014c; phylogeny, outline), holotype of the type: CBS 118292, ex-type strain of type: CBS 118292.

Extrusothecium Matsush. 1996, Dothideomycetes genera incertae sedis, one species, type: E. caffrum Matsush., asexual morph unknown, saprobes, terrestrial, see Kirk et al. (2008; treated as a synonym of Leptosphaerulina), Lumbsch and Huhndorf (2010; outline), Kirk et al. (2013; did not list), Wijayawardene et al. (2014c; outline), sequences are unavailable, needs generic revision.

Fabrella Kirschst. 1941, Cenangiaceae, Helotiales, Leotiomycetes, one species, type: F. tsugae (Farl.) Kirschst., asexual morph unknown, saprobes, pathogens, terrestrial, Europe, North America, see Lumbsch and Huhndorf (2010; outline), Kirk et al. (2013; genus accepted), cultures and sequences are available.

Fairmaniella Petr. \& Syd. 1927, Ascomycota genera incertae sedis, one species, type: F. leprosa (Fairm.) Petr. \& Syd., coelomycetous, sexual morph unknown, saprobes, terrestrial, India, see Wijayawardene et al. (2012, 2016; outline, morphology, taxonomic notes), Kirk et al. (2013; genus accepted), holotype of the type: IMI 57994, cultures and sequences are unavailable, needs generic revision.

Falciformispora K.D. Hyde 1992, Trematosphaeriaceae, Pleosporales, Dothideomycetes, three species, type: F. lignatilis K.D. Hyde, asexual morph unknown, saprobes on mangrove wood or pathogenic on human, Mexico, Senegal, see Lumbsch and Huhndorf (2010; outline), Hyde et al. (2013; outline, accepted as a genus in Trematosphaeriaceae), Kirk et al. (2013; genus accepted), Ahmed et al. (2014a; taxonomy, phylogeny), Wijayawardene et al. (2014c; outline), holotype of type species BRIP 16972, cultures and squences are available.

Falcocladium S.F. Silveira, Alfenas, Crous \& M.J. Wingf. 1994, Falcocladiaceae, Falcocladiales, Sordariomycetes, four species, type: F. multivesiculatum S.F. Silveira, Alfenas, Crous \& M.J. Wingf., hyphomycetous, sexual morph unknown, saprobes, terrestrial, India, see Cruz and Gusmão (2009; diversity), Seifert et al. (2011; morphology), Wijayawardene et al. (2012, 2017; outline), Kirk et al. (2013; genus accepted), Jones et al. (2014; phylogeny), Maharachchikumbura et al. (2015, 2016; outline), holotype of the type: PREM 51541, cultures and sequences are available.

Fanniomyces T. Majewski 1972, Laboulbeniaceae, Laboulbeniales, Laboulbeniomycetes, two species, type: F. ceratophorus (Whisler) T. Majewski, asexual morph unknown, parasites, terrestrial, Europe, North America, see Lumbsch and Huhndorf (2010; outline), Kirk et al. (2013; genus accepted), cultures and sequences are unavailable.

Fantasmomyces DongHyeon Lee, Marinc., Z.W. de Beer, M.J. Wingf. 2016, Sordariomycetes genera incertae sedis, one species, type: F. hyalinus DongHyeon Lee, Marinc., Z.W. de Beer, M.J. Wingf., asexual morph hyphomycetous, saprobes, terrestrial, South Africa, see Crous et al. (2016a; taxonomy, phylogeny), holotype and ex-type culture of the type: PREM 61340, CBS 139038.

Farasanispora Abdel-Wahab, Bahkali \& E.B.G. Jones 2016, Pleosporales genera incertae sedis, Dothideomycetes, one species, type: F. avicenniae Abdel-Wahab, Bahkali \& E.B.G. Jones, asexual morph unknown, saprobes, marine, Saudi Arabia, see Li et al. (2016a; taxonomy, phylogeny), holotype and ex-type culture of the type: CBS H-22559, MF 1207.

Farnoldia Hertel 1983, Lecideaceae, Lecideales, Lecanoromycetes, six species, type: F. jurana (Schaer.) Hertel, lichenized, see Lumbsch and Huhndorf (2010; outline), Schmull et al. 
(2011; taxonomy), Kirk et al. (2013; genus accepted), Lücking et al. (2016; classification), sequences are available.

Farriolla Norman 1884, Ascomycota genera incertae sedis, one species, type: F. distans Norman, asexual morph unknown, saprobes, terrestrial, Norway, see Lumbsch and Huhndorf (2010; outline), Kirk et al. (2013; genus accepted), cultures and sequences are unavailable, needs generic revision.

Farrowia D. Hawksw. 1975, Chaetomiaceae, Sordariales, Sordariomycetes, four species, type: F. longicollis (Krzemien. \& Badura) D. Hawksw., asexual morph botyrotrichum-like, on cellulosic substrata, Europe, Asia and North America, see Lumbsch and Huhndorf (2010; outline), Maharachchikumbura et al. (2015, 2016; outline), cultures and sequences are available, lectotype of type: BPI-A 1212.

Fasciatispora K.D. Hyde 1991, Xylariales genera incertae sedis, Sordariomycetes, eight species, type: $F$. nypae K.D. Hyde, asexual morph unknown, saprobes, terrestrial, pantropical, see Lumbsch and Huhndorf (2010; outline), Kirk et al. (2013; genus accepted), Liu et al. (2015a; designate reference speciemen and deposited cultures), Maharachchikumbura et al. (2015, 2016; outline), Wendt et al. (2017; accepted as a genus in Xylariales genera incertae sedis), reference speciemen and available cultures for type: MFLU 15-0042, MFLUCC 11-0382.

Fassia Dennis 1964, Sordariomycetes genera incertae sedis, eight species, type: F. scabrosa Dennis, asexual morph unknown, saprobes, terrestrial, pantropical, see Lumbsch and Huhndorf (2010; outline), Kirk et al. (2013; genus accepted), Maharachchikumbura et al. (2015, 2016; outline), Wendt et al. (2017; accepted as a genus in Sordariomycetes genera incertae sedis), cultures and sequences are unavailable.

Faurelina Locq.-Lin. 1975, Chadefaudiellaceae, Microascales, Sordariomycetes, four species, type: F. fimigena Locq.-Lin., asexual morph arthrographis-like, coprophilous, terrestrial, worldwide, see Lumbsch and Huhndorf (2010; outline), Réblová et al. (2011; DNA), Rossman et al. (2012; DNA), Kirk et al. (2013; genus accepted), Maharachchikumbura et al. (2015, 2016; outline), cultures and sequences are avaible $F$. indica (CBS 301.78), F. elongate.

Fauriea S.Y.Kondr., L.Lőkös \& J.-S.Hur 2016, Teloschistaceae, Teloschistales, Lecanoromycetes, two species, type: F. orientochinensis S.Y. Kondr., X.Y. Wang \& Hur, lichenized, see Kondratyuk et al. (2016b; taxonomy), Lücking et al. (2016b; classification), sequences are available.

Favostroma B. Sutton \& E.M. Davison 1983, Ascomycota genera incertae sedis, one species, type: F. crypticum B. Sutton \& E.M. Davison, coelomycetous, sexual morph unknown, saprobes, terrestrial, Australia, see Wijayawardene et al. (2012, 2017; outline), Kirk et al. (2013; genus accepted), holotype of the type: IMI 266341, cultures and sequences are unavailable, genus need revision.

Feigeana Mies, Lumbsch \& Tehler 1995, Roccellaceae, Arthoniales, Arthoniomycetes, one species, type: F. socotrana Mies, Lumbsch \& Tehler, lichenized, see Lumbsch and Huhndorf (2010; outline), Kirk et al. (2013; genus accepted), Lücking et al. (2016b; classification), sequences unavailable.

Felipes Frisch \& G.Thor 2014, Arthoniales genera incertae sedis, Arthoniomycetes, one species, type: F. leucopellaeus (Ach.) Frisch \& G. Thor, lichenized, see Frisch et al. (2014a; taxonomy), Lücking et al. (2016b; classification), sequences are available.

Felisbertia Viégas 1944, Drepanopezizaceae, Helotiales, Leotiomycetes, seven species, type: F. melastomacearum (Speg.) Viégas, asexual morph unknown, saprobes, terrestrial, South America, see Lumbsch and Huhndorf (2010; outline), Kirk et al. (2013; genus accepted), cultures and sequences are unavailable, needs generic revision. 
Fellhanera Vězda 1986, Pilocarpaceae, Lecanorales, Lecanoromycetes, 97 species, type: F. fuscatula (Müll. Arg.) Vězda, lichenized, see Lumbsch and Huhndorf (2010; outline), Kirk et al. (2013; genus accepted), Kondratyuk et al. (2013b; new species), Lücking et al. (2016b; classification), sequences are available.

Fellhaneropsis Sérus. \& Coppins 1996, Pilocarpaceae, Lecanorales, Lecanoromycetes, seven species, type: F. myrtillicola (Erichsen) Sérus. \& Coppins, lichenized, see Lumbsch and Huhndorf (2010; outline), Kirk et al. (2013; genus accepted), Lücking et al. (2016b; classification), sequences are available.

Feltgeniomyces Dieder. 1990, Ascomycota genera incertae sedis, five species, type: $F$. luxemburgensis, hyphomycetous, lichenicolous, terrestrial, worldwide, see Seifert et al. (2011; morphology), Wijayawardene et al. (2012, 2017; outline), Kirk et al. (2013; genus accepted), holotype of type: Diederich 8477 (LG: holotype; IMI 335016, UPS, herb. Diederich: isotypes), cultures and sequences are unavailable, needs generic revision.

Fenestella Tul. \& C. Tul. 1863, Fenestellaceae, Dothideomycetes families incertae sedis, c. two species, type: F. princeps Tul. \& C. Tul., asexual morph unknown, saprobes or biotrophic or hemibiotrophic, terrestrial, worldwide, see Lumbsch and Huhndorf (2010; outline), Hyde et al. (2013; accepted as a genus in Fenestellaceae), Kirk et al. (2013; genus accepted), Wijayawardene et al. (2014c; outline), Phookamsak and Hyde (2015; taxonomy), cultures and sequences are unavailable.

Fenestroconidia Calatayud \& Etayo 1999, Ascomycota genera incertae sedis, one species, type: F. caloplacae Calat. \& Etayo, hyphomycetous, sexual morph unknown, lichenicolous, terrestrial, Spain, see Seifert et al. (2011; morphology), Wijayawardene et al. (2012, 2017; outline), Kirk et al. (2013; genus accepted), holotype of the type: VAB (lich.) 15301, cultures and sequences are unavailable, needs generic revision.

Ferrarisia Sacc. 1919, Parmulariaceae, Dothideomycetes families incertae sedis, ten species, type: F. philippina Sacc., asexual morph unknown, epiphytes, terrestrial, worldwide, see Hofmann (2009; review), Lumbsch and Huhndorf (2010; outline), Hyde et al. (2013; accepted as a genus in Parmulariaceae), Wijayawardene et al. (2014c; outline), placement in Parmulariaceae is supported by morphology, cultures and sequences are unavailable.

Ferraroa Lücking, Sérus. \& Vězda 2005, Gomphillaceae, Ostropales, Lecanoromycetes, one species, type: F. hyalina (Lücking) Lücking, Sérus. \& Vězda, lichenized, see Lumbsch and Huhndorf (2010; outline), Lücking et al. (2016b; classification), sequences are unavailable.

Fibrillithecis Frisch 2006, Graphidaceae, Ostropales, Lecanoromycetes, 16 species, type: F. vernicosa (Zahlbr.) Frisch, asexual morph unknown, lichenized fungi, terrestrial, tropical, placement in Graphidaceae supported by molecular data, see Rivas Plata et al. (2010a, 2012a; key, taxonomy), Lumbsch and Huhndorf (2010; outline), Lücking et al. (2016b; classification), sequences are available.

Filariomyces Shanor 1952, Laboulbeniaceae, Laboulbeniales, Laboulbeniomycetes, two species, type: F. forficulae Shanor, asexual morph unknown, parasites, terrestrial, Europe, North America, see Lumbsch and Huhndorf (2010; outline), Kirk et al. (2013; genus accepted), cultures and sequences are unavailable.

Filicupula Y.J. Yao \& Spooner 1996, Pezizales genera incertae sedis, Pezizomycetes, two species, type: F. suboperculata (Döbbeler \& P. James) Y.J. Yao \& Spooner, asexual morph unknown, parasites, terrestrial, Europe, see Lumbsch and Huhndorf (2010; outline), Kirk et al. (2013; genus accepted),cultures and sequences are unavailable.

Filiella Videira \& Crous 2016, Mycosphaerellaceae, Capnodiales, Dothideomycetes, one species, type: F. pastinacae (P. Karst.) Videira \& Crous, hyphomycetous, sexual morph unknown, plant pathogenic, see Videira et al. (2016; morphology, phylogeny), cultures and sequences are available, neotype is in HAL. 
Filosporella Nawawi 1976, Helotiaceae, Helotiales, Leotiomycetes, six species, type: F. aquatica Nawawi, hyphomycetous, sexual morph unknown, saprobes, terrestrial, Europe, North America, see Seifert et al. (2011; morphology), Wijayawardene et al. (2012, 2017; outline), Baschien et al. (2013; phylogeny), Kirk et al. (2013; genus accepted), cultures and sequences are available, needs generic revision.

Filsoniana S.Y.Kondr., Kärnefelt, Elix, A.Thell \& Hur 2013, Teloschistaceae, Teloschistales, Lecanoromycetidae, Lecanoromycetes, five species, type: F. australiensis (S.Y. Kondr., Kärnefelt \& Filson) S.Y. Kondr., Kärnefelt, Elix, A. Thell \& J.S. Hur, lichenized, see Kondratyuk et al. (2013a; taxonomy), Lücking et al. (2016b; classification), sequences are available.

Fimetariella N. Lundq. 1964, Lasiosphaeriaceae, Sordariales, Sordariomycetes, one species, type: F. rabenhorstii (Niessl) N. Lundq., asexual morph unknown, saprobes, terrestrial, Europe, Canada, see Lumbsch and Huhndorf (2010; outline), Kirk et al. (2013; genus accepted), Maharachchikumbura et al. (2015, 2016; outline), cultures and sequences are unavailable.

Finkia Vain. 1929, Lichinaceae, Lichinales, Lichinomycetes, one species, type: F. portoricensis Vain., lichenized, see Lumbsch and Huhndorf (2010; outline), Kirk et al. (2013; genus accepted), Lücking et al. (2016b; classification), sequences unavailable.

Fischerula Mattir. 1928, Morchellaceae, Pezizales, Pezizomycetes, two species, type: F. macrospora Mattir., asexual morph unknown, ectomycorrhizal, saprobes, terrestrial, Italy, USA, see Lumbsch and Huhndorf (2010; outline, accepted as Morchellaceae), Trappe et al. (2010; DNA, phylogeny), Alvarado et al. (2011a; DNA, phylogeny, accepted as a genus in Helvellaceae), Healy et al. (2013; DNA, phylogeny, ectomycorrhizal), Kirk et al. (2013; genus accepted), Jaklitsch et al. (2016a; accepted as a genus in Morchellaceae), cultures and sequences are available.

Fissuricella Pore, D'Amatao \& Ajello 1977, Trichosporonaceae, Tremellales, Tremellomycetes, one species, type: F. filamenta, non-filamentous (yeast forming), arthroconidia present, sexual morph unknown, often associated with superficial trichosporonosis, but few cases of disseminated trichosporonosis were reported, human body and bovine mastitis, considered rare, worldwide, ITS sequence data available for ex-type strains, clinical Trichosporon species were reviewed by Taj-Aldeen et al. (2009), Kirk et al. 2013 (genus accepted), ex-type strain of basionym (Prototheca filamenta) of type: CBS 7623 = ATCC $22432=$ JCM $9196=45-681-69$; Ex-type strains of synonym (Parendomyces asteroides) of type: CBS $2481=$ IFM $48559=$ IGC $3471=$ JCM $2937=$ UAMH $7656=$ PYCC 3471.

Fissurina Fée 1824, Graphidaceae, Ostropales, Lecanoromycetes, over 150 species, type: F. dumastii Fée, asexual morph unknown, lichenized, terrestrial, mostly tropical, see Archer (2009; key Australia), Lumbsch and Huhndorf (2010; outline), Lücking et al. (2014, 2016), Kirk et al. (2013; genus accepted), sequences are available

Fissuroma Jian K. Liu, Phook., E.B.G. Jones \& K.D. Hyde 2011, Aigialaceae, Pleosporales, Dothideomycetes, two species, type: F. maculans (Rehm) J.K. Liu, E.B.G. Jones \& K.D. Hyde, asexual morph unknown, saprobes, Japan, Thailand, see Liu et al. (2011b; morphology, DNA, phylogeny), Hyde et al. (2013; accepted as agenus in Aigialaceae), Wijayawardene et al. (2014c; outline), holotype and ex-type of the type: MFLU 11-1143, MFLUCC 10-0886.

Fitzpatrickella Benny, Samuelson \& Kimbr. 1985, Coryneliaceae, Coryneliales, Eurotiomycetes, one species: F. operculata Benny, Samuelson \& Kimbr., asexual morph unknown, terrestrial, parasitic on fruits of Drimys confertifolia Phil., Juan Fernández Island, Chile, see Lumbsch and Huhndorf (2010; outline), Kirk et al. (2013; genus accepted), Wood 
et al. (2016; morphotaxonomy), cultures and sequences are unavailable, needs phylogenetic assessment.

Flabellocladia Nawawi 1985, Ascomycota genera incertae sedis, four species, type: $F$. gigantea, hyphomycetous, from foam, aquatic, worldwide, Seifert et al. (2011; morphology), Wijayawardene et al. (2012, 2017; outline), Fiuza and Gusmão (2013; morphology), Kirk et al. (2013; genus accepted), cultures and sequences are unavailable, needs generic revision.

Flabellospora Alas. 1968, Ascomycota genera incertae sedis, six species, type: F. crassa, hyphomycetous, on submerged plant material, aquatic, worldwide, see Patil et al. (2010; morphology), Seifert et al. (2011; morphology), Wijayawardene et al. (2012, 2017; outline), cultures and sequences are unavailable, needs generic revision.

Flagellosphaeria Aptroot 1995, Amphisphaeriaceae, Xylariales, Sordriomycetes, one species, type: F. polytrichospora (Lucas \& Sousa de Câmara) Aptroot, asexual morph unknown, saprobes, terrestrial, tropical, see Lumbsch and Huhndorf (2010; outline), Kirk et al. (2013; genus accepted), Maharachchikumbura et al. (2015; outline), cultures and sequences are unavailable.

Flagellospora Ingold 1942, Leotiaceae, Helotiales, Leotiomycetes, six species, type: F. curvula Ingold, hyphomycetous, saprobes, aquatic, worldwide, see Seifert et al. (2011; morphology), Wijayawardene et al. (2012, 2017; outline), Baschien et al. (2013; phylogeny), Kirk et al. (2013; genus accepted), Lombard et al. (2014; phylogeny), cultures and sequences are available.

Flakea O.E.Erikss. 1992, Verrucariaceae, Verrucariales, Eurotiomycetes, one species, type: F. papillata O.E. Erikss., lichenized, see Lumbsch and Huhndorf (2010; outline), Lücking et al. (2016b; classification), sequences are available.

Flammeascoma Phook. \& K.D. Hyde 2015, Anteagloniaceae, Pleosporales, Dothideomycetes, two species, type: F. bambusae Phookamsak \& K.D. Hyde, saprobes, terrestrial, Thailand, see Ariyawansa et al. (2015a; taxonomy, new species), Liu et al. (2015a; taxonomy), holotype and ex-type culture of the type: MFLU 10-0061, MFLUCC 10-0551.

Flammispora Pinruan, Sakay., K.D. Hyde \& E.B.G. Jones 2004, Savoryellales, genera incertae sedis, Sordariomycetes, two species, type: F. bioteca Pinruan, Sakay., K.D. Hyde \& E.B.G. Jones, asexual morph unknown, saprobes, Thailand, USA, see Lumbsch and Huhndorf (2010; outline, as a genus in Hypocreomycetidae, genera incertae sedis), Maharachchikumbura et al. (2015, 2016; outline), holotype and ex-type culture of the type: BBH WAH134, BCC13368.

Flammocladiella Crous, L. Lombard \& R.K. Schumach. 2015, Flammocladiaceae, Hypocreales, Sordariomycetes, one species, type: F. aceris Crous, L. Lombard \& R.K. Schumach., asexual morph coelomycetous, saprobes, Germany, see Crous et al. (2015c; taxonomy, phylogeny), Wijayawardene et al. (2017; outline), holotype and ex-type culture of the type: CBS H-22263, CPC 24422.

Flavobathelium Lücking, Aptroot \& G. Thor 1997, Strigulaceae, Strigulales, Dothideomycetes, one species, type: F. epiphyllum Lücking, Aptroot \& G. Thor, asexual morph unknown, lichenized, terrestrial, tropical, see Lumbsch and Huhndorf (2010; outline), Nelsen et al. (2011b; DNA, phylogeny), Hyde et al. (2013; accepted as a genus in Strigulaceae), Kirk et al. (2013; genus accepted), Wijayawardene et al. (2014c; outline), Lücking et al. (2016b; classification), cultures available for the type: MPN67 (fide Nelsen et al. 2011).

Flavocetraria Kärnefelt \& A. Thell 1994, Parmeliaceae, Lecanorales, Lecanoromycetes, three species, type: F. cucullata (Bellardi) Kärnefelt \& A. Thell, asexual morph, unknown, terrestrial, widely distributed, see Lumbsch and Huhndrf (2010; outline), Schmull et al. (2011; phylogeny), Lücking et al. (2016b; classification), sequences are available. 
Flavomyces D.G. Knapp, Kovács, Groenewald \& Crous 2015, Massarinaceae, Pleosporales, Dothideomycetes, one species, type: F. fulophazii D.G. Knapp, Kovács, Groenewald \& Crous, endophytes, see Knapp et al. (2015; phylogeny), cultures and sequences are available.

Flavoparmelia Hale 1986, Parmeliaceae, Lecanorales, Lecanoromycetes, 40 species, type: F. caperata (L.) Hale, asexual morph unknown, lichenized, terrestrial, widely distributed, see Lumbsch and Huhndorf (2010; outline), Kirk et al. (2013; genus accepted), Del-Prado et al. (review, phylogeny), Lücking et al. (2016b; classification), sequences are available.

Flavoplaca Arup, Søchting \& Frödén 2013, Teloschistaceae, Teloschistales, Lecanoromycetes, 27 species, type: F. citrina (Hoffm.) Arup, Frödén \& Søchting, asexual morph unknown, lichenized, terrestrial, widely distributed, see Arup et al. (2013; taxonomy), Helici et al. (2014; taxonomy, molecular), Helici (2015; new records), Vondrak and Malicek (2015; taxonomy), Lücking et al. (2016b; classification), sequences are available.

Flavopunctelia (Krog) Hale 1984, seven species, Parmeliaceae, Lecanorales, Lecanoromycetes, type: F. flaventior (Stirt.) Hale, asexual morph unknown, terrestrial, widely distributed, see Lumbsch and Huhndorf (2010; outline), Schmull et al. (2011; phylogeny, molecular), Divakar et al. (2015; evolutionary study of family), Kirk et al. (2013; genus accepted), Lücking et al. (2016b; classification), sequences are available.

Flegographa A.Massal. 1860, Graphidaceae, Ostropales, Lecanoromycetes, one species, type: F. leprieurii (Mont.) A. Massal., lichenized, see Rivas Plata et al. (2013; taxonomy, reinstated the genus), Lücking et al. (2016b; classification), sequences are available.

Flosculomyces B. Sutton 1978, Ascomycota genera incertae sedis, two species, type: F. floridaensis B. Sutton, hyphomycetous, sexual morph unknown, saprobes, terrestrial, USA, Ivory Coast, see Seifert et al. (2011; morphology), Wijayawardene et al. (2012, 2017; outline), holotype of the type: IMI 215981c, cultures and sequences are unavailable, genus need revision.

Fluctua Marbach 2000, Caliciaceae, Caliciales, Lecanoromycetes, one species, type: F. megapotamica (Malme) Marbach, lichenized, see Lücking et al. (2016b; classification), sequences are unavailable.

Fluminicola S.W. Wong, K.D. Hyde \& E.B.G. Jones 1999, Papulosaceae, Diaportheomycetidae, families incertae sedis, Sordariomycetes, one species, type: $F$. bipolaris S.W. Wong, K.D. Hyde \& E.B.G. Jones, asexual morph unknown, saprobes, Philippines, see Lumbsch and Huhndorf (2010; outline, as a genus in Annulatascaceae), Kirk et al. (2013; genus accepted), Réblová et al. (2013; placed in Papulosaceae), Maharachchikumbura et al. (2015, 2016; outline, accepted as a genus in Papulosaceae), holotype of the type: HKU (M) 3127.

Fluviatispora K.D. Hyde 1994, Halosphaeriaceae, Microascales, Sordariomycetes, three species, type: F. tunicata K.D. Hyde, saprobes, aquatic, Brunei, Papua New Guinea, see Lumbsch and Huhndorf (2010; outline), Kirk et al. (2013; genus accepted), Maharachchikumbura et al (2016), cultures and sequences re unavailable, holotype of type: BRIP 21391.

Fodinomyces Vázquez-Campos \& Neilan 2014, Teratosphaeriaceae, Capnodiales, Dothideomycetes, one species, type: F. uranophilus X. Vázquez-Campos, hyphomycetous, sexual morph unknown, from soil, terrestrial, Australia, see Vazquéz-Campos et al. (2014; morphology, DNA, phylogeny), Wijayawardene et al. (2017; outline), holotype and ex-type culture of the type: CBS 136962.

Foliocryphia Cheew. \& Crous 2009, Cryphonectriaceae, Diaporthales, Sordariomycetes, two species, type: F. eucalypti Cheew. \& Crous, coelomycetous, sexual morph unknown, pathogens, terrestrial, Australia, see Cheewangkoon et al. (2009; morphology, DNA, 
phylogeny), Maharachchikumbura et al. (2015, 2016; outline), holotype and ex-type cultures of type: CBS H-20299, ex-type CPC 12494 = CBS 124779.

Follmannia C.W. Dodge 1967, Teloschistaceae, Teloschistales, Lecanoromycetes, two species, type: F. rufa C.W. Dodge, lichenized, see Arup et al. (2013; reinstated the genus), Lücking et al. (2016b; classification), sequences are available.

Follmanniella Peine \& B. Werner 1995, Roccellaceae, Arthoniales, Arthoniomycetes, one species, type: F. scutellata Peine \& B. Werner, lichenized, see Lumbsch and Huhndorf (2010; outline), Kirk et al. (2013; genus accepted), Lücking et al. (2016b; classification), sequences unavailable.

Fonsecaea Negroni 1936, Herpotrichiellaceae, Chaetothyriales, Eurotiomycetes, eight species, type: F. pedrosoi (Brumpt) Negroni, hyphomycetous, mostly terrestrial, in soil and on plant material, but also reported from aquatic environments, most species are pathogenic to animals, ranging from crustaceans to humans, America, Asia, Europe and Africa, see Vicente et al. (2008, 2012; environmental reservoirs, new species), Najafzadeh et al. (2010, 2011a, 2011b; phylogeny, new species, molecular epidemiology), Seifert et al. (2011; morphology), Wijayawardene et al. (2012, 2017; outline), Kirk et al. (2013; genus accepted), Seyedmousavi et al. (2013; pathogenicity to animals), de Azevedo et al. (2015; new species), ex-neotype: CBS 271.37.

Fontanospora Dyko 1978, Helotiaceae, Helotiales, Leotiomycetes, one species, type: F. eccentrica (R.H. Petersen) Dyko, hyphomycetous, sexual morph unknown, saprobes, aquatic, USA, see Baschien et al. (2013; DNA, phylogeny), Kirk et al. (2013; genus accepted), Wijayawardene et al. (2017; outline), cultures and sequences are available.

Forliomyces Phukhamsakda, Camporesi \& K.D. Hyde 2016, Sporormiaceae, Pleosporales, Dothideomycetes, one species, type: F. uniseptata Phukhamsakda, Camporesi \& K.D. Hyde, coelomycetous, saprobes, terrestrial, Italy, see Phukhamsakda et al. (2016; taxonomy, phylogeny), Wijayawardene et al. (2016b, 2017; taxonomy, outline), holotype and ex-type culture of the type: MFLU 16-0031, MFLUCC 15-0765.

Fouragea Trevis. 1880, Opegraphaceae, Arthoniales, Arthoniomycetes, three species, type: F. filicina (Mont.) Trevis., lichenized, see Frisch et al. (2014a; reinstated), Lücking et al. (2016b; classification), sequences are available.

Foveostroma DiCosmo 1978, Ascomycota genera incertae sedis, six species, type: $F$. drupacearum (Lév.) DiCosmo, coelomycetous, sexual morph unknown, saprobes, terrestrial, worldwide, see Wijayawardene et al. (2012, 2017; outline), Kirk et al. (2013; genus accepted), cultures and sequences are unavailable, needs generic revision.

Fracchiaea Sacc. 1873, Nitschkiaceae, Coronophorales, Sordariomycetes, three species, type: F. heterogenea Sacc., asexual morph unknown, lichenicolous, terrestrial, South America, see Lumbsch and Huhndorf (2010; outline), Mugambi and Huhndorf (2010; DNA), Vasilyeva et al. (2010; new species), Maharachchikumbura et al. (2015, 2016; outline), cultures and sequences are available for Fracchiaea broomeana (SMH347 fide Mugambi and Huhndorf 2010).

Fragosphaeria Shear 1923, Ophiostomataceae, Ophiostomatales, Sordariomycetes, four species, type: $F$. purpurea Shear, asexual morph hyphomycetous, from soil, pathogens (human), worldwide, see Yaguchi et al. (2006; DNA), Lumbsch and Huhndorf (2010; outline), Kirk et al. (2013; did not accept), Maharachchikumbura et al. (2015, 2016; outline), cultures available for type: CBS 133.34.

Franwilsia S.Y. Kondr., Kärnefelt, Elix, A.Thell \& Hur 2014, Teloschistaceae, Teloschistales, Lecanoromycetes, three species, type: F. bastowii (S.Y. Kondr. \& Kärnefelt) S.Y. Kondr., Kärnefelt, Elix, A. Thell, J. Kim, A.S. Kondr. \& Hur; lichenized, see Kondratyuk et al. (2014a; taxonomy), Lücking et al. (2016b; classification), sequences are available. 
Fremineavia Nieuwl. 1916, Melanconidaceae, Diaporthales, Sordariomycetes, four species, type: Fremineavia berkeleyi (Berl.) Nieuwl., asexual morph unknown, saprobes, North America, see Kirk et al. (2013; genus accepted), Maharachchikumbura et al. (2015, 2016; outline), cultures and sequences are unavailable.

Fremitomyces P.F. Cannon \& H.C. Evans 1999, Phyllachoraceae, Phyllachorales, Sordariomycetes, two species, type: F. punctatus P.F. Cannon \& H.C. Evans, sexual morph unknown, saprobes, terrestrial, East Africa, Seychelles, see Lumbsch and Huhndorf (2010; outline), Kirk et al. (2013; genus accepted), Maharachchikumbura et al. (2015, 2016; outline), cultures and sequences are unavailable.

Friedmanniomyces Onofri 1999, Teratosphaeriaceae, Capnodiales, Dothideomycetes, two species, type: F. endolithicus Onofri, hyphomycetous, sexual morph unknown, saprobes, terrestrial, Antarctica, see Schoch et al. (2009; phylogeny), Selbmann et al. (2008, 2014; DNA, review, phylogeny), Wijayawardene et al. (2012, 2014c, 2017; outline), Hyde et al. (2013; accepted as a genus in Teratosphaeriaceae), Kirk et al. (2013; genus accepted), Egidi et al. (2014; phylogeny), Ertz et al. (2014b; phylogeny), Quaedvlieg et al. (2014; phylogeny), cultures available for the type: CBS 119427= CCFEE 524.

Frigidispora K.D. Hyde \& Goh 1999, Ascomycota genera incertae sedis, six species, type: $F$. colnensis K.D. Hyde \& Goh, coelomycetous, sexual morph unknown, saprobes, aquatic, British Isles, see Wijayawardene et al. (2012, 2017; outline), Kirk et al. (2013; genus accepted), cultures and sequences are unavailable, needs generic revision.

Frigidopyrenia Grube 2005, Ascomycota genera incertae sedis, one species, type: $F$. bryospila (Nyl.) Grube, lichenized, subarctic, see Lumbsch and Huhndorf (2010; outline, accepted as a genus in Xanthopyreniaceae), Lücking et al. (2016b; classification), sequences are unavailable.

Frondicola K.D. Hyde 1992, Hyponectriaceae, Xylariales, Sordariomycetes, nine species, type: F. tunitricuspis K.D. Hyde, asexual morph unknown, saprobes, terrestrial, Brunei, see Lumbsch and Huhndorf (2010; outline), Kirk et al. (2013; genus accepted), Maharachchikumbura et al. (2015, 2016; outline), cultures and sequences are unavailable.

Frondisphaeria K.D. Hyde 1996, Dothideomycetes genera incertae sedis, two species, type: F. palmicola K.D. Hyde, asexual morph unknown, saprobes, terrestrial, Brazil, see Lumbsch and Huhndorf (2010; outline, misspelled as Frondisphaera), Kirk et al. (2013; genus accepted), Maharachchikumbura et al. (2015, 2016; outline, misspelled as Frondisphaera), cultures and sequences are unavailable, needs generic revision.

Frondispora K.D. Hyde 1993, Amphisphaeriaceae, Xylariales, Sordariomycetes, one species, type: F. bicalcarata (Ces.) K.D. Hyde, asexual morph unknown, saprobes, terrestrial, Europe, see Lumbsch and Huhndorf (2010; outline), Kirk et al. (2013; genus accepted), Maharachchikumbura et al. (2015, 2016; outline), cultures and sequences are available.

Frutidella Kalb 1994, Ramalinaceae, Lecanorales, Lecanoromycetes, two species, type: F. caesioatra (Schaer.) Kalb, lichenized, see Lumbsch and Huhndorf (2010; outline), Kirk et al. (2013; genus accepted), Lücking et al. (2016b; classification), sequences are available.

Fujimyces Minter \& Caine 1980, Ascomycota genera incertae sedis, two species, type: $F$. oödes (Bayl. Ell.) Minter \& Caine, coelomycetous, sexual morph unknown, saprobes, terrestrial, British Isles, see Wijayawardene et al. (2012, 2017; outline), Kirk et al. (2013; genus accepted), holotype of the type: IMI35344, cultures and sequences are unavailable, needs generic revision.

Fulgidea Bendiksby \& Timdal 2013, Umbilicariaceae, Umbilicariales, Lecanoromycetes, two species, type: F. oligospora (Timdal) Bendiksby \& Timdal, lichenized, see Bendiksby and Timdal (2013; taxonomy), Lücking et al. (2016b; classification), sequences are available. holotype of type species: O-L-767, 
Fuligomyces Morgan-Jones \& Kamal 1984, Ascomycota genera incertae sedis, two species, type: F. macrosporus, asexual morph hyphomycetous, saprobes (symptoms on leaves similar to sooty mould), terrestrial, India, (Seifert et al. (2011; morphology), Wijayawardene et al. (2012, 2017; outline), Kirk et al. (2013; genus accepted), holotype of type: AUA, IMI 248960, GPU (KA 69), cultures and sequences are unavailable, needs generic revision.

Fulvia Cif. 1954, Mycosphaerellaceae, Capnodiales, Dothideomycetes, one species, type: F. fulva (Cooke) Cif., hyphomycetous, sexual morph unknown, on Lycopersicon esculentum, plant pathogenic, see Videira et al. (2016; morphology, phylogeny), holotype BPI 426698, for epitypification see Videira et al. (2017).

Fulvocentrum E.B.G. Jones \& Abdel-Wahab 2014, Juncigenaceae, Torpedosporales, Sordariomycetes, two species, type: F. aegyptiaca (Abdel-Wahab, El-Shar. \& E.B.G. Jones) E.B.G. Jones \& Abdel-Wahab, asexual morph undermined, marine, tropical/subtropical, see Jones et al. (2014, 2015; morphology, phylogeny, outline), Maharachchikumbura et al. (2015, 2016; outline), cultures and sequences are available.

Fulvoflamma Crous 2006, Helotiales genera incertae sedis, Leotiomycetes, one species, type: F. eucalypti Crous, coelomycetous, sexual morph unknown, saprobes, endophytes, terrestrial, Spain, see Wijayawardene et al. (2012, 2017; outline), holotype and ex-type strains of the type: CBS H-18045, 1243 = CBS 118549.

Fulvophyton Ertz \& Tehler 2011, Roccellographaceae, Arthoniales, Arthoniomycetes, nine species, type: F. stalactinum (Nyl.) Ertz \& Tehler, sexual morph with punctiform or shortly lirellate ascomata, lichenized, terrestrial, tropical, see Ertz and Tehler (2011; morphology, phylogeny), Tehler et al. (2013a; one new combination), Lücking et al. (2016a; classification), sequences are available.

Fumagopsis Speg. 1911, Ascomycota genera incertae sedis, two species, type: $F$. triglifioides, hyphomycetous, sexual morph unknown, saprobes or plant pathogenic on plant leaves, terrestrial, known from Argentina and India, see Seifert et al. (2011; morphology), Wijayawardene et al. (2012, 2017; outline), Kirk et al. (2013; genus accepted), holotype of type: in LPS, cultures and sequences are unavailable, needs generic revision.

Fumiglobus D.R. Reynolds \& G.S. Gilbert 2006, Capnodiaceae, Capnodiales, Dothideomycetes, 15 species, type: F. ficinus (Bat., Nascim. \& Cif.) D.R. Reynolds \& G.S. Gilbert, coelomycetous, sexual morph unknown, saprobes, terrestrial, cosmopolitan, see Wijayawardene et al. (2014c; outline), Bose et al. (2014; DNA, new species), cultures and sequences are available, needs generic revision.

Funbolia Crous \& Seifert 2011, Dothideomycetes genera incertae sedis, one species, type: $F$. dimorpha Crous \& Seifert, hyphomycetous, sexual morph unknown, saprobes, terrestrial, USA, see Crous et al. (2011a; morphology, DNA), Wijayawardene et al. (2012, 2014c; outline), holotype and ex-type strains of the type: CBS H-20577, CPC 14170.

Funiliomyces Aptroot 2004, Amphisphaeriaceae, Xylariales, Sordriomycetes, one species, type: F. biseptatus Aptroot, asexual morph unknown, saprobes, terrestrial, tropical, see Lumbsch and Huhndorf (2010; outline), Kirk et al. (2013; genus accepted), Maharachchikumbura et al. (2015, 2016; outline), sequences are available for the type: AY772015 (LSU) (fide Aptroot 2004).

Furcaspora Bonar 1965, Ascomycota genera incertae sedis, two species, type: F. pinicola Bonar, coelomycetous, sexual morph unknown, saprobes, terrestrial, USA, Australia, see Wijayawardene et al. (2012, 2017; outline), Kirk et al. (2013; genus accepted), holotype of the type: IMI35344, ex-type cultures and sequences are available for Furcaspora eucalypti Crous \& Verkley (CPC $12556=$ CBS 119111), needs generic revision.

Fusamen (Sacc.) P. Karst. 1890, Ascomycota genera incertae sedis, two species, type: $F$. fungicola P. Karst., coelomycetous, sexual morph unknown, saprobes, terrestrial, Euope, see 
Wijayawardene et al. (2012, 2017; outline), Kirk et al. (2013; genus accepted), cultures and sequences are unavailable, needs generic revision.

Fusariella Sacc. 1884, Ascomycota genera incertae sedis, 19 species, type: F. atrovirens, asexual morph hyphomycetous, on plants, leaf litter, dung and in soil, terrestrial, worldwide, Seifert et al. (2011; morphology), Wijayawardene et al. (2012, 2017; outline), Kirk et al. (2013; genus accepted), cultures and sequences are available (unpublished), needs generic revision.

Fusarium Link 1809 (= Gibberella Sacc. 1877 fide Maharachchikumbura et al. 2016; see Lombard et al. 2015 for all synonyms), Nectriaceae, Hypocreales, Sordariomycetes, c. 120 species, type: F. sambucinum Fuckel, hyphomycetous, sexual morph Gibberella, terrestrial, pathogens, worldwide, see Seifert et al. (2011; morphology), Wijayawardene et al. (2012, 2017; outline), Lombard et al. (2015b; phylogeny, taxonomy), Maharachchikumbura et al. (2015, 2016; outline), cultures and sequences are available.

Fuscidea V.Wirth \& Vězda 1972, Fuscideaceae, Umbilicariales, Lecanoromycetes, 35 species, type: F. aggregata (Flot.) V. Wirth \& Vězda, lichenized, see Lumbsch and Huhndorf (2010; outline), Bendiksby and Timdal (2013; taxonomy), Kirk et al. (2013; genus accepted), Miądlikowska et al. (2014a; taxonomy), Lücking et al. (2016b; classification), sequences are available.

Fuscoderma (D.J. Galloway \& P.M. Jørg.) P.M. Jørg. \& D.J. Galloway 1989, Pannariaceae, Peltigerales, Lecanoromycetes, five species, type: F. applanatum (D.J. Galloway \& P.M. Jørg.) P.M. Jørg. \& D.J. Galloway, lichenized, see Lumbsch and Huhndorf (2010; outline), Kirk et al. (2013; genus accepted), Lücking et al. (2016b; classification), sequences are available.

Fuscolachnum J.H. Haines 1989, Hyaloscyphaceae, Helotiales, Leotiomycetes, seven species, type: F. pteridis (Alb. \& Schwein.) J.H. Haines, asexual morph unknown, saprobes, epiphytes, terrestrial, Europe, North America, see Lumbsch and Huhndorf (2010; outline), Kirk et al. (2013; genus accepted), cultures and sequences are unavailable, needs generic revision.

Fuscopannaria P.M. Jørg. [nom. cons. prop.] 1994 (= Kroswia P.M. Jørg. 2002 ; = Moelleropsis Gyeln. 1939 fide Jørgensen et al. 2013; Species Fungorum 2017), Pannariaceae, Peltigerales, Lecanoromycetes, 58 species, type: F. leucosticta (Tuck.) P.M. Jørg., lichenized, see Ekman et al. (2014; taxonomy), Lumbsch and Huhndorf (2010; outline), Kirk et al. (2013; genus accepted), Jørgensen et al. (2013; Fuscopannaria over Moelleropsis), Lücking et al. (2016b; classification), sequences are available.

Fuscophialis B. Sutton 1977, Ascomycota genera incertae sedis, four species, type: $F$. brasiliensis B. Sutton, hyphomycetous, sexual morph unknown, saprobes, terrestrial, Brazil, Cuba, Mauritius, see Seifert et al. (2011; morphology), Wijayawardene et al. (2012, 2017; outline), holotype of the type:, cultures and sequences are unavailable, genus need revision.

Fuscostagonospora Kaz. Tanaka \& K. Hiray. 2015, Pleosporales genera incertae sedis, Dothideomycetes, one species, type: F. sasae Kaz. Tanaka \& K. Hiray., coelomycetous, saprobes, terrestrial, Japan, see Tanaka et al. (2015; morphology, phylogeny), Wijayawardene et al. (2016b; taxonomy), holotype and ex-type strain of the type: HHUF 29106, CBS 139687. Fusichalara S. Hughes \& Nag Raj 1973, Ascomycota genera incertae sedis, two species, type: F. dimorphospora S. Hughes \& Nag Raj, hyphomycetous, sexual morph unknown, saprobes, terrestrial, worldwide, see Seifert et al. (2011; morphology), Wijayawardene et al. (2012; outline, treated as a genus in Chaetosphaeriaceae), Kirk et al. (2013; genus accepted), Maharachchikumbura et al. (2016; excluded from Chaetosphaeriaceae and placed in Ascomycota genera incertae sedis), cultures and sequences are unavailable, needs generic revision. 
Fusicladiella Höhn. 1919, Ascomycota genera incertae sedis, five species, type: F. aronici (Sacc.) Höhn., hyphomycetous, sexual morph unknown, saprobes, terrestrial, North America, see Seifert et al. (2011; morphology) and Wijayawardene et al. (2012; treatd as Mycosphaerellaceae), Kirk et al. (2013; genus accepted), Wijayawardene et al. (2017; outline), cultures and sequences are unavailable, needs generic revision.

Fusicladium Bonord. 1851, Sympoventuriaceae, Venturiales, Dothideomycetes, c. 75 species, type: P. virescens Bonord., hyphomycetous, sexual morph unknown, saprobes, terrestrial, cosmopolitan, see Braun (2009; new species), Seifert et al. (2011; morphology), Crous et al. (2016b; new species, phylogeny), Wijayawardene et al. (2017; outline), cultures are available. Fusicolla Bonord. 1851, Nectriaceae, Hypocreales, Sordariomycetes, eight species, type: F. betae Bonord., hyphomycetous, holomorph, diverse substrates and hosts, terrestrial and aquatic, worldwide, see Gräfenhan et al. (2011; DNA, phylogeny) Lombard et al. (2015b; phylogeny), Maharachchikumbura et al. (2015, 2016; outline), Crous et al. (2016a; new species, phylogeny), cultures and sequences are available.

Fusoidiella Videira \& Crous 2016, Mycosphaerellaceae, Capnodiales, Dothideomycetes, two species, type: F. depressa (Berk. \& Broome) Videira \& Crous, hyphomycetous, sexual morph mycosphaerella-like, plant pathogenic, see Videira et al. (2016; morphology, phylogeny), no ex-type strain available, authentic specimen (herb. K(M) 29181, on Angelica sylvestris, Great Britain).

Fusoidispora Vijaykr., Jeewon \& K.D. Hyde 2005, Annulatascaceae, Annulatascales, Sordariomycetes, one species, type: F. aquatica Vijaykr., Jeewon \& K.D. Hyde, asexual morph unknown, saprobes, aquatic, Hong Kong, see Lumbsch and Huhndorf (2010; outline), Kirk et al. (2013; genus accepted), Maharachchikumbura et al. (2015, 2016; outline), holotype of the type: HKU (M) 17484, cultures and sequences are available.

Fusticeps Webster \& R.A. Davey 1980, Ascomycota genera incertae sedis, five species, type: F. bullatus Webster \& R.A. Davey, hyphomycetous, sexual morph unknown, on plant litter in water, aquatic, Tropics, see Seifert et al. (2011; morphology), Wijayawardene et al. (2012, 2017; outline), Kirk et al. (2013; genus accepted), Chuaseeharonnachai et al. (2014; key), holotype of type: IMI 245198, cultures and sequences are unavailable, needs generic revision. Gaeumanniella Petr. 1952, Ascomycota genera incertae sedis, one species, type: $G$. singularis Petr., asexual morph unknown, saprobes, terrestrial, USA, see Lumbsch and Huhndorf (2010; outline), Kirk et al. (2013; genus accepted), cultures and sequences are unavailable, needs generic revision.

Gaeumannomyces Arx \& D.L. Olivier 1952 (= Harpophora W. Gams 2000 fide Jing et al. 2015), Magnaporthaceae, Magnaporthales, Sordariomycetes, c. 13 species, type: G. graminis (Sacc.) Arx \& D.L. Olivier, asexual morph unknown, saprobes, terrestrial, worldwide, see Lumbsch and Huhndorf (2010; outline), Zhang et al. (2011c; phylogeny), Kirk et al. (2013; genus accepted), Jing et al. (2015; phylogeny), Luo et al. (2015; new species, phylogeny), Maharachchikumbura et al. (2015, 2016; outline), cultures and sequences are available.

Gaillardiella Pat. 1895, Bertiaceae, Coronophorales, Sordariomycetes, one species, type: Gaillardiella pezizoides Pat., asexual morph unknown, saprobes, terrestrial, South America, see Mugambi and Huhndorf (2010; DNA, phylogeny), Lumbsch and Huhndorf (2010; outline), Kirk et al. (2013; genus accepted), Maharachchikumbura et al. (2016; outline, phylogeny), cultures available for the type: GKM1245.

Galactomyces Redhead \& Malloch 1977, ?Dipodascaceae, Saccharomycetales, Saccharomycetes, five species, type: G. geotrichum (E.E. Butler \& L.J. Petersen) Redhead \& Malloch, asexual reproduction is present, saprophytic, soil, rotted fruit and other plant parts, tree exudates, worldwide, see Lumbsch and Huhndorf (2010; outline), Kirk et al. (2013; genus accepted), sequences are available. 
Galeoscypha Svrček \& J. Moravec 1989, Pyronemataceae, Pezizales, Pezizomycetes, one species, type: G. pileiformis (Svrček) Svrček \& J. Moravec, asexual morph unknown, saprobes, terrestrial, Europe, see Lumbsch and Huhndorf (2010; outline), Kirk et al. (2013; genus accepted), cultures and sequences are unavailable.

Galiella Nannf. \& Korf 1957, Sarcosomataceae, Pezizales, Pezizomycetes, eight species, type: G. rufa (Schwein.) Nannf. \& Korf, asexual morph unknown, saprobes, terrestrial, North temperate, see Lumbsch and Huhndorf (2010; outline), Kirk et al. (2013; genus accepted), cultures and sequences are available.

Galiicola Tibpromma, Camporesi \& K.D. Hyde 2015, Phaeosphaeriaceae, Pleosporales, Dothideomycetes, one species, type: Galliicola pseudophaeosphaeria Tibpromma, Camporesi \& K.D. Hyde, asexual morph unknown, saprobes, terrestrial, Italy, see Ariyawansa et al. (2015a; taxonomy, phylogeny), cultures available for type: MFLUCC 14-0524.

Gampsonema Nag Raj 1975, Ascomycota genera incertae sedis, one species, type: G.. exile (Tassi) Nag Raj, coelomycetous, sexual morph unknown, saprobes, terrestrial, worldwide, Wijayawardene et al. (2012, 2017; outline), Kirk et al. (2013; genus accepted), cultures and sequences are unavailable, needs generic revision.

Gamsia M. Morelet 1969, Microascaceae, Microascales, Sordariomycetes, three species, type: G. dimera (W. Gams) M. Morelet, hyphomycetous, sexual morph unknown, saprobes, terrestrial, worldwide, Wijayawardene et al. (2012, 2017; outline), Kirk et al. (2013; genus accepted), Sandoval-Denis et al. (2016b; DNA, phylogeny), cultures and sequences are available for $G$. simplex (CBS 546.69) and $G$. aggregata (CBS 251.69), needs generic revision.

Gamsylella M. Scholler, Hagedorn \& A. Rubner 1999, Orbiliaceae, Orbiliales, Orbiliomycetes, type: G. arcuata (Scheuer \& J. Webster) M. Scholler, Hagedorn \& A. Rubner, cf. six species, hyphomycetous, saprobes, terrestrial, worldwide, see Seifert et al. (2011; morphology), Wijayawardene et al. (2012, 2017; outline), Kirk et al. (2013; genus accepted), cultures and sequences are available.

Gangliophora Subram. 1992, Ascomycota genera incertae sedis, one species, type: $G$. casuarinae (Matsush.) Subram., hyphomycetous, sexual morph unknown, saprobes, terrestrial, Taiwan, see Seifert et al. (2011; morphology), Wijayawardene et al. (2012, 2017; outline), Kirk et al. (2013; genus accepted), cultures and sequences are unavailable, needs generic revision.

Gangliostilbe Subram. \& Vittal 1976, Ascomycota genera incertae sedis, one species, type: G. indica Subram. \& Vittal, hyphomycetous, sexual morph unknown, saprobes, terrestrial, pantropical, see Seifert et al. (2011; morphology), Wijayawardene et al. (2012, 2017; outline), Kirk et al. (2013; genus accepted), Ma et al. (2014; new species, China), cultures and sequences are unavailable, needs generic revision.

Garnaudia Borowska 1977, Ascomycota genera incertae sedis, three species, type: $G$. elegans Borowska, hyphomycetous, synanamorph selenosporella-like, on wood, bark and dead leaves, terrestrial, Cuba, Poland, see Seifert et al. (2011; morphology), Wijayawardene et al. (2012, 2017; outline), Kirk et al. (2013; genus accepted), holotype of type: WA 20592, cultures and sequences are unavailable, needs generic revision.

Gassicurtia Feé 1825, Caliciaceae, Caliciales, Lecanoromycetes, 27 species, type: G. coccinea Fée, lichenized, see Lumbsch and Huhndorf (2010; outline), Gaya et al. (2012; taxonomy), Lücking et al. (2016b; classification), Prieto and Wedin (2016; phylogeny), sequences are available.

Gaubaea Petr. 1942, Ascomycota genera incertae sedis, two species, type: G. insignis Petr., coelomycetous, sexual morph unknown, saprobes, terrestrial, central Asia, see Wijayawardene et al. (2012, 2016, 2017; outline, morphology), Kirk et al. (2013; genus accepted), cultures and sequences are unavailable, needs generic revision. 
Geastrumia Bat. 1960, Ascomycota genera incertae sedis, one species, type: G. polystigmatis Bat. \& M.L. Farr, coelomycetous, sexual morph unknown, saprobes, terrestrial, worldwide, see Wijayawardene et al. (2012, 2017; outline), Kirk et al. (2013; genus accepted), cultures and sequences are unavailable, needs generic revision.

Geejayessia Schroers, Gräfenhan \& Seifert 2011, Nectriaceae, Hypocreales, Sordariomycetes, c. five species, type: G. cicatricum (Berk.) Schroers (current name: Fusarium cicatricum (Berk.) O'Donnell \& Geiser fide Geiser et al. 2013), sexual morph unknown, saprobes, pathogens, terrestrial, cosmopolitan, see Geiser et al. 2013; treated the type species as a synonym of Fusarium cicatricum), Maharachchikumbura et al. (2015, 2016), needs generic revision, cultures and sequences are available.

Geisleria Nitschke 1861, Stictidaceae, Ostropales, Lecanoromycetes, one species, type: G. sychnogonoides Nitschke, lichenized, see Aptroot et al. (2015b; taxonomy), Lücking et al. (2016b; classification), sequences are available.

Gelasinospora Dowding 1933, Sordariaceae, Sordariales, Sordariomycetes, one species, type: G. tetrasperma Dowding, asexual morph unknown, saprobes, terrestrial, Ivory Coast, see Lumbsch and Huhndorf (2010; outline), Nygren et al. (2011; DNA, phylogeny), Kirk et al. (2013; genus accepted), Maharachchikumbura et al. (2015, 2016; outline, phylogeny), cultures and sequences are available for type: ATCC 11345.

Gelatinipulvinella Hosoya \& Y. Otani 1995 (= Aureohyphozyma Hosoya \& Y. Otani fide Johnston et al. 2014b), Helicogoniaceae, Phacidiales, Leotiomycetes, two species, type: G. astraeicola Hosoya \& Y. Otani, asexual morph hyphomycetous, saprobe, marine, worldwide, see Lumbsch and Huhndorf (2010; outline), Kirk et al. (2013; genus accepted), Johnston et al. (2014b; nomenclature), holotype of the type: TNS-F-52070.

Gelatinocrinis Matsush. 1995, Ascomycota genera incertae sedis, one species, type: $G$. roseus Matsush., hyphomycetous, sexual morph unknown, saprobes, terrestrial, Japan, see Seifert et al. (2011; morphology), Wijayawardene et al. (2012, 2017; outline), Kirk et al. (2013; genus accepted), cultures and sequences are unavailable, needs generic revision.

Gelatinomyces N. Sanoamuang, W. Jitjak, S. Rodtong \& A.J.S. Whalley 2013, Leotiomycetes genera incertae sedis, one species, type: G. siamensis N. Sanoamuang, W. Jitjak, S. Rodtong \& A.J.S. Whalley, asexual morph hyphomycetous, saprobes, terrestrial, Thailand, see Sanoamuang et al. (2013; morphology, DNA, phylogeny), Jaklitsch et al. (2016a; classification, treated as a synonym of Myriodiscus), holotype and ex-type cultures of the type: K(M) 188078, CBS 135071, close to Leotiomycetes in phylogenetic analyses.

Gelatinopsis Rambold \& Triebel 1990, Helicogoniaceae, Phacidiales, Leotiomycetes, cf. eight species, type: G. geoglossi (Ellis \& Everh.) Rambold \& Triebel, asexual morph unknown, saprobes, lichenicolous, terrestrial, worldwide, see Navarro-Rosinés et al. (2008; new species), Kocourková and Knudsen (2009; new species), Lumbsch and Huhndorf (2010; outline), Kirk et al. (2013; genus accepted), cultures and sequences are unavailable, needs generic revision.

Gelatinopycnis Dyko \& B. Sutton 1979, Ascomycota genera incertae sedis, one species, type: G. hartigiana (Allesch.) Dyko \& B. Sutton, coelomycetous, sexual morph unknown, saprobes, terrestrial, Japan, see Wijayawardene et al. (2012, 2017; outline), Kirk et al. (2013; genus accepted), cultures and sequences are unavailable, needs generic revision.

Gelatinosporium Peck 1873, Ascomycota genera incertae sedis, one species, type: $G$. betulinum Peck, coelomycetous, sexual morph unknown, saprobes, terrestrial, USA, see Wijayawardene et al. (2012, 2017; outline), Kirk et al. (2013; genus accepted), cultures and sequences are unavailable, needs generic revision.

Gelineostroma H.J. Swart 1988, Rhytismataceae, Rhytismatales, Leotiomycetes, one species, type: G. athrotaxis H.J. Swart, asexual morph unknown, saprobes, terrestrial, Australia, see 
Lumbsch and Huhndorf (2010; outline), Kirk et al. (2013; genus accepted), cultures and sequences are unavailable, needs generic revision.

Geltingia Alstrup \& D. Hawksw. 1990, Helicogoniaceae, Phacidiales, Leotiomycetes, one species, type: G. associata (Th.Fr.) Alstrup \& D. Hawksw., asexual morph unknown, on lichens, terrestrial, Arctic, see Lumbsch and Huhndorf (2010; outline, accepted as a genus in Odontotremataceae), Kirk et al. (2013; genus accepted), Suija et al. (2014; phylogeny), Jaklitsch et al.(2016; position), holotype of type: UPS, cultures and sequences are unavailable, needs generic revision.

Geminispora Pat. 1893, Phyllachoraceae, Phyllachorales, Sordariomycetes, two species, type: G. mimosae Pat., sexual morph unknown, saprobes, terrestrial, East Africa, Seychelles, see Lumbsch and Huhndorf (2010; outline), Kirk et al. (2013; genus accepted), Maharachchikumbura et al. (2015, 2016; outline), cultures and sequences are unavailable.

Geminoarcus K. Ando 1993, Ascomycota genera incertae sedis, three species, type: $G$. pachysporus K. Ando, hyphomycetous, sexual morph unknown, saprobes, terrestrial, Japan, see Seifert et al. (2011; morphology), Wijayawardene et al. (2012, 2017; outline), Kirk et al. (2013; genus accepted), cultures and sequences are unavailable, needs generic revision.

Gemmaspora D. Hawksw. \& Halici 2007, Verrucariaceae, Verrucariales, Eurotiomycetes, one species, type: G. lecanorae (Werner) D. Hawksw. \& Halici, lichenicolous, Syria, Turkey and Uzbekistan, see Lumbsch and Huhndorf (2010; outline), Jaklitsch et al. (2016a; position), holotype of type: BC and epitype ERC- MGH 02274, cultures and sequences are unavailable, needs generic revision.

Gemmulina Descals \& Marvanová 1999, Ascomycota genera incertae sedis, one species, type: G. botryosa (Descals) Descals \& Marvanová, asexual morph hyphomycetous, has a yeast-like phase, from foam in streams, aquatic, Canada and United Kingdom, see Seifert et al. (2011; morphology), Wijayawardene et al. (2012, 2017; outline), Kirk et al. (2013; genus accepted), holotype of type: IMI 254853, cultures and sequences are unavailable, needs generic revision.

Genea Vittad. 1831, Pyronemataceae, Pezizales, Pezizomycetes, one species, type: $G$. pileiformis (Svrček) Svrček \& J. Moravec, asexual morph unknown, saprobes, terrestrial, Europe, see Lumbsch and Huhndorf (2010; outline), Kirk et al. (2013; genus accepted), Alvarado et al. (2014; new species, phylogeny), Alvarado et al. (2016; revisit), Kaounas et al. (2016; new species), cultures and sequences are available.

Geniculospora Sv. Nilsson ex Marvanová \& Sv. Nilsson 1971, Helotiaceae, Helotiales, Leotiomycetes, two species, type: G. inflata (Ingold) Sv. Nilsson ex Marvanová \& Sv. Nilsson, sexual morph unknown, saprobes, aquatic, worldwide, see Wijayawardene et al. (2012, 2017; outline), Duarte et al. (2012; DNA), Kirk et al. (2013; did not accept as a valid genus), cultures and sequences are available, needs generic revision.

Geodina Denison 1965, Sarcoscyphaceae, Pezizales, Pezizomycetes, one species, type: G. guanacastensis Denison, asexual morph unknown, saprobe, terrestrial, Costa Rica, Canary Islands, see Lumbsch and Huhndorf (2010; outline), Kirk et al. (2013; genus accepted), cultures and sequences are unavailable, needs generic revision.

Geoglossum Pers. 1794, Geoglossaceae, Geoglossales, Geoglossomycetes, two species, type: G. glabrum Pers., asexual morph unknown, saprobe, terrestrial, temperate, see Lumbsch and Huhndorf (2010; outline), Kirk et al. (2013; genus accepted), Arauzo and Iglesias (2014; new species), Loizides et al. (2015; new species), Crous et al. (2016b; new species), cultures and sequences are available, needs generic revision.

Geopora Harkn. 1885, Pyronemataceae, Pezizales, Pezizomycetes, c. 20 species, type: G. cooperi Harkn., asexual morph unknown, saprobes, terrestrial, Europe, see Lumbsch and Huhndorf (2010; outline), Frank et al. (2011; new species), Kirk et al. (2013; genus accepted), Flores-Rentería et al. (2014; new species), cultures and sequences are available. 
Geopyxis (Pers.) Sacc. 1889, Pezizales genera incertae sedis, Pezizomycetes, one species, type: G. carbonaria (Alb. \& Schwein.) Sacc., asexual morph unknown, biotrophic, terrestrial, worldwide, see Lumbsch and Huhndorf (2010; outline), Kirk et al. (2013; genus accepted), Wang et al. (2016c; taxonomy), cultures and sequences are available.

Geosmithia Pitt 1979, Hypocreales genera incertae sedis, six species, type: G. lavendula (Raper \& Fennell) Pitt, sexual morph unknown, saprobes, terrestrial, Ecuador, see Kolařík et al. (2010, 2011, 2015b; new species), Lumbsch and Huhndorf (2010; outline), Kirk et al. (2013; genus accepted), Wu et al. (2013b; new species), Maharachchikumbura et al. (2015, 2016; outline), cultures and sequences are available.

Geotrichum Link 1809, ?Dipodascaceae, Saccharomycetales, Saccharomycetes, three species, type: G. candidum Link, asexual morph present, saprophytic, soil, rotted fruit and other plant parts, tree exudates, worldwide, see Kirk et al. (2013; genus accepted), cultures and sequences are unavailable.

Gesasha Abdel-Wahab \& Nagahama 2011, Halosphaeriaceae, Microascales, Sordariomycetes, three species, type: G. peditatus Abdel-Wahab \& Nagah., saprobes, marine, Japan, asexual morph unknown, see Abdel-Wahab and Nagahama (2011; phylogeny), Maharachchikumbura et al. (2015, 2016; outline, phylogeny), holotype of the type: IMI 397958.

Gibbago E.G. Simmons 1986, Dothideomycetes genera incertae sedis, one species, type: $G$. trianthemae E.G. Simmons, sexual morph unknown, pathogens, terrestrial, USA, see Wijayawardene et al. (2012, 2014c; outline), Akhta et al. (2013; pathogens, Pakistan), Kirk et al. (2013; genus accepted), cultures and sequences are available.

Gibbera Fr. 1825, Dothideomycetes genera incertae sedis, c. 28 species, tpye: G. trianthemae E.G. Simmons, sexual morph unknown, saprobes, terrestrial, worldwide, see Schoch et al. (2009; DNA, phylogeny), Lumbsch and Huhndorf (2010; outline, accepted as a genus in Venturiaceae), Hyde et al. (2013; excluded from Venturiaceae), Kirk et al. (2013; genus accepted), Wijayawardene et al. (2014c; outline, accepted as a genus in Dothideomycetes, genera incertae sedis), cultures and sequences are available.

Gibberidea Fuckel 1870, Dothideomycetes genera incertae sedis, one species, type: G. visci Fuckel, sexual morph unknown, saprobes, terrestrial, Europe, see Lumbsch and Huhndorf (2010; outline), Kirk et al. (2013; genus accepted), Wijayawardene et al. (2014c; outline), cultures and sequences are unavailable.

Gibbosporina Elvebakk, Hong \& P.M. Jørg. 2016, Pannariaceae, Peltigerales, Lecanoromycetes, 13 species, type: G. boninensis (Kurok.) Elvebakk \& P.M. Jørg., lichenized, see Elvebakk et al. (2016; taxonomy), Lücking et al. (2016b; classification), sequences are available.

Gibellia Sacc. 1885, Melanconidaceae, Diaporthales, Sordariomycetes, one species, type: G. dothideoides Sacc. \& Berl., asexual morph unknown, saprobes, terrestrial, Australia, see Lumbsch and Huhndorf (2010; outline), Kirk et al. (2013; genus accepted), Maharachchikumbura et al. (2015, 2016; outline), cultures and sequences are unavailable.

Gibellina Pass. 1886, Phyllachoraceae, Phyllachorales, Sordariomycetes, three species, type: G. cerealis (Pass.) Pass., asexual morph unknown, pathogens, terrestrial, Asia, Europe, see Lumbsch and Huhndorf (2010; outline), Kirk et al. (2013; genus accepted), Maharachchikumbura et al. (2015, 2016; outline), cultures and sequences are available for type: MF-C22704 (unpublished).

Gibellula Cavara 1894, Cordycipitaceae, Hypocreales, Sordariomycetes, two species, type: G. pulchra Cavara, hyphomycetous, sexual morph unknown, parasitic, terrestrial, worldwide, see Seifert et al. (2011; morphology), Wijayawardene et al. (2012, 2017; outline), Han et al. (2013; new species, China), Kirk et al. (2013; genus accepted), Maharachchikumbura et al. (2015, 2016; outline), cultures and sequences are available for Gibellula leiopus. 
Gibellulopsis Bat. \& H. Maia 1959, Plectosphaerellaceae, Glomerellales, Sordariomycetes, two species, type: G. piscis Bat. \& H. Maia, hyphomycetous, sexual morph unknown, saprobes, terrestrial, worldwide, see Seifert et al. (2011; morphology), Wijayawardene et al. (2012, 2017; outline), Han et al. (2013; new species, China), Kirk et al. (2013; genus accepted), Hirooka et al. (2014; new species), Maharachchikumbura et al. (2015, 2016; outline, phylogeny), cultures and sequences are available.

Gigantospora B.S. Lu \& K.D. Hyde 2003, Xylariales genera incertae sedis, Sordariomycetes, one species, type: G. gigaspora B.S. Lu \& K.D. Hyde, asexual morph unknown, saprobes, terrestrial, USA, see Lumbsch and Huhndorf (2010; outline), Maharachchikumbura et al. (2015, 2016; outline), Wendt et al. (2017; accepted as a genus in Xylariales genera incertae sedis), cultures and sequences are unavailable.

Gilkeya M.E. Sm., Trappe \& Rizzo 2007, Pyronemataceae, Pezizales, Pezizomycetes, one species, type: G. compacta (Harkn.) M.E. Sm. \& Trappe, asexual morph unknown, biotrophic, terrestrial, worldwide, see Gladdish et al. (2010; DNA), Lumbsch and Huhndorf (2010; outline), cultures and sequences are available.

Gilletiella Sacc. \& P. Syd. 1899, Dothideomycetes genera incertae sedis, one species, type: G. chusqueae (Pat.) Sacc. \& P. Syd., asexual morph coelomycetous (ascochyta-like), saprobes, terrestrial, USA, see Lumbsch and Huhndorf (2010; outline), Kirk et al. (2013; genus accepted), Wijayawardene et al. (2014c; outline), cultures and sequences are unavailable.

Gillotia Sacc. \& Trotter 1913, Mycosphaerellaceae, Capnodiales, Dothideomycetes, two species, type: G. orbicularis (Syd. \& P. Syd.) Sacc. \& Trotter, asexual morph asteromellalike, saprobes, terrestrial, tropical, see Lumbsch and Huhndorf (2010; outline), Hyde et al. (2013; accepted as a genus in Mycosphaerellaceae), Kirk et al. (2013; genus accepted), Wijayawardene et al. (2014c; outline), cultures and sequences are unavailable, needs generic revision.

Gilmaniella G.L. Barron 1964, Ascomycota genera incertae sedis, nine species, type: $G$. humicola, hyphomycetous, from soil, dung, litter and bamboo, terrestrial, worldwide, see Dubey et al. (2011; new species, India), Seifert et al. (2011; morphology), Wijayawardene et al. (2012, 2017; outline), Goh et al. (2013; new species, Malaysia), Kirk et al. (2013; genus accepted), ex-type strain of type: ATCC $16013=$ O.A.C. 10076. = CBS $220.65=$ IFO 9235, Holotype of type: O.A.C. 10076 (dried culture).

Gintarasia Kraichak, Lücking \& Lumbsch 2013, Graphidaceae, Ostropales, Lecanoromycetes, four species, type: G. megalophthalma (Müll. Arg.) Kraichak, Lücking \& Lumbsch, lichenized, terrestrial, tropical, see Kraichak et al. (2013; taxonomy), Lücking et al. (2016b; classification), sequences are available.

Giulia Tassi 1904, Ascomycota genera incertae sedis, one species, type: G. tenuis (Sacc.) Tassi ex Sacc. \& D. Sacc., coelomycetous, sexual morph unknown, saprobes, terrestrial, Europe, see Wijayawardene et al. (2012, 2017; outline), Kirk et al. (2013; genus accepted), cultures and sequences are unavailable, needs generic revision.

Glaphyriopsis B. Sutton \& Pascoe 1987, Ascomycota genera incertae sedis, two species, type: G. brunnea B. Sutton \& Pascoe, coelomycetous, sexual morph unknown, saprobes, terrestrial, Australia, see Wijayawardene et al. (2012, 2017; outline), Kirk et al. (2013; genus accepted), cultures and sequences are unavailable, needs generic revision.

Glarea Bills \& Paláez 1999, Helotiaceae, Helotiales, Leotiomycetes, two species, type: G. lozoyensis Bills \& Peláez, sexual morph unknown, saprobes, terrestral, Spain, see Wijayawardene et al. (2012; outline, listed as a genus in Dermateaceae), Chen et al. (2013d; DNA, phylogeny, accepted as a genus in Helotiaceae), Kirk et al. (2013; genus accepted), cultures and sequences are available for type: ATCC 20868. 
Glaucotrema Rivas Plata \& Lumbsch 2012, Graphidaceae, Ostropales, Lecanoromycetes, four species, type: G. glaucophaenum (Kremp.) Rivas Plata \& Lumbsch, lichenized, see Rivas Plata et al. (2012b; taxonomy), Lücking et al. (2016b; classification), sequences are available.

Glaxoa P.F. Cannon 1997, Pleosporales genera incertae sedis, one species, type: $G$. pellucida P.F. Cannon, asexual morph unknown, saprobes, terrestrial, UK, see Lumbsch and Huhndorf (2010; outline, accepted as a genus in Tubeufiaceae), Boonmee et al. (2014b; accepted as genus in Pleosporales genera incertae sedis), Kirk et al. (2013; genus accepted), Wijayawardene et al. (2014c; outline, cultures and sequences are unavailable.

Glaziella Berk. 1880, Glaziellaceae, Pezizales, Pezizomycetes, two species, type: $G$. vesiculosa Berk., asexual morph unknown, biotrophic, terrestrial, worldwide, see Lumbsch and Huhndorf (2010; outline), Hansen et al. (2013; DNA), Kirk et al. (2013; genus accepted), cultures and sequences are available.

Glioannellodochium Matsush. 1989, Ascomycota genera incertae sedis, one species, type: Glioannellodochium australiense Matsush., hyphomycetous, sexual morph unknown, saprobes, terrestrial, Australia, see Seifert et al. (2011; morphology), Wijayawardene et al. (2012, 2017; outline), Kirk et al. (2013; genus accepted), holotype of the type: Matsushima, MFC-8A230, cultures and sequences are unavailable, needs generic revision.

Glioblastocladium Matsush. 1989, Ascomycota genera incertae sedis, one species, type: G. australiense Matsush., hyphomycetous, sexual morph unknown, saprobes, terrestrial, Australia, see Wijayawardene et al. (2012, 2017; outline), Kirk et al. (2013; genus accepted), holotype of the type: Matsushima, MFC-8A329, cultures and sequences are unavailable, needs generic revision.

Gliocephalis Matr. 1899, Pyxidiophoraceae, Pyxidiophorales, Laboulbeniomycetes, two species, type: G. hyalina Matr., asexual morph unknown, parasitic, terrestrial, worldwide, see Lumbsch and Huhndorf (2010; outline), Kirk et al. (2013; genus accepted), cultures and sequences are available (fide Jacobs et al. 2005).

Gliocephalotrichum J.J. Ellis \& Hesselt. 1962, Nectriaceae, Hypocreales, Sordariomycetes, 13 species, type: G. bulbilium J.J. Ellis \& Hesselt., hyphomycetous, sexual morph unknown, in soil, associated with post-harvest fruit spoilage of several important tropical fruit crops, terrestrial, cosmopolitan, see Seifert et al. (2011; morphology), Wijayawardene et al. (2012, 2017; outline), Kirk et al. (2013; genus accepted), Lombard et al. (2014, 2015b; phylogeny), Maharachchikumbura et al. (2015, 2016; outline), holotype of the type: BPI 414619, ex-type of the type: CBS 242.62 = ATCC $22228=$ IFO $9325=$ IMI $096357=$ MUCL $18575=$ NRRL $2899=$ QM 9007.

Gliocladiopsis S.B. Saksena 1954, Nectriaceae, Hypocreales, Sordariomycetes, ten species, type G. sagariensis S.B. Saksena., soil-borne fungi, worldwide, see Seifert et al. (2011; morphology), Lombard and Crous (2012), Wijayawardene et al. (2012, 2017; outline), Lombard et al. (2015b; phylogeny), holotype of the type: CBS 199.55, ex-type of the type: CBS 199.55.

Gliomastix Guég. 1905, Bionectriaceae, Hypocreales, Sordariomycetes, c. 25 species, type: G. chartarum (Cooke) Guég., hyphomycetous, sexual morph unknown, saprobes, in soil, terrestrial, cosmopolitan, see Seifert et al. (2011; morphology), Summerbell et al. (2011; revision, phylogeny), Whitton et al. (2012a; new species), Wijayawardene et al. (2012, 2017; outline), Kirk et al. (2013; genus accepted), cultures and sequences are available, needs generic revision.

Globoa Bat. \& H. Maia 1962, Dothideomycetes genera incertae sedis, one species, type: $G$. toddaliae Bat. \& H. Maia, asexual morph unknown, saprobes, terrestrial, Uganda, see Lumbsch and Huhndorf (2010; outline), Kirk et al. (2013; genus accepted), Wijayawardene et al. (2014c; outline), cultures and sequences are unavailable. 
Globobotrys L. Lombard \& Crous 2016, Stachybotriaceae, Hypocreales, Sordariomycetes, one species, type: G. sansevieriicola (Crous \& M.J. Wingf.) L. Lombard \& Crous, hyphomycetous, sexual morph unknown, saprobes, terrestrial, Tanzania, see Lombard et al. (2016; taxonomy, phylogeny), holotype and ex-type culture of the type: CBS H-22220, CBS 138872 .

Globoconidiopsis G.F. Sepúlveda, Pereira-Carv. \& Dianese 2009, Ascomycota genera incertae sedis, one species, type: G. cerradensis, hyphomycetous, sexual morph unknown, superficial on leaf trichomes, terrestrial, Brazil, see Seifert et al. (2011; morphology), Wijayawardene et al. (2012, 2017; outline), holotype of type: UB Mycol. Col. 9926, cultures and sequences are unavailable, needs generic revision.

Globoconidium G.F. Sepúlveda, Pereira-Carv. \& Dianese 2009, Ascomycota genera incertae sedis, one species, type: G. cerradense, hyphomycetous, sexual morph unknown, superficial on leaf trichomes, terrestrial, Brazil, see Seifert et al. (2011; morphology), Wijayawardene et al. (2012, 2017; outline), holotype of type: UB Mycol. Col. 8387, cultures and sequences are unavailable, needs generic revision.

Globonectria Etayo 2008, Bionectriaceae, Hypocreales, Sordariomycetes, one species, type: G. cochensis Etayo, asexual morph unknown, lichenicolous, terrestrial, South America, see Etayo (2008; morphology, distinction of similar lichenicolous genera), holotype of the type: COL Etayo 15859, sequences are unavailable.

Globosphaeria D. Hawksw. 1990, Sordariales genera incertae sedis, Sordariomycetes, one species, type: G. jamesii D. Hawksw., lichenicolous, terrestrial, Australia (Tasmania), see Lumbsch and Huhndorf (2010; outline), Kirk et al. (2013; genus accepted), Maharachchikumbura et al. (2015, 2016; outline), holotype of type: NSW L14339, sequences are unavailable.

Globulina Speg. 1889, Dothideomycetes genera incertae sedis, one species, type: $G$. toddaliae Bat. \& H. Maia, asexual morph unknown, saprobes, terrestrial, Uganda, see Lumbsch and Huhndorf (2010; outline), Kirk et al. (2013; genus accepted), Wijayawardene et al. (2014c; outline), cultures and sequences are unavailable.

Gloeandromyces Thaxt. 1931, Laboulbeniaceae, Laboulbeniales, Laboulbeniomycetes, five species (est. spp. 5+), type: G. streblae (Peyr.) Thaxt., asexual morph unknown, biotrophic, hosts are Streblidae (Diptera: Hippoboscoidea), neotropics, see Lumbsch and Huhndorf (2010; outline), Kirk et al. (2013; genus accepted), Haelewaters et al. (2015b, 2017b; DNA, taxonomy), ribosomal sequence data available but not for the type:.

Gloeodiscus Dennis 1961, Dothideomycetes genera incertae sedis, one species, type: $G$. nigrorufus (Berk.) Dennis, asexual morph unknown, saprobes, terrestrial, New Zealand, see Lumbsch and Huhndorf (2010; outline), Kirk et al. (2013; genus accepted), Wijayawardene et al. (2014c; outline), cultures and sequences are unavailable.

Gloeoheppia Gyeln. 1935, Gloeoheppiaceae, Lichinales, Lichinomycetes, five species, type: G. turgida (Ach.) Gyeln., lichenized, see Lumbsch and Huhndorf (2010; outline), Kirk et al. (2013; genus accepted), Lücking et al. (2016b; classification), sequences unavailable.

Gloeopeziza Zukal 1891, Helotiales genera incertae sedis, Leotiomycetes, c. eight species, type: G. rehmii Zukal, asexual morph unknown, saprobes, terrestrial, worldwide, see Lumbsch and Huhndorf (2010; outline), Kirk et al. (2013; genus accepted), cultures and sequences are unavailable, needs generic revision.

Gloeosporidiella Petr. 1921, Ascomycota genera incertae sedis, one species, type: G. ribis (Lib.) Petr., coelomycetous, asexual morph unknown, saprobes, terrestrial, worldwide, see Wijayawardene et al. (2012, 2017; outline), Kirk et al. (2013; genus accepted), cultures and sequences are unavailable, needs generic revision.

Gloeosporidina Petr. 1921, Gnomoniaceae, Diaporthales, Sordariomycetes, two species, type: G. moravica Petr., coelomycetous, sexual morph unknown, saprobes, terrestrial, 
Europe, see Wijayawardene et al. (2012, 2017; outline), Kirk et al. (2013; genus accepted), Maharachchikumbura et al. (2015, 2016; outline), cultures and sequences are unavailable.

Gloeosporiella Cavara 1892, Ascomycota genera incertae sedis, one species, type: $G$. rosicola Cavara, hyphomycetous, asexual morph unknown, saprobes, terrestrial, Europe, see Seifert et al. (2011; morphology), Wijayawardene et al. (2012, 2017; outline), Kirk et al. (2013; genus accepted), cultures and sequences are unavailable, needs generic revision.

Gloeotinia M. Wilson, Noble \& E.G. Gray 1954 (= Endoconidium Prill. \& Delacr. fide Johnston et al. 2014b), Helotiaceae, Helotiales, Leotiomycetes, two species, type: $G$. temulenta (Prill. \& Delacr.) M. Wilson, Noble \& E.G. Gray, asexual morph Endoconidium, saprobe, terrestrial, India, Canary Islands, see Lumbsch and Huhndorf (2010; outline), Kirk et al. (2013; genus accepted), Johnston et al. (2014b; nomenclature), cultures and sequences are available for unidentified species, needs generic revision.

Gloiosphaera Höhn. 1902, Ascomycota genera incertae sedis, two species, type: $G$. globuligera Höhn., hyphomycetous, sexual morph unknown, saprobes, terrestrial, Europe, North America, see Wijayawardene et al. (2012, 2017; outline), Kirk et al. (2013; genus accepted), cultures and sequences are unavailable, needs generic revision.

Glomerilla Norman 1869, Verrucariaceae, Verrucariales, Eurotiomycetes, one species, type: G. subtilis Norman, lichenized, terrestrial, Norway, see Lumbsch and Huhndorf (2010; outline), Kirk et al. (2013; genus accepted), Lücking et al. (2016b; classification), sequences are unavailable.

Glomerobolus Kohlm. \& Volkm.-Kohlm. 1996, Stictidaceae, Ostropales, Lecanoromycetes, one species, type: G. gelineus Kohlm. \& Volkm.-Kohlm., saprobes, North America, see Seifert et al. (2011; morphology), Wijayawardene et al. (2012, 2017; outline), Kirk et al. (2013; genus accepted), holotype of the type: IMS, Kohlmeyer 5555, cultures and sequences are available, needs generic revision.

Glomerulophoron Frisch, Ertz \& G.Thor 2015, Arthoniaceae, Arthoniales, Arthoniomycetes, two species, type: G. mauritiae Frisch, Ertz \& G. Thor, lichenized, see Frisch et al. (2015; taxonomy), Lücking et al. (2016b; classification), sequences are available.

Gloniella Sacc. 1883, Hysteriaceae, Hysteriales, Dothideomycetes, twelve species, type: $G$. sardoa Sacc. \& Traverso, asexual morph unknown, saprobes, terrestrial/aquatic, cosmopolitan, see Boehm et al. (2009a, b; overview of genus) Lumbsch and Huhndorf (2010; outline), Hyde et al. (2013; accepted as a genus in Hysteriaceae), Kirk et al. (2013; genus accepted), Wijayawardene et al. (2014c; outline), sequences are unavailable, needs generic revision.

Gloniopsis De Not. 1847, Hysteriaceae, Hysteriales, Dothideomycetes, seven species, type: G. decipiens De Not., asexual morph coelomycetous (aposphaeria-like fide Lohman 1933a), saprobes, terrestrial, see Boehm et al. (2009a, b; overview of genus), Lumbsch and Huhndorf (2010; outline), Kirk et al. (2013; genus accepted), Wijayawardene et al. (2014c; outline), sequence data indicate this genus is polyphyletic.

Glonium Muhl. ex Fr. 1823, Gloniaceae, Mytilinidiales, Dothideomycetes, c. 13 species, type: G. stellatum Mühl., asexual morph asteromella-like, saprobes, terrestrial, tropical, see Lumbsch and Huhndorf (2010; outline), Hyde et al. (2013; accepted as a genus in Gloniaceae), Kirk et al. (2013; genus accepted), Wijayawardene et al. (2014c; outline), cultures and sequences are available, needs generic revision.

Glutinium Fr. 1849, Ascomycota genera incertae sedis, two species, type: G. exasperans Fr., hyphomycetous, asexual morph unknown, saprobes, terrestrial, Europe, North America, see Wijayawardene et al. (2012, 2017; outline), Kirk et al. (2013; genus accepted), cultures and sequences are unavailable, needs generic revision.

Glutinoglossum Hustad, A.N. Mill, Dentinger \& P.F. Cannon 2013, Geoglossaceae, Geoglossales, Geoglossomycetes, two species, type: G. glutinosum (Pers.) Hustad, A.N. 
Mill., Dentinger \& P.F. Cannon, asexual morph unknown, from soil, terrestrial, worldwide, see Hustad et al. (2013; morphology, taxonomy, DNA, phylogeny), Kirk et al. (2013; genus accepted), holotype of the type: 910.261-767 (L 0110938 [Persoon Herb.], cultures and sequences are available: ANM 2231.

Glyphis Ach. 1814, Graphidaceae, Ostropales, Lecanoromycetes, seven species, type: $G$. cicatricosa Ach., lichenized, tropical, see Lumbsch and Huhndorf (2010; outline), Rivas Plata et al. (2012a; taxonomy), Kirk et al. (2013; genus accepted), Lücking et al. (2016b; classification), sequences are available.

Glyphium Nitschke ex F. Lehm. 1886, Patellariaceae, Patellariales, Dothideomycetes, three species, type: G. dolabriforme (Wallr.) F. Lehm., asexual morph unknown, saprobes, worldwide, see Lumbsch and Huhndorf (2010; outline), Kirk et al. (2013; genus accepted), Boehm et al. (2015; phylogeny, taxonomy), cultures and sequences are available.

Glypholecia Nyl. 1853, Acarosporaceae, Acarosporales, Lecanoromycetes, one species; type: G. candidissima Nyl., lichenized, Europe, North America, see Lumbsch and Huhndorf (2010; outline), Kirk et al. (2013; genus accepted), Lücking et al. (2016b; classification), sequences are available.

Glyphopeltis Brusse 1985, Psoraceae, Lecanorales, Lecanoromycetes, one species, type: G. eburina Brusse, lichenized, Mediterranean Europe, South Africa, Brazil, see Lumbsch and Huhndorf (2010; outline), Kirk et al. (2013; genus accepted), Lücking et al. (2016b; classification), sequences are available.

Glyphopsis Aptroot 2014, Arthoniales genera incertae sedis, Arthoniomycetes, one species, type: G. aurantiodisca Aptroot, lichenized, see Aptroot (2014; taxonomy), Lücking et al. (2016b; classification), sequences are unavailable.

Gnomonia Ces. \& De Not. 1863, Gnomoniaceae, Diaporthales, Sordariomycetes, c. 70 species, type: G. vulgaris Ces. \& De Not., asexual morph unknown, saprobes, terrestrial, Europe, see Mejía et al. (2008; DNA, phylogeny), Sogonov et al. (2008; new species, phylogeny), Lumbsch and Huhndorf (2010; outline), Kirk et al. (2013; genus accepted), Maharachchikumbura et al. (2015, 2016; outline, phylogeny), cultures and sequences are available but lacks for the type.

Gnomoniella Sacc. 1881, Gnomoniaceae, Diaporthales, Sordariomycetes, c. 70 species, type: G. tubaeformis (Tode) Sacc., asexual morph unknown, saprobes, terrestrial, Europe, see Sogonov et al. (2008; DNA, phylogeny), Singh et al. (2009; new species, India), Lumbsch and Huhndorf (2010; outline), Kirk et al. (2013; genus accepted), Maharachchikumbura et al. (2015, 2016; outline, phylogeny), cultures and sequences are available but lacks for the type.

Gnomoniopsis Berl. 1893, Gnomoniaceae, Diaporthales, Sordariomycetes, c. 20 species, type: G. chamaemori (Fr.) Berl., asexual morph unknown, saprobes, pathogens, terrestrial, worldwide, see Sogonov et al. (2008; reinstated the genus), Lumbsch and Huhndorf (2010; outline), Walker et al. (2010; new species, revision), Visentin et al. (2012; new species, pathogens), Kirk et al. (2013; genus accepted), Maharachchikumbura et al. (2015, 2016; outline), cultures and sequences are available.

Godronia Moug. \& Lév. 1846 (= Cenangiella Lambotte 1887; = Cenangium trib. Scleroderris Fr. 1822; = Crumenula De Not. 1864; Scleroderris (Fr.) Bonord. $1851=$ Sphaeronaema Fr. fide Johnston et al. 2014b; Species Fungorum 2017), Godroniaceae, Helotiales, Leotiomycetes, c. 30 species, type: G. muehlenbeckii Moug. \& Lév., asexual morph unknown, saprobes, terrestrial, worldwide, see de Gruyter et al. (2009; DNA), Lumbsch and Huhndorf (2010; outline), Kirk et al. (2013; genus accepted), Johnston et al. (2014b; nomenclature), cultures and sequences are available but lacks for type, needs generic revision.

Godroniopsis Diehl \& E.K. Cash 1929 (= Sphaeronaema Fr., fide Johnston et al. 2014b), Helotiales genera incertae sedis, Leotiomycetes, three species, type: G. quernea (Schwein.) 
Diehl \& E.K. Cash, asexual morph ?Sphaeronaema, saprobes, terrestrial, worldwide, see Lumbsch and Huhndorf (2010; outline), Kirk et al. (2013; genus accepted), Johnston et al. (2014b; nomenclature), cultures and sequences are unavailable, needs generic revision.

Golovinomyces (U. Braun) Heluta 1988 (= Euoidium Y.L. Paul \& J.N. Kapoor 1985 fide Rossman et al. 2016a), Erysiphaceae, Erysiphales, Leotiomycetes, c. 63 species, type: $G$. cichoracearum (DC.) Heluta, asexual morphs hyphomycetous, biotrophic, obligate plant pathogens, terrestrial, worldwide, see Cunnington et al. (2010; phylogeny), Takamatsu et al. (2013; phylogeny), Braun and Cook (2012; taxonomy), Rossman et al. (2016a; nomenclature), lectotype of type: France, on Scorzonera hispanica, "Erysiphe cichoracearum ad.fl. fr. in Scorzonera hispanica [ex herb. de Candolle] (G 00298360).

Gomphillus Nyl. 1855, Gomphillaceae, Ostropales, Lecanoromycetes, six species, type: G. calycioides (Delise ex Duby) Nyl., lichenized, see Lumbsch and Huhndorf (2010; outline), Kirk et al. (2013; genus accepted), Lücking et al. (2016b; classification), sequences are available.

Gonatobotrys Corda 1839, Ceratostomataceae, Melanosporales, Sordariomycetes, type: G. simplex Bonord., hyphomycetous, sexual morph unknown, fungicolous, terrestrial, worldwide, see Seifert et al. (2011; morphology), Wijayawardene et al. (2012, 2017; outline), Kirk et al. (2013; genus accepted), Maharachchikumbura et al. (2015, 2016; outline, phylogeny), cultures and sequences are unavailable, needs generic revision, Index Fungorum (2016) listed Gonatobotrys as a synonym of Melanospora Corda.

Gonatobotryum Sacc. 1880, Ascomycota genera incertae sedis, four species, type: G. fuscum (Sacc.) Sacc., hyphomycetous, sexual morph unknown, fungicolous, terrestrial, worldwide, see Seifert et al. (2011; morphology), Wijayawardene et al. (2012, 2017; outline), Kirk et al. (2013; genus accepted), cultures and sequences are available for Gonatobotryum apiculatum (unpublished) but lacks for type, needs generic revision.

Gonatophragmium Deighton 1969, Acrospermaceae, Acrospermales, Dothideomycetes, 15 species, type: G. mori (Sawada) Deighton, hyphomycetous, sexual morph unknown, saprobes, terrestrial, cosmopolitan, see Seifert et al. (2011; morphology), Wijayawardene et al. (2012, 2014c, 2017; outline), Kirk et al. (2013; genus accepted), Crous et al. (2014d; new species, DNA), Berger et al. (2015; new species, lichenicolous, Austria), cultures and sequences are available, needs generic revision.

Gonatorrhodum Corda 1839, Ascomycota genera incertae sedis, one species, type: $G$. speciosum Corda, hyphomycetous, sexual morph unknown, saprobes, terrestrial, Europe, see Seifert et al. (2011; morphology), Wijayawardene et al. (2012, 2017; outline), Kirk et al. (2013; genus accepted), cultures and sequences are unavailable, needs generic revision.

Gondwania Søchting, Frödén \& Arup 2013, Teloschistaceae, Teloschistales, Lecanoromycetes, four species, type: G. cribrosa (Hue) Søchting, Frödén \& Arup, lichenized, see Arup et al. (2013; taxonomy), Lücking et al. (2016b; classification), sequences are available.

Goniopila Marvanová \& Descals 1985, Ascomycota genera incertae sedis, one species, type: G. monticola (Dyko) Marvanová \& Descals, hyphomycetous, sexual morph unknown, saprobes, aquatic, USA, Europe, see Seifert et al. (2011; morphology), Wijayawardene et al. (2012, 2017; outline), Kirk et al. (2013; genus accepted), cultures and sequences are available for type: CCM F-11686, needs generic revision.

Goosia B. Song 2003, Englerulaceae, Dothideomycetes family incertae sedis, one species, type: G. melastomatis B. Song, asexual morph unknown, parasitic, terrestrial, China, see Lumbsch and Huhndorf (2010; outline), Dai et al. (2014c; morphology), Wijayawardene et al. (2014c; outline), cultures and sequences are unavailable.

Goosiella Morgan-Jones, Kamal \& R.K. Verma 1986, Ascomycota genera incertae sedis, one species, type: G. helicospora Morgan-Jones, Kamal \& R.K. Verma, hyphomycetous, sexual 
morph unknown, saprobes, terrestrial, India, see Seifert et al. (2011; morphology), Wijayawardene et al. (2012, 2017; outline), Kirk et al. (2013; genus accepted), cultures and sequences are unavailable, needs generic revision.

Goosiomyces N.K. Rao \& Manohar. 1989, Ascomycota genera incertae sedis, one species, type: G. digitatus N.K. Rao \& Manohar., hyphomycetous, sexual morph unknown, saprobes, terrestrial, India, see Seifert et al. (2011; morphology), Wijayawardene et al. (2012, 2017; outline), Kirk et al. (2013; genus accepted), Dubey and Neelima (2014; new species), cultures and sequences are unavailable, needs generic revision.

Gordonomyces Crous \& Marinc. 2011, Pleosporales, genera incertae sedis, Dothideomycetes, one species, type: G. mucovaginatus Crous \& Marinc., coelomycetous, sexual morph unknown, saprobes, terrestrial, South Africa, see Crous et al. (2011d; morphology, DNA), Wijayawardene et al. (2012, 2014c, 2016; outline, morphology, phylogeny), holotype and extype strains of the type: PREM 59592, CMW 22212.

Gorgadesia Tav. 1964, Roccellaceae, Arthoniales, Arthoniomycetes, one species, type: G. mira Tav., lichenized, see Lumbsch and Huhndorf (2010; outline), Kirk et al. (2013; genus accepted), Lücking et al. (2016b; classification), sequences are available.

Gorgomyces M. Gönczöl \& Révay 1985, Leotiomycetes genera incertae sedis, two species, type: G. hungaricus J. Gönczöl \& Révay, hyphomycetous, sexual morph unknown, nematophagous, aquatic, Hungary, Spain, see Seifert et al. (2011; morphology), Wijayawardene et al. (2012, 2017; outline), Baschien et al. (2013; DNA, phylogeny), Kirk et al. (2013; genus accepted), ex-type culture of the of the type: CCM F-12696.

Gorgoniceps (P. Karst.) P. Karst. 1871, Helotiales genera incertae sedis, Leotiomycetes, three species, type: G. aridula (P. Karst.) P. Karst., asexual morph unknown, saprobes, terrestrial, worldwide, see Lumbsch and Huhndorf (2010; outline), Kirk et al. (2013; genus accepted), cultures and sequences are unavailable, needs generic revision.

Gossypiothallon Aptroot 2014, Arthoniales genera incertae sedis, Arthoniomycetes, one species, type: G. appendisporum Aptroot, lichenized, see Aptroot (2014; taxonomy), Lücking et al. (2016b; classification), sequences are unavailable.

Govindua Bat. \& H. Maia 1960, Dothideomycetes, genera incertae sedis, one species, type: G. shoreae Bat. \& H. Maia, asexual morph unknown, saprobes, terrestrial, India, see Lumbsch and Huhndorf (2010; outline, accepted as a genus in Microthyriaceae), Wu et al. (2011; transferred to Asterinaceae), Hyde et al. (2013) and Hongsanan et al. (2014c) did not accept as Asterinaceae, Kirk et al. (2013; genus accepted), Wijayawardene et al. (2014c; accepted as a genus in Dothideomycetes genera incertae sedis), cultures and sequences are unavailable, needs generic revision.

Gowardia Halonen, Myllys, Velmala \& Hyvärinen 2009, Parmeliaceae, Lecanorales, Lecanoromycetes, two species, type: G. nigricans (Ach.) Halonen, Myllys, Velmala \& Hyvärinen, lichenized, see Myllys et al. (2014; taxonomy), Lücking et al. (2016b; classification), sequences are available.

Gracilistilbella Seifert 2000, Bionectriaceae, Hypocreales, Sordariomycetes, four species, type: G. clavulata (Mont.) Seifert, asexual morph unknown, saprobes, terrestrial, worldwide, see Lumbsch and Huhndorf (2010; outline), Maharachchikumbura et al. (2015, 2016; outline), cultures and sequences are unavailable, needs generic revision.

Graddonia Dennis 1955, Helotiaceae, Helotiales, Leotiomycetes, seven species, type: G. coracina (Bres.) Dennis, asexual morph unknown, saprobes, terrestrial, Europe, see Lumbsch and Huhndorf (2010; outline, accepted as a genus in Dermateaceae), Hustad and Miller (2011b; DNA, phylogeny), Raja et al. (2011a; DNA, phylogeny), Kirk et al. (2013; genus accepted), cultures available for type: ILLS60491.

Graddonidiscus Raitv. \& R. Galán 1992, Hyaloscyphaceae, Helotiales, Leotiomycetes, three species, type: G. coruscatus (Graddon) Raitv. \& R. Galán, asexual morph unknown, 
saprobes, terrestrial, Europe, North America, see Lumbsch and Huhndorf (2010; outline), Kirk et al. (2013; genus accepted), cultures and sequences are unavailable, needs generic revision.

Grahamiella Spooner 1981, Hyaloscyphaceae, Helotiales, Leotiomycetes, three species, type: G. dryadis (Nannf. ex L. Holm) Spooner, asexual morph unknown, saprobes, terrestrial, Europe, see Lumbsch and Huhndorf (2010; outline), Kirk et al. (2013; genus accepted), cultures and sequences are unavailable, needs generic revision.

Grallomyces F. Stevens 1918, Ascomycota genera incertae sedis, one species, type: $G$. portoricensis F. Stevens, hyphomycetous, sexual morph unknown, saprobes, terrestrial, tropical, see Seifert et al. (2011; morphology), Wijayawardene et al. (2012, 2017; outline), Kirk et al. (2013; genus accepted), cultures and sequences are unavailable, needs generic revision.

Grandibotrys L. Lombard \& Crous 2016, Stachybotriaceae, Hypocreales, Sordariomycetes, two species, type: G. pseudotheobromae L. Lombard \& Crous, hyphomycetous, sexual morph unknown, saprobes, terrestrial, Nepal, see Lombard et al. (2016; taxonomy, phylogeny), holotype and ex-type culture of the type: CBS H-22443, CBS 136170.

Grandigallia M.E. Barr, Hanlin, Cedeño, Parra \& R. Hern. 1987, Shiraiaceae, Pleosporales, Dothideomycetes, one species, type: G. dictyospora M.E. Barr, Hanlin, Cedeño, Parra \& R. Hern., asexual morph unknown, saprobes, terrestrial, Venezuela., see Lumbsch and Huhndorf (2010; outline, accepted as a genus in Dothideomycetes, genera incertae sedis), Ariyawansa et al. (2013c; accepted as a genus in Shiraiaceae), Hyde et al. (2013; accepted as a genus in Shiraiaceae), Kirk et al. (2013; genus accepted), Wijayawardene et al. (2014c; outline), cultures and sequences are unavailable, needs generic revision.

Granulomanus de Hoog \& Samson 1978, Cordycipitaceae, Hypocreales, Sordariomycetes, two species, type: G. aranearum (Petch) de Hoog \& Samson, hyphomycetous, sexual morph unknown, parasitic on Arachnida, terrestrial, British Isles, see Seifert et al. (2011; morphology), Wijayawardene et al. (2012, 2017; outline), Kirk et al. (2013; genus accepted), Maharachchikumbura et al. (2015, 2016; outline), cultures and sequences are available for Gibellula leiopus.

Granulopyrenis Aptroot 1991, Pyrenulaceae, Pyrenulales, Eurotiomycetes, six species, type: G. antillensis Aptroot, lichenized, see Lumbsch and Huhndorf (2010; outline), Kirk et al. (2013; genus accepted), Lücking et al. (2016b; classification), sequences are available.

Graphidastra (Redinger) G. Thor 1991, Roccellaceae, Arthoniales, Arthoniomycetes, four species, type: G. multiformis (Mont. \& Bosch) G. Thor, lichenized, see Lumbsch and Huhndorf (2010; outline), Kirk et al. (2013; genus accepted), Lücking et al. (2016b; classification), sequences unavailable.

Graphiopsis Trail 1889, Cladosporiaceae, Capnodiales, Dothideomycetes, one species, type: G. chlorocephala (Fresen.) Trail, hyphomycetous, terrestrial, Asia, Europe, North America, New Zealand, see Braun et al. (2008; nomenclature), Crous et al. (2009d; phylogeny), Seifert et al. (2011; morphology), Wijayawardene et al. (2012, 2014c, 2017; outline), Kirk et al. (2013; genus accepted), ex-neotype strain of type: CBS $121523=$ CPC 11969, neotype of type: HAL $1924 \mathrm{~F}$.

Graphiothecium Fuckel 1870, Ascomycota genera incertae sedis, six species, type: $G$. fresenii Fuckel, hyphomycetous, sexual morph unknown, saprobes, terrestrial, India, see Seifert et al. (2011; morphology), Wijayawardene et al. (2012, 2017; outline), Kirk et al. (2013; genus accepted), cultures and sequences are unavailable, needs generic revision.

Graphis Adans. 1763, Graphidaceae, Ostropales, Lecanoromycetes, c. 500 species, type: $G$. scripta (L.) Ach., asexual morph unknown, lichenized, terrestrial, mostly tropical, see Lücking et al. (2008a, 2009, 2016b; key, Costa Rica, classification), Archer 2009 (key, Australia), Lumbsch and Huhndorf (2010; outline), Kirk et al. (2013; genus accepted), 
Barcenas Peña et al. (2014; key), Rivas Plata et al. (2012a; taxonomy), Kraichak et al. (2015; taxonomy), sequences are available.

Graphium Corda 1837, Graphiaceae, Microascales, Sordariomycetes, three species, type: $G$. penicillioides Corda, hyphomycetous, sexual morph unknown, saprobes or from soil terrestrial, worldwide, see Cruywagen et al. (2010; new species, South Africa), Paciura et al. (2010b; new species, China), Seifert et al. (2011; morphology), Wijayawardene et al. (2012, 2017; outline), Kirk et al. (2013; genus accepted), Kolařík et al. (2015b; new species; Costa Rica), Wu et al. (2015; new species, China), Maharachchikumbura et al. (2015, 2016; outline), ex-type strain of the type: JCM 1049.

Graphostroma Piroz. 1974, Graphostromataceae, Xylariales, Sordariomycetes, one species, type: G. platystoma (Schwein.) Piroz., asexual morph hyphomycetous (nodulisporium-like), saprobes, terrestrial, North America, see Lumbsch and Huhndorf (2010; outline), Kirk et al. (2013; genus accepted), Koukol et al. (2014; DNA, phylogeny), Maharachchikumbura et al. (2015, 2016; outline, phylogeny), cultures available for the type: AFTOL-ID 1249.

Graphyllium Clem. 1901, Hyseriales genera incertae sedis, eleven species, type: G. chloës Clem., asexual morph unknown, saprobes, terrestrial, North America, see Lumbsch and Huhndorf (2010; outline, accepted as a genus in Diademaceae), Hyde et al. (2013) did not accept as Diademaceae, Kirk et al. (2013; genus accepted), Almeida et al. (2014b; DNA, new species, phylogenetic analyses showed that G. caracolinense D.A.C. Almeida et al. belongs to Hysteriales), Wijayawardene et al. (2014c; accepted as a genus in Dothideomycetes, genera incertae sedis), cultures and sequences are available only for G. caracolinense, needs generic revision.

Greeneria Scribn. \& Viala 1887, Diaporthales genera incertae sedis, three species, type: $G$. fuliginea Scribn. \& Viala, coelomycetous, sexual morph unknown, saprobes, terrestrial, worldwide, see Wijayawardene et al. (2012, 2016, 2017; outline, taxonomy, phylogeny), Tangthirasunun et al. (2014a; DNA, phylogeny), cultures and sequence available for $G$. saprophytica (MFLUCC 12-0298 fide Tangthirasunun et al. 2014).

Gregarithecium Kaz. Tanaka \& K. Hiray. 2015, Dictyosporiaceae, Pleosporales, Dothideomycetes, one species, type: G. curvisporum Kaz. Tanaka \& K. Hiray., asexual morph unknown, saprobes, terrestrial, Japan, see Tanaka et al. (2015; morphology, phylogeny), holotype and ex-type strain of the type: HHUF 30134, CBS 139688.

Gregatothecium L. Lombard \& Crous 2016, Stachybotriaceae, Hypocreales, Sordariomycetes, one species, type: G. humicola L. Lombard \& Crous, hyphomycetous, sexual morph unknown, saprobes, terrestrial, Papua New Guinea, see Lombard et al. (2016; taxonomy, phylogeny), Wijayawardene et al. (2017; outline), holotype and ex-type culture of the type: CBS H-22445, CBS 205.96.

Gregorella Lumbsch 2005, Arctomiaceae, Arctomiales, Lecanoromycetes, one species, type: G. humida (Kullh.) Lumbsch, asexual morph coelomycetous, lichenized, terrestrial, Europe, see Lumbsch and Huhndorf (2010; outline), Miądlikowska et al. (2014a; taxonomy), Lücking et al. (2016b; classification), sequences are available.

Gremmenia Korf 1962, Helotiaceae, Helotiales, Leotiomycetes, four species, type: G. pinicembrae (Rehm) Crous, asexual morph unknown, saprobes, pathogens, terrestrial, worldwide, see Crous et al. (2014b; DNA, phylogeny), cultures and sequences are available.

Gremmeniella M. Morelet 1969 (= Brunchorstia Erikss 1891 fide Johnston et al. 2014b), Godroniaceae, Helotiales, Leotiomycetes, three species, type: G. abietina (Lagerb.) M. Morelet, asexual morph Brunchorstia, pathogens, terrestrial, Europe, see Lumbsch and Huhndorf (2010; outline), Laflamme and Smerlis (2012; DNA, new species, Canada), Kirk et al. (2013; genus accepted), Johnston et al. (2014b; nomenclature), cultures and sequences are available. 
Griggsia F. Stevens \& Dalbey 1919, Dothideomycetes genera incertae sedis, one species, type: G. cyathea F. Stevens \& Dalbey, asexual morph unknown, saprobes, terrestrial, West Indies, see Lumbsch and Huhndorf (2010; outline), Kirk et al. (2013; genus accepted), Thambugala et al. (2014c; taxonomy), cultures and sequences are unavailable, needs generic revision.

Grimmicola Döbbeler \& Hertel 1983, Helotiales genera incertae sedis, Leotiomycetes, one species, type: $G$. parasiticus Döbbeler \& Hertel, asexual morph unknown, saprobes, terrestrial, Marion Island, see Lumbsch and Huhndorf (2010; outline), Kirk et al. (2013; genus accepted), cultures and sequences are unavailable.

Griphosphaerioma Höhn. 1918 (= Labridella Brenckle 1929 fide Maharachchikumbura et al. 2015; Wijayawardene et al. 2016b), Amphisphaeriaceae, Xylariales, Sordariomycetes, two species, type: G. symphoricarpi (Ellis \& Everh.) Höhn. ex Petr., asexual morphs Labridella, saprobes, terrestrial, North America, see Lumbsch and Huhndorf (2010; outline), Kirk et al. (2013; genus accepted), Maharachchikumbura et al. (2015, 2016; outline, nomenclature), Wijayawardene et al. (2016b; taxonomy, nomenclature), Rossman et al. (2016a) proposed to protect Labridella over Griphosphaerioma, cultures and sequences are unavailable.

Groenewaldozyma Kurtzman 2016, Trichomonascaceae, Saccharomycetales, Saccharomycetes, three species, type: G. auringiensis (Santa María) Kurtzman, saprophytic, worldwide, see Kurtzman (2016; taxonomy), cultures and sequences are available.

Groenhiella Jorg., E.B.G. Jones \& S.T. Moss 1983, Nitschkiaceaem, Coronophorales, Sordariomycetes, one species, type: G. bivestia Jørg. Koch, E.B.G. Jones \& S.T. Moss, asexual morph unknown, marine, on wood often associated with sand, temperate, see Lumbsch and Huhndorf (2010; outline), Kirk et al. (2013; genus accepted), Jones et al. (2015; outline), Maharachchikumbura et al. (2015, 2016; outline) cultures and sequences are unavailable.

Grosmannia Goid. 1936, Ophiostomataceae, Ophiostomatales, Sordariomycetes, one species, type: G. penicillata (Grosmann) Goid., holomorph, asexual morph hyphomycetous, associated with bark beetles, terrestrial, worldwide, see Masuya et al. (2009; new species), Lumbsch and Huhndorf (2010; outline), Duong et al. (2012; new species, phylogeny), Linnakoski et al. (2012, 2016; new species, DNA, phylogeny), Kirk et al. (2013; genus accepted), Andoa et al. (2016; DNA, phylogeny), cultures available for the type: CMW43738.

Groveolopsis Boedijn 1951, Ascomycota genera incertae sedis, six species, type: G. pandani (Höhn.) Boedijn, coelomycetous, sexual morph unknown, saprobes, terrestrial, India, see Wijayawardene et al. (2012, 2017; outline), Kirk et al. (2013; genus accepted), cultures and sequences are unavailable, needs generic revision.

Grovesia Dennis 1960, Helotiales genera incertae sedis, Leotiomycetes, one species, type: $G$. parasiticus Döbbeler \& Hertel, asexual morph unknown, saprobes, terrestrial, Venezuela, see Lumbsch and Huhndorf (2010; outline), Kirk et al. (2013; genus accepted), cultures and sequences are unavailable.

Grovesiella M. Morelet 1969, Tympanidaceae, Phacidiales, Leotiomycetes, one species, type: G. abieticola (Zeller \& Goodd.) M. Morelet \& Gremmen, asexual morph unknown, saprobes, terrestrial, USA, Europe, see Lumbsch and Huhndorf (2010; outline), Kirk et al. (2013; genus accepted), cultures available for the type: ZT 91110.

Grovesinia M.N. Cline, J.L. Crane \& S.D. Cline 1983 (= Hinomyces Narumi \& Y. Harada 2006 fide Johnston et al. 2014b), Sclerotiniaceae, Helotiales, Leotiomycetes, two species, type: G. pyramidalis M.N. Cline, J.L. Crane \& S.D. Cline, asexual morph Hinomyces, saprobes, terrestrial, worldwide, see Lumbsch and Huhndorf (2010; outline), Kirk et al. (2013; genus accepted), Johnston et al. (2014b; nomenclature). 
Guanomyces M.C. González, Hanlin \& Ulloa 2000, Chaetomiaceae, Sordariales, Sordariomycetes, one species, type: G. polythrix M.C. González, Hanlin \& Ulloa, asexual morph unknown, saprobes, terrestrial, Mexico, Trinidad, see Lumbsch and Huhndorf (2010; outline), Kirk et al. (2013; did not accept as a valid genus), Maharachchikumbura et al. (2015, 2016; outline), cultures and sequences are available (see Gonzalez et al. 2000).

Gudelia Henssen 1995, Gloeoheppiaceae, Lichinales, Lichinomycetes, one species, type: G. mexicana Henssen, lichenized, Mexico, see Lumbsch and Huhndorf (2010; outline), Kirk et al. (2013; genus accepted), Lücking et al. (2016b; classification), sequences unavailable.

Guedea Rambelli \& Bartoli 1978, Ascomycota genera incertae sedis, six species, type: G. sacra Rambelli \& Bartoli, hyphomycetous, sexual morph unknown, saprobes, terrestrial, worldwide, see Seifert et al. (2011; morphology), Wijayawardene et al. (2012, 2017; outline), Kirk et al. (2013; genus accepted), cultures and sequences are unavailable, needs generic revision.

Guelichia Speg. 1886, Ascomycota genera incertae sedis, six species, type: G. paradoxa Speg., hyphomycetous, sexual morph unknown, saprobes, terrestrial, South America, see Seifert et al. (2011; morphology), Wijayawardene et al. (2012; outline, accepted as a genus in Tubeufiaceae), Kirk et al. (2013; genus accepted), Boonmee et al. (2014b) and Wijayawardene et al. (2014c) did not accept as a genus in Tubeufiaceae, cultures and sequences are unavailable, needs generic revision.

Guestia G.J.D. Sm. \& K.D. Hyde 2001, Xylariales genera incertae sedis, Sordariomycetes, one species, type: G. gonetropospora G.J.D. Sm. \& K.D. Hyde, asexual morph unknown, saprobes, terrestrial, USA, see Lumbsch and Huhndorf (2010; outline), Maharachchikumbura et al. (2015, 2016; outline), Wendt et al. (2017; accepted as a genus in Xylariales genera incertae sedis), cultures and sequences are unavailable.

Guilliermondia Boud. 1904, Sordariaceae, Sordariales, Sordariomycetes, one species, type: G. saccoboloides Boud., asexual morph unknown, saprobes, terrestrial, Europe, see Lumbsch and Huhndorf (2010; outline), Kirk et al. (2013; genus accepted), Maharachchikumbura et al. (2015, 2016; outline), cultures and sequences are unavailable, needs generic revision.

Guttulispora Thambugala, Qing Tian \& K.D. Hyde 2015, Lophiostomataceae, Pleosporales, Dothideomycetes, one species, type: G. crataegi Qing Tian, Thambugala, Camporesi \& K.D. Hyde, asexual morph unknown, saprobes, terrestrial, Italy, see Thambugala et al. (2015b; morphology, phylogeny), holotype of type: MFLU 14-0584, ex-type strains of type: MFLUCC 13-0442.

Gyalecta Ach. 1808, Gyalectaceae, Ostropales, Lecanoromycetes, 50 species, type: G. cupularis (Hedw.) Schaer., lichenized, terrestrial (corticolous, saxicolous, terricolous), mainly temperate, see Baloch et al. (2010, 2013; txonomy), Lumbsch and Huhndorf (2010; outline), Schmull et al. (2011; DNA), Kirk et al. (2013; genus accepted), Miądlikowska et al. (2014; DNA), Aptroot and Moon (2015; new species), Resl et al. (2015; DNA), Lücking et al. (2016b; classification), sequences are available but lacks for the type.

Gyalectaria Lumbsch, Kalb \& Schmitt 2010, Coccotremataceae, Pertusariales, Lecanoromycetes, three species, type: G. jamesii (Kantvilas) I. Schmitt, Kalb \& Lumbsch, lichenized, terrestrial (corticolous), Chile, New Guinea, North America, Tasmania, from lowland to subalpine, see Schmitt et al. (2010b; taxonomy), Resl et al. (2015; DNA), Lücking et al. (2016b; classification), sequences are available.

Gyalectidium Müll. Arg. 1881, Gomphillaceae, Ostropales, Lecanoromycetes, 52 species, type: G. filicinum Müll. Arg., lichenized, tropical, see Lumbsch and Huhndorf (2010; outline), Kirk et al. (2013; genus accepted), Lücking et al. (2016b; classification), sequences are available.

Gyalidea Lettau ex Vězda [nom. cons.] 1966, Gomphillaceae, Ostropales, Lecanoromycetes, 50 species, type: G. lecideopsis (A. Massal.) Lettau ex Vězda, lichenized, widespread, see 
Lumbsch and Huhndorf (2010; outline), Kirk et al. (2013; genus accepted), Lücking et al. (2016b; classification), sequences are available.

Gyalideopsis Vězda [nom. cons.] 1972, Gomphillaceae, Ostropales, Lecanoromycetes, 95 species, type: G. peruviana G. Merr. ex Vězda, lichenized, worldwide, see Lumbsch and Huhndorf (2010; outline), Kirk et al. (2013; genus accepted), Lücking et al. (2016b; classification), sequences are available.

Gyalolechia A. Massal. 1852, Teloschistaceae, Teloschistales, Lecanoromycetes, 30 species, type: G. aurea (Schaer.) A. Massal., lichenized, see Arup et al. (2013; taxonomy), Kondratyuk et al. (2014a; taxonomy), Jaklitsch et al. (2016a; outline), Lücking et al. (2016b; classification), sequences are available.

Gymnascella Peck 1884, Gymnoascaceae, Onygenales, Eurotiomycetes, 14 species, type: G. aurantiaca Peck, asexual morphs unknown, saprobes, terrestrial, worldwide, see Lumbsch and Huhndorf (2010; outline), Kirk et al. (2013; genus accepted), cultures and sequences are available.

Gymnoascoideus G.F. Orr, K. Roy \& G.R. Ghosh 1977, Gymnoascaceae, Onygenales, Eurotiomycetes, one species, type: G. petalosporus G.F. Orr, K. Roy \& G.R. Ghosh, asexual morphs unknown, saprobes, terrestrial, worldwide, see Lumbsch and Huhndorf (2010; outline), Kirk et al. (2013; genus accepted), cultures and sequences are available.

Gymnoascus Baran. 1872, Gymnoascaceae, Onygenales, Eurotiomycetes, eight species, type: G. reessii Baran., asexual morphs unknown, saprobes, terrestrial, north temperate, see Lumbsch and Huhndorf (2010; outline), Kirk et al. (2013; genus accepted), cultures and sequences are available.

Gymnoderma Nyl. 1860, Cladoniaceae, Lecanorales, Lecanoromycetes, three species, type: G. coccocarpum Nyl., lichenized, see Lumbsch and Huhndorf (2010; outline), Kirk et al. (2013; genus accepted), Lücking et al. (2016b; classification), sequences are available.

Gymnographopsis C.W. Dodge 1967, Graphidaceae, Ostropales, Lecanoromycetes, two species; type: G. chilena C.W. Dodge, lichenized, tropical, see Lumbsch and Huhndorf (2010; outline), Kirk et al. 2013 (genus accepted), Rivas Plata et al. (2012a; taxonomy), Lücking et al. (2016b; classification), sequences are unavailable.

Gymnohydnotrya B.C. Zhang \& Minter 1989, Discinaceae, Pezizales, Pezizomycetes, three species, type: G. australiana B.C. Zhang \& Minter, asexual morphs unknown, saprobes, terrestrial, Australia, see Lumbsch and Huhndorf (2010; outline), Kirk et al. (2013; genus accepted), cultures and sequences are available.

Gymnostellatospora Udagawa, Uchiy. \& Kamiya 1993, Myxotrichaceae, Leotiomycetes, families incertae sedis, two species, type: G. japonica Udagawa, Uchiy. \& Kamiya, asexual morph unknown, saprobes, terrestrial, worldwide, see Lumbsch and Huhndorf (2010; outline), Kirk et al. (2013; genus accepted), holotype of the type: BF 24290, cultures available for type: UAMH 9239 (fide Rice and Currah 2006).

Gymnoxyphium Cif., Bat. \& I.J. Araújo 1963, Ascomycota genera incertae sedis, six species, type: G. malum Bat., Nascim. \& Cif., coelomycetous, sexual morph unknown, saprobes, terrestrial, Europe, see Wijayawardene et al. (2012, 2017; outline), Kirk et al. (2013; genus accepted), cultures and sequences are unavailable, needs generic revision.

Gynonectria Döbbeler 2012, Hypocreales genera incertae sedis, six species, type: $G$. intraspora Döbbeler, asexual morph unknown, saprobes, terrestrial, South America, see Döbbeler (2012; outline), cultures and sequences are unavailable, needs generic revision.

Gyoerffyella Kol 1928 Helotiales genera incertae sedis, nine species, type: G. tatrica Kol, hyphomycetous, sexual morph unknown, saprobes, pathogens, saprobes, aquatic, Europe, North America, see Wijayawardene et al. (2012, 2017; outline), Baschien et al. (2013; DNA, phylogeny), Kirk et al. (2013; genus accepted), cultures unavailable for the type:, ex-type 
strains available for G. entomobryoides (CBS268.63 fide Baschien et al. 2013), $G$. tricapillata (CBS 451.64 fide Baschien et al. 2013).

Gypsoplaca Timdal 1990, Gypsoplacaceae, Lecanorales, Lecanoromycetes, one species, type: G. macrophylla (Zahlbr.) Timdal, lichenized, see Lumbsch and Huhndorf (2010; outline), Kirk et al. (2013; genus accepted), Lücking et al. (2016b; classification), sequences are available.

Gyrocollema Vain. 1929, Lichinaceae, Lichinales, Lichinomycetes, two species, type: $G$. scyphuliferum Vain., with ascomata, lichenized (Nostoc), terrestrial (saxicolous), North and Central America, see Lümbsch and Huhndorf (2010; outline), Kirk et al. (2013; genus accepted), Lücking et al. (2016b; classification), cultures and sequences are unavailable.

Gyrographa Ertz \& Tehler 2015, Roccellaceae, Arthoniales, Arthoniomycetes, three species, type: G. gyrocarpa (Flot.) Ertz \& Tehler, sexual morph with knot-like or clustered-gyrose to lirelliform ascomata, asexual morph coelomycetous, lichenized, terrestrial, worldwide, see Ertz et al. (2015b, c; taxonomy, phylogeny), Lücking et al. (2016b; classification), cultures and sequences are available.

Gyromitra Fr. 1849, Discinaceae, Pezizales, Pezizomycetes, 20 species, type: G. esculenta (Pers.) Fr., asexual morph unknown, saprobes, terrestrial, worldwide, see Lumbsch and Huhndorf (2010; outline), Kirk et al. (2013; genus accepted), Methven et al. (2013; DNA, phylogeny), cultures available for the type: AFTOL-ID 5017.

Gyronactis Ertz \& Tehler 2015, Roccellaceae, Arthoniales, Arthoniomycetes, two species, type: G. asiatica Ertz \& Tehler, sexual morph with apothecioid ascomata, asexual morph coelomycetous, lichenized, terrestrial, tropical, see Ertz et al. (2015b, c; morphology, phylogeny), Lücking et al. (2016b; classification), sequences are available.

Gyrophthorus Hafellner \& Sancho 1990, Ascomycota genera incertae sedis, two species, type: G. perforans Hafellner \& Sancho, asexual morph unknown, lichenicolous, terrestrial, Europe, see Lumbsch and Huhndorf (2010; outline), Kirk et al. (2013; genus accepted), cultures and sequences are unavailable, needs generic revision.

Gyrostroma Naumov 1914, Diaporthales genera incertae sedis, one species, type: Gy. sinuosum Naumov, sexual morph unknown, saprobes, terrestrial, Europe, see Hirooka et al. (2012; morphology, accepted as a genus in Diaporthales, genera incertae sedis), Wijayawardene et al. (2012; accepted as a genus in Hypocreales), Kirk et al. (2013; genus accepted), Maharachchikumbura et al. (2015, 2016; outline, accepted as a genus in Diaporthales, genera incertae sedis), cultures and sequences are unavailable for the type: thus Gyrostroma s. str. uncertain, needs generic revision.

Gyrothrix Corda 1842 (= Campsotrichum sect. Gyrothrix Corda 1839; = Peglionia Goid. 1937 fide Species Fungorum 2017), Ascomycota genera incertae sedis, c. 22 species, type: $G$. podosperma (Corda) Rabenh, hyphomycetous, sexual morph unknown, saprobes, terrestrial, widespread, see Seifert et al. (2011; morphology), Rambelli et al. (2011; morphology), Hyde et al. (2011; outline), Wijayawardene et al. (2012, 2017; outline), Kirk et al. (2013; genus accepted), cultures and sequences are unavailable, needs generic revision.

Gyrotrema A. Frisch 2006, Graphidaceae, Ostropales, Lecanoromycetes, five species, type: G. sinuosum (Sipman) Frisch, with ascomata, lichenized (green algae), terrestrial (corticolous), Central and South America see Rivas Plata et al. (2008; outline), Kalb (2009; outline), Lümbsch and Huhndorf (2010; outline), Lümbsch et al. (2011; outline); Cáceres et al. (2014; DNA), Kraichak et al. (2014; DNA), Lücking et al. (2016b; classification), sequences are available but lacks for type.

Hadronema Syd. \& P. Syd. 1909, Ascomycota genera incertae sedis, four species, type: $H$. orbiculare Syd. \& P. Syd., hyphomycetous, sexual morph unknown, saprobes, terrestrial, China, UK see Seifert et al. (2011; morphology), Wijayawardene et al. (2012, 2017; outline), 
Kirk et al. (2013; genus accepted), cultures and sequences are unavailable, needs generic revision.

Hadrospora Boise 1989, Trematosphaeriaceae, Pleosporales, Dothideomycetes, one species, type: H. fallax (Mouton) Boise, asexual morph unknown, saprobes, terrestrial, worldwide, see Lumbsch and Huhndorf (2010; outline, accepted as a genus in Phaeosphaeriaceae), Hyde et al. (2013; accepted as a genus in Phaeosphaeriaceae), Kirk et al. (2013; genus accepted), Phookamsak et al. (2014b; accepted as a genus in Trematosphaeriaceae), Wijayawardene et al. (2014c; outline), cultures and sequences are unavailable, needs generic revision.

Hadrosporium Syd. 1938, Ascomycota genera incertae sedis, two species, type: $H$. fraserianum Syd., hyphomycetous, saprobes, terrestrial, Austaralia, New Zealand, see Seifert et al. (2011; morphology), Wijayawardene et al. (2012, 2017; outline), Kirk et al. (2013; genus accepted), cultures and sequences are unavailable, needs generic revision.

Hadrotrichum Fuckel 1865, Xylariales genera incertae sedis, Sordariomycetes, one species, type: H. phragmitis Fuckel, hyphomycetous, sexual morph unknown, saprobes, terrestrial, temperate, see Seifert et al. (2011; morphology), Wijayawardene et al. (2012, 2017; outline), Kirk et al. (2013; did not accept as a valid genus), Maharachchikumbura et al. (2015, 2016; outline), cultures and sequences are available for $H$. pyrenaicum (YMJ 320 fide Hsieh et al. 2005).

Haematomma A. Massal. 1852, Haematommataceae, Lecanorales, Lecanoromycetes, c. 40 species, type: H. vulgare A. Massal., with ascomata, lichenized (Pseudotreobuxia), terrestrial (corticolous, lignicolous or saxicolous), cosmopolitan, but most diverse in the tropics, see Brodo et al. (2008; outline and chemistry), Ekman et al. (2008; DNA), Kalb et al. (2008; DNA), Lumbsch et al. (2008; DNA), Stocker-Wörgötter et al. (2009; chemistry, mycobionts), Lümbsch and Huhndorf (2010; outline), Miądlikowska et al. (2014a; DNA), Lücking et al. (2016b; classification), sequences are available but lacks for the type:.

Haematomyxa Sacc. 1884, Ascomycota genera incertae sedis, two species, type: $H$. vinosa (Cooke \& Ellis) Sacc., asexual morph unknown, saprobes, terrestrial, North America, see Lumbsch and Huhndorf (2010; outline), Kirk et al. (2013; genus accepted), cultures and sequences are unavailable, needs generic revision.

Hagleromyces Sousa, Morais, Lachance \& Rosa 2014, Saccharomycetaceae, Saccharomycetales, Saccharomycetes, one species, type: H. auroranensis Sousa, asexual reproduction by multilateral budding, saprophytic, from water tanks (phytotelmata) of Bromelia karatas in the cerrado ecosystem of Aurora do Tocantins, Brazil, see Sousa et al. (2014; taxonomy), cultures and sequences are available.

Haiyanga K.L. Pang \& E. B. G. Jones 2008, Halosphaeriaceae, Microascales, Sordariomycetes, one species, type: H. salina (Meyers) K.L. Pang \& E.B.G. Jones, asexual morph unknown, saprobes, marine, worldwide, see Pang et al. (2008b; taxonomy), Maharachchikumbura et al. (2015, 2016; outline), cultures and sequences are available.

Halazoon Abdel-Aziz, Abdel-Wahab \& Nagah. 2010, Lulworthiaceae, Lulworthiales, Sordariomycetes, two species, type: H. melhae Abdel-Aziz, Abdel-Wahab \& Nagah., coelomycetous, sexual morph unknown, saprobes, marine, worldwide, see Abdel-Wahab et al. (2010; morphology, phylogeny), Wijayawardene et al. (2012, 2017; outline), Maharachchikumbura et al. (2015, 2016; outline), holotype and ex-type strain of the type: IMI 397964, MF819.

Halbania Racib. 1889, Asterinaceae, Asterinales, Dothideomycetes, three species, type: $H$. cyathearum Racib., asexual morph unknown, epiphytes, terrestrial, worldwide, see Hofmann (2009; review), Lumbsch and Huhndorf (2010; outline), Hyde et al. (2013; accepted as a genus in Asterinaceae), Hongsanan et al. (2014c; taxonomy, keys), Wijayawardene et al. (2014c; outline), placement in Asterinaceae supported by morphology, holotype of type: ZT Myc 1488, cultures and sequences are unavailable. 
Halecania M. Mayrhofer 1987, Catilliariaceae, Lecanorales, Lecanoromycetes, 22 species, type: H. alpivaga (Th. Fr.) M. Mayrhofer, with ascomata, lichenized (green algae), terrestrial (saxicolous, corticolous, lichenicolous or growing on mosses and plant debris), cosmopolitan, see Ekman et al. (2008; DNA), van den Boom (2009; new species), Andreev (2010; new species), Lümbsch and Huhndorf (2010; outline), Kirk et al. (2013; genus accepted), Lendemer and Hodkinson (2013; taxonomy), Aptroot and Moon (2015; new species), Kondratyuk (2015; new species), Lücking et al. (2016b; classification), sequences are available for type: AY756368 (LSU).

Halegrapha Rivas Plata \& Lücking 2011, Graphidaceae, Ostropales, Lecanoromycetes, eight species, type: Ha. chimaera Rivas Plata \& Lücking, asexual morph unknown, lichenized, terrestrial, tropical, Lücking et al. (2011; taxonomy), Lücking et al. (2016b; classification), sequences are available.

Halenospora E.B.G. Jones 2009, Leotiaceae, Helotiales, Leotiomycetes, one species, type: $H$. varia (Anastasiou) E.B.G. Jones, hyphomycetous, sexual morph unknown, saprobe, marine, worldwide, see Jones et al. (2009b, 2015; outline, phylogeny), Abdel-Wahab et al. (2010; phylogeny), Seifert et al. (2011; morphology), Wijayawardene et al. (2012, 2017; outline), cultures and sequences are available.

Haleomyces D. Hawksw. \& Essl. 1993, ?Verrucariacae, Verrucariales, Eurotiomycetes, one species, type: H. oropogonicola D. Hawksw. \& Essl., lichenicolous, terrestrial, Mexico, asexual morph unknown, see Lumbsch and Huhndorf (2010; outline), Kirk et al. (2013; genus accepted), Jaklitsch et al. (2016a; outline), holotype of type: K(M)-IMI 3551875.

Haligena Kohlm. 1961, Halosphaeriaceae, Microascales, Sordariomycetes, one species, type: H. elaterophora Kohlm., asexual morph unknown, saprobes, marine, worldwide, see Lumbsch and Huhndorf (2010; outline), Sakayaroj et al. (2011a; phylogeny), Kirk et al. (2013; genus accepted), Maharachchikumbura et al. (2015, 2016; outline), cultures and sequences are available, holotype of type: IMI 297765.

Halodiatrype Dayarathne \& K.D. Hyde 2016, Diatrypaceae, Xylariales Sordariomycetes, three species, type: H. salinicola Dayarathne \& K.D. Hyde, saprobes, found on decaying wood at mangrove stands, Thailand, see Dayarathne et al. (2016b; taxonomy, phylogeny), holotype of type: MFLU 15-0179.

Halographis Kohlm. \& Volkm.Kohlm. 1988, Roccellaceae, Arthoniales, Arthoniomycetes, one species, type: $H$. runica Kohlm. \& Volkm.-Kohlm., endolithic lichenoid from corals and snails, marine, tropical, see Lumbsch and Huhndorf (2010; outline), Kirk et al. (2013; genus accepted), Jones et al. (2015; outline), Lücking et al. (2016b; classification), sequences unavailable.

Haloguignardia Cribb \& J. W. Cribb 1956, Lulworthiaceae, Lulworthiales, Sordariomycetes, five species, type: $H$. decidua Cribb \& J.W. Cribb, asexual morph unknown, endophytes or parasites, marine, worldwide, see Lumbsch and Huhndorf (2010; outline), Kirk et al. (2013; genus accepted), Jones et al. (2015; outline), Maharachchikumbura et al. (2015, 2016; outline), cultures and sequences are available.

Halojulella Suetrong, K.D. Hyde \& E.B.G. Jones 2013, Halojulellaceae, Pleosporales, Dothideomycetes, one species, type: H. avicenniae (Borse) Suetrong, K.D. Hyde \& E.B.G. Jones, asexual morph coelomycetous, saprobes, on woody substrates in mangrove habitats, worldwide, sequence data available, see Ariyawansa et al. (2013a, 2014a, c; phylogeny, morphology), Hyde et al (2013; phylogeny, morphology, outline), Abdel-Wahab et al. (2014; diversity), Gnavi et al. (2014, phylogeny), Wijayawardene et al. (2014c; outline), Jones et al. (2015; classification, marine), Liu et al. (2015a; phylogeny), holotype of type: IMI 304217, cultures and sequences are available.

Halokirschsteiniothelia Boonmee \& K.D. Hyde 2012, Dothideomycetes genera incertae sedis, one species, type: H. maritima (Linder) Boonmee \& K.D. Hyde, asexual morph 
unknown, saprobes, marine, USA, see Boonmee et al. (2012; taxonomy, phylogeny; treated as a genus in Mytilinidiaceae), Hyde et al. (2013; did not accepta a genus in Mytilinidiaceae), Wijayawardene et al. (2014c; listed as Dothideomycetes genera incertae sedis), cultures available for the type: CBS 221.60.

Halomassarina (Kohlm. \& Volkm.-Kohlm.) Suetrong, Sakay., E.B.G. Jones, Kohlm., Volkm.-Kohlm. \& C.L. Schoch 2009, Trematosphaeriaceae, Pleosporales, Dothideomycetes, one species, type: H. thalassiae (Kohlm. \& Volkm.-Kohlm.) Suetrong, Sakay., E.B.G. Jones, Kohlm., Volkm.-Kohlm. \& C.L. Schoch, asexual morph unknown, saprobes, marine, worldwide, see Suetrong et al. (2009; phylogeny, morphology), Schoch et al. (2009; phylogeny), Alias et al. (2010; diversity), Lumbsch and Huhndorf (2010; outline), Zainuddin et al. (2010; antimicrobial activities), Sakayaroj et al. (2011b; diversity), Boonmee et al. (2012; phylogeny), Dai et al. (2012; phylogeny), Lee et al. (2012; checklist), Jones et al. (2012; phylogeny), Zhang et al. (2012e; morphology, phylogeny), Borse et al. (2013; checklist), Hyde et al. (2013; morphology, phylogeny), Ahmed et al. (2014a; phylogeny), Gnavi et al. (2014; phylogeny), Shearer et al. (2014; phylogeny), Wijayawardene et al. (2014c; outline), Singtripop et al. (2015; phylogeny), Sarma (2015; key), Sharma et al. (2015; phylogeny), holotype and ex-isotype strain of type: J.K. 4804a, J.K.4804b.

Halonectria E.B.G. Jones 1965, Bionectriaceae, Hypocreales, Sordariomycetes, one species, type: $H$. milfordensis E.B.G. Jones, asexual morph unknown, marine, on wood, mostly temperate, see Lumbsch and Huhndorf (2010; outline), Kirk et al. (2013; genus accepted), Jones et al. (2015; outline), Maharachchikumbura et al. (2015, 2016; outline), cultures and sequences are available.

Haloplaca Arup, Søchting \& Frödén 2013, Teloschistaceae, Teloschistales, Lecanoromycetes, three species, type: H. britannica (R. Sant.) Arup, Frödén \& Søchting, lichenized (with green algae), saxicolous, corticolous, lignicolous, lichenicolous, terrestrial, United Kingdom, Greece, Morocco, Turkey, see Vondrák et al. (2012; DNA as Caloplaca suaesae s. 1.), Arup et al. (2013, DNA), Lücking et al. (2016b; classification), sequences are available for all species KC179292 (ITS) (fide Arup et al. 2013).

Halorosellinia Whalley, E.B.G. Jones, K.D. Hyde \& Laessoe, 2000, Xylariaceae, Xylariales, Sordariomycetes, two species, type: H. oceanica (S. Schatz) Whalley, E.B.G. Jones, K.D. Hyde \& Læssøe, asexual morph unknown, tropical, on wood especially mangrove substrates, sequence data for both species, see Lumbsch and Huhndorf (2010; outline), Maharachchikumbura et al. (2015, 2016; outline), Senanayake et al. (2015; morphology, phylogeny), Jones et al. (2015; outline), cultures and sequences are available.

Halosarpheia Kohlm. \& E. Kohlm. 1977, Halosphaeriaceae, Microascales, Sordariomycetes, polyphyletic, four species, type: H. fibrosa Kohlm. \& E. Kohlm., asexual morph unknown, marine, freshwater, saprobes on herbaceous material, wood, widespread, see Lumbsch and Huhndorf (2010; outline), Sakayaroj et al. (2011a; phylogeny), Kirk et al. (2013; genus accepted), Maharachchikumbura et al. (2015, 2016; outline), Jones et al. (2015; outline), holotype of the type: NY J.K. 3726a, cultures available for type: AFTOL-ID 409, CBS 197.60.

Halosphaeria Linder 1944, Halosphaeriaceae, Microascales, Sordariomycetes, c. 20 species, type: $H$. appendiculata Linder, asexual morph unknown, saprobes, marine, temperates, subtropics, see Lumbsch and Huhndorf (2010; outline), Sakayaroj et al. (2011a; phylogeny), Kirk et al. (2013; genus accepted), Jones et al. (2015; outline, marine), Maharachchikumbura et al. (2015, 2016; outline), sequence are available.

Halosphaeriopsis T.W. Johnson 1958 (= Culcitalna Meyers \& R.T. Moore fide Maharachchikumbura et al. 2016), Halosphaeriaceae, Microascales, Sordariomycetes, one species, type: H. mediosetigera (Cribb \& J.W. Cribb) T.W. Johnson, asexual morph unknown, saprobes, marine, temperates, subtropics, see Lumbsch and Huhndorf (2010; 
outline), Sakayaroj et al. (2011a; phylogeny), Kirk et al. (2013; genus accepted), Jones et al. (2015; outline), Maharachchikumbura et al. (2015, 2016; outline), sequence are available.

Halotthia Kohlm. 1963, Halotthiaceae, Pleosporales, Dothideomycetes, one species, type: $H$. posidoniae (Durieu \& Mont.) Kohlm., asexual morph coelomycetous, saprobes, marine habitats, mediterranean, see Suetrong et al. (2009; phylogeny, morphology), Jones et al. (2009b; classification), Zhang et al. (2012e, 2013c; morphology, phylogeny), Hyde et al. (2013; morphology, phylogeny), Kirk et al. (2013; genus accepted), Wijayawardene et al. (2014c; outline), Jones et al. (2015; classification).

Halysiomyces E.G. Simmons 1981, Ascomycota genera incertae sedis, one species, type: $H$. saxatilis E.G. Simmons, hyphomycetous, epiphyte, free living, USA, see Seifert et al. (2011; morphology), Wijayawardene et al. (2012, 2017; outline), Kirk et al. (2013; genus accepted), cultures and sequences are unavailable, needs generic revision.

Hamatocanthoscypha Svrček 1977, Pezizellaceae, Helotiales, Leotiomycetes, three species, type: H. laricionis (Velen.) Svrček, asexual morph unknown, saprobes, terrestrial, temperate, see Lumbsch and Huhndorf (2010; outline), Kirk et al. (2013; genus accepted), Han et al. (2014; DNA, phylogeny), Jaklitsch et al. (2016a; classification), cultures available for the type: TNS-F13530.

Hamigera Stolk \& Samson 1971 (= Merimbla Pitt 1979 fide Houbraken and Samson 2011), Aspergillaceae, Eurotiales, Eurotiomycetes, two species, type: H. avellanea Stolk \& Samson, asexual morph formerly named in Merimbla, saprobes, terrestrial, temperate, see Peterson et al. (2010; phylogeny), Houbraken and Samson (2011; phylogeny, nomenclature), Seifert et al. (2011; morphology), Wijayawardene et al. (2012, 2017; outline), cultures and sequences are available.

Hamigera Stolk \& Samson 1971, Aspergillaceae, Eurotiales, Eurotiomycetes, 13 species, type: H. avellanea Stolk \& Samson, asexual morph unknown, terrestrial, saprobes, occurring on decaying plant material, wood and dung, worldwide, see Peterson et al. (2010; new species), Houbraken and Samson (2011), cultures and sequences are unavailable, needs phylogenetic assessment.

Hanliniomyces Raja \& Shearer 2008, Sordariomycetes genera incertae sedis, one species, type: H. hyaloapicalis Raja \& Shearer, asexual morph unknown, freshwater, northern and southern Florida, see Raja and Shearer (2008; taxonomy), Raja et al. (2009b; phylogeny), Maharachchikumbura et al. (2015, 2016; outline), holotype: R037-3, ILL 40116, cultures and sequences are unavailable.

Hanseniaspora Zikes 1912 (= Kloeckera Janke 1928), Saccharomycodaceae, Saccharomycetales, Saccharomycetes, 15 species, type: H. valbyensis Klöcker, asexual reproduction is by bipolar budding on a broad base (bud-fission), saprophytic, in soil, fresh water, sea water, rotting plants, fruit, fruit juices, fruit flies, grape must, beer, worldwide, see Lumbsch and Huhndorf (2010; outline), Kirk et al. (2013; genus accepted), sequences are available.

Hansfordia Hughes 1951, Ascomycota genera incertae sedis, seven species, type: $H$. ovalispora S. Hughes, hyphomycetous, saprobes, terrestrial, marine, China, UK, Spain, and India, see Seifert et al. (2011; morphology), Wijayawardene et al. (2012; outline), Kirk et al. (2013; genus accepted), cultures and sequences are unavailable, needs generic revision.

Hansfordiella Hughes 1951, Microthyriaceae, Microthyriales, Dothideomycetes, eight species, type: $H$. asterinearum S. Hughes, hyphomycetous, saprobes, on fungi, terrestrial, wide spread, see see Seifert et al. (2011; morphology), Wijayawardene et al. (2012, 2017; outline), Kirk et al. (2013; genus accepted), cultures and sequences are unavailable, needs generic revision.

Hansfordiellopsis Deighton 1960, Dothideomycetes genera incertae sedis, one species, type: H. aburiensis Deighton, hyphomycetous, sexual morph unknown, saprobes, lichenicolous, 
terrestrial, Africa, South America, see Seifert et al. (2011; morphology), Wijayawardene et al. (2012, 2017; outline), holotype of the type: IMI 4778, cultures and sequences are unavailable. Hansfordiopeltis Bat. \& C.A.A. Costa (1956), Ascomycota genera, incertae sedis, incertae sedis, five species, type: H. congoensis Bat. \& C.A.A. Costa, coelomycetous, saprobes, terrestrial, Congo and Brazil, see Wijayawardene et al. (2012, 2017), Kirk et al. (2013; genus accepted), cultures and sequences are unavailable, needs generic revision.

Hansfordiopeltopsis M.L. Farr 1986, Ascomycota genera incertae sedis, one species, type: $H$. amazonensis M.L. Farr, ceolomycetous, saprobes, terrestrial, Brazil, see Wijayawardene et al. (2012, 2017), Kirk et al. (2013; genus accepted), cultures and sequences are unavailable, needs generic revision.

Hansfordiopsis Bat. 1959, Dothideomycetes genera incertae sedis, one species, type: $H$. phaeospora (Hansf.) Bat., asexual morph unknown, saprobes, terrestrial, Australia, see Lumbsch and Huhndorf (2010; outline, accepted as a genus in Micropeltidaceae), Hyde et al. (2013; did not accept as a genus Micropeltidaceae), Kirk et al. (2013; genus accepted), Wijayawardene et al. (2014c; outline, Dothideomycetes genera incertae sedis), holotype of the type: PDD 6788 (as Microthyriella phaeospora Hansf.), cultures and sequences are unavailable.

Hapalocystis Auersw. ex Fuckel 1863, Sydowiellaceae, Diaporthales, Sordariomycetes, four species, type: $H$. berkeleyi Auersw. ex Fuckel, asexual morphs coelomycetous (phoma-like), saprobes, terrestrial, Europe, North America, see de Silva et al. (2009; DNA, phylogeny), Lumbsch and Huhndorf (2010; outline), Liu et al. (2016; DNA, phylogeny), Maharachchikumbura et al. (2016; outline, phylogeny), cultures available for the type: AR 3851.

Hapalosphaeria Syd. 1908, Ascomycota genera incertae sedis, one species, type: $H$. deformans (Syd.) Syd., coelomycetous, pathogens, terrestrial, Germany, see Wijayawardene et al. (2012, 2017; outline), Kirk et al. (2013; genus accepted), cultures and sequences are unavailable, needs generic revision

Haplariopsis Oudem. 1903, Ascomycota genera incertae sedis, two species, type: H. fagicola Oudem., hyphomycetous, saprobes, terrestrial, India, Holland, Europe, see Seifert et al. (2011; morphology), Wijayawardene et al. (2012, 2017; outline), Kirk et al. (2013; genus accepted), cultures and sequences are unavailable, needs generic revision.

Haplobasidion Erikss. 1889, Ascomycota genera incertae sedis, three species, type: $H$. thalictri Erikss., hyphomycetous, saprobes, pathogens, terrestrial, Sweden, Asia, Malaysia, India, see Seifert et al. (2011; morphology), Wijayawardene et al. (2012, 2017; outline), Kirk et al. (2013; genus accepted), cultures and sequences are unavailable, needs generic revision. Haplodina Zahlbr. 1930, Roccellaceae, Arthoniales, Arthoniomycetes, three species, need typification, lichenized, terrestrial (corticolous, saxicolous), China, see Lümbsch and Huhndorf (2010; outline), Kirk et al. (2013; genus accepted), Lücking et al. (2016b; classification), sequences are unavailable, needs generic revision.

Haplographium Berk. \& Broome 1859, Hyaloscyphaceae, Helotiales, Leotiomycetes, 15 species, type: $H$. delicatum Berk. \& Broome, hyphomycetous, sexual morph unknown, saprobes, terrestrial, widespread, see Seifert et al. (2011; morphology), Hyde et al. (2011; outline), Wijayawardene et al. (2012, 2017; outline), Kirk et al. (2013; genus accepted), cultures available for type species FMR 11585, TNS-F17834.

Haplolepis Syd. 1925, Ascomycota genera incertae sedis, three species, type: H. polyadelpha Syd., coelomycetous, saprobes, terrestrial, Sri Lanka, Africa, see Wijayawardene et al. (2012, 2017; outline), Kirk et al. (2013; genus accepted), cultures and sequences are unavailable, needs generic revision.

Haploloma Trevis. 1857, Lecanoromycetes genus incertae sedis, one species, type: $H$. fraudulentum Trevis., lichenicolous, terrestrial, Europe, see Lümbsch and Huhndorf (2010; 
outline), Kirk et al. (2013; did not accept), Lücking et al. (2016b; classification), cultures and sequences are unavailable, needs generic revision.

Haplomyces Thaxt. 1893, Laboulbeniaceae, Laboulbeniales, Laboulbeniomycetes, three species, type: H. californicus Thaxt., asexual morph unknown, biotrophic, North America, Europe, see Lumbsch and Huhndorf (2010; outline), Rossi (2010; new species, Ecuador), Kirk et al. (2013; genus accepted), cultures and sequences are unavailable.

Haplopeltheca Bat., J.L. Bezerra \& Cavalc. 1963, Micropeltidaceae, Microthyriales, Dothideomycetes, one species, type: H. hyleensis Bat., J.L. Bezerra \& Cavalc., asexual morph unknown, saprobes, terrestrial, Brazil, see Lumbsch and Huhndorf (2010; outline), Hyde et al. (2013; accepted as a genus in Micropeltidaceae), Wijayawardene et al. (2014c; outline), cultures and sequences are unavailable.

Haplophyse Theiss. 1916, Rhytismatales genera incertae sedis, Leotiomycetes, ten species, type: H. oahuensis Theiss., asexual morph unknown, saprobes, terrestrial, worldwide, see Lumbsch and Huhndorf (2010; outline), Kirk et al. (2013; genus accepted), cultures and sequences are unavailable.

Hapsidascus Kohlm. \& Volkm.-Kohlm. 1991, Sordariomycetes genera incertae sedis, one species, type: H. hadrus Kohlm. \& Volkm.-Kohlm., asexual morph unknown, marine, on mangrove wood and salt marsh sedge, tropical, see Jones et al. (2009b, 2015; marine, outline), Lumbsch and Huhndorf (2010; outline), Kirk et al. (2013; genus accepted), Maharachchikumbura et al. (2015, 2016; outline), cultures and sequences are unavailable.

Hapsidospora Malloch \& Cain 1970, Hypocreales genera incertae sedis, Sordariomycetes, two species, type: $H$. irregularis Malloch \& Cain, asexual morph hyphomycetous (acremonium-like), saprobes, terrestrial, Canada, see Lumbsch and Huhndorf (2010; outline), Kirk et al. (2013; genus accepted), Maharachchikumbura et al. (2015, 2016; outline), cultures available for the type: ATCC 22087.

Haptocara Drechsler 1975, Ascomycota genera incertae sedis, one species, type: $H$. latirostrum Drechsler, hyphomycetous, saprobes, insect-trapping, terrestrial, USA, see Seifert et al. (2011; morphology), Wijayawardene et al. (2012, 2017; outline), Kirk et al. (2013; genus accepted), cultures and sequences are unavailable, needs generic revision.

Haptospora G.L. Barron 1991, Hypocreales genera incertae sedis, Sordariomycetes, two species, type: H. appendiculata G.L. Barron, hyphomycetous, sexual morph unknown, saprobes, terrestrial, West Indies, New Zealand, see Seifert et al. (2011; morphology), Wijayawardene et al. (2012, 2017; outline), Lumbsch and Huhndorf (2010; outline), Kirk et al. (2013; genus accepted), Maharachchikumbura et al. (2015, 2016; outline), cultures and sequences are unavailable.

Haradamyces Masuya, Kusunoki, Kosaka \& Aikawa 2009, Sclerotiniaceae, Helotiales, Leotiomycetes, one species, type: H. foliicola Masuya, Kusunoki, Kosaka \& Aikawa, hyphomycetous, sexual morph unknown, saprobes, terrestrial, Asia, see Seifert et al. (2011; morphology), Wijayawardene et al. (2012, 2017; outline), holotype of the type: TFM FPH7930, cultures available for the type: MAFF 411026.

Haraea Sacc. \& P. Syd. 1913, Ascomycota genera incertae sedis, one species, type: E. dingleyae S. Hughes \& Piroz., asexual morph unknown, saprobes, terrestrial, New Zealand, see Lumbsch and Huhndorf (2010; outline, accepted as a genus in Meliolaceae), Kirk et al. (2013; genus accepted), Maharachchikumbura et al. (2015, 2016; outline), holotype and extype culture of the type: DAOM 167533, MAFF 411026.

Harknessia Cooke 1881, Harknessiaceae, Diaporthales, Sordariomycetes, c. 50 species, holomorph with wuestneia-like sexual morphs, pathogens, saprobes, terrestiral, worldwide, have sequence data, see Crous et al. (2012f; morphology, phylogeny), Maharachchikumbura et al. (2015, 2016; outline, phylogeny), Wijayawardene et al. (2012, 2016, 2017; morphology, phylogeny), Rossman et al. (2016b; new combination), cultures and sequences are available. 
Harknessiella Sacc. 1889, Dothideomycetes genera incertae sedis, one species, type: $H$. purpurea (W. Phillips \& Harkn.) Sacc., asexual morph unknown, saprobes, terrestrial, North America, see Lumbsch and Huhndorf (2010; outline), Kirk et al. (2013; genus accepted), Wijayawardene et al. (2014c; outline), cultures and sequences are unavailable.

Harmoniella V.N. Boriss. 1981, Ascomycota genera incertae sedis, one species, type: $H$. chrysocephalus V.N. Boriss, hyphomycetouss, saprobes, terrestrial, Ukraine, see Seifert et al. (2011; morphology), Wijayawardene et al. (2012, 2017; outline), Kirk et al. (2013; genus accepted), cultures and sequences are unavailable, needs generic revision.

Harpidium Körb. 1855, Lichinaceae, Lichinales, Lichinomycetes, three species, type: $H$. rutilans Körb., with ascomata and conidia, lichenized (with green algae), terrestrial (saxicolous), Eurasian mountains, North America, South Africa, see Lümbsch and Huhndorf (2010; outline), Lümbsch et al. (2011; new species), Kirk et al. (2013; genus accepted), Lücking et al. (2016b; classification), sequences are available.

Harpographium Sacc. 1880, Ascomycota genera incertae sedis, five species, type: $H$. fasciculatum Sacc., hyphomycetous, saprobes, terrestrial, worldwide, see Seifert et al. (2011; morphology), Wijayawardene et al. (2012, 2017; outline), Kirk et al. (2013; genus accepted), cultures and sequences are unavailable, needs generic revision.

Harposporium Lohde 1874 (= Podocrella Seaver 1928; Atricordyceps Samuels 1983; Polyrhina Sorokīn 1876 fide Quandt et al. 2014; Maharachchikumbura et al. 2015), Ophiocordycipitaceae, Hypocreales, Sordariomycetes, two species, type: H. anguillulae Lohde, hyphomycetous, sexual morph unknown, parasitic on nematodes, terrestrial, temperate, see Kuo et al. (2008; taxonomy, DNA, phylogeny), Seifert et al. (2011; morphology), Wijayawardene et al. (2012, 2017; outline), Kirk et al. (2013; genus accepted), Maharachchikumbura et al. (2015; outline, phylogeny), Spatafora et al. (2015; new species), cultures available for the type: ARSEF 5593.

Harpostroma Höhn. 1928, Ascomycota genera incertae sedis, one species, type: H. notha (Sacc.) Höhn., coelomycetous, sexual morph unknown, on cheese and fungi, terrestrial, Europe, North America, see Kirk et al. (2013; genus accepted), Maharachchikumbura et al. (2015, 2016; outline, accepted as a genus in Valsaceae), Wijayawardene et al. (2017; outline), cultures and sequences are unavailable, needs generic revision.

Harzia Costantin 1888, Hypocreales genera incertae sedis, Sordariomycetes, four species, type: H. acremonioides (Harz) Costantin, hyphomycetous, sexual morph unknown, saprobes, foliicolous, terrestrial, worldwide, see Seifert et al. (2011; morphology), Wijayawardene et al. (2012, 2017; outline), Crous et al. (2013b; new species, DNA), Kirk et al. (2013; genus accepted), Maharachchikumbura et al. (2015; outline, phylogeny), ex-type cultures available for H. cameroonensis Crous \& Jol. Roux (CPC 22065, 22066 = CBS 136420).

Hassea Zahlbr. 1902, Dothideomycetes genera incertae sedis, one species, type: H. bacillosa (Nyl.) Zahlbr., asexual morph unknown, saprobes, terrestrial, USA, see Lumbsch and Huhndorf (2010; outline), Kirk et al. (2013; genus accepted), Wijayawardene et al. (2014c; outline), cultures and sequences are unavailable.

Havispora K. L. Pang \& Vrijmoed 2008, Halosphaeriaceae, Microascales, Sordariomycetes, one species, type: H. longyearbyenensis K.L. Pang \& Vrijmoed, asexual morph unknown, saprobes, marine, Arctic, see Pang et al. (2008a, 2011a; taxonomy), Lumbsch and Huhndorf (2010; outline), Maharachchikumbura et al. (2015, 2016; outline), holotype of type: BBH 18329 , cultures and sequences are available.

Hawksworthiana U. Braun 1988, Ascomycota genera incertae sedis, one species, type: $H$. peltigericola (D. Hawksw.) U. Braun, hyphomycetous, sexual morph unknown, lichenicolous, terrestrial, UK, see Seifert et al. (2011; morphology), Wijayawardene et al. (2012, 2017; outline), Kirk et al. (2013; genus accepted), cultures and sequences are unavailable, needs generic revision. 
Hegermila Raitv. 1995, Hyaloscyphaceae, Helotiales, Leotiomycetes, four species, type: $H$. andina (Pat.) Raitv., asexual morph unknown, saprobes, terrestrial, temperate, see Lumbsch and Huhndorf (2010; outline), Kirk et al. (2013; genus accepted), cultures and sequences are unavailable.

Heimiodora Nicot 1960, Ascomycota genera incertae sedis, one species, type: $H$. verticillata Nicot, hyphomycetous, saprobes, terrestrial, Thailand, see Seifert et al. (2011; morphology), Wijayawardene et al. (2012, 2017; outline), Kirk et al. (2013; genus accepted), cultures and sequences are unavailable, needs generic revision.

Heiomasia Nelsen, Lücking \& Rivas Plata 2010, Graphidaceae, Ostropales, Lecanoromycetes, three species, type: H. sipmanii (Aptroot, Lücking \& Rivas Plata) Nelsen, Lücking \& Rivas Plata, lichenized, see Nelsen et al. (2010; taxonomy), Lücking et al. (2016b; classification), sequences are available.

Heleiosa Kohlm., Volkm.-Kohlm. \& O.E. Erikss. 1996, Pleosporales genera incertae sedis, Dothideomycetes, one species, type: H. barbatula Kohlm., Volkm.-Kohlm. \& O.E. Erikss., asexual morph unknown, tropical, marine on maritime sedge, see Lumbsch and Huhndorf (2010; outline), Kirk et al. (2013; genus accepted), Wijayawardene et al. (2014c; outline), Jones et al. (2015; outline), cultures and sequences are unavailable, needs generic revision.

Helensiella (R.F. Castañeda, Heredia \& R.M. Arias) Minter, R.F. Castañeda \& Heredia 2015, Ascomycota genera incertae sedis, one species, type: H. rigidophora (R.F. Castañeda, Heredia \& R.M. Arias) Minter, R.F. Castañeda \& Heredia, hyphomycetous, sexual morph unknown, saprobes, terrestrial, Mexico, see Index Fungorum (2017), holotype: XAL CB1692, cultures and sequences are unavailable, compare with Ceratosporella and Dendryphion.

Heleococcum C.A. Jørg. 1922, Bionectriaceae, Hypocreales, Sordariomycetes, four species, type: H. aurantiacum C.A. Jørg., isolated from soil, marine or freshwater, Asia and Europe see Lumbsch and Huhndorf (2010; outline), Kirk et al. (2013; genus accepted), Maharachchikumbura et al. (2015, 2016; outline), ex-type of the type: CBS 201.35, slides of holotype of the type: C, NY (few remaining ascomata were broken).

Helhonia B. Sutton 1980, Ascomycota genera incertae sedis, one species, type: $H$. rhamnigena (Fautrey) B. Sutton, coelomycetous, sexual morph unknown, saprobes, terrestrial, France, see Wijayawardene et al. (2012, 2017; outline), Kirk et al. (2013; genus accepted), sequence are unavailable.

Heliastrum Petr. 1931, Sordariomycetes genera incertae sedis, one species, type: $H$. concinnum Petr., asexual morph unknown, saprobes, terrestrial, Philipplnes, see Lumbsch and Huhndorf (2010; outline), Kirk et al. (2013; genus accepted), Maharachchikumbura et al. (2015, 2016; outline), cultures and sequences are unavailable, needs generic revision.

Helicangiospora Boonmee, Bhat \& K.D. Hyde 2014, Tubeufiaceae, Tubeufiales, Dothideomycetes, type: H. lignicola Boonmee, Bhat \& K.D. Hyde, asexual morph hyphomycetous, saprobes, terrestrial, temperate, see Boonmee et al. (2014b; taxonomy, phylogeny), Wijayawardene et al. (2014c; outline), holotype and ex-type cultures of the type: MFLU11-0137, MFLUCC 11-0378 = BCC 52029 = ICMP 20069.

Helicascus Kohlm. 1969, Morosphaeriaceae, Pleosporales, Dothideomycetes, six species, type: H. kanaloanus Kohlm., asexual morph unknown, saprobes, terrestrial, aquatic, worldwide, see Amnuaykanjanasin et al. (2009; DNA), Lumbsch and Huhndorf (2010; outline), Hyde et al. (2013; phylogeny), Kirk et al. (2013; genus accepted), Zhang et al. (2013a, 2014c; new species, phylogeny), Wijayawardene et al. (2014c; outline), cultures available for the type: F1R2B2 (fide Amnuaykanjanasin et al. 2009).

Helicobolomyces Matzer 1995, Arthoniaceae, Arthoniales, Arthoniomycetes, one species, type: H. lichenicola Matzer, with conidiomata, lichenized (with green algae) or lichenicolous, terrestrial, tropical, see Wijayawardene et al. (2012, 2017; outline), Kirk et al. (2013; genus accepted), cultures and sequences are unavailable. 
Helicocentralis Sri-indr., Chuaseehar., Boonyuen, K. Yamag., Suetrong \& C.K.M. Tsui 2015, Leotiomycetes genera incertae sedis, one species, type: $H$. hyalina Sri-indr., Chuaseehar., Boonyuen, K. Yamag., Suetrong \& C.K.M. Tsui, sexual morph unknown, saprobes, freshwater, Thailand, see Sri-indrasutdhi (2015; morphology, phylogeny), Cultures and sequences are available, holotype of type: BBH27889.

Helicodendron Peyronel 1918 (= Belospora Clem. 1909; Ciboriella Seaver 1951; Hymenoscypha (Fr.) W. Phillips 1887; Lambertellinia Korf \& Lizoň 1994; = Peziza trib. Hymenoscypha Fr. 1822; Poculopsis Kirschst. 1935; Septatium Velen. 1934 fide Jaklitsch et al. 2016; Species Fungorum 2017), Helotiaceae, Helotiales, Leotiomycetes, three species, type: H. paradoxum Peyr., hyphomycetous, sexual morph unknown, saprobes, aero-aquatic, worldwide, see Seifert et al. (2011; morphology), Wijayawardene et al. (2012, 2017; outline), Chuaseeharonnachai et al. (2013; diversity, Thailand), Kirk et al. (2013; genus accepted), Panzer et al. (2015; DNA, phylogeny), Sri-indrasutdhi et al. (2015; DNA, phylogeny), cultures available for the type: KF767.

Helicodochium S. Monteiro, R.F. Castañeda, A.C. Cruz \& Gusmão 2014, Ascomycota genera incertae sedis, one species, type: H. amazonicum J.S. Monteiro, R.F. Castañeda, A.C. Cruz \& Gusmão, hyphomycetous, sexual morph unknown, lignicolous, terrestrial, Brazil, see Monteiro et al. (2014c; taxonomy), Wijayawardene et al. (2012, 2017; outline), cultures and sequences are unavailable.

Helicofilia Matsush. 1983, Ascomycota genera incertae sedis, one species, type: $H$. madrasensis Matsush., hyphomycetous, sexual morph unknown, saprobes, terrestrial, India, UK, see Wijayawardene et al. (2012, 2017; outline), Kirk et al. (2013; genus accepted), holotype of the type: MFC-11630, cultures and sequences are unavailable, needs generic revision.

Helicogermslita Lodha \& D. Hawksw. 1983, Xylariaceae, Xylariales, Sordariomycetes, one species, type: H. celastri (S.-V. Kale \& S.V.S. Kale) Lodha \& D. Hawksw., asexual morphs unknown, on twigs, terrestrial, India, see Lumbsch and Huhndorf (2010; outline), Kirk et al. (2013; genus accepted), Stadler et al (2013; genus accepted), Jaklitsch et al. (2016a; position), Maharachchikumbura et al. (2015, 2016; outline), cultures and sequences are unavailable, holotype of type: HCIO 29374.

Helicogonium W.L. White 1942 (= Myriogonium Cain 1948 fide Jaklitsch et al. 2016a), Helicogoniaceae, Phacidiales, Leotiomycetes, 19 species, type: H. jacksonii W.L. White, asexual reproduction is present or absent, and when present, produce phialides directly on the hyphae, or form small phialide-bearing penicilli, mycoparasitic, Europe, North America, see Baral and Kutorga (2010; new species), Lumbsch and Huhndorf (2010; outline), Kirk et al. (2013; genus accepted), sequences are unavailable.

Helicogoosia Hol.-Jech. 1991, Ascomycota genera incertae sedis, one species, type: $H$. paradoxa Hol.-Jech., hyphomycetous, saprobes, terrestrial, Czechoslovakia, see see Seifert et al. (2011; morphology), Wijayawardene et al. (2012, 2017; outline), Kirk et al. (2013; genus accepted), cultures and sequences are unavailable, needs generic revision.

Helicoma Corda 1837, Tubeufiaceae, Tubeufiales, Dothideomycetes, type: H. muelleri Corda, hyphomycetous, saprobes, terrestrial, worldwide, see Boonmee et al. (2011, 2014b; taxonomy, phylogeny), Seifert et al. (2011; morphology), Wijayawardene et al. (2012, 2014c, 2017; outline), Kirk et al. (2013; genus accepted), Hyde et al. (2013; accepted as a genus in Tubeufiaceae), available cultures for the type: CBS 964.69.

Helicomyces Link 1809, Tubeufiaceae, Tubeufiales, Dothideomycetes, c. 15, type: H. roseus Link, hyphomycetous, saprobes, aero-aquatic, worldwide, see Boonmee et al. (2011, 2014b; taxonomy, phylogeny), Hyde et al. (2013; accepted as a genus in Tubeufiaceae), Wijayawardene et al. (2014c; outline), available cultures for the type: AFTOL-ID 1613, CBS 283.51 . 
Helicoön Morgan 1892, Orbiliaceae, Orbiliales, Orbiliomycetes, c. 20 species, type: $H$. sessile Morgan, hyphomycetous, sexual morph unknown, saprobes, terrestrial, cosmopolitan, see Seifert et al. (2011; morphology), Kirk et al. (2013; genus accepted), Wijayawardene et al. (2017; outline), cultures and sequences are unavailable.

Helicorhoidion S. Hughes 1958, Ascomycota genera incertae sedis, six species, type: $H$. botryoideum (Cooke) S. Hughes, hyphomycetous, sexual morph unknown, saprobes, terrestrial, Australia, Asia, North America, see Seifert et al. (2011; morphology), Wijayawardene et al. (2012, 2017; outline), Kirk et al. (2013; genus accepted), cultures and sequences are unavailable, needs generic revision.

Helicosingula P.S. van Wyk, Marasas, Baard \& Knox-Dav. 1985, Ascomycota genera incertae sedis, one species, type: H. leucadendri P.S. van Wyk, Marasas, Baard \& Knox-Dav., hyphomycetous, pathogen, terrestrial, South Africa, see Seifert et al. (2011; morphology), Wijayawardene et al. (2012, 2017; outline), Kirk et al. (2013; genus accepted), cultures and sequences are unavailable, needs generic revision.

Helicosporium Nees 1816, Tubeufiaceae, Tubeufiales, Dothideomycetes, c. 15, type: H. vegetum Nees, hyphomycetous, saprobes, terrestrial, worldwide, see Cruz et al. (2009; new species, Brazil), Dharkar et al. (2010; new species, India), Boonmee et al. (2011, 2014b; taxonomy, phylogeny), Seifert et al. (2011; morphology), Hyde et al. (2013; accepted as a genus in Tubeufiaceae), Kirk et al. (2013; genus accepted), Wijayawardene et al. (2014c; outline), available cultures for the type: BCC 3332.

Helicothyrium I. Hino \& Katum. 1961, Ascomycota genera incertae sedis, one species, type: H. ryukyuense I. Hino \& Katum., coelomycetouss, pathogen, Japan, see Wijayawardene et al. (2012; 2017, outline), Kirk et al. (2013; genus accepted), cultures and sequences are unavailable, needs generic revision.

Helicoubisia Lunghini \& Rambelli 1979, Ascomycota genera incertae sedis, one species, type: $H$. coronata Lunghini \& Rambelli, hyphomycetous, saprobe, terrestrial, Ivory Coast, see see Seifert et al. (2011; morphology), Wijayawardene et al. (2012, 2017; outline), Kirk et al. (2013; genus accepted), cultures and sequences are unavailable, needs generic revision.

Heliocephala V. Rao, K.A. Reddy \& de Hoog 1984 (= Holubovaniella R.F. Castañeda 1985 fide Abarca et al. 2010), Micropeltidaceae, Microthyriales, Dothideomycetes, three species, type: $H$. proliferans V. Rao, K.A. Reddy \& de Hoog, hyphomycetous, sexual morph unknown, saprobes, terrestrial, India, see Abarca et al. (2010; genus revised), Seifert et al. (2011; morphology), Wijayawardene et al. (2012, 2017; outline), Kirk et al. (2013; genus accepted), Mel'nik et al. (2013; new species), cultures and sequences are available, needs generic revision, compare with Holubovaniella, Gonatobotrys and Uncispora.

Heliscella Marvanová 1980, Ascomycota genera incertae sedis, two species, type: H. stellata (Ingold \& V.J. Cox) Marvanová, hyphomycetous, saprobes, terrestrial, former Czechoslovakia, see Seifert et al. (2011; morphology), Wijayawardene et al. (2012, 2017; outline), Kirk et al. (2013; genus accepted), cultures and sequences are unavailable, needs generic revision.

Heliscina Marvanová 1980, Ascomycota genera, incertae sedis, two species, type: $H$. campanulata Marvanová, hyphomycetous, saprobes, aquatic, former Czechoslovakia, see see Seifert et al. (2011; morphology), Wijayawardene et al. (2012, 2017; outline), Kirk et al. (2013; genus accepted), cultures and sequences are unavailable, needs generic revision.

Helminthascus Tranzschel 1898, Clavicipitaceae, Hypocreales, Sordariomycetes, one species, type: $H$. arachnophthorus Tranzschel, asexual morphs unknown, on insects, terrestrial, former USSR, see Lumbsch and Huhndorf (2010; outline), Kirk et al. (2013; genus accepted), Maharachchikumbura et al. (2015, 2016; outline), cultures and sequences are unavailable. 
Helminthocarpon Fée 1837, Arthoniales genera incertae sedis, Arthoniomycetes, one species, type: H. leprevostii Fée, lichenized, terrestrial (corticolous, saxicolous), tropical, see Kirk et al. (2013; genus accepted), Bungartz et al. (2013a; outline), Lücking et al. (2016b; classification), sequences are available.

Helminthopeltis Sousa da Câmara 1950, Dothideomycetes, genera incertae sedis, one species, type: H. almeidaeana Sousa da Câmara, asexual morph unknown, saprobes, terrestrial, Europe, see Lumbsch and Huhndorf (2010; outline, Microthyriaceae), Hyde et al. (2013) did not accept as a genus in Microthyriaceae, Kirk et al. (2013; genus accepted), Wijayawardene et al. (2014c; outline, accepted as a genus in Dothideomycetes, genera incertae sedis), cultures and sequences are unavailable.

Helminthosphaeria Fuckel 1870, Helminthosphaeriaceae, Chaetosphaeriales, Sordariomycetes, c. 20 species, type: H. clavariarum (Desm.) Fuckel, asexual morph diplococcium-like, saprobes, terrestrial, worldwide, see Lumbsch and Huhndorf (2010; outline), Kirk et al. (2013; genus accepted), Miller et al. (2014; new species, DNA, phylogeny), Maharachchikumbura et al. (2015, 2016; outline), Bell and Mahoney (2016; new species), culture available for the type: SMH4609 (fide Huhndorf et al. 2004).

Helminthosporiella Hern.-Restr., G.A. Sarria \& Crous 2016, Massarinaceae, Pleosporales, Dothideomycetes, one species, type: H. stilbacea (Moreau) Hern.-Restr., G.A. Sarria \& Crous, hyphomycetous, saprobes, terrestrial, Colombia, see Crous et al. (2016b; taxonomy, phylogeny), Wijayawardene et al. (2017; outline), cultures and sequences are available.

Helminthosporiomyces G.F. Sepúlveda, Pereira-Carv. \& Dianese 2009, Ascomycota genera incertae sedis, one species, type: H. cerradensis G.F. Sepúlveda, Pereira-Carv. \& Dianese, hyphomycetous, sexual morph unknown, saprobes, terrestrial, Brazil, see Pereira-Carvalho et al. (2009b; taxonomy), Wijayawardene et al. (2012, 2017; outline), cultures and sequences are unavailable, needs generic revision.

Helminthosporium Link 1809, Dothideomycetes, genera incertae sedis, c. 40 species, type: $H$. velutinum Link, hyphomycetous, sexual morph unknown, saprobes, lignicolous, terrestrial, aquatic, worldwide, see Seifert et al. (2011; morphology), Wijayawardene et al. (2012; outline, listed under Massarinaceae), Hyde et al. (2013) did not accepte as a genus in Massarinaceae, Wijayawardene et al. (2014c; outline, accepted as Dothideomycetes, genera incertae sedis), Zhu et al. (2016; DNA, new species), cultures and reference specimen available for the type: MFLUCC 15-0243, HKAS 84015 (fide Zhu et al. 2016).

Helocarpon Fr. 1860, Helocarpaceae, Lecanoromycetes family incertae sedis, three species; type: H. crassipes Th. Fr., lichenized, see Lumbsch and Huhndorf (2010; outline), Miądlikowska et al. (2014a; taxonomy), Lücking et al. (2016b; classification), sequences are available.

Helochora Sherwood 1979, Ascomycota genera incertae sedis, one species, type: $H$. hypertropha Sherwood, asexual morph unknown, saprobes, terrestrial, India, UK, see Lumbsch and Huhndorf (2010; outline, accepted as agenus in Mesnieraceae), Kirk et al. (2013; genus accepted), Hyde et al. (2013) Wijayawardene et al. (2014c) did not regard as a Dothideomycetes, cultures and sequences are unavailable, needs generic revision.

Helodiomyces F. Picard 1913, Ceratomycetaceae, Laboulbeniales, Laboulbeniomycetes, two species, type: H. elegans F. Picard, asexual morph unknown, biotrophic, USA, see Lumbsch and Huhndorf (2010; outline), Kirk et al. (2013; genus accepted), cultures and sequences are unavailable.

Helotiella Sacc. 1884, Leotiomycetes genera incertae sedis, ?one species, type: H. citri (Penz.) Sacc., asexual morph unknown, saprobes, Europe, see Kirk et al. (2008; accepted as nom. dub.), Lumbsch and Huhndorf (2010; outline, treated as Helotiales, genera incertae sedis), Jaklitsch et al. (2016a; classification), needs generic revision. 
Helvella L. 1753, Helvellaceae, Pezizales, Pezizomycetes, c. 60 species, type: H. mitra L., asexual morph unknown, saprobes, ?from soil, terrestrial, North temperate, see Lumbsch and Huhndorf (2010; outline), Kirk et al. (2013; genus accepted), Hwang et al. (2015; DNA, phylogeny), Landerosa et al. (2015; phylogeny), Zhao et al. (2015; DNA, phylogeny), cultures and sequences are available but lacks for the type.

Hemibeltrania Piroz. 1963, Ascomycota genera incertae sedis, eleven species, type: $H$. cinnamomi (Deighton) Piroz., hyphomycetous, sexual morph unknown, saprobes, terrestrial, tropical, see Seifert et al. (2011; morphology), Wijayawardene et al. (2012, 2017; outline), Kirk et al. (2013; genus accepted), cultures and sequences are available, needs generic revision as have different opinions.

Hemicorynespora M.B. Ellis 1972, Chaetosphaeriaceae, Chaetosphaeriales, Sordariomycetes, twelve species, type: $H$. deightonii M.B. Ellis, hyphomycetous, sexual morph unknown, saprobes, terrestrial, widespread, see Seifert et al. (2011; morphology), Whiton et al. (2012; new species), Jian et al (2012; new species), Hyde et al. (2011; outline), Wijayawardene et al. (2012, 2017; outline), Kirk et al. (2013; genus accepted), Maharachchikumbura et al. (2016; outline), cultures and sequences are available but lacks for the type species, needs generic revision.

Hemicorynesporella Subram. 1992, Ascomycota genera incertae sedis, one species, type: $H$. guadalcanalensis (Matsush.) Subram., hyphomycetous, sexual morph unknown, saprobes, terrestrial, Guadalcanal, see Seifert et al. (2011; morphology), Wijayawardene et al. (2012, 2017; outline), Kirk et al. (2013; genus accepted), cultures and sequences are unavailable, needs generic revision.

Hemidothis Syd. \& P. Syd. 1916, Ascomycota genera incertae sedis, one species, type: $H$. miconiae Syd. \& P. Syd., coelomycetous, sexual morph unknown, saprobes, terrestrial, tropical, see Wijayawardene et al. (2012, 2017; outline), Kirk et al. (2013; genus accepted), cultures and sequences are unavailable, needs generic revision.

Hemiglossum Pat. 1890, Helotiales genera incertae sedis, two species, type: H. yunnanense Pat., asexual morph unknown, saprobes, terrestrial, China, Japan, see Lumbsch and Huhndorf (2010; outline), Kirk et al. (2013; genus accepted), cultures and sequences are unavailable, needs generic revision.

Hemigrapha (Müll. Arg.) R. Sant. ex D. Hawksw. 1975, Parmulariaceae, Dothideomycetes families incertae sedis, eight species, type: H. asteriscus (Müll. Arg.) R. Sant. ex D. Hawksw., asexual morph unknown, epiphytes, terrestrial, worldwide, see Hofmann (2009; review), Lumbsch and Huhndorf (2010; outline), Hyde et al. (2013; review, keys), Wijayawardene et al. (2014c; outline), placement in Parmulariaceae supported by morphology, cultures and sequences are unavailable, needs generic revision.

Hemileucoglossum S. Arauzo 2014, Geoglossaceae, Geoglossales, Geoglossomycetes, four species, type: H. littorale (Rostr.) S. Arauzo, asexual morph unknown, saprobes, terrestrial, China, Japan, see Hustud and Miller (2014; taxonomy, phylogeny), cultures available for the type: C: 35673.

Hemimyriangium J. Reid \& Piroz. 1966, Myriangiaceae, Myriangiales, Dothideomycetes, one species, type: $H$. betulae J. Reid \& Piroz., asexual morph unknown, saprobes, terrestrial, Sweden, see Lumbsch and Huhndorf (2010; outline), Dissanayake et al. (2014; morphology), the genus was not accepted in Kirk et al. (2013).

Hemisphaericaspora Hui, Ren, Chen, Li, Zhang \& Niu 2014, Debaryomycetaceae, Saccharomycetales, Saccharomycetes, two species, type: H. nanyangensis F.L. Hui, Y.C. Ren, L. Chen, Z.H. Li, L. Zhang, Q.H. Niu, asexual reproduction is by multilateral budding, saprophytic, frass of beetle larvae, South Africa, China, see Hui et al. (2014; taxonomy), sequences are unavailable. 
Hemisphaeropsis Petr. 1947, Ascomycota genera incertae sedis, one species, type: $H$. magnoliae Petr., coelomycetous, sexual morph unknown, saprobes, terrestrial, USA, see Wijayawardene et al. (2012, 2017; outline), Kirk et al. (2013; genus accepted), cultures and sequences are unavailable, needs generic revision.

Hemisynnema Subram. (1995) [1992], Ascomycota genera incertae sedis, one species, type: H. malayasianum Subram., hyphomycetous, sexual morph unknown, saprobes, terrestrial, Malaysia, see Seifert et al. (2011; morphology), Wijayawardene et al. (2012, 2017; outline), Kirk et al. (2013; did not genus accepted), cultures and sequences are unavailable, needs generic revision.

Hemithecium Trevis. 1853, Graphidaceae, Ostropales, Lecanoromycetes, c. 50 species, type: H. balbisii (Fée) Trevis., asexual morph unknown, lichenized, terrestrial, tropical, see Archer 2009 (key, Australia), Lumbsch and Huhndorf (2010; outline), Kirk et al. (2013; genus accepted), Rivas Plata et al. (2012a; taxonomy), Lücking et al. (2014, 2016; classification), sequences are available.

Hendersoniella (Sacc.) Tassi 1900, Ascomycota genera incertae sedis, one species, type: $H$. epixyla Tassi, coelomycetous, sexual morph unknown, saprobes, terrestrial, Italy, see Wijayawardene et al. (2012, 2017; outline), Kirk et al. (2013; genus accepted), cultures and sequences are unavailable, needs generic revision.

Hendersonina E.J. Butler 1913, Ascomycota genera incertae sedis, one species, type: $H$. sacchari E.J. Butler, coelomycetous, sexual morph unknown, saprobes, terrestrial, Asia, see Wijayawardene et al. (2012, 2016; outline, taxonomy), Kirk et al. (2013; genus accepted), cultures and sequences are unavailable, needs generic revision.

Hendersoniopsis Höhn. 1918, Ascomycota genera incertae sedis, one species, type: $H$. thelebola (Sacc.) Höhn., coelomycetous, sexual morph unknown, saprobes, terrestrial, temperate, see Wijayawardene et al. (2012, 2016; outline, taxonomy), Kirk et al. (2013; genus accepted), cultures and sequences are unavailable, needs generic revision.

Hendersonula Speg. 1880, Ascomycota genera incertae sedis, c. 20, species, type: $H$. australis Speg., coelomycetous, sexual morph unknown, saprobes or plant pathogenic, worlwide, see Wijayawardene et al. (2012, 2016b, 2017; outline), Kirk (2013; genus accepted), cultures and sequences are unavailable, needs generic revision.

Hendersonulina Tassi 1902, Ascomycota genera incertae sedis, one species, type: need typification, coelomycetous, sexual morph unknown, saprobes, terrestrial, temperate, see Wijayawardene et al. (2012, 2017; outline), Kirk et al. (2013; genus accepted), cultures and sequences are unavailable, needs generic revision.

Henfellra Halici, D. Hawksw., Z. Kocak \& M. Kocak. 2016, Ascomycota genera incertae sedis, one species, type: H. muriformis Halici, D. Hawksw., Z. Kocak \& M. Kocak, sexual morph unknown, lichenicolous, cultures and sequences are unavailable, holotyper of the type: ERC-MGH 1.231.

Henicospora P.M. Kirk \& B. Sutton 1980, Ascomycota genera incertae sedis, six species, type: H. minor P.M. Kirk \& B. Sutton, hyphomycetous, sexual morph unknown, saprobes, terrestrial, worldwide, see Seifert et al. (2011; morphology), Wijayawardene et al. (2012, 2017; outline), Kirk et al. (2013; genus accepted), Monteiro et al. (2014b; Brazil), cultures and sequences are unavailable, needs generic revision.

Henningsiella Rehm 1895, Schizothyriaceae, Dothideomycetes, families incertae sedis, two species, type: H. quitensis Rehm, asexual morph unknown, saprobes, terrestrial, Philippines, see Lumbsch and Huhndorf (2010; outline), Hyde et al. (2013, accepted as Schizothyriaceae), Kirk et al. (2013; genus accepted), Wijayawardene et al. (2014c; outline), cultures and sequences are unavailable.

Henrica B.de Lesd. 1921, Verrucariaceae, Verrucariales, Eurotiomycetes, four species, type: H. ramulosa B. de Lesd., lichenized, Europe, North America, see Savić and Tibell (2008b; 
taxonomy, revision), Lumbsch and Huhndorf (2010; outline), Kirk et al. (2013; genus accepted), Lücking et al. (2016b; classification), sequences are available.

Heppia Nägeli 1854, Lichinaceae, Lichinales, Lichinomycetes, seven species, type: $H$. adglutinata A. Massal., lichenized, worldwide, see Lumbsch and Huhndorf (2010; outline), Kirk et al. (2013; genus accepted), Lücking et al. (2016b; classification), sequences are available.

Heppsora D.D. Awasthi \& K.Singh 1977, Ramalinaceae, Lecanorales, Lecanoromycetes, two species, type: $H$. indica D.D. Awasthi \& Kr.P. Singh, lichenized, India, Middle East, see Lumbsch and Huhndorf (2010; outline), Kirk et al. (2013; genus accepted), Lücking et al. (2016b; classification), sequences unavailable.

Heptameria Rehm \& Thüm. 1879, Dothideomycetes, genera incertae sedis, two species, type: H. elegans Rehm \& Thüm., asexual morph unknown, saprobes, terrestrial, Philippines, see Lumbsch and Huhndorf (2010; outline), Kirk et al. (2013; genus accepted), Wijayawardene et al. (2014cc; outline), cultures and sequences are unavailable, needs generic revision.

Heracleicola Tibpromma, Camporesi \& K.D. Hyde 2015, Didymellaceae, Pleosporales, Dothideomycetes, one species, type: H. premilcurensis Tibpromma, Camporesi \& K.D. Hyde, saprobes, Italy, see Ariyawansa et al. (2015a; morphology, phylogeny), cultures available for type: MFLUCC 14-0518.

Herbampulla Scheuer \& Nograsek 1993, Magnaporthaceae, Magnaporthales, Sordariomycetes, one species, type: H. crassirostris Scheuer \& Nograsek, asexual morph unknown, saprobes, terrestrial, Austria, see Lumbsch and Huhndorf (2010; outline), Kirk et al. (2013; genus accepted), Maharachchikumbura et al. (2015, 2016; outline), cultures and sequences are available.

Hercospora Fr. 1825, Diaporthales genera incertae sedis, Sordariomycetes, one species, type: H. tiliae (Pers.) Tul. \& C. Tul., asexual morph unknown, saprobes, terrestrial, Austria, see Lumbsch and Huhndorf (2010; outline), Kirk et al. (2013; genus accepted), Maharachchikumbura et al. (2016; outline), holotype and ex-type of the type: BPI 748440, AR3526.

Hermatomyces Speg. 1911, Lophiotremataceae, Pleosporales, Dothideomycetes, eleven species, type: H. tucumanensis Speg., saprobes, terrestrial, Africa, Asia, Caribbean, South America, see Seifert et al. (2011; morphology), Wijayawardene et al. (2012, 2017; outline), Kirk et al. (2013; genus accepted), Doilom et al. (2016; new species, phylogeny), Hyde et al. (2016; new species), Tibpromma et al. (2016a; new species), cultures and sequences are available.

Herpomyces Thaxt. 1902, Herpomycetaceae, Laboulbeniales, Laboulbeniomycetes, 25 species (est. spp. 25+), type: H. chaetophilus Thaxt., asexual morph unknown, biotrophic, dioecious, hosts are Blattodea, worldwide, see Lumbsch and Huhndorf (2010; outline), Kirk et al. (2013; genus accepted), Haelewaters et al. (2015b; DNA), sequences are available for type: (SSU, ITS, LSU), GenBank accession number for ITS of Herpomyces chaetophilus: KT800039

Herposira Syd. 1938, Ascomycota genera incertae sedis, one species, type: H. velutina Syd., hyphomycetous, sexual morph unknown, saprobes, terrestrial, Australia, see Seifert et al. (2011; morphology), Wijayawardene et al. (2012, 2017; outline), Kirk et al. (2013; genus accepted), cultures and sequences are unavailable, needs generic revision.

Herpothallon Tobler 1937, Arthoniaceae, Arthoniales, Arthoniomycetes, 46 species, type: $H$. sanguineum (Vain.) Tobler, lichenized, see Lumbsch and Huhndorf (2010; outline), Lücking et al. (2016b; classification), sequences are available.

Herpotrichia Fuckel 1868, Melanommataceae, Pleosporales, Dothideomycetes, 101 species, type: H. herpotrichoides (Fuckel) P.F.Cannon, asexual morph ceolomycetous, parasitic or 
saprobes, terrestrial, worldwide, see Lumbsch and Huhndorf (2010; outline), Wijayawardene et al. (2012; 2014; 2016; outline; phylogeny, coelomycetous taxa), Kirk et al. (2013; genus accepted), Tian et al. (2015; morphology, nomenclature, phylogeny), cultures and sequences are available but lacks for the type, needs generic revision.

Herreromyces R.F. Castañeda \& W.B. Kendr. 1991, Ascomycota genera incertae sedis, one species, type: H. catenosporus R.F. Castañeda \& W.B. Kendr., hyphomycetous, sexual morph unknown, saprobes, terrestrial, Cuba, see Seifert et al. (2011; morphology), Wijayawardene et al. (2012, 2017; outline), Kirk et al. (2013; genus accepted), holotype of the type: INIFAT C91/47, cultures and sequences are unavailable, compare with Exochalara, Chloridium and Monilochaetes, cultures and sequences are unavailable, needs generic revision.

Herteliana P. James 1980, Ramalinaceae, Lecanorales, Lecanoromycetes, three species, type: H. taylorii (Salwey) P. James, lichenized, see Lumbsch and Huhndorf (2010; outline), Kirk et al. (2013; genus accepted), Lücking et al. (2016b; classification), sequences are available.

Hertelidea Printzen \& Kantvilas 2004, Stereocaulaceae, Lecanorales, Lecanoromycetes, six species, type: H. botryosa (Fr.) Printzen \& Kantvilas, lichenized, see Lumbsch and Huhndorf (2010; outline), Lücking et al. (2016b; classification), sequences are available.

Hertella Henssen 1985, Placynthiaceae, Peltigerales, Lecanoromycetes, Ascomycota; three species; type: H. subantarctica Henssen, lichenized, see Lumbsch and Huhndorf (2010; outline), Kirk et al. (2013; genus accepted), Lücking et al. (2016b; classification), sequences unavailable.

Hesperomyces Thaxt. 1891, Laboulbeniaceae, Laboulbeniales, Laboulbeniomycetes, eleven species (est. spp. 11+), type: H. virescens Thaxt., no asexual state, biotrophic, hosts are Biphyllidae, Coccinellidae, Mycetophagidae (Coleoptera), and Anthocoridae (Hemiptera: Heteroptera), worldwide, see Lumbsch and Huhndorf (2010; outline), Kirk et al. (2013; genus accepted), Haelewaters et al. (2015b, 2016; DNA), sequences are available for the type: (SSU, ITS, LSU), GenBank accession numbers for ITS of Hesperomyces virescens: JN127409, KF192910-KF192920, KT800043-KT800048, KU574864

Heterocarpon Müll. Arg. 1885, Verrucariaceae, Verrucariales, Eurotiomycetes, one species, type: H. ochroleucum (Tuck.) Müll. Arg., lichenized, see Lumbsch and Huhndorf (2010; outline), Kirk et al. (2013; genus accepted), Lücking et al. (2016b; classification), sequences unavailable.

Heterocephalum Thaxt. 1903, Ascomycota genera incertae sedis, two species, type: $H$. aurantiacum Thaxt., hyphomycetous, sexual morph unknown, coprophilous, saprobes, terrestrial, worldwide, see Matei and Fendrihan (2008; Antarctica), Puangsombat et al. (2010; Thailand), Seifert et al. (2011; morphology), Silva et al. (2011; Amazon forest), Cort (2012; distribution), Wijayawardene et al. (2012, 2017; outline), Kirk et al. (2013; genus accepted), cultures and Sequences are unavailable, neotype of type: CBS H-15402.

Heteroconium Petr. 1949, Dothideomycetes genera incerte sedis, 20 species, type: $H$. citharexyli Petr., hyphomycetous, sexual morph unknown, saprobes, endophytes, terrestrial, worldwide, see Ruíz et al. (2008; new species), Zhang et al. (2010c; new species), Seifert et al. (2011; morphology), Ma et al. (2012f; new species), Ren et al. (2012b; new species), Wijayawardene et al. (2012, 2017; outline), Kirk et al. (2013; genus accepted), Xia et al. (2013b; new species), Lahlali et al. (2014; resistance to clubroot), sequences are available for most of the species.

Heterocyphelium Vain. 1927, Lecanographaceae, Arthoniales, Arthoniomycetes, one species, type: H. leucampyx (Tuck.) Vain., lichenized, see Lumbsch and Huhndorf (2010; outline), Tibell and Frisch (2010; Africa), Kirk et al. (2013; genus accepted), Pandit (2015; India), Lücking et al. (2016b; classification), sequences are available. 
Heterodermia Trevis. 1868, Physciaceae, Caliciales, Lecanoromycetes, 90 species, type: $H$. speciosa (Wulfen) Trevis., lichenized, see Lumbsch and Huhndorf (2010; outline), Gaya et al. (2012; taxonomy), Kirk et al. (2013; genus accepted), Lücking et al. (2016b; classification), Prieto and Wedin (2016; phylogeny), sequences are available.

Heteroepichlö̈ E. Tanaka, C. Tanaka, Gafur \& Tsuda 2002, Clavicipitaceae, Hypocreales, Sordariomycetes, type: H. bambusae (Pat.) E. Tanaka, C. Tanaka, Gafur \& Tsuda, asexual morphs unknown, saprobes, terrestrial, Japan, see Lumbsch and Huhndorf (2010; outline), Kirk et al. (2013; genus accepted), Maharachchikumbura et al. (2015, 2016; outline, nomenclature), cultures and sequences are available

Heteromyces Müll. Arg. 1889, Cladoniaceae, Lecanorales, Lecanoromycetes, one species, type: H. rubescens Müll. Arg., lichenized, see Lumbsch and Huhndorf (2010; outline), Kirk et al. (2013; genus accepted), Lücking et al. (2016b; classification), sequences unavailable.

Heterophoma Q. Chen \& L. Cai 2015, Didymellaceae, Pleosporales, Dothideomycetes, five species, type: H. sylvatica (Sacc.) Q. Chen \& L. Cai, coelomycetous, saprobes, ?pathogens, terrestrial, cosmopolitan, see Chen et al. (2015b; taxonomy, phylogeny), Wijayawardene et al. (2017; outline), neotype and ex-neotype culture of the type: HMAS 246700, CBS 874.97.

Heteroplacidium Breuss 1996, Verrucariaceae, Verrucariales, Eurotiomycetes, twelve species, type: H. imbricatum (Nyl.) Breuss, lichenized; see Lumbsch and Huhndorf (2010; outline), Kirk et al. (2013; genus accepted), Lücking et al. (2016b; classification), sequences are available.

Heteroseptata E.F. Morris 1972, Ascomycota genera incertae sedis, one species, type: $H$. bacillospora E.F. Morris, sexual morph unknown, saprobes, terrestrial, Costa Rica, see Seifert et al. (2011; morphology), Wijayawardene et al. (2012, 2017; outline), Kirk et al. (2013; genus accepted), cultures and sequences are unavailable, needs generic revision.

Heterosphaeria Grev. 1824 (= Heteropatella Fuckel fide Johnston et al. 2014b), Heterosphaeriaceae, Helotiales, Leotiomycetes, seven species, type: H. patella (Tode) Grev., asexual morph hyphomycetous, saprobes, Europe, see Lumbsch and Huhndorf (2010; outline), Kirk et al. (2013; genus accepted), Johnston et al. (2014b; nomenclature; new combinaion), cultures and sequences are unavailable, needs generic revision.

Heterosphaeriopsis Hafellner 1979, Dothideomycetes genera incertae sedis, one species, type: H. fulvodisca (Pat.) Hafellner, hyphomycetous, sexual morph unknown, saprobes, terrestrial, South America, see Seifert et al. (2011; morphology), Wijayawardene et al. (2012, 2017; outline), Kirk et al. (2013; genus accepted), Holotype of type: (FH, Sweden).cultures and sequences are unavailable, needs generic revision.

Heterosporicola Crous, nom. nov. MycoBank MB821707

三 Phoma sect. Heterospora Boerema, Gruyter \& Noordel., Persoonia 16(3): 336. 1997.

三Heterospora (Boerema, Gruyter \& Noordel.) Gruyter, Aveskamp \& Verkley, Stud. Mycol. 75: 18. 2012 [2013]. nom. illeg., [ICN (Melbourne) Art. 53.1], non Heterospora P. Kuckuck 1895 (Tilopteridaceae)

Leptosphaeriaceae, Pleosporales, Dothideomycetes, two species, coelomycetous, sexual morph unknown, saprobic or pathogenic on stems and leaves of Chenopodium spp., Argentina, Belgium, Peru, The Netherlands, see de Gruyter et al. (2012; morphology, phylogeny).

Holotype: Belgium, Beverloo, from leaves of Chenopodium suecicum (album) and Chenopodium urbicum (Chenopodiaceae), no date, G.D. Westendorp, Herb. Crypt. (Ed. Beyaert-Feys), No. 959. BR, holotype of Phyllosticta chenopodii Westend. ex herb. G.D. Westendorp. Epitype (designated by de Gruyter et al. 2012): Netherlands, Baarn, from leaf 
spots in Chenopodium album, 3 Jul. 1968, H.A. van der Aa, CBS H-16386; culture exepitype, CBS 448.68.

Heterosporicola chenopodii (Westend.) Crous, comb. nov. MycoBank: MB821708

$\equiv$ Phyllosticta chenopodii Westend., Bull. Acad. R. Sci. Belg., Cl. Sci., sér. 2 2(7):

567. 1857.

三 Heterospora chenopodii (Westend.) Gruyter, Aveskamp \& Verkley, Stud. Mycol.

75: 18. 2012 [2013].

ESeptoria westendorpii G. Winter, Hedwigia 26: 26. 1887. nom. inval., [ICN (Melbourne) Art. 36.1(b)],

三 Phoma variospora Aa \& Kesteren, Persoonia 10: 268. 1979. nom. illeg., [ICN

(Melbourne) Art. 53.1],

$\equiv$ Phoma heteromorphospora Aa \& Kesteren, Persoonia 10: 542. 1980.

Heterosporicola dimorphospora (Speg.) Crous, comb. nov. MycoBank: MB821709

$\equiv$ Phyllosticta dimorphospora Speg., Anal. Mus. nac. B. Aires, Ser. 3 13: 334. 1911.

$\equiv$ Phoma dimorphospora (Speg.) Aa \& Kesteren, Persoonia 10(2): 269. 1979.

$\equiv$ Heterospora dimorphospora (Speg.) Gruyter, Aveskamp \& Verkley, Stud. Mycol.

75: 18. 2012 [2013].

= Stagonospora chenopodii Peck, Rep. (Annual) New York State Mus. Nat. Hist. 40: 60. 1887.

Notes: The genus Heterospora (Boerema, Gruyter \& Noordel.) Gruyter, Verkley \& Crous 2012 is illegitimate, being a later homonym of the algal genus Heterospora P. Kuckuck 1895. In order to replace this name, the new name Heterosporicola nom. nov. is provided for this genus. Species of the genus are known plant pathogens of Chenopodiaceae in South America and Europe (de Gruyter et al. 2012).

Heuflera Bail 1860, Ascomycota genera incertae sedis, type: Heuflera betulae Bail, asexual morph unknown, saprobes, terrestrial, Europe, see Lumbsch and Huhndorf (2010; outline), Kirk et al. (2013; genus accepted), cultures and sequences are unavailable, needs generic revision.

Heufleridium Müll. Arg. 1883, Pyrenulales genera incertae sedis, Eurotiomycetes, two species, type: $H$. pentagastricum (Müll. Arg.) Müll. Arg., asexual morphs unknown, lichenized, terrestrial, tropical, see Lumbsch and Huhndorf (2010; outline), Kirk et al. (2013; genus accepted), cultures and sequences are unavailable.

Hexacladium D.L. Olivier 1983, Ascomycota genera incertae sedis, one species, type: $H$. corynephorum D.L. Olivier, hyphomycetous, sexual morph unknown, saprobes, terrestrial, South Africa, see Seifert et al. (2011; morphology), Wijayawardene et al. (2012, 2017; outline), Kirk et al. (2013; genus accepted), cultures and sequences are unavailable, needs generic revision.

Hexagonella F. Stevens \& Guba ex F. Stevens 1925, Schizothyriaceae, Dothideomycetes, families incertae sedis, two species, type: H. peleae F. Stevens \& Guba ex F. Stevens, asexual morph unknown, saprobes, terrestrial, Hawaii, see Lumbsch and Huhndorf (2010; outline), Hyde et al. (2013, accepted as Schizothyriaceae), Kirk et al. (2013; genus accepted), Wijayawardene et al. (2014c; outline), cultures and sequences are unavailable.

Heydenia Fresen. 1852, Pezizales genera incertae sedis, Pezizomycetes, four species, type: $H$. alpina Fresen., hyphomycetous, sexual morph unknown, saprobes, terrestrial, North temperate, see Seifert et al. (2011; morphology), Leuchtmann and Clemencon (2012; DNA, phylogeny), Wijayawardene et al. (2012, 2017; outline), Kirk et al. (2013; did not list), cultures available for the type: 0732 .

Heyderia Link 1833, Cenangiaceae, Helotiales, Leotiomycetes, six species, type: H. abietis (Fr.) Link, asexual morph unknown, saprobes, terrestrial, worldwide, see Lumbsch and 
Huhndorf (2010; outline, accepted as a genus in Hemiphacidiaceae), Kirk et al. (2013; genus accepted), Pärtel et al. (2017; DNA, phylogeny, accepted as a genus in Cenangiaceae), cultures available for the type: KL20.

Hidakaea I. Hino \& Katum. 1955, Dothideomycetes genera incertae sedis, two species, type: H. peleae F. Stevens \& Guba ex F. Stevens, asexual morph unknown, saprobes, terrestrial, Hawaii, see Lumbsch and Huhndorf (2010; outline, accepted as a genus in Microthyriaceae), Wu et al. (2010; placed in Hypocreales genera incertae cedis), Kirk et al. (2013; genus accepted), Wijayawardene et al. (2014c; outline, accepted as Dothideomycetes genera incertae sedis), cultures and sequences are unavailable, generic revesion is essential as it has different opinions.

Hiemsia Svrček 1969, Pezizales genera incertae sedis, Pezizomycetes, two species, type: $H$. pseudoampezzana (Svrček) Svrček, asexual morph unknown, saprobes, terrestrial, Europe, see Lumbsch and Huhndorf (2010; outline), Kirk et al. (2013; genus accepted), cultures and sequences are unavailable.

Hilberina Huhndorf \& A.N. Mill. 2004, Helminthosphaeriaceae, Chaetosphaeriales, Sordariomycetes, c. 20 species, type: H. caudata (Fuckel) Huhndorf \& A.N. Mill., asexual morph diplococcium-like, saprobes, terrestrial, worldwide, see Declercq (2009; new species), Lumbsch and Huhndorf (2010; outline), Kirk et al. (2013; genus accepted), Miller et al. (2014; new species, DNA, phylogeny), Maharachchikumbura et al. (2015, 2016; outline), Bell and Mahoney (2016; new species), culture available for the type: SMH1542 (fide Miller et al. 2014).

Himantormia I.M. Lamb 1964, Parmeliaceae, Lecanorales, Lecanoromycetes, two species, type: H. lugubris (Hue) I.M. Lamb, lichenized, see Lumbsch and Huhndorf (2010; outline), Kirk et al. (2013; genus accepted), Lücking et al. (2016b; classification), sequences are available.

Hinoa Hara \& 1. Hino 1961, Ascomycota genera incertae sedis, two species, type: H. sasae (Hara \& I. Hino) Hara \& I. Hino, ?coelomycetous, sexual morph unknown, saprobes, terrestrial, Japan, see Wijayawardene et al. (2012, 2017; outline), Kirk et al. (2013; genus accepted), cultures and sequences are unavailable, needs generic revision.

Hippocrepidea Sérus. 1997, Gomphillaceae, Ostropales, Lecanoromycetes, one species, type: H. nigra Sérus., lichenized, see Lumbsch and Huhndorf (2010; outline), Kirk et al. (2013; genus accepted), Lücking et al. (2016b; classification), sequences are unavailable.

Hirudinaria Ces., 1856, Ascomycota genera incertae sedis, two species, type: H. mespili Ces., hyphomycetous, sexual morph unknown, saprobes, terrestrial, Europe, North America, see Wijayawardene et al. (2012, 2017; outline), Kirk et al. (2013; genus accepted), cultures and sequences are unavailable, needs generic revision.

Hispidicarpomyces Nakagiri 1993, Hispidicarpomycetaceae, Spathulosporales, Sordariomycetes, one species (probably more than this), type: H. galaxauricola Nakagiri, spermatiophores or asexual morph hyphomycetous, biotrophic on marine red alga, Japan, see Kirk et al. (2013; genus accepted), Jones et al. (2015; outline), Maharachchikumbura et al. (2016; outline, the family accepted as in Spathulosporales), cultures and sequences are unavailable, holotype of the type: IFO H-12135 and paratype IFO H-12136, needs generic revision since have different opinions.

Hispidoconidioma Tsuneda \& M.L. Davey 2010, Teratosphaeriaceae, Capnodiales, Dothideomycetes, two species, type: H. alpinum Tsuneda \& M.L. Davey, hyphomycetous, sexual morph unknown, saprobes, terrestrial, Asia, see Tsuneda et al. (2010; taxonomy), Wijayawardene et al. (2012, 2014c; outline), holotype and ex-type culture of the type: UAMH 11010, L2-2.

Histeridomyces Thaxt. 1931, Laboulbeniaceae, Laboulbeniales, Laboulbeniomycetes, six species, type: $H$. ramosus Thaxt., asexual morph unknown, biotrophic, worldwide, see 
Lumbsch and Huhndorf (2010; outline), Kirk et al. (2013; genus accepted), cultures and sequences are unavailable.

Histoplasma Darling 1906, Ajellomycetaceae, Onygenales, Eurotiomycetes, seven species, type: H. capsulatum Darling, hyphomycetous, sexual morph unknown, on humans and animals, bat guano, terrestrial, Africa, North and South America, see Seifert et al. (2011; morphology), Wijayawardene et al. (2012, 2017; outline), Kirk et al. (2013; genus accepted), cultures and sequences are available.

Hobsoniopsis D. Hawksw. 2001, Ascomycota genera incertae sedis, one species, type: $H$. santessoniii (Lowen \& D. Hawksw., sexual morphs unknown, lichenicolous, Europe, terrestrial, see Seifert et al. (2011; morphology), cultures and sequences are available, holotype of type: UPS.

Hoehneliella Bres. \& Sacc. 1902, Ascomycota genera incertae sedis, two species, type: $H$. perplexa Bres. \& Sacc., coelomycetous, sexual morph unknown, saprobes, terrestrial, Austria, see Wijayawardene et al. (2012, 2017; outline, taxonomy), Kirk et al. (2013; genus accepted), cultures and sequences are unavailable, needs generic revision.

Hoffmannoscypha Stielow, Göker \& Klenk 2012 [2013], Pyronemataceae, Pezizales, Pezizomycetes, one species, type: H. pellita (Sacc.) Stielow, Göker \& Klenk, asexual morph unknown, saprobes, terrestrial, Europe, see Stielow et al. (2013; taxonomy, phylogeny), epitype of the type: M-0156529 (holotype of Peziza pellita), cultures and sequences are available.

Holmiella Petrini, Samuels \& E. Müll. 1979, Patellariaceae, Patellariales, Dothideomycetes, two species, type: H. sabina (De Not.) Petrini, Samuels \& E. Müll., asexual morph unknown, saprobes, terrestrial, worldwide, see Lumbsch and Huhndorf (2010; outline), Hyde et al. (2013; accepted as a genus in Patellariaceae), Kirk et al. (2013; genus accepted), Wijayawardene et al. (2014c; outline), Yacharoen et al. (2015; accepted as a genus in Patellariaceae), cultures and sequences are unavailable, needs generic revision.

Holocryphia Gryzenh. \& M.J. Wingf. 2006, Cryphonectriaceae, Diaporthales, Sordariomycetes, one species, type: H. eucalypti (M. Venter \& M.J. Wingf.) Gryzenh. \& M.J. Wingf., asexual morph unknown, pathogens, terrestrial, Australia, New Zealand, South Africa, see Lumbsch and Huhndorf (2010; outline), Chen et al. (2013b; DNA, phylogeny), Maharachchikumbura et al. (2015, 2016; outline), holotype of type: PREM 56211, cultures and sequences are available.

Holubovaea Mercado 1983, Ascomycota genera incertae sedis, two species, type: $H$. roystoneicola Mercado, hyphomycetous, sexual morph unknown, saprobes, terrestrial, Cuba, see Seifert et al. (2011; morphology), Wijayawardene et al. (2012, 2017; outline), Kirk et al. (2013; genus accepted), cultures and sequences are unavailable, needs generic revision.

Holwaya Sacc. 1889 (= Crinula Fr. 1821 fide Johnston et al. 2014b), Tympanidaceae, Phacidiales, Leotiomycetes, two species, type: H. ophiobolus (Ellis) Sacc., asexual morph Crinula, saprobes, terrestrial, temperate, see Lumbsch and Huhndorf (2010; outline), Johnston et al. (2014b; nomenclature), living cultures and sequences are available for sexual morph (fide Wang et al. 2006).

Homaromyces R.K. Benj. 1955, Laboulbeniaceae, Laboulbeniales, Laboulbeniomycetes, one species, type: H. epieri R.K. Benj., asexual morph unknown, biotrophic, USA, Europe, see Lumbsch and Huhndorf (2010; outline), Kirk et al. (2013; genus accepted), cultures and sequences are unavailable.

Homortomyces Crous \& M.J. Wingf. 2012, Homortomycetaceae, Dothideomycetes family incertae sedis, type: H. combreti Crous \& M.J. Wingf., two species, saprobes, South Africa, Italy, see Crous et al. (2012b; morphology, phylogeny), Wijayawardene et al. (2014c, 2016b; morphology, phylogeny), ex-epitype strains of type: CPC 19800; epitype CBS H-21049. 
Homostegia Fuckel 1870 [1869-70], Dothideomycetes, genera incertae sedis, five species, type: H. adusta Fuckel, asexual morph unknown, saprobes, terrestrial, Cuba, see Lumbsch and Huhndorf (2010; outline), Kirk et al. (2013; genus accepted), Wijayawardene et al. (2014c; outline), cultures and sequences are unavailable, needs generic revision.

Homothecium A. Massal. 1853, Pannariaceae, Peltigerales, Lecanoromycetes, five species, type: H. opulentum (Mont.) A. Massal., lichenized, see Kirk et al. (2013; genus accepted), Ekman et al. (2014; taxonomy), Lücking et al. (2016b; classification), sequences are unavailable.

Hongkongmyces C.C.C. Tsang, J.F.W. Chan, N.J. Trendell-Sm., A.H.Y. Ngan, I.W.H. Ling, K.Y. Yuen, S.K.P. Lau \& P.C.Y. Wood 2014, Lindgomycetaceae, Pleosporales, Dothideomycetes, two species, type: H. pedis C.C.C. Tsang et al., asexual morph unknown, human pathogen, Hong Kong, see Tsang et al. (2014b; taxonomy, phylogeny), Wijayawardene et al. (2014c; outline), holotype and ex-type strain of the HKU35.

Hoornsmania Crous 2007, Cladosporiaceae, Capnodiales, Dothideomycetes, one species, type: $H$. pyrina Crous, hyphomycetous, sexual morph unknown, hyperparasitic on Neonectria ditissima, terrestrial, France, see Seifert et al. (2011; morphology), Wijayawardene et al. (2012, 2014c, 2017; outline), holotype of the type: CBS H-19769, cultures and sequences are unavailable.

Hormiactis Preuss 1851, Ascomycota genera incertae sedis, five species, type: $H$. alba Preuss, hyphomycetous, sexual morph unknown, saprobes, terrestrial, Europe, Sri Lanka, see Seifert et al. (2011; morphology), Wijayawardene et al. (2012, 2017; outline), Kirk et al. (2013; genus accepted), cultures and sequences are unavailable, needs generic revision.

Hormiokrypsis Bat. \& Nascim. 1957, Ascomycota genera incertae sedis, one species, type: H. libocedri Bat. \& Nascim., coelomycetous, sexual morph unknown, sooty mould on plants, terrestrial, Australasia, North America, Oceania, see Seifert et al. (2011; morphology, accepted as a genus in Metacapnodiaceae), Wijayawardene et al. (2012, 2014c; outline, accepted as a genus in Metacapnodiaceae), Kirk et al. (2013; genus accepted), Wijayawardene et al. (2017; outline), cultures and sequences are unavailable, needs generic revision.

Hormiscioideus M. Blackw. \& Kimbr. 1979, Ascomycota genera incertae sedis, one species, type: H. filamentosus M. Blackw. \& Kimbr., hyphomycetous, sexual morph unknown, on isects, terrestrial, USA, see Seifert et al. (2011; morphology), Wijayawardene et al. (2012, 2017; outline), Kirk et al. (2013; genus accepted), cultures and sequences are unavailable, needs generic revision.

Hormisciomyces Bat. \& Nascim. 1957, Euantennariaceae, Dothideomycetes families incertae sedis, eight species, type: H. prepusus Bat. \& Nascim., sooty mould, terrestrial, Australasia, Europe, South America, see Lumbsch and Huhndorf (2010; outline), Hyde et al. (2013; taxonomy), Kirk et al. (2013; genus accepted), Wijayawardene et al. (2014c; outline), cultures and sequences are unavailable.

Hormocephalum Syd. 1939, Ascomycota genera incertae sedis, five species, type: $H$. ecuadorense Syd., hyphomycetous, sexual morph unknown, saprobes, terrestrial, Europe, Sri Lanka, see Seifert et al. (2011; morphology), Wijayawardene et al. (2012, 2017; outline), Kirk et al. (2013; genus accepted), cultures and sequences are unavailable, needs generic revision.

Hormocladium Höhn. 1923, Ascomycota genera incertae sedis, one species, type: $H$. ecuadorense Syd., hyphomycetous, sexual morph unknown, saprobes, terrestrial, Japan, see Seifert et al. (2011; morphology), Wijayawardene et al. (2012, 2017; outline), Kirk et al. (2013; genus accepted), cultures and sequences are unavailable, needs generic revision.

Hormoconis Arx \& G.A. de Vries 1973, Amorphothecaceae, Leotiomycetes, families incertae sedis, two species, type: H. resinae (Lindau) Arx \& G.A. de Vries, hyphomycetous, 
sexual morph unknown, saprobes on resins, hydrocarbons, terrestrial, worldwide, see Seifert et al. (2011; morphology), Wijayawardene et al. (2012, 2017; outline), Kirk et al. (2013; genus accepted), sequences are available, needs generic revision.

Hormographis Guarro, Punsola \& Arx 1986, Ascomycota genera incertae sedis, one species, type: H. ramirezii Guarro, Punsola \& Arx, hyphomycetous, sexual morph unknown, from soil, terrestrial, Spain, see Seifert et al. (2011; morphology), Wijayawardene et al. (2012, 2017; outline), Kirk et al. (2013; genus accepted), cultures and sequences are unavailable, needs generic revision.

Hormonema Lagerb. \& Melin 1927, Dothideaceae, Dothideales, Dothideomycetes, six species, type: Hormonema dematioides Lagerb. \& Melin, saprobes, human pathogen, terrestrial, Spain, see Seifert et al. (2011; morphology), Kirk et al. (2013; genus accepted), Thambugala et al. (2014a; taxonomy, phylogeny), Wijayawardene et al. (2014c; outline), Crous et al. (2015d; new species, DNA), ?polyphyletic, needs generic revision and epitypification.

Hormosphaeria Lév. 1863, Arthoniales genera incertae sedis, Arthoniomycetes, one species, type: H. tessellata Lév., lichenized, see Lumbsch and Huhndorf (2010; outline), Lücking et al. (2016b; classification), sequences are unavailable.

Hortaea Nishim. \& Miyaji 1984, Teratosphaeriaceae, Capnodiales, Dothideomycetes, two species, type: $H$. werneckii (Horta) Nishim. \& Miyaji, hyphomycetous, sexual morph unknown, saprobes, terrestrial, worldwide, see Schoch et al. (2009; new species, phylogeny), Seifert et al. (2011; morphology), Wijayawardene et al. (2012, 2014c; outline, phylogeny), Hyde et al. (2013; accepted as a genus in Teratosphaeriaceae), Egidi et al. (2014; phylogeny), Quaedvlieg et al. (2014; phylogeny), cultures available for the type: CBS 117931= TRN122 (fide Egidi et al. 2014).

Hosseusia Gyeln. 1940, Pannariaceae, Peltigerales, Lecanoromycetes, one species, type: $H$. gertrudiana Gyeln., lichenized, see Lumbsch and Huhndorf (2010; outline), Lücking et al. (2016b; classification), sequences unavailable.

Houjia G.Y. Sun \& Crous 2010, Dothideomycetes genera incertae sedis, two species, hyphomycetous, sexual morph unknown, saprobes, ?pathogens, terrestrial, USA, China, see Yang et al. (2010; morphology, phylogeny), Seifert et al. (2011; morphology), Wijayawardene et al. (2012, 2014c, 2017; outline), holotype and ex-type strains of the type: CBS H-20325, CPC 16114.

Huangshania O.E. Erikss. 1992, Triblidiaceae, Triblidiales, Leotomycetes, two species, type: H. verrucosa O.E. Erikss., asexual morph unknown, saprobes, terrestrial, China, see Lumbsch and Huhndorf (2010; outline), Kirk et al. (2013; genus accepted), Jaklitsch et al. (2016a; classification), cultures and sequences are unavailable, needs generic revision.

Huea C.W. Dodge \& G.E. Baker 1938, Lecanoraceae, Lecanorales, Lecanoromycetes, 20 species, type: H. flava C.W. Dodge \& G.E. Baker, lichenized, see Lumbsch and Huhndorf (2010; outline, accepted as a genus in Teloschistaceae), Lücking et al. (2016b; classification), sequences are available.

Hueidea Kantvilas \& P.M. McCarthy 2003, Fuscideaceae, Umbilicariales, Lecanoromycetes, one species, type: H. australiensis Kantvilas \& P.M. McCarthy, lichenized, see Lücking et al. (2016b; classification), sequences are unavailable.

Hughesinia J.C. Lindq. \& Gamundí 1970, Ascomycota genera incertae sedis, one species, type: H. chusqueae J.C. Lindq. \& Gamundí, hyphomycetous, sexual morph unknown, from soil, terrestrial, Chile, Cuba, see Seifert et al. (2011; morphology), Wijayawardene et al. (2012, 2017; outline), Kirk et al. (2013; genus accepted), cultures and sequences are unavailable, needs generic revision.

Humaria Fuckel 1870, Pyronemataceae, Pezizales, Pezizomycetes, c. 16 species, type: $H$. hemisphaerica (F.H. Wigg.) Fuckel, asexual morph unknown, saprobes, terrestrial, North 
temperate, see Palmer et al. (2008; DNA, phylogeny), Lumbsch and Huhndorf (2010; outline), Gaitnieks et al. (2016; DNA), Klavina et al. (2016; DNA, mycorrhization), cultures and sequences are available.

Humicola Traaen 1914, Chaetomiaceae, Sordariales, Sordariomycetes, one species, type: $H$. fuscoatra Traaen, hyphomycetous, sexual morph unknown, saprobes, from soil, terrestrial, worldwide, see Jiang and Zhang (2010; new species, China), Ko et al. (2011; new species), Wu and Zhang (2013; new species), Kirk et al. (2013; genus accepted), Geng and Zhang (2014; new species), Zhang and Zhang (2014; new species, China), Maharachchikumbura et al. (2015, 2016; outline), cultures available for the type: NRRL 22980, DAOM 35882.

Humicolopsis Cabral \& S. Marchand 1976, Helotiales genera incertae sedis, Leotiomycetes, one species, type: H. cephalosporioides Cabral \& Marchand, hyphomycetous, sexual morph unknown, saprobes, terrestrial, Argentina, see Seifert et al. (2011; morphology), Wijayawardene et al. (2012, 2017; outline), Kirk et al. (2013; genus accepted), cultures and sequences are available, needs generic revision.

Huneckia S.Y. Kondr., Elix, Kärnefelt, A. Thell \& Hur 2014, Teloschistaceae, Teloschistales, Lecanoromycetes, two species, type: H. pollinii (A. Massal.) S.Y. Kondr., Kärnefelt, A. Thell, Elix, J. Kim, A.S. Kondr. \& Hur, lichenized, see Kondratyuk et al. (2014a; txonomy), Lücking et al. (2016b; classification), sequences are available.

Huntiella Z.W. de Beer, T.A. Duong \& M.J. Wingf. 2014, Ceratocystidaceae, Microascales, Sordariomycetes, 17 species, type: H. moniliformis (Hedgc.) Z.W. de Beer, T.A. Duong \& M.J. Wingf., asexual morph hyphomycetous, saprobes, terrestrial, worldwide, see De Beer et al. (2014; phylogeny), Maharachchikumbura et al. (2015; phylogeny, outline), sequences are available.

Hyalacrotes (Korf \& L.M. Kohn) Raitv. 1991, Calloriaceae, Helotiales, Leotiomycetes, two species, type: H. laricionis (Velen.) Svrček, asexual morph unknown, saprobes, terrestrial, Europe, see Lumbsch and Huhndorf (2010; outline), Kirk et al. (2013; genus accepted), cultures and sequences are unavailable.

Hyalobelemnospora Matsush. 1993, Ascomycota genera incertae sedis, one species, type: $H$. amazonica Matsush., hyphomycetous, sexual morph unknown, saprobes, terrestrial, Peru, see Seifert et al. (2011; morphology), Wijayawardene et al. (2012, 2017; outline), Kirk et al. (2013; genus accepted), cultures and sequences are unavailable, needs generic revision.

Hyalocamposporium Révay \& J. Gönczöl 2007, Ascomycota genera incertae sedis, four species, type: $H$. longiflagellatum Révay \& J. Gönczöl, hyphomycetous, sexual morph unknown, saprobes, terrestrial, worldwide, see Seifert et al. (2011; morphology), Wijayawardene et al. (2012, 2017; outline), Kirk et al. (2013; genus accepted), holotype of the type: BP 98968, cultures and sequences are unavailable, needs generic revision.

Hyalocephalotrichum Nagaraju, Kunwar, Sureshk. \& Manohar. 2011, Ascomycota genera incertae sedis, one species, type: Hyalocephalotrichum indicum Nagaraju, Kunwar, Sureshk. \& Manohar., hyphomycetous, sexual morph unknown, saprobes, terrestrial, India, see holotype of the type: HCIO 50144, cultures and sequences are unavailable, needs generic revision.

Hyalocladium Moustafa 1977 [1976], Ascomycota genera incertae sedis, one species, type: H. moubasheri Moustafa, hyphomycetous, sexual morph unknown, saprobes, terrestrial, Kuwait, see Seifert et al. (2011; morphology), Wijayawardene et al. (2012, 2017; outline), Kirk et al. (2013; genus accepted), cultures and sequences are unavailable, needs generic revision.

Hyalocrea Syd. \& P. Syd. 1917, Dothideomycetes, genera incertae sedis, four species, type: H. epimyces Syd. \& P. Syd., asexual morph unknown, saprobes, terrestrial, tropical, see 
Lumbsch and Huhndorf (2010; outline), Kirk et al. (2013; genus accepted), Wijayawardene et al. (2014c; outline), cultures and sequences are unavailable, needs generic revision.

Hyalocylindrophora J.L. Crane \& Dumont 1978, Ascomycota genera incertae sedis, three species, type: H. rosea (Petch) Réblová \& W. Gams, hyphomycetous, sexual morph unknown, on cheese and fungi, terrestrial, Europe, North America, see Reblova et al. (2011; reinstated the genus), Seifert et al. (2011; morphology), Maharachchikumbura et al. (2015, 2016; outline, treated as a genus in Australiascaceae), Wijayawardene et al. (2017; outline), cultures and sequences are unavailable, needs generic revision.

Hyalodendriella Crous 2007, Helotiales genera incertae sedis, Leotiomycetes, one species, type: $H$. betulae Crous, hyphomycetous, sexual morph unknown, saprobes, terrestrial, Netherlands, see Seifert et al. (2011; morphology), Wijayawardene et al. (2012, 2017; outline), holotype and ex-type strains of the type: CBS-H 19895, CBS 261.82.

Hyaloderma Speg. 1884, Sordariomycetes, genera incertae sedis, one species, type: $H$. imperspicuum Speg., asexual morph unknown, saprobes, terrestrial, South America, see Lumbsch and Huhndorf (2010; outline), Kirk et al. (2013; genus accepted), Maharachchikumbura et al. (2015, 2016; outline), cultures and sequences are unavailable, needs generic revision.

Hyalodermella Speg. 1918, Ascomycota genera incertae sedis, one species, type: $H$. gardeniae (Keissl.) Speg., asexual morph unknown, saprobes, terrestrial, South America, see Lumbsch and Huhndorf (2010; outline), Kirk et al. (2013; genus accepted), cultures and sequences are unavailable, needs generic revision.

Hyalodictyum Woron. 1916, Ascomycota genera incertae sedis, one species, type: $H$. colchicum Woron., coelomycetous, sexual morph unknown, saprobes, terrestrial, former USSR, see Wijayawardene et al. (2012, 2017; outline), Kirk et al. (2013; genus accepted), cultures and sequences are unavailable, needs generic revision.

Hyalohelicomina T. Yokoy. 1974, Ascomycota genera incertae sedis, one species, type: $H$. deutziae (T. Yokoy.) T. Yokoy., hyphomycetous, sexual morph unknown, saprobes, terrestrial, Japan, see Seifert et al. (2011; morphology), Wijayawardene et al. (2012, 2017; outline), Kirk et al. (2013; genus accepted), cultures and sequences are unavailable, needs generic revision.

Hyalomeliolina F. Stevens 1924, Perisporiopsidaceae, Dothideomycetes, families incertae sedis, two species, type: H. guianensis F. Stevens, asexual morph unknown, saprobes, terrestrial, central and south America, see Lumbsch and Huhndorf (2010; outline), Hyde et al. (2013; accepted as a genus in Perisporiopsidaceae), Kirk et al. (2013; genus accepted), Wijayawardene et al. (2014c; outline, accepted as a genus in Perisporiopsidaceae), cultures and sequences are unavailable.

Hyalopeziza Fuckel 1870, Hyaloscyphaceae, Helotiales, Leotiomycetes, two species, type: $H$. patula (Pers.) Fuckel, asexual morph phialophora-like, saprobes, ?lichenicolous, terrestrial, worldwide, see Huhtinen et al. (2008; new species, Alaska), Lumbsch and Huhndorf (2010; outline), Kirk et al. (2013; genus accepted), Han et al. (2014; DNA, phylogeny), cultures and sequences are available but lacks for the type.

Hyalopleiochaeta R.F. Castañeda, Guarro \& Cano 1996, Ascomycota genera incertae sedis, one species, type: H. delicata R.F. Castañeda, Guarro \& Cano, hyphomycetous, sexual morph unknown, saprobes, terrestrial, Cuba, see Seifert et al. (2011; morphology), Wijayawardene et al. (2012, 2017; outline), Kirk et al. (2013; genus accepted), cultures and sequences are unavailable, holotype of the type: INIFAT C94/140, cultures and sequences are unavailable, compare with Camposporium.

Hyalorbilia Baral \& G. Marson 2001, Orbiliaceae, Orbiliales, Orbiliomycetes, 13 species, type: H. berberidis (Velen.) Baral, asexual morph ?hyphomycetous, saprobes, terrestrial, 
widespread, see Lumbsch and hunduf (2010; outline), cultures and sequences are available but lacks for type species, needs generic revision.

Hyalorhinocladiella H.P. Upadhyay \& W.B. Kendr. 1975, Ophiostomataceae, Ophiostomatales, Sordariomycetes, one species, type: H. minuta-bicolor (R.W. Davidson) H.P. Upadhyay \& W.B. Kendr., hyphomycetous, saprobes, worldwide, see Lu et al. (2009; DNA, phylogeny), Seifert et al. (2011; morphology), Wijayawardene et al. (2012, 2017; outline), Lumbsch and Huhndorf (2010; outline), Kirk et al. (2013; genus accepted), Maharachchikumbura et al. (2015, 2016; outline), cultures and sequences are available but lacks for the type:.

Hyalorostratum Raja \& Shearer 2010, Diaporthales genera incertae sedis, Sordariomycetes, one species, type: H. brunneisporum Raja \& Shearer, freshwater, Alaska and New Hampshire see Raja et al. (2010a; taxonomy, phylogeny), Maharachchikumbura et al. (2015, 2016; outline), holotype: A573-1 ILL 40792.

Hyaloscolecostroma Bat. \& J. Oliveira 1967, Dothideomycetes genera incertae sedis, one species, type: $H$. rondoniense Bat. \& J. Oliveira, asexual morph unknown, lichenicolous, terrestrial, Brazil, see Lumbsch and Huhndorf (2010; outline), Kirk et al. (2013; outline, genus accepted), Wijayawardene et al. (2014c; outline), culture and sequence are unavailable, needs generic revision.

Hyaloscypha Boud. 1885 (= Eupezizella Höhn. 1926; = Meliniomyces Hambl. \& Sigler 2005; = Orbiliopsis Höhn. 1926; = Parorbiliopsis Spooner \& Dennis 1986 [1985]; = Pseudaegerita J.L. Crane \& Schokn. 1981; = Truncicola Velen. 1934 fide Jaklitsch et al. 2016a; Species Fungorum 2017), Hyaloscyphaceae, Helotiales, Leotiomycetes, c. 45 species, type: $H$. vitreola (P. Karst.) Boud., asexual morph hyphomycetous in H. albohyalina var. spiralis and $H$. albohyalina var. monodictys, saprobes, terrestrial, worldwide, see Baral et al. (2009; new species), Lumbsch and Huhndorf (2010; outline), Kirk et al. (2013; genus accepted), Han et al. (2014; DNA, phylogeny), cultures and sequences are available for the type: M220 (fide Baral et al. 2009).

Hyaloseta A.W. Ramaley 2001, Niessliaceae, Hypocreales, Sordariomycetes, one species, type: H. nolinae A.W. Ramaley, asexual morph unknown, saprobes, terrestrial, USA, see Lumbsch and Huhndorf (2010; outline), Maharachchikumbura et al. (2015, 2016; outline), ex-type culture for the type: CBS 109837 (fide Lombard et al. 2015).

Hyalosphaera F. Stevens 1917, Dothideomycetes genera incertae sedis, four species, type: $H$. miconiae F. Stevens, asexual morph unknown, saprobes, terrestrial, North and Central America, see Alves et al. (2010; new species, Costa Rica), Lumbsch and Huhndorf (2010; outline), Kirk et al. (2013; genus accepted), Wijayawardene et al. (2014c; outline), sequence data available for unidentified Hyalosphaera species, needs generic revision.

Hyalosynnema Matsush. 1975, Ascomycota genera incertae sedis, one species, type: $H$. multiseptatum Matsush., hyphomycetous, sexual morph unknown, saprobes, terrestrial, Japan, Taiwan, see Seifert et al. (2011; morphology), Wijayawardene et al. (2012, 2017; outline), Kirk et al. (2013; genus accepted), cultures and sequences are unavailable, needs generic revision.

Hyalotheles Speg. 1908, Dothideomycetes, genera incertae sedis, one species, type: $H$. dimerosperma Speg., asexual morph unknown, saprobes, terrestrial, South America, see Alves et al. (2010; new species, Costa Rica), Lumbsch and Huhndorf (2010; outline, accepted as a genus in Elsinoaceae), Li et al. (2011; excluded from Elsinoaceae), Kirk et al. (2013; genus accepted), Wijayawardene et al. (2014c; outline), sequence data available for unidentified Hyalosphaera species, needs generic revision.

Hyalothyridium Tassi 1900, Ascomycota genera incertae sedis, one species, type: $H$. viburnicola Tassi, coelomycetous, sexual morph unknown, saprobes, terrestrial, worldwide, 
see Wijayawardene et al. (2012, 2017; outline), Kirk et al. (2013; genus accepted), cultures and sequences are unavailable, needs generic revision.

Hyalotiella Papendorf 1967, Bartaliniaceae, Xylariales, Sordariomycetes, four species, type: $H$. transvalensis Papendorf, coelomycetous, sexual morph unknown, saprobes, terrestrial, worldwide, see Wijayawardene et al. (2012, 2016; outline, taxonomy), Kirk et al. (2013; genus accepted), Li et al. (2015d; new species); Maharachchikumbura et al. (2015, 2016; outline), Senanayake et al. (2015; outline), sequence data and cultures available but lacks for the type:, needs generic revision.

Hyalotiopsis Punith. 1970 (= Ellurema Nag Raj \& W.B. Kendr. fide Réblová et al. 2016c), Sordariomycetes genera incertae sedis, one species, type: H. subramanianii (Agnihothr. \& Luke) Punith., coelomycetous, sexual morph formerly known in Ellurema, saprobes, terrestrial, worldwide, see Wijayawardene et al. (2012, 2016; outline, taxonomy), Kirk et al. (2013; genus accepted), Réblová et al. (2016c; nomenclature), cultures and sequences are unavailable, needs generic revision.

Hydea K.L. Pang \& E.B.G. Jones 2010, Lulworthiaceae, Lulworthiales, Sordariomycetes, one species, type: H. pygmea (Kohlm.) K.L. Pang \& E.B.G. Jones, hyphomycetous, sexual morph unknown, saprobes, marine, pantropical, see Abdel-Wahab et al. (2010; morphology, phylogeny), Maharachchikumbura et al. (2015, 2016; outline, phylogeny), cultures and sequences are available.

Hydnobolites Tul. \& C. Tul. 1843, Pezizaceae, Pezizales, Pezizomycetes, one species, type: H. cerebriformis Tul. \& C. Tul., asexual morph unknown, hypogeous, terrestrial, North America, Europe, see Lumbsch and Huhndorf (2010; outline), Healy et al. (2013; DNA, phylogeny), Kirk et al. (2013; genus accepted), cultures available for type: PA9 (fide Kalvina et al. 2016).

Hydnocystis Tul. \& C. Tul. 1845, Pezizales genera incertae sedis, Pezizomycetes, two species, type: $H$. arenaria Tul. \& C. Tul., asexual morph unknown, hypogeous, terrestrial, Japan, Europe, see Lumbsch and Huhndorf (2010; outline), Kirk et al. (2013; genus accepted), Jaklitsch et al. (2016a; classification), cultures and sequences are available (unpublished) but lacks for the type.

Hydnotrya Berk. \& Broome 1846, Discinaceae, Pezizales, Pezizomycetes, c. 15 species, type: H. tulasnei (Berk.) Berk. \& Broome, asexual morph unknown, hypogeous, terrestrial, worldwide, see Lumbsch and Huhndorf (2010; outline), Stielow et al. (2010; DNA), Kirk et al. (2013; genus accepted), Li et al. (2013; DNA, phylogeny, new species), Methven et al. (2013; DNA, phylogeny), cultures available for the type: BB70 (766) (fide Stielow et al. 2010).

Hydnotryopsis Gilkey 1916, Pezizaceae, Pezizales, Pezizomycetes, two species, type: $H$. setchellii Gilkey, asexual morph unknown, hypogeous, terrestrial, North America, see Brock et al. (2009; DNA), Lumbsch and Huhndorf (2010; outline), Stielow et al. (2010; DNA), Kirk et al. (2013; genus accepted), cultures available for the type: RBG Kew K(M)99871.

Hydraeomyces Thaxt. 1896, Laboulbeniaceae, Laboulbeniales, Laboulbeniomycetes, one species, type: H. halipli (Thaxt.) Thaxt., asexual morph unknown, biotrophic, terrestrial, worldwide, see Lumbsch and Huhndorf (2010; outline), Kirk et al. (2013; genus accepted), cultures and sequences are unavailable.

Hydrocina Scheuer 1991, Helotiales genera incertae sedis, Leotiomycetes, one species, type: H. chaetocladia Scheuer, asexual morph unknown, saprobes, aquatic, worldwide, see Lumbsch and Huhndorf (2010; outline), Baschien et al. (2013; DNA, phylogeny), Kirk et al. (2013; genus accepted), cultures and sequences are available for the type: HME4375 (fide Wang et al. 2005), CCM F-10890 (fide Baschien et al. 2013).

Hydromelitis A. Ferrer, A.N. Mill., C. Sarmiento \& Shearer 2012, Sordariomycetidae genera incertae sedis, one species, H. pulchella A. Ferrer, A.N. Mill., Sarmiento \& Shearer, 
freshwater, submerged substrates, Costa Rica, see Ferrer et al. (2012; taxonomy), Maharachchikumbura et al. (2015, 2016; outline), holotype: AF284-2, ILL 40117.

Hydrometrospora J. Gönczöl \& Révay 1985, Ascomycota genera incertae sedis, one species, type: $H$. symmetrica J. Gönczöl \& Révay, hyphomycetous, sexual morph unknown, saprobes, aquatic, Hungary, see Seifert et al. (2011; morphology), Wijayawardene et al. (2012, 2017; outline), Kirk et al. (2013; genus accepted), Cultures and sequences are unavailable, Holotype and cultures of type species unavailable, needs generic revision.

Hydronectria Kirschst. 1925, Sordariomycetes genera incertae sedis, one species, type: $H$. kriegeriana Kirschst., asexual morph unknown, algicolous, terrestrial, Europe, see Lumbsch and Huhndorf (2010; outline), Kirk et al. (2013; genus accepted), Maharachchikumbura et al. (2015, 2016; outline), cultures and sequences are unavailable, cultures and sequences of type species are unavailable, needs generic revision.

Hydrophilomyces Thaxt. 1908, Laboulbeniaceae, Laboulbeniales, Laboulbeniomycetes, twelve species, type: H. rhynchophorus (Thaxt.) Thaxt., asexual morph unknown, biotrophic, terrestrial, worldwide, see Lumbsch and Huhndorf (2010; outline), Kirk et al. (2013; genus accepted), cultures and sequences are unavailable.

Hydropisphaera Dumort. 1822, Bionectriaceae, Hypocreales, Sordariomycetes, 25 species, type: H. peziza (Tode) Dumort., asexual morph unkniwn, terrestrial, aquatic, worldwide, Farr and Platas (2008; new species), Lechat et al. (2010; asexual morph), Luo and Zhuang (2010; new species), Zeng and Zhuang (2016; new species), Cultures and sequences are available.

Hydropunctaria C. Keller, Gueidan \& Thüs 2009, Verrucariaceae, Verrucariales, Eurotiomycetes, eight species, type: H. maura (Wahlenb.) C. Keller, Gueidan \& Thüs, marine, lichenized, Asia, Europe, Australia, South America, see Gueidan et al. (2009; description, phylogeny), Roux et al. (2011; new species), Lücking et al. (2016b; classification), cultures and sequences are available, but not from type material.

Hymenelia Kremp. 1852, Hymeneliaceae, Hymeneliales, Lecanoromycetes, 25 species, type: H. prevostii (Duby) Kremp., lichenized, worldwide, see Wirth et al. (2011; Germany), Himelbrant et al. (2013; Russia), Aptroot and Moon (2014; Korea), Kantvilas (2014b; new species), Hansen (2015; Greenland), Lücking et al. 2016 (classification), Cultures and sequences are available but lacks for type species.

Hymenella Fr. 1822, Ascomycota genera incertae sedis, eleven species, type: $H$. arundinis Fr., coelomycetous, sexual morph unknown, saprobes, terrestrial, worldwide, see Hyde et al. (2011; checklist), Wijayawardene et al. (2012, 2017; outline), Kirk et al. (2013; genus accepted), Cultures and sequences are unavailable, Holotype or ex-type of type species unavailable, needs generic revision.

Hymeniopeltis Bat. 1959, Ascomycota genera incertae sedis, three species, type: $H$. erythroxyli Bat. \& A.F. Vital, coelomycetous, sexual morph unknown, saprobes, terrestrial, Brazil, see Wijayawardene et al. (2012, 2017; outline), Kirk et al. (2013; genus accepted), Cultures and sequences are unavailable, Holotype and ex-type of type species unavailable, needs generic revision.

Hymenobia Nyl. 1854, Ascomycota genera incertae sedis, one species, type: $H$. insidiosa Nyl., asexual morph unknown, lichenicolous, terrestrial, Europe, see Lumbsch and Huhndorf (2010; outline), Kirk et al. (2013; genus accepted), Cultures and sequences are unavailable, Holotype or ex-type of type species unavailable, needs generic revision.

Hymenobolus Durieu \& Mont. 1845, Helotiales genera incertae sedis, Leotiomycetes, three species, type: $H$. agaves Durieu \& Mont., asexual morph unknown, saprobes, terrestrial, North America, see Lumbsch and Huhndorf (2010; outline), Kirk et al. (2013; genus accepted), cultures and sequences are unavailable, needs generic revision.

Hymenopsis Sacc. 1886, Ascomycota genera incertae sedis, 13 species, type: H. trochiloides (Sacc.) Sacc., sexual morph unknown, saprobes, fungicolous, terrestrial, worldwide, see 
Schmidt et al. (2010a; extrolites), Wijayawardene et al. (2012, 2017; outline), Kirk et al. (2013; genus accepted), Cultures and sequences are available, holotype and ex-type of type species unavailable, needs generic revision.

Hymenoscyphus Gray 1821, Helotiaceae, Helotiales, Leotiomycetes, c. 170 species, type: $H$. fructigenus (Bull.) Gray, asexual morph ?hyphomycetous, pathogens, saprobes, terrestrial, North and South America, see Lumbsch and Huhndorf (2010; outline), Queloz et al. (2011; cryptic species), Kirk et al. (2013; genus accepted), Baral et al. (2014; nomenclature), Gross et al. (2014; pathogens), Zheng and Zhuang (2014; new species, China), cultures and sequences are available.

Hymenotorrendiella P.R. Johnst., Baral \& R. Galán 2014, Helotiaceae, Helotiales, Leotiomycetes, nine species, type: H. eucalypti (Berk.) P.R. Johnst., Baral \& R. Galán, asexual morph unknown, saprobes, terrestrial, Europe, see Johnston et al. (2014a; taxonomy, DNA, phylogeny), cultures and sequences are available.

Hyperdermium J.F. White, R.F. Sullivan, Bills \& Hywel-Jones 2000, Cordycipitaceae, Hypocreales, Sordariomycetes, three species, type: H. caulium (Berk. \& M.A. Curtis) Chaverri \& K.T. Hodge, asexual morph unknown, pathogens or saprobes, terrestrial, Central and South America, see Chaverri et al. (2008; recombined), Lumbsch and Huhndorf (2010; outline), Kirk et al. (2013; genus accepted), Maharachchikumbura et al. (2015, 2016; outline), Cultures and sequences are available, holotype of type: K(M) 120327 (as Corticium caulium Berk. \& M.A. Curtis).

Hyperphyscia Müll. Arg. 1894, Physciaceae, Caliciales, Lecanoromycetes, nine species, type: H. synthalea (C. Knight) Müll. Arg., lichenized, worldwide, see Charak et al. (2009; effect of coal mines), Kinalioglu (2010; Turkey), Esslinger et al. (2012; new species), Estrabou et al. (2014; Argentina), Lücking et al. (2016b; classification), Cultures and sequences are available.

Hyphochlaena Cif. 1962, Ascomycota genera incertae sedis, one species, type: $H$. caespitosa Cif., sterile mycelium, sexual morph unknown, saprobes, terrestrial, Dominican Republic, see Wijayawardene et al. (2012, 2017; outline), Kirk et al. (2013; genus accepted), Cultures and sequences are unavailable, needs generic revision.

Hyphoconis Egidi \& Quaedvlieg 2014, Capnodiales genera incertae saedis, Dothideomycetes, one species, type: H. sterilis Egidi \& Quaedvlieg, hyphomycetous, sexual morph unknown, rock-inhabiting fungus, see Egidi et al. (2014; taxonomy), Wijayawardene et al. (2017; outline), cultures available for the type: CBS $118321=$ TRN278.

Hyphodiscosia Lodha \& K.R.C. Reddy 1974, Ascomycota genera incertae sedis, five species, type: H. jaipurensis Lodha \& K.R.C. Reddy, hyphomycetous, saprobes, pathogen, terrestrial, Argentina, Australia, Brazil, Cuba, Czechoslovakia, India, Japan, Mexico, Nigeria, Poland, Russia, Taiwan, Thailand, see Seifert et al. (2011; morphology), Wijayawardene et al. (2012, 2016; outline), Kirk et al. (2013; genus accepted), Cultures and sequences are available but lacks for the type species, Holotype and ex-type of type species RUBL 730, needs generic revision.

Hyphodiscosioides Matsush. 1993, Ascomycota genera incertae sedis, one species, type: $H$. tambopataensis Matsush., hyphomycetous, saprobes, terrestrial, Peru, see Seifert et al. (2011; morphology), Wijayawardene et al. (2012, 2017; outline), Kirk et al. (2013; genus accepted), Cultures and sequences are unavailable, Holotype and ex-type of type species MFC 1P-449,?, needs generic revision.

Hyphodiscus Kirschst. 1907 (= Catenulifera Hosoya 2002 fide Johnston et al. 2014b), Hyaloscyphaceae, Helotiales, Leotiomycetes, seven species, type: H. gregarius Kirschst., asexual morph Catenulifera (hyphomycetous), saprobes, North temperate, see Huhtinen et al. (2010; new species), Lumbsch and Huhndorf (2010; outline), Hosoya et al. (2011; DNA, phylogeny, new species), Pärtel and Põldmaa (2011; new species), Kirk et al. (2013; genus 
accepted), Johnston et al. (2014b; nomenclature; new combinations), Cultures and sequences are available but lacks for the type species, Holotype and ex-type of type species unavailable. Hyphopeziza J.G. Han, Hosoya \& H.D. Shin 2014, Hyaloscyphaceae, Helotiales, Leotiomycetes, one species, type: H. pygmaea (Mouton) J.G. Han, Hosoya \& H.D. Shin, asexual morph unknown, saprobes, terrestrial, worldwide, see Han et al. (2014; taxonomy), Cultures and sequences are unavailable, Holotype and available cultures of the type species Mouton 473 (BR), KUS F51564.

Hyphopichia von Arx \& van der Walt 1976, Debaryomycetaceae, Saccharomycetales, Saccharomycetes, nine species, type: H. burtonii (Boidin, Pignal, Lehodey, Vey \& Abadie) von Arx \& van der Walt, asexual reproduction is by multilateral budding, saprophytic, on pollen, alfalfa silage, grain, various fruits, human skin, sputum, decaying insect infested wood, see Lumbsch and Huhndorf (2010; outline), Kirk et al. (2013; genus accepted), sequences are available.

Hyphopolynema Nag Raj 1977, Ascomycota genera incertae sedis, six species, type: $H$. tropicale Nag Raj, hyphomycetous, sexual morph unknown, saprobes, terrestrial, Australia, Brazil, Colombia, India, USA, UK, see Pinho et al. (2010; morphology, new species), Seifert et al. (2011; morphology), Wijayawardene et al. (2012, 2017; outline), Cultures and sequences are unavailable.

Hyphoscypha Velen. 1934, Helotiales genera incertae sedis, Leotiomycetes, one species, type: H. loricata Velen., asexual morph unknown, saprobes, terrestrial, Europe, see Lumbsch and Huhndorf (2010; outline), Kirk et al. (2013; genus accepted), Cultures and sequences are unavailable, needs generic revision.

Hyphosoma Syd. 1924, Metacapnodiaceae, Capnodiales, Dothideomycetes, one species, type: H. hypoxyloides Syd., see Kirk et al. (2008; nom. conf.), needs generic revision.

Hyphostereum Pat. 1892, Ascomycota genera incertae sedis, one species, type: H. pendulum Pat., coelomycetous, sexual morph unknown, saprobes, terrestrial, South America, see Wijayawardene et al. (2012, 2017; outline), Kirk et al. (2013; genus accepted), cultures and sequences are unavailable, needs generic revision.

Hyphothyrium B. Sutton \& Pascoe 1989, Ascomycota genera incertae sedis, one species, type: H. pallidum B. Sutton \& Pascoe, hyphomycetous, sexual morph unknown, saprobes, terrestrial, Australia, Seifert et al. (2011; morphology), Wijayawardene et al. (2012, 2017; outline), Kirk et al. (2013; genus accepted), Cultures and sequences are unavailable.

Hypobryon Döbbeler 1983, Dothideomycetes, genera incertae sedis, seven species, type: $H$. poeltii (Döbbeler) Döbbeler, asexual morph unknown, on hepatics, terrestrial, Europe, see Lumbsch and Huhndorf (2010; outline), Kirk et al. (2013; genus accepted), Wijayawardene et al. (2014c; outline), Cultures and sequences are unavailable, needs generic revision.

Hypocenomyce M.Choisy 1951, Ophioparmaceae, Umbilicariales, Lecanoromycetes, four species, type: H. scalaris (Ach. ex Lilj.) M. Choisy, lichenized, worldwide, see Romanova (2009; Novosibirsk), Björk (2010; USA), Bendiksby and Timdal (2013, phylogeny, taxonomy), Stepanchikova et al. (2013; Russia), Miądlikowska et al. (2014a; Poland), Lücking et al. (2016b; classification), Cultures and sequences are available, holotype and extype of type species unavailable.

Hypocline Syd. 1939, Ascomycota genera incertae sedis, one species, type: H. penniseti Syd., hyphomycetous, sexual morph unknown, saprobes, terrestrial, Dominican Republic, see Wijayawardene et al. (2012, 2017; outline), Kirk et al. (2013; genus accepted), Cultures and sequences are unavailable, needs generic revision.

Hypocopra (Fr.) J. Kickx f. 1867 (=Coprolepa Fuckel 1870 fide Wendt et al. 2017), Xylariaceae, Xylariales, Sordariomycetes, c. 35 species, type: H. merdaria (Fr.) J.J. Kickx, asexual morph unknown, terrestrial, saprobes, mainly coprophilous, worldwide, see Lumbsch and Huhndorf (2010; outline), Kirk et al. (2013; genus accepted), Jayanetti et al. (2014; 
applications), Maharachchikumbura et al. (2015, 2016; outline), cultures and sequences are available but lacks for the type species.

Hypocrella Sacc. 1878 (= Aschersonia Mont. fide Maharachchikumbura et al. 2015, 2016; Rossman et al. 2016a), Clavicipitaceae, Hypocreales, Sordariomycetes, 43 species, type: $H$. discoidea (Berk. \& Broome) Sacc., asexual morph Aschersonia, saprobes, terrestrial, Ecuador, see Lumbsch and Huhndorf (2010; outline), Kirk et al. (2013; genus accepted), Maharachchikumbura et al. (2015, 2016; outline, nomenclature), Rossman et al. (2016a; nomenclature), Cultures and sequences are available.

Hypocreodendron Henn. 1897 (=Discoxylaria J.C. Lindq. \& J.E. Wright 1964 fide Réblová et al. 2016c), Xylariaceae, Xylariales, Sordariomycetes, one species, type: H. sanguineum Henn., hyphomycetous, sexual morph formerly known in Discoxylaria, saprobes, Argentina, Mexico, see Lumbsch and Huhndorf (2010; outline), Seifert et al. (2011; morphology), Kirk et al. (2013; genus accepted), Stadler et al. (2013), Réblová et al. (2016c; nomenclature), Daranagama et al. (2017; morphology, taxonomy, key, sexual-asexual link), sequence data available for one species D. myrmecophila.

Hypocreopsis P. Karst. 1873, Hypocreaceae, Hypocreales, Sordariomycetes, three species, type: H. lichenoides, asexual morph hyphomycetous, saprobes and/or pathogens, terrestrial, Atlantic coast of Europe, Eastern USA, South-Eastern Australia, New Zealand, see Lumbsch and Huhndorf (2010; outlineStasiska (2011; Poland), Grundy et al. (2012; molecular analysis), ), Kirk et al. (2013; genus accepted), Maharachchikumbura et al. (2015, 2016; outline), sequences are available.

Hypoderma De Not. 1847, Rhytismataceae, Rhytismatales, Leotiomycetes, one species, type: H. rubi (Pers.) DC., asexual morph unknown, saprobes, terrestrial, worldwide, see Lumbsch and Huhndorf (2010; outline), Lantieri et al. (2011; phylogeny, new species), Lantz et al. (2011; DNA, phylogeny), Wang et al. (2013d; phylogeny), Kirk et al. (2013; genus accepted), Cultures and sequences are available, lectotype 'Hb. Pers. mis Chaill.

Hypodermella Tubeuf 1895, Rhytismataceae, Rhytismatales, Leotiomycetes, three species, type: H. laricis Tubeuf, asexual morph unknown, saprobes, terrestrial, worldwide, see Lumbsch and Huhndorf (2010; outline), Kirk et al. (2013; genus accepted), Cultures and sequences are unavailable, needs generic revision.

Hypodermellina Höhn. 1917, Rhytismataceae, Rhytismatales, Leotiomycetes, one species, type: H. ruborum Höhn., asexual morph unknown, saprobes, terrestrial, Europe, see Lumbsch and Huhndorf (2010; outline), Kirk et al. (2013; genus accepted), Cultures and sequences are unavailable, needs generic revision.

Hypodermina Höhn. 1916, Ascomycota genera incertae sedis, one species, type: $H$. nervisequa (Link) Höhn., coelomycetous, sexual morph unknown, saprobes, terrestrial, South America, see Wijayawardene et al. (2012, 2017; outline), Kirk et al. (2013; genus accepted), cultures and sequences are unavailable, needs generic revision.

Hypoflavia Marbach 2000, Caliciaceae, Caliciales, Lecanoromycetes, three species, type: $H$. velloziae (Kalb) Marbach, lichenized, Brazil, Thailand, Chile, see Lumbsch and Huhndorf (2010; outline), Lücking et al. (2016b; classification), cultures and sequences are unavailable. Hypogloeum Petr. 1923, Ascomycota genera incertae sedis, one species, type: H. euonymi Petr., coelomycetous, sexual morph unknown, saprobes, terrestrial, Europe, see Wijayawardene et al. (2012, 2017; outline), Kirk et al. (2013; genus accepted), cultures and sequences are unavailable, needs generic revision.

Hypogymnia (Nyl.) Nyl. 1896, Parmeliaceae, Lecanorales, Lecanoromycetes, 90 species, type: H. physodes (L.) Nyl., lichenized, worldwide, see Hauck (2008; metal homeostatis), McCune (2008; new species), Ranković et al. (2008; antimicrobial activity), McCune and Schoch (2009; new species), Solhaug et al. (2009; morphology), Lumbsch and Huhndorf (2010; outline), Wei et al. (2010; new species), McCune (2011; new species), Miądlikowska 
et al. (2011, phylogeny), Balabanova et al. (2012; biomonitoring), Goward et al. (2012; new species), Kirk et al. (2013; genus accepted), Lücking et al. (2016b; classification), Cultures and sequences are available. Holotype and ex-type of type species unavailable.

Hypohelion P.R. Johnst. 1990 (= Leptostroma Fr. 1815 fide Johnston et al. 2014b), Rhytismataceae, Rhytismatales, Leotiomycetes, three species, type: H. scirpinum (DC.) P.R. Johnst., asexual morph Leptostroma, saprobes, north temperate, see Lumbsch and Huhndorf (2010; outline), Lantz et al. (2011; DNA, phylogeny), Kirk et al. (2013; genus accepted), Johnston et al. (2014b; nomenclature), Wang et al. (2014b; DNA, phylogeny), Cultures and sequences are available, cultures available for type: Lantz 394 (UPS) (fide Lantz et al. 2011), Holotype and ex-type of type species unknown.

Hypomyces (Fr.) Tul. 1870 (= Cladobotryum Nees 1816; = Sepedonium Link 1809; = Stephanoma Wallr. 1833 fide Jaklitsch et al. 2016a), Hypocreaceae, Hypocreales, Sordariomycetes, more than 150 species, type: $H$. lactifluorum, asexual morph hyphomycetous, fungicolous, worldwide, see Jaklitsch et al (2008; new species), Lumbsch and Huhndorf (2010; outline), Põldmaa (2011; new species, red pigment), Seifert et al. (2011; morphology of asexual morphs), Kirk et al. (2013; genus accepted), Maharachchikumbura et al. (2015, 2016; outline), Wijayawardene et al. (2012, 2017; outline), Gea et al. (2016; pathogenicicity of Cladobotryum), Jaklitsch et al. (2016a; classification, nomenclature), sequence data available, holotype of type: CBS H-19806 (as Sphaeria lactifluorum Schw., Syn. Fung. 1190-44 Herb.), ex-type strains are unavailable for type species.

Hyponectria Sacc. 1878, Hyponectriaceae, Xylariales, Sordariomycetes, 17 species, type: $H$. buxi (DC.) Sacc., asexual morph unknown, saprobes, terrestrial, worldwide, see Lumbsch and Huhndorf (2010; outline), Zhao and Zhao (2012; new species), Kirk et al. (2013; genus accepted), Maharachchikumbura et al. (2015, 2016; outline, phylogeny), DNA sequences and cultures available (fide Winka and Eriksson 2000), type specimen of type: CBS H-4954.

Hypophloeda K.D. Hyde \& E.B.G. Jones 1989, Melanconidaceae, Diaporthales, Sordariomycetes, one species, type: H. rhizospora K.D. Hyde \& E.B.G. Jones, asexual morph unknown, marine, mangrove roots, Brunei, Seychelles, see Jones et al. (2009b; key, description), Lumbsch and Huhndorf (2010; outline), Kirk et al. (2013; genus accepted), Maharachchikumbura et al. (2015, 2016; outline), Cultures and sequences are unavailable.

Hypospilina (Sacc.) Traverso 1913, Valsaceae, Diaporthales, Sordariomycetes, four species, type: H. bifrons (DC.) Traverso, asexual morph unknown, saprobes, terrestrial, Europe, see Lumbsch and Huhndorf (2010; outline), Kirk et al. (2013; genus accepted), Maharachchikumbura et al. (2015, 2016; outline), Cultures and sequences are unavailable, needs generic revision.

Hypotarzetta Donadini 1985, Pezizales genera incertae sedis, Pezizomycetes, one species, type: $H$. insignis (Berthet \& Riousset) Donadini, asexual morph unknown, saprobes, terrestrial, worldwide, see Lumbsch and Huhndorf (2010; outline), Kirk et al. (2013; genus accepted), Jaklitsch et al. (2016a; classification), cultures and sequences are available, holotype and ex-type of type species unavailable.

Hypotrachyna (Vain.) Hale 1974, Parmeliaceae, Lecanorales, Lecanoromycetes, 260 species, type: H. brasiliana (Nyl.) Hale, lichenized, worldwide, see Sipman et al. (2009; review), Yánez-Ayabaca and Eliasaro (2009; new species), Lumbsch and Huhndorf (2010; outline), Flakus et al. (2012; new species), Divakar et al. (2013a; phylogeny), Kirk et al. (2013; genus accepted), Lücking et al. (2016b; classification), Cultures and sequences are available.

Hypotrachynicola Etayo 2002, Ascomycota genera incertae sedis, one species, type: $H$. rubra Etayo, asexual morph unknown, lichenicolous, terrestrial, South America, see Lumbsch and Huhndorf (2010; outline), Cultures and sequences are unavailable, holotype of the type: COL Etayo 16515. 
Hypoxylon Bull. 1791 (= Nodulisporium Preuss 1849 fide Réblová et al. 2016c; see Wendt et al. 2017 for synonyms), Hypoxylaceae, Xylariales, Sordariomycetes, c. 140 species, type: $H$. fragiforme (Pers.) J. Kickx f., asexual morph formerly known in Nodulisporium, terrestrial, saprobes, mainly coprophilous, worldwide, see Lumbsch and Huhndorf (2010; outline), Kirk et al. (2013; genus accepted), Maharachchikumbura et al. (2015, 2016; outline), Réblová et al. (2016c; nomenclature), Wendt et al. (2017; phylogeny, resurrected Hypoxylaceae), cultures and sequences are available, needs generic revision as the genus comprises more than 1000 species epithets (Index Fungorum 2017).

Hypsostroma Huhndorf 1992, Hypsostromataceae, Pleosporales, Dothideomycetes, two species, type: $H$. saxicola Huhndorf, asexual morph unknown, saprobes, terrestrial, worldwide, see Mugambi and Huhndorf (2009a; DNA, phylogeny), Lumbsch and Huhndorf (2010; outline), Hyde et al. (2013; accepted as a genus in Hypsostromataceae), Kirk et al. (2013; genus accepted), Wijayawardene et al. (2014c; outline), Cultures and sequences are available, cultures available for the type: SMH 5005, holotype of type species NY, Harris 26462, needs generic revision.

Hysteridium P. Karst. 1905, Ascomycota genera incertae sedis, one species, type: $H$. phragmitis P. Karst., coelomycetous, sexual morph unknown, saprobes, terrestrial, Europe, see Wijayawardene et al. (2012, 2017; outline), Kirk et al. (2013; genus accepted), cultures and sequences are unavailable, needs generic revision.

Hysterium Pers. 1791, Hysteriaceae, Hysteriales, Dothideomycetes, 14 species, type: $H$. pulicare (Lightf.: Fr.) Pers., asexual morph unknown, saprobes, terrestrial, worldwide, see Boehm et al. (2009a, b, overview of genus), Lumbsch and Huhndorf (2010; outline), Hyde et al. (2013; taxonomy), Kirk et al. (2013; genus accepted), Wijayawardene et al. (2014c; outline), Cultures and sequences are available, cultures available for type species CBS 123377, holotype of type: CBS H-5484.

Hysterobrevium E. Boehm \& C.L. Schoch 2010, Hysteriaceae, Hysteriales, Dothideomycetes, four species, type: H. mori (Schwein.) E.W.A. Boehm \& C.L. Schoch, asexual morph coelomycetous (aposphaeria-like), saprobes, terrestrial, worldwide, see Boehm et al. (2009a, b; overview), Lumbsch and Huhndorf (2010; outline), Wijayawardene et al. (2014c; outline), Cultures and sequences are available, holotype and ex-type of type: BPI878733, CBS 123336. Hysterocarina H. Zogg 1949, Hysteriaceae, Hysteriales, Dothideomycetes, one species, type: H. paulistae H. Zogg, asexual morph unknown, saprobes, terrestrial, Brazil, see Lumbsch and Huhndorf (2010; outline), Kirk et al. (2013; genus accepted), Wijayawardene et al. (2014c; outline), Cultures and sequences are unavailable, needs generic revision.

Hysterodifractum D.A.C. Almeida, Gusmão \& A.N. Mill. 2014, Hysteriaceae, Hysteriales, Dothideomycetes, one specie, type: H. partisporum D.A.C. Almeida, Gusmão \& A.N. Mill, asexual morph unknown, saprobes, terrestrial, Brazil, see Almeida et al. (2014b; taxonomy), Cultures and sequences are available, holotype of type: HUEFS:42865

Hysterodiscula Petr. 1942, Ascomycota genera incertae sedis, one species, type: H. kalmiae Petr., coelomycetous, sexual morph unknown, saprobes, terrestrial, Europe, see Wijayawardene et al. (2012, 2017; outline), Kirk et al. (2013; genus accepted), cultures and sequences are unavailable, needs generic revision.

Hysteroglonium Rehm ex Lindau 1896, Hysteriaceae, Hysteriales, Dothideomycetes, two species, type: H. ovatum (Cooke) Lindau, asexual morph unknown, saprobes, terrestrial, cosmopolitan, see Lumbsch and Huhndorf (2010; outline), Kirk et al. (2013; genus accepted), Wijayawardene et al. (2014c; outline), Cultures and sequences are unavailable, needs generic revision.

Hysterographium Corda 1842, Dothideomycetes genera incertae sedis, two species, type: $H$. elongatum (Wahlenb.) Corda, asexual morph unknown, saprobes, terrestrial, worldwide, see Boehm et al. (2009a, b; taxonomy, DNA, phylogeny), Mugambi and Huhndorf (2009b; DNA, 
phylogeny), Lumbsch and Huhndorf (2010; outline), Hyde et al. (2013; key to distinguish from other hysteriaceous genera), Kirk et al. (2013; genus accepted), Logesh et al. (2013; new species, India), Wijayawardene et al. (2014c; outline), Cultures and sequences are available, needs generic revision.

Hysteronaevia Nannf. 1984, Helotiales genera incertae sedis, Leotiomycetes, twelve species, type: H. holoschoeni (De Not.) Nannf., asexual morph unknown, saprobes, terrestrial, north temperate, see Lumbsch and Huhndorf (2010; outline), Kirk et al. (2013; genus accepted), cultures and sequences are unavailable.

Hysteropatella Rehm 1890, Patellariaceae, Patellariales, Dothideomycetes, three species, type: H. prostii (Duby) Rehm, asexual morph unknown, saprobes, terrestrial, Switzerland, see Boehm et al. (2009a; phylogeny), Lumbsch and Huhndorf (2010; outline, accepted as genus in Hysteriaceae), Kirk et al. (2013; genus accepted), Hyde et al. (2013) did not accept as a genus in Hysteriaceae, Yacharoen et al. (2015; accepted as agenus in Patellariaceae), Cultures and sequences are available, cultures available for the type species H.B. 9934b

Hysteropeltella Petr. 1923, Schizothyriaceae, Dothideomycetes family incertae sedis, one species, type: $H$. moravica Petr., asexual morph unknown, saprobes, terrestrial, Europe, see Lumbsch and Huhndorf (2010; outline, accepted as Dothideomycetes, genera incertae sedis), Ariyawansa et al. (2013c; trasferred to Schizothyriaceae), Kirk et al. (2013; genus accepted), Wijayawardene et al. (2014c; outline), cultures and sequences are unavailable, needs generic revision.

Hysteropezizella Höhn. 1917, Helotiales genera incertae sedis, Leotiomycetes, 19 species, type: H. subvelata (Rehm) Höhn., asexual morph unknown, saprobes, terrestrial, worldwide, see Lumbsch and Huhndorf (2010; outline), Kirk et al. (2013; genus accepted), cultures and sequences are unavailable.

Hysteropsis Rehm 1887, Dothideomycetes genera incertae saedis, four species, type: $H$. culmigena Rehm, asexual morph unknown, saprobes, terrestrial, Europe, see Lumbsch and Huhndorf (2010; outline), Kirk et al. (2013; genus accepted), cultures and sequences are unavailable.

Hysteropycnis Hilitzer 1929, Ascomycota genera incertae sedis, one species, type: need typification, coelomycetous, sexual morph unknown, saprobes, terrestrial, Europe, see Wijayawardene et al. (2012, 2017; outline), Kirk et al. (2013; genus accepted), cultures and sequences are unavailable, needs generic revision.

Hysterostegiella Höhn. 1917, Cenangiaceae, Helotiales, Leotiomycetes, ten species, type: $H$. fenestrata (Roberge ex Desm.) Höhn., asexual morph unknown, saprobes, terrestrial, Europe, see Lumbsch and Huhndorf (2010; outline), Kirk et al. (2013; genus accepted), Cultures and sequences are unavailable, holotype and ex-type of type species unavailable, needs generic revision.

Hysterostomella Speg. 1885, Parmulariaceae, Dothideomycetes families incertae sedis, 40 species, type: $H$. guaranitica Speg., asexual morph unknown. Epiphytes, terrestrial, worldwide, see Hofmann (2009; review), Lumbsch and Huhndorf (2010; outline), Hyde et al. (2013; review, keys), Wijayawardene et al. (2014c; outline), Cultures and sequences are unavailable.

Hyweljonesia R.G. Shivas, Y.P. Tan, Marney \& Abell 2016, Teratosphaeriaceae, Capnodiales, Dothideomycetes, one species, type: H. queenslandica R.G. Shivas, Y.P. Tan, Marney \& Abell, hyphomycetous, sexual morph unknown, saprobes, terrestrial, Australia, see Crous et al. (2016a; new species, phylogeny), holotype and ex-type culture of the type: BRIP $61322 b$.

Ialomitzia Gruia 1964, Ascomycota genera incertae sedis, one species, type: I. cavernicola Gruia, hyphomycetous, sexual morph unknown, saprobes, terrestrial, Europe, see 
Wijayawardene et al. (2012, 2017; outline), Kirk et al. (2013; genus accepted), cultures and sequences are unavailable, needs generic revision.

Icmadophila Trevis. [nom. cons.] 1852, Icmadophilaceae, Pertusariales, Lecanoromycetes, eight species, type: I. aeruginosa (Scop.) Trevis., lichenized, worldwide, see Lumbsch and Huhndorf (2010; outline), Kirk et al. (2013; genus accepted), Lücking et al. (2016b; classification), Cultures and sequences are available.

Idiocercus B. Sutton 1967, Ascomycota genera incertae sedis, two species, type: I. pirozynskii B. Sutton, coelomycetous, sexual morph unknown, saprobes, pathogens, terrestrial, Australia, Tanzania, Sierra Leone, see Wijayawardene et al. (2012, 2017; outline), Cultures and sequences are unavailable, holotype of the type species IMI 107154a.

Idiomyces Thaxt. 1893, Laboulbeniaceae, Laboulbeniales, Laboulbeniomycetes, one species, type: I. peyritschii Thaxt., asexual morph unknown, biotrophic, terrestrial, Europe, Japan, see Lumbsch and Huhndorf (2010; outline), Kirk et al. (2013; genus accepted), cultures and sequences are unavailable.

Idriella P.E. Nelson \& S. Wilh. 1956, Microdochiaceae, Xylariles, Sordariomycetes, c. 30 species, type: I. lunata P.E. Nelson \& S. Wilh., hyphomycetous, sexual morphs unknown, in soil, terrestrial, worldwide, see Seifert et al. (2011; morphology), Wijayawardene et al. (2012, 2017; outline), Kirk et al. (2013; genus accepted), Hernández-Restrepo et al. (2016b; DNA, phylogeny), cultures and sequences are available, needs generic revision.

Idriellopsis Hern.-Restr. \& Crous 2015, Xylariales, genera incertae sedis, Sordariomycetes, one species, type: I. uncinospora (R.F. Castañeda \& W.B. Kendr.) Hern.-Restr. \& Crous, hyphomycetous, sexual morph unknown, saprobes, terrestrial, Cuba, see Hernández-Restrepo et al. (2016b; taxonomy, phylogeny), Maharachchikumbura et al. (2015, 2016; outline), cultures and sequences are available.

Igneocumulus A.W. Ramaley 2003, Ascomycota genera incertae sedis, ten species, type: I. yuccae A.W. Ramaley, asexual morph hyphomycetous (lecythophora-like), saprobes, terrestrial, USA, see Lumbsch and Huhndorf (2010; outline), Kirk et al. (2013; genus accepted), Cultures and sequences are unavailable, holotype of type species UC 1713843, needs generic revision.

Ijuhya Starbäck 1899, Bionectriaceae, Hypocreales, Sordariomycetes, 14 species, type: I. vitrea Starbäck, asexual morph acremonium-like, saprobes, terrestrial, worldwide, see Lechat and Courtecuisse (2010; new species), Lumbsch and Huhndorf (2010; outline), Kirk et al. (2013; genus accepted), Maharachchikumbura et al. (2015, 2016; outline), Lechat and Fournier (2017; new species), cultures and sequences are available, needs generic revision.

Illosporiopsis D. Hawksw. 2001, Incertae sedis, Hypocreales, Sordariomycetes, one species, type: I. christiansenii (B.L. Brady \& D. Hawksw.) D. Hawksw., lichenicolous, Europe, terrestrial, see Seifert et al. (2011; genus accepted), Wijayawardene et al. (2012, 2017; outline), Kirk et al. (2013; genus accepted), cultures and sequences are unavailable, needs generic revision, holotype of type: K(M)-IMI 226836.

Illosporium Mart. 1817, Hypocreales genera incertae sedis, Sordariomycetes, 18 species, type: I. carneum Fr., asexual morph hyphomycetous, lichenicolous, USA and Europe, see Pindi (2012; marine), Kossowska and Szczepańska (2013; Poland), Maharachchikumbura et al. (2015, 2016; outline), Cultures and sequences are available.

Ilyomyces F. Picard 1917, Laboulbeniaceae, Laboulbeniales, Laboulbeniomycetes, two species, type: I. mairei F. Picard, asexual morph unknown, biotrophic, terrestrial, Europe, Japan, see Lumbsch and Huhndorf (2010; outline), Kirk et al. (2013; genus accepted), cultures and sequences are unavailable.

Ilyonectria P. Chaverri \& C. Salgado 2011, Nectriaceae, Hypocreales, Sordariomycetes, 22 species, type: I. destructans (Zinssm.) Rossman, L. Lombard \& Crous, root pathogenic or saprobes, cosmopolitan, see Chaverri et al. (2011; phylogeny), Cabral et al. (2012; new 
species), Lombard et al. (2015b; phylogeny), Cultures and sequences are available, Ex-type of type species CBS 264.65.

Ilytheomyces Thaxt. 1917, Laboulbeniaceae, Laboulbeniales, Laboulbeniomycetes, 15 species, type: I. elegans Thaxt., asexual morph unknown, biotrophic, terrestrial, worldwide, see Lumbsch and Huhndorf (2010; outline), Kirk et al. (2013; genus accepted), cultures and sequences are unavailable.

Imaia Trappe \& Kovács 2008, Morchellaceae, Pezizales, Pezizomycetes, two species, type: I. gigantea (S. Imai) Trappe \& Kovács, asexual morph unknown, ectomycorrhizal, saprobes, terrestrial, North American, East Asia, see Kovács et al. (2008; DNA, taxonomy, phylogeny), Lumbsch and Huhndorf (2010; outline), Cultures and sequences are available, Holotype and ex-type of type species unavailable.

Imazekia Tak. Kobay. \& Y. Kawabe 1992, Phyllachoraceae, Phyllachorales, Sordariomycetes, two species, type: I. ryukyuensis Tak. Kobay. \& Y. Kawabe, asexual morph unknown, from living leaves, terrestrial, Japan, see Lumbsch and Huhndorf (2010; outline), Kirk et al. (2013; genus accepted), Maharachchikumbura et al. (2015, 2016; outline), Cultures and sequences are unavailable Holotype of type species TFM, FPH-7163.

Imicles Shoemaker \& Hambl. 2001, Ascomycota genera incertae sedis, six species, type: I. leptospora (Sacc. \& Roum.) Shoemaker \& Hambl., hyphomycetous, saprobes, terrestrial, worldwide, see Seifert et al. (2011; morphology), Wijayawardene et al. (2012, 2017; outline), cultures and sequences are unavailable, compare with Sporidesmium, needs generic revision.

Immersaria Rambold \& Pietschm. 1989, Lecideaceae, Lecideales, Lecanoromycetes, eight species; type: I. athroocarpa (Ach.) Rambold \& Pietschm., lichenized, Asia, Africa, Europe, Australia, see Lumbsch and Huhndorf (2010; outline), Valadbeigi et al. (2011b; new species), Kirk et al. (2013; genus accepted), Pandit (2014; India), Gasparyan et al. (2016; Armenia), Lücking et al. (2016b; classification), Cultures and sequences are available.

Immersidiscosia Kaz. Tanaka, Okane \& Hosoya 2011, Sporocadaceae, Xylariales, Sordariomycetes, one species, type: I. eucalypti (Pat.) Kaz. Tanaka, Okane \& Hosoya, sexual morph unknown, saprobes, terrestrial, France, Japan, Tunisia, see Tanaka et al. (2011a; morphology, phylogeny), Jaklitsch et al. (2016a; phylogeny), Cultures and sequences are available, holotype of the type species in $\mathrm{FH}$, ex-type strain unavailable.

Immersiella A.N. Mill. \& Huhndorf 2004, Lasiosphaeriaceae, Sordariales, Sordariomycetes, two species, type: I. immersa (P. Karst.) A.N. Mill. \& Huhndorf, asexual morph unknown, saprobes, terrestrial, USA, see Lumbsch and Huhndorf (2010; outline), Kirk et al. (2013; genus accepted), Maharachchikumbura et al. (2015, 2016; outline), cultures available for the type species SMH2589, SMH4104, holotype and ex-type of type species unavailable.

Immersiporthe S.F. Chen, M.J. Wingf. \& Jol. Roux [2012] 2013, Cryphonectriaceae, Diaporthales, Sordariomycetes, one species, type: I. knoxdaviesiana S.F. Chen, M.J. Wingf. \& Jol. Roux, coelomycetous, sexual morph unknown, pathogens, terrestrial, South Africa, see Chen et al. (2013e; taxonomy, DNA, phylogeny), Maharachchikumbura et al. (2015, 2016; outline), Wijayawardene et al. (2017; outline), cultures and sequences are available, holotype and the ex-type of type: PREM 60738, CMW37314 = CBS132862.

Immersisphaeria Jaklitsch 2007, Xylariales genera incertae sedis, Sordariomycetes, one species, type: I. eichleriana (Bres.) Jaklitsch, asexual morph unknown, pathogens, terrestrial, South Africa, see Lumbsch and Huhndorf (2010; outline), Maharachchikumbura et al. (2015, 2016; outline), Daranagama et al. (2016b; accepted in Xylariales), cultures and sequences are unavailable.

Immotthia M.E. Barr 1987, Dothideomycetes genera incertae sedis, one species, type: I. hypoxylon (Ellis \& Everh.) M.E. Barr, asexual morph coniothyrium-like, saprobes, terrestrial, Europe, North America, see Lumbsch and Huhndorf (2010; outline, misspelled as Immotthia), Kirk et al. (2013; genus accepted), cultures and sequences are unavailable. 
Imshaugia F.C. Mey. 1985, Parmeliaceae, Lecanorales, Lecanoromycetes, seven species, type: I. aleurites (Ach.) S.L.F. Mey., lichenized, boreal and temperate regions of the Northern Hemisphere and from cool-montane regions in the Southern Hemisphere, see Hauck et al. (2009; acid tolerance), Lumbsch and Huhndorf (2010; outline), Thell et al. (2012; description, phylogeny), Kirk et al. (2013; genus accepted), Kharpukhaeva and Mukhortova (2016; Baikal), Lücking et al. (2016b; classification), sequences are available.

Inaequalispora L. Lombard \& Crous 2016, Stachybotriaceae, Hypocreales, Sordariomycetes, one species, type: I. prestonii (M.C. Tulloch) L. Lombard \& Crous, hyphomycetous, sexual morph unknown, from forest soil, terrestrial, Malaysia, see Lombard et al. (2016; taxonomy, phylogeny), holotype and ex-isotype culture of the type: CBS H-7392, CBS 175.73.

Incertomyces Egidi \& Zucconi 2014, Teratosphaeriaceae, Capnodiales, Dothideomycetes, two species, type: I. perditus Egidi \& Zucconi, hyphomycetous, sexual morph unknown rockinhabiting fungus, see Egidi et al. (2014; taxonomy), Wijayawardene et al. (2014c, 2017; outline), cultures available for the type: CBS 136105 = CCFEE 5385.

Incrucipulum Baral 1985, Lachnaceae, Helotiales, Leotiomycetes, six species, type: I. ciliare (Schrad.) Baral, asexual morph unknown, saprobes, terrestrial, temperate, see Hosoya et al. (2010; new species, Japan, DNA), Lumbsch and Huhndorf (2010; outline), cultures and sequences are available.

Incrupila Raitv. 1970, Hyaloscyphaceae, Helotiales, Leotiomycetes, ten species, type: I. aspidii (Lib.) Raitv., asexual morph unknown, saprobes, terrestrial, temperate, see Lumbsch and Huhndorf (2010; outline), cultures and sequences are unavailable, needs generic revision. Induratia Samuels, E. Müll. \& Petrini 1987, Xylariales genera incertae sedis, Sordariomycetes, one species, type: I. apiospora Samuels, E. Müll. \& Petrini, asexual morph nodulosporium-like, saprobes, New Zeland, see Lumbsch and Huhndorf (2010; outline), Kirk et al. (2013; genus accepted), Stadler et al. (2013), Daranagama et al. (2017; morphology, taxonomy, key), Wendt et al. (2017; accepted as a genus in Xylariales genera incertae sedis), sequences are unavailable, needs generic revision.

Inesiosporium R.F. Castañeda \& W. Gams 1997, Ascomycota genera incertae sedis, two species, type: I. longispirale (R.F. Castañeda) R.F. Castañeda \& W. Gams, hyphomycetous, sexual morph unknown, saprobes, terrestrial, Cuba, see Hyde et al. (2011; outline), Wijayawardene et al. (2012, 2017; outline), Kirk et al. (2013; valid genus), Argôlo Magalhães et al. (2014; Bahia), Castañeda-Ruiz et al. (2016a; distribution), compare with Ceratophorum and Zalerion, Cultures and sequences are unavailable, holotype of the type species INIFAT C84/107.

Inflatispora Yin. Zhang, J. Fourn. \& K.D. Hyde 2011, Pleosporales genera incertae sedis, Dothideomycetes, two species, type: I. pseudostromatica Ying Zhang, J. Fourn. \& K.D. Hyde, asexual morph unknown, saprobes, terrestrial, France and Thailand, see Zhang et al. (2011e; taxonomy, phylogeny), Tibpromma et al. (2017b; taxonomy, phylogeny), cultures and sequences are available, holotype and ex-type of type: IFRD 8989, CBS 123110.

Infundibulomyces Plaingam, Somrith. \& E.B.G. Jones 2003, Chaetosphaeriaceae, Chaetosphaeriales, Sordariomycetes, two species, type: I. cupulata Plaingam, Somrith. \& E.B.G. Jones, coelomycetous, sexual morph unknown, saprobes, terrestrial, worldwide, see Wijayawardene et al. (2012, 2017; outline), Maharachchikumbura et al. (2016; outline), cultures and sequences are available, epitype and ex-epitype of the type: SFC 1615, BCC 13400 .

Infundichalara Réblová \& W. Gams 2011, Helotiales genera incertae sedis, Leotiomycetes, two species, type: I. microchona (W. Gams) Réblová \& W. Gams, hyphomycetous, sexual morph unknown, saprobes, terrestrial, Netherlands, Czech Republic, see Réblová and Gams (2011; morphology, phylogeny), Koukol (2012; morphology, new species), Wijayawardene 
et al. (2012, 2017; outline), cultures and sequences are available, holotype and ex-type strains of the type: CBS-H 19895, CBS 261.82.

Ingaderia Darb. 1897, Opegraphaceae, Arthoniales, Arthoniomycetes, three species, type: I. pulcherrima Darb., lichenized, Chile, Europe, see Lumbsch and Huhndorf (2010; outline), Ertz and Tehler (2011; phylogeny), Notov (2014; outline), Lücking et al. (2016b; classification), sequences are available.

Ingvariella Guderely \& Lumbsch 1997, Stictidaceae, Ostropales, Lecanoromycetes, one species, type: I. bispora (Bagl.) Guderley \& Lumbsch, lichenized, arid and semi-arid area, see Lumbsch and Huhndorf (2010; outline), Fernández-Brime et al. (2011; phylogeny), Kirk et al. (2013; genus accepted), Lücking et al. (2016b; classification), cultures and sequences are available.

Inifatiella R.F. Castañeda, Ascomycota genera incertae sedis, one species, type: I. nectandrae R.F. Castañeda, coelomycetous, sexual morph unknown, saprobes, terrestrial, Caribbean, see Seifert et al. (2011; morphology), Wijayawardene et al. (2012, 2017; outline), Kirk et al. (2013; genus accepted), cultures and sequences are unavailable, needs generic revision.

Inocyclus Theiss. \& Syd. 1915, Parmulariaceae, Dothideomycetes families incertae sedis, eight species, type: I. psychotriae (Syd. \& P. Syd.) Theiss. \& Syd, asexual morph unknown, epiphytes, pathogens, biotrophic, terrestrial, worldwide, see Hofmann (2009; review, placed in Parmulariaceae), Lumbsch and Huhndorf (2010; outline), Hyde et al. (2013; review, keys), Wijayawardene et al. (2014c; outline), Guatimosim et al. (2015; phylogeny), Cultures and sequences are available.

Inoderma (Ach.) Gray 1821, Arthoniaceae, Arthoniales, Arthoniomycetes, three species, type: I. byssaceum (Weigel) Gray, lichenized, temperate Europe, North America, Eastern Siberia, Japan, and eastern Africa (Uganda), see Frisch et al. (2015; phylogeny, key, description), Lücking et al. 2016 (classification), sequences are available.

Intercalarispora J.L. Crane \& Schokn. 1983, Ascomycota genera incertae sedis, one species (probably more described as synasexual morphs of Helicoma, Monodictys or Xenosporium), type: I. nigra J.L. Crane \& Schokn., hyphomycetous, sexual morph unknown (probably Tubeufia), saprobes, on rotten submerged wood, America and Africa, see Hyde et al. (2011; checklist), Kirk et al. (2013; valid genus), cultures and sequences are unavailable, holotype of type: ILLS 43047.

Intralichen D. Hawksw. \& M.S. Cole 2002, Ascomycota genera incertae sedis, four species, type: I. christiansenii (D. Hawksw.) D. Hawksw. \& M.S. Cole, sexual morph unknown, lichenicolous, North Temperate, see Seifert et al. (2011; genus accepted), Wijayawardene et al. (2012, 2017; outline), cultures and sequences are unavailable, needs generic revision.

Involucropyrenium Breuss 1996, Verrucariaceae, Verrucariales, Eurotiomycetes, nine species, type: I. waltheri (Kremp.) Breuss, lichenized, Europe, North America, Asia, see Sun et al. (2008; China), Prieto et al. (2010a; key, description), Prieto et al. (2012; phylogeny), Breuss (2016; nomenclature), Lücking et al. (2016b; classification), sequences are available, holotype of type species unavailable.

Involucroscypha Raitv. 2002, Helotiales genera incertae sedis, Leotiomycetes, ten species, type: I. involucrata (B. Erikss.) Raitv., asexual morph unknown, saprobes, terrestrial, Europe, see Lumbsch and Huhndorf (2010; outline), Kirk et al. (2013; genus accepted), Cultures and sequences are unavailable, holotype of the type species TAA165831, needs generic revision.

Iodophanus Korf 1967, Pezizaceae, Pezizales, Pezizomycetes, 16 species, type: I. carneus (Pers.) Korf, asexual morph unknown, coprophilous, terrestrial, worldwide, see Schmitt et al. (2008; DNA), Lumbsch and Huhndorf (2010; outline), Kirk et al. (2013; genus accepted), cultures and sequences are available, type material of type species CBS H-6320. 
Iodosphaeria Samuels, E. Müll. \& Petrini 1987, Iodosphaeriaceae, Xylariales, Sordariomycetes, three species, type: I. phyllophila (Mouton) Samuels, E. Müll. \& Petrini, asexual morph hyphomycetous (selenosporella-like and ceratosporium-like), saprobes, terrestrial, worldwide, see Lumbsch and Huhndorf (2010; outline), Kirk et al. (2013; genus accepted), Maharachchikumbura et al. (2015, 2016; outline), cultures and sequences are available, holotype of the type: PDD 47872.

Iodowynnea Medel, Guzmán \& S. Chacón 1996, Pezizaceae, Pezizales, Pezizomycetes, one species, type: I. auriformis (Pat. ex Le Gal) Medel, Guzmán \& S. Chacón, asexual morph unknown, coprophilous, terrestrial, worldwide, see Schmitt et al. (2008; DNA), Lumbsch and Huhndorf (2010; outline), Kirk et al. (2013; genus accepted), cultures and sequences are available.

Ionaspis Th.Fr. 1871, Hymeneliaceae, Hymeneliales, Lecanoromycetes, seven species, type: I. chrysophana (Körb.) Th. Fr., lichenized, worldwide, see Kınalığlu (2010; Turkey), Lumbsch and Huhndorf (2010; outline), Kirk et al. (2013; genus accepted), Miądlikowska et al. (2014a; phylogeny), Lücking et al. (2016b; classification), cultures and sequences are available.

Ionophragmium Peres 1961, Ascomycota genera incertae sedis, one species, type: I. notatum Peres \& L. Xavier, coelomycetous, saprobes, terrestrial, Brazil, see Wijayawardene et al. (2012, 2017; outline), Kirk et al. (2013; genus accepted), sequences are unavailable, compare with Asterostomella, holotype of type: IMUR 20676, needs generic revision.

Ioplaca Poelt 1977, Teloschistaceae, Teloschistales, Lecanoromycetes, two species, type: I. sphalera Poelt, lichenized, Himalayas, see Lumbsch and Huhndorf (2010; outline), Arup et al. (2013; taxonomy), Kirk et al. (2013; genus accepted), Lücking et al. (2016b; classification); cultures and sequences are available.

Iraniella Petr. 1949, Sordariomycetes genera incertae sedis, one species, type: I. rechingeri Petr., asexual morph unknown, saprobes, terrestrial, Iran, see Lumbsch and Huhndorf (2010; outline), Kirk et al. (2013; genus accepted), Maharachchikumbura et al. (2015, 2016; outline), sequences are unavailable, needs generic revision.

Irenopsis F. Stevens 1927, Meliolaceae, Meliolales, Sordariomycetes, 75 species, type: I. tortuosa (G. Winter) F. Stevens, asexual morph produced from the hyphae, saprobes, pathogens, terrestrial, worldwide, see Hosagoudar and Archana (2010b; new species, India), Hosagoudar and Sabeena (2010; new species, India), Lumbsch and Huhndorf (2010; outline), Kirk et al. (2013; genus accepted), Pinho et al. (2013; new species, Brazil, DNA, phylogeny), Hosagoudar et al. (2014; new species, Andaman Islands), Hongsanan et al. (2015c; new species, taxonomy), Maharachchikumbura et al. (2015, 2016; outline), Rodríguez et al. (2015; new species), Cultures and sequences are available, holotype and ex-type of type species unavailable.

Iridinea Velen. 1934, Calloriaceae, Helotiales, Leotiomycetes, two species, type: need typification, asexual morph unknown, saprobes, terrestrial, former Czechoslovakia, see Lumbsch and Huhndorf (2010; outline), Kirk et al. (2013; genus accepted), Cultures and sequences are unavailable, data inadequate, needs generic revision.

Irpicomyces Deighton 1969, Ascomycota genera incertae sedis, three species, type: I. schiffnerulae Deighton, hyphomycetous, sexual morph unknown, on leaves or twigs, Malaysia and Japan, see Hyde et al. (2011; checklist), Seifert et al. (2011; morphology), Wijayawardene et al. (2012, 2017; outline), Kirk et al. (2013; genus accepted), Cultures and sequences are unavailable, holotype of type species IMI 54929b.

Irydyonia Racib. 1900, Rhytismatales genera incertae sedis, Leotiomycetes, one species, type: I. filicis Racib., asexual morph unknown, saprobes, Java, see Lumbsch and Huhndorf (2010; outline), holotype and ex-type of type species unavailable, needs generic revision.

Isalonactis Ertz, Tehler, Eb. Fisch., Killmann, Razafin. \& Sérus. 2014, Roccellaceae, 
Arthoniales, Arthoniomycetes, one species, type: I. madagascariensis Ertz, Tehler, Eb. Fisch., Killmann, Razafin. \& Sérus., sexual morph with apothecioid ascomata, lichenized, terrestrial, Madagascar, see Ertz et al. (2014c; morphology, phylogeny), Lücking et al. (2016b; classification), sequences are available, lectotype and ex-type strain of type: Ertz 13024.

Isaria Pers. 1794 (= Alphitomyces Reissek 1856; = Amphichorda Fr. 1825; = Coremiopsis Sizova \& Suprun 1957; = Beejasamuha Subram. \& Chandrash. 1977), Cordycipitaceae, Hypocreales, Sordariomycetes, c. 13 species, type: I. farinosa (Holmsk.) Fr., hyphomycetous, entomogenous, worldwide, see Jiang et al. (2008; metabolite properties), Meyer et al. (2008; Florida), Zimmermann (2008; biology, ecology), Avery et al. (2009; in vitro infection), Ali et al. (2010; enzyme evaluation), Kim et al. (2010; thermotolerance), Ma et al. (2010; extrolites), Hoy et al. (2010; Diaphorina citri control), Asai et al. (2011; Tenuipyrone ), Seifert et al. (2011; morphology), Wijayawardene et al. (2012, 2017; outline), Kirk et al. (2013; genus accepted), cultures and sequences are available, epitype and ex-type of type: CBS-H6586, CBS 111113.

Isariella Henn. 1909, Ascomycota genera incertae sedis, two species, type: I. auerswaldiae Henn., hyphomycetous, saprobes, terrestrial, Brazil, Dominican Replublic, see Seifert et al. (2011; morphology), Wijayawardene et al. (2012, 2016; outline), Kirk et al. (2013; genus accepted), compare with Atractilina, sequences are unavailable, holotype of type species SF40445, needs generic revision.

Ischnostroma Syd. \& P. Syd. 1914, Ascomycota genera incertae sedis, one species, type: I. merrillii Syd. \& P. Syd., coelomycetous, saprobes, terrestrial, Philippines, see Wijayawardene et al. (2012, 2016; outline), Kirk et al. (2013; genus accepted), compare with Trachythyriolum, sequences are unavailable, needs generic revision.

Isia D. Hawksw. \& Manohar. 1978, Sordariales genera incertae sedis, Sordariomycetes, two species, type: I. neocaledoniensis (C. Moreau) D. Hawksw. \& Manohar, on plant material, Asia and Pacific, terrestrial, see Lumbsch and Huhndorf (2010; outline), Kirk et al. (2013; genus accepted), Maharachchikumbura et al. (2015, 2016; outline), sequences are unavailable, needs generic revision.

Isomunkia Theiss. \& Syd. 1915, Dothideomycetes genera incertae sedis, one species, type: I. pulvinula (Pat.) Theiss. \& Syd., asexual morph unknown, saprobes, terrestrial, Ecuador, see Kirk et al. (2013; genus accepted), cultures and sequences are unavailable.

Isothea Fr. 1849, Phyllachoraceae, Phyllachorales, Sordariomycetes, two species, type: I. rhytismoides (Bab.) Fr., asexual morph unknown, from living leaves, terrestrial, worldwide, see Lumbsch and Huhndorf (2010; outline), Kirk et al. (2013; genus accepted), Maharachchikumbura et al. (2015, 2016; outline), DNA sequences are unavailable.

Isthmoconidium Etayo \& Berger 2013, Ascomycota genera incertae sedis, one species, type: I. bacidiicola Etayo \& F. Berger, coelomycetous, sexual morph unknown, parasymbiont on Bacidia, terrestrial, Caribbean, see Etayo and Berger (2013; morphology, distinction of similar lichenicolous genera), sequences are unavailable, holotype of the type species LI, F. Berger 22323 \& S. La Greca.

Isthmolongispora Matsush. 1971, Ascomycota genera incertae sedis, eleven species, type: I. intermedia Matsush., hyphomycetous, saprobes, aquatic and terrestrial, Argentina, Australia, Brazil, China, Cuba, Hungary, Japan, Malaysia, Papua New Guinea, Peru, Portugal, Scotland, Taiwan, United Kingdom, Venezuela and West Indies, see Seifert et al. (2011; morphology), Wijayawardene et al. (2012, 2017; outline), Kirk et al. (2013; genus accepted), compare with Isthmophragmospora and Wiesneriomyces, cultures and sequences are available, holotype of type: MFC-3052, needs generic revision.

Isthmophragmospora Kuthub. \& Nawawi 1992, Ascomycota genera incertae sedis, two species, type: I. verruculosa Kuthub. \& Nawawi, hyphomycetous, sexual morph unknown, saprobes, on submerged rotten angiosperms twigs, on submerged decaying leaves in a black 
water stream, Malaysia and Brazil, see Hyde et al. (2011; outline), Seifert et al. (2011; morphology), Wijayawardene et al. (2012, 2017; outline), Kirk et al. (2013; genus accepted), Monteiro et al. (2014b; new species), sequences are unavailable, holotype of type: IMI 344358.

Isthmospora F. Stevens 1918, Ascomycota genera incertae sedis, three species, type: I. spinosa F. Stevens, hyphomycetous, sexual morph unknown, saprobes, terrestrial, Pantropical, see Seifert et al. (2011; morphology, accepted as a genus in Microthyriaceae), Wijayawardene et al. (2012, 2014c; outline, accepted as a genus in Microthyriaceae), Kirk et al. (2013; genus accepted), Wijayawardene et al. (2017; outline), cultures and sequences are unavailable, needs generic revision.

Isthmosporella Shearer \& J.L. Crane 1999, Dothideomycetes genera incertae sedis, one species, type: I. pulchra Shearer \& J.L. Crane, asexual morph unknown, saprobes, fresh water, USA, see Lumbsch and Huhndorf (2010; outline, placed in Phaeosphaeriaceae), Zhang et al. (2012e; placed in Pleosporales), Hyde et al. (2013; accepted in Phaeosphaeriaceae), Phookamsak et al. (2014b; excluded from Phaeosphaeriaceae), Kirk et al. (2013; genus accepted), Wijayawardene et al. (2014c; outline, accepted as Dothideomycetes), sequences are unavailable, holotype of type: ILLS 53086, needs generic revision.

Isthmotricladia Matsush. 1971, Ascomycota genera incertae sedis, three species, type: I. laeensis Matsush., hyphomycetous, saprobes, aquatic and terrestrial, worldwide, see Seifert et al. (2011; morphology), Wijayawardene et al. (2012, 2017; outline), Kirk et al. (2013; genus accepted), compare with Articulospora, holotype of type: MFC-2803, cultures are available, needs generic revision.

Ityorhoptrum P.M. Kirk 1986, Ascomycota genera incertae sedis, four species, type: I. verruculosum (M.B. Ellis) P.M. Kirk, hyphomycetous, sexual morph unknown, saprobes, terrestrial, widespread, see Hyde et al. (2011; outline), Seifert et al. (2011; morphology), Whitton et al. (2012a; new species), Wijayawardene et al. (2012, 2017; outline), Mel'nik et al. (2014; key species), Kirk et al. (2013; genus accepted), cultures and sequences are unavailable, needs generic revision.

Ivanpisutia S.Y. Kondr., L. Lokös \& Hur 2015, Lecanorales genera incertae sedis, Lecanoromycetes, one species, type: I. oxneri S.Y. Kondr., Lőkös \& Hur, lichenized, Russia, see Kondratyuk et al. (2015e; outline), Lücking et al. (2016b; classification), Cultures and sequences are unavailable, holotype of type: KoLRI 020233.

Iwilsoniella E.B.G. Jones 1991, Halosphaeriaceae, Microascales, Sordariomycetes, one species, type: I. rotunda E.B.G. Jones, asexual morph unknown, marine on wood, Great Britain, see Lumbsch and Huhndorf (2010; outline), Kirk et al. (2013; genus accepted), Jones et al. (2015; outline), Maharachchikumbura et al. (2015, 2016; outline),Cultures and sequences are unavailable, holotype of type species IMI 271838.

Iyengarina Subram. 1958, Ascomycota genera incertae sedis, three species, type: I. elegans Subram., hyphomycetous, sexual morph unknown, saprobes, lignicolous, India, Malaysia, see Seifert et al. (2011; morphology), Wijayawardene et al. (2012, 2017; outline), Kirk et al. (2013; genus accepted), sequences are unavailable, holotype of type: MUBL 2015 (Madras, India) (?IMI 113126)

Jackrogersella L. Wendt, Kuhnert \& M. Stadler 2017, Hypoxylaceae, Xylariales, Sordariomycetes, seven species, type: J. multiformis (Fr. . Fr.) L. Wendt, Kuhnert \& M. Stadler, four species, asexual morph hyphomycetous, terrestrial, saprobes, cosmopolitan, see Wendt et al. (2017; taxonomy, phylogeny), cultures and sequences are available.

Jacobsonia Boedijn 1935, Helotiales genera incertae sedis, Leotiomycetes, one species, type: J. glauca Boedijn, asexual morph unknown, saprobes, terrestrial, Sumatra, see Lumbsch and Huhndorf (2010; outline), Kirk et al. (2013; genus accepted), sequences are unavailable. 
Jaffuela Speg. 1921, Pseudoperisporiaceae, Dothideomycetes families incertae sedis, one species, type: J. chilensis Speg., asexual morph unknown, saprobes, terrestrial, Chile, see Lumbsch and Huhndorf (2010; outline, accepted as a genus in Dothioraceae), Kirk et al. (2013; genus accepted), Thambugala et al. (2014a; transferred to Pseudoperisporiaceae), Wijayawardene et al. (2014c; outline), cultures and sequences are unavailable.

Jafnea Korf 1960, Otideaceae, Pezizales, Pezizomycetes, four species, type: J. fusicarpa (W.R. Gerard) Korf, saprobes, terrestrial, north temperate, Australia, Tasmania, see Antonín and Moravec (2010; Czech Republic), Lumbsch and Huhndorf (2010; outline), Gates and van Vooren (2016; new species), cultures and sequences are available.

Jahniella Petr. 1921, Ascomycota genera incertae sedis, three species, type: J. bohemica Petr., coelomycetous, saprobe, pathogen, terrestrial, Czechoslovakia, France, Germany, Russia, Ukraine, see Wijayawardene et al. (2012, 2017; outline), Kirk et al. (2013; genus accepted), compare with Septoria, sequences are unavailable, holotype of type: IMI 204129, needs generic revision.

Jahnula Kirschst. 1936, Aliquandostipitaceae, Jahnulales, Dothideomycetes, 16 species, type: J. aquatica (Plöttner \& Kirschst.) Kirschst., asexual morph unknown, saprobes, aquatic, worldwide, see Raja et al. (2008a; new species), Sivichai and Boonyuen (2010; new species), Sivichai et al. (2011; asexual morph), Jones et al. (2012; phylogeny), Fournier et al. (2015; new species), cultures and sequences are available, GenBank Number: NR_120015 (Jahnula bipileata), holotype and ex-type of type species unavailable.

Jalapriya D'souza, Su, Luo \& K.D. Hyde 2016, Dictyosporiaceae, Pleosporales, Dothideomycetes, three species, type: J. pulchra D'souza, Su, Luo \& K.D. Hyde, hyphomycetous, sexual morph unknown, saprobes, aquatic, cosmopolitan, see Boonmee et al. (2016; phylogeny), Wijayawardene et al. (2017; outline), cultures and sequences are available. Jamesiella Lücking, Sérus. \& Vězda 2005, Gomphillaceae, Ostropales, Lecanoromycetes, four species, type: J. anastomosans (P. James \& Vězda) Lücking, Sérus. \& Vězda, lichenized, cosmopolitan, see Hauck (2009, Europe), Lumbsch and Huhndorf (2010; outline), Motiejūnaité (2011; Lithuania), Khodosovtsev et al. (2013; Ukaraine), Yatsyna and Motiejūnaitė (2015; Belarus), Lücking et al. (2016b; classification), sequences are unavailable, holotype of type species unavailable.

Janannfeldtia Subram. \& Sekar 1993, Nitschkiaceae, Coronophorales, Sordariomycetes, one species, type: J. karwarensis Subram. \& Sekar, asexual morph unknown, saprobes, terrestrial, India, see Lumbsch and Huhndorf (2010; outline), Maharachchikumbura et al. (2015, 2016; outline), sequences are unavailable, isotype of the type: IMI 324682.

Janetia M.B. Ellis 1976, Ascomycota genera incertae sedis, 22 species, type: J. euphorbiae M.B. Ellis, hyphomycetous, saprobes, terrestrial, worldwild, see Seifert et al. (2011; morphology), Wijayawardene et al. (2012, 2017; outline), Kirk et al. (2013; genus accepted), Silva et al. (2016; morphology and phylogeny), compare with Sporidesmium and Stanjehughesia, cultures and sequences are available but lacks for the type species, holotype of type: IMI 163941, needs generic revision.

Japewia Tønsberg 1990, Ramalinaceae, Lecanorales, Lecanoromycetes, three species, type: J. tornoënsis (Nyl.) Tønsberg, lichenized, cool temperate Northern Hemisphere, see Czarnota (2009; Carpathians), Lumbsch and Huhndorf (2010; outline), Kantvilas (2011; Australia), Kirk et al. (2013; genus accepted), Allen and Lendemer (2015; key), Lücking et al. (2016b; classification), cultures and sequences are available.

Japewiella Printzen 1999, Lecanoraceae, Lecanorales, Lecanoromycetes, six species, type: J. carrollii (Coppins \& P. James) Printzen, lichenized, humid temperate and subtropical regions, see Giordani and Incerti (2008; climate effects), Lumbsch and Huhndorf (2010; outline), Kantvilas (2011; Australia), Kirk et al. (2013; genus accepted), Allen and Lendemer (2015; new species, key), Lücking et al. (2016b; classification), sequences are unavailable. 
Jarmania Kantvilas 1996, Ramalinaceae, Lecanorales, Lecanoromycetes, two species, type: J. tristis Kantvilas, lichenized, Australia, New Zealand, Kerguelen Islands, see Kantvilas (2008; Australia), Øvstedal and Gremmen (2009; Kerguelen Islands), Lumbsch and Huhndorf (2010; outline), Ludwig and kantvilas (2015; New Zealand), Lücking et al. (2016b; classification), sequences are unavailable.

Jarxia D. Hawksw. 1989, Naetrocymbaceae, Pleosporales, Dothideomycetes, two species, type: J. thelenula (Müll. Arg.) D. Hawksw., on twigs, terrestrial, Caribbean, see Lumbsch and Huhndorf (2010; outline), Hyde et al. (2013; accepted as a genus in Naetrocymbaceae), Kirk et al. (2013; genus accepted), Wijayawardene et al. (2014c; outline), Jaklitsch et al. (2016a; position), sequences are unavailable, holotype of type species G.

Jasonhuria S.Y. Kondr., L. Lökös \& S.O. Oh 2015, Teloschistaceae, Teloschistales, Lecanoromycetes, one species, type: J. bogilana (Y. Joshi \& Hur) S.Y. Kondr., L. Lőkös, J. Kim, A.S. Kondr. \& S.O. Oh, lichenized, South Korea, see Kondratyuk et al. (2015h; genera proposed), Lücking et al. (2016b; classification), Cultures and sequences are available, holotype of type species KoLRI, Hur 041679.

Jattaea Berl. 1900, Calosphaeriaceae, Calosphaeriales, Sordariomycetes, twelve species, type: J. algeriensis Berl., asexual morph hyphomycetous (phialophora-like), from living leaves, terrestrial, worldwide, see Marincowitz et al. (2008; new species), Lumbsch and Huhndorf (2010; outline), Réblová et al. (2011; taxonomy, revision, new species), Kirk et al. (2013; genus accepted), Réblová et al. (2015b; new species, phylogeny), Maharachchikumbura et al. (2015, 2016; outline), cultures and sequences are available; GenBank Number: NR_135946, verified culture for type species STE-U 6201 (fide Damm et al. 2008).

Javaria Boise 1984, Astrosphaeriellaceae, Pleosporales, Dothideomycetes, two species, type: $J$. samuelsii Boise, asexual morph unknown, saprobes, terrestrial, Brazil, see Lumbsch and Huhndorf (2010; outline), Zhang et al. (2012e; morphology, phylogeny), Kirk et al. (2013; genus accepted), Tian et al. (2015; morphology, nomenclature, phylogeny), Phookamsak et al. (2015b; phylogeny), sequences are unvailable, needs generic revision.

Javonarxia Subram. ex Subram. 1995, Ascomycota genera incertae sedis, two species, type: J. triseptata Subram. ex Subram., hyphomycetous, sexual morph unknown, saprobes, on twigs, Malaysia, see Hyde et al. (2011; outline), Seifert et al. (2011; morphology), Wijayawardene et al. (2012, 2017; outline), Kirk et al. (2013; genus accepted), sequences are unavailable, holotype of type: MUBL 3124.

Jayarambhatia J. Pratibha 2013, Ascomycota genera incertae sedis, one species, type: J. mangrovei J. Pratibha, hyphomycetous, sexual morph unknown, saprobes, terrestrial, India, see Pratibha (2013; taxonomy), Wijayawardene et al. (2017; outline), cultures and sequences are unavailable, holotype of the type: HCIO 51502.

Jenmania W.Wächt. 1897, Lichinaceae, Lichinales, Lichinomycetes, two species, type: J. goebelii W. Wächt., lichenized, British Guinea, see Lumbsch and Huhndorf (2010; outline), Kirk et al. (2013; genus accepted), Lücking et al. (2016b; classification), cultures and sequences are available, holotype of type species unknown.

Jerainum Nawawi \& Kuthub. 1992, Ascomycota genera incertae sedis, one species, type: J. triquetrum Nawawi \& Kuthub., hyphomycetous, sexual morph unknown, saprobes, on submerged rotten twigs, Malaysia, see Hyde et al. (2011; checklist), Lumbsch and Huhndorf (2010; outline), Kirk et al. (2013; genus accepted), sequences are unavailable, holotype of type species KLU 300009.

Jobellisia M.E. Barr 1993, Jobellisiaceae, Jobellisiales, Sordariomycetes, five species, type: J. luteola (Ellis \& Everh.) M.E. Barr, asexual morph unknown, saprobes, terrestrial, fresh water, worldwide, see Lumbsch and Huhndorf (2010; outline), Liu et al. (2012; new species, DNA, phylogeny), Kirk et al. (2013; genus accepted), Untereiner et al. (2013; new species), 
Maharachchikumbura et al. (2015, 2016; outline), cultures and sequences are available, GenBank Number: NR_138381 (Jobellisia guangdongensis), holotype of the type: J.P. Morgan 1109.

Joergensenia Passo, Stenroos \& Calvelo 2008, Lecanorales genera incertae sedis, Lecanoromycetes, one species, type: J. cephalodina (Zahlbr.) Passo, S. Stenroos \& Calvelo, lichenized, Chile, see Lumbsch and Huhndorf (2010; outline), Lücking et al. (2016b; classification), cultures and sequences are available, holotype of type: UPS L-78746.

Johansonia Sacc. 1889, Saccardiaceae, Ascomycota families incertae sedis, c.12 species, type: J. setosa (G. Winter) Sacc., asexual morph unknown, saprobes, terrestrial, widespread (tropical), see Crous et al. (2010a; phylogeny), Lumbsch and hunduf (2010; outline), Kirk et al. (2013; genus accepted), cultures and sequences are unavailable for type species, needs generic revision.

Johnalcornia Y.P. Tan \& R.G. Shivas 2014, Pleosporaceae, Pleosporales, Dothideomycetes, one species, type: J. aberrans (Alcorn) Y.P. Tan \& R.G. Shivas, asexual morph hyphomycetous, associated with leaf spots, terrestrial, Australia, see Tan et al. (2014; morphology, phylogeny), cultures and sequences are available, holotype and ex-type of the type: BRIP 16281, isotype: IMI 335210, ex-isotype: CBS 510.91.

Josefpoeltia S.Y.Kondr. \& Kärnefelt 1997, Teloschistaceae, Teloschistales, Lecanoromycetes, three species, type: J. boliviensis S.Y. Kondr. \& Kärnefelt, lichenized, Peru, Chile, see Gaya et al. (2008; phylogeny), Arup et al. (2013, taxonomy), Lücking et al. (2016b; classification), cultures and sequences are available, holotype of type species MIN (2732).

Jubispora B. Sutton \& H.J. Swart 1986, Ascomycota genera incertae sedis, one species, type: J. acaciae B. Sutton \& H.J. Swart, coelomycetous, sexual morph unknown, saprobes, terrestrial, South Africa, see Wijayawardene et al. (2012, 2016, 2017; morphology, outline), sequences are unavailable, holotype of the type: IMI 167364.

Jugulospora N. Lundq. 1972, Lasiosphaeriaceae, Sordariales, Sordariomycetes, two species, type: J. rotula (Cooke) N. Lundq., asexual morph unknown, saprobes, terrestrial, Europe, North America, see Lumbsch and Huhndorf (2010; outline), Kirk et al. (2013; genus accepted), Maharachchikumbura et al. (2015, 2016; outline), cultures and sequences are available, cultures available for the type species ATCC 38359, type material of type species CBS H-13717.

Julella Fabre 1879, Didymosphaeriaceae, Pleosporales, Dothideomycetes, c. 20 species, type: J. buxi Fabre, asexual morph unknown, saprobes, lichenized, worldwide, see Lumbsch and Huhndorf (2010; outline), Nelsen et al. (2011b; phylogeny), Kirk et al. (2013; genus accepted), Ariyawansa et al. (2014d; phylogeny), cultures and sequences are available, holotype of type: S F599, needs generic revision.

Jumillera J.D. Rogers, Y.M. Ju \& F. San Martín 1997, Lopadostomataceae, Xylariales, Sordariomycetes, eight species, type: J. mexicana J.D. Rogers, Y.M. Ju \& F. San Martín, asexual morph libertella-like, with geniculosporium-like synanamorph, saprobes, Rio Grande do Sul, Hawaiian Island, Mexico, Taiwan, see Lumbsch and Huhndorf (2010; outline), Kirk et al. (2013; genus accepted), Stadler et al. (2013), Daranagama et al. (2017 morphology, taxonomy, key), sequences are unavailable, placement in Lopadostomataceae needs to be confirmed by molecular data.

Juncaceicola Tennakoon, Camporesi, Phookamsak \& K.D. Hyde 2016, Phaeosphaeriaceae, Pleosporales, Dothideomycetes, eight species, type: J. luzulae Tennakoon, Camporesi, Phookamsak \& K.D. Hyde, asexual morph unknown, saprobes, Italy, see Tennakoon et al. (2016; taxonomy, phylogeny), Hyde et al. (2016; new species, phylogeny), holotype of the type: HKAS 93700, cultures and sequences are available. 
Juncigena Kohlm., Volkm.-Kohlm. \& O.E. Erikss. 1997 (= Moheitospora Abdel-Wahab et al. 2010 fide Réblová et al. 2016c), Juncigenaceae, Torpedosporales, Sordariomycetes, two species, type: J. adarca Kohlm., Volkm.-Kohlm. \& O.E. Erikss., asexual morph formerly known in Moheitospora, saprobes, marine, widespread, see Abdel-Wahab et al. (2010, phylogeny), Maharachchikumbura et al. (2015, 2016; outline), Wijayawardene et al. (2017; outline), cultures and sequences are available.

Junctospora Minter \& Hol.-Jech. 1981, Ascomycota genera incertae sedis, one species, type: J. pulchra Minter \& Hol.-Jech., hyphomycetous, sexual morph unknown, saprobes, terrestrial, former Czechoslovakia, see Seifert et al. (2011; morphology), Wijayawardene et al. (2012, 2017; outline), Kirk et al. (2013; genus accepted), cultures and sequences are unavailable, holotype of type species IMI 243573, needs generic revision.

Junewangia W.A. Baker \& Morgan-Jones 2002, Ascomycota genera incertae sedis, four species, type: J. sphaerospora W.A. Baker \& Morgan-Jones, sexual morph unknown, saprobes, terrestrial, see Seifert et al. (2011; morphology), Wijayawardene et al. (2012, 2017; outline), cultures and sequences are available, holotype of type species AUA.

Kabatia Bubák. 1904, Ascomycota genera incertae sedis, ten species, type: K. latemarensis Bubák, coelomycetous, pathogen, terrestrial, Armenia, Canada, China, Czechoslovakia, Germany, Italy, Japan, Poland, Russia, Spain, Scotland, Switzerland, Turkey, USA, see Wijayawardene et al. (2012, 2017; outline), Kirk et al. (2013; genus accepted), compare with Leptothyrium, sequences are unavailable, holotype of type: IMI 213594, needs generic revision.

Kabatiella Bubák 1907, Saccotheciaceae, Dothideales, Dothideomycetes, 18 species, type: K. microsticta Bubák, hyphomycetous, sexual morph unknown, saprobes, pathogen, terrestrial, worldwide, see Simon et al. (2009; DNA), Seifert et al. (2011; morphology), Bai et al. (2012; pathogens), Bills et al. (2012; new species), Wijayawardene et al. (2012, 2014c, 2017; outline), Kirk et al. (2013; genus accepted), Thambugala et al. (2014a; genus accepted), cultures and sequences are available, needs generic revision.

Kabatina R. Schneid. \& Arx 1966, Dothideaceae, Dothideales, Dothideomycetes, five species, type: $K$. thujae R. Schneid. \& Arx, hyphomycetous, sexual morph unknown, saprobes, pathogen, terrestrial, Europe, North America, see Seifert et al. (2011; morphology), Wijayawardene et al. (2012, 2014c, 2017; outline), Kirk et al. (2013; genus accepted), Thambugala et al. (2014a; accepted as a genus in Dothideaceae), cultures and sequences are available, needs generic revision.

Kacosphaeria Speg. 1887, Calosphaeriaceae, Calosphaeriales, Sordariomycetes, one species, type: Kacosphaeria antarctica Speg., asexual morph unknown, from living leaves, terrestrial, worldwide, see Lumbsch and Huhndorf (2010; outline), Kirk et al. (2013; genus accepted), Maharachchikumbura et al. (2015, 2016; outline), cultures and sequences are unavailable, holotype of type species unavailable, needs generic revision.

Kaernefeltia Thell \& Goward 1996, Parmeliaceae, Lecanorales, Lecanoromycetes, two species, type: K. californica (Tuck.) A. Thell \& Goward, lichenized, North America, see Lumbsch and Huhndorf (2010; outline), Kirk et al. (2013; genus accepted), Lücking et al. (2016b; classification), cultures and sequences are available.

Kaernefia S.Y.Kondr., Elix, A.Thell \& Hur 2013, Teloschistaceae, Teloschistales, Lecanoromycetes, three species, type: K. kaernefeltii (S.Y. Kondr., Elix \& A. Thell) S.Y. Kondr., A.Thell, Elix, J. Kim, A.S. Kondr. \& J.-S. Hur, lichenized, Australia, see Kondratyuk et al. (2013a; taxonomy), Lücking et al. (2016b; classification), cultures and sequences are available.

Kainomyces Thaxt. 1901, Laboulbeniaceae, Laboulbeniales, Laboulbeniomycetes, three species, type: K. isomali Thaxt., asexual morph unknown, biotrophic, terrestrial, Western 
Africa, Asia, see Lumbsch and Huhndorf (2010; outline), Kirk et al. (2013; genus accepted), cultures and sequences are unavailable.

Kalaallia Alstrup \& D. Hawksw. 1990, Dacampiaceae, Dothideomycetes families incertae sedis, one genus, type: K. reactiva Alstrup \& D. Hawksw., on lichens, Europe, see Etayo and Sancho (2008; synonym of Opegrapha, Roccellaceae), Lumbsch and Huhndorf (2010; outline), Kirk et al. (2013; genus accepted), Jaklitsch et al. (2016a; classification), cultures and sequences are unavailable, holotype of type: $\mathrm{C}$.

Kalaharituber Trappe \& Kagan-Zur 2005, Pezizaceae, Pezizales, Pezizomycetes, one species, type: K. pfeilii (Henn.) Trappe \& Kagan-Zur, mycorrhizal, terrestrial, see Adeleke and Dames (2014; interaction with bacteria), Trappe et al. (2008; desert truffles), Chaturvedi et al. (2015; antioxidant property), cultures and sequences are available, holotype and ex-type of type species unavailable.

Kalamarospora G. Delgado 2010 [2011], Ascomycota genera incertae sedis, one species, type: K. multiflagellata G. Delgado, hyphomycetous, sexual morph unknown, saprobes, terrestrial, USA, see Seifert et al. (2011; morphology), Wijayawardene et al. (2012, 2017; outline), cultures and sequences are unavailable, holotype of the type: BPI 879811A.

Kalapuya M.J. Trappe, Trappe \& Bonito 2010, Morchellaceae, Pezizales, Pezizomycetes, two species, type: K. brunnea M.J. Trappe, Trappe \& Bonito, asexual morph unknown, epigeous, saprobes, mycorrhizal, terrestrial, Italy, USA, see Trappe et al. (2010; DNA, phylogeny), Jaklitsch et al. (2016a; accepted as a genus in Morchellaceae), cultures and sequences are available.

Kalbiana Henssen 1988, Verrucariales genera incertae sedis, Eurotiomycetes, one species, type: K. brasiliensis Henssen, lichenized, Brazil, see Lumbsch and Huhndorf (2010; outline), Kirk et al. (2013; genus accepted), Lücking et al. (2016b; classification), sequences are unavailable.

Kalbographa Lücking 2007, Graphidaceae, Ostropales, Lecanoromycetes, five species, type: $K$. caracasana (Müll. Arg.) Lücking, asexual morph unknown, lichenized fungi, terrestrial, tropical, see Kalb et al. (2009; Thailand), Plata et al. (2012a; placed in family), Lumbsch and Huhndorf (2010; outline), Kirk et al. (2013; genus accepted), Cultures and sequences are available, holotype of type species unavailable.

Kalchbrenneriella Diederich \& M. S. Christ. 2002, Ascomycota genera incertae sedis, one species, type: K. cyanescens (Kalchbr.) Diederich \& M.S. Christ., hyphomycetous, sexual morph unknown, lichenicolous, non-lichenized, terrestrial, Europe, North America and Papua New Guinea, see Hyde et al. (2011; outline), Seifert et al. (2011; morphology), Wijayawardene et al. (2012, 2017; outline), Joshi et al. (2016; India), sequences are unavailable.

Kaleidosporium Van Warmelo \& B. Sutton 1981, Ascomycota genera incertae sedis, one species, type: K. fenestratum (Ellis \& Everh.) Van Warmelo \& B. Sutton, coelomycetous, sexual morph unknown, saprobes, terrestrial, South Africa, see Hyde et al. (2011; outline), Kirk et al. (2013; genus accepted), Wijayawardene et al. (2016b; morphology), cultures and sequences are unavailable.

Kallichroma Kohlm. \& Volkm.-Kohlm. 1993, Bionectriaceae, Hypocreales, Sordariomycetes, type: K. tethys (Kohlm. \& E. Kohlm.) Kohlm. \& Volkm.-Kohlm., two species, asexual morph unknown, saprobes, terrestrial, aquatic, temperate and tropical regions of the Atlantic, Indian and Pacific Oceans and east coast of Australia, see Dethoup and Manoch (2009; Thailand), Lumbsch and Huhndorf (2010; outline), Kirk et al. (2013; genus accepted), Jones et al. (2015; outline), Maharachchikumbura et al. (2015, 2016; outline), Abdel-Wahab et al. (2016; new species, phylogeny), cultures and sequences are available.

Kallistoskypha Pfister, Agnello, Lantieri \& LoBuglio 2013, Caloscyphaceae, Pezizales, Pezizomycetes, one species, type: K. incarnata (Duvernoy \& Maire) Pfister, Agnello, Lantieri 
\& LoBuglio, on soil associated with Eucalyptus, Mediterranean region, see Pfister et al. (2013; proposed genera), sequences are unavailable.

Kalmusia Niessl 1872 (= Dendrothyrium Verkley et al. 2013 fide Wijayawardene et al. 2014c), Didymosphaeriaceae, Pleosporales, Dothideomycetes, 15 species, type: K. ebuli Niessl, asexual morph unknown, saprobes, terrestrial, worldwide, see Lumbsch and Huhndorf (2010; outline), Hyde et al. (2013; accepted as a genera in Didymosphaeriaceae), Ariyawansa et al. (2014d; taxonomy, phylogeny), Wijayawardene et al. (2014c, 2016; phylogeny, taxonomy, outline, nomenclature), Zhang et al. (2014d; neotypified Kalmusia ebuli), Liu et al. (2015a; new species, Italy), Tanaka et al. (2015; phylogeny), cultures and sequences are available, neotype and ex-neotype culture for type: BJFC 200201, CBS 123120.

Kamalomyces R.K. Verma, N. Sharma \& Soni 2008, Tubeufiaceae, Tubeufiales, Dothideomycetes, three species, type: K. indicus R.K. Verma, N. Sharma \& Soni, asexua morph unknown, saprobes, India, see Boonmee et al. (2014b; taxonomy), Wijayawardene et al. (2014c; outline), cultures and sequences are unavailable.

Kamatella Anahosur 1969, Ascomycota genera incertae sedis, one species, type: K. indica Anahosur, coelomycetous, sexual morph unknown, saprobes, terrestrial, South Africa, India, see Wijayawardene et al. (2012, 2016, 2017; outline, morphology), Kirk et al. (2013; genus accepted), sequences are unavailable, holotype of type species unavailable.

Kameshwaromyces Kamal, R.K. Verma \& Morgan-Jones 1986, Ascomycota genera incertae sedis, two species, type: K. globosus Kamal, R.K. Verma \& Morgan-Jones, hyphomycetous, sexual morph unknown, saprobes, terrestrial, India, see Verma et al. (2008; new species, India), Seifert et al. (2011; morphology), Wijayawardene et al. (2012, 2017; outline), Kirk et al. (2013; genus accepted), sequences are unavailable.

Kananascus Nag Raj 1984, Trichosphaeriaceae, Trichosphaeriales, Sordariomycetes, three species, type: $K$. verrucisporus Nag Raj, hyphomycetous, sexual morph unknown, saprobes, terrestrial, worldwide, see Lumbsch and Huhndorf (2010; outline), Kirk et al. (2013; genus accepted), Maharachchikumbura et al. (2015, 2016; outline), cultures and sequences are available.

Kantvilasia P.M. McCarthy, Elix \& Sérus. 2000, Pilocarpaceae, Lecanorales, Lecanoromycetes, one species, type: K. hians P.M. McCarthy, Elix \& Sérus., lichenized, Australia, see Lumbsch and Huhndorf (2010; outline), Lücking et al. (2016b; classification), sequences are unavailable, holotype of type species HO 445410.

Kapooria J. Reid \& C. Booth 1989, Valsaceae, Diaporthales, Sordariomycetes, one species, type: K. musarum (J.N. Kapoor) J. Reid \& C. Booth, asexual morph unknown, saprobes, terrestrial, India, see Lumbsch and Huhndorf (2010; outline), Kirk et al. (2013; genus accepted), Maharachchikumbura et al. (2015, 2016; outline), cultures and sequences are unavailable, holotype of type species unknown, needs generic revision.

Karschia Körb. 1865, Asterinales genera incertae sedis, Dothideomycetes, four species, type: K. talcophila (Ach.) Körb., asexual morph unknown, lichenicolous, terrestrial, Europe, see Lumbsch and Huhndorf (2010; outline, accepted as a genus in Dothideomycetes, genera incertae sedis), Kirk et al. (2013; genus accepted), Muggia et al. (2013; phylogeny), Thambugala et al. (2014b; transferred to Lichenotheliaceae ), Wijayawardene et al. (2014c; outline, accepted as a genus in Lichenotheliaceae), Ertz and Diederich (2015; phylogeny, accepted as Asterinales), cultures and sequences are available.

Karstenella Harmaja 1969, Karstenellaceae, Pezizales, Pezizomycetes, one species, type: $K$. vernalis Harmaja, saprobes, terrestrial, Europe (Finland) and North America (New Mexico), see Lumbsch and Huhndorf (2010; outline), Kirk et al. (2013; genus accepted), Pfister et al. (2013; genus accepted), cultures and sequences are available, holotype of type species unavailable. 
Karstenia Fr. 1885, Stictidaceae, Ostropales, Lecanoromycetes, ten species, type: K. sorbina (P. Karst.) P. Karst., asexual morph unknown, saprobes, Europe, USA, see Lumbsch and Huhndorf (2010; outline), Baral (2015; new combination), sequences are unavailable, holotype of type species unavailable, needs generic revision.

Karsteniomyces D. Hawksw. 1980, Ramalinaceae, Lecanorales, Lecanoromycetes, three species, type: K. peltigerae (P. Karst.) D. Hawksw., asexual macroconidial morphs of Scutula Tul. (Wedin et al. 2007), lichenicolous, widespread, see Hyde et al. (2011; checklist), Wijayawardene et al. (2012, 2017; outline), cultures and sequences are unavailable, holotype of type species H-Karst 2041.

Karstenula Speg. 1879, Didymosphaeriaceae, Pleosporales, Dothideomycetes, 16 species, type: K. rhodostoma (Alb. \& Schwein.) Speg., asexual morph unknown, saprobes, terrestrial, temperate, see Lumbsch and Huhndorf (2010; outline), Zhang et al. (2012e; accepted in Didymosphaeriaceae), Hyde et al. (2013; accepted in Didymosphaeriaceae), Ariyawansa et al. (2014d; taxonomy, accepted in Didymosphaeriaceae, phylogeny), Wijayawardene et al. (2014c; outline), Tanaka et al. (2015; DNA, phylogeny), holotype of the type species PH 01048835 (holotype of Sphaeria rhodostoma), cultures available for type species CBS 690.94, CBS 691.94.

Kashiwadia S.Y.Kondr., L.Lökös \& Hur 2014, Physciaceae, Caliciales, Lecanoromycetes, one species, type: K. orientalis (Kashiw.) SY Kondr., L. Lökös et J.-S. Hur, lichenized, eastern Asia, see Kondratyuk et al. (2014c; taxonomy, phylogeny), Lücking et al. (2016b; classification), cultures and sequences are available.

Kastanostachys L. Lombard \& Crous 2016, Stachybotriaceae, Hypocreales, Sordariomycetes, one species, type: K. aterrima (Fuckel) L. Lombard \& Crous, asexual morph hyphomycetous, from forest soil, terrestrial, Czech Republic, see Lombard et al. (2016; taxonomy, phylogeny), Wijayawardene et al. (2017; outline), epitype and ex-epitype culture of the type: PRM 934970, CBS 101310.

Kathistes Malloch \& M. Blackw. 1990, Kathistaceae, Ophiostomatales, Sordariomycetes, type: K. calyculata Malloch \& M. Blackw., three species, saprobes, worldwide, see Lumbsch and Huhndorf (2010; outline), Kirk et al. (2013; genus accepted), Maharachchikumbura et al. (2015, 2016; outline), sequences and cultures are available (unpublished), holotype of type species TRTC 51145.

Katumotoa Kaz. Tanaka \& Y. Harada 2005, Lentitheciaceae, Pleosporales, Dothideomycetes, one species, type: K. bambusicola Kaz. Tanaka \& Y. Harada, asexual morph unknown, saprobes, terrestrial, Japan, see Tanaka et al. (2009, 2015; morphology, phylogeny), cultures and sequences are available, holotype and ex-type strain of the type species HHUF 28661, JCM 13131.

Kazachstania Zubkova 1971, Saccharomycetaceae, Saccharomycetales, Saccharomycetes, 35 species, type: $K$. viticola Zubcova, asexual reproduction is by multilateral budding, saprophytic, but a few species are opportunistic pathogens of mammals, in soil, maize silage, waste water, soft drinks, fermented foods, tree fluxes, feces, infected mammals, worldwide, see Lumbsch and Huhndorf (2010; outline), Kirk et al. (2013; genus accepted), sequences are available.

Keinstirschia J. Reid \& C. Booth 1989, Diaporthales incertae sedis, Sordariomycetes, one species, type: K. megalosperma (Kirschst.) J. Reid \& C. Booth, terrestrial, saprobes, Germany, see Lumbsch and Huhndorf (2010; outline), Maharachchikumbura et al. (2015, 2016; outline), cultures and sequences are unavailable, holotype of type species (see MBT\#133497), needs generic revision.

Keissleriella Höhn. 1919, Lentitheciaceae, Pleosporales, Dothideomycetes, c. 34, type: K. aesculi (Höhn.) Höhn., asexual morph dendrophoma-like, saprobes, terrestrial, worldwide, Lumbsch and Huhndorf (2010; outline), Zhang et al. (2012e; accepted as a genus in 
Lentitheciaceae), Kirk et al. (2013; genus accepted), Hyde et al. (2013; outline, accepted as a genus in Lentitheciaceae), Crous et al. (2014c; new species, The Netherlands), Ariyawansa et al. (2015a; new species), Liu et al. (2015a; new species, Italy), Singtripop et al. (2015; new specie, phylogeny), Tanaka et al. (2015; new specie, phylogeny), Thambugala et al. (2016; new species, Italy), cultures and sequences are available.

Keissleriomyces D. Hawksw. 1981, Ascomycota genera incertae sedis, one species, type: $K$. sansteadeans (Keissl.) D. Hawksw., lichenicolous, Europe, see Kirk et al. (2013; genus accepted), cultures and sequences are unavailable, holotype of type species W 1921/185.

Kellermania Ellis \& Everh. 1885 (= Planistromella A.W. Ramaley 1993 fide Wijayawardene et al. 2014c; Rossman et al. 2015b), Planistromellaceae, Botryosphaeriales, Dothideomycetes, c. 20 species, type: K. yuccigena Ellis \& Everh., coelomycetous, sexual morph Planistromella, saprobes, terrestrial, worldwide, see Minnis et al. (2012; taxonomy, phylogeny), Wijayawardene et al. (2012, 2014c, 2017; outline, nomenclature), Hyde et al. (2013; taxonomy), Monkai et al. (2013; phylogeny), Kirk et al. (2013; genus accepted), Rossman et al. (2015b; nomenclature), cultures and sequences are available, needs generic revision.

Kendrickomyces B. Sutton, V.G. Rao \& Mhaskar 1976, Ascomycota genera incertae sedis, two species, type: K. indicus B. Sutton, V.G. Rao \& Mhaskar, hyphomycetous, sexual morph unknown, saprobes, terrestrial, India, see Kirk et al. (2013; genus accepted), sequences are unavailable, holotype of the type species IMI 190465.

Kensinjia J. Reid \& C. Booth 1989, Melanconidaceae, Diaporthales, Sordariomycetes, one species, type: K. umbrina (Jenkins) J. Reid \& C. Booth, asexual morph unknown, saprobes, terrestrial, Australia, see Lumbsch and Huhndorf (2010; outline), Kirk et al. (2013; genus accepted), Maharachchikumbura et al. (2015, 2016; outline), cultures and sequences are unavailable.

Kephartia R.C. Harris \& Lendemer 2013, Ascomycota genera incertae sedis, two species, type: $K$. crystalligera R.C. Harris \& Lendemer, asexual morph unknown, lichenized, terrestrial, USA, see Lendemer et al. (2013; taxonomy), sequences are unavailable, holotype of type: NY(26883).

Keratosphaera H.B.P. Upadhyay 1964, Pseudoperisporiaceae, Dothideomycetes families incertae sedis, six species, type: K. batistae H.B.P. Upadhyay, asexual morph unknown, lichenicolous, terrestrial, worldwide, see Farkas (2010; new species), Lumbsch and Huhndorf (2010; outline), Hyde et al. (2013; accepted as a genus in Pseudoperisporiaceae), Wijayawardene et al. (2014c; outline), cultures and sequences are unavailable, needs generic revision.

Kernia Nieuwl. 1916, Microascaceae, Microascales, Sordariomycetes, five species, type: $K$. nitida (Sacc.) Nieuwl., asexual morph unknown, coprophilous, terrestrial, worldwide, see Lumbsch and Huhndorf (2010; outline), Kirk et al. (2013; genus accepted), Maharachchikumbura et al. (2015, 2016; outline), cultures and sequences are available, holotype material of type: CBS H-13743, needs generic revision.

Kerniomyces Toro 1939, Schizothyriaceae, Dothideomycetes families incertae sedis, one species, type: K. costi Toro, asexual morph unknown, saprobes, terrestrial, South America, see Lumbsch and Huhndorf (2010; outline), Hyde et al. (2013; accepted as a genus in Schizothyriaceae), Kirk et al. (2013; genus accepted), Wijayawardene et al. (2014c; outline), cultures and sequences are unavailable.

Ketubakia Kamat, Varghese \& V.G. Rao, 1987, Ascomycota genera incertae sedis, one species, type: $K$. indica Kamat, Varghese \& V.G. Rao, hyphomycetous, sexual morph unknown, saprobes, lignicolous, India, see Seifert et al. (2011; morphology), Wijayawardene et al. (2012, 2017; outline), Kirk et al. (2013; genus accepted), sequences are unavailable. 
Kiehlia Viégas 1944, Parmulariaceae, Dothideomycetes families incertae sedis, one species, type: K. obscura Viégas, asexual morph unknown, epiphytes, terrestrial, Brazil, see Lumbsch and Huhndorf (2010; outline), Hyde et al. (2013; accepted as a genus in Parmulariaceae), Wijayawardene et al. (2014c; outline), Cultures and sequences are unavailable, Holotype of type species IACM.

Kiliophora Kuthub. \& Nawawi 1993, Ascomycota genera incertae sedis, three species, type: $K$. fusispora Kuthub. \& Nawawi, hyphomycetous, sexual morph unknown, saprobes, foliicolous, Ivory Coast, Malaysia and Vietnam, see Wijayawardene et al. (2012, 2017; outline), Kirk et al. (2013; genus accepted), Hidayat et al. (2014; phylogeny, placed in Amphisphaeriaceae), Rajeshkumar et al. (2016; family needs revision), Cultures and sequences are available, holotype of type species IMI 355816.

Kimbropezia Korf \& W.Y. Zhuang 1991, Pezizaceae, Pezizales, Pezizomycetes, one species, type: K. campestris Korf \& W.Y. Zhuang, saprobes, terrestrial, Canary Island, cultures and sequences are available, holotype of type: CUP-MM 2762.

Kionocephala P.M. Kirk 1986, Ascomycota genera incertae sedis, one species, type: $K$. catenulata (M.B. Ellis) P.M. Kirk, hyphomycetous, sexual morph unknown, saprobes, lignicolous, UK, Russia, Cuba, see Hyde et al. (2011; checklist), Seifert et al. (2011; morphology), Wijayawardene et al. (2012, 2017; outline), Kirk et al. (2013; genus accepted), sequences are unavailable.

Kionochaeta P.M. Kirk \& B. Sutton 1986, Chaetosphaeriaceae, Chaetosphaeriales, Sordariomycetes, seven species, type: K. ramifera (Matsush.) P.M. Kirk \& B. Sutton, hyphomycetous, sexual morph unknown, saprobes, terrestrial, worldwide, see Seifert et al. (2011; morphology), Wijayawardene et al. (2012, 2017; outline), Kirk et al. (2013; genus accepted), Maharachchikumbura et al. (2015, 2016; outline), cultures and sequences are available but lacks for the type species, holotype of the type: IMI188783.

Kirschsteiniothelia D. Hawksw. 1985 (= Dendryphiopsis S. Hughes 1953 fide Wijayawardene et al. 2014c; Rossman et al. 2015b), Kirschsteiniotheliaceae, Dothideomycetes family incertae sedis, 19 species, type: K. aethiops (Berk. \& Curtis) D. Hawksw., asexual morph Dendryphiopsis, on wood, terrestrial, aquatic, worldwide, see Lumbsch and Huhndorf (2010; outline, accepted as a genus in Dothideomycetes genera incertae sedis), Boonmee et al. (2012; phylogeny), Hyde et al. (2013; accepted as a genus in Kirschsteiniotheliaceae), Kirk et al. (2013; genus accepted), Wijayawardene et al. (2014c; outline, nomenclature), Rossman et al. (2015b; nomenclature), Jaklitsch et al. (2016a; classification), cultures and sequences are available, holotype of type species $\mathrm{K}(\mathrm{M})$, genus remains polyphyletic.

Kirstenboschia Quaedvlieg, Verkley \& Crous 2013, Ascomycota genera incertae sedis, one species, type: $K$. diospyri Quaedvl., Verkley \& Crous, coelomycetous, sexual morph unknown, saprobes, terrestrial, South Africa, see Quaedvlieg et al. (2013; morphology, phylogeny), cultures and sequences are available, holotype and ex-type of the type: CBS H21326, CBS 134911.

Kitesporella Jheng \& K. L. Pang 2012, Halosphaeriaceae, Microascales, Sordariomycetes, one species, type: K. keelungensis J.S. Jheng \& K.L. Pang, asexual morph unknown, saprobes, marine, Taiwan, see Pang and Jheng (2012a; placement in Halosphaeriaceae), Maharachchikumbura et al. (2015, 2016; genus accepted), sequence are unavailable, holotype of type: BBH30190.

Klasterskya Petr. 1940, Ophiostomataceae, Ophiostomatales, Sordariomycetes, one species, type: K. acuum (Mouton) Petr., asexual morph hyalorhinocladiella-like, saprobes, terrestrial, Europe, see Lumbsch and Huhndorf (2010; outline), Kirk et al. (2013; genus accepted), Maharachchikumbura et al. (2015, 2016; outline), cultures and sequences are available, needs generic revision. 
Kleidiomyces Thaxt. 1908, Laboulbeniaceae, Laboulbeniales, Laboulbeniomycetes, three species, type: K. furcillatus (Thaxt.) Thaxt., asexual morph unknown, biotrophic, terrestrial, America, see Lumbsch and Huhndorf (2010; outline), Kirk et al. (2013; genus accepted), cultures and sequences are unavailable.

Kluyveromyces van der Walt 1971, Saccharomycetaceae, Saccharomycetales, Saccharomycetes, eight species, type: K. marxianus (E.C. Hansen) van der Walt, asexual reproduction is by multilateral budding, saprophytic, sea water, Drosophila spp., mushrooms, tree fluxes, cacti, dairy products, worldwide, see Lumbsch and Huhndorf (2010; outline), Kirk et al. (2013; genus accepted), sequences are available.

Kmetia Bres. \& Sacc. 1902, Ascomycota genera incertae sedis, one species, type: K. exigua Bres. \& Sacc., hyphomycetous, sexual morph unknown, saprobes, terrestrial, Europe, see Seifert et al. (2011; morphology), Wijayawardene et al. (2012, 2017; outline), Kirk et al. (2013; genus accepted), cultures and sequences are unavailable, needs generic revision.

Kmetiopsis Bat. \& Peres 1960, Ascomycota genera incertae sedis, one species, type: $K$. hymenaeae Bat. \& Peres, hyphomycetous, sexual morph unknown, saprobes, terrestrial, Brazil, see Seifert et al. (2011; morphology), Wijayawardene et al. (2012, 2017; outline), Kirk et al. (2013; genus accepted), cultures and sequences are unavailable, needs generic revision.

Knemiothyrium Bat. \& J.L. Bezerra 1960, Ascomycota genera incertae sedis, one species, type: K. weldenii Bat. \& J.L. Bezerra, coelomycetous, sexual morph unknown, saprobes, terrestrial, Jamaica, see Wijayawardene et al. (2012, 2017; outline), Kirk et al. (2013; genus accepted), cultures and sequences are unavailable, needs generic revision.

Knoxdaviesia M.J. Wingf., P.S. van Wyk \& Marasas 1988 (= Gondwanamyces G.J. Marais \& M.J. Wingf. 1998 fide Réblová et al. 2016c), Microascaceae, Microascales, Sordariomycetes, two species, type: K. proteae M.J. Wingf., P.S. van Wyk \& Marasas, hyphomycetous, sexual morph unknown, coprophilous, terrestrial, South Africa, see Lumbsch and Huhndorf (2010; outline), de Beer et al. (2013; new species), Kirk et al. (2013; genus accepted), Aylward et al. (2014, 2015; DNA, phylogeny), Maharachchikumbura et al. (2015, 2016; outline), Réblová et al. (2016c; nomenclature), cultures and sequences are available, holotype of the type: PREM48928, cultures and sequences are available.

Knufia L.J. Hutchison \& Unter. 1996, Trichomeriaceae, Chaetothyriales, Eurotiomycetes, 13 species, type: K. cryptophialidica L.J. Hutchinson \& Unter., hyphomycetous, mostly terrestrial, associated with soil, bark, rock surfaces and human skin, America, Asia and Europe, see Li et al. (2008; human infection, as "Coniosporium"), Tsuneda et al. (2011b; outline), Seifert et al. (2011; morphology), Untereiner et al. (2011; phylogeny, sexual morph), Wijayawardene et al. (2012, 2017; outline), Crous et al. (2013b; new species), Réblová et al. (2013; phylogeny, new combination), Isola et al. (2015; new species), holotype and exisotype strain of the type: TRTC 51492, DAOM 216555.

Kochiella Sakayaroj, K.L. Pang \& E.B.G. Jones 2011, Halosphaeriaceae, Microascales, Sordariomycetes, one species, type: K. crispa (Kohlm.) Sakay., K.L. Pang \& E.B.G. Jones, asexual morph unknown, saprobes, marine, Denmark, Hawaii, Japan, Liberia, Martinique, Taiwan, see Sakayaroj et al. (2011a; morphology, phylogeny), cultures and sequences are available.

Kockiozyma Jindam., Yukphan, \& Y. Yamada 2012, Lipomycetaceae, Saccharomycetales, Saccharomycetes, one species, type: K. suomiensis (M.T. Sm., Van der Walt \& Y. Yamada) Jindam., Yukphan \& Y. Yamada, saprophytic, see Jindamorakot et al. (2012; taxonomy).

Kodamaea Y. Yamada, T. Suzuki, Matsuda \& Mikata emend. Rosa, Lachance, Starmer, Barker, Bowles \& Schlag-Edler 1999, ?Metschnikowiaceae, Saccharomycetales, Saccharomycetes, seven species, type: K. ohmeri (Etchells \& T.A. Bell) Y. Yamada, Suzuki, M. Matsuda \& Mikata, saprophytic, on flowers of morning glory, (Hibiscus spp.) and other 
plants including cacti, various beetles, on Drosophila, pickle brines, see Lumbsch and Huhndorf (2010; outline), Freitas et al. (2013; DNA), Kirk et al. (2013; genus accepted), sequences are available.

Kodonospora K. Ando 1993, Ascomycota genera incertae sedis, one species, type: $K$. tetracolumnaris K. Ando, hyphomycetous, sexual morph unknown, saprobes, on leaves, Japan, see Hyde et al. (2011; outline), Seifert et al. (2011; morphology), Wijayawardene et al. (2012, 2017; outline), sequences are unavailable, holotype of type: TNS F-176499.

Koerberia A. Massal. 1854, Koerberiaceae, Peltigerales, Lecanoromycetes, two species, type: K. biformis A. Massal., lichenized, Europe, Asia, USA,?, see Lumbsch and Huhndorf (2010; outline, accepted as a genus in Placynthiaceae), Kirk et al. (2013; genus accepted), Spribille and Muggia (2013, phylogeny), Lücking et al. (2016b; classification), cultures and sequences are available, holotype of type species unavailable.

Koerberiella Stein 1879, Lecideaceae, Lecideales, Lecanoromycetes, two species, type: $K$. wimmeriana (Körb.) Stein, lichenized, Europe, North America, Asia, see Lumbsch and Huhndorf (2010; outline), Kirk et al. (2013; genus accepted), Schmull et al. (2011; phylogeny), Lücking et al. 2016 (classification), cultures and sequences are available, holotype of type species unavailable.

Kohlmeyeriella E. B. G. Jones, R. G. Johnson \& S. T. Moss 1983, Lulworthiaceae, Lulworthiales, Sordariomycetes, two species, type: K. tubulata (Kohlm.) E.B.G. Jones, R.G. Johnson \& S.T. Moss, asexual morph unknown, saprobes, marine, worldwide, see Lumbsch and Huhndorf (2010; outline), Kirk et al. (2013; genus accepted), Maharachchikumbura et al. (2016; genus accepted), cultures and sequences are available.

Kohlmeyeriopsis S. Klaubauf, M.H. Lebrun \& P.W. Crous 2014, Magnaporthaceae, Magnaporthales, Sordariomycetes, one species, type: K. medullaris (Kohlm., Volkm.-Kohlm. \& O.E. Erikss.) Klaubauf, Lebrun \& Crous, holomorph, asexual morph hyphomycetous, saprobes, marine, USA, see Abdel-Wahab et al. (2014; phylogeny), Klaubauf et al. (2014; phylogeny), Maharachchikumbura et al. (2015, 2016; genus accepted), cultures and sequences are available, ex-type culture of type species unavailable, holotype of type species J.K. $5528=01315596-99=01315600-05$, NYBG.

Kohninia Holst-Jensen, Vrålstad \& T. Schumach. 2004, Sclerotiniaceae, Helotiales, Leotiomycetes, one species, type: K. linnaeicola Holst-Jensen, Vrålstad \& T. Schumach., asexual morph unknown, saprobes, terrestrial, Norway, see Lumbsch and Huhndorf (2010; outline), Kirk et al. (2013; genus accepted), Pärtel et al. (2017; phylogeny), cultures and sequences are available.

Kolletes Kohlm. \& Volkm.-Kohlm. 2005, Ascomycota genera incertae sedis, one species, type: K. undulatus Kohlm. \& Volkm.-Kohlm., hyphomycetous, sexual morph unknown, saprobes, terrestrial, USA, see Seifert et al. (2011; morphology), Wijayawardene et al. (2012, 2017; outline), Kirk et al. (2013; not accepted as valid genus), cultures and Cultures and sequences are unavailable, holotype of the type: IMS, Kohlmeyer 5728, needs generic revision.

Komagataella Y. Yamada, Matsuda, Maeda \& Mikata 1995, ?Pichiaceae, Saccharomycetales, Saccharomycetes, six species, type: K. pastoris (Guilliermond) Y. Yamada, M. Matsuda, K. Maeda \& Mikata, asexual reproduction is by multilateral budding, saprophytic, fluxes from various trees and from rotted wood, worldwide, see Kurtzman (2009; taxonomy), Lumbsch and Huhndorf (2010; outline), Kirk et al. (2013; genus accepted), sequences are available.

Kompsoscypha Pfister 1989, Sarcoscyphaceae, Pezizales, Pezizomycetes, four species, type: $K$. chudei (Pat. ex Le Gal) Pfister, saprobes, on leaves, fruits and twigs, tropical and subtropical, worldwide, see Lumbsch and Huhndorf (2010; outline), Kirk et al. (2013; genus accepted), cultures and sequences are available. 
Konenia Hara 1913, Sordariomycetes genera incertae sedis, two species, type: K. bambusae Hara, asexual morph unknown, saprobes, terrestrial, Japan, see Lumbsch and Huhndorf (2010; outline), Kirk et al. (2013; genus accepted), Maharachchikumbura et al. (2015, 2016; outline), cultures and sequences are unavailable.

Konradia Racib. 1900, Clavicipitaceae, Hypocreales, Sordariomycetes, two species, type: K. bambusina Racib., asexual morph unknown, sapbrobe, terrestrial, Java, Indonesia, see Lumbsch and Huhndorf (2010; outline), Kirk et al. (2013; genus accepted), Maharachchikumbura et al. (2015, 2016; outline), cultures and sequences are unavailable.

Kontospora A. Roldán, Honrubia \& Marvanová 1990, Ascomycota genera incertae sedis, one species, type: K. halophila A. Roldán, Honrubia \& Marvanová, hyphomycetous, sexual morph unknown, saprobes, aquatic, Spain, see Seifert et al. (2011; morphology), Wijayawardene et al. (2012, 2017; outline), Kirk et al. (2013; genus accepted), cultures and sequences are unavailable, needs generic revision.

Koorchaloma Subram. 1953, Trichosphaeriaceae, Trichosphaeriales, Sordariomycetes, nine species, type: K. madreeya Subram., hyphomycetous, sexual morph unknown, saprobes, terrestrial, widespread (pantropical), see Allegrucci et al. (2011; key to species), Hyde et al. (2011; outline), Seifert et al. (2011; morphology), Wijayawardene et al. (2012, 2017; outline), Kirk et al. (2013; genus accepted), Maharachchikumbura et al. (2016; outline), cultures and sequences are unavailable for type species, needs generic revision.

Koorchalomella Chona, Munjal \& J.N. Kapoor 1958, Ascomycota genera incertae sedis, one species, type: K. oryzae Chona, Munjal \& J.N. Kapoor, hyphomycetous, sexual morph unknown, saprobes, terrestrial, India, USA, see Seifert et al. (2011; morphology), Wijayawardene et al. (2012, 2017; outline), Kirk et al. (2013; genus accepted), cultures and sequences are unavailable, needs generic revision.

Koordersiella Höhn. 1909 (= Hansfordiellopsis Deighton 1960; Ascohansfordiellopsis D. Hawksw. 1979 fide Rossman et al. 2016a), Dothideomycetes genera incertae sedis, three species, type: K. javanica Höhn., asexual morph unknown, lichenicolous, terrestrial, tropical, see Lumbsch and Huhndorf (2010; outline), Kirk et al. (2013; genus accepted), Wijayawardene et al. (2014c; outline), Rossman et al. (2016a; nomenclature), cultures and sequences are unavailable, needs generic revision.

Koralionastes Kohlm. \& Volkm.-Kohlm. 1987, Koralionastetaceae, Koralionastetales, Sordariomycetes, five species, type: K. ovalis Kohlm. \& Volkm.-Kohlm., asexual morph unknown, saprobes, marine, worldwide, see Campbell et al. (2009a; phylogeny), Lumbsch and Huhndorf (2010; outline), Kirk et al. (2013; genus accepted), Maharachchikumbura et al. (2015, 2016; genus accepted), holotype: J.K. 4965a, cultures and sequences are available.

Korfia J. Reid \& Cain 1963, Cenangiaceae, Helotiales, Leotiomycetes, one species, type: $K$. tsugae (E.K. Cash \& R.W. Davidson) J. Reid \& Cain, asexual morph unknown, saprobes, terrestrial, USA, see Lumbsch and Huhndorf (2010; outline), Kirk et al. (2013; genus accepted), cultures and sequences are available, holotype of type species unavailable.

Korfiella D.C. Pant \& V. P. Tewari 1970, Sarcosomataceae, Pezizales, Pezizomycetes, one species, type: K. karnika D.C. Pant \& V.P. Tewari, saprobes, on conifer needles, India, see Lumbsch and Huhndorf (2010; outline), Kirk et al. (2013; genus accepted), cultures and sequences are unavailable.

Korfiomyces Iturr. \& D. Hawksw. 2004, Lecanoromycetes genera incertae sedis, one species, type: K. gelatinosus Iturr. \& D. Hawksw. (as "gelatinosum"), asexual morph unknown, on resin and wood, Venezuela, see Lumbsch and Huhndorf (2010; outline), Jaklitsch et al. (2016a; classification), cultures and sequences are unavailable, holotype of type: VEN Iturriaga 615.

Korunomyces Hodges \& F.A. Ferreira 1981, Ascomycota genera incertae sedis, three species, type: K. terminaliae Hodges \& F.A. Ferreira, hyphomycetous, sexual morph unknown, 
saprobes, terrestrial, Brazil, Cuba, see Seifert et al. (2011; morphology), Wijayawardene et al. (2012, 2017; outline), Kirk et al. (2013; genus accepted), sequences are unavailable, ex-type of type: CBS 224.80, needs generic revision.

Kostermansinda Rifai 1968, Ascomycota genera incertae sedis, three species, type: K. magna (Boedijn) Rifai, hyphomycetous, sexual morph unknown, saprobes, terrestrial, pantropical, see Seifert et al. (2011; morphology), Wijayawardene et al. (2012, 2017; outline), Kirk et al. (2013; genus accepted), cultures and sequences are unavailable, needs generic revision.

Kostermansindiopsis R.F. Castañeda 1986, Ascomycota genera incertae sedis, one species, type: K. theobromae R.F. Castañeda, hyphomycetous, sexual morph unknown, saprobes, terrestrial, Caribbean, see Seifert et al. (2011; morphology), Wijayawardene et al. (2012, 2017; outline), Kirk et al. (2013; genus accepted), cultures and sequences are unavailable, needs generic revision.

Kramabeeja G.V. Rao \& K.A. Reddy 1981, Ascomycota genera incertae sedis, one species, type: K. shrungashakha G.V. Rao \& K.A. Reddy, hyphomycetous, sexual morph unknown, saprobes, on dead rachis of Areca, India, see Hyde et al. (2011; checklist), Seifert et al. (2011; morphology), Wijayawardene et al. (2012, 2017; outline), Kirk et al. (2013; genus accepted), cultures and sequences are unavailable.

Kramasamuha Subram. \& Vittal 1973, Ascomycota genera incertae sedis, one species, type: K. sibika Subram. \& Vittal, hyphomycetous, sexual morph unknown, saprobes, on leaves, widespread, see Hyde et al. (2011; outline), Seifert et al. (2011; morphology), Wijayawardene et al. (2012, 2017; outline), Kirk et al. (2013; genus accepted), cultures and sequences are unavailable.

Kraurogymnocarpa Udagawa \& Uchiy. 1999, Gymnoascaceae, Onygenales, Eurotiomycetes, two species, type: K. lenticulispora Udagawa \& Uchiy., asexual morphs unknown, saprobes, terrestrial, Japan, see Lumbsch and Huhndorf (2010; outline), Kirk et al. (2013; genus accepted), Sigler et al. (2013; DNA), cultures and sequences are available, needs generic revision.

Kravtzevia Schwarzman 1961, Sordariomycetes genera incertae sedis, three species, type: $K$. halimodendri Schwarzman, asexual morph unknown, saprobes, terrestrial, former USSR, see Lumbsch and Huhndorf (2010; outline), Kirk et al. (2013; genus accepted), Maharachchikumbura et al. (2015, 2016; outline), cultures and sequences are unavailable, needs generic revision.

Kregervanrija Kurtzman 2006, Pichiaceae, Saccharomycetales, Saccharomycetes, three species, type: K. fluxuum (Phaff \& E.P. Knapp) Kurtzman, asexual reproduction multilateral budding, saprophytic, on tree fluxes, apples, apple juice, wine and other fermented beverages, pickle brines, Europe and North America, see Lumbsch and Huhndorf (2010; outline), Kirk et al. (2013; genus accepted), sequences are available.

Kreiseliella U. Braun 1991, Ascomycota genera incertae sedis, one species, type: K. typhae (Vasyag.) U. Braun, coelomycetous, terrestrial, foliicolous, leaf-spotting, Asia (Kazakhstan), see Hyde et al. (2011; outline), Kirk et al. (2013; genus accepted), Wijayawardene et al. (2012, 2017; outline), Kirk et al. (2013; genus accepted), cultures and sequences are unavailable, needs generic revision.

Kretzschmaria Fr. 1849 (= Ustulina Tul. \& C. Tul. 1863; = Ascostroma Bonord. 1851; = Rhopalopsis Cooke 1883 fide Wedt et al. 2017), Xylariaceae, Xylariales, Sordariomycetes, more than 50 species, type: K. clavus (Fr.) Sacc., asexual morph unkown, saprobes, worldwide, see Lumbsch and Huhndorf (2010; outline), Kirk et al. (2013; genus accepted), Stadler et al. (2013), Daranagama et al. (2017 morphology, taxonomy, key), sequences are available but lacks for the type species.

Kretzschmariella Viégas 1944, Xylariaceae, Xylariales, Sordariomycetes, one species, type: K. culmorum (Cooke) Y.-M. Ju \& J. D. Rogers, asexual morph present, saprobes, Thaiwan, 
see Lumbsch and Huhndorf (2010; outline), Kirk et al. (2013; genus accepted), Stadler et al. (2013), Daranagama et al. (2017 morphology, taxonomy, key), sequences are unavailable.

Kriegeriella Höhn. 1918, Dothideomycetes genera incertae sedis, four species, type: $K$. mirabilis Höhn., asexual morph unknown, saprobes, terrestrial, Europe, North America, see Lumbsch and Huhndorf (2010; outline, placed in Pleosporaceae), Wu et al. (2011; classification), Zhang et al. (2012e; placed in Microthyriaceae), Hyde et al. (2013; classification), Kirk et al. (2013; genus accepted), Wijayawardene et al. (2014c; outline), cultures and sequences are unavailable, generic revision is essential

Krishnamyces Hosag. 2003, Ascomycota genera incertae sedis, one species, type: $K$. indica Hosag., ?hyphomycetous, sexual morph unknown, saprobes, terrestrial, pantropical, see Wijayawardene et al. (2012, 2017; outline), cultures and sequences are unavailable, needs generic revision.

Krogia Timdal 2002, Ramalinaceae, Lecanorales, Lecanoromycetes, three species, type: $K$. coralloides Timdal, lichenized, Asia, Africa, see Timdal (2009; new species), Lumbsch and Huhndorf (2010; outline), Lücking et al. (2016b; classification), cultures and sequences are unavailable, holotype of type species O L21909.

Kroswia P.M.Jørg. 2002, Pannariaceae, Peltigerales, Lecanoromycetes, four species, type: $K$. crystallifera P.M. Jørg., lichenized, Asia, see Lumbsch and Huhndorf (2010; outline), Liu et al. (2015a; China), Magain and Sérusiaux (2015; nomenclature), Lücking et al. 2016 (classification), Cultures and sequences are available, holotype of type species US Hale 43843.

Kruphaiomyces Thaxt. 1931, Laboulbeniaceae, Laboulbeniales, Laboulbeniomycetes, one species, type: $K$. trochoidei Thaxt., asexual morph unknown, biotrophic, terrestrial, Fiji, see Lumbsch and Huhndorf (2010; outline), Kirk et al. (2013; genus accepted), cultures and sequences are unavailable.

Kuehniella G.F. Orr 1976, Onygenaceae, Onygenales, Eurotiomycetes, two species, type: K. racovitzae (Lagarde) G.F. Orr, asexual morph unknown, saprobes, terrestrial, Northern America, see Lumbsch and Huhndorf (2010; outline), Kirk et al. (2013; genus accepted), cultures and sequences are available.

Kullhemia P. Karst. 1878, Dothideomycetes genera incertae sedis, three species, type: $K$. moriformis (Ach.) P. Karst., asexual morph unknown, saprobes, terrestrial, tropical, see Lumbsch and Huhndorf (2010; outline), Kirk et al. (2013; genus accepted), Wijayawardene et al. (2014c; outline), cultures and sequences are unavailable, needs generic revision.

Kumanasamuha P.Rag. Rao \& D. Rao 1964, Ascomycota genera incertae sedis, four species, type: K. sundara P.Rag. Rao \& D. Rao, hyphomycetous, sexual morph unknown, saprobes, lignocolous, widespread, see Nagao et al. (2009; new species), Hyde et al. (2011; outline), Wijayawardene et al. (2012, 2017; outline), Kirk et al. (2013; genus accepted), cultures and sequences are unavailable, needs generic revision.

Kundalinella Hande \& Subhedar 2001, Ascomycota genera incertae sedis, one species, type: $K$. raoella Hande \& Subhedar, asexual morph unknown, saprobes, terrestrial, India, see Wijayawardene et al. (2012, 2017; outline), cultures and sequences are unavailable, needs generic revision.

Kuraishia Y. Yamada, Maeda \& Mikata 1994, Pichiaceae, Saccharomycetales, Saccharomycetes, seven species, type: K. capsulata (Wickerham) Y. Yamada, K. Maeda \& Mikata, asexual reproduction is by multilateral budding, saprophytic, on insect frass, rotted wood, soil, mushroom, worldwide, Lumbsch and Huhndorf (2010; outline), Kirk et al. (2013; genus accepted), sequences are available.

Kurssanovia Kravtzev 1955, Sordariomycetes genera incertae sedis, three species, type: $K$. vassiljevskii Kravtzev, asexual morph unknown, saprobes, terrestrial, former USSR, see Lumbsch and Huhndorf (2010; outline), Kirk et al. (2013; did not accept), 
Maharachchikumbura et al. (2015, 2016; outline), cultures and sequences are unavailable, needs generic revision.

Kurtzmaniella Lachance \& Starmer 2008, Debaryomycetaceae, Saccharomycetales, Saccharomycetes, twelve species, type: K. cleridarum Lachance \& Starmer, in asexual reproduction cells produced by asexual reproduction are ovoid to ellipsoid and form by multilateral budding, saprophytic, one species is an opportunistic human pathogen, cactus flowers, mushrooms, tree fluxes, beetles, rotted wood, insect frass, apple cider, rotted fruit, olives, soil, seawater, human feces, sputum, worldwide, see Lumbsch and Huhndorf (2010; outline), Lachance et al. (2013b; DNA), sequences are available.

Kusanobotrys Henn. 1904, Dothideomycetes genera incertae sedis, three species, type: $K$. bambusae Henn., asexual morph unknown, saprobes, terrestrial, tropical, see Lumbsch and Huhndorf (2010; outline), Kirk et al. (2013; genus accepted), Wijayawardene et al. (2014c; outline), cultures and sequences are unavailable, needs generic revision.

Kylindria DiCosmo, S.M. Berch \& W.B. Kendr. 1983, Reticulascaceae, Glomerellales, Sordariomycetes, nine species, type: K. triseptata (Matsush.) DiCosmo, S.M. Berch \& W.B. Kendr., hyphomycetous, sexual morph unknown, saprobes, terrestrial, worldwide, see Zhang et al. (2010e; new species, China), Réblová et al. (2011; DNA, phylogeny), Seifert et al. (2011; morphology), Wijayawardene et al. (2012, 2017; outline), Kirk et al. (2013; genus accepted), Maharachchikumbura et al. (2015, 2016; outline, phylogeny), cultures and sequences are available but lacks for type species.

Kyphomyces I.I. Tav. 1985, Laboulbeniaceae, Laboulbeniales, Laboulbeniomycetes, 14 species, type: K. ansatus (Thaxt.) I.I. Tav., asexual morph unknown, biotrophic, terrestrial, worldwide, see Lumbsch and Huhndorf (2010; outline), Kirk et al. (2013; genus accepted), cultures and sequences are unavailable.

Kyphophora B. Sutton 1991, Ascomycota genera incertae sedis, one species, type: $K$. avicenniae B. Sutton, coelomycetous, sexual morph unknown, saprobes, terrestrial, Australia, see Wijayawardene et al. (2012, 2017; outline), cultures and sequences are unavailable, needs generic revision.

Laboulbenia Mont. \& C.P. Robin 1853, Laboulbeniaceae, Laboulbeniales, Laboulbeniomycetes, c. 625 species, type: L. rougetii Mont. \& C.P. Robin, asexual morph unknown, biotrophic, hosts are diverse, including Acari, Blattodea, Coleoptera (Carabidae, Chrysomelidae, Curculionidae, Erotylidae, Gyrinidae, Staphylinidae, and others), Diptera, Hemiptera, Hymenoptera (Formicidae), and Orthoptera (Gryllotalpidae), worldwide, see Lumbsch and Huhndorf (2010; outline), Kirk et al. (2013; genus accepted), Haelewaters et al. (2015b; DNA), Rossi et al. (2016a; morphology), Wang et al. (2016b; morphology), cultures and sequences are available but lacks for the type species, needs generic revision.

Laboulbeniopsis Thaxt. 1920, Laboulbeniomycetes genera incertae sedis, one species, type: L. termitarius Thaxt., asexual morph unknown, parasitic on termites, terrestrial, North America, Caribbean, see Lumbsch and Huhndorf (2010; outline), Kirk et al. (2013; genus accepted), sequences are available.

Labrocarpon Pérez-Ortega \& Etayo 2010, Asterinales genera incertae sedis, Dothideomycetes, one species, type: L. canariense (D. Hawksw.) Etayo \& Pérez-Ortega, asexual morph unknown, lichenicolous on Pertusaria species, parasymbiont, Canary Islands, Madeira, mainland Spain and Portugal, Italy and Greece, see Pérez-Ortega and Etayo (2010; genus proposed), Ertz and Diederich (2015, phylogeny), cultures and sequences are available, holotype of type: IMI 259313.

Laburnicola Wanasinghe, Camporesi, E.B.G. Jones \& K.D. Hyde 2016, Didymosphaeriaceae, Pleosporales, Dothideomycetes, four species, type: L. muriformis Wanasinghe, E. Camporesi, E.B.G. Jones \& K.D. Hyde, asexual morph unknown, saprobes, terrestrial, Europe, Russia, see Wanasinghe et al. (2016; morphology, phylogeny), cultures 
and sequences are available, holotype and ex-type of type: MFLU 16-0230, MFLUCC 160290.

Labyrintha Malcolm, Elix \& OweLarsson 1995, Lecideaceae, Lecideales, Lecanoromycetes, one species, type: L. implexa Malcolm, Elix \& Owe-Larss., lichenized, New Zealand, see Lumbsch and Huhndorf (2010; outline), Kirk et al. (2013; genus accepted), Lücking et al. (2016b; classification), cultures and sequences are unavailable, holotype of type species CHR 470232 .

Labyrinthomyces Boedijn 1939, Tuberaceae, Pezizales, Pezizomycetes, two species, type: L. steenisii Boedijn, truffles, ectomycorrhizal, terrestrial, Australia, see Trappe et al. (2008; desert truffles), Vellinga et al. (2009; distribution pattern), Lumbsch and Huhndorf (2010; outline), Kirk et al. (2013; genus accepted), cultures and sequences are available.

Lacazia Taborda, V.A. Taborda \& McGinnis 1999, Onygenales, genera incertae sedis, Eurotiomycetes, two species, type: L. loboi Taborda, V.A. Taborda \& McGinnis, asexual morph unknown, on humans and animals, terrestrial, neotropics, see Seifert et al. (2011; morphology), Wijayawardene et al. (2012, 2017; outline), Kirk et al. (2013; genus accepted), cultures and sequences are available.

Lacellina Sacc. 1913, Ascomycota genera incertae sedis, three species, type: L. graminicola (Berk. \& Broome) Petch, hyphomycetous, sexual morph unknwon, on plants, widespread (pantropical), see Hyde et al. (2011; outline), Seifert et al. (2011; morphology), Wijayawardene et al. (2012, 2017; outline), Kirk et al. (2013; genus accepted), cultures and sequences are unavailable, needs generic revision.

Lacellinopsis Subram. 1953, Ascomycota genera incertae sedis, three species, type: L. sacchari Subram., hyphomycetous, sexual morph unknown, saprobes, on leaves (grasses) and litter, widespread (pantropical), see Hyde et al. (2011; checklist), Seifert et al. (2011; morphology), Wijayawardene et al. (2012, 2017; outline), Kirk et al. (2013; genus accepted), Cultures and sequences are unavailable, needs generic revision.

Lachancea Kurtzman 2003, Saccharomycetaceae, Saccharomycetales, Saccharomycetes, ten species, type: L. thermotolerans (Filippov) Kurtzman, asexual reproduction is by multilateral budding, saprophytic, tree fluxes, rotted wood, alpechin, fruit, fruit flies, spoiled beverages, soil, seawater near mangroves, worldwide, see Lumbsch and Huhndorf (2010; outline), sequences are available.

Lachnellula P. Karst. 1884, Lachnaceae, Helotiales, Leotiomycetes, c. 40 species, type: L. chrysophthalma (Pers.) P. Karst., asexual morph unknown, saprobes, pathogen, terrestrial, widespread (temperate), see Lumbsch and hunduf (2010; outline), Whitton et al. (2012b; morphology), Kirk et al. (2013; genus accepted), Schumacher et al. (2015; pathogens), Jaklitsch et al. (2016a; classification), cultures and sequences are available but lacks for type species, needs generic revision.

Lachnodochium Marchal 1895, Ascomycota genera incertae sedis, one species, type: L. candidum Marchal, hyphomycetous, sexual morph unknown, saprobes, terrestrial, Europe, see Seifert et al. (2011; morphology), Wijayawardene et al. (2012, 2017; outline), Kirk et al. (2013; genus accepted), cultures and sequences are unavailable, needs generic revision.

Lachnum Retz. 1769 (see Species Fungorum 2017 for synonyms), Lachnaceae, Helotiales, Leotiomycetes, c. 50 species, type: L. agaricinum Retz., asexual morph unknown, saprobes on ferns, bamboo culms, herbs, herbaceous stems, cones, cupules, wood or leaves of palms, coniferous or broadleaved trees, cosmopolitan, see Nagao (2008; Japan), Hosoya et al. (2010; phylogeny, cultures), Lumbsch and Huhndorf (2010; outline), Kirk et al. (2013; genus accepted), cultures and sequences are available, needs generic revision.

Laciniocladium Petri 1917, Ascomycota genera incertae sedis, one species, type: L. candidum Marchal, hyphomycetous, sexual morph unknown, saprobes, terrestrial, Europe, 
see Seifert et al. (2011; morphology), Wijayawardene et al. (2012, 2017; outline), Kirk et al. (2013; genus accepted), cultures and sequences are unavailable, needs generic revision.

Laciniocladium Petri 1917, Ascomycota genera incertae sedis, one species, type: $L$. castaneae Petri, hyphomycetous, sexual morph unknown, saprobes, terrestrial, Europe, see Seifert et al. (2011; morphology), Wijayawardene et al. (2012, 2017; outline), Kirk et al. (2013; genus accepted), cultures and sequences are unavailable, needs generic revision.

Lacrymospora Aptroot 1991, Requienellaceae, Xylariales, Sordariomycetes, one species, type: L. parasitica Aptroot, asexual morph unknown, lichenicolous, terrestrial, tropical, see Lumbsch and Huhndorf (2010; outline), Kirk et al. (2013; genus accepted), cultures and sequences are unavailable, holotype of the type: herb. Aptroot, Aptroot and Hensen 12613.

Lacunospora Cailleux 1969, Lasiosphaeriaceae, Sordariales, Sordariomycetes, two species, type: L. stercoraria Cailleux, asexual morph unknown, saprobes, terrestrial, Europe, North America, see Lumbsch and Huhndorf (2010; outline), Kirk et al. (2013; genus accepted), Maharachchikumbura et al. (2015, 2016; outline), cultures and sequences are unavailable.

Laetinaevia Nannf. 1932, Calloriaceae, Helotiales, Leotiomycetes, c. 15 species, type: L. lapponica (Nannf.) Nannf., asexual morph unknown, saprobes, terrestrial, Europe, see Lumbsch and Huhndorf (2010; outline), Kirk et al. (2013; genus accepted), Baral and Rama (2015; DNA), cultures and sequences are available but lacks for type species, needs generic revision.

Laeviomyces D. Hawksw. 1981, Ascomycota genera incertae sedis, four species, type: L. pertusariicola (Nyl.) D. Hawksw., sexual morphs unknown, lichenicolous, terricolous, widespread, see Kirk et al. (2013; genus accepted), Zhurbenko and Otte (2012; genus accepted, illustrations), cultures and sequences are unavailable, holotype of type species $\mathrm{H}$ Nyl 23576.

Lagenulopsis Fitzp. 1942, Coryneliaceae, Coryneliales, Eurotiomycetes, one species, type: Lagenulopsis bispora Fitzp., asexual morph unknown, saprobes, terrestrial, Northern America, see Lumbsch and Huhndorf (2010; outline), Kirk et al. (2013; genus accepted), Wood et al. (2016; phylogeny, taxonomy), cultures and sequences are available.

Lahmia Körb. 1861, Lahmiaceae, Lahmiales, Leotiomycetes, one species, type: Lahmia kunzei Körb., asexual morph unknown, saprobes, terrestrial, north temperate, see Lumbsch and Huhndorf (2010; outline), Kirk et al. (2013; genus accepted), Jaklitsch et al. (2016a; classification), cultures and sequences are unavailable, holotype of type species unavailable.

Lahmiomyces Cif. \& Tomas. 1953, Helotiales genera incertae sedis, Leotiomycetes, one species, type: L. piceae Cif. \& Tomas., asexual morph unknown, saprobes, terrestrial, Italy, see Lumbsch and Huhndorf (2010; outline), Jaklitsch et al. (2016a; classification, treated as a genus in Patellariaceae),cultures and sequence are unavailable, needs generic revision.

Lambdasporium Matsush. 1971, Ascomycota genera incertae sedis, three species, type: $L$. wauense Matsush., hyphomycetous, sexual morph unknown, saprobes, terrestrial, Asia, Europe, North America, see Seifert et al. (2011; morphology), Wijayawardene et al. (2012, 2017; outline), Kirk et al. (2013; genus accepted), cultures and sequences are unavailable, needs generic revision.

Lambertella Höhn., 1918, Rutstroemiaceae, Helotiales, Leotiomycetes, c. six species, type: L. corni-maris Höhn., asexual morph helicodendron-like, terrestrial, aquatic, saprobes, widespread, see Lumbsch and Huhndorf (2010; outline), Zhao et al. (2013b; Japan), Kirk et al. (2013; genus accepted), Galán et al. (2015; phylogeny), sequence data available for ten species, holotype and extype of type species unavailable..

Lambiella Hertel 1984, Xylographaceae, Trapeliales, Lecanoromycetes, twelve species, type: L. psephota (Tuck.) Hertel, lichenized, see Spribille et al. (2014a; phylogeny), Resl et al. (2015; phylogeny), Lücking et al. (2016b; classification), cultures and sequences are available. 
Lambinonia Sérus. \& Diederich 2005, Ascomycota genera incertae sedis, one species, type: L. strigulae (Elenkin \& Woron.) Sérus. \& Diederich, hyphomycetous, sexual morph unknown, lichenicolous, non-lichenized, on foliicolous lichens, terrestrial, worldwide, see Wijayawardene et al. (2012, 2017; outline), cultures and sequences are unavailable.

Lambro Racib. 1900, Sydowiellaceae, Diaporthales, Sordariomycetes, two species, type: L. insignis Racib., asexual morphs unknown, saprobes, terrestrial, Indonesia, see Lumbsch and Huhndorf (2010; outline), Kirk et al. (2013; genus accepted), Maharachchikumbura et al. (2015, 2016; outline, phylogeny), cultures and sequence are unavailable, needs generic revision.

Lamproconium (Grove) Grove 1937, Lamproconiaceae, Diaporthales, Sordariomycetes, one species, type: L. desmazieri (Berk. \& Broome) Grove, coelomycetous, sexual morph unknown, saprobes, terrestrial, Europe, see Wijayawardene et al. (2012, 2016; outline, taxonomy), Kirk et al. (2013; genus accepted), Norphanphoun et al. (2016; taxonomy, phylogeny), Wijayawardene et al. (2016b; taxonomy), cultures and sequences are available, holotype of type: CBS H-13785, needs generic revision.

Lamprospora De Not. 1864 (= Moravecia Benkert, Caillet \& Moyne 1987 fide Jaklitsch et al. 2016a), Pezizales genera incertae sedis, Pezizomycetes, c. 60 species, type: L. miniata (P. Crouan \& H. Crouan) De Not., parasitic on mosses, worldwide, see Eckstein and Eckstein (2009; Germany), Mann (2009; laccase production), Lumbsch and Huhndorf (2010; outline), Kirk et al. (2013; genus accepted), Pradhan et al. (2013; India), Egertova et al. (2015; Czech), Jaklitsch et al. (2016a; classification), cultures and sequences are available, holotype of the type: CBS H-14139.

Lanatosphaera Matzer 1996, Dothideomycetes genera ncertae sedis, two species, type: L. porinicola Matzer, asexual morph unknown, saprobes, terrestrial, tropical, see Lumbsch and Huhndorf (2010; outline), Kirk et al. (2013; genus accepted), Wijayawardene et al. (2014c; outline), cultures and sequences are unavailable, holotype of the type species GZU, Matzer 1422 \& Pelzmann, needs generic revision.

Lanceispora Nakagiri, Okane, Tad. Ito \& Katum. 1997, Xylariaceae, Xylariales, Sordariomycetes, two species, type: L. amphibia Nakagiri, Okane, Tad. Ito \& Katum., asexual morph unknown, endophytic, saprophytic, subtropics, see Lumbsch and Huhndorf (2010; outline, accepted as a genus in Amphisphaeriaceae), Kirk et al. (2013; genus accepted), Jones et al. (2015; outline), Maharachchikumbura et al. (2016; outline), cultures and sequences are available, holotype and ex-type of the type: IFO H-12218, NBRC 32918.

Lanspora K.D. Hyde \& E.B.G. Jones 1986, Ophiostiomatales genera incertae sedis, Sordariomycetes, one species, type: L. coronata K.D. Hyde \& E.B.G. Jones, asexual morph unknown, saprobes, marine, Seychelles, see Lumbsch and Huhndorf (2010; outline), Kirk et al. (2013; genus accepted), Jones et al. (2015; outline), Maharachchikumbura et al. (2015, 2016; outline), cultures and sequences are available.

Lanzia Sacc. 1884, Rutstroemiaceae, Helotiales, Leotiomycetes, 55 species, type: L. flavorufa (Sacc.) Sacc., asexual morph unknown, terrestrial, saprobes, worldwide, see Lumbsch and Huhndorf (2010; outline), Johnston and Park (2013; DNA, phylogeny), Kirk et al. (2013; genus accepted), Han et al. (2014; DNA, phylogeny), cultures and sequences are available but lacks for the type species, holotype of type species unavailable.

Laocoön J.C. David 1997, Ascomycota genera incertae sedis, one species, type: L. paradoxus (Syd. \& P. Syd.) J.C. David, hyphomycetous, sexual morph unknown, saprobes, terrestrial, North America, see Seifert et al. (2011; morphology), Wijayawardene et al. (2012, 2014c; outline, accepted as a genus in Mycosphaerellaceae), Kirk et al. (2013; genus accepted), Wijayawardene et al. (2017; outline, transferred to Ascomycota genera incertae sedis), cultures and sequences are unavailable, needs generic revision. 
Lapidomyces de Hoog \& Stielow 2014, Teratosphaeriacae, Capnodiales, Dothideomycetes, one species, type: L. hispanicus de Hoog \& Stielow, hyphomycetous, sexual morph unknown, rock-inhabiting fungus, see Egidi et al. (2014; taxonomy, phylogeny), Quaedvlieg et al. (2014; phylogeny), Wijayawardene et al. (2017; outline), cultures available for the type: CBS $118355=$ TRN500.

Lappodochium Matsush. 1975, Ascomycota genera incertae sedis, one species, type: Lappodochium langeniforme Matsush., hyphomycetous, sexual morph unknown, on soil, terrestrial, South America, see Seifert et al. (2011; morphology), Wijayawardene et al. (2012, 2017; outline), Kirk et al. (2013; genus accepted), cultures and sequences are unavailable, needs generic revision.

Laquearia Fr. 1849, Rhytismatales genera incertae sedis, Leotiomycetes, one species, type: $L$. sphaeralis (Fr.) Fr., asexual morph unknown, saprobes, terrestrial, Europe, see Lumbsch and Huhndorf (2010; outline), Kirk et al. (2013; genus accepted), cultures and sequences are unavailable, needs generic revision.

Lareunionomyces Crous \& M.J. Wingf. 2016, Helotiales genera incertae sedis, Leotiomycetes, one species, type: L. syzygii Crous \& M.J. Wingf., hyphomycetous, saprobes, terrestrial, France, see Crous et al. (2016b; taxonomy, phylogeny), Wijayawardene et al. (2017; outline), holotype and ex-type culture of the type species CBS H-22623, CPC 26531.

Larissia Raitv. 2008, Helotiales genera incertae sedis, Leotiomycetes, one species, type: L. pyrolae Raitv., asexual morph unknown, saprobes, terrestrial, Russia, see Raitviir (2008; taxonomy), the genus was not listed in any recent outlines or checklists, cultures and sequences are unavailable, holotype of type species TAA-182408.

Lasallia Mérat 1821, Umbilicariaceae, Umbilicariales, Lecanoromycetes, 17 species, type: L. pustulata (L.) Mérat, lichenized, worldwide, see Lumbsch and Huhndorf (2010; outline), Bendiksby and Timdal (2013; phylogeny), Kirk et al. (2013; genus accepted), Lücking et al. (2016b; classification), cultures and sequences are available.

Lasiobelonium Ellis \& Everh. 1897, Lachnaceae, Helotiales, Leotiomycetes, c. 20 species, type: L. subflavidum Ellis \& Everh., asexual morph unknown, saprobes, terrestrial, widespread, see Lumbsch and hunduf (2010; outline), Kirk et al. (2013; genus accepted), cultures and sequences are available but lacks for type species, needs generic revision.

Lasiobertia Sivan. 1978, Xylariales genera incertae sedis, Sordariomycetes, two species, type: L. africana Sivan., asexual morph unknown, saprobes, terrestrial, Ghana, Puerto Rico, see Lumbsch and Huhndorf (2010; outline), Maharachchikumbura et al. (2015, 2016; outline), cultures and sequences are available but lack for the type species, holotype of the type: IMI 38816.

Lasiobolidium Malloch \& Cain 1971, Pezizales genera incertae sedis, Pezizomycetes, seven species, type: L. spirale Malloch \& Cain, asexual morph unknown, saprobes, on dung, North America, see Doveri et al. (2013; key, Italy), Hansen et al. (2013; polyphyletic genus), cultures and sequences are available.

Lasiobolus Sacc. 1884, Ascodesmidaceae, Pezizales, Pezizomycetes, eleven species, type: L. pilosus (Fr.) Sacc., coprophilous, sexual morph unknown, saprobes, on herbivore dung, worldwide, see Güngör et al. (2008; proposed family), Chang and Wang (2009; new species), Lumbsch and Huhndorf (2010; outline), Kirk et al. (2013; genus accepted), cultures and sequences are available, holotype of type: CBS H-13792.

Lasiobotrys Kunze 1823, Venturiales genera incertae sedis, Dothideomycetes, one species, type: Lasiobotrys lonicerae (Fr.) Kunze, asexual morph unknown, saprobes, terrestrial, ulocladium-like, see Lumbsch and Huhndorf (2010; outline, accepted as a genus in Venturiaceae), Hyde et al. (2013) did not accept as a genus in Venturiaceae, Zhang et al. (2011d; accepted as a genus in Venturiales genera incertae sedis), Kirk et al. (2013; genus 
accepted), Wijayawardene et al. (2014c; outline), cultures and sequences are unavailable, needs generic revision.

Lasiodiplodia Ellis \& Everh. 1896, Botryosphaeriaceae, Botryosphaeriales, Dothideomycetes, at least 31 species, type: L. theobromae (Pat.) Griffon \& Maubl., asexual morph coelomycetous, saprobes, pathogens, terrestrial, worldwide, see Pavlic et al. (2008; new species), Phillips et al. (2008, 2013; taxonomy, phylogeny), Abdollahzadeh et al. (2010; new species), Liu et al. (2012; taxonomy, phylogeny), Úrbez-Torres et al. (2012; new species), Hyde et al. (2013; accepted as a genus in Botryosphaeriaceae), Slippers et al. (2013; phylogeny), Wijayawardene et al. (2014c, 2016; outline, taxonomy, phylogeny), Dissanayake et al.(2016; taxonomy), neotype and ex-neotype of the type: CBS H-21411, CBS 164.96 (fide Phillips et al. 2013).

Lasiodiplodiella Zambett 1955, Ascomycota genera incertae sedis, three species, type: L. triflorae (B.B. Higgins) Zambett., coelomycetes, sexual morph unknown, widespread, see Hyde et al. (2011; checklist), Wijayawardene et al. (2012, 2017; outline), Kirk et al. (2013; genus accepted), cultures and sequences are unavailable, holotype of type species unavailable. Lasioloma R.Sant. 1952, Pilocarpaceae, Lecanorales, Lecanoromycetes, nine species, type: L. arachnoideum (Kremp.) R. Sant., lichenized, Asia, Africa, see Lumbsch and Huhndorf (2010; outline), Kirk et al. (2013; genus accepted), Lücking et al. (2016b; classification), cultures and sequences are available.

Lasiomollisia Raitv. \& Vesterh. 2006, Ploettnerulaceae, Helotiales, Leotiomycetes, one species, type: L. phalaridis Raitv. \& Vesterh., asexual morph unknown, saprobes, terrestrial, Sweden, cultures and sequences are unavailable, holotype of the type: TAA (M), Hanson 2003-147.

Lasionectria (Sacc.) Cooke 1884, Bionectriaceae, Hypocreales, Sordariomycetes, twelve species, type: L. mantuana (Sacc.) Cooke, asexual morph acremonium-like, saprobes, terrestrial, temperate, see Lumbsch and Huhndorf (2010; outline), Kirk et al. (2013; genus accepted), Lechat and Fournier (2013; new species), Maharachchikumbura et al. (2015, 2016; outline), cultures and sequences are available, needs generic revision.

Lasiosphaeria Ces. \& De Not. 1863, Lasiosphaeriaceae, Sordariales, Sordariomycetes, 72 species, type: L. ovina (Pers.) Ces. \& De Not., asexual morph unknown, saprobes, terrestrial, worldwide, see Lumbsch and Huhndorf (2010; outline), Raja et al. (2011a; DNA), Kirk et al. (2013; genus accepted), Miller et al. (2014; phylogeny), Kruys et al. (2015; phylogeny), Maharachchikumbura et al. (2015, 2016; outline), Bell and Mahoney (2016; new species, phylogeny), cultures available for the type species ANM 1295 (Raja et al. 2011), holotype of type: CBS H-13806.

Lasiosphaeriella Sivan. 1975, Chaetosphaeriales genera incertae sedis, Sordariomycetes, twelve species, type: L. dennisii Sivan., asexual morph acremonium-like, saprobes, terrestrial, pantropical, see Lumbsch and Huhndorf (2010; outline, accepted as Sordariomycetidae, genera incertae sedis), Huhndorf and Miller (2011; DNA, phylogeny), Kirk et al. (2013; genus accepted), Maharachchikumbura et al. (2015, 2016; outline), cultures and sequences are available, needs generic revision.

Lasiosphaeriopsis D. Hawksw. \& Sivan. 1980, Nitschkiaceae, Coronophorales, Sordariomycetes, seven species, type: L. salisburyi D. Hawksw. \& Sivan, asexual morph unknown, lichenicolous, widespread, terrestrial, see Lumbsch \& Huhndorf (2010; outline), Kirk et al. (2013; genus accepted), Maharachchikumbura et al. (2015, 2016; outline), cultures and sequences are unavailable, holotype of type: K(M)-IMI 80468.

Lasiosphaeris Clem. 1909 (= Lasiadelphia Réblová \& W. Gams 2011 fide Maharachchikumbura et al. 2015, 2016; Réblová et al. 2016c), Sordariales genera incertae sedis, Sordariomycetes, three species, type: L. hispida (Tode) Clem., asexual morph formerly known in Lasiadelphia, saprobes, terrestrial, temperate, see Lumbsch and Huhndorf (2010; 
outline), Kirk et al. (2013; genus accepted), Miller et al. (2014; phylogeny), Maharachchikumbura et al. (2015, 2016; outline), Réblová et al. (2016c; nomenclature), cultures available for the type: TL6019, SMH 3336 (Miller and Huhndorf 2004).

Lasiostemma Theiss., Syd. \& P. Syd. 1917, Pseudoperisporiaceae, Dothideomycetes, families incertae sedis, five species, type: L. melioloides (Berk. \& Ravenel) Theiss., Syd. \& P. Syd., asexual morph unknown, saprobes, terrestrial, Chile, see Lumbsch and Huhndorf (2010; outline), Hyde et al. (2013; accepted as a genus in Pseudoperisporiaceae), Kirk et al. (2013; genus accepted), Mapook et al. (2016; transferred to Pseudoperisporiaceae), Wijayawardene et al. (2014c; outline), cultures and sequences are unavailable.

Lasiostictella Sherwood 1986, Rhytismataceae, Rhytismatales, Leotiomycetes, one species, type: L. bambusae Sherwood, asexual morph unknown, saprobes, terrestrial, France, see Lumbsch and Huhndorf (2010; outline), Kirk et al. (2013; genus accepted), cultures and sequences are unavailable, needs generic revision.

Lasiothyrium Syd. \& P. Syd. 1913, Ascomycota genera incertae sedis, one species, type: L. cycloschizon Syd. \& P. Syd., coelomycetous, sexual morph unknown, saprobes, terrestrial, Philippines, see Wijayawardene et al. (2012, 2017; outline), Kirk et al. (2013; genus accepted), cultures and sequences are unavailable, needs generic revision.

Lasmenia Speg. 1886, Cryphonectriaceae, Diaporthales, Sordariomycetes, five species, type: L. balansae Speg., coelomycetous, sexual morph unknown, saprobes, pathogens, terrestrial, South America, Australia, Hong Kong, Philippines, see Serrato-Diaz et al. (2011; DNA), Wijayawardene et al. (2012, 2016, 2017; outline, taxonomy), Kirk et al. (2013; genus accepted), Maharachchikumbura et al. (2015, 2016; outline), cultures and sequences are available, needs generic revision.

Lasmeniella Petr. \& Syd. 1927, Ascomycota genera incertae sedis, 13 species, type: L. guaranitica (Speg.) Petr. \& Syd., coelomycetous, sexual morph unknown, saprobes, terrestrial, worldwide, see Wijayawardene et al. (2012, 2016, 2017; outline, taxonomy), Kirk et al. (2013; genus accepted), cultures and sequences are unavailable, needs generic revision.

Lasseria Dennis 1960, Helotiales genera incertae sedis, Leotiomycetes, one species, type: L. chrysophthalma Dennis, asexual morph unknown, saprobes, terrestrial, Argentina, see Lumbsch and Huhndorf (2010; outline), Kirk et al. (2013; genus accepted), living cultures and sequences are unavailable, needs generic revision.

Latericonis G.V. Rao, K.A. Reddy \& de Hoog 1984, Ascomycota genera incertae sedis, one species, type: L. obscura V. Rao, K.A. Reddy \& de Hoog, hyphomycetous, sexual morph unknown, saprobes, terrestrial, Asia, see Seifert et al. (2011; morphology), Wijayawardene et al. (2012, 2017; outline), Kirk et al. (2013; genus accepted), cultures and sequences are unavailable, needs generic revision.

Lateriramulosa Matsush. 1971, Ascomycota genera incertae sedis, five species, type: L. uniinflata Matsush., hyphomycetous, sexual morph unknown, saprobes, terrestrial, worldwide, see Seifert et al. (2011; morphology), Wijayawardene et al. (2012, 2017; outline), Kirk et al. (2013; genus accepted), cultures and sequences are unavailable, needs generic revision.

Laterispora Uecker, W.A. Ayers \& P.B. Adams 1982, Ascomycota genera incertae sedis, one species, type: L. brevirama Uecker, W.A. Ayers \& P.B. Adams, hyphomycetous, sexual morph unknown, saprobes, terrestrial, USA, see Seifert et al. (2011; morphology), Wijayawardene et al. (2012, 2017; outline), Kirk et al. (2013; genus accepted), cultures and sequences are unavailable, needs generic revision.

Lathagrium (Ach.) Gray 1821, Collemataceae, Peltigerales, Lecanoromycetes, ten species, type: ?L. nigrescens (Huds.) Gray, lichenized, North America, Europe, Russia,?, see Otálora et al. (2013, 2014; phylogeny, review), Lücking et al. (2016b; classification), Cultures and sequences are available, holotype of type species?. 
Lathraeodiscus Dissing \& Sivertsen 1989, Pyronemataceae, Pezizales, Pezizomycetes, one species, type: L. arcticus Dissing \& Sivertsen, on soil with mosses with Octospora, Lamprospora, Geopora, high arctic, see Lumbsch and Huhndorf (2010; outline), Kirk et al. (2013; genus accepted), cultures and sequences are unavailable, holotype of type species C, isotype TRH.

Latorua Crous 2015, Latoruaceae, Pleosporales, Dothideomycetes, one species, type: L. caligans (Bat. \& H.P. Upadhyay) Crous, hyphomycetous, saprobes, Brazil, see Crous et al. (2015a; taxonomy, phylogeny), Wijayawardene et al. (2017; outline, phylogeny), holotype and ex-type culture of the type: CBS H-22267, CBS 576.65.

Lauderlindsaya J.C. David \& D. Hawksw. 1989, Verrucariaceae, Verrucariales, Eurotiomycetes, three species, type: L. borrerei (Tul.) J.C. David \& D. Hawksw., some species lichenicolous, some species lichenized, Europe, Japan, Papua New Guinea, see Lumbsch and Huhndorf (2010; outline), Muggia et al. (2010; phylogeny), Kirk et al. (2013; genus accepted), Jaklitsch et al. (2016a; classification), cultures and sequences are unavailable, lectotype of type species K-Borrer.

Lauriomyces R.F. Castañeda 1990, Leotiomycetes, genera incertae sedis, five species, type: L. pulcher R.F. Castañeda \& W.B. Kendr., hyphomycetous, sexual morph unknown, saprobes, terrestrial, North America, see Crous et al. (2009a; DNA, phylogeny), Seifert et al. (2011; morphology), Kirk et al. (2013; genus accepted), Liu et al. (2015a; new species, Thailand, accepted as Ascomycota incertae sedis), Wijayawardene et al. (2017; outline), cultures and sequences are unavailable, needs generic revision.

Lautitia S. Schatz 1984, Phaeosphaeriaceae, Pleosporales, Dothideomycetes, one species, type: Lautitia danica (Berl.) S. Schatz, asexual morph unknown, parasites, marine, Denmark, France, UK, USA, see Jones et al. (2009b; review), cultures and sequences are unavailable, holotype and ex-type unavailable.

Lautospora K.D. Hyde \& E.B.G. Jones 1989, Lautosporaceae, Diaporthales, Sordariomycetes, two species, type: L. gigantea K.D. Hyde \& E.B.G. Jones, asexual morph unknown, saprobes, marine, Australia, USA, see Lumbsch and Huhndorf (2010; outline), Kirk et al. (2013; genus accepted), Maharachchikumbura et al. (2015, 2016; outline), Jones et al. (2015; outline, phylogeny), cultures and sequences are unavailable, holotype of the type species IMI 327273.

Lawalreea Diederich 1990, Ascomycota genera incertae sedis, one species, type: L. lecanorae Diederich, coelomycetous, sexual morph unknown, saprobes, terrestrial, USA, see Wijayawardene et al. (2012, 2017; outline), Kirk et al. (2013; genus accepted), cultures and sequences are unavailable, holotype of type: LG (66/14656), needs generic revision.

Lazarenkoa Zerova 1938, Incertae sedis, Incertae sedis, Dothideomycetes, three species, type: L. selaginellae Zerova, asexual morph unknown, saprobes, terrestrial, Siberia, see Lumbsch and Huhndorf (2010; outline), Kirk et al. (2013; genus accepted), Wijayawardene et al. (2014c; outline), cultures and sequences are unavailable, needs generic revision.

Lazarenkoella S.Y. Kondr., Kärnefelt, A.Thell, Elix \& Hur 2015, Teloschistaceae, Teloschistales, Lecanoromycetes, one species, type: L. zoroasteriorum S.Y. Kondr. \& M. Haji Moniri ex S.Y. Kondr., Kärnefelt, A. Thell, Elix, J. Kim, A.S. Kondr. \& Hur, lichenized, Iran, Uzbekistan, see Kondratyuk et al. (2015c; phylogeny), Lücking et al. (2016b; classification), cultures and sequences are available, holotype of type species KW-L.

Lazuardia Rifai 1988, Pezizales genera incertae sedis, Pezizomycetes, one species, type: L. lobata (Berk. \& M.A. Curtis) Rifai, asexual morph unknown, hypogeous, terrestrial, pantropical, see Lumbsch and Huhndorf (2010; outline), Kirk et al. (2013; genus accepted), cultures and sequences are available, cultures available for type: AAU 43756.

Lecanactis Körb. [nom. cons.] 1855, Roccellaceae, Arthoniales, Arthoniomycetes, 25 species, type: L. abietina (Ehrh. ex Ach.) Körb., lichenized, worldwide, see Ertz et al. (2015b, c; 
phylogeny), Lücking et al. (2016b; classification), sequences are available, holotype of type species unavailable.

Lecania A.Massal. 1853, Ramalinaceae, Lecanorales, Lecanoromycetes, 50 species, type: L. fuscella (Schaer.) A. Massal., lichenized, worldwide, see Lumbsch and Huhndorf (2010; outline), Kirk et al. (2013; genus accepted), Lücking et al. (2016b; classification), van den Boom (2016; new species), cultures and sequences are available.

Lecanicillium W. Gams \& Zare 2001, Cordycipitaceae, Hypocreales, Sordariomycetes, 26 species, type: L. lecanii (Zimm.) Zare \& W. Gams, hyphomycetous, entomogenous, fungicolous and in soil, see Goettal et al. (2008; disease management), Zare and gams (2008; phylogeny), Vandermeer et al. (2009; hyperparasitism), Kouvelis et al. (2008; phylogeny), Seifert et al. (2011; morphology), Wijayawardene et al. (2012, 2017; outline), cultures and sequences are available, neotype and ex-neotype of type: IMI 331550, CBS 102067.

Lecanidiella Sherwood 1986, Patellariaceae, Patellariales, Dothideomycetes, one species, type: L. contortae Sherwood, asexual morph unknown, saprobes, terrestrial, USA, see Lumbsch and Huhndorf (2010; outline), Hyde et al. (2013; accepted as a genus in Patellariaceae), Kirk et al. (2013; genus accepted), Wijayawardene et al. (2014c; outline), Yacharoen et al. (2015; accepted as a genus in Patellariaceae), holotype of the type: CBS, Aptroot 38022, cultures and sequences are unavailable, needs generic revision.

Lecaniocola Brain 1923, Ascomycota genera incertae sedis, one species, type: L. parasitica (Linder) Brain, coelomycetous, sexual morph unknown, saprobes, terrestrial, USA, see Wijayawardene et al. (2012, 2017; outline), Kirk et al. (2013; genus accepted), cultures and sequences are unavailable, holotype of type species unavailable, needs generic revision.

Lecanographa Egea \& Torrente 1994, Lecanographaceae, Arthoniales, Arthoniomycetes, 37 species, type: L. lyncea (Sm.) Egea \& Torrente, sexual morph with rounded to lirelliform ascomata, lichenized, rarely lichenicolous, terrestrial, rather world-wide with a preference for coastal habitats with a Mediterranean or Desert type climate, see Ertz and Tehler (2011; phylogeny), Lumbsch and Huhndorf (2010; outline), Kirk et al. (2013; genus accepted), Lücking et al. (2016b; classification), sequences are available.

Lecanora Ach. 1809, Lecanoraceae, Lecanorales, Lecanoromycetes, 550 species, type: L. allophana Nyl., lichenized, worldwide, see Brand (2008; new species), Laundon (2010; new species), Lumbsch and Huhndorf (2010; outline), Pérez-Ortega et al. (2010; phylogeny), Ranković et al. (2011; Antioxidant, antimicrobial and anticancer activity), Kirk et al. (2013; genus accepted), Lücking et al. (2016b; classification), cultures and sequences are available.

Lecanosticta Syd. 1922 (= Eruptio M.E. Barr 1996 fide Wijayawardene et al. 2014c; Rossman et al. 2015b), Mycosphaerellaceae, Capnodiales, Dothideomycetes, seven species, type: L. pini Syd., coelomycetous, sexual morph formerly named in Eruptio, pathogens, see Quaedvlieg et al. (2012; morphology, phylogeny), Wijayawardene et al. (2014c, 2016; taxonomy, phyloeny), cultures and sequences are available, epitype and ex-epitype of type: CBS H-21113, CBS 133791.

Lecanostictopsis B. Sutton \& Crous 1997, Ascomycota genera incertae sedis, four species, type: L. kamatii (Ullasa) B. Sutton \& Crous, coelomycetous, sexual morph unknown, saprobes, terrestrial, France, India, South Africa, see Wijayawardene et al. (2012, 2016; outline, morphology), cultures and sequences are unavailable, holotype of the type: IMI 147817.

Lecidea Ach. 1803, Lecideaceae, Lecideales, Lecanoromycetes, 100 species, type: L. fuscoatra (L.) Ach., lichenized, worldwide, see Lumbsch and Huhndorf (2010; outline), Schmull et al. (2011; phylogeny), Kirk et al. (2013; genus accepted), Lücking et al. (2016b; classification), cultures and sequences are available.

Lecidella Körb. 1855, Lecanoraceae, Lecanorales, Lecanoromycetes, 80 species, type: Lecidella viridans (Flot.) Körb., lichenized, worldwide, see Lumbsch and Huhndorf (2010; 
outline), Kantvilas and Elix (2013; review), Kirk et al. (2013; genus accepted), Lücking et al. (2016b; classification), cultures and sequences are available, holotype of type species unavailable.

Lecideopsella Höhn. 1909, Schizothyriaceae, Dothideomycetes, families incertae sedis, c. eleven species, type: L. gelatinosa Höhn., asexual morph unknown, saprobes, terrestrial, South America, see Lumbsch and Huhndorf (2010; outline), Hyde et al. (2013; accepted as a genus in Schizothyriaceae), Kirk et al. (2013; genus accepted), Wijayawardene et al. (2014c; outline), Phookamsak et al. (2016; new species, taxonomy), cultures and sequences are unavailable.

Lecidoma Gotth. Schneid. \& Hertel 1981, Lecideaceae, Lecideales, Lecanoromycetes, one species, type: L. demissum (Rutstr.) Gotth. Schneid. \& Hertel, lichenized, clearings of alpine grasslands and in places with prolonged snow cover, see Lumbsch and Huhndorf (2010; outline), Schmull et al. (2011; phylogeny), Kirk et al. (2013; genus accepted), Lücking et al. (2016b; classification), cultures and sequences are available.

Lecidopyrenopsis Vain. 1907, Lichinaceae, Lichinales, Lichinomycetes, one species, type: L. corticola Vain., lichenized, Thailand, see Lumbsch and Huhndorf (2010; outline), Kirk et al. (2013; genus accepted), Lücking et al. (2016b; classification), cultures and sequences are unavailable.

Leciophysma Th. Fr. 1865, Pannariaceae, Peltigerales, Lecanoromycetes, three species, type: L. finmarkicum Th. Fr., asexual morph unknown, lichenized, terrestrial, Siberia, see Wedin et al. (2009b; DNA), Lumbsch and Huhndorf (2010; outline), Øvstedal and Lewis Smith (2011; new species, Antarctica), Kirk et al. (2013; genus accepted), Ekman et al. (2014; new species), cultures and sequences are available.

Lecophagus M.W. Dick 1999, Ascomycota genera incertae sedis, two species, type: $L$. fasciculatus M.W. Dick, hyphomycetous, sexual morph unknown, saprobes, terrestrial, Australasia, North America, see Seifert et al. (2011; morphology), Wijayawardene et al. (2012, 2017; outline), Kirk et al. (2013; genus accepted), cultures and sequences are available, needs generic revision.

Lectera P.F. Cannon 2012, Plectosphaerellaceae, Glomerellales, Sordariomycetes, two species, type: L. colletotrichoides (J.E. Chilton) P.F. Cannon, coelomycetous, sexual morph unknown, pathogens, terrestrial, worldwide, see Cannon et al. (2012; taxonomy, phylogeny), Wijayawardene et al. (2012, 2017; outline), Maharachchikumbura et al. (2015, 2016; outline, phylogeny), cultures and sequences are available, lectotype and cultures of the type species ISC 217496, CBS 109728

Lecythiomyces Doweld 2013, Sordariomycetes genera incertae sedis, three species, type: L. aeruginea (Zukal) Doweld, asexual morph unknown, saprobes, terrestrial, Austria, see Maharachchikumbura et al. (2015, 2016; outline), cultures and sequences are unavailable, needs generic revision.

Lecythothecium Réblová \& Winka 2001, Chaetosphaeriaceae, Chaetosphaeriales, Sordariomycetes, four species, type: L. duriligni Réblová \& Winka, asexual morph hyphomycetous (sporidesmium-like), terrestrial, saprobes, worldwide, see Lumbsch and Huhndorf (2010; outline), Maharachchikumbura et al. (2015, 2016; outline), cultures and sequences are available, holotype and ex-type of the type: PRM 842977, CBS 101317.

Leeina Petr. 1923, Ascomycota genera incertae sedis, one species, type: L. philippinensis Petr., coelomycetous, sexual morph unknown, saprobes, terrestrial, Philippines, see Wijayawardene et al. (2012, 2017; outline), Kirk et al. (2013; genus accepted), cultures and sequences are unavailable, needs generic revision.

Leifidium Wedin 1993, Sphaerophoraceae, Lecanorales, Lecanoromycetes, one species, type: L. tenerum (Laurer) Wedin, asexual morph unknown, lichenized, terrestrial, Australia, 
South America, see Lumbsch and Huhndorf (2010; outline), Kirk et al. (2013; genus accepted), Lücking et al. (2016b; classification), cultures and sequences are available.

Leightoniella Henssen 1965, Pannariaceae, Peltigerales, Lecanoromycetes, one species, type: L. zeylanensis (Leight.) Henssen, lichenized, Europe, see Lumbsch and Huhndorf (2010; outline), Kirk et al. (2013; genus accepted), Weerakoon et al. (2016, phylogeny), Lücking et al. (2016b; classification), cultures and sequences are available, holotype of type species unavailable.

Leightoniomyces D. Hawksw. \& B. Sutton 1977, Ascomycota genera incertae sedis, two species, type: L. phillipsii (Berk. \& Leight.) D. Hawksw. \& B. Sutton, hyphomycetous, sexual morph unknown, lichenicolous, terrestrial, Europe, North America, see Seifert et al. (2011; genus accepted), Wijayawardene et al. (2012, 2017; outline), Pérez-Vargas et al. (2013; morphology, new species), cultures and sequences are unavailable, holotype of the type: TFC Lich 12742.

Leimonis R.C. Harris 2009, Pilocarpaceae, Lecanorales, Lecanoromycetes, one species, type: L. erratica (Körb.) R.C. Harris \& Lendemer, asexual morph unknown, lichenized, terrestrial, North America, see Harris (2009; taxonomy), Lumbsch and Huhndorf (2010; outline), Lücking et al. (2016b; classification), cultures and sequences are available, holotype of type species unavailable.

Leioderma Nyl. 1888, Pannariaceae, Peltigerales, Lecanoromycetes, one species, type: L. pycnophorum Nyl., asexual morph unknown, lichenized, terrestrial, worldwide, see Lumbsch and Huhndorf (2010; outline), Kirk et al. (2013; genus accepted), Ekman et al. (2014; DNA, phylogeny), Lücking et al. (2016b; classification), sequences and cultures are available.

Leiorreuma Eschw. 1824, Graphidaceae, Ostropales, Lecanoromycetes, 15 species, type: L. hepaticum Eschw., asexual morph unknown, lichenized, terrestrial, North America, see Lendemer and Knudsen (2008; new species), Moon et al. (2008; new species), Dubey et al. (2010; new species), Joshi et al. (2013a; Taiwan), Kirk et al. (2013; genus accepted), McDonald et al. (2013; DNA), Lücking et al. (2014, 2016; taxonomy), Poengsungnoen et al. (2014; new species), Wang et al. (2015c; China), sequences and cultures are available.

Leiosphaerella Höhn. 1919, Xylariales genera incertae sedis, Sordariomycetes, nine species, type: L. praeclara (Rehm) Höhn., asexual morph unknown, saprobes, terrestrial, worldwide, see Lumbsch and Huhndorf (2010; outline), Jaklitsch and Voglmayr (2012; taxonomy, phylogeny), Maharachchikumbura et al. (2015, 2016; outline), cultures and sequences are available, isotype of the type: W11860, epitype and ex-epitype of the type species WU 31314, CBS 125586.

Leiothecium Samson \& Mouch. 1975, Aspergillaceae, Eurotiales, Eurotiomycetes, two species, type: L. ellipsoideum Samson \& Mouch., saprobes, asexual morph unknown, saprobes, terrestrial, South America, see Lumbsch and Huhndorf (2010; outline), Houbraken and Samson (2011; DNA), Kirk et al. (2013; genus accepted), Marin-Felix et al. (2014; new species, phylogeny), cultures and sequences are available.

Lemalis Fr. 1825, Helotiales genera incertae sedis, Leotimycetes, three species, type: L. alismatis (Pers.) Fr., asexual morph unknown, saprobes, terrestrial, worldwide, see Lumbsch and Huhndorf (2010; outline), cultures and sequences are unavailable, holotype of type species unavailable, needs generic revision.

Lembosia Lév. 1845, Asterinaceae, Asterinales, Dothideomycetes, 257 species, type: L. tenella Lév., asexual morph unknown, epiphytes, biotrophic, terrestrial, worldwide, see Hofmann (2009; review), Lumbsch and Huhndorf (2010; outline), Hyde et al. (2013; accepted as a genus in Asterinaceae), Hongsanan et al. (2014c; taxonomy, DNA, keys), Wijayawardene et al. (2014c; outline), Guatimosim et al. (2015; phylogeny, DNA), most species do not have molecular data, needs generic revision. 
Lembosiella Sacc. 1891, Aulographaceae, Dothideomycetes families incertae sedis, one species, type: L. polyspora (Pat.) Sacc., asexual morph unknown, saprobes, terrestrial, Africa, see Lumbsch and Huhndorf (2010; outline, accepted as a genus in Microthyriaceae), Hyde et al. (2013; accepted as a genus in Aulographaceae), Kirk et al. (2013; genus accepted), Hongsanan et al. (2014; accepted as a genus in Aulographaceae), Wijayawardene et al. (2014c; outline), cultures and sequences are unavailable.

Lembosina Theiss. 1913, Aulographaceae, Dothideomycetes, families incertae sedis, 21 species, type: L. aulographoides (E. Bommer, M. Rousseau \& Sacc.) Theiss., asexual morph unknown, saprobes, terrestrial, worldwide, see Lumbsch and Huhndorf (2010; outline, accepted as a genus in Asterinaceae), Hyde et al. (2013; accepted as a genus in Aulographaceae), Kirk et al. (2013; genus accepted), Hongsanan et al. (2014c; accepted as a genus in Aulographaceae), Wijayawardene et al. (2014c; outline), cultures and sequences are unavailable.

Lembosiopeltis Bat. \& J.L. Bezerra 1967, Dothideomycetes genera incertae sedis, two species, type: L. nectandrae Bat. \& J.L. Bezerra, asexual morph unknown, saprobes, terrestrial, Brazil, see Lumbsch and Huhndorf (2010; outline), Kirk et al. (2013; did not list), Wijayawardene et al. (2014c; outline), sequences are unavailable, needs generic revision.

Lembosiopsis Theiss. 1918, Mycosphaerellaceae, Capnodiales, Dothideomycetes, one species, type: L. andromedae (Tracy \& Earle) Theiss., asexual morph unknown, saprobes, terrestrial, North America, see Lumbsch and Huhndorf (2010; outline, accepted as a genus in Asterinaceae), Hyde et al. (2013; accepted as a genus in Aulographaceae), Kirk et al. (2013; genus accepted), Hongsanan et al. (2014c; transferred to Mycosphaerellaceae from Asterinaceae), Wijayawardene et al. (2014c; outline), cultures and sequences are unavailable.

Lembuncula Cif. 1954, Ascomycota genera incertae sedis, one species, type: L. pothoidei Cif., coelomycetous, sexual morph unknown, saprobes, terrestrial, Santo Domingo, see Wijayawardene et al. (2012, 2017; outline), Kirk et al. (2013; genus accepted), cultures and sequences are unavailable, needs generic revision.

Lemkea Morgan-Jones \& R.C. Sinclair 1983, Ascomycota genera incertae sedis, one species, type: L. sphaerospora Morgan-Jones \& R.C. Sinclair, hyphomycetous, sexual morph unknown, saprobes, lignicolous, North America, South Africa, Spain, Seifert et al. (2011; morphology), Wijayawardene et al. (2012, 2017; outline), Kirk et al. (2013; genus accepted), cultures and sequences are unavailable, needs generic revision.

Lemmopsis (Vain.) Zahlbr. 1906, Lichinaceae, Lichinales, Lichinomycetes, three species, type: L. arnoldiana (Hepp) Zahlbr., asexual morph unknown, lichenized, terrestrial, Europe, see van den Boom and Brand (2008; Netherlands), Lumbsch and Huhndorf (2010; outline), Motiejūnaitè (2012; Lithuania), Kirk et al. (2013; genus accepted), Lücking et al. (2016b; classification), cultures and sequences are unavailable, needs generic revision.

Lemonniera De Wild. 1894, Helotiales genera incertae sedis, Leotiomycetes, seven species, type: L. aquatica De Wild., hyphomycetous, sexual morph unknown, saprobes, aquatic, cosmopolitan, see Seifert et al. (2011; morphology), Wijayawardene et al. (2012, 2017; outline), Kirk et al. (2013; genus accepted), cultures and sequences are available, needs generic revision.

Lempholemma Körb. 1855, Lichinaceae, Lichinales, Lichinomycetes, 35 species, type: L. compactum (Wallr.) Körb., asexual morph unknown, lichenized, terrestrial, worldwide, see Lumbsch and Huhndorf (2010; outline), Prieto et al. (2012; DNA, phylogeny), Kirk et al. (2013; genus accepted), Lücking et al. (2016b; classification), cultures and sequences are available but lack for the type species.

Lentithecium K.D. Hyde, J. Fourn. \& Ying Zhang 2009, Lentitheciaceae, Pleosporales, Dothideomycetes, ten species, type: L. fluviatile (Aptroot \& Van Ryck.) K.D. Hyde, asexual morph coelomycetous, saprobes, aquatic (freshwater or marine), Europe, Japan, Africa, See, 
Zhang et al (2009; taxonomy, phylogeny), Hyde et al. (2013, 2016; taxonomy, phylogeny), Wijayawardene et al. (2014c, 2017; outline), Tibpromma et al. (2017b; taxonomy, phylogeny), cultures and sequence are available, holotype of type species GENT (509).

Lentomitella Höhn. 1906, Sordariomycetidae, genera incertae sedis, seven species, type: L. vestita (Sacc.) Höhn., saprobes, terrestrial, temperate, see Huhndorf et al. (2008; new species, DNA, phylogeny), Marincowitz et al. (2008; new species, South Africa), Raja and Shearer (2009; compare with Hanliniomyces), Réblová and Štěpánek (2009; phylogeny), Lumbsch and Huhndorf (2010; outline), Réblová et al. (2014; phylogeny), Maharachchikumbura et al. (2015, 2016; outline), sequence data and cultures available but lacks for the type species.

Leohumicola N.L. Nick. 2005, Leotiomycetes genera incertae sedis, seven species, type: L. verrucosa N.L. Nick., Hambl. \& Seifert, saprobes, from soil, terrestrial, worldwide, see Nguyen and Seifert (2008; new species, phylogeny), Chen et al. (2009; new records to China), Wijayawardene et al. (2012, 2017; outline), Takashima et al. (2014; symbiotic associations with Lycopodiaceae roots), holotype and ex-type culture of the type: DAOM 226889, DAOM226889.

Leotia Pers. 1797, Leotiaceae, Helotiales, Leotiomycetes, four species, type: L. lubrica (Scop.) Pers., asexual morph unknown, lichenized, terrestrial, worldwide, see Palmer et al. (2008; DNA), Lumbsch and Huhndorf (2010; outline), Kirk et al. (2013; genus accepted), cultures and sequences are available, type specimen of type species CBS H-13841.

Lepidocollema Vain. 1890, Pannariaceae, Peltigerales, Lecanoromycetes, two species, type: L. carassense Vain., lichenized, Brazil, Solomon Islands, see Lumbsch and Huhndorf (2010; outline), Ekman et al. (2014; new species), Lücking et al. (2016b; classification), cultures and sequences are available, holotype of type species unavailable.

Lepidopterella Shearer \& J.L. Crane 1980, Argynnaceae, Dothideomycetes families incertae sedis, two species, type: L. palustris Shearer \& J.L. Crane, asexual morph unknown, saprobes, aquatic, USA, see Shearer et al. (2009; taxonomy, phylogeny), Lumbsch and Huhndorf (2010; outline), Hyde et al. (2013; accepted as a genus in Argynnaceae), Kirk et al. (2013; genus accepted), Wijayawardene et al. (2014c; outline), Peter et al. (2016; DNA, comparison), cultures available for the type species CBS 459.81.

Lepidosphaeria Parg.-Leduc 1970, Testudinaceae, Pleosporales, Dothideomycetes, two species, type: L. nicotiae Parg.-Leduc, asexual morph unknown, saprobes, aquatic, USA, see Kruys and Wedin (2009; DNA), Schoch et al. (2009; phylogeny), Lumbsch and Huhndorf (2010; outline), Hyde et al. (2013; accepted as a genus in Testudinaceae), Kirk et al. (2013; genus accepted), Wijayawardene et al. (2014c; outline), cultures and sequences are available, type specimen and cultures available for type species CBS H-7282, CBS 559.71 (fide Kruys and Wedin 2009).

Lepidotia Boud. 1885, Pezizaceae, Pezizales, Pezizomycetes, one species, type: L. hispida (Quél.) Boud., asexual morph unknown, saprobes, see Lumbsch and hunduf (2010; outline), Kirk et al. (2013; did not list the genus), Jaklitsch et al. (2016a; classification), cultures and sequences are unavailable.

Lepisticola W. Gams 2009, Ascomycota genera incertae sedis, one species, type: L. capitata (Costantin \& Matr.) W. Gams, hyphomycetous, sexual morph unknown, saprobes, terrestrial, North America, Europe, see Gams et al. (2009; taxonomy), Seifert et al. (2011; morphology), Wijayawardene et al. (2012, 2017; outline), cultures and sequences are unavailable, holotype of type species unavailable, needs generic revision.

Leprantha Dufour ex Körb. 1855, Arthoniaceae, Arthoniales, Arthoniomycetes, one species, type: need typification, lichenized, see Lücking et al. (2016b; classification), sequences are unavailable.

Lepraria Ach. 1803, Stereocaulaceae, Lecanorales, Lecanoromycetes, 74 species, type: L. incana (L.) Ach., sterile, terrestrial (various substrata), cosmopolitan, see Nelsen et al. (2008; 
phylogeny), Lendemer (2010a, 2011, 2012, 2013; new species, DNA, phylogeny), Lumbsch and Huhndorf (2010; outline), Flakus and Kukwa (2011; new species), Flakus et al. (2011; new species), Bungartz et al. (2013b; new species), Elix (2013; new species), Lendemer and Hodkinson (2013; DNA, phylogeny), Miądlikowska et al. (2014, DNA), sequences are available.

Leprieuria Læssøe, J.D. Rogers \& Whalley 1989, Xylariaceae, Xylariales, Sordariomycetes, one species, type: L. bacillum (Mont.) Læssøe, J.D. Rogers \& Whalley, asexual morph geniculosporium-like, saprobes, Ecuador, see Lumbsch and Huhndorf (2010; outline), Kirk et al. (2013; genus accepted), Stadler et al. (2013), Daranagama et al. (2017 morphology, taxonomy, key), sequences are unavailable.

Leprieurinella Bat. \& H. Maia 1961, Ascomycota genera incertae sedis, one species, type: $L$. ingae Bat. \& H. Maia, coelomycetous, sexual morph unknown, saprobes, terrestrial, Brazil, see Wijayawardene et al. (2012, 2017; outline), Kirk et al. (2013; genus accepted), cultures and sequences are unavailable, needs generic revision.

Leprocaulon Nyl. 1879, Leprocaulaceae, Leprocaulales, Lecanoromycetes, 17 species, type: L. nanum Nyl., coelomycetous, lichenized, worldwide, see Wijayawardene et al. (2012, 2017; outline), Kirk et al. (2013; genus accepted), Lendemer and Hodkinson (2013; new species), Lücking et al. (2016b; classification), cultures and sequences are available, needs generic revision.

Leprocollema Vain. 1890, Lichinaceae, Lichinales, Lichinomycetes, three species, type: L. americanum Vain., lichenized, Europe, USA, see Lumbsch and Huhndorf (2010; outline), Kirk et al. (2013; genus accepted), Lücking et al. 2016 (classification), cultures and sequences are unavailable.

Leproplaca (Nyl.) Nyl. 1888, Teloschistaceae, Teloschistales, Lecanoromycetes, six species, type: L. xantholyta (Nyl.) Nyl., lichenized, Europe, see Arup et al. (2013; phylogeny), Lücking et al. (2016b; classification), cultures and sequences are available.

Leptascospora Speg. 1918, Ascomycota genera incertae sedis, one species, type: L. uredinis (Racib.) Speg., asexual morph unknown, saprobes, terrestrial, Java, see Lumbsch and Huhndorf (2010; outline, accepted as a genus in Meliolaceae), Kirk et al. (2013; genus accepted), Hongsanan et al. (2015c; excluded the genus from Meliolaceae), cultures and sequences are unavailable, holotype of type species unavailable.

Lepteutypa Petr. 1923, Amphisphaeriaceae, Xylariales, Sordariomycetes, c. 20 species, type: L. fuckelii (Nitschke) Petr., asexual morph unknown, saprobes, worldwide, see Lumbsch and Huhndorf (2010; outline), Kirk et al. (2013; genus accepted), Maharachchikumbura et al. (2015, 2016; outline), Jaklitsch et al. (2016b; new species, phylogeny), needs generic revision, cultures and sequences are unavailable.

Leptochidium M. Choisy 1952, Massalongiaceae, Peltigerales, Lecanoromycetes, two species, type: Leptochidium albociliatum (Desm.) M. Choisy, lichenized, Europe, North America, see Lücking et al. (2016b; classification), cultures and sequences are available.

Leptochlamys Died. 1921, Ascomycota genera incertae sedis, one species, type: L. scapicola (P. Karst.) Died., coelomycetous, sexual morph unknown, saprobes, terrestrial, Europe, see Wijayawardene et al. (2012, 2017; outline), Kirk et al. (2013; genus accepted), cultures and sequences are unavailable, needs generic revision.

Leptocucurthis Aptroot 1998, Dacampiaceae, Dothideomycetes families incertae sedis, one species, type: L. quadrata Aptroot, asexual morph unknown, saprobes, terrestrial, tropical, see Lumbsch and Huhndorf (2010; outline), Hyde et al. (2013; accepted in Dacampiaceae), Kirk et al. (2013; genus accepted), Wijayawardene et al. (2014c; outline), cultures and sequences are unavailable, holotype of the type species CBS, Aptroot 37234.

Leptodermella Höhn. 1915, Ascomycota genera incertae sedis, one species, type: L. incarnata (Bres.) Höhn., coelomycetous, sexual morph unknown, saprobes, terrestrial, 
Europe, see Wijayawardene et al. (2012, 2017; outline), Kirk et al. (2013; genus accepted), cultures and sequences are unavailable, needs generic revision.

Leptodiscella Papendorf 1969, Ascomycota genera incertae sedis, three species, type: L. africana (Papendorf) Papendorf, hyphomycetous, sexual morph unknown, saprobes, terrestrial, Japan, Spain, South Africa, see Madrid et al. (2011b; new species, DNA), Seifert et al. (2011; morphology), Wijayawardene et al. (2012, 2017; outline), Kirk et al. (2013; genus accepted), cultures and sequences are available, cultures for the type: CBS 400.65, type specimen of type species CBS H-720.

Leptodontidium de Hoog 1979, Helotiales genera incertae sedis, Leotiomycetes, eleven species, type: L. elatius (F. Mangenot) de Hoog, sexual morph unknown, saprobes, terrestrial, Europe, North America, Africa, see Seifert et al. (2011; morphology), Wijayawardene et al. (2012, 2017; outline), Kirk et al. (2013; genus accepted), cultures and sequences are available, holotype and cultures for the type species CBS H-7283, CBS 329.53 (Sogonov et al. 2005).

Leptogidium Nyl. 1873, Pannariaceae, Peltigerales, Lecanoromycetes, three species, type: $L$. dendriscum (Nyl.) Nyl., lichenized, Europe, North America, see Muggia et al. (2011b; phylogeny), Lücking et al. (2016b; classification), cultures and sequences are available.

Leptogium (Ach.) Gray 1821, Collemataceae, Peltigerales, Lecanoromycetes, 70 species, type: L. lacerum (Sw.) Gray, lichenized, North America, Europe, see Lumbsch and Huhndorf (2010; outline), Kirk et al. (2013; genus accepted), Schultz et al. (2015; phylogeny), Lücking et al. (2016b; classification), cultures and sequences are available, holotype of type species unavailable.

Leptographium Lagerb. \& Melin 1927, Ophiostomataceae, Ophiostomatales, Sordariomycetes, 68 species, type: L. lundbergii Lagerb. \& Melin, asexual morph unknown, hyphomycetous, saprobes, worldwide, see Zhou et al. (2008; new species), Seifert et al. (2011; morphology), Duong et al. (2012; new species), Wijayawardene et al. (2012, 2017; outline), Paciura et al. (2010a; new species), Beer et al. (2013; new species), Kirk et al. (2013; genus accepted), Huang and Chen (2014; new species), Romón et al. (2014; new species), Maharachchikumbura et al. (2015, 2016; outline), Yin et al. (2015; new species), cultures and sequences are available.

Leptoguignardia E. Müll. 1955, Phyllostictaceae, Botryosphaeriales, Dothideomycetes, three species, type: L. onobrychidis E. Müll., asexual morph unknown, saprobes, terrestrial, North temperate, see Lumbsch and Huhndorf (2010; outline, accepted as a genus in Botryosphaeriaceae), Kirk et al. (2013; genus accepted), Wijayawardene et al. (2014c, 2017; outline, accepted as a genus in Phyllostictaceae), cultures and sequences are unavailable, type specimen of type species CBS H-13858, needs generic revision.

Leptokalpion Brumm. 1977, Thelebolaceae, Thelebolales, Leotiomycetes, two species, type: L. albicans Brumm., asexual morph unknown, saprobes, terrestrial, Asia, see Lumbsch and Huhndorf (2010; outline), Kirk et al. (2013; genus accepted), cultures and sequences are unavailable, needs generic revision.

Leptomassaria Petr. 1914, Xylariales genera incertae sedis, Sordariomycetes, one species, type: L. simplex (Nitschke ex G.H. Otth) Petr., asexual morph unknown, saprobes, Europe and Australia, see Lumbsch and Huhndorf (2010; outline), Kirk et al. (2013; genus accepted), Daranagama et al. (2017 morphology, taxonomy, key), Wendt et al. (2017; accepted as a genus in Xylariales genera incertae sedis), sequences are unavailable, placement in Xylariaceae needs to be confirmed by molecular data.

Leptomelanconium Petr. 1923, Teratosphaeriaceae, Capnodiales, Dothideomycetes, three species, type: L. asperulum (Moesz) Petr., coelomycetous, sexual morph teratosphaeria-like, saprobes, terrestrial, North temperate, see Crous et al. (2009f; transferred L. australiense to Teratosphaeria), Zhao and Zhao (2012; new species), Kirk et al. (2013; genus accepted), 
Wijayawardene et al. (2016b; outline, taxonomy, accepted as a genus in Teratosphaeriaceae), cultures and sequences are unavailable, needs generic revision.

Leptomeliola Höhn. 1919, Perisporiopsidaceae, Dothideomycetes family incertae sedis, nine species, type: L. hyalospora (Lév.) Höhn., asexual morph unknown, saprobes, terrestrial, tropical, see Lumbsch and Huhndorf (2010; outline), Stenroos et al. (2010; symbiosis with bryophytes, DNA), Silvério et al. (2011; taxonomy, South America), Hyde et al. (2013; accepted in Perisporiopsidaceae), Kirk et al. (2013; genus accepted), Wijayawardene et al. (2014c; outline), cultures and sequences are available but lacks for the type species.

Leptopeltis Höhn. 1917, Leptopeltidaceae, Dothideomycetes genera incertae sedis, one species, type: L. filicina (Lib.) Höhn., asexual morph leptothyrium-like, saprobes, terrestrial, north temperate, see Lumbsch and Huhndorf (2010; outline), Hyde et al. (2013; outline, accepted as a genus in Leptopeltidaceae), Kirk et al. (2013; genus accepted), Wijayawardene et al. (2014c; outline), cultures and sequences are unavailable, available specimen of type: CBS H-13860, needs generic revision.

Leptoperidia Rappaz 1987, Diatrypaceae, Xylariales, Sordariomycetes, two species, type: $L$. macropunctata (Rehm) Rappaz, asexual morph unknown, saprobes, terrestrial, worldwide, see Lumbsch and Huhndorf (2010; outline), Kirk et al. (2013; genus accepted), Maharachchikumbura et al. (2015, 2016; outline), cultures and sequences are unavailable, available specimen of type: CBS H-6460, needs generic revision.

Leptophyllosticta I.E. Brezhnev 1939, Ascomycota genera incertae sedis, two species, type: L. lychnitis I.E. Brezhnev, coelomycetous, sexual morph unknown, saprobes, terrestrial, former USSR, see Wijayawardene et al. (2012, 2017; outline), Kirk et al. (2013; genus accepted), cultures and sequences are unavailable, needs generic revision.

Leptorhaphis Körb. 1855, Naetrocymbaceae, Dothideomycetes genera incertae sedis, 15 species, type: L. oxyspora (Nyl.) Körb., asexual morph unknown, saprobes, terrestrial, worldwide, see Lumbsch and Huhndorf (2010; outline), Hyde et al. (2013; outline, accepted in Naetrocymbaceae), Kirk et al. (2013; genus accepted), Wijayawardene et al. (2014c; outline), cultures and sequences are unavailable, needs generic revision.

Leptosacca Syd. 1928, Sordariomycetes genera incertae sedis, two species, type: L. lumae Syd., asexual morph unknown, saprobes, terrestrial, Chile, see Lumbsch and Huhndorf (2010; outline), Kirk et al. (2013; genus accepted), Maharachchikumbura et al. (2015, 2016; outline), cultures and sequences are unavailable, holotype of type species (see MBT\# 199061), needs generic revision.

Leptosillia Höhn. 1928, Valsaceae, Diaporthales, Sordariomycetes, one species, type: L. notha Höhn., asexual morph unknown, saprobes, terrestrial, Europe, see Lumbsch and Huhndorf (2010; outline), Kirk et al. (2013; genus accepted), Maharachchikumbura et al. (2015, 2016; outline), cultures and sequences are unavailable, needs generic revision.

Leptosphaerella Speg. 1909, Sordariomycetes genera incertae sedis, seven species, type: L. fagaricola Speg., asexual morph unknown, saprobes, terrestrial, South America, see Lumbsch and Huhndorf (2010; outline), Kirk et al. (2013; genus accepted), Maharachchikumbura et al. (2015, 2016; outline), cultures and sequences are unavailable, needs generic revision.

Leptosphaeria Ces. \& De Not. 1863, Leptosphaeriaceae, Pleosporales, Dothideomycetes, 148 species, type: L. doliolum (Pers.) Ces. \& De Not., asexual morph coelomycetous, saprobes or parasitic, terrestrial, worldwide, see Lumbsch and Huhndorf (2010; outline), Zhang et al (2012; taxonomy, phylogeny), Hyde et al. (2013, 2016; taxonomy, phylogeny), Kirk et al. (2013; genus accepted), Wijayawardene et al. (2014c, 2017; outline), Ariyawansa et al. (2015b; taxonomy, phylogeny), cultures and sequence are available, available specimen for type: CBS H-13880.

Leptosphaerulina McAlpine 1902, Didymellaceae, Pleosporales, Dothideomycetes, 30 species, type: L. australis McAlpine, asexual morph hyphomycetous (pithomyces-like), 
saprobes, terrestrial, worldwide, see de Gruyter et al. (2009; DNA, phylogeny), Lumbsch and Huhndorf (2010; outline), Crous et al. (2011d; DNA, phylogeny, on Proteaceae), Zhang et al. (2012e; DNA, phylogeny), Hyde et al. (2013; accepted as a genus in Didymellaceae), Kirk et al. (2013; genus accepted), Phookamsak et al. (2013; new species with asexual morphs), Wijayawardene et al. (2014c; outline), Chen et al. (2015b; phylogeny), cultures and sequences are available, available specimen and cultures for type: CBS H-13980, CBS 311.51 .

Leptospora Rabenh. 1857, Dothideomycetes genera incertae sedis, 15 species, type: L. porphyrogona (Tode) Rabenh., asexual morph unknown, saprobes, terrestrial, Europe, North America, see Lumbsch and Huhndorf (2010; outline), Hyde et al. (2013; outline, accepted in Naetrocymbaceae), Kirk et al. (2013; genus accepted), Wijayawardene et al. (2014c; outline), Hyde et al. (2016; new species), cultures and sequences are available, holotype of type species unavailable, needs generic revision.

Leptosporella Penz. \& Sacc. 1897, Chaetosphaeriales genera incertae sedis, Sordariomycetes, twelve species, type: L. gregaria Penz. \& Sacc., asexual morph unknown, saprobes, terrestrial, widely distributed, see Lumbsch and Huhndorf (2010; outline), Huhndorf and Miller (2011; morphology, phylogeny), Kirk et al. (2013; genus accepted), Maharachchikumbura et al. (2015, 2016; outline), Dai et al. (2016; morphology, phylogeny, new species), cultures and sequences are available but lacks for type material, needs generic revision.

Leptostromella (Sacc.) Sacc. 1884, Ascomycota genera incertae sedis, two species, type: L. septorioides Sacc. \& Roum., coelomycetous, sexual morph unknown, saprobes, terrestrial, worldwide, see Wijayawardene et al. (2012, 2017; outline), Kirk et al. (2013; genus accepted), cultures and sequences are unavailable, needs generic revision.

Leptothyrella Sacc. 1885, Ascomycota genera incertae sedis, ten species, type: $L$. mougeotiana Sacc. \& Roum., coelomycetous, sexual morph unknown, saprobes, terrestrial, worldwide, see Wijayawardene et al. (2012, 2017; outline), Kirk et al. (2013; genus accepted), cultures and sequences are unavailable, holotype of type species unavailable, needs generic revision.

Leptothyrina Höhn. 1915, Ascomycota genera incertae sedis, one species, type: L. rubi (Duby) Höhn., coelomycetous, sexual morph unknown, saprobes, terrestrial, Switzerland, see Wijayawardene et al. (2012, 2017; outline), Kirk et al. (2013; genus accepted), cultures and sequences are unavailable, holotype of type species unavailable, needs generic revision.

Leptothyrium Kunze 1823, Ascomycota genera incertae sedis, two species, type: L. lunariae Kunze, coelomycetous, sexual morph unknown, saprobes, terrestrial, worldwide, see Wijayawardene et al. (2012, 2017; outline), Kirk et al. (2013; genus accepted), cultures and sequences are unavailable, needs generic revision.

Leptotrochila P. Karst. 1871 (= Sporonema Desm. 1874 fide Johnston et al. 2014b), Drepanopezizaceae, Helotiales, Leotiomycetes, 15 species, type: L. radians (Desm.) P. Karst., asexual morphs formerly named in Sporonema, saprobes, terrestrial, Europe, see Lumbsch and Huhndorf (2010; outline), Kirk et al. (2013; genus accepted), Johnston et al. (2014b; nomenclature), cultures and sequence are unavailable, needs generic revision.

Leptoxyphium Speg. 1918, Capnodiaceae, Capnodiales, Dothideomycetes, five species, type: L. graminum (Pat.) Speg., asexual morph unknown, sooty moulds, terrestrial, cosmopolitan, see Cheewangkoon et al. (2009; DNA, phylogeny), Chomnunti et al. (2011; taxonomy, new species), Crous et al. (2011a; new species), Wijayawardene et al. (2012, 2014c, 2017; outline), Kirk et al. (2013; genus accepted), Yang et al. (2014; DNA, new species), Kajale et al. (2015; associated with insects), Park et al. (2015; pathogens), cultures and sequences are available, needs generic revision. 
Letendraea Sacc. 1880, Didymosphaeriaceae, Pleosporales, Dothideomycetes, one species, type: L. eurotioides Sacc. asexual morph unknown, saprobes, terrestrial, Thailand, see Ariyawansa et al. (2014d; taxonomy, DNA, phylogeny), Hyde et al. (2013; accepted in Didymosphaeriaceae), Wijayawardene et al. (2014c; outline), Bolanos et al. (2015; phylogeny), cultures available for the type species CBS 212.31 (fide Kodsueb et al. 2016).

Letendraeopsis K.F. Rodrigues \& Samuels 1994, Dothideomycetes genera incertae sedis, , one species, type: L. palmarum K.F. Rodrigues \& Samuels, asexual morph unknown, saprobes, terrestrial, Brazil, see Lumbsch and Huhndorf (2010; outline, accepted as a genus in Tubeufiaceae), Hyde et al. (2013; not accepted in Tubeufiaceae), Kirk et al. (2013; genus accepted), Boonmee et al. (2014b; not listed in Tubeufiaceae),Wijayawardene et al. (2014c; outline), cultures and sequences are unavailable, needs generic revision.

Letharia (Th. Fr.) Zahlbr. 1892, Parmeliaceae, Lecanorales, Lecanoromycetes, three species, type: L. vulpina (L.) Hue, asexual morph unknown, lichenized, terrestrial, worldwide, see McCune and Altermann (2009; new species), Lumbsch and Huhndorf (2010; outline), Kirk et al. (2013; genus accepted), cultures and sequences are available, holotype of type species unavailable.

Lethariella (Motyka) Krog 1976, Parmeliaceae, Lecanorales, Lecanoromycetes, ten species, type: L. intricata (Moris) Krog, asexual morph unknown, lichenized, terrestrial, worldwide, see Lumbsch and Huhndorf (2010; outline), Kirk et al. (2013; genus accepted), Lücking et al. (2016b; classification), cultures and sequences are available.

Letrouitia Hafellner \& Bellem. 1982, Letrouitiaceae, Teloschistales, Lecanoromycetes, 16 species, type: L. domingensis (Pers.) Hafellner \& Bellem., asexual morph unknown, lichenized, terrestrial, worldwide, see Elix and Kondratyuk (2008; new species), Lumbsch and Huhndorf (2010; outline), Gays et al. (2012; DNA, phylogeny), Joshi et al. (2013b; Vietnam), Kirk et al. (2013; genus accepted), Shi et al. (2015; Cambodia), cultures available for type species AFTOL-ID 102.

Lettauia D. Hawksw. \& R. Sant. 1990, Fuscideaeaceae, Umbilicariales, Lecanoromycetes, three species, type: L. cladoniicola D. Hawksw. \& R. Sant., asexual morph unknown, on lichens, terrestrial, see Lumbsch and Huhndorf (2010; outline), Kirk et al. (2103; genus accepted), Jaklitsch et al. (2016a; classification), cultures and sequences not available, holotype of type species B 7700.

Leucangium Quél. 1883, Morchellaceae, Pezizales, Pezizomycetes, one species, type: L. ophthalmosporum Quél., asexual morph unknown, saprobes, hypogeous, worldwide, see Trappe (2009; North America), Lumbsch and Huhndorf (2010; outline), Sbissi et al. (2010; phylogeny, comparison), Trappe et al. (2010; phylogeny), Kirk et al. (2013; genus accepted), cultures and sequences are available but lacks for the type species.

Leucoconiella Bat., H. Maia \& Peres 1960, Ascomycota genera incertae sedis, type species L. paraguayensis Bat., H. Maia \& Peres, asexual morph unknown, saprobes, terrestrial, Paraguay, see Lumbsch and Huhndorf (2010; outline), Kirk et al. (2013; genus accepted), cultures and sequences are unavailable, needs generic revision.

Leucoconis Theiss. \& Syd. 1918, Ascomycota genera incertae sedis, one species, type: L. erysiphina (Syd. \& P. Syd.) Theiss. \& Syd., asexual morph unknown, saprobes, terrestrial, India, see Lumbsch and Huhndorf (2010; outline), Kirk et al. (2013; genus accepted), cultures and sequences are unavailable, needs generic revision.

Leucodecton A. Massal. 1860, Graphidaceae, Ostropales, Lecanoromycetes, type: L. compunctum (Ach.) A. Massal., asexual morph unknown, lichenized, terrestrial, pantropical, see Mangold et al. (2009; key, Australia), Rivas Plata et al. (2010a; key), Sipman et al. (2012; key, Costa Rica), Joshi et al. (2010b; Korea, India), Lumbsch and Huhndorf (2010; outline), Lücking and Breuss (2012; new combination), Kirk et al. (2013; genus accepted), Lücking et 
al. (2016b; classification), cultures and sequences are available but lacks for the type species, needs generic revision.

Leucodermia Kalb 2015, Physciaceae, Caliciales, Lecanoromycetes, ten species, type: L. leucomelos (L.) Kalb, lichenized, see Mongkolsuk et al. (2015; phylogeny), Lücking et al. (2016b; classification), Cultures and sequences are available, holotype of type species GB, Arvidsson \& Arvidsson 4158 (as Heterodermia fertilis Moberg).

Leucodiaporthe Lar.N. Vassiljeva 2007, Diaporthaceae, Diaporthales, Sordariomycetes, four species, type: L. acerina M.E. Barr \& Lar.N. Vassiljeva, asexual morphs unknown, saprobes, terrestrial, North temperate zone, see Lumbsch and Huhndorf (2010; outline), Maharachchikumbura et al. (2015, 2016; outline), cultures and sequences are unavailable, holotype of type: VLA P-2941.

Leucodochium Syd. \& P. Syd. 1917, Ascomycota genera incertae sedis, type: L. pipturi Syd. \& P. Syd., coelomycetous, sexual morph unknown, saprobes, terrestrial, Philippines, see Seifert et al. (2011; morphology), Wijayawardene et al. (2012, 2017; outline), Kirk et al. (2013; genus accepted), cultures and sequences are unavailable, needs generic revision.

Leucoglossum S. Imai 1942, Geoglossaceae, Geoglossales, Geoglossomycetes, two species, type: L. durandii (Teng) S. Imai, asexual morph unknown, saprobes, terrestrial, Asia, see Lumbsch and Huhndorf (2010; outline, accepted as Leotiomycetes), Arauzo and Iglesias (2014; new species), Fedosova and Kovalenko (2015; DNA, phylogeny, Russia), cultures and sequences are available but lacks for the type species, needs generic revision.

Leuconeurospora Malloch \& Cain 1970, Pseudeurotiaceae, Leotiomycetes family incertae sedis, three species, type: L. pulcherrima (G. Winter) Malloch \& Cain, asexual morph unknown, saprobes, terrestrial, Europe, Asia, see Lumbsch and Huhndorf (2010; outline), Kirk et al. (2013; genus accepted), cultures and sequences are available, type specimen and cultures available for type species CBS H-14009, CBS 343.76.

Leucoscypha Boud. 1885, Pezizales genera incertae sedis, Pezizomycetes, two species, type: L. leucotricha (Alb. \& Schwein.) Boud., asexual morph unknown, hypogeous, terrestrial, temperate, see Lumbsch and Huhndorf (2010; outline), Kirk et al. (2013; genus accepted), cultures and sequences are available, needs generic revision.

Leucosphaerina Arx 1987, Hypocreales genera incertae sedis, Hypocreales, Sordariomycetes, two species, type: L. indica (Arx, Mukerji \& N. Singh) Arx, asexual morph hyphomycetous, terrestrial, saprobes, see Lumbsch and Huhndorf (2010; outline, accepted as a genus in Bionectriaceae), Giraldo et al. (2012; phylogeny), cultures and sequences are available, cultures available for type: CBS 123.78 .

Leucothecium Arx \& Samson 1973, Onygenaceae, Onygenales, Eurotiomycetes, three species, type: L. emdenii Arx \& Samson, asexual morph unknown, saprobes, on marine and river sediments, Spain, see Gueidan et al. (2008; DNA, phylogeny), Lumbsch and Huhndorf (2010; outline, accepted in Onygenaceae), Kirk et al. (2013; genus accepted), Giraldo et al. (2014a; DNA, phylogeny), cultures and sequences are available, available specimen and cultures for the type: CBS H-7299 CBS 576.73.

Leucovibrissea (A. Sánchez) Korf 1990, Vibrisseaceae, Helotiales, Leotiomycetes, one species, type: L. obconica (Kanouse) Korf, asexual morph unknown, from fine roots of Pinus, terrestrial, USA, see Lumbsch and Huhndorf (2010; outline), Kirk et al. (2013; genus accepted), cultures and sequences are unavailable, needs generic revision.

Leuliisinea Matsush. 1985, [as 'Leuiisinea'], Ascomycota genera incertae sedis, two species, type: L. bambusicola Matsush., hyphomycetous, sexual morph unknown, saprobes, lignicolous, Australia, Peru and Taiwan, see Hyde et al. (2011; outline), Seifert et al. (2011; morphology), Wijayawardene et al. (2012, 2017; outline), Kirk et al. (2013; genus accepted), cultures and sequences are unavailable, needs generic revision. 
Leveillella Theiss. \& Syd. 1915, Dothideomycetes genera incertae sedis, one species, type: $L$. drimydis (Lév.) Theiss. \& Syd., asexual morph unknown, epiphytes, terrestrial, Chile, see Hofmann (2009; review, accepted in Asterinaceae), Lumbsch and Huhndorf (2010; outline, accepted in Asterinaceae), Hongsanan et al. (2014c; taxonomy, excluded from Asterinaceae), Wijayawardene et al. (2014c; outline, accepted in Dothideomycetes), Cultures and sequences are unavailable, type specimen of type species PC 0084470.

Leveillina Theiss. \& Syd. 1915, Dothideomycetes genera incertae sedis, two species, type: $L$. arduinae (Kalchbr. \& Cooke) Theiss. \& Syd., asexual morph unknown, saprobes, terrestrial, Africa, South America, see Lumbsch and Huhndorf (2010; outline), Kirk et al. (2013; genus accepted), Wijayawardene et al. (2014c; outline), cultures and sequences are unavailable, needs generic revision.

Leveillula G. Arnaud 1921, Erysiphaceae, Erysiphales, Leotiomycetes, 40 species, type: Leveillula taurica (Lév.) G. Arnaud (三Erysiphe taurica Lév.), hyphomycetous asexual morphs, obligate plant pathogens, terrestrial, worldwide, see Khodaparast et al. (2012, 2016; phylogeny), Braun \& Cook (2012; taxonomy), cultures and sequences are available, lectotype of type: Tauria, "Balaklava", ex herb. Léveillé (G 00298357).

Libartania Nag Raj 1979, Helotiales genera incertae sedis, Leotiomycetes, two species, type: Libartania laserpitii (Bres.) Nag Raj, coelomycetous, sexual morph unknown, saprobes, terrestrial, worldwide, see Wijayawardene et al. (2012, 2017; outline), Kirk et al. (2013; genus accepted), cultures and sequences are unavailable, needs generic revision, needs generic revision.

Liberomyces Pažoutová, M. Kolařík \& Kubátová 2012, Sordariomycetes genera incertae sedis, two species, type: L. saliciphilus Paoutová, M. Kolarík \& Kubátová, coelomycetous, sexual morph unknown, endophytes, terrestrial, Czech Republic, see Pažoutová et al. (2012; morphology, DNA), Wijayawardene et al. (2012, 2017; outline), Maharachchikumbura et al. (2016; outline, phylogeny), cultures and sequences are available, holotype and ex-type strain of the type species PRM 921954, CCF 4020.

Libertasomyces Crous \& Roets 2016, Pleosporales genera incertae sedis, Dothideomycetes, two species, type: L. myopori Crous \& Roets, coelomycetous, sexual morph unknown, saprobes, terrestrial, South Africa, New Zealand, see Crous et al. (2016a, b; new species, phylogeny), Wijayawardene et al. (2017; outline), holotype and ex-type culture of the type: CBS H-22617, CPC 27354.

Libertiella Speg. \& Roum. 1880, Ascomycota genera incertae sedis, six species, type: $L$. malmedyensis Speg. \& Roum., coelomycetous, sexual morph unknown, saprobes, terrestrial, Europe, see Motiejūnaite et al. (2011; record from Lithuania), Wijayawardene et al. (2012, 2017; outline), Kirk et al. (2013; genus accepted), current generic concept is uncertain, cultures and sequences are unavailable, needs generic revision.

Lichenobactridium Diederich \& Etayo 1995, Ascomycota genera incertae sedis, one species, type: L. pertusariae Diederich \& Etayo, hyphomycetous, sexual morph unknown, lichenicolous, non-lichenized, terrestrial, France, see Wijayawardene et al. (2012, 2017; outline), Kirk et al. (2013; genus accepted), cultures and sequences are unavailable, holotype of the type species LG, Diederich 9219.

Lichenobarya Etayo, Diederich \& Lawrey 2015, Hypocreaceae, Hypocreales, Sordariomycetes, one species, type: L. usneae (Etayo) Etayo, Diederich \& Lawrey, asexual morphs unknown, lichenicolous, terrestrial, Europe, see Lawrey et al. (2015; taxonomy, phylogeny), sequences are available.

Lichenochora Hafellner 1989, Phyllachoraceae, Phyllachorales, Sordariomycetes, five species, type: L. thallina (Cooke) Hafellner, asexual morph unknown, lichenicolous, terrestrial, worldwide, see Etayo and Navarro-Rosines (2008; new species), Zhurbenko (2008; new species, Italy), Halc et al. (2009a; new species), Lumbsch and Huhndorf (2010; 
outline), Etayo (2011; new species), Hafellner and Zimmermann (2012; new species), Etayo et al. (2013; new species), Kirk et al. (2013; genus accepted), Zhurbenko (2103; new species), Lender et al. (2016; new species), Maharachchikumbura et al. (2015, 2016; outline), cultures and sequences are unavailable, holotype of type: K.

Lichenoconium Petr. \& Syd. 1927, Lichenoconiaceae, Lichenoconiales, Dothideomycetes, five species, type: L. lichenicola (P. Karst.) Petr. \& Syd., coelomycetous, sexual morph unknown, lichenicolous, terrestrial, worldwide, see Lawrey et al. (2011; new species), Wijayawardene et al. (2012, 2014c, 2016b; outline, taxonomy), Hyde et al. (2013; taxonomy), cultures and sequences are available but lacks for the type species, needs generic revision.

Lichenodiplis Dyko \& D. Hawksw. 1979, Chaetothyriales genera incertae sedis, Eurotiomycetes, 13 species, type: L. lecanorae (Vouaux) Dyko \& D. Hawksw., coelomycetous, sexual morph unknown, lichenicolous, terrestrial, worldwide, see Atienza et al. (2009; morphology, new species), Knudsen and Kocourkova (2009; morphology, new species), Kirk et al. (2013; genus accepted), Pérez-Vargas et al. (2013; new species), Muggia et al. (2015b; phylogeny), Wijayawardene et al. (2016b; outline, morphology, phylogeny), Cultures and sequences are available, lectotype of type species ANGUC.

Lichenohendersonia Calatayud \& Etayo 2001, Ascomycota genera incertae sedis, three species, type: L. squamarinae Calat. \& Etayo, sexual morph unknown, parasymbiont on different lichens, terrestrial, Northern Hemisphere, see Wijayawardene et al. (2016b; morphology), sequence data and cultures unavailable, holotype of the type: IMI 363556.

Lichenopeltella Höhn. 1919, Trichothyriaceae, Dothideomycetes, families incertae sedis, c. 31 species, type: L. maculans (Zopf) Höhn., asexual morph unknown, saprobes, lichenicolous, terrestrial, worldwide, see Pérez-Ortega and Spribille (2009; new species), Etayo (2010; new species), Lumbsch and Huhndorf (2010; outline, accepted as a genus in Asterinaceae), Zhurbenko (2010a; new species), Brackel (2010b, 2011b; new species),Flakus and Kukwa (2012; new records in Bolivia), van den Boom and Giralt (2012; records in Portugal), Hyde et al. (2013; accepted as a genus in Aulographaceae), Kirk et al. (2013; genus accepted), Hongsanan et al. (2014a; transferred to Mycosphaerellaceae from Asterinaceae), Wijayawardene et al. (2014c; outline), Zhurbenko and Pino-Bodas (2015; new species, New Zealand), cultures and sequences are unavailable.

Lichenopeziza Zukal 1884, Ascomycota genera incertae sedis, one species, type: L. bryophile Zukal, asexual morph unknown, saprobes, terrestrial, Europe, see Lumbsch and Huhndorf (2010; outline), Kirk et al. (2013; genus accepted), current generic concept is uncertain, cultures and sequences are unavailable, needs generic revision.

Lichenopuccinia D. Hawksw. \& Hafellner 1984, Ascomycota genera incertae sedis, one species, type: L. poeltii D. Hawksw. \& Hafellner, sexual morphs unknown, terrestrial, lichenicolous, Europe, see Seifert et al. (2011; morphology), Wijayawardene et al. (2012, 2017; outline), Kirk et al. (2013; genus accepted), cultures and sequences are unavailable, needs generic revision, holotype of type species K(M)-IMI 281393.

Lichenopyrenis Calat., M.J. Sanz \& Aptroot 2001, Pleomassariaceae, Pleosporales, Dothideomycetes, one species, type: L. galligena Calat., M.J. Sanz \& Aptroot, asexual morph unknown, lichenicolous, terrestrial, Spain, Canada, Japan, see Lumbsch and Huhndorf (2010; outline), Zhang et al. (2012e; accepted as a genus in Pleomassariaceae), Hyde et al. (2013; accepted as a genus in Pleomassariaceae), Wijayawardene et al. (2014c; outline), Cultures and sequences are unavailable, holotype of the type species MA (Lich.) 12715.

Lichenostella Etayo \& Calat. 1999, Ascomycota genera incertae sedis, one species, type: L. hypotrachynae Etayo \& Calat., hyphomycetous, sexual morph unknown, lichenicolous, terrestrial, South America, see Seifert et al. (2011; morphology), Wijayawardene et al. (2012, 
2017; outline), Kirk et al. (2013; genus accepted), cultures and sequences are unavailable, needs generic revision.

Lichenosticta Zopf 1898, Ascomycota genera incertae sedis, one species, type: L. podetiicola Zopf, coelomycetous, sexual morph unknown, lichenicolous, terrestrial, North temperate, see Wijayawardene et al. (2012, 2017; outline), Kirk et al. (2013; genus accepted), current generic concept is uncertain, cultures and sequences are unavailable, needs generic revision.

Lichenostigma Hafellner 1983, Phaeococcomycetaceae, Lichenostigmatales, Arthoniomycetes, type: L. maureri Hafellner, asexual morph hyphomycetous, lichenicolous, terrestrial, worldwide, see Pérez-Ortega and Calatayud (2009; new species, Spain), Fernández-Brime et al. (2010; new species), Knudsen and Kocourkova (2010; new species), Lumbsch and Huhndorf (2010; outline), Valadbeigi and Brackel (2011; new species), Kirk et al. (2013; genus accepted), Kondratyuk et al. (2013b; new species), Ertz et al. (2014b; new species; phylogeny), Cultures and sequences are available, current generic concept is uncertain, cultures available for type species Diederich 1730, Diederich 17337, Diederich 17326, Diederich 17337.

Lichenothelia D. Hawksw. 1981, Lichenotheliaceae, Lichenotheliales, Dothideomycetes, 29 species, type: L. scopularia (Nyl.) D. Hawksw., asexual morphs pycnidial or hyphomycetous, on rock or lichenicolous, terrestrial, widespread, some species may belong in Lichenostigma Hafellner, see Lumbsch \& Huhndorf (2011; outline), Kirk et al. (2013; genus accepted), Hyde et al. (2013; genus accepted), Muggia et al. (2015a; phylogeny), Jaklitsch et al. (2016a; position), cultures and sequences are available, isotypes of type species BM and $\mathrm{K}(\mathrm{M})$ [Anzi, Lich. Langob. 35].

Lichenoverruculina Etayo 2011, Sordariomycetes genera incertae sedis, one species, type: $L$. sigmatospora (Speg.) Etayo \& Sharuddin, asexual morph unknown, lichenicolous on Heterodermia, terrestrial, South America, see Etayo and Sharuddin (2011; genus proposed), cultures and sequences are unavailable, holotype of the type species J. Puiggari 124 (LPS1715).

Lichina C. Agardh [nom. cons.] 1817, Lichinaceae, Lichinales, Lichinomycetes, nine species, type: L. pygmaea (Lightf.) C. Agardh, lichenized, marine, west-european coast, see Lumbsch and Huhndorf (2010; outline), Kirk et al. (2013; genus accepted), Lücking et al. (2016b; classification), cultures and sequences are available, needs generic revision.

Lichinella Nyl. 1873, Lichinaceae, Lichinales, Lichinomycetes, 30 species, type: L. stipatula Nyl., lichenized, North America, Europe, Asia, Africa, see Lumbsch and Huhndorf (2010; outline), Kirk et al. (2013; genus accepted), Lücking et al. (2016b; classification), cultures and sequences are available, needs generic revision.

Lichinodium Nyl. 1875, Lichinaceae, Lichinales, Lichinomycetes, four species, type: L. sirosiphoideum Nyl., lichenized, North America, Europe, see Lumbsch and Huhndorf (2010; outline), Kirk et al. (2013; genus accepted), Lücking et al. (2016b; classification), cultures and sequences are unavailable, needs generic revision.

Licopolia Sacc., Syd. \& P. Syd. 1900, Dothideomycetes genera incertae sedis, two species, type: L. franciscana Sacc., Syd. \& P. Syd., asexual morph unknown, saprobes, terrestrial, Brazil, Kenya, see Lumbsch and Huhndorf (2010; outline), Kirk et al. (2013; genus accepted), Wijayawardene et al. (2014c; outline), cultures and sequences are unavailable.

Lignincola Höhnk 1955, Halosphaeriaceae, Microascales, Sordariomycetes, five species, type: L. laevis Höhnk, asexual morph unknown, saprobes, marine, worldwide, see Jones et al. (2009b, 2015; classification), Alias et al. (2010; diversity), Jones (2010; diversity), AbdelWahab (2011a; diversity), Liu et al. (2011a; morphology), Pang et al. (2011b, 2013b; monograph, phylogeny), Sakayaroj et al. (2011a,b; phylogeny, diversity), Lee et al. (2012; checklist), Pang and Jheng (2012a; checklist), Alsheikh-Hussain et al. (2014, review), Overy 
et al. (2014; natural product), Maharachchikumbura et al. (2015, 2016; outline), cultures and sequences are available, neotype of type species J.K. 4459a.

Ligninsphaeria J.F. Zhang, J.K. Liu, K.D. Hyde \& Z.Y. Liu 2016, Pleosporales genera incertae sedis, Dothideomycetes, one species, type: L. jonesii J.F. Zhang, J.K. Liu, K.D. Hyde \& Z.Y. Liu, saprobes, Thailand, see Zhang et al. (2016a; taxonomy, phylogeny), holotype: MFLU 15-2718, cultures and sequences are available.

Lignoscripta B.D.Ryan 2004, Trapeliaceae, Trapeliales, Lecanoromycetes, one species, type: L. atroalba B.D. Ryan \& T.H. Nash, lichenized, Pacific Northwest, see Lumbsch and Huhndorf (2010; outline), Hodkinson and Lendemer (2011b; taxonomy), Lücking et al. 2016 (classification), cultures and sequences are unavailable, holotype of type species ASU (9092).

Lignosphaeria Boonmee, Thambugala \& K.D. Hyde 2015, Pleosporales genera incertae sedis, Dothideomycetes, two species, type: L. thailandica Boonmee, Thambugala \& K.D. Hyde, asexual morph coelomycetous, saprobes, terrestrial, Thailand, see Thambugala et al. (2015b; morphology, phylogeny), holotype and ex-type of type species MFLU 11-0135, MFLUCC 11-0376.

Lillicoa Sherwood 1977, Stictidaceae, Ostropales, Lecanoromycetes, one species, type: L. palicoureae (Seaver \& Whetzel) Sherwood, saprobes, North America, see Lumbsch and Huhndorf (2010; outline), Kirk et al. (2013; genus accepted), cultures and sequences are unavailable, needs generic revision.

Limaciniaseta D.R. Reynolds 1988, Capnodiaceae, Capnodiales, Dothideomycetes, one species, type: L. californica D.R. Reynolds, asexual morph unknown, saprobes, terrestrial, USA, see Kirk et al. (2013; genus accepted), cultures and sequences are unavailable, needs generic revision.

Limaciniopsis J.M. Mend. 1925, Dothideomycetes genera incertae sedis, type: L. rollandiae J.M. Mend., data inadequate, see Kirk et al. (2008; treated as nom. dub.), Lumbsch and Huhndorf (2010; outline), Kirk et al. (2013; did not list), Wijayawardene et al. (2014c; outline), sequences are unavailable,

Limacinula Höhn. 1907, Coccodiniaceae, Chaetothyriales, Eurotiomycetes, c. 16 species, type: L. samoënsis Höhn., aerial surface of living plants, epifoliar fungus, tropical, see Lumbsch and Huhndorf (2010; outline), Kirk et al. (2013; genus accepted), cultures and sequences are unavailable, needs generic revision.

Limacospora Jørg. Koch \& E.B.G. Jones 1995, Halosphaeriaceae, Microascales, Sordariomycetes, one species, type: L. sundica (Jørg. Koch \& E.B.G. Jones) Jørg. Koch \& E.B.G. Jones, asexual morph unknown, saprobes, marine, cosmopolitan, see Lumbsch and Huhndorf (2010; outline), Kirk et al. (2013; genus accepted), Jones et al. (2015; outline), Maharachchikumbura et al. (2015, 2016; outline), cultures and sequences are unavailable, needs generic revision.

Limnaiomyces Thaxt. 1900, Laboulbeniaceae, Laboulbeniales, Laboulbeniomycetes, three species, type: L. tropisterni Thaxt., asexual morph unknown, biotrophic, terrestrial, worldwide, see Lumbsch and Huhndorf (2010; outline), Kirk et al. (2013; genus accepted), cultures and sequences are unavailable.

Limtongia Jindam., Am-in, Yukphan \& Y. Yamada 2011, Lipomycetaceae, Saccharomycetales, Saccharomycetes, one species, type: L. smithiae (Van der Walt, M.J. Wingf. \& Y. Yamada) Jindam., Am-in, Yukphan \& Y. Yamada, saprophytic, see Jindamorakot et al. (2011; taxonomy), cultures and sequences are unavailable.

Lindauella Rehm 1900, Phyllachoraceae, Phyllachorales, Sordariomycetes, two species, type: L. pyrenocarpoidea Rehm, asexual morph unknown, from living leaves, terrestrial, South America, see Lumbsch and Huhndorf (2010; outline), Kirk et al. (2013; genus accepted), Maharachchikumbura et al. (2015, 2016; outline), cultures and sequences are unavailable, needs generic revision, needs generic revision. 
Lindgomyces K. Hiray., Kaz. Tanaka \& Shearer 2010, Lindgomycetaceae, Pleosporales, Dothideomycetes, eleven species, type species: L. ingoldianus (Shearer \& K.D. Hyde) K. Hirayama, Kaz. Tanaka \& Shearer, asexual morph unknown, saprobes, aquatic, China, Japan, USA, see Hirayama et al. (2010; morphology, phylogeny), Raja et al. (2011b, 2013a; morphology, phylogeny), Zhang et al. (2014e; morphology, phylogeny), Crous et al. (2015e; morphology, phylogeny), Li et al. (2016a; morphology, phylogeny), cultures and sequences are available, holotype and ex-type strain of the type species ILLS 52289, ATCC 200398.

Lindquistomyces Aramb., E. Müll. \& Gamundí 1982, Amphisphaeriaceae, Xylariales, Sordariomycetes, one species, type: L. antarcticus (Speg.) Aramb., E. Müll. \& Gamundí (Art. 33.3; Invalid), asexual morph unknown, saprobes, terrestrial, Argentina, see Lumbsch and Huhndorf (2010; outline), Kirk et al. (2013; genus accepted), cultures and sequences are unavailable, needs generic revision.

Lindra I. M. Wilson 1956, Lulworthiaceae, Lulworthiales, Sordariomycetes, five species, type: L. inflate I.M. Wilson, asexual morph hyphomycetous, saprobes, marine, worldwide, see Lumbsch and Huhndorf (2010; outline), Kirk et al. (2013; genus accepted), Maharachchikumbura et al. (2016; review), sequences are available, holotype of type: IMI 62909.

Lineolata Kohlm. \& Volkm.-Kohlm. 1990, Dothideomycetes genera incertae sedis, one species, type: L. rhizophorae (Kohlm. \& E. Kohlm.) Kohlm. \& Volkm.-Kohlm., asexual morph unknown, saprobes, marine, worldwide, see Suetrong et al. (2009; phylogeny, morphology), Jones et al. (2009b, 2015; classification), Alias et al. (2010; diversity), Sakayaroj et al. (2011b; diversity), Zhang et al. 2012e; phylogeny, morphology), AbdelWahab et al. (2014; diversity), Wijayawardene et al. (2014c; outline), holotype of type: J.K. 2390a.

Lineostroma H.J. Swart 1988, Didymosphaeriaceae, Pleosporales, Dothideomycetes, one species, type: L. banksiae (Cooke) H.J. Swart, asexual morph unknown, saprobes, terrestrial, Australia, see Lumbsch and Huhndorf (2010; outline), Kirk et al. (2013; genus accepted), Wijayawardene et al. (2014c; outline), Jayasiri et al. (2015; classification), cultures and sequences are unavailable, available specimen for type: CBS H-5512, needs generic revision.

Linkosia A. Hern.-Gut. \& B. Sutton 1997, Ascomycota genera incertae sedis, ten species, type: L. coccothrinacis (A. Hern. Gut. \& J. Mena) A. Hern. Gut. \& B. Sutton, hyphomycetous, sexual morph unknown, saprobes, terrestrial, worldwide, see Ma et al. (2011a; morphology), Seifert et al. (2011; morphology), Wijayawardene et al. (2012, 2017; outline), Almeida et al. (2014c; morphology, new species), Delgado (2014; morphology), sequence data available, holotype of the type species HAC, HACCM 206.

Linocarpon Syd. \& P. Syd. 1917, Xylariales genera incertae sedis, Sordariomycetes, 42 species, type: L. pandani Syd. \& P. Syd., asexual morph phialophora-like, saprobes, pathogen, endophytes, terrestrial, worldwide, see Lumbsch and Hunduf (2010; outline), Kirk et al. (2013; genus accepted), Maharachchikumbura et al. (2016; outline), cultures available for type: HKUM16278, HKUM16279.

Linochora Höhn. 1910, Phyllachoraceae, Phyllachorales, Sordariomycetes, five species, type: L. leptospermi Höhn., coelomycetous, sexual morph unknown, from living leaves, terrestrial, worldwide, see Wijayawardene et al. (2012, 2017; outline), Kirk et al. (2013; genus accepted), Maharachchikumbura et al. (2015, 2016; outline), cultures and sequences are unavailable, holotype of type species unknown, needs generic revision.

Linochorella Syd. \& P. Syd. 1912, Ascomycota genera incertae sedis, one species, type: L. striiformis Syd. \& P. Syd., coelomycetous, sexual morph unknown, lichenicolous, terrestrial, South Africa, see Wijayawardene et al. (2012, 2017; outline, taxonomy), Kirk et al. (2013; genus accepted), cultures and sequences are unavailable, needs generic revision. 
Linodochium Höhn. 1909, Ascomycota genera incertae sedis, two species, type: L. hyalinum (Lib.) Höhn., hyphomycetous, sexual morph unknown, saprobes, terrestrial, Europe, North America, see Seifert et al. (2011; morphology, accepted as a genus in Helotiaceae), Wijayawardene et al. (2017; outline), Kirk et al. (2013; did not accept), cultures and sequences are unavailable, needs generic revision, needs generic revision.

Linopeltis I. Hino \& Katum. 1961, Schizothyriaceae, Dothideomycetes family incertae sedis, two species, type: L. ryukyuensis I. Hino \& Katum., asexual morph unknown, saprobes, terrestrial, Hawaii, see Lumbsch and Huhndorf (2010; outline), Hyde et al. (2013, accepted as a genus in Schizothyriaceae), Kirk et al. (2013; genus accepted), Wijayawardene et al. (2014c; outline), cultures and sequences are unavailable, needs generic revision.

Lipomyces Lodder \& Kreger-van Rij 1952 (= Myxozyma van der Walt, Weijman \& von Arx 1981), Lipomycetaceae, Saccharomycetales, Saccharomycetes, 20 species, type: L. starkeyi Lodder \& Kreger, asexual reproduction is by multilateral budding, saprophytic, predominantly from soil, but not uncommon in tree frass from bark beetles, worldwide, see Lumbsch and Huhndorf (2010; outline), Kirk et al. (2013; genus accepted), Yamazaki and Kawasaki (2014; new species, DNA), sequences are available.

Lirellodisca Aptroot 1998, Patellariaceae, Patellariales, Dothideomycetes, one species, type: L. pyrenulispora Aptroot, asexual morph unknown, saprobes, terrestrial, tropical, see Lumbsch and Huhndorf (2010; outline), Hyde et al. (2013; accepted as a genus in Patellariaceae), Kirk et al. (2013; genus accepted), Wijayawardene et al. (2014c; outline), Yacharoen et al. (2015; accepted as a genus in Patellariaceae), cultures and sequences are unavailable, holotype of the type species CBS, Aptroot 38022, needs generic revision.

Lirula Darker 1967, Rhytismataceae, Rhytismatales, Leotiomycetes, three species, type: L. nervisequa (DC.) Darker, asexual morph unknown, saprobes, worldwide, see Lumbsch and Huhndorf (2010; outline), Lantz et al. (2011; DNA, phylogeny), Fan et al. (2012b; new species, China, DNA, phylogeny), Kirk et al. (2013; genus accepted), cultures and sequences are available but lacks for the type species.

Listeromyces Penz. \& Sacc. 1901, Ascomycota genera incertae sedis, one species, type: L. insignis Penz. \& Sacc., hyphomycetous, sexual morph unknown, saprobes, lignicolous, Asia, Oceania, see Hyde et al. (2011; checklist), Seifert et al. (2011; morphology), Wijayawardene et al. (2012, 2017; outline), Kirk et al. (2013; genus accepted), cultures and sequences are unavailable, needs generic revision.

Lithoglypha Brusse 1988, Acarosporaceae, Acarosporales, Lecanoromycetes, one species, type: L. aggregata Brusse, lichenized, South Africa, see Lumbsch and Huhndorf (2010; outline), Lücking et al. (2016b; classification), cultures and sequences are unavailable, needs generic revision.

Lithographa Nyl. 1857, Xylographaceae, Trapeliales, Lecanoromycetes, ten species, type: L. petraea (Nyl.) Nyl., lichenized, North and South America, Australia, see Resl et al. (2015; phylogeny), Lücking et al. (2016b; classification), Cultures and sequences are available, needs generic revision.

Lithogyalideopsis Lücking, Sérus. \& Vězda 2005, Gomphillaceae, Ostropales, Lecanoromycetes, four species, type: L. poeltii (Vězda) Lücking, Sérus. \& Vězda, lichenized,?, see Lücking et al. (2016b; classification), cultures and sequences are unavailable, needs generic revision.

Lithophila Selbmann \& Isola, MB811675. For diagnosis see Fungal Diversity 76: 88 (2016). Trichomeriacaeae, Chaetothyriales, Eurotiomycetes, rock-inhabiting fungus, monospecific; sexual morph unknown; type species Lithophila guttulata Selbmann \& Isola, MB811676. For diagnosis see Fungal Diversity 76: 90 (2016). Holotypus: CBS 139723. From marble stone, Cortile della Pigna (Vatican City State); = CCFEE 5907 (NCBI accession numbers: KP791773 (ITS), KR781061 (LSU)), taxonomic species delimitation supported by molecular 
data. Lithophila Selbmann \& Isola (2016), introduced as a genus of Trichomeriacaeae, is a later homonym of Lithophila Sw., Prodr, 14, 1788, a name previously and validly published for a genus of Amaranthaceae.

Notes: Lithophila Selbmann \& Isola is illegitimate and unavailable for use [ICN (Melbourne) Art. 53.1]; it is here renamed Lithohypha Selbmann \& Isola nom. nov., MB819853. For diagnosis see Fungal Diversity 76: 88 (2016). The type species is here renamed Lithohypha guttulata (Selbmann \& Isola) Selbmann \& Isola comb. nov., MB819854.

Lithopythium Bornet \& Flahault 1891, Ascomycota genera incertae sedis, three species, type: L. gangliiforme Bornet \& Flahault, asexual morph unknown, saprobes, Europe, see Lumbsch and Huhndorf (2010; outline), Kirk et al. (2013; genus accepted), cultures and sequences are unavailable, needs generic revision.

Lithothelium Müll. Arg. 1885, Pyrenulaceae, Pyrenulales, Eurotiomycetes, eight species, type: L. cubanum Müll. Arg., asexual morph unknown, lichenized, terrestrial, tropical, see Lumbsch and Huhndorf (2010; outline), Valadbeigi and Sipman (2010; Iran), Valadbeigi et al. (2010; checklist), Weerakoon et al. (2012a; DNA, phylogeny), Kirk et al. (2013; genus accepted), Gueidan et al. (2016; phylogeny), cultures and sequences are available but lacks for the type species, needs generic revision.

Livia Velen. 1947, Helotiales genera incertae sedis, Leotiomycetes, one species, type: L. aurea Velen., asexual morph unknown, saprobes, Europe, see Lumbsch and Huhndorf (2010; outline), Kirk et al. (2013; genus accepted), cultures and sequences are available, needs generic revision.

Lizonia (Ces. \& De Not.) De Not. 1863, Pseudoperisporiaceae, Dothideomycetes family incertae sedis, one species, type: L. empirigonia (Auersw.) De Not., asexual morph unknown, saprobes, terrestrial, Central America, see Lumbsch and Huhndorf (2010; outline), Stenroos et al. (2010; DNA), Hyde et al. (2013; accepted in Pseudoperisporiaceae), Kirk et al. (2013; genus accepted), Wijayawardene et al. (2014c; outline), cultures and sequences are unavailable, type specimen of type species CBS H-14093.

Llimonaea Egea \& Torrente 1991, Opegraphaceae, Arthoniales, Arthoniomycetes, four species, type: L. occulta Egea \& Torrente, saprobes, terrestrial, Central America, see Lumbsch and Huhndorf (2010; outline, accepted as a genus in Arthoniales), Ertz and Tehler (2014; DNA, phylogeny), Lücking et al. (2016b; classification), sequences are available, holotype of type: MUB 13619.

Llimoniella Hafellner \& Nav.-Ros. 1993, Cordieritidaceae, Helotiales, Leotiomycetes, one species, type: L. scabridula (Müll. Arg.) Nav.-Ros. \& Hafellner, asexual morph unknown, lichenicolous, terrestrial, Europe, see Lumbsch and Huhndorf (2010; outline), Kirk et al. (2013; genus accepted), Suija et al. (2015b; phylogeny), Pärtel et al. (2017; DNA, phylogeny), cultures and sequences are available, needs generic revision.

Lobaria (Schreb.) Hoffm. 1796, Lobariaceae, Peltigerales, Lecanoromycetes, 60 species, type: L. pulmonaria (L.) Hoffm., lichenized, see Lumbsch and Huhndorf (2010; outline), Kirk et al. (2013; genus accepted), Moncada et al. (2013a; classification), Miądlikowska et al. (2014a; phylogeny), Cornejo and Scheidegger (2015; phylogeny), Lücking et al. (2016b; classification), Cultures and sequences are available, needs generic revision.

Lobariella Yoshim. 2002, Lobariaceae, Peltigerales, Lecanoromycetes, 35 species, type: L. crenulata (Hook.) Yoshim., lichenized, neo- tropical distribution, see Lumbsch and Huhndorf (2010; outline, accepted as a synonym of Lobaria), Moncada et al. (2013a; phylogeny), Lücking et al. (2016b; classification), cultures and sequences are available, needs generic revision.

Lobarina Nyl. ex Cromb. 1894, Lobariaceae, Peltigerales, Lecanoromycetes, 15 species, type: L. scrobiculata (Scop.) Nyl., lichenized, Northern Hemisphere and in oceanic areas of 
Africa, Australia, New Zealand and South America, see Moncada et al. (2013a; phylogeny), Lücking et al. (2016b; classification), cultures and sequences are available, needs generic revision.

Lobatopedis P.M. Kirk 1979, Ascomycota genera incertae sedis, five species, type: L. foliicola P.M. Kirk, hyphomycetous, sexual morph unknown, saprobes, on leaf litter, widespread, see Hyde et al. (2011; checklist), Seifert et al. (2011; morphology), Wijayawardene et al. (2012, 2017; outline), Kirk et al. (2013; genus accepted), Heredia et al. (2014; new species), cultures and sequences are unavailable, needs generic revision, holotype of type species IMI 222919.

Lobothallia (Clauzade \& Cl.Roux) Hafellner 1991, Megasporaceae, Pertusariales, Lecanoromycetes, nine species, type: L. alphoplaca (Wahlenb.) Hafellner, lichenized, Asia, Europe, North America, see Lücking et al. (2016b; classification), cultures and sequences are available, needs generic revision.

Lockerbia K. D. Hyde 1994, Sordariales genera incertae sedis, Sordariomycetes, two species, type: L. palmicola K.D. Hyde, asexual morph unknown, freshwater, Australia, Florida, see Raja and Shearer (2008; new species), Kirk et al. (2013; genus accepted), cultures and sequences are unavailable, holotype of type: BRIP 21334.

Loculistroma F. Patt. \& Charles 1910, Clavicipitaceae, Hypocreales, Sordariomycetes, one species, type: L. bambusae F. Patt., Charles \& Veihmeyer, asexual morph hyphomycetous, terrestrial, saprobes, USA, see Lumbsch and Huhndorf (2010; outline), Kirk et al. (2013; genus accepted), Maharachchikumbura et al. (2015, 2016; outline), cultures and sequences are unavailable, holotype of type: BPI 632466.

Loculohypoxylon M.E. Barr 1976, Teichosporaceae, Pleosporales, Dothideomycetes, one species, type: L. grandineum (Berk. \& Ravenel) M.E. Barr, asexul morph unknown, saprobes, terrestrial, North America, see Lumbsch and Huhndorf (2010; outline), Hyde et al. (2013; accepted as a genus in Teichosporaceae), Kirk et al. (2013; genus accepted), Wijayawardene et al. (2014c; outline), cultures and sequences are unavailable.

Loculotuber Trappe, Parladé \& I.F. Alvarez 1993, Pezizales genera incertae sedis, Pezizomycetes, two species, type: L. gennadii (Chatin) Trappe, Parladé \& I.F. Alvarez, asexual morph unknown, saprobes, hypogeous, terrestrial, Europe, see Lumbsch and Huhndorf (2010; outline), Kirk et al. (2013; genus accepted), cultures and sequences are unavailable, needs generic revision.

Lodderomyces van der Walt 1971, Debaryomycetaceae, Saccharomycetales, Saccharomycetes, c. 40 species, type: L. elongisporus (Recca \& Mrak) van der Walt, asexual reproduction is by multilateral budding, saprophytic, but some species are common human and animal pathogens, clinical isolates, soil, plant debris, beetles, water, yeast cake, worldwide, Lumbsch and Huhndorf (2010; outline), Kirk et al. (2013; genus accepted), sequences are available.

Loekoesia S.Y. Kondr., S.O. Oh \& Hur 2015, Teloschistaceae, Teloschistales, Lecanoromycetes, one species, type: L. austrocoreana (S.Y. Kondr., L. Lökös \& J.S. Hur) S.Y. Kondr., J. Kim, A.S. Kondr., S.O. Oh \& J.S. Hur, lichenized, South Korea, see Kondratyuk et al. (2015d; phylogeny), Lücking et al. (2016b; classification), cultures and sequences are available, holotype of type species KoLRI 015504.

Loflammia Vězda 1986, Pilocarpaceae, Lecanorales, Lecanoromycetes, five species, type: L. flammea (Müll. Arg.) Vězda, lichenized, Australia, Africa, see Lumbsch and Huhndorf (2010; outline), Kirk et al. (2013; genus accepted), Lücking et al. (2016b; classification), cultures and sequences are unavailable, needs generic revision.

Loflammiopsis Lücking \& Kalb 2000, Pilocarpaceae, Lecanorales, Lecanoromycetes, one species, type: L. brasiliensis Lücking \& Kalb, lichenized, Brazil, see Lumbsch and Huhndorf 
(2010; outline), Lücking et al. (2016b; classification), cultures and sequences are unavailable, holotype of type species Kalb, Kalb \& Kalb 27140.

Logilvia Vězda 1986, Pilocarpaceae, Lecanorales, Lecanoromycetes, one species, type: L. gilva (Müll. Arg.) Vězda, lichenized, South America, see Lumbsch and Huhndorf (2010; outline), Kirk et al. (2013; genus accepted), Lücking et al. (2016b; classification), cultures and sequences are unavailable, needs generic revision.

Lohwagia Petr. 1942, Phyllachoraceae, Phyllachorales, Sordariomycetes, three species, type: L. intermedia (Speg.) Petr., asexual morph unknown, from living leaves, terrestrial, central and South America, see Lumbsch and Huhndorf (2010; outline), Kirk et al. (2013; genus accepted), Maharachchikumbura et al. (2015, 2016; outline), cultures and sequences are unavailable, needs generic revision.

Lojkania Rehm 1905, Fenestellaceae, Dothideomycetes family incertae sedis, ten species, type: L. hungarica Rehm, asexual morph unknown, saprobes, terrestrial, temperate, see Lumbsch and Huhndorf (2010; outline), Hyde et al. (2013; accepted as a genus in Fenestellaceae), Kirk et al. (2013; genus accepted), Wijayawardene et al. (2014c; outline), Phookamsak and Hyde (2015; taxonomy), cultures and sequences are available but lacks for the type species, needs generic revision.

Lolia Abdel-Aziz \& Abdel-Wahab 2011, Lindgomycetaceae, Pleosporales, Dothideomycetes, two species, type: L. aquatica Abdel-Aziz \& Abdel-Wahab, coelomycetous, saprobes, aquatic, Egypt, see Abdel-Aziz and Abdel-Wahab (2010; taxonomy, phylogeny), Hyde et al. (2013; accepted in Lindgomycetaceae), Kirk et al. (2013; genus accepted), Wijayawardene et al. (2012, 2014c; outline), Abdel-Aziz (2016; new species, phylogeny), cultures and sequences are available, holotype and ex-type strain of the type species IMI 398675, MF644.

Loliomyces Maire 1937, Ascomycota genera incertae sedis, one species, type: L. temulenti Maire, hyphomycetous, saprobes, Morocco, see Seifert et al. (2011; taxonomy), Wijayawardene et al. (2012, 2017; outline), Kirk et al. (2013; genus accepted), cultures and sequences are unavailable, needs generic revision.

Lollipopaia Inderb. 2001, Diaporthales genera incertae sedis, Sordariomycetes, one species, type: L. minuta Inderb., asexual morph unknown, saprobes, terrestrial, Thailand, see Lumbsch and Huhndorf (2010; outline), Maharachchikumbura et al. (2015, 2016; outline), cultures and sequences are available.

Lomaantha Subram. 1954, Ascomycota genera incertae sedis, three species, type: L. pooga Subram., hyphomycetous, sexual morph unknown, saprobes, dead wood and culms, India and China, see Seifert et al. (2011; morphology), Wijayawardene et al. (2012, 2017; outline), Ma et al. (2011c; new species, revision), Kirk et al. (2013; genus accepted), cultures and sequences are unavailable, needs generic revision.

Lomachashaka Subram. 1956, Ascomycota genera incertae sedis, one species, type: L. kera Subram., hyphomycetous, saprobes, Western Africa, India, see Yadav and Bhat (2009b; new species, India), Seifert et al. (2011; taxonomy), Wijayawardene et al. (2012, 2017; outline), Kirk et al. (2013; genus accepted), cultures and sequences are unavailable, needs generic revision.

Longicollum Zelski, F.R. Barbosa, Raja, A.N. Mill. \& Shearer 2011, Annulatascaceae, Annulatascales, Sordariomycetes, one species, type: L. biappendiculatum Zelski, F.R. Barbosa, Raja, A.N. Mill. \& Shearer, asxual morph unknown, saprobes, aquatic, USA, South America, see Zelski et al. (2011a; taxonomy), cultures and sequences are unavailable, holotype of the type: ILL 40794, needs generic revision.

Longiostiolum Doilom, Ariyawansa \& K.D. Hyde 2016, Massarinaceae, Pleosporales, Dothideomycetes, one species, type: L. tectonae Doilom, Ariyawansa \& K.D. Hyde, saprobes, terrestrial, Thailand, see Li et al. (2016a; taxonomy, phylogeny), cultures and sequences are 
available, ex-type strains of type: MFLUCC 12-0562, MKT 078, ICMP 21259, Holotype of type species MFLU 15-3532.

Lopadium Körb. [nom. cons.] 1855, Lopadiaceae, Lecideales, Lecanoromycetes, five species, type: L. pezizoideum (Ach.) Körb., lichenized, worldwide, see Ekman et al. (2008; phylogeny), Lücking et al. (2016b; classification), cultures and sequences are available, needs generic revision.

Lopadostoma (Nitschke) Traverso 1906, Lopadostomataceae, Xylariales, Sordariomycetes, twelve species, type: L. turgidum (Pers.) Traverso, asexual morph libertella-like, saprobes, Europe, see Lumbsch and Huhndorf (2010; outline), Kirk et al. (2013; genus accepted), Jaklitsch et al. (2014a), Senanayake et al. (2015), Maharachchikumbura et al. (2015, 2016; outline), Daranagama et al. (2017 morphology, phylogeny), cultures and sequence are available but lacks for the type species.

Lopezaria Kalb \& Hafellner 1990, Ramalinaceae, Lecanorales, Lecanoromycetes, one species, type: L. versicolor (Fée) Kalb \& Hafellner, asexual morph unknown, lichenized, Morocco, see Seifert et al. (2011; taxonomy), Wijayawardene et al. (2012, 2017; outline), Kirk et al. (2013; genus accepted), cultures and sequences are available, cultures available for type species AFTOL-ID 108, needs generic revision.

Lophiella Sacc. 1878, Dothideomycetes genera incertae sedis, one species, type: L. cristata (Pers.) Sacc., asexual morph unknown, saprobes, terrestrial, Europe, see Lumbsch and Huhndorf (2010; outline, accepted as a genus in Lophiostomataceae), Kirk et al. (2013; genus accepted), Wijayawardene et al. (2014c; outline), cultures and sequences are unavailable, Index Fungorum (2016) treated type species as a synonym of Lophiostoma angustilabrum (Berk. \& Broome) Cooke, holotype of type material unavailable, needs generic revision.

Lophiohelichrysum Dayarathne, Camporesi \& K.D. Hyde 2015, Lophiostomataceae, Pleosporales, Dothideomycetes, one species, type: L. helichrysi Dayarathne, Camporesi \& K.D. Hyde, asexual morph unknown, saprobes, terrestrial, Italy, see Ariyawansa et al. (2015a; taxonomy, phylogeny), holotype and ex-type culture of the type: MFLU 15-0175, MFLUCC 15-0701.

Lophionema Sacc. 1883, Dothideomycetes genera incertae sedis, nine species, type: L. vermisporum (Ellis) Sacc., asexual morph unknown, saprobes, terrestrial, worldwide, see Lumbsch and Huhndorf (2010; outline, accepted as a genus in Lophiostomataceae), Kirk et al. (2013; genus accepted), Wijayawardene et al. (2014c; outline), cultures and sequences are unavailable, needs generic revision, needs generic revision.

Lophiopoacea Ariyaw., Thambug., Camporesi \& K.D. Hyde 2015, Lophiostomataceae, Pleosporales, Dothideomycetes, two species, type: L. arundinis Ariyawansa, Thambugala, Camporesi \& K.D. Hyde, asexual morph unknown, saprobes on Poaceae, terrestrial, Italy, Japan, see Thambugala et al. (2015b; morphology, phylogeny), cultures and sequenced are available, holotype and ex-type of type species MFLU 14-0590, MFLUCC 11-0463.

Lophiosphaerella Hara 1948, Mycosphaerellaceae, Capnodiales, Dothideomycetes, one species, type: L. euryae (Syd.) Hara, asexual morph unknown, saprobes, terrestrial, Asia, see Lumbsch and Huhndorf (2010; outline, accepted as a genus in Dothideomycetes genera incertae sedis), Kirk et al. (2013; genus accepted), Li et al. (2014b; transferred to Mycosphaerellaceae), Wijayawardene et al. (2014c; outline), cultures and sequences are unavailable.

Lophiostoma Ces. \& De Not. 1863, Lophiostomataceae, Pleosporales, Dothideomycetes, c. 100 species, type: L. macrostomum (Tode) Ces. \& De Not., asexual morph coelomycetous, only known for L. semiliberum, saprobes, terrestrial, aquatic, worldwide, sequence data available for four species, see Lumbsch and Huhndorf (2010; outline), Hirayama and Tanaka (2011; phylogeny), Hyde et al. (2013; outline), Kirk et al. (2013; genus accepted), 
Wijayawardene et al. (2014c; outline), Thambugala et al. (2015b; phylogeny, review), cultures and sequences are available, epitype of the type: IFRD 2005.

Lophiotrema Sacc. 1878, Lophiotremataceae, Pleosporales, Dothideomycetes, 15 species, type: L. nucula (Fr.) Sacc., asexual morph coelomycetous, saprobes, terrestrial habitats, worldwide, See Hirayama and Tanaka (2011; taxonomy, phylogeny), Zhang et al. (2012e; taxonomy, phylogeny), Hyde et al. (2013, 2016; taxonomy, phylogeny), Kirk et al. (2013; genus accepted), cultures and sequences are available, holotype of type: Scler. suec. n. 230.

Lophium Fr. 1818, Mytilinidiaceae, Mytilinidiales, Dothideomycetes, five species, type: L. mytilinum (Pers.) Fr., asexual morph papulaspora-like, saprobes, terrestrial, Europe, America, see Lumbsch and Huhndorf (2010; outline), Hyde et al. (2013; accepted as agenus in Mytilinidiaceae), Kirk et al. (2013; genus accepted), Wijayawardene et al. (2014c; outline), Hernández-Restrepo et al. (2016a; new species), cultures and sequences are available.

Lophodermella Höhn. 1917, Rhytismataceae, Rhytismatales, Leotiomycetes, nine species, type: L. sulcigena (Link) Tubeuf, asexual morph unknown, saprobes, terrestrial, worldwide, see Lumbsch and Huhndorf (2010; outline), Kirk et al. (2013; genus accepted), cultures and sequences are available but lacks for the type species, needs generic revision.

Lophodermium Chevall. 1826 (= Lophomerum Quell. \& Magasi 1966 fide Jaklitsch et al. 2016a), Rhytismataceae, Rhytismatales, Leotiomycetes, c. 145 species, type: L. arundinaceum (Schrad.) Chevall., asexual morph unknown, pathogens, saprobes, endophytes, terrestrial, widespread, see Lumbsch and hunduf (2010; outline), Kirk et al. (2013; genus accepted), cultures and sequences are available.

Lophophacidium Lagerb. 1949, Phacidiaceae, Phacidiales, Leotiomycetes, five species, type: L. hyperboreum Lagerb., asexual morph unknown, pathogens, saprobes, terrestrial, North temperate, see Lumbsch and Huhndorf (2010; outline), Kirk et al. (2013; genus accepted), Lafalmme et al. (2015; pathogens, phylogeny), cultures and sequences are available but lacks for the type species, needs generic revision.

Lophotrichus R.K. Benj. 1949, Microascaceae, Microascales, Sordariomycetes, one species, type: L. ampullus R.K. Benj., asexual morph hyphomycetous (humicola-like), saprobes, human pathogens, terrestrial, worldwide, see Lumbsch and Huhndorf (2010; outline), Kirk et al. (2013; genus accepted), Eghrari et al. (2015; human pathogens, DNA), Maharachchikumbura et al. (2015, 2016; outline), cultures and sequences are available, available specimen and cultures for the type: CBS H-14124, UAMH 11809.

Loramyces W. Weston 1929, Loramycetaceae, Helotiales, Leotiomycetes, two species, type: Loramyces juncicola W. Weston, asexual morph unknown, saprobes, terrestrial, North temperate, see Lumbsch and Huhndorf (2010; outline), Kirk et al. (2013; genus accepted), Han et al. (2014; phylogeny), Tanney et al. (2016; DNA, phylogeny), cultures and sequences are available.

Loranitschkia Lar.N. Vassiljeva 1990, Nitschkiaceae, Coronophorales, Sordariomycetes, one species, type: L. viticola Lar.N. Vassiljeva, asexual morph unknown, saprobes, terrestrial, Asia, see Vasilyeva et al. (2009, 2010, 2013; taxonomy, distributon), Lumbsch and Huhndorf (2010; outline), Kirk et al. (2013; genus accepted), Maharachchikumbura et al. (2015, 2016; outline), cultures and sequences are unavailable, holotype of the type: VLA, Vasil'eva.

Loratospora Kohlm. \& Volkm. 1993, Phaeosphariaceae, Pleosporales, Dothideomycetes, two species, type: L. aestuarii Kohlm. \& Volkm.-Kohlm., asexual morph unknown, saprobes, terrestrial, USA, Italy, see Lumbsch and Huhndorf (2010; outline), Kirk et al. (2013; genus accepted), Phookamsak et al. (2014b; revision), Wijayawardene et al. (2014c; outline), Ariyawansa et al. (2015a; phylogeny), cultures and sequences are available, holotype and cultures available for the type: IMS J.K. 5505, JK 5535B.

Loricella Velen. 1934, Calloriaceae, Helotiales, Leotiomycetes, two species, type: L. juncina Velen., asexual morph unknown, saprobes, terrestrial, former Czechoslovakia, see Lumbsch 
and Huhndorf (2010; outline), Kirk et al. (2013; genus accepted), Jaklitsch et al. (2016a; classification), cultures and sequences are unavailable, needs generic revision.

Lotinia Pérez-Butrón, Fern.-Vic. \& P. Alvarado 2015, Pyronemataceae, Pezizales, Pezizomycetes, one species, type: L. verna Pérez-Butrón, Fern.-Vic. \& P. Alvarado, asexual morph unknown, saprobes, Spain, see Crous et al. (2015e; taxonomy, phylogeny), Wijayawardene et al. (2017; outline), cultures and sequences are available.

Loxospora A.Massal. 1852, Sarrameanaceae, Sarrameanales, Lecanoromycetes, 13 species, type: L. elatina (Ach.) A. Massal., lichenized, Australia, Asia, Europe, North America, see Lumbsch and Huhndorf (2010; outline), Hodkinson and Lendemer (2011b; phylogeny), Kirk et al. (2013; genus accepted), Lücking et al. (2016bb; classification), cultures and sequences are available, needs generic revision.

Loxosporopsis Henssen 1995, Pertusariaceae, Pertusariales, Lecanoromycetes, one species, type: L. corallifera Brodo, Henssen \& Imshaug, asexual morph unknown, lichenized, terrestrial, USA, see Lumbsch and Huhndorf (2010; outline), Kirk et al. (2013; genus accepted), Resl et al. (2015; DNA, phylogeny), cultures and sequences are available, holotype of type: herb. Henssen, Henssen 13604; isotypes CANL, FH, GZU, UPS, US.

Lucidascocarpa A. Ferrer, Raja \& Shearer 2008, Dothideomycetes genera incertae sedis, one species, type: L. pulchella A. Ferrer, Raja \& Shearer, asexual morph unknown, submerged wood from freshwater, Panama, Ecuador, see Ferrer et al. (2008; genus proposed), Lumbsch and Huhndorf (2010; outline), Wijayawardene et al. (2014c; outline), cultures and sequences are unavailable, holotype of type: ILL 40558 (AF178-2).

Luciotrichus R. Galán \& Raitv. 1995, Ascodesmidaceae, Pezizales, Pezizomycetes, one species, type: L. lasioboloides R. Galán \& Raitv., asexual morph unknown, saprobes, terrestrial, Spain, see Lumbsch and Huhndorf (2010; outline), Kirk et al. (2013; genus accepted), cultures and sequences are unavailable, holotype of type: RG [sic] 6808.

Ludwigomyces Kirschst. 1939, Ascomycota genera incertae sedis, one species, type: L. parasiticus Kirschst., asexual morph unknown, saprobes, Europe, see Lumbsch and Huhndorf (2010; outline), Kirk et al. (2013; genus accepted), cultures and sequences are unavailable, needs generic revision.

Lueckingia Aptroot \& Umaña 2006, Ramalinaceae, Lecanorales, Lecanoromycetes, one species, type: L. polyspora Aptroot \& Umaña, asexual morph unknown, lichenized, terrestrial, tropical, Costa Rica, see Lumbsch and Hundorf (2010; outline), Lücking et al. (2016b; classification), cultures and sequences are unavailable, holotype of type species INB, Aptroot 60206.

Lulwoana Kohlm., Volkm.-Kohlm., J. Campb., Spatafora \& Gräfenhan 2005, Lulworthiaceae, Lulworthiales, Sordariomycetes, one species, type: L. uniseptata (Nakagiri) Kohlm., Volkm.-Kohlm., J. Campb., Spatafora \& Gräfenhan, asexual morph unknown, endophytic, saprobes, marine, Japan, see Lumbsch and Huhndorf (2010; outline), Jones et al. (2015; outline of marine genera), Maharachchikumbura et al. (2015, 2016; outline), Panzer et al. (2015; DNA, distribution), Torta et al. (2015; endophytes, DNA), cultures and sequences are available.

Lulwoidea Kohlm., Volkm.-Kohlm., J. Campbell, Spatafora \& Gräfenhan 2005, Lulworthiaceae, Lulworthiales, Sordariomycetes, one species, type: L. lignoarenaria (Jørg. Koch \& E. B. G. Jones) Kohlm., Volkm.-Kohlm., J. Campb., Spatafora \& Gräfenhan, asexual morph unknown, saprobes, marine, worldwide, see Lumbsch and Huhndorf (2010; outline), Maharachchikumbura et al. (2015, 2016; outline), holotype of type: Herb. J. Koch 398, slides 1-5 (CP).

Lulworthia G. K. Sutherl. 1915, Lulworthiaceae, Lulworthiales, Sordariomycetes, eleven species, type: L. fucicola G.K. Sutherl., asexual morph hyphomycetous, saprobes, marine, worldwide, see Lumbsch and Huhndorf (2010; outline), Kirk et al. (2013; genus accepted), 
Jones et al. (2015; outline, marine), Maharachchikumbura et al. (2015, 2016; outline), exneotype of type: ATCC 64288.

Lunatiannulus Daranagama, Camporesi \& K.D. Hyde 2015, Xylariaceae, Xylariales, Sordariomycetes, two species, type: L. irregularis Daranagama, Camporesi \& K.D. Hyde, asexual morph libertella-like, saprobes, terrestrial, Italy, Europe, see Daranagama et al. (2015a; morphology, phylogeny), Maharachchikumbura et al. (2016; morphology, phylogeny), holotype and ex-type strains of type species MFLU 14-0236, MFLUCC 14-0014. Lunulospora Ingold 1942, Sordariales genera incertae sedis, two species, type: L. curvula Ingold, hyphomycetous, sexual morph unknown, aquatic, worldwide, see Seifert et al. (2011; morphology), Wijayawardene et al. (2012, 2017; outline), cultures and sequences are available.

Luteocirrhus C.F. Crane, B.L. Shearer \& T.I. Burgess 2013, Cryphonectriaceae, Diaporthales, Sordariomycetes, one species, type: L. shearii C.F. Crane, B.L. Shearer \& T.I. Burgess, coelomycetous, sexual morph unknown, pathogens, terrestrial, Australia, see Crane and Burgess (2013; taxonomy, phylogeny), Shearer and Crane (2014; pathogens), Norphanphoun et al. (2016; phylogeny), Maharachchikumbura et al. (2015, 2016; outline), cultures and sequences are available, holotype and the ex-type cultures of the type species PERTH 08439362, CBS 130776 = WAC 13425.

Luttrellia Shearer 1978, Halosphaeriaceae, Microascales, Sordariomycetes, four species, type: L. estuarina Shearer, asexual morph unknown, saprobes, marine, fresh water, USA, see Lumbsch and Huhndorf (2010; outline), Kirk et al. (2013; did not accepted), Jones et al. (2015; outline), Maharachchikumbura et al. (2015, 2016; outline, phylogeny), cultures and sequences are unavailable, needs generic revision.

Luzfridiella R.F. Castañeda \& W.B. Kendr. 1991, Ascomycota genera incertae sedis, one species, type: L. insignis R.F. Castañeda \& W.B. Kendr., hyphomycetous, sexual morph unknown, saprobes, terrestrial, Caribbean, see Seifert et al. (2011; morphology), Wijayawardene et al. (2012, 2017; outline), Kirk et al. (2013; genus accepted), cultures and sequences are unavailable, needs generic revision.

Lylea Morgan-Jones 1975, Ascomycota genera incertae sedis, six species, type: L. catenulata Morgan-Jones, hyphomycetous, sexual morph unknown, saprobes, Europe, see Karandikar and Singh (2010; new species, India), McKenzie (2009; new species, New Zealand), Seifert et al. (2011; morphology), Wijayawardene et al. (2012, 2017; outline), Kirk et al. (2013; genus accepted), Xia et al. (2014; new species, China), cultures and sequences are unavailable, needs generic revision.

Lyromma Bat. \& H. Maia 1965, Lyrommataceae, Chaetothyriales, Eurotiomycetes, seven species, type: L. nectandrae Bat. \& H. Maia, coelomycetous, sexual morph unknown, lichenicolous, lichenized, worldwide, see Lücking (2008; new species, taxonomy), Wijayawardene et al. (2012; outline, accepted as Pyrenulales), Kirk et al. (2013; genus accepted), Flakus and Farkas (2013; new species, Bolivia), Farkas and Flakus (2015; South Africa), Lücking et al. (2016b; classification), cultures and sequences are unavailable, needs generic revision.

Lysotheca Cif. 1962, Ascomycota genera incertae sedis, six species, type: L. suprastromatica Cif., coelomycetous, sexual morph unknown, saprobes, Dominican Republic, see Wijayawardene et al. (2012, 2017; outline), Kirk et al. (2013; genus accepted), cultures and sequences are unavailable, needs generic revision, needs generic revision.

Maasoglossum K.S. Thind \& R. Sharma 1985, Geoglossaceae, Geoglossales, Geoglossomycetes, one species, type: M. verrucisporum K.S. Thind \& R. Sharma, asexual morph unknown, saprobes, terrestrial, Asia, Europe, see Lumbsch and Huhndorf (2010; outline, accepted as Leotiomycetes), Kirk et al. (2013; genus accepted), Hustad and Miller 
(2015c; revision, phylogeny), cultures and sequences are available, cultures available for the type: CUP-IN-000606, needs generic revision.

Macgarvieomyces Klaubauf, Lebrun \& Crous 2014, Pyriculariaceae, Magnaporthales, Sordariomycetes, two species, type: M. borealis (de Hoog \& Oorschot) Klaubauf, Lebrun \& Crous, hyphomycetous, pathogens, terrestrial, UK, Netherlands, see Klaubauf et al. (2014; phylogeny, morphology, asexual morph), Wijayawardene et al. (2017; outline), cultures and sequences available, ex-type strain of type species CBS 461.65, needs generic revision.

Mackenziella Yanna \& K.D. Hyde 2009, Ascomycota genera incertae sedis, one species, type: M. livistonae (Yanna \& K.D. Hyde) Yanna \& K.D. Hyde, hyphomycetous, sexual morph unknown, saprobes, terrestrial, Australia, see Yanna and Hyde (2009; morphology), Seifert et al. (2011; morphology), Wijayawardene et al. (2012, 2017; outline), cultures and sequences are unavailable, holotype of the type: HKU (M) 13304.

Macowaniella Doidge 1921, Dothideomycetes genera incertae sedis, two species, type: $M$. congesta (G. Winter) Doidge, epiphytes, terrestrial, see Hofmann (2009; review, accepted in Asterinaceae), Lumbsch and Huhndorf (2010; outline, accepted in Asterinaceae), Hongsanan et al. (2014c; taxonomy, treated as a doubtful genus in Asterinales), Wijayawardene et al. (2014c; outline, accepted as a genus in Dothideomycetes, genera incertae sedis), cultures and sequences are unavailable, needs generic revision.

Macroallantina Speer 1987, Ascomycota genera incertae sedis, one species, type: Metazythia caespitosa Petr., hyphomycetous, sexual morph unknown, saprobes, terrestrial, North America, see Seifert et al. (2011; morphology), Wijayawardene et al. (2012, 2017; outline), Kirk et al. (2013; genus accepted), cultures and sequences are unavailable, needs generic revision.

Macroconia (Wollenw.) Gräfenhan, Seifert \& Schroers 2011, Nectriaceae, Hypocreales, Sordariomycetes, five species, type: Macroconia leptosphaeriae (Niessl) Gräfenhan \& Schroers, hyphomycetous, terrestrial, mostly fungicolous, Northern hemisphere, see Gräfenhan et al. (2011; phylogeny), Lombard et al. (2015b; phylogeny), Cultures and sequences are available, lectotype of type: K(M) 165805.

Macroderma Höhn. 1917, Rhytismataceae, Rhytismatales, Leotiomycetes, one species, type: M. curtisii (Berk. \& Ravenel) Höhn., asexual morph unknown, saprobes, terrestrial, North America, Brazil, see Lumbsch and Huhndorf (2010; outline), Kirk et al. (2013; genus accepted), cultures and sequences are unavailable, needs generic revision.

Macrodiaporthe Petr. 1920, Melanconidaceae, Diaporthales, Sordariomycetes, two species, type: M. occulta (Fuckel) Petr., asexual morph unknown, saprobes, terrestrial, Europe, North America, see Lumbsch and Huhndorf (2010; outline), Kirk et al. (2013; genus accepted), Maharachchikumbura et al. (2015, 2016; outline), cultures and sequences are unavailable, Needs generic revision.

Macrodiplodia Sacc. 1884, Ascomycota genera incertae sedis, two species, type: M. curreyi (Sacc. \& Roum.) Sacc., coelomycetous, sexual morph unknown, saprobes, Europe, see Wijayawardene et al. (2012, 2017; outline), Kirk et al. (2013; genus accepted), cultures and sequences are unavailable, needs generic revision.

Macrodiplodiopsis Petr. 1922, Macrodiplodiopsidaceae, Pleosporales, Dothideomycetes, two species, type: $M$. desmazieri (Mont.) Petr., asexual morph coelomycetous, saprobes, Europe, see Wijayawardene et al. (2012, 2014b, 2016b; outline, taxonomy), Kirk et al. (2013; genus accepted), Crous et al. (2015a; taxonomy, sexual morph, typification), Tanaka et al. (2015; phylogeny), cultures and sequences are available, lectotype: PC 0142158, epitype and exepitype: CBS H-22269, CBS 140062.

Macrographa Etayo 2008, Microthyriaceae, Microthyriales, Dothideomycetes, one species, type: $M$. antarctica Etayo, asexual morph unknown, terrestrial, parasymbiont, or parasite on 
Nephroma antarcticum, South America, see Etayo and Sancho (2008; morphology), Hyde et al. (2013; accepted as Trichothyriaceae, but without molecular data), cultures and sequences are unavailable, holotype of the type species MAF, Etayo 23269.

Macrohilum H.J. Swart 1988, Macrohilaceae, Diaporthales, Sordariomycetes, one species, type: M. eucalypti H.J. Swart, coelomycetous, sexual morph unknown, saprobes, terrestrial, Australia, see Wijayawardene et al. (2012, 2016b; outline, morphology, phylogeny), Crous et al. (2015a; morphology, phylogeny), cultures and sequences are available, epitype and exepitype of the type: CBS H-22279, CBS 140063.

Macrophomina Petr. 1923, Botryosphaeriaceae, Botryosphaeriales, Dothideomycetes, three species, type: $M$. phaseolina (Tassi) Goid., coelomycetous, sexual morph unknown, saprobes, pathogens, in soil, terrestrial, cosmopolitan, see Phillips et al. (2008, 2013; taxonomy, phylogeny), Liu et al. (2012; taxonomy, phylogeny), Hyde et al. (2013; accepted as a genus in Botryosphaeriaceae), Slippers et al. (2013; phylogeny), Wijayawardene et al. (2014c, 2016b; outline, taxonomy, phylogeny), Dissanayake et al. (2016; taxonomy), cultures and sequences are available.

Macrorhabdus Tomaszewski, Logan, Snowden, Kurtzman \& Phalen 2003, Saccharomycetales genera incertae sedis, Saccharomycetes, one species, type: $M$. ornithogaster Tomasz., asexual reproduction is by fission, yypically infects the stomach area of budgerigars (Melopsittacus undulates) and other birds causing a wasting disease, on Budgerigars and other birds, worldwide, sequences are available.

Macroskyttea Etayo, Flakus, Suija \& Kukwa 2015, Cordieritidaceae, Helotiales, Leotiomycetes, one species, type species: M. parmotrematis Etayo, Flakus \& Kukwa, asexual morph unknown, lichenicolous, terrestrial, Bolivia, see Etayo et al (2015; DNA, description), DNA sequences available, cultures unavailable, holotype of type species in UGDA.

Macrovalsaria Petr. 1962, Dothideomycetes genera incertae sedis, two species, type: $M$. leonensis (Deighton) Petr., asexual morph unknown, saprobes, Europe, see Lumbsch and Huhndorf (2010; outline), Hyde et al. (2013; accepted in Botryosphaeriaceae), Kirk et al. (2013; genus accepted), Wijayawardene et al. (2014c; outline, accepted in Botryosphaeriaceae), Doilom et al. (2016; DNA, phylogeny), cultures and sequences are available but lacks for the type species, needs generic revision.

Macroventuria Aa 1971, Didymellaceae, Pleosporales, Dothideomycetes, three species, type: M. anomochaeta Aa, asexual morph unknown, saprobes, ?pathogens, terrestrial, cosmopolitan, see Aveskamp et al. (2010; phylogeny), Lumbsch and Huhndorf (2010; outline), Hyde et al. (2013; accepted as a genus in Didymellaceae), Kirk et al. (2013; genus accepted), Wijayawardene et al. (2014c; outline), Chen et al. (2015b; taxonomy, phylogeny), cultures and sequences are available.

Maculatifrondes K.D. Hyde 1996, Phyllachoraceae, Phyllachorales, Sordariomycetes, one species, type: $M$. aequatoriensis K.D. Hyde, asexual morph unknown, saprobes, terrestrial, Ecuador, see Lumbsch and Huhndorf (2010; outline), Kirk et al. (2013; genus accepted), Maharachchikumbura et al. (2015, 2016; outline), cultures and sequences are unavailable, holotype of type: BRIP 23240, needs generic revision.

Maculatipalma J. Fröhl. \& K.D. Hyde 1995, Valsaceae, Diaporthales, Sordariomycetes, one species, type: M. frondicola J. Fröhl. \& K.D. Hyde, asexual morph unknown, saprobes, terrestrial, Australia, see Lumbsch and Huhndorf (2010; outline), Kirk et al. (2013; genus accepted), Maharachchikumbura et al. (2015, 2016; outline), cultures and sequences are unavailable, holotype of type: BRIP 21402, needs generic revision.

Madurella Brumpt 1905, Chaetomiaceae, Sordariales, Sordariomycetes, nine species, type: M. mycetomatis (Laveran) Brumpt, hyphomycetous, sexual morph unknown, saprobes, human (causal agent of black-grain mycetoma) and animal pathogens, worldwide, see Fahala et al. (2010; pathogen, treatments), Seifert et al. (2011; morphology), de Hoog et al. (2012, 
2013; new species, Sudan, Sumatera), Wijayawardene et al. (2012, 2017; outline), Kirk et al. (2013; genus accepted), Irinyi et al. (2015; barcode), Maharachchikumbura et al. (2015, 2016; outline), cultures and sequences are available, cultures available for the type species CBS 247.48, needs generic revision.

Magmopsis Nyl. 1875, Arthopyreniaceae, Pleosporales, Dothideomycetes, one species, type: M. pertenella Nyl., lichenized, see Lücking et al. (2016b; classification), cultures and sequences are unavailable, needs generic revision.

Magnaporthiopsis J. Luo \& N. Zhang 2013, Magnaporthaceae, Magnaporthales, Sordariomycetes, six species, type: M. poae (Landsch. \& N. Jacks.) J. Luo \& N. Zhang, asexual morph hyphomycetous, pathogens, terrestrial, worldwide, see Luo and Zhang (2013; taxonomy, phylogeny), Klaubauf et al. (2014; new species, phylogeny), Luo et al. (2014; new species, phylogeny), Crous et al. (2015e; new species), Maharachchikumbura et al. (2015, 2016; outline), Khemmuk et al. (2016; phylogeny), holotype and cultures available for the type species DAR 59044, M47.

Magnibotryascoma Thambugala \& K.D. Hyde 2015, Floricolaceae, Pleosporales, Dothideomycetes, one species, type: M. uniseriatum (Mugambi, A.N. Mill. \& Huhndorf) Thambug. \& K.D. Hyde, asexual morph unknown, saprobes, terrestrial, USA, see Thambugala et al. (2015b; phylogeny), cultures and sequences are available, holotype of type species ANM 909.

Magnicamarosporium Kaz. Tanaka \& K. Hiray. 2015, Sulcatisporaceae, Pleosporales, Dothideomycetes, one species, type species: M. iriomotense Kaz. Tanaka \& K. Hiray., coelomycetous, sexual morph unknown, saprobes, terrestrial, Japan, see Tanaka et al. (2015; morphology, phylogeny), Wijayawardene et al. (2016b, 2017; morphology, phylogeny, outline), cultures and sequences are available, holotype and ex-type: HHUF 30125, CBS 139696.

Magnisphaera J. Campb., J.L. Anderson \& Shearer 2003 (= Matsusphaeria K.L. Pang \& E.B.G. Jone fide Maharachchikumbura et al. 2015, 2016), Halosphaeriaceae, Microascales, Sordariomycetes, two species, type: Magnisphaera spartinae (E.B.G. Jones) J. Campb., J.L. Anderson \& Shearer, asexual morph unknown, saprobes, marine, USA, see Lumbsch and Huhndorf (2010; outline), Kirk et al. (2013; did not accept as a valid genus), Jones et al. (2015; outline), Maharachchikumbura et al. (2015, 2016; outline, phylogeny), Réblová et al. (2017; DNA, phylogeny), cultures and sequences are available.

Magnohelicospora R.F. Castañeda, Hern.-Restr., Gené \& Guarro 2013, Ascomycota genera incertae sedis, one species, type: M. iberica R.F. Castañeda, Hern.-Restr., Gené \& Guarro, hyphomycetous, sexual morph unknown, saprobes, terrestrial, Portugal, see Castañeda-Ruiz et al. (2013c; taxonomy), Wijayawardene et al. (2017; outline), holotype of the type: HAL (Fungi) 2447, cultures and sequences are unavailable, needs generic revision.

Magnusiomyces Zender 1977 (= Saprochaete Coker \& Shanor ex D.T.S. Wagner \& Dawes 1970), Dipodascaceae, Saccharomycetales, Saccharomycetes, eight species, type: $M$. ludwigii Zender, asexual reproduction consists of true hyphae that branch at acute angles with acuminate apices, and that disarticulate into arthroconidia, saprophytic, but clinical isolates are not uncommon, soil, tree fluxes, waste water, insect tunnels in trees, worldwide, cultures and sequences are available.

Mahabalella B. Sutton \& S.D. Patil 1966, Ascomycota genera incertae sedis, two species, type: M. acutisetosa B. Sutton \& S.D. Patil, hyphomycetous, with acremonium-like synasexual morph, sexual morph unknown, saprobes, Asia, Caribbean, see Seifert et al. (2011; morphology), Wijayawardene et al. (2012, 2017; outline), Kirk et al. (2013; genus accepted), cultures and sequences are unavailable, needs generic revision.

Maheshwaramyces Hosag. 2009, Dothideomycetes genera incertae sedis, one species, type: M. pachygones Hosag., Archana \& Dan, asexual morph unknown, living on leves, India, see 
Hosagoudar and Archana (2009; taxonomy), Wijayawardene et al. (2014c; outline), cultures and sequences are unavailable.

Maireella Syd. ex Maire 1908, Dothideomycetes genera incertae sedis, type: M. maculans Syd. ex Maire, data inadequate, see Kirk et al. (2008; treated as a synonym of Gibbera), Lumbsch and Huhndorf (2010; outline), Kirk et al. (2013; did not list), Wijayawardene et al. (2014c; outline), sequences are unavailable.

Majewskia Y.B. Lee \& K. Sugiy. 1986, Laboulbeniaceae, Laboulbeniales, Laboulbeniomycetes, one species, type: $M$. japonica Y.B. Lee \& K. Sugiy., asexual morph unknown, biotrophic, terrestrial, worldwide, see Lumbsch and Huhndorf (2010; outline), Kirk et al. (2013; genus accepted), cultures and sequences are unavailable.

Malacaria Syd. 1930, Dothideomycetes genera incertae sedis, two species, type: $M$. meliolicola Syd., asexual morph unknown, saprobes, pantropical, see Lumbsch and Huhndorf (2010; outline, accepted in Tubeufiaceae), Hyde et al. (2013; not accepted in Tubeufiaceae), Kirk et al. (2013; genus accepted), Boonmee et al. (2014b; not listed in Tubeufiaceae), Wijayawardene et al. (2014c; outline), cultures and sequences are unavailable, needs generic revision.

Malaysiasca Crous \& M.J. Wingf. 2016, Glomerellales genera incertae sedis, Sordariomycetes, one species, type: $M$. phaii Crous \& M.J. Wingf., asexual morph coelomycetous, saprobes, terrestrial, Malaysia, see Crous et al. (2016b; taxonomy, phylogeny), Wijayawardene et al. (2017; outline), holotype and ex-type: CBS H-22616, CPC 27548.

Malbranchea Sacc. 1882, Onygenaceae, Onygenales, Eurotiomycetes, 22 species, type: $M$. pulchella Sacc. \& Penz., hyphomycetous, sexual morph unknown, in soil, dung, keratin, cellulose, man and other substrata, terrestrial, Northern America, see Seifert et al. (2011; morphology), Wijayawardene et al. (2012, 2017; outline), Kirk et al. (2013; genus accepted), cultures and sequences are available.

Malcolmiella Vězda 1997, Teloschistales genera incertae sedis, Lecanoromycetes, one species, type: $M$. cinereovirens Vězda, lichenized, New Zealand, see Lumbsch and Huhndorf (2010; outline), Kalb et al. (2011; phylogeny), Kirk et al. (2013; genus accepted), Lücking et al. (2016b; classification), sequences are available, holotype of type: CHR (2757).

Mallochia Arx \& Samson 1986, Gymnoascaceae, Onygenales, Eurotiomycetes, four species, type: M. echinulata (B.G. Dutta \& G.R. Ghosh) Arx \& Samson, asexual morph unknown, saprobes, paleotropical, see Lumbsch and Huhndorf (2010; outline, accepted in Onygenaceae), Kirk et al. (2013; genus accepted), cultures and sequences are unavailable, available specimen for type: CBS H-6703, needs generic revision.

Malmeomyces Starbäck 1899, Niessliaceae, Hypocreales, Sordariomycetes, one species, type: M. pulchellus Starbäck, asexual morph unknown, terrestrial, saprobes, see Lumbsch and Huhndorf (2010; outline), Kirk et al. (2013; genus accepted), cultures and sequences are unavailable.

Malmidea Kalb, Rivas Plata \& Lumbsch 2011, Malmideaceae, Lecanorales, Lecanoromycetes, 50 species, type: $M$. piperis (Spreng.) Kalb, Rivas Plata \& Lumbsch, ascomata apotheciate, conidiomata pycnidial, lichen-forming, mostly on bark, pantropical, see Kalb et al. (2011; phylogeny), Miądlikowska et al. (2014; phylogeny), Lücking et al. (2016b; classification), cultures and sequences are available, needs generic revision.

Malmographina M. Cáceres, Rivas Plata \& Lücking 2012, Graphidaceae, Ostropales, Lecanoromycetes, one species, type: M. plicosa (C.F.W. Meissn.) M. Cáceres, Rivas Plata \& Lücking, asexual morph unknown, lichenized, terrestrial, pantropical, see Cáceres et al. (2012a; taxonomy), Lumbsch et al. (2014a, b; phylogeny), Lücking et al. (2016b; classification), cultures and sequences are available, needs generic revision. 
Malthomyces K.D. Hyde \& P.F. Cannon 1999, Phyllachoraceae, Phyllachorales, Sordariomycetes, one species, type: M. calamigena (Berk. \& Broome) K.D. Hyde \& P.F. Cannon, asexual morph unknown, saprobes, terrestrial, India, Sri Lanka, see Lumbsch and Huhndorf (2010; outline), Kirk et al. (2013; genus accepted), Maharachchikumbura et al. (2015, 2016; outline), cultures and sequences are unavailable, needs generic revision, needs generic revision.

Mamiania Ces. \& De Not. 1863, Gnomoniaceae, Diaporthales, Sordariomycetes, three species, type: M. fimbriata (Pers.) Ces. \& De Not., asexual morph unknown, saprobes, terrestrial, North temperate, see Lumbsch and Huhndorf (2010; outline), Kirk et al. (2013; genus accepted), Maharachchikumbura et al. (2015, 2016; outline, phylogeny), cultures and sequences are unavailable, needs generic revision, needs generic revision.

Mamianiella Höhn. 1917, Diaporthales genera incertae sedis, Sordariomycetes, three species, type: M. coryli (Batsch) Höhn., asexual morph unknown, saprobes, terrestrial, Europe, North America, see Sogonov et al. (2008; accepted as Diaporthales), Lumbsch and Huhndorf (2010; outline, accepted asa genus in Gnomoniaceae), Kirk et al. (2013; genus accepted), Maharachchikumbura et al. (2015, 2016; outline, accepted as Diaporthales), cultures and sequences are available, available specimen and cultures for the type: CBS H14211, BPI 877578.

Mamillisphaeria K.D. Hyde, S.W. Wong \& E.B.G. Jones 1996, Melanommataceae, Pleosporales, Dothideomycetes, one species, type: M. dimorphospora K.D. Hyde, S.W. Wong \& E.B.G. Jones, asexual morph unknown, saprobes, terrestrial, Australia, see Lumbsch and Huhndorf (2010; outline), Hyde et al. (2013; accepted as a genus in Melanommataceae), Wijayawardene et al. (2014c; outline), Tian et al. (2015; accepted as a genus in Melanommataceae), holotype of the type: BRIP 22967, cultures and sequences are unavailable.

Mammaria Ces. ex Rabenh. 1854 (= Pseudocercophora Subram. \& Sekar 1986 fide Réblová et al. 2016c), Lasiosphaeriaceae, Sordariales, Sordariomycetes, two species, type: $M$. echinobotryoides Ces., sexual morph unknown, saprobes, terrestrial, Europe, North America, see Seifert et al. (2011; morphology), Wijayawardene et al. (2012, 2017; outline), Kirk et al. (2013; genus accepted), Maharachchikumbura et al. (2015, 2016; outline), cultures and sequences are unavailable, available specimen for type: CBS H-14212.

Manglicola Kohlm. \& E. Kohlm. 1971, Manglicolaceae, Jahnulales, Dothideomycetes, two species, type: M. guatemalensis Kohlm. \& E. Kohlm., asexual morph unknown, saprobes, marine, Brunei, Guatemala, Thailand, see Jones et al. (2009b, 2015; classification), Suetrong et al. (2010, 2011a; morphology, phylogeny), Jones et al. (2012; morphology, phylogeny), Hyde et al. (2013; morphology, phylogeny), Shearer et al. (2014; phylogeny), Wijayawardene et al. (2014c; outline), cultures and sequences are available, holotype and ex-isotype strain of type species J.K. Nos. 2700 (NY), J.K. 2700a (IMS).

Mangoldia Lücking, Parnmen \& Lumbsch 2012, Graphidaceae, Ostropales, Lecanoromycetes, two species, type: M. australiana Lücking, Parnmen \& Lumbsch, asexual morph unknown, lichenized, terrestrial, Australia, see Lücking et al. (2012, 2014; taxonomy), Lumbsch et al. (2014a, b; phylogeny), sequences are available, holotype: CANB, Mangold $27 \mathrm{zB}$.

Mangrovispora K.D. Hyde \& Nakagiri 1991, Sordariomycetes genera incertae sedis, two species, type: $M$. pemphii K.D. Hyde \& Nakagiri, asexual morph unknown, saprobes, marine, Australia, Hong Kong, see Lumbsch and Huhndorf (2010; outline), Kirk et al. (2013; genus accepted), Jones et al. (2015; accepted as Phyllachorales), Maharachchikumbura et al. (2015, 2016; outline), cultures and sequences are available (unpublished), holotype of the type: BRIP 17112. 
Manoharachariella Bagyan., N.K. Rao \& Kunwar 2009, Tubeufiaeae, Tubeufiales, Dothidiomycetes, four species, type: M. lignicola Bagyan., N.K. Rao \& Kunwar, sexual morph unknown, saprobes, terrestrial, Asia and Turkey, see Bagyanarayana et al. (2009; established genera), Rajeshkumar and Singh (2012; new species), Faruk et al. (2014; new species), Doilom et al. (2016; new species), cultures and sequences are available for $M$. tectonae, holotype of type: IMI 296857.

Manokwaria K.D. Hyde 1993, Amphisphaeriaceae, Xylariales, Sordariomycetes, one species, type: Manokwaria notabilis K.D. Hyde, asexual morph unknown, saprobes, fresh water, Indonesia, see Lumbsch and Huhndorf (2010; outline), Kirk et al. (2013; genus accepted), cultures and sequences are unavailable, holotype of the type: BRIP 20854, needs generic revision.

Mapletonia B. Sutton 1991, Ascomycota genera incertae sedis, one species, type: M. falcata B. Sutton, coelomycetous, sexual morph unknown, saprobes, terrestrial, Australia, see Wijayawardene et al. (2012, 2017; outline), Kirk et al. (2013; genus accepted), cultures and sequences are unavailable, holotype of the type species IMI $263431 \mathrm{a}$.

Marasasiomyces Crous 2015, Botryosphaeriaceae, Botryosphaeriales, Dothideomycetes, one species, type: M. karoo (B. Sutton \& Marasas) Crous, coelomycetous, sexual morph unknown, saprobes, terrestrial, South Africa, see Crous et al. (2015b; taxonomy, phylogeny), Wijayawardene et al. (2017; outline), holotype and ex-isotype culture of the type: PREM 44967, CBS 118718.

Marcelaria Aptroot, Nelsen \& Parnmen 2013, Trypetheliaceae, Trypetheliales, Dothideomycetes, three species, type: M. purpurina (Nyl.) Aptroot, Nelsen \& Parnmen, asexual morph unknown, lichenized, terrestrial, worldwide, see Aptroot et al. (2013b; taxonomy), Nelsen et al. (2014b; DNA, phylogeny), Luangsuphabool et al. (2016; DNA, phylogeny), cultures and sequences are available, holotype and cultures available for the type species 236 (PC), MPN323A (fide Nelsen et al. 2014).

Marcelleina Brumm., Korf \& Rifai 1967, Pezizaceae, Pezizales, Pezizomycetes, one species, type: M. persoonii (P. Crouan \& H. Crouan) Brumm., asexual morph unknown, hypogeous, terrestrial, worldwide, see Lantieri and Pfister (2010; new species), Lumbsch and Huhndorf (2010; outline), Kirk et al. (2013; genus accepted), Rubio et al. (2011; new species, Spain), cultures and sequences are available, cultures available for type: TL-5696, needs generic revision.

Marchantiana S.Y. Kondr., Kärnefelt, Elix, A. Thell \& Hur 2014, Teloschistaceae, Teloschistales, Lecanoromycetes, three species, type: M. occidentalis (Elix, S. Y. Kondr. \& Kärnefelt) S.Y. Kondr., Kärnefelt, Elix, A. Thell, J. Kim, A.S. Kondr. \& Hur, asexual morph unknown, lichenized, terrestrial, Australia, see Kondratyuk et al. (2014, 2015b; taxonomy), Lücking et al. (2016b; classification), cultures and sequences are available, holotype and available cultures of the type: CANB Elix 32479, SK981 and SK982.

Margaritispora Ingold 1942, Helotiales genera incertae sedis, one species, type: M. aquatica Ingold, hyphomycetous, sexual morph unknown, saprobes, aquatic, cosmopolitan, see Seifert et al. (2011; morphology), Wijayawardene et al. (2012, 2017; outline), Kirk et al. (2013; genus accepted), cultures and sequences are available, needs generic revision.

Mariannaea G. Arnaud ex Samson 1974, Nectriaceae, Hypocreales, Sordariomycetes, five species, type: Mariannaea elegans (Corda) Samson, asexual morph hyphomycetous, terrestrial, saprobes and in soil, Asia, see Gräfenhan et al. (2011; phylogeny), Lombard et al. (2015b; phylogeny), cultures and sequences are available, holotype of type species in herb. Corda (as Penicillium elegans).

Marielliottia Shoemaker 1999, Pleosporaceae, Pleosporales, Dothideomycetes, three species, type: P. nolinae A.W. Ramaley, hyphomycetous, sexual morph unknown, saprobes, terrestrial, cosmopolitan, see Seifert et al. (2011; morphology, accepted AY004786 (DAOM 
208987) as the ITS barcode), Wijayawardene et al. (2012, 2014c, 2017; outline), Ariyawansa et al. (2015c; accepted as a genus in Phaeosphaeriaceae), cultures and sequences are available.

Marinokulati E.B.G. Jones \& K.L. Pang 2014, Juncigenaceae, Torpedosporales, Sordariomycetes, one species, type: M. chaetosa (Kohlm.) E.B.G. Jones \& K.L. Pang, saprobes, marine, temperate, asexual morph unknown, see Jones et al. (2014, 2015; morphology, phylogeny; outline), cultures and sequences are available.

Marinosphaera K.D. Hyde 1989, Phyllachoraceae, Phyllachorales, Sordariomycetes, one species, type: M. mangrovei K.D. Hyde, asexual morph unknown, saprobes, terrestrial, Brunei, see Jones et al. (2009b, 2015; phylogeny, outline), Lumbsch and Huhndorf (2010; outline), Kirk et al. (2013; genus accepted), Maharachchikumbura et al. (2015, 2016; outline), cultures and sequences are unavailable, holotype of the type: IMI 325412, needs generic revision.

Marinospora A.R. Caval 1966, Halosphaeriaceae, Microascales, Sordariomycetes, two species, type: M. calyptrata (Kohlm.) A.R. Caval., asexual morph unknown, saprobes, marine, Argentina, Belgium, Denmark, France, Germany, Scotland, Iceland, Spain, USA, Canada, see Lumbsch and Huhndorf (2010; outline), Sakayaroj et al. (2011a; phylogeny), Kirk et al. (2013; genus accepted), Jones et al. (2015; outline), cultures and sequences are available, needs generic revision.

Marisolaris Jørgen Koch \& E.B.G. Jones 1989, Sordariomycetes genera incertae sedis, one species, type: M. ansata Jørg. Koch \& E.B.G. Jones, asexual morph unknown, marine, temperate, on wood associated with sand, see Lumbsch and Huhndorf (2010; outline, accepted as a genus in Ascomycota genera incertae sedis), Kirk et al. (2013; genus accepted), Jones et al. (2015; outline), no sequence data, needs generic revision.

Maronea A.Massal. 1856, Fuscideaceae, Umbilicariales, Lecanoromycetes, 13 species, type: M. berica A. Massal., lichenized, worldwide, see Lumbsch and Huhndorf (2010; outline), Bendiksby and Timdal (2013; phylogeny), Kirk et al. (2013; genus accepted), Miądlikowska et al. (2014a; phylogeny), Lücking et al. (2016b; classification), cultures and sequences are available, needs generic revision.

Maronella M. Steiger 1959, Lecanoromycetes genera incertae sedis, one species, type: $M$. laricina M. Steiner, lichenized, temperate northern hemisphere, see Lumbsch and Huhndorf (2010; outline), Kirk et al. (2013; genus accepted), Lücking et al. (2016b; classification), cultures and sequences are unavailable, needs generic revision.

Marthamyces Minter 2003, Marthamycetaceae, Rhytismatales, Leotiomycetes, nine species, type: $M$. emarginatus (Cooke \& Massee) Minter, asexual morph unknown, saprobes, terrestrial, worldwide, see Lumbsch and Huhndorf (2010; outline), Kirk et al. (2013; genus accepted), Lantz et al. (2011; DNA, phylogeny), cultures and sequences are available.

Martinellisia V.G. Rao \& Varghese 1977, Ascomycota genera incertae sedis, one species, type: $M$. indica V.G. Rao \& Varghese, hyphomycetous, sexual morph unknown, saprobes, terrestrial, India, see Seifert et al. (2011; morphology), Wijayawardene et al. (2012, 2017; outline), Kirk et al. (2013; genus accepted), cultures and sequences are unavailable, needs generic revision.

Martininia Dumont \& Korf 1970, Sclerotiniaceae, Helotiales, Leotiomycetes, ten species, type: $M$. panamaensis Dumont \& Korf, asexual morph unknown, saprobes, terrestrial, worldwide, see Lumbsch and Huhndorf (2010; outline), Kirk et al. (2013; genus accepted), cultures and sequences are unavailable.

Martiniozyma Kurtzman 2015, Pichiaceae, Saccharomycetales, Saccharomycetes, two species, type: M. abiesophila (Kurtzman) Kurtzman, asexual reproduction is by multilateral budding, saprophytic, water, soil, fruit, sap of red fir, worldwide, see Kurtzman (2015; taxonomy), cultures and sequences are available. 
Martinjahnsia S.Y. Kondr., Fedorenko, S. Stenroos, Kärnefelt, Elix, J.S. Hur \& A. Thell 2012, Teloschistaceae, Teloschistales, Lecanoromycetes, ten species, type: M. resendei (Poelt \& C. Tav.) S.Y. Kondr., Fedorenko, S. Stenroos, Kärnefelt, Elix, J.S. Hur \& A. Thell, asexual morph unknown, lichenized, terrestrial, worldwide, see Fedorenko et al. (2012; taxonomy), cultures and sequences are unavailable.

Masonhalea Kärnefelt 1977, Parmeliaceae, Lecanorales, Lecanoromycetes, two species, type: $M$. richardsonii (Hook.) Kärnefelt, lichenized, Arctic, see Lumbsch and Huhndorf (2010; outline), Kirk et al. (2013; genus accepted), Lücking et al. (2016b; classification), sequences are available, needs generic revision.

Massalongia Körb. 1855, Massalongiaceae, Peltigerales, Lecanoromycetes, two species, type: M. carnosa (Dicks.) Körb., lichenized, worldwide, see Lumbsch and Huhndorf (2010; outline), Kirk et al. (2013; genus accepted), Lücking et al. (2016b; classification), sequences are available, needs generic revision.

Massalongina Bubák 1916, Ascomycota genera incertae sedis, one species, type: M. aquilina (C. Massal.) Bubák, coelomycetous, sexual morph unknown, saprobes, terrestrial, Europe, see Wijayawardene et al. (2012, 2017; outline), Kirk et al. (2013; genus accepted), cultures and sequences are unavailable, needs generic revision.

Massaria De Not. 1844, Massariaceae, Pleosporales, Dothideomycetes, 31 species, type: $M$. inquinans (Tode) De Not., asexual morph coelomycetous, saprobes or weak parasitic, terrestrial, northern temperate climate zone, see Lumbsch and Huhndorf (2010; outline), Voglmayr and Jaklitsch (2011; taxonomy, phylogeny), Hyde et al. (2013, 2016; taxonomy, phylogeny), Kirk et al. (2013; genus accepted), Wijayawardene et al. (2014c; outline), sequence data available for 17 species, holotype of type species WU 30526.

Massarina Sacc. 1883, Massarinaceae, Pleosporales, Dothideomycetes, c. 100 species, type: M. eburnea (Tul. \& C. Tul.) Sacc., asexual morph coelomycetous, saprobes, terrestrial, worldwide, see Zhang et al. (2009a, b; taxonomy, phylogeny), Lumbsch and Huhndorf (2010; outline), Hyde et al. (2013; taxonomy, phylogeny), Kirk et al. (2013; genus accepted), Wijayawardene et al. (2014c; outline), Tanaka et al (2015; taxonomy, phylogeny), cultures and sequences are available.

Massariola Füisting 1868, Dothideomycetes genera incertae sedis, two species, type: need typification, asexual morph unknown, saprobes, terrestrial, Europe, see Lumbsch and Huhndorf (2010; outline), Kirk et al. (2013; genus accepted), Wijayawardene et al. (2014c; outline), cultures and sequences are unavailable, needs generic revision.

Massariosphaeria (E. Müll.) Crivelli 1983, Pleosporales genera incertae sedis, Dothideomycetes, 25 species, type: M. phaeospora (E. Müll.) Crivelli, asexual morph unknown, saprobes, terrestrial, worldwide, see Schoch et al. (2009; DNA, phylogeny), Lumbsch and Huhndorf (2010; outline, accepted as a genus in Lophiostomataceae), Tanaka et al. (2011b; new species, Pakistan), Hyde et al. (2013; excluded from Lophiostomataceae) Kirk et al. (2013; genus accepted), Thambugala et al. (2015b; excluded from Lophiostomataceae), Wijayawardene et al. (2014c; outline, accepted as a genus in Pleosporales), cultures available for the type: CBS 611.86 (fide Schoch et al. 2009), needs generic revision.

Massariothea Syd. 1939, Ascomycota genera incertae sedis, eight species, type: $M$. themedae Syd., coelomycetous, sexual morph unknown, saprobes, terrestrial, Europe, see Wijayawardene et al. (2012, 2016b, 2017; outline, taxonomy), Kirk et al. (2013; genus accepted), cultures and sequences are unavailable, needs generic revision.

Massariovalsa Sacc. 1882 (= Melanconiopsis Ellis \& Everh. fide Rossman et al. 2015a), Melanconidaceae, Diaporthales, Sordariomycetes, four species, type: M. sudans (Berk. \& M.A. Curtis) Sacc., asexual morph unknown, saprobes, terrestrial, worldwide, see Lumbsch and Huhndorf (2010; outline), Kirk et al. (2013; genus accepted), Maharachchikumbura et al. 
(2015, 2016; outline), cultures and sequences are unavailable, available specimen for type: CBS H-14272, needs generic revision.

Masseea Sacc. 1889, Helotiales genera incertae sedis, Leotiomycetes, one species, type: $M$. quisquiliarum (Berk. \& M.A. Curtis) Sacc., asexual morph unknown, saprobes, terrestrial, North America, see Lumbsch and Huhndorf (2010; outline), Kirk et al. (2013; genus accepted), cultures and sequences are unavailable.

Mastigosporella Höhn. 1914 (= Wuestneiopsis J. Reid \& Dowsett 1990 fide Rossman et al. 2015a), Cryphonectriaceae, Diaporthales, Sordariomycetes, four species, type: M. hyalina (Ellis \& Everh.) Höhn., asexual morph coelomycetous, pathogens, saprobes, terrestrial, worldwide, see Crous et al. (2013b; new species), Kirk et al. (2013; genus accepted), Maharachchikumbura et al. (2015, 2016; outline), Rossman et al. (2015a; nomenclature), Wijayawardene et al. (2017; outline), cultures and sequences are available but lack for the type, needs generic revision.

Mastigosporium Riess 1852, Helotiales genera incertae sedis, Leotiomycetes, four species, type: . album Riess, coelomycetous, sexual morph unknown, pathogens, terrestrial, temperate, see Kirk et al. (2013; genus accepted), Crous et al. (2014a; taxonomy, epitypification, phylogeny), cultures and sequences are available but lacks for the type species, needs generic revision.

Mastodia Hook.f. \& Harv. 1847, Verrucariaceae, Verrucariales, Eurotiomycetes, five species, type: M. tessellata (Hook. f. \& Harv.) Hook. f. \& Harv., lichenized, Southern hemisphere, especially Anctartica, see Lumbsch and Huhndorf (2010; outline, accepted as a genus in Mastodiaceae), Pérez-Ortega et al. (2010; phylogeny), Kirk et al. (2013; genus accepted), Lücking et al. (2016b; classification), cultures and sequences are available, needs generic revision.

Matsushimaea Subram. 1978, Ascomycota genera incertae sedis, three species, type: $M$. fasciculata (Matsush.) Subram., sexual morph unknown, saprobes, terrestrial, Asia, North America, Africa, see Hyde et al. (2011; checklist), Rambelli (2011; Mediterranean), Seifert et al. (2011; morphology), Wijayawardene et al. (2012, 2017; outline), Kirk et al. (2013; genus accepted), cultures and sequences are unavailable.

Matsushimamyces Rahul Sharma \& Rohit Sharma 2015, Latoruaceae, Pleosporales, Dothideomycetes, one species, type: M. bohaniensis Rahul Sharma, Rohit Sharma \& Crous, hyphomycetous, keratinophilic, from soil, India, see Sharma et al. (2015; taxonomy), Wijayawardene et al. (2017; outline), cultures and sequences are available.

Matsushimiella R.F. Castañeda \& Heredia 2001, Ascomycota genera incertae sedis, two species, type: M. queenslandica (Matsush.) R.F. Castañeda \& Heredia, hyphomycetous, sexual morph unknown, saprobes, terrestrial, Australia, see Hyde et al. (2011; checklist), Seifert et al. (2011; morphology), Hernández-Restrepo et al. (2012a; new species), Wijayawardene et al. (2012, 2017; outline), Monteiro et al. (2015a; new species, Brazil), holotype of type: MFC-8A063, cultures and sequences are unavailable, compare with Minimelanolocus, Nigrolentilocus, Pseudospiropes and Spiropes.

Matsushimomyces V.G. Rao \& Varghese 1979, Ascomycota genera incertae sedis, two species, type: M. indicus V.G. Rao \& Varghese, hyphomycetous, sexual morph unknown, saprobes, terrestrial, Asia, see Seifert et al. (2011; morphology), Wijayawardene et al. (2012, 2017; outline), Kirk et al. (2013; genus accepted), cultures and sequences are unavailable, needs generic revision.

Matsusporium E.B.G. Jones \& K.L. Pang 2010, Lulworthiaceae, Lulworthiales, Sordariomycetes, one species, type: M. tropicale (Kohlm.) E.B.G. Jones \& K.L. Pang, hyphomycetous, sexual morph unknown, saprobes, marine, pantropical, see Abdel-Wahab et al. (2010; phylogeny), cultures and sequences are available, holotype of type: IMI 325412. 
Mattirolella S. Colla 1929, Kathistaceae, Ophiostomatales, Sordariomycetes, one species, type: M. silvestrii S. Colla, saprobes, Africa, see Wijayawardene et al. (2012, 2017; outline), Kirk et al. (2013; genus accepted), Maharachchikumbura et al. (2015, 2016; outline), cultures and sequences are unavailable, needs generic revision.

Mattirolia Berl. \& Bres. 1889, Thyridiaceae, Sordariomycetes family incertae sedis, one species, type: M. roseovirens Berl. \& Bres., saprobes, Africa, see Lumbsch and Huhndorf (2010; outline), Checa et al. (2013; new species), Kirk et al. (2013; genus accepted), Maharachchikumbura et al. (2015, 2016; outline), sequences and cultures are unavailable, epitype of type: WU 32154.

Mattirolomyces E. Fisch. 1938, Pezizaceae, Pezizales, Pezizomycetes, one species, type: M. terfezioides (Mattir.) E. Fisch., asexual morph unknown, hypogeous, terrestrial, worldwide, see Trappe et al. (2010; DNA), Kovács et al. (2011b; DNA, new combination), Kirk et al. (2013; genus accepted), cultures and sequences are available, needs generic revision.

Maublancia G. Arnaud 1918, Dothideomycetes genera incertae sedis, one species, type: $M$. myrtacearum G. Arnaud, asexual morph unknown, saprobes, terrestrial, South America, South Africa, see Lumbsch and Huhndorf (2010; outline, accepted in Microthyriaceae), Wu et al. (2011; excluded from Microthyriaceae), Hyde et al. (2013; excluded from Microthyriaceae), Wijayawardene et al. (2014c, accepted in Dothideomycetes), cultures and sequences are unavailable, available specimen of type: CBS H-14276.

Mauginiella Cavara 1925, Phaeosphaeriaceae, Pleosporales, Dothideomycetes, one species, type: M. scaettae Cavara, asexual morph unknown, saprobes, pathogens, terrestrial, South America, South Africa, see Seifert et al. (2011; morphology), Abdullah et al. (2015; pathogens), Wijayawardene et al. (2017; outline), cultures and sequences are available, needs generic revision.

Mauritiana Poonyth, K.D. Hyde, Aptroot \& Peerally 2000, Halotthiaceae, Pleosporales, Dothideomycetes, one species, type: M. rhizophorae Poonyth, K.D. Hyde, Aptroot \& Peerally, asexual morph unknown, saprobes, marine, see Alias and Jones (2009; monograph), Suetrong et al. (2009; phylogeny, morphology), Jones et al. (2009b, 2015; outline, marine), Zainuddin et al. (2010; antimicrobial activities), Lee et al. (2012; checklist, Malaysia), Zhang et al. (2012e; phylogeny, morphology), Hyde et al. (2013; phylogeny), Wijayawardene et al. (2014c; outline),cultures and sequences are available, holotype of type: HKU(M) 10219.

Mawsonia C.W.Dodge 1948, Lichinaceae, Lichinales, Lichinomycetes, one species, type: $M$. harrissonii C.W. Dodge, lichenized, Brazil, Antarctica, see Lumbsch and Huhndorf (2010; outline), Lücking et al. (2016b; classification), cultures and sequences are unavailable.

Mazaediothecium Aptroot 1991, Pyrenulaceae, Pyrenulales, Eurotiomycetes, three species, type: M. rubiginosum Aptroot, asexual morph unknown, lichenized, terrestrial, Papua New Guinea, Costa Rica, Malaysia, see Lumbsch and Huhndorf (2010; outline), Kirk et al. (2013; genus accepted), Lücking et al. (2016b; classification), Cultures and sequences are available, holotype of type: Aptroot (17464).

Mazosia A. Massal. 1854, Roccellaceae, Arthoniales, Arthoniomycetes, 27 species, type: M. rotula (Mont.) A. Massal., sexual morph with apothecioid ascomata, asexual morph coelomycetous, lichenized, rarely lichenicolous, terrestrial, tropical to subtropical regions, see Lücking (2008, morphology), Lumbsch and Huhndorf (2010; outline), Kirk et al. (2013; genus accepted), Ertz et al. (2015b, c; phylogeny), Frisch et al. (2014; phylogeny), Lücking et al. (2016b; classification), sequence data available for a few species, holotype of species unavailable.

Mazzantia Mont. 1855 (= Mazzantiella Höhn. 1925 fide Rossman et al. 2015a), Diaporthaceae, Diaporthales, Sordariomycetes, four species, type: M. galii (Fr.) Mont., asexual morph coelomycetous, saprobes, terrestrial, Europe, America, see Sogonov et al. (2008; DNA, phylogeny), Lumbsch and Huhndorf (2010; outline), Kirk et al. (2013; genus 
accepted), Maharachchikumbura et al. (2015, 2016; outline), cultures and sequences are available for the type: AR4658 (fide Udayanga et al. 2014).

Mebarria J. Reid \& C. Booth 1989, Melanconidaceae, Diaporthales, Sordariomycetes, two species, type: M. thujina (Nag Raj \& DiCosmo) J. Reid \& C. Booth, asexual morph unknown, saprobes, terrestrial, USA, see Lumbsch and Huhndorf (2010; outline), Kirk et al. (2013; genus accepted), Maharachchikumbura et al. (2015, 2016; outline), cultures and sequences are unavailable, needs generic revision.

Medeolaria Thaxt. 1922, Medeolariaceae, Medeolariales, Leotiomycetes, one species, type: M. farlowii Thaxt., asexual morph unknown, saprobes, terrestrial, North America, see Lumbsch and Huhndorf (2010; outline), Kirk et al. (2013; genus accepted), Jaklitsch et al. (2016a; classification), cultures and sequences are unavailable, needs generic revision.

Medusamyces G.L. Barron \& Szijarto 1990, Ascomycota genera incertae sedis, two species, type: M. lunulosporus G.L. Barron \& Szijarto, hyphomycetous, sexual morph unknown, on rotifers, aquatic, Canada, see Seifert et al. (2011; morphology), Wijayawardene et al. (2012, 2017; outline), Kirk et al. (2013; genus accepted), cultures and sequences are unavailable, holotype of the type: OAC 10845.

Megacapitula J.L. Chen \& Tzean 1993, Ascomycota genera incertae sedis, two species, type: M. villosa J.L. Chen \& Tzean, hyphomycetous, sexual morph unknown, saprobes, terrestrial, Asia, see Prabhugaonkar and Bhat (2011; record in India, phylogeny), Seifert et al. (2011; morphology), Wijayawardene et al. (2012, 2017; outline), Kirk et al. (2013; genus accepted), holotype and cultures available for the type: PPH17, GUFCC 15515.

Megalaria Hafellner 1984, Ramalinaceae, Lecanorales, Lecanoromycetes, 29 species, type: M. grossa (Pers. ex Nyl.) Hafellner, lichenized, worldwide, see Ekman et al. (2008; Ancestral state reconstructions), Schmull et al. (2011; phylogeny), Miądlikowska et al. (2014a; phylogeny), Lücking et al. (2016b; classification), cultures and sequences are available, needs generic revision.

Megaloblastenia Sipman 1983, Megalosporaceae, Teloschistales, Lecanoromycetes, two species, type: M. flavidoatra (Nyl.) Sipman, lichenized, Australia, New Zealand, see Lumbsch and Huhndorf (2010; outline), Kirk et al. (2013; genus accepted), Lücking et al. (2016b; classification), cultures and sequences are available, needs generic revision.

Megalodochium Deighton 1960, Ascomycota genera incertae sedis, four species, type: $M$. palmicola Deighton, hyphomycetous, sexual morph unknown, saprobes, pathogens, terrestrial, China, India, Sierra Leone (tropical Africa), see Tiwari and Rai (2009; morphology), Wijayawardene et al. (2012, 2017; outline), Zhao and Zhao (2012; morphology), Crous et al. (2015d; compare with Melanconium), cultures and sequences are unavailable, needs generic revision.

Megalohypha A. Ferrer \& Shearer 2007, Aliquandostipitaceae, Jahnulales, Dothideomycetes, one species, type: M. aqua-dulces A. Ferrer \& Shearer, freshwater, Panama, Thailand, see Suetrong et al. (2011a; phylogeny), cultures and sequences are available, holotype of type: AF005 ILL.

Megaloseptoria Naumov 1925, Ascomycota genera incertae sedis, one species, type: $M$. mirabilis Naumov, coelomycetous, sexual morph unknown, saprobes, terrestrial, Russia, see Kirk et al. (2013; genus accepted), Wijayawardene et al. (2017; outline), cultures and sequences are unavailable, needs generic revision.

Megalospora Meyen 1843, Megalosporaceae, Teloschistales, Lecanoromycetes, 35 species, type: $M$. sulphurata Meyen, lichenized, tropical and warm temperate zones, see Lumbsch and Huhndorf (2010; outline), Kantvilas and Lumbsch (2012; phylogeny), Kirk et al. (2013; genus accepted), Lücking et al. (2016b; classification), cultures and sequences are available, needs generic revision. 
Megalotremis Aptroot 1991, Monoblastiaceae, Monoblastiales, Dothideomycetes, twelve species, type: $M$. verrucosa (Makhija \& Patw.) Aptroot, asexual morph unknown, lichenized, terrestrial, tropical, India, Costa Rica, Sri Lanka, see Nelsen et al. (2009, 2011; phylogeny), Lumbsch and Huhndorf (2010; outline), Kirk et al. (2013; genus accepted), Lücking et al. (2016b; classification), cultures available for type: MPN104 (fide Nelsen et al. 2011), needs generic revision.

Megaspora (Clauzade \& Cl. Roux) Hafellner \& V.Wirth 1987, Megasporaceae, Pertusariales, Lecanoromycetes, three species, type: M. verrucosa (Ach.) Hafellner \& V. Wirth, lichenized, Austria, Iran, Armenia, see Lumbsch and Huhndorf (2010; outline), Valadbeigi et al. (2011a; new species), Kirk et al. (2013; genus accepted), Lücking et al. (2016b; classification), Zakeri et al. (2016; new species), cultures and sequences are available, needs generic revision.

Meionomyces Thaxt. 1931, Laboulbeniaceae, Laboulbeniales, Laboulbeniomycetes, six species, type: $M$. asteni Thaxt., asexual morph unknown, biotrophic, terrestrial, tropical, see Lumbsch and Huhndorf (2010; outline), Kirk et al. (2013; genus accepted), cultures and sequences are unavailable.

Melanamphora Lafl. 1976, Melanconidaceae, Diaporthales, Sordariomycetes, two species, type: M. spinifera (Wallr.) Lafl., asexual morph unknown, saprobes, terrestrial, worldwide, see Lumbsch and Huhndorf (2010; outline), Kirk et al. (2013; genus accepted), Maharachchikumbura et al. (2015, 2016; outline), cultures and sequences are unavailable, needs generic revision.

Melanconiella Sacc. 1882, Melanconidaceae, Diaporthales, Sordariomycetes, two species, type: M. spodiaea (Tul. \& C. Tul.) Sacc., asexual morph discosporina-like and melanconiumlike, saprobes, terrestrial, worldwide, see Lumbsch and Huhndorf (2010; outline), Voglmayr et al. (2012; taxonomy, phylogeny, asexual morph, typification), Kirk et al. (2013; genus accepted), Maharachchikumbura et al. (2015, 2016; outline), Crous et al. (2016a; new species, phylogeny), cultures and sequences are available, cultures available for type species SPOD1, SPOD, MVS, MSH (fide Voglmayr et al. 2012), needs generic revision.

Melanconis Tul. \& C. Tul. 1863 (= Melanconium Link 1809 fide Rossman et al. 2015a), Melanconidaceae, Diaporthales, Sordariomycetes, c. 100 species, type: M. stilbostoma (Fr.) Tul. \& C. Tul., asexual morph forrmerly known in Melanconium, saprobes, USA, see Lumbsch and Huhndorf (2010; outline), Kirk et al. (2013; genus accepted), Maharachchikumbura et al. (2015, 2016; outline), Wijayawardene et al. (2016b, 2017; taxonomy of Melanconium, outline), cultures and sequences are available.

Melanelia Essl. 1978, Parmeliaceae, Lecanorales, Lecanoromycetes, six species, type: Melanelia stygia (L.) Essl., lichenized, worldwide, see Lumbsch and Huhndorf (2010; outline), Kirk et al. (2013; genus accepted), Lücking et al. (2016b; classification), cultures and sequences are available, needs generic revision.

Melanelixia O. Blanco, A. Crespo, Divakar, Essl., D. Hawksw. \& Lumbsch 2004, Parmeliaceae, Lecanorales, Lecanoromycetes, eight species, type: M. glabra (Schaer.) O. Blanco, A. Crespo, Divakar, Essl., D. Hawksw. \& Lumbsch (syn. Parmelia olivacea f. glabra Schaer.), lichenized, widespread, terrestrial, see Lumbsch and Huhndorf (2010; outline), Jaklitsch et al. (2016a; position), Lücking et al. (2016b; classification), cultures and sequences are available, lectotype of type species G.

Melanocamarosporium Wijayaw., Camporesi, D.J. Bhat \& K.D. Hyde 2016, Melanommataceae, Pleosporales, Dothideomycetes, one species, type: M. galicola Wijayaw., Camporesi, D.J. Bhat \& K.D. Hyde, coelomycetous, sexual morph unknown, saprobes, terrestrial, Italy, see Wijayawardene et al. (2016b, 2017; taxonomy, phylogeny, outline), holotype and ex-type culture of the type: MFLU 15-3451, MFLUCC 13-0545. 
Melanocarpus Arx 1975, Lasiosphaeriaceae, Sordariales, Sordariomycetes, three species, type: M. albomyces (Cooney \& R. Emers.) Arx, asexual morph unknown, saprobes, terrestrial, worldwide, see Lumbsch and Huhndorf (2010; outline, accepted in Sordariales), Kirk et al. (2013; genus accepted), Maharachchikumbura et al. (2015, 2016; outline), van den Brink et al. (2015; thermophilic nature), cultures and sequences are available.

Melanocephala S. Hughes 1979, Ascomycota genera incertae sedis, five species, type: $M$. cupulifera S. Hughes, hyphomycetous, sexual morph unknown, saprobes, terrestrial, cosmopolitan, see Seifert et al. (2011; morphology), Wijayawardene et al. (2012, 2017; outline), Kirk et al. (2013; genus accepted), cultures and sequences are unavailable, needs generic revision.

Melanodothis R.H. Arnold 1972, Mycosphaerellaceae, Capnodiales, Dothideomycetes, one species, type: Melanodothis caricis R.H. Arnold, asexual morph ramularia-like, terrestrial, Asia, see Lumbsch and Huhndorf (2010; outline), Kirk et al. (2013; genus accepted), Hyde et al. (2013; accepted as a genus in Mycosphaerellaceae), Wijayawardene et al. (2014c; outline), cultures and sequences are unavailable, needs generic revision.

Melanographium Sacc. 1913, Sordariomycetes genera incertae sedis, nine species, type: $M$. spleniosporum Sacc., hyphomycetous, sexual morph unknown, saprobes, terrestrial, worldwide, see Wijayawardene et al. (2012, 2017; outline), Kirk et al. (2013; genus accepted), Maharachchikumbura et al. (2015, 2016; outline), cultures and sequences are unavailable, needs generic revision.

Melanohalea O. Blanco, A. Crespo, Divakar, Essl., D. Hawksw. \& Lumbsch 2004, Parmeliaceae, Lecanorales, Lecanoromycetes, 19 species, type: M. exasperata (De Not.) O. Blanco, A. Crespo, Divakar, Essl., D. Hawksw. \& Lumbsch (syn. Parmelia exasperata De Not.), lichenized, widespread, terrestrial, see Jaklitsch et al. (2016a; position), Lücking et al. (2016b; classification), cultures and sequences are available, holotype of type species RO.

Melanolecia Hertel 1981, Hymeneliaceae, Hymeneliales, Lecanoromycetes, eight species, type: M. transitoria (Arnold) Hertel, asexual morph unknown, lichenized, terrestrial, worldwide, see Lumbsch and Huhndorf (2010; outline), Kirk et al. (2013; genus accepted), Lücking et al. (2016b; classification), cultures and sequences are available, cultures available for the type: Meltra167, needs generic revision.

Melanomma Nitschke ex Fuckel 1870, Melanommataceae, Pleosporales, Dothideomycetes, c. 30 species, type: $M$. pulvis-pyrius (Pers.) Fuckel, asexual morph unknown, see Lumbsch and hunduf (2010; outline), Hyde et al. (2013; accepted as a genus in Melanommataceae), Kirk et al. (2013; genus accepted), Wijayawardene et al. (2014c; outline), cultures available for type: CBS 371.75, CBS 109.77, CBS 124080, CBS 371.75.

Melanopeziza Velen. 1939, Helotiales genera incertae sedis, Leotiomycetes, one species, type: $M$. artemisiae Velen., asexual morph unknown, saprobes, terrestrial, former Czechoslovakia, see Lumbsch and Huhndorf (2010; outline), Kirk et al. (2013; genus accepted), cultures and sequences are unavailable.

Melanophloea P.James \& Vězda 1971, Ascomycota genera incertae sedis, one species, type: M. pacifica P. James \& Vězda, lichenized, Mid-Atlantic region of eastern North America, see Lumbsch and Huhndorf (2010; outline, accepted as a genus in Thelocarpaceae), Aptroot and Schumm (2012b; evolution), Kirk et al. (2013; genus accepted), Lücking et al. (2016b; classification), cultures and sequences are unavailable, needs generic revision.

Melanophoma Papendorf \& J.W. du Toit 1967, Ascomycota genera incertae sedis, one species, type: $M$. karroo Papendorf \& G.W. du Toit, coelomycetous, sexual morph unknown, saprobes, terrestrial, South Africa, see Wijayawardene et al. (2012, 2017; outline), cultures and sequences are unavailable, needs generic revision.

Melanops Nitschke ex Fuckel 1870, Melanopsaceae, Botryosphaeriales, Dothideomycetes, one species, type: M. tulasnei Fuckel, asexual morph coelomycetous, saprobes, terrestrial, 
cosmopolitan, see Phillips and Alves (2009; taxonomy, phylogeny), Kirk et al. (2013; genus accepted), Slippers et al. (2014; phylogeny, introduced of a new family Melanopsaceae), Wijayawardene et al. (2014c; outline, phylogeny), epitype and ex-epitype of the type: LISE 95179, CBS 116805.

Melanopsamma Niessl 1876, Stachybotriaceae, Hypocreales, Sordariomycetes, c. 40 species, type: M. pomiformis (Pers.) Sacc., asexual morph custingophora-like, saprobes, terrestrial, widespread, see Lumbsch and Hunduf (2010; outline, accepted as a genus in Niessliaceae), Kirk et al. (2013; genus accepted), Wang et al. (2015e; phylogeny), Maharachchikumbura et al. (2015, 2016; outline), Lombard et al. (2016; phylogeny), cultures available for type: CBS 114119, CBS 325.50, CBS 114119, CBS 101322.

Melanormia Körb. 1865, Leotiomycetes genera incertae sedis, one species, type: M. velutina Körb., asexual morph unknown, saprobes, terrestrial, Germany, see Lumbsch and Huhndorf (2010; outline), Kirk et al. (2013; genus accepted), cultures and sequences are unavailable.

Melanospora Corda 1836 (= Gonatobotrys Corda 1839 fide Réblová et al. 2016c), Ceratostomataceae, Melanosporales, Sordariomycetes, 35 species, type: Melanospora zamiae Corda, asexual morphs formerly named in Gonatobotrys, saprobes, from soil, fungicolous, terrestrial, worldwide, see Lumbsch and Huhndorf (2010; outline), Fan et al. (2012a; species from China), Kirk et al. (2013; genus accepted), Maharachchikumbura et al. (2015, 2016; outline), Réblová et al. (2016c; nomenclature), cultures and sequences are available.

Melanotopelia Lumbsch \& Mangold 2008, Graphidaceae, Ostropales, Lecanoromycetes, four species, type: $M$. toensbergii (Vězda \& Kantvilas) Lumbsch \& Mangold, asexual morph unknown, lichenized, terrestrial, worldwide, see Mangold et al. (2008a; taxonomy), Sérusiaux et al. (2009a; new species, Rwanda), Lumbsch and Huhndorf (2010; outline), Lumbsch et al. (2010a, 2015; new species, Falkland Island, accepted in Graphidaceae), Rivas Plata et al. (2012; accepted in Graphidaceae), Lücking et al. (2016b; classification), cultures and sequences are available but lacks for the type species, holotype of the type species BG, Tønsberg 25545 (holotype of Topeliopsis toensbergii Kantvilas \& Vězda).

Melanotrema Frisch 2006, Graphidaceae, Ostropales, Lecanoromycetes, eleven species, type: M. platystomum (Mont.) Frisch, asexual morph unknown, lichenized, terrestrial, worldwide, see Mangold et al. (2009; new species, Australia), Lumbsch and Huhndorf (2010; outline), Papong et al. (2010; new species), Rivas Plata et al. (2013; DNA, phylogeny), Kraichak et al. (2014; new species), Sipman (2014; new species), Lumbsch et al. (2015; accepted in Graphidaceae), Lücking et al. (2016b; classification), cultures and sequences are available, cultures available for the type: DNA3492, needs generic revision.

Melanotrigonum Réblová 2015, Pleurotheciaceae, Pleurotheciales, Sordariomycetes, one species, type: $M$. ovale Réblová, asexual morph hyphomycetous, saprobes, terrestrial, Czech Republic, see Maharachchikumbura et al. (2015, 2016; outline), Réblová et al. (2017; taxonomy), holotype and ex-type: PRM 933852, CBS 138743.

Melarthonis Frisch \& G. Thor 2014, Chrysotrichaceae, Arthoniales, Arthoniomycetes, one species, type: Melarthonis piceae Frisch \& G. Thor, asexual morph unknown, saprobes, terrestrial, see Frisch et al. (2014a; taxonomy), Lücking et al. (2016b; classification), holotype of the type: UPS, Thor 25995, sequences are available.

Melaspilea Nyl. 1857, Melaspileaceae, Eremithallales, Dothideomycetes, 163 species, type: M. arthonioides (A. Massal.) Nyl., asexual morph unknown, saprobes, marine and terrestrial, worldwide, see Jones et al. (2009b, 2015; classification), Pérez-Ortega and Etayo (2010; morphology), Zainuddin et al. (2010; antimicrobial activities), Zhurbenko and Zhdanov (2013; morphology), Flakus et al. (2014; morphology), Ertz and Diederich (2015; phylogeny), Perlmutter et al. (2015; morphology), Lücking et al. (2016b; classification), sequences are available but lacks for the type, needs generic revision. 
Melaspileopsis (Müll. Arg.) Ertz \& Diederich 2015, Melaspileaceae, Eremithallales, Dothideomycetes, one species, type: M. diplasiospora (Nyl.) Ertz \& Diederich, sexual morph with lirelliform ascomata, saprobes, terrestrial, tropical and subtropical, see Ertz and Diederich (2015; morphology, phylogeny), Ertz et al. (2016, phylogeny), sequences are available, lectotype of the type: Lindig 846 (PC0146198).

Melastiza Boud. 1885, Pyronemataceae, Pezizales, Pezizomycetes, 14 species, type: M. miniata (Fuckel) Boud., asexual morph unknown, saprobes, terrestrial, worldwide, see Lumbsch and Huhndorf (2010; outline), Kirk et al. (2013; genus accepted), cultures and sequences are available but lacks for the type species, needs generic revision.

Melchioria Penz. \& Sacc 1897, Niessliaceae, Hypocreales, Sordariomycetes, six species, type: M. leucomelaena Penz. \& Sacc., asexual morph unknown, terrestrial, saprobes, Indonesia and South America, cultures and sequences are unavailable, Holotype and ex-type strain unavailable.

Meliniomyces Hambl. \& Sigler 2005, Hyaloscyphaceae, Helotiales, Leotiomycetes, three species, type: M. variabilis Hambl. \& Sigler, hyphomycetous, sexual morph unknown, saprobes, terrestrial, Europe, North America, see Seifert et al. (2011; morphology), Wijayawardene et al. (2012, 2017; outline), Jaklitsch et al. (2016a; classification), cultures and sequences are available.

Meliola Fr. 1825, Meliolaceae, Meliolales, Sordariomycetes, c. 1300, type: M. nidulans (Schwein.) Cooke, asexual morph produced from the hyphae, saprobes, terrestrial, worldwide, see Lumbsch and Huhndorf (2010; outline), Kirk et al. (2013; genus accepted), Hongsanan et al. (2015c; taxonomy), Maharachchikumbura et al. (2015, 2016; outline), cultures and sequences are unavailable, needs generic revision.

Meliolaster Höhn. 1918, Asterinaceae, Asterinales, Dothideomycetes, three species, type: $M$. clavisporus (Pat.) Höhn., asexual morph unknown, epiphytes, terrestrial, worldwide, see Hofmann (2009; review), Lumbsch and Huhndorf (2010; outline), Hyde et al. (2013; accepted as a genus in Asterinaceae), Wijayawardene et al. (2014c; outline), Hongsanan et al. (2014c; taxonomy, keys), cultures and sequences unavailable, holotype of type: FH 258798.

Meliolina Syd. \& P. Syd. 1914, Meliolinaceae, Dothideomycetes, families incertae sedis, c. 40 species, type: $M$. cladotricha (Lév.) Syd. \& P. Syd., asexual morph unknown, saprobes, terrestrial, worldwide, see Lumbsch and Huhndorf (2010; outline), Hyde et al. (2013; listed the family under excluded, doubtful and poorly known families), Kirk et al. (2013; genus accepted), Wijayawardene et al. (2014c; outline), cultures and sequences are available, needs generic revision.

Melioliphila Speg. 1921, Dothideomycetes genera incertae sedis, Incertae sedis, , seven species, type: M. graminicola (F. Stevens) Speg., asexual morph unknown, saprobes, terrestrial, worldwide, see Lumbsch and Huhndorf (2010; outline, accepted in Tubeufiaceae), Hyde et al. (2013; excluded from Tubeufiaceae), Boonmee et al. (2014b; excluded from Tubeufiaceae), Kirk et al. (2013; genus accepted), Wijayawardene et al. (2014c; outline), cultures and sequences are unavailable, needs generic revision.

Mellitiosporiella Höhn. 1919, Marthamycetaceae, Rhytismatales, Leotiomycetes, two species, type: M. pulchella Höhn., asexual morph unknown, saprobes, terrestrial, Europe, North America, see Kirk et al. (2013; genus accepted), Index Fungorum (2015), Jaklitsch et al. (2016a; classification), cultures and sequences are available, needs generic revision.

Mellitiosporium Corda 1838, Marthamycetaceae, Rhytismatales, Leotiomycetes, one species, type: $M$. versicolor Corda, asexual morph unknown, saprobes, terrestrial, Java, see Lumbsch and Huhndorf (2010; outline, accepted as Rhytismatales, genera incertae sedis), Lantz et al. (2011; phylogeny), Kirk et al. (2013; genus accepted), cultures and sequences are available.

Melnikia Wijayaw., Goonas., D.J. Bhat \& K.D. Hyde, 2016, Phaeosphaeriacea, Pleosporales, Dothideomycetes, one species, type: M. anthoxanthii Wijayaw., Goonas., 
Camporesi, D.J. Bhat \& K.D. Hyde, coelomycetous, sexual morph unknown, saprobes, terrestrial, Italy, see Wijayawardene et al. (2016b, 2017; taxonomy, phylogeny, outline), holotype and ex-type culture of the type: MFLU 15-2657, MFLUCC 14-1010.

Melnikomyces Crous \& U. Braun 2014, Chaetothyriales genera incertae sedis, Eurotiomycetes, one species, type: M. vietnamensis Crous \& U. Braun, hyphomycetous, sexual morph unknown, saprobes, terrestrial, Vietnam, see Crous et al. (2014; taxonomy, phylogeny), Wijayawardene et al. (2017; outline), holotype and ex-type strain of type: CBS H-21715, CPC 23554.

Meloderma Darker 1967, Rhytismataceae, Rhytismatales, Leotiomycetes, nine species, type: M. desmazieri (Duby) Darker, asexual morph unknown, saprobes, pathogens, terrestrial, worldwide, see Lumbsch and Huhndorf (2010; outline), Kirk et al. (2013; genus accepted), Lantz et al. (2011; DNA, phylogeny), cultures and sequences are available.

Melogramma Fr. 1849, Melogrammataceae, Xylariales, Sordariomycetes, three species, type: M. campylosporum Fr., asexual morph unknown, saprobes, Europe, see Lumbsch and Huhndorf (2010; outline, accepted in Melanconidaceae), Jaklitsch and Voglmayr. (2012; phylogeny, accepted in Melogrammataceae), Kirk et al. (2013; genus accepted), Senanayake et al. (2015; outline, phylogeny), Maharachchikumbura et al. (2016; outline, phylogeny), cultures and sequences are available, needs generic revision.

Melomastia Nitschke ex Sacc. 1875, Sordariomycetes genera incertae sedis, four species, type: $M$. friesii Nitschke, asexual morph unknown, saprobes, terrestrial, worldwide, see Lumbsch and Huhndorf (2010; outline), Kirk et al. (2013; genus accepted), Maharachchikumbura et al. (2015, 2016; outline), cultures and sequences are unavailable, needs generic revision.

Melophia Sacc. 1884, Ascomycota genera incertae sedis, four species, type: M. ophiospora (Lév.) Sacc., asexual morph unknown, saprobes, terrestrial, worldwide, see Wijayawardene et al. (2012, 2017; outline), Kirk et al. (2013; genus accepted), cultures and sequences are unavailable, needs generic revision.

Memnoniella Höhn. 1923, Stachybotriaceae, Hypocreales, Sordariomycetes, twelve species, type: M. echinata (Riv.) Galloway (三 Penicillium echinatum Riv.), hyphomycetous, sexual morph unknown, saprobes, terrestrial, South Africa, see Seifert et al. (2011; synonym of Stachybotrys), Wang et al. (2015e; synonym of Stachybotrys), Lombard et al. (2016; reinstated the genus, phylogeny), Wijayawardene et al. (2017; outline), Cultures and sequences are available, epitype and ex-epitype culture of type species CBS H-22447, CBS 216.32

Mendogia Racib. 1900, Schizothyriaceae, Dothideomycetes family incerte sedis, four species, type: M. bambusina Racib. , asexual morph unknown, epiphytic, terrestrial, Indonesia, Philippine, Thailand, see Lumbsch and Huhndorf (2010; outline), Kirk et al. (2013; genus accepted), Hyde et al. (2013; accepted as a genus in Schizothyriaceae), Wijayawardene et al. (2014c; outline), cultures and sequences are unavailable, needs generic revision.

Mendoziopeltis Bat. 1959, Dothideomycetes genera incertae sedis, four species, type: $M$. byrsonimae Bat. \& Nascim. ex Bat., asexual morph unknown, saprobes, terrestrial, worldwide, see Lumbsch and Huhndorf (2010; outline, accepted as Micropeltidaceae), Hyde et al. (2013; excluded from Micropeltidaceae), Kirk et al. (2013; genus accepted), Wijayawardene et al. (2014c; outline, accepted as a genus Dothideomycetes), cultures and sequences are unavailable, needs generic revision.

Menegazzia A. Massal. 1854, Parmeliaceae, Lecanorales, Lecanoromycetes, 70 species, type: M. terebrata (Hoffm.) A. Massal., lichenized, worldwide, see Lumbsch and Huhndorf (2010; outline), Kirk et al. (2013; genus accepted), Lücking et al. (2016b; classification), cultures and sequences are available, needs generic revision. 
Menidochium R.F. Castañeda \& W.B. Kendr. 1990, Ascomycota genera incertae sedis, one species, type: $M$. formosum R.F. Castañeda \& W.B. Kendr., hyphomycetous, sexual morph unknown, saprobes, terrestrial, Caribbean, see Seifert et al. (2011; morphology), Wijayawardene et al. (2012, 2017; outline), Kirk et al. (2013; genus accepted), cultures and sequences are unavailable, needs generic revision.

Menispora Pers. 1822 (= Zignoëlla sacc. 1878 fide Réblová et al. 2016c), Chaetosphaeriaceae, Chaetosphaeriales, Sordariomycetes, 14 species, type: Melomastia friesii Nitschke, hyphomycetous, sexual morph formerly named in Zignoëlla, saprobes, terrestrial, temperate, see Seifert et al. (2011; morphology), Wijayawardene et al. (2012, 2017; outline), Kirk et al. (2013; genus accepted), Maharachchikumbura et al. (2015, 2016; outline), Réblová et al. (2016; nomenclature), cultures and sequences are unavailable, needs generic revision.

Menisporopsis S. Hughes 1952 (= Menisporopascus Matsush. 2003 fide Réblová et al. 2016c), Chaetosphaeriaceae, Chaetosphaeriales, Sordariomycetes, nine species, type: Menisporopsis theobromae S. Hughes, hyphomycetous, sexual morph formerly named in Menisporopascus, saprobes, terrestrial, temperate, see Seifert et al. (2011; morphology), Wijayawardene et al. (2012, 2017; outline), Kirk et al. (2013; genus accepted), Maharachchikumbura et al. (2015, 2016; outline), Réblová et al. (2016c; nomenclature), cultures and sequences are available, available specimen of type: CBS H-19592.

Mercadomyces J. Mena 1988, Ascomycota genera incertae sedis, one species, type: $M$. camagueyensis J. Mena, hyphomycetous, sexual morph unknown, saprobes, terrestrial, Caribbean, see Seifert et al. (2011; morphology), Wijayawardene et al. (2012, 2017; outline), Kirk et al. (2013; genus accepted), cultures and sequences are unavailable, needs generic revision.

Meridianelia Kantvilas \& Lumbsch 2009, Elixiaceae, Umbilicariales, Lecanoromycetes, one species, type: $M$. maccarthyana Kantvilas \& Lumbsch, lichenized, corticolous, Tasmania, see Kantvilas and Lumbsch (2010; outline), Bendiksby and Timdal (2013; phylogeny), Miądlikowska et al. (2014a; phylogeny), Lücking et al. (2016b; classification), cultures and sequences are available.

Merismatium Zopf 1898, Verrucariaceae, Verrucariales, Eurotiomycetes, eleven species, type: M. lopadii (Anzi) Zopf, asexual morph unknown, lichenicolous, terrestrial, Europe, Asia, see Lumbsch and Huhndorf (2010; outline), Kirk et al. (2013; genus accepted), Yazici and Aslan (2016; Asia, Turkey), cultures and sequences are unavailable.

Merismella Syd. 1927, Ascomycota genera incertae sedis, six species, type: M. concinna Syd., sexual morph Chaetothyrium Speg., epiphytic, terrestrial, Brazil, Greece, India, Panama, see Wijayawardene et al. (2012, 2017; outline), Kirk et al. (2013; genus accepted), cultures and sequences are unavailable, needs generic revision.

Meristemomyces Isola \& Onofri 2014, Teratosphaeriacae, Capnodiales, Dothideomycetes, one species, type: $M$. frigidus Isola \& Onofri, hyphomycetous, sexual morph unknown, rockinhabiting fungus, see Egidi et al. (2014; taxonomy), Quaedvlieg et al. (2014; phylogeny), Wijayawardene et al. (2017; outline), Crous et al. (2016b; new species), cultures available for the type: CBS $136109=$ CCFEE 5508.

Merodontis Clem. 1909, Helotiales genera incertae sedis, Leotiomycetes, one species, type: M. tenella (Penz. \& Sacc.) Clem., asexual morph unknown, saprobes, terrestrial, Java, see Lumbsch and Huhndorf (2010; outline), Kirk et al. (2013; genus accepted), cultures and sequences are unavailable, needs generic revision.

Merugia Rogerson \& Samuels 1990, Sordariomycetidae genera incertae sedis, seven species, type: M. palicoureae Rogerson \& Samuels, saprobes, terrestrial, Guyana, see Lumbsch and Huhndorf (2010; outline), Maharachchikumbura et al. (2015, 2016; outline), cultures and sequences are unavailable, holotype of the type: NY, Samuels 6552, needs generic revision. 
Mesniera Sacc. \& P. Syd. 1902, Mesnieraceae, Dothideomycetes family incertae sedis, one species, type: M. rottlerae (Racib.) Sacc. \& P. Syd., asexual morph unknown, saprobes, terrestrial, Java, see Lumbsch and Huhndorf (2010; outline), Hyde et al. (2013; taxonomy), Kirk et al. (2013; genus accepted), Wijayawardene et al. (2014c; outline), cultures and sequences are unavailable, available specimen of type: CBS H-4212, needs generic revision.

Metacapnodium Speg. 1918 (= Antennularia Rchb. 1828; = Capnocybe S. Hughes 1966; = Capnophialophora S. Hughes 1966; = Capnobotrys S. Hughes 1970; Capnosporium S. Hughes 1976 fide Rossman et al. 2016a), Metacapnodiaceae, Capnodiales, Dothideomycetes, 13 species, type: M. juniperi (W. Phillips \& Plowr.) Speg., asexual morph unknown, sooty mould on living plants, terrestrial, worldwide, see Lumbsch and Huhndorf (2010; outline), Hughes et al. (2012; morphology), Hyde et al. (2013; accepted as a genus in Metacapnodiaceae), Kirk et al. (2013; genus accepted), Wijayawardene et al. (2014c; outline), Rossman et al. (2016a; nomenclature), cultures and sequences are unavailable, needs generic revision.

Metacoleroa Petr. 1927, Venturiaceae, Venturiales, Dothideomycetes, one species, type: M. dickiei (Berk. \& Broome) Petr., asexual morph unknown, saprobes, terrestrial, worldwide, see Kirk et al. (2008; treated as a synonym of Venturia Sacc.), Lumbsch and Huhndorf (2010; outline), Raja et al. (2011a; DNA), Zhang et al. (2011d; morphology, phylogeny), Hyde et al. (2013; accepted as in Venturiaceae, phylogeny), Wijayawardene et al. (2014c; outline), cultures and sequences are available.

Metacordyceps G.H. Sung, J.M. Sung, Hywel-Jones \& Spatafora 2007, Clavicipitaceae, Hypocreales, Sordariomycetes, 16 species, type: M. taii (Z.Q. Liang \& A.Y. Liu) G.H. Sung, J.M. Sung, Hywel-Jones \& Spatafora, asexual morph hyphomycetous, terrestrial, entomogenous and in soil and dung, cosmopolitan, see Lumbsch and Huhndorf (2010; outline), Kepler et al. (2012a; sexual morph), Maharachchikumbura et al. (2015, 2016; outline), cultures and sequences are available.

Metadiplodia Syd. 1937, Ascomycota genera incertae sedis, c. 40 species, type: M. eucalypti Syd., coelomycetous, sexual morph unknown, saprobes, terrestrial, worlwide, see Wijayawardene et al. (2012, 2017; outline), Kirk et al. (2013; genus accepted), cultures and sequences are unavailable, needs generic revision.

Metadothella Henn. 1904, Hypocreales genera incertae sedis, Sordariomycetes, one species, type: M. stellata Henn., asexual morph hyphomycetous, terrestrial, Peru, see Lumbsch and Huhndorf (2010; outline), Kirk et al. (2013; genus accepted), Maharachchikumbura et al. (2015, 2016; phylogeny), cultures and sequences are unavailable, holotype and ex-type strain not available.

Metahyphopichia Sipiczki \& Pfliegler 2016, Saccharomycetaceae, Saccharomycetales, Saccharomycetes, one species, type: M. laotica Sipiczki, Pfliegler, Safar, Morais, \& Rosa, dimorphic, asexual morph unknown, on plants, terrestrial, Southeast Asia, South America, see Sipiczki et al. (2016; taxonomy), cultures and sequences are available.

Metamelanea Henssen 1989, Lichinaceae, Lichinales, Lichinomycetes, three species, type: $M$. umbonata Henssen, lichenized, asexual morph unknown, terrestrial, Europe, North America, see Kirk et al. (2013; genus accepted), Prieto et al. (2015; records in Sweden), Lücking et al. (2016b; classification), cultures and sequences are unavailable, needs generic revision.

Metameris Theiss. \& Syd. 1915, Botryosphaeriaceae, Botryosphaeriales, Dothideomycetes, three species, type: M. japonica (Syd. \& P. Syd.) Syd., asexual morph unknown, saprobes, terrestrial, worldwide, see Lumbsch and Huhndorf (2010; outline, accepted as a genus in Phaeosphaeriaceae), Kirk et al. (2013; genus accepted), Hyde et al. (accepted as a genus in Phaeosphaeriaceae), Phookamsak et al. (2014b; placed in Botryosphaeriaceae), Wijayawardene et al. (2014c; outline, accepted in Botryosphaeriaceae), cultures and sequences are unavailable, needs generic revision. 
Metapezizella Petr. 1968, Leotiomycetes genera incertae sedis, one species, type: $M$. phyllachorivora Petr., asexual morph unknown, saprobes, terrestrial, Mexico, see Lumbsch and Huhndorf (2010; outline), Kirk et al. (2013; genus accepted), cultures and sequences are unavailable.

Metapochonia Kepler, S.A. Rehner \& Humber 2014, Clavicipitaceae, Hypocreales, Sordariomycetes, five species, type: M. suchlasporia (W. Gams \& Dackman) Kepler, Rehner $\&$ Humber, asexual morph hyphomycetous, terrestrial, nematogenous and in soil, rotifers and plant roots, cosmopolitan, see Kepler et al. (2014; taxonomy), cultures and sequences are available, Holotype and ex-type of type species in Suecia, C. Dackman No. 10 (1983); CBS 251.83 .

Metarhiziopsis D.W. Li, R.S. Cowles, Vossbrinck 2008, Clavicipitaceae, Hypocreales, Sordariomycetes, one species, type: M. microspora D.W. Li, R.S. Cowles \& Vossbrinck, hyphomycetous, sexual morph unknown, terrestrial, entomogenous, USA, see Li et al. (2008b; taxonomy), Seifert et al. (2011; morphology), Wijayawardene et al. (2012, 2017; outline), cultures and sequences are available, holotype and ex-type of type: BPI $878276=$ UAMH 10901.

Metarhizium Sorokin 1879, Clavicipitaceae, Hypocreales, Sordariomycetes, 24 species, type: M. anisopliae (Metschn.) Sorokīn, hyphomycetous, sexual morph unknown, terrestrial, entomogenous and in soil, cosmopolitan, see Seifert et al. (2011; morphology), Wijayawardene et al. (2012, 2017; outline), Kepler et al. (2014; phylogeny), cultures and sequences are available.

Metathyriella Syd. 1927, Schizothyriaceae, Dothideomycetes family incertae sedis, three species, type: $M$. roupalae Syd., asexual morph unknown, saprobes, terrestrial, tropical, see Lumbsch and Huhndorf (2010; outline), Hyde et al. (2013, accepted as a genus in Schizothyriaceae), Kirk et al. (2013; genus accepted), Wijayawardene et al. (2014c; outline), Phookamsak et al. (2016; taxonomy), cultures and sequences are unavailable, needs generic revision.

Metazythia Petr. 1950, Ascomycota genera incertae sedis, one species, type: M. caespitosa Petr., coelomycetous, sexual morph unknown, saprobes, terrestrial, North America, see Wijayawardene et al. (2012, 2017; outline), Kirk et al. (2013; genus accepted), cultures and sequences are unavailable, needs generic revision.

Metazythiopsis M. Morelet 1988, Ascomycota genera incertae sedis, one species, type: $M$. halepensis M. Morelet, coelomycetous, sexual morph unknown, saprobes, terrestrial, France, see Wijayawardene et al. (2012, 2017; outline), Kirk et al. (2013; genus accepted), cultures and sequences are unavailable, needs generic revision.

Metschnikowia Kamienski 1899, Metschnikowiaceae, Saccharomycetales, Saccharomycetes, c. 100 species (including c. 50 Candida species in the Metschnikowia clade), type: $M$. bicuspidata (Metschnikoff) T. Kamienski, asexual reproduction is by multilateral budding, saprophytic, on beetles, fruit flies, rotted plants, berries, water, seawater, flowers of various plant species, worldwide, see Lumbsch and Huhndorf (2010; outline), Kirk et al. (2013; genus accepted), Crous et al. (2015d; new species, phylogeny), asexual species in this clade are classified in the genus Candida, but will be transferred to Metschnikowia as new combinations, sequences are available.

Metulocladosporiella Crous, Schroers, J.Z. Groenew., U. Braun \& K. Schub. 2006, Herpotrichiellaceae, Chaetothyriales, Eurotiomycetes, two species, type: M. musae (E.W. Mason) Crous, Schroers, J.Z. Groenew., U. Braun \& K. Schub., hyphomycetous, sexual morph unknown, saprobes, terrestrial, Africa, Neotropics, see Seifert et al. (2011; morphology), Xu et al. (2011; phylogeny), Wijayawardene et al. (2012, 2017; outline), cultures and sequences are available, needs generic revision. 
Metus D.J. Galloway \& P. James 1987, Cladoniaceae, Lecanorales, Lecanoromycetes, three species, type: M. conglomeratus (F. Wilson) D.J. Galloway \& P. James, asexual morph unknown, lichenized, terrestrial, Australasia, see Lumbsch et al. (2010b; DNA, phylogeny), Lumbsch and Huhndorf (2010; outline), Kirk et al. (2013; genus accepted), Miądlikowska et al. (2014; DNA, phylogeny), Lücking et al. (2016b, classification), cultures and sequences are available, cultures available for the type: AFTOL-ID 4945 (Miądlikowska et al. 2014), needs generic revision.

Meyerozyma Kurtzman \& M. Suzuki 2010, Debaryomycetaceae, Saccharomycetales, Saccharomycetes, five species, type: M. guilliermondii (Wickerham) Kurtzman \& M. Suzuki, asexual reproduction is by multilateral budding, saprophytic, but $M$. guilliermondii is a common clinical species, atmosphere, soil, water, sugar cane and other plants, plant debris, fruit, mammals, worldwide, see Kurtzman and Suzuki (2010; taxonomy), Bautista-Rosales et al. (2013; bio control agent of Colletotrichum sp.), Coda et al. (2013; antifungal properties), sequences are available.

Micarea Fr. [nom. cons.] 1825, Pilocarpaceae, Lecanorales, Lecanoromycetes, 100 species, type: M. prasina Fr., lichenized, worldwide, see Lumbsch and Huhndorf (2010; outline), Kirk et al. (2013; genus accepted), Lücking et al. (2016b; classification), cultures and sequences are available, needs generic revision.

Micareopsis R.C. Harris \& Lendemer 2013, Ramalinaceae, Lecanorales, Lecanoromycetes, three species, type: M. irriguata R.C. Harris \& Lendemer, asexual morph unknown, lichenized, terrestrial, USA, see Lendemer et al. (2013; taxonomy), cultures and sequences are unavailable, holotype of the type species NY, Buck 49935.

Micraspis Darker 1963, Tympanidaceae, Helotiales, Leotiomycetes, three species, type: M. acicola Darker, asexual morph unknown, saprobes, North America, British Isles, see Lumbsch and Hunduf (2010; outline), Kirk et al. (2013; genus accepted), Index Fungorum (2015; new family), cultures and sequences are available, needs generic revision.

Microascus Zukal 1886, Microascaceae, Microascales, Sordariomycetes, 51 species, type: M. longirostris Zukal, asexual morph hyphomycetous, coprophilous, on human, terrestrial, cosmopolitan, see Lumbsch and Huhndorf (2010; outline), Kirk et al. (2013; genus accepted), Maharachchikumbura et al. (2015, 2016; outline, phylogeny), Sandoval-Denis et al. (2016a; new species, phylogeny), Crous et al. (2016b; new species), Jagielski et al. (2016; new species, phylogeny), neotype and ex-neotype of type: CBS H-14440, MUCL 9058.

Microblastosporon Cif., 1930, Ascomycota genera incertae sedis, one species, type: $M$. botryoideum (Chaborski) Cif., hyphomycetous, saprobes or plant pathogenic, Europe, See Wijayawardene et al. (2012, 2017; outline), Kirk (2013; accepted as valid genus), cultures and sequences are unavailable, needs generic revision.

Microcalicium Vain. 1927, Microcaliciaceae, Ascomycota family Incertae sedis, four species, type: M. disseminatum (Ach.) Vain., asexual morph unknown, lichenicolous, terrestrial, worldwide, see Lumbsch and Huhndorf (2010; outline), Prieto et al. (2012; phylogeny), Kirk et al. (2013; genus accepted), culture for the type species (sequence data also deposited under this number) Wedin 6353 (Prieto et al. 2012), needs generic revision.

Microcallis Syd. 1926, Chaetothyriaceae, Chaetothyriales, Eurotiomycetes, ten species, type: M. phoebes Syd., asexual morph unknown, saprobes, terrestrial, tropical, see Lumbsch and Huhndorf (2010; outline), Kirk et al. (2013; genus accepted), cultures and sequences are unavailable.

Microcera Desm. 1848, Nectriaceae, Hypocreales, Sordariomycetes, nine species, type: $M$. coccophila Desm., asexual morph hyphomycetous, terrestrial, entomogenous, cosmopolitan, see Lumbsch and Huhndorf (2010; outline), Gräfenhan et al. (2011; phylogeny), Kirk et al. (2013; genus accepted), Lombard et al. (2015b; phylogeny), Maharachchikumbura et al. (2015, 2016; outline), cultures and sequences are available, lectotype of type: K(M) 165807. 
Microclava F. Stevens 1917, Ascomycota genera incertae sedis, six species, type: $M$. miconiae F. Stevens, hyphomycetous, saprobes or plant pathogenic, pantropical, see Seifert et al. (2011; morphology), Wijayawardene et al. (2012, 2017; outline), Kirk (2013; genus accepted), cultures and sequences are unavailable, needs generic revision.

Microcyclella Theiss. 1914, Dothideomycetes genera incertae sedis, one species, type: $M$. nervisequia (Höhn.) Theiss., asexual morph unknown, saprobes, terrestrial, Africa, see Lumbsch and Huhndorf (2010; outline), Kirk et al. (2013; genus accepted), Wijayawardene et al. (2014c; outline), cultures and sequences are unavailable, needs generic revision.

Microcyclephaeria Bat. 1958, Hypocreales, genera incertae sedis, one species, type: $M$. palmicola (Syd.) Bat. \& H. Maia ex Bat., asexual morph unknown, saprobes, terrestrial, Australia, see Lumbsch and Huhndorf (2010; outline, accepted as a genus in Sordariomycetes genera incertae sedis), Kirk et al. (2013; genus accepted), Maharachchikumbura et al. (2015, 2016; outline), cultures and sequences are unavailable, needs generic revision.

Microcyclospora J. Frank, Schroers \& Crous 2010, Teratosphaeriaceae, Capnodiales, Dothideomycetes, seven species, type: M. pomicola J. Frank, B. Oertel, Schroers \& Crous, hyphomycetous, sexual morph unknown, saprobes, terrestrial, Europe, Canada, Iran, see Frank et al. (2010; taxonomy, phylogeny), Arzanlou and Bakhshi (2011; new species), Seifert et al. (2011; morphology), Crous et al. (2012c; new species, phylogeny), Wijayawardene et al. (2012, 2017; outline), Kirk et al. (2013; genus accepted), cultures and sequences are availabl.

Microcyclosporella J. Frank, Schroers \& Crous 2010, Mycosphaerellaceae, Capnodiales, Dothideomycetes, one species, type: M. mali J. Frank, Schroers \& Crous, hyphomycetous, sexual morph unknown, plant pathogenic, epiphytic, Slovenia, see Frank et al. (2010; morphology, phylogeny), Seifert et al. (2011; morphology), Wijayawardene et al. (2012, 2017; outline), cultures and sequences are available, holotype and ex-type of type: CBS H20413; CBS 126136.

Microcyclus Sacc., Syd. \& P. Syd. 1904, Dothideomycetes genera incertae sedis, c. 15 species, type: M. angolensis Sacc., Syd. \& P. Syd., asexual morph unknown, pathogen, saprobes, endophytes, see Lumbsch and Hunduf (2010; outline), Kirk et al. (2013; genus accepted), Wijayawardene et al. (2014c; outline), cultures and sequences are unavailable for type species, needs generic revision.

Microdiplodia Allesch. 1901, Ascomycota genera incertae sedis, 30 species, type: $M$. conigena Allesch., sexual morph unknown, saprobes, terrestrial, Europe, Canada, Iran, see Wijayawardene et al. (2016b; outline, taxonomic notes and treated as doubtful), cultures and sequences are available, need generic revision and epitypification.

Microdiscula Höhn. 1915, Ascomycota genera incertae sedis, two species, type: $M$. rubicola (Bres.) Höhn., coelomycetous, sexual morph unknown, saprobes or plant pathogenic, North America, see Wijayawardene et al. (2012, 2017; outline), Kirk (2013; genus accepted); cultures and sequences are unavailable, needs generic revision.

Microdiscus Sacc. 1916, Helotiales genera incertae sedis, Leotiomycetes, one species, type: M. americanus (Sacc.) Trotter, asexual morph unknown, saprobes, terrestrial, North America, see Lumbsch and Huhndorf (2010; outline), Kirk et al. (2013; genus accepted), cultures and sequences are unavailable.

Microdochiella M. Hern.-Restr. \& Crous 2016, Orbiliales, genera incertae sedis, Orbiliomycetes, one species, type: M. fusarioides (D.C. Harris) M. Hern.-Restr. \& Crous, hyphomycetous, sexual morph unknown, fungicolous, see Hernández-Restrepo et al. (2016; taxonomy, phylogeny), Wijayawardene et al. (2017; outline), holotype and ex-type culture of the type: IMI 281715, CBS 741.83.

Microdochium Syd. \& P. Syd. 1924 (= Monographella Petr. 1924 fide Réblová et al. 2016c), Microdochiaceae, Xylariales, Sordariomycetes, 25 species, type: M. phragmitis Syd., 
hyphomycetous, sexual morph formerly named in Monographella, saprobes, terrestrial, worldwide, see Seifert et al. (2011; morphology), Wijayawardene et al. (2012, 2017; outline), Kirk et al. (2013; genus accepted), Maharachchikumbura et al. (2015, 2016; outline), Hernández-Restrepo et al. (2016b; phylogeny, introduced Microdochiaceae), Réblová et al. (2016c; nomenclature), holotype and epitype of the type: K-IMI 193888, CBS H-22135, exepitype culture CBS 285.71.

Microdothella Syd. \& P. Syd. 1914, Dothideomycetes genera incertae sedis, two species, type: M. culmicola Syd. \& P. Syd., asexual morph unknown, saprobes, terrestrial, North America, Philippines, see Lumbsch and Huhndorf (2010; outline), Kirk et al. (2013; genus accepted), Wijayawardene et al. (2014c; outline), cultures and sequences are unavailable, needs generic revision.

Microdothiorella C.A.A. Costa \& Sousa da Câmara 1955, Ascomycota genera incertae sedis, one species, type: M. sphaeralceae M.E.A. Costa \& Sousa da Câmara, hyphomycetous, sexual morph unknown, saprobes, terrestrial, Portugal, see Wijayawardene et al. (2012, 2017; outline), Kirk et al. (2013; genus accepted), cultures and sequences are unavailable, needs generic revision.

Microeurotium Ghatak 1936, Pezizales genera incertae sedis, Pezizomycetes, two species, type: M. albidum Ghatak, asexual morph unknown, saprobes or coprophilous, terrestrial, UK, see Lumbsch and Huhndorf (2010; outline), Kirk et al. (2013; genus accepted), cultures and sequences are unavailable, needs generic revision.

Microglossum Gillet 1879, Leotiaceae, Helotiales, Leotiomycetes, ten species, type: $M$. olivaceum (Pers.) Gillet, asexual morph unknown, saprobes, on soil, terrestrial, worldwide, see Schoch et al. (2009; phylogeny), Lumbsch and Huhndorf (2010; outline), Kirk et al. (2013; genus accepted), Kucera et al. (2014; new species, phylogeny), Pärtel et al. (2017; phylogeny), cultures and sequences are available for the type species SAV 9902 (Kucera et al. 2014) and KL220, needs generic revision.

Microhendersonula Dias \& Sousa da Câmara 1952, Ascomycota genera incertae sedis, one species, type: $M$. cestri Dias \& Sousa da Câmara, coelomycetous, saprobes or plant pathogenic, Portugal, see Wijayawardene et al. (2012, 2017; outline), Kirk (2013; genus accepted), cultures and sequences are unavailable, needs generic revision.

Microhilum H.Y. Yip \& A.C. Rath 1989, Cordycipitaceae, Hypocreales, Sordariomycetes, one species, type: M. oncoperae H.Y. Yip \& A.C. Rath, hyphomycetous, terrestrial, entomogenous, Australia, see Hyde et al. (2011; checklist), Wijayawardene et al. (2011; checklist), Kirk et al. (2013; genus accepted), Maharachchikumbura et al. (2015, 2016; Sordariomycetes), cultures and sequences are available, holotype of type species DATH 64D6.

Microidium (To-anun \& S. Takam.) To-anun \& S. Takam. 2012, Erysiphaceae, Erysiphales, Leotiomycetes, four species, type: M. phyllanthi (J.M. Yen) To-anun \& S. Takam. (三Oidium phyllanthi J.M. Yen), hyphomycetous, sexual morphs unknown, biotrophic, obligate plant pathogens, terrestrial, Asia, South America, see Braun and Cook (2012; taxonomy), Tam et al. (2015; Vietnam), cultures and sequences are available, needs generic revision.

Micromastia Speg. 1909, Ascomycota genera incertae sedis, two species, type: $M$. trigonospora Speg., asexual morph unknown, saprobes, on soil, terrestrial, worldwide, see Lumbsch and Huhndorf (2010; outline), Kirk et al. (2013; genus accepted), cultures and sequences are unavailable, needs generic revision.

Micronectria Speg. 1885, Hyponectriaceae, Xylariales, Sordariomycetes, one species, type: M. guaranitica Speg., asexual morph unknown, saprobes, see Kirk et al. (2008; treated as nom. dub.), Lumbsch and Huhndorf (2010; outline), Kirk et al. (2013; did not list), Maharachchikumbura et al. (2015, 2016; outline), cultures and sequences are available. 
Micronematobotrys Xiang Sun \& L.D. Guo 2010, Pyronemataceae, Pezizales, Pezizomycetes, 14 species, type: M. verrucosus Xiang Sun \& L.D. Guo, hyphomycetous, sexual morph unknown, saprobes, terrestrial, China, see Sun and Guo (2010; taxonomy, phylogeny), Wijayawardene et al. (2012, 2017; outline), cultures and sequences are available, holotype and cultures available for type species HMAS 186049; E13-2151.

Micropeltis Mont. 1842, Micropeltidaceae, Microthyriales, Dothideomycetes, c. 110 species, type: M. applanata Mont., asexual morph unknown, epiphytes, terrestrial, worldwide, see Lumbsch and Huhndorf (2010; outline), Hyde et al. (2013; accepted as a genus in Micropeltidaceae), Wijayawardene et al. (2014c; outline), Hongsanan et al. (2015a; new species), cultures and sequences are unavailable.

Microperella Höhn. 1909, Ascomycota genera incertae sedis, one species, type: M. quercus Höhn., coelomycetous, sexual morph unknown, saprobes, terrestrial, Japan, see Wijayawardene et al. (2012, 2017; outline), Kirk et al. (2013; genus accepted), cultures and sequences are unavailable, needs generic revision.

Micropeziza Fuckel 1870 (= Actinoscypha P. Karst. 1888; = Calloriella Höhn. 1918; = Crustomollisia Svrček 1987 [1986]; = Niesslella Höhn. 1919 [1918] fide Jaklitsch et al. 2016a; Species Fungorum 2017), Pezizellaceae, Helotiales, Leotiomycetes, twelve species, type: $M$. cornea (Berk. \& Broome) Nannf., asexual morph unknown, saprobes, terrestrial, cosmopolitan, see Lumbsch and Huhndorf (2010; outline), Kirk et al. (2013; genus accepted), cultures and sequences are unavailable.

Micropodia Boud. 1885, Calloriaceae, Helotiales, Leotiomycetes, two species, type: $M$. pteridina (Nyl.) Boud., asexual morph unknown, saprobes, terrestrial, cosmopolitan, see Lumbsch and Huhndorf (2010; outline), Kirk et al. (2013; genus accepted), cultures and sequences are unavailable, needs generic revision.

Micropustulomyces R.W. Barreto 1995, Ascomycota genera incertae sedis, one species, type: M. mucilaginosus R.W. Barreto, coelomycetous, sexual morph unknown, saprobes, terrestrial, Brazil, see Wijayawardene et al. (2012, 2017; outline), Kirk et al. (2013; genus accepted), cultures and sequences are unavailable, needs generic revision.

Microscypha Syd. \& P. Syd. 1919, Pezizellaceae, Helotiales, Leotiomycetes, six species, type: M. grisella (Rehm) Syd. \& P. Syd., asexual morph unknown, saprobes, terrestrial, Europe, China, see Huhtinen et al. (2010; new species), Lumbsch and Huhndorf (2010; outline), Kirk et al. (2013; genus accepted), cultures and sequences are available, needs generic revision.

Microsomyces Thaxt. 1931, Laboulbeniaceae, Laboulbeniales, Laboulbeniomycetes, two species, type: M. psammoechi Thaxt., asexual morph unknown, biotrophic, terrestrial, tropical, see Lumbsch and Huhndorf (2010; outline), Kirk et al. (2013; genus accepted), cultures and sequences are unavailable.

Microsphaeropsis Höhn. 1917, Microsphaeropsidaceae, Pleosporales, Dothideomycetes, 37 species, type: M. olivacea (Bonord.) Höhn., coelomycetous, sexual morph unknown, saprobes, pathogens of both plants and animals, lichenicolous, terrestrial, worldwide, see Etayo and Sancho (2008; new species), Marincowitz et al. (2008; new species), Pethybridge et al. (2008; new species, Australia), de Gruyter et al. (2009; DNA, phylogeny), Etayo and Yazici (2009; new species, lichenicolous), Alves et al. (2010; new species, Costa Rica), Crous et al. (2011d; new species, pathogens, Proteaceae), Wijayawardene et al. (2012, 2016b, 2017; outline, taxonomy), Hyde et al. (2013; accepted as a genus in Didymellaceae), Kirk et al. (2013; genus accepted), Brackel (2014; new species), Chen et al. (2015b; taxonomy, phylogeny), cultures available for the type: CBS 116669, CBS 442.83.

Microsporum Gruby 1843, Arthrodermataceae, Onygenales, Eurotiomycetes, c. 17 species, type: M. audouinii Gruby, hyphomycetous, sexual morph unknown, on humans and other mammals, causing microsporoses, terrestrial, worldwide, see Seifert et al. (2011; taxonomy), 
Choi et al. (2012; new species), Wijayawardene et al. (2012, 2017; outline), Hubka et al. (2014a; new species), Mirhendi et al. (2014; DNA, phylogeny), cultures and sequences are available, culture available for the type: CBS 280.63 (fide Mirhendi et al. 2014), needs generic revision.

Microstoma Bernstein 1852, Sarcoscyphaceae, Pezizales, Pezizomycetes, one species, type: M. hiemale Bernstein, asexual morph unknown, saprobe, terrestrial, Costa Rica, Canary Islands, see Lumbsch and Huhndorf (2010; outline), Kirk et al. (2013; genus accepted), cultures and sequences are unavailable, needs generic revision.

Microtheliopsis Müll. Arg. 1890, Microtheliopsidaceae, Dothideomycetes family incertae sedis, four species, type: M. uleana Müll. Arg., asexual morph unknown, saprobe, terrestrial, Central and South America, Australasia, see Lumbsch and Huhndorf (2010; outline), Hyde et al. (2013; taxonomy), Kirk et al. (2013; genus accepted), Jaklitsch et al. (2016a; phylogeny), Lücking et al. (2016b; classification), cultures and sequences are unavailable, needs generic revision.

Microthia Gryzenh. \& M.J. Wingf. 2006, Cryphonectriaceae, Diaporthales, Sordariomycetes, two species, type: M. havanensis (Bruner) Gryzenh. \& M.J. Wingf., asexual morph unknown, pathogens, terrestrial, worldwide, see Lumbsch and Huhndorf (2010; outline), Maharachchikumbura et al. (2015, 2016; outline), holotype and cultures available for the type: BPI 614275; CMW 10879 = CBS 115758, PREM 57522.

Microthyrium Desm. 1841, Microthyriaceae, Microthyriales, Dothideomycetes, c. 60 species, type: M. microscopicum Desm., asexual morph unknown, epiphytes, terrestrial, worldwide, see Schoch et al. (2009; phylogeny), Lumbsch and Huhndorf (2010; outline), Wu et al. (2011; taxonomy, phylogeny), Hyde et al. (2013; accepted as a genus in Microthyriaceae), Wijayawardene et al. (2014c; outline), cultures and sequences are available, needs generic revision.

Microtyle Speg. 1919, Ascomycota genera incertae sedis, one species, type: M. bergii Speg., asexual morph coelomycetous, saprobes or plant pathogenic, South America, See Wijayawardene et al. (2012, 2017; outline), Kirk (2013; genus accepted), cultures and cultures and sequences are unavailable, needs generic revision.

Microxiphium (Harv. ex Berk. \& Desm.) Thüm. 1879 (= Dennisiella Bat. \& Cif. 1962 fide Rossman et al. 2016a), Coccodiniaceae, Chaetothyriales, Eurotiomycetes, two species, type: M. footii (Harv. ex Berk. \& Desm.) Thüm., hyphomycetous, sexual morph formerly known in Dennisiella, sooty moulds, Europe, North America, South America, see Seifert et al. (2011; morphology), Wijayawardene et al. (2017; outline), Rossman et al. (2016a; nomenclature), cultures and sequences are unavailable, needs generic revision.

Microxyphiella Speg. 1918, Ascomycota genera incertae sedis, 15 species, type: M. fuligo (Berk. \& Desm.) Speg., coelomycetous, saprobes or plant pathogenic, worldwide, see Wijayawardene et al. (2012, 2017; outline), Kirk (2013; genus accepted), cultures and sequences are unavailable, needs generic revision.

Microxyphiopsis Bat. 1963, Ascomycota genera incertae sedis, two species, type: $M$. byrsonimae Bat., coelomycetous, saprobes or plant pathogenic, Brazil, see Wijayawardene et al. (2012, 2017; outline), Kirk (2013; genus accepted), cultures and sequences are unavailable, needs generic revision.

Micularia Boedijn 1961, Myriangiaceae, Myriangiales, Dothideomycetes, one species, type: M. merremiae Boedijn, asexual morph unknown, saprobes, parasitic, terrestrial, Java, see Lumbsch and Huhndorf (2010; outline, accepted genus as in Elsinoaceae), Hyde et al. (2013; accepted in Myriangiaceae), Dissanayake et al. (2014; accepted in Myriangiaceae), Wijayawardene et al. (2014c; outline), cultures and sequences are unavailable, needs generic revision. 
Middelhovenomyces Kurtzman \& Robnett 2014, ?Trichomonascaceae, Saccharomycetales, Saccharomycetes, two species, type: M. tepae (J. Grinbergs) C.P. Kurtzman \& C.J. Robnett, asexual reproduction is by multilateral budding and from formation of pseudohyphae, saprophytes, rotted wood, Chile, see Kurtzman and Robnett (2014; taxonomy), sequences are available.

Midotiopsis Henn. 1902, Cordieritidaceae, Helotiales, Leotiomycetes, two species, type: M. bambusicola Henn., asexual morph unknown, saprobes, terrestrial, America (tropical), see Lumbsch and Huhndorf (2010; outline), Kirk et al. (2013; genus accepted), cultures and sequences are unavailable.

Miladina Svrček 1972 (= Actinosporella Descals et al. 1999 fide Healy et al. 2016), Pyronemataceae, Pezizales, Pezizomycetes, two species, type: M. lecithina (Cooke) Svrček, asexual morph formerly named in Actinosporella, saprobes, hypogeous, terrestrial, temperate, see Lumbsch and Huhndorf (2010; outline), Hansen et al. (2013; DNA, phylogeny), Kirk et al. (2013; genus accepted), sequences are available for the type species from voucher KH.04.22 (Hansen et al. 2013), needs generic revision.

Millerburtonia Cif. 1951, Gnomoniaceae, Diaporthales, Sordariomycetes, one species, type: M. oyedaeae Cif., coelomycetes, sexual morph unknown, saprobes, terrestrial, Venezuela, see Wijayawardene et al. (2012, 2017; outline), Kirk et al. (2013; genus accepted), Maharachchikumbura et al. (2015, 2016; outline), cultures and sequences are unavailable, needs generic revision.

Millerozyma Kurtzman \& M. Suzuki 2010, Debaryomycetaceae, Saccharomycetales, Saccharomycetes, five species, type: Millerozyma farinosa (Lindner) Kurtzman \& M. Suzuki, asexual reproduction is by multilateral budding, saprophytic, on beetle larvae, food contaminants, dung, worldwide, see Kurtzman and Suzuki (2010; taxonomy), sequences are available.

Milospium D. Hawksw. 1975, Ascomycota genera incertae sedis, three species, type: $M$. graphideorum (Nyl.) D. Hawksw., lichenicolous, terrestrial, sexual morph unknown, Europe, see Seifert et al. (2011; genus accepted), Kirk et al. (2013; genus accepted), Crous et al. (2015a; phylogeny), cultures and sequences are available, conserved type and epitype of type species BM (Herb. Lich. Paris 72), CBS H-22271.

Miltidea Stirt. 1898, Miltideaceae, Pertusariales, Lecanoromycetes, one species, type: L. rubricatula Stirt., lichenized, Southern Hemisphere, see Lumbsch and Huhndorf (2010; outline), Widhelm and Lumbsch (2011; phylogeny), Kirk et al. (2013; genus accepted), Lücking et al. (2016b; classification), Cultures and sequences are available, needs generic revision.

Mimeomyces Thaxt. 1912, Laboulbeniaceae, Laboulbeniales, Laboulbeniomycetes, 16 species, type: $M$. decipiens Thaxt., asexual morph unknown, parasites, worldwide, see Lumbsch and Huhndorf (2010; outline), Rossi (2010; new species), Kirk et al. (2013; genus accepted), sequences and culture unavailable.

Mindoa Petr. 1949, Ascomycota genera incertae sedis, two species, type: M. ingae Petr., coelomycetous, saprobes or plant pathogenic, South America, See Wijayawardene et al. (2012, 2017; outline), Kirk (2013; genus accepted), cultures and sequences are unavailable, needs generic revision.

Miniancora Marvanová \& Bärl. 1989, Leotiaceae, Helotiales, Leotiomycetes, one species, type: M. allisoniensis Marvanová and Bärl., hyphomycetous, sexual morph unknown, saprobes, freshwater, Canada, see Wijayawardene et al. (2012, 2017; outline), Barchien et al. (2013; phylogeny), sequence is available, ex-type strain CCM F-30487, needs generic revision.

Minimelanolocus R.F. Castañeda \& Heredia 2001, Herpotrichiellaceae, Chaetothyriales, Eurotiomycetes, 26 species, type: M. navicularis (R.F. Castañeda) R.F. Castañeda, 
hyphomycetous, sexual morph unknown, saprobes, terrestrial, aquatic, China, Portugal, Mexico, Cuba, see Ma et al. (2011a, b; China; new species), Hernández-Restrepo et al. (2013; Portugal), Heredia et al. (2014; Mexico), Xia et al. (2014; China), Liu et al. (2015a; phylogeny), Hyde et al. (2016; new species), sequence available but lacks for the type species, holotype of the type: INIFAT C86/157, compare with Pseudospiropes, Spiropes and Sympodioplanus.

Minimidochium B. Sutton 1970 (= Neottiosporella Hohn. ex Graniti 1951 fide Seifert et al. 2011), Ascomycota genera incertae sedis, eight species, type: M. setosum B. Sutton, hyphomycetous, saprobes or plant pathogenic, widespread (tropical), see Seifert et al. (2011; morphology), Wijayawardene et al. (2012, 2017; outline), Kirk (2013; genus accepted), cultures and sequences are unavailable, holotype of type: IMI 103360c, needs generic revision.

Minksia Müll. Arg. 1882, Arthoniales genera incertae sedis, Arthoniomycetes, six species, type: M. caesiella Müll. Arg., lichenized, terrestrial, worldwide, see Lumbsch and Huhndorf (2010; outline), Kirk et al. (2013; genus accepted), Lücking et al. (2016b; classification), sequences are unavailable, needs generic revision.

Mintera Inácio \& P.F. Cannon 2003, Parmulariaceae, Dothideomycetes families incertae sedis, one species, type: $M$. reticulata (Starbäck) Inácio \& P.F. Cannon, asexual morph unknown, epiphytes, terrestrial, worldwide, see Hofmann (2009; review), Lumbsch and Huhndorf (2010; outline), Hyde et al. (2013; outline, keys), Wijayawardene et al. (2014c; outline), cultures and sequences are unavailable, Isotype of type species S F20503.

Minteriella Heredia, R.F. Castañeda \& R.M. Arias 2013, Dothideomycetes genera incertae sedis, one species, type: $M$. cenotigena Heredia, R.F. Castañeda \& R.M. Arias, hyphomycetous, sexual morph unknown, saprobes, aquatic, Mexico, see Heredia et al. (2013; morphology), cultures and sequences are unavailable, holotype of the type: XAL CB897, compare with Cylindrosympodium, Polyscytalum and Sympodioplanus.

Minutiella Crous 2015, Phaeomoniellaceae, Phaeomoniellales, Eurotiomycetes, one species, type: M. tardicola (Damm \& Crous), coelomcetous, sexual morph unknown, on living leaves, pathogens, terrestrial, South Africa, see Damm et al. (2010b; as Phaeomoniella tardicola, morphology), Crous et al. (2015d; phylogeny), cultures and sequences are available, holotype and ex-type culture of type: CBS H-20000, CBS 121757.

Minutisphaera Shearer, A.N. Mill. \& A. Ferrer 2011, Minutisphaeraceae, Minutisphaerales, Dothidiomycetes, four species, type: M. fimbriatispora Shearer, A.N. Mill. \& A. Ferrer, freshwater, USA, Japan, see Ferrer et al. (2011; taxonomy), Raja et al. (2013b, 2015; phylogeny, new species), cultures and sequences are available, holotype of type: A242-8 (ILL).

Minutoexcipula V. Atienza \& D. Hawksw. 1994, Ascomycota genera incertae sedis, seven species, type: $M$. tuckerae V. Atienza \& D. Hawksw., coelomycetous, sexual morph unknown, terrestrial, lichenicolous, Europe, North America, see Atienza et al. (2009; generic concept), Kirk et al. (2013; genus accepted), Wijayawardene et al. (2016b; morphology), cultures and sequences are unavailable, holotype of type: K(M)-IMI 352335.

Minutophoma D. Hawksw. 1981, Ascomycota genera incertae sedis, one species, type: $M$. chrysophthalmae D. Hawksw., sexual morph unknown, lichenicolous, Europe, terrestrial, see Kirk et al. (2013; genus accepted), Wijayawardene et al. (2017; outline), cultures and sequences are unavailable.

Mirandina G.Arnaud ex Matsush. 1975 (= Chaetonectrioides Matsush. 1996 fide Rossman et al. 2016a), Ascomycota genera incertae sedis, eleven species, type: M. corticola G. Arnaud ex Matsush., hyphomycetous, sexual morph unknown, saprobes, terrestrial and aquatic, worldwide, see Seifert et al. (2011; morphology), Wijayawardene et al. (2012, 2017; outline), 
Kirk et al. (2013; genus accepted), Ma et al. (2015: morphology), Fiuza et al. (2016: morphology), Rossman et al. (2016a; nomenclature), cultures and sequences are unavailable. Mirannulata Huhndorf, F.A. Fernández, A.N. Mill. \& Lodge 2003, Sordariomycetidae genera incertae sedis, four species, type: M. samuelsii Huhndorf, F.A. Fernández, A.N. Mill. \& Lodge, asexual morph unknown, saprobes, terrestrial, neotropics, see Lumbsch and Huhndorf (2010; outline), Kirk et al. (2013; genus accepted), Maharachchikumbura et al. (2015, 2016; outline), cultures and sequences are available, holotype and cultures for the type species F (Huhndorf 1880); SMH 1880.

Miricatena Punith. \& Spooner 2011, Ascomycota genera incertae sedis, two species, type: $M$. prunicola Punith. \& Spooner, hyphomycetous, sexual morph unknown, pathogens, terrestrial, UK, see Punithalingam and Spooner (2011b; taxonomy), Wijayawardene et al. (2017; outline), cultures and sequences are unavailable, needs generic revision.

Mirimyces Nag Raj 1993, Ascomycota genera incertae sedis, one species, type: M. pulcher Nag Raj, coelomycetous, saprobes or plant pathogenic, worldwide, see Wijayawardene et al. (2012, 2017; outline), Kirk (2013; genus accepted), cultures and sequences are unavailable, holotype of type: DAOM 215253.

Miriquidica Hertel \& Rambold 1987, Lecanoraceae, Lecanorales, Lecanoromycetes, 30 species, type: M. complanata (Körb.) Hertel \& Rambold (Lecanora complanata Körb.), lichenized fungi, saxicolous, lichenicolous, worldwide temperate, see Lumbsch and Huhndorf (2010; outline), Kirk et al. (2013; genus accepted), Singh et al. (2013a; phylogeny), Miądlikowska et al. (2014; phylogenetic placement), Lücking et al. (2016b; classification), sequence are available, needs generic revision.

Misgomyces Thaxt. 1900, Laboulbeniaceae, Laboulbeniales, Laboulbeniomycetes, four species, type: $M$. dyschirii Thaxt., asexual morph unknown, biotrophic, terrestrial, worldwide, see Lumbsch and Huhndorf (2010; outline), Kirk et al. (2013; genus accepted), cultures and sequences are unavailable.

Mitopeltis Speg. 1921, Dothideomycetes genera incertae sedis, two species, type: $M$. chilensis Speg., asexual morph unknown, saprobes, terrestrial, South America, see Lumbsch and Huhndorf (2010; outline, accepted in Micropeltidaceae), Hyde et al. (2013; excluded from Micropeltidaceae), Kirk et al. (2013; genus accepted), Wijayawardene et al. (2014c; outline), cultures and sequences are unavailable, needs generic revision.

Mitrula Fr. 1821, Mitrulaceae, Helotiales, Leotiomycetes, eight species, type: M. paludosa Fr., asexual morph unknown, saprobes, terrestrial, temperate, see Lumbsch and Huhndorf (2010; outline), Kirk et al. (2013; genus accepted), Jaklitsch et al. (2016a; classification), cultures and sequences are available.

Mitrulinia Spooner 1987, Helotiales genera incertae sedis, Leotiomycetes, one species, type: M. ushuaiae (Rehm) Spooner, asexual morph unknown, saprobes, terrestrial, southern hemisphere, see Lumbsch and Huhndorf (2010; outline), Kirk et al. (2013; genus accepted), cultures or sequence are unavailable, needs generic revision, needs generic revision.

Miuraea Hara 1948, Mycosphaerellaceae, Capnodiales, Dothideomycetes, three species, type: M. degenerans (Syd. \& P. Syd.) Hara, hyphomycetous, sexual morph mycosphaerellalike, plant pathogenic, see Crous et al. (2012a; phylogeny), Wijayawardene et al. (2012, 2017; outline), Kirk et al. (2013; genus accepted), cultures and sequences are available, holotype of type: M. Miura 572 (S-F1753).

Mixtoconidium Etayo 1995, Ascomycota genera incertae sedis, one species, type: $M$. canariense Etayo, coelomycetous, sexual morph unknown, parasymbiont on Ramalina, terrestrial, Canary Islands, see Hyde et al. (2011; checklist), Wijayawardene et al. (2012, 2017; outline), Kirk et al. (2013; genus accepted), cultures and sequences are unavailable, holotype of the type: IMI Etayo 3470. 
Mixtura O.E. Erikss. \& J.Z. Yue 1990, Didymellaceae, Pleosporales, Dothideomycetes, one species, type: M. saginata (Syd.) O.E. Erikss. \& J.Z. Yue, asexual morph unknown, saprobes, terrestrial, South America, see Lumbsch and Huhndorf (2010; outline, accepted as a genus in Phaeosphaeriaceae), Hyde et al. (2013; accepted as a genus in Phaeosphaeriaceae), Kirk et al. (2013; genus accepted), Phookamsak et al. (2014b; placed in Didymellaceae), Wijayawardene et al. (2014c; outline), cultures and sequence are unavailable, needs generic revision.

Miyakeomyces Hara 1913, Niessliaceae, Hypocreales, Sordariomycetes, one species, type: M. bambusae Hara, asexual morph hyphomycetous, terrestrial, saprobes, Japan, see Lumbsch and Huhndorf (2010; outline), Maharachchikumbura et al. (2015, 2016; phylogeny), Kirk et al. (2013; genus accepted), cultures and sequence are unavailable, needs generic revision.

Miyoshiella Kawam. 1929, Chaetosphaeriaceae, Chaetosphaeriales, Sordariomycetes, one species, type: M. fusispora Kawam., asexual morph unknown, terrestrial, saprobes, temperate, see Lumbsch and Huhndorf (2010; outline), Kirk et al. (2013; not accepted as valid genus), Index Funogrum (2016; synonym of Chaetosphaeria), Maharachchikumbura et al. (2015, 2016; outline), cultures and sequence are unavailable, needs generic revision.

Moana Kohlm. \& Volkman-Kohlm. 1989, Halosphaeriaceae, Microascales, Sordariomycetes, one species, type: M. turbinulata Kohlm. \& Volkm.-Kohlm., asexual morph unknown, marine, tropical, see Lumbsch and Huhndorf (2010; outline), Kirk et al. (2013; genus accepted), Jones et al. (2015; outline), Maharachchikumbura et al. (2015, 2016; outline), cultures and sequences are unavailable, needs generic revision.

Mobergia H. Mayrhofer \& Sheard 1992, Physciaceae, Teloschistales, Lecanoromycetes, one species, type: M. calculiformis (W.A. Weber) H. Mayrhofer \& Sheard, asexual morph unknown, terrestrial, saprobes, temperate, see Lumbsch and Huhndorf (2010; outline), Kirk et al. (2013; genus accepted), Lücking et al. (2016b; classification), sequences are available, needs generic revision.

Moelleriella Bres. 1896, Clavicipitaceae, Hypocreales, Sordariomycetes, 25 species, type: $M$. sulphurea Bres., asexual morph hyphomycetous or coelomycetous, terrestrial, entomogenous, tropical South America and French Guiana, see Chaverri et al. (2008; phylogeny), Lumbsch and Huhndorf (2010; outline), Kirk et al. (2013; genus accepted), Li et al. (2016a; new species, coelomycetous), cultures and sequences are available, neotype of type: CUP 067787, ex-type strain P.C. 756.

Moleospora Abdel-Wahab, Abdel-Aziz \& Nagah. 2010, Lulworthiaceae, Lulworthiales, Sordariomycetes, one species, type: Moleospora maritima Abdel-Wahab, Abdel-Aziz \& Nagah., hyphomycetous, sexual morph unknown, saprobes, marine, Egypt, Saudi Arabia, see Abdel-Wahab et al. (2010, phylogeny), Jones et al. (2015; phylogeny, outline), Maharachchikumbura et al. (2015, 2016; phylogeny, outline), cultures and sequences are available.

Molleriella G. Winter 1886, Elsinoaceae, Myriangiales, Dothideomycetes, four species, type: M. mirabilis G. Winter, asexual morph unknown, saprobes, terrestrial, Africa, see Lumbsch and Huhndorf (2010; outline), Kirk et al. (2013; genus accepted), Jayawardena et al. (2014; phylogeny), Wijayawardene et al. (2014c; outline), cultures and sequences are unavailable.

Mollicamarops Lar.N. Vassiljeva 2007, Boliniaceae, Boliniales, Sordariomycetes, one species, type: M. stellata Lar.N. Vassiljeva, asexual morphs unknown, saprobes, terrestrial, north temperate zone, see Huhndorf and Miller (2008; morphology), Lumbsch and Huhndorf (2010; outline), Untereiner et al. (2013; accepted in Boliniaceae), Maharachchikumbura et al. (2015, 2016; outline), cultures and sequences are unavailable, holotype of type: VLA P-2942. Mollisia (Fr.) P. Karst. 1871 (= Aleuriella (P. Karst.) P. Karst. 1871; = ?Atrocybe Velen. 1947; = Belonopsis (Sacc.) Rehm 1891; = Crustula Velen. 1934; = Cystodendron Bubák 1914; = Dibeloniella Nannf. 1932; = Haglundia Nannf. 1932; Mollisiella Boud. 1885; Peziza 
sect. Aleuriella P. Karst. 1869; Peziza trib. Mollisia Fr. 1822; = Syntexis Theiss. 1916; = Tapesia (Pers.) Fuckel 1870 fide Jaklitsch et al. 2016a; Species Fungorum 2017), Mollisiaceae, Helotiales, Leotiomycetes, c. 130 species, type: M. cinerea (Batsch) P. Karst., asexual morph unknown, saprobes, terrestrial, Europe, see Lumbsch and Huhndorf (2010; outline), Kirk et al. (2013; genus accepted), Tanney et al. (2016; DNA), cultures and sequences are available, available specimen and cultures for the type: CBS H-14530, AFTOL-ID 76.

Mollisina Höhn. ex Weese 1926, Pezizellaceae, Helotiales, Leotiomycetes, eleven species, type: $M$. rubi (Rehm) Höhn., asexual morph unknown, saprobes, terrestrial, Europe, Asia, see Lumbsch and Huhndorf (2010; outline), Kirk et al. (2013; genus accepted), Han et al. (2014; DNA, phylogeny), cultures and sequences are available.

Mollisinopsis Arendh. \& R. Sharma 1984, Pezizellaceae V, Helotiales, Leotiomycetes, three species, type: Mollisinopsis filicis Arendh. \& R. Sharma, asexual morph unknown, saprobes, terrestrial, India, see Lumbsch and Huhndorf (2010; outline), Kirk et al. (2013; genus accepted), Han et al. (2014; DNA, phylogeny), cultures and sequences are unavailable.

Mollisiopsis Rehm 1908, ?Helotiales genera incertae sedis, Leotiomycetes, seven species, type: $M$. subcinerea Rehm, asexual morph unknown, saprobes, terrestrial, Europe, see Kirk et al. (2013; genus accepted), Han et al. (2014; DNA, phylogeny), Jaklitsch et al. (2016a; classification; treated as a synonym of Pyrenopeziza Fuckel), cultures and sequences are unavailable.

Monandromyces R.K. Benj. 1999, Laboulbeniaceae, Laboulbeniales, Laboulbeniomycetes, eleven species, type: M. microveliae (Thaxt.) R.K. Benj., asexual morph unknown, biotrophic, terrestrial, tropical, see Lumbsch and Huhndorf (2010; outline), Kirk et al. (2013; genus accepted), cultures and sequences are unavailable.

Monascella Guarro \& Arx 1986, Onygenaceae, Onygenales, Eurotiomycetes, one species, type: $M$. botryosa Guarro \& Arx, asexual morph unknown, saprobes, Spain, see Lumbsch and Huhndorf (2010; outline), Hansen et al. (2013; DNA), Kirk et al. (2013; genus accepted), cultures and sequences are available, cultures available for the type: CBS 233.85, needs generic revision.

Monascostroma Höhn. 1918, Didymellaceae, Pleosporales, Dothideomycetes, c. five species, type: M. innumerosum (Desm.) Höhn., asexual morph unknown, saprobes, terrestrial, cosmopolitan, see Kirk et al. (2008; treated as a synonym of Hendersonia Berk.), Lumbsch and Huhndorf (2010; outline), Wijayawardene et al. (2014c; outline), Hyde et al. (2013; accepted as a genus in Didymellaceae), cultures and sequences are available, needs generic revision.

Monascus Tiegh. 1884 (= Basipetospora G.T. Cole \& W.B. Kendr. 1968; Backusia Thirum. et al. 1965 fide Rossman et al. 2016a), Monascaceae, Eurotiales, Eurotiomycetes, 14 species, type: Monascus ruber Tiegh., asexual morph unknown, saprobes, terrestrial, worldwide, see Lumbsch and Huhndorf (2010; outline), Kirk et al. (2013; genus accepted), Rossman et al. (2016a; nomenclature), cultures and sequences are available, available specimen for type: CBS H-14541.

Monerolechia Trevis. 1857, Caliciaceae, Caliciales, Lecanoromycetes, five species, type: $M$. bayrhofferi (Schaer.) Trevis., lichenized, Asia, Australia, Europe, see Gaya et al. (2012; phylogeny), Prieto et al. (2013; phylogeny), Prieto and Wedin (2016; phylogeny), Lücking et al. (2016b; classification), Cultures and sequences are available, needs generic revision.

Monilinia Honey 1928 (= Monilia Bonord. 1851 fide Johnston et al. 2014b), Sclerotiniaceae, Helotiales, Leotiomycetes, c. 30 species, type: M. fructicola (G. Winter) Honey, asexual morph formerly named in Monilia, saprobes, pathogens, terrestrial, worldwide, see Lumbsch and Huhndorf (2010; outline), Kirk et al. (2013; genus accepted), Johnston et al. (2014b; 
nomenclature), Zhu et al. (2016; pathogens, phylogeny), Wijayawardene et al. (2017; outline), cultures and sequences are available.

Monilochaetes Halst. ex Harter 1916 (= Australiasca sivan. \& Alcorn 2002 fide Réblová et al. 2016c), Australiascaceae, Glomerellales, Sordariomycetes, two species, type: M. infuscans Harter, hyphomycetous, sexual morph formerly named in Australiasca, saprobes, terrestrial, worldwide, see Wijayawardene et al. (2012, 2017; outline), Kirk et al. (2013; genus accepted), Réblová et al. (2011, 2016c; taxonomy, phylogeny, nomenclature), Maharachchikumbura et al. (2015, 2016; outline, phylogeny), cultures and sequences are available, available specimen and cultures for the type: CBS H-1013, CBS 869.96.

Monoblastia Riddle 1923, Monoblastiaceae, Monoblastiales, Dothideomycetes, eleven species, type: M. palmicola Riddle, asexual morph unknown, lichenized, Spain, see Lumbsch and Huhndorf (2010; outline), Hyde et al. (2013; taxonomy), Kirk et al. (2013; genus accepted), Wijayawardene et al. (2014c; outline), cultures and sequences are unavailable, needs generic revision.

Monoblastiopsis R.C. Harris \& C.A. Morse 2008, Dothideomycetes genera incertae sedis, two species, type: M. konzana R.C. Harris \& C.A. Morse, asexual morph unknown, saprobes, terrestrial, USA, see Lumbsch and Huhndorf (2010; outline), Kirk et al. (2013; genus accepted), Wijayawardene et al. (2014c; outline), cultures and sequences are unavailable, holotype of type: KANU 371963, needs generic revision.

Monochaetia (Sacc.) Allesch. 1902, Amphisphaeriaceae, Xylariales, Sordariomycetes, 28 species, type: M. monochaeta (Desm.) Allesch., coelomycetous, sexual morph unknown, saprobes, terrestrial, worldwide, see Wijayawardene et al. (2012, 2016b, 2017; outline, taxonomy), Kirk et al. (2013; genus accepted), Maharachchikumbura et al. (2015, 2016; outline), Senanayake et al. (2015; phylogeny), cultures and sequences are available, available specimen and cultures for the type: CBS H-14561; CBS 115004, CBS 191.82.

Monochaetiella E. Castell. 1943, Ascomycota genera incertae sedis, three species, type: $M$. hyparrheniae E. Castell., asexual morph coelomycetous, saprobes or plant pathogenic, widespread, see Wijayawardene et al. (2012, 2017; outline), Kirk (2013; genus accepted), cultures and sequences are unavailable, needs generic revision.

Monochaetiellopsis B. Sutton \& DiCosmo 1977 (= Hypnotheca Tommerup 1970 fide Johnston et al. 2014b), Helotiales genera incertae sedis, Leotiomycetes, two species, type: $M$. themedae (M. Kandasw. \& Sundaram) B. Sutton \& DiCosmo, coelomycetous, sexual morph Hypnotheca, saprobes, terrestrial, India, Australia, Tanzania, see Wijayawardene et al. (2012, 2017; outline), Johnston et al. (2014b; nomenclature), cultures and sequences are unavailable, holotype of the type species is not designated, other specimens IM I78370a, 151159a, 62200. Monochaetinula Muthumary, Abbas \& B. Sutton 1996, Ascomycota genera incertae sedis, six species, type: M. terminaliae (Bat. \& J.L. Bezerra) Muthumary, Abbas \& B. Sutton, coelomycetous, sexual morph unknown, saprobes, terrestrial, worldwide, see Wijayawardene et al. (2012, 2016b, 2017; outline, taxonomy), Kirk et al. (2013; genus accepted), cultures and sequences are unavailable, needs generic revision.

Monocillium S.B. Saksena 1955, Niessliaceae, Hypocreales, Sordariomycetes, c. 15 species, type: $M$. indicum S.B. Saksena, asexual morph unknown, saprobes, on fungi and lichens, terrestrial, cosmopolitan, see Seifert et al. (2011; morphology), Wijayawardene et al. (2012, 2017; outline), Kirk (2013; genus accepted), Maharachchikumbura et al. (2015, 2016), needs generic revision, cultures and sequences are available.

Monodia Breton \& Faurel 1970, Ascomycota genera incertae sedis, two species, type: $M$. elegans Breton \& Faurel, coelomycetous, coprophilous and saprobes, see Wijayawardene et al. (2012, 2017; outline), Kirk (2013; genus accepted), cultures and sequences are unavailable, needs generic revision. 
Monodictys S. Hughes 1958, Dothideomycetes genera incertae sedis, c. 50 species, type: $M$. putredinis (Wallr.) S. Hughes, hyphomycetous, sexul morph unknown, saprobes, terrestrial, cosmopolitan, see Seifert et al. (2011; morphology, treated as heterogenous), Wijayawardene et al. (2012, 2017; outline), Kirk et al. (2013; genus accepted), cultures and sequences are available but lacks for the type species.

Monodidymaria U. Braun 1994, Ascomycota genera incertae sedis, five species, type: $M$. canadensis (Ellis \& Everh.) U. Braun (三Ramularia canadensis Ellis \& Everh.), asexual morphs hyphomycetous, terrestrial, plant pathogenic, leaf-spotting, Asia, Europe, North and South America, see Hyde et al. (2011; checklist), Seifert et al. (2011; morphology), Wijayawardene et al. (2012, 2017; outline), Kirk et al. (2013; genus accepted), cultures and sequence are unavailable, lectotype of type: NY 1293230.

Monodisma Alcorn 1975, Ascomycota genera incertae sedis, one species, type: M. fragilis Alcorn, hyphomycetous, sexual morph unknown, pathogens, terrestrial, widespread, see Wijayawardene et al. (2012, 2017; outline), cultures and sequences are unavailable, cultures available for type: IMI 73184, IMI 41189, needs generic revision.

Monoicomyces Thaxt. 1900, Laboulbeniaceae, Laboulbeniales, Laboulbeniomycetes, 49 species, type: $M$. homalotae Thaxt, asexual morph unknown, biotrophic, terrestrial, worldwide, see Lumbsch and Huhndorf (2010; outline), Rossi (2010; new species, Ecuador), Kirk et al. (2013; genus accepted), Haelewaters et al. (2014; DNA, phylogeny), cultures and sequences are available only for MT004.

Monorhizina Theiss. \& Syd. 1916, Microthyriaceae, Microthyriales, Dothideomycetes, one species, type: M. filicina (Berk. \& Broome) Theiss. \& Syd., terrestrial, on leaves, Sri Lanka, see Kirk et al. (2013; genus accepted), cultures and sequences are unavailable, needs generic revision.

Monosporascus Pollack \& Uecker 1974, Diatrypaceae, Xylariales, Sordariomycetes, two species, type: M. cannonballus Pollack \& Uecker, asexual morph unknown, thermophilic, terrestrial, worldwide, see Lumbsch and Huhndorf (2010; outline, accepted in Sordariomycetes), Kirk et al. (2013; genus accepted), Correia et al. (2014; chemical compounds), Maharachchikumbura et al. (2015, 2016; outline), cultures and sequences are available, available specimen and cultures for the type: BPI 71820; ATCC 26931 (unpublished), FMR6682 (fide Collado et al. 2002), needs generic revision.

Monostichella Höhn. 1916, Ascomycota genera incertae sedis, 15 species, type: M. robergei (Desm.) Höhn., coelomycetous, sexual morph unknown, saprobes, terrestrial, worldwide, see Kirk et al. (2013; genus accepted), Wijayawardene et al. (2017; outline), cultures and sequences are unavailable, needs generic revision.

Monotosporella S. Hughes 1958, Savoryellaceae, Savoryellales, Sordariomycetes, probably polyphyletic, c. 10 species, type: M. albida G. Weber, Spaaij \& Oberw., asexual morph unknown, saprobes, Asia, Australia, see Seifert et al. (2011; morphology, treated as Pleosporales), Kirk et al. (2013; genus did not list), Wijayawardene et al. (2012, 2017; outline), Maharachchikumbura et al. (2015, 2016; outline), cultures and sequences are available, needs generic revision.

Montagnella Speg. 1881, Dothideomycetes genera incertae sedis, nine species, type: $M$. curumamuel Speg., asexual morph unknown, saprobes, terrestrial, worldwide, see Lumbsch and Huhndorf (2010; outline), Kirk et al. (2013; genus accepted), Wijayawardene et al. (2014c; outline, accepted as a genus in Dothideomycetes), cultures and sequences are unavailable, needs generic revision.

Montagnula Berl. 1896, Didymosphaeriaceae, Pleosporales, Dothideomycetes, 30 species, type: M. infernalis (Niessl) Berl., asexual morph unknown, saprobes, terrestrial, worldwide, see Zhang et al. (2012e; taxonomy, phylogeny), Kirk et al. (2013; genus accepted), Hyde et al. (2014; taxonomy, phylogeny), Ariyawansa et al. (2014a, d; taxonomy, phylogeny), 
Wijayawardene et al. (2014c; outline), Wanasinghe et al. (2016; phylogeny), Tennakoon et al. (2016; taxonomy, phylogeny), cultures and sequences are available, needs generic revision.

Montanelia Divakar, A. Crespo, Wedin \& Essl. 2012, Parmeliaceae, Lecanorales, Lecanoromycetes, five species, type: M. panniformis (Nyl.) Divakar, A. Crespo, Wedin \& Essl., asexual morph unknown, lichenized, terrestrial, worldwide, see Divakar et al. (2012; taxonomy), Leavitt et al. (2015; morphology, phylogeny), Steven et al. (2015; phylogeny), Szczepańska et al. (2015; distribution in Poland and Europe), cultures and sequences are available.

Monticola Selbmann \& Egidi 2014, Teratosphaeriacae, Capnodiales, Dothideomycetes, one species, type: $M$. elongata Selbmann \& Egidi, hyphomycetous, sexual morph unknown, rockinhabiting, see Egidi et al. (2014; taxonomy), Quaedvlieg et al. (2014; phylogeny), Wijayawardene et al. (2014c, 2017; outline), cultures available for the type: CBS $136206=$ CCFEE 5394.

Moorella P.Rag. Rao \& D. Rao 1964, Tubeufiaceae, Tubeufiales, Dothideomycetes, one species, type: M. speciosa P.Rag. Rao \& D. Rao, sexual morph unknown, saprobes, terrestrial, worldwide, see Seifert et al (2011; morphology), Wijayawardene et al. (2012, 2017; outline), cultures and sequences are unavailable, needs generic revision.

Morakotiella (C.A. Farrant \& E.B.G. Jones) Sakay. 2005, Halosphaeriaceae, Microascales, Sordariomycetes, one species, type: M. salina (C.A. Farrant \& E.B.G. Jones) Sakay., asexual morph unknown, saprobes, marine, USA, see Lumbsch and Huhndorf (2010; outline), Jones et al. (2015; outline), Maharachchikumbura et al. (2015, 2016; outline), cultures and sequences are available, holotype of the type: IMI 297765.

Moralesia Urries 1956, Ascomycota genera incertae sedis, one species, type: M. arundinis Urries, sexual morph unknown, saprobes, terrestrial, Canary Islands, see Wijayawardene et al. (2012, 2017; outline), Kirk et al. (2013; genus accepted), cultures and sequences are unavailable, needs generic revision.

Morchella Dill. ex Pers. 1794 (= Costantinella Matr. 1892 fide Healy et al. 2016), Morchellaceae, Pezizales, Pezizomycetes, 40 species, type: Morchella esculenta (L.) Pers., asexual morph unknown, saprobes, terrestrial, temperate, see Isiloglu et al. (2010; new species), Lumbsch and Huhndorf (2010; outline), Clowez (2012; new species, France), Kirk et al. (2013; genus accepted), Elliott et al. (2014; new species, New South Wales), Loizides et al. (2016; new species, Cyprus), cultures and sequences are available, epitype of type: PhC10. Morenoina Theiss. 1913, Aulographaceae, Dothideomycetes families incertae sedis, Dothideomycetes, 25 species, type: M. antarctica (Speg.) Theiss., asexual morph coelomycetous (acarella-like), epiphytes, terrestrial, worldwide, see Hofmann (2009; review, accepted in Asterinaceae), Lumbsch and Huhndorf (2010; outline, accepted in Asterinaceae), Hongsanan et al. (2014c; taxonomy, accepted in Aulographaceae), Wijayawardene et al. (2014c; outline, accepted in Aulographaceae), cultures and sequences are unavailable, epitype of type: IMI 349680.

Morinia Berl. \& Bres. 1889, Bartaliniaceae, Xylariales, Sordariomycetes, two species, type: M. pestalozzioides Berl. \& Bres., coelomycetous, sexual morph unknown, saprobes, terrestrial, worldwide, see Wijayawardene et al. (2012, 2016b, 2017; outline, taxonomy), Maharachchikumbura et al. (2015, 2016; outline), Senanayake et al. (2015; outline), cultures and sequences are available, needs generic revision.

Moriola Norman 1872, Verrucariaceae, Verrucariales, Eurotiomycetes, 15 species, type: M. descensa Norman, asexual morph unknown, saprobes, terrestrial, Europe, see Lumbsch and Huhndorf (2010; outline), Kirk et al. (2013; genus accepted), Lücking et al. (2016b; classification), cultures and sequences are unavailable, needs generic revision. 
Moriolomyces Cif. \& Tomas. 1953, Dothideomycetes genera incertae sedis, one species, type: $M$. descensae Cif. \& Tomas., asexual morph unknown, saprobes, terrestrial, Europe, see Lumbsch and Huhndorf (2010; outline), Kirk et al. (2013; genus accepted), Wijayawardene et al. (2014c; outline), cultures and sequences are unavailable, needs generic revision.

Moristroma A.I. Romero \& Samuels 1991, Chaetothyriomycetidae, genera incertae sedis, Eurotiomycetes, four species, type: M. polysporum A.I. Romero \& Samuels, asexual morph unknown, saprobes, worldwide, see Lumbsch and Huhndorf (2010; outline), Kirk et al. (2013; genus accepted), cultures and sequences are available.

Moromyces Abdel-Wahab, K.L. Pang, Nagah., Abdel-Aziz \& E.B.G. Jones 2010, Lulworthiaceae, Lulworthiales, Sordariomycetes, one species, type: M. varius (Chatmala \& Somrith.) Abdel-Wahab, K.L. Pang, Nagah., Abdel-Aziz \& E.B.G. Jones, hyphomycetous, sexual morph unknown, saprobes, marine, Egypt, Japan and Thailand, see Abdel-Wahab et al. (2010; phylogeny), Wijayawardene et al. (2012, 2017; outline), Jones et al. (2015; phylogeny, outline), Maharachchikumbura et al. (2015, 2016; phylogeny, outline), cultures and sequences are available, holotype of the type: BBH IT152.

Morosphaeria Suetrong, Sakay., E.B.G. Jones \& C.L. Schoch 2009, Morosphaeriaceae, Pleosporales, Dothideomycetes, three species, type: M. velatispora (K.D. Hyde \& Borse) Suetrong, Sakay., E.B.G. Jones \& C.L. Schoch, asexual morph unknown, saprobes, on wood in mangrove habitats, worldwide, see Schoch et al. (2009; phylogeny), Suetrong et al. (2009, 2011a, b; phylogeny, morphology), Lumbsch and Huhndorf (2010; outline), Zainuddin et al. (2010; antimicrobial activity), Pang et al. (2011b; monograph), Sakayaroj et al. (2011b; diversity), Boonmee et al. (2012; phylogeny), Zhang et al. (2012e; phylogeny, morphology), Hyde et al (2013; phylogeny, morphology, outline), Sarma and Raghukumar, (2013; diversity), Ariyawansa et al. (2014a, b; phylogeny), Gnavi et al.(2014; phylogeny), Shearer et al. (2014; phylogeny, freshwater), Wijayawardene et al. (2014c; outline), Jones et al. (2015; outline, marine), Liu et al. (2015a; phylogeny), Tanaka et al. (2015, phylogeny), Singtripop et al. (2015; phylogeny), sequence data available for two species, holotype of type species IMI297770.

Morrisographium M. Morelet 1968, Ascomycota genera incertae sedis, eight species, type: M. pilosum M. Morelet, hyphomycetous, sexual morph unknown, saprobes, terrestrial, freshwater, widespread, see Seifert et al. (2011; morphology), Wijayawardene et al. (2012, 2017; outline), cultures and sequences are unavailable, needs generic revision.

Moserella Pöder \& Scheuer 1994, Pezizellaceae, Helotiales, Leotiomycetes, one species, type: $M$. radicicola Pöder \& Scheuer, asexual morph unknown, on roots, terrestrial, Austria, see Lumbsch and Huhndorf (2010; outline), Kirk et al. (2013; genus accepted), Jaklitsch et al. (2016a; classification), cultures and sequences are unavailable.

Mouliniea C.P. Robin 1853, Ascomycota genera incertae sedis, accepted as a genus in Pezizomycotinain Kirk et al. (2008) and Kirk et al. (2013) genus accepted. However, previous outlines i.e. Lumbsch and Huhndorf (2010) or Wijayawardene et al. $(2012,2017)$ did not list as a genus in Pezizomycotinain.

Moutoniella Penz. \& Sacc. 1902, Rhytismataceae, Rhytismatales, Leotiomycetes, one species, type: $M$. polita Penz. \& Sacc., asexual morph unknown, saprobes, terrestrial, Java, see Lumbsch and Huhndorf (2010; outline), Kirk et al. (2013; genus accepted), cultures and sequences are unavailable.

Muciturbo P.H.B. Talbot 1989, Pezizaceae, Pezizales, Pezizomycetes, three species, type: $M$. reticulatus P.H.B. Talbot, asexual morph unknown, saprobes, terrestrial, Australia, see Kirk et al. (2008; genus accepted), Lumbsch and Huhndorf (2010; genus not accepted), Wijayawardene et al. (2012, 2017; genus not accepted), Healy et al. (2013; DNA), Kirk et al. (2013; genus not accepted), Index Fungorum (2016; genus accepted), cultures and sequences are available, needs generic revision. 
Mucoharknessia Crous, R.M. Sánchez \& Bianchin. 2015, Botryosphaeriaceae, Botryosphaeriales, Dothideomycetes, two species, type: M. cortaderiae Crous, R.M. Sánchez \& Bianchin, coelomycetous, sexual morph unknown, saprobes, terrestrial, Argentina, Italy, see Crous et al. (2015b; taxonomy, phylogeny), Li et al. (2016a; new species, phylogeny), Wijayawardene et al. (2017; outline), isotype and ex-isotype culture of the type: CBS H21853, CBS 131032.

Mucomassaria Petr. \& Cif. 1932, Mucomassariaceae, Ascomycota genera incertae sedis, one species, type: $M$. maxima Petr. \& Cif., asexual morph unknown, saprobes, terrestrial, Central America, see Lumbsch and Huhndorf (2010; outline), Kirk et al. (2013; genus accepted), cultures and sequences are unavailable, needs generic revision, needs generic revision.

Mucomycosphaerella Quaedvl. \& Crous 2014, Capnodiales genera incertae sedis, Dothideomycetes, one species, type: M. eurypotami (Kohlm., Volkm.-Kohlm. \& O.E. Erikss.) Quaedvl. \& Crous, asexual morph unknown, terrestrial, USA, see Quaedvlieg et al. (2014; morphology, phylogeny), Wijayawardene et al. (2014c; phylogeny, outline), cultures and sequences available, holotype and ex-type of type: JK5586; JK5586J.

Muellerella Hepp ex Müll. Arg. 1862, Verrucariaceae, Verrucariales, Eurotiomycetes, 18 species, type: M. polyspora Hepp ex Müll. Arg., asexual morph unknown, lichenicolous, terrestrial, worldwide, see Etayo and Sancho (2008; new species, Magallanes) Lumbsch and Huhndorf (2010; outline), Kirk et al. (2013; genus accepted), Berger and LaGreca (2014; new species, Bermuda), Muggia et al. (2015b; DNA), cultures and sequences are available but lacks for the type species, needs generic revision.

Muellerites L. Holm 1968, Dothidotthiaceae, Pleosporales, Dothideomycetes, one species, type: M. juniperi (E. Müll. \& Arx) L. Holm, asexual morph unknown, saprobes, terrestrial, temperate, Switzerland, see Lumbsch and Huhndorf (2010; outline, accepted in Dothideomycetes), Hyde et al. (2013; outline, phylogeny), Kirk et al. (2013; genus accepted), Dai et al. (2014a; transferred to Dothidotthiaceae), Wijayawardene et al. (2014c; outline), cultures and sequences are available but lacks for the type species, needs generic revision.

Muelleromyces Kamat \& Anahosur 1968, Phyllachoraceae, Phyllachorales, Sordariomycetes, one species, type: $M$. indicus Kamat \& Anahosur, asexual morph unknown, saprobes, terrestrial, India, see Lumbsch and Huhndorf (2010; outline), Kirk et al. (2013; genus accepted), Maharachchikumbura et al. (2015, 2016; outline), cultures and sequences are unavailable, needs generic revision.

Muiaria Thaxt. 1914, Laboulbeniales genera incertae sedis, one species, type: M. gracilis Thaxt., hyphomycetous, sexual morph unknown, on insects, terrestrial, Africa, Borneo, see Seifert et al. (2011; morphology), Wijayawardene et al. (2012, 2017; phylogeny), Kirk et al. (2013; genus accepted), cultures and sequences are unavailable, needs generic revision.

Muiogone Thaxt. 1914, Ascomycota genera incertae sedis, two species, type: $M$. chromopteri Thaxt., hyphomycetous, sexual morph unknown, pathogen, terrestrial, West Africa, see Seifert et al. (2011; morphology), Wijayawardene et al. (2012, 2017; outline), cultures and sequences are unavailable, needs generic revision.

Muirella R. Sprague 1959, Ascomycota genera incertae sedis, one species, type: $M$. alascensis R. Sprague, hyphomycetous, sexual morph unknown, pathogens, terrestrial, USA, see Seifert et al. (2011; morphology), Wijayawardene et al. (2012, 2017; outline), cultures and sequences are unavailable, needs generic revision.

Mulderomyces Crous, Jacq. Edwards \& P.W.J. Taylor 2016, Ostropales genera incertae sedis, Lecanoromycetes, one species, type: M. natalis Crous, Jacq. Edwards \& P.W.J. Taylor, coelomycetous, sexual morph unknown, saprobes, terrestrial, Australia, see Crous et al. (2016b; taxonomy, phylogeny), Wijayawardene et al. (2017; outline), holotype and ex-type culture of the type: CBS H-22609, CPC 25519. 
Multiclavula R.H.Petersen 1967, Clavulinaceae, Cantharellales, Agaricomycetes, 16 species, type: Multiclavula corynoides (Peck) R.H. Petersen, lichenized, see Lücking et al. (2016b; classification), Cultures and sequences are available, needs generic revision.

Multilocularia Phook., Ariyawansa \& K.D. Hyde 2016, Parabambusicolaceae, Pleosporales, Dothideomycetes, one species, type: M. bambusae Phook., Ariyaw. \& K.D. Hyde, asexual morph unknown, saprobes, terrestrial, Thailand, see Li et al. (2016a; taxonomy, phylogeny), holotype and ex-isotype culture of the type: MFLU 11-0216, MFLUCC 11-0180.

Multiseptospora Phookamsak \& K.D. Hyde 2015, Pleosporales genera incertae sedis, Dothideomycetes, one species, type: Multiseptospora thailandica Phookamsak \& K.D. Hyde, asexual morph unknown, saprobes, terrestrial, Thailand, see Liu et al. (2015a; taxonomy, phylogeny), Li et al. (2016a; new species), holotype and ex-type culture of the type: MFLU 11-0219, MFLUCC 11-0183.

Multisporascus Marinc., M.J. Wingf. \& Crous 2008, Ascomycota genera incertae sedis, one species, type: $M$. proteae Marinc., M.J. Wingf. \& Crous, asexual morph unknown, saprobes, terrestrial, South Africa, see Marincowitz et al. (2008; morphology), cultures and sequences are unavailable, holotype of the type: PREM 59465.

Munkia Speg. 1886, Hypocreales genera incertae sedis, Sordariomycetes, four species, type: M. martyris Speg., asexual morph hyphomycetous, terrestrial, saprobes, South America, see Hyde et al. (2011; checklist), Wijayawardene et al. (2012, 2017; outline), Maharachchikumbura et al. (2015, 2016; phylogeny), cultures and sequences are unavailable.

Munkiella Speg. 1885, Polystomellaceae, Dothideomycetes families incertae sedis, three species, type: M. caa-guazu Speg., asexual morph unknown, saprobes, terrestrial, tropical, see Lumbsch and Huhndorf (2010; outline), Hyde et al. (2013; outline), Kirk et al. (2013; genus accepted), Wijayawardene et al. (2014c; outline), cultures and sequences are unavailable, needs generic revision.

Munkovalsaria Aptroot 1995, Dacampiaceae, Dothideomycetes families incertae sedis, three species, type: $M$. donacina (Niessl) Aptroot, asexual morph hyphomycetous (lecythophoralike), saprobes, pathogens, terrestrial, worldwide, see Lumbsch and Huhndorf (2010; outline), Hyde et al. (2013; outline), Kirk et al. (2013; genus accepted), Pitt et al. (2014; from grapevine, DNA), Wijayawardene et al. (2014c; outline), cultures and sequences are available, type specimen and cultures available for the type: CBS H-14398; HVVV01.

Muraeriata Huhndorf, Greif, Mugambi \& A.N. Mill. 2008, Magnaporthaceae, Magnaporthales, Sordariomycetes, one species, type: M. collapsa Huhndorf, Greif, Mugambi \& A.N. Mill., asexual morph unknown, saprobes, terrestrial, Austria, see Huhndorf et al. (2008; taxonomy), Lumbsch and Huhndorf (2010; outline), Kirk et al. (2013; genus accepted), Maharachchikumbura et al. (2016; outline), cultures and sequences are available, holotype and available cultures for the type: GKM1084, SMH4553.

Murangium Seaver 1951, Patellariaceae, Patellariales, Dothideomycetes, one species, type: M. sequoiae (Plowr. ex W. Phillips) Seaver, asexual morph unknown, saprobes, terrestrial, North America, see Lumbsch and Huhndorf (2010; outline), Hyde et al. (2013; accepted in Patellariaceae), Kirk et al. (2013; genus accepted), Wijayawardene et al. (2014c; outline), Yacharoen et al. (2015; accepted in Patellariaceae), cultures and sequences are unavailable, needs generic revision.

Muricopeltis Viégas 1944, Dothideomycetes genera incertae sedis, one species, type: $M$. brasiliensis Viégas, asexual morph unknown, saprobes, terrestrial, North America, see Lumbsch and Huhndorf (2010; outline, accepted as a genus in Micropeltidaceae), Hyde et al. (2013; did not accept in Micropeltidaceae), Kirk et al. (2013; genus accepted), cultures and sequences are unavailable, needs generic revision.

Muriformistrickeria Q. Tian, Wanasinghe, Camporesi \& K.D. Hyde 2015, Melanommataceae, Pleosporales, Dothideomycetes, one species, type: M. rubi Q. Tian, 
Wanasinghe, Camporesi \& K.D. Hyde, asexual morph ceolomycetous, saprobes, terrestrial, Italy, see Tian et al. (2015; morphology, nomenclature, phylogeny), cultures and sequences are available for type species, holotype and ex-type strains of type: MFLU 15-1409; MFLUCC 15-0681 = KUMCC15-0079.

Murilentithecium Wanasinghe, Camporesi, E.B.G. Jones \& K.D. Hyde 2014, Lentitheciaceae, Pleosporales, Dothideomycetes, one species, type: M. clematidis Wanas., Camporesi, E.B.G. Jones \& K.D. Hyde, asexual morph camarosporium-like, saprobes, terrestrial, Europe, see Wanasinghe et al. (2014b; morphology, phylogeny), cultures and sequences are available, holotype and ex-type strains of type species MFLU 14-0334; MFLUCC 14-0562 = MUCL 55405.

Muriphaeosphaeria Phukhams., Bulgakov \& K.D. Hyde 2015, Phaeosphaeriaceae, Pleosporales, Dothideomycetes, one species, type: M. galatellae Phukhams., Bulgakov \& K.D. Hyde, asexual morph coelomycetous, saprobes, terrestrial, Russia, see Phukhamsakda et al. (2015; taxonomy, phylogeny), Wijayawardene et al. (2017; outline), holotype: MFLU 150087 , cultures and sequences are available.

Murispora Y. Zhang bis, J. Fourn. \& K.D. Hyde 2009, Amniculicolaceae, Pleosporales, Dothideomycetes, seven species, type: M. rubicunda (Niessl) Y. Zhang ter, J. Fourn. \& K.D. Hyde, asexual morph phoma-like, saprobes, terrestrial and aquatic, Europe, significantly substrate stained purple, see Zhang et al. (2009a, 2009b, 2012e; morphology, phylogeny), Lumbsch and Huhndorf (2010; outline), Hyde et al. (2013; accepted as a genus in Amniculicolaceae), Wijayawardene et al. (2014c; outline), Wanasinghe et al. (2015; morphology, phylogeny), cultures and sequences are available, needs generic revision.

Muroia I. Hino \& Katum. 1958, Dothideomycetes genera incertae sedis, one species, type: M. nipponica I. Hino \& Katum., asexual morph unknown, saprobes, terrestrial, Japan, see Lumbsch and Huhndorf (2010; outline, accepted as a genus in Lophiostomataceae), Hyde et al. (2013; did not accept in Lophiostomataceae), Kirk et al. (2013; genus accepted), Wijayawardene et al. (2014c; outline), cultures and sequences are unavailable, needs generic revision.

Muscicola Velen. 1934, Helotiaceae, Helotiales, Leotiomycetes, one species, type: M. dubia (Velen.) Svrček, asexual morph unknown, saprobes, terrestrial, Europe, see Lumbsch and Huhndorf (2010; outline), Kirk et al. (2013; genus accepted), cultures and sequences are unavailable.

Muscodor Worapong, Strobel \& W.M. Hess 2001, Sordariomycetes genera incetae sedis, 19 species, type: M. albus Worapong, Strobel \& W.M. Hess, saprobes, worldwide, see Lumbsch and Huhndorf (2010; outline), Kirk et al. (2013; genus accepted), Daranagama et al. (2017 morphology, taxonomy, phylogeny, key), Wendt et al. (2017; accepted as a genus in Sordariomycetes genera incertae sedis), cultures and sequences are available, needs generic revision.

Musicillium Zare \& W. Gams 2007, Plectosphaerellaceae, Glomerellales, Sordariomycetes, one species, type: M. theobromae (Turconi) Zare \& W. Gams, hyphomycetous, sexual morph unknown, saprobes, terrestrial, pantropical, see Seifert et al. (2011; morphology), Wijayawardene et al. (2012, 2017; outline), Maharachchikumbura et al. (2015, 2016; outline, phylogeny), cultures and sequences are available, neotype (dry culture) and ex-type culture of the type: Herb. CBS 19864, CBS 968.72.

Muyocopron Speg. 1881, Muyocopronaceae, Muyocopronales, Dothideomycetes, one species, type: $M$. corrientinum Speg., asexual morph unknown, saprobes, terrestrial, worldwide, see Lumbsch and Huhndorf (2010; outline, accepted in Microthyriaceae), Hyde et al. (2013; introduced Muyocopronaceae), Kirk et al. (2013; genus accepted), Wijayawardene et al. (2014c; outline), Mapook et al. (2016c; taxonomy, phylogeny), cultures and sequences are available but lacks for the type, needs generic revision. 
Mycelephas R.F. Castañeda 2009, Ascomycota genera incertae sedis, one species, type: $M$. robustus (R.F. Castañeda) R.F. Castañeda, hyphomycetous, sexual morph unknown, saprobes, terrestrial, Cuba, see Seifert et al. (2011; morphology), Wijayawardene et al. (2012, 2017; outline), cultures and sequences are unavailable, needs generic revision.

Myceliophthora Costantin 1892 (= Corynascus Arx 1973 fide Maharachchikumbura et al. 2015, 2016), Chaetomiaceae, Sordariales, Sordariomycetes, one species, type: M. lutea Costantin, sexual morph unknown, saprobes, terrestrial, temperate, see Lumbsch and Huhndorf (2010; outline), Kirk et al. (2013; genus accepted), Maharachchikumbura et al. (2015, 2016; outline, nomenclature), van den Brink et al. (2015; DNA, phylogeny), cultures and sequences are available for the type species CBS 146.50, CBS 145.77 (van den Brink et al. 2015), available specimen for type: CBS H-10236.

Mycerema Bat., J.L. Bezerra \& Cavalc. 1963, Schizothyriaceae, Dothideomycetes families incertae sedis, two species, type: M. vochysiacearum Bat., J.L. Bezerra \& Cavalc., asexual morph plenotrichaius-like, saprobes, terrestrial, South America, see Lumbsch and Huhndorf (2010; outline), Hyde et al. (2013; accepted as a genus in Schizothyriaceae), Kirk et al. (2013; genus accepted), Wijayawardene et al. (2014c; outline), Phookamsak et al. (2016; new species, taxonomy), cultures and sequences are unavailable.

Mycoarachis Malloch \& Cain 1970, Hypocreales genera incertae sedis, Sordariomycetes, two species, type: $M$. inversa Malloch \& Cain, asexual morph hyphomycetous, terrestrial, dung, Africa and North America, see Hirooka et al. (2010; phylogeny), Lumbsch and Huhndorf (2010; outline, accepted as a genus in Bionectriaceae), Maharachchikumbura et al. (2015, 2016; phylogeny), Cultures and sequences are available, holotype and ex-type of type: TRTC 662166f; CBS 517.70.

Mycoarctium K.P. Jain \& Cain 1973, Pezizales genera incertae sedis, Pezizomycetes, one species, type: $M$. ciliatum K.P. Jain \& Cain, asexual morph unknown, coprophilous, terrestrial, Canary Islands, see Lumbsch and Huhndorf (2010; outline), Kirk et al. (2013; genus accepted), Jaklitsch et al. (2016a; classification), cultures and sequences are unavailable, needs generic revision.

Mycoarthris Marvanová \& P.J. Fisher 2002, Hyaloscyphaceae, Helotiales, Leotiomycetes, one species, type: $M$. corallina Marvanová \& P.J. Fisher, hyphomycetous, sexual morph unknown, saprobes, aquatic, Europe, see Seifert et al. (2011; morphology), Wijayawardene et al. (2012, 2017; outline), Kirk et al. (2013; genus accepted), cultures and sequences are available.

Mycobilimbia Rehm 1890, Lecideaceae, Lecideales, Lecanoromycetes, five species, type: $M$. obscurata (Sommerf.) Rehm, asexual morph unknown, lichenized, terrestrial, worldwide, see Lumbsch and Huhndorf (2010; outline), Joshi and Hur (2012; Korea), Kirk et al. (2013; genus accepted), Miądlikowska et al. (2014; phylogeny), Lücking et al. (2016b; classification), cultures and sequences are available but lacks for the type species, needs generic revision.

Mycoblastus Norman [nom. cons.] 1853, Tephromelataceae, Lecanorales, Lecanoromycetes, ten species, type: $M$. sanguinarius (L.) Norman, lichenized, worldwide, see Spribille et al. (2011; phylogeny), Lücking et al. (2016b; classification), cultures and sequences are available, needs generic revision.

Mycocalicium Vain. 1890, Mycocaliciaceae, Mycocaliciales, Eurotiomycetes, twelve species, type: $M$. ciliatum K.P. Jain \& Cain, asexual morph phialophora-like, saprobes, terrestrial, temperate, see Lumbsch and Huhndorf (2010; outline), Kirk et al. (2013; genus accepted), cultures and sequences are available, needs generic revision.

Mycocentrodochium K. Matsush. \& Matsush. 1996, Ascomycota genera incertae sedis, one species, type: M. curvisporum K. Matsush. \& Matsush., asexual morph hyphomycetous, Japan, saprobes or plant pathogenic, see Seifert et al. (2011; morphology), Wijayawardene et 
al. (2012, 2017; outline), Kirk (2013; genus accepted), cultures and sequences are unavailable, holotype of type: Matsushima Fungus Collection, Kobe, 5M406, needs generic revision.

Mycocentrospora Deighton 1972, Pleosporales genera incertae sedis, Dothideomycetes, four species, type: $M$. acerina (R. Hartig) Deighton ( $\equiv$ Cercospora acerina R. Hartig), hyphomycetous, terrestrial, plant pathogenic (leaves, roots) and saprobes (isolated from soil), Asia, Australia, Europe, North America, New Zealand, see Seifert et al. (2011; phylogeny), Wijayawardene et al. (2012, 2017; outline), Kirk (2013; genus accepted), cultures and sequences are available, neotype of type: Herb. Mycol. Oecon. 743 (B).

Mycochaetophora Hara \& Ogawa 1931, Ploettnerulaceae, Helotiales, Leotiomycetes, two species, type: $M$. japonica Hara \& Ogawa, hyphomycetous, sexual morph unknown, saprobes, terrestrial, Europe, see Kobayashi et al. (2009; morphology, phylogeny), Seifert et al. (2011; phylogeny), Wijayawardene et al. (2012, 2017; outline), Jaklitsch et al. (2016a; classification), cultures and sequences are available but lacks for the type species, needs generic revision.

Mycochlamys S. Marchand \& Cabral 1976, Ascomycota genera incertae sedis, one species, type: M. macrospora S. Marchand \& Cabral, hyphomycetous, sexual morph unknown, saprobes, terrestrial, Argentina, see Wijayawardene et al. (2012, 2017; outline), cultures available for type: CBS 639.76, BAFC 2663, IMI 185605, F277901, needs generic revision.

Mycocitrus A. Møller 1901, Bionectriaceae, Hypocreales, Sordariomycetes, three species, type: $M$. aurantium Möller, asexual morph hyphomycetous, terrestrial, plant pathogen, South America, Japan, see Lumbsch and Huhndorf (2010; outline), Maharachchikumbura et al. (2015, 2016; phylogeny), cultures and sequences are unavailable, epitype of type: BPI 631727.

Mycoclelandia Trappe \& G.W. Beaton 1984, Pezizaceae, Pezizales, Pezizomycetes, one species, type: $M$. arenacea (Trappe) Trappe \& G.W. Beaton, asexual morph unknown, hypogeous, terrestrial, Australia, see Lumbsch and Huhndorf (2010; outline), Trappe et al. (2010; DNA), Kirk et al. (2013; genus accepted), cultures and sequences are available, cultures available for the type: OSC:131132, needs generic revision.

Mycocryptospora J. Reid \& C. Booth 1987, Dothideomycetes genera incertae sedis, one species, type: Mycocryptospora anthostomoides (Rehm) J. Reid \& C. Booth, asexual morph unknown, saprobes, terrestrial, Germany, see Lumbsch and Huhndorf (2010; outline), Kirk et al. (2013; genus accepted), Wijayawardene et al. (2014c; outline), cultures and sequences are unavailable, needs generic revision.

Mycodidymella C.Z. Wei, Y. Harada \& Katum. 1998, Dothideomycetes genera incertae sedis, one species, type: Mycodidymella aesculi C.Z. Wei, Y. Harada \& Katum., asexual morph unknown, saprobes, terrestrial, Germany, see Lumbsch and Huhndorf (2010; outline), Kirk et al. (2013; genus accepted), Wijayawardene et al. (2014c; outline), cultures and sequences are unavailable, holotype of type: HHUF 22892.

Mycodiella Crous 2016, Mycosphaerellaceae, Capnodiales, Dothideomycetes, three species, type: M. eucalypti Crous, asexual morph unknown, saprobes, terrestrial, Australia, see Crous et al. (2016a; new species, phylogeny), holotype and ex-type: CBS H-22885, CPC 29226.

Mycoënterolobium Goos 1970, Ascomycota genera incertae sedis, one species, type: $M$. platysporum Goos, asexual morph unknown, saprobes, terrestrial, Hawaii, India, see Seifert et al. (2011; morphology), Wijayawardene et al. (2012, 2017; outline), Kirk et al. (2013; genus accepted), Karandikar et al. (2015; morphology), cultures and sequences are unavailable, needs generic revision.

Mycofalcella Marvanová, Om-Kalth. \& J. Webster 1993, Helotiaceae, Helotiales, Leotiomycetes, two species, type: M. calcarata Marvanová, Om-Kalth. \& J. Webster, hyphomycetous, sexual morph unknown, saprobes, freshwater, British Isles (Great Britain), Pakistan, see Baschien et al. (2013; phylogeny), Benucci et al. (2016; phylogeny), 
Wijayawardene et al. (2017; outline), cultures and sequences are available, holotype and culture available for type species IMI 351879; CCM F-10289.

Mycogalopsis Gjurašin 1925, Pezizales genera incertae sedis, Pezizomycetes, one species, type: $M$. retinospora Gjurašin, asexual morph unknown, saprobes or plant pathogenic, Europe, see Wijayawardene et al. (2012, 2017; outline), Kirk (2013; genus accepted), cultures and sequences are unavailable, needs generic revision.

Mycoglaena Höhn. 1909, Dothideomycetes genera incertae sedis, 16 species, type: $M$. subcoerulescens (Nyl.) Höhn., asexual morph unknown, saprobes and plant pathogens, Europe, North America, see Lumbsch and Huhndorf (2010; outline), Kirk (2013; genus accepted), cultures and sequences are unavailable, needs generic revision.

Mycogone Link 1809, Hypocreaceae, Hypocreales, Sordariomycetes, 29 species, type: M. rosea Link, hyphomycetous, widespread, mycoparasites (mushroom), saprobes or plant pathogenic, see Seifert et al. (2011; morphology), Wijayawardene et al. (2012, 2017; outline), Rossman et al. (2013b; phylogeny), Kirk (2013; genus accepted), cultures and sequences are available, cultures available for the type: CBS 132.97, CBS 260.39, CBS 488.67, CBS 527.80, CBS 563.78A, CBS 563.78B, available specimen of type: CBS H-14849, CBS H-14850.

Mycohypallage B. Sutton 1963, Ascomycota genera incertae sedis, three species, type: $M$. congesta (Berk. \& Broome) B. Sutton, coelomycetous, sexual morph unknown, saprobes, terrestrial, Africa, South Asia, Russia, see Marincowitz et al. (2010; morphology, new species), Wijayawardene et al. (2016b; morphology), cultures and sequences are unavailable, holotype of the type: IM I84983.

Mycoleptodiscus Ostaz. 1968, Magnaporthaceae, Magnaporthales, Sordariomycetes, c. eleven species, type: $M$. terrestris (Gerd.) Ostaz., sexual morph unknown, saprobes, terrestrial, cosmopolitan, see Seifert et al. (2011; morphology), Whitton et al. (2012a; new species), Kirk et al. (2013; did not list), Maharachchikumbura et al. (2015, 2016; outline), Wijayawardene et al. (2017; outline), cultures and sequences are available.

Mycomalus Möller 1901, Clavicipitaceae, Hypocreales, Sordariomycetes, one species, type: M. bambusinus Möller, asexual morph unknown, saprobes, terrestrial, Brazil, see Tanaka et al. (2008; compare with Ustilaginoidea), Lumbsch and Huhndorf (2010; outline), Kirk et al. (2013; genus accepted), Maharachchikumbura et al. (2015, 2016; outline), cultures and sequences are unavailable, needs generic revision.

Mycomedusiospora G.C. Carroll \& Munk 1964, Ascomycota genera incertae sedis, one species, type: $M$. flavida (Rick) Carroll \& Munk, asexual morph unknown, saprobes, terrestrial, Brazil, see Tanaka et al. (2008; compare with Ustilaginoidea), Lumbsch and Huhndorf (2010; outline), Kirk et al. (2013; genus accepted), Maharachchikumbura et al. (2015, 2016; outline), cultures and sequences are unavailable, needs generic revision.

Mycomelanea Velen. 1947, Rhytismataceae, Rhytismatales, Leotiomycetes, one species, type: M. ludmilae Velen., asexual morph unknown, saprobes, terrestrial, former Czechoslovakia, see Lumbsch and Huhndorf (2010; outline, misspelled as Mycomelaena), Kirk et al. (2013; genus accepted), Jaklitsch et al. (2016a; classification, treated as a synonym of Coccomyces De Not.),cultures and sequences are unavailable.

Mycomicrothelia Keissl. 1936, Trypetheliaceae, Trypetheliales, Dothideomycetes, three species, type: M. macularis (Hampe ex A. Massal.) Keissl., asexual morph unknown, lichenized, terrestrial, worldwide, see Lumbsch and Huhndorf (2010; outline), Nelsen et al. (2011b; DNA, phylogeny), Hyde et al. (2013; accepted as a genus in Trypetheliaceae), Wijayawardene et al. (2014c; outline), cultures available but lacks for the type species, needs generic revision.

Myconeesia Kirschst. 1936, Xylariaceae, Xylariales, Sordariomycetes, one species, type: $M$. formosa (Kirschst.) Kirschst., asexual morph unknown, saprobes, see Kirk et al. (2008; treated as a synonym of Anthostomella Sacc.), Lumbsch and Huhndorf (2010; outline), Kirk 
et al. (2013; did not list), Maharachchikumbura et al. (2015, 2016; outline, accepted as a distinct genus), cultures and sequences are unavailable.

Mycopappus Redhead \& G.P. White 1985, Melanommataceae, Pleosporales, Dothideomycetes, four species, type: M. alni (Dearn. \& Barthol.) Redhead \& G.P. White, hyphomycetous, sexual morph unknown, saprobes, pathogens, terrestrial, Asia, Europe, North America, see Seifert et al. (2011; morphology), Wijayawardene et al. (2012, 2014c, 2017; outline), Kirk et al. (2013; genus accepted), Lee et al. (2013b; pathogens, DNA), Phookamsak et al. (2014b; phylogeny), Tian et al. (2015; accepted as a genus in Melanommataceae), cultures and sequences are available.

Mycopara Bat. \& J.L. Bezerra 1960, Ascomycota genera incertae sedis, one species, type: $M$. shawii Bat. \& J.L. Bezerra, coelomycetous, sexual morph unknown, on insects, terrestrial, Africa, Borneo, see Wijayawardene et al. (2012, 2017; outline), Kirk et al. (2013; genus accepted), cultures and sequences are unavailable, needs generic revision.

Mycopepon Boise 1987, Dothideomycetes genera incertae sedis, two species, type: $M$. anensis Boise, asexual morph unknown, saprobes, terrestrial, Germany, see Lumbsch and Huhndorf (2010; outline), Kirk et al. (2013; genus accepted), Wijayawardene et al. (2014c; outline), cultures and sequences are available but lacks for the type, needs generic revision.

Mycophilomyces Crous \& M.J. Wingf. 2016, Clavicipitaceae, Hypocreales, Sordariomycetes, one species, type: M. periconiae Crous \& M.J. Wingf., hyphomycetous, sexual morph unknown, saprobes, terrestrial, Malaysia, see Crous et al. (2016a; new species, phylogeny), holotype and ex-type culture of the type: CBS H-22878, CPC 27558.

Mycophycias Kohlm. \& Volkm.-Kohlm. 1998, Teratosphaeriaceae, Capnodiales, Dothideomycetes, two species, type: M. ascophylli (Cotton) Kohlm. \& Volkm.-Kohlm., saprobes, marine, cosmopolitan, see see Lumbsch and Huhndorf (2010; outline, accepted as a genus in Verrucariaceae), Toxopeus et al. (2011; DNA, phylogeny), Kirk et al. (2013; genus accepted), Wijayawardene et al. (2014c; outine), Jaklitsch et al. (2016a; classification, accepted as a genus in Verrucariaceae), cultures and sequences are available.

Mycoporellum Müll. Arg. 1884, Dothideomycetes genera incertae sedis, seven species, type: M. sparsellum (Nyl.) Müll. Arg., asexual morph unknown, saprobes, terrestrial, worldwide, see Kirk et al. (2013; genus accepted), Wijayawardene et al. (2014c; outline), cultures and sequences are unavailable, needs generic revision.

Mycoporis Clem. 1909, Mycosphaerellaceae, Capnodiales, Dothideomycetes, one species, type: M. perexigua (Müll. Arg.) Clem., asexual morph unknown, saprobes, terrestrial, Asia, see Lumbsch and Huhndorf (2010; outline, accepted as a genus in Dothideaceae), Kirk et al. (2013; genus accepted), Thambugala et al. (2014a; transferred to Mycosphaerellaceae), Wijayawardene et al. (2014c; outline), cultures and sequences are unavailable.

Mycoporopsis Müll. Arg. 1885, Dothideomycetes genera incertae sedis, six species, type: $M$. sorenocarpa (C. Knight) Müll. Arg., asexual morph unknown, saprobes, terrestrial, worldwide, see Lumbsch and Huhndorf (2010; outline), Kirk et al. (2013; genus accepted), Wijayawardene et al. (2014c; outline), cultures and sequences are unavailable, needs generic revision.

Mycoporum Flot. ex Nyl. [nom. cons.] 1855, Mycoporaceae, Pleosporales, Dothideomycetes, 25 species, type: M. elabens (A. Massal.) Flot. ex Nyl., asexual morph unknown, nonlichenized or facultatively lichenized, terrestrial, worldwide, see Lumbsch and Huhndorf (2010; outline), Hyde et al. (2013; accepted as a genus in), Kirk et al. (2013; genus accepted), Jaklitsch et al. (2016a; phylogeny), Lücking et al. (2016b; classification), cultures and sequences are unavailable, needs generic revision.

Mycorhynchidium Malloch \& Cain 1971, Pyxidiophoraceae, Pyxidiophorales, Laboulbeniomycetes, one species, type: M. saccatum Malloch \& Cain, asexual morph 
unknown, coprophilous, terrestrial, Kenya, see Lumbsch and Huhndorf (2010; outline), Kirk et al. (2013; genus accepted), cultures and sequences are unavailable.

Mycosphaerangium Verkley 1999, Helotiales genera incertae sedis, Leotiomycetes, three species, type: $M$. tetrasporum (Ellis) Verkley, asexual morph unknown, saprobes, terrestrial, USA, see Lumbsch and Huhndorf (2010; outline, misspelled as Mycomelaena), Kirk et al. (2013; genus accepted), cultures and sequences are unavailable.

Mycosphaerelloides Videira \& Crous 2016, Mycosphaerellaceae, Capnodiales, Dothideomycetes, one species, type: M. madeirae (Crous \& Denman) Videira \& Crous, asexual morph unknown, plant pathogens, see Videira et al. (2016; morphology, phylogeny), holotype and ex-type of type species CBS H-9898; CBS $112895=$ CPC 3745.

Mycospraguea U. Braun 1993, Ascomycota genera incertae sedis, one species, type: $M$. campicola (Rogerson \& R. Sprague) U. Braun, coelomycetous (acervular), terrestrial, plant pathogenic, leaf-spotting, North America, see Hyde et al. (2011; outline), Wijayawardene et al. (2012, 2017; outline), cultures and sequences are unavailable, lectotype and isotypes of type: WSP 42832; NY 256526, 1028516.

Mycosticta Höhn. 1918, Ascomycota genera incertae sedis, one species, type: M. ovalis (Pass.) Höhn., coelomycetous, sexual morph unknown, on insects, terrestrial, Europe, see Wijayawardene et al. (2012, 2017; outline), Kirk et al. (2013; genus accepted), cultures and sequences are unavailable, needs generic revision.

Mycosylva M.C. Tulloch 1973, Ascomycota genera incertae sedis, three species, type: $M$. clarkii M.C. Tulloch, hyphomycetous, sexual morph unknown, saprobes, terrestrial, Great Britain, Finland, Japan, see Seifert et al. (2011; morphology), Wijayawardene et al. (2012, 2017; outline), cultures for type: CBS 608.73, ATCC 32970, IMI 163345, type specimen of type species CBS H-14862.

Mycosymbioces J.L. Frank 2014, Leotiomycetes genera incertae sedis, one species, type: $M$. mycenophila J.L. Frank [as 'mycenaphila'], asexual morph unknown, saprobes, terrestrial, USA, see Index Fungorum (2017; taxonomy), holotype of the type: JLF2627 (OSC148294), sequences are available.

Mycothyridium Petr. 1962, Dothideomycetes genera incertae sedis, 30 species, type: X. elliptica G.H. Otth, asexual morph unknown, saprobes, terrestrial, worldwide, see Lumbsch and Huhndorf (2010; outline), Kirk et al. (2013; genus accepted), Wijayawardene et al. (2014c; outline), cultures and sequences are unavailable, needs generic revision, needs generic revision.

Mycotodea Kirschst. 1936, Ascomycota genera incertae sedis, 14 species, type: Mycotodea heufleri (Niessl) Kirschst., asexual morph unknown, saprobes, terrestrial, worldwide, see Lumbsch and Huhndorf (2010; outline), Kirk et al. (2013; genus accepted), cultures and sequences are unavailable, needs generic revision.

Mycousteria M.L. Farr 1986, Ascomycota genera incertae sedis, two species, type: $M$. morulinae (Bat. \& H. Maia) M.L. Farr, coelomycetous, sexual morph unknown, saprobes, terrestrial, Brazil, see Wijayawardene et al. (2012, 2016), Kirk et al. (2013; genus accepted), cultures and sequences are unavailable, needs generic revision.

Mycovellosiella Rangel 1917, Mycosphaerellaceae, Capnodiales, Dothideomycetes, one species, type: $M$. cajani Henn., hyphomycetous, sexual morph unknown, plant pathogenic, ?, see Videira et al. (2017; morphology, phylogeny, and designation of neotype), cultures and sequences are available, needs generic revision.

Mycowinteria Sherwood 1986, Protothelenellaceae, Lecanoromycetes family incertae sedis, three species, type: M. anodonta (Nyl.) Sherwood \& Boise, asexual morph unknown, lichenized, terrestrial, worldwide, see Lumbsch and Huhndorf (2010; outline), Kirk et al. (2013; genus accepted), Lücking et al. (2016b; classification), cultures and sequences are unavailable, needs generic revision. 
Myelochroa (Asahina) Elix \& Hale 1987, Parmeliaceae, Lecanorales, Lecanoromycetes, 30 species, type: $M$. aurulenta (Tuck.) Elix \& Hale, lichenized, Asia, see Lumbsch and Huhndorf (2010; outline), Kirk et al. (2013; genus accepted), Lücking et al. (2016b; classification), cultures and sequences are available, needs generic revision.

Myeloconis P.M. McCarthy \& Elix 1996, Porinacea, Ostropales, Lecanoromycetes, three species, type: $M$. fecunda P.M. McCarthy \& Elix, asexual morph unknown, lichenized, terrestrial, tropical, see Lumbsch and Huhndorf (2010; outline), Kirk et al. (2013; genus accepted), Nelsen et al. (2014a; DNA, phylogeny), Lücking et al. (2016b; classification), cultures and sequences are available, cultures available for the type: MPN3C, MPN759, holotype of type: E, Coppins 5131.

Myelorrhiza Verdon \& Elix 1986, Cladoniaceae, Lecanorales, Lecanoromycetes, two species, type: $M$. antrea Verdon \& Elix, asexual morph unknown, lichenized, terrestrial, Australaia, see Lumbsch et al. (2010b; DNA, phylogeny), Lumbsch and Huhndorf (2010; outline), Kirk et al. (2013; genus accepted), Lücking et al. (2016b; classification), cultures are available but lacks for the type species, needs generic revision.

Myelosperma Syd. \& P. Syd. 1915, Myelospermataceae, Xylariales, Sordariomycetes, four species, type: M. tumidum Syd. \& P. Syd., asexual morph unknown, saprobes, terrestrial, Brazil, see Lumbsch and Huhndorf (2010; outline), Kirk et al. (2013; genus accepted), Maharachchikumbura et al. (2015, 2016; outline), cultures and sequences are unavailable, needs generic revision.

Myiocoprula Petr. 1955, Ascomycota genera incertae sedis, two species, type: M. gregaria Petr., coelomycetous, sexual morph unknown, saprobes, terrestrial, USA, see Wijayawardene et al. (2012, 2017; outline), Kirk et al. (2013; genus accepted), cultures and sequences are unavailable, needs generic revision.

Myochroidea Printzen, T. Sprib. \& Tønsberg 2008, Lecanorales genera incertae sedis, Lecanoromycetes, four species, type: M. rufofusca (Anzi) Printzen, T. Sprib. \& Tønsberg, asexual morph unknown, lichenized, terrestrial, worldwide, see Printzen et al. (2008; taxonomy), Lücking et al. (2016b; classification), cultures and sequences are unavailable, needs generic revision.

Myriangiella Zimm. 1902, Schizothyriaceae, Dothideomycetes family incerte sedis, five species, type: $M$. orbicularis Zimm., asexual morph unknown, saprobes, terrestrial, tropical, see Lumbsch and Huhndorf (2010; outline), Kirk et al. (2013; genus accepted), Hyde et al. (2013; accepted as a genus in Schizothyriaceae), Wijayawardene et al. (2014c; outline), cultures and sequences are unavailable, needs generic revision.

Myriangiopsis Henn. 1902, Dothideomycetes genera incertae sedis, two species, type: $M$. sulfurea (G. Winter) Henn., asexual morph unknown, saprobes, terrestrial, Mexico, see Lumbsch and Huhndorf (2010; outline), Kirk et al. (2013; genus accepted), Wijayawardene et al. (2014c; outline), cultures and sequences are available but lacks for the type species, needs generic revision.

Myriangium Mont. \& Berk. 1845, Myriangiaceae, Myriangiales, Dothideomycetes, one species, type: $M$. duriaei Mont. \& Berk., asexual morph unknown, saprobes, terrestrial, Algeria, see Lumbsch and Huhndorf (2010; outline), Hyde et al. (2013; morphology), Kirk et al. (2013; genus accepted), Dissanayake et al. (2014; morphology), Wijayawardene et al. (2014c; outline), cultures and sequences are available, holotype of the type species NL 8414.

Myriellina Höhn. 1915, Ascomycota genera incertae sedis, two species, type: M. cydoniae (Desm.) Höhn., coelomycetous, sexual morph unknown, saprobes, terrestrial, Europe, Papua New Guinea, see Wijayawardene et al. (2012, 2017; outline), Kirk et al. (2013; genus accepted), cultures and sequences are unavailable, holotype of type: Pl. crypt. Fr. nr. 79, needs generic revision. 
Myriochapsa M. Cáceres, Lücking \& Lumbsch 2013, Graphidaceae, Ostropales, Lecanoromycetes, three species, type: M. psoromica (M. Cáceres, Santos de Jesus \& Santos Vieira) M. Cáceres, Lücking \& Lumbsch, asexual morph unknown, lichenized, terrestrial, worldwide, see Parnmen et al. (2013; taxonomy), Lumbsch et al. (2014a, b; accepted in Graphidaceae), Lücking et al. (2016b; classification), cultures and sequences are available, holotype of the type: ASE, Cáceres 7595 (holotype of Chapsa psoromica M. Cáceres, L.S. de Jesus \& T.S. Vieira), cultures available for the type: CHAR106 (fide Lumbsch et al. 2014).

Myrioconium Syd. \& P. Syd. 1912, Sclerotiniaceae, Helotiales, Leotiomycetes, c. ten species, type: M. scirpi Syd. \& P. Syd., hyphomycetous, sexual morph unknown, in soil, saprobes, cosmopolitan, see Seifert et al. (2011; morphology), Wijayawardene et al. (2012, 2017; outline), cultures and sequences are unavailable, needs generic revision.

Myriodiscus Boedijn 1935, Tympanidaceae, Phacidiales, Leotiomycetes, one species, type: M. sparassoides Boedijn, asexual morph unknown, saprobes on bamboo culms, Asia, see Lumbsch and Huhndorf (2010; outline), Kirk et al. (2013; genus accepted), cultures and sequences are unavailable, needs generic revision.

Myriodontium Samson \& Polon. 1978, Onygenaceae, Onygenales, Eurotiomycetes, one species, type: M. keratinophilum Samson \& Polon., sexual morph unknown, human pathogen, saprobes, Spain, see Seifert et al. (2011; morphology), Wijayawardene et al. (2012, 2017; outline), Man et al. (2015; DNA), cultures and sequences are available, available specimen and cultures for the type: CBS H-7385; S7-P-3-16 (fide Man et al. 2015).

Myriogenospora G.F. Atk. 1894, Clavicipitaceae, Hypocreales, Sordariomycetes, one species, type: M. paspali G.F. Atk., asexual morph unknown, saprobes, terrestrial, Brazil, see Lumbsch and Huhndorf (2010; outline), Kirk et al. (2013; genus accepted), Maharachchikumbura et al. (2015, 2016; outline), cultures and sequences are available but lacks for the type, needs generic revision.

Myriolecis Clements 1909, Lecanoraceae, Lecanorales, Lecanoromycetes, 31 species, type: M. sambuci (Pers.) Clem., lichenized, worldwide, see Śliwa et al. (2012; phylogeny), Zhao et al. (2016; phylogeny), Lücking et al. (2016b; classification), cultures and sequences are available, needs generic revision.

Myrionora R.C. Harris 1988, Lecanoraceae, Lecanorales, Lecanoromycetes, one species, type: M. albidula (Willey) R.C. Harris, asexual morph unknown, lichenized, terrestrial, worldwide, see Lumbsch and Huhndorf (2010; outline), Kirk et al. (2013; genus accepted), Lücking et al. (2016b; classification), cultures and sequences are unavailable, needs generic revision.

Myriophacidium Sherwood 1974, Rhytismataceae, Rhytismatales, Leotiomycetes, six species, type: $M$. aphyophyllicum Sherwood, asexual morph unknown, saprobes, terrestrial, worldwide, see Hou and Piepenbring (2009; new species), Lumbsch and Huhndorf (2010; outline), Kirk et al. (2013; genus accepted), cultures and sequences are available.

Myriosclerotinia N.F. Buchw. 1947 (= Myrioconium Syd. \& P. Syd. 1912 fide Jaklitsch et al. 2016a), Sclerotiniaceae, Helotiales, Leotiomycetes, ten species, type: M. scirpicola (Rehm) N.F. Buchw., asexual morph unknown, on roots, terrestrial, Austria, see Lumbsch and Huhndorf (2010; outline), Andrew et al. (2012; DNA), Kirk et al. (2013; genus accepted), cultures and sequences are available.

Myriospora Nägeli ex Uloth 1861, Acarosporaceae, Acarosporales, Lecanoromycetes, nine species, type: M. rufescens (Ach.) Nägeli, lichenized, Europe, USA, Africa, see Arcadia and Knudsen (2012; phylogeny), Gueidan et al. (2014c; phylogeny), Westberg et al. (2015; phylogeny), Roux et al. (2016; phylogeny), Lücking et al. (2016b; classification), cultures and sequences are available, needs generic revision.

Myriostigma Kremp. 1874, Arthoniaceae, Arthoniales, Arthoniomycetes, seven species, type: M. candidum Kremp., lichenized,?, see Frisch et al. (2014a; phylogeny), Ertz et al. (2015b, 
new combination), Jagadeesh Ram and Sinha (2016; phylogeny), Lücking et al. (2016bb; classification), sequences are available, needs generic revision.

Myriostigmella G. Arnaud 1952, Dothideomycetes genera incertae sedis, one species, type: M. guatteriae (G. Arnaud) G. Arnaud, asexual morph unknown, saprobes, terrestrial, Brazil, see Lumbsch and Huhndorf (2010; outline), Kirk et al. (2013; genus accepted), Wijayawardene et al. (2014c; outline), cultures and sequences are available but lacks for the type species, needs generic revision.

Myriotrema Fée 1825, Graphidaceae, Ostropales, Lecanoromycetes, 54 species, type: $M$. olivaceum Fée, asexual morph unknown, lichenized fungi, terrestrial, tropical, see Mangold et al. (2009; key, Australia), Lumbsch and Huhndorf (2010; outline), Sipman et al. (2012; key, Costa Rica), Rivas Plata et al. (2012a; phylogeny), Kirk et al. (2013; accepted as a valid genus), Lücking et al. (2014, 2016b; phylogeny, cassification), cultures and sequences are available, needs generic revision.

Myrmaeciella Lindau 1897, Niessliaceae, Hypocreales, Sordariomycetes, one species, type: M. endoleuca (Sacc.) Lindau, asexual morph unknown, saprobes or fungicolous, terrestrial, Puerto Rico, see Lumbsch and Huhndorf (2010; outline), Jaklitsch and Voglmayr (2011; taxonomic notes), Kirk et al. (2013; genus accepted), Maharachchikumbura et al. (2015, 2016; outline), cultures and sequences are available but lacks for the type species, needs generic revision.

Myrmaecium Nitschke ex Fuckel 1870, Valsariaceae, Valsariales, Dothideomycetes, two species, type: Myrmaecium rubricosum (Fr.) Fuckel asexual morph unknown, saprobes, terrestrial, Europe, see Lumbsch and Huhndorf (2010; outline), Kirk et al. (2013; genus accepted), Jaklitsch et al. (2015; taxonomy, and phylogeny), cultures and sequences are available, lectotype of the type: L9118162, cultures available for the type: CBS 139067.

Myrmecomyces Jouvenaz \& Kimbr. 1991, Ascomycota genera incertae sedis, two species, type: M. annellisiae Jouvenaz \& Kimbr., hyphomycetous, sexual morph unknown, saprobes, terrestrial, USA, Argentina, see Seifert et al. (2011; morphology), Wijayawardene et al. (2012, 2017; outline), cultures and sequences are unavailable, holotype of type: FLAS 55591, needs generic revision.

Myrmecridium Arzanlou, W. Gams \& Crous 2007, Myrmecridiaceae, Myrmecridiales, Sordariomycetes, eleven species, type: M. schulzeri (Sacc.) Arzanlou, W. Gams \& Crous, sexual morph unknown, saprobes, terrestrial, worldwide, see Crous et al. (2012e, 2015d, 2016a; new species, phylogeny), Jie et al. (2013; new species), Maharachchikumbura et al. (2015, 2016; outline, accepted in Hypocreomycetidae), Réblová et al. (2016a; new species, phylogeny), cultures and sequences are available for the type: CBS 134.68 = ATCC 16310, needs generic revision.

Myrotheciastrum Abbas \& B. Sutton 1988, Ascomycota genera incertae sedis, one species, type: M. salvadorae Abbas \& B. Sutton, coelomycetous, sexual morph unknown, saprobes, terrestrial, Pakistan, see Wijayawardene et al. (2012, 2016b, 2017; morphology, outline), Kirk et al. (2013; genus accepted), cultures and sequences are unavailable, holotype of the type: IMI 139985i.

Myrothecium Tode 1790, Stachybotryaceae, Hypocreales, Sordariomycetes, 83 species, type: $M$. inundatum Tode, hyphomycetous, sexual morph unknown, saprobes, pathogens, terrestrial, worldwide, see Seifert et al. (2011; morphology), Wijayawardene et al. (2012, 2017; outline), Kirk et al. (2013; genus accepted), Crous et al. (2014c; notes), Maharachchikumbura et al. (2015; outline), Chen et al. (2016; review, phylogeny), Dai et al. (2016; morphology, phylogeny, new species), Lombard et al. (2016; phylogeny), cultures and sequences are available but lacks for type, epitype of type: CBS H-14898.

Myrtapenidiella Quaedvlieg \& Crous 2014, Teratosphaeriaceae, Capnodiales, Dothideomycetes, four species, type: M. tenuiramis (Crous \& Summerell) Quaedvl. \& Crous, 
hyphomycetous, sexual morph unknown, pathogens, saprobes, terrestrial, Australia, Thailand, see Quaedvlieg et al. (2014; morphology, phylogeny), Wijayawardene et al. (2014c; outline), Crous et al. (2015d, 2016a, b; new species, phylogeny), sequence data available, holotype and ex-type of the type species CBS H-20253; CPC 13692.

Mystrosporiella Munjal \& Kulshr. 1969, Ascomycota genera incertae sedis, two species, type: M. litseae Munjal \& Kulshr., hyphomycetous, sexual morph unknown, saprobes, terrestrial, India, see Seifert et al. (2011; morphology), Wijayawardene et al. (2012, 2017; outline), Kirk et al. (2013; genus accepted), cultures and sequences are unavailable, needs generic revision.

Mytilinidion Duby 1861, Mytilinidiaceae, Mytilinidiales, Dothideomycetes, twelve species, type: M. aggregatum (DC.) Duby, asexual morph septonema-like, saprobes, terrestrial, Europe, North America, see Lumbsch and Huhndorf (2010; outline), Hyde et al. (2013; accepted as a genus in Mytilinidiaceae), Kirk et al. (2013; genus accepted), Wijayawardene et al. (2014c; outline), cultures and sequences are available.

Mytilodiscus Kropp \& S.E. Carp. 1984, Helotiaceae, Helotiales, Leotiomycetes, one species, type: M. alnicola Kropp \& S.E. Carp., asexual morph unknown, saprobes, terrestrial, India, see Lumbsch and Huhndorf (2010; outline), Kirk et al. (2013; genus accepted), cultures and sequences are unavailable.

Mytilostoma P. Karst. 1879, Dothideomycetes genera incertae sedis, two species, type: $M$. deflectens P. Karst., asexual morph unknown, saprobes, terrestrial, Finland, see Lumbsch and Huhndorf (2010; outline), Kirk et al. (2013; genus accepted), Wijayawardene et al. (2014c; outline), cultures and sequences are unavailable, needs generic revision, needs generic revision.

Myxocephala G. Weber, Spaaij \& Oberw. 1989, Sordariomycetes genera incertae sedis, one species, type: M. setosa (Berk. \& M.A. Curtis) S. Hughes, hyphomycetous, sexual morph unknown, saprobes, Germany, see Kirk et al. (2008, 2013; genus accepted), cultures and sequences are available, needs generic revision.

Myxocyclus Riess 1852, Pleomassariaceae, Pleosporales, Dothideomycetes, one species, type: $M$. confluens Riess, coelomycetous, sexual morph Splanchnonema sensu lato, saprobes, terrestrial, USA, Canada, Japan, see Pastirčáková and Pastirčák (2010; morphology), Wijayawardene et al. (2016b, 2017; morphology, outline), cultures and sequences are unavailable, holotype of the type species IMI 180178.

Myxoparaphysella Caball. 1941, Ascomycota genera incertae sedis, two species, type: $M$. cocoës Caball., coelomycetous, sexual morph unknown, saprobes, terrestrial, Spain, see Seifert et al. (2011; morphology), Wijayawardene et al. (2012, 2017; outline), Kirk et al. (2013; genus accepted), cultures and sequences are unavailable, needs generic revision.

Myxophora Döbbeler \& Poelt 1978, Pseudoperisporiaceae, Dothideomycetes families incertae sedis, seven species, type: $M$. amerospora Döbbeler \& Poelt, asexual morph unknown, lichenicolous, terrestrial, worldwide, see Lumbsch and Huhndorf (2010; outline), Hyde et al. (2013; accepted as a genus in Pseudoperisporiaceae), Kirk et al. (2013; genus accepted), Wijayawardene et al. (2014c; outline), cultures and sequences are unavailable, needs generic revision.

Myxospora L. Lombard \& Crous 2016, Stachybotriaceae, Hypocreales, Sordariomycetes, five species, type: M. masonii (M.C. Tulloch) L. Lombard \& Crous, hyphomycetous, sexual morph unknown, from forest soil, terrestrial, cosmopolitan, see Lombard et al. (2016; taxonomy, phylogeny), Wijayawardene et al. (2017; outline), ex-type culture of the type: CBS 174.73.

Myxosporella Sacc. 1881, Ascomycota genera incertae sedis, one species, type: M. miniata Sacc., coelomycetous, sexual morph unknown, saprobes, terrestrial, Italy, see Wijayawardene 
et al. (2012, 2017; outline), Kirk et al. (2013; genus accepted), cultures and sequences are unavailable, needs generic revision.

Myxosporidiella Negru 1960, Ascomycota genera incertae sedis, one species, type: $M$. fritillariae Negru, coelomycetous, sexual morph unknown, saprobes, terrestrial, Roumania, see Wijayawardene et al. (2012, 2017; outline), Kirk et al. (2013; genus accepted), cultures and sequences are unavailable, needs generic revision.

Myxostomellina Syd. 1931, Ascomycota genera incertae sedis, one species, type: M. apoensis Syd., coelomycetous, sexual morph unknown, saprobes, terrestrial, Philippines, see Wijayawardene et al. (2012, 2017; outline), Kirk et al. (2013; genus accepted), cultures and sequences are unavailable, needs generic revision.

Myxothyriopsis Bat. \& A.F. Vital 1956, Ascomycota genera incertae sedis, one species, type: M. astronifolia Bat. \& A.F. Vital, coelomycetous, sexual morph unknown, saprobes, terrestrial, Brazil, see Wijayawardene et al. (2012, 2017; outline), Kirk et al. (2013; genus accepted), cultures and sequences are unavailable, needs generic revision.

Myxothyrium Bubák \& Kabát 1915, Ascomycota genera incertae sedis, one species, type: $M$. leptideum (Fr.) Bubák \& Kabát, coelomycetous, sexual morph unknown, saprobes, terrestrial, Europe, see Wijayawardene et al. (2012, 2017; outline), Kirk et al. (2013; genus accepted), cultures and sequences are unavailable, needs generic revision.

Myxotrichum Kunze 1823, Myxotrichaceae, Leotiomycetes families incertae sedis, twelve species, type: $M$. chartarum Kunze, asexual morph unknown, saprobes, terrestrial, worldwide, see Lumbsch and Huhndorf (2010; outline), Kirk et al. (2013; genus accepted), cultures and sequences are available.

Nadsonia Sydow 1912 (= Schizoblastosporion Cif. 1930), ?Trichomonascaceae, Saccharomycetales, Saccharomycetes, four species, type: $N$. fulvescens (Nadson \& Konokotina) Syd., asexual reproduction is by budding, saprophytic, on exudates of various trees, soil, peat, worldwide, see Lumbsch and Huhndorf (2010; outline), Kirk et al. (2013; genus accepted), Kurtzman and Robnett (2014; DNA, taxonomy), sequences are available.

Nadsoniella Issatsch. 1914, Herpotrichiellaceae, Chaetothyriales, Eurotiomycetes, one species, type: $N$. nigra Issatsch., hyphomycetous, sexual morph unknown, saprobes, marine, USSR, see Wijayawardene et al. (2012, 2017; outline), Kirk et al. (2013; genus accepted), sequences are unavailable, needs generic revision.

Nadvornikia Tibell 1984, Graphidaceae, Ostropales, Lecanoromycetes, four species, type: $N$. hawaiiensis (Tuck.) Tibell, asexual morph unknown, lichenized, terrestrial, worldwide, see Lumbsch and Huhndorf (2010; outline), Plata et al. (2012; DNA, phylogeny), Lumbsch et al. (2014a, b; accepted in Graphidaceae), Lücking et al. (2016b; classification), cultures and sequences are available, needs generic revision.

Naemacyclus Fuckel 1874, Marthamycetaceae, Rhytismatales, Leotiomycetes, six species, type: N. pinastri Fuckel, asexual morph unknown, saprobes, terrestrial, worldwide, see Lumbsch and Huhndorf (2010; outline, accepted as a genus in Helotiales), Kirk et al. (2013; genus accepted), cultures and sequences are available but lacks for the type species, needs generic revision.

Naemosphaera P. Karst. 1888, Ascomycota genera incertae sedis, one species, type: N. rudis P. Karst., coelomycetous, sexual morph unknown, saprobes, marine, Finland, see Wijayawardene et al. (2012, 2017; outline), Kirk et al. (2013; genus accepted), cultures and sequences are unavailable, needs generic revision.

Naemosphaerella Höhn. 1923, Ascomycota genera incertae sedis, two species, type: $N$. ceratophora (Speg.) Petr. \& Syd., coelomycetous, sexual morph unknown, saprobes, marine, Brazil, Japan, see Wijayawardene et al. (2012, 2017; outline), Kirk et al. (2013; genus accepted), cultures and sequences are unavailable, needs generic revision, needs generic revision. 
Naetrocymbe Körb. 1865, Naetrocymbaceae, Dothideomycetes families incertae sedis, six species, type: $N$. fuliginea Körb., asexual morph unknown, epiphytes, terrestrial, worldwide, see Alstrup et al. (2009; new species, USA), Knudsen and Lendemer (2009; new species), Lumbsch and Huhndorf (2010; outline), Kirk et al. (2013; genus accepted), Minter et al. (2015; new species), cultures and sequences are unavailable, needs generic revision.

Naevala B. Hein 1976, Calloriaceae, Helotiales, Leotiomycetes, six species, type: Naevala minutissima (Auersw.) B. Hein, asexual morph unknown, saprobes, terrestrial, Europe, see Lumbsch and Huhndorf (2010; outline), Kirk et al. (2013; genus accepted), cultures and sequences are available, cultures available for the type: CBS 115920, CBS 115003 (Verkley and van Kempen unpub.), available specimen for type: CBS H-15904.

Naeviella Clem. 1909, Calloriaceae, Helotiales, Leotiomycetes, three species, type: $N$. paradoxa (Rehm) Clem., asexual morph unknown, saprobes, terrestrial, Europe, see Chlebicki (2009b; endophytes, Poland), Lumbsch and Huhndorf (2010; outline), Kirk et al. (2013; genus accepted), cultures and sequences are unavailable, needs generic revision.

Naeviopsis B. Hein 1976, Calloriaceae, Helotiales, Leotiomycetes, three species, type: N. epilobii (P. Karst.) B. Hein, asexual morph unknown, saprobes, terrestrial, Europe, see Raitviir (2008; Magadan), Lumbsch and Huhndorf (2010; outline), Kirk et al. (2013; genus accepted), cultures and sequences are unavailable, needs generic revision.

Nagrajia R.F. Castañeda \& W.B. Kendr. 1991, Ascomycota genera incertae sedis, one species, type: $N$. havanensis R.F. Castañeda, coelomycetous, sexual morph unknown, saprobes, terrestrial, Cuba, see Wijayawardene et al. (2012, 2017; outline), Kirk et al. (2013; genus accepted), cultures and sequences are unavailable, holotype of type: INIFAT C91/10-3, needs generic revision.

Nagrajomyces Melnik 1984, Ascomycota genera incertae sedis, one species, type: $N$. dictyosporus Melnik, coelomycetous, sexual morph unknown, saprobes, terrestrial, Russia, see Wijayawardene et al. (2012, 2016, 2017; outline, taxonomy), Kirk et al. (2013; genus accepted), cultures and sequences are unavailable, needs generic revision.

Naïs Kohlm. 1962, Halosphaeriaceae, Microascales, Sordariomycetes, two species, type: N. inornata Kohlm., asexual morph unknown, marine, freshwater, on wood, worldwide, see Pang (2011; review), Sakayaroj et al. (2011a; phylogeny), Jones et al. (2015; outline, marine), Maharachchikumbura et al. (2015, 2016; outline), cultures and sequences are available, needs generic revision.

Nakaseomyces Kurtzman 2003, Saccharomycetaceae, Saccharomycetales, Saccharomycetes, seven species, type: $N$. delphensis (van der Walt \& Tscheuschner) Kurtzman, asexual reproduction is by multilateral budding, saprophytic, but several of the species are important human pathogens, on exudate of oaks, figs, human pathogens, worldwide, see Lumbsch and Huhndorf (2010; outline), Limtong et al. (2011; asexual morph as Candida sp.), sequences are available.

Nakataea Hara 1939 (= Magnaporthe R.A. Krause \& R.K. Webster 1972 fide Zhang et al. 2016b), Magnaporthaceae, Magnaporthales, Sordariomycetes, c. ten species, type: N. oryzae (Catt.) J. Luo \& N. Zhang, sexual morph formerly known in Magnaporthe, saprobes, terrestrial, worldwide, see Lumbsch and Huhndorf (2010; outline, sexual morph), Seifert et al. (2011; morphology), Kirk et al. (2013; genus accepted), Maharachchikumbura et al. (2015, 2016; outline), Wijayawardene et al. (2017; outline), cultures and sequences are available.

Nakatopsis Whitton, McKenzie \& K.D. Hyde 2001, Ascomycota genera incertae sedis, two species, type: N. malaysiana Whitton, McKenzie \& K.D. Hyde, hyphomycetous, sexual morph unknown, saprobes, terrestrial, Malaysia, see Wijayawardene et al. (2012, 2017; outline), cultures and sequences are unavailable, holotype of the type: HKU (M) 5093.

Nakazawaea Y. Yamada, Maeda \& Mikata 1994, Pichiaceae, Saccharomycetales, Saccharomycetes, ten species, type: N. holstii (Wickerham) Y. Yamada, K. Maeda \& Mikata, 
asexual reproduction is by multilateral budding, saprophytic, on beetle larvae tunnels in spruce and pine trees, alpechin, cider, grapes, sauerkraut, silage, mastitis milk, embalmed human corpse, human feces, worldwide, see Lumbsch and Huhndorf (2010; outline), Kirk et al. (2013; genus accepted), Kaewwichian and Limtong (2014; new species, DNA), Kurtzman and Robnett (2014; taxonomy), sequences are available.

Nalanthamala Subram. 1956 (= Rubrinectria Rossman \& Samuels 1999 fide Rossman et al. 2013b), Nectriaceae, Hypocreales, Sordariomycetes, six species, type: N. madreeya Subram., sexual morph formerly known in Rubrinectria, saprobes, plant pathogens, terrestrial, worldwide, see Ligoxigakis et al. (2013; Greece), Hong et al. (2013; selective medium), Severn-Ellis et al. (2012; South Africa), Li et al. (2013; indoor, phylogeny), Peršoh et al. (2011; EcoChip), Rossman et al. (2013b; acceptance of genus), Su et al. (2013; secondary metabolite), Wilk et al. (2009; secondary metabolite), Summerbell et al. (2011; phylogeny), Maharachchikumbura et al. (2015, 2016; outline), cultures and sequences are available, but lacks for type.

Nannfeldtia Petr. 1947, Leptopeltidaceae, Dothideomycetes family incertae sedis, one species, type: N. atra Petr., asexual morph unknown, saprobes, terrestrial, Austria, see Lumbsch and Huhndorf (2010; outline), Hyde et al. (2013; outline, phylogeny), Kirk et al. (2013; genus accepted), Wijayawardene et al. (2014c; outline), cultures and sequences are unavailable, needs generic revision.

Nannizziopsis Currah 1985, Nannizziopsidaceae, Onygenales, Eurotiomycetes, one species, type: N. vriesii (Apinis) Currah, asexual morph hyphomycetous, saprobes, animal pathogens, terrestrial, worldwide, see Lumbsch and Huhndorf (2010; outline), Kirk et al. (2013; genus accepted), Stchigel et al. (2016; taxonomy, phylogeny), Wijayawardene et al. (2017; outline), type specimen and ex-type of the type: CBS H-6714; IMI 149994 (fide Stchigel et al. 2016).

Nanomyces Thaxt. 1931, Laboulbeniaceae, Laboulbeniales, Laboulbeniomycetes, three species, type: $N$. fijianus Thaxt., asexual morph unknown, biotrophic, terrestrial, Pacific, see Lumbsch and Huhndorf (2010; outline), Kirk et al. (2013; genus accepted), cultures and sequences are unavailable.

Nanoschema B. Sutton 1980, Ascomycota genera incertae sedis, one species, type: $N$. elaeocarpi B. Sutton, hyphomycetous, sexual morph unknown, saprobes, terrestrial, British Solomon Islands, see Wijayawardene et al. (2012, 2017; outline), Kirk et al. (2013; genus accepted), cultures and sequences are unavailable, holotype of the type species IMI 187436.

Nanoscypha Denison 1972, Sarcoscyphaceae, Pezizales, Pezizomycetes, ten species, type: $N$. tetraspora (Seaver) Denison, asexual morph unknown, saprobes, terrestrial, worldwide, see Lumbsch and Huhndorf (2010; outline), Kirk et al. (2013; genus accepted), cultures and sequences are available.

Nanostictis M.S. Christ. 1954, Stictidaceae, Ostropales, Lecanoromycetes, four species, type: N. peltigerae M.S. Christ., asexual morph unknown, lichenicolous, terrestrial, worldwide, see Etayo and Sancho (2008; new species), Lumbsch and Huhndorf (2010; outline), Kirk et al. (2013; genus accepted), cultures and sequences are unavailable, needs generic revision.

Naothyrsium Bat. 1960, Ascomycota genera incertae sedis, one species, type: N. splendidum Bat. \& J.L. Bezerra, coelomycetous, sexual morph unknown, saprobes, terrestrial, Brazil, see Wijayawardene et al. (2012, 2017; outline, taxonomy), Kirk et al. (2013; genus accepted), cultures and sequences are unavailable, needs generic revision.

Narasimhella Thirum. \& P.N. Mathur 1966, Gymnoascaceae, Onygenales, Eurotiomycetes, one species, type: N. poonensis Thirum. \& P.N. Mathur, asexual morph unknown, from bee hive, Venezuela, see Lumbsch and Huhndorf (2010; outline), Jaklitsch et al. (2016a; classification), sequences and culture unavailable.

Natantiella Réblová 2009, Sordariomycetes genera incertae sedis, one species, type: $N$. ligneola (Berk. \& Broome) Réblová, asexual morph unknown, saprobes, terrestrial, Europe, 
see Réblová and Štěpánek (2009; morphology), Maharachchikumbura et al. (2016; outline), holotype and culture of the type species K 84426 (holotype of Sphaeria ligneola); CBS 123470.

Natantispora J. Campb., J.L. Anderson \& Shearer 2003, Halosphaeriaceae, Microascales, Sordariomycetes, three species, type: N. retorquens (Shearer \& J.L. Crane) J. Campb., J.L. Anderson \& Shearer, marine, freshwater, see Lumbsch and Huhndorf (2010; outline), Liu et al. (2015a; new species), Maharachchikumbura et al. (2015, 2016; outline, phylogeny), cultures and sequences are available, needs generic revision.

Natarajania Pratibha \& Bhat 2006, Stilbosporaceae, Diaporthales incertae sedis, Sordariomycetes, one species, type: N. indica Pratibha \& Bhat, hyphomycetous, sexual morph unknown, saprobes, terrestrial, India, see Shenoy et al. (2010; phylogeny), Seifert et al. (2011; morphology), Crous et al. (2012f; phylogeny, familial position unresolved), Wijayawardene et al. (2012, 2017; outline), Maharachchikumbura et al. (2015, 2016; outline, phylogeny), cultures and sequences are available.

Natipusilla A. Ferrer, A.N. Mill. \& Shearer 2011, Natipusillaceae, Natipusillales, Dothideomycetes, four species, type: N. decorospora A. Ferrer, A.N. Mill. \& Shearer, saprobes, on submerged wood, Central and South America, see Raja et al. (2012; placed in Natipusillaceae), Hyde et al. (2013; accepted as a genus in Natipusillaceae), Wijayawardene et al. (2014c; outline), cultures and sequences are available, holotype of type: AF236-1 (ILL 86249).

Naumovela Kravtzev 1955, Sordariomycetes genera incertae sedis, two species, type: need typification, saprobes, terrestrial, former USSR, see Lumbsch and Huhndorf (2010; outline), Kirk et al. (2013; genus accepted), Maharachchikumbura et al. (2015, 2016; outline), cultures and sequences are unavailable, needs generic revision.

Naumovozyma Kurtzman 2008, Saccharomycetaceae, Saccharomycetales, Saccharomycetes, two species, type: $N$. dairenensis (H. Naganiishi) Kurtzman, asexual reproduction is by multilateral budding, saprophytic, soil, spoiled milk, ensiled maize, fermented vegetables, dried fruit, cecum of baboon, worldwide, see Lumbsch and Huhndorf (2010; outline), sequences are available.

Nautosphaeria E.B.G. Jones 1964, Halosphaeriaceae, Microascales, Sordariomycetes, one species, type: N. cristaminuta E.B.G. Jones, asexual morph unknown, marine, on submerged wood, temperate, tropical, see Lumbsch and Huhndorf (2010; outline), Sakayaroj et al. (2011a; phylogeny), Kirk et al. (2013; genus accepted), Jones et al. (2015; outline, marine), Maharachchikumbura et al. (2015; outline), cultures and sequences are available, needs generic revision.

Navicella Fabre 1879, Melanommataceae, Pleosporales, Dothideomycetes, five species, type: N. julii Fabre, asexual morph unknown, saprobes, terrestrial, worldwide, see Lumbsch and Huhndorf (2010; outline), Kirk et al. (2013; genus accepted), Ariyawansa et al. (2014e; transferred to Melanommataceae), Wijayawardene et al. (2014c; outline), Tian et al. (2015; accepted as a genus in Melanommataceae), cultures and sequences are unavailable.

Nawawia Marvanová 1980, Chaetosphaeriales genera incertae sedis, type: N. filiformis (Nawawi) Marvanová, hyphomycetous, sexual morph unknown, saprobes, aquatic, worldwide, see Crous et al. (2009b; new species), Wijayawardene et al. (2012, 2017; outline), Kirk et al. (2013; genus accepted), Goh et al. (2014a; new species), cultures and sequences are available but lacks for the type, needs generic revision.

Nebularia P.M. Jørg. 2014, Pannariaceae, Peltigerales, Lecanoromycetes, two species, type: N. incrassata (P.M. Jørg.) P.M. Jørg., lichenized, Ecuador, see Ekman (2014; taxonomy), Lücking et al. (2016b; classification), cultures and sequences are available, needs generic revision. 
Nectria (Fr.) Fr. 1849 (= Tubercularia Tode 1790 fide Rossman et al. 2013b), Nectriaceae, Hypocreales, Sordariomycetes, around 1000 species, type: N. cinnabarina (Tode) Fr., saprobes, pathogens, worldwide, see Lumbsch and Huhndorf (2010; outline), Hirooka et al. (2011; monograph), Kirk et al. (2013; genus accepted), Maharachchikumbura et al. (2015, 2016; outline), Lombard et al. (2015b; phylogeny), cultures and sequences are available, epitype and ex-epitype of the type: BPI 879981; CBS $125165=$ AR $4477=$ CLL 7152.

Nectriella Nitschke ex Fuckel 1870, Bionectriaceae, Hypocreales, Sordariomycetes, 74 species, type: $N$. fuckelii Nitschke ex Fuckel, saprobes, worldwide, see Lumbsch and Huhndorf (2010; outline), Kirk et al. (2013; genus accepted), Maharachchikumbura et al. (2015, 2016; outline), cultures and sequences are unavailable, needs generic revision.

Nectriopsis Maire 1911, Bionectriaceae, Hypocreales, Sordariomycetes, c. 70 species, type: N. violacea (J.C. Schmidt ex Fr.) Maire, asexual morph acremonium-like, saprobes, fungicolous, lichenicolous, terrestrial, worldwide, see Etayo (2010; new species), Lumbsch and Huhndorf (2010; outline), Luo and Zhuang (2010; new species), Brackel and Zimmermann (2012; new species), Whitton et al. (2012b; new species), Kirk et al. (2013; genus accepted), Lombard et al. (2015b; new species, phylogeny), Maharachchikumbura et al. (2015, 2016; outline), Kondratyuk et al. (2016a; new species), Zare and Gams (2016; phylogeny), cultures and sequences are available, needs generic revision.

Neelakesa Udaiyan \& Hosag. 1992, Pseudeurotiaceae, Leotiomycetes family incertae sedis, three species, type: N. lignicola Udaiyan \& V.S. Hosag., saprobes, submerged wood, freshwater, India, see Lumbsch and Huhndorf (2010; outline), Kirk et al. (2013; genus accepted), cultures and sequences are unavailable, needs generic revision, needs generic revision.

Nemania Gray 1821 (= Geniculosporium Chesters \& Greenh. 1964; = Gamosphaera Dumort. 1822; = Geniculisynnema Okane \& Nakagiri 2007 fide Réblová et al. 2016c; Wendt et al. 2017), Xylariaceae, Xylariales, Sordariomycetes, 68 species, type: N. serpens (Pers.) Gray, asexual morph formerly named in Geniculosporium, saprobes or endophytes, terrestrial or marine, worldwide, see Lumbsch and Huhndorf (2010; outline), Kirk et al. (2013; genus accepted), Maharachchikumbura et al. (2015, 2016; outline), cultures and sequences are avilable, needs generic revision.

Nematococcomyces C.L. Hou, M. Piepenbr. \& Oberw. 2004, Rhytismataceae, Rhytismatales, Leotiomycetes, nine species, type: N. rhododendri C.L. Hou, M. Piepenbr. \& Oberw., asexual morph unknown, saprobes, terrestrial, worldwide, see Lumbsch and Huhndorf (2010; outline), Tian et al. (2013; new species, China, phylogeny), cultures and sequences are available, holotype and culture available for type: HMAS (112); voucher HOU 469A.

Nematogonum Desm. 1834, Ascomycota genera incertae sedis, one species, type: $N$. aurantiacum Desm., hyphomycetous, sexual morph unknown, mycoparsites, terrestrial, temperate, see Wijayawardene et al. (2012, 2017; outline), Kirk et al. (2013; genus accepted), cultures and sequences are unavailable, needs generic revision.

Nematographium Goid. 1935, Ascomycota genera incertae sedis, one species, type: Nematographium hippotrichoides (Lindau) Goid., hyphomycetous, sexual morph unknown, saprobes, terrestrial, Europe, see Seifert et al. (2011; morphology), Wijayawardene et al. (2012, 2017; outline), Kirk et al. (2013; genus accepted), cultures and sequences are unavailable, type specimen of type species B herb. Lindau, needs generic revision.

Nematostoma Syd. \& P. Syd. 1914, Pseudoperisporiaceae, Dothideomycetes family incertae sedis, 13 species, type: N. artemisiae Syd. \& P. Syd., asexual morph unknown, saprobes, terrestrial, worldwide, see Lumbsch and Huhndorf (2010; outline), Hyde et al. (2013; accepted as a genus in Pseudoperisporiaceae), Kirk et al. (2013; genus accepted), Wijayawardene et al. (2014c; outline), cultures and sequences are unavailable, needs generic revision. 
Nematothecium Syd. \& P. Syd. 1912, Pseudoperisporiaceae, Dothideomycetes family incertae sedis, two species, type: N. vinosum Syd. \& P. Syd., asexual morph unknown, saprobes, terrestrial, worldwide, see Lumbsch and Huhndorf (2010; outline), Hyde et al. (2013; accepted as a genus in Pseudoperisporiaceae), Kirk et al. (2013; genus accepted), Wijayawardene et al. (2014c; outline), cultures and sequences are unavailable, needs generic revision.

Nemozythiella Höhn. 1925, Ascomycota genera incertae sedis, one species, type: $N$. lonicerae (Died.) Höhn., coelomycetous, sexual morph unknown, saprobes, terrestrial, Europe, see Wijayawardene et al. (2012, 2017; outline), Kirk et al. (2013; genus accepted), cultures and sequences are unavailable, needs generic revision.

Neoacanthostigma Boonmee, Bhat \& K.D. Hyde 2014, Tubeufiaceae, Tubeufiales, Dothideomycetes, three species, type: N. fusiforme Boonmee, Bhat \& K.D. Hyde, asexual morph hyphomycetous, saprobes, terrestrial, worldwide, Boonmee et al. (2014b; taxonomy, phylogeny), Wijayawardene et al. (2014c; outline), cultures and sequences are available, holotype and available ex-type cultures for the type: MFLU 11-1146; MFLUCC 11-0510= BCC 52383 = ICMP 20073.

Neoalpakesa Punith. 1981, Ascomycota genera incertae sedis, one species, type: N. poae Punith., coelomycetous, sexual morph unknown, saprobes, terrestrial, UK, see Wijayawardene et al. (2012, 2017; outline), cultures and sequences are unavailable, holotype of the type: IMI 252188.

Neoanthostomella D.Q. Dai \& K.D. Hyde 2016, Xylariales genera incertae sedis, Sordariomycetes, one species, type: N. pseudostromatica D.Q. Dai \& K.D. Hyde, lichenicolous, asexual morph unknown, saprobes, terrestrial, Thailand, see Dai et al. (2016; phylogeny, morphology, sexual morph), Wendt et al. (2017; accepted as a genus in Xylariales genera incertae sedis), holotype and ex-type of type species MFLU 15-1190; MFLUCC 110610 .

Neoarachnotheca Ulfig, Cano \& Guarro 1997, Onygenaceae, Onygenales, Eurotiomycetes, one species, type: N. keratinophila Ulfig, Cano \& Guarro, asexual morph unknown, saprobes, on marine and river sediments, Spain, see Lumbsch and Huhndorf et al. (2010; outline), Kirk et al. (2013; genus accepted), cultures and sequences are unavailable, holotype of the type: IMI 351982.

Neoarbuscula B. Sutton 1983, Ascomycota genera incertae sedis, one species, type: $N$. eugeniae (Bat. \& Peres) B. Sutton, hyphomycetous, sexual morph unknown, saprobes, terrestrial, India, see Seifert et al. (2011; morphology), Wijayawardene et al. (2012, 2017; outline), cultures and sequences are unavailable, specimens available for the type: IMI 159330, 192110, 198635, 199104, 227705a, 227705b, 296847.

Neoascochyta Q. Chen \& L. Cai 2015, Didymellaceae, Pleosporales, Dothideomycetes, seven species, type: N. exitialis (Morini) Q. Chen \& L. Cai, coelomycetous, sexual morph unknown, saprobes, terrestrial, cosmopolitan, see Chen et al. (2015b; taxonomy, phylogeny), Crous et al. (2016a, b; new species, phylogeny), Wijayawardene et al. (2017; outline), cultures and sequences are available, needs generic revision.

Neoastrosphaeriella Jian K. Liu, E.B.G. Jones \& K.D. Hyde 2011, Aigialaceae, Pleosporales, Dothideomycetes, two species, type: N. krabiensis J.K. Liu, E.B.G. Jones \& K.D. Hyde, asexual morph unknown, saprobes, Thailand, see Liu et al. (2011b; morphology, DNA, phylogeny), Hyde et al. (2013; accepted as agenus in Aigialaceae), Wijayawardene et al. (2014c; outline), holotype: MFLU 11-1148.

Neobambusicola Crous \& M.J. Wingf. 2014, Sulcatisporaceae, Ploesporales, Dothideomycetes, one species, type: N. strelitziae Crous \& M.J. Wingf., coelomycetous, sexual morph unknown, saprobes, terrestrial, South Africa, see Crous et al. (2014d; 
morphology, DNA), Tanaka et al. (2015; phylogeny), Cultures and sequences are available, holotype and ex-type strain of the type species CBS H-22000; CPC $24182=$ CBS 138869.

Neobarclaya Kuntze 1898, Ascomycota genera incertae sedis, one species, type: Neobarclaya primaria (Ellis \& Everh.) Kuntze, coelomycetous, sexual morph unknown, saprobes, terrestrial, USA, see Wijayawardene et al. (2012, 2017; outline), Kirk et al. (2013; genus accepted), cultures and sequences are unavailable, needs generic revision.

Neobarya Lowen 1986, Clavicipitaceae, Hypocreales, Sordariomycetes, ten species, type: $N$. parasitica (Fuckel) Lowen, asexual morph acremonium-like, mycoparasites, lichenicolous, terrestrial, worldwide, see Lumbsch and Huhndorf (2010; outline), Kirk et al. (2013; genus accepted), Lawrey et al. (2015; lichenicolous, DNA, phylogeny), Maharachchikumbura et al. (2015, 2016; outline), sequence available for type species; GenBank Number: KP899626, needs generic revision.

Neobroomella Petr. 1947, Amphisphaeriaceae, Xylariales, Sordariomycetes, one species, type: $N$. ciliata Petr., asexual morph unknown, saprobes, terrestrial, Syria, see Lumbsch and Huhndorf (2010; outline), Kirk et al. (2013; genus accepted), Senanayake et al. (2015; accepted in Phlogicylindriaceae), Maharachchikumbura et al. (2015, 2016; outline), cultures and sequences are unavailable, needs generic revision.

Neobulgaria Petr. 1921, Gelatinodiscaceae, Helotiales, Leotiomycetes, eleven species, type: N. pura (Pers.) Petr., asexual morph hyphomycetous (phialophora-like), saprobes, terrestrial, worldwide, see Lumbsch and Huhndorf (2010; outline), Johnston et al. (2010; new species, New Zealand, asexual morph, DNA), Kirk et al. (2013; genus accepted), cultures and sequences are available, available specimen and cultures for type: CBS H-15111; AFTOL-ID 1259 (Schoch unpub.).

Neocamarosporium Crous \& M.J. Wingf. 2014, Pleosporaceae, Pleosporales, Dothideomycetes, four species, type: N. goegapense Crous \& M.J. Wingf., coelomycetous, saprobes, terrestrial, worldwide, see Crous et al. (2014d; taxonomy, phylogeny), Wijayawardene et al. (2016b; outline, taxonomy), Ariyawansa et al. (2015c; phylogeny, new combination), cultures and sequences are available, holotype and ex-type strains of the type species CBS H-21722; CPC 23676.

Neocarpenteles Udagawa \& Uchiy. 2002, Trichocomaceae, Eurotiales, Eurotiomycetes, one species, type: $N$. acanthosporum (Udagawa \& Takada) Udagawa \& Uchiy., asexual morph unknown, saprobes, terrestrial, temperate, see Lumbsch and Huhndorf (2010; outline), cultures and sequences are available, holotype and cultures available for the type: NHL 22462; CBS 447.65, CBS 558.71.

Neocatapyrenium H. Harada 1993, Verrucariaceae, Verrucariales, Eurotiomycetes, four species, type: $N$. cladonioideum (Vain.) H. Harada, asexual morph unknown, lichenicolous, terrestrial, worldwide, see Lumbsch and Huhndorf (2010; outline), Kirk et al. (2013; genus accepted), cultures and sequences are available but lacks for the type species, holotype of type species TUR (142).

Neocatenulostroma Quaedvlieg \& Crous 2014, Teratosphaeriaceae, Capnodiales, Dothideomycetes, three species, type: N. microsporum (Joanne E. Taylor \& Crous) Quaedvl. $\&$ Crous, hyphomycetous, pathogens, saprobes, terrestrial, Sweden, Germany, South Africa, see Quaedvlieg et al. (2014; morphology, phylogeny), Wijayawardene et al. (2014c; phylogeny, nomenclature), holotype and ex-type of the type species PREM 56207a; CPC 1960.

Neoceratosperma Crous \& Cheew. 2014, Mycosphaerellaceae, Capnodiales, Dothideomycetes, four species, type: N. eucalypti Crous \& Cheew., hyphomycetous, sexual morph mycosphaerella-like, pathogens or associated with leaf spots, Brazil, China, Thailand, see Crous et al. (2014c; morphology, phylogeny), Wijayawardene et al. (2014c, 2017; 
outline), Guatimosim et al. (2016; morphology, phylogeny), cultures and sequences are available, holotype and ex-type of the type species CBS H-21712; CPC 23465.

Neocercospora M. Bakhshi et al. 2015, Mycosphaerellaceae, Capnodiales, Dothideomycetes, one species, type: N. ammicola M. Bakhshi, Arzanlou, Babai-ahari \& Crous, hyphomycetous, sexual morph unknown, plant pathogenic, see Bakhshi et al. (2015; morphology, phylogeny), cultures and sequences are available, holotype and ex-type of type: IRAN $16461 \mathrm{~F}$; CCTU $1186=$ CBS 136450 .

Neochaetosphaerella Lar. N. Vassiljeva, S.L. Stephenson \& Chernyshev 2012, Nitschkiaceae, Coronophorales, Sordariomycetes, one species, type: N. thaxteriospora Lar. N. Vassiljeva, S.L. Stephenson \& Chernyshev, asexual morphs unknown, saprobes, terrestrial, southern USA, see Vasilyeva et al. (2012; morphology), Maharachchikumbura et al. (2015, 2016; outline), cultures and sequences are unavailable, holotype of type: VLA P-2489.

Neochaetospora B. Sutton \& Sankaran 1991, Ascomycota genera incertae sedis, one species, type: N. quezelii (Faurel \& Schotter) B. Sutton \& Sankaran, coelomycetous, sexual morph unknown, coprophilous, terrestrial, Sahara, see Kirk et al. (2013; genus accepted), cultures and sequences are unavailable, needs generic revision.

Neocladophialophora Crous \& R.K. Schumach. 2014, Eurotiomycetes genera incertae sedis, one species, type: N. quercina Crous \& R.K. Schumach., hyphomycetous, sexual morph unknown, saprobes, terrestrial, Germany, see Crous et al. (2014c; morphology, phylogeny), cultures and sequences are available, holotype and ex-type of type: CBS H-22003; CPC 24426.

Neoclaviceps J.F. White, Bills, S.C. Alderman \& Spatafora 2001, Clavicipitaceae, Hypocreales, Sordariomycetes, one species, type: N. monostipa J.F. White, Bills, S.C. Alderman \& Spatafora, asexual morph unknown, saprobes, terrestrial, Costa Rica, see Lumbsch and Huhndorf (2010; outline), Kirk et al. (2013; genus accepted), Maharachchikumbura et al. (2015, 2016; outline), cultures and sequences are available, cultures available for the type species INBio 6-141, holotype: RUTPP INBio 6-141.

Neococcomyces Y.R. Lin, C.T. Xiang \& Z.Z. Li 1999, Rhytismataceae, Rhytismatales, Leotiomycetes, three species, type: N. rhododendri Y.R. Lin, C.T. Xiang \& Z.Z. Li, asexual morph unknown, saprobes, terrestrial, China, see Hou and Piepenbring (2009; new species), Lumbsch and Huhndorf (2010; outline), Kirk et al. (2013; genus accepted), cultures and sequences are unavailable, holotype of the type: AAU [Anhui] AAUFP 67, needs generic revision.

Neocoleroa Petr. 1934, Pseudoperisporiaceae, Dothideomycetes families incertae sedis, six species, type: N. sibirica Petr., asexual morph unknown, lichenicolous, terrestrial, worldwide, see Farkas (2010; new species), Lumbsch and Huhndorf (2010; outline), Hyde et al. (2013; accepted as a genus in Pseudoperisporiaceae), Wijayawardene et al. (2014c; outline), cultures and sequences are unavailable, needs generic revision.

Neocordana Hern.-Restr. \& Crous 2015, Pyriculariaceae, Magnaporthales, Sordariomycetes, five species, type: N. musae (Zimm.) M. Hern.-Rest. \& Crous, hyphomycetous, sexual morph unknown, saprobes, terrestrial, cosmopolitan, see Hernández-Restrepo et al. (2015b; taxonomy, phylogeny), Crous et al. (2016a, b; new species, phylogeny), Wijayawardene et al. (2017; outline), neotype and ex-neotype culture of the type: CBS H-22054, CPC 18127.

Neocordyceps Kobayasi 1984, Clavicipitaceae, Hypocreales, Sordariomycetes, one species, type: N. kohyasanensis Kobayasi, asexual morph unknown, saprobes, terrestrial, Japan, see Lumbsch and Huhndorf (2010; outline), Kirk et al. (2013; genus accepted), Maharachchikumbura et al. (2015, 2016; outline), cultures and sequences are unavailable, needs generic revision.

Neocosmospora E.F. Sm. 1899, Nectriaceae, Hypocreales, Sordariomycetes, 25 species, type: N. vasinfecta E.F. Sm., asexual morph hyphomycetous (acremonium-like), saprobes, 
pathogens on human, terrestrial, worldwide, see Lumbsch and Huhndorf (2010; outline), Nalim et al. (2011; new species), Hirooka et al. (2012; new species), Kirk et al. (2013; genus accepted), Lombard et al. (2015b; new species, DNA, phylogeny), Maharachchikumbura et al. (2015, 2016; outline), cultures and sequences are available.

Neocrinula Crous 2016, Helotiaceae, Helotiales, Leotiomycetes, one species, type: N. xanthorrhoeae Crous, hyphomycetous, sexual morph unknown, saprobes, terrestrial, Australia, see Crous et al. (2016a; new species, phylogeny), Wijayawardene et al. (2017; outline), holotype and ex-type culture of the type: CBS H-22859, CPC 29474.

Neocryptospora Petr. 1959, Sordariomycetes genera incertae sedis, one species, type: N. rickii Petr., asexual morph unknown, saprobes, terrestrial, Brazil, see Lumbsch and Huhndorf (2010; outline), Kirk et al. (2013; genus accepted), Maharachchikumbura et al. (2016; outline), cultures and sequences are unavailable, needs generic revision.

Neocudoniella S. Imai 1941, Gelatinodiscaceae, Helotiales, Leotiomycetes, two species, type: $N$. jezoënsis (S. Imai) S. Imai, asexual morph unknown, saprobes, terrestrial, Japan, Canada, see Lumbsch and Huhndorf (2010; outline), Kirk et al. (2013; genus accepted), Jaklitsch et al. (2016a; classification), cultures and sequences are available, needs generic revision.

Neocylindroseptoria K.M. Thambugala \& K.D. Hyde 2014, Dothideaceae, Dothideales, Dothideomycetes, one species, type: N. pistaciae (Quaedvl., Verkley \& Crous) Thambug. \& K.D. Hyde, coelomycetous, sexual morph unknown, saprobes, terrestrial, Spain, see Thambugala et al. (2015c; phylogeny), cultures and sequences are available, holotype and extype of type: CBS H-21301; CBS 471.69.

Neodasyscypha Suková \& Spooner 2005, Lachnaceae, Helotiales, Leotiomycetes, two species, type: $N$. cerina (Pers.) Spooner, asexual morph unknown, saprobes, terrestrial, temperate, see Lumbsch and Huhndorf (2010; outline), Whitton et al. (2012b; on Pandunus), Jaklitsch et al. (2016a; classification), cultures and sequences are available, available specimen of type: CBS H-15118.

Neodeightonia C. Booth 1970, Botryosphaeriaceae, Botryosphaeriales, Dothideomycetes, six species, type: N. subglobosa Booth, asexual morph coelomycetous, saprobes, pathogens, in soil, terrestrial, cosmopolitan, see Phillips et al. (2008, 2013; taxonomy, phylogeny), Liu et al. (2012; taxonomy, phylogeny), Hyde et al. (2013; accepted as a genus in Botryosphaeriaceae), Slippers et al. (2013; phylogeny), Wijayawardene et al. (2014c, 2016b; outline, taxonomy, phylogeny), Dissanayake et al.(2016; taxonomy), holotype and ex-type culture of the type: IMI 57769(f), CBS 448.91.

Neodeightoniella Crous \& W.J. Swart 2013, Mycosphaerellaceae, Capnodiales, Dothideomycetes, one species, type: N. phragmiticola Crous \& W.J. Swart, hyphomycetous, sexual morph unknown, saprobes, terrestrial, South Africa, see Crous et al. (2013b; morphology), cultures and sequences are available, holotype and ex-type of type: CBS H21427; CPC 22059.

Neodevriesia Quaedvl. \& Crous 2014, Neodevriesiaceae, Capnodiales, Dothideomycetes, 17 species, type: N. hilliana (Crous \& U. Braun) Quaedvl. \& Crous, hyphomycetous, with teratosphaeria-like sexual morph, saprobes, terrestrial, worldwide, see Quaedvlieg et al. (2014; morphology, phylogeny), Wijayawardene et al. (2014c; phylogeny, outline), Crous et al. (2015d; morphology, phylogeny, sexual morph), cultures and sequences are available, holotype and ex-type of the type: CBS H-20340; CPC 15382.

Neodidymella Phookamsak, R.H. Perera \& K.D. Hyde 2015, Didymellaceae, Pleosporales, Dothideomycetes, four species, type: N. thailandicum Phookamsak \& K.D. Hyde, asexual morph unknown, saprobes, terrestrial, Thailand, see Ariyawansa et al. (2015a; taxonomy, phylogeny), holotype and ex-type culture of the type: MFLU11-0176, MFLUCC 11-0140. 
Neodidymelliopsis Q. Chen \& L. Cai 2015, Didymellaceae, Pleosporales, Dothideomycetes, four species, type: $N$. cannabis (G. Winter) Q. Chen \& L. Cai, asexual morph coelomycetous, saprobes, ?pathogens, terrestrial, cosmopolitan, see Chen et al. (2015b; taxonomy, phylogeny), Wijayawardene et al. (2017; outline), ex-type culture of the type: CBS 121.75.

Neodiplodina Petr. 1954, Ascomycota genera incertae sedis, one species, type: $N$. verruciformis Petr., coelomycetous, sexual morph unknown, saprobes, terrestrial, USA, see Wijayawardene et al. (2012, 2017; outline), Kirk et al. (2013; genus accepted), cultures and sequences are unavailable, needs generic revision, needs generic revision.

Neoeriomycopsis Crous \& M.J. Wingf. 2015, Sordariomycetes, genera incertae sedis, one species, type: N. aristata (B. Sutton \& Hodges) Crous \& M.J. Wingf., coelomycetous, saprobes, Brazil, see Crous et al. (2015d; taxonomy, phylogeny), Wijayawardene et al. (2017; outline, phylogeny), epitype and ex-epitype culture of the type: CBS H-22243, CPC 25050.

Neoërysiphe U. Braun 1999, Erysiphaceae, Erysiphales, Leotiomycetes, c. 15 species, type species: Neoerysiphe galeopsidis (DC.) U. Braun, sexual and hyphomycetous asexual morphs, obligate plant pathogens, terrestrial, almost worldwide, asexual morph: Striatoidium (R.T.A. Cook, A.J. Inman \& C. Billings) R.T.A. Cook \& U. Braun, see Takamatsu (2008a; phylogeny), Heluta et al. (2010; phylogeny), Braun \& Cook (2012; taxonomy), DNA sequences available, lectotype of type species "Erysiphe galeopsidis No. 233" [in herb. de Candolle] (G 00122104).

Notes: Striatoidium was originally described as Oidium subgen. Striatoidium R.T.A. Cook, A.J. Inman \& C. Billings, typified by Oidium leucas-javanicae Sawada, which is a synonym of Oidium lamii Rabenh. according to Braun and Cook (2012). This subgenus was subsequently raised to genus status by Braun and Cook (2012), but no binomial in Striatoidium was given to the type species. In addition, four species in Striatoidium which lack a Neoërysiphe sexual morph are known, i.e. S. aloysiae (S. Wolcan, S. Takam. \& Havryl.) S. Wolcan, S. Takam. \& Havryl., S. baccharidis (Havryl. \& U. Braun) U. Braun \& Havryl., S. jaborosae M.G. Cabrera \& U. Braun, and S. maquii (Havryl. \& U. Braun) U. Braun \& Havryl. Oidium lamii is the asexual morph of N. galeopsidis (Braun and Cook 2012) and under unitary nomenclature, the genus Striatoidium should be considered a synonym of Neoërysiphe. Oidium leonuri-sibiricae Sawada is also a synonym of $O$. lamii (Braun \& Cook 2012), therefore these names and O. leucas-javanicae need to be synonymized with $N$. galeopsidis. In addition, molecular phylogenetic studies have revealed the placement of $S$. aloysiae, S. baccharidis, and S. maquii in Neoërysiphe, indicating that these names need to be reallocated accordingly. The phylogenetic placement of $S$. jaborosae is unknown and therefore no new combination can be proposed for this taxon in the current state.

Neoërysiphe galeopsidis (DC.) U. Braun, Schlechtendalia 3:50. 1999

= Oidium lamii Rabenh., Flora 36:204. 1853.

= Oidium leucas-javanicae Sawada, Bull. Dept. Agric. Gov. Res. Inst. Formosa 24:22.

1927

= Oidium leonuri-sibiricae Sawada, loc. cit.:24

Additional synonyms of N. galeopsidis are listed in Braun and Cook (2012)

Neoërysiphe aloysiae (S. Wolcan, S. Takam. \& Havryl.) S. Takam., comb. nov. IndexFungorum number: IF553242

Basionym: Oidium aloysiae S. Wolcan, S. Takam. \& Havryl., in Takamatsu et al. Mycol Res. 112:644, 2008.

三Striatoidium aloysiae (S. Wolcan, S. Takam. \& Havryl.) S. Wolcan, S. Takam. \& Havryl., in U. Braun \& R.T.A. Cook, Taxonomic Manual of the Erysiphales (Powdery Mildews): 347. 2012. 
Neö̈rysiphe baccharidis (Havryl. \& U. Braun) S. Takam., comb. nov. IndexFungorum number: IF553243

Basionym: Oidium baccharidis Havryl. \& U. Braun, Nova Hedwigia 66(3-4):515. 1998.

$\equiv$ Striatoidium baccharidis (Havryl. \& U. Braun) U. Braun \& Havryl., Taxonomic Manual of the Erysiphales (Powdery Mildews):348. 2012.

Neoërysiphe maquii (Havryl. \& U. Braun) S. Takam., comb. nov. IndexFungorum number: IF553244

Basionym: Oidium maquii Havryl. \& U. Braun, Nova Hedwigia 66(3-4):518. 1998.

三Striatoidium maquii (Havryl. \& U. Braun) U. Braun \& Havryl., Taxonomic Manual of the Erysiphales (Powdery Mildews):349. 2012.

Neofabraea H.S. Jacks. 1913 (= Allantozythia Höhn. 1924; = Phlyctema Desm. 1847 fide Johnston et al. 2014b), Dermateaceae, Helotiales, Leotiomycetes, seven species, type: N. malicorticis H.S. Jacks., asexual morph hyphomycetous, saprobes, pathogens, terrestrial, worldwide, see Raitviir (2008; Magadan), Lumbsch and Huhndorf (2010; outline), Kirk et al. (2013; genus accepted), Johnston et al. (2014b; nomenclature, new combination), Crous et al. (2015e; new species), de Jong et al. (2015; phylogeny), Chen et al. (2016b; new species), cultures and sequences are available, cultures available for the type: DAOM 227090, neotype of type: CBS H-22219.

Neoflageoletia J. Reid \& C. Booth 1966, Phyllachoraceae, Phyllachorales, Sordariomycetes, one species, type: N. bambusina (Syd.) J. Reid \& C. Booth, asexual morph unknown, saprobes, terrestrial, Philippines, see Lumbsch and Huhndorf (2010; outline), Kirk et al. (2013; genus accepted), Maharachchikumbura et al. (2015, 2016; outline), cultures and sequences are unavailable, needs generic revision.

Neofracchiaea Teng 1938, Scortechiniaceae, Coronophorales, Sordariomycetes, one species, type: N. callista (Berk. \& M.A. Curtis) Teng, asexual morph unknown, saprobes, see Mugambi and Huhndorf (2010; phylogeny), Maharachchikumbura et al. (2015, 2016; outline), Jaklitsch et al. (2016a; classification), cultures and sequences are unavailable.

Neofuckelia Zeller \& Goodd. 1935, Ascomycota genera incertae sedis, one species, type: $N$. pinicola (Zeller \& Goodd.) Zeller \& Goodd., coelomycetous, sexual morph unknown, saprobes, terrestrial, North America, see Wijayawardene et al. (2012, 2017; outline), Kirk et al. (2013; genus accepted), cultures and sequences are unavailable, needs generic revision.

Neofusicoccum Crous, Slippers \& A.J.L. Phillips 2006, Botryosphaeriaceae, Botryosphaeriales, Dothideomycetes, c. 29 species, type: N. parvum (Pennycook \& Samuels) Crous, Slippers \& A.J.L. Phillips, coelomycetous (with dichomera-like synasexual morphs), saprobes, pathogens, terrestrial, cosmopolitan, see Phillips et al. (2008, 2013; taxonomy, phylogeny), Pavlic et al. (2009; new species), Inderbitzin et al. (2010; new species), Liu et al. (2012; taxonomy, phylogeny), Hyde et al. (2013; accepted as a genus in Botryosphaeriaceae), Slippers et al. (2013; phylogeny), Wijayawardene et al. (2014c, 2017; outline, taxonomy, phylogeny), Dissanayake et al.(2016; taxonomy), holotype and ex-type culture of the type: PDD 45438, ATCC 58191.

Neogaeumannomyces D.Q. Dai \& K.D. Hyde 2015, Magnaporthaceae, Magnaporthales, Sordariomycetes, one species, type: Neogaeumannomyces bambusicola D.Q. Dai \& K.D. Hyde, asexual morph unknown, saprobes, terrestrial, Thailand, see Liu et al. (2015a; phylogeny, taxonomy), Maharachchikumbura et al. (2016; outline), cultures and sequences are available, holotype and ex-type of type: MFLU 14-0822; MFLUCC 11-0390.

Neogymnomyces G.F. Orr 1970, Onygenaceae, Onygenales, Eurotiomycetes, one species, type: N. demonbreunii (Ajello \& S.L. Cheng) G.F. Orr, asexual morph unknown, saprobes, 
Spain, see Lumbsch and Huhndorf (2010; outline), Hansen et al. (2013; DNA), Kirk et al. (2013; genus accepted), cultures and sequences are available, available specimen and cultures for the type: CBS H-7197; CBS 233.85.

Neohaplomyces R.K. Benj. 1955, Laboulbeniaceae, Laboulbeniales, Laboulbeniomycetes, three species, type: N. medonalis R.K. Benj., asexual morph unknown, biotrophic, terrestrial, worldwide, see Lumbsch and Huhndorf (2010; outline), Kirk et al. (2013; genus accepted), cultures and sequences are unavailable.

Neohendersonia Petr. 1921, Ascomycota genera incertae sedis, four species, type: $N$. piriformis (G.H. Otth) Petr., coelomycetous, sexual morph unknown, saprobes, terrestrial, worldwide, see Wijayawardene et al. (2012, 2016b, 2017; outline), Kirk et al. (2013; genus accepted), cultures and sequences are unavailable, needs generic revision.

Neoheppia Zahlbr. 1909, Peltulaceae, Lichinales, Lichinomycetes, one species, type: N. brasiliensis Zahlbr., asexual morph unknown, saprobes, Brazil, see Lumbsch and Huhndorf (2010; outline), Kirk et al. (2013; genus accepted), cultures and sequences are unavailable, needs generic revision.

Neoheteroceras Nag Raj 1993, Ascomycota genera incertae sedis, two species, type: $N$. flageoletii (Sacc.) Nag Raj, coelomycetous, sexual morph unknown, saprobes, terrestrial, France, Japan, see Yonezawa and Tanaka (2008; morphology, new species), Wijayawardene et al. (2012, 2016b, 2017; morphology, outline), Kirk et al. (2013; genus accepted), cultures and sequences are unavailable, holotype of the type: PAD 940.

Neohortaea Quaedvl. \& Crous 2014, Capnodiales genera incertae sedis, Dothideomycetes, one species, type: N. acidophila (Hölker, Bend, Pracht, Tetsch, Tob. Müll., M. Höfer \& de Hoog) Quaedvl. \& Crous, hyphomycetous, sexual morph unknown, saprobes, terrestrial, Germany, see Quaedvlieg et al. (2014; morphology, phylogeny), Wijayawardene et al. (2014c; phylogeny, outline), cultures and sequences are available, ex-type strain of type: CBS 113389.

Neohypodiscus J.D. Rogers, Y.M. Ju \& Læssøe 1994, Boliniaceae, Boliniales, Sordariomycetes, three species, type: N. rickii (Lloyd) J.D. Rogers, Y.M. Ju \& Læssøe, asexual morph unknown, saprobes, terrestrial, worldwide, see Lumbsch and Huhndorf (2010; outline), Kirk et al. (2013; genus accepted), Senanayake et al. (2015; accepted in Xylariomycetidae), Maharachchikumbura et al. (2015, 2016; outline), cultures and sequences are unavailable, needs generic revision.

Neoidriella M. Hern.-Restr. \& Crous 2015, Xylariales genera incertae sedis, Sordariomycetes, one species, type: N. desertorum (Nicot \& Mouch.) Hern.-Restr. \& Crous, hyphomycetous, sexual morph unknown, saprobes, terrestrial, Egypt, see HernándezRestrepo et al. (2016b; taxonomy, phylogeny), Maharachchikumbura et al. (2015, 2016; outline), cultures and sequences are available.

Neojohnstonia B. Sutton 1983, Ascomycota genera incertae sedis, two species, type: $N$. colocasiae (M.B. Ellis) B. Sutton, hyphomycetous, sexual morph unknown, saprobes, terrestrial, worldwide, see Wijayawardene et al. (2012, 2017; outline), cultures and sequences are unavailable, holotype of the type was not designated but several specimens are at IMI and CBS (CBS H-4370).

Neokalmusia Ariyaw. \& K.D. Hyde 2014, Didymosphaeriaceae, Pleosporales, Dothideomycetes, three species, type: N. brevispora (Nagas. \& Y. Otani) Kaz. Tanaka, Ariyawansa \& K.D. Hyde, asexual morph unknown, saprobes, terrestrial, Japan, Thailand, see Ariyawansa et al. (2014d; taxonomy, phylogeny), Dai et al. (2015; taxonomy, phylogeny), Tanaka et al. (2015; taxonomy, phylogeny), cultures and sequences are available. Neolamya Theiss. \& Syd. 1918, Sordariomycetes genera incertae sedis, two species, type: $N$. peltigerae (Mont.) Theiss. \& Syd., asexual morph unknown, saprobes, terrestrial, Brazil, see Kocourková (2009; new species), Lumbsch and Huhndorf (2010; outline), Kirk et al. (2013; 
genus accepted), Maharachchikumbura et al. (2015, 2016; outline), cultures and sequences are unavailable, needs generic revision.

Neolecta Speg. 1881, Neolectaceae, Neolectales, Neolectomycetes, three species, type: $N$. flavovirescens Speg., asexual morph unknown, saprobes, terrestrial, Brazil, north teperate, see Lumbsch and Huhndorf (2010; outline), Kirk et al. (2013; genus accepted), cultures available but lacks for the type species, needs generic revision.

Neoligniella Naumov 1951, Ascomycota genera incertae sedis, four species, type: $N$. immersa Naumov, coelomycetous, sexual morph unknown, saprobes, terrestrial, former USSR, see Wijayawardene et al. (2012, 2017; outline), Kirk et al. (2013; genus accepted), cultures and sequences are unavailable, needs generic revision.

Neolinocarpon K.D. Hyde 1992, Xylariales genera incertae sedis, Sordariomycetes, ten species, type: N. globosicarpum K.D. Hyde, hyphomycetous, sexual morph unknown, saprobes, terrestrial, worldwide, see Lumbsch and Huhndorf (2010; treated as a genus in Sordariomycetes), Maharachchikumbura et al. (2015, 2016; outline), needs generic revision, cultures and sequences are available.

Neolophiostoma S. Boonmee \& K.D. Hyde 2015, Halotthiaceae, Pleosporales, Dothideomycetes, one species, type: N. pigmentatum Boonmee \& K.D. Hyde, asexual morph unknown, saprobes, terrestrial, Thailand, see Ariyawansa et al. (2015a; taxonomy, phylogeny), holotype and ex-type culture of the type: MFLU 10-0062, MFLUCC 10-0129.

Neomassaria Mapook, Camporesi \& K.D. Hyde 2016, Massariaceae, Pleosporales, Dothideomycetes, one species, type: N. fabacearum Mapook, Camporesi \& K.D. Hyde, asexual morph unknown, saprobes, terrestrial, Italy, see Hyde et al. (2016; taxonomy, phylogeny), holotype and ex-type culture of the type: MFLU 16-1875, MFLUCC 14-1117.

Neomassariosphaeria Y. Zhang bis, J. Fourn. \& K.D. Hyde 2009, Lindgomycetaceae, Pleosporales, Dothideomycetes, one species, type: N. typhicola (P. Karst.) Y. Zhang ter, J. Fourn. \& K.D. Hyde, asexual morph unknown, saprobes, aquatic, cosmopolitan, see Zhang et al. (2009d; taxonomy, accepted as a genus in Amniculicolaceae), Hyde et al. (2013; accepted as a genus in Amniculicolaceae), Ariyawansa et al. (2015a; acceptd as a genus in Lindgomycetaceae), Jones et al. (2015; outline, accepted as a genus in Amniculicolaceae), cultures and sequences are unavailable, needs generic revision.

Neomelanconium Petr. 1940, Ascomycota genera incertae sedis, three species, type: $N$. gelatosporum (Zimm.) Petr., coelomycetous, sexual morph unknown, saprobes, terrestrial, former USSR, see Wijayawardene et al. (2012, 2016b, 2017; outline, taxonomy, new species), Kirk et al. (2013; genus accepted), cultures and sequences are unavailable, needs generic revision.

Neomicrosphaeropsis Thambug., Camporesi \& K.D. Hyde 2016, Didymellaceae, Pleosporales, Dothideomycetes, seven species, type: N. italica Thambug., Camporesi \& K.D. Hyde, asexual morph unknown, saprobes, terrestrial, Italy, see Thambugala et al. (2016; taxonomy, phylogeny), Hyde et al. (2016; taxonomy, phylogeny), holotype and ex-type culture of the type: MFLU 16-0674, MFLUCC 16-0284.

Neomunkia Petr. 1947, Hypocreales genera incertae sedis, Sordariomycetes, one species, type: N. sydowii Petr., hyphomycetous, sexual morph unknown, saprobes, terrestrial, South America, see Seifert et al. (2011; morphology), Wijayawardene et al. (2012, 2017; outline), Kirk et al. (2013; genus accepted), Maharachchikumbura et al. (2015, 2016; phylogeny), cultures and sequences are available.

Neomycosphaerella Crous 2013, Mycosphaerellaceae, Capnodiales, Dothideomycetes, one species, type: N. pseudopentameridis Crous, asexual morph unknown, foliicolous, South Africa, see Crous et al. (2013b; morphology, phylogeny), Wijayawardene et al. (2014c; phylogeny, outline), cultures and sequences are available, holotype and ex-type of type: CBS H-21416; CPC 21127. 
Neomyrothecium L. Lombard \& Crous 2016, Stachybotriaceae, Hypocreales, Sordariomycetes, one species, type: N. humicola L. Lombard \& Crous, hyphomycetous, sexual morph unknown, from soil, terrestrial, Papua New Guinea, see Lombard et al. (2016; taxonomy, phylogeny), Wijayawardene et al. (2014c; outline), holotype and ex-type culture of the type: CBS H-22456, CBS 310.96.

Neonectria Wollenw. 1917 (= Heliscus Sacc. 1880; = Cylindrocarpon Wollenw. 1913 fide Rossman et al. 2013b, 2016a), Nectriaceae, Hypocreales, Sordariomycetes, 28 species, type $N$. ramulariae Wollenw., on bark, sometimes causing cankers, cosmopolitan, mostly in temperate regions, see Chaverri et al. (2011; phylogeny), Rossman et al. (2013b; Neonectria protected against Cylindrocarpon), Lombard et al. (2015b; synonymised Heliscus under Neonectria), Maharachchikumbura et al. (2015, 2016; phylogeny), Rossman et al. (2016a; nomenclature), cultures and sequences are available, cultures available for type: CBS 151.29 = IMI 113894 = MUCL 28083), holotype of the type species B.

Neooccultibambusa Doilom \& K.D. Hyde 2016, Occultibambusaceae, Pleosporales, Dothideomycetes, one species, type: N. chiangraiensis Doilom \& K.D. Hyde, saprobes, terrestrial, see Dai et al. (2016; phylogeny), Doilom et al. (2016; phylogeny), cultures and sequences are available, holotype and ex-type strains of type: MFLU 15-3531; MFLUCC 12-0559, MKT 075, ICMP 21165.

Neoophiosphaerella Kaz. Tanaka \& K. Hiray. 2015, Lentitheciaceae, Pleosporales, Dothideomycetes, one species, type: N. sasicola (Nagas. \& Y. Otani) Kaz. Tanaka \& K. Hiray., asexual morph unknown, saprobes, terrestrial, Japan, see Tanaka et al. (2015; morphology, phylogeny), cultures and sequences are available, holotype, epitype and exepitype strain of the type species TMI 3176, HHUF 29443; CBS 120247.

Neoovularia U. Braun 1992, Ascomycota genera incertae sedis, six species, type: $N$. nomuriana (Sacc.) U. Braun (三 Tuberculina nomuriana Sacc.), asexual morphs hyphomycetous, terrestrial, plant pathogenic, leaf-spotting, Asia, Europe, North America, see Wijayawardene et al. (2014c; outline), cultures and cultures and sequences are unavailable. Holotype of type species Nomura (PAD).

Neoparodia Petr. \& Cif. 1932, Perisporiopsidaceae, Dothideomycetes families incertae sedis, one species, type: Neoparodia ekmanii Petr. \& Cif., asexual morph chuppia-like or sarcinella-like, saprobes, terrestrial, West Indies, see Lumbsch and Huhndorf (2010; outline), Hyde et al. (2013; accepted as a genus in Perisporiopsidaceae), Kirk et al. (2013; genus accepted), Wijayawardene et al. (2014c; outline), cultures and sequences are unavailable, needs generic revision.

Neopeckia Sacc. 1883, Dothideomycetes genera incertae sedis, one species, type: $N$. coulteri (Peck) Sacc., asexual morph unknown, saprobes, terrestrial, widespread, see Lumbsch and Huhndorf (2010; outline), Kirk et al. (2013; genus accepted), cultures and sequences are available but unavailable for type species, needs generic revision.

Neopeltella Petr. 1950, Micropeltidaceae, Microthyriales, Dothideomycetes, three species, type: $N$. aequatoriensis Petr., asexual morph unknown, saprobes, terrestrial, tropical, see Lumbsch and Huhndorf (2010; outline, accepted in Schizothyriaceae), Hyde et al. (2013, accepted in Schizothyriaceae), Kirk et al. (2013; genus accepted), Wijayawardene et al. (2014c; outline, accepted as a genus in Schizothyriaceae), Phookamsak et al. (2016; placed in Micropeltidaceae), cultures and sequences are unavailable, needs generic revision.

Neopeltis Syd. 1937, Ascomycota genera incertae sedis, three species, type: N. brenesii Syd., coelomycetous, sexual morph unknown, saprobes, terrestrial, central America, see Wijayawardene et al. (2012, 2017; outline), Kirk et al. (2013; genus accepted), cultures and sequences are unavailable, needs generic revision.

Neopenidiella Quaedvl. \& Crous 2014, Mycosphaerellaceae, Capnodiales, Dothideomycetes, one species, type: N. nectandrae (Crous, U. Braun \& R.F. Castañeda) Quaedvlieg \& Crous, 
hyphomycetous, sexual morph unknown, foliicolous, terrestrial, Cuba, see Quaedvlieg et al. (2014; morphology, phylogeny), Wijayawardene et al. (2014c; phylogeny, outline), cultures and sequences are available, holotype and ex-type culture of type: INIFAT C87/45; CBS 734.87.

Neopericonia Kamal, A.N. Rai \& Morgan-Jones 1983, Ascomycota genera incertae sedis, three species, type: $N$. indica Kamal, A.N. Rai \& Morgan-Jones, hyphomycetous, sexual morph unknown, saprobes, terrestrial, India, see Wijayawardene et al. (2012, 2017; outline), Kirk et al. (2013; genus accepted), cultures and sequences are unavailable, needs generic revision.

Neopestalotiopsis Maharachch., K.D. Hyde \& Crous 2014, Pestalotiopsidaceae, Xylariales, Sordariomycetes, 27 species, type: N. protearum (Crous \& L. Swart) Maharachch., K.D. Hyde \& Crous, coelomycetous, sexual morph unknown, saprobes, pathogens on plants, worldwide, see Maharachchikumbura et al. (2014; phylogeny, morphology), Wijayawardene et al. (2016b; outline, taxonomy), sequence data available for all species, holotype and extype strain of the type: PREM 56186; CBS 114178.

Neopetromyces Frisvad \& Samson 2000, Trichocomaceae, Eurotiales, Eurotiomycetes, one species, type: N. muricatus (Udagawa, Uchiy. \& Kamiya) Frisvad \& Samson, asexual morph unknown, saprobes, terrestrial, Philippines, see Lumbsch and Huhndorf (2010; outline), cultures and sequences are available, holotype and ex-type strain of type species CBM BF42515 ; NRRL 35674.

Neophacidium Petr. 1950, Rhytismataceae, Rhytismatales, Leotiomycetes, two species, type: N. macrocarpum (Pat.) Petr., asexual morph unknown, saprobes, terrestrial, Philippines, see Lumbsch and Huhndorf (2010; outline), Kirk et al. (2013; genus accepted), cultures and sequences are unavailable, needs generic revision.

Neophaeococcomyces Crous \& M.J. Wingf. 2015, Strelitzianaceae, Chaetothyriales, Eurotiomycetes, two species, type: N. aloes (Crous \& M.J. Wingf.) Crous \& M.J. Wingf., hyphomycetous, sexual morph unknown, saprobes, South Africa, Switzerland, see Crous et al. (2015e; taxonomy, phylogeny), Wijayawardene et al. (2017; outline), holotype and ex-type culture of the type: CBS H-21441, CPC 21873.

Neophaeocryptopus Wanasinghe, Camporesi, E.B.G. Jones \& K.D. Hyde 2016, Dothideaceae, Dothideales, Dothideomycetes, one species, type: N. cytisi Wanasinghe, Camporesi, E.B.G. Jones \& K.D. Hyde, asexual morph coelomycetous, sexual morph bitunicate ascomycetous, saprobes, terrestrial, Europe, see Li et al. (2016a; taxonomy, phylogeny), holotype and ex-type strain of type: MFLU 15-3542; MFLUCC 14-0970.

Neophaeomoniella Rooney-Latham \& Crous 2015, Phaeomoniellaceae, Phaeomoniellales, Eurotiomycetes, three species, type: N. eucalypti Rooney-Latham \& Crous, coelomycetous, sexual morph unknown, on living leaves, endophytic, terrestrial, USA, South Korea, South Africa, see Crous et al. (2015d; morphology, phylogeny), cultures and sequences are available, holotype and ex-type culture of type: CBS H-22249; CPC 25161.

Neophaeosphaeria M.P.S. Câmara, M.E. Palm \& A.W. Ramaley 2003, Neophaeosphaeriaceae, Pleosporales, Dothideomycetes, five species, type: $N$. filamentosa (Ellis \& Everh.) M.P.S. Câmara, M.E. Palm \& A.W. Ramaley, asexual morph coelomycetous, saprobes or pathogenic, terrestrial, Mexico, USA, see Lumbsch and Huhndorf (2010; outline, accepted as a genus in Leptosphaeriaceae), Crous et al. (2013b; taxonomy), Ariyawansa et al. (2015a; taxonomy, phylogeny), Wijayawardene et al. (2014c; outline), sequence data available for all species, needs generic revision.

Neophaeothecoidea Quaedvl. \& Crous 2014, Teratosphaeriaceae, Capnodiales, Dothideomycetes, one species, type: $N$. proteae (Crous) Quaedvlieg \& Crous, hyphomycetous, saprobes, terrestrial, South Africa, see Quaedvlieg et al. (2014; morphology, 
phylogeny), Wijayawardene et al. (2014c; outline), cultures and sequences are available, holotype and ex-type strain of the type: CBS H-20092; CPC 2828.

Neophoma Petr. \& Syd. 1927, Ascomycota genera incertae sedis, two species, type: $N$. graminella (Sacc.) Petr. \& Syd., coelomycetous, sexual morph unknown, saprobes, terrestrial, Europe, North America., see Wijayawardene et al. (2012, 2017; outline), Kirk et al. (2013; genus accepted), cultures and sequences are unavailable, needs generic revision.

Neophyllis F. Wilson 1891, Sphaerophoraceae, Lecanorales, Lecanoromycetes, two species, type: Neophyllis melacarpa F. Wilson, asexual morph unknown, lichenized, terrestrial, Australasia, see Lumbsch and Huhndorf (2010; outline), Kirk et al. (2013; genus accepted), Lücking et al. (2016b; classification), sequences are available for the type species, holotype of type species available.

Neophysalospora Crous \& M.J. Wingf. 2014, Hypocreomycetidae, genera incertae sedis, Sordariomycetes, one species, type: N. eucalypti Crous \& M.J. Wingf., asexual morph coelomycetous, saprobes, terrestrial, Mozambique, South Africa, see Crous et al. (2014d; taxonomy), Maharachchikumbura et al. (2015, 2016; outline), Wijayawardene et al. (2017; outline), needs generic revision, cultures and sequences are available.

Neoplaconema B. Sutton 1977, Ascomycota genera incertae sedis, two species, type: N. napelli (Maire \& Sacc.) B. Sutton, coelomycetous, sexual morph unknown, saprobes, terrestrial, Australia, Germany, see Wijayawardene et al. (2012, 2017; outline), sequences are available, holotype of the type species was not designated (IMI 24787).

Neoplatysporoides Crous \& M.J. Wingf. 2015, Pleosporaceae, Pleosporales, Dothideomycetes, one species, type: N. aloeicola Crous \& M.J. Wingf., asexual morph coelomycetous, saprobes, Tanzania, see Crous et al. (2015d; taxonomy, phylogeny), Wijayawardene et al. (2017; outline, phylogeny), holotype and ex-type culture of the type: CBS H-22230, CPC 24435.

Neopodoconis Rifai 2008, Ascomycota genera incertae sedis, three species, type: $N$. ampullacea (Petch) Rifai, hyphomycetous, sexual morph unknown, saprobes, terrestrial, Indonisia, see Rifai (2008; taxonomy), Wijayawardene et al. (2017; outline), cultures and sequences are unavailable, holotype of type species available, needs generic revision.

Neopseudocercospora Crous 2013, Mycosphaerellaceae, Capnodiales, Dothideomycetes, two species, type: $N$. terminaliae Crous, hyphomycetous, sexual morph unknown, saprobes, terrestrial, Zambia, type, see Crous et al. (2013b; morphology), Braun et al. (2014b; morphology, keys), cultures and sequences are available, holotype and ex-type of the type: CBS H- 21431; CPC 22685.

Neopseudocercosporella Videira \& Crous 2016, Mycosphaerellaceae, Capnodiales, Dothideomycetes, two species, type: N. capsellae (Ellis \& Everh.) Videira \& Crous, hyphomycetous, sexual morph mycosphaerella-like, plant pathogenic on Brassica species, USA, see Videira et al. (2016; morphology, phylogeny), Cultures and sequences are available, holotype and isotype of type species NY 883641; BPI 399944.

Neopseudolachnella A. Hashim. \& Kaz. Tanaka 2015, Chaetosphaeriaceae, Chaetosphaeriales, Sordariomycetes, three species, type: N. acutispora A. Hashim., Sat. Hatak. \& Kaz. Tanaka, coelomycetous, sexual morph unknown, saprobes, Japan, see Hashimoto et al. (2015b; morphology, pgylogeny), sequences are available, holotype and extype strain of type: HHUF 29727; MAFF 244358.

Neopsoromopsis Gyeln. 1940, Parmeliaceae, Lecanorales, Lecanoromycetes, one species, type: Neopsoromopsis argentina Gyeln., asexual morph unknown, lichenized, terrestrial, Argentina, see Lumbsch and Huhndorf (2010; outline), Thell et al. (2012; review), Lücking et al. (2016b; classification), cultures and sequences are unavailable, needs generic revision.

Neopyricularia Klaubauf, Lebrun \& Crous 2014, Pyriculariaceae, Magnaporthales, Sordariomycetes, one species, type: N. commelinicola (M.J. Park \& H.D. Shin) Klaubauf, 
Lebrun \& Crous, asexual morph unknown, saprobes, terrestrial, South Korea, see Klaubauf et al. (2014; taxonomy, phylogeny), Maharachchikumbura et al. (2015, 2016; outline), cultures and sequences are available, holotype and available cultures for the type: KUS (F) 22838; CBS $128308=$ KACC 43081

Neoramularia U. Braun 1991, Ascomycota genera incertae sedis, nine species, type: $N$. eurotiae (Gamalizk.) U. Braun, hyphomycetous, sexual morph unknown, terrestrial, plant pathogenic, leaf-spotting, Asia, Europe, North America, see Ruszkiewicz-Michalska and Wolczanska (2008; Europe), Hyde et al. (2011; checklist), Wijayawardene et al. (2012, 2017; outline), Kirk et al. (2013; genus accepted), cultures and cultures and sequences are unavailable, holotype of type: LE 41968.

Neorehmia Höhn. 1902, Trichosphaeriaceae, Trichosphaeriales, Sordariomycetes, two species, type: N. ceratophora Höhn., asexual morph tritirachium-like, saprobes, Austria, see Lumbsch and Huhndorf (2010; outline), Maharachchikumbura et al. (2015, 2016; outline), cultures and sequences are available.

Neoroussoella J.K. Liu, Phook. \& K.D. Hyde 2014, Roussoellaceae, Pleosporales, Dothideomycetes, two species, type: N. bambusae Phook., J.K. Liu \& K.D. Hyde, asexual morph coelomycetous, saprobes, terrestrial, Asia, see Liu et al. (2014b; taxonomy, phylogeny), Hyde et al. (2016; outline), cultures and sequences are available.

Neosartorya Malloch \& Cain 1973, Trichocomaceae, Eurotiales, Eurotiomycetes, 15 species, type: N. fischeri (Wehmer) Malloch \& Cain, asexual morph Aspergillus, saprobes, terrestrial, worldwide, see Lumbsch and Huhndorf (2010; outline), Kirk et al. (2013; genus accepted), cultures and sequences are available, available specimen of type: CBS H-15123.

Neoscolecobasidium Crous 2016, Microthyriales genera incertae sedis, Dothideomycetes, one species, type: $N$. agapanthi Crous, hyphomycetous, sexual morph unknown, saprobes, terrestrial, USA, see Crous et al. (2016a; new species, phylogeny), holotype and ex-type culture of the type: CBS H-22870, CPC 28778.

Neoscytalidium Crous \& Slippers 2006, Botryosphaeriaceae, Botryosphaeriales, Dothideomycetes, two species, type: N. dimidiatum (Penz.) Crous \& Slippers, coelomycetous, sexual morph unknown, saprobes, pathogen, tropical and sub-tropical regions of Europe, Africa, Asia, North and South America, see Liu et al. (2012; phylogeny), Phillips et al. (2013; morphology, phylogeny, new comb. for type species), cultures and sequences are available, isotype and ex-isotype strain of the type species CBS H-7745; CBS 145.78.

Neoseptoria Quaedvlieg, Verkley \& Crous 2013, Mycosphaerellaceae, Capnodiales, Dothideomycetes, one species, type: N. caricis W. Quaedvlieg, G.J.M. Verkley \& Crous, coelomycetous, sexual morph unknown, saprobes, terrestrial, Netherlands, see Quaedvlieg et al. (2013; morphology, phylogeny), sequence data available, holotype and ex-type strain of the type: CBS H-21293; CBS 135097.

Neoseptorioides Crous, J. Edwards \& I.G. Pascoe 2015, Saccharataceae, Botryosphaeriales, Dothideomycetes, two species, type: N. eucalypti Crous, J. Edwards \& I.G. Pascoe, coelomycetous, sexual morph unknown, saprobes, Australia, see Crous et al. (2015e; taxonomy, phylogeny), Wijayawardene et al. (2017; outline), holotype and ex-type culture of the type: CBS H-22395, CPC 25529.

Neosergipea M. Cáceres, Ertz \& Aptroot 2016, Roccellaceae, Arthoniales, Arthoniomycetes, one species, type: N. aurata (M. Cáceres, Ertz \& Aptroot) Lücking, M. Gut. \& Moncada, lichenized, terrestrial, tropical, see Lücking et al. (2016a, b; taxonomy, classification), cultures and sequences are available, holotype of type species ISE, Céceres \& Jesus 12539 (as Sergipea aurata M. Cáceres, Ertz \& Aptroot).

Neosetophoma Gruyter, Aveskamp \& Verkley 2010, Phaeosphaeriaceae, Pleosporales, Dothideomycetes, three species, type: N. samararum (Desm.) Gruyter, Aveskamp \& Verkley, asexual morph coelomycetous, saprobes and plant endophytes, terrestrial, aquatic, worldwide, 
see Wijayawardene et al. (2012, 2017; outline), Kirk (2013; genus accepted), Li et al. (2015c; phylogeny), Phookamsak et al. (2014b; phylogeny), cultures and sequences are available, holotype and ex-type strains of type: CBS H-20319; CBS 138.96 = PD 82/653.

Neospegazzinia Petr. \& Syd. 1936, Ascomycota genera incertae sedis, two species, type: $N$. pulchra Petr. \& Syd., coelomycetous, sexual morph unknown, saprobes, terrestrial, South America, see Wijayawardene et al. (2012, 2017; outline), Kirk et al. (2013; genus accepted), cultures and sequences are unavailable, needs generic revision.

Neosphaerellopsis Crous \& Trakun. 2014, Phaeosphaeriaceae, Pleosporales, Dothideomycetes, one species, type: $N$. thailandica Crous \& Trakun., on uredinio rust sori on leaves of Bothriochloa bladhii, terrestrial, Thailand, see Trakunyingcharoen et al. (2014; morphology, phylogeny), cultures and sequences are available, holotype and ex-type strain of the type: CBS H-21847; CPC 21659.

Neosporidesmium Mercado \& J. Mena 1988, Ascomycota genera incertae sedis, two species, type: N. maestrense Mercado \& J. Mena, hyphomycetous, sexual morph unknown, saprobes, terrestrial, Cuba, see Ma et al. (2011b; new species), Mel'nik and Braun (2013; new species), Wijayawardene et al. (2012, 2017; outline), Kirk et al. (2013; genus accepted), Prasher and Verma (2014; new species, India), cultures and sequences are unavailable, needs generic revision.

Neostagonospora Quaedvl., Verkley \& Crous 2013, Phaeosphaeriaceae, Pleosporales, Dothideomycetes, two species, type: N. caricis Quaedvlieg, Verkley \& Crous, coelomycetous, sexual morph unknown, saprobes, terrestrial, Netherlands, South Africa, see Quaedvlieg et al. (2013; morphology, phylogeny), Phookamsak et al. (2014b; phylogeny), cultures and sequences are available, holotype and ex-type of the type: CBS H-21306; CBS 135092.

Neostrelitziana Crous \& M.J. Wingf. 2015, Chaetothyriales genera incertae sedis, Sordariomycetes, one species, type: N. acaciigena Crous \& M.J. Wingf., hyphomycetous, sexual morph unknown, saprobes, Malaysia, see Crous et al. (2015d; taxonomy, phylogeny), Wijayawardene et al. (2017; outline), holotype and ex-type culture of the type: CBS H-22232, CPC 24873.

Neosulcatispora Crous \& M.J. Wingf. 2015, Phaeosphaeriaceae, Pleosporales, Dothideomycetes, two species, type: $N$. agave Crous \& M.J. Wingf., coelomycetous, sexual morph unknown, saprobes, terrestrial, South Africa, France, see Crous et al. (2015e, 2016b; new species, phylogeny), Wijayawardene et al. (2016b, 2017; outline, phylogeny), holotype and ex-type culture of the type: CBS H-22404, CPC 26407.

Neotapesia E. Müll. \& Hütter 1963, Mollisiaceae, Helotiales, Leotiomycetes, three species, type: N. graddonii E. Müll. \& Hütter, asexual morph unknown, saprobes, terrestrial, Europe, see Lumbsch and Huhndorf (2010; outline), Kirk et al. (2013; genus accepted), cultures and sequences are unavailable, needs generic revision.

Neotestudina Segretain \& Destombes 1961, Testudinaceae, Pleosporales, Dothideomycetes, three species, type: $N$. rosatii Segretain \& Destombes, asexual morph unknown, saprobes, terrestrial, worldwide, see Lumbsch and Huhndorf (2010; outline), Hyde et al. (2013; accepted as a genus in Testudinaceae), Kirk et al. (2013; genus accepted), cultures and sequences are available, available specimen and cultures for the type: CBS H-200; CBS 690.82 .

Neothyridaria Petr. 1934, Sordariomycetes genera incertae sedis, one species, type: $N$. moravica Petr., asexual morph unknown, saprobes, terrestrial, Europe, see Kocourková (2009; new species), Lumbsch and Huhndorf (2010; outline), Kirk et al. (2013; genus accepted), Maharachchikumbura et al. (2016; outline), cultures and sequences are unavailable, needs generic revision, needs generic revision. 
Neothyronectria Crous \& Thangavel 2016, Hypocreales genera incertae sedis, Sordariomycetes, one species, type: N. sophorae Crous \& Thangavel, coelomycetous, sexual morph unknown, saprobes, terrestrial, New Zealand, see Crous et al. (2016a; new species, phylogeny), holotype and ex-type culture of the type: CBS H-22880, CPC 29690.

Neotorula Ariyawansa, Z.L. Luo \& K.D. Hyde 2016, Torulaceae, Pleosporales, Dothideomycetes, two species, type: N. aquatica Z.L. Luo \& K.D. Hyde, hyphomycetous, sexual morph unknown, saprobes, aquatic, worldwide, see Hyde et al. (2016; new species), Su et al. (2016a; taxonomy, phylogeny), Wijayawardene et al. (2017; outline), cultures and sequences are available.

Neotrematosphaeria Thambugala, Kaz. Tanaka \& K.D. Hyde 2015, Lophiostomataceae, Pleosporales, Dothideomycetes, one species, type: N. biappendiculata (Kaz. Tanaka, Y. Harada \& M.E. Barr) Thambugala, Kaz. Tanaka \& K.D. Hyde, asexual morph pleurophomopsis-like, saprobes, freshwater, Japan, see Thambugala et al. (2015b; morphology, phylogeny), sequence data available, holotype and ex-type of type species HHUF 28026; MAFF 239297.

Neotrimmatostroma Quaedvl. \& Crous 2014, Teratosphaeriaceae, Capnodiales, Dothideomycetes, three species, type: N. excentricum (B. Sutton \& Ganapathi) Quaedvl. \& Crous, with hyphomycetous asexual morph, foliicolous, terrestrial, Australia, New Zealand, see Quaedvlieg et al. (2014; morphology, phylogeny), Crous et al. (2016b; new species, phylogeny), Wijayawardene et al. (2017; outline), cultures and sequences are available, holotype of sexual morph of the type: CBS H-19829, ex-type strain of the type: CPC 13092.

Neotrotteria Sacc. 1921, Nitschkiaceae, Coronophorales, Sordariomycetes, two species, type: A N. pulchella Sacc., asexual morph unknown, saprobes, terrestrial, worldwide, see Lumbsch and Huhndorf (2010; outline), Mugambi and and Huhndorf (2010; DNA), Maharachchikumbura et al. (2015, 2016; outline), cultures and sequences are available.

Neotruncatella Hyang B. Lee \& T.T.T. Nguyen 2016, Bartaliniaceae, Xylariales, Sordariomycetes, one species, type: N. endophytica Hyang B. Lee, P.M. Kirk, K.D. Hyde, S.S.N. Maharachch., \& T.T.T. Nguyen, coelomycetous, sexual morph unknown, endophytes, terrestrial, Korea, see Hyde et al. (2016; taxonomy, phylogeny), holotype and ex-type culture of the type: MFLU 15-0399, EMLAS5-1.

Neottiella Cooke Sacc. 1889, Pezizales genera incertae sedis, Pezizomycetes, 13 species, type: N. albocincta (Berk. \& M.A. Curtis) Sacc., asexual morph unknown, saprobes, terrestrial, Europe, see Lumbsch and Huhndorf (2010; outline), Kirk et al. (2013; genus accepted), cultures and sequences are available, needs generic revision.

Neottiospora Desm. 1843, Ascomycota genera incertae sedis, two species, type: N. caricum Desm., coelomycetous, sexual morph unknown, saprobes, terrestrial, worldwide, see Wijayawardene et al. (2012, 2017; outline), Kirk et al. (2013; genus accepted), cultures and sequences are unavailable, needs generic revision.

Neottiosporina Subram. 1961, Dothideomycetes, genera incertae sedis, eleven species, type: N. apoda (Speg.) Subram., sexual morph unknown, saprobes, terrestrial, Asia, Australia, South America, see de Gruyter et al. (2009; phylogeny), Wijayawardene et al. (2012, 2016b, 2017; outline), Trakunyingcharoen et al. (2014; phylogeny), cultures and sequences are available for one species ( $N$. paspali).

Neotyphodium Glenn, C.W. Bacon \& Hanlin 1996, Clavicipitaceae, Hypocreales, Sordariomycetes, three species, type: N. coenophialum (Morgan-Jones \& W. Gams) Glenn, C.W. Bacon \& Hanlin, hyphomycetous, sexual morph unknown, saprobes, terrestrial, worldwide, see Seifert et al. (2011; morphology), Kirk et al. (2013; genus accepted), Maharachchikumbura et al. (2015, 2016; outline), cultures and sequences are available, available specimen and culture for type: CBS H-3511; CBS 494.82. 
Neournula Paden \& Tylutki 1969, Chorioactidaceae, Pezizales, Pezizomycetes, two species, type: $N$. nordmanensis Paden \& Tylutki, asexual morph unknown, saprobes, terrestrial, USA, Europe, North Africa, see Pfister et al. (2008; taxonomy), Lumbsch and Huhndorf (2010; outline), cultures and sequences are available but lacks for the type species, holotype of type: WSP 56281.

Neoventuria Syd. \& P. Syd. 1919, Dothideomycetes genera incertae sedis, two species, type: N. argentinensis (Speg.) Syd. \& P. Syd., asexual morph unknown, saprobes, terrestrial, South America, see Lumbsch and Huhndorf (2010; outline), Kirk et al. (2013; genus accepted), Wijayawardene et al. (2014c; outline), cultures and sequences are unavailable, needs generic revision.

Neozythia Petr. 1958, Ascomycota genera incertae sedis, one species, type: N. nectrioidea (Petr.) Petr., coelomycetous, sexual morph unknown, saprobes, terrestrial, Iran, see Kirk et al. (2013; genus accepted), Wijayawardene et al. (2017; outline), cultures and sequences are unavailable, needs generic revision.

Nephroma Ach. 1809, Nephromataceae, Peltigerales, Lecanoromycetes, 36 species, type: $N$. polaris (Ach.) Ach., lichenized, worldwide, see Lumbsch and Huhndorf (2010; outline), Kirk et al. (2013; genus accepted), Lücking et al. (2016b; classification), cultures and sequences are available, needs generic revision.

Nephromopsis Müll. Arg. 1891 (= Cetrariopsis Kurok. 1980; = Flavocetrariella D.D. Awasthi 2007 fide Lücking et al. 2016b), Parmeliaceae, Lecanorales, Lecanoromycetes, 24 species, type: N. stracheyi (C. Bab.) Müll. Arg., asexual morph unknown, lichenized, terrestrial, Argentina, see Thell et al. (2009; DNA, phylogeny), Lumbsch and Huhndorf (2010; outline), Kirk et al. (2013; genus accepted), Randlane et al. (2013; new species), Lücking et al. (2016b; classification), sequences are available, needs generic revision.

Neptunella K.L. Pang \& E.B.G. Jones 2003, Halosphaeriaceae, Microascales, Sordariomycetes, one species, type: N. longirostris (Cribb \& J.W. Cribb) K.L. Pang \& E.B.G. Jones, asexual morph unknown, saprobes, marine, Australia, see Lumbsch and Huhndorf (2010; outline), Jones et al. (2015; review), Maharachchikumbura et al. (2015, 2016; outline), sequences are available, needs generic revision.

Nereiospora E.B.G. Jones, R.G. Johnson \& S.T. Moss 1983, Halosphaeriaceae, Microascales, Sordariomycetes, two species, type: N. comata (Kohlm.) E.B.G. Jones, R.G. Johnson \& S.T. Moss, asexual morph hyphomycetous, on wood, marine, worldwide, see Sakayaroj et al. (2011a; phylogeny), Jones et al. (2015; outline), Maharachchikumbura et al. (2015; outline), Cultures and sequences are available, needs generic revision.

Neta Shearer \& J.L. Crane 1971, Ascomycota genera incertae sedis, two species, type: $N$. patuxentica Shearer \& J.L. Crane, hyphomycetous, sexual morph unknown, saprobes, terrestrial and aquatic, worldwide, see Wijayawardene et al. (2012, 2017; outline), Kirk et al. (2013; genus accepted), cultures and sequences are unavailable, holotype of type: ILLS 34520 , needs generic revision.

Neurospora Shear \& B.O. Dodge 1927 (= Chrysonilia Arx 1981 fide Réblová et al. 2016c), Sordariaceae, Sordariales, Sordariomycetes, 52 species, type: N. sitophila Shear \& B.O. Dodge, asexual morph formerly named in Chrysonilia, saprobes, terrestrial, worldwide, see Villalta et al. (2009; new species), Lumbsch and Huhndorf (2010; outline), Nygren et al. (2011; DNA, phylogeny), Kirk et al. (2013; genus accepted), Maharachchikumbura et al. $(2015,2016$; outline, phylogeny), cultures and sequences are available for type species, needs generic revision.

Nevesia P.M. Jørg, L. Lindblom, Wedin \& S. Ekman 2014, Pannariaceae, Peltigerales, Lecanoromycetes, one species, type: N. sampaiana (Tavares) P.M. Jørg., L. Lindblom, Wedin \& S. Ekman, lichenized, terrestrial, worldwide, see Ekman et al. (2014; taxonomy), Lücking et al. (2016b; classification), cultures and sequences are available, needs generic revision. 
Nidulispora Nawawi \& Kuthub. 1990, Ascomycota genera incertae sedis, one species, type: N. quadrifida Nawawi \& Kuthub., hyphomycetous, sexual morph unknown, saprobes, aquatic, Malaysia, see Wijayawardene et al. (2012, 2017; outline), Kirk et al. (2013; genus accepted), cultures and sequences are unavailable, needs generic revision.

Nidulispora Nawawi \& Kuthub. 1990, Ascomycota genera incertae sedis, one species, type: N. quadrifida Nawawi \& Kuthub., hyphomycetous, sexual morph unknown, saprobes, aquatic, Malaysia, see Seifert et al. (2011; morphology), Wijayawardene et al. (2012, 2017; outline), Kirk et al. (2013; genus accepted), cultures and sequences are unavailable, needs generic revision.

Niebla Rundel \& Bowler 1978, Ramalinaceae, Lecanorales, Lecanoromycetes, 22 species, type: N. homalea (Ach.) Rundel \& Bowler, lichenized, New World, see Lumbsch and Huhndorf (2010; outline), Sérusiaux et al. (2010; phylogeny), Lücking et al. (2016b; classification), cultures and sequences are available, needs generic revision.

Niesslia Auersw. 1869, Niessliaceae, Hypocreales, Sordariomycetes, 42 species, type: $N$. chaetomium (Corda) Auersw., asexual morph unknown, lichenicolus, parasitizing members of Peltigerales, terrestrial, Australia, Asia and Europe, see Etayo and Sancho (2008; three new species), Motiejūnaitè et al. (2008; Poland), Zhurbenko and Dillman (2010; Alaska), Etayo et al. (2013; new species), Himelbrant et al. (2014; Russia), Judith et al. (2015; phylogeny), Zhurbenko and Pino-Bodas (2015; New Zealand), sequence data available for Niesslia exilis.

Nigrocornus Ryley \& Langdon 2003, Clavicipitaceae, Hypocreales, Sordariomycetes, one species, type: N. scleroticus (Pat.) Ryley, asexual morph contains simple conidiophores, endophytes, terrestrial, Africa, SE Asia, Australia, see Cheplick and Faeth (2009; ecology), Wijaywardene et al. (2012, 2017; outline), Pańka et al. (2013; Poland), Maharachchikumbura et al. (2015, 2016; outline), DNA sequence data available (as Balansia sclerotica), culture data unavailable, neotype of the type species FH (Farlow Herbarium).

Nigrolentilocus R.F. Castañeda \& Heredia 2001, Ascomycota genera incertae sedis, five species, type: N. africanus (B. Sutton) R.F. Castañeda \& Heredia, hyphomycetous, sexual morph unknown, saprobes, terrestrial \& aquatic, Malawi, see Hyde et al. (2011; outline), Wijayawardene et al. (2012, 2017; outline), cultures and sequences are unavailable, holotype of type: IMI 347112a, compare with Matsushimiella, Minimelanolocus, Pseudospiropes, Spiropes and Sympodioplanus.

Nigromacula Etayo 2002, Ascomycota genera incertae sedis, one species, type: $N$. hypotrachynae Etayo, hyphomycetous, sexual morph unknown, lichenicolous, terrestrial, South America, Europe, see Hyde et al. (2011; outline), Wijayawardene et al. (2012, 2017; outline), cultures and sequences are unavailable, holotype of the type: COL Etayo 16185.

Nigromammilla K.D. Hyde \& J. Fröhl. 2003, Sordariomycetes genera incertae sedis, one species, type: N. calami K.D. Hyde \& J. Fröhl. [as 'Nigramammilla calami'], asexual morph unknown, saprobes, terrestrial, Hong Kong, see Lumbsch and Huhndorf (2010; outline), Maharachchikumbura et al. (2015, 2016; outline), cultures and sequences are unavailable, holotype of type: HKU (M) JF212.

Nigropuncta D. Hawksw. 1981, Ascomycota genera incertae sedis, two species, type: $N$. rugulosa D. Hawksw., coelomycetous, lichenized, lichenicolous, Europe, terrestrial, sexual morph unknown, see Wijayawardene et al. (2012, 2016b, 2017; morphology, outline), Kirk et al. (2013; genus accepted), cultures and sequences unavailable, holotype of type: K(M)-IMI 241409.

Nigrosabulum Malloch \& Cain 1970, Hypocreales genera incertae sedis, Sordariomycetes, twelve species, type: N. globosum Malloch \& Cain, asexual morph acremonium-like, saprobes, coprophilous, terrestrial, worldwide, see Lumbsch and Huhndorf (2010; outline, accepted in Bionectriaceae), Kirk et al. (2013; genus accepted), Maharachchikumbura et al. 
(2015, 2016; accepted in Hypocreales), cultures and sequences are available, holotype of type species TRTC 43288.

Nigrospora Zimm. 1902 (= Khuskia H.J. Huds. 1963 fide Réblová et al. 2016c), Sordariomycetes, genera incertae sedis, four species, type: N. panici Zimm., hyphomycetous, sexual morph formerly named in Khuskia, saprobes, terrestrial, cosmopolitan, see Seifert et al. (2011; morphology), Wijayawardene et al. (2012, 2017; outline), Kirk et al. (2013; genus accepted), Maharachchikumbura et al. (2015, 2016; outline), Réblová et al. (2016c; nomenclature), cultures and sequences are available, needs generic revision.

Nigrovothelium Lücking, M.P.Nelsen \& Aptroot 2016, Trypetheliaceae, Trypetheliales, Dothideomycetes, two species, type: N. tropicum (Ach.) Lücking, M.P. Nelsen \& Aptroot, asexual morph unknown, lichenized fungi, terrestrial, tropical, see Aptroot and Lücking (2016; monograph), Lücking et al. (2016b, c; phylogeny, classification), cultures and sequences are available, lectotype and iso-lectotype of type: H-ACH 707A; BM-ACH.

Nimbospora Jørg. Koch 1982, Halosphaeriaceae, Microascales, Sordariomycetes, two species, type: N. effusa Jørg. Koch, asexual morph unknown, saprobes, marine, worldwide, see Lumbsch and Huhndorf (2010; outline), Kirk et al. (2013; genus accepted), Maharachchikumbura et al. (2015, 2016; phylogeny), Chu et al. (2015; phylogeny), sequences are available, holotype of type species J. Koch 387, Herbarium CP, Denmark.

Nimisiostella Calat., Barreno \& O.E. Erikss. 1997, Lecanoromycetes genera incertae sedis, one species, type: N. lichenicola Calat., Barreno \& O.E. Erikss., lichenized, terrestrial, Spain, see Lumbsch and Huhndorf (2010; outline), Kirk et al. (2013; genus accepted), cultures and sequences are unavailable, holotype of type species VAB (Lich.) 7546.

Nipholepis Syd. 1935, Arthoniales genera incertae sedis, Arthoniomycetes, one species, type: N. filicina Syd., lichenized, terrestrial, South America, see Lumbsch and Huhndorf (2010; outline), Kirk et al. (2013; genus accepted), cultures and sequences are unavailable, needs generic revision.

Nipicola K.D. Hyde 1992, Xylariales genera incertae sedis, Sordariomycetes, four species, type: N. carbospora K.D. Hyde, asexual morph unkown, saprobes, Australia, see Lumbsch and Huhndorf (2010; outline), Kirk et al. (2013; genus accepted), Daranagama et al. (2017 morphology, taxonomy, phylogeny, key), Wendt et al. (2017; accepted as a genus in Xylariales genera incertae sedis), cultures and sequences are unavailable, needs generic revision.

Nipponoparmelia (Kurok.) K.H. Moon, Y. Ohmura \& Kashiw. 2010, Parmeliaceae, Lecanorales, Lecanoromycetes, five species, type: N. laevior (Nyl.) K.H. Moon, Y. Ohmura \& Kashiw., asexual morph unknown, lichenized, terrestrial, Argentina, see Crespo et al. (2010b; taxonomy, phylogeny), Kondratyuk et al. (2013d; new species), Divakar et al. (2015; DNA, phylogeny), Lücking et al. (2016b; classification), sequences are available, needs generic revision.

Niptera Fr. 1849 (= Nimbomollisia Nannf. 1983 fide Jaklitsch et al. 2016a), Mollisiaceae, Helotiales, Leotiomycetes, c. ten species, type: N. lacustris (Fr.) Fr., asexual morph unknown, saprobes, terrestrial, Europe, see Lumbsch and Huhndorf (2010; outline), Whitton et al. (2012b; morphology), Kirk et al. (2013; genus accepted), cultures and sequences are unavailable for type species, needs generic revision.

Nipterella Starbäck ex Dennis 1962, Mollisiaceae, Helotiales, Leotiomycetes, two species, type: N. duplex (Starbäck) Starbäck \& Dennis, asexual morph unknown, saprobes, terrestrial, Europe, North America, see Lumbsch and Huhndorf (2010; outline), Kirk et al. (2013; genus accepted), cultures and sequences are unavailable, needs generic revision.

Nitidochapsa Parnmen, Lücking \& Lumbsch 2013, Graphidaceae, Ostropales, Lecanoromycetes, one species, type: N. leprieurii (Mont.) Parnmen, Lücking \& Lumbsch, asexual morph unknown, lichenized fungi, terrestrial, tropical, see Parnmen et al. (2013; 
genus proposed), Lücking et al. (2016b; classification), cultures and sequences are available, needs generic revision.

Nitschkia G.H. Otth ex P. Karst. 1873, Nitschkiaceae, Coronophorales, Sordariomycetes, 27 species, type: N. cupularis (Pers.) P. Karst., asexual morph unknown, saprobes, terrestrial, worldwide, see Lumbsch and Huhndorf (2010; outline), Kirk et al. (2013; genus accepted), Maharachchikumbura et al. (2015, 2016; outline), cultures and sequences are available but lacks for the type, available specimen of type: CBS H-4803.

Nitschkiopsis Nannf. \& R. Sant. 1975, Sordariales genera incertae sedis, Sordariomycetes, one species, type: N. stictarum Nannf. \& R. Sant., asexual morph unknown, saprobes, see Kirk et al. (2008; treated as a synonym of Niesslia Auersw.), Lumbsch and Huhndorf (2010; outline), Maharachchikumbura et al. (2015, 2016; outline, accepted as a distinct genus), cultures and sequences are unavailable.

Nodobryoria Common \& Brodo 1995, Parmeliaceae, Lecanorales, Lecanoromycetes, three species, type: N. abbreviata (Müll. Arg.) Common \& Brodo, asexual morph unknown, lichenized, terrestrial, North America, Greenland, see Lumbsch and Huhndorf (2010; outline), Kirk et al. (2013; genus accepted), Divakar et al. (2015; DNA, phylogeny), cultures and sequences are available, voucher specimen of type: St. Clair 52291 (BRY-C).

Nodulosphaeria Rabenh. 1858, Phaeosphaeriaceae, Pleosporales, Dothideomycetes, c. 52 species, type: $N$. hirta Rabenh., asexul morph coelomycetous, saprobes, terrestrial, aquatic, worldwide, see Schoch et al. (2009; phylogey), Lumbsch and Huhndorf (2010; outline), Zang et al. (2012; taxonomy), Hyde et al. (2013; accepted as a genus in Phaeosphaeriaceae), Kirk et al. (2013; genus accepted), Phookamsak et al. (2014b; taxonomy, phylogeny), Wijayawardene et al. (2014c; outline, phylogeny), Ariyawansa et al. (2015a; new species, Italy), Li et al. (2015c; new species, phylogeny, asexual morph), Hyde et al. (2016; new species, Italy), Mapook et al. (2016a; new species, revision), cultures and sequences are available.

Nohea Kohlm. \& Volkm.-Kohlm. 1991, Halosphaeriaceae, Microascales, Sordariomycetes, three species, type: N. umiumi Kohlm. \& Volkm.-Kohlm., asexual morph unknown, saprobes, marine, worldwide, see Abdel-Wahab (2011b; phylogeny), Maharachchikumbura et al. (2015, 2016; phylogeny), cultures and sequences are available, holotype of type: J.K. $4847=$ 01348233, NYBG.

Nomuraea Maubl. 1903, Clavicipitaceae, Hypocreales, Sordariomycetes, one species, type: $N$. prasina Maubl., hyphomycetous, sexual morph unknown, saprobes, terrestrial, Japan, see Seifert et al. (2011; morphology), Wijayawardene et al. (2012, 2017; outline), Kirk et al. (2013; genus accepted), Maharachchikumbura et al. (2015, 2016; outline), cultures and sequences are available, needs generic revision.

Noosia Crous, R.G. Shivas \& McTaggart 2011, Pleosporales genera incertae sedis, Dothideomycetes, one species, type: N. banksiae Crous, R.G. Shivas \& McTaggart, hyphomycetous, sexual morph unknown, saprobes, terrestrial, Australia, see Crous et al. (2011a; morphology, DNA), Wijayawardene et al. (2012, 2014c; outline), holotype and extype: of the type CBS H-20587; CPC $17282=$ CBS 129526.

Normandina Nyl. 1855, Verrucariaceae, Verrucariales, Eurotiomycetes, three species, type: $N$. jungermanniae (Nyl.) Nyl., asexual morph unknown, lichenized, saprobes, terrestrial, worldwide, see Lumbsch and Huhndorf (2010; outline, accepted as a genus in Ascomycota), Kirk et al. (2013; genus accepted), Muggia et al. (2010; phylogeny), Frisch and Ohmura (2015; phylogeny), Lücking et al. (2016b; classification), Cultures and sequences are available, needs generic revision.

Norrlinia Theiss. \& Syd. 1918, Verrucariaceae, Verrucariales, Eurotiomycetes, one species, type: N. peltigericola (Nyl.) Theiss. \& Syd., asexual morph unknown, lichenized, worldwide, 
see Lumbsch and Huhndorf (2010; outline), Kirk et al. (2013; genus accepted), cultures and sequences are available for the type species, needs generic revision.

Nosophloea Fr. 1849, Ascomycota genera incertae sedis, three species, type: need typification, coelomycetous, sexual morph unknown, saprobes, terrestrial, Europe, see Wijayawardene et al. (2012, 2017; outline), Kirk et al. (2013; genus accepted), cultures and sequences are unavailable, needs generic revision.

Nothojafnea Rifai 1968, Otideaceae, Pezizales, Pezizomycetes, two species, type: N. cryptotricha Rifai, asexual morph unknown, saprobes, terrestrial, Australia, South America, see Lumbsch and Huhndorf (2010; outline, treated as Pyronemataceae), Kirk et al. (2013; genus accepted), Jaklitsch et al. (2016a; classification), cultures and sequences are available.

Nothomitra Maas Geest. 1964, Geoglossomycetes genera incertae sedis, three species, type: $N$. cinnamomea Maas Geest., asexual morph unknown, lichenized, worldwide, see Lumbsch and Huhndorf (2010; outline), Hustad and Miller (2011a; taxonomy), Kirk et al. (2013; genus accepted), Hustad et al. (2013; taxonomy, phylogeny), cultures and sequences are available, needs generic revision.

Nothophacidium J. Reid \& Cain 1962, Ploettnerulaceae, Helotiales, Leotiomycetes, one species, type: $N$. abietinellum (Dearn.) J. Reid \& Cain, asexual morph unknown, saprobes, terrestrial, North America, see Lumbsch and Huhndorf (2010; outline), Kirk et al. (2013; genus accepted), cultures and sequences are unavailable, holotype of type: DAOM herb. J. Dearness 5748, needs generic revision.

Nothophoma Q. Chen \& L. Cai 2015, Didymellaceae, Pleosporales, Dothideomycetes, six species, type: N. infossa (Ellis \& Everh.) Q. Chen \& L. Cai, coelomycetous, saprobes, terrestrial, cosmopolitan, see Chen et al. (2015b; taxonomy, phylogeny), Crous et al. (2016b; new species, phylogeny), Wijayawardene et al. (2017; outline), neootype and ex-neotype culture of the type: CBS H-20145, CBS 123395.

Nothorhytisma Minter, P.F. Cannon, A.I. Romero \& Peredo 1998, Rhytismataceae, Rhytismatales, Leotiomycetes, three species, type: N. nahuelitae Minter, P.F. Cannon, A.I. Romero \& Peredo, asexual morph unknown, saprobes, terrestrial, South America, see Lumbsch and Huhndorf (2010; outline), Kirk et al. (2013; genus accepted), cultures and sequences are unavailable, holotype of type: BAFC, needs generic revision.

Nothospora Peyronel 1913, Ascomycota genera incertae sedis, one species, type: N. ambigua Peyronel, hyphomycetous, sexual morph unknown, saprobes, terrestrial, Italy, see Seifert et al. (2011; morphology), Wijayawardene et al. (2012, 2017; outline), Kirk et al. (2013; genus accepted), cultures and sequences are unavailable, needs generic revision.

Notocladonia S. Hammer 2003, Cladoniaceae, Lecanorales, Lecanoromycetes, two species, type: N. cochleata (Müll. Arg.) S. Hammer, asexual morph unknown, lichenized, terrestrial, Australasia, see Lumbsch and Huhndorf (2010; outline), Kirk et al. (2013; genus accepted), cultures and sequences are unavailable.

Notolecidea Hertel 1984, Lecanoromycetes genera incertae sedis, one species, type: $N$. subcontinua (Nyl.) Hertel, lichenized, see Lumbsch and Huhndorf (2010; outline), Kirk et al. (2013; genus accepted), Lücking et al. (2016b; classification), cultures and sequences are available, needs generic revision.

Notoparmelia A.Crespo, Ferencova \& Divakar 2014, Parmeliaceae, Lecanorales, Lecanoromycetes, 16 species, type: N. signifera (Nyl.) A. Crespo, Ferencova \& Divakar, lichenized, Australasia, see Ferencova et al. (2014; phylogeny), Lücking et al. (2016b; classification), cultures and sequences are available, needs generic revision.

Novomicrothelia Aptroot, M.P. Nelsen \& Lücking 2016, Trypetheliaceae, Trypetheliales, Dothideomycetes, one species, type: N. oleosa (Aptroot) Aptroot, M.P. Nelsen \& Lücking, asexual morph unknown, lichenized fungi, terrestrial, tropical, see Aptroot and Lücking 
(2016; monograph), Lücking et al. (2016b; phylogeny), cultures and sequences are available, holotype of type: F, ISE.

Novozymia W.P. Wu 2005, Ascomycota genera incertae sedis, one species, type: N. elegans W.P. Wu, hyphomycetous, sexual morph unknown, saprobes, terrestrial, see Seifert et al. (2011; morphology), Wijayawardene et al. (2012, 2017; outline), Kirk et al. (2013; genus accepted), cultures and sequences are unavailable, needs generic revision.

Nummospora E. Müll. \& Shoemaker 1964, Ascomycota genera incertae sedis, one species, type: $N$. hexamera E. Müll. \& Shoemaker, coelomycetous, sexual morph unknown, saprobes, terrestrial, Switzerland, see Wijayawardene et al. (2012, 2017; outline), Kirk et al. (2013; genus accepted), cultures and sequences are unavailable, needs generic revision.

Nusia Subram. 1995, Ascomycota genera incertae sedis, two species, type: $N$. scheeleae Subram., hyphomycetous, sexual morph unknown, saprobes, terrestrial, Asia, see Seifert et al. (2011; morphology), Wijayawardene et al. (2012, 2017; outline), Kirk et al. (2013; genus accepted), cultures and sequences are unavailable, needs generic revision.

Nyctalospora E.F. Morris 1972, Ascomycota genera incertae sedis, one species, type: $N$. compacta E.F. Morris, hyphomycetous, sexual morph unknown, saprobes, terrestrial, Costa Rica, see Seifert et al. (2011; morphology), Wijayawardene et al. (2012, 2017; outline), Kirk et al. (2013; genus accepted), cultures and sequences are unavailable, needs generic revision.

Nycteromyces Thaxt. 1917, Laboulbeniaceae, Laboulbeniales, Laboulbeniomycetes, one species, type: $N$. streblidinus Thaxt., asexual morph unknown, biotrophic, only known from Strebla wiedemanni, Venezuela, see Lumbsch and Huhndorf (2010; outline), Kirk et al. (2013; genus accepted), cultures and sequences are unavailable.

Nymanomyces Henn. 1899, Rhytismatales genera incertae sedis, Leotiomycetes, one species, type: N. aceris-laurini Henn., asexual morph unknown, saprobes, terrestrial, Java, see Lumbsch and Huhndorf (2010; outline), Kirk et al. (2013; genus accepted), cultures and sequences are unavailable, needs generic revision.

Nypaella K.D. Hyde \& B. Sutton 1992, Ascomycota genera incertae sedis, two species, type: N. frondicola K.D. Hyde \& B. Sutton, coelomycetous, sexual morph unknown, saprobes, marine, on intertidal fronds of Nypa fruticans, Brunei, see Wijayawardene et al. (2012, 2017; outline), Kirk et al. (2013; genus accepted), cultures and sequences are unavailable, holotype of the type: IMI 348629.

Nyungwea Sérus., Eb. Fisch. \& Killmann 2006, Opegraphaceae, Arthoniales, Arthoniomycetes, one species, type: N. pallida Sérus., Eb. Fischer \& Killmann, lichenized, terrestrial, see Lumbsch and Huhndorf (2010; outline), Frisch et al. (2014; phylogeny), sequences are available.

Obconicum Velen. 1939, Helotiales genera incertae sedis, Leotiomycetes, two species, type: need typification, asexual morph unknown, saprobes, terrestrial, former Czechoslovakia, see Lumbsch and Huhndorf (2010; outline), Jaklitsch et al. (2016a; classification), cultures and sequences are unavailable, needs generic revision.

Obeliospora Nawawi \& Kuthub. 1990, Ascomycota genera incertae sedis, three species, type: $O$. basispira Nawawi \& Kuthub., hyphomycetous, sexual morph unknown, saprobes, terrestrial, Asia, see Seifert et al. (2011; morphology), Wijayawardene et al. (2012, 2017; outline), Kirk et al. (2013; genus accepted), cultures and sequences are unavailable, needs generic revision.

Obolarina Pouzar 1986, Graphostromataceae, Xylariales, Sordariomycetes, two species, type: O. dryophila (Tul. \& C. Tul.) Pouzar, asexual morph hyphomycetous (rhinocladiellalike), saprobes, terrestrial, Europe, see Lumbsch and Huhndorf (2010; outline), Pažoutová et al. (2010; DNA, phylogeny), Mirabolfathy et al. (2013; new species, Iran), Maharachchikumbura et al. (2015, 2016; outline), Wendt et al. (2017; trnsferred to Graphostromataceae), cultures available for the type: H76, needs generic revision. 
Obryzum Wallr. 1825, Obryzaceae, Ascomycota family incertae sedis, two species, type: $O$. corniculatum (Hoffm.) Wallr., asexual morph unidentified, lichenicolous, terrestrial, Europe, see Lumbsch and Huhndorf (2010; outline), Maharachchikumbura et al. (2015, 2016; outline), cultures and sequences are unavailable, needs generic revision.

Obstipipilus B. Sutton 1968, Ascomycota genera incertae sedis, one species, type: $O$. malabaricus (T.S. Ramakr. \& K. Ramakr.) B. Sutton, coelomycetous, sexual morph unknown, pathogens, terrestrial, India, see Wijayawardene et al. (2012, 2016b; outline, morphology), cultures and sequences are unavailable, holotype of the type: IMI 110502.

Obstipispora R.C. Sinclair \& Morgan-Jones., 1979, Ascomycota genera incertae sedis, one species, type: O. chewaclensis R.C. Sinclair \& Morgan-Jones, sexual morph unknown, submerged decaying leaves, Alabama, see Wijayawardene et al. (2012; phylogeny), Kirk et al. (2013; genus accepted), cultures and sequences are unavailable, holotype of type: BPI.

Obtectodiscus E. Müll., Petrini \& Samuels 1980, Loramycetaceae, Helotiales, Leotiomycetes, two species, type: O. aquaticus E. Müll., Petrini \& Samuels, asexual morph unknown, saprobes, terrestrial, Switzerland, South America, see Lumbsch and Huhndorf (2010; outline), Kirk et al. (2013; genus accepted), cultures and sequences are unavailable, needs generic revision.

Ocala Raja \& Shearer 2009, Natipusillales genera incertae sedis, Dothideomycetes, one species, type: $O$. scalariformis Raja \& Shearer, submerged wood, Florida, see Raja et al. (2009a, 2015; taxonomy, phylogeny), Lumbsch and Huhndorf (2010; outline, accepted as a genus in Phaeosphaeriaceae), Shearer et al. (2009; phylogeny), Wijayawardene et al. (2014c; accepted as a genus in Dothideomycetes), cultures and sequences are available, holotype of type: F121-1, ILL

Occultibambusa D.Q. Dai \& K.D. Hyde 2016, Occultibambusaceae, Pleosporales, Dothideomycetes, three species, type: O. bambusae D.Q. Dai \& K.D. Hyde, asexual morph coelomycetous, saprobes, terrestrial, Thailand, see Dai et al. (2016; phylogeny, morphology, sexual and asexual morphs), cultures and sequences are available, holotype and ex-type cultures of type: MFLU 15-1212; MFLUCC 13-0855 = CBS 139960 = MUCL 55882.

Occultitheca J.D. Rogers \& Y.M. Ju 2003, Xylariales genera incertae sedis, Sordariomycetes, one species, type: $O$. costaricensis J.D. Rogers \& Y.M. Ju, asexual morph unknown, saprobes, terrestrial, Costa Rica, see Lumbsch and Huhndorf (2010; outline), Maharachchikumbura et al. (2015, 2016; outline), Wendt et al. (2017; accepted as a genus in Xylariales genera incertae sedis), cultures and sequences are unavailable, holotype of type: INB Rogers, needs generic revision.

Occultocarpon L.C. Mejía \& Zhu L. Yang 2012, Gnomoniaceae, Diaporthales, Sordariomycetes, one species, type: O. ailaoshanense L.C. Mejía \& Zhu L. Yang, asexual morph unknown, saprobes, terrestrial, China, see Mejía et al. (2012; taxonomy), Maharachchikumbura et al. (2015, 2016; outline), cultures and sequences are available, holotype and ex-type cultures of the type: BPI 879253, LCM524.01.

Oceanitis Kohlm. 1977, Halosphaeriaceae, Microascales, Sordariomycetes, four species, type: O. scuticella Kohlm., asexual morph unknown, saprobes, freshwater or marine, worldwide, see Dupont et al. (2009; phylogeny), Lumbsch and Huhndorf (2010; outline), Kirk et al. (2013; genus accepted), Maharachchikumbura et al. (2015, 2016; outline), sequence data available for all species, holotype of type: J.K. 2971a, not found in NYBG.

Ocellomma Ertz \& Tehler 2015, Roccellaceae, Arthoniales, Arthoniomycetes, one species, type: O. picconianum (Bagl.) Ertz \& Tehler, sexual morph with apothecioid ascomata, lichenized, terrestrial, Mediterranean, see Ertz et al. (2014b; morphology, phylogeny), Lücking et al. (2016b; classification), sequences are available, lectotype and ex-type strain of type: Ertz 17143; 17132. 
Ocellularia G. Mey. 1825, Graphidaceae, Ostropales, Lecanoromycetes, 400 species, type: O. obturata (Ach.) Spreng., asexual morph unknown, lichenized fungi, terrestrial, tropical, see Mangold et al. (2009; key, Australia), Lumbsch and Huhndorf (2010; outline), Rivas Plata et al. (2012a; phylogeny), Sipman et al. (2012; key, Costa Rica), Kirk et al. (2013; genus accepted), Lücking (2014; key), Lücking et al. (2014, 2016b; classification, phylogeny), cultures and sequences are available, needs generic revision.

Ochotrichobolus Kimbr. \& Korf 1983, Ascodesmidaceae, Pezizales, Pezizomycetes, one species, type: $O$. polysporus Kimbr. \& Korf, asexual morph unknown, saprobes, terrestrial, USA, see Lumbsch and Huhndorf (2010; outline), Kirk et al. (2013; genus accepted), cultures and sequences are unavailable, holotype of the type: CUP 59844.

Ochrocladosporium Crous \& U. Braun 2007, Pleosporales genera incertae sedis, Dothideomycetes, three species, type: O. elatum (Harz) Crous \& U. Braun, hyphomycetous, terrestrial, Africa, Europe, see Hyde et al. (2011; outline), Wijayawardene et al. (2014c; outline), cultures and sequences are available, needs generic revision.

Ochroconis de Hoog \& Arx 1974, Sympoventuriaceae, Venturiales, Dothideomycetes, 25 species, type: O. constricta (E.V. Abbott) de Hoog \& Arx, asexual morph hyphomycetous, saprobes, opportunistic pathogens on human and animals, terrestrial, worldwide, see Ge et al. (2012; human pathogen), Giraldo et al. (2014b; new species), Machouart et al. (2014; phylogeny), Samerpitak et al. (2014, 2015; human and animal pahogens, phylogeny), Wijayawardene et al. (2014c, 2017; outline), Crous et al. (2015e, 2016a; new species, phylogeny), cultures and sequences are available, available specimen and cultures for type: CBS H-15203; CBS 211.53, CBS 202.27.

Ochrolechia A. Massal. 1852, Ochrolechiaceae, Pertusariales, Lecanoromycetes, 60 species, type: $O$. tartarea (L.) A. Massal., asexual morph unknown, lichenized, terrestrial, worldwide, see Lumbsch and Huhndorf (2010; outline), Aptroot and Aslan (2012; new records), Kirk et al. (2013; genus accepted), sequence are available for the type, needs generic revision.

Ochronectria Rossman \& Samuels 1999, Bionectriaceae, Hypocreales, Sordariomycetes, three species, type: O. calami (Henn. \& E. Nyman) Rossman \& Samuels, asexual morph unknown, saprobes, terrestrial, Asia, South America, see Guu et al. (2010; Taiwan), Pinruan et al. (2010; Thailand), Luo and Zhuang (2010; China), Li et al. (2016a; new species), cultures and sequences are available, holotype and culture data unavailable.

Ocostaspora E.B.G. Jones, R.G. Johnson \& S.T. Moss 1983, Halosphaeriaceae, Microascales, Sordariomycetes, one species, type: O. apilongissima E.B.G. Jones, R.G. Johnson \& S.T. Moss, asexual morph unknown, saprobes, marine, Wales, Denmark, temperate, see Lumbsch and Huhndorf (2010; outline), Sakayaroj et al. (2011a; DNA, phylogeny), Kirk et al. (2013; genus accepted), Jones et al. (2015; outline), Maharachchikumbura et al. (2015, 2016; outline), cultures and sequences are available.

Ocotomyces H.C. Evans \& Minter 1985 (= Uyucamyces H.C. Evans \& Minter fide Johnston et al. 2014b), Leotiomycetes genera incertae sedis, one species, type: O. parasiticus H.C. Evans \& Minter, asexual morph formerly named in Uyucamyces, saprobes, terrestrial, France, see Lumbsch and Huhndorf (2010; outline), Kirk et al. (2013; genus accepted), Johnston et al. (2014b; nomenclature), Wijayawardene et al. (2017; outline), cultures and sequences are unavailable, holotype of type: IMI 286340, needs generic revision.

Octopodotus Kohlm. \& Volkm.-Kohlm. 2003, Ascomycota genera incertae sedis, one species, type: O. stupendous Kohlm. \& Volkm.-Kohlm, coelomycetous, sexual morph unknown, saprobes, marine, USA, see Wijayawardene et al. (2012, 2017; outline), Kirk et al. (2013; genus accepted), cultures and sequences are unavailable, needs generic revision.

Octospora Hedw. 1789, Pezizales genera incertae sedis, Pezizales, c. 60 species, type: $O$. leucoloma Hedw., asexual morph unknown, saprobes, terrestrial, Europe, see Lumbsch and 
Huhndorf (2010; outline), Kirk et al. (2013; genus accepted), Jaklitsch et al. (2016a; classification), cultures and sequences are available.

Octosporella Döbbeler 1980, Pezizales genera incertae sedis, Pezizomycetes, nine species, type: O. jungermanniarum (P. Crouan \& H. Crouan) Döbbeler, asexual morph unknown, on mosses and liverwarts, terrestrial, Europe, Venezuela, see Lumbsch and Huhndorf (2010; outline), Stenroos et al. (2010; DNA), Döbbeler (2011; new species, Costa Rica and French Guiana), Kirk et al. (2013; genus accepted), Jaklitsch et al. (2016a; classification), cultures and sequences are available, needs generic revision.

Octosporopsis U. Lindem. \& M. Vega 2014, Pezizales genera incertae sedis, Pezizomycetes, nine species, type: $O$. nicolai U. Lindemann, M. Vega \& T. Richter, asexual morph unknown, saprobes, terrestrial, Europe, see Lindemann et al. (2014; taxonomy, phylogeny), sequences are available, voucher specimen for type: MV20130205-1.

Oculimacula Crous \& W. Gams 2003 (= Helgardia Crous \& W. Gams 2003 fide Johnston et al. 2014b), Ploettnerulaceae, Helotiales, Leotiomycetes, six species, type: O. yallundae (Wallwork \& Spooner) Crous \& W. Gams, asexual morph formerly named in Helgardia, saprobes, pathogens, terrestrial, Germany, Australia, France, see Wijayawardene et al. (2012, 2017; outline), Cultures and sequences are available, holotype of the type species unavailable. Odontodictyospora Mercado 1984, Ascomycota genera incertae sedis, one species, type: $O$. comasii Mercado, hyphomycetous, sexual morph unknown, saprobes, terrestrial, see Seifert et al. (2011; morphology), Wijayawardene et al. (2012, 2017; outline), Kirk et al. (2013; genus accepted), cultures and sequences are unavailable, needs generic revision.

Odontotrema Nyl. 1858, Odontotremataceae, Ostropales, Lecanoromycetes, c. seven species, type: O. phacidioides Nyl., asexual morph unknown, lichenized, temperate, see Baloch et al. (2010; DNA), Lumbsch and Huhndorf (2010; outline), Kirk et al. (2013; genus accepted), Zhurbenko (2010a; new species), sequences are available.

Oedocephalum Preuss 1851, Pezizaceae, Pezizales, Pezizomycetes, c. 23 species, type: $O$. elegans Preuss, hyphomycetous, sexual morph unknown, Nematode trapping, in soil, terrestrial, aquatic, Asia, Europe, see Davisonet al. (2009; new species), Seifert et al. (2011; morphology), Wijayawardene et al. (2012, 2017; outline), cultures and sequences are available, needs generic revision.

Oedocephalum Preuss 1851, Pezizaceae, Pezizales, Pezizomycetes, ten species, type: $O$. elegans Preuss, hyphomycetous, sexual morph unknown, saprobes, hypogeous, terrestrial, worldwide, see Davison et al. (2009; new species), Seifert et al. (2011; morphology), Wijayawardene et al. (2012, 2017; outline), cultures and sequences are available for the type species, needs generic revision.

Oedohysterium E.W.A. Boehm \& C.L. Schoch 2009, Hysteriaceae, Hysteriales, Dothideomycetes, three species, type: O. insidens (Schwein.) E. Boehm \& C.L. Schoch, saprobes, terrestrial, North and South America, Europe, South Africa, China, see Boehm et al. (2009a, b; generic review), Lumbsch and Huhndorf (2010; outline), Wijayawardene et al. (2014c; outline), cultures and sequences are available, needs generic revision.

Oedothea Syd. 1930, Ascomycota genera incertae sedis, one species, type: O. vismiae Syd., hyphomycetous, sexual morph unknown, saprobes, terrestrial, South America, see Seifert et al. (2011; morphology), Wijayawardene et al. (2012, 2017; outline), Kirk et al. (2013; genus accepted), cultures and sequences are unavailable, needs generic revision.

Oevstedalia Ertz \& Diederich 2004, Ascomycota genera incertae sedis, one species, type: $O$. antarctica (C.W. Dodge) Ertz \& Diederich, sexual morph perithecioid, asexual morph represented by true ascoconidia, lichenized, on wood, rock, detritus and whale bones, Antarctica, probably endemic, first lichenized ascomycete known to produce true ascoconidia, see Lumbsch and Huhndorf (2010; outline), Lücking et al. (2016b; 
classification), cultures and sequences are unavailable, holotype of the type: Follmann 14173 (FH-Dodge).

Ogataea Y. Yamada, K. Maeda \& Mikata 1994, Pichiaceae, Saccharomycetales, Saccharomycetes, 40 species, type: $O$. minuta (Wickerham) Y. Yamada, K. Maeda \& Mikata, asexual reproduction is by multilateral budding, saprophytic, soil, flowers, tree leaves, tree sap, rotted wood, insect frass in trees and other plants, animal feces, fruit of osage orange, worldwide, see Lumbsch and Huhndorf (2010; outline), Kirk et al. (2013; genus accepted), sequences are available.

Ohleria Fuckel 1868, Melanommataceae, Pleosporales, Dothideomycetes, 13 species, type: O. modesta Fuckel, asexual morph hyphomyctous, saprobes, terrestrial, worldwide, see Lumbsch and Huhndorf (2010; outline), Kirk et al. (2013; genus accepted), Tian et al. (2015; morphology, nomenclature, phylogeny), cultures and sequences are unavailable, holotype of type species Rhenani exsicc. 2173 present in $\mathrm{G}$, needs generic revision.

Ohleriella Earle 1902, Delitschiaceae, Pleosporales, Dothideomycetes, one species, type: $O$. neomexicana Earle, asexual morph unknown, saprobes, terrestrial, North America, see Lumbsch and Huhndorf (2010; outline), Hyde et al. (2013; accepted as a genus in Delitschiaceae), Kirk et al. (2013; genus accepted), Wijayawardene et al. (2014c; outline), cultures and sequences are unavailable, needs generic revision.

Oidiodendron Robak 1932, Myxotrichaceae, Leotiomycetes families incertae sedis, two species, type: O. fuscum Robak, hyphomycetous, sexual morph unknown, saprobes, terrestrial, worldwide, see Seifert et al. (2011; morphology), Wijayawardene et al. (2012, 2017; outline), Kirk et al. (2013; genus accepted), cultures and sequences are available, cultures available for type: CBS 238.31, MUCL 1057, needs generic revision.

Ojibwaya B. Sutton 1973, Ascomycota genera incertae sedis, one species, type: $O$. perpulchra B. Sutton, hyphomycetous, sexual morph unknown, saprobes, terrestrial, Belarus, Canada, Malawi, see Seifert et al. (2011; morphology), Wijayawardene et al. (2012, 2017; outline), cultures and sequences are unavailable, holotype of the type: IMI 132708.

Okeanomyces K. L. Pang \& E. B. G. Jones 2004, Halosphaeriaceae, Microascales, Sordariomycetes, one species, type: O. cucullatus (Kohlm.) K.L. Pang \& E.B.G. Jones, asexual morph hyphomycetous, saprobes, marine, worldwide, Lumbsch and Huhndorf (2010; outline), Maharachchikumbura et al. (2015, 2016; outline), sequence data available, holotype of type: J.K. $1686=00966750$, NYBG.

Olegblumia S.Y.Kondr., L.Lőkös \& Hur 2015, Teloschistaceae, Teloschistales, Lecanoromycetes, one species, type: $O$. demissa Flot. ex S.Y. Kondr., L. Lökös, J. Kim, A.S. Kondr., S.O. Oh \& J.S. Hur, lichenized, Europe and North America, see Kondratyuk et al. (2015d; phylogeny), Lücking et al. (2016b; classification), cultures and sequences are available, needs generic revision.

Oleoguttula Selbmann \& de Hoog 2014, Teratosphaeriacae, Capnodiales, Dothideomycetes, one species, type: $O$. mirabilis Selbmann \& de Hoog, hyphomycetous, sexual morph unknown, rock-inhabiting fungus, see Egidi et al. (2014; taxonomy), Quaedvlieg et al. (2014; phylogeny), Wijayawardene et al. (2014c, 2017; outline), cultures available for the type: CBS 136102 = CCFEE 5523.

Oletheriostrigula Huhndorf \& R.C. Harris 1996, Strigulaceae, Strigulales, Dothideomycetes, one species, type: O. papulosa (Durieu \& Mont.) Huhndorf \& R.C. Harris, asexual morph unknown, lichenized, saprobes, terrestrial, worldwide, see Lumbsch and Huhndorf (2010; outline), Kirk et al. (2013; genus accepted), Jaklitsch et al. (2016a; classification), Lücking et al. (2016b; classification), cultures and sequence are unavailable, needs generic revision.

Olla Velen. 1934, Hyaloscyphaceae, Helotiales, Leotiomycetes, twelve species, type: $O$. ulmariae Velen., asexual morph unknown, saprobes, terrestrial, Europe, see Lumbsch and 
Huhndorf (2010; outline), Kirk et al. (2013; genus accepted), cultures and sequences are unavailable, needs generic revision.

Olpitrichum G.F. Atk. 1894, Ascomycota genera incertae sedis, three species, type: $O$. carpophilum G.F. Atk., hyphomycetous, sexual morph unknown, saprobes, terrestrial, widespread, see Seifert et al. (2011; morphology), Wijayawardene et al. (2012, 2017; outline), Kirk et al. (2013; genus accepted), cultures and sequences are available, needs generic revision.

Ombrophila Fr. 1849, Gelatinodiscaceae, Helotiales, Leotiomycetes, eleven species, type: $O$. violacea (Hedw.) Fr., asexual morph unknown, saprobes, terrestrial, worldwide, see Lumbsch and Huhndorf (2010; outline), Kirk et al. (2013; genus accepted), Osmundson et al. (2013; DNA), Jaklitsch et al. (2016a; classification), cultures and sequences are available.

Omega B. Sutton \& Minter 1988, Ascomycota genera incertae sedis, one species, type: $O$. coenobiticum B. Sutton \& Minter, coelomycetous, sexual morph unknown, saprobes, terrestrial, Greece, see Wijayawardene et al. (2012, 2017; outline), Kirk et al. (2013; genus accepted), cultures and sequences are unavailable, holotype of the type species IMI 326014.

Ommatomyces Kohlm., Volkm.-Kohlm. \& O.E. Erikss. 1995, Xylariales genera incertae sedis, Sordariomycetes, three species, type: O. coronatus Kohlm., Volkm.-Kohlm. \& O.E. Erikss., asexual morph unknown, saprobes, marine or terrestrial, see Lumbsch and Huhndorf (2010; outline), Kirk et al. (2013; genus accepted), cultures and sequences are unavailable, holotype of type: IMS JK5509, needs generic revision.

Omnidemptus P.F. Cannon \& Alcorn 1994, Magnaporthaceae, Magnaporthales, Sordariomycetes, one species, type: O. affinis P.F. Cannon \& Alcorn, asexual morph unknown, saprobes, terrestrial, Australia, see Lumbsch and Huhndorf (2010; outline), Maharachchikumbura et al. (2015, 2016; outline), cultures and sequences are unavailable, holotype of the type: BRIP 17195.

Omphalodium Meyen \& Flot. 1843, Parmeliaceae, Lecanorales, Lecanoromycetes, four species, type: $O$. pisacomense Meyen \& Flot., asexual morph unknown, lichenized, terrestrial, North and South America, see Lumbsch and Huhndorf (2010; outline), Kirk et al. (2013; genus accepted), Divakar et al. (2015; DNA, phylogeny), Lücking et al. (2016b; classification), cultures and sequences are available.

Omphalora T.H. Nash \& Hafellner 1990, Parmeliaceae, Lecanorales, Lecanoromycetes, one species, type: $O$. arizonica (Tuck. ex Willey) T.H. Nash \& Hafellner, asexual morph unknown, lichenized, terrestrial, North America, see Crespo et al. (2010b; DNA, phylogeny), Lumbsch and Huhndorf (2010; outline), Kirk et al. (2013; genus accepted), Lücking et al. (2016b; classification), cultures and sequences are available.

Omphalospora Theiss. \& Syd. 1915, Dothideomycetes genera incertae sedis, two species, type: O. stellariae (Lib.) Theiss. \& Syd., asexual morph unknown, saprobes, terrestrial, South America, see Lumbsch and Huhndorf (2010; outline), Kirk et al. (2013; genus accepted), Wijayawardene et al. (2014c; outline), cultures and sequences are unavailable, needs generic revision.

Oncocladium Wallr. 1833, Gymnoascaceae, Onygenales, Eurotiomycetes, one species, type: O. flavum Wallr., hyphomycetous, sexual morph unknown, soilborne, Europe, Canada, see Seifert et al. (2011; morphology), Wijayawardene et al. (2012, 2017; outline), Kirk et al. (2013; genus accepted), cultures and cultures are unavailable, needs generic revision.

Oncopodiella G. Arnaud ex Rifai 1965, Ascomycota genera incertae sedis, 14 species, type: O. trigonella (Sacc.) Rifai, hyphomycetous, soilborne, Europe, see Seifert et al. (2011; morphology), Wijayawardene et al. (2012, 2017; outline), Kirk (2013; accepted as valid genus), cultures and sequences are unavailable, cultures available for the type: CBS 126413, MUCL 52643, needs generic revision. 
Oncopodium Sacc. 1904, Ascomycota genera incertae sedis, twelve species, type: $O$. antoniae Sacc. \& D. Sacc., hyphomycetous, soilborne, Europe and North America, see Seifert et al. (2011; morphology), Wijayawardene et al. (2012, 2017; outline), Kirk (2013; accepted as valid genus), cultures and sequences are unavailable, needs generic revision, needs generic revision.

Oncospora Kalchbr. 1880, Ascomycota genera incertae sedis, eight species, type: O. bullata Kalchbr. \& Cooke , coelomycetous, widespread, see Wijayawardene et al. (2012, 2017; outline), Kirk (2013; genus accepted), cultures and sequences are unavailable, needs generic revision.

Oncosporella P. Karst. 1887, Ascomycota genera incertae sedis, one species, type: $O$. punctiformis P. Karst. 1887, coelomycetous, Finland, see Wijayawardene et al. (2012, 2017; outline), Kirk (2013; genus accepted), cultures and sequences are unavailable, needs generic revision.

Oncostroma Bat. \& Marasas 1966, Ascomycota genera incertae sedis, one species, type: $O$. toddaliae Bat. \& Marasas, hyphomycetous, South Africa, see Wijayawardene et al. (2012, 2017; outline), Kirk (2013; genus accepted), cultures and sequences are unavailable, needs generic revision, needs generic revision.

Ondiniella E.B.G. Jones, R.G. Johnson \& S.T. Moss 1984, Halosphaeriaceae, Microascales, Sordariomycetes, one species, type: O. torquata (Kohlm.) E.B.G. Jones, R.G. Johnson \& S.T. Moss, asexual morph unknown, saprobes on wood, marine, see Lumbsch and Huhndorf (2010; outline), Kirk et al. (2013; genus accepted), Jones et al. (2015; phylogeny), Maharachchikumbura et al. (2015, 2016; outline), cultures and sequences are available, needs generic revision.

Onychocola Sigler 1990, Arachnomycetaceae, Arachnomycetales, Eurotiomycetes, five species, type: $O$. canadensis Sigler, human pathogens, widespread, see Wijayawardene et al. (2012, 2017; outline), Kirk (2013; genus accepted), cultures and sequences are available, UTMB 3250, needs generic revision.

Onychophora W. Gams, P.J. Fisher \& J. Webster 1984, Ascomycota genera incertae sedis, one species, type: $O$. coprophila W. Gams, P.J. Fisher \& J. Webster, hyphomycetous, sexual morph unknown, coprophilous (rabbit dung), terrestrial, UK, see Seifert et al. (2011; morphology), Wijayawardene et al. (2012, 2017; outline), cultures and sequences are unavailable, holotype of the type: CBS 1740.

Onygena Pers. 1800, Onygenaceae, Onygenales, Eurotiomycetes, one species, type: $O$. equina (Willd.) Pers., asexual morph unknown, on feathers, bones, Europe, North America, see Lumbsch and Huhndorf (2010; outline), Kirk et al. (2013; genus accepted), Huang et al. (2015b; DNA, protein degrading taxa), cultures and sequences are available, cultures available for the type species (Huang et al. 2013), type specimen of type species CBS H15271.

Onygenopsis Henn. 1910, Sordariales genera incertae sedis, Sordariomycetes, one species, type: O. engleriana Henn., asexual morph unknown, saprobes, see Lumbsch and Huhndorf (2010; outline), Maharachchikumbura et al. (2015, 2016; outline), needs generic revision, cultures and sequences are unavailable.

Oomyces Berk. \& Broome 1851, Acrospermaceae, Acrospermales, Dothideomycetes, ten species, type: O. carneoalbus (Lib.) Berk. \& Broome, asexual morph unknown, saprobes, terrestrial, widespread, see Lumbsch and Huhndorf (2010; outline), cultures and sequences are unavailable, need generic revision.

Oosporidium Stautz 1931, Saccharomycetes genera incertae sedis, two species, type: $O$. margaritiferum Stautz, saprobes, terrestrial, Europe and North America, Wijayawardene et al. (2012, 2017; outline), Kirk (2013; genus accepted), cultures available for type species CBS 
2531, ATCC 10676, CCRC 21536, DSM 70351, IFO 1208, NRRL Y-1519, VKM Y-816, needs generic revision.

Oothyrium Syd. 1939, Ascomycota genera incertae sedis, one species, type: O. butyrospermi Syd., coelomycetous, sexual morph unknown, Africa, see Wijayawardene et al. (2012, 2017; outline), Kirk (2013; genus accepted), cultures and sequences are unavailable, needs generic revision.

Opegrapha Ach. 1809, Opegraphaceae, Arthoniales, Arthoniomycetes, but strongly polyphyletic, 300 species, type: $O$. vulgata (Ach.) Ach., asexual morph unknown, lichenized, saprobes, lichenicolous, terrestrial, worldwide, see Ertz et al. (2009; DNA), Lumbsch and Huhndorf (2010; outline), Ertz and Tehler (2011; phylogeny), Kirk et al. (2013; genus accepted), Lücking et al. (2016b; classification), cultures and sequences are available, needs generic revision.

Ophidiomyces Sigler, Hambl. \& Paré 2013, Onygenaceae, Onygenales, Eurotiomycetes, one species, type: O. ophiodiicola (Guarro, Deanna A. Sutton, Wickes \& Rajeev) Sigler, Hambleton \& Paré, asexual morph unknown, pathogens on snakes, Nothern America, see Sigler et al. (2013; taxonomy, phylogeny), Allender et al. (2015; pathogens), Cultures and sequences are available, cultures available for the type species UAMH 10717 (Sigler et al. 2013), needs generic revision.

Ophiobolus Riess 1854, Phaeosphaeriaceae, Pleosporales, Dothideomycetes, one species, type: $O$. disseminans Riess, asexul morph coniothyrium-like; phoma-like, saprobes, terrestrial, North America, see Lumbsch and Huhndorf (2010; outline), Zang et al. (2012e; taxonomy), Hyde et al. (2013; accepted as a genus in Phaeosphaeriaceae), Kirk et al. (2013; genus accepted), Phookamsak et al. (2014b; taxonomy, phylogeny), Wijayawardene et al. (2014c; outline), cultures and sequences are available.

Ophioceras Sacc. 1883, Ophioceraceae, Magnaporthales, Sordariomycetes, 39 species, type: O. dolichostomum (Berk. \& M.A. Curtis) Sacc., saprobes, aquatic, terrestrial, worldwide, see Lumbsch and Huhndorf (2010; outline), Hu et al. (2012b; new species), Kirk et al. (2013; genus accepted), Klaubauf et al. (2014; phylogeny), Maharachchikumbura et al. (2015, 2016; outline), cultures and sequences are available.

Ophiociliomyces Bat. \& I.H. Lima 1955, Ascomycota genera incertae sedis, one species, type: O. bauhiniae Bat. \& I.H. Lima, asexual morph unknown, from living leaves, tropical, see Lumbsch and Huhndorf (2010; outline, accepted as a genus in Meliolaceae), Kirk et al. (2013; genus accepted), Hongsanan et al. (2015c; excluded the genus from Meliolaceae), cultures and sequences are unavailable, needs generic revision.

Ophiocordyceps Petch 1931 (= Cordycepioideus Stifler 1941 fide Index Fungorum 2017), Ophiocordycipitaceae, Hypocreales, Sordariomycetes, c. 200 species, type: O. blattae (Petch) Petch, asexual morph acremonium-like, on insects, terrestrial, worldwide, see Lumbsch and Huhndorf (2010; outline), Evans et al. (2011; new species), Kirk et al. (2013; genus accepted), Wen et al. (2014; new species), Araújo et al. (2015; new species), Ban et al. (2015; new species), Kobmoo et al. (2015; new species), Sanjuan et al. (2015; new species), Spatafora et al. (2015; new species, nomenclature), Maharachchikumbura et al. (2015, 2016; outline), Crous et al. (2016a; new species), cultures and sequences are available, needs generic revision.

Ophiodeira Kohlm. \& Volkm.-Kohlm. 1988, Halosphaeriaceae, Microascales, Sordariomycetes, three species, type: O. monosemeia Kohlm. \& Volkm.-Kohlm., marine, Caribbean, see Lumbsch and Huhndorf (2010; outline), Jones et al. (2015; outline, marine), Maharachchikumbura et al. (2015, 2016; outline, phylogeny), cultures and sequences available, needs generic revision.

Ophiodiaporthe Y.M. Ju, H.M. Hsieh, C.H. Fu, C.Y. Chen \& T.T. Chang 2013, Diaporthaceae, Diaporthales, Sordariomycetes, one species, type: O. cyatheae Y.M. Ju, H.-M. 
Hsieh, C.H. Fu, C.Y. Chen \& T.T. Chang, asexual morph coelomycetous, pathogens, terrestrial, Taiwan, see Fu et al. (2013; phylogeny, taxonomy), Maharachchikumbura et al. (2015, 2016; outline, phylogeny), Wijayawardene et al. (2017; outline), cultures and sequences are available, holotype and ex-type strain of type: YMJ1364; CRC 34961.

Ophiodothella (Henn.) Höhn. 1910, Phyllachoraceae, Phyllachorales, Sordariomycetes, 31 species, type: O. atromaculans (Henn.) Höhn., asexual morph unknown, saprobes, terrestrial, worldwide, see Lumbsch and Huhndorf (2010; outline), Hanlin and González (2013; new species), Fu et al. (2013; DNA), Kirk et al. (2013; genus accepted), Maharachchikumbura et al. (2015, 2016; outline), cultures and sequences are available, needs generic revision.

Ophiognomonia (Sacc.) Speg. 1896, Gnomoniaceae, Diaporthales, Sordariomycetes, 46 species, type: O. melanostyla (DC.) Sacc., asexual morph unknown, endophytes, pathogens, saprobes, primarily temperate and rarely subtropics, worldwide, see Lumbsch and Huhndorf (2010; outline), Walker et al. (2012; phylogeny), Kirk et al. (2013; genus accepted), Maharachchikumbura et al. (2015, 2016), sequences are available, needs generic revision.

Ophioirenina Sawada \& W. Yamam. 1959, Dothideomycetes genera incertae sedis, one species, type: $O$. theae Sawada \& W. Yamam., asexual morph unknown, from leaves, terrestrial, India, Taiwan, see Lumbsch and Huhndorf (2010; outline, accepted as a genus in Meliolaceae), Kirk et al. (2013; genus accepted), Hongsanan et al. (2015c; outline, excluded the genus from Meliolaceae and placed in Dothideomycetes), cultures and sequences are unavailable, needs generic revision.

Ophiomassaria Jacz. 1894, Sordariomycetes genera incertae sedis, one species, type: $O$. selenospora (G.H. Otth) Jacz., asexual morph unknown, saprobes or endophytes, terrestrial, Europe, see Lumbsch and Huhndorf (2010; outline), Kirk et al. (2013; genus accepted), Maharachchikumbura et al. (2015, 2016; outline), cultures and sequences are unavailable, needs generic revision.

Ophiomeliola Starbäck 1899, Sordariomycetes genera incertae sedis, four species, type: $O$. lindmanii Starbäck, asexual morph unknown, saprobes, terrestrial, tropical, see Lumbsch and Huhndorf (2010; outline), Hyde et al. (2013; accepted in Perisporiopsidaceae), Kirk et al. (2013; genus accepted), Wijayawardene et al. (2014c; outline), Hongsanan et al. (2015c; accepted as a genus in Sordariomycetes), cultures and sequences are unavailable, needs generic revision.

Ophionectria Sacc. 1878 (= Antipodium Piroz. 1974 fide Rossman et al. 2016a), Nectriaceae, Hypocreales, Sordariomycetes, two species, type: O. trichospora (Berk. \& Broome) Sacc., asexual morph unknown, saprobes, terrestrial, tropical, see Lumbsch and Huhndorf (2010; outline), Kirk et al. (2013; genus accepted), Maharachchikumbura et al. (2015, 2016; outline), Rossman et al. (2016a; nomenclature), cultures and sequences are available, type specimen and cultures available for the type: CBS H-6331; CBS 109876.

Ophioparma Norman 1852, Ophioparmaceae, Umbilicariales, Lecanoromycetes, two species, type: $O$. ventosa (L.) Norman, asexual morph unknown, saprobes, terrestrial, tropical, see Khare et al. (2010; taxonomy, India), Lumbsch and Huhndorf (2010; outline), Kirk et al. (2013; genus accepted), Le Pogam et al. (2016; taxonomy), Lücking et al. (2016b; classification), cultures available for the type: AFTOL-ID 1694, needs generic revision.

Ophioparodia Petr. \& Cif. 1932, Perisporiopsidaceae, Dothideomycetes families incertae sedis, one species, type: O. pulchra Petr. \& Cif., asexual morph unknown, saprobes, terrestrial, West Indies, see Lumbsch and Huhndorf (2010; outline), Hyde et al. (2013; accepted in Perisporiopsidaceae), Kirk et al. (2013; genus accepted), Wijayawardene et al. (2014c; outline), cultures and sequences are unavailable, needs generic revision.

Ophiorosellinia J.D. Rogers, A. Hidalgo, F.A. Fernández \& Huhndorf 2004, Xylariales genera incertae sedis, Sordariomycetes, one species, type: O. costaricensis J.D. Rogers, A. Hidalgo, F.A. Fernández \& Huhndorf, asexual morph unknown, saprobes, terrestrial, Costa 
Rica, see Lumbsch and Huhndorf (2010; outline), Maharachchikumbura et al. (2015, 2016; outline), Wendt et al. (2017; accepted as a genus in Xylariales genera incertae sedis), cultures and sequences are unavailable, holotype of the type: USJ72848.

Ophiosira Petr. 1955, Ascomycota genera incertae sedis, one species, type: O. austriaca Petr., coelomycetous, sexual morph unknown, saprobes, terrestrial, Australia, see Wijayawardene et al. (2012, 2017; outline), Kirk et al. (2013; genus accepted), cultures and sequences are unavailable, needs generic revision.

Ophiosphaerella Speg. 1909, Phaeosphaeriaceae, Pleosporales, Dothideomycetes, ten species, type: O. graminicola Speg., asexul morph wojnowicia-like, saprobes, terrestrial, aquatic, worldwide, see Schoch et al. (2009; phylogey), Lumbsch and Huhndorf (2010; outline), Zang et al. (2012; taxonomy), Hyde et al. (2013; accepted as a genus in Phaeosphaeriaceae), Kirk et al. (2013; genus accepted), Phookamsak et al. (2014b; taxonomy, phylogeny), Wijayawardene et al. (2014c; outline, phylogeny), Ariyawansa et al. (2015a; new species, phylogeny), cultures and sequences are available.

Ophiostoma Syd. \& P. Syd. 1919, Ophiostomataceae, Ophiostomatales, Sordariomycetes, c. 230 species, type: $O$. piliferum (Fr.) Syd. \& P. Syd., saprobes, worldwide, see Linnakoski et al. (2008, 2010; new species), Kamgan Nkuekam et al. (2010, 2012; taxonomy), Lumbsch and Huhndorf (2010; outline), Beer et al. (2013; new species), Kirk et al. (2013; genus accepted), Romón et al. (2014; new species), Maharachchikumbura et al. (2015, 2016; outline), cultures and sequences are available.

Oplothecium Syd. \& P. Syd. 1923, Trichosphaeriaceae, Trichosphaeriales, Sordariomycetes, two species, type: $O$. arecae Syd. \& P. Syd., asexual morph unknown, saprobes, Austria, see Kirk et al. (2008; treated as a synonym of Neorehmia), Lumbsch and Huhndorf (2010; outline), Maharachchikumbura et al. (2015, 2016; outline), cultures and sequences are available.

Orbicula Cooke 1871, Pezizales genera incertae sedis, Pezizomycetes, one species, type: $O$. cyclospora Cooke, asexual morph unknown, saprobes, terrestrial, North temperate, see Lumbsch and Huhndorf (2010; outline), Kirk et al. (2013; genus accepted), cultures and sequences are available, needs generic revision.

Orbilia Fr. 1836, Orbiliaceae, Orbiliales, Orbiliomycetes, c. 75 species, type: O. leucostigma (Fr.) Fr., asexul morph unknown, saprobes, terrestrial, aquatic, worldwide, see Zhang et al. (2009f; new species, China), Lumbsch and Huhndorf (2010; outline), Su et al. (2011b; new species, China), Quijada et al. (2013; new species, Spain), Kirk et al. (2013; genus accepted), cultures and sequences are available.

Orbiliopsis (Sacc. \& D. Sacc.) Syd. \& P. Syd. 1924, Helotiales genera incertae sedis, Leotiomycetes, two species, type: O. coleosporioides (Sacc.) Syd. \& P. Syd., asexual morph unknown, saprobes, terrestrial, New Zealand, see Lumbsch and Huhndorf (2010; outline), Kirk et al. (2013; genus accepted), sequences are available but lacks for the type species, needs generic revision.

Orbimyces Linder 1944, Ascomycota genera incertae sedis, one species, type: O. spectabilis Linder, sexual morph unknown, hyphomycetous, marine, see Jones et al. (2008; phylogeny), Seifert et al. (2011; morphology), Wijayawardene et al. (2012, 2017; outline), Kirk (2013; genus accepted), cultures and sequences are available, holotype: CBS H-15318.

Orbiocrella D. Johnson, G.H. Sung, Hywel-Jones \& Spatafora 2009, Clavicipitaceae, Hypocreales, Sordariomycetes, one species, type: O. petchii (Hywel-Jones) D. Johnson, G.H. Sung, Hywel-Jones \& Spatafora, asexual morphs unknown, on insects, terrestrial, Thailand, see Johnson et al. (2009; taxonomy, phylogeny), Lumbsch and Huhndorf (2010; outline), Kirk et al. (2013; genus accepted), Maharachchikumbura et al. (2015, 2016; outline, nomenclature), cultures and sequences are available. 
Orcadia G.K. Sutherl. 1914, Pezizales genera incertae sedis, Pezizomycetes, one species, type: O. ascophylli G.K. Sutherl., asexual morph unknown, marine, on brown algae, terrestrial, UK, Norway, see Lumbsch and Huhndorf (2010; outline, accepted as a genus in Pezizales), Kirk et al. (2013; genus accepted), Jones et al. (2015; outline, maine), cultures and sequences are unavailable, cultures and sequences are unavailable, needs generic revision.

Orceolina Hertel 1970, Trapeliaceae, Trapeliales, Lecanoromycetes, two species, type: O. kerguelensis (Tuck.) Hertel, asexual morph unknown, lichenized, terrestrial, subantarctic islands, see Lumbsch and Huhndorf (2010; outline), Lumbsch et al. (2012; phylogeny), Kirk et al. (2013; genus accepted), Kantvilas et al. (2015; phylogeny), Lücking et al. (2016b; classification), sequences are available, needs generic revision.

Orcularia (Malme) Kalb \& Giralt 2011, Caliciaceae, Caliciales, Lecanoromycetes, four species, type: $O$. insperata (Nyl.) Kalb \& Giralt, asexual morph present (in the original description, authors mentioned that genus has filiform conidia), lichenized, terrestrial, worldwide, see Kalb and Giralt (2011; taxonomy), Lücking et al. (2016b; classification), cultures and sequences are unavailable, needs generic revision.

Orientophila Arup, Søchting \& Frödén 2013, Teloschistaceae, Teloschistales, Lecanoromycetes, four species, type: O. loekoesii (S.Y. Kondr. \& J.S. Hur) Arup, Søchting \& Frödén, asexual morph unknown, lichenized, terrestrial, worldwide, see Arup et al. (2013; taxonomy, phylogeny), Kondratyuk et al. (2014, 2016; new species, phylogeny), Lücking et al. (2016b; classification), cultures and sequences are available.

Ormomyces I.I. Tav. 1985, Laboulbeniaceae, Laboulbeniales, Laboulbeniomycetes, one species, type: O. clivinae (Thaxt.) I.I. Tav., asexual morph unknown, biotrophic, terrestrial, Africa, Indonesia, see Lumbsch and Huhndorf (2010; outline), Kirk et al. (2013; genus accepted), cultures and sequences are unavailable.

Oropogon Th. Fr. 1861, Parmeliaceae, Lecanorales, Lecanoromycetes, 30 species, type: Oropogon loxensis (Fée) Th. Fr., asexual morph unknown, lichenized, terrestrial, worldwide, see Lumbsch and Huhndorf (2010; outline), Leavitt et al. (2012; diversity in Neotropical), Kirk et al. (2013; genus accepted), Divakar et al. (2015; DNA, phylogeny), Lücking et al. (2016b; classification), cultures and sequences are available, voucher specimen for the type: Nelson 4197A (F).

Orphanocoela Nag Raj 1989, Ascomycota genera incertae sedis, three species, type: $O$. calamagrostidis (H.C. Greene) Nag Raj, coelomycetous, sexual morph unknown, pathogens, terrestrial, USA, Africa, Colombia, Mexico, Nicaragua, Mexico, see Kirk et al. (2013; genus accepted), Wijayawardene et al. (2017; morphology), cultures and sequences are unavailable, holotype of the type species unavailable.

Orphniospora Körb. 1874, Elixiaceae, Umbilicariales, Lecanoromycetes, three species, type: O. groenlandica Körb., asexual morph unknown, lichenized, terrestrial, worldwide, see Lumbsch and Huhndorf (2010; outline), Leavitt et al. (2012; diversity in Neotropical), Kirk et al. (2013; genus accepted), Bilovitz and Mayrhofer (2014; new records in Vorarlberg, Australia), cultures and sequences are unavailable, needs generic revision.

Orphnodactylis Malloch \& A. Mallik 1998, Phyllachoraceae, Phyllachorales, Sordariomycetes, 31 species, type: O. kalmiae Malloch \& A. Mallik, asexual morph unknown, saprobes, terrestrial, worldwide, see Lumbsch and Huhndorf (2010; outline), Kirk et al. (2013; genus accepted), Maharachchikumbura et al. (2015, 2016; outline), cultures and sequences are unavailable, needs generic revision.

Orromyces B. Sur \& G.R. Ghosh 1987, Gymnoascaceae, Onygenales, Eurotiomycetes, four species, type: $O$. spiralis B. Sur \& G.R. Ghosh, asexual morph chrysosporium-like, saprobes, from soil, India, see Lumbsch and Huhndorf (2010; outline), Kirk et al. (2013; genus accepted), cultures and sequences are unavailable, needs generic revision. 
Orthobellus A.A. Silva \& Cavalc. 1973, Dothideomycetes genera incertae sedis, three species, type: O. leguminosarum A.A. Silva \& Cavalc., asexual morph unknown, saprobes, terrestrial, South America, see Lumbsch and Huhndorf (2010; outline, accepted as a genus in Schizothyriaceae), Kirk et al. (2013; genus accepted), Hyde et al. (2013; accepted as a genus in Schizothyriaceae), Wijayawardene et al. (2014c; outline, accepted as a genus in Schizothyriaceae), Phookamsak et al. (2016; taxonomy, transferred to Dothideomycetes genera incertae sedis), cultures and sequences are unavailable.

Oscarbrefeldia Holterm. 1898, Saccharomycetes genera incertae sedis, one species, type: $O$. pellucida Holterm., information unavailable, see Kirk et al. (2008; genus accepted in Saccharomycetes), Kirk et al. (2013; genus accepted), cultures and sequences are unavailable, needs generic revision.

Osoriomyces Terada 1981, Laboulbeniaceae, Laboulbeniales, Laboulbeniomycetes, one species, type: $O$. rhizophorus Terada, asexual morph unknown, biotrophic, terrestrial, Taiwan, see Lumbsch and Huhndorf (2010; outline), Kirk et al. (2013; genus accepted), cultures and sequences are unavailable, needs generic revision.

Ostracoderma Fr. 1825, Ascomycota genera incertae sedis, three species, type: O. pulvinatum Fr., coelomycetous, sexual morph unknown, saprobes, terrestrial, worldwide, see Wijayawardene et al. (2012, 2017; outline), cultures and sequences are unavailable, needs generic revision.

Ostracodermidium Mukerji 1973, Ascomycota genera incertae sedis, one species, type: $O$. serpentinum (J.N. Rai \& J.P. Tewari) Mukerji, hyphomycetous, sexual morph unknown, saprobes, terrestrial, India, see Seifert et al. (2011; morphology), Wijayawardene et al. (2012, 2017; outline), Kirk et al. (2013; genus accepted), cultures and sequences are unavailable, needs generic revision.

Ostreichnion Duby 1861, Hysteriaceae, Hysteriales, Dothideomycetes, three species, type: $O$. americanum Duby, asexual morph unknown, saprobes, terrestrial, Atlantic, China, see Boehm et al. (2009a, b; taxonomy), Lumbsch and Huhndorf (2010; outline), Kirk et al. (2013; genus accepted), Wijayawardene et al. (2014c; outline), cultures and sequences are available, needs generic revision.

Ostreola Darker 1963, Mytilinidiaceae, Mytilinidiales, Dothideomycetes, twelve species, type: O. consociata Darker, asexual morph septonema-like, saprobes, terrestrial, Europe, North America, see Lumbsch and Huhndorf (2010; outline), Hyde et al. (2013; accepted as agenus in Mytilinidiaceae), Kirk et al. (2013; genus accepted), Wijayawardene et al. (2014c; outline), cultures and sequences are unavailable.

Ostropa Fr. 1825, Stictidaceae, Ostropales, Lecanoromycetes, one species, type: O. barbara (Fr.) Nannf., asexual morph unknown, lichenized, terrestrial, north temperate, see Lumbsch and Huhndorf (2010; outline), Kirk et al. (2013; genus accepted), available specimen and cultures for the type: CBS H-15322; AFTOL-ID 77.

Ostropella (Sacc.) Höhn. 1918, Pleosporales genera incertae sedis, Dothideomycetes, five species, type: $O$. albocincta (Berk. \& M.A. Curtis) Höhn., asexual morph unknown, saprobes, worldwide, see Lumbsch and Huhndorf (2010; outline, treated as Pleosporales, genera incertae sedis), Hyde et al. (2013; accepted as a genus in Platystomaceae), Wijayawardene et al. (2014c; outline), cultures and sequences are available.

Oswaldina Rangel 1921, Ascomycota genera incertae sedis, one species, type: $O$. icarahyensis Rangel, coelomycetous, sexual morph unknown, saprobes, terrestrial, Brazil, see Kirk et al. (2013; genus accepted), Maharachchikumbura et al. (2015, 2016; outline, accepted as a genus in Phyllachoraceae), Wijayawardene et al. (2017; not accepted in Phyllachoraceae), cultures and sequences are unavailable, needs generic revision.

Otidea (Pers.) Bonord. 1851, Otideaceae, Pezizales, Pezizomycetes, 40 species, type: O. onotica (Pers.) Fuckel, asexual morph unknown, saprobes, terrestrial, worldwide, see 
Lumbsch and Huhndorf (2010; outline), Carbone and Van Vooren (2011; new species), Kirk et al. (2013; genus accepted), Olariaga et al. (2015; taxonomy, monograph), cultures and sequences are available, epitype and cultures are available for the type species KH.10.284 (S - epitype); KH.10.284.

Otthia Nitschke ex Fuckel 1870, Dothideomycetes genera incertae sedis, eleven species, type: O. spiraeae (Fuckel) Fuckel, asexual morph unknown, saprobes, terrestrial, worldwide, see Lumbsch and Huhndorf (2010; outline), Kirk et al. (2013; genus accepted), Wijayawardene et al. (2014c; outline), cultures and sequences are available, cultures available for the type: HKUCC 10896 (unpublished), needs generic revision.

Otwaya G.W. Beaton 1978, Helotiales genera incertae sedis, Leotiomycetes, twelve species, type: O. verruculospora G.W. Beaton, asexual morph unknown, saprobes, or endophytes, terrestrial, Australia, see Lumbsch and Huhndorf (2010; outline), Kirk et al. (2013; genus accepted), Jaklitsch et al. (2016a; classification, treatead as a synonym of Aeruginoscyphus Dougoud), cultures and sequences are unavailable, needs generic revision.

Ovadendron Sigler \& J.W. Carmich. 1976, Ascomycota genera incertae sedis, one species, type: O. sulphureo-ochraceum (J.F.H. Beyma) Sigler \& J.W. Carmich., hyphomycetous, sexual morph unknown, human pathogen, Europe, see Seifert et al. (2011; morphology), Wijayawardene et al. (2012, 2017; outline), Kirk et al. (2013; genus accepted), cultures and sequences are unavailable, needs generic revision.

Ovadendron Sigler \& J.W. Carmich. 1976, Ascomycota genera incertae sedis, one species, type: O. sulphureo-ochraceum (J.F.H. Beyma) Sigler \& J.W. Carmich., hyphomycetous, sexual morph unknown, from human, Europe, see Wijayawardene et al. (2012, 2017; outline), Kirk et al. (2013; genus accepted), cultures and sequences are unavailable, needs generic revision.

Oviascoma Y.J. Yao \& Spooner 1996, Pyronemataceae, Pezizales, Pezizomycetes, one species, type: O. paludosum (Dennis) Y.J. Yao \& Spooner, asexual morph unknown, saprobes, terrestrial, worldwide, see Lumbsch and Huhndorf (2010; outline), Kirk et al. (2013; genus accepted), cultures and sequences are unavailable, needs generic revision.

Ovicuculispora Etayo 2010, Bionectriaceae, Hypocreales, Sordariomycetes, two species, type: $O$. parmeliae Etayo, asexual morph unknown, lichenicolous, terrestrial, tropical, see Etayo (2010; morphology), cultures and sequences are available, needs generic revision.

Ovulinia F.A. Weiss 1940 (= Ovulitis N.F. Buchw 1970 fide Johnston et al. 2014b), Sclerotiniaceae, Helotiales, Leotiomycetes, nine species, type: O. azaleae F.A. Weiss, asexual morph formerly named in Ovulitis, saprobes, terrestrial, Europe, North America, see Lumbsch and Huhndorf (2010; outline), Kirk et al. (2013; genus accepted), Johnston et al. (2014b; nomenclature), cultures and sequences are unavailable, needs generic revision.

Oxnerella S.Y.Kondr., Lőkös \& Hur 2014, Physciaceae, Caliciales, Lecanoromycetes, one species, type: O. safavidiorum S.Y. Kondr., Zarei-Darki, Lökös \& Hur, lichenized, see Kondratyuk et al. (2014d; phylogeny), Resl et al. (2016; phylogeny), Lücking et al. (2016b; classification), cultures and sequences are available, holotype of type: KW-L 70296.

Oxodeora K.D. Hyde \& P.F. Cannon 1999, Phyllachoraceae, Phyllachorales, Sordariomycetes, one species, type: O. petrakii (Cif.) K.D. Hyde \& P.F. Cannon, asexual morph unknown, on living palm leaves, terrestrial, Caribbean, see Lumbsch and Huhndorf (2010; outline), Kirk et al. (2013; genus accepted), Maharachchikumbura et al. (2015, 2016; outline), cultures and sequences are unavailable, needs generic revision.

Oxydothis Penz. \& Sacc. 1898, Xylariales genera incertae sedis, Sordariomycetes, 31 species, type: O. grisea Penz. \& Sacc., asexual morph unknown, saprobes, terrestrial, worldwide, see Lumbsch and Huhndorf (2010; outline), Kirk et al. (2013; genus accepted), Liu et al. (2015a; new species, phylogeny), Maharachchikumbura et al. (2015, 2016; outline), cultures and sequences are available but lacks for the type species, needs generic revision. 
Paathramaya Subram. 1956, Ascomycota genera incertae sedis, five species, type: $P$. sundara Subram., hyphomycetous, sexual morph unknown, India, see Seifert et al. (2011; morphology), Wijayawardene et al. (2012, 2017; outline), Kirk et al. (2013; genus accepted), cultures and sequences are unavailable, holotype: CBS H-194, need generic revision.

Pachnolepia A. Massal. 1855, Arthoniaceae, Arthoniales, Arthoniomycetes, one species, type: P. pruinata (Pers.) Frisch \& G. Thor, lichenized, see Frisch et al. (2014a; reinstated), Lücking et al. (2016b; classification), sequences are available, need generic revision.

Pachyascus Poelt \& Hertel 1968, Pachyascaceae, Lecanorales, Lecanoromycetes, one species, type: P. lapponicus Poelt \& Hertel, asexual morph unknown, lichenized, terrestrial, Europe, see Lumbsch and Huhndorf (2010; outline), Kirk et al. (2013; genus accepted), cultures and sequences are available but lacks for the type species, needs generic revision.

Pachycladina Marvanová 1987, Ascomycota genera incertae sedis, three species, type: $P$. mutabilis Marvanová, hyphomycetous, sexual morph unknown, Europe, North America, see Seifert et al. (2011; morphology), Wijayawardene et al. (2012, 2017; outline), Kirk et al. (2013; genus accepted), cultures and sequences are unavailable, need generic revision.

Pachydisca Boud. 1885, Helotiales genera incertae sedis, Leotiomycetes, one species, type: P. guernisacii (P. Crouan \& H. Crouan) Boud., asexual morph unknown, saprobes, terrestrial, Europe, see Lumbsch and Huhndorf (2010; outline), Kirk et al. (2013; genus accepted), Jaklitsch et al. (2016a; classification, treated as a synonym of Discinella Boud.), cultures and sequences are available but lacks for the type species, needs generic revision.

Pachyella Boud. 1907, Pezizaceae, Pezizales, Pezizomycetes, 19 species, type: P. barlaeana (Bres.) Boud., asexual morph unknown, saprobes, terrestrial, worldwide, see Healy et al. (2009b; species in USA and Mexico), Lumbsch and Huhndorf (2010; outline), Kirk et al. (2013; genus accepted), cultures and sequences are available but lacks for the type species, needs generic revision.

Pachypatella Theiss. \& Syd. 1915, Parmulariaceae, Dothideomycetes families incertae sedis, one species, type: P. alsophilae (Racib.) Theiss. \& Syd., asexual morph unknown, epiphytes, terrestrial, Brazil, see Hofmann (2009; review), Lumbsch and Huhndorf (2010; outline), Hyde et al. (2013; outline, keys), Wijayawardene et al. (2014c; outline), cultures and sequences are unavailable, holotype and isotype of type species KRAM?; S F9863.

Pachypeltis Søchting, Arup \& Frödén 2013, Teloschistaceae, Teloschistales, Lecanoromycetes, four species, type: P. castellana (Räsänen) Søchting, Frödén \& Arup, asexual morph unknown, lichenized, terrestrial, Europe, see Arup et al. (2013; taxonomy), Lücking et al. (2016b; classification), cultures and sequences are available, needs generic revision.

Pachyphlodes Zobel 1854 (= Pachyphloeus Tul. \& C. Tul. 1845 fide Jaklitsch et al. 2016a), Pezizaceae, Pezizales, Pezizomycetes, 19 species, type: P. ligericus Zobel, asexual morph unknown, saprobes, saprobes, terrestrial, worldwide, see Doweld (2013; new combinations), Healy et al. (2015; new species, DNA), cultures and sequences are available, needs generic revision.

Pachyphysis R.C. Harris \& Ladd 2007, Lecideaceae, Lecideales, Lecanoromycetes, one species, type: $P$. ozarkana R.C. Harris \& Ladd, asexual morph unknown, on dolomite, terrestrial, worldwide, see Lumbsch and Huhndorf (2010; outline), cultures and sequences are available, holotype and cultures are available for the type species Pacoza51; NY, Harris 44707.

Pachysacca Syd. 1930, Teratosphaeriaceae, Capnodiales, Dothideomycetes, one species, type: P. eucalypti Syd., asexual morph unknown, saprobes, terrestrial, Australia, see Lumbsch and Huhndorf (2010; outline, accepted as genus in Dothideaceae), Kirk et al. (2013; genus accepted), Thambugala et al. (2014a; excluded from Dothideaceae and place in 
Teratosphaeriaceae), Wijayawardene et al. (2014c; outline), cultures and sequences are unavailable, needs generic revision.

Pachysolen Boidin \& Adzet 1957, Pichiaceae, Saccharomycetales, Saccharomycetes, one species, type: P. tannophilus Boidin \& Adzet, asexual reproduction is by multilateral budding, saprophytic, extracts of chestnut (Castanea vesca) and mimosa (Acacia mollissima) for use in leather tanning, France, Germany, Spain, see Lumbsch and Huhndorf (2010; outline), Kirk et al. (2013; genus accepted), sequences are available.

Pachythyrium G. Arnaud ex Spooner \& P.M. Kirk 1990, Trichothyriaceae, Dothideomycetes, family incertae sedis, one species, type: P. parasiticum (Fabre) G. Arnaud ex Spooner \& P.M. Kirk, asexual morph unknown, saprobes, terrestrial, Europe, see Lumbsch and Huhndorf (2010; outline, accepted as a genus in Microthyriaceae), Hyde et al. (2013; accepted as a genus in Trichothyriaceae), Kirk et al. (2013; genus accepted), Wijayawardene et al. (2014c; outline), cultures and sequences are unavailable.

Pachytrype Berl. ex M.E. Barr, J.D. Rogers \& Y.M. Ju 1993, Valsaceae, Diaporthales, Sordariomycetes, one species, type species: P. princeps (Penz. \& Sacc.) M.E. Barr, J.D. Rogers \& Y.M. Ju, asexual morph cytospora-like, saprobes, terrestrial, worldwide, see Lumbsch and Huhndorf (2010; outline), Kirk et al. (2013; genus accepted), Maharachchikumbura et al. (2015, 2016; outline), cultures and sequences are available, needs generic revision.

Paecilomyces Bainier 1907 (= Byssochlamys Westling 1909 fide Rossman et al. 2016a), Thermoascaceae, Eurotiales, Eurotiomycetes, c. 50 species, type: P. variotii Bainier, hyphomycetous, sexual morph formerly known in Byssochlamys, widespread, see Liang et al. (2009b; taxonomy), Hyde et al. (2011; outline), Seifert et al. (2011; morphology), Wijayawardene et al. (2012, 2017; outline), Kirk et al. (2013; genus accepted), Rossman et al. (2016a; nomenclature), cultures available for type species CBS 102.74, CBS 110431.

Palawania Syd. \& P. Syd. 1914, Microthyriaceae, Microthyriales, Dothideomycetes, one species, type: P. grandis (Niessl) Syd. \& P. Syd., asexual morph unknown, saprobes, terrestrial, Asia, see Lumbsch and Huhndorf (2010; outline), Wu et al. (2011; accepted as a genus in Microthyriaceae), Hyde et al. (2013; accepted as a genus in Microthyriaceae), Kirk et al. (2013; genus accepted), Wijayawardene et al. (2014c; outline), cultures and sequences are unavailable.

Palawaniella Doidge 1921, Parmulariaceae, Dothideomycetes families incertae sedis, eight species, type: P. eucleae Doidge, asexual morph unknown, epiphytes, terrestrial, worldwide, see Hofmann (2009; review), Lumbsch and Huhndorf (2010; outline), Hyde et al. (2013; outline, keys), Wijayawardene et al. (2014c; outline), cultures and sequences are unavailable, holotype of type: PREM 12375.

Palicella Rodr. Flakus \& Printzen 2014, Lecanoraceae, Lecanorales, Lecanoromycetes, three species, type: P. glaucopa (Hook. f. \& Taylor) Rodr. Flakus \& Printzen, lichenized, Argentina, Canada, Europe, see Rodriguez-Flakus \& Printzen (2014; phylogeny), Lücking et al. (2016b; classification), cultures and sequences are available, needs generic revision.

Paliphora Sivan. \& B. Sutton 1985, Ascomycota genera incertae sedis, six species, type: $P$. aurea Sivan. \& B. Sutton, hyphomycetous, sexual morph unknown, saprobes, terrestrial, worldwide, see Gusmão et al. (2008; morphology, new species, distribution), Goh et al. (2014b; morphology, new species), Wijayawardene et al. (2017; outline), sequences are available, holotype: IMI $263424 \mathrm{~g}$.

Pallidocercospora Crous 2012, Mycosphaerellaceae, Capnodiales, Dothideomycetes, eight species, type: P. heimii (Crous) Crous, hyphomycetous, sexual morph reported, pathogenic, terrestrial, worldwide, see Crous et al. (2012a; morphology; phylogeny), cultures and sequences are available, holotype: PREM 51749 (sexual morph), holotype of the type: PREM 51748 (asexual morph), ex-type strain of type: CPC 760. 
Pallidogramme Staiger, Kalb \& Lücking 2008, Graphidaceae, Ostropales, Lecanoromycetes, twelve species, type: P. chrysenteron (Mont.) Staiger, Kalb \& Lücking, asexual morph unknown, lichenized fungi, terrestrial, tropical, see Archer (2009; key, Australia), Lumbsch and Huhndorf (2010; outline), Rivas Plata et al. (2012a; phylogeny), Kirk et al. (2013; genus accepted), Lücking et al. (2014, 2016b; phylogeny, classification), Cultures and sequences are available, holotype of type species PC (Leprieur 23).

Palmiascoma Phook. \& K.D. Hyde 2015, Bambusicolaceae, Pleosporales, Dothideomycetes, one species, type: P. gregariascomum Phookamsak \& K.D. Hyde, asexual morph coelomycetous, saprobes, terrestrial, Thailand, see Liu et al. (2015a; taxonomy, phylogeny), holotype and ex-type culture of the type: MFLU 11-0211, MFLUCC 11-0175.

Palmicola K.D. Hyde 1993, Xylariales genera incertae sedis, Sordariomycetes, four species, type: P. archontophoenicis K.D. Hyde, asexual morph unknown, saprobes, terrestrial, Australia, Ecuador, see Lumbsch and Huhndorf (2010; outline), Kirk et al. (2013; genus accepted), Maharachchikumbura et al. (2015, 2016; outline), cultures and sequences are available but lacks for the type species, holotype of the type: BRIP 20438.

Pandanicola K.D. Hyde 1994, Xylariales genera incertae sedis, Sordariomycetes, two species, type: P. calocarpa (Syd. \& P. Syd.) K.D. Hyde, asexual morph unknown, saprobes, terrestrial, pantropical, see Lumbsch and Huhndorf (2010; outline), Kirk et al. (2013; genus accepted), Maharachchikumbura et al. (2015, 2016; outline), Wendt et al. (2017; accepted as a genus in Xylariales genera incertae sedis), cultures and sequences are unavailable, needs generic revision.

Pannaria Delise ex Bory 1828, Pannariaceae, Peltigerales, Lecanoromycetes, 60 species, type: P. rubiginosa (Thunb.) Delise, lichenized, terrestrial, worldwide, see Lumbsch and Huhndorf (2010; outline), Lumbsch et al. (2011; new species), Passo and Calvelo (2011; new species), Elvebakk (2012; new species), Jørgensen and Gjerde (2012; new species), Kirk et al. (2013; genus accepted), Magain and Serusiaux (2014; phylogeny), cultures and sequences are available, needs generic revision.

Pannoparmelia (Müll. Arg.) Darb. 1912, Parmeliaceae, Lecanorales, Lecanoromycetes, five species, type: P. angustata (Pers.) Zahlb., asexual morph unknown, lichenized, terrestrial, worldwide, see Lumbsch and Huhndorf (2010; outline), Thell et al. (2012; phylogeny), Kirk et al. (2013; genus accepted), cultures and sequences are available, needs generic revision.

Panorbis J. Campb., J.L. Anderson \& Shearer 2003, Halosphaeriaceae, Microascales, Sordariomycetes, three species, type: P. viscosus (I. Schmidt) J. Campb., J.L. Anderson \& Shearer, on debries near sea, Germany, USA, see Lumbsch and Huhndorf (2010; outline), Sakayaroj et al. (2011a; phylogeny), Jones et al. (2015; outline), Maharachchikumbura et al. (2015, 2016; outline, phylogeny), cultures and sequences are available, needs generic revision.

Pantospora Cif. 1938, Mycosphaerellaceae, Capnodiales, Dothideomycetes, one species, type: P. guazumae Cif., hyphomycetous, sexual morph unknown, plant pathogenic, terrestrial, see Minnis et al. (2011; morphology; phylogeny), Seifert et al. (2011; morphology), Wijayawardene et al. (2017; outline), cultures and sequences are available, epitype and ex-type of type: BPI 880778; CBS 130299.

Paoayensis Cabanela, Jeewon \& K.D. Hyde 2007, Sordariomycetes genera incertae sedis, one species, type: P. lignicola Cabanela, Jeewon \& K.D. Hyde, asexual morph unknown, saprobes, terrestrial, Philipines, see Lumbsch and Huhndorf (2010; outline), Maharachchikumbura et al. (2015, 2016; outline), cultures available for the type species HKU(M) 17516, holotype of type: HKUCC 10927.

Papilionospora V.G. Rao \& B. Sutton 1976, Ascomycota genera incertae sedis, one species, type: P. aspergilloides (Speg.) V. Rao \& B. Sutton, hyphomycetous, sexual morph unknown, saprobes, terrestrial, Myanmar, see Seifert et al. (2011; morphology), Wijayawardene et al. 
(2012, 2017; outline), Kirk et al. (2013; genus accepted), cultures and sequences are unavailable.

Papilionovela Aptroot 1997, Hyponectriaceae, Xylariales, Sordariomycetes, 17 species, type: $P$. albothallina Aptroot, asexual morph unknown, saprobes, terrestrial, worldwide, see Lumbsch and Huhndorf (2010; outline), Kirk et al. (2013; genus accepted), Maharachchikumbura et al. (2015, 2016; outline, phylogeny), cultures and sequences are unavailable, holotype of type: CBS Aptroot 33014.

Pappimyces B. Sutton \& Hodges 1975, Ascomycota genera incertae sedis, one species, type: P. hastatus B. Sutton \& Hodges, hyphomycetous, sexual morph unknown, Brazil, see Seifert et al. (2011; morphology), Wijayawardene et al. (2012, 2017; outline), Kirk et al. (2013; genus accepted), cultures and sequences are unavailable, need generic revision.

Papulaspora Preuss 1851, Melanosporales genera incertae sedis, Sordariomycetes, 24 species, type: $P$. sepedonioides Preuss, sexual morph unknown, saprobes, terrestrial, worldwide, see Seifert et al. (2011; morphology), Wijayawardene et al. (2012, 2017; outline), Kirk et al. (2013; genus accepted), Maharachchikumbura et al. (2015, 2016; outline, phylogeny), Ahmed et al. (2016; DNA, phylogeny), cultures and sequences are available, type specimen for type species B.

Papulosa Kohlm. \& Volkm.-Kohlm. 1993, Papulosaceae, Diaportheomycetidae family incertae sedis, Sordariomycetes, one species, type: P. amerospora Kohlm. \& Volkm.-Kohlm., asexual morph unknown, saprobes, USA, see Lumbsch and Huhndorf (2010; outline), Kirk et al. (2013; genus accepted), Maharachchikumbura et al. (2015, 2016; outline), cultures and sequences are available, holotype and cultures available for the type species IMS J.K. 5491; AFTOL-ID 748.

Paraaoria R.K. Verma \& Kamal 1987, Ascomycota genera incertae sedis, one species, type: $P$. himalayana R.K. Verma \& Kamal, coelomycetous, sexual morph unknown, Nepal, see Wijayawardene et al. (2012, 2017; outline, taxonomy), Kirk et al. (2013; genus accepted), cultures and sequences are unavailable, holotype of type: IMI 294092, needs generic revision. Paraarthrocladium Matsush. 1993, Ascomycota genera incertae sedis, one species, type: $P$. amazonense Matsush, hyphomycetous, sexual morph unknown, Peru, see Seifert et al. (2011; morphology), Wijayawardene et al. (2012, 2017; outline), Kirk et al. (2013; genus accepted), cultures and sequences are unavailable, holotype of type: Matsushima Fungus Collection Kobe 0P-146, need generic revision.

Parabagliettoa Gueidan \& Cl. Roux 2009, Verrucariaceae, Verrucariales, Eurotiomycetes, three species, type: Parabagliettoa dufourii (DC.) Gueidan \& Cl. Roux, asexual morph unknown, lichenicolous, terrestrial, Europe, Asia, see Diederich et al. (2009), Gueidan et al. (2009; taxonomy), Lücking et al. (2016b; classification), cultures and sequences are available, available specimen and cultures for the type: G; AFTOL-ID 2254.

Parabambusicola Kaz. Tanaka \& K. Hiray. 2015, Parabambusicolaceae, Pleosporales, Dothideomycetes, one species, type: P. bambusina (Teng) Kaz. Tanaka \& K. Hiray., asexual morph unknown, saprobes, terrestrial, Japan, see Tanaka et al. (2015; morphology, phylogeny), cultures and sequences are available.

Parablastocatena Y.D. Zhang \& X.G. Zhang 2012, Ascomycota genera incertae sedis, one species, type: P. tetracerae Y.D. Zhang \& X.G. Zhang, hyphomycetous, sexual morph unknown, saprobes, terrestrial, China, see Zhang et al. (2012g; taxonomy), Wijayawardene et al. (2017; outline), holotype of the type: HSAUP H3357, cultures and sequences are unavailable, needs generic revision.

Paraboeremia Q. Chen \& L. Cai 2015, Didymellaceae, Pleosporales, Dothideomycetes, three species, type: P. selaginellae (Sacc.) Q. Chen \& L. Cai, coelomycetous, saprobes, ?pathogens, terrestrial, cosmopolitan, see Chen et al. (2015b; taxonomy, phylogeny), 
Wijayawardene et al. (2017; outline), neotype and ex-neotype culture of the type: HMAS 246693, CBS 122.93.

Paracainiella Lar.N. Vassiljeva 1983, Amphisphaeriaceae, Xylariales, Sordariomycetes, one species, type: $P$. dryadis Lar.N. Vassiljeva, asexual morphs unknown, saprobes, terrestrial, arctic north-eastern Asia, see Lumbsch and Huhndorf (2010; outline), Kirk et al. (2013; genus accepted), Maharachchikumbura et al. (2016; outline), cultures and sequences are unavailable, holotype of type species VLA P-2943.

Paracamarosporium Wijayaw. \& K.D. Hyde 2014, Didymosphaeriaceae, Pleosporales, Dothideomycetes, five species, type: P. psoraleae (Crous \& M.J. Wingf.) Wijayaw. \& K.D. Hyde, asexual morph coelomycetous, sexual morph unknown, saprobes, terrestrial, Europe, Africa, USA, see Hyde et al. (2013; accepted in Didymosphaeriaceae), Wijayawardene et al. (2014c, d, 2016b; outline, phylogeny), Crous et al. (2015c; new species, phylogeny), Thambugala et al. (2016; new species), cultures and sequences are available, holotype and ex-type cultures available for the type: CBS H-21440; CPC 21632.

Paracapsulospora Konta. \& K. D. Hyde 2016, Sordariomycetidae, genera incertae sedis, one species, type: P. metroxyli Konta. \& K.D. Hyde, asexual morph unknown, saprobes, terrestrial, Thailand, see Hyde et al. (2016; taxonomy, phylogeny), holotype and ex-type culture of the type: MFLU 15-0704, MFLUCC 15-0250.

Paraceratocladium R.F. Castañeda 1987, Ascomycota genera incertae sedis, six species, type: $P$. silvestre R.F. Castañeda, hyphomycetous, sexual morph unknown, saprobes, terrestrial, Africa, Asia, Caribbean, South America, see Seifert et al. (2011; morphology), Wijayawardene et al. (2012, 2017; outline), Kirk et al. (2013; genus accepted), cultures and sequences are unavailable, needs generic revision.

Paracercospora Deighton 1979, Mycosphaerellaceae, Capnodiales, Dothideomycetes, three species, type: P. egenula (Syd.) Deighton, hyphomycetous, sexual morph unknown, plant pathogenic, terrestrial, see Crous et al. (2012a; morphology; phylogeny), Braun et al. (2013; morphology), Cultures and sequences are available, reference specimen and culture of type: CBS H-20836; CPC 12537, holotype and isotype of type species PRE 25999; IMI 89597, genus requires epitypification.

Parachionomyces Thaung 1979, Ascomycota genera incertae sedis, one species, type: $P$. acroconidiellinae Thaung, asexual morph hyphomycetous, sexual morph unknown, Myanmar, see Seifert et al. (2011; morphology), Wijayawardene et al. (2012, 2017; outline), Kirk et al. (2013; genus accepted), cultures and sequences are unavailable, need generic revision.

Parachnopeziza Korf 1978, Arachnopezizaceae, Helotiales, Leotiomycetes, eight species, type: P. miniopsis (Ellis) Korf, asexual morph unknown, saprobes, terrestrial, worldwide, see Lumbsch and Huhndorf (2010; outline), Kirk et al. (2013; genus accepted), cultures and sequences are unavailable, needs generic revision.

Paracladophialophora Crous 2016, Chaetothyriales genera incertae sedis, Eurotiomycetes, one species, type: P. carceris Crous \& Roets, hyphomycetous, sexual morph unknown, saprobes, terrestrial, South Africa, see Crous et al. (2016a; new species, phylogeny), holotype and ex-type culture of the type: CBS H-22865, CPC 27596.

Paracoccidioides F.P. Almeida 1930, Ajellomycetaceae, Onygenales, Eurotiomycetes, two species, type: P. brasiliensis (Splend.) F.P. Almeida, hyphomycetous, sexual morph unknown, humn pathogen, terrestrial, North America, see Seifert et al. (2011; morphology), Wijayawardene et al. (2012, 2017; outline), Kirk et al. (2013; genus accepted), de Melo Teixeira et al. (2014; clinical control), cultures and sequences are available, needs generic revision.

Paracollema Otálora \& Wedin 2014, Collemataceae, Peltigerales, Lecanoromycetes, two species, type: P. italicum (B. de Lesd.) Otálora, P.M. Jørg. \& Wedin, asexual morph coelomycetous, lichenized, terrestrial, Southern Europe, Northern Africa, see Otálora et al. 
(2014; taxonomy), Wijayawardene et al. (2017; outline), cultures and sequences are unavailable, needs generic revision.

Paraconiothyrium Verkley 2004, Didymosphaeriaceae, Pleosporales, Dothideomycetes, five species, type: P. estuarinum Verkley \& M. da Silva, asexual morph coelomycetous, saprobes, terrestrial, worldwide, see de Gruyter et al. (2012; new species), Wijayawardene et al. (2012, 2014c, 2016b; outline, phylogeny, taxonomy), Hyde et al. (2013; accepted in Didymosphaeriaceae), Verkley et al. (2014; new species, phylogeny), Ariyawansa et al. (2015a; new species, phylogeny), cultures and sequences are available, holotype and cultures available for the type species CBS H-10528, CCT6596 = CBS 109850.

Paracostantinella Subram. \& Sudha 1989, Ascomycota genera incertae sedis, one species, type: P. pulchra Subram. \& Sudha, hyphomycetous, sexual morph unknown, India, see Seifert et al. (2011; morphology), Wijayawardene et al. (2012, 2017; outline), Kirk et al. (2013; genus accepted), cultures and sequences are available for unidetified species, needs generic revision.

Paracremonium L. Lombard \& Crous 2015, Nectriaceae, Hypocreales, Sordariomycetes, two species, type: P. inflatum L. Lombard \& Crous, asexual morph unknown, pathogens, saprobes, terrestrial, tropical, see Lombard et al. (2015b; taxonomy, phylogeny), Maharachchikumbura et al. (2015, 2016; outline), Lynch et al. (2016; new species, phylogeny), Wijayawardene et al. (2017; outline), holotype and cultures of the type: CBS H21946; CBS 110348.

Paracryptophiale Kuthub. \& Nawawi 1994, Ascomycota genera incertae sedis, two species, type: P. kamaruddinii Kuthub. \& Nawawi, hyphomycetous, sexual morph unknown, Malaysia, China, see Seifert et al. (2011; morphology), Wijayawardene et al. (2012, 2017; outline), Kirk et al. (2013; genus accepted), cultures and sequences are unavailable, holotype of type: KLU 300030, needs generic revision.

Paracylindrocarpon Crous, Roets \& L. Lombard 2016, Bionectriaceae, Hypocreales, Sordariomycetes, one species, type: P. aloicola Crous, Roets \& L. Lombard., hyphomycetous, sexual morph unknown, saprobes, terrestrial, cosmopolitan, see Crous et al. (2016b; taxonomy, phylogeny), Wijayawardene et al. (2017; outline), holotype and ex-type culture of the type: CBS H-22613, CPC 27362.

Paracytospora Petr. 1925, Ascomycota genera incertae sedis, one species, type: P. salicis Petr., coelomycetous, sexual morph unknown, saprobes, terrestrial, America, see Wijayawardene et al. (2012, 2017; outline), Kirk et al. (2013; genus accepted), cultures and sequences are unavailable, needs generic revision.

Paradendryphiella Woudenberg \& Crous 2013, Dictyosporiaceae, Pleosporales, Dothideomycetes, two species, type: P. salina (G.K. Sutherl.) Woudenberg \& Crous, hyphomycetous, sexual morph unknown, saprobes, terrestrial, France, Europe, see Woudenberg et al. (2013; morphology, phylogeny), cultures and sequences are available, holotype of the type species and culture ex-type were not mentioned.

Paradendryphiopsis M.B. Ellis 1976, Ascomycota genera incertae sedis, five species, type: $P$. cambrensis M.B. Ellis, hyphomycetous, sexual morph unknown, Europe, South Africa, see Seifert et al. (2011; morphology), Wijayawardene et al. (2012, 2017; outline), Kirk et al. (2013; genus accepted), cultures and sequences are unavailable, holotype of type species IMI 6151c, need generic revision.

Paradictyoarthrinium Matsush. 1996, Paradictyoarthriniaceae, Pleosporales, Dothideomycetes, two species, type: P. diffractum Matsush., hyphomycetous, sexual morph unknown, Transvaal, Thailand, see Seifert et al. (2011; morphology), Wijayawardene et al. (2012, 2017; outline), Kirk et al. (2013; genus accepted), Isaka et al. (2015; DNA, secondary metabolites), Liu et al. (2015a; new species, Thailand, phylogeny), cultures and sequences 
are available, holotype and ex-type available for the type: Matsushima Fungus Collection Kobe 5A135; MFC-5A135.

Paradidymobotryum C.J.K. Wang \& B. Sutton 1984, Ascomycota genera incertae sedis, one species, type: P. oblongum C.J.K. Wang \& B. Sutton, asexual morph hyphomycetous, sexual morph unknown, USA, see Seifert et al. (2011; morphology), Wijayawardene et al. (2012, 2017; outline), Kirk et al. (2013; genus accepted), cultures and sequences are unavailable, need generic revision.

Paradiplodia Speg. ex Trotter 1931, Ascomycota genera incertae sedis, six species, type: $P$. aurantiorum (Speg.) Clem. \& Shear, coelomycetous, sexual morph unknown, widespread, see Wijayawardene et al. (2012, 2017; outline), Kirk et al. (2013; genus accepted), cultures and sequences are unavailable, need generic revision.

Paradischloridium Bhat \& B. Sutton 1985, Ascomycota genera incertae sedis, one species, type: P. ychaffrei Bhat \& B. Sutton, hyphomycetous, sexual morph unknown, saprobes, terrestrial, New Zealand, see Seifert et al. (2011; morphology), Wijayawardene et al. (2012, 2017; outline), Kirk et al. (2013; genus accepted), cultures and sequences are unavailable, needs generic revision.

Paradiscula Petr. 1941, Ascomycota genera incertae sedis, one species, type: P. spuria (Vestergr.) Petr., coelomycetous, sexual morph unknown, saprobes, terrestrial, Europe, see Wijayawardene et al. (2012, 2017; outline), Kirk et al. (2013; genus accepted), cultures and sequences are unavailable, needs generic revision.

Paradoxa Mattir. 1935, Tuberaceae, Pezizales, Pezizomycetes, two species, type: $P$. monospora Mattir., asexual morph unknown, saprobes, hypogeous, terrestrial, Italy, see Lumbsch and Huhndorf (2010; outline), Kirk et al. (2013; did not accept genus), cultures and sequences are available, need generic revision.

Paradoxomyces Matzer 1996, Arthoniaceae, Arthoniales, Arthoniomycetes, one species, type: $P$. nymanii Matzer, sexual morph with lirellate ascomata, lichenicolous, terrestrial, Indonesia, see Lumbsch and Huhndorf (2010; outline), Kirk et al. (2013; genus accepted), sequences are unavailable, holotype of type: Nyman 87b (UPS).

Paraëpicoccum Matsush. 1993, Ascomycota genera incertae sedis, one species, type: $P$. amazonense Matsush., hyphomycetous, sexual morph unknown, saprobes, terrestrial, Peru, see Seifert et al. (2011; morphology), Wijayawardene et al. (2012, 2017; outline), Kirk et al. (2013; genus accepted), cultures and sequences are unavailable, needs generic revision.

Parafulvia Kamal, A.N. Rai \& Morgan-Jones 1983, Ascomycota genera incertae sedis, one species, type: P. indica Kamal, A.N. Rai \& Morgan-Jones., hyphomycetous, sexual morph unknown, saprobes, terrestrial, India, see Seifert et al. (2011; morphology), Wijayawardene et al. (2012, 2017; outline), Kirk et al. (2013; genus accepted), cultures and sequences are unavailable, needs generic revision.

Parahaplotrichum W.A. Baker \& Partr. 2001, Ascomycota genera incertae sedis, one species, type: P. idahoense W.A. Baker \& Partr., hyphomycetous, sexual morph unknown, saprobes, terrestrial, USA, see Seifert et al. (2011; morphology), Wijayawardene et al. (2012, 2017; outline), Kirk et al. (2013; genus accepted), cultures and sequences are unavailable, needs generic revision.

Paraharknessia Matsush. 2003, Ascomycota genera incertae sedis, one species, type: $P$. ellipsoidea Matsush., hyphomycetous, sexual morph unknown, saprobes, terrestrial, Japan, see Seifert et al. (2011; morphology), Wijayawardene et al. (2012, 2017; outline), Kirk et al. (2013; genus accepted), cultures and sequences are unavailable, needs generic revision.

Parahyalotiopsis Nag Raj 1976, Ascomycota genera incertae sedis, one species, type: P. borassi (Thaung) Nag Raj 1976., coelomycetous, sexual morph unknown, saprobes, terrestrial, Myanmar, see Wijayawardene et al. (2012, 2017; outline), Kirk et al. (2013; genus accepted), cultures and sequences are unavailable, needs generic revision. 
Paraidriella M. Hern.-Restr. \& Crous 2015, Xylariales genera incertae sedis, Sordariomycetes, one species, type: P. jambosae (R.F. Castañeda \& W.B. Kendr.) M. Hern.Restr. \& Crous, hyphomycetous, sexual morph unknown, saprobes, terrestrial, Cuba, see Hernández-Restrepo et al. (2016b; taxonomy, phylogeny), Maharachchikumbura et al. (2015, 2016; outline), cultures and sequences are available.

Paraidriella M. Hern.-Restr. \& Crous 2016, Sordariomycetes genera incertae sedis, one species, type: P. jambosae (R.F. Castañeda \& W.B. Kendr.) M. Hern.-Restr. \& Crous 2015, hyphomycetous, sexual morph unknown, saprobes, Asia, see Hernández-Restrepo et al. (2016b; taxonomy) Maharachchikumbura et al. (2016; outline), Wijayawardene et al. (2017; outline), cultures and sequences are available.

Paraingaderia Ertz \& Tehler 2011, Opegraphaceae, Arthoniales, Arthoniomycetes, one species, type: P. placodioidea Ertz \& Tehler, sexual morph with punctiform to shortly lirelliform ascomata in groups (synascomata), lichenized, terrestrial, Socotra island, see Ertz and Tehler (2011; morphology, phylogeny), Lücking et al. (2016b; classification), sequences are available, holotype of type: Tehler 9344 (S).

Parainoa Resl \& T. Sprib. 2014, Baeomycetaceae, Baeomycetales, Lecanoromycetes, one species, type: P. subconcolor (Anzi) Resl \& T. Sprib., lichenized, see Resl et al. (2015; taxonomy), Lücking et al. (2016b; classification), cultures and sequences are available, needs generic revision.

Paralecanographa Ertz \& Tehler 2011, Opegraphaceae, Arthoniales, Arthoniomycetes, one species, type: P. grumulosa (Dufour) Ertz \& Tehler, lichenicolous (becoming sometimes lichenized), terrestrial, mainly (sub-)tropical, Mediterranean, see Ertz and Tehler (2011; morphology, phylogeny), sequences are available, needs generic revision.

Paralecia Brackel, Greiner, Peršoh \& Rambold 2015, Squamarinaceae, Lecanorales, Lecanoromycetes, five species, type: P. pratorum Brackel, Greiner, Peršoh \& Rambold, asexual morph unknown, lichenized, terrestrial, worldwide, see Liu et al. (2015a; taxonomy, phylogeny), Thell et al. (2012; phylogeny), cultures and sequences are available, holotype of the type: M-0045925.

Paraleptosphaeria Gruyter, Verkley \& Crous 2012, Leptosphaeriaceae, Pleosporales, Dothideomycetes, five species, type: P. nitschkei (Rehm ex G. Winter) Gruyter, Aveskamp \& Verkley, asexual morph coelomycetous, saprobes, terrestrial, worldwide, see de Gruyter et al. (2012; morphology; phylogeny), Wijayawardene et al. (2014c; outline), Ariyawansa et al. (2015b; phylogeny), cultures and sequences are available, epitype and ex-epitype of the type: CBS H-20822; CBS 306.51.

Paralethariicola Calatayud, Etayo \& Diederich 2001, Odontotremataceae, Ostropales, Lecanoromycetes, one species, type: P. aspiciliae Calat., Etayo \& Diederich, asexual morph unknown, lichenicolous, non-lichenized, Italy and Spain, see Lumbsch and Huhndorf (2010; outline), cultures and sequences are unavailable, holotype of the type species MA (Fungi) 49914.

Paraliomyces Kohlm. 1959, Pleosporales genera incertae sedis, one species, type: P. lentifer Kohlm., asexual morph unknown, saprobes, marine, worldwide, see Suetrong et al. (2009; phylogeny, morphology), Jones et al. (2009b, 2015; classification), Pang and Jheng (2012a; checklist), Zhang et al. (2012e; morphology), Wijayawardene et al. (2014c; outline), cultures and sequences are available, type specimen of type: CBS H-5921.

Paramassariothea Subram. \& Muthumary 1979, Ascomycota genera incertae sedis, one species, type: P. falcata Subram. \& Muthumary., coelomycetous, sexual morph unknown, saprobes, terrestrial, India, see Wijayawardene et al. (2012, 2017; outline), Kirk et al. (2013; genus accepted), cultures and sequences are unavailable, needs generic revision.

Parameliola Hongsanan, Peršoh \& K.D. Hyde 2016, Pleosporales genera incertae sedis, Dothideomycetes, two species, type: P. dimocarpi Hongsanan \& K.D. Hyde, coelomycetous, 
sexual morph unknown, saprobes, terrestrial, Saudi Arabia, see Li et al. (2016a; taxonomy, phylogeny), holotype of the type: MFLU 15-0045.

Paramenisporopsis Matsush. 2003, Ascomycota genera incertae sedis, one species, type: $P$. undulosetulata Matsush., hyphomycetous, sexual morph unknown, saprobes, terrestrial, Japan, see Seifert et al. (2011; morphology), Wijayawardene et al. (2012, 2017; outline), cultures and sequences are unavailable, needs generic revision.

Paramicrodochium M. Hern.-Restr. \& Crous 2015, Microdochiaceae, Xylariles, Sordariomycetes, one species, type: P. gracile (Mouch. \& Samson) M. Hern.-Restr. \& Crous, hyphomycetous, sexual morphs unknown, on rabbit dung, terrestrial, worldwide, see Hernández-Restrepo et al. (2016b; DNA, phylogeny), Maharachchikumbura et al. (2015, 2016; outline), Wijayawardene et al. (2017; outline), cultures and sequences are available.

Paramicrothyrium H.X. Wu \& K.D. Hyde 2011, Microthyriaceae, Microthyriales, Dothideomycetes, one species, type: Paramicrothyrium chinensis H.X. Wu \& K.D. Hyde, saprobes, terrestrial, Phillipines, see Wu et al. (2011; taxonomy), Hyde et al. (2013; accepted as agenus in Microthyriaceae), cultures and sequences are available, holotype and ex-type culture of the type: IFRD 8987; IFRDCC2258.

Paramphisphaeria F.A. Fernández, J.D. Rogers, Y.M. Ju, Huhndorf \& Umaña 2004, Xylariales genera incertae sedis, Sordariomycetes, one species, type: P. costaricensis F.A. Fernández, J.D. Rogers, Y.M. Ju, Huhndorf \& L. Umaña, saprobes, terrestrial, Costa Rica, see Lumbsch and Huhndorf (2010; outline), Senanayake et al. (2015; accepted as a genus in Xylariaceae), Maharachchikumbura et al. (2015, 2016; outline), Wendt et al. (2017; accepted as a genus in Xylariales genera incertae sedis), cultures and sequences are unavailable, holotype of the type: INB 3466410.

Paramycoleptodiscus Crous \& M.J. Wingf. 2016, Acrospermales genera incertae sedis, Dothideomycetes, one species, type: P. albizziae Crous \& M.J. Wingf., coelomycetous, sexual morph unknown, saprobes, terrestrial, Malaysia, see Crous et al. (2016b; taxonomy, phylogeny), Wijayawardene et al. (2017; outline), holotype and ex-type culture of the type: CBS H-22615, CPC 27552.

Paramycosphaerella Crous \& Jol. Roux 2013, Mycosphaerellaceae, Capnodiales, Dothideomycetes, 15 species, type: P. brachystegia Crous \& Jol. Roux, asexual morph hyphomycetous (zasmidium-like), foliicolous, terrestrial, worldwide, see Crous et al. (2013b; morphology, phylogeny), Quaedvlieg et al. (2014; phylogeny), Guatimosim et al. (2016; phylogeny, new comb.), cultures and sequences are available, holotype and ex-type culture of type: CBS H-21445; CPC 21136.

Paramyrothecium L. Lombard \& Crous 2016, Stachybotriaceae, Hypocreales, Sordariomycetes, twelve species, type: $P$. roridum (Tode) L. Lombard \& Crous, hyphomycetous, sexual morph unknown, saprobes, from soil, terrestrial, cosmopolitan, see Lombard et al. (2016; taxonomy, phylogeny), epitype and ex-epitype culture of the type: CBS H-22438, CBS 357.89.

Paranannizziopsis Sigler, Hambl. \& Paré 2013, Onygenaceae, Onygenales, Eurotiomycetes, four species, type: $P$. australasiensis Sigler, Hambleton \& Paré, asexual morph hyphomycetous, animal pathogens, USA, see Sigler et al. (2013; taxonomy, phylogeny), Wijayawardene et al. (2017; outline), cultures and sequences are available, holotype of the type: UAMH 11645, cultures available for the type: UAMH 10439, UAMH 11719.

Paranectria Sacc. 1878, Bionectriaceae, Hypocreales, Sordariomycetes, three species, type: $P$. affinis (Grev.) Sacc., asexual morph unknown, lichenicolous, terrestrial, Europe, see Lumbsch and Huhndorf (2010; outline), Kirk et al. (2013; genus accepted), Maharachchikumbura et al. (2015, 2016; outline), cultures and sequences are unavailable, needs generic revision. 
Paraniesslia K.M. Tsui, K.D. Hyde \& Hodgkiss 2001, Niessliaceae, Hypocreales, Sordariomycetes, one species, type: P. tuberculata K.M. Tsui, K.D. Hyde \& Hodgkiss, asexual morph unknown, saprobes, terrestrial, Hong Kong, see Lumbsch and Huhndorf (2010; outline), Maharachchikumbura et al. (2015, 2016; outline), cultures and sequences are unavailable, holotype: HKU (M) 4647.

Parapenidiella Crous \& Summerell 2012, Teratosphaeriaceae, Capnodiales, Dothideomycetes, two species, type: P. tasmaniensis (Crous \& M.J. Wingf.) Crous, hyphomycetous, sexual morph unknown, saprobes, terrestrial, worldwide, see Crous et al. (2012c; morphology; phylogeny), cultures and sequences are available, holotype of the type: PREM 55340.

Parapericonia M.B. Ellis 1976, Ascomycota genera incertae sedis, one species, type: $P$. angusii M.B. Ellis., hyphomycetous, sexual morph unknown, saprobes, terrestrial, Africa and Australia, see Seifert et al. (2011; morphology), Wijayawardene et al. (2012, 2017; outline), Kirk et al. (2013; genus accepted), cultures and sequences are unavailable, needs generic revision.

Parapericoniella U. Braun, Heuchert \& K. Schub. 2005, Ascomycota genera incertae sedis, one species, type: P. asterinae (Deighton) U. Braun, Heuchert \& K. Schub., hyphomycetous, terrestrial, fungicolous, Africa, see Hyde et al. (2011; outline), Seifert et al. (2012; morphology), Wijayawardene et al. (2012, 2017; outline), cultures and sequences are unavailable, holotype of type: (K(M) IMI 11851b).

Paraphaeoisaria de Hoog \& Morgan-Jones 1978, Ascomycota genera incertae sedis, one species, type: P. alabamensis de Hoog \& Morgan-Jones., hyphomycetous, sexual morph unknown, saprobes, terrestrial, USA, see Seifert et al. (2011; morphology), Wijayawardene et al. (2012, 2017; outline), Kirk et al. (2013; genus accepted), cultures and sequences are unavailable, needs generic revision.

Paraphaeomoniella Crous 2015, Phaeomoniellaceae, Phaeomoniellales, Eurotiomycetes, one species, type: P. capensis Crous \& A.R. Wood, coelomycetous, sexual morph unknown, on living leaves, endophytic, terrestrial, South Africa, see Crous et al. (2015d; taxonomy, phylogeny), cultures and sequences are available, holotype and ex-type culture of type: CBS H-20159; CPC 15416.

Paraphaeosphaeria O.E. Erikss. 1967, Didymosphaeriaceae, Pleosporales, Dothideomycetes, 33 species, type: P. michotii (Westend.) O.E. Erikss., asexual morph coelomycetous, saprobes, terrestrial, worldwide, see Lumbsch and Huhndorf (2010; outline), Kirk et al. (2013; genus accepted), Ariyawansa et al (2014a; taxonomy, phylogeny), Verkley et al. (2014; taxonomy, phylogeny), Wijayawardene et al. (2014c; outline), Liu et al. (2015a; taxonomy, phylogeny), Tanaka et al. (2015; taxonomy, phylogeny), sequence data available for 12 species, holotype for type species.

Paraphoma Morgan-Jones \& J.F. White 1983, Phaeosphaeriaceae, Pleosporales, Dothideomycetes, five species, type: P. radicina (McAlpine) Morgan-Jones \& J.F. White, coelomycetous, sexual morph unknown, saprobes, terrestrial, worldwide, see de Gruyter et al. (2012; phylogeny), Wijayawardene et al. (2012, 2014c, 2017; outline), Hyde et al. (2013; accepted as a genus in Phaeosphaeriaceae), Quaedvlieg et al. (2013; new species, phylogeny), Phookamsak et al. (2014b; accepted as a genus in Phaeosphaeriaceae), cultures and sequences are available.

Parapithomyces Thaung 1976, Ascomycota genera incertae sedis, one species, type: $P$. brideliae Thaung., hyphomycetous, sexual morph unknown, saprobes, terrestrial, Myanmar and Australia, see Seifert et al. (2011; morphology), Wijayawardene et al. (2012, 2017; outline), Kirk et al. (2013; genus accepted), cultures and sequences are unavailable, needs generic revision. 
Parapleurotheciopsis P.M. Kirk 1982, Beltraniaceae, Xylariales, Sordariomycetes, one species, type: P. inaequiseptata (Matsush.) P.M. Kirk, hyphomycetous, sexual morph unknown, saprobes, terrestrial, British Isles, Japan, Cuba, see Seifert et al. (2011; morphology), Wijayawardene et al. (2012, 2017; outline), Maharachchikumbura et al. (2015, 2016; outline), DNA sequence available, available specimen and cultures for the type: IMI 234741; MUCL 41089.

Paraporpidia Rambold \& Pietschm. 1989, Lecideaceae, Lecideales, Lecanoromycetes, one species, type: P. aboriginum Rambold, asexual morph unknown, lichenized, on soil and boulders, terrestrial, Australasia, see Lumbsch and Huhndorf (2010; outline), Kirk et al. (2013; genus accepted), cultures and sequences are unavailable, needs generic revision.

Parapyrenis Aptroot 1991, Requienellaceae, Xylariales, Sordariomycetes, eight species, type: $P$. aurora (Zahlbr.) Aptroot, asexual morph unknown, lichenized, terrestrial, tropical, see Lumbsch and Huhndorf (2010; outline), Kirk et al. (2013; genus accepted), cultures and sequences are unavailable, needs generic revision.

Parapyricularia M.B. Ellis 1972, Ascomycota genera incertae sedis, one species, type: $P$. musae M.B. Ellis \& Peregrine., hyphomycetous, sexual morph unknown, saprobes, terrestrial, Japan, see Seifert et al. (2011; morphology), Wijayawardene et al. (2012, 2017; outline), Kirk et al. (2013; genus accepted), cultures and sequences are unavailable, needs generic revision.

Pararobillarda Matsush. 1996, Ascomycota genera incertae sedis, one species, type: P. caffra Matsush., coelomycetous, sexual morph unknown, saprobes, terrestrial, Cape Province, see Wijayawardene et al. (2012, 2017; outline), cultures and sequences are unavailable, needs generic revision.

Parasarcopodium Mel'nik, S.J. Lee \& Crous 2004, Stachybotriaceae, Hypocreales, Sordariomycetes, one species, type: P. ceratocaryi Melnik, S.J. Lee \& Crous, hyphomycetous, saprobes, terrestrial, South Africa, see Lombard et al. (2016; phylogeny), Wijayawardene et al. (2017; outline), cultures and sequences are available, holotype and extype culture of type: PREM 57603; STE-U 5494.

Parascedosporium Gilgado, Gené, Cano \& Guarro 2007, Microascaceae, Microascales, Sordariomycetes, two species, type: P. tectonae (C. Booth) Gilgado, Gené, Cano \& Guarro, asexual morph unknown, saprobes, terrestrial, worldwide, see Seifert et al. (2011; morphology), Wijayawardene et al. (2012, 2017; outline), Maharachchikumbura et al. (2015, 2016; outline, phylogeny), cultures and sequences are available, available specimen and extype strain of the type species CBS H-7195; CBS 127.84.

Paraschismatomma Ertz \& Tehler 2011, Opegraphaceae, Arthoniales, Arthoniomycetes, one species, type: P. ochroleucum (Zahlbr.) K. Knudsen, Ertz \& Tehler, sexual morph with apothecioid ascomata, lichenized, terrestrial, Californian coast and Baja California, see Ertz and Tehler (2011; morphology, phylogeny), Lücking et al. (2016b; classification), sequences are available.

Parascutellinia Svrček 1975, Pyronemataceae, Pezizales, Pezizomycetes, three species, type: $P$. violacea (Velen.) Svrček, asexual morph unknown, saprobes, terrestrial, Europe, see Lumbsch and Huhndorf (2010; outline), Kirk et al. (2013; genus accepted), cultures and sequences are available but lacks for the type species, needs generic revision.

Parasiphula Kantvilas \& Grube 2006, Coccotremataceae, Pertusariales, Lecanoromycetes, seven species, type: Parasiphula fragilis (Hook. f. \& Taylor) Kantvilas \& Grube, asexual morph unknown, lichenized, terrestrial, USA, see Lumbsch and Huhndorf (2010; outline), cultures and sequences are unavailable, needs generic revision.

Parasphaeropsis Petr. 1953, Ascomycota genera incertae sedis, one species, type: P. shearii Petr., coelomycetous, sexual morph unknown, saprobes, terrestrial, Hawaii, see Wijayawardene et al. (2012, 2017; outline), Kirk et al. (2013; genus accepted), cultures and sequences are unavailable, needs generic revision. 
Parastagonospora Quaedvl., Verkley \& Crous 2013, Phaeosphaeriaceae, Pleosporales, Dothideomycetes, five species, type: P. nodorum (Berk.) Quaedvlieg, Verkley \& Crous, coelomycetous, pathogenic, saprobes, terrestrial, Germany, Netherlands, Denmark, see Quaedvlieg et al. (2013; taxonomy, phylogeny), Phookamsak et al. (2014b; accepted as a genus in Phaeosphaeriaceae), Wijyawardene et al. (2014, 2017; outline), Crous et al. (2016a; new species, phylogeny), Li et al. (2016a; new species), culture of type species CBS 110109 (no ex-type cultures), needs generic revision.

Parastenella J.C. David 1991, Mycosphaerellaceae, Capnodiales, Dothideomycetes, three species, type: P. magnoliae (Weedon) J.C. David, coelomycetous, sexual morph unknown, saprobes, asscociated with leaf spots, USA, Brazil (Rondônia), Taiwan, see Dornelo-Silva et al. (2008; new species), Wijayawardene et al. (2012, 2017; outline), Kirschner and Chen (2010; new species), cultures and sequences are available but lacks for the type species, needs generic revision.

Parasterinopsis Bat. 1960, Asterinaceae, Asterinales, Dothideomycetes, three species, type: $P$. sersalisiae (Hansf.) Bat., asexual morph unknown, epiphytes, terrestrial, worldwide, see Hofmann (2009; review), Lumbsch and Huhndorf (2010; outline), Hyde et al. (2013; outline, keys), Hongsanan et al. (2014c; taxonomy, keys), Wijayawardene et al. (2014c; outline), cultures and sequences are unavailable, isotype of type: URM 11923, needs generic revision.

Parastigmatea Doidge 1921, Polystomellaceae, Dothideomycetes family incertae sedis, three species, type: $P$. nervisita Doidge, sexual morph unknown, widespread (tropical), see Lumbsch and Huhndorf (2010; outline), Kirk et al. (2013; genus accepted), Hyde et al. (2013; accepted as a genus in Polystomellaceae), Wijayawardene et al. (2014c; outline), cultures and sequences are unavailable for type species, needs generic revision.

Parastigmatellina Bat. \& C.A.A. Costa 1959, Ascomycota genera incertae sedis, one species, type: P. asiatica Bat. \& C.A.A. Costa, coelomycetous, sexual morph unknown, saprobes, terrestrial, Philippines and Australia, see Wijayawardene et al. (2012, 2017; outline), Kirk et al. (2013; genus accepted), cultures and sequences are unavailable, needs generic revision.

Parasympodiella Ponnappa 1975, Scortechiniaceae, Coronophorales, Sordariomycetes, seven species, type: P. laxa (Subram. \& Vittal) Ponnappa, hyphomycetous, sexual morph unknown, saprobes, pathogens, terrestrial, worldwide, see Cheewangkoon et al. (2009; new species, phylogeny), Seifert et al. (2011; morphology), Wijayawardene et al. (2012, 2017; outline), cultures and sequences are available, specimens available for the type: IMI 50645, IMI 173095h, cultures available for the type: CBS 102698.

Parateratosphaeria Quaedvl. \& Crous 2014, Teratosphaeriaceae, Capnodiales, Dothideomycetes, four species, type: P. bellula (Crous \& M.J. Wingf.) Quaedvl. \& Crous, asexual morph unknown, pathogens, terrestrial, South Africa, see Quaedvlieg et al. (2014; morphology, phylogeny), Wijayawardene et al. (2014c; phylogeny, outline), cultures and sequences are available, epitype and ex-epitype strain of the type: CBS H-20094; CPC 1821.

Paratetraploa M.K.M. Wong \& K.D. Hyde 2002, Ascomycota genera incertae sedis, one species, type: P. exappendiculata M.K.M. Wong, Goh \& K.D. Hyde, hyphomycetous, sexual morph unknown, saprobes, aquatic, Hong Kong, see Seifert et al. (2011; morphology), Wijayawardene et al. (2012, 2017; outline), cultures and sequences are unavailable, holotype of the type species HKU (M) 12646, needs generic revision.

Paratomenticola M.B. Ellis 1976, Ascomycota genera incertae sedis, one species, type: $P$. lanceolata (Cooke) M.B. Ellis, hyphomycetous, sexual morph unknown, saprobes, terrestrial, USA, see Seifert et al. (2011; morphology), Wijayawardene et al. (2012, 2017; outline), cultures and sequences are unavailable, needs generic revision, needs generic revision.

Paratopeliopsis Mercado-Díaz, Lücking \& Parnmen 2014, Graphidaceae, Ostropales, Lecanoromycetes, one species, type: P. caraibica Mercado-Díaz, Lücking \& Parnmen, asexual morph unknown, lichenized, terrestrial, worldwide, see Mercado-Díaz et al. (2011; 
taxonomy), Lumbsch et al. (2014a, b; taxonomy), Lücking et al. (2016b; classification), cultures and sequences are available, holotype of type: Mercado-Díaz 836.

Paratricharia Lücking 1997, Gomphillaceae, Ostropales, Lecanoromycetes, three species, type: $P$. paradoxa (Lücking) Lücking, asexual morph unknown, saprobes, terrestrial, Costa Rica, see Lumbsch and Huhndorf (2010; outline), Plata et al. (2012; taxonomy), Kirk et al. (2013; genus accepted), cultures and sequences are unavailable, holotype of type: UPS (114).

Paratricharina Van Vooren, U. Lindemann, M. Vega, Ribes, Illescas \& Matočec 2015, Pyronemataceae, Pezizales, Pezizomycetes, one species, type: P. poiraultii (Boud.) Van Vooren, U. Lindemann, M. Vega, Ribes, Illescas \& Matočec, asexual morph unknown, saprobes, terrestrial, Europe, see Van Vooren et al. (2015; taxonomy), sequences are available, voucher specimen of the type: U.L. 178-14.

Paratrichoconis Deighton \& Piroz. 1972, Ascomycota genera incertae sedis, four species, type: P. chinensis (Hansf.) Deighton \& Piroz., hyphomycetous, sexual morph unknown, saprobes or fungicolous, terrestrial, worldwide, see Seifert et al. (2011; morphology), Wijayawardene et al. (2012, 2017; outline), Kirk et al. (2013; genus accepted), cultures and sequences are unavailable, needs generic revision.

Paratrichophaea Trigaux 1985, Pyronemataceae, Pezizales, Pezizomycetes, five species, type: P. macrocystis Trigaux, asexual morph unknown, from soil, saprobes, terrestrial, Europe, North America, see Benkert et al. (2010; new species), Lumbsch and Huhndorf (2010; outline), Kirk et al. (2013; genus accepted), sequences are available but lacks for the type species, needs generic revision.

Paraulocladium R.F. Castañeda 1986, Ascomycota genera incertae sedis, two species, type: P. angulosporum R.F. Castañeda, hyphomycetous, sexual morph unknown, saprobes, aquatic, Asia, Caribbean, see Seifert et al. (2011; morphology), Wijayawardene et al. (2012, 2017; outline), Kirk et al. (2013; genus accepted), cultures and sequences are unavailable, needs generic revision.

Parauncinula S. Takam. \& U. Braun 2005, Erysiphaceae, Erysiphales, Leotiomycetes, two species, type: P. septata (E.S. Salmon) S. Takam. \& U. Braun, biotrophic, obligate plant pathogens, terrestrial, Asia (China, Japan), see Lumbsch and Huhndorf (2010; outline), Braun and Cook (2012; taxonomy), Cultures and sequences are available, Lectotype of type species TNS-F-214605.

Paravalsa Ananthap. 1990, Valsaceae, Diaporthales, Sordariomycetes, one species, type: P. indica Ananthap., asexual morph unknown, saprobes, terrestrial, India, see Lumbsch and Huhndorf (2010; outline), Kirk et al. (2013; genus accepted), Maharachchikumbura et al. (2015, 2016; outline), cultures and sequences are unavailable, needs generic revision.

Parawiesneriomyces Crous \& M.J. Wingf. 2016, Wiesneriomycetaceae, Tubeufiales, Dothideomycetes, one species, type: P. syzygii Crous \& M.J. Wingf., hyphomycetous, saprobes, terrestrial, France, see Crous et al. (2016b; taxonomy, phylogeny), Wijayawardene et al. (2017; outline), holotype and ex-type culture of the type: CBS H-22630, CPC 26528.

Parberya C.A. Pearce \& K.D. Hyde 2001, Phyllachoraceae, Phyllachorales, Sordariomycetes, two species, type: P. kosciuskoa C.A. Pearce \& K.D. Hyde, asexual morph unknown, saprobes, terrestrial, Australia, see Lumbsch and Huhndorf (2010; outline), Kirk et al. (2013; genus accepted), Maharachchikumbura et al. (2015, 2016; outline), cultures and sequences are unavailable, holotype of type: DAR 28023, needs generic revision.

Parencoelia Petr. 1950, Helotiales genera incertae sedis, Leotiomycetes, four species, type: $P$. andina Petr., asexual morph unknown, saprobes, terrestrial, Central America, West Indies, see Lumbsch and Huhndorf (2010; outline), Kirk et al. (2013; genus accepted), cultures and sequences are unavailable, needs generic revision.

Parenglerula Höhn. 1910, Englerulaceae, Dothideomycetes families incertae sedis, nine species, type: P. macowaniana (Thüm.) Höhn., asexual morph unknown, epiphytic, terrestrial, 
tropical region, see Lumbsch and Huhndorf (2010; outline), Kirk et al. (2013; genus accepted), Dai et al. (2014c; morphology), cultures and sequences are unavailable, needs generic revision.

Pareutypella Y.M. Ju \& J.D. Rogers 1996, Sordariomycetes genera incertae sedis, one species, type: P. sulcata Y.M. Ju \& J.D. Rogers, asexual morph unknown, saprobes, terrestrial, Taiwan, see Lumbsch and Huhndorf (2010; outline), Kirk et al. (2013; genus accepted), Maharachchikumbura et al. (2015, 2016; outline), cultures and sequences are unavailable.

Parmelia Ach. [nom. cons.] 1803, Parmeliaceae, Lecanorales, Lecanoromycetes, 50 species, type: P. saxatilis (L.) Ach., lichenized, worldwide, see Crespo et al. (2010a, b; phylogeny), Kirk et al. (2013; genus accepted), Lumbsch and Huhndorf (2010; outline), Divakar (2012, 2013; India, phylogeny), Ferencova et al. (2014; new species), Lücking et al. (2016b; classification), cultures and sequences are available, needs generic revision.

Parmeliella Müll. Arg. 1862, Pannariaceae, Peltigerales, Lecanoromycetes, 90 species, type: P. triptophylla (Ach.) Müll. Arg., lichenized (with cyanobacteria), terrestrial (saxicolous, corticolous or lignicolous), worldwide, see Lumbsch and Huhndorf (2010; outline), Kirk et al. (2013; genus accepted), Ekman et al. (2014; phylogeny), sequences are available, needs generic revision.

Parmelina Hale 1974 (= Parmeliomyces E.A. Thomas ex Cif. \& Tomas. 1953 fide Species Fungorum 2017), Parmeliaceae, Lecanorales, Lecanoromycetes, seven species, type: $P$. tiliacea (Hoffm.) Hale, lichenized (with green algae), terrestrial (saxicolous, corticolous or lignicolous), Northern Hemisphere with a center of distribution in western North America and Europe, see Crespo et al. (2010a, b; phylogeny), Lumbsch and Huhndorf (2010; outline), Núñez-Zapata et al. (2011; phylogeny), Kirk et al. (2013; genus accepted), sequence data available for six species, including the generic type, needs generic revision.

Parmelinella Elix \& Hale 1987, Parmeliaceae, Lecanorales, Lecanoromycetes, nine species, type: P. wallichiana (Taylor) Elix \& Hale, lichenized (with green algae), terrestrial (saxicolous, corticolous or lignicolous), tropical, see Crespo et al. (2010a, b; phylogeny), Lumbsch and Huhndorf (2010; outline), Kirk et al. (2013; genus accepted), Benatti (2014; current status), Lücking et al. (2016b; classification), sequence data available only for the type species, needs generic revision.

Parmeliopsis (Nyl.) Nyl. 1866, Parmeliaceae, Lecanorales, Lecanoromycetes, eight species, type: P. ambigua (Wulfen) Nyl., asexual morph unknown, lichenized, terrestrial, worldwide, see Lumbsch and Huhndorf (2010; outline), Kirk et al. (2013; genus accepted), Miądlikowska et al. (2014; DNA, phylogeny), Lücking et al. (2016b; classification), Mark et al. (2016; DNA, phylogeny), cultures available for the type: AFTOL-ID 199, needs generic revision.

Parmostictina Nyl. 1875, Lobariaceae, Peltigerales, Lecanoromycetes, 15 species, type: Sticta hirsuta Mont., lichenized,?, rejected against Pseudocyphellaria Vain. 1890, see Moncada et al. (2013a; phylogeny), Lücking et al. (2016b; classification), cultures and sequences are available, needs generic revision.

Parmotrema A.Massal. 1860, Parmeliaceae, Lecanorales, Lecanoromycetes, 300 species, type: P. perforatum (Jacq.) A. Massal., lichenized, terrestrial (corticolous, saxicolous, terricolous or lignicolous), worldwide, but with the center of distribution in tropical regions, see Crespo et al. (2010a, b; phylogeny), Lumbsch and Huhndorf (2010; outline), Del-Prado et al. (2011; Parmotrema reticulatum), Lendemer and Hodkinson (2012; phylogeny), Divakar et al. (2013b; phylogeny), Kirk et al. (2013; genus accepted), Lücking et al. (2016b; classification), cultures and sequences are available, needs generic revision.

Parmotremopsis Elix \& Hale 1987, Parmeliaceae, Lecanorales, Lecanoromycetes, three species, type: P. antillensis (Nyl.) Elix \& Hale, asexual morph unknown, lichenized, 
terrestrial, Central America, West Indies, see Lumbsch and Huhndorf (2010; outline), Kirk et al. (2013; genus accepted), cultures and sequences are unavailable, needs generic revision.

Parmularia Lév. 1846, Parmulariaceae, Dothideomycetes families incertae sedis, 31 species, type: P. styracis Lév., asexual morph unknown, pathogens, epiphytes, terrestrial, Brazil, Paraguay, Uruguay, see Inácio and Cannon (2008; morphlogy), Lumbsch and Huhndorf (2010; outline), Kirk et al. (2013; genus accepted), Guatimosim et al. (2015; phylogeny), cultures and sequences are available but lacks for type material, holotype and epitype of type: PC; VIC 42447.

Parmulariella Henn. 1904, Dothideomycetes genera incertae sedis, one species, type: $P$. vernoniae Henn., asexual morph unknown, saprobes, terrestrial, South America, see Lumbsch and Huhndorf (2010; outline), Kirk et al. (2013; genus accepted), Wijayawardene et al. (2014c; outline), cultures and sequences are unavailable, isotype of type: K, NY, needs generic revision.

Parmulariopsella Sivan. 1970, Parmulariaceae, Dothideomycetes families incertae sedis, one species, type: $P$. burseracearum Sivan., asexual morph unknown, epiphytes, terrestrial, worldwide, see Hofmann (2009; review), Lumbsch and Huhndorf (2010; outline), Hyde et al. (2013; outline, keys), Wijayawardene et al. (2014c; outline), cultures and sequences are unavailable, holotype of type: IMI 34052.

Parmulariopsis Petr. 1954, Parmulariaceae, Dothideomycetes families incertae sedis, one species, type: $P$. pulchella Petr., asexual morph unknown., epiphytes, terrestrial, Malaysia, see Hofmann (2009; review), Lumbsch and Huhndorf (2010; outline), Hyde et al. (2013; accepted as a genus in Parmulariaceae), Wijayawardene et al. (2014c; outline), cultures and sequences are unavailable, isotype of type: IMI 330018.

Parmulina Theiss. \& Syd. 1914, Parmulariaceae, Dothideomycetes families incertae sedis, six species, type: P. exsculpta (Berk.) Theiss. \& Syd., asexual morph unknown, epiphytes, terrestrial, worldwide, see Hofmann (2009; review), Lumbsch and Huhndorf (2010; outline), Hyde et al. (2013; accepted as a genus in Parmulariaceae), Wijayawardene et al. (2014c; outline), cultures and sequences are unavailable, neotype of type: K Herb. C.E. Broome 593.

Parodiella Speg. 1880, Parodiellaceae, Dothideomycetes families incertae sedis, four species, type: P. perisporioides (Berk. \& M.A. Curtis) Speg., asexual morph unknown, biotrophic, terrestrial, America, see Lumbsch and Huhndorf (2010; outline), Hyde et al. (2013; accepted as a genus in Parodiellaceae), Kirk et al. (2013; genus accepted), Wijayawardene et al. (2014c; outline), cultures and sequences are unavailable, available specimen of type: CBS H-15496, needs generic revision.

Parodiellina Henn. ex G. Arnaud 1918, Perisporiopsidaceae, Dothideomycetes families incertae sedis, one species, type: P. manaosensis (Henn.) G. Arnaud, asexual morph unknown, saprobes, terrestrial, tropical, see Lumbsch and Huhndorf (2010; outline), Hyde et al. (2013; accepted as a genus in Perisporiopsidaceae), Kirk et al. (2013; genus accepted), Wijayawardene et al. (2014c; outline), cultures and sequences are unavailable, needs generic revision.

Paropodia Cif. \& Bat. 1956, Dothideomycetes genera incertae sedis, type: P. intermedia Cif. \& Bat., data inadequate, see Kirk et al. (2008; treated as a synonym of Triposporiopsis), Lumbsch and Huhndorf (2010; outline), Kirk et al. (2013; did not list), Wijayawardene et al. (2014c; outline), sequences are unavailable.

Parorbiliopsis Spooner \& Dennis 1986, Hyaloscyphaceae, Helotiales, Leotiomycetes, five species, type: P. minuta Spooner \& Dennis, asexual morph unknown, saprobes, terrestrial, Europe, see Lumbsch and Huhndorf (2010; outline), Kirk et al. (2013; genus accepted), cultures and sequences are unavailable, needs generic revision.

Parvacoccum R.S. Hunt \& A. Funk 1988, Rhytismataceae, Rhytismatales, Leotiomycetes, one species, type: P. pini R.S. Hunt \& A. Funk, asexual morph unknown, saprobes, 
terrestrial, Canada, see Lumbsch and Huhndorf (2010; outline), Kirk et al. (2013; genus accepted), cultures and sequences are unavailable, holotype of the type: DAVFP 23419, needs generic revision.

Parvomyces Santam. 1995, Laboulbeniaceae, Laboulbeniales, Laboulbeniomycetes, one species, type: $P$. merophysiae Santam., asexual morph unknown, biotrophic, terrestrial, Taiwan, see Lumbsch and Huhndorf (2010; outline), Kirk et al. (2013; genus accepted), cultures and sequences are unavailable.

Parvoplaca Arup, Søchting \& Frödén 2013, Teloschistaceae, Teloschistales, Lecanoromycetes, five species, type: P. tiroliensis (Zahlbr.) Arup, Søchting \& Frödén, asexual morph unknown, lichenized, terrestrial, worldwide, see Arup et al. (2013, 2015; taxonomy, phylogeny), Lücking et al. (2016b; classification), cultures and sequences are available, culture available for the type: U1289, U1290, needs generic revision.

Parvothecium L. Lombard \& Crous 2016, Stachybotriaceae, Hypocreales, Sordariomycetes, one species, type: P. terrestre L. Lombard \& Crous, hyphomycetous, sexual morph unknown, saprobes, from soil, terrestrial, Brazil, see Lombard et al. (2016; taxonomy, phylogeny), Wijayawardene et al. (2017; outline), epitype and ex-epitype culture of the type: CBS H4380, CBS 198.89.

Paschelkiella Sherwood 1987, Odontotremataceae, Ostropales, Lecanoromycetes, three species, type: P. pini (Romell) Sherwood, asexual morph unknown, saprobes, terrestrial, Europe, North America, see Lumbsch and Huhndorf (2010; outline), Kirk et al. (2013; genus accepted), cultures and sequences are unavailable, needs generic revision.

Paspalomyces Linder 1933, Ascomycota genera incertae sedis, one species, type: P. aureus Linder, hyphomycetous, sexual morph unknown, saprobes, terrestrial, USA, see Seifert et al. (2011; morphology), Wijayawardene et al. (2012, 2017; outline), Kirk et al. (2013; genus accepted), cultures and sequences are unavailable, needs generic revision.

Passalora Fr. 1849, Mycosphaerellaceae, Capnodiales, Dothideomycetes, c. 250 species, type: $P$. bacilligera Fr. \& Mont., hyphomycetous, sexual morph unknown, plant pathogens, terrestrial, see Seifert et al. (2011; morphology), Wijayawardene et al. (2012, 2014c, 2017; outline), Guatimosim et al. (2013; new species), Kirk et al. (2013; genus accepted), MorenoRico et al. (2014; new species), Braun et al. 2015; new species), Rossman et al. (2016b; new combination), cultures and sequences are available, needs generic revision.

Passeriniella Berl. 1890, Dothideomycetes genera incertae sedis, seven species, type: $P$. dichroa (Pass.) Berl., asexual morph unknown, saprobes, marine habitat, see Suetrong et al. (2009; phylogeny, morphology), Zhang et al. (2009b, 2012e; phylogeny), Jones et al. (2009b, 2015; outline, marine), Alias et al. (2010; diversity), Besitulo et al. (2010; diversity), Lee et al. (2012; checklist), Wijayawardene et al. (2014c; outline), cultures and sequences are available, needs generic revision.

Passerinula Sacc. 1875, Dothideomycetes genera incertae sedis, one species, type: $P$. candida Sacc., asexual morph unknown, saprobes or fungicolous, terrestrial, Europe, see Lumbsch and Huhndorf (2010; outline), Kirk et al. (2013; genus accepted), Wijayawardene et al. (2014c; outline), cultures and sequences are unavailable, needs generic revision.

Patellaria Fr. 1822, Patellariaceae, Patellariales, Dothideomycetes, twelve species, type: $P$. atrata (Hedw.) Fr., asexual morph unknown, saprobes, terrestrial, temperate, see Schoch et al. (2009; DNA, phylogeny), Lumbsch and Huhndorf (2010; outline), Hyde et al. (2013; accepted in Patellariaceae, phylogeny), Kirk et al. (2013; genus accepted), Wijayawardene et al. (2014c; outline), Yacharoen et al. (2015; taxonomy), cultures and sequences are available, cultures available for the type: CBS 958.97, BCC 28876, holotype of type: CBS H-17437.

Patellariopsis Dennis 1964, Helotiales genera incertae sedis, Leotiomycetes, five species, type: P. clavispora (Berk. \& Broome) Dennis, asexual morph unknown, saprobes, terrestrial, Europe, Australia, see Lumbsch and Huhndorf (2010; outline), Kirk et al. (2013; genus 
accepted), Jaklitsch et al. (2016a; classification), cultures and sequences are unavailable, needs generic revision.

Patescospora Abdel-Wahab \& El-Sharouny 2002, Aliquandostipitaceae, Jahnulales, Dothideomycetes, one species, type: P. separans Abdel-Wahab \& El-Shar., asexual morph unknown, saprobes, freshwater, Egypt, see Suetrong et al. (2010; phylogeny), cultures and sequences are available, holotype of the type: IMI 386405, ?

Patinella Sacc. 1875, Helotiales genera incertae sedis, Leotiomycetes, three species, type: $P$. hyalophaea Sacc., asexual morph unknown, saprobes, terrestrial, worldwide, see Lumbsch and Huhndorf (2010; outline), Kirk et al. (2013; genus accepted), cultures are available for the type (unpublished), needs generic revision.

Patinellaria P. Karst. 1885, Helotiales genera incertae sedis, Leotiomycetes, one species, type: P. sanguinea (Pers.) P. Karst., asexual morph unknown, saprobes, terrestrial, Europe, Mexico, see Lumbsch and Huhndorf (2010; outline), Kirk et al. (2013; genus accepted), cultures and sequences are unavailable, needs generic revision.

Patriciomyces D. Hawksw. 2001, Ascomycota genera incertae sedis, one species, type: $P$. valentinianus D. Hawskw., hyphomycetous, sexual morph unknown, lichenicolous, North America, see Seifert et al. (2011; morphology), Wijayawardene et al. (2012, 2017; outline), Kirk et al. (2013; genus accepted), cultures are sequences unavailable.

Pauahia F. Stevens 1925, Dothideomycetes genera incertae sedis, one species, type: $P$. sideroxyli F. Stevens, asexual morph unknown, saprobes, terrestrial, Hawaii, see Lumbsch and Huhndorf (2010; outline, accepted as a genus in Meliolaceae), Kirk et al. (2013; genus accepted), Hongsanan et al. (2015c; excluded from Meliolaceae and placed in Dothideomycetes), cultures and sequences are unavailable, needs generic revision.

Paucispora Thambugala, Kaz. Tanaka \& K.D. Hyde 2015, Lophiostomataceae, Pleosporales, Dothideomycetes, two species, type: P. quadrispora (K. Hiray. \& Kaz. Tanaka) Thambugala, Kaz. Tanaka \& K.D. Hyde, asexual morph unknown, saprobes, terrestrial, Japan, see Thambugala et al. (2015b; morphology, phylogeny), cultures and sequences are available, holotype and ex-type of type: HHUF 27321; MAFF 239455.

Paucithecium Lloyd 1923, Xylariales genera incertae sedis, Sordariomycetes, one species, type: $P$. rickii Lloyd, asexual morph unknown, saprobes, terrestrial, Brazil, see Lumbsch and Huhndorf (2010; outline), Kirk et al. (2013; genus accepted), Maharachchikumbura et al. (2015, 2016; outline), Wendt et al. (2017; accepted as a genus in Xylariales genera incertae sedis), cultures and sequences are unavailable, needs generic revision.

Paulia Fée 1836, Lichinaceae, Lichinales, Lichinomycetes, ten species, type: P. pullata Fée, asexual morph unknown, lichenized, terrestrial, worldwide, see Lumbsch and Huhndorf (2010; outline), Kirk et al. (2013; genus accepted), Lücking et al. (2016b; classification), sequences are available but lack for the type, needs generic revision.

Paulkirkia Wijayaw., Wanasinghe, Tangthirasunun, Camporesi \& K.D. Hyde 2016, Teichosporaceae, Pleosporales, Dothideomycetes, one species, type: P. arundinis Wijayaw., Wanasinghe, Tangthirasunun, Camporesi \& K.D. Hyde, coelomycetous, sexual morph unknown, saprobes, terrestrial, Italy, see Wijayawardene et al. (2016b, 2017; taxonomy, phylogeny, outline), holotype and ex-type culture of the type: MFLU 13-0315, MFLUCC 12-0328.

Paurocotylis Berk. 1855, Pezizales genera incertae sedis, Pezizomycetes, one species, type: $P$. pila Berk., asexual morph unknown, from soil, hypogeous, terrestrial, Europe, New Zealand, see Lumbsch and Huhndorf (2010; outline), Kirk et al. (2013; genus accepted), Wang et al. (2016c; DNA, phylogeny), cultures and sequences are available, voucher specimen of the type: Trappe 12583 (OSC).

Payosphaeria H.Y.M. Leung 1990, Nectriaceae, Hypocreales, Sordariomycetes, one species, type: P. minuta H.Y.M. Leung, asexual morph unknown, marine, on wood, mangrove, 
tropical, see Lumbsch and Huhndorf (2010; outline), Kirk et al. (2013; genus accepted), Jones et al. (2015; outline), Maharachchikumbura et al. (2015, 2016; outline), cultures and sequences are unavailable, holotype of type: IMI 327472.

Payosphaeria W.F. Leong 1990, Hypocreaceae, Hypocreales, Sordariomycetes, one species, type: P. minuta H.Y.M. Leung, asexual morphs unknown, saprobes, marine, Singapore, see Lumbsch and Huhndorf (2010; outline, accepted as Hypocreales genera incertae sedis), Kirk et al. (2013; genus accepted), Maharachchikumbura et al. (2016; outline, mispelled as Payoshaeria), cultures and sequences are unavailable.

Peccania A. Massal. ex Arnold 1858, Lichinaceae, Lichinales, Lichinomycetes, eight species, type: P. coralloides (A. Massal.) A. Massal., asexual morph unknown, lichenized, terrestrial, Europe, North America, see Lumbsch and Huhndorf (2010; outline), Kirk et al. (2013; genus accepted), sequences are available, needs generic revision.

Pectenia P.M. Jørg., L. Lindblom, Wedin \& S. Ekman 2014, Pannariaceae, Peltigerales, Lecanoromycetes, four species, type: P. plumbea (Lightf.) P.M. Jørg., L. Lindblom, Wedin \& S. Ekman, lichenized, terrestrial, Europe, Africa, mostly along the Atlantic coast, see Ekman et al. (2014; taxonomy), cultures and sequences are unavailable, needs generic revision.

Pectinotrichum Varsavsky \& G.F. Orr 1971, Onygenaceae, Onygenales, Eurotiomycetes, one species, type: P. llanense Varsavsky \& G.F. Orr, asexual morph unknown, saprobes, terrestrial, Venezuela, see Lumbsch and Huhndorf (2010; outline), Kirk et al. (2013; genus accepted), sequence available for the type, available specimen of type: CBS H-7460.

Pedumispora K.D. Hyde \& E.B.G. Jones 1992, Diatrypaceae, Xylariales, Sordariomycetes, one species, type: Pedumispora rhizophorae K.D. Hyde \& E.B.G. Jones, asexual morph unknown, saprobes, mangroves, marine, Republic of Seychelles, Guam, Thailand, see Lumbsch and Huhndorf (2010; outline), Kirk et al. (2013; genus accepted), Klaysuban et al. (2014; DNA, phylogeny), Jones et al. (2015; outline, marine), Maharachchikumbura et al. (2015, 2016; outline), sequence data available, holotype of type: BRIP 19201.

Peethambara Subram. \& Bhat 1978, Stachybotriaceae, Hypocreales, Sordariomycetes, one species, type: $P$. sundara Subram. \& Bhat, asexual morph unknown, saprobes, terrestrial, pantropical, see Lumbsch and Huhndorf (2010; outline), Maharachchikumbura et al. (2015, 2016; outline), Lombard et al. (2016; phylogeny), cultures and sequences are available, extype culture of type: CBS 646.77, needs generic revision.

Peethasthabeeja P.Rag. Rao 1981, Ascomycota genera incertae sedis, one species, type: $P$. krishna P. Rag. Rao, hyphomycetous, sexual morph unknown, saprobes, terrestrial, India, see Seifert et al. (2011; morphology), Wijayawardene et al. (2012, 2017; outline), Kirk et al. (2013; genus accepted), cultures and sequences are unavailable, needs generic revision.

Pellionella (Sacc.) Sacc. 1902, Ascomycota genera incertae sedis, one species, type: $P$. deformans Penz. \& Sacc., coelomycetous, sexual morph unknown, saprobes, terrestrial, Java, see Wijayawardene et al. (2012, 2017; outline), Kirk et al. (2013; genus accepted), cultures and sequences are unavailable, needs generic revision, needs generic revision.

Pellucida Dulym., Sivan., P.F. Cannon \& Peerally 2001, Hyponectriaceae, Xylariales, Sordariomycetes, one species, type: P. pendulina Dulym., Sivan., P.F. Cannon \& Peerally, asexual morph unknown, saprobes, terrestrial, Mauritius, see Lumbsch and Huhndorf (2010; outline), Kirk et al. (2013; genus accepted), Maharachchikumbura et al. (2015, 2016; outline), cultures and sequences are unavailable, holotype of type: Mauritius (Dulymamode P6), needs generic revision.

Pellucida Dulym., Sivan., P.F. Cannon \& Peerally 2001, Hyponectriaceae, Xylariales, Sordariomycetes, one species, type: P. pendulina Dulym., Sivan., P.F. Cannon \& Peerally, sexual morph unknown, see Kirk et al. 2008, Lumbsch and Huhndorf (2010; outline), Maharachchikumbura et al. (2015, 2016; outline), cultures and sequences are unavailable for type, needs generic revision. 
Peloronectria Möller 1901, Hypocreales genera incertae sedis, Sordariomycetes, one species, type: P. vinosa Möller, asexual morph unknown, South America, see Kirk et al. (2008; treated as nom. dub.), Lumbsch and Huhndorf (2010; outline), Kirk et al. (2013; did not list), Maharachchikumbura et al. (2015, 2016; outline), sequences are unavailable.

Peltaster Syd. \& P. Syd. 1917, Dothideomycetes genera incertae sedis, seven species, type: P. hedyotidis Syd. \& P. Syd., coelomycetous, sexual morph unknown, saprobes or pathogens, terrestrial, Philippines, South America, Slovenia, see Wijayawardene et al. $(2012,2014 \mathrm{c}$, 2017; outline), Kirk et al. (2013; genus accepted), Medjedović et al. (2014; new species, phylogeny), cultures and sequences are available but lacks for the type, needs generic revision.

Peltasterella Bat. \& H. Maia 1959, Ascomycota genera incertae sedis, one species, type: $P$. ocoteae Bat. \& Cavalc., coelomycetous, sexual morph unknown, saprobes, terrestrial, tropical, see Wijayawardene et al. (2012, 2017; outline), Kirk et al. (2013; genus accepted), cultures and sequences are unavailable, needs generic revision.

Peltasterinostroma Punith. 1975, Ascomycota genera incertae sedis, one species, type: $P$. rubi Punith., coelomycetous, sexual morph unknown, saprobes, terrestrial, British Isles, see Wijayawardene et al. (2012, 2017; outline), Kirk et al. (2013; genus accepted), cultures and sequences are unavailable, needs generic revision.

Peltasteropsis Bat. \& H. Maia 1959, Ascomycota genera incertae sedis, seven species, type: P. discreta Bat. \& H. Maia, coelomycetous, sexual morph unknown, saprobes, terrestrial, tropical, see Wijayawardene et al. (2012, 2017; outline), Kirk et al. (2013; genus accepted), cultures and sequences are unavailable, needs generic revision.

Peltigera Willd. [nom. cons.] 1787, Peltigeraceae, Peltigerales, Lecanoromycetes, 100 species, type: P. canina (L.) Willd., lichenized (green algae or, and cyanobacteria), terrestrial (saxicolous, terricolous, corticolous or lignicolous) or aquatic, worldwide, see Sérusiaux et al. (2009b; phylogeny), Lumbsch and Huhndorf (2010; outline), Kirk et al. (2013; genus accepted), Miądlikowska et al. (2014b; taxonomy), Lücking et al. (2016b; classification), cultures and sequences are available, needs generic revision.

Peltigeromyces Möller 1901, Helotiales genera incertae sedis, Leotiomycetes, three species, type: P. microsporus Möller, asexual morph unknown, saprobes, terrestrial, Africa, see Lumbsch and Huhndorf (2010; outline), Kirk et al. (2013; genus accepted), Pärtel et al. (2017; phylogeny), cultures and sequences are available for unidentified species, needs generic revision, needs generic revision.

Peltistroma Henn. 1904, Ascomycota genera incertae sedis, one species, type: P. juruanum Henn., coelomycetous, sexual morph unknown, saprobes, terrestrial, Brazil, see Wijayawardene et al. (2012, 2017; outline), Kirk et al. (2013; genus accepted), cultures and sequences are unavailable, lectotype of type: K (Mycotheca Brasiliensis no. 93), needs generic revision.

Peltistromella Höhn. 1907, Ascomycota genera incertae sedis, one species, type: $P$. brasiliensis Höhn., coelomycetous, sexual morph unknown, saprobes, terrestrial, Brazil, see Wijayawardene et al. (2012, 2017; outline), Kirk et al. (2013; genus accepted), cultures and sequences are unavailable, needs generic revision.

Peltosoma Syd. 1925, Ascomycota genera incertae sedis, one species, type: P. freycinetiae Syd. \& P. Syd., coelomycetous, sexual morph unknown, saprobes, terrestrial, Philippines, see Wijayawardene et al. (2012, 2017; outline), Kirk et al. (2013; genus accepted), cultures and sequences are unavailable, needs generic revision.

Peltostromellina Bat. \& A.F. Vital 1959, Ascomycota genera incertae sedis, one species, type: P. atra Bat. \& A.F. Vital, coelomycetous, sexual morph unknown, saprobes, terrestrial, Sri Lanka, see Wijayawardene et al. (2012, 2017; outline), Kirk et al. (2013; genus accepted), cultures and sequences are unavailable, needs generic revision. 
Peltostromopsis Bat. \& A.F. Vital 1959, Ascomycota genera incertae sedis, one species, type: P. artocarpi Bat. \& A.F. Vital, coelomycetous, sexual morph unknown, saprobes, terrestrial, Sri Lanka, see Wijayawardene et al. (2012, 2017; outline), Kirk et al. (2013; genus accepted), cultures and sequences are unavailable, needs generic revision.

Peltula Nyl. 1853, Peltulaceae, Lichinales, Lichinomycetes, 32 species, type: P. radicata Nyl., asexual morph unknown, lichenized, worldwide, see Lumbsch and Huhndorf (2010; outline), Kirk et al. (2013; genus accepted), McDonald et al. (2013; DNA, phylogeny), Marques et al. (2013; new species, Portugal), sequences are available, needs generic revision.

Peltularia R. Sant. 1944, Coccocarpiaceae, Peltigerales, Lecanoromycetes, three species, type: $P$. gyrophoroides (Räsänen) R. Sant., asexual morph unknown, lichenized, terrestrial, South America, Australia, see Lumbsch and Huhndorf (2010; outline), Kirk et al. (2013; genus accepted), cultures and sequences are unavailable, needs generic revision.

Pemphidium Mont. 1840, Xylariales genera incertae sedis, Sordariomycetes, 17 species, type: P. nitidum Mont., coelomycetous, common on palms, terrestrial, South America, Australia, Indonesia, see Lumbsch and Huhndorf (2010; outline), Kirk et al. (2013; genus accepted), cultures and sequences are unavailable, type specimen of type: CBS H-6336, needs generic revision.

Pendulispora M.B. Ellis., 1961, Dothideomycetes genera incertae sedis, one species, type: $P$. venezuelanica M.B. Ellis, sexual morph unknown, hyphomycetous, on dead branches, Venezuela, see Seifert et al. (2011; morphology), Wijayawardene et al. (2012, 2017; outline), Kirk et al. (2013; genus accepted), cultures and sequences are unavailable, needs generic revision.

Penicillifer Emden 1968 (= Viridispora Samuels \& Rossman 1999 fide Maharachchikumbura et al. 2015, 2016; outline; Lombard et al. 2016; Rossman et al. 2016a), Nectriaceae, Hypocreales, Sordariomycetes, seven species, type: P. pulcher Emden, asexual morph hyphomycetous, saprobes, from soil, terrestrial, pantropical, see Lumbsch and Huhndorf (2010; outline), Wijayawardene et al. (2012, 2017; outline), Kirk et al. (2013; genus accepted), Crous et al. (2014c; new species), Maharachchikumbura et al. (2015, 2016; outline), Lombard et al. (2016; phylogeny), Rossman et al. (2016a; nomenclature), cultures and sequences are available, type specimen and culture available for type: CBS H-7461; CBS 560.67.

Penicilliopsis Solms 1887, Aspergillaceae, Eurotiales, Eurotiomycetes, three species, type: $P$. clavariiformis Solms, asexual morph unknown, saprobes, terrestrial, worldwide, see Houbraken and Samson (2011; taxonomy, phylogeny), Lumbsch and Huhndorf (2010; outline, accepted as a genus in Trichocomaceae), Kirk et al. (2013; genus accepted), cultures and sequences are available, lectotype and culture available for type: Hauman (BR); CBS 761.68 .

Penicillium Link 1809, Aspergillaceae, Eurotiales, Eurotiomycetes, c. 300 species, type: $P$. crustaceum Link, hyphomycetous, pathogens, saprobes, widespread (common moulds), see Houbraken and Samson (2011; morphology, phylogeny), Hyde et al. (2011; outline), Seifert et al. (2011; morphology), Wijayawardene et al. (2012, 2017; outline), Kirk et al. (2013; genus accepted), cultures and sequences available.

Penidiella Crous \& U. Braun 2007, Teratosphaeriaceae, Capnodiales, Dothideomycetes, six species, type: P. columbiana Crous \& J.K. Stone, hyphomycetous, sexual morph teratosphaeria-like, pathogens, associated with leaf spots, terrestrial, worldwide, see Crous et al. (2009e; morphology, phylogeny), Crous and Groenewald (2011; morphology, phylogeny), Wijayawardene et al. (2014c; phylogeny, outline), cultures and sequences are available, epitype and ex-epitype strain of the type: CBS H-9937; CBS 486.80.

Penidiellopsis Sandoval-Denis, Gené, Deanna A. Sutton \& Guarro 2016, Teratosphaeriaceae, Capnodiales, Dothideomycetes, one species, type: P. syzygii Crous \& M.J. Wingf., 
hyphomycetous, human pthogen, terrestrial, USA, see Crous et al. (2016b; taxonomy, phylogeny), Wijayawardene et al. (2017; outline), holotype and ex-type culture of the type: CBS H-22389, CBS 140695.

Pentagenella Darb. 1897, Opegraphaceae, Arthoniales, Arthoniomycetes, three species, type: P. fragillima Darb., lichenized, terrestrial, neotropical, see Lumbsch and Huhndorf (2010; outline), Ertz and Tehler (2011; new species, phylogeny), Kirk et al. (2013; genus accepted), Lücking et al. (2016b; classification), sequences are available.

Penzigomyces Subram. 1992, Ascomycota genera incertae sedis, 13 species, type: P. nodipes (Penz. \& Sacc.) Subram., hyphomycetous, sexual morph unknown, saprobes, terrestrial, worldwide, see Seifert et al. (2011; morphology), Wijayawardene et al. (2012, 2017; outline), Kirk et al. (2013; genus accepted), cultures and sequences are unavailable, needs generic revision.

Perelegamyces R.F. Castañeda \& W.B. Kendr. 1990, Ascomycota genera incertae sedis, one species, type: P. parviechinulatus W.B. Kendr. \& R.F. Castañeda, hyphomycetous, sexual morph unknown, saprobes, terrestrial, Caribbean, see Seifert et al. (2011; morphology), Wijayawardene et al. (2012, 2017; outline), Kirk et al. (2013; genus accepted), cultures and sequences are unavailable, needs generic revision.

Perennicordyceps Matočec \& I. Kušan 2014, Hypocreales genera incertae sedis, Sordariomycetes, four species, type: P. prolifica (Kobayasi) Matočec \& I. Kušan, asexual morph unknown, South America, see Matočec et al. (2014; taxonomy), Maharachchikumbura et al. (2015, 2016; outline), sequences are unavailable.

Periamphispora J.C. Krug 1989, Lasiosphaeriaceae, Sordariales, Sordariomycetes, one species, type: P. phacelodes J.C. Krug, asexual morph unknown, on dung, terrestrial, Spain, see Lumbsch and Huhndorf (2010; outline, accepted as a genus in Sordariales), Kirk et al. (2013; genus accepted), Maharachchikumbura et al. (2015, 2016; outline), cultures and sequences are unavailable, needs generic revision.

Periconia Tode 1791, Periconiaceae, Pleosporales, Dothideomycetes, c. 45 species, type: $P$. lichenoides Tode, hyphomycetous, terrestrial, aquatic, worldwide, see Seifert et al. (2011; morphology), Hyde et al. (2011; outline), Wijayawardene et al. (2012, 2017; outline), Jones et al. (2015; outline, marine), Tanaka et al. (2015: phylogeny), sequence data available, needs generic revision.

Periconiella Sacc. 1885, Mycosphaerellaceae, Capnodiales, Dothideomycetes, 70 species, type: P. velutina (G. Winter) Sacc., hyphomycetous, sexual morph unknown, plant pathogens, terrestrial, see cultures and sequences are available, Seifert et al. (2011; morphology), Wijayawardene et al. (2012, 2017; outline), Kirk et al. (2013; genus accepted), epitype and ex-epitype of type: CBS H-15612; CBS 101948.

Peridiothelia D. Hawksw. 1985, Pleomassariaceae, Pleosporales, Dothideomycetes, three species, type: P. fuliguncta (Norman) D. Hawksw., asexual morph unknown, on bark, Europe, terrestrial, see Lumbsch \& Huhndorf (2010; outline), Hyde et al. (2013; accepted as a genus in Peridiothelia), Kirk et al. (2013; genus accepted), Wijayawardene et al. (2014c; outline), cultures and sequences are unavailable, lectotype of type: O.

Periglandula U. Steiner, Leistner \& Leuchtm. 2011, Clavicipitaceae, Hypocreales, Sordariomycetes, two species, type: P. ipomoeae U. Steiner, E. Leistner \& Schardl, asexual morph unknown, on living leavs, terrestrial, Ecuador, Panama, see Steiner et al. (2011; taxonomy, outline), Beaulieu et al. (2015; DNA), Maharachchikumbura et al. (2015, 2016; outline), cultures and sequences are available, needs generic revision.

Perigrapha Hafellner 1996, Arthoniales genera incertae sedis, Arthoniomycetes, four species, type: P. superveniens (Nyl.) Hafellner, lichenicolous, terrestrial, Asia, Europe and North America, see Lumbsch and Huhndorf (2010; outline), Kirk et al. (2013; genus accepted), sequences are available. 
Perischizon Syd. \& P. Syd. 1914, Dothideomycetes genera incertae sedis, three species, type: P. oleifolium (Kalchbr. \& Cooke) Syd. \& P. Syd., asexual morph unknown, epiphytes, terrestrial, worldwide, see Hofmann (2009; review, accepted in Parmulariaceae), Lumbsch and Huhndorf (2010; outline), Hyde et al. (2013; excluded from Parmulariaceae), Wijayawardene et al. (2014c; outline, accepted in Dothideomycetes), cultures and sequences unavailable, Holotype of type: K (P. MacOwan 7).

Perisporiopsis Henn. 1904, Perisporiopsidaceae, Dothideomycetes families incertae sedis, Dothideomycetes, 17 species, type: P. struthanthi Henn., asexual morph unknown, saprobes, endophytes, terrestrial, tropical, see Chaverri and Gazis (2010, 2011; new species, endophytes), Kawada et al. (2010; antitumour compounds), Lumbsch and Huhndorf (2010; outline), Hyde et al. (2013; accepted as a genus in Perisporiopsidaceae), Kirk et al. (2013; genus accepted), Wijayawardene et al. (2014c; outline), cultures and sequences are available. Peristomialis (W. Phillips) Boud. 1907, Bionectriaceae, Hypocreales, Sordariomycetes, c. five species, type: $P$. berkeleyi Boud., asexual morph unknown, saprobes, terrestrial, cosmopolitan, see Maharachchikumbura et al. (2015, 2016), cultures and sequences are available.

Perizomella Syd. 1927, Ascomycota genera incertae sedis, one species, type: P. inquinans Syd., coelomycetous, sexual morph unknown, saprobes, terrestrial, Central America, see Wijayawardene et al. (2012, 2017; outline), Kirk et al. (2013; genus accepted), cultures and sequences are unavailable, needs generic revision.

Peroneutypa Berl. 1902, Diatrypaceae, Xylariales, Sordariomycetes, 47 species, type: $P$. bellula (Desm.) Berl., asexual morph unknown, saprobes, pathogens, terrestrial, widely distributed, see Lumbsch and Huhndorf (2010; outline), Maharachchikumbura et al. (2015, 2016; outline), Dai et al. (2016; morphology, phylogeny), cultures and sequences are available but lacks for type, needs generic revision.

Peroschaeta Bat. \& A.F. Vital 1957, Dothideomycetes genera incertae sedis, one species, type: P. artocarpi Bat. \& A.F. Vital, asexual morph unknown, saprobes, terrestrial, Philippines, see Lumbsch and Huhndorf (2010; outline), Kirk et al. (2013; genus accepted), Wijayawardene et al. (2014c; outline), cultures and sequences are unavailable, needs generic revision.

Perrotia Boud. 1901, Lachnaceae, Helotiales, Leotiomycetes, 19 species, type: P. flammea (Alb. \& Schwein.) Boud., asexual morph unknown, saprobes, terrestrial, worldwide, see Monaghan et al. (2009; DNA), Lumbsch and Huhndorf (2010; outline), Kirk et al. (2013; genus accepted), Pärtel et al. (2017; DNA, phylogeny), sequence available for the type, needs generic revision.

Persiciospora P.F. Cannon \& D. Hawksw. 1982, Nectriaceae, Hypocreales, Sordariomycetes, four species, type: P. moreaui P.F. Cannon \& D. Hawksw., fungicolous, widespread, terricolous, see Lumbsch and Huhndorf (2010; outline), Kirk et al. (2013; genus accepted), Maharachchikumbura et al. (2015, 2016; outline), Jaklitsch et al. (2016a; position), cultures and sequences are available, holotype of type: K(M)-IMI 238745.

Pertusaria DC. [nom. cons.] 1805, Pertusariaceae, Pertusariales, Lecanoromycetes, 500 species, type: P. communis DC., lichenized, worldwide, see Lumbsch and Huhndorf (2010; outline), Kirk et al. (2013; genus accepted), Lücking et al. (2016b; classification), cultures and sequences are available, needs generic revision.

Perusta Egidi \& Sielow 2014, Capnodiales genera incertae saedis, Dothideomycetes, one species, type: $P$. inaequalis Egidi \& Sielow, sexual morph unknown, rock-inhabiting fungus, see Egidi et al. (2014; taxonomy), Quaedvlieg et al. (2014; phylogeny), Wijayawardene et al. (2014c, 2017; outline), cultures available for the type: CBS $118271=$ TRN272.

Pesotum J.L. Crane \& Schokn. 1973 (= Phialographium H.P. Upadhyay \& WB. Kendr. 1974 fide Seifert et al. 2011), Ophiostomataceae, Ophiostomatales, Sordariomycetes, seven 
species, type: P. ulmi (M.B. Schwarz) J.L. Crane \& Schokn., hyphomycetous, saprobes, pathogens, worldwide, see Kamgan Nkuekam et al. (2008; new species), Grobbelaar et al. (2009; new species), Seifert et al. (2011; morphology), Wijayawardene et al. (2012, 2017; outline), Kirk et al. (2013; genus accepted), Maharachchikumbura et al. (2015, 2016; outline), cultures and sequences are available but lacks for the type.

Pestalopezia Seaver 1942, Helotiales genera incertae sedis, Leotiomycetes, three species, type: P. brunneopruinosa (Zeller) Seaver, asexual morph unknown, saprobes, terrestrial, North America, see Lumbsch and Huhndorf (2010; outline), Kirk et al. (2013; genus accepted), cultures and sequences are unavailable, needs generic revision.

Pestalotiopsis Steyaert 1949 (= Pestalosphaeria M.E. Barr 1975 fide Réblová et al. 2016c), Pestalotiopsidaceae, Xylariales, Sordariomycetes, c. 300 species, type: P. maculans (Corda) Nag Raj, coelomycetous, sexual morph formerly named in Pestalosphaeria, saprobes or pathogens on plants, worldwide, see Maharachchikumbura et al. (2012, 2014; phylogeny, morphology), Wijayawardene et al. (2012, 2016b, 2017; outline, taxonomy), Réblová et al. (2016c; nomenclature), 55 species have ex-type sequences, type specimen of type: CBS H15678, needs generic revision.

Pestalozziella Sacc. \& Ellis ex Sacc. 1882, Ascomycota genera incertae sedis, four species, type: $P$. inquinans Syd., coelomycetous, sexual morph unknown, saprobes, terrestrial, temperate, see Wijayawardene et al. (2012, 2017; outline), Kirk et al. (2013; genus accepted), cultures and sequences are unavailable, needs generic revision.

Petchiomyces E. Fisch. \& Mattir. 1938, Pyronemataceae, Pezizales, Pezizomycetes, one species, type: P. thwaitesii (Berk. \& Broome) E. Fisch. \& Mattir., asexual morph unknown, saprobes, terrestrial, North America, Sri Lanka, see Lumbsch and Huhndorf (2010; outline), Kirk et al. (2013; genus accepted), cultures and sequences are unavailable, needs generic revision.

Peterozyma Kurtzman \& Robnett 2010, Pichiaceae, Saccharomycetales, Saccharomycetes, two species, type: P. toletana (Socias, C. Ramírez \& Peláez) Kurtzman \& Robnett, asexual reproduction is by multilateral budding, saprophytic, tanning fluid, insect frass from trees and tree bark, Europe, North America, see Kurtzman and Suzuki (2010; taxonomy), sequences are available.

Petractis Fr. 1845, Stictidaceae, Ostropales, Lecanoromycetes, six species, type: $P$. exanthematica (Sm.) Fr., asexual morph unknown, lichenized, terrestrial, worldwide, see Orange (2009a; new species, DNA), Lumbsch and Huhndorf (2010; outline), Schmull et al. (2011; phylogeny), Kirk et al. (2013; genus accepted), cultures and sequences are available but lacks for the type, needs generic revision.

Petrakia Syd. \& P. Syd. 1913, Dothideomycetes genera incertae sedis, three species, type: $P$. echinata (Peglion) Syd. \& P. Syd., hyphomycetous, sexual morph unknown, saprobes, terrestrial, Europe, Asia, see Wijayawardene et al. (2012, 2017; outline), Butin et al. (2013; DNA, phylogeny), Kirk et al. (2013; genus accepted), Li et al. (2016a; phylogeny, taxonomy), cultures available for the type: $\mathrm{OH} 080921.4$, needs generic revision.

Petrakiella Syd. 1924, Phyllachoraceae, Phyllachorales, Sordariomycetes, two species, type: $P$. insignis Syd., asexual morph unknown, saprobes, terrestrial, Brazil, see Lumbsch and Huhndorf (2010; outline), Kirk et al. (2013; genus accepted), Maharachchikumbura et al. (2015, 2016; outline), cultures and sequences are unavailable, needs generic revision.

Petrakina Cif. 1932, Dothideomycetes genera incertae sedis, two species, type: P. mirabilis Cif., asexual morph unknown, epiphytes, terrestrial, see Hofmann (2009; review, accepted as a genus in Asterinaceae), Lumbsch and Huhndorf (2010; outline, accepted as a genus in Asterinaceae), Hongsanan et al. (2014c; taxonomy, keys, accepted as a genus in Dothideomycetes), Wijayawardene et al. (2014c; outline, accepted in Dothideomycetes), cultures and sequences unavailable, syntype of type: NY 00936794. 
Petrakiopeltis Bat., A.F. Vital \& Cif. 1958, Dothideomycetes genera incertae sedis, one species, type: P. byrsonimae Bat., A.F. Vital \& Cif., asexual morph unknown, epiphytes, terrestrial, Guyana, see Lumbsch and Huhndorf (2010; outline, accepted as a genus in Microthyriaceae), Wu et al. (2011; not accepted as Microthyriaceae), Kirk et al. (2013; genus accepted), Hyde et al. (2013; not accepted as as a genus in Microthyriaceae), Wijayawardene et al. (2014c; outline, accepted as a genus in Dothideomycetes), cultures and sequences are unavailable, needs generic revision.

Petrakiopsis Subram. \& K.R.C. Reddy 1968, Ascomycota genera incertae sedis, one species, type: P. elegans Subram. \& K.R.C. Reddy, hyphomycetous, sexual morph unknown, saprobes, terrestrial, India, see Wijayawardene et al. (2012, 2017; outline), Kirk et al. (2013; genus accepted), cultures and sequences are unavailable, needs generic revision.

Petriella Curzi 1930, Microascaceae, Microascales, Sordariomycetes, two species, type: $P$. asymmetrica Curzi, asexual morph unknown, saprobes, terrestrial, worldwide, see Lumbsch and Huhndorf (2010; outline), Kirk et al. (2013; genus accepted), Maharachchikumbura et al. (2015, 2016; outline, phylogeny), cultures and sequences are available, available specimen and cultures for the type: CBS H-7548; CBS 238.38.

Petrophila de Hoog \& Quaedvlieg 2014, Extremaceae, Capnodiales, Dothideomycetes, one species, type: P. incerta de Hoog \& Quaedvlieg, hyphomycetous, sexual morph unknown, rock-inhabiting fungus, see Egidi et al. (2014; taxonomy), Quaedvlieg et al. (2014; phylogeny), Wijayawardene et al. (2017; outline), cultures available for the type: CBS $118608=$ TRN139b.

Peyritschiella Thaxt. 1890, Laboulbeniaceae, Laboulbeniales, Laboulbeniomycetes, 47 species, type: $P$. curvata Thaxt., asexual morph unknown, biotrophic, terrestrial, worldwide, see Lumbsch and Huhndorf (2010; outline), Kirk et al. (2013; genus accepted), cultures and sequences are unavailable.

Peyronelia Cif. \& Gonz. Frag. 1927, Ascomycota genera incertae sedis, six or seven species (fide Seifert et al. 2011) but Index Fungorum (2017) lists only four epithets, type: $P$. sirodesmioides Cif. \& Gonz. Frag., hyphomycetous, sexual morph unknown, saprobes, terrestrial, Europe, North America, South America, see Seifert et al. (2011; morphology), Wijayawardene et al. (2012, 2017; outline), Kirk et al. (2013; genus accepted), cultures and sequences are unavailable, needs generic revision.

Peyronellaea Goid. ex Togliani emend. Aveskamp, Gruyter \& Verkley 2010, Didymellaceae, Pleosporales, Dothideomycetes, c. 20 species, type: P. glomerata (Corda) Goid. ex Togliani, asexual morph unknown, saprobes, pathogens, terrestrial, worldwide, see Aveskampet al. (2009, 2010; generic emendment, treated as a distinct genus), Wijayawardene et al. (2012, 2014c, 2017; outline), cultures and sequences are available, needs generic revision.

Pezicula Tul. \& C. Tul. 1865 (= Cryptosporiopsis Bubák \& Kabát 1912; = Lagynodella Petr. 1922; Ocellaria (Tul. \& C. Tul.) P. Karst. 1871 fide Johnston et al. 2014b; Jaklitsch et al. 2016a), Dermateaceae, Helotiales, Leotiomycetes, c. 50 species, type: P. carpinea (Pers.) Tul. ex Fuckel, asexual morph Cryptosporiopsis, saprobes, pathogens, terrestrial, worldwide, see Lumbsch and Huhndorf (2010; outline), Kirk et al. (2013; genus accepted), Johnston et al. (2014b; nomenclature), Chen et al. (2016b; new species), epitype and cultures available for the type: CBS H-17476; CBS 923.96, CBS 921.96, needs generic revision.

Peziza Dill. ex Fr. 1822 (see Species Fungorum 2017 for synonyms), Pezizaceae, Pezizales, Pezizomycetes, one species, type: P. vesiculosa Bull., asexual morph unknown, hypogeous, terrestrial, worldwide, see Lumbsch and Huhndorf (2010; outline), Ashraf et al. (2012; Pakistan, ectomycorrhizae), Barseghyan and Solomon (2011; Israel). Kirk et al. (2013; genus accepted), cultures and sequences are available, available specimen and cultures for type: CBS H-15930; AFTOL-ID 507. 
Pezolepis Syd. 1925, Helotiales genera incertae sedis, Leotiomycetes, two species, type: $P$. denigrata Syd., asexual morph unknown, saprobes, saprobes, terrestrial, tropical, see Lumbsch and Huhndorf (2010; outline), Kirk et al. (2013; genus accepted), cultures and sequences are unavailable, needs generic revision.

Pezoloma Clem. 1909, Helotiales genera incertae sedis, Leotiomycetes, 14 species, type: P. denigrata Clem., asexual morph unknown, saprobes, terrestrial, temperate, see Huhtinen et al. (2010; new species, Sweden), Lumbsch and Huhndorf (2010; outline), Kirk et al. (2013; genus accepted), Bruzone et al. (2016; DNA), cultures and sequences are available but lacks for the type, needs generic revision.

Pezomela Syd. 1928, Helotiales genera incertae sedis, Leotiomycetes, one species, type: $P$. saxegothaeae Syd., asexual morph unknown, saprobes, terrestrial, Chile, see Lumbsch and Huhndorf (2010; outline), Kirk et al. (2013; genus accepted), Pärtel et al. (2017; phylogeny), cultures and sequences are available for unidentified species, needs generic revision.

Phacellium Bonord. 1860, Teratosphaeriaceae, Capnodiales, Dothideomycetes, 27 species, type: P. inhonestum Bonord., hyphomycetous, saprobes, pathogens, terrestrial, Asia, Europe, North America, South America, see Crous et al. (2009d; DNA, phylogeny), Seifert et al. (2011; morphology), Wijayawardene et al. (2012, 2014c, 2017; outline), Kirk et al. (2013; genus accepted), cultures and sequences are available, needs generic revision.

Phacidiella P. Karst. 1884, Helotiales genera incertae sedis, Leotiomycetes, one species, type: $P$. salicina P. Karst., coelomycetous, sexual morph unknown, saprobes, terrestrial, worldwide, see Wijayawardene et al. (2012, 2017; outline), Kirk et al. (2013; genus accepted), Crous et al. (2014d; new species, treated as in Ostropales), cultures and sequences are available but lacks for the type, needs generic revision since have different opinions.

Phacidina Höhn. 1917, Leptopeltidaceae, Dothideomycetes families incertae sedis, one species, type: $P$. gracilis (Niessl) Höhn., asexual morph unknown, saprobes, terrestrial, Europe, see Lumbsch and Huhndorf (2010; outline), Hyde et al. (2013; accepted as a genus in Leptopeltidaceae), Kirk et al. (2013; genus accepted), Wijayawardene et al. (2014c; outline), cultures and sequences are unavailable, needs generic revision.

Phacidiopycnis Potebnia 1912 (= Potebniamyces Smerlis 1962, = Discosporiopsis Petr. 1921 fide Johnston et al. 2014b), Phacidiaceae, Phacidiales, Leotiomycetes, five species, type: $P$. malorum Potebnia, asexual morph coelomycetous, saprobes, pathogens terrestrial, worldwide, see Wijayawardene et al. (2012, 2017; outline), Kirk et al. (2013; genus accepted), Crous et al. (2014b; phylogeny), Johnston et al. (2014b; nomenclature), Díaz et al. (2015; pathogens, DNA), cultures and sequences are available but lacks for the type, needs generic revision.

Phacidium Fr. 1815 (= Ceuthospora Grev. 1826; = Basilocula Bubák 1914; = Coccobolus Wallr. 1833; = Melanostroma Corda 1829; = Phacidiostroma Höhn.1917; Siroplaconema Petr. 1922 fide Johnston et al. 2014b; Species Fungorum 2017), Phacidiaceae, Phacidiales, Leotiomycetes, 270 species, type: P. lacerum Fr., asexual morph formerly named in Ceuthospora, saprobes, plant pathogens, terrestrial, worldwide, see Barbeito et al. (2013; pathogensity), Petäistö et al. (2013; pathogensity), Crous et al. (2014b, 2015a, b; phylogeny, new species), Johnston et al. (2014b; nomenclature), Suija et al. (2015b; phylogeny), Wiseman et al. (2016; new disease), cultures and sequences are available, epitype and exepitype of type: CBS H-10302; CBS 761.73.

Phacographa Hafellner 2009, Lecanographaceae, Arthoniales, Arthoniomycetes, three species, type: P. glaucomaria (Nyl.) Hafellner, sexual morph with rounded ascomata, lichenicolous, terrestrial, Northern Hemisphere, see Hafellner (2009; morphology), Frisch et al. (2014; phylogeny), sequences are available, lectotype of the type: Nylander (H-Nyl. 11019). 
Phacopsis Tul. 1852, Parmeliaceae, Lecanorales, Lecanoromycetes, 22 species, type: $P$. vulpina Tul., asexual morph unknown, lichenicolous, terrestrial, worldwide, see Lumbsch and Huhndorf (2010; outline), Zhurbenko (2010b; new species), Kirk et al. (2013; genus accepted), cultures and sequences are available.

Phacostroma Petr. 1955, Ascomycota genera incertae sedis, one species, type: $P$. hypodermium Petr., coelomycetous, sexual morph unknown, saprobes, terrestrial, former Czechoslovakia, see Wijayawardene et al. (2012, 2017; outline), Kirk et al. (2013; genus accepted), cultures and sequences are unavailable, needs generic revision.

Phacostromella Petr. 1955, Ascomycota genera incertae sedis, one species, type: $P$. coronata (Fuckel) Petr., coelomycetous, sexual morph unknown, saprobes, terrestrial, Gennany, see Wijayawardene et al. (2012, 2017; outline), Kirk et al. (2013; genus accepted), cultures and sequences are unavailable, needs generic revision.

Phacothecium Trevis. 1856, Lecanographaceae, Arthoniales, Arthoniomycetes, one species, type: P. varium (Tul.) Trevis., lichenicolous, terrestrial, Northern Hemisphere, see Hafellner (2009; morphology), sequences are unavailable, epitype of the type: J. Hafellner 47633 \& A. Hafellner.

Phaeangellina Dennis 1955, Gelatinodiscaceae, Helotiales, Leotiomycetes, one species, type: P. empetri (W. Phillips) Dennis, asexual morph unknown, saprobes, terrestrial, Europe, see Lumbsch and Huhndorf (2010; outline), Kirk et al. (2013; genus accepted), cultures and sequences are unavailable, needs generic revision.

Phaeangium Pat. 1894, Pyronemataceae, Pezizales, Pezizomycetes, one species, type: P. lefebvrei Pat., asexual morph unknown, saprobes, terrestrial, North Africa, Arabian peninsula, see Lumbsch and Huhndorf (2010; outline), Kirk et al. (2013; genus accepted), Zitouni-Haouar et al. (2016; DNA), cultures available for the type: BMBH4 (Zitouni-Haouar et al. 2016), needs generic revision.

Phaeoacremonium W. Gams, Crous \& M.J. Wingf. 1996 (= Romellia Berl. 1900 fide Réblová et al. 2016c), Togniniaceae, Togniniales, Sordariomycete, 50 species, type: $P$. parasiticum (Ajello, Georg \& C.J.K. Wang) W. Gams, Crous \& M.J. Wingf., hyphomycetous, with subverticillium-like synasexual morph, sexual morph formerly named in Romellia, saprobes, terrestrial, cosmopolitan, see Seifert et al. (2011; morphology), Wijayawardene et al. (2012, 2017; outline), Kirk et al. (2013; genus accepted), Crous et al. (2016a; new species, phylogeny), Dai et al. (2016; sexual morph), holotype and ex-type culture of the type: CBS H-22886, CPC 27637.

Phaeoblastophora Partr. \& Morgan-Jones 2002, Ascomycota genera incertae sedis, two species, type: P. resinae (Fr.) Partr. \& Morgan-Jones, hyphomycetous, sexual morph unknown, saprobes, terrestrial, Europe, North America, see Seifert et al. (2011; morphology), Wijayawardene et al. (2012, 2017; outline), cultures and sequences are unavailable, needs generic revision.

Phaeobotryon Theiss. \& Syd. 1915, Botryosphaeriaceae, Botryosphaeriales, Dothideomycetes, four species, type: P. cercidis (Cooke) Theiss. \& Syd., asexual morph coelomycetous, saprobes, pathogens, terrestrial, cosmopolitan, see Phillips et al. (2008, 2013; taxonomy, phylogeny), Liu et al. (2012; taxonomy, phylogeny), Hyde et al. (2013; accepted as a genus in Botryosphaeriaceae), Slippers et al. (2013; phylogeny), Wijayawardene et al. (2014c, 2016; outline, taxonomy, phylogeny), Dissanayake et al.(2016; taxonomy), cultures and sequences are available.

Phaeocalicium A.F.W. Schmidt 1970, Mycocaliciaceae, Mycocaliciales, Eurotiomycetes, eleven species, type: P. praecedens (Nyl.) A.F.W. Schmidt, asexual morph unknown, saprobes, terrestrial, temperate, see Lumbsch and Huhndorf (2010; outline), Kirk et al. (2013; genus accepted), Tibell et al. (2014; new species), Tuovila et al. (2014; DNA), Telfer et al. 
(2015; DNA, phylogeny), sequences are available, voucher specimen of the type: Tuovila 09240 (TUR).

Phaeocandelabrum R.F. Castañeda, Gusmão, Guarro \& Iturr. 2009, Ascomycota genera incertae sedis, three species, type: P. elegans (R.F. Castañeda) R.F. Castañeda, Heredia, Saikawa, hyphomycetous, sexual morph unknown, saprobes, terrestrial, Neotropics, see Seifert et al. (2011; morphology), Wijayawardene et al. (2012, 2017; outline), Kirk et al. (2013; genus accepted), cultures and sequences are unavailable, needs generic revision.

Phaeocercospora Crous 2012, Mycosphaerellaceae, Capnodiales, Dothideomycetes, one species, type: P. colophospermi Crous, hyphomycetous, pathogens, South Africa, see Crous et al. (2012a; morphology; phylogeny), Wijayawardene et al. (2012, 2014c, 2017; outline), sequence data available, holotype and ex-type strain of the type: CBS H-20966; CPC 19813.

Phaeochora Höhn. 1909, Phaeochoraceae, Phyllachorales, Sordariomycetes, five species, type: P. chamaeropis (Cooke) Höhn., saprobes, worldwide, see Lumbsch and Huhndorf (2010; outline), Kirk et al. (2013; genus accepted), Maharachchikumbura et al. (2015, 2016; outline), cultures and sequences are unavailable, needs generic revision.

Phaeochorella Theiss. \& Syd. 1915, Phyllachoraceae, Phyllachorales, Sordariomycetes, six species, type: P. parinarii (Henn.) Theiss. \& Syd., from living leaves, South Affrica, Phillipines, see Lumbsch and Huhndorf (2010; outline), Kirk et al. (2013; genus accepted), Maharachchikumbura et al. (2015, 2016; outline), cultures and sequences are unavailable, available specimen of type: CBS H-15956, needs generic revision.

Phaeochoropsis K.D. Hyde \& P.F. Cannon 1999, Phaeochoraceae, Phyllachorales, Sordariomycetes, four species, type: P. neowashingtoniae (Shear) K.D. Hyde \& P.F. Cannon, saprobes, North and South America, see Lumbsch and Huhndorf (2010; outline), Kirk et al. (2013; genus accepted), Maharachchikumbura et al. (2015, 2016; outline), cultures and sequences are unavailable, needs generic revision.

Phaeococcomyces de Hoog 1979, Phaeococcomycetaceae, Lichenostigmatales, Arthoniomycetes, eight species, type: P. nigricans (M.A. Rich \& A.M. Stern) de Hoog, hyphomycetous, sexul morph unknown, on human, saprobes, Asia, Europe, North America, South America, see Seifert et al. (2011; morphology), Kirk et al. (2013; genus accepted), Crous et al. (2014c; new species), Moreno-Rico et al. (2014; new species), Wijayawardene et al. (2017; outline), cultures and sequences are available.

Phaeocryptopus Naumov 1915, Dothideaceae, Dothideales, Dothideomycetes, eight species, type: P. abietis Naumov, asexual morph unknown, growing on conifer needles, terrestrial, worldwide, see Kirk et al. (2013; genus accepted), Thambugala et al. (2014a; review), cultures and sequences are available, holotype of type: F67760.

Phaeocyrtidula Vain. 1921, Dothideomycetes genera incertae sedis, two species, type: P. pinea (Nyl.) Vain., saprobes, Europe, see Lumbsch and Huhndorf (2010; outline), Kirk et al. (2013; genus accepted), Wijayawardene et al. (2014c; outline), cultures and sequences are unavailable, needs generic revision.

Phaeocytostroma Petr. 1921, Diaporthaceae, Diaporthales, Sordariomycetes, four species, type: P. istrica Petr., coelomycetous, sexual morph unknown, pathogens, terrestrial, worldwide, see Wijayawardene et al. (2012, 2017; phylogeny, taxonomy), Kirk et al. (2013; genus accepted), cultures and sequences are available but lacks for the type, needs generic revision.

Phaeodactylium Agnihothr. 1968, Ascomycota genera incertae sedis, five species, type: $P$. venkatesanum Agnihothr., hyphomycetous, sexual morph unknown, saprobes, terrestrial, worldwide, see Castañeda-Ruiz et al. (2009c, 2013c; new species), Seifert et al. (2011; morphology), Zhang et al. (2011h; new species), Wijayawardene et al. (2012, 2017; outline), Kirk et al. (2013; genus accepted), cultures and sequences are available (unpublished), needs generic revision, needs generic revision. 
Phaeodimeriella Speg. 1908, Pseudoperisporiaceae, Dothideomycetes family incertae sedis, 15 species, type: P. occulta (Racib.) Speg, asexual morph unknown, saprobes, terrestrial, worldwide, see Lumbsch and Huhndorf (2010; outline), Hyde et al. (2013; accepted as a genus in Pseudoperisporiaceae), Kirk et al. (2013; genus accepted), Wijayawardene et al. (2014c; outline), Mapook et al. (2016b; taxonomy, phylogeny), cultures and sequences are available but lacks for the type, needs generic revision.

Phaeodiscula Cub. 1891, Ascomycota genera incertae sedis, one species, type: P. celottii Cub., coelomycetous, sexual morph unknown, saprobes, terrestrial, Europe, see Wijayawardene et al. (2012, 2017; outline), Kirk et al. (2013; genus accepted), cultures and sequences are unavailable, needs generic revision.

Phaeodomus Höhn. 1909, Ascomycota genera incertae sedis, three species, type: $P$. lauracearum Höhn., coelomycetous, sexual morph unknown, saprobes, terrestrial, Cuba, South America, see Wijayawardene et al. (2012, 2017; outline), Kirk et al. (2013; genus accepted), cultures and sequences are unavailable, needs generic revision.

Phaeodothis Syd. \& P. Syd. 1904, Didymosphaeriaceae, Pleosporales, Dothideomycetes, five species, type: P. tricuspidis Syd. \& P. Syd., asexual morph unknown, saprobes, terrestrial, worldwide, see Schoch et al. (2009; phylogeny), Lumbsch and Huhndorf (2010; outline), Hyde et al. (2013; accepted in Didymosphaeriaceae), Ariyawansa et al. (2014d; accepted in Didymosphaeriaceae), Wijayawardene et al. (2014c; outline), Verkley et al. (2014; new species, phylogeny), sequences and cultures available only for $P$. winteri but lacks for the type, available specimen for type: CBS H-4793.

Phaeofabraea Rehm 1909, Helotiales genera incertae sedis, Leotiomycetes, one species, type: $P$, miconiae Rehm, asexual morph unknown, saprobes, terrestrial, South America, Taiwan, see Lumbsch and Huhndorf (2010; outline), Kirk et al. (2013; genus accepted), cultures and sequences are unavailable, needs generic revision.

Phaeographis Müll. Arg. 1882, Graphidaceae, Ostropales, Lecanoromycetes, c. 180 species, type: $P$. dendritica (Ach.) Müll. Arg., asexual morph unknown, lichenized, see Lumbsch and Huhndorf (2010; outline), Rivas Plata et al. (2012a; classification), Kirk et al. (2013; genus accepted), Lücking et al. (2016b; classification), cultures and sequences are available.

Phaeographis Müll. Arg. 1882, Graphidaceae, Ostropales, Lecanoromycetes, 150 species, type: $P$. dendritica (Ach.) Müll. Arg., asexual morph unknown, lichenized, terrestrial, mostly tropical, see Rivas Plata et al. (2012a; phylogeny), Archer (2009; key, Australia), Lücking et al. (2014; phylogeny), Lumbsch and Huhndorf (2010; outline), Kirk et al. (2013; genus accepted), Lücking et al. (2016b; classification), cultures and sequences are available, needs generic revision.

Phaeographopsis Sipman 2007, Graphidaceae, Ostropales, Lecanoromycetes, three species, type: P. indica (Patw. \& Nagarkar) Sipman \& Aptroot, asexual morph unknown, lichenized fungi, terrestrial, tropical, see Lumbsch and Huhndorf (2010; outline), Rivas Plata et al. (2013; phylogeny), Lücking et al. (2016b; classification), cultures and sequences are available, needs generic revision.

Phaeohelotium Kanouse 1935, Helotiaceae, Helotiales, Leotiomycetes, 41 species, type: P. flavum Kanouse, asexual morph unknown, saprobes, terrestrial, worldwide, see Hengstmengel (2009; outline), Kaya (2009; Turkey), Lumbsch and Huhndorf (2010; outline), Baral et al. (2013a; new combination), Kirk et al. (2013; genus accepted), cultures and sequences are available.

Phaeohiratsukaea Udagawa \& Iwatsu 1990, Ascomycota genera incertae sedis, one species, type: $P$. expansa Udagawa \& Iwatsu, hyphomycetous, sexual morph unknown, saprobes, terrestrial, Japan, see Seifert et al. (2011; morphology), Wijayawardene et al. (2012, 2017; outline), Kirk et al. (2013; genus accepted), cultures and sequences are unavailable, holotype of type: National Insitute of Hygienic Sciences, Tokyo, NHL2968, needs generic revision. 
Phaeoidiomyces Dorn.-Silva \& Dianese 2004, Ascomycota genera incertae sedis, one species, type: P. qualeae Dorn.-Silva \& Dianese, hyphomycetous, sexual morph unknown, saprobes, terrestrial, Brazil, see Seifert et al. (2011; morphology), Wijayawardene et al. (2012, 2017; outline), Kirk et al. (2013; genus accepted), cultures and sequences are unavailable, holotype of type: UB (col. micol.) 9851, needs generic revision.

Phaeoisaria Höhn. 1909, Pleurotheciaceae, Pleurotheciales, Sordariomycetes, 20 species, type: P. bambusae Höhn., hyphomycetous, sexual morph unknown, pathogens, terrestrial, worldwide, see Seifert et al. (2011; morphology), Mel'nik (2012; new species, Vietnam), Wijayawardene et al. (2012, 2017; outline), Kirk et al. (2013; genus accepted), Cheng et al. (2014; new species, China), Crous et al. (2015c; new species), Liu et al. (2015a; new species), Maharachchikumbura et al. (2015, 2016; outline), Réblová et al. (2017; phylogeny), cultures and sequences are available but lacks for the type, needs generic revision.

Phaeolabrella Speg. 1912, Ascomycota genera incertae sedis, one species, type: $P$. eryngicola Speg., hyphomycetous, sexual morph unknown, saprobes, terrestrial, South America, see Seifert et al. (2011; morphology), Wijayawardene et al. (2012, 2017; outline), Kirk et al. (2013; genus accepted), cultures and sequences are unavailable, needs generic revision.

Phaeomoniella Crous \& W. Gams 2000, Phaeomoniellaceae, Phaeomoniellales, Eurotiomycetes, one species, type: P. chlamydospora (W. Gams, Crous, M.J. Wingf. \& Mugnai) Crous \& W. Gams, hyphomycetous, sexual morph unknown, with coelomycetous synasexual morph, pathogens, saprobes, endophytic, terrestrial, Italy, see Chen et al. (2015a; phylogeny), Crous et al. (2015d; phylogeny), Wijayawardene et al. (2017; outline), cultures and sequences are available, holotype of type: CBS H-229.95 as Phaeoacremonium chlamydosporum W. Gams et al., reference culture of type: CBS 229.95.

Phaeomonilia R.F. Castañeda, Heredia \& R.M. Arias 2007, Ascomycota genera incertae sedis, four species, type: P. pleiomorpha R.F. Castañeda, Heredia \& R.M. Arias, hyphomycetous, sexual morph unknown, saprobes, terrestrial and aquatic, Mexico, see Hyde et al. (2011; checklist), Seifert et al. (2011; morphology), Ma et al. (2015; new species), Yang et al. (2016; new species), Wijayawardene et al. (2017; outline), cultures and sequences are unavailable, holotype of the type: XAL CB746, compare with Botryomonilia, Pseudaegerita, Staheliella and Oidiodendron.

Phaeomonostichella Keissl. ex Petr. 1941, Ascomycota genera incertae sedis, one species, type: P. symploci (Keissl.) Petr., coelomycetous, sexual morph unknown, saprobes, terrestrial, China, see Wijayawardene et al. (2012, 2017; outline), Kirk et al. (2013; genus accepted), cultures and sequences are unavailable, needs generic revision.

Phaeonectriella R.A. Eaton \& E.B.G. Jones 1971, Halosphaeriaceae, Microascales, Sordariomycetes, two species, type: P. lignicola R.A. Eaton \& E.B.G. Jones, asexual morph unknown, saprobes on wood, marine, temperate, tropical, see Lumbsch and Huhndorf (2010; outline), Kirk et al. (2013; genus accepted), Jones et al. (2015; outline, marine), Maharachchikumbura et al. (2015, 2016; outline), sequences are available, needs generic revision.

Phaeopeltosphaeria Berl. \& Peglion 1892, Dothideomycetes genera incertae sedis, two species, type: P. caudata Berl. \& Peglion, asexual morph unknown, saprobes, terrestrial, worldwide, see Lumbsch and Huhndorf (2010; outline), Kirk et al. (2013; genus accepted), Wijayawardene et al. (2014c; outline), cultures and sequences are unavailable, needs generic revision.

Phaeophacidium Henn. \& Lind 1897, Rhytismataceae, Rhytismatales, Leotiomycetes, four species, type: Phaeophacidium escalloniae Henn. \& Lindau, asexual morph unknown, saprobes, causing leaf spots, terrestrial, Asia, Australia, Europe, South America, see Lumbsch 
and Huhndorf (2010; outline), Kirk et al. (2013; genus accepted), cultures and sequences are unavailable, needs generic revision.

Phaeophleospora Rangel 1916, Mycosphaerellaceae, Capnodiales, Dothideomycetes, eleven species, type: P. eugeniae Rangel, coelomycetous, with mycosphaerella-like sexual morphs, plant pathogens, see Wijayawardene et al. (2012, 2017; outline), Quaedvlieg et al. (2014; morphology; phylogeny), Crous et al. (2015d, 2016b; new species), Cultures and sequences are available, neotype of type: IMI 372655.

Phaeophloeosporella Crous \& B. Sutton 1997, Ascomycota genera incertae sedis, one species, type: P. ekebergiae (Syd.) Crous \& B. Sutton, coelomycetous, sexual morph unknown, Wijayawardene et al. (2012, 2017; outline), Kirk et al. (2013; genus accepted), cultures and sequences are unavailable, needs generic revision.

Phaeophyscia Moberg 1977, Physciaceae, Teloschistales, Lecanoromycetes, 66 species, type: Phaeophyscia orbicularis (Neck.) Moberg, foliose lichen, terrestrial, worldwide, see Shukla \& Upreti (2009; bioindicator), Lendemer (2009; record), Brackel (2011b; Iceland), Arslan et al. (2011; Turkey), Shukla et al. (2012; physiology), Pindaru et al. (2013; chemical composition), Lücking et al. (2016b; classification), cultures and sequences are available for most of the species including type, needs generic revision.

Phaeopyxis Rambold \& Triebel 1990, Helotiales genera incertae sedis, Leotiomycetes, five species, type: P. punctum (A. Massal.) Rambold, lichenicolous, terrestrial, Europe, Asia, North and South America, Australia, see Diederich et al. (2009; Europe), Motiejūnaite et al. (2011; Lithuanaia), Matwiejuk and Bohdan (2011; Poland), Himelbrant et al. (2013; Russia), Suija et al. (2015b; phylogeny), sequences are available, needs generic revision.

Phaeoramularia Munt.-Cvetk. 1960, Mycosphaerellaceae, Capnodiales, Dothideomycetes, more than 100 species names, but genus appears one species, type: P. gomphrenicola (Speg.) Munt.-Cvetk., hyphomycetous, plant pathogens, see Videira et al. (2017; morphology, phylogeny), cultures and sequences are available, holotype of type: LPS 914, isotypes of type: BPI 436740, BPI 722393; K(M) IMI 7706 (slide), MICH 15302.

Phaeorrhiza H. Mayrhofer \& Poelt 1979, Physciaceae, Teloschistales, Lecanoromycetes, two species, type: Phaeorrhiza nimbosa (Fr.) H. Mayrhofer \& Poelt, asexual morph unknown, terrestrial, saprobes, worldwide, see Lumbsch and Huhndorf (2010; outline), Kirk et al. (2013; genus accepted), Lücking et al. (2016b; classification), Resl et al. (2016; phylogeny), cultures and sequences are available, cultures available for the type: T805, needs generic revision.

Phaeosaccardinula Henn. 1905, Chaetothyriaceae, Chaetothyriales, Eurotiomycetes, 16 species, type: $P$. diospyricola Henn., asexual morph unknown, epiphytes, sooty moulds, terrestrial, China, Thailand, see Chomnunti et al. (2012; 2014; morphology; phylogeny), Lumbsch and Huhndorf (2010; outline), Kirk et al. (2013; genus accepted), Yang et al. (2014; morphology; phylogeny), cultures and sequences are available for some species, available specimen of type: CBS H-4260, needs generic revision.

Phaeoschizotrichum C.R. Silva, Gusmão \& R.F. Castañeda 2015, Ascomycota genera incertae sedis, one species, type: $P$. ramosum Silva, Gusmão \& R.F. Castañeda, hyphomycetous, sexual morph unknown, saprobes, terrestrial, Brazil, see Silva et al. (2015; morphology), cultures and sequences are unavailable, holotype of the type: HUEFS 210423, compare with Passalora, Pseudocercospora and Schizotrichum.

Phaeosclera Sigler, Tsuneda \& J.W. Carmich. 1981, Dothideomycetes genera incertae sedis, two species, type: P. dematioides Sigler, Tsuneda \& J.W. Carmich., hyphomycetous, sexual morph unknown, terrestrial, saprobes, worldwide, see Raja et al. (2011a; DNA, phylogeny), Seifert et al. (2011; morphology), Wijayawardene et al. (2012, 2017; outline), Kirk et al. (2013; genus accepted), cultures and sequences are available, isotype and cultures available for the type: CBS H-7557; CBS 157.81. 
Phaeosclerotinia Hori 1916, Sclerotiniaceae, Helotiales, Leotiomycetes, one species, type: P. nipponica Hori, asexual morph hyphomycetous, saprobes, terrestrial, Japan, see Lumbsch and Huhndorf (2010; outline), Kirk et al. (2013; genus accepted), cultures and sequences are unavailable, needs generic revision.

Phaeoscypha Spooner 1984, Pezizellaceae, Helotiales, Leotiomycetes, one species, type: P. cladii (Nag Raj \& W.B. Kendr.) Spooner, asexual morph unknown, saprobes, terrestrial, British Isles, see Lumbsch and Huhndorf (2010; outline), Kirk et al. (2013; genus accepted), Jaklitsch et al. (2016a; classification), cultures and sequences are unavailable, needs generic revision.

Phaeoseptum Ying Zhang, J. Fourn. \& K.D. Hyde 2013, Halotthiaceae, Pleosporales, Dothideomycetes, one species, type: P. aquaticum Ying Zhang, J. Fourn. \& K.D. Hyde, asexual morph unknown, saprobes, freshwater, France, see Zhang et al. (2013c; taxonomy, phylogeny), Wijayawardene et al. (2014c; outline), sequence data available for the type, holotype and ex-type strains of type: IFRD 8986; CBS 123113.

Phaeosperma Nitschke ex Fuckel 1870, Dothideomycetes genera incertae sedis, one species, type: $P$. dryophilum Nitschke ex G.H. Otth, asexual morph unknown, saprobes, terrestrial, Switzerland, see Lumbsch and Huhndorf (2010; outline), Kirk et al. (2013; genus accepted), cultures and sequences are unavailable, epitype and ex-epitype strains of type: WU 32035; CBS 133213, LG21, needs generic revision.

Phaeosphaeria I. Miyake 1909, Phaeosphaeriaceae, Pleosporales, Dothideomycetes, 90 species, type: P. oryzae I. Miyake, asexual morph coelomycetous, saprobes or pathogens, terrestrial, worldwide, see Zhang et al. (2012e; taxonomy, phylogeny), Hyde et al. (2013; accepted as a genus in Phaeosphaeriaceae), Kirk et al. (2013; genus accepted), Phookamsak et al. (2014b; taxonomy, phylogeny), Wijayawardene et al. (2014c; outline), sequence data available for more than 10 species, need adequate sequence data, needs generic revision, exepitype strains of type: CBS 110110; lectotype of type: S-F9572.

Phaeosphaeriopsis M.P.S. Câmara, M.E. Palm \& A.W. Ramaley 2003, Phaeosphaeriaceae, Pleosporales, Dothideomycetes, ten species, type: Phaeosphaeriopsis glaucopunctata (Grev.) M.P.S. Câmara, M.E. Palm \& A.W. Ramaley, asexual morph unknown coelomycetous, saprobes, terrestrial, cosmopolitan, see Lumbsch and Huhndorf (2010; outline), Hyde et al. (2013 accepted as a genus in Phaeosphaeriaceae), Phookamsak et al. (2014b; accepted as a genus in Phaeosphaeriaceae), Wijayawardene et al. (2014c, 2017; outline), Crous et al. (2016a; new species, phylogeny), cultures and sequences are available, needs generic revision.

Phaeospora Hepp 1867, Verrucariaceae, Verrucariales, Eurotiomycetes, 17 species, type: $P$. rimosicola (Leight. ex Mudd) Hepp, asexual morph unknown, lichenicolous, terrestrial, worldwide, see Etayo (2010; new species), Lumbsch and Huhndorf (2010; outline), Kirk et al. (2013; genus accepted), van den Boom and Etayo (2014; new species), cultures and sequences are unavailable for the type, needs generic revision.

Phaeosporis Clem. 1909, Sordariales genera incertae sedis, Sordariomycetes, two species, type: P. melasperma (Nyl.) Clem., asexual morph unknown, saprobes, terrestrial, France, see Lumbsch and Huhndorf (2010; outline), Kirk et al. (2013; genus accepted), Maharachchikumbura et al. (2015, 2016; outline), cultures and sequences are unavailable, needs generic revision.

Phaeosporobolus D. Hawksw. \& Hafellner 1986, six species, Ascomycota genera incertae sedis, type: P. usneae D.Hawksw. \& Hafellner, hyphomycetous, sexual morph unknown, lichenicolous, widespread, see Seifert et al. (2011; morphology), Ertz et al (2015; phylogeny), cultures and sequences are available, holotype of type: K(M)-IMI 281394.

Phaeostagonospora A.W. Ramaley 1997, Phaeosphaeriaceae, Pleosporales, Dothideomycetes, one species, type: P. nolinae A.W. Ramaley, coelomycetous, sexual morph 
paraphaeosphaeria-like, saprobes, terrestrial, worldwide, see Wijayawardene et al. (2012, 2014c, 2017; outline), Hyde et al. (2013; accepted as a genus in Phaeosphaeriaceae), Quaedvlieg et al. (2013; accepted phaeostagonospora-like asexual morphs in Paraphaeosphaeria), Phookamsak et al. (2014b; accepted as a genus in Phaeosphaeriaceae), cultures and sequences are unavailable.

Phaeostalagmus W. Gams 1976, Ascomycota genera incertae sedis, seven species, type: $P$. cyclosporus (Grove) W. Gams, hyphomycetous, sexual morph unknown, saprobes, terrestrial, worldwide, see Seifert et al. (2011; morphology, treated as Chaetosphaeriaceae), Wijayawardene et al. (2012, 2017; outline, accepted as a genus in Ascomycota), Kirk et al. (2013; genus accepted), Maharachchikumbura et al. (2015, 2016; outline, listed in Chaetosphaeriaceae), cultures and sequences are unavailable, available specimen of type: CBS H-19245, needs generic revision.

Phaeostigme Syd. \& P. Syd. 1917, Pseudoperisporiaceae, Dothideomycetes families incertae sedis, c. 20 species, type: P. picea (Berk. \& M.A. Curtis) Syd. \& P. Syd., asexual morph unknown, saprobes, terrestrial, worldwide, see Lumbsch and Huhndorf (2010; outline), Hyde et al. (2013; accepted as a genus in Pseudoperisporiaceae), Wijayawardene et al. (2014c; outline), cultures and sequences are unavailable, needs generic revision.

Phaeostilbelloides Armando, Z.M. Chaves \& Dianese 2015, Ascomycota genera incertae sedis, one species, type: P. velloziae Armando, Z.M. Chaves \& Dianese, hyphomycetous, sexual morph unknown, on living leaves, terrestrial, Brazil, see de Souza Armando et al. (2015; morphology), Wijayawardene et al. (2017; outline), cultures and sequences are unavailable, holotype of the type: UBMC 18404, compare with Myrothecium and Phaeostilbella.

Phaeotheca Sigler et al. 1981 Capnodiales, genera incertae sedis, four species, type: $P$. fissurella Sigler, Tsuneda \& J.W. Carmich., hyphomycetous, sexual morph unknown, saprobes, terrestrial, cosmopolitan, see Seifert et al. (2011; morphology), Wijayawardene et al. (2012, 2017; outline), Crous et al. (2016b; new species, phylogeny), cultures are available. Phaeothecoidea Crous 2007, Mycosphaerellaceae, Capnodiales, Dothideomycetes, three species, type: P. eucalypti Crous \& Summerell, hyphomycetous, sexual morph unknown, pathogens, saprobes, Australia, see Crous et al. (2009e; morphology, phylogeny), Seifert et al. (2011; morphology), Wijayawardene et al. (2012, 2017; outline), cultures and sequences are available, holotype and ex-type culture of type: CBS-H 19836, CPC 12918.

Phaeothecoidiella Batzer \& Crous 2010, Capnodiales genera incertae sedis, Dothideomycetes, two species, type: P. missouriensis Batzer \& Crous, hyphomycetous, sexual morph unknown, pathogens, saprobes, USA, see Yang et al. (2010; morphology, phylogeny), Seifert et al. (2011; morphology), Wijayawardene et al. (2012, 2017; outline), cultures and sequences are available, holotype and ex-type culture of type: CBS H-20322, CPC 16116.

Phaeothyriolum Syd. 1938, Dothideomycetes genera incertae sedis, one species, type: $P$. eucalyptinum Syd., asexual morph unknown, saprobes, terrestrial, China, see Lumbsch and Huhndorf (2010; outline), Kirk et al. (2013; genus accepted), Wijayawardene et al. (2014c; outline), cultures and sequences are unavailable, needs generic revision.

Phaeothyrium Petr. 1947, Ascomycota genera incertae sedis, one species, type: $P$. pulchellum Petr., coelomycetous, sexual morph unknown, saprobes, terrestrial, China, see Wijayawardene et al. (2012, 2017; outline), Kirk et al. (2013; genus accepted), cultures and sequences are unavailable, needs generic revision.

Phaeotomasellia Katum. 1981, Dothideomycetes genera incertae sedis, one species, type: $P$. ruwenzorensis Katum., asexual morph unknown, saprobes, terrestrial, Uganda, see Lumbsch and Huhndorf (2010; outline), Kirk et al. (2013; genus accepted), Wijayawardene et al. (2014c; outline), cultures and sequences are unavailable, needs generic revision. 
Phaeotrichoconis Subram. 1956, Ascomycota genera incertae sedis, two species, type: $P$. crotalariae (M.A. Salam \& P.N. Rao) Subram., hyphomycetous, sexual morph unknown, saprobes, terrestrial, worldwide, see Seifert et al. (2011; morphology), Wijayawardene et al. (2012, 2017; outline), Kirk et al. (2013; genus accepted), cultures and sequences are unavailable, needs generic revision.

Phaeotrichosphaeria Sivan. 1983, Sordariomycetes genera incertae sedis, two species, type: $P$. indica Sivan. \& N.D. Sharma, asexual morph unknown, pathogens, terrestrial, India, UK, New Zealand, see Lumbsch and Huhndorf (2010; outline), Kirk et al. (2013; genus accepted), Maharachchikumbura et al. (2015, 2016; outline), cultures and sequences are unavailable, needs generic revision.

Phaeotrichum Cain \& M.E. Barr 1956, Phaeotrichaceae, Phaeotrichales, Dothideomycetes, two species, type: P. hystricinum Cain \& M.E. Barr, asexual morph unknown, saprobes, terrestrial, worldwide, see Schoch et al. (2009; phylogeny), Lumbsch and Huhndorf (2010; outline), Zhang et al. (2012e; accepted as a genus in Phaeotrichaceae), Hyde et al. (2013; accepted as a genus in Phaeotrichaceae), Kirk et al. (2013; genus accepted), Wijayawardene et al. (2014c; outline), cultures and sequences are available but lacks for the type, needs generic revision.

Phaeoxyphiella Bat. \& Cif. 1963, Ascomycota genera incertae sedis, seven species, type: $P$. morototoni Bat. \& Cif., coelomycetous, sexual morph unknown, saprobes, terrestrial, worldwide, see Kirk et al. (2013; genus accepted), Wijayawardene et al. (2017; outline), cultures and sequences are unavailable, needs generic revision.

Phaeoxyphium Bat. \& Cif. 1963, Ascomycota genera incertae sedis, type: P. dubium (Sacc.) Bat. \& Cif., Kirk et al. (2008; treated as nom. dub.), Kirk et al. (2013; genus accepted.

Phaffomyces Y. Yamada 1997, Phaffomycetaceae, Saccharomycetales, Saccharomycetes, five species, type: P. opuntiae (Starmer, Phaff, M. Miranda, M.W. Miller \& J.S.F. Barker) Y. Yamada, asexual reproduction is by multilateral budding, saprophytic, necrotic tissue of the columnar cactus (Cephalocereus royenii), the prickly pear cactus (Opuntia inermis) and the senita cactus (Lophocereus schottii), Australia, USA, islands of the Caribbean, see Lumbsch and Huhndorf (2010; outline), Kirk et al. (2013; genus accepted), sequences are available.

Phalacrichomyces R.K. Benj. 1992, Laboulbeniaceae, Laboulbeniales, Laboulbeniomycetes, two species, type: P. normalis R.K. Benj., asexual morph unknown, biotrophic, terrestrial, Venezuela, see Lumbsch and Huhndorf (2010; outline), Kirk et al. (2013; genus accepted), cultures and sequences are unavailable.

Phalangispora Nawawi \& J. Webster 1982, Ascomycota genera incertae sedis, three species, type: $P$. constricta Nawawi \& J. Webster, hyphomycetous, sexual morph unknown, saprobes, aquatic, Asia, Caribbean, see Seifert et al. (2011; morphology), Wijayawardene et al. (2012, 2017; outline), Kirk et al. (2013; genus accepted), sequences are available (unpublished), needs generic revision.

Phanerococculus Cif. 1954, Ascomycota genera incertae sedis, two species, type: $P$. rapaneae Cif., coelomycetous, sexual morph unknown, saprobes, terrestrial, Santo Domingo, see Wijayawardene et al. (2012, 2017; outline), Kirk et al. (2013; genus accepted), cultures and sequences are unavailable, needs generic revision.

Phaneromyces Speg. \& Har. 1889, Phaneromycetaceae, Ostropales, Lecanoromycetes, one species, type: P. macrosporus (Boud.) Speg., asexual morph unknown, saprobes, terrestrial, South America, see Lumbsch and Huhndorf (2010; outline), Kirk et al. (2013; genus accepted), cultures and sequences are unavailable.

Phaulomyces Thaxt. 1931, Laboulbeniaceae, Laboulbeniales, Laboulbeniomycetes, 14 species, type: $P$. corylophodis Thaxt., asexual morph unknown, biotrophic, terrestrial, worldwide, see Lumbsch and Huhndorf (2010; outline), Kirk et al. (2013; genus accepted), cultures and sequences are unavailable. 
Phellostroma Syd. \& P. Syd. 1914, Ascomycota genera incertae sedis, one species, type: P. hypoxyloides Syd. \& P. Syd., asexual morph unknown, saprobes, terrestrial, Philippines, see Lumbsch and Huhndorf (2010; outline), Kirk et al. (2013; genus accepted), cultures and sequences are unavailable, needs generic revision.

Phialemoniopsis Perdomo, Dania García, Gené, Cano \& Guarro 2013, Sordariomycetes genera incertae sedis, six species, type: P. ocularis (Gené \& Guarro) Perdomo, Dania García, Gené \& Guarro, asexual morph unknown, pathogens on human, endophytes, terrestrial, America, China, see Perdomo et al. (2013; taxonomy, phylogeny), Desoubeaux et al. (2014; pathogens, phylogeny), Tsang et al. (2014a; new species), Maharachchikumbura et al. (2015, 2016; outline), Su et al. (2016b; new species), cultures and sequences are available, cultures available for the type: FMR 6632, needs generic revision.

Phialemonium W. Gams \& McGinnis 1983, Cephalothecaceae, Sordariomycetes families incertae sedis, six species, type: P. obovatum W. Gams \& McGinnis, hyphomycetous, sexual morph unknown, saprobes, human pathogen, terrestrial, aquatic, worldwide, see Seifert et al. (2011; morphology), Wijayawardene et al. (2012, 2017; outline), Perdomo et al. (2013; new species, phylogeny), Crous et al. (2015d; new species), Maharachchikumbura et al. (2016; outline, phylogeny), cultures and sequences are available, available specimen and cultures for the type: CBS H-1665; CBS 279.76.

Phialoarthrobotryum Matsush. 1975, Ascomycota genera incertae sedis, one species, type: $P$. triseptatum Matsush., hyphomycetous, sexual morph unknown, saprobes, terrestrial, Japan, see Seifert et al. (2011; morphology), Wijayawardene et al. (2012, 2017; outline), Kirk et al. (2013; genus accepted), cultures and sequences are unavailable, available specimen for type: CBS H-7561, needs generic revision.

Phialoascus Redhead \& Malloch 1977, ?Saccharomycetales genera incertae sedis, ? Saccharomycetes one species, type: P. borealis Redhead \& Malloch, asexual reproduction unknown, mycoparasitic on the mushroom Cortinarius huronensis, Canada, see Lumbsch and Huhndorf (2010; outline), Kirk et al. (2013; genus accepted), cultures and sequences are unavailable, needs generic revision.

Phialocephala W.B. Kendr. 1961 (= Phaeomollisia T.N. Sieber \& Grünig 2009 fide Johnston et al. 2014b), Dermateaceae, Helotiales, Leotiomycetes, 27 species, type: P. dimorphospora W.B. Kendr., hyphomycetous, sexual morph formerly named in Phaeomollisia, saprobes, terrestrial, aquatic, worldwide, see Grünig et al. (2009; new species), Wang et al. (2009b; new species, Missouri), Lumbsch and Huhndorf (2010; outline), Day et al. (2012; new species), Kirk et al. (2013; genus accepted), Johnston et al. (2014b; nomenclature), cultures available for the type: CBS 300.62, needs generic revision.

Phialogeniculata Matsush. 1971, Ascomycota genera incertae sedis, one species, type: P. guadalcanalensis Matsush., hyphomycetous, sexual morph unknown, saprobes, terrestrial, Guadeloupe, see Seifert et al. (2011; morphology), Wijayawardene et al. (2012, 2017; outline), Kirk et al. (2013; genus accepted), cultures and sequences are unavailable, needs generic revision.

Phialomyces P.C. Misra \& P.H.B. Talbot 1964, Aspergillaceae, Eurotiales, Eurotiomycetes, three species, type: P. macrosporus P.C. Misra \& P.H.B. Talbot, asexual morph unknown, saprobes, terrestrial, worldwide, see Houbraken and Samson (2011; taxonomy, phylogeny), Wijayawardene et al. (2012, 2017; outline), Kirk et al. (2013; genus accepted), cultures and sequences are available, available specimen and culture for type: CBS H-7563; CBS 430.64.

Phialophaeoisaria Matsush. 1995, Ascomycota genera incertae sedis, one species, type: $P$. spongiosa Matsush., hyphomycetous, sexual morph unknown, saprobes, terrestrial, Japan, see Seifert et al. (2011; morphology), Wijayawardene et al. (2012, 2017; outline), Kirk et al. (2013; genus accepted), cultures and sequences are unavailable, holotype of type: Matsushima Fungus Collection, Kobe, MFC-2J770, needs generic revision. 
Phialophora Medlar 1915, Herpotrichiellaceae, Chaetothyriales, Eurotiomycetes, nine species, type: P. verrucosa Medlar, hyphomycetous, mostly saprobes, terrestrial, isolated from soil, decaying plant material and other substrates, also including important clinicallyrelevant fungi, cosmopolitan, see Seifert et al. (2011; morphology), Wijayawardene et al. (2012, 2017; outline), Kirk et al. (2013; genus accepted), Réblová et al. (2013; reallocation of selected taxa), Madrid et al. (2016; reallocation), Li et al. (2017; outline, new species), cultures and sequences are available, ex-epitype of the type: CBS 140325.

Phialophorophoma Linder 1944, Pleosporales genera incertae sedis, one species, type: $P$. litoralis Linder, coelomycetous, sexual morph unknown, marine, saprobes, Europe, USA, see Kirk et al. (2013; genus accepted), Jones et al. (2015; outline, marine), Wijayawardene et al. (2017; outline), cultures and sequences are available, available specimen of type: CBS H17521, needs generic revision.

Phialosporostilbe Mercado \& J. Mena 1985, Ascomycota genera incertae sedis, five species, type: P. turbinata Mercado \& J. Mena, hyphomycetous, sexual morph unknown, saprobes, in soil, terrestrial, Asia, Caribbean, South America, see Seifert et al. (2011; morphology), Wijayawardene et al. (2012, 2017; outline), Kirk et al. (2013; genus accepted), sequences are available (unpublished), needs generic revision.

Phialostele Deighton 1969, Ascomycota genera incertae sedis, one species, type: $P$. scytopetali Deighton, hyphomycetous, sexual morph unknown, saprobes, terrestrial, Africa, see Seifert et al. (2011; morphology), Wijayawardene et al. (2012, 2017; outline), Kirk et al. (2013; genus accepted), cultures and sequences are unavailable, needs generic revision.

Phialotubus R.Y. Roy \& Leelav. 1966, Ascomycota genera incertae sedis, one species, type: P. microsporus R.Y. Roy \& Leelav., hyphomycetous, sexual morph unknown, saprobes, terrestrial, India, see Seifert et al. (2011; morphology), Wijayawardene et al. (2012, 2017; outline), Kirk et al. (2013; genus accepted), cultures and sequences are unavailable, available specimen of type: CBS H-7598, needs generic revision.

Phillipsia Berk. 1881, Sarcoscyphaceae, Pezizales, Pezizomycetes, 17 species, type: P. domingensis Berk., asexual morph hyphomycetous, saprobes, terrestrial, worldwide, see Lumbsch and Huhndorf (2010; outline), Romero et al. (2012; phylogeny), Kirk et al. (2013; genus accepted), cultures and sequences are available, cultures available for the type: DHP 7169 , needs generic revision.

Phillipsiella Cooke 1878, Capnodiales genera incertae sedis, Dothideomycetes, twelve species, type: P. atra Cooke, asexual morph unknown, saprobes, terrestrial, cosmopolitan, see Lumbsch and Huhndorf (2010; outline, accepted as a genus in Saccardiaceae), Kirk et al. (2013; genus accepted), da Silva et al. (2016; phylogeny), cultures and sequences are available.

Philobryon Döbbeler 1988, Dothideomycetes genera incertae sedis, one species, type: $P$. anuliferum Döbbeler, on Bryophyta, Papua New Guinea, see Lumbsch and Huhndorf (2010; outline), Kirk et al. (2013; genus accepted), Wijayawardene et al. (2014c; outline), cultures and sequences are unavailable, needs generic revision.

Philonectria Hara 1914, Dothideomycetes genera incertae sedis, three species, type: $P$. variabilis Hara, saprobes, Japan, Uganda, see Lumbsch and Huhndorf (2010; outline), Kirk et al. (2013; genus accepted), Wijayawardene et al. (2014c; outline), cultures and sequences are unavailable, needs generic revision.

Phloeopeccania J. Steiner 1902, Lichinaceae, Lichinales, Lichinomycetes, four species, type: $P$. pulvinulina J. Steiner, asexual morph unknown, lichenized, terrestrial, Asia, Africa, North America, see Schultz et al. (2009; Namibia, South Africa), Lumbsch and Huhndorf (2010; outline), Kirk et al. (2013; genus accepted), Candan and Schultz (2015; new species, taxonomy), Lücking et al. (2016b; classification), sequence data available for one species, needs generic revision. 
Phloeospora Wallr. 1833, Mycosphaerellaceae, Capnodiales, Dothideomycetes, c. 150 species but need a revision, type: P. ulmi (Fr.) Wallr., coelomycetous, terrestrial, worldwide, see Wijayawardene et al. (2012, 2017; outline), Kirk et al. (2013; genus accepted), Quaedvlieg et al. (2013; phylogeny), cultures and sequences are unavailable, needs generic revision.

Phloeosporina Höhn. 1924, Ascomycota genera incertae sedis, one species, type: P. minor (Ellis \& Kellerm.) Höhn., coelomycetous, sexual morph unknown, saprobes, terrestrial, Europe, see Wijayawardene et al. (2012, 2017; outline), Kirk et al. (2013; genus accepted), cultures and sequences are unavailable, needs generic revision.

Phlogicylindrium Crous, Summerb. \& Summerell 2006, Phlogicylindriaceae, Xylariales, Sordariomycetes, three species, type: P. eucalypti Crous, Summerb. \& Summerell, asexual morph unknown, saprobes, all occurring on Eucalyptus species, Australia, see Wijayawardene et al. (2012, 2017; outline), Maharachchikumbura et al. (2012, 2014; phylogeny, morphology), Crous et al. (2016a; new species, phylogeny), sequence data available for all species, holotype and ex-type strain of the type: CBS H-19749; CBS 120080. Phlyctaeniella Petr. 1922, Ascomycota genera incertae sedis, two species, type: P. polonica Petr., coelomycetous, sexual morph unknown, saprobes, terrestrial, Europe, Australia, see Tiwari et al. (2012; new species, India), Wijayawardene et al. (2012, 2017; outline), Kirk et al. (2013; genus accepted), cultures and sequences are unavailable, needs generic revision.

Phlyctema Desm. 1847, Dermateaceae, Helotiales, Leotiomycetes, c. 30, type: M. caespitosa Petr., coelomycetous, sexual morph unknown, saprobes, terrestrial, North America, see Wijayawardene et al. (2012, 2017; outline), Kirk et al. (2013; genus accepted), Quaedvlieg et al. (2013; new species), Johnston et al. (2014b; treated as a synonym of Neofabraea), Chen et al. (2016b; resurrected the genus), Crous et al. (2016a; new species, phylogeny), cultures and sequences are available, needs generic revision.

Phlyctis (Wallr.) Flot., 1850, Phlyctidaceae, Lecanorales, Lecanoromycetes, 20 species, type: $P$. agelaea (Ach.) Flot., asexual morph unknown, lichenized, terrestrial, worldwide, see Lumbsch and Huhndorf (2010; outline), Fernandez-Brime et al. (2011; phylogeny), Kelly et al. (2011; DNA barcoding), Kirk et al. (2013; genus accepted), Gasparyan and Sipman (2015; diversity and conservation), Gerra-Inohosa et al. (2015; epiphytes diversity), Lücking et al. (2016b; classification), Weerakoon et al. (2016; new species and records), sequence data available, needs generic revision.

Phoebus R.C. Harris \& Ladd, 2007, Arthoniales genera incertae sedis, Arthoniomycetes, one species, type: P. hydrophobius R.C. Harris \& Ladd, asexual morph unknown, lichenized, terrestrial, USA, see Lumbsch and Huhndorf (2010; outline), Lücking et al. (2016b; classification), sequences are unavailable.

Phoma Sacc. 1880, Didymellaceae, Pleosporales, Dothideomycetes, c. 100 species, type: P. herbarum Westend., coelomycetous, sexual morph didymella-like, saprobes, pathogens, terrestrial, worldwide, see de Gruyter et al. (2009, 2010, 2013; taxonomy, phylogeny), Aveskamp et al. (2010; phylogeny), Woudenberg et al. (2009; sexual morph), Wijayawardene et al. (2012, 2014c, 2017; outline), Hyde et al. (2013; accepted as a genus in Didymellaceae), Kirk et al. (2013; genus accepted), Chen et al. (2015b; phylogeny), cultures and sequences are available.

Phomachora Petr. \& Syd. 1925, Ascomycota genera incertae sedis, two species, type: $P$. lucida (Berk. \& M.A. Curtis) Petr. \& Syd., coelomycetous, sexual morph unknown, saprobes, terrestrial, America, Australia, see Wijayawardene et al. (2012, 2017; outline), Kirk et al. (2013; genus accepted), cultures and sequences are unavailable, needs generic revision.

Phomachorella Petr. 1947, Ascomycota genera incertae sedis, one species, type: P. parinarii Petr., coelomycetous, sexual morph unknown, saprobes, terrestrial, South Africa, see 
Wijayawardene et al. (2012, 2017; outline), Kirk et al. (2013; genus accepted), cultures and sequences are unavailable, needs generic revision.

Phomatodes Q. Chen \& L. Cai 2015, Didymellaceae, Pleosporales, Dothideomycetes, c. 20 species, type: P. aubrietiae (Moesz) Q. Chen \& L. Cai, coelomycetous, sexual morph unknown, saprobes, pathogens, terrestrial, worldwide, see Chen et al. (2015b; taxonomy, phylogeny), Wijayawardene et al. (2017; outline), cultures and sequences are available.

Phomatospora Sacc., 1875, Magnaporthaceae, Magnaporthales, Sordariomycetes, c. 100 species, type: P. berkeleyi Sacc., saprobes on submerged wood or decaying twigs, widespread, asexual morph sporothrix-like reported from culture, see Raja and Shearer (2008; overview), Lumbsch and Huhndorf (2010; outline), Jones et al. (2015; marine species, outline), Maharachchikumbura et al. (2015, 2016; outline), Senanayake et al. (2016), sequences are available for four species but lacks for the type:, available specimen of type: CBS H-5533.

Phomatosporella Tak. Kobay. \& K. Sasaki 1982, Ascomycota genera incertae sedis, one species, type: P. albomaculans Tak. Kobay. \& K. Sasaki, coelomycetous, sexual morph unknown, saprobes, terrestrial, South Africa, Japan, see Wijayawardene et al. (2012, 2017; outline), Kirk et al. (2013; genus accepted), Maharachchikumbura et al. (2015, 2016; outline, accepted in as a genus in Sordariomycetes), cultures and sequences are unavailable, needs generic revision.

Phomyces Clem. 1931, Ascomycota genera incertae sedis, one species, type: P. meliolicola (Speg.) Clem., coelomycetous, sexual morph unknown, saprobes, terrestrial, Brazil, see Wijayawardene et al. (2012, 2017; outline), Kirk et al. (2013; genus accepted), cultures and sequences are unavailable, needs generic revision.

Phragmaspidium Bat. 1960, Dothideomycetes genera incertae sedis, three species, type: $P$. corruscans (Rehm) Bat., asexual morph unknown, terrestrial, worldwide, see Lumbsch and Huhndorf (2010; outline, accepted as a genus in Microthyriaceae), Kirk et al. (2013; genus accepted), Wijayawardene et al. (2014c; outline), cultures and sequences are unavailable, needs generic revision.

Phragmeriella Hansf. 1946, Pseudoperisporiaceae, Dothideomycetes families incertae sedis, one species, type: $P$. ireninae Hansf., asexual morph unknown, saprobes, terrestrial, Africa, see Lumbsch and Huhndorf (2010; outline), Hyde et al. (2013; accepted as a genus in Pseudoperisporiaceae), Kirk et al. (2013; genus accepted), Wijayawardene et al. (2014c; outline), cultures and sequences are unavailable, needs generic revision.

Phragmitensis K.M. Wong, Poon \& K.D. Hyde 1998, Hyponectriacae, Xylariales, Sordariomycetes, two species, type: P. marina M.K.M. Wong, Poon \& K.D. Hyde, asexual morph unknown, intertidal, in salt marsh, on Phragmites, tropical, see Lumbsch and Huhndorf (2010; outline), Kirk et al. (2013; genus accepted), Maharachchikumbura et al. (2015, 2016; outline), cultures and sequences are unavailable, holotype of type: HKU (M) 5151.

Phragmiticola Sherwood 1987, Marthamycetaceae, Rhytismatales, Leotiomycetes, one species, type: P. rhopalospermum (Kirschst.) Sherwood, asexual morph unknown, saprobes, terrestrial, Europe, see Lumbsch and Huhndorf (2010; outline), Kirk et al. (2013; genus accepted), cultures and sequences are unavailable, needs generic revision.

Phragmocamarosporium Wijayaw., Yong Wang bis \& K.D. Hyde 2015, Lentitheciaceae, Pleosporales, Dothideomycetes, two speies, type: P. platani Wijayaw., Yong Wang bis \& K.D. Hyde, coelomycetous, sexual morph unknown, saprobes, Germany, China, see Wijayawardene et al. (2015, 2016b, 2017; taxonomy, phylogeny), holotype: HGUP NNW G0928-1, cultures and sequences are unavailable.

Phragmocapnias Theiss. \& Syd. 1918, Capnodiaceae, Capnodiales, Dothideomycetes, five species, typ: P. betle (Syd., P. Syd. \& E.J. Butler) Theiss. \& Syd., asexual morph unknown, tropical, see Lumbsch and Huhndorf (2010; outline), Chomnunti et al. (2011, 2014; accepted 
as a genus in Capnodiaceae), Kirk et al. (2013; genus accepted), Wijayawardene et al. (2014c; outline), cultures and sequences are available.

Phragmocephala E.W. Mason \& S. Hughes 1951, Pleurotheciaceae, Pleurotheciales, Sordariomycetes, nine species, type: P. cookei E.W. Mason \& S. Hughes, hyphomycetous, sexual morph unknown, saprobes, terrestrial, aquatic, worldwide, see Seifert et al. (2011; morphology), Wijayawardene et al. (2012, 2017; outline), Kirk et al. (2013; genus accepted), Maharachchikumbura et al. (2015, 2016; outline), Réblová et al. (2017; phylogeny), cultures and sequences are available but lacks for the type, needs generic revision.

Phragmoconidium G.F. Sepúlveda, Pereira-Carv. \& Dianese 2009, Ascomycota genera incertae sedis, two species, type: P. cerradense G.F. Sepúlveda, Pereira-Carv. \& Dianese, hyphomycetous, sexual morph unknown, saprobes, terrestrial, South America, see Seifert et al. (2011; morphology), Wijayawardene et al. (2012, 2017; outline), Kirk et al. (2013; genus accepted), cultures and sequences are unavailable, needs generic revision.

Phragmodiaporthe Wehm. 1941, Melanconidaceae, Xylariales, Sordariomycetes, five species, type: $P$. caryae (Peck) Wehm., asexual morph unknown, saprobes, North America, China, see Vasilyeva et al. (2008; new species, China), Lumbsch and Huhndorf (2010; outline), Kirk et al. (2013; genus accepted), Senanayake et al. (2015; outline), Maharachchikumbura et al. (2016; outline, phylogeny), cultures and sequences are unavailable, needs generic revision.

Phragmodiscus Hansf. 1947, Sordariomycetes genera incertae sedis, two species, type: $P$. arundinariae Hansf., asexual morph unknown, saprobes, tropical, see Lumbsch and Huhndorf (2010; outline), Kirk et al. (2013; genus accepted), Maharachchikumbura et al. (2015, 2016; outline, phylogeny), cultures and sequences are unavailable, needs generic revision.

Phragmogibbera Samuels \& Rogerson 1990, Dothideomycetes genera incertae sedis, three species, type: P. xylariicola Samuels \& Rogerson, saprobes, Venezuela, see Lumbsch and Huhndorf (2010; outline, accepted in Venturiaceae), Hyde et al. (2013; not accepted in Venturiaceae), Kirk et al. (2013; genus accepted), Wijayawardene et al. (2014c; outline), cultures and sequences are unavailable, holotype of type: VEN.

Phragmopeltis Henn. 1904, Ascomycota genera incertae sedis, five species, type: $P$. siparunae Henn., coelomycetous, sexual morph unknown, saprobes, terrestrial, tropical, see Wijayawardene et al. (2012, 2017; outline), Kirk et al. (2013; genus accepted), cultures and sequences are unavailable, needs generic revision.

Phragmoporthe Petr. 1934, Gnomoniaceae, Diaporthales, Sordariomycetes, one species, type: P. ploettneriana (Henn.) Petr., asexual morph unknown, saprobes, terrestrial, Europe, North America., see Sogonov et al. (2008; DNA, phylogeny), Lumbsch and Huhndorf (2010; outline), Kirk et al. (2013; genus accepted), Maharachchikumbura et al. (2015, 2016; outline), cultures and sequences are available but lacks for the type, needs generic revision.

Phragmoscutella Woron. \& Abramov 1927, Dothideomycetes genera incertae sedis, one species, type: $P$. abchasica Woron. \& Abramov, saprobes, former USSR, see Lumbsch and Huhndorf (2010; outline), Kirk et al. (2013; genus accepted), Wijayawardene et al. (2014c; outline), cultures and sequences are unavailable, needs generic revision.

Phragmospathula Subram. \& N.G. Nair 1966, Ascomycota genera incertae sedis, one species, type: P. phoenicis Subram. \& N.G. Nair, hyphomycetous, sexual morph unknown, saprobes, terrestrial, India, see Seifert et al. (2011; morphology), Wijayawardene et al. (2012, 2017; outline), Kirk et al. (2013; genus accepted), cultures and sequences are unavailable, needs generic revision.

Phragmospathulella J. Mena \& Mercado 1986, Ascomycota genera incertae sedis, one species, type: P. matsushimae J. Mena \& Mercado, hyphomycetous, sexual morph unknown, saprobes, terrestrial, Cuba, see Seifert et al. (2011; morphology), Wijayawardene et al. (2012, 
2017; outline), Kirk et al. (2013; genus accepted), cultures and sequences are unavailable, needs generic revision.

Phragmosperma Theiss. \& Syd. (1917) [1916], Dothideomycetes genera incertae sedis, type: P. marattiae (Henn.) Theiss. \& Syd., data inadequate, see Lumbsch and Huhndorf (2010; outline), Kirk et al. (2013; did not list), Wijayawardene et al. (2014c; outline), sequences are unavailable,

Phragmotrichum Kunze 1823, Ascomycota genera incertae sedis, four species, type: $P$. chailletii Kunze, coelomycetous, sexual morph unknown, saprobes, terrestrial, Europe, Asia, see Wijayawardene et al. (2012, 2016b, 2017; outline, taxonomy), Kirk et al. (2013; genus accepted), cultures and sequences are unavailable, available specimen for type: CBS H16912, needs generic revision.

Phthora d'Hérelle 1909, Ascomycota genera incertae sedis, one species, type: P. vastatrix d'Hérelle, asexual morph unknown, saprobes, terrestrial, Guatemala, see Lumbsch and Huhndorf (2010; outline), Kirk et al. (2013; genus accepted), cultures and sequences are unavailable, needs generic revision.

Phurmomyces Thaxt. 1931, Ceratomycetaceae, Laboulbeniales, Laboulbeniomycetes, one species, type: P. obtusus Thaxt., asexual morph unknown, saprobes, Asia, see Lumbsch and Huhndorf (2010; outline), Kirk et al. (2013; genus accepted), cultures and sequences are unavailable.

Phycomelaina Kohlm., 1968, Phyllachorales genera incertae sedis, Sordariomycetes, one species, type: P. laminariae (Rostr.) Kohlm., asexual morph unknown, on marine alga Laminaria, temperate, see Lumbsch and Huhndorf (2010; outline, accepted as a gemus in Phyllachoraceae), Kirk et al. (2013; genus accepted), Jones et al. (2015; review), Maharachchikumbura et al. (2015, 2016; outline, accepted as a genus in Phyllachorales), cultures and sequences are unavailable, needs generic revision.

Phycorella Döbbeler 1980, Dothideomycetes genera incertae sedis, one species, type: $P$. scytonematis Döbbeler, parasites, Australia, see Lumbsch and Huhndorf (2010; outline), Kirk et al. (2013; genus accepted), Wijayawardene et al. (2014c; outline), cultures and sequences are unavailable, needs generic revision.

Phylacia Lév. 1845 (= Henningsina Möller 1901; = Leveillea Fr. 1849 fide Wendt et al. 2017), Hypoxylaceae, Xylariales, Sordariomycetes, eight species, type: P. globosa Lév., asexual morph unknown, terrestrial, saprobes, mainly coprophilous, worldwide, see Lumbsch and Huhndorf (2010; outline), Kirk et al. (2013; genus accepted), Maharachchikumbura et al. (2015, 2016; outline), Wendt et al. (2017; accepted as a genus in Hypoxylaceae), cultures and sequences are available.

Phyllachora Nitschke ex Fuckel 1870, Phyllachoraceae, Phyllachorales, Sordariomycetes, c. 1000 species (need revision), type: P. graminis (Pers.) Fuckel, saprobes, North and South America, see Lumbsch and Huhndorf (2010; outline), Santos et al. (2012; phylogeny), Kirk et al. (2013; genus accepted), Maharachchikumbura et al. (2015, 2016; outline), DNA sequence available for the voucher UB21307 of the type, available specimen of type: CBS H-5212, needs generic revision.

Phyllachorella Syd. 1914, Botryosphaeriaceae, Botryosphaeriales, Dothideomycetes, one species, type: P. micheliae Syd., asexual morph unknown, saprobes, terrestrial, India, see Lumbsch and Huhndorf (2010; outline, accepted as a genus in Dothideaceae), Kirk et al. (2013; genus accepted), Hyde et al. (accepted as a genus in Botryosphaeriaceae), Wijayawardene et al. (2014c; outline), cultures and sequences are unavailable, available specimen of type: CBS H-4052, needs generic revision.

Phyllactinia Lév. 1851, Erysiphaceae, Erysiphales, Leotiomycetes, 111 species, type: P. guttata (Wallr.: Fr. ) Lév., asexual morph hyphomycetous, biotrophic, obligate plant pathogens, terrestrial, worldwide, see Takamatsu et al. (2008b, 2016; phylogeny), Lumbsch 
and Huhndorf (2010; outline), Braun and Cook (2012; taxonomy), Kirk et al. (2013; genus accepted), cultures and sequences are available, lectotype of type: ex herb. de Candolle (G 00122109).

Phylleutypa Petr. 1934, Phyllachoraceae, Phyllachorales, Sordariomycetes, two species, type: P. dioscoreae (Wakef.) Petr., saprobes, Africa, north temperate, see Lumbsch and Huhndorf (2010; outline), Kirk et al. (2013; genus accepted), Maharachchikumbura et al. (2015, 2016; outline), cultures and sequences are unavailable, needs generic revision.

Phylliscidiopsis Sambo 1937, Lichinaceae, Lichinales, Lichinomycetes, one species, type: P. abissinica Sambo., asexual morph unknown, lichenized, terrestrial, Africa, see Lumbsch and Huhndorf (2010; outline), Kirk et al. (2013; genus accepted), Lücking et al. (2016b; classification), cultures and sequences are unavailable, needs generic revision.

Phylliscidium Forssell 1885, Lichinaceae, Lichinales, Lichinomycetes, one species, type: P. monophyllum (Kremp.) Forssell, asexual morph unknown, lichenized, terrestrial, see Lumbsch and Huhndorf (2010; outline) Kirk et al. (2013; genus accepted), Lücking et al. (2016b; classification), cultures and sequences are unavailable, Needs generic revision.

Phyllisciella Henssen 1984, Lichinaceae, Lichinales, Lichinomycetes, three species, type: P. marionensis Henssen, asexual morph unknown, lichenized, terrestrial, Africa, see de Lange et al. (2012; conservation), Lumbsch and Huhndorf (2010; outline) Kirk et al. (2013; genus accepted), Lücking et al. (2016b; classification), cultures and sequences are unavailable, needs generic revision.

Phylliscum Nyl. 1855, Lichinaceae, Lichinales, Lichinomycetes, eight species, type: Phylliscum demangeonii (Moug. \& Mont.) Nyl., asexual morph unknown, lichenized, terrestrial, worldwide, see Bajpai et al. (2009; biodeterioration), Sheik et al. (2009, 2016; taxonomy), Lumbsch and Huhndorf (2010; outline), Anderson and Neily (2012, Nova Scotia), Prieto et al. (2012; phylogeny), Kirk et al. (2013; genus accepted), Goni et al. (2014; Jammu), Shukla et al. (2014b; diversity), Lücking et al. (2016b; classification), Uppadhyay et al. (2016, diversity), sequences are available.

Phyllobaeis Kalb \& Gierl 1993, Baeomycetaceae, Baeomycetales, Lecanoromycetes, six species, type: Phyllobaeis imbricata (Hook.) Kalb \& Gierl, asexual morph unknown, lichenized, terrestrial, worldwide, see Lumbsch and Huhndorf (2010; outline), Cao et al. (2013; new species, phylogeny), Kirk et al. (2013; genus accepted), Flakus et al. (2015; taxonomy), Mittermeier et al. (2015; metabolic profiling), Lücking et al. (2016b; classification), sequences are available.

Phyllobathelium (Müll. Arg.) Müll. Arg. 1890, Strigulaceae, Strigulales, Dothideomycetes, five species, type: P. epiphyllum (Müll. Arg.) Müll. Arg., asexual morph unknown, lichenized fungi, terrestrial, tropical, see Nelsen et al. (2009, 2011; description, phylogeny), Lücking (2008; partial monograph), Lumbsch and Huhndorf (2010; outline), Kirk et al. (2013; genus accepted), Wijayawardene et al. (2014c; outline), Lücking et al. (2016b; classification), cultures and sequences are available, needs generic revision.

Phylloblastia Vain. 1921, Verrucariaceae, Verrucariales, Eurotiomycetes, twelve species, type: $P$. dolichospora Vain., asexual morph unknown, lichenicolous, terrestrial, pantropical, see Flakus and Lücking (2008; new species, Bolivia), Lücking (2008; new species), Lumbsch and Huhndorf (2010; outline), McCarthy (2010; new species), Kirk et al. (2013; genus accepted), McCarthy and Stajsic (2013; new species), van den Broeck et al. (2014; new species), Lücking et al. (2016b; classification), cultures and sequences are unavailable for the type, needs generic revision.

Phyllocelis Syd. 1925, Sordariomycetes genera incertae sedis, two species, type: P. oyedaeae Syd., saprobes, Central America, see Lumbsch and Huhndorf (2010; outline), Kirk et al. (2013; genus accepted), Maharachchikumbura et al. (2015, 2016; outline), cultures and sequences are unavailable, needs generic revision. 
Phyllocratera Sérusiaux \& Aptroot 1997, Strigulaceae, Strigulales, Dothideomycetes, two species, type: $P$. papuana Sérusiaux \& Aptroot, asexual morph unknown, lichenized, terrestrial, tropical, see Lumbsch and Huhndorf (2010; outline), Hyde et al. (2013; accepted in Strigulaceae), Kirk et al. (2013; genus accepted), Wijayawardene et al. (2014c; outline), cultures and sequences are unavailable, holotype of type: LG (Lambinon 87.427).

Phyllocrea Höhn. 1918, Phyllachoraceae, Phyllachorales, Sordariomycetes, one species, type: P. quitensis (Pat.) Höhn., from living leaves, South America, see Lumbsch and Huhndorf (2010; outline), Kirk et al. (2013; genus accepted), Maharachchikumbura et al. (2015, 2016; outline), cultures and sequences are unavailable, needs generic revision.

Phylloedium Fr. 1825, Ascomycota genera incertae sedis, one species, type: P. epiphylla Fr., coelomycetous, sexual morph unknown, saprobes, terrestrial, Europe, see Wijayawardene et al. (2012, 2017; outline), Kirk et al. (2013; genus accepted), cultures and sequences are unavailable, needs generic revision.

Phyllogyalidea Lücking \& Aptroot 2008, Gomphillaceae, Ostropales, Lecanoromycetes, two species, type: P. epiphylla (Vězda) Lücking \& Aptroot, asexual morph unknown, lichenized, terrestrial, tropical, see Lücking (2008; taxonomy), Lumbsch and Huhndorf (2010; outline), Lücking et al. (2016b; classification), cultures and sequences are unavailable, needs generic revision.

Phyllohendersonia Tassi 1902, Ascomycota genera incertae sedis, 25 species, type: $P$. mahoniae Unamuno, coelomycetous, sexual morph unknown, saprobes, terrestrial, Europe, see Wijayawardene et al. (2012, 2017; outline, taxonomy), Kirk et al. (2013; genus accepted), cultures and sequences are unavailable, needs generic revision.

Phyllopezis Petr. 1949, Leotiomycetes genera incertae sedis, one species, type: P. andina Petr., asexual morph unknown, saprobes, terrestrial, South America, see Lumbsch and Huhndorf (2010; outline), Kirk et al. (2013; genus accepted), cultures and sequences are unavailable, needs generic revision.

Phylloporthe Syd. 1925, Gnomoniaceae, Diaporthales, Sordariomycetes, one species, type: $P$. vernoniae Syd., asexual morph unknown, saprobes, terrestrial, tropical, see Lumbsch and Huhndorf (2010; outline), Kirk et al. (2013; genus accepted), Maharachchikumbura et al. (2015, 2016; outline), cultures and sequences are unavailable, needs generic revision.

Phyllosticta Pers. 1818 (= Guignardia Viala \& Ravaz 1892 fide Wijayawardene et al. 2014c), Phyllostictaceae, Botryosphaeriales, Dothideomycetes, c. 100 species, type: P. convallariae Pers., coelomycetous, sexual morph formerly named in Guignardia, saprobes, pathogens, endophytes, terrestrial, worlwide, see Wulandari et al. (2009; pathogens), Glienke et al. (2011; taxonomy), Wikee et al. (2011, 2013a, b; review), Su and Cai (2012; phylogeny), Hyde et al. (2013; taxonomy, phylogeny), Kirk et al. (2013; genus accepted), Slippers et al. (2013; phylogeny), Wijayawardene et al. (2014c; outline, phylogeny), cultures and sequences are available, available specimen of type: CBS H-16994, needs generic revision.

Phymatotrichopsis Hennebert 1973, Rhizinaceae, Pezizales, Pezizomycetes, 17 species, type: P. omnivora (Duggar) Hennebert, hyphomycetous, sexual morph unknown, pathogens, terrestrial, North America, see Wijayawardene et al. (2012, 2017; outline), Kirk et al. (2013; genus accepted), cultures and sequences are available, needs generic revision.

Physalidiella Rulamort 1990, Ascomycota genera incertae sedis, three species, type: $P$. elegans (Mosca) Rulamort, hyphomycetous, sexual morph unknown, saprobes, terrestrial, Asia, Caribbean, Europe, South America, see Seifert et al. (2011; morphology), Wijayawardene et al. (2012, 2017; outline), Kirk et al. (2013; genus accepted), cultures and sequences are unavailable, needs generic revision.

Physalidiopsis R.F. Castañeda \& W.B. Kendr. 1990, Ascomycota genera incertae sedis, one species, type: P. carbonis (R.F. Castañeda) R.F. Castañeda \& W.B. Kendr., hyphomycetous, sexual morph unknown, saprobes, terrestrial, Caribbean, see Seifert et al. (2011; morphology), 
Wijayawardene et al. (2012, 2017; outline), Kirk et al. (2013; genus accepted), cultures and sequences are unavailable, needs generic revision.

Physalospora Niessl 1876, Hyponectriaceae, Xylariales, Sordariomycetes, 37 species, type: $P$. alpestris Niessl, asexual morph unknown, terrestrial, aquatic, saprobes and endophytic, widespread, see Raja and Shearer (2008; new species, freshwater), Polashock et al. (2009; phylogeny), Lumbsch and Huhndorf (2010; outline), Kirk et al. (2013; genus accepted), Maharachchikumbura et al. (2015, 2016; outline), sequences are available for three species, needs generic revision.

Physalosporopsis Bat. \& H. Maia 1955, Dothideomycetes genera incertae sedis, 17 species, type: P. rhizophoricola Bat. \& H. Maia, asexual morph unknown, pathogens, terrestrial, Brazil, see Lumbsch and Huhndorf (2010; outline), Kirk et al. (2013; genus accepted), Wijayawardene et al. (2014c; outline), cultures and sequences are unavailable, needs generic revision.

Physcia (Schreb.) Michaux 1803, Physciaceae, Caliciales, Lecanoromycetes, 80 species, type: P. tenella (Scop.) DC., lichenized, worldwide, see Lumbsch and Huhndorf (2010; outline), Aptroot and Aslan (2012; new records), Gaya et al. (2012; phylogeny), Prieto et al. (2013; phylogeny), Kirk et al. (2013; genus accepted), Kondratyuk et al. (2015g; new species), Prieto and Wedin (2016; phylogeny), Lücking et al. (2016b; classification), cultures and sequences are available, needs generic revision.

Physcidia Tuck 1862, Ramalinaceae, Lecanorales, Lecanoromycetes, ten species, type: $P$. wrightii (Tuck.) Tuck., asexual morph unknown, lichenized, terrestrial, worldwide, see Lumbsch and Huhndorf (2010; outline), Kirk et al. (2013; genus accepted), Aptroot and Caceres (2014; key), Dong et al. (2015; new records), Lücking et al. (2016b; classification), cultures and sequences are unavailable, needs generic revision.

Physciella Essl. 1986, Physciaceae, Caliciales, Lecanoromycetes, four species, type: P. chloantha (Ach.) Essl., lichenized, see Lumbsch and Huhndorf (2010; outline), Gaya et al. (2012; phylogeny), Prieto et al. (2013; phylogeny), Prieto and Wedin (2016; phylogeny), Lücking et al. (2016b; classification), cultures and sequences are available, needs generic revision.

Physconia Poelt 1965, Physciaceae, Lecanorales, Lecanoromycetes, 25 species, type: $P$. pulverulenta (Schreb.) Poelt, asexual morph unknown, lichenized, terrestrial, worldwide, see Lendemer et al. (2009; taxonomy), Begum and HariKrishna (2010; air pollution), Björk (2010; new record), Esslinger and Dillman (2010; new record), Loppi and Nascimbene (2010; bioindicators), Stamenković and Cvijan (2010; air pollution). Stamenković et al. (2010; bioindicators), Lisowska (2011; air pollution), Lumbsch and Huhndorf (2010; outline), Tsurykau et al. (2011; checklist), Yatsyna (2011; taxonomy), Gaya et al. (2012; sequence), Vicol (2012; list), Jury (2013; list), Kirk et al. (2013; genus accepted), Bilovitz (2014; biodiversity), Goni et al. (2014; checklist), Karakoti et al. (2014; taxonomy), Paoli et al. (2015; air pollution), Yavuz et al. (2015; epiphytes diversity), Lücking et al. (2016b; classification), Motiejūnaite et al. (2016; list), sequences are available for few species, needs generic revision.

Physma A. Massal. 1854, Pannariaceae, Peltigerales, Lecanoromycetes, 51 species, type: P. boryanum (Pers.) A. Massal., asexual morph unknown, lichenized, terrestrial, worldwide, see Wedin et al. (2009b; phylogeny), Diederich et al. (2010b; lectotypification), Otálora et al. (2010; phylogeny), Lumbsch and Huhndorf (2010; outline), Din et al. (2010; chemoprofile), Jayalal et al. (2013a; Vietnam), Kirk et al. (2013; genus accepted), Magain and Sérusiaux (2014; drivers in lichen symbiosis), Kerr (2014; checklist), Magain and Serusiaux (2014; partial sequence), Ekman et al. (2014; transferred to Pannariaceae), Aptroot and John (2015; taxonomy), Lücking et al. (2016b; classification), Ohmura et al. (2016; Japan), Rangsiruji et al. (2016; phylogeny), sequences are available but lacks for type, needs generic revision. 
Physmatomyces Rehm 1900, Leotiomycetes genera incertae sedis, one species, type: P. compacti E.A. Thomas ex Cif. \& Tomas., asexual morph unknown, saprobes, terrestrial, Brazil, see Lumbsch and Huhndorf (2010; outline), Kirk et al. (2013; genus accepted), cultures and sequences are unavailable, needs generic revision.

Picardella I.I. Tav. 1985, Laboulbeniaceae, Laboulbeniales, Laboulbeniomycetes, two species, type: P. endogaea (F. Picard) I.I. Tav., asexual morph unknown, biotrophic, terrestrial, Europe, see Lumbsch and Huhndorf (2010; outline), Kirk et al. (2013; genus accepted), cultures and sequences are unavailable.

Piccolia A. Massal. 1856, Lecanoromycetes genera incertae sedis, seven species, type: $P$. crocea (Spreng.) A. Massal., lichenized, see Lumbsch and Huhndorf (2010; outline), Lücking et al. (2016b; classification), cultures and sequences are unavailable, needs generic revision.

Piceomphale Svrček 1957, Sclerotiniaceae, Helotiales, Leotiomycetes, one species, type: P. bulgarioides (P. Karst.) Svrček, asexual morph unknown, saprobes, cosmopolitan, see Lumbsch and Huhndorf (2010; outline, accepted as a genus in Rutstroemiaceae), Jaklitsch et al (2016a; classification), cultures and sequences are available.

Pichia E.C. Hansen 1904, Pichiaceae, Saccharomycetales, Saccharomycetes, 35 species, type: P. membranifaciens (E.C. Hansen) E.C. Hansen, asexual reproduction is by multilateral budding, saprophytic, but a few strains are of clinical origin, insect frass from various trees, cacti, rotted fruit, spoiled fruit juice, soil, tanning liquor, sputum, cecum of a cow, human and animal feces, various clinical sources $(P$. kudriavzevii $=$ Candida krusei), worldwide, see Lumbsch and Huhndorf (2010; outline), Kirk et al. (2013; genus accepted), a few asexual species of this clade presently remain in Candida, but will be transferred to Pichia as new combinations, cultures and sequences are available, needs generic revision.

Picoa Vittad. 1831, Pyronemataceae, Pezizales, Pezizomycetes, three species, type: $P$. juniperi Vittad., asexual morph unknown, saprobes, hypogeous, terrestrial, worldwide, see Guecin et al. (2010; Turkey), Lumbsch and Huhndorf (2010; outline), Sbissi et al. (2010; DNA, phylogeny), Ammarellou et al. (2011; phylogeny), Kirk et al. (2013; genus accepted), cultures and sequences are available, needs generic revision.

Pidoplitchkoviella Kiril. 1975, Xylariales genera incertae sedis, Sordariomycetes, one species, type: $P$. terricola Kiril., asexual morph unknown, from soil, terrestrial, British Islesraine, see Lumbsch and Huhndorf (2010; outline), Kirk et al. (2013; genus accepted), Maharachchikumbura et al. (2015, 2016; outline), cultures and sequences are available, needs generic revision.

Piedraia Fonseca \& Leão 1928, Piedraiaceae, Capnodiales, Dothideomycetes, two species, type: P. hortae Fonseca \& Leão, asexual morph unknown, human pathogen, terrestrial, tropical, see Lumbsch and Huhndorf (2010; outline), Hyde et al. (2013; taxonomy), Kirk et al. (2013; genus accepted), Wijayawardene et al. (2014c; outline), cultures and sequences are available.

Piggotia Berk. \& Broome 1851, Ascomycota genera incertae sedis, three species, type: $P$. astroidea (Berk.) Berk. \& Broome, coelomycetous, sexual morph unknown, saprobes, terrestrial, temperate, see Wijayawardene et al. (2012, 2017; outline), Kirk et al. (2013; genus accepted), cultures and sequences are unavailable, needs generic revision.

Pileomyces K.L. Pang \& Jheng 2012, Halosphaeriaceae, Microascales, Sordariomycetes, one species, type: P. formosanus K.L. Pang \& J.S. Jheng, asexual morph unknown, saprobes, marine, Taiwan, see Pang and Jheng (2012b; phylogeny), Maharachchikumbura et al. (2015, 2016; outline), cultures and sequences are available, holotype of type: BBH 30192, BIOTEC Bangkok Herbarium.

Pilgeriella Henn. 1900, Perisporiopsidaceae, Dothideomycetes families incertae sedis, two species, type: $P$. perisporioides Henn., asexual morph unknown, saprobes, terrestrial, South America, see Lumbsch and Huhndorf (2010; outline), Hyde et al. (2013; accepted as a genus 
in Perisporiopsidaceae), Kirk et al. (2013; genus accepted), Wijayawardene et al. (2014c; outline), cultures and sequences are unavailable, needs generic revision.

Pilidium Kunze 1823 (= Discohainesia Nannf. 1932; Hainesia Ellis \& Sacc. 1884; Sclerotiopsis Speg. 1882 fide Johnston et al. 2014b), Chaetomellaceae, Helotiales, Leotiomycetes, six species, type: P. acerinum (Alb. \& Schwein.) Kunze, coelomycetous, sexual morph formerly named in Discohainesia, saprobes, terrestrial, South America, see Lumbsch and Huhndorf (2010; outline), Wijayawardene et al. (2012, 2017; outline), Kirk et al. (2013; genus accepted), Crous et al. (2013b, 2015e; new species), Johnston et al. (2014b; nomenclature, new combination), cultures and sequences are available, available specimen and cultures for the type: CBS H-17074; CBS 736.68.

Pilophorus Th. Fr., 1857, Cladoniaceae, Lecanorales, Lecanoromycetes, 38 species, type: $P$. robustus $\mathrm{Th}$. Fr., asexual morph unknown, lichenized, terrestrial, worldwide, see Wang et al. (2010c, 2011a, b; new species, taxonomy), Lim et al. (2010; pyrosequencing), Lumbsch and Huhndorf (2010; outline), Kirk et al. (2013; genus accepted), Lücking et al. (2016b; classification), sequence data available, needs generic revision.

Pinatubo J.B. Manandhar \& Mew 1996, Ascomycota genera incertae sedis, one species, type: $P$. oryzae J.B. Manandhar \& Mew, hyphomycetous, sexual morph unknown, saprobes, terrestrial, Asia, see Seifert et al. (2011; morphology), Wijayawardene et al. (2012, 2017; outline, taxonomy), Kirk et al. (2013; genus accepted), cultures and sequences are unavailable, holotype of type: ?CALP [as 'UPLB'] 10284, needs generic revision.

Piperivora Siboe, P.M. Kirk \& P.F. Cannon 1999, Ascomycota genera incertae sedis, one species, type: P. nodosa Siboe, P.M. Kirk \& P.F. Cannon, hyphomycetous, sexual morph unknown, saprobes, terrestrial, Africa, see Seifert et al. (2011; morphology), Wijayawardene et al. (2012, 2017; outline, taxonomy), Kirk et al. (2013; genus accepted), cultures and sequences are unavailable, holotype of type: IMI 376523, needs generic revision.

Piricauda Bubák 1914, Ascomycota genera incertae sedis, eight species, type: P. uleana (Sacc. \& P. Syd.) Bubák, hyphomycetous, sexual morph unknown, saprobes, terrestrial, cosmopolitan, see Seifert et al. (2011; morphology), Whitton et al. (2012a; morphology), Hyde et al. (2011; outline), Wijayawardene et al. (2012, 2017; outline, taxonomy), Kirk et al. (2013; genus accepted), cultures and sequences are unavailable, needs generic revision.

Piricaudilium Hol.-Jech. 1988, Ascomycota genera incertae sedis, two species, type: $P$. lobatum Hol.-Jech., hyphomycetous, sexual morph unknown, saprobes, terrestrial, Asia, Cribbean, see Seifert et al. (2011; morphology), Wijayawardene et al. (2012, 2017; outline, taxonomy), Kirk et al. (2013; genus accepted), cultures and sequences are unavailable, available specimen for type: CBS H-4357, needs generic revision.

Piricaudiopsis J. Mena \& Mercado 1987, Ascomycota genera incertae sedis, one species, type: P. elegans J. Mena \& Mercado, hyphomycetous, sexual morph unknown, saprobes, terrestrial, Asia, Caribbean, see Seifert et al. (2011; morphology), Wijayawardene et al. (2012, 2017; outline, taxonomy), Kirk et al. (2013; genus accepted), Zhang et al. (2014b; transferred five species to new genus Xiuguozhangia), cultures and sequences are unavailable, needs generic revision.

Pirispora Faurel \& Schotter 1966, Ascomycota genera incertae sedis, one species, type: $P$. trisetosa Faurel \& Schotter, coelomycetous, sexual morph unknown, saprobes, terrestrial, Algeria, see Wijayawardene et al. (2012, 2017; outline), Kirk et al. (2013; genus accepted), cultures and sequences are unavailable, needs generic revision.

Pirostomella Sacc. 1914, Ascomycota genera incertae sedis, two species, type: P. raimundi Sacc., hyphomycetous, sexual morph unknown, saprobes, terrestrial, Philippines, see Wijayawardene et al. (2012, 2017; outline), Kirk et al. (2013; genus accepted), cultures and sequences are unavailable, needs generic revision. 
Pirottaea Sacc. 1878, Ploettnerulaceae, Helotiales, Leotiomycetes, 28 species, type: P. veneta Sacc. \& Speg., asexual morph unknown, saprobes, terrestrial, aquatic, worldwide, see Lumbsch and Huhndorf (2010; outline), Chlebicka and Konvalinkova (2011; new species), Kirk et al. (2013; genus accepted), cultures available but lacks for the type, needs generic revision.

Pirozynskia Subram. 1972, Dothideomycetes genera incertae sedis, two species, type: $P$. farriae Subram., sexual morph maurodothina-like, epiphytes, terrestrial, worldwide, see Hofmann (2009; review, accepted as a genus in Asterinaceae), Wijayawardene et al. (2014c; outline, accepted as a genus in Dothideomycetes), cultures and sequences unavailable, needs generic revision.

Pirozynskiella S. Hughes 2007, Ascomycota genera incertae sedis, two species, type: P. solaninum (Sacc. \& P. Syd.) S. Hughes, hyphomycetous, sexual morph unknown, saprobes, terrestrial, Asia, Caribbean, see Seifert et al. (2011; morphology), Wijayawardene et al. (2012, 2017; outline, taxonomy), Kirk et al. (2013; genus accepted), cultures and sequences are unavailable, needs generic revision.

Pisomyxa Corda 1837, Eurotiomycetidae genera incertae sedis, one species, type: $P$. rhacodioides Corda, asexual morph unknown, saprobes, terrestrial, South America, seeLumbsch and Huhndorf (2010; outline), Kirk et al. (2013; genus accepted), cultures available but lacks for the type, needs generic revision.

Pisorisporium Réblová \& J. Fourn. 2015, Pisorisporiaceae, Pisorisporiales, Sordariomycetes, one species, type: $P$. cymbiforme Réblová \& J. Fourn., asexual morph unknown, from submerged branch, aquatic, France, Belgium, see Réblová et al. (2015a; taxonomy, phylogeny), Maharachchikumbura et al. (2015, 2016; outline), cultures and sequences are available, holotype and ex-type cultures available for the type: PRM 924377; CBS 138884.

Pithomyces Berk. \& Broome 1873, Pleosporaceae, Pleosporales, Dothideomycetes, c. 38 species, type: P. flavus Berk. \& Broome, hyphomycetous, sexual morph didymella-like, saprobes, human and plant pathogens, terrestrial, worldwide, see Seifert et al. (2011; morphology), Kirk et al. (2013; genus accepted), Irinyi et al. (2015; DNA barcodes for clinically important species), Wijayawardene et al. (2017; outline), cultures and sequences are available, needs generic revision.

Pithosira Petr. 1949, Ascomycota genera incertae sedis, two species, type: P. sydowii Petr., hyphomycetous, sexual morph unknown, saprobes, terrestrial, Asia, Ecuador, Caribbean, see Seifert et al. (2011; morphology, accepted as a genus in Venturiaceae), Wijayawardene et al. (2012, 2017; outline), Kirk et al. (2013; genus accepted), cultures and sequences are unavailable, needs generic revision.

Pithya Fuckel 1870, Sarcoscyphaceae, Pezizales, Pezizomycetes, five species, type: $P$. cupressina (Batsch) Fuckel, asexual morph unknown, saprobes, terrestrial, north temperate, see Lumbsch and Huhndorf (2010; outline), Kirk et al. (2013; genus accepted), cultures and sequences are available.

Pithyella Boud. 1885, ?Helotiaceae, Helotiales, Leotiomycetes, eight species, type: $P$. hypnina (Quél.) Boud., asexual morph unknown, saprobes, on bryophytes, terrestrial, British Isles, see Lumbsch and Huhndorf (2010; outline), Kirk et al. (2013; genus accepted), Jaklitsch et al. (2016a; classification), cultures and sequences are unavailable, needs generic revision.

Pittostroma Kowalski \& T.N. Sieber 1992, Ascomycota genera incertae sedis, one species, type: P. abietinum Kowalski \& T.N. Sieber, coelomycetous, sexual morph unknown, saprobes, terrestrial, Poland, see Wijayawardene et al. (2012, 2017; outline), Kirk et al. (2013; genus accepted), cultures and sequences are unavailable, holotype of type: ZT, needs generic revision. 
Placella Syd. 1938, Ascomycota genera incertae sedis, one species, type: P. fraseriana Syd., coelomycetous, sexual morph unknown, saprobes, terrestrial, Australia, see Wijayawardene et al. (2012, 2017; outline), Kirk et al. (2013; genus accepted), cultures and sequences are unavailable, needs generic revision.

Placidiopsis Beltr. 1858, Verrucariaceae, Verrucariales, Eurotiomycetes, 20 species, type: $P$. grappae Beltr., asexual morph unknown, lichenicolous, terrestrial, worldwide, see Lumbsch and Huhndorf (2010; outline), Prieto et al. (2010a; new species), Kirk et al. (2013; genus accepted), cultures and sequences are available but lacks for the type, needs generic revision.

Placidium A. Massal. 1855, Verrucariaceae, Verrucariales, Eurotiomycetes, 28 species, type: P. michelii A. Massal., asexual morph unknown, lichenicolous, lichenized, terrestrial, worldwide, see Gueidan et al. (2009; new species), Lumbsch and Huhndorf (2010; outline), Prieto et al. (2012; new species), Kirk et al. (2013; genus accepted), sequences are available for the voucher M. Prieto 702 of the type, needs generic revision.

Placoasterella Sacc. ex Theiss. \& Syd. 1915, Parmulariaceae, Dothideomycetes families incertae sedis, four species, type: P. schweinfurthii (Henn.) Theiss. \& Syd., asexual morph unknown, epiphytes, terrestrial, worldwide, see Hofmann (2009; review, accepted in Asterinaceae), Lumbsch and Huhndorf (2010; outline, accepted as a genus in Asterinaceae), Hongsanan et al. (2014c; taxonomy, keys, transferred to Parmulariaceae), Wijayawardene et al. (2014c; outline), cultures and sequences are unavailable, needs generic revision.

Placoasterina Toro 1930, Dothideomycetes genera incertae sedis, three species, type: $P$. antioquensis Toro, asexual morph unknown, terrestrial, worldwide, see Lumbsch and Huhndorf (2010; outline, accepted as a genus in Asterinaceae), Kirk et al. (2013; genus accepted), Wijayawardene et al. (2014c; outline), cultures and sequences are unavailable, needs generic revision.

Placocarpus Trevis. 1860, Verrucariaceae, Verrucariales, Eurotiomycetes, five species, type: P. schaereri (Fr.) Breuss, asexual morph unknown, lichenized, terrestrial, worldwide, see Knudsen et al. (2009a; new species, USA), Moon and Aptroot (2009; new species, South Korea), Lumbsch and Huhndorf (2010; outline), Prieto et al. (2010a; new species), Roux and Gueidan (2011; new specis, France), Kirk et al. (2013; genus accepted), cultures and sequences are available, needs generic revision.

Placocrea Syd. 1939, Mycosphaerellaceae, Capnodiales, Dothideomycetes, four species, type: Placocrea pulchella Syd., asexual morph unknown, saprobes, terrestrial, Ecuador, see Lumbsch and Huhndorf (2010; outline), Kirk et al. (2013; genus accepted), cultures and sequences are unavailable, needs generic revision.

Placodiplodia Bubák 1916, Ascomycota genera incertae sedis, two species, type: $P$. copelandii Bubák, coelomycetous, sexual morph unknown, saprobes, terrestrial, Philippines, see Wijayawardene et al. (2012, 2017; outline), Kirk et al. (2013; genus accepted), cultures and sequences are unavailable, needs generic revision.

Placodothis Syd. 1928, Dothideomycetes genera incertae sedis, one species, type: P. petrakii Syd., asexual morph unknown, saprobes, terrestrial, West Indies, see Lumbsch and Huhndorf (2010; outline), Kirk et al. (2013; genus accepted), Wijayawardene et al. (2014c; outline), cultures and sequences are unavailable, needs generic revision.

Placolecis Trevis 1857, Catillariaceae, Lecanorales, Lecanoromycetes, three species, type: P. balaniana (Fr.) Trevis., asexual morph unknown, lichenized, terrestrial, Asia, Europe, see Lumbsch and Huhndorf (2010; outline), Rizzi et al. (2011; Sardinia), Tufan-Çetin and Sümbül (2011; taxonomy), Kirk et al. (2013; genus accepted), Aptroot and Moon (2014; Korea), Sipman and Raus (2015; Greece), Lücking et al. (2016b; classification), cultures and sequences are unavailable, needs generic revision.

Placomaronea Räsänen 1944, Candelariaceae, Lecanorales, Lecanoromycetes, six species, type: $P$. candelarioides Räsänen, asexual morph unknown, lichenized, terrestrial, America, 
Africa, see Westberg et al. (2009; monograph), Lumbsch and Huhndorf (2010; outline), Westberg and Sohrabi (2012; taxonomy), Kirk et al. (2013; genus accepted), Flakus et al. (2015; taxonomy), Lücking et al. (2016b; classification), sequences are available, needs generic revision.

Placomelan Cif. 1962, Dothideomycetes genera incertae sedis, one species, type: $P$. dipteridis Cif., sexual morph dothidasteroma-like, epiphytes, terrestrial, see Hofmann (2009; review, accepted as a genus in Parmulariaceae), Wijayawardene et al. (2012, 2014c; outline), cultures and sequences are unavailable, needs generic revision.

Placonema (Sacc. \& D. Sacc.) Petr. 1921, Ascomycota genera incertae sedis, three species, type: P. bambusacearum (Sacc., Syd. \& P. Syd.) Petr., coelomycetous, sexual morph unknown, saprobes, terrestrial, South Americ, see Wijayawardene et al. (2012, 2017; outline), Kirk et al. (2013; genus accepted), cultures and sequences are unavailable, needs generic revision, needs generic revision.

Placonemina Petr. 1921, Ascomycota genera incertae sedis, one species, type: $P$. dothideoides (Mont.) Petr., coelomycetous, sexual morph unknown, saprobes, terrestrial, former Czechoslovakia, see Wijayawardene et al. (2012, 2017; outline), Kirk et al. (2013; genus accepted), cultures and sequences are unavailable, needs generic revision.

Placopsis (Nyl.) Linds. 1866, Trapeliaceae, Trapeliales, Lecanoromycetes, 60 species, type: P. gelida (L.) Linds., asexual morph unknown, lichenized, terrestrial, worldwide, see Brackel and Berger (2010; Polycoccum host), Galloway (2010, 2013; taxonomy), Singh et al. (2010; ecology), de los Ríos et al. (2011; ecophysiology), Lumbsch and Huhndorf (2010; outline), Lumbsch et al. (2011; taxonomy, new specie), Øvstedal and Lewis Smith (2011; new species), Schmull et al. (2011; phylogeny), Raggio et al. (2012; ecophysiology), Kukwa, et al. (2012; new records), Gao and Ren (2013; new records), Kirk et al. (2013; genus accepted), Lücking et al. (2016b; classification), Schneider et al. (2016; phylogeny), sequences are available, needs generic revision.

Placopyrenium Breuss 1987, Verrucariaceae, Verrucariales, Eurotiomycetes, 22 species, type: P. bucekii (Nádv. \& Servít) Breuss, asexual morph unknown, lichenized, terrestrial, worldwide, see Ertz et al. (2008; Europe), Gueidan et al. (2009; phylogeny), Breuss (2009; description, key), Orange (2009b; partial sequence), Lumbsch and Huhndorf (2010; outline), Aptroot et al. (2010; biodiversity), Prieto et al. (2010a, 2012; genus considered polyphyletic, phylogeny), Breuss (2011; Spain), Miller et al. (2011a, b; USA), Aptroot and Yazici (2012; new species), Kirk et al. (2013; genus accepted), Valadbeigi (2014; Iran), Sipman and Raus (2015; taxonomy), Lücking et al. (2016b; classification), Urbanavichus and Ismailov (2016; new records), sequences are available, needs generic revision.

Placosoma Syd. 1924, Parmulariaceae, Dothideomycetes families incertae sedis, two species, type: $P$. nothopanacis Syd., asexual morph unknown, epiphytes, terrestrial, worldwide, see Hofmann (2009; review, accepted as a genus in Asterinaceae), Lumbsch and Huhndorf (2010; outline, accepted as a genus in Asterinaceae), Hongsanan et al. (2014c; taxonomy, keys, transferred to Parmulariaceae), Wijayawardene et al. (2014c; outline), cultures and sequences are unavailable, holotype of type: PDD 1003.

Placosphaerina Maire 1917, Ascomycota genera incertae sedis, one species, type: $P$. myriospora (Pat.) Maire, coelomycetous, sexual morph unknown, saprobes, terrestrial, Algeria, see Kirk et al. (2013; genus accepted), Wijayawardene et al. (2017; outline), cultures and sequences are unavailable, needs generic revision.

Placostromella Petr. 1947, Parmulariaceae, Dothideomycetes families incertae sedis, two species, type: P. macrospora Petr., asexual morph unknown, saprobes, terrestrial, China, see Lumbsch and Huhndorf (2010; outline, accepted as a genus in Dothideomyctes), Kirk et al. (2013; genus accepted), Thambugala et al. (2014b; accepted as a genus in Parmulariaceae), 
Wijayawardene et al. (2014c; outline), cultures and sequences are unavailable, needs generic revision.

Placothea Syd. 1931, Ascomycota genera incertae sedis, one species, type: P. philippinensis Syd., coelomycetous, sexual morph unknown, saprobes, terrestrial, Philippines, see Kirk et al. (2013; genus accepted), Wijayawardene et al. (2017; outline), cultures and sequences are unavailable, needs generic revision.

Placothelium Müll. Arg. 1893, Verrucariaceae, Verrucariales, Eurotiomycetes, one species, type: $P$. staurothelioides Müll. Arg., asexual morph unknown, lichenized, terrestrial, USA, see Lumbsch and Huhndorf (2010; outline), Kirk et al. (2013; genus accepted), Lücking et al. (2016b; classification), cultures and sequences are unavailable, needs generic revision.

Placothyrium Bubák 1916, Ascomycota genera incertae sedis, one species, type: $P$. athyrinum Bubák, coelomycetous, sexual morph unknown, saprobes, terrestrial, Europe, see Kirk et al. (2013; genus accepted), Wijayawardene et al. (2017; outline), cultures and sequences are unavailable, needs generic revision.

Placynthiella Elenkin 1909, Trapeliaceae, Trapeliales, Lecanoromycetes, seven species, type: $P$. perfurfurea (Nyl.) Gyeln., asexual morph unknown, lichenized, terrestrial, worldwide, see Lumbsch and Huhndorf (2010; outline), Voytsekhovich et al. (2011; photobiont), Joshi et al. (2011b; new records from South Korea), Kirk et al. (2013; genus accepted), Kantvilas et al. (2015; phylogeny), cultures ans sequences are available but lacks for the type, needs generic revision.

Placynthiopsis Zahlbr. 1932, Placynthiaceae, Peltigerales, Lecanoromycetes, one species, type: P. africana Zahlbr., lichenized, terrestrial, central Africa, see Lumbsch and Huhndorf (2010; outline), Kirk et al. (2013; genus accepted), Lücking et al. (2016b; classification), cultures and sequences are unavailable, needs generic revision.

Placynthium (Ach.) Gray. 1821, Placynthiaceae, Peltigerales, Lecanoromycetes, 25 species, type: $P$. nigrum (Huds.) Gray, asexual morph unknown, lichenized, terrestrial, worldwide, see Øvstedal et al. (2009; new species), Wedin, et al. (2009; phylogeny), Schmull et al. (2011; phylogeny) Lumbsch and Huhndorf (2010; outline), Muggia et al. (2011; partial sequence), Westberg, et al. (2011, new records), Urbanavichus et al. (2011; new records), Wirth et al. (2011; checklist), Yatsyna (2011; new record), Aptroot and Iqbal (2012; checklist), Hansen (2012; new records, 2014; taxonomy), Aslan (2013; new records), Kirk et al. (2013; genus accepted), McCarthy and Kantvilas (2014; new species), Miądlikowska et al. (2014a; phylogeny, systematics), Aptroot et al. (2015d; new reords), Malícek et al. (2015a; taxonomy), Košuthová et al. (2016; phylogenetic relationship), Lücking et al. (2016b; classification), sequences are available, needs generic revision.

Plagiascoma Réblová \& J. Fourn. 2015, Pleurotheciaceae, Pleurotheciales, Sordariomycetes, one species, type: P. frondosum Réblová \& J. Fourn., asexual morph hyphomycetous, saprobes, terrestrial, France, see Maharachchikumbura et al. (2015, 2016; outline), Réblová et al. (2017; taxonomy), holotype and ex-type: PRM 933854, CBS 139031.

Plagiophiale Petr. 1955, Melanconidaceae, Xylariales, Sordariomycetes, two species, type: Plagiophiale eucarpa (P. Karst.) Petr., asexual morph unknown, saprobes, North America, Sweden, see Lumbsch and Huhndorf (2010; outline), Kirk et al. (2013; genus accepted), Maharachchikumbura et al. (2015, 2016; outline, phylogeny), cultures and sequences are unavailable, needs generic revision.

Plagiosphaera Petr. 1941, Sordariomycetes genera incertae sedis, five species, type: $P$. moravica (Petr.) Petr., asexual morph unknown, saprobes, worldwide, see Lumbsch and Huhndorf (2010; outline), Kirk et al. (2013; genus accepted), Maharachchikumbura et al. (2015, 2016; outline, phylogeny), cultures and sequences are unavailable, needs generic revision. 
Plagiostigme Syd. 1925, Melanconidaceae, Xylariales, Sordariomycetes, one species, type: $P$. couraliae Syd., asexual morph unknown, saprobes, Central America, see Lumbsch and Huhndorf (2010; outline), Kirk et al. (2013; genus accepted), Maharachchikumbura et al. (2015, 2016; outline, phylogeny), cultures and sequences are unavailable, needs generic revision.

Plagiostigmella Petr. 1949, Ascomycota genera incertae sedis, one species, type: P. clypeata Petr., coelomycetous, sexual morph unknown, saprobes, terrestrial, South America, see Wijayawardene et al. (2012, 2017; outline), Kirk et al. (2013; genus accepted), cultures and sequences are unavailable, needs generic revision.

Plagiostoma Fuckel 1870 (= Diplodina Westend. 1857; = Septomyxa Sacc. 1884; = Cryptodiaporthe Petrak 1921 fide Rossman et al. 2015a), Gnomoniaceae, Diaporthales, Sordariomycetes, 50 species, type: P. euphorbiae (Fuckel) Fuckel, asexual morph coelomycetous, saprobes, terrestrial, tropical, see Sogonov et al. (2008; new species, phylogeny), Lumbsch and Huhndorf (2010; outline), Mejía et al. (2011; new species, phylogeny), Kirk et al. (2013; genus accepted), Walker et al. (2014; new species), Maharachchikumbura et al. (2015, 2016; outline), cultures and sequences are available, available specimen and cultures or the type: CBS H-17115; CBS 817.79.

Plagiostromella Höhn. 1917, Dothideomycetes genera incertae sedis, one species, type: $P$. pleurostoma Höhn., asexual morph unknown, saprobes, India, Japan, see Lumbsch and Huhndorf (2010; outline), Kirk et al. (2013; genus accepted), Wijayawardene et al. (2014c; outline), cultures and sequences are unavailable, needs generic revision.

Planistroma A.W. Ramaley 1991, Planistromellaceae, Botryosphaeriales, Dothideomycetes, two species, type: P. yuccigenum A.W. Ramaley, asexual morph unknown, saprobes, terrestrial, cosmopolitan, see Lumbsch and Huhndorf (2010; outline), Minnis et al. (2012; treated as a synonym of Kellermania), Kirk et al. (2013; genus accepted), Monkai et al. (2013; treated as a distinct genus), Wijayawardene et al. (2014c; outline), cultures and sequences are available, needs generic revision.

Plasia Sherwood 1981, Ascomycota genera incertae sedis, one species, type: P. ramicola (Cooke \& Massee) Sherwood, coelomycetous, sexual morph unknown, saprobes, terrestrial, Europe, see Kirk et al. (2013; genus accepted), Wijayawardene et al. (2017; outline), cultures and sequences are unavailable, needs generic revision.

Platismatia W.L. Culb. \& C.F. Culb. 1968, Parmeliaceae, Lecanorales, Lecanoromycetes, ten species, type: P. glauca (L.) W.L. Culb. \& C.F. Culb., asexual morph unknown, lichenized, terrestrial, worldwide, see Lumbsch and Huhndorf (2010; outline), Thell et al. (2012; phylogeny, accepted as a genus in Parmeliaceae), Kirk et al. (2013; genus accepted), Mitrovic et al. (2014; antimicrobial properties), cultures available for the type: AFTOL-ID 201, needs generic revision.

Platychora Petr. 1925, Didymellaceae, Pleosporales, Dothideomycetes, one species, type: $P$. ulmi (J. Schröt.) Petr., asexual morph coelomycetous, lichenized, terrestrial, north temperate, see Lumbsch and Huhndorf (2010; outline), Hyde et al. (2013, 2016; accepted as a genus in Didymellaceae, coelomycetous), Kirk et al. (2013; genus accepted), cultures and sequences are available.

Platygramme Fée 1874, Graphidaceae, Ostropales, Lecanoromycetes, 30 species, type: Platygramme caesiopruinosa (Fée) Fée, asexual morph unknown, lichenized, terrestrial, tropical, see Lumbsch and Huhndorf (2010; outline), Rivas Plata et al. (2012a; phylogeny), Kirk et al. (2013; genus accepted), Lücking et al. (2014, 2016b; phylogeny, classification), cultures and sequences are available, needs generic revision.

Platypeltella Petr. 1929, Asterinaceae, Asterinales, Dothideomycetes, three species, type: $P$. smilacis Petr., asexual morph unknown, epiphytes, terrestrial, worldwide, see Hofmann (2009; review, accepted as a genus in Microthyriaceae), Lumbsch and Huhndorf (2010; outline, 
accepted as a genus in Microthyriaceae), Hongsanan et al. (2014c; keys, accepted as a genus in Asterinaceae), Wijayawardene et al. (2014c; outline, accepted as a genus in Asterinaceae), $\mathrm{Wu}$ et al. (2014; taxonomy, transferred to Asterinaceae), cultures and sequences are unavailable, holotype of type: W 257.

Platysporoides (Wehm.) Shoemaker \& C.E. Babc., Can. J. Bot. 1992, Pleosporaceae, Pleosporales, Dothideomycetes, twelve species, type: P. chartarum (Fuckel) Shoemaker \& C.E. Babc., asexual morph unknown, saprobes, terrestrial, California, Europe and India, See Lumbsch and Huhndorf (2010; outline), Zhang et al. (2012e; taxonomy), Kirk et al. (2013; genus accepted), Wijayawardene et al. (2014c; outline), Ariyawansa et al. (2015c; taxonomy), cultures and sequences are unavailable, needs generic revision, needs generic revision.

Platystomum Trevis. 1877, Lophiostomataceae, Pleosporales, Dothideomycetes, c. 20 species, type: P. compressum (Pers.) Trevis., asexual morph unknown, saprobes, worldwide, see Kirk et al. (2008; treated as a synonym of Lophiostoma Ces. \& De Not.), Lumbsch and Huhndorf (2010; outline, treated as Pleosporales, genera incertae sedis), Hyde et al. (2013; accepted as a genus in Platystomaceae), Wijayawardene et al. (2014c; outline, accepted as a genus in Platystomaceae), Thambugala et al. (2015; accepted as a genus in Lophiostomataceae), cultures and sequences are available, needs generic revision.

Platythecium Staiger 2002, Graphidaceae, Ostropales, Lecanoromycetes, 25 species, type: $P$. grammitis (Fée) Staiger, asexual morph unknown, lichenized, terrestrial, tropical, see Lumbsch and Huhndorf (2010; outline), Rivas Plata et al. (2012a; phylogeny), Kirk et al. (2013; genus accepted), Lücking et al. (2016b; classification), Neuwirth et al. (2017; key), cultures and sequences are available, needs generic revision.

Platytrachelon Réblová 2013, Sordariomycetes genera incertae sedis, one species, type: $P$. abietis (Réblová) Réblová, asexual morph unknown, saprobes, Czech Republic, Ukraine, see Réblová (2013; taxonomy phylogeny), Maharachchikumbura et al. (2015, 2016; outline, phylogeny), cultures and sequences are available, holotype and cultures available for the type: PRM 842974; CBS 125235.

Plectania Fuckel 1870, Sarcosomataceae, Pezizales, Pezizomycetes, c. 20 species, type: P. melastoma (Sowerby) Fuckel, asexual morph conoplea-like, saprobes, terrestrial, north temperate, see Lumbsch and Huhndorf (2010; outline), Kirk et al. (2013; genus accepted), cultures and sequences are available.

Plectocarpon Fée 1825, Lecanographaceae, Arthoniales, Arthoniomycetes, 37 species, type: $P$. pseudosticta (Fée) Fée, sexual morph with mainly multilocular-lirelliform stromatic ascomata, lichenicolous (only one lichenized), terrestrial, worldwide, see Lumbsch and Huhndorf (2010; outline), Kirk et al. (2013; genus accepted), Frisch et al. (2014; phylogeny), Lücking et al. (2016b; classification), sequences are available but lacks for the type.

Plectomyces Thaxt. 1931, Ceratomycetaceae, Laboulbeniales, Laboulbeniomycetes, one species, type: $P$. gracilis Thaxt., asexual morph unknown, saprobes, Philippines, see Lumbsch and Huhndorf (2010; outline), Kirk et al. (2013; genus accepted), cultures and sequences are unavailable.

Plectonaemella Höhn. 1915, Ascomycota genera incertae sedis, one species, type: $P$. fuckeliana Höhn., coelomycetous, sexual morph unknown, saprobes, terrestrial, Europe, see Wijayawardene et al. (2012, 2017; outline), Kirk et al. (2013; genus accepted), cultures and sequences are unavailable, needs generic revision.

Plectopeltis Syd. 1927, Ascomycota genera incertae sedis, one species, type: P. egenula Syd., coelomycetous, sexual morph unknown, saprobes, terrestrial, Central America, Australia, see Wijayawardene et al. (2012, 2017; outline), Kirk et al. (2013; genus accepted), cultures and sequences are unavailable, needs generic revision. 
Plectophomopsis Petr. 1922, Ascomycota genera incertae sedis, one species, type: $P$. rivularis Petr., coelomycetous, sexual morph unknown, saprobes, terrestrial, Europe, see Wijayawardene et al. (2012, 2017; outline), Kirk et al. (2013; genus accepted), cultures and sequences are unavailable, needs generic revision.

Plectosira Petr. 1929, Ascomycota genera incertae sedis, one species, type: P. adeana Petr., coelomycetous, sexual morph unknown, saprobes, terrestrial, Europe, see Wijayawardene et al. (2012, 2017; outline), Kirk et al. (2013; genus accepted), cultures and sequences are unavailable, needs generic revision, needs generic revision.

Plectosphaera Theiss. 1916, Xylariales genera incertae sedis, Sordariomycetes, 38 species epithets in Index Fungorum (2017), type: P. bersamae (Lingelsh.) Theiss., hyphomycetous, sexual morph unknown, saprobes, terrestrial, worldwide, see Kirk et al. (2008; treated as a synonym of Phyllachora Nitschke ex Fucke), Maharachchikumbura et al. (2015, 2016; outline), needs generic revision, cultures and sequences are available.

Plectosphaerella Kleb. 1929 (= Plectosporium M.E. Palm et al. 1995 fide Maharachchikumbura et al. 2015, 2016; Réblová et al. 2016c), Plectosphaerellaceae, Glomerellales, Sordariomycetes, 13 species, type: P. cucumeris Kleb., asexual morph formerly known in Plectosporium, pathogens, nematophagous, terrestrial, worldwide, see Lumbsch and Huhndorf (2010; outline), Carlucci et al. (2012; new species, phylogeny), Liu et al. (2013; new species), Kirk et al. (2013; genus accepted), Crous et al. (2015d; new species), Maharachchikumbura et al. (2015, 2016; outline, phylogeny), Réblová et al. (2016c; nomenclature), cultures and sequences are available but lacks for the type, needs generic revision.

Plectronidiopsis Nag Raj 1979, Ascomycota genera incertae sedis, one species, type: $P$. chilensis (Speg.) Nag Raj, coelomycetous, sexual morph unknown, saprobes, terrestrial, Chile, see Wijayawardene et al. (2012, 2017; outline), Kirk et al. (2013; genus accepted), cultures and sequences are unavailable, needs generic revision.

Plectronidium Nag Raj 1977, Ascomycota genera incertae sedis, four species, type: $P$. sinense Nag Raj, coelomycetous, sexual morph unknown, saprobes, terrestrial, worldwide, see Wijayawardene et al. (2012, 2017; outline), Kirk et al. (2013; genus accepted), cultures and sequences are unavailable, needs generic revision.

Plectrothrix Shear 1902, Ascomycota genera incertae sedis, one species, type: P. globosa Shear, hyphomycetous, sexual morph unknown, saprobes, terrestrial, North America, see Wijayawardene et al. (2012, 2017; outline), Kirk et al. (2013; genus accepted), cultures and sequences are unavailable, needs generic revision.

Pleiochaeta (Sacc.) S. Hughes 1951, Pleosporineae, Pleosporales, Dothideomycetes, four species, type: P. setosa (Kirchn.) S. Hughes, hyphomycetous, sexual morph unknown, pathogens, saprobes, terrestrial, North America, see Garibaldi et al. (2012; pathogens, DNA), Wijayawardene et al. (2012, 2017; outline), Kirk et al. (2013; genus accepted), Gur and Frenkel (2015; pathogens, DNA), Cultures and sequences are available, cultures are available, holotype: CBS H-17161.

Pleiopatella Rehm 1908, Ostropomycetidae genera incertae sedis, Lecanoromycetes, one species, type: $P$. harperi Rehm, asexual morph unknown, saprobes, terrestrial, South America, see Lumbsch and Huhndorf (2010; outline), Kirk et al. (2013; genus accepted), Jaklitsch et al. (2016a; classification), cultures and sequences are unavailable, needs generic revision.

Pleiostomellina Bat., J.L. Bezerra \& H. Maia 1964, Dothideomycetes genera incertae sedis, one species, type: Pleiostomellina pernambucensis Bat., J.L. Bezerra \& Cavalc., asexual morph unknown, saprobes, terrestrial, Brazil, see Lumbsch and Huhndorf (2010; outline), Kirk et al. (2013; genus accepted), Wijayawardene et al. (2014c; outline), cultures and sequences are unavailable, needs generic revision. 
Plejobolus (E. Bommer, M. Rousseau \& Sacc.) O.E. Erikss. 1967, Dothideomycetes genera incertae sedis, type: P. arenarius (E. Bommer, M. Rousseau \& Sacc.) O.E. Erikss., data inadequate, see Kirk et al. (2008; treated as a synonym of Robergea), Lumbsch and Huhndorf (2010; outline), Kirk et al. (2013; did not list), Wijayawardene et al. (2014c; outline), sequences are unavailable,

Plenocatenulis Bat. \& Cif. 1959, Ascomycota genera incertae sedis, one species, type: $P$. magnoliae Bat. \& Cif., coelomycetous, sexual morph unknown, saprobes, terrestrial, USA, see Wijayawardene et al. (2012, 2017; outline), Kirk et al. (2013; genus accepted), cultures and sequences are unavailable, needs generic revision.

Plenodomus Preuss 1851, Leptosphaeriaceae, Pleosporales, Dothideomycetes, 18 species, type: P. lingam (Tode: Fr.) Höhn., asexual morph coelomycetous, pathogens, saprobes, terrestrial, worldwide, see de Gruyter et al. (2012; taxonomy, phylogeny, treated Plenodomus rabenhorstii Preuss as a nom. Dub. and reduced under Plenodomus lingam), Hyde et al. (2013; accepted as a genus in Leptosphaeriaceae), Wijayawardene et al. (2014c, 2017; outline), Ariyawansa et al. (2015b; phylogeny), Cultures and sequences are available, cultures available for the type: CBS 260.94 (de Gruyter et al. 2013), needs generic revision.

Plenophysa Syd. \& P. Syd. 1920, Ascomycota genera incertae sedis, one species, type: P. mirabilis Syd. \& P. Syd., coelomycetous, sexual morph unknown, saprobes, terrestrial, Philippines, Sri Lanka, see Wijayawardene et al. (2012, 2017; outline), Kirk et al. (2013; genus accepted), cultures and sequences are unavailable, needs generic revision.

Plenotrichaius Bat. \& Valle 1961, Ascomycota genera incertae sedis, one species, type: $P$. swartziae Bat. \& Valle, coelomycetous, sexual morph unknown, saprobes, terrestrial, Brazil, see Wijayawardene et al. (2012, 2017; outline), Kirk et al. (2013; genus accepted), cultures and sequences are unavailable, needs generic revision.

Plenotrichopsis Bat. 1961, Ascomycota genera incertae sedis, one species, type: P. coffeae Bat., H. Maia \& C.T. Vasconc., coelomycetous, sexual morph unknown, saprobes, terrestrial, Brazil, see Wijayawardene et al. (2012, 2017; outline), Kirk et al. (2013; genus accepted), cultures and sequences are unavailable, needs generic revision.

Plenotrichum Syd. 1927, Ascomycota genera incertae sedis, two species, type: P. mirabile Syd., coelomycetous, sexual morph unknown, saprobes, terrestrial, Central America, China, see Wijayawardene et al. (2012, 2017; outline), Kirk et al. (2013; genus accepted), cultures and sequences are unavailable, needs generic revision.

Plenozythia Syd. \& P. Syd. 1916, Ascomycota genera incertae sedis, two species, type: P. euphorbiae Syd. \& P. Syd., coelomycetous, sexual morph unknown, saprobes, terrestrial, Asia, see Wijayawardene et al. (2012, 2017; outline), Kirk et al. (2013; genus accepted), cultures and sequences are unavailable, needs generic revision.

Pleochaeta Sacc. \& Speg. 1881 emend. Kimbrough \& Korf 1963, Erysiphaceae, Erysiphales, Leotiomycetes, five species, type: P. lynckii (Speg.) Speg., sexual and hyphomycetous asexual morphs, biotrophic, obligate plant pathogens, terrestrial, Asia, North and South America, see Lumbsch and Huhndorf (2010; outline), Lee et al. (2011; phylogeny, Korea), Kirk et al. (2013; genus accepted), Takamatsu (2013, 2016; phylogeny, phenotypic evolution), cultures and sequences are available but lacks for the type, holotype of type: C.L. Spegazini (LPS), needs generic revision.

Pleocouturea G. Arnaud 1911, Ascomycota genera incertae sedis, two species, type: $P$. castagnei G. Arnaud, coelomycetous, sexual morph unknown, saprobes, terrestrial, France, see Wijayawardene et al. (2012, 2017; outline), Kirk et al. (2013; genus accepted), cultures and sequences are unavailable, needs generic revision.

Pleocryptospora J. Reid \& C. Booth 1969, Sordariomycetes genera incertae sedis, two species, type: Pleocryptospora bambusae (Speg.) J. Reid \& C. Booth, asexual morph unknown, saprobes, terrestrial, Brazil, see Lumbsch and Huhndorf (2010; outline), Kirk et al. 
(2013; genus accepted), Maharachchikumbura et al. (2015, 2016; outline, phylogeny), cultures and sequences are unavailable, needs generic revision.

Pleogibberella Sacc. ex Berl. \& Voglino 1886, Nectriaceae, Hypocreales, Sordariomycetes, two species, type: P. calamia (Cooke) Berl. \& Voglino, asexual morph unknown, saprobe, saprobes, terrestrial, India, Brazil, see Lumbsch and Huhndorf (2010; outline), Kirk et al. (2013; genus accepted), Maharachchikumbura et al. (2015, 2016; outline), cultures and sequences are unavailable, needs generic revision.

Pleomeliola (Sacc.) Sacc. 1899, Ascomycota genera incertae sedis, one species, type: $P$. fenestrata (Cooke \& Ellis) Sacc., asexual morph unknown, saprobes, terrestrial, Europe, North America, see Lumbsch and Huhndorf (2010; outline, accepted as a genus in Meliolaceae), Kirk et al. (2013; genus accepted), Hongsanan et al. (2015c; excluded from Meliolaceae), cultures and sequences are unavailable, needs generic revision.

Pleomelogramma Speg. 1909, Herpotrichiellaceae, Chaetothyriales, Chaetothyriomycetes, one species, type: P. argentinensis Speg., asexual morph unknown, saprobes, South America, see Lumbsch and Huhndorf (2010; outline), Kirk et al. (2013; genus accepted), cultures and sequences are unavailable, needs generic revision.

Pleomerium Speg. 1918, Dothideomycetes genera incertae sedis, one species, type: $P$. fuscoviridescens (Rehm) Speg., asexual morph unknown, saprobes, terrestrial, Brazil, see Lumbsch and Huhndorf (2010; outline, accepted as a genus in Meliolaceae), Kirk et al. (2013; genus accepted), Hongsanan et al. (2015c; excluded from Meliolaceae and placed in Dothideomycetes), cultures and sequences are unavailable, needs generic revision.

Pleophragmia Fuckel 1870, Sporormiaceae, Pleosporales, Dothideomycetes, one species, type: P. leporum Fuckel, asexual morph unknown, saprobes, terrestrial, see Lumbsch and Huhndorf (2010; outline), Kirk et al. (2013; did not list), Hyde et al. (2013; accepted as Sporormiaceae), Wijayawardene et al. (2014c; outline), cultures and sequences are unavailable, needs generic revision.

Pleopsidium Körb. 1855, Acarosporaceae, Acarosporales, Lecanoromycetes, four species, type: P. flavum Körb., asexual morph unknown, lichenized, terrestrial, worldwide, see Lumbsch and Huhndorf (2010; outline), Knudsen (2011; new species), Kirk et al. (2013; genus accepted), Maharachchikumbura et al. (2015, 2016; outline), Lücking et al. (2016b; classification), sequences are available, needs generic revision.

Pleoscutula Vouaux 1913, Helotiales genera incertae sedis, Leotiomycetes, three species, type: P. arsenii Vouaux, asexual morph unknown, lichenicolous, terrestrial, terrestrial, worldwide, see Lumbsch and Huhndorf (2010; outline), Kirk et al. (2013; genus accepted), cultures available but lacks for the type, needs generic revision.

Pleoseptum A.W. Ramaley \& M.E. Barr 1995, Pleosporaceae, Pleosporales, Dothideomycetes, one species, type: P. yuccaesedum A.W. Ramaley \& M.E. Barr, asexual morph unknown, saprobes, terrestrial, USA, see Lumbsch and Huhndorf (2010; outline, accepted as a genus in Phaeosphaeriaceae), Hyde et al. (2013; accepted as a genus in Phaeosphaeriaceae), Kirk et al. (2013; genus accepted), Phookamsak et al. (2014b; excluded from Phaeosphaeriaceae and placed in Pleosporaceae), Wijayawardene et al. (2014c; accepted as a genus in Pleosporaceae), cultures and sequences are unavailable, holotype of the type: BPI 802381, needs generic revision.

Pleosphaerellula Naumov \& Czerepan. 1952, Pleosporales genera incertae sedis, Dothideomycetes, two species, type: P. cornicola Naumov \& Czerepan., asexual morph unknown, saprobes, terrestrial, former USSR, see Lumbsch and Huhndorf (2010; outline, accepted as a genus in Dothideomycetes), Kirk et al. (2013; genus accepted), Wijayawardene et al. (2014c; accepted as Pleosporales), cultures and sequences are unavailable, needs generic revision. 
Pleosphaeria Speg. 1881, Sordariomycetes genera incertae sedis, 15 species, type: $P$. australis Speg., asexual morph unknown, saprobes, terrestrial, worldwide, see Lumbsch and Huhndorf (2010; outline), Kirk et al. (2013; genus accepted), Maharachchikumbura et al. (2015, 2016; outline), cultures and sequences are unavailable, needs generic revision.

Pleostigma Kirschst. 1939, Dothideomycetes genera incertae sedis, type: data inadequate, see Kirk et al. (2008; treated as a synonym of Teichosporella), Lumbsch and Huhndorf (2010; outline), Kirk et al. (2013; did not list), Wijayawardene et al. (2014c; outline), sequences are unavailable.

Pleotrichiella Sivan. 1984, Dothideomycetes genera incertae sedis, one species, type: $P$. australiensis Sivan., asexual morph unknown, saprobes, terrestrial, Australia, see Lumbsch and Huhndorf (2010; outline), Kirk et al. (2013; genus accepted), Wijayawardene et al. (2014c; outline), cultures and sequences are unavailable, needs generic revision.

Plesiospora Drechsler 1971, Ascomycota genera incertae sedis, one species, type: P. globosa Drechsler, hyphomycetous, sexual morph unknown, saprobes, terrestrial, USA, see Seifert et al. (2011; morphology), Wijayawardene et al. (2012, 2017; outline), Kirk et al. (2013; genus accepted), cultures and sequences are unavailable, needs generic revision.

Pleuroascus Massee \& E.S. Salmon 1901, Pseudeurotiaceae, Leotiomycetes families incertae sedis, eleven species, type: P. nicholsonii Massee \& E.S. Salmon, saprobes, from soil, terrestrial, USA, see Lumbsch and Huhndorf (2010; outline), Crous et al. (2013b; new species), Kirk et al. (2013; genus accepted), cultures available for the type: CBS 345, available specimen for type: CBS H-7657, needs generic revision.

Pleurocatena G. Arnaud ex Aramb., Gamundí, W. Gams \& G.R.W. Arnold 2007, Pyxidiophoraceae, Pyxidiophorales, Laboulbeniomycetes, three species, hyphomycetous, sexual morph unknown, on nematodes, leaf litter, Europe, South America, see Seifert et al. (2011; morphology), Wijayawardene et al. (2012, 2017; outline), cultures and sequences are unavailable, needs generic revision.

Pleuroceras Riess 1854, Gnomoniaceae, Diaporthales, Sordariomycetes, twelve species, type: $P$. ciliatum Riess, asexual morph unknown, saprobes, terrestrial, north temperate, see Mejía et al. (2008; DNA, phylogeny), Sogonov et al. (2008; DNA, phylogeny), Lumbsch and Huhndorf (2010; outline), Kirk et al. (2013; genus accepted), Maharachchikumbura et al. (2015, 2016; outline), cultures and sequences are available but lacks for the type:, needs generic revision.

Pleurocytospora Petr. 1923, Ascomycota genera incertae sedis, three species, type: P. vestita Petr., coelomycetous, sexual morph unknown, saprobes, terrestrial, Europe, China, see Wijayawardene et al. (2012, 2017; outline), Kirk et al. (2013; genus accepted), cultures and sequences are unavailable, needs generic revision.

Pleurodesmospora Samson, W. Gams \& H.C. Evans 1979, Ascomycota genera incertae sedis, one species, type: P. coccorum (Petch) Samson, W. Gams \& H.C. Evans, hyphomycetous, sexual morph unknown, parasites, on insects (Aleyrodes, aphids, leaf hoppers), mites (Tydeus, Paratetranychus) and fungi (Meliola), Africa, Asia, Central America, Europe, see Seifert et al. (2011; morphology), Wijayawardene et al. (2012, 2017; outline), Kirk et al. (2013; genus accepted), cultures and sequences are unavailable, needs generic revision.

Pleurodiscula Höhn. 1926, Ascomycota genera incertae sedis, one species, type: P. neglecta (Desm.) Höhn, coelomycetous, sexual morph unknown, saprobes, Europe, see Wijayawardene et al. (2012, 2017; outline), Kirk et al. (2013; genus accepted), cultures and sequences are unavailable, needs generic revision.

Pleurodomus Petr. 1934, Ascomycota genera incertae sedis, one species, type: P. humuli Petr., coelomycetous, sexual morph unknown, saprobes, on decaying stems of Humuli lupuli, Siberia, see Wijayawardene et al. (2012, 2017; outline), Kirk et al. (2013; genus accepted), cultures and sequences are unavailable, needs generic revision. 
Pleuropedium Marvanová \& S.H. Iqbal., 1973, Ascomycota genera incertae sedis, three species, type: $P$. tricladioides Marvanová \& S.H. Iqbal, sexual morph unknown, on submerged dead Juncus effususaxes and from foam in mountain streams, North America, see Seifert et al. (2011; morphology), Wijayawardene et al. (2012, 2017; outline), Kirk et al. (2013; genus accepted), cultures and sequences are unavailable, holotype of type: BRNU 445.796

Pleurophoma Höhn. 1914, Lentitheciaceae, Pleosporales, Dothideomycetes, nine species, type: P. pleurospora (Sacc.) Höhn., sexual morph unknown, saprobes, terrestrial, UK, see Wijayawardene et al. (2012, 2017; outline), de Gruyter et al. (2012; taxonomy, phylogeny), Kirk et al. (2013; genus accepted), Crous et al. (2015d, 2016a; new species, phylogeny), cultures and sequences are available, cultures available for the type: CBS 130329, needs generic revision.

Pleurophomopsis Petr. 1924, Ascomycota genera incertae sedis, seven species, type: $P$. salicicola Petr., coelomycetous, sexual morph unknown, saprobes, terrestrial, worldwide, see Kirk et al. (2013; genus accepted), Wijayawardene et al. (2017; outline), cultures and sequences are unavailable, needs generic revision.

Pleurophragmium Costantin 1888, Sordariomycetes genera incertae sedis, 29 species, type: $P$. bicolor Costantin, hyphomycetous, sexual morph unknown, saprobes, terrestrial, widely distributed, see Réblová (2009; phylogeny), D’Souza and Bhat (2012; key), Kirk et al. (2013; genus accepted), Maharachchikumbura et al. (2015; outline), Dai et al. (2016; morphology, phylogeny), cultures and sequences are available but lacks for type, needs generic revision.

Pleuroplaconema Petr. 1923, Ascomycota genera incertae sedis, two species, type: $P$. sambuci Petr., coelomycetous, sexual morph unknown, endophytes, Europe and Asia, see Wijayawardene et al. (2012, 2017; outline), Kirk et al. (2013; genus accepted), cultures and sequences are unavailable, needs generic revision.

Pleuroplacosphaeria Syd. 1928, Ascomycota genera incertae sedis, one species, type: $P$. negeriana Syd., coelomycetous, sexual morph unknown, saprobes, Chile, see Wijayawardene et al. (2012, 2017; outline), Kirk et al. (2013; genus accepted), cultures and sequences are unavailable, needs generic revision.

Pleurosticta Petr.1931, Parmeliaceae, Lecanorales, Lecanoromycetes, three species, type: $P$. lichenicola Petr., asexual morph unknown, lichenized, terrestrial, Asia, Europe, Africa, see Lumbsch and Huhndorf (2010; outline), Crespo et al. (2011; generic concept), Hawksworth et al. (2011a; checklist), Schmull et al. (2011; sequence), Vicol (2012; Romania), Matwiejuk and Korobkiewicz (2012; taxonomy), Kirk et al. (2013; genus accepted), Millot et al. (2014; cancer), Lumbsch (2014; taxonomy), Favero-Longo et al. (2015; saxicolous community), Papazi et al. (2015; symbiosis), Kaźmierska and Kossowska (2016; taxonomy), Lücking et al. (2016b; classification), cultures and sequences are available, needs generic revision.

Pleurostoma Tul. \& C. Tul. 1863 (= Pleurostomophora Vijaykr. et al. 2004 fide Maharachchikumbura et al. 2015, 2016; Réblová et al. 2016c), Pleurostomataceae, Calosphaeriales, Sordariomycetes, seven species, type: P. candollei Tul. \& C. Tul., asexual morph hyphomycetous, saprobes, terrestrial, North temperate, see Lumbsch and Huhndorf (2010; outline), Kirk et al. (2013; genus accepted), Maharachchikumbura et al. (2015, 2016; outline), Réblová et al. (2015b, 2016; new species, nomenclature), cultures and sequences are available but lacks for the type, needs generic revision.

Pleurostromella Petr. 1922, Ascomycota genera incertae sedis, 15 species, type: P. ulmicola Petr., coelomycetous, sexual morph unknown, saprobes, terrestrial, Europe, see Wijayawardene et al. (2012, 2017; outline), Kirk et al. (2013; genus accepted), cultures and sequences are unavailable, needs generic revision.

Pleurotheciella Réblová, Seifert \& J. Fourn. 2012, Pleurotheciaceae, Pleurotheciales, Sordariomycetes, nine species, type: P. rivularia Réblová, Seifert \& J. Fourn., asexual morph 
hyphomycetous, saprobes, terrestrial, terrestrial, Europe, Canada, see Réblová et al. (2012; taxonomy, phylogeny), Maharachchikumbura et al. (2015, 2016; outline), cultures and sequences are available, holotype and ex-type cultures of the type: PRM 899852; CBS 125238.

Pleurotheciopsis B. Sutton 1973, Ascomycota genera incertae sedis, seven species, type: P. pusilla B. Sutton, hyphomycetous, sexual morph unknown, saprobes, on litter (Calophyllum, Castanea, Rubus) and bank (Betula, Ilex, Salix), Caribbean, Europe, South America, see Seifert et al. (2011; morphology), Wijayawardene et al. (2012, 2017; outline), Kirk et al. (2013; genus accepted), cultures and sequences are unavailable, holotype of the type: IMI 168990, needs generic revision.

Pleurothecium Höhn. 1919 (= Carpoligna F.A. Fernández \& Huhndorf 1999 fide Réblová et al. 2016c), Pleurotheciaceae, Pleurotheciales, Sordariomycetes, nine species, type: P. recurvatum (Morgan) Höhn., hyphomycetous, sexual morph formerly named in Carpoligna, saprobes, terrestrial, terrestrial, Europe, Canada, see Wu and Zhang (2009; new species), Seifert et al. (2011; morphology), Wijayawardene et al. (2012, 2017; outline), Réblová et al. (2012, 2016c; taxonomy, phylogeny, nomenclature), Kirk et al. (2013; genus accepted), Maharachchikumbura et al. (2015, 2016; outline), cultures available for the type: CBS 138686, needs generic revision.

Pleurothyriella Petr. \& Syd. 1925, Ascomycota genera incertae sedis, one species, type: $P$. pinastri (Oudem.) Petr. \& Syd., coelomycetous, sexual morph unknown, saprobes, see Wijayawardene et al. (2012, 2017; outline), Kirk et al. (2013; genus accepted), cultures and sequences are unavailable, needs generic revision.

Pleurovularia R. Kirschner \& U. Braun 2002, Ascomycota genera incertae sedis, one species, type: P. polliniae (Henn.) R. Kirschner \& U. Braun (三Ovularia polliniae Henn.), hyphomycetous, terrestrial, plant pathogens, Asia, see Seifert (2011; morphology), Wijayawardene et al. (2012, 2017; outline), cultures and cultures and sequences are unavailable, holotype of type: Yoshinaga 25 (B).

Pliariona A. Massal. 1860, Graphidaceae, Ostropales, Lecanoromycetes, one species, type: P. montagnei (Bosch) A. Massal., asexual morph unknown, lichenized, terrestrial, tropical, see Rivas Plata et al. (2013; phylogeny), Lücking et al. (2016b; classification), cultures and sequences are available, needs generic revision.

Plicaria Fuckel 1870, Pezizaceae, Pezizales, Pezizomycetes, ten species, type: P. trachycarpa (Curr.) Boud., asexual morph unknown, hypogeous, terrestrial, worldwide, see Lumbsch and Huhndorf (2010; outline), Kirk et al. (2013; genus accepted), cultures and sequences are available, cultures available for the type: DAOM 195830, genus needs revision since it is polyphyletic.

Plicariella (Sacc.) Rehm 1894, Pezizaceae, Pezizales, Pezizomycetes, two species, type: P. radula (Berk. \& Broome) Rehm, asexual morph unknown, saprobes, see Kirk et al. (2013; did not list the genus), Jaklitsch et al. (2016a; classification), cultures and sequences are unavailable.

Plochmopeltis Theiss. 1914, Schizothyriaceae, Dothideomycetes families incertae sedis, five species, type: P. intricata (Ellis \& G. Martin) Theiss., asexual morph unknown, saprobes, terrestrial, pantropical, see Lumbsch and Huhndorf (2010; outline), Kirk et al. (2013; genus accepted), Hyde et al. (2013, accepted as a genus in Schizothyriaceae), Wijayawardene et al. (2014c; outline), Phookamsak et al. (2016; taxonomy), cultures and sequences are unavailable, needs generic revision.

Ploettnera Henn. 1900, Calloriaceae, Helotiales, Leotiomycetes, five species, type: $P$. caeruleoviridis (Rehm) Henn., asexual morph unknown, saprobes, terrestrial, Europe, see Lumbsch and Huhndorf (2010; outline), Kirk et al. (2013; genus accepted), cultures and sequences are unavailable, needs generic revision. 
Ploioderma Darker 1967 (= Cryocaligula Minter 1986 fide Johnston et al. 2014b), Rhytismataceae, Rhytismatales, Leotiomycetes, seven species, type: P. hedgcockii (Dearn.) Darker, asexual morph coelomycetous, saprobes, terrestrial, worldwide, see Lumbsch and Huhndorf (2010; outline), Shi et al. (2010; new species, China), Kirk et al. (2013; genus accepted), Johnston et al. (2014b; nomenclature), cultures and sequences are available but lacks for the type, needs generic revision.

Plokamidomyces Bat., C.A.A. Costa \& Cif. 1957, Euantennariaceae, Dothideomycetes families incertae sedis, two species, type: P. colensoi Bat., C.A.A. Costa \& Cif., hyphomycetous, sexual morph unknown, saprobes, terrestrial, Oceania, South America, see Seifert et al. (2011; morphology), Wijayawardene et al. (2012, 2017; outline), Kirk et al. (2013; genus accepted), cultures and sequences are unavailable, needs generic revision.

Plowrightia Sacc. 1883, Dothideaceae, Dothideales, Dothideomycetes, more than 50 species, type: P. ribesia (Pers.) Sacc., asexual morph coelomycetous, parasitic or saprobes on leaves, twigs and wood in terrestrial habitats, worldwide, see Lumbsch and Huhndorf (2010; outline), Kirk et al. (2013; genus accepted), Thambugala et al. (2014b; phylogeny), Wijayawardene et al. (2014c; outline), sequence data available for two species, holotype of type: cannot be located.

Plurisperma Sivan. 1970, Verrucariaceae, Verrucariales, Eurotiomycetes, one species, type: P. dalbergiae Sivan., asexual morph unknown, saprobes, terrestrial, Pakistan, see Lumbsch and Huhndorf (2010; outline), Kirk et al. (2013; genus accepted), cultures and sequences are unavailable, needs generic revision.

Plurispermiopsis Pereira-Carv., Inácio \& Dianese 2010, Capnodiaceae, Capnodiales, Dothideomycetes, one species, type: P. cerradensis Pereira-Carvalho, Inacio \& Dianese, asexual morph unknown, saprobes, terrestrial, Brazil, see Pereira-Carvalho et al. (2010; taxonomy), cultures and sequences are unavailable, needs generic revision.

Pneumocystis Delanoë \& Delanoë 1912, Pneumocystidaceae, Pneumocystidales, Pneumocystidomycetes, five species, type: P. carinii P. Delanoë \& Delanoë, asexual reproduction occurs by binary fission, pathogens, on mammals (frequent cause of pneumonia in HIV/AIDS patients), worldwide, Lumbsch and Huhndorf (2010; outline), Kirk et al. (2013; genus accepted), cultures and sequences are available.

Poaceascoma Phookamsak \& K.D. Hyde 2015, Lentitheciaceae, Pleosporales, Dothideomycetes, two species, type: P. helicoides Phookamsak \& K.D. Hyde, asexual morph unknown, saprobes, Asia, see Phookamsak et al. (2015a; taxonomy), Luo et al. (2016b; new species), cultures and sequences are available.

Poaceicola W.J. Li, Camporesi, D.J. Bhat \& K.D. Hyde 2015, Phaeosphaeriaceae, Pleosporales, Dothideomycetes, three species, type: P. arundinis W.J. Li, Camporesi, D.J. Bhat \& K.D. Hyde, asexual morph coelomycetous, saprobes, terrestrial, Italy, see Li et al. (2015c; taxonomy, phylogeny), Wijayawawardene et al. (2016; taxonomy, phylogeny), Hyde et al. (2016; taxonomy, phylogeny), holotype of the type: MFLU 15-0702.

Pochonia Bat. \& O.M. Fonseca 1965, Clavicipitaceae, Hypocreales, Sordariomycetes, four species, type: P. humicola Bat. \& O.M. Fonseca, asexual morph unknown, saprobes, from soil, terrestrial, worldwide, see Kirk et al. (2013; genus accepted), Nonaka et al. (2013c; new species, Japan), Huang et al. (2015a; new species, Tibet, China), Maharachchikumbura et al. (2015, 2016; outline), cultures and sequences are available but lacks for the type, type specimen of type: CBS H-7885, needs generic revision.

Pocillopycnis Dyko \& B. Sutton 1979, Ascomycota genera incertae sedis, one species, type: P. umensis (Bubák \& Vleugel) Dyko \& B. Sutton, coelomycetous, sexual morph unknown, saprobes, terrestrial, Sweden, see Wijayawardene et al. (2012, 2017; outline), Kirk et al. (2013; genus accepted), cultures and sequences are unavailable, needs generic revision. 
Pocillum De Not. 1864, Vibrisseaceae, Helotiales, Leotiomycetes, one species, type: P. cesatii (Mont.) De Not., asexual morph unknown, saprobes on fruits and leaves, Europe and America, see Lumbsch and Huhndorf (2010; outline), Kirk et al. (2013; genus accepted), DNA sequences and cultures unavailable, needs generic revision.

Poculinia Spooner 1987, Pezizellaceae, Helotiales, Leotiomycetes, one species, type: P. nothofagi (Rodway) Spooner, asexual morph unknown, saprobes, terrestrial, Tasmania, see Lumbsch and Huhndorf (2010; outline, listed as Poculina), Kirk et al. (2013; genus accepted), cultures and sequences are unavailable, needs generic revision.

Podocapsa Tiegh. 1887, Ascomycota genera incertae sedis, one species, type: P. palmata Tiegh., asexual morph unknown, saprobes, terrestrial, Europe, see Kirk et al. (2013; genus accepted), cultures and sequences are unavailable, needs generic revision.

Pododimeria E. Müll. 1959, Pseudoperisporiaceae, Dothideomycetes families incertae sedis, four species, type: $P$. gallica E. Müll., asexual morph unknown, saprobes, terrestrial, Europe, North America, see Lumbsch and Huhndorf (2010; outline), Hyde et al. (2013; accepted as a genus in Pseudoperisporiaceae), Kirk et al. (2013; genus accepted), Wijayawardene et al. (2014c; outline), cultures and sequences are unavailable, needs generic revision.

Podonectria Petch 1921, Tubeufiaceae, Tubeufiales, Dothideomycetes, nine species, type: $P$. coccicola (Ellis \& Everh.) Petch, asexual morph unknown, associated with scale insects, widespread in tropical regions, see Lumbsch and Huhndorf (2010; outline), Hyde et al. (2013; accepted as a genus in Tubeufiaceae), Kirk et al. (2013; genus accepted), Boonmee et al. (2014b; phylogeny), Wijayawardene et al. (2014c; outline), cultures and sequences are available, needs generic revision.

Podophacidium Niessl 1868, Helotiales genera incertae sedis, Leotiomycetes, two species, type: P. terrestre Niessl, asexual morph unknown, saprobes, terrestrial, terrestrial, Europe, North America see Lumbsch and Huhndorf (2010; outline), Kirk et al. (2013; genus accepted), cultures and sequences are unavailable, needs generic revision.

Podoplaconema Petr. 1921, Ascomycota genera incertae sedis, one species, type: $P$. melaenum (Fr.) Petr., coelomycetous, sexual morph unknown, saprobes, terrestrial, Europe, see Wijayawardene et al. (2012, 2014c; genus accepted, in Dothideaceae), Hyde et al. (2013; genus accepted, in Dothideaceae), Kirk et al. (2013; genus accepted), Wijayawardene et al. (2017; listed genus as Ascomycota), cultures and sequences are unavailable, isosyntype of type: B (also distributed in Scleromyceti Suecicae no. 200), needs generic revision.

Podosordaria Ellis \& Holw. 1897 (= Pedisordaria Clem. 1909 fide Wedt et al. 2017), Xylariaceae, Xylariales, Sordariomycetes, one species, type: P. mexicana Ellis \& Holw., asexual morph hyphomycetous, saprobes, coprophilous, terrestrial, worldwide, see Hsieh et al. (2010; DNA, phylogeny), Lumbsch and Huhndorf (2010; outline), Kirk et al. (2013; genus accepted), Maharachchikumbura et al. (2015, 2016; outline), Senanayake et al. (2015; phylogeny), sequences are available for the voucher 176 (WSP) of the type, needs generic revision.

Podosphaera Kunze 1823 emend. Braun \& Takamatsu 2000, Erysiphaceae, Erysiphales, Leotiomycetes, 95 species, type: $P$. myrtillina (Schub.: Fr.) Kunze, sexual and hyphomycetous asexual morphs, biotrophic, obligate plant pathogens, terrestrial, worldwide, see Lumbsch and Huhndorf (2010; outline), Braun and Cook (2012; taxonomy), Kirk et al. (2013; genus accepted), cultures and sequences are available, neotype of type: Fungi Saxon. Exs. 72b. (HAL).

Podospora Ces. 1856, Lasiosphaeriaceae, Sordariales, Sordariomycetes, c. 100 species, type: $P$. fimiseda (Ces. \& De Not.) Niessl, asexual morph consist of dark celled phialides such as Cladorrhinum, Phialophora, Rhizoctonia, Ramophialophora, saprobes on dung of animals, worldwide, see Lumbsch and Huhndorf (2010; outline), Chang et al. (2010; phylogeny), Mungai et al. (2012a; from dung), Kirk et al. (2013; genus accepted), Kruys et al. (2015; 
phylogeny), about 24 species have sequence data, cultures available for the type: CBS 482.64, needs generic revision.

Podosporiella Ellis \& Everh. 1895, Ascomycota genera incertae sedis, four species, type: $P$. humilis Ellis \& Everh, hyphomycetous, sexual morph unknown, saprobes, on leaves (Garry, Faurea), Africa, North America, see Seifert et al. (2011; morphology), Wijayawardene et al. (2012, 2017; outline), Kirk et al. (2013; genus accepted), cultures and sequences are unavailable, needs generic revision.

Podosporium Schwein. 1832, Ascomycota genera incertae sedis, 67 species, type: P. rigidum Schwein, hyphomycetous, sexual morph unknown, saprobes, on dead stems and litter (Ampelopsis, Bambusa, Rhus and others), terrestrial, North America, see Seifert et al. (2011; morphology), Wijayawardene et al. (2012, 2017; outline), Kirk et al. (2013; genus accepted), cultures and sequences are unavailable, needs generic revision.

Podostictina Clem. 1909, Lobariaceae, Peltigerales, Lecanoromycetes, six species, type: $P$. endochrysoides (Müll. Arg.) Clem., lichenized, see Moncada et al. (2013a; phylogeny), Lücking et al. (2016b; classification), cultures and sequences are available, needs generic revision.

Podotara Malcolm \& Vězda 1996, Pilocarpaceae, Lecanorales, Lecanoromycetes, one species, type: $P$. pilophoriformis Malcolm \& Vězda, asexual morph unknown, lichenized, terrestrial, New Zealand, see Hsieh et al. (2010; DNA, phylogeny), Lumbsch and Huhndorf (2010; outline), Kirk et al. (2013; genus accepted), Lücking et al. (2016b; classification), cultures and sequences are available, holotype of type: CHR 486638.

Poeltiaria Hertel 1984, Lecideaceae, Lecideales, Lecanoromycetes, six species, type: P. turgescens (Körb.) Hertel, asexual morph unknown, lichenized, terrestrial, worldwide, see Lumbsch and Huhndorf (2010; outline), Kirk et al. (2013; genus accepted), Fryday and Hertel (2014; new species, Antarctica, Tasmenia), Lücking et al. (2016b; classification), cultures and sequences are available for an unidentified species but lacks for the type, needs generic revision.

Poeltidea Hertel \& Hafellner 1984, Lecideaceae, Lecideales, Lecanoromycetes, three species, type: P. perusta (Nyl.) Hertel \& Hafellner, asexual morph unknown, lichenized, terrestrial, Kerguelen, Australasia, see Lumbsch and Huhndorf (2010; outline), Kirk et al. (2013; genus accepted), Fryday and Hertel (2014; new species, New Zealand), Lücking et al. (2016b; classification), cultures and sequences are unavailable, lectotype of type: BM.

Poeltinula Hafellner 1984, Rhizocarpaceae, Rhizocarpales, Lecanoromycetes, two species, type: P. cerebrina (DC.) Hafellner, asexual morph unknown, lichenized, terrestrial, Europe, see Lumbsch and Huhndorf (2010; outline), Kirk et al. (2013; genus accepted), Lücking et al. (2016b; classification), sequences are available, needs generic revision.

Poetschia Körb. 1861, Patellariaceae, Patellariales, Dothideomycetes, four species, type: $P$. buellioides Körb., asexual morph unknown, saprobes, terrestrial, Europe, South America, see Lumbsch and Huhndorf (2010; outline), Hyde et al. (2013; accepted as a genus in Patellariaceae), Kirk et al. (2013; genus accepted), Wijayawardene et al. (2014c; outline), Yacharoen et al. (2015; taxonomy), cultures and sequences are unavailable, needs generic revision.

Poikilosperma Bat. \& J.L. Bezerra 1961, Ascomycota genera incertae sedis, one species, type: P. scutellare Bat. \& J.L. Bezerra, coelomycetous, sexual morph unknown, saprobes, on leaves of Brosimum, Brazil, see Wijayawardene et al. (2012, 2017; outline), Kirk et al. (2013; genus accepted), cultures and sequences are unavailable, needs generic revision.

Polaroscyphus Huhtinen 1987, Hyaloscyphaceae, Helotiales, Leotiomycetes, one species, type: $P$. spetsbergianus Huhtinen, asexual morph unknown, saprobes, terrestrial, Svalbard, Norway, see Lumbsch and Huhndorf (2010; outline), Kirk et al. (2013; genus accepted), cultures and sequences are unavailable, needs generic revision. 
Polistroma Clemente 1807, Graphidaceae, Ostropales, Lecanoromycetes, one species, type: $P$. fernandezii Clemente, asexual morph unknown, lichenized, terrestrial, tropical, see Lumbsch and Huhndorf (2010; outline), Kirk et al. (2013; genus accepted), Lumbsch et al. (2014a, b; taxonomy), Lücking et al. (2016b; classification), sequences and cultures are unavailable, needs generic revision.

Polyancora Voglmayr \& Yule. 2006, Xylariaceae, Xylariales, Sordariomycetes, one species, type: P. globosa Voglmayr \& Yule, sexual morph unknown, saprobes, submerged leaves, Peninsular Malaysia, see Seifert et al. (2011; morphology), Wijayawardene et al. (2012, 2017; outline), Maharachchikumbura et al. (2015, 2016; outline), cultures and sequences are available, holotype and ex-type strains of type: WU 26489; CBS 118182.

Polyandromyces Thaxt. 1920, Laboulbeniaceae, Laboulbeniales, Laboulbeniomycetes, one species, type: P. coptosomatis Thaxt., asexual morph unknown, saprobes, worldwide, see Lumbsch and Huhndorf (2010; outline), Kirk et al. (2013; genus accepted), cultures and sequences are unavailable.

Polyascomyces Thaxt. 1900, Laboulbeniaceae, Laboulbeniales, Laboulbeniomycetes, one species, type: P. trichophyae Thaxt., asexual morph unknown, saprobes, British Isles, see Lumbsch and Huhndorf (2010; outline), Kirk et al. (2013; genus accepted), cultures and sequences are unavailable.

Polyblastia A. Massal. 1852, Verrucariaceae, Verrucariales, Eurotiomycetes, 120 species, type: P. cupularis A. Massal., asexual morph unknown, saprobes, terrestrial, worldwide, see Savić et al. (2008; phylogeny), Lumbsch and Huhndorf (2010; outline), Savić and Tibell (2012; northern Europe, adjacent Arctic), Kirk et al. (2013; genus accepted), Lücking et al. (2016b; classification), cultures and sequences are available, needs generic revision.

Polyblastidium Kalb 2015, Physciaceae, Caliciales, Lecanoromycetes, 18 species, type: $P$. japonicum (M. Satô) Kalb, lichenized, worldwide, see Mongkolsuk et al. (2015; phylogeny), Lücking et al. (2016b; classification), cultures and sequences are available, needs generic revision.

Polybulbophiale Goh \& K.D. Hyde 1998, Ascomycota genera incertae sedis, one species, type: P. palmicola Goh \& K.D. Hyde, hyphomycetous, sexual morph unknown, saprobes, on palm petiole (Licuala), Brunei, see Seifert et al. (2011; morphology), Wijayawardene et al. (2012, 2017; outline), Kirk et al. (2013; genus accepted), cultures and sequences are unavailable, holotype of the type: HKU (M) 4717, needs generic revision.

Polycauliona Hue 1908, Teloschistaceae, Teloschistales, Lecanoromycetes, 25 species, type: $P$. regalis (Vain.) Hue, lichenized, see Arup et al. (2013; phylogeny), Kondratyuk et al. (2014b; phylogeny), Jaklitsch et al. (2016a; notes), Lücking et al. (2016b; classification), cultures and sequences are available, needs generic revision.

Polycephalomyces Kobayasi 1941, Ophiocordycipitaceae, Hypocreales, Sordariomycetes, twelve species, type: $P$. formosus Kobayasi, hyphomycetous, on insects, cosmopolitan, see Seifert et al. (2011; morphology), Wijayawardene et al. (2012, 2017; outline), Kepler et al. (2013; new species), Kirk et al. (2013; genus accepted), Matočec et al. (2014; revision), Quandt et al. (2014; nomenclature), cultures and sequences are available.

Polychaetella Speg. 1918, Ascomycota genera incertae sedis, three species, type: $P$. schweinitzii (Berk. \& Desm.) Speg., coelomycetous, sexual morph unknown, saprobes, terrestrial, Europe, North America, see Wijayawardene et al. (2012, 2017; outline), Kirk et al. (2013; genus accepted), cultures and sequences are unavailable, needs generic revision.

Polychidium (Ach.) Gray 1821, Massalongiaceae, Peltigerales, Lecanoromycetes, c. 10 species, type: P. muscicola (Sw.) Gray, asexual morph unknown, lichenized, terrestrial, worldwide, see Wedin et al. (2009b; phylogeny), Hansen (2009; Iceland), Lumbsch and Huhndorf (2010; outline), Muggia et al. (2011c; phylogeny, systematics), Anderson and Neily (2012; Nova Scotia), Jayalal et al. (2012a; new records), Kirk et al. (2013; genus 
accepted), Weerakoon and Aptroot (2016; checklist), Lücking et al. (2016b; classification), sequences are available, needs generic revision.

Polycladium Ingold. 1959, Ascomycota genera incertae sedis, one species, type: P. equiseti Ingold, sexual morph unknown, found on dead internodes of Equisetum fluviatile, see Seifert et al. (2011; morphology), Wijayawardene et al. (2012, 2017; outline), Kirk et al. (2013; genus accepted), cultures and sequences are unavailable, needs generic revision, holotype of type: IMI 73532.

Polyclypeolina Bat. \& I.H. Lima 1959, Dothideomycetes genera incertae sedis, one species, type: P. brideliae (Hansf.) Bat., asexual morph unknown, epiphytes, terrestrial, worldwide, see Hofmann (2009; review, accepted as a genus in Aulographaceae), Lumbsch and Huhndorf (2010; outline, accepted as a genus in Aulographaceae), Hyde et al. (2013; review, excluded from Aulographaceae), Wijayawardene et al. (2014c; outline, accepted as a genus in Dothideomycetes), cultures and sequences are unavailable, holotype of type: K(M) 177972. Polycoccum Saut. ex Körb. 1865, Polycoccaceae, Trypetheliales, Dothideomycetes, 66 species, type: $P$. sauteri Körb., asexual morph unknown, saprobes, lichenicolous, terrestrial, worldwide, see Halc et al. (2009b; new species), Etayo (2010; new species), Brackel and Berger (2010; new species), Lumbsch and Huhndorf (2010; outline), Zhurbenko and Dillman (2010; new species), van den Boom (2012; new species), Hyde et al. (2013; outline, accepted as a genus in Dacampiaceae), Halici et al. (2013; new species, Turkey), Kirk et al. (2013; genus accepted), Wijayawardene et al. (2014c; outline), Ertz et al. (2015a; phylogeny, introducd Polycoccaceae), Hafellner (2015; new species), cultures and sequences are available but lacks for the type, needs generic revision.

Polycyclina Theiss. \& Syd. 1915, Parmulariaceae, Dothideomycetes families incertae sedis, Dothideomycetes, one species, type: P. rhytismoides (Speg.) Theiss. \& Syd., asexual morph unknown, epiphytes, terrestrial, worldwide, see Hofmann (2009; review), Lumbsch and Huhndorf (2010; outline), Hyde et al. (2013; outline, keys), Wijayawardene et al. (2014c; outline), cultures and sequences are unavailable, needs generic revision.

Polycyclinopsis Bat., A.F. Vital \& I.H. Lima 1958, Dothideomycetes genera incertae sedis, one species, type: P. solani Bat., A.F. Vital \& I.H. Lima, asexual morph unknown, saprobes, terrestrial, Brazil, see Lumbsch and Huhndorf (2010; outline, accepted as a genus in Microthyriaceae), Kirk et al. (2013; genus accepted), Wijayawardene et al. (2014c; accepted as a genus in Dothideomycetes genera incertae sedis), cultures and sequences are unavailable, needs generic revision.

Polycyclus Höhn. 1909, Parmulariaceae, Dothideomycetes families incertae sedis, Dothideomycetes, two species, type speices: P. andinus (Pat.) Theiss. \& Syd., asexual morph unknown, epiphytes, terrestrial, São Paulo, see Hofmann (2009; review), Lumbsch and Huhndorf (2010; outline), Hyde et al. (2013; outline, keys), Wijayawardene et al. (2014c; outline), cultures and sequences are unavailable, needs generic revision.

Polydesmia Boud. 1885, Helotiales genera incertae sedis, Leotiomycetes, seven species, type: P. pruinosa (Berk. \& Broome) Boud., asexual morph unknown, saprobes, terrestrial, worldwide, see Lumbsch and Huhndorf (2010; outline), Kirk et al. (2013; genus accepted), cultures and sequences are available, needs generic revision.

Polydesmus Mont. 1845, Ascomycota genera incertae sedis, 14 species, type: P. elegans Durieu \& Mont., hyphomycetous, sexual morph unknown, saprobes, terrestrial, American, see Seifert et al. (2011; morphology), Wijayawardene et al. (2012, 2017; outline), Kirk et al. (2013; genus accepted), cultures and sequences are available, needs generic revision.

Polydiscidium Wakef. 1934, Leotiomycetes genera incertae sedis, seven species, type: $P$. martynii Wakef., asexual morph unknown, saprobes, Africa, Guyana, worldwide, see Lumbsch and Huhndorf (2010; outline), Kirk et al. (2013; genus accepted), cultures and sequences are unavailable, needs generic revision. 
Polydiscina Syd. 1930, Leotiomycetes genera incertae sedis, one species, type: P. boliviana Syd., asexual morph unknown, saprobes, terrestrial, Bolivia, see Lumbsch and Huhndorf (2010; outline), Kirk et al. (2013; genus accepted), cultures and sequences are unavailable, needs generic revision.

Polyetron Bat. \& Peres 1963, Ascomycota genera incertae sedis, one species, type: P. myrtaceicola Bat. \& Peres, coelomycetous, sexual morph unknown, saprobes, terrestrial, Brazil, see Wijayawardene et al. (2012, 2017; outline), Kirk et al. (2013; genus accepted), cultures and sequences are unavailable, needs generic revision.

Polylobatispora Matsush. 1996, Ascomycota genera incertae sedis, two species, type: $P$. deltoidea Matsush., coelomycetous, sexual morph unknown, saprobes, terrestrial, Malaysia, see Wijayawardene et al. (2012, 2017; outline), Kirk et al. (2013; genus accepted), cultures and sequences are unavailable, holotype of the type: Matsushima Fungus Collection, Kobe, 5T195, needs generic revision.

Polymeridium (Müll. Arg.) R.C. Harris 1980, Trypetheliaceae, Trypetheliales, Dothideomycetes, 50 species, type: P. contendens (Nyl.) R.C. Harris, asexual morph unknown, lichenized, terrestrial, tropical, see Lumbsch and Huhndorf (2010; outline), Kirk et al. (2013; genus accepted), Aptroot and Cáceres (2014; key), Aptroot and Lücking (2016; monograph), Lücking et al. (2016b; classification), cultures and sequences are available, needs generic revision.

Polypedia Bat. \& Peres 1959, Micropeltidaceae, Microthyriales, Dothideomycetes, one species, type: P. leopoldinensis Bat. \& Peres, asexual morph unknown, saprobes, terrestrial, Brazil, see Lumbsch and Huhndorf (2010; outline, accepted as a genus in Micropeltidaceae), Hyde et al. (2013; not accepted as a genus in Micropeltidaceae), Wijayawardene et al. (2014c; not accepted as a genus in Micropeltidaceae), Kirk et al. (2013; genus accepted), cultures and sequences are unavailable, needs generic revision.

Polyphialoseptoria Quaedvl., R.W. Barreto, Verkley \& Crous 2013, Mycosphaerellaceae, Capnodiales, Dothideomycetes, one species, type: P. terminaliae Quaedvlieg, R.W. Barreto, Verkley \& Crous, coelomycetous, sexual morph unknown, pathogens, terrestrial, Brazil, see Quaedvlieg et al. (2013; morphology, phylogeny), cultures and sequences are available, holotype and ex-type of the type: CBS H-21298; CBS 135106.

Polyplosphaeria Kaz. Tanaka \& K. Hiray. 2009, Tetraplosphaeriaceae, Pleosporales, Dothideomycetes, two species, type: P. fusca Kaz. Tanaka \& K. Hiray., asexual morph hyphomycetous, saprobes, terrestrial, Japan, Thailand, see Tanaka et al. (2009; morphology, phylogeny), Li et al. (2016a; morphology, phylogeny), cultures and sequences are available, holotype and ex-type strain of the type: HHUF 29399; JCM 13175.

Polypyrenula D. Hawksw. 1985, Trypetheliaceae, Trypetheliales, Dothideomycetes, one species, type: P. sexlocularis (Müll. Arg.) D. Hawksw., asexual morph unknown, on bark, doubtfully lichenized, terrestrial, Caribbean, see Lumbsch and Huhndorf (2010; outline), Kirk et al. (2013; genus accepted), Jaklitsch et al. (2016a; classification), Lücking et al. (2016b; classification), cultures and sequences are unavailable, holotype of type: G.

Polyrhizon Theiss., Syd. \& P. Syd. 1914, Dothideomycetes genera incertae sedis, two species, type: P. terminaliae Syd. \& P. Syd., asexual morph unknown, saprobes, terrestrial, India, South Africa, see Lumbsch and Huhndorf (2010; outline, accepted as a genus in Venturiaceae), Kirk et al. (2013; genus accepted), Wijayawardene et al. (2014c; outline), cultures and sequences are unavailable, needs generic revision.

Polyrostrata T.P. Devi \& N. Mathur 2009, Ascomycota genera incertae sedis, two species, type: $P$. indica T.P. Devi \& N. Mathur, coelomycetous, sexual morph unknown, pathogens, terrestrial, India, see Mathur et al. (2009; taxonomy), Wijayawardene et al. (2017; outline), cultures and sequences are unavailable, holotype of the type: HCIO 46892, needs generic revision. 
Polyschema H.P. Upadhyay 1966, Latoruaceae, Pleosporales, Dothideomycetes, 21 species, type: P. terricola H.P. Upadhyay 1966, hyphomycetous, sexual morph not unknown, Saprobes, one species from human clinical sample, terrestrial, cosmopolitan, see Mota et al. (2008; new species, key), Shenoy et al. (2010; monophyly within Pleosporales), Seifert et al. (2011; morphology), Wijayawardene et al. (2012, 2017; outline), Kirk et al. (2013; genus accepted), Crous et al. (2015d; placement in Latoruaceae), ex-type culture of the type: CBS 301.65 .

Polyscytalum Riess 1853, Xylariales genera incertae sedis, Sordariomycetes, 13 species, type: P. fecundissimum Riess, hyphomycetous, saprobes, pathogens, terrestrial, worldwide, see Cheewangkoon et al. (2009; new species, Portugal), Seifert et al. (2011; morphology), Kirk et al. (2013; genus accepted), Wijayawardene et al. (2017; outline), Senanayake et al. (2015; phylogeny), Crous et al. (2016a; new species, phylogeny), cultures and sequences are available, available specimen and cultures for the type: CBS H-6049; CBS 100506.

Polysporella Woron. 1916, Mycosphaerellaceae, Capnodiales, Dothideomycetes, one species, type: P. woronowii Woron., see Lumbsch and Huhndorf (2010; outline), Kirk et al. (2013; did not list), needs generic revision.

Polysporidiella Petr. 1960, Dothideomycetes genera incertae sedis, one species, type: $P$. iranica Petr., asexual morph unknown, saprobes, terrestrial, Iran, see Lumbsch and Huhndorf (2010; outline, accepted as a genus in Venturiaceae), Kirk et al. (2013; genus accepted), Wijayawardene et al. (2014c; outline), cultures and sequences are unavailable, needs generic revision.

Polysporina Vězda [nom. cons.] 1978, Acarosporaceae, Acarosporales, Lecanoromycetes, ten species, type: $P$. simplex (Taylor) Vězda, lichenized, worldwide, see Lumbsch and Huhndorf (2010; outline), Kirk et al. (2013; genus accepted), Lücking et al. (2016b; classification), cultures and sequences are available, needs generic revision.

Polystigma DC. 1815 (= Polystigmina Sacc. 1884, Rhodoseptoria Naumov 1913 fide Maharachchikumbura et al. 2015, 2016; Réblová et al. 2016c), Phyllachoraceae, Phyllachorales, Sordariomycetes, 25 species, type: P. rubrum (Pers.) DC., pathogens, worldwide, see Suzuki et al. (2008; pathogens, Japan), Lumbsch and Huhndorf (2010; outline), Kirk et al. (2013; genus accepted), Habibi and Banihashemi (2015, 2016; phylogeny), Maharachchikumbura et al. (2015, 2016; outline), cultures and sequences are available but lacks for the type, needs generic revision.

Polystomellina Bat. \& A.F. Vital 1958, Dothideomycetes genera incertae sedis, one species, type: P. didymopanacis Bat. \& A.F. Vital, asexual morph unknown, saprobes, terrestrial, Brazil, see Lumbsch and Huhndorf (2010; outline, accepted as a genus in Microthyriaceae), Kirk et al. (2013; genus accepted), Wijayawardene et al. (2014c; accepted as a genus in Dothideomycetes genera incertae sedis), cultures and sequences are unavailable, needs generic revision.

Polystomellomyces Bat. 1959, Ascomycota genera incertae sedis, one species, type: $P$. atheniensis Bat., coelomycetous, sexual morph unknown, saprobes, terrestrial, Greece, see Wijayawardene et al. (2012, 2017; outline), Kirk et al. (2013; genus accepted), cultures and sequences are unavailable, needs generic revision.

Polystomellopsis F. Stevens 1924 [1923], Dothideomycetes genera incertae sedis, one species, type: P. mirabilis F. Stevens, asexual morph unknown, saprobes, terrestrial, South America, see Lumbsch and Huhndorf (2010; outline), Kirk et al. (2013; genus accepted), Wijayawardene et al. (2014c; outline), cultures and sequences are unavailable, needs generic revision.

Polystratorictus Matsush. 1993, Ascomycota genera incertae sedis, two species, type: $P$. fusarioideus Matsush., hyphomycetous, sexual morph unknown, saprobes, terrestrial, Peru, see Wijayawardene et al. (2012, 2017; outline), Kirk et al. (2013; genus accepted), cultures 
and sequences are unavailable, holotype of type: Matsushima Fungus Collection, Kobe, OP353, needs generic revision.

Polythrincium Kunze 1817 (= Cymadothea F.A. Wolf 1935 fide Wijayawardene et al. 2014c; Rossman et al. 2015b), Mycosphaerellaceae, Capnodiales, Dothideomycetes, two species, type: P. trifolii Kunze, hyphomycetous, sexual morph formerly known in Cymadothea, saprobes, terrestrial, temperate, see Lumbsch and Huhndorf (2010; outline, sexual morph), Kirk et al. (2013; genus accepted), Wijayawardene et al. (2014c; nomenclature), Rossman et al. (2015b; nomenclature), cultures and sequences are available.

Polytolypa J.A. Scott \& Malloch 1993, Onygenaceae, Onygenales, Eurotiomycetes, one species, type: $P$. hystricis J.A. Scott \& Malloch, asexual morph unknown, coprophilous, terrestrial, Canada, see Lumbsch and Huhndorf (2010; outline), Kirk et al. (2013; genus accepted), Hirooka et al. (2016; phylogeny), cultures and sequences are available, cultures available for the type: UAMH 7299, holotype of type: TRTC 51349.

Polytretophora Mercado 1983, Ascomycota genera incertae sedis, one species, type: $P$. calcarata Mercado, hyphomycetous, sexual morph unknown, saprobes, terrestrial, pantropical, see Seifert et al. (2011; morphology), Wijayawardene et al. (2012, 2017; outline), Kirk et al. (2013; genus accepted), cultures and sequences are unavailable, needs generic revision.

Pontogeneia Kohlm. 1975, Koralionastetaceae, Koralionastetales, Sordariomycetes, eight species, type: P. padinae Kohlm., asexual morph unknown, saprobes, marine, worldwide, Campbell et al. (2009a; phylogeny), Lumbsch and Huhndorf (2010; outline), Kirk et al. (2013; genus accepted), Maharachchikumbura et al. (2015, 2016; outline), sequence data available for one species, holotype of type: J.K. 3541a = 00985934, NYBG.

Pontoporeia Kohlm. 1963, Halotthiaceae, Pleosporales, Dothideomycetes, one species, type: P. biturbinata (Durieu \& Mont.) Kohlm., asexual morph coelomycetous, saprobes, marine, Mediterranean Sea, see Jones et al. (2009b, 2015; classification), Suetrong et al. (2009; phylogeny, morphology), Zhang et al. (2012e, 2013c; morphology, phylogeny), Hyde et al. (2013; morphology, phylogeny), Wijayawardene et al. (2014c; phylogeny, nomenclature), cultures and sequences are available, needs generic revision.

Populocrescentia Wanasinghe, E.B.G. Jones \& K.D. Hyde 2015, Phaeosphaeriaceae, Pleosporales, Dothideomycetes, one species, type: P. forlicesenensis Wanas., Camporesi, E.B.G. Jones \& K.D. Hyde, asexual morph unknown, saprobes, terrestrial, Europe, Russia, see Ariyawansa et al. (2015a; taxonomy, phylogeny), cultures and sequences are available, holotype and ex-type strains of type: MFLU 15-1504; MFLUCC 14-0651.

Porina Müll. Arg. [nom. cons.] 1883, Porinaceae, Ostropales, Lecanoromycetes, 140 species, type: P. nucula Ach., lichenized, worldwide, see Lumbsch and Huhndorf (2010; outline), Kirk et al. (2013; genus accepted), Lücking et al. (2016b; classification), cultures and sequences are available, needs generic revision.

Porobeltraniella Gusmão 2004, Beltraniaceae, Xylariales, Sordariomycetes, one species, type: P. porosa (Piroz. \& S.D. Patil) Gusmão, hyphomycetous, sexual morph unknown, saprobes, terrestrial, India, America, see Seifert et al. (2011; morphology), Wijayawardene et al. (2012, 2017; outline), Grandi and da Silva (2014; South America), Maharachchikumbura et al. (2015, 2016; outline), Rajeshkumar et al. (2016; phylogeny), cultures and sequences are available, available specimen and cultures available for the type: IMI 234741; NFCCI 3994 (Rajeshkumar et al. 2016).

Porocercospora Amaradasa, Amundsen, Madrid \& Crous 2014, Pleosporaceae, Pleosporales, Dothideomycetes, one species, type: P. seminalis (Ellis \& Everh.) Amaradasa, Amundsen, H. Madrid \& Crous, hyphomycetous, sexual morph unknown, pathogens, USA, see Amaradasa et al. (2014; morphology, phylogeny), cultures and sequences are available, epitype and ex-epitype culture of type: CBS H-21149, CBS 134906. 
Porocladium Descals., 1976, Ascomycota genera incertae sedis, one species, type: $P$. aquaticum Descals, hyphomycetous, sexual morph unknown, saprobes, terrestrial, see Seifert et al. (2011; morphology), Wijayawardene et al. (2012, 2017; outline), Kirk et al. (2013; genus accepted), cultures and sequences are unavailable, holotype of type: IMI 199900.

Porocyphus Körb. 1855, Lichinaceae, Lichinales, Lichinomycetes, eight species, type: $P$. coccodes Flot. ex Körb., asexual morph unknown, lichenized, terrestrial, worldwide, see Högnabba et al. (2009a, b; evolution of photobiont), Lumbsch and Huhndorf (2010; outline), Kirk et al. (2013; genus accepted), Lücking et al. (2016b; classification), cultures and sequences are available but lacks for the type, needs generic revision.

Poroleprieuria M.C. González, Hanlin, Ulloa \& Elv. Aguirre 2004, Xylariales genera incertae sedis, Sordariomycetes, one species, type: P. rogersii M.C. González, Hanlin, Ulloa \& Elv. Aguirre, asexual morph hyphomycetous, saprobes, terrestrial, Mexico, see Lumbsch and Huhndorf (2010; outline), Maharachchikumbura et al. (2015, 2016; outline), Senanayake et al. (2015; phylogeny), Wendt et al. (2017; accepted as a genus in Xylariales genera incertae sedis), cultures and sequences are unavailable, holotype of the type: MEXU 23019.

Poronia Willd. 1787, Xylariaceae, Xylariales, Sordariomycetes, one species, type: $P$. gleditschii Willd., asexual morph unknown, saprobes, coprophilous, terrestrial, worldwide, see Lumbsch and Huhndorf (2010; outline), Hembrom et al. (2013; new species, India), Maharachchikumbura et al. (2015, 2016; outline), Senanayake et al. (2015; phylogeny), cultures and sequences are available but lacks for the type:, needs generic revision.

Poropeltis Henn. 1904, Ascomycota genera incertae sedis, one species, type: P. davillae Henn., coelomycetous, sexual morph unknown, saprobes, terrestrial, South America, see Wijayawardene et al. (2012, 2016b, 2017; outline, taxonomy), Kirk et al. (2013; genus accepted), cultures and sequences are unavailable, needs generic revision.

Porophilomyces U. Braun 2000, Ascomycota genera incertae sedis, one species, type: P. poricola (Bonar) U. Braun, hyphomycetous, terrestrial, fungiicolous, North America, see Seifert (2011; morphology), Wijayawardene et al. (2012, 2017; outline), cultures and sequences are unavailable, holotype and isolectotype of type: UC 1272179; UC 568840.

Porophoromyces Thaxt. 1926, Laboulbeniaceae, Laboulbeniales, Laboulbeniomycetes, one species, type: P. tmesiphori Thaxt., asexual morph unknown, biotrophic, terrestrial, Africa, see Lumbsch and Huhndorf (2010; outline), Kirk et al. (2013; genus accepted), cultures and sequences are unavailable.

Porosubramaniania Hol.-Jech. 1985, Ascomycota genera incertae sedis, two species, type: P. moniliformis Hol.-Jech., hyphomycetous, sexual morph unknown, saprobes, terrestrial, Asia, Europe, see Seifert et al. (2011; morphology), Wijayawardene et al. (2012, 2017; outline), Kirk et al. (2013; genus accepted), cultures and sequences are unavailable, needs generic revision.

Porpidia Körb. 1855, Lecideaceae, Lecideales, Lecanoromycetes, 50 species, type: $P$. trullisata (Kremp.) Körb., lichenized, temperate, see Lumbsch and Huhndorf (2010; outline), Kirk et al. (2013; genus accepted), Schmull et al. (2011; phylogeny), Lücking et al. (2016b; classification), cultures and sequences are available, needs generic revision.

Porpidinia Timdal 2010, Porpidiaceae, Lecideales, Lecanoromycetes, one species, type: Porpidinia tumidula (Sm.) Timdal (Lichen tumidulus Sm.), lichenized fungi, saxicolous, Europe, North Africa, see Timdal (2010; phylogenetic placement based on anatomical characters), sequences are unavailable, holotype of type: Smith s.n., LINN.

Psora Hoffm. 1796, Psoraceae, Lecanorales, Lecanoromycetes, c. 35 species, type: $P$. decipiens (Hedw.) Hoffm. (Lichen decipiens Hedw.), lichenized fungi, saxicolous, terricolous, worldwide, see Lumbsch and Huhndorf (2010; outline), Kirk et al. (2013; genus accepted), Lücking et al. (2016b; classification), cultures and sequences are available, needs generic revision. 
Psorinia Gotth. Schneid. 1980, Lecanoraceae, Lecanorales, Lecanoromycetes, one species, type: P. conglomerata (Ach.) Gotth. Schneid. (Lecidea conglomerata Ach.), lichenized, saxicolous, temperate northern hemisphere, see Lumbsch and Huhndorf (2010; outline), Kirk et al. (2013; genus accepted), Lücking et al. (2016b; classification), sequences are unavailable. Mischoblastia A.Massal. 1852, Physciaceae, Caliciales, Lecanoromycetes, three species, type: M. oxydata A. Massal., lichenized, see Gaya et al. (2012; phylogeny), Prieto et al. (2013; phylogeny), Prieto \& Wedin (2016; phylogeny), Lücking et al. (2016b; classification), cultures and sequences are available, needs generic revision.

Porrectotheca Matsush. 1996, Ascomycota genera incertae sedis, one species, type: $P$. divaricata Matsush., coelomycetous, sexual morph unknown, saprobes, terrestrial, Japan, see Wijayawardene et al. (2012, 2017; outline), Kirk et al. (2013; genus accepted), cultures and sequences are unavailable, holotype of type: Matsushima Fungus Collection, Kobe, 5H436, needs generic revision.

Potamomyces K.D. Hyde 1995, Ascomycota genera incertae sedis, one species, type: $P$. armatisporus K.D. Hyde, asexual morph unknown, saprobes, terrestrial, Japan, see Lumbsch and Huhndorf (2010; outline), Kirk et al. (2013; genus accepted), cultures and sequences are unavailable, holotype of type: BRIP 21490, needs generic revision.

Potridiscus Döbbeler \& Triebel 2000, Helotiales genera incertae sedis, Leotiomycetes, one species, type: $P$. polymorphus Döbbeler \& Triebel, asexual morph unknown, saprobes, terrestrial, Australia, see Lumbsch and Huhndorf (2010; outline), Kirk et al. (2013; genus accepted), cultures and sequences are unavailable, holotype of type: M Rambold 3269, needs generic revision.

Potriphila Döbbeler 1996, Odontotremataceae, Ostropales, Lecanoromycetes, three species, type: P. navicularis Döbbeler, asexual morph unknown, saprobes, terrestrial, Austria, see Lumbsch and Huhndorf (2010; outline), Kirk et al. (2013; genus accepted), cultures and sequences are unavailable, holotype of type: M (Döbbeler 6759), needs generic revision.

Praelongicaulis E.B.G. Jones, Abdel-Wahab \& K.L. Pang 2015, Halosphaeriaceae, Microascales, Sordariomycetes, one species, type: P. kandeliae (Abdel-Wahab \& E.B.G. Jones) E.B.G. Jones, Abdel-Wahab \& K.L. Pang, asexual morph unknown, saprobes, marine, Hong Kong, see Sakayaroj et al. (2011a; phylogeny), Jones et al. (2015, phylogeny, nomenclature), Maharachchikumbura et al. (2015, 2016; outline), cultures and sequences are available, holotype and ex-type strain of the type: IMI 379307; CY 1492.

Pragmopora A. Massal 1855 (= Pragmopycnis B. Sutton \& A. Funk 1975 fide Johnston et al. 2014b), Tympanidaceae, Phacidiales, Leotiomycetes, seven species, type: P. amphibola A. Massal., asexual morph formerly known in Pragmopycnis, saprobes, common in temperate northern hemisphere, see Kirk et al. (2013; genus accepted), Quijada et al. (2015; phylogeny), cultures and sequences are unavailable for the type of the type, lectotype in Royal Botanic Gardens (K).

Prataprajella Hosag. 1992, Meliolaceae, Meliolales, Sordariomycetes, two species, type: $P$. turpiniicola (Hosag.) Hosag., asexual morph unknown, saprobes, terrestrial, India, Taiwan, see Lumbsch and Huhndorf (2010; outline), Kirk et al. (2013; genus accepted), Hongsanan et al. (2015c; treated as a doubtful genus in Meliolaceae), cultures and sequences are unavailable, needs generic revision.

Preussia Fuckel 1867 (= Sporormiella Ellis \& Everh. 1892; = Spororminula Arx \& Aa 1987 fide Hyde et al. 2013), Sporormiaceae, Pleosporales, Dothideomycetes, 49 species, type: $P$. funiculata (Preuss) Fuckel, asexual morph unknown, saprobes, terrestrial, worldwide, see Chang and Wang (2009; new species), Kruys and Wedin (2009; new species), Schoch et al. (2009; phylogeny), Asgari and Zare (2010; new species), Lumbsch and Huhndorf (2010; outline), Mungai et al. (2012d; from dung), Hyde et al. (2013; accepted as a genus in Sporormiaceae, phylogeny), Kirk et al. (2013; genus accepted), Mapperson et al. (2014; 
endophytes), Wijayawardene et al. (2014c; outline), Kruys (2015; new species, Sweden), cultures and sequences are available, type specimen and cultures available for the type: CBS H-17339; CBS 659.74.

Priceomyces Kurtzman \& M. Suzuki 2010, Debaryomycetaceae, Saccharomycetales, Saccharomycetes, nine species, type: P. haplophilus (Shifrine \& Phaff) M. Suzuki, asexual reproduction is by multilateral budding, saprophytic, in tree fluxes, spoiled wine, alpechin, soil, insect frass in various trees, worldwide, see Kurtzman and Suzuki (2010; taxonomy), Crous et al. (2016b; new species), cultures and sequences are available.

Prillieuxina G. Arnaud 1918 (= Leprieurina G. Arnaud 1918 fide Wijayawardene et al. 2014c; Rossman et al. 2015a), Asterinaceae, Asterinales, Dothideomycetes, 55 species, type: P. winteriana (Pazschke) G. Arnaud, asexual morph unknown, parasymbiont on Pertusaria, terrestrial, tropical, see Hosagoudar and Chandraprabha (2009b; new species), Lumbsch and Huhndorf (2010; outline), Hosagoudar (2012; new species, India), Hosagoudar and Divya (2013; new species, India), Hyde et al. (2013; accepted as a genus in Asterinaceae), Kirk et al. (2013; genus accepted), Wijayawardene et al. (2014c; outline, nomenclature), Gautam (2015; new species), Guatimosim et al. (2015; phylogeny), Rossman et al. (2015b; nomenclature), cultures and sequences are available but lacks for the type, needs generic revision.

Pringsheimia Schulzer 1866, Dothideaceae, Dothideales, Dothideomycetes, nine species, type: $P$. rosarum Schulzer, asexual morph unknown, parasitic or saprobes, terrestrial habitats, worldwide, see Kirk et al. (2013; genus accepted), Thambugala et al. (2014a; review), Wijayawardene et al. (2014c; outline), sequence data available for one species, but no ex-type sequence data are available, needs generic revision.

Proboscispora Punith. 1984, Ascomycota genera incertae sedis, one species, type: $P$. manihotis Punith., coelomycetous, sexual morph unknown, saprobes, terrestrial, Malysia, see Wijayawardene et al. (2012, 2017; outline), Kirk et al. (2013; genus accepted), cultures and sequences are unavailable, needs generic revision.

Proliferodiscus J.H. Haines \& Dumont 1983, Lachnaceae, Helotiales, Leotiomycetes, eight species, type: P. inspersus (Berk. \& M.A. Curtis) J.H. Haines \& Dumont, asexual morph unknown, saprobes, terrestrial, worldwide, see Hofton et al. (2009; new species), Lumbsch and Huhndorf (2010; outline), Kirk et al. (2013; genus accepted), cultures and sequences are available for unidentified species, needs generic revision.

Proliferosphaera T.P. Devi 2012, Dothideomycetes genera incertae sedis, one species, type: $P$. capsici T.P. Devi, coelomycetous, sexual morph unknown, saprobes, terrestrial, worldwide, see Devi et al. (2012; taxonomy), Wijayawardene et al. (2017; outline), Cultures and sequences are available, cultures available for the type: PP-2011 isolate 6494, holotype of type: ITCC 6494, needs generic revision.

Prolixandromyces R.K. Benj. 1970, Laboulbeniaceae, Laboulbeniales, Laboulbeniomycetes, eight species, type: P. veliae R.K. Benj., asexual morph unknown, parasitic on Veliid bugs, semiaquatic, Africa, Asia, Central America, Europe, see Weir (2008; review), Lumbsch and Huhndorf (2010; outline), Kirk et al. (2013; genus accepted), Pfliegler et al. (2016b; taxonomy), cultures and sequences are available, cultures available for the type: DAH 18, needs generic revision.

Pronectria Clem. 1931, Bionectriaceae, Hypocreales, Sordariomycetes, 41 species, type: $P$. lichenicola (Ces.) Clem., asexual morph hyphomycetous, parasymbiont to parasites on lichens, more rarely algae, worldwide, see Etayo and Sancho (2008; morphology, keys), López et al. (2009; new species), Brackel (2014; morphology), Maharachchikumbura et al. (2015, 2016; outline), sequence data only for the type P. robergei as Illosporium carneum (ATCC 201590), lectotype of type: PC, Roberge. 
Propolidium Sacc. 1884, Rhytismataceae, Rhytismatales, Leotiomycetes, two species, type: P. glaucum (Ellis) Sacc., asexual morph unknown, saprobes, terrestrial, Africa, North America, see Lumbsch and Huhndorf (2010; outline), Kirk et al. (2013; genus accepted), Jaklitsch et al. (2016a; classification), cultures and sequences are unavailable, needs generic revision.

Propolina Sacc. 1884, Marthamycetaceae, Rhytismatales, Leotiomycetes, one species, type: $P$. cervina Sacc., asexual morph unknown, saprobes, terrestrial, Europe, see Lumbsch and Huhndorf (2010; outline), Kirk et al. (2013; genus accepted), cultures and sequences are unavailable, needs generic revision.

Propolis (Fr.) Corda 1838, Marthamycetaceae, Rhytismatales, Leotiomycetes, one species, type: P. farinosa (Pers.) Fr., asexual morph unknown, saprobes, terrestrial, Asia, North America, see Lumbsch and Huhndorf (2010; outline), Kirk et al. (2013; genus accepted), cultures and sequences are unavailable, needs generic revision.

Proprioscypha Spooner 1987, Hyaloscyphaceae, Helotiales, Leotiomycetes, one species, type: P. corticicola Spooner, asexual morph unknown, saprobes, pathogens, terrestrial, Australia, see Lumbsch and Huhndorf (2010; outline), Kirk et al. (2013; genus accepted), cultures and sequences are available for unidentified species, needs generic revision.

Prosopidicola Crous \& C.L. Lennox 2004, Cryphonectriaceae, Diaporthales, Sordariomycetes, two species, type: P. mexicana Crous \& C.L. Lennox, coelomycetous, sexual morph unknown, saprobes, terrestrial, cosmopolitan, see Wijayawardene et al. (2012, 2017; outline), Crous et al. (2016b; new species, phylogeny), cultures are available.

Prosthemium Kunze 1817 (= Pleomassaria Speg. 1880 fide Wijayawardene et al. 2014c; Rossman et al. 2015b), Pleomassariaceae, Pleosporales, Dothideomycetes, one species, type: $P$. betulinum Kunze, coelomycetous, sexual morph formerly known in Pleomassaria, saprobes, terrestrial, temperate, see Lumbsch and Huhndorf (2010; outline, sexual morph), Tanaka et al. (2010; taxonomy, phylogeny), Wijayawardene et al. (2012, 2014c, 2016b; outline, taxonomy, nomenclature), Zhang et al. (2012e; accepted as a genus in Pleomassariaceae, phylogeny), Hyde et al. (2013; accepted as a genus in Pleomassariaceae), Rossman et al. (2015b; nomenclature), cultures available for the type: CBS 279.74, needs generic revision.

Prostratus Sivan., W.H. Hsieh \& Chi Y. Chen 1993, Melanconidaceae, Xylariales, Sordariomycetes, one species, type: P. cyclobalanopsidis Sivan., W.H. Hsieh \& Chi Y. Chen, asexual morph unknown, saprobes, Taiwan, see Lumbsch and Huhndorf (2010; outline), Kirk et al. (2013; genus accepted), Maharachchikumbura et al. (2015, 2016; outline, phylogeny), cultures and sequences are unavailable, holotype of type: IMI 354625.

Protoblastenia (Zahlbr.) J. Steiner 1911, Psoraceae, Lecanorales, Lecanoromycetes, 30 species, type: P. rupestris (Scop.) J. Steiner, asexual morph unknown, lichenized, terrestrial, worldwide, see Lumbsch and Huhndorf (2010; outline), Kirk et al. (2013; genus accepted), cultures available for the type: Prorup415, needs generic revision.

Protocrea Petch 1937, Hypocreaceae, Hypocreales, Sordariomycetes, six species, type: P. farinosa (Berk. \& Broome) Petch, asexual morph acremonium-like, saprobes, terrestrial, worldwide, see Jaklitsch et al. (2008; new species, phylogeny), Lumbsch and Huhndorf (2010; outline), Kirk et al. (2013; genus accepted), Maharachchikumbura et al. (2015, 2016; outline), cultures and sequences are available, epitype and cultures available for the type: BPI 747356; CBS 121554.

Protocreopsis Yoshim. Doi 1977, Bionectriaceae, Hypocreales, Sordariomycetes, twelve species, type: P. zingibericola Yoshim. Doi, asexual morph acremonium-like, saprobes, terrestrial, tropical, see Lumbsch and Huhndorf (2010; outline), Kirk et al. (2013; genus accepted), Lechat and Fournier (2013; new species), Maharachchikumbura et al. (2015, 2016; outline), cultures and sequences are available, needs generic revision. 
Protocucurbitaria Naumov 1951, Sordariomycetes genera incertae sedis, six species, type: $P$. ribicola Naumov, asexual morph unknown, saprobes, terrestrial, former USSR, see Lumbsch and Huhndorf (2010; outline), Kirk et al. (2013; genus accepted), Maharachchikumbura et al. (2015, 2016; outline), cultures and sequences are unavailable, needs generic revision.

Protomicarea Hafellner 2001, Pilocarpaceae, Lecanorales, Lecanoromycetes, one species, type: P. limosa (Ach.) Hafellner, asexual morph unknown, lichenized, terrestrial, Europe, Turkey, see Lumbsch and Huhndorf (2010; outline), Kınalıoglu and Aptroot (2011; new records in Turkey), Schmull et al. (2011; phylogeny), cultures available for the type: Obermayer 07939 (Schmull et al. 2011), needs generic revision.

Protomyces Unger 1833, Protomycetaceae, Taphrinales, Taphrinomycetes, ten species, type: P. macrosporus Unger, asexual morph unknown, biotrophic on plants, terrestrial, worldwide, see Lumbsch and Huhndorf (2010; outline), Kirk et al. (2013; genus accepted), sequences are available, available specimen of type: CBS H-17359, needs generic revision.

Protomycopsis Magnus 1905, Protomycetaceae, Taphrinales, Taphrinomycetes, ten species, type: P. leucanthemi Magnus, asexual morph unknown, biotrophic on plants, terrestrial, worldwide, see Lumbsch and Huhndorf (2010; outline), Kirk et al. (2013; genus accepted), cultures and sequences are unavailable, needs generic revision.

Protopannaria (Gyeln.) P.M. Jørg. \& S. Ekman 2000, Pannariaceae, Peltigerales, Lecanoromycetes, five species, type: P. pezizoides (Weber) P.M. Jørg. \& S. Ekman, lichenized, Southern Hemisphere, see Lumbsch and Huhndorf (2010; outline), Lücking et al. (2016b; classification), cultures and sequences are available, needs generic revision.

Protoparmelia M. Choisy 1929, Parmeliaceae, Lecanorales, Lecanoromycetes, 35 species, type: P. badia (Hoffm.) Hafellner, lichenized, worldwide, see Lumbsch and Huhndorf (2010; outline), Papong et al. (2011; phylogeny), Kirk et al. (2013; genus accepted), Lücking et al. (2016b; classification), cultures and sequences are available, needs generic revision.

Protoparmeliopsis Choisy 1929, Lecanoraceae, Lecanorales, Lecanoromycetes, 20 species, type: P. muralis (Schreb.) M. Choisy, lichenized, see Kondratyuk et al. (2015f; taxonomy), Zhao et al. (2016; phylogeny), Lücking et al. (2016b; classification), cultures and sequences are available, needs generic revision.

Protoroccella Follmann 2001, Roccellaceae, Arthoniales, Arthoniomycetes, two species, type: P. minima (R. Sant.) Follmann ex Follmann, lichenized, terrestrial, Chile, see Lumbsch and Huhndorf (2010; outline), cultures and sequences are unavailable, needs generic revision.

Protoscypha Syd. 1925, Protoscyphaceae, Dothideomycetes families incertae sedis, one species, type: P. pulla Syd., asexual morph unknown, biotrophic, terrestrial, tropical, see Lumbsch and Huhndorf (2010; outline), Kirk et al. (2013; genus accepted), cultures and sequences are unavailable.

Protostegia Cooke 1880, Mycosphaerellaceae, Capnodiales, Dothideomycetes, one species, type: P. eucleae Kalchbr. \& Cooke, coelomycetous, sexual morph unknown, saprobes, terrestrial, South Africa, see Kirk et al. (2013; genus accepted), Crous et al. (2015a; phylogeny, epitypification), Wijayawardene et al. (2017; outline), epitype and ex-epitype of the type: PREM 60879; CPC 23549.

Protostegiomyces Bat. \& A.F. Vital 1955, Ascomycota genera incertae sedis, one species, type: P. lembosiae Bat. \& A.F. Vital, coelomycetous, sexual morph unknown, saprobes, terrestrial, Brazil, see Wijayawardene et al. (2012, 2017; outline), Kirk et al. (2013; genus accepted), cultures and sequences are unavailable, needs generic revision.

Protostroma Bat. 1957, Ascomycota genera incertae sedis, one species, type: P. hyphaenes Bat., coelomycetous, sexual morph unknown, saprobes, terrestrial, USA, see Wijayawardene et al. (2012, 2017; outline), Kirk et al. (2013; genus accepted), cultures and sequences are unavailable, needs generic revision. 
Protothelenella Räsänen 1943, Protothelenellaceae, Ostropales, Lecanoromycetes, eleven species, type: P. reducta (Th. Fr.) Räsänen, lichenized, Asia, Europe, North America, see Lumbsch and Huhndorf (2010; outline), Kirk et al. (2013; genus accepted), Resl et al. (2015; phylogeny), Lücking et al. (2016b; classification), cultures and sequences are available, needs generic revision.

Protothyrium G. Arnaud 1917, Parmulariaceae, Dothideomycetes families incertae sedis, two species, type: P. salvadorae (Cooke) G. Arnaud, asexual morph unknown, saprobes, terrestrial, tropical, see Lumbsch and Huhndorf (2010; outline), Kirk et al. (2013; genus accepted), Hyde et al. (2013; accepted as a genus in Parmulariaceae), Wijayawardene et al. (2017; outline), cultures and sequences are unavailable, isotype of type: IMI 158625, needs generic revision.

Protounguicularia Raitv. \& R. Galán 1986, Hyaloscyphaceae, Helotiales, Leotiomycetes, one species, type: P. brevicapitata Raitv. \& R. Galán, asexual morph unknown, saprobes, saprobes, terrestrial, Europe, see Lumbsch and Huhndorf (2010; outline), Kirk et al. (2013; genus accepted), cultures and sequences are available for unidentified species, needs generic revision.

Protousnea (Motyka) Krog 1976, Parmeliaceae, Lecanorales, Lecanoromycetes, eight species, type: P. magellanica (Mont.) Krog, lichenized, South America, see Lumbsch and Huhndorf (2010; outline), Kirk et al. (2013; genus accepted), Lücking et al. (2016b; classification), cultures and sequences are available, needs generic revision.

Protoventuria Berl. \& Sacc. 1887 (= Ramalia Bat. 1957 fide Rossman et al. 2016a), Venturiaceae, Venturiales, Dothideomycetes, c. five species, type: P. rosae (De Not.) Berl. \& Sacc., asexual morph unknown, saprobes, terrestrial, worldwide, see Lumbsch and Huhndorf (2010; outline), Zhang et al. (2011d; morphology, phylogeny), Hyde et al. (2013; accepted as in Venturiaceae, phylogeny), Wijayawardene et al. (2014c; outline), Rossman et al. (2016a; nomenclature), cultures and sequences are available.

Proxipyricularia Klaubauf, Lebrun \& Crous 2014, Pyriculariaceae, Magnaporthales, Sordariomycetes, two species, type: P. zingiberis (Y. Nisik.) Klaubauf, Lebrun \& Crous, hyphomycetous, sexual morph unknown, pathogens, terrestrial, Japan, see Klaubauf et al. (2014; taxonomy, phylogeny), Maharachchikumbura et al. (2015, 2016; outline, phylogeny), Wijayawardene et al. (2017; outline), available cultures for the type: CBS 133594, needs generic revision.

Psammina Sacc. \& M. Rousseau ex E. Bommer \& M. Rousseau 1891, Ascomycota genera incertae sedis, eight species, type: P. bommeriae Sacc. \& M. Rousseau, hyphomycetous, sexual morph unknown, saprobes, lichenicolous, terrestrial, Africa, Europe, see Seifert et al. (2011; morphology), Wijayawardene et al. (2012, 2017; outline), Kirk et al. (2013; genus accepted), cultures and sequences are unavailable, type specimen of type: CBS H-17363, needs generic revision.

Psathyrophlyctis Brusse 1987, Phlyctidaceae, Ostropales, Lecanoromycetes, one species, type: $P$. serpentaria Brusse, asexual morph unknown, lichenized, terrestrial, South Africa, see Lumbsch and Huhndorf (2010; outline), cultures and sequences are unavailable, needs generic revision.

Pselaphidomyces Speg. 1917, Laboulbeniaceae, Laboulbeniales, Laboulbeniomycetes, one species, type: P. corticalis (Peck) J.L. Crane \& Schokn., asexual morph unknown, biotrophic, terrestrial, North America, see Lumbsch and Huhndorf (2010; outline), Kirk et al. (2013; genus accepted), cultures and sequences are unavailable.

Pseudaleuria Lusk 1987, Pyronemataceae, Pezizales, Pezizomycetes, one species, type: P. quinaultiana Lusk, asexual morph unknown, from soil, saprobes, terrestrial, USA, see Lumbsch and Huhndorf (2010; outline), Xu et al. (2012; soil fungi), Kirk et al. (2013; genus 
accepted), Nouhra et al. (2013; DNA, ectomycorrhizal), sequences are available, needs generic revision.

Pseudallescheria Negroni \& I. Fisch. 1944, Microascaceae, Microascales, Sordariomycetes, nine species, type: P. shearii Negroni \& I. Fisch., asexual morph unknown, saprobes, human pathogens, terrestrial, worldwide, see Gilgado et al. (2010; new species, human pathogen), Lumbsch and Huhndorf (2010; outline), Kirk et al. (2013; genus accepted), Maharachchikumbura et al. (2015, 2016; outline, phylogeny), cultures and sequences are available but lacks for the type, needs generic revision.

Pseudarctomia Gyeln. 1939, Lichinaceae, Lichinales, Lichinomycetes, one species, type: P. microleuca (Nyl.) Gyeln., asexual morph unknown, lichenized, terrestrial, France, see Lumbsch and Huhndorf (2010; outline), Kirk et al. (2013; genus accepted), Lücking et al. (2016b; classification), cultures and sequences are unavailable, needs generic revision.

Pseudascozonus Brumm. 1985, Thelebolaceae, Thelebolales, Leotiomycetes, one species, type: P. racemosporus Brumm., asexual morph unknown, saprobes, terrestrial, France, see Lumbsch and Huhndorf (2010; outline), Kirk et al. (2013; genus accepted), cultures and sequences are unavailable, needs generic revision.

Pseudephebe M. Choisy 1930, Parmeliaceae, Lecanorales, Lecanoromycetes, two species, type: P. pubescens (L.) M. Choisy, asexual morph unknown, lichenized, terrestrial, worldwide, see Lumbsch and Huhndorf (2010; outline), Wang and McCune (2010; China), Thell et al. (2012; phylogeny, accepted as a genus in Parmeliaceae), Kirk et al. (2013; genus accepted), Mitrovic et al. (2014; antimicrobial properties), Boluda et al. (2016; cryptic species), sequences are available, needs generic revision.

Pseudeurotium J.F.H. Beyma 1937, Pseudeurotiaceae, Leotiomycetes family incertae sedis, six species, type: P. zonatum J.F.H. Beyma, asexual morph unknown, biotrophic, terrestrial, worldwide, see Lumbsch and Huhndorf (2010; outline), Kirk et al. (2013; genus accepted), Minnis and Lindner (2013; new species), cultures and sequences are available.

Pseudevernia Zopf 1903, Parmeliaceae, Lecanorales, Lecanoromycetes, four species, type: P. furfuracea (L.) Zopf, lichenized, North America, Europe, see Lumbsch and Huhndorf (2010; outline), Kirk et al. (2013; genus accepted), Lücking et al. (2016b; classification), cultures and sequences are available, needs generic revision.

Pseudoacremonium Crous 2014, Hypocreales genera incertae sedis, Sordariomycetes, one species, type: P. sacchari Crous, hyphomycetous, sexual morph unknown, Vietnam, see Crous et al. (2014c; taxonomy), Maharachchikumbura et al. (2015, 2016; outline), holotype and ex-type CBS H-21704, CPC 2315.

Pseudoacrodictys W.A. Baker \& Morgan-Jones 2003, Ascomycota genera incertae sedis, 14 species, type: P. eickeri (Morgan-Jones) W.A. Baker \& Morgan-Jones, sexual morph unknown, saprobes, terrestrial, see Castaneda Ruiz et al. (2010; new species), Zhang et al. (2011g; new species), Dubey and Pandey (2012; new species), Fiuza et al.(2014; new species), Ma et al (2015; new species), two species have sequence data, needs generic revision.

Pseudoamauroascus Cano, M. Solé \& Guarro 2002, Onygenaceae, Onygenales, Eurotiomycetes, one species, type: P. australiensis Cano, M. Solé \& Guarro, asexual morph unknown, saprobes, terrestrial, Australia, see Lumbsch and Huhndorf (2010; outline), sequences are available for the type (unpublished), holotype of type: IMI 370014.

Pseudoanguillospora S.H. Iqbal 1974, Ascomycota genera incertae sedis, two species, type: $P$. stricta S.H. Iqbal, hyphomycetous, sexual morph unknown, saprobes, terrestrial, Europe, see Seifert et al. (2011; morphology), Wijayawardene et al. (2012, 2017; outline), Kirk et al. (2013; genus accepted), cultures and sequences are unavailable, needs generic revision.

Pseudoannulatascus Z.L. Luo, Maharachch. \& K.D. Hyde 2015, Annulatascaceae, Annulatascales, Sordariomycetes, one species, type: P. biatriisporus (K.D. Hyde) Z.L. Luo, 
Maharachch. \& K.D. Hyde, asexual morph unknown, aquatic, Australia, Thailand, see Luo et al. (2015; taxonomy, phylogeny), Maharachchikumbura et al. (2015, 2016; outline), holotype: BRIP 21481, cultures and sequences are available.

Pseudoanthostomella Daranag., Camporesi \& K.D. Hyde 2016, Xylariales genera incertae sedis, Sordariomycetes, one species, type: P. pini-nigrae Daranag., Camporesi \& K.D. Hyde, asexual morph unknown, terrestrial, saprobes, Italy, see Daranagama et al. (2016a; taxonomy), Wendt et al. (2017; placed in Xylariales), cultures and sequences are available.

Pseudoaristastoma Suj. Singh 1979, Ascomycota genera incertae sedis, one species, type: $P$. indicum Suj. Singh, coelomycetous, sexual morph unknown, saprobes, terrestrial, India, see Wijayawardene et al. (2012, 2017; outline), Kirk et al. (2013; genus accepted), cultures and sequences are unavailable, needs generic revision.

Pseudoascochyta Valenzuela-Lopez, Stchigel, Cano-Canals, Guarro \& Cano 2016, Didymellaceae, Pleosporales, Dothideomycetes, two species, type: P. pratensis ValenzuelaLopez, CanoCanals, Stchigel, Guarro \& Cano, coelomycetous, sexual morph unknown, saprobes, terrestrial, Spain, see Crous et al. (2016a; taxonomy, phylogeny), holotype and extype culture of the type: CBS H-22735, FMR 14524.

Pseudoasperisporium U. Braun 2000, Ascomycota genera incertae sedis, three species, type: P. tupae (Speg.) U. Braun, hyphomycetous, terrestrial, plant pathogens, leaf-spotting, Asia, South America, see Seifert (2011; morphology), Wijayawardene et al. (2012, 2017; outline), cultures and sequences are unavailable, holotype of type: LPS 959.

Pseudoasteromassaria Matsumura \& Kaz. Tanaka 2015, Latoruaceae, Pleosporales, Dothideomycetes, one species, type: P. fagi M. Matsum. \& Kaz. Tanaka, asexual morph coelomycetous (stagonospora-like), saprobes, terrestrial, Japan, see Ariyawansa et al. (2015a; morphology, phylogeny), cultures and sequences are available, holotype and ex-type strain of the type: HHUF 30471; MAFF 245221.

Pseudoastrosphaeriella Phookamsak, Z.L. Luo \& K.D. Hyde 2015, Pseudoastrosphaeriellaceae, Pleosporales, Dothideomycetes, one species, type: $P$. thailandensis Phookamsak, Z.L. Luo \& K.D. Hyde, asexual morph coelomycetous, saprobes, Asia, see Phookamsak et al. (2015b; taxonomy, phylogeny), cultures and sequences are available.

Pseudobaeomyces M. Satô 1940, Icmadophilaceae, Pertusariales, Lecanoromycetes, one species, type: P. insignis (Zahlbr.) M. Satô, asexual morph unknown, lichenized, terrestrial, Asia, see Lumbsch and Huhndorf (2010; outline), Kirk et al. (2013; genus accepted), cultures and sequences are unavailable, needs generic revision.

Pseudobasidiospora Dyko \& B. Sutton., 1978, Ascomycota genera incertae sedis, one species, type: P. caroliniana Dyko \& B. Sutton, ceolomycetous, see Wijayawardene et al. (2012, 2017; outline), Kirk et al. (2013; genus accepted), sexual morph unknown, cultures and sequences are unavailable, holotype of type: IMI 208458.

Pseudobeltrania Henn. 1902, Beltraniaceae, Xylariales, Sordariomycetes, one species, type: P. cedrelae Henn., hyphomycetous, sexual morph unknown, saprobes, terrestrial, widespread, see Seifert et al. (2011; morphology), Wijayawardene et al. (2012, 2017; outline), Crous et al. (2015e; new species), Maharachchikumbura et al. (2015, 2016; outline), Rajeshkumar et al. (2016; phylogeny), cultures and sequences are available but lacks for the type, needs generic revision.

Pseudocalopadia Lücking 1999, Pilocarpaceae, Lecanorales, Lecanoromycetes, one species, type: P. mira Lücking, lichenized, Costa Rica, see Lumbsch and Huhndorf (2010; outline), Kirk et al. (2013; genus accepted), Lücking et al. (2016b; classification), cultures and sequences are unavailable, holotype of type: M.

Pseudocamarosporium Wijayaw. \& K.D. Hyde 2014, Didymosphaeriaceae, Pleosporales, Dothideomycetes, ten species, type: P. propinquum (Sacc.) Wijayaw., Camporesi \& K.D. 
Hyde, coelomycetous, sexual morph unknown, has camarosporium-like and coniothyriumlike morphologies, saprobes, Europe, see Wijayawardene et al. (2014c, d, 2016a, b; morphology, phylogeny), Crous et al. (2015c; new species, phylogeny, coniothyrium-like species), sequence data available, holotype and ex-type strains of type: MFLU 14-0090; MFLUCC 14-0192 = ICMP 20203.

Pseudocanalisporium R.F. Castañeda \& W.B. Kendr. 1991, Ascomycota genera incertae sedis, one species, type: P. circumfecundum R.F. Castañeda \& W.B. Kendr., hyphomycetous, sexual morph unknown, saprobes, terrestrial, Caribbean, see Seifert et al. (2011; morphology), Wijayawardene et al. (2012, 2017; outline), Kirk et al. (2013; genus accepted), cultures and sequences are unavailable, needs generic revision.

Pseudocatenomycopsis Crous \& L.A. Shuttlew. 2013, Coronophorales genera incertae sedis, Sordariomycetes, one species, type: P. rothmanniae Crous \& L.A. Shuttlew., hyphomycetous, sexual morph unknown, saprobes, terrestrial, Zambia, see Crous et al. (2013b; morphology, phylogeny), Maharachchikumbura et al. (2015, 2016; phylogeny, outline), holotype and ex-type of the type: CBS H- 21432; CBS 22733.

Pseudocenangium P. Karst. 1886, Ascomycota genera incertae sedis, one species, type: $P$. pinastri P. Karst., coelomycetous, sexual morph unknown, saprobes, terrestrial, Europe, North America, see Wijayawardene et al. (2012, 2017; outline), Kirk et al. (2013; genus accepted), cultures and sequences are unavailable, needs generic revision.

Pseudocercospora Speg. 1910, Mycosphaerellaceae, Capnodiales, Dothideomycetes, c. 1500 accepted species (Mycobank), type: P. vitis (Lév.) Speg., hyphomycetous, sexual morph mycosphaerella-like, plant pathogens, endophytes or saprobes, cosmopolitan, worldwide, see Seifert et al. (2011; morphology), Wijayawardene et al. (2012, 2014c, 2017; outline), Kirk et al. (2013; genus accepted), Yusef M (2013; review), Crous et al. (2012a: phylogeny), Bakhshi et al. (2014; phylogeny), Shivas et al. (2015; new species), Osorio et al. (2015; new species), Silva et al. (2016; new species), sequences are available, epitype of type: CBS HAL (MBT 102230).

Pseudocercosporella Deighton 1973, Mycosphaerellaceae, Capnodiales, Dothideomycetes, 150 species, type: P. ipomoeae Sawada ex Deighton, hyphomycetous, sexual morph mycosphaerella-like, plant pathogens, terrestrial, five species confirmed based on DNA, see Wijayawardene et al. (2012, 2014c, 2017; outline), Kirk et al. (2013; genus accepted), Frank et al. (2010; morphology, phylogeny), Rossman et al. (2016b; new combination), epitype and ex-epitype of type: CBS H-20409; CBS 125685.

Pseudocercosporidium Deighton 1973, Mycosphaerellaceae, Capnodiales, Dothideomycetes, one species, type: $P$. venezuelanum (Syd.) Deighton, hyphomycetous, sexual morph unknown, saprobes, terrestrial, South America, see Seifert et al. (2011; morphology), Wijayawardene et al. (2012, 2017; outline), Kirk et al. (2013; genus accepted), cultures and sequences are available, needs generic revision.

Pseudochapsa Parnmen, Lücking \& Lumbsch 2012, Graphidaceae, Ostropales, Lecanoromycetes, 17 species, type: Pseudochapsa dilatata (Müll. Arg.) Parnmen, Lücking \& Lumbsch, asexual morph unknown, lichenized, terrestrial, tropical, see Parnmen et al. (2012; genus proposed), cultures and sequences are available, needs generic revision.

Pseudochuppia Kamal, A.N. Rai \& Morgan-Jones 1984, Ascomycota genera incertae sedis, one species, type: P. sarcinispora Kamal, A.N. Rai \& Morgan-Jones, hyphomycetous, sexual morph unknown, saprobes, terrestrial, India, see Seifert et al. (2011; morphology), Wijayawardene et al. (2012, 2017; outline), Kirk et al. (2013; genus accepted), cultures and sequences are unavailable, needs generic revision.

Pseudociboria Kanouse 1944, Sclerotiniaceae, Helotiales, Leotiomycetes, one species, type: P. umbrina Kanouse, asexual morph unknown, saprobes, terrestrial, worldwide, see Lumbsch 
and Huhndorf (2010; outline), Kirk et al. (2013; genus accepted), cultures and sequences are unavailable, needs generic revision.

Pseudoclathrosphaerina Voglmayr 1997, Ascomycota genera incertae sedis, one species, type: P. evamariae Voglmayr, hyphomycetous, sexual morph unknown, saprobes, from submerged deciduous leaves, USA, New Zealand, see Seifert et al. (2011; morphology), Wijayawardene et al. (2012, 2017; outline), Kirk et al. (2013; genus accepted), cultures and sequences are unavailable (unpublished), holotype of the type: WU 17015, needs generic revision.

Pseudocoleodictyospora Doilom \& K.D. Hyde 2016, Pseudocoleodictyosporaceae, Pleosporales, Dothideomycetes, three species, type: P. tectonae Doilom, D.J. Bhat \& K.D. Hyde, saprobes, terrestrial, see Doilom et al. (2016; phylogeny), cultures and sequences are available, holotype and ex-holotype type strains of type: MFLU 15-3527; MFLUCC 12-0385, MKT 058, ICMP 21160.

Pseudocoleophoma Kaz. Tanaka \& K. Hiray. 2015, Dictyosporiaceae, Pleosporales, Dothideomycetes, two species, type: P. calamagrostidis Kaz. Tanaka \& K. Hiray., asexual morph coelomycetous, saprobes, terrestrial, Japan, see Tanaka et al. (2015; morphology, phylogeny), cultures and sequences are available, holotype and ex-type strain of the type: HHUF 30450; CBS 139700.

Pseudoconium Petr. 1969, Ascomycota genera incertae sedis, one species, type: P. pallescens (Bäumler) Petr., coelomycetous, sexual morph unknown, saprobes, terrestrial, Europe, see Wijayawardene et al. (2012, 2017; outline), Kirk et al. (2013; genus accepted), cultures and sequences are available (unpublished), needs generic revision.

Pseudocosmospora C. Herrera \& P. Chaverri 2013, Nectriaceae, Hypocreales, Sordariomycetes, two species, type: P. eutypellae C. Herrera \& P. Chaverri, asexual morph hyphomycetous (acremonium-like to verticillium-like), saprobes, terrestrial, worldwide, see Herrera et al. (2013; taxonomy, phylogeny), Lombard et al. (2015b; phylogeny), Maharachchikumbura et al. (2015, 2016; outline), cultures and sequences are available, holotype and ex-type cultures of the type: BPI 884165; CBS $133966=$ A.R. 4562.

Pseudocryptosporella J. Reid \& C. Booth 1969, Diaporthales genera incertae sedis, Sordariomycetes, one species, type: P. polylepidis (E. Müll.) J. Reid \& C. Booth, asexual morph unknown, saprobes, terrestrial, Venezuela, see Lumbsch and Huhndorf (2010; outline), Kirk et al. (2013; genus accepted), Maharachchikumbura et al. (2015, 2016; outline), cultures and sequences are unavailable, needs generic revision.

Pseudocyphellaria Vain. [nom. cons.] 1890 (= Crocodia Link 1833; = Cyanisticta Gyeln. 1931; = Diphaeosticta Clem. 1909; = Diphanosticta Clem. 1909; = Merostictina Clem. 1909); = Parmosticta Nyl. 1875; = Parmostictina Nyl. 1875; = Phaeosticta Trevis. 1869; Phanosticta Clem. 1909; Podostictina Clem. 1909; = Saccardoa Trevis. 1869; = Stictina Nyl. 1860), Lobariaceae, Peltigerales, Lecanoromycetes, 100 species, type: Ps. curvata (Ach.) Vain., lichenized, South America, Asia, see Lumbsch and Huhndorf (2010; outline), Quilhot, et al. (2010; taxonomy), Miller et al. (2011; taxonomy), Pandit and Sharma (2012; new record), Fritis et al. (2013; biological activity), Kirk et al. (2013; genus accepted), Moncada et al. (2014b; taxonomy, phylogeny), Yoshiaki and Ohmura (2014; transplant experiment), Beese et al. (2015; ecology), Lücking et al. (2016b; classification), Messuti et al. (2016; sequence), sequences are available but lacks for type, needs generic revision.

Pseudocytoplacosphaeria Punith. \& Spooner 2002, Ascomycota genera incertae sedis, one species, type: $P$. coniicola Punith. \& Spooner, coelomycetous, sexual morph unknown, saprobes, British Isles, see Wijayawardene et al. (2012, 2017; outline), cultures and sequences are unavailable, holotype of the type: $\mathrm{K}(\mathrm{M})$ 85582, needs generic revision.

Pseudocytospora Petr. 1923, Ascomycota genera incertae sedis, one species, type: $P$. allantospora Petr., coelomycetous, sexual morph unknown, saprobes, Europe, see 
Wijayawardene et al. (2012, 2017; outline), Kirk et al. (2013; genus accepted), cultures and sequences are unavailable, needs generic revision.

Pseudodichomera Höhn. 1918, Ascomycota genera incertae sedis, three species, type: $P$. varia (Pers.) Höhn., coelomycetous, sexual morph unknown, saprobes, Europe, see Wijayawardene et al. (2012, 2017; outline), Kirk et al. (2013; genus accepted), cultures and sequences are unavailable, needs generic revision.

Pseudodictyosporium Matsush. 1971, Dictyosporiaceae, Pleosporales, Dothideomycetes, four species, type: $P$. wauense Matsush., hyphomycetous, sexual morph unknown, saprobes, Asia, South America, see Menkis and Vasaitis (2011; DNA), Wijayawardene et al. (2012, 2017; outline), Kirk et al. (2013; genus accepted), Kirschner et al. (2013; new species, Taiwan), Hyde et al. (2016; new species, Thailand), Boonmee et al. (2016; phylogeny), cultures and sequences are available, type specimen and cultures available for the type: CBS H-5642; KRP88-6 (Menkis and Vasaitis 2011).

Pseudodidymaria U. Braun 1993, Ascomycota genera incertae sedis, three species, type: $P$. wyethiae (Ellis \& Everh.) U. Braun, hyphomycetous, sexual morph unknown, terrestrial, foliicolous, leaf-spotting, Asia, North America, see Seifert (2011; morphology), Wijayawardene et al. (2012, 2017; outline), cultures and sequences are unavailable, lectotype of type: NY 1087025.

Pseudodidymella C.Z. Wei, Y. Harada \& Katum. 1997 (= Pycnopleiospora C.Z. Wei et al. fide Wijayawardene et al. 2014c; Rossman et al. 2015b), Dothideomycetes genera incertae sedis, one species, type: P. fagi C.Z. Wei, Y. Harada \& Katum., asexual morph formerly known in Pycnopleiospora, saprobes, Japan, see Lumbsch and Huhndorf (2010; outline), Wijayawardene et al. (2012, 2014c, 2017; outline, nomenclature), Kirk et al. (2013; genus accepted), Rossman et al. (2015b; nomenclature), cultures and sequences are unavailable,holotype of type: HHUF 22903, needs generic revision.

Pseudodidymosphaeria Thambugala \& K.D. Hyde 2015, Massarinaceae, Pleosporales, Dothideomycetes, two species, type: P. spartii Thambugala, Camporesi \& K.D. Hyde, asexual morph coelomycetous, saprobes, Europe, see Thambugala et al. (2015a; morphology, phylogeny), Li et al. (2016a; new species), sequence data available, reference specimen and ex-type of type: MFLU 14-0578; MFLUCC 13-0273.

Pseudodinemasporium A. Hashim. \& Kaz. Tanaka 2015, Chaetosphaeriaceae, Chaetosphaeriales, Sordariomycetes, one species, type: P. fabiformis A. Hashim., G. Sato \& Kaz. Tanaka, coelomycetous, sexual morph unknown, saprobes, Japan, Malaysia, see Hashimoto et al. (2015b; morphology, phylogeny), Crous et al. (2015c; phylogeny), holotype and ex-type strain of the type: HHUF 29716; MAFF 244361.

Pseudodiplodia (P. Karst.) Sacc. 1884, Ascomycota genera incertae sedis, 45 species, type: P. ligniaria (P. Karst.) Sacc., coelomycetous, sexual morph unknown, saprobes, worldwide, see Wijayawardene et al. (2012, 2016b, 2017; outline, taxonomy), Kirk et al. (2013; genus accepted), culture and sequences are available for an unidentified species, needs generic revision.

Pseudodiscula Laubert 1911, Ascomycota genera incertae sedis, two species, type: $P$. endogenospora Laubert, coelomycetous, sexual morph unknown, saprobes, Europe, see Wijayawardene et al. (2012, 2016; outline, taxonomy), Kirk et al. (2013; genus accepted), cultures and sequences are unavailable, needs generic revision.

Pseudodiscus Arx \& E. Müll. 1959, Saccardiaceae, Ascomycota families incertae sedis, one species, type: P. nootkatensis (Terrier) Arx \& E. Müll., asexual morph unknown, saprobes, Europe, see Lumbsch and Huhndorf (2010; outline), Kirk et al. (2013; genus accepted), cultures and sequences are unavailable, available specimen of type: CBS H-17396, needs generic revision. 
Pseudoecteinomyces W. Rossi 1977, Euceratomycetaceae, Laboulbeniales, Laboulbeniomycetes, one species, type: P. zuphiicola (Speg.) W. Rossi, asexual morph unknown, biotrophic, Africa, Asia, see Lumbsch and Huhndorf (2010; outline), Kirk et al. (2013; genus accepted), cultures and sequences are unavailable.

Pseudoepicoccum M.B. Ellis 1971, Ascomycota genera incertae sedis, two species, type: $P$. $\operatorname{cocos}$ (F. Stevens) M.B. Ellis, hyphomycetous, sexual morph unknown, saprobes, worldwide, see Seifert et al. (2011; morphology), Wijayawardene et al. (2012, 2017; outline), Kirk et al. (2013; genus accepted), cultures and sequences are unavailable, needs generic revision.

Pseudofuscophialis Sivan. \& H.S. Chang 1995, Ascomycota genera incertae sedis, one species, type: P. lignicola Sivan. \& H.S. Chang, hyphomycetous, sexual morph unknown, saprobes, Asia, see Seifert et al. (2011; morphology), Wijayawardene et al. (2012, 2017; outline), Kirk et al. (2013; genus accepted), cultures and sequences are unavailable, holotype of type: IMI 356633, needs generic revision.

Pseudofusicoccum Mohali, Slippers \& M.J. Wingf. 2006, Pseudofusicoccumaceae, Botryosphaeriales, Dothideomycetes, seven species, type: P. stromaticum (Mohali, Slippers \& M.J. Wingf.) Mohali, Slippers \& M.J. Wingf., coelomycetous, sexual morph unknown, saprobes, endophytes, terrestrial, cosmopolitan, see Pavlic et al. (2008; new species), Phillips et al. (2008, 2013; taxonomy, phylogeny), Liu et al. (2012; taxonomy, phylogeny), Hyde et al. (2013; accepted as a genus in Botryosphaeriaceae), Slippers et al. (2013; phylogeny), Wijayawardene et al. (2014c, 2017; outline), Dissanayake et al.(2016; taxonomy), Yang et al. (2017; phylogeny), holotype and ex-type culture of the type: PREM 58237, CMW 13366.

Pseudogaster Höhn. 1907, Ascomycota genera incertae sedis, one species, type: P. singularis Höhn., hyphomycetous, sexual morph unknown, saprobes, South America, see Seifert et al. (2011; morphology), Wijayawardene et al. (2012, 2017; outline), Kirk et al. (2013; genus accepted), cultures and sequences are unavailable, needs generic revision.

Pseudogibellula Samson \& H.C. Evans 1973, Clavicipitaceae, Hypocreales, Sordariomycetes, one species, type: P. formicarum (Mains) Samson \& H.C. Evans, hyphomycetous, sexual morph unknown, on insects, terrestrial, Asia, see Seifert et al. (2011; morphology), Wijayawardene et al. (2012, 2017; outline), Kirk et al. (2013; genus accepted), Maharachchikumbura et al. (2015, 2016; outline), cultures and sequences are available, needs generic revision.

Pseudogliophragma Phadke \& V.G. Rao 1980, Wiesneriomycetaceae, Tubeufiales, Dothideomycetes, one species, type: $P$. indicum [as india] Phadke \& V.G. Rao, hyphomycetous, sexual morph unknown, saprobes, India, see Seifert et al. (2011; morphology), Wijayawardene et al. (2012, 2017; outline), Kirk et al. (2013; genus accepted), Pratibha et al. (2015; phylogeny, typification), cultures and sequences are available, ex-type of the type: MTCC 11985.

Pseudographiella E.F. Morris 1966, Ascomycota genera incertae sedis, one species, type: $P$. variiseptata E.F. Morris., hyphomycetous, sexual morph unknown, saprobes, South America, see Seifert et al. (2011; morphology), Wijayawardene et al. (2012, 2017; outline), Kirk et al. (2013; genus accepted), cultures and sequences are unavailable, needs generic revision.

Pseudographis Nyl. 1855, Triblidiaceae, Triblidiales, Leotiomycetes, three species, type: $P$. elatina (Ach.) Nyl., asexual morph unknown, saprobes, terrestrial, worldwide, see Lumbsch and Huhndorf (2010; outline), Kirk et al. (2013; genus accepted), Jaklitsch et al. (2016a; classification), cultures and sequences are unavailable, available specimen of type: CBS H17399, needs generic revision.

Pseudogymnoascus Raillo 1929, Myxotrichaceae, Leotiomycetes family incertae sedis, ten species, type: $P$. roseus Raillo, asexual morph unknown, animal pathogens, worldwide, see Lumbsch and Huhndorf (2010; outline), Kirk et al. (2013; genus accepted), Minnis and 
Lindner (2013; new species), Hoyt et al. (2015; control disease), cultures and sequences are available.

Pseudohalonectria Minoura \& T. Muroi 1978, Magnaporthales genera incertae sedis, Sordariomycetes, eleven species, type: P. lignicola Minoura \& T. Muroi, asexual morph unknown, saprobes, terrestrial, aquatic, worldwide, see Lumbsch and Huhndorf (2010; outline), Hu et al. (2012a; phylogeny), Kirk et al. (2013; genus accepted), Maharachchikumbura et al. (2015, 2016; outline), Perera et al. (2016; new species, phylogeny), type specimen and cultures available for the type: CBS H-19515; SMH2440 IFRDCC 3110.

Pseudohelicomyces Garnica \& E. Valenz. 2000, Ascomycota genera incertae sedis, one species, type: P. albus Garnica \& E. Valenz., hyphomycetous, sexual morph unknown, saprobes, South America, see Seifert et al. (2011; morphology), Wijayawardene et al. (2012, 2016; outline, taxonomy), Kirk et al. (2013; genus accepted), cultures and sequences are unavailable, holotype of type: AH 19575, needs generic revision.

Pseudohelotium Fuckel 1870, Helotiales genera incertae sedis, Leotiomycetes, c. 50 species, type: P. pineti (Batsch) Fuckel, asexual morph unknown, saprobes, terrestrial, Europe, see Lumbsch and Huhndorf (2010; outline), Kirk et al. (2013; genus accepted), cultures and sequences are unavailable.

Pseudohendersonia Crous \& M.E. Palm 1999, Didymellaceae, Pleosporales, Dothideomycetes, two species, type: $P$. proteae Crous \& M.E. Palm, coelomycetous, sexual morph unknown, saprobes, associated with leaf spots, USA, Italy, see Wijayawardene et al. (2016b; morphology, phylogeny), cultures and sequences are available, holotype of type: BPI 1107849.

Pseudohepatica P.M. Jørg. 1993, Ascomycota genera incertae sedis, one species, type: P. pachyderma P.M. Jørg., asexual morph unknown, lichenized, Venezuela, see Lumbsch and Huhndorf (2010; outline), Kirk et al. (2013; genus accepted), cultures and sequences are unavailable, holotype of type: US, Steyermark 93298, needs generic revision.

Pseudoheppia Zahlbr. 1903, Heppiaceae, Lichinales, Lichinomycetes, one species, type: P. schuleri Zahlbr., asexual morph unknown, lichenized, terrestrial, Europe, see Lumbsch and Huhndorf (2010; outline), Kirk et al. (2013; genus accepted), cultures and sequences are unavailable, needs generic revision.

Pseudohypocrea Yoshim. Doi 1972, Hypocreaceae, Hypocreales, Sordariomycetes, one species, type: P. citrinella (Ellis) Yoshim. Doi, asexual morph acremonium-like, saprobes, terrestrial, North America, see Lumbsch and Huhndorf (2010; outline), Kirk et al. (2013; genus accepted), Maharachchikumbura et al. (2015, 2016; outline), cultures and sequences are unavailable, needs generic revision.

Pseudoidriella Crous \& R.G. Shivas 2011, Hypocreales genera incertae sedis, Sordariomycetes, one species, type: $P$. syzygii Crous \& R.G. Shivas, hyphomycetous, sexual morph unknown, saprobe, associated with insect damaged leaves, terrestrial, Australia, see Crous et al. (2011c; morphology, DNA, phylogeny), Wijayawardene et al. (2012, 2017; outline), holotype and ex-type culture of type: CBS H-20758; CBS 131307.

Pseudolachnea Ranoj. 1910, Chaetosphaeriaceae, Chaetosphaeriales, Sordariomycetes, five species, type: P. insignis Velen., coelomycetous, sexual morph unknown, terrestrial, saprobes, worldwide, see Wijayawardene et al. (2012, 2017; outline), Kirk et al. (2013; genus accepted), Hashimoto et al. (2015b; DNA, phylogeny), Maharachchikumbura et al. (2015, 2016; outline), cultures and sequences are available but lacks for the type, needs generic revision.

Pseudolachnella Teng. 1936, Chaetosphaeriaceae, Chaetosphaeriales, Sordariomycetes, 18 species, type: P. scolecospora (Teng \& C.I. Chen) Teng, coelomycetous, sexual morph unknown, saprobes, worldwide, see Hashimoto et al. (2015b; morphology, phylogeny), Li et 
al. (2016a; new species), cultures and sequences are available, holotype of the type: "Ling 138 ".

Pseudolachnum Velen. 1934, Helotiales genera incertae sedis, Leotiomycetes, one species, type: P. lateritium Velen., asexual morph unknown, saprobes, terrestrial, former Czechoslovakia, see Lumbsch and Huhndorf (2010; outline), Kirk et al. (2013; genus accepted), cultures and sequences are unavailable, needs generic revision.

Pseudolecanactis Zahlbr. 1907, Roccellaceae, Arthoniales, Arthoniomycetes, one species, type: P. filicicola Zahlbr., lichenized, see Lumbsch and Huhndorf (2010; outline), Kirk et al. (2013; genus accepted), Ertz et al. (2015b, c; phylogenetic study), Lücking et al. (2016bb; classification), sequences are unavailable, needs generic revision.

Pseudolembosia Theiss. 1913, Parmulariaceae, Dothideomycetes families incertae sedis, two species, type: P. geographica (Massee) Theiss., asexual morph unknown, saprobes, terrestrial, Australia, Central America, see Lumbsch and Huhndorf (2010; outline), Kirk et al. (2013; genus accepted), Hyde et al. (2013; accepted as a genus in Parmulariaceae), Wijayawardene et al. (2014c; outline), cultures and sequences are unavailable, holotype of type: NY, needs generic revision.

Pseudoleptogium Müll.Arg. 1885, Collemataceae, Peltigerales, Lecanoromycetes, one species, type: P. diffractum (Kremp.) Müll. Arg., lichenized, see Otálora et al. (2013, 2014; phylogeny), Lücking et al. (2016b; classification), Cultures and sequences are available, needs generic revision.

Pseudolignincola Chatmala \& E.B.G. Jones 2006, Halosphaeriaceae, Microascales, Sordariomycetes, one species, type: $P$. siamensis Chatmala \& E.B.G. Jones, asexual morph unknown, on wood, marine, tropical, see Sakayaroj et al. (2011a; phylogeny), Jones et al. (2015; outline), Maharachchikumbura et al. (2015, 2016; outline), sequences are available, needs generic revision.

Pseudolophiostoma Thambugala, Kaz. Tanaka \& K.D. Hyde 2015, Lophiostomataceae, Pleosporales, Dothideomycetes, one species, type: P. vitigenum (Kaz. Tanaka \& Y. Harada) Thambugala, Kaz. Tanaka \& K.D. Hyde, asexual morph unknown, saprobes, terrestrial, Japan, see Thambugala et al. (2015b; morphology, phylogeny), cultures and sequences are available, holotype and ex-type of type: HHUF 26930; MAFF 239459.

Pseudomassaria Jacz. 1894, Pseudomassariaceae, Xylariales, Sordariomycetes, c. 20 species, type: P. chondrospora (Ces.) Jacz., asexual morph unknown, saprobes, terrestrial, widespread, see Lumbsch and Huhndorf (2010; outline), Jaklitsch and Voglmayr (2012; phylogeny), Senanayake et al. (2015; phylogeny), Kirk et al. (2013; genus accepted), Maharachchikumbura et al. (2015, 2016, outline, phylogeny), cultures available for type: MFLUCC 15-0545.

Pseudomassariosphaeria Phukhams., Ariyaw., Campor. \& K.D. Hyde 2015, Amniculicolaceae, Pleosporales, Dothideomycetes, two species, type: $P$. bromicola Phukhams., Ariyaw., Campor. \& K.D. Hyde, asexual morph unknown, saprobes, aquatic and terrestrial, see Ariyawansa et al. (2015a; taxonomy, phylogeny), holotype and ex-type culture of type: MFLU 15-1403, MFLUCC 15-0031.

Pseudombrophila Boud. 1885, Pezizales genera incertae sedis, Pezizomycetes, 28 species, type: P. pedrottii Boud., asexual morph unknown, coprophilous, saprobes, terrestrial, worldwide, see Lumbsch and Huhndorf (2010; outline), Hansen et al. (2013; phylogeny), Kirk et al. (2013; genus accepted), cultures and sequences are available but lacks for the type, needs generic revision.

Pseudomeliola Speg. 1889, Hypocreales genera incertae sedis, Sordariomycetes, four species, type: P. brasiliensis Speg., asexual morph aunknown, saprobes, terrestrial, tropical, see Lumbsch and Huhndorf (2010; outline), Kirk et al. (2013; genus accepted), 
Maharachchikumbura et al. (2015, 2016; outline), cultures and sequences are unavailable, needs generic revision.

Pseudomeria G.L. Barron 1980, Ascomycota genera incertae sedis, one species, type: $P$. mucosa G.L. Barron, hyphomycetous, sexual morph unknown, on nematodes, terrestrial, Canada, see Seifert et al. (2011; morphology), Kirk et al. (2013; genus accepted), Wijayawardene et al. (2017; outline), cultures and sequences are unavailable, needs generic revision.

Pseudomicrodochium B. Sutton 1975, Ascomycota genera incertae sedis, nine species, type: $P$. aciculare B. Sutton, hyphomycetous, sexual morph unknown, saprobes, worldwide, see Seifert et al. (2011; morphology), Wijayawardene et al. (2012, 2017; outline), Kirk et al. (2013; genus accepted), Réblová et al. (2013; compare with Cyphellophora), cultures and sequences are unavailable, holotype of type: IMI 169711, needs generic revision.

Pseudomitrula Gamundí 1980, Cenangiaceae, Helotiales, Leotiomycetes, one species, type: $P$. horakii Gamundí, asexual morph unknown, saprobes, terrestrial, South America, see Lumbsch and Huhndorf (2010; outline), Kirk et al. (2013; genus accepted), cultures and sequences are unavailable, needs generic revision.

Pseudomonodictys Doilom, Ariyawansa, D.J. Bhat \& K.D. Hyde 2015, Macrodiplodiopsidaceae, Pleosporales, Dothideomycetes, one species, type: P. tectonae Doilom, Ariyawansa, D.J. Bhat \& K.D. Hyde, saprobes, terrestrial, see Ariyawansa et al. (2015a; phylogeny), Doilom et al. (2016; phylogeny), cultures and sequences are available, holotype and ex-holotype type strains of type: MFLU 15-1413; MFLUCC 12-0552.

Pseudomorfea Punith. 1981, Dothideomycetes genera incertae sedis, one species, type: $P$. coffeae Punith., asexual morph unknown, saprobes, terrestrial, India, Argentina, see Lumbsch and Huhndorf (2010; outline), Kirk et al. (2013; genus accepted), Wijayawardene et al. (2014c; outline), cultures and sequences are unavailable, needs generic revision.

Pseudonaevia Dennis \& Spooner 1993, Mollisiaceae, Helotiales, Leotiomycetes, two species, type: $P$. caricina Dennis \& Spooner, asexual morph unknown, saprobes, terrestrial, British Isles, see Raitviir (2008; new species), Lumbsch and Huhndorf (2010; outline), Kirk et al. (2013; genus accepted), cultures and sequences are unavailable, holotype of type: K, needs generic revision.

Pseudonectria Seaver 1909, Nectriaceae, Hypocreales, Sordariomycetes, c. 10 species, type: P. rousseliana (Mont.) Wollenw., hyphomycetous, Lumbsch and Huhndorf (2010; outline), Kirk et al. (2013; genus accepted), Maharachchikumbura et al. (2016, outline), cultures available for type: AFTOL-ID 191, AR2716, CBS 114049, CBS 122566, CBS 114049, AR 2714.

Pseudonectriella Petr. 1959, Niessliaceae, Hypocreales, Sordariomycetes, one species, type: P. ahmadii Petr., asexual morph unknown, saprobes, terrestrial, South Africa, see Kirk et al. (2008; treated as a synonym of Catabotrys Theiss. \& Syd.), Lumbsch and Huhndorf (2010; outline), Kirk et al. (2013; not listed), Maharachchikumbura et al. (2015, 2016), needs generic revision, cultures and sequences are available.

Pseudoneottiospora Faurel \& Schotter 1965, Ascomycota genera incertae sedis, two species, type: P. cunicularia Faurel \& Schotter, coelomycetous, sexual morph unknown, saprobes, Algeria, ltaly, see Wijayawardene et al. (2012, 2017; outline), Kirk et al. (2013; genus accepted), cultures and sequences are unavailable, needs generic revision.

Pseudoneurospora Dania García, Stchigel \& Guarro 2004, Sordariaceae, Sordariales, Sordariomycetes, two species, type: P. amorphoporcata (Udagawa) Dania García, Stchigel \& Guarro, asexual morph unknown, saprobes, from soil, terrestrial, Thailand, Spain, see Lumbsch and Huhndorf (2010; outline), Nygren et al. (2011; DNA, phylogeny), Kirk et al. (2013; genus accepted), Crous et al. (2014c; new species), Maharachchikumbura et al. (2015, 
2016; outline, phylogeny), cultures and sequences are available but lacks for the type, needs generic revision.

Pseudoniptera Velen. 1947, Helotiaceae, Helotiales, Leotiomycetes, 25 species, type: P. quercina Velen., asexual name unknown, saprobes, terrestrial, ?Europe, see Kirk et al. (2008; treated as a synonym of Hymenoscyphus Gray), Lumbsch and Huhndorf (2010; outline, accepted as in Dermateaceae), Jaklitsch et al. (2016a; classification, placed in Helotiaceae), cultures and sequences are unavailable, needs generic revision.

Pseudonitschkia Coppins \& S.Y. Kondr. 1995, Dacampiaceae, Dothideomycetes families incertae sedis, one species, type: P. parmotrematis Coppins \& S.Y. Kondr., asexual morph unknown, saprobes, terrestrial, North temperate, see Lumbsch and Huhndorf (2010; outline, accepted as a genus in Dothideomycetes), Hyde et al. (2013; outline, accepted as a genus in Dacampiaceae), Kirk et al. (2013; genus accepted), Wijayawardene et al. (2014c; outline), cultures and sequences are unavailable, holotype of the type: BM, Alston 5836.

Pseudopannaria (B.de Lesd.) Zahlbr. 1924, Lecideaceae, Lecideales, Lecanoromycetes, one species, type: P. marcii (B. de Lesd.) Zahlbr., lichenized, see Lumbsch and Huhndorf (2010; outline), Schmull et al. (2011; taxonomy), Lücking et al. (2016b; classification), cultures and sequences are unavailable, needs generic revision.

Pseudoparmelia Lynge 1914, Parmeliaceae, Lecanorales, Lecanoromycetes, 15 species, type: P. cyphellata Lynge, lichenized, pantropical, see Lumbsch and Huhndorf (2010; outline), Kirk et al. (2013; genus accepted), Buaruang et al. (2015; phylogeny), Lücking et al. (2016b; classification), cultures and sequences are available, needs generic revision.

Pseudoparodia Theiss. \& Syd. 1917, Patellariaceae, Patellariales, Dothideomycetes, one species, type: P. pseudopeziza (Pat.) Theiss. \& Syd., asexual morph unknown, saprobes, terrestrial, South America, see Lumbsch and Huhndorf (2010; outline), Hyde et al. (2013; accepted as a genus in Patellariaceae), Kirk et al. (2013; genus accepted), Wijayawardene et al. (2014c; outline), Yacharoen et al. (2015; accepted as a genus in Patellariaceae), cultures and sequences are unavailable, holotype of type: FH 7735, needs generic revision.

Pseudoparodiella F. Stevens 1927, Venturiaceae, Venturiales, Dothideomycetes, one species, type: P. vernoniae F. Stevens, asexual morph unknown, saprobes, terrestrial, Costa Rica, see Lumbsch and Huhndorf (2010; outline), Zhang et al. (2011d; morphology, phylogeny), Hyde et al. (2013; accepted as in Venturiaceae, phylogeny), Wijayawardene et al. (2014c; outline), cultures and sequences are unavailable, needs generic revision.

Pseudopassalora Crous 2011, Pleosporales genera incertae sedis, Dothideomycetes, one species, type: P. gouriqua Crous, hyphomycetous, sexual morph unknown, saprobes, South Africa, see Crous et al. (2011d; morphology, phylogeny), Wijayawardene et al. (2014c, 2017; outline), epitype and ex-epitype culture of type: CBS H-20682, CBS 101954.

Pseudopatellina Höhn. 1908, Ascomycota genera incertae sedis, one species, type: $P$. conigena (Niessl) Höhn., coelomycetous, sexual morph unknown, saprobes, Europe, see Wijayawardene et al. (2012, 2017; outline), Kirk et al. (2013; genus accepted), cultures and sequences are unavailable, type specimen of type: CBS H-17414, needs generic revision.

Pseudopaulia M.Schultz 2002, Lichinaceae, Lichinales, Lichinomycetes, one species, type: $P$. tessellata M. Schultz, lichenized, see Lumbsch and Huhndorf (2010; outline), Lücking et al. (2016b; classification), cultures and sequences are unavailable, holotype of type: B (Schultz 14042a).

Pseudopeltis L. Holm \& K. Holm 1978, Helotiales genera incertae sedis, Leotiomycetes, one species, type: P. filicum L. Holm \& K. Holm, asexual morph unknown, saprobes, terrestrial, Sweden, see Lumbsch and Huhndorf (2010; outline), Kirk et al. (2013; genus accepted), cultures and sequences are unavailable, needs generic revision.

Pseudopeltistroma Katum. 1975, Ascomycota genera incertae sedis, one species, type: $P$. kyusyuense Katum., coelomycetous, sexual morph unknown, saprobes, Japan, see 
Wijayawardene et al. (2012, 2017; outline), Kirk et al. (2013; genus accepted), cultures and sequences are unavailable, needs generic revision.

Pseudopeltula Henssen 1995, Gloeoheppiaceae, Lichinales, Lichinomycetes, four species, type: P. myriocarpa Henssen, lichenized, Mexico, see Lumbsch and Huhndorf (2010; outline), Kirk et al. (2013; genus accepted), Lücking et al. (2016b; classification), cultures and sequences are unavailable, holotype of type: COLO.

Pseudopenidiella Crous \& Koukol 2012, Ascomycota genera incertae sedis, one species, type: P. piceae Crous \& Koukol, hyphomycetous, saprobes, Czech Republic, see Crous et al. (2012e; morphology; phylogeny), Wijayawardene et al. (2012, 2017; outline), cultures and sequences are available, holotype of the type: CBS H-20964, ex-type strain of the type: CPC 19969.

Pseudoperitheca Elenkin 1922, Ascomycota genera incertae sedis, one species, type: $P$. murmanica Elenkin, asexual morph unknown, saprobes, former USSR, see Lumbsch and Huhndorf (2010; outline), Kirk et al. (2013; genus accepted), cultures and sequences are unavailable, needs generic revision.

Pseudopestalotiopsis Maharachch., K.D. Hyde \& Crous 2014, Pestalotiopsidaceae, Xylariales, Sordariomycetes, seven species, type: P. theae (Sawada) Maharachch., K.D. Hyde $\&$ Crous, coelomycetous, sexual morph unknown, saprobes or pathogens on leaves, China, India, Indonesia, Malaysia, Thailand, see Maharachchikumbura et al. (2014, 2016; morphology, phylogeny), Wijayawardene et al. (2016b; outline, morphology), all species have sequence data, epitype and ex-epitype: MFLU 12-0116, MFLUCC 12-0055.

Pseudopetrakia M.B. Ellis 1971, Ascomycota genera incertae sedis, two species, type: $P$. kambakkamensis (Subram.) M.B. Ellis, hyphomycetous, sexual morph unknown, saprobes, Asia, Australasia, see Seifert et al. (2011; morphology), Wijayawardene et al. (2012, 2017; outline), Kirk et al. (2013; genus accepted), cultures and sequences are unavailable, needs generic revision.

Pseudopezicula Korf 1986, Drepanopezizaceae, Helotiales, Leotiomycetes, two species, type: P. tetraspora Korf, Pearson \& Zhuang, asexual morph Phialophora-like, pathogen of Vitaceae, Europe and North America, see Kirk et al. (2013; genus accepted), cultures and sequences are unavailable, holotype of the type: CUP-061765.

Pseudopeziza Fuckel 1870, Drepanopezizaceae, Helotiales, Leotiomycetes, three species, type: P. trifolii (Biv.) Fuckel, asexual morph unknown, saprobes, terrestrial, worldwide, see Lumbsch and Huhndorf (2010; outline), Kirk et al. (2013; genus accepted), cultures and sequences are available (unpublished) but lacks for the type, needs generic revision.

Pseudophacidium P. Karst. 1885, Phacidiaceae, Phacidiales, Leotiomycetes, five species, type: P. ledi (Alb. \& Schwein.) P. Karst., asexual morph unknown, saprobes, terrestrial, worldwide, see Lumbsch and Huhndorf (2010; outline, accepted as a genus in Ascodichaenaceae), Crous et al. (2014b; phylogeny), cultures and sequences are available for the type: CBS 377.59 , needs generic revision.

Pseudophaeomoniella Nigro, Antelmi \& Crous 2015, Phaeomoniellaceae, Phaeomoniellales, Eurotiomycetes, one species, type: P. oleae Nigro, Antelmi \& Crous, coelomcetous, sexual morph unknown, on living leaves, pathogens, terrestrial, Italy, see Crous et al. (2015d; morphology, phylogeny), cultures and sequences are available, holotype and ex-type culture of type: CBS H-22250, FV84 = CBS 139191.

Pseudophaeosphaeria Jayasiri, Camporesi \& K.D. Hyde 2016, Phaeosphaeriaceae, Pleosporales, Dothideomycetes, one species, type: P. rubi Jayasiri, Camporesi \& K.D. Hyde, asexual morph unknown, saprobes, terrestrial, Italy, see Hyde et al. (2016; taxonomy, phylogeny), holotype and ex-type culture of the type: MFLU 15-1400, MFLUCC 14-0259.

Pseudophloeospora Crous \& R.G. Shivas 2010, Xylariales genera incertae sedis, Sordariomycetes, two species, type: P. syzygii Crous \& M.J. Wingf., coelomycetous, 
associated with leaf spots, terrestrial, Australia, see Crous et al. (2010c, 2016b; new species, phylogeny), Wijayawardene et al. (2017; outline), holotype and ex-type culture of the type: CBS H 20493, CPC 17051.

Pseudophloeosporella U. Braun 1993, Ascomycota genera incertae sedis, one species, type: P. dioscoreae (Miyabe \& S. Ito) U. Braun, coelomycetous, sexual morph unknown, terrestrial, plant pathogens, leaf-spotting, Asia, see Hong et al. (2010; Korea), Hyde et al. (2011; outline), Kirk et al. (2013; genus accepted), cultures and sequences are unavailable, holotype of type: Miyabe \& Hanzawa 9 (SAPA).

Pseudophragmotrichum W.P. Wu, B. Sutton \& Gange 1998, Ascomycota genera incertae sedis, one species, type: P. cubense W.P. Wu, B. Sutton \& Gange, coelomycetous, sexual morph unknown, saprobes, Cuba, see Wijayawardene et al. (2012, 2017; outline), Kirk et al. (2013; genus accepted), cultures and sequences are unavailable, holotype of type: IMI 372456, needs generic revision

Pseudopithomyces Ariyawansa \& K.D. Hyde 2015, Didymosphaeriaceae, Pleosporales, Dothideomycetes, seven species, type: P. chartarum (Berk. \& M.A. Curtis) J.F. Li, Ariyawansa \& K.D. Hyde, hyphomycetous, sexual morph unknown, saprobes, from human, cosmopolitan, see Ariyawansa et al. (2015a; taxonomy, phylogeny), Crous et al. (2016a; new species, phylogeny), cultures and sequences are available.

Pseudopithyella Seaver 1928, Sarcoscyphaceae, Pezizales, Pezizomycetes, two species, type: P. minuscula (Boud. \& Torrend) Seaver, asexual morph unknown, saprobes, terrestrial, worldwide, see Lumbsch and Huhndorf (2010; outline), Romero et al. (2012; phylogeny), Kirk et al. (2013; genus accepted), cultures available for the type: AFTOL-ID 69 (unpublished), needs generic revision.

Pseudoplagiostoma Cheew., M.J. Wingf. \& Crous 2010, Pseudoplagiostomataceae, Diaporthales, Sordariomycetes, four species, type: P. eucalypti Cheew., M.J. Wingf. \& Crous, asexual morph coelomycetous, saprobes, terrestrial, tropical, see Cheewangkoon et al. (2010; taxonomy, phylogeny), Maharachchikumbura et al. (2015, 2016; outline), Wijayawardene et al. (2017; outline), holotype and ex-type cultures of the type: CBS H20303, CPC 13341=CBS 124807.

Pseudoplatystomum Thambugala \& K.D. Hyde 2015, Lophiostomataceae, Pleosporales, Dothideomycetes, one species, type: P. scabridisporum (Abdel-Wahab \& E.B.G. Jones) Thambugala \& K.D. Hyde, asexual morph unknown, saprobes, on marine driftwood, Australia, see Thambugala et al. (2015b; taxonomy), cultures and sequences are available, holotype of type: IMI 379750.

Pseudoplectania Fuckel 1870, Sarcosomataceae, Pezizales, Pezizomycetes, ten species, type: $P$. nigrella (Pers.) Fuckel, asexual morph unknown, saprobes, terrestrial, Europe, North America, see Lumbsch and Huhndorf (2010; outline), Romero et al. (2012; phylogeny), Holec and Kříž (2013; morphology), Carbone (2013; taxonomy), Kirk et al. (2013; genus accepted), Glejdura et al. (2015; new species), cultures available for the type: KL BK-4914, neotype: KL BK-4914.

Pseudopleospora Petr. 1920, Dothideomycetes genera incertae sedis, three species, type: P.a ruthenica Petr., asexual morph unknown, saprobes, terrestrial, Europe, see Lumbsch and Huhndorf (2010; outline), Kirk et al. (2013; genus accepted), Wijayawardene et al. (2014c; outline), cultures and sequences are unavailable, needs generic revision.

Pseudopolystigmina Murashk. 1928, Ascomycota genera incertae sedis, two species, type: $P$. spiraeicola Murashk., coelomycetous, sexual morph unknown, saprobes, Russia, see Wijayawardene et al. (2012, 2017; outline), Kirk et al. (2013; genus accepted), cultures and sequences are unavailable, needs generic revision.

Pseudoproboscispora Punith. 1999, Annulatascuaceae, Annulatascales, Sordariomycetes, two species, type: P. aquatica (S.W. Wong \& K.D. Hyde) Punith., asexual morph unknown, 
saprobes, aquatic, widespread, see Lumbsch and Huhndorf (2010; outline), Kirk et al. (2013; genus accepted), Maharachchikumbura et al. (2015, 2016; outline), cultures and sequences are available, holotype of type: CC63 (HKU(M) 2792).

Pseudopyrenidium Nav.-Ros., Zhurb. \& Cl. Roux 2010, Adelococcaceae, Verrucariales, Eurotiomycetes, one species, type: P. tartaricola (Linds.) Nav.-Ros., Zhurb. \& Cl. Roux, coelomycetous, asexual morph unknown, lihenicolous, Asia, USA, see Navarro-Rosinés et al. (2010; taxonomy), cultures and sequences are unavailable, needs generic revision.

Pseudopyrenula Müll. Arg. 1883, Trypetheliaceae, Trypetheliales, Dothideomycetes, 20 species, type: P. diluta (Fée) Müll. Arg., asexual morph unknown, lichenized, terrestrial, tropical, see Lumbsch and Huhndorf (2010; outline), Kirk et al. (2013; genus accepted), Aptroot and Lücking (2016; monograph), Lücking et al. (2016b; classification), cultures and sequences are available, needs generic revision.

Pseudopyricularia Klaubauf, Lebrun \& Crous 2014, Pyriculariaceae, Magnaporthales, Sordariomycetes, one species, type: P. kyllingae Klaubauf, Lebrun \& Crous, sexual morph unknown, pathogens, terrestrial, worldwide, see Klaubauf et al. (2014; taxonomy, phylogeny), Maharachchikumbura et al. (2015, 2016; outline), Wijayawardene et al. (2017; outline), holotype and ex-type cultures for the type: CBS H-21840, CBS 133595.

Pseudoramichloridium Cheew. \& Crous 2009, Extremaceae, Capnodiales, Dothideomycetes, one species, type: P. henryi Cheew. \& Crous, hyphomycetous, sexual morph unknown, saprobes, pathogens, Australia, see Cheewangkoon et al. (2010; taxonomy, phylogeny), Quaedvlieg et al. (2014; phylogeny), Wijayawardene et al. (2014c, 2017; outline), holotype and ex-type cultures for the type: CBS H-20293, CPC $13121=$ CBS 124775.

Pseudoramonia Kantvilas \& Vězda 2000, Graphidaceae, Ostropales, Lecanoromycetes, three species, type: P. stipitata (Vězda \& Hertel) Kantvilas \& Vězda, asexual morph unknown, lichenized fungi, terrestrial, tropical, see Lumbsch and Huhndorf (2010; outline), Rivas Plata et al. (2012a; key), Kirk et al. (2013; genus accepted), Lücking et al. (2016b; classification), cultures and sequences are available, needs generic revision.

Pseudoramularia Matsush. 1983, Ascomycota genera incertae sedis, two species, type: $P$. ponapensis Matsush., hyphomycetous, sexual morph unknown, saprobes, Uganda, Pacific islands, see Wijayawardene et al. (2012, 2017; outline), Kirk et al. (2013; genus accepted), cultures and sequences are unavailable, needs generic revision.

Pseudorbilia Y. Zhang bis, Z.F. Yu, Baral \& K.Q. Zhang 2007, Orbiliaceae, Orbiliales, Orbiliomycetes, one species, type: P. bipolaris Y. Zhang bis, Z.F. Yu, Baral \& K.Q. Zhang, saprobes, terrestrial, China, see Lumbsch and Huhndorf (2010; outline), cultures and sequences are unavailable, holotype of type: XBL17 (M H.B. 8310), needs generic revision.

Pseudorhizina Jacz. 1913, Discinaceae, Pezizales, Pezizomycetes, three species, type: P. korshinskii Jacz., asexual morph unknown, saprobes, terrestrial, North America, see Kirk et al. (2013; genus accepted), Jaklitsch et al. (2016a; classification), cultures and sequences are unavailable, needs generic revision.

Pseudorhizopogon Kobayasi 1983, Ascomycota genera incertae sedis, one species, type: $P$. sudae Kobayasi, coelomycetous, sexual morph unknown, saprobes, Japan, see Wijayawardene et al. (2012, 2017; outline), Kirk et al. (2013; genus accepted), cultures and sequences are unavailable, needs generic revision.

Pseudorhynchia Höhn. 1909, Niessliaceae, Hypocreales, Sordariomycetes, one species, type: P. polyrrhyncha (Penz. \& Sacc.) Höhn., asexual morph unknown, saprobes, terrestrial, see Kirk et al. (2008; treated as a synonym of Trichosphaeria Fuckel), Lumbsch and Huhndorf (2010; outline), Kirk et al. (2013; not listed), Maharachchikumbura et al. (2015, 2016), needs generic revision, cultures and sequences are available.

Pseudorhytisma Juel 1894, Rhytismataceae, Rhytismatales, Leotiomycetes, one species, type: $P$. bistortae (DC.) Juel, asexual morph unknown, saprobes, terrestrial, worldwide, see 
Lumbsch and Huhndorf (2010; outline), Kirk et al. (2013; genus accepted), cultures and sequences are unavailable, type specimen of type: CBS H-17420, needs generic revision.

Pseudorobillarda M. Morelet 1968, Dothideomycetes genera incertae sedis, twelve species, type: $P$. phragmitis (Cunnell) M. Morelet, coelomycetous, sexual morph unknown, saprobes, marine, terrestrial, worldwide, see Suetrong et al. (2009; phylogeny, morphology), Rungindamai et al. (2012; morphology, phylogeny), Wijayawardene et al. (2012, 2017; outline), Kirk et al. (2013; genus accepted), Moreno-Pérez et al. (2014; antagonist), Tangthirasunun et al. (2014b; new species, Thailand), Crous et al. (2015a; phylogeny), Jones et al. (2015; outline), available specimen and cultures for the type: CBS 842.84, CBS H17422.

Pseudosaccharomyces Briosi \& Farneti 1906, Ascomycota genera incertae sedis, 20 species, type: P. citri Briosi \& Farneti, hyphomycetous, sexual morph unknown, saprobes, Italy, see Wijayawardene et al. (2012, 2017; outline), Kirk et al. (2013; genus accepted), cultures and sequences are unavailable, needs generic revision.

Pseudosagedia (Müll.Arg.) Choisy 1949, Porinaceae, Ostropales, Lecanoromycetes, 80 species, type: P. cerasi (Schrad.) M. Choisy, lichenized, see Lücking et al. (2016b; classification), cultures and sequences are available, needs generic revision.

Pseudosarcosoma M. Carbone, Agnello \& P. Alvarado 2013, Chorioactidaceae, Pezizales, Pezizomycetes, two species, type: P. latahense (Paden \& Tylutki) M. Carbone, Agnello \& P. Alvarado, asexual morph unknown, saprobes, terrestrial, USA, see Carbone et al. (2013; taxonomy), sequences are available of the voucher TUR-A 195801 of the type:, holotype of the type: WTU-F-33051.

Pseudoschismatomma Ertz \& Tehler 2014, Roccellaceae, Arthoniales, Arthoniomycetes, one species, type: P. rufescens (Pers.) Ertz \& Tehler, sexual morph with lirelliform ascomata, lichenized, terrestrial, Europe, Macaronesia, North America, Asia, Australia, see Ertz et al. (2014b; morphology, phylogeny), Lücking et al. (2016b; classification), sequences are available.

Pseudoschizothyra Punith. 1980, Ascomycota genera incertae sedis, one species, type: $P$. thaungii Punith., coelomycetous, sexual morph unknown, saprobes, Myanmar, see Wijayawardene et al. (2012, 2017; outline), Kirk et al. (2013; genus accepted), cultures and sequences are unavailable, needs generic revision.

Pseudoscopulariopsis Sandoval-Denis, Gené \& Guarro 2015, Microascaceae, Microascales, Sordariomycetes, one species, type: P. schumacheri (E.C. Hansen) M. Sandoval-Denis, J. Gené \& J. Guarro, asexual morph hyphomycetous, saprobes, terrestrial, North America, see Maharachchikumbura et al. (2015, 2016; outline, phylogeny), Wijayawardene et al. (2017; outline), cultures and sequences are unavailable, needs generic revision.

Pseudoscypha Duby 1861, Hysteriaceae, Hysteriales, Dothideomycetes, three species, type: P. abietis J. Reid \& Piroz., asexual unknown, terrestrial, Lumbsch and Huhndorf (2010; outline), Kirk et al. (2013; genus accepted), Wijayawardene et al. (2014c; outline), sequences are unavailable, needs generic revision.

Pseudoseptoria Speg. 1911, Saccotheciaceae, Dothideales, Dothideomycetes, eight species, type: $P$. donacicola Speg., coelomycetous, sexual morph unknown, saprobes, terrestrial, worldwide, see Wijayawardene et al. (2012, 2014c, 2017; outline), Kirk et al. (2013; genus accepted), Quaedvlieg et al. (2013; accepted as a genus in Dothioraceae, phylogeny), Thambugala et al. (2015c; phylogeny), cultures and sequences are available but lacks for the type, needs generic revision.

Pseudosigmoidea K. Ando \& N. Nakam. 2000, Ascomycota genera incertae sedis, one species, type: P. cranei K. Ando \& N. Nakam., hyphomycetous, sexual morph unknown, saprobes, North America, see Seifert et al. (2011; morphology), Wijayawardene et al. (2012, 
2017; outline), Diene et al. (2013; new species), Kirk et al. (2013; genus accepted), cultures and sequences are available.

Pseudospiromastix Guarro, Stchigel \& Cano 2014, Spiromastigaceae, Onygenales, Eurotiomycetes, one species, type: P. tentaculata (Guarro, Gené \& De Vroey) Guarro, asexual morph unknown, from soil, terrestrial, Somalia, see Rizzo et al. (2014; morphology; phylogeny), Hirooka et al. (2016; phylogeny), holotype and ex-type strains of type: IMI 351264; RV $24167=$ CBS $184.92=$ FMR 3842.

Pseudosporidesmium K.D. Hyde \& McKenzie 2016, Xylariomycetidae genera incertae sedis, Sordariomycetes, one species, type: P. knawiae (Crous) K.D. Hyde \& McKenzie, hyphomycetous, sexul morph unknown, saprobes, KwaZulu-Natal, see Su et al. (2016a; phylogeny), Wijayawardene et al. (2017; outline), holotype of the type: CBS H-20158 (as Sporidesmium knawiae Crous).

Pseudostegia Bubák 1906, Ascomycota genera incertae sedis, one species, type: P. nubilosa Bubák, coelomycetous, sexual morph unknown, saprobes, North America, see Wijayawardene et al. (2012, 2017; outline), Kirk et al. (2013; genus accepted), cultures and sequences are unavailable, needs generic revision.

Pseudostigmidium Etayo 2008, Mycosphaerellaceae, Capnodiales, Dothideomycetes, five species, type: $P$. nephromiarium (Linds.) Etayo, asexual morph unknown, lichenicolous, South America, see Etayo and Sancho (2008; morphology, keys), Hyde et al. (2013; accepted as a genus in Mycosphaerellaceae), Wijayawardene et al. (2014c; outline), cultures and sequences are unavailable, holotype of the type: E, J.D. Hooker.

Pseudostrickeria Q. Tian,Wanasinghe, Camporesi \& K.D. Hyde 2015, Melanommataceae, Pleosporales, Dothideomycetes, two species, type: P. muriformis Wanasinghe, Q. Tian, Camporesi \& K.D. Hyde, asexual morph unknown, saprobes, terrestrial, Italy, see Tian et al. (2015; taxonomy), cultures and sequences are available for type, holotype and ex-type strains of type: MFLU 15-1407; MFLUCC 13-0764 = KUMCC15-0062.

Pseudosydowia K.M. Thambugala \& K.D. Hyde 2014, Saccotheciaceae, Dothideales, Dothideomycetes, one species, type: P. eucalypti (Verwoerd \& du Plessis) Thambug. \& K.D. Hyde, asexual morphs unknown, saprobes, terrestrial, South Africa, see Thambugala et al. (2015c; phylogeny), cultures and sequences are available, holotype of type: PREM 46423.

Pseudotaeniolina J.L. Crane \& Schokn. 1986, Teratosphaeriacae, Capnodiales, Dothideomycetes, two species, type: P. convolvuli (Esfand.) J.L. Crane \& Schokn., hyphomycetous, sexual morph unknown, on litter, rock-inhabiting, cosmopolitan, see Egidi et al. (2014; taxonomy, phylogeny), Wijayawardene et al. (2017; outline), cultures and sequences are available.

Pseudoteratosphaeria Quaedvl. \& Crous 2014, Teratosphaeriaceae, Capnodiales, Dothideomycetes, six species, type: P. perpendicularis (Crous \& M.J. Wingf.) Quaedvl. \& Crous, asexual morph unknown, foliicolous, pathogens, saprobes, Brazil, Colombia, South Africa, see Quaedvlieg et al. (2014; morphology, phylogeny), cultures and sequences are available, holotype and ex-type culture of type: CBS H-19691, CBS 118367.

Pseudotetraploa Kaz. Tanaka \& K. Hiray. 2009, Tetraplosphaeriaceae, Pleosporales, Dothideomycetes, three species, type: P. curviappendiculata (Sat. Hatak., Kaz. Tanaka \& Y. Harada) Kaz. Tanaka \& K. Hiray., hyphomycetous, saprobes, terrestrial, Indonesia, Japan, see Tanaka et al. (2009; phylogeny), Seifert et al. (2011; morphology), Wijayawardene et al. (2012, 2017; outline), cultures and sequences are available, holotype and ex-type strain of the type: HHUF 28582, JCM 12852.

Pseudothelomma M.Prieto \& Wedin 2016, Caliciaceae, Caliciales, Lecanoromycetes, two species, type: P. ocellatum (Körb.) M. Prieto and Wedin, lichenized, see Prieto \& Wedin (2016; genus proposed, phylogeny), Lücking et al. (2016b; classification), cultures and sequences are available, voucher specimen of type: Tehler 8063 (S), needs generic revision. 
Pseudothiella Petr. 1928 (= Pseudothiopsella Petr. 1928 fide Réblová et al. 2016c), Phyllachoraceae, Phyllachorales, Sordariomycetes, six species, type: P. hirtellae (Henn.) Petr., asexual morph formerly named in Pseudothiopsella, from living leaves, Brazil, see Lumbsch and Huhndorf (2010; outline), Kirk et al. (2013; genus accepted), Maharachchikumbura et al. (2015, 2016; outline), Réblová et al. (2016c; nomenclature), cultures and sequences are unavailable, needs generic revision.

Pseudothis Theiss. \& Syd. 1914, Diaporthales genera incertae sedis, Sordariomycetes, one species, type: Pseudothis machaerii (Rehm) Theiss. \& Syd., asexual morph unknown, saprobes, terrestrial, tropical, see Lumbsch and Huhndorf (2010; outline), Kirk et al. (2013; genus accepted), Maharachchikumbura et al. (2015, 2016; outline), cultures and sequences are unavailable, needs generic revision.

Pseudothyrium Höhn. 1927, Ascomycota genera incertae sedis, one species, type: $P$. polygonati (Tassi) Höhn., coelomycetous, sexual morph unknown, saprobes, Europe, see Wijayawardene et al. (2012, 2017; outline), Kirk et al. (2013; genus accepted), cultures and sequences are unavailable, needs generic revision.

Pseudotopeliopsis Parnmen, Lücking \& Lumbsch 2012, Graphidaceae, Ostropales, Lecanoromycetes, four species, type: P. laceratula (Müll. Arg.) Parnmen, Lücking \& Lumbsch, asexual morph unknown, lichenized fungi, terrestrial, tropical, see Parnmen et al. (2012; genus proposed, phylogeny), Lücking et al. (2016b; classification), Cultures and sequences are available, lectotype of type: Sayer s.n. - G (Australia).

Pseudotorula Subram. 1958, Ascomycota genera incertae sedis, three species, type: $P$. heterospora Subram., hyphomycetous, sexual morph unknown, saprobes, Asia, see Seifert et al. (2011; morphology), Wijayawardene et al. (2012, 2017; outline), Kirk et al. (2013; genus accepted), cultures and sequences are unavailable, needs generic revision.

Pseudotracylla B. Sutton \& Hodges 1976, Ascomycota genera incertae sedis, three species, type: P. dentata B. Sutton \& Hodges, coelomycetous, sexual morph unknown, saprobes, Brazil, USA, see Wijayawardene et al. (2012, 2017; outline), Kirk et al. (2013; genus accepted), cultures and sequences are unavailable, needs generic revision.

Pseudotrichia Kirschst. 1939, Pleomassariaceae, Pleosporales, Dothideomycetes, eight species, type: P. stromatophila Kirschst., asexual morph unknown, saprobes, terrestrial, cosmopolitan, see Lumbsch and Huhndorf (2010; outline, accepted as a genus in Melanommataceae), Hyde et al. (2013; accepted as a genus in Melanommataceae), Wijayawardene et al. (2014c; outline), Liu et al. (2015a; new species, Thailand), Tian et al. (2015; phylogeny, accepted as a genus in Pleomassariaceae), cultures and sequences are available.

Pseudotrichoconis W.A. Baker \& Morgan-Jones 2001, Ascomycota genera incertae sedis, one species, type: P. echinophila (C. Massal.) W.A. Baker \& Morgan-Jones, hyphomycetous, sexual morph unknown, saprobes, Europe, see Seifert et al. (2011; morphology), Wijayawardene et al. (2012, 2017; outline), Kirk et al. (2013; genus accepted), cultures and sequences are unavailable, needs generic revision.

Pseudotripoconidium Z.F. Yu \& K.Q. Zhang 2011, Orbiliaceae, Orbiliales, Orbiliomycetes, one species, type: $P$. sinense Z.F. Yu \& K.Q. Zhang, saprobes, terrestrial, China, see Yu et al. (2011; taxonomy), Wijayawardene et al. (2012, 2017; outline), cultures and sequences are unavailable, holotype of the type: YMF 1.01843, needs generic revision.

Pseudotrochila Höhn. 1917, Rhytismatales genera incertae sedis, Leotiomycetes, two species, type: P. rhododendri (Racib.) Höhn., asexual morph unknown, saprobes, terrestrial, Java, see Lumbsch and Huhndorf (2010; outline), Kirk et al. (2013; genus accepted), cultures and sequences are unavailable, needs generic revision.

Pseudotryblidium Rehm 1890, Helotiales genera incertae sedis, Leotiomycetes, one species, type: P. neesii (Flot.) Rehm, asexual morph unknown, saprobes, terrestrial, Europe, see 
Lumbsch and Huhndorf (2010; outline), Kirk et al. (2013; genus accepted), cultures and sequences are unavailable, needs generic revision.

Pseudotulostoma O.K. Mill. \& T.W. Henkel 2001, Elaphomycetaceae, Eurotiales, Eurotiomycetes, two species, type: P. volvatum O.K. Mill. \& T.W. Henkel, asexual morph unknown, saprobes, terrestrial, Europe, see Lumbsch and Huhndorf (2010; outline), Smith et al. (2011; DNA), cultures and sequences are available.

Pseudovalsaria Spooner 1986, Boliniaceae, Boliniales, Sordariomycetes, four species, type: P. foedans (P. Karst.) Spooner, asexual morphs unknown, saprobes, terrestrial, Europe, China, see Lumbsch and Huhndorf (2010; outline, accepted as a genus in Clypeosphaeriaceae), Untereiner et al. (2013; accepted as a genus in Boliniaceae, phylogeny), Maharachchikumbura et al. (2015, 2016; outline, phylogeny), cultures and sequences are available but lacks for the type, needs generic revision.

Pseudovalsella Höhn. 1918, Melanconidaceae, Xylariales, Sordariomycetes, one species, type: P. thelebola (Fr.) Höhn., asexual morph unknown, saprobes, worldwide, see Lumbsch and Huhndorf (2010; outline), Kirk et al. (2013; genus accepted), Maharachchikumbura et al. (2015, 2016; outline), cultures and sequences are unavailable, needs generic revision.

Pseudoveronaea Crous \& Batzer 2012, Dissoconiaceae, Capnodiales, Dothideomycetes, two species, type: P. ellipsoidea Batzer \& Crous, hyphomycetous, sexual morph unknown, saprobes, terrestrial, USA, see Li et al. (2012a; morphology; phylogeny), Wijayawardene et al. (2014c; outline), cultures and sequences are available, holotype and ex-type of the type: CBS H-20927, CBS 132086.

Pseudovirgaria H.D. Shin, U. Braun, Arzanlou \& Crous 2007, Capnodiales genera incertae sedis, Dothideomycetes, two species, type: P. hyperparasitica H.D. Shin, U. Braun, Arzanlou $\&$ Crous, asexual morphs hyphomycetous, fungiicolous, Asia, Europe, see Braun et al. (2011, taxonomy), Seifert (2011; morphology), Wijayawardene et al. (2012, 2017; outline), holotype and ex-type strains of type: HAL 2054 F; CBS 121739-121741.

Pseudoxylomyces Kaz. Tanaka \& K. Hiray. 2015, Pleosporales genera incertae sedis, Dothideomycetes, one species, type: P. elegans (Goh, W.H. Ho, K.D. Hyde \& K.M. Tsui) Kaz. Tanaka \& K. Hiray., sexual morph unknown, saprobes, aquatic, worldwide, see Tanaka et al. (2015; morphology, phylogeny), cultures and sequences are available, holotype of the type: HKU (M) 2777.

Pseudoyuconia Lar.N. Vassiljeva 1983, Pleosporaceae, Pleosporales, Dothideomycetes, one species, type: P. thalictri (G. Winter) Lar.N. Vassiljeva, asexual morph unknown, saprobe, terrestrial, North temperate, see Lumbsch and Huhndorf (2010; outline), Zhang et al. (2012e; accepted as a genus in Pleosporaceae), Wijayawardene et al. (2014c; outline), Ariyawansa et al. (2015c; accepted as a genus in Pleosporaceae), cultures and sequences are unavailable, needs generic revision.

Pseudozythia Höhn. 1902, Ascomycota genera incertae sedis, one species, type: P. pusilla Höhn., coelomycetous, sexual morph unknown, saprobes, Europe, see Wijayawardene et al. (2012, 2017; outline), Kirk et al. (2013; genus accepted), cultures and sequences are unavailable, needs generic revision.

Psilachnum Höhn. 1926, Pezizellaceae, Helotiales, Leotiomycetes, 28 species, type: P. lateritioalbum (P. Karst.) Höhn., asexual morph unknown, saprobes, terrestrial, worldwide, see Han et al. (2009, 2014; new species, phylogeny), Lumbsch and Huhndorf (2010; outline), Kirk et al. (2013; genus accepted), cultures and sequences are available but lacks for the type, needs generic revision.

Psilocistella Svrček 1977, Hyaloscyphaceae, Helotiales, Leotiomycetes, ten species, type: P. obsoleta (Velen.) Svrček, asexual morph unknown, saprobes, terrestrial, worldwide, see Lumbsch and Huhndorf (2010; outline), Kirk et al. (2013; genus accepted), cultures and sequences are available, needs generic revision. 
Psiloglonium Höhn. 1918, Hysteriaceae, Hysteriales, Dothideomycetes, c. 15 species, type: P. lineare (Fr.) Petr., asexual morph unknown, saprobes, pathogens, terrestrial, cosmopolitan, see Kirk et al. (2008; treated as a synonym of Glonium Muhl. ex Fr.), Boehm et al. (2009a, b; overview of genus), Lumbsch and Huhndorf (2010; outline), Hyde et al. (2013; accepted as a genus in Hysteriaceae), Wijayawardene et al. (2014c; outline), Li et al. (2016a; new species), Rossman et al. (2016b; new combination, pathogen), sequences are available, needs generic revision.

Psilolechia A.Massal. 1860, Psilolechiaceae, Lecanorales, Lecanoromycetes, four species, type: P. lucida (Ach.) M. Choisy, lichenized, see Lumbsch and Huhndorf (2010; outline), Kirk et al. (2013; genus accepted), Miądlikowska et al. (2014a; phylogeny), Lücking et al. (2016b; classification), cultures and sequences are available, needs generic revision.

Psiloparmelia Hale 1989, Parmeliaceae, Lecanorales, Lecanoromycetes, 13 species, type: P. distincta (Nyl.) Hale, lichenized, see Lumbsch and Huhndorf (2010; outline), Kirk et al. (2013; genus accepted), Lücking et al. (2016b; classification), cultures and sequences are available, needs generic revision.

Psilopezia Berk. 1847, Rhizinaceae, Pezizales, Pezizomycetes, five species, type: $P$. nummularia Berk., asexual morph unknown, pathogens, terrestrial, North America, see Lumbsch and Huhndorf (2010; outline, accepted as a genus in Pezizales), Kirk et al. (2013; genus accepted), cultures and sequences are available but lacks for the type, needs generic revision.

Psilophana Syd. 1939, Helotiales genera incertae sedis, Leotiomycetes, one species, type: $P$. andina Syd., asexual morph unknown, saprobes, terrestrial, Ecuador, see Lumbsch and Huhndorf (2010; outline), Kirk et al. (2013; genus accepted), cultures and sequences are unavailable, needs generic revision.

Psilosphaeria Cooke 1879, Ascomycota genera incertae sedis, one species, type: need typification, Lumbsch and Huhndorf (2010; outline), Kirk et al. (2013; genus accepted), cultures and sequences are unavailable, needs generic revision.

Psilothecium Clem. 1903, Leotiomycetes genera incertae sedis, one species, type: $P$. incurvum Clem., asexual morph unknown, saprobes, North America, see Lumbsch and Huhndorf (2010; outline, accepted as a genus in Helotiales), Jaklitsch et al. (2016a; classification), cultures and sequences are unavailable, needs generic revision.

Psora Hoffm. [nom. cons.] 1796, Psoraceae, Lecanorales, Lecanoromycetes, 35 species, type: Lecidea decipiens (Hedw.) Ach., lichenized, worldwide, see Lumbsch and Huhndorf (2010; outline), Kirk et al. (2013; genus accepted), Lücking et al. (2016b; classification), cultures and sequences are available, needs generic revision.

Psoroglaena Müll. Arg. 1891, Verrucariaceae, Verrucariales, Eurotiomycetes, 17 species, type: $P$. cubensis Müll. Arg., lichenized, see Muggia et al. (2010; phylogeny), Lumbsch and Huhndorf (2010; outline), Kirk et al. (2013; genus accepted), McCarthy and Kantvilas (2013a; new species), Yatsyna (2014; new records), Himelbrant et al. (2015; new records), Käffer et al. (2015; new records), Kubiak et al. (2016; biodiversity), Lücking et al. (2016b; classification), Weerakoon and Aptroot (2016; new records), cultures and sequences are available, needs generic revision.

Psoroma Michaux 1803, Pannariaceae, Peltigerales, Lecanoromycetes, 70 species, type: $P$. hypnorum (Vahl) Gray, lichenized, worldwide, see Ekman et al. (2014; phylogeny), Lücking et al. (2016b; classification), cultures and sequences are available, needs generic revision.

Psoromella Gyeln. 1940, Lecanorales genera incertae sedis, Lecanoromycetes, one species, type: P.a pampana Gyeln., lichenized, see Lumbsch and Huhndorf (2010; outline), Thell et al. (2012; overview), Lücking et al. (2016b; classification), cultures and sequences are unavailable, needs generic revision. 
Psoromidium Stirt. 1877, Pannariaceae, Peltigerales, Lecanoromycetes, two species, type: $P$. wellingtonii Stirt., lichenized, Southern Hemisphere, see Lumbsch and Huhndorf (2010; outline), Rubio et al. (2013; taxonomy), Jørgensen and Andersen (2015; genus re-evaluation, sequence), Lücking et al. (2016b; classification), cultures and sequences are available, needs generic revision.

Psoronactis Ertz \& Tehler 2015, Roccellaceae, Arthoniales, Arthoniomycetes, one species, type: $P$. dilleniana (Ach.) Ertz \& Tehler, sexual morph with apothecioid ascomata, asexual morph coelomycetous, lichenized, terrestrial, Euro-Siberian, see Ertz et al. (2015b, c; morphology, phylogeny), Lücking et al. (2016b; classification), sequences are available, needs generic revision.

Psorophorus Elvebakk \& S.G. Hong 2010, Pannariaceae, Peltigerales, Lecanoromycetes, two species, type: P. pholidotus Elvebakk \& S.G. Hong, asexual morph unknown, lichenized, terrestrial, South America, see Elvebakk et al (2010; new genus, sequence), sequences are available, needs generic revision.

Psorotheciopsis Rehm 1900, Gomphillaceae, Ostropales, Lecanoromycetes, seven species, type: P. decipiens Rehm, lichenized, tropical, see Lumbsch and Huhndorf (2010; outline), Kirk et al. (2013; genus accepted), Lücking et al. (2016b; classification), cultures and sequences are unavailable, needs generic revision.

Psorotichia A.Massal. 1855, Lichinaceae, Lichinales, Lichinomycetes, 50 species, type: P. murorum A. Massal., lichenized, tropical, see Lumbsch and Huhndorf (2010; outline), Kirk et al. (2013; genus accepted), Lücking et al. (2016b; classification), cultures and sequences are available, needs generic revision.

Psorula Gotth. Schneid. 1980, Psoraceae, Lecanorales, Lecanoromycetes, three species, type: Psorula rufonigra (Tuck.) Gotth. Schneid., lichenized, North America, Europe, Asia, see Lumbsch and Huhndorf (2010; outline), Kirk et al. (2013; genus accepted), Lücking et al. (2016b; classification), Cultures and sequences are available, needs generic revision.

Pteridiosperma J.C. Krug \& Jeng 1979, Ceratostomataceae, Melanosporales, Sordariomycetes, one species, type: Pteridiosperma foveolatum (Udagawa \& Y. Horie) J.C. Krug \& Jeng, asexual morph unknown, saprobes, terrestrial, Japan, see Lumbsch and Huhndorf (2010; outline), Kirk et al. (2013; genus accepted), Maharachchikumbura et al. (2015, 2016; outline), cultures and sequences are unavailable, needs generic revision.

Pteridiospora Penz. \& Sacc. 1897, Astrosphaeriellaceae, Pleosporales, Dothideomycetes, one species, type: P. javanica Penz. \& Sacc., asexual morph unknown, saprobes, terrestrial, worldwide, see Lumbsch and Huhndorf (2010; outline, accepted as Dothideomycetes), Kirk et al. (2013; genus accepted), Phookamsak et al. (2014a, 2015b; pylogeny), Wijayawardene et al. (2014c; outline, accepted as Dothideomycetes), available cultures for the type: MFLUCC 11-0195, needs generic revision.

Pteromyces E. Bommer, M. Rousseau \& Sacc. 1906, Helotiales genera incertae sedis, Leotiomycetes, one species, type: P. ambiguus E. Bommer, M. Rousseau \& Sacc. ex Sacc., asexual morph unknown, saprobes, terrestrial, Europe, see Lumbsch and Huhndorf (2010; outline), Kirk et al. (2013; genus accepted), cultures and sequences are unavailable, needs generic revision.

Pteromycula P.F. Cannon 1997, Ascomycota genera incertae sedis, one species, type: P. clypeiformis P.F. Cannon, asexual morph unknown, saprobes, terrestrial, Great Britain, see Lumbsch and Huhndorf (2010; outline), Kirk et al. (2013; genus accepted), cultures and sequences are unavailable, holotype of type: IMI 362154a, needs generic revision.

Pterosporidium W.H. Ho \& K.D. Hyde 1996, Phyllachoraceae, Phyllachorales, Sordariomycetes, one species, type: P. rhizophorae (Vizioli) W.H. Ho \& K.D. Hyde, from living leaves, worldwide, see Lumbsch and Huhndorf (2010; outline), Kirk et al. (2013; 
genus accepted), Maharachchikumbura et al. (2015, 2016; outline), cultures and sequences are unavailable, needs generic revision.

Pterulopsis Wakef. \& Hansf. 1943, Ascomycota genera incertae sedis, one species, type: $P$. dummeri Wakef. \& Hansf., hyphomycetous, sexual morph unknown, saprobes, Uganda, see Seifert et al. (2011; morphology), Wijayawardene et al. (2012, 2017; outline), Kirk et al. (2013; genus accepted), cultures and sequences are unavailable, needs generic revision.

Pterygiopsis Vain. 1890, Lichinaceae, Lichinales, Lichinomycetes, 17 species, type: P. atra Vain., lichenized, North America, South America, Europe, Australia, Africa, see Eichler et al. (2010; list), Schultz and Moon (2011; taxonomy), Lumbsch and Huhndorf (2010; outline), Kirk et al. (2013; genus accepted), Lücking et al. (2016b; classification), cultures and sequences are available, needs generic revision.

Pterygosporopsis P.M. Kirk 1983, Ascomycota genera incertae sedis, two species, type: P. fragilis P.M. Kirk, hyphomycetous, sexual morph unknown, saprobes, Europe, see Seifert et al. (2011; morphology), Wijayawardene et al. (2012, 2017; outline), Kirk et al. (2013; genus accepted), cultures and sequences are unavailable, needs generic revision.

Ptychographa Nyl. 1874, Xylographaceae, Trapeliales, Lecanoromycetes, one species, type: P. xylographoides Nyl., lichenized, Europe, see Lumbsch and Huhndorf (2010; outline), Kirk et al. (2013; genus accepted), Spribille et al. (2014a; sequence), Resl et al. (2015; sequence, partial sequence), Lücking et al. (2016b; classification), cultures and sequences are available, needs generic revision.

Pubigera Baral, Gminder \& Svrček 2014 (= Pubigera Baral, Gminder \& Svrček 1995; Nom. inval., Art. 40.6 (Melbourne) fide Species Fungorum 2017), Helotiales genera incertae sedis, Leotiomycetes, one species, type: P. subvillosula (Rehm) Baral, Gminder \& Svrček, sexual morph unknown, saprobes, Europe, see Lumbsch and Huhndorf (2010; outline), Kirk et al. (2013; accepted as in Hyaloscyphaceae), Jaklitsch et al. (2016a; classification), cultures and sequences are unavailable.

Pucciniospora Speg. 1886, Ascomycota genera incertae sedis, one species, type: $P$. chusqueae Speg., coelomycetous, sexual morph unknown, saprobes, South America, see Wijayawardene et al. (2012, 2017; outline), Kirk et al. (2013; genus accepted), cultures and sequences are unavailable, needs generic revision.

Pulchromyces Hennebert 1973, Ascomycota genera incertae sedis, one species, type: $P$. fimicola (V. Dring) Hennebert, coelomycetous, sexual morph unknown, coprophilous, Ghana, see Wijayawardene et al. (2012, 2017; outline), Kirk et al. (2013; genus accepted), cultures and sequences are available, cultures available for the type: ATCC 18595 (unpublished), needs generic revision.

Pulmosphaeria Joanne E. Taylor, K.D. Hyde \& E.B.G. Jones 1996, Xylariales genera incertae sedis, Sordariomycetes, one species, type: P. archontophoenicis Joanne E. Taylor, K.D. Hyde \& E.B.G. Jones, asexual morph unknown, saprobes, terrestrial, Australia, see Lumbsch and Huhndorf (2010; outline), Kirk et al. (2013; genus accepted), Maharachchikumbura et al. (2015, 2016; outline), cultures and sequences are unavailable, needs generic revision.

Pulvinaria Bonord. 1851, Sordariomycetes genera incertae sedis, one species, type: $P$. bohemica Velen., asexual morph unknown, saprobes, terrestrial, Europe, see Lumbsch and Huhndorf (2010; outline), Kirk et al. (2013; genus accepted), Maharachchikumbura et al. (2015, 2016; outline), cultures and sequences are unavailable, needs generic revision.

Pulvinella A.W. Ramaley 2001, Ascomycota genera incertae sedis, one species, type: $P$. nolinae A.W. Ramaley, hyphomycetous, sexual morph unknown, coprophilous, USA, see Seifert et al. (2011; morphology), Wijayawardene et al. (2012, 2017; outline), Kirk et al. (2013; genus accepted), cultures and sequences are unavailable, holotype of type: UC 1512945, needs generic revision. 
Pulvinodecton Henssen \& G.Thor 1998, Roccellaceae, Arthoniales, Arthoniomycetes, two species, type: P. kurzii (Kremp.) Henssen \& G. Thor, lichenized, Seychelles, Asia, Australia, see Jaklitsch et al. (2016a; phylogeny), Lücking et al. (2016b; classification), sequences are unavailable, needs generic revision.

Pulvinula Boud. 1885, Pezizales genera incertae sedis, Pezizomycetes, 28 species, type: $P$. convexella (P. Karst.) Pfister, asexual morph unknown, coprophilous, saprobes, terrestrial, worldwide, see Lumbsch and Huhndorf (2010; outline), Hansen et al. (2013; phylogeny), Kirk et al. (2013; genus accepted), sequences are available, voucher specimen of the type: KH.03.19 (FH), needs generic revision.

Pumilus Viala \& Marsais 1934, Sordariomycetes genera incertae sedis, one species, type: $P$. medullae Viala \& Marsais, asexual morph unknown, saprobes, terrestrial, Europe, see Lumbsch and Huhndorf (2010; outline), Kirk et al. (2013; genus accepted), Maharachchikumbura et al. (2015, 2016; outline), needs generic revision, cultures and sequences are unavailable.

Punctelia Krog 1982, Parmeliaceae, Lecanorales, Lecanoromycetes, 45 species, type: P. borreri (Sm.) Krog, lichenized, worldwide, see Lumbsch and Huhndorf (2010; outline), Kirk et al. (2013; genus accepted), Lücking et al. (2016b; classification), Cultures and sequences are available, needs generic revision.

Punctillina Toro 1934, Ascomycota genera incertae sedis, one species, type: P. solteroi Toro, coelomycetous, sexual morph unknown, saprobes, South America, see Wijayawardene et al. (2012, 2017; outline), Kirk et al. (2013; genus accepted), cultures and sequences are unavailable, needs generic revision.

Punctillum Petr. \& Syd. 1924, Dothideomycetes genera incertae sedis, two species, type: $P$. hepaticarum (Cooke) Petr. \& Syd., asexual morph unknown, saprobes, widespread, see Lumbsch and Huhndorf (2010; outline), Kirk et al. (2013; genus accepted), Wijayawardene et al. (2014c; outline), cultures and sequences are unavailable, needs generic revision.

Punctonora Aptroot 1997, Lecanoraceae, Lecanorales, Lecanoromycetes, one species, type: $P$. nigropulvinata Aptroot, asexual morph unknown, lichenized, terrestrial, tropical, see Lumbsch and Huhndorf (2010; outline), Kirk et al. (2013; genus accepted), cultures and sequences are unavailable, holotype of the type: B, Aptroot 33356.

Pureke P.R. Johnst. 1991, Rhytismataceae, Rhytismatales, Leotiomycetes, seven species, type: P. zelandicum P.R. Johnst., asexual morph unknown, saprobes, terrestrial, New Zealand, see Lumbsch and Huhndorf (2010; outline), Kirk et al. (2013; genus accepted), cultures and sequences are available but lacks for the type, holotype of type: PDD 45591, needs generic revision.

Purpureocillium Luangsa-ard, Hywel-Jones, Houbraken \& Samson 2011, Ophiocordycipitaceae, Hypocreales, Sordariomycetes, one species, type: P. lilacinum (Thom) Luangsa-ard, Houbraken, Hywel-Jones \& Samson, hyphomycetous, sexual morph unknown, saprobes, terrestrial, cosmopolitan, see Luangsa-ard et al. (2011; taxonomy), Maharachchikumbura et al. (2015, 2016; outline), Spatafora et al. (2015; new combinations), Hyde et al. (2016; new species), Wijayawadene et al. (2017; outline), cultures and sequences are available.

Pustulipora P.F. Cannon 1982, Ceratostomataceae, Melanosporales, Sordariomycetes, one species, type: $P$. corticola P.F. Cannon, asexual morph unknown, saprobes, terrestrial, British Isles, see Lumbsch and Huhndorf (2010; outline), Kirk et al. (2013; genus accepted), Maharachchikumbura et al. (2015, 2016; outline), cultures and sequences are unavailable, needs generic revision.

Pustulomyces D.Q. Dai, D.J. Bhat \& K.D. Hyde 2014, Diaporthaceae, Diaporthales, Sordariomycetes, one species, type: P. bambusicola D.Q. Dai, D.J. Bhat \& K.D. Hyde, asexual morph coelomycetous, sexual morph unknown, saprobes on dead bamboo culms, 
terrestrial, only know in Thailand, see Dai et al. (2014d; phylogeny, morphology), Wijayawardene et al. (2016b; morphology, phylogeny), sequence data available, holotype and ex-type strain of type: MFLU 13-0369; MFLUCC 11-0436.

Puttea S.Stenroos \& Huhtinen 2009, Lecanorales genera incertae sedis, Lecanoromycetes, three species, type: P. margaritella (Hulting) S. Stenroos \& Huhtinen, lichenized, Eastern Europe, America, Russia, see Stenroos et al. (2009, 2010; taxonomy, DNA), Lumbsch and Huhndorf (2010; list), Davydov and Printzen (2012; taxonomy), Czarnota and Hernik (2013; taxonomy, new report), Dillman et al. (2014; new combination), Lücking et al. (2016b; classification), cultures and sequences are available, needs generic revision.

Puttemansia Henn. 1902, Paranectriellaceae, Dothideomycetes families incertae sedis, 19 species, type: Puttemansia lanosa Henn., asexual morph hyphomycetous, parasitic on Nectandra, worldwide, see Hyde et al. (2013; accepte as a genus in Paranectriellaceae), Wijayawardene et al. (2014c; outline), Kirk et al. (2013; genus accepted), cultures and sequences are unavailable, needs generic revision.

Pycnidioarxiella Punith. \& N.D. Sharma 1980, Ascomycota genera incertae sedis, one species, type: P. indica Punith. \& N.D. Sharma, coelomycetous, sexual morph unknown, saprobes, India, see Wijayawardene et al. (2012, 2017; outline), Kirk et al. (2013; genus accepted), cultures and sequences are unavailable, needs generic revision.

Pycnidiopeltis Bat. \& C.A.A. Costa 1959, Ascomycota genera incertae sedis, one species, type: P. smilacina Bat. \& C.A.A. Costa, coelomycetous, sexual morph unknown, saprobes, USA, Brazil, see Wijayawardene et al. (2012, 2017; outline), Kirk et al. (2013; genus accepted), cultures and sequences are unavailable, needs generic revision.

Pycnis Bref. 1881, Ascomycota genera incertae sedis, one species, type: P. sclerotivora Bref., coelomycetous, sexual morph unknown, saprobes, Europe, see Wijayawardene et al. (2012, 2017; outline), Kirk et al. (2013; genus accepted), cultures and sequences are unavailable, needs generic revision.

Pycnocarpon Theiss. 1913, Dothideomycetes genera incertae sedis, two species, type: $P$. magnificum (Syd., P. Syd. \& E.J. Butler) Theiss., asexual morph unknown, saprobes, terrestrial, India, Philippines, see Lumbsch and Huhndorf (2010; outline), Kirk et al. (2013; genus accepted), Wijayawardene et al. (2014c; outline), cultures and sequences are unavailable, needs generic revision.

Pycnodactylus Bat., A.A. Silva \& Cavalc. 1967, Ascomycota genera incertae sedis, one species, type: P. maranhensis Bat., A.A. Silva \& Cavalc., coelomycetous, sexual morph unknown, saprobes, terrestrial, Brazil, see Wijayawardene et al. (2012, 2017; outline), Kirk et al. (2013; genus accepted), cultures and sequences are unavailable, needs generic revision.

Pycnodallia Kohlm. \& Volkm.-Kohlm. 2001, Ascomycota genera incertae sedis, one species, type: P. dupla Kohlm. \& Volkm.-Kohlm., coelomycetous, sexual morph unknown, saprobes, marine, USA, see Wijayawardene et al. (2012, 2017; outline), Kirk et al. (2013; genus accepted), Jones et al. (2015; marine genera), cultures and sequences are unavailable, holotype of type: IMS Kohlmeyer \& Volkmann-Kohlmeyer 5650, needs generic revision.

Pycnoderma Syd. \& P. Syd. 1914, Cookellaceae, Dothideomycetes families incertae sedis, one species, type: P. bambusinum Syd. \& P. Syd., asexual morph unknown, saprobes, terrestrial, tropical, see Lumbsch and Huhndorf (2010; outline), Hyde et al. (2013; accepted as a genus in Cookellaceae), Hongsanan et al. (2014a; accepted as a genus in Cookellaceae), Wijayawardene et al. (2014c; outline), cultures and sequences are unavailable, needs generic revision.

Pycnoharknessia Matsush. 1996, Ascomycota genera incertae sedis, one species, type: P. pakistanica Matsush., coelomycetous, sexual morph unknown, saprobes, terrestrial, Pakistan, see Wijayawardene et al. (2012, 2017; outline), Kirk et al. (2013; genus accepted), cultures 
and sequences are unavailable, holotype of the type: Matsushima Fungus Collection, Kobe, IPX295, needs generic revision.

Pycnomma Syd. 1924, Ascomycota genera incertae sedis, one species, type: P. canariense Syd., coelomycetous, sexual morph unknown, saprobes, terrestrial, Canary Islands, see Wijayawardene et al. (2012, 2017; outline), Kirk et al. (2013; genus accepted), cultures and sequences are unavailable, needs generic revision.

Pycnomoreletia Rulamort 1990, Ascomycota genera incertae sedis, two species, type: $P$. aristata (J. Ahmad) Rulamort, coelomycetous, sexual morph unknown, saprobes, terrestrial, Africa, Pakistan, see Wijayawardene et al. (2012, 2017; outline), Kirk et al. (2013; genus accepted), cultures and sequences are unavailable, needs generic revision.

Pycnopeziza W.L. White \& Whetzel 1938 (= Acarosporium Bubák \& Vleugel ex Bubák 1911; = Chaetalysis Peyronel 1922; = Ciliosira Syd. 1942 fide Johnston et al. 2014b), Sclerotiniaceae, Helotiales, Leotiomycetes, four species, type: P. sympodialis W.L. White \& Whetzel, asexual morphs formerly known in Acarosporium, Chaetalysis, Ciliosira, saprobes, terrestrial, Europe, North America, see Lumbsch and Huhndorf (2010; outline), Kirk et al. (2013; genus accepted), Johnston et al. (2014b; nomenclature), Pärtel et al. (2017; DNA, phylogeny), cultures and sequences are available, needs generic revision.

Pycnopsammina Diederich \& Etayo 1995, Ascomycota genera incertae sedis, one species, type: $P$. lobariae Diederich \& Etayo, coelomycetous, sexual morph unknown, lichenicolous, non-lichenized, terrestrial, France, Spain, UK, see Wijayawardene et al. (2012, 2017; outline), cultures and sequences are unavailable, holotype of the type: LG (Diederich 9697).

Pycnora Hafellner 2001, Pycnoraceae, Candelariales, Lecanoromycetes, three species, type: Pycnora xanthococca (Sommerf.) Hafellner, lichenized, Europe, Asia, North America, see Bendiksby \& Timdal (2013; phylogeny), Lücking et al. (2016b; classification), Cultures and sequences are available, needs generic revision.

Pycnoseynesia Kuntze 1898, Ascomycota genera incertae sedis, one species, type: $P$. caronae (Pass.) Kuntze, coelomycetous, sexual morph unknown, saprobes, terrestrial, worldwide, see Wijayawardene et al. (2012, 2017; outline), Kirk et al. (2013; genus accepted), cultures and sequences are unavailable, needs generic revision.

Pycnothelia Duf. 1821, Cladoniaceae, Lecanorales, Lecanoromycetes, two species, type: $P$. papillaria (Ehrh.) L.M. Dufour, lichenized, see Coste and Dufrêne (2009; checklist), Crisan and Ardelean (2010; ecology), Ketner-Oostra et al. (2010; outline), Lumbsch and Huhndorf (2010; outline), Schmull et al. (2011; sequence), Zarabska and Rosadzinski (2011; new records), Grochowski (2012; ecology), Kirk et al. (2013; genus accepted), McCune and Rosentreter (2014; new record), Miądlikowska et al. (2014; sequence), Lücking et al. (2016b; classification), Şenkardeşler et al (2016; taxonomy), cultures and sequences are available, needs generic revision.

Pycnothera N.D. Sharma \& G.P. Agarwal 1974, Ascomycota genera incertae sedis, two species, type: P. cordiae G.P. Agarwal \& N.D. Sharma, coelomycetous, sexual morph unknown, saprobes, terrestrial, India, see Wijayawardene et al. (2012, 2017; outline), Kirk et al. (2013; genus accepted), cultures and sequences are unavailable, needs generic revision.

Pycnothyriella Bat. 1952, Ascomycota genera incertae sedis, two species, type: P. discreta Bat., coelomycetous, sexual morph unknown, saprobes, terrestrial, Brazil, see Wijayawardene et al. (2012, 2017; outline), Kirk et al. (2013; genus accepted), cultures and sequences are unavailable, needs generic revision.

Pycnothyrium Died. 1913, Ascomycota genera incertae sedis, six species, type: P. litigiosum (Desm.) Died., Hyde et al. (2011; outline), Wijayawardene et al. (2012, 2017; outline), Kirk et al. (2013; genus accepted), cultures and sequences are unavailable, needs generic revision.

Pycnotrema Rivas Plata \& Lücking 2012, Graphidaceae, Ostropales, Lecanoromycetes, three species, type: P. pycnoporellum (Nyl.) Rivas Plata \& Lücking, lichenized, terrestrial, 
tropical, see Rivas Plata et al. (2012a; phylogeny), Lücking et al. (2016b; classification), cultures and sequences are available, needs generic revision.

Pyramidospora Sv. Nilsson., 1962, Ascomycota genera incertae sedis, seven species, type: $P$. casuarinae Sv. Nilsson, hyphomycetous, sexual morph unknown, on submerged decaying branches of Casuarina, South America, see Seifert et al. (2011; morphology), Wijayawardene et al. (2012, 2017; outline), Kirk et al. (2013; genus accepted), cultures and sequences are unavailable, needs generic revision.

Pyrenidium Nyl. 1865, Dacampiaceae, Dothideomycetes families incertae sedis, one species, type: $P$. actinellum Nyl., asexual morph unknown, lichenicolous, terrestrial, worldwide, see Lumbsch and Huhndorf (2010; outline), Hyde et al. (2013; outline, accepted as a genus in Dacampiaceae), Kirk et al. (2013; genus accepted), Wijayawardene et al. (2014c; outline), cultures and sequences are unavailable, needs generic revision.

Pyrenobotrys Theiss. \& Syd. 1914, Dothideomycetes genera incertae sedis, one species, type: P. conferta (Fr.) Theiss. \& Syd., asexual morph unknown, saprobes, terrestrial, America, Scandinavia, see Lumbsch and Huhndorf (2010; outline, accepted as a genus in Venturiaceae), Zhang et al. (2011d; did not accept as a genus in Venturiaceae), Hyde et al. (2013; not accepted as a genus in Venturiaceae), Kirk et al. (2013; genus accepted), Wijayawardene et al. (2014c; outline), cultures and sequences are unavailable, needs generic revision.

Pyrenocarpon Trevis. 1855, Lichinaceae, Lichinales, Lichinomycetes, one species, type: $P$. flotowianum (Hepp) Trevis., lichenized, see Lumbsch and Huhndorf (2010; outline), Kirk et al. (2013; genus accepted), Medeiros et al. (2014; ecology and new record), Lücking et al. (2016b; classification), cultures and sequences are unavailable, needs generic revision.

Pyrenochaeta De Not. 1849, Cucurbitariaceae, Pleosporales, Dothideomycetes, five species, type: P. nobilis De Not., coelomycetous, saprobes, plant endophytes, terrestrial, aquatic, worldwide, see Wijayawardene et al. (2012, 2014c, 2017; outline), Kirk (2013; genus accepted), de Gruyter et al. (2010, 2013; phylogeny), Doilom et al. (2013; phylogeny), cultures and sequences are available, holotype and ex-type strains of type: CBS H-500; CBS 407.76.

Pyrenochaetopsis Gruyter, Aveskamp \& Verkley 2010, Cucurbitariaceae, Pleosporales, Dothideomycetes, seven species, type: P. leptospora (Sacc. \& Briard) Gruyter, Aveskamp \& Verkley, coelomycetous, saprobes, plant endophytes, terrestrial, aquatic, worldwide, see de Gruyter et al. (2010, 2013; phylogeny), Wijayawardene et al. (2012, 2014c, 2017; outline) Kirk (2013; genus accepted), Doilom et al. (2013; phylogeny), Papizadeh et al. (2017; phylogeny), cultures and sequences are available, holotype and ex-type strains of type: CBS H-20313; CBS 101635= PD 71/1027.

Pyrenochium Link 1833, Dothideomycetes genera incertae sedis, one species, type: P. pini Link, asexual morph unknown, saprobes, terrestrial, Europe, see Lumbsch and Huhndorf (2010; outline), Kirk et al. (2013; genus accepted), Wijayawardene et al. (2014c; outline), cultures and sequences are unavailable, needs generic revision.

Pyrenocollema Reinke 1895, Ascomycota genera incertae sedis, 19 species, type: $P$. tremelloides Reinke, lichenized, marine, terrestrial, near sea shores, see Lumbsch and Huhndorf (2010; outline), Kirk et al. (2013; genus accepted), Lücking et al. (2016b; classification), Pérez-Ortega et al. (2016; phylogeny), cultures and sequences are available, holotype of type: H9505110.

Pyrenocyclus Petr. 1955, Dothideomycetes genera incertae sedis, one species, type: $P$. ambiguus Petr., asexual morph unknown, saprobes, terrestrial, Hawaii, see Lumbsch and Huhndorf (2010; outline), Kirk et al. (2013; genus accepted), Wijayawardene et al. (2014c; outline), cultures and sequences are unavailable, needs generic revision. 
Pyrenodesmia A.Massal. 1853, Teloschistaceae, Teloschistales, Lecanoromycetes, six species, type: P. chalybaea (Fr.) A. Massal., lichenized, Europe, North America, China, see Arup et al. (2013; phylogeny), Lücking et al. (2016b; classification), cultures and sequences are available, needs generic revision.

Pyrenographa Aptroot 1991, Pyrenulaceae, Pyrenulales, Eurotiomycetes, three species, type: P. xylographoides Aptroot, asexual morph unknown, lichenized, terrestrial, tropical, see Lumbsch and Huhndorf (2010; outline), Kirk et al. (2013; genus accepted), cultures and sequences are unavailable, holotype of the type: CBG, Streimann 37582.

Pyrenomyxa Morgan 1895 (= Pulveria Malloch \& Rogerson 1977 fide Wendt et al. 2017), Hypoxylaceae, Xylariales, Sordariomycetes, eight species, type: P. globosa Lév., asexual morph unknown, terrestrial, saprobes, mainly coprophilous, worldwide, see Lumbsch and Huhndorf (2010; outline), Kirk et al. (2013; genus accepted), Maharachchikumbura et al. (2015, 2016; outline), Wendt et al. (2017; accepted as a genus in Hypoxylaceae), cultures and sequences are available.

Pyrenomyxa Morgan 1895, Xylariaceae, Xylariales, Sordariomycetes, three species, type: P. invocans Morgan, asexual morph unknown, saprobes, North America, Asia, see Lumbsch and Huhndorf (2010; outline), Kirk et al. (2013; did not list), Maharachchikumbura et al. (2015, 2016; outline), cultures and sequences are available.

Pyrenopeziza Fuckel 1870 (= Cylindrosporium Grev. 1822 fide Johnston et al. 2014b), Ploettnerulaceae, Helotiales, Leotiomycetes, three species, type: P. chailletii (Pers.) Fuckel, asexual morph formerly named in Cylindrosporium, saprobes, pathogens, terrestrial, worldwide, see Lumbsch and Huhndorf (2010; outline), Carter et al. (2013; DNA, pathogens), Kirk et al. (2013; genus accepted), Johnston et al. (2014b; nomenclature), cultures and sequences are available but lacks for the type, needs generic revision.

Pyrenophora Fr. 1849, Pleosporaceae, Pleosporales, Dothideomycetes, 16 species, type: $P$. phaeocomes (Rebent.) Fr., asexual morph hyphomycetous, saprobes or pathogens (phytopathogens) in terrestrial habitats, worldwide, see Lumbsch and Huhndorf (2010; outline), Zhang et al. (2012e; taxonomy, phylogeny), Hyde et al. (2013; accepted as a genus in Pleosporaceae), Kirk et al. (2013; genus accepted), Ariyawansa et al. (2014b, 2015c; taxonomy, phylogeny), Wijayawardene et al. (2014c; outline), cultures and sequences are available, needs generic revision.

Pyrenopolyporus Lloyd 1917, Hypoxylaceae, Xylariales, Sordariomycetes, five species, type: $P$. hunteri Lloyd, asexual morph hyphomycetous, terrestrial, saprobes, worldwide, see Wendt et al. (2017; ressurected the genus, placed in Hypoxylaceae), cultures and sequences are available.

Pyrenopsis Nyl. [nom. cons.] 1858, Lichinaceae, Lichinales, Lichinomycetes, 40 species, type: P. fuscatula Nyl., lichenized, worldwide, see Lumbsch and Huhndorf (2010; outline), Kirk et al. (2013; genus accepted), Lücking et al. (2016b; classification), cultures and sequences are available, needs generic revision.

Pyrenostigme Syd. 1926, Dothideomycetes genera incertae sedis, one species, type: $P$. siparunae Syd., asexual morph unknown, saprobes, terrestrial, Central America, see Lumbsch and Huhndorf (2010; outline), Kirk et al. (2013; genus accepted), Wijayawardene et al. (2014c; outline), cultures and sequences are unavailable, needs generic revision.

Pyrenothrix Riddle 1917, Pyrenotrichaceae, Chaetothyriales, Eurotiomycetes, two species, type: P. nigra Riddle, lichenized, asexual morph unknown, saprobes, terrestrial, North America, New Zealand, see Lumbsch and Huhndorf (2010; outline), Kirk et al. (2013; genus accepted), Jaklitsch et al. (2016a; phylogeny), Lücking et al. (2016b; classification), Cultures and sequences are available, needs generic revision.

Pyrenowilmsia R.C. Harris \& Aptroot 1991, Pyrenulaceae, Pyrenulales, Eurotiomycetes, one species, type: P. ferruginosa (Müll. Arg.) R.C. Harris \& Aptroot, asexual morph unknown, 
lichenized, terrestrial, tropical, see Lumbsch and Huhndorf (2010; outline), Kirk et al. (2013; genus accepted), cultures and sequences are unavailable, needs generic revision.

Pyrenula Ach. 1814, Pyrenulaceae, Pyrenulales, Eurotiomycetes, 175 species, type: Pyrenula nitida (Weig.) Ach., asexual morph unknown, lichenized, terrestrial, mostly tropical, see Lumbsch and Huhndorf (2010; outline), Aptroot (2012; key), Weerakoon et al. (2012a; phylogeny), Aptoort et al. (2013c; new species), Kirk et al. (2013; genus accepted), Gueidan et al. (2016; phylogeny), Lücking et al. (2016b; classification), sequences are available for the voucher F 5929 of the type, needs generic revision.

Pyrenyllium Clem. 1909, Ascomycota genera incertae sedis, two species, type: P. analeptum (Ach.) Clem., coelomycetous, sexual morph unknown, lichenized, terrestrial, distribution unknown, see Wijayawardene et al. (2012, 2017; outline), Kirk et al. (2013; genus accepted), cultures and sequences are unavailable, needs generic revision.

Pyrgidium Nyl. 1867, Sphinctrinaceae, Mycocaliciales, Eurotiomycetes, twelve species, type: $P$. bengaliense Nyl., asexual morph unknown, saprobes, terrestrial, worldwide, see Lumbsch and Huhndorf (2010; outline), Kirk et al. (2013; genus accepted), cultures and sequences are unavailable, needs generic revision.

Pyrgillus Nyl. 1857, Pyrenulaceae, Pyrenulales, Eurotiomycetes, four species, type: Pyrgillus americanus Nyl., asexual morph unknown, lichenized, terrestrial, tropical, see Lumbsch and Huhndorf (2010; outline), Kirk et al. (2013; genus accepted), Weerakoon et al. (2012a; phylogeny), Gueidan et al. (2016; phylogeny), Lücking et al. (2016b; classification), cultures and sequences are available but lacks for the type, needs generic revision.

Pyrgostroma Petr. 1951, Ascomycota genera incertae sedis, two species, type: P. shearii Petr., coelomycetous, sexual morph unknown, saprobes, terrestrial, USA, see Wijayawardene et al. (2012, 2017; outline), Kirk et al. (2013; genus accepted), cultures and sequences are unavailable, needs generic revision.

Pyricularia (Sacc.) Sacc. 1886, Pyriculariaceae, Magnaporthales, Sordariomycetes, 83 species, type: P. grisea (Sacc.) Sacc., sexual morph unknown, plant pathogens, saprobes, terrestrial, worldwide. See Consolo et al. (2008; pathotype diversity in Argentina), Hayashi and Fukuta (2009; Blast differentiation), Park and Shin (2009; new species), McKenzie et al. (2010; new species), Suzuki et al. (2010; fungicide resistence), Zhang et al. (2010a; spot disease in banana), Kohli et al. (2011; pathology), Netam et al. (2011; plant extract for controlling rice blast), Debona et al. (2012; pathological biochemistry), Yang et al. (2012; early detection of rice blast), Alexandrova et al. (2013; new species), Crous et al. (2013b, 2015a, 2016a; new species), Choi et al. (2013a; relationship of pathogensity and phylogeny), Sousa et al. (2013; phytopathology), Klaubauf et al. (2014; phylogeny, new species), Murata et al. (2014; phylogeny), Castroagudín et al. (2016; new species), sequence data available for most of the species, including type, epitype and ex-epitype of the type: CBS H-22280, CBS 138707.

Pyriculariopsis M.B. Ellis 1971, Magnaporthaceae, Magnaporthales, Sordariomycetes, six species, type: P. parasitica (Sacc. \& Berl.) M.B. Ellis, hyphomycetous, sexual morph unknown, saprobes, terrestrial, worldwide, see Thongkantha et al. (2009; DNA, phylogeny), Seifert et al. (2011; morphology), Wijayawardene et al. (2012, 2017; outline), Kirk et al. (2013; genus accepted), Maharachchikumbura et al. (2015, 2016; outline), Silva et al. (2015; new species), cultures and sequences are available, needs generic revision.

Pyriformiascoma Daranagama, Camporesi \& K.D. Hyde 2015, Xylariales genera incertae sedis, Sordariomycetes, one species, type: P. trilobatum Daranagama, Camporesi \& K.D. Hyde, asexual morph hyphomycetous, saprobes, terrestrial, Italy, Europe, see Daranagama et al. (2015a; morphology, phylogeny), Maharachchikumbura et al. (2015, 2016; outline), Wendt et al. (2017; accepted as a genus in Xylariales genera incertae sedis), cultures and 
sequences are available, holotype and ex-type strains of type: MFLU 14-0231; MFLUCC 140012.

Pyrigemmula D. Magyar \& Shoemaker 2011, Chaetosphaeriaceae, Chaetosphaeriales, Sordariomycetes, one species, type: P. aurantiaca D. Magyar \& R. Shoemaker, hyphomycetous, sexual morph unknown, terrestrial, saprobes, worldwide, see Magyar et al. (2011; taxonomy), Crous et al. (2012g; phylogeny), Maharachchikumbura et al. (2015, 2016; outline), Wijayawardene et al. (2017; outline), cultures and sequences are available, holotype and ex-type cultures of the type: BP 101176, CBS 126743.

Pyripnomyces Cavalc. 1972, Ascomycota genera incertae sedis, one species, type: $P$. maranhensis Cavalc., coelomycetous, sexual morph unknown, lichenized, terrestrial, Brazil, see Wijayawardene et al. (2012, 2017; outline), Kirk et al. (2013; genus accepted), cultures and sequences are unavailable, needs generic revision.

Pyronema Carus 1834, Pyronemataceae, Pezizales, Pezizomycetes, two species, type: P. marianum Carus, asexual morph unknown, saprobes, terrestrial, worldwide, see Lumbsch and Huhndorf (2010; outline), Hansen et al. (2013; phylogeny), Kirk et al. (2013; genus accepted), Traeger et al. (2013; evolution), sequences are available but lacks for the type, needs generic revision.

Pyropyxis Egger 1984, Otideaceae, Pezizales, Pezizomycetes, one species, type: P. rubra (Peck) Egger, asexual morph unknown, saprobes, terrestrial, North America, see Lumbsch and Huhndorf (2010; outline), Hansen et al. (2013; phylogeny), Kirk et al. (2013; genus accepted), sequences are available for the voucher K. Egger 323 (DAOM) of the type, needs generic revision.

Pyrrhospora Körb. 1855, Lecanoraceae, Lecanorales, Lecanoromycetes, one species, type: $P$. quernea (Dicks.) Körb., lichenized, see Rotter (2010; checklist), Lumbsch and Huhndorf (2010; list), Perlmutter et al. (2012; checklist), Kirk et al. (2013; genus accepted), Singh et al. (2015; sequence), Urbanavichus and Urbanavichene (2015; checklist), Gasparyan and Sipman (2016; new records), Lücking et al. (2016b; classification), cultures and sequences are available, needs generic revision.

Pyxidiophora Bref. \& Tavel 1891, Pyxidiophoraceae, Pyxidiophorales, Laboulbeniomycetes, 17 species, type: $P$. nyctalidis Bref. \& Tavel, asexual morph hyphomycetous, mainly coprophilous, terrestrial, worldwide, see Schoch et al. (2009; phylogeny), Lumbsch and Huhndorf (2010; outline), Kirk et al. (2013; genus accepted), cultures and sequences are available.

Pyxine Fr. 1825, Caliciaceae, Caliciales, Lecanoromycetes, 75 species, type: $P$. sorediata (Ach.) Mont., lichenized, see Maier (2009; natural product), Rout et al. (2010; ecology), Jungbluth and Marcelli (2011; taxonomy), Jungbluth et al. (2011; new species and new records), Lumbsch and Huhndorf (2010; list), Bajpai and Upreti (2012; ecology), Gaya et al. (2012; sequence), Mongkolsuk et al. (2012; taxonomy), Danesh et al. (2013; air pollution), Kirk et al. (2013; genus accepted), Nayaka et al. (2013; new species), Prieto et al. (2013; taxonomy, phylogeny), Shukla et al. (2013; bioaccumulation), Karakoti et al. (2014; ecology), Aptroot et al. (2014e; key, taxonomy), Pandit (2014; ecology), Bajpai et al. (2015; genotoxicity), Aptroot (2016; new records), Prieto and Wedin (2016; taxonomy), Lücking et al. (2016b; classification), cultures and sequences are available, needs generic revision.

Quadracaea Lunghini, Pinzari \& Zucconi 1996, Ascomycota genera incertae sedis, three species, type: Q. mediterranea Lunghini, Pinzari \& Zucconi, hyphomycetous, sexual morph unknown, saprobes, terrestrial, Asia, Europe, see Seifert et al. (2011; morphology), Zhang et al. (2012i; new species), Wijayawardene et al. (2012, 2017; outline), Barbosa et al. (2013; new species), Kirk et al. (2013; genus accepted), holotype: IMI 367816, cultures and sequences are unavailable, needs generic revision. 
Quadricladium Nawawi \& Kuthub. 1989, Ascomycota genera incertae sedis, one species, type: Q. aquaticum Nawawi \& Kuthub., hyphomycetous, sexual morph unknown, saprobes, aquatic, Malaysia, see Seifert et al. (2011; morphology), Wijayawardene et al. (2012, 2017; outline), Kirk et al. (2013; genus accepted), holotype of the type: IMI 327415, cultures and sequences are unavailable, needs generic revision.

Quadricrura Kaz. Tanaka, K. Hiray. \& Sat. Hatak. 2009, Tetraplosphaeriaceae, Pleosporales, Dothideomycetes, three species, type: Q. septentrionalis Kaz. Tanaka, K. Hirayama \& Sat. Hatak., sexual morph unknown, saprobes, terrestrial, Japan, see Tanaka et al. (2009; morphology, phylogeny), Hyde et al. (2013; accepted as a genus in Tetraplosphaeriaceae), Wijayawardene et al. (2014c; outline), holotype and ex-type strain of the type: HHUF 28782, CBS 125430, cultures and sequences are available.

Quasiconcha M.E. Barr \& M. Blackw. 1981, Mytilinidiaceae, Mytilinidiales, Dothideomycetes, one species, type: $Q$. reticulata M.E. Barr \& M. Blackw., asexual morph hyphomycetous, mainly coprophilous, terrestrial, USA, see Boehm et al. (2009a, b; phylogeny), Lumbsch and Huhndorf (2010; outline), Hyde et al. (2013; accepted as a genus in Mytilinidiaceae), Kirk et al. (2013; genus accepted), Wijayawardene et al. (2014c; outline), cultures and sequences are available.

Quasidiscus B. Sutton 1991, Ascomycota genera incertae sedis, one species, type: $Q$. simmondsii B. Sutton, coelomycetous, sexual morph unknown, saprobes, Australia, see Wijayawardene et al. (2012, 2017; outline), Kirk et al. (2013; genus accepted), holotype of the type: IMI 263349c, cultures and sequences are unavailable, needs generic revision.

Quasiphloeospora B. Sutton, Crous \& Shamoun 1996, Mycosphaerellaceae, Capnodiales, Dothideomycetes, one species, type: Q. saximontanensis (Deighton) B. Sutton, Crous \& Shamoun, sexual morph unknown, one species, foliicolous, pathogens, North America, see Seifert et al. (2011; morphology), Braun et al. (2013; Cercosporoid fungi), Kirk et al. (2013; genus accepted), Wijayawardene et al. (2014c, 2017; outline), holotype of type: IMI 98069, cultures and sequences are unavailable.

Quaternaria Tul. \& C. Tul. 1863, Diatrypaceae, Xylariales, Sordariomycetes, two species, type: $Q$. persoonii Tul. \& C. Tul., asexual morph unknown, saprobes, temperate, see Lumbsch and Huhndorf (2010; outline), Kirk et al. (2013; did not list), Maharachchikumbura et al. (2015, 2016; outline), cultures and sequences are available.

Queenslandia Bat. \& H. Maia 1959, Ascomycota genera incertae sedis, five species, two varieties, type: $Q$. pulchella Bat. \& H. Maia, coelomycetous, sexual morph unknown, saprobes, worldwide, see Wijayawardene et al. (2012, 2017; outline), Kirk et al. (2013; genus accepted), cultures and sequences are unavailable, needs generic revision.

Queenslandipenidiella Quaedvl. \& Crous 2014, Teratosphaeriaceae, Capnodiales, Dothideomycetes, one species, type: Q. kurandae (Crous \& J.K. Stone) Quaedvlieg \& Crous, hyphomycetous, sexual morph unknown, pathogens, saprobes, Australia, see Quaedvlieg et al. (2014; morphology, phylogeny), Wijayawardene et al. (2017; outline), holotype and ex-type culture of type: CBS H-19932, CPC 13333. GenBank number: KF903538.

Queirozia Viégas \& Cardoso 1944, Erysiphaceae, Erysiphales, Leotiomycetes, one species, type: Q. turbinata Viégas \& Cardoso, sexual and hyphomycetous asexual morph, biotrophic, obligate plant pathogens, terrestrial, South America, see Liberato et al. 2006 (morphology, phylogeny, taxonomy), Braun and Cook 2012 (taxonomy), Kirk et al. (2013; genus accepted), holotype of the type: IACM 26560, cultures and sequences are unavailable.

Quezelia Faurel \& Schotter 1965, Ascomycota genera incertae sedis, one species, type: $Q$. hoggariana Faurel \& Schotter, coelomycetous, sexual morph unknown, coprophilous, Sahara, see Wijayawardene et al. (2012, 2017; outline), Kirk et al. (2013; genus accepted), cultures and sequences are unavailable, needs generic revision. 
Quintaria Kohlm. \& Volkm.-Kohlm. 1991, Dothideomycetes genera incertae sedis, four species, type: Q. lignatilis (Kohlm.) Kohlm. \& Volkm.-Kohlm., asexual morph unknown, saprobes, freshwater or marine, worldwide, see Schoch et al. (2009; phylogeny), Suetrong et al. (2009; placement in Testudinaceae), Hirayama et al. (2010), Wijayawardene et al. (2014c; accepted as a genus in Dothideomycetes), cultures and sequences are available, holotype of type: J.K.4365a = 01097442, NYBG.

Phyllopsora Müll. Arg. 1894, Ramalinaceae, Lecanorales, Lecanoromycetes, 70 species, type: P. breviuscula (Nyl.) Müll. Arg. (Lecidea breviuscula Nyl.), lichenized, corticolous, tropical, extending into oseanic temperate, see Rikkinen and Poinar (2008; new species), Timdal (2008; Peru), Timdal (2011; West Indies), Mishra et al. (2011; India), Lücking et al. (2016b; classification), sequence data available.

Rachicladosporium Crous, U. Braun \& C.F. Hill 2007, Cladosporiaceae, Capnodiales, Dothideomycetes, twelve species, type: R. luculiae Crous, U. Braun \& C.F. Hill, asexual morphs hyphomycetous, terrestrial, Antarctica, Europe, New Zealand, North America, See Crous et al. (2009d; phylogeny), Hyde et al. (2011; outline), Wijayawardene et al. (2012, 2014c, 2017; outline) Egidi et al. (2014; rock-inhabiting species), Qadri et al. (2014; endophyte), Selbmann et al. (2015; distributional records of Antarctic fungi), cultures and equences are available, ex-type strains of type: CBS 121620 = CPC 11407, Holotype of type: CBS H-19891.

Rachidicola K.D. Hyde \& J. Fröhl. 1995, Hyponectriaceae, Xylariales, Sordariomycetes, one species, type: R. palmae K.D. Hyde \& J. Fröhl., asexual morph unknown, saprobes, terrestrial, Hong Kong, see Lumbsch and Huhndorf (2010; outline, misspelled as Rhachidicola), Kirk et al. (2013; genus accepted), Maharachchikumbura et al. (2015, 2016; outline, misspelled as Rhachidicola), holotype of the type: BRIP 22762, cultures and sequences are unavailable, needs generic revision.

Raciborskiomyces Siemaszko 1925, Pseudoperisporiaceae, Dothideomycetes families incertae sedis, c. four species, type: $R$. polonicus Siemaszko, asexual morph unknown, saprobes, terrestrial, worldwide, see Lumbsch and Huhndorf (2010; outline), Hyde et al. (2013; accepted as a genus in Pseudoperisporiaceae), Wijayawardene et al. (2014c; outline), cultures and sequences are unavailable, needs generic revision.

Racodium Fr. [nom. cons.] 1829, Racodiaceae, Capnodiales, Dothideomycetes, one species, type: $R$. rupestre Pers., lichenized, see Muggia et al. (2008; phylogeny), Nelsen et al. (2009; phylogeny), Hawksworth et al. (2011b; typification), Anderson (2014; checklist), Schoch and Grube (2015; systematics), Lücking et al. (2016b; classification); sequences are available, holotype of type: UPS:BOT:L-024182.

Racoleus R. Sant. \& D. Hawksw. 2011, Capnodiales genera incertae sedis, Dothideomycetes, one species, type: $R$. trichoporus R. Sant. \& D. Hawksw., filamentous lichen, tropical, Africa, Asia, and South America, sexual morph unknown, see Hawksworth et al. (2011b; morphology, taxonomy), Jaklitsch et al. (2016a; position), Lücking et al. (2016b; classification), cultures and sequences are unavailable, holotype of type: UPS:BOT:L-638266. Radiatispora Matsush. 1995, Ascomycota genera incertae sedis, one species, type: $R$. yunnanensis Matsush., coelomycetous, sexual morph unknown, coprophilous, China, see Wijayawardene et al. (2012, 2017; outline), Kirk et al. (2013; genus accepted), cultures and sequences are unavailable, needs generic revision, holotype of type: MFC-0Y237.

Radotinea Velen. 1934, Helotiales genera incertae sedis, Leotiomycetes, one species, type: $R$. caudata Velen., asexual morph unknown, saprobes, former Czechoslovakia, see Kirk et al. (2008; mentioned as Helotiales, genera incertae sedis, Lumbsch and Huhndorf (2010; did not accept as genus in Helotiales), Kirt et al. (2013; genus accepted), data inadequate, cultures and sequences are unavailable, needs generic revision. 
Radulidium Arzanlou, W. Gams \& Crous 2007, Dothideomycetes genera incertae sedis, three species, type: $R$. subulatum (de Hoog) Arzanlou, W. Gams \& Crous, hyphomycetous, sexual morph unknown, saprobes, terrestrial, Czech Republic, USA, see Wu et al. (2013c; new species, morphology), Wijayawardene et al. (2017; outline), ex-type culture of type: CBS 405.76.

Raesaenenia D. Hawksw. C. Boluda \& H. Lindgren 2015, Parmeliaceae, Lecanorales, Lecanoromycetes, one species, type: R. huuskonenii (Räsänen) D. Hawksw. C. Boluda \& H. Lindgren, asexual morph unknown, on lichens, Europe, terrestrial, see Divakar et al. (2015; phylogeny), cultures and sequences are unavailable, isotype of type: K(M)-IMI 209424.

Raesaeneniana S.Y.Kondr., Kärnefelt, A.Thell, Elix \& Hur 2015, Teloschistaceae, Teloschistales, Lecanoromycetes, one species, type: R. maulensis (S.Y. Kondr. \& J.-S. Hur) S.Y. Kondr., Elix, Kärnefelt \& A. Thell, lichenized, see Kondratyuk et al. (2015c; classification), Lücking et al. (2016b; classification), sequences are available.

Raffaelea Arx \& Hennebert 1965, Ophiostomataceae, Ophiostomatales, Sordariomycetes, 31 species, type: $R$. ambrosiae Arx \& Hennebert, sexual morph unknown, symbionts of Ambrosia beetle, plant pathogen, terrestrial, worldwide, see Harrington et al. (2008, new species), Mayfield et al. (2008; laurel wilt on avocado), Kim et al. (2009a, c; effect of Silver nanoparticles, new species), Kolarík and Hulcr (2009; Scolytodes unipunctatus mycobiota), Smith et al. (2009; laurel wilt on Camphor), Harrington et al. (2010, 2011; phylogeny, new species, origin of Raffaelea lauricola), Matsuda et al. (2010; phylogeny), Seo et al. (2012; phylogeny), Dreaden et al. (2014a, b; multilocus PCR assays, phylogeny), Jeyaprakash et al. (2014; molecular diagnostics), Musvuugwa et al. (2015; sexual state), Simmons et al. (2016; new species), cultures and sequences are available, holotype and ex type of the type: CBS H7710, CBS 185.64.

Raizadenia S.L. Srivast. 1981, Ascomycota genera incertae sedis, one species, type: $R$. garhwalensis S.L. Srivast, hyphomycetous, sexual morph unknown, saprobes, India, see Hyde et al. (2011; outline), Seifert et al. (2011; morphology), Wijayawardene et al. (2012, 2017; outline), Kirk et al. (2013; genus accepted), Chomnunti et al. (2014; morphology), cultures and sequences are unavailable, needs generic revision.

Ramakrishnanella Kamat \& Ullasa ex Ullasa 1970, Ascomycota genera incertae sedis, one species, type: $R$. indica Ullasa, coelomycetous, sexual morph unknown, saprobes, India, see Hyde et al. (2011; outline), Wijayawardene et al. (2012, 2017; outline), Kirk et al. (2013; genus accepted), cultures and sequences are unavailable, needs generic revision.

Ramalea Nyl. 1866, Lecanorales genera incertae sedis, Lecanoromycetes, four species; type: Ramalea tribulosa Nyl.; lichenized; see Lücking et al. (2016b; classification); sequences are available.

Ramalina Ach. 1809, Ramalinaceae, Lecanorales, Lecanoromycetes, c. 230 species, type: $R$. fraxinea (L.) Ach., lichenized, worldwide, see Bermudez et al. (2009; air pollution), Del Campo et al (2010; taxonomy), Hoskeri et al. (2010; bactericidal study), Lumbsch and Huhndorf (2010; outline), Luo et al (2010; antioxidant study), Paudel et al. (2010, 2011; chemistry), Riddle et al. (2010; air quality), Werth and Sork (2010; photobiont genetics), Aptroot and Bruyn (2011; new record), Arroyo et al. (2011; new species), Cordeiro et al. (2011; experimental study), Casano et al. (2011; physiology), del Hoyo et al. (2011; oxidative stress), Quedensley and Véliz Pérez (2011; new species), Timsina et al. (2012; phylogeny), Türkez et al. (2012; cytogenetic and biochemical study), Del Campo et al. (2013; photobiont coexistence), Kirk et al. (2013; genus accepted), Sisodia et al. (2013; bioactivity study), Duman et al. (2014; genotoxicity), Moncada et al. (2014a; taxonomy), Oh et al. (2014; taxonomy), Perez-Vargas and Perez-Ortega (2014; new and endemic species), Sork and Werth (2014; phylogeography), Blanchon et al. (2015; new records), Ly et al. (2015; chemistry), Moreira et al. (2015; chemistry and biological activity), Catala et al. (2016; 
phylogenomic analyses), Cornejo et al. (2016; chemistry), Lücking et al. (2016b; classification), Ristic et al. (2016; biopharmaceutical potential study), Zrnzević et al. (2016; Gc-Ms analysis), sequences are available for few species, needs generic revision.

Ramalodium Nyl. 1879, Pannariaceae, Peltigerales, Lecanoromycetes, five species, type: $R$. succulentum Nyl., lichenized, see Wedin et al. (2009b; molecular), Hill et al. (2011; new record), Lumbsch and Huhndorf (2010; outline), Kirk et al. (2013; genus accepted), de Lange and Blanchon (2014; endemic record), Ekman et al. (2014; phylogeny), Lücking et al. (2016b ; classification), sequences are available.

Ramboldia Kantvilas \& Elix 1994, Ramboldiaceae, Lecanorales, Lecanoromycetes, 33 species, two varieties, type: $R$. stuartii (Hampe) Kantvilas \& Elix, lichenized, see Kalb et al. (2009; new species), Upreti et al. (2009; new species), Lumbsch and Huhndorf (2010; outline), Kirika et al. (2012; new record), Kuznetsova et al. (2012; new record), Mayrhofer et al. (2012; new record), Gumboski (2014; new records), Kirk et al. (2013; genus accepted), Miądlikowska et al. (2014; phylogeny), Resl et al. (2015; partial sequence), Singh et al. (2015; molecular), Kantvilas (2016; new specis, taxonomy), Zhao et al. (2016; classification), Miądlikowska et al. 2014, Lücking et al. (2016b; classification), sequences are available for few species, needs generic revision.

Ramgea Brumm. 1992, Thelebolaceae, Thelebolales, Leotiomycetes, one species, type: $R$. annulispora Brumm., asexual morph unknown, saprobes, terrestrial, Netherlands, see Lumbsch and Huhndorf (2010; outline), Kirk et al. (2013; genus accepted), cultures and sequences are unavailable, needs generic revision.

Ramicapitulum Whitton, K.D. Hyde \& McKenzie 2012, Ascomycota genera incertae sedis, one species, type: $R$. chinense Whitton, K.D. Hyde \& McKenzie, hyphomycetous, sexual morph unknown, saprobes, Hong Kong, see Wijayawardene et al. (2012, 2017; outline), Kirk et al. (2013; genus accepted), cultures and sequences are unavailable, needs generic revision.

Ramicephala Voglmayr \& G. Delgado 2002, Ascomycota genera incertae sedis, one species, type: R. sphaerospora Voglmayr \& G. Delgado, hyphomycetous, sexual morph unknown, saprobes, aquatic, Cuba, see Seifert et al. (2011; morphology), Wijayawardene et al. (2012, 2017; outline), holotype of the type: WU 22035, cultures and sequences are unavailable, needs generic revision.

Ramichloridium Stahel ex de Hoog 1977, Dissoconiaceae, Capnodiales, Dothideomycetes, 35 species, type: R. apiculatum (J.H. Mill., Giddens \& A.A. Foster) de Hoog, hyphomycetous, sexual morph unknown, saprobes, from soil terrestrial, USA, see Braun et al. (2009; new species), Crous et al. (2009d, e, f, 2014c; phylogeny, new species), Kirschner and Chen (2010; new species), Shivas et al. (2010; new species), Li et al. (2012a; new species; phylogeny), Wijayawardene et al. (2012, 2014c, 2017; outline), cultures and sequences are available, extype cultures of the type: QM 7716, MUCL 7991, MUCL 15753, JCM 6972, IMI 100716, CBS 156.59, ATCC 13211 (fide Videira et al. 2016).

Ramimonilia Stielow \& Quaedvl. 2014, Capnodiales genera incertae sedis, Dothideomycetes, one species, type: $R$. apicalis B. Stielow.\& W. Quaedvl., hyphomycetous, sexual morph unknown, saprobes, terrestrial, Spain, see Egidi et al. (2014; morphology, phylogeny), Wijayawardene et al. (2014c, 2017; outline), cultures and sequences are available, holotype of type: CBS 118327.

Ramoconidiifera B. Sutton, Carmarán \& A.I. Romero 1996, Ascomycota genera incertae sedis, three species, type: $R$. verrucosa B. Sutton, Carmarán \& A.I. Romero, hyphomycetous, sexual morph unknown, saprobes, South America, see Seifert et al. (2011; morphology), Whitton et al. (2012a; new species, morphology), Wijayawardene et al. (2012, 2017; outline), Kirk et al. (2013; genus accepted), cultures and sequences are unavailable, holotype BAFC 33.275 , needs generic revision. 
Ramonia Stizenb. 1862, Gyalectaceae, Ostropales, Lecanoromycetes, 24 species, type: $R$. valenzueliana (Mont.) Stizenb., lichenized, cosmopolitan, see Lendemer et al. (2009; new species), Knudsen and Kocourková (2010; checklist), Lumbsch and Huhndorf (2010; outline), Kirk et al. (2013; genus accepted), Stepanchikova et al. (2013; new records), Aptroot et al. (2015c; new species), Lücking et al. (2016b; classification), sequences are available.

Ramopenidiella Crous \& R.G. Shivas 2014, Teratosphaeriaceae, Capnodiales, Dothideomycetes, one species, type: $R$. cycadicola Crous \& R.G. Shivas, hyphomycetous, sexual morph unknown, saprobe, associated with leaf spots, terrestrial, Australia, see Crous et al. (2014c; morphology, phylogeny), Wijayawardene et al. (2017; outline), culture and sequence are available, holotype and ex-type culture of type: CBS 137973, CBS H-21684.

Ramophialophora M. Calduch, Stchigel, Gené \& Guarro 2004, Sordariales, genera incertae sedis, Sordariomycetes, two species, type: $R$. vesiculosa M. Calduch, Stchigel, Gené \& Guarro, hyphomycetous, sexual morph unknown, in soil, terrestrial, Europe, see Madrid et al. (2010; new species, phylogeny), Seifert et al. (2011; morphology), Wijayawardene et al. (2012, 2017; outline), Maharachchikumbura et al. (2015, 2016; outline), cultures and sequences are unavailable, needs generic revision.

Ramsbottomia W.D. Buckley 1924, Pyronemataceae, Pezizales, Pezizomycetes, two species, type: $R$. lamprosporoidea W.D. Buckley, asexual morph unknown, saprobes, terrestrial, worldwide, see Lumbsch and Huhndorf (2010; outline), Hansen et al. (2013; phylogeny), Kirk et al. (2013; genus accepted), Shcherbakova (2016, new record), cultures and sequences are available, needs generic revision.

Ramularia Unger 1833 (= Mycosphaerella Johanson 1884 fide Wijayawardene et al. 2014c; Rossman et al. 2015b), Mycosphaerellaceae, Capnodiales, Dothideomycetes, 1047 species, of which 100 species are presently recognized based on DNA, type: R. pusilla Unger, hyphomycetous, sexual morph formerly named in Mycosphaerella, plant pathogens, terrestrial, mostly foliicolous, see Walters et al. (2008; pathology), Crous (2009, 2011, 2016; taxonomy, phylogeny, new species), Kirschner (2009; monograph), Bakhshi et al. (2012; checklist), Braun (2013; monograph), Jaiman et al. (2013; pathology), Bruckart et al. (2014; characterization and evaluation, biological control), Ruszkiewicz-Michalska and Połeć (2014; new species, records), Kaczmarek (2015; infection biology and life cycle), Videira et al. (2015, 2016; morphology, phylogeny), McGrann et al. (2016; whole genome sequencing), Park and Shin (2016; new species, taxonomy), Rossman et al. (2016b; new combination), cultures and sequences are available for most of the species, epitype and ex-epitype culture of type: CBS H-22527, CBS 124973.

Ramulariopsis Speg. 1910, Mycosphaerellaceae, Capnodiales, Dothideomycetes, five species, type: $R$. cnidoscoli Speg., hyphomycetous, with mycosphaerella-like sexual morph (only known for $R$. gossypii), plant pathogens, associated with leaf spots, Africa, Asia, Australia, Europe, North and South America, Oceania, see Delgado (2011; checklist), Seifert (2011), Pirnia et al. (2012; taxonomy), Wijayawardene (2012, 2014, 2017; outline), Videira et al. (2016, phylogeny), sequence data only available for the non-type: $R$. gossypii and $R$. pseudoglycines, holotype of type: LPS 12851.

Ramulispora Miura 1920, Mycosphaerellaceae, Capnodiales, Dothideomycetes, twelve species, type: $R$. andropogonis Miura, hyphomycetous, sexual morph unknown, plant pathogens, on Poaceae, see Malinski (2008; antimicrobial), Crous et al. (2009d, f; review, phylogeny, taxonomy), Brady et al. (2011; pathology), Wijayawardene et al. (2012, 2017; outline), Videira et al. (2017; morphology, phylogeny), cultures and sequences are available.

Rasamsonia Houbraken \& Frisvad 2011, Trichocomaceae, Eurotiales, Eurotiomycetes, twelve species, type: $R$. emersonii (Stolk) Houbraken \& Frisvad, thermotolerant, saprobes, human pathogen, terrestrial, worldwide, see Houbraken et al. (2012; description, morphology, phylogeny), Doyon et al. (2013; pulmonary and graft infection), Giraud et al. (2013; 
pathogenesis), Houbraken et al. (2013; antifungal susceptibility), Salgüero et al. (2013; infection in dog), Su and Cai (2013; new species), Tanney and Seifert (2013; new species), Steinmann et al. (2014; real time PCR, clinical diagnosis), Matos et al. (2015; isolation from cystic fibrosis patient), Crous et al. (2016b; new species, phylogeny), Gudmundsson et al. (2016; extrolite profiling), Ishiwada et al. (2016; mixed infection), Jurjević et al. (2016; new species), Mouhajir et al. (2016; rep-PCR, clinical diagnosis), Steinmann et al. (2016; isavuconazole drug response), cultures and sequences are available for all species, holotype and ex-type of type: CBS H-7817; CBS 393.64.

Rasutoria M.E. Barr 1987, Euantennariaceae, Capnodiales, Dothideomycetes, four species, type: $R$. abietis (Dearn.) M.E. Barr, asexual morph unknown, plant pathogens, see Crous et al. (2009d, e, f; morphology, phylogeny), Wijayawardene et al. (2012, 2014c; outline), GenBank: GU371809, holotype of type: BPI 691065, cultures are unavailable.

Rattania Prabhug. \& Bhat 2009, Chaetosphaeriaceae, Chaetosphaeriales, Sordariomycetes, one species, type: $R$. setulifera Prabhug. \& Bhat, hyphomycetous, sexual morph unknown, Endophytic, Terrestrial, India, see Shenoy et al. (2010; phylogeny), Seifert et al. (2011; morphology), Wijayawardene et al. (2012, 2017; outline), cultures and sequences are available, ex-type culture: GUFCC15501 (MTCC 9698).

Readeriella Syd. \& P. Syd. 1908, Teratosphaeriaceae, Capnodiales, Dothideomycetes, five species, type: $R$. mirabilis Syd. \& P. Syd., coelomycetous, sexual morph unknown, with Cibiessia synasexual morph, saprobes, pathogens, terrestrial, cosmopolitan, see Crous et al. (2009c, d, e, f, 2016a, b; new species, phylogeny), Wijayawardene et al. (2012, 2014c, 2016b, 2017; outline, taxonomy, phylogeny), Quaedvlieg et al. (2014; new species, phylogeny), cultures and sequences are available.

Readerielliopsis Crous \& C. Decock 2015, Capnodiales genera incertae sedis, Dothideomycetes, two species, type: $R$. fuscoporiae Crous \& C. Decock, coelomycetes, sexual morph unknown, saprobes, French Guiana, see Crous et al. (2015d; taxonomy, phylogeny), Wijayawardene et al. (2016b, 2017; outline, phylogeny), holotype and ex-type culture of the type: CBS H-22229, CPC 24637.

Rebentischia P. Karst. 1869, Pleosporales genera incertae sedis, Dothideomycetes, 16 species, type: $R$. pomiformis P. Karst., saprobes on decaying wood, widespread, asexual morph unknown, Virginia Bianchinotti, M. and Sánchez (2009; new record: Argentina), Lumbsch and Huhndorf (2010; outline), Kirk et al. (2013; genus accepted), Wijayawardene et al. (2014c; outline), cultures and sequences are unavailable, needs generic revision.

Rechingeriella Petr. 1940, Zopfiaceae, Pleosporales, Dothideomycetes, two species, type: $R$. insignis Petr., asexual morph unknown, saprobes, terrestrial, Asia, Europe, see Lumbsch and Huhndorf (2010; outline), Hansen et al. (2013; phylogeny), Kirk et al. (2013; genus accepted), Hyde et al. (2013; morphology, outline), Wijayawardene et al. (2014c; outline), cultures and sequences are unavailable, needs generic revision.

Reconditella Matzer \& Hafellner 1990, Sordariales genera incertae sedis, Sordariomycetes, one species, type: $R$. physconiarum Matzer \& Hafellner, asexual morph unknown, lichenicolous, terrestrial, Europ, see Lumbsch and Huhndorf (2010; outline), Kirk et al. (2013; genus accepted), Maharachchikumbura et al. (2015, 2016; outline), cultures and sequences are unavailable, needs generic revision.

Rectifusarium L. Lombard, Crous \& W. Gams 2015, Nectriaceae, Hypocreales, Sordariomycetes, two species, type: $R$. ventricosum (Appel \& Wollenw.) L. Lombard \& Crous, asexual morph hyphomycetous, saprobes, terrestrial, Germany, see Lombard et al. (2015b; taxonomy, phylogeny), Maharachchikumbura et al. (2015, 2016; outline), Wijayawardene et al. (2017; outline), holotype and ex-type cultures of the type: CBS H21948, CBS 430.91 = NRRL 25729. 
Recurvomyces Selbmann \& de Hoog 2008, Teratosphaeriaceae, Capnodiales, Dothideomycetes, hyphomycetous, one species, type: R. mirabilis Selbmann \& de Hoog, sexual morph unknown, saprobes, terrestrial, Antarctica, see Selbmann et al. (2008; morphology; phylogeny), Onofri et al. (2011; biodiversity, Italy), Seifert et al. (2011; morphology), Wijayawardene et al. (2012, 2014c, 2017; outline), Quaedvlieg et al. (2014; phylogeny), Selbmann et al. (2015; distributional pattern), holotype and ex-type strain of the type: CBS H-20178, CBS 119434.

Redbia Deighton \& Piroz. 1972, Ascomycota genera incertae sedis, two species, type: $R$. pucciniicola Deighton \& Piroz., hyphomycetous, sexual morph unknown, fungicolous, tropical, see Seifert et al. (2011; morphology), Wijayawardene et al. (2012, 2017; outline), Kirk et al. (2013; genus accepted), cultures and sequences are unavailable, needs generic revision.

Reddellomyces Trappe, Castellano \& Malajczuk 1992, Tuberaceae, Pezizales, Pezizomycetes, four species, type: $R$. westraliensis (G.W. Beaton \& Malajczuk) Trappe, Castellano \& Malajczuk, asexual morph unknown, saprobes, saprobes, terrestrial, Australasia, Mediterranean, see Lumbsch and Huhndorf (2010; outline), Kirk et al. (2013; genus accepted), Kušan et al. (2014: review of the hypogeous species), Rana et al. 92015: biodiversity), cultures and sequences are available for unidentified species (unpublished).

Redheadia Y. Suto \& Suyama 2005, Sclerotiniaceae, Helotiales, Leotiomycetes, one species, type: R. quercus $Y$. Suto \& Suyama, asexual morph unknown, saprobes, Honshu, see Lumbsch and Huhndorf (2010; outline), Jaklitsch et al (2016a; classification), cultures and sequences are unavailable.

Redingeria Frisch 2006, Graphidaceae, Ostropales, Lecanoromycetes, twelve species, type: R. leiostoma (Nyl.) Frisch, asexual morph unknown, lichenized fungi, terrestrial, tropical, placement in Graphidaceae supported by molecular data, see Lumbsch and Huhndorf (2010; outline), Cáceres et al. (2012b; new combinations), Rivas Plata et al. (2012a, b; molecular, classification), Kirk et al. (2013; genus accepted), van den Broeck et al. (2014; new species), Lücking et al. (2016b; classification), sequences are available.

Redonia C.W.Dodge 1973, Caliciaceae, Caliciales, Lecanoromycetes, two species, type: $R$. chilena C.W. Dodge, lichenized, see Lumbsch and Huhndorf (2010; outline), Gaya et al. (2012; taxonomy), Lücking et al. (2016b; classification), Prieto and Wedin (2016; phylogeny), sequences are unavailable.

Redonographa Lücking, Tehler \& Lumbsch 2013, Graphidaceae, Ostropales, Lecanoromycetes, five species, type: $R$. chilensis (Zahlbr.) Lücking \& Tehler, asexual morph unknown, lichenized fungi, terrestrial, tropical, see Lücking et al. (2013, 2014, 2016b; phylogeny, new species, classification), sequences are available.

Refractohilum D. Hawksw. 1977, Ascomycota genera incertae sedis, six species, type: $R$. galligenum D. Hawksw., hyphomycetous, sexual morph unknown, lichenicolous, fungicolous, widespread, terrestrial, see Seifert et al. (2011; genus accepted), Wijayawardene et al. (2012, 2017; outline), Kirk et al. (2013; genus accepted), cultures and sequences are unavailable, holotype of type: K(M)-IMI 212682.

Regiocrella P. Chaverri \& K.T. Hodge 2006, Clavicipitaceae, Hypocreales, Sordariomycetes, two species, type: $R$. camerunensis P. Chaverri \& H.C. Evans, asexual morph unknown, mainly coprophilous, terrestrial, Cameroon, China, see Schoch et al. (2009; phylogeny), Lumbsch and Huhndorf (2010; outline), Maharachchikumbura et al. (2015, 2016; outline), holotype of the type: CUP 67512, cultures and sequences are available.

Rehmiodothis Theiss. \& Syd. 1914, Phyllachoraceae, Phyllachorales, Sordariomycetes, one species, type: R. osbeckiae (Berk. \& Broome) Theiss. \& Syd., from living leaves, Asia, see Lumbsch and Huhndorf (2010; outline), Kirk et al. (2013; genus accepted), 
Maharachchikumbura et al. (2015, 2016; outline), cultures and sequences are unavailable, needs generic revision.

Rehmiomycella E. Müll. 1962, Sordariomycetes genera incertae sedis, one species, type: Rehmiomycella phoradendri (Rehm) E. Müll., saprobes, Brazil, see Lumbsch and Huhndorf (2010; outline), Kirk et al. (2013; genus accepted), Maharachchikumbura et al. (2015, 2016; outline), cultures and sequences are unavailable, needs generic revision.

Reichlingia Diederich \& Scheid. 1996, Arthoniaceae, Arthoniales, Arthoniomycetes, four species, type: $R$. leopoldii Diederich \& Scheid., two species known from the sexual stage, the generic type only known from the asexual stage with loose, sporodochia-like conidiomata, lichenized, on saxicolous and corticolous, Europe and Africa (Uganda), see Motiejūnaitè (2011; taxonomy), Seifert et al. (2011; morphology), Kirk et al. (2013; genus accepted), Frisch et al. (2014a, b), Lücking et al. (2016b; classification), holotype of the type: STU Wirth 23450, sequences are available.

Reimnitzia Kalb 2001, Graphidaceae, Ostropales, Lecanoromycetes, one species, type: $R$. santensis (Tuck.) Kalb, asexual morph unknown, lichenized fungi, terrestrial, tropical, see Rivas Plata et al. (2012a; phylogeny), see Lumbsch and Huhndorf (2010; outline), Kraichak et al. (2014: phylogeny), Lücking et al. (2015, 2016: phylogeny, classification), sequences are available.

Relicina (Hale \& Kurok.) Hale, 1974, Parmeliaceae, Lecanorales, Lecanoromycetes, 60 species, type: $R$. eumorpha (Hepp) Hale, asexual morph, undetermined, terrestrial, widely distributed, see Lumbsch and Huhndorf (2010; outline), Benatti (2011; taxonomy), Kirk et al. (2013; genus accepted), Sethy et al. (2012; taxonomy), Crespo et al. (2010b; phylogeny), de Paz et al (2011; phlogeny), Buaruang et al. (2015; lineage), Kirika et al. (2016; txonomy), Lücking et al. (2016b; classification), sequences are available.

Remersonia Samson \& Seifert 1997, Sordariales genera incertae sedis, Sordariomycetes, two species, type: $R$. thermophila (Fergus) Seifert \& Samson, hyphomycetous, sexual morph unknown, in soil, terrestrial, Asia, Australasia, Europe, see Seifert et al. (2011; morphology), Wijayawardene et al. (2012, 2017; outline), Kirk et al. (2013; genus accepted), cultures and sequences are available, needs generic revision.

Remispora Barghoon \& Linder 1944, Halosphaeriaceae, Microascales, Sordariomycetes, six species, type: $R$. maritima Linder, asexual morph unknown, saprobes, marine, worldwide, see Jones et al. (2009b, 2015; outline), Lumbsch and Huhndorf (2010; outline), Abdel-Wahab (2011b; phylogeny), Sakayaroj et al. (2011a; outline), Kirk et al. (2013; genus accepted), Maharachchikumbura et al. (2015, 2016; outline, phylogeny), cultures and sequences are available.

Remototrachyna Divakar \& A. Crespo 2009, Parmeliaceae, Lecanorales, Lecanoromycetes 20 species, type: $R$. flexilis (Kurok.) Divakar \& A. Crespo, asexual morph, undetermined, terrestrial, see Flakus et al (2012; taxonomy), Crespo et al. (2010b; phylogeney), de Paz et al. (2011; origin and diversification), Divakar et al. (2012; data partial sequencing), Thell et al. (2012; review of the family Parmeliaceae), Masson et al. (2015; sequencing data), Lücking et al. (2016b; classification), cultures and sequences are available.

Renispora Sigler \& J.W. Carmich. 1979, Onygenaceae, Onygenales, Eurotiomycetes, two species, type: R. flavissima Sigler, P.K. Gaur, Lichtw. \& J.W. Carmich., asexual morph unknown, saprobes, terrestrial, USA, see Lumbsch and Huhndorf (2010; outline), Kirk et al. (2013; genus accepted), Pitt et al. (2013; partial sequence), cultures available for the type: ATCC 38503.

Repetoblastiella R.F. Castañeda, Minter \& M. Stadler 2010, Ascomycota genera incertae sedis, one species, type: R. olivacea R.F. Castañeda, Minter \& M. Stadler, hyphomycetous, sexual morph unknown, saprobes, terrestrial, Caribbean, see Seifert et al. (2011; 
morphology), Wijayawardene et al. (2012, 2017; outline), Kirk et al. (2013; genus accepted), cultures and sequences are unavailable, needs generic revision.

Repetophragma Subram. 1992, Pleosporales genera incertae sedis, Dothideomycetes, 29 species, type: R. biseptatum (M.B. Ellis) Subram., hyphomycetous, sexual morph unknown, saprobes, terrestrial, worldwide, see Marincowitz et al. (2008; new species), Silvera-Simón et al. (2009; new species), Zhang et al. (2009c; phylogeny), Castañeda-Ruiz et al. (2011, 2013b; new species, revision), Seifert et al. (2011; morphology), Wijayawardene et al. (2012, 2014c, 2017; outline), Kirk et al. (2013; genus accepted), Ma et al. (2014; new species), cultures and sequences are available but lacks for the type, needs generic revision.

Requienella Fabre 1883, Requienellaceae, Xylariales, Sordariomycetes, one species, type: $R$. seminuda (Pers.) Boise, saprobes, worldwide, see Lumbsch and Huhndorf (2010; outline), Kirk et al. (2013; genus accepted), Nordén and Jordal (2014; new record), Maharachchikumbura et al. (2015, 2016; outline), Jaklitsch et al. (2016a; phylogeny), Lücking et al. (2016b; classification), cultures available for the type: RS12, RS13, sequences are available.

Resendea Bat. 1961, Dothideomycetes genera incertae sedis, two species, type: $R$. paraguayensis Bat., asexual morph unknown, saprobes, terrestrial, South America, see Lumbsch and Huhndorf (2010; outline, accepted as a genus in Microthyriaceae), Kirk et al. (2013; genus accepted), Wijayawardene et al. (2014c; outline), cultures and sequences are unavailable.

Retiarius D.L. Olivier 1978, Orbiliaceae, Orbiliales, Orbiliomycetes, two species, type: $R$. superficiaris D.L. Olivier, hyphomycetous, sexual morph unknown, on pollen, South Africa, see Wijayawardene et al. (2012, 2017; outline), Kirk et al. (2013; genus accepted), cultures and sequences are unavailable, needs generic revision.

Reticulosphaeria Sivan. \& Bahekar 1982, Xylariales genera incertae sedis, Sordariomycetes, one species, type: $R$. indica Sivan. \& Bahekar, asexual morph unknown, on stems of Achyranthes aspera, India, see Lumbsch and Huhndorf (2010; outline), Kirk et al. (2013; genus accepted), holotype of the type: IMI 254813, cultures and sequences are unavailable.

Retroa P.F. Cannon 1991, Phyllachoraceae, Phyllachorales, Sordariomycetes, one species, type: $R$. dimorphandrae (F. Stevens) P.F. Cannon, from living leaves, South America, see Lumbsch and Huhndorf (2010; outline), Kirk et al. (2013; genus accepted), Maharachchikumbura et al. (2015, 2016; outline), cultures and sequences are unavailable, needs generic revision.

Retroconis de Hoog \& Bat. Vegte 1989, Ascomycota genera incertae sedis, one species, type: R. fusiformis (S.M. Reddy \& Bilgrami) de Hoog \& Bat. Vegte, hyphomycetous, sexual morph unknown, saprobes, on human skin, terrestrial, Africa, Asia, Europe, see Seifert et al. (2011; morphology), Wijayawardene et al. (2012, 2017; outline), Kirk et al. (2013; genus accepted), cultures available for the type: CBS 452.71, needs generic revision.

Retrostium Nakagiri \& Tad. Ito 1997, Spathulosporaceae, Lulworthiales, Sordariomycetes, one species, type: $R$. amphiroae Nakagiri \& Tad. Ito, spermatiophores or asexual morph hyphomycetous, biotrophic on marine red alga, Japan, see Nakagiri and T. Ito (1997; morphology), Inderbitizin et al. (2004), Business et al. (2012; taxonomy), Loque et al. (2014; taxonomy), holotype of the type: IFO H-12210, cultures and sequences are unavailable

Rhabdoclema Syd. 1939, Ascomycota genera incertae sedis, two species, type: $R$. chusqueae Syd., coelomycetous, sexual morph unknown, saprobes, South America, see Wijayawardene et al. (2012, 2017; outline), Kirk et al. (2013; genus accepted), cultures and sequences are unavailable, needs generic revision.

Rhabdocline Syd. 1922 (= Meria Vuill. 1896; Hartigiella Syd. \& P. Syd. 1900, Rhabdogloeum Syd. 1922, fide Johnston et al. 2014b), Cenangiaceae, Helotiales, Leotiomycetes, four species, type: $R$. pseudotsugae Syd., asexual morph hyphomycetous, 
saprobes, pathogens, terrestrial, north temperate, see Lumbsch and Huhndorf (2010; outline), Kirk et al. (2013; genus accepted), Morgenstern et al. (2013; pathogens), Johnston et al. (2014b; nomenclature), Sweet et al. (2015; pathogens, DNA), cultures available for the type.

Rhabdodiscus Vain. 1921, Graphidaceae, Ostropales, Lecanoromycetes, 42 species, type: $R$. auberianus (Mont.) Vain., asexual morph unknown, lichenized, terrestrial, tropical, see Rivas Plata et al. (2012a; phylogeny), Caceres et al. (2014; taxonomy), Papong et al. (2014; taxonomy), Peláez et al. (2014; new combination), Lücking et al. (2016b; classification), Ohmura et al. (2016; taxonomy), sequences are available

Rhabdogloeopsis Petr. 1925, Ascomycota genera incertae sedis, two species, type: $R$. balsameae (Davis) Petr., coelomycetous, sexual morph unknown, saprobes, USA, see Wijayawardene et al. (2012, 2017; outline), Kirk et al. (2013; genus accepted), cultures and sequences are unavailable, needs generic revision.

Rhabdomyces Balbiani 1889, Ascomycota genera incertae sedis, one species, type: $R$. lobjoyi Balbiani., coelomycetous, sexual morph unknown, saprobes, France, see Wijayawardene et al. (2012, 2017; outline), Kirk et al. (2013; genus accepted), cultures and sequences are unavailable, needs generic revision.

Rhabdopsora Müll. Arg. 1888, Verrucariaceae, Verrucariales, Eurotiomycetes, two species, type: R. polymorpha Müll. Arg., lichenized; see Lumbsch and Huhndorf (2010; outline), Kirk et al. (2013; genus accepted), Lücking et al. (2016b; classification), sequences are unavailable. Rhabdospora (Durieu \& Mont.) Sacc. 1884, Dothideomycetes genera incertae sedis, c. 150 species, type: S. oleandri Durieu \& Mont., coelomycetous, sexual morph unknown, saprobes, terrestrial, worldwide, see Wijayawardene et al. (2012, 2014c, 2017; outline), Kirk et al. (2013; genus accepted), cultures and sequences are unavailable.

Rhabdostromella Höhn. 1915, Ascomycota genera incertae sedis, one species, type: $R$. rubi Höhn., coelomycetous, sexual morph unknown, saprobes, France, see Wijayawardene et al. (2012, 2017; outline), Kirk et al. (2013; genus accepted), cultures and sequences are unavailable, needs generic revision.

Rhabdostromina Died. 1921, Ascomycota genera incertae sedis, three species, type: $R$. empetri (Rostr.) Died., coelomycetous, sexual morph unknown, saprobes, terrestrial, Europe, see Punithalingam and Spooner (2011; reinstated the genus, morphology, new comb.), Wijayawardene et al. (2017; outline), cultures and sequences are unavailable, needs generic revision.

Rhachomyces Thaxt. 1895, Laboulbeniaceae, Laboulbeniales, Laboulbeniomycetes, c. 80 species, type: $R$. lasiophorus (Thaxt.) Thaxt., asexual morph unknown, biotrophic, worldwide, see Rossi and Proano (2009; new species), Santamaría and Faille (2009; new species), Lumbsch and Huhndorf (2010; outline), Kirk et al. (2013; genus accepted), Haelewaters et al. (2015b; DNA, review), sequences are available.

Rhagadolobiopsis Guatim. \& R.W. Barreto 2014, Parmulariaceae, Dothideomycetes families incertae sedis, Dothideomycetes families incertae sedis, two species, type: $R$. thelypteris Guatimosim \& R.W. Barreto, asexual morph unknown, saprobes, terrestrial, Brazil, see Guatimosim et al. (2014; taxonomy), holotype of the type: VIC 31939, cultures and sequences are available.

Rhagadolobium Henn. \& Lindau 1897, Parmulariaceae, Dothideomycetes families incertae sedis, Dothideomycetes, seven species, type: R. hemitheliae Henn. \& Lindau, asexual morph unknown. Epiphytes, terrestrial, worldwide, see Hofmann (2009; review), Lumbsch and Huhndorf (2010; outline), Inácio et al. (2012; taxonomy), Hyde et al. (2013; accepted as a genus in Parmulariaceae), Wijayawardene et al. (2014c; outline), cultures and sequences are unavailable.

Rhagadostoma Körb. 1865, Nitschkiaceae, Coronophorales, Sordariomycetes, six species, type: $R$. corrugatum Körb., asexual morph unknown, saprobes, lichenicolous, terrestrial, 
Europe, see Lumbsch and Huhndorf (2010; outline), Kirk et al. (2013; genus accepted), Maharachchikumbura et al. (2015, 2016; outline), cultures and sequences are unavailable, needs generic revision.

Rhagadostomella Etayo 2002, Nitschkiaceae, Coronophorales, Sordariomycetes, one species, type: $R$. gregaria Etayo, asexual morph unknown, lichenicolous on Sticta, terrestrial, South America, see Etayo (2002; morphology, distinction of similar lichenicolous genera), Maharachchikumbura et al. (2015, 2016; outline), need revision, holotype of the type: COL, Etayo 15943, cultures and sequences are unavailable.

Rhamphoria Niessl 1876, Annulatascaceae, Annulatascales, Sordariomycetes, 14 species, type: $R$. delicatula Niessl, asexual morph hyphomycetous (phaeoisaria-like), saprobes, terrestrial, worldwide, see Lumbsch and Huhndorf (2010; outline), Kirk et al. (2013; genus accepted), Maharachchikumbura et al. (2015, 2016; outline), sequences are available.

Rhamphosphaeria Kirschst. 1936, Sordariomycetes genera incertae sedis, one species, type: $R$. capillata Kirschst., asexual morph unknown, saprobes, terrestrial, Europe, see Lumbsch and Huhndorf (2010; outline), Kirk et al. (2013; genus accepted), Maharachchikumbura et al. (2015, 2016; outline), cultures and sequences are unavailable, needs generic revision.

Rhaphidicyrtis Vain. 1921, Pyrenulales incertae sedis, Eurotiomycetes, one species, type: $R$. trichosporella (Nyl.) Vain., asexual morph unknown, lichenized, terrestrial, temperate, see Lumbsch and Huhndorf (2010; outline), Kirk et al. (2013; genus accepted), Lücking et al. (2016b; classification), cultures and sequences are unavailable, needs generic revision.

Rhexoacrodictys W.A. Baker \& Morgan-Jones 2002, Ascomycota genera incertae sedis, five species, type: $R$. erecta (Ellis \& Everh.) W.A. Baker \& Morgan-Jones, sexual morph unknown, saprobes, terrestrial, see Seifert et al. (2011; morphology), Zhao et al. (2011a; outline), Wijayawardene et al. (2012, 2017; outline), cultures and sequences are unavailable, needs generic revision.

Rhexoampullifera P.M. Kirk 1982, Pyrenulales incertae sedis, Eurotiomycetes, three species, type: $R$. fagi (M.B. Ellis) P.M. Kirk \& C.M. Kirk, hyphomycetous, sexual morph unknown, saprobes, terrestrial, British Isles, Brazil, Czech Republic, see Seifert et al. (2011; morphology), Koukol (2012; new species), Wijayawardene et al. (2012, 2017; outline), Kirk et al. (2013; genus accepted), cultures and sequences are unavailable, needs generic revision.

Rhexocercosporidium U. Braun 1994, Helotiales genera incertae sedis, Leotiomycetes, two species, type: $R$. carotae (Årsvoll) U. Braun, hyphomycetous, terrestrial, soil-borne pathogens, root-inhabiting and on foliage, Asia, Europe, North America, see Nekoduka et al. (2010, phylogeny), Seifert et al. (2011; morphology), Wijayawardene et al. (2012, 2017; outline), Kirk et al. (2013; genus accepted), ex-type strains of type: ATCC 18513 = CBS 418.65 = DAOM 116857.

Rhexodenticula W.A. Baker \& Morgan-Jones 2001, Cordanaceae, Cordanales, Sordariomycetes, four species, type: $R$. cylindrospora (R.F. Castañeda, Saikawa \& Hennebert) W.A. Baker \& Morgan-Jones, saprobes, saprobes, cosmopolitan, Seifert et al. (2011; morphology), Wijayawardene et al. (2012, 2017; outline), Klaubauf et al. (2014; taxonomy, phylogeny), Crous et al. (2016a, b; new species, phylogeny), cultures and sequences are available.

Rhexophiale Th. Fr. 1860, Sagiolechiaceae, Ostropales, Lecanoromycetes, one species, type: $R$. coronata Th. Fr., lichenized, see Baloch et al. (2010; phylogeny), Lücking et al. (2016b; classification), sequences are available.

Rhexoprolifer Matsush. 1996, Ascomycota genera incertae sedis, one species, type: $R$. variabilis Matsush., hyphomycetous, sexual morph unknown, saprobes, France, see Seifert et al. (2011; morphology), Wijayawardene et al. (2012, 2017; outline), Kirk et al. (2013; genus accepted), cultures and sequences are unavailable, needs generic revision. 
Rhexosporium Udagawa \& Furuya 1977, Sordariales incertae sedis, Sordariomycetes, one species, type: $R$. terrestre Udagawa \& Furuya, asexual morph unknown, saprobes, terrestrial, Japan, see Lumbsch and Huhndorf (2010; outline), Kirk et al. (2013; genus accepted), Maharachchikumbura et al. (2015, 2016; outline), cultures and sequences are unavailable, needs generic revision.

Rhexothecium Samson \& Mouch. 1975, Eremomycetaceae, Dothideomycetes families incertae sedis, one species, type: $R$. terrestre Udagawa \& Furuya, asexual morph hyphomycetous (trichosporiella-like), saprobes, terrestrial, Egypt, Kenya, see Lumbsch and Huhndorf (2010; outline), Hyde et al. (2013; accepted as a genus in Eremomycetaceae), Kirk et al. (2013; genus accepted), Giraldo et al. (2014a; phylogeny), Wijayawardene et al. (2014c; outline), cultures and sequences are available but lacks for the type, needs generic revision.

Rhinocladiella Nannf. 1934, Herpotrichiellaceae, Chaetothyriales, Eurotiomycetes, c. 13 species, type: $R$. atrovirens Nannf., hyphomycetous, sexual morph unknown, saprobes, terrestrial, cosmopolitan, see Seifert et al. (2011; morphology), Wijayawardene et al. (2012, 2017; outline), Kirk et al. (2013; genus accepted), Wu et al. (2013c; new species), Hernandez-Restrepo et al. (2016; new pecies), Madrid et al. (2016; new species, phylogeny), cultures and sequences are available.

Rhinocladium Sacc. \& Marchal 1885, Microascaceae, Microascales, Sordariomycetes, nine species, type: $R$. coprogenum Sacc. \& Marchal ex Marchal, hyphomycetous, sexual morph unknown, saprobes, terrestrial, worldwide, see Seifert et al. (2011; morphology), Lackner et al. (2012; DNA), Kirk et al. (2013; genus accepted), Wijayawardene et al. (2017; outline), cultures and sequences are available but lacks for the type.

Rhinotrichella G. Arnaud ex de Hoog 1977, Ascomycota genera incertae sedis, four species, type: R. globulifera G. Arnaud ex de Hoog, hyphomycetous, sexual morph unknown, saprobes, Japan, see Seifert et al. (2011; morphology), Wijayawardene et al. (2012, 2017; outline), Kirk et al. (2013; genus accepted), cultures and sequences are unavailable, needs generic revision.

Rhipidiomyces Thaxt. 1926, Laboulbeniaceae, Laboulbeniales, Laboulbeniomycetes, one species, type: $R$. acriti Thaxt., asexual morph unknown, biotrophic, South America, see Lumbsch and Huhndorf (2010; outline), Kirk et al. (2013; genus accepted), sequences are available.

Rhipidocarpon (Theiss.) Theiss. \& Syd. 1915, Parmulariaceae, Dothideomycetes families incertae sedis, two species, type: $R$. javanicum (Pat.) Theiss. \& Syd., asexual morph unknown, saprobes, terrestrial, Java, Philippines, see Lumbsch and Huhndorf (2010; outline), Kirk et al. (2013; genus accepted), Wijayawardene et al. (2014c; outline), cultures and sequences are unavailable, needs generic revision.

Rhipidocephalum Trail 1888, Ascomycota genera incertae sedis, two species, type: $R$. abietis Trail, hyphomycetous, sexual morph unknown, saprobes, British Isles, see Seifert et al. (2011; morphology), Wijayawardene et al. (2012, 2017; outline), Kirk et al. (2013; genus accepted), cultures and sequences are unavailable, needs generic revision.

Rhizina Fr. 1815, Rhizinaceae, Pezizales, Pezizomycetes, two species, type: $R$. undulata Fr., asexual morph unknown, saprobes, terrestrial, north temperate, see Lumbsch and Huhndorf (2010; outline), Kirk et al. (2013; genus accepted), Palomares-Rius et al. (2014; DNA), cultures available for the type: AFTOL-ID 918.

Rhizoblepharia Rifai 1968, Pyronemataceae, Pezizales, Pezizomycetes, two species, type: $R$. jugispora Rifai, asexual morph unknown, saprobes, terrestrial, Australia, Jamaica, see Lumbsch and Huhndorf (2010; outline), Kirk et al. (2013; genus accepted), cultures and sequences are unavailable, needs generic revision.

Rhizocarpon Ramond ex DC.,1805, Rhizocarpaceae, Lecanorales, Lecanoromycetes, 325 species, 71 subspecies, 197 varieties, 188 forma species, type: Rhizocarpon geographicum 
(L.) DC. morph, undetermined, terrestrial, Europe, Middle East, South Korea, Turkey, see Lumbsch and Huhndorf (2010; outline), Kirk et al. (2013; genus accepted), Bradwell (2010; applied studies), Matthews and Trenbirth (2011; lichenometry), Sánchez et al. (2014a; physiology), Joshi et al. (2010a; rare lichens), Aptroot and Aslan (2011; rare lichens), Fleischhacker et al. (2015; partial sequencing, ribosomal RNA), Lücking et al. (2016b; classification), sequences are available.

Rhizocladosporium Crous \& U. Braun 2007, Helotiales genera incertae sedis, Leotiomycetes, one species, type: $R$. argillaceum (Minoura) Crous \& U. Braun asexual morph hyphomycetous, terrestrial, Asia, see Seifert et al. (2011; morphology), Wijayawardene et al. (2017; outline), ex-type strains of type: CBS 241.67 = IFO 7055; holotype of type: Tubaki 4262 (IFO).

Rhizodermea Verkley \& Zijlstra 2010, Dermateaceae, Helotiales, Leotiomycetes, one species, type: $R$. veluwensis Verkley \& Zijlstra, produced only chalmydospores, sexual morph unknown, from roots, terrestrial, Europe, see Verkley and Hofland-Zijlstra (2010; taxonomy), holotype of the type: CBS 110605 (deposited as culture).

Rhizodiscina Hafellner 1979, Patellariaceae, Patellariales, Dothideomycetes, one species, type: R. lignyota (Fr.) Hafellner, asexual morph unknown, saprobes, terrestrial, temperate, see Lumbsch and Huhndorf (2010; outline), Hyde et al. (2013; accepted as a genus in Patellariaceae), Kirk et al. (2013; genus accepted), Wijayawardene et al. (2014c; outline), Yacharoen et al. (2015; accepted as a genus in Patellariaceae), cultures and sequences are unavailable, needs generic revision.

Rhizogene Syd. \& P. Syd. 1921, Dothideomycetes genera incertae sedis, one species, type: $R$. symphoricarpi (Syd. \& P. Syd.) Syd. \& P. Syd., asexual morph unknown, saprobes, terrestrial, North America, see Lumbsch and Huhndorf (2010; outline, accepted as a genus in Venturiaceae), Zhang et al. (2011d; provisionally accepted as a genus in Venturiaceae), Hyde et al. (2013; excluded the genus from Venturiaceae), Kirk et al. (2013; genus accepted), Wijayawardene et al. (2014c; outline), cultures and sequences are unavailable, needs generic revision.

Rhizolecia Hertel 1984, Lecideaceae, Lecanorales, Lecanoromycetes, one species, one species, type: $R$. hybrida (Zahlbr.) Hertel, asexual morph, undetermined, terrestrial, See Lumbsch and Huhndorf (2010; outline), Kirk et al. (2013; genus accepted), Hertel (2014; taxonomy revision), cultures and sequences are unavailable.

Rhizomyces Thaxt. 1896, Laboulbeniaceae, Laboulbeniales, Laboulbeniomycetes, ten species, type: $R$. ctenophorus Thaxt., asexual morph unknown, biotrophic, Africa, see Lumbsch and Huhndorf (2010; outline), Kirk et al. (2013; genus accepted), sequences are unavailable.

Rhizophila K.D. Hyde \& E.B.G. Jones 1989, Sordariomycetes genera incertae sedis, one species, type: R. marina K.D. Hyde \& E.B.G. Jones, asexual morph unknown, saprobes, marine, Seychelles, Brunei, Thailand, North Sumatra, Bali, see Lumbsch and Huhndorf (2010; outline), Kirk et al. (2013; genus accepted), Jones et al. (2015; outline), Maharachchikumbura et al. (2015, 2016; outline), holotype of type: IMI 325411, cultures and sequences are unavailable.

Rhizoplaca Zopf 1905, Lecanoraceae, Lecanoromycetes, Lecanorales, eleven species, five sub species, seven varieties, type: $R$. opaca (Ach.) Zopf., asexual morph unknown, lichenized, terrestrial, see Castello (2010; new combination), Leavitt (2010; circumscription), Sinha and Jagadeesh Ram (2011; taxonomy), Leavitt et al. (2011a; species delimitation, phylogeny), Lumbsch and Huhndorf (2010; outline), Kirk et al. (2013; genus accepted), Tuthill (2013; checklist), Goni et al. (2014; checklist), Houshyar et al. (2014; antimicrobial), Kondratyuk et al. (2014; molecular phylogeny), Zhao et al. (2016; generic concepts, taxonomy), Lücking et al. (2016b; classification), sequences are available. 
Rhizopodomyces Thaxt. 1931, Laboulbeniaceae, Laboulbeniales, Laboulbeniomycetes, seven species, type: $R$. merragatae Thaxt., asexual morph unknown, biotrophic, Africa, see Lumbsch and Huhndorf (2010; outline), Kirk et al. (2013; genus accepted), sequences are unavailable.

Rhizosphaera L. Mangin \& Har. 1907, Dothideaceae, Dothideales, Dothideomycetes, six species, type: $R$. abietis L. Mangin \& Har., sexual morph unknown, saprobes, terrestrial, worldwide, see Wijayawardene et al. (2012, 2014c; outline), Thambugala et al. (2014a; accepted as a genus in Dothideaceae, phylogeny), Kirk et al. (2013; genus accepted), Azeem et al. (2015; DNA, fungi on confier), cultures and sequences are available but lacks for the type, needs generic revision.

Rhizosphaerina B. Sutton 1986, Ascomycota genera incertae sedis, two species, type: $R$. variabilis B. Sutton, coelomycetous, sexual morph unknown, saprobes, Australia, South East Asia, see Wijayawardene et al. (2012, 2017; outline), Kirk et al. (2013; genus accepted), cultures and sequences are unavailable, needs generic revision.

Rhizotexis Theiss. \& Syd. 1917, Dothideomycetes genera incertae sedis, one species, type: $R$. bauhiniarum (Henn.) Theiss. \& Syd., asexual morph unknown, epiphytes, terrestrial, Brazil, see Lumbsch and Huhndorf (2010; outline), Kirk et al. (2013; genus accepted), Dai et al. (2014a; taxonomy), cultures and sequences are unavailable, needs generic revision.

Rhizothyrium Naumov 1915 (= Rhizocalyx Petr. 1928; Bactrexcipula Höhn. 1918 fide Johnston et al. 2014b), Helotiales genera incertae sedis, Leotiomycetes, one species, type: $R$. abietis Naumov, asexual morph coelomycetous, saprobes, terrestrial, Russia, Chile, Siberia, see Lumbsch and Huhndorf (2010; outline), Wijayawardene et al. (2012, 2017; outline), Kirk et al. (2013; genus accepted), Johnston et al. (2014b; nomenclature), cultures and sequences are unavailable, needs generic revision.

Rhodesia Grove 1937, genera Ascomycota genera incertae sedis, two species, type: $R$. subtecta (Roberge ex Desm.) Grove, coelomycetous, sexual morph unknown, saprobes, Gennany, see Wijayawardene et al. (2012, 2017; outline), Kirk et al. (2013; genus accepted), cultures and sequences are unavailable, needs generic revision.

Rhodesiopsis B. Sutton \& R. Campb. 1979, Ascomycota genera incertae sedis, two species, type: $R$. gelatinosa B. Sutton \& R. Campb., coelomycetous, sexual morph unknown, saprobes, British Isles, Australia, see Wijayawardene et al. (2012, 2017; outline), Kirk et al. (2013; genus accepted), cultures and sequences are unavailable, needs generic revision.

Rhodopeziza Hohmeyer \& J. Moravec 1995, Pezizaceae, Pezizales, Pezizomycetes, one species, type: $R$. tuberculata (Gamundí) J. Moravec \& Hohmeyer, asexual morph unknown, saprobes, terrestrial, South America, see Lumbsch and Huhndorf (2010; outline), Kirk et al. (2013; genus accepted), cultures and sequences are unavailable, needs generic revision.

Rhodoscypha Dissing \& Sivertsen 1983, Pezizales genera incertae sedis, Pezizomycetes, one species, type: $R$. ovilla (Peck) Dissing \& Sivertsen, asexual morph unknown, saprobes, terrestrial, worldwide, see Lumbsch and Huhndorf (2010; outline), Hansen et al. (2013; phylogeny), Kirk et al. (2013; genus accepted), cultures available for the type: HMAS97505, needs generic revision.

Rhodosticta Woron. 1911, Phyllachoraceae, Phyllachorales, Sordariomycetes, two species, type: $R$. caraganae Woron., coelomycetous, sexual morph unknown, saprobes, Asia, USA, see Wijayawardene et al. (2012, 2017; outline), Kirk et al. (2013; genus accepted), cultures and sequences are unavailable, needs generic revision.

Rhodotarzetta Dissing \& Sivertsen 1983, Pezizales genera incertae sedis, Pezizomycetes, one species, type: $R$. rosea (Rea) Dissing \& Sivertsen, asexual morph unknown, saprobes, terrestrial, Europe, see Lumbsch and Huhndorf (2010; outline), Hansen et al. (2013; phylogeny), Kirk et al. (2013; genus accepted), cultures and sequences are available. 
Rhodothallus Bat. \& Cif. 1959, Ascomycota genera incertae sedis, two species, type: $R$. caseariaefolius Bat., Cif. \& C.A.A. Costa ex Bat. \& Cif., coelomycetous, sexual morph unknown, saprobes, Brazil, see Wijayawardene et al. (2012, 2017; outline), Kirk et al. (2013; genus accepted), cultures and sequences are unavailable, needs generic revision.

Rhodoveronaea Arzanlou, W. Gams \& Crous, 2007, Sordariomycetes genera incertae sedis, type: $R$. varioseptata Arzanlou, W. Gams \& Crous, hyphomycetous, sexual morph unknown, one species, saprobes, terrestrial, Germany, see Seifert et al. (2011; morphology), Wijayawardene et al. (2012, 2017; outline), holotype and ex-type culture of type: CBS-H 19932, CBS 431.88.

Rhombostilbella Zimm. 1902, Ascomycota genera incertae sedis, two species, type: $R$. rosae Zimm., hyphomycetous, sexual morph unknown, fungicolous, Asia, North and South America, see Seifert et al. (2011; morphology), Wijayawardene et al. (2012, 2017; outline), Kirk et al. (2013; genus accepted), cultures and sequences are unavailable, needs generic revision.

Rhopalocladium Schroers, Samuels \& W. Gams 1999, Ascomycota genera incertae sedis, two species, type: $R$. myxophilum Schroers, Samuels \& W. Gams, hyphomycetous, sexual morph unknown, fungicolous, Asia, North and South America, see Seifert et al. (2011; morphology), Wijayawardene et al. (2012, 2017; outline), Kirk et al. (2013; genus accepted), cultures and sequences are unavailable, needs generic revision.

Rhopalostroma D. Hawksw. 1977, Hypoxylaceae, Xylariales, Sordariomycetes, eleven species, type: $R$. indicum D. Hawksw. \& Muthappa, on wood and bark, tropical, Africa and Asia, asexual morph nodulisporium-like, see Lumbsch and Huhndorf (2010; outline), Stadler et al. (2010a, 2013; phylogeny), Kirk et al. (2013; genus accepted), Daranagama et al. (2014; phylogeny), Daranagama et al. (2015b; includes description of type), Maharachchikumbura et al. (2015, 2016; outline), Jaklitsch et al. (2016a; position), Wendt et al. (2017; accepted as a genus in Hypoxylaceae), cultures and sequences are available but lacks for the type:), holotype of type: K(M)-IMI 190605.

Rhopographella (Henn.) Sacc. \& Trotter 1913, Sordariomycetes genera incertae sedis, one species, type: R. gaduae (Henn.) Sacc. \& Trotter, asexual morph unknown, saprobes, terrestrial, Brazil, see Lumbsch and Huhndorf (2010; outline), Kirk et al. (2013; genus accepted), Maharachchikumbura et al. (2015, 2016; outline), cultures and sequences are unavailable, needs generic revision.

Rhopographus Nitschke ex Fuckel 1870, Dothideomycetes genera incertae sedis, six species, type: R. filicinus (Fr.) Nitschke ex Fuckel, asexual morph unknown, saprobes, terrestrial, worldwide, see Lumbsch and Huhndorf (2010; outline), Kirk et al. (2013; genus accepted), Wijayawardene et al. (2014c; outline), cultures and sequences are unavailable, needs generic revision.

Rhymbocarpus Zopf 1896, Cordieritidaceae, Helotiales, Leotiomycetes, 17 species, type: $R$. punctiformis Zopf, asexual morph unknown, lichenicolous, terrestrial, Europe, see Diederich et al. (2010b; new species), Lumbsch and Huhndorf (2010; outline), Kirk et al. (2013; genus accepted), Suija et al. (2015b; phylogeny), cultures and sequences are available but lacks for the type, needs generic revision.

Rhynchodiplodia Briosi \& Farneti 1904, Ascomycota genera incertae sedis, one species, type: R. citri Briosi \& Farneti, coelomycetous, sexual morph unknown, saprobes, Italy, see Wijayawardene et al. (2012, 2017; outline), Kirk et al. (2013; genus accepted), cultures and sequences are unavailable, needs generic revision.

Rhynchomeliola Speg. 1884, Rhynchostomataceae, Eurotiomycetes families incertae sedis, three species, type: $R$. pulchella Speg., asexual morph unknown, lichenicolous, terrestrial, South America, Australasia, see Lumbsch and Huhndorf (2010; outline), Kirk et al. (2013; 
genus accepted), cultures and sequences are available but lacks for the type, needs generic revision.

Rhynchophoromyces Thaxt. 1908, Ceratomycetaceae, Laboulbeniales, Laboulbeniomycetes, eight species, type: $R$. rostratus (Thaxt.) Thaxt., asexual morph unknown, biotrophic on Coleoptera (Hydrophilidae), worldwide, see Lumbsch and Huhndorf (2010; outline), Kirk et al. (2013; genus accepted), cultures and sequences are unavailable, needs generic revision.

Rhynchoseptoria Unamuno 1940, Ascomycota genera incertae sedis, one species, type: $R$. caballeroana Unamuno, coelomycetous, sexual morph unknown, saprobes, Morocco, see Wijayawardene et al. (2012, 2017; outline), Kirk et al. (2013; genus accepted), cultures and sequences are unavailable, needs generic revision.

Rhynchosphaeria (Sacc.) Berl. 1890, Sordariomycetes genera incertae sedis, one species, type: R. dusenii Henn., asexual morph unknown, saprobes, terrestrial, worldwide, see Lumbsch and Huhndorf (2010; outline), Kirk et al. (2013; genus accepted), Maharachchikumbura et al. (2015, 2016; outline), cultures and sequences are unavailable, needs generic revision.

Rhynchosporina Arx 1957, Ascomycota genera incertae sedis, two species, type: $R$. meinersii (R. Sprague) Arx, hyphomycetous, sexual morph unknown, saprobes, North America, see Seifert et al. (2011; morphology), Wijayawardene et al. (2012, 2017; outline), Kirk et al. (2013; genus accepted), cultures and sequences are unavailable, needs generic revision.

Rhynchosporium Heinsen ex A.B. Frank 1897, Ploettnerulaceae, Helotiales, Leotiomycetes, five species, type: $R$. graminicola Heinsen ex A.B. Frank, hyphomycetous, terrestrial, plant pathogens, leaf spotting, worldwide, see Seifert et al. (2011; morphology), Zaffarano et al. (2011, taxonomy, phylogeny), King et al. (2013, 2014, genetics, taxonomy), Torriani et al. (2014, genetics), Braun (2016, nomenclature of the type), Jaklitsch et al. (2016a; classification), ex-epitype: RS99CH6-C1a.

Rhynchostoma P. Karst. 1870 (= Rhynchostoma P. Karst. 1873 fide Species Fungorum 2017), Rhynchostomataceae, Eurotiomycetes families incertae sedis, c. 10 species, type: $R$. minutum P. Karst., asexual morph unknown, saprobes, terrestrial, worldwide, see Marincowitz et al. (2008; DNA), Lumbsch and Huhndorf (2010; outline), Kirk et al. (2013; genus accepted), cultures and sequences are available, needs generic revision.

Rhytidenglerula Höhn.1918, Englerulaceae, Dothideomycetes families incertae sedis, eleven species type: $R$. carnea (Ellis \& G. Martin) Höhn., asexual morph coelomycetous, saprobes, terrestrial, widely distributed, see Lumbsch and Huhndorf (2010; outline), Kirk et al. (2013; genus accepted), Dai et al. (2014c; morphology), cultures and sequences are unavailable, type specimen need recollect and sequence.

Rhytidhysteron Speg. 1881 (= Brunaudia (Sacc.) 1898; = Eutryblidiella (Rehm) Höhn., 1959; = Rhytidopeziza Speg. 1885; = Triblidium subgen. Brunaudia Sacc. 1883; = Tryblidiella Sacc. 1883; = Tryblidiella sect. Eutryblidiella Rehm 1881 fide Species Fungorum 2017), Hysteriaceae, Hysteriales, Dothideomycetes, 19 species, type: R. brasiliense Speg, diplodiaand aposphaeria-like, saprobes, terrestrial, worldwide, see Boehm et al. (2009a, b; phylogeny), Murillo et al. (2009; morphology, chemistry, phylogeny), Schoch et al. (2009; phylogeny), Lumbsch and Huhndorf (2010; outline), Méndez-Mayboca et al. (2010; diversity), Hyde et al. (2013; outline, key, phylogeny), Almeida et al. (2014a; diversity), Chacón et al. (2014; diversity), Mahajan et al. (2014; pathogensity), Mishra et al. (2014a; pathogensity), Pudhom and Teerawatananond (2014; chemistry), Yacharoe et al. (2015; revision, classification, morphology), Chokpaiboon et al. (2016; chemistry), Doilom et al. (2016; morphology, phylogeny), Thambugala et al. (2016; morphology, phylogeny), cultures and sequences are available, holotype of type: LPS 1189. 
Rhytidiella Zalasky 1968, Cucurbitariaceae, Pleosporales, Dothideomycetes, four species, type: Rhytidiella moriformis Zalasky, asexual morph coelomycetous (phaeoseptoria-like), pathogen, terrestrial, see Lumbsch and Huhndorf (2010; outline), Doilom et al. (2013; accepted as a genus in Cucurbitariaceae), Kirk et al. (2013; genus accepted), Wijayawardene et al. (2014c; outline), cultures and sequences are available.

Rhytidospora Jeng \& Cain 1977, Ceratostomataceae, Melanosporales, Sordariomycetes, five species, type: $R$. tetraspora Jeng \& Cain, asexual morph unknown, saprobes, terrestrial, worldwide, see Lumbsch and Huhndorf (2010; outline), Kirk et al. (2013; genus accepted), Maharachchikumbura et al. (2015, 2016; outline), cultures and sequences are unavailable, needs generic revision.

Rhytisma Fr. 1819 (= Melasmia Lév. 1846 fide Johnston et al. 2014b), Rhytismataceae, Rhytismatales, Leotiomycetes, 127 species, type: R. acerinum (Pers.) Fr., asexual morph unknown, saprobes, terrestrial, worldwide, see Suto (2009; new species, Japan), Wang et al. (2009a; new species), Hou et al. (2010; new species), Lumbsch and Huhndorf (2010; outline), Kirk et al. (2013; genus accepted), Masumoto et al. (2014, 2015; new species, Japan, phylogeny), sequences are available for voucher Hou 203 (AAUF), needs generic revision.

Ricasolia De Not. 1846, Lobariaceae, Peltigerales, Lecanoromycetes, 15 species; type: Ri. amplissima (Scop.) De Not.; lichenized; see Moncada et al. (2013a; taxonomy), Cornejo and Scheidegger (2015; phylgoeny), Lücking et al. (2016b; classification), Tønsberg et al. (2016; new combination), sequences are available.

Richonia Boud. 1885, Zopfiaceae, Pleosporales, Dothideomycetes, one species, type: $R$. variospora Boud., asexual morph unknown, France, see Lumbsch and Huhndorf (2010; outline), Hyde et al. (2013; accepted as a genus in Zopfiaceae), Kirk et al. (2013; genus accepted), Wijayawardene et al. (2014c; outline), cultures and sequences are unavailable, needs generic revision.

Rickia Cavara 1899, Laboulbeniaceae, Laboulbeniales, Laboulbeniomycetes, 161 species, type: $R$. wasmannii Cavara, asexual morph unknown, biotrophic hosts are Acari (Chelicerata), Diplopoda (Myriapoda), Formicidae (Hexapoda: Hymenoptera), and several other groups of insects (Hexapoda: Blattodea, Coleoptera, Orthoptera), worldwide, see Lumbsch and Huhndorf (2010; outline), Kirk et al. (2013; genus accepted), Haelewaters et al. (2015a; PCR amplification of DNA), Santamaría et al. (2016; most recent species descriptions), Pfliegler et al. (2016a; host specificity), sequences are available.

Rikatlia P.F. Cannon 1993, Phyllachoraceae, Phyllachorales, Sordariomycetes, one species, type: R. lungusaensis (Henn.) P.F. Cannon, from living leaves, Eastern America, see Lumbsch and Huhndorf (2010; outline), Kirk et al. (2013; genus accepted), Maharachchikumbura et al. (2015, 2016; outline), cultures and sequences are unavailable, needs generic revision.

Rileya A. Funk 1979, Ascomycota genera incertae sedis, one species, type: R. piceae A. Funk, coelomycetous, sexual morph unknown, saprobes, Canada, see Wijayawardene et al. (2012, 2017; outline), Kirk et al. (2013; genus accepted), cultures and sequences are unavailable, needs generic revision.

Rimaconus Huhndorf, F.A. Fernández, Joanne E. Taylor \& K.D. Hyde 2001, Chaetosphaeriales genera incertae sedis, Sordariomycetes, two species, type: $R$. jamaicensis (Seaver) Huhndorf, F.A. Fernández, Joanne E. Taylor \& K.D. Hyde, hyphomycetous, sexual morph unknown, terrestrial, saprobes, worldwide, see Lumbsch and Huhndorf (2010; outline, accepted as a genus in Sordariomycetidae, genera incertae sedis), Huhndorf and Miller (2011; phylogeny), Maharachchikumbura et al. (2015, 2016; outline), cultures available for voucher SMH 5212 of the type.

Rimora (Kohlm. \& Vittal) Kohlm., Volkm.-Kohlm., Suetrong, Sakay. \& E.B.G. Jones 2009, Aigialaceae, Pleosporales, Dothideomycetes, one species, type: R. mangrovei (Kohlm. \& 
Vittal) Kohlm., Volkm.-Kohlm., Suetrong, Sakay. \& E.B.G. Jones, asexual morph unknown, saprobes, Marine, Belize, India, Thailand, see Suetrong et al. (2009; morphology, phylogeny), Hyde et al. (2013; accepted as a genus in Aigialiaceae), Wijayawardene et al. (2014c; outline, accepted as Aigialiaceae), Jones et al. (2015; outline, marine), sequences are available.

Rimula Velen. 1934, Helotiales genera incertae sedis, Leotiomycetes, one species, type: $R$. faginea Velen., asexual morph unknown, saprobes, terrestrial, former Czechoslovakia, see Lumbsch and Huhndorf (2010; outline), Kirk et al. (2013; genus accepted), Jaklitsch et al. (2016a; classification, treated as Patellariaceae), cultures and sequences are unavailable, needs generic revision.

Rimularia Nyl., 1868, Trapeliaceae, Baeomycetales, Lecanoromycetes, 40 species, type, $R$. limborina Nyl., asexual morph, undetermined, terrestrial, terricolous, See Lumbsch and Huhndorf (2010; outline), Øvstedal (2012; taxonomy),, Kirk et al. (2013; genus accepted), Kantvilas (2014a; taxonomy), Spribille et al. (2014a; molecular systematics), Resl et al. (2015; phylogenetic studies), Lücking et al. (2016b; classification), cultures and sequences are available.

Rinaldiella Deanna A. Sutton, Y. Marín, Guarro \& E.H. Thomps. 2014, Lasiosphaeriaceae, Sordariales, Sordariomycetes, one species, type: R. pentagonospora D.A. Sutton, Y. Marín, Guarro \& E.H. Thomps., asexual morph unknown, human pathogens, Georgia, see Crous et al. (2014c; taxonomy), Maharachchikumbura et al. (2015, 2016; outline), cultures and sequences are available.

Rinodina (Ach.) Gray, 1821, Physciaceae, Lecanorales, Lecanoromycetes, 692 species, nine sub species, 148 varieties, 122 forma species, type: $R$. sophodes (Ach.) A. Massal., asexual morph unknown, terrestrial, corticolous, muscicolous, worldwide, see Lumbsch and Huhndorf (2010; outline), Muggia et al. (2011b; new species), Kirk et al. (2013; genus accepted), Giralt et al (2009; new species), Giralt and Klaus (2010; taxonomy), Nadyeina et al. (2010; sequencing and taxonomy), Sheard (2010; taxonomy), Kinalioglu and Aptroot (2011; new records), Muggia et al (2011; molecular,data, unpublished), Sheard et al. (2011; new species), ), Gaya et al (2012; comprehensive phylogenetic studies), Upreti and Patel (2012; environmental studies, ecology), Lücking et al. (2016b; classification), Resl et al (2016, sequencing data, unpublished), sequences are available.

Rinodinella H. Mayrhofer \& Poelt, 1978, Physciaceae, Lecanorales, Lecanoromycetes, six species, four varieties, type: $R$. controversa (A. Massal.) H. Mayrhofer \& Poelt, asexual morph unknown, terrestrial, see Elix (2009; taxonomy), Lumbsch and Huhndorf (2010; outline), Gaya et al. (2012; taxonomy), Gasparyan and Sipman (2013; new records), Kirk et al. (2013; genus accepted), Grube and Arup (2001; molecular). Prieto et al. (2013; phylogeny), Lücking et al. (2016b; classification), Prieto and Wedin (2016; phylogeny), sequences are available.

Riomyces A. Ferrer, A.N. Mill., C. Sarmiento et Shearer 2012, Sordariomycetes genera incertae sedis, one species, type: $R$. rotundus A. Ferrer, A.N. Mill., Costa Rica, see Ferrer et al. (2012; taxonomy), cultures and sequences are available.

Rivilata Kohlm., Volkm.-Kohlm. \& O.E. Erikss. 1998, Dothideomycetes genera incertae sedis, one species, type: R. ius Kohlm., Volkm.-Kohlm. \& O.E. Erikss, asexual morph unknown, saprobes, USA, see Lumbsch and Huhndorf (2010; outline), Kirk et al. (2013; genus accepted), cultures and sequences are unavailable, needs generic revision.

Rivulicola K.D. Hyde 1997, Sordariomycetes genera incertae sedis, three species, type: $R$. incrustata K.D. Hyde, saprobes, found on decaying woody substrates in freshwater habitats, Queensland, Florida, Hong Kong, see Raja et al. (2009a; morphology), Lumbsch and Huhndorf (2010; outline), Kirk et al. (2013; genus accepted), Maharachchikumbura et al (2015, 2016; outline), holotype of type: BRIP 23340. 
Rizalia Syd. \& P. Syd. 1914, Trichosphaeriaceae, Trichosphaeriales, Sordariomycetes, two species, type: $R$. fasciculata Syd. \& P. Syd, asexual morph unknown, saprobes, terrestrial, tropical, see Lumbsch and Huhndorf (2010; outline), Kirk et al. (2013; genus accepted), Maharachchikumbura et al. (2015, 2016; outline), cultures and sequences are unavailable, needs generic revision.

Robakia Petr. 1952, Ascomycota genera incertae sedis, one species, type: $R$. arctica Petr., coelomycetous, sexual morph unknown, saprobes, Norway, see Wijayawardene et al. (2012, 2017; outline), Kirk et al. (2013; genus accepted), cultures and sequences are unavailable, needs generic revision.

Robergea Desm., 1847, Stictidaceae, Ostropales, Lecanoromycetes, 13 species, two varieties and two forma species, type: $R$. unica Desm., asexual morph, undetermined, terrestrial, see Lumbsch and Huhndorf (2010; outline), Lücking et al. (2016b; classification), cultures and sequences are unavailable.

Robillarda Sacc. 1880, Robillardaceae, Xylariales, Sordariomycetes, eight species, type: $R$. sessilis (Sacc.) Sacc., sexual morph unknown, saprobes, worldwide, see Wijayawardene et al. (2012, 2017; outline), Kirk et al. (2013; genus accepted), Crous et al. (2015a; phylogeny, epitypification, new species), Maharachchikumbura et al. (2015, 2016; outline), epitype and ex-epitype culture of the type: CBS H-22273, CBS114312.

Robillardiella S. Takim. 1943, Dothideomycetes genera incertae sedis, type: data inadequate, see Kirk et al. (2008; treated as nom. dub.), Lumbsch and Huhndorf (2010; outline), Kirk et al. (2013; did not list), Wijayawardene et al. (2014c; outline), sequences are unavailable.

Robincola Velen. 1947, Lecanoromycetes genera incertae sedis, one species, type: $R$. gregaria Velen., asexual morph unknown, saprobes, terrestrial, former Czechoslovakia, see Lumbsch and Huhndorf (2010; outline), Kirk et al. (2013; genus accepted), Jaklitsch et al. (2016a; classification, treated as Lecanoromycetes), cultures and sequences are unavailable, needs generic revision.

Roburnia Velen. 1947, Lecanoromycetes genera incertae sedis, one species, type: $R$. karschioides Velen., asexual morph unknown, saprobes, terrestrial, former Czechoslovakia, see Lumbsch and Huhndorf (2010; outline), Kirk et al. (2013; genus accepted), Jaklitsch et al. (2016a; classification, treated as Lecanoromycetes), cultures and sequences are unavailable, needs generic revision.

Roccella DC. 1805, Roccellaceae, Arthoniales, Arthoniomycetes, 24 species, type: $R$. fuciformis (L.) DC., asexual morph unknown, lichenized, terrestrial, Africa, Asia, see Karthikaidevi et al. (2009; antibacterial activity), Lumbsch and Huhndorf (2010; outline), Tehler et al. (2009b, 2010; evolution, molecular taxonomy), Aptroot and Schumm (2011; worldwide key), Bates et al. (2011; ecology), Devi et al. (2011; antimicrobial activities), Tehler (2011, 2012; taxonomy), Aydin and Kinalioglu (2013, 2016; antibacterial study, antioxidant activity), Kirk et al. (2013; genus accepted), Ertz et al. (2014b; taxonomy), Doherty et al. (2014; experimental), Kambar et al. (2014; antimicrobial), Notov (2014; taxonomy), Shukla et al. (2014a; natural dyes), Fiorentino (2015; notes), Lücking et al. (2016b; classification, but wrongly citing 40 species), sequences are available.

Roccellina Darb. 1898, Roccellaceae, Arthoniales, Arthoniomycetes, 35 species, type: $R$. condensata Darb., asexual morph unknown, lichenized, terrestrial, see Kocourková et al. (2010; taxonomy), Lumbsch and Huhndorf (2010; outline), Norvell (2010; nomenclature), Printzen (2010; systematic study), Rotter (2010; list), Ertz and Tehler (2011; phylogeny), Tehler (2012; taxonomy), Kirk et al. (2013; genus accepted), de Lange (2014; taxonomy), Ertz et al. (2015b, c; phylogeny), Lücking et al. (2016bb; classification), sequences are available.

Roccellinastrum Follmann 1968, Micareaceae, Lecanorales, Lecanoromycetes, six species, type: Roccellinastrum spongoideum Follmann, asexual morph unknown, lichenized, 
terrestrial, Chile, Tasmania, see Lumbsch and Huhndorf (2010; outline), Kirk et al. (2013; genus accepted), Jaklitsch et al. (2016a; outline), Lücking et al. (2016b; classification); cultures and sequences are unavailable, needs generic revision.

Roccellographa J. Steiner, 1902, Roccellaceae, Arthoniales, Arthoniomycetes, four species, type: $R$. cretacea J. Steiner, lichenized, see Lumbsch and Huhndorf (2010; outline), Kirk et al. (2013; genus accepted), Lücking et al. (2016b; classification), sequences are available.

Rodaucea W. Rossi \& Santam. 2012, Teratomyceteae, Laboulbeniales, Laboulbeniomycetes, one species, type: $R$. salgadoi W. Rossi \& Santam., asexual morph unknown, biotrophic only host known is Eucatops curtus Salgado (Coleoptera, Cholevidae), Ecuador, see Rossi and Santamaría (2012; taxonomy, morphology), Haelewaters et al. (2015b; extracted ribosomal DNA).

Rodentomyces Doveri, Pecchia, Sarrocco \& Vannacci 2010, Hypocreales genera incertae sedis, Sordariomycetes, two species, type: $R$. reticulatus Doveri, Pecchia, Sarrocco \& Vannacci, asexual morph unknown, saprobes, terrestrial, Italy, see Doveri et al. (2010; taxonomy, phylogeny), Lombard et al. (2015b; taxonomy, phylogeny, doubt the placement in Nectriaceae since low bootstrap values in phylogenetic analyses), Maharachchikumbura et al. (2015, 2016; outline), Index Fungorum (2016; fixed the nomenclature issue), holotype and ex-type cultures of the type: CBS H-21948, CBS 128675.

Rodwayella Spooner 1986 (= Remleria Raitv. 2004 fide Jaklitsch et al. 2016a), Pezizellaceae, Helotiales, Leotiomycetes, three species, type: R. sessilis (Rodway) Spooner, asexual morph unknown, saprobes, terrestrial, temperate, see Lumbsch and Huhndorf (2010; outline), Kirk et al. (2013; genus accepted), cultures and sequences are unavailable, needs generic revision.

Roesleria Thüm. \& Pass. 1877, Roesleriaceae, Helotiales, Leotiomycetes, c. 50 species, type: R. subterranea (Weinm.) Redhead, asexual morph unknown, saprobes, terrestrial, Europe, see Kirchmair et al. (2008; DNA, phylogeny), Lumbsch and Huhndorf (2010; outline), Kirk et al. (2013; genus accepted), cultures and sequences are available.

Roeslerina Redhead 1985, Ascomycota genera incertae sedis, two species, type: $R$. radicella Redhead, asexual morph unknown, saprobes, terrestrial, Europe, North America, see Lumbsch and Huhndorf (2010; outline), Kirk et al. (2013; genus accepted), sequences are available for the type (unpublished), needs generic revision.

Rogellia Döbbeler 1999, Odontotremataceae, Ostropales, Lecanoromycetes, three species, type: $R$. nectrioidea Döbbeler, asexual morph unknown, saprobes, terrestrial, Tierra del Fuego, see Lumbsch and Huhndorf (2010; outline), Kirk et al. (2013; genus accepted), cultures and sequences are unavailable, needs generic revision.

Rogergoosiella A. Hern.-Gut. \& J. Mena 1996, Ascomycota genera incertae sedis, one species, type: $R$. roystoneicola A. Hern. Gut. \& J. Mena, hyphomycetous, sexual morph unknown, saprobes, terrestrial, Africa, Caribbean, see Seifert et al. (2011; morphology), Wijayawardene et al. (2012, 2017; outline), Kirk et al. (2013; genus accepted), cultures and sequences are unavailable, needs generic revision.

Rogersonia Samuels \& Lodge 1996, Hypocreaceae, Hypocreales, Sordariomycetes, one species, type: $R$. striolata Samuels \& Lodge, asexual morph unknown, saprobes, terrestrial, Puerto Rico, see Lumbsch and Huhndorf (2010; outline), Kirk et al. (2013; genus accepted), Maharachchikumbura et al. (2015, 2016; outline), cultures and sequences are unavailable, needs generic revision.

Rolfidium Moberg, 1986, Ramalinaceae, Lecanorales, Lecanoromycetes, two species, $R$. peltatum Moberg, asexual morph, undetermined, terrestrial, East Africa, Sri Lanka, Mascarenes, see Ekman et al. (2008; evolution of the ascus), Lumbsch and Huhndorf (2010; outline), Kirk et al. (2013; genus accepted), Lücking et al. (2016b; classification); Molecular and culture data unavailable. 
Rolueckia Papong, Thammath. \& Boonpr. 2008, Gomphillaceae, Ostropales, Lecanoromycetes, three species; type: $R$. conspersa (Stirt.) Papong, Thammath. \& Boonpr., lichenized, see Lumbsch and Huhndorf (2010; outline), Plata et al. (2012; classification), Lücking et al. (2016b; classification), sequences are unavailable, needs generic revision.

Romellina Petr. 1955, Sordariomycetes genera incertae sedis, one species, type: Romellina variabilis Petr., asexual morph unknown, on insects, terrestrial, Java, see Lumbsch and Huhndorf (2010; outline), Kirk et al. (2013; genus accepted), Maharachchikumbura et al. (2016; outline), cultures and sequences are unavailable, needs generic revision.

Romjularia Timdal 2007, Lecideaceae, Lecideales, Lecanoromycetes, one species, type: $R$. lurida (Ach.) Timdal, lichenized, see Lumbsch and Huhndorf (2010; outline), Schmull et al. (2011; phylogeny), Miądlikowska et al. (2014; phylogeny), Lücking et al. (2016b; classification), sequences are available.

Rommelaarsia Baral \& Haelew. 2015, Hyaloscyphaceae, Helotiales, Leotiomycetes, one species, type: R. flavovirens Baral, Tanchaud \& Romm., asexual morph hyphomycetous, saprobes, terrestrial, see Baral and Haelewaters (2015; morphology, DNA, phylogeny), Guatimosim et al. (2016; phylogeny), sequences are available.

Ronnigeria Petr. 1947, Leptopeltidaceae, Dothideomycetes families incertae sedis, one species, type: $R$. arctica (Oudem.) Petr., asexual morph unknown, saprobes, terrestrial, Europe, see Lumbsch and Huhndorf (2010; outline), Hyde et al. (2013; outline, accepted as a genus in Leptopeltidaceae), Kirk et al. (2013; genus accepted), Wijayawardene et al. (2014c; outline), cultures and sequences are unavailable, needs generic revision.

Ropalospora A. Massal. 1860, Ropalosporaceae, Umbilicariales, Lecanoromycetes, eight species and three forma species, type: R. caffra A. Massal., asexual morph, unknown, terrestrial, Europe, Japan, see Hauck et al. (2009; biochemical studies), Lõhmus and Lõhmus (2010; conservation studies), Lumbsch and Huhndorf (2010; outline), Kirk et al. (2013; genus accepted), Lendemer (2012; floristic studies), Lücking et al. (2016b; classification), sequences re available.

Rosasphaeria Jaklitsch \& Voglmayr 2012, Niessliaceae, Hypocreales, Sordariomycetes, one species, type: $R$. moravica (Petr.) Jaklitsch \& Voglmayr, asexual morph unknown, saprobes, terrestrial, Europe, see Lumbsch and Huhndorf (2010; outline), Maharachchikumbura et al. (2015, 2016; outline), epitype and ex-epitype of the type: WU 31334, LMM = CBS124270.

Roscoepoundia Kuntze 1898, Ascomycota genera incertae sedis, one species, type: Roscoepoundia croceola (Sacc.) Kuntze, coelomycetous, sexual morph unknown, saprobes, terrestrial, Europe, see Wijayawardene et al. (2012, 2017; outline), Kirk et al. (2013; genus accepted), cultures and sequences are unavailable, needs generic revision.

Rosellinia De Not. 1844 (= Amphisphaerella Henn. 1902; = Byssitheca Bonord. 1864; = Dematophora R. Hartig 1883; = Vrikshopama D. Rao \& P.Rag. Rao fide Réblová et al. 2016c; Wendt et al. 2017), Xylariaceae, Xylariales, Sordariomycetes, two species, type: $R$. aquila (Fr.) Ces. \& De Not., asexual morph unknown, saprobes, terrestrial, Italy, see Lumbsch and Huhndorf (2010; outline), Kirk et al. (2013; genus accepted), Petrini and Petrini (2013; taxonomy, monograph), Maharachchikumbura et al. (2015, 2016; outline), Li et al. (2016a; taxonomy, phylogeny), Réblová et al. (outline; 2016c), cultures and sequences are available.

Rosellinia De Not. 1844, Xylariaceae, Xylariales, Sordariomycetes, c. 120 species, type: $R$. aquila (Fr.) Ces. \& De Not., asexual morph unknown, saprobes, Asia, see Lumbsch and Huhndorf (2010; outline), Kirk et al. (2013; genus accepted), Jaklitsch et al. (2016a; classification), Maharachchikumbura et al. (2016; outline), cultures and sequences are available, needs generic revision.

Roselliniella Vain. 1921, Hypocreales genera incertae sedis, Sordariomycetes, 15 species, type: Roselliniella nephromatis (P. Crouan \& H. Crouan) Matzer \& Hafellner, asexual morph aunknown, saprobes, lichenicolous, terrestrial, worldwide, see Zhurbenko et al. (2009; new 
species), Hawksworth et al. (2010; new species, phylogeny), Lumbsch and Huhndorf (2010; outline, accepted as a genus in Sordariales, genera incertae sedis), Kirk et al. (2013; genus accepted), Maharachchikumbura et al. (2015, 2016; outline), van den Boom (2015; new species), cultures and sequences are available but lacks for the type, needs generic revision.

Roselliniomyces Matzer \& Hafellner 1990, Sordariales genera incertae sedis, Sordariomycetes, one species, type: R. trichotheliorum Matzer \& Hafellner, asexual morph unknown, lichenicolous, terrestrial, Costa Rica, see Lumbsch and Huhndorf (2010; outline), Kirk et al. (2013; genus accepted), Maharachchikumbura et al. (2015, 2016; outline), cultures and sequences are unavailable, needs generic revision.

Roselliniopsis Matzer \& Hafellner 1990, Sordariales, genera incertae sedis, Sordariomycetes, nine species, type: $R$. groedensis (Zopf) Matzer \& Hafellner, asexual morph unknown, lichenicolous, terrestrial, worldwide, see Lumbsch and Huhndorf (2010; outline), Kaur And Gehlot (2011; new species, India), Kirk et al. (2013; genus accepted), Kondratyuk et al. (2013b; new species, South Korea), Maharachchikumbura et al. (2016; outline), cultures and sequences are unavailable, needs generic revision.

Rosellinula R. Sant. 1986, Dothideomycetes genera incertae sedis, one species, type: $R$. haplospora (Th. Fr. \& Almq.) R. Sant., asexual morph unknown, lichenicolous, terrestrial, worldwide, see Lumbsch and Huhndorf (2010; outline), Kirk et al. (2013; genus accepted), Wijayawardene et al. (2014c; outline), cultures and sequences are unavailable, needs generic revision.

Rosenscheldia Speg. 1885, Dothideomycetes genera incertae sedis, one species, type: $R$. paraguaya Speg., asexual morph unknown, saprobes, terrestrial, worldwide, see Lumbsch and Huhndorf (2010; outline), Kirk et al. (2013; genus accepted), Wijayawardene et al. (2014c; outline), cultures and sequences are unavailable, needs generic revision.

Rosenscheldiella Theiss. \& Syd. 1915, Dothideomycetes genera incertae sedis, one species, type: R. styracis (Henn.) Theiss. \& Syd., asexual morph unknown, saprobes, terrestrial, worldwide, see Lumbsch and Huhndorf (2010; outline, accepted as a genus in Venturiaceae), Sultan et al. (2011; new species, phylogeny), Kirk et al. (2013; genus accepted), Wijayawardene et al. (2014c; outline, accepted as a genus in Dothideomycetes, genera incertae sedis), cultures and sequences are available only for $R$. korthalsellae Sultan, P.R. Johnst., D.C. Park \& A.W. Robertson, needs generic revision.

Roseodiscus Baral 2006, Helotiales genera incertae sedis, Leotiomycetes, six species, type: $R$. rhodoleucus (Fr.) Baral, asexual morph unknown, from soil, saprobes, terrestrial, worldwide, see Lumbsch and Huhndorf (2010; outline, accepted as a genus in Hyaloscyphaceae), Wieschollek et al. (2011; new species), Kirk et al. (2013; genus accepted), Zheng and Zhuang (2013; new species, China), Baral and Haelewaters (2015; DNA, phylogeny), cultures and sequences are available.

Rossiomyces R.K. Benj. 2001, Laboulbeniaceae, Laboulbeniales, Laboulbeniomycetes, one species, type: Rossiomyces falcatus (T. Majewski) R.K. Benj., asexual morph unknown, biotrophic on Coleoptera in fungi (Cryptophagus species, Cryptophagidae), Europe, see Lumbsch and Huhndorf (2010; outline), cultures and sequences are unavailable, needs generic revision.

Rossmania Lar.N. Vassiljeva 2001, Sydowiellaceae, Diaporthales, Sordariomycetes, one species, type: R. ukurunduensis Lar.N. Vassiljeva, asexual morphs unknown, saprobes, terrestrial, temperate north-eastern Asia, see Cheewangkoon et al. (2010; phylogeny), Lumbsch and Huhndorf (2010; outline), Kruys and Castlebury (2012; phylogeny), Voglmayr and Jaklitsch (2014; phylogeny), Maharachchikumbura et al. (2015, 2016; outline, phylogeny), holotype of type: VLA P-2944.

Rostania Trevis. 1880, Collemataceae, Peltigerales, Lecanoromycetes, eight species, type: $R$. quadrata (J. Lahm ex Körb.) Trevis., lichenized, see Otálora et al. (2013, 2014; 
classification), Tagirdzhanova et al. (2014; new report, Russia), Jørgensen and Palice (2015; new combination), McMullin (2015; checklist), Stehn et al. (2015; list), Lücking et al. (2016b; classification), Westberg et al. (2016; new records, Sweden), culture and sequences are unavailable.

Rostraureum Gryzenh. \& M.J. Wingf. 2005, Cryphonectriaceae, Diaporthales, Sordariomycetes, three species, type: $R$. tropicale Gryzenh. \& M.J. Wingf., asexual morph unknown, pathogens, terrestrial, worldwide, see Lumbsch and Huhndorf (2010; outline), Maharachchikumbura et al. (2015, 2016; outline), holotype and ex-type cultures of type: PREM 57519, CMW 9972.

Rostrohypoxylon J. Fourn. \& M. Stadler 2010, Hypoxylaceae, Xylariales, Sordariomycetes, eight species, type: $R$. terebratum J. Fourn. \& M. Stadler, asexual morph hyphomycetous (sporothrix-like to virgariella-like), terrestrial, saprobes, Thailand, see Fournier et al. (2010; taxonomy), Maharachchikumbura et al. (2015, 2016; outline), Wendt et al. (2017; accepted as a genus in Hypoxylaceae), cultures and sequences are available.

Rostrupiella Jørg. Koch, K. L. Pang \& E. B. G. Jones 2007, Lulworthiaceae, Lulworthiales, Sordariomycetes, one species, type: $R$. danica Jørg. Koch, K.L. Pang \& E.B.G. Jones, asexual morph unknown, saprobes, marine, Denmark, Norway, see Rama et al. (2012; taxonomy, new species), Maharachchikumbura et al. (2015, 2016; review), sequences are available, holotype of type: JK 539.

Rosulomyces S. Marchand \& Cabral 1976, Ascomycota genera incertae sedis, one species, type: $R$. arthrosporioides Marchand \& Cabral, hyphomycetous, sexual morph unknown, from soil, terrestrial, South America, see Seifert et al. (2011; morphology), Wijayawardene et al. (2012, 2017; outline), Kirk et al. (2013; genus accepted), cultures and sequences are unavailable, needs generic revision.

Rota Bat., Cif. \& Nascim. 1959, Ascomycota genera incertae sedis, one species, type: $R$. pulchra Bat., Cif. \& Nascim., coelomycetous, sexual morph unknown, saprobes, terrestrial, Brazil, see Wijayawardene et al. (2012, 2017; outline), Kirk et al. (2013; genus accepted), cultures and sequences are unavailable, needs generic revision.

Rotiferophthora G.L. Barron 1991, Clavicipitaceae, Hypocreales, Sordariomycetes, 27 species, type: $R$. globospora G.L. Barron, hyphomycetous, sexual morph unknown, saprobes, terrestrial, Asia, Australasia, Europe, North America, see Seifert et al. (2011; morphology), Wijayawardene et al. (2012, 2017; outline), Kirk et al. (2013; genus accepted), Maharachchikumbura et al. (2015, 2016; outline), cultures and sequences are available, needs generic revision.

Roumegueria (Sacc.) Henn. 1908, Dothideomycetes genera incertae sedis, one species, type: R. goudotii (Lév.) Sacc. ex Clem. \& Shear, asexual morph unknown, saprobes, terrestrial, tropical, see Lumbsch and Huhndorf (2010; outline), Kirk et al. (2013; genus accepted), Wijayawardene et al. (2014c; outline), cultures and sequences are unavailable, needs generic revision.

Roumegueriella Speg. 1880, Bionectriaceae, Hypocreales, Sordariomycetes, three species, type: $R$. muricospora Speg., asexual morph gliocladium-like, coprophilous, saprobes, terrestrial, temperate, see Hirooka et al. (2010; phylogeny), Lumbsch and Huhndorf (2010; outline), Kirk et al. (2013; genus accepted), Maharachchikumbura et al. (2015, 2016; outline), cultures and sequences are available but lacks for the type, needs generic revision.

Roussoella Sacc. 1888, Roussoellaceae, Pleosporales, Dothideomycetes, 34 species, type: $R$. nitidula Sacc. \& Paol., asexual morph coelomycetous, saprobes, terrestrial, worldwide, see Lumbsch and Huhndorf (2010; outline), Kirk et al. (2013; genus accepted), Ahmed et al. (2014b; new species, oppetunistic pathogens), Crous et al. (2014d, 2015a, 2016b; new species), Liu et al. (2014b; new species, phylogeny), Ariyawansa et al. (2015a; new species), 
Wijayawardene et al. (2014c, 2016b; taxonomy), Dai et al. (2016; new species, phylogeny), cultures available for the type: MFLUCC 11-0182, MFLUCC 11-0634.

Roussoëllopsis I. Hino \& Katum. 1965, Roussoellaceae, Pleosporales, Dothideomycetes, three species, type: $R$. japonica (I. Hino \& Katum.) I. Hino \& Katum., asexual morph coelomycetous, saprobes, terrestrial, Asia, see Kirk et al. (2013; genus accepted), Liu et al. (2014b; new species, phylogeny), Phookamsak et al. (2014a; phylogeny), Wijayawardene et al. (2014c; outline), cultures and sequences are available but lacks for the type, needs generic revision.

Rubikia H.C. Evans \& Minter 1985, Graphidaceae, Ostropales, Lecanoromycetes, three species, type: $R$. samsonii H.C. Evans \& Minter, coelomycetous, sexual morph unknown, saprobes, terrestrial, pantropical, see Wijayawardene et al. (2012, 2016b, 2017; outline, taxonomy), Kirk et al. (2013; genus accepted), Crous et al. (2016a; new species, phylogeny), cultures and sequences are available, needs generic revision.

Rubrotricha Lücking, Sérus. \& Vězda 2005, Gomphillaceae, Ostropales, Lecanoromycetes, two species, type: $R$. helminthospora (R. Sant.) Lücking, Sérus. \& Vězda; lichenized, see Lumbsch and Huhndorf (2010; outline), Lücking et al. (2016b; classification), sequences are unavailable.

Rufoplaca Arup, Søchting \& Frödén 2013, Teloschistaceae, Teloschistales, Lecanoromycetes, six species, type: $R$. subpallida (H. Magn.) Arup, Søchting \& Frödén, asexual morph unknown, lichenized, terrestrial, worldwide, see Gaya et al. (2012; phylogeny), Arup et al. (2013, 2015; taxonomy, phylogeny), Montes (2013; new species), Diederich et al. (2014; new records), Halıc et al. (2014b; DNA, phylogeny), Lücking et al. (2016b; classification), sequences are available.

Ruggieria Cif. \& Montemart. 1958, Ascomycota genera incertae sedis, one species, type: $R$. glaucescens (Trab.) Cif. \& Montemart., coelomycetous, sexual morph unknown, saprobes, terrestrial, pantropical, see Wijayawardene et al. (2012, 2017; outline), Kirk et al. (2013; genus accepted), cultures and sequences are unavailable, needs generic revision.

Rugonectria P. Chaverri \& Samuels 2011, Nectriaceae, Hypocreales, Sordariomycetes, four species, type: $R$. rugulosa (Pat. \& Gaillard) Samuels, P. Chaverri \& C. Salgado, hyphomycetous asexual morph (cylindrocarpon-like), saprobes, pathogens, terrestrial, pantropical, Japan, Indonesia, see Chaverri et al. (2011; morphology, phylogeny), Lombard et al. (2015b; taxonomy, phylogeny), Maharachchikumbura et al. (2015, 2016; outline), cultures available for the type: CBS 126565.

Ruhlandiella Henn. 1903, Pezizaceae, Pezizales, Pezizomycetes, four species, type: $R$. berolinensis Henn., asexual morph unknown, saprobes, terrestrial, worlwide, see Lumbsch and Huhndorf (2010; outline), Rubio et al. (2010; new species), Lantieri et al. (2012; new species, Italy), Kirk et al. (2013; genus accepted), sequence are available for the voucher Mycoflora of Macaronesia 1230 (C) of the type, needs generic revision.

Ruptoseptoria Quaedvl., Verkley \& Crous 2013, Mycosphaerellaceae, Capnodiales, Dothideomycetes, one species, type: R. unedonis (Roberge ex Desm.) Quaedvl., Verkley \& Crous, coelomycetous, sexual morph unknown, pathogens, terrestrial, France, see Quaedvlieg et al. (2013; morphology, phylogeny), Wijayawardene et al. (2017; outline), holotype and extype culture of the type: CBS H-14645, CBS 355.86.

Rusavskia S.Y.Kondr. \& Kärnefelt 2003, Teloschistaceae, Teloschistales, Lecanoromycetes, 17 species, type: $R$. elegans (Link) S.Y. Kondr. \& Kärnefelt, lichenized, see Arup et al. (2013; taxonomy), Kondratyuk et al. (2013c, 2015; new species), Urbanavichus and Ismailov (2013; taxonomy), Ahti et al. (2015; new combinations), Halici (2015; new record), Kaźmierska and Kossowska (2016; taxonomy), Lücking et al. (2016b; classification), Prieto and Wedin (2016; phylogeny), sequences are available. 
Rutola J.L. Crane \& Schokn. 1978, Pleosporales genera incertae sedis, Dothideomycetes, one species, type: $R$. graminis (Desm.) J.L. Crane \& Schokn., hyphomycetous, sexual morph unknown, saprobes, terrestrial, worldwide, see Seifert et al. (2011; morphology). Wijayawardene et al. (2012, 2017; outline, taxonomy), Kirk et al. (2013; genus accepted), Crous et al. (2015a; typification, phylogeny), isotype of the type: L0054599, cultures and sequences are unavailable, needs generic revision.

Rutstroemia P. Karst. 1871 (= Poculum Velen. 1934 fide Jaklitsch et al. 2016a), Rutstroemiaceae, Helotiales, Leotiomycetes, c. 111 species, type: R. firma (Pers.) P. Karst., asexual morph unknown, terrestrial, saprobes, worldwide, see Lumbsch and Huhndorf (2010; outline), Kirk et al. (2013; genus accepted), Han et al. (2014; phylogeny), Dougoud (2015; new species), Galán et al. (2015; new species), Pärtel et al. (2017; phylogeny), cultures available for the type: KL292.

Ruwenzoria J. Fourn., M. Stadler, Læssøe \& Decock 2010, Hypoxylaceae, Xylariales, Sordariomycetes, eight species, type: $R$. pseudoannulata J. Fourn., M. Stadler, Laessøe \& Decock, asexual morph hyphomycetous (sporothrix- or nodulisporium-like), terrestrial, saprobes, Democratic Republic of Congo, see Stadler et al. (2010c; taxonomy), Maharachchikumbura et al. (2015, 2016; outline), Wendt et al. (2017; accepted as a genus in Hypoxylaceae), holotype of the type: MUCL 51394, cultures and sequences are available.

Ruzenia Hilber 2002, Lasiosphaeriaceae, Sordariales, Sordariomycetes, one species, type: $R$. spermoides (Hoffm.) O. Hilber, asexual morph unknown, saprobes, terrestrial, worldwide, see Lumbsch and Huhndorf (2010; outline), Miller et al. (2014; new species, DNA, phylogeny), Maharachchikumbura et al. (2015, 2016; outline), culture available for the type: SMH4655.

Saagaromyces K. L. Pang \& E. B. G. Jones 2003, Halosphaeriaceae, Microascales, Sordariomycetes, four species, type: S. ratnagiriensis (S.D. Patil \& Borse) K.L. Pang \& E.B.G. Jones, asexual morph unknown, saprobes, marine, worldwide, see Lumbsch and Huhndorf (2010; outline), Liu et al. (2015a; new species), Jones et al. (2015; outline, marine), Maharachchikumbura et al. (2015, 2016; outline), cultures and sequences are available.

Sabahriopsis Crous \& M.J. Wingf. 2015, Helotiales genera incertae sedis, Leotiomycetes, one species, type: S. eucalypti Crous \& M.J. Wingf., hyphomycetous, saprobes, Malaysia, see Crous et al. (2015d; taxonomy, phylogeny), Wijayawardene et al. (2017; outline, phylogeny), holotype and ex-type culture of the type: CBS H-22235, CPC 24957.

Sabalicola K.D. Hyde 1995, Xylariaceae, Xylariales, Sordariomycetes, one species, type: $S$. sabalensioides (Ellis \& G. Martin) K.D. Hyde, asexual morph unknown, terrestrial, saprobes, USA, see Lumbsch and Huhndorf (2010; outline), Kirk et al. (2013; genus accepted), Maharachchikumbura et al. (2015, 2016; outline), holotype: MUCL 51394, cultures and sequences are unavailable.

Sablicola E.B.G. Jones, K.L. Pang \& Vrijmoed 2004, Halosphaeriaceae, Microascales, Sordariomycetes, one species, type: S. chinensis E.B.G. Jones, K.L. Pang \& Vrijmoed, asexual morph unknown, on beached driftwood, Guangdong-China, see Lumbsch and Huhndorf (2010; outline), Sakayaroj et al. (2011a; phylogeny), Maharachchikumbura et al. (2015, 2016; outline, phylogeny), holotype of the type: IMI 389302.

Sabuloglossum Hustad, A.N. Mill, Dentinger \& P.F. Cannon 2013, Geoglossaceae, Geoglossales, Geoglossomycetes, one species, type: S. arenarium (Rostr.) Hustad, A.N. Mill., Dentinger \& P.F. Cannon, asexual morph unknown, saprobes, terrestrial, worldwide, see Hustad et al. (2013; taxonomy, phylogeny), holotype of the type: C, no. C-F-70804, sequences are available, NCBI RefSeq: NR_120040, NG_042605.

Saccardia Cooke 1878, Saccardiaceae, Ascomycota families incertae sedis, three species, type: S. quercina Cooke, asexual morph unknown, saprobes, USA, see Lumbsch and 
Huhndorf (2010; outline), Kirk et al. (2013; genus accepted), cultures and sequences are unavailable, needs generic revision.

Saccardinula Speg. 1885, Trichopeltinaceae, Dothideomycetes families incertae sedis, eleven species, type: S. guaranitica Speg., asexual morph unknown, saprobes, worldwide, see Lumbsch and Huhndorf (2010; outline, accepted as a genus in Elsinoaceae), Kirk et al. (2013; genus accepted), Jayawardena et al. (2014; excluded from Elsinoaceae and placed in Trichopeltinaceae), Wijayawardene et al. (2014c; outline), cultures and sequences are unavailable, needs generic revision.

Saccardoëlla Speg. 1879, Sordariomycetes genera incertae sedis, 18 species, type: S. montellica Speg., asexual morph unknown, terrestrial, saprobes, aquatic, widespread, see Suetrong et al. (2009; molecular), Lumbsch and Huhndorf (2010; outline), Kirk et al. (2013; genus accepted), Maharachchikumbura et al. (2015, 2016; outline), sequences are available for S. rhizophorae in GenBank: GU479860.

Saccharata Denman \& Crous 2004, Saccharataceae, Botryosphaeriales, Dothideomycetes, 19 species, type: S. proteae (Wakef.) Denman \& Crous, asexual morph coelomycetous, saprobes, associated with leaf spots, terrestrial, South Africa, see Crous et al. (2008, 2016a, b; new species, morphology, phylogeny), Slippers et al. (2013; phylogeny), Wijayawardene et al. (2014c, 2017; outline), holotype and ex-type culture of type: K(M) 49510 as Phyllachora proteae Wakef., CBS 115206.

Saccharomyces Meyen 1870, Saccharomycodaceae, Saccharomycetales, Saccharomycetes, seven species, type: S. cerevisiae Meyen ex E.C. Hansen, asexual reproduction is by multilateral budding, saprophytic, but some strains are of clinical origin, in beer, wine and other alcoholic beverages, grain-based fermented foods, occasionally in soil, tree bark, fruit flies, occasional clinical isolates, worldwide, see Lumbsch and Huhndorf (2010; outline), Kirk et al. (2013; genus accepted), Saccharomyces cerevisiae is a model organism for studies of genetics and molecular biology and was the first eukaryote to have its genome sequence determined.

Saccharomycodes E.C. Hansen 1904, Saccharomycodaceae, Saccharomycetales, Saccharomycetes, one species, type: S. ludwigii (E.C. Hansen) E.C. Hansen, asexual reproduction is by bipolar budding on a broad base (bud-fission) and are lemon-shaped (apiculate), saprophytic, in tree exudates, soil, spoiled alcoholic beverages, worldwide, see Lumbsch and Huhndorf (2010; outline), Kirk et al. (2013; genus accepted), Wang et al. (2015a; classification), cultures and sequences are available.

Saccharomycopsis Schiönning 1903, Saccharomycopsidaceae, Saccharomycetales, Saccharomycetes, 15 species, type: S. capsularis Schiønning, asexual reproduction is by multilateral budding and production of arthroconidia by some species, saprophytic, on hawthorne fruit, grapes and other fruit, soil of fruit orchards, starchy foods, beetles, tree exudates, tanning fluids, worldwide, see Lumbsch and Huhndorf (2010; outline), Kirk et al. (2013; genus accepted), cultures and sequences are available.

Saccobolus Boud. 1869, Ascobolaceae, Pezizales, Pezizomycetes, about 27 species, type: S. kervernii (P. Crouan \& H. Crouan) Boud., asexual morph hyphomycetous, coprophilous, terrestrial, worldwide, see Lumbsch and Huhndorf (2010; outline), Ramos et al. (2011; molecular studies), Mungai et al. (2012b; ecology, taxonomy), Kirk et al. (2013; genus accepted), Doveri (2014; taxonomy, keys), Melo et al. (2014; ecology, taxonomy, keys), evolutionary lineages of Pezizales has been confirmed and refined by ascus septal ultrastructure, number of nuclei in spores and molecular phylogenetics.

Saccothecium Fr. 1836, Saccotheciaceae, Dothideales, Dothideomycetes, two species, type: S. sepincola (Fr.) Fr., asexual morph hyphomycetous, terrestrial, Italy, saprobes, terrestrial, Italy, see Lumbsch and Huhndorf (2010; outline), Kirk et al. (2013; genus accepted), 
Wijayawardene et al. (2014c; outline), Li et al. (2016a; new species), cultures available for the type: CBS 278.32 .

Sadasivania Subram. 1957, Ascomycota genera incertae sedis, three species, type: Sadasivania girisa Subram., hyphomycetous, sexual morph unknown, saprobes, Asia, North America, see Seifert et al. (2011; morphology), Wijayawardene et al. (2012, 2017; outline), Kirk et al. (2013; genus accepted), cultures and sequences are unavailable, needs generic revision.

Sagedia Ach. 1809, Megasporaceae, Pertusariales, Lecanoromycetes, three species, type: $S$. zonata Ach., lichenized, see Nordin et al. (2010; reinstated the genus), Lücking et al. (2016b; classification), sequences are available.

Sagediopsis Sacc. ex Vain. 1921, Adelococcaceae, Verrucariales, Eurotiomycetes, one species, type: S. tartarina (Nyl.) Vain., asexual morph unknown, lichenicolous, terrestrial, temperate, see Lumbsch and Huhndorf (2010; outline), Kirk et al. (2013; genus accepted), cultures and sequences are unavailable, needs generic revision.

Sagema Poelt \& Grube 1993, Lecanoraceae, Lecanorales, Lecanoromycetes, one species, type: S. potentillae Poelt \& Grube, lichenized, see Lumbsch and Huhndorf (2010; outline), Kirk et al. (2013; genus accepted), Lücking et al. (2016b; classification), sequences are unavailable.

Sagenidiopsis R.W.Rogers \& Hafellner 1987, Roccellaceae, Arthoniales, Arthoniomycetes, six species; type: S. merrotsyi R.W. Rogers \& Hafellner, lichenized, Aftica, Asia, Europe, Europe, Asia, see Lumbsch and Huhndorf (2010; outline), Zambare and Christopher (2012; biopharmaceutical potential), Kirk et al. (2013; genus accepted), Ram (2014; new species Andaman), Ertz et al. (2015b, c; phylogeny), Lücking et al. (2016b; classification), sequences are available.

Sagenomella W. Gams 1978, Trichocomaceae, Eurotiales, Eurotiomycetes, 13 species, type: S. diversispora (J.F.H. Beyma) W. Gams, hyphomycetous, sexual morph unknown, saprobes, terrestrial, worldwide, see Hsieh et al. (2009; new species), Houbraken and Samson (2011; phylogeny), Samson et al. (2011; phylogeny), Seifert et al. (2011; morphology), Wijayawardene et al. (2012, 2017; outline), Kirk et al. (2013; genus accepted), cultures available for the type: CBS 399.69, CBS 398.69.

Sageria A. Funk 1975, Helotiales genera incertae sedis, Leotiomycetes, one species, type: S. tsugae A. Funk, sexual morph unknown, saprobes, Canada, see Lumbsch and Huhndorf (2010; outline), Kirk et al. (2013; genus accepted), Jaklitsch et al. (2016a; classification), cultures and sequences are unavailable.

Sagiolechia A. Massal. 1854, Sagiolechiaceae, Ostropales, Lecanoromycetes, nine species, three varieties, three forma species, type: S. protuberans (Ach.) A. Massal., asexual morph unknown, lichenized, terrestrial, Europe, see Baloch et al. (2010; phylogeny), Lumbsch and Huhndorf (2010; outline, accepted as a genus in Gomphillaceae), Thor and Nascimbene (2010; checklist), Kirk et al. (2013; genus accepted), Miądlikowska et al. (2014; phylogeny), Lücking et al. (2016b; classification), cultures available for the type: AFTOL-ID 4896.

Saitoëlla S. Goto, Sugiyama, Hamamoto \& Komagata 1987, Protomycetaceae, Taphrinales, Taphrinomycetes, two species, type: S. complicata Goto, Sugiyama, Hamamoto \& Komagata, asexual reproduction is mainly by multipolar enteroblastic budding, saprophyte, soil, insect frass, Bhutan, western USA, see Kirk et al. (2013; genus accepted), cultures and sequences are available.

Sakireeta Subram. \& K. Ramakr. 1957, Botryosphaeriaceae, Botryosphaeriales, Dothideomycetes, one species, type: S. madreeya Subram. \& K. Ramakr., coelomycetous, sexual morph unknown, saprobes, pathogens, terrestrial, India, see Crous et al. (2015b; reinstated the genus, phylogeny), Wijayawardene et al. (2017; outline), cultures and sequences are available. 
Salsuginea K.D. Hyde 1991, Salsugineaceae, Pleosporales, Dothideomycetes, one species, type: S. ramicola K.D. Hyde, asexual morph unknown, saprobes, marine, worldwide, see Suetrong et al. (2009; phylogeny, morphology), Jones et al. (2009b, 2015; classification), Alias et al. (2010; diversity), Zainuddin et al. (2010; antimicrobial activity), Zhang et al. (2012e; phylogeny, morphology), Hyde et al. (2013; morphology, phylogeny), Wijayawardene et al. (2014c; outline), holotype of type: BRIP 17102, cultures and sequences are available.

Samarospora Rostr. 1892, Eurotiomycetidae genera incertae sedis, one species, type: $S$. potamogetonis Rostr., asexual morph unknown, saprobes, terrestrial, Europe, see Lumbsch and Huhndorf (2010; outline), Kirk et al. (2013; genus accepted), cultures and sequences are unavailable, needs generic revision.

Sambucina Velen. 1947, Helotiales genera incertae sedis, Leotiomycetes, one species, type: S. aculeata Velen., asexual morph unknown, saprobes, terrestrial, former Czechoslovakia, see Lumbsch and Huhndorf (2010; outline), Kirk et al. (2013; genus accepted), cultures and sequences are unavailable, needs generic revision.

Samuelsia P. Chaverri \& K.T. Hodge 2008, Clavicipitaceae, Hypocreales, Sordariomycetes, one species, type: S. rufobrunnea Chaverri \& K.T. Hodge, asexual morph coelomycetous (aschersonia-like), saprobes, on insects, terrestrial, Bolivia, Thailand, see Chaverri et al. (2008; taxonomy), Lumbsch and Huhndorf (2010; outline), Mongkolsamrit et al. (2011; new species), Maharachchikumbura et al. (2015, 2016; outline), holotype of the type: CUP 067858, cultures and sequences are available.

Sandersoniomyces R.K. Benj. 1968, Laboulbeniaceae, Laboulbeniales, Laboulbeniomycetes, one species, type: S. divaricatus R.K. Benj., asexual morph unknown, biotrophic on Coleoptera, Staphylinidae (Quedius sp.), America, see Lumbsch and Huhndorf (2010; outline), Kirk et al. (2013; genus accepted), cultures and sequences are unavailable, needs generic revision.

Sanguinotrema Lücking 2015, Graphidaceae, Ostropales, Lecanoromycetes, one species, type: $S$. rightii (Taylor) Lücking, asexual morph unknown, lichenized, terrestrial, tropical, see Lücking et al. (2015, 2016; phylogeny, classification), cultures and sequences are unavailable, Santessonia Hale \& Vobis 1978, Caliciaceae, Caliciales, Lecanoromycetes, ten species, type: S. namibensis Hale \& Vobis, asexual morph unknown, lichenized, terrestrial, see Farkas (2011; list), Lumbsch and Huhndorf (2010; outline, accepted as a genus in Physciaceae), Mayrhofer and Wirth (2011; taxonomy), Gaya et al. (2012; phylogeny), Kirk et al. (2013; genus accepted), Lücking et al. (2016b; classification), sequences are unavailable.

Sapucchaka K. Ramakr. 1956, Dothideomycetes genera incertae sedis, two species, type: $S$. madreeya K. Ramakr., asexual morph unknown, saprobes, terrestrial, India, see Lumbsch and Huhndorf (2010; outline, accepted as a genus in Microthyriaceae), Kirk et al. (2013; genus accepted), Wijayawardene et al. (2014c; outline), cultures and sequences are unavailable.

Sarcinella Sacc. 1880 (= Schiffnerula Höhn. 1909; = Questieriella G. Arnaud ex S. Hughes 1983 fide Rossman et al. 2016a), Englerulaceae, Dothideomycetes genera incertae sedis, 71 species type: S. heterospora Sacc., schiffnerulaceous fungi, Questieriella, Digitosarcinella and Mitteriella synanamorphs of Schiffnerula, saprobes, plant pathogens, terrestrial, worldwide. see Hosagoudar and Riju (2009, 2011; morpholgy), Hosagoudar et al. (2010b, 2011b; new species), Hosagoudar et al. (2010b, 2011a, b; Schiffnerulaceous fungi), Soni et al. (2011; neem disease) Singh and Singh (2012; new species), Bhise et al. (2014; new species), Dai et al. (2014c; family description), Rossman et al. (2016a; nomenclature), sequences are unavailable.

Sarcinomyces Lindner 1898, Eurotiomycetes genera incertae sedis, five species, type: S. crustaceus Lindner, sexual morph unknown, saprobes, plant and animal pathogen, terrestrial, worldwide, see Ruibal et al. (2008, 2009; phylogeny, ecology), Hallman et al. (2011; Burg 
Gleichen), Tsuneda et al. (2011b; phylogeny), Muggia et al. (2013; lichen connection), Nagano et al. (2014; deep sea), sequences are available.

Sarcinosporon D.S. King \& S.C. Jong 1975, Ascomycota genera incertae sedis, one species, type: S. inkin (Oho) D.S. King \& S.C. Jong, hyphomycetous, sexual morph unknown, saprobes, terrestrial, widespread, see Seifert et al. (2011; morphology), Wijayawardene et al. (2012, 2017; outline), Kirk et al. (2013; genus accepted), cultures and sequences are unavailable, needs generic revision.

Sarcoexcipula Etayo 2008, Ascomycota genera incertae sedis, one species, type: S. pannariae Etayo, asexual morph unknown, parasymbiont on Pannaria, terrestrial, South America, see Etayo and Sancho (2008; morphology, distinction of similar lichenicolous genera), needs generic revision, holotype of the type: MAF Etayo 23100, cultures and sequences are unavailable.

Sarcographa Fée 1921, Graphidaceae, Ostropales, Lecanoromycetes, c. 40 species, type: S. cinchonarum Fée, asexual morph unknown, lichenized, terrestrial, tropical, see Rivas Plata et al. 2012a, Lumbsch and Huhndorf (2010; outline), Kirk et al. (2013; genus accepted). Lücking et al. (2016b; classification); sequences are available.

Sarcographina Müll. Arg. 1887, Graphidaceae, Ostropales, Lecanoromycetes, eight species, type: S. cyclospora Müll. Arg., asexual morph unknown, lichenized, terrestrial, tropical, see Plata et al. (2012; classification), Kirk et al. (2013; genus accepted), Joshi et al. (2014; report), Kraichak et al. (2014; phylogeny), Lücking et al. (2016b; classification), sequences are available.

Sarcogyne Flot., 1851, Acarosporaceae, Lecanorales, Lecanoromycetes, 88 species, 38 varieties, two subspecies, 32 forma species, type: $S$. corrugata Flot., asexual morph unknown, terrestrial, terricolous, saxicolous, crustose, squamulose, America, Australia, Japan, Turkey, see Knudsen et al. (2009b, 2013a; new species), Lumbsch and Huhndorf (2010; outline), Kirk et al. (2013; genus accepted), Knudsen and Kocourková (2012; neotypification), McCarthy and Kantvilas (2013b; new species), Knudsen and McCune (2013; new species), Tokizawa et al. (2015; new species), Westberg et al. (2015; phylogeny), Lücking et al. (2016b; classification), sequences are available.

Sarcoleotia S. Ito \& S. Imai 1934, Geoglossaceae, Geoglossales, Geoglossomycetes, one species, type: S. nigra S. Ito \& S. Imai, asexual morph unknown, saprobes, terrestrial, worldwide, see Schoch et al. (2009; phylogeny, accepted as a genus in Rutstroemiaceae), Lumbsch and Huhndorf (2010; outline), Hustad et al. (2013; taxonomy, phylogeny), sequences are available but lacks for type.

Sarcomyces Massee 1891, Helotiales genera incertae sedis, Leotiomycetes, one species, type: S. vinosus Massee, asexual morph unknown, saprobes, America, see Lumbsch and Huhndorf (2010; outline), Kirk et al. (2013; genus accepted), Jaklitsch et al. (2016a; classification, treated as a synonym of Haematomyxa Sacc. in Ptellariales), cultures and sequences are unavailable, needs generic revision.

Sarconiptera Raitv. 2003, Mollisiaceae, Helotiales, Leotiomycetes, one species, type: S. vinacea Raitv., asexual morph unknown, saprobes, terrestrial, Greenland, see Lumbsch and Huhndorf (2010; outline), Jaklitsch et al. (2016a; classification), holotype of the type: TAA 137803, cultures and sequences are unavailable, needs generic revision.

Sarcophoma Höhn. 1916, Ascomycota genera incertae sedis, three species, type: $S$. endogenospora Höhn., asexual morph unknown, saprobes, widespread, see Wijayawardene et al. (2012, 2017; outline), Kirk et al. (2013; genus accepted), cultures and sequences are unavailable, needs generic revision.

Sarcopodium Ehrenb. 1818 (= Lanatonectria Samuels \& Rossman 1999; Actinostilbe Petch 1925 fide Rossman et al. 2016a), Nectriaceae, Hypocreales, Sordariomycetes, 14 species, type: S. circinatum Ehrenb., hyphomycetous, sexual morph unknown, saprobes, pathogens, 
terrestrial, worldwide, see Seifert et al. (2011; morphology), Wijayawardene et al. (2012, 2017; outline), Lombard et al. (2015b; taxonomy, phylogeny), Maharachchikumbura et al. (2015, 2016; outline), Rossman et al. (2016a; nomenclature), cultures available for the type: CBS 587.92.

Sarcopyrenia Nyl. 1858, Sordariomycetes genera incertae sedis, one species, type: S. gibba Nyl., asexual morph unknown, lichenicolous, terrestrial, worldwide, see Lumbsch and Huhndorf (2010; outline), Kirk et al. (2013; genus accepted), Maharachchikumbura et al. (2015, 2016; outline), cultures and sequences are unavailable, needs generic revision.

Sarcosagium A. Massal. 1856, Thelocarpaceae, Thelocarpales, Ascomycota orders incertae sedis, one species, type: S. biatorellum A. Massal., asexual morph unknown, lichenized, terrestrial, worldwide, see Lumbsch and Huhndorf (2010; outline), Kirk et al. (2013; genus accepted), Lücking et al. (2016b; classification), cultures and sequences are unavailable, needs generic revision.

Sarcoscypha (Fr.) Boud. 1885 (= Molliardiomyces Paden 1984 fide Healy et al. 2016), Sarcoscyphaceae, Pezizales, Pezizomycetes, c. 30 species, type: S. coccinea (Jacq.) Sacc., asexual morph formerly named in Molliardiomyces, saprobes, terrestrial, worldwide, see Lumbsch and Huhndorf (2010; outline), Romero et al. (2012; phylogeny), Kirk et al. (2013; genus accepted), Wang et al. (2016e; new species), cultures available for the type: AFTOLID 930 (unpublished).

Sarcosoma Casp. 1891, Sarcosomataceae, Pezizales, Pezizomycetes, five species, type: S. globosum (Schmidel) Casp., asexual morph unknown, saprobes, terrestrial, worldwide, see Lumbsch and Huhndorf (2010; outline), Hansen et al. (2013; DNA), Kirk et al. (2013; genus accepted), cultures and sequences are available.

Sarcosphaera Auersw. 1869, Pezizaceae, Pezizales, Pezizomycetes, one species, type: S. macrocalyx (Riess) Auersw., asexual morph unknown, hypogeous, terrestrial, worldwide, see Lumbsch and Huhndorf (2010; outline), Romero et al. (2012; phylogeny), Kirk et al. (2013; genus accepted), cultures and sequences are available.

Sarcostroma Cooke 1871, Sporocadaceae, Xylariales, Sordariomycetes, 28 species, type: $S$. berkeleyi Cooke, asexual morph coelomycetous, sexual morph unknown, saprobes, endophytes, foliar pathogens in tropical and temperate regions, see Maharachchikumbura et al. (2015, 2016; outline), Norphanphoun et al. (2015; phylogeny), need generic revision.

Sarcotrochila Höhn. 1917, Cenangiaceae, Helotiales, Leotiomycetes, four species, type: S. alpina (Fuckel) Höhn., asexual morph unknown, saprobes, terrestrial, North America, Europe, see Lumbsch and Huhndorf (2010; outline), Kirk et al. (2013; genus accepted), Jaklitsch et al. (2016a; classification), cultures and sequences are available but lacks for the type.

Sarcoxylon Cooke 1883, Xylariaceae, Xylariales, Sordariomycetes, two species, type: S. compunctum (Jungh.) Cooke, asexual morph unknown, terrestrial, saprobes, Asia, Africa, see Lumbsch and Huhndorf (2010; outline), Kirk et al. (2013; genus accepted), Maharachchikumbura et al. (2015, 2016; outline), Senanayake et al. (2015; DNA, phylogeny), cultures and sequences are available.

Sardiniella Linaldeddu, A. Alves \& A.J.L. Phillips 2016, Botryosphaeriaceae, Botryosphaeriales, Dothideomycetes, nine species, type: S. urbana Linaldeddu, A. Alv es \& A.J.L. Phillips, coelomycetous, sexual morph unknown, pathogens, terrestrial, Italy, see Linaldeddu et al. (2016; taxonomy, phylogeny), Wijayawardene et al. (2017; outline), holotype and ex-type culture of the type: LISE 96308, CBS $141580=$ BL179.

Sarea Fr. 1825, Trapeliaceae, Trapeliales, Lecanoromycetes, two species, type: S. difformis (Fr.) Fr., asexual morph unknown, on resins, terrestrial, worldwide, see Lumbsch and Huhndorf (2010; outline), Hodkinson and Lendemer (2011b; reinstated the genus), Kirk et al. (2013; genus accepted), Sanz-Ros et al. (2015; DNA, phylogeny), Burneviča et al. (2016; DNA), Lücking et al. (2016b; classification), cultures and sequences are available. 
Sarimanas Matsumura, K. Hiray. \& Kaz. Tanaka 2015, Melanommataceae, Pleosporales, Dothideomycetes, two species, type: S. shirakamiense Matsumura, K. Hiray. \& Kaz. Tanaka, asexual morph unknown, saprobes, terrestrial, Japan, see Liu et al. (2015a; morphology, phylogeny), Tian et al. (2015; phylogeny), holotype and ex-type strain of the type: HHUF 30454, MAFF 244768.

Sarocladium W. Gams \& D. Hawksw. 1976, Hypocreales genera incertae sedis, Sordariomycetes, eight species, type: S. oryzae (Sawada) W. Gams \& D. Hawksw., hyphomycetous, sexual morph unknown, on plants, isolated from soil, human tissues, widespread, terrestrial, see Seifert et al. (2011; genus accepted), Summerbell et al. (2011; phylogeny and cicumscription), Kirk et al. (2013; genus accepted), Maharachchikumbura et al. (2015, 2016; outline), Jaklitsch et al. (2016a; position), cultures and sequences are available, holotype of type: TAI.

Sarrameana Vězda \& P. James 1973, Sarrameanaceae, Sarrameanales, Lecanoromycetes, three species, type: S. paradoxa Vězda \& P. James, asexual morph unknown, lichenized, terrestrial, worldwide, see Lumbsch and Huhndorf (2010; outline), Hodkinson and Lendemer (2011b; taxonomy), Kirk et al. (2013; genus accepted), cultures and sequences are unavailable, needs generic revision.

Sartorya Vuill. 1927, Sordariomycetes, genera incertae sedis, one species, type: S. fumigata Vuill., see Kirk et al. (2008; treated as nom. dub.), Lumbsch and Huhndorf (2010; outline), Kirk et al. (2013; did not list), Maharachchikumbura et al. (2015, 2016; outline).

Satchmopsis B. Sutton \& Hodges 1975, Ascomycota genera incertae sedis, one species, type: S. brasiliensis B. Sutton \& Hodges, coelomycetous, sexual morph unknown, saprobes, terrestrial, widespread, see Wijayawardene et al. (2012, 2017; outline), cultures and sequences are available, needs generic revision.

Sativumoides S.C. Ren, Jian Ma \& X.G. Zhang 2012, Ascomycota genera incertae sedis, one species, type: S. punicae S.C. Ren, Jian Ma \& X.G. Zhang, hyphomycetous, saprobes, terrestrial, China, see Ren et al. (2012a; taxonomy), Wijayawardene et al. (2017; outline), cultures and sequences are available, needs generic revision.

Saturnispora Liu \& Kurtzman 1991, Pichiaceae, Saccharomycetales, Saccharomycetes, 20 species, type: S. dispora (Dekker) Z.W. Liu \& Kurtzman, asexual reproduction is by multilateral budding, saprophytic, in plant rhizosphere in salt marsh, tree exudates, grapes, fruit flies, sauerkraut, soil, worldwide, see Lumbsch and Huhndorf (2010; outline), Kirk et al. (2013; genus accepted), many species in this genus represent asexual taxa originally classified in the genus Candida, but have been transferred to the genus Saturnispora as new combinations, cultures and sequences are available.

Savoronala Ertz, Eb. Fisch., Killmann, Razafindr. \& Sérus. 2013, Malmideaceae, Lecanorales, Lecanoromycetes, one species; type: S. madagascariensis Ertz, Eb. Fisch., Killmann, Razafindr. \& Sérus., lichenized, see Ertz et al. (2013c; taxonomy), Lücking et al. (2016b; classification), sequences are available.

Savoryella E.B.G. Jones \& R.A. Eaton. 1969, Savoryellaceae, Savoryellales, Sordariomycetes, ten species, type: S. lignicola E.B.G. Jones \& R.A. Eaton, asexual morph unknown, saprobes, freshwater and marine, Australia, Brunei, China, Hong Kong, India, Japan, Malaysia, Mauritius, Mexico, Philippines, South Africa, Thailand, Taiwan, UK, see Gayatri Mambiar and Raveendran et al. (2009; diversity), Nambiar and Raveendran (2009a, b; diversity), Nambiar et al. (2009; diversity), Dethoup and Manoch (2009; diversity), Kurniawati et al. (2010; diversity), Alias et al. (2010; diversity), Boonyuen et al. (2011; outline, phylogeny, morphology, classification), Awaluddin et al. (2015; diversity), Maharachchikumbura et al. (2015, 2016; outline), cultures and sequences are available, holotype of type: IMI 129784. 
Savulescua Petr. 1959, Diaporthales genera incertae sedis, Sordariomycetes, type: S. insignis Petr., asexual morph unknown, Puerto Rico, see Lumbsch and Huhndorf (2010; outline), Kirk et al. (2013; genus accepted), Maharachchikumbura et al. (2015, 2016; outline), sequences are unavailable.

Sawadaea Miyabe 1914, Erysiphaceae, Erysiphales, Leotiomycetes, ten species, type: S. bicornis (Wallr. Fr.) Homma, sexual and hyphomycetous asexual morphs, biotrophic, obligate plant pathogens, terrestrial, worldwide, see Takamatsu et al. (2008c; phylogeny and taxonomy of S. nankinensis), Lumbsch and Huhndorf (2010; outline), Braun and Cook (2012; taxonomy), Kirk et al. (2013; genus accepted), cultures and sequences are available.

Saxomyces Selbmann \& Isola, MB802899. For diagnosis see Fungal Diversity 65(1): 174 2014, Dothideomycetes genera incertae sedis, type: Saxomyces alpinus Zucconi \& Selbmann, MB802892, rock-inhabiting fungus; teleomorph unknown; For diagnosis see Fungal Diversity 65(1): 174 (2014). From granite, Val de La Mare, Passo Stelvio, Alps, Italy; CCFEE 5470. Culture preserved in liquid nitrogen and in dried condition (NCBI accession numbers: KC315861 (SSU), KC315872 (LSU), KC315883 (mtSSU), taxonomic species delimitation supported by molecular data.

Notes: The genus Saxomyces was invalidly published because the type: S. alpinus was invalidly published [ICN (Melbourne) Art. 40].

The genus and the type: are here validated as follows:

Saxomyces Selbmann \& Isola gen. nov., MB819855. For diagnosis see Fungal Diversity 65(1): 174 (2014).

Type: Saxomyces alpinus Zucconi \& Selbmann sp. nov., MB819851. For diagnosis see Fungal Diversity 65(1): 174 (2014). Holotype: CBS 135222. From granite, Val de La Mare, Passo Stelvio, Alps, Italy; = CCFEE 5470.

Additional species: Saxomyces penninicus Zucconi \& Onofri, MB802900. For diagnosis see Fungal Diversity 65(1): 175 (2014). From sandstone, Punta Indren, Monte Rosa, Alps, Italy; CCFEE 5495. Culture preserved in dried condition (NCBI accession numbers: KC315864 (SSU), KC315875 (LSU), KC315886 (mtSSU)), taxonomic species delimitation supported by molecular data. The species was invalidly published because the type: S. alpinus was invalidly published [ICN (Melbourne) Art. 40]. It is here validated as follows:

Saxomyces penninicus Zucconi \& Onofri sp. nov., MB819852. For diagnosis see Fungal Diversity 65(1): 175 (2014). Holotype: CBS H-22053. From sandstone, Punta Indren, Monte Rosa, Alps, Italy; = CCFEE 5495.

Saxophila Selbmann \& de Hoog 2016, Extremaceae, Capnodiales, Dothideomycetes, one species, type: S. tyrrhenica Selbmann \& de Hoog, hyphomycetous, sexual morph unknown, rock-inhabiting, see Isola et al. (2016; taxonomy, phylogeny), Wijayawardene et al. (2017; outline), cultures available for the type: CBS 139725 = CCFEE 5935.

S. S. Ahmad 1961, Ascomycota genera incertae sedis, three species, type: S. gaubae (Petr.) S. Ahmad, coelomycetous, sexual morph unknown, saprobes, terrestrial, Asia, Australasia, tropical, see Wijayawardene et al. (2012, 2017; outline), Kirk et al. (2013; genus accepted), cultures and sequences are available but lacks for the type, needs generic revision.

Scalenomyces I.I. Tav. 1985, Laboulbeniaceae, Laboulbeniales, Laboulbeniomycetes, one species, type: S. endogaeus (F. Picard) I.I. Tav., asexual morph unknown, parasites, Sardinia, see Lumbsch and Huhndorf (2010; outline), Rossi (2010; new species), Kirk et al. (2013; genus accepted), sequences and culture unavailable.

Scaphidiomyces Thaxt. 1912, Laboulbeniaceae, Laboulbeniales, Laboulbeniomycetes, five species, type: $S$. baeocerae Thaxt., asexual morph unknown, biotrophic on Coleoptera (Scaphidiinae), South America, West Africa, see Lumbsch and Huhndorf (2010; outline), 
Kirk et al. (2013; genus accepted), cultures and sequences are unavailable, needs generic revision.

Scaphidium Clem. 1901, Ascomycota genera incertae sedis, one species, type: S. boutelouae Clem., coelomycetous, sexual morph unknown, saprobes, terrestrial, USA, see Wijayawardene et al. (2012, 2017; outline), Kirk et al. (2013; genus accepted), sequences are available, needs generic revision.

Scedosporium Sacc. ex Castell. \& Chalm. 1919, Microascaceae, Microascales, Sordariomycetes, seven species, type: S. apiospermum Sacc. ex Castell. \& Chalm., hyphomycetous, sexual morph unknown, saprobes, human pathogen, terrestrial, worldwide, see Gilgado et al. (2008; new species), Seifert et al. (2011; morphology), Wijayawardene et al. (2012, 2017; outline), Kirk et al. (2013; genus accepted), Lackner et al. (2014; new species), Vandeputte et al. (2014; genome study), Maharachchikumbura et al. (2015, 2016; outline, phylogeny), Crous et al. (2016a; taxonomy, phylogeny), cultures available for the type: IHEM 14462.

Scelophoromyces Thaxt. 1912, Laboulbeniaceae, Laboulbeniales, Laboulbeniomycetes, one species, type: S. osorianus Thaxt., asexual morph unknown, biotrophic on Coleoptera (Staphylinidae, Osorius sp.), South America, see Lumbsch and Huhndorf (2010; outline), Kirk et al. (2013; genus accepted), cultures and sequences are unavailable, needs generic revision.

Scepastocarpus Santam. 2004, Laboulbeniaceae, Laboulbeniales, Laboulbeniomycetes, one species, type: S. peritheciiformis Santam., asexual morph unknown, biotrophic on aquatic Coleoptera (Hydrophilidae, Hydrochus sp.), Spain, see Lumbsch and Huhndorf (2010; outline), related to Zodiomyces Thaxt., cultures and sequences are unavailable, needs generic revision.

Sceptrifera Deighton 1965, Ascomycota genera incertae sedis, one species, type: S. pulchra Deighton, hyphomycetous, sexual morph unknown, saprobes, terrestrial, Philippines, see Seifert et al. (2011; morphology), Wijayawardene et al. (2012, 2017; outline), Kirk et al. (2013; genus accepted), cultures and sequences are unavailable, needs generic revision.

Schadonia Körb. 1859, Ramalinaceae, Lecanorales, Lecanoromycetes, three species, type: S. alpina Körb., asexual morph unknown, lichenized, terrestrial, see Ekman et al. (2008; molecular), Lumbsch and Huhndorf (2010; outline), Kirk et al. (2013; genus accepted), Lücking et al. (2016b; classification), culture and sequences are unavailable for type.

Schaereria Th. Fr. 1855, Schaereriaceae, Sarrameanales, Lecanoromycetes, 16 species, type: S. lugubris (A. Massal.) Körb., lichenized, Africa, Europe, Asia, see Kukwa and Flakus (2009; taxonomy), Lewis Smith (2009; taxonomy), Spribille et al. (2009; taxonomy, new species), Lumbsch and Huhndorf (2010; outline), Hodkinson and Lendemer (2011b; taxonomy), Schmull et al (2011; phylogeny), Klepsland and Tønsberg (2012; taxonomy), Kirk et al. (2013; genus accepted), Resl et al. (2015; phylogeny), Tarasova et al. (2016; ecology), Lücking et al. (2016b; classification), sequences are available.

Scharifia Petr. 1955, Sordariomycetes genera incertae sedis, one species, type: $S$. procumbens Petr., asexual morph unknown, saprobes, terrestrial, Iran, see Lumbsch and Huhndorf (2010; outline), Kirk et al. (2013; genus accepted), Maharachchikumbura et al. (2015, 2016; outline), cultures and sequences are unavailable, needs generic revision.

Scheffersomyces Kurtzman \& M. Suzuki 2010, Debaryomycetaceae, Saccharomycetales, Saccharomycetes, ten species, type: S. stipitis (Pignal) Kurtzman \& M. Suzuki, asexual reproduction is by multilateral budding, saprophytic, in beetles and beetle larvae in various trees, rotted wood, one species ( $S$. spartinae) was isolated from oyster grass (Spartina alterniflora) marshes, worldwide, see Kurtzman and Suzuki (2010; taxonomy), S. stipitis (formerly Pichia stipitis) and S. shehatae (formerly Candida) are important for biomass utilization because of their ability to ferment D-xylose, cultures and sequences are available. 
Schenckiella Henn. 1893 (= Allothyrium Syd. 1939 fide Hongsanan et al. 2014c), Asterinaceae, Asterinales, Dothideomycetes, one species, type: S. marcgraviae Henn., asexual morph unknown. Epiphytes, terrestrial, Spain, see Lumbsch and Huhndorf (2010; outline; accepted as a genus in Saccardiaceae), Hongsanan et al. (2014c; taxonomy, keys, nomenclature, accepted as a genus in Asterinaceae), Wijayawardene et al. (2014c; outline), placement in Asterinaceae supported by morphology, cultures and sequences are unavailable. Schiffnerula Höhn. 1909, Englerulaceae, Dothideomycetes families incertae sedis, 98 species, type: S. mirabilis Höhn. 1909, asexual morph hyphomycetous, epiphytes, pathogens, terrestrial, widely distributed, see Lumbsch and Huhndorf (2010; outline), Hosagoudar (2011; morphology, key), Kirk et al. (2013; genus accepted), Dai et al. (2014c; morphology), cultures and sequences are unavailable, type specimen need recollect and sequence.

Schismatomma Flot. \& Körb. ex A. Massal. 1852, Roccellaceae, Arthoniales, Arthoniomycetes, ten species, type: S. pericleum (Ach.) Branth \& Rostr., Asia, North America, Europe, see Hauck and Wirth (2010; ecology), Kocourková et al. (2010; taxonomy), Lumbsch and Huhndorf (2010; outline), Ertz and Tehler (2011; phylogeny), Stepanchikova et al. (2011; new records), Kirk et al. (2013; genus accepted), Tehler et al. (2013a; phylogeny), Lendemer and Harris (2014; taxonomy), Himelbrant et al. (2016; new records), London (2016; new record), Motiejūnaite et al. (2016; new records), Lücking et al. (2016b; classification), sequences are available.

Schistophoron Stirt. 1876, Graphidaceae, Lecanorales, Lecanoromycetes, five species, type: S. tenue Stirt., Asia, see Tehler et al. (2009a; systematic study), Lumbsch and Huhndorf (2010; outline), Singh and Swarnalatha (2011; new species), Plata et al. (2012; classification), Luecking et al. (2013; molecular phylogeny), Prieto et al. (2012; classification), Kirk et al. (2013; genus accepted), Weerakoon and Aptroot (2016; new species from Sri Lanka), sequences are available.

Schizochora Syd. \& P. Syd. 1913, Phyllachoraceae, Phyllachorales, Sordariomycetes, one species, type: S. elmeri Syd. \& P. Syd., from living leaves, worldwide, see Lumbsch and Huhndorf (2010; outline), Kirk et al. (2013; genus accepted), Maharachchikumbura et al. (2015, 2016; outline), cultures and sequences are unavailable, needs generic revision.

Schizodiscus Brusse 1888, Lecideaceae, Lecideales, Lecanoromycetes, one species, type: $S$. afroalpinus Brusse, subpolar region, see Lumbsch and Huhndorf (2010; outline), Hertel (2014; taxonomy), Lücking et al. (2016b; classification), sequences are unavailable.

Schizopelte Th. Fr. 1875, Opegraphaceae, Arthoniales, Arthoniomycetes, four species, type: S. californica Th. Fr., lichenized, see Lumbsch and Huhndorf (2010; outline), Ertz, and Tehler (2011; phylogeny), Kirk et al. (2013; genus accepted), Lücking et al. (2016b; classification), sequences are available.

Schizosaccharomyces Lindner 1893, Schizosaccharomycetaceae, Schizosaccharomycetales, Schizosaccharomycetes, four species, type: S. pombe Lindner, asexual reproduction is by fission, saprophytic, fruit wines and fruit, honey, dried figs, sugar cane molasses, tree fluxes, worldwide, see Lumbsch and Huhndorf (2010; outline), Kirk et al. (2013; genus accepted), cultures and sequences are available.

Schizothecium Corda 1838, Lasiosphaeriaceae, Sordariales, Sordariomycetes, one species, type: S. fimicola Corda, asexual morph unknown, on dung, terrestrial, Spain, see Chang et al. (2010; phylogeny), Lumbsch and Huhndorf (2010; outline, accepted as a genus in Sordariales genera incertae sedis), Kirk et al. (2013; genus accepted), Maharachchikumbura et al. (2015, 2016; outline), cultures and sequences are available but lacks for the type, needs generic revision.

Schizothyra Bat. \& C.A.A. Costa 1957, Ascomycota genera incertae sedis, one species, type: S. minuta Bat. \& C.A.A. Costa, coelomycetous, sexual morph unknown, saprobes, terrestrial, 
see Wijayawardene et al. (2012, 2017; outline), Kirk et al. (2013; genus accepted), cultures and sequences are unavailable, needs generic revision.

Schizothyrella Thüm. 1880, Ascomycota genera incertae sedis, one species, type: $S$. quercina (Lib.) Thüm., coelomycetous, sexual morph unknown, saprobes, terrestrial, Europe, USA, see Wijayawardene et al. (2012, 2017; outline), Kirk et al. (2013; genus accepted), cultures and sequences are unavailable, needs generic revision.

Schizothyrioma Höhn. 1917, Dermateaceae, Helotiales, Leotiomycetes, one species, type: Sc. ptarmicae (Desm.) Höhn., asexual morph unknown, saprobes, terrestrial, Europe, see Lumbsch and Huhndorf (2010; outline), Kirk et al. (2013; genus accepted), cultures and sequences are unavailable, needs generic revision.

Schizothyrium Desm. 1849 (= Zygophiala E.W. Mason 1945 fide Rossman et al. 2015b, Schizothyriaceae, Dothideomycetes family incertae sedis, five species, type: S. acerinum Desm., asexual morph unknown, saprobes, terrestrial, pantropical, see Lumbsch and Huhndorf (2010; outline), Kirk et al. (2013; genus accepted), Hyde et al. (2013, accepted as a genus in Schizothyriaceae), Quaedvlieg et al. (2014; phylogeny), Wijayawardene et al. (2014c; outline), Phookamsak et al. (2016; taxonomy), cultures and sequences are available, needs generic revision.

Schizothyropsis Bat. \& A.F. Vital 1960, Ascomycota genera incertae sedis, one species, type: S. citri Bat. \& A.F. Vital., coelomycetous, sexual morph unknown, saprobes, terrestrial, see Wijayawardene et al. (2012, 2017; outline), Kirk et al. (2013; genus accepted), cultures and sequences are unavailable, needs generic revision.

Schizotrema Mangold \& Lumbsch 2009, Graphidaceae, Ostropales, Lecanoromycetes, 13 species, type: S. zebrinum Mangold, asexual morph unknown, lichenized, terrestrial, tropical, see Kalb et al. (2009; new report), Rivas Plata et al. (2010a; key), Sipman et al. (2012; key), Lumbsch and Huhndorf (2010; outline), Lücking et al. (2016b; classification), sequences are available.

Schizotrichum McAlpine 1903, Ascomycota genera incertae sedis, one species, type: S. lobeliae McAlpine, hyphomycetous, sexual morph unknown, saprobes, terrestrial, Australia, see Seifert et al. (2011; morphology), Wijayawardene et al. (2012, 2017; outline), Kirk et al. (2013; genus accepted), cultures and sequences are unavailable, needs generic revision.

Schizoxylon Pers. 1811, Stictidaceae, Ostropales, Lecanoromycetes, one species, type: S. sepincola Pers., Asia, see Lumbsch and Huhndorf (2010; outline), Muggia et al. (2011a; partial sequence), Kirk et al. (2013; genus accepted), Aptroot et al. (2014f; molecular phylogeny), Konoreva et al. (2016; taxonomy), Lücking et al. (2016b; classification), sequences are available.

Schnablia Sacc. \& P. Syd. 1899, Leotiomycetes genera incertae sedis, one species, type: $B$. schnablianum Rehm, asexual morph unknown, saprobes, terrestrial, Europe, see Lumbsch and Huhndorf (2010; outline), Kirk et al. (2013; genus accepted), Jaklitsch et al. (2016a; classification), cultures and sequences are unavailable.

Schrakia Hafellner 1979, Patellariaceae, Patellariales, Dothideomycetes, two species, type: S. crassula (Starbäck) Hafellner, asexual morph unknown, saprobes, South and North America, see Lumbsch and Huhndorf (2010; outline), Kirk et al. (2013; genus accepted), cultures and sequences are unavailable.

Schroeteria G. Winter 1881, Ascomycota genera incertae sedis, one species, type: $S$. delastrina (Tul. \& C. Tul.) G. Winter, hyphomycetous, sexual morph unknown, saprobes, terrestrial, Asia, Europe, see Seifert et al. (2011; morphology), Wijayawardene et al. (2012, 2017; outline), Kirk et al. (2013; genus accepted), cultures and sequences are unavailable, needs generic revision.

Schwanniomyces Klöcker emend. M. Suzuki \& Kurtzman 2010, Debaryomycetaceae, Saccharomycetales, Saccharomycetes, one species, type: S. occidentalis Klöcker, asexual 
reproduction is by multilateral budding, saprophytic, soil, tree exudates, cucumber brines, fruit flies, human feces, worldwide, see Lumbsch and Huhndorf (2010; outline), Kirk et al. (2013; genus accepted), Kurtzman and Suzuki (2010; revision), cultures and sequences are available.

Schwarzmannia Pisareva 1968, Ascomycota genera incertae sedis, one species, type: S. goebeliae Pisareva, coelomycetous, sexual morph unknown, saprobes, terrestrial, see Wijayawardene et al. (2012, 2017; outline), Kirk et al. (2013; genus accepted), cultures and sequences are unavailable, needs generic revision.

Schweinitziella Speg. 1888, Trichosphaeriaceae, Trichosphaeriales, Sordariomycetes, three species, type: S. styracum Speg., asexual morph unknown, fungicolous, terrestrial, worldwide, see Lumbsch and Huhndorf (2010; outline), Kirk et al. (2013; genus accepted), Maharachchikumbura et al. (2015, 2016; outline), cultures and sequences are unavailable, needs generic revision.

Scirrhia Nitschke ex Fuckel 1870, Dothideomycetes genera incertae sedis, ten species, type: S. rimosa (Alb. \& Schwein.) Fuckel, asexual morph unknown, saprobes, pathogens, terrestrial, marine, worldwide, see Lumbsch and Huhndorf (2010; outline), Crous et al. (2011b; phylogeny), Kirk et al. (2013; genus accepted), Wijayawardene et al. (2014c; outline, accepted as Dothideomycetes genera incertae sedis), cultures and sequences are available but lacks for the type, needs generic revision.

Scirrhophoma Petr. 1941, Ascomycota genera incertae sedis, one species, type: $S$. dothideoides (Mont.) Petr., coelomycetous, sexual morph unknown, saprobes, terrestrial, Europe, see Wijayawardene et al. (2012, 2017; outline), Kirk et al. (2013; genus accepted), cultures and sequences are unavailable, needs generic revision.

Sclerococcum Fr. 1825, Dactylosporaceae, Eurotiomycetes families incertae sedis, 18 species, type: S. sphaerale (Ach.) Fr., hyphomycetous, sexual morph unknown, saprobes, lichenicolous, terrestrial, Europe, see Seifert et al. (2011; morphology), Wijayawardene et al. (2012, 2017; outline), Kirk et al. (2013; genus accepted), Lücking et al. (2016b; classification); sequences are available.

Scleroconidioma Tsuneda, Currah \& Thormann 2000, Dothideomycetes genera incertae sedis, one species, type: S. sphagnicola Tsuneda, Currah \& Thormann, hyphomycetous, sexual morph unknown, saprobes, pathogens, terrestrial, worldwide, see Seifert et al. (2011; morphology), Wijayawardene et al. (2012, 2014c, 2017; outline), cultures available for the type: UAMH 9731.

Sclerocrana Samuels \& L.M. Kohn 1987, Helotiales genera incertae sedis, Leotiomycetes, four species, type: S. atra Samuels \& L.M. Kohn, asexual morph unknown, saprobes, terrestrial, New Zealad, see Lumbsch and Huhndorf (2010; outline), Kirk et al. (2013; genus accepted), cultures and sequences are unavailable, needs generic revision.

Sclerographiopsis Deighton 1973, Ascomycota genera incertae sedis, one species, type: $S$. dalbergiae Deighton, hyphomycetous, sexual morph unknown, saprobes, Africa, Caribbean, see Seifert et al. (2011; morphology), Wijayawardene et al. (2012, 2017; outline), Kirk et al. (2013; genus accepted), cultures and sequences are unavailable, needs generic revision.

Sclerographium Berk. 1854, Ascomycota genera incertae sedis, three species, type: $S$. aterrimum Berk., hyphomycetous, sexual morph unknown, saprobes, Africa, Asia, see Seifert et al. (2011; morphology), Wijayawardene et al. (2012, 2017; outline), Kirk et al. (2013; genus accepted), cultures and sequences are unavailable, needs generic revision.

Scleromeris Syd. 1926, Ascomycota genera incertae sedis, three species, type: S. guazumae Syd., coelomycetous, sexual morph unknown, saprobes, Central America, see Wijayawardene et al. (2012, 2017; outline), Kirk et al. (2013; genus accepted), cultures and sequences are unavailable, needs generic revision. 
Scleromitrula S. Imai 1941, Sclerotiniaceae, Helotiales, Leotiomycetes, six species, type: S. shiraiana (Henn.) S. Imai, asexual morph unknown, terrestrial, saprobes, worldwide, see Lumbsch and Huhndorf (2010; outline), Kirk et al. (2013; genus accepted), Pärtel et al. (2017; phylogeny, strains of type were grouped in Rutstroemiaceae and Sclerotiniaceae), needs generic revision.

Scleropezicula Verkley 1999 (= Cryptosympodula Verkley 1999 fide Johnston et al. 2014b), Pezizellaceae, Helotiales, Leotiomycetes, six species, type: S. alnicola (J.W. Groves) Verkley, asexual morph formerly known in Cryptosympodula, terrestrial, saprobes, worldwide, see Lumbsch and Huhndorf (2010; outline), Kirk et al. (2013; genus accepted), Johnston et al. (2014b; nomenclature), Jaklitsch et al. (2016a; classification), cultures and sequences are unavailable, needs generic revision.

Sclerophoma Höhn. 1909, Ascomycota genera incertae sedis, 30 species, type: needs typification, coelomycetous, sexual morph unknown, saprobes, worldwide, see Wijayawardene et al. (2012, 2017; outline), Kirk et al. (2013; genus accepted), cultures and sequences are unavailable, needs generic revision.

Sclerophora Chevall. 1826, Coniocybaceae, Coniocybales, Coniocybomycetes, six species; type: S. furfuracea (L.) Chevall., lichenized, see Lumbsch and Huhndorf (2010; outline), Kirk et al. (2013; genus accepted), Prieto et al. (2013; phylogeny), Lücking et al. (2016b; classification), Suija et al. (2016; pylogeny), sequences are available.

Sclerophyton Eschw. 1824, Opegraphaceae, Arthoniales, Arthoniomycetes, 14 species, (probably less, needs revision), type: S. elegans Eschw., asexual morph unknown, lichenized, terrestrial, see Lumbsch and Huhndorf (2010; outline), Ertz. and Tehler (2011; phylogeny, molecular), Kirk et al. (2013; genus accepted), Seavey and Seavey (2014; new records), Lücking et al. (2016b; classification), sequences are available

Scleropycnis Syd. \& P. Syd. 1911, Ascomycota genera incertae sedis, two species, type: S. abietina Syd. \& P. Syd., coelomycetous, sexual morph unknown, saprobes, Europe, see Wijayawardene et al. (2012, 2017; outline), Kirk et al. (2013; genus accepted), cultures and sequences are unavailable, needs generic revision.

Scleropyrenium H. Harada 1993, Verrucariaceae, Verrucariales, Eurotiomycetes, two species, type: S. japonicum H. Harada, asexual morph unknown, lichenized, terrestrial, Japan, see Lumbsch and Huhndorf (2010; outline), Prieto et al. (2012; phylogeny), Kirk et al. (2013; genus accepted), Lücking et al. (2016b; classification), sequences are unavailable.

Sclerostagonospora Höhn. 1917, Phaeosphaeriaceae, Pleosporales, Dothideomycetes, eight species, type: S. heraclei (Sacc.) Höhn., coelomycetous, sexual morph unknown, saprobes, terrestrial, cosmopolitan, see Crous et al. (2011a, 2016b; new species, phylogeny), Quaedvlieg et al. (2013; new species, phylogeny), Wijayawardene et al. (2016b, 2017; taxonomy, outline, phylogeny), cultures are available.

Sclerotinia Fuckel 1870, Sclerotiniaceae, Helotiales, Leotiomycetes, 15 species, type: S. libertiana Fuckel, asexual morph unknown, saprobes, terrestrial, worldwide, see Lumbsch and Huhndorf (2010; outline), Kirk et al. (2013; genus accepted), Pärtel et al. (2017; pylogeny), cultures and sequences are available, needs generic revision.

Sclerotium Tode 1790, Sclerotiniaceae, Helotiales, Leotiomycetes, c. 100 species (probably more than this), type: $S$. complanatum Tode, hyphomycetous, sexual morph unknown, see Seifert et al. (2011; morphology), Hyde et al. (2011; outline), Wijayawardene et al. (2012, 2017; outline), Kirk et al. (2013; genus accepted), cultures and sequences are unavailable for type, needs generic revision.

Sclerozythia Petch 1937, Ascomycota genera incertae sedis, one species, type: S. brassicae Petch, coelomycetous, sexual morph unknown, saprobes, British Isles, see Wijayawardene et al. (2012, 2017; outline), Kirk et al. (2013; genus accepted), cultures and sequences are unavailable, needs generic revision. 
Scolecobasidiella M.B. Ellis 1971, Ascomycota genera incertae sedis, two species, type: $S$. avellanea (Sappa \& Mosca) M.B. Ellis, hyphomycetous, sexual morph unknown, saprobes, Africa, Caribbean, see Shenoy et al. (2010; DNA), Seifert et al. (2011; morphology), Wijayawardene et al. (2012, 2017; outline), Kirk et al. (2013; genus accepted), sequences are available, needs generic revision.

Scolecobasidium E.V. Abbott 1927, Pleosporales genera incertae sedis, Dothideomycetes, one species, type: S. terreum E.V. Abbott, hyphomycetous, sexual morph unknown, saprobes, British Isles, see Seifert et al. (2011; morphology), Wijayawardene et al. (2012, 2017; outline), Kirk et al. (2013; genus accepted), cultures and sequences are unavailable, needs generic revision.

Scolecobasidium E.V. Abbott 1927, Sympoventuriaceae, Venturiales, Dothideomycetes, 64 species, type: S. terreum E.V. Abbott, sexual stage unknown, animal pathogens, saprobes, terrestrial, aquatic, worldwide, see Hamada and Niichiro (2008; bathroom), Jiang and Zhang (2008; new species), YueMing and TianYu (2008; China, soil), Hamayun et al. (2009; growth enhancement in plant), Abe and Hamada (2011; detergent rich environment), Punithalingam and Spooner (2011; new species), Ge et al (2012; human pathogen), Muthukrishnan et al. (2012; alkalotolerance in scrub forest), D'Souza and Bhat (2013; litter and endophyte), Hao et al. (2013; new species), Mahmoud and Narisawa (2013; new species), Ren et al. (2013a; new species), Samerpitak et al. (2014; phylogeny, taxonomy, classification), Garzoli et al. (2015; marine), Hou et al. (2015; corals), Oliveira et al. (2016a; drinking water, Brazil), Pundhir et al. (2016; pneumonia), Shi et al. (2016; human pathogen), sequences are available, ex type of type: CBS 203.27.

Scolecobeltrania Iturr., R.F. Castañeda \& R. Fernández 2013, Ascomycota genera incertae sedis, one species, type: S. vermispora Iturr., R.F. Castañeda \& R. Fernández, hyphomycetous, sexual morph unknown, saprobes, terrestrial, Venezuela, see Iturriaga et al. (2013; taxonomy), Wijayawardene et al. (2017; outline), cultures and sequences are unavailable, needs generic revision.

Scolecobonaria Bat. 1962, Dothideomycetes genera incertae sedis, two species, type: $S$. filiformis (W. Yamam.) Bat., asexual morph unknown, saprobes, terrestrial, Taiwan, USA, see Lumbsch and Huhndorf (2010; outline), Kirk et al. (2013; genus accepted), Wijayawardene et al. (2014c; outline), cultures and sequences are unavailable, needs generic revision.

Scolecodochium K. Matsush. \& Matsush. 1996, Ascomycota genera incertae sedis, one species, type: S. malayense K. Matsush. \& Matsush., hyphomycetous, sexual morph unknown, saprobes, Malaysia, see Seifert et al. (2011; morphology), Wijayawardene et al. (2012, 2017; outline), Kirk et al. (2013; genus accepted), cultures and sequences are unavailable, needs generic revision.

Scolecopeltidium F. Stevens \& Manter 1925, Micropeltidaceae, Microthyriales, Dothideomycetes, c. 80 species, type: S. salacensis (Racib.) F. Stevens \& Manter, asexual morph unknown, epiphytes, terrestrial, tropical, see Lumbsch and Huhndorf (2010; outline, accepted as a genus in Microthyriaceae), Wu et al. (2011; taxonomy), Hyde et al. (2013; accepted as a genus in Micropeltidaceae), Wijayawardene et al. (2014c; outline), cultures and sequences are unavailable.

Scolecosporiella Petr. 1921, Ascomycota genera incertae sedis, six species, type: S. typhae (Oudem.) Petr., coelomycetous, sexual morph unknown, saprobes, terrestrial, worldwide, see Wijayawardene et al. (2012, 2016, 2017; outline, taxonomy), Kirk et al. (2013; genus accepted), cultures and sequences are unavailable, needs generic revision.

Scolecostigmina U. Braun 1998, Mycosphaerellaceae, Capnodiales, Dothideomycetes, 25 species, type: S. mangiferae (Koord.) U. Braun \& Mouch., hyphomycetous, plant pathogens, leaf spotting, Africa, Asia, Australia, North and South America, Oceania, West Indies, see 
Seifert (2011; morphology), Wijayawardene et al. (2012, 2014c, 2017; outline), Crous et al. (2012a; phylogeny), Braun et al. (2014b; taxonomy), cultures available for the type: CBS 125467, holotype of type species: Indonesia, Java, Prov. Kedu, Purworedjo, on Mangifera indica, 21 Sep. 1905, S.H. Koorders, no. 6, ser. 5 (unknown).

Scolecotheca Søchting \& B. Sutton 1997, Ascomycota genera incertae sedis, one species, type: S. cornuta Søchting \& B. Sutton, coelomycetous, sexual morph unknown, saprobes, Europe, see Wijayawardene et al. (2012, 2017; outline), Kirk et al. (2013; genus accepted), cultures and sequences are unavailable, needs generic revision.

Scolecoxyphium Cif. \& Bat. 1956, Dothideomycetes genera incertae sedis, four species, type: S. fraserae Cif. \& Bat., coelomycetous, sexual morph unknown, saprobes, terrestrial, tropical, see Wijayawardene et al. (2012, 2014c, 2017; outline), Kirk et al. (2013; genus accepted), cultures and sequences are unavailable, needs generic revision.

Scolecozythia Curzi 1927, Ascomycota genera incertae sedis, one species, type: S. valsivora Curzi, coelomycetous, sexual morph unknown, saprobes, Italy, see Wijayawardene et al. (2012, 2017; outline), Kirk et al. (2013; genus accepted), cultures and sequences are unavailable, needs generic revision.

Scoliciosporum A. Massal. 1852, Scoliciosporaceae, Lecanorales, Lecanoromycetes, 15 species; type: S. holomelaeum (Flörke) A. Massal., lichenized, see Spribille et al. (2009; new species), Dolnik et al. (2010; new report: Germany), Lumbsch and Huhndorf (2010; outline), Dymytrova (2011; notes), Kukwa et al. (2012; new records: poland), Matwiejuk et al. (2012; new report), Kirk et al. (2013; genus accepted), Marmor et al. (2013; new record), Ardelean et al. (2015; ecology), Lücking et al. (2016b; classification), sequences are available.

Scolicosporium Lib. ex Roum. 1880, ?Phaeosphaeriaceae, Pleosporales, Dothideomycetes, 13 species, type: $S$. fagi Lib. ex Roum., coelomycetous, sexual morph unknown, saprobes, worldwide, see Seifert et al. (2011; treated as hyphomycetous), Wijayawardene et al. (2012, 2013, 2016; outline, treated as coelomycetous, phylogeny, taxonomy), Kirk et al. (2013; genus accepted), cultures and sequences are available but lacks for the type, needs generic revision.

Scoliocarpon Nyl. 1858, Sordariomycetes genera incertae sedis, one species, type: S. pupula (Tuck.) Nyl., asexual morph unknown, saprobes, terrestrial, North America, see Lumbsch and Huhndorf (2010; outline), Kirk et al. (2013; genus accepted), Maharachchikumbura et al. (2015, 2016; outline), cultures and sequences are unavailable, needs generic revision.

Scolionema Theiss. \& Syd. 1918, Perisporiopsidaceae, Dothideomycetes families incertae sedis, one species, type: S. palmarum (Kunze \& Fr.) Theiss. \& Syd., asexual morph unknown, saprobes, terrestrial, tropical, see Lumbsch and Huhndorf (2010; outline), Hyde et al. (2013; accepted as a genus in Perisporiopsidaceae), Kirk et al. (2013; genus accepted), Wijayawardene et al. (2014c; outline), cultures and sequences are unavailable.

Scoliotidium Bat. \& Cavalc. 1963, Ascomycota genera incertae sedis, one species, type: $S$. lauracearum Bat. \& Cavalc., coelomycetous, sexual morph unknown, saprobes, Brazil, see Wijayawardene et al. (2012, 2017; outline), Kirk et al. (2013; genus accepted), cultures and sequences are unavailable, needs generic revision.

Scopaphoma Dearn. \& House 1925, Ascomycota genera incertae sedis, one species, type: $S$. corioli Dearn. \& House, coelomycetous, sexual morph unknown, saprobes, USA, see Wijayawardene et al. (2012, 2017; outline), Kirk et al. (2013; genus accepted), cultures and sequences are unavailable, needs generic revision.

Scopinella Lév. 1846, Stachybotryaceae, Hypocreales, Sordariomycetes, nine species, type: S. pleiospora (J. Schröt.) Sacc., asexual morph aunknown, saprobes, lichenicolous, terrestrial, worldwide, see Lumbsch and Huhndorf (2010; outline, accepted as a genus in Hypocreales, genera incertae sedis), Kirk et al. (2013; genus accepted), Sánchez et al. (2013; new species), 
Maharachchikumbura et al. (2015, 2016; outline), cultures and sequences are available but lacks for the type, needs generic revision.

Scopulariella Gjaerum 1971, Ascomycota genera incertae sedis, one species, type: S. vaccinii Gjaerum, hyphomycetous, sexual morph unknown, saprobes, Europe, see Seifert et al. (2011; morphology), Wijayawardene et al. (2012, 2017; outline), Kirk et al. (2013; genus accepted), cultures and sequences are unavailable, needs generic revision.

Scopulariopsis Bainier 1907, Microascaceae, Microascales, Sordariomycetes, 32 species, type: S. brevicaulis (Sacc.) Bainier, hyphomycetous, sexual morph unknown, from soil, saprobes, human pathogen, terrestrial, worldwide, see Seifert et al. (2011; morphology), Iwen et al. (2012; human pathogen, phylogeny), Wijayawardene et al. (2012, 2017; outline), Kirk et al. (2013; genus accepted), Pan et al. (2014; new species, China), Maharachchikumbura et al. (2015, 2016; outline, phylogeny), Grum-Grzhimaylo et al. (2016; DNA), cultures available for the type: UAMH 10915.

Scoriadopsis J.M. Mend. 1930, Capnodiaceae, Capnodiales, Dothideomycetes, one species, type: S. miconiae J.M. Mend., asexual morph unknown, epiphytes, terrestrial, South America, see Lumbsch and Huhndorf (2010; outline), Chomnunti et al. (2011; taxonomy), Hyde et al. (2013; accepted as a genus in Capnodiaceae), Wijayawardene et al. (2014c; outline), cultures and sequences are unavailable.

Scorias Fr. 1832, Capnodiaceae, Capnodiales, Dothideomycetes, three species, type: $S$. spongiosa (Schwein.) Fr., asexual morph unknown, epiphytes, terrestrial, tropical, see Crous et al. (2009d; DNA, phylogeny), Lumbsch and Huhndorf (2010; outline), Chomnunti et al. (2011; taxonomy), Hyde et al. (2013; accepted as a genus in Capnodiaceae), Wijayawardene et al. (2014c; outline), cultures and sequences are available.

Scortechinia Sacc. 1891, Scortechiniaceae, Coronophorales, Sordariomycetes, eight species, type: S. culcitella (Berk. \& Ravenel) Speg., asexual morph unknown, saprobes, cosmopolitan, see Mugambi and Huhndorf (2010; phylogeny), Maharachchikumbura et al. (2015, 2016; outline), Jaklitsch et al. (2016a; classification), cultures and sequences are unavailable.

Scortechiniella Arx \& E. Müll. 1954, Scortechiniaceae, Coronophorales, Sordariomycetes, one species, type: S. similis (Bres.) Arx \& E. Müll., asexual morph unknown, saprobes, see Kirk et al. (2008; treated as a synonym of Nitschkia), Mugambi and Huhndorf (2010; phylogeny), Maharachchikumbura et al. (2015, 2016; outline), Jaklitsch et al. (2016a; classification), cultures and sequences are unavailable.

Scortechiniellopsis Sivan. 1974, Scortechiniaceae, Coronophorales, Sordariomycetes, one species, type: S. leonensis Sivan., asexual morph unknown, saprobes, cosmopolitan, see Mugambi and Huhndorf (2010; phylogeny), Maharachchikumbura et al. (2015, 2016; outline), Jaklitsch et al. (2016a; classification), cultures and sequences are available.

Scothelius Bat., J.L. Bezerra \& Cavalc. 1965, Ascomycota genera incertae sedis, one species, type: S. guianensis Bat., J.L. Bezerra \& Cavalc., coelomycetous, sexual morph unknown, saprobes, Brazil, see Wijayawardene et al. (2012, 2017; outline), Kirk et al. (2013; genus accepted), cultures and sequences are unavailable, needs generic revision.

Scotiosphaeria Sivan. 1977, Sordariomycetes genera incertae sedis, one species, type: S. endoxylinae Sivan., asexual morph unknown, saprobes, terrestrial, British Isles, see Lumbsch and Huhndorf (2010; outline), Kirk et al. (2013; genus accepted), Maharachchikumbura et al. (2015, 2016; outline), cultures and sequences are unavailable, needs generic revision.

Sculptolumina Marbach 2000, Caliciaceae, Caliciales, Lecanoromycetes, three species, type: S. japonica (Tuck.) Marbach, asexual morph unknown, lichenized, terrestrial, see Giralt et al. (2009; taxonomy), Joshi et al. (2010a; new record, taxonomy), Lumbsch and Huhndorf (2010; outline), Giralt et al. (2014; taxonomy), Kondratyuk (2015; new records), Lücking et al. (2016b; classification), sequences are unavailable. 
Scutaria Søchting, Arup \& Frödén 2013, Teloschistaceae, Teloschistales, Lecanoromycetes, one species, type: S. andina (Räsänen) Søchting, Frödén \& Arup., lichenized, see Arup et al. (2013; taxonomy), Lücking et al. (2016b; classification), sequences are available.

Scutellinia (Cooke) Lambotte 1887, Pyronemataceae, Pezizales, Pezizomycetes, 75 species, type: S. scutellata (L.) Lambotte, asexual morph unknown, from soil, saprobes, terrestrial, Europe, see Zhuang and Yang (2008; new species), Han et al. (2010a; new species, Korea), Lumbsch and Huhndorf (2010; outline), Zhuang (2010; new species), Choi et al. (2013b; new species), Hansen et al. (2013; phylogeny), Izquierdo-San et al. (2013; new species, Mexico), Kirk et al. (2013; genus accepted), Zhuang (2013; new species, key to species in China), cultures and sequences are available but lacks for the type.

Scutisporus Ando \& Tubaki 1985, Ascomycota genera incertae sedis, one species, type: $S$. brunneus K. Ando \& Tubaki, hyphomycetous, saprobes, terrestrial, aquatic, worldwide, see Seifert et al. (2011; morphology), Wijayawardene et al. (2012, 2017; outline), Kirk et al. (2013; genus accepted), Fiuza et al. (2015a; taxonomy), holotype of type: TKB-F-5093, cultures and sequences are unavailable, needs generic revision, compare with Biflagellosporella.

Scutobelonium Graddon 1984, Mollisiaceae, Helotiales, Leotiomycetes, one species, type: S. amorilens Graddon, asexual morph unknown, saprobes, terrestrial, British Isles, see Lumbsch and Huhndorf (2010; outline), Kirk et al. (2013; genus accepted), Jaklitsch et al. (2016a; classification), cultures and sequences are unavailable, needs generic revision.

Scutomollisia Nannf. 1976, Mollisiaceae, Helotiales, Leotiomycetes, 14 species, type: S. punctum (Rehm) Nannf., asexual morph unknown, saprobes, terrestrial, Europe, see Lumbsch and Huhndorf (2010; outline), Kirk et al. (2013; genus accepted), cultures and sequences are unavailable, needs generic revision.

Scutopeltis Bat. \& H. Maia 1957, Ascomycota genera incertae sedis, two species, type: S. alafiae Bat. \& H. Maia, coelomycetous, sexual morph unknown, saprobes, Ghana, see Wijayawardene et al. (2012, 2017; outline), Kirk et al. (2013; genus accepted), cultures and sequences are unavailable, needs generic revision.

Scutopycnis Bat. 1957, Ascomycota genera incertae sedis, two species, type: S. osmanthi Bat., coelomycetous, sexual morph unknown, saprobes, USA, see Wijayawardene et al. (2012, 2017; outline), Kirk et al. (2013; genus accepted), cultures and sequences are unavailable, needs generic revision.

Scutula Tul. 1852, Pilocarpaceae, Lecanorales, Lecanoromycetes, 41 species, two subspecies, three varieties, four forma species, type: $S$. wallrothii Tul., asexual morph unknown, lichenicolous, see Hawksworth et al. (2008; artificial key), Egan (2009; recent literature), Etayo and Triebel (2010; new records), Lumbsch and Huhndorf (2010; outline), Kirk et al. (2013; genus accepted), cultures and sequences are unavailable

Scutulopsis Velen. 1934, Helotiales genera incertae sedis, Leotiomycetes, one species, type: S. pinacea Velen., asexual morph unknown, saprobes, terrestrial, former Czechoslovakia, see Lumbsch and Huhndorf (2010; outline), Kirk et al. (2013; genus accepted), cultures and sequences are unavailable, needs generic revision.

Scyphospora L.A. Kantsch. 1928, Apiosporaceae, Xylariales, Sordariomycetes, one species, type: S. phyllostachydis L.A. Kantsch., coelomycetous, sexual morph apiospora-like, saprobes, worldwide, see Wijayawardene et al. (2012, 2016b, 2017; taxonomy, outline), Maharachchikumbura et al. (2015, 2016; outline), probably a synonym of Arthrinium Kunze, needs generic revision, cultures and sequences are unavailable.

Scytalidium Pesante 1957, Helotiaceae, Helotiales, Leotiomycetes, 23 species, type: S. lignicola Pesante, hyphomycetous, sexual morph unknown, saprobes, terrestrial, Russia, Chile, Siberia, see Kang et al. (2010; new species), Wu and Zhang (2010; new species), Seifert et al. (2011; morphology), Wijayawardene et al. (2012, 2017; outline), Kirk et al. 
(2013; genus accepted), Gautam et al. (2015; new species, India), ex-type culture available for the type: UAMH 1502, needs generic revision as genus is hetergenous (fide Seifert et al. 2011).

Scytinium (Ach.) Gray 2014, Collemataceae, Lecanorales, Lecanoromycetes, 48 species; type: S. palmatum (Huds.) Gray, lichenized; see Otálora et al. (2013, 2014; taxonomy, new combination), Diederich et al. (2014; new records: France), Carlberg et al. (2016; new species: California), Gasparyan et al. (2016; new records, Armenia), Lücking et al. (2016b; classification), sequences unavailable.

Seaverinia Whetzel 1945 (= Verrucobotrys Hennebert 1973 fide Johnston et al. 2014b), Sclerotiniaceae, Helotiales, Leotiomycetes, two species, type: Verrucobotrys geranii (Seaver) Hennebert, asexual morph formerly named in Verrucobotrys, saprobes, terrestrial, worldwide, see Lumbsch and Huhndorf (2010; outline), Kirk et al. (2013; genus accepted), Johnston et al. (2014b; nomenclature), cultures and sequences are unavailable, needs generic revision.

Sedecimiella K. L. Pang, Alias \& E. B. G. Jones 2010, Hypocreales genera incertae sedis, Sordariomycetes, one species, type: S. taiwanensis K.L. Pang, Alias \& E.B.G. Jones, asexual morph unknown, saprobes, marine, Hong Kong, Taiwan, see Pang et al. (2010a; taxonomy), Maharachchikumbura et al. (2015, 2016; outline), holotype of type: BBH 26390.

Sedelnikovaea S.Y. Kondr., M.H. Jeong \& Hur 2015, Lecanoraceae, Lecanorales, Lecanoromycetes, one species, type: S. baicalensis (Zahlbr.) S.Y. Kondr., M.H. Jeong \& Hur, asexual morph unknown, lichenized, see Kondratyuk et al. (2015b; taxonomy), Lücking et al. (2016b; classification).

Segestria Fr. 1825, Porinaceae, Ostropales, Lecanoromycetes, 70 species, type: S. lectissima Fr., lichenized, see Lücking (2008; taxonomy), Lumbsch and Huhndorf (2010; outline), Lücking et al. (2016b; classification); sequences are available but lcks for type.

Seifertia Partr. \& Morgan-Jones 2002, Melanommataceae, Pleosporales, Dothideomycetes, two species, type: S. azaleae (Peck) Partr. \& Morgan-Jones, hyphomycetous, sexual morph unknown, saprobes, worldwide, see Seifert et al. (2011; morphology), Wijayawardene et al. (2012, 2017; outline), Kirk et al. (2013; genus accepted), Li et al. (2016b; new species, China), cultures available for the type: DAOM 239135.

Seimatosporiopsis B. Sutton, Ghaffer \& Abbas 1972, Ascomycota genera incertae sedis, two species, type: S. salvadorae B. Sutton, Ghaffer \& Abbas, coelomycetous, sexual morph unknown, saprobes, Pakistan, see Wijayawardene et al. (2012, 2016b, 2017; outline, taxonomy), Kirk et al. (2013; genus accepted), cultures and sequences are unavailable, needs generic revision.

Seimatosporium Corda 1833 (= Discostroma Clem. 1909 fide Réblová et al. 2016c), Sporocadaceae, Xylariales, Sordariomycetes, 75 species, type: $S$. rosae Corda, asexual morph coelomycetous, saprobes, ?pathogens, worldwide, see Barber et al. (2011; new species, phylogeny), Tanaka et al. (2011a; phylogeny), Wijayawardene et al. (2012, 2016a, b, 2017; outline, taxonomy, new species), Crous et al. (2014c; new species), Ariyawansa et al. (2015a; new species), Norphanphoun et al. (2015; new species, phylogeny), Maharachchikumbura et al. (2015, 2016; outline, phylogeny), Senanayake et al. (2015; outline, phylogeny), Réblová et al. (2016c; nomenclature), Rossman et al. (2016b; new combination), cultures available for the type: MFLUCC 14-0621.

Seiridium Nees 1816 (= Blogiascospora Shoemaker et al. 1966 fide Réblová et al. 2016c), Pestalotiopsidaceae, Xylariales, Sordariomycetes, 35 species, type: S. marginatum Nees, asexual morph coelomycetous, saprobes, ?pathogens, worldwide, see Wijayawardene et al. (2012, 2016b; outline, taxonomy, new species), Crous et al. (2012c, 2014c; new species), Senanayake et al. (2015; outline, phylogeny), Maharachchikumbura et al. (2015, 2016; outline, phylogeny), Jaklitsch et al. (2016a; phylogeny), Réblová et al. (2016c; nomenclature), cultures available for the type: SEI1. 
Seirophora Poelt 1983, Teloschistaceae, Teloschistales, Lecanoromycetes, twelve species, type: S. magara (Kremp.) Poelt, lichenized, see Lumbsch and Huhndorf (2010; outline), Moniri and Sipman (2011; new record), Arup et al. (2013; phylogeny), Benesperi et al. (2013; ecology), Kirk et al. (2013; genus accepted), Zhurbenko (2013; new record), Giordani et al. (2015; ecology), Kondratyuk et al. (2014, 2015a, b; taxonomy, phylogeny), Moniri et al. (2014; new record, Iran), Lücking et al. (2016b; classification), sequences are available.

Selenaspora R. Heim \& Le Gal 1936, Pyronemataceae, Pezizales, Pezizomycetes, two species, type: S. batava R. Heim \& Le Gal, asexual morph unknown, saprobes, terrestrial, Europe, North America, see Lumbsch and Huhndorf (2010; outline), Kirk et al. (2013; genus accepted), cultures and sequences are unavailable for the type.

Selenodriella R.F. Castañeda \& W.B. Kendr. 1990, Microdochiaceae, Xylariales, Sordariomycetes, seven species, type: S. fertilis (Piroz. \& Hodges) R.F. Castañeda \& W.B. Kendr., hyphomycetous, sexual morph unknown, saprobes, terrestrial, cosmopolitan, see Seifert et al. (2011; morphology), Kirk et al. (2013; genus accepted), Maharachchikumbura et al. (2015, 2016; outline), Hernández-Restrepo et al. (2016a; new species, phylogeny), Wijayawardene et al. (2017; outline), cultures and sequences are available.

Selenophoma Maire 1907, Saccotheciaceae, Dothideales, Dothideomycetes, 13 species, type: S. catananches Maire, coelomycetous, sexual morph unknown, saprobes, terrestrial, worldwide, see Cheewangkoon et al. (2009; new species, phylogeny), Wijayawardene et al. (2012, 2014c, 2017; outline), Kirk et al. (2013; genus accepted), Thambugala et al. (2015c; phylogeny), cultures and sequences are available but lacks for the type.

Selenosira Petr. 1957, Ascomycota genera incertae sedis, one species, type: S. unica Petr., coelomycetous, sexual morph unknown, saprobes, terrestrial, Australia, see Wijayawardene et al. (2012, 2017; outline), Kirk et al. (2013; genus accepted), cultures and sequences are unavailable, needs generic revision.

Selenosporella G. Arnaud ex MacGarvie 1968, Ascomycota genera incertae sedis, twelve species, type: S. curvispora G. Arnaud ex MacGarvie, hyphomycetous, saprobes, on decaying leaves, terrestrial, worldwide, Castañeda-Ruiz et al. (2009a; key and new species), Seifert et al. (2011; morphology), Wijayawardene et al. (2012, 2017; outline), Kirk et al. (2013; genus accepted), Fiuza et al. (2015b;new species), holotype of type: IMI 129890, cultures and sequences are unavailable.

Selenosporopsis R.F. Castañeda \& W.B. Kendr. 1991, Ascomycota genera incertae sedis, one species, type: S. elegans R.F. Castañeda \& W.B. Kendr., hyphomycetous, sexual morph unknown, saprobes, terrestrial, Caribbean, see Seifert et al. (2011; morphology), Wijayawardene et al. (2012, 2017; outline), Kirk et al. (2013; genus accepted), cultures and sequences are unavailable, needs generic revision.

Selenozyma Yarrow 1977, Saccharomycetes genera incertae sedis, two species, type: S. intestinalis (Krassiln.) Yarrow, yeast, sexual morph unknown, saprobes, terrestrial, Netherlands, see Wijayawardene et al. (2012, 2017; outline), Kirk et al. (2013; genus accepted), cultures and sequences are unavailable for the type.

Selinia P. Karst. 1876, Bionectriaceae, Hypocreales, Sordariomycetes, two species, type: S. pulchra (G. Winter) Sacc., asexual morph tubercularia-like, coprophilous, saprobes, terrestrial, worldwide, see Lumbsch and Huhndorf (2010; outline), Chaverri et al. (2011; phylogeny), Kirk et al. (2013; genus accepted), Maharachchikumbura et al. (2015, 2016; outline), cultures are available.

Semidelitschia Cain \& Luck-Allen 1969, Delitschiaceae, Pleosporales, Dothideomycetes, two species, type: S. agasmatica Cain \& Luck-Allen, asexual morph unknown, coprophilous, terrestrial, worldwide, see Lumbsch and Huhndorf (2010; outline), Hyde et al. (2013; accepted as a genus in Delitschiaceae), Kirk et al. (2013; genus accepted), Wijayawardene et al. (2014c; outline), cultures and sequences are unavailable, needs generic revision. 
Semifissispora H.J. Swart 1982, Massarinaceae, Pleosporales, Dothideomycetes, four species, type: S. fusiformis H.J. Swart, asexual morph unknown, saprobes, pathogens, terrestrial, worldwide, see Lumbsch and Huhndorf (2010; outline, accepted as a genus in Dothideomycetes, genera incertae sedis), Kirk et al. (2013; genus accepted), Wijayawardene et al. (2014c; outline), Crous et al. (2015e; DNA, new species, phylogeny), cultures and sequences are available but lacks for the type:.

Semigyalecta Vain. 1921, Gyalectaceae, Ostropales, Lecanoromycetes, one species, type: $S$. paradoxa Vain., lichenized, terrestrial, see Lumbsch and Huhndorf (2010; outline), Kirk et al. (2013; genus accepted), Lücking et al. (2016b; classification), sequences are unavailable.

Semisphaeria K. Holm \& L. Holm 1991, Dothideomycetes genera incertae sedis, one species, type: S. sigmundii K. Holm \& L. Holm, asexual morph unknown, saprobes, terrestrial, Norway, Sweden, see Lumbsch and Huhndorf (2010; outline), Kirk et al. (2013; genus accepted), Wijayawardene et al. (2014c; outline), cultures and sequences are unavailable, needs generic revision.

Sepedonium Link 1809, Hypocreaceae, Hypocreales, Sordariomycetes, 13 species, type: S. mycophilum (Pers.) Nees, hyphomycetous, on fungi, terrestrial, cosmopolitan, see Seifert et al. (2011; morphology), Maharachchikumbura et al. (2015, 2016; outline), Wijayawardene et al. (2017; outline), cultures and sequences are available, needs generic revision.

Septocyta Petr. 1927, Capnodiales genera incertae sedis, Dothideomycetes, five species, type: $S$. ramealis (Roberge ex Desm.) Petr., coelomycetous, sexual morph unknown, saprobes, terrestrial, worldwide, see Aleksić et al. (2011; use in disease control, DNA), Wijayawardene et al. (2012, 2017; outline), Kirk et al. (2013; genus accepted), cultures and sequences are available but lacks for the type, needs generic revision.

Septocytella Syd. 1929, Ascomycota genera incertae sedis, one species, type: S. bambusina Syd., coelomycetous, sexual morph unknown, saprobes, China, see Wijayawardene et al. (2012, 2017; outline), Kirk et al. (2013; genus accepted), cultures and sequences are unavailable, needs generic revision.

Septofusidium W. Gams 1971, Tilachlidiaceae, Hypocreales, Sordariomycetes, five species, type: S. elegantulum (Pidopl.) W. Gams, hyphomycetous, sexual morph unknown, saprobes, pathogens, terrestrial, worldwide, see Seifert et al. (2011; morphology), Wijayawardene et al. (2012, 2017; outline), Kirk et al. (2013; genus accepted), Lombard et al. (2015b; phylogeny), Maharachchikumbura et al. (2015, 2016; outline), cultures and sequences are available but lacks for the type.

Septogloeum Sacc. 1880, Ascomycota genera incertae sedis, two species, type: $S$. carthusianum (Sacc.) Sacc., coelomycetous, sexual morph unknown, saprobes, worldwide, see Wijayawardene et al. (2012, 2017; outline), Kirk et al. (2013; genus accepted), cultures and sequences are unavailable, needs generic revision.

Septomyrothecium Matsush. 1971 (= Sporothrix Hektoen \& C.F. Perkins 1901 fide Maharachchikumbura et al. 2016), Stachybotriaceae, Hypocreales, Sordariomycetes, three species, type: $S$. uniseptatum, asexual morph unknown, saprobes, terrestrial, Asia, Caribbean, South America, see Seifert et al. (2011; morphology), Wijayawardene et al. (2012, 2017; outline), Kirk et al. (2013; genus accepted), Liu et al. (2015a; new species), Maharachchikumbura et al. (2015, 2016; outline), Lombard et al. (2016; phylogeny), cultures available for the type: CBS 100966.

Septomyxella (Höhn.) Höhn. 1923, Ascomycota genera incertae sedis, one species record, type speceies: Myxosporium spaethianum Allesch., coelomycetous, sexual morph unknown, saprobes, terrestrial, Italy, see Wijayawardene et al. (2012, 2017; outline), Kirk et al. (2013; genus accepted), cultures and sequences are unavailable, needs generic revision.

Septonema Corda 1837, Mytilinidiaceae, Mytilinidiales, Dothideomycetes, c. 15 species, type: S. secedens Corda, sexual stage unknown, terrestrial, saprobes, lichenized, Asia, Europe, 
Africa, North America. See Jankowiak and Rossa (2008; associations with Pityogenes), Wang et al. (2008a; fallen leaves), Koukol (2010; new species), Hyde et al. (2011; outline), Seifert et al. (2011; morphology), Wijayawardene et al. (2012, 2017; outline), Wiewióra (2012; seed health), Chigoziri and Ekefan (2013; seed borne fungi), Álvarez et al. (2015; ophiostomatoid fungus), sequences are unavailable.

Septopatella Petr. 1925, Ascomycota genera incertae sedis, one species, type: S. septata (Jaap) Petr., coelomycetous, sexual morph unknown, saprobes, terrestrial, Europe, North America, see Wijayawardene et al. (2012, 2017; outline), Kirk et al. (2013; genus accepted), cultures and sequences are unavailable, needs generic revision.

Septoria Sacc. 1884, Mycosphaerellaceae, Capnodiales, Dothideomycetes, c. 1000 (200 are presently recognized based on DNA), type: Septoria cytisi Desm., coelomycetous, sexual morph mycosphaerella-like, of which, plant pathogens, terrestrial, worldwide, see Quaedvlieg et al. (2011, 2013; morphology, phylogeny), Wijayawardene et al. (2012, 2017; outline), Kirk et al. (2013; genus accepted), Verkley et al. (2013; morphology, phylogeny), cultures and sequences are available.

Septoriella Oudem. 1889 (= Wojnowicia Sacc. 1892 fide Crous et al. 2015a), Phaeosphaeriaceae, Pleosporales, Dothideomycetes, 19 species, type: S. phragmitis Oudem., coelomycetous, sexual morph unknown, saprobes, worldwide, see Wijayawardene et al. (2012, 2014c, 2017; outline, taxonomy), Kirk et al. (2013; genus accepted), Crous et al. (2014c, 2015a; new species, phylogeny), Li et al. (2015c; new species), epitype and exepitype cultures of the type: CBS H-22281, CPC $24118=$ CBS 140065.

Septorioides Quaedvl., Verkley \& Crous 2013, Septorioideaceae, Botryosphaeriales, Dothideomycetes, one species, type: S. pini-thunbergii (S. Kaneko) Quaedvlieg, Verkley \& Crous, coelomycetous, sexual morph unknown, pathogens, terrestrial, Japan, see Quaedvlieg et al. (2013; morphology, phylogeny), cultures and sequences are available.

Septosporiopsis W.A. Baker \& Morgan-Jones 2009, Ascomycota genera incertae sedis, one species, type: S. elaeidis (J.M. Yen \& Sulmont) W.A. Baker \& Morgan-Jones, hyphomycetous, sexual morph unknown, saprobes, on palm litter, Africa, Caribbean, see Seifert et al. (2011; morphology), Wijayawardene et al. (2012, 2017; outline), Kirk et al. (2013; genus accepted), cultures and sequences are unavailable, needs generic revision.

Septosporium Corda 1831, Ascomycota genera incertae sedis, 28 species, type: S. atrum Corda, hyphomycetous, sexual morph unknown, saprobes, on wood (Acer, Carpinus, Sorbus, and many others) and litter (Bambusa), cosmopolitan, see Seifert et al. (2011; morphology), Wijayawardene et al. (2012, 2017; outline), Kirk et al. (2013; genus accepted), ), cultures and sequences are unavailable, needs generic revision.

Septotinia Whetzel ex J.W. Groves \& M.E. Elliott 1961 (= Septotis N.F. Buchw. ex Arx 1970 fide Johnston et al. 2014b), Sclerotiniaceae, Helotiales, Leotiomycetes, two species, type: S. podophyllina Whetzel, asexual morph formerly known in Septotis, saprobes, terrestrial, worldwide, see Lumbsch and Huhndorf (2010; outline), Kirk et al. (2013; genus accepted), Johnston et al. (2014b; nomenclature), cultures and sequences are unavailable, needs generic revision.

Septotrapelia Aptroot \& Chaves 2007, Pilocarpaceae, Lecanorales, Lecanoromycetes, four species, seven species, type: S. glauca Aptroot \& Chaves, lichenized, asexual morph unknown, lichenized, terrestrial, tropical, see Lumbsch and Huhndorf (2010; outline), Aptroot and Iqbal (2012; new record, Pakistan), Bungartz et al. (2013b; taxonomy), Aptroot and Moon (2014; new species: Korea), Lücking et al. (2016b; classification), holotype of the type: INB, Aptroot 60426, cultures and sequences are unavailable

Septotrullula Höhn. 1902, Ascomycota genera incertae sedis, four species, type: S. elaeidis (J.M. Yen \& Sulmont) W.A. Baker \& Morgan-Jones, hyphomycetous, sexual morph unknown, saprobes, on bark (Betula, Fagus, Quercus), Australasia, Europe, North America, 
see Seifert et al. (2011; morphology), Wijayawardene et al. (2012, 2017; outline), Kirk et al. (2013; genus accepted), cultures and sequences are unavailable, needs generic revision.

Serenomyces Petr. 1952, Lasiosphaeriaceae, Sordariales, Sordariomycetes, five species, type: S. shearii Petr., saprobes, worldwide, see Lumbsch and Huhndorf (2010; outline, accepted as a genus in Phaeochoraceae), Kirk et al. (2013; genus accepted), Elliott and Des Jardin (2014; species associated with palms in southeastern USA), Maharachchikumbura et al. (2015, 2016; outline), cultures are available for unidentified species (unpublished), needs generic revision.

Seriascoma Phookamsak, D.Q. Dai \& K.D. Hyde 2016, Occultibambusaceae, Pleosporales, Dothideomycetes, one species, type: S. didymospora Phook., D.Q. Dai, Karunar. \& K.D. Hyde, asexual morph coelomycetous, saprobes, terrestrial, Thailand, see Dai et al. (2016; phylogeny, morphology, sexual and asexual morphs), ex-type culture of type: MFLUCC 110179.

Servazziella J. Reid \& C. Booth 1987, Sordariomycetes genera incertae sedis, five species, type: S. longispora (Servazzi) J. Reid \& C. Booth, saprobes, worldwide, see Lumbsch and Huhndorf (2010; outline), Kirk et al. (2013; genus accepted), Maharachchikumbura et al. (2015, 2016; outline), cultures and sequences are unavailable.

Servitia M.S. Christ. \& Alstrup 2001, Verrucariaceae, Verrucariales, Eurotiomycetes, species, type: S. inconspicuum (Lynge) M.S. Christ. \& Alstrup, asexual morph unknown, lichenized, terrestrial, Greenland, see Lumbsch and Huhndorf (2010; outline), Lücking et al. (2016b; classification), cultures and sequences are unavailable, needs generic revision.

Sessiliospora D. Hawksw. 1979, Ascomycota genera incertae sedis, one species, type: S. bicolor D. Hawksw., sexual morph unknown, lichenicolous on foliicolous lichens, Asia, terrestrial, see Seifert et al. (2011; genus accepted), Kirk et al. (2013; genus accepted), cultures and sequences are unavailable, holotype of type: K(M)-IMI 41011c.

Setameliola D.R. Reynolds 2010, Meliolaceae, Meliolales, Sordariomycetes, 26 species, type: Setameliola argentina (Speg.) D.R. Reynolds, asexual morph unknown, saprobes, terrestrial, Singapore, see Reynolds (2010; taxonomy), cultures and sequences are unavailable, needs generic revision.

Setiferotheca Matsush. 1995, Ceratostomataceae, Melanosporales, Sordariomycetes, one species, type: S. nipponica Matsush., asexual morph unknown, saprobes, terrestrial, worldwide, see Lumbsch and Huhndorf (2010; outline), Kirk et al. (2013; genus accepted), Maharachchikumbura et al. (2015, 2016; outline), cultures and sequences are unavailable, needs generic revision.

Setocampanula Sivan. \& W.H. Hsieh 1989, Trichosphaeriaceae, Trichosphaeriales, Sordariomycetes, one species, type: S. taiwanensis Sivan. \& W.H. Hsieh, see Lumbsch and Huhndorf (2010; outline), Kirk et al. (2013; genus accepted), cultures and sequences unavailable, needs generic revision.

Setolibertella Punith. \& Spooner 1999, Ascomycota genera incertae sedis, one species, type: S. solani Punith. \& Spooner, sexual morph unknown, coelomycetous, saprobes, on dead stems of Solanum mauritanium, Azores, see Wijayawardene et al. (2012, 2017; outline), Kirk et al. (2013; genus accepted), holotype of the type: KM 58669, cultures and sequences are unavailable, needs generic revision.

Setomelanomma M. Morelet 1980, Phaeosphaeriaceae, Pleosporales, Dothideomycetes, one species, type: S. holmii M. Morelet, asexual morph coelomycetous, saprobes or pathogens, terrestrial, cosmopolitan, see Zhang et al. (2012e; taxonomy, phylogeny), Hyde et al. (2013; accepted as a genus in Phaeosphaeriaceae), Kirk et al. (2013; genus accepted), Phookamsak et al. (2014b; taxonomy, phylogeny), Wijayawardene et al. (2014c; outline), cultures and sequences are available.

Setophaeosphaeria Crous \& Y. Zhang ter 2014, Pleosporales genera incertae sedis, Dothideomycetes, three species, type: S. hemerocallidis Crous \& Y. Zhang ter, with 
coelomycetous asexual morph, saprobes, ?pathogens, terrestrial, China, see Crous et al. (2014c; morphology, phylogeny), Wijayawardene et al. (2014c; outline), holotype and extype culture of type: CBS H-21720, CPC 23645.

Setophiale Matsush. 1995, Ascomycota genera incertae sedis, one species, type: $S$. unisetulata Matsush, sexual morph unknown, hyphomycetous, saprobes, on palm petioles, Peru, see Seifert et al. (2011; morphology), Wijayawardene et al. (2012, 2017; outline), Kirk et al. (2013; genus accepted), holotype of the type: Matsushima Fungus Collection, Kobe, MFC-4P766, cultures and sequences are unavailable, needs generic revision.

Setophoma Gruyter, Aveskamp \& Verkley 2010, Phaeosphaeriaceae, Pleosporales, Dothideomycetes, asexual morph coelomycetous, five species, type: S. terrestris (H.N. Hansen) Gruyter, Aveskamp \& Verkley, saprobes, ?pathogens, terrestrial, Brazil, North America, see de Gruyter et al. (2010; morphology, phylogeny), Quaedvlieg et al. (2013; morphology, phylogeny), Crous et al. (2014c, 2016b; morphology, phylogeny, sexual morph), Wijayawardene et al. (2014c; outline), lectotype and ex-lectotype culture of type: CBS H20311, CBS 335.29.

Setoseptoria Quaedvl., Verkley \& Crous 2013, Lentitheciaceae, Pleosporales, Dothideomycetes, one species, type: S. phragmitis Quaedvlieg, Verkley \& Crous coelomycetous, sexual morph unknown, pathogens, terrestrial, Hong Kong, see Quaedvlieg et al. (2013; morphology, phylogeny), Wijayawardene et al. (2014c; outline), holotype of the type: CBS H-21324, culture ex-type CBS 114802.

Setosporella Mustafa \& Abdul-Wahid 1989, Ascomycota genera incertae sedis, one species, type: S. mahmoudii Moustafa \& Abdul-Wahid, sexual morph unknown, hyphomycetous, saprobes, isolated from soil, Egypt, see Seifert et al. (2011; morphology), Wijayawardene et al. (2012, 2017; outline), Kirk et al. (2013; genus accepted), holotype of the type: IMI 326932, cultures and sequences are unavailable, needs generic revision.

Setosynnema D.E. Shaw \& B. Sutton 1985, Ascomycota genera incertae sedis, one species, type: S. isthmosporum D.E. Shaw \& B. Sutton, hyphomycetous, sexual morph unknown, saprobes, aquatic, Asia, Australasia, see Seifert et al. (2011; morphology), Wijayawardene et al. (2012, 2017; outline), Kirk et al. (2013; genus accepted), cultures and sequences are unavailable, needs generic revision.

Seuratiopsis Woron. 1934, Seuratiaceae, Ascomycota families incertae sedis, one species, type: S. epiphylla Woron., asexual morph unknown, saprobes, terrestrial, worldwide, see Lumbsch and Huhndorf (2010; outline), Kirk et al. (2013; genus accepted), cultures and sequences are unavailable, needs generic revision.

Seychellomyces Matsush. 1981, Ascomycota genera incertae sedis, one species, type: S. hexagonus Matsush, sexual morph unknown, hyphomycetous, saprobes, isolated from soil, Seychelles, see Seifert et al. (2011; morphology), Wijayawardene et al. (2012, 2017; outline), Kirk et al. (2013; genus accepted), cultures and sequences are available.

Seynesia Sacc. 1883, Cainiaceae, Xylariales, Sordariomycetes, two species, type: S. nobilis (Welw. \& Curr.) Sacc., tropical, see Lumbsch \& Huhndorf (2010; outline), Maharachchikumbura et al. (2015, 2016; outline), Kirk et al. (2013; genus accepted), cultures and sequences are unavailable for type, needs generic revision.

Seynesiella G. Arnaud 1918, Microthyriaceae, Microthyriales, Dothideomycetes, c. 80 species, type: S. juniperi (Desm.) G. Arnaud, asexual morph unknown, saprobes, terrestrial, tropical, see Lumbsch and Huhndorf (2010; outline), Wu et al. (2011; taxonomy), Hyde et al. (2013; accepted as a genus in Micropeltidaceae), Wijayawardene et al. (2014c; outline), cultures and sequences are unavailable.

Seynesiopeltis F. Stevens \& R.W. Ryan 1925, Seynesiopeltidaceae, Dothideomycetes, incertae sedis, one species, type: S. epiphylla Woron., asexual morph unknown, saprobes, terrestrial, worldwide, see Lumbsch and Huhndorf (2010; outline), Hyde et al. (2013; 
taxonomy), Kirk et al. (2013; genus accepted), Wijayawardene et al. (2014c; outline), cultures and sequences are unavailable, needs generic revision.

Seynesiopsis Henn. 1904, Ascomycota genera incertae sedis, one species, type: $S$. rionegrensis Henn., sexual morph unknown, coelomycetous, saprobes, see Wijayawardene et al. (2012, 2017; outline), Kirk et al. (2013; genus accepted), cultures and sequences are unavailable, needs generic revision.

Shackletonia Søchting, Frödén \& Arup 2013, Teloschistaceae, Teloschistales, Lecanoromycetes, five species, type: S. hertelii (Søchting, Øvstedal \& Sancho) Søchting, Frödén \& Arup, asexual morph unknown, lichenized, terrestrial, see Arup et al. (2013; taxonomy), Kondratyuk et al. (2014; phylogeny), Garrido-Benavent et al. (2016; new species), Lücking et al. (2016b; classification), sequences are available.

Shanorella R.K. Benj. 1956, Arthrodermataceae, Onygenales, Eurotiomycetes, 17 species, type: S. spirotricha R.K. Benj., a sexual morph unknown, on humans and other mammals, causing microsporoses, terrestrial, USA, Europe, see Lumbsch and Huhndorf (2010; outline), Kirk et al. (2013; genus accepted), culture available for the type: CBS 305.56.

Shawiella Hansf. 1957, Ascomycota genera incertae sedis, one species, type: S. grevilleae Hansf., sexual morph unknown, coelomycetous, saprobes, on leaves of Grevillea robusta, New Guinea, see Wijayawardene et al. (2012, 2017; outline), Kirk et al. (2013; genus accepted), cultures and sequences are unavailable, needs generic revision.

Shearia Petr. 1924, Ascomycota genera incertae sedis, two species, type: S. magnoliae (Shear) Petr., coelomycetous, sexual morph unknown, saprobes, worldwide, see Wijayawardene et al. (2012, 2016b, 2017; outline, taxonomy), Kirk et al. (2013; genus accepted), cultures and sequences are unavailable, needs generic revision.

Sheariella Petr. 1952, Ascomycota genera incertae sedis, one species, type: S. carbonacea Petr., sexual morph unknown, coelomycetous, saprobes, India, see Wijayawardene et al. (2012, 2017; outline), Kirk et al. (2013; genus accepted), cultures and sequences are unavailable, needs generic revision.

Sheathnema Dubey \& Moonnambeth 2014, Ascomycota genera incertae sedis, two species, type: $S$. indicum Dubey \& Moonambeth, hyphomycetous, sexual morph unknown, saprobes, epiphytes, India, see Dubey and Moonnambeth (2014a; taxonomy), Wijayawardene et al. (2012, 2017; outline), Kirk et al. (2013; genus accepted), cultures and sequences are unavailable, needs generic revision.

Shimizuomyces Kobayasi 1981, Clavicipitaceae, Hypocreales, Sordariomycetes, four species, type: S. paradoxus Kobayasi, asexual morph unknown, saprobes, terrestrial, Asia, see Lumbsch and Huhndorf (2010; outline), Sung et al. (2010, 2011; culture characters of the type, applications), Kirk et al. (2013; genus accepted), Maharachchikumbura et al. (2015, 2016; outline), cultures available for the type: EFCC 6279.

Shiraia Henn. 1900, Shiraiaceae, Pleosporales, Dothideomycetes, one species, type: S. bambusicola Henn., asexual morph ceolomycetous, parasitic, terrestrial, China and Japan, see Lumbsch and Huhndorf (2010; outline), Liu et al. (2013; morphology, nomenclature, phylogeny), Kirk et al. (2013; genus accepted), Wijayawardene et al. (2014c; 2017; outline), cultures and sequences are available, ex-epitype strains of type: GZAAS2.0708 = CGMCC $3.15200=$ MFLUCC 13-0408; holotype of type: Shirai (B!), epitype of type: GZAAS K-2002. Shivomyces Hosag. 2004, Ascomycota genera incertae sedis, two species, type: S. ligustri Hosag. \& Kamar., hyphomycetous, sexual morph unknown, saprobes, terrestrial, Asia, see Seifert et al. (2011; morphology), Wijayawardene et al. (2012, 2017; outline), cultures and sequences are unavailable, needs generic revision.

Shrungabeeja V.G. Rao \& K.A. Reddy 1981, Tetraplosphaeriaceae, Pleosporales, Dothideomycetes, four species, type: $S$. vadirajensis V.G. Rao \& K.A. Reddy, hyphomycetous, saprobes, on bamboo (Bambusa) and other plants (Begonia, Melicope), Asia, 
see Seifert et al. (2011; morphology), Wijayawardene et al. (2012, 2017; outline), Kirk et al. (2013; genus accepted), Ariyawansa et al. (2015a; new species, phylogeny), cultures and sequences are unavailable, needs generic revision.

Sibirina G.R.W. Arnold 1970, Hypocreaceae, Hypocreales, Sordariomycetes, one species, type: S. fungicola G.R.W. Arnold, hyphomycetous, sexual morphs unknown, mycoparasites, worldwide, see Seifert et al. (2011; morphology), Wijayawardene et al. (2012, 2017; outline), Kirk et al. (2013; genus accepted), Maharachchikumbura et al. (2016; outline), cultures and sequences are available.

Siemaszkoa I.I. Tav. \& T. Majewski 1976, Laboulbeniaceae, Laboulbeniales, Laboulbeniomycetes, seven species, type: S. flexa (T. Majewski) I.I. Tav. \& T. Majewski, asexual morph unknown, biotrophic on Coleoptera (Ptiliidae), Europe, Southern America, see Lumbsch and Huhndorf (2010; outline), Kirk et al. (2013; genus accepted), cultures and sequences are unavailable, needs generic revision.

Sigarispora Thambugala \& K.D. Hyde 2015, Lophiostomataceae, Pleosporales, Dothideomycetes, eight species, type: S. ravennica (Tibpromma, Camporesi \& K.D. Hyde) Thambug. \& K.D. Hyde, asexual morph unknown, saprobes, terrestrial, Italy and Japan, six species, see Thambugala et al. (2015b; morphology, phylogeny), Li et al. (2016a; new species), holotype of type: MFLU 14-0692, ex-type strains of type: MFLUCC 14-0005.

Sigleria Hirooka, Tanney \& Seifert 2015, Spiromastigaceae, Onygenales, Eurotiomycetes, one species, type: $S$. carmichaelii Hirooka, Tanney \& Seifert, hyphomycetous, sexual morph unknown, saprobes, terrestrial, Vietnam, see Hirooka et al. (2016; taxonomy, phylogeny), Wijayawardene et al. (2017; outline), holotype of type: DAOM 571575.

Sigmatomyces Sacc. \& P. Syd. 1913, Ascomycota genera incertae sedis, one species, type: S. bakeri Sacc., Syd. \& P. Syd., sexual morph unknown, hyphomycetous, saprobes, Philippines, see Seifert et al. (2011; morphology), Wijayawardene et al. (2012, 2017; outline), Kirk et al. (2013; genus accepted), cultures and sequences are unavailable, needs generic revision.

Sigmoidea J.L. Crane 1968, Halosphaeriaceae, Microascales, Sordariomycetes, six species, type: S. prolifera (R.H. Petersen) J.L. Crane, hyphomycetous, polyphyletic, marine, freshwater, sexual morph unknown, on wood and leaves, worldwide, see Jones et al. (2009a; taxonomy), Seifert et al. (2011; morphology), Wijayawardene et al. (2012, 2017; outline), Kirk et al. (2013; genus accepted), cultures and sequences are available, needs generic revision.

Sigridea Tehler 1993, Roccellaceae, Arthoniales, Arthoniomycetes, six species, type: S. californica (Tuck.) Tehler, lichenized (only one lichenicolous), terrestrial, tropical to subtropical with a preference for coastal habitats with a Mediterranean climate, see Ertz and Tehler (2011; phylogeny), Lumbsch and Huhndorf (2010; outline), Kirk et al. (2013; genus accepted), Ertz et al. (2015b, c; morphology, phylogeny), Lücking et al. (2016b; classification), lectotype and ex-type strain of type: Bolander $129(\mathrm{FH})$.

Sillia P. Karst. 1873, Sydowiellaceae, Diaporthales, Sordariomycetes, three species, type: S. ferruginea (Pers.) P. Karst., asexual morphs unknown, saprobes, terrestrial, Europe, America, see Da Silva et al. (2009; phylogeny), Lumbsch and Huhndorf (2010; outline), Kruys and Castlebury (2012; phylogeny), Maharachchikumbura et al. (2015, 2016; outline), cultures available for the type: CBS 126567.

Simonyella J.Steiner 1902, Lecanographaceae, Arthoniales, Arthoniomycetes, one species, type: S. variegata J. Steiner, lichenized, see Lumbsch and Huhndorf (2010; outline), Kirk et al. (2013; genus accepted), Lücking et al. (2016b; classification, treated as Roccellaceae), sequences are available.

Simplicillium W. Gams \& Zare 2001, Cordycipitaceae, Hypocreales, Sordariomycetes, nine species, type: S. lanosoniveum (J.F.H. Beyma) Zare \& W. Gams, hyphomycetous, sexual morph unknown, saprobes, terrestrial, Asia, Australasia, Europe, North America, see Seifert 
et al. (2011; morphology), Liu and Cai (2012; new species, China), Wijayawardene et al. (2012, 2017; outline), Nonaka et al. (2013b; new species, Japan), Maharachchikumbura et al. (2015, 2016; outline), cultures and sequences are available.

Sinodidymella J.Z. Yue \& O.E. Erikss. 1985, Teichosporaceae, Pleosporales, Dothideomycetes families incertae sedis, five species, type: S. verrucosa (Petr.) J.Z. Yue \& O.E. Erikss., see Lumbsch and Huhndorf (2010; outline), Kirk et al. (2013; genus accepted), Wijayawardene et al. (2014c; outline), sequences are unavailable, needs generic revision.

Sinotrichium Juan Wang, S.Q. Xu \& Strongman 2010, Ascomycota genera incertae sedis, one species, type: S. chironomidarum Juan Wang, S.Q. Xu \& Strongman, asexual morph unknown, from the hindgut of a chironomid larva, China, see Wang et al. (2010b; taxonomy), holotype of the type: XIN-4, cultures and sequences are unavailable, needs generic revision.

Siphula Fr. [nom. cons.] 1824, Icmadophilaceae, Pertusariales, Lecanoromycetes, 26 species; type: S. ceratites (Wahlenb.) Fr., lichenized, see Valadbeigi and Sipman (2010; new records), Lumbsch and Huhndorf (2010; outline), Kirk et al. (2013; genus accepted), Resl et al. (2015; phylogeny), Lücking et al. (2016b; classification), sequences are available.

Siphulastrum Müll.Arg. 1889, Pannariaceae, Peltigerales, Lecanoromycetes, four species; type: S. triste Müll. Arg., lichenizedm see Lumbsch and Huhndorf (2010; outline), Kirk et al. (2013; genus accepted), Ekman et al. (2014; phylogeny), Jørgensen and Andersen (2015; taxonomy), Lücking et al. (2016b; classification), sequences are unavailable.

Siphulella Kantvilas, Elix \& P.James 1992, Icmadophilaceae, Pertusariales, Lecanoromycetes, one species, type: S. coralloidea Kantvilas, Elix \& P. James, lichenized, see Lumbsch and Huhndorf (2010; outline), Kirk et al. (2013; genus accepted), Lücking et al. (2016b; classification), sequences are available.

Sipmania Egea \& Torrente 1994, Roccellaceae, Arthoniales, Arthoniomycetes, one species, type: S. peltata Egea \& Torrente, lichenized, see Lumbsch and Huhndorf (2010; outline), Kirk et al. (2013; genus accepted), Lücking et al. (2016b; classification), sequences are unavailable.

Sipmaniella Kalb 2009, Megalosporaceae, Teloschistales, Lecanoromycetes, two species, type: S. sulphureofusca (Fée) Kalb, lichenized, see Lumbsch and Huhndorf (2010; outline), Gaya et al. (2012; phylogeny), Lücking et al. (2016b; classification), sequences are available. Sirastachys L. Lombard \& Crous 2016, Stachybotriaceae, Hypocreales, Sordariomycetes, seven species, type: S. phaeospora L. Lombard \& Crous, hyphomycetous, sexual morph unknown, saprobes, terrestrial, cosmopolitan, see Lombard et al. (2016; taxonomy, phylogeny), Wijayawardene et al. (2017; outline), holotype and ex-type culture of the type: CBS H-22460, CBS 100155.

Sirenophila Søchting, Arup \& Frödén 2013, Teloschistaceae, Teloschistales, Lecanoromycetes, seven species, type: S. gintarasii (S.Y. Kondr. \& Kärnefelt) Arup, Frödén \& Søchting, lichenized, see Arup et al. (2013; taxonomy), Lücking et al. (2016b; classification), Søchting et al. (2016; new species, southern heisphere), sequences are available.

Sirexcipula Bubák 1907, Ascomycota genera incertae sedis, one species, type: S. kabatiana Bubák, coelomycetous, sexual morph unknown, saprobes, terrestrial, Europe, Norh America, see Wijayawardene et al. (2012, 2017; outline), Kirk et al. (2013; genus accepted), cultures and sequences are unavailable, needs generic revision.

Sirococcus Preuss 1855, Gnomoniaceae, Diaporthales, Sordariomycetes, three species, type: S. strobilinus Preuss, coelomycetous, sexual morph unknown, saprobes, terrestrial, temperate, see Crous et al. (2012f, 2016a, b; phylogeny, new species), Wijayawardene et al. (2012, 2017; outline), Kirk et al. (2013; genus accepted), Maharachchikumbura et al. (2015, 2016; outline), cultures and sequences are available but lacks for the type:. 
Sirocyphis Clem. 1909, Ascomycota genera incertae sedis, one species, type: S. kabatiana Bubák, coelomycetous, sexual morph unknown, saprobes, terrestrial, USA, see Wijayawardene et al. (2012, 2017; outline), Kirk et al. (2013; genus accepted), cultures and sequences are unavailable, needs generic revision.

Sirogloea Petr. 1923, Ascomycota genera incertae sedis, one species, type: S. euonymi Petr., coelomycetous, sexual morph unknown, saprobes, terrestrial, Europe, see Wijayawardene et al. (2012, 2017; outline), Kirk et al. (2013; genus accepted), cultures and sequences are unavailable, needs generic revision.

Siroligniella Naumov 1926, Ascomycota genera incertae sedis, one species, type: $S$. salicicola Naumov, coelomycetous, sexual morph unknown, saprobes, terrestrial, former USSR, see Wijayawardene et al. (2012, 2017; outline), Kirk et al. (2013; genus accepted), cultures and sequences are unavailable, needs generic revision.

Sirophoma Höhn. 1917, Ascomycota genera incertae sedis, three species, type: S. singularis Höhn., coelomycetous, sexual morph unknown, saprobes, terrestrial, Europe, see Wijayawardene et al. (2012, 2017; outline), Kirk et al. (2013; genus accepted), cultures and sequences are unavailable, needs generic revision.

Siroplacodium Petr. 1940, Ascomycota genera incertae sedis, six species, type: S. atrum Petr., coelomycetous, sexual morph unknown, saprobes, terrestrial, Europe, China, see Wijayawardene et al. (2012, 2017; outline), Zhao and Zhao (2012; new species, China), Kirk et al. (2013; genus accepted), cultures and sequences are unavailable, needs generic revision.

Siropleura Petr. 1934, Ascomycota genera incertae sedis, one species, type: S. pulchella Petr., coelomycetous, sexual morph unknown, saprobes, terrestrial, Europe, see Wijayawardene et al. (2012, 2017; outline), Kirk et al. (2013; genus accepted), cultures and sequences are unavailable, needs generic revision.

Siroscyphellina Petr. 1923, Ascomycota genera incertae sedis, two species, type: S. arundinacea Petr., coelomycetous, sexual morph unknown, saprobes, terrestrial, Austria, North America, see Wijayawardene et al. (2012, 2017; outline), Kirk et al. (2013; genus accepted), cultures and sequences are unavailable, needs generic revision.

Sirosperma Syd. \& P. Syd. 1917, Ascomycota genera incertae sedis, two species, type: S. hypocrellae Syd. \& P. Syd., coelomycetous, sexual morph unknown, saprobes, terrestrial, Papua New Guinea, USA, see Wijayawardene et al. (2012, 2017; outline), Kirk et al. (2013; genus accepted), cultures and sequences are unavailable, needs generic revision.

Sirosphaera Syd. \& P. Syd. 1913, Ascomycota genera incertae sedis, two species, type: S. botryosa Syd. \& P. Syd., coelomycetous, sexual morph unknown, saprobes, terrestrial, Philippines, see Wijayawardene et al. (2012, 2017; outline), Kirk et al. (2013; genus accepted), cultures and sequences are unavailable, needs generic revision.

Sirosporium Bubák \& Serebrian. 1912, ?Dothideomycetes genera incertae sedis, c. 26 species, type: S. antenniforme (Berk. \& M.A. Curtis) Bubák \& Serebrian., hyphomycetous, sexual morph unknown, saprobes, terrestrial, cosmopolitan, see Seifert et al. (2011; morphology), Wijayawardene et al. (2012, 2017; outline), cultures and sequences are available, needs generic revision.

Sirosporonaemella Naumov 1951, Ascomycota genera incertae sedis, one species, type: $S$. strobilina Naumov, coelomycetous, sexual morph unknown, saprobes, terrestrial, Russia, see Wijayawardene et al. (2012, 2017; outline), Kirk et al. (2013; genus accepted), cultures and sequences are unavailable, needs generic revision.

Sirothecium P. Karst. 1887, Ascomycota genera incertae sedis, three species, type: S. saepiarium P. Karst., coelomycetous, sexual morph unknown, saprobes, terrestrial, worldwide, see Wijayawardene et al. (2012, 2016b, 2017; outline, txonomy), Kirk et al. (2013; genus accepted), cultures and sequences are unavailable, needs generic revision. 
Sirothyriella Höhn. 1910, Ascomycota genera incertae sedis, two species, type: S. pinastri Höhn. ex Sacc., coelomycetous, saprobes, terrestrial, Europe, see Kirk et al. (2013; genus accepted), Wijayawardene et al. (2017; outline), cultures and sequences are unavailable, needs generic revision.

Sirothyrium Syd. \& P. Syd. 1916, Ascomycota genera incertae sedis, one species, type: Sirothyrium taxi Syd. \& P. Syd., coelomycetous, sexual morph unknown, saprobes, terrestrial, India, see Wijayawardene et al. (2012, 2017; outline), Kirk et al. (2013; genus accepted), cultures and sequences are unavailable, needs generic revision.

Sirozythia Höhn. 1904, Ascomycota genera incertae sedis, two species, type: S. rosea Höhn., coelomycetous, sexual morph unknown, saprobes, terrestrial, Europe, see Wijayawardene et al. (2012, 2017; outline), Kirk et al. (2013; genus accepted), cultures and sequences are unavailable, needs generic revision.

Sirozythiella Höhn. 1909, Ascomycota genera incertae sedis, one species, type: S. sydowiana (Sacc.) Höhn., coelomycetous, sexual morph unknown, saprobes, terrestrial, Europe, see Wijayawardene et al. (2012, 2017; outline), Kirk et al. (2013; genus accepted), cultures and sequences are unavailable, needs generic revision.

Sitochora H.B.P. Upadhyay 1964, Ascomycota genera incertae sedis, one species, type: S. ellipsospora H.B.P. Upadhyay, coelomycetous, sexual morph unknown, saprobes, terrestrial, Brazil, see Wijayawardene et al. (2012, 2017; outline), Kirk et al. (2013; genus accepted), cultures and sequences are unavailable, needs generic revision.

Sivanesania W.H. Hsieh \& Chi Y. Chen 1996, Botryosphaeriaceae, Botryosphaeriales, Dothideomycetes, one species, type: S. rubi W.H. Hsieh \& Chi Y. Chen, asexual morph unknown, saprobes, terrestrial, Taiwan, see Lumbsch and Huhndorf (2010; outline), Kirk et al. (2013; genus accepted), Hyde et al. (accepted as a genus in Botryosphaeriaceae), Wijayawardene et al. (2014c; outline), cultures and sequences are unavailable, needs generic revision.

Sivanesaniella Gawande \& D.K. Agarwal 2004, Dothideomycetes genera incertae sedis, one species, type: S. prunicola Gawande \& D.K. Agarwal, asexual morph unknown, saprobes, terrestrial, India, see Lumbsch and Huhndorf (2010; outline, accepted as agenus in Venturiaceae), Kirk et al. (2013; genus accepted), Hyde et al. (2013; did not accept as a genus in Venturiaceae), Wijayawardene et al. (2014c; outline), cultures and sequences are unavailable, needs generic revision.

Skottsbergiella Petr. 1927, Gnomoniaceae, Diaporthales, Sordariomycetes, one species, type: S. diaporthoides Petr., asexual morph unknown, saprobes, terrestrial, Chile, see Lumbsch and Huhndorf (2010; outline), Kirk et al. (2013; genus accepted), Maharachchikumbura et al. (2015, 2016; outline), cultures and sequences are available but lacks for the type.

Skyathea Spooner \& Dennis 1986, ?Gelatinodiscaceae, Helotiales, Leotiomycetes, one species, type: S. hederae Spooner \& Dennis, asexual morph unknown, sabrobe of wood, Skye Island, see Lumbsch and Huhndorf (2010; outline), Kirk et al. (2013; genus accepted), holotype of the type: K 32267, cultures and sequences are unavailable, needs generic revision. Skyttea Sherwood, D. Hawksw. \& Coppins 1981, Cordieritidaceae, Leotiomycetes families incertae sedis, 29 species, type: S. nitschkei (Körb.) Sherwood, D. Hawksw. \& Coppins (syn. Nesolechia nitschkei Körb.), lichenicolous, widespread, terrestrial, see Lumbsch \& Huhndorf (2010; outline), Kirk et al. (2013; genus accepted), Suija et al. (2014, 2015b; phylogeny), Jaklitsch et al. (2016a; position), sequences are available, holotype of type: L 910.195-559.

Skyttella D. Hawksw. \& R. Sant. 1988, ?Cordieritidaceae, Leotiomycetes families incertae sedis, one species, type: S. muelleri (Willey) D. Hawksw. \& R. Sant., on lichens, terrestrial, Europe and North America, see Lumbsch and Huhndorf (2010; outline), Kirk et al. (2013; genus accepted), Jaklitsch et al. (2016a; position), sequences are available, holotype of type: $\mathrm{FH}$. 
Slimacomyces Minter 1986, Ascomycota genera incertae sedis, two species, type: $S$. monosporus (W.B. Kendr.) Minter, hyphomycetous, sexual morph unknown, saprobes, terrestrial, Asia, Europe, see Seifert et al. (2011; morphology), Koukol et al. (2012; enzymes), Wijayawardene et al. (2012, 2017; outline), Kirk et al. (2013; genus accepted), cultures and sequences are unavailable, needs generic revision.

Slopeiomyces Klaubauf, Lebrun \& Crous 2014, Magnaporthaceae, Magnaporthales, Sordariomycetes, one species, type: S. cylindrosporus (D. Hornby, Slope, Gutter. \& Sivan.) Klaubauf, Lebrun \& Crous, asexual morph hyphomycetous, saprobes, terrestrial, UK, see Klaubauf et al. (2014; morphology, phylogeny), Maharachchikumbura et al. (2015; outline), ex-type culture of type: CBS 609.75.

Smaragdiniseta L. Lombard \& Crous 2016, Stachybotriaceae, Hypocreales, Sordariomycetes, one species, type: S. bisetosa (V.G. Rao \& de Hoog) L. Lombard \& Crous, hyphomycetous, sexual morph unknown, saprobes, terrestrial, India, see Lombard et al. (2016; taxonomy, phylogeny), Wijayawardene et al. (2017; outline), ex-type culture of the type: CBS 459.82.

Smardaea Svrček 1969, Otideaceae, Pezizales, Pezizomycetes, eight species, type: S. amethystina (W. Phillips) Svrček, asexual morph unknown, saprobes, terrestrial, North temperate, see Van Vooren (2009; new species), Lumbsch and Huhndorf (2010; outline), Kirk et al. (2013; genus accepted), sequences are available.

Smarodsia Raitv. \& Vimba 2006, Pyronemataceae, Pezizales, Pezizomycetes, one species, type: S. stollii Raitv. \& Vimba, asexual morph unknown, from soil, terrestrial, Latvia, see Lumbsch and Huhndorf (2010; outline), holotype of the type: RIG 6493, cultures and sequences are unavailable, needs generic revision.

Smeringomyces Thaxt. 1908, Laboulbeniaceae, Laboulbeniales, Laboulbeniomycetes, four species, type: $S$. anomalus (Thaxt.) Thaxt., asexual morph unknown, biotrophic on Coleoptera (Staphilinidae), USA, Europe, Japan, Trinidad, Sumatra, see Lumbsch and Huhndorf (2010; outline), Kirk et al. (2013; genus accepted), cultures and sequences are unavailable, needs generic revision.

Sodiomyces Grum-Grzhimaylo, Debets \& Bilanenko 2013, Plectosphaerellaceae, Glomerellales, Sordariomycetes, two species, type: S. alkalinus (Bilanenko \& M. Ivanova) A.A. Grum-Grzhimaylo, A.J.M. Debets \& E.N. Bilanenko, asexual morph unknown, saprobes, terrestrial, worldwide, see Grum-Grzhimaylo et al. (2013a; taxonomy), Maharachchikumbura et al. (2015, 2016; outline, phylogeny), Wijayawardene et al. (2017; outline), cultures and sequences are available.

Solanella Vaňha 1910, Pezizales genera incertae sedis, Pezizomycetes, one species, type: S. rosea Van̆ha, asexual morph unknown, saprobes, terrestrial, Europe, see Lumbsch and Huhndorf (2010; outline), Kirk et al. (2013; genus accepted), Jaklitsch et al. (2016a; classification, treated as Pezizales), cultures and sequences are unavailable, needs generic revision.

Soleella Darker 1967, Rhytismataceae, Rhytismatales, Leotiomycetes, seven species, type: S. striiformis (Darker) Darker, asexual morph unknown, saprobes, terrestrial, North America, China, see Lumbsch and Huhndorf (2010; outline), Kirk et al. (2013; genus accepted), cultures and sequences are available but lacks for the type, needs generic revision.

Solenopezia Sacc. 1889, Lachnaceae, Helotiales, Leotiomycetes, seven species, type: S. solenia Sacc., asexual morph unknown, saprobes, terrestrial, widespread, see Lumbsch and Huhndorf (2010; outline), Kirk et al. (2013; genus accepted), cultures and sequences are unavailable for type, needs generic revision.

Solenopsora A. Massal. 1855, Catillariaceae, Rhizocarpales, Lecanoromycetes, 20 species, type: S. requienii A. Massal., lichenized, see Lumbsch and Huhndorf (2010; outline), Van Den Boom (2010; new records, Spain), Farkas et al. (2011; distributionm Hungary), Kinalioglu and Aptroot (2011; new reords, Turkey), Kirk et al. (2013; genus accepted), 
Guttová et al. (2014; generic diveristy), Lücking et al. (2016b; classification), Yazici and Aslan (2016; new species, Turkey), sequences are available.

Solicorynespora R.F. Castañeda \& W.B. Kendr. 1990, Ascomycota genera incertae sedis, 27 species, type: S. zapatensis R.F. Castañeda \& W.B. Kendr., hyphomycetous, sexual morph unknown, saprobes, terrestrial, worldwide, see McKenzie (2010; new species), Seifert et al. (2011; morphology), Ma et al. (2012d, 2016; new species), Wijayawardene et al. (2012, 2017; outline), Kirk et al. (2013; genus accepted), Hernández-Restrepo et al. (2014a; new species), cultures and sequences are unavailable, needs generic revision.

Solitaria Arup, Søchting \& Frödén 2013, Teloschistaceae, Teloschistales, Lecanoromycetes, one species, type: S. chrysophthalma (Degelius) Arup, Søchting \& Frödén, asexual morph unknown, lichenized, terrestrial, see Arup et al. (2013; taxonomy), Gaya et al. (2015; phylogeny), Lücking et al. (2016b; classification); sequences are

Soloacrospora W.B. Kendr. \& R.F. Castañeda 1991, Ascomycota genera incertae sedis, two species, type: S. flagellisetosa W.B. Kendr. \& R.F. Castañeda, hyphomycetous, sexual morph unknown, saprobes, terrestrial, Caribbean, South America, see Seifert et al. (2011; morphology), Wijayawardene et al. (2012, 2017; outline), Kirk et al. (2013; genus accepted), cultures and sequences are unavailable, needs generic revision.

Soloacrosporiella Crous \& M.J. Wingf. 2015, Dothideomycetes genera incertae sedis, one species, type: S. acaciae Crous \& M.J. Wingf., hyphomycetous, sexual morph unknown, saprobes, Malaysia, see Crous et al. (2015d; taxonomy, phylogeny), Wijayawardene et al. (2017; outline), holotype and ex-type culture of the type: CBS H-22223, CPC 24871.

Solorina Ach. 1808, Peltigeraceae, Peltigerales, Lecanoromycetes, ten species, type: S. crocea (L.) Ach., lichenized, Asia, Europe, North America, see Gagunashvili et al. (2009; molecular), Björk (2010; new record), Lumbsch and Huhndorf (2010; outline), Wedin et al. (2011; molecular), Grube et al. (2012; symbiosis), Lisov et al. (2012; ecology), Kirk et al. (2013; genus accepted), Miądlikowska et al. (2014; molecular), Centeno et al. (2016; metabolic profiling), Magain et al. (2016; molecular), Lücking et al. (2016b; classification), sequences are available.

Solorinaria (Vain.) Gyeln., 1935, Lichinaceae, Lichinales, Lichinomycetes, one species, type: S. fuscata (Vain.) Gyeln., asexual morph unknown, lichenized, terrestrial, see Lumbsch and Huhndorf (2010; outline), Aptroot and Iqbal (2012; checklist), Kirk et al. (2013; genus accepted), Brackel (2013; taxonomy), Lücking et al. (2016b; classification), sequences are unavailable.

Solosympodiella Matsush. 1971, Ascomycota genera incertae sedis, eight species, type: S. clavata Matsush., hyphomycetous, sexual morph unknown, saprobes, terrestrial, Asia, Australasia, South America, see Seifert et al. (2011; morphology), Wijayawardene et al. (2012, 2017; outline), Kirk et al. (2013; genus accepted), cultures and sequences are unavailable, needs generic revision.

Soloterminospora Matsush. 1996, Ascomycota genera incertae sedis, one species, type: $S$. caffra Matsush., hyphomycetous, sexual morph unknown, saprobes, terrestrial, South Africa, see Seifert et al. (2011; morphology), Wijayawardene et al. (2012, 2017; outline), Kirk et al. (2013; genus accepted), holotype of the type: Matsushima Fungus Collection, Kobe, 5A089, cultures and sequences are unavailable, needs generic revision.

Sonderhenia H.J. Swart \& J. Walker 1988, Mycosphaerellaceae, Capnodiales, Dothideomycetes, two species, type: S. eucalyptorum (Hansf.) H.J. Swart \& J. Walker coelomycetous, sexual morph mycosphaerella-like, two species, plant pathogens on Eucalyptus, terrestrial, see Crous et al. (2013a; morphology, phylogeny), Videira et al. (2017; typification), Wijayawardene et al. (2017; outline), holotype DAR 45719, isotype IMI 280474 (sexual morph), holotype WARI 2007 (asexual morph); representative cultures CBS $120220=$ CPC 12553, CPC 12554-12555. 
Soosiella Hujslová \& M. Kolařík 2013, Helotiales genera incertae sedis, Leotiomycetes, one species, type: S. minima Hujslová \& M. Kolařík, hyphomycetous, sexual morph unknown, saprobes, terrestrial, Czech Republic, see Hujslová et al. (2013, 2014; phylogeny), holotype and ex-type of the type: PRM 922619, CBS 136257.

Sordaria Ces. \& De Not. 1863, Sordariaceae, Sordariales, Sordariomycetes, twelve species, type: S. fimicola (Roberge ex Desm.) Ces. \& De Not., asexual morph unknown, terrestrial, saprobes, coprophilous, worldwide, see Lumbsch and Huhndorf (2010; outline), Kirk et al. (2013; genus accepted), Maharachchikumbura et al. (2015, 2016; outline), Senanayake et al. (2015; phylogeny), cultures and sequences are available.

Sorocybe Fr. 1849, Herpotrichiellaceae, Chaetothyriales, Eurotiomycetes, three species, type: S. resinae (Fr.) Fr., coelomycetous, sexual morph unknown, saprobes, terrestrial, Asia, see Seifert et al. (2011; morphology, genus accepted), Wijayawardene et al. (2012, 2017; outline), Kirk et al. (2013; did not accept genus), cultures and sequences are available, needs generic revision.

Sorokina Sacc. 1892, Helotiales genera incertae sedis, Leotiomycetes, six species, type: S. microspora (Berk.) Sacc., asexual morph unknown, saprobes, terrestrial, pantropical, see Lumbsch and Huhndorf (2010; outline), Kirk et al. (2013; genus accepted), cultures and sequences are unavailable, needs generic revision.

Sorokinella J. Fröhl. \& K.D. Hyde 2000, Helotiales genera incertae sedis, Leotiomycetes, two species, type: S. appendicospora J. Fröhl. \& K.D. Hyde, asexual morph unknown, saprobes, terrestrial, Hong Kong, see Lumbsch and Huhndorf (2010; outline), cultures and sequences are unavailable, needs generic revision.

Sowerbyella Nannf. 1938, Otideaceae, Pezizales, Pezizomycetes, eight species, type: S. radiculata (Sowerby) Nannf., asexual morph unknown, saprobes, terrestrial, Europe, China, see Zhuang (2009; new species), Lumbsch and Huhndorf (2010; outline), Hansen et al. (2013; DNA, phylogeny), Kirk et al. (2013; genus accepted), sequences are available.

Spadicoides S. Hughes 1958, Sordariomycetes genera incertae sedis, c. 40 species, type: S. bina (Corda) S. Hughes 1958, hyphomycetous, sexual morph unknown, phialophora-like and selenosporella-like synanamorphs, saprobes, terrestrial and aquatic, cosmopolitan, see Wongsawas (2008, new record from China), Li (2010, new species), Ma et al. (2010, 2014, 2016; new species), Shenoy et al. (2010, polyphyly, affinities with Dothideomycetes and Sordariomycetes), Seifert et al. (2011; morphology), Ma et al. (2012a, new species), Wijayawardene et al. (2012, 2017; outline), Kirk et al. (2013; genus accepted), Heredia et al. (2015, new species), sequences are available but lacks for the type.

Sparria Ertz \& Tehler 2011, Opegraphaceae, Arthoniales, Arthoniomycetes, two species, type: S. cerebriformis (Egea \& Torrente) Ertz \& Tehler, lichenized, see Californian coast, Baja California and Europe, see Ertz and Tehler (2011; morphology, phylogeny), Lücking et al. (2016b; classification), sequences are available.

Sparticola Phukhams., Ariyaw., Camporesi \& K.D. Hyde 2016, Sporormiaceae, Pleosporales, Dothideomycetes, three species, type: S. forlicesenae Wanas., Phukhams., Camporesi \& K.D. Hyde, asexual morph hyphomycetous, saprobes, terrestrial, Italy, see Phukhamsakda et al. (2016; taxonomy, phylogeny), Wijayawardene et al. (2017; outline), holotype and ex-type culture of the type: MFLU 15-1405, MFLUCC 15-0030.

Spataporthe Bronson, Klymiuk, Stockey \& Tomescu 2013, Gnomoniaceae, Diaporthales, Sordariomycetes, one species, type: S. taylorii Bronson, Klymiuk, Stockey \& Tomescu, asexual morph unknown, fossil fungi, see Bronson et al. (2013; taxonomy), Maharachchikumbura et al. (2015, 2016; outline), cultures and sequences are unavailable.

Spathaspora N.-H. Nguyen, S.-O. Suh \& M. Blackwell 2006, Debaryomycetaceae, Saccharomycetales, Saccharomycetes, ten species, type: S. passalidarum N.H. Nguyen, S.O. Suh \& M. Blackwell, asexual reproduction is by multilateral budding, saprophytic, associated 
with wood boring insect larvae, possibly worldwide, see Lumbsch and Huhndorf (2010; outline), S. passalidarum and other species in the clade are noted for fermentation of Dxylose, which is important for fermention of biomass to fuel ethanol, many species in this genus represent asexual taxa originally classified in the genus Candida, but which have been transferred to the genus Spathaspora as new combinations, cultures and sequences are available.

Spathularia Pers. 1797, Cudoniaceae, Rhytismatales, Leotiomycetes, twelve species, type: S. flavida Pers., asexual morph unknown, saprobes, terrestrial, North temperate, see Lumbsch and Huhndorf (2010; outline), Kirk et al. (2013; genus accepted), Ge et al. (2014; DNA, phylogeny), cultures and sequences are available, needs generic revision.

Spathulospora A.R. Caval. \& T.W. Johnson 1965, Lulworthiaceae, Lulworthiales, Sordariomycetes, five species, type: S. phycophila A.R. Caval. \& T.W. Johnson, spermatiophores or asexual morph hyphomycetous, biotrophic on marine red alga, temperate to Antarctic sea of Southern hemisphere, see Lumbsch and Huhndorf (2010; outline), Kirk et al. (2013; genus accepted), Jones et al. (2015; outline), Maharachchikumbura et al. (2015, 2016; outline), holotype of the type: (R.E. Norris, 3892), needs generic revision.

Speerschneidera Trevis. 1861, Leprocaulaceae, Leprocaulales, Lecanoromycetes, one species, type: S. euploca (Tuck.) Trevis., lichenized, see Lumbsch and Huhndorf (2010; outline, accepted as a genus in Lecanorales, genera incertae sedis), Kirk et al. (2013; genus accepted), Lendemer and Hodkinson 2013, Lücking et al. (2016b; classification); sequences are available.

Spegazzinia Sacc. 1880, Apiosporaceae, Xylariale, Sordariomycetes, nine species, type: S. ornata Sacc., hyphomycetous, saprobes, terrestrial, widespread, see Seifert et al. (2011; morphology), Hyde et al. (2011; outline), Whitton et al. (2012a; morphology with two types of conidia), Wijayawardene et al. (2012, 2017; outline), Kirk et al. (2013; genus accepted), Maharachchikumbura et al. (2015, 2016; outline), cultures and sequences are available, needs generic revision.

Speiropsis Tubaki 1958, Dothideomycetes genera incertae sedis, nine species, type: $S$. pedatospora Tubaki, hyphomycetous, sexual morph unknown, saprobes, terrestrial, Asia, Caribbean, North and South America, see Prihatini et al. (2010; phylogeny), Seifert et al. (2011; morphology), Wijayawardene et al. (2012, 2017; outline), Kirk et al. (2013; genus accepted), Pratibha et al. (2016; DNA, phylogeny), cultures available for the type: GUFCC 18008.

Spencermartinsia A.J.L. Phillips, A. Alves \& Crous 2008, Botryosphaeriaceae, Botryosphaeriales, Dothideomycetes, nine species, type: S. viticola (A.J.L. Phillips \& J. Luque) A.J.L. Phillips, A. Alves \& Crous, asexual morph coelomycetous, saprobes, weakly pathogens, terrestrial, worldwide, see Lumbsch and Huhndorf (2010; outline), Liu et al. (2012; phylogeny), Hyde et al. (2013; accepted as a genus in Botryosphaeriaceae), Phillips et al. (2013; phylogeny), Abdollahzadeh et al. (2014; new species), Slippers et al. (2014; phylogeny), Wijayawardene et al. (2014c, 2016b; outline, taxonomy), Dissanayake et al. (2016; taxonomy), holotype and ex-type culture of the type: LISE 95177, CBS 117009.

Spencermartinsiella Péter, Dlauchy, Tornai-Lehoczki, M. Suzuki \& Kurtzman 2011, Trichomonascaceae, Saccharomycetales, Saccharomycetes, four species, type: S. europaea G. Péter, Dlauchy, Tornai-Leh., M. Suzuki \& Kurtzman, cell division is by multilateral budding, saprophytic, rotted wood, Europe, South America, see Péter et al. (2011; taxonomy), cultures and sequences are available.

Spermatoloncha Speg. 1908, Ascomycota genera incertae sedis, one species, type: S. maticola Speg., hyphomycetous, sexual morph unknown, saprobes, terrestrial, South America, Africa, see Seifert et al. (2011; morphology), Wijayawardene et al. (2012, 2017; outline), 
Kirk et al. (2013; genus accepted), cultures and sequences are unavailable, needs generic revision.

Spermochaetella Cif. 1954, Ascomycota genera incertae sedis, one species, type: S. tecomae (Chardón \& Toro) Cif., coelomycetous, sexual morph unknown, saprobes, terrestrial, South America, see Wijayawardene et al. (2012, 2017; outline), Kirk et al. (2013; genus accepted), cultures and sequences are unavailable, needs generic revision.

Spermospora R. Sprague 1948, Ascomycota genera incertae sedis, nine species, type: $S$. subulata (R. Sprague) R. Sprague, hyphomycetous, sexual morph unknown, saprobes, terrestrial, Australasia, Europe, North America, see Seifert et al. (2011; morphology), Wijayawardene et al. (2012, 2017; outline), Kirk et al. (2013; genus accepted), cultures and sequences are unavailable, needs generic revision.

Spermosporella Deighton 1969, Ascomycota genera incertae sedis, nine species, type: $S$. aggregata Deighton, hyphomycetous, sexual morph unknown, saprobes, terrestrial, Africa, Asia, North America, see Seifert et al. (2011; morphology), Wijayawardene et al. (2012, 2017; outline), Kirk et al. (2013; genus accepted), cultures and sequences are unavailable, needs generic revision.

Spermotrichum Kuntze 1898, Ascomycota genera incertae sedis, one species, type: $S$. pulchellum (Speg.) Kuntze, coelomycetous, sexual morph unknown, saprobes, terrestrial, Paraguay, see Wijayawardene et al. (2012, 2017; outline), Kirk et al. (2013; genus accepted), cultures and sequences are unavailable, needs generic revision.

Sphacelia Lév. 1827, Clavicipitaceae, Hypocreales, Sordariomycetes, seven species, type: S. segetum Lév., hyphomycetous, sexual morph unknown, saprobes, terrestrial, worldwide, see Pažoutová et al. (2008; DNA, phylogeny), Wijayawardene et al. (2012, 2017; outline, txonomy), Kirk et al. (2013; genus accepted), Maharachchikumbura et al. (2015, 2016; outline), cultures and sequences are available but lacks for the type.

Sphaerellopsis Cooke 1883, Leptosphaeriaceae, Pleosporales, Dothideomycetes, five species, type: $S$. quercuum Cooke, asexual morph coelomycetous, pathogens, lichenicolous, terrestrial, worldwide, see Wijayawardene et al. (2012, 2014c, 2017; outline), Trakunyingcharoen et al. (2014; new species, phylogeny), Crous et al. (2016a, b; new species, phylogeny), cultures and sequences are available but lacks for the type:.

Sphaerellothecium Zopf 1897, Mycosphaerellaceae, Capnodiales, Dothideomycetes, type: S. araneosum (Rehm) Zopf, c. 30 species, asexual morph unknown, terrestrial, on lichens, worldwide, see Lumbsch and Huhndorf (2010; outline), Hyde et al. (2013; accepted as a genus in Mycosphaerellaceae), Kirk et al. (2013; genus accepted), Wijayawardene et al. (2014c; outline), van den Boom (2016; new species), cultures and sequences are unavailable. Sphaeriostromella Bubák 1916, Ascomycota genera incertae sedis, one species, type: S. pteridina (Sacc. \& Roum.) Bubák, coelomycetous, sexual morph unknown, saprobes, terrestrial, Europe, see Wijayawardene et al. (2012, 2017; outline), Kirk et al. (2013; genus accepted), cultures and sequences are unavailable, needs generic revision.

Sphaeriothyrium Bubák 1916, Ascomycota genera incertae sedis, two species, type: S. filicinum Bubák, coelomycetous, sexual morph unknown, saprobes, terrestrial, Europe, see Wijayawardene et al. (2012, 2017; outline), Kirk et al. (2013; genus accepted), cultures and sequences are unavailable, needs generic revision.

Sphaerocordyceps Kobayasi 1981, Clavicipitaceae, Hypocreales, Sordariomycetes, two species, type: S. palustris (Berk.) Kobayasi, asexual morph unknown, saprobes, terrestrial, worldwide, see Lumbsch and Huhndorf (2010; outline), Kirk et al. (2013; genus accepted), Maharachchikumbura et al. (2015, 2016; outline), holotype of the type: CUP 067858, cultures and sequences are unavailable.

Sphaerodes Clem. 1909, Ceratostomataceae, Melanosporales, Sordariomycetes, 13 species, type: S. episphaerium (W. Phillips \& Plowr.) Clem., asexual morph unknown, saprobes, 
terrestrial, worldwide, see Vujanovic and Goh (2009; new species), Lumbsch and Huhndorf (2010; outline), Kirk et al. (2013; genus accepted), Maharachchikumbura et al. (2015, 2016; outline), cultures and sequences are available but lacks for the type, needs generic revision.

Sphaerodothella C.A. Pearce \& K.D. Hyde 2001, Phyllachoraceae, Phyllachorales, Sordariomycetes, one species, type: S. danthoniae (McAlpine) C.A. Pearce \& K.D. Hyde, saprobes, Australia, see Lumbsch and Huhndorf (2010; outline), Maharachchikumbura et al. (2015, 2016; outline), cultures and sequences are unavailable, needs generic revision.

Sphaerodothis (Sacc. \& P. Syd.) Shear 1909, Phyllachoraceae, Phyllachorales, Sordariomycetes, 20 species, type: S. arengae (Racib.) Shear ex Theiss. \& Syd., saprobes, South East Asia, see Lumbsch and Huhndorf (2010; outline), Kirk et al. (2013; genus accepted), Maharachchikumbura et al. (2015, 2016; outline), cultures and sequences are unavailable, needs generic revision.

Sphaerognomoniella Naumov \& Kusnezowa 1952, Diaporthales genera incertae sedis, Sordariomycetes, one species, type: S. cornicola Naumov \& Kusnezowa, asexual morph unknown, saprobes, terrestrial, former USSR, see Lumbsch and Huhndorf (2010; outline), Kirk et al. (2013; genus accepted), Maharachchikumbura et al. (2015, 2016; outline), cultures and sequences are unavailable, needs generic revision.

Sphaerographium Sacc. 1884, Chaetomellaceae, Helotiales, Leotiomycetes, twelve species, type: S. squarrosum Riess, coelomycetous, sexual morph unknown, saprobes, terrestrial, worldwide, see Minnis et al. (2010; new species, DNA), Wijayawardene et al. (2012, 2017; outline), Kirk et al. (2013; accepted as valid genus), cultures available but lacks for the type.

Sphaeromma H.B.P. Upadhyay 1964, Ascomycota genera incertae sedis, two species, type: $S$. mazosiae H.B.P. Upadhyay, coelomycetous, sexual morph unknown, lichenicolous, terrestrial, Brazil, see Wijayawardene et al. (2012, 2017; outline), Kirk et al. (2013; genus accepted), cultures and sequences are unavailable, needs generic revision.

Sphaeronaemella P. Karst. 1884 (= Gabarnaudia Samson \& W. gams 1974 fide Réblová et al. 2016c), Microascales genera incertae sedis, Sordariomycetes, ten species, type: $S$. helvellae (P. Karst.) P. Karst., asexual morph unknown, saprobes, terrestrial, worldwide, see Lumbsch and Huhndorf (2010; outline), de Beer et al. (2013; new species), Kirk et al. (2013; genus accepted), Maharachchikumbura et al. (2015, 2016; outline), Réblová et al. (2016c; nomenclature), Wijayawardene et al. (2017; outline), sequences are available.

Sphaerophoma Petr. 1924, Ascomycota genera incertae sedis, two species, type: S. brencklei Petr., coelomycetous, sexual morph unknown, saprobes, terrestrial, North Americ, see Wijayawardene et al. (2012, 2017; outline), Kirk et al. (2013; genus accepted), cultures and sequences are unavailable, needs generic revision.

Sphaerophoropsis Vain. 1890, Cladoniaceae, Lecanorales, Lecanoromycetes, one species, type: S. stereocauloides Vain., lichenized, see Lumbsch and Huhndorf (2010; outline), Kirk et al. (2013; genus accepted), Lücking et al. (2016b; classification), sequences are unavailable. Sphaerophorus Pers. 1794, Sphaerophoraceae, Lecanorales, Lecanoromycetes, 6 species, type: S. coralloides Pers., asexual morph unknown, fruticose, terrestrial, saxicolous, see Wedin et al. (2009a; taxonomy), Hua-Jie et al. (2010; metal studies), Lumbsch and Huhndorf (2010; outline), Kirk et al. (2013; genus accepted), Mcmullin and Arsenault (2016; new records), Root et al. (2014; climate indicator), Chamizo et al (2016, spatial distribution), Lücking et al. (2016b; classification), sequences are available.

Sphaeropsis Sacc. 1880 (= Phaeobotryosphaeria Speg. 1908 fide Phillips et al. 2013; Wijayawardene et al. 2014c; Rossman et al. 2015b), Botryosphaeriaceae, Botryosphaeriales, Dothideomycetes, five species, type: S. visci (Alb. \& Schwein.) Sacc, coelomycetous, sexual morph formerly known in Phaeobotryosphaeria, saprobes, endophytes, terrestrial, cosmopolitan, see Phillips et al. (2008, 2013; taxonomy, phylogeny), Liu et al. (2012; taxonomy, phylogeny), Hyde et al. (2013; accepted as a genus in Botryosphaeriaceae), 
Slippers et al. (2013; phylogeny), Wijayawardene et al. (2014c, 2016b; outline, taxonomy, phylogeny, nomenclature), Rossman et al. (2015b; nomenclature), Dissanayake et al.(2016; taxonomy), neotype and ex-neotype culture of the type: CWU (MYC) AS 2271 (MBT176099), CBS 122527.

Sphaerosoma Klotzsch 1839, Pezizales genera incertae sedis, Pezizomycetes, three species, type: S. fuscescens Klotzsch, asexual morph unknown, hypogeous, terrestrial, Europe, North America, see Lumbsch and Huhndorf (2010; outline), Kirk et al. (2013; genus accepted), cultures and sequences are unavailable, needs generic revision.

Sphaerosporella (Svrček) Svrček \& Kubička 1961, Pyronemataceae, Pezizales, Pezizomycetes, three species, type: S. brunnea (Alb. \& Schwein.) Svrček \& Kubička, asexual morph hyphomycetous, hypogeous, terrestrial, worldwide, see Lumbsch and Huhndorf (2010; outline), Kirk et al. (2013; genus accepted), Sánchez et al. (2014b; asexual reproduction, DNA), cultures and sequences are available for the type.

Sphaerosporium Schwein. 1832, Onygenales genera incertae sedis, two species, type: $S$. lignatile Schwein., coelomycetous, sexual morph unknown, saprobes, terrestrial, Europe, North and South America, see Seifert et al. (2011; morphology), Ropars et al. (2012; DNA, phylogeny), Wijayawardene et al. (2012, 2017; outline), Kirk et al. (2013; genus accepted), cultures and sequences are available but lacks for the type, needs generic revision.

Sphaerostilbella (Henn.) Sacc. \& D. Sacc. 1905 (= Gliocladium Corda 1840 fide Rossman et al. 2013b; Maharachchikumbura et al. 2016), Hypocreaceae, Hypocreales, Sordariomycetes, four species, type: S. lutea (Henn.) Sacc. \& D. Sacc., asexual morph hyphomycetous, saprobes, terrestrial, worldwide, see Lumbsch and Huhndorf (2010; outline), Kirk et al. (2013; genus accepted), Maharachchikumbura et al. (2015, 2016; outline), cultures and sequences are available, needs generic revision.

Sphaerozone Zobel 1854, Pezizaceae, Pezizales, Pezizomycetes, four species, type: S. tulasnei Zobel, asexual morph unknown, hypogeous, terrestrial, worldwide, see Lumbsch and Huhndorf (2010; outline), Kirk et al. (2013; genus accepted), cultures and sequences are unavailable, needs generic revision.

Sphaerulina Sacc. 1878, Mycosphaerellaceae, Capnodiales, Dothideomycetes, 66 species, type: S. myriadea (DC.) Sacc., asexual morph coelomycetous, asexual morph septoria-like, saprobes or plant pathogens, terrestrial, freshwater or marine, worldwide, see Lumbsch and Huhndorf (2010; outline), Crous et al. (2011e; taxonomy), Kirk et al. (2013; genus accepted), Hyde et al. (2013; accepted as a genus in Mycosphaerellaceae), Verkley et al. (2013; phylogeny), Wijayawardene et al. (2014c; outline), cultures and sequences are available.

Sphaerulomyces Marvanová. 1977, Ascomycota genera incertae sedis, one species, type: S. coralloides Marvanová, hyphomycetous, saprobes, Czechoslovakia, see Seifert et al. (2011; morphology), Wijayawardene et al. (2012, 2017; outline), Kirk et al. (2013; genus accepted), cultures and sequences are unavailable, needs generic revision.

Sphaleromyces Thaxt. 1894, Laboulbeniaceae, Laboulbeniales, Laboulbeniomycetes, four species, type: S. lathrobii Thaxt., asexual morph unknown, biotrophic on Coleoptera (Staphylinidae), Europe, America, India, see Lumbsch and Huhndorf (2010; outline), Kirk et al. (2013; genus accepted), cultures and sequences are unavailable, needs generic revision.

Spheconisca (Norman) Norman 1876, Verrucariaceae, Verrucariales, Eurotiomycetes, twenty species, type: S. hypocrita Norman, asexual morph unknown, lichenized, terrestrial, Europe, see Lumbsch and Huhndorf (2010; outline), Kirk et al. (2013; genus accepted), Lücking et al. (2016b; classification), sequences are unavailable.

Sphinctrina Fr. 1825, Sphinctrinaceae, Mycocaliciales, Eurotiomycetes, ten species, type: $S$. turbinata (Pers.) De Not., asexual morph unknown, lichenicolous, terrestrial, worldwide, see Lumbsch and Huhndorf (2010; outline), Kirk et al. (2013; genus accepted), Muniz et al. 
(2013; new species), Tibell et al. (2014; new species, DNA), cultures available for the type: AFTOL-ID 1721.

Sphinctrinopsis Woron. 1927, Caliciaceae, Caliciales, Lecanoromycetes, one species, type: S. pertusariae Woron., lichenized, see Gaya et al. (2012; taxonomy), Lücking et al. (2016b; classification), Prieto and Wedin (2016; phylogeny), sequences are unavailable.

Spicellum Nicot \& Roquebert 1976, Bionectriaceae, Hypocreales, Sordariomycetes, two species, type: $S$. roseum Nicot \& Roquebert, hyphomycetous, sexual morph unknown, saprobes, terrestrial, France, see Seifert et al. (2011; morphology), Wijayawardene et al. (2012, 2017; outline), Kirk et al. (2013; genus accepted), Maharachchikumbura et al. (2015, 2016; outline), sequences are available.

Spilodochium Syd. 1927, Ascomycota genera incertae sedis, four species, type: S. vernoniae Syd., hyphomycetous, sexual morph unknown, saprobes, terrestrial, Australasia, Neotropics, see Seifert et al. (2011; morphology), Wijayawardene et al. (2012, 2017; outline), Kirk et al. (2013; genus accepted), cultures and sequences are unavailable, needs generic revision.

Spilonema Bornet 1856, Coccocarpiaceae, Peltigerales, Lecanoromycetes, five species, type: S. paradoxum Bornet, lichenized, see Lumbsch and Huhndorf (2010; outline), Anderson and Neily (2012; new records), Kirk et al. (2013; genus accepted), Medeiros et al. (2014; ecology), Spribille et al. (2014b; evolution), Mcmullin et al. (2015; new records), Prieto et al. (2015; new record), Lücking et al. (2016b; classification), sequences are available.

Spilopodia Boud. 1885, Drepanopezizaceae, Helotiales, Leotiomycetes, four species, type: S. nervisequa (Pers.) Boud., asexual morph unknown, saprobes, terrestrial, Europe, see Lumbsch and Huhndorf (2010; outline), Kirk et al. (2013; genus accepted), Jaklitsch et al. (2016a; classification), cultures and sequences are unavailable, needs generic revision.

Spilopodiella E. Müll. 1989, Drepanopezizaceae, Helotiales, Leotiomycetes, one species, type: S. arxii E. Müll., asexual morph unknown, saprobes, terrestrial, Switzerland, see Lumbsch and Huhndorf (2010; outline), Kirk et al. (2013; genus accepted), cultures and sequences are unavailable, needs generic revision.

Spinulosphaeria Sivan. 1974, Chaetosphaerellaceae, Coronophorales, Sordariomycetes, 14 species, type: S. thaxteri (Pat.) Sivan., asexual morph unknown, saprobes, terrestrial, widespread, see Lumbsch and Huhndorf (2010; outline), Mugambi and Huhndorf (2010; new species, phylogeny), Maharachchikumbura et al. (2016; outline, phylogeny), Kirk et al. (2013; genus accepted), cultures and sequences are available but lacks for the type.

Spinulospora Deighton 1973, Ascomycota genera incertae sedis, four species, type: S. pucciniiphila Deighton, hyphomycetous, sexual morph unknown, fungicolous, terrestrial, Africa, see Seifert et al. (2011; morphology), Wijayawardene et al. (2012, 2017; outline), Kirk et al. (2013; genus accepted), cultures and sequences are unavailable, needs generic revision.

Spiralum J.L. Mulder 1975, Ascomycota genera incertae sedis, two species, type: S. helicosporum J.L. Mulder, hyphomycetous, sexual morph unknown, fungicolous, terrestrial, Asia, see Seifert et al. (2011; morphology), Wijayawardene et al. (2012, 2017; outline), Kirk et al. (2013; genus accepted), cultures and sequences are unavailable, needs generic revision.

Spirodecospora B.S. Lu, K. D. Hyde \& W. H. Ho 1998, Xylariales genera incertae sedis, Sordariomycetes, two species, type: S. bambusicola B.S. Lu et al., asexual morph unknown, see Lumbsch and Huhndorf (2010; outline), Kirk et al. (2013; genus accepted), Maharachchikumbura et al. (2015, 2016: outline), Wendt et al. (2017; accepted as a genus in Xylariales genera incertae sedis), cultures and sequences are unavailable.

Spirographa Zahlbr. 1903 (= Pleospilis Clem. 1909 fide Jaklitsch et al. 2016a), Ostropomycetidae genera incertae sedis, Lecanoromycetes, four species, type: S. spiralis (Müll. Arg.) Zahlbr., asexual morph unknown, saprobes, lichenicolous, see Lumbsch and Huhndorf (2010; outline, accepted as a genus in Helotiales), Jaklitsch et al. (2016a; 
classification), Flakus and Kukwa (2012; new species), cultures and sequences are unavailable, needs generic revision.

Spiromastigoides Doweld 2013, Spiromastigaceae, Onygenales, Eurotiomycetes, 17 species, type: S. warcupii (Kuehn \& G.F. Orr) Doweld, asexual morph unknown, ?saprobes, from soil, terrestrial, Australia, see Index Fungorum (2013), culture available for the type: AFTOL-ID 430.

Spiromastix Kuehn \& G.F. Orr 1962, Spiromastigaceae, Onygenales, Eurotiomycetes, eleven species, type: $S$. warcupii Kuehn \& G.F. Orr, asexual morph hyphomycetous, from dung, soil, animal, terrestrial, worldwide, see Lumbsch and Huhndorf (2010; outline), Doweld (2013; nomenclatural), Hirooka et al. (2016; new species), holotype and ex-type culture of the type: NRRL A-10679, CBS 576.63.

Spiroplana Voglmayr, M.J. Park \& H.D. Shin 2011, Pleosporales genera incertae sedis, Dothideomycetes, two species, type: S. centripetala Voglmayr, M.J. Park \& H.D. Shin, hyphomycetous, sexual morph unknown, parasitic, terrestrial, Korea, see Seifert et al. (2011; morphology), Wijayawardene et al. (2012, 2017; outline), holotype and ex-type culture of the type: KUS-F22135, KACC42611.

Spirosphaera Beverw. 1953, Helotiales genera incertae sedis, nine species, type: S. floriformis Beverw, hyphomycetous, sexual morph unknown, on decaying birch leaves in water, see Seifert et al. (2011; morphology), Voglmayr et al. (2011; taxonomy), Wijayawardene et al. (2012, 2017; outline), Kirk et al. (2013; genus accepted), cultures and sequences are available.

Splanchnonema Corda 1829, Pleomassariaceae, Pleosporales, Dothideomycetes, 37 species, type: S. pustulatum Corda, asexual morph unknown, saprobes, terrestrial, Europe, North America, China, India, see Lumbsch and Huhndorf (2010; outline, sexual morph), Zhang et al. (2012e; accepted as a genus in Pleomassariaceae, phylogeny), Zhao and Zhao (2012; new species, China), Hyde et al. (2013; accepted as a genus in Pleomassariaceae, phylogeny), Wijayawardene et al. (2014c; outline), cultures and sequences are available but lacks for the type.

Splanchospora Lar.N. Vassiljeva 1998, Ascomycota genera incertae sedis, one species, type: S. ampullacea (Pers.) Lar.N. Vassiljeva, asexual morphs unknown, saprobes, terrestrial, north temperate zone, see Honda et al. (2012; taxonomy), Kirk et al. (2013; genus accepted), cultures and sequences are unavailable.

Spondylocladiella Linder 1934, Ascomycota genera incertae sedis, two species, type: S. botrytioides Linder, hyphomycetous, sexual morph unknown, saprobes, terrestrial, Asia, Europe, North America, see Seifert et al. (2011; morphology), Wijayawardene et al. (2012, 2017; outline), Kirk et al. (2013; genus accepted), cultures and sequences are unavailable, needs generic revision.

Spondylocladiopsis M.B. Ellis 1963, Ascomycota genera incertae sedis, two species, type: $S$. cupulicola M.B. Ellis, hyphomycetous, sexual morph unknown, saprobes, terrestrial, Europe, India, see Pratibha et al. (2009; new species), Seifert et al. (2011; morphology), Wijayawardene et al. (2012, 2017; outline), Kirk et al. (2013; genus accepted), cultures and sequences are unavailable, needs generic revision.

Spooneromyces T. Schumach. \& J. Moravec 1989, Pyronemataceae, Pezizales, Pezizomycetes, five species, type: S. laeticolor (P. Karst.) T. Schumach. \& J. Moravec, asexual morph unknown, saprobes, terrestrial, Europe, see Lumbsch and Huhndorf (2010; outline), Hansen et al. (2013; phylogeny), Kirk et al. (2013; genus accepted), Van Vooren (2014; new species), cultures and sequences are available.

Sporastatia A. Massal. 1854, Sporastatiaceae, Rhizocarpales, Lecanoromycetes, four species, type: S. testudinea (Ach.) A. Massal., lichenized, saxicolous, worldwide temperate, see Lumbsch and Huhndorf (2010; outline), Bendiksby and Timdal (2013; phylogenetic 
placement), Kirk et al. (2013; genus accepted), Miądlikowska et al. (2014; phylogenetic placement), Lücking et al. (2016b; classification), sequences are available.

Sporendocladia G. Arnaud ex Nag Raj \& W.B. Kendr. 1975, Microascales genera incertae sedis, Sordariomycetes, seven species, type: S. castaneae G. Arnaud ex Nag Raj \& W.B. Kendr., asexual morph unknown, saprobes, terrestrial, worldwide, see Seifert et al. (2011; morphology), Kiyuna et al. (2012; DNA), Wijayawardene et al. (2012, 2017; outline), Kirk et al. (2013; genus accepted), Maharachchikumbura et al. (2015, 2016; outline), cultures and sequences are available but lacks for the type.

Sporendonema Desm. 1827, Onygenaceae, Onygenales, Eurotiomycetes, nine species, type: $S$. casei Desm., coelomycetous, sexual morph unknown, on cheese and fungi, terrestrial, Europe, North America, see Seifert et al. (2011; morphology), Wijayawardene et al. (2012, 2017; outline), Kirk et al. (2013; genus accepted), cultures and sequences are available, needs generic revision.

Sporhaplus H.B.P. Upadhyay 1964, Ascomycota genera incertae sedis, one species, type: $S$. rondoniensis H.B.P. Upadhyay, asexual morph unknown, lichenized, terrestrial, see Kirk et al. (2013; genus accepted), Wijayawardene et al. (2017; outline), cultures and sequences are unavailable.

Sporidesmajora Batzer \& Crous 2010, Dothideomycetes genera incertae sedis, Dothideomycetes, one species, type: S. pennsylvaniensis Batzer \& Crous, hyphomycetous, sexual morph unknown, one species, saprobes, ?pathogens, terrestrial, USA, see Yang et al. (2010; morphology, phylogeny), Wijayawardene et al. (2017; outline), holotype and ex-type culture of type: CBS H-20326, CPC 16112.

Sporidesmiella P.M. Kirk 1982, Didymosphaeriaceae, Pleosporales, Dothideomycetes, 32 species, type: S. claviformis P.M. Kirk, hyphomycetous, sexual morph unknown, saprobes, on dung, terrestrial, worldwide, see Braun and Heuchert (2010; new species), Seifert et al. (2011; morphology), Ma et al. (2012e, 2016; new species, China), Wijayawardene et al. (2012, 2017; outline), Kirk et al. (2013; genus accepted), Monteiro et al. (2014b; new species, Brazil), Heredia et al. (2015; new species, Mexico), Tian et al. (2015; excluded Melanommataceae from and placed in Didymosphaeriaceae), holotype of the type: IMI 246982, cultures and sequences are available but lacks for the type, needs generic revision.

Sporidesmina Subram. \& Bhat 1989, Xylariales genera incertae sedis, Sordariomycetes, one species, type: S. malabarica Subram. \& Bhat, hyphomycetous, sexual morph unknown, saprobes, terrestrial, Asia, see Seifert et al. (2011; morphology), Wijayawardene et al. (2012, 2017; outline), Kirk et al. (2013; genus accepted), Maharachchikumbura et al. (2015, 2016; outline), cultures available for the type: NN43118.

Sporidesmioides J.F. Li, R. Phookamsak \& K.D. Hyde 2016, Torulaceae, Pleosporales, Dothideomycetes, one species, type: S. thailandica J.F. Li, R. Phookamsak \& K.D. Hyde, hyphomycetous, sexual morph unknown, saprobes, terrestrial, Thailand, see Li et al. (2016c; taxonomy, phylogeny), Wijayawardene et al. (2017; outline), holotype: MFLU14-0827, cultures and sequences are available.

Sporidesmiopsis Subram. \& Bhat 1989, Ascomycota genera incertae sedis, one species, type: S. malabarica Subram. \& Bhat, hyphomycetous, sexual morph unknown, saprobes, terrestrial, Asia, Caribbean, South America, see Seifert et al. (2011; morphology), Kirk et al. (2013; genus accepted), Wijayawardene et al. (2017; outline, treated as Ascomycota genera incertae sedis), cultures and sequences are unavailable, needs generic revision.

Sporidesmiopsis Subram. \& Bhat, Kavaka 1989, Ascomycota genera incertae sedis, three species, type: S. malabarica Subram. \& Bhat, hyphomycetous, sexual morph unknown, saprobes, Asia, Caribbean, South America, see Seifert et al. (2011; morphology), Wijayawardene et al. (2012, 2017; outline), Kirk et al. (2013; did not list), cultures and sequences are unavailable, need generic revision. 
Sporidesmium Link 1809, Sporidesmiaceae, Diaportheomycetidae families incertae sedis, Sordariomycetes, around 330 species, type: S. atrum Link, hyphomycetous, saprobes, mycoparasites, terrestrial and aquatic, cosmopolitan, see Seifert et al. (2011; morphology), Wijayawardene et al. (2012, 2017; outline), Kirk et al. (2013; genus accepted), Hyde et al. (2016; new species, phylogeny), Mena-Portales et al. (2016; new species), Su et al. (2016a; phylogeny of Sporidesmiaceae), cultures and sequences are available.

Sporoctomorpha J.V. Almeida \& Sousa da Câmara 1903, Sordariomycetes genera incertae sedis, one species, type: S. magnoliae J.V. Almeida \& Sousa da Câmara, asexual morph unknown, saprobes, terrestrial, Europe, see Lumbsch and Huhndorf (2010; outline), Kirk et al. (2013; genus accepted), Maharachchikumbura et al. (2015, 2016; outline), cultures and sequences are unavailable, needs generic revision.

Sporodictyon A. Massal. 1852, Verrucariaceae, Verrucariales, Eurotiomycetes, five species, 38 species, type: S. schaererianum A. Massal., lichenized, see Dillman et al. (2014; new records, Alaska), Lücking et al. (2016b; classification); sequences are available.

Sporodochiolichen Aptroot \& Sipman 2011, Ascomycota genera incertae sedis, four species, type: S. lecanoricus Aptroot \& Sipman, hyphomycetous, sexual morph unknown, lichenized, terrestrial, pantropical, see Aptroot and Sipman (2011; taxonomy), Diederich (2013; taxonomy), holotype of the type: ABL, Aptroot 31060, cultures and sequences are unavailable, needs generic revision.

Sporodophoron Frisch, Y. Ohmura, Ertz \& G. Thor 2015, Arthoniaceae, Arthoniales, Arthoniomycetes, four species, type: S. gossypinum Frisch, Y. Ohmura \& G. Thor, lichenized, see Frisch et al. (2015), Lücking et al. (2016b; classification), sequences are available.

Sporoglena Sacc., 1894, Ascomycota genera incertae sedis, one species, type: S. velutina Sacc., hyphomycetous, sexual morph unknown, Papua New Guinea see Seifert et al. (2011; mentioned as a doubtful genus), Kirk et al. (2013; genus accepted), cultures and sequences are unavailable, need generic revision.

Sporomega Corda 1842, Rhytismataceae, Rhytismatales, Leotiomycetes, seven species, type: $S$. degenerans (Fr.) Corda, asexual morph unknown, saprobes, terrestrial, North America, Europe, see Lumbsch and Huhndorf (2010; outline), Lantz et al. (2011; DNA, phylogeny), Kirk et al. (2013; genus accepted), sequences are available.

Sporopachydermia Rodrigues de Miranda 1978, Saccharomycetales genera incertae sedis, Saccharomycetes, five species, type: S. lactativora Rodrigues de Miranda, asexual reproduction is by multilateral budding, saprophytic, in cacti, seawater, tree exudates, waste lagoon, clinical, Europe, North America, Antarctica, see Lumbsch and Huhndorf (2010; outline), Kirk et al. (2013; genus accepted), cultures and sequences are available.

Sporophagomyces K. Põldmaa \& Samuels 1999, Hypocreaceae, Hypocreales, Sordariomycetes, three species, type: S. chrysostomus (Berk. \& Broome) K. Põldmaa \& Samuels., asexual morph unknown, fungicolous, terrestrial, worldwide, see Jaklitsch et al. (2008; DNA, phylogeny), Lumbsch and Huhndorf (2010; outline), Kirk et al. (2013; genus accepted), Maharachchikumbura et al. (2015, 2016; outline), cultures and sequences are available.

Sporophiala P.Rag. Rao 1970, Ascomycota genera incertae sedis, three species, type: S. prolifica P.Rag. Rao, hyphomycetous, sexual morph unknown, Asia, USA, see Seifert et al. (2011; morphology), Wijayawardene et al. (2012, 2017; outline), Kirk et al. (2013; genus accepted), cultures and sequences are unavailable, need generic revision.

Sporopodiopsis Sérusiaux 1997, Pilocarpaceae, Lecanorales, Lecanoromycetes, two species, type: S. sipmanii Sérus., lichenized, see Lumbsch and Huhndorf (2010; outline), Kirk et al. (2013; genus accepted), Lücking et al. (2016b; classification), sequences are unavailable.

Sporopodium Mont. 1851, Pilocarpaceae, Lecanorales, Lecanoromycetes, 24 species, type: S. leprieurii Mont., lichenized, see Nelson et al. (2008; molecular), Lumbsch and Huhndorf 
(2010; outline), Weerakoon et al. (2012a; taxonomy), Kirk et al. (2013; genus accepted), Rashmi and Rajkumar (2015; new report), Lücking et al. (2016b; classification), sequences are available.

Sporormia De Not. 1845, Sporormiaceae, Pleosporales, Dothideomycetes, 29 species, type: Sporormia fimetaria De Not., asexual morph unknown, saprobes on dung, terrestrial, worldwide, see Lumbsch and Huhndorf (2010; outline), Kirk et al. (2013; accepted genus), Hyde et al. (2013; phylogeny), Wijayawardene et al. (2014c; outline), cultures and sequences are available.

Sporoschisma Berk. \& Broome 1847 (= Melanochaeta E. Müll., Harr \& Sulmont 1969 fide Maharachchikumbura et al. 2016; Réblová et al. 2016c), Chaetosphaeriaceae, Chaetosphaeriales, Sordariomycetes, type: M. hemipsila (Berk. \& Broome) E. Müll., Harr \& Sulmont., hyphomycetous, sexual morphs formerly named in Melanochaeta, saprobes, terrestrial (wood), Europe, Asia, see Lumbsch and hunduf (2010; outline), Kirk et al. (2013; genus accepted), Maharachchikumbura et al. (2015, 2016; outline, phylogeny), Réblová et al. (2016c; nomenclature), cultures available for type: SMH 3251, SMH 2125, AR4690, GKM1247, GKM1112.

Sporoschismopsis Hol.-Jech. \& Hennebert 1972 (= Porosphaerellopsis Samuels \& E. Müll. 1982 fide Réblová et al. 2016c), Reticulascaceae, Glomerellales, Sordariomycetes, eight species, type: S. moravica Hol.-Jech. \& Hennebert, asexual morph hyphomycetous, saprobes, terrestrial, worldwide, see Seifert et al. (2011; morphology), Wijayawardene et al. (2012, 2017; outline), Zhao and Zhao (2012; new species, China), Kirk et al. (2013; genus accepted), Réblová (2014; new species, holomorph, phylogeny), Maharachchikumbura et al. (2015, 2016; outline, phylogeny), Réblová et al. (2016c; nomenclature), cultures and sequences are available but lacks for the type.

Sporostigma Grube 2001, Arthoniales genera incertae sedis, Arthoniomycetes, one species, type: S. melaspora (Tuck.) Grube, lichenized, see Lumbsch and Huhndorf (2010; outline), Lücking et al. (2016b; classification), sequences are unavailable.

Sporotretophora Whitton, K.D. Hyde \& McKenzie 2012, Ascomycota genera incertae sedis, one species, type: S. punctata Whitton, K.D. Hyde \& McKenzie, hyphomycetous, sexual morph unknown, saprobes, terrestrial, Philippines, see Whitton et al. (2012a; taxonomy), cultures and sequences are unavailable, needs generic revision.

Spumatoria Massee \& E.S. Salmon 1901, Ophiostomataceae, Ophiostomatales, Sordariomycetes, one species, type: S. longicollis Massee \& E.S. Salmon, asexual morph unknown, saprobes, worldwide, see Lumbsch and Huhndorf (2010; outline), Kirk et al. (2013; genus accepted), Maharachchikumbura et al. (2015, 2016; outline), cultures and sequences are unavailable, needs generic revision.

Squamarina Poelt, 1958, Stereocaulaceae, Lecanorales, Lecanoromycetes, species, sub species, varieties, forma species, type: S. gypsacea (Sm.) Poelt, asexual morph, undetermined, terricolous, saxicolous, widespread, see Dietrich and Buergi-Meyer (2010; taxonomy, rare occurrences in surroundings), Lumbsch and Huhndorf (2010; outline), Miralles-Mellado et al. (2011; indicator species), Jorge-Villar et al. (2011; Raman spectroscopy study), Bevan et al. (2012; transplant experiments), Cansaran-Duman and Halici (2012; biochemistry and antimicrobial study), Kirk et al. (2013; genus accepted), Bastida et al. (2014; ecology), Martellos et al. (2014; ecology, species distribution) Delgado Baquerizo et al. (2015, chemistry), Lange and Belnap (2016; soil crust studies), Lücking et al. (2016b; classification); sequences are available.

Squamella S. Hammer 2001, Cladoniaceae, Lecanorales, Lecanoromycetes, one species, type: S. spumosa S. Hammer, lichenized, see Lumbsch and Huhndorf (2010; outline), Lücking et al. (2016b; classification), sequences are unavailable. 
Squamotubera Henn. 1903, Xylariaceae, Xylariales, Sordariomycetes, one species, type: S. leratii Henn., see Maharachchikumbura et al. (2015, 2016; outline), Wendt et al. (2017; genus accepted).

Squamulea Arup, Søchting \& Frödén, 2013, Teloschistaceae, Teloschistales, Lecanoromycetidae, five species, type: S. subsoluta (Nylander) Arup, Søchting \& Frödén, asexual morph unknown, lichenized, terrestrial, Antartica, see Arup et al. (2013; taxonomy), Kirk et al. (2013; genus accepted), Kondratyuk and Kondratyuk (2014; taxonomy), Kondratyuk et al. (2014, 2016; revised taxonomy), Søchting et al. (2014; taxonomy and new species), Lücking et al. (2016b; classification), sequences are available.

Squamulea Arup, Søchting \& Frödén, 2013, Teloschistaceae, Teloschistales, Lecanoromycetes, five species, type: S. subsoluta (Nylander) Arup, Søchting \& Frödén, asexual morph unknown, lichenized, terrestrial, see Lumbsch and Huhndorf (2010; outline), Arup et al. (2013; taxonomy), Kirk et al. (2013; genus accepted), Kondratyuk et al. (2014, 2016; taxonomy, phylogeny), Søchting et al. (2014; taxonomy and new species), Kondratyuk and Kondratyuk (2014; phylogeny), Lücking et al. (2016b; classification), sequences are available.

Stachybotryella Ellis \& Barthol. 1902, Ascomycota genera incertae sedis, three species, type: S. repens Ellis \& Barthol., hyphomycetous, sexual morph unknown, America, see Seifert et al. (2011; mentioned as a doubtful genus), Kirk et al. (2013; genus accepted), cultures and sequences are unavailable, need generic revision.

Stachybotryna Tubaki \& T. Yokoy. 1971, Ascomycota genera incertae sedis, five species, type: S. columaris Tubaki \& T. Yokoy., hyphomycetous, sexual morph unknown, saprobes, ?pathogens, terrestrial, Asia, Caribbean, Europe, see Seifert et al. (2011; morphology), Heredia et al. (2012; new species, Mexico), Wijayawardene et al. (2012, 2017; outline), Kirk et al. (2013; genus accepted), culture available for an unidentified species, needs generic revision.

Stachybotrys Corda 1837, Stachybotryaceae, Hypocreales, Sordariomycetes, c. 60 species, type: S. chartarum (Ehrenb.) S. Hughes, hyphomycetous, sexual morph available, saprobes, terrestrial, worldwide, see Seifert et al. (2011; morphology), Wijayawardene et al. (2012, 2017; outline), Kirk et al. (2013; genus accepted), Crous et al. (2014c; new species), Wang et al. (2015e; new species, revision, phylogeny), Maharachchikumbura et al. (2015, 2016; outline, phylogeny), Lombard et al. (2016; phylogeny, revision, sexual morph), cultures and sequences are available, needs generic revision.

Stachylidium Link 1809, Plectosphaerellaceae, Glomerellales, Sordariomycetes, two species, type: S. bicolor Link, hyphomycetous, sexual morph unknown, pathogens, nematophagous, terrestrial, worldwide, see Réblová et al. (2011; phylogeny), Seifert et al. (2011; morphology), Wijayawardene et al. (2012, 2017; outline), Kirk et al. (2013; genus accepted), Maharachchikumbura et al. (2015, 2016; outline, phylogeny), cultures sequences are available for the type: DAOM 226658.

Stagonopatella Petr. 1927, Ascomycota genera incertae sedis, one species, type: S. aeruginosa Petr., coelomycetous, sexual morph unknown, saprobes, terrestrial, Europe, see Wijayawardene et al. (2012, 2017; outline), Kirk et al. (2013; genus accepted), cultures and sequences are unavailable, needs generic revision.

Stagonopsis Sacc. 1884, Ascomycota genera incertae sedis, four species, type: S. pallida (Berk. \& M.A. Curtis) Sacc., coelomycetous, sexual morph unknown, saprobes, terrestrial, temperate, see Wijayawardene et al. (2012, 2017; outline), Kirk et al. (2013; genus accepted), cultures and sequences are unavailable, needs generic revision.

Stagonospora (Sacc.) Sacc. 1884, Massarinaceae, Pleosporales, Dothideomycetes, 220 species, type: S. paludosa (Sacc. \& Speg.) Sacc., coelomycetous, sexual morph unknown, saprobes, pathogens, terrestrial, worldwide, see Wijayawardene et al. (2012, 2014c, 2017; 
outline), Kirk et al. (2013; genus accepted), Quaedvlieg et al. (2013; new species, phylogeny), Crous et al. (2014c, d, 2015a; DNA, new species, phylogeny), Tanaka et al. (2015; new species, phylogeny), neotype and ex-neotype of the type: CBS H-21317, S601 = CBS 135088 . Stagonosporina Tassi 1902, Ascomycota genera incertae sedis, one species, type: S. sparti Tassi, coelomycetous, sexual morph unknown, saprobes, terrestrial, worldwide, see Wijayawardene et al. (2012, 2017; outline), Kirk et al. (2013; genus accepted), cultures and sequences are unavailable, needs generic revision.

Stagonosporopsis Died. 1912, Didymellaceae, Pleosporales, Dothideomycetes, 22 species, type: S. hortensis (Sacc. \& Malbr.) Petr., coelomycetous, with sexual morph, saprobes, ?pathogens, terrestrial, cosmopolitan, see Vaghefi et al. (2012; species associated with ray blight disease of Asteraceae), Chen et al. (2015b; taxonomy, phylogeny), Hyde et al. (2016; sexual morph), Wijayawardene et al. (2017; outline), cultures and sequences are available.

Stagonostromella Petr. \& Syd. 1927, Ascomycota genera incertae sedis, one species, type: S. sparti Tassi, coelomycetous, sexual morph unknown, saprobes, terrestrial, Brazil, see Wijayawardene et al. (2012, 2017; outline), Kirk et al. (2013; genus accepted), cultures and sequences are unavailable, needs generic revision.

Staheliella Emden 1974, Ascomycota genera incertae sedis, two species, type: S. nodosa Emden, hyphomycetous, sexual morph unknown, saprobes, terrestrial, Neotropics, see Seifert et al. (2011; morphology), Wijayawardene et al. (2012, 2017; outline), Kirk et al. (2013; genus accepted), cultures and sequences are unavailable, needs generic revision.

Staibia Bat. \& Peres 1966, Leptopeltidaceae, Dothideomycetes families incertae sedis, one species, type: S. connari Bat. \& Peres, asexual morph unknown, saprobes, terrestrial, Brazil, see Lumbsch and Huhndorf (2010; outline), Hyde et al. (2013; outline, accepted as a genus in Leptopeltidaceae), Kirk et al. (2013; genus accepted), Wijayawardene et al. (2014c; outline), cultures and sequences are unavailable, needs generic revision.

Stalagmochaetia Cif. \& Bat. 1963, Ascomycota genera incertae sedis, two species, type: S. basilisca Bat., Cif. \& Nascim., coelomycetous, sexual morph unknown, saprobes, terrestrial, USA, see Wijayawardene et al. (2012, 2017; outline), Kirk et al. (2013; genus accepted), cultures and sequences are unavailable, needs generic revision.

Stamnaria Fuckel 1870 (= Titaeospora Bubák 1916 fide Johnston et al. 2014b), Helotiales genera incertae sedis, Leotiomycetes, five species, type: S. persoonii (Moug.) Fuckel, asexual morph formerly known in Titaeospora, saprobes, terrestrial, worldwide, see Lumbsch and Huhndorf (2010; outline), Kirk et al. (2013; genus accepted), Johnston et al. (2014b; nomenclature), Baral and Haelewaters (2015; DNA), Wijayawardene et al. (2017; outline), cultures and sequences are available but lacks for the type.

Stanhughesia Constant. 1989, Chaetothyriaceae, Chaetothyriales, Eurotiomycetes, four species, type: $S$. linnaeae Constant., sexual morph unknown, epiphytes, epiphyllous, hyphomycetous, terrestrial, Sweden, South Africa, see Seifert et al. (2011; morphology), Hyde et al. (2011; outline), Kirk et al. (2013; genus accepted), cultures and sequences are unavailable.

Staninwardia B. Sutton 1971, Extremaceae, Capnodiales, Dothideomycetes, two species, type: S. breviuscula B. Sutton, coelomycetous, sexual morph unknown, saprobes, pathogens, Australia, see Quaedvlieg et al. (2014; phylogeny), Wijayawardene et al. (2014c, 2017; outline, taxonomy), cultures and sequences are available but lacks for the type.

Stanjehughesia Subram. 1992 (= Umbrinosphaeria Réblová 1999 fide Réblová et al. 2016c), Sordariomycetes genera incertae sedis, 16 species, type: S. hormiscioides (Corda) Subram., hyphomycetous, sexual morph formerly named in Umbrinosphaeria, saprobes, terrestrial, worldwide, see Delgado (2008; new species, USA), Marincowitz et al. (2008; new species), Ma et al. (2011c; new species, China), Seifert et al. (2011; morphology), Wijayawardene et al. (2012, 2017; outline), Kirk et al. (2013; genus accepted), Carneiro et al. (2014; new species), 
Maharachchikumbura et al. (2015, 2016; outline), Réblová et al. (2016c; nomenclature), cultures and sequences are available but lacks for the type, needs generic revision.

Stanjemonium W. Gams, O'Donnell, Schroers \& M. Chr. 1999, Hypocreales genera incertae sedis, Sordariomycetes, four species, type: S. grisellum W. Gams, Schroers \& M. Chr., hyphomycetous, sexual morph unknown, from soil, worldwide, see Seifert et al. (2011; morphology), Wijayawardene et al. (2012, 2017; outline), Kirk et al. (2013; genus accepted), Maharachchikumbura et al. (2015, 2016; outline), cultures available for the type: CBS 655.79. Staphylotrichum J. Mey. \& Nicot 1957, Chaetomiaceae, Sordariales, Sordariomycetes, four species, type: S. coccosporum J.A. Mey. \& Nicot, sexual morph unknown, saprobes, from soil, terrestrial, Africa, Asia, Europe, see Seifert et al. (2011; morphology), Nonaka et al. (2012; new species, Japan phylogeny), Wijayawardene et al. (2012, 2017; outline), Kirk et al. (2013; genus accepted), Maharachchikumbura et al. (2015, 2016; outline), cultures and sequences are available for the type.

Starbaeckia Rehm ex Starbäck 1899, Phacidiaceae, Phacidiales, Leotiomycetes, one species, type: S. pseudotryblidioides Rehm \& Starbäck, asexual morph unknown, saprobes, terrestrial, Europe, see Lumbsch and Huhndorf (2010; outline), Kirk et al. (2013; genus accepted), Jaklitsch et al. (2016a; classification), cultures and sequences are unavailable, needs generic revision.

Starmera Y. Yamada, Higashi, Ando \& Mikata 1997, Phaffomycetaceae, Saccharomycetales, Saccharomycetes, ten species, type: S. amethionina (Starmer, Phaff, M. Miranda \& M.W. Miller) Y. Yamada, Higashi, S. Ando \& Mikata, cell division is by multilateral budding, saprophytic, in cacti, tunnels of wood boring insects, slime fluxes of trees, worldwide, see Lumbsch and Huhndorf (2010; outline), Kirk et al. (2013; genus accepted), cultures and sequences are available.

Starmerella Rosa \& Lachance 1998, Trichomonascaceae, Saccharomycetales, Saccharomycetes, 25 species, type: S. bombicola C.A. Rosa \& Lachance, cell division is by multilateral budding, saprophytic, in honey, fruit juice concentrate, flowers, various beetles, bees, worldwide, see Kurtzman et al. (2010a; phylogeny, revision), Lumbsch and Huhndorf (2010; outline), Kirk et al. (2013; genus accepted), most of the species in this genus represent asexual forms originally classified in the genus Candida thus, they hey will be transferred to Starmerella as new combinations, cultures and sequences are available.

Staurolemma Körb. 1867, Pannariaceae, Peltigerales, Lichinomycetes, three species, type: S. dalmaticum Körb., asexual morph unknown, lichenized, terrestrial, see Wedin et al. (2009b; taxonomy), Jørgensen (2010; taxonomy), Lumbsch and Huhndorf (2010; outline), Kirk et al. (2013; genus accepted), Bendiksby et al. (2014; long-distance dispersal), Dixon et al. (2014; mapping), Ekman et al. (2014; taxonomy), Otálora et al. (2013, 2014; revised generic classification), Tapper et al. (2014; endemics on granite), Boutabia et al. (2015; floristic), Paoli et al. (2015; indicator species), Lücking et al. (2016b; classification), sequences are available..

Stauronema (Sacc.) Syd., P. Syd. \& E.J. Butler 1916, Ascomycota genera incertae sedis, four species, type: S. cruciferum (Ellis) Syd., P. Syd. \& E.J. Butler, coelomycetous, sexual morph unknown, saprobes, terrestrial, worldwide, see Wijayawardene et al. (2012, 2017; outline), Kirk et al. (2013; genus accepted), cultures and sequences are unavailable, needs generic revision.

Stauronematopsis Abbas, B. Sutton \& Ghaffar 2002, Ascomycota genera incertae sedis, one species, type: S. sojae (Uecker \& Kulik) Abbas, B. Sutton \& Ghaffar, coelomycetous, sexual morph unknown, saprobes, terrestrial, USA, see Wijayawardene et al. (2012, 2017; outline), Kirk et al. (2013; genus accepted), cultures and sequences are unavailable, needs generic revision. 
Staurophoma Höhn. 1907, Ascomycota genera incertae sedis, one species, type: S. panici Höhn., coelomycetous, sexual morph unknown, saprobes, terrestrial, Hong Kong, South America, see Wijayawardene et al. (2012, 2017; outline), Kirk et al. (2013; genus accepted), cultures and sequences are unavailable, needs generic revision.

Staurothele Norman 1853, Verrucariaceae, Verrucariales, Eurotiomycetes, 40 species, type: S. clopima (Wahlenb.) Th. Fr., asexual morph unknown, lichenized, terrestrial, worldwide, see Lumbsch and Huhndorf (2010; outline), Thüs et al. (2011; phylogeny), Kirk et al. (2013; genus accepted), Gueidan et al. (2014a; phylogeny), Lücking et al. (2016b; classification), sequences are available, needs generic revision.

Stearophora L. Mangin \& Viala 1905, Sordariomycetes genera incertae sedis, one species, type: $S$. radicicola L. Mangin \& Viala, asexual morph unknown, saprobes, terrestrial, North Africa, see Lumbsch and Huhndorf (2010; outline), Kirk et al. (2013; genus accepted), Maharachchikumbura et al. (2015, 2016; outline), cultures and sequences are unavailable, needs generic revision.

Steganopycnis Syd. \& P. Syd. 1916, Sordariomycetes genera incertae sedis, one species, type: S. oncospermatis Syd. \& P. Syd., see Lumbsch and Huhndorf (2010; outline), Senanayake et al. (2015; outline), Maharachchikumbura et al. (2015, 2016: outline), Wendt et al. (2017; accepted as a genus in Sordariomycetes genera incertae sedis), the genus was not accepted as a genus in Kirk et al. (2008, 2013).

Stegasphaeria Syd. \& P. Syd. 1916, Mesnieraceae, Dothideomycetes families incertae sedis, five species, type: S. pavonina Syd. \& P. Syd., see Lumbsch and Huhndorf (2010; outline), Hyde et al. (2013; accepted as a genus in Mesnieraceae), Wijayawardene et al. (2014c; outline), cultures and sequences are unavailable, needs generic revision.

Stegobolus Mont. 1845, Graphidaceae, Ostropales, Lecanoromycetes, 15 species, type: S. berkeleyanus Mont., asexual morph unknown, lichenized, terrestrial, tropical, see Lumbsch and Huhndorf (2010; outline), Sipman et al. (2012; key: Costa Rica), Rivas Plata et al. (2012a; phylogeny), Kirk et al. (2013; genus accepted), Lücking et al. (2016b; classification); sequences are available.

Stegonsporiopsis Van Warmelo \& B. Sutton 1981, Ascomycota genera incertae sedis, one species, type: S. cenangioides (Ellis \& Rothr.) Van Warmelo \& B. Sutton, coelomycetous, sexual morph unknown, saprobes, terrestrial, Hong Kong, South America, see Wijayawardene et al. (2012, 2016; outline, taxonomy), Kirk et al. (2013; genus accepted), cultures and sequences are unavailable, needs generic revision.

Stegonsporium Corda 1827, Stilbosporaceae, Diaporthales, Sordariomycetes, eight species, type: S. pyriforme (Hoffm.) Corda, asexual morph coelomycetous, saprobes, terrestrial, worldwide, see Voglmayr and Jaklitsch (2008, 2014; phylogeny, taxonomy, holomorph), Kirk et al. (2013; genus accepted), Wijayawardene et al. (2016b, 2017; taxonomy, outline), Maharachchikumbura et al. (2015, 2016; outline), cultures and sequences are available.

Stegophora Syd. \& P. Syd. 1916, Sydowiellaceae, Diaporthales, Sordariomycetes, three species, type: S. ulmea (Fr.) Syd. \& P. Syd., asexual morphs unknown, saprobes, terrestrial, North America, see Da Silva et al. (2009; phylogeny), Lumbsch and Huhndorf (2010; outline), Maharachchikumbura et al. (2015, 2016; outline), cultures and sequences are unavailable, needs generic revision.

Stegophorella Petr. 1947, Sordariomycetes genera incertae sedis, one species, type: S. lagerheimii Petr., asexual morph unknown, saprobes, terrestrial, Ecuador, see Lumbsch and Huhndorf (2010; outline), Kirk et al. (2013; genus accepted), Maharachchikumbura et al. (2015, 2016; outline), cultures and sequences are unavailable, needs generic revision.

Stegothyrium Höhn. 1918, Dothideomycetes genera incertae sedis, two species, type: $S$. denudans (Rehm) Höhn., asexual morph unknown, saprobes, terrestrial, Europe, see Lumbsch and Huhndorf (2010; outline, accepted as a genus in Microthyriaceae), Kirk et al. 
(2013; genus accepted), Wu et al. (2011) and Hyde et al. (2013) did not accept as Microthyriaceae, Wijayawardene et al. (2014c; outline), cultures and sequences are unavailable, needs generic revision.

Steinera Zahlbr. 1906, Koerberiaceae, Peltigerales, Lecanoromycetes, four species, type: S. molybdoplaca (Nyl.) Zahlbr., asexual morph unknown, lichenized, terrestrial, see Lumbsch and Huhndorf (2010; outline), Kirk et al. (2013; genus accepted), Spribille and Muggia (2013; evolutionary), Lücking et al. (2016b; classification), sequences are available.

Steineropsis T. Sprib. \& Muggia 2010, Pannariaceae, Peltigerales, Lecanoromycetes, one species, type: S. alaskana T. Sprib. \& Muggia, lichenized, Europe, Africa, mostly along the Atlantic coast, see Spribille et al. (2010; taxonomy), Spribille and Muggia (2013; phylogenetics), Arup et al. (2014; taxonomy), Schneider et al. (2015; DNA, pylogeny), Lücking et al. (2016b; classification), sequences are available.

Steinia Körb., 1873, Aphanopsidaceae, Pezizomycotina families incertae sedis, three species, type: S. luridescens Körb., asexual morph unknown, lichenized, terrestrial, european distribution, see Lumbsch and Huhndorf (2010; outline), Kärnefelt et al. (2012; systematic, biodiversity), Printzen et al. (2012; partial sequencing), Kirk et al. (2013; genus accepted), Czarnota and Hernik (2014; ecology), Yatsyna and Motiejūnaite (2015; new contributions), Kondratyuk et al (2015; molecular phylogeny), Lücking et al. (2016b; classification); sequences are available.

Stellarangia Frödén, Arup \& Søchting 2013, Teloschistaceae, Teloschistales, Lecanoromycetes, three species, type: S. elegantissima (Nyl.) Frödén, Arup \& Søchting, lichenized, see Arup et al. (2013; taxonomy), Gaya et al. (2015; adaptations, phylogeny), Lücking et al. (2016b; classification), sequences are available.

Stellatospora Tad. Ito \& Nakagiri 1994, Sordariaceae, Sordariales, Sordariomycetes, one species, type: Stellatospora terricola Tad. Ito \& Nakagiri asexual morph unknown, saprophytic, Japan, see Lumbsch and Huhndorf (2010; outline), Kirk et al. (2013; genus accepted), Maharachchikumbura et al. (2015, 2016; outline), holotype of the type: IFO H12166, ex-type cultures of type: NBRC 32597.

Stellifraga Alstrup \& Olech 1993, Ascomycota genera incertae sedis, one species, type: $S$. cladoniicola Alstrup \& Olech, asexual morph unknown, saprobes, terrestrial, Spitsbergen, see Lumbsch and Huhndorf (2010; outline), Kirk et al. (2013; genus accepted), cultures and sequences are unavailable, needs generic revision.

Stellomyces Morgan-Jones, R.C. Sinclair \& Eicker 1987, Ascomycota genera incertae sedis, two species, type: S. suidafrikanus Morgan-Jones, R.C. Sinclair \& Eicker, hyphomycetous, sexual morph unknown, saprobes, terrestrial, Africa, Asia, see Seifert et al. (2011; morphology), Wijayawardene et al. (2012, 2017; outline), Kirk et al. (2013; genus accepted), cultures and sequences are unavailable, needs generic revision.

Stellopeltis Bat. \& A.F. Vital 1959, Ascomycota genera incertae sedis, two species, type: $S$. philodendricola (Bat.) Bat. \& A.F. Vital, coelomycetous, sexual morph unknown, saprobes, terrestrial, Brazil, see Wijayawardene et al. (2012, 2017; outline), Kirk et al. (2013; genus accepted), cultures and sequences are unavailable, needs generic revision.

Stellosetifera Matsush. 1996, Sordariomycetes genera incertae sedis, one species, type: Stellosetifera malaysiana Matsush., asexual morph unknown, saprobes, terrestrial, Malaysia, see Lumbsch and Huhndorf (2010; outline), Kirk et al. (2013; genus accepted), Maharachchikumbura et al. (2015, 2016; outline), cultures and sequences are unavailable, needs generic revision.

Stellospora Alcorn \& B. Sutton 1984, Ascomycota genera incertae sedis, two species, type: $S$. appendiculellae Alcorn \& B. Sutton, coelomycetous, sexual morph unknown, saprobes, terrestrial, Australia, Phillipines, see Wijayawardene et al. (2012, 2017; outline), Kirk et al. (2013; genus accepted), cultures and sequences are unavailable, needs generic revision. 
Stellothyriella Bat. \& Cif. 1959, Ascomycota genera incertae sedis, two species, type: S. graminis (Wehm.) Bat. \& Cif., coelomycetous, sexual morph unknown, saprobes, terrestrial, USA, see Wijayawardene et al. (2012, 2017; outline), Kirk et al. (2013; genus accepted), cultures and sequences are unavailable, needs generic revision.

Stemmatomyces Thaxt. 1931, Laboulbeniaceae, Laboulbeniales, Laboulbeniomycetes, two species, type: S. anoplischii (Thaxt.) Thaxt., asexual morph unknown, biotrophic on Coleoptera (Elateridae), USA, see Lumbsch and Huhndorf (2010; outline), Kirk et al. (2013; genus accepted), cultures and sequences are unavailable, needs generic revision.

Stemphylium Wallr. (= Pleospora Rabenh. ex Ces. \& De Not. 1863 fide Wijayawardene et al. 2014c), Pleosporaceae, Pleosporales, Dothideomycetes, 56 species, type: S. botryosum Sacc., hyphomycetous, sexual morph formerly known in Pleospora, saprobes or pathogens in terrestrial habitats, worldwide, see Seifert et al. (2011; morphology), Zhang et al. (2012e; taxonomy, phylogeny), Kirk et al. (2013; genus accepted), Wijayawardene et al. (2014c; outline, nomenclature), Ariyawansa et al. (2015c; taxonomy, phylogeny), Rossman et al. (2015b; nomenclature), Crous et al. (2016b; new species, phylogeny), sequences are available. Stenella Syd. 1930, Teratosphaeriaceae, Capnodiales, Dothideomycetes, c. 140 species, type: $S$. araguata Syd., hyphomycetous, saprobes, pathogens, terrestrial, cosmopolitan, see Seifert et al. (2011; morphology), Wijayawardene et al. (2012, 2014c, 2017; outline), Kirk et al. (2013; genus accepted), Quaedvlieg et al. (2014; phylogeny), cultures and sequences are available, needs generic revision.

Stenhammarella Hertel 1967, Lecideaceae, Lecideales, Lecanoromycetes, one species, type: S. turgida (Ach.) Hertel, asexual morph unknown, lichenized, terrestrial, Europe, Central Asia, see Lumbsch and Huhndorf (2010; outline), Kirk et al. (2013; genus accepted), Lücking et al. (2016b; classification), cultures available for the type: Stetur3861.

Stenocarpella Syd. \& P. Syd. 1917, Diaporthaceae, Diaporthales, Sordariomycetes, two species, type: S. zeae Syd. \& P. Syd., coelomycetous, sexual morph unknown, pathogens, terrestrial, worldwide, see Wicklow et al. (2011; bioactive metabolites), Wijayawardene et al. (2012, 2016b; phylogeny, taxonomy), Kirk et al. (2013; genus accepted), Maharachchikumbura et al. (2015, 2016; outline), cultures and sequences are available for the type: NRRL:13609.

Stenocephalopsis Chamuris \& C.J.K. Wang 1998, Ascomycota genera incertae sedis, one species, type: S. subalutacea (Peck) Chamuris \& C.J.K. Wang, hyphomycetous, sexual morph unknown, saprobes, terrestrial, Australasia, Europe, North America, see Seifert et al. (2011; morphology), Wijayawardene et al. (2012, 2017; outline), Kirk et al. (2013; genus accepted), cultures and sequences are unavailable, needs generic revision.

Stenocladiella Marvanová \& Descals 1987, Ascomycota genera incertae sedis, one species, type: S. neglecta (Marvanová \& Descals) Marvanová \& Descals, hyphomycetous, sexual morph unknown, saprobes, aquatic, Europe, see Seifert et al. (2011; morphology), Wijayawardene et al. (2012, 2017; outline), Kirk et al. (2013; genus accepted), cultures and sequences are unavailable, needs generic revision.

Stenocybe Nyl. ex Körb. 1855, Mycocaliciaceae, Mycocaliciales, Eurotiomycetes, 14 species, type: S. byssacea (Fr.) Nyl. ex Körb., asexual morph unknown, saprobes, terrestrial, worldwide, see Lumbsch and Huhndorf (2010; outline), Kirk et al. (2013; genus accepted), cultures and sequences are available but lacks for the type.

Stenospora Deighton 1969, Ascomycota genera incertae sedis, one species, type: S. neglecta (Marvanová \& Descals) Marvanová \& Descals, hyphomycetous, sexual morph unknown, fungicolous, terrestrial, Asia, see Seifert et al. (2011; morphology), Wijayawardene et al. (2012, 2017; outline), Kirk et al. (2013; genus accepted), cultures and sequences are unavailable, needs generic revision. 
Stephanocyclos Hertel 1983, Lecideaceae, Lecideales, Lecanoromycetes, one species, type: S. henssenianus Hertel; lichenized, see Lumbsch and Huhndorf (2010; outline), Kirk et al. (2013; genus accepted), Schmull et al. (2011; phylogeny), Lücking et al. (2016b; classification), sequences are available.

Stephanonectria Schroers \& Samuels 1999, Bionectriaceae, Hypocreales, Sordariomycetes, two species, type: S. keithii (Berk. \& Broome) Schroers \& Samuels, asexual morph unknown, saprobes, terrestrial, British Isles, see Lumbsch and Huhndorf (2010; outline), Kirk et al. (2013; genus accepted), Maharachchikumbura et al. (2015, 2016; outline), cultures and sequences are available.

Stephanotheca Syd. \& P. Syd. 1914, Dothideomycetes genera incertae sedis, four species, type: S. micromera Syd. \& P. Syd., asexual morph unknown, foliar epiphytes, terrestrial, India, Philippines, see Lumbsch and Huhndorf (2010; outline), Kirk et al. (2013; genus accepted), Jayawardena et al. (2014; morphology), Wijayawardene et al. (2014c; outline), cultures and sequences are unavailable, holotype of the species S-F6581.

Stephembruneria R.F. Castañeda 1988, Ascomycota genera incertae sedis, one species, type: S. elegans R.F. Castañeda, hyphomycetous, sexual morph unknown, saprobes, terrestrial, Caribbean, see Seifert et al. (2011; morphology), Wijayawardene et al. (2012, 2017; outline), Kirk et al. (2013; genus accepted), cultures and sequences are unavailable, needs generic revision.

Stephensia Tul. \& C. Tul. 1845 (= Densocarpa Gilkey 1954; = Elderia McLennan 1961 fide Species Fungorum 2017), Pezizales genera incertae sedis, Pezizomycetes, seven species, type: S. bombycina (Vittad.) Tul., asexual morph unknown, hypogeous, terrestrial, worldwide, see Lumbsch and Huhndorf (2010; outline), Kirk et al. (2013; genus accepted), Wang et al. (2016c; DNA, phylogeny), sequences are available.

Stereocaulon Hoffm. 1795. Stereocaulaceae, Lecanorales, Lecanoromycetes, 140 species, type: S. paschale (L.) Hoffm., asexual morph unknown, lichenized, terrestrial, worldwide, see Khare et al. (2009; taxonomy), Morita et al. (2009; antimitotic study), Seo et al. (2009b; bioavtivity study), Wedin et al. (2009b; molecular), Fryday (2010; taxonomy), Hafellner et al. (2010; biodiversity), Huang (2010; environment), Lumbsch and Huhndorf (2010; outline), Melechin (2010; taxonomy), Goel et al. (2011; antifungal study), Hansen (2011; taxonomy), Ismed et al. (2012; chemistry), Bhattarai et al. (2013; bioactivity study), Kim et al. (2013; antimicrobial study), Kirk et al. (2013; genus accepted), Rincon-Espitia and Mateus (2013; taxonomy), Motiejūnaite (2013; taxonomy), Singh et al. (2013b; physiology), Högnabba et al. (2014; phylogeny), Meunier et al. (2014; environment), Nayaka and Saxena (2014; physiology), Oset and Kukwa (2014; typification), Ranković et al. (2014; bioactivity), Oset (2015; taxonomy), Doering et al. (2016; taxonomy), Kossowska and Szczepańska (2016; taxonomy), Lücking et al. (2016b; classification), Shukla et al. (2016; amino acids), sequences are available.

Stereocrea Syd. \& P. Syd. 1917, Clavicipitaceae, Hypocreales, Sordariomycetes, one species, type: S. schizostachyi Syd. \& P. Syd., asexual morph unknown, saprobes, terrestrial, paleotropics, see Lumbsch and Huhndorf (2010; outline), Kirk et al. (2013; genus accepted), Maharachchikumbura et al. (2015, 2016; outline), holotype of the type: CUP 067858, cultures and sequences are unavailable.

Stereosphaeria Kirschst. 1939, Sordariomycetes genera incertae sedis, two species, type: S. phloeophila Kirschst., widespread in temperate regions, see Lumbsch and Huhndorf (2010; outline), Kirk et al. (2013; genus accepted), Maharachchikumbura et al. (2015, 2016: outline), Jaklitsch et al. (2016a), one sequence is available.

Sterigmatobotrys Oudem. 1886, Pleurotheciaceae, Pleurotheciales, Sordariomycetes, three species, type: S. elata (Sacc.) Oudem., hyphomycetous, sexual morph unknown, saprobes, terrestrial, north temperate, see Réblová and Seifert (2011; epitypification, holomorph), 
Seifert et al. (2011; morphology), Wijayawardene et al. (2012, 2017; outline), Kirk et al. (2013; genus accepted), Maharachchikumbura et al. (2015, 2016; outline), cultures available but lacks for the type.

Stevensonula Petr. 1952, Ascomycota genera incertae sedis, one species, type: S. ciliata Petr., coleomycetous, sexual morph unknown, saprobes, terrestrial, USA, New Caledonia, see Seifert et al. (2011; morphology), Wijayawardene et al. (2012, 2017; outline), Kirk et al. (2013; genus accepted), cultures and sequences are unavailable, needs generic revision.

Stichomyces Thaxt. 1901, Laboulbeniaceae, Laboulbeniales, Laboulbeniomycetes, three species, type: S. conosomatis Thaxt., asexual morph unknown, biotrophic on Coleoptera (Staphylinidae), Europe, Africa, USA, Japan, see Lumbsch and Huhndorf (2010; outline), Kirk et al. (2013; genus accepted), cultures and sequences are unavailable, needs generic revision.

Sticta (Schreb.) Ach. 1803, Lobariaceae, Peltigerales, Lecanoromycetes, c. 200 species, type: $Y$. coronate D.J. Galloway, lichenized, see Lumbsch and Huhndorf (2010; outline), Kirk et al. (2013; genus accepted), Moncada and Lücking (2012; new species), Moncada et al. (2013b; new species), Lücking et al. (2016b; classification), cultures and sequences are available.

Stictis Pers. 1800, Stictidaceae, Ostropales, Lecanoromycetes, four species, type: S. radiata (L.) Pers., lichenized, see Lumbsch and Huhndorf (2010; outline), Kirk et al. (2013; genus accepted), Lücking et al. (2016b; classification), cultures available for type: AFTOL-ID 398, MW6493, P164, F907E267.

Stictopatella Höhn. 1918, Ascomycota genera incertae sedis, one species, type: S. euonymi (Desm.) Höhn., coleomycetous, sexual morph unknown, saprobes, terrestrial, Europe, see Wijayawardene et al. (2012, 2017; outline), Kirk et al. (2013; genus accepted), cultures and sequences are unavailable, needs generic revision.

Stictosepta Petr. 1964, Ascomycota genera incertae sedis, one species, type: S. cupularis Petr., coleomycetous, sexual morph unknown, saprobes, terrestrial, former Czechoslovakia, see Wijayawardene et al. (2012, 2017; outline), Kirk et al. (2013; genus accepted), cultures and sequences are unavailable, needs generic revision.

Stictospora Cif., 1957, Stictidaceae, Ostropales, Ostropomycetes, one species, type: S. oleae (De Not.) Cif., asexual morph unknown, lichenized, terrestrial, see Kirk et al. (2013; genus accepted), cultures and sequences are unavailable.

Stigmatellina Bat. \& H. Maia 1960, Ascomycota genera incertae sedis, one species, type: $S$. epilobii Bat. \& H. Maia, coleomycetous, sexual morph unknown, saprobes, terrestrial, Belgium, see Wijayawardene et al. (2012, 2017; outline), Kirk et al. (2013; genus accepted), cultures and sequences are unavailable, needs generic revision.

Stigmatochroma Marbach, 2000, Caliciaceae, Caliciales, Lecanoromycetes, nine species, type: S. epimarta (Nyl.) Marbach, asexual morph unknown, lichenized, terrestrial, Asia, see Lumbsch and Huhndorf (2010; outline), Cavalcante (2012; comparative studies), Gaya et al. (2012; taxonomy), Kirk et al. (2013; genus accepted), Menezes et al. (2013; taxonomy), Prieto et al. (2013; phylogeny), Giralt et al. (2014; new species), Logesh et al. (2015; floristics), Mohabe et al. (2015; new species), Prieto and Wedin (2016; phylogeny), Lücking et al. (2016b; classification), sequences are available.

Stigmatodiscus Voglmayr \& Jaklitsch 2016, Stigmatodiscaceae, Stigmatodiscales, Dothideomycetes, two speies, type: S. enigmaticus Voglmayr \& Jaklitsch, asexual morph coelomycetous, saprobes, Europe, see Voglmayr et al. (2016; taxonomy, phylogeny), Wijayawardene et al. (2017; outline), holotype: WU 35914, cultures and sequences are available.

Stigmatodothis Syd. \& P. Syd. 1914, Dothideomycetes genera incertae sedis, one species, type: S. palawanensis Syd. \& P. Syd., asexual morph unknown, saprobes, terrestrial, Philippines, Australia, see Lumbsch and Huhndorf (2010; outline, accepted as a genus in 
Micropeltidaceae), Hyde et al. (2013; did not recognize this genus as in Micropeltidaceae), Kirk et al. (2013; genus accepted), Wijayawardene et al. (2014c; outline) cultures and sequences are unavailable, needs generic revision.

Stigmatomyces H. Karst. 1869, Laboulbeniaceae, Laboulbeniales, Laboulbeniomycetes, 145 species, type: S. baeri (Knoch) Peyritsch, asexual morph unknown, biotrophic on Diptera, worldwide, see Lumbsch and Huhndorf (2010; outline), Kirk et al. (2013; genus accepted), Rossi and Leonardi (2012, most recent species descriptions Africa), cultures and sequences are available but lacks for the type.

Stigmatophragmia Tehon \& G.L. Stout 1929, Dothideomycetes genera incertae sedis, one species, type: S. sassafrasicola Tehon \& G.L. Stout, asexual morph unknown, saprobes, terrestrial, North America, see Lumbsch and Huhndorf (2010; outline, accepted as a genus in Micropeltidaceae), Hyde et al. (2013; did not recognize this genus as in Micropeltidaceae), Kirk et al. (2013; genus accepted), Wijayawardene et al. (2014c; outline), cultures and sequences are unavailable, needs generic revision.

Stigmatula (Sacc.) Syd. \& P. Syd. 1901, Phyllachoraceae, Phyllachorales, Sordariomycetes, ten species, type: S. sutherlandiae (Kalchbr. \& Cooke) Syd. \& P. Syd., saprobes, temperate, see Kirk et al. (2013; genus accepted), Maharachchikumbura et al. (2015, 2016; outline), cultures and sequences are unavailable, needs generic revision.

Stigmea Fr. 1836, Ascomycota genera incertae sedis, one species, type: S. submaculans Mont., saprobes, temperate, see Lumbsch and Huhndorf (2010; outline), Kirk et al. (2013; genus accepted), cultures and sequences are unavailable, needs generic revision.

Stigmella Lév. 1842, Ascomycota genera incertae sedis, 28 species, type: S. dryina (Corda) Lév., coleomycetous, sexual morph unknown, saprobes, terrestrial, worldwide, see Wijayawardene et al. (2012, 2016b; outline, taxonomy), Kirk et al. (2013; genus accepted), Wang et al. (2013e; new species, China), cultures and sequences are unavailable, needs generic revision.

Stigmidium Trevis. 1860, Mycosphaerellaceae, Capnodiales, Dothideomycetes, one species, type: S. schaereri (A. Massal.) Trevis., lichenicolous or lichenized, see Lumbsch and Huhndorf (2010; outline), Kirk et al. (2013; genus accepted), Lücking et al. (2016b; classification), sequences are unavailable.

Stigmochora Theiss. \& Syd. 1914, Phyllachoraceae, Phyllachorales, Sordariomycetes, twelve species, type: S. controversa (Starbäck) Theiss. \& Syd., saprobes, temperate, see Lumbsch and Huhndorf (2010; outline), Kirk et al. (2013; genus accepted), Maharachchikumbura et al. (2015, 2016; outline), cultures and sequences are unavailable, needs generic revision.

Stigmopeltis Syd. 1927, Ascomycota genera incertae sedis, two species, type: S. roupalae Syd., coleomycetous, sexual morph unknown, saprobes, terrestrial, Central America, see Wijayawardene et al. (2012, 2017; outline), Kirk et al. (2013; genus accepted), cultures and sequences are unavailable, needs generic revision.

Stilbella Lindau 1900, Hypocreales genera incertae sedis, Sordariomycetes, four species, type: S. fimetaria (Pers.) Lindau, hyphomycetous, sexual morph unknown, from soil and dung, saprobes, worldwide, see Mazzaferro et al. (2010; secondary metabolites), Seifert et al. (2011; morphology), Summerbell et al. (2011; phylogeny), Wijayawardene et al. (2012, 2017; outline), Kirk et al. (2013; genus accepted), Maharachchikumbura et al. (2015, 2016; outline), cultures and sequences are available.

Stilbellula Boedijn 1951, Ascomycota genera incertae sedis, one species, type: S. pallida Boedijn, hyphomycetous, sexual morph unknown, saprobes, terrestrial, Asia, see Wijayawardene et al. (2012, 2017; outline), Kirk et al. (2013; genus accepted), cultures and sequences are unavailable, needs generic revision. 
Stilbocrea Pat. 1900, Bionectriaceae, Hypocreales, Sordariomycetes, two species, type: S. dussii Pat., asexual morph hyphomycetous, saprobes, terrestrial, worldwide, see Sung et al. (2008; DNA), Lumbsch and Huhndorf (2010; outline), Kirk et al. (2013; genus accepted), Maharachchikumbura et al. (2015, 2016; outline), cultures and sequences are available but lacks for the type.

Stilbodendron Syd. \& P. Syd. 1916, Ascomycota genera incertae sedis, one species, type: S. camerunense Syd. \& P. Syd., hyphomycetous, sexual morph unknown, saprobes, terrestrial, Africa, see Wijayawardene et al. (2012, 2017; outline), Kirk et al. (2013; genus accepted), cultures and sequences are unavailable, needs generic revision.

Stilbohypoxylon Henn. 1902, Xylariaceae, Xylariales, Sordariomycetes, ten species, type: S. moelleri Henn., asexual morph unknown, terrestrial, saprobes, subtropical, see Hsieh et al. (2010; DNA, phylogeny), Lumbsch and Huhndorf (2010; outline), Kirk et al. (2013; genus accepted), Maharachchikumbura et al. (2015, 2016; outline), cultures and sequences are available.

Stilbopeziza Speg. 1908, Helotiales genera incertae sedis, Leotiomycetes, one species, type: S. yerbae Speg., asexual morph unknown, saprobes, terrestrial, South America, see Lumbsch and Huhndorf (2010; outline), Kirk et al. (2013; genus accepted), cultures and sequences are unavailable, needs generic revision.

Stilbophoma Petr. 1942, Ascomycota genera incertae sedis, one species, type: S. microspora Petr., coelomycetous, sexual morph unknown, saprobes, terrestrial, India, Africa, see Wijayawardene et al. (2012, 2017; outline), Kirk et al. (2013; genus accepted), cultures and sequences are unavailable, needs generic revision.

Stilbospora Pers. 1794 (= Prosthecium Fresen. 1852 fide Rossman et al. 2015a; Voglmayr and Jaklitsch 2014), Stilbosporaceae, Diaporthales, Sordariomycetes, 20 species, type: S. macrosperma Pers., asexual morph coelomycetous, saprobes, terrestrial, worldwide, see Voglmayr and Jaklitsch (2008, 2014; phylogeny, taxonomy, holomorph), Kirk et al. (2013; genus accepted), Maharachchikumbura et al. (2015, 2016; outline), Wijayawardene et al. (2016b, 2017; taxonomy, outline, phylogeny), cultures and sequences are available.

Stioclettia Dennis 1975, Diaporthales genera incertae sedis, Sordariomycetes, one species, type: S. luzulina Dennis, asexual morph unknown, saprobes, terrestrial, British Isles, see Lumbsch and Huhndorf (2010; outline), Kirk et al. (2013; genus accepted), Maharachchikumbura et al. (2015, 2016; outline), cultures and sequences are unavailable, needs generic revision.

Stirtonia A.L. Sm. 1926, Arthoniaceae, Arthoniales, Arthoniomycetes, 25 species, type: S. obvallata A.L. Sm., lichenized, see Lumbsch and Huhndorf (2010; outline), Lücking et al. (2016b; classification), sequences are available.

Stirtoniella D.J. Galloway, Hafellner \& Elix 2005, Ramalinaceae, Lecanorales, Lecanoromycetes, one species, type: S. kelica (Stirt.) D.J. Galloway, Hafellner \& Elix, asexual morph unknown, lichenized, terrestrial, Australasia, see Lumbsch and Huhndorf (2010; outline), Lücking et al. (2016b; classification), cultures and sequences are unavailable. Stomatogene Theiss. 1917, Perisporiopsidaceae, Dothideomycetes families incertae sedis, two species, type: $S$. agaves (Ellis \& Everh.) Theiss., asexual morph unknown, saprobes, terrestrial, North America, see Lumbsch and Huhndorf (2010; outline), Kirk et al. (2013; genus accepted), Wijayawardene et al. (2014c; outline), cultures and sequences are unavailable, needs generic revision.

Stomatogenella Petr. 1955, Sordariomycetes genera incertae sedis, incertae sedis, two species, type: Stomatogenella mirabilis Petr., asexual morph unknown, saprobes, terrestrial, North Australia, see Lumbsch and Huhndorf (2010; outline), Kirk et al. (2013; genus accepted), Maharachchikumbura et al. (2015, 2016; outline), cultures and sequences are unavailable, needs generic revision. 
Stomiopeltis Theiss. 1914, Micropeltidaceae, Microthyriales, Dothideomycetes, 25 species, type: S. aspersa (Berk.) Theiss., asexual morph unknown, saprobes, terrestrial, widespread, see Lumbsch and Huhndorf (2010; outline), Kirk et al. (2013; genus accepted), Wijayawardene et al. (2014c; outline), cultures and sequences are available but lacks for type, needs generic revision.

Stomiopeltopsis Bat. \& Cavalc. 1963, Micropeltidaceae, Microthyriales, Dothideomycetes, two species, type: $S$. linacearum Bat. \& Cavalc., asexual morph unknown, saprobes, terrestrial, Brazil, New Mexico, see Lumbsch and Huhndorf (2010; outline, accepted as a genus in Microthyriaceae), Hyde et al. (2013; accepted as a genus in Micropeltidaceae), Wijayawardene et al. (2014c; outline), cultures and sequences are unavailable.

Stomiotheca Bat. 1959, Micropeltidaceae, Microthyriales, Dothideomycetes, two species, type: S. amazonensis Bat, asexual morph unknown, saprobes, terrestrial, cosmopolitan, see Lumbsch and Huhndorf (2010; outline, accepted as a genus in Microthyriaceae), Wu et al. (2011; new combination), Hyde et al. (2013; accepted as a genus in Micropeltidaceae), Wijayawardene et al. (2014c; outline), cultures and sequences are unavailable.

Stouffera Kovács \& Trappe 2011, Pezizaceae, Pezizales, Pezizomycetes, four species, type: S. longii (Gilkey) Kovács, Trappe, asexual morph unknown, hypogeous, terrestrial, Argentina, USA, see Kovács et al. (2011b; taxonomy, phylogeny), sequences and cultures are unavailable.

Strangospora Körb. 1860, Strangosporaceae, Pezizomycotina families incertae sedis, nine species, type: S. pinicola (A. Massal.) Körb., asexual morph unknown, lichenized, terrestrial distribution, Lumbsch and Huhndorf (2010; outline), Stepanchikova et al (2011; new records), Kirk et al. (2013; genus accepted), Miądlikowska et al. (2014a; phylogeny), Rogers et al. (2015; lichen monitoring), Urbanavichene and Zapovednik (2015; new findings), Lücking et al. (2016b; classification), Urbanavichus and Ismailov (2016; new records), sequences are available.

Strasseria Bres. \& Sacc. 1902, Ascomycota genera incertae sedis, one species, type: S. carpophila Bres. \& Sacc., coelomycetous, sexual morph unknown, saprobes, terrestrial, worldwide, see Wijayawardene et al. (2012, 2017; outline), Kirk et al. (2013; genus accepted), cultures and sequences are unavailable, needs generic revision.

Strasseriopsis B. Sutton \& Tak. Kobay. 1970, Ascomycota genera incertae sedis, one species, type: S. tsugae (Tak. Kobay.) B. Sutton \& Tak. Kobay., coelomycetous, sexual morph unknown, saprobes, terrestrial, Japan, see Wijayawardene et al. (2012, 2017; outline), Kirk et al. (2013; genus accepted), cultures and sequences are unavailable, needs generic revision.

Stratiphoromyces Goh \& K.D. Hyde 1998, Ascomycota genera incertae sedis, one species, type: S. brunneisporus Goh \& K.D. Hyde, hyphomycetous, sexual morph unknown, saprobes, terrestrial, Asia, Australasia, see Seifert et al. (2011; morphology), Wijayawardene et al. (2012, 2017; outline), Kirk et al. (2013; genus accepted), cultures and sequences are unavailable, needs generic revision.

Stratisporella Hafellner 1979, Patellariaceae, Patellariales, Dothideomycetes, one species, type: S. episemoides (Nyl.) Hafellner, asexual morph unknown, lichenicolous, terrestrial, worldwide, see Lumbsch and Huhndorf (2010; outline), Hyde et al. (2013; accepted as a genus in Patellariaceae), Kirk et al. (2013; genus accepted), Wijayawardene et al. (2014c; outline), Yacharoen et al. (2015; accepted as a genus in Patellariaceae), cultures and sequences are unavailable, needs generic revision.

Strattonia Cif. 1954, Lasiosphaeriaceae, Sordariales, Sordariomycetes, nine species, type: S. tetraspora (R. Stratton) Cif., asexual morph unknown, coprophilous, terrestrial, worldwide, see Lumbsch and Huhndorf (2010; outline, accepted as a genus in Sordariales genera incertae sedis), Kirk et al. (2013; genus accepted), Maharachchikumbura et al. (2015, 2016; outline), cultures and sequences are available but lacks for the type. 
Streimannia G. Thor 1991, Roccellaceae, Arthoniales, Arthoniomycetes, one species, type: S. varieseptata G. Thor., lichenized, terrestrial, Lumbsch and Huhndorf (2010; outline), Kirk et al. (2013; genus accepted), Lücking et al. (2016b; classification); sequences unavailable.

Streimanniella S.Y.Kondr., Kärnefelt, A.Thell, Elix \& Hur 2015, Teloschistaceae, Teloschistales, Lecanoromycetes, four species, type: S. michelagoensis (Elix, S.Y. Kondr. \& Kärnefelt) S.Y. Kondr., Kärnefelt, A. Thell, Elix, J. Kim, A.S. Kondr. \& Hur, lichenized, see Kondratyuk et al. (2015c; taxonomy), Lücking et al. (2016b; classification), sequences are available.

Strelitziana Arzanlou \& Crous 2006, Strelitzianaceae, Chaetothyriales, Eurotiomycetes, seven species, type: S. africana Arzanlou \& Crous, hyphomycetous, sexual morph unknown, saprobes, cosmopolitan, see Zhang et al. (2009b; new species), Crous et al. (2010b, 2015e; new species, phylogeny), Seifert et al. (2011; morphology), Wijayawardene et al. (2017; outline), cultures and sequences are available.

Streptotinia Whetzel 1945 (= Streptobotrys Hennebert 1973 fide Johnston et al. 2014b), Sclerotiniaceae, Helotiales, Leotiomycetes, three species, type: S. arisaematis Whetzel, asexual morph unknown, saprobes, terrestrial, worldwide, see Lumbsch and Huhndorf (2010; outline), Kirk et al. (2013; genus accepted), Johnston et al. (2014b; nomenclature), Wijayawardene et al. (2017; outline), cultures and sequences are unavailable, needs generic revision.

Striatibotrys L. Lombard \& Crous 2016, Stachybotriaceae, Hypocreales, Sordariomycetes, six species, type: S. eucylindrospora (D.W. Li) L. Lombard \& Crous, asexual morph hyphomycetous, saprobes, from soil, terrestrial, cosmopolitan, see Lombard et al. (2016; taxonomy, phylogeny), Wijayawardene et al. (2017; outline), ex-type culture of the type: MUCL 9483.

Striaticonidium L. Lombard \& Crous 2016, Stachybotriaceae, Hypocreales, Sordariomycetes, four species, type: S. cinctum (Corda) L. Lombard \& Crous, hyphomycetous, sexual morph unknown, saprobes, terrestrial, India, see Lombard et al. (2016; taxonomy, phylogeny), Wijayawardene et al. (2017; outline), epitype, ex-epitype culture of the type: CBS H-22471, CBS 932.69.

Striatodecospora D.Q. Zhou, K.D. Hyde \& B.S. Lu. 2000, Xylariales genera incertae sedis, Sordariomycetes, one species, type: S. bambusae D.Q. Zhou, K.D. Hyde \& B.S. Lu., asexual morph unknown, on dead bamboo culm, see Lumbsch and Huhndorf (2010; outline), Senanayake et al. (2015; outline), Maharachchikumbura et al. (2015, 2016; outline), Wendt et al. (2017; accepted as a genus in Xylariales genera incertae sedis), cultures and sequences are unavailable.

Striatosphaeria Samuels \& E. Müll. 1979, Chaetosphaeriaceae, Chaetosphaeriales, Sordariomycetes, one species, type: S. codinaeaphora Samuels \& E. Müll., asexual morph unknown, saprobes, Central and South America, see Lumbsch and Huhndorf (2010; outline), Kirk et al. (2013; genus accepted), Maharachchikumbura et al. (2015, 2016; outline), cultures and sequences are available for the type.

Strickeria Körb. 1865, Sporocadaceae, Xylariales, Sordariomycetes, ten species, type: S. kochii Körb., asexual morph coelomycetous, saprobes, terrestrial, worldwide, see Lumbsch and Huhndorf (2010; outline, accepted as a genus in Sordariales genera incertae sedis), Kirk et al. (2013; genus accepted), Maharachchikumbura et al. (2015, 2016; outline), Jaklitsch et al. (2016a; taxonomy, phylogeny, holomorph), cultures available for the type: C149, C138.

Strigopodia Bat. 1957, Euantennariaceae, Dothideomycetes families incertae sedis, two species, type: S. piceae Bat., asexual morph unknown, saprobes, terrestrial, temperate, see Lumbsch and Huhndorf (2010; outline, accepted as a genus in Microthyriaceae), Hyde et al. (2013; accepted as a genus in Euantennariaceae), Kirk et al. (2013; genus accepted), 
Wijayawardene et al. (2014c; outline), cultures and sequences are unavailable, needs generic revision.

Strigula Fr. 1823, Strigulaceae, Strigulales, Dothideomycetes, one species, type: S. smaragdula Fr., asexual morph unknown, lichenized, foliicolous, terrestrial, worldwide, see Lumbsch and Huhndorf (2010; outline), Nelsen et al. (2011b; DNA, phylogeny), Hyde et al. (2013; accepted as a genus in Strigulaceae), Jayalal et al. (2013b; DNA, South Korea), Kirk et al. (2013; genus accepted), Wijayawardene et al. (2014c; outline), Lücking et al. (2016b; classification), sequences are available.

Striosphaeropsis Verkley \& Aa 1997, Ascomycota genera incertae sedis, one species, type: S. mirabilis Verkley \& Aa, coelomycetous, sexual morph unknown, saprobes, terrestrial, Papua New Guinea, see Wijayawardene et al. (2012, 2017; outline), Kirk et al. (2013; genus accepted), cultures and sequences are unavailable, needs generic revision.

Strobiloscypha N.S. Weber \& Denison 1995, Chorioactidaceae, Pezizales, Pezizomycetes, two species, type: S. keliae N.S. Weber \& Denison, asexual morph unknown, saprobes, terrestrial, Montenegro, USA, see Lumbsch and Huhndorf (2010; outline), Kirk et al. (2013; genus accepted), Perić et al. (2013; new species, DNA, phloheny), sequences are available.

Stromaster Höhn. 1930, Phyllachoraceae, Phyllachorales, Sordariomycetes, twelve species, type: S. tuberculatus (Pat.) Höhn., saprobes, South America, see Lumbsch and Huhndorf (2010; outline), Kirk et al. (2013; genus accepted), Maharachchikumbura et al. (2015, 2016; outline), cultures and sequences are unavailable, needs generic revision.

Stromatella Henssen 1989, Lichinaceae, Lichinales, Lichinomycetes, one species, type: S. bermudana (Riddle) Henssen, lichenized, see Lumbsch and Huhndorf (2010; outline), Kirk et al. (2013; genus accepted), Lücking et al. (2016b; classification), sequences are available.

Stromatinia (Boud.) Prill. 1907, Sclerotiniaceae, Helotiales, Leotiomycetes, seven species, type: S. rapulum (Bull.) Boud., asexual morph unknown, saprobes, terrestrial, Europe, North America, see Lumbsch and Huhndorf (2010; outline), Kirk et al. (2013; genus accepted), sequence available for the type: Z73801 (ITS), needs generic revision.

Stromatocrea W.B. Cooke 1952, Ascomycota genera incertae sedis, one species, type: S. cerebriformis W.B. Cooke, hyphomycetous, sexual morph unknown, saprobes, terrestrial, Europe, North America, see Seifert et al. (2011; morphology), Wijayawardene et al. (2012, 2017; outline), Kirk et al. (2013; genus accepted), Maharachchikumbura et al. (2015, 2016; outline, treated as a genus in Bionectriaceae or Hypocreaceae), cultures and sequences are unavailable, needs generic revision.

Stromatographium Höhn. 1907 (= Fluviostroma Samuels \& E. Müll. 1980; = Stromatostilbella Samuels \& E. Müll. 1980 fide Réblová et al. 2016c; Species Fungorum 2017), Trichosphaeriaceae, Trichosphaeriales, Sordariomycetes, one species, type: S. stromaticum (Berk.) Höhn., hyphomycetous, sexual morph unknown, saprobes, terrestrial, pantropical, see Seifert et al. (2011; morphology), Wijayawardene et al. (2012, 2017; outline), Kirk et al. (2013; genus accepted), Réblová et al. (2016c; nomenclature), cultures and sequences are unavailable, needs generic revision.

Stromatonectria Jaklitsch \& Voglmayr 2011, Bionectriaceae, Hypocreales, Sordariomycetes, two species, type: S. caraganae (Höhn.) Jaklitsch \& Voglmayr, asexual morph coelomycetous, saprobes, terrestrial, Austria, see Jaklitsch and Voglmayr (2011; taxonomy, phylogeny), Maharachchikumbura et al. (2015, 2016; outline), Jaklitsch et al. (2016a; phylogeny), ex-epitype culture of the type: CBS 127387.

Stromatoneurospora S.C. Jong \& E.E. Davis. 1973, Xylariales genera incertae sedis, Sordariomycetes, one species, type: S. phoenix S.C. Jong \& E.E. Davis., tropical, widespread, see Lumbsch and Huhndorf (2010; outline), Kirk et al. (2013; genus accepted), Senanayake et al. (2015; outline), Maharachchikumbura et al. (2015, 2016: outline), Wendt et al. (2017; accepted as a genus in Xylariales genera incertae sedis), a sequence is available. 
Stromatopogon Zahlbr. 1897, Ascomycota genera incertae sedis, three species, type: $S$. baldwinii Zahlbr., coelomycetous, sexual morph unknown, lichenicolous, terrestrial, Australia, see Wijayawardene et al. (2012, 2017; outline), Kirk et al. (2013; genus accepted), cultures and sequences are unavailable, needs generic revision.

Stromatopycnis A.F. Vital 1956, Ascomycota genera incertae sedis, one species, type: Stromatopycnis rosetum A.F. Vital, coelomycetous, sexual morph unknown, saprobes, terrestrial, Brazil, see Wijayawardene et al. (2012, 2017; outline), Kirk et al. (2013; genus accepted), cultures and sequences are unavailable, needs generic revision.

Stromatoseptoria Quaedvl., Verkley \& Crous 2013, Mycosphaerellaceae, Capnodiales, Dothideomycetes, one species, type: S. castaneicola (Desmazières) Quaedvlieg, Verkley \& Crous, coelomycetous, sexual morph unknown, pathogens, terrestrial, Austria, France, Netherlands, one species, see Quaedvlieg et al. (2013; morphology, phylogeny), holotype PC0084574, reference specimens: CBS H-21200, culture CBS 102322; requires epitypification.

Stromatostysanus Höhn. 1919, Ascomycota genera incertae sedis, three species, type: S. caprifoliorum (Desm.) Höhn., hyphomycetous, sexual morph unknown, saprobes, terrestrial, Europe, North America, see Wijayawardene et al. (2012, 2017; outline), Kirk et al. (2013; genus accepted), cultures and sequences are unavailable, needs generic revision.

Stromatothecia D.E. Shaw \& D. Hawksw. 1971, Odontotemataceae, Ostropales, Lecanoromycetes, one species, type: S. nothofagi D.E. Shaw \& D. Hawksw, on bark, Papua New Guinea, see Lumbsch and Huhndorf (2010; outline), Kirk et al. (2013; genus accepted), Jaklitsch et al. (2016a; classification), cultures and sequences are unavailable, holotype of type: K(M)-IMI 151852a.

Stromatothelium Trevis. 1861, Pyrenulales genera incertae sedis, Eurotiomycetes, four species, need typification, hyphomycetous, sexual morph unknown, saprobes, terrestrial, tropical, see Lumbsch and Huhndorf (2010; outline), Kirk et al. (2013; genus accepted), cultures and sequences are unavailable, needs generic revision.

Strongylothallus Bat. \& Cif. 1959, Ascomycota genera incertae sedis, one species, type: S. scutatus Bat., Cif. \& C.A.A. Costa, coelomycetous, sexual morph unknown, saprobes, terrestrial, Brazil, see Wijayawardene et al. (2012, 2017; outline), Kirk et al. (2013; genus accepted), cultures and sequences are unavailable, needs generic revision.

Strossmayeria Schulzer 1881 (= Pseudospiropes M.B. Ellis 1971 fide Johnston et al. 2014b), Helotiales genera incertae sedis, Leotiomycetes, 16 species, type: S. rackii Schulzer, asexual morph hyphomycetous, saprobes, terrestrial, worldwide, see Lumbsch and Huhndorf (2010; outline), Hustad and Miller (2011a; DNA, phylogeny), Kirk et al. (2013; genus accepted), Johnston et al. (2014b; nomenclature), Wijayawardene et al. (2017; outline), cultures and sequences are available but lacks for the type.

Stuartella Fabre 1879, Dothideomycetes genera incertae sedis, three species, type: S. formosa Fabre, asexual morph unknown, saprobes, terrestrial, Europe, North America, see Lumbsch and Huhndorf (2010; outline), Kirk et al. (2013; genus accepted), Wijayawardene et al. (2014c; outline), cultures and sequences are unavailable, needs generic revision.

Stygiomyces Coppins \& S.Y. Kondr. 1995, Ascomycota genera incertae sedis, one species, type: S. galliformis Coppins \& S.Y. Kondr., coelomycetous, sexual morph unknown, saprobes, terrestrial, Tasmania, see Wijayawardene et al. (2012, 2017; outline), Kirk et al. (2013; genus accepted), holotype of the type: HO 34310, cultures and sequences are unavailable, needs generic revision.

Stylaspergillus B. Sutton, Alcorn \& P.J. Fisher 1982, Ascomycota genera incertae sedis, one species, type: S. laxus B. Sutton, Alcorn \& P.J. Fisher, hyphomycetous, sexual morph unknown, saprobes, terrestrial, Australasia, South America, see Seifert et al. (2011; 
morphology), Wijayawardene et al. (2012, 2017; outline), Kirk et al. (2013; genus accepted), cultures and sequences are unavailable, needs generic revision.

Stylodothis Arx \& E. Müll. 1975, Dothideaceae, Dothideales, Dothideomycetes, two species, type: S. puccinioides (DC.) Arx \& E. Müll., asexual morph unknown, saprobes, terrestrial, Europe, Asia, see Lumbsch and Huhndorf (2010; outline), Kirk et al. (2013; genus accepted), Thambugala et al. (2014a; accepted as a genus in Dothideaceae), Wijayawardene et al. (2014c; outline), sequences are available.

Stylonectria Höhn. 1915, Nectriaceae, Hypocreales, Sordariomycetes, five species, type: S. applanata Höhn., sexual morph unknown, saprobes, terrestrial, cosmopolitan, see Gräfenhan et al. (2011; new species), Kirk et al. (2013; genus accepted), Maharachchikumbura et al. (2015, 2016), needs generic revision, cultures and sequences are available.

Subbaromyces Hesselt. 1953, Ophiostomataceae, Ophiostomatales, Sordariomycetes, two species, type: S. splendens Hesselt., asexual morph unknown, saprobes, North America, India, see Lumbsch and Huhndorf (2010; outline), Kirk et al. (2013; genus accepted), Maharachchikumbura et al. (2015, 2016; outline), sequences are available, needs generic revision.

Suberoteratosphaeria Quaedvlieg \& Crous 2014, Teratosphaeriaceae, Capnodiales, Dothideomycetes, three species, type: S. suberosa (Crous, F.A. Ferreira, Alfenas \& M.J. Wingf.) Quaedvlieg \& Crous asexual morph unknown, pathogens, Australia, Brazil, Uruguay, see Quaedvlieg et al. (2014; morphology, phylogeny), holotype and ex-type culture of type: PREM 51082, CPC 515.

Subglobosporium Doilom \& K.D. Hyde 2016, Pseudocoleodictyosporaceae, Pleosporales, Dothideomycetes, one species, type: S. tectonae Doilom \& K.D. Hyde, saprobes, terrestrial, see Doilom et al. (2016; taxonomy), ex-type: MFLUCC 12-0393, MKT 066, ICMP 21258; holotype of type: MFLU 15-3560.

Subhysteropycnis Wedin \& Hafellner, 1998, Ascomycota genera incertae sedis, one species, type: S. maculiformans Wedin \& Hafellner, lichenized, lichenicolous, terrestrial, restricted distribution, see Hyde et al (2011; outline), Kirk et al. (2013; genus accepted), Zhurbenko and Tugi (2013; records), Wijayawardene et al. (2017; outline), sequences are unavailable, needs generic revision.

Submersisphaeria K.D. Hyde 1996, Annulatascuaceae, Annulatascales, Sordariomycetes, five species, type: S. aquatica K.D. Hyde, asexual morph unknown, terrestrial, saprobes, aquatic, widespread, see Lumbsch and Huhndorf (2010; outline), Kirk et al. (2013; genus accepted), Maharachchikumbura et al. (2015, 2016; outline), holotype of type: BRIP 22743, one putative strain is available of $S$. aquatica.

Subplenodomus Gruyter, Aveskamp \& Verkley 2012, Leptosphaeriaceae, Pleosporales, Dothideomycetes, four species, type: S. violicola (P. Syd.) Gruyter, Aveskamp \& Verkley coelomycetous, saprobes, terrestrial, worldwide, see de Gruyter et al. (2012; morphology; phylogeny), Wijayawardene et al. (2014c, 2017; outline), Ariyawansa et al. (2015b; phylogeny), cultures and sequences are available.

Subramaniomyces Varghese \& V.G. Rao 1980, Beltraniaceae, Xylariales, Sordariomycetes, three species, type: $S$. indicus Varghese \& V.G. Rao, hyphomycetous, sexual morph unknown, saprobes, terrestrial, Asia, Australasia, South America, see Seifert et al. (2011; morphology), Wijayawardene et al. (2012, 2017; outline), Maharachchikumbura et al. (2015, 2016; outline), cultures and sequences are available but lacks for the type.

Subramaniula Arx 1985, Chaetomiaceae, Sordariales, Sordariomycetes, four species, type: S. thielavioides (Arx, Mukerji \& N. Singh) Arx, asexual morph unknown, saprobes, opportunistic pathogen on human, terrestrial, India, South Africa, see Lumbsch and Huhndorf (2010; outline), Kirk et al. (2013; genus accepted), Ahmed et al. (2015; new species, 
phylogeny), Maharachchikumbura et al. (2015, 2016; outline), cultures available for the type: CBS 560.84, CBS 122.78.

Subulispora Tubaki 1971, Ascomycota genera incertae sedis, eight species, type: $S$. procurvata Tubaki, hyphomycetous, sexual morph unknown, saprobes, terrestrial, Australasia, tropical, see Seifert et al. (2011; morphology), Wijayawardene et al. (2012, 2017; outline), Kirk et al. (2013; genus accepted), cultures and sequences are available but lacks for the type, needs generic revision.

Sugiyamaella Kurtzman \& Robnett 2007, Trichomonascaceae, Saccharomycetales, Saccharomycetes, 20 species, type: S. smithiae (Giménez-Jurado) Kurtzman \& Robnett, asexual reproduction is by multilateral budding and through formation of blastoconidia, saprophytic, insect frass in trees, soil, worldwide, Lumbsch and Huhndorf (2010; outline), cultures and sequences are available.

Sugiyamaemyces I.I. Tav. \& Balazuc 1989, Laboulbeniaceae, Laboulbeniales, Laboulbeniomycetes, one species, type: S. oroussetii I.I. Tav. \& Balazuc, asexual morph unknown, biotrophic, only known from Clidicus formicarius (Coleoptera: Scydmaenidae), Malaysian Borneo, a second species on Clidicus laticeps (from India) is suggested but not formally described because of lack of material, see Lumbsch and Huhndorf (2010; outline), Kirk et al. (2013; genus accepted), cultures and sequences are unavailable.

Suhomyces M. Blackwell \& Kurtzman 2016, Debaryomycetaceae, Saccharomycetales, Saccharomycetes, 24 species, type: S. tanzawaensis (Nakase \& Itoh) M. Blackwell \& Kurtzman, asexual reproduction is by multilateral budding, saprophytic, soil, insects, moss, gum exudates of black cherry, maize kernels, rotted mushroom, worldwide, see Kurtzman et al. (2016; taxonomy, phylogeny), sequences are available.

Sulcaria Bystrek 1971, Parmeliaceae, Lecanorales, Lecanoromycetes, five species, four variety, type: $S$. sulcata (Lév.) Bystrek, asexual morph unknown, lichenized, terrestrial, see Lumbsch and Huhndorf (2010; outline), Zhang et al. (2012c; chemistry), Kirk et al. (2013; genus accepted), Myllys et al (2014; taxonomy), Wang et al (2014; taxonomy), Hisayoshi et al. (2015; molecular), Lücking et al. (2016b; classification); sequences are available.

Sulcatispora Kaz. Tanaka \& K. Hiray. 2015, Sulcatisporaceae, Pleosporales, Dothideomycetes, two species, type: S. acerina Kaz. Tanaka \& K. Hiray., asexual morph coelomycetous, saprobes, terrestrial, Japan, see Tanaka et al. (2015; taxonomy, phylogeny), Wijayawardene et al. (2016b, 2017; morphology, phylogeny), holotype and ex-type strain of the type: HHUF 30449, CBS 139703.

Sulcatistroma A.W. Ramaley 2005, Calosphaeriaceae, Calosphaeriales, Sordariomycetes, one species, type: Sulcatistroma nolinae A.W. Ramaley, asexual morph unknown, saprobes, terrestrial, USA, see Lumbsch and Huhndorf (2010; outline), Maharachchikumbura et al. (2015, 2016; outline), cultures and sequences are unavailable, needs generic revision.

Sulcopyrenula H. Harada 1999, Pyrenulaceae, Pyrenulales, Eurotiomycetes, four species, type: S. staurospora (Tuck.) H. Harada, asexual morph unknown, lichenized, terrestrial, tropical, see Lumbsch and Huhndorf (2010; outline), Aptroot (2012; new species), Kirk et al. (2013; genus accepted), Lücking et al. (2016b; classification), cultures and sequences are unavailable.

Sulcosporium Phookamsak \& K.D. Hyde 2015, Halotthiaceae, Pleosporales, Dothideomycetes, one species, type: S. thailandicum Phookamsak \& K.D. Hyde, asexual morph unknown, saprobes, terrestrial, Thailand, see Ariyawansa et al. (2015a; taxonomy, phylogeny), holotype and ex-type culture of the type: MFLU 11-0243, MFLUCC 12-0004.

Sungaiicola Fryar \& K.D. Hyde 2004, Sordariomycetes genera incertae sedis, two species, type: S. bactrodesmiella Fryar \& K.D. Hyde, asexual morph unknown, saprobes, marine, Brunei, see Lumbsch and Huhndorf (2010; outline), Maharachchikumbura et al. (2015, 2016; 
outline), holotype of the type: HKU (M) 15201, cultures and sequences are unavailable, needs generic revision.

Surculiseries Okane, Nakagiri \& Tad. Ito 2001, Xylariaceae, Xylariales, Sordariomycetes, one species, type: S. rugispora Okane, Nakagiri \& Tad., sexual morph unknown, endophytic on mangroves, saprophytic, Japan, see Seifert et al. (2011; morphology), Wijayawardene et al. (2012, 2017; outline), holotype of the type: IFO H-12236, ex-type cultures of type: NBRC 33167.

Suttonina H.C. Evans 1984, Ascomycota genera incertae sedis, one species, type: S. guatemaltica H.C. Evans, coelomycetous, sexual morph unknown, saprobes, terrestrial, Gautemala, see Wijayawardene et al. (2012, 2017; outline), Kirk et al. (2013; genus accepted), cultures and sequences are available but lacks for the type, needs generic revision.

Suttonomyces Wijayaw., Camporesi \& K.D. Hyde 2015, Massarinaceae, Pleosporales, Dothideomycetes, one species, type: S. clematidis Wijayaw., Camporesi \& K.D. Hyde, coelomycetous, sexual morph unknown, saprobes, terrestrial, Italy, see Tanaka et al. (2015; morphology, phylogeny), Wijayawardene et al. (2015, 2016b; taxonomy, phylogeny), holotype and ex-type strain of the type: HHUF 28661, JCM 13131.

Swampomyces Kohlm. \& Volkm.-Kohlm. 1987, Etheirophoraceae, Torpedosporales, Sordariomycetes, two species, type: S. armeniacus Kohlm. \& Volkm.-Kohlm., asexual morph unknown, saprobes, mangroves, Australia, Belize, Brunei, Egypt, North Sumatra, Papua New Guinea, Philippines, Saudi Arabia, South Africa, Thailand, see Besitulo et al. (2010; diversity), Sakayaroj et al. (2011b; diversity), Abdel-Wahab et al. (2014; diversity), Jones et al. (2014, 2015; outline, phylogeny, morphology, re-classification), Maharachchikumbura et al. (2015, 2016; outline), cultures and sequences are available.

Syamithabeeja Subram. \& Natarajan 1976, Ascomycota genera incertae sedis, one species, type: S. girisa Subram. \& Natarajan, hyphomycetous, sexual morph unknown, saprobes, terrestrial, Asia, see Seifert et al. (2011; morphology), Wijayawardene et al. (2012, 2017; outline), Kirk et al. (2013; genus accepted), cultures and sequences are unavailable, needs generic revision.

Sydowia Bres., 1895, Dothideaceae, Dothideales, Dothideomycetes, 19 species, type: S. gregaria Bres., asexual morph coelomycetous, parasitic or saprobes on conifer plants or branches and wood, terrestrial, worldwide, see Lumbsch and Huhndorf (2010; outline), Kirk et al. (2013; genus accepted), Thambugala et al. (2014a; taxonomy), Wijayawardene et al. (2014c; outline), holotype of type: S-F6473, cultures and sequences are available.

Sydowiella Petr. 1923, Sydowiellaceae, Diaporthales, Sordariomycetes, four species, type: S. fenestrans (Duby) Petr., asexual morphs unknown, saprobes, terrestrial, Europe, North America, see Marincowitz et al. (2008; new species), Lumbsch and Huhndorf (2010; outline), Kruys and Castlebury (2012; phylogeny), Maharachchikumbura et al. (2015, 2016; outline), cultures available for the type: CBS 125530.

Sylviacollaea Cif. 1963, Ascomycota genera incertae sedis, one species, type: S. termitaria Cif., coelomycetous, sexual morph unknown, on termites, terrestrial, Asia, see Wijayawardene et al. (2012, 2017; outline), Kirk et al. (2013; genus accepted), cultures and sequences are unavailable, needs generic revision.

Symbiotaphrina Kühlw. \& Jurzitza ex W. Gams \& Arx 1980, Xylonomycetaceae, Xylonomycetales, Xylonomycetes, two species, type: S. buchneri Gräbner ex W. Gams \& Arx, coelomycetous, sexual morph unknown, on termites, terrestrial, Asia, see Wijayawardene et al. (2012, 2017; outline), Kirk et al. (2013; genus accepted), Gazis et al. (2016; phylogeny), cultures and sequences are unavailable, needs generic revision.

Symphaeophyma Speg. 1912, Parmulariaceae, Dothideomycetes families incertae sedis, one species, type: S. subtropicale Speg., asexual morph unknown, saprobes, terrestrial, South America, see Lumbsch and Huhndorf (2010; outline), Hyde et al. (2013; accepted as a genus 
in Parmulariaceae), Kirk et al. (2013; genus accepted), Wijayawardene et al. (2014c; outline), cultures and sequences are unavailable, needs generic revision.

Symphaster Theiss. \& Syd. 1915, Dothideomycetes genera incertae sedis, incertae sedis, one species, type: S. gesneraceae (Henn.) Theiss. \& Syd., asexual morph unknown, saprobes, terrestrial, South Africa, South America, see Lumbsch and Huhndorf (2010; outline, accepted as a genus in Asterinaceae), Kirk et al. (2013; genus accepted), Wijayawardene et al. (2014c; outline), cultures and sequences are unavailable, needs generic revision.

Symphyosirinia E.A. Ellis 1956 (= Symphyosirella Seifert 2009 fide Johnston et al. 2014b), Helotiaceae, Helotiales, Leotiomycetes, six species, type: S. galii E.A. Ellis, asexual morph formerly known in Symphyosirella, saprobes, terrestrial, Europe, North America, see Lumbsch and Huhndorf (2010; outline), Kirk et al. (2013; genus accepted), Johnston et al. (2014b; nomenclature), Wijayawardene et al. (2017; outline), cultures and sequences are unavailable.

Symphysos Bat. \& Cavalc. 1967, Ascomycota genera incertae sedis, one species, type: S. sapindaceifolii Bat. \& Cavalc., coelomycetous, sexual morph unknown, saprobes, terrestrial, Brazil, see Wijayawardene et al. (2012, 2017; outline), Kirk et al. (2013; genus accepted), cultures and sequences are unavailable, needs generic revision.

Symplectromyces Thaxt. 1908, Laboulbeniaceae, Laboulbeniales, Laboulbeniomycetes, one species, type: S. vulgaris (Thaxt.) Thaxt., asexual morph unknown, worldwide, see Lumbsch and Huhndorf (2010; outline), Kirk et al. (2013; genus accepted), sequences are unavailable.

Sympodiella W.B. Kendr. 1958, Ascomycota genera incertae sedis, one species, type: S. acicola W.B. Kendr., hyphomycetous, sexual morph unknown, saprobes, terrestrial, Europe, Cuba, see Seifert et al. (2011; morphology), Kirk et al. (2013; genus accepted), Wijayawardene et al. (2017; outline), cultures and sequences are available (unpublished), needs generic revision.

Sympodiocladium Descals 1982, Ascomycota genera incertae sedis, one species, type: S. acicola W.B. Kendr., hyphomycetous, sexual morph unknown, saprobes, terrestrial, Europe, North America, see Seifert et al. (2011; morphology), Kirk et al. (2013; genus accepted), Wijayawardene et al. (2017; outline), cultures and sequences are unavailable, needs generic revision.

Sympodioclathra Voglmayr 1997, Ascomycota genera incertae sedis, one species, type: S. globosa Voglmayr, hyphomycetous, sexual morph unknown, saprobes, aquatic, North America, see Seifert et al. (2011; morphology), Wijayawardene et al. (2017; outline), holotype of the type: WU 17019, cultures and sequences are unavailable, needs generic revision.

Sympodioplanus R.C. Sinclair \& Boshoff 1997, Ascomycota genera incertae sedis, one species, type: S. capensis R.C. Sinclair \& Boshoff, hyphomycetous, sexual morph unknown, saprobes, terrestrial, Africa, see Seifert et al. (2011; morphology), Wijayawardene et al. (2017; outline), holotype: PREM 55315, cultures and sequences are unavailable, needs generic revision.

Sympodomyces R.K. Benj. 1973, Laboulbeniaceae, Laboulbeniales, Laboulbeniomycetes, one species, type: S. pentacellularis R.K. Benj., asexual morph unknown, biotrophic on Coleoptera (Tenebrionoideae), Papua-New Guinea, see Lumbsch and Huhndorf (2010; outline), Kirk et al. (2013; genus accepted), cultures and sequences are unavailable, needs generic revision.

Sympoventuria Crous \& Seifert 2007, Sympoventuriaceae, Venturiales, Dothideomycetes, one species, type: S. vulgaris (Thaxt.) Thaxt., asexual morph unknown, worldwide, see Lumbsch and Huhndorf (2010; outline), Zhang et al. (2011d; phylogeny), Hyde et al. (2013; accepted as a genus in Sympoventuriaceae), Wijayawardene et al. (2014c; outline), sequences are available. 
Synalissa Fr. 1825, Lichinaceae, Lichinales, Lichinomycetes, 39 species, type: S. ramulosa (Bernh.) Körb., asexual morph unknown, lichenized, terrestrial, see Dietrich and BuergiMeyer (2010; taxonomy). Eichler et al. (2010; new species), Lumbsch and Huhndorf (2010; outline), Schultz and Moon (2011; taxonomy), Paukov and Teptina (2012; new record), de la Rosa (2013; ecology), Kirk et al. (2013; genus accepted), Stordeur et al. (2015; new record), Lücking et al. (2016b; classification), sequences unavailable.

Synandromyces Thaxt. 1912, Laboulbeniaceae, Laboulbeniales, Laboulbeniomycetes, ten species, type: S. telephani Thaxt., no asexual state, biotrophic, hosts are Biphyllidae, Cryptophagidae, Cucujidae, Nitidulidae, and Tenebrionidae (Coleoptera: Cucujiformia), widespread but not in Europe, see Lumbsch and Huhndorf (2010; outline), Kirk et al. (2013; genus accepted), sequences are available.

Synaptomyces Thaxt. 1912, Ceratomycetaceae, Laboulbeniales, Laboulbeniomycetes, one species, type: $S$. argentinus Thaxt., no asexual state, biotrophic, only known from Hydrochara sp. [as Hydrocharis] (Coleoptera, Hydrophilidae), Argentina, two more species are suggested but not formally described, see Lumbsch and Huhndorf (2010; outline), Kirk et al. (2013; genus accepted), sequences are unavailable.

Synaptospora Cain 1957, Helminthosphaeriaceae, Chaetosphaeriales, Sordariomycetes, four species, type: S. petrakii Cain, asexual morph unknown, saprobes, terrestrial, Europe, see Lumbsch and Huhndorf (2010; outline), Miller et al. (2014; DNA, phylogeny), Maharachchikumbura et al. (2015, 2016; outline), sequences are available but lacks for the type.

Synarthonia Müll. Arg. 1891, Arthoniaceae, Arthoniales, Arthoniomycetes, three species, type: S. bicolor Müll. Arg., lichenized, see Lumbsch and Huhndorf (2010; outline), Kirk et al. (2013; genus accepted), Menezes et al. (2013; new species), Joseph and Sinha (2015; taxonomy), Lücking et al. (2016b; classification, treated as Arthoniales genera incertae sedis), sequences are unavailable.

Synarthothelium Sparrius 2009, Arthoniales genera incertae sedis, Arthoniomycetes, one species, type: S. sipmanianum Sparrius, lichenized, terrestrial, Venezuela, see Sparrius (2009; taxonomy), Lumbsch and Huhndorf (2010; outline), Lücking et al. (2016b; classification), holotype B Sipman 26697, cultures and sequences are unavailable.

Syncarpella Theiss. \& Syd. 1915 (= Syntholus A.W. Ramaley \& M.E. Barr 1997; Art. 59), Cucurbitariaceae, Pleosporales, Dothideomycetes, c. six species, type: S. tumefaciens (Ellis \& Harkn.) Theiss. \& Syd., asexual morph coelomycetous, saprobes, terrestrial, cosmopolitn, see Lumbsch and Huhndorf (2010; outline), Hyde et al. (2013; accepted as a genus in Cucurbitariaceae), Kirk et al. (2013; genus accepted), Wijayawardene et al. (2014c; outline), in here we propose to consider Syntholus as a synonym of Syncarpella, ex-holotype type strains of type: NY, 1677.

Syncesia Taylor 1938, Roccellaceae, Arthoniales, Arthoniomycetes, 27 species, type: S. albida Taylor, terrestrial, see Lumbsch and Huhndorf (2010; outline), Ertz and Tehler (2011; phylogeny), Joshi et al. (2011a; new species), Kirk et al. (2013; genus accepted), Joseph et al. (2013; new record), Menezes et al. (2013; new species), Ertz et al. (2010, 2015b, c; phylogeny), Cáceres and Aptroot (2016; inventory), Lücking et al. (2016b; classification), sequences are available.

Synchaetomella Decock \& Seifert 2005, Chaetomellaceae, Helotiales, Leotiomycetes, three species, type: S. lunatospora Decock, G. Delgado \& Seifert, hyphomycetous, saprobes, terrestrial, Brazil, Singapore, USA, see Seifert et al. (2011; morphology), Wijayawardene et al. (2012, 2017; outline), Crous et al. (2012c; taxonomy), Fiuza et al. (2015c; taxonomy), sequences are available for two species, compare with Chaetomella, Sphaerographium, holotype of type: MUCL 43804. 
Synchronoblastia Uecker \& F.L. Caruso 1988, Ascomycota genera incertae sedis, one species, type: S. crypta Uecker \& F.L. Caruso, coelomycetous, sexual morph unknown, saprobes, terrestrial, USA, see Wijayawardene et al. (2012, 2017; outline), Kirk et al. (2013; genus accepted), cultures and sequences are unavailable, needs generic revision.

Syncladium Rabenh. 1859, Ascomycota genera incertae sedis, one species, type: S. nietneri Rabenh., coelomycetous, sexual morph unknown, saprobes, terrestrial, worldwide, see Wijayawardene et al. (2012, 2017; outline), Kirk et al. (2013; genus accepted), cultures and sequences are unavailable, needs generic revision.

Synnemacrodictys W.A. Baker \& Morgan-Jones 2009, Ascomycota genera incertae sedis, one species, type: S. stilboidea (J. Mena \& Mercado) W.A. Baker \& Morgan-Jones, hyphomycetous, sexual morph unknown, saprobes, terrestrial, Caribbean, see Seifert et al. (2011; morphology), Wijayawardene et al. (2012, 2017; outline), cultures and sequences are unavailable, needs generic revision.

Synnemadiella Crous \& M.J. Wingf. 2016, Xylariales, genera incertae sedis, Sordariomycetes, one species, type: S. eucalypti Crous \& M.J. Wingf., hyphomycetous, sexual morph unknown, with subverticillium-like synasexual morph, saprobes, terrestrial, Malaysia, see Crous et al. (2016a; new species, phylogeny), Wijayawardene et al. (2017; outline), holotype and ex-type culture of the type: CBS H-22886, CPC 27637.

Synnemapestaloides T. Handa \& Y. Harada 2004, Xylariales genera incertae sedis, Sordariomycetes, one species, type: S. rhododendri T. Handa \& Y. Harada, coelomycetes, sexual morph unknown, leaves and twigs of Rhododendron brachycarpum, Japan, see Seifert et al. (2011; morphology), Wijayawardene et al. (2012, 2017; outline), holotype and ex-type culture of the type: HHUF26527, MAFF239201.

Synnemaseimatoides K. Matsush. \& Matsush. 1996, Ascomycota genera incertae sedis, one species, type: S. nipponica K. Matsush. \& Matsush., hyphomycetous, sexual morph unknown, saprobes, terrestrial, Asia, see Seifert et al. (2011; morphology), Wijayawardene et al. (2012, 2017; outline), Kirk et al. (2013; genus accepted), cultures and sequences are unavailable, needs generic revision.

Synnematomyces Kobayasi 1981, Ascomycota genera incertae sedis, one species, type: S. capitatus Kobayasi, hyphomycetous, sexual morph unknown, saprobes, terrestrial, Asia, see Seifert et al. (2011; morphology), Wijayawardene et al. (2012, 2017; outline), Kirk et al. (2013; genus accepted), sequences are available (unpublished), needs generic revision.

Synnemellisia N.K. Rao, Manohar. \& Goos 1989, Bionectriaceae, Hypocreales, Sordariomycetes, two species, type: S. hyalospora N.K. Rao, Manohar. \& Goos, hyphomycetous, sexual morph unknown, saprobes, terrestrial, Asia, see Seifert et al. (2011; morphology), Wijayawardene et al. (2012, 2017; outline), Kirk et al. (2013; genus accepted), Crous et al. (2016a; new species, phylogeny), cultures and sequences are available, needs generic revision.

Synostomina andina Petr. 1949, Ascomycota genera incertae sedis, one species, type: $S$. andina Petr., coelomycetous, sexual morph unknown, saprobes, terrestrial, South America, see Wijayawardene et al. (2012, 2017; outline), Kirk et al. (2013; genus accepted), cultures and sequences are unavailable, needs generic revision.

Synsphaeria Bonord. 1851, Sordariomycetes, genera incertae sedis, one species, type: $S$. fumigata Vuill., asexual morph unknown, Europe, see Lumbsch and Huhndorf (2010; outline), Kirk et al. (2013; genus accepted), Maharachchikumbura et al. (2015, 2016; outline). Syphosphaera Dumort. 1822, Ascomycota genera incertae sedis, one species, type: S. coronata Dumort., asexual morph unknown, saprobes, terrestrial, Europe, see Lumbsch and Huhndorf (2010; outline), Kirk et al. (2013; genus accepted), cultures and sequences are unavailable, needs generic revision. 
Syrropeltis Bat., J.L. Bezerra \& Matta 1964, Dothideomycetes genera incertae sedis, one species, type: S. xylopiae Bat., J.L. Bezerra \& Matta, asexual morph unknown, saprobes, terrestrial, Brazil, see Lumbsch and Huhndorf (2010; outline), Kirk et al. (2013; genus accepted), Wijayawardene et al. (2014c; outline), cultures and sequences are unavailable, needs generic revision.

Syspastospora P.F. Canon \& D. Hawksw. 1982, Cordycipitaceae, Hypocreales, Sordariomycetes, one species, type: S. parasitica (Tul.) P.F. Cannon \& D. Hawksw., fungicolous, widespread, terrestrial, see Lumbsch and Huhndorf 2010; outline, accepted as a genus in Hypocreaceae), Kirk et al. (2013; genus accepted), cultures and sequences are available, holotype of type: ? PC.

Systremmopsis Petr. 1923, Ascomycota genera incertae sedis, one species, type: S. ribesia Petr., coelomycetous, sexual morph unknown, saprobes, terrestrial, Europe, see Wijayawardene et al. (2012, 2017; outline), Kirk et al. (2013; genus accepted), cultures and sequences are unavailable, needs generic revision.

Szczawinskia A. Funk, 1984, Pilocarpaceae, Lecanorales, Lecanoromycetes, five species, type: S. tsugae A. Funk, asexual morph unknown, lichenized, terrestrial, see Lumbsch and Huhndorf (2010; outline), Øvstedal and Gremmen (2010; new species), Kirk et al. (2013; genus accepted), Lücking et al. (2016b; classification), sequences are unavailable.

Taeniolella S. Hughes 1958, Kirschsteiniotheliaceae, Dothideomycetes family incertae sedis, c. 40 species, type: T. exilis (P. Karst.) S. Hughes, sexual morph unknown, saprophytic, endophytic, lichenicolous, terrestrial, worldwide, see Seifert et al. (2011; morphology), Kirk et al. (2013; genus accepted), Ertz et al. (2016; phylogeny), Wijayawardene et al. (2017; outline), cultures and sequences are available.

Taeniolina M.B. Ellis 1976, Ascomycota genera incertae sedis, six species, type: T. centaurii (Fuckel) M.B. Ellis, hyphomycetous, sexual morph unknown, saprobes, terrestrial, Europe, Asia, see Seifert et al. (2011; morphology), Wijayawardene et al. (2012, 2017; outline), Zhang et al. (2012h; new species, China), Kirk et al. (2013; genus accepted), Prasher and Verma (2014; new species, India), cultures and sequences are unavailable, needs generic revision.

Tainosphaeria F.A. Fernández \& Huhndorf 2005, Chaetosphaeriaceae, Chaetosphaeriales, Sordariomycetes, one species, type: T. crassiparies F.A. Fernández \& Huhndorf, asexual morph unknown, saprobes, Puerto Rico, see Lumbsch and Huhndorf (2010; outline), Kirk et al. (2013; genus accepted), Maharachchikumbura et al. (2015, 2016; outline), sequence available for the type: AF466056 (beta tubulin).

Taiwanascus Sivan. \& H.S. Chang 1997, Niessliaceae, Hypocreales, Sordariomycetes, two species, type: T. tetrasporus Sivan. \& H.S. Chang asexual morph unknown, saprobes, lignicolous, terrestrial, Asia, see Lumbsch and Huhndorf (2010; outline), Kirk et al. (2013; genus accepted), Rajeshkumar and Rossman (2013; new species), Maharachchikumbura et al. (2015, 2016; outline), holotype of the type: IMI 364835, cultures and sequences are unavailable.

Takamatsuella U. Braun \& A. Shi 2012, Erysiphaceae, Erysiphales, Leotiomycetes, one species, type: $U$. circinata Cooke \& Peck, asexual morph unknown, biotrophic, obligate plant pathogens, terrestrial, North America, see Braun and Cook (2012; taxonomy), sequences are available, lectotype of type: USA, New York, Watkins, on Acer spicatum, Sep., Peck (NYS). Talaromyces C.R. Benj. 1955 (= Erythrogymnotheca Yaguchi \& Udagawa; = Paratalaromyces Matsush.; = Penicillium Link subgenus Biverticillium Dierckx; = Penicillium Link subgenus Biverticillata-Symmetrica Thom; = Sagenoma Stolk \& G.F. Orr fide Samson et al. 2011), Trichocomaceae, Eurotiales, Eurotiomycetes, c. 114 species, type: T. flavus (Klöcker) Stolk \& Samson, terrestrial, but sometimes also isolated from aquatic habitats, associated with diverse substrates, including living or decaying plant material, soil, 
compost, dung, house dust, foodstuffs, leather, arthropods, rodents, air, cosmopolitan, the genus includes some clinically-relevant species, of which the most important is Talaromyces marneffei (Segretain, Capponi \& Sureau) Samson, Yilmaz, Frisvad \& Seifert (= Penicillium marneffei Segretain, Capponi \& Sureau), a thermally dimorphic fungus which commonly infects immunocompromised patients in southeast Asia, see Proksa (2010; secondary metabolites), Samson et al. (2011; phylogeny, new combinations, epitypification of the type:), Houbraken and Samson (2011; phylogeny), Guarro et al. (2012; soilborne species), Yilmaz et al. (2012, 2014, 2016a, 2016b; phylogeny, revision, new species), Frisvad et al. (2013; new species), Sang et al. (2013; new species), Visagie et al. (2015; new species), Chen et al. (2016a; new species), Luo et al. (2016a; new species), Wang et al. (2016a; new species), ex-epitype strain of the type: $=$ CBS 310.38 .

Talekpea Lunghini \& Rambelli 1979, Ascomycota genera incertae sedis, one species, type: $T$. foeticia Lunghini \& Rambelli, hyphomycetous, sexual morph unknown, saprobes, terrestrial, Ivory Coast, see Seifert et al. (2011; morphology), Wijayawardene et al. (2012, 2017; outline), Kirk et al. (2013; genus accepted), cultures and sequences are unavailable, needs generic revision.

Talpapellis Alstrup \& M.S. Cole 1998, Ascomycota genera incertae sedis, one species, type: T. peltigerae Alstrup \& M.S. Cole, hyphomycetous, sexual morph unknown, lichenicolous, Canada, see Kirk et al. (2008; genus accepted), Wijayawardene et al. (2017; outline), cultures and sequences are unavailable.

Tamaricicola Thambugala, E. Camporesi \& K.D. Hyde 2016, Pleosporaceae, Pleosporales, Dothideomycetes, one species, type: T. muriformis Thambugala, Camporesi \& K.D. Hyde, asexual morph coelomycetous, saprobes, terrestrial, Italy, see Thambugala et al. (2016; taxonomy, phylogeny), holotype and ex-type culture of the type: MFLU 16-0676, MFLUCC 15-0488.

Tamhinispora Rajeshkumar \& Rahul Sharma 2013, Tubeufiaceae, Tubeufiales, Dothideomycetes, one species, type: T. indica Rajeshkumar \& Rahul Sharma, hyphomycetous, sexual morph unknown, saprobes, see Rajeshkumar and Sharma (2013; morphology), Boonmee et al. (2014b; placed in Tubeufiales, phylogeny, key), holotype and ex-type strain of the type: AMH 9555, NFCCI 2924.

Tamsiniella S.W. Wong, K.D. Hyde, W.H. Ho \& S.J. Stanley 1998, Sordariomycetes genera incertae sedis, two species, type: T. labiosa S.W. Wong, K.D. Hyde, W.H. Ho \& S.J. Stanley, asexual morph unknown, saprobes, terrestrial, Australia, see Lumbsch and Huhndorf (2010; outline), Maharachchikumbura et al. (2015, 2016; outline), holotype of the type: HKU (M) 2276, cultures and sequences are unavailable, needs generic revision.

Tandonea M.D. Mehrotra 1991, Ascomycota genera incertae sedis, one species, type: T. dargentiana M.D. Mehrotra, coelomycetous, sexual morph unknown, saprobes, terrestrial, India, see Wijayawardene et al. (2012, 2017; outline), Kirk et al. (2013; genus accepted), holotype of the type: IMI 269926, cultures and sequences are unavailable, needs generic revision.

Tangerinosporium L. Lombard \& Crous 2016, Stachybotriaceae, Hypocreales, Sordariomycetes, one species, type: T. thalitricola L. Lombard \& Crous, hyphomycetous, sexual morph unknown, saprobes, terrestrial, UK, see Lombard et al. (2016; taxonomy, phylogeny), Wijayawardene et al. (2017; outline), holotype and ex-type culture of the type: CBS H-22472, CBS 317.61.

Tania Egea, Torrente \& Sipman 1995, Roccellaceae, Arthoniales, Arthoniomycetes, two species, type: T. lanosa Egea, Torrente \& Sipman, lichenized, terrestrial, Africa, see Lumbsch and Huhndorf (2010; outline), Kirk et al. (2013; genus accepted), Jaklitsch et al. (2016a; classifiction), Lücking et al. (2016b; classification), sequences unavailable. 
Tapellaria Müll. Arg. 1898, Pilocarpaceae, Lecanorales, Lecanoromycetes, 22 species, type: T. herpetospora Müll. Arg., asexual morph unknown, lichenized, terrestrial, see Lumbsch and Huhndorf (2010; outline), Lumbsch et al. (2011; new species), Messuti et al. (2011; new species), Kirk et al. (2013; genus accepted), Farkas (2014; taxonomy), van den Broeck et al. (2014; taxonomy), Lücking et al. (2016b; classification), McCarthy and Elix (2016; new species), sequences are unavailable

Tapellariopsis Lücking 1999, Pilocarpaceae, Lecanorales, Lecanoromycetes, one species, type: T. octomera Lücking, lichenized, see Lumbsch and Huhndorf (2010; outline), Lücking et al. (2016b; classification), sequences are unavailable.

Taphridium Lagerh. \& Juel 1902, Protomycetaceae, Taphrinales, Taphrinomycetes, two species, type: T. umbelliferarum (Rostr.) Lagerh. \& Juel, asexual morph unknown, ?saprobes, terrestrial, worldwide, see Lumbsch and Huhndorf (2010; outline), Kirk et al. (2013; genus accepted), cultures and sequences are unavailable, needs generic revision.

Taphrina Fr. 1815, Taphrinaceae, Taphrinales, Taphrinomycetes, two species, type: T. aurea (Pers.) Fr., asexual morph unknown, ?saprobes, terrestrial, worldwide, see Lumbsch and Huhndorf (2010; outline), Kirk et al. (2013; genus accepted), cultures and sequences are unavailable, needs generic revision.

Taphrophila Scheuer 1988, Dothideomycetes genera incertae sedis, incertae sedis, four species, type: T. cornu-capreoli Scheuer, asexual morph unknown, on rotten leaves, widespread, see Lumbsch and Huhndorf (2010; outline), Kirk et al. (2013; genus accepted), cultures and sequences are unavailable.

Tarasginia S.Y.Kondr., Kärnefelt, A.Thell, Elix \& Hur 2015, Teloschistaceae, Teloschistales, Lecanoromycetes, two species, type: T. whinrayi (S.Y. Kondr. \& Kärnefelt) S.Y. Kondr., Kärnefelt, A. Thell, Elix, J. Kim, A.S. Kondr. \& Hur, lichenized, see Kondratyuk et al. (2015c; taxonomy), Lücking et al. (2016b; classification), sequences are available.

Tarbertia Dennis 1974, Arthoniales genera incertae sedis, one species, type: T. juncina Dennis, ?lichenized or saprobes, terrestrial, British Isles, see Lumbsch and Huhndorf (2010; outline), Kirk et al. (2013; genus accepted), Lücking et al. (2016b; classification), sequences are unavailable.

Tarsodisporus Bat. \& A.A. Silva 1965, Ascomycota genera incertae sedis, one species, type: T. paraensis Bat. \& A.A. Silva, coelomycetous, sexual morph unknown, saprobes, terrestrial, Brazil, see Wijayawardene et al. (2012, 2017; outline), Kirk et al. (2013; genus accepted), cultures and sequences are unavailable, needs generic revision.

Tarzetta (Cooke) Lambotte 1887, Pezizales genera incertae sedis, Pezizomycetes, nine species, type: $P$. tarzetta Cooke, asexual morph unknown, hypogeous, terrestrial, worldwide, see Hansen et al. (2013; phylogeny), Olariagaet al. (2015; taxonomy), culture and sequences are available but lacks for the type.

Tasmidella Kantvilas, Hafellner \& Elix 1999, Ramalinaceae, Lecanorales, Lecanoromycetes, one species, type: T. variabilis Kantvilas, Hafellner \& Elix, lichenized, see Ekman et al. (2008; taxonomy), Lendemer (2010b; taxonomy), Lumbsch and Huhndorf (2010; outline), Schmull et al. (2011; phylogeny), Lumbsch et al. (2012; phylogeny), Kirk et al. (2013; genus accepted), Miądlikowska et al. (2014a; phylogeny), Lücking et al. (2016b; classification), sequences unavailable.

Tassiloa S.Y.Kondr., Kärnefelt, A.Thell, Elix \& Hur 2015, Teloschistaceae, Teloschistales, Lecanoromycetes, two species, type: T. digitaurea (Søgaard, Søchting \& Sancho) S.Y. Kondr., Kärnefelt, A. Thell, Elix, J. Kim, A.S. Kondr. \& Hur, lichenized, see Kondratyuk et al. 2015e, Lücking et al. (2016b; classification), sequences are available.

Tatraea Svrček 1993, ?Helotiaceae, Helotiales, Leotiomycetes, two species, type: T. dumbirensis (Velen.) Svrček, asexual morph unknown, sabrobe of wood, widespread 
(temperate), see Lumbsch and Huhndorf (2010; outline), Kirk et al. (2013; genus accepted), holotype of the type: PRM 148876 (Svrček 1993), cultures and sequences are unavailable.

Tavaresiella T. Majewski 1980, Laboulbeniaceae, Laboulbeniales, Laboulbeniomycetes, four species, type: T. hebri T. Majewski, asexual morph unknown, biotrophic, hosts are Hebridae (Hemiptera: Heteroptera), Africa, Asia, and Europe, see Lumbsch and Huhndorf (2010; outline), Kirk et al. (2013; genus accepted), cultures and sequences are unavailable.

Tayloriellina S.Y.Kondr., Kärnefelt., A.Thell, Elix \& Hur 2016, Teloschistaceae, Teloschistales, Lecanoromycetes, one species, type: T. erythrosticta (Taylor) S.Y. Kondr., Kärnefelt., A. Thell, Elix, J. Kim, A.S. Kondr. \& Hur, lichenized, see Kondratyuk et al. (2016a; taxonomy), Lücking et al. (2016b; classification), sequences are available.

Tectacervulus A.W. Ramaley 1992, Ascomycota genera incertae sedis, one species, type: T. mahoniae A.W. Ramaley, coelomycetous, sexual morph unknown, pathogens, on leaf spots, terrestrial, USA, see Wijayawardene et al. (2012, 2017; outline), Kirk et al. (2013; genus accepted), holotype of the type: BPI 1107358, cultures and sequences are unavailable, needs generic revision.

Teichospora Fuckel 1870, Teichosporaceae, Pleosporales, Dothideomycetes, 35 species, type: T. trabicola Fuckel, asexual morph coelomycetous, terrestrial, saprobes, widespread, see Lumbsch and Huhndorf (2010; outline), Kirk et al. (2013; genus accepted), Hyde et al. (2013; accepted as a genus in Teichosporaceae), Wijayawardene et al. (2014c; outline), Crous et al. (2016a; new species, phylogeny), Jaklitsch et al. (2016c; new species, phylogeny), cultures available for type: C160, C134, C141.

Teichosporella (Sacc.) P. Karst. 1895, Dothideomycetes genera incertae sedis, 26 species, type: T. dura Sacc., asexual morph unknown, saprobes, terrestrial, America, Germania, Germany, Italy, temperate, Lumbsch and Huhndorf (2010; outline), Kirk et al. (2013; genus accepted), Wijayawardene et al. (2014c; outline), cultures and sequences are unavailable, needs generic revision.

Telimena Racib. 1900, Phyllachoraceae, Phyllachorales, Sordariomycetes, eleven species, type: T. erythrinae Racib., from living leaves, worldwide, see Lumbsch and Huhndorf (2010; outline), Kirk et al. (2013; genus accepted), Maharachchikumbura et al. (2015, 2016; outline), cultures and sequences are unavailable, needs generic revision.

Telimenella Petr. 1940, Phyllachoraceae, Phyllachorales, Sordariomycetes, two species, type: T. persica Petr., from living leaves, temperate, see Lumbsch and Huhndorf (2010; outline), Kirk et al. (2013; genus accepted), Maharachchikumbura et al. (2015, 2016; outline), cultures and sequences are unavailable, needs generic revision.

Telimenochora Sivan. 1987, Phyllachoraceae, Phyllachorales, Sordariomycetes, one species, type: T. abortiva (F. Stevens) Sivan., from living leaves, Mexico, Puerto Rico, see Lumbsch and Huhndorf (2010; outline), Kirk et al. (2013; genus accepted), Maharachchikumbura et al. (2015, 2016; outline), cultures and sequences are unavailable, needs generic revision.

Telioclipeum Viégas 1962, Ascomycota genera incertae sedis, one species, type: T. lavrense Viégas, saprobes, Brazil, see Lumbsch and Huhndorf (2010; outline), Kirk et al. (2013; genus accepted), cultures and sequences are unavailable, needs generic revision.

Telogalla Nik. Hoffm. \& Hafellner 2000, Verrucariaceae, Verrucariales, Eurotiomycetes, one species, type: T. olivieri (Vouaux) Nik. Hoffm. \& Hafellner, asexual morph unknown, lichenicolous, terrestrial, Europe, see Lumbsch and Huhndorf (2010; outline), van den Broeck et al. (2012; new records), cultures and sequences are unavailable, needs generic revision.

Teloschistes Norman 1853, Teloschistaceae, Teloschistales, Lecanoromycetes, 20 species, type: T. flavicans (Sw.) Norman, asexual morph unknown, lichenized, terrestrial, worldwide, see Muggia et al. (2008; taxonomy, phylogeny), Lumbsch and Huhndorf (2010; outline), 
Gaya et al. (2012, 2015; DNA, phylogeny), Kirk et al. (2013; genus accepted), cultures available for the type: AFTOL-ID 315.

Teloschistopsis Frödén, Søchting \& Arup 2013, Teloschistaceae, Teloschistales, Lecanoromycetes, three species, type: T. chrysocarpoides (Vainio) Frödén, Arup \& Søchting, asexual morph unknown, lichenized, terrestrial, see Arup et al. (2013; taxonomy), Lücking et al. (2016b; classification); sequences are available.

Temerariomyces B. Sutton 1993, Ascomycota genera incertae sedis, one species, type: $T$. acutulus B. Sutton, hyphomycetous, sexual morph unknown, saprobes, terrestrial, Malawi, see Seifert et al. (2011; morphology), Wijayawardene et al. (2012, 2017; outline), Kirk et al. (2013; genus accepted), holotype of the type: IMI 347181, cultures and sequences are unavailable, needs generic revision.

Temperantia K. Hansen, Healy \& Kovács 2011, Pezizaceae, Pezizales, Pezizomycetes, nine species, type: T. tiffanyae (Healy) K. Hansen, Healy \& Kovács, asexual morph unknown, hypogeous, terrestrial, USA, see Kovács et al. (2011b; taxonomy, pylogeny), holotype of the type: ISC, Healy 231, sequence are available.

Tengiomyces Réblová 1999, Helminthosphaeriaceae, Chaetosphaeriales, Sordariomycetes, four species, type: T. indicus (Varghese \& V.G. Rao) Réblová, asexual morph unknown, saprobes, terrestrial, India, China, see Lumbsch and Huhndorf (2010; outline), Maharachchikumbura et al. (2015, 2016; outline), cultures and sequences are unavailable.

Tenuimurus Senan., Camporesi \& K.D. Hyde 2016, Phomatosporaceae, Phomatosporales, Sordariomycetes, one species, type: T. clematis Senan., Camporesi \& K.D. Hyde, asexual morph unknown, saprobes, terrestrial, temperate, Italy, see Senanayake et al. (2016; taxonomy, phylogeny), cultures and sequences are available.

Tephromela M. Choisy 1929, Tephromelataceae, Lecanorales, Lecanoromycetes, 30 species, type: T. atra (Huds.) Hafellner, asexual morph unknown, lichenized, terrestrial, see Lumbsch and Huhndorf (2010; outline), Muggia et al. (2010, 2014; morphology, phylogeny, taxonomy), Pérez-Vargas et al. (2010a; new species), Fryday (2011; new speces), Spribille et al. (2011; molecular), Elix (2012; new species), Kirk et al. (2013; genus accepted), Wang et al (2013; taxonomy), Muggia et al. (2014; taxonomy), Kantvilas (2015; taxonomy), Szczepańska (2015; new records), Cestaro et al. (2016; phylogeny), Lücking et al. (2016b; classification), sequences are available.

Teracosphaeria Réblová \& Seifert 2007, Sordariomycetes genera incertae sedis, two species, type: T. petroica Réblová \& Seifert, asexual morph unknown, saprobes, terrestrial, New Zealand, see Lumbsch and Huhndorf (2010; outline, accepted as a genus in Annulatascaceae and Sordariomycetidae, genera incertae sedis), Maharachchikumbura et al. (2015, 2016; outline), holotype of the type: PDD 81436, cultures and sequences are available, needs generic revision.

Teratomyces Thaxt. 1893, Laboulbeniaceae, Laboulbeniales, Laboulbeniomycetes, nine species, type: T. mirificus Thaxt., asexual morph unknown, biotrophic, hosts are Staphylininae (Coleoptera: Staphylinidae), widespread, see Lumbsch and Huhndorf (2010; outline), Kirk et al. (2013; genus accepted), Rossi (2010; most recent species description), Haelewaters et al. (2015c; synonymy of $T$. brevicaulis with $T$. actobii), cultures and sequences are unavailable, needs generic revision.

Teratoschaeta Bat. \& O.M. Fonseca 1967, Dothideomycetes genera incertae sedis, two species, type: T. rondoniensis Bat. \& O.M. Fonseca, asexual morph unknown, lichenicolous, terrestrial, Brazil, see Lumbsch and Huhndorf (2010; outline), Kirk et al. (2013; genus accepted), Wijayawardene et al. (2014c; outline), cultures and sequences are unavailable, needs generic revision.

Teratosperma Syd. \& P. Syd. 1909, Ascomycota genera incertae sedis, one species, type: T. singulare Syd. \& P. Syd., saprobes, Africa, North America, Asia, see Seifert et al. (2011; 
morphology), Wijayawardene et al. (2012, 2017; outline), Kirk et al. (2013; genus accepted), cultures and sequences are unavailable, needs generic revision.

Teratosphaeria Syd. \& P. Syd. 1912 (= Colletogloeopsis Crous \& M.J. Wingf. 1997; = Kirramyces J. Walker et al. 1992 fide Crous et al. 2009f; Wijayawardene et al. 2014c; Rossman et al. 2015b), Teratosphaeriaceae, Capnodiales, Dothideomycetes, c. 90 species, type: T. fibrillosa Syd. \& P. Syd., asexual morph coelomycetous (formerly known in Colletogloeopsis, Kirramyces), saprobes, pathogens, terrestrial, cosmopolitan, see Crous et al. (2009c, d, e, f, 2011e; taxonomy, phylogeny), Andjic et al. (2010, 2016; new species, Australia, cryptic species), Lumbsch and Huhndorf (2010; outline), Yamazaki et al. (2010; acidophilic), Hunter et al. (2011; diseases), Taole et al. (2012; T. suttonii complex), Taylor et al. (2012; pathogens), Kirk et al. (2013; genus accepted), Wijayawardene et al. (2014c; outline, nomenclature), Quaedvlieg et al. (2014; phylogeny), cultures and sequences are available, needs generic revision.

Teratosphaericola Quaedvlieg \& Crous 2014, Teratosphaeriaceae, Capnodiales, Dothideomycetes, one species, type: T. pseudoafricana (Crous \& T.A. Cout.) Quaedvlieg \& Crous, asexual morph unknown, pathogens, Zambia, see Quaedvlieg et al. (2014; morphology, phylogeny), holotype and ex-type culture of type: PREM 54973, CPC 1229.

Teratosphaeriopsis Quaedvl. \& Crous 2014, Teratosphaeriaceae, Capnodiales, Dothideomycetes, one species, type: T. pseudoafricana Quaedvlieg \& Crous asexual morph unknown, one species, pathogens, South Africa, see Quaedvlieg et al. (2014; morphology, phylogeny), holotype and ex-type culture of type: CBS H-21137, CBS 111171.

Terfezia (Tul. \& C. Tul.) Tul. \& C. Tul. 1851, Pezizaceae, Pezizales, Pezizomycetes, 21 species, type: T. arenaria (Moris) Trappe, asexual morph unknown, hypogeous, terrestrial, worldwide, see Lumbsch and Huhndorf (2010; outline), Kovács et al. (2011a; new species), Bordallo et al. (2012, 2013, 2015; new species), Kirk et al. (2013; genus accepted), sequences are available.

Termitaria Thaxt. 1920, Ascomycota genera incertae sedis, three species, type: T. snyderi Thaxt., hyphomycetous, sexual morp unknown, America, Sardinia, see Seifert et al. (2011; morphology), Wijayawardene et al. (2012, 2017; outline), Kirk et al. (2013; genus accepted), cultures and sequences are unavailable, needs generic revision.

Termitariopsis M. Blackw., Samson \& Kimbr. 1980, Ascomycota genera incertae sedis, three species, type: T. cavernosa M. Blackw., Samson \& Kimbr., hyphomycetous, sexual morph unknown, saprobes, terrestrial, North and Central America, see Seifert et al. (2011; morphology), Wijayawardene et al. (2012, 2017; outline), Kirk et al. (2013; genus accepted), cultures and sequences are unavailable, needs generic revision.

Terriera B. Erikss. 1970, Rhytismataceae, Rhytismatales, Leotiomycetes, 26 species, type: T. cladophila (Lév.) B. Erikss., asexual morph unknown, saprobes, terrestrial, China, Europe, Thailand, see Lumbsch and Huhndorf (2010; outline), Lantz et al. (2011; DNA, phylogeny), Chen et al. (2012; new species, China), Kirk et al. (2013; genus accepted), Zhou et al. (2013; new species, China), Wu et al. (2015; new species), Hyde et al. (2016; new species, Thailand), sequences are available.

Testudina Bizz. 1885, Testudinaceae, Pleosporales, Dothideomycetes, one species, type: T. terrestris Bizz., asexual morph unknown, saprobes, terestrrial, Europe, see Lumbsch and Huhndorf (2010; outline), Hyde et al. (2013; accepted as a genus in Testudinaceae), Kirk et al. (2013; genus accepted), Wijayawardene et al. (2014c; outline), cultures and sequences are unavailable.

Testudomyces Cano, M. Solé \& Guarro 2002, Onygenaceae, Onygenales, Eurotiomycetes, one species, type: $T$. verrucosus M. Solé, Cano \& Guarro, asexual morph unknown, saprobes, terrestrial, Spain, see Lumbsch and Huhndorf (2010; outline), Kirk et al. (2013; genus accepted), sequences is available for the type (unpublished). 
Tetrabrachium Nawawi \& Kuthub. 1987, Ascomycota genera incertae sedis, three species, type: T. elegans Nawawi \& Kuthub., hyphomycetous, sexual morph unknown, saprobes, aquatic, Asia, see Seifert et al. (2011; morphology), Wijayawardene et al. (2012, 2017; outline), Kirk et al. (2013; genus accepted), cultures and sequences are unavailable, needs generic revision.

Tetrabrunneospora Dyko 1978, Ascomycota genera incertae sedis, two species, type: $T$. ellisii Dyko, hyphomycetous, sexual morph unknown, saprobes, aquatic, USA, see Seifert et al. (2011; morphology), Wijayawardene et al. (2012, 2017; outline), Kirk et al. (2013; genus accepted), cultures and sequences are unavailable, needs generic revision.

Tetrachaetum Ingold 1942, Leotiomycetes genera incertae sedis, three species, type: $T$. elegans Ingold, hyphomycetous, sexual morph unknown, saprobes, aquatic, Asia, North and South America, see Seifert et al. (2011; morphology), Wijayawardene et al. (2012, 2017; outline), Kirk et al. (2013; genus accepted), cultures and sequences are available (unpublished), needs generic revision.

Tetracladium De Wild. 1893, Helotiales genera incertae sedis, Leotiomycetes, eight species, type: T. marchalianum De Wild., hyphomycetous, sexual morph unknown, saprobes, aquatic, terrestrial, worldwide, see Sati et al. (2009; new species), Letourneau et al. (2010; DNA, phylogeny), Seifert et al. (2011; morphology), Wijayawardene et al. (2012, 2017; outline), Kirk et al. (2013; genus accepted), cultures available for the type: CCM F-11001.

Tetracoccosporium Szabó 1905, Ascomycota genera incertae sedis, three species, type: $T$. paxianum Szabó, hyphomycetous, sexual morph unknown, on dung and soil, terrestrial, worlwide, see Seifert et al. (2011; morphology), Wijayawardene et al. (2012, 2017; outline), Kirk et al. (2013; genus accepted), cultures and sequences are unavailable, needs generic revision.

Tetracrium Henn., 1902, Dothideomycetes genera incertae sedis, nine species, type: T. aurantii Henn., hyphomycetous, sexual morph unknown, see Seifert et al. (2011; morphology), Wijayawardene et al. (2012, 2014c, 2017; outline), Kirk et al. (2013; genus accepted), cultures and sequences are unavailable.

Tetramelas Norman 1853, Caliciaceae, Caliciales, Lecanoromycetes, 16 species, type: need typification, lichenized, see Giralt and Clerc (2011; comb. nov.), Gaya et al. (2012; phylogeny), Prieto et al. (2013; phylogeny), Lücking et al. (2016b; classification), Prieto and Wedin (2016; taxonomy), sequences are available.

Tetrameronycha Speg. ex W. Rossi \& M. Blackw. 1990, Ascomycota genera incertae sedis, one species, type: T. bonaerensis (Speg.) W. Rossi \& M. Blackw., hyphomycetous, sexual morph unknown, on insects, terrestrial, Africa, South America, see Seifert et al. (2011; morphology), Wijayawardene et al. (2012, 2017; outline), Kirk et al. (2013; genus accepted), cultures and sequences are unavailable, needs generic revision.

Tetranacriella Kohlm. \& Volkm.-Kohlm. 2001, Ascomycota genera incertae sedis, one species, type: T. papillata Kohlm. \& Volkm.-Kohlm., coelomycetous, sexual morph unknown, saprobes, terrestrial, USA, see Wijayawardene et al. (2012, 2017; outline), Kirk et al. (2013; genus accepted), cultures and sequences are unavailable, needs generic revision.

Tetranacrium H.J. Huds. \& B. Sutton 1964, Ascomycota genera incertae sedis, one species, type: T. gramineum H.J. Huds. \& B. Sutton, coelomycetous, sexual morph unknown, saprobes, terrestrial, West Indies, India, see Wijayawardene et al. (2012, 2017; outline), Kirk et al. (2013; genus accepted), cultures and sequences are unavailable, needs generic revision.

Tetrandromyces Thaxt. 1912, Laboulbeniaceae, Laboulbeniales, Laboulbeniomycetes, six species, type: T. brachidae Thaxt., no asexual state, biotrophic, hosts are Anthicidae and Staphylinidae (Coleoptera), widespread, see Lumbsch and Huhndorf (2010; outline), Kirk et al. (2013; genus accepted), cultures and sequences are unavailable, needs generic revision. 
Tetrapisispora Ueda-Nishimura \& Mikata emend. Kurtzman 2003, Saccharomycetaceae, Saccharomycetales, Saccharomycetes, seven species, type: T. phaffii (van der Walt) UedaNishimura \& Mikata, asexual reproduction is by multilateral budding, aaprophytic, in soil, Japanese blueberry, mangrove trees, cockroach, food processing plant, worldwide, see Lumbsch and Huhndorf (2010; outline), cultures and sequences are available.

Tetraploa Berk. \& Broome 1850 (= Tetraplosphaeria Kaz. Tanaka \& K. Hiray fide Wijayawardene et al. 2014c; Rossman et al. 2015b), Tetraplosphaeriaceae, Pleosporales, Dothideomycetes, 16 species, type: $T$. aristata Berk. \& Broome asexual morph coelomycetous, saprobes, terrestrial or aquatic, worldwide, see Tanaka et al. (2009; phylogeny, morphology), Wijayawardene et al. (2014c; nomenclature), Rossman et al. (2015b; nomenclature), holotype of the type: IMI 17841, cultures and sequences are available. Tetraposporium S. Hughes 1951, Ascomycota genera incertae sedis, two species, type: $T$. asterinearum S. Hughes, hyphomycetous, sexual morph unknown, fungicolous, terrestrial, Africa, see Seifert et al. (2011; morphology), Wijayawardene et al. (2012, 2017; outline), Kirk et al. (2013; genus accepted), cultures and sequences are unavailable, needs generic revision.

Tettigomyces Thaxt. 1915, Ceratomycetaceae, Laboulbeniales, Laboulbeniomycetes, 16 species, type: T. gryllotalpae Thaxt., asexual morph unknown, biotrophic, hosts are Gryllotalpa species and Scapteriscus sp. (Orthoptera: Gryllotalpidae), widespread, see Lumbsch and Huhndorf (2010; outline), Kirk et al. (2013; genus accepted), cultures and sequences are unavailable.

Teunomyces Kurtzman \& M. Blackwell 2016, Debaryomycetaceae, Saccharomycetales, Saccharomycetes, twelve species, type: T. kruisii ((Kocková-Kratochvílová \& Ondrušová) Kurtzman \& M. Blackwell, asexual reproduction is by multilateral budding, saprophytic, in insects, often the guts of insects, worldwide, see Kurtzman et al. (2016; taxonomy), cultures and sequences are available.

Teuvoa Sohrabi \& S.Leavitt 2013, Megasporaceae, Pertusariales, Lecanoromycetes, three species, type: T. uxoris (Werner) Sohrabi, V. J. Rico \& S. Leavitt, lichenized, see Sohrabi et al. (2013b; taxonomy), Lücking et al. (2016b; classification), sequences are available.

Texosporium Nádv. ex Tibell \& Hofsten 1968, Caliciaceae, Caliciales, Lecanoromycetes, two species, type: T. sancti-jacobi (Tuck.) Nádv. ex Tibell \& Hofsten, asexual morph unknown, lichenized, terrestrial, see Lumbsch and Huhndorf (2010; outline), Kirby et al. (2011; ecology), Kirk et al. (2013; genus accepted), Root et al. (2011, 2012, 2013; ecology), Rosentreter et al. (2014; ecology), Lücking et al. (2016b; classification), Prieto and Wedin (2016; ecology), sequences are available.

Textotheca Matsush. 1996, Ascomycota genera incertae sedis, one species, type: T. caffra Matsush., coelomycetous, sexual morph unknown, saprobes, terrestrial, South Africa, see Wijayawardene et al. (2012, 2017; outline), Kirk et al. (2013; genus accepted), cultures and sequences are unavailable, needs generic revision.

Thailandiomyces Pinruan, Sakay., K.D. Hyde \& E.B.G. Jones 2008, Tirisporellaceae, Tirisporellales, Sordariomycetes, one species, type: T. bisetulosus Pinruan, Sakay., Hyde \& E.B.G. Jones, saprobes, aquatic, see Lumbsch and Huhndorf (2010; outline), Jones et al (2015; classification, phylogeny, marine), Maharachchikumbura et al. (2015, 2016; classification, phylogeny), Suetrong et al. (2015; phylogeny), holotype and cultures available for the type: BBH, Pinruan, Wah 110, BCC18.

Thalassoascus Ollivier 1926, Dothideomycetes genera incertae sedis, three species, type: $T$. tregoubovii Ollivier, asexual morph unknown, parasites, marine, worldwide, see Lumbsch and Huhndorf (2010; outline), Jones et al (2015; classification, marine), Wijayawardene et al. (2014c; outline), cultures and sequences are unavailable, needs generic revision. 
Thalassogena Kohlm. \& Volkm.-Kohlm. 1987, Halosphaeriaceae, Microascales, Sordariomycetes, one species, type: T. sphaerica Kohlm. \& Volkm.-Kohlm., asexual morph unknown, saprobes, marine, worldwide, Lumbsch and Huhndorf (2010; outline), Kirk et al. (2013; genus accepted), Maharachchikumbura et al. (2015, 2016; outline), holotype of type: J.K. 5044a = 01390521, NYBG.

Thalespora Chatmala \& E.B.G. Jones 2006, Halosphaeriaceae, Microascales, Sordariomycetes, one species, type: T. appendiculata Chatmala \& E.B.G. Jones, asexual morph unknown, marine, on wood, tropical, see Sakayaroj et al. (2011a; phylogeny), Jones et al. (2015; outline), Maharachchikumbura et al. (2015, 2016; outline), cultures and sequences are available.

Thallinocarpon Å.E.Dahl 1950, Lichinaceae, Lichinales, Lichinomycetes, two species, type: T. pulvinatum Å.E. Dahl, lichenized, see Lücking et al. (2016b; classification), sequences are unavailable.

Thalloloma Trevis. 1853, Graphidaceae, Ostropales, Lecanoromycetes, 19 species, type: T. anguinum (Mont.) Trevis., asexual morph unknown, lichenized fungi, terrestrial, tropical, placement in Graphidaceae supported by molecular data, see Rivas Plata et al. (2012a; phylogeny), Lumbsch and Huhndorf (2010; outline), Kirk et al. (2013; genus accepted), Lücking et al. (2016b; classification), sequences are available.

Thallomyces H.J. Swart 1975, Parmulariaceae, Dothideomycetes families incertae sedis, one species, type: T. oritis (Hansf.) H.J. Swart, asexual morph unknown, saprobes, terrestrial, Australia, see Lumbsch and Huhndorf (2010; outline), Hyde et al. (2013; accepted as a genus in Parmulariaceae), Kirk et al. (2013; genus accepted), Wijayawardene et al. (2014c; outline), cultures and sequences are unavailable, needs generic revision.

Thamnochrolechia Aptroot \& Sipman 1991, Pertusariaceae, Pertusariales, Lecanoromycetes, one species, type: T. verticillata Aptroot \& Sipman, asexual morph unknown, lichenized, terrestrial, tropical, see Lumbsch and Huhndorf (2010; outline), Kirk et al. (2013; genus accepted), Lücking et al. (2016b; classification), sequences are available. holotype of the type: B, Aptroot 18622.

Thamnogalla D. Hawksw. 1980, Cordieritidaceae, Leotiomycetes families incertae sedis, one species, type: T. crombiei (Mudd) D. Hawksw., lichenicolous, Europe and North America, terrestrial, see Kirk et al. (2013; genus accepted), Suija et al. (2015b; phylogeny), Jaklitsch et al. (2016a; classification), cultures and sequences are available, lectotype of type: BM.

Thamnolecania (Vain.) Gyeln., 1933, Ramalinaceae, Lecanorales, Lecanoromycetes, eight species, type: L. brialmontii Vain., asexual morph unknown, lichenized, terrestrial, see Lumbsch and Huhndorf (2010; outline), Kirk et al. (2013; genus accepted), Lücking et al. (2016b; classification), sequences are available.

Thamnolia Ach. ex Schaer. 1850, Icmadophilaceae, Pertusariales, Lecanoromycetes four species, type: T. vermicularis (Sw.) Schaer., asexual morph unknown, lichenized, terrestrial, see Nelsen. and Gargas (2009; molecular), Diederich et al. (2010b; taxonomy), Manojlović et al. (2010a, b; HPLC analysis, bioactivity)), Guo et al. (2011; chemistry), Schmull et al. (2011; molecular), Lumbsch and Huhndorf (2010; outline), Hansen (2013; taxonomy), Kirk et al. (2013; genus accepted), Knight et al. (2013; chemotaxonomy), Árnason (2014; chemistry), Plazaa et al. (2014; antioxidant property), Lücking et al. (2016b; classification), sequences are available.

Thamnomyces Ehrenb. 1820, Hypoxylaceae, Xylariales, Sordariomycetes, five species, type: T. chamissonis Ehrenb., asexual morph hyphomycetous, terrestrial, saprobes, tropical, see Lumbsch and Huhndorf (2010; outline), Stadler et al. (2010b; new species), Kirk et al. (2013; genus accepted), Maharachchikumbura et al. (2015, 2016; outline), Wendt et al. (2017; 
accepted as a genus in Hypoxylaceae), cultures and sequences are available for unidentified species.

Thaptospora B. Sutton \& Pascoe 1987, Ascomycota genera incertae sedis, one species, type: T. atrobrunnea B. Sutton \& Pascoe, coelomycetous, sexual morph unknown, saprobes, terrestrial, Australia, see Wijayawardene et al. (2012, 2017; outline), Kirk et al. (2013; genus accepted), cultures and sequences are unavailable, needs generic revision.

Thaumasiomyces Thaxt. 1931, Ceratomycetaceae, Laboulbeniales, Laboulbeniomycetes, three species, type: T. scabellularius Thaxt., no asexual state, biotrophic, hosts are Hydrophilidae (Coleoptera), Africa and Asia, see Lumbsch and Huhndorf (2010; outline), Kirk et al. (2013; genus accepted), cultures and sequences are unavailable.

Thaxteria Sacc. 1891, Lasiosphaeriaceae, Sordariales, Sordariomycetes, nine species, type: T. kunkelii Giard, asexual morph unknown, coprophilous, terrestrial, worldwide, see Lumbsch and Huhndorf (2010; outline), Kirk et al. (2013; genus accepted), Maharachchikumbura et al. (2015, 2016; outline), cultures and sequences are available but lacks for the type.

Thaxteriella Petr., 1924, Tubeufiaceae, Tubeufiales, Dothideomycetes, nine species, type: $T$. corticola Petr., saprobes on decaying wood, Puerto Rico, Thailand, asexual morph hyphomycetous, see Lumbsch and Huhndorf (2010; outline), Kirk et al. (2013; genus accepted), Boonmee et al. (2014b; taxonomy), Wijayawardene et al. (2014c; outline), cultures and sequences are unavailable.

Thaxteriellopsis Sivan., Panwar \& S.J. Kaur 1976 [1977], Tubeufiaceae, Tubeufiales, Dothideomycetes, three species, type: T. lignicola Sivan., Panwar \& S.J. Kaur, saprobes on decaying wood, India, see Lumbsch and Huhndorf (2010; outline), Kirk et al. (2013; genus accepted), Boonmee et al. (2014b; taxonomy), Wijayawardene et al. (2014c; outline), cultures and sequences are available.

Thecaria Fée 1824, Graphidaceae, Ostropales, Lecanoromycetes, three species, type: T. quassiicola Fée, asexual morph unknown, lichenized, terrestrial, tropical, see Lumbsch and Huhndorf (2010; outline), Rivas Plata et al. (2012a; txonomy), Kirk et al. (2013; genus accepted), Lücking et al. (2016b; classification), sequences are available.

Thecographa A. Massal. 1860, Graphidaceae, Ostropales, Lecanoromycetes, three species, type: T. ceramia A. Massal., asexual morph unknown, lichenized fungi, terrestrial, tropical, see Rivas Plata et al. (2012a; taxonomy), Lücking et al. (2016b; classification), sequences are unavailable.

Thecotheus Boud. 1869, Ascobolaceae, Pezizales, Pezizomycetes, 20 species, type: T. pelletieri (P. Crouan \& H. Crouan) Boud., asexual morph unknown, coprophilous, terrestrial, worldwide, see Lumbsch and Huhndorf (2010; outline), Kirk et al. (2013; genus accepted), Kušan et al. (2015; new species), cultures and sequences are available but lacks for the type.

Thedgonia B. Sutton 1973, Helotiales genera incertae sedis, one species, type: T. ligustrina (Boerema) B. Sutton, hyphomycetous, sexual morph unknown, terrestrial, plant pathogens, leaf-spotting, Asia, Europe, North America, see Crous et al. (2009a, 2012a, phylogeny), Seifert et al. (2011), Wijayawardene et al. (2017; outline), ex-type culture: CBS 148.59, holotype of type: the Netherlands, Eefelde, on Ligustrum ovalifolium, 23 Mar. 1959, G.H. Boerema (L).

Theissenia Maubl. 1914, Xylariales genera incertae sedis, Sordariomycetes, four species, type: T. pyrenocrata (Theiss.) Maubl, asexual morph hyphomycetous, terrestrial, saprobes, pantropical, see Hsieh et al. (2010; DNA, phylogeny), Lumbsch and Huhndorf (2010; outline), Kirk et al. (2013; genus accepted), Maharachchikumbura et al. (2015, 2016; outline), Wendt et al. (2017; accepted as a genus in Xylariales genera incertae sedis), cultures and sequences are available. 
Thelebolus Tode 1790 (= Lasiothelebolus Kimbr. \& Luck-Allen 1974; = Pezizella P. Karst., 1873; = Pezizula P. Karst. 1871; = Ryparobius Boud. 1869; = Telebolus Lindau 1905 fide Species Fungorum 2017), Thelebolaceae, Thelebolales, Leotiomycetes, c. 13 species, type: $T$. stercoreus Tode, asexual morph unknown, saprobes, from soil, on dung, terrestrial, worldwide, see Lumbsch and Huhndorf (2010; outline), Kirk et al. (2013; genus accepted), Mukhopadhyay et al. (2014; extracellular enzymes), Singh et al. (2014; extracellular enzymes), Crous et al. (2015d; new species), cultures available for the type: CBS 709.69, CBS 717.69 (unpublished), needs generic revision.

Thelenella Nyl. 1855, Thelenellaceae, Ostropales, Lecanoromycetes, 30 species, type: T. modesta (Nyl.) Nyl., asexual morph unknown, lichenized, terrestrial, worldwide, see Lumbsch and Huhndorf (2010; outline), Kinalioglu and Aptroot (2011; new records of Turkey), Aptroot and Schumm (2012; new species), Kirk et al. (2013; genus accepted), Aptroot et al. (2014a; new species), Cáceres and Aptroot (2016; new species), Nelsen et al. 2016, Lücking et al. (2016b; classification), sequences are available.

Thelenidia Nyl. 1886, Dothideomycetes genera incertae sedis, one species, type: $T$. monosporella Nyl., asexual morph unknown, lichenized, terrestrial, Greenland, Switzerland, see Lumbsch and Huhndorf (2010; outline), Kirk et al. (2013; genus accepted), Wijayawardene et al. (2014c; outline, accepted as Dothideomycetes), Lücking et al. (2016b; classification), sequences are unavailable.

Thelidiella Fink 1933, Sordariomycetes genera incertae sedis, two species, type: $T$. blastenicola Fink ex J. Hedrick, asexual morph unknown, lichenicolous, terrestrial, North America, see Lumbsch and Huhndorf (2010; outline), Kirk et al. (2013; genus accepted), Maharachchikumbura et al. (2015, 2016; outline), cultures and sequences are unavailable, needs generic revision.

Thelidiopsis Vain. 1921, Verrucariaceae, Verrucariales, Eurotiomycetes, one species, type: T. robinsonii Vain., asexual morph unknown, lichenized, terrestrial, Europe, Asia, see Lumbsch and Huhndorf (2010; outline), Kirk et al. (2013; genus accepted), Lücking et al. (2016b; classification), sequences are unavailable.

Thelidium A. Massal. 1855, Verrucariaceae, Verrucariales, Eurotiomycetes, c. 100 species, type: T. amylaceum A. Massal., asexual morph unknown, lichenized, terrestrial, fresh water, Europe, Asia, see Holger et al. (2008; fresh water species), Lumbsch and Huhndorf (2010; outline), Pykälä et al. (2012; species in Russia), Kirk et al. (2013; genus accepted), Lücking et al. (2016b; classification), sequences are available.

Thelignya A. Massal.1856, Lichinaceae, Lichinales, Lichinomycetes, three species, type: $T$. fuliginea (Ach.) A. Massal., asexual morph unknown, lichenized, terrestrial, see Jørgensen and Palice (2010; taxonomy), Lumbsch and Huhndorf (2010; outline), Kirk et al. (2013; genus accepted), Kristinsson et al. (2014; taxonomy), Lücking et al. (2016b; classification), sequences unavailable.

Thelliana S.Y.Kondr., Kärnefelt, Elix \& Hur 2015, Teloschistaceae, Teloschistales, Lecanoromycetes, one species; type: T. pseudokiamae S.Y. Kondr., Kärnefelt, Elix \& Hur; lichenized; see Kondratyuk et al. (2015c; taxonomy), Lücking et al. (2016b; classification), sequences are available.

Thelocarpella Nav.-Ros. \& Cl. Roux, 1999, Acarosporaceae, Lecanorales, Lecanoromycetes, one species, type: T. gordensis Nav.-Ros. \& Cl. Roux, asexual morph unknown, lichenized, terrestrial, see Lumbsch and Huhndorf (2010; outline), Tonouchi (2010; characterization), Knudsen et al. (2012; taxonomy), Kirk et al. (2013; genus accepted), Gueidan et al. (2014c; taxonomy), Westberg et al. (2015; phylogeny), Knudsen and Lendemer (2016; taxonomy), Roux et al. (2016; taxonomy), Lücking et al. (2016b; classification); sequences are available.

Thelocarpon Nyl. 1853, Thelocarpaceae, Thelocarpales, Ascomycota orders incertae sedis, 27 species, type: T. laureri (Flot.) Nyl., asexual morph unknown, lichenized or non- 
lichenized, terrestrial, worldwide, see Moon and Aptroot (2009; new species, South Korea), Lumbsch and Huhndorf (2010; outline), Kirk et al. (2013; genus accepted), Flakus and Kukwa (2014; new species), Cáceres and Aptroot (2016; new species, Brazil), van den Boom (2016; new species), Jaklitsch et al. (2016a; classification), Lücking et al. (2016b; classification), sequences are available, needs generic revision.

Thelomma A.Massal. 1860, Caliciaceae, Caliciales, Lecanoromycetes, seven species; type: $T$. mammosum (Hepp) A. Massal., lichenized, see Lumbsch and Huhndorf (2010; outline), Gaya et al. (2012; phylogeny), Kirk et al. (2013; genus accepted), Prieto et al. (2013; phylogeny), Lücking et al. (2016b; classification), Prieto and Wedin (2016; phylogeny), sequences are available.

Thelonectria P. Chaverri \& C. Salgado 2011, Nectriaceae, Hypocreales, Sordariomycetes, 43 species, type: T. discophora (Mont.) P. Chaverri \& C. Salgado, asexual morph cylindrocarpon-like, saprobes, terrestrial, worldwide, see Chaverri et al. (2011; taxonomy, phylogeny), Salgado-Salazar et al. (2012, 2014, 2016; new species, phylogeny), Zeng and Zhuang (2013b; new species, China), Maharachchikumbura et al. (2015, 2016; outline), Lombard et al. (2016; phylogeny), cultures available for the type: CBS 125153.

Thelopsis Nyl. 1855, Stictidaceae, Ostropales, Lecanoromycetes, nine species, type: T. rubella Nyl., asexual morph unknown, lichenized, terrestrial, see Giordani et al. (2009; new records), Øvstedal. and Gremmen (2009; new record), Aptroot et al. (2010; biodiversity), Potenza et al. (2010; new records), Lumbsch and Huhndorf (2010; outline), Dymytrova et al. (2013; taxonomy), Gundersen (2013; ecology), Kirk et al. (2013; genus accepted), Aptroot et al. (2014c; world key), Mies (2015; new records), Stehn et al. (2015; list), Lücking et al. (2016b; classification), sequences unavailable.

Thelotrema Ach. 1803, Graphidaceae, Ostropales, Lecanoromycetes, 106 species, type: T. lepadinum (Ach.) Ach., asexual morph unknown, lichenized fungi, terrestrial, mostly tropical, see Mangold et al. (2009; key, Australia), Lumbsch and Huhndorf (2010; outline), Rivas Plata et al. (2010a, 2012a; key), Sipman et al. (2012; key, Costa Rica), Weerakoon et al. (2012b; new species), Kirk et al. (2013; genus accepted), Lücking et al. (2016b; classification), sequences are available.

Themisia Velen. 1939, Helotiales genera incertae sedis, Leotiomycetes, eight species, type: $T$. nuda Velen., asexual morph unknown, saprobes, terrrestrial, former Czechoslovakia, see Lumbsch and Huhndorf (2010; outline), Kirk et al. (2013; genus accepted), cultures and sequences are unavailable, needs generic revision.

Thermoascus Miehe 1907, Thermoascaceae, Eurotiales, Eurotiomycetes, five species, type: T. aurantiacus Miehe, asexual morph unknown, saprobes, worldwide, see Lumbsch and Huhndorf (2010; outline, accepted as in Trichocomaceae), Houbraken and Samson (2011; DNA, phylogeny), Kirk et al. (2013; genus accepted), Jaklitsch et al. (2016a; classification), cultures and sequences are available.

Thermothelomyces Y. Marín, Stchigel, Guarro \& Cano 2015, Chaetomiaceae, Sordariales, Sordariomycetes, four species, type: T. thermophila (Apinis) Y. Marín, Stchigel, Guarro \& Cano, see Marin-Felix et al. (2015; taxonomy), Maharachchikumbura et al. (2016; outline), cultures and sequences are available.

Thermutis Fr. 1825, Lichinaceae, Lichinales, Lichinomycetes, two species, type: T. velutina (Ach.) Flot., asexual morph unknown, lichenized, terrestrial, see Schutz (2009; taxonomy), Lumbsch and Huhndorf (2010; outline), Urbanavichus and Urbanavichene (2011; new records), Kirk et al. (2013; genus accepted), Lücking et al. (2016b; classification), sequences are unavailable.

Thermutopsis Henssen 1990, Lichinaceae, Lichinales, Lichinomycetes, one species, type: $T$. jamesii Henssen, asexual morph unknown, lichenized, terrestrial, see Lumbsch and Huhndorf 
(2010; outline), Kirk et al. (2013; genus accepted), Lücking et al. (2016b; classification); sequences are unavailable.

Therrya Sacc. 1882, Rhytismataceae, Rhytismatales, Leotiomycetes, seven species, type: $T$. gallica Sacc. \& Penz., asexual morph unknown, saprobes, terrestrial, worldwide, see Lumbsch and Huhndorf (2010; outline), Kirk et al. (2013; genus accepted), Solheim et al. (2013; DNA, phylogeny), cultures and sequences are available but lacks for the type.

Thielavia Zopf 1876, Chaetomiaceae, Sordariales, Sordariomycetes, 31 species, type: T. basicola Zopf, asexual morph unknown, saprobes, saprobes, terrestrial, worldwide, see Kusari et al. (2009; enophytes, secondary metabolites), Lumbsch and Huhndorf (2010; outline), Berka et al. (2011; genomic analysis), Kirk et al. (2013; genus accepted), Van den Brink et al. (2015; DNA, thermophilic properties), Maharachchikumbura et al. (2015, 2016; outline), cultures available for the type: CBS 229.82.

Thielaviopsis Went 1893, Ceratocystidaceae, Microascales, Sordariomycetes, six species, type: T. ethacetica Went, asexual morph unknown, saprobes, pathogens, terrestrial, worldwide, see de Beer et al. (2014; new species), Mbenoun et al. (2014, 2016; DNA, phylogeny), Maharachchikumbura et al. (2015, 2016; outline), de Melo et al. (2016; pathogens), Rossman et al. (2016b; new combination), cultures available for the type: CMW37775.

Thindia Korf \& Waraitch 1971, Sarcoscyphaceae, Pezizales, Pezizomycetes, one species, type: T. cupressi Korf \& Waraitch, asexual morph unknown, saprobes, terrestrial, India, see Lumbsch and Huhndorf (2010; outline), Kirk et al. (2013; genus accepted), cultures and sequences are unavailable, needs generic revision.

Thindiomyces Arendh. \& R. Sharma 1983, Hyaloscyphaceae, Helotiales, Leotiomycetes, one species, type: T. epiphyllus Aredh. \& Sharma, asexual morph unknown, saprobes of leaves, Bhutan, Lumbsch and Huhndorf (2010; outline), Kirk et al. (2013; genus accepted), Jaklitsch et al. (2016a; classification), holotype: PAN 17589, cultures and sequences are unavailable.

Thirumalacharia Rathaiah 1981, Ascomycota genera incertae sedis, one species, type: $T$. curcumae Rathaiah, hyphomycetous, sexual morph unknown, saprobes, terrestrial, Asia, see Seifert et al. (2011; morphology), Wijayawardene et al. (2012, 2017; outline), Kirk et al. (2013; genus accepted), cultures and sequences are unavailable, needs generic revision.

Tholomyces Matsush. 2003, Ascomycota genera incertae sedis, one species, type: $T$, flagellifer Matsush., coelomycetous, sexual morph unknown, saprobes, terrestrial, Honshu, see Wijayawardene et al. (2012, 2017; outline), Kirk et al. (2013; genus accepted), cultures and sequences are unavailable, needs generic revision.

Tholurna Norman 1861, Caliciaceae, Caliciales, Lecanoromycetes, one species, type: T. dissimilis Norman, asexual morph unknown, lichenized, terrestrial, North America, see Lumbsch and Huhndorf (2010; outline), Gaya et al. 2012; molecular), Allen and Lendemer (2013; molecular), Kirk et al. (2013; genus accepted), Prieto et al. (2013; phylogeny), Beese et al. (2015; ecology), Lücking et al. (2016b; classification), Prieto and Wedin (2016; phylogeny), sequences are available.

Thoracella Oudem. 1901, Ascomycota genera incertae sedis, one species, type: T. ledi Oudem., coelomycetous, sexual morph unknown, saprobes, terrestrial, Europe, see Wijayawardene et al. (2012, 2017; outline), Kirk et al. (2013; genus accepted), cultures and sequences are unavailable, needs generic revision.

Thozetella Kuntze 1891, Chaetosphaeriaceae, Chaetosphaeriales, Sordariomycetes, 17 species, type: T. nivea (Berk.) Kuntze, hyphomycetous, sexual morph unknown, saprobes, terrestrial, cosmopolitan, see Seifert et al. (2011; morphology), Whitton et al. (2012a; new species), Wijayawardene et al. (2012, 2017; outline), Kirk et al. (2013; genus accepted), cultures and sequences are available for unidentified species, needs generic revision. 
Thrauste Theiss. 1916, Englerulaceae, Dothideomycetes families incertae sedis, three species, type: T. medinillae (Racib.) Theiss., sexual morph hyphomycetous, epiphytes, saprobes, terrestrial, Philippines, see Lumbsch and Huhndorf (2010; outline), Kirk et al. (2013; genus accepted), Dai et al. (2014c; morphology), cultures and sequences are unavailable, needs generic revision.

Thrinacospora Petr. 1948, Ascomycota genera incertae sedis, one species, type: T. insignis Petr., coelomycetous, sexual morph unknown, saprobes, terrestrial, Ecuador, see Wijayawardene et al. (2012, 2017; outline), Kirk et al. (2013; genus accepted), cultures and sequences are unavailable, needs generic revision.

Thripomyces Speg. 1915, Ceratomycetaceae, Laboulbeniales, Laboulbeniomycetes, two species, type: T. italicus Speg., asexual morph unknown, biotrophic, hosts are Hydraena species (Coleoptera: Hydraenidae), Europe, see Lumbsch and Huhndorf (2010; outline), Kirk et al. (2013; genus accepted), cultures and sequences are unavailable, needs generic revision.

Thrombium Wallr. 1831, Thrombiaceae, Ostropales, Lecanoromycetes, five species, type: $T$. epigaeum (Pers.) Wallr., Russia, America, see Nadyeina (2009; taxonomy), Kukwa (2010; 1sit), Lumbsch and Huhndorf (2010; outline), Stepanchikova et al. (2011; new reords), Kirk et al. (2013; genus accepted), Resl et al. (2015), Lücking et al. (2016b; classification), sequences are available.

Thryptospora Petr. 1947, Dothideomycetes genera incertae sedis, one species, type: T. singularis Petr., asexual morph unknown, saprobes, terrestrial, Syria, see Lumbsch and Huhndorf (2010; outline), Kirk et al. (2013; genus accepted), Wijayawardene et al. (2014c; outline), cultures and sequences are unavailable, needs generic revision.

Thuemenella Penz. \& Sacc. 1898 (= Chromocreopsis Seaver 1910 fide Wendt et al. 2017), Hypoxylaceae, Xylariales, Sordariomycetes, one species, type: T. javanica Penz. \& Sacc., asexual morph hyphomycetous, terrestrial, saprobes, worldwide, see Lumbsch and Huhndorf (2010; outline), Kirk et al. (2013; genus accepted), Maharachchikumbura et al. (2015, 2016; outline), Wendt et al. (2017; accepted as a genus in Hypoxylaceae), cultures and sequences are available.

Thyrea A. Massal. 1856, Lichinaceae, Lichinales, Lichinomycetes, 13 species, type: T. plectospora A. Massal. asexual morph unknown, lichenized, terrestrial, South Korea, Iran, Turkey, USA, see Björk (2010; new records), Lumbsch and Huhndorf (2010; outline), Schultz and Moon (2011; taxonomy), Kirk et al. (2013; genus accepted), Candan and Schultz (2015; new records), Ahti et al. (2016; checklist), Lücking et al. (2016b; classification); sequences are available.

Thyridaria Sacc. 1875, Thyridariaceae, Pleosporales, Dothideomycetes, 52 species, type: T. incrustans Sacc., asexual morph unknown, saprobes, terrestrial, see Lumbsch and Huhndorf (2010; outline), Hyde et al. (2013; morphology; phylogeny), Kirk et al. (2013; genus accepted), Wijayawardene et al. (2014c; outline), cultures and sequences are available, needs generic revision.

Thyridella (Sacc.) Sacc. 1895, Sordariomycetes genera incertae sedis, three species, type: $T$. colliculus Sacc., asexual morph unknown, saprobes, terrestrial, worldwide, see Lumbsch and Huhndorf (2010; outline), Kirk et al. (2013; genus accepted), Maharachchikumbura et al. (2015, 2016; outline), cultures and sequences are unavailable, needs generic revision.

Thyridium Nitschke 1867, Thyridiaceae, Diaportheomycetidae families incertae sedis, Sordariomycetes, c. 20 species, type: T. vestitum (Fr.) Fuckel, asexual morph unknown, saprobes, terrestrial, worldwide, see Lumbsch and Huhndorf (2010; outline), Kirk et al. (2013; genus accepted), Maharachchikumbura et al. (2015, 2016; outline), sequence are available.

Thyrinula Petr. \& Syd. 1924, Ascomycota genera incertae sedis, incertae sedis, one species, type: T. eucalypti (Cooke \& Massee) H.J. Swart, coelomycetous, sexual morph unknown, saprobes, terrestrial, South Africa, Australia, see Kirk et al. (2013; genus accepted), 
Wijayawardene et al. (2017; outline), cultures and sequences are unavailable, needs generic revision.

Thyriodictyella Cif. 1962, Dothideomycetes genera incertae sedis, one species, type: T. microsperma (Syd. \& P. Syd.) Cif., asexual morph unknown, saprobes, terrestrial, Dominian Republic, see Lumbsch and Huhndorf (2010; outline, accepted as a genus in Micropeltidaceae), Kirk et al. (2013; genus accepted), Wijayawardene et al. (2014c; outline), cultures and sequences are unavailable, needs generic revision.

Thyriopsis Theiss. \& Syd. 1915, Aulographaceae, Dothideomycetes families incertae sedis, one species, type: T. halepensis (Cooke) Theiss. \& Syd., asexual morph unknown, saprobes, terrestrial, worldwide, see Lumbsch and Huhndorf (2010; outline, accepted as a genus in Asterinaceae), Hyde et al. (2013; accepted as a genus in Aulographaceae), Kirk et al. (2013; genus accepted), Hongsanan et al. (2014c; taxonomy, accepted as a genus in Aulographaceae), Wijayawardene et al. (2014c; outline), cultures and sequences are unavailable, needs generic revision.

Thyriostromella Bat. \& C.A.A. Costa 1959, Ascomycota genera incertae sedis, one species, type: T. calophylli (Sacc.) Bat. \& C.A.A. Costa, coelomycetous, sexual morph unknown, saprobes, terrestrial, Malaysia, see Wijayawardene et al. (2012, 2017; outline), Kirk et al. (2013; genus accepted), cultures and sequences are unavailable, needs generic revision.

Thyronectria Sacc. 1875 (= Pleonectria Sacc. 1876; = Chilonectria Sacc. 1878; = Nectria subg. Aponectria Sacc. 1878; $\equiv$ Aponectria (Sacc.) Sacc. 1883; = Mattirolia Berl. \& Bres. 1889; = Scoleconectria Seaver 1909; = Thyronectroidea Seaver 1909 fide Jaklitsch and Voglmayr 2014), Nectriaceae, Hypocreales, Sordariomycetes, c. 40 species, type: T. patavina Sacc., asexual morph unknown, saprobes, terrestrial, tropical, see Lumbsch and Huhndorf (2010; outline), Kirk et al. (2013; genus accepted), Jaklitsch and Voglmayr (2014; revisited, phylogeny), Lombard et al. (2015; phylogeny), Maharachchikumbura et al. (2015, 2016; outline), cultures and sequences are available.

Thyrostroma Höhn. 1911, Dothidotthiaceae, Pleosporales, Dothideomycetes, c. 45 species, type: T. compactum (Sacc.) Höhn., hyphomycetous, sexual morph unknown, saprobes, pathogens, terrestrial, worldwide, see Phillips et al. (2008; accepted as genus in Dothidotthiaceae), Seifert et al. (2011; morphology), Hyde et al. (2013; accepted as genus in Dothidotthiaceae), Kirk et al. (2013; genus accepted), Wijayawardene et al. (2014c; outline), Crous et al. (2016b; phylogeny), cultures available but lacks for the type.

Thyrostromella Höhn. 1919, Ascomycota genera incertae sedis, three species, type: T. myriana (Desm.) Höhn., hyphomycetous, sexual morph unknown, saprobes, terrestrial, Asia, Australia, Europe, see Seifert et al. (2011; morphology), Wijayawardene et al. (2012, 2017; outline), Kirk et al. (2013; genus accepted), cultures and sequences are unavailable, needs generic revision.

Thyrotheca Kirschst. 1944, Sordariomycetes genera incertae sedis, three species, type: T. nyssae (Berk. \& M.A. Curtis) Kirschst., asexual morph unknown, saprobes, terrestrial, North America, see Lumbsch and Huhndorf (2010; outline), Kirk et al. (2013; genus accepted), Maharachchikumbura et al. (2015, 2016; outline), cultures and sequences are unavailable, needs generic revision.

Thyrsidiella Höhn. 1909, Ascomycota genera incertae sedis, two species, type: T. lignicola (Höhn.) Clem. \& Shear, coelomycetous, sexual morph unknown, saprobes, terrestrial, Europe, see Wijayawardene et al. (2012, 2017; outline), Kirk et al. (2013; genus accepted), cultures and sequences are unavailable, needs generic revision.

Thyrsidina Höhn. 1905, Ascomycota genera incertae sedis, one species, type: $T$. carneominiata Höhn., coelomycetous, sexual morph unknown, saprobes, terrestrial, Europe, see Wijayawardene et al. (2012, 2017; outline), cultures and sequences are unavailable, needs generic revision. 
Thysanorea Arzanlou, W. Gams \& Crous 2007, Herpotrichiellaceae, Chaetothyriales, Eurotiomycetes, one species, type: T. papuana (Aptroot) Arzanlou, W. Gams \& Crous, hyphomycetous, sexual morph unknown, saprobes, South America, see Seifert et al. (2011; morphology), Wijayawardene et al. (2012, 2017; outline), holotype and cultures available for the type: CBS, Aptroot 36647, CBS 212.96.

Thysanothecium Mont. \& Berk. 1846, Cladoniaceae, Lecanorales, Lecanoromycetes, three species, type: T. hookeri Mont. \& Berk., lichenized, see Lumbsch and Huhndorf (2010; outline), Kirk et al. (2013; genus accepted), Lücking et al. (2016b; classification), sequences are available.

Tiarospora Sacc. \& Marchal 1885, Phaeosphaeriaceae, Pleosporales, Dothideomycetes, three species, type: T. westendorpii Sacc. \& Marchal, coelomycetous, sexual morph unknown, saprobes, terrestrial, Europe, see Wijayawardene et al. (2012, 2014c, 2017; outline), Kirk et al. (2013; genus accepted), Phookamsak et al. (2014b; accepted as a genus in Phaeosphaeriaceae), cultures and sequences are unavailable, needs generic revision.

Tiarosporella Höhn. 1919, Botryosphaeriaceae, Botryosphaeriales, Dothideomycetes, c. five species, type: Sphaeropsis visci (Alb. \& Schwein.) Sacc., coelomycetous, sexual morph Phaeobotryosphaeria, saprobes, endophytes, terrestrial, cosmopolitan, see Phillips et al. (2008, 2013; taxonomy, phylogeny), Liu et al. (2012; taxonomy, phylogeny), Hyde et al. (2013; accepted as a genus in Botryosphaeriaceae), Slippers et al. (2013; phylogeny), Crous et al. (2015b; phylogeny), Wijayawardene et al. (2014c, 2017; outline), Dissanayake et al.(2016; taxonomy), cultures and sequences are available.

Tiarosporellivora Punith. 1981, Ascomycota genera incertae sedis, one species, type: T. caricina Punith., coelomycetous, sexual morph unknown, lichenicolous, terrestrial, Germany, see Wijayawardene et al. (2012, 2017; outline), Kirk et al. (2013; genus accepted), cultures and sequences are unavailable, needs generic revision.

Tibellia Vezda \& Hafellner 1992, Ramalinaceae, Lecanorales, Lecanoromycetes, one species, type: T. dimerelloides Vezda \& Hafellner, asexual morph unknown, lichenized, terrestrial, see Lumbsch and Huhndorf (2010; outline), Kirk et al. (2013; genus accepted), Lücking et al. (2016b; classification), sequences are unavailable.

Ticogloea G. Weber, Spaaij \& W. Gams 1994, Ascomycota genera incertae sedis, one species, type: T. guttulata G. Weber, Spaaij \& W. Gams, hyphomycetous, sexual morph unknown, saprobes, ?endophytes, terrestrial, Europe, Central America, see Seifert et al. (2011; morphology), Wijayawardene et al. (2012, 2017; outline), cultures and sequences are unavailable, needs generic revision.

Ticomyces Toro 1952, Sordariomycetes genera incertae sedis, one species, type: $T$. psychotriae (F. Stevens) Toro, asexual morph unknown, saprobes, terrestrial, Central America, see Lumbsch and Huhndorf (2010; outline, accepted as a genus in Meliolaceae), Kirk et al. (2013; genus accepted), Hongsanan et al. (2015c; excluded the genus from Meliolaceae and placed in Sordariomycetes genera incertae sedis), cultures and sequences are unavailable, needs generic revision.

Ticonectria Döbbeler 1998, Hypocreales genera incertae sedis, Sordariomycetes, one species, type: T. perianthii Döbbeler, asexual morph unknown, on liver worts, Costa Rica, see Lumbsch and Huhndorf (2010; outline), Kirk et al. (2013; genus accepted), Maharachchikumbura et al. (2015, 2016; outline), cultures and sequences are unavailable, needs generic revision.

Ticosynnema R.F. Castañeda, Granados \& Mardones 2013, Ascomycota genera incertae sedis, one species, type: T. carranzae R.F. Castañeda, Granados \& Mardones, hyphomycetous, sexual morph unknown, saprobes, terrestrial, Costa Rica, see CastañedaRuiz et al. (2013a; taxonomy), Wijayawardene et al. (2017; outline), holotype of the type: HAL 2454F, cultures and sequences are unavailable, needs generic revision. 
Tilachlidium Preuss 1851, Tilachlidiaceae, Hypocreales, Sordariomycetes, two species, type: T. pinnatum Preuss, hyphomycetous, sexual morph unknown, saprobes, terrestrial, North America, see Seifert et al. (2011; morphology), Kirk et al. (2013; genus accepted), Lombard et al. (2015b; phylogeny, new family), Maharachchikumbura et al. (2015, 2016; outline), Wijayawardene et al. (2017; outline), cultures and sequences are available, needs generic revision.

Tilakidium Vaidya, C.D. Naik \& Rathod 1986, Hypocreales genera incertae sedis, Sordariomycetes, one species, type: T. indicum Vaidya, C.D. Naik \& Rathod, asexual morph unknown, saprobes, India, see Lumbsch and Huhndorf (2010; outline), Kirk et al. (2013; genus accepted), Maharachchikumbura et al. (2015, 2016; outline), cultures and sequences are unavailable, needs generic revision.

Tilakiella Srinivas. 1973, Dothideomycetes genera incertae sedis, one species, type: Tilakiella indica Srinivas., asexual morph unknown, saprobes, India, see Lumbsch and Huhndorf (2010; outline), Kirk et al. (2013; genus accepted), Wijayawardene et al. (2014c; outline), cultures and sequences are unavailable, needs generic revision.

Timdalia Hafellner 2001, Acarosporaceae, Acarosporales, Lecanoromycetes, one species, type: T. intricata (H. Magn.) Hafellner, lichenized, see Lumbsch and Huhndorf (2010; outline), Westberg et al. (2015; DNA, phylogeny), Lücking et al. (2016b; classification), sequences are available.

Tingoldiago K. Hiray. \& Kaz. Tanaka 2010, Lentitheciaceae, Pleosporales, Dothideomycetes, one species, type: T. graminicola K. Hiray. \& Kaz. Tanaka, saprobes, Japan, see Hirayama et al. (2010; taxonomy, phylogeny), Wijayawardene et al. (2014c; outline), cultures and sequences are available.

Tinhaudeus K.L. Pang, S.Y. Guo \& E.B.G. Jones 2015, Halosphaeriaceae, Microascales, Sordariomycetes, one species, type: T. formosanus K.L. Pang, S.Y. Guo \& E.B.G. Jones, asexual morph unknown, saprobes, marine, Taiwan, see Ariyawansa et al. (2015a; morphology, phylogeny), Maharachchikumbura et al. (2016; phylogeny, outline), holotype and ex-type strains of type: F28727, BCRC FU30496.

Tirispora E.B.G. Jones \& Vrijmoed, 1994, Halosphaeriaceae, Microascales, Sordariomycetes, two species, type: T. unicaudata E.B.G. Jones \& Vrijmoed, asexual morph unknown, two species, marine, on mangrove wood, tropical, see Lumbsch and Huhndorf (2010; outline), Sakayaroj et al. (2011a; phylogeny), Kirk et al. (2013; genus accepted), Jones et al. (2015; outline), Maharachchikumbura et al. (2015, 2016; outline), cultures and sequences are unavailable.

Tirisporella E.B.G. Jones, K.D. Hyde \& Alias, 1996, Tirisporellaceae, Tirisporellales, Sordariomycetes, one species, type: T. beccariana (Ces.) E.B.G. Jones, K.D. Hyde \& Alias asexual morph phialophora-like, on petiols of mangrove palm Nypa, tropical, see Lumbsch and Huhndorf (2010; outline), Kirk et al. (2013; genus accepted), Jones et al. (2015; outline), Maharachchikumbura et al. (2015, 2016; outline), cultures and sequences are available.

Tirmania Chatin 1892, Pezizaceae, Pezizales, Pezizomycetes, three species, type: T. nivea (Desf.) Trappe, asexual morph unknown, hypogeous, terrestrial, worldwide, see Al-Laith (2010; Antioxidant components and antioxidant/antiradical activities), Lumbsch and Huhndorf (2010; outline), Dib-Bellahouel and Fortas (2011; antibacterial activity), Kirk et al. (2013; genus accepted), Osmundson et al. (2013; DNA), sequences are available.

Titaea Sacc. 1876, Ascomycota genera incertae sedis, 23 species, type: T. callispora Sacc., hyphomycetous, see Seifert et al. (2011; morphology), Wijayawardene et al. (2017; outline), Kirk et al. (2013; genus accepted), cultures and sequences are unavailable.

Titaeopsis B. Sutton \& Deighton 1984, Ascomycota genera incertae sedis, one species, type: T. ugandae (Hansf.) B. Sutton \& Deighton, hyphomycetous, sexual morph unknown, 
lichenicolous, terrestrial, Africa, see Seifert et al. (2011; morphology), Wijayawardene et al. (2012, 2017; outline), cultures and sequences are unavailable, needs generic revision.

Titaeospora Bubák 1916, Ascomycota genera incertae sedis, two species, type: T. detospora (Sacc.) Bubák, coelomycetous, sexual morph unknown, lichenicolous, terrestrial, temperate, see Wijayawardene et al. (2012, 2017; outline), Kirk et al. (2013; genus accepted), cultures and sequences are unavailable, needs generic revision.

Toensbergia Bendiksby \& Timdal 2013, Sporastatiaceae, Rhizocarpales, Lecanoromycetes, one species, type: T. leucococca (R. Sant.) Bendiksby \& Timdal, lichenized, corticolous, temperate northern hemisphere, see Bendiksby and Timdal (2013; phylogenetic placement), Lücking et al. (2016b; classification), sequences are available, type specimen UPS- L-86993 (holotype).

Togniniella Réblová, L. Mostert, W. Gams \& Crous 2004 (= Phaeocrella Réblová et al. 2004 fide Réblová et al. 2016c), Calosphaeriaceae, Calosphaeriales, Sordariomycetes, twelve species, type: T. acerosa Réblová, L. Mostert, W. Gams \& Crous, asexual morph formerly named in Phaeocrella, from living leaves, terrestrial, New Zealand, see Damm et al. (2008; DNA, morphology of asci), Lumbsch and Huhndorf (2010; outline), Réblová (2011; phylogeny), Réblová et al. (2016c; phylogeny), Kirk et al. (2013; genus accepted), Maharachchikumbura et al. (2015, 2016; outline), cultures available for the type: CBS 113726.

Tolypocladium W. Gams 1971 (= Elaphocordyceps G.H. Sung \& Spatafora 2007 fide Maharachchikumbura et al. 2016), Ophiocordycipitaceae, Hypocreales, Sordariomycetes, c. 15 species, type: T. inflatum W. Gams, hyphomycetous, sexual morph formerly known in Elaphocordyceps, on soil, rotifers and mosquito larvae, terrestrial, cosmopolitan, see Sato et al. (2010a, b; new species), Seifert et al. (2011; morphology), Kirk et al. (2013; genus accepted), Maharachchikumbura et al. (2015, 2016; outline), Wijayawadene et al. (2017; outline), cultures and sequences are available.

Tomasellia A. Massal. 1856, Naetrocymbaceae, Dothideomycetes, incertae sedis, 50 species, type: T. arthonioides (A. Massal.) A. Massal., asexual morph unknown, epiphytes, terrestrial, worldwide, see Lumbsch and Huhndorf (2010; outline), Hyde et al. (2013; accepted as a genus in Naetrocymbaceae), Kirk et al. (2013; genus accepted), cultures and sequences are unavailable, needs generic revision.

Tomenticola Deighton 1969, Ascomycota genera incertae sedis, two species, type: $T$. trematis Deighton, hyphomycetous, sexual morph unknown, on living leaves, terrestrial, Africa, see Seifert et al (2011; morphology), Wijayawardene et al. (2012, 2017; outline), cultures and sequences are unavailable, needs generic revision.

Tomeoa I. Hino 1954, Dothideomycetes genera incertae sedis, one species, type: $T$. viridicolliculosa I. Hino, asexual morph unknown, saprobes, Japan, see Lumbsch and Huhndorf (2010; outline), Kirk et al. (2013; genus accepted), Wijayawardene et al. (2014c; outline), cultures and sequences are unavailable, needs generic revision.

Tompetchia Subram. 1985, Ascomycota genera incertae sedis, one species, type: T. webberi (H.S. Fawc.) Subram., hyphomycetous, sexual morph unknown, on insects, terrestrial, Australasia, North and South America, see Seifert et al (2011; morphology), Wijayawardene et al. (2012, 2017; outline), cultures and sequences are unavailable, needs generic revision.

Toninia A. Massal. [nom. cons.] 1852, Ramalinaceae, Lecanorales, Lecanoromycetes, species, 85 species, type: T. squalida (Ach.) A. Massal., asexual morph unknown, lichenized, terrestrial, worldwide, see Moniri et al. (2009; taxonomy), Lumbsch and Huhndorf (2010; outline), Farkas et al. (2011; ecology), Schmull et al. (2011; phylogeny), Urbanavichus et al. (2011; new records), Bendiksby and Timdal (2013; phylogeny), Kirk et al. (2013; genus accepted), Zhurbenko and Zhdanov (2013; taxonomy), Maier et al. (2014; ecology), Joshi et 
al. (2015; new records), Sezer et al. (2016; taxonomy), Lücking et al. (2016b; classification), sequences are available

Toniniopsis Frey 1926, Ramalinaceae, Lecanorales, Lecanoromycetes, one species, type: $T$. obscura Frey, lichenized, see Lumbsch and Huhndorf (2010; outline), Lücking et al. (2016b; classification), sequences are unavailable.

Topelia P.M. Jørg. \& Vezda, 1984, Stictidaceae, Ostropales, Lecanoromycetes, six species, type: T. rosea (Servít) P.M. Jørg. \& Vezda, asexual morph unknown, lichenized, terrestrial, see Lumbsch and Huhndorf (2010; outline), Kirk et al. (2013; genus accepted), Aptroot et al. (2014c; checklist), Lücking et al. (2016b; classification), sequences are unavailable.

Topeliopsis Kantvilas \& Vezda 2000, Graphidaceae, Ostropales, Lecanoromycetes, 20 species, type: T. muscicola Kantvilas \& Vezda, asexual morph unknown, lichenized, terrestrial, see Messuti et al. (2010; new species), Lumbsch and Huhndorf (2010; outline), Plata et al. (2010; key), Sipman et al. (2012; new combinations), Mangold et al. 2009 (key Australia), Rivas Plata et al. (2010a, 2012a; taxonomy), Plata and Lücking (2013; taxonomy), Aptroot et al. (2014; phylogeny), Lücking et al. (2014; new species), Lumbsch et al. (2014a, b; phylogeny), Weerakoon et al. (2015; new species), Lücking et al. (2016b; classification), sequences are available.

Toriella (Kohlm.) Sakay., K.L. Pang \& E.B.G. Jones 2011, Halosphaeriaceae, Microascales, Sordariomycetes, one species, type: Toriella tubulifera (Kohlm.) Sakay., K.L. Pang \& E.B.G. Jones, asexual morph unknown, saprobes, marine, Canada, Denmark, England, Germany, Iceland, Norway, Sweden, USA, Wales, see Sakayaroj et al. (2011a; morphology, phylogeny), Jones et al. (2015; outline), Maharachchikumbura et al. (2015, 2016; outline, phylogeny), holotype and ex-type strain of the type: BCC33511, BCC33512, BCC33513.

Tornabea Østh.1980, Physciaceae, Caliciales, Lecanoromycetes, one species, type: $T$. montagnei Trevis. asexual morph unknown, lichenized, terrestrial, Iran, Pakistan, KayseriAdamna, see Lumbsch and Huhndorf (2010; outline), Moniri (2010; taxonomy), Sohrabi et al.(2010; taxonomy), Aptroot and Iqbal (2012; checklist), Gaya et al. (2012; phylogeny), Kirk et al. (2013; genus accepted), Parsa et al. (2013; taxonomy), Halici et al. (2014a; taxonomy), Nattah et al. (2014, taxonomy, inventory), Lücking et al. (2016b; classification), Prieto and Wedin (2016; phylogeny), sequences are available.

Toroa Syd. 1926, Pseudoperisporiaceae, Dothideomycetes families incertae sedis, one species, type: T. dimerosporioides (Speg.) Syd., asexual morph unknown, saprobes, terrestrial, tropical, see Lumbsch and Huhndorf (2010; outline), Hyde et al. (2013; accepted as a genus in Pseudoperisporiaceae), Kirk et al. (2013; genus accepted), Wijayawardene et al. (2014c; outline), cultures and sequences are unavailable, needs generic revision.

Torpedospora Meyers 1957 (= Glomerulispora Abdel-Wahab \& Nagah. fide Réblová et al. 2016c), Torpedosporaceae, Torpedosporales, Sordariomycetes, five species, type: T. radiata Meyers, asexual morph formerly named in Glomerulispora, saprobes, marine, worldwide, see Abdel-Wahab et al. (2010; phylogeny), Lumbsch and Huhndorf (2010; outline), Kirk et al. (2013; genus accepted), Réblová et al. (2016c; nomenclature), holotype and ex-type strains of the type:

Torrendiella Boud. \& Torrend 1911, Rutstroemiaceae, Helotiales, Leotiomycetes, three species, type: T. ciliata Boud., asexual morph unknown, saprobes, terrestrial, Europe, North America, see Lumbsch and Huhndorf (2010; outline), Kirk et al. (2013; genus accepted), Johnston et al. (2014b; taxonomy, phylogeny), Jaklitsch et al. (2016a; classification), cultures available for the type: F132996, needs generic revision.

Torrentispora K.D. Hyde, W.H. Ho, E.B.G. Jones, K.M. Tsui \& S.W. Wong 2000, Annulatascaceae, Annulatascales, Sordariomycetes, one species, type: T. fibrosa K.D. Hyde, Wai H. Ho, E.B.G. Jones, K.M. Tsui \& S.W. Wong, asexual morph unknown, saprobes, aquatic, Hong Kong, Brunei, Costa Rica, see Lumbsch and Huhndorf (2010; outline), Kirk et 
al. (2013; genus accepted), Barbosa et al. (2014; new species, Costa Rica), Maharachchikumbura et al. (2016; outline), holotype of the type: HKU (M) 4519, cultures and sequences are available.

Torrubiella Boud. 1885, Cordycipitaceae, Hypocreales, Sordariomycetes, 71 species, type: $T$. aranicida Boud., asexual morph unknown, saprobes, terrestrial, cosmopolitan, see Johnson et al. (2009; taxonomy, DNA, phylogeny), Lumbsch and Huhndorf (2010; outline), Sato et al. (2010a; new species), Kirk et al. (2013; genus accepted), Maharachchikumbura et al. (2015, 2016; outline), cultures and sequences are available.

Tortispora Lachance \& Kurtzman 2013, Trigonopsidaceae, Saccharomycetales, Saccharomycetes, eight species, type: T. ganteri Lachance \& Kurtzman, asexual growth is by multilateral budding, saprophytic, in rotted cacti, Costa Rica, Hawaii, USA, Argentina, Brazil, Mexico, see Lachance et al. (2013a; taxonomy), cultures and sequences are available.

Tortulomyces Lar.N. Vassiljeva, S.L. Stephenson, Chernyshev \& K.D. Hyde 2013, Nitschkiaceae, Coronophorales, Sordariomycetes, one species, type: Tortulomyces thailandicus Lar.N. Vassiljeva, S.L. Stephenson, A.V. Chernyshev \& K.D. Hyde, asexual morphs unknown, saprobes, terrestrial, south-eastern Asia, see Maharachchikumbura et al. (2016; outline), holotype of type: MFLU 11-1163, cultures and sequences are unavailable.

Torula Pers. 1795, Torulaceae, Pleosporales, Dothideomycetes, eleven species, type: T. herbarum (Pers.) Link, hyphomycetous, sexual morph unknown, saprobes, terrestrial, worldwide, see Seifert et al (2011; morphology), Wijayawardene et al. (2012, 2017; outline), Kirk et al. (2013; genus accepted), Crous et al. (2015a, 2016a; typification, new species, phylogeny), neotype and exepitype of the type: CBS H-22275, CPC 24114.

Torulaspora Lindner 1904, Saccharomycetaceae, Saccharomycetales, Saccharomycetes, six species, type: T. delbrueckii (Lindner) Lindner, asexual reproduction is by multilateral budding, saprophytic, soil, plant material, Indonesian ragi, grapes, tree bark, mangrove trees, spoiled fruit juice, dough, worldwide, see Lumbsch and Huhndorf (2010; outline), Kirk et al. (2013; genus accepted), cultures and sequences are available.

Torulopsiella Bender 1932, Ascomycota genera incertae sedis, one species, type: $T$. fumaginea (Speg.) Bender, hyphomycetous, sexual morph unknown, on leaves (sooty moulds), terrestrial, Australasia, South America, see Seifert et al (2011; morphology), Wijayawardene et al. (2012, 2017; outline), cultures and sequences are unavailable, needs generic revision.

Tothia Bat. 1960, Venturiaceae, Venturiales, Dothideomycetes, two species, type: T. fuscella (Sacc.) Bat., asexual morph unknown, saprobes, terrestrial, Austria, Niederösterreich, Hungary and Italy, see Lumbsch and Huhndorf (2010; outline), Wu et al. (2011; morphology; phylogeny), Kirk et al. (2013; genus accepted), Wijayawardene et al. (2014c; outline; phylogeny), Liu et al. (2015a; morphology; phylogeny), cultures and sequences are available for all species.

Tovariella Syd. 1930, Helotiales genera incertae sedis, Leotiomycetes, one species, type: T. pittieriana Syd., asexual morph unknown, saprobes, terrrestrial, South America, see Lumbsch and Huhndorf (2010; outline), Kirk et al. (2013; genus accepted), cultures and sequences are unavailable, needs generic revision.

Towyspora Wanasinghe, E.B.G. Jones \& K.D. Hyde 2016, Lentitheciaceae, Pleosporales, Dothideomycetes, one species, type: T. aestuari Wanasinghe, E.B.G. Jones \& K.D. Hyde, coelomycetous, sexual morph unknown, saprobes, terrestrial, UK, see Li et al. (2016a; taxonomy, phylogeny), holotype and ex-isotype culture of the type: MFLU 15-3543, MFLUCC 15-1274.

Toxicocladosporium Crous \& U. Braun 2007, Cladosporiaceae, Capnodiales, Dothideomycetes, 14 species, type: T. irritans Crous \& U. Braun asexual morphs hyphomycetous, terrestrial, Africa, Asia, Australia, South America, see Seifert et al. (2011; 
morphology), Hyde et al. (2013; accepted as a genus in Cladosporiaceae), Wijayawardene et al. (2012, 2014c, 2017; outline), Crous et al. (2016b; new species, phylogeny), holotype and ex-type strains of type: CBS-H 19892, CBS 185.58.

Toxosporiella B. Sutton 1986, Ascomycota genera incertae sedis, one species, type: $T$. bactrodesmioides B. Sutton, coelomycetous, sexual morph unknown, on leaves (sooty moulds), terrestrial, Australia, see Wijayawardene et al. (2012, 2017; outline), Kirk et al. (2013; genus accepted), cultures and sequences are unavailable, needs generic revision.

Toxosporiopsis B. Sutton \& Sellar 1966, Ascomycota genera incertae sedis, one species, type: T. capitata B. Sutton \& Sellar, coelomycetous, sexual morph unknown, on leaves (sooty moulds), terrestrial, Australia, see Wijayawardene et al. (2012, 2017; outline, taxonomy), Kirk et al. (2013; genus accepted), cultures and sequences are unavailable, needs generic revision.

Trabutia Sacc. \& Roum. 1881, Phyllachoraceae, Phyllachorales, Sordariomycetes, one species, type: T. abortiva (F. Stevens) Sivan., from living leaves, worldwide, see Lumbsch and Huhndorf (2010; outline), Kirk et al. (2013; not genus accepted), Maharachchikumbura et al. (2015, 2016; outline), cultures and sequences are unavailable, needs generic revision.

Tracylla (Sacc.) Tassi 1904, Ascomycota genera incertae sedis, two species, type: T. spartinae (Peck) Tassi, coelomycetous, saprobes, terrestrial, Brazil, Dominican Replublic, see Seifert et al. (2011; morphology), Wijayawardene et al. (2012, 2017; outline), Kirk et al. (2013; genus accepted), cultures and sequences are unavailable, needs generic revision.

Trailia G.K. Sutherl. 1915, Halosphaeriaceae, Microascales, Sordariomycetes, three species, type: T. ascophylli G.K. Sutherl, asexual morph unknown, terrestrial, one marine on brown seaweeds, temperate, see Lumbsch and Huhndorf (2010; outline), Kirk et al. (2013; genus accepted), Jones et al. (2015; outline), Maharachchikumbura et al. (2015, 2016; outline), cultures and sequences are unavailable, needs generic revision.

Trapelia M. Choisy [nom. cons.] 1929, Trapeliaceae, Trapeliales, Lecanoromycetes, 13 species, type: T. coarctata (Turner ex Sm.) M. Choisy, asexual morph unknown, lichenized, terrestrial, Macaronesia, Korea, Australia, Romania, Poland, Italy, Iraq, India, see Czarnota and Kukwa (2009; taxonomy), Baloch et al. (2010; phylogeny), Çobanoğlu eta. (2010; new records), Hodkinson (2010; biodiversity), Lumbsch and Huhndorf (2010; outline), Hodkinson and Lendemer (2011b; taxonomy), Tsurykau and Khramchankova (2011; checklist), Aptroot and Schumm (2012a; new species and new records), Hernandez et al. (2012; ecology), Łubek (2012; ecology), Rajakaruna et al. (2012; new record), Wieczorek and Łysko (2012; taxonomy), Joshi eta al. (2013; new records), Kirk et al. (2013; genus accepted), Vondrák and Liška (2013; checklist), Ertz et al. (2014a; new species), Giralt et al. (2014; taxonomy), Ohmura et al. (2014; key), Brodo and Lendemer (2015; new species), Goni and Sharma (2015; new records), Kantvilas et al. (2015; new species), Resl et al. (2015; phylogeny), Telfer et al. (2015; biodiversity inventory, DNA barcoding), Aziz and Qadir (2016; new records), Kondratyuk et al. (2016; new records), Schneider et al. (2016; phylogeny and partial sequence), Lücking et al. (2016b; classification), sequences are available.

Trapeliopsis Hertel \& Gotth. Schneid. 1980, Trapeliaceae, Trapeliales, Lecanoromycetes, 20 species, type: T. wallrothii (Flörke ex Spreng.) Hertel \& Gotth. Schneid., asexual morph unknown, lichenized, terrestrial, worldwide, see Lumbsch and Huhndorf (2010; outline), Hodkinson and Lendemer (2011b; taxonomy), Aptroot and Schumm (2012a; new species), Elix et al. (2013; Trapeliopsis granulosa var. australis, new species), Kirk et al. (2013; genus accepted), Sanz- Resl et al. (2015; DNA, phylogeny), Lücking et al. (2016b; classification), sequences are available for the type: CP956.

Traponora Aptroot 1997, Lecanoraceae, Lecanorales, Lecanoromycetes, five species, type: T. asterella Aptroot, asexual morph unknown, lichenized, terrestrial, tropical, see see Aptroot 
(2009; monograph), Lumbsch and Huhndorf (2010; outline), Kirk et al. (2013; genus accepted), Lücking et al. (2016b; classification), sequences are unavailable.

Tremateia Kohlm., Volkm.-Kohlm. \& O.E. Erikss. 1995, Didymosphaeriaceae, Pleosporales, Dothideomycetes, one species, type: T. halophila Kohlm., Volkm.-Kohlm. \& O.E. Erikss., asexual morph phoma-like., saprobes, marine, Atlantic Coast, see Suetrong et al. (2009; phylogeny, morphology), Jones et al. (2009b, 2015; classification), Azevedo et al. (2013; morphological identification), Ariyawansa et al. (2014d; accepted as a genus in Didymosphaeriaceae), Wijayawardene et al. (2014c; outline), holotype of type: J.K. 5522 (IMS).

Trematophoma Petr. 1924, Ascomycota genera incertae sedis, two species, type: T. lignicola Petr., coelomycetous, saprobes, terrestrial, Brazil, Dominican Replublic, see Wijayawardene et al. (2012, 2017; outline), Kirk et al. (2013; genus accepted), cultures and sequences are available for unidentified species, needs generic revision.

Trematosphaeria Fuckel 1870, Trematosphaeriaceae, Pleosporales, Dothideomycetes, c. 20 species, type: T. pertusa Fuckel, asexual morph unknown, saprobes, terrestrial, worldwide, see Lumbsch and Huhndorf (2010; outline, accepted as a genus in Pleosporales, genera incertae sedis), Suetrong et al. (2011b; phylogeny, new family), Hyde et al. (2013; accepted as a genus in Trematosphaeriaceae, phylogeny), Kirk et al. (2013; genus accepted), Zhang et al. (2012e; phylogeny), Ahmed et al. (2014a; new species), Wijayawardene et al. (2014c; outline), Zhou et al. (2014; new species), Tanaka et al. (2015; phylogeny), cultures and sequences are available, needs generic revision.

Trematosphaeriopsis Elenkin 1901, Dothideomycetes genera incertae sedis, one species, type: T. parmeliana Jacz. \& Elenkin, lichenicolous, see Lumbsch and Huhndorf (2010; outline), Kirk et al. (2013; did not list), Wijayawardene et al. (2014c; outline), sequences are unavailable,

Trematovalsa Jacobesco 1906, Diaporthales genera incertae sedis, Sordariomycetes, one species, type: T. matruchotii Iacobescu, asexual morph unknown, saprobes, terrestrial, France, see Lumbsch and Huhndorf (2010; outline), Kirk et al. (2013; genus accepted), Maharachchikumbura et al. (2015, 2016; outline), cultures and sequences are unavailable, needs generic revision.

Tremellidium Petr. 1927, Ascomycota genera incertae sedis, one species, type: T. piskorzii Petr., coelomycetous, saprobes, terrestrial, Europe, see Wijayawardene et al. (2012, 2017; outline), Kirk et al. (2013; genus accepted), cultures and sequences are unavailable, needs generic revision.

Tremolecia M. Choisy 1953, Hymeneliaceae, Lecanorales, Lecanoromycetes, six species, type: T. dicksonii (Ach.) M. Choisy, asexual morph unknown, lichenized, terrestrial, Australia, Asia, North America, see Hansen (2009. 2014, 2015; taxonomy), Lumbsch and Huhndorf (2010; outline), Aptroot and Iqbal (2012; checklist), Kirk et al. (2013; genus accepted), Kantvilas (2014b; taxonomy, new species), McCune and Rosentreter (2014; new records), Miądlikowska et al. (2014a; molecular), Lücking et al. (2016b; classification); sequences are available

Trenomyces Chatton \& F. Picard 1909, Laboulbeniaceae, Laboulbeniales, Laboulbeniomycetes, eleven species, type: T. histophtorus Chatton \& F. Picard, asexual morph unknown, biotrophic, dioecious, hosts are Mallophaga (Arthropoda: Phthiraptera), widespread, see Lumbsch and Huhndorf (2010; outline), Kirk et al. (2013; genus accepted), sequence are unavailable.

Tretocephala Subram. 1995, Ascomycota genera incertae sedis, one species, type: T. decidua Subram., hyphomycetous, saprobes, terrestrial, Asia, see Seifert et al. (2011; morphology), Wijayawardene et al. (2012, 2017; outline), Kirk et al. (2013; genus accepted), cultures and sequences are unavailable, needs generic revision. 
Tretolylea Cantillo, R.F. Castañeda \& Gusmão 2015, Ascomycota genera incertae sedis, one species, type: T. pleiomorpha T. Cantillo, R.F. Castañeda \& . Gusmão, hyphomycetous, sexual morph unknown, saprobes, terrestrial, Brazil, see Cantillo-Pérez et al. (2015; morphology), holotype of the type: HUEFS 211337, cultures and sequences are unavailable, compare with Capnophialophora, Capnosporium Heteroconium, Lylea, Taeniolella and Taeniolina.

Tretospeira Piroz. 1972, Ascomycota genera incertae sedis, one species, type: T. ugandensis (Hansf.) Piroz., hyphomycetous, saprobes, terrestrial, Africa, Caribbean, see Seifert et al. (2011; morphology), Wijayawardene et al. (2012, 2017; outline), Kirk et al. (2013; genus accepted), cultures and sequences are unavailable, needs generic revision.

Tretovularia Deighton 1984, Ascomycota genera incertae sedis, one species, type: T. villiana (Magnus) Deighton, hyphomycetous, saprobes, terrestrial, Europe, see Seifert et al. (2011; morphology), Wijayawardene et al. (2012, 2017; outline), Kirk et al. (2013; genus accepted), cultures and sequences are unavailable, needs generic revision.

Treubiomyces Höhn. 1909, Chaetothyriaceae, Chaetothyriales, Eurotiomycetes, seven species, type: T. pulcherrimus Höhn., asexual morph unknown, epiphytes, sooty moulds, terrestrial, America, Lumbsch and Huhndorf (2010; outline), Kirk et al. (2013; genus accepted), cultures and sequences are unavailable, needs generic revision.

Triacutus G.L. Barron \& Tzean 1981, Sordariomycetes genera incertae sedis, 18 species, type: T. subcuticularis G.L. Barron \& Tzean, hyphomycetous, saprobes, from soil, on immunocompromised patients, terrestrial, North America, see Seifert et al. (2011; morphology), Wijayawardene et al. (2012, 2017; outline), Edathodu et al. (2013; human pathogens Triadelphia pulvinata, DNA, treated as Hypocreomycetidae incertae sedis), Kirk et al. (2013; genus accepted), cultures and sequences are unavailable for the type, genus could be polyphyletic, needs generic revision.

Triadelphia Shearer \& J.L. Crane 1971, Microascales genera incertae sedis, Sordariomycetes, 18 species, type: T. heterospora Shearer \& J.L. Crane, hyphomycetous, sexual morph unknown, saprobes, human pathogen, terrestrial, cosmopolitan, see Seifert et al. (2011; morphology), Crous et al. (2015d; taxonomy, phylogeny), Wijayawardene et al. (2017; outline), cultures and sequences are available.

Triainomyces W. Rossi \& A. Weir 1998, Laboulbeniaceae, Laboulbeniales, Laboulbeniomycetes, one species, T. hollowayanus W. Rossi \& A. Weir, asexual morph unknown, biotrophic, known from Procyliosoma tuberculatum (Diplopoda: Chilognatha: Oniscomorpha: Sphaerotheriidae), New Zealand, see Lumbsch and Huhndorf (2010; outline), Kirk et al. (2013; genus accepted), sequences are unavailable, needs revision.

Triangularia Boedijn 1934, Lasiosphaeriaceae, Sordariales, Sordariomycetes, six species, type: T. bambusae (J.F.H. Beyma) Boedijn, asexual morph unknown, saprobes, terrestrial, worldwide, see Lumbsch and Huhndorf (2010; outline), Kirk et al. (2013; genus accepted), Maharachchikumbura et al. (2015, 2016; outline), cultures and sequences are available but lacks for the type.

Triblidium Rebent. 1805, Triblidiaceae, Triblidiales, Leotiomycetes, one or six species, type: T. caliciforme Rebent, asexual morph unknown, saprobes, terrestrial, worldwide, see Lumbsch and Huhndorf (2010; outline), Kirk et al. (2013; genus accepted), Jaklitsch et al. (2016a; classification), cultures and sequences are unavailable, needs generic revision.

Tribolospora D. A. Reid 1966, Ascomycota genera incertae sedis, one species, type: $T$. sycopsidis D.A. Reid, coelomycetous, sexual morph unknown, saprobes, on leaves of Sycopsis dunnii, New Guinea, see Wijayawardene et al. (2012, 2017; outline), Kirk et al. (2013; genus accepted), cultures and sequences are unavailable, needs generic revision.

Tribulatia Joanne E. Taylor, K.D. Hyde \& E.B.G. Jones 2003, Phyllachoraceae, Phyllachorales, Sordariomycetes, one species, type: T. appendicospora Joanne E. Taylor, 
K.D. Hyde \& E.B.G. Jones, saprobes, Queensland, see Lumbsch and Huhndorf (2010; outline), Maharachchikumbura et al. (2015, 2016; outline), cultures and sequences are unavailable, needs generic revision.

Tricellula Beverw. 1954, Ascomycota genera incertae sedis, one species, type: T. inaequalis Beverw., hyphomycetous, sexual morph unknown, saprobes, terrestrial, Europe, see Seifert et al. (2011; morphology, accepted as a genus in Orbiliaceae), Wijayawardene et al. (2012, 2017; outline), Kirk et al. (2013; genus accepted), cultures and sequences are unavailable, needs generic revision.

Triceromyces T. Majewski 1980, Laboulbeniaceae, Laboulbeniales, Laboulbeniomycetes, eight species, type: T. balazucii T. Majewski, no asexual state, biotrophic, monoecious, dioecious, and trioecious, hosts are Hebridae, Hydrometridae, and Veliidae (Hemiptera: Heteroptera), worldwide, see Santamaría (2008; morphology, review), Lumbsch and Huhndorf (2010; outline), Kirk et al. (2013; genus accepted), sequences are unavailable.

Tricharia Fée 1825 Gomphillaceae, Ostropales, Lecanoromycetes, 30 species, type: T. gilva (Boud.) Boud., asexual morph unknown, lichenized, terrestrial, India, Brazil, Colombia, see Lumbsch and Huhndorf (2010; outline), Lumbsch et al. (2011; new species), Messuti et al. (2011; new species), Mateus et al. (2012; taxonomy), Kirk et al. (2013; genus accepted), Rashmi and Rajkumar (2015; taxonomy, new record), Sanders and Lücking (2015; new species), Sanders and de los Rios (2016; morphotaxonomy), Gupta and Sinha (2016; new report), Lücking et al. (2016b; classification), van den Boom and Sipman (2016; new records), sequences are available.

Tricharina Eckblad 1968, Pyronemataceae, Pezizales, Pezizomycetes, 15 species, type: T. gilva (Boud. ex Cooke) Eckblad, asexual morph unknown, hypogeous, terrestrial, temperate, see Benkert (2010; new species), Lumbsch and Huhndorf (2010; outline), Hansen et al. (2013; DNA, phylogeny), Kirk et al. (2013; genus accepted), Stielow et al. (2013; phylogeny), Kušan et al. (2015; new species), Lindemann and Böhning (2016; new species), sequences are available for voucher DED 7356 (SFSU) of the type: (fide Hansen et al. 2013).

Trichasterina G. Arnaud 1918, Asterinaceae, Asterinales, Dothideomycetes, nine species, type: T. styracis (Theiss.) G. Arnaud, asexual morph unknown, foliar epiphytes, terrestrial, tropical, three species, cultures and sequences are unavailable, see Lumbsch and Huhndorf (2010; outline), Hyde et al. (2013; accepted as a genus in Asterinaceae), Kirk et al. (2013; genus accepted), Hongsanan et al. (2014c; taxonomy, accepted as a genus in Asterinaceae), Wijayawardene et al. (2014c; outline), cultures and sequences are unavailable, needs generic revision.

Trichobolbus Bat. 1964, Ascomycota genera incertae sedis, one species, type: T. palmae Bat. \& Cavalc, coelomycetous, sexual morph unknown, saprobes, on leaves of Palmae, Brazil, see Wijayawardene et al. (2012, 2017; outline), Kirk et al. (2013; genus accepted), cultures and sequences are unavailable, needs generic revision.

Trichobolus (Sacc.) Kimbr. \& Cain 1967, Ascodesmidaceae, Pezizales, Pezizomycetes, one species, type: T. zukalii (Heimerl) Kimbr., asexual morph unknown, saprobes, from soil, on dung, terrestrial, Europe, North America, see Lumbsch and Huhndorf (2010; outline), Doveri (2012; new species, coprophilous, Italy), Kirk et al. (2013; genus accepted), Jaklitsch et al. (2016a; classification), cultures and sequences are unavailable, needs generic revision.

Trichobotrys Penz. \& Sacc. 1902, Ascomycota genera incertae sedis, four species, type: T. pannosa Penz. \& Sacc., hyphomycetous, saprobes, from soil, terrestrial, Africa, Asia, see Seifert et al. (2011; morphology), Wijayawardene et al. (2012, 2017; outline), Kirk et al. (2013; genus accepted), cultures and sequences are unavailable, needs generic revision.

Trichocladium Harz 1871, Ascomycota genera incertae sedis, 31 species, type: T. asperum Harz, hyphomycetous, sexual morph unknown, terrestrial, aquatic, saprobes, worldwide, see Abdel-Wahab (2011b; phylogeny), Seifert et al. (2011; morphology), Abdel-Wahab and 
Bahkali (2012; phylogeny), Wijayawardene et al. (2012, 2017; outline), polyphyletic, needs generic revision.

Trichocoma Jungh. 1838, Trichocomaceae, Eurotiales, Eurotiomycetes, two species, type: $T$. paradoxa Jungh., asexual morph unknown, saprobes, terrestrial, temperate, see Lumbsch and Huhndorf (2010; outline), Houbraken and Samson (2011; phylogeny), Kirk et al. (2013; genus accepted), cultures available for the type: CBS 247.57, CBS 788.83 (fide Houbraken and Samson 2011).

Trichoconis Clem. 1909, Ascomycota genera incertae sedis, 20 species, type: T. caudata (Appel \& Strunk) Clem., hyphomycetous, saprobes, terrestrial, pantropic, Europe, see Seifert et al. (2011; morphology), Wijayawardene et al. (2012, 2017; outline), Kirk et al. (2013; genus accepted), Brackel (2014; new species), Silvansilva et al. (2015; new species, Brazil), cultures and sequences are available but lacks for the type, needs generic revision.

Trichodelitschia Munk 1953, Phaeotrichaceae, Phaeotrichales, Dothideomycetes, four species, type: T. bisporula (P. Crouan \& H. Crouan) Munk, asexual morph unknown, saprobes, terrestrial, worldwide, see Schoch et al. (2009; phylogeny), Lumbsch and Huhndorf (2010; outline), Hyde et al. (2013; outline, phylogeny), Kirk et al. (2013; genus accepted), Wijayawardene et al. (2014c; outline), cultures available for the type: CBS 262.69.

Trichoderma Pers. 1794 (= Hypocrea Fr. 1825; = Aphysiostroma Barrasa, A.T. Martínez \& G. Moreno 1986 fide Rossman et al. 2013b; Jaklitsch and Voglmayr 2015), Hypocreaceae, Hypocreales, Sordariomycetes, c. 100 species, type: T. viride Pers., hyphomycetous, sexual morph Hypocrea, in soil, saprobes, terrestrial, cosmopolitan, see Seifert et al. (2011; morphology), Wijayawardene et al. (2012, 2017; outline), Kirk et al. (2013; genus accepted), Rossman et al. (2013b; nomenclature), Jaklitsch and Voglmayr (2015; taxonomy, phylogeny), Maharachchikumbura et al. (2015, 2016; outline), cultures and sequences are available, needs generic revision.

Trichodiscula Vouaux 1910, Ascomycota genera incertae sedis, one species, type: $T$. lesdainii Vouaux, coelomycetous, saprobes, terrestrial, France, see Wijayawardene et al. (2012, 2017; outline), Kirk et al. (2013; genus accepted), cultures and sequences are unavailable, needs generic revision.

Trichodochium Syd. 1927, Ascomycota genera incertae sedis, one species, type: $T$. disseminatum Syd., hyphomycetous, saprobes, terrestrial, Asia, Central and South America, see Seifert et al. (2011; morphology), Wijayawardene et al. (2012, 2017; outline), Kirk et al. (2013; genus accepted), cultures and sequences are unavailable, needs generic revision.

Trichodothella Petr. 1946, Dothideomycetes genera incertae sedis, one species, type: $T$. blumeri Petr. ex S. Blumer, asexual morph unknown, saprobes, terrestrial, Europe, see Lumbsch and Huhndorf (2010; outline, accepted as a genus in Venturiaceae), Zhang et al. (2011d; morphology, accepted as a genus in Venturiaceae), Hyde et al. (2013) did not accept as a genus in Venturiaceae, Wijayawardene et al. (2014c; outline), cultures and sequences are unavailable, needs generic revision.

Trichodothis Theiss. \& Syd. 1914, Dothideomycetes genera incertae sedis, three species, type: T. comata (Berk. \& Ravenel) Theiss. \& Syd., asexual morph unknown, saprobes, North America, Africa, see Lumbsch and Huhndorf (2010; outline, accepted as a genus in Venturiaceae), Zhang et al. (2011d; provisionally included in Venturiaceae), Hyde et al. (2013) did not accept as a genus in Venturiaceae, Kirk et al. (2013; genus accepted), Wijayawardene et al. (2014c; outline), cultures and sequences are unavailable, needs generic revision.

Trichoglossum Boud. 1885, Geoglossaceae, Geoglossales, Geoglossomycetes, 20 species, type: T. hirsutum (Pers.) Boud., asexual morph unknown, on soil, saprobes, terrestrial, temperate, see Schoch et al. (2009; phylogeny, accepted as a genus in Rutstroemiaceae), Kučera et al. (2010; new records in Slovakia), Lumbsch and Huhndorf (2010; outline), Akata 
and Kaya (2013; new records in Turkey), Hustad et al. (2013; DNA, phylogeny), sequences are available for the type.

Trichohelotium Killerm. 1935, Helotiales genera incertae sedis, Leotiomycetes, two species, need typification, asexual morph unknown, saprobes, terrrestrial, Europe, see Lumbsch and Huhndorf (2010; outline), Kirk et al. (2013; genus accepted), cultures and sequences are unavailable, needs generic revision.

Trichomaris Hibbits, G.C. Hughes \& Sparks 1981, Halosphaeriaceae, Microascales, Sordariomycetes, one species, type: T. invadens Hibbits, G.C. Hughes \& Sparks, on tanner crab, marine, Alaska, see Lumbsch and Huhndorf (2010; outline), Kirk et al. (2013; genus accepted), Jones et al. (2015; outline), Maharachchikumbura et al. (2015, 2016; outline), cultures and sequences are unavailable, needs generic revision.

Trichomatoclava G.F. Sepúlveda, Pereira-Carv. \& Dianese 2009, Ascomycota genera incertae sedis, one species, type: T. cerradensis G.F. Sepúlveda, Pereira-Carv. \& Dianese, hyphomycetous, saprobes, terrestrial, South America, see Pereira-Carvalho et al. (2009b; taxonomy), Seifert et al. (2011; morphology), Wijayawardene et al. (2012, 2017; outline), holotype of type: UB (Mycol. Col.) 19442, cultures and sequences are unavailable, needs generic revision.

Trichomatomyces Dorn.-Silva \& Dianese 2004, Ascomycota genera incertae sedis, one species, type: T. byrsonimae (Bat. \& Peres) Dorn.-Silva \& Dianese, hyphomycetous, saprobes, terrestrial, South America, see Seifert et al. (2011; morphology), Wijayawardene et al. (2012, 2017; outline), cultures and sequences are unavailable, needs generic revision.

Trichomatosphaera Pereira-Carv., G.F. Sepúlveda \& Dianese 2009, Ascomycota genera incertae sedis, one species, type: T. cerradensis Pereira-Carv., G.F. Sepúlveda \& Dianese, hyphomycetous, saprobes, terrestrial, South America, see Pereira-Carvalho et al. (2009b; taxonomy), Seifert et al. (2011; morphology), Wijayawardene et al. (2012, 2017; outline), holotype of the type: UB (Mycol. Col.) 19597, cultures and sequences are unavailable, needs generic revision.

Trichomerium Speg. 1918, Trichomeriaceae, Chaetothyriales, Eurotiomycetes, 32 species, type: T. coffeicola (Puttemans) Speg., asexual morph hyphomycetous, possibly Tripospermum Speg., epiphytes or saprobes, sooty moulds, terrestrial, Australia, Brazil, Thailand, see Lumbsch and Huhndorf (2010; outline), Chomnunti et al. (2012; morphology; phylogeny), Liu et al. (2015a; morphology, phylogeny), Hyde et al. (2016; morphology, phylogeny), cultures and sequences are available but lacks for type, needs generic revision.

Trichometasphaeria Munk 1953, Dothideomycetes genera incertae sedis, eight species, type: T. dianthi (Rostr.) Munk, asexual morph coelomycetous, saprobes, North America, see Chlebicki (2009a; new species), Kirk et al. (2013; genus accepted), Wijayawardene et al. (2014c; outline), cultures and sequences are unavailable, needs generic revision.

Trichonectria Kirschst. 1907, Bionectriaceae, Hypocreales, Sordariomycetes, 19 species, type: T. aculeata Kirschst., asexual morph unknown, saprobes, lichenicolous, terrestrial, Austria, see Etayo and Sancho (2008; new species), Lumbsch and Huhndorf (2010; outline), Gardiennet and Lechat (2011; new species), Brackel (2014; new species), Maharachchikumbura et al. (2015, 2016; outline), Farkas and Flakus (2016; new species), cultures and sequences are available but lacks for the type.

Trichopeltella Höhn. 1910, Trichopeltinaceae, Dothideomycetes families incertae sedis, one species, type: T. montana (Racib.) Höhn., asexual morph unknown, epiphytes, Java, see Lumbsch and Huhndorf (2010; outline), Hyde et al. (2013; morphology), Kirk et al. (2013; genus accepted), Hongsanan et al. (2014a; accepted as a genus in Trichopeltinaceae), Wijayawardene et al. (2014c; outline), cultures and sequences are unavailable, needs generic revision. 
Trichopeltheca Bat., C.A.A. Costa \& Cif. 1958, Trichopeltinaceae, Dothideomycetes families incertae sedis, two species, type: T. montana (Racib.) Höhn., asexual morph unknown, epiphytes, Asia, Pacific, see Lumbsch and Huhndorf (2010; outline), Hyde et al. (2013; morphology), Kirk et al. (2013; genus accepted), Hongsanan et al. (2014a; accepted as a genus in Trichopeltinaceae), Wijayawardene et al. (2014c; outline), cultures and sequences are unavailable, needs generic revision.

Trichopeltina Theiss. 1914, Trichopeltinaceae, Dothideomycetes families incertae sedis, two species, type: T. labecula (Mont.) Theiss., asexual morph unknown, epiphytes, South America, see Lumbsch and Huhndorf (2010; outline), Hyde et al. (2013; morphology), Kirk et al. (2013; genus accepted), Hongsanan et al. (2014a; accepted as a genus in Trichopeltinaceae), Wijayawardene et al. (2014c; outline), cultures and sequences are unavailable, needs generic revision.

Trichopeltospora Bat. \& Cif. 1958, Asterinaceae, Asterinales, Dothideomycetes, two species, type: T. pipericola Bat., Cif. \& C.A.A. Costa, asexual morph unknown. Epiphytes, terrestrial, worldwide, no molecular data, see Hofmann (2009; review), Lumbsch and Huhndorf (2010; outline), Wu et al. (2011; taxonomy), Hongsanan et al. (2014c; keys), Wijayawardene et al. (2014c; outline), holotype of type: URM 2492, cultures and sequences are unavailable.

Trichopeltulum Speg. 1889, Ascomycota genera incertae sedis, one species, type: $T$. pulchellum Speg., coelomycetes, sexual morph unknown, saprobes, terrestrial, Hawaii, see Wijayawardene et al. (2012, 2017; outline), Kirk et al. (2013; genus accepted), cultures and sequences are unavailable, needs generic revision.

Trichopeltum Bat., Cif. \& C.A.A. Costa (1958) [1957], ?Microthyriaceae, Microthyriales, Dothideomycetes, type: T. hawaiiense Bat. \& C.A.A. Costa, see Lumbsch and Huhndorf (2010; outline), Kirk et al. (2013; genus accepted), Wu wt al. (2011; did not accept the placement), needs generic revision.

Trichopeziza Fuckel 1870, Lachnaceae, Helotiales, Leotiomycetes, 30 species, type: T. sulphurea (Pers.) Fuckel, asexual morph unknown, saprobes, terrestrial, temperate, see Lumbsch and Huhndorf (2010; outline), Kirk et al. (2013; genus accepted), Han et al. (2014; DNA, phylogeny), cultures available for the type: KUS-F52218, needs generic revision.

Trichophaea Boud. 1885 (= Dichobotrys Hennebert 1973 fide Healy et al. 2016), Pyronemataceae, Pezizales, Pezizomycetes, 32 species, type: T. woolhopeia (Cooke \& W. Phillips) Boud., asexual morph unknown, hypogeous, saprobes, terrestrial, worldwide, see Benkert (2010; new species), Lumbsch and Huhndorf (2010; outline), Rubini et al. (2011; DNA, phylogeny), Hansen et al. (2013; DNA, phylogeny), Kirk et al. (2013; genus accepted), Stielow et al. (2013; phylogeny), Perić et al. (2014; new species), sequences are available.

Trichophaeopsis Korf \& Erb 1972, Pyronemataceae, Pezizales, Pezizomycetes, three species, type: T. bicuspis (Boud.) Korf \& Erb, asexual morph unknown, hypogeous, saprobes, terrestrial, worldwide, see Lumbsch and Huhndorf (2010; outline), Kirk et al. (2013; genus accepted), sequences are available.

Trichophyma Rehm 1904, Arthoniales genera incertae sedis, two species, type: $T$. bunchosiae Rehm, asexual morph unknown, lichenicolous, terrestrial, tropical, see Lumbsch and Huhndorf (2010; outline), Kirk et al. (2013; genus accepted), holotype of the type: E. Ule 1120 (S), cultures and sequences are unavailable.

Trichophyton Malmsten 1848, Arthrodermataceae, Onygenales, Eurotiomycetes, 32 species, type: T. tonsurans Malmsten, hyphomycetous, sexual morph unknown, on humans and other animal, saprobes, on soil, terrestrial, worldwide, see Seifert et al. (2011; morphology), Wijayawardene et al. (2012, 2017; outline), Kirk et al. (2013; genus accepted), Hubka et al. (2014c; new species), Lorch et al. (2014; new species), Hiruma et al. (2016; DNA, mating types), culture and sequences are available for the type. 
Trichoseptoria Cavara 1892, Ascomycota genera incertae sedis, two species, type: T. alpei Cavara, coelomycetes, sexual morph unknown, saprobes, terrestrial, Europe, North America, see Wijayawardene et al. (2012, 2017; outline), Kirk et al. (2013; genus accepted), cultures and sequences are unavailable, needs generic revision.

Trichospermella Speg. 1912, Sordariomycetes genera incertae sedis, one species, type: T. pulchella Speg., asexual morph unknown, saprobes, terrestrial, South America, see Lumbsch and Huhndorf (2010; outline), Kirk et al. (2013; genus accepted), Maharachchikumbura et al. (2015, 2016; outline), cultures and sequences are unavailable, needs generic revision.

Trichosphaerella E. Bommer, M. Rousseau \& Sacc. 1891, Niessliaceae, Hypocreales, Sordariomycetes, four species, type: T. decipiens E. Bommer, M. Rousseau \& Sacc., asexual morph unknown, saprobes, terrestrial, widespread, see Lumbsch and Huhndorf (2010; outline), Whiton et al. (2012; morphology), Kirk et al. (2013; genus accepted), Döbbeler et al. (2015; new species), Maharachchikumbura et al. (2015, 2016; outline), Lendemer et al. (2016; new species), cultures and sequences are unavailable for type, needs generic revision.

Trichosphaeria Fuckel 1870, Trichosphaeriaceae, Trichosphaeriales, Sordariomycetes, c. 20 new species, type: T. pilosa (Pers.) Fuckel, saprobes, terrestrial, widespread, see Lumbsch and Huhndorf (2010; outline), Kirk et al. (2013; genus accepted), Maharachchikumbura et al. (2015, 2016; outline), cultures available for type: 089319.

Trichosphaeropsis Bat. \& Nascim. 1960, Sordariomycetes genera incertae sedis, one species, type: T. crescentiae Bat. \& Nascim., asexual morph unknown, saprobes, terrestrial, Brazil, see Lumbsch and Huhndorf (2010; outline), Kirk et al. (2013; genus accepted), Maharachchikumbura et al. (2015, 2016; outline), cultures and sequences are unavailable, needs generic revision.

Trichosporiella Kamyschko 1960, Ascomycota genera incertae sedis, two species, type: $T$. hyalina Kamyschko, hyphomycetous, sexual morph unknown, saprobes, oh human, on soil, terrestrial, Asia, Europe, see Seifert et al. (2011; morphology, accepted as a genus in Sordariales), Wijayawardene et al. (2012, 2017; outline), Kirk et al. (2013; genus accepted), sequence available for unidentified species, needs generic revision.

Trichosporodochium Dorn.-Silva \& Dianese 2004, Ascomycota genera incertae sedis, two species, type: T. cerradensis Dorn.-Silva \& Dianese, hyphomycetous, sexual morph unknown, saprobes, terrestrial, South America, see Seifert et al. (2011; morphology), Wijayawardene et al. (2012, 2017; outline), Kirk et al. (2013; genus accepted), cultures and sequences are unavailable, needs generic revision.

Trichothallus F. Stevens 1925 (= Plokamidomyces Bat. et al. 1958; Trichopeltheca Bat. et al. 1958 fide Rossman et al. 2016a), Euantennariaceae, Dothideomycetes families incertae sedis, two species, type: T. hawaiiensis F. Stevens, hyphomycetous, sexual morph unknown, saprobes, terrestrial, Australasia, Oceania, see Seifert et al. (2011; morphology), Wijayawardene et al. (2012, 2014c, 2017; outline), Kirk et al. (2013; genus accepted), Rossman et al. (2016a; nomenclature), cultures and sequences are unavailable, needs generic revision.

Trichothecium Link 1809, Hypocreales genera incertae sedis, nine species, type: T. roseum (Pers.) Link, hyphomycetous, sexual morph unknown, saprobes, terrestrial, cosmopolitan, see Seifert et al. (2011; morphology), Summerbell et al. (2011; new species), Wijayawardene et al. (2012, 2017; outline), Kirk et al. (2013; genus accepted), Maharachchikumbura et al. (2015, 2016; outline), cultures and sequences are available, needs generic revision.

Trichothelium Müll. Arg. 1885, Porinaceae, Ostropales, Lecanoromycetes, 40 species, type: T. epiphyllum Müll. Arg., lichenized, see Lumbsch and Huhndorf (2010; outline), Kirk et al. (2013; genus accepted), Lücking et al. (2016b; classification), sequences are available.

Trichothyriella Theiss. 1914, Dothideomycetes genera incertae sedis, one species, type: T. quercigena (Berk. ex Cooke) Theiss., asexual morph unknown, terrestrial, South East Asia, 
see Lumbsch and Huhndorf (2010; outline, accepted as a genus in Microthyriaceae), Wu et al. (2011; trated as a doubtful genus), Kirk et al. (2013; genus accepted), Wijayawardene et al. (2014c; outline), cultures and sequences are unavailable, needs generic revision.

Trichothyrinula Petr. 1950, Trichopeltinaceae, Dothideomycetes families incertae sedis, one species, type: T. labecula (Mont.) Theiss., asexual morph unknown, epiphytes, Ecuador, see Lumbsch and Huhndorf (2010; outline), Hyde et al. (2013; morphology), Kirk et al. (2013; genus accepted), Hongsanan et al. (2014a; accepted as a genus in Trichopeltinaceae), Wijayawardene et al. (2014c; outline), cultures and sequences are unavailable, needs generic revision.

Trichothyrium Speg. 1889, Trichothyriaceae, Dothideomycetes families incertae sedis, twelve species, type: T. sarciniferum Speg., asexual morph unknown, saprobes, terrestrial, subtropical, see Lumbsch and Huhndorf (2010; outline, accepted as a genus in Microthyriaceae), Hyde et al. (2013; accepted as a genus in Trichothyriaceae), Kirk et al. (2013; genus accepted), Wijayawardene et al. (2014c; outline), cultures and sequences are unavailable.

Tricladiella K. Ando \& Tubaki 1984, Ascomycota genera incertae sedis, one species, type: $T$. pluvialis K. Ando \& Tubaki, hyphomycetous, sexual morph unknown, saprobes, aquatic, Asia, see Seifert et al. (2011; morphology), Wijayawardene et al. (2012, 2017; outline), Kirk et al. (2013; genus accepted), cultures and sequences are unavailable, needs generic revision.

Tricladiopsis Descals 1982, Ascomycota genera incertae sedis, two species, type: T. foliosa Descals, hyphomycetous, sexual morph unknown, saprobes, aquatic, Asia, Europe, Central and South America, see Seifert et al. (2011; morphology), Wijayawardene et al. (2012, 2017; outline), Kirk et al. (2013; genus accepted), cultures and sequences are unavailable, needs generic revision.

Tricladiospora Nawawi \& Kuthub. 1988, Ascomycota genera incertae sedis, three species, type: T. stricta Nawawi \& Kuthub., hyphomycetous, sexual morph unknown, saprobes, aquatic, Asia, see Seifert et al. (2011; morphology), Wijayawardene et al. (2012, 2017; outline), Kirk et al. (2013; genus accepted), cultures and sequences are unavailable, needs generic revision.

Tricladium Ingold 1942, Helotiaceae, Helotiales, Leotiomycetes, 25 species, type: T. splendens Ingold, hyphomycetous, saprobes, aquatic, worldwide, see Campbell et al. (2009b; evolutionary relationships), Seifert et al. (2011, polyphyletic), Gulis et al. (2012; new species), Wijayawardene et al. (2012, 2017; outline), Kirk et al. (2013; genus accepted), Baschien et al. (2013; molecular phylogeny), sequences are available for 15 species, compare with Varicosporium, holotype of type: CBS 234.46, MUCL 28105, needs generic revision.

Trifurcospora K. Ando \& Tubaki 1988, Ascomycota genera incertae sedis, two species, type: T. irregularis (Matsush.) K. Ando \& Tubaki, hyphomycetous, sexual morph unknown, saprobes, aquatic, Asia, North America, see Seifert et al. (2011; morphology), Wijayawardene et al. (2012, 2017; outline), Kirk et al. (2013; genus accepted), cultures and sequences are unavailable, needs generic revision.

Trigonopsis Schachner emend. Kurtzman \& Robnett 2007, Trigonopsidaceae, Saccharomycetales, Saccharomycetes, four species, type: T. variabilis Schachner, asexual reproduction is by multilateral budding, saprophytic, grape must, wine, beer, worldwide, cultures and sequences are available.

Trigonosporium Tassi 1900, Ascomycota genera incertae sedis, two species, type: $T$. australiense Tassi, hyphomycetous, sexual morph unknown, saprobes, terrestrial, Australasia, see Wijayawardene et al. (2012, 2017; outline), Kirk et al. (2013; genus accepted), cultures and sequences are unavailable, needs generic revision.

Trimmatostroma Corda 1837, Mollisiaceae, Helotiales, Leotiomycetes, c. 30 species type: T. salicis Corda, sexual morph unknown, saprobes, terrestrial, aquatic, halophillic, worldwide, 
see Vaupotič et al. (2008; physiology), Bartosik et al. (2010; biodeterioration), Diederich et al. (2010a; new species), El-Said et al. (2010; Egypt), Mansour (2010; Lybia), Sepcic et al. (2010; metabolite profiling), Shenoy et al. (2010; phylogeny), Mohammadi (2011; spectrofluorometry), Ruiz-González et al. (2013; isolation protocol), Sarma and Raghukumar (2013; India), Gessler et al. (2014; review), Gunde-Cimerman and Zalar (2014; solar salterns), Heuchert and Braun (2014; new species), cultures and sequences are available.

Trimmatothele Norman ex Zahlbr. 1903, Verrucariaceae, Verrucariales, Eurotiomycetes, three species, type: T. perquisita (Norman) Norman ex Zahlbr., lichenized, see Lücking et al. (2016b; classification), sequences are available.

Trimmatothelopsis Zschacke 1934, Acarosporaceae, Acarosporales, Lecanoromycetes, one species, type: T. versipellis (Nyl.) Zschacke, lichenized, see Gueidan et al. (2014c; taxonomy), Knudsen and Lendemer (2016; taxonomy), Roux et al. (2016; taxonomy), Lücking et al. (2016b; classification), sequences are available.

Trinacrium Riess 1852, Orbiliaceae, Orbiliales, Orbiliomycetes, ten species, type: T. subtile Riess, hyphomycetous, sexual morph unknown, saprobes, terrestrial, Asia, Europe, North America, see Seifert et al. (2011; morphology), Wijayawardene et al. (2012, 2017; outline), Kirk et al. (2013; genus accepted), cultures and sequences are unavailable, needs generic revision.

Trinathotrema Lücking, Rivas Plata \& Mangold 2011, Stictidaceae, Ostropales, Lecanoromycetes, three species, type: T. stictideum (Nyl.) Lücking, R.Miranda \& Kalb, asexual morph unknown, lichenized, terrestrial, Bolivia, Canary Iceland, see Lücking et al. 2011b, Boom and Ertz (2012; new species, new records), Flakus et al. (2013; taxonomy), Lücking et al. (2016b; classification); sequences are available.

Trinosporium Crous \& Decock 2012, Xylonomycetaceae, Xylonomycetales, Xylonomycetes, T. guianense Crous \& C. Decock, coelomycetous, sexual morph unknown, as a contaminant, see Crous et al. (2012e; taxonomy), Gazis et al. (2016; phylogeny), Wijayawardene et al. (2017; outline), cultures and sequences are available.

Triplosphaeria Kaz. Tanaka \& K. Hiray. 2009, Tetraplosphaeriaceae, Pleosporales, Dothideomycetes, four species, type: T. maxima Kaz. Tanaka \& K. Hirayama, asexual morph hyphomycetous, saprobes, terrestrial, Japan, see Tanaka et al. (2009; morphology, phylogeny), Lumbsch and Huhndorf (2010; outline), Wijayawardene et al. (2014c; outline), holotype and ex-type strain of the type: HHUF29330, JCM 13172.

Tripoconidium Subram. 1978, Ascomycota genera incertae sedis, one species, type: T. aphanophagum (Drechsler) Subram., hyphomycetous, sexual morph unknown, on nematodes, terrestrial, North America, see Seifert et al. (2011; morphology), Wijayawardene et al. (2012, 2017; outline), Kirk et al. (2013; genus accepted), cultures and sequences are unavailable, needs generic revision.

Tripospermum Speg. 1918, Neodevriesiaceae, Capnodiales, Dothideomycetes, 27 species, type: M. caespitosa Petr., hyphomycetous, sexual morph unknown, saprobes, terrestrial, North America, see Rocha et al. (2010; new species), Seifert et al. (2011; morphology), Kirk et al. (2013; genus accepted), Quaedvlieg et al. (2014; phylogeny), Wijayawardene et al. (2017; outline), cultures and sequences are available, needs generic revision.

Tripospora Sacc. 1886, Coryneliaceae, Coryneliales, Eurotiomycetes, four species, type: T. cookei Sacc., asexual morph unknown, saprobes, South Africa, South America, see Lumbsch and Huhndorf (2010; outline), Kirk et al. (2013; genus accepted), Jaklitsch et al. (2016a; classification), cultures and sequences are available.

Triposporina Höhn. 1912, Ascomycota genera incertae sedis, two species, type: $T$. uredinicola Höhn., hyphomycetous, sexual morph unknown, fungicolous, terrestrial, Asia, see Seifert et al. (2011; morphology), Wijayawardene et al. (2012, 2017; outline), Kirk et al. (2013; genus accepted), cultures and sequences are unavailable, needs generic revision. 
Triposporium Corda 1837, Helotiales genera incertae sedis, Leotiomycetes, 41 species, type: T. elegans Corda, hyphomycetous, sexual morph unknown, fungicolous, terrestrial, worldwide, see Seifert et al. (2011; morphology), Wijayawardene et al. (2012, 2014c; outline, accepted as a genus in Asterinaceae), Kirk et al. (2013; genus accepted), Crous et al. (2014c; new species, phylogeny, accepted as a Helotiales), Wijayawardene et al. (2017; outline), cultures and sequences are available but lacks for the type, taxonomic placement is based on sequence of non-type, needs generic revision.

Tripterosporella Subram. \& Lodha 1968, Lasiosphaeriaceae, Sordariales, Sordariomycetes, six species, type: T. coprophila Subram. \& Lodha, asexual morph unknown, saprobes, coprophilous, terrestrial, Asia, Africa, see Doveri (2010; new species and two varities), Lumbsch and Huhndorf (2010; outline), Kirk et al. (2013; genus accepted), Maharachchikumbura et al. (2015, 2016; outline), cultures and sequences are unavailable, needs generic revision.

Triramulispora Matsush. 1975, Ascomycota genera incertae sedis, three species, type: $T$. gracilis Matsush., hyphomycetous, sexual morph unknown, saprobes, terrestrial, Asia, see Seifert et al. (2011; morphology), Wijayawardene et al. (2012, 2017; outline), Kirk et al. (2013; genus accepted), cultures and sequences are unavailable, needs generic revision.

Triscelophorus Ingold 1943, Ascomycota genera incertae sedis, eight species, type: $T$. monosporus Ingold, hyphomycetous, saprobes, aquatic, worldwide, see Seifert et al. (2011; morphology), Wijayawardene et al. (2012, 2017; outline), Kirk et al. (2013; genus accepted), Fiuza et al. (2015a; morphology), cultures and sequences are available, needs generic revision.

Triscelosporium Nawawi \& Kuthub. 1987, Ascomycota genera incertae sedis, one species, type: T. verrucosum Nawawi \& Kuthub., hyphomycetous, sexual morph unknown, saprobes, aquatic, Asia, see Seifert et al. (2011; morphology), Wijayawardene et al. (2012, 2017; outline), Kirk et al. (2013; genus accepted), holotype of the type: IMI 313480, cultures and sequences are unavailable, needs generic revision.

Tristratiperidium Daranagama, Camporesi \& K.D. Hyde 2015, Xylariales genera incertae sedis, Sordariomycetes, one s[pecies, type: Tristratiperidium microsporum Daranag., Camporesi \& K.D. Hyde, asexual morph hyphomycetous, saprobes, terrestrial, Italy, Europe, one species, see Daranagama et al. (2016b; taxonomy), Maharachchikumbura et al. (2015, 2016; outline), ex-type strains of type: MFLUCC 15-0413; holotype MFLU 15-0656.

Trisulcosporium H.J. Huds. \& B. Sutton 1964, Ascomycota genera incertae sedis, one species, type: T. acerinum H.J. Huds. \& B. Sutton, hyphomycetous, sexual morph unknown, saprobes, aquatic, Africa, Asia, Europe, South America, see Seifert et al. (2011; morphology), Wijayawardene et al. (2012, 2017; outline), Kirk et al. (2013; genus accepted), cultures and sequences are unavailable, needs generic revision.

Trizodia Laukka 2010, Ascomycota genera incertae sedis, one species, type: T. acrobia Laukka, lichenized, terrestrial, Finland, see Stenroos et al. (2010; taxonomy), Lücking et al. (2016b; classification), sequences are available.

Trochila Fr. 1849, Cenangiaceae, Helotiales, Leotiomycetes, 15 species, type: T. craterium (DC.) Fr., asexual morph unknown, saprobes, terrestrial, temperate, see Lumbsch and Huhndorf (2010; outline, accepted as a genus in Dermateaceae), Kirk et al. (2013; genus accepted), Pärtel et al. (2017; DNA, phylogeny, accepted as a genus in Cenangiaceae), cultures available for the type: KL333.

Trochoideomyces Thaxt. 1931, Laboulbeniaceae, Laboulbeniales, Laboulbeniomycetes, one species, T. gracilicaulis Thaxt., asexual morph unknown, biotrophic, only known from Trochoideus desjardinsii (Coleoptera: Endomychidae), Malaysian Borneo, see Lumbsch and Huhndorf (2010; outline), Kirk et al. (2013; genus accepted), cultures and sequences are unavailable. 
Trochophora R.T. Moore 1955, Mycosphaerellaceae, Capnodiales, Dothideomycetes, one species, type: T. simplex (Petch) R.T. Moore, hyphomycetous, sexual morph unknown, plant pathogens on Daphnphyllum shrubs and trees in Asia, terrestrial, see Crous et al. (2009a; morphology, phylogeny), Wijayawardene et al. (2012, 2017; outline), Kirk et al. (2013; genus accepted), holotype NY00945981, for epitype see Videira et al. (2017).

Troglomyces S. Colla 1932, Laboulbeniaceae, Laboulbeniales, Laboulbeniomycetes, six species, type: T. manfredii S. Colla, asexual morph unknown, biotrophic on millipedes (Blaniulidae \& Julidae), mostly Europe, Madeira, Tenerife, see Lumbsch and Huhndorf (2010; outline), Kirk et al. (2013; genus accepted), Santamaría et al. (2014 morphology), Enghoff and Santamaría (2015, morphology, taxonomy, key, specificity and transmission), cultures and sequences are unavailable, needs generic revision.

Tromeropsis Sherwood 1981, Ascomycota genera incertae sedis, one species, type: $T$. microtheca (P. Karst.) Sherwood, asexual morph unknown, saprobes, terrestrial, Finland, see Lumbsch and Huhndorf (2010; outline), Kirk et al. (2013; genus accepted), cultures and sequences are available, needs generic revision.

Troposporella P. Karst. 1892, Dothideomycetes genera incertae sedis, four species, type: $T$. fumosa P. Karst., hyphomycetous, sexual morph unknown, saprobes, aquatic, Australasia, Europe, North and South America, see Tsui and Berbee (2010; new species, DNA, phylogeny), Seifert et al. (2011; morphology), Wijayawardene et al. (2012, 2014c, 2017; outline), Kirk et al. (2013; genus accepted), cultures available for the type: MUCL 15695.

Troposporium Harkn. 1884, Ascomycota genera incertae sedis, one species, type: T. album Harkn., hyphomycetous, sexual morph unknown, saprobes, terrestrial, North America, see Seifert et al. (2011; morphology), Wijayawardene et al. (2012, 2017; outline), Kirk et al. (2013; genus accepted), cultures and sequences are unavailable, needs generic revision.

Troposporopsis Whitton, McKenzie \& K.D. Hyde 1999, Ascomycota genera incertae sedis, two species, type: T. atroapicis Whitton, McKenzie \& K.D. Hyde, hyphomycetous, sexual morph unknown, saprobes, terrestrial, Asia, Australasia, Caribbean, see Seifert et al. (2011; morphology), Wijayawardene et al. (2012, 2017; outline), Kirk et al. (2013; genus accepted), cultures and sequences are unavailable, needs generic revision.

Trullula Ces. 1852, Leotiomycetes genera incertae sedis, 15 species, type: T. oreoselini Ces., coelomycetous, sexual morph unknown, saprobes, terrestrial, North temperate, see Wijayawardene et al. (2012, 2016b; outline, taxonomy, phylogeny), Kirk et al. (2013; genus accepted), cultures and sequences are available but lacks for the type, taxonomic placement is based od sequences of non-type:, needs generic revision.

Truncatella Steyaert 1949, Bartaliniaceae, Xylariales, Sordariomycetes, eleven species, type: T. truncata (Lév.) Steyaert, coelomycetous, sexual morph unknown, saprobes, terrestrial, worldwide, see Wijayawardene et al. (2012, 2016b, 2017; outline, morphology), Kirk et al. (2013; genus accepted), Maharachchikumbura et al. (2015, 2016; outline), Senanayake et al. (2015; new species, phylogeny), cultures and sequences are available, needs generic revision.

Tryblidaria (Sacc.) Rehm 1903, Patellariaceae, Patellariales, Dothideomycetes, nine species, type: T. breutelii Rehm, asexual morph unknown, saprobes, terrestrial, subtropical, see Lumbsch and Huhndorf (2010; outline), Hyde et al. (2013; accepted as a genus in Patellariaceae), Kirk et al. (2013; genus accepted), Wijayawardene et al. (2014c; outline), Yacharoen et al. (2015; accepted as a genus in Patellariaceae), cultures and sequences are unavailable, needs generic revision.

Tryblidiopsis P. Karst. 1871, Rhytismataceae, Rhytismatales, Leotiomycetes, three species, type: T. pinastri (Pers.) P. Karst., asexual morph unknown, saprobes, terrestrial, worldwide, see Lumbsch and Huhndorf (2010; listed as Triblidiopsis), Kirk et al. (2013; genus accepted), 
Wang et al. (2014a; DNA, phylogeny), cultures and sequences are available for the type: AFTOL-ID 1319.

Tryblidiopycnis Höhn. 1918, Ascomycota genera incertae sedis, one species, type: T. pinastri Höhn., coelomycetous, sexual morph unknown, saprobes, terrestrial, worldwide, see Wijayawardene et al. (2012, 2017; outline), Kirk et al. (2013; genus accepted), cultures and sequences are unavailable, needs generic revision.

Tryblis Clem. 1931, Odontotremataceae, Ostropales, Lecanoromycetes, two species, type: $T$. arnoldii (Rehm) Clem., asexual morph unknown, ?saprobes, terrestrial, see Lumbsch and Huhndorf (2010; outline), Kirk et al. (2013; genus accepted), sequences are unavailable

Trypetheliopsis Asah. 1937, Monoblastiaceae, Monoblastiales, Dothideomycetes, six species, type: T. boninensis Asah., asexual morph unknown, lichenized, terrestrial, tropical, new synonym Musaespora Aptroot \& Sipman, see Kashiwadani et al. (2009; taxonomy), Nelsen et al. (2009, 2011' phylogeny), Lumbsch and Huhndorf (2010; outline), Kirk et al. (2013; genus accepted), Lücking et al. (2016b; classification), sequences are available.

Trypethelium Spreng. [nom. cons.] 1804, Trypetheliaceae, Trypetheliales, Dothideomycetes, 16 species, type: T. eluteriae Spreng., asexual morph unknown, lichenized, terrestrial, tropical, see Lumbsch and Huhndorf (2010; outline), Kirk et al. (2013; genus accepted), Aptroot and Lücking (2016; taxonomy, monograph), Lücking et al. (2016b; classification); sequences are available.

Tryssglobulus B. Sutton \& Pascoe 1987, Ascomycota genera incertae sedis, one species, type: T. aspergilloides B. Sutton \& Pascoe, hyphomycetous, sexual morph unknown, saprobes, terrestrial, Australasia, see Seifert et al. (2011; morphology), Wijayawardene et al. (2012, 2017; outline), Kirk et al. (2013; genus accepted), cultures and sequences are unavailable, needs generic revision.

Tubakia B. Sutton 1973, Diaporthales genera incertae sedis, Sordariomycetes, eight species, type: T. japonica (Sacc.) B. Sutton, coelomycetous, sexual morph unknown, saprobes, terrestrial, worldwide, see Seifert et al. (2011; treated as coelomycetous), Yun and Rossman (2011; new species), Harrington et al. (2012; new species), Wijayawardene et al. (2012, 2017; outline), Kirk et al. (2013; genus accepted), Braun et al. (2014a; new species), cultures and sequences are available but lacks for the type, needs generic revision.

Tubakiella (Tubaki) Sakay., K.L. Pang \& E.B.G. Jones 2011, Halosphaeriaceae, Microascales, Sordariomycetes, one species, type: T. galerita (Tubaki) Sakay., K.L. Pang \& E.B.G. Jones, asexual morph unknown, saprobes, marine, France, Denmark, Germany, Japan, Taiwan, USA, Yugoslavia, see Sakayaroj et al. (2011a; morphology, phylogeny), Jones et al. (2015; outline), Maharachchikumbura et al. (2015; outline, phylogeny), holotype and ex-type strain of the type: BCC33500, PP5577.

Tuber P. Micheli ex F.H. Wigg. 1780 (= ?Loculotuber Trappe, Parladé \& I.F. Alvarez 1993 fide Jaklitsch et al. 2016a), Tuberaceae, Pezizales, Pezizomycetes, 135 species, type: T. aestivum Vittad., asexual morph unknown, saprobes, saprobes, hypogeous, terrestrial, worldwide, see Bonito et al. (2010a, b; new species), Culleré et al. (2010; aromatic compounds), Lumbsch and Huhndorf (2010; outline), Benucci et al. (2011; ectomycorrhizal), Fan et al. (2013; new species), Kirk et al. (2013; genus accepted), Li et al. (2014a; new species, China), Su et al. (2014; new species), Guevara-Guerrero et al. (2015; new species), Qing et al. (2015; new species), cultures and sequences are available.

Tuberculispora Deighton \& Piroz. 1972, Ascomycota genera incertae sedis, one species, type: T. jamaicensis Deighton \& Piroz., hyphomycetous, sexual morph unknown, saprobes, terrestrial, Caribbean, see Seifert et al. (2011; morphology), Wijayawardene et al. (2012, 2017; outline), Kirk et al. (2013; genus accepted), cultures and sequences are unavailable, needs generic revision. 
Tubeufia Penz. \& Sacc., 1898, Tubeufiaceae, Tubeufiales, Dothideomycetes, 29 species, type: T. javanica Penz. \& Sacc., saprobes on decaying wood or sheaths of bamboo, widespread, asexual morph hyphomycetous, see Lumbsch and Huhndorf (2010; outline), Hyde et al. (2013; taxonomy), Kirk et al. (2013; genus accepted), Boonmee et al. (2014b; taxonomy, phylogeny), Wijayawardene et al. (2014c, 2017; outline), cultures and sequences are available, ex-type strains of type: MFLUCC12-0545; epitype of type: MFLU13-0371.

Tubolachnum Velen. 1934, Lachnaceae, Helotiales, Leotiomycetes, two species, type: need typification, asexual morph unknown, saprobes, terrrestrial, former Czechoslovakia, see Lumbsch and Huhndorf (2010; outline), Kirk et al. (2013; genus accepted), cultures and sequences are unavailable, needs generic revision.

Tuckermanella Essl. 2003, Parmeliaceae, Lecanorales, Lecanoromycetes, six species, type: T. weberi (Essl.) Essl., asexual morph unknown, lichenized, terrestrial, Mexico, Colorado, Wisconsi, Norh Crolina, Colorado, see Shrestha and St. Clair (2009; new records), Lumbsch and Huhndorf (2010; outline), Harris and Rogers (2011; sequencing), Nelsen et al. (2011a, 2013; molecular), Perlmutter (2013; inventory), Saag et al. (2013; list), Bartkowiak and Bennett (2016; taxonomy), Herrera Campos et al. (2016; taxonomy), Lücking et al. (2016b; classification); sequences are available.

Tuckermanopsis Gyeln. 1933, Parmeliaceae, Lecanorales, Lecanoromycetes, nine species, type: T. ciliaris (Ach.) Gyeln., asexual morph unknown, lichenized, terrestrial, see Lumbsch and Huhndorf (2010; outline), Büdel (2011; taxonomy), Kelly et al. (2011; molecular), Grochowski (2012; ecology), Kirk et al. (2013; genus accepted), Mcmullin et al. (2013; conservation), Lücking et al. (2016b; classification), Mark et al. (2016; molecular), sequences are available.

Tulipispora Révay \& J. Gönczöl 2009, Ascomycota genera incertae sedis, one species, type: T. ingoldii Révay \& J. Gönczöl, hyphomycetous, sexual morph unknown, saprobes, terrestrial, Europe, see Seifert et al. (2011; morphology), Wijayawardene et al. (2012, 2017; outline), holotype of the type: BP 99766, cultures and sequences are unavailable, needs generic revision.

Tumidispora Hongsanan \& K.D. Hyde 2015, Microthyriaceae, Microthyriales, Dothideomycetes, one species, type: T. shoreae Hongsanan \& K.D. Hyde, asexual morph unknown, saprobes, terrestrial, Thailand, see Ariyawansa et al. (2015a; taxonomy, phylogeny), holotype and ex-type culture of the type: MFLU 15-1391, MFLUCC 12-0409.

Tumularia Descals \& Marvanová 1987, Lophiostomataceae, Pleosporales, Dothideomycetes, two species, type: T. tuberculata (J. Gönczöl) Descals \& Marvanová, hyphomycetous, sexual morph unknown, saprobes, aquatic, Europe, North and South Americ, see Seifert et al. (2011; morphology), Wijayawardene et al. (2012, 2014c, 2017; morphology, phylogeny), Hyde et al. (2013; accepted as a genus in Lophiostomataceae), Kirk et al. (2013; genus accepted), cultures and sequences are available but lacks for the type, needs generic revision.

Tunicago B. Sutton \& Pollack 1977, Ascomycota genera incertae sedis, two species, type: T. uniolae B. Sutton \& Pollack, coelomycetous, sexual morph unknown, saprobes, terrestrial, USA, Australia, see Wijayawardene et al. (2012, 2016b, 2017; outline, taxonomy), Kirk et al. (2013; genus accepted), cultures and sequences are unavailable, needs generic revision.

Tunicatispora K.D. Hyde 1990, Halosphaeriaceae, Microascales, Sordariomycetes, one species, type: T. australiensis K.D. Hyde, saprobes, marine, Australia, see Lumbsch and Huhndorf (2010; outline), Kirk et al. (2013; genus accepted), Maharachchikumbura et al. (2015, 2016; outline), cultures and sequences are unavailable, needs generic revision.

Tunstallia Agnihothr. 1961, Sordariomycetes genera incertae sedis, one species, type: T. aculeata (Petch) Agnihothr., asexual morph unknown, saprobes, pathogens, terrestrial, India, see Lumbsch and Huhndorf (2010; outline), Kirk et al. (2013; genus accepted), 
Maharachchikumbura et al. (2015, 2016; outline), cultures and sequences are unavailable, needs generic revision.

Turgidosculum Kohlm. \& E. Kohlm. 1972, Ascomycota genera incertae sedis, two species, type: T. ulvae (M. Reed) Kohlm. \& E. Kohlm., asexual morph unknown, symbiotic, marine, worldwide, Lumbsch and Huhndorf (2010; outline), Kirk et al. (2013; genus accepted), Jones et al. (2015; outline, marine), Maharachchikumbura et al. (2015, 2016; outline), cultures and sequences are unavailable, needs generic revision.

Turturconchata J.L. Chen, T.L. Huang \& Tzean 1999, Ascomycota genera incertae sedis, two species, type: T. reticulata J.L. Chen, T.L. Huang \& Tzean, hyphomycetous, sexual morph unknown, saprobes, terrestrial, Asia, South America, see Seifert et al. (2011; morphology), Wijayawardene et al. (2012, 2017; outline), Kirk et al. (2013; genus accepted), cultures and sequences are unavailable, needs generic revision.

Tylophorella Vain. 1890, Arthoniales genera incertae sedis, Arthoniomycetes, one species, type: T. polyspora Vain., lichenized, terrestrial, Bolivia, New guinea, see Lumbsch et al. (2009b; molecular), Lumbsch and Huhndorf (2010; outline), Kirk et al. (2013; genus accepted), McCarthy (2014; new record), Ertz et al (2015; new record), Lücking et al. (2016b; classification), sequences are unavailable.

Tylophoron Nyl. ex Stizenb. 1862, Arthoniaceae, Arthoniales, Lecanoromycetes, eight species, type: T. protrudens Nyl., lichenized, terrestrial, mainly tropical, see Lumbsch et al. (2009b; molecular), Lumbsch and Huhndorf (2010; outline), Aptroot et al. (2010; biodiversity), Ertz et al. (2011; molecular), Reddy et al. (2011; new record), Sethy et al. (2012; new record), Kirk et al. (2013; genus accepted), Lendemer et al. (2013; new species), Lendemer and Harris (2014; taxonomy), Gupta and Sinha (2015; new records), Pérez-Pérez et al. (2015; taxonomy), Lücking et al. (2016b; classification), sequences are available.

Tylophoropsis Sambo 1938, Caliciaceae, Caliciales, Lecanoromycetes, one species, type: T. nyeriana Sambo, lichenized, see Lumbsch and Huhndorf (2010; outline, accepted as a genus in Physciaceae), Gaya et al. (2012; taxonomy), Lücking et al. (2016b; classification), Prieto and Wedin (2016; phylogeny), sequences are unavailable.

Tylothallia P. James \& H. Kilias 1981, Lecanoraceae, Lecanorales, Lecanoromycetes, three species, type: T. biformigera (Leight.) P. James \& H. Kilias, asexual morph unknown, lichenized, terrestrial, see Lumbsch and Huhndorf (2010; outline), Elix and Kantvilas (2013; new records), Kirk et al. (2013; genus accepted), Øvstedal and Gremmen (2014; new combination), Lücking et al. (2016b; classification), sequences are available.

Tympanis Tode 1790 (= Sirodothis Clem. 1909; Pleurophomella Höhn 1914 fide Johnston et al. 2014b), Tympanidaceae, Phacidiales, Leotiomycetes, 27 species, type: T. saligna Tode, asexual morphs formerly known in Sirodothis and Pleurophomella, weak parasite of gymnoand angyosperms trees commonly associated with cankers, worldwide, common in temperate areas, Kirk et al. (2013; genus accepted), Quijada et al. (2015; phylogeny), Kowalski et al. (2016; distribution), cultures and sequences are available but lacks for the type, needs typification and generic revision.

Tympanopsis Starbäck 1894, Scortechiniaceae, Coronophorales, Sordariomycetes, one species, type: T. euomphala (Berk. \& M.A. Curtis) Starbäck, asexual morph unknown, saprobes, cosmopolitan, see Mugambi and Huhndorf (2010; phylogeny), Vasilyeva et al. (2012; new species), Maharachchikumbura et al. (2015, 2016; outline), Jaklitsch et al. (2016a; classification), cultures and sequences are available.

Tympanosporium W. Gams 1974, Ascomycota genera incertae sedis, one species, type: T. parasiticum W. Gams, hyphomycetous, sexual morph unknown, saprobes, terrestrial, Europe, see Seifert et al. (2011; morphology), Wijayawardene et al. (2012, 2017; outline), Kirk et al. (2013; genus accepted), cultures and sequences are unavailable, needs generic revision. 
Typhulochaeta S. Ito \& Hara 1915, Erysiphaceae, Erysiphales, Leotiomycetes, four species, type: T. japonica S. Ito \& Hara, biotrophic, obligate plant pathogens, terrestrial, Asia, North America, see Lumbsch and Huhndorf (2010; outline), Kirk et al. (2013; genus accepted), Jaklitsch et al. (2016a; classification), cultures and sequences are available.

Tyrannicordyceps Kepler \& Spatafora 2012, Clavicipitaceae, Hypocreales, Sordariomycetes, five species, type: T. fratricida (Tanda \& Kobayasi) Kepler \& Spatafora, asexual morph unknown, saprobes, terrestrial, cosmopolitan, see Kepler et al. (2012b; taxonomy), Maharachchikumbura et al. (2015, 2016; outline), cultures and sequences are available.

Tyrannosorus Unter. \& Malloch 1995, Venturiaceae, Venturiales, Dothideomycetes, one species, type: T. pinicola (Petrini \& P.J. Fisher) Unter. \& Malloch, asexual morph unknown, saprobes, terrestrial, Canada, Pakistan, see Lumbsch and Huhndorf (2010; outline, accepted as a genus in Dothideomycetes genera incertae sedis), Zhang et al. (2011d; accepted as in Venturiaceae), Hyde et al. (2013; accepted as in Venturiaceae, phylogeny), Wijayawardene et al. (2014c; outline), cultures available for the type: AFTOL-ID 1235.

Uberispora Piroz. \& Hodges 1973, Ascomycota genera incertae sedis, four species, type: $U$. simplex (Ichinoe) Piroz. \& Hodges, hyphomycetous, sexual morph unknown, saprobes, terrestrial, Africa, Asia, Caribbean, North America, see Seifert et al. (2011; morphology), Wijayawardene et al. (2012, 2017; outline), Kirk et al. (2013; genus accepted), Jian et al. (2014; new species), Ma et al. (2014; new species, China), cultures and sequences are unavailable, needs generic revision.

Ubrizsya Negru 1965, Ascomycota genera incertae sedis, one species, type: U. oxycocci Negru \& R. Sandor, coelomycetous, sexual morph unknown, saprobes, terrestrial, Rumania, see Wijayawardene et al. (2012, 2017; outline), Kirk et al. (2013; genus accepted), cultures and sequences are unavailable, needs generic revision.

Uleodothis Theiss. \& Syd. 1915, Dothideomycetes genera incertae sedis, four species, type: U. balansiana (Sacc., Roum. \& Berl.) Theiss. \& Syd., saprobes, terrestrial, South America, see Lumbsch and Huhndorf (2010; outline), Kirk et al. (2013; genus accepted), Wijayawardene et al. (2014c; outline), cultures and sequences are unavailable, needs generic revision.

Uleomyces Henn. 1895, Cookellaceae, Myriangiales, Dothideomycetes family incertae sedis, four species, type: $U$. parasiticus Henn., asexual morph unknown, on rusts and ascomycetes, terrestrial, worldwide, see Lumbsch and Huhndorf (2010; outline), Hyde et al. (2013; accepted as a genus in Cookellaceae), Kirk et al. (2013; genus accepted), Wijayawardene et al. (2014c; outline), cultures and sequences are unavailable, needs generic revision.

Uleoporthe Petr. 1941, Sydowiellaceae, Diaporthales, Sordariomycetes, one species, type: $U$. orbiculata (Syd. \& P. Syd.) Petr., asexual morphs unknown, saprobes, terrestrial, America, see Lumbsch and Huhndorf (2010; outline), Kirk et al. (2013; genus accepted), Maharachchikumbura et al. (2015, 2016; outline), cultures and sequences are unavailable, needs generic revision.

Uleothyrium Petr. 1929, Asterinaceae, Asterinales, Dothideomycetes, two species, type: $U$. amazonicum Petr., asexual morph coelomycetous (= Septothyrella-like, fide Hofmann 2009), epiphytes, terrestrial, worldwide, see Hofmann (2009; review), Lumbsch and Huhndorf (2010; outline), Wu et al. (2011; taxonomy), Hongsanan et al. (2014c; keys), Wijayawardene et al. (2014c; outline), placement in Asterinaceae supported by morphology, cultures and sequences are unavailable, holotype of type: W 10746.

Ulocoryphus Michaelides, L. Hunter \& W.B. Kendr. 1982, Ascomycota genera incertae sedis, one species, type: U. mastigophorus Michaelides, L. Hunter \& W.B. Kendr., hyphomycetous, sexual morph unknown, saprobes, terrestrial, Australasia, see Seifert et al. (2011; morphology), Wijayawardene et al. (2012, 2017; outline), Kirk et al. (2013; genus accepted), cultures and sequences are unavailable, needs generic revision. 
Ulospora D. Hawksw., Malloch \& Sivan. 1979, Tesudinaceae, Pleosporales, Dothideomycetes, one species, type: U. bilgramii (D. Hawksw., C. Booth \& Morgan-Jones) D. Hawksw., Malloch \& Sivan., marine sediments and plant material, Asia, terrestrial and marine, see Zhang et al. (2008b; phylogeny), Lumbsch and Huhndorf (2010; outline), Kirk et al. (2013; genus accepted), Jaklitsch et al. (2016a; classification), cultures available, holotype of type: K(M)-IMI 12081.

Ulurua Trappe, Claridge \& Kovács 2010, Pezizaceae, Pezizales, Pezizomycetes, one species, type: $U$. nonparaphysata Trappe \& Claridge, asexual morph unknown, hypogeous, terrestrial, Northern Territory, see Trappe et al. (2010; taxonomy, phylogeny), isotype of the type: OSC 131126, sequences are available.

Umbellidion B. Sutton \& Hodges 1975, Ascomycota genera incertae sedis, one species, type: $U$. radulans B. Sutton \& Hodges, hyphomycetous, sexual morph unknown, saprobes, terrestrial, South America, see Seifert et al. (2011; morphology), Wijayawardene et al. (2012, 2017; outline), Kirk et al. (2013; genus accepted), cultures and sequences are unavailable, needs generic revision.

Umbilicaria Hoffm [nom. cons.] 1789, Umbilicariaceae, Umbilicariales, Lecanoromycetes, 70 species, type: $U$. exasperata Hoffm.,asexual morph unknown, lichenized, terrestrial, worldwide, see Hájek et al. (2009; physiological exp.), Hestmark (2009, 2010, 2014, 2016; taxonomy, new records), Krzewicka and Wilk (2009; new species), Krzewicka et al. (2009; taxonomy), Lee et al. (2009a; bioactivity study), Luo et al. (2009; antioxidant study), Ranković et al. (2009; bioactivity study), Seo et al. (2009a; bioactivity study), Hestmark (2010; taxonomy), Hestmark et al. (2010, 2014; phylogeny), Kim et al. (2010; bioactivity study), Krzewicka (2010; combination), Lumbsch and Huhndorf (2010; outline), Manojlović et al. (2011; antimicrobial study), Harańczyk et al. (2012; experimental study), Jupa et al. (2012; physiology), Kosanić et al. (2012; bioactivity study), McCune and Curtis (2012; taxonomy), Bendiksby \& Timdal 2013, Buçukoglu et al. (2013; antioxidant study), Singh and Ravindra (2013; environmental study), Kirk et al. (2013; genus accepted), Park et al. (2013;mutagenic study), Hestmark (2014; taxonomy), McCune et al. (2014; new species), Tibell (2014; taxonomy), Wang et al. (2014d; antithrombotic study), Cao et al. (2015; molecular), Du et al. (2015; bioactivity study), Bogdanović et al. (2016; floristic), Davydov, and Ohmura (2016; taxonomy), Hestmark (2016; taxonomy), Lücking et al. (2016b; classification), sequences are available.

Umbilithecium Etayo 2002, Lecanoromycetes genera incertae sedis, one species, type: $U$. pseudocyphellariae Etayo., asexual morph unknown, parasymbiont on macrolichens of Pseudocyphellaria, terrestrial, South America, see Etayo and Sancho (2008; morphology, distinction of similar lichenicolous genera), needs revision, holotype of the type: MAF Etayo 23090, cultures and sequences are unavailable.

Umthunziomyces Crous \& M.J. Wingf. 2016, Planistromellaceae, Botryosphaeriales, Dothideomycetes, one species, type: U. hagahagensis Crous \& M.J. Wingf., coelomycetous, sexual morph unknown, saprobes, terrestrial, South Africa, see Crous et al. (2016a; taxonomy, phylogeny), holotype and ex-type culture of the type: CBS H-22873, CPC 29917.

Umushamyces Etayo 2002, Scoliciosporaceae, Lecanorales, Lecanoromycetes, one species, type: U. kuturnum Etayo., asexual morph unknown, parasymbiont on Coccotrema, terrestrial, South America, see Etayo and Sancho (2008; morphology, distinction of similar lichenicolous genera), need revision, holotype of the type: MAF Etayo 22460, cultures and sequences are unavailable.

Uncinocarpus Sigler \& G.F. Orr 1976, Onygenaceae, Onygenales, Eurotiomycetes, three species, type: U. reesii Sigler \& G.F. Orr, asexual morph unknown, saprobes, terrestrial, USA, see Lumbsch and Huhndorf (2010; outline), Kirk et al. (2013; genus accepted), sequences are available for the type (unpublished). 
Uncispora R.C. Sinclair \& Morgan-Jones 1979, Chaetothyriales genera incertae sedis, Eurotiomycetes, three species, type: U. harroldiae R.C. Sinclair \& Morgan-Jones, hyphomycetous, sexual morph unknown, saprobes, terrestrial, China, North America, see Seifert et al. (2011; morphology), Yang et al. (2011a; new species, China, DNA), Wijayawardene et al. (2012, 2017; outline), Kirk et al. (2013; genus accepted), Li et al. (2015a; new species; DNA), cultures and sequences are available but lacks for the type:, generic placement is based on no-type:, needs generic revision.

Underwoodia Peck 1890, ?Helvellaceae, Pezizales, Pezizomycetes, three species, type: $U$. columnaris Peck., asexual morph unknown, saprobes, from soil, terrestrial, worldwide, see Bonito et al. (2013; DNA, phylogeny, stated that the genus is polyphyletic), Kirk et al. (2013; genus accepted), sequences are available for the type: U42658 (SSU).

Unguicularia Höhn. 1905, Hyaloscyphaceae, Helotiales, Leotiomycetes, seven species, type: $U$. unguiculata Höhn., asexual morph unknown, saprobes, terrestrial, Europe, see Lumbsch and Huhndorf (2010; outline), Kirk et al. (2013; genus accepted), cultures and sequences are available (unpublished), needs generic revision.

Unguiculariella K.S. Thind \& R. Sharma 1990, Hyaloscyphaceae, Helotiales, Leotiomycetes, one species, type: $U$. bhutanica K.S. Thind \& R. Sharma, asexual morph unknown, saprobes, terrestrial, Bhutan, see Lumbsch and Huhndorf (2010; outline), Kirk et al. (2013; genus accepted), cultures and sequences are unavailable, needs generic revision.

Unguiculariopsis Rehm 1909 (= Deltosperma W.Y. Zhuang 1988 fide Johnston et al. 2014b), Cordieritidaceae, Helotiales, Leotiomycetes, 25 species, type: U. ilicincola (Berk. \& Broome) Rehm, asexual morph formerly known in Deltosperma, fungicolous and lichenicolous, terrestrial, worldwide, see Etayo and Sancho (2008; new species), Lumbsch and Huhndorf (2010; outline, accepted as a genus in Helotiaceae), Brackel (2011a; new species), Kirk et al. (2013; genus accepted), Johnston et al. (2014b; nomenclature), Pärtel et al. (2017; DNA, phylogeny), Wijayawardene et al. (2017; outline, taxonomy), cultures and sequences are available but lacks for the type.

Unguiculella Höhn. 1906, Hyaloscyphaceae, Helotiales, Leotiomycetes, 17 species, type: $U$. falcipila Höhn., asexual morph unknown, saprobes, terrestrial, Europe, see Lumbsch and Huhndorf (2010; outline), Kirk et al. (2013; genus accepted), cultures and sequences are unavailable, needs generic revision.

Uniseta Ciccar. 1948, Ascomycota genera incertae sedis, one species, type: U. flagellifera (Ellis \& Everh.) Ciccar., coelomycetous, sexual morph unknown, saprobes, terrestrial, USA, see Wijayawardene et al. (2012, 2017; outline), Kirk et al. (2013; genus accepted), cultures and sequences are unavailable, needs generic revision.

Unisetosphaeria Pinnoi, E.B.G. Jones, McKenzie \& K.D. Hyde 2003, Trichosphaeriaceae, Trichosphaeriales, Sordariomycetes, one species, type: S. styracum Speg., asexual morph unknown, saprobes, terrestrial, Thailand, see Lumbsch and Huhndorf (2010; outline), Maharachchikumbura et al. (2015, 2016; outline), cultures and sequences are unavailable, needs generic revision.

Urceolella Boud. 1885, Hyaloscyphaceae, Helotiales, Leotiomycetes, 24 species, type: $U$. crispula (P. Karst.) Boud., asexual morph unknown, saprobes, terrestrial, worldwide, see Baral et al. (2009; new species), Lumbsch and Huhndorf (2010; outline), Kirk et al. (2013; genus accepted), Han et al. (2014; DNA, phylogeny), sequences are available for voucher TNS-F18014 of the type, needs generic revision.

Uredinophila Rossman 1987, Dothideomycetes genera incertae sedis, two species, type: $U$. tropicalis (Speg.) Rossman, asexual morph unknown, parasitic on Pucciniales on leaves of Dryopteris tetragona, Venezuela, see Lumbsch and Huhndorf (2010; outline), Kirk et al. (2013; genus accepted), Wijayawardene et al. (2014c; outline), cultures and sequences are unavailable. 
Urnula Fr. 1849, Sarcosomataceae, Pezizales, Pezizomycetes, ten species, type: U. craterium (Schwein.) Fr., asexual morph unknown, saprobes, terrestrial, Europe, North America, see Pfister et al. (2008; phylogeny), Lumbsch and Huhndorf (2010; outline), Carbone et al. (2013; new species, DNA, phylogeny), Kirk et al. (2013; genus accepted), Wang and Huang (2015; new species, DNA, phylogeny), sequences are available for voucher DHP 04-511 (FH) of the type.

Urohendersonia Speg. 1902, Ascomycota genera incertae sedis, five species, type: $U$. platensis Speg., coelomycetous, sexual morph unknown, saprobes, terrestrial, Australia, South America, India, see Wijayawardene et al. (2012, 2016b, 2017; outline, taxonomy), Kirk et al. (2013; genus accepted), cultures and sequences are unavailable, needs generic revision.

Urohendersoniella Petr. 1955, Ascomycota genera incertae sedis, one species, type: $U$. mastigospora Petr., coelomycetous, sexual morph unknown, saprobes, terrestrial, Australia, see Wijayawardene et al. (2012, 2016b, 2017; outline, taxonomy), Kirk et al. (2013; genus accepted), cultures and sequences are unavailable, needs generic revision.

Uropolystigma Maubl. 1920, Phyllachoraceae, Phyllachorales, Sordariomycetes, one species, type: U. atrotestaceum Maubl., in living leaves, Brazil, see Lumbsch and Huhndorf (2010; outline), Maharachchikumbura et al. (2015, 2016; outline), cultures and sequences are unavailable, needs generic revision.

Urosporella G.F. Atk. 1897, Clypeosphaeriacea, Xylariales, Sordariomycetes, two species, type: U. americana G.F. Atk., cosmopolitan, Lumbsch and Huhndorf (2010; outline), Kirk et al. (2013; genus accepted), Maharachchikumbura et al. (2015, 2016; outline), cultures and sequences are unavailable, needs generic revision.

Urosporellopsis W.H. Hsieh, Chi Y. Chen \& Sivan. 1994, Amphisphaeriaceae, Xylariales, Sordariomycetes, one species, type: U. taiwanensis W.H. Hsieh, Chi Y. Chen \& Sivan., asexual morph unknown, saprobes, Taiwan, Lumbsch and Huhndorf (2010; outline), Kirk et al. (2013; genus accepted), holotype IMI 354629, cultures and sequences are unavailable.

Ursicollum Gryzenh. \& M.J. Wingf. 2006, Cryphonectriaceae, Diaporthales, Sordariomycetes, one species, type: U. fallax Gryzenh. \& M.J. Wingf., coelomycetous, sexual morph unknown, pathogens, saprobes, terrestrial, USA, see Wijayawardene et al. (2012, 2017; outline), Maharachchikumbura et al. (2015, 2016; outline), holotype and ex-type cultures of type: PREM 58840, CMW $18119=$ CBS 118663.

Urupe Viégas 1944, Sordariomycetes genera incertae sedis, one species, type: U. guaduae Viégas, asexual morph unknown, saprobes, terrestrial, Central America, see Lumbsch and Huhndorf (2010; outline, accepted as a genus in Meliolaceae), Kirk et al. (2013; genus accepted), Hongsanan et al. (2015c; excluded from Meliolaceae and placed in Sordariomycetes genera incertae sedis), cultures and sequences are unavailable, needs generic revision.

Usnea Dill. ex Adans. 1763, Parmeliaceae, Lecanorales, Lecanoromycetes, c. 350 species, type: $U$. florida (L.) Weber ex Wigg., asexual morph unknown, lichenized, terrestrial, world wide, see Duman et al. (2008; usnic acid content), Hauck and Jürgens (2008; acidity tolerance), Malhotra et al. (2008; traditional medicine), Schmeda-Hirschmann et al. (2008; antifungal and antiprotozoal depside), Verma et al. (2008; antioxidant and hepatoprotective activity), Wirtz et al. (2008; ecology, cohesion approach), Behera et al. (2009; culture optimization and antioxidant), Kolanko and Matwiejuk (2009; new to Białowieża Primeval Forest), Lumbsch and Huhndorf (2010; outline), Öztürk and Güvenç (2010; records from Black Sea region of Turkey), Suetina and Glotov (2010; Ontogeny and morphogenesis), Clerc (2011, Notes), Çobanoğlu (2011, new records), Kelly et al. (2011; DNA barcoding), Lauri et al. (2011; phylogenetic relations), Li et al. (2011; biomass, diversity), Ohmura (2012; synopsis of Usnea), Schiefelbein et al. (2012; floristic), Thippeswamy et al. (2012; 
antimicrobial activity), Türkez et al. (2012; cytogenetic and biochemical study), Wirtz (2012; phylogeny), Kirk et al. (2013; accepted as a valid genus), Truong et al. (2013; molecular, species delimitation), Ohmura (2014; New to Asia), Shukla et al. (2014b; taxonomy, India), Tõrra (2014; marker characterization), Sivas (2015; antigenotoxic effect), Çobanoğlu et al. (2016; antimicrobial activity), Lücking et al. (2016b; classification), Mark et al. (2016; circumscribed species, phylogeny), Yang et al. (2016; anticancer activity), sequences are available.

Usnocetraria M.J. Lai \& J.C. Wei 2007, Parmeliaceae, Lecanorales, Lecanoromycetes, one species, type: U. oakesiana (Tuck.) M.J. Lai \& J.C. Wei, lichenized, see Thell et al. (2009, 2012; taxonomy), Lücking et al. (2016b; classification), sequences are available.

Usnochroma Søchting, Arup \& Frödén 2013, Teloschistaceae, Teloschistales, Lecanoromycetes, two species, type: U. carphineum (Fr.) Søchting, Arup \& Frödén, asexual morph unknown, lichenized, terrestrial, France, South Africa, see Arup et al. (2013; taxonomy, phylogeny), Gaya et al. (2015; DNA), Lücking et al. (2016b; classification); sequences are available. cultures available for the type: Ccar201 (fide Gaya et al. 2015).

Ustilaginoidea Bref. 1895 (= Villosiclava E. Tanaka \& C. Tanaka 2009 fide Rossman et al. 2016a), Clavicipitaceae, Hypocreales, Sordariomycetes, six species, type: U. oryzae (Pat.) Bref., hyphomycetous, sexual morph unknown, saprobes, terrestrial, subtropical, see Seifert et al. (2011; morphology), Kepler et al. (2012; DNA), Wijayawardene et al. (2012, 2017; outline), Kirk et al. (2013; genus accepted), Maharachchikumbura et al. (2015, 2016; outline), Rossman et al. (2016a; nomenclature), cultures and sequences are available.

Utriascus Réblová 2003, Sordariales genera incertae sedis, Sordariomycetes, one species, type: U. gabretae Réblová, asexual morph unknown, lichenicolous, terrestrial, Czech Republic, see Lumbsch and Huhndorf (2010; outline), Kirk et al. (2013; genus accepted), Maharachchikumbura et al. (2016; outline), cultures and sequences are unavailable, needs generic revision.

Uvarispora Goos \& Piroz. 1975, Ascomycota genera incertae sedis, one species, type: $U$. lignicola Goos \& Piroz., hyphomycetous, sexual morph unknown, saprobes, terrestrial, Central America, see Seifert et al. (2011; morphology), Wijayawardene et al. (2012, 2017; outline), Kirk et al. (2013; genus accepted), cultures and sequences are unavailable, needs generic revision.

Uwebraunia Crous \& M.J. Wingf. 1996, Dissoconiaceae, Capnodiales, Dothideomycetes, seven species, type: U. juvenis Crous \& M.J. Wingf., hyphomycetous, sexual morph unknown, saprobes, worldwide, see Seifert et al. (2011; morphology), Li et al. (2012a; phylogeny), Wijayawardene et al. (2012, 2014c, 2017; outline), Kirk et al. (2013; genus accepted), cultures and sequences are available.

Uwemyces Hern. -Restr., G.A. Sarria \& Crous 2016, Mycosphaerellaceae, Capnodiales, Dothideomycetes, one species, type: U. elaeidis Hern. -Restr., G.A. Sarria \& Crous, hyphomycetous, associated with leaf spots, terrestrial, Australia, see Crous et al. (2016b; taxonomy, phylogeny), Wijayawardene et al. (2017; outline), culture and sequences are available.

Vagicola K.W.T. Chethana \& K.D. Hyde 2015, Phaeosphaeriaceae, Pleosporales, Dothideomycetes, three species, type: V. vagans (Niessl) O. Eriksson, asexual morph unnown, saprobes, terrestrial, worldwide, see Ariyawansa et al. (2015a; taxonomy), holotype of type species UPS:BOT:F-169873, cultures and sequences are available for the type species.

Vaginatispora K.D. Hyde 1995, Lophiostomataceae, Pleosporales, Dothideomycetes, four species, type: V. aquatica K.D. Hyde, asexual morph unknown, saprobic, fresh water or terrestrial, Hong Kong, Japan, Thailand, all species have sequence data, see Kirk et al. (2013; genus accepted), Thambugala et al. (2015b; morphology, phylogeny, accepted as a genus in 
Lophiostomataceae), Wanasinghe et al. (2016; morphology, phylogeny), ex-type strains of type: MFLUCC 11-0083 = IFRDCC 2462; holotype MFLU 11-1115.

Vagnia D. Hawksw. \& Miadl. 1997, Ascomycota genera incertae sedis, one species, type: $V$. cirriformia D. Hawksw. \& Miadl., lichenicolous, Europe, terrestrial, see Kirk et al. (2013; genus accepted), culture and sequences are unavailable, holotype of type: K(M)-IMI 371358.

Vahliella P.M. Jørg. 2008, Vahliellaceae, Peltigerales, Lecanoromycetes, eight species, type: V. leucophaea (Vahl) P.M. Jørg., asexual morph unknown, lichenized, terrestrial, Europe, see Jørgensen (2008; taxonomy) Lumbsch and Huhndorf (2010; outline), Wedin and Jørgensen (2011; new species), Wedin et al. (2011; phylogeny), Perez-Vargas et al. (2014; new species), Lücking et al. (2016b; classification), cultures and sequences are available, sequences are available.

Vainionora Kalb 1991, Lecanoraceae, Lecanorales, Lecanoromycetes, nine species, type: V. pallidostraminea (Vain.) Kalb, asexual morph unknown, lichenized, terrestrial, see Lumbsch and Huhndorf (2010; outline), Papong and Lumbsch (2011; taxonomy), Menezes et al. (2011; taxonomy), Kirk et al. (2013; genus accepted), Papong et al. (2013; molecular), Lücking et al. (2016b; classification), sequences are unavailable.

Valdensia Peyronel 1923 (= Valdensinia Peyronel 1953 fide Johnston et al. 2014b), Sclerotiniaceae, Helotiales, Leotiomycetes, three species, type: V. heterodoxa Peyronel, asexual morph formerly known in Valdensinia, saprobes, terrestrial, Europe, Japan, see Lumbsch and Huhndorf (2010; outline), Nekoduka et al. (2012; pathogens, Japan), Kirk et al. (2013; genus accepted), cultures available for the type: HBI0401, needs generic revision.

Valetoniella Höhn. 1909, Niessliaceae, Hypocreales, Sordariomycetes, three species, type: V. crucipila Höhn., asexual morph unknown, saprobes, or fungicolous, terrestrial, tropics, see Lumbsch and Huhndorf (2010; outline), Maharachchikumbura et al. (2015, 2016; outline), Kirk et al. (2013; genus accepted), cultures and sequences are unavailable, needs generic revision.

Valetoniellopsis Samuels \& M.E. Barr 1998, Niessliaceae, Hypocreales, Sordariomycetes, three species, type: $V$. laxa Samuels \& M.E. Barr, asexual morph unknown, saprobes, terrestrial, North America, see Lumbsch and Huhndorf (2010; outline), Maharachchikumbura et al. (2015, 2016; outline), Kirk et al. (2013; genus accepted), cultures available for the type: CBS 191.97.

Valsalnicola D.M. Walker \& Rossman 2012, Diaporthales genera incertae sedis, Sordariomycetes, one species, type: V. oxystoma (Rehm) D. Walker \& Rossman, asexual morph dimorphic, pathogens, saprobes, terrestrial, Europe, America, see Crous et al. (2012c; taxonomy, phylogeny), Maharachchikumbura et al. (2015, 2016; outline), lectotype of the type: BPI 884138, cultures available for the type: AR4833.

Valsaria Ces. \& De Not., Comm. 2015, Valsariaceae, Valsariales, Dothideomycetes, 140 epithets, type: $V$. insitiva (Tode) Ces. \& De Not. 1863, asexual morph coelomycetous, saprobes, terrestrial, widely distributed, see Glawe (1985; sexual and asexual morphs, morphology), Ju et al. (1996), Lumbsch and Huhndorf (2010; outline), Jaklitsch et al. (2015; sexual and asexual morphs, morphology, phylogeny).

Vamsapriya Gawas \& Bhat 2006, Xylariaceae, Xylariales, Sordariomycetes, four species, type: V. indica Gawas \& Bhat 2006, hyphomycetous, saprobes, terrestrial, India, Thailand, see Gawas and Bhat (2005, morphology), Pratibha and Bhat (2008, morphology), Dai et al. (2014b; asexual morph, morphology, phylogeny, 2016; sexual morph, morphology, phylogeny), ex-epitype culture of type: MFLUCC 12-0544 = ICMP 20734.

Vanakripa Bhat, W.B. Kendr. \& Nag Raj 1993, Ascomycota genera incertae sedis, nine species, type: V. gigaspora Bhat, W.B. Kendr. \& Nag Raj, hyphomycetous, sexual morph unknown, saprobes, terrestrial, Asia, Brazil, see Arias Mota et al. (2008; new species), Hu et al. (2010a; new species, China), Mel'nik et al. (2011; new species, Vietnam), Seifert et al. 
(2011; morphology), Wijayawardene et al. (2012, 2017; outline), Kirk et al. (2013; genus accepted), Leão-Ferreira et al. (2013; new species; Brazil), cultures and sequences are unavailable, needs generic revision.

Vanbeverwijkia Agnihothr. 1961, Ascomycota genera incertae sedis, one species, type: $V$. spirospora Agnihothr., hyphomycetous, sexual morph unknown, saprobes, terrestrial, Assam, USA, see Seifert et al. (2011; morphology), Wijayawardene et al. (2012, 2017; outline), Kirk et al. (2013; genus accepted), cultures and sequences are unavailable, needs generic revision.

Vanderwaltozyma Kurtzman 2003, Saccharomycetaceae, Saccharomycetales, Saccharomycetes, two species, type: V. polyspora (van der Walt) Kurtzman, asexual reproduction is by multilateral budding, saprophytic, soil, cactus fruit, tanning fluids, worldwide, see Lumbsch and Huhndorf (2010; outline), cultures and sequences are available. Vanderystiella Henn. 1908, Ascomycota genera incertae sedis, one species, type: $V$. leopoldvilleana Henn., coelomycetous, sexual morph unknown, saprobes, terrestrial, Africa, see Wijayawardene et al. (2012, 2017; outline), Kirk et al. (2013; genus accepted), cultures and sequences are unavailable, needs generic revision.

Vanterpoolia A. Funk 1982, Ascomycota genera incertae sedis, one species, type: V. tsugae A. Funk, hyphomycetous, sexual morph unknown, saprobes, terrestrial, North America, see Seifert et al. (2011; morphology), Wijayawardene et al. (2012, 2017; outline), Kirk et al. (2013; genus accepted), cultures and sequences are unavailable, needs generic revision.

Varicellaria Nyl. 1858, Ochrolechiaceae, Pertusariales, Lecanoromycetes, seven species, type: V. microsticta Nyl., asexual morph unknown, lichenized, terrestrial, see Lumbsch and Huhndorf (2010; outline), Schmitt et al. (2012; circumscription), Kirk et al. (2013; genus accepted), Ren and Li (2013; new record), Miądlikowska et al. (2014; molecular), Lücking et al. (2016b; classification), cultures and sequences are unavailable for type.

Varicosporium W. Kegel 1906, Helotiales genera incertae sedis, Leotiomycetes, eleven species, type: V. elodeae W. Kegel, hyphomycetous, sexual morph unknown, in soil, saprobes, terrestrial, aquatic, worldwide, see Campbell et al. (2009b; phylogeny, polyphyletic), Seifert et al. (2011; morphology), Wijayawardene et al. (2012, 2017; outline), Kirk et al. (2013; genus accepted), Baschien et al. (2016; DNA, phylogeny), cultures available for the type: CBS 541.92, needs generic revision.

Variocladium Descals \& Marvanová 1998, Mollisiaceae, Helotiales, Leotiomycetes, one species, type: V. rangiferinum (Descals) Descals \& Marvanová, hyphomycetous, sexual morph unknown, saprobes, terrestrial, aquatic, temperate, see Campbell et al. (2009b; phylogeny), Seifert et al. (2011; morphology), Wijayawardene et al. (2012, 2017; outline), Kirk et al. (2013; genus accepted), cultures available for the type: CBS 508.71 (unpublished), needs generic revision.

Variospora Arup, Søchting \& Frödén 2013, Teloschistaceae, Teloschistales, Lecanoromycetes, twelve species, type: V. velana (A. Massal.) Arup, Søchting \& Frödén, asexual morph unknown, lichenized, terrestrial, Europe, North Africa, see Arup et al. (2013; taxonomy, phylogeny), Kondratyuk et al. (2014; DNA), Gaya et al. (2015; DNA, phylogeny), Lücking et al. (2016b; classification); cultures available for the type: Cavel192, sequences are available.

Vasudevella Chona, Munjal \& Bajaj 1957, Ascomycota genera incertae sedis, one species, type: V. sporoboli Chona, Munjal \& Bajaj, coelomycetous, sexual morph unknown, saprobes, terrestrial, India, see Wijayawardene et al. (2012, 2017; outline), Kirk et al. (2013; genus accepted), cultures and sequences are unavailable, needs generic revision.

Velloziomyces Armando, Z.M. Chaves \& Dianese 2015, Ascomycota genera incertae sedis, one species, type: V. ramosiconidialis Armando, Z.M. Chaves \& Dianese, hyphomycetous, sexual morph unknown, on living leaves, terrestrial, Brazil, see de Souza Armando et al. 
(2015; morphology), holotype of the type: UBMC 8849, cultures and sequences are unavailable, compare with Dictyodochium, Minimidochium and Iyengarina.

Velutaria Fuckel 1870, Pezizellaceae, Helotiales, Leotiomycetes, one species, type: V. griseovitellina (Fuckel) Fuckel, asexual morph unknown, saprobes, terrestrial, Europe, see Lumbsch and Huhndorf (2010; outline), Kirk et al. (2013; genus accepted), Jaklitsch et al. (2016a; classification), cultures and sequences are unavailable, needs generic revision.

Velutarina Korf 1971, Cenangiaceae, Helotiales, Leotiomycetes, three species, type: V. rufoolivacea (Alb. \& Schwein.) Korf, asexual morph unknown, saprobes, terrestrial, Europe, see Lumbsch and Huhndorf (2010; outline), Kirk et al. (2013; genus accepted), Perić et al. (2015; new species), Jaklitsch et al. (2016a; classification), Pärtel et al. (2017; DNA, phylogeny), cultures and sequences are available.

Velutipila D. Hawksw. 1987, Ascomycota genera incertae sedis, one species, type: V. poeltii D. Hawksw., algicolous, terrestrial, Europe, hyphomycetous, sexual morph unknown, see Seifert et al. (2011; genus accepted), Wijayawardene et al. (2012, 2017; outline), Kirk et al. (2103; genus accepted), cultures and sequences are unavailable, needs generic revision, holotype of type: K(M)-IMI 309488.

Ventrographium H.P. Upadhyay, Cavalc. \& A.A. Silva 1986, Ascomycota genera incertae sedis, one species, type: $V$. nervicola H.P. Upadhyay, Cavalc. \& A.A. Silva, hyphomycetous, sexual morph unknown, saprobes, terrestrial, South America, see Seifert et al. (2011; morphology), Wijayawardene et al. (2012, 2017; outline), Kirk et al. (2013; genus accepted), cultures and sequences are unavailable, needs generic revision.

Venturia Sacc. 1882 (= Fusicladium Bonord. 1851; = Pollaccia E. Bald. \& Cif. 1937; = Pseudocladosporium U. Braun 1998 fide Rossman et al. 2015b), Venturiaceae, Venturiales, Dothideomycetes, c. 60 species, type: V. inaequalis (Cooke) G. Winter, asexual morph hyphomycetous, worldwide, see Schoch et al. (2009; phylogeny), Lumbsch and Huhndorf (2010; outline), Zhang et al. (2011d; phylogeny), Hyde et al. (2013; taxonomy), Kirk et al. (2013; genus accepted), Rossman et al. (2015b; nomenclature), cultures and sequences are available.

Venturiocistella Raitv. 1979, Hyaloscyphaceae, Helotiales, Leotiomycetes, seven species, type: V. venturioides (Sacc. \& Roum.) Raitv., asexual morph unknown, saprobes, terrestrial, worldwide, see Lumbsch and Huhndorf (2010; outline), Hosoya et al. (2011; taxonomy, DNA, phylogeny), Kirk et al. (2013; genus accepted), cultures and sequences are available but lacks for the type, needs generic revision.

Venustocephala Matsush. 1995, Ascomycota genera incertae sedis, two species, type: $V$. aequatorialis Matsush., hyphomycetous, sexual morph unknown, saprobes, terrestrial, Neotropics, see Seifert et al. (2011; morphology), Wijayawardene et al. (2012, 2017; outline), Kirk et al. (2013; genus accepted), cultures and sequences are unavailable, needs generic revision.

Venustosynnema R.F. Castañeda \& W.B. Kendr. 1990, Ascomycota genera incertae sedis, three species, type: V. ciliatum (R.F. Castañeda, G.R.W. Arnold \& A.G. Guerra) R.F. Castañeda \& W.B. Kendr., hyphomycetous, sexual morph unknown, saprobes, terrestrial, Caribbean, Taiwan, see Castañeda-Ruiz et al. (2009b; new species),Seifert et al. (2011; morphology), Wijayawardene et al. (2012, 2017; outline), Kirk et al. (2013; genus accepted), Kirschner and Liu (2014; new species, Taiwan), cultures and sequences are unavailable, needs generic revision.

Veracruzomyces Mercado, Guarro, Heredia \& J. Mena 2002, Ascomycota genera incertae sedis, one species, type: V. obclavatus Mercado, Guarro, Heredia \& J. Mena, hyphomycetous, sexual morph unknown, fungicolous, terrestrial, North America, see Seifert et al. (2011; morphology), Wijayawardene et al. (2012, 2017; outline), cultures and sequences are unavailable, needs generic revision. 
Veramycella G. Delgado 2009, Ascomycota genera incertae sedis, one species, type: V. bispora G. Delgado, hyphomycetous, sexual morph unknown, saprobes, terrestrial, North America, see Seifert et al. (2011; morphology), Wijayawardene et al. (2012, 2017; outline), cultures and sequences are unavailable, needs generic revision.

Veramyces Matsush. 1993, Ascomycota genera incertae sedis, one species, type: $V$. manuensis Matsush., hyphomycetous, sexual morph unknown, saprobes, terrestrial, South America, see Seifert et al. (2011; morphology), Wijayawardene et al. (2012, 2017; outline), Kirk et al. (2013; genus accepted), cultures and sequences are unavailable, needs generic revision.

Verdipulvinus A.W. Ramaley 1999, Ascomycota genera incertae sedis, one species, type: $V$. nolinae A.W. Ramaley, hyphomycetous, sexual morph unknown, saprobes, terrestrial, North America, see Seifert et al. (2011; morphology), Wijayawardene et al. (2012, 2017; outline), Kirk et al. (2013; genus accepted), cultures and sequences are unavailable, needs generic revision.

Vermiconia Egidi \& Onofri 2014, Extremaceae, Capnodiales, Dothideomycetes genera incertae saedis, four species, type: V. foris D. Isola \& L. Selbmann, hyphomycetous, sexual morph unknown, rock-inhabiting fungus, see Egidi et al. (2014; taxonomy), Quaedvlieg et al. (2014; phylogeny), Isola et al. (2016; new species, phylogeny), Wijayawardene et al. (2017; outline), cultures available for the type: CBS $136106=$ CCFEE 5459.

Vermiculariopsiella Bender 1932, Microascales genera incertae sedis, Sordariomycetes, 19 species, type: $V$. immersa (Desm.) Bender, hyphomycetous, sexual morph unknown, saprobes, worldwide, see Dhargalkar and Bhat (2009; new species), Seifert et al. (2011; morphology), Wijayawardene et al. (2012, 2017; outline), Hernández-Restrepo et al. (2012a; new species), Kirk et al. (2013; genus accepted), Dubey and Moonambeth (2014b; new species), Crous et al. (2016b; new species, phylogeny), cultures and sequence available but lack for the type, generic placement is based on non-type, needs generic revision.

Vermispora Deighton \& Piroz. 1972, Orbiliaceae, Orbiliales, Orbiliomycetes, seven species, type: $V$. grandispora Deighton \& Piroz., hyphomycetous, sexual morph unknown, fungicolous, nematode cysts, in soil, terrestrial, Africa, Asia, Europe, North America, see Seifert et al. (2011; morphology), Wijayawardene et al. (2012, 2017; outline), Kirk et al. (2013; genus accepted), cultures and sequences are available but lacks for the type, needs generic revision.

Veronaea Cif. \& Montemart. 1957, Herpotrichiellaceae, Chaetothyriales, Eurotiomycetes, 21 species, type: V. botryosa Cif. \& Montemart., hyphomycetous, sexual morph unknown, saprobes, fungicolous, on dung, on soil, worldwide, see Soares, and Barreto (2008; new species), Chlebicki (2009a; new species), Pan et al. (2009; new species, China), de Hoog et al. (2011; DNA), Seifert et al. (2011; morphology), Wijayawardene et al. (2012, 2017; outline), Kirk et al. (2013; genus accepted), cultures available for the type: CBS 254.57.

Veronaella Subram. \& K.R.C. Reddy 1975, Ascomycota genera incertae sedis, one species, type: V. indica Subram. \& K.R.C. Reddy, coelomycetous, sexual morph unknown, saprobes, terrestrial, India, see Wijayawardene et al. (2012, 2017; outline), Kirk et al. (2013; genus accepted), cultures and sequences are unavailable, needs generic revision.

Veronaeopsis Arzanlou \& Crous 2007, Sympoventuriaceae, Venturiales, Dothideomycetes, one species, type: V. simplex (Papendorf) Arzanlou \& Crous, hyphomycetous, sexual morph unknown, saprobes, terrestrial, South Africa, see Seifert et al. (2011; morphology), Zhang et al. (2011d; accepted as a genus in Sympoventuriaceae), Wijayawardene et al. (2012, 2014c, 2017; outline), Hyde et al. (2013; accepted as a genus in Sympoventuriaceae), Samerpitak et al. (2014; phylogeny), holotype and ex-type culture of the type: CBS H-7810, CBS 588.66 = IMI 203547. 
Veronaia Benedek 1961, Eurotiomycetidae genera incertae sedis, Eurotiomycetes, two species, type: $V$. castellanii Benedek, asexual morph unknown, saprobes, terrestrial, worldwide, see Lumbsch and Huhndorf (2010; outline), Kirk et al. (2013; genus accepted), cultures and sequences are unavailable, needs generic revision.

Veronidia Negru 1964, Ascomycota genera incertae sedis, one species, type: $V$. oxycocci Negru, coelomycetous, sexual morph unknown, saprobes, terrestrial, Rumania, see Wijayawardene et al. (2012, 2017; outline), Kirk et al. (2013; genus accepted), cultures and sequences are unavailable, needs generic revision.

Verpa Sw. 1815, Morchellaceae, Pezizales, Pezizomycetes, five species, type: V. conica (O.F. Müll.) Sw., asexual morph unknown, saprobes, terrestrial, north temperate, see Lumbsch and Huhndorf (2010; outline), Kirk et al. (2013; genus accepted), Osmundson et al. (2013; DNA), cultures available for type: AFTOL-ID 74 (unpublished).

Verrucaria Schrad. [nom. cons.] 1794, Verrucariaceae, Verrucariales, Eurotiomycetes, 300 species, type: V. rupestris Schrad., lichenized, see Lumbsch and Huhndorf (2010; outline), Kirk et al. (2013; genus accepted), Lücking et al. (2016b; classification), sequences are available, needs generic revision.

Verrucariella S. Ahmad 1967, Ascomycota genera incertae sedis, one species, type: V. capparicola S. Ahmad, coelomycetous, sexual morph unknown, saprobes, terrestrial, Pakistan, see Wijayawardene et al. (2012, 2017; outline), Kirk et al. (2013; genus accepted), cultures and sequences are unavailable, needs generic revision.

Verrucocladosporium K. Schub., Crous \& Aptroot 2007, Cladosporiaceae, Capnodiales, Dothideomycetes, two species, type: V. dirinae K. Schub., Crous \& Aptroot, hyphomycetous, sexual morph unknown, lichenicolous, terrestrial, temperate, see Braun et al. (2009; new species), Seifert et al. (2011; morphology), Wijayawardene et al. (2012, 2014c, 2017; outline), Zhurbenko et al. (2015c; new species), holotype and available cultures of the type: CBS H19883, CBS 112794.

Verrucoconiothyrium Crous 2015, Didymosphaeriaceae, Pleosporales, Dothideomycetes, one species, type: $V$. nitidae (Crous \& Denman) Crous, coelomycetous, sexual morph unknown, saprobes, Germany, see Crous et al. (2015c; taxonomy, phylogeny), Wijayawardene et al. (2016b, 2017; outline, phylogeny), holotype of the type species PREM 55346.

Verruconis Samerp., H.J. Choi, Van den Ende, Horré \& de Hoog 2013, Sympoventuriaceae, Venturiales, Dothideomycetes, one species, type: V. gallopava (W.B. Cooke) Samerpitak \& de Hoog, hyphomycetous, sexual morph unknown, saprobes, human pathogen, terrestrial, South Africa, see Giraldo et al. (2014b; phylogeny), Samerpitak et al. (2014, 2016; phylogeny, barcoding), Seyedmousavi et al. (2014; antifungal susceptibility), Wijayawardene et al. (2014c, 2017; outline), Geltner et al. (2015; Necrotizing mycosis), ex-type cultures of the type: CBS 437.64= MUCL 6683=IFM 52605.

Verrucophragmia Crous, M.J. Wingf. \& W.B. Kendr. 1994, Ascomycota genera incertae sedis, one species, type: V. splendens Crous, M.J. Wingf. \& W.B. Kendr., hyphomycetous, sexual morph unknown, saprobes, terrestrial, Africa, see Seifert et al. (2011; morphology), Wijayawardene et al. (2012, 2017; outline), Kirk et al. (2013; genus accepted), holotype of the type: PREM 51441, cultures and sequences are unavailable, needs generic revision.

Verrucoplaca S.Y. Kondr., Kärnefelt, Elix, A. Thell \& J.S. Hur 2014, Teloschistaceae, Teloschistales, Lecanoromycetes, one species, type: V. verruculifera (Vain.) S.Y. Kondr., Kärnefelt, Elix, A. Thell, J. Kim, M.-H. Jeong, N.N. Yu, A.S. Kondratiuk \& J.S. Hur, asexual morph unknown, lichenized, terrestrial, Europe, see Kondratyuk et al. (2014; taxonomy, DNA), Gaya et al. (2015; DNA, phylogeny), cultures and sequences are unavailable, needs generic revision. 
Verrucostoma Hirooka, Tak. Kobay. \& P. Chaverri 2010, Bionectriaceae, Hypocreales, Sordariomycetes, two species, type: V. freycinetiae Hirooka, Tak. Kobay. \& P. Chaverri, asexual morph acremonium-like, saprobes, terrestrial, tropical, see Hirooka et al. (2010; taxonomy), Crous et al. (2015d; new specie), Maharachchikumbura et al. (2015, 2016; outline), holotype of the type: BPI 878948, cultures and sequences are available.

Verruculina Kohlm. \& Volkm.-Kohlm. 1990, Testudinaceae, Pleosporales, Dothideomycetes, one species, type: V. enalia (Kohlm.) Kohlm. \& Volkm.-Kohlm., asexual morph unknown, saprobes, marine, Liberia, see Suetrong et al. (2009; DNA, phylogeny), Lumbsch and Huhndorf (2010; outline, accepted as a genus in Didymosphaeriaceae), Hyde et al. (2013; accepted as a genus in Testudinaceae), Kirk et al. (2013; genus accepted), Jones et al. (2015; outline, marine), cultures available for the type: BCC 18402.

Verruculopsis Gueidan, Nav.-Ros. \& Cl. Roux 2007, Verrucariaceae, Verrucariales, Eurotiomycetes, six species, type: V. poeltiana (Clauzade \& Cl. Roux) Gueidan, Nav.-Ros. \& Cl. Roux, asexual morph unknown, lichenized, lichenicolous, terrestrial, Europe, see Lumbsch and Huhndorf (2010; outline), Krzewicka (2012; new species, Poland), Kukwa and Pérez-Ortega (2012; phylogeny), Lücking et al. (2016b; classification); sequences are available,.cultures available for the type: AFTOL-ID 2298, needs generic revision.

Versicolorisporium Sat. Hatak., Kaz. Tanaka \& Y. Harada 2008, Occultibambusaceae, Pleosporales, Dothideomycetes, one species, type: V. triseptatum Sat. Hatak., Kaz. Tanaka \& Y. Harada, coelomycetous, saprobes, terrestrial, Asia, see Wijayawardene et al. (2012, 2016b, 2017; outline, morphology), Dai et al. (2016; phylogeny, morphology, sexual and asexual morphs), ex-type culture of type: MFLUCC 11-0179.

Vertexicola K.D. Hyde, Ranghoo \& S.W. Wong 2000, Annulatascaceae, Annulatascales, Sordariomycetidae, two species, type: V. caudatus K.D. Hyde, S.W. Wong \& Ranghoo, asexual morph unknown, saprobes, fresh water, terrestrial, Philippines, Hong Kong, Costa Rica, see Lumbsch and Huhndorf (2010; outline), Barbosa et al. (2013; new species, Costa Rica), Maharachchikumbura et al. (2016; outline), holotype of the type: HKU (M) 3108, cultures and sequences are available but lacks for the type, needs generic revision.

Verticicladus Matsush. 1993, Ascomycota genera incertae sedis, three species, type: V. amazonensis Matsush.., hyphomycetous, sexual morph unknown, saprobes, terrestrial, aquatic, Africa, South America, see Seifert et al. (2011; morphology), Wijayawardene et al. (2012, 2017; outline), Kirk et al. (2013; genus accepted), Guo et al. (2015; new species), cultures and sequences are unavailable, needs generic revision.

Verticillium Nees 1816, Plectosphaerellaceae, Glomerellales, Sordariomycetes, c. 20 species (in strict sense), type: V. dahliae Kleb., hyphomycetous, Hyde et al. (2011; outline), Seifert et al. (2011; morphology), Wijayawardene et al. (2012, 2017; outline), Kirk et al. (2013; genus accepted), Maharachchikumbura et al. (2015, 2016; outline), cultures available for type species ATCC 16535.

Verticimonosporium Matsush. 1971, Hypocreaceae, Hypocreales, Sordariomycetes, two species, type: $V$. diffractum Matsush., hyphomycetous, sexual morph unknown, saprobes, terrestrial, Asia, North and South America, see Seifert et al. (2011; morphology), Kirk et al. (2013; genus accepted), Wijayawardene et al. (2017; outline), cultures available for the type: NRRL 26545, needs generic revision.

Vesicladiella Crous \& M.J. Wingf. 1994, Ascomycota genera incertae sedis, two species, type: V. capitata (B. Sutton) Crous \& M.J. Wingf., hyphomycetous, sexual morph unknown, saprobes, Australia, see Seifert et al. (2011; morphology), Kirk et al. (2013; genus accepted), Wijayawardene et al. (2017; outline), holotype of type: IMI163277a.

Vesiculohyphomyces Armando, Pereira-Carv. \& Dianese 2009, Ascomycota genera incertae sedis, one species, type: V. cerradensis Armando, Pereira-Carv. \& Dianese, hyphomycetous, sexual morph unknown, saprobes, terrestrial, South America, see Pereira-Carvalho et al. 
(2009b; taxonomy), Seifert et al. (2011; morphology), Wijayawardene et al. (2012, 2017; outline), Kirk et al. (2013; genus accepted), holotype of the type: UB (Mycol. Col.) 14595, cultures and sequences are unavailable, needs generic revision.

Vestergrenia Rehm 1901, Botryosphaeriaceae, Botryosphaeriales, Dothideomycetes, 13 species, type: V. nervisequia Rehm, asexual morph unknown, saprobes, terrestrial, worldwide, see Lumbsch and Huhndorf (2010; outline, accepted as a genus in Dothideaceae), Kirk et al. (2013; genus accepted), Hyde et al. (2013; accepted as a genus in Botryosphaeriaceae), Wijayawardene et al. (2014c; outline), cultures and sequences are unavailable.

Vestergrenopsis Gyeln. 1940, Koerberiaceae, Peltigerales, Lecanoromycetes, two species, type: V. elaeina (Wahlenb. ex Ach.) Gyeln., asexual morph unknown, lichenized, terrestrial, worldwide, see Lumbsch and Huhndorf (2010; outline), Kirk et al. (2013; genus accepted), Spribille and Muggia (2013; new species, DNA, phylogeny), sequences are available for voucher Spribille 24525 (KLGO) of the type, Lücking et al. (2016b; classification), sequences are available.

Vestigium Piroz. \& Shoemaker 1972, Ascomycota genera incertae sedis, two species, type: $V$. felicis Piroz. \& Shoemaker, coelomycetous, sexual morph unknown, saprobes, aquatic, cosmopolitan, see Wijayawardene et al. (2012, 2017; outline), Kirk et al. (2013; genus accepted), Shoemaker et al. (2013; new species), cultures and sequences are available, needs generic revision.

Vezdaea Tscherm.-Woess \& Poelt 1976, Vezdaeaceae, Vezdaeales, Ascomycota orders incertae sedis, twelve species, type: V. aestivalis (Ohlert) Tscherm.-Woess \& Poelt, asexual morph unknown, lichenized, saprobes, Europe, see Czarnota and Kukwa (2009; Poland), Lumbsch et al. (2009a; DNA, phylogeny), Lumbsch and Huhndorf (2010; outline), Kirk et al. (2013; genus accepted), Lücking et al. (2016b; classification) cultures and sequences are available, needs generic revision.

Vialaea Sacc. 1896, Vialaeaceae, Xylariales, Sordariomycetes, three species, type: V. insculpta (Fr.) Sacc., asexual morph unknown, saprobes, terrestrial, worldwide, see Lumbsch and Huhndorf (2010; outline), Senanayake et al. (2014; new species), Maharachchikumbura et al. (2015, 2016; outline, phylogeny), cultures available for the type: AFTOL-ID:1302.

Vibrissea Fr. 1822 (= Anavirga B. Sutton 1975 fide Johnston et al. 2014b), Vibrisseaceae, Helotiales, Leotiomycetes, 34 species, type: V. truncorum (Alb. \& Schwein.) Fr., asexual morph formerly known in Anavirga, saprobes, aquatic or semiaquatic, worldwide, see Grünig et al. (2009; DNA, phylogeny), Lumbsch and Huhndorf (2010; outline), Hustad and Miller (2011b; DNA, phylogeny), Raja et al. (2011a; DNA, phylogeny), Kirk et al. (2013; genus accepted), Johnston et al. (2014b; nomenclature), cultures available for the type: CBS 143.92. Viegasella Inácio \& P.F. Cannon 2003, Parmulariaceae, Dothideomycetes genera incertae sedis, one species, type: $V$. pulchella (Speg.) Inácio \& P.F. Cannon, asexual morph unknown, saprobes, terrestrial, Brazil, see Lumbsch and Huhndorf (2010; outline, listed as Viegasiella), Hyde et al. (2013; accepted as a genus in Parmulariaceae), Wijayawardene et al. (2014c; outline), holotype of type: LPS, cultures and sequences are unavailable, needs generic revision.

Vigneronia Ertz 2015, Roccellaceae, Arthoniales, Arthoniomycetes, three species, type: V. spieri (Aptroot \& Sparrius) Ertz \& Bungartz, sexual morph with lirelliform ascomata, lichenized, terrestrial, neotropical, see Ertz et al. (2015b, c; morphology, phylogeny); Lücking et al. (2016b; classification); sequences are available, holotype and ex-type strain of the type: Aptroot 65014 (CDS31595).

Vikalpa D'souza, Boonmee, Bhat \& K.D. Hyde 2016, Dictyosporiaceae, Pleosporales, Dothideomycetes, three species, type: V. australiense (B. Sutton) D'souza, Boonmee \& K.D. Hyde, hyphomycetous, sexual morph unknown, saprobes, Thailand, China, see Boonmee et 
al. (2016; phylogeny), Wijayawardene et al. (2017; outline), holotype: HKAS 83979, cultures and sequences are available.

Villophora Søchting, Arup \& Frödén 2013, Teloschistaceae, Teloschistales, Lecanoromycetes, two species, type: V. isidioclada (Zahlbr.) Søchting, Frödén \& Arup, asexual morph unknown, lichenized, saxicolous or epiphytic, terrestrial, southern hemisphere, see Arup et al. (2013; taxonomy, phylogeny), Kondratyuk et al. (2015c; new species, DNA, phylogeny), Lücking et al. (2016b; classification); sequence available for the type: KC179325 (ITS) (fide Arup et al. 2013).

Violella T.Sprib. 2011, Tephromelataceae, Lecanorales, Lecanoromycetes, two species, type: V. fucata (Stirt.) T. Sprib., lichenized, see Spribille et al. (2011; taxonomy), Lücking et al. (2016b; classification), sequences are available.

Virgaria Nees 1816 (= Ascovirgaria J.D. Rogers \& Y.M. Ju 2002 fide Réblová et al. 2016c), Xylariaceae, Xylariales, Sordariomycetes, 16 species, type: V. nigra (Link) Nees, sexual morph formerly known in Ascovirgaria, saprobes, terrestrial, Africa, Australia, Europe, Japan, North America, see Seifert et al. (2011; morphology), Wijayawardene et al. (2012, 2017; outline), Kirk et al. (2013; genus accepted), Nonaka et al. (2013a; new species, Japan, DNA), Maharachchikumbura et al. (2015, 2016; outline), Réblová et al. (2016c; nomenclature), cultures available for the type: NBRC 9453.

Virgariella S. Hughes 1953, Ascomycota genera incertae sedis, eleven species, type: $V$. globigera (Sacc. \& Ellis) S. Hughes, hyphomycetous, sexual morph unknown, saprobes, terrestrial, Asia, Caribbean, Europe, North America, see Seifert et al. (2011; morphology), Wijayawardene et al. (2012, 2017; outline), Kirk et al. (2013; genus accepted), cultures and sequences are unavailable, needs generic revision.

Virgatospora Finley 1967, Stachybotriaceae, Hypocreales, Sordariomycetes, one species, type: V. echinofibrosa Finley, hyphomycetous, sexual morph unknown, saprobes, terrestrial, pantropical, see Seifert et al. (2011; morphology), Lombard et al. (2016; phylogeny), Wijayawardene et al. (2017; outline), culture available for the type: CBS.

Virgella Darker 1967, Rhytismataceae, Rhytismatales, Leotiomycetes, one species, type: V. robusta (Tubeuf) Darker, asexual morph unknown, saprobes, terrestrial, North America, see Lumbsch and Huhndorf (2010; outline), Kirk et al. (2013; genus accepted), cultures and sequences are unavailable.

Viridiannula Etayo 2002, Ascomycota genera incertae sedis, one species, type: $V$. pertusariae Etayo, coelomycetous, sexual morph unknown, parasymbiont, terrestrial, Spain, see Wijayawardene et al. (2012, 2017; outline), cultures and sequences are unavailable, needs revision, holotype of the type: hb. Etayo, Etayo 14496.

Viridothelium Lücking, M.P. Nelsen \& Aptroot 2016, Trypetheliaceae, Trypetheliales, Dothideomycetes, ten species, type: V. virens (Tuck. ex Michener) Lücking, M.P. Nelsen \&Aptrootasexual morph unknown, lichenized fungi, terrestrial, tropical, see Aptroot and Lücking (2016; taxonomy), Lücking et al. (2016b, c; classification), sequences are available.

Vishnumyces Hosag. 2010, Dothideomycetes genera incertae sedis, one species, type: V, otonephelii Hosag. \& Harish, saprobes, terrestrial, South America, see Lumbsch and Huhndorf (2010; outline, accepted as a genus in Asterinaceae), Hosagoudar and Harish (2010; taxonomy, accepted as a genus in Asterinaceae), Hyde et al. (2013) and Hongsanan et al. (2014c) did not treat as a genus in Asterinaceae, Wijayawardene et al. (2014c; outline), cultures and sequences are unavailable, needs generic revision.

Vismaya V.V. Sarma \& K.D. Hyde 2001, Diaporthales genera incertae sedis, one species, type: V. chaturbeeja V.V. Sarma \& K.D. Hyde, asexual morph unknown, saprobes, terrestrial, Hong Kong, see Lumbsch and Huhndorf (2010; outline, listed as Vismya), Maharachchikumbura et al. (2015, 2017; outline), lectotype of the type: HKU (M) 12457, cultures and sequences are unavailable, needs generic revision. 
Vitreostroma P.F. Cannon 1991, Phyllachoraceae, Phyllachorales, Sordariomycetes, one species, type: V. desmodii (Henn.) P.F. Cannon, in living leaves, montane paleotropics, see Lumbsch and Huhndorf (2010; outline), Kirk et al. (2013; genus accepted), Maharachchikumbura et al. (2015, 2017; outline), cultures and sequences are unavailable, needs generic revision.

Vittalia Gawas \& Bhat 2007, Ascomycota genera incertae sedis, one species, type: $V$. indica Gawas \& Bhat, hyphomycetous, sexual morph unknown, saprobes, terrestrial, India, see Seifert et al. (2011; morphology), Wijayawardene et al. (2012, 2017; outline), cultures and sequences are unavailable, needs generic revision.

Vittatispora P. Chaudhary, J. Campb., D. Hawksw. \& K.N. Sastry 2006, Ceratostomataceae, Melanosporales, Sordariomycetes, one species, type: V. coorgii P. Chaudhary, J. Campb., D. Hawksw. \& K.N. Sastry, asexual morph unknown, saprobes, terrestrial, India, see Lumbsch and Huhndorf (2010; outline), Kirk et al. (2013; genus accepted), Maharachchikumbura et al. (2015, 2016; outline, phylogeny), cultures available for the type: BICC 7817.

Vivantia J.D. Rogers, Y.M. Ju \& Cand. 1996, Graphostromataceae, Xylariales, Sordariomycetes, one species, type: V. guadalupensis J.D. Rogers, Y.M. Ju \& Cand., asexual morph hyphomycetous, terrestrial, saprobes, Guadeloupe, see Lumbsch and Huhndorf (2010; outline), Kirk et al. (2013; genus accepted), Maharachchikumbura et al. (2015, 2016; outline), Wendt et al. (2017; trnsferred to Graphostromataceae), cultures and sequences are unavailable.

Vizella Sacc. 1883, Vizellaceae, Dothideomycetes genera incertae sedis, eleven species, type: $V$. conferta (Cooke) Sacc., asexual morph unknown, saprobes, terrestrial, tropical, see Lumbsch and Huhndorf (2010; outline), Hyde et al. (2013; accepted as a genus in Vizellaceae), Wijayawardene et al. (2014c; outline), cultures and sequences are unavailable, needs generic revision.

Vizellopsis Bat., J.L. Bezerra \& T.T. Barros 1969, Asterinaceae, Asterinales, Dothideomycetes, one species, type: V. grevilleae Bat., J.L. Bezerra \& T.T. Barros, asexual morph unknown, foliar epiphytes, terrestrial, New Caledonia, see Lumbsch and Huhndorf (2010; outline, accepted as Dothideomycetes genera incertae sedis), Kirk et al. (2013; genus accepted), Dai et al. (2014a; accepted as a genus in Asterinaceae based on morphology), Hongsanan et al. (2014c; taxonomy, accepted as a genus in Asterinaceae), Wijayawardene et al. (2014c; 2017; outline), cultures and sequences are unavailable, needs generic revision.

Vladracula P.F. Cannon, Minter \& Kamal 1986, Rhytismataceae, Rhytismatales, Leotiomycetes, two species, type: V. annuliformis (Syd., P. Syd. \& E.J. Butler) P.F. Cannon, Minter \& Kamal, asexual morph unknown, saprobes, terrestrial, Asia, see Lumbsch and Huhndorf (2010; outline), Kirk et al. (2013; genus accepted), cultures and sequences are unavailable.

Vleugelia J. Reid \& C. Booth 1969, Sordariomycetes genera incertae sedis, one species, type: $V$. betulina (Bubák \& Vleugel) J. Reid \& C. Booth, asexual morph unknown, saprobes, terrestrial, Sweden, see Lumbsch and Huhndorf (2010; outline), Kirk et al. (2013; genus accepted), Maharachchikumbura et al. (2015, 2016; outline), cultures and sequences are unavailable, needs generic revision.

Volkartia Maire 1907, Protomycetaceae, Taphrinales, Taphrinomycetes, one species, type: $V$. rhaetica (Volkart) Maire, asexual reproduction is unknown, plant parasite, parasitic on species of Asteraceae, Europe, see Lumbsch and Huhndorf (2010; outline), Kirk et al. (2013; genus accepted), cultures and sequences are unavailable.

Volutella Fr. 1832 (= Volutellonectria J. Luo \& W.Y. Zhuang fide Rossman et al. 2016a), Nectriaceae, Hypocreales, Sordariomycetes, c. 25 species, type: V. ciliata (Alb. \& Schwein.) Fr., hyphomycetous, sexual morph formerly known in Volutellonectria, saprobes, terrestrial, widespread, see Seifert et al. (2011; morphology), Gräfenhan et al. (2011, morphology, 
phylogeny), Hyde et al. (2011; outline), Kirk et al. (2013; genus accepted), Maharachchikumbura et al. (2016; outline), Rossman et al. (2016a; nomenclature), cultures available for type: WBS025, YIMPH30011, GJS 85.205, DAOM 226718, CBS 483.61.

Vonarxella Bat., J.L. Bezerra \& Peres 1965, Saccardiaceae, Ascomycota families incertae sedis, one species, type: V. dipterygis Bat., J.L. Bezerra \& Peres, asexual morph unknown, saprobes, Brazil, see Lumbsch and Huhndorf (2010; outline), Kirk et al. (2013; genus accepted), cultures and sequences are unavailable, needs generic revision.

Vonarxia Bat. 1960, Chaetothyriaceae, Chaetothyriales, Eurotiomycetes, one species, type: $V$. anacardii Bat. \& J.L. Bezerra, hyphomycetous, sexual morph unknown, saprobes, terrestrial, Brazil, see Crous et al. (2009a; DNA, phylogeny, treated as hyphomycetous-i.e. with sporodochial conidioma), Seifert et al. (2011; treated as coelomycetous), Wijayawardene et al. (2012, 2017; outline), Kirk et al. (2013; genus accepted), cultures and sequences are available, needs generic revision.

Vouauxiella Petr. \& Syd. 1927, Ascomycota genera incertae sedis, five species, type: V. verrucosa (Vouaux) Petr. \& Syd., coelomycetous, sexual morph unknown, lichenicolous, terrestrial, Europe, South America, see Wijayawardene et al. (2012, 2017; outline, taxonomy), Kirk et al. (2013; genus accepted), cultures and sequences are unavailable, needs generic revision.

Vrystaatia Quaedvl., W.J. Swart, Verkley \& Crous 2013, Phaeosphaeriaceae, Pleosporales, Dothideomycetes, one species, type: V. aloeicola Quaedvlieg, Verkley, W.J. Swart \& Crous coelomycetous, sexual morph unknown, pathogenic, terrestrial, South Africa, see Quaedvlieg et al. (2013; morphology, phylogeny), ex-type strains of type: CBS 135107, holotype of type: CBS H-21313.

Vulpicida J.-E. Mattsson \& M.J. Lai 1993, Parmeliaceae, Lecanorales, Lecanoromycetes, six species, type: V. juniperinus (L.) J.-E. Mattsson \& M.J. Lai, asexual morph unknown, lichenized, terrestrial, see Lumbsch and Huhndorf (2010; outline), Kowalski et al. (2011; bioactivity study), Kristiina et al. (2012; molecular), Mark et al. (2012; molecular), Kirk et al. (2013; genus accepted), Kubiak and Guzow (2014; taxonomy), Saag et al. (2014; phylogeny), Lücking et al. (2016b; classification), sequences are available.

Wadeana Coppins \& P. James 1978, Ascomycota genera incertae sedis, two species, type: W. dendrographa (Nyl.) Coppins \& P. James, asexual morph unknown, lichenized, terrestrial, Europe, see Lumbsch and Huhndorf (2010; outline), Kirk et al. (2013; genus accepted), Lücking et al. (2016b; classification); sequences unavailable.

Wahlenbergiella Gueidan \& Thüs 2009, Verrucariaceae, Verrucariales, Eurotiomycetes, three species, type: W. mucosa (Wahlenb.) Gueidan \& Thüs, asexual morph unknown, lichenized, terrestrial, Europe, see Gueidan et al. (2009, 2011; taxonomy), Lumbsch and Huhndorf (2010; outline), Shivarov et al. (2013; new records, Bulgaria), Higgins et al. (2015; factors in distributing), Lücking et al. (2016b; classification), sequences are available, cultures available for the type: AFTOL-ID 2264.

Waihonghopes Yanna \& K.D. Hyde 2002, Ascomycota genera incertae sedis, one species, type: W. australiensis Yanna \& K.D. Hyde, hyphomycetous, sexual morph unknown, saprobes, terrestrial, Australasia, see Seifert et al. (2011; morphology), Wijayawardene et al. (2012, 2017; outline), cultures and sequences are unavailable, needs generic revision.

Wallrothiella Sacc. 1882, Amplistromataceae, Amplistromatales, Sordariomycetes, ten species, type: W. congregata (Wallr.) Sacc., asexual morph unknown, saprobes, terrestrial, worldwide, see Huhndorf et al. (2009; DNA, phylogeny), Lumbsch and Huhndorf (2010; outline), Kirk et al. (2013; genus accepted), Maharachchikumbura et al. (2015, 2016; outline), cultures available for the type: ANM81, needs generic revision.

Waltonia Saho 1970, Helotiales genera incertae sedis, Leotiomycetes, one species, type: W. pinicola Saho, asexual morph unknown, saprobes, terrestrial, Japan, see Lumbsch and 
Huhndorf (2010; outline), Kirk et al. (2013; genus accepted), Jaklitsch et al. (2016a; classification), cultures and sequences are unavailable, needs generic revision.

Warcupia Paden \& J.V. Cameron 1972, Otideaceae, Pezizales, Pezizomycetes, three species, type: W. terrestris Paden \& J.V. Cameron, asexual morph unknown, hypogeous, saprobes, terrestrial, Canada, see Lumbsch and Huhndorf (2010; outline), Barua et al. (2012; environmental adaptations), Hansen et al. (2013; DNA, phylogeny), Kirk et al. (2013; genus accepted), cultures available for the type: CBS 891.69.

Warcupiella Subram. 1972, Aspergillaceae, Eurotiales, Eurotiomycetes, three species, type: W. spinulosa (Warcup) Subram., asexual morph unknown, saprobes, terrestrial, worldwide, see Houbraken and Samson (2011; taxonomy, phylogeny), Kirk et al. (2013; genus accepted), culture available for type: CBS 430.64.

Wardinella Bat. \& Peres 1960, Ascomycota genera incertae sedis, one species, type: W. jaboatonensis Bat. \& Peres, coelomycetous, sexual morph unknown, saprobes, terrestrial, Brazil, see Wijayawardene et al. (2012, 2017; outline), Kirk et al. (2013; genus accepted), cultures and sequences are unavailable, needs generic revision.

Wardomyces F.T. Brooks \& Hansf. 1923, Microascaceae, Microascales, Sordariomycetes, ten species, type: $W$. anomalus F.T. Brooks \& Hansf., hyphomycetous, saprobes, Asia, Europe, North America, see Seifert et al. (2011; morphology), Wijayawardene et al. (2012, 2017; outline), Maharachchikumbura et al. (2015, 2016; outline), Sandoval-Denis et al. (2016b; new species, phylogeny), cultures and sequences are available.

Wardomycopsis Udagawa \& Furuya 1978, Microascaceae, Microascales, Sordariomycetes, four species, type: W. inopinata Udagawa \& Furuya, hyphomycetous, saprobes, Asia, Europe, North America, see Seifert et al. (2011; morphology), Wijayawardene et al. (2012, 2017; outline), Maharachchikumbura et al. (2015, 2016; outline), Sandoval-Denis et al. (2016b; new species, phylogeny), cultures and sequences are available.

Wawea Henssen \& Kantvilas 1985, Arctomiaceae, Arctomiales, Lecanoromycetes, one species, type: W. fruticulosa Henssen \& Kantvilas, asexual morph unknown, lichenized, terrestrial, see Lumbsch and Huhndorf (2010; outline), Kirk et al. (2013; genus accepted), Miądlikowska et al. (2014; phylogeny), Lücking et al. (2016b; classification), sequences are available.

Wawelia Namysł. 1908, Xylariaceae, Xylariales, Sordariomycetes, three species, type: W. regia Namysl., asexual morph unknown, terrestrial, coprophilous, Europe, see Lumbsch and Huhndorf (2010; outline), Kirk et al. (2013; genus accepted), Maharachchikumbura et al. (2015, 2016; outline), cultures and sequences are unavailable.

Waydora B. Sutton 1976, Valsaceae, Diaporthales, Sordariomycetes, one species, type: W. typica (Rodway) B. Sutton, coelomycetous, sexual morph unknown, saprobes, terrestrial, Brazil, see Wijayawardene et al. (2012, 2017; outline), Kirk et al. (2013; genus accepted), cultures available for voucher PDD 103894 of the type: (unpublished), needs generic revision. Waynea Moberg 1990, Ramalinaceae, Lecanorales, Lecanoromycetes, seven species; type: W. californica Moberg; lichenized; see Lücking et al. (2016b; classification); sequences are available.

Websteromyces W.A. Baker \& Partr. 2000, Ascomycota genera incertae sedis, one species, type: W. verruculosus W.A. Baker \& Partr., hyphomycetous, sexual morph unknown, saprobes, terrestrial, Africa, see Seifert et al. (2011; morphology), Wijayawardene et al. (2012, 2017; outline), holotype of the type: AUA, Webster, 11 Jul. 1991, cultures and sequences are unavailable, needs generic revision.

Weddellomyces D. Hawksw. 1986, Dacampiaceae, Dothideomycetes familie incertae sedis 14 species, type: W. epicallopisma (Weddell) D. Hawksw. (syn. Verrucaria epicallopisma Weddell), see Lumbsch \& Huhndorf (2010; outline), Kirk et al. (21013; accepted), Jaklitsch et al. 2016; classification), sequences are unavailable, isotype of type: H-Nyl 391. 
Wegea Aptroot \& Tibell 1997, Arthoniales genera incertae sedis, Arthoniomycetes, one species, type: W. tylophorelloides Aptroot \& Tibell, lichenized, terrestrial, tropical, see Lumbsch and Huhndorf (2010; outline), Kirk et al. (2013; genus accepted), sequences are unavailable.

Wehmeyera J. Reid \& C. Booth 1989, Melanconidaceae, Diaporthales, Sordariomycetes, one species, type: W. acerina (Wehm.) J. Reid \& C. Booth, asexual morph unknown, saprobes, USA, see Lumbsch and Huhndorf (2010; outline), Kirk et al. (2013; genus accepted), Maharachchikumbura et al. (2015, 2016; outline), cultures and sequences are unavailable.

Wentiomyces Koord. 1907, Dothideomycetes genera incertae sedis, c. 50 species, type: W. javanicus Koord., Kirk et al. (2013; genus accepted), Wijayawardene et al. (2014c; outline), cultures and sequences are unavailable, needs generic revision.

Wenyingia Zheng Wang \& Pfister 2001, Otideaceae, Pezizales, Pezizomycetes, one species, type: W. sichuanensis Zheng Wang \& Pfister, asexual morph unknown, saprobes, terrestrial, China, see Lumbsch and Huhndorf (2010; outline), cultures and sequences are unavailable, needs generic revision.

Westea H.J. Swart 1988, Dothideomycetes genera incertae sedis, one species, type: W. banksiae H.J. Swart, saprobes, terrestrial, Australia, see Lumbsch and Huhndorf (2010; outline), Kirk et al. (2013; genus accepted), Wijayawardene et al. (2014c; outline), cultures and sequences are unavailable, needs generic revision.

Westerdykella Stolk 1955, Sporormiaceae, Pleosporales, Dothideomycetes, 49 species, type: W. ornata Stolk, asexual morph unknown, saprobes, terrestrial, worldwide, see Kruys and Wedin (2009; new species), Schoch et al. (2009; phylogeny), Asgari and Zare (2010; new species), Lumbsch and Huhndorf (2010; outline), Ebead et al. (2012; new species), Armentano et al. (2013; pathogens of dogs), de Gruyter et al. (2012; new species, phylogeny), Hyde et al. (2013; accepted as a genus in Sporormiaceae, phylogeny), Wijayawardene et al. (2014c; outline), Kirk et al. (2013; genus accepted), cultures available for the type: CBS 379.55 .

Wettsteinina Höhn. 1907, Dothideomycetes genera incertae sedis, 29 species, type: W. gigantospora (Rehm) Höhn., saprobes, terrestrial, Europe, North America, see Lumbsch and Huhndorf (2010; outline), Kirk et al. (2013; genus accepted), Wijayawardene et al. (2014c; outline), cultures and sequences are available but lacks for the type, needs generic revision.

Weufia Bhat \& B. Sutton 1985, Ascomycota genera incertae sedis, one species, type: W. tewoldei Bhat \& B. Sutton, hyphomycetous, sexual morph unknown, Africa, Caibbe, see Seifert et al. (2011; morphology), Wijayawardene et al. (2012, 2017; outline), Kirk et al. (2013; genus accepted), cultures and sequences are unavailable, need generic revision.

Whalleya J.D. Rogers, Y.M. Ju \& F. San Martín 1997, Lopadostomataceae, Xylariales, Sordariomycetes, two species, type: W. microplaca (Berk. \& M.A. Curtis) J.D. Rogers, Y.M. Ju \& F. San Martín, asexual morph unknown, terrestrial, saprobes, tropical, see Lumbsch and Huhndorf (2010; outline), Kirk et al. (2013; genus accepted), Maharachchikumbura et al. (2015, 2016; outline), Wedt et al. (2017; transferred to Lopadostomataceae), cultures and sequences are available.

Wickerhamia Soneda 1960, Metschnikowiaceae, Saccharomycetales, Saccharomycetes, one species, type: W. fluorescens (Soneda) Soneda, saprophytic, Japan, France, see Lumbsch and Huhndorf (2010; outline), Kirk et al. (2013; genus accepted), cultures and sequences are available.

Wickerhamiella van der Walt 1973, Trichomonascaceae, Saccharomycetales, Saccharomycetes, 25 species, type: W. domercqiae van der Walt \& Liebenberg, asexual reproduction is by multilateral budding on either a narrow or a broad base, saprophytic, on nitidulid beetles, flowers of morning glory (Hibiscus spp.) and cacti, wine, worldwide, see 
Lumbsch and Huhndorf (2010; outline), Kirk et al. (2013; genus accepted), cultures and sequences are available.

Wickerhamomyces Kurtzman, Robnett \& Basehoar-Powers 2008, Phaffomycetaceae, Saccharomycetales, Saccharomycetes, 20 species, type: W. canadensis (Wickerham) Kurtzman, Robnett \& Basehoar-Powers, asexual reproduction is by multilateral budding, saprophytic, but several species are infrequent clinical isolates, in tree sap fluxes, insect tunnels in trees, leaf litter, berries, soil, tanned leather, soy sauce, blood, lung, eye, worldwide, see de García et al. (2010; new species, DNA), Lumbsch and Huhndorf (2010; outline), cultures and sequences are available.

Wicklowia Raja, A. Ferrer \& Shearer 2010, Wicklowiaceae, Pleosporales, Dothideomycetes, one species, type: W. aquatica Raja, A. Ferrer \& Shearer, asexual morph unknown, saprobes, aquatic, USA, see Raja et al. (2010b; taxonomy, phylogeny), holotype of the type: ILL 40790. Wiesneriomyces Koord. 1907, Wiesneriomycetaceae, Tubeufiales, Dothideomycetes, two species, type: W. javanicus Koord., hyphomycetous, saprobe, terrestrial, widespread, see Hyde et al. (2011; outline), Kirk et al. (2013; genus accepted), Suetrong et al. (2014; morphology, phylogeny), Wijayawardene et al. (2017; outline), cultures and sequences are available, needs generic revision.

Wilcoxina Chin S. Yang \& Korf 1985, Pyronemataceae, Pezizales, Pezizomycetes, three species, type: W. mikolae (Chin S. Yang \& H.E. Wilcox) Chin S. Yang \& Korf, asexual morph unknown, hypogeous, saprobes, terrestrial, Europe, North America, see Siemens and Zwiazek (2008; mycorrhizal with Hebeloma crustuliniforme), Lumbsch and Huhndorf (2010; outline), Kirk et al. (2013; genus accepted), cultures are available for the type: but unpublished, sequence available for the type: DQ220468 (LSU).

Willeya Müll. Arg. 1883, Verrucariaceae, Verrucariales, Eurotiomycetes, eleven species; type: W. diffractella (Nyl.) Müll. Arg., lichenized, see Gueidan et al. (2014a; taxonomy), Gueidan and Lendemer (2015; taxonomy), Lücking et al. (2016b; classification), sequences are available.

Wirthiotrema Rivas Plata, Kalb, Frisch \& Lumbsch 2010, Graphidaceae, Ostropales, Lecanoromycetes, seven species, type: W. glaucopallens (Nyl.) Rivas Plata \& Kalb, asexual morph unknown, lichenized fungi, terrestrial, tropical, see Rivas Plata et al. (2010a; classification), Sipman et al. (2012; key), Lücking et al. (2016b; classification), sequences are available.

Wojnowiciella Crous, M. Hern.-Restr. \& M.J. Wingf. 2015, Phaeosphaeriaceae, Pleosporales, Dothideomycetes, seven species, type: W. eucalypti Crous, M. Hern.-Restr. \& M.J. Wingf., coelomycetous, sexual morph unknown, saprobes, terrestrial, cosmopolitan, see Crous et al. (2015a, d, 2016a, b; new species, phylogeny), Hernandez-Restrepo et al. (2016; new species, new species, phylogeny), Wijayawardene et al. (2016b, 2017; taxonomy, outline, phylogeny), cultures are available.

Wolfina Seaver ex Eckblad 1968, Chorioactidaceae, Pezizales, Pezizomycetes, three species, type: W. aurantiopsis (Ellis) Seaver, asexual morph unknown, saprobes, terrestrial, USA, China, see Lumbsch and Huhndorf (2010; outline), Hustad and Miller (2011b; DNA, phylogeny), Kirk et al. (2013; genus accepted), sequences are available.

Wolkia Ramsb. 1915, Ascomycota genera incertae sedis, one species, type: W. decolorans (Wolk) Ramsb., asexual morph unknown, saprobes, terrestrial, Java, see Lumbsch and Huhndorf (2010; outline), Kirk et al. (2013; genus accepted), cultures and sequences are unavailable, need generic revision.

Wongia Khemmuk, Geering \& R.G. Shivas 2016, Papulosaceae, Diaportheomycetidae family incertae sedis, Sordariomycetes, two species, type: W. garrettii (P. Wong \& M.L. Dickinson) Khemmuk, Geering \& R.G. Shivas, asexual morph unknown, pathogen, Australia, 
see Khemmuk et al. (2016; taxonomy, phylogeny), holotype: DAR 76937, cultures and sequences are available.

Woodiella Sacc. \& P. Syd. 1899, Helotiales genera incertae sedis, Leotiomycetes, three species, type: W. natalensis Sacc. \& P. Syd., asexual morph unknown, saprobes, terrestrial, South Africa, see Lumbsch and Huhndorf (2010; outline), Kirk et al. (2013; genus accepted), cultures and sequences are unavailable, need generic revision.

Woswasia Jaklitsch, Réblová \& Voglmayr 2012, Sordariomycetidae genera incertae sedis, Sordariomycetes, one species, type: W. atropurpurea Jaklitsch, Réblová \& Voglmayr, asexual morph formed in culture only (penicilliate heads with terminally arranged, sympodially proliferating conidiogenous cells producing simple ellipsoid to obovoid, hyaline, nonseptate conidia holoblastically), myotrophic saprobes, terrestrial, Italy, see Jaklitsch et al. (2013; original description, phylogeny), Réblová et al. (2014; close relationship with Xylochrysis), Maharachchikumbura et al. (2015, 2016; outline), sequence are available, holotype and ex-type of type: WU 32007, CBS 133167.

Wuestneia Auersw. ex Fuckel 1864, Melanconidaceae, Diaporthales, Sordariomycetes, 20 species, type: W. aurea (Fuckel) Auersw., forms pycnidial asexual morphs harknessia-like, saprobes, terrestrial, worldwide, see Crous et al. (2012f; placement in new family Harknessiaceae), Wijayawardene et al. (2012, 2017; outline), Maharachchikumbura et al. (2015, 2016; outline), cultures and sequences are available.

Wynnea Berk. \& M.A. Curtis 1867, Sarcoscyphaceae, Pezizales, Pezizomycetes, seven species and two variants, type: W. gigantea Berk. \& M.A. Curtis, saprobes, terrestrial, Asia, North and Central America, see Lumbsch and Huhndorf (2010; outline), Romero et al. (2012; phylogeny), Kirk et al. (2013; genus accepted), sequences are available

Wynnella Boud. 1885, Helvellaceae, Pezizales, Pezizomycetes, three species, type: $W$. auricula (Schaeff.) Boud., saprobes, terrestrial, Europe, Asia, North America, see Parslow and Spooner (2009, new species), Kirk et al. (2013; genus accepted), Landeros et al. (2015; phylogeny), Zhao et al. (2015; new species, phylogeny), sequences are available.

Xalocoa Kraichak, Lücking \& Lumbsch 2013, Graphidaceae, Ostropales, Lecanoromycetes, one species, type: X. ocellata (Fr.) Kraichak, Lücking \& Lumbsch, asexual morph unknown, lichenized fungi, terrestrial, temperate, see Kraichak et al. (2013; taxonomy), Lücking et al. (2016b; classification), sequences are available.

Xanthocarpia A.Massal. \& De Not. 1853, Teloschistaceae, Teloschistales, Lecanoromycetes, 13 species, type: $X$. ochracea (Schaer.) A. Massal. \& De Not., lichenized, see Arup et al. (2013; taxonomy), Lücking et al. (2016b; classification), sequences are available.

Xanthodactylon P.A. Duvign 1941, Teloschistaceae, Teloschistales, Lecanoromycetes, seven species, type: $X$. perforatum P.A. Duvign, asexual morph unknown, lichenized, terrestrial, see Fedorenko et al. (2009; phylogeny), Lumbsch and Huhndorf (2010; outline), Kirk et al. (2013; genus accepted), Nyati et al. (2013; phylogeny), sequences are unavailable for type species.

Xanthomendoza S.Y. Kondr. \& Kärnefelt 1997, Teloschistaceae, Teloschistales, Lecanoromycetes, 20 species, type: X. mendozae (Räsänen) S.Y. Kondr. \& Kärnefelt, asexual morph unknown, lichenized, terrestrial, see Fedorenko et al. (2009; phylogeny), Lumbsch and Huhndorf (2010; outline), Lamit et al. (2011; ecology), Messuti et al. (2011; new species), Moniri, et al. (2011; new record), Riddell et al. (2011; air pollution), Bomble (2012; taxonomy), Arup et al. (2013; taxonomy), Hauck et al. (2013a; new records), Kirk et al. (2013; genus accepted), Leavitt et al. (2013; taxonomy), Lindblom and Søchting (2013; genetic diversity of photobiont), Nyati et al. (2013; phylogeny), Diederich et al. (2014; new combination), Kondratyuk et al. (2014; phylogeny), Lindblom (2014; taxonomy), Palmer (2014; ecology), Valadbeigi (2014; floristic), Crittenden et al. (2015; ecology), Gaya et al. (2012, 2015; molecular), Holt et al. (2015; ecology), Mcmullin et al. (2015; new records), Miralles et al. (2015; biostrategy), Suija et al. (2015c; new record), Tripp (2015; inventory), 
Jaklitsch et al. (2016a; classification), Lücking et al. (2016b; classification), sequences are available.

Xanthoparmelia (Vain.) Hale 1974, Parmeliaceae, Lecanorales, Lecanoromycetes, 820 species, type: $X$. conspersa (Ehrh. ex Ach.) Hale, asexual morph unknown, lichenized, terrestrial, worldwide, see Elix and Kantvilas (2009; new species), Tuzen et al. (2009; biosorptive study), Dailey et al. (2010; chemical study), Lumbsch and Huhndorf (2010; outline), Pérez-Vargas et al. (2010b; new species), Yazici et al. (2010; new records), Hawksworth et al. (2011a; checklist), Hodkinson and Lendemer (2011a; molecular), Leavitt and Clair (2011; ecology), Leavitt et al. (2011b, c; taxonomy and molecular), Biazrov (2012; physiology), de Paz et al. (2012; molecular taxonomy), Favero-Longo. and Piervittori (2012; transplant expt.), Molnár et al. (2012; molecular), Kirk et al. (2013; genus accepted), Rizzi and Giordani (2013; ecology), Goni et al. (2014; checklist), Jayalal et al. (2014; new species, taxonomy), Laska et al. (2015; chemopreventive activity), Cao et al. (2015; molecular), Diaz (2016; diversity), Lücking et al. (2016b; classification), Kanigowski et al. (2016; taxonomy), sequences are available.

Xanthopeltis R.Sant. 1949, Teloschistaceae, Teloschistales, Lecanoromycetes, one species, type: X. rupicola R. Sant., lichenized, see Lumbsch and Huhndorf (2010; outline), Arup et al. (2013; taxonomy), Kirk et al. (2013; genus accepted), Lücking et al. (2016b; classification), sequences are available.

Xanthopsorella Kalb \& Hafellner 1984, Catillariaceae, Lecanorales, Lecanoromycetes, one species, type: X. texana (W.A. Weber) Kalb \& Hafellner, asexual morph unknown, lichenized, Mexico, USA, see Lumbsch and Huhndorf (2010; outline), Kirk et al. (2013; genus accepted), Lücking et al. (2016b; classification); COLO 448, COLO (holotype), cultures and sequences are unavailable, need generic revision.

Xanthopsoroma Elvebakk \& S.G. Hong 2010, Pannariaceae, Peltigerales, Lecanoromycetes, two, species, type: $X$. contextum Elvebakk \& S.G. Hong, asexual morph unknown, lichenized, terrestrial, see Elvebakk et al. (2010; molecular), sequences are available for type.

Xanthoria (Fr.) Th. Fr. 1861, Teloschistaceae, Teloschistales, Lecanoromycetes, ten species, type: X. parietina (L.) Beltr., asexual morph unknown, lichenized, terrestrial, see Lumbsch and Huhndorf (2010; outline), Sarı and Tuzen (2010; biosorption), Karagöz et al. (2011; new species), Pisani et al. (2011; physiology), Aptroot and Aslan (2012; new records), Beck and Mayr (2012; physiology), Demiray et al. (2012; biomonitoring), Arup et al. 2013, Kirk et al. (2013; genus accepted), Kondratyuk et al. (2013c; new species), Nyati et al. (2013; phylogeny), Motiejunaite and Grochowski (2014; new records), Joshi et al. (2015; checklist), Kaya et al. (2015; natural product), Anar et al. (2016; antigenotoxic and Antioxidant study), Lücking et al. (2016b; classification), sequences are available.

Xanthoriicola D. Hawksw. 1973, Teratosphaeriaceae, Capnodiales, Dothideomycetes, one species, type: $X$. physciae (Kalchbr.) D. Hawksw., sexual morph unknown, lichenicolous, mainly in Europe Seifert et al. (2011; morphology), Ruibal et al. (2011; sequences), Ertz et al. (2013; phylogeny), , Kirk et al. (2013; genus accepted), Pérez-Ortega et al. (2015; position), sequences are available, isotype of type: S.

Xanthothecium Arx \& Samson 1973, Onygenaceae, Onygenales, Eurotiomycetes, one species, type: $X$. peruvianum (Cain) Arx \& Samson, asexual morph unknown, saprobes, terrestrial, worldwide, see Lumbsch and Huhndorf (2010; outline), Kirk et al. (2013; genus accepted), sequence available for the type: AB053453.

Xenidiocercus Nag Raj 1993, Ascomycota genera incertae sedis, one species, type: $X$. macarangae (T.S. Ramakr.) Nag Raj, coelomycetous, sexual morph unknown, saprobes, terrestrial, India, West Africa, see Wijayawardene et al. (2012, 2017; outline), Kirk et al. (2013; genus accepted), cultures and sequences are unavailable, needs generic revision. 
Xenoacremonium L. Lombard \& Crous 2015, Nectriaceae, Hypocreales, Sordariomycetes, two species, type: $X$. recifei (Leão \& Lôbo) L. Lombard \& Crous, hyphomycetous, sexual morph unknown, saprobes, Brazil, New Zealand, see Lombard et al. (2015b; morphology, phylogeny), Wijayawardene et al. (2017; outline), ex-type of type: CBS 137.3.

Xenocamarosporium Crous \& M.J. Wingf. 2015, Didymosphaeriaceae, Pleosporales, Dothideomycetes, one species, type: X. acaciae Crous \& M.J. Wingf., coelomycetous, sexual morph unknown, saprobes, Malaysia, see Crous et al. (2015d; taxonomy, phylogeny), Wijayawardene et al. (2016b, 2017; outline, phylogeny), holotype and ex-type culture of the type: CBS H-22224, CPC 24755.

Xenochalara M.J. Wingf. \& Crous 2000, Dermateaceae, Helotiales, Leotiomycetes, one species, type: $X$. juniperi M.J. Wingf. \& Crous, hyphomycetous, sexual morph unknown, saprobes, The Netherlands, see Seifert et al. (2011; morphology), Wijayawardene et al. (2017; outline), holotype and ex-type of type: PREM 26210, CBS 670.75.

Xenochora Petr. 1948, Ascomycota genera incertae sedis, one species, type: X. sydowii Petr., coelomycetous, sexual morph unknown, saprobes, terrestrial, Ecuador, see Kirk et al. (2013; genus accepted), Wijayawardene et al. (2017; outline), cultures and sequences are unavailable, need generic revision.

Xenoconiothyrium Crous \& Marinc. 2011, Teratosphaeriaceae, Capnodiales, Dothideomycetes, one species, type: X. catenatum Crous \& Marinc. coelomycetous, saprobes, South Africa, see Crous et al. (2011c; morphology, phylogeny), Wijayawardene et al. (2016b, 2017; morphology, phylogeny, outline), holotype and ex-type: PREM 59486, CMW 22113.

Xenocylindrocladium Decock, Hennebert \& Crous 1997 (= Xenocalonectria Crous \& C.L. Schoch 2000 fide Rossman et al. 2016a), Nectriaceae, Hypocreales, Sordariomycetes, three species, type: $X$. serpens Decock, Hennebert \& Crous, hyphomycetous, sexual morph formerly known in Xenocalonectria, saprobes, terrestrial, South America, see Seifert et al. (2011; morphology), Lombard et al. (2015b; phylogeny), Maharachchikumbura et al. (2015, 2016; outline), Rossman et al. (2016a; nomenclature), Wijayawardene et al. (2017; outline), cultures and sequences are available.

Xenocylindrosporium Crous \& Verkley 2009, Phaeomoniellaceae, Phaeomoniellales, Eurotiomycetes, one species, type: X. kirstenboschense Crous \& Verkley, hyphomycetous, pathogens, South Africa, see Crous and Verkley (2009; morphology, phylogeny), Wijayawardene et al. (2017; outline), holotype and ex-type culture of type: CBS H-20346, CPC 16311.

Xenodidymella Q. Chen \& L. Cai 2015, Didymellaceae, Pleosporales, Dothideomycetes, four species, type: X. applanata (Niessl) Q. Chen \& L. Cai, coelomycetous, saprobes, ?pathogens, terrestrial, cosmopolitan, see Chen et al. (2015b; taxonomy, phylogeny), Wijayawardene et al. (2017; outline), epitype and ex-epitype culture of the type: HMAS 246688, CBS 195.36.

Xenodium Syd. 1935 (= Xenodiella Syd. 1935 fide Rossman et al. 2016a), Sordariomycetes genera incertae sedis, two species, type: $X$. petrakii Syd., asexual morph formerly known in Xenodiella, saprobes, terrestrial, South America, see Lumbsch and Huhndorf (2010; outline), Jayawardena et al. (2014) excluded from Elsinoaceae and placed in Sordariomycetes, Rossman et al. (2016a; nomenclature), cultures and sequences are available.

Xenodomus Petr. 1922, Ascomycota genera incertae sedis, one species, type: X. sydowii Petr., coelomycetous, sexual morph unknown, saprobes, terrestrial, North America, see Wijayawardene et al. (2012, 2017; outline), Kirk et al. (2013; genus accepted), cultures and sequences are unavailable, need generic revision.

Xenogliocladiopsis Crous \& W.B. Kendr. 1994, Nectriaceae, Hypocreales, Sordariomycetes, two species, type: X. eucalyptorum Crous \& W.B. Kendr., hyphomycetous, saprobes, Australia, South Africa, see Seifert et al. (2011; morphology), Wijayawardene et al. (2012, 
2017; outline), Kirk et al. (2013; genus accepted), Lombard et al. (2015b; morphology, phylogeny), epitype and ex-epitype of type: CBS H-21952, CBS 138758.

Xenoheteroconium Bhat, W.B. Kendr. \& Nag Raj 1993, Ascomycota genera incertae sedis, one species, type: X. bicolor Bhat, W.B. Kendr. \& Nag Raj, hyphomycetous, sexual morph unknown, Asia, see Seifert et al. (2011; morphology), Wijayawardene et al. (2012, 2017; outline), Kirk et al. (2013; genus accepted), cultures and sequences are unavailable, need generic revision.

Xenolecia Hertel 1984, Lecideaceae, Lecideales, Lecanoromycetes, one species, type: X. spadicomma (Nyl.) Hertel, lichenized, see Lumbsch and Huhndorf (2010; outline), Schmull et al. (2011; taxonomy), Kirk et al. (2013; genus accepted), Lücking et al. (2016b; classification), sequences are unavailable.

Xenoleptographium Marinc., T.A. Duong, Z.W. de Beer \& M.J. Wingf. 2015, Nectriaceae, Hypocreales, Sordariomycetes, one species, type: X. phialoconidium Marinc., T.A. Duong, Z.W. de Beer \& M.J. Wingf., hyphomycetous, sexual morph unknown, saprobes, Indonesia, see Crous et al. (2015e; taxonomy, phylogeny), Wijayawardene et al. (2017; outline), holotype and ex-type culture of the type: PREM 61244, CBS 134694.

Xenolophium Syd. 1925, Pleosporales genera incertae sedis, Dothideomycetes, c. five species, type: X. leve Syd., asexual morph unknown, saprobes, worldwide, see Lumbsch and Huhndorf (2010; outline, treated as Pleosporales, genera incertae sedis), Hyde et al. (2013; accepted as a genus in Platystomaceae), Wijayawardene et al. (2014c; outline, accepted as a genus in Platystomaceae), cultures and sequences are available.

Xenomeris Syd. 1924, Dothideomycetes genera incertae sedis, eleven species, type: X. pruni Syd., asexual morph hormonema-like, Asia, see Lumbsch and Huhndorf (2010; outline), Kirk et al. (2013; genus accepted), Wijayawardene et al. (2014c; outline), cultures and sequences are available but lacks for the type, need generic revision.

Xenomycosphaerella Quaedvl. \& Crous 2014, Mycosphaerellaceae, Capnodiales, Dothideomycetes, three species, type: X. elongata (Crous \& M.J. Wingf.) Quaedvl. \& Crous asexual morph unknown, pathogens, Brazil, Venezuela, see Quaedvlieg et al. (2014; morphology, phylogeny), Guatimosim et al. (2016; morphology, phylogeny), holotype and ex-type culture of type: CBS-H 19824, CPC 13378.

Xenomyxa Syd. 1939, Ascomycota genera incertae sedis, one species, type: X. disseminata Syd., asexual morph unknown, saprobes, terrestrial, Ecuador, see Lumbsch and Huhndorf (2010; outline), Kirk et al. (2013; genus accepted), cultures and sequences are unavailable, need generic revision.

Xenonectriella Weese 1919, Nectriaceae, Hypocreales, Sordariomycetes, twelve species, type: X. lutescens (Arnold) Weese, asexual morph unknown, saprobes, terrestrial, worldwide, see Lumbsch and Huhndorf (2010; outline), Etayo and van den Boom (2013; new species, Dominican Republic), Kirk et al. (2013; genus accepted), Brackel et al. (2014; new species), Maharachchikumbura et al. (2015, 2016; outline), cultures and sequences are unavailable.

Xenopeltis Syd. \& P. Syd. 1919, Ascomycota genera incertae sedis, one species, type: X. philippinensis Syd. \& P. Syd., coelomycetous, sexual morph unknown, saprobes, terrestrial, Philippines, see Wijayawardene et al. (2012, 2017; outline), Kirk et al. (2013; genus accepted), cultures and sequences are unavailable, need generic revision.

Xenopenidiella Quaedvlieg \& Crous 2014, Teratosphaeriaceae, Capnodiales, Dothideomycetes, one species, type: X. rigidophora (Crous, R.F. Castañeda \& U. Braun) Quaedvlieg \& Crous hyphomycetous, saprobes, Cuba, see Quaedvlieg et al. (2014; morphology, phylogeny), holotype and ex-type culture of type: CBS H-19938, CBS 314.95.

Xenophacidiella Crous 2011, Dothideomycetes genera incertae sedis, one species, type: X. pseudocatenata Crous, hyphomycetous, sexual morph unknown, saprobes, South Africa, 
terrestrial, see Crous and Groenewald (2011; morphology, phylogeny), Wijayawardene et al. (2017; outline), holotype and ex-type culture of type: CBS H-20536, CPC 18472.

Xenophaeosphaeria Crous \& M.J. Wingf. 2014, Phaeosphaeriaceae, Pleosporales, Dothideomycetes, one species, type: X. grewiae Crous \& M.J. Wingf., asexual morph unknown, Tanzania, terrestrial, see Crous et al. (2014d; morphology, phylogeny), holotype and ex-type culture of type: CBS H-21999, CPC 24398.

Xenoplaca Petr. 1949, Ascomycota genera incertae sedis, one species, type: X. aequatoriensis Petr., hyphomycetous, sexual morph unknown, South America, see Seifert et al. (2011; morphology), Wijayawardene et al. (2012, 2017; outline), Kirk et al. (2013; genus accepted), cultures and sequences are unavailable, need generic revision.

Xenopolyscytalum Crous 2010, Helotiales genera incertae sedis, Leotiomycetes, one species, type: $X$. pinea Crous, hyphomycetous, sexual morph unknown, The Netherlands, terrestrial, see Crous and Groenewald (2010; morphology, phylogeny), Wijayawardene et al. (2017; outline), holotype and ex-type culture of type: CBS-H 20488, CPC 14225.

Xenopyricularia Klaubauf, Lebrun \& Crous 2014, Pyriculariaceae, Magnaporthales, Sordariomycetes, one species, type: X. zizaniicola (Hashioka) Klaubauf, Lebrun \& Crous, hyphomycetous, sexual morph unknown, pathogens, terrestrial, worldwide, see Klaubauf et al. (2014; taxonomy, phylogeny), Maharachchikumbura et al. (2015, 2016; outline), Wijayawardene et al. (2017; outline), neotype and ex-neotype cultures for the type: CBS H21846, CBS133593 = MAFF 240219.

Xenoramularia Videira, H.D. Shin \& Crous 2016, Mycosphaerellaceae, Capnodiales, Dothideomycetes, three species, type: X. polygonicola Videira, H.D. Shin \& Crous hyphomycetous, sexual morph unknown, plant pathogens, see Videira et al. (2016; morphology, phylogeny), holotype KUS-F19688, isotype CBS H-22541, culture ex-type CBS $141102=$ CPC 10852 .

Xenoseptoria Quaedvl., H.D. Shin, Verkley \& Crous 2013, Phaeosphaeriaceae, Pleosporales, Dothideomycetes, one species, type: X. neosaccardoi W. Quaedvlieg, H.D. Shin, G.J.M. Verkley \& Crous, coelomycetous, sexual morph unknown, pathogenic, terrestrial, South Korea, see Quaedvlieg et al. (2013; morphology, phylogeny), ex-type strains of type: CBS 128665, holotype of type: CBS H-21312.

Xenosonderhenia Crous 2012, Capnodiales genera incertae sedis, Dothideomycetes, two species, type: X. syzygii Crous, coelomycetous, saprobes, terrestrial, worldwide, see de Gruyter et al. (2012; morphology; phylogeny), Wijayawardene et al. (2017; outline), holotype of the type: CBS H-20968, ex-type strain of type: CPC 19790.

Xenosporium Penz. \& Sacc. 1902, Dothideomycetes genera incertae sedis, 18 species, type: $X$. mirabile Penz. \& Sacc., hyphomycetous, sexual morph unknown, see Seifert et al. (2011; morphology), Wijayawardene et al. (2012, 2017; outline), Kirk et al. (2013; genus accepted), cultures and sequences are available, needs generic revision.

Xenostigme Syd. 1930, Sordariomycetes genera incertae sedis, one species, type: $X$. trichophila Syd., asexual morph unknown, saprobes, terrestrial, South America, see Lumbsch and Huhndorf (2010; outline, accepted as a genus in Meliolaceae), Kirk et al. (2013; genus accepted), Hongsanan et al. (2015c; excluded from Meliolaceae and placed in Sordariomycetes genera incertae sedis), cultures and sequences are unavailable, needs generic revision.

Xenostigmina Crous 1998, Melanommataceae, Pleosporales, Dothideomycetes, two species, type: X. zilleri (A. Funk) Crous, hyphomycetous, saprobes, terrestrial, Canada, British Columbia, see Crous et al. (2009a; morphylogy, phylogeny), Wijayawardene et al. (2012, 2014c, 2017; outline; phylogeny), Kirk et al. (2013; genus accepted), Tian et al. (2015; morphology, nomenclature, phylogeny), cultures and sequences are available, ex-type strains of type: CBS 115685 = CPC 4010; holotype of type: DAVFP 23272. 
Xenostomella Syd. 1930, Dothideomycetes genera incertae sedis, two species, type: X. tovarensis Syd., asexual morph unknown, saprobes, terrestrial, South America, see Lumbsch and Huhndorf (2010; outline, accepted as a genus in Microthyriaceae), Kirk et al. (2013; genus accepted), Wu et al. (2011) and Hyde et al. (2013) did not accept as Microthyriaceae, Wijayawardene et al. (2014c; outline), cultures and sequences are unavailable, needs generic revision.

Xenostroma Höhn. 1915, Ascomycota genera incertae sedis, one species, type: X. caespitosum (Fuckel) Höhn., coelomycetous, sexual morph unknown, saprobes, terrestrial, Europe, see Wijayawardene et al. (2012, 2017; outline), Kirk et al. (2013; genus accepted), cultures and sequences are unavailable, need generic revision.

Xenoteratosphaeria Quaedvl. \& Crous 2014, Teratosphaeriaceae, Capnodiales, Dothideomycetes, one species, type: X. jonkershoekensis (P.S. van Wyk, Marasas \& KnoxDav.) Quaedvlieg \& Crous, asexual morph unknown, pathogens, South Africa, see Quaedvlieg et al. (2014; morphology, phylogeny), epitype and ex-epitype culture of type: CBS H-20095, CBS 122897.

Xenothecium Höhn. 1919, Hyponectriaceae, Xylariales, Sordariomycetes, one species, type: $X$. jodophilum Höhn., asexual morph unknown, saprobes, terrestrial, South America, see Lumbsch and Huhndorf (2010; outline), Kirk et al. (2013; genus accepted), Maharachchikumbura et al. (2015, 2016; outline), holotype of the type: BRIP 22762, cultures and sequences are unavailable, needs generic revision.

Xenotypa Petr. 1955, Gnomoniaceae, Diaporthales, Sordariomycetes, one species, type: X. aterrima (Fr.) Petr., asexual morph unknown, saprobes, terrestrial, Europe, North America, see Lumbsch and Huhndorf (2010; outline), Kirk et al. (2013; genus accepted), Maharachchikumbura et al. (2015, 2016; outline), cultures and sequences are unavailable, needs generic revision.

Xenus Kohlm. \& Volkm.-Kohlm., 1992, Pyrenulales genera incertae sedis, Eurotiomycetes, one species, type: X. lithophylli Kohlm. \& Volkm.-Kohlm., asexual morph unknown, saprobes, lichenized, marine on coral, tropical, see Lumbsch and Huhndorf (2010; outline), Kirk et al. (2013; genus accepted), Jones et al. (2015; outline), Lücking et al. (2016b; classification), cultures nd sequences are unavailable.

Xepicula Nag Raj 1993, Stachybotriaceae, Hypocreales, Sordariomycetes, four species, type: $X$. leucotricha (Peck) Nag Raj, coelomycetous, sexual morph unknown, saprobes, terrestrial, worldwide, see Kirk et al. (2013; genus accepted), Lombard et al. (2016; new species, phylogeny), Wijayawardene et al. (2016b, 2017; outline, taxonomy), ex-type culture of the type: CBS 256.57 = MUCL 9860, need generic revision.

Xepiculopsis Nag Raj 1993, Stachybotriaceae, Hypocreales, Sordariomycetes, two species, type: X. perpulchra Nag Raj, coelomycetous, sexual morph unknown, saprobes, terrestrial, worldwide, see Wijayawardene et al. (2016b, 2017; outline, taxonomy), Kirk et al. (2013; genus accepted), Lombard et al. (2016; taxonomic notes), cultures are unavailable, needs generic revision.

Xerochrysium Pitt 2013, Trichocomaceae, Eurotiales, Eurotiomycetes, two species, type: X. dermatitidis (A. Agostini) Pitt, hyphomycetous, sexual morph unknown, saprobes, terrestrial, Europe, Australia, see Pitt et al. (2013; taxonomy, phylogeny), lectotype and ex-lectotype of the type: CBS 132.31, IMI 96729=UAMH 802.

Xeroconium D. Hawksw. 1981, Ascomycota genera incertae sedis, one species, type: X. borealis (P. Karst.) D. Hawksw., on wood, Europe, terrestrial, sexual morph unknown, see Wijayawardene et al. (2012, 2017; outline), Kirk et al. (2013; genus accepted), cultures and sequences are unavailable, holotype of type: H-Karst 1493.

Xerombrophila Baral 2013, Gelatinodiscaceae, Helotiales, Leotiomycetes, one species, type: $X$. crystallifera Baral, G. Marson \& Unter., asexual morph hyphomycetous, saprobes, 
terrestrial, Europe, see Baral et al. (2013b; taxonomy, phylogeny), Wijayawardene et al. (2017; outline), ex-type cultures of the type: CBS 128289.

Xeromedulla Korf \& W.Y. Zhuang 1987, Helotiales genera incertae sedis, Leotiomycetes, three species, type: X. leptospora W.Y. Zhuang \& Korf, asexual morph hyphomycetous, saprobes, terrestrial, China, Phillipines, see Lumbsch and Huhndorf (2010; outline), Kirk et al. (2013; genus accepted), cultures and sequences are unavailable, needs generic revision.

Xeromyces L.R. Fraser 1954 (= Fraseriella Cif. \& A.M. Corte fide Rossman et al. 2016a), Aspergillaceae, Eurotiales, Eurotiomycetes, one species: X. bisporus L.R. Fraser, type: Xeromyces bisporus L.R. Fraser asexual morph hyphomycetous (Fraseriella bispora Cif. \& A.M. Corte fide Petterson et al. 2011 and Seifert et al. 2011), terrestrial, strongly xerophilic, isolated from dry, sugar-rich foodstuffs, cosmopolitan, see Fraser (1954; morphology), Seifert et al. (2011; morphology), Pettersson et al. (2011; phylogeny, morphology), Under unitary nomenclature (Hawksworth et al. 2011), the names Xeromyces and Fraseriella compete for use. Since the former genus name is more widely used and older than the latter, we consider Fraseriella to represent a synonym of Xeromyces. The synonymy is formally proposed herein as follows:

Xeromyces bisporus L.R. Fraser Proc. Linn. Soc. N.S.W. 78:245. 1954.

三Monascus bisporus (L.R. Fraser) Arx, Gen. Fungi Spor. Pure Cult.: 84. 1970.

$=$ Fraseriella bispora Cif. \& A.M. Corte, in Corte Atti Ist. Bot. Univ. Lab. crittog. Pavia Ser. 4 14:109. 1957.

Xerotrema Sherwood \& Coppins 1980, Odontotremataceae, Ostropales, Lecanoromycetes, two species, type: X. megalospora Sherwood \& Coppins, asexual morph unknown, ?saprobes, terrestrial, see Lumbsch and Huhndorf (2010; outline), Purvis (2012; floristic), Kirk et al. (2013; genus accepted), cultures and sequences are unavailable.

Xiambola Minter \& Hol.-Jech. 1981, Ascomycota genera incertae sedis, one species, type: X. mirabilis Minter \& Hol.-Jech., hyphomycetous, sexual morph unknown, saprobes, terrestrial, Europe, see Seifert et al. (2011; morphology), Wijayawardene et al. (2012, 2017; outline), Kirk et al. (2013; genus accepted), cultures and sequences are unavailable, needs generic revision.

Xiphomyces Syd. \& P. Syd. 1916, Ascomycota genera incertae sedis, two species, type: X. sacchari Syd. \& P. Syd., hyphomycetous, sexual morph unknown, saprobes, terrestrial, Asia, see Seifert et al. (2011; morphology), Wijayawardene et al. (2012, 2017; outline), Kirk et al. (2013; genus accepted), cultures and sequences are unavailable, needs generic revision.

Xiuguozhangia K. Zhang, R.F. Castañeda, Jian Ma \& L.G. Ma 2014, Ascomycota genera incertae sedis, five species, type: X. rosae (K. Zhang \& X.G. Zhang) K. Zhang \& R.F. Castañeda, hyphomycetous, sexual morph unknown, saprobes, terrestrial, cosmopolitan, see Zhang et al. (2014b; taxonomy), Wijayawardene et al. (2017; outline), cultures and sequences are unavailable, needs generic revision.

Xylaria Hill ex Schrank 1789 (= Moelleroclavus Henn. 1902; =Xylocoremium J.D. Rogers 1984 fide Réblová et al. 2016c), Xylariaceae, Xylariales, Sordariomycetes, c. 350 species, type: X. hypoxylon (L.) Grev., asexual morph hyphomycetous, terrestrial, saprobes, worldwide, see Lumbsch and Huhndorf (2010; outline), Fournier et al. (2011; new species), Rogers and Ju (2012; new species), Ma et al. (2012a, 2013; new species), Kirk et al. (2013; genus accepted), Gu et al. (2014; new species), Maharachchikumbura et al. (2015, 2016; outline, phylogeny), Senanayke et al. (2015; outline, phylogeny), Réblová et al. (2016c; new species; nomenclature), cultures and sequences are available.

Xyleborus R.C. Harris \& Ladd 2007, Stereocaulaceae, Lecanorales, Lecanoromycetes, two species, type: X. sporodochifer R.C. Harris \& Ladd., asexual morph unknown, lichenized, terrestrial, see Lumbsch and Huhndorf (2010; outline), Lendemer et al. (2013; list), Lendemer and Harris (2015; new species), Lücking et al. (2016b; classification), sequences unavailable. 
Xylobotryum Pat. 1895, Ascomycota genera incertae sedis, two species, type: X. andinum Pat., asexual morph unknown, saprobes, terrestrial, tropical, see Lumbsch and Huhndorf (2010; outline), Kirk et al. (2013; genus accepted), cultures and sequences are unavailable, needs generic revision.

Xylochia B. Sutton 1983, Ascomycota genera incertae sedis, one species, type: X. stegonsporioides B. Sutton, hyphomycetous, sexual morph unknown, saprobes, terrestrial, Asia, see Seifert et al. (2011; morphology), Wijayawardene et al. (2012, 2017; outline), Kirk et al. (2013; genus accepted), cultures and sequences are unavailable, needs generic revision.

Xylochora Arx \& E. Müll. 1954, Amphisphaeriaceae, Xylariales, Sordariomycetes, three species, type: X. craticola (H. Wegelin) Arx \& E. Müll., asexual morph unknown, saprobes, Sweden, Switzerland and India, Lumbsch and Huhndorf (2010; outline), Kirk et al. (2013; genus accepted), cultures and sequences are unavailable.

Xylocrea Möller 1901, Xylariales genera incertae sedis, Sordariomycetes, one species, type: $X$. piriformis Möller, asexual morph unknown, saprobes, see Kirk et al. (2008; treated as a synonym of Sarcoxylo Cooke), Lumbsch and Huhndorf (2010; outline), Kirk et al. (2013; did not list), Maharachchikumbura et al. (2015, 2016; outline, accepted as a distinct genus), Wendt et al. (2017; accepted as a genus in Xylariales genera incertae sedis), cultures and sequences are unavailable.

Xyloglyphis Clem. 1909, Ascomycota genera incertae sedis, one species, type: X. striola (Fr.) Clem., coelomycetous, sexual morph unknown, saprobes, terrestrial, Europe, see Wijayawardene et al. (2012, 2017; outline), Kirk et al. (2013; genus accepted), cultures and sequences are unavailable, needs generic revision.

Xylogramma Wallr. 1833, Helotiaceae, Helotiales, Leotiomycetes, 18 species, type: X. sticticum (Fr.) Wallr., asexual morph unknown, saprobes, terrestrial, China, worldwide, see Lumbsch and Huhndorf (2010; outline), Kirk et al. (2013; genus accepted), cultures and sequences are unavailable, needs generic revision.

Xylographa (Fr.) Fr., 1836, Xylographaceae, Trapeliales, Lecanoromycetes, 20 species, type: need typification, see Heininger and Spribille (2009; new species), Wetmore (2009; floristic study), Zhdanov (2009; new record), Agnello et al. (2010; ecology), Bilovitz et al. (2010; biodiversity), Brodo (2010; new record), Lumbsch and Huhndorf (2010; outline), Hansen (2012; new record), Mayrhofer et al. (2012; new records), Bennett (2013; review), Hauck et al. (2013b; new record), Kirk et al. (2013; genus accepted), Mayrhofer et al. (2013; new record), Svensson (2013; biodiversity), Svensson et al. (2013, 2016; ecology, biodiversity), Tønsberg (2013; new species), Urbanavichene et al. (2013, new record), Abbas et al. (2014; new records), Goni et al. (2014; new record), Spribille et al. (2014; systematic, new species), Hämäläinen et al. (2015; biodiversity), Malíček et al. (2015b; new reord), Resl et al. (2015; phylogeny), Tarasova et al. (2015, 2016; new record), Węgrzyn et al. (2015; new record), Himelbrant et al. (2016; new record), Kharpukhaeva and Mukhortova (2016; ecology), Motiejūnaitè et al. (2016; new record), Lücking et al. (2016b; classification), sequences are available.

Xylohypha (Fr.) E.W. Mason 1960, Ascomycota genera incertae sedis, six species, type: X. nigrescens (Pers.) E.W. Mason, hyphomycetous, sexual morph unknown, saprobes, terrestrial, worldwide, see Seifert et al. (2011; morphology), Wijayawardene et al. (2012, 2017; outline), Kirk et al. (2013; genus accepted), cultures and sequences are unavailable, needs generic revision.

Xylohyphopsis W.A. Baker \& Partr. 2000, Ascomycota genera incertae sedis, two species, type: X. curta (Corda) W.A. Baker \& Partr., hyphomycetous, sexual morph unknown, saprobes, terrestrial, South Africa, see Seifert et al. (2011; morphology), Wijayawardene et al. (2012, 2017; outline), Kirk et al. (2013; genus accepted), cultures and sequences are unavailable, needs generic revision. 
Xylomelasma Réblová 2006, Sordariomycetidae genera incertae sedis, Sordariomycetes, three species, type: $X$. sordida Réblová, asexual morph hyphomycetous, saprobes, worldwide, see Lumbsch and Huhndorf (2010; outline), Kirk et al. (2013; genus accepted), Vasilyeva and Stephenson (2014; new species), Maharachchikumbura et al. (2015, 2016; outline, phylogeny), Réblová et al. (2016a; DNA, phylogeny), cultures are available for the type: CBS 131683.

Xylomyces Goos, R.D. Brooks \& Lamore, 1977, Aliquandostipitaceae, Jahnulales, Dothideomycetes, ten species, type: X. chlamydosporus Goos, R.D. Brooks \& Lamore, hyphomycetous, sexual morph unknown, aquatic (freshwater/marine), see Shearer et al. (2009; phylogeny), Sivichai and Boonyuen (2010; association with Jahula), Seifert et al. (2011; morphology), Hose et al. (2010; chemistry), Hu et al. (2010a; diversity), Barbosa and Gusmão (2011; diversity), Suetrong et al. (2011a; phylogeny), Sivichai et al. (2011; taxonomy), Zhang et al. (2011a; checklist), Kirk et al. (2013; genus accepted), Wijayawardene et al. (2012, 2014c, 2017; outline), Hyde et al. (2013; accepted as a genus in Aliquandostipitaceae), Borse et al. (2014; diversity), da Silva et al. (2015; diversity), Jones et al. (2015; marine genera), Oliveira et al. (2015; diversity), cultures available for the type: SS2917.

Xylona Gazis \& P. Chaverri 2012, Xylonomycetaceae, Xylonomycetales, Xylonomycetes, T. guianense Crous \& C. Decock, coelomycetous, sexual morph unknown, endophytes, see Gazis et al. (2016; phylogeny), Wijayawardene et al. (2017; outline), cultures and sequences are available.

Xylopezia Höhn. 1917, Dothideomycetes genera incertae sedis, type: data inadequate, see Kirk et al. (2008; treated as a synonym of Exarmidium), Lumbsch and Huhndorf (2010; outline), Kirk et al. (2013; did not list), Wijayawardene et al. (2014c; outline), sequences are unavailable.

Xylopsora Bendiksby \& Timdal 2013, Umbilicariaceae, Umbilicariales, Lecanoromycetes, two species, type: X. friesii (Ach.) Bendiksby \& Timdal, lichenized, lignicolous, corticolous, often on charred substrata, temperate northern hemisphere, Australia, see Bendiksby and Timdal (2013; phylogenetic placement), Lücking et al. (2016b; classification), type specimen $\mathrm{H}-\mathrm{ACH}-436 \mathrm{~A}$ sequences are available.

Xyloschistes Vain. ex Zahlbr. 1903, Stictidaceae, Ostropales, Lecanoromycetes, one species, type: X. platytropa (Nyl.) Vain. ex Zahlbr., lichenized, see Lumbsch and Huhndorf (2010; outline), Kirk et al. (2013; genus accepted), Miądlikowska et al. (2014a; phylogeny), Lücking et al. (2016b; classification), sequences are available.

Xyloschizon Syd. 1922, Rhytismataceae, Rhytismatales, Leotiomycetes, two species, type: X. weirianum Syd., asexual morph unknown, saprobes, terrestrial, North America, see Lumbsch and Huhndorf (2010; outline), Kirk et al. (2013; genus accepted), cultures and sequences are unavailable.

Xylotumulus J.D. Rogers, Y.M. Ju \& Hemmes 2006, Xylariales genera incertae sedis, Sordariomycetes, one species, type: X. gibbisporus J.D. Rogers, Y.M. Ju \& Hemmes, asexual morph unknown, saprobes, terrestrial, Hawaii, see Lumbsch and Huhndorf (2010; outline), Rogers and Ju (2012; Hawaii fungi), Chang et al. (2014; secondary compounds), Maharachchikumbura et al. (2015, 2016; outline), Wendt et al. (2017; accepted as a genus in Xylariales genera incertae sedis), holotype: BISH, Rogers, 2 Aug. 2005, cultures available for the type: NBRC 9453, ATCC MYA-4109.

Yalomyces Nag Raj 1993, Ascomycota genera incertae sedis, six species, type: Y. pulcher Nag Raj, coelomycetous, sexual morph unknown, saprobes, terrestrial, worldwide, see Wijayawardene et al. (2012, 2017; outline), Kirk et al. (2013; genus accepted), cultures and sequences are unavailable, needs generic revision. 
Yamadazyma Billon-Grand 1989, Debaryomycetaceae, Saccharomycetales, Saccharomycetes, 20 species, type: Y. philogaea (van der Walt \& Johannsen) Billon-Grand, asexual reproduction is by multilateral budding, saprophytic, in tree exudates and insect frass, insect guts, soil, cactus rots, seawater, soy sauce, infrequent clinical isolates, worldwide, see Lumbsch and Huhndorf (2010; outline), Kirk et al. (2013; genus accepted), many species in this genus represent asexual taxa originally classified in the genus Candida, thus they will be transferred to Yamadazyma as new combinations, cultures and sequences are available.

Yarrowia van der Walt \& von Arx 1980, ?Trichomonascaceae, Saccharomycetales, Saccharomycetes, 13 species, type: Y. lipolytica (Wickerham, Kurtzman \& Herman) van der Walt \& von Arx, asexual reproduction is by multilateral budding, saprophytic, but clinical isolates are not uncommon, on wet milled maize, refrigerated meats, soil, clinical, worldwide, see Lumbsch and Huhndorf (2010; outline), Kirk et al. (2013; genus accepted), some species in this genus represent asexual taxa originally classified in the genus Candida thus they will be transferred to Yarrowia as new combinations, cultures and sequences are available.

Yarrumia D.J. Galloway 2015, Lobariaceae, Peltigerales, Lecanoromycetes, two species, type: Y. coronate D.J. Galloway, lichenized, see Galloway (2015; taxonomy), Lücking et al. (2016b; classification); sequences are available.

Yatesula Syd. \& P. Syd. 1917, Chaetothyriaceae, Chaetothyriales, Eurotiomycetes, two species, type: Y. calami Syd. \& P. Syd., asexual morph unknown, epiphytic, sooty moulds, terrestrial, America, Philippines, Lumbsch and Huhndorf (2010; outline), Kirk et al. (2013; genus accepted), cultures and sequences are unavailable, needs generic revision.

Yinmingella Goh, K.M. Tsui \& K.D. Hyde 1999, Ascomycota genera incertae sedis, six species, type: Y. mitriformis Goh, K.M. Tsui \& K.D. Hyde, hyphomycetous, sexual morph unknown, saprobes, terrestrial, Asia, South America, see Seifert et al. (2011; morphology), Wijayawardene et al. (2012, 2017; outline), Kirk et al. (2013; genus accepted), cultures and sequences are unavailable, needs generic revision.

Yoshimuria S.Y.Kondr., Kärnefelt, Elix, A.Thell \& Hur 2014, Teloschistaceae, Teloschistales, Lecanoromycetes, three species, type: Y. spodoplaca (Nyl.) S.Y. Kondr., Kärnefelt, Elix, A. Thell, J. Kim, A.S. Kondr. \& Hur, lichenized, see Kondratyuk et al. (2014a; taxonomy), Lücking et al. (2016b; classification), cultures available for the type: SK725, SK724.

Yoshimuriella Moncada \& Lücking 2013, Lobariaceae, Peltigerales, Lecanoromycetes, eight species, type: $Y$. fendleri (Tuck. \& Mont.) Moncada \& Lücking, lichenized, see Moncada et al. (2013a; taxonomy), Lücking et al. (2016b; classification), sequences are available but lacks for the type species.

Yoshinagaia Henn. 1904 (= Japonia Höhn. 1909; = Yoshinagamyces Hara 1912; Monoloculia Hara 1927 fide Rossman et al. 2016a), Dothideomycetes genera incertae sedis, two species, type: Y. quercus Henn., asexual morph unknown, saprobes, terrestrial, Japan, see Lumbsch and Huhndorf (2010; outline), Kirk et al. (2013; genus accepted), Wijayawardene et al. (2014c; outline), Rossman et al. (2016a; nomenclature), cultures and sequences are unavailable.

Yoshinagella Höhn. 1913, Dothideomycetes genera incertae sedis, four species, type: $Y$. japonica Höhn, asexual morph unknown, saprobes and parasitic, reported from Japan and Hawaii, see Kirk et al. (2013; genus accepted), Wijayawardene et al. (2014c; outline), Dai et al. (2014a; phylogeny, Dothideomycetes), cultures and sequences are unavailable, needs generic revision.

Ypsilina J. Webster, Descals \& Marvanová 1999, Ascomycota genera incertae sedis, one species, type: $Y$. graminea (Ingold, P.J. McDougall \& Dann) Descals, J. Webster \& Marvanová 1999, hyphomycetous, sexual morph unknown, aquatic, see Seena et al. (2010; DNA barcoding of fungi), Hyde et al. (2011; checklist), Seifert et al. (2011; morphology), 
Wijayawardene et al. (2012, 2017; outline), Kirk et al. (2013; genus accepted), sequences are available:

Ypsilomyces D.A.C. Almeida \& Gusmão 2014, Ascomycota genera incertae sedis, one species, type: $Y$. elegans D.A.C. Almeida \& Gusmão, hyphomycetous, sexual morph unknown, one species, saprobes, terrestrial, Brazil, see Almeida and Gusmão (2014; morphology), holotype of the type: HUEFS 155081, cultures and sequences are unavailable, compare with Biflagellospora, Diademospora, Diplocladiella, Iyengarina, Vanterpoolia, Weufia and Ypsilina.

Ypsilomyces D.A.C. Almeida \& Gusmão 2014, Ascomycota genera incertae sedis, one species, type species $Y$. elegans D.A.C. Almeida \& Gusmão, hyphomycetous, sexual morph unknown, saprobes, reported from Brazilian semi arid region, see Almeida and Gusmão (2014; taxonomy), Wijayawardene et al. (2017; outline), cultures and sequences are unavailable.

Ypsilonia Lév. 1846, Sordariales genera incertae sedis, five species, type: Y. cuspidata Lév., coelomycetous, sexual morph of unknown, saprobes, aquatic, see Hyde et al. (2011; outline), Wijayawardene et al. (2012, 2017; outline), Kirk et al. (2013; genus accepted), cultures and sequences are unavailable, needs generic revision.

Yuccamyces Gour, Dyko \& B. Sutton 1979, Ascomycota genera incertae sedis, seven species, type: Y. purpureus Gour, Dyko \& B. Sutton, hyphomycetous, sexual morph unknown, saprobes, Canada and Cuba, see Hyde et al. (2011; outline), Seifert et al. (2011; morphology), Wijayawardene et al. (2012, 2017; outline), Kirk et al. (2013; genus accepted), cultures and sequences are unavailable, needs generic revision.

Yuea O.E. Erikss. 2003, Xylariales genera incertae sedis, Sordariomycetes, one species, type: $Y$. chusqueicola O.E. Erikss., asexual morph unknown, terrestrial, saprobes, Chile, see Lumbsch and Huhndorf (2010; outline), Maharachchikumbura et al. (2015, 2016; outline, phylogeny), cultures and sequences are unavailable.

Yueomyces Q.M. Wang, L. Wang, M. Groenewald \& T. Boekhout 2015, Saccharomycetaceae, Saccharomycetales, Saccharomycetes, one species, type: Y. sinensis (J.Z. Yue) Q.M. Wang, L. Wang, M. Groenewald \& T. Boekhout, asexual reproduction is by bipolar budding, saprophytic, Soil, China, see Wang et al. (2015a; taxonomy), cultures and sequences are available.

Zahlbrucknerella Herre 1912, Lichinaceae, Lichinales, Lichinomycetes, eight species, type: Z. calcarea (Herre) Herre, asexual morph unknown, lichenized, terrestrial, worldwide, see Lumbsch and Huhndorf (2010; outline), Kirk et al. (2013; genus accepted), cultures and sequences are unavailable, needs generic revision.

Zakatoshia B. Sutton 1973, Ascomycota genera incertae sedis, two species, type: Z. hirschiopori B. Sutton, hyphomycetous, sexual morph unknown, fungicolous, terrestrial, worldwide, see Seifert et al. (2011; morphology), Wijayawardene et al. (2012, 2017; outline), Kirk et al. (2013; genus accepted), cultures and sequences are unavailable, needs generic revision.

Zalerion R.T. Moore \& Meyers 1962, Sordariomycetes genera incertae sedis, six species, type: Z. nepura R.T. Moore \& Meyers, hyphomycetous, sexual morph unknown, saprobes, terrestrial, cosmopolitan, see Seifert et al. (2011; morphology), Wijayawardene et al. (2012, 2017; outline), Kirk et al. (2013; genus accepted), Maharachchikumbura et al. (2015, 2016; outline), cultures and sequences are available, needs generic revision.

Zanclospora S. Hughes \& W.B. Kendr. 1965, Ascomycota genera incertae sedis, nine species, type: Z. novae-zelandiae S. Hughes \& W. B. Kendr., hyphomycetous, sexual morph unknown, saprobes, tropical and subtropical distribution with only two records in temperate region, see Hyde et al. (2011; outline), Seifert et al. (2011; morphology), Wijayawardene et al. (2012, 
2017; outline), Almeida et al. (2013; new species), Kirk et al. (2013; genus accepted), needs generic revision.

Zasmidium Fr. 1849, Mycosphaerellaceae, Capnodiales, Dothideomycetes, c. 70 species names, type: Z. cellare (Pers.) Fr., hyphomycetous, sexual morph mycosphaerella-like, five species confirmed based on DNA, plant pathogens, see Seifert et al. (2011; morphology), Wijayawardene et al. (2012, 2017; outline), Braun et al. (2013; morphology), Videira et al. (2017; morphology, phylogeny), cultures and sequences are available.

Zebrospora McKenzie 1991, Ascomycota genera incertae sedis, two species, type: Z. bicolor McKenzie, hyphomycetous, sexual morph unknown, saprobes, terrestrial, Australasia, Pacific Islands, see Seifert et al. (2011; morphology), Wijayawardene et al. (2012, 2017; outline), Kirk et al. (2013; genus accepted), cultures and sequences are unavailable, needs generic revision.

Zelandiocoela Nag Raj 1993, Ascomycota genera incertae sedis, one species, type: Z. ambigua (Nag Raj \& W.B. Kendr.) Nag Raj, coelomycetous, sexual morph unknown, saprobes, terrestrial, New Zealand, see Wijayawardene et al. (2012, 2017; outline), Kirk et al. (2013; genus accepted), cultures and sequences are unavailable, needs generic revision.

Zeloasperisporium R.F. Castañeda 1996 (= Neomicrothyrium Boonmee, H.X. Wu \& K.D. Hyde 2014 fide Hongsanan et al. 2015b), Zeloasperisporiaceae, Zeloasperisporiales, Dothideomycetes, seven species, type: Z. hyphopodioides R.F. Castañeda, hyphomycetous, sexual morph unknown, in air, saprobes, Asia, Australasia, Caribbean, see Cheewangkoon et al. (2009; new species, phylogeny), Seifert et al. (2011; morphology), Crous et al. (2015e; new species, phylogeny), Hongsanan et al. (2015b; new species, phylogeny), Wijayawardene et al. (2017; outline), cultures and sequences are available.

Zelodactylaria A.C. Cruz, Gusmão \& R.F. Castañeda 2012, Ascomycota genera incertae sedis, one species, type: Z. verticillata A.C. Cruz, Gusmão \& R.F. Castañeda, hyphomycetous, sexual morph unknown, saprobes, terrestrial, Brazil, see Cruz et al. (2012; taxonomy), Wijayawardene et al. (2017; outline), cultures and sequences are unavailable, needs generic revision.

Zelopelta B. Sutton \& R.D. Gaur 1984, Ascomycota genera incertae sedis, one species, type: Z. thrinacospora B. Sutton \& R.D. Gaur, coelomycetous, sexual morph unknown, saprobes, terrestrial, India, see Wijayawardene et al. (2012, 2017; outline), Kirk et al. (2013; genus accepted), cultures and sequences are unavailable, needs generic revision.

Zelosatchmopsis Nag Raj 1991, Ascomycota genera incertae sedis, one species, type: $Z$. sacciformis (R.F. Castañeda) Nag Raj \& R.F. Castañeda, coelomycetous, sexual morph unknown, saprobes, terrestrial, Cuba, see Wijayawardene et al. (2012, 2017; outline), Kirk et al. (2013; genus accepted), cultures and sequences are unavailable, needs generic revision.

Zernya Petr. 1947, Ascomycota genera incertae sedis, one species, type: Z. clypeata Petr., coelomycetous, sexual morph unknown, saprobes, terrestrial, Brazil, see Wijayawardene et al. (2012, 2017; outline), Kirk et al. (2013; genus accepted), cultures and sequences are unavailable, needs generic revision.

Zeroviella S.Y.Kondr. \& J.-S.Hur 2015, Teloschistaceae, Teloschistales, Lecanoromycetes, eight species, type: Z. papillifera (Vain.) S.Y. Kondr. \& Hur, lichenized, see Kondratyuk et al. (2015d; taxonomy), Lücking et al. (2016b; classification), sequences are available.

Zetesimomyces Nag Raj 1988, Ascomycota genera incertae sedis, one species, type: Z. setibicolor (R.F. Castañeda) Nag Raj, coelomycetous, sexual morph unknown, saprobes, terrestrial, Cuba, see Wijayawardene et al. (2012, 2017; outline), Kirk et al. (2013; genus accepted), cultures and sequences are unavailable, needs generic revision.

Zetiasplozna Nag Raj 1993, Bartaliniaceae, Xylariales, Sordariomycetes, six species, type: $Z$. caffra Matsush., coelomycetous, sexual morph unknown, saprobes, terrestrial, cosmopolitan, see Nicoletti et al. (2010; endophytes), Wijayawardene et al. (2012, 2016b, 2017; outline, 
taxonomy), Kirk et al. (2013; genus accepted), Crous et al. (2014c; new species), Senanayake et al. (2015; outline), Jaklitsch et al. (2016a; accepted as a genus in Sporocadaceae), Maharachchikumbura et al. (2015, 2016; outline), cultures and sequences are vailable, needs generic revision.

Zeugandromyces Thaxt. 1912, Laboulbeniaceae, Laboulbeniales, Laboulbeniomycetes, four species, type: Z. australis Thaxt., asexual morph unknown, biotrophic on Coleoptera (Staphylinidae, Paederini), America, Phillipines, Sumatra, Sri Lanka, see Lumbsch and Huhndorf (2010; outline), Kirk et al. (2013; genus accepted), cultures and sequences are unavailable, needs generic revision.

Zeus Minter \& Diam. 1987, Rhytismataceae, Rhytismatales, Leotiomycetes, two species, type: Z. olympius Minter \& Diam., asexual morph unknown, saprobes, terrestrial, Greece, see Lumbsch and Huhndorf (2010; outline), Kirk et al. (2013; genus accepted), cultures and sequences are unavailable.

Zevadia J.C. David \& D. Hawksw. 1995, Ascomycota genera incertae sedis, one species, type: Z. peroccidentalis J.C. David \& D. Hawksw., lichenicolous, Europe, sexual morph unknown, see Seifert et al. (2011; genus accepted), Kirk et al. (2013; genus accepted), no cultures or sequences are available, holotype of type: K(M)-IMI 401823.

Zilingia Petr. 1934, Ascomycota genera incertae sedis, one species, type: Z. sibirica Petr., coelomycetous, sexual morph unknown, saprobes, terrestrial, Siberia, see Wijayawardene et al. (2012, 2017; outline), Kirk et al. (2013; genus accepted), cultures and sequences are unavailable, needs generic revision.

Zimmermanniella Henn. 1902, Phyllachoraceae, Phyllachorales, Sordariomycetes, one species, type: Z. trispora Henn., from living leaves, South East Asia, see Lumbsch and Huhndorf (2010; outline), Kirk et al. (2013; genus accepted), Maharachchikumbura et al. (2015, 2016; outline), cultures and sequences are unavailable, needs generic revision.

Zinzipegasa Nag Raj 1993, Ascomycota genera incertae sedis, one species, type: $Z$. argentinensis (Speg.) Nag Raj, coelomycetous, sexual morph unknown, saprobes, terrestrial, Argentina, see Wijayawardene et al. (2012, 2017; outline), Kirk et al. (2013; genus accepted), cultures and sequences are unavailable, needs generic revision.

Zodiomyces Thaxt. 1891, Laboulbeniaceae, Laboulbeniales, Laboulbeniomycetes, four species, type: Z. vorticellarius Thaxt., asexual morph unknown, biotrophic on aquatic Coleoptera (Hydrophilidae), worldwide, see Lumbsch and Huhndorf (2010; outline), Kirk et al. (2013; genus accepted), Rossi et al. (2016b; most recent species description), ribosomal sequence are available.

Zoggium Lar.N. Vassiljeva 2001, Mytilinidiaceae, Mytilinidiales, Dothideomycetes, one species, type: Z. mayorii (H. Zogg) Lar.N. Vassiljeva, asexual morphs unknown, saprobes, terrestrial, north temperate, Boehm et al. (2009a, b; accepted as in Mytilinidiaceae), Hyde et al. (2013; accepted as in Mytilinidiaceae), Wijayawardene et al. (2014c; outline), cultures and sequences are unavailable.

Zopfia Rabenh. 1874, Zopfiaceae, Pleosporales, Dothideomycetes, five species, type: Z. rhizophila Rabenh., asexual morph unknown, saprobes, terrestrial, worldwide, see Schoch et al. (2009; phylogeny), Lumbsch and Huhndorf (2010; outline), Hyde et al. (2013; accepted as a genus in Zopfiaceae), Kirk et al. (2013; genus accepted), Wijayawardene et al. (2014c; outline), cultures and sequences are available, needs generic revision.

Zopfiella G. Winter 1884, Lasiosphaeriaceae, Sordariales, Sordariomycetes, 30 species, type: Z. tabulata (Zopf) G. Winter, asexual morph unknown, coprophilous, saprobes, terrestrial, marine, worldwide, see Lumbsch and Huhndorf (2010; outline), Kirk et al. (2013; genus accepted), Kruys et al. (2014; phylogeny), cultures and sequences are available.

Zopfiofoveola D. Hawksw. 1979, Zopfiaceae, Pleosporales, Dothideomycetes, one species, type: Z. punctata (D.Hawksw. \& C. Booth) D. Hawksw., on earthworm excrements, Sweden, 
see Lumbsch and Huhndorf (2010; outline), Kirk et al. (2013; genus accepted), Jaklitsch et al. (2016a; classification), cultures and sequences are unavailable, holotype of type: (microscope slide) UPS.

Zopheromyces B. Sutton \& Hodges 1977, Ascomycota genera incertae sedis, one species, type: Z. fasciatus B. Sutton \& Hodges, hyphomycetous, sexual morph unknown, saprobes, terrestrial, Australasia, see Seifert et al. (2011; morphology), Wijayawardene et al. (2012, 2017; outline), Kirk et al. (2013; genus accepted), cultures and sequences are unavailable, needs generic revision.

Zugazaea Korf, Iturr. \& Lizon̆ 1998, Helotiales genera incertae sedis, Leotiomycetes, one species, type: Z. agyrioides Korf, Iturr. \& Lizoň, asexual morph unknown, saprobes, Canary Islands, Lumbsch and Huhndorf (2010; outline), Kirk et al. (2013; genus accepted), holotype of the type: CUP-MM 2844, cultures and sequences are unavailable

Zukaliopsis Henn. 1904, Myriangiaceae, Myriangiales, Dothideomycetes, one species, type: Z. amazonica Henn., asexual morph unknown, parasitic, terrestrial, Peru, isotype of the type: S, F5604, see Dissanayake et al. (2014; morphology), Wijayawardene et al. (2014c; outline), needs generic revision.

Zunura Nag Raj 1993, Ascomycota genera incertae sedis, one species, type: Z. appendiculata (B. Sutton) Nag Raj, coelmycetous, sexual morph unknown, saprobes, terrestrial, India, see Wijayawardene et al. (2012, 2017; outline), Kirk et al. (2013; genus accepted), cultures and sequences are unavailable, needs generic revision.

Zwackhia Körb. 1855, Lecanographaceae, Arthoniales, Arthoniomycetes, six species, type: $Z$. viridis (Ach.) Poetsch \& Schied., lichenized, see Ertz and Tehler (2011; taxonomy) Diederich et al. (2012a; taxonomy), Lücking et al. (2016b; classification); sequences are available.

Zwackhiomacromyces Etayo \& van den Boom 2014, ?Xanthopyrenaceae, Collemopsidiales, Dothideomycetes, one species, type: Z. constrictocarpus Etayo \& Van den Boom asexual morph unknown, parasymbiont on Megalospora, terrestrial, Mediterranean Europe, see van den Boom and Etayo (2014; morphology, distinction of similar lichenicolous genera), holotype of the type: P. \& B. van den Boom $27046(\mathrm{BCN})$, cultures and sequences are unavailable.

Zwackhiomyces Grube \& Hafellner 1990, Xanthopyreniaceae, Collemopsidiales, Dothideomycetes, 35 species, type: Z. coepulonus (Norman) Grube \& R. Sant., asexual morph unknown, lichenicolous, terrestrial, worldwide, see Brackel (2008; new species), Diederich and Schultz (2009; new species), Halici and Candan (2009; new species), Roux (2009; new species), Boom (2010; new species), Lumbsch and Huhndorf (2010; outline, family placed as Ascomycota families incertae sedis), Kocakaya et al. (2011; new species), Pérez-Ortega et al. (2011a, 2016; new species, phylogeny), Kirk et al. (2013; genus accepted), Boom and Etayo (2014; new species), holotype of type: O-F72536, cultures available for the type: RO31.

Zygoascus M. Th. Smith 1986, ?Trichomonascaceae, Saccharomycetales, Saccharomycetes, six species, type: Z. hellenicus M.T. Smith, asexual reproduction is by multilateral budding, saprophytic, but there are some clinical isolates, in soft drinks, fruit juices, insect tunnels, cactus fruits, soil, tanning fluids, clinical isolates, worldwide, see Lumbsch and Huhndorf (2010; outline), Kirk et al. (2013; genus accepted), cultures and sequences are available.

Zygopleurage Lasiosphaeriaceae, Sordariales, Sordariomycetes, type: Z. zygospora (Speg.) Boedijn, saprobes, coprophilous, asexual morph phialophora-like, terrestrial, worldwide, see Richardson (2008, taxonomy), Chang et al. (2010, phylogeny), Mungai et al. (2011; taxonomy), Kruys et al. (2015, phylogeny).

Zygosaccharomyces B.T.P. Barker 1901, Saccharomycetaceae, Saccharomycetales, Saccharomycetes, eleven species, type: Z. rouxii (Boutroux) Yarrow, asexual morph 
unknown, saprobes, terrestrial, worldwide, see Lumbsch and Huhndorf (2010; outline), Kirk et al. (2013; genus accepted), cultures and sequences are available, needs generic revision.

Zygospermella Cain 1935, Lasiosphaeriaceae, Sordariales, Sordariomycetes, six species, type: Z. setosa (Cain) Cain, asexual morph unknown, saprobes, terrestrial, worldwide, see Lumbsch and Huhndorf (2010; outline), Kirk et al. (2013; genus accepted), Kruys et al. (2015; DNA, phylogeny), Maharachchikumbura et al. (2015, 2016; outline), cultures and sequences are available but lacks for the type.

Zygosporium Mont. 1842, Ascomycota genera incertae sedis, 16 species, type species $Z$. oscheoides Mont., hyphomycetous, saprobe, terrestrial, widespread, see Hyde et al. (2011; outline), Seifert et al. (2011; morphology), Kirk et al. (2013; genus accepted), Wijayawardene et al. (2012, 2017; outline), cultures and sequences are unavailable for type species, needs generic revision.

Zygotorulaspora Kurtzman 2003, Saccharomycetaceae, Saccharomycetales, Saccharomycetes, two species, type: Z. mrakii (Capriotti) Kurtzman, asexual reproduction is by multilateral budding, saprophytic, fruit drinks, fruit flies, grape must, silage, worldwide, see Lumbsch and Huhndorf (2010; outline), cultures and sequences are available.

Zymoseptoria Quaedvl. \& Crous 2011, Mycosphaerellaceae, Capnodiales, Dothideomycetes, seven species, type: Z. tritici (Desm.) Quaedvlieg \& Crous, coelomycetous, sexual morph mycosphaerella-like, plant pathogens on Poaceae, worldwide, see Quaedvlieg et al. (2011, 2014; morphology, phylogeny), epitype and ex-epitype culture of type: CBS H-20545, IPO $323=$ CBS 115943 .

Zythia Fr. 1849, Gnomoniaceae, Diaporthales, Sordariomycetes, type: Z. resinae (Ehrenb.) P. Karst. 1890, coelomycetous, sexual morph unknown, endophytic, saprobes, widespread, see Ding et al. (2010; antimicrobial activity), Hyde et al. (2011; checklist), Wijayawardene et al. (2012, 2017; outline), Kirk et al. (2013; genus accepted), Maharachchikumbura et al. (2015, 2016; outline), cultures and sequences are unavailable, needs generic revision.

Zyxiphora B. Sutton 1981, Ascomycota genera incertae sedis, one species, type: Z. appendiculata (B. Sutton) Nag Raj, hyphomycetous, sexual morph unknown, saprobes, terrestrial, Asia, see Seifert et al. (2011; morphology), Wijayawardene et al. (2012, 2017; outline), Kirk et al. (2013; genus accepted), cultures and sequences are unavailable, needs generic revision.

\section{Invalid and illegitimate generic names}

In this section (Table 2) we list all the invalid and illegitimate genera in Ascomycota.

Table 2. Invalid and illegtimate generic names and nomenclature comments based on Index Fungorum (2017)

\begin{tabular}{llll}
\hline Genus name & Authors & Year & $\begin{array}{l}\text { Nomenclature } \\
\text { comments }\end{array}$ \\
\hline Acantharia & Theiss. \& Syd., & 1918 & $\begin{array}{l}\text { Nom. illegit., Art. } \\
53.1\end{array}$ \\
Acerbia & (Sacc.) Sacc. \& P. Syd. & 1899 & $\begin{array}{l}\text { Nom. illegit., Art. } \\
53.1\end{array}$ \\
Aciculariella & G. Arnaud & 1954 & $\begin{array}{l}\text { Nom. inval., Art. } \\
\text { Acidomyces }\end{array}$ \\
Bcremoniula & B.J. Baker, M.A. Lutz, S.C. & 2004 & $\begin{array}{l}\text { Nom. inval., Art. } \\
\text { Dawson, P.L. Bond \& Banfield }\end{array}$ \\
& G. Arnaud & 1954 & $\begin{array}{l}\text { Nom. (Melbourne) } \\
\text { Nold. Art. }\end{array}$ \\
& & & 39.1 (Melbourne) \\
\hline
\end{tabular}




\begin{tabular}{|c|c|c|c|}
\hline Acrostaphylus & G. Arnaud & 1954 & $\begin{array}{l}\text { Nom. inval., Art. } \\
39.1 \text { (Melbourne) }\end{array}$ \\
\hline Adelphella & Pfister, Matočec \& I. Kušan & 2008 & $\begin{array}{l}\text { Nom. inval., Art. } \\
39.1,40.1 \\
\text { (Melbourne) }\end{array}$ \\
\hline Agyrium & Fr. & 1821 & $\begin{array}{l}\text { Nom. inval., Art. } \\
\text { 38.1(a) (Melbourne) }\end{array}$ \\
\hline Allantozythia & Petr. & 1923 & $\begin{array}{l}\text { Nom. inval., Art. } \\
\text { 38.1(a) (Melbourne) }\end{array}$ \\
\hline Allarthonia & (Nyl.) Müll. Arg. & 1895 & $\begin{array}{l}\text { Nom. inval., Art. } \\
\text { 38.1(a) (Melbourne) }\end{array}$ \\
\hline Amandinea & M. Choisy & 1950 & $\begin{array}{l}\text { Nom. inval., Art. } \\
39.1 \text { (Melbourne) }\end{array}$ \\
\hline Ambrosiella & Brader & 1964 & $\begin{array}{l}\text { Nom. inval., Art. } \\
40.1 \text { (Melbourne) }\end{array}$ \\
\hline Ampliotrema & Kalb & 2004 & $\begin{array}{l}\text { Nom. inval., Art. } \\
40.1 \text { (Melbourne) }\end{array}$ \\
\hline Ancorasporella & J. Mena, Mercado \& Heredia & 1998 & $\begin{array}{l}\text { Nom. inval., Art. } \\
\text { 40.1, see Arts 6.6, } \\
\text { 10.1 (Melbourne) }\end{array}$ \\
\hline Ancylospora & Sawada & 1944 & $\begin{array}{l}\text { Nom. inval., Art. } \\
39.1 \text { (Melbourne) }\end{array}$ \\
\hline Anekabeeja & Udaiyan \& Hosag. & 1992 & $\begin{array}{l}\text { Nom. inval., Arts } \\
40.1 \text { (see Art. } 8.5 \text { ), } \\
40.3 \text { (Melbourne) }\end{array}$ \\
\hline Anema & Nyl. & 1879 & $\begin{array}{l}\text { Nom. inval., Art. } \\
\text { 38.1(a) (Melbourne) }\end{array}$ \\
\hline Anomomorpha & Nyl. & 1889 & Nom. inval. \\
\hline Ansatospora & A.G. Newhall & 1944 & $\begin{array}{l}\text { Nom. inval., Art. } \\
39.1 \text { (Melbourne) }\end{array}$ \\
\hline Aponectria & (Sacc.) Sacc. & 1879 & $\begin{array}{l}\text { Nom. inval., Art. } \\
\text { 38.1(a) (Melbourne) }\end{array}$ \\
\hline Arniella & Jeng \& J.C. Krug & 1977 & $\begin{array}{l}\text { Nom. illegit., Art. } \\
53.1\end{array}$ \\
\hline Arthrocladia & Golovin & 1956 & $\begin{array}{l}\text { Nom. inval., Art. } \\
39.1 \text { (Melbourne); } \\
\text { Nom. illegit., Art. } \\
\text { 53.1 }\end{array}$ \\
\hline Arthrographis & G. Cochet & 1939 & $\begin{array}{l}\text { Nom. inval., Art. } \\
39.1 \text { (Melbourne) }\end{array}$ \\
\hline Arthrophiala & $\begin{array}{l}\text { W.S. Lisboa, Meir. Silva \& R.W. } \\
\text { Barreto }\end{array}$ & 2016 & $\begin{array}{l}\text { Nom. inval., Art. } \\
40.1 \text { (Melbourne) }\end{array}$ \\
\hline Ascobrunneispora & $\begin{array}{l}\text { K.D. Hyde, Ranghoo \& S.W. } \\
\text { Wong }\end{array}$ & 1999 & $\begin{array}{l}\text { Nom. inval., Art. } \\
\text { 36.1(c) (Melbourne) }\end{array}$ \\
\hline Ascocollumdensa & $\begin{array}{l}\text { K.D. Hyde, Ranghoo \& S.W. } \\
\text { Wong }\end{array}$ & 2000 & $\begin{array}{l}\text { Nom. inval., Art. } \\
\text { 36.1(c) (Melbourne) }\end{array}$ \\
\hline Ashtaangam & Subram. & 1992 & $\begin{array}{l}\text { Nom. inval., Art. } \\
40.1 \text { (Melbourne) }\end{array}$ \\
\hline Aspergillus & P. Micheli & 1729 & $\begin{array}{l}\text { Nom. inval., Art. } \\
\text { 32.1(a) (Melbourne) }\end{array}$ \\
\hline Assoa & Urries & 1944 & $\begin{array}{l}\text { Nom. illegit., Art. } \\
53.1\end{array}$ \\
\hline Asteridium & Speg. & 1884 & $\begin{array}{l}\text { Nom. inval., Art. } \\
\text { 38.1(a) (Melbourne) }\end{array}$ \\
\hline
\end{tabular}




\begin{tabular}{|c|c|c|c|}
\hline & & & $\begin{array}{l}\text { 40.1; see Art. } 6.3 \\
\text { (Melbourne) }\end{array}$ \\
\hline Austrographa & Sparrius, Elix \& A.W. Archer & 2011 & $\begin{array}{l}\text { Nom. inval., Art. } \\
\text { 40.1, see Arts 6.3, } \\
\text { 12.1 (Melbourne) }\end{array}$ \\
\hline Bainieria & G. Arnaud & 1952 & $\begin{array}{l}\text { Nom. inval., Art. } \\
39.1 \text { (Melbourne) }\end{array}$ \\
\hline Basauxia & Subram. & 1992 & $\begin{array}{l}\text { Nom. inval., Art. } \\
\text { 35.1 (Melbourne) }\end{array}$ \\
\hline Basitorula & G. Arnaud & 1954 & $\begin{array}{l}\text { Nom. inval., Art. } \\
39.1 \text { (Melbourne) }\end{array}$ \\
\hline Bhargavaella & Sud. Singh \& K.S. Srivast. & 1979 & $\begin{array}{l}\text { Nom. inval., Art. } \\
39.1 \text { (Melbourne) }\end{array}$ \\
\hline Blastodendrion & M. Ota & 1924 & $\begin{array}{l}\text { Nom. inval., Art. } \\
\text { 38.1(a) (Melbourne) }\end{array}$ \\
\hline Blumeria & Golovin & 1958 & $\begin{array}{l}\text { Nom. inval., Art. } \\
39.1 \text { (Melbourne) }\end{array}$ \\
\hline Bombardioidea & C. Moreau & 1954 & $\begin{array}{l}\text { Nom. inval., Art. } \\
39.1 \text { (Melbourne) }\end{array}$ \\
\hline Botanamphora & Nograsek \& Scheuer & 1990 & $\begin{array}{l}\text { Nom. inval., Art. } \\
\text { 41.3(Melbourne) }\end{array}$ \\
\hline Botrypes & Preuss & 1851 & $\begin{array}{l}\text { Nom. inval., Art. } \\
\text { 38.1(a) (Melbourne) }\end{array}$ \\
\hline Botrytis & P. Micheli & 1729 & $\begin{array}{l}\text { Nom. inval., Art. } \\
\text { 32.1(a) (Melbourne) }\end{array}$ \\
\hline Brachydesmiella & G. Arnaud & 1954 & $\begin{array}{l}\text { Nom. inval., Art. } \\
39.1 \text { (Melbourne) }\end{array}$ \\
\hline Brachyhelicoon & G. Arnaud & 1952 & $\begin{array}{l}\text { Nom. inval., Art. } \\
39.1 \text { (Melbourne) }\end{array}$ \\
\hline Brettanomyces & Kuff. \& Van Laer ex Custers & 1921 & $\begin{array}{l}\text { Nom. inval., Art. } \\
\text { 38.1(a) (Melbourne) }\end{array}$ \\
\hline Bryomyces & Döbbeler & 1978 & $\begin{array}{l}\text { Nom. illegit., Art. } \\
53.1\end{array}$ \\
\hline Caeruleoconidia & Zhurb. \& Diederich & 2015 & $\begin{array}{l}\text { Nom. inval., Art. } \\
40.1 \text { (Melbourne) }\end{array}$ \\
\hline Calycella & Pat. & 1883 & $\begin{array}{l}\text { Nom. inval., Art. } \\
\text { 38.1(a) (Melbourne) }\end{array}$ \\
\hline Capnodinula & Bat. \& Peres & 1962 & $\begin{array}{l}\text { Nom. inval., Art. } \\
39.1 \text { (Melbourne); } \\
\text { Nom. illegit., Art. } \\
53.1\end{array}$ \\
\hline Capnodinula & Bat. \& Cif. & 1963 & $\begin{array}{l}\text { Nom. inval., Art. } \\
39.1 \text { (Melbourne); } \\
\text { Nom. illegit., Art. } \\
53.1\end{array}$ \\
\hline Carlosia & G. Arnaud & 1954 & $\begin{array}{l}\text { Nom. inval., Art. } \\
39.1 \text { (Melbourne) }\end{array}$ \\
\hline Catapyrenium & Flot. & 1849 & $\begin{array}{l}\text { Nom. inval., Art. } \\
\text { 38.1(a) (Melbourne) }\end{array}$ \\
\hline Catenolaria & G.Y. Sun \& H.Y. Li & 2009 & $\begin{array}{l}\text { Nom. inval., Arts } \\
39.1,40.1 \\
\text { (Melbourne) }\end{array}$ \\
\hline Cateractispora & $\begin{array}{l}\text { Ranghoo, K.D. Hyde \& E.C.Y. } \\
\text { Liew }\end{array}$ & 1999 & $\begin{array}{l}\text { Nom. inval., Art. } \\
\text { 36.1(c) (Melbourne) }\end{array}$ \\
\hline Cephalocladium & Rchb. ex Mussat & 1901 & Nom. inval., Art. \\
\hline
\end{tabular}




\begin{tabular}{|c|c|c|c|}
\hline & & & $\begin{array}{l}\text { 36.1(a), (c) } \\
\text { (Melbourne) }\end{array}$ \\
\hline Ceracella & (P. Karst.) Rehm & 1892 & $\begin{array}{l}\text { Nom. inval., Art. } \\
\text { 36.1(d) (Melbourne) }\end{array}$ \\
\hline Ceratospermum & P. Micheli & 1729 & $\begin{array}{l}\text { Nom. inval., Art. } \\
\text { 32.1(a) (Melbourne) }\end{array}$ \\
\hline Cercosperma & G. Arnaud & 1954 & $\begin{array}{l}\text { Nom. inval., Art. } \\
39.1 \text { (Melbourne) }\end{array}$ \\
\hline Cercosporula & G. Arnaud & 1954 & $\begin{array}{l}\text { Nom. inval., Art. } \\
39.1 \text { (Melbourne) }\end{array}$ \\
\hline Chaetomeliola & (Cif.) Bat., H. Maia \& M.L. Farr & 1962 & $\begin{array}{l}\text { Nom. inval., Art. } \\
39.1 \text { (Melbourne) }\end{array}$ \\
\hline Chloridiella & G. Arnaud & 1954 & $\begin{array}{l}\text { Nom. inval., Art. } \\
39.1 \text { (Melbourne) }\end{array}$ \\
\hline Chlorociboria & Seaver & 1936 & Nom. inval. \\
\hline Chondropsis & Nyl. & 1863 & $\begin{array}{l}\text { Nom. inval., Art. } \\
\text { 36.1(b) (Melbourne) }\end{array}$ \\
\hline Chorioactis & Kupfer & 1902 & $\begin{array}{l}\text { Nom. inval., Art. } \\
\text { 32.1(d); see Art. 38.5, } \\
\text { Ex. } 1 \text { (Melbourne) }\end{array}$ \\
\hline Chroocybe & Räsänen & 1943 & $\begin{array}{l}\text { Nom. inval., Art. } \\
39.1 \text { (Melbourne) }\end{array}$ \\
\hline Chrysoporthella & Gryzenh. \& M.J. Wingf. & 2004 & $\begin{array}{l}\text { Nom. inval., Arts } \\
40.1,40.3 \\
\text { (Melbourne) }\end{array}$ \\
\hline Ciliaria & Quél. & 1880 & $\begin{array}{l}\text { Nom. inval., Art. } \\
\text { 38.5(b) (Melbourne) }\end{array}$ \\
\hline Cladosphaeria & G.H. Otth & 1869 & $\begin{array}{l}\text { Nom. inval., Art. } \\
\text { 38.1(a) (Melbourne) }\end{array}$ \\
\hline Collemopsis & Nyl. & 1873 & $\begin{array}{l}\text { Nom. inval., Art. } \\
\text { 38.1(a) (Melbourne) }\end{array}$ \\
\hline Coniolaria & $\begin{array}{l}\text { Seigle-Mur., Guiraud, Steiman \& } \\
\text { Sage }\end{array}$ & 1995 & $\begin{array}{l}\text { Nom. inval., Arts } \\
39.1,40.1 \\
\text { (Melbourne) }\end{array}$ \\
\hline Corynesporina & Subram. & 1994 & $\begin{array}{l}\text { Nom. inval., Art. } \\
35.1 \text { (Melbourne) }\end{array}$ \\
\hline Crinigera & I. Schmidt & 1969 & $\begin{array}{l}\text { Nom. inval., Art. } \\
40.1 \text { (Melbourne) }\end{array}$ \\
\hline Curculiospora & G. Arnaud & 1954 & $\begin{array}{l}\text { Nom. inval., Art. } \\
39.1 \text { (Melbourne) }\end{array}$ \\
\hline Curvicladium & Decock \& Crous & 1998 & $\begin{array}{l}\text { Nom. illegit., Art. } \\
53.1\end{array}$ \\
\hline Curvidigitus & Sawada & 1943 & $\begin{array}{l}\text { Nom. inval., Art. } \\
39.1 \text { (Melbourne) }\end{array}$ \\
\hline Cystotrichiopsis & Abbas, B. Sutton \& Ghaffar & 2001 & $\begin{array}{l}\text { Nom. inval., Art. } \\
\text { 40.2, see Arts 6.6, } \\
\text { 10.1 (Melbourne) }\end{array}$ \\
\hline Cytopleastrum & $\begin{array}{l}\text { Abbas, B. Sutton, Ghaffar \& A. } \\
\text { Abbas }\end{array}$ & 2004 & $\begin{array}{l}\text { Nom. inval., Art. } \\
\text { 40.1, see Arts 6.3, } \\
\text { 12.1 (Melbourne) }\end{array}$ \\
\hline Dactylina & G. Arnaud & 1952 & $\begin{array}{l}\text { Nom. inval., Art. } \\
39.1 \text { (Melbourne) }\end{array}$ \\
\hline Dasyscypha & Nees & 1816 & $\begin{array}{l}\text { Nom. inval., Art. } \\
\text { 38.1(a) (Melbourne) }\end{array}$ \\
\hline Deakozyma & C.P. Kurtzman \& C.J. Robnett & 2014 & Nom. inval., Art. \\
\hline
\end{tabular}




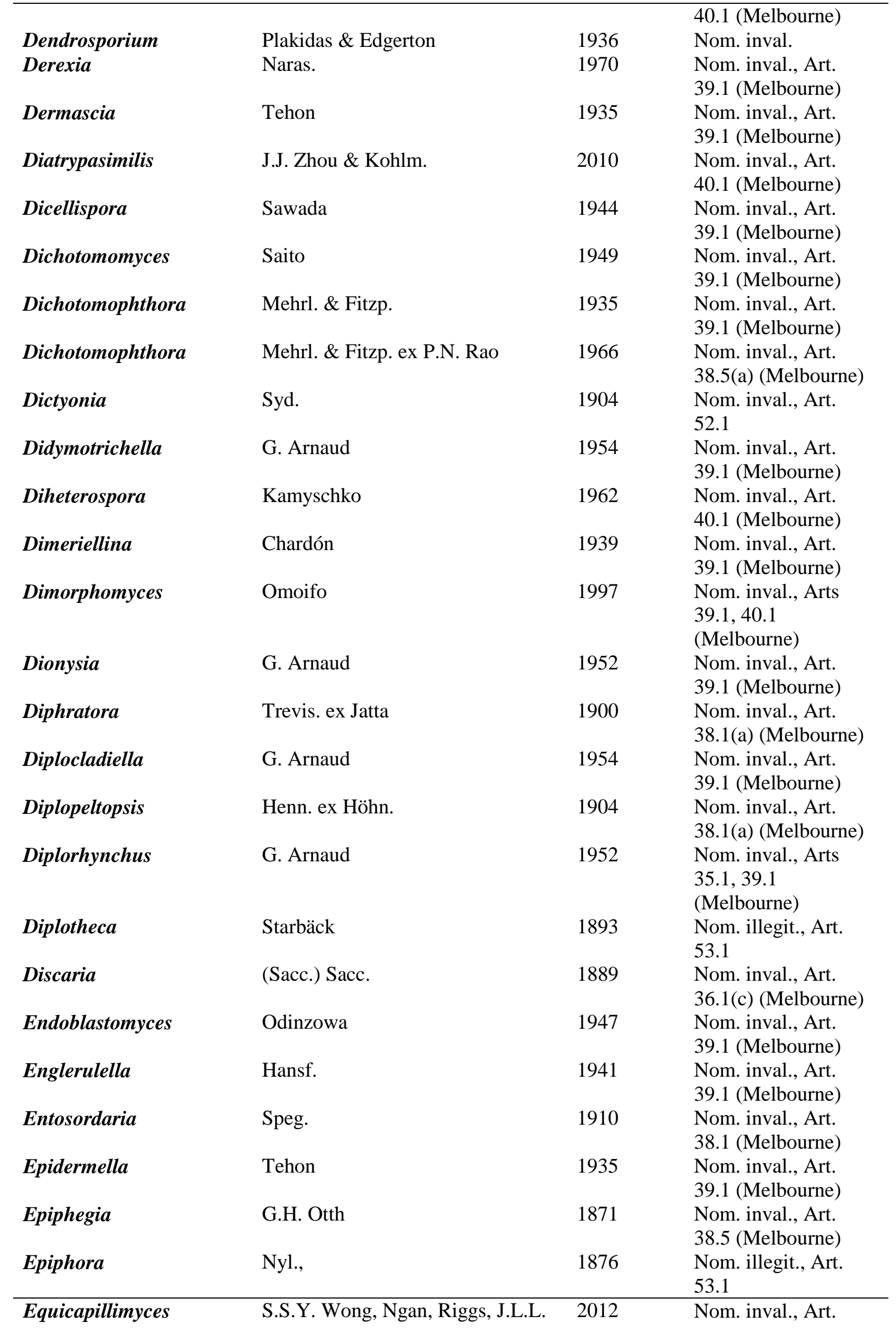




\begin{tabular}{|c|c|c|c|}
\hline & $\begin{array}{l}\text { Teng, G.K.Y. Choi, R.W.S. Poon, } \\
\text { J.J.Y. Hui, F.J. Low, Luk \& K.Y. } \\
\text { Yuen }\end{array}$ & & $\begin{array}{l}\text { 40.1, see Arts 6.3, } \\
\text { 12.1 (Melbourne) }\end{array}$ \\
\hline Euspheconisca & Norman ex Bachm. & 1926 & $\begin{array}{l}\text { Nom. inval., Art. } \\
\text { 38.1(a) (Melbourne) }\end{array}$ \\
\hline Everniastrum & Hale & 1976 & $\begin{array}{l}\text { Nom. inval., Art. } \\
39.1 \text { (Melbourne) }\end{array}$ \\
\hline Evicentia & Barreno & 2000 & $\begin{array}{l}\text { Nom. inval., Art. } \\
\text { 40.1, see Arts 6.6, } \\
\text { 10.1 (Melbourne) }\end{array}$ \\
\hline Farmanomyces & Y.S. Paul \& V.K. Thakur & 2006 & $\begin{array}{l}\text { Nom. inval., Art. } \\
\text { 40.1, see Arts 6.3, } \\
\text { 10.1, } 12.1 \\
\text { (Melbourne) }\end{array}$ \\
\hline Fecundostilbum & T.P. Devi \& Chowdhry & 2009 & $\begin{array}{l}\text { Nom. inval., Art. } \\
40.6 \text { (Melbourne) }\end{array}$ \\
\hline Filaspora & Preuss & 1851 & $\begin{array}{l}\text { Nom. inval., Art. } \\
\text { 38.1(a) (Melbourne) }\end{array}$ \\
\hline Fuscidea & V. Wirth \& Vězda & 1972 & $\begin{array}{l}\text { Nom. inval., Art. } \\
40.1 \text { (Melbourne) }\end{array}$ \\
\hline Fuscopannaria & P.M. Jørg. & 1993 & $\begin{array}{l}\text { Nom. inval., Arts } \\
39.1,40.2 \\
\text { (Melbourne) }\end{array}$ \\
\hline Fusicatena & K. Matsush. \& Matsush. & 1996 & $\begin{array}{l}\text { Nom. inval., Art. } \\
40.1 \text {, see Arts 6.6, } \\
\text { 10.1 (Melbourne) }\end{array}$ \\
\hline Fusicladina & G. Arnaud & 1952 & $\begin{array}{l}\text { Nom. inval., Art. } \\
39.1 \text { (Melbourne) }\end{array}$ \\
\hline Geniculospora & Sv. Nilsson & 1964 & $\begin{array}{l}\text { Nom. inval., Art. } \\
40.1 \text { (Melbourne) }\end{array}$ \\
\hline Geotrichella & G. Arnaud & 1954 & $\begin{array}{l}\text { Nom. inval., Art. } \\
39.1 \text { (Melbourne) }\end{array}$ \\
\hline Glabrotheca & Chardón & 1939 & $\begin{array}{l}\text { Nom. inval., Art. } \\
39.1 \text { (Melbourne) }\end{array}$ \\
\hline Glenosporopsis & O.M. Fonseca & 1943 & $\begin{array}{l}\text { Nom. inval., Art. } \\
39.1 \text { (Melbourne) }\end{array}$ \\
\hline Gloeocercospora & D.C. Bain \& Edgerton & 1943 & $\begin{array}{l}\text { Nom. inval., Art. } \\
39.1 \text { (Melbourne) }\end{array}$ \\
\hline Glonium & Muhl. & 1813 & $\begin{array}{l}\text { Nom. inval., Art. } \\
\text { 38.1(a) (Melbourne) }\end{array}$ \\
\hline Goidanichia & G. Arnaud & 1954 & $\begin{array}{l}\text { Nom. inval., Art. } \\
39.1 \text { (Melbourne) }\end{array}$ \\
\hline Goidanichiella & G. Arnaud & 1954 & $\begin{array}{l}\text { Nom. inval., Art. } \\
39.1 \text { (Melbourne) }\end{array}$ \\
\hline Goidanichiella & G. Arnaud ex G.L. Barron & 1968 & $\begin{array}{l}\text { Nom. inval., Art. } \\
39.1 \text { (Melbourne) }\end{array}$ \\
\hline Goidanichiella & G.L. Barron ex W. Gams & 1990 & $\begin{array}{l}\text { Nom. inval., Arts } \\
40.1,35.1 \\
\text { (Melbourne) }\end{array}$ \\
\hline Gyalolechia & Trevis. & 1851 & $\begin{array}{l}\text { Nom. inval., Art. } \\
\text { 38.1(a) (Melbourne) }\end{array}$ \\
\hline Gymnoascopsis & C. Moreau \& M. Moreau & 1959 & $\begin{array}{l}\text { Nom. inval., Art. } \\
39.1 \text { (Melbourne) }\end{array}$ \\
\hline Haplocarpon & M. Choisy & 1931 & $\begin{array}{l}\text { Nom. inval., Art. } \\
\text { 38.1(a) (Melbourne) }\end{array}$ \\
\hline
\end{tabular}


Helicosporina

G. Arnaud

Hemialysidium

Hol.-Jech.

1992

Hemisynnema

Subram.

1994

Heteroconidium

Sawada

Homodium

Nyl.

Hormococcus

Preuss

1875

1851

Hyalobotrys

Pidopl.

1948

Hyalomelanconis

Naumov

1954

Hyalotiastrum

Abbas, B. Sutton, Ghaffar \& Abbas

2003

Egidi \& Quaedvl.

2014

Hyphoconis

Sawada

1959

Ach.

1794

Isidium

Javonarxia

Subram.

1992

Katherinomyces

Khodos.

2016

Kurssanovia

Pidopl.

1948

Lambertellinia

Korf \& Lizoň

1993

Lambottiella

Speg.

1910

Sacc. \& Berl.

1885

M. Verm., Gryzenh. \& Jol. Roux

2011

E.B.G. Jones, Yusoff \& S.T. Moss

1994

Lautisporopsis

E.B.G. Jones, Yusoff \& S.T. Moss 39.1 (Melbourne)

Nom. inval., Art. 38.1(a) (Melbourne) Nom. inval., Art. 39.1 (Melbourne) Nom. inval., Art. 39.1 (Melbourne) Nom. inval., Art. 39.1 (Melbourne) Nom. inval., Arts 39.1, 40.1

(Melbourne)

Nom. inval., Art. 40.1, see Arts 6.6, 10.1 (Melbourne) Nom. inval., Art. 39.1 (Melbourne) Nom. inval. Nom. inval., Art. 38.1(a) (Melbourne) Nom. inval., Art. 39.1 (Melbourne) Nom. inval., Art. 39.1 (Melbourne) Nom. inval., Art. 40.1, see Arts 6.3, 12.1 (Melbourne) Nom. inval., Art. 40.1 (Melbourne) Nom. inval., Art. 39.1 (Melbourne) Nom. inval., Art. 36.1(a) (Melbourne) Nom. inval., Art. 40.1 (Melbourne) Nom. inval., Art. 42.1 (Melbourne) Nom. inval., Art. 39.1 (Melbourne) Nom. inval., Art. 39.1 (Melbourne) Nom. inval., Art. 38.1(a) (Melbourne) Nom. inval., Art. 36.1(b) (Melbourne) Nom. inval., Art. 40.6 (Melbourne) Nom. inval., Art. 41.3 (Melbourne) Nom. inval., Art. 40.1, see Arts 6.6, 10.1 (Melbourne) Nom. inval., Art. 34.1 (Melbourne) 


\begin{tabular}{|c|c|c|c|}
\hline Lecidorina & Motyka & 1996 & $\begin{array}{l}\text { Nom. inval., Art. } \\
34.1 \text { (Melbourne) }\end{array}$ \\
\hline Lembosiopsis & Theiss. & 1913 & $\begin{array}{l}\text { Nom. inval., Art. } \\
\text { 38.1(a) (Melbourne) }\end{array}$ \\
\hline Leptosporina & Chardón & 1939 & $\begin{array}{l}\text { Nom. inval., Art. } \\
39.1 \text { (Melbourne) }\end{array}$ \\
\hline Leucographa & Nyl. & 1857 & $\begin{array}{l}\text { Nom. inval., Art. } \\
\text { 38.1(a) (Melbourne) }\end{array}$ \\
\hline Lichen & P. Micheli & 1729 & $\begin{array}{l}\text { Nom. inval., Art. } \\
\text { 32.1(a) (Melbourne) }\end{array}$ \\
\hline Lichenagaricus & P. Micheli & 1729 & $\begin{array}{l}\text { Nom. inval., Art. } \\
\text { 32.1(a) (Melbourne) }\end{array}$ \\
\hline Lichenoides & P. Micheli & 1729 & $\begin{array}{l}\text { Nom. inval., Art. } \\
\text { 32.1(a) (Melbourne) }\end{array}$ \\
\hline Linkomyces & Golovin & 1958 & $\begin{array}{l}\text { Nom. inval., Art. } \\
39.1 \text { (Melbourne) }\end{array}$ \\
\hline Linopeltis & I. Hino \& Katum. & 1960 & $\begin{array}{l}\text { Nom. inval., Art. } \\
40.1 \text { (Melbourne) }\end{array}$ \\
\hline Lithophila & L. Selbmann \& D. Isola & 2015 & $\begin{array}{l}\text { Nom. inval., Art. } \\
40.1 \text { (Melbourne); } \\
\text { Nom. illegit., Art. } \\
53.1\end{array}$ \\
\hline Lobarina & Nyl. & 1877 & $\begin{array}{l}\text { Nom. inval., Art. } \\
\text { 38.1(a) (Melbourne) }\end{array}$ \\
\hline Lobarina & Nyl. & 1889 & $\begin{array}{l}\text { Nom. inval., Art. } \\
\text { 38.1(a) (Melbourne) }\end{array}$ \\
\hline Lobularia & Velen. & 1934 & $\begin{array}{l}\text { Nom. illegit., Art. } \\
53.1\end{array}$ \\
\hline Locelliderma & Tehon & 1935 & $\begin{array}{l}\text { Nom. inval., Art. } \\
39.1 \text { (Melbourne) }\end{array}$ \\
\hline Lyonella & Syd. & 1925 & $\begin{array}{l}\text { Nom. illegit., Art. } \\
53.1\end{array}$ \\
\hline Magdalaenaea & G. Arnaud & 1952 & $\begin{array}{l}\text { Nom. inval., Art. } \\
39.1 \text { (Melbourne) }\end{array}$ \\
\hline Mariannaea & G. Arnaud & 1952 & $\begin{array}{l}\text { Nom. inval., Art. } \\
39.1 \text { (Melbourne) }\end{array}$ \\
\hline Martinia & Whetzel & 1942 & $\begin{array}{l}\text { Nom. inval., Art. } \\
39.1 \text { (Melbourne) }\end{array}$ \\
\hline Maxibeltrania & Rambelli & 2011 & $\begin{array}{l}\text { Nom. inval., Arts } \\
\text { 40.1, 40.3, see Arts } \\
6.3,12.1 \text { (Melbourne) }\end{array}$ \\
\hline Megacladosporium & Vienn.-Bourg. & 1949 & $\begin{array}{l}\text { Nom. inval., Art. } \\
39.1 \text { (Melbourne) }\end{array}$ \\
\hline Meliothecium & Mussat & 1901 & $\begin{array}{l}\text { Nom. inval., Art. } \\
36.1(\mathrm{a}),(\mathrm{c}) \\
\text { (Melbourne) }\end{array}$ \\
\hline Microides & De Vroey & 1970 & $\begin{array}{l}\text { Nom. inval., Art. } \\
40.1 \text { (Melbourne) }\end{array}$ \\
\hline Mirandina & G. Arnaud & 1952 & $\begin{array}{l}\text { Nom. inval., Art. } \\
39.1 \text { (Melbourne) }\end{array}$ \\
\hline Mirandina & G. Arnaud ex Matsush. & 1971 & $\begin{array}{l}\text { Nom. inval., Art. } \\
40.1 \text { (Melbourne) }\end{array}$ \\
\hline Mobergia & H. Mayrhofer \& Sheard & 1992 & $\begin{array}{l}\text { Nom. inval., Arts } \\
39.1,40.1 \\
\text { (Melbourne) }\end{array}$ \\
\hline
\end{tabular}




\begin{tabular}{|c|c|c|c|}
\hline Monostachys & G. Arnaud & 1954 & $\begin{array}{l}\text { Nom. inval., Art. } \\
39.1 \text { (Melbourne) }\end{array}$ \\
\hline \multirow[t]{2}{*}{ Mycothermus } & D.O. Natvig, J.W. Taylor, A. & 2015 & \\
\hline & $\begin{array}{l}\text { Tsang, M.I. Hutchinson \& A.J. } \\
\text { Powell }\end{array}$ & & Nom. inval., Art. \\
\hline Myriospora & Nägeli & 1853 & Nom. inval., Art. \\
\hline Naetrocymbe & Bat. \& Cif. & 1963 & $\begin{array}{l}\text { 38.1(a) (Melbourne) } \\
\text { Nom. inval., Art. } \\
39.1 \text { (Melbourne) }\end{array}$ \\
\hline Nakataea & Hara & 1936 & $\begin{array}{l}\text { Nom. inval., Art. } \\
\text { 38.1(a) (Melbourne) }\end{array}$ \\
\hline Nemadiplodia & Zambett. & 1955 & $\begin{array}{l}\text { Nom. inval., Art. } \\
39.1 \text { (Melbourne) }\end{array}$ \\
\hline Nematostigma & Syd. \& P. Syd. & 1913 & $\begin{array}{l}\text { Nom. illegit., Art. } \\
53.1\end{array}$ \\
\hline Neodasyscypha & Spooner & 1987 & $\begin{array}{l}\text { Nom. inval., Art. } \\
41.5 \text { (Melbourne) }\end{array}$ \\
\hline Neomicrothyrium & Boonmee, H.X. Wu \& K.D. Hyde & 2011 & $\begin{array}{l}\text { Nom. inval., Art. } \\
40.6 \text { (Melbourne) }\end{array}$ \\
\hline Nitschkia & Nitschke ex Fuckel & 1870 & $\begin{array}{l}\text { Nom. inval., Art. } \\
\text { 38.1(a) (Melbourne) }\end{array}$ \\
\hline Nitschkia & G.H. Otth ex Fuckel & 1870 & $\begin{array}{l}\text { Nom. inval., Art. } \\
\text { 38.1(a) (Melbourne) }\end{array}$ \\
\hline Ocellis & Clem. & 1909 & $\begin{array}{l}\text { Nom. inval., Art. } \\
32.1(\mathrm{c}) \text {, see Art. } 20.2 \\
\text { (Melbourne) }\end{array}$ \\
\hline Ochrosphaera & Sawada & 1959 & $\begin{array}{l}\text { Nom. inval., Art. } \\
39.1 \text { (Melbourne); } \\
\text { Nom. illegit., Art. } \\
53.1\end{array}$ \\
\hline Olegblumia & S.Y. Kondr., S.O. Oh \& J.S. Hur & 2015 & $\begin{array}{l}\text { Nom. inval., Art. } \\
40.1 \text { (Melbourne) }\end{array}$ \\
\hline Omnidemptus & P.F. Cannon \& Alcorn & 1994 & $\begin{array}{l}\text { Nom. inval., Art. } \\
39.1 \text { (Melbourne) }\end{array}$ \\
\hline Oncopodiella & G. Arnaud & 1954 & $\begin{array}{l}\text { Nom. inval., Art. } \\
39.1 \text { (Melbourne) }\end{array}$ \\
\hline Ophiodendron & G. Arnaud & 1952 & $\begin{array}{l}\text { Nom. inval., Art. } \\
39.1 \text { (Melbourne) }\end{array}$ \\
\hline Ophiopodium & G. Arnaud & 1954 & $\begin{array}{l}\text { Nom. inval., Art. } \\
39.1 \text { (Melbourne) }\end{array}$ \\
\hline Orthochaeta & Sawada & 1943 & $\begin{array}{l}\text { Nom. inval., Art. } \\
39.1 \text { (Melbourne) }\end{array}$ \\
\hline Overeemia & G. Arnaud & 1954 & $\begin{array}{l}\text { Nom. inval., Art. } \\
39.1 \text { (Melbourne) }\end{array}$ \\
\hline Ovulitis & N.F. Buchw. & 1949 & $\begin{array}{l}\text { Nom. inval., Art. } \\
39.1 \text { (Melbourne) }\end{array}$ \\
\hline Pachythyrium & G. Arnaud & 1954 & $\begin{array}{l}\text { Nom. inval., Art. } \\
39.1 \text { (Melbourne) }\end{array}$ \\
\hline Pallidogramme & Staiger, Kalb \& Lücking & 2008 & $\begin{array}{l}\text { Nom. inval., Art. } \\
41.5 \text { (Melbourne) }\end{array}$ \\
\hline Palmomyces & Maire & 1926 & $\begin{array}{l}\text { Nom. illegit., Art. } \\
53.1\end{array}$ \\
\hline Paracapsulospora & Konta \& K.D. Hyde & 2016 & $\begin{array}{l}\text { Nom. inval., Art. } \\
42.1 \text { (Melbourne) }\end{array}$ \\
\hline Paraplacodium & Motyka & 1996 & Nom. inval., Art. \\
\hline
\end{tabular}




\begin{tabular}{|c|c|c|c|}
\hline & & & 34.1 (Melbourne) \\
\hline Parepichlö̈ & J.F. White \& P.V. Reddy & 1998 & $\begin{array}{l}\text { Nom. inval., Art. } \\
\text { 40.1, see Arts 6.6, } \\
\text { 10.1 (Melbourne) }\end{array}$ \\
\hline Parvosympodium & A.W. Ramaley & 2002 & $\begin{array}{l}\text { Nom. inval., Art. } \\
\text { 40.1, see Arts 6.3, } \\
\text { 10.1 (Melbourne) }\end{array}$ \\
\hline Pectenia & $\begin{array}{l}\text { P.M. Jørg., L. Lindblom, Wedin \& } \\
\text { S. Ekman }\end{array}$ & 2014 & $\begin{array}{l}\text { Nom. inval., Art. } \\
\text { 41.3, Art. 41.8(a) } \\
\text { does not apply } \\
\text { (Melbourne) }\end{array}$ \\
\hline Peltigeropsis & V. Marcano \& A. Morales & 1994 & $\begin{array}{l}\text { Nom. inval., Arts } \\
39.1,40.4 \\
\text { (Melbourne) }\end{array}$ \\
\hline Petriellopsis & Gilgado, Cano, Guarro \& Gené & 2007 & $\begin{array}{l}\text { Nom. inval., Art. } \\
\text { 40.1, see Arts } 6.3 \text {, } \\
\text { 10.1, 12.1 } \\
\text { (Melbourne) }\end{array}$ \\
\hline Peyronellaea & Goid. & 1946 & $\begin{array}{l}\text { Nom. inval., Art. } \\
39.1 \text { (Melbourne) }\end{array}$ \\
\hline Phaeoxyphium & Bat. \& J.L. Bezerra & 1960 & $\begin{array}{l}\text { Nom. inval., Art. } \\
39.1 \text { (Melbourne) }\end{array}$ \\
\hline Phalloboletus & P. Micheli & 1729 & $\begin{array}{l}\text { Nom. inval., Art. } \\
\text { 32.1(a) (Melbourne) }\end{array}$ \\
\hline Phialicorona & Subram. & 1993 & $\begin{array}{l}\text { Nom. inval., Art. } \\
35.1 \text { (Melbourne) }\end{array}$ \\
\hline Phloeosporella & Höhn. & 1920 & $\begin{array}{l}\text { Nom. inval., Art. } \\
\text { 38.1(a) (Melbourne) }\end{array}$ \\
\hline Phloeosporina & Höhn. & 1916 & $\begin{array}{l}\text { Nom. inval., Art. } \\
\text { 38.1(a) (Melbourne) }\end{array}$ \\
\hline Phlyctidia & Müll. Arg. & 1880 & $\begin{array}{l}\text { Nom. inval., Art. } \\
\text { 38.1(a) (Melbourne) }\end{array}$ \\
\hline Pilulina & G. Arnaud & 1954 & $\begin{array}{l}\text { Nom. inval., Art. } \\
39.1 \text { (Melbourne) }\end{array}$ \\
\hline Piminella & G. Arnaud & 1954 & $\begin{array}{l}\text { Nom. inval., Art. } \\
39.1 \text { (Melbourne) }\end{array}$ \\
\hline Pittierodothis & Chardón & 1939 & $\begin{array}{l}\text { Nom. inval., Arts } \\
35.1,39.1 \\
\text { (Melbourne) }\end{array}$ \\
\hline Plectomyriangium & C. Moreau \& M. Moreau & 1959 & $\begin{array}{l}\text { Nom. inval., Art. } \\
39.1 \text { (Melbourne) }\end{array}$ \\
\hline Pleurocatena & G. Arnaud & 1952 & $\begin{array}{l}\text { Nom. inval., Art. } \\
39.1 \text { (Melbourne) }\end{array}$ \\
\hline Pleurocatena & G. Arnaud ex Aramb. & 1981 & $\begin{array}{l}\text { Nom. inval., Art. } \\
40.1 \text { (Melbourne) }\end{array}$ \\
\hline Polycornum & Malcolm \& Vězda & 1995 & $\begin{array}{l}\text { Nom. inval., Art. } \\
\text { 40.1, see Arts 6.6, } \\
\text { 10.1 (Melbourne) }\end{array}$ \\
\hline Polyscytalina & G. Arnaud & 1954 & $\begin{array}{l}\text { Nom. inval., Art. } \\
39.1 \text { (Melbourne) }\end{array}$ \\
\hline Porodiscella & Viégas & 1944 & $\begin{array}{l}\text { Nom. inval., Art. } \\
39.1 \text { (Melbourne) }\end{array}$ \\
\hline Porodiscus & Lloyd & 1919 & $\begin{array}{l}\text { Nom. illegit., Art. } \\
53.1\end{array}$ \\
\hline Protoplacodium & Motyka & 1995 & Nom. inval., Art. \\
\hline
\end{tabular}




\begin{tabular}{|c|c|c|c|}
\hline Protoroccella & Follmann & 1995 & $\begin{array}{l}34.1 \text { (Melbourne) } \\
\text { Nom. inval., Art. } \\
39.1 \text { (Melbourne) }\end{array}$ \\
\hline Protoroccella & L.M. Sánchez-Pinto \& M. Schulz & 2001 & $\begin{array}{l}\text { Nom. inval., Art. } \\
39.1 \text { (Melbourne) }\end{array}$ \\
\hline Pseudoalternaria & $\begin{array}{l}\text { D.P. Lawr., Gannibal, F.M. Dugan } \\
\text { \& B.M. Pryor }\end{array}$ & 2013 & $\begin{array}{l}\text { Nom. inval., Art. } \\
42.1 \text { (Melbourne) }\end{array}$ \\
\hline Pseudohansfordia & S.M. Reddy \& Bilgrami & 1975 & $\begin{array}{l}\text { Nom. inval., Art. } \\
40.1 \text {; Nom. illegit., } \\
\text { Art. 53.1 } \\
\text { (Melbourne) }\end{array}$ \\
\hline Pseudophyscia & Müll. Arg. & 1893 & $\begin{array}{l}\text { Nom. inval., Art. } \\
\text { 38.1(a) (Melbourne) }\end{array}$ \\
\hline Pseudoplacodium & Motyka & 1996 & $\begin{array}{l}\text { Nom. inval., Art. } \\
34.1 \text { (Melbourne) }\end{array}$ \\
\hline Pubigera & Baral, Gminder \& Svrček & 1995 & $\begin{array}{l}\text { Nom. inval., Art. } \\
40.6 \text { (Melbourne) }\end{array}$ \\
\hline Pyrgillocarpon & Nádv. & 1942 & $\begin{array}{l}\text { Nom. inval., Art. } \\
39.1 \text { (Melbourne) }\end{array}$ \\
\hline Pyrgillocarpon & Nádv. ex Tibell & 1984 & $\begin{array}{l}\text { Nom. inval., Art. } \\
39.1 \text { (Melbourne) }\end{array}$ \\
\hline Quadrisporomyces & Sekunova & 1960 & $\begin{array}{l}\text { Nom. inval., Art. } \\
39.1 \text { (Melbourne) }\end{array}$ \\
\hline Questieriella & G. Arnaud & 1954 & $\begin{array}{l}\text { Nom. inval., Art. } \\
39.1 \text { (Melbourne) }\end{array}$ \\
\hline Rabenhorstia & Fr. & 1849 & $\begin{array}{l}\text { Nom. illegit., Art. } \\
53.1\end{array}$ \\
\hline Racemosporium & Moreau \& F. Moreau & 1941 & $\begin{array}{l}\text { Nom. inval., Art. } \\
39.1 \text { (Melbourne) }\end{array}$ \\
\hline Racodium & Dill. & 1741 & $\begin{array}{l}\text { Nom. inval., Art. } \\
\text { 32.1(a) (Melbourne) }\end{array}$ \\
\hline Racovitziella & Döbbeler \& Poelt & 1937 & $\begin{array}{l}\text { Nom. illegit., Art. } \\
53.1\end{array}$ \\
\hline Ramichloridium & Stahel & 1954 & $\begin{array}{l}\text { Nom. inval., Art. } \\
39.1 \text { (Melbourne) }\end{array}$ \\
\hline Rhinotrichella & G. Arnaud & 1888 & $\begin{array}{l}\text { Nom. inval., Art. } \\
39.1 \text { (Melbourne) }\end{array}$ \\
\hline Rhipidocephalum & Trail & 1966 & $\begin{array}{l}\text { Nom. inval., Art. } \\
\text { 38.1(a) (Melbourne) }\end{array}$ \\
\hline Rhynchostrigula & Bat., J.L. Bezerra \& Cavalc. & 2010 & $\begin{array}{l}\text { Nom. inval., Art. } \\
40.1 \text { (Melbourne) }\end{array}$ \\
\hline Rodentomyces & $\begin{array}{l}\text { Doveri, Pecchia, Sarrocco \& } \\
\text { Vannacci }\end{array}$ & 1941 & $\begin{array}{l}\text { Nom. inval., Arts } \\
40.1 \text { (Melbourne) }\end{array}$ \\
\hline Romanoa & Thirum. & 1954 & $\begin{array}{l}\text { Nom. illegit., Art. } \\
53.1\end{array}$ \\
\hline Royella & R.S. Dwivedi & 1960 & $\begin{array}{l}\text { Nom. inval., Art. } \\
39.1 \text { (Melbourne) }\end{array}$ \\
\hline Saliastrum & Kujala & 1946 & $\begin{array}{l}\text { Nom. inval., Art. } \\
39.1 \text { (Melbourne) }\end{array}$ \\
\hline Santapauinda & Subram. & 1994 & $\begin{array}{l}\text { Nom. inval., Art. } \\
40.1 \text { (Melbourne) }\end{array}$ \\
\hline Saprochaete & Coker \& Shanor & 1939 & $\begin{array}{l}\text { Nom. inval., Art. } \\
39.1 \text { (Melbourne) }\end{array}$ \\
\hline Sarcoscypha & Roum. & 1882 & $\begin{array}{l}\text { Nom. inval., Art. } \\
\text { 38.1(a) (Melbourne) }\end{array}$ \\
\hline
\end{tabular}




\begin{tabular}{|c|c|c|c|}
\hline Saxomyces & L. Selbmann \& D. Isola & 2013 & $\begin{array}{l}\text { Nom. inval., Art. } \\
40.1 \text { (Melbourne) }\end{array}$ \\
\hline Saxophila & L. Selbmann \& de Hoog & 2015 & $\begin{array}{l}\text { Nom. inval., Art. } \\
40.1 \text { (Melbourne) }\end{array}$ \\
\hline Sciniatosporium & Kalchbr. & 1866 & $\begin{array}{l}\text { Nom. inval., Art. } \\
\text { 38.1(a) (Melbourne) }\end{array}$ \\
\hline Scopula & G. Arnaud & 1952 & $\begin{array}{l}\text { Nom. inval., Art. } \\
39.1 \text { (Melbourne) }\end{array}$ \\
\hline Seimatosporiella & Abbas, B. Sutton \& Ghaffar & 1998 & $\begin{array}{l}\text { Nom. inval., Art. } \\
\text { 40.1, see Arts 6.6, } \\
\text { 10.1 (Melbourne) }\end{array}$ \\
\hline Selenosporella & G. Arnaud & 1954 & $\begin{array}{l}\text { Nom. inval., Art. } \\
39.1 \text { (Melbourne) }\end{array}$ \\
\hline Semilecanora & Motyka & 1996 & $\begin{array}{l}\text { Nom. inval., Art. } \\
34.1 \text { (Melbourne) }\end{array}$ \\
\hline Septocylindrium & Sacc. & 1876 & $\begin{array}{l}\text { Nom. inval., Art. } \\
\text { 38.1(a) (Melbourne) }\end{array}$ \\
\hline Septorella & Berk. ex Ainsw. \& Bisby & 1971 & $\begin{array}{l}\text { Nom. inval., Art. } \\
\text { 38.1(a) (Melbourne) }\end{array}$ \\
\hline Septotinia & Whetzel & 1937 & Nom. inval. \\
\hline Septotis & N.F. Buchw. & 1949 & $\begin{array}{l}\text { Nom. inval., Art. } \\
39.1 \text { (Melbourne) }\end{array}$ \\
\hline Septotis & N.F. Buchw. ex Arx & 1970 & $\begin{array}{l}\text { Nom. inval., Art. } \\
39.1 \text { (Melbourne) }\end{array}$ \\
\hline Septotrapelia & Aptroot \& Chaves & 2006 & $\begin{array}{l}\text { Nom. inval., Art. } \\
\text { 38.5(a) (Melbourne) }\end{array}$ \\
\hline Sepultariella & Kutorga & 2000 & $\begin{array}{l}\text { Nom. inval., Arts } \\
39.1,40.4 \\
\text { (Melbourne) }\end{array}$ \\
\hline Setomyces & Bat. \& J.L. Bezerra & 1960 & $\begin{array}{l}\text { Nom. inval., Art. } \\
\text { 38.1(a) (Melbourne) }\end{array}$ \\
\hline Sivanesania & W.H. Hsieh \& Chi Y. Chen & 1994 & $\begin{array}{l}\text { Nom. inval., Art. } \\
\text { 40.1, see Art. } 9.1 \\
\text { (Melbourne) }\end{array}$ \\
\hline Slafractonia & $\begin{array}{l}\text { Alhawatema, Baucom, Sanogo \& } \\
\text { Creamer }\end{array}$ & 2015 & $\begin{array}{l}\text { Nom. inval., Art. } \\
40.6 \text { (Melbourne) }\end{array}$ \\
\hline Sphaeromyces & G. Arnaud & 1954 & $\begin{array}{l}\text { Nom. inval., Art. } \\
39.1 \text { (Melbourne) }\end{array}$ \\
\hline Sphaeromycetella & G. Arnaud & 1954 & $\begin{array}{l}\text { Nom. inval., Art. } \\
39.1 \text { (Melbourne) }\end{array}$ \\
\hline Sporendocladia & G. Arnaud & 1954 & $\begin{array}{l}\text { Nom. inval., Art. } \\
39.1 \text { (Melbourne) }\end{array}$ \\
\hline Sporocephalum & G. Arnaud & 1952 & $\begin{array}{l}\text { Nom. inval., Art. } \\
39.1 \text { (Melbourne) }\end{array}$ \\
\hline Sporophora & Luteraan & 1952 & $\begin{array}{l}\text { Nom. inval., Art. } \\
39.1 \text { (Melbourne) }\end{array}$ \\
\hline Sporotrichopsis & Guég. & 1911 & $\begin{array}{l}\text { Nom. inval., Art. } \\
\text { 38.1(a) (Melbourne) }\end{array}$ \\
\hline Stalagmites & Theiss. \& Syd. & 1914 & $\begin{array}{l}\text { Nom. illegit., Art. } \\
53.1\end{array}$ \\
\hline Stenhammara & A. Massal. ex Zahlbr. & 1924 & $\begin{array}{l}\text { Nom. inval., Art. } \\
\text { 38.1(a) (Melbourne) }\end{array}$ \\
\hline Stirtoniopsis & Groenh. & 1938 & $\begin{array}{l}\text { Nom. inval., Art. } \\
39.1 \text { (Melbourne) }\end{array}$ \\
\hline Symbiotaphrina & Kühlw. \& Jurzitza & 1961 & Nom. inval., Art. \\
\hline
\end{tabular}


Synciboria

Synnmukerjiomyces

Tapellariopsis

Tapellariopsis

Tetracytum

Texosporium

Thyrospora

Thyrsidiella

Torulopsis

Trapelina

Tretendophragmia

Tretocephala

Tridens

Tuber

Tyrannicordyceps

Uncinulella

Vanbreuseghemia

Velutarina

Korf

1953

Veramyces

Vertexicola

Vezdaea

Viennotidia

Wakefieldia

Subram.

1994

Ranghoo, K.D. Hyde \& E.C.Y.

Liew

Poelt \& Döbbeler

Negru \& Verona

1966

G. Arnaud

1954

Wernerella

Nav.-Ros., Cl. Roux \& Giralt

1996
1975

39.1 (Melbourne)

Nom. inval., Arts 39.1, 40.1

(Melbourne)

Nom. inval., Art. 40.1 (Melbourne) Nom. inval., Art. 39.1 (Melbourne) Nom. inval., Art. 39.1 (Melbourne) Nom. inval., Art. 39.1 (Melbourne) Nom. inval., Art. 39.1 (Melbourne) Nom. illegit., Art. 53.1

1905 Nom. inval., Art. 32.1(c) (Melbourne) Nom. inval., Art. 38.1(a) (Melbourne) Nom. inval., Art. 34.1 (Melbourne) Nom. inval., Art. 40.1, see Arts 6.6, 10.1 (Melbourne) Nom. inval., Art. 40.1 (Melbourne) Nom. illegit., Art. 53.1

Nom. inval., Art. 32.1(a) (Melbourne) Nom. inval., Art. 40.6 (Melbourne) Nom. inval., Art. 39.1 (Melbourne) Nom. inval., Art. 39.1 (Melbourne); Nom. illegit., Art. 52.1

Nom. inval., Art. 39.1 (Melbourne)

Nom. inval., Art. 40.1 (Melbourne) Nom. inval., Art. 38.1(a) (Melbourne) Nom. inval., Art. 38.1(a) (Melbourne) Nom. inval., Art. 40.1 (Melbourne) Nom. inval., Art. 39.1 (Melbourne) Nom. inval., Art. 40.1 (Melbourne) Nom. inval., Arts 40.1 (see Arts 6.6, 


\begin{tabular}{|c|c|c|c|}
\hline & & & $\begin{array}{l}\text { 10.1), } 40.4 \\
\text { (Melbourne) }\end{array}$ \\
\hline Wetmoreana & Arup, Søchting \& Frödén & 2013 & $\begin{array}{l}\text { Nom. inval., Art. } \\
42.1 \text { (Melbourne) }\end{array}$ \\
\hline Wilsonia & Cheel \& Dughi & 1944 & $\begin{array}{l}\text { Nom. inval., Art. } \\
39.1 \text { (Melbourne) }\end{array}$ \\
\hline Wolfina & Seaver & 1937 & $\begin{array}{l}\text { Nom. inval., Art. } \\
39.1 \text { (Melbourne) }\end{array}$ \\
\hline Xylohypha & (Fr.) E.W. Mason & 1953 & $\begin{array}{l}\text { Nom. inval., Art. } \\
39.1 \text { (Melbourne) }\end{array}$ \\
\hline Zelotriadelphia & $\begin{array}{l}\text { R.F. Castañeda, Saikawa, M. } \\
\text { Stadler \& Iturr. }\end{array}$ & 2005 & $\begin{array}{l}\text { Nom. inval., Art. } \\
40.6 \text { (Melbourne) }\end{array}$ \\
\hline Zwackhiomyces & Grube \& Triebel & 1989 & $\begin{array}{l}\text { Nom. inval., Art. } \\
\text { 38.1(a) (Melbourne) }\end{array}$ \\
\hline Zygolipomyces & Krassiln., Babeva \& Meavahd & 1967 & $\begin{array}{l}\text { Nom. inval., Art. } \\
39.1 \text { (Melbourne) }\end{array}$ \\
\hline Zygorenospora & Krassiln. & 1954 & $\begin{array}{l}\text { Nom. inval., Art. } \\
39.1 \text { (Melbourne) }\end{array}$ \\
\hline Zymodebaryomyces & E.K. Novák \& Zsolt & 1961 & $\begin{array}{l}\text { Nom. inval., Art. } \\
40.1 \text { (Melbourne) }\end{array}$ \\
\hline Zymopichia & E.K. Novák \& Zsolt & 1961 & $\begin{array}{l}\text { Nom. inval., Art. } \\
40.1 \text { (Melbourne) }\end{array}$ \\
\hline
\end{tabular}

\section{Doubtful genera}

In Table 3, we listed the genera in Ascomycota which have been listed as nom. dub. in Kirk et al. 2008 and have not been included in recent literature.

Table 3. Nom. dub. genera in Ascomycota (based on Kirk et al. 2008) which were not included in recent literature.

\begin{tabular}{llll}
\hline Generic name & Authors & Year & Comments \\
\hline Aciesia & Bat. & 1961 \\
Asteronema & Trevis. & 1845 \\
Blastotrichum & Corda & 1838 \\
Borinquenia & F. Stevens & 1917 \\
Botryodiplodia & Sacc. & 1884 \\
Byssocladium & Link & 1816 \\
Calothyriopeltis & F. Stevens \& & 1925 \\
& R.W. Ryan & \\
Cellulosporium & Peck & 1879 \\
Chaetobasidiella & Höhn. & 1918 \\
Chmelia & Svob.-Pol. & 1966 \\
Coccosporium & Corda & 1831 \\
Coniothecium & Corda & 1833 \\
Cyphellopus & Fayod & 1889 \\
Dinemasporiella & Speg. & 1911 \\
Diplodiella & (P. Karst.) Sacc. & 1884 \\
Endaematus & Raf. & 1814 \\
Halterophora & Endl. & 1836 \\
Hypha & Pers. & 1822 \\
Hyphasma & Rebent. ex Nocca & 1821 \\
& \& Balb. &
\end{tabular}




\begin{tabular}{|c|c|c|c|}
\hline Leptodothis & Theiss. \& Syd. & 1914 & \\
\hline Leucosporium & Corda & 1833 & $\begin{array}{l}\text { Seifert et al. } 2011 \text { also treated as nom. } \\
\text { dub. }\end{array}$ \\
\hline Levieuxia & Fr. & 1849 & \\
\hline Maurya & Pat. & 1898 & $\begin{array}{l}\text { Nom. illegit., Art. } 53.1 \text { (Index Fungorum } \\
\text { 2017) }\end{array}$ \\
\hline Microstelium & Pat. & 1899 & \\
\hline Myxonyphe & Rchb. & 1841 & \\
\hline Neottiosporella & Höhn. ex Falck & 1923 & $\begin{array}{l}\text { Seifert et al. } 2011 \text { treated as a synonym } \\
\text { of Minimidochium B. Sutton } 1969\end{array}$ \\
\hline Phaeoantenariella & Cavalc. & 1969 & \\
\hline Piptostoma & Berk. \& Broome & 1873 & \\
\hline Piptostomum & Lév. & 1845 & \\
\hline Rhinotrichum & Corda & 1837 & \\
\hline Scopularia & Preuss & 1851 & $\begin{array}{l}\text { Nom. illegit., Art. } 53.1 \text { (Index Fungorum } \\
\text { 2017) }\end{array}$ \\
\hline Spermatodium & Fée ex Trevis. & 1860 & \\
\hline Stemmaria & Preuss & 1851 & \\
\hline Variolaria & Pers. & 1794 & $\begin{array}{l}\text { Nom. illegit., Art. 53.1; Nom. rejic., see } \\
\text { Arts 14.6, Ex. } 5 \text { and } 14.7 \text { (Index } \\
\text { Fungorum 2017) }\end{array}$ \\
\hline Voglinoana & Kuntze & 1891 & \\
\hline Weinmannodora & Fr. & 1849 & \\
\hline Xylodon & (Pers.) Gray & 1821 & $\begin{array}{l}\text { Nom. rejic., see Arts 14.6, Ex. } 5 \text { and } 14.7 \\
\text { (Index Fungorum 2017) }\end{array}$ \\
\hline
\end{tabular}

\section{Acknowledgements}

Nalin Wijayawardene would like to thank Lechat Christian, Emma, Danushka Sandaruwan, Paul Mungai, Huang Zhang, Ishani Goonasekara, C. Norphanphoun, Ishara Manawasingha, Thilini Chethana for their assistances. K.D. Hyde would like to thank the Thailand Research Fund (TRF) grant no RSA5980068 entitled Biodiversity, phylogeny and role of fungal endophytes on above parts of Rhizophora apiculata and Nypa fruticans, National Research Council of Thailand (NRCT) entitled Diseases of mangrove trees and maintenance of good forestry practice (Grant number: 60201000201) and Mae Fah Luang University grant "Biodiversity, phylogeny and role of fungal endophytes of Pandanaceae" (Grant number: 592010200112). Hugo Madrid was funded by Comisión Nacional de Investigación Científica y Tecnológica (CONICYT), Fondo Nacional de Desarrollo Científico y Tecnológico (FONDECYT), Chile, project no. 11140562." Dong Qin Dai would like to thank the Key Laboratory of Yunnan Province Universities of the Diversity and Ecological Adaptive Evolution for Animals and plants on Yun-Gui Plateau for the support. Ka-Lai Pang thanks Ministry of Science and Technology, Taiwan for financial support (105-2621-B-019 -002-). Guo Zhu Zhao was funded by the National Natural Science Foundation of China (No. 31570019). Mingkwan Doilom acknowledges the Royal Golden Jubilee Ph.D. Program (PHD./0072/2553 in 4.S.M.F./53/A.2. K. Tanaka would like to thank the Japan Society for the Promotion of Science (JSPS; 26291084 and 16K07474). Walter P. Pfliegler was supported through the ÚNKP--16--4--IV New National Excellence Program of the Hungarian Ministry of Human Capacities. The authors extend their appreciation to the International Scientific Partnership Program ISPP at King Saud University for funding this research work through ISPP\#0089

\section{References}


Abarca GH, Ruiz RF, Mota RM, Hérnandez CI, Gómez S, Bogale M, Untereiner WA (2011) A new species of Heliocephala from Mexico with an assessment of the systematic positions of the anamorph genera Heliocephala and Holubovaniella. Mycologia 103(3):631-40.

Abbas A, Mamut R, Abudoula A, Ababakri G (2014) A newly recorded lichen genus Xylographa (Fr.) Fr. from China. Plant Diversity and Resources 36:578-580.

Abdel-Aziz FA (2016) The genus Lolia from freshwater habitats in Egypt with one new species. Phytotaxa 267:279-288.

Abdel-Aziz FA, Abdel-Wahab MA (2010) Lolia aquatica gen. et sp. nov. (Lindgomycetaceae, Pleosporales), a new coelomycete from freshwater habitats in Egypt. Mycotaxon 114:33-42.

Abdel-Wahab MA (2011a) Lignicolous marine fungi from Yokosuka, Japan. Bot Mar 54:209-221.

Abdel-Wahab MA (2011b) Marine fungi from Sarushima Island, Japan, with a phylogenetic evaluation of the genus Naufragella. Mycotaxon 115:443-456.

Abdel-Wahab MA, Bahkali AH (2012) Taxonomy of filamentous anamorphic marine fungi: morphology and molecular evidence. In: Jones EBG, Pang KL (Eds.) Marine fungi and fungal-like organisms Labyrinthulomycetes and oomycetes. De Gruyter Series: Marine and Freshwater Botany, Walter De Gruyter GMBH, Germany, pp 59-82.

Abdel-Wahab MA, Bahkali AH, Jones EBG, Elgorban AM, Abdel-Aziz FA, Hodhod MS, Al-Hebshi MO (2016) Two new species of Kallichroma (Bionectriaceae, Hypocreales) from Saudi Arabian mangroves. Phytotaxa 260:66-74.

Abdel-Wahab MA, Hodhod MS, Bahkali AHA, Jones EBG (2014) Marine fungi of Saudi Arabia. Bot Mar 57:323-335.

Abdel-Wahab MA, Nagahama T (2011) Gesasha (Halosphaeriaceae, Ascomycota), a new genus from the Gesashi mangroves in Japan. Nova Hedwigia 92:497-512.

Abdel-Wahab MA, Nagahama T, Abdel-Aziz FA (2009) Two new Corollospora species and one anamorph based on morphological and molecular data. Mycoscience 50:147-155.

Abdel-Wahab MA, Pang KL, Nagahama T, Abdel-Aziz FA, Jones EBG (2010) Phylogenetic evaluation of anamorphic species of Cirrenalia and Cumulospora with the description of eight new genera and four new species. Mycol Prog 9:537-558.

Abdollahzadeh J, Goltapeh EM, Javadi A, Shams-Bakhsh M, Zare R, Phillips AJ (2009) Barriopsis iraniana and Phaeobotryon cupressi: two new species of the Botryosphaeriaceae from trees in Iran. Persoonia-Molecular Phylogeny and Evolution of Fungi 23:1-8.

Abdollahzadeh J, Javadi A, Goltapeh EM, Zare R, Phillips AJ (2010) Phylogeny and morphology of four new species of Lasiodiplodia from Iran. Persoonia-Molecular Phylogeny and Evolution of Fungi 25(1):1-10.

Abdollahzadeh J, Javadi A, Zare R, Phillips AJ (2014) A phylogenetic study of Dothiorella and Spencermartinsia species associated with woody plants in Iran, New Zealand, Portugal and Spain. Persoonia: Molecular Phylogeny and Evolution of Fungi 32:1-12.

Abdollahzadeh J, Zare R, Phillips AJ (2013) Phylogeny and taxonomy of Botryosphaeria and Neofusicoccum species in Iran, with description of Botryosphaeria scharifii sp. nov. Mycologia 105(1):210-20.

Abdullah SK, Asensio L, Monfort E, Gomez-Vidal S, Palma-Guerrero J, Salinas J, Lopez-Llorca LV, Jansson HB, Guarro J (2015) Occurrence in Elx, SE Spain of Inflorescence Rot Disease of Date Palms Caused by Mauginiella scaettae. J. Phytopathol 153(7-8):417-422. 
Abe N, Hamada N (2011) Molecular characterization and surfactant utilization of Scolecobasidium isolates from detergent-rich indoor environments. Biocontrol science 16(4), pp.139-147.

Acharya K, Dutta AK, Pradhan P (2011) Bipolaris sorokiniana (Sacc.) Shoem.: The most destructive wheat fungal pathogen in the warmer areas. Australian journal of crop science 5(9):1064.

Adamčík S, Cai L, Chakraborty D, Chen XH, Cotter HVT et al. (2015) Fungal Biodiversity Profiles 1-10. Cryptogam Mycol 36:121-166.

Aggarwal R, Das S, Jahani M, Singh D (2008) Histopathology of spot blotch disease of wheat caused by Bipolaris sorokiniana (Teleomorph: Cochliobolus sativus). Acta Phytopathologica et Entomologica Hungarica 43(1):23-30.

Aggarwal R, Gupta S, Banerjee S, Singh, VB (2011a) Development of a SCAR marker for detection of Bipolaris sorokiniana causing spot blotch of wheat. Canadian journal of microbiology 57(11):934-942.

Aggarwal R, Purwar S, Kharbikar L, Gupta S (2011b) Induction of a wheat $\beta$-1, 3-glucanase gene during the defense response to Bipolaris sorokiniana. Acta Phytopathologica et Entomologica Hungarica 46(1):39-47.

Aggarwal R, Singh VB, Gurjar MS, Gupta S, Srinivas P (2009). Intraspecific variations in Indian isolates of Bipolaris sorokiniana infecting wheat based on morphological, pathogenic and molecular characters. Indian Phytopathology 62(4):449-460.

Aggarwal R, Singh VB, Shukla R, Gurjar MS, Gupta S, Sharma TR (2010) URP-based DNA Fingerprinting of Bipolaris sorokiniana Isolates Causing Spot Blotch of Wheat. Journal of phytopathology 158(4):210-216.

Agnello G, Catinon M, Ayrault S, Asta J, Tissut M, Ravanel P (2010) A comparative study of atmospheric deposits and lichen populations in a protected alpine area in the Grenoble region (France). International Journal of Environment and Health 4(2-3):235-249

Agnihothrudu V (1962) Notes on fungi from North East India X. Chaetospermum camelliae sp. nov. on tea (Camellia sinensis (L.) O. Kuntze). Mycopathologia et Mycologia Applicata 16:113-116.

Ahmadpour A, Donyadoost-Chelan M, Heidarian Z, Javan-Nikkhah M (2011) New species of Bipolaris and Curvularia on grass species in Iran. Rostaniha 12(1):39-49.

Ahmadpour A, Heidarian Z, Donyadoost-Chelan M, Javan-Nikkhah, M, Tsukiboshi T (2012) A new species of Bipolaris from Iran. Mycotaxon 120(1):301-307.

Ahmed S, Imdad SS, Jamil A (2012) Comparative study for the kinetics of extracellular xylanases from Trichoderma harzianum and Chaetomium thermophilum. Electronic Journal of Biotechnology 15(3):3.

Ahmed SA, de Sande WWJV, Stevens DA, Fahal A, van Diepeningen AD, Menken SBJ, de Hoog GS (2014a) Revision of agents of black-grain eumycetoma in the order Pleosporales. Persoonia 33:141-154.

Ahmed SA, Desbois N, Quist D, Miossec C, Atoche C, Bonifaz A, de Hoog S (2015) Phaeohyphomycosis Caused by a Novel Species: Pseudochaetosphaeronema martinelli. J. Clin. Microbiol 53:2927-2934.

Ahmed SA, Khan Z, Wang XW, Moussa TA, Al-Zahrani HS, Almaghrabi OA, Sutton DA, Ahmad S, Groenewald JZ, Alastruey-Izquierdo A, van Diepeningen A (2016) Chaetomium-like fungi causing opportunistic infections in humans: a possible role for extremotolerance. Fungal Divers 76(1):11-26. 
Ahmed SA, Stevens DA, van de Sande WWJ, Meis JF, de Hoog GS (2014b) Roussoella percutanea, a novel opportunistic pathogen causing subcutaneous mycoses. Medical Mycology. 52(7):689-698.

Ahti T, Mayrhofer H, Schultz M, Tehler A, Fryday AM (2016) First supplement to the lichen checklist of South Africa: original research. Bothalia-African Biodiversity \& Conservation, 46(1):1-8.

Ahti T, Stenroos S (2013) Cladonia. In Ahti T, Stenroos S, Moberg R (eds) Nordic Lichen Flora 5:8-87.

Ahti TE, Kondratyuk SY, Kärnefelt I, Thell A (2015) Nomenclatural corrections and notes on some taxa in the Teloschistaceae (lichenized ascomycetes). Graphis Scripta 27(12):37-41.

Akata I, Kaya A (2013) Two earth-tongue genera new for Turkey. Mycotaxon 125(1):87-90.

Alamouti SM, Tsui CK, Breuil C (2009) Multigene phylogeny of filamentous ambrosia fungi associated with ambrosia and bark beetles. Mycological Research 113:822-835.

Aleksić M, Stepanović M, Duduk B, Rekanović E (2011) Septocyta ruborum: occurence and possibility of disease control in Serbia. InX International Rubus and Ribes Symposium 946:277-281.

Alexandrova AV, Braun U, Mel'nik VA (2013) Pyricularia contorta sp. nov. - a new species from Vietnam. Schlechtendalia. 25:73-76.

Ali H, Ahmad W, Haq T (2009) Decolorization and degradation of malachite green by Aspergillus flavus and Alternaria solani. African Journal of Biotechnology 8(8).

Alias AS, Jones EBG (2009) Marine fungi from mangrove of Malaysia: IOES Monograph Series No. 8. Institute of Ocean and Earth Sciences, University of Malaya, Malaysia.

Alias AS, Zainuddin N, Jones EBG (2010) Biodiversity of marine fungi in Malaysian mangroves. Bot Mar. 53:545-554.

Al-Laith AA (2010) Antioxidant components and antioxidant/antiradical activities of desert truffle (Tirmania nivea) from various Middle Eastern origins. Journal of Food Composition and Analysis 23(1):15-22.

Allegrucci N, Eliades L, Cabello M, Arambarri A (2011) New species Koorchaloma and Ciliochorella from xeric forests in Argentina. Mycotaxon 115:175-181.

Allen JL, Lendemer JC (2013) Uncovering chemical variability: molecular data reveal the identity of a sterile crustose lichen from the Yukon and affirm an expanded circumscription for Buellia griseovirens. North American Fungi, 8:1-14.

Allen JL, Lendemer JC (2015) Japewiella dollypartoniana, a New Widespread Lichen in the Appalachian Mountains of Eastern North America. Castanea. 80(1):59-65.

Almaguer M, Rojas TI, Dobal V, Batista A, Aira MJ (2013) Effect of temperature on growth and germination of conidia in Curvularia and Bipolaris species isolated from the air. Aerobiologia 29(1):13-20.

Almeida DA, Gusmão LF, Miller AN (2014a) Brazilian Semi-Arid Ascomycetes I: New and interesting records of hysteriaceous ascomycetes. Mycosphere. 5(2):379-91.

Almeida DA, Santa Izabel TD, Gusmão LF, Castañeda-Ruíz RF (2015) A new species of Diplococcium from the Brazilian semi-arid region. Mycotaxon 130(2):495-8.

Almeida DAC, Cruz ACR, Marques MFO, Gusmão LFP (2013) Conidial fungi from the semi-arid Caatinga biome of Brazil. New and interesting Zanclospora species. Mycosphere 4:684-692.

Almeida DAC, Gusmão LFP (2014) Ypsilomyces, a new thallic genus of conidial fungi from the semi-arid Caatinga biome of Brazil. Mycotaxon 129:181-186.

Almeida DAC, Gusmao LFP, Miller AN (2014b) A new genus and three new species of hysteriaceous ascomycetes from the semiarid region of Brazil. Phytotaxa 176(1):298308. 
Almeida DAC, Gusmão LFP, Miller AN (2016) Taxonomy and molecular phylogeny of Diatrypaceae (Ascomycota, Xylariales) species from the Brazilian semi-arid region, including four new species. Mycological Progress 15:1-27.

Almeida DAC, Miller AN, Gusmão LFP (2014c) New species and combinations of conidial fungi from the semi-arid Caatinga biome of Brazil. Nova Hedwigia. 98:431-447.

Al-Nasrawi HG, Hughes AR (2012) Fungal Divers associated with salt marsh plants Spartina alterniflora and Juncus roemerianus in Florida. Jordan Journal of Biological Sciences 5:247-254.

Alsheikh-Hussain A, Altenaiji E, Yousef LF (2014) Fungal cellulases from mangroves forests- a short review. J Biochem Tech 5:765-774.

Alstrup V, Kocourkova J, Kukwa M, Motiejunaite J, Brackel W, von Suija A (2009) The lichens and lichenicolous fungi of south Greenland. Folia cryptog. Estonica 46:1-24.

Aluoch AM, Obonyo MA, Okun DO, Akinyi A, Otiende YM, Mungai PG (2015) Morphological Diversity of Ascobolus and Pilobolus Fungi from Wild Herbivore Dung in Nairobi National Park, Kenya. Journal of Microbiology Research 5(4):134141.

Alvarado P, Cabero J, Moreno G, Bratek Z, Van Vooren N, Kaounas V, Konstantinidis G, Agnello C, Merényi Z, Smith ME (2014) Species diversity of Genea (Ascomycota, Pezizales) in Europe. Ascomycete. 6(3):41-51.

Alvarado P, Moreno G, Manjón JL, Gelpi C, Kaounas V, Konstantinidis G, Barseghyan G, Venturella G (2011a) First molecular data on Delastria rosea, Fischerula macrospora and Hydnocystis piligera. Boletín de la Sociedad Micológica de Madrid 35:75-81

Alvarado P, Moreno G, Manjón JL, Sanz MA (2011b) Eremiomyces magnisporus (Pezizales), a new species from central Spain. Mycotaxon 118:103-111.

Álvarez G, Fernández M, Diez JJ (2015) Ophiostomatoid fungi associated with declined Pinus pinaster stands in Spain. Forest Systems 24(1):6.

Alvarez LV, Groenewald JZ, Crous PW (2016) Revising the Schizoparmaceae: Coniella and its synonyms Pilidiella and Schizoparme. Studies in mycology 85:1-34.

Alves A, Linaldeddu BT, Deidda A, Scanu B, Phillips AJL (2014) The complex of Diplodia species associated with Fraxinus and some other woody hosts in Italy and Portugal. Fungal Divers 67:143-156.

Alves JL, Barreto RW, Pereira OL, Soares DJ (2010) Additions to the mycobiota of the invasive weed Miconia calvescens (Melastomataceae). Mycologia 102(1):69-82.

Alves JL, Woudenberg JHC, Duarte LL, Crous PW, Barreto RW (2013) Reappraisal of the genus Alternariaster (Dothideomycetes). Persoonia 31:77-85.

Aly AH, Edrada-Ebel R, Indriani ID, Wray V, Müller WE, Totzke F, Zirrgiebel U, Schächtele C, Kubbutat MH, Lin WH, Proksch P (2008) Cytotoxic metabolites from the fungal endophyte Alternaria sp. and their subsequent detection in its host plant Polygonum senegalense. Journal of natural products 71(6):972-980.

Amaradasa BS, Amundsen K (2014) First report of Curvularia inaequalis and Bipolaris spicifera causing leaf blight of buffalograss in Nebraska. The American Phytopathological Society 98 (2):279.

Ammarellou A, Smith ME, Tajick MA, Trappe JM (2011) The phylogenetic placement of Picoa, with a first report on Picoa lefebvrei (Pat.) Maire (= Phaeangium lefebvrei) from Iran. International Journal of Environmental Research 5(2):509-14.

An KD, Degawa Y, Fujihara E, Mikawa T, Ohkuma M, Okada G (2012) Molecular phylogenetic analyses based on the nuclear rRNA genes and the intron-exon structures of the nuSSU rRNA gene in Dictyocatenulata alba (anamorphic Ascomycota). Fungal Biology 116:1134-1145. 
Anand T, Bhaskaran R, Raguchander T, Samiyappan R, Prakasam V, Gopalakrishnan C, (2009) Defence responses of chilli fruits to Colletotrichum capsici and Alternaria alternata. Biologia plantarum 53(3):553-559.

Anar M, Aslan A, Agar G, Ozgencli I (2016) Antigenotoxic and Antioxidant Activity of Lichens Anaptychia ciliaris, Bryoria fuscescens, Parmotrema chinensa and Xanthoria candelaria: An in vitro Study. Med Aromat Plants, 5(233):2167-0412.

Andersen B, Dongo A, Pryor BM (2008) Secondary metabolite profiling of Alternaria dauci, A. porri, A. solani, and A. tomatophila. Mycological Research 112(2):241-250.

Andersen B, Sørensen JL, Nielsen KF, van den Ende BG, de Hoog S (2009) A polyphasic approach to the taxonomy of the Alternaria infectoria species-group. Fungal Genetics and Biology 46(9):642-656.

Anderson F, Neily TH (2012) New and noteworthy macrolichen records for Nova Scotia. Evansia 29(1):1-3.

Andjic V, Maxwell A, Hardy GE, Burgess TI (2016) New cryptic species of Teratosphaeria on Eucalyptus in Australia. IMA fungus 7(2):253-63.

Andjic V, Whyte G, Hardy G, Burgess T (2010) New Teratosphaeria species occurring on eucalypts in Australia. Fungal Divers 43(1):27-38.

Ando Y, Masuya H, Motohashi K, Linnakoski R, Yamaoka Y (2016) Phylogenetic relationship of Japanese isolates belonging to the Grosmannia piceiperda complex (Ophiostomatales). Mycoscience 57(2): 123-135

Andreev M (2010) Halecania santessonii, a new lichenicolous lichen from Russia. Lichenologist 42(3):249-252.

Andrew M, Barua R, Short SM, Kohn LM (2012) Evidence for a common toolbox based on necrotrophy in a fungal lineage spanning necrotrophs, biotrophs, endophytes, host generalists and specialists. PLoS One 7(1):e29943.

Andrew M, Peever TL, Pryor BM (2009) An expanded multilocus phylogeny does not resolve morphological species within the small-spored Alternaria species complex. Mycologia 101(1):95-109.

Antoniazzi N, Deschamps C, Bach EE (2008) Effect of xanthan gum and allicin as elicitors against Bipolaris sorokiniana on barley in field experiments. Journal of Plant Diseases and Protection 115(3):104-107.

Aoki N, Moriyama H, Kodama M, Arie T, Teraoka T, Fukuhara T (2009) A novel mycovirus associated with four double-stranded RNAs affects host fungal growth in Alternaria alternata. Virus research 140(1):179-187.

Aptroot A (2008) Lichens of St Helena and Ascension Island. Bot J Linn Soc 158:147-171

Aptroot A (2012) A world key to the species of Anthracothecium and Pyrenula. The Lichenologist 44(01):5-3.

Aptroot A (2014) Two new genera of Arthoniales from New Caledonia and the Solomon Islands, with the description of eight further species. The Bryologist 117:282-289.

Aptroot A (2016) Preliminary checklist of the lichens of Madagascar, with two new thelotremoid Graphidaceae and 131 new records. Willdenowia 46(3):349-365.

Aptroot A, Andrade DS, Mendonça C, Lima ELde, Cáceres MES (2014a) Ten new species of corticolous pyrenocarpous lichens from NE Brazil. Phytotaxa 197(3):197-206.

Aptroot A, Aslan A (2011) Lecanora wrightiana and Rhizocarpon inimicum, rare lichens new to Turkey and the Middle East. Mycotaxon 117(1):145-148.

Aptroot A, Aslan A (2012) Candelariella, Ochrolechia, Physcia, and Xanthoria species new to Turkey. Mycotaxon 119(1):149-156.

Aptroot A, Cáceres MES (2013) Pyrenocarpous lichens (except Trypetheliaceae) in Rondônia. The Lichenologist 45(6):763-785. 
Aptroot A, Cáceres MES (2014) A refined species concept in the tropical lichen genus Polymeridium (Trypetheliaceae) doubles the number of known species, with a worldwide key to the species. Nova Hedwigia 98:1-29.

Aptroot A, da Silva, Caceres ME (2014b) A key to the corticolous microfoliose, foliose and related crustose lichens from Rondônia, Brazil, with the description of four new species. The Lichenologist 46(06):783-799.

Aptroot A, de Oliveira MC, Ferraro LI, da Silva Caceres ME (2014c) A world key to species of the genera Topelia and Thelopsis (Stictidaceae), with the description of three new species from Brazil and Argentina. The Lichenologist 46(06):801-807.

Aptroot A, Ertz D, Lima EL, de Jesus KA, Maia LC, Cáceres MES (2013a) Two new species of Roccellaceae (Ascomycota: Arthoniales) from Brazil, with the description of the new genus Sergipea. Lichenologist 45:627-634.

Aptroot A, Ertz D, Silva JR, Grube M, Cáceres MES (2015a) The phylogenic position of Coniarthonia, with a key to the species and new information about the polyphyly of Cryptothecia and Stirtonia and the transfer of Cryptothecia miniata to Myriostigma (Arthoniaceae, lichenized ascomycetes). Phytotaxa. 218:128-136.

Aptroot A, Ferraro LI, da Silva Caceres ME (2014d) New pyrenocarpous lichens from NE Argentina. The Lichenologis 46(1):95.

Aptroot A, Iqbal SH (2012) Annotated checklist of the lichens of Pakistan, with reports of new records. Herzogia 25(2):211-229.

Aptroot A, John V (2015) An historical lichen collection from New Caledonia. Herzogia 28(2):307-321.

Aptroot A, Jungbluth P, Caceres ME (2014e) A world key to the species of Pyxine with lichexanthone, with a new species from Brazil. The Lichenologist 46(05):669-672.

Aptroot A, Lücking R (2016) A revisionary synopsis of the Trypetheliaceae. (Ascomycota: Trypetheliales). Lichenologist 48:763-982.

Aptroot A, Moon KH (2014) 114 New Reports of Microlichens from Korea, Including the Description of Five New Species, Show that the Microlichen Flora is Predominantly Eurasian. Herzogia 27:347-365.

Aptroot A, Moon KH (2015) New lichen records from Korea, with the description of the lichenicolous Halecania parasitica. Herzogia 28:193-203.

Aptroot A, Nelsen MP, Parnmen S (2013b) Marcelaria, a new genus for the Laurera purpurina group in the Trypetheliaceae (Ascomycota: Dothideomycetes). Glalia $5(2): 1-14$.

Aptroot A, Parnmen S, Lücking R, Baloch E, Jungbluth P, Cáceres MES, Lumbsch HT (2015b) Molecular phylogeny resolves taxonomic misunderstanding and places Geisleria close to Absconditella s. str. (Ostropales: Stictidaceae). Lichenologist 46(1):115-128.

Aptroot A, Parnmen S, Luecking R, Baloch E, Jungbluth P, Caceres ME, Lumbsch HT (2014f) Molecular phylogeny resolves a taxonomic misunderstanding and places Geisleria close to Absconditella s. str. (Ostropales: Stictidaceae). The Lichenologist 46(01):115-128.

Aptroot A, Schumm F (2011) Fruticose Roccellaceae: An Anatomical-microscopical Atlas and Guide with a Worldwide Key and Further Notes on Some Crustose Roccellaceae Or Similar Lichens. BoD-Books on Demand. GmbH, Norderstedt 374 pp.

Aptroot A, Schumm F (2012a) A new terricolous Trapelia and a new Trapeliopsis (Trapeliaceae, Baeomycetales) from Macaronesia. The Lichenologist 44(04):449-56.

Aptroot A, Schumm F (2012b) The genus Melanophloea, an example of convergent evolution towards polyspory. The Lichenologist. 44:501-509. 
Aptroot A, Seaward MR, Sparrius LB (2010) Biodiversity and ecology of lichens. Acta Botanica Hungarica 52:1-2.

Aptroot A, Sipman HJ (2011) Sporodochiolichen, a new genus of tropical hyphomycetous lichens. The Lichenologist 43(04):357-62.

Aptroot A, Sipman HJM, Cáceres MES (2013c) Twenty-one new species of Pyrenula from South America, with notes on overmature ascospores. Lichenologist 45:169-198.

Aptroot A, Sobreira P, Da Silva, Caceres ME (2015c) A remarkable new Ramonia (Gyalectaceae) from Brazil, with a key to the species. The Lichenologist 47(01):2129.

Aptroot A, Sparrius LB, LaGreca S, Bungartz F (2008) Angiactis, a new crustose lichen genus in the family Roccellaceae with species from Bermuda, the Galapagos islands, and Australia. The Bryologist 111:510-516.

Aptroot A, Yazici K (2012) A new Placopyrenium (Verrucariaceae) from Turkey. The Lichenologist 44(06):739-741.

Aptroot A, Yazici K, Košuthová A (2015d) Three Placynthiaceae reported new to Asia from limestone in Turkey, with the description of the apothecia of Placynthium posterulum. Herzogia 28(1):288-292.

Araújo JP, Evans HC, Geiser DM, Mackay WP, Hughes DP (2015) Unravelling the diversity behind the Ophiocordyceps unilateralis (Ophiocordycipitaceae) complex: Three new species of zombie-ant fungi from the Brazilian Amazon. Phytotaxa 220(3):224-38.

Arauzo S, Iglesias P (2014) La familia Geoglossaceae en la península Ibérica y la Macaronesia. Errotari 11:166-259.

Arcadia L, Knudsen K (2012) The name Myriospora is available for the Acarospora smaragdula group. Opuscula Philolichenum 11:19-25.

Archer AW (2009) Graphidaceae. Fl. Austr 57:84-194.

Arias MS, Suárez J, Cazapal-Monteiro CF, Francisco I, López-Arellano ME, Piñeiro P, Suárez JL, Sánchez-Andrade R, de Gives PM, Paz-Silva A (2013) Trematodes enhance the development of the nematode-trapping fungus Arthrobotrys (Duddingtonia) flagrans. Fungal biology 117(7):540-544.

Ariyawansa HA, Camporesi E, Thambugala KM, Mapook A, Kang JC, Alias SA, Chukeatirote E, Thines M, Mckenzie EHC, Hyde KD (2014a) Confusion surrounding Didymosphaeria phylogenetic and morphological evidence suggest Didymosphaeriaceae is not a distinct family. Phytotaxa 176(1):102-119.

Ariyawansa HA, Hyde KD, Jayasiri SC, Buyck B, Chethana KWT et al. (2015a) Fungal Diversity notes 111-252 taxonomic and phylogenetic contributions to fungal taxa. Fungal Divers 75:27-274.

Ariyawansa HA, Jones EBG, Suetrong S, Alias AS, Kang JC, Hyde KD (2013a) Halojulellaceae a new family of the order Pleosporales. Phytotaxa 130:14-24.

Ariyawansa HA, Kang JC, Alias SA, Chukeatirote E, Hyde KD (2014b) Pyrenophora. Mycosphere 5 (2):351-362.

Ariyawansa HA, Maharachchikumbura SS, Karunarathne SC, Chukeatirote E, Bahkali AH, Kang JK, Bhat DJ, Hyde KD (2013b) Deniquelata barringtoniae gen. et sp. nov., associated with leaf spots of Barringtonia asiatica. Phytotaxa. 105(1):11-20.

Ariyawansa HA, Phookamsak R, Tibpromma S, Kang JC, Hyde KD (2014c) A Molecular and Morphological Reassessment of Diademaceae. The Scientific World Journal Article ID 675348:1-11.

Ariyawansa HA, Phukhamsakda C, Thambugala KM, Bulgakov TS, Wanasinghe DN, Perera RH, Mapook A, Camporesi E, Kang JC, Jones EG, Bahkali AH (2015b) Revision and phylogeny of Leptosphaeriaceae. Fungal Divers 74(1):19-51. 
Ariyawansa HA, Tanaka K, Thambugala KM, Phookamsak R, Tian Q, Camporesi E, Hongsanan S, Monkai J, Wanasinghe DN, Chukeatirote E, Kang JC, Xu JC, McKenzie EHC, Jones EBG, Hyde KD (2014d) A molecular phylogenetic reappraisal of the Didymosphaeriaceae (Montagnulaceae). Fungal Divers 68(1):69-104.

Ariyawansa HA, Thambugala KM, Kang JC, Alias SA, Chukeatirote E, Hyde KD (2014e) Towards a natural classification of Dothideomycetes 2: The genera Cucurbidothis, Heterosphaeriopsis, Hyalosphaera, Navicella and Pleiostomellina (Dothideomycetes incertae sedis). Phytotaxa 176(1):7-17.

Ariyawansa HA, Thambugala KM, Manamgoda DS, Jayawardena R, Camporesi E, Boonmee S, Wanasinghe DN, Phookamsak R, Hongsanan S, Singtripop C, Chukeatirote E. (2015c) Towards a natural classification and backbone tree for Pleosporaceae. Fungal Divers 71(1):85-139.

Ariyawansaa HA, Kang JC, Alias SA, Chukeatirote E, Hyde KD (2013c) Towards a natural classification of Dothideomycetes: The genera Dermatodothella, Dothideopsella, Grandigallia, Hysteropeltella and Gloeodiscus (Dothideomycetes incertae sedis). Phytotaxa 147(2):35-47.

Armentano RA, Cooke KL, Wickes BL (2013) Disseminated mycotic infection caused by Westerdykella species in a German Shepherd Dog. Journal of the American Veterinary Medical Association 242(3):381-7.

Árnason H (2014) Isolation and structure determination of a heteroglycan from whiteworm lichen (Thamnolia subuliformis).

Arslan B, Öztürk Ş, Oran S (2011) Lecanora, Phaeophyscia and Rinodina species new to Turkey. Mycotaxon 116(1):49-52.

Arunpanichlert J, Rukachaisirikul V, Tadpetch K, Phongpaichit S, Hutadilok-Towatana N, Supaphon O, Sakayaroj J (2012) A dimeric chromanone and a phthalide: Metabolites from the seagrass-derived fungus Bipolaris sp. PSU-ES64. Phytochemistry Letters 5(3):604-608.

Arup U, Søchting U, Frödén P (2013) A new taxonomy of the family Teloschistaceae. Nordic J Bot 31:16-83.

Arx JA von, Müller E (1954) Die Gattungen der amerosporen Pyrenomyceten. Beiträge zur Kryptogamenflora der Schweiz 11 (1): 1-434

Arzanlou M, Bakhshi M (2011) Microcyclospora rumicis, a new species on Rumex crispus from Iran. Mycotaxon. 118:181-186.

Arzanlou M, Ghasemi S, Baradaran Bagheri M (2016a) Collophora hispanica, a New Pathogen and Potential Threat to the Almond Industry in Iran. Journal of Phytopathology 164(10):833-9.

Arzanlou M, Samadi R, Frisvad JC, Houbraken J, Ghosta Y (2016b) Two novel Aspergillus species from hypersaline soils of the National Park of Lake Urmia, Iran. Mycological Progress 15:1081-1092.

Asad S, Iftikhar S, Munir A, Ahmad I (2009) Characterization of Bipolaris sorokiniana isolated from different agro-ecological zones of wheat production in Pakistan. Pakistan Journal of Botany 41(1):301-308.

Asam S, Lichtenegger M, Liu Y, Rychlik M (2012) Content of the Alternaria mycotoxin tenuazonic acid in food commodities determined by a stable isotope dilution assay. Mycotoxin research 28(1):9-15.

Asgari B, Zare R (2010) Two new species of Preussia from Iran. Nova Hedwigia 90(34):533-548. 
Asgari B, Zare R (2011) A contribution to the taxonomy of the genus Coniocessia (Xylariales). Mycological Progress 10(2):189-206.

Asgari B, Zare R, Zamanizadeh HR, Rezaee S (2014) Aspergillus osmophilus sp. nov. and a new teleomorph for A. proliferans. Mycoscience 55:53-62.

Ashraf T, Hanif M, Khalid AN (2012) Peziza michelii and its ectomycorrhizae with Alnus nitida (Betulaceae) from Pakistan. Mycotaxon 120(1):181-8.

Aslan A (2013) New Lecanora, Lecidea, Melaspilea, Placynthium, and Verrucaria records for Turkey and Asia. Mycotaxon 123(1):321-326.

Atienza V, Pérez-Ortega S, Etayo J (2009) Two new conidial lichenicolous fungi from Spain indicate the distinction of Lichenodiplis and Minutoexcipula. Lichenologist 41:223229.

Augustin JO, Elliot SL, Nascimento RJ, Mizubuti ESG, Barreto RW, Evans HC (2012) Novelties in the Taxonomy and Ecology of Mycoparasites Associated With Nests of Acromyrmex Leaf-Cutting Ants. PloS ONE 8:1-17.

Avenot H, Morgan, DP, Michailides TJ (2008) Resistance to pyraclostrobin, boscalid and multiple resistance to Pristine ${ }^{\circledR}$ (pyraclostrobin+ boscalid) fungicide in Alternaria alternata causing Alternaria late blight of pistachios in California. Plant pathology 57(1):135-140.

Avenot H, Sellam A, Michailides T (2009) Characterization of mutations in the membrane-anchored subunits AaSDHC and AaSDHD of succinate dehydrogenase from Alternaria alternata isolates conferring field resistance to the fungicide boscalid. Plant pathology 58(6):1134-1143.

Aveskamp MM, De Gruyter J, Woudenberg JH, Verkley GJ, Crous PW. 2010 Highlights of the Didymellaceae: a polyphasic approach to characterise Phoma and related pleosporalean genera. Studies in Mycology. 65:1-60.

Aveskamp MM, Verkley GJM, Gruyter J de, Murace MA, Perelló A, Woudenberg JHC, Groenewald JZ, Crous PW (2009) DNA phylogeny reveals polyphyly of Phoma section Peyronellaea and multiple taxonomic novelties. Mycologia 101: 359-378.

Awaluddin HH, Nor NAM, Nor HM, Sharuddin SS, Pang K-, Mohamad-Fauzi N, RizmanIdid M, Alias SA (2015) Biodiversity of marine lignicolous fungi from mangroves of sulu sea. Malaysian Journal of Medical Sciences 34(1):43-57.

Aylward J, Dreyer LL, Steenkamp ET, Wingfield MJ, Roets F (2014) Development of polymorphic microsatellite markers for the genetic characterisation of Knoxdaviesia proteae (Ascomycota: Microascales) using ISSR-PCR and pyrosequencing. Mycological Progress 13(2):439-444.

Aylward J, Dreyer LL, Steenkamp ET, Wingfield MJ, Roets F (2015) Knoxdaviesia proteae is not the only Knoxdaviesia-symbiont of Protea repens. IMA Fungus 6 (2):471-476.

Azcarate MP, Patriarca A, Terminiello L, Pinto VF (2008) Alternaria toxins in wheat during the 2004 to 2005 Argentinean harvest. Journal of Food Protection 71(6):1262-1265.

Azeem M, Terenius O, Rajarao GK, Nagahama K, Nordenhem H, Nordlander G, BorgKarlson AK (2015) Chemodiversity and biodiversity of fungi associated with the pine weevil Hylobius abietis. Fungal Biology 119(8):738-746.

Aziz FH, Qadir SB (2016) Common and new records of Lichens from Iraqi Kurdistan Region, Iraq. Bulletin of the Iraq Natural History Museum 14(1):51-68.

Back CG, Kim YH, Jo WS, Chung H, Jung HY (2010) Cobweb disease on Agaricus bisporus caused by Cladobotryum mycophilum in Korea. Journal of general plant pathology 76(3):232-5.

Badali H, Carvalho VO, Vicente V, Attili-Angelis D, Kwiatkowski LB, Gerrits van den Ende AHG, de Hoog GS (2009) Cladophialophora saturnica sp. nov., a new opportunistic 
species of Chaetothyriales revealed using molecular data. Medical Mycology 47:5566.

Badali H, Gueidan C, Najafzadeh MJ, Bonifaz A, Gerrits van den Ende AHG, de Hoog GS (2008) Biodiversity of the genus Cladophialophora. Studies in Mycology 61:175-191.

Badali H, Prenafeta-Boldú FX, Guarro J, Klaassen CH, Meis JF, de Hoog GS (2011) Cladophialophora psammophila, a novel species of Chaetothyriales with a potential use in the bioremediation of volatile aromatic hydrocarbons. Fungal Biology 115:1019-1029.

Bagyanarayana G, Rao NK, Kunwar IK (2009) Manoharachariella, a new dematiaceous hyphomycetous genus from India. Mycotaxon 109(1):301-305.

Bai QR, Han S, Xie YY, Dong R, Gao J, Li Y (2012) First report of daylily leaf streak caused by Kabatiella microsticta in China. Plant Disease (10):1579.

Bajpai R, Shukla V, Singh N, Rana TS, Upreti DK (2015) Physiological and genetic effects of chromium $(+\mathrm{VI})$ on toxitolerant lichen species, Pyxine cocoes. Environmental Science and Pollution Research 22(5):3727-3738.

Bajpai R, Upreti DK (2012) Accumulation and toxic effect of arsenic and other heavy metals in a contaminated area of West Bengal, India, in the lichen Pyxine cocoes (Sw.) Nyl. Ecotoxicology and environmental safety 83:63-70.

Bajpai R, Upreti DK, Dwivedi SK, Nayaka S (2009) Lichen as quantitative biomonitors of atmospheric heavy metals deposition in Central India. Journal of atmospheric chemistry, 63(3):235-246.

Bakhshi M, Arzanlou M, Babai-Ahari A, Groenewald JG, Crous PW (2015a) Is morphology in Cercospora a reliable reflection of generic affinity? Phytotaxa 213:22-34.

Bakhshi M, Arzanlou M, Babai-Ahari A, Groenewald JZ, Braun U, Crous PW (2015b) Application of the consolidated species concept to Cercospora spp. from Iran. Persoonia: Molecular Phylogeny and Evolution of Fungi 34:65.

Baloch E, Gilenstam G, Wedin M (2009) Phylogeny and classification of Cryptodiscus, with taxonomic synopsis of the Swedish species. Fungal Divers. 38:51-68.

Baloch E, Gilenstam G, Wedin M (2013) The relationships of Odontotrema (Odontotremataceae) and the resurrected Sphaeropezia (Stictidaceae) - new combinations and three new Sphaeropezia species. Mycologia 105:384-397.

Baloch E, Lücking R, Lumbsch HT, Wedin M (2010) Major clades and phylogenetic relationships between lichenized and non-lichenized lineages in Ostropales (Ascomycota: Lecanoromycetes). Taxon 59(5):1483-1494.

Ban S, Sakane T, Nakagiri A (2015) Three new species of Ophiocordyceps and overview of anamorph types in the genus and the family Ophiocordyceptaceae. Mycological Progress 14(1): 1017.

Bansal H, Srivastava S, Chaurasia A, Jabalia NA (2014) Comparative Study of Antifreeze Proteins from Antarctomyces psychrotrophicus and Typhula ishikariensis using Computational Tools and Servers. VIVECHAN International Journal of Research $5(1): 21-8$.

Baral HO (2015) Nomenclatural novelties. Index Fungorum no. 255:1-3.

Baral H-O, De Sloover JR, Huhtinen S, Laukka T, Stenroos S (2009) An emendation of the genus Hyaloscypha to include Fuscoscypha (Hyaloscyphaceae, Helotiales, Ascomycotina). Karstenia 49(1):1-17.

Baral HO, Galán R, Platas G, Tena R. 2013a Phaeohelotium undulatum comb. nov. and Phaeoh. succineoguttulatum sp. nov., two segregates of the Discinella terrestris aggregate found under Eucalyptus in Spain: taxonomy, molecular biology, ecology and distribution. Mycosystema 32(3):386-428. 
Baral HO, Garcia G, Bogale M, O'Hara MJ, Untereiner WA (2012) Colipila, a new genus in the Helotiales. Mycological progress 11(1):201-14.

Baral H-O, Haelewaters D (2015) Rommelaarsia flavovirens gen. et sp. nov. (Helotiales), a new discomycete on Equisetum with a peculiar asexual state. Ascomycete org 7 (6):321-330.

Baral HO, Haelewaters D, Pärtel K (2015) A new attempt to classify the families of the Helotiales. The Second International Workshop on Ascomycete Systematics. CBS Symposium. 22-24 April. Amsterdam.

Baral HO, Kutorga E (2010) Helicogonium fusisporum sp. nov., an intrahymenial parasite in Orbilia eucalypti. Mycotaxon 113:331-336.

Baral H-O, Marson G (2012). Deltopyxis triangulispora gen. et sp. nov., a polysporus Tromeropsis-like discomycete of unclear relationships. Andrias 19:176.

Baral HO, Marson G, Bogale M, Untereiner WA (2013b) Xerombrophila crystallifera, a new genus and species in the Helotiales. Mycological progress 1,12(3):475-88.

Baral HO, Queloz VK, Hosoya TS (2014) Hymenoscyphus fraxineus, the correct scientific name for the fungus causing ash dieback in Europe. IMA fungus. 1,5(1):79-80.

Baral HO, Rämä T (2015) Morphological update on Calycina marina (Pezizellaceae, Helotiales, Leotiomycetes), a new combination for Laetinaevia marina. Botanica Marina 58(6):523-534.

Barbeito I, Brücker RL, Rixen C, Bebi P (2013) Snow fungi-induced mortality of Pinus cembra at the alpine treeline: evidence from plantations. Arctic, Antarctic, and Alpine Research 45(4):455-470.

Barber PA, Crous PW, Groenewald JZ, Pascoe IG, Keane P (2011) Reassessing Vermisporium (Amphisphaeriaceae), a genus of foliar pathogens of Eucalypts. Persoonia 27:90-118.

Barbosa FR, Gusmão LF, Raja HA, Shearer CA (2013) New species and new records of freshwater ascomycetes from Brazil and Costa Rica. MycologiaMar 1,105(2):335-43.

Barbosa FR, Gusmão LFP (2011) Conidial fungi from semi-arid Caatinga Biome of Brazil. Rare freshwater hyphomycetes and other new records. Mycosphere 2(4):475-485.

Barbosa FR, Raja HA, Shearer CA, Gusmão LFP (2013) Some Freshwater Fungi from the Brazilian Semi-Arid Region, Including Two New Species of Hyphomycetes. Cryptogam Mycol 34:243-258.

Barbosa MA, Costa PM, Malosso E, Castañeda-Ruiz RF (2016) Codinaea leomaiae sp. nov. from the Brazilian Atlantic Forest. Mycotaxon 131(2):423-8.

Barcenas Peña A, Lücking R, Miranda-González R, Herrera-Campos MA (2014) Three new species of Graphis (Ascomycota: Ostropales: Graphidaceae) from Mexico, with updates to taxonomic key entries for 41 species described between 2009 and 2013. The Lichenologist 46(1):69-82.

Barchien C, Tsui CK, Gulis V, Szewzyk U, Marvanová L (2013) The molecular phylogeny of aquatic hyphomycetes with affinity to the leotiomycetes. Fungal Biology 117:660672.

Barnes I, Van der Nest A, Mullett MS, Crous PW, Drenkhan R, Musolin DL, Wingfield MJ (2016) Neotypification of Dothistroma septosporum and epitypification of D. pini, causal agents of Dothistroma needle blight of pine. Forest Pathology 46(5):388-407.

Barreto RW, Johnston PR, Crous PW, Evans HC (2012) A new species of the lenticel fungal genus Claviradulomyces (Ostropales) from the Brazilian Atlantic forest tree Xylopia sericea (Annonaceae). IMA Fungus 3:135-141.

Barseghyan GS, Solomon P (2011) The genus Peziza Dill. ex Fr.(Pezizales, Ascomycota) in Israel. Ascomycete Org. 2(4):39-50. 
Bartkowiak ME, Bennett JP (2016) Floristic study of lichens in Portage County, Wisconsin.

Bartosik M, Żakowska Z, Cedzińska K, Rożniakowski K (2010) Biodeterioration of Optical Glass Induced by Lubricants Used in Optical Instruments Technology. Polskie Towarzystwo Mikrobiologów Polish Society of Microbiologists 59(4):295-300.

Bartra J, Belmonte J, Torres-Rodriguez JM, Cistero-Bahima A (2008) Sensitization to Alternaria in patients with respiratory allergy. Frontiers in bioscience (Landmark edition), 14:3372-3379.

Barua BS, Suzuki A, Pham HN, Inatomi S (2012) Adaptation of ammonia fungi to urea enrichment environment. Journal of Agricultural Technology 8(1):173-89.

Baschien C, Tsui CKM, Gulis V, Szewzyk U, Marvanová L (2013) The molecular phylogeny of aquatic hyphomycetes with affinity to the Leotiomycetes. Fungal Biology 117:660-672.

Bashir G, Hussain W, Rizvi A (2009) Bipolaris hawaiiensis keratomycosis and endophthalmitis. Mycopathologia 167(1):51-53.

Bashya L B, Chand R, Prasad L, Joshi A (2011) Partial resistance components for the management of spot blotch pathogen Bipolaris sorokiniana of barley (Hordeum vulgare L.). Acta Phytopathologica et Entomologica Hungarica 46(1):49-57.

Bashyal BM, Chand R, Kushwaha C, Sen D, Prasad LC, Joshi AK (2010) Association of melanin content with conidiogenesis in Bipolaris sorokiniana of barley (Hordeum vulgare L.). World Journal of Microbiology and Biotechnology 26(2):309-316.

Bastida F, Jehmlich N, Ondoño S, von Bergen M, García C, Moreno JL (2014) Characterization of the microbial community in biological soil crusts dominated by Fulgensia desertorum (Tomin) Poelt and Squamarina cartilaginea (With.) P. James and in the underlying soil. Soil Biology and Biochemistry 76:70-79.

Bates ST, Bungartz F, Lücking R, Herrera-Campos MA, Zambrano A (2011) Biomonitoring, Ecology and Systematics of Lichens. Acta Botanica Hungarica 53(3-4):442-443.

Baturo-Ciesniewska A (2011) Genetic variability and pathogenicity among polish isolates of Bipolaris sorokiniana from spring barley. Journal of Plant Pathology, 291-302.

Bautista-Rosales PU, Calderon-Santoyo M, Servín-Villegas R, Ochoa-Álvarez NA, RagazzoSánchez JA (2013) Action mechanisms of the yeast Meyerozyma caribbica for the control of the phytopathogen Colletotrichum gloeosporioides in mangoes. Biological control 65(3):293-301.

Beaulieu WT, Panaccione DG, Ryan KL, Kaonongbua W, Clay K (2015) Phylogenetic and chemotypic diversity of Periglandula species in eight new morning glory hosts (Convolvulaceae). Mycologia 107(4):667-78.

Beck A, Mayr C (2012) Nitrogen and carbon isotope variability in the green-algal lichen Xanthoria parietina and their implications on mycobiont-photobiont interactions. Ecology and evolution 2(12):3132-3144.

Beese WJ, Sandford J, Symon M, Major S (2015) Distribution and abundance of Pseudocyphellaria rainierensis (old-growth specklebelly lichen) on Vancouver Island and a portion of the Central Mainland Coast of British Columbia. Evansia 32(3):136153.

Begoude ADB, Gryzenhout M, Wingfield MJ, Roux J (2010) Aurifilum, a new fungal genus in the Cryphonectriaceae from Terminalia species in Cameroon. Antonie van Leeuwenhoek 98(3):263-278.

Begum A, HariKrishna S (2010) Monitoring Air pollution using lichens species in South Bangalore, Karnataka. International Journal of ChemTech Research 2(1):255-260. 
Bell A (2010) Echinosphaeria cincinnat, a new species from Rimutaka Forest park near Wellington New Zealanda. Australasian Mycologist. 29:24-26.

Bell A, Mahoney DP (2008) Echinosphaeria medusa, a new species from New Zealand, with notes on related species. Australasian Mycologist. 27(3):141-148.

Bell A, Mahoney DP (2016) Field studies in the Lasiosphaeriaceae and Helminthosphaeriaceae sensu lato. CBS Biodiversity Series 15:3-124.

Benatti MN (2011) A simple clearing technique to aid in the recognition of cilia and rhizinae structure in the Parmeliaceae. Opuscula Philolichenum 9:21-5.

Benatti MN (2014) An update on the genus Parmelinella Elix \& Hale (Parmeliaceae, lichenized ascomycetes). Mycosphere 5(6):770-789.

Bencsik O, Papp T, Berta M, Zana A, Forgó P, Dombi G, Andersson MA, Salkinoja-Salonen M, Vágvölgyi C, Szekeres A (2014) Ophiobolin A from Bipolaris oryzae perturbs motility and membrane integrities of porcine sperm and induces cell death on mammalian somatic cell lines. Toxins 6(9):2857-2871.

Bendiksby M, Haugan R, Spribille T, Timdal E (2015) Molecular phylogenetics and taxonomy of the Calvitimela aglaea complex (Tephromelataceae, Lecanorales). Mycologia 107:1172-1183.

Bendiksby M, Mazzoni S, Jørgensen MH, Halvorsen R, Holien H (2014) Combining genetic analyses of archived specimens with distribution modelling to explain the anomalous distribution of the rare lichen Staurolemma omphalarioides: long-distance dispersal or vicariance?. Journal of Biogeography 41(11):2020-2031.

Bendiksby M, Timdal E (2013) Molecular phylogenetics and taxonomy of Hypocenomyce sensu lato (Ascomycota: Lecanoromycetes): extreme polyphyly and morphological/ecological convergence. Taxon 62(5):940-956.

Benesperi R, Lastrucci L, Nascimbene J (2013) Human Disturbance Threats the Red-Listed Macrolichen Seirophora villosa (Ach.) Frödén in Coastal Juniperus Habitats: Evidence From Western Peninsular Italy. Environmental management 52(4):939-945.

Benkert D (2010) Seltene und kritische Pezizales-Funde (Ascomycota) aus der Bundesrepublik Deutschland. Zeitschrift für Mykologie 76(1):27-58.

Bennett JP (2013) The Lichens and Allied Fungi of Great Smoky Mountains National Park. The Bryologist 116(2):218-220.

Bensch K, Braun U, Groenewald JZ, Crous PW (2012) The genus Cladosporium. Stud Mycol 72:1-401.

Bensch K, Groenewald JZ, Braun U, Dijksterhuis J, de Jesús Yáñez-Morales M, Crous PW (2015) Common but different: The expanding realm of Cladosporium. Studies in mycology 82:23-74.

Benucci GM, Raggi L, Albertini E, Grebenc T, Bencivenga M, Falcinelli M, Di Massimo G (2011) Ectomycorrhizal communities in a productive Tuber aestivum Vittad. orchard: composition, host influence and species replacement. FEMS microbiology ecology 76(1):170-84.

Benucci GMN, Lefevre C, Bonit G (2016). Characterizing root-associated fungal communities and soils of Douglas-fir (Pseudotsuga menziesii) stands that naturally produce Oregon white truffles (Tuber oregonense and Tuber gibbosum). Mycorrhiza 26:367-376.

Ben-Ze'ev IS, Assouline I, Levy E, Elkind G (2011) First report of Bipolaris cactivora causing fruit blotch and stem rot of dragon fruit (pitaya) in Israel. Phytoparasitica 39(2):195-197

Berger F, Braun U, Heuchert B (2015) Gonatophragmium lichenophilum sp. nov.-a new lichenicolous hyphomycete from Austria. Mycobiota 5:7-13. 
Berger F, LaGreca S (2014) Contributions to the lichen flora of Bermuda-Part 1. Evansia 31(2):41-68.

Berka RM, Grigoriev IV, Otillar R, Salamov A, Grimwood J, Reid I, Ishmael N, John T, Darmond C, Moisan MC, Henrissat B (2011) Comparative genomic analysis of the thermophilic biomass-degrading fungi Myceliophthora thermophila and Thielavia terrestris. Nature biotechnology (10):922-7.

Berkeley MJ (1876) Notices of North American fungi. Grevillea 4(31): 105-106

Bernardi M, Barragán A, Rossi W (2014) New records of Laboulbeniales (Fungi: Ascomycota) from Ecuador and other countries. Webbia 69(2):281-9.

Besitulo A, Moslem MA, Hyde KD (2010) Occurrence and distribution of fungi in a mangrove forest on Siargao Island, Philippines. Bot Mar 53:535-543.

Bevan J, Alexander R,Lazaro-Suau R (2012) Transplant experiments to examine the habitat exclusivity of lichen dominated soil crust communities in the El Cautivo badlands, SE Spain. In EGU General Assembly Conference Abstracts 14:11040.

Bhattarai HD, Kim T, Oh H, Yim JH (2013) A new pseudodepsidone from the Antarctic lichen Stereocaulon alpinum and its antioxidant, antibacterial activity. Journal of Antibiotics 66(9):559.

Bhise MR, Patil CR, Salunkhe CB (2014) Three new black mildew fungi from Mahabaleshwar, Maharashtra, India. Int. J. of Life Sciences 2(4):304-310.

Biazrov LG (2012) Stable nitrogen isotopes (d15N) in thalli of arid vagrant lichen Xanthoparmelia camtschadalis across an altitudinal gradient of the Khangai Plateau of Mongolia. Contemporary Problems of Ecology 5(2):200-207.

Bills GF, Menéndez VG, Platas G (2012) Kabatiella bupleuri sp. nov. (Dothideales), a pleomorphic epiphyte and endophyte of the Mediterranean plant Bupleurum gibraltarium (Apiaceae). Mycologia 104(4):962-973.

Bilovitz PO (2014) The importance of old deciduous trees and wooden fences for lichen diversity-an example from the Teichalm area (Eastern Alps). Herzogia 27(1):199.

Bilovitz PO, Mayrhofer H (2014) Lichenized and lichenicolous fungi from the valley 'Ochsental'(Eastern Alps, Vorarlberg, Austria). Fritschiana: Veroffentlichungen aus dem Herbarium des Instituts fur Botanik der Karl-Franzens-Universitat Graz (GZU) 78:47.

Bilovitz PO, Stešević D, Mayrhofer H (2010) Epiphytic lichens and lichenicolous fungi from the northern part of Montenegro. Herzogia 23(2):249.

Björk CR (2010) Additions to the Lichen Flora of Washington State, United States. I. Evansia 27(1):18-20.

Boehm E, Marson G, Mathiassen GH, Schoch CL (2015) An overview of the genus Glyphium and its phylogenetic placement in Patellariales. Mycologia 107:607-618.

Boehm EWA, Mugambi G, Miller AN, Huhndorf S, Marincowitz S, Schoch CL, Spatafora JW (2009a) A molecular phylogenetic reappraisal of the Hysteriaceae, Mytilinidiaceae and Gloniaceae (Pleosporomycetidae, Dothideomycetes) with keys to world species. Studies in Mycology 64:49-83.

Boehm EWA, Schoch CL, Spatafora JW (2009b) On the evoluation of the Hysteriaceae and Mytilinidiaceae (Pleosporomycetidae, Dothideomyceetes, Ascomycota) using fore nuclear genes. Mycological Research 113:461-479.

Bogdanović G, Trajković S, Micić T (2016) Flora lichen western mountains Vranje place. Journal of Process Management. New Technologies 4(3):69.

Boitano S, Flynn AN, Sherwood CL, Schulz SM, Hoffman J, Gruzinova I, Daines MO (2011) Alternaria alternata serine proteases induce lung inflammation and airway epithelial 
cell activation via PAR2. American Journal of Physiology-Lung Cellular and Molecular Physiology 300(4):605-L614.

Boluda CG, Hawksworth DL, Divakar PK, Crespo A, Rico VJ (2016) Microchemical and molecular investigations reveal Pseudephebe species as cryptic with an environmentally modified morphology. The Lichenologist 48(5):527-43.

Bomble FW (2012) Candelaria pacifica and Xanthomendoza borealis in the region of Aachen, North Rhine-Westphalia-new to Germany. Veröff. Bochumer Bot. Ver. 4(1):1-8.

Bonito G, Smith ME, Nowak M, Healy RA, Guevara G, Cázares E, Kinoshita A, Nouhra ER, Domínguez LS, Tedersoo L, Murat C (2013) Historical biogeography and diversification of truffles in the Tuberaceae and their newly identified southern hemisphere sister lineage. PLoS One 8(1):e52765.

Bonito G, Smith ME, Nowak M, Healy RA, Guevara G, Cázares E, Kinoshita A, Nouhra ER, Domínguez LS, Tedersoo L, Murat C. (2013) Historical biogeography and diversification of truffles in the Tuberaceae and their newly identified southern hemisphere sister lineage. PloS one. 8(1):e52765.

Bonito G, Trappe JM, Rawlinson P, Vilgalys R (2010b) Improved resolution of major clades within Tuber and taxonomy of species within the Tuber gibbosum complex. Mycologia 102(5):1042-1057.

Bonito GM, Gryganskyi AP, Trappe JM, Vilgalys R (2010a) A global meta-analysis of Tuber ITS rDNA sequences: species diversity, host associations and long-distance dispersal. Molecular Ecology. 19(22):4994-5008.

Boom PVD, Ertz D (2012) Lichens and lichenicolous fungi from El Hierro (Canary Islands), a survey, including five new species. Cryptogam Mycol 33(1):59-97.

Boonmee S, Bhat JD, Maharachchikumbura SS, Hyde KD (2014a) Clavatispora thailandica gen. et sp. nov., a novel taxon of Venturiales (Dothideomycetes) from Thailand. Phytotaxa 176(1):92-101.

Boonmee S, D'souza MJ, Luo Z, Pinruan U, Tanaka K, Su H, Bhat DJ, McKenzie EHC, Jones EBG, Taylor JE, Phillips AJL, Hirayama K, Eungwanichayapant PD, Hyde KD (2016) Dictyosporiaceae fam. nov. Fungal Divers 80(1):457-482.

Boonmee S, Ko Ko TW, Chukeatirote E, Hyde KD, Chen H, Cai L, McKenzie EHC, Jones EBG, Kodsueb R, Hassan BA (2012) Two new Kirschsteiniothelia species with Dendryphiopsis anamorphs cluster in Kirschsteiniotheliaceae fam. nov. Mycologia 104(3):698-714.

Boonmee S, Rossman AY, Liu JK, Li WJ, Dai DQ, et al. (2014b) Tubeufiales, ord. nov., integrating sexual and asexual generic names. Fungal Divers 68:239-298.

Boonmee S, Zhang Y, Chomnunti P, Chukeatirote E, Tsui CKM, Bahkali AH, Hyde KD (2011) Revision of lignicolous Tubeufiaceae based on morphological reexamination and phylogenetic analysis. Fungal Divers 51:63-102.

Boonyuen N, Chuaseeharonnachai C, Suetrong S, Veera VS, Sivichai S, Jones EBG, Pang K (2011) Savoryellales (hypocreomycetidae, sordariomycetes): A novel lineage of aquatic ascomycetes inferred from multiple-gene phylogenies of the genera ascotaiwania, ascothailandia, and savoryella. Mycologia 103(6):1351-71.

Boonyuen N, Sri-Indrasutdhi V, Suetrong S, Sivichai S, Jones EG (2012) Annulatascus aquatorba sp. nov., a lignicolous freshwater ascomycete from Sirindhorn Peat Swamp Forest, Narathiwat, Thailand. Mycologia 104 (3):746-757.

Bordallo JJ, Rodríguez A, Kounas V, Camello F, Honrubia M, Morte A (2015) Two new Terfezia species from Southern Europe. Phytotaxa 230(3):239-49.

Bordallo JJ, Rodríguez A, Muñoz-Mohedano JM, Suz LM, Honrubia M, Morte A (2013) Five new Terfezia species from the Iberian Peninsula. Mycotaxon 124(1):189-208. 
Bordallo JJ, Rodriguez AN, Honrubia MA, Morte AS (2012) Terfezia canariensis sp. nov. una nueva especie de trufa encontrada en las Islas Canarias. Cantarela 56:1-8.

Borse BD, Borse KN, Pawar NS, Tuwar AR (2013) Marine fungi from India-XII. A revised checklist. Indian Journal of Geo-Marine Sciences 42:110-119.

Borse BD, Jagdale PE, Patil SY (2014) Fresh water higher fungi from Pune district (MS, India) I: the mitosporic genus Xylomyces. BIOINFOLET-A Quarterly Journal of Life Sciences 11(3a):730-4.

Bose T, Reynolds DR, Berbee ML (2014) Common, unsightly and until now undescribed: Fumiglobus pieridicola sp. nov., a sooty mold infesting Pieris japonica from western North America. Mycologia 106(4):746-56.

Boutabia L, Telailia S, de Belair G (2015) Corticolous lichen flora on Quercus suber L. in the wetlands of El Kala national park (North-Eastern Algeria). Advances in Environmental Biology 360-373.

Boyce RD, Deziel PJ, Otley CC, Wilhelm MP, Eid AJ, Wengenack NL, Razonable RR (2010) Phaeohyphomycosis due to Alternaria species in transplant recipients. Transplant Infectious Disease 12(3):242-250.

Brackel WV (2008) Zwackhiomyces echinulatus sp. nov. and other lichenicolous fungi from Sicily, Italy. Herzogia 21:181-198.

Brackel WV (2010a) Dacampia cyrtellae, a new name for Dacampia lecaniae Brackel. Herzogia 23:315-316.

Brackel WV (2010b) Some lichenicolous fungi and lichens from Iceland, including Lichenopeltella uncialicola sp. nov. Herzogia 23(1):93-109.

Brackel WV (2011a) Lichenicolous fungi and lichens from Puglia and Basilicata (southern Italy). Herzogia 24(1):65-101.

Brackel WV (2011b) Lichenopeltella rangiferinae sp. nov. and some other lichenicolous fungi from Iceland. Acta Botanica Islandica 15:51-60.

Brackel WV (2013) Miscellaneous records of lichenicolous fungi from the Italian Alps. Herzogia 26(1):141-157.

Brackel WV (2014) Kommentierter Katalog der flechtenbewohnenden Pilze Bayerns. Bibliotheca Lichenologica. 109:1-476.

Brackel WV, Berger F. (2010). Gall-inducing species of Polycoccum (Ascomycota) on the lichen genus Placopsis. Herzogia 23(2):195-204.

Brackel WV, Zimmermann DG (2012) A new species of Nectriopsis on Cladonia from Nordrhein-Westfalen (Germany). Herzogia 25(2):231-4.

Bradwell T (2010) Studies on the growth of Rhizocarpon geographicum in NW Scotland, and some implications for lichenometry. Geografiska Annaler: Series A, Physical Geography 92(1):41-52.

Braga FR, Carvalho RO, Araujo JM, Silva AR, Araújo JV, Lima WS, Tavela AO, Ferreira SR (2009) Predatory activity of the fungi Duddingtonia flagrans, Monacrosporium thaumasium, Monacrosporium sinense and Arthrobotrys robusta on Angiostrongylus vasorum first-stage larvae. Journal of helminthology 83(4):303-308.

Braga FR, Carvalho RO, Silva AR, Araújo JV, Frassy LN, Lafisca A, Soares FE (2014) Predatory capability of the nematophagous fungus Arthrobotrys robusta preserved in silica gel on infecting larvae of Haemonchus contortus. Tropical animal health and production 46(3):571-574.

Braga FR, Silva AR, Carvalho RO, Araújo JV, Guimarães PHG, Fujiwara RT, Frassy LN (2010) In vitro predatory activity of the fungi Duddingtonia flagrans, Monacrosporium thaumasium, Monacrosporium sinense and Arthrobotrys robusta on Ancylostoma ceylanicum third-stage larvae. Veterinary microbiology 146(1):183-186. 
Braganca H, Rigling D, Diogo, E, Capelo J, Phillips A, Tenreiro R (2011) Cryphonectria naterciae: a new species in the Cryphonectria-Endothia complex and diagnostic molecular markers based on microsatellite-primed PCR. Fungal Biology 115(9):852861.

Braun U (1995) A monograph of Cercosporella, Ramularia and allied genera (phytopathogenic hyphomycetes). Vol. 1. IHW-Verlag Eching (333 pp.).

Braun U (1998) A monograph of Cercosporella, Ramularia and allied genera (phytopathogenic hyphomycetes). Vol. 2. IHW-Verlag Eching (493 pp.).

Braun U (2009) New species, combinations and records of hyphomycetes. Schlechtendalia 19:63-71.

Braun U (2013a) (2210-2232) Proposals to conserve the teleomorph-typified name Blumeria against the anamorph-typified name Oidium and twenty-two teleomorph-typified powdery mildew species names against competing anamorph-typified names (Ascomycota: Erysiphaceae). Taxon 62(6):1262-1331.

Braun U (2013b) A monograph of Cercosporella, Ramularia and allied genera (phytopathogenic hyphomycetes) Additions to host range and distribution. Schlechtendalia, 1, pp.41-43.

Braun U (2016). Rhynchosporium graminicola revisited and reinstated. Schlechtendalia 30:39-40.

Braun U, Bien S, Hantsch L, Heuchert B (2014a) Tubakia chinensis sp. nov. and a key to the species of the genus Tubakia. Schlechtendalia 28:23-28.

Braun U, Cook RTA (2012). Taxonomic Manual of the Erysiphales (Powdery Mildews). CBS Biodiversity Series No. 11:1-707.

Braun U, Crous P (2016) (2415) Proposal to conserve the name Cercospora (Ascomycota: Mycosphaerellaceae) with a conserved type. Taxon 65(1):185-185.

Braun U, Crous PW, Groenewald JZ, Scheuer C (2011) Pseudovirgaria, a fungicolous hyphomycete genus. IMA Fungus 2:65-69.

Braun U, Crous PW, Nakashima C (2014b) cercosporoid fungi (Mycosphaerellaceae) 2. Species on monocots (Acoraceae to Xyridaceae, excluding Poaceae). IMA Fungus 5:203-390.

Braun U, Crous PW, Nakashima C (2015) cercosporoid fungi (Mycosphaerellaceae) 4. Species on dicots (Acanthaceae to Amaranthaceae). IMA fungus, 6(2):373-469.

Braun U, Crous PW, Schubert K (2008) Taxonomic revision of the genus Cladosporium s. lat.8. Reintroduction of Graphiopsis (=Dichocladosporium) with further reassessments of cladosporioid hyphomycetes. Mycotaxon103:207-216.

Braun U, Heuchert B (2010) Sporidesmiella lichenophila sp. nov. a new lichenicolous hyphomycete. Herzogia 23(1):69-74.

Braun U, Heuchert B, Diederich P (2009) Two new and another interesting lichenicolous hyphomycete. Herzogia 22:165-171.

Braun U, Nakashima C, Crous PW (2013) Cercosporoid fungi (Mycosphaerellaceae) 1. Species on other fungi, Pteridophyta and Gymnospermae. IMA Fungus 4:265-345.

Braun U, Urtiaga R (2013) New species and new records of cercosporoid hyphomycetes from Cuba and Venezuela (Part 2). Mycosphere 4(2):176-216.

Breuss O (2009) A synopsis of the lichen genus Placopyrenium (Verrucariaceae), with descriptions of new taxa and a key to all species. Biblioth. Lichenol 99:93-112.

Breuss O (2011) Notable records of pyrenocarpous lichens (Verrucariaceae) from Spain. Herzogia 24(2):375-378.

Breuss O (2016) Involucropyrenium romeanum is the correct name for I. squamulosum (lichenised Ascomycota, Verrucariaceae). Herzogia 29(1):196-7. 
Brock PM, Döring H, Bidartondo MI (2009) How to know the unknown fungi: the role of a herbarium. New Phytol 181:719-724.

Brodo IM (2010) The lichens and lichenicolous fungi of Haida Gwaii (Queen Charlotte Islands), British Columbia, Canada. 5. A new species of Lecanora from shoreline rocks This paper is one of a selection of papers published as part of the special Schofield Gedenkschrift. Botany 88(4):352-358.

Brodo IM, Culberson WL, Culberson CF (2008) Haematomma (Lecanoraceae) in North and Central America, including the West Indies. The Bryologist 111(3):363-423.

Brodo IM, Lendemer JC (2015) A revision of the saxicolous, esorediate species of Ainoa and Trapelia (Baeomycetaceae and Trapeliaceae, lichenized Ascomycota) in North America, with the description of two new species. The Bryologist 118(4): pp. 385399.

Brown EM, McTaggart LR, Zhang SX, Low DE, Stevens DA, Richardson SE (2013) Phylogenetic analysis reveals a cryptic species Blastomyces gilchristii, sp. nov. within the human pathogenic species Blastomyces dermatitidis. PLoS ONE 8:e59237.

Bruzone MC, Fehrer J, Fontenla SB (2016) Vohník M. First record of Rhizoscyphus ericae in Southern Hemisphere's Ericaceae. Mycorrhiza 25:1-7.

Buaruang K, Scharnagl K, Divakar PK, Leavitt SD, Crespo A, Nash III TH, Manoch L, Lücking R, Lumbsch HT (2015) Molecular data support Pseudoparmelia as a distinct lineage related to Relicina and Relicinopsis (Ascomycota, Lecanorales). Lichenologist 47: 43-49

Buçukoglu TZ, Albayrak S, Halici MG, Tay T (2013) Antimicrobial and antioxidant activities of extracts and lichen acids obtained from some Umbilicaria species from Central Anatolia, Turkey. Journal of Food Processing and Preservation, 37(6):11031110.

Büdel B (2011) Lichens of the Namib Desert-A Guide to Their Identification. Herzogia, 24(1):167-167.

Bungartz F, Dután-Patiño VL, Elix JA (2013a) The lichen genera Cryptothecia, Herpothallon and Helminthocarpon (Arthoniales) in the Galapagos Islands, Ecuador. The Lichenologist 45(6):739-762.

Bungartz F, Elix JA, Kalb K, Giralt M (2016) New and overlooked species from the Galapagos Islands: the generic concept of Diploicia reassessed. Lichenologist 48:489515.

Bungartz F, Hillmann G, Kalb K, Elix JA (2013b) Leprose and leproid lichens of the Galapagos, with a particular focus on Lepraria (Stereocaulaceae) and Septotrapelia (Pilocarpaceae). Phytotaxa 150:1-28.

Bungartz FR, Grube J, Elix JA, Heininger C, Mayrhofer H (2011) A taxonomic revision of the Buellia subalbula-group in the Southern Hemisphere using fluorescence microscopy. Bibliotheca Lichenologica 106:21-39.

Burgos MRG, Katimbang MLB, Paz MD, Beligan GA, Goodwin PH, Ona IP, Mauleon RP, Ardales EY, Cruz CV (2013) Genotypic variability and aggressiveness of Bipolaris oryzae in the Philippines. European journal of plant pathology 137(2):415-429.

Burneviča N, Jansons Ā, Zaļuma A, Kḷaviņa D, Jansons J, Gaitnieks T. (2016) Fungi Inhabiting Bark Stripping Wounds Made by Large Game on Stems of Picea abies (L.) Karst. in Latvia. Baltic Forestry 22(1):2-7.

Butin H, Holdenrieder O, Sieber TN (2013) The complete life cycle of Petrakia echinata. Mycological progress 12(2):427-35.

Buyck B, Hosaka K, Masi S, Hofstetter V (2016) Molecular analyses of first collections of Elaphomyces Nees (Elaphomycetaceae, Eurotiales, Ascomycota) from Africa and 
Madagascar indicate that the current concept of Elaphomyces is polyphyletic. Cryptogam Mycol 37:3-14.

Cabral A, Groenewald JZ, Rego C, Oliveira H, Crous PW (2012) Cylindrocarpon root rot: multi-gene analysis reveals novel species within the Ilyonectria radicicola species complex. Mycological Progress, 11(3):655-688.

Cáceres MES, Aptroot A (2016) First inventory of lichens from the Brazilian Amazon in Amapá State. The Bryologist. 119(3):250-265.

Cáceres MES, Aptroot A, Parnmen S, Lücking R (2014) Remarkable diversity of the lichen family Graphidaceae in the Amazon rain forest of Rondônia, Brazil. Phytotaxa 189:87-136.

Cáceres MES, da Silva, Plata ER, Lücking R (2012a) Malmographina, a new genus for Graphina malmei (Ascomycota: Ostropales: Graphidaceae). The Lichenologist. 44(1):115-120.

Cáceres MES, Santos Viera T, Santos De Jesus L, Lücking R (2012b) New and interesting lichens from the Caxiuanã National Forest in the Brazilian Amazon. Lichenologist 44:807-812.

Cai L, Guo XY, Hyde KD (2008) Morphological and molecular characterisation of a new anamorphic genus Cheirosporium, from freshwater in China. Persoonia. 20:53-58.

Cai L, Hu D-M, Liu F, Hyde KD, Gareth-Jones E (2014) The molecular phylogeny of freshwater Sordariomycetes and discomycetes. Freshwater Fungi and Fungal-like Organisms De Gruyter, Berlin 47-72.

Calado ML, Carvalho L, Pang KL, Barata M (2015) Diversity and Ecological Characterization of Sporulating Higher Filamentous Marine Fungi Associated with Spartina maritima (Curtis) Fernald in Two Portuguese Salt Marshe. Microb Ecol. 70:612-33.

Cameron RP, Bondrup-Nielsen S (2012) Coral Lichen (Sphaerophorus globosus (Huds.) Vain) as an Indicator of Coniferous Old-Growth Forest in Nova Scotia. Northeastern Naturalist 19(4):535-540.

Campbell J, Inderbitzin P, Kohlmeyer J, Volkmann-Kohlmeyer B (2009a) Koralionastetales, a new order of marine Ascomycota in the Sordariomycetes. Mycol Res 113:373-380.

Campbell J, Marvanová L, Gulis V (2009b) Evolutionary relationships between aquatic anamorphs and teleomorphs: Tricladium and Varicosporium. Mycological research. 113(11):1322-34.

Candan M, Schultz M (2015) New and additional records of cyanolichens from Turkey. Herzogia, 28(2):359-369.

Cannon PF, Damm U, Johnston PR, Weir BS (2012) Colletotrichum-current status and future directions. Studies in mycology 73:181-213.

Cansaran-Duman D, Halici MG (2012) Squamarina lentigera türlerinde usnik asit konsantrasyonunun antimikrobiyal aktivitesi. Turk Hijyen ve Deneysel Biyoloji Dergisi.

Cao S, Wei X, Zhou Q, Wei J (2013) Phyllobaeis crustacea sp. nov. from China. Mycotaxon 126:31-36.

Cao S, Zhang F, Liu C, Hao Z, Tian Y, Zhu L, Zhou Q (2015) Distribution patterns of haplotypes for symbionts from Umbilicaria esculenta and U. muehlenbergii reflect the importance of reproductive strategy in shaping population genetic structure. BMC microbiology 15(1):212.

Capdet M, Romero AI (2010) Fungi from palms in Argentina. 1. Mycotaxon 112:339-355

Carbone M (2013) A type study of Pseudoplectania stygia (Pezizales). Ascomycete 5(1):338 
Carbone M, Agnello C, Alvarado P (2013) Phylogenetic studies in the family Sarcosomataceae (Ascomycota, Pezizales). Ascomycete 5(1):1-2.

Carbone M, Agnello C, Alvarado P, Krom I (2014) Donadinia sibirica (Ascomycota, Pezizales) a new species from Russia. Mycologia Montenegrina 17:53-64.

Carbone M, Van Vooren N (2011) Otidea fuckelii, una nuova specie pubblicata per chiarire le differenti interpretazioni di Otidea leporina. Rivista di Micologia 52(4):313-330.

Carissimi M, Giraudo MS, Germani JC, Van Der Sand ST (2010) Antifungal activity of Bacillus sp. E164 against Bipolaris sorokiniana. Biociências (On-line) 17(1).

Carlucci A, Raimondo M, Santos J, Phillips AJL (2012) Plectosphaerella species associated with root and collar rots of horticultural crops in southern Italy. Persoonia 28:34-48.

Carmarán CC, Berretta M, Martínez S, Barrera V, Munaut F, Gasoni L (2015) Species diversity of Cladorrhinum in Argentina and description of a new species, Cladorrhinum australe. Mycological Progress 14(10):94.

Carmarán CC, Pildain MB, Vassiljeva LN (2009) The family Diatrypaceae (Ascomycota) in Argentina: new species and new records. Nova Hedwigia 88(3-4):521-530.

Carmo LT, Monteiro JS, Gusmão LF, Sotão HM, Gutiérrez AH, Castañeda-Ruiz RF (2014) Anabahusakala, a new genus from the Brazilian Amazon rainforest. Mycotaxon 127(1):11-5.

Carneiro de Almeida DA, Miller AN, Pascholati Gusmão LF (2014) New species and combinations of conidial fungi from the semi-arid Caatinga biome of Brazil. Nova Hedwigia 98(3-4):431-47.

Carris LM, Peever T, McCotter SW (2016) Mitosporic stages of Disciotis, Gyromitra and Morchella in the inland Pacific Northwest USA. Mycologia.

Carter HE, Cools HJ, West JS, Shaw MW, Fraaije BA (2013) Detection and molecular characterisation of Pyrenopeziza brassicae isolates resistant to methyl benzimidazole carbamates. Pest management science 69(9):1040-8.

Carvalho RO, Braga FR, Araújo JV (2011) Viability and nematophagous activity of the freeze-dried fungus Arthrobotrys robusta against Ancylostoma spp. infective larvae in dogs. Veterinary parasitology 176(2):236-239.

Casaregola S, Jacques N, Louis-Mondesir C, Coton M, Coton E (2013) Citeromyces nyonsensis sp. nov., a novel yeast species isolated from black olive brine. International Journal of Systematic and Evolutionary Microbiology 63:3086-3090.

Castañeda R, Rafael F, Gusmão LFP, de Moraes Júnior VO, Leão-Ferreira SM, Saikawa M, Minter DW, Stadler M (2009b) Two setose anamorphic fungi: Ampullicephala gen. nov. and Venustosynnema grandiae. Mycotaxon 109:275-288.

Castañeda-Ruiz RF, Abarca GH, Mota RM, Stadler M, Saikawa M, Minter DW (2010a) Anaselenosporella sylvatica gen. \& sp. nov. and Pseudoacrodictys aquatica sp. nov., two new anamorphic fungi from Mexico. Mycotaxon 112(1):65-74.

Castañeda-Ruiz RF, Granados MM, Mardones M, Stadler M, Minter DW, HernándezRestrepo M, Gené J, Guarro J (2013a) A microfungus from Costa Rica: Ticosynnema gen. nov. Mycotaxon 122(1):255-9.

Castañeda-Ruiz RF, Guerrero B, Adamo GM, Morillo O, Minter DW, Stadler M, Gené J, Guarro J (2009a) A new species of Selenosporella and two microfungi recorded from a cloud forest in Mérida, Venezuela. Mycotaxon 109:63-74.

Castañeda-Ruíz RF, Heredia Abarca G, Arias Mota RM, Becerra CI, Saikawa M, Minter DW, Stadler M (2010b) Elotespora, an enigmatic anamorphic fungus from Tabasco, Mexico. Mycotaxon 111:197-203. 
Castañeda-Ruiz RF, Heredia G, Arias RM, McKenzie EH, Hyde KD, Stadler M, Saikawa M, Gené J, Guarro J, Iturriaga T, Minter DW (2011) A new species and re-disposed taxa in Repetophragma. Mycosphere 2(3):273-89.

Castañeda-Ruiz RF, Heredia G, Arias-Mota RM, Stadler M, Saikawa M, McKenzie EH (2012a) Two new fungi from Mexico: Anaseptoidium gen. nov. and Cylindrosympodium sosae sp. nov. Mycotaxon 119(1):141-148.

Castañeda-Ruiz RF, Heredia G, Gusmão LF, Li DW. 2016a Fungal Divers of Central and South America. InBiology of Microfungi (pp. 197-217). Springer International Publishing.

Castañeda-Ruiz RF, Hernández-Restrepo M, Gené J, Granados M, Guarro J (2013b) Two new species of Repetophragma from the Iberian Peninsula. Mycotaxon 125(1):209-15.

Castañeda-Ruiz RF, Hernández-Restrepo M, Gené J, Guarro J, Minter DW, Saikawa M. (2013c) Two new microfungi from Portugal: Magnohelicospora iberica gen. \& sp. nov. and Phaeodactylium stadleri sp. nov. Mycotaxon 121(1):171-9.

Castañeda-Ruiz RF, Hernández-Restrepo M, Gené J, Guarro J, Minter DW, Saikawa M (2012b) Two new microfungi from Portugal: Magnohelicospora iberica gen. \& sp. nov. and Phaeodactylium stadleri sp. nov. Mycotaxon 121:171-179.

Castañeda-Ruiz RF, Iturriaga T, Minter DW, Heredia Abarca G, Stadler M, Saikawa M, Fernández R (2009c) Two new anamorphic fungi and some microfungi recorded from 'El Ávila', Venezuela. Mycotaxon. 107:225-237.

Castañeda-Ruiz RF, Ma YR, Xia JW, Zhang XG (2016b) Two new species of Pseudoacrodictys from Hainan, China. Nova Hedwigia 102(1-2):69-75.

Castañeda-Ruiz RF, Silvera-Simón C, Gené J, Guarro J, Minter DW, Stadler M, Saikawa M (2010c) A new species of Corynesporopsis from Portugal. Mycotaxon, 114(1), pp.407-415.

Castellano MA, Beever RE, Trappe JM (2012a) Sequestrate fungi of New Zealand: Elaphomyces (Ascomycota, Eurotiales, Elaphomycetaceae). N Z J Bot 50:423-433.

Castellano MA, Dentinger BTM, Séné O, Elliott TF, Truong C, Henkel TW (2016) New species of Elaphomyces (Elaphomycetaceae, Eurotiales, Ascomycota) from tropical rainforests of Cameroon and Guyana. IMA Fungus 7:59-73.

Castellano MA, Guevara Guerrero G, García Jiménez J, Trappe JM (2012b) Elaphomyces appalachiensis and E. verruculosus sp. nov. (Ascomycota, Eurotiales, Elaphomycetaceae) from Eastern North America. Rev Mex Micol 35:17-22.

Castellano MA, Trappe JM, Vernes K (2011) Australian species of Elaphomyces (Elaphomycetaceae, Eurotiales, Ascomycota). Aust Syst Bot 24:32-57.

Castillo JD, Lawrence KS, Kloepper JW, Van Santen E (2010) Evaluation of Drechslerella dactyloides, Drechslerella brochopaga, and Paecilomyces lilacinus for biocontrol of Rotylenchulus reniformis. Nematropica 40(1):71-86.

Castroagudín VL, Moreira SI, Pereira DAS, Moreira SS, Brunner PC, Maciel JLN, Crous PW, McDonald BA, Alves E, Ceresini PC (2016) Pyricularia graminis-tritici, a new Pyricularia species causing wheat blast. Persoonia 37:199-216.

Catal M, Jordan SA, Butterworth SC, Schilder AM (2007) Detection of Eutypa lata and Eutypella vitis in Grapevine by Nested Multiplex Polymerase Chain Reaction. Phytopathology 97(6):737-47.

Catania MD, Romero AI, Huhndorf SM, Miller AN (2011) A new species and new records of Cercophora from Argentina. Mycologia 103(6):1372-1383.

Catania MD, Romero A (2012) Crassoascus monocaudatus and Iodosphaeria podocarpi, two new species on Podocarpus parlatorei from" Las Yungas", Argentina. Mycosphere 3(1):37-44. 
Cavalcante JG (2012) fatores associados à estrutura da comunidade de liquens corticícolas crostosos em duas áreas de caatinga no estado de alagoas.

Centeno DC, Hell AF, Braga MR, del Campo EM, Casano LM (2016) Contrasting strategies used by lichen microalgae to cope with desiccation-rehydration stress revealed by metabolite profiling and cell wall analysis. Environmental microbiology 18(5):154660.

Cestaro L, Tønsberg T, Muggia L (2016) Phylogenetic Data and Chemical Traits Characterize a New Species in the Lichen Genus Tephromela. Herzogia 29(2):383402.

Chacón S, Dörge D, Weisenborn J, Piepenbring M (2013) A new species and a new record of Diatrypaceae from Panama. Mycologia 105(3):681-688.

Chacón S, Tapia F, Esqueda M (2014) New records of dothideomycetes from mexico. Mycotaxon 128:145-57.

Chakraborty S, Basak B, Dutta S, Bhunia B, Dey A (2013) Decolorization and biodegradation of congo red dye by a novel white rot fungus Alternaria alternata CMERI F6. Bioresource technology 147:662-666.

Chamizo S, Rodríguez-Caballero E, Roncero B, Román JR, Cantón Y (2016) April. Factors controlling spatial distribution patterns of biocrusts in a heterogeneous and topographically complex semiarid area. In EGU General Assembly Conference Abstracts 18:7937.

Chand R, Kumar M, Kushwaha C, Shah K, Joshi AK (2014) Role of melanin in release of extracellular enzymes and selection of aggressive isolates of Bipolaris sorokiniana in barley. Current microbiology 69(2):202-211.

Chand R, Sen D, Prasad KD, Singh AK, Bashyal BM, Prasad LC, Joshi AK (2008) Screening for disease resistance in barley cultivars against Bipolaris sorokiniana using callus culture method. Indian journal of experimental biology 46(4):249.

Chang J-H, Kao H-W, Wang Y-Z (2010) Molecular phylogeny of Cercophora, Podospora, Schizothecium (Lasiosphaeriaceae, Pyrenomycetes). Taiwania 55:110-116.

Chang JH, Wang YZ (2009) The genera Sporormia and Preussia (Sporormiaceae, Pleosporales) in Taiwan. Nova Hedwigia 88(1-2):245-254.

Chang YC, Lu CK, Chiang YR, Wang GJ, Ju YM, Kuo YH, Lee TH (2014) Diterpene glycosides and polyketides from Xylotumulus gibbisporus. Journal of natural products 77(4):751-7.

Chaverri P, Gazis RO (2010) Perisporiopsis lateritia, a new species on decaying leaves of Hevea spp. from the Amazon basin in Peru. Mycotaxon 113:163-169.

Chaverri P, Gazis RO (2011) Linking ex planta fungi with their endophytic stages: Perisporiopsis, a common leaf litter and soil fungus, is a frequent endophyte of Hevea spp. and other plants. Fungal Ecology 4(1):94-102.

Chaverri P, Liu M, Hodge KT (2008) A monograph of the entomopathogenic genera Hypocrella, Moelleriella, and Samuelsiagen. nov. (Ascomycota, Hypocreales, Clavicipitaceae), and their aschersonia-like anamorphs in the Neotropics. Stud Mycol 60:1-66.

Chaverri P, Salgado C, Hirooka Y, Rossman AY, Samuels GJ (2011) Delimitation of Neonectria and Cylindrocarpon (Nectriaceae, Hypocreales, Ascomycota) and related genera with Cylindrocarpon-like anamorphs. Studies in Mycology 68:57-78.

Checa J, Blanco M.N, Moreno G (2013) Contributions to the family Thyridiaceae. New data on Sphaeria mutabilis. Mycotaxon 125:149-164. 
Checa J,Arenal F, Blanco N, Rogers JD (2008) Coniolariella hispanica sp. nov. and other additions to Coniolariella. Mycological Research 112(7):795-801.

Cheewangkoon R, Groenewald JZ, Hyde KD, To-anun C, Crous PW (2012) Chocolate Spot disease of Eucalyptus. Mycological Progress. 11:61-69.

Cheewangkoon R, Groenewald JZ, Summerell BA, Hyde KD, To-anun C, Crous PW (2009)

Myrtaceae, a cache of fungal biodiversity. Persoonia 23:55-85.

Cheewangkoon R, Groenewald JZ, Verkley HJM et al. (2010) Re-evaluation of Cryptosporiopsis eucalypti and Cryptosporiopsis-like species occurring on Eucalyptus leaves. Fungal Divers 44:89-105.

Chen AJ, Sun BD, Houbraken J, Frisvad JC, Yilmaz N, Zhou YG, Samson RA (2016a) New Talaromyces species from indoor environments in China. Stud Mycol 84:119-144.

Chen C, Verkley GJ, Sun G, Groenewald JZ, Crous PW (2016b) Redefining common endophytes and plant pathogens in Neofabraea, Pezicula, and related genera. Fungal Biology 120(11):1291-322.

Chen H, Jiang XJ, Yu Z, Duns GJ, Sgao R, Xu W, Chen J (2014) A novel mitovirus isolated from Buergenerula spartinae. Virilogica Sinica 29:257-260.

Chen J, Meng ZX, Chen XM, Lv YL, Li FSZXD, Guo SX (2009) Leohumicola, a genus new to China. Mycotaxon 108:337-340.

Chen JL, Lin YR, Hou CL, Wang SJ (2012) Species of Rhytismataceae on Camellia spp. from the Chinese mainland. Mycotaxon 118(1):219-30.

Chen KH, Miadlikowska J, Molnár K, Arnold AE, U’Ren JM, Gaya E, Gueidan C, Lutzoni F. (2015a) Phylogenetic analyses of eurotiomycetous endophytes reveal their close affinities to Chaetothyriales, Eurotiales, and a new order-Phaeomoniellales. Molecular Phylogenetics and Evolution 85:117-30.

Chen L, Yue Q, Zhang X, Xiang M, Wang C, Li S, CheY, Ortiz-Lopez FJ, Bills GF, Liu X, An Z (2013d) Genomics-driven discovery of the pneumocandin biosynthetic gene cluster in the fungus Glarea lozoyensis. BMC Genomics 14:339.

Chen Q, Jiang JR, Zhang GZ, Cai L, Crous PW (2015b) Resolving the Phoma enigma. Studies in mycology 82:137-217.

Chen S, Gryzenhout M, Roux J, Xie Y, Wingfield MJ, Zhou X (2011) Novel species of Celoporthe from Eucalyptus and Syzygium trees in China and Indonesia. Mycologia 103(6):1384-410.

Chen S, Van Wyk M, Roux J, Wingfield MJ, Xie Y, Zhou X (2013a) Taxonomy and pathogenicity of Ceratocystis species on Eucalyptus trees in South China, including $C$. chinaeucensis sp. nov. Fungal Divers 58(1):267-79.

Chen SF, Wingfield MJ, Roets F, Roux J (2013e) A serious canker disease caused by Immersiporthe knoxdaviesiana gen. et sp. nov. (Cryphonectriaceae) on native Rapanea melanophloeos in South Africa. Plant Pathology 62:667-678.

Chen SF, Wingfield MJ, Roux J (2013b) Diversimorbus metrosiderotis gen. et sp. nov. and three new species of Holocryphia (Cryphonectriaceae) associated with cankers on native Metrosideros angustifoliatrees in South Africa. Fungal Biol 117(5):289-310.

Chen YL, Gao Y, Zhang KQ, Zou CG (2013c) Autophagy is required for trap formation in the nematode-trapping fungus Arthrobotrys oligospora. Environmental microbiology reports 5(4):511-517.

Cheng X, Li W, Cai L (2015) Molecular phylogeny of Ascotricha, including two new marine algae-associated species. Mycologia 27:14-210.

Cheng XL, Li W, Zhang TY (2014) A new species of Phaeoisaria from intertidal marine sediment collected in Weihai, China. Mycotaxon 127(1):17-24. 
Cheplick GP, Faeth S (2009) Ecology and evolution of the grass-endophyte symbiosis. Oxford university press.

Chhikara S, Chaudhury D, Dhankher OP, Jaiwal PK (2012) Combined expression of a barley class II chitinase and type I ribosome inactivating protein in transgenic Brassica juncea provides protection against Alternaria brassicae. Plant Cell, Tissue and Organ Culture (PCTOC) 108(1):83-89.

Chigoziri E, Ekefan EJ (2013) Seed-borne fungi of Chilli pepper (Capsicum frutescens) from pepper producing areas of Benue state, Nigeria. Agriculture and Biology Journal of America 4:370-374.

Chlebicka M, Konvalinkova T (2010) Pirottaea lychnidis comb. nov. from the Bohemian Switzerland National Park, Czech Republic. Czech Mycol 62(1):19-32.

Chlebicki A (2009a) Fungi on higher plants of the upper limit of the alpine zone: new species from Tian Shan. Mycotaxon 110:443-450.

Chlebicki A (2009b) Some endophytes of Juncus trifidus from Tatra Mts. in Poland. Acta Mycologica 44 (1):11-17.

Cho SE, Park JH, Choi JK, Shin HD (2015) First report of zonate leaf spot of Glycine max caused by Cristulariella moricola in Korea. Journal of Phytopathology 163(1112):1019-22.

Cho Y, Kim KH, La Rota M, Scott D, Santopietro G, Callihan M, Mitchell TK, Lawrence CB (2009) Identification of novel virulence factors associated with signal transduction pathways in Alternaria brassicicola. Molecular microbiology 72(6):1316-1333.

Cho Y, Srivastava A, Ohm RA, Lawrence CB, Wang KH, Grigoriev IV, Marahatta SP, (2012) Transcription factor Amr1 induces melanin biosynthesis and suppresses virulence in Alternaria brassicicola. PLoS Pathog 8(10):1002974.

Choi IY, Kim BS, Park JH, Cho SE, Shin HD (2014) First report of black stem caused by Botryosporium longibrachiatum on statice in Korea. Plant Disease 98(10):1431.

Choi J, Park SY, Kim BR, Roh JH, Oh IS, Han SS, Lee YH (2013a) Comparative analysis of pathogenicity and phylogenetic relationship in Magnaporthe grisea species complex. PloS one 8(2):57196.

Choi JS, Graser Y, Walther G, Peano A, Symoens F, Hoog, S. De (2012) Microsporum mirabile and its teleomorph Arthroderma mirabile, a new dermatophyte species in the M. cookei clade. Med Mycol 50(2):161-169.

Choi YJ, Shin HD, Han JG, Pfister DH (2013b) Scutellinia (Pezizales) in Korea, with a new species and eight new records. Nova Hedwigia 97(3-4):457-76.

Chokpaiboon S, Choodej S, Boonyuen N, Teerawatananond T, Pudhom K (2016) Highly oxygenated chromones from mangrove-derived endophytic fungus rhytidhysteron rufulum. Phytochemistry 122:172-7.

Chomnunti P, Hongsanan S, Hudson BA, Tian Q, Peršoh D, Dhami MK, Alias AS, Xu J, Liu X, Stadler M, Hyde KD (2014) The sooty moulds. Fungal Divers 66:1-36.

Chomnunti P, Ko TW, Chukeatirote E, Hyde KD, Cai L, Jones EG, Kodsueb R, Hassan BA, Chen H (2012) Phylogeny of Chaetothyriaceae in northern Thailand including three new species. Mycologia 104(2):382-95.

Chomnunti P, Schoch CL, Aguirre-Hudson B, Ko Ko TW, Hongsanan S, Jones EBG, Kodsueb R, Phookamsak R, Chukeatirote E, Bahkali AH, Hyde KD (2011) Capnodiaceae. Fungal Divers 51:103-134.

Chowdhary A, Randhawa HS, Singh V, Khan ZU, Ahmad S, Kathuria S, Roy P, Khanna, G, Chandra J (2011) Bipolaris hawaiiensis as etiologic agent of allergic 
bronchopulmonary mycosis: first case in a paediatric patient. Medical mycology 49(7):760-765.

Chruszcz M, Chapman MD, Osinski T, Solberg R, Demas M, Porebski PJ, Majorek K.A., Pomés A, Minor W (2012) Alternaria alternata allergen Alt a 1: a unique $\beta$-barrel protein dimer found exclusively in fungi. Journal of Allergy and Clinical Immunology 130(1):241-247.

Chu Y, Alias SA, Idid R, Guo SY, Pang KL (2015) A molecular reappraisal of Nimbospora

(Halosphaeriaceae, Microascales) and a new genus Ebullia for $N$. octonae. Mycoscience 56:34-41.

Chuaseeharonnachai C, Somrithipol S, Boonyuen N (2014) A new species of Fusticeps from Thailand. Mycosphere 5(2):313-317.

Chuaseeharonnachai C, Yamaguchi K, Sri-Indrasutdhia V, Somrithipol S, Okanec I, Nakagirid A, Boonyuen N (2013) Diversity of aero-aquatic hyphomycetes from six streams in Doi Inthanon and Khao Yai tropical forests, Thailand. Cryptogam Mycol 34(2):183-97.

CHUNG KR (2011) Elsinoë fawcettii and Elsinoë australis: the fungal pathogens causing citrus scab. Molecular plant pathology 12(2):123-35.

Chungu D, Gryzenhout M, Muimba-Kankolongo A, Wingfield MJ, Roux J (2010) Taxonomy and pathogenicity of two novel Chrysoporthe species from Eucalyptus grandis and Syzygium guineense in Zambia.. Mycological Progressr 9(3):379-393.

Clowez P (2012) Les morilles, une nouvelle approche mondiale du genre Morchella. Bulletin de la Société Mycologique de France 126(3-4):199-376.

Çobanoğlu G (2011) Additional and New Lichen Records for the Province of Giresun. Fen Bilimleri Dergisi 23(2):83-8.

Çobanoğlu G, Sesal C, Açıkgöz B, Karaltı İ (2016) Evaluation of antimicrobial activity of the lichens Physcia aipolia, Xanthoria parietina, Usnea florida, Usnea subfloridana and Melanohalea exasperata. Modern Phytomorphology10:19-24.

Çobanoğlu G, Yavuz M, Costache I, Radu I (2010) Additional and new lichen records from Cozia National Park, Romania. Mycotaxon 114(1):193-196.

Coda R, Rizzello CG, Di Cagno R, Trani A, Cardinali G, Gobbetti M (2013) Antifungal activity of Meyerozyma guilliermondii: identification of active compounds synthesized during dough fermentation and their effect on long-term storage of wheat bread. Food microbiology 33(2):243-51.

Consolo VF, Cordo CA, Salerno GL (2008) DNA fingerprint and pathotype diversity of Pyricularia oryzae populations from Argentina. Australasian Plant Pathology 37(4):357-364.

Cooper JA (2005) New Zealand hyphomycete fungi: additional records, new species, and notes on interesting collections. New Zealand Journal of Botany 43:323-349.

Coppins BJ (2008) Ameliella, a new genus of lichen-forming fungi from north-west Europe and western Canada. The Lichenologist 40(05):387-397.

Cort C (2012) A Phylogenetic Analysis of Heterocephalum: Using Molecular Tools to Reassess the Taxonomic Placement of an Unusual and Infrequently Collected Fungus. Honors Theses. Paper 7.

Coste C, Dufrêne P (2009) Reasoned Inventory of the Lichens and Lichenicolous Fungi of the Cascades of Mortain (department of Manche, 50). Société Tarnaise de Sciences Naturelles 57-80.

Cota BB, Rosa LH, Caligiorne RB, Rabello ALT, Alves TMA, Ros CA, Zani CL (2008) Altenusin, a biphenyl isolated from the endophytic fungus Alternaria sp., inhibits 
trypanothione reductase from Trypanosoma cruzi. FEMS Microbiology letters, 285(2):177-182.

Crane C, Burgess TI (2013) Luteocirrhus sheariigen. sp. nov. (Diaporthales, Cryphonectriaceae) pathogenic to Proteaceaein the south Western Australian Floristic Region. IMA Fungus 4(1):111-122.

Craven KD, Vélëz H, Cho Y, Lawrence CB, Mitchell TK (2008) Anastomosis is required for virulence of the fungal necrotroph Alternaria brassicicola. Eukaryotic cell 7(4):675683

Crespo A, Divakar PK, Hawksworth DL (2011) Generic concepts in parmelioid lichens, and the phylogenetic value of characters used in their circumscription. The Lichenologist 43(06):511-535.

Crespo A, Ferencova Z, Pérez-Ortega S, Elix JA, Divakar PK (2010a) Austroparmelina, a new Australian lineage in parmelioid lichens (Parmeliaceae, Ascomycota). Syst Biodivers 8:209-221.

Crespo A, Kauff F, Divakar PK, del Prado R, Pérez-Ortega S, et al. (2010b) Phylogenetic generic classification of parmelioid lichens (Parmeliaceae, Ascomycota) based on molecular, morphological and chemical evidence. Taxon 59:1735-1753.

Crisan F, Ardelean I (2010) The analysis of ecological behaviour of the macrolichens from Rosia Montana (Romania). Studia Universitatis Vasile Goldis Seria Stiintele Vietii (Life Sciences Series) 20(4).

Crittenden PD, Scrimgeour CM, Minnullina G, Sutton MA, Tang YS, Theobald MR (2015) Lichen response to ammonia deposition defines the footprint of a penguin rookery. Biogeochemistry 122(2-3):295-311.

Crous PW, Barreto RW, Alfenas AC, Alfenas RF, Groenewald JZ (2010a) what is Johansonia?. IMA fungus. 1(2):117-22.

Crous PW, Braun U, Hunter GC, Wingfield MJ, Verkley GJM, Shin H-D, Nakashima C, Groenewald JZ (2012a) Phylogenetic lineages in Pseudocercospora. Studies in Mycology 75:37-114

Crous PW, Braun U, Wingfield MJ, Wood AR, Shin HD, Summerell BA, Alfenas AC, Cumagun JCR, Groenewald JZ (2009a) Phylogeny and taxonomy of obscure genera of microfungi. Persoonia 22: 139-161.

Crous PW, Carris LM, Giraldo A, Groenewald JZ, Hawksworth DL, Hernández-Restrepo M, Jaklitsch WM, Lebrun MH, Schumacher RK, Stielow JB, van der Linde EJ, Vilcāne J, Voglmayr H, Wood AR (2015a) The Genera of Fungi: fixing the application of the type species of generic names - G 2: Allantophomopsis, Latorua, Macrodiplodiopsis, Macrohilum, Milospium, Protostegia, Pyricularia, Robillarda, Rotula, Septoriella, Torula, and Wojnowicia. IMA Fungus 6: 163-198

Crous PW, Giraldo A, Hawksworth DL, Robert V, Kirk PM, Guarro J, Robbertse B, Schoch CL, Damm U, Trakunyingcharoen T, Groenewald JZ (2014a) The Genera of Fungi: fixing the application of type species of generic names. IMA Fungus 5 (1), 141-160

Crous PW, Groenewald JZ (2010) Fungal planet 55. Xenopolyscytalum pinea gen. et sp. nov.. Persoonia 25: 130-131

Crous PW, Groenewald JZ (2011) Why everlastings dont last. Persoonia 26:70-84

Crous PW, Groenewald JZ, Lee SS (2009b) Fungal planet 41. Nawawia malaysiana. Persoonia 23:194-195

Crous PW, Groenewald JZ, Lombard L, Wingfield MJ (2012b) Homortomyces gen. nov., a new dothidealean pycnidial fungus from the Cradle of Humankind. IMA fungus 3(2):109-15. 
Crous PW, Groenewald JZ, Shin HD (2010b) Fungal planet 56. Strelitziana albiziae sp. nov.. Persoonia 25:132-133

Crous PW, Groenewald JZ, Shivas RG (2010c) Fungal planet 60. Pseudophloeospora eucalypti gen. et sp. nov.. Persoonia 25: 140-141

Crous PW, Groenewald JZ, Shivas RG, Edwards J, Seifert KA, Alfenas AC, Alfenas RF, Burgess TI, Carnegie AJ, Hardy GS, Hiscock N (2011a) Fungal Planet description sheets: 69-91. Persoonia-Molecular Phylogeny and Evolution of Fungi 26(1):108-156.

Crous PW, Groenewald JZ, Summerell BA, Wingfield BD, Wingfield MJ (2009c) Cooccurring species of Teratosphaeria on Eucalyptus. Persoonia 22:38-48

Crous PW, Groenewald JZ. 2013 A phylogenetic re-evaluation of Arthrinium. IMA fungus. Jul;4(1):133-54.

Crous PW, Minnis AM, Pereira OL, Alfenas AC, Alfenas RF, Rossman AY, Groenewald JZ (2011b) What is Scirrhia? IMA fungus 2(2):127-33

Crous PW, Muller MM, Sánchez RM, Giordano L, Bianchinotti M, Anderson FE, Groenewald JZ (2015b) Resolving Tiarosporella spp. allied to Botryosphaeriaceae and Phacidiaceae. Phytotaxa 202 (2): 73-93.

Crous PW, Quaedvlieg W, Hansen K, Hawksworth DL, Groenewald JZ (2014b) Phacidium and Ceuthospora (Phacidiaceae) are congeneric: taxonomic and nomenclatural implications. IMA fungus 5(2):173-193

Crous PW, Quaedvlieg W, Sarpkaya K, Can C, Erkılıç A (2013a) Septoria-like pathogens causing leaf and fruit spot of pistachio. IMA fungus. Dec 15;4(2):187-99.

Crous PW, Schoch CL, Hyde KD, Wood AR, Gueidan C, De Hoog GS, Groenewald JZ. (2009d) Phylogenetic lineages in the Capnodiales. Studies in mycology. Dec 31;64:17-47.

Crous PW, Schumacher RK, Wingfield MJ, Lombard L, Giraldo A, Christensen M, Gardiennet A, Nakashima C, Pereira O, Smith AJ, Groenewald JZ (2015c) Fungal Systematics and Evolution: FUSE 1. Sydowia. 67:81-118

Crous PW, Shivas RG, Quaedvlieg W, van Der Bank M, Zhang Y, Summerell EA et al. (2014c) Fungal Planet description sheets: 214-280. Persoonia 32:184-306

Crous PW, Shivas RG, Wingfield MJ, Summerell BA, Rossman AY, et al (2012c) Fungal Planet description sheets 128-153

Crous PW, Summerell BA, Alfenas AC, Edwards J, Pascoe IG, Porter IJ, Groenewald JZ (2012d) Genera of diaporthalean coelomycetes associated with leaf spots of tree hosts. Persoonia-Molecular Phylogeny and Evolution of Fungi 28(1):66-75

Crous PW, Summerell BA, Carnegie AJ, Wingfield MJ, Groenewald JZ (2009e) Novel species of Mycosphaerellaceae and Teratosphaeriaceae. Persoonia-Molecular Phylogeny and Evolution of Fungi 23(1):119-46

Crous PW, Summerell BA, Carnegie AJ, Wingfield MJ, Hunter GC, Burgess TI, Andjic V, Barber PA, Groenewald JZ. (2009f) Unravelling Mycosphaerella: do you believe in genera? Persoonia-Molecular Phylogeny and Evolution of Fungi. 23(1):99-118.

Crous PW, Summerell BA, Shivas RG, Burgess, TI, Decock CA, et al. (2012e) Fungal Planet Description Sheets: 107-127. Persoonia. 28:138-182.

Crous PW, Summerell BA, Shivas RG, et al. (2012f) A re-appraisal of Harknessia (Diaporthales), and the introduction of Harknessiaceae fam. nov. Persoonia 28: 59-65

Crous PW, Summerell BA, Shivas RG, Romberg M, Mel'nik VA, Verkley GJM, Groenewald JZ (2011c) Fungal Planet description sheets: 92-106. Persoonia 27:130-162 
Crous PW, Summerell BA, Swart L, Denman S, Taylor JE, Bezuidenhout CM, Palm ME, Marincowitz S, Groenewald JZ (2011d) Fungal pathogens of Proteaceae. Persoonia 27:20-45

Crous PW, Tanaka K, Summerell BA, Groenewald JZ (2011e) Additions to the Mycosphaerella complex. IMA fungus 2(1):49-64

Crous PW, Verkley GJM (2009) Xenocylindrosporium. Fungal Planet. 44

Crous PW, Verkley GJM, Christensen M, Groenewald JZ (2012g) How important are conidial appendages ? Persoonia 28:126-137

Crous PW, Wingfield MJ, Burgess TI, Hardy GS, Crane C, Barrett S, Cano-Lira JF, Leroux JJ, Thangavel R, Guarro J, Stchigel AM (2016a) Fungal Planet description sheets: 469-557. Persoonia-Molecular Phylogeny and Evolution of Fungi. Dec 28;37(1):218403

Crous PW, Wingfield MJ, Guarro J, Cheewangkoon R, van der Bank M, et al. (2013b) Fungal Planet description sheets: 154-213. Persoonia 31:188-296.

Crous PW, Wingfield MJ, Guarro J, Hernandez-Restrepo M, Sutton DA, Acharya, et al. (2015d) Fungal Planet description sheets: 320-370. Persoonia: Molecular Phylogeny and Evolution of Fungi 34:167

Crous PW, Wingfield MJ, Le Roux JJ, Richardson DM, Strasberg D, Shivas RG, Alvarado P, Edwards J, Moreno G, Sharma R, Sonawane MS et al (2015e) Fungal Planet description sheets: 371-399. Persoonia: Molecular Phylogeny and Evolution of Fungi. Dec;35:264.

Crous PW, Wingfield MJ, Richardson DM, Leroux JJ, Strasberg D, et al. (2016b) Fungal Planet description sheets: 400-468. Persoonia 36:316-458

Crous PW, Wingfield MJ, Schumacher RK, Summerell BA, Giraldo A, Gené J, Guarro J, Wanasinghe DN, Hyde KD, Camporesi E, Garethjones EB et al. (2014d) Fungal Planet description sheets: 281-319. Persoonia-Molecular Phylogeny and Evolution of Fungi. Dec 10;33(1):212-89.

Crous PW, Wood AR, Okada G, Groenewald JZ (2008) Foliicolous microfungi occurring on Encephalartos. Persoonia-Molecular Phylogeny and Evolution of Fungi 21(1):135-46.

Cruywagen EM, de Beer ZW, Roux J, Wingfield MJ (2010) Three new Graphium species from baobab trees in South Africa and Madagascar. Persoonia 25:61-71

Cruz AC, Gusmão LF, Castañeda-Ruiz RF, Stadler M, Minter DW (2012) Zelodactylaria, an interesting new genus from semi-arid northeast Brazil. Mycotaxon 119(1):241-248

Cruz ACR, dos Santos SIT, Leão-Ferreira SM, Gusmão LFP (2009) Conidial fungi from the semi-arid Caatinga biome of Brazil. New species and new records of Helicosporium. Mycotaxon 110:53-64

Cui Y, Jia H, He D, Yu H, Gao S, Yokoyama K, Li J, Wang L (2013) Characterization of Edenia gomezpompae isolated from a patient with keratitis. Mycopathologia 176(12):75-81

Culleré L, Ferreira V, Chevret B, Venturini ME, Sánchez-Gimeno AC, Blanco D (2010) Characterisation of aroma active compounds in black truffles (Tuber melanosporum) and summer truffles (Tuber aestivum) by gas chromatography-olfactometry. Food Chemistry 122(1):300-6

Cunnington JH, Lawrie AC, Pascoe IG (2010) Genetic characterization of the Golovinomyces cichoracearum complex in Australia. Plant Pathology 59:158-164

Czarnota P (2009) Japewia tornoensis and further localities of J. subaurifera found in the Carpathians. Acta Mycologica 44(2):59-264 
Czarnota P, Guzow-Krzeminska B (2012) ITS rDNA data confirm a delimitation of Bacidina arnoldiana and $B$. sulphurella and support a description of a new species within the genus Bacidina. Lichenologist 44:743-755

Czarnota P, Hernik E (2013) Mniaecia jungermanniae and Puttea margaritella (lichenized Ascomycota) found in Poland. Acta Societatis Botanicorum Poloniae 82(2)

Czarnota P, Hernik E (2014) Some peltigericolous microlichens from southern Poland. Acta Botanica Croatica 73(1):159-170

Czarnota P, Kukwa M (2009) Contribution to the knowledge of some poorly known lichens in Poland. III. Trapelia corticola and the genus Vezdaea. Folia Cryptog Estonica 46:25-31

D'Souza MA, Bhat DJ (2013) Occurrence of microfungi as litter colonizers and endophytes in varied plant species from the Western Ghats forests, Goa, India. Mycosphere 4(3):567-582

da Cruz ACR, Gusmão LFP (2009) Conidial fungi from caatinga: Lignicolous species. Acta Bot Bras 23(4):1133-44

Da Cunha KC, Sutton DA, Fothergill AW, Cano J, Gené J, Madrid H, De Hoog S, Crous PW, Guarro J (2012) Diversity of Bipolaris species in clinical samples in the United States and their antifungal susceptibility profiles. Journal of clinical microbiology 50(12): 4061-4066

da Silva M, Pinho DB, Pereira OL, Fernandes FM, Barreto RW (2016) Naming potentially endangered parasites: foliicolous mycobiota of Dimorphandra wilsonii, a highly threatened Brazilian tree species. PloS one 11(2):e0147895

da Silva SS, Gusmão LF (2015) Some facultative-aquatic conidial fungi from the Caatinga biome II: new records for Brazil and Americas. Brazilian Journal of Botany 38(2):323-31

da Silva SS, Gusmão LFP, Castañeda-Ruiz RF (2015) Cryptocoryneum parvulum, a new species on Araucaria angustigolia (Brazilian pine). Mycotaxon 130:465-469

Dai D, Bhat DJ, Liu J, Chukeatirote E, Zhao R, Hyde KD (2012) Bambusicola, a new genus from bamboo with asexual and sexual morphs. Cryptogamie Mycologie 33:363-379

Dai DQ, Bahkali AH, Ariyawansa HA, Li WJ, Bhat DJ, Hyde KD (2015) Neokalmusia didymospora (Didymosphaeriaceae), a new species from bamboo. Sydowia 68:17-25

Dai D-Q, Bahkali AH, Bhat DJ, Xiao Y-P, Chukeatirote E, Zhao R-L, McKenzie EHC, Xu JC, Hyde KD (2014a) Towards a natural classification of Dothideomycetes 3: The genera Muellerites, Trematosphaeriopsis, Vizellopsis and Yoshinagella (Dothideomycetes incertae sedis). Phytotaxa 176:18-27

Dai DQ, Bahkali AH, Li QR, Bhat DJ, Wijayawardene NN, Li WJ, Chukeatirote E, Zhao RL, Xu JC, Hyde KD (2014) Vamsapriya (Xylariaceae) re-described, with two new species and molecular sequence data. Cryptogamie, Mycologie 35(4):339-57

Dai DQ, Boonmee S, Tian Q, Xiao YP, Bhat DJ, Chukeatirote E, Alias S, Zhao RL, Wang Y, Hyde KD (2014c) Englerulaceae (Dothideomycetes). Phytotaxa 176(1):139-155

Dai DQ, Phookamsak R, Wijayawardene NN, Li WJ, Bhat DJ, Xu JC, Taylor JE, Hyde KD, Chukeatirote E (2016) Bambusicolous fungi. Fungal Diversity 82(1):1-105

Dai DQ, Wijayawardene NN, Bhat DJ, Chukeatirote E, Bahkali AH, Zhao RL, Xu JC, Hyde KD (2014d) Pustulomyces gen. nov. accommodated in Diaporthaceae, Diaporthales, 
as revealed by morphology and molecular analyses. Cryptogamie Mycologie 35(1):63-72

Dai DQ, Wijayawardene NN, Bhat DJ, Chukeatirote E, Zhao RL, Wang Y, Bahkali AH, Hyde KD (2014e) The Phylogenetic Placement of Eriosporella bambusicola sp. nov. in Capnodiales. Cryptogamie, Mycologie 35(1):41-9

Dailey R, Siemion R, Raisbeck M, Jesse C (2010) Analysis of salazinic, norstictic, and usnic acids in Xanthoparmelia chlorochroa by ultra-performance liquid chromatography/tandem mass spectrometry. Journal of AOAC International 93(4):1137-1142

Dallagnol LJ, Rodrigues FA, Chaves ARM, Vale FXR, DaMatta FM (2013) Photosynthesis and sugar concentration are impaired by the defective active silicon uptake in rice plants infected with Bipolaris oryzae. Plant pathology 62(1):120-129

Dallagnol LJ, Rodrigues FA, DaMatta FM, Mielli MV, Pereira SC (2011a) Deficiency in silicon uptake affects cytological, physiological, and biochemical events in the riceBipolaris oryzae interaction. Phytopathology 101(1):92-104

Dallagnol LJ, Rodrigues FA, Martins SC, Cavatte PC, DaMatta FM (2011b) Alterations on rice leaf physiology during infection by Bipolaris oryzae. Australasian Plant Pathology 40(4):360-365

Damm U, Baroncelli R, Cai L, Kubo Y, O'Connell R, Weir B, Yoshino K, Cannon PF (2010a) Colletotrichum: species, ecology and interactions. IMA fungus (2):161-5

Damm U, Cannon PF, Liu F, Barreto RW, Guatimosim E, Crous PW (2013) The Colletotrichum orbiculare species complex: Important pathogens of field crops and weeds. Fungal Diversity 61(1):29-59

Damm U, Cannon PF, Woudenberg JH, Crous PW (2012a) The Colletotrichum acutatum species complex. Studies in mycology 73:37-113

Damm U, Cannon PF, Woudenberg JH, Johnston PR, Weir BS, Tan YP, Shivas RG, Crous PW (2012b) The Colletotrichum boninense species complex. Studies in Mycology 73:1-36

Damm U, Crous PW, Fourie PH (2008) A fissitunicate ascus mechanism in the Calosphaeriaceae, and novel species of Jattaea and Calosphaeria on Prunus wood. Persoonia-Molecular Phylogeny and Evolution of Fungi 20(1):39-52

Damm U, Fourie PH, Crous PW (2010b) Coniochaeta (Lecythophora), Collophora gen. nov. and Phaeomoniella species associated with wood necroses of Prunus trees. PersooniaMolecular Phylogeny and Evolution of Fungi 24:60-80

Danesh N, Puttaiah ET, Basavarajappa BE (2013) Studies on diversity of lichen, Pyxine cocoes to air pollution in Bhadravathi town, Karnataka, India. Journal of Environmental Biology, 34(3):579

Daranagagama DA, Liu X-Z, Chamyuang S, Stadler M, Bahkali AH, Hyde KD (2015b) Rhopalostroma brevistipitatum sp. nov. from Thailand with an extended generic description for Rhopalostroma. Phytotaxa 227:229-242

Daranagama DA, Camporesi E, Tian Q, Liu X, Chamyuang S, Stadler M, Hyde KD (2015a) Anthostomella is polyphyletic comprising several genera in Xylariaceae. Fungal Diversity 73(1):203-238 
Daranagama DA, Jones EBG, Liu XZ, To-anun C, Stadler M, Hyde KD. 2016 - Mycosphere Essays 13 - Do xylariaceous macromycetes make up most of the Xylariomycetidae? Mycosphere 7(5):582-601

Daranagama DA, Thambugala KM, Jayasiri SC, Liu XZ, Stadler M, Hyde KD (2017) Towards a natural classification and backbone tree for Amplistromataceae, Lopadostomataceae and Xylariaceae. Fungal Diversity 74(1):199-266

Darangagama DA, Liu X-Z, Chamyuang S, Stadler M, Hyde KD (2014) A multiple gene genealogy reveals phylogenetic placement of Rhopalostroma lekae. Phytotaxa 186:177-187

Davey ML, Currah RS (2009) Atradidymella muscivora gen. et sp. nov. (Pleosporales) and its anamorph Phoma muscivora sp. nov.: a new pleomorphic pathogen of boreal bryophytes. American Journal of Botany 96(7): 1281-1288.

Davison EM, Davison PJN, Tan YP, Shivas RG (2009) Fungal Planet 31. Oedocephalum adhaerens. Persoonia 22:166-167

Davydov EA, Ohmura Y (2016) Lectotypification of the name Umbilicaria esculenta. Mycotaxon 131(2):407-412

Davydov EA, Printzen C (2012) Rare and noteworthy boreal lichens from the Altai Mountains (South Siberia, Russia). The Bryologist 115(1):61-73

Day MJ, Hall JC, Currah RS (2012) Phialide arrangement and character evolution in the helotialean anamorph genera Cadophora and Phialocephala. Mycologia. 104(2):371-8

de Azevedo CMPS, Gomes RR, Vicente VA, Santos DWCL, Marques SG, do Nascimento MMF, Andrade CEW, Silva RR, Queiroz-Telles F, de Hoog GS (2015) Fonsecaea pugnacius, a novel agent of disseminated chromoblastomycosis. Journal of Clinical Microbiology 53:2674-2685.

De Beer ZW, Duong TA, Barnes I, Wingfield BD, Wingfield MJ (2014) Redefining Ceratocystis and allied genera. Studies in Mycology 79:187-219

De Beer ZW, Seifert KA, Wingfield MJ (2013A) Nomenclator for ophiostomatoid genera and species in the Ophiostomatales and Microascales. The ophiostomatoid fungi: expanding frontiers 12:245-322

de García V, Brizzio S, Libkind D, Rosa CA, van Broock M (2010) Wickerhamomyces patagonicus sp. nov., an ascomycetous yeast species from Patagonia, Argentina. International journal of systematic and evolutionary microbiology 60(7):1693-6

de Gruyter J, Aveskamp MM, Woudenberg JH, Verkley GJ, Groenewald JZ, Crous PW (2009) Molecular phylogeny of Phoma and allied anamorph genera: towards a reclassification of the Phoma complex. Mycological research 113(4):508-519

de Gruyter J, Woudenberg JH, Aveskamp MM, Verkley GJ, Groenewald JZ, Crous PW (2010) Systematic reappraisal of species in Phoma section Paraphoma, Pyrenochaeta and Pleurophoma. Mycologia 102(5):1066-81

de Gruyter J, Woudenberg JHC, Aveskamp MM, Verkley GJM, Groenewald JZ, Crous PW (2012) Redisposition of Phoma-like anamorphs in Pleosporales. Studies in Mycology 75:1-36

de Hoog GS, Ahmed SA, Najafzadeh MJ, Sutton DA, Keisari MS, Fahal AH, Eberhardt U, Verkleij GJ, Xin L, Stielow B, van de Sande WW (2013) Phylogenetic findings 
suggest possible new habitat and routes of infection of human eumyctoma. PLoS Negl Trop Dis 7 (5):E2229

de Hoog GS, Dukik K, Monod M, Packeu A, Stubbe D, Hendrickx M, Kupsch C, Stielow JB, Freeke J, Göker M, Rezaei-Matehkolaei A, Mirhendi H, Gräser Y (2016) Toward a novel multilocus phylogenetic taxonomy for the dermatophytes. Mycopathologia 127

de Hoog GS, Redhead SA, Feng P, Jiang Y, Dukik K, Sigler L (2016) (2465-2466) Proposals to conserve Blastomyces Gilchrist \& W.R. Stokes against Blastomyces Costantin \& Rolland and Ajellomycetaceae against Paracoccidioidaceae (Ascomycota: Onygenales). Taxon 65:1167-1169

de Hoog GS, van Diepeningen AD, Mahgoub E-S, van de SandeWWJ (2012) New species of Madurella, causative agents of black-grain mycetoma. Journal of Clinical Microbiology. 50(3):988-994

de Hoog GS, Vicente VA, Najafzadeh MJ, Harrak MJ, Badali H, Seyedmousavi S (2011) Waterborne Exophiala species causing disease in cold-blooded animals. PersooniaMolecular Phylogeny and Evolution of Fungi 27(1):46-72

de Jong SN, Levesque CA, Verkley GJM, Abeln ECA, Rahe JE, Braun PG (2015) Phylogenetic relationships among Neofabraea species causing tree cankers and bull'seye rot of apple based on DNA sequencing of ITS nuclear rDNA, mitochondrial rDNA, and the beta-tubulin gene. Mycol. Res 105(6):658-669

de la Rosa JPM, Porcel MC, Warke PA (2013) Mapping stone surface temperature fluctuations: Implications for lichen distribution and biomodification on historic stone surfaces. Journal of Cultural Heritage 14(4):346-353

de Lange PJ (2014) The Flora of Egeria Rock, Northern Kermadec Island Group. Wellington Botanical Society Bulletin 55:41-49

de Lange PJ, Blanchon D (2014) The hunt for Ramalodium dumosum (Pannariaceae, lichenised ascomycetes)-an enigmatic lichen endemic to the southern Waitakere Ranges

de Lange PJ, Galloway DJ, Blanchon DJ, Knight A, Rolfe JR, Crowcroft GM, Hitchmough R (2012) Conservation status of New Zealand lichens. New Zealand Journal of Botany 50(3):303-363

de los Ríos A, Raggio J, Pérez-Ortega S, Vivas M, Pintado A, Green TA, Ascaso C, Sancho LG (2011) Anatomical, morphological and ecophysiological strategies in Placopsis pycnotheca (lichenized fungi, Ascomycota) allowing rapid colonization of recently deglaciated soils. Flora-Morphology, Distribution, Functional Ecology of Plants 206(10):857-864

de Melo MP, da Silva Matos K, Júnior JE, Moreira SI, Silva FF, de Alcântara Neto F, Alves E, Pereira OL (2016) Thielaviopsis musarum causes postharvest crown and fruit rot of banana in Northeastern Brazil. Tropical Plant Pathology 41(4):258-63

de Melo Teixeira M, Theodoro RC, de Oliveira FF, Machado GC, Hahn RC, Bagagli E, SanBlas G, Felipe MS (2014) Paracoccidioides lutzii sp. nov. biological and clinical implications. Medical mycology 52(1):19-28 
de Moura Nascimento EJ, Van Der Sand ST (2008) Restriction analysis of the amplified ribosomal DNA spacers ITS1 and ITS2 of Bipolaris sorokiniana isolates. World Journal of Microbiology and Biotechnology 24(5):647-652

de Paz AG, Cubas P, Divakar PK, Lumbsch HT, Crespo A (2011) Origin and Diversification of major clades in parmelioid lichens (Parmeliaceae, Ascomycota) during the Paleogene inferred by Bayesian analysis. PLoS One 6(12):e28161

de Paz GA, Cubas P, Crespo A, Elix JA, Lumbsch HT (2012) Transoceanic dispersal and subsequent diversification on separate continents shaped diversity of the Xanthoparmelia pulla group (Ascomycota). Plos One 7(6):e39683

de Silva H, Castlebury LA, Green S, Stone JK (2009) Characterisation and phylogenetic relationships of Anisogramma virgultorum and A. anomala in the Diaporthales (Ascomycota). mycological research 113(1):73-81

de Souza Armando EA, Chaves ZM, Dianese JC (2015) Phaeostilbelloides and Velloziomyces - new dematiaceous genera from the Brazilian Cerrado. Mycotaxon 130(3):757-67

Debona D, Rodrigues FÁ, Rios JA, Nascimento KJT (2012) Biochemical changes in the leaves of wheat plants infected by Pyricularia oryzae. Phytopathology 102(12):11211129

Declercq B (2009) Omtrent Lasiosphaeria s.1. Sterbeeckia 28:35-41

Delgado Baquerizo M, Gallardo A, Covelo F, Prado Comesaña A, Ochoa V, Maestre FT (2015) Differences in thallus chemistry are related to species-specific effects of biocrust forming lichens on soil nutrients and microbial communities. Functional Ecology 29(8):1087-1098

Delgado G (2008) South Florida microfungi: a new species of Stanjehughesia (hyphomycetes) from Sabal palm Mycotaxon 103:229-234

Delgado G (2013) South Florida microfungi: a new species of Ellisembia (hyphomycetes) with new records from the USA. Mycotaxon 123(1):445-450

Delgado G (2014) South Florida microfungi: Linkosia longirostrata, a new hyphomycete on paurotis palm. Mycotaxon 129(1):41-46

Dellavalle PD, Cabrera A, Alem D, Larrañaga P, Ferreira F, Dalla Rizza M (2011) Antifungal activity of medicinal plant extracts against phytopathogenic fungus Alternaria spp. Chilean Journal of Agricultural Research 71(2):231

Del-Prado R, Blanco O, Lumbsch HT, Divakar PK, Elix JA, Molina MC, Crespo A (2013) Molecular phylogeny and historical biogeography of the lichen-forming fungal genus Flavoparmelia (Ascomycota:Parmeliaceae). Taxon 62 (5):928-939

Del-Prado R, Divakar PK, Crespo A (2011) Using genetic distances in addition to ITS molecular phylogeny to identify potential species in the Parmotrema reticulatum complex: a case study. The Lichenologist 43(6):569-583

Demiray AD, Yolcubal I, Akyol NH, Çobanoğlu G (2012) Biomonitoring of airborne metals using the Lichen Xanthoria parietina in Kocaeli Province, Turkey. Ecological Indicators, 18:632-643

Desoubeaux G, García D, Bailly E, Augereau O, Bacle G, De Muret A, Bernard L, Cano-Lira JF, Garcia-Hermoso D, Chandenier J (2014) Subcutaneous phaeohyphomycosis due 
to Phialemoniopsis ocularis successfully treated by voriconazole. Medical mycology case reports 5:4-8

Dethoup T, Manoch L (2009) Diversity of marine fungi in eastern thailand. Kasetsart J Nat Sci 43:100-6

Dey P, Banerjee J, Maiti MK (2011) Comparative lipid profiling of two endophytic fungal isolates-Colletotrichum sp. and Alternaria sp. having potential utilities as biodiesel feedstock. Bioresource technology 102(10):5815-5823

Dhargalkar S, Bhat DJ (2009) Echinosphaeria pteridis sp. nov. and its Vermiculariopsiella anamorph. Mycotaxon 108:115-122

Dharkar N, Subhedar A, Hande D, Shahezad MA (2010) Two new fungal species from Vidarbha, India. J Mycol Pl Pathol 40(2):235-7

Díaz GA, Zoffoli JP, Lolas M, Blanco A, Latorre BA, Ferrada EE, Elfar K, Naranjo P (2015) Occurrence of Phacidiopycnis washingtonensis Causing Speck Rot on Stored Pink Lady Apple Fruit in Chile. Plant Disease 100(1):211

Dib-Bellahouel S, Fortas Z (2011) Antibacterial activity of various fractions of ethyl acetate extract from the desert truffle, Tirmania pinoyi, preliminarily analyzed by gas chromatography-mass spectrometry (GC-MS). African Journal of Biotechnology 10(47):9694-9

Diederich P, Braun U, Heuchert, B, Ertz D (2010a) Four new lichen-associated Trimmatostroma species (hyphomycetes). Bulletin de la Société des naturalistes luxembourgeois 111:47-55

Diederich P, Ertz D, Eichler M, Cezanne R, van den Boom P, Fischer E, Killmann D, Van den Broeck D, Sérusiaux E (2012a) New or interesting lichens and lichenicolous fungi from Belgium, Luxembourg and northern France. XIV. Bulletin de la Société des naturalistes luxembourgeois 113:95-115

Diederich P, Ertz D, Eichler M, Cezanne R, van den Boom P, Van den Broeck D, Sérusiaux E (2014) New or interesting lichens and lichenicolous fungi from Belgium, Luxembourg and northern France. XV. Bull Soc Nat Luxemb115:157-65

Diederich P, Ertz D, Etayo J (2010b) An enlarged concept of Llimoniella (lichenicolous Helotiales), with a revised key to the species and notes on related genera. Lichenologist 42(3):253-269

Diederich P, Ertz D, Lawrey JD, Sikaroodi M, Untereiner WA (2013) Molecular data place the hyphomycetous lichenicolous genus Sclerococcum close to Dactylospora (Eurotiomycetes) and S. parmeliae in Cladophialophora (Chaetothyriales). Fungal Divers 58:61-72

Diederich P, Ertz D, Van den Broeck D, van den Boom P, Brand M, Sérusiaux E (2009) New or interesting lichens and lichenicolous fungi from Belgium, Luxembourg and northern France. XII. Bulletin de la Société des naturalistes luxembourgeois 110:7592

Diederich P, Lawrey JD, Sikaroodi M, van den Boom P, Ertz D (2012b) Briancoppinsia, a new coelomycetous genus of Arthoniaceae (Arthoniales) for the lichenicolous Phoma cytospora, with a key to this and similar taxa. Fungal Diversity 52(1):1-12 
Diederich P, Palice Z, Ertz D (2008) Cheiromycina ananas is a synonym of Dictyocatenulata $a l b a$, a widespread, lichenized, synnematous hyphomycete herewith reported as new for Europe. Sauteria 15:205-214

Diederich P, Schultz M (2009) Zwackhiomyces namibiensis, a new lichenicolous ascomycete (Xanthopyreniaceae) on Psorotichia from Namibia. Herzogia 22:73-176

Diederich PA (2013) Redescription of Sporodochiolichen flavus (lichenized sporodochial Ascomycetes). Bull. Soc. Nat. luxemb114:55

Diene O, Wang W, Narisawa K (2013) Pseudosigmoidea ibarakiensis sp. nov., a dark septate endophytic fungus from a cedar forest in Ibaraki, Japan. Microbes and Environments. 28(3):381-387

Dietrich M, Buergi-Meyer K (2010) Interesting saxicolous lichens at Tossen near Schimbrigbad in the UNESCO Biosphere Entlebuch (Canton of Lucerne, Central Switzerland). Herzogia 23:75-84

Dillman KL, Ahti T, Björk CR, Clerc P, Ekman S, Goward T, Hafellner J, Pérez-Ortega S, Printzen C, SaviĆ S, Schultz M (2014) New records, range extensions and nomenclatural innovations for lichens and lichenicolous fungi from Alaska, USA.

Din LB, Zakaria Z, Samsudin MW, Elix JA (2010) Chemical profile of compounds from lichens of Bukit Larut, Peninsular Malaysia. Sains Malaysiana 39(6):901-908

Ding T, Jiang T, Zhou J, Xu L, Gao ZM (2010) Evaluation of antimicrobial activity of endophytic fungi from Camptotheca acuminata (Nyssaceae). Genetics and Molecular Research 9:2104-2112

Dissanayake AJ, Camporesi E, Hyde KD, Phillips AJL, Fu CY, Yan JY, Li XH (2016) Dothiorella species associated with woody hosts in Italy. Mycosphere 7:51-63

Dissanayake AJ, Jayawardena RS, Boonmee S, Thambugala KM, Tian Q, Mapook A, Senanayake IC, Yan JY, Liu M, Li XH, Chukeatirote E, Hyde KD (2014) The status of Myriangiaceae (Dothideomycetes). Phytotaxa 176:219-237

Dissanayake AJ, Phillips AJL, Li XH, Hyde KD (2016) Botryosphaeriaceae: Current status of genera and species. Mycosphere 7(7):1001-1073

Divakar PK, Crespo A, Núnez-Zapata, Flakus A, Sipman HJM, Elix JA, Lumbsch T (2013a) A molecular perspective on generic concepts in the Hypotrachyna clade (Parmeliaceae, Ascomycota). Phytotaxa 132(1):21-38

Divakar PK, Crespo A, Wedin M, Leavitt SD, Hawksworth DL, Myllys L, McCune B, Randlane T, Bjerke JW, Ohmura Y, Schmitt I, Boluda CG, Alors D, Roca-Valiente B, Del-Prado R, Ruibal C, Buaruang K, Núñez-Zapata J, Amo de Paz G, Rico VJ, Molina MC, Elix JA, Esslinger TL, Tronstad IKK, Lindgren H, Ertz D, Gueidan C, Saag L, Mark K, Singh G, Dal Grande F, Parnmen S, Beck A, Benatti MN, Blanchon D, Candan M, Clerc P, Goward T, Grube M, Hodkinson BP, Hur J-S, Kantvilas G, Kirika PM, Lendemer J, Mattsson J-E, Messuti MI, Miadlikowska J, Nelsen M, Ohlson JI, Pérez-Ortega S, Saag A, Sipman HJM, Sohrabi M, Thell A, Thor G, Truong C, Yahr R, Upreti DK, Cubas P, Lumbsch HT (2015) Evolution of complex symbiotic relationships in a morphologically derived family of lichen-forming fungi. New Phytologist 208:1217-1226

Divakar PK, Del-Prado R, Lumbsch HT, Wedin M, Esslinger TL, Leavitt SD, Crespo A (2012) Diversification of the newly recognized lichen-forming fungal lineage 
Montanelia (Parmeliaceae, Ascomycota) and its relation to key geological and climatic events. American Journal of Botany 99(12):2014-2026

Divakar PK, Kauff F, Crespo A, Leavitt SD, Lumbsch HT (2013b) Understanding phenotypical character evolution in parmelioid lichenized fungi (Parmeliaceae, Ascomycota). PLoS ONE 8(11):e83115

Divakar PK, Lumbsch HT, Ferencova Z, Del Prado R, Crespo A (2010) Remototrachyna, a newly recognized tropical lineage of lichens in the Hypotrachyna clade (Parmeliaceae, Ascomycota), originated in the Indian subcontinent. American Journal of Botany, 97(4):579-590

Dixon AP, Faber-Langendoen D, Josse C, Morrison J, Loucks CJ (2014) Distribution mapping of world grassland types. Journal of Biogeography 41(11):2003-2019

Döbbeler P (2010) New species and records of Bryocentria-a hypocrealean genus of bryophilous ascomycetes. Karstenia 50:11-23

Döbbeler P (2011) Two new hepaticolous species of the genus Octosporella (Pezizales). Herzogia 24(2):357-365

Döbbeler P (2012) Gynonectria intraspora gen. et sp. nov. (Hypocreales), a perianthicolous phyllosphere fungus with a novel ascospore type. Mycological Progress 11(2):473481

Doering J, Deduke C, Piercey-Normore MD (2016) Variation in lichen species assemblages and secondary metabolites surrounding Stereocaulon species in the boreal forest of Northwestern Manitoba. Evansia 33(2):70-82

Doherty TA, Khorram N, Chang JE, Kim HK, Rosenthal P, Croft M, Broide DH (2012) STAT6 regulates natural helper cell proliferation during lung inflammation initiated by Alternaria. American Journal of Physiology-Lung Cellular and Molecular Physiology 303(7):L577-L588

Doilom M, Dissanayake AJ, Wanasinghe AN, Boonmee S, Liu JK, Bhat J, Taylor JE, Bahkali AH, McKenzie, EHC, Hyde KD (2016) Microfungi on Tectona grandis (teak) in Northern Thailand. Fungal Divers DOI 10.1007/s13225-016-0368-7

Doilom M, Liu JK, Jaklitsch WM, Ariyawansa H, Wijayawardene NN, Chukeatirote E, Zhang M, McKenzie EHC, Geml J, Voglmayr H, Hyde KD (2013) An outline of the family Cucurbitariaceae. Sydowia 65:167-192

Dong L, Park JS, Woo JJ (2015) A-34: Contribution to the Lichen Flora of Vietnam, with Ten New Record Species. 균학회소식 27(2):62-62

Dong N, Liu X, Lu Y, Du L, Xu H, Liu H, Xin Z, Zhang Z (2010) Overexpression of TaPIEP1, a pathogen-induced ERF gene of wheat, confers host-enhanced resistance to fungal pathogen Bipolaris sorokiniana. Functional \& integrative genomics 10(2):215226

Dornelo-Silva D, Pereira-Carvalho RC, Dianese JC (2008) [2007] New Stenella and Parastenella species from the Brazilian cerrado. Mycologia 99(5):753-764

Dougoud R (2012) Aeruginoscyphus, un nouveau genre pour Peziza sericea (Helotiales, Hyaloscyphaceae). Ascomycete.org 4(1):1-4

Dougoud R (2015) Rutstroemia alnobetulae sp. nov. (Helotiales, Rutstroemiaceae), une espèce nouvelle des aulnes verts. Ascomycete.org 7(6):336-340 
Dougoud R, Van Vooren N, Vega M (2015) Cupulina montana (Pezizales, Pyronemataceae), un nouveau genre et une nouvelle espèce des montagnes d'Europe. Ascomycete 7:3944

Doveri F (2008) Pagine di micologia, Associazone Micologica Bresadola Centro Studi Micologici 65-66:110

Doveri F (2010) Une nouvelle variete de Tripterosporella sur crottin une occasion de recombiner le pyrenomycete cleistothecial Cercophora heterospora dans le genre Tripterosporella. Bull. Mycol. Bot. Dauphiné-Savoie 50:49-55

Doveri F (2012) Coprophilous discomycetes from the Tuscan archipelago (Italy). Description of two rare species and a new Trichobolus. Mycosphere 3(4):503-22

Doveri F, Pecchia S, Sarrocco S, Minnocci A, Vannacci G (2010) Rodentomyces, a new hypocrealean genus from Italy. Fungal Diversity 42:57-69

Doveri F, Sarrocco S (2013) Sporormiella octomegaspora, a new hairy species with eightcelled ascospores from Spain. Mycotaxon 123:129-140

Doveri F, Sarrocco S, Vannacci G (2013) Studies on three rare coprophilous plectomycetes from Italy. Mycotaxon 124(1):279-300

Doveri F. (2011) Addition to "Fungi Fimicoli Italici": An update on the occurrence of coprophilous Basidiomycetes and Ascomycetes in Italy with new records and descriptions. Mycosphere 2(4):331-427

Doveri F. (2014) An update on the genera Ascobolus and Saccobolus with keys and descriptions of three Coprophilous species, new to Italy. Mycosphere 5(1):86-135, Doi 10.5943/mycosphere/5/1/4

Doweld G (2013) Index Fungorum 31, 1 ,

Doyon JB, Sutton DA, Theodore P, Dhillon G, Jones KD, Thompson EH, Fu J, Wickes BL, Koehler JE, Schwartz BS (2013) Rasamsonia argillacea pulmonary and aortic graft infection in an immune-competent patient. Journal of clinical microbiology 51(2):719-722

Dreaden TJ, Davis JM, De Beer ZW, Ploetz RC, Soltis PS, Wingfield MJ, Smith JA (2014a) Phylogeny of ambrosia beetle symbionts in the genus Raffaelea. Fungal biology, 118(12):970-978

Dreaden TJ, Davis JM, Harmon CL, Ploetz RC, Palmateer AJ, Soltis PS, Smith JA (2014b) Development of multilocus PCR assays for Raffaelea lauricola, causal agent of laurel wilt disease. Plant Disease 98(3):379-383

D'Souza MA, Bhat DJ (2012) A new species of Pleurophragmium from India. Mycotaxon 119(1):477-482

Du YQ, Liu Y, Wang JH (2015) Polysaccharides from Umbilicaria esculenta cultivated in Huangshan Mountain and immunomodulatory activity. International journal of biological macromolecules 72:1272-1276

Duarte S, Batista D, Bärlocher F, Cássio F, Pascoal C (2015) Some new DNA barcodes of aquatic hyphomycete species. Mycoscience 56:102-108

Duarte S, Seena S, Barlocher F, Cassio F, Pascoal C (2012) Preliminary insights into the phylogeography of six aquatic hyphomycete species. PLoS ONE 7 (9):E45289 
Dubey R, Moonnambeth AM (2013) Custingophora ratnagiriensis sp.nov. - A novel species of Custingophora from Konkan, Maharashtra, India. NEBIO - An international Journal of Environment and Biodiversity 4(6):31-32

Dubey R, Moonnambeth AM (2014a) Sheathnema indicum gen. et sp. nov. a new sooty mold fungus from northern Western Ghats, India. Journal of Threatened Taxa. 6(12):65496555

Dubey R, Moonnambeth AM (2014b) Vermiculariopsiella papaye sp. nov.- A new species of Vermiculasporiella from Western Ghats, India. International Journal of Scientific Research 3(6):35-36

Dubey R, Neelima A (2014) Goosiomyces bambusicola - A new cheirosporous anamorphic species from Western Ghats, India. Current Research in Environmental \& Applied Mycology. 4(2):211-6

Dubey R, Pandey AK (2011) Bispora aeglei sp. nov. - a new follicolous hyphomycete from India. Journal of Mycopathological Research 49:357-359

Dubey R, Pandey AK (2012) Pseudoacrodictys steviae- a new generic and species record for India. J Mycol Pl Pathol 42 (2):251-253

Dubey R, Pandey AK, Manoharachary C (2011) Beltramono - a hitherto undescribed Hyphomycetes genus. J. Mycopathol. Res. 49(2):321-324

Dubey RK, Rai AN, Shrivastava S, Verma NK (2011) Two new records of hyphomycetes from India. Indian Phytopathology 64(4): 390-391

Dubey U, Upreti DK, Nayaka S (2010) A new species of Leiorreuma Eschw. from India. Lichenologist 42(6):711-713

Duong TA, de Beer ZW, Wingfield BD, Wingfield MJ (2012) Phylogeny and taxonomy of species in the Grosmannia serpens complex. Mycologia. 104(3):715-732

Dupont J, Magnin S, Rousseau F, Zbinden M, Frebourg G, Samadi S, Richer de Forges B, Jones EBG (2009) Molecular and ultrastructural characterization of two ascomycetes found on sunken wood off Vanuatu Islands in the deep Pacific Ocean. Mycol Res 112:1351-1364

Durkin SR, Henderson T, Raju R, Ellis D (2008) Successful treatment of phaeohyphomycotic keratitis caused by Bipolaris australiensis. Clinical \& experimental ophthalmology 36(7):697-699

Dyer, ZA, Wright RS, Rong IH, Jacobs A (2008) Back pain associated with endobronchial mucus impaction due to Bipolaris australiensis colonization representing atypical allergic bronchopulmonary mycosis. Medical mycology 46(6):589-594

Dymytrova L, Nadyeina O, Naumovych A, Keller C, Scheidegger C (2013) Primeval beech forests of Ukrainian Carpathians are sanctuaries for rare and endangered epiphytic lichens. Herzogia 26(1):73-89

Dymytrova LV, Breuss O, Kondratyuk SY. (2011) Agonimia borysthenica, a new lichen species (Verrucariales) from Ukraine. Österreichische Zeitschrift für Pilzkunde 20:25-8.

Ebead GA, Overy DP, Berrué F, Kerr RG (2012) Westerdykella reniformis sp. nov., producing the antibiotic metabolites melinacidin IV and chetracin B. IMA fungus 3(2):189-201 
Edathodu J, Al-Abdely HM, AlThawadi S, Wickes BL, Thompson EH, Wiederhold NP, Madrid H, Guarro J, Sutton DA (2013) Invasive fungal infection due to Triadelphia pulvinata in a patient with acute myeloid leukemia. Journal of clinical microbiology 51(10):3426-9

Egan RS (2009) Recent literature on lichens-212. The Bryologist 112(1):239-256

Eghrari AO, Gibas C, Watkins T, Vahedi S, Lee R, Houle E, Suarez MJ, Eberhart C, Sutton DA, Wiederhold NP, Sikder S, Zhang SX (2015) First Human Case of Fungal Keratitis Caused by a Putatively Novel Species of Lophotrichus. Journal of Clinical Microbiology 53 (9):3063-3067

Eghtedari M (2015) Asyptomatic fungal cyst of conjunctiva caused by Bipolaris spicifera. Iranian Journal of Medical Sciences 31(1):56-58

Egidi E, De Hoog GS, Isola D, Onofri S, Quaedvlieg W, De Vries M, Verkley GJ, Stielow JB, Zucconi L, Selbmann L (2014). Phylogeny and taxonomy of meristematic rockinhabiting black fungi in the Dothideomycetes based on multi-locus phylogenies. Fungal Diversity 65:127-165

Eichler M, Cezanne R, Diederich P, Ertz D, Van den Broeck D, van den Boom P, Sérusiaux E (2010) New or interesting lichens and lichenicolous fungi from Belgium, Luxembourg and northern France. XIII. Bulletin de la Société des naturalistes luxembourgeois 111:33-46

Eisa M, Chand R, Joshi AK (2013) Biochemical and histochemical traits: a promising way to screen resistance against spot blotch (Bipolaris sorokiniana) of wheat. European journal of plant pathology 137(4):805-820

Ekanayaka AH, Zhao Q, Jones GE, Pu ED, Hyde KD (2016) Two novel Acervus species extend their distribution within Yunnan, China. Phytotaxa 283(1):74-82

Ekman S, Andersen HL, Wedin M (2008) The limitations of ancestral state reconstruction and the evolution of the ascus in the Lecanorales (lichenized Ascomycota). Syst Biol 57:141-156

Ekman S, Svensson M (2014) Brianaria (Psoraceae), a new genus to accommodate the Micarea sylvicola group. The Lichenologist 46:285-294

Ekman S, Wedin M, Lindblom L, Jørgensen PM (2014) Extended phylogeny and a revised generic classification of the Pannariaceae (Peltigerales, Ascomycota). Lichenologist 46:627-656

El Mhadri M, Benkirane R, Touhami AO, Douira A (2009) Citrullus lanatus, a new host of Bipolaris spicifera in Morocco. Phytopathologia mediterranea 48(2):291-293

Elix JA (2009a) New saxicolous species and new records of Buellia sens. lat. and Rinodinella (Ascomycota, Physciaceae) in Australia. Australasian Lichenology 65:10-19

Elix JA (2012) Four new species and a new record of Tephromela (lichenized Ascomycota) from Australia. Australas Lichenol 71:3-11

Elix JA (2013) New crustose lichen taxa (lichenized Ascomycota) from Australia. Australasian Lichenology 73:45-54

Elix JA, Kantvilas G (2009) Further new species of Xanthoparmelia (Parmeliaceae, Ascomycota) from Tasmania. Bibliotheca Lichenologica 99:123-132

Elix JA, Kantvilas G (2013) New taxa and new records of Amandinea (Physciaceae, Ascomycota) in Australia. Australasian Lichenology 72:3-19 
Elix JA, Kantvilas G (2014) New species and new records of the lichen genus Baculifera (Physciaceae, Ascomycota) in Australia. Australasian Lichenology 75:28-37

Elix JA, Kantvilas G (2015) New taxa and new records of crustose lichens in the familiy Physciaceae (Ascomycota) in Australia. Australian Lichenology 76:16-23

Elix JA, Kondratyuk SY (2008) Two new species of Letrouitia (Letrouitiaceae, Ascomycota) from Australia. Australas. Lichenol 62:16-19

Elix JA, Mayrhofer H (2016) Two new species of Buellia sens. lat. (Ascomycota, Physciaceae) from New Zealand with 1-septate ascospores. Australasian Lichenology 79:10-15

Elliott ML, Des Jardin EA (2014) Serenomyces associated with palms in southeastern USA: isolation, culture storage and genetic variation. Mycologia 106(4):698-707

Elliott TF, Bougher NL, O’Donnell K, Trappe JM (2014) Morchella australiana sp. nov., an apparent Australian endemic from New South Wales and Victoria. Mycologia 106(1):113-8

El-Said AH, Sohair TH, El-Hadi AG (2010) Studies on the mycoflora associated with sugarcane factory waste and pollution of River Nile in upper Egypt. Journal of Yeast and Fungal Research 1(10):188-196

Elvebakk A (2012) Pannaria howeana and Pannaria streimannii, two related new lichen species endemic to Lord Howe Island, Australia. The Lichenologist 44(04):457-63

Elvebakk A, Robertsen EH, Park CH, Hong SG (2010) Psorophorus and Xanthopsoroma, two new genera for yellow-green, corticolous and squamulose lichen species, previously in Psoroma. Lichenologist (Lond.) 42(5):563-585

Endoh R, Suzuki M, Benno Y (2008) Ambrosiozyma kamigamensis sp. nov. and A. neoplatypodis sp. nov., two new ascomycetous yeasts from ambrosia beetle galleries. Antonie van Leeuwenhoek 94(3):365-76

Enghoff H, Santamaría S (2015) Infectious intimacy and contaminated caves-three new species of ectoparasitic fungi (Ascomycota: Laboulbeniales) from blaniulid millipedes (Diplopoda: Julida) and inferences about their transmittal mechanisms. Org Divers Evol 15:249-263

Ertz D, Aptroot A, Van de Vijver B, Sliwa L, Moermans C, Øvstedal D (2014a) Lichens from the Utsteinen Nunatak (Sør Rondane Mountains, Antarctica), with the description of one new species and the establishment of permanent plots. Phytotaxa 191(1):99-114

Ertz D, Bungartz F, Diederich P, Tibell L (2011) Molecular and morphological data place Blarneya in Tylophoron (Arthoniaceae). Lichenologist 43:345-356

Ertz D, Diederich P (2015) Dismantling Melaspileaceae: a first phylogenetic study of Buelliella, Hemigrapha, Karschia, Labrocarpon and Melaspilea. Fungal Divers 71:41-164

Ertz D, Diederich P, Brand AM, van den Boom P, Sérusiaux E (2008) New or interesting lichens and lichenicolous fungi from Belgium, Luxembourg and northern France. XI. Bulletin de la Société des naturalistes luxembourgeois 109:35-51

Ertz D, Diederich P, Lawrey JD, Berger F, Freebury CE, Coppins BJ, Gardiennet A, Hafellner J (2015a) Phylogenetic insights resolve Dacampiaceae (Pleosporales) as polyphyetic: Didymocyrtis (Pleosporales, Phaeosphaeriaceae) with Phoma-like 
anamorphs resurrected and segregated form Polycoccum (Trypetheliales, Polycoccaceae fam. nov.). Fungal Diversity 74:53-89

Ertz D, Fischer E, Killmann D, Razafindrahaja T, Sérusiaux E (2013) Savoronala, a new genus of Malmideaceae (Lecanorales) from Madagascar with stipes producing sporodochia. Mycological progress 12(4):645-56

Ertz D, Flakus A, Oset M, Sipman HJ, Kukwa M (2015b) A first assessment of lichenized Arthoniales in Bolivia with descriptions of two new species. Phytotaxa 217(1):1-25

Ertz D, Heuchert B, Braun U, Freebury CE, Common RS, Diederich P (2016) Contribution to the phylogeny and taxonomy of the genus Taeniolella, with a focus on lichenicolous taxa. Fungal Biology 120(11):1416-47

Ertz D, Killmann D, Razafindrahaja T, Sérusiaux E, Fischer E (2010) Two new species of Syncesia (Arthoniales, Roccellaceae) from Africa. The Lichenologist 42(01):43-49

Ertz D, Lawrey JD, Common RS, Diederich P (2014b) Molecular data resolve a new order of Arthoniomycetes sister to the primarily lichenized Arthoniales and composed of black yeasts, lichenicolous and rock-inhabiting species. Fungal Diversity 66:113-137

Ertz D, Miadlikowska J, Lutzoni F, Dessein S, Raspé O, Vigneron N, Hofstetter V, Diederich P (2009) Towards a new classification of the Arthoniales (Ascomycota) based on a three-gene phylogeny focussing on the genus Opegrapha. Mycological Research 113:141-152

Ertz D, Tehler A (2011) The phylogeny of Arthoniales (Pezizomycotina) inferred from nucLSU and RPB2 sequences. Fungal Diversity 49:47-71

Ertz D, Tehler A, Fischer E, Killmann D, Razafindrahaja T, Sérusiaux E (2014c) Isalonactis, a new genus of Roccellaceae (Arthoniales), from southern Madagascar. The Lichenologist 46(02):159-167

Ertz D, Tehler A, Irestedt M, Frisch A, Thor G, Van den Boom P (2015c) A large-scale phylogenetic revision of Roccellaceae (Arthoniales) reveales eight new genera. Fungal Divers 70:31-53

Escuredo O, Seijo MC, Fernández-González M, Iglesias I (2011) Effects of meteorological factors on the levels of Alternaria spores on a potato crop. International Journal of Biometeorology 55(2):243-252

Esslinger TL, Dillman KL (2010) Physconia grumosa in North America. The Bryologist 113(1):77-80

Esslinger TL, Morse CA, Leavitt SD (2012) A new North American species of Hyperphyscia (Physciaceae). The Bryologist 115(1):31-41

Etayo J (2010a) Hongos liquenícolas de Perú. Homenaje a Rolf Santesson. Bulletin de la Société linnéenne de Provence 61:83-128

Etayo J (2010b) Euskal Herriko Unibertsitatea/Universidad del Pais Vasco.Guineana 16:501

Etayo J (2010c) Lichenicolous fungi from the western Pyrenees. V. Three new ascomycetes. Opuscula Philolichenum 8:131-139

Etayo J (2011) Lichenochora hyperphysciae, a new lichenicolous fungus found in Mexico and Spain. Biblthca Lichenol 106:54

Etayo J, Berger Fr (2013) Isthmoconidium bacidiicola, a new genus and species of lichenicolous hyphomycetes on Bacidia from Bermuda. Opuscula Philolichenum $13: 1-5$ 
Etayo J, Flakus A, Kukwa M (2013) Niesslia echinoides (Niessliaceae, Ascomycota), a new lichenicolous fungus on Erioderma from Bolivia. The Lichenologist 45(01):21-24

Etayo J, Flakus A, Kukwa M, Rodriguez Flakus P (2013) Lichenochora tertia (Phyllachorales): the third species of the genus growing on Xanthoria elegans. Mycotaxon 123:9-13

Etayo J, Flakus A, Suija A, Kukwa M (2015) Macroskyttea parmotrematis gen. et sp. nov. (Helotiales, Leotiomycetes, Ascomycota), a new lichenicolous fungus from Bolivia. Phytotaxa 224 (3): 247-257

Etayo J, Navarro-Rosines P (2008) [A combination and three new species of Lichenochora (Phyllachorales, lichenicolous Ascomycota), and additional reports for the genus]. Revta Catal. Micol 30:27-44

Etayo J, Sancho LG (2008) Hongos liquenícolas del sur de Sudamérica, especialmente de Isla Navarino (Chile). Bibliotheca Lichenologica 98:1-302

Etayo J, Sharuddin SS (2011) Verruculina and Licheno verruculina nom. nov. Herzogia 24:379-380

Etayo J, Triebel D (2010) New and interesting lichenicolous fungi at the Botanische Staatssammlung München. The Lichenologist 42(03):231-240

Etayo J, Yazici K (2009) Microsphaeropsis caloplacae sp. nov. on Caloplaca persica in Turkey. Mycotaxon 107:297-302

Etayo JA, Berger FR (2009) Carnegieispora rimeliae, a new genus of lichenicolous fungus from the Azores. Opuscula Philolichenum 7:17-20

Etayo JA, van den Boom PI (2013) A first checklist of lichenicolous fungi from the Dominican Republic, including the description of a new species of Xenonectriella. Opuscula Philolichenum 12:142-50

Evans HC, Elliot S, Hughes DP (2011) Hidden diversity behind the zombie-ant fungus Ophiocordyceps unilateralis: four new species described from carpenter ants in Minas Gerais, Brazil. PLoS ONE 6(3): e17024

Evans HC, Johnston PR, Park D, Barreto RW, Soares DR (2010) Claviradulomyces, a new genus of Odontotremataceae from West African rainforest. Fungal Biol 114:41-48

Evidente A, Punzo B, Andolfi A, Berestetskiy A, Motta, A (2009) Alternethanoxins A and B, polycyclic ethanones produced by Alternaria sonchi, potential mycoherbicides for Sonchus arvensis biocontrol. Journal of agricultural and food chemistry 57(15):66566660

Fahala AH, Rahmana IA, El-Hassana AM, Abdel ME, Rahmana EL, Zijlstra EE (2010) The safety and efficacy of itraconazole for the treatment of patients with eumycetoma due to Madurella mycetomatis. Transactions Royal Soc Tropical Med \& Hyg 105(3):127132

Falbo MK, Soccol VT, Sandini IE, Vicente VA, Robl D, Socco CR, (2013) Isolation and characterization of the nematophagous fungus Arthrobotrys conoides. Parasitology research 112(1):177-185

Fan L, Cao JZ, Hou CL (2013) Tuber subglobosum and T. wenchuanense-two new species with spino-reticulate ascospores. Mycotaxon 123(1):95-101

Fan L, Hou C, Cannon PF, Li Y (2012a) A new species of Melanospora on truffles from China. Mycologia 104:1433-1442 
Fan L, Lin YR, Wang S, Hou CL (2012b) Two species of Lirula on Abies from Yunnan, southwest China. Mycological Progress 11(1):279-286

Fan X, Du Z, Liang Y, Tian C (2016) Melanconis (Melanconidaceae) associated with Betula spp. in China. Mycol. Prog 15:40

Fan X, Hyde KD, Liu M, Liang Y, Tian C. (2015) Cytospora species associated with walnut canker disease in China, with description of a new species $C$. gigalocus. Fungal biology 119(5):310-9

Fan XL, Liang YM, Ma R, Tian CM. (2014) Morphological and phylogenetic studies of Cytospora (Valsaceae, Diaporthales) isolates from Chinese scholar tree, with description of a new species. Mycoscience 55(4):252-9

Fangyan Z, Danyang Q, Changsheng L (2013) Studies on control effects of different density of 5 fungicides against Agaricodochium camellia. Guangdong Forestry Science and Technology 2:005

Farkas E (2010) Notes and schedae to Lichenes delicati exsiccati editae in memoriam Antonin Vezda (1920-2008), fasc. 1. Acta bot. hung. 52(3-4): 331-340

Farkas E (2014) Bibliography of foliicolous lichenized fungi, 1952-2013. Acta Botanica Hungarica 56(1-2):33-68

Farkas E (2015) Names of Bacidia s. 1. in current use for foliicolous lichens-an annotated nomenclatural study. Acta Botanica Hungarica 57(1-2):51-70

Farkas E, Flakus A (2015) Rare or Overlooked? - Two Species of Lyromma (Lyrommataceae, Lichenized Ascomycota) are New for Africa. Herzogia 28(1):204-211

Farkas E, Flakus A (2016) Trichonectria calopadiicola sp. nov. (Hypocreales, Ascomycota): the second species of the family Bionectriaceae parasitic on foliicolous lichens discovered in Tanzania. Phytotaxa 278(3):281-6

Farkas E, Veres K, Czúcz B (2011) Statistical analysis of substrate investigations of terricolous Toninia species in Hungary. Acta Botanica Hungarica 53(3-4):313-320

Fatima F, Bajpai P, Pathak N, Singh S, Priya S, Verma SR (2015) Antimicrobial and immunomodulatory efficacy of extracellularly synthesized silver and gold nanoparticles by a novel phosphate solubilizing fungus Bipolaris tetramera. BMC microbiology 15(1):1

Favero-Longo SE, Matteucci E, Morando M, Rolfo F, Harris TB, Piervittori R (2015) Metals and secondary metabolites in saxicolous lichen communities on ultramafic and nonultramafic rocks of the western Italian Alps. Australian Journal of Botany 63(4):276291

Favero-Longo SE, Piervittori R (2012) Cultivation of isidia and transplantation of adult thalli of Xanthoparmelia tinctina in an abandoned asbestos mine. The Lichenologist, 44(06):840-844

Fawzi EM, Khalil AA, Afifi AF (2009) Antifungal effect of some plant extracts on Alternaria alternata and Fusarium oxysporum. African Journal of Biotechnology 8(11)

Fedorenko N, Stenroos S, Thell A, Kärnefelt I, Kondratyuk S (2009) A phylogenetic analysis of xanthorioid lichens (Teloschistaceae, Ascomycota) based on ITS and mtSSU sequences. Bibliotheca Lichenologica. Diversity of Lichenology-Anniversary 100:49_ 84 
Fedorenko NM, Stenroos S, Thell A, Kärnefelt I, Elix JA, Hur JS, Kondratuyk SY (2012) Molecular phylogeny of xanthorioid lichens (Teloschistaceae, Ascomycota), with notes on their morphology. Systematics, biodiversity and ecology of lichens. Bibliotheca Lichenologica 108:45-64

Fedosova AG, Kovalenko AE (2015) Studies on the Geoglossoid fungi of Russia: the genus Leucoglossum. Mycol. Prog 14:26

Felle HH, Herrmann A, Schäfer P, Hückelhoven R, Kogel KH (2008) Interactive signal transfer between host and pathogen during successful infection of barley leaves by Blumeria graminis and Bipolaris sorokiniana. Journal of plant physiology 165(1):5259

Feng P, Lu Q, Najafzadeh MJ, van den Ende AG, Sun J, Li R, Xi L, Vicente VA, Lai W, Lu C, De Hoog GS (2014) Cyphellophora and its relatives in Phialophora: biodiversity and possible role in human infection. Fungal Diversity 65(1):17-45

Feng P-Y, de Hoog GS, Najafzadeh MJ, Gerrits van den Ende AHG, Stielow JB, Badali H, Boeger WA, Vicente VA (2013) Cladophialophora abundans, a novel species of Chaetothyriales isolated from the natural environment. Mycological Progress 13:381391

Ferencova Z, Cubas P, Divakar PK, Molina MC, Crespo A (2014) Notoparmelia, a new genus of Parmeliaceae (Ascomycota) based on overlooked reproductive anatomical features, phylogeny and distribution pattern. Lichenologist 46(1):51-67

Fermández-Brime S, Llimona X, Lutzoni F, Gaya E (2013) Phylogenetic study of Diploschistes (lichen-forming Ascomycota: Ostropales: Graphidaceae), based on morphological, chemical, and molecular data. Taxon 62(2):267-280

Fernandes MDRV, Pfenning LH, Costa-Neto CMD, Heinrich TA, Alencar SMD, Lima MAD, Ikegaki M (2009) Biological activities of the fermentation extract of the endophytic fungus Alternaria alternata isolated from Coffea arabica L. Brazilian Journal of Pharmaceutical Sciences 45(4):677-685

Fernandez-Brime S, Llimona X, Molnar K, Stenroos S, Hognabba F, Bjork C, Lutzoni FM, Gaya E (2011) Expansion of the Stictidaceae by the addition of the saxicolous lichenforming genus Ingvariella. Mycologia 103(4):755-63. doi: 10.3852/10-287

Fernández-Brime S, Llimona X, Navarro-Rosinés P (2010) Lichenostigma rupicolae (Lichenotheliaceae), a new lichenicolous species growing on Pertusaria rupicola. Lichenologist 42(3):242-247

Ferrer A, Miller AN, Sarmiento C, Shearer CA (2012) Three new genera representing novel lineages of Sordariomycetidae (Sordariomycetes, Ascomycota) from tropical freshwater habitats in Costa Rican. Mycologia 104 (4):865-879. doi:10.3852/11-111

Ferrer A, Miller AN, Shearer CA (2011) Minutisphaera and Natipusilla: two new genera of freshwater Dothideomycetes. Mycologia 103(2):411-423. doi:10.3852/10-177

Ferrer A, Raja HA, Shearer CA (2008) Lucidascocarpa pulchella, a new ascomycete genus and species from freshwater habitats in the American tropics. Mycologia 100 (4):642646. doi:Doi 10.3852/07-152r2

Feuerstein SH, Cunha-Dias IPR, Aptroot A, Eliasaro S, Cáceres MES (2014) Three new Diorygma (Graphidaceae) species from Brazil, with a revised world key. Lichenologist 46:753-761 
Filippova NV (2012) Discomycetes from plant, leave and sphagnum litter in ombrotrophic bog (West Siberia). Environmental dynamics and global climate change 3(1):5

Fiorentino J (2015) Clarification regarding old records of Roccella in the Maltese Islands. Mycosphere 6(6):673-680

Fischer M, Schneider P, Kraus C, Molnar M, Dubois C, d'Aguiar D, Haag N (2017) Grapevine trunk disease in German viticulture: occurrence of lesser known fungi and first report of Phaeoacremonium viticola and P. fraxinopennsylvanicum. VITISJournal of Grapevine Research 55(4):145-56

Fiuza PO, Gusmão LFP (2013) Ingoldian fungi from the semi-arid Caatinga biome of Brazil. Mycosphere 4:1133-1150

Fiuza PO, Gusmão LFP, Castañeda-Ruiz RF (2015a) Conidial fungi from the semiarid Caatinga biome of Brazil: a new species of Selenosporella from submerged leaves. Mycotaxon 130:601-605

Fiuza PO, Gusmão LFP, Castañeda-Ruiz RF (2015b) Synchaetomella aquatica sp. nov. from submerged leaves from Brazil. Mycotaxon 130(4):1135-1139. doi: 10.5248/130.1135

Fiuza PO, Monteiro JS, Gusmão LFP, Castañeda-Ruiz RF (2016) Mirandina uncinata sp. nov. from submerged leaves from Brazil. Mycotaxon 131:141-144

Fiuza PO, Ottoni-Boldrini BMP, Monteiro JS, Catena NR, Hamada N, Gusmão LFP (2015c) First records of Ingoldian fungi from the Brazilian Amazon. Brazilian Journal of Botany 38(3):615-621. doi: 10.1007/s40415-015-0157-7

Flakus A, Elix JA, Rodriguez P, Kukwa M (2011) New species and records of Lepraria (Stereocaulaceae, lichenized Ascomycota) from South America. Lichenologist 43:5766

Flakus A, Etayo J, Kukwa M (2014) Melaspilea tucumana, a new gall-forming lichenicolous fungus from the tropical Andes in Bolivia. The Lichenologist 46:657-662

Flakus A, Farkas, E (2013) A contribution to the taxonomy of Lyromma (Lyrommataceae, lichenized Ascomycota) with a species key. Mycotaxon 124:127-141

Flakus A, Kukwa M (2011) Lepraria maderensis Kukwa \& Flakus, a new lichen species containing gyrophoric and lecanoric acids. Nova Hedwigia 92:95-99

Flakus A, Kukwa M (2014) The first squamulose Thelecarpon species (Thelocarpaceae, Ascomycota) discovered in the biological soil crusts in the Bolivian Andes. Phytotaxa 175(5):281-286

Flakus A, Lücking R (2008) New species and additional records of foliicolous lichenized fungi from Bolivia. Lichenologist 40(5):423-436

Flakus A, Rodriguez Saavedra, P, Kukwa M (2012) A new species and new combinations and records of Hypotrachyna and Remototrachyna from Bolivia. Mycotaxon 119(1):157-166

Flakus A, Sipman HJ, Bach K, Flakus PR, Knudsen K, Ahti T, Schiefelbein U, Palice Z, Meneses Q, Rosa I, Jabłońska A (2013) Contribution to the knowledge of the lichen biota of Bolivia. 5. Polish Botanical Journal 58(2):697-733

Flakus A, Sipman HJ, Rodriguez Flakus P, Jabłońska A, Oset M, Kukwa M, Meneses Q, Rosa I (2015) Contribution to the knowledge of the lichen biota of Bolivia. 7. Polish Botanical Journal 60(1):81-98 
Flakus AD, Kukwa MA (2012) New records of lichenicolous fungi from Bolivia. Opuscula Philolichenum 11:36-48

Fleck SC, Burkhardt B, Pfeiffer E, Metzler M (2012) Alternaria toxins: altertoxin II is a much stronger mutagen and DNA strand breaking mycotoxin than alternariol and its methyl ether in cultured mammalian cells. Toxicology letters 214(1):27-32

Flores-Rentería L, Lau MK, Lamit LJ, Gehring CA (2014) An elusive ectomycorrhizal fungus reveals itself: a new species of Geopora (Pyronemataceae) associated with Pinus edulis. Mycologia 106(3):553-63

Flors V, Ton J, Van Doorn R, Jakab G, García-Agustín P, Mauch-Mani B (2008) Interplay between JA, SA and ABA signalling during basal and induced resistance against Pseudomonas syringae and Alternaria brassicicola. The Plant Journal 54(1):81-92

Fotouhifar KB, Hedjaroude GA, Leuchtmann A (2010) ITS rDNA phylogeny of Iranian strains of Cytospora and associated teleomorphs. Mycologia102:1369-1382

Fournier J, Flessa F, Peršoh D, Stadler M (2011) Three new Xylaria species from southwestern Europe. Mycological Progress 10(1):33-52

Fournier J, Lechat C (2011) Eutypella phaeospora, a new species on Chenopodiaceae. Mycotaxon 118:441-446

Fournier J, Raja HA, Shearer CA (2015) Freshwater Ascomycetes: Jahnula purpurea (Jahnulales, Dothideomycetes), a new species on submerged wood from Martinique Island, Lesser Antilles. MycoKeys. doi:10.3897/mycokeys.9.4440

Fournier J, Stadler M, Hyde KD, Duong ML (2010) The new genus Rostrohypoxylon and two new Annulohypoxylon species from Northern Thailand. Fungal Diversity 40(1):2336

Frank J, Crous PW, Groenewald JZ, Oertel B, Hyde KD, Phengsintham P, Schroers HJ (2010) Microcyclospora and Microcyclosporella: novel genera accommodating epiphytic fungi causing sooty blotch on apple. Persoonia 24:93-105

Frank JL, Southworth D, Reha C (2011) From mycorrhiza to fruiting body: a new species of Geopora on Cercocarpus ledifolius (Rosaceae). Mycologia. 103(6):1194-1200

Freire ES, Campos VP, Pinho RSC, Oliveira DF, Faria MR, Pohlit AM, Noberto NP, Rezende EL, Pfenning LH, Silva JRC (2012) Volatile substances produced by Fusarium oxysporum from coffee rhizosphere and other microbes affect Meloidogyne incognita and Arthrobotrys conoides. Journal of nematology 44(4):321

Freitas LF, Barriga EJ, Barahona PP, Lachance MA, Rosa CA (2013) Kodamaea transpacifica fa, sp. nov., a yeast species isolated from ephemeral flowers and insects in the Galápagos Islands and Malaysia: further evidence for ancient human transpacific contacts. International journal of systematic and evolutionary microbiology 63(11):4324-9

Friebes G (2012) A key to the non-lichenicolous species of the genus Capronia (Herpotrichiellaceae). Ascomycete.org 4(3):55-64

Friebes G, Wendelin I (2014) Über einige seltene und interessante Ascomyceten-Funde vom Reinerkogel (Graz, Steiermark. Österreich). Joannea Botanik 11:5-33

Frisch A, Thor G (2010) Crypthonia, a new genus of byssoid Arthoniaceae (lichenised Ascomycota). Mycological Progress 9(2):281-303 
Frisch A, Thor G, Ertz D, Grube M (2014) The Arthonialean challenge: restructuring Arthoniaceae. Taxon 63:727-744

Frisvad JC, Yilmaz N, Thrane U, Rasmussen KB, Samson RA (2013) Talaromyces atroroseus, a new species efficiently producing industrially relevant red pigments PLoS ONE 8:e84102

Fritis MC, Lagos CR, Sobarzo NQ, Venegas IM, Sánchez CS, Altamirano HC, Catalán LE, Palma WQ (2013) Depsides and triterpenes in Pseudocyphellaria coriifolia (lichens) and biological activity against Trypanosoma cruzi. Natural product research 27(17):1607-1610

Fryday AM (2010) A brief lichen foray in the Mount Washington alpine zone-including Claurouxia chalybeioides, Porina norrlinii and Stereocaulon leucophaeopsis new to North America. Opuscula Philolichenum 8:1-10

Fryday AM (2011) New species and combinations in Calvitimela and Tephromela from the southern subpolar region. The Lichenologist 43(3):225

Fryday AM, Hertel HA (2014) contribution to the family Lecideaceae s. lat. (Lecanoromycetidae inc. sed., lichenized Ascomycota) in the southern subpolar region; including eight new species and some revised generic circumscriptions. The Lichenologist 46(03):389-412

Fryday AM, Printzen C, Ekman S (2014) Bryobilimbia, a new generic name for Lecidea hypnorum and closely related species. Lichenologist 46:25-37

Fryday AM, Tønsberg T (2015) Ameliella-A Bryicolous Lichen Genus Rediscovered in North America after 50 Years. Evansia 32(4):171-5

Fu CH, Hsieh HM, Chen CY, Chang TT, Huang YM, Ju YM (2013) Ophiodiaporthe cyatheae gen. et sp. nov., a diaporthalean pathogen causing a devastating wilt disease of Cyathea lepifera in Taiwan. Mycologia. 105(4):861-72

Fuiano N, Fusilli S, Incorvaia C (2012) A role for measurement of nasal IgE antibodies in diagnosis of Alternaria-induced rhinitis in children. Allergologia et immunopathologia 40(2):71-74

Funck JA, Bec A, Perrière F, Felten V, Danger M (2015) Aquatic hyphomycetes: a potential source of polyunsaturated fatty acids in detritus-based stream food webs. Fungal Ecology 13:205-10

Gagunashvili AN, Davíðsson SP, Jónsson ZO, Andrésson ÓS (2009) Cloning and heterologous transcription of a polyketide synthase gene from the lichen Solorina crocea. Mycological research 113(3):354-363

Gaitnieks T, Klavina D, Muiznieks I, Pennanen T, Velmala S, Vasaitis R, Menkis A (2016) Impact of Heterobasidion root-rot on fine root morphology and associated fungi in Picea abies stands on peat soils. Mycorrhiza 26(5):465-473

Galán R, Checa J, Blanco MN, Platas G, Tena R, Tello S, Hermosilla CE, Jaklitsch WM, Voglmayr H (2015) Taxonomic position of the genus Bicornispora and the appearance of a new species Bicornispora seditiosa. Mycologia 107:793-807

Galloway DJ (2010) Additions to the Placopsis mycobiota (Trapeliaceae, Ascomycota) of southern South America, with notes on new records (including Aspiciliopsis macrophthalma), and a revised regional key to the species. The Lichenologist 42(06):727-737 
Galloway DJ (2013) The lichen genera Aspiciliopsis, and Placopsis (Trapeliales: Trapeliaceae: Ascomycota) in New Zealand. Phytotaxa 120(1):1-194

Galloway DJ, Elix JA (2013) Reinstatement of Crocodia Link (Lobariaceae: Ascomycota) for five species formerly included in Pseudocyphellaria Vain. Australasian Lichenology 72: 32-42

Gams W, Seifert KA, Morgan-Jones G (2009) New and validated hyphomycete taxa to resolve nomenclatural and taxonomic issues. Mycotaxon 110:89-108

Gao JM, Xia, JW, Ma Y, Li Z, Zhang XG (2015a) Blastophragma chongqingense sp. nov. and a new record of Bahusutrabeeja angularis from southern China. Mycotaxon 130(3):821-825

Gao L, Ma Y, Zhao W, Wei Z, Gleason ML, Chen H, Hao L, Sun G, Zhang R (2015b) Three new species of Cyphellophora (Chaetothyriales) associated with Sooty Blotch and Flyspeck. PloS one 10(9):e0136857

Gao SS, Li XM, Wang BG (2009) Perylene derivatives produced by Alternaria alternata, an endophytic fungus isolated from Laurencia species. Natural product communications, 4(11):1477-1480

Gao TL, Ren Q (2013) New records of Ochrolechia and Placopsis from the Hengduan Mountains, China. Mycotaxon 122(1):461-466

Garibaldi A, Bertetti D, Poli A, Gullino ML (2012) First Report of Leaf Spot of Garden Lupin (Lupinus polyphyllus) Caused by Pleiochaeta setosa in Italy. Plant Disease 96(6):909

Garrido-Benavent I, Pérez-Ortega S (2015) Unravelling the diversity of European Caliciopsis (Coryneliaceae, Ascomycota): Caliciopsis valentina sp. nov. and C. beckhausii comb. nov., with a worldwide key to Caliciopsis. Mycological Progress 14(3):1-1

Garrido-Benavent I, Søchting U, de los Ríos Murillo A, Pérez-Ortega S (2016) Shackletonia cryodesertorum (Teloschistaceae. Mycological Progress 15(7):743-754

Garzoli L, Gnavi G, Tamma F, Tosi S, Varese GC, Picco AM (2015) Sink or swim: Updated knowledge on marine fungi associated with wood substrates in the Mediterranean Sea and hints about their potential to remediate hydrocarbons. Progress in Oceanography 137:140-148

Gasparyan A, Sipman HJ (2013) New lichen records from Armenia. Mycotaxon 123:491492

Gasparyan A, Sipman HJ (2016) The Epiphytic Lichenized Fungi in Armenia: Diversity and Conservation. Phytotaxa 281(1):1-68

Gates G, Van Vooren N (2016) Jafnea pallida (Pezizales), a new name for a cup fungus rediscovered in Tasmania. Ascomycete. Org 8(3):101-104

Gautam AK, Avasthi S, Bhadauria R. (2015) A new species of Scytalidium from Himachal Pradesh, India. Journal on New Biological Reports 4(1):7-10

Gautam AK. Prillieuxina aeglicola sp. nov. (ascomycota), a new black mildew fungus from Himachal Pradesh, India. Current Research in Environmental \& Applied Mycology 5(1):70-3

Gaya E, Fernández-Brime S, Vargas R, Lachlan RF, Gueidan C, Ramírez-Mejía M, Lutzoni F (2015) The adaptive radiation of lichen-forming Teloschistaceae is associated with 
sunscreening pigments and a bark-to-rock substrate shift. Proceedings of the National Academy of Sciences 112(37):11600-5

Gaya E, Högnabba F, Holguin Á, Molnar K, Fernández-Brime S, et al (2012) Implementing a cumulative supermatrix approach for a comprehensive phylogenetic study of the Teloschistales (Pezizomycotina, Ascomycota). Molecular Phylogenetics and Evolution 63(2):374-87

Gaya E, Navarro-Rosinés P, Llimona X, Hladun N, Lutzoni F (2008) Phylogenetic reassessment of the Teloschistaceae (lichen-forming Ascomycota, Lecanoromycetes). Mycological Research 112(5):528-46

Gayatri Mambiar R, Raveendran K. Eco-biodiversity of marine mycoflora of gulf of mannar biosphere reserve (india). Ecol Environ Conserv 15(4):739-43

Gazis R, Kuo A, Riley R, LaButti K, Lipzen A, Lin J, Amirebrahimi M, Hesse CN, Spatafora JW, Henrissat B, Hainaut M (2016) The genome of Xylona heveae provides a window into fungal endophytism. Fungal biology 120(1):26-42

Gazis R, Miadlikowska J, Lutzoni F, Arnold AE, Chaverri P (2012) Culture-based study of endophytes associated with rubber trees in Peru reveals a new class of Pezizomycotina: Xylonomycetes. Molecular phylogenetics and evolution 65(1):294304

Ge YP, Lv GX, Shen YN, Li M, Deng SW, Hoog SD, Samerpitak K, Liu WD (2012) First report of subcutaneous phaeohyphomycosis caused by Ochroconis tshawytschae in an immunocompetent patient. Medical mycology 50(6):637-640

Ge ZW, Yang ZL, Pfister DH, Carbone M, Bau T, Smith ME (2014) Multigene molecular phylogeny and biogeographic diversification of the earth tongue fungi in the genera Cudonia and Spathularia (Rhytismatales, Ascomycota). PloS one 9(8):e103457

Gea FJ, Navarro MJ, Suz LM (2016) First report of Cladobotryum mycophilum causing cobweb on cultivated king oyster mushroom in Spain. Plant disease 100(11):2334

Geltner C, Sorschag S, Willinger B, Jaritz T, Saric Z, Lass-Flörl C (2015) Necrotizing mycosis due to Verruconis gallopava in an immunocompetent patient. Infection 43(6):743-6

Geng RM, Fu Y, Zhang WM, Zhang JP, Yu, LQ (2008) Efficacy and Safety of Bipolaris sorokiniana and Bipolaris coicis for the Control of Echinochloa crus-galli in Paddy Field [J]. Chinese Journal of Rice Science 3:015

Geng YH, Zhang TY (2014) Two new species of Humicola from soil. Mycotaxon 33:800805

Gerra-Inohosa L, Puspure I, Bambe B (2015) Epiphytic bryophyte and lichen species diversity on retained trees in young forest stands. Forest science 2015

Gessler NN, Egorova AS, Belozerskaya TA (2014) Melanin pigments of fungi under extreme environmental conditions (Review). Applied biochemistry and microbiology 50(2):105-113

Ghazvini H, Tekauz A (2008) Host-pathogen interactions among barley genotypes and Bipolaris sorokiniana isolates. Plant Disease 92(2):225-233

Giełwanowska I, Olech M (2012) New ultrastructural and physiological features of the thallus in Antarctic lichens. Acta Biologica Cracoviensia Series Botanica 54(1):40-52 
Gilbert OL, Hawksworth, DL (2009) Claurouxia D. Hawksw (1988). In: Smith CW, Aptroot A, Coppins BJ, Fletcher A, Gilbert OL, James PW, Wolseley PA (eds) The Lichens of Great Britain and Ireland, 2nd ed. British Lichen Society, London 338-339

Gilgado F, Cano J, Gené J, Sutton DA, Guarro J (2008) Molecular and phenotypic data supporting distinct species statuses for Scedosporium apiospermum and Pseudallescheria boydii and the proposed new species Scedosporium dehoogii. J. Clin. Microbiol 46(2):766-771

Gilgado F, Gene J, Cano JF, Guarro J (2010). Heterothallism in Scedosporium apiospermum and description of its teleomorph Pseudallescheria apiosperma sp. nov. Medical Mycol 48(1):122-128

Giordani P, Benesperi R, Mariotti MG (2015) Local dispersal dynamics determine the occupied niche of the red-listed lichen Seirophora villosa (Ach.) Frödén in a Mediterranean Juniperus shrubland. Fungal Ecology 13:77-82

Giordani P, Benesperi R, Rizzi G, Brunialti G (2009) New records for lichen regional floras of Italy. Webbia 64(1):153-158

Giraldo A, Gené J, Cano J, de Hoog GS, Guarro J (2012) Two new species of Acremonium from Spanish soils. Mycologia 8:11-402

Giraldo A, Gené J, Sutton DA, Madrid H, Cano J, Crous PW, Guarro J (2014a) Phylogenetic circumscription of Arthrographis (Eremomycetaceae, Dothideomycetes). Persoonia: Molecular Phylogeny and Evolution of Fungi 32:102

Giraldo A, Sutton DA, Samerpitak K, de Hoog GS, Wiederhold NP, Guarro J, Gené J (2014b) Occurrence of Ochroconis and Verruconis species in clinical specimens from the United States. Journal of clinical microbiology 52(12):4189-201

Giralt M (2009) Rinodina etayoi, a new saxicolous lichen species from the Canary Islands. The Lichenologist 41(02):141-145

Giralt M, Klaus KALB (2010) Rinodina fuscoisidiata, a new muscicolous, isidiate species from Venezuela. The Lichenologist 42(01):73-76

Giralt M, Klaus KALB, Mayrhofer H (2009) Rinodina brasiliensis, a new corticolous isidiate species, and closely related taxa. The Lichenologist 41(02):179-187

Giralt M, Van den Boom PP, Mayrhofer H, Elix JA (2014) Three new species of crustose Physciaceae from Guatemala, with notes on some additional species. Phytotaxa 164(2):79-90

Giralt M, van den Boom PPG, Elix JA (2010) Endohyalina, the genus in the Physciaceae to accommodate the species of the Rinodina ericina-group. Mycological Progress 9(1):37-48

Giraud S, Favennec L, Bougnoux ME, Bouchara JP (2013) Rasamsonia argillacea species complex: taxonomy, pathogenesis and clinical relevance. Future microbiology 8(8):967-978

Giri DK, Sims WP, Suran R, Cooper JJ, Gavrilov BK, Mansell J (2011) Cerebral and renal phaeohyphomycosis in a dog infected with Bipolaris species. Veterinary Pathology Online 48(3):754-757

Gladdish S, Frank JL, Southworth D (2010) The serpentine syndrome belowground: hypogeous fungi and ectomycorrhizas associated with conifers. Canadian Journal of Forest Research 40(8):1671-1679 
Glejdura S, Kučera V, Lizoň P, Kunca V (2015) Pseudoplectania lignicola sp. nov. described from central Europe. Mycotaxon 130(1):1-10

Glienke C, Pereira OL, Stringari D, Fabris J, Kava-Cordeiro V, GalliTerasawa L, Cunnington J, Shivas RG, Groenewald JZ, Crous PW (2011) Endophytic and pathogenic Phyllosticta species, with reference to those associated with Citrus Black Spot. Persoonia 26:47-56

Gnavi G, Ercole E, Panno L, Vizzini A, Varese GC (2014) Dothideomycetes and Leotiomycetes sterile mycelia isolated from the Italian seagrass Posidonia oceanica based on rDNA data. Springerplus 3:508

Goel M, Sharma PK, Dureja P, Rani A, Uniyal PL (2011) Antifungal activity of extracts of the lichens Parmelia reticulata, Ramalina roesleri, Usnea longissima and Stereocaulon himalayense. Archives of Phytopathology and Plant Protection 44(13):1300-1311

Goh TK, Lau WY, Teo KC (2014a) A new species of Nawawia from Malaysia, with a synopsis of the genus. Mycotaxon 129(1):109-18

Goh TK, Lau WY, Teo KC (2014b) Paliphora curviapicis sp. nov. from Malaysia, and a synopsis of the genus. Mycotaxon 127:145-153

Goh TK, Lee LL, Teo KC (2013) A new coprophilous Gilmaniella species from Malaysia. Mycotaxon. Nov 20;125(1):234-40

Goldmann L, Weir A (2012) Position specificity in Chitonomyces (Ascomycota, Laboulbeniomycetes) on Laccophilus (Coleoptera, Dytiscidae): a molecular approach resolves a century-old debate. Mycologia 104(5):1143-58

Gomathinayagam S, Rekha M, Murugan SS, Jagessar JC (2010) The biological control of paddy disease brown spot (Bipolaris oryzae) by using Trichoderma viride in vitro condition. Journal of Biopesticides 3(1):93-95

Gomes RR, Glienke C, Videira SIR, Lombard L, Groenewald JZ, Crous PW (2013) Diaporthe: a genus of endophytic, saprobic and plant pathogenic fungi. Persoonia 31:1-41

Goni R, Raina AK, Magotra R, Sharma N (2014) Lichen flora of Jammu and Kashmir State, India: An updated checklist. Tropical Plant Research 2(1):64-71

Goni R, Sharma N (2015) Additions to lichen flora of Jammu and Kashmir, India. Tropical Plant Research 2(2):78-81

Gonzalez-Menendez V, Perez-Bonilla M, Martin J, Munoz F, Reyes F, Tormo JR, Genilloud O (2016) Multicomponent analysis of the differencial induction of secondary metabolite profiles in fungal endophytes. Molecules, In press

Gräfenhan T, Schroers H-J, Nirenberg HI, Seifert KA (2011) An overview of the taxonomy, phylogeny, and typification of nectriaceous fungi in Cosmospora, Acremonium, Fusarium, Stilbella, and Volutella. Studies in Mycology 68:79-113

Gramaje D, Agustí-Brisach C, Pérez-Sierra A, Moralejo E, Olmo D, Mostert L, Damm D, Armengol J (2012) Fungal trunk pathogens associated with wood decay of almond trees on Mallorca (Spain). Persoonia 28:1-13

Granados M, Castañeda-Ruiz RF, Castro O, Minter DW, Kendrick B (2014) Microfungi from Costa Rica. A new species and a new combination in Codinaea. Mycotaxon 127(1):115-20 
Greif MD, Stchigel AM, Miller AN, Huhndorf SM (2009) A re-evaluation of genus Chaetomidium based on molecular and morphological characters. Mycologia 101(4):554-64

Grinn-Gofroń A, Rapiejko P (2009) Occurrence of Cladosporium spp. and Alternaria spp. spores in Western, Northern and Central-Eastern Poland in 2004-2006 and relation to some meteorological factors. Atmospheric Research 93(4):747-758

Grinn-Gofroń A, Strzelczak A (2008) Artificial neural network models of relationships between Alternaria spores and meteorological factors in Szczecin (Poland). International journal of biometeorology 52(8):859-868

Grobbelaar JW, Aghayeva DN, de Beer ZW, Bloomer P, Wingfield MJ, Wingfield BD (2009) Delimitation of Ophiostoma quercus and its synonyms using multiple gene phylogenies. Mycol. Progr 8(3):221-236

Grochowski P (2012) Secondary succession with the participation of protected species of lichens in the charred areas of the forest inspectorate of Lubsko. W: Lipnicki L.(red) Lichen protection-Protected lichen species, Sonar Literacki, Gorzów Wielkopolski 205-212

Groenewald JZ, Nakashima C, Nishikawa J, Shin HD, Park JH, Jama AN, Groenewald M, Braun U, Crous PW (2013) Species concepts in Cercospora: spotting the weeds among the roses. Studies in Mycology 75:115-170

Groenewald M, Linde CC, Groenewald JZ, Crous PW (2008) Indirect evidence for sexual reproduction in Cercospora beticola populations from sugar beet. Plant Pathology 57(1): 25-32

Gross A, Holdenrieder O, Pautasso M, Queloz V, Sieber TN (2014) Hymenoscyphus pseudoalbidus, the causal agent of European ash dieback. Molecular Plant Pathology 15(1):5-21

Grube M, Köberl M, Lackner S, Berg C, Berg G (2012) Host-parasite interaction and microbiome response: effects of fungal infections on the bacterial community of the Alpine lichen Solorina crocea. FEMS microbiology ecology 82(2):472-481

Grum-Grzhimaylo AA, Debets AJ, van Diepeningen AD, Georgieva ML, Bilanenko EN (2013a) Sodiomyces alkalinus, a new holomorphic alkaliphilic ascomycete within the Plectosphaerellaceae. Persoonia: Molecular Phylogeny and Evolution of Fungi 31:147

Grum-Grzhimaylo AA, Georgieva ML, Bondarenko SA, Debets AJ, Bilanenko EN (2016) On the diversity of fungi from soda soils. Fungal Diversity 76(1):27-74

Grum-Grzhimaylo AA, Georgieva ML, Debets AJM, Bilanenko EN (2013b) Are alkalitolerant fungi of the Emericellopsis lineage (Bionectriaceae) of marine origin? IMA Fungus 4(2):213-228

Grundy KC, Woodward S, Genney DR, Taylor AF (2012) A molecular approach to explore the extent of the threatened fungus Hypocreopsis rhododendri within wood. Fungal. Biol 116:354-362

Grünig CR, Queloz V, Duò A, Sieber TN (2009) Phylogeny of Phaeomollisia piceae gen. sp. nov. a dark, septate, conifer-needle endophyte and its relationships to Phialocephala and Acephala. Mycological research 113(2):207-21 
Gryzenhout M, Tarigan M, Clegg PA, Wingfield MJ (2010) Cryptometrion aestuescens gen. [et] sp. nov. (Cryphonectriaceae) pathogenic to Eucalyptus in Indonesia. Australas. Pl. Path 39(2):161-169

Gryzenhout M, Wingfield BD, Wingfield MJ (2009) Taxonomy, phylogeny, and ecology of bark-inhabiting and tree-pathogenic fungi in the Cryphonectriaceae. American Phytopathological Society (APS Press)

$\mathrm{Gu} \mathrm{H}$, Lin G, Na (2014) Xylaria byttneriae sp. nov. from Yunnan Province in China. Mycosystema 33(3):567-70

Gu W (2009) Bioactive metabolites from Alternaria brassicicola ML-P08, an endophytic fungus residing in Malus halliana. World Journal of Microbiology and Biotechnology 25(9): 1677-1683

Guang-yu X, Bi-fa S, Ke-ming C, Si-ai F (2008) Study on the control of Agaricodochium camellia. Journal of Hebei Agricultural Sciences 9:017

Guarro J, Gené J, Stchigel A, Figueras MJ (2012) Atlas of soil ascomycetes. CBS Biodiversity Series 10, Utrecht

Guatimosim E, Firmino A, Bezerra J, Pereira O, Barreto R, Crous P (2015) Towards a phylogenetic reappraisal of Parmulariaceae and Asterinaceae (Dothideomycetes). Persoonia 35:230-241

Guatimosim E, Pinto HJ, Barreto RW, Prado J (2014) Rhagadolobiopsis, a new genus of Parmulariaceae from Brazil with a description of the ontogeny of its ascomata. Mycologia 106(2):276-81

Guatimosim E, Schwartsburd PB, Barreto RW, Crous PW (2016a) Novel fungi from an old niche: cercosporoid and related sexual morphs on ferns. Persoonia 37:106-141

Guatimosim E, Schwartsburd PB, Crous PW, Barreto RW (2016b) Novel fungi from an ancient niche: lachnoid and chalara-like fungi on ferns. Mycological Progress 15(12):1239-67

Gudmundsson M, Hansson H, Karkehabadi S, Larsson A, Stals I, Kim S, Sunux S, Fujdala M, Larenas E, Kaper T, Sandgren M (2016) Structural and functional studies of the glycoside hydrolase family $3 \beta$-glucosidase Cel3A from the moderately thermophilic fungus Rasamsonia emersonii. Acta Crystallographica Section D: Structural Biology 72(7):860-870

Guecin F, Kaya A, Soylu MK, Uzun Y. Picoa Vittad (2010) A new truffle genus record for Turkey. Biological Diversity and Conservation 3(3):23-5

Gueidan C, Aptroot A, Cáceres MES (2016) Molecular phylogeny of the tropical family Pyrenulaceae: contribution from dried specimens and FTA card samples. Mycological progress 15(7):1-21

Gueidan C, Aptroot A, Cáceres MES, Badali H, Stenroos S (2014a) A reappraisal of orders and families within the subclass Chaetothyriomycetidae (Eurotiomycetes, Ascomycota). Mycol Prog 13:1027-1039

Gueidan C, Monnat J-Y, Navarro-Rosines P, Roux, C (2014b) Trimmatothelopsis versipellis: discovery of several localities in the department of Finistere (France), phylogenetic placement and taxonomic consequences. Bull Soc Linn Provence 65:47-65

Gueidan C, Savić S, Thüs H, Roux C, Keller C, Tibell L, Prieto M, Heiðmarsson S, Breuss O, Orange A, Fröberg L (2009) Generic classification of the Verrucariaceae 
(Ascomycota) based on molecular and morphological evidence: recent progress and remaining challenges. Taxon 58(1):184-208

Gueidan C, Thüs H, Pérez-Ortega S (2011) Phylogenetic position of the brown algaeassociated lichenized fungus Verrucaria tavaresiae (Verrucariaceae). The Bryologist 114(3):563-9

Gueidan C, Truong VD, Lu NT (2014c) Phylogeny and taxonomy of Staurothele (Verrucariaceae, lichenized ascomycetes) from the karst of northern Vietnam. The Lichenologist 46(04):515-33

Gueidan C, Villaseñor CR, de Hoog GS, Gorbushina AA, Untereiner WA, Lutzoni F (2008) A rock-inhabiting ancestor for mutualistic and pathogen-rich fungal lineages. Studies in Mycology 61:111-119

Guevara-Guerrero G, Bonito G, Cázares-González E, Healy RA, Trappe J (2015) Novel Tuber spp. (Tuberaceae, Pezizales) in the Puberulum Group from North American. ascomycets.org. journal 7(6):367-374

Guinea J, Sandoval-Denis M, Escribano P, Peláez T, Guarro J, Bouza E (2015) Aspergillus citrinoterreus, a new species of the section Terrei isolated from samples of patients with nonhematological predisposing conditions. Journal of Clinical Microbiology 53:611-617

Gulder TA, Hong H, Correa J, Egereva E, Wiese J, Imhoff JF, Gross H (2012) Isolation, structure elucidation and total synthesis of lajollamide A from the marine fungus Asteromyces cruciatus. Mar Drugs 10(12):2912-2935

Gulis V, Baschien C, Marvanová L (2012) Two new Tricladium species from streams in Alaska. Mycologia 104(6):1510-1516. doi: 10.3852/12-081

Gumboski EL (2014) Contribution to the knowledge of lichenized mycota from Southern Brazil. I-Species of Ramboldia (Ascomycota: Lecanoraceae). Acta Biológica Catarinense 1(2)

Gunde-Cimerman N, Zalar P (2014) Extremely halotolerant and halophilic fungi inhabit brine in solar salterns around the globe. Food Technology and Biotechnology 52(2):170

Gundersen A (2013) Temporal trends in shade sensitive epiphytic cryptogams residing on old trees

Guo MT, Qiao M, Li JY, Wang W, Yu ZF (2015) Verticicladus hainanensis, a new aquatic hyphomycete. Mycotaxon 130(1):275-8

Gupta P, Sinha GP (2015) Additions to the lichen flora of Sikkim, India

Gupta P, Sinha GP (2016) A first note on foliicolous lichens of Assam, India. Journal of Threatened Taxa 8(7):9014-9023

Gupta V, Shamas N, Razdan VK, Sharma BC, Sharma R, Kaur K, Singh I, John D, Kumar A, (2013) Foliar application of fungicides for the management of brown spot disease in rice (Oryza sativa L.) caused by Bipolaris oryzae. African Journal of Agricultural Research 8(25):3303-3309

Gur L, Frenkel O (2015) First report of leaf spot on blue lupin (Lupinus pilosus) caused by Pleiochaeta setosa in Israel. Plant Disease 100:525

Gusmao LF, Leao-Ferreira SM, Marques MF, de Almeida DA (2008) New species and records of Paliphora from the Brazilian semi-arid region. Mycologia 100(2):306-309 
Guu JR, Ju YM, Hsieh HJ (2010) Bionectriaceous fungi collected from forests in Taiwan. Botanical Studies 51(1)

Guzow-Krzemińska B, Halda JP, Czarnota P (2012) A new Agonimia from Europe with a flabelliform thallus. The Lichenologist 44(1):55-66

Kashiwadani H, Aptroot A, Moon KH (2009) Pyrenocarpous lichens of Japan, with the resurrection of the genus Trypetheliopsis. Bibliotheca Lichenologica 99:247-258

Habibi A, Banihashemi Z, Mostowfizadeh-Ghalamfarsa R (2015) Phylogenetic analysis of Polystigma and its relationship to Phyllachorales. Phytopathologia Mediterranea 54(1):45

Habibi A, Banihashemi Z (2016) Mating system and role of pycnidiospores in biology of Polystigma amygdalinum, the causal agent of almond red leaf blotch. Phytopathologia Mediterranea 55(1):98

Hadizadeh I, Peivastegan B, Hamzehzarghani H (2009) Antifungal activity of essential oils from some medicinal plants of Iran against Alternaria alternate. American Journal of Applied Sciences 6(5):857-861

Haelewaters D, De Kesel A (2013) A new species of Cantharomyces (Laboulbeniales, Ascomycota) from the Netherlands. Mycotaxon 123:467-472

Haelewaters D, Schilthuizen M, Pfister DH (2014a) On Diphymyces (Laboulbeniales, Ascomycota) in Malaysian Borneo. Plant Ecology and Evolution 147:93-100

Haelewaters D, Vorst O, De Kesel, André (2014b) New and interesting Laboulbeniales (Fungi, Ascomycota) from the Netherlands. Nova Hedwigia 98:113-125

Haelewaters D, Yaakop S (2014c) New and interesting Laboulbeniales from southern and southeastern Asia. Mycotaxon 129(2):493-454

Haelewaters D, Boer P, Noordijk J (2015a) Studies of Laboulbeniales (Fungi, Ascomycota) on Myrmica ants: Rickia wasmannii in the Netherlands. Journal of Hymenoptera Research 44:39

Haelewaters D, Gorczak M, Pfliegler W, Tartally A, Tischer M, Wrzosek M, Pfister D (2015b) Bringing Laboulbeniales into the 21st century: enhanced techniques for extraction and PCR amplification of DNA from minute ectoparasitic fungi. IMA Fungus 6(2):363-372

Haelewaters D, Zhao SY, De Kesel A, Handlin RE, Royer IR, Farrell BD, Pfister DH (2015c) Laboulbeniales (Ascomycota) of the Boston Harbor Islands I: species parasitizing Coccinellidae and Staphylinidae, with comments on typification. Northeastern Naturalist 22(3):459-77

Haelewaters D, Minnaar IA, Clusella-Trullas S (2016) First finding of the parasitic fungus Hesperomyces virescens (Laboulbeniales) on native and invasive ladybirds (Coleoptera, Coccinellidae) in South Africa. Parasite 23:5

Hafellner J, Herzog G, Mayrhofer H (2008) Zur Diversitat von lichenisierten and lichenicolen Pilzen in den Ennstaler Alpen (Osterreich: Steiermark, Oberosterreich). Mitt. naturw. Ver. Steierm. 137:131-204

Hafellner J (2009) Phacothecium resurrected and the new genus Phacographa (Arthoniales) proposed. Bibliotheca Lichenologica 100:85-121

Hafellner J, Karnefelt I, Wirth V (2010) Diversity and ecology of lichens in polar and mountain ecosystems. Nova Hedwigia 91:3-4

Hafellner J, Zimmermann E (2012) A lichenicolous species of Pleospora (Ascomycota) and a key to the fungi invading Physcia species. Herzogia 25(1):47-59

Hafellner J (2015) Distributional and other data for some species of Didymocyrtis (Dothideomycetes, Pleosporales, Phaeosphaeriaceae), including their Phoma-type anamorphs. Fritschiana 80:43-88 
Hajek J, Vaczi P, Bartak M (2009) Photosynthetic electron transport at low temperatures in the green algal foliose lichens Lasallia pustulata and Umbilicaria hirsuta affected by manipulated levels of ribitol. Photosynthetica 47(2):199-205

Halici MG, Ozdemir Turk A, Candan M (2008) Dacampia cladoniicola sp. nov. (Ascomycota, Dacampiaceae) on Cladonia sp. from Turkey. Mycotaxon 103:53-57

Halici MG, Candan M (2009a) New lichenicolous fungi from Turkey. Nova Hedwigia 88:483-490

Halici MG, Etayo J, Candan M (2009b) Two new lichenicolous species of Dacampia on Teloschistaceae. Mycotax on 109:393-398

Halici MG, Knudsen K, Candan M (2009c) Lichenochora atrans (Phyllachoraceae), a new lichenicolous species on Psora decipiens from Turkey. Mycotaxon 109:239-243

Halici MG, Knudsen K, Candan M, Turk AO (2009d) A new species of Polycoccum (Dothideales, Dacampiaceae) from Turkey. Nova Hedwigia 89:431-436

Halici M, Hawksworth DL, Candan M, Ozdemir Turk A (2010) A new lichenicolous species of Capronia (Ascomycota, Herpotrichiellaceae), with a key to the known lichenicolous species of the genus. Fungal Divers 40:37-40

Halici MG, Akgül HE, Öztürk C, Kiliç E (2013) Polycoccum anatolicum sp. nov. on Lepraria incana and a key to Polycoccum species known from Turkey. Mycotaxon 124(1):4550

Halici M, Kocakaya M, Kiriş Z (2014a) Lichenized and lichenicolous fungi of Bakirdağ (Kayseri, Adana). Acta Botanica Hungarica 56:319-332

Halici MG, Vondrak J, Demirel R, Ceylan A, Candan M (2014b) Teloschistaceae (lichenized Ascomycetes) in Turkey II.-Some poorly known taxa. Supported by molecular data. Nova Hedwigia 98:449-58

Halici MG (2015) New records of crustose Teloschistaceae and lichenicolous fungi from Turkey. Mycotaxon 130(3):769-773

Halonen P, Myllys L, Velmala S, Hyvarinen H (2009) Gowardia (Parmeliaceae) - a new alectorioid lichen genus with two species. Bryologist 112:138-146

Hamada N, Niichiro ABE (2008) Characteristics of recent fungal contamination in bathrooms. SEIKATSU EISEI Journal of Urban Living and Health Association 52(2):98-106

Hamalainen A, Kouki J, Lohmus P (2015) Potential biodiversity impacts of forest biofuel harvest: lichen assemblages on stumps and slash of Scots pine. Canadian Journal of Forest Research 45(10):1239-1247

Hamayun M, Khan SA, Kim HY, Chaudhary MF, Hwang YH, Shin DH, Kim IK, Lee BH, Lee IJ (2009) Gibberellin production and plant growth enhancement by newly isolated strain of Scolecobasidium tshawytschae. J Microbiol Biotechnol 19(6):560565

Han HB, Yang XY, Yang LR, Wang R, Zhang XD, Zhao ZG (2008) Determination of contents of

crude protein and amino acids in Arthrobotrys oligospora [J]. Chinese Veterinary Science $7: 17$

Han JG, Park MJ, Shin HD (2009) Psilachnum staphyleae, a new member of foliicolous Hyaloscyphaceae from Korea. Mycotaxon 110:219-224

Han JG, Choi YJ, Pfister DH, Shin HD (2010a) Scutellinia jejuensis (Pezizales), a new species from Korea. Mycotaxon 112:47-53

Han Q, Huang L, Buchenauer H, Wang C. Kang Z (2010b) Cytological study of wheat spike infection by Bipolaris sorokiniana. Journal of Phytopathology 158(1):22-29

Han JG, Hosoya T, Shin HD (2012) Amicodisca castaneae sp. nov. (Hyaloscyphaceae, Helotiales) on Japanese chestnut bur. Mycotaxon 118(1):89-94 
Han YF, Chen WH, Zou X, Liang ZQ (2013) Gibellula curvispora, a new species of Gibellula. Mycosystema 32(5):778

Han JG, Hosoya T, Sung GH, Shin HD (2014) Phylogenetic reassessment of Hyaloscyphaceae sensu lato (Helotiales, Leotiomycetes) based on multigene analyses. Fungal biology 118(2):150-67

Hanlin RT, González MC (2013) Ophiodothella angustissima comb. nov., a new name for Acerviclypeatus poriformans and O. vaccinii. Mycotaxon 123:327-334

Hansen ES (2009) A contribution to the lichen flora of Iceland. Folia Cryptogamica Estonica $46: 45-54$

Hansen ES (2011) A contribution to lichen flora of the Kobbefjord area, West Greenland. Botanica Lithuanica 17(4):151-156

Hansen ES (2012) Notes on some new and interesting Greenland lichens IX. Graphis Scripta, 24:55-59

Hansen ES (2013a) Lichens from Peary Land, North Greenland. Folia Cryptogamica Estonica 50:3-11

Hansen K, Perry BA, Dranginis AW, Pfister DH (2013b) A phylogeny of the highly diverse cup-fungus family Pyronemataceae (Pezizomycetes, Ascomycota) clarifies relationships and evolution of selected life history traits. Molecular Phylogenetics and Evolution 67(2):311-35

Hansen ES (2014) Contribution to the lichen flora of South East Greenland. I. The Kangerlussuaq area. Botanica Lithuanica 20(2):153-158

Hansen ES (2015) Contribution To The lichen Ffora of South East Greenland. III. The coastal area between $63^{\circ}$ and $65^{\circ} \mathrm{N}$. Botanica Lithuanica 21(2):119-124

Hanying Y, Wei X, Xingxi G (2012) Development of a transformation method for the nematophagous fungus Dactylellina cionopaga. African Journal of Biotechnology 11(14):3370-3378

Hao L, Chen C, Zhang R, Zhu M, Sun G, Gleason ML (2013) A new species of Scolecobasidium associated with the sooty blotch and flyspeck complex on banana from China. Mycol Prog 12(3):489-495

Harada H (2013) Agonimia deguchii (lichenized Ascomycota, Verrucariaceae), a new saxicolous species from central Japan. Hikobia 16:307-310

Harada H (2014) Cresporhaphis chibaensis sp. nov. (lichenized Ascomycota, Trichosphaeriaceae) from Chiba-ken, central Japan. Lichenology 12(1):31-36

Haranczyk H, Nowak P, Bacior M, Lisowska M, Marzec M, Florek M, Olech MA (2012) Bound water freezing in Antarctic Umbilicaria aprina from Schirmacher Oasis. Antarctic Science, 24(4):342-352

Harimoto Y, Tanaka T, Kodama M, Yamamoto M, Otani H, Tsuge T (2008) Multiple copies of AMT2 are prerequisite for the apple pathotype of Alternaria alternata to produce enough AM-toxin for expressing pathogenicity. Journal of General Plant Pathology 74(3):222-229

Harrington TC, Fraedrich SW, Aghayeva DN (2008) Raffaelea lauricola, a new ambrosia beetle symbiont and pathogen on the Lauraceae. Mycotaxon 104:399-404

Harrington TC, Aghayeva DN, Fraedrich SW (2010) New combinations in Raffaelea, Ambrosiella, and Hyalorhinocladiella, and four new species from the redbay ambrosia beetle, Xyleborus glabratus. Mycotaxon 111(1):337-361

Harrington TC, Yun HY, Lu SS, Goto H, Aghayeva DN, Fraedrich SW (2011) Isolations from the redbay ambrosia beetle, Xyleborus glabratus, confirm that the laurel wilt pathogen, Raffaelea lauricola, originated in Asia. Mycologia 103(5):1028-1036

Harrington TC, McNew D, Yun HY. (2012) Bur oak blight, a new disease on Quercus macrocarpa caused by Tubakia iowensis sp. nov. Mycologia 104(1):79-92 
Harrington TC, McNew D, Mayers C, Fraedrich SW, Reed SE (2014) Ambrosiella roeperi sp. nov. is the mycangial symbiont of the granulate ambrosia beetle, Xylosandrus crassiusculus. Mycologia 106:835-845

Harris RC (2009) Four novel lichen taxa in the lichen biota of eastern North America. Opuscula Philolichenum 6:149-156

Harris LB, Rogers SO (2011) Evolution of small putative group I introns in the SSU rRNA gene locus of Phialophora species. BMC research notes 4(1):258

Hashimoto A, Sato G, Matsuda T, Hirayama K, Hatakeyama S, Harada Y, Shirouzu T, Tanaka K (2015a) Molecular taxonomy of Dinemasporium and its allied genera. Mycoscience 56:86-101

Hashimoto A, Sato G, Matsuda T, Matsumura M, Hatakeyama S, Harada Y, Ikeda H, Tanaka K (2015b) Taxonomic revision of Pseudolachnea and Pseudolachnella and establishment of Neopseudolachnella and Pseudodinemasporium gen. nov. Mycologia 107:383-408

Hashimoto A, Matsumura M, Hirayama K, Yonezawa H, Tanaka K (2016) Taxonomy and phylogeny of Cryptocoryneum (Pleosporales, Dothideomycetes). Mycol Prog 15:45

Hauck M, Jurgens SR, Huneck S Leuschner C (2009) High acidity tolerance in lichens with fumarprotocetraric, perlatolic or thamnolic acids is correlated with low $\mathrm{pK}$ al values of these lichen substances. Environmental pollution 157(10):2776-2780

Hauck M, Wirth V (2010) Preference of lichens for shady habitats is correlated with intolerance to high nitrogen levels. The Lichenologist 42(4):475-484

Hauck M, Tonsberg T, Mayrhofer H, Breuss O (2013a) Lichen-forming and lichenicolous fungi new to Kazakhstan. Herzogia 26(1):103-116

Hauck M, Tonsberg T, Mayrhofer H, de Bruyn U, Enkhtuya O, Javkhlan S (2013b) New records of lichen species from western Mongolia. Folia Cryptogamica Estonica 50:13-22

Hawksworth DL, Millanes AM, Wedin M. (2010) Roselliniella revealed as an overlooked genus of Hypocreales, with the description of a second species on parmelioid lichens. Persoonia-Molecular Phylogeny and Evolution of Fungi 24(1):12-7

Hawksworth DL, Divakar PK, Crespo A, Teuvo AHTI (2011a) The checklist of parmelioid and similar lichens in Europe and some adjacent territories: additions and corrections. The Lichenologist 43(6):639-645

Hawksworth DL, Etayo J (2011b) Calongea, Calongia, and Calongeomyces nom. nov. Lichenologist 43:275-276

Hawksworth DL, Santesson R, Tibell L (2011c) Racoleus, a new genus of sterile filamentous lichen-forming fungi from the tropics, with observations on the nomenclature and typification of Cystocoleus and Racodium. IMA Fungus 2:71-79

Hawksworth DL, Aguirre-Hudson B, Ainsworth AM (2014) Sphinctrina tigillaris, an overlooked species of Chaenothecopsis growing on Perenniporia meridionalis, a polypore new to the UK. The Lichenologist 46(6):729-35

Hawksworth DL (2016a) A synopsis of the tropical pleomorphic lichenicolous genus Koordersiella (syn. Hansfordiellopsis) under a unified nomenclature. Journal of Fungal Research 13:227-232

Hawksworth DL, van Geel B, Wiltshire PWJ (2016b) The enigma of the Diporotheca palynomorph. Review of Palaeobotany and Palynology 235:94-98

Hayashi N, Fukuta Y (2009) Proposal for a new international system of differentiating races of blast (Pyricularia oryzae Cavara) by using LTH monogenic lines in rice (Oryza sativa L.). JIRCAS Working report 63:11-15

Healy RA, Bonito G, Guevara G (2009a) The truffle genus Pachyphloeus in the US and Mexico: phylogenetic analysis and a new species. Mycotaxon 107(1):61-71 
Healy RA, Bonito G, Trappe JM (2009b) Calongea, a new genus of truffles in the Pezizaceae (Pezizales). In Anales del Jardín Botánico de Madrid, Real Jardín Botánico 66(1):2532

Healy RA, Smith ME, Bonito GM, Pfister DH, Ge ZW, Guevara GG, Williams G, Stafford K, Kumar L, LeeT, Hobart C, Trappe J, Vilgalys R, McLaughlin DJ (2013) High diversity and widespread occurrence of mitotic spore mats in ectomycorrhizal Pezizales. Mol Ecol 22(6):1717-1732

Healy R, Hobart C, Tocci GLG, Conde IP, Smith ME (2015) Fun with the discomycetes: revisiting collections of Korf's anamorphic Pezizales and Thaxter's New England truffles leads to a connection between forms and the description of two new truffle species: Pachyphlodes pfisteri and P. nemoralis. Ascomycete Org 7(6):357-366

Healy R, Pfister DH, Rossman AY, Marvanova L, Hansen K (2016) Competing sexualasexual generic names of Pezizomycetes and recommendations for use. IMA fungus 7(2):285-288

Hedayati MT, Arabzadehmoghadam A, Hajheydari Z (2009) Specific IgE against Alternaria alternata in atopic dermatitis and asthma patients. Eur Rev Med Pharmacol Sci 13(3):187-191

Heininger C, Spribille T (2009) The sorediate species of Xylographa in Austria (Baeomycetales, lichenized Ascomycetes). Herzogia 22:129-134

Heluta VP, Takamatsu S, Harada M, Voytyuk S (2010) Molecular phylogeny and taxonomy of Eurasian Neoerysiphe species infecting Asteraceae and Geranium. Persoonia 24:81-92

Hembrom ME, Parihar A, Das K (2013) A new species of Poronia from India. Current Reserch in Enviromnment and Applied Mycology 3(2):182-5

Hengstmengel J (2009) Notes on Hymenoscyphus-3: On the nomenclature of Hymenoscyphus subcarneus (Ascomycota, Helotiales). Mycotaxon 107(1):267-276

Heredia G, Arias-Mota RM, Castaneda-Ruiz RF, Gamboa-Angulo M (2012) New species of Hughesinia and Stachybotryna and new records of anamorphic fungi from the Yucatan Peninsula, Mexico. Mycol Prog (4):927-35

Heredia G, Ruiz RF, Arias RM, Gamboa-Angulo M, Susana C (2013) Minteriella cenotigena anam. gen. \& sp. nov. from submerged plant material in Mexico. Mycol Prog 12(2):271-5

Heredia G, Arias RM, Castaneda-Ruiz RF, Minter DW (2014) New species of Lobatopedis and Minimelanolocus (anamorphic fungi) from a Mexican cloud forest. Nova Hedwigia 98:31-40

Heredia G, Gamboa-Angulo M, Arias RM, Castañeda-Ruiz RF (2015) Two new species of Spadicoides and Sporidesmiella from Yucatán, Mexico. Mycotaxon 130(2):511-516

Hernandez-Gutiérrez A (2013) New or rare fungi from eastern Amazonia. 1. Circinoconiopsis amazonica gen. and sp. nov. Mycotaxon 123:107-111

Hernandez-Restrepo M, Castañeda-Ruiz RF, Gené J, Guarro J, Minter DW, Stadler M (2012a) Microfungi from Portugal: Minimelanolocus manifestus sp. nov. and Vermiculariopsiella pediculata comb. nov. Mycotaxon. 122:135-143

Hernandez-Restrepo M, Silvera-Simón C, Mena-Portales J, Mercado-Sierra A, Guarro J, Gene J (2012b) Three new species and a new record of Diplococcium from plant debris in Spain. Mycol Prog 11(1):191-9

Hernandez-Restrepo M, Mena-Portales J, Gene J, Cano J, Guarro J (2013) New Bactrodesmiastrum and Bactrodesmium from decaying wood in Spain. Mycologia 105(1):172-80

Hernandez-Restrepo M, Castañeda-Ruiz RF, Gene J, Silvera-Simón C, Cano J, Guarro J (2014a) Two new species of Solicorynespora from Spain. Mycol Prog 13(1):157-64 
Hernandez-Restrepo M, Gené J, Castañeda-Ruiz RF, Kirk PM, Guarro J (2014b) A new species of Corynesporopsis from Spain. Mycotaxon 127(1):155-160

Hernandez-Restrepo M, Groenewald JZ, Crous PW (2015) (Neocordana) gen. nov., the causal organism of Cordana leaf spot of banana. Phytotaxa 205:229-238

Hernandez-Restrepo M, Schumacher RK, Wingfield MJ, Ahmad I, Cai L, Duong TA, Edwards J, Gené J, Groenewald JZ, Jabeen S, Khalid AN (2016a) Fungal Systematics and Evolution: FUSE 2. Sydowia 68:193-230

Hernandez-Restrepo M, Groenewald JZ, Crous PW (2016b) Taxonomic and phylogenetic reevaluation of Microdochium, Monographella and Idriella. Persoonia 36:57-82

Herrera CS, Rossman AY, Samuels GJ, Lechat C, Chaverri P (2013) Revision of the genus Corallomycetella with Corallonectria gen. nov. for C. jatrophae (Nectriaceae, Hypocreales). Mycosystema 32(3):518-44

Hertel H (2014) A contribution to the family Lecideaceae s. lat.(Lecanoromycetidae inc. sed., lichenized Ascomycota) in the southern subpolar region; including eight new species and some revised generic circumscriptions. The Lichenologist 46(03):389-412

Hesami S, Khodaparast SA Zare R (2011) New reports on Cercospora and Cercospora-like fungi from Guilan Province, Iran. Iranian Journal of Plant Pathology 47(4)

Hestmark G (2009) New observations and records for Umbilicaria (Umbilicariaceae) in Bolivia. The Bryologist 112(4):833-838

Hestmark G (2010a) Typification of the Andean taxa of Umbilicaria described by William Nylander. Mycotaxon 111:51

Hestmark G, Miadlikovska J, Kauff F, Fraker E, Molnar K, Lutzoni FM (2010b) Single origin and subsequent diversification of Central Andean endemic Umbilicaria species. Mycologia 103(1):45-56

Hestmark G (2014a) Lectotypification of the name Umbilicaria nylanderiana (Umbilicariaceae). Taxon 63(4):914-917

Hestmark G, Lendemer J, Lumbsch HT, Schmull M, Schoch CL, Serusiaux E, Maddison DR, Arnold E, Lutzoni F, Stenroos S (2014b) A multigene phylogenetic synthesis for the class Lecanoromycetes Ascomycota): 1307 fungi representing 1139 infrageneric taxa, 317 genera and 66 families. Mol Phylogenet Evol 79:132-68

Hestmark G (2016) The lichen genus Umbilicaria in Ecuador. Nordic Journal of Botany 34(3):257-268

Hettiarachchige IK, Ekanayake PN, Mann RC, Guthridge KM, Sawbridge TI, Spangenberg GC, Forster JW (2015) Phylogenomics of asexual Epichloe fungal endophytes forming associations with perennial ryegrass. BMC Evolutionary Biology 15:72

Heuchert B, Braun U (2014a) Two new lichen-associated Trimmatostroma species. Herzogia 27(2):227-236

Heuchert B, Zhurbenko MP, Braun U (2014b) Reassessment of the lichenicolous hyphomycete genus Talpapellis. Herzogia 27:83-92

Heuchert B, Sancho LG, Braun U, Hawksworth DL (2015) Bicoloromyces kyffinensis: a new genus and species of lichen-inhabiting conidial fungi from $83^{\circ} 46$ 'S. Antarctic Science 27(5):421-8

Hidayat I, Harahap I, Rahayu G (2014) The first phylogenetic study of Kiliophora (Fungi, Anamorphic Xylariales). Mycosphere 5(1):78-84

Higgins NF, Connan S, Stengel DB (2015) Factors influencing the distribution of coastal lichens Hydropunctaria maura and Wahlenbergiella mucosa. Marine Ecology 36(4):1400-1414

Hill DJ, Jorgensen PM, Aptroot A (2011) Ramalodium fecundissimum Henssen discovered in New Guinea. The Lichenologist 43(02):175-177 
Himelbrant DE, Motiejunaitė J, Pykala J, Schiefelbein U, Stepanchikova IS, (2013) New records of lichens and allied fungi from the Leningrad Region, Russia. IV. Folia Cryptogamica Estonica 50:23-31

Himelbrant DE, Motiejunaite J, Stepanchikova IS Tagirdzhanova GM (2014) New records of lichens and allied fungi from the Leningrad Region, Russia. V. Folia Cryptogamica Estonica 51:49-55

Himelbrant D, Stepanchikova I, Motiejunaite J, Vondrak J, Tagirdzhanova G, Gagarina L, Kuznetsova E (2015) New records of lichens and allied fungi from the Leningrad Region, Russia. VI. Folia Cryptogamica Estonica 52:21-28

Himelbrant DE, Stepanchikova IS, Motiejunaite J, Gagarina LV, Dyomina AV (2016) New records of lichens and allied fungi from the Leningrad Region, Russia. VII. Folia Cryptogamica Estonica 53:25-34

Hipolito E, Faria E, Alves AF, De Hoog GS, Anjos J, Goncalves T, Morais PV, Estevao H (2009) Alternaria infectoria brain abscess in a child with chronic granulomatous disease. European journal of clinical microbiology \& infectious diseases 28(4):377380

Hirayama K, Tanaka K, Raja HA, Miller AN, Shearer CA (2010) A molecular phylogenetic assessment of Massarina ingoldiana sensu lato. Mycologia 102(3):729-746

Hirayama K, Tanaka K (2011) Taxonomic revision of Lophiostoma and Lophiotrema based on re-evaluation of morphological characters and molecular analyses. Mycoscience 52:401-412

Hirooka Y, Kobayashi T, Ono T, Rossman AY, Chaverri P (2010) Verrucostoma, a new genus in the Bionectriaceae from the Bonin Islands, Japan. Mycologia 102(2):418429

Hirooka Y, Rossman AY, Chaverri P (2011) A morphological and phylogenetic revision of the Nectria cinnabarina complex. Stud Mycol 68:35-56

Hirooka Y, Rossman AY, Samuels GJ, Lechat C, Chaverri P (2012) A monograph of Allantonectria, Nectria, and Pleonectria (Nectriaceae, Hypocreales, Ascomycota) and their pycnidial, sporodochial, and synnematous anamorphs. Stud Mycol 71:1-210

Hirooka Y, Kawaradani M, Sato T (2014). Description of Gibellulopsis chrysanthemi sp. nov. from leaves of garland chrysanthemum. Mycol Progr 13(1):13-19

Hirooka Y, Tanney JB, Nguyen HD, Seifert KA (2016) Xerotolerant fungi in house dust: taxonomy of Spiromastix, Pseudospiromastix and Sigleria gen. nov. in Spiromastigaceae (Onygenales, Eurotiomycetes). Mycologia 108(1):135-56

Hiruma J, Okubo M, Kano R, Kumagawa M, Hiruma M, Hasegawa A, Kamata H, Tsuboi R (2016) Mating Type Gene (MAT) and Itraconazole Susceptibility of Trichophyton tonsurans Strains Isolated in Japan. Mycopathologia 181:441-4

Hisayoshi T, Shinomura M, Yokokawa K, Kuze I, Konishi A, Kawaji K, Kodama EN, Hata K, Takahashi S, Nirasawa S, Sakuda S (2015) Inhibition of the DNA polymerase and RNase $\mathrm{H}$ activities of HIV-1 reverse transcriptase and HIV-1 replication by Brasenia schreberi (Junsai) and Petasites japonicus (Fuki) components. Journal of natural medicines 69(3):432-440

Hladki AI, Romero AI (2009) Taxonomic and nomenclatural aspects of Hypoxylon taxa from southern South America proposed by Spegazzini. Mycologia 101(5):733-744

Hodhod MS, Abdel-Wahab MA, Bahkali AH, Hyde KD (2012) Amarenographium solium sp. nov. from Yanbu mangroves in the Kingdom of Saudi Arabia. Cryptogamie Mycologie 33(3):285-94

Hodkinson BP (2010) A first assessment of lichen diversity for one of North America's' biodiversity hotspots' in the southern Appalachians of Virginia. Castanea 75(1):126133 
Hodkinson BP, Lendemer JC (2011a) Molecular analyses reveal semi-cryptic species in Xanthoparmelia tasmanica. Bibliotheca Lichenologica 106:108-119

Hodkinson BP, Lendemer JC (2011b) The orders of Ostropomycetidae (Lecanoromycetes, Ascomycota): recognition of Sarrameanales and Trapeliales with a request to retain Pertusariales over Agyriales. Phytologia 93(3):407-12

Hodkinson BP, Lendemer JC (2013) Next-generation sequencing reveals sterile crustose lichen phylogeny. Mycosphere 4(6):1028-1039

Hofmann TA (2009) Plant parasitic Asterinaceae and Microthyriaceae from the Neotropics (Panama). Johann Wolfgang Goethe-University, Germany

Hofton TH, Baral HO, Homble K (2009) The ascomycete Proliferodiscus tricolor (Sowerby: Fr.) Baral comb. nov., recollected in Scandinavia after 60 years. Agarica 28:33-42

Hognabba F, Stenroos S, Thell A (2009a) Evolution of cyanobacterial symbioses in Ascomycota. Biodiversity and Ecology of lichens. Liber Amicorum Harrie Sipman. Bibliotheca Lichenologica 99:163-84

Hognabba F, Stenroos S, Thell A (2009b) Phylogenetic relationship and evolution of photobiont associations in the Lobariaceae (Peltigerales, Lecanoromycetes, Ascomycota). Bibl Lichenol 100:157-187

Hognabba F, Raquel PB, Nordin A, Myllys L Stenroos S (2014) Phylogenetic position of the crustose Stereocaulon species. The Lichenologist 46(01):103-114

Holec J, Kriz M (2013) Current occurrence of Pseudoplectania melaena (Fungi, Ascomycota) in the Boubínský Prales National Nature Reserve. Silva Gabreta 19(2):73-80

Holger TH, Nascimbene J (2008) Contributions toward a new taxonomy of Central European freshwater species of the lichen genus Thelidium (Verrucariales, Ascomycota). The Lichenologist 40(6):499-521

Holt EA, Zemp N, Van Orman, M, Perry J, Williams BT Ogden M, (2015) Macrolichen substrate selection: Patterns among aspen, non-aspen hardwood, and coniferdominated forests in the Wasatch Mountains, Utah. The Bryologist 118(4):357-366

Honda K, Kamiyama M, Hirayama K, Me'nik VA (2012) Taxonomic revision of pleomassariaceous fungi based on phylogenetic analyses of SSU and LSU nrDNA. The 55th Annual Meeting of the Mycological Society of Japan (https://www.jstage.jst.go.jp/article/)

Hong SK, Kim WG, Lee YK, Choi HW, Choi KJ, Lee SY (2010) Leaf Spot of Yam Caused by Pseudophloeosporella dioscoreae in Korea. Mycobiology 38(1):78-80

Hong CF, Hsieh HY, Chen CT Huang HC (2013) Development of a Semiselective Medium for Detection of Nalanthamala psidii, Causal Agent of Wilt of Guava. Plant Disease 97(9):1132-1136

Hongsanan S, Bahkali AH, McKenzie EHC, Chukeatirote E, Hyde KD (2014a) Trichopeltinaceae (Dothideomycetes), an earlier name for Brefeldiellaceae, with a new species of Trichopeltina. Phytotaxa 176(1):270-282

Hongsanan S, Chomnunti P, Crous PW, Chukeatirote E, Hyde KD (2014b) Introducing Chaetothyriothecium, a new genus of Microthyriales. Phytotaxa 161(2):157-64

Hongsanan S, Li YM, Liu JK, Hofmann T, Piepenbring M, Bhat JD, Boonmee S, Doilom M, Singtripop C, Tian Q, Mapook A, Zeng XY, Bahkali AH, Xu JC, Mortimer PE, Wu HX, Yang JB, Hyde KD (2014c) Revision of genera in Asterinales. Fungal Divers 68(1):1-68

Hongsanan S, Hyde KD, Bahkali AH, Camporesi E, Chomnunti P, Ekanayaka H, Gomes AA, Hofstetter V, Jones EG, Pinho DB, Pereira OL (2015a) Fungal biodiversity profiles 11-20. Cryptogamie Mycologie 36(3):355-80 
Hongsanan S, Tian Q, Bahkali AH, Yang JB, McKenzie EH, Chomnunti P, Hyde KD (2015b) Zeloasperisporiales ord. nov., and two new species of Zeloasperisporium. Cryptogamie Mycologie 36(3):301-17

Hongsanan S, Tian Q, Persoh D, Zeng XY, Hyde KD, Chomnunti P, Boonmee S, Bahkali AH, Wen TC (2015c) Meliolales. Fungal Divers 74(1):91-141

Horsfield A, Wicks T, Davies K, Wilson D, Paton S (2010) Effect of fungicide use strategies on the control of early blight (Alternaria solani) and potato yield. Australasian Plant Pathology 39(4):368-375

Hosagoudar VB, Archana GR (2009a) Host range of meliolaceous fungi in India. Journal of Threatened Taxa 1(5):269-82

Hosagoudar VB, Archana GR, Dan M (2009b) Maheshwaramyces, a new genus of the family Lembosiaceae. Indian Journal of Science and Technology 2(6):12-13

Hosagoudar VB, Chandraprabha A (2009c) Bramhamyces, a new anomorphic genus from India. Indian Journal of Science and Technology 2 (6):17-17

Hosagoudar VB, Chandraprabha A (2009d) Two new Prillieuxina species from Kerala, India. Indian Journal of Science and Technology 2(6):18-18

Hosagoudar VB, Riju MC (2009e) Studies on foliicolous fungi-XXXI: the genus Schiffnerula and Sarcinella. Indian Journal of Science and Technology 2(6):7-8

Hosagoudar VB, Archana GR (2010a) A new species of the genus Ectendomeliola (Meliolaceae) from Kerala, India. Journal of Threatened Taxa 2(8):1092-1095

Hosagoudar VB, Archana GR (2010b) Meliolaceae of Kerala, India - XXXI. Journal of Threatened Taxa 2(5):889-891

Hosagoudar VB, Harish M (2010c) Vishnumyces a new genus of the family Asterinaceae. Indian Phytopath 63(1):85-86

Hosagoudar VB, Sabeena A (2010d) Five new Meliolaceae members from Kerala, India. Bioscience Discovery 2(1):117-121

Hosagoudar VB, Sabeena A, Riju M (2010e) Bheemamyces, a new genus of the family Asterinaceae (Ascomycetes). Journal of Threatened Taxa 2(12):1323-1324

Hosagoudar VB, Sabeena A, Riju MC (2010f) Sarcinella limoniae sp. nov. from Kerala, India. Indian Phytopathology 63(2):236-237

Hosagoudar VB, Thomas J, Agarwal DK (2010g) Additions to Meliolales of India. Nelumbo $52: 1-8$

Hosagoudar VB, Riju MC (2011a) Sarcinella tamarindi sp. nov. from Kerala, India. Mycosphere 2:157-160

Hosagoudar VB, Robin PJ (2011b) Five new black mildews from the Western Ghats of Peninsular India. Bioscience Discovery Journal 2(2):264-267

Hosagoudar VB, Thimmaiah CJ, Jayashankara M (2011c) Schiffnerulaceous fungi of Kodagu, Karnataka, India. Journal of Threatened Taxa 3(12):2268-2271

Hosagoudar VB, Thomas J, Agarwal DK (2011d) Two new schifffnerulaceous fungi from

Kerala, India. Journal of Yeast and Fungal Research 2(5):85-87

Hosagoudar VB (2012). Asterinales of India. Mycosphere 3(5):617-852

Hosagoudar VB (2013a) My contribution to the fungal knowledge of India. Journal of Threatened Taxa 5(8):4129-4348

Hosagoudar V, Divya B (2013b) Additions to black mildews. IJBPAS 2(2):430-438

Hosagoudar VB, Sabeena A, Divya B (2013c) CEPF Western Ghats Special Series: New fungi from Kerala, India. Journal of Threatened Taxa 5(13):4805-4807

Hosagoudar VB, Mathew SP, Babu D (2014) Foliicolous fungi of Andaman Islands. Journal of Threatened Taxa 6(2):5447-463 
Hosoya T, Sasagawa R, Hosaka K, Gi-Ho S, Sung, GH, Hirayama Y, Yamaguchi K, Toyama K, Kakishima M (2010) Molecular phylogenetic studies of Lachnum and its allies based on the Japanese material. Mycoscience 51(3):170-181

Hosoya T, Han JG, Sung GH, Hirayama Y, Tanaka K, Hosaka K, Tanaka I, Shin HD (2011) Molecular phylogenetic assessment of the genus Hyphodiscus with description of Hyphodiscus hyaloscyphoides sp. nov. Mycol Progr 10(2):239-248

Hou CL, Piepenbring M (2009a) Two new Rhytismatales on Rhododendron from China. Mycologia 101(3):383-389

Hou CL, Piepenbring M (2009b) New species and new records of Rhytismatales from Panama. Mycologia 101(4):565-572

Hou CL, Trampe T, Piepenbring M (2010) A new species of Rhytisma causes tar spot on Comarostaphylis arbutoides (Ericaceae) in Panama. Mycopathologia 169(3):225-229

Hou XM, Xu RF, Gu YC, Wang CY, Shao CL (2015) Biological and chemical diversity of coral-

derived microorganisms. Current Medicinal Chemistry 22(32):3707-3762

Houbraken J, Samson R (2011) Phylogeny of Penicillium and segregation of Trichocomaceae into

three families. Stud Mycol 70:1-51

Houbraken J, Spierenburg H, Frisvad JC (2012) Rasamsonia, a new genus comprising thermotolerant and thermophilic Talaromyces and Geosmithia species. Antonie van Leeuwenhoek 101(2):403-421

Houbraken J, Giraud S, Meijer M, Bertout S, Frisvad JC, Meis JF, Bouchara JP, Samson RA (2013) Taxonomy and antifungal susceptibility of clinically important Rasamsonia species. Journal of clinical microbiology 51(1):22-30

Hoyt JR, Cheng TL, Langwig KE, Hee MM, Frick WF, Kilpatrick AM (2015) Bacteria isolated from bats inhibit the growth of Pseudogymnoascus destructans, the causative agent of white-nose syndrome. Plos One 10(4):e0121329

Hsieh HM, Ju YM, Hsueh PR, Lin HY, Hu FR, Chen WL (2009) Fungal keratitis caused by a new filamentous hyphomycete Sagenomella keratitidis. Bot Studies 50(3):331-335

Hsieh HM, Lin CR, Fang MJ, Rogers JD, Fournier J, Lechat C, Ju YM (2010) Phylogenetic status of Xylaria subgenus Pseudoxylaria among taxa of the subfamily Xylarioideae (Xylariaceae) and phylogeny of the taxa involved in the subfamily. Molecular Phylogenetics and Evolution 54(3):957-969

Hu D, Cai L, Chen H, Bahkali AH, Hyde KD (2010a) Fungal diversity on submerged wood in a tropical stream and an artificial lake. Biodiversity And Conservation 19(13):3799-3808

$\mathrm{Hu}$ DM, Cai L, Chen H, Bahkali AH, Hyde KD (2010b) Four new freshwater fungi associated with submerged wood from Southwest Asia. Sydowia 62(2):191-203

Hu DM, Cai L, Bahkali AH, Hyde KD (2012a) Two new freshwater species of Annulatascaceae from China. Mycotaxon 120(1):81-8

Hu DM, Chen H, Cai L, Bahkali AH, Hyde KD (2012b) Aquapeziza: a new genus from freshwater and its morphological and phylogenetic relationships to Pezizaceae. Mycologia 104(2):540-6

Hu DM, Cai L, Hyde KD (2012c) Three new Ascomycetes from freshwater in China. Mycologia 11-430

Hu J, Chen C, Peever T, Dang H, Lawrence C, Mitchell T (2012d) Genomic characterization of the conditionally dispensable chromosome in Alternaria arborescens provides evidence for horizontal gene transfer. BMC genomics 13(1):1

Hua-Jie L, Zhen C, QingFeng W, (2010) Differences in enrichment capability of Co, Cr, Pb, $\mathrm{Cu}$ among five Antarctic lichens. Mycosystema 29(5):719-725 
Hua H, Luo H, Bai Y, Wang K, Niu C, Huang H, Shi P, Wang C, Yang P,Yao B (2014) A thermostable glucoamylase from Bispora sp. MEY-1 with stability over a broad $\mathrm{pH}$ range and significant starch hydrolysis capacity. Plos One 9(11):e113581

Huang MR (2010) Altitudinal patterns of Stereocaulon (lichenized Ascomycota) in China. Acta Oecologica 36(2):173-178

Huang CH, Pan JH, Chen B, Yu M, Huang HB, Zhu X, Lu YJ, She ZG Lin YC (2011) Three bianthraquinone derivatives from the mangrove endophytic fungus Alternaria sp. ZJ96B from the South China Sea. Marine Drugs 9(5):832-843

Huang YT, Chen CY (2014) Leptographium globosum sp. nov., a new species with globose conidia. Mycol Prog 13:841-848

Huang Y, Busk PK, Herbst FA Lange L (2015a) Genome and secretome analyses provide insights into keratin decomposition by novel proteases from the non-pathogenic fungus Onygena corvine. Appl Microbiol Biotechnol 99 (22):9635-9649

Huang H, Wang M, Zhang L, Yue HM, Gong WF, Cai L (2015b) Pochonia cordycepisociata, a new species associated with Chinese cordyceps in Tibet, China. Phytotaxa 208(4):278-86

Hubka V, Dobiasova S, Lyskova P, Mallatova N, Chlebkova J, Skorepova M, Kubatova A, Dobias R, Chudickova M, Kolarik M (2013a) Auxarthron ostraviense sp. nov., and A. umbrinum associated with non-dermatophytic onychomycosis. Medical mycology 51(6):614-24

Hubka V, Kolarik M, Kubatova A, Peterson SW (2013b) Taxonomic revision of Eurotium and transfer of species to Aspergillus. Mycologia 105:912-937

HubkaV, Cmokova A, Skorepova M, Mikula P, Kolarik M (2014a) Trichophyton onychocola sp. nov. isolated from human nail. Medical Mycology 52:285-292

Hubka V, Dobiasova S, Dobias R, Kolarik M (2014b) Microsporum aenigmaticum sp. nov. from M. gypseum complex, isolated as a cause of tinea corporis. Medical Mycology 52(4):387-396

Hubka V, Reblova, M, Rehulka J, Selbmann L, Isola D, de Hoog GS, Kolarik M (2014c) Bradymyces gen. nov. (Chaetothyriales, Trichomeriaceae), a new ascomycete genus accommodating poorly differentiated melanized fungi. Antonie van Leeuwenhoek Journal of Microbiology 106:979-992

Hubka V, Novakova A, Kolarik M, Jurjevic Z, Peterson SW (2015) Revision of Aspergillus section Flavipedes: seven new species and proposal of section Jani sect. nov. Mycologia 107:169-208

Hubka V, Novakova A, Peterson SW, Frisvad JC, Sklenar F, Matsuzawa T, Kubatova A, Kubatova A (2016a) A reappraisal of Aspergillus section Nidulantes with descriptions of two new sterigmatocystin-producing species. Plant Systematics and Evolution 302:1267-1299

Hubka V, Novakova A, Samson RA, Houbraken J, Frisvad JC, Sklenar F, Varga J, Kolarik M (2016b) Aspergillus europaeus sp. nov., a widely distributed soil-borne species related to A. wentii (section Cremei). Plant Systematics and Evolution 302:641-650

Hubka V, Peterson SW, Frisvad JC, Yaguchi T, Kubatova A, Kolarik M (2013b) Aspergillus waksmanii sp. nov. and Aspergillus marvanovae sp. nov., two closely related species in section Fumigati. International Journal of Systematic and Evolutionary Microbiology 63:783-789

Hughes SJ, Atkinson TJ, Seifert KA (2012a) New Zealand fungi 37: two new species of the sooty mould genus Metacapnodium with dictyoseptate ascospores. New Zealand Journal of Botany 50(4):381-7 
Hughes SJ, Seifert KA (2012b) Taxonomic and nomenclatural notes on sooty mould names based on species mixtures: Hormiscium handelii and Torula lechleriana. Mycoscience 53(1):17-24

Huhndorf SM, Miller AN (2008) A new species of Camarops and phylogenetic analysis of related taxa in the Boliniaceae. North American Fungi 3(7):231-239

Huhndorf SM, Miller AN, Greif M, Samuels GJ (2009) Amplistroma gen. nov. and its relation to Wallrothiella, two genera with globose ascospores and acrodontium-like anamorphs. Mycologia 101(6):904-919

Huhndorf SM, Greif M, Mugambi GK, Miller AN (2008) Two new genera in the Magnaporthaceae, a new addition to Ceratosphaeria and two new species of Lentomitella. Mycologia 100(6):940-955

Huhtinen S, Hawksworth DL, Ihlen PG (2008) Observations of two glassy-haired lichenicolous discomycetes. Lichenologist 40(6):549-557

Huhtinen S, Laukka T, Dobbeler P, Stenroos S (2010) Six novelties to European bryosymbiotic discomycetes. Nova Hedwigia 90:413-431

Hui F, Ren Y, Chen L, Li Y, Zhang L, Niu Q (2014) Molecular Phylogenetic Analysis Reveals the New Genus Hemisphaericaspora of the Family Debaryomycetaceae. Plos One 9(7): e103737

Hujslova M, Kubatova A, Kostovcik M, Kolarik M (2013) Acidiella bohemica gen. et sp. nov. and Acidomyces spp. (Teratosphaeriaceae), the indigenous inhabitants of extremely acidic soils in Europe. Fungal Divers 58:33-45

Hujslova M, Kubatova A, Kostovcik M, Blanchette RA, de Beer ZW (2014) Three new genera of fungi from extremely acidic soils. Mycol Progr 13:819-831

Humber RA, Rocha LF, Inglis PW, Kipnis A, Luz C (2013) Morphology and molecular taxonomy of Evlachovaea-like fungi, and the status of this unusual conidial genus. Fungal Biol 117(1):1-12

Hunter GC, Crous PW, Carnegie AJ, Burgess TI, Wingfield MJ (2011) Mycosphaerella and Teratosphaeria diseases of Eucalyptus; easily confused and with serious consequences. Fungal Divers 50(1):145

Huseyin E, Selcuk F, Churakov BP (2014) A new species of Berkleasmium from Ulyanovsk, Russia. Mycosphere 5(3):462-466

Hustad VP, Miller AN (2011a) Phylogenetic placement of four genera within the Leotiomycetes. N Am Fungi 6 (9):1-13

Hustad VP, Miller AN, Moingeon JM, Priou JP (2011b) Inclusion of Nothomitra in Geoglossomycetes. Mycosphere 2(6):646-654

Hustad VP, Miller AN, Dentinger BT, Cannon PF (2013) Generic circumscriptions in Geoglossomycetes. Persoonia, Molecular Phylogeny and Evolution of Fungi 31:101

Hustad VP, Miller AN (2015) Maasoglossum, a basal genus in Geoglossomycetes. Mycoscience 56(6):572-579

Hwang J, Zhao Q, Yang ZL, Wang Z, Townsend JP (2015) Solving the ecological puzzle of mycorrhizal associations using data from annotated collections and environmental samples - an example of saddle fungi. Environ Microbiol Rep 7 (4):658-667

Hyde KD, Cai L, Cannon PF, Crouch JA, Crous PW, Damm U, Goodwin PH, Chen H, Johnston PR, Jones EB, Liu ZY (2009) Colletotrichum-names in current use. Fungal Divers 39(1):147-82

Hyde KD, McKenzie EHC, Koko TW (2011) Towards incorporating anamorphic fungi in a natural classification-checklist and notes for 2010. Mycosphere 2:1-88

Hyde KD, Jones EBG, Liu JK, Ariyawansa H, Boehm E, Boonmee S, Braun U, Chomnunti P, Crous PW, Dai DQ, Diederich P, Dissanayake A, Doilom M, Doveri F, Hongsanan S, Jayawardena R, Lawrey JD, Li YM, Liu YX, Lu “cking R, Monka J, Muggia L, 
Nelsen MP, Pang KL, Phookamsak R, Senanayake IC, Shearer CA, Suetrong S, Tanaka K, Thambugala KM, Wijayawardene NN, Wikee S, Wu HX, Zhang Y, Begon a AH, Alias SA, Aptroot A, Bahkali AH, Bezerra JL, Bhat DJ, Camporesi E, Chukea E, Gueidan C, Hawksworth DL, Hirayama K, Hoog SD, Kang JK, Knudsen K, Li WJ, Li XH, Liu ZY, Mapook A, Mckenzie EHC, Miller AN, Mortimer PE, Phillips AJL, Raja HA, Scheuer C, Schumm F, Taylor JE, Tian Q, Tibpromma S, Wanasinghe DN, Wang Y, Xu JC, Yacharoen S, Yan JY, Zang M (2013) Families of dothideomycetes. Fungal Divers 63:1-313

Hyde KD, Nilsson RH, Alias SA, Ariyawansa HA, Blair JE, Cai L, de Cock AWAM, Dissanayake AJ, Glockling SL, Goonasekara ID, Gorczak M, Hahn M, Jayawardena RS, van Kan JAL, Laurence MH, Lévesque CA, Li XH, Liu JK, Maharachchikumbura SSN, Manamgoda DS, Martin FN, McKenzie EHC, McTaggart AR, Mortimer PE, Nair PVR, Pawłowska J, Rintoul TL, Shivas RG, Spies CFJ, Summerell BA, Taylor PWJ, Terhem RB, Udayanga D, Vaghefi N, Walther G, Wilk M, Wrzosek M, Xu JC, Yan JY, Zhou N (2014) One stop shop: backbones trees for important pytopathogenic genera: I. Fungal Divers 67:21-125

Hyde KD, Hongsanan S, Jeewon R, Bhat DJ, McKenzie EHC, Jones EBG, Phookamsak R, Ariyawansa HA, Boonmee S, Zhao Q, Abdel-Aziz FA, Abdel-Wahab MA, Banmai S, Chomnunti P, Cui BK, Daranagama DA, Das K, Dayarathne MC, de Silva NI, Dissanayake AJ, Doilom M, Ekanayaka AH, Gibertoni TB, Go 'es-Neto A, Huang SK, Jayasiri SC, Jayawardena RS, Konta S, Lee HB, Li WJ, Lin CG, Liu JK, Lu YZ, Luo ZL, Manawasinghe IS, Manimohan P, Mapook A, Niskanen T, Norphanphoun C, Papizadeh M, Perera RH, Phukhamsakda C, Richter C, de Santiago ALCMA, Drechsler-Santos ER, Senanayake IC, Tanaka K, Tennakoon TMDS, Thambugala KM, Tian Q, Tibpromma S, Thongbai B, Vizzini A, Wanasinghe DN, Wijayawardene NN, Wu HX, Yang J, Zeng XY, Zhang H, Zhang JF, Bulgakov TS, Camporesi E, Bahkali AH, Amoozegar AM, Araujo-Neta LS, Ammirati JF, Baghela A, Bhatt RP, Bojantchev S, Buyck B, da Silva GA, de Lima CLF, de Oliveira RJV, de Souza CAF, Dai YC, Dima B, Duong TT, Ercole E, Mafalda-Freire F, Ghosh A, Hashimoto A, Kamolhan S, Kang JC, Karunarathna SC, Kirk PM, Kyto "vuori I, Lantieri A, Liimatainen K, Liu ZY, Liu XZ, Lu “cking R, Medardi G, Mortimer PE, Nguyen TTT, Promputtha I, Raj KNA, Reck MA, Lumyong S, Shahzadeh-Fazeli SA, Stadler M, Soudi MR, Su HY, Takahashi T, Tangthirasunun N, Uniyal P, Wang Y, Wen TC, Xu JC, Zhang ZK, Zhao YC, Zhou JZ, Zhu L (2016) Fungal diversity notes 367-490: taxonomic and phylogenetic contributions to fungal taxa. Fungal Divers 80:1-270

Iftikhar S, Asad S, Mujeeb-Kazi A, Ahmad I (2009a) In vitro screening of synthetic hexaploid wheat lines against Bipolaris sorokiniana in Pakistan. Pak $\mathbf{J}$ Bot 41(4):1989-2001

Iftikhar S, Asad S, Munir A, Sultan A, Ahmad I (2009b) Hosts of Bipolaris sorokiniana, the major pathogen of spot blotch of wheat in Pakistan. Pak J Bot 41(3):1433-1436

Imazaki A, Tanaka A, Harimoto Y, Yamamoto M, Akimitsu K, Park P, Tsuge T (2010) Contribution of peroxisomes to secondary metabolism and pathogenicity in the fungal plant pathogen Alternaria alternata. Eukaryotic cell 9(5):682-694

Imoulan A, Wu HJ, Lu WL, Li Y, Li BB, Yang RH, Wang WJ, Wang XL, Kirk PM, Yao YJ (2016) Beauveria medogensis sp. nov., a new fungus of the entomopathogenic genus from China. Journal of invertebrate pathology 139:74-81

Inacio CA, Cannon PF (2008) The genera of the 'Parmulariaceae'. CBS Fungal Biodiversity Centre

Inacio CA, Arauz K, Piepenbring M (2012) A new genus of Parmulariaceae from Panama. Mycol Progr 11(1):1-6 
Index Fungorum (2016) http://www.indexfungorum.org, Accessed in December 2016

Inuma T, Khodaparast SA, Takamtsu S (2007) Multilocus phylogenetic analyses within Blumeria graminis, a powdery mildew fungus of cereals. Molecular Phylogenetics and Evolution 44(2):741-751

Irinyi L, Serena C, Garcia-Hermoso D, Arabatzis M, Desnos-Ollivier M, Vu D, Cardinali G, Arthur I, Normand AC, Giraldo A, da Cunha KC, Sandoval-Denis M, Hendrickx M, Nishikaku AS, de Azevedo Melo AS, Merseguel KB, Khan A, Parente Rocha JA, Sampaio P, da Silva BMR, Ferreira RC, de Medeiros Muniz M, Castanon-Olivares LR, Estrada-Barcenas D, Cassagne C, Mary C, Duan SY, Kong F, Sun AY, Zeng X, Zhao Z, Gantois N, Botterel F, Robbertse B, Schoch C, Gams W, Ellis D, Halliday C, Chen S, Sorrell TC, Piarroux R, Colombo AL, Pais C, de Hoog S, Zancope-Oliveira RM, Taylor ML, Toriello C, de Almeida Soares CM, Delhaes L, Stubbe D, Dromer F, Ranque S, Guarro J, Cano-Lira JF, Robert V, Velegraki A, Meyer W (2015) International Society of Human and Animal Mycology (ISHAM)-ITS reference DNA barcoding database-the quality controlled standard tool for routine identification of human and animal pathogenic fungi. Med Mycol 53 (4):313-337

Isaka M, Yangchum A, Intamas S, Kocharin K, Jones EBG, Kongsaeree P, Prabpai S (2009) Aigialomycins and related polyketide metabolites from the mangrove fungus Aigialus parvus BCC 5311. Tetrahedron 65:4396-4403

Isaka M, Palasarn S, Prathumpai W, Laksanacharoen P (2011) Pimarane diterpenes from the endophytic fungus Eutypella sp. BCC 13199. Chem Pharm Bull (Tokyo) 59(9):11571159

Isaka M, Chinthanom P, Rachtawee P, Srichomthong K, Srikitikulchai P, Kongsaeree P, Prabpai S (2015) Cytotoxic hydroanthraquinones from the mangrove-derived fungus Paradictyoarthrinium diffractum BCC 8704. The Journal of antibiotics 68(5):334-338

Ishihara A, Nakao T, Mashimo Y, Murai M, Ichimaru N, Tanaka C, Nakajima H, Wakasa K, Miyagawa H (2011) Probing the role of tryptophan-derived secondary metabolism in defense responses against Bipolaris oryzae infection in rice leaves by a suicide substrate of tryptophan decarboxylase. Phytochemistry 72(1):7-13

Ishiwada N, Takeshita K, Yaguchi T, Nagasawa K, Takeuchi N, Hishiki H, Watanabe A, Kamei K, Shimojo N (2016) The First Case of Invasive Mixed-Mold Infections due to Emericella nidulans var. echinulata and Rasamsonia piperina in a Patient with Chronic Granulomatous Disease. Mycopathologia 181:305-309

Isiloglu M, Alli H, Spooner BM, Solak MH (2010) Morchella anatolica (Ascomycota), a new species from southwestern Anatolia, Turkey. Mycologia 102(2):455-458

Ismed F, Lohézic-Le Dévéhat F, Delalande O, Sinbandhit S, Bakhtiar A, Boustie J (2012) Lobarin from the Sumatran lichen, Stereocaulon halei. Fitoterapia 83(8):1693-1698

Isola D, Selbmann L, de Hoog GS, Fenice M, Onofri S, Prenafeta-Boldú FX, Zucconi L (2013) Isolation and screening of black fungi as degraders of volatile aromatic hydrocarbons. Mycopathologia 175:369-379

Isola D, Zucconi L, Onofri S, Caneva G, De Hoog GS, Selbmann L (2016) Extremotolerant rock inhabiting black fungi from Italian monumental sites. Fungal Divers 76(1):75-96

Iturriaga T, Fernandez R, Castaneda-Ruiz RF, Minter DW, da Cruz AC (2013) Scolecobeltrania, an interesting new microfungus from Venezuela. Mycotaxon 124(1):143-148

Iwen PC, Schutte SD, Florescu DF, Noel-Hurst RK, Sigler L (2012) Invasive Scopulariopsis brevicaulis infection in an immunocompromised patient and review of prior cases caused by Scopulariopsis and Microascus species. Medical mycology 50(6):561-569

Izquierdo-San Al, Sierra S, Rodriguez-Gutierrez I, Castro-Santiuste S, Cifuentes J (2013). A new species of Scutellinia from Mexico. Mycotaxon 125:258 
Jagadeesh Ram TAM, Sinha, GP (2016) A world key to Cryptothecia and Myriostigma (Arthoniaceae), with new species and new records from the Andaman and Nicobar Islands, India. Phytotaxa 266(2):103-114

Jagielski T, Sandoval-Denis M, Yu J, Yao L, Bakuła Z, Kalita J, Skora M, Krzysciak P, de Hoog GS, Guarro J, Gené J (2016) Molecular taxonomy of scopulariopsis-like fungi with description of new clinical and environmental species. Fungal Biology 120(4):586-602

Jaklitsch W, Poldmaa K, Samuels GJ (2008) Reconsideration of Protocrea (Hypocreales, Hypocreaceae). Mycologia 100:962-984

Jaklitsch WM, Voglmayr H (2011) Stromatonectria gen. nov. and notes on Myrmaeciella. Mycologia 103(2):431-40

Jaklitsch WM, Voglmayr H (2012) Phylogenetic relationships of five genera of Xylariales and Rosasphaeria gen. nov. (Hypocreales). Fungal Divers 52(1):75-98

Jaklitsch WM, Reblova M, Voglmayr H (2013) Molecular systematics of Woswasia atropurpurea gen. et sp. nov. (Sordariomycetidae), a fungicolous ascomycete with globose ascospores and holoblastic conidiogenesis. Mycologia 105(2):476-85

Jaklitsch WM, Fournier J, Rogers JD, Voglmayr H (2014a) Phylogenetic and taxonomic revision of Lopadostoma. Persoonia 32:52-82

Jaklitsch WM, Lechat C, Voglmayr H (2014b) The rise and fall of Sarawakus (Hypocreaceae, Ascomycota). Mycologia 106(1):133-44

Jaklitsch WM, Fournier J, Dai DQ, Hyde KD, Voglmayr H (2015a) Valsaria and the Valsariales. Fungal Divers 73(1), 159-202

Jaklitsch WM, Voglmayr H. (2015b) Biodiversity of Trichoderma (Hypocreaceae) in Southern Europe and Macaronesia. Stud Mycol 80:1-87

Jaklitsch W, Baral HO, Lucking R, Lumbsch HT (2016a) Ascomycota. In Syllabus of Plant Families (Frey W, ed.) 1 (2). 23th edn. Stuttgart, Borntraeger Science Publishers.

Jaklitsch WM, Gardiennet A, Voglmayr H (2016b) Resolution of morphology-based taxonomic delusions: Acrocordiella, Basiseptospora, Blogiascospora, Clypeosphaeria, Hymenopleella, Lepteutypa, Pseudapiospora, Requienella, Seiridium and Strickeria. Persoonia 37:82-105

Jaklitsch WM, Olariaga I, Voglmayr H (2016c) Teichospora and the Teichosporaceae. Mycol Prog 15(3):1-20

Jaklitsch W.M. \& Voglmayr H. (2017): Three former taxa of Cucurbitaria and considerations on Petrakia in the Melanommataceae. Sydowia 69:81-95

Jamshidnejad V, Sahebani N Etebarian H (2013) Potential biocontrol activity of Arthrobotrys oligospora and Trichoderma harzianum BI against Meloidogyne javanica on tomato in the greenhouse and laboratory studies. Archives of Phytopathology and Plant Protection 46(13): 1632-1640

Jankowiak R, Rossa R (2008) Associations between Pityogenes bidentatus and fungi in young managed Scots pine stands in Poland. Forest Pathology 38(3):169-177

Janni M, Sella L, Favaron F, Blechl AE, De Lorenzo G, D'Ovidio R (2008) The expression of a bean PGIP in transgenic wheat confers increased resistance to the fungal pathogen Bipolaris sorokiniana. Molecular Plant-Microbe Interactions 21(2):171-177

Jayalal U, Aptroot A, Hur JS (2012a) The lichen genus Polychidium new to South Korea. Mycobiology 40(4):252-254

Jayalal U, Wolseley P, Gueidan C, Aptroot A, Wijesundara S, Karunaratne V (2012b) Anzia mahaeliyensis and Anzia flavotenuis, two new lichen species from Sri Lanka. Lichenologist 44:381-389

Jayalal U, Aptroot A, Nguyen TT, Dzung NA, Joshi S, Oh SO, Hur JS (2013a) Further additions to the macrolichen mycota of Vietnam. Mycotaxon 124(1):51-59 
Jayalal U, Oh SO, Lucking R, Joshi S, Kim JA, Park JS, Hur JS (2013b) Contributions to the foliicolous lichens flora of South Korea. Mycobiology 41(4):202-209

Jayalal U, Divakar PK, Joshi S, Oh SO, Kim JA Hur JS (2014) Overview of Xanthoparmelia taxa from South Korea including the description of two new species (Parmeliaceae, Ascomycota). Phytotaxa 181(2):96-109

Jayanetti DR, Yue Q, Bills GF, Gloer JB (2014) Hypocoprins A-C: new sesquiterpenoids from the coprophilous fungus Hypocopra rostrata. Journal of natural products 78(3):396-401

Jayasiri SC, Ariyawansa HA, Jones EBG, Kang JC (2015) Towards a natural classification of Dothideomycetes: 8. The genera Cocconia, Dianesea, Endococcus and Lineostroma, Phytotaxa 255(1):066-074

Jayasiri SC, Jones EBG, Kang JC, Promputtha I, Bahkali AH, Hyde KD (2016) A new species of genus Anteaglonium (Anteagloniaceae, Pleosporales) with its asexual morph. Phytotaxa 263:233-244

Jayawardena RS, Ariyawansa HA, Singtripop C, Li YM, Yan JY, Li XH, Nilthong S, Hyde KD (2014) A re-assessment of Elsinoaceae (Myriangiales, Dothideomycetes). Phytotaxa 176(1):120-138

Jeyaprakash A, Davison DA, Schubert TS (2014) Molecular detection of the laurel wilt fungus, Raffaelea lauricola. Plant Disease 98(4):559-564

Jia GJ, Lin YR, Hou CL (2011) A new species of Coccomyces (Rhytismatales, Ascomycota) from Mt Huangshan, China. Mycotaxon 118:231-235

Jia C, Zhang L, Liu L, Wang J, Li C, Wang Q (2013) Multiple phytohormone signalling pathways modulate susceptibility of tomato plants to Alternaria alternata f. sp. lycopersici. Journal of experimental botany 64(2):637-650

Jian Ma, Ji-Wen X, Rafael F, Castañeda-Ruíz, Xiu-Guo Z (2014) Antinakataea setulosa gen. et sp. nov. and Uberispora formosa sp. nov. from southern China. Mycologia 13:753758

Jiang YL, Zhang TY (2008) New species of Bipolaris, Scolecobasidium and Torula from soil. Mycotaxon 104:135-140

Jiang YL, Zhang TY (2010) Two new species of Humicola from soil. Mycotaxon 111:117120

Jiang YL, Xu JJ, Wu, YM, Zhang YL, Liu HM, Pan HQ, Zhang TY (2011) Studies on Cephalotrichum from soils in China twelve new species and two new combinations. Mycotaxon 117:207-225

Jiao JIA, Xing JH, Dong JG, Han JM Liu JS (2011) Functional analysis of MYB73 of Arabidopsis thaliana against Bipolaris oryzae. Agricultural Sciences in China 10(5):721-727

Jie CY, Zhou QX, Zhao WAS, Jinag YL, Hyde KD, Mckenzie EHC, Wang Y (2013) A new Myrmecridium species from Guizhou, China. Mycotaxon 124:1-8

Jindamorakot S, Am-in S, Yukphan P, Yamada Y (2011) Limtongia gen. nov. for Zygozyma smithiae (Lipomycetaceae). Annals of Microbiology 61(3):689-693

Jindamorakot S, Yukphan P, Yamada Y (2012) Kockiozyma gen. nov., for Zygozyma suomiensis: the phylogeny of the Lipomycetaceous yeasts. Annals of microbiology 62(4):1831-40

Jing Luo, Emily W, Ning Zhang (2015) Toward monophyletic generic concepts in Magnaporthales: species with Harpophora asexual states. Mycologia 170(3):641-664

Johnson D, Sung GH, Hywel-Jones NL, Luangsa-ard JJ, Bischoff JF, Kepler RM, Spatafora JW (2009) Systematics and evolution of the genus Torrubiella (Hypocreales, Ascomycota). Mycol Res 113(3):279-289 
Johnston PR, Park D, Manning MA (2010) Neobulgaria alba sp. nov. and its Phialophora-like anamorph in native forests and kiwifruit orchards in New Zealand. Mycotaxon 113:385-396

Johnston PR, Park D (2013a) The phylogenetic position of Lanzia berggrenii and its sister species. Mycosystema 32:366-385

Johnston PR, Steel JB, Park D, Ludwig LR (2013b) A bryophilous member of the Leotiomycetes from New Zealand, Bryoclaviculus campylopi gen. et sp. nov. New Zealand Journal of Botany 51(4):321-7

Johnston PR, Park D, Baral HO, Galán R, Platas G, Tena R (2014a) The phylogenetic relationships of Torrendiella and Hymenotorrendiella gen. nov. within the Leotiomycetes. Phytotaxa 177:1-25

Johnston PR, Seifert KA, Stone JK, Rossman AY, Marvanova L (2014b) Recommendations on generic names competing for use in Leotiomycetes (Ascomycota). IMA Fungus 5(1):91-120

Jones EBG, Sakayaroj J, Suetrong S, Somrithipol S, Pang KL (2009a) Classification of marine Ascomycota, anamorphic taxa and Basidiomycota. Fungal Divers 35:1 • 187

Jones EB, Zuccaro A, Nakagiri A, Mitchell JL, Pang KL (2009b). Phylogenetic relationships of the genus Sigmoidea and a new genus Halosigmoidea gen. nov. Bot 52:349-59

Jones (2010) Fungi. Biol Mar Mediterr 17:681-684

Jones EBG, Hyde KD, Pang KL, Suetrong S (2012) Phylogeny of the Dothideomycetes and other classes of marine Ascomycota. In: Jones EBG and Pang KL (eds.) Marine Fungi and Fungal-like Organisms. De Gruyter 17-34

Jones EBG, Suetrong S, Cheng WH, Rungjindamai N, Sakayaroj J, Boonyuen N, Somrothipol S, Abdelwahab MA, Pang KL (2014) An additional fungal lineage in the Hypocreomycetidae (Falcocladiumspecies) and the taxonomic revaluation of Chaetosphaeria chaetosa and Swampomyces species, based on morphology, ecology and phylogeny. Cryptogam Mycol 35(2):119-138

Jones EBG, Suetrong S, Sakayaroj J, Bahkali AH, Abdel-Wahab MA, Boekhout T, Pang KL (2015) Classification of marine Ascomycota, Basidiomycota, Blastocladiomycota and Chytridiomycota. Fungal Divers 73:1-72

Jorgensen PM (2008) Vahliella, a new lichen genus. Lichenologist 40:221-225

Jorgensen PM, Nordin A (2009) Lichens in Scandinavia known mainly from Norwegian type-specimens. Graphis Scripta 21(1):1-20

Jorgensen PM (2010a) New discoveries in the lichen genus Staurolemma Korber. Nova Hedwigia 90:153-159

Jorgensen PM, Palice Z (2010b) Additions to the lichen family Pannariaceae in Ecuador. Nordic Journal of Botany 28(5):623-628

Jorgensen PM, Gjerde I (2012) Notes on some pannariaceous lichens from New Caledonia. Cryptogamie Mycologie 33(1):3-9

Jorgensen PM, Ekman S, Wedin M (2013) Proposal to conserve the name Fuscopannaria against Moelleropsis (lichenized Ascomycota). Taxon 62(3):629-39

Jorgensen PM, Andersen HL (2015) The lichen genus Psoromidium (Pannariaceae) reevaluated, with nomenclatural notes on Degeliella and Psoromaria. Lichenologist 47:343-348

Jorge-Villar SE, Miralles I, Ferrón CC, Hernandez V (2011) Raman spectroscopy study of lichens using three spectrometers under different experimental conditions: analyses of the results with relevance for extraplanetary exploration. Analytical Methods 3(12):2783-2791

Joseph S, Sinha GP (2015) Contributions to the genus Synarthonia (lichenized Ascomycota, Arthoniaceae). The Lichenologist, 47(2):123-130 
Joseph S, Sinha GP, Ramachandran VS (2013) A new record of Syncesia (Lichenized ascomycota) from India with additional taxonomic characters. Taiwania 58(4):300304

Joshi S, Upreti DK, Divakar PK (2011a) A new species of lichen genus Syncesia (Roccellaceae) from India. The Bryologist 114(1):215-219

Joshi S, Hur JS (2012a) A New Record of the Genus Mycobilimbia (Ramalinaceae) from South Korea. Mycobiology 40(2):91-93

Joshi S, Upreti DK, Haridas, Biju (2012b) Nomenclatural notes on the lichen genera Leucodecton and Myriotrema (Graphidaceae) in India. Mycotaxon 122:467-482

Joshi S, Jayalal U, Lokos L, Park JS, Oh SO, Koh YJ, Hur JS (2013a) Leiorreuma exaltatum and Trapelia coarctata, New to Korean Lichen Flora. Mycobiology 41(1):56-8

Joshi S, Nguyen TT, Dzung NA, Jayalal U, Oh SO Hur JS (2013b) New records of corticolous lichens from Vietnam. Mycotaxon 123(1):479-489

Joshi Y, Koh YJ, Hur JS (2010a) Three new records of lichen genus Rhizocarpon from South Korea. Mycobiology 38(3):219-221

Joshi Y, Wang XY, Nguyen TT, Koh YJ, Hur JS (2010b) Notes on the existence of Leucodecton desquamescens (Thelotremoid Graphidaceae) in South Korea. Mycobiology 38(2):149-52

Joshi Y, Nguyen TT, Lokos L, Koh YJ, Hur JS (2011) Two new records of the lichen genus Placynthiella elenkin in South Korea. Mycobiology 39(1):54-6

Joshi Y, Upadhyay S, Shukla S, Nayaka S, Rawal RS (2015) New records and an updated checklist of lichenicolous fungi from India. Mycosphere 6(2):195-200

Josphine A, Senthilkumar G, Madhanraj P, Panneerselvam A (2011) Diversity of fungi from drift wood of muthupet mangroves. Asian J Pharm Ana 1:53-55

Joubert A, Bataille-Simoneau N, Campion C, Guillemette T, Hudhomme P, Iacomi-Vasilescu B, Leroy T, Pochon S, Poupard P, Simoneau P (2011a) Cell wall integrity and high osmolarity glycerol pathways are required for adaptation of Alternaria brassicicola to cell wall stress caused by brassicaceous indolic phytoalexins. Cellular microbiology 13(1):62-80

Joubert A, Simoneau P, Campion C, Bataillé-Simoneau N, Iacomi-Vasilescu B, Poupard P, Francois JM, Georgeault S, Sellier E, Guillemette T (2011b) Impact of the unfolded protein response on the pathogenicity of the necrotrophic fungus Alternaria brassicicola. Molecular microbiology 79(5):1305-1324

Judith C, Rossman AY, Kennedy AH, Cáceres O, Piepenbring M (2015) Microchrysosphaera graminicola, an enigmatic new genus and species in the Hypocreales from Panama. Mycological Progress 14(9):1-12

Jungbluth P, Marcelli MP (2011a) The Pyxine pungens complex in São Paulo State, Brazil. The Bryologist 114(1):166-177

Jungbluth P, Marcelli MP, Kalb K (2011b) A new species and a new record of Pyxine (Physciaceae) with norstictic acid from São Paulo State, Brazil. Mycotaxon 115(1):435-442

Jupa R, Hajek J, Hazdrova J, Bartak M (2012) Interspecific differences in photosynthetic efficiency and spectral reflectance in two Umbilicaria species from Svalbard during controlled desiccation. Czech Polar Rep 2:31-41

Jurjevic Z, Kubatova A, Kolarik M, Hubka V (2015) Taxonomy of Aspergillus section Petersonii sect. nov. encompassing indoor and soil-borne species with predominant tropical distribution. Plant Systematics and Evolution 301:2441-2462

Jurjevic Z, Hubka V, Peterson S (2016) Rasamsonia columbiensis. Persoonia 36:404-405

Jury SL (2013) Lichens collected during the fifth "Iter Mediterraneum" in Morocco, 8-27 June, 1992. Bocconea 26:145-149 
Kaewwichian R, Limtong S (2014) Nakazawaea siamensis fa, sp. nov., a yeast species isolated from phylloplane. International journal of systematic and evolutionary microbiology 64(1):266-70

Kaffer MI, Koch NM, Aptroot A, de AM, Suzana M (2015) New records of corticolous lichens for South America and Brazil. Plant Ecology and Evolution 148(1):111-118

Kajale SC, Sonawane MS, Sharma R, Shouche YS (2015) Leptoxyphium kurandae-new record of insect gut associated sooty mould fungus from India. Mycosphere 6(2):133138

Kajitani Y, Masuya H (2011) Ceratocystis ficicola sp. nov., a causal fungus of fig canker in Japan. Mycoscience 52(5):349-353

Kalb K, Staiger B, Elix JA, Lange U, Lumbsch HT (2008) A new circumscription of the genus Ramboldia (Lecanoraceae, Ascomycota) based on morphological and molecular evidence. Nova Hedwigia 86:23-42

Kalb K (2009a) New taxa and new records of thelotremoid Graphidaceae. Herzogia 22:17-42

Kalb K, Archer AW, Sutjaritturakan J, Boonpragob K (2009b) New or otherwise interesting lichens V. Biblioth. Lichenol 99:225-246

Kalb K, Giralt M (2011) Orcularia, a segregate from the lichen genera Buellia and Rinodina (Lecanoromycetes, Caliciaceae). Phytotaxa 38:53-60

Kalb K, Buaruang K, Mongkolsuk P, Boonpragob K (2012) New or otherwise interesting lichens. VI, including a lichenicolous fungus. Phytotaxa 42:35-47

Kalb K, Polyiam W, Rivas PE, Bawingan PA, Kalb K, Lücking R (2016) 'Missing links' alive? Novel taxa represent morphological transitions between distinctive phenotypes among extant Graphidaceae (lichenized Ascomycota: Ostropales). Phytotaxa 268(2):110-122

Kalko GV (2011) New for Russia and rare species of anamorphic fungi on conifers from saint petersburg suburbs. Mikol Fitopatol 45(4):356-61

Kamal MM, Mia MAT (2009) Diversity and pathogenicity of the rice brown spot pathogen, Bipolaris oryzae (Breda de Haan) Shoem. in Bangladesh assessed by genetic fingerprint analysis. Bangladesh Journal of Botany 38(2) :119-125

Kambar Y, Vivek MN, Manasa M, Vinayaka KS, Mallikarjun N, Kekuda PTR (2014) Antimicrobial Activity of Leptogium burnetiae, Ramalina hossei, Roccella montagnei and Heterodermia diademata. International Journal of Pharmaceutical and Phytopharmacological Research 4(3):164-168

Kamgan NG, Jacobs K, Beer ZW, de Wingfield MJ, Roux J (2008) Pesotum australi [sic] sp. nov. and Ophiostoma quercus associated with Acacia mearnsii trees in Australia and Uganda, respectively. Australas Pl Path 37(4):406-416

Kamgan NG, Solheim H, Beer ZW, de Grobbelaar JW, Jacobs K, Wingfield MJ, Roux J (2010) Ophiostoma species, including Ophiostoma borealis sp. nov., infecting wounds of native broad-leaved trees in Norway. Cryptog Mycol 31(3):285-303

Kamgan NG, Beer ZW, de Wingfield MJ, Roux J (2012) A diverse assemblage of Ophiostoma species, including two new taxa on eucalypt trees in South Africa. Mycol Progr 11(2):526

Kang HJ, Sigler L, Lee J, Gibas CF, Yun SH, Lee YW (2010) Xylogone ganodermophthora sp. nov., an ascomycetous pathogen causing yellow rot on cultivated mushroom Ganoderma lucidum in Korea. Mycologia 102(5):1167-84

Kanigowski P, Flakus A, Oset M, Kowalewska A, Rykaczewki M, Kukwa M (2016) The lichen family Parmeliaceae in Poland. Xanthoparmelia species containing usnic acid. Herzogia 29(1):108-119

Kantvilas G, Lumbsch HT (2009). Meridianelia, a new genus in the Elixiaceae (Ascomycota) from Tasmania. The Lichenologist 41:261-270 
Kantvilas G (2012) Cameronia (lichenized Ascomycetes), a remarkable new alpine genus from Tasmania. The Lichenologist 44(1):91-100

Kantvilas G, Divakar PK (2013a) New combinations in Austroparmelina (Parmeliaceae). Australasian Lichenology 73:6-7

Kantvilas G, Elix JA (2013b) The lichen genus Lecidella (Lecanoraceae), with special reference to the Tasmanian species. Muelleria 31:31-47

Kantvilas G (2014a) New species of the genus Rimularia Nyl. from Tasmania. The Lichenologist 46(3):349-364

Kantvilas G (2014b) The lichen family Hymeneliaceae in Tasmania, with the description of a new species. Kanunnah 7:127-140

Kantvilas G (2015a) Observations on the genus Tephromela (lichenised Ascomycetes) in Tasmania, with the description of a new species. Herzogia 28(2): 430-444

Kantvilas G, Leavitt SD, Elix JA, Lumbsch HT (2015b) Additions to the genus Trapelia (Trapeliaceae: lichenised Ascomycetes). Australian Systematic Botany 27(6):395-402

Kantvilas G (2016) Further additions to the lichen genus Ramboldia (Lecanoraceae) from Australia. Muelleria 34:103-109

Kaounas V, Agnello C, Alvarado P (2016) Genea cephalonicae sp. nov. (Ascomycota, Pezizales), a new hypogeous species from Greece. Ascomycete org 8(3):105-110

Karagoz Y, Aslan A, Aptroot A (2011) Diplotomma, Lecanora, and Xanthoria lichen species new to Turkey. Mycotaxon 115(1):115-119

Karakehian JM, LoBuglio KF, Pfister DH (2014) Placement of the genus Angelina within Rhytismatales and observations of Angelina rufescens. Mycologia 106(1):154-62

Karakoti N, Bajpai R, Upreti DK, Mishra GK, Srivastava A Nayaka S (2014) Effect of metal content on chlorophyll fluorescence and chlorophyll degradation in lichen Pyxine cocoes (Sw.) Nyl.: a case study from Uttar Pradesh, India. Environmental earth sciences 71(5):2177-2183

Karandikar KG, Singh SK (2010) Lylea indica: a new hyphomycete species from India. Mycotaxon 112:257-260

Karandikar KG, Singh PN Singh SK (2015) Mycoenterolobium flabelliforme: a new anamorphic fungus from India. Plant Pathology \& Quarantine 5:49-51

Karaoglanidis GS, Luo Y, Michailides TJ (2011) Competitive ability and fitness of Alternaria alternata isolates resistant to QoI fungicides. Plant Disease 95(2):178-182

Karnefelt I, Seaward MR, Thell A (2012) Systematics, biodiversity and ecology of lichens. Acta Botanica Hungarica 54:3-4

Kasahara K, Miyamoto T, Fujimoto T, Oguri H, Tokiwano T, Oikawa H, Ebizuka Y, Fujii I (2010) Solanapyrone synthase, a possible Diels-Alderase and iterative type I polyketide synthase encoded in a biosynthetic gene cluster from Alternaria solani. Chem Bio Chem, 11(9):1245-1252

Kashiwadani H, Aptroot A, Moon KH (2009) Pyrenocarpous lichens of Japan, with the resurrection of the genus Trypetheliopsis. Bibliotheca Lichenologica 99:247-258

Kaur S, Gehlot P (2011) New pyrenomycetous genus from India. Journal of Mycology and Plant Pathology 41(3):487

Kawada M, Someno T, Inoue H, Ohba SI, Masuda T, Kato T, Ikeda D (2010) a new antitumor compound against human prostate cancer cells, produced by Perisporiopsis melioloides Mer-f16716. The Journal of antibiotics 63(6):319-23

Kawahigashi H, Kasuga S, Ando T, Kanamori H, Wu J, Yonemaru JI, Sazuka T, Matsumoto $\mathrm{T}$ (2011) Positional cloning of ds1, the target leaf spot resistance gene against Bipolaris sorghicola in sorghum. Theoretical and applied genetics 123(1):131-142

Kaya A (2009) Macrofungi of Huzurlu high plateau (Gaziantep-Turkey). Turkish Journal of Botany 33(6):429-437 
Kaya M, Halıcı MG, Duman F, Erdoğan S, Baran T (2015) Characterisation of $\alpha$-chitin extracted from a lichenised fungus species Xanthoria parietina. Natural product research 29(13):1280-1284

Kazmierska E, Kossowska M (2016) Contribution to the lichen biota of the Stawy Milickie nature reserve and its adjacent area (Lower Silesia, southwestern Poland). Histry 51(1):1075

Keca N, Milenkovic I, Keca L (2015) Mycological complex of poplars in Serbia. J For Sci 61(4):169-74

Keilor Rojas-Jimenez K, Hernandez M, Blanco J, Vargas LD, Acosta-Vargas LG, Tamayo G (2016) Richness of cultivable endophytic fungi along an altitudinal gradient in wet forests of Costa Rica. Fungal Ecol 20:124-131

Kekuda PTR, Akarsh S, Nawaz AN, Ranjitha MC, Darshini SM Vidya P (2016) In vitro Antifungal Activity of Some Plants Against Bipolaris sorokiniana (Sacc.) Shoem. International Journal of Current Microbiology and Applied Sciences 5(6):331-337

Kelly LJ, Hollingsworth PM, Coppins BJ, Ellis CJ, Harrold P, Tosh J, Yahr R (2011) DNA barcoding of lichenized fungi demonstrates high identification success in a floristic context. New Phytol 191(1):288-300

Kepler RM, Sung GH, Ban S, Nakagiri A, Chen MJ, Huang B, Li Z, Spatafora JW (2012a) New teleomorph combinations in the entomopathogenic genus Metacordyceps. Mycologia 104:182-197

Kepler RM, Sung GH, Harada Y, Tanaka K, Tanaka E, Hosoya T, Bischoff JF, Spatafora JW (2012b) Host jumping onto close relatives and across kingdoms by Tyrannicordyceps (Clavicipitaceae) gen. nov. and Ustilaginoidea (Clavicipitaceae). Am J Bot 99(3):552-561

Kepler R, Ban S, Nakagiri A, Bischoff J, Hywel-Jones N, Owensby CA, Spatafora JW (2013) The phylogenetic placement of hypocrealean insect pathogens in the genus Polycephalomyces: an application of One Fungus One Name. Fungal biology 117(9):611-622

Kepler RM, Humber RA, Bischoff JF, Rehner SA (2014) Clarification of generic and species boundaries for Metarhizium and related fungi through multigene phylogenetics. Mycologia 106:811-829

Kerr AM (2014) Catalogue of the Lichens of the Mariana Islands ex Elix \& McCarthy's (2008) Checklist of Pacific Island Lichens.

Ketner-Oostra R, Sparrius LB, Sýkora KV (2010) Development of lichen-rich communities. Inland drift sand landscapes 235-254

Khare R, Upreti DK, Nayaka S, Gupta RK (2009) Diversity of Soil lichens in India. Soil Microflora, Daya Publishing House, New Delhi. 64-75

Khare R, Rai H, Upreti DK, Dubey U, Gupta RK (2010) Occurrence of rare, crustose lichen, Ophioparma ventosa (Ophioparmaceae, lichenized Ascomycota), from alpine regions of Arunachal Pradesh, India. Feddes Repertorium 121:184-188

Kharpukhaeva TM, Mukhortova LV (2016) Dynamics of interaction between lichens and fallen deadwood in forest ecosystems of the eastern Baikal region. Contemporary Problems of Ecology 9(1):125-139

Khodaparast SA, Takamatsu S, Harada M, Abbasi M, Samadi S (2012) Additional rDNA ITS sequences and its phylogenetic consequences for the genus Leveillula with emphasis on conidium morphology. Mycological Progress 11:741-752

Khodaparast SA, Takamatsu S, Shadlou A, Damadi M, Pirnia M, Jahani M (2016) Notes on the genus Leveillula (Erysiphaceae): a new unrecorded species and notes on Leveillula infecting Ficus, Cucurbita and Tropaeolum in Iran. Phytotaxa 260(3):267275 
Khunnamwong P, Lertwattanasakul N, Jindamorakot S, Limtong S, Lachance MA (2015) Description of Diutina gen. nov., Diutina siamensis, fa sp. nov., and reassignment of Candida catenulata, Candida mesorugosa, Candida neorugosa, Candida pseudorugosa, Candida ranongensis, Candida rugosa and Candida scorzettiae to the genus Diutina. International journal of systematic and evolutionary microbiology 65(12):4701-4709

Kihara J, Moriwaki A, Tanaka N, Tanaka C, Ueno M, Arase S (2008) Characterization of the BMR1 gene encoding a transcription factor for melanin biosynthesis genes in the phytopathogenic fungus Bipolaris oryzae. FEMS microbiology letters 281(2):221-227

Kihara J, Tanaka N, Ueno M, Arase S (2009) Cloning and expression analysis of two opsinlike genes in the phytopathogenic fungus Bipolaris oryzae. FEMS microbiology letters 295(2):289-294

Kilic M, Altintas DU, Yilmaz M, Kendirli SG, Karakoc GB, Taskin E, Ceter T, Pinar NM (2010) The effects of meteorological factors and Alternaria spore concentrations on children sensitised to Alternaria. Allergologia et immunopathologia 38(3):122-128

Kim KH, Choi YJ, Seo ST, Shin HD (2009a) Raffaelea quercus-mongolicae sp. nov. associated with Platypus koryoensis on oak in Korea. Mycotaxon 110(1):189-197

Kim SW, Kim KS, Lamsal K, Kim YJ, Kim SB, Jung M, Sim SJ, Kim HS, Chang SJ, Kim JK, Lee YS (2009b) An in vitro study of the antifungal effect of silver nanoparticles on oak wilt pathogen Raffaelea sp. J Microbiol Biotechnol 19(8):760-764

Kim MY, Sohn JH, Ahn JS, Oh H (2009c) Alternaramide, a cyclic depsipeptide from the marine-derived fungus Alternaria sp. SF-5016. Journal of natural products 72(11):2065-2068

Kim HS, Kim JY, Lee HK, Kim MS, Lee SR, Kang JS, Kim HM, Lee K, Hong JT, Kim Y, Han SB (2010) Dendritic cell activation by glucan isolated from Umbilicaria esculenta. Immune network 10(6):188-197

Kim MK, Park H, Oh TJ (2013) Antimicrobial properties of the bacterial associates of the Arctic lichen Stereocaulon sp. African Journal of Microbiology Research 7(28):36513657

Kınalioglu K, Aptroot A (2011) Carbonea, Gregorella, Porpidia, Protomicarea, Rinodina, Solenopsora, and Thelenella lichen species new to Turkey. Mycotaxon 115(1):125129

King KM, West JS, Brunner PC, Dyer PS, Fitt BDL (2013) Evolutionary relationships between Rhynchosporium lolii sp. nov. and other Rhynchosporium species on grasses. Plos One 8(10): e72536

King KM, West JS, Fitt BDL, Dyer PS (2014) Differences in MAT gene distribution and expression between Rhynchosporium species on grasses. Plant Pathology 64:344-354

Kirby BM, Barnard D, Tuffin IM Cowan DA (2011) Ecological distribution of microorganisms in terrestrial, psychrophilic habitats. In Extremophiles Handbook, Springer Japan 839-863

Kirchmair M, Neuhauser S, Buzina W, Huber L (2008) The taxonomic position of Roesleria subterranea. Mycological research 112(10):1210-9

Kirika P, Mugambia G, Lucking R, Lumbsch HT (2012) New records of lichen-forming fungi from Kenya. Journal of East African Natural History 101(1):73-98

Kirika PM, Leavitt SD, Divakar PK, Crespo A, Gatheri GW, Mugambi G, Lumbsch HT (2015) The monotypic genus Bulborrhizina belongs to Bulbothrix sensu lato (Parmeliaceae, Ascomycota). The Bryologist 118(2):164-9

Kirika PM, Divakar PK, Crespo A, Leavitt SD, Mugambi G, Gatheri GW, Lumbsch HT (2016) Polyphyly of the genus Canoparmelia-uncovering incongruences between phenotype-based classification and molecular phylogeny within lichenized Ascomycota (Parmeliaceae). Phytotaxa 289(1):36-48 
Kirk P, Cannon PF, Minter DW, Stalpers JA (2008) Ainsworth \& Bisby's Dictionary of the Fungi. 10th edn CAB International, Wallingford, UK

Kirk PM, Stalpers JA, Braun U, Crous PW, Hansen K, Hawksworth DL, Hyde KD, Lucking R, Lumbsch TH, Rossman AY, Seifert KA, Stadler M (2013) A without-prejudice list of generic names of fungi for protection under the International Code of Nomenclature for algae, fungi, and plants. IMA Fungus 4:381-443

Kirschner R (2009) Cercosporella and Ramularia. Mycologia 101:110-119

Kirschner R, Chen CJ (2010) Two new species of Ramichloridium-like hyphomycetes from senescent leaves of night-scented lily (Alocasia odora) in Taiwan. Fungal Divers 40:41-50

Kirschner R, Pang KL, Jones EBG (2013) Two cheirosporous hyphomycetes reassessed based on morphological and molecular examination. Mycological Progress 12:29-36

Kirschner R, Liu LC (2014) Mycosphaerellaceous fungi and new species of Venustosynnema and Zasmidium on ferns and fern allies in Taiwan. Phytotaxa 176(1):309-23

Kirschner R (2015) Phylogenetic placement of a new species of Corynesporopsis from dead acacia wood indicates occurrence of tretic conidiogenesis within Xylariales. Phytotaxa 192(1):24-34

Kiyuna T, An KD, Kigawa R, Sano C, Miura S, Sugiyama J (2012) Bristle-like fungal colonizers on the stone walls of the Kitora and Takamatsuzuka Tumuli are identified as Kendrickiella phycomyces. Mycoscience 53(6):446-59

Kjer J, Wray V, Edrada-Ebel R, Ebel R, Pretsch A, Lin W, Proksch P (2009) Xanalteric acids I and II and related phenolic compounds from an endophytic Alternaria sp. isolated from the mangrove plant Sonneratia alba. Journal of natural products 72(11):20532057

Klaubauf S, Tharreau D, Fournier E, Groenewald JZ, Crous PW, De Vries RP, Lebrun MH (2014) Resolving the polyphyletic nature of Pyricularia (Pyriculariaceae). Stud Mycol 79:85-120

Klavina D, Muiznieks I, Gaitnieks T, Lazdins A, Nikolajeva V, Bardule A, Menkis A (2016) Fine root development and mycorrhization in Norway spruce stands a year after fertilization with potassium sulphate and wood ash. Journal of Forest Science 62(1):17-23

Klaysuban A, Sakayaroj J Jones EBG (2014) An additional marine fungal lineage in the Diatrypaceae, Xylariales: Pedumispora rhizophorae, Botanica Marina 57(5):413-420

Kleczewski NM, Flory SL (2010) Leaf Blight Disease on the Invasive Grass Microstegium vimineum caused by a Bipolaris sp. Plant Disease 94(7):807-811

Knapp DG, Kovacs GM, Zajta E, Groenewald JZ, Crous PW (2015) Dark septate endophytic pleosporalean genera from semiarid areas. Persoonia 35:87-100

Knight NL, Platz GJ, Lehmensiek A, Sutherland MW (2010) An investigation of genetic variation among Australian isolates of Bipolaris sorokiniana from different cereal tissues and comparison of their abilities to cause spot blotch on barley. Australasian Plant Pathology 39(3):207-216

Knight A, Bannister JM, Ludwig LR, Malcolm WM Orlovich DA (2013) Rediscovery of pycnidia in Thamnolia vermicularis: implications for chemotype occurrence and distribution. The Lichenologist 45(03):397-411

Knudsen K, Elix JA, Reeb V (2008) A preliminary study of the genera Acarospora and Pleopsidium in South America. Opuscula Phil 5:1-22

Knudsen K, Breuss O, Kocourkova, J (2009a). A new species of Placocarpus (Verrucariaceae) from southern California. Lichenologist 41(6):627-630 
Knudsen K, Gokhan Halici M, Kocakaya M (2009b) Sarcogyne magnispora (Acarosporaceae), a new species in the nivea group from Turkey. Mycotaxon 107(1):413-417

Knudsen K, Kocourkova J (2009c) Lichens, lichenicolous and allied fungi of the Santa Monica mountains, Part 4: Additions and corrections to the annotated checklist. Opuscula Phil 7:29-48

Knudsen K, Lendemer JC (2009d). Naetrocymbe herrei (Pleosporales: Ascomycetes), a new lichenized saxicolous species from the coast of central California, USA. Opuscula Phil 6:59-64

Knudsen K, Kocourkova J (2010a) A new Lichenostigma species (genus incertae sedis) from southern California. Bryologist 113(2):229-234

Knudsen K, Kocourkova J (2010b) Lichens, lichenicolous and allied fungi of the Santa Monica Mountains, Part 5: additions and corrections to the Annotated Checklist. Opuscula Phil 8:83-100

Knudsen K (2011a) A preliminary study of Pleopsidium stenosporum (Stizenb. ex Hasse) K. Knudsen. Opuscula Phil 9:77-83

Knudsen K, Lendemer JC, Harris RC (2011b) Lichens and lichenicolous fungi-no. 15: miscellaneous notes on species from eastern North America. Opuscula Phil 108(4):709-71

Knudsen K, Flakus A, Kukwa M (2012a) A contribution to the study of Acarosporaceae in South America. Lichenologist 44:253-262

Knudsen K, Kocourkova J (2012b) Lichenological notes 5: Neotypification of Sarcogyne magnussonii (Acarosporaceae). Mycotaxon 121:139-145

Knudsen K, Kocourkova J, McCune B (2013a) Sarcogyne mitziae (Acarosporaceae), a new species from biotic soil crusts in western North America. The Bryologist 116(2):122126

Knudsen K, McCune B (2013b) A New Squamulose Sarcogyne from Oregon. North American Fungi 8:1-6

Knudsen K, Sheard JW, Kocourkova J, Mayrhofer H (2013c) A new lichenicolous lichen from Europe and western North America in the genus Dimelaena (Physciaceae). Bryologist 116:257-262

Knudsen K, Lendemer JC (2016) A new perspective on Melanophloea, Thelocarpella and Trimmatothelopsis: species previously placed in multiple families are united within a single genus in the Acarosporaceae. The Bryologist 119(3):266-279

Knudsen K, Lendemer JC, Harris RC (2011) Lichens and lichenicolous fungi-no. 15: miscellaneous notes on species from eastern North America. Opuscula Philolichenum.;9:45-75. 108(4): 709-715

Knudsen K, McCune B (2013) A New Squamulose Sarcogyne from Oregon. North American Fungi, 8, pp.1-6.

Knudsen K, Sheard JW, Kocourkova J, Mayrhofer H (2013b) A new lichenicolous lichen from Europe and western North America in the genus Dimelaena (Physciaceae). Bryologist 116:257-262.

Kobayashi, H., Sano, A., Aragane, N., Fukuoka, M., Tanaka, M., Kawaura, F., Fukuno, Y., Matsuishi, E. and Hayashi, S., 2008. Disseminated infection by Bipolaris spicifera in an immunocompetent subject. Medical mycology, 46(4), pp.361-365.

Kobayashi, T., Iijima, K., Radhakrishnan, S., Mehta, V., Vassallo, R., Lawrence, C.B., Cyong, J.C., Pease, L.R., Oguchi, K. and Kita, H., 2009. Asthma-related environmental fungus, Alternaria, activates dendritic cells and produces potent Th2 adjuvant activity. The Journal of Immunology, 182(4), pp.2502-2510. 
Kobmoo N, Mongkolsamrit S, Wutikhun T, Tasanathai K, Khonsanit A, Thanakitpipattana D, Luangsa-Ard JJ. New species of Ophiocordyceps unilateralis, an ubiquitous pathogen of ants from Thailand. Fungal biology. 2015 Jan 31;119(1):44-52.

Kocakaya M, Halıcı MG, Aksoy A. Zwackhiomyces turcicus sp. nov.(Ascomycota, Xanthopyreniaceae) from Turkey. Mycotaxon. 2011 Apr 1;116(1):329-33.

Kocharin K, Supothina S, Prathumpai W (2013) Hypothemycin production and its derivatives diversifying of Aigialus parvus BCC 5311 influenced by cultural condition. Advances in Bioscience and Biotechnology 4:1049-1056

Kocourková J, Hawksworth DL (2008) Acaroconium punctiforme gen. sp. nov., a new lichenicolous coelomycete on Acarospora species and Sarcogyne regularis. Lichenologist 40(2):105-109

Kocourková J. (2009). Observations on the genus Neolamya, with the description of the new species N. xanthoparmeliae (Ascomycota, genera incertae sedis). Opuscula Philolichenum 6: 137-148

Kocourková, J., Fryday, A.M., Knudsen, K. and Lendemer, J.C., 2010. Studies in lichens and lichenicolous fungi: more notes on taxa from North America 6. Mycotaxon, 111(1), pp.423-429.

Kocourkova, J.; Knudsen, K. (2011). Endococcus thelommatis, a new lichenicolous fungus from southern California. Biblthca Lichenol. 106: 173-178

Kocourková, J.; Knudsen, K. 2009. Gelatinopsis acarosporicola (Helotiaceae), a new lichenicolous fungus on Acarospora socialis from western North America. The Bryologist. 112(2):363-367.

Kohli, M.M., Mehta, Y.R., Guzman, E., Viedma, L.D. and Cubilla, L.E., 2011. Pyricularia blast-a threat to wheat cultivation. Czech J. Genet. Plant Breed, 47, pp.S130-S134.

Kolařík M, Hujslová M, Vazquéz-Campos X (2015a) Acidotolerant genus Fodinomyces (Ascomycota: Capnodiales) is a synonym of Acidiella. Czech Mycol 67:37-38

Kolařík M, Hulcr J, Kirkendall LR (2015b) New species of Geosmithia and Graphium associated with ambrosia beetles in Costa Rica. Czech Mycology. 67:29-35.

Kolarík, M.; Freeland, E.; Utley, C.; Tisserat, N. 2011. Geosmithia morbida sp. nov., a new phytopathogenic species living in symbiosis with the walnut twig beetle (Pityophthorus juglandis) on Juglans in USA. Mycologia. 103(2):325-332

Kolarík, M.; Hulcr, J. 2009. Mycobiota associated with the ambrosia beetle Scolytodes unipunctatus Blandford (Coleoptera: Curculionidae, Scolytinae). Mycological Research. 113(1):44-60

Kondratyuk S, Jeong MH, Yu NH, Kärnefelt I, Thell A, Elix J, Kim J, Kondratyuk A, Hur JS (2013a) Four new genera of Teloschistoid lichens (Teloschistaceae, Ascomycota) based on molecular phylogeny. Acta Botanica Hungarica, 55(3-4): 251-274.

Kondratyuk S, Kärnefelt I, Thell A, Elix J, Kim J, Jeong MH, Yu NN, Kondratiuk A, Hur JS. (2014) A revised taxonomy for the subfamily Caloplacoideae (Teloschistaceae, Ascomycota) based on molecular phylogeny. Acta Botanica Hungarica. 56(1-2):14178.

Kondratyuk S, Kondratyuk A (2014) Molecular Phylogeny and Current Taxonomy of the Teloschistaceae (Lecanoromycetes, Ascomycota). 균학회소식, 26(2), pp.72-72.

Kondratyuk S, Lőkös L, Kim JA, Kondratyiuk AS, Jeong, M-H, Jang SH, Oh S-O, Hur J-S (2015a) New members of the Pertusariales (Ascomycota) proved by combined phylogenetic analysis. Studia Botanica Hungarica 46(2):95-110.

Kondratyuk S, Lokos L, Tschabanenko S, Haji Moniri M, Farkas E, Wang XY, Oh SO, Hur JS (2013b). New and noteworthy lichen-forming and lichenicolous fungi. Acta bot. hung. 55(3-4): 275-349. 
Kondratyuk S, Yatsyna A, Lökös L, Galanina I, Haji Moniri M, Hur JS (2013c) Three new Xanthoria and Rusavskia species (Teloschistaceae, Ascomycota) from Europe. Acta Botanica Hungarica, 55(3-4), pp.351-365.

Kondratyuk S., 2016. Current Stage of Molecular Phylogeny of the Teloschistaceae (LichenForming Ascomycota). 균학회소식, 28(2), pp.67-67.

Kondratyuk SY (2015) Agonimia blumii sp. n. (Verrucariales, lichen-forming Ascomycota), a new taxon from Eastern Asia. Ukr. Bot. J. 72(3):246-51.

Kondratyuk SY, Jeong MH, Galanina IA, Yakovchenko LS, Yatsyna AP, Hur JS (2015b) Molecular phylogeny of placodioid lichen-forming fungi reveal a new genus, Sedelnikovaea. Mycotaxon, 129(2), pp.269-282.

Kondratyuk SY, Kärnefelt I, Thell A, Elix JA, Kim J, Kondratiuk AS, Hur JS. (2015c) Brownlielloideae, a new subfamily in the Teloschistaceae (Lecanoromycetes, Ascomycota). Acta Botanica Hungarica. Sep;57(3-4):321-43.

Kondratyuk SY, Kim JA, Yu N-H, Jeong M-H, Jang SH, Kondratiuk AS, Zarei-Darki B, Hur J-S (2015d) Zeroviella, a new genus of xanthorioid lichens (Teloschistaceae, Ascomycota) proved by three gene phylogeny. Ukr. Bot. J 72(6): 574—584.

Kondratyuk SY, Lőkös L, Farkas E, Oh S-O, Hur J-S (2015e) New and noteworthy lichenforming and lichenicolous fungi 2. Acta Botanica Hungarica. 57(1-2):77-141

Kondratyuk SY, Lokös L, Farkas E, Oh S-O, Hur J-S (2015f) New and noteworthy lichenforming and lichenicolous fungi 3. Acta Bot. Hung. 57(3-4): 345-382

Kondratyuk SY, Lőkös L, Halda JP, Haji Moniri M, Farkas E, Park JS, Lee BG, Oh SO, Hur JS. (2016a) New and noteworthy lichen-forming and lichenicolous fungi 4. Acta Botanica Hungarica 58(1-2):75-136.

Kondratyuk SY, Lőkös L, Kapetz NV, Pleskach LY, Kim J, Kondratiuk AS, Hur JS, (2015g) Physcia ucrainica sp. nova (Physciaceae, Ascomycota) from the Crimean Peninsula, proved by molecular phylogeny. Acta Botanica Hungarica, 57(1-2), pp.143-163.

Kondratyuk SY, Lökös L, Kim JA, Kondratiuk AS, Jeong MH, Jang SH, Oh SO, Wang XY, Hur JS. Fauriea, a new genus of the lecanoroid caloplacoid lichens (Teloschistaceae, lichen-forming ascomycetes). Acta Botanica Hungarica. 2016b Sep;58(3-4):303-18.

Kondratyuk SY, Lőkös L, Kim JA, Kondratiuk AS, Jeong MH, Jang, S.H., Oh, S.O. and Hur, J.S., (2015h). Three New Monotypic Genera of the Caloplacoid Lichens (Teloschistaceae, Lichen-Forming Ascomycetes). Mycobiology, 43(3), pp.195-202.

Kondratyuk SY, Tschabanenko SI, Elix JA, Oh S, Thell A, Hur JS (2013d) Nipponoparmelia perplicata sp. nov. (Parmeliaceae, Ascomycota) from eastern Asia. Mycotaxon. 126:37-44

Konoreva, L.A., Chesnokov, S.V. and Davydov, E.A., 2016. Stictis and Schizoxylon (Stictidaceae, Ostropales) in Russia. Herzogia, 29(2), pp.706-711.

Kosanić, M., Ranković, B. and Stanojković, T., 2012. Antioxidant, antimicrobial, and anticancer activity of 3 Umbilicaria species. Journal of food science, 77(1), pp.T20$\mathrm{T} 25$.

Kossowska, M. and Szczepańska, K., 2016. Current distribution and ecology of lichens in a biodiversity hotspot in the Mały Śnieżny Kocioł glacial cirque, Sudetes, Poland. Herzogia, 29(1), pp.120-136.

Koukol O, Kolárová Z (2010) Bactrodesmium gabretae (anamorphic Helotiales), a new sporodochial species described from spruce needles. Nova Hedwigia 91 (1-2):243-248

Koukol O. New species of Chalara occupying coniferous needles. Fungal Diversity. 2011 Jul 1;49(1):75-91.

Koukol, O. 2012. A new species of Infundichalara from pine litter. Mycotaxon. 120:343-352 
Koukol, O., 2010. Revision of "Septonema ochraceum" revealed three new species of Venturiaceae and Herpotrichiellaceae. Mycological progress, 9(3), pp.369-378.

Koukol,O., Kelnarova,I. and Cerny,K. 2014 Recent observations of sooty bark disease of sycamore maple in Prague (Czech Republic) and the phylogenetic placement of Cryptostroma corticale. Forest Pathology 45(1): 21-27.

Kovács GM, Balázs TK, Calonge FD, Martín MP. 2011a The diversity of Terfezia desert truffles: new species and a highly variable species complex with intrasporocarpic nrDNA ITS heterogeneity. Mycologia. Jul 1;103(4):841-53.

Kovács GM, Trappe JM, Alsheikh AM, Hansen K, Healy RA, Vági P. 2011b Terfezia disappears from the American truffle mycota as two new genera and Mattirolomyces species emerge. Mycologia. Jul 1;103(4):831-40.

Kovács, G. M., J. M. Trappe,A.M.Alsheikh,K.Boka, And T. F. Elliott. 2008. Imaia, a new truffle genus to accommodate Terfezia gigantea. Mycologia, 100:930-939.

Kowalski T, Holdenrieder O. The teleomorph of Chalara fraxinea, the causal agent of ash dieback. Forest Pathology. 2009 Oct 1;39(5):304-8.

KOWALSKI T., KRAI W. \& BEDNARZ B. (2016) Fungi on stems and twigs in initial and advanced stages of dieback of European ash (Fraxinus excelsior) in Poland. European Journal of Forest Research 135: 565-579.

Kowalski, M., Hausner, G. and Piercey-Normore, M.D., 2011. Bioactivity of secondary metabolites and thallus extracts from lichen fungi. Mycoscience, 52(6), pp.413-418.

Kraichak E, Parnmen S, Lücking R, Plata ER, Aptroot A, Caceres MES, Ertz D, Mangold A, Mercado-Diaz JA, Papong K,van den Broeck D, Weerakoon G, Lümbsch HT (2014) Revisiting the phylogeny of Ocellularieae, the second largest tribe within Graphidaceae (lichenized Ascomycota: Ostropales). Phytotaxa 189 (1): 52-81

Kraichak E., R. Lücking, A. Aptroot, A. Beck, P. Dornes, V. John, J.C. Lendemer, M.P. Nelsen, G. Neuwirth, A. Nutakki, S. Parnmen, M. Sohrabi, T. Tønsberg \& H.T. Lumbsch. 2015. Hidden diversity in the morphologically variable script lichen (Graphis scripta) complex (Ascomycota, Ostropales, Graphidaceae). Organisms, Diversity and Evolution 15: 447-458.

Kraichak ES, Parnmen/ R. Lücking/ H. T. Lumbsch 2013: Gintarasia and Xalocoa, two new genera to accommodate temerate to subtropical species in the predominantly tropical Graphidaceae (Ostropales, Ascomycota). - Australian Systematic Botany 26: 466-474.

Kristiina M, Lauri, S. Andres, S.., Thell, A. and Randlane, T., 2012. Testing morphologybased delimitation of Vulpicida juniperinus and V. tubulosus (Parmeliaceae) using three molecular markers. The Lichenologist, 44(06), pp.757-772.

Kristinsson H., Heiðmarsson, S. and Hansen, E.S., 2014. Lichens from Iceland in the collection of Svanhildur Svane. Botanica Lithuanica, 20(1), pp.14-18.

Kruys $\AA$ (2015) New species of Preussia with 8-celled ascospores (Sporormiaceae, Pleosporales, Ascomycota). Phytotaxa 234 (2): 143-150.

Kruys Å, Castlebury LA (2012) Molecular phylogeny of Sydowiellaceae-resolving the position of Cainiella. Mycologia 104(2):419-26.

Kruys A, Huhndorf S, Miller A (2015) Coprophilous contributions to the phylogeny of Lasiosphaeriaceae and allied taxa withinSordariales (Ascomycota, Fungi). Fungal Divers 70(1):101-113.

Kruys Å, Wedin M. (2009). Phylogenetic relationships and an assessment of traditionally used taxonomic characters in the Sporormiaceae (Pleosporales, Dothideomycetes, Ascomycota), utilising multi-gene phylogenies Systematics and Biodiversity 7 (4): 465-478, doi:10.1017/S1477200009990119 C_ The Natural History Museum.

Krzewicka B (2010) Umbilicaria rhizinata comb. nov.(lichenized Ascomycota). The Lichenologist, 42(04), pp.491-493. 
Krzewicka B, Wilk K (2009) Umbilicaria isidiosa (lichenized Ascomycota), a new species from Bolivia. Mycotaxon, 109(1), pp.165-170.

Krzewicka B. A revision of Verrucaria sl (Verrucariaceae) in Poland. Polish Botanical Studies. 2012;27(3):143.

Krzewicka, B., Garcia, M.A., Johansen, S.D., Sancho, L.G. and MartIN, M.P., 2009. Morphological and nuclear ribosomal DNA data support distinguishing two new species of Umbilicaria (Umbilicariaceae, Ascomycota) from Europe. The Lichenologist, 41(06), pp.631-648.

Kuan C.S., Yew, S.M., Toh, Y.F., Chan, C.L., Ngeow, Y.F., Lee, K.W., Na, S.L., Yee, W.Y., Hoh, C.C. and Ng, K.P., 2015. Dissecting the fungal biology of Bipolaris papendorfii: from phylogenetic to comparative genomic analysis. DNA Research, p.dsv007.

Kubiak, D. and Guzow-Krzemińska, B., 2014. Herbarium record of Vulpicida tubulosus (Lichenized Ascomycota) from locality beyond its known distribution range. Polish Journal of Environmental Studies, 23(2), pp.577-583.

Kubiak, D., Osyczka, P. and Rola, K., 2016. Spontaneous restoration of epiphytic lichen biota in managed forests planted on habitats typical for temperate deciduous forest. Biodiversity and Conservation, 25(10), pp.1937-1954.

KUČERA V, LIZOŇ P, KAUTMANOVÁ I. Geoglossoid fungi in Slovakia II. Trichoglossum octopartitum, a new species for the country. Czech Mycology. 2010;62(1):13-8.

Kuhnert E, Sir EB, Lambert C, Hyde KD, Hladki AI, Romero AI, Rohde M, Stadler M (2017). Phylogenetic and chemotaxonomic resolution of the genus Annulohypoxylon (Xylariaceae) including four new species. Fungal Diversity 1-43.

Kukwa M, Łubek, A., Szymczyk, R. and Zalewska, A., 2012. Seven lichen species new to Poland. Mycotaxon, 120(1), pp.105-118.

Kukwa M, Pérez-Ortega S. (2010) A second species of Botryolepraria from the Neotropics and the phylogenetic placement of the genus within Ascomycota. Mycological progress. Aug 1;9(3):345-51.

Kukwa M, Schiefelbein U, Flakus A (2013) A contribution to the lichen family Graphidaceae (Ostropales, Ascomycota) of Bolivia. Herzogia 26:231-252

Kukwa, M. and Flakus, A., 2009. New or interesting records of lichenicolous fungi from Poland VII. Species mainly from Tatra Mountains. Herzogia, 22, pp.191-211.

Kukwa, M., 2010. Additions to the list of lichens and lichenicolous fungi of Gdanskie Pomerania. order.

Kumar JV, Kumari, B.R., Sujatha, G. and Castano, E., 2008a. Production of plants resistant to Alternaria carthami via organogenesis and somatic embryogenesis of safflower cv. NARI-6 treated with fungal culture filtrates. Plant Cell, Tissue and Organ Culture, 93(1), pp.85-96.

Kumar P, Anshu V, Kumar, S., 2011. Morpho-pathological and Molecular Characterization of Bipolaris oryzae in Rice (Oryzae sativa). Journal of phytopathology, 159(1), pp.5156.

Kumar U, Joshi AK, Kumar, S., Chand, R. and Röder, M.S., 2009. Mapping of resistance to spot blotch disease caused by Bipolaris sorokiniana in spring wheat. Theoretical and Applied Genetics, 118(4), pp.783-792.

Kumar U, Joshi, A.K., Kumar, S., Chand, R. and Röder, M.S., 2010. Quantitative trait loci for resistance to spot blotch caused by Bipolaris sorokiniana in wheat (T. aestivum L.) lines 'Ning 8201' and 'Chirya 3'. Molecular breeding, 26(3), pp.477-491. 
Kumar V, Haldar S, Pandey, K.K., Singh, R.P., Singh, A.K. and Singh, P.C., 2008b. Cultural, morphological, pathogenic and molecular variability amongst tomato isolates of Alternaria solani in India. World Journal of Microbiology and Biotechnology, 24(7), pp.1003-1009.

Kuna, P., Kaczmarek, J. and Kupczyk, M., 2011. Efficacy and safety of immunotherapy for allergies to Alternaria alternata in children. Journal of Allergy and Clinical Immunology, 127(2), pp.502-508.

Kuo C-C, Chen P, Chen C-Y (2008) Harposporium from Taiwan. Fung. Sci 23:35-41.

Kurniawati E, Zhang H, Chukeatirote E, Sulistyowati L, Moslem MA, Hyde KD. Diversity of freshwater ascomycetes in freshwater bodies at amphoe mae chan, chiang rai. Cryptogam Mycol. 2010;31(3):323-31.

Kurtzman CP 2012. Citeromyces hawaiiensis sp. nov., an ascosporic yeast associated with Myoporum sandwicense. International Journal of Systematic and Evolutionary Microbiology. 62:1215-1219.

Kurtzman CP, Albertyn J, Basehoar-Powers E (2007) Multigene phylogenetic analysis of the Lipomycetaceae and the proposed transfer of Zygozyma species to Lipomyces and Babjevia anomala to Dipodascopsis. FEMS yeast research 7(6):1027-34.

Kurtzman CP, Price NP, Ray KJ, Kuo TM. 2010 Production of sophorolipid biosurfactants by multiple species of the Starmerella (Candida) bombicola yeast clade. FEMS microbiology letters 311(2):140-6.

Kurtzman CP, Robnett CJ (2013a) Alloascoidea hylecoeti gen. nov., comb. nov., Alloascoidea africana comb. nov., Ascoidea tarda sp. nov., and Nadsonia starkeyihenricii comb. nov., new members of the Saccharomycotina (Ascomycota). FEMS yeast research 13(5):423-32.

Kurtzman CP, Robnett CJ, Blackwell M. 2016 Description of Teunomyces gen. nov. for the Candida kruisii clade, Suhomyces gen. nov. for the Candida tanzawaensis clade and Suhomyces kilbournensis sp. nov. FEMS yeast research. Aug 1;16(5):fow041.

Kurtzman CP, Robnett CJ. (2013b) Relationships among genera of the Saccharomycotina (Ascomycota) from multigene phylogenetic analysis of type species. FEMS yeast research. Feb 1;13(1):23-33.

Kurtzman CP, Robnett CJ. 2014 Three new anascosporic genera of the Saccharomycotina: Danielozyma gen. nov., Deakozyma gen. nov. and Middelhovenomyces gen. nov. Antonie van Leeuwenhoek. May 1;105(5):933-42.

Kurtzman CP, Suzuki M. 2010 Phylogenetic analysis of ascomycete yeasts that form coenzyme Q-9 and the proposal of the new genera Babjeviella, Meyerozyma, Millerozyma, Priceomyces, and Scheffersomyces. Mycoscience. Jan 1;51(1):2-14.

Kurtzman CP. Biotechnological strains of Komagataella (Pichia) pastoris are Komagataellaphaffii as determined from multigene sequence analysis. Journal of industrial microbiology \& biotechnology. 2009 Nov 1;36(11):1435.

Kurtzman CP. Description of Groenewaldozyma gen. nov. for placement of Candida auringiensis, Candida salmanticensis and Candida tartarivorans. Antonie van Leeuwenhoek. 2016 Jul 1;109(7):1041-5.

Kurtzman CP. Description of Martiniozyma gen. nov. and transfer of seven Candida species to Saturnispora as new combinations. Antonie van Leeuwenhoek. 2015 Oct 1;108(4):803-9. 
Kurtzman, C.P.; Robnett, C.J.; Basehoar-Powers, E. (2008). Phylogenetic relationships among species of Pichia, Issatchenkia and Williopsis determined from multigene sequence analysis, and the proposal of Barnettozyma gen. nov., Lindnera gen. nov. and Wickerhamomyces gen. nov.. FEMS Yeast Res. 8(6): 939-954

Kušan I, Matočec N, Mešić A, Tkalčec Z. A new species of Thecotheus from Croatia with a key to the known species with apiculate spores. Sydowia. 2015 Jan 1;67:51-63.

Kušan I, Matočec N, Mešić A, Tkalčec Z. Tricharina tophiseda-a new species from Croatia, with a revision of T. japonica (Pyronemataceae, Pezizales). Phytotaxa. 2015 Jul 28;221(1):35-47.

Kusari S, Zühlke S, Košuth J, Čellárová E, Spiteller M. Light-independent metabolomics of endophytic Thielavia subthermophila provides insight into microbial hypericin biosynthesis. Journal of natural products. 2009 Sep 11;72(10):1825-35.

Kuznetsova, E.S., Motiejūnaitè, J., Stepanchikova, I.S., Himelbrant, D.E. and Czarnota, P., 2012. New records of lichens and allied fungi from the Leningrad Region, Russia. III. Folia Cryptogamica Estonica, 49, pp.31-37.

Lachance MA, Kurtzman CP. The yeast genus Tortispora gen. nov., description of Tortispora ganteri sp. nov., Tortispora mauiana fa, sp. nov., Tortispora agaves fa, sp. nov., Tortispora sangerardonensis fa, sp. nov., Tortispora cuajiniquilana fa, sp. nov., Tortispora starmeri fa, sp. nov. and Tortispora phaffii fa, sp. nov., reassignment of Candida caseinolytica to Tortispora caseinolytica fa, comb. nov., emendation of Botryozyma, and assignment of Botryozyma, Tortispora gen. nov. and Trigonopsis to the family Trigonopsidaceae fam .... International journal of systematic and evolutionary microbiology. 2013a Aug 1;63(8):3104-14.

Lachance MA, Perri AM, Farahbakhsh AS, Starmer WT. Genetic structure of Kurtzmaniella cleridarum, a cactus flower beetle yeast of the Sonoran and Mojave Deserts: speciation by distance?. FEMS yeast research. 2013b Nov 1;13(7):674-81.

Lackner M, de Hoog GS, Yang L, Moreno, LF, Ahmed, SA, Andreas, F, Kaltseis, J, Nagl, M, Lass-Floerl, C, Risslegger, B, Rambach, G, Speth, C, Robert, V, Buzina, W, Chen, S, Bouchara, J-P, Cano-Lira, JF, Guarro, J, Gene, J, Fernandez Silva, F, Haido, R, Haase, G, Havlicek, V, Garcia-Hermoso, D, Meis, JF, Hagen, F, Kirchmair, M, Rainer, J, Schwabenbauer, K, Zoderer, M, Meyer, W, Gilgado, F, Schwabenbauer, K, Vicente, VA, Pieckova, E, Regenermel, M, Rath, P-M, Steinmann, J, de Alencar, XW, Symoens, F, Tintelnot, K, Ulfig, K, Velegraki, A, Tortorano, AM, Giraud, S, Mina, S, Rigler-Hohenwarter, K, Hernando, FL, Ramirez-Garcia, A, Pellon, A, Kaur, J, Bergter, EB, de Meirelles, JV, da Silva, ID, Delhaes, L, Alastruey-Izquerdo, A, Li, R, Lu, Q, Moussa, T, Almaghrabi, O, Al-Zahrani, H, Okada, G, Deng, S, Liao, W, Zeng, J, Issakainen, J \& Liporagi Lopes, LC 2014a, 'Proposed nomenclature for Pseudallescheria, Scedosporium and related genera' Fungal Diversity 67: 1-10., 10.1007/s13225-014-0295-4

Lackner M, Klaassen CH, Meis JF, van den Ende AG, de Hoog GS. Molecular identification tools for sibling species of Scedosporium and Pseudallescheria. Medical mycology. 2012 Jul 1;50(5):497-508.

Læssøe, T; Srikitikulchai, P.; Luangsa-ard, J.J.D.; Stadler, M. 2013. Theissenia reconsidered, including molecular phylogeny of the type species T. pyrenocrata and a new genus Durotheca (Xylariaceae, Ascomycota). IMA Fungus. 4(1):57-69

Lafalmme,G., Broders,K.D., Cote,C., Munck,I. Iriarte G, Innes,L. 2015 Priority of Lophophacidium over Canavirgella: taxonomic status of Lophophacidium dooksii and 
Canavirgella banfieldii, causal agents of a white pine needle disease. Mycologia 107 no. 4 745-753.

Lahlali, R., McGregor, L., Song, T., Gossen, B.D., Narisawa, K. and Peng, G., 2014. Heteroconium chaetospira induces resistance to clubroot via upregulation of host genes involved in jasmonic acid, ethylene, and auxin biosynthesis. PloS one, 9(4), p.e94144.

Lamit, L.J., Bowker, M.A., Holeski, L.M., Næsborg, R.R., Wooley, S.C., Zinkgraf, M., Lindroth, R.L., Whitham, T.G. and Gehring, C.A., 2011. Genetically-based trait variation within a foundation tree species influences a dominant bark lichen. Fungal Ecology, 4(1), pp.103-109.

Landeros F, Iturriaga T, Rodríguez A, Vargas-Amado G, Guzmán-Dávalos L. Advances in the phylogeny of Helvella (Fungi: Ascomycota), inferred from nuclear ribosomal LSU sequences and morphological data. Revista Mexicana de Biodiversidad. 2015 Dec 31;86(4):856-71.

Lang, S.I., Cornelissen, J.H., Shaver, G.R., Ahrens, M., Callaghan, T.V., Molau, U., ter Braak, C.J., Hölzer, A. and Aerts, R., 2012. Species occurrence and richness of lichen, bryophytes and vascular plants near Abisko, Sweden and Toolik lake, Alaska.

Lange OL, Belnap J (2016) How Biological Soil Crusts Became Recognized as a Functional Unit: A Selective History. In Biological Soil Crusts: An Organizing Principle in Drylands (pp. 15-33). Springer International Publishing.

Lantieri A, Smith ME, Pfister DH. A new species of Ruhlandiella (Pezizaceae) from Italy. Mycological progress. 2012 May 1;11(2):509-13.

Lantieri, A.; Pfister, D.H. 2010. A new species of Marcelleina from Italy. Mycotaxon. 111:465-469

Lantieri,A., Johnston,P.R., Park,D., Lantz,H. and Merdadi,G. 2011 Hypoderma siculum sp. nov. from Italy. Mycotaxon 118, 393-401

Lapmak, K., Lumyong, S., Thongkuntha, S., Wongputtisin, P. and Sardsud, U., 2010. Lasparaginase production by Bipolaris sp. BR438 isolated from brown rice in Thailand. Chiang Mai J. Sci., 37(1), pp. 160-164.

Laska, G., Kiercul, S., Stocki, M., Bajguz, A. and Pasco, D., 2015. Cancer-chemopreventive actvity of secondary metabolites isolated from Xanthoparmelia conspersa lichen. Planta Medica, 81(16), p.PM_59.

Latha, P., Anand, T., Ragupathi, N., Prakasam, V. and Samiyappan, R., 2009. Antimicrobial activity of plant extracts and induction of systemic resistance in tomato plants by mixtures of PGPR strains and Zimmu leaf extract against Alternaria solani. Biological Control, 50(2), pp.85-93.

Laundon JR (2012) Proposal to conserve Chrysothrix, nom. cons., against an additional name, Alysphaeria (lichenised Ascomycota). Taxon 61(6):1321.

Lawrence, C.B., Mitchell, T.K., Craven, K.D., Cho, Y.R., Cramer, R.A. and Kim, K.H., 2008. At death's door: Alternaria pathogenicity mechanisms. The Plant Pathology Journal, 24(2), pp.101-111.

Lawrence, D.P., Gannibal, P.B., Peever, T.L. and Pryor, B.M., 2013. The sections of Alternaria: formalizing species-group concepts. Mycologia, 105(3), pp.530-546.

Lawrey J.D., Marson,G., Etayo,J., Dal-Forno,M., Driscoll,K. Diederich,P. 2015 Molecular data support establishment of a new genus for the lichenicolous species Neobarya usneae (Hypocreales). Bryologist 118 (1), 83-92

LAWREY, J.D.; DIEDERICH, P.; NELSEN, M.P.; SIKAROODI, M.; GILLEVET, P.M.; BRAND, A.M.; VAN DEN BOOM, P. (2011). The obligately lichenicolous genus Lichenoconium represents a novel lineage in the Dothideomycetes. Fungal Biol. 2011 Feb;115(2):176-87. 
Le Pogam P, Le Lamer AC, Siva B, Legouin B, Bondon A, Graton J, Jacquemin D, Rouaud I, Ferron S, Obermayer W, Babu KS. Minor Pyranonaphthoquinones from the Apothecia of the Lichen Ophioparma ventosa. Journal of natural products. 2016 Mar 2;79(4):1005-11

Leão-Ferreira SM, Gusmão LF, de Almeida DA, Castañeda-Ruiz RF. Digicatenosporium polyramosum, a new hyphomycete from Brazil. Mycotaxon. 2015 Jul 9;130(2):47982.

Leão-Ferreira SM, Pascholati Gusmão LF, Castañeda Ruiz RF. Conidial fungi from the semiarid Caatinga biome of Brazil. Three new species and new records. Nova Hedwigia. 2013 May 1;96(3-4):479-94.

Leavitt SD, Clair L.L.S., 2011. Estimating Xanthoparmelia (Parmeliaceae) population density in subalpine communities in southern Utah, USA using two distance methods, with implications for assessing community composition. The Bryologist, 114(3), pp.625636.

Leavitt SD, Divakar PK, Ohmura Y, Wang LS, Esslinger TL, Lumbsch HT. Who's getting around? Assessing species diversity and phylogeography in the widely distributed lichen-forming fungal genus Montanelia (Parmeliaceae, Ascomycota). Molecular phylogenetics and evolution. 2015 Sep 30;90:85-96.

Leavitt SD, Fankhauser JD, Leavitt DH, Porter LD, Johnson LA, Clair LL. Complex patterns of speciation in cosmopolitan "rock posy" lichens-Discovering and delimiting cryptic fungal species in the lichen-forming Rhizoplaca melanophthalma species-complex (Lecanoraceae, Ascomycota). Molecular Phylogenetics and Evolution. 2011a Jun 30;59(3):587-602.

Leavitt SD, Johnson LA, Goward T, Clair L.L.S., 2011b. Species delimitation in taxonomically difficult lichen-forming fungi: an example from morphologically and chemically diverse Xanthoparmelia (Parmeliaceae) in North America. Molecular Phylogenetics and Evolution, 60(3), pp.317-332.

Leavitt SD, Johnson LA, St Clair L.L. 2011c. Species delimitation and evolution in morphologically and chemically diverse communities of the lichen-forming genus Xanthoparmelia (Parmeliaceae, Ascomycota) in western North America. Am. J. Bot. 98 (2), 175-188.

Leavitt, S.D., Lumbsch, H.T. and St. Clair, L.L., 2013. Contrasting demographic histories of two species in the lichen-forming fungal genus Xanthomendoza (Teloschistaceae, Ascomycota). The Bryologist, 116(4), pp.337-349.

Lechat C, Courtecuisse R (2010). A new species of Ijuhya, I. antillana, from the French West Indies. Mycotaxon 113: 443-447.

Lechat C, Farr DF, Hirooka Y, Minnis AM, Rossman AY. A new species of Hydropisphaera, $\mathrm{H}$. bambusicola, is the sexual state of Gliomastix fusigera. Mycotaxon. 2010 Mar 31;111(1):95-102.

Lechat C, Fournier 2013 J Two new species of Lasionectria (Bionectriaceae, Hypocreales) from Guadeloupe and Martinique (French West Indies). Mycotaxon. Jan 9;121(1):275-80.

Lechat C,. Fournier J. 2017 Four new species of Ijuhya (Bionectriaceae) from Belgium, metropolitan France and French Guiana. Ascomyceteorg 9 (1), 11-18

Lee JS, Min GH, Lee, J.S., 2009a. Nutritional and physicochemical characteristics of the antidementia acetylcholinesterase-inhibiting methanol extracts from Umbilicaria esculenta. Mycobiology, 37(3), pp.203-206.

Lee LW, Wang GJ, Lin MH, Ju YM, Lin YW, Chen FY, Lee TH (2013a) Isolation and characterization of sesquiterpenes from Arecophila saccharicola YMJ96022401 with NO production inhibitory activity. Phytochemistry 85:129-136 
Lee S, Tamayo-Castillo G, Pang C, Clardy J, Cao S, Kim KH (2016) Diketopiperazines from Costa Rican endolichenic fungus Colpoma sp. CR1465A. Bioorg Med Chem Lett. 26(10): 2438-41.

Lee SB, Go YS, Bae, H.J., Park, J.H., Cho, S.H., Cho, H.J., Lee, D.S., Park, O.K., Hwang, I. and Suh, M.C., 2009b. Disruption of glycosylphosphatidylinositol-anchored lipid transfer protein gene altered cuticular lipid composition, increased plastoglobules, and enhanced susceptibility to infection by the fungal pathogen Alternaria brassicicola. Plant Physiology, 150(1), pp.42-54.

Lee SC, Han KS, Park JH, Cho SE, Shin HD. 2013b First report of frosty mildew caused by Mycopappus alni on Asian pear in Korea. Journal of Phytopathology. Dec;161(1112):866-9.

Lee SJ, Strobel GA, Eisenman, K.; Geary, B.; Vargas, P.N.; Strobel, S.A. (2009c). Aurosphaeria, a novel coelomycetous genus. Mycotaxon 107: 463-472.

Lee SK, Lee SH, Cho SE, Park JH, Shin HD. Confirmation of the Presence of Pleochaeta shiraiana Associated with Powdery Mildew of Celtis sinensis in Korea. Research in Plant Disease. 2011;17(3):391-5.

Lee SS, Alias SA, Jones EBG, Zainuddin N, Chan HT (2012) Checklist of Fungi of Malaysia. Research Pamphlet No.132. Swan Printing Sdn. Bhd., Seri Kembangan, Malaysia

Lee YB, Na YH (2009). A new species of the genus Coreomyces (Laboulbeniales, Ascomycotina) collected from the island of Java, Indonesia. Mycobiology 37(4): 300301

Lee YB, Na YH (2011) A New Species of the Genus Euphoriomyces (Laboulbeniales Ascomycotina) Collected in Korea. Mycobiology, 39(1), 59, 2011.

Lendemer JC (2009) Another Record of the Rare and Endangered Species Phaeophyscia leana. Evansia, 26(3), pp.142-143.

Lendemer JC (2010a) Lepraria larrainiana (Stereocaulaceae, Lichenized Ascomycetes), a new species from Central Chile. Gayana Bot 67:238-241

Lendemer JC (2010a) Notes on Lepraria sl (Lecanoromycetes, Ascomycota) in North America: New species, new reports, and preliminary keys. Brittonia 62(3):267-92.

Lendemer JC (2010b) Notes on Lepraria s.l. (Lecanoromycetes, Ascomycota) in North America: New species, new reports, and preliminary keys. Brittonia 62: 267-292

Lendemer JC (2010b) Reassessment of the genus Catillochroma (lichenized Ascomycota, Ramalinaceae). The Lichenologist, 42(05), pp.587-600.

Lendemer JC (2011) A taxonomic revision of the North American species of Lepraria s.l. that produce divaricatic acid, with notes on the type species of the genus L. incana. Mycologia 103:1216-1229

Lendemer JC (2012) Contributions to the Lichen Flora of Pennsylvania.-Further New and Interesting Reports of Lichens and Lichenicolous Fungi, Part 2.

Lendemer JC (2012) Perspectives on chemotaxonomy: molecular data confirm the existence of two morphologically distinct species within a chemically defined Lepraria caesiella (Stereocaulaceae). Castanea 77:89-105

Lendemer JC (2013) Molecular phylogenetic evidence corroborates morphology but not chemistry in the Lepraria neglecta group (Stereocaulaceae). Mem New York Bot Garden 108:127-153

Lendemer JC, Harris RC (2014) Studies in lichens and lichenicolous fungi-No. 19: Further notes on species from the Coastal Plain of southeastern North America. Opuscula Philolichenum, 13, pp.155-176. 
Lendemer JC, Harris RC (2015) Xyleborus nigricans, a second species for the previously monospecific genus newly found in the Mid-Atlantic Coastal Plain of North America. The Bryologist, 118(3), pp.284-292.

Lendemer JC, Harris RC, Ruiz AM (2016) A Review of the Lichens of the Dare Regional Biodiversity Hotspot in the Mid-Atlantic Coastal Plain of North Carolina, eastern North America. Castanea. 81:1-77.

Lendemer JC, Harris RC, Tripp EA (2013) The lichens and allied fungi of Great Smoky Mountains National Park. Memoires of the New York Botanical Garden, 104, pp.1152.

Lendemer JC, Hodkinson BP (2012) Chirleja buckii, a new genus and species of lichenizedfungi from Tierra del Fuego, southern South America. New Zealand J Bot 50(4):449456.

Lendemer JC, Hodkinson BP (2012) Recognition of the Parmelia crozalsiana group as the genus Crespoa. North American Fungi 7(2): 1-5.

Lendemer JC, Hodkinson BP (2013) A radical shift in the taxonomy of Lepraria s.l.: Molecular and morphological studies shed new light on the evolution of asexuality and lichen growth form diversification. Mycologia 105:994-1018

Lendemer JC, Knudsen K (2008) Studies in lichens and lichenicolous fungi: further notes on North American taxa. Mycotaxon. 103:75-86

Lendemer JC, Kocourková J, Knudsen K (2009) Studies in lichen and lichenicolous fungi: more notes on taxa from North America. Mycotaxon, 108, pp.491-497.

Leonardo L, Mazzilli BP, Damatto SR, Saiki M, De Oliveira SM. Assessment of atmospheric pollution in the vicinity of a tin and lead industry using lichen species Canoparmelia texana. Journal of environmental radioactivity. 2011 Oct 31;102(10):906-10.

Letourneau A, Seena S, Marvanová L, Bärlocher F. Potential use of barcoding to identify aquatic hyphomycetes. Fungal Diversity. 2010 Jan 1;40(1):51-64.

Leuchtmann,A. and Clemencon,H. 2012 The taxonomic position of the genus Heydenia (Pyronemataceae, Pezizales) based on molecular and morphological data. Mycological Progress 11 (3), 699-710

Lewis Smith, R.I., 2009. Further additions to the lichen flora of Antarctica and South Georgia. Nova Hedwigia, 88(1-2), pp.157-168.

Li DM, de Hoog GS, Lindhardt Saunte DM, Gerrits van den Ende AHG, Chen XR. 2008a. Coniosporium epidermidis sp. nov., a new species from human skin. Studies in Mycology 61:131-136.

Li DW, Cowles R, Vossbrinck C (2008b) Metarhiziopsis microspora gen. et sp. nov. associated with the elongate hemlock scale. Mycologia 100: 460-466.

Li DW, Zhao G, Yang C, Jalsrai A, Kerin B (2013) Four noteworthy hyphomycetes from indoor environments. Mycotaxon 125(1), pp.111-121.

Li GJ, Hyde KD, Zhao RL, Hongsanan S, Abdel-Aziz FA et al. (2016a) Fungal diversity notes 253-366: taxonomic and phylogenetic contributions to fungal taxa Fungal Divers 78, 1-237

Li HY, Sun GY, Zhai XR, Batzer JC, Mayfield DA, Crous PW, Groenewald JZ, Gleason ML. Dissoconiaceae associated with sooty blotch and flyspeck on fruits in China and the United States. Persoonia-Molecular Phylogeny and Evolution of Fungi. 2012a 28(1):113-25.

Li J, Phookamsak R, Mapook A, Boonmee S, Bhat JD, Hyde KD, Lumyong S (2016b) Seifertia shangrilaensis sp. nov. (Melanommataceae), a new species from Southwest China. Phytotaxa 273(1):34-42.

Li J, Yang J, Liang L, Zhang KQ (2008c) Taxonomic revision of the nematode-trapping fungus Arthrobotrys multisecundaria. The Journal of Microbiology 46(5):513-8. 
Li JF, Bhat DJ, Phookamsak R, Mapook A, Lumyong S, Hyde KD (2016c) Sporidesmioides thailandica gen. et sp. nov.(Dothideomycetes) from northern Thailand. Mycological Progress 15(10-11):1169-1178.

Li JY, Qiao M, Peng J, Qian WY, Yang GZ, Yu ZF (2015a). Uncispora hainanensis sp. nov. isolated from decayed leaves. Mycotaxon 129(2):473-6.

Li Q, Chen YX, Zheng CT, Lu DD, Lin YR (2015b) Coccomyces neolitseae sp. nov. from Zhangjiajie, China. Mycotaxon 130(1):289-93.

Li S, Yu Z, Zhang Y, Qiao M, Guo J, Zhang K (2009a) Arthrobotrys nonseptata, a new anamorph from an Orbilia species. Mycotaxon. Jul 1;109(1):247-54.

Li SH, Zheng LY, Liu CY, Wang Y, Li L, Zhao YC, Zhang XL, Yang M, Xiong HK, Qing Y, Wang L (2014a) Two new truffles species, Tuber alboumbilicum and Tuber pseudobrumale from China. Mycological Progress 13(4):1157-63.

Li WH, Xiao YX, Wang CS, Zhang R, Batzer JC, Sun GY, Gleason ML (2012b) A new species of Devriesia causing sooty blotch and flyspeck on Rubber Tree in China. 12:733-738.

Li WJ, Bhat DJ, Camporesi E, Tian Q, Wijayawardene NN, Dai DQ, Phookamsak R, Chomnunti P, Bahkali AH, Hyde KD (2015c) New asexual morph taxa in Phaeosphaeriaceae. Mycosphere 6(6):681-708.

Li WJ, Bhat JD, Hyde KD, Wang Y (2014b) Towards a natural classification of Dothideomycetes 4: The genera Bryopelta, Bryorella, Bryosphaeria, Lophiosphaerella and Maireella (Dothideomycetes incertae sedis) Phytotaxa 176 (1): 28-41.

Li WJ, Maharachchikumbura SSN, Li QR, Bhat DJ, Camporesi E, Tian Q, Senanayake IC, Dai DQ, Chomnunti P, Hyde KD (2015d) Epitypification of Broomella vitalbae and introduction of a novel species of Hyalotiella. Cryptogam Mycol 36(1):93-108

Li XF, Lu T, Lu BS, Hyde KD (2009b) Emarcea rostrispora nom. nov. (Xylariaceae, Ascomycota) on wood from Taiwan. Mycosystema. 28(1):151-153

Li Y, Xiao J, de Hoog GS, Wang X, Wan Z, Yu J, Liu W, Li R. 2017. Biodiversity and human-pathogenicity of Phialophora verrucosa and relatives in Chaetothyriales. Persoonia 38:1-19.

Li YM, Haixia WU, Hang C, Hyde KD (2011) Morphological studies in Doithideomycetes: Elsinoe (Elsinoaceae), Butleria and three excluded genera. Mycotaxon 115: 507-520.

Li ZJ, Cao N, Chen HF, Taylor JE, Hou CL (2014c) New species and new records of Rhytismataceae from Japan. Mycological progress 13(3):951-8.

Liang J, Han Y, Du W, Liang Z, Li Z. 2009a Chrysosporium linfenense: a new Chrysosporium species with keratinolytic activity. Mycotaxon. Oct 1;110(1):65-71.

Liang ZQ, Han YF, Chu HL, Fox RT. 2009b Studies on the genus Paecilomyces in China V. Taifanglania gen. nov. for some monophialidic species. Fungal Diversity. Jan 31;34:69.

Liang, L., Shen, R., Mo, Y., Yang, J., Ji, X. and Zhang, K.Q., 2015. A proposed adhesin AoMad1 helps nematode-trapping fungus Arthrobotrys oligospora recognizing host signals for life-style switching. Fungal Genetics and Biology, 81, pp.172-181.

Liang, L., Wu, H., Liu, Z., Shen, R., Gao, H., Yang, J. and Zhang, K., 2013. Proteomic and transcriptional analyses of Arthrobotrys oligospora cell wall related proteins reveal complexity of fungal virulence against nematodes. Applied microbiology and biotechnology, 97(19), pp.8683-8692.

Ligoxigakis, E.K., Papaioannou, I.A., Markakis, E.A. and Typas, M.A., 2013. First report of pink rot of Phoenix and Washingtonia species caused by Nalanthamala vermoesenii in Greece. Plant Disease, 97(2), pp.285-285. 
Lim, Y.W., Kim, B.K., Kim, C., Jung, H.S., Kim, B.S., Lee, J.H. and Chun, J., 2010. Assessment of soil fungal communities using pyrosequencing. The Journal of Microbiology, 48(3), pp.284-289.

Limtong S, Jindamorakot S, Am-In S, Kaewwichian R, Nitiyon S, Yongmanitchai W, Nakase T. Candida uthaithanina sp. nov., an anamorphic yeast species in Nakaseomyces clade isolated in Thailand. Antonie van Leeuwenhoek. 2011 May 1;99(4):865-71.

Lin, C.H. and Chung, K.R., 2010. Specialized and shared functions of the histidine kinaseand HOG1 MAP kinase-mediated signaling pathways in Alternaria alternata, a filamentous fungal pathogen of citrus. Fungal Genetics and Biology, 47(10), pp.818827.

Lin, C.H., Yang, S.L. and Chung, K.R., 2009. The YAP1 homolog-mediated oxidative stress tolerance is crucial for pathogenicity of the necrotrophic fungus Alternaria alternata in citrus. Molecular plant-microbe interactions, 22(8), pp.942-952.

Lin, C.H., Yang, S.L. and Chung, K.R., 2011. Cellular responses required for oxidative stress tolerance, colonization, and lesion formation by the necrotrophic fungus Alternaria alternata in citrus. Current microbiology, 62(3), pp.807-815.

Lin, C.H., Yang, S.L., Wang, N.Y. and Chung, K.R., 2010. The FUS3 MAPK signaling pathway of the citrus pathogen Alternaria alternata functions independently or cooperatively with the fungal redox-responsive AP1 regulator for diverse developmental, physiological and pathogenic processes. Fungal Genetics and Biology, 47(4), pp.381-391.

Linaldeddu BT, Alves A, Phillips AJL. 2016 - Sardiniella urbana gen. et sp. nov., a new member of the Botryosphaeriaceae isolated from declining Celtis australis trees in Sardinian streetscapes. Mycosphere Doi 10.5943/mycosphere/si/1b/5.

Lindblom, L. and Søchting, U., 2013. Genetic diversity of the photobiont of the bipolar lichen-forming ascomycete Xanthomendoza borealis. Herzogia, 26(2), pp.307-322.

Lindblom, L., 2014. Xanthomendoza poeltii is a synonym of X. oregana (Teloschistaceae, lichen-forming ascomycetes). The Lichenologist, 46(06), pp.829-832.

Lindemann U, Vega M, Richter T, Alvarado P (2014):Octosporopsis nicolai - a mysterious member of the Pyronemataceae. Zeitschrift für Mykologie 80/2: 565-592.

Lindemann U., Vega M., Alvarado, P. 2015. Revision der Gattung Kotlabaea: K. deformis, K. delectans und K. Benkertii. Deutsche Gesellschaft fur Mykologie. 81: 373 - 402

Lindemann, U; Böhning, T. 2016. Tricharina glabra (Pezizales) - eine neue Art in einer schwierigen Gattung. Zeitschrift für Mykologie. 82(2):449-458

Linnakoski, R.; Beer, Z.W. de; Ahtiainen, J.; Sidorov, E.; Niemela, P.; Pappinen, A.; Wingfield, M.J. (2010). Ophiostoma spp. associated with pine- and spruce-infesting bark beetles in Finland and Russia. Persoonia 25: 72-93

Linnakoski, R.; Beer, Z.W. de; Rousi, M.; Niemelä, P.; Pappinen, A.; Wingfield, M.J. (2008). Fungi, including Ophiostoma karelicum sp. nov., associated with Scolytus ratzeburgi infesting birch in Finland and Russia. Mycol. Res. 112(12): 1475-1488.

Linnakoski, R.; de Beer, Z.W.; Duong, T.A.; Niemelä, P., Pappinen, A.; Wingfield, M.J. 2012. Grosmannia and Leptographium spp. associated with conifer-infesting bark beetles in Finland and Russia, including Leptographium taigensis sp. nov. Antonie van Leeuwenhoek. 102:375-399

Linnakoski,R., Mahilainen,S., Harrington,A., Vanhanen,H., Eriksson,M., Mehtatalo,L., Pappinen,A. and Wingfield,M.J. Seasonal Succession of Fungi Associated with Ips typographus Beetles and Their Phoretic Mites in an Outbreak Region of Finland. PLoS ONE 11 (5), E0155622 (2016) 
Lisov, A., Zavarzina, A., Zavarzin, A., Demin, V. and Leontievsky, A., 2012. Dimeric and monomeric laccases of soil-stabilizing lichen Solorina crocea: purification, properties and reactions with humic acids. Soil Biology and Biochemistry, 45, pp.161-167.

Lisowska, M., 2011. Lichen recolonisation in an urban-industrial area of southern Poland as a result of air quality improvement. Environmental monitoring and assessment, 179(14), pp.177-190.

Liu F, Cai L. Morphological and molecular characterization of a novel species of Simplicillium from China. Cryptogamie, Mycologie. 2012 Jun;33(2):137-44.

Liu F, Hu D.M.; Cai, L. 2012a. Conlarium duplumascospora gen. et. sp. nov. and Jobellisia guangdongensis sp. nov. from freshwater habitats in China. Mycologia. 104(5):11781186

Liu JK, Hyde KD, Jones KBG, et al. (2015a). Fungal diversity 1-110: taxonomic and phylogenetic contributions to fungal species. Fungal Diversity 72: 1-197.

Liu JK, Jones EBG, Chukeatirote E, Bahkali AH, Hyde KD (2011a) Lignincola conchicola from palms with a key to the species of Lignincola. Mycotaxon 117:343-349

Liu JK, Phookamsak R, Dai DQ, Tanaka K, Jones EBG, Xu JC, Chukeatirote E, Hyde KD (2014b) Roussoellaceae, a new pleosporalean family to accommodate the genera Neoroussoella gen. nov., Roussoella and Roussoellopsis. Phytotaxa 181:1-33

Liu JK, Phookamsak R, Doilom M, Wikee S, Li YM, et al. 2012b - Towards a natural classification of Botryosphaeriales. Fungal Diversity 57, 149-210.

Liu JK, Phookamsak R, Jones EBG, Zhang Y, Ko-Ko TW, Hu HL, Boonmee S, Doilom M, Chukeatirote E, Bahkali AH, Wang Y, Hyde KD (2011b) Astrosphaeriella is polyphyletic, with species in Fissuroma gen. nov., and Neoastrosphaeriella gen. nov. Fungal Divers 51:135-154

Liu K, Zhang W, Lai Y, Xiang M, Wang X, Zhang X, Liu X. 2014c Drechslerella stenobrocha genome illustrates the mechanism of constricting rings and the origin of nematode predation in fungi. Bmc Genomics. Feb 8;15(1):114.

Liu Q, Wang Y, Luo H, Wang L, Shi P, Huang H, Yang P, Yao B (2015b) Isolation of a novel cold-active family 11 Xylanase from the filamentous fungus Bispora antennata and deletion of its N-terminal amino acids on thermostability. Applied Biochemistry and Biotechnology 175:925-936. doi: 10.1007/s12010-014-1344-X

Liu S, Su H, Su, X., Zhang, F., Liao, G. and Yang, X., 2014d. Arthrobotrys xiangyunensis, a novel nematode-trapping taxon from a hot-spring in Yunnan Province, China. Phytotaxa, 174(2), pp.89-96.

Liu TT, Hu DM, Liu F, Cai L. 2013 Polyphasic characterization of Plectosphaerella oligotrophica, a new oligotrophic species from China. mycoscience. Sep 30;54(5):387-93.

Liu XX, Zhuang,W.Y., Zeng,Z.Q. and Zhao,P. 2016 Newly discovered sclerotiniaceous fungi from China. Nova Hedwigia, Volume 102, Numbers 3-4, pp. 347-357(11).

Logesh AR, Chinlampianga M, Shukla, A.C. and Upreti, D.K., 2015. Studies on Lichens of Mizoram, Northeast India. Proceedings of the National Academy of Sciences, India Section B: Biological Sciences, pp.1-13.

Logesh AR, Kalaiselvam M, Upreti DK. A new species of non-lichenized ascomata from India. Mycosphere. 2013 Jan 1;4(1):152-4.

Logrieco, A., Moretti, A. and Solfrizzo, M., 2009. Alternaria toxins and plant diseases: an overview of origin, occurrence and risks. World Mycotoxin Journal, 2(2), pp.129-140.

Lõhmus, A. and Lõhmus, P., 2010. Epiphyte communities on the trunks of retention trees stabilise in 5years after timber harvesting, but remain threatened due to tree loss. Biological Conservation, 143(4), pp.891-898. 
Loizides, M; Bellanger, J-M; Clowez, P; Richard, F; Moreau, P-A. 2016. Combined phylogenetic and morphological studies of true morels (Pezizales, Ascomycota) reveal Cyprus as the new hotspot of Morchella diversity. Mycological Progress. 15(4/39):1-16

Loizides, M; Carbone, M; Alvarado, P. 2015. Geoglossum dunense (Ascomycota, Geoglossales): a new species from the Mediterranean islands of Cyprus and Malta. Mycological Progress. 14(6/41):1-8

Lombard L, Chen SF, Mou X, Zhou XD, Crous PW, Wingfield MJ (2015a) New species, hyper-diversity and potential importance of Calonectria spp. from Eucalyptus in South China. Studies in mycology 80:151-188

Lombard L, Crous PW, Wingfield BD, Wingfield MJ (2010a). Phylogeny and systematics

Lombard L, Crous PW, Wingfield BD, Wingfield MJ (2010b). Species concepts in Calonectria (Cylindrocladium). Studies in Mycology 66: 1-14

Lombard L, Houbraken J, Decock C, Samson RA, Meijer M, et al (2016) Generic hyperdiversity in Stachybotriaceae. Persoonia: Molecular Phylogeny and Evolution of Fungi 36: 156-246.

Lombard L, Merwe NA van der, Groenewald JZ, Crous PW (2014) Lineages in Nectriaceae: re-evaluating the generic status of Ilyonectria and allied genera. Phytopathologia Mediterranea 53(3):515-32.

Lombard L, Shivas RG, To-Anun C, Crous PW. Phylogeny and taxonomy of the genus Cylindrocladiella. Mycological Progress. 2012 Nov 1;11(4):835-68.

Lombard L, van der Merwe NA, Groenewald JZ, Crous PW (2015b) Generic concepts in Nectriaceae. Stud Mycol 80:189-245

London, L.S., 2016. Schismatomma galactinum (lichenized ascomycota), a lichen species new to India. CURRENT SCIENCE, 110(5), p.770.

López de Silanes, M.E.; Etayo, J.; Paz-Bermúdez, G. 2009. Pronectria pilosa (Hypocreaceae) sp. nov. and other lichenicolous fungi found on Collemataceae in the Iberian Peninsula. The Bryologist. 112(1):101-108.

Loppi, S. and Nascimbene, J., 2010. Monitoring H2S air pollution caused by the industrial exploitation of geothermal energy: the pitfall of using lichens as bioindicators. Environmental Pollution, 158(8), pp.2635-2639.

Lorch,J.M;Minnis,A.M;Meteyer,C.U;Redell,J.A;White,J.P;Kaarakka,H.M;Muller,L.M;Lindn er,D.L;Verant,M.L;Shearn-Bochsler,V;Blehert,D.S. 2014. The Fungus Trichophyton redellii sp. nov. Causes Skin Infections that Resemble White-nose Syndrome of Hibernating Bats. Journal of Wildlife Diseases. 51:36-47

Lou, J., Fu, L., Peng, Y. and Zhou, L., 2013. Metabolites from Alternaria fungi and their bioactivities. Molecules, 18(5), pp.5891-5935.

Lu,M., Zhou,X.D., De Beer,Z.W., Wingfield,M.J. and Sun,J.-H. 2009 Ophiostomatoid fungi associated with the invasive pine-infesting bark beetle, Dendroctonus valens, in China. Fungal Divers. 38, 133-145

Luangsa-ard, J.J.; Houbraken, J.A.M.P.; Doorn, T. van; Hong, S.B.; Borman, A.M.; HywelJones, N.L.; Samson, R.A. (2011). Purpureocillium, a new genus for the medically important Paecilomyces lilacinus. FEMS Microbiol. Lett. 321(2): 141-149.

Luangsuphabool,T., Piapukiew,J., Parnmen,S., Nelsen,M.P., Lumbsch,H.T. and Sangvichien,E. 2016 Diversity of the Trypethelium eluteriae group in Thailand(Ascomycota, Trypetheliales). Lichenologist (Lond.) 48, 53-60

Łubek, A., 2012. The lichen biota of Skałki Piekło pod Niekłaniem "Nature Reserve-current state and changes in species composition over the past 100 years. Pol. J. Natur. Sci, 27(2), pp.135-150.

Lücking R (2008) Foliicolous lichenized fungi. Fl Neotrop Monogr 103:1-866. 
Lücking R (2014) A key to species of the Ocellularia papillata, perforata and terebrata morphodemes. Glalia 6(3): 1-35.

Lücking R, Archer AW, Aptroot A (2009) A world-wide key to the genus Graphis (Ostropales: Graphidaceae). Lichenologist 41:363-452

Lücking R, Breuss O (2012) A new species of Thelotrema, a new combination, Leucodecton isidioides, and a key to thelotremoid lichens of Macaronesia (lichenised Ascomycota: Graphidaceae). Österr. Z. Pilzk. 21: 127-133.

Lücking R, Chaves JL, Sipman HJM, Umana L, Aptroot A (2008a) A first assessment of the Ticolichen biodiversity inventory in Costa Rica: The genus Graphis, with notes on the genus Hemithecium (Ascomycota: Ostropales: Graphidaceae). Fieldiana, Botany, New series 46: 1-140.

Lücking R, Gutiérrez MC, Moncada B (2016a) Neosergipea, a new name for the lichen fungus Sergipea, with an updated phylogeny and notes on the genus Dichosporidium (lichenized Ascomycota: Arthoniales: Roccellaceae). - The Lichenologist 48(4): 269273.

Lücking R, Hodkinson BP, Leavitt SD. (2016b) The 2016 classification of lichenized fungi in the Ascomycota and Basidiomycota-Approaching one thousand genera. The Bryologist. Dec;119(4):361-416.

Lücking R, Johnston MK, Aptroot A, Kraichak E, Lendemer JC, et al. (2014) One hundred and seventy-five new species of Graphidaceae: closing the gap or a drop in the bucket? Phytotaxa 189 (1): 7-8

Lücking R, Lumbsch HT, Di Stefano JF, Lizano D, Carranza J, et al. (2008b). Eremithallus costaricensis (Ascomycota: Lichinomycetes: Eremothallales), a new fungal lineage with a novel lichen symbiotic lifestyle discovered in an urban relict forest in Costa Rica. Symbiosis 46 (3), 161-170.

Lücking R, Nelsen MP, Aptroot A, Barillas de Klee R, Bawingan PA, et al. (2016c). A phylogenetic framework for reassessing generic concepts and species delimitation in the lichenized family Trypetheliaceae (Ascomycota: Dothideomycetes). Lichenologist 48: 739-762.

Lücking R, Parnmen S, Lumbsch HT (2012) Mangoldia, a new lichen genus in the family Graphidaceae (Ascomycota: Ostropales). Phytotaxa69: 1-5.

Lücking R, Rivas Plata E, Kalb, K., Common, R., Barcenas Peña, A \& Duya, M. V. 2011 Halegrapha (Ascomycota: Graphidaceae), an enigmatic new genus of tropical lichenized fungi dedicated to Mason E. Hale. Jr. Lichenologist 43: 331-344

Lücking R, Tehler A, Bungartz F, Rivas Plata E, Lümbsch HT (2013) Journey from the West: Did tropical Graphidaceae (lichenized Ascomycota: Ostropales) evolve from a saxicolous ancestor along the American Pacific coast. Am J Bot. 100(5):844-56

Lumbsch HT, Ahti T, Altermann S, Amo De Paz G, Aptroot A, et al. (2011) One hundred new species of lichenized fungi: a signature of undiscovered global diversity. Phytotaxa 18:1-127

Lumbsch HT, Divakar PK, Messuti, M.I.; Mangold, A.; Lücking, R. (2010a). A survey of thelotremoid lichens (Ascomycota: Ostropales) in subantarctic regions excluding Tasmania. Lichenologist 42(2): 203-224.

Lümbsch HT, Huhndorf SM (2010) Outline of Ascomycota 2009. Myconet 14:1-64.

Lumbsch HT, Kraichak E, Parnmen S, Rivas Plata E, Aptroot A, et al. (2014a) New higher taxa in the lichen family Graphidaceae (lichenized Ascomycota: Ostropales) based on a three-gene skeleton phylogeny. Phytotaxa 189:89-51

Lumbsch HT, Lücking, R.O.B.E.R.T. and Tibell, L.E.I.F., 2009b. Molecular data place Tylophoron as an additional calicioid genus in the Arthoniales (Ascomycota). Biblioth Lichenol, 99, pp.285-296. 
Lumbsch HT, Nelsen MP, Lücking R (2008) The phylogenetic position of Haematommataceae (Lecanorales, Ascomycota), with notes on secondary chemistry and species delimitation. Nova Hedwigia 86(1-2): 105-114

Lumbsch HT, Parnmen S, A. Rangsiruji \& J. A. Elix. 2010b. Phenotypic disparity and adaptive radiation in the genus Cladia (Lecanorales, Ascomycota). Australian Systematic Botany 23: 239-247.

Lumbsch HT, Parnmen S, Kraichak E, Papong,K.B. and Luecking,R. 2014b High frequency of character transformations is phylogenetically structured within the lichenized fungal family Graphidaceae (Ascomycota: Ostropales). System. Biodivers. 12 (3), 271-291 (2014)

Lumbsch HT, Zimmermann DG, Schmitt I. 2009a Phylogenetic position of ephemeral lichens in Thelocarpaceae and Vezdaeaceae (Ascomycota). Bibliotheca Lichenologica.; 100:389-98.

Lumbsch T, Kantvilas G, Parnmen S. 2012 Molecular data support placement of Cameronia in Ostropomycetidae (Lecanoromycetes, Ascomycota). MycoKeys. Nov 30;5:31.

Lumbsch, H.T., 2014. Steven D. Leavitt, Theodore L. Esslinger, Eric Steen Hansen, Pradeep K. Divakar, Ana Crespo, Bradley F. Loomis \&. Org Divers Evol, 14, pp.11-20.

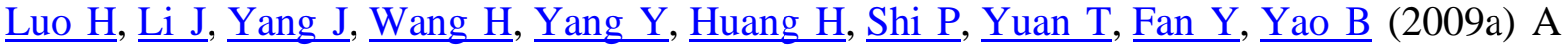
thermophilic and acid stable family-10 xylanase from the acidophilic fungus Bispora sp. MEY-1. Extremophiles 13:849-857. doi:10.1007/s00792-0090272-0

$\underline{\text { Luo H}}$, Wang Y, Wang H, Yang J, Yang Y, Huang H, Yang P, Bai Y, Shi P, Fan Y, Yao B (2009b) A novel highly acidic beta-mannanase from the acidophilic fungus Bispora sp. MEY-1: gene cloning and overexpression in Pichia pastoris. Applied Microbiology and Biotechnology 82:453-461. doi: 10.1007/s00253-008-1766-x

Luo J, Walsh E, Zhang N (2014) Four new species in Magnaporthaceae from grass roots in New Jersey Pine Barrens. Mycologia. 106(3):580-588

Luo J, Zhang N (2013) Magnaporthiopsis, a new genus in Magnaporthaceae (Ascomycota). Mycologia105:1019-29

Luo J, Zhuang, W.Y., 2010. New species and new Chinese records of Bionectriaceae (Hypocreales, Ascomycota). Mycological progress, 9(1), pp.17-25.

Luo Y, Lu XH, Bi W, Liu F, Gao W. 2016a. Talaromyces rubrifaciens, a new species discovered from heating, ventilation, and air conditioning systems in China. Mycologia 108:773-779.

Luo ZL, Bahkali AH, Liu XY, Phookamsak R. Zhao YC, Xhou DQ, Su HY, Hyde KD (2016b) Poaceascoma aquaticum sp. nov. (Lentitheciaceae), a new species from submerged bamboo in freshwater. Phytotaxa 253:71-80

Luo ZL, Maharachchikumbur SSN, Liu X, Chen L, Zhou D, Su H, Hyde K. 2015 Annulatascus saprophyticus sp. nov. and Pseudoannulatascus gen. nov. to accommodate Annulatascus biatriisporus (Annulatascales, Sordariomycetes) from Thailand. Phytotaxa 239(2):174-82.

Luo, H., Yamamoto, Y., Kim, J.A., Jung, J.S., Koh, Y.J. and Hur, J.S., 2009. Lecanoric acid, a secondary lichen substance with antioxidant properties from Umbilicaria antarctica in maritime Antarctica (King George Island). Polar Biology, 32(7), pp.1033-1040.

Lysková P, Hubka V, Navrátilová P, Kolařík M, Skořepová M. Two cases of fungal infection of nails with participation of Cryptendoxyla hypophloia. Klinicka mikrobiologie a infekcni lekarstvi. 2014 Mar;20(1):23-6.

Ma HX, Vasilyeva L, Li Y. 2012a The genus Xylaria in the south of China-3. X. atroglobosa sp. nov. Mycotaxon. Apr 12;119(1):381-4. 
Ma HX, Vasilyeva L, Li Y. Xylaria in southern China-8. X. bannaensis sp. nov. and X. brunneovinosa new to the mainland. Mycotaxon. 2013 Nov 20;125(1):251-6.

Ma J 2016. Sporidesmiella guangdongensis and S. jiangxiensis spp. nov. on dead branches from southern China. Sydowia. 68:113-118

Ma J, Ma LG, Zhang YD, Castañeda-Ruíz RF, Zhang XG (2012b) New species and record of Corynesporopsis and Hemicorynespora from southern China. Nova Hedwigia, 95(1-2), pp.233-241.

Ma J, Ma LG, Zhang YD, Castañeda-Ruíz RF, Zhang XG (2012c) New species or records of Endophragmiella and Heteroconium from southern China. Cryptogamie, Mycologie, 33(2), pp.127-135.

Ma J, Ma LG, Zhang YD, Xia JW, Zhang XG (2012d) New species and a new record of Solicorynespora from southern China. Mycotaxon. Apr 12;119(1):95-102.

Ma J, Ma LG, Zhang YD, Zhang XG 2011a. Three new hyphomycetes from southern China. Mycotaxon, 117, pp. 247-253.

Ma J, Ren SC, Ma, L.G., Zhang, Y.D. and Zhang, X.G., 2010a. New records of Corynesporopsis from China. Mycotaxon, 114(1), pp.423-428.

Ma J, Wang Y, Ma LG, Zhang YD, Castañeda-Ruíz RF, Zhang XG 2011b. Three new species of Neosporidesmium from Hainan, China. Mycological Progress. May $1 ; 10(2): 157-62$.

Ma J, Xia JW, Zhang XG, Luo YQ, Castañeda-Ruíz RF. Solicorynespora species associated with dead branches of subtropical forests in southern china. Cryptogamie, Mycologie. 2016 Apr 8.

Ma J, Zhang K, Zhang, X.G., 2008. Two new Ellisembia species from Hainan, China. Mycotaxon, 104, pp. 141-145.

Ma J, Zhang XG, Castañeda-Ruiz RF. New species of Acrodictys and Repetophragma from dead branches in China. Mycotaxon. 2014 May 29;127(1):129-34.

Ma J, Zhang XG. \& Castaneda-Ruiz, R.F. 2014. New species of Acrodictys and Repetophragma from dead branches in China. Mycotaxon 127: 129-134

Ma J, Zhang YD, Ma LG, Castañeda-Ruíz RF, Zhang XG 2012e Three new species of Sporidesmiella from southern China. Mycoscience. May 1;53(3):187-93.

Ma J, Zhang, Y.D., Ma, L.G., Ren, S.C., Zhang, X.G., 2010b. Taxonomic studies of Ellisembia from Hainan, China. Mycotaxon, 114,pp.417-421.

Ma LG, Ma J, Zhang YD, Castañeda-Ruíz RF, Zhang XG (2012f) New species and records of Heteroconium (anamorphic fungi) from southern China. Mycoscience, 53(6), pp.466-470.

Ma LG, Ma J, Zhang YD, Zhang XG (2012g) A new Corynesporella species and two first records from China. Mycotaxon, 119(1), pp.83-88.

Ma LG, Ma J, Zhang YD, Zhang XG. 2012h Spadicoides camelliae and Diplococcium livistonae, two new hyphomycetes on dead branches from Fujian Province, China. Mycoscience. Jan 1;53(1):25-30.

Ma LG, Ma J, Zhang YD, Zhang, X.G. 2011c. Craspedodidymum and Corynespora spp. nov. and a new anamorph recorded from southern China. Mycotaxon. 117:351-358.

Ma LG, Xia JW, Ma YR, Castañeda-Ruíz RF, Zhang, X.G. 2014. Two new species of Spadicoides and Gangliostilbe from southern China. Mycological Progress. 13:547552

Ma YR, Xia JW, Zhang XG, Castañeda-Ruiz, R.F. 2015. New species of Phaeomonilia and Mirandina from dead branches in China. Mycotaxon 130(3): 775-781. http://dx.doi.org/10.5248/130.775 
Machado, A.R., Pinho, D.B., Silva, M. and Pereira, O.L., 2012. First report of leaf spot disease caused by Cercosporella pfaffiae on Brazilian ginseng (Pfaffia glomerata) in Brazil. Plant Disease, 96(11), pp.1702-1702.

Machouart M, Samerpitak K, de Hoog GS, Gueidan C (2014) A multigene phylogeny reveals that Ochroconis belongs to the family Sympoventuriaceae (Venturiales, Dothideomycetes). Fungal Divers 65:77-88.

Maciá-Vicente JG, Glynou K, Piepenbring M. 2016. A new species of Exophiala associated with roots. Mycol Progress 15:18.

Madrid H, Cano J, Gené J, Guarro J (2011a) Two new species of Cladorrhinum. Mycologia. 103(4):795-805

Madrid H, Gené J, Cano, J.; Guarro, J. 2011b. A new species of Leptodiscella from Spanish soil. Mycological Progress. 11:535-541.

Madrid H, Hernández-Restrepo M, Gené J, Cano J, Guarro J, Silva V. New and interesting chaetothyrialean fungi from Spain. Mycological Progress. 2016 Oct 1;15(1011):1179-201.

Madrid H.; Cano, J.F.; Stchigel, A.; Gené, J.; Guarro, J. (2010). Ramophialophora humicola and Fibulochlamys chilensis, two new microfungi from soil. Mycologia 102(3): 605612.

Magain N, Sérusiaux E (2012) A further new species in the lichen genus Arctomia: A. borbonica from Reunion (Mascarene archipelago). MycoKeys 4:9-21

Magain N, Sérusiaux E. 2014 Do photobiont switch and cephalodia emancipation act as evolutionary drivers in the lichen symbiosis? A case study in the Pannariaceae (Peltigerales). PloS one. Feb 24;9(2):e89876.

Magain, N., Miadlikowska, J., Goffinet, B., Serusiaux, E. and Lutzoni, F.2016. Macroevolution of Specificity in Cyanolichens of the Genus Peltigera Section Polydactylon (Lecanoromycetes, Ascomycota). Syst. Biol. 2016 Aug 6. pii: syw065. [Epub ahead of print]

Magain, N.; Sérusiaux, E. 2015. Dismantling the treasured flagship lichen Sticta fuliginosa (Peltigerales) into four species in Western Europe. Mycological Progress. (2015) 14:97:1-33

Magalhães, D.M.A., Luz, E.D.M.N., Magalhães, A.F., Dos Santos, M.V.O., Barbosa, F.R., Magalhães, L.A. andBezerra, J.L. (2014). Anamorphic fungi of the Atlantic forest of southern Bahia: new records and Dactylaria pseudomanifesta sp. nov. Mycotaxon 128: 185-194.

Magyar D, Shoemaker RA, Bobvos J, Crous PW, Groenewald JZ. Pyrigemmula, a novel hyphomycete genus on grapevine and tree bark. Mycological Progress. 2011 Aug 1;10(3):307-14.

Mahajan VK, Sharma V, Prabha N, Thakur K, Sharma NL, Rudramurthy SM, Chauhan PS, Mehta KS, Abhinav C. A rare case of subcutaneous phaeohyphomycosis caused by a rhytidhysteron species: A clinico-therapeutic experience. Int $\mathrm{J}$ Dermatol. 2014;53(12):1485-9.

Maharachchikumbura SN, Hyde KD, Jones EBG, McKenzie EHC, Huang SK, et al. (2015) Towards a natural classification and backbone tree for Sordariomycetes. Fungal Divers 72:199-301

Maharachchikumbura SSN, Hyde KD, Jones EBG, McKenzie EHC, Bhat JD, et al. 2016 Families of Sordariomycetes. Fungal Diversity 79:1-317.

Mahmoud, R.S. and Narisawa, K., 2013. A new fungal endophyte, Scolecobasidium humicola, promotes tomato growth under organic nitrogen conditions. PloS one, 8(11), p.e78746. 
Maier, S., Schmidt, T.S., Zheng, L., Peer, T., Wagner, V. and Grube, M., 2014. Analyses of dryland biological soil crusts highlight lichens as an important regulator of microbial communities. Biodiversity and conservation, 23(7), pp.1735-1755.

Malíček J, Bouda F, Liška J, Palice Z, Peksa, O., 2015a. Contribution to the lichen biota of the Romanian Carpathians. Herzogia, 28(2), pp.713-735.

Malíček J, Palice Z, Vondrák J 2015b. New lichen records and rediscoveries from the Czech Republic and Slovakia.

Mamgain, A., Roychowdhury, R. and Tah, J., 2013. Alternaria pathogenicity and its strategic controls. Res J Biol, 1, pp.1-9.

Man,B., Wang,H., Xiang,X., Wang,R., Yun,Y. and Gong,L. 2015 Phylogenetic diversity of culturable fungi in the Heshang Cave, central China. Front Microbiol 6, 1158

Manamgoda, D.S., Cai, L., McKenzie, E.H., Crous, P.W., Madrid, H., Chukeatirote, E., Shivas, R.G., Tan, Y.P. and Hyde, K.D., 2012. A phylogenetic and taxonomic reevaluation of the Bipolaris-Cochliobolus-Curvularia complex. Fungal Diversity, 56(1), pp.131-144.

Manamgoda, D.S., Rossman, A.Y., Castlebury, L.A., Crous, P.W., Madrid, H., Chukeatirote, E. and Hyde, K.D., 2014. The genus Bipolaris. Studies in mycology, 79, pp.221-288.

Mangold A, Elix, J.A.; Lumbsch, H.T. 2009. Thelotremataceae. Flora of Australia. 57:653659

Mangold A, Martin MP, Kalb, K.; Lucking, R.; Lumbsch, H.T. (2008a). Molecular data shows that Topeliopsis (Ascomycota, Thelotremataceae) is polyphyletic. Lichenologist 40(1): 39-46.

Mangold A, Martin MP, Luecking R., Lumbsch HT (2008b) Molecular phylogeny suggests synonymy of Thelotremataceae within Graphidaceae (Ascomycota: Ostropales). Taxon 57(2): 476-486

Manoharachary C, Bagyanarayana G, Rao NK, Kunwar IK (2009) Chasakopama, a new dematiaceous hyphomycetous genus from India. Mycotaxon 110(1): 459-463.

Manoharachary C, Kunwar IK, Kumar GS, Reddy BS (2010) Two new species of Actinocladium Ehrenb. from India. Indian Phytopathology 63:83-84

Manojlović NT, Vasiljevic P, Juskovic M., Najman, S., Bogdanovic-Duanovic, G., Joksimovic, Z. and Milenkovic-Andjelkovic, A., 2010a. Screening of Thamnolia vermicularis var. subuliformis for antimicrobial, antioxidant and cytotoxic activities. Planta Medica, 76(12), p.P442.

Manojlović NT, Vasiljević P, Jusković, M. and Janković, S.N.S., 2010b HPLC analysis and cytotoxic potential of extracts from the lichen, Thamnolia vermicularis var. subuliformis. Journal of Medicinal Plants Research, 4(9), pp.817-823.

Manojlović NT, Vasiljevic, P.J., Maskovic, P.Z., Juskovic, M. and Bogdanovic-Dusanovic, G., 2011. Chemical composition, antioxidant, and antimicrobial activities of lichen Umbilicaria cylindrica (L.) Delise (Umbilicariaceae). Evidence-based complementary and alternative medicine, 2012.

Mansour, A.M., 2010. Contribution to knowledge of some soil fungi in eastern region in Lybia. J Product Dev, 15(3), pp.395-404.

Mapook A, Boonmee S, Ariyawansa HA, Tibpromma S, Campesori E, Jones EG, Bahkali AH, Hyde KD. 2016a Taxonomic and phylogenetic placement of Nodulosphaeria. Mycological progress. Apr 1;15(4):1-5.

Mapook A, Boonmee S, Liu JK, Jones EG, Bahkali AH, Hyde KD 2016b. Taxonomic and phylogenetic placement of Phaeodimeriella (Pseudoperisporiaceae, Pleosporales). Cryptogamie, Mycologie 37(2):157-176. 
Mapook A, Hyde KD, Dai,D.-Q., Li,J., Jones,E.B.G., Bahkali,A.H. Boonmee,S. 2016c Muyocopronales, ord. nov., (Dothideomycetes, Ascomycota) and a reappraisal of Muyocopron species from northern Thailand. Phytotaxa 265 (3), 225-237.

Mapperson, R.R., Kotiw, M., Davis, T.A. \& Dearnaley, J.D.W. (2014). The diversity and antimicrobial activity of Preussia sp. Endophytes isolated from Australian dry rainforests. Current Microbiology 68: 30-37. http://dx.doi.org/10.1007/s00284-0130415-5

Marincowitz S, Crous PW, Groenewald JZ, Wingfield MJ (2008) Microfungi occurring on the Proteaceae in the fynbos. CBS Diversity Ser. 7: [iii], 166 pp.+ incl. colour plates Utrecht: Centraalbureau voor Schimmelcultures.

Marincowitz S, Duong TA, de Beer ZW, Wingfield MJ. Cornuvesica: A little known mycophilic genus with a unique biology and unexpected new species. Fungal biology. 2015 Jul 31;119(7):615-30.

Marincowitz, S., Gryzenhout, M. and Wingfield, M.J., 2010. New and rare coelomycetes with appendage-bearing conidia from Pondoland, South Africa. Mycotaxon, 111(1), pp.309-322.

Marin-Felix Y, Cano-Lira JF, Guarro J, Stchigel AM. Leiothecium cristatum sp. nov. and Aspergillus posadasensis sp. nov., two species of Eurotiales from rainforest soils in South America. International journal of systematic and evolutionary microbiology. 2014 Aug 1;64(8):2871-7.

Marin-Felix Y, Stchigel AM, Miller AN, Guarro J, Cano-Lira JF. A re-evaluation of the genus Myceliophthora (Sordariales, Ascomycota): its segregation into four genera and description of Corynascus fumimontanus sp. nov. Mycologia. 2015 May 1;107(3):619-32.

Mark, K., Cornejo, C., Keller, C., Fluck, D. and Scheidegger, C. 2016. Barcoding lichenforming fungi using 454 pyrosequencing is challenged by artifactual and biological sequence variation Genome 59 (9), 685-704.

Mark, K., Saag, L., Saag, A., Thell, A. and Randlane, T. 2012. Testing morphology-based delimitation of Vulpicida juniperinus and V. tubulosus (Parmeliaceae) using three molecular markers. Lichenologist (Lond.) 44 (6), 757-772.

Martellos, S., Attorre, F., Farcomeni, A., Francesconi, F., Pittao, E. and Tretiach, M., 2014. Species distribution models backing taxa delimitation: the case of the lichen Squamarina cartilaginea in Italy. Flora-Morphology, Distribution, Functional Ecology of Plants, 209(12), pp.698-703.

Martinez, A.D.S., Franzener, G. and Stangarlin, J.R., 2010. Damages caused by Bipolaris maydis in Panicum maximum cv. Tanzânia. Semina: Ciências Agrárias (Londrina), 31(4), pp.863-870.

Martinović T, Koukol O, Hirose D. Distinct phylogeographic structure recognized within Desmazierella acicola. Mycologia. 2016 Jan 1;108(1):20-30.

Marvanová L \& Laichmanová M. (2014) Campylospora leptosoma sp. nov. and characteristics of Campylospora spp., based on morphology and on ITS sequences. Mycosphere 5(2): 245-261.

Masiulionis,V.E;Cabello,M;Seifert, ～K.A.;Rodrigues,A;Pagnocca,F.C. 2015. Escovopsis trichodermoides sp. nov., isolated from a nest of the lower attine ant Mycocepurus goeldii. Antonie van Leeuwenhoek. 107:731-740.

Masson, D., Divakar, P. K. and Serusiaux, E. Hypotrachyna penduliloba and Remototrachyna pandani, two new species in the hyperdiverse lichen family Parmeliaceae from Reunion in the Mascarene archipelago 2015. Mycological Progress 14, 22. 
Masumoto S, Tojo M, Uchida M, Imura S. Morphological and molecular characterization of Rhytisma filamentosum sp. nov. from Nagano Prefecture, Japan. Mycological Progress. 2015 Jun 1;14(6):1-6.

Masumoto S, Tojo M, Uchida M, Imura S. Rhytisma polaris: morphological and molecular characterization of a new species from Spitsbergen Island, Norway. Mycological progress. 2014 Feb 1;13(1):181-8.

Masuya, H.; Yamaoka, Y.; Wingfield, M.J. 2009. Ophiostomatoid fungi and their associations with bark beetles in Japan. CBS Biodiversity Series. 96:275-293.

Matei, S. and Fendrihan, S., 2008. Microbiological studies of East Antarctic soils. Geophysical Research Abstracts,Vol. 10.

Mateus, N., Aguirre, J. and Luecking, R., 2012. Contributions to the foliicolous lichen biota of Chocó (Colombia). Caldasia, 34(1), pp.25-32.

MATHUR N, SINGH O, MAHESWARI CU. 2009 Polyrostrata, a new genus of Sphaeropsidaceae from India. Indian Phytopathology.;62(2):233-6.

Matočec N, Kušan I, Ozimec R (2014) The genus Polycephalomyces (Hypocreales) in the frame of monitoring Veternica cave (Croatia) with a new segregate genus Perennicordyceps. Ascomycete.org, 6 (5) : 125-133.

Matos, T., Cerar, T., Praprotnik, M., Krivec, U. and Pirš, M., 2015. First recovery of Rasamsonia argillacea species complex isolated in adolescent patient with cystic fibrosis in Slovenia-case report and review of literature. Mycoses, 58(8), pp.506-510.

Matsuda, Y., Kimura, K. and Ito, S.I., 2010. Genetic characterization of Raffaelea quercivora isolates collected from areas of oak wilt in Japan. Mycoscience, 51(4), pp.310-316.

Matsuwaki, Y., Wada, K., White, T., Moriyama, H. and Kita, H., 2012. Alternaria fungus induces the production of GM-CSF, interleukin-6 and interleukin-8 and calcium signaling in human airway epithelium through protease-activated receptor 2 . International archives of allergy and immunology, 158(Suppl. 1), pp.19-29.

Matthews, J.A. and Trenbirth, H.E., 2011. Growth rate of a very large crustose lichen (Rhizocarpon subgenus) and its implications for lichenometry. Geografiska Annaler: Series A, Physical Geography, 93(1), pp.27-39.

Matusinsky, P., Frei, P., Mikolasova, R., Svacinova, I., Tvaruzek, L. and Spitzer, T., 2010. Species-specific detection of Bipolaris sorokiniana from wheat and barley tissues. Crop Protection, 29(11), pp.1325-1330.

Matwiejuk, A. and Bohdan, A., 2011. New Records of Plectocarpon lichenum from Bialowieza Forest (Poland). Herzogia, 24(2), pp.381-383.

Matwiejuk, A. and Korobkiewicz, K., 2012. Lichens of Narew and its surroundings (Podlasie, North-Eastern Poland). Roczniki Akademii Rolniczej w Poznaniu. Botanika-Steciana, 16.

Mayers CG, McNew DL, Harrington TC, Roeper RA, Fraedrich SW, Biedermann PH, Castrillo LA, Reed SE (2015) Three genera in the Ceratocystidaceae are the respective symbionts of three independent lineages of ambrosia beetles with large, complex mycangia. Fungal Biology 119:1075-1092

Mayfield III, A.E., Smith, J.A., Hughes, M. and Dreaden, T.J., 2008. First report of laurel wilt disease caused by a Raffaelea sp. on avocado in Florida. Plant Disease, 92(6), pp.976-976.

Mayrhofer, H., Drescher, A., Stešević, D. and Bilovitz, P.O., 2013. Lichenized fungi of a chestnut grove in Livari (Rumija, Montenegro). Acta Botanica Croatica, 72(2), pp.337-346.

Mayrhofer, H., Malíček, J., Rohrer, A., Svoboda, D. and Bilovitz, P.O., 2012. New or otherwise interesting lichenized and lichenicolous fungi from Macedonia. Inst. für Pflanzenwiss.. 
Mazzaferro L, Piñuel L, Minig M, Breccia JD. Extracellular monoenzyme deglycosylation system of 7-O-linked flavonoid $\beta$-rutinosides and its disaccharide transglycosylation activity from Stilbella fimetaria. Archives of microbiology. 2010 May 1;192(5):38393.

Mbenoun M, De Beer ZW, Wingfield MJ, Wingfield BD, Roux J. Reconsidering species boundaries in the Ceratocystis paradoxa complex, including a new species from oil palm and cacao in Cameroon. Mycologia. 2014 Jul 1;106(4):757-84.

Mbenoun M, Wingfield MJ, Begoude Boyogueno AD, Nsouga Amougou F, Petchayo Tigang S, Hoopen GM, Mfegue CV, Dibog L, Nyassé S, Wingfield BD, Roux J. Diversity and pathogenicity of the Ceratocystidaceae associated with cacao agroforests in Cameroon. Plant Pathology. 2016 Jan 1;65(1):64-78.

McCarthy P, Elix J (2016) Five new lichen species (Ascomycota) from south-eastern Australia. Telopea, 19, pp.137-151.

McCarthy PM (2010) New and interesting foliicolous lichens from Australia. Australas. Lichenol. 66: 4-15.

McCarthy PM (2014) Additional lichen records from Australia 77. Verrucariaceae. Australasian Lichenology, 75, pp.3-5.

McCarthy PM, Kantvilas G (2013a) Psoroglaena halmaturina sp. nov.(lichenised Ascomycota, Verrucariaceae) from Kangaroo Island, South Australia. Journal of the Adelaide Botanic Garden, pp.1-4.

McCarthy PM, Kantvilas G (2013b) Two new species of Sarcogyne (lichenised Ascomycota: Acarosporaceae) from central and southern Australia. Journal of the Adelaide Botanic Garden, pp.15-21.

McCarthy PM, Kantvilas G (2014) Placynthium australiense sp. nov.(lichenised Ascomycota, Placynthiaceae) from South Australia. Journal of the Adelaide Botanic Gardens, pp.15.

McCarthy PM, Stajsic V. (2013) Phylloblastia blechnicola (Ascomycota, Verrucariaceae), a new leaf-inhabiting lichen from southern Victoria, Australia. Muelleria.;31:49-52.

McCune B, Altermann S (2009) Letharia gracilis (Parmeliaceae), a new species from California and Oregon. Bryologist 112(2): 375-378.

McCune B, Curtis MJ (2012) Umbilicaria semitensis (lichenized fungi: Umbilicariaceae) resurrected. The Bryologist, 115(2), pp.255-264.

McCune B, Di Meglio J, Curtis MJ (2014) An unusual ascospore shape and a new species, Umbilicaria nodulospora (Umbilicariaceae), from California and Oregon. The Bryologist, 117(2), pp.170-178.

McCune B, Rosentreter R (2014) New lichen records from Oregon to Alaska in North America. Evansia, 31(1), pp.1-7.

McCune B, Stone J (2009) Leightoniomyces phillipsii, a synnematous soil-dwelling hyphomycete new to North America. North American Fungi 4 (5): 1-4.

Mckenzie EHC (2008) Two new dictyosporous hyphomycetes on Pandanaceae. Mycotaxon 104: $23-28$

McKenzie EHC (2009) A new species of Lylea (hyphomycetes) on Rhopalostylis (Arecaceae) in New Zealand. Mycotaxon 109: 39-42.

McKenzie EHC, Park D, Bellgard SE.; Johnston, P.R. 2010. A new species of Pyricularia (hyphomycetes) on Cortaderia (Poaceae) in New Zealand. Mycosphere. 1(3):223-228

McKenzie, E.H.C. (2010). Three new phragmosporous hyphomycetes on Ripogonum from an 'ecological island' in New Zealand. Mycotaxon 111: 183-196.

McMullin R, Lendemer J, Heather B (2016) Molecular insights into the lichen genus Alectoria (Parmeliaceae) in North America. Canadian Science Publishing, Botany 94(3):165-75. 
McMullin RT. The Lichens of Prince Edward Island, Canada: A Second Checklist, with Species Ranked for Conservation Status. Rhodora. 2015 117(972):454-84.

Mcmullin, R.T. and Arsenault, A., 2016. The Calicioids of Newfoundland, Canada. Opuscula Philolichenum, 15, pp.92-104.

Mcmullin, R.T., Maloles, J.R. and Newmaster, S.G., 2015. New and interesting lichens from Ontario, Canada-II. Opuscula Philolichenum, 14, pp.93-108.

Mcmullin, R.T., Thompson, I.D. and Newmaster, S.G., 2013. Lichen conservation in heavily managed boreal forests. Conservation Biology, 27(5), pp.1020-1030.

Medeiros ID, Kraichak E, Lücking R, Mangold A, Lumbsch HT. Assembling a taxonomic monograph of tribe Wirthiotremateae (lichenized Ascomycota: Ostropales: Graphidaceae). Fieldiana Life and Earth Sciences. 2017 Apr 28;9(1):1-31.

Medeiros, I.D., Fryday, A.M. and Rajakaruna, N., 2014. Additional lichen records and mineralogical data from metal-contaminated sites in Maine. Rhodora, 116(967), pp.323-347.

Meena N, Mishra, V.K., Baranwal, D.K., Singh, A.K., Rai, V.P., Prasad, R., Arun, B. and Chand, R., 2014. Genetic Evaluation of Spring Wheat (Triticum aestivum L.) Recombinant Inbred Lines for Spot Blotch (Bipolaris Sorokiniana) Resistance and Yield Components under Natural Conditions for South Asia. Journal of Agricultural Science and Technology, 16(6), pp.1429-1440.

Meena, P.D., Awasthi, R.P., Chattopadhyay, C., Kolte, S.J. and Kumar, A., 2016. Alternaria blight: a chronic disease in rapeseed-mustard. Journal of Oilseed Brassica, 1(1), pp.111.

Meirelles L. A.; Montoya Q. V.; Solomon, S. E.; Rodrigues, A. 2015. New Light on the Systematics of Fungi Associated with Attine Ant Gardens and the Description of Escovopsis kreiselii sp. nov. PloS ONE. 10:1-14.

Mejia, L.C.; Castlebury, L.A.; Rossman, A.Y.; Sogonov, M.V.; White, J.F. 2008. Phylogenetic placement and taxonomic review of the genus Cryptosporella and its synonyms Ophiovalsa and Winterella (Gnomoniaceae, Diaporthales). Mycological Research. 112(1):23-35.

Mejía, L.C.; Rossman, A.Y.; Castlebury, L.A.; Yang, Z.L.; White, J.F. Jr. 2012. Occultocarpon, a new monotypic genus of Gnomoniaceae on Alnus nepalensis from China. Fungal Diversity. 52(1):99-105

Mejia, L.C.; Rossman, A.Y.; Castlebury, L.C.; White, J.F. 2011. New species, phylogeny, host-associations, and geographic distribution of genus Cryptosporella (Gnomoniaceae, Diaporthales). Mycologia. 103(2):379-399

Mel'nik VA, Alexandrova AV, Braun U. 2014 Two new species and new records of hyphomycetes from Vietnam. Mycosphere. Jan 1;5:591-600.

Mel'nik VA, Braun U. 2013 Atractilina alinae sp. nov. and Neosporidesmium vietnamense sp. nov.-two new synnematous hyphomycetes from Vietnam. Mycobiota.;3:1-9.

Mel'nik VA, Crous PW. Braunomyces dictyosporus gen. sp. nov. from vietnam. IMA fungus. 2014 Jun $1 ; 5(1): 1-5$.

Mel'nik VA. 2012 Phaeoisaria vietnamensis sp. nov. and P. clematidis (hyphomycetes) from Vietnam. Mycosphere. Jan 1;3(6):957-60.

Mel'nik VA. Anamorphic fungi of Vietnam. I. Mikologiya i Fitopatologiya. 2011;45:323-31.

Melechin, A.V., 2010. Stereocaulon leucophaeopsis and S. tornense new to Russia from the Murmansk region. Graphis Scripta, 22(2), pp.63-64.

Mel'nik VA, Braun U, Alexandrova V (2013) Dactylaria mucoglobifera sp. nov. - a new species from Vietnam. Schlechtendalia 25: 49-52. 
Mel'nik VA, Castañeda-Ruiz RF, Granados M. 2013 A new species of Heliocephala from Vietnam. Mycotaxon. Aug 1;123(1):281-4.

Melo R.F.R., Miller A.N., Santiago ALCMA, Maia L.C. (2014). The genera Ascobolus and Saccobolus (Ascobolaceae, Pezizales) in Brazil. Mycosphere 5(6), 790-804, Doi 10.5943/mycosphere/5/6/9.

Méndez-Mayboca F, Checa J, Esqueda M, Chacón S. New records of loculoascomycetes from natural protected areas in sonora, mexico. Mycotaxon. 2010;111:19-30.

Menezes A, Leite A, Otsuka A, Jesus L, Cáceres M (2011) New records of crustose and microfoliose corticicolous lichens in Caatinga vegetation of the semi-arid region in Alagoas. Acta Botanica Brasilica, 25(4), pp.885-889.

Menezes AA, Lima EL, Xavier-Leite AB, Maia LC, Aptroot A, Cáceres MES (2013) New species of Arthoniales from NE Brazil. The Lichenologist 45(5):611-617.

Menezes AA, Xavier-Leite AB, De Jesus KA, Aptroot A, Cáceres MEDS (2013) Two new Crypthonia species and a new Syncesia from Chapada do Araripe, Ceará, NE Brazil (Ascomycota: Arthoniales), with a key to Crypthonia. Lichenologist 45:657-664.

Menkis A, Urbina H, James TY, Rosling A (2014) Archaeorhizomyces borealis sp. nov. and a sequence-based classification of related soil fungal species. Fungal biology. 118(12):943-55.

Menkis A, Vasaitis R. 2011 Fungi in roots of nursery grown Pinus sylvestris: ectomycorrhizal colonisation, genetic diversity and spatial distribution. Microbial ecology. Jan 1;61(1):52-63.

Mercado-Díaz JA, Lücking R, Parnmen S (2014) Two new genera and twelve new species of Graphidaceae from Puerto Rico suggest a high degree of endemism. Phytotaxa 189:186-203

Messuti MI, Codesal PL, Mangold A, Luecking, R. and Lumbsch, H.T., 2010. New or interesting Chapsa and Topeliopsis species (Ascomycota: Ostropales) from Argentina. The Lichenologist, 42(02), pp.191-195.

Messuti, M.I., Lumbsch, H.T., Luecking, R. and Altermann, S., 2011. One hundred new species of lichenized fungi: a signature of undiscovered global diversity.

Messuti, M.I., Passo, A., Scervino, J.M. and Vidal-Russell, R. 2016. The species pair Pseudocyphellaria pilosella-piloselloides (lichenized Ascomycota: Lobariaceae) is a single species Lichenologist (Lond.) 48 (2), 141-146.

Methven,A.S., Zelski,S.E. and Miller,A.N. 2013 A molecular phylogenetic assessment of the genus Gyromitra in North America. Mycologia. 105(5):1306-14.

Meunier JD, Kirman S, Strasberg D, Grauby O, Dussouillez P (2014) Incipient weathering by Stereocaulon vulcani at Réunion volcanic island. Chemical Geology, 382, pp.123-131.

Miądlikowska J, Kauff F, Högnabba F, Oliver JC, Molnár K, et al. (2014a) A multigene phylogenetic synthesis for the class Lecanoromycetes (Ascomycota): 1307 fungi representing 1139 infrageneric taxa, 317 genera and 66 families. Mol Phylogenet Evol 79:132-168

Miądlikowska J, Richardson D, Magain N, Ball B, Anderson F, et al. (2014b) Phylogenetic placement, species delimitation, and cyanobiont identity of endangered aquatic Peltigera species (lichen-forming Ascomycota, Lecanoromycetes). American Journal of Botany 101(7): 1141-1156.

Miądlikowska J, Schoch CL, Kageyama SA, Molnar K, Lutzoni F, McCune B (2011) Hypogymnia phylogeny, including Cavernularia, reveals biogeographic structure. The Bryologist 114(2):392-400.

Mies BA (2015) New or interesting lichens from the Limousin region (Western Massif Central, France). Herzogia, 28(2), pp.473-483. 
Miller AN, Huhndorf SM, Fournier J (2014) Phylogenetic relationships of five uncommon species of Lasiosphaeria and three new species in the Helminthosphaeriaceae (Sordariomycetes). Mycologia. 106(3):505-524

Miller JE, McCune B., Kofranek, D., Villella, J., Demmer, R., Mergenthaler, K. and Barber, A.C., 2011a. Lichens from the South Slough and Horsfall Dunes on the southern Oregon coast. Evansia, 28(4), pp.92-99.

Miller JE, Rossman A, Rosentreter, R. and Ponzetti, J., 2011b. Lichen ecology and diversity of a sagebrush steppe in Oregon: 1977 to the present. North American Fungi, 6: 1-14.

Millot M., Delebassée, S., Liagre, B., Vignaud, L., Sol, V. and Mambu, L., 2014. Screening of lichen extracts on HT-29 human colon-cancer cells. Planta Medica, 80(16), p.P1N5.

Minckler, D., Small, K.W. and Walsh, T.J., 2014. Clinical and pathologic features of Bipolaris endophthalmitis after intravitreal triamcinolone. JAMA ophthalmology, 132(5), pp.630-632.

Minnis AM, Kennedy AH, Grenier DB, Palm ME, Rossman AY (2012) Phylogeny and taxonomic revision of the Planistromellaceae including its coelomycetous anamorphs: contributions towards a monograph of the genus Kellermania. Persoonia 29:11-28

Minnis AM, Kennedy AH, Grenier DB, Rehner SA, Bischoff JF (2011) Asperisporium and Pantospora (Mycosphaerellaceae): epitypifications and phylogenetic placement. Persoonia 27:1-8

Minnis AM, Lindner DL. 2013 Phylogenetic evaluation of Geomyces and allies reveals no close relatives of Pseudogymnoascus destructans, comb. nov., in bat hibernacula of eastern North America. Fungal biology. Sep 30;117(9):638-49.

Minnis AM, Rossman, A.Y.; Farr, D.F.; Olsen, R.T. (2010). Fungal planet 51. Sphaerographium nyssicola sp. nov.. Persoonia 25: 122-123

Minter, D. W.; Aguirre-Hudson, B.; Cannon, P. F. 2015 Naetrocymbe nitescens. [Descriptions of Fungi and Bacteria]. IMI Descriptions of Fungi and Bacteria No.206 pp. Sheet 2059 ref. 10

Minter, D.W. (2009). Cyberlindnera, a replacement name for Lindnera Kurtzman et al., nom. illegit.. Mycotaxon 110: 473-476

Mirabolfathy, M.; Ju, Y.M.; HSIEH, H.M.; Rogers, J.D. (2013). Obolarina persica sp. nov., associated with dying Quercus in Iran. Mycoscience 54, Issue 5, 315-320

Miralles, I., Edwards, H.G., Domingo, F. and Jorge-Villar, S.E., 2015. Lichens around the world: a comprehensive study of lichen survival biostrategies detected by Raman spectroscopy. Analytical Methods, 7(16), pp.6856-6868.

Miralles-Mellado, I., Cantón, Y. and Solé-Benet, A., 2011. Two-dimensional porosity of crusted silty soils: indicators of soil quality in semiarid rangelands?. Soil Science Society of America Journal, 75(4), pp.1330-1342.

Mishra K, Das S, Goyal S, Gupta C, Rai G, Ansari MA, Saha R, Singal A. Subcutaneous mycoses caused by rhytidhysteron species in an immunocompetent patient. Med Mycol Case Rep. 2014a;5(1):32-4.

Mishra S, Singh, B.R., Singh, A., Keswani, C., Naqvi, A.H. and Singh, H.B., 2014b. Biofabricated silver nanoparticles act as a strong fungicide against Bipolaris sorokiniana causing spot blotch disease in wheat. PloS one, 9(5), p.e97881.

Mishra, A.K., Mishra, A., Kehri, H.K., Sharma, B. and Pandey, A.K., 2009. Inhibitory activity of Indian spice plant Cinnamomum zeylanicum extracts against Alternaria solani and Curvularia lunata, the pathogenic dematiaceous moulds. Annals of Clinical Microbiology and Antimicrobials, 8(1), p.1. 
Mitrovic T, Stamenkovic S, Cvetkovic V, Radulovic N, Mladenovic M, Stankovic M, Topuzovic M, Radojevic I, Stefanovic O, Vasic S, Comic L. Platismatia glaucia and Pseudevernia furfuracea lichens as sources of antioxidant, antimicrobial and antibiofilm agents. EXCLI journal. 2014;13:938.

Mittermeier, V.K., Schmitt, N., Volk, L.P., Suárez, J.P., Beck, A. and Eisenreich, W., 2015. Metabolic Profiling of Alpine and Ecuadorian Lichens. Molecules, 20(10), pp.1804718065.

Miyamoto, Y., Ishii, Y., Honda, A., Masunaka, A., Tsuge, T., Yamamoto, M., Ohtani, K., Fukumoto, T., Gomi, K., Peever, T.L. and Akimitsu, K., 2009. Function of genes encoding acyl-CoA synthetase and enoyl-CoA hydratase for host-selective ACT-toxin biosynthesis in the tangerine pathotype of Alternaria alternata. Phytopathology, 99(4), pp.369-377.

Miyamoto, Y., Masunaka, A., Tsuge, T., Yamamoto, M., Ohtani, K., Fukumoto, T., Gomi, K., Peever, T.L. and Akimitsu, K., 2008. Functional analysis of a multicopy hostselective ACT-toxin biosynthesis gene in the tangerine pathotype of Alternaria alternata using RNA silencing. Molecular plant-microbe interactions, 21(12), pp.1591-1599.

Mizuno, H., Kawahigashi, H., Kawahara, Y., Kanamori, H., Ogata, J., Minami, H., Itoh, T. and Matsumoto, T., 2012. Global transcriptome analysis reveals distinct expression among duplicated genes during sorghum-Bipolaris sorghicola interaction. BMC plant biology, 12(1), p.1.

Mohabe S, Nayaka S, Reddy AM. 2015 Stigmatochroma microspora (Physciaceae), a new species from India. J. New Biolog. Rep. 4(2): 128

Mohammadi, P., 2011. Spectrofluorometry as a tool to evaluate biocide efficiency on deteriorating rock fungi. Iranian Journal Of Biology, 24 (6), pp. 818 - 825.

Molnár, K., Lökös, L., Schrett-Major, Á. and Farkas, E., 2012. Molecular genetic analysis of Xanthoparmelia pulvinaris (Ascomycota, Lecanorales, Parmeliaceae). Acta Botanica Hungarica, 54(1-2), pp.125-130.

Monaghan MT, Wild R, Elliot M, Fujisawa T, Balke M, Inward DJ, Lees DC, Ranaivosolo R, Eggleton P, Barraclough TG, Vogler AP. Accelerated species inventory on Madagascar using coalescent-based models of species delineation. Systematic biology. 2009:syp027.

Moncada B, Lücking R 2012. Ten new species of Sticta and counting: Colombia as a hot spot for unrecognized diversification in a conspicuous macrolichen genus. Phytotaxa. Nov 30;74(1):1-29.

Moncada B, Lücking R, Betancourt-Macuase L (2013a) Phylogeny of the Lobariaceae (lichenized Ascomycota: Peltigerales), with a reappraisal of the genus Lobariella. Lichenologist 45(2):203-263.

Moncada B, Lücking R, Suárez A (2014a) Molecular phylogeny of the genus Sticta (lichenized Ascomycota: Lobariaceae) in Colombia. Fungal Divers 64(1):205-231.

Moncada B, Luecking R, COCA LF. 2013b Six new apotheciate species of Sticta (lichenized Ascomycota: Lobariaceae) from the Colombian Andes. The Lichenologist. Sep 1;45(05):635-56.

Moncada B, Reidy B, and Lücking, R., 2014b. A phylogenetic revision of Hawaiian Pseudocyphellaria sensu lato (lichenized Ascomycota: Lobariaceae) reveals eight new species and a high degree of inferred endemism. The Bryologist, 117(2), pp.119-160.

Mongkolsamrit, S.; Luangsa-ard, J.J.; Hywel-Jones, N.L. (2011). Samuelsia mundiveteris sp. nov. from Thailand. Mycologia 103(4): 921-927 
Mongkolsuk P, Meesim S, Poengsungnoen V, Buaruang K, Schumm F, Kalb K. The lichen family Physciaceae in Thailand-II. Contributions to the genus Heterodermia sensu lato. Phytotaxa. 2015 Nov 20;235(1):1-66.

Mongkolsuk, P., Meesim, S., Poengsungnoen, V. and Kalb, K., 2012. The lichen family Physciaceae in Thailand-I. The genus Pyxine. Phytotaxa, 59(1), pp.32-54.

Moniri, M.H. and Sipman, H.J., 2011. Lichens from three mountain sites in Khorasan provinces, Iran, including four species new to Iran. Cryptogamie, Mycologie, 32(2), pp.145-150.

Moniri, M.H., 2010. A Small Lichen Collection from Darkesh, NE Iran. Journal of Environmental Science and Engineering, 4(4), p.36.

Moniri, M.H., Sipman, H.J. and Schultz, M., 2014. New records of lichenized and lichenicolous fungi from Northeastern Iran. Herzogia 27 (2): 367-376

Moniri, M.H., Soltani, A. and Kamyabi, S., 2009. Some lichens from Kashmar, NE Iran. Journal of Applied and Natural Science, 1(2), pp.286-290.

Monkai J, Liu JK, Boonmee S, Chomnunti P, Chukeatirote E, Jones EBG, Wang Y, Hyde KD (2013) Planistromellaceae (Botryosphaeriales). Cryptogam Mycol 34:45-77

Monteiro JS, Carmo LT, Fiúza PO, Ottoni BM, Gusmão LF, Castañeda-Ruiz RF. 2014a New species of microfungi from Brazilian Amazon rainforests. Mycotaxon. May 29;127(1):81-7.

Monteiro JS, Carmo LT, Fiúza PO, Ottoni, B.M.P.; Gusmão, L.F.P.; Castañeda-Ruiz, R.F. 2014b. New species of microfungi from Brazilian Amazon rainforests. Mycotaxon. $127: 81-87$

Monteiro JS, Castañeda-Ruiz RF, Gusmão LFP (2014c) Helicodochium, a new microfungus from submerged wood from Brazil. Mycotaxon. 127:5-9

Monteiro JS, Gusmão LF, Castañeda-Ruiz RF (2014d) Two new microfungi from Brazilian Amazon Forest: Atrogeniculata submersa and Nigrolentilocus amazonicus. Mycotaxon 127(1):39-45.

Monteiro JS, Gusmão LF, Castañeda-Ruiz RF. A new species of Matsushimiella from submerged leaves in the Brazilian Amazon Forest. Mycotaxon. 2015a Jul 9;130(2):311-4.

Monteiro JS, Gusmão LF, Castañeda-Ruiz RF. Brachycephala exotica, a new hyphomycete from Brazil. Mycotaxon. 2015b Jul 9;130(2):489-93.

Monteiro, J.S. and Gusmão, L.F.P., 2014. Two new species of Ceratosporella (anamorphic fungi) from Brazilian Amazon forest. Nova Hedwigia, 98(3-4), pp.481-490.

Moon, K.H.; Aptroot, A. (2009). Pyrenocarpous lichens in Korea. Biblthca Lichenol. 99: 297-314

Moon, K.H.; Nakanishi, S.; Kashiwadani, H. (2008). Notes on species of Graphidaceae (Ascomycotina) from eastern Asia with three new species. Mem. Natn Sci. Mus Tokyo, 45: 85-91.

Moreno G, Alvarado P, Manjón JL. 2012a Phylogenetic affiliation of Choiromyces magnusii and C. venosus Tuberaceae Ascomycota) from Spain. Mycological progress. May 1;11(2):463-71.

Moreno G, Lizárraga M, Esqueda M, Galán R, Alvarado P. 2012b New records of littleknown species of Carbomyces (Carbomycetaceae, Ascomycota). Mycotaxon. Sep 28;120(1):89-98.

Moreno-Pérez P, Gamboa-Angulo M, Heredia G, Canto-Canché B, Rosado-Vallado M, Medina-Baizabal IL, Tapia-Tusell R (2014) Antagonistic properties of micromycetes isolated from sinkholes of the Yucatán Península against fungal phytopathogens.Rev. Mex. Mic 40:27-36 
Moreno-Rico O, Groenewald JZ, Crous PW. 2014. Foliicolous fungi from Arctostaphylos pungens in Mexico. IMA Fungus. 5(1):7-15

Morgenstern K, Döring M, Krabel D. Rhabdocline needle cast-investigations on various Douglas fir tissue types. European journal of plant pathology. 2013 Nov 1;137(3):495-504.

Morin L., Shivas RG, Piper MC, Tan YP (2010) Austropleospora osteospermi gen. et sp. nov. and its host specificity and distribution on Chrysanthemoides monilifera ssp. rotundata in Australia. Fungal Diversity 40: 65-74.

Morita, H., Tsuchiya, T., Kishibe, K., Noya, S., Shiro, M. and Hirasawa, Y., 2009. Antimitotic activity of lobaric acid and a new benzofuran, sakisacaulon A from Stereocaulon sasakii. Bioorganic \& medicinal chemistry letters, 19(13), pp.3679-3681.

Mostafanezhad, H., Sahebani, N. and Nourinejhad Zarghani, S., 2014. Control of root-knot nematode (Meloidogyne javanica) with combination of Arthrobotrys oligospora and salicylic acid and study of some plant defense responses. Biocontrol Science and Technology, 24(2), pp.203-215.

Mota RMA, Abarca GH, Ruíz RFC, Hernández CIB (2008) Two new species of Polyschema and Vanakripa and other microfungi recorded from mangrove in Veracruz, Mexico. Mycotaxon 106:29-40.

Mota RMA, Abarca GH, Ruíz RFC, Hernández CIB (2008) Two new species of Polyschema and Vanakripa and other microfungi recorded from mangrove in Veracruz, Mexico. Mycotaxon 106: 29-40

Motiejūnaite J 2012 New data on distribution of Lemmopsis pelodes in Lithuania. Botanica Lithuanica 18(2): 166-168

Motiejūnaitė J, Chesnokov SV, Czarnota P, Gagarina, L.V., Frolov, I., Himelbrant, D., Konoreva L.A., Kubiak, D., Kukwa, M., Moisejevs, R. and Stepanchikova, I., 2016. Ninety-one species of lichens and allied fungi new to Latvia with a list of additional records from Kurzeme. Herzogia, 29(1), pp.143-163.

Motiejūnaitė J, Czyżewska K 2008. Additions to the biota of lichens and lichenicolous fungi of Poland with note on Lecania prasinoides in eastern and central Europe. Polish Bot. J, 53(2), pp.155-162.

Motiejunaite J, Grochowski, P., 2014. Miscellaneous new records of lichens and lichenicolous fungi. Herzogia, 27(1), pp.193-198.

Motiejūnaitė J, Kukwa M, Lõhmus P, Markovskaja, S., Oset, M., Lukošienė, I.P., Stončius, D. and Useliene, A., 2013. Contribution to the Lithuanian flora of lichens and allied fungi. IV. Botanica Lithuanica, 19(1), pp.3-7.

Motiejūnaite J, von Brackel W, Stončius D, and Preikša, Ž., 2011. Contribution to the Lithuanian flora of lichens and allied fungi. III. Botanica Lithuanica, 17(1), pp.39-46.

Motlagh, M.R.S. and Anvari, M., 2010. Genetic variation in a population of Bipolaris oryzae based on RAPD-PCR in north of Iran. African Journal of Biotechnology, 9(36).

Motlagh, M.R.S. and Kaviani, B., 2008. Characterization of new Bipolaris spp.: the causal agent of rice brown spot disease in the north of Iran. International Journal of Agriculture and Biology, 10(6), pp.638-642.

Mouhajir, A., Matray, O., Giraud, S., Mély, L., Marguet, C., Sermet-Gaudelus, I., Le Gal, S., Labbé, F., Person, C., Troussier, F. and Ballet, J.J., 2016. Long-term Rasamsonia argillacea complex species colonization revealed by rep-PCR in cystic fibrosis patients. Journal of Clinical Microbiology, pp.JCM-01462.

Moya-Elizondo, E.A., Jacobsen, B.J., Hogg, A.C. and Dyer, A.T., 2011. Population dynamics between Fusarium pseudograminearum and Bipolaris sorokiniana in wheat stems using real-time qPCR. Plant disease, 95(9), pp.1089-1098. 
Mugambi GK, Huhndorf SM (2009a) Molecular phylogenetics of Pleosporales: Melanommataceae and Lophiostomataceae recircumscribed (Plesporomycetidae, Dothideomycetes, Ascomycota). Stud Mycol 64:103-121

Mugambi GK, Huhndorf SM (2010) Multigene phylogeny of the Coronophorales: morphology and new species in the order. Mycologia 102(1): 185-210.

Mugambi GK, Huhndorf SM, Rogers JD. Two new xylariaceous species from Kenya. Mycotaxon. 2009 Apr 1;108(1):499-504.

Mugambi GK, SM Huhndorf (2009b) Parallel evolution of hysterothecial ascomata in ascolocularous fungi (Ascomycota, Fungi). Systematics and Biodiversity 7, 453-464.

Muggia L, Baloch E, Stabentheiner, E., Grube, M. and Wedin, M. 2011a. Photobiont association and genetic diversity of the optionally lichenized fungus Schizoxylon albescens FEMS Microbiol. Ecol. 75 (2): 255-272

Muggia L, Gueidan C, Grube M (2010) Phylogenetic placement of some morphologically unusual members of Verrucariale. Mycologia 102: 835-846.

Muggia L, Gueidan C, Knudsen, K., Perlmutter, G. and Grube, M., 2013. The lichen connections of black fungi. Mycopathologia, 175(5-6), pp.523-535.

Muggia L, Hafellner J, Obermayer,W. 2011b. New species of Rinodina Unpublished 2 (bases 1 to 470) Submitted (05-JUL-2011).

Muggia L, Hafellner J, Wirtz N, Hawksworth DL, Grube M. The sterile microfilamentous lichenized fungi Cystocoleus ebeneus and Racodium rupestre are relatives of plant pathogens and clinically important dothidealean fungi. Mycological Research. 2008 Jan 31;112(1):50-6.

Muggia L, Kocourková J, Knudsen K (2015a) Disentangling the complex of Lichenothelia species from rock communities in the desert. Mycologia 107: 1233-1253

Muggia L, Kopun T, and Ertz,D. 2015b Phylogenetic placement of the lichenicolous, anamorphic genus Lichenodiplis and its connection to Muellerella-like teleomorphs. Fungal Biol 119 (11), 1115-1128.

Muggia L, Nelson P, Wheeler T, Yakovchenko, L.S., Tonsberg, T. and Spribille, T. 2011c. Convergent evolution of a symbiotic duet: The case of the lichen genus Polychidium (Peltigerales, Ascomycota). Am. J. Bot. 98 (10), 1647-1656.

Muggia L, Pérez-Ortega S, Fryday A, Spribille, T. and Grube, M., 2014. Global assessment of genetic variation and phenotypic plasticity in the lichen-forming species Tephromela atra. Fungal Diversity, 64(1), pp.233-251.

Muggia L, Zellnig G, Rabensteiner J. and Grube, M., 2010. Morphological and phylogenetic study of algal partners associated with the lichen-forming fungus Tephromela atra from the Mediterranean region. Symbiosis, 51(2), pp.149-160.

Mukherjee, A.K., Carp, M.J., Zuchman, R., Ziv, T., Horwitz, B.A. and Gepstein, S., 2010. Proteomics of the response of Arabidopsis thaliana to infection with Alternaria brassicicola. Journal of proteomics, 73(4), pp.709-720.

Mukhopadhyay SK, Chatterjee S, Gauri SS, Das SS, Mishra A, Patra M, Ghosh AK, Das AK, Singh SM, Dey S. Isolation and characterization of extracellular polysaccharide Thelebolan produced by a newly isolated psychrophilic Antarctic fungus Thelebolus. Carbohydrate polymers. 2014 Apr 15;104:204-12.

Müller, M.E. and Korn, U., 2013. Alternaria mycotoxins in wheat-A 10 years survey in the Northeast of Germany. Food Control, 34(1), pp.191-197.

Mungai P, Hyde K.D., Cai L., Njogu J.G., Chukeatirote K. (2011). Coprophilous ascomycetes of northern Thailand. Current Research in E \& AM 1 (2), 135-159.

Mungai PG, Chukeatirote E, Njogu J.G., Hyde K.D. (2012a). Studies of coprophilous ascomycetes in Kenya. Podospora species from wildlife dung. Mycosphere 3(6), 978981, Doi 10.5943 /mycosphere/3/6/12. 
Mungai PG, Chukeatirote E, Njogu JG, Hyde KD. Coprophilous ascomycetes in Kenya: Saccobolus species from wildlife dung. Mycosphere. 2012b Jan 1;3:111-29.

Mungai PG, Njogu J.G., Chukeatirote E., Hyde KD (2012c) Studies of coprophilous ascomycetes in Kenya - Ascobolus species from wildlife dung. Current Research in Environmental \& Applied Mycology 2(1), 1-16, Doi 10.5943/cream/2/1/1.

Mungai PG, Njogu JG, Chukeatirote E, Hyde KD (2012) Coprophilous ascomycetes in Kenya: Sporormiella from wildlife dung. Mycology 3: 234-251.

Muniz D, Llop E, Hladun NL. Sphinctrina paramerae, a new Mediterranean lichenicolous species with non-septate spores. The Lichenologist. 2013 Mar 1;45(02):137-43.

Munzenberger B, Bubner B, Wollecke J, Sieber TN, Bauer R (2009). The ectomycorrhizal morphotype Pinirhiza sclerotia is formed by Acephala macrosclerotiorum sp. nov., a close relative of Phialocephala fortinii. Mycorrhiza 19(7): 481-492.

Murata, N., Aoki, T., Kusaba, M., Tosa, Y. and Chuma, I., 2014. Various species of Pyricularia constitute a robust clade distinct from Magnaporthe salvinii and its relatives in Magnaporthaceae. Journal of General Plant Pathology, 80(1), pp.66-72.

Murillo C, Albertazzi FJ, Carranza J, Lumbsch HT, Tamayo G. Molecular data indicate that rhytidhysteron rufulum (ascomycetes, patellariales) in costa rica consists of four distinct lineages corroborated by morphological and chemical characters. Mycol Res. 2009;113(4):405-16.

Musvuugwa T, Dreyer LL, De Beer WZ, Oberlander K, Duong T, Roets F. 2015. New species of Ophiostomatales from Scolytinae and Platypodinae beetles in the Cape Floristic Region, including the discovery of the sexual state of Raffaelea. Antonie van Leeuwenhoek. 108:933-950

Muthukrishnan, S., Sanjayan, K.P. and Jahir, H.K., 2012. Species composition, seasonal changes and community ordination of alkalotolerant micro fungal diversity in a natural scrub jungle ecosystem of Tamil Nadu, India. Mycosphere, 3, pp.92-109.

Mycobank (2016) http://www.mycobank.org, Accessed in December 2016

Myllys L, Velmla S, Holien H, Halonen P, Wang L-S, Goward T (2011) Phylogeny of the genus Bryoria. Lichenologist 43: 617-638.

Myllys, L., Velmala, S., Lindgren, H., Glavich, D., Carlberg, T., Li-Song, W.A.N.G. and Goward, T., 2014. Taxonomic delimitation of the genera Bryoria and Sulcaria, with a new combination Sulcaria spiralifera introduced. The Lichenologist, 46(06), pp.737752.

Nadyeina, O., 2009. The lichen-forming and lichenicolous fungi of the Donetsk Upland (Ukraine). Mycologia Balcanica, 6, pp.37-53.

Nadyeina, O., Grube, M. and Mayrhofer, H., 2010. A contribution to the taxonomy of the genus Rinodina (Physciaceae, lichenized Ascomycotina) using combined ITS and mtSSU rDNA data. The Lichenologist, 42(05), pp.521-531.

Nagahama T, Abdel-Wahab MA, Nogi Y, Miyazaki M, Uematsu K, Hamamoto M, Horikoshi K. Dipodascus tetrasporeus sp. nov., an ascosporogenous yeast isolated from deep-sea sediments in the Japan Trench. International journal of systematic and evolutionary microbiology. 2008 Apr 1;58(4):1040-6.

Nagano, Y., Nagahama, T. and Abe, F., 2014. Cold-adapted yeasts in deep-sea environments. In Cold-adapted Yeasts (pp. 149-171). Springer Berlin Heidelberg.

Nagao H, Kurogi SI, Kiyota E, Sasatomi K. Kumanasamuha geaster sp. nov., an anamorph of Chorioactis geaster from Japan. Mycologia. 2009 Nov 1;101(6):871-7.

Nagao H. (2008) Discomycetes on decayed tree fern. (3) Lachnum lanariceps and Lachnum oncospermaum new to Japan. Mycoscience 49: 403-406. 
Nagaraju D, Kunwar IK, Suresh Kumar G, Manoharachary C (2011a) Custingophora lignicola sp. nov. and Chaetopsina indica sp. nov. from India. Journal of Mycology and Plant Pathology, 41(1), 9,

Nagaraju D, Kunwar IK, Sureshkumar G, Manoharachary C (2011b) A new synnematous hyphomycetous fungus-Bhadradriella gen. nov. from India. Journal of Mycology and Plant Pathology.;41(2):238.

Najafzadeh MJ, Sun J, Vicente V, Xi L, Gerrits van den Ende AHG, de Hoog GS. 2010. Fonsecaea nubica sp. nov., a new agent of human chromoblastomycosis revealed using molecular data. Medical Mycology 48:800-806.

Najafzadeh MJ, Sun J, Vicente VA, Klaassen CHW, Bonifaz A, Gerrits van den Ende AHG, Menken SBJ, de Hoog GS. 2011a. Molecular epidemiology of Fonsecaea species. Emerging Infectious Diseases 17:464-469.

Najafzadeh MJ, Vicente VA, Sun J, Meis JF, de Hoog GS. 2011b. Fonsecaea multimorphosa sp. nov., a new species of Chaetothyriales isolated from a feline cerebral abscess. Fungal Biology 115:1066-1076.

NALIM, F.A.; SAMUELS, G.J.; WIJESUNDERA, R.L.; GEISER, D.M. (2011). New species from the Fusarium solani species complex derived from perithecia and soil in the Old World tropics. Mycologia 103(6):1302-30.

Nallathambi, P., Umamaheswari, C., Thakore, B.B.L. and More, T.A., 2009. Post-harvest management of ber (Ziziphus mauritiana Lamk) fruit rot (Alternaria alternata Fr. Keissler) using Trichoderma species, fungicides and their combinations. Crop Protection, 28(6), pp.525-532.

Nambiar GR, Raveendran K (2009a) Manglicolous Marine Fungi on Avicennia and Rhizophora along Kerala Coast (India). Middle-East Journal of Scientific Research 4:48-51

Nambiar GR, Raveendran K, Jaleel CA (2009) Marine mycoflora of south India with special emphasis on Lignicolous Marine Fungi. Front. Biol. China 4:436-441

Nambiar GR, Raveendran K. Marine mycoflora in backwater ecosystem of kerala, india. J Environ Biol. 2009b;30(5):647-9.

Nascimento MM, Selbmann L, Sharifynia S, Al-Hatmi AM, Voglmayr H, Vicente VA, Deng S, Kargl A, Moussa TA, Al-Zahrani HS, Almaghrabi OA (2016) Arthrocladium, an unexpected human opportunist in Trichomeriaceae (Chaetothyriales). Fungal Biology 120(2):207-18.

Nattah, I., Ajaj, A., Chliyeh, M., Touhami, A.O., Benkirane, R. and Douira, A., 2014. Contribution to the inventory of lichens encountered in the reserve of Sidi Boughaba (Morocco). Int. J. Pure App. Biosci, 2(6), pp.103-107.

Naumann, T.A., Wicklow, D.T. and Kendra, D.F., 2009. Maize seed chitinase is modified by a protein secreted by Bipolaris zeicola. Physiological and molecular plant pathology, 74(2), pp.134-141.

Navarrete F, Abreo E, Martínez S, Bettucci L, Sandra LU. Pathogenicity and molecular detection of Uruguayan isolates of Greeneria uvicola and Cadophora luteo-olivacea associated with grapevine trunk diseases. Phytopathologia Mediterranea. 2011 Dec 18;50(4):166-75.

Navarro-Rosinés, P.; Hladun, N.L.; Llimona, X. 2008. Gelatinopsis heppiae sp. nov. (Leotiales, Ascomycota) un hongo liquenícola sobre Heppia despraeuxii de Aragón (NE de España). Revista Catalana de Micologia. 30:57-64.

Navarro-Rosinés, P.; Zhurbenko, M.; Roux, C. 2010. Pseudopyrenidium un nouveau genre pour inclure Weddellomyces tartaricola (champignon lichénicole non lichénisé, Ascomycota). Bulletin de la Société Linnéenne de Provence. 61:129-140 
Nayaka S, Saxena P 2014 Physiological responses and ecological success of lichen Stereocaulon foliolosum and moss Racomitrium subsecundum growing in same habitat in Himalaya. Indian J. fundam. appl. Life Sci, 4, pp.167-179.

Nayaka, S., Upreti, D.K., Ponmurugan, P. and Ayyappadasan, G., 2013. Two new species of saxicolous Pyxine with yellow medulla from southern India. The Lichenologist, 45(01), pp.3-8.

Nekoduka S, Kanematsu S, Tanaka K, Harada Y, Sano T. 2012 Valdensia leaf blight of highbush blueberry caused by Valdensinia heterodoxa, a new fungal disease in Japan. Journal of General Plant Pathology. May 1;78(3):151-9.

Nekoduka S, Tanaka K, Harada Y, Sano T (2010). Phylogenetic affinity of Mycochaetophora gentianae, the causal fungus of brown leaf spot on gentian (Gentiana triflora), to Pseudocercosporella-like hyphomycetes in Helotiales.

Nelsen MP, Chavez N, Sackett-Hermann E, Thell A, Randlane T, et al. (2011a) The cetrarioid core group revisited (Lecanorales: Parmeliaceae). The Lichenologist, 43(06), pp.537-551.

Nelsen MP, Gargas A (2009) Assessing clonality and chemotype monophyly in Thamnolia (Icmadophilaceae). The Bryologist, 112(1), pp.42-53.

Nelsen MP, Lücking R, Andrew CJ, Aptroot A, Caceres MES, et al (2014a) Molecular phylogeny reveals the true colors of Myeloconidaceae (Ascomycota: Ostropales). Aust. Syst. Bot. 27, 38-47

Nelsen MP, Lücking R, Andrew CJ, Plata ER, Chaves JL, et al. (2012) Dismantling Herpothallon: Herpothallon antillarum (Arthoniomycetes: Arthoniaceae) is a member of the genus Diorygma (Lecanoromycetes: Graphidaceae). The Bryologist. Aug 7;115(2):313-21.

Nelsen MP, Lücking R, Aptroot A, Andrew CJ, Caceres M, et al (2014b) Elucidating phylogenetic relationships and genus-level classification within the fungal family Trypetheliaceae (Dothideomycetes: Ascomycota). Taxon 63 (5): 974-992

Nelsen MP, Lücking R, Grube M, Mbatchou JS, Muggia L, et al (2009) Unravelling the phylogenetic relationships of lichenised fungi in Dothideomyceta. Studies in Mycology64: 135-144.

Nelsen MP, Lücking R, Mbatchou JS, Andrew CJ, Spielmann AA, Lumbsch HT (2011b) New insights into relationships of lichen-forming Dothideomycetes. Fungal Divers 51:155-162

Nelsen MP, Lücking R, Plata ER, Mbatchou JS (2010) Heiomasia, a new genus in the lichenforming family Graphidaceae (Ascomycota: Lecanoromycetes: Ostropales) with disjunct distribution in Southeastern North America and Southeast Asia. - Bryologist 113(4): 742-751.

Nelsen MP, Lumbsch HT, Lucking R, Elix JA. (2008) Further evidence for the polyphyly of Lepraria (Lecanorales: Stereocaulaceae). Nova Hedwigia 87, 361-371

Nelsen MP, Thell A, Leavitt SD, Hampton-Miller CJ, et al. (2013) A reappraisal of Masonhalea (Parmeliaceae, Lecanorales) based on molecular and morphological data. The Lichenologist, 45(06), pp.729-738.

Nelsen, M. P., R. Lucking, M. E. S. Ca ' 'ceres \& A. Aptroot. 2016. Assessing the phylogenetic placement and redundancy of Aspidotheliaceae (Ascomycota), an orphaned family of lichenforming fungi. Systematics and Biodiversity 15: 63-73.

Netam RS, Bahadur AN, Tiwari U, Tiwari RKS (2011) Efficacy of plant extracts for the Control of (Pyricularia grisea) Blast of Rice under Field Condition of Bastar, Chhattisgarh. Research Journal of Agricultural Sciences, 2(2): 269-271. 
Neuwirth G, Aptroot A, Stocker-Woergoetter E. Platythecium seychellense, a new species in the family Graphidaceae (lichenized Ascomycota: Ostropales) from the Seychelles and a world key to the genus. The Lichenologist. 2017 Jan;49(1):85-91.

Nguanhom, J., Cheewangkoon, R., Groenewald, J.Z., Braun, U., To-Anun, C. and Crous, P.W., 2015. Taxonomy and phylogeny of Cercospora spp. from Northern Thailand. Phytotaxa, 233(1), pp.27-48.

Nguyen, H.D.T.; Seifert, K.A. 2008. Description and DNA barcoding of three new species of Leohumicola from South Africa and the United States. Persoonia. 21:57-69

Nicoletti R, Wołczańska A, Carella A. Occurrence of Zetiasplozna unicolor as an endophyte of myrtle (Myrtus communis) in Italy. PETRIA. 2010;20(2):p-581.

Niu, X.M. and Zhang, K.Q., 2011. Arthrobotrys oligospora: a model organism for understanding the interaction between fungi and nematodes. Mycology, 2(2), pp.5978.

Nizam, S., Verma, S., Singh, K., Aggarwal, R., Srivastava, K.D. and Verma, P.K., 2012. High reliability transformation of the wheat pathogen Bipolaris sorokiniana using Agrobacterium tumefaciens. Journal of microbiological methods, 88(3), pp.386-392.

Nkuekam GK, Wingfield MJ, Mohammed C, Carnegie AJ, Pegg GS, Roux J. Ceratocystis species, including two new species associated with nitidulid beetles, on eucalypts in Australia. Antonie van Leeuwenhoek. 2012 Feb 1;101(2):217-41.

Nonaka K, Ishii T, Shiomi K, Ōmura S, Masuma R. Virgaria boninensis, a new hyphomycete (Xylariaceae) from soils in the Bonin Islands, Japan. Mycoscience. 2013a Sep 30;54(5):394-9.

Nonaka K, Kaifuchi S, Ōmura S, Masuma R. Five new Simplicillium species (Cordycipitaceae) from soils in Tokyo, Japan. Mycoscience. 2013b Jan 31;54(1):4253.

Nonaka K, Kaifuchi S, Omura S, Masuma R. Three new Pochonia taxa (Clavicipitaceae) from soils in Japan. Mycologia. 2013c Aug 6:12-32.

Nonaka K, Miyazaki H, Iwatsuki M, Shiomi K, Tomoda H, Ōmura S, Masuma R. Staphylotrichum boninense, a new hyphomycete (Chaetomiaceae) from soils in the Bonin Islands, Japan. Mycoscience. 2012 Jul 1;53(4):312-8.

Nordin A, Savić S, Tibell L (2010) Phylogeny and taxonomy of Aspicilia and Megasporaceae. Mycologia 102(6): 1339-1349.

Norphanphoun C, Hongsanan S, Doilom M, Bhat DJ, Wen TC, Senanayake IC, Bulgakov TS, Hyde KD. Lamproconiaceae fam. nov. to accommodate Lamproconium desmazieri. Phytotaxa. 2016 Aug 17;270(2):89-102.

Norphanphoun C, Maharachchikumbura SSN, Daranagama A, Bulgakov TS, Bhat DJ, Bahkali AH, Hyde KD. 2015 - Towards a backbone tree for Seimatosporium, with S. physocarpi sp. nov. Mycosphere 6(3), 385-400.

Norvell, L.L., 2010. Report of the nomenclature committee for fungi: 15. Taxon, 59(1), pp.291-293.

Noser, J., Schneider, P., Rother, M. and Schmutz, H., 2011. Determination of six Alternaria toxins with UPLC-MS/MS and their occurrence in tomatoes and tomato products from the Swiss market. Mycotoxin research, 27(4), pp.265-271.

Notov, A.A., 2014. Fruticose lichens: structural diversity, taxonomic characteristics and evolution. Wulfenia, 21, pp.21-31.

Nouhra E, Urcelay C, Longo S, Tedersoo L. Ectomycorrhizal fungal communities associated to Nothofagus species in Northern Patagonia. Mycorrhiza. 2013 Aug 1;23(6):487-96.

Nowicki, M., Nowakowska, M., Niezgoda, A. and Kozik, E., 2012. Alternaria black spot of crucifers: symptoms, importance of disease, and perspectives of resistance breeding. Vegetable Crops Research Bulletin, 76, pp.5-19. 
Ntui, V.O., Thirukkumaran, G., Azadi, P., Khan, R.S., Nakamura, I. and Mii, M., 2010. Stable integration and expression of wasabi defensin gene in "Egusi" melon (Colocynthis citrullus L.) confers resistance to Fusarium wilt and Alternaria leaf spot. Plant cell reports, 29(9), pp.943-954.

Núñez-Zapata, J.,, P. K. Divakar, R. Del-Prado, P. Cubas, D. L. Hawksworth, A. Crespo 2011: Conundrums in species concepts: the discovery of a new cryptic species segregated from Parmelina tiliacea (Ascomycota: Parmeliaceae). Lichenologist 43(6), 603-616

Nyati, S., Bhattacharya, D., Werth, S. and Honegger, R., 2013. Phylogenetic analysis of LSU and SSU rDNA group I introns of lichen photobionts associated with the genera Xanthoria and Xanthomendoza (Teloschistaceae, lichenized ascomycetes). Journal of phycology, 49(6), pp.1154-1166

Nygren K, Strandberg R, Wallberg A, Nabholz B, Gustafsson T, García D, Cano J, Guarro J, Johannesson H. A comprehensive phylogeny of Neurospora reveals a link between reproductive mode and molecular evolution in fungi. Molecular phylogenetics and evolution. 2011 Jun 30;59(3):649-63.

O'Connell,R.J., Thon,M.R., Hacquard,S., Amyotte,S.G., Kleemann,J., Torres,M.F., Damm,U., Buiate,E.A., Epstein,L., Alkan,N., Altmuller,J., Alvarado-Balderrama,L., Bauser,C.A., Becker,C., Birren,B.W., Chen,Z., Choi,J., Crouch,J.A., Duvick,J.P., Farman,M.A., Gan,P., Heiman,D., Henrissat,B., Howard,R.J., Kabbage,M., Koch,C., Kracher,B., Kubo,Y., Law,A.D., Lebrun,M.H., Lee,Y.H., Miyara,I., Moore,N., Neumann,U., Nordstrom,K., Panaccione,D.G., Panstruga,R., Place,M., Proctor,R.H., Prusky,D., Rech,G., Reinhardt,R., Rollins,J.A., Rounsley,S., Schardl,C.L., Schwartz,D.C., Shenoy,N., Shirasu,K., Sikhakolli,U.R., Stuber,K., Sukno,S.A., Sweigard,J.A., Takano,Y., Takahara,H., Trail,F., van der Does,H.C., Voll,L.M., Will,I., Young,S., Zeng,Q., Zhang,J.,Zhou,S., Dickman,M.B., Schulze-Lefert,P., van Themaat,E.V., Ma,L.J. and Vaillancourt,L.J. 2012 Lifestyle transitions in plant pathogenic Colletotrichum fungi deciphered by genome and transcriptome analyses. Nat. Genet.

Ohmura, Y., Frisch, A., Lendemer, J.C. and Nakanishi, M., 2016. Lichens of Mikura-jima Island, Izu Islands, Central Japan. Bull. Natl. Mus. Nat. Sci., Ser. B, 42(1), pp. 1-18

Ohmura, Y., Thor, G., Frisch, A., Kashiwadani, H. and Moon, K.H., 2014. Increase of lichen diversity in the Imperial Palace Grounds, Tokyo, Japan. Memoirs of the National Museum of Nature and Science, 49.

Olariaga, I; Vooren, N. Van; Carbone, M; Hansen, K. 2015. A monograph of Otidea (Pyronemataceae, Pezizomycetes). Persoonia. 35:166-229

Oliveira H, Santos C, Paterson, R.R.M., Gusmão, N.B. and Lima, N., 2016a. Fungi from a Groundwater-Fed Drinking Water Supply System in Brazil. International journal of environmental research and public health, 13(3), p.304.

Oliveira MS, Malosso E, Barbosa MA, Araújo MA, Castañeda-Ruiz RF. Xylomyces acerosisporus sp. nov. from submerged leaves from Brazil. Mycotaxon. 2015 Oct 9;130(3):875-8.

Oliveira MS, Malosso E, Castañeda-Ruiz RF. 2016b A new species and a new combination in Codinaea from Brazil. Mycotaxon. Jan 11;130(4):1045-9.

Oliveira RJ, Lima TE, Cunha IB, Coimbra VR, Silva GA, Bezerra JL, Cavalcanti MA. Corniculariella brasiliensis, a new species of coelomycetes in the rhizosphere of Caesalpinia echinata (Fabaceae, Caesalpinioideae) in Brazil. Phytotaxa. 2014 Sep 17;178(3):197-204.

Orange A. 2009a A new species of Petractis (Ostropales s. lat., lichenized Ascomycota) from Wales. The Lichenologist. May 1;41(03):213-21. 
Orange A. 2009b Two parasitic species of Placopyrenium (Verrucariaceae) from freshwater habitats in North-west Europe. Lichenologist (Lond.) 41: 131-139

Oset, M. and Kukwa, M., 2014. Typification of two Stereocaulon names (Lecanorales, Ascomycota). Phytotaxa, 181(3), pp.188-191.

Oset, M., 2015. The lichen genus Stereocaulon (Schreb.) Hoffm. in Poland-a taxonomic and ecological study. Monographiae Botanicae, 104, pp.1-81.

Osmundson TW, Robert VA, Schoch CL, Baker LJ, Smith A, Robich G, Mizzan L, Garbelotto MM. Filling gaps in biodiversity knowledge for macrofungi: contributions and assessment of an herbarium collection DNA barcode sequencing project. PLoS one. 2013 Apr 30;8(4):e62419.

Osono T, Masuya H (2012) Endophytic fungi associated with leaves of Betulaceae in Japan. Canadian journal of microbiology 58(4):507-15.

Ostry, V., 2008. Alternaria mycotoxins: an overview of chemical characterization, producers, toxicity, analysis and occurrence in foodstuffs. World Mycotoxin Journal, 1(2), pp.175-188.

Otálora MAG, Wedin M (2013) Collema fasciculare belongs in Arctomiaceae. Lichenologist 45:295-304

Otálora, M. A., Aragon, G., Martinez, I. and Wedin, M. 2013. Cardinal characters on a slippery slope - A re-evaluation of phylogeny, character evolution, and evolutionary rates in the jelly lichens (Collemataceae s. str) Mol. Phylogenet. Evol. 68 (2), 185-198.

Otálora, M.A., Aragón, G., Molina, M.C., Martinez, I. and Lutzoni, F., 2010. Disentangling the Collema-Leptogium complex through a molecular phylogenetic study of the Collemataceae (Peltigerales, lichen-forming Ascomycota). Mycologia, 102(2), pp.279-290.

Otálora, M.A., Jørgensen, P.M. and Wedin, M., 2014. A revised generic classification of the jelly lichens, Collemataceae. Fungal diversity, 64(1), pp.275-293.

Ouda, S.M., 2014. Antifungal activity of silver and copper nanoparticles on two plant pathogens, Alternaria alternata and Botrytis cinerea. Research Journal of Microbiology, 9(1), p.34.

Overy DP, Baymane P, Kerr RG, Bills GF (2014) An assessment of natural product discovery from marine (sensu strictu) and marine-derived fungi. Mycology 5:145-167

$\varnothing$ VSTEDAL DO 2012. New species, combinations and records of lichenized fungi from the Falkland Islands (Islas Malvinas). The Lichenologist. Jul 1;44(04):483-500.

Øvstedal, D., Tønsberg, T. and Elvebakk, A., 2009. The lichen flora of Svalbard. Sommerfeltia, 33, pp.3-393.

Øvstedal, D.G. and Gremmen, N.J., 2010. New lichen species from Tristan da Cunha and Gough Island. Folia Cryptogamica Estonica, 47, pp.43-49.

Øvstedal, D.O. and Gremmen, N.J., 2014. Additional lichen records from Subantarctica III. Marion Island. Australasian Lichenology, 74, pp.2-7.

Øvstedal, D.O. and Gremmen, N.J.M., 2009. Additional lichen records from Subantarctica 1. The Kerguelen Islands. Australasian Lichenology, 64, pp.3-9.

Øvstedal, D.O. and Lewis Smith, R.I., 2011. Four additional lichens from the Antarctic and South Georgia, including a new Leciophysma species. Folia Cryptog. Estonica, 48, pp.65-68.

Paciura D, de Beer, Z.W.; Jacobs, K.; Zhou, X.D.; Ye, H.; Wingfield, M.J. 2010a. Eight new Leptographium species associated with tree-infesting bark beetles in China. Persoonia. 25:94-108

Paciura D, Zhou, X.D.; De Beer, Z.W.; Jacobs, K.; Ye, H. (2010b). Characterisation of synnematous bark beetle-associated fungi from China, including Graphium carbonarium sp. nov.. Fungal Diversity 40: 75-88. 
Palmateer,A.J., Perez,J.M., Cating,R.A. and Ploetz,R.C. 2008First report of tar spot on orange geiger (Cordia sebestena) caused by Diatractium cordianum in the US. Plant Disease 92(8) 1250.

Palmer, B., 2014. Nitrogen content of lichens as an indicator of inversion-based deposition.

Palmer,J.M., Lindner,D.L. and Volk,T.J. 2008 Ectomycorrhizal characterization of an American chestnut (Castanea dentata)-dominated community in Western Wisconsin. Mycorrhiza 19 (1), 27-36.

Palomares-Rius JE, Hirooka Y, Tsai IJ, Masuya H, Hino A, Kanzaki N, Jones JT, Kikuchi T. Distribution and evolution of glycoside hydrolase family 45 cellulases in nematodes and fungi. BMC evolutionary biology. 2014 Apr 1;14(1):1.

PAN HQ, WANG HF, JIANG YL, ZHANG TY. Scopulariopsis: three new species and a key to species from soils in China. Mycosystema. 2014;33:1-6.

Pan, H.Q.; Zhang, T.Y.; Kong, J.H. (2009). Notes on soil dematiaceous hyphomycetes from the Yellow River source area, China I. Mycosystema 28(1): 14-19.

Pandey, S.P., Sharma, S., Chand, R., Shahi, P. and Joshi, A.K., 2008. Clonal variability and its relevance in generation of new pathotypes in the spot blotch pathogen, Bipolaris sorokiniana. Current microbiology, 56(1), pp.33-41.

Pandit, G., 2015. Review of lichens of the high level Ferricretes and Mesas of the North Western Ghats, India. Current Research in Environmental \& Applied Mycology, 5(3), pp.180-195.

Pandit, G.S. and Sharma, B.O., 2012. New records in the lichen family Lobariaceae from the Western Ghats of India. MYCOSPHERE, 3(4), pp.430-435.

Pandit, G.S., 2014. Lichens of the Mahabaleshwar Panchgani Ecosensitive zone (MPESZ), Maharashtra, India. Journal of Threatened Taxa, 6(5), pp.5784-5791.

Pandit, R.J., Bhatt, V.D., Mukhopadhyaya, P.N., Joshi, C.G. and Kunjadia, A.P., 2014. Biochemical and molecular characterization of protease from Arthrobotrys conoides and Duddingtonia flagrans. Int. J. Adv. Biotechnol. Res, 5(3), pp.552-561.

Pane, C., Celano, G., Villecco, D. and Zaccardelli, M., 2012. Control of Botrytis cinerea, Alternaria alternata and Pyrenochaeta lycopersici on tomato with whey compost-tea applications. Crop Protection, 38, pp.80-86.

Pang KL, Alias SA, Chiang MWL, Vrijmoed LLP, Jones EBG (2010a) Sedecimiella taiwanensis gen. et sp. nov., a marine mangrove fungus in the Hypocreales (Hypocreomycetidae, Ascomycota). Bot Mar 53:493-498

Pang KL, Chiang MWL, Vrijmoed LLP (2008a) Havispora longyearbyenensis gen. et sp nov.: an arctic marine fungus from Svalbard, Norway. Mycologia 100:291-295

Pang KL, Chow RKK, Chan CW, Vrijmoed LLP (2011a) Diversity and physiology of marine lignicolous fungi in Arctic waters: a preliminary account. Polar Res 30:1-5

Pang KL, Guo SY, Alias SA, Hafellner J, Jones EBG (2014) A new species of marine Dactylospora and its phylogenetic affinities within the Eurotiomycetes, Ascomycota. Bot Mar 57:315-321

Pang KL, Hyde KD, Alias SA, Suetrong S, Guoc SY, Idid R, Jones EBG (2013a) Dyfrolomycetaceae, a new family in the Dothideomycetes. Cryptogamie Mycologie 34:223-232

Pang KL, Jheng JS (2012a) Checklist of marine fungi of Taiwan with a description of Kitesporella keelungensis gen. et sp. Nov. Bot Mar 55:459-466

Pang KL, Jheng JS (2012b) Pileomyces formosanus gen. et sp. nov. (Halosphaeriaceae, Ascomycota) from a rocky shore of Taiwan. Bot Stud 53:535-539

Pang KL, Jheng JS, Jones EBG (2011b) Marine mangrove fungi of Taiwan. National Taiwan Ocean University Press. Keelung, Taiwan 
Pang KL, Jones EBG, Vrijmoed LLP (2008b) Autecology of Antennospora (Ascomycota, Fungi) and its phylogeny. Raff Bull Zool 19:1-10

Pang KL, Sharuddin SS, Alias SA, Nor NAM, Awaluddin HH (2010b) Diversity and abundance of lignicolous marine fungi from the east and west coasts of Peninsular Malaysia and Sabah (Borneo Island). Bot Mar 53:515-523

Pang KL, Vrijmoed LLP, Jones EBG (2013b) Genetic variation within the cosmopolitan aquatic fungus Lignincola laevis (Microascales, Ascomycota). Org Divers Evol 13:301-309

Pańka, D., Jeske, M. and Troczyński, M., 2013. Occurrence of Neotyphodium and Epichloë fungi in meadow fescue and red fescue in Poland and screening of endophyte isolates as potential biological control agents. Acta Sci. Pol., Hortorum Cultus, 12(4), pp.6783.

Panzer,K., Yilmaz,P., Weiss,M., Reich,L., Richter,M., Wiese,J., Schmaljohann,R., Labes,A., Imhoff,J.F., Glockner,F.O. and Reich,M. 2015 Identification of Habitat-Specific Biomes of Aquatic Fungal Communities Using a Comprehensive Nearly Full-Length 18S rRNA Dataset Enriched with Contextual Data. PLoS ONE 10 (7), E0134377

Paoli, L., Munzi, S., Guttová, A., Senko, D., Sardella, G. and Loppi, S., 2015. Lichens as suitable indicators of the biological effects of atmospheric pollutants around a municipal solid waste incinerator (S Italy). Ecological Indicators, 52, pp.362-370.

Papazi, A., Kastanaki, E., Pirintsos, S. and Kotzabasis, K., 2015. Lichen Symbiosis: Nature's High Yielding Machines for Induced Hydrogen Production. PloS one, 10(3), p.e0121325.

Papong K, Lücking R, Thammathaworn A, Boonpragob K (2009a) Four new taxa of Chroodiscus (thelotremoid Graphidaceae) from Southeast Asia. Bryologist 112:152163

Papong K, Mangold A, Corush J, Lücking R, Lumbsch HT. (2009b) Phylogenetic position of the foliicolous genus Chroodiscus (Ostropales, Ascomycota) inferred from nuclear and mitochondrial ribosomal DNA sequences. Fungal Divers 38:147-153

Papong, K. and Lumbsch, H.T., 2011. A taxonomic survey of Lecanora sensu stricto in Thailand (Lecanoraceae; Ascomycota). The Lichenologist, 43(04), pp.299-320.

Papong, K., Boonpragob, K., Parnmen, S. and Lumbsch, H.T., 2013. Molecular phylogenetic studies on tropical species of Lecanora sensu stricto (Lecanoraceae, Ascomycota). Nova Hedwigia, 96(1-2), pp.1-13.

Papong, K.; Boonpragob, K.; Mangold, A.; Divakar, P.K.; Lumbsch, H.T. (2010). Thelotremoid lichen species recently described from Thailand: a re-evaluation. Lichenologist 42(2): 131-137.

Parada, R.Y., Sakuno, E., Mori, N., Oka, K., Egusa, M., Kodama, M. and Otani, H., 2008. Alternaria brassicae produces a host-specific protein toxin from germinating spores on host leaves. Phytopathology, 98(4), pp.458-463.

Park JH, Cho SE, Hong SH, Choi IY, Shin HD. Sooty Mould on Hibiscus rosa-sinensis Caused by Leptoxyphium kurandae is Associated with Extrafloral Nectaries. Journal of Phytopathology. 2015 Dec 1;163(11-12):1027-30.

Park JH, Shin HD. Ramularia hydrangeicola sp. nov. with distinctive traits on Hydrangea serrata f. acuminata in Korea. Mycotaxon. 2016 Apr 29;131(1):95-102.

Park MJ, Choi YJ, Hong SB, Shin HD (2010) Genetic variability and mycohost association of Ampelomyces quisqualis isolates inferred from phylogenetic analyses of ITS rDNA and actin gene sequences. Fungal Biology 114(2):235-47.

Park, M.J. and Shin, H.D., 2009. A new species of Pyricularia on Commelina communis. Mycotaxon, 108(1), pp.449-456. 
Park, M.S., Romanoski, C.E. and Pryor, B.M., 2008. A re-examination of the phylogenetic relationship between the causal agents of carrot black rot, Alternaria radicina and $A$. carotiincultae. Mycologia, 100(3), pp.511-527.

Park, S.Y., Jeong, M.H., Wang, H.Y., Kim, J.A., Yu, N.H., Kim, S., Cheong, Y.H., Kang, S., Lee, Y.H. and Hur, J.S., 2013. Agrobacterium tumefaciens-mediated transformation of the lichen fungus, Umbilicaria muehlenbergii. PloS one, 8(12), p.e83896.

Parnmen S, Lücking R, Lumbsch HT (2012) Phylogenetic classification at generic level in the absence of distinct phylogenetic patterns of phenotypical variation: a case study in Graphidaceae (Ascomycota). PLoS One 7(12):e51392

Parnmen S, Rangsiruji A, Mongkolsuk P, Boonpragob K, Elix JA, Lumbsch HT (2010) Morphological disparity in Cladoniaceae: the foliose genus Heterodea evolved from fruticose Cladia species (Lecanorales, lichenized Ascomycota). Taxon 59:841-849.

Parnmen, S, Cáceres, M.E.S/ Lücking, R./ Lumbsch, H.T. 2013: Myriochapsa and Nitidochapsa, two new genera in Graphidaceae (Ascomycota: Ostropales) for chroodiscoid species in the Ocellularia clade. - The Bryologist 116(2): 127-133.

Parsa, S.G., Moniri, M.H. and Asoodeh, A., 2013. A study on Tornabea scutellifera (Lichenized Ascomycete, Lecanorales) in northeastern Iran. Journal of Applied and Natural Science, 5(1), pp.148-152.

Pärtel K, Baral HO, Tamm H, Põldmaa K. 2017 Evidence for the polyphyly of Encoelia and Encoelioideae with reconsideration of respective families in Leotiomycetes. Fungal Diversity.: 82, Issue 1, pp 183-219.

Pärtel, K.; Põldmaa, K. 2011. A new species of Hyphodiscus (Helotiales) on Stereum. Mycotaxon. 115:11-17

Pasche, J.S. and Gudmestad, N.C., 2008. Prevalence, competitive fitness and impact of the F129L mutation in Alternaria solani from the United States. Crop Protection, 27(3), pp.427-435.

Passo A, Calvelo S. Pannaria byssoidea (Pannariaceae), a new squamulose species from southern South America. The Bryologist. 2011;114(4):756-63.

Pastirčáková K, Pastirčák M (2010) Two important ascomycetes and their anamorphs on twigs ofBetula pendulain Slovakia. Pol Bot J 55(2): 373-380.

Pastor, F.J. and Guarro, J., 2008. Alternaria infections: laboratory diagnosis and relevant clinical features. Clinical Microbiology and Infection, 14(8), pp.734-746.

Patil SY, Patil VR, Nemade LC. Biodiversity of Freshwater Mitosporic Fungi from Dhule District (MS), India. Journal of Ecobiotechnology. 2010 Nov 2;2(6).

Paukov, A.G. and Teptina, A.Y., 2012. New records of lichens from Middle Urals, Russia. Folia Cryptogamica Estonica, 49, pp.39-43.

Paz A, Lavoise C, Barrio L, Richard F, Moreau P-A. 2012. Propuesta de dos nuevas especies del género Elaphomyces, dos primeras citas para la Península Ibérica y una clave de identificación de las especies del género para Europa. Bol Micol FAMCAL 7:85-104.

Pažoutová S, Kolařík M, Odvody GN, Frederickson DE, Olšovská J, Man P. A new species complex including Claviceps fusiformis and Claviceps hirtella. Fungal. 2008;504(31):95-110.

Pažoutová S, Pešicová K, Chudičková M, Šrůtka P, Kolařík M. Delimitation of cryptic species inside Claviceps purpurea. Fungal biology. 2015 Jan 31;119(1):7-26.

Pažoutová, S.; Odvody, G.N.; Frederickson, D.E.; Chudickova, M.; Olsovska, J.; Kolarik, M. (2011). New Claviceps species from warm-season grasses. Fungal Diversity 49: 145165 
Pažoutová, S.; Srutka, P.; Holusa, J.; Chudícková, M.; Kubátová, A.; Kolarík, M. 2012. Liberomyces gen. nov. with two new species of endophytic coelomycetes from broadleaf trees. Mycologia. 104(1):198-210.

Pažoutová,S., Srutka,P., Holusa,J., Chudickova,M. and Kolarik,M. 2010 The phylogenetic position of Obolarina dryophila (Xylariales) Mycological Progress 9 (4), 501-507.

Pedras, M.S.C., Chumala, P.B., Jin, W., Islam, M.S. and Hauck, D.W., 2009. The phytopathogenic fungus Alternaria brassicicola: phytotoxin production and phytoalexin elicitation. Phytochemistry, 70(3), pp.394-402.

PELÁEZ F., COLLADO J., PLATAS G., OVERY D.P., MARTÍN J., VICENTE F., GONZÁLEZ DEL VAL A., BASILIO A., DE LA CRUZ M., TORMO J.R., FILLOLA A., ARENAL F., VILLAREAL M., RUBIO V., BARAL H.O., GALAN R. \& BILLS G.F. (2011) Phylogeny and intercontinental distribution of the pneumocandin-rpoducing anamorphic fungus Glarea lozoyensis. Mycology 2(1): 1-17.

Perdomo H, García D, Gené J, Cano J, Sutton DA, Summerbell R, Guarro J (2013) Phialemoniopsis, a new genus of Sordariomycetes, and new species ofPhialemoniumandLecythophora. Mycologia105(2):398-421

Pereira J, Rogers JD, Bezerra JL (2010) New Annulohypoxylon species from Brazil. Mycologia 102(1): 248-252.

Pereira-Carvalho RC, Dornelo-Silva D, Inácio CA, Dianese JC. 2009a Chaetothyriomyces: a new genus in family Chaetothyriaceae. Mycotaxon.;107:483-8.

Pereira-Carvalho RC, Sepúlveda-Chavera GF, Armando, E.A.S.; Inácio, C.A.; Dianese, J.C. (2009b). An overlooked source of fungal diversity: novel hyphomycete genera on trichomes of cerrado plants. Mycol. Res. 113(2): 261-274.

Pereira-Carvalho RD, Inácio CA, Dianese JC. Plurispermiopsis: a new capnodiaceous genus from the Brazilian Cerrado. Mycologia. 2010 Sep 1:1163-6.

Perello, A., Moreno, M. and Sisterna, M., 2008. Alternaria infectoria species-group associated with black point of wheat in Argentina. Plant Pathology, 57(2), pp.379379.

PERERA RH, MAHARACHCHIKUMBURA SS, ARIYAWANSA H, BAHKALI AH, JONES EG, AL-SADI AM, HYDE KD, LIU ZY. Two new Pseudohalonectria species on beech cupules (Fagus sylvatica) and a new genus to accommodate $\mathrm{P}$. suthepensis. Phytotaxa. 2016 Oct 7;278(2):115-31.

Pérez-Ortega S, Calatayud V (2009) Lichenostigma epirupestre, a new lichenicolous species on Pertusariaceae from Spain. Mycotaxon 107: 189-195.

Pérez-Ortega S, de los Ríos A, Crespo A, Sancho LG. Symbiotic lifestyle and phylogenetic relationships of the bionts of Mastodia tessellata (Ascomycota, incertae sedis). American journal of botany. 2010 May 1;97(5):738-52.

Pérez-Ortega S, Etayo J (2010). Labrocarpon gen. nov. for Melaspilea canariensis, with the description of Buelliella protoparmeliopsis sp. nov. from South America. Lichenologist 42(3): 271-276.

Pérez-Ortega S, Etayo J, Elix JA, Crespo A. 2011a A new species of Zwackhiomyces (Xanthopyreniaceae, Ascomycota) growing on Austroparmelina from Australia. Nova Hedwigia. Nov 1;93(3-4):395-400.

Pérez-Ortega S, Garrido-Benavent I, de Los Ríos A (2015) Austrostigmidium, a new austral genus of lichenicolous fungi close to rock-inhabiting meristematic fungi in Teratosphaeriaceae. Lichenologist 47: 143-156

Pérez-Ortega S, Garrido-Benavent I, Grube M./ Olmo, R./ de los Ríos, A. 2016: Hidden diversity of marine borderline lichens and a new order of fungi: Collemopsidiales (Dothideomyceta). - Fungal Diversity 80: 285-300. 
Pérez-Ortega S, Spribille T. (2009). Three new species of Lichenopeltella (Microthyriaceae, Ascomycota) from norhwest North America. Nova Hedwigia 89(1-2): 219-228.

Pérez-Ortega S, Suija A, Crespo A, de los Rios A (2014) Lichenicolous fungi of the genus Abrothallus (Dothideomycetes: Abrothallales ordo nov.) are sister to the predominantly aquatic Jahnulales. Fungal Diversity 64: 295-304.

Pérez-Ortega S, Suija A, de los Rios A (2011b) The connection between Abrothallus and its anamorph state Vouauxiomyces established by denaturing gradient gel electrophoresis (DGGE). Lichenologist 43: 277-279.

Pérez-Pérez RE, Castillo-Campos G, and da Silva Cáceres, M.E., 2015. Diversity of corticolous lichens in cloud forest remnants in La Cortadura, Coatepec, Veracruz, México in relation to phorophytes and habitat fragmentation. Cryptogamie, Mycologie, 36(1), pp.79-92.

Pérez-Vargas I, Etayo J, Hernández-padrón C (2013) New species of lichenicolous fungi from the Canary Islands. Phytotaxa 99(2):58-64.

Perez-Vargas I, Hernández-Padrón C, De Paz PP, Van Den PP, Jørgensen PM. 2014 A new species in the lichen genus Vahliella from the Canary Islands, including a key to Vahliellaceae, Pannariaceae, and Coccocarpiaceae in Macaronesia. Phytotaxa 167 (2): 183-188

Pérez-Vargas I, Padrón CH, Pérez de Paz PL, Elix JA 2010a Tephromela follmannii (lichenized Ascomycota), a new species from the Canary Islands. Mycotaxon, 112(1), pp.9-14.

Pérez-Vargas I, Padrón CH, Pérez de Paz PL, Elix JA 2010b Xanthoparmelia teydea, a new brown Xanthoparmelia (Parmeliaceae) from the Canary Islands. The Bryologist. Mar;113(1):51-4.

PERIĆ B, BARAL HO, PÄRTEL K. CENANGIOPSIS RAGHAVANII AND C. JUNIPERICOLA SPP. NOV.(CENANGIACEAE, HELOTIALES) COLLECTED IN MONTENEGRO, WITH REDESCRIPTION OF A RECENT COLLECTION OF C. QUERCICOLA. Mycologia Montenegrina. 2015 Jan 1;18.

Perić B, LOBUGLLIO KF, PFister DH. THE GENUS STROBILOSCYPHA: A NEW SPECIES AND AN UNRESOLVED PHYLOGENETIC PLACEMENT. Mycologia Montenegrina. 2013 Jan 1;16.

Perić B, Van Vooren N, HEALY R, LAZAREVIĆ J. UNE TRICHOPHAEA RARE RÉCOLTÉE EN FRANCE ET AU MONTÉNÉGRO: T. FLAVOBRUNNEA COMB. NOV.(PEZIZALES). Mycologia Montenegrina. 2014 Jan 1(17).

Perlmutter GB, Tucker SC, Plata ER, Cerc P, Lücking R (2015) Melaspilea demissa (Tuck.) Zahlbr. (lichenized Ascomycota) in eastern North America with a key to North American species of Melaspilea s. lat. The Lichenologist 47:167-182

Perlmutter, G.B., 2013. Lichen Biotic Inventory of Turnipseed Preserve, North Carolina, USA. Evansia, 30(2), pp.1-10.

Perlmutter, G.P., Lendemer, J.C., Guccion, J.C., Harris, R.C., Hodkinson, B.P., Kubilius, W.P., Lay, E.L.I.S.A.B.E.T.H. and Schaefer, H.P., 2012. A provisional survey of lichen diversity in south-central South Carolina, USA, from the 19th Tuckerman Lichen Workshop. Opuscula Philolichenum, 11, pp.104-119.

Peršoh, D., Weig, A.R. and Rambold, G., 2011. A transcriptome-targeting EcoChip for assessing functional mycodiversity. Microarrays, 1(1), pp.25-41.

Persson, M., Falk, A. and Dixelius, C., 2009. Studies on the mechanism of resistance to Bipolaris sorokiniana in the barley lesion mimic mutant bst1. Molecular plant pathology, 10(5), pp.587-598. 
Persson, M., Rasmussen, M., Falk, A. and Dixelius, C., 2008. Barley mutants with enhanced level of resistance to Swedish isolates of Bipolaris sorokiniana, casual agent of spot blotch. Plant Breeding, 127(6), pp.639-643.

Petäistö, R.L., Lilja, A.R.J.A. and Hantula, J., 2013. Artificial infection and development of snow mold fungus (Phacidium infestans) in container-grown Norway spruce seedlings. Baltic For, 19, pp.31-38.

Péter G, Dlauchy D, Price NP, Kurtzman CP. Diddensiella caesifluorescens gen. nov., sp. nov., a riboflavin-producing yeast species of the family Trichomonascaceae. International journal of systematic and evolutionary microbiology. 2012 Dec 1;62(12):3081-7.

Péter G, Dlauchy D, Tornai-Lehoczki J, Suzuki M, Kurtzman CP. Spencermartinsiella europaea gen. nov., sp. nov., a new member of the family Trichomonascaceae. International journal of systematic and evolutionary microbiology. 2011 Apr 1;61(4):993-1000.

Peter, M., Kohler,A., Ohm,R.A., Kuo,A., Krutzmann,J., Morin,E., Arend,M., Barry,K.W., Binder,M., Choi,C., Clum,A., Copeland,A., Grisel,N., Haridas,S., Kipfer,T., LaButti,K., Lindquist,E., Lipzen,A., Maire,R., Meier,B., Mihaltcheva,S., Molinier,V., Murat,C., Poggeler,S., Quandt,C.A., Sperisen,C., Tritt,A., Tisserant,E., Crous,P.W., Henrissat,B., Nehls,U., Egli,S., Spatafora,J.W., Grigoriev,I.V. and Martin,F.M. 2016 Ectomycorrhizal ecology is imprinted in the genome of the dominant symbiotic fungus Cenococcum geophilum Nat Commun 7, 12662.

Peterson KR, Pfister DH 2010 Phylogeny of Cyttaria inferred from nuclear and mitochondrial sequence and morphological data. Mycologia. 2010 Nov-Dec;102(6):1398-416.

Peterson SW, Manitchotpisit P, Leathers TD. Aureobasidium thailandense sp. nov. isolated from leaves and wooden surfaces. International journal of systematic and evolutionary microbiology. 2013 Feb 1;63(2):790-5.

Peterson SW. 2008 Phylogenetic analysis of Aspergillus species using DNA sequences from four loci. Mycologia. Mar 1;100(2):205-26.

Peterson SW., Jurjevic,Z., Bills,G.F., Stchigel,A.M., Guarro,J. and Vega,F.E. 2010 Genus Hamigera, six new species and multilocus DNA sequence based phylogeny. Mycologia 102 (4), 847-864.

Pethybridge, S.J.; Jones, S.J.; Shivas, R.G.; Hay, F.S.; Wilson, C.R.; Groom, T. (2008). Tan spot: a new disease of pyrethrum caused by Microsphaeropsis tanaceti sp. nov.. Pl. Path. 57(6): 1058-1065

Petrini LE, Petrini O. Rosellinia species (Xylariaceae) from South and Central America-An annotated list. Kurtziana. 2012;37:127-39.

Petterson OV, Leong SL, Lantz H, Rice T, Dijksterhuis J, Houbraken J, Samson RA, Schnürer J. 2011. Phylogeny and intraspecific variation of the extreme xerophile, Xeromyces bisporus. Fungal Biology 115:1100-1111.

Pfister DH, Agnello C, Lantieri A, LoBuglio KF. 2013 The Caloscyphaceae (Pezizomycetes, Ascomycota), with a new genus. Mycological progress. Nov 1;12(4):667-74.

Pfister DH, Slater C, Hansen K. Chorioactidaceae: a new family in the Pezizales (Ascomycota) with four genera. Mycological research. 2008 May 31;112(5):513-27.

Pfliegler WP, Báthori F., Haelewaters D., Tartally A. 2016a. Studies of Laboulbeniales on Myrmica ants (III): myrmecophilous arthropods as alternative hosts of Rickia wasmannii. Parasite. doi:10.1051/parasite/2016060

Pfliegler WP, Fekete, J.; Báthori, F. \& Tartally, A. (2016b) First Central European record of the fungus Prolixandromyces triandrus Santam., 1988 (Ascomycota: Laboulbeniales), 
a parasite of Veliid bugs (Heteroptera: Veliidae), with notes on its biology and DNAbarcoding. Aquatic Insects 37(3): 215-223.

Phillips AJL, Alves A, Abdollahzadeh J, Slippers B, Wingfield MJ, et al. 2013 - The Botryosphaeriaceae: genera and species known from culture. Studies in Mycology 76, 51-167.

Phillips AJL, Alves A, Pennycook SR, Johnston PR, Ramaley A, et al. 2008 - Resolving the phylogenetic and taxonomic status of dark-spored teleomorph genera in the Botryosphaeriaceae. Persoonia 21, 29-55.

Phookamsak R, Boonmee S, Norphanphoun C, Wanasinghe DN, de Silva N, Dayarathne MC, Hongsanan S, Bhat DJ, Hyde KD 2016. Schizothyriaceae. Mycosphere. Jan $1 ; 7(2): 154-89$.

Phookamsak R, Liu JK, Manamgoda DS, Wanasinghe DN, Ariyawansa H, Mortimer PE, Chukeatirote E, McKenzie EH, Hyde KD. (2014a) Epitypification of two bambusicolous fungi from Thailand. Cryptogamie, Mycologie. Sep;35(3):239-56.

Phookamsak R, Liu JK, McKenzie EHC, Manamgoda DS et al. 2014b. Revision of Phaeosphaeriaceae. Fungal Diversity 68, 159-238

Phookamsak R, Liu, J.K.; Chukeatirote, E.; McKenzie, E.H.C.; Hyde, K.D. 2013. Convergent evolution: Phylogeny and morphology of Leptosphaerulina saccharicola sp. nov. and Pleosphaerulina oryzae and relationships with Pithomyces. 34:303-319

Phookamsak R, Manamgoda DS, Li WJ, Dai DQ, Singtripop C, Hyde KD. Poaceascoma helicoides gen et sp. nov., a new genus with scolecospores in Lentitheciaceae. Cryptogamie, mycologie. 2015a Jul 13;36(2):225-36.

Phookamsak R, Norphanphoun C, Tanaka K, Dai DQ, Luo ZL, Liu JK, Su HY, Bhat DJ, Bahkali AH, Mortimer PE, Xu JC, Hyde KD (2015b) Astrosphaeriella-like species; introducing Astrosphaeriellaceae and Pseudoastrosphaeriellaceae fam. nov. and Astrosphaeriellopsis, gen. nov. Fungal Divers 74:143-197

Phukhamsakda C, Ariyawansa HA, Phillips AJ, Wanasinghe DN, Bhat DJ, McKenzie EH, Singtripop C, Camporesi E, Hyde KD. 2016 Additions to Sporormiaceae: Introducing two novel genera, Sparticola and Forliomyces, from Spartium. Cryptogamie, Mycologie. 37 (1): 75-97.

Phukhamsakda C, Ariyawansa HA, Phookamsak R, Chomnunti P, Bulgakov TS, Yange JB, Bhat DJ, Bahkalih AH, Hyde KD. (2015) Muriphaeosphaeria galatellae gen. et sp. nov. in Phaeosphaeriaceae (Pleosporales). Phytotaxa 227(1):55-65.

Phuwapraisirisan, P., Rangsan, J., Siripong, P. and Tip-pyang, S., 2009. New antitumour fungal metabolites from Alternaria porri. Natural product research, 23(12), pp.10631071.

Pili,N.N., Franca,S.C., Kyndt,T., Makumba,B.A., Skilton,R., Hoefte,M., Mibey,R.K. and Gheysen,G. 2015 Analysis of fungal endophytes associated with rice roots from irrigated and upland ecosystems in Kenya. Plant and Soil 405, Issue 1, pp 371-380

Pindaru, D.M., Tanase, C., Olariu, R.I. and Arsene, C., 2013. Chemical composition and ions concentration in Xanthoria parietina and Phaeophyscia orbicularis lichenised fungi species from Iasi, North-Eastern Romania. Revista de Chimie, 64(8), pp.807-814.

Pinho DB, Firmino AL, Ferreira-Junior WG, Pereira OL (2013) New Meliolaceae from the Brazilian Atlantic Forest 2: species on host families Annonaceae, Cecropiaceae, Meliaceae, Piperaceae, Rubiaceae, Rutaceae and Tiliaceae. Mycologia. 105(3):697711

Pinho DB, Firmino AL, Pereira OL (2010) Hyphopolynema ingae sp. nov., associated with leaf spot disease on Inga edulis in Brazil. Mycotaxon. 114:55-59 
Pinho DB, Honorato J, Nicoli A, Hora BT, Braganca CAD, Pereira OL (2012) Phylogenetic placement of the genus Anhellia and the description of A. nectandrae sp. nov. Mycologia 104: 1291-1298.

Pinnoi, A.; Phongpaichit, P.; Jeewon, R.; Tang, A.M.C.; Hyde, K.D.; Jones, E.B.G. (2010). Phylogenetic relationships of Astrocystis eleiodoxae sp. nov. (Xylariaceae). Mycosphere 1(1): 1-9

Pino-Bodas, R., Martin, M.P. and Burgaz, A.R. 2012. Cladonia subturgida and C. iberica (Cladoniaceae) form a single, morphologically and chemically polymorphic species. Mycological Progress 11 (1), 269-278.

Pinruan, U, Rungjindamai N, Sakayaroj J, Lumyong S, Hyde KD, Jones EBG (2010) Baipadisphaeria gen. nov., a freshwater ascomycete (Hypocreales, Sordariomycetes) from decaying palm leaves in Thailand. Mycosphere 1(1):53-63

Pirnia, M., Zare, R., Zamanizadeh, H.R. and Khodaparast, A., 2012. New records of cercosporoid hyphomycetes from Iran. Mycotaxon, 120(1), pp.157-169.

Pisani, T., Munzi, S., Paoli, L., Bačkor, M. and Loppi, S., 2011. Physiological effects of arsenic in the lichen Xanthoria parietina (L.) Th. Fr. Chemosphere, 82(7), pp.963-969.

Pitt JI, Hocking AD. 2009. Fungi and food spoilage. Springer Science \& Business Media, New York.

Pitt JI, Lantz H, Pettersson OV, Leong SL. 2013. Xerochrysium gen. nov. and Bettsia, genera encompassing xerophilic species of Chrysosporium. IMA Fungus 4:229-241.

Pitt,W.M., Urbez-Torres,J.R. and Trouillas,F.P. 2014 Munkovalsaria donacina from grapevines and Desert Ash in Australia. Mycosphere 5 (5), 656-661.

Plattner A, Kim JJ, Reid J, Hausner G, Lim YW, Yamaoka Y, Breuil C. Resolving taxonomic and phylogenetic incongruence within species Ceratocystiopsis minuta. Mycologia. 2009 Nov 1;101(6):878-87.

Plazaa CM, de Torresc, L.E.D., Lückingf, R.K., Vizcayaa, M. and Medinaa, G.E., 2014. Antioxidant activity, total phenols and flavonoids of lichens from Venezuelan Andes. Journal of Pharmacy \& Pharmacognosy Research, 2(5), pp.138-147.

Poengsungnoen,V;Manoch,L;Mongkolsuk,P;Kalb,K. 2014. New species of Graphidaceae from Loei Province, Thailand. Phytotaxa. 189(1):255-267.

Pogány, M., von Rad, U., Grün, S., Dongó, A., Pintye, A., Simoneau, P., Bahnweg, G., Kiss, L., Barna, B. and Durner, J., 2009. Dual roles of reactive oxygen species and NADPH oxidase RBOHD in an Arabidopsis-Alternaria pathosystem. Plant Physiology, 151(3), pp.1459-1475.

Polashock JJ, Caruso FL, Oudemans PV, McManus PS, Crouch JA (2009) The North American cranberry fruit rot fungal community: a systematic overview using morphological and phylogenetic affinities. Plant Pathology 58:1116-1127.

Põldmaa K. 2011. Tropical species of Cladobotryum and Hypomyces producing red pigments. Studies in Mycology 68: 1-34.

Poloni, A., Pessi, I.S., Frazzon, A.P.G. and Van Der Sand, S.T., 2009a. Morphology, physiology, and virulence of Bipolaris sorokiniana isolates. Current microbiology, 59(3), pp.267-273.

Poloni, A., Pessi, I.S., Frazzon, A.P.G. and Van Der Sand, S.T., 2009b. Vegetative incompatibility among monoconidial isolates of Bipolaris sorokiniana. Current microbiology, 58(2), pp.153-158.

Pose, G., Patriarca, A., Kyanko, V., Pardo, A. and Pinto, V.F., 2009. Effect of water activity and temperature on growth of Alternaria alternata on a synthetic tomato medium. International journal of food microbiology, 135(1), pp.60-63. 
Potenza, G., Fascetti, S., Ravera, S. and Puntillo, D., 2010. Lichens from sandy dune habitats on the Ionian Coast (Basilicata, southern Italy). Cryptogamie Mycol, 31, pp.59-65.

Prabhugaonkar A, Bhat DJ. 2011 - New record of Megacapitula villosa and Paradictyoarthrinium diffractum from India. Mycosphere 2(4), 463-467.

Prasher IB, Verma RK. Neosporidesmium appendiculatus sp. nov. from North-Western India. Mycological Progress. 2015 Oct 1;14(10):87.

Prasher,I.B;Verma,R.K. 2014. Taeniolina echinata sp. nov. from North India. Kavaka. 43:1113

Pratibha J, Bhat DJ, Prabhugaonkar A. 2016 Molecular phylogeny of Speiropsis pedatospora. Mycosphere 7 (5), 679-686

Pratibha J, Bhat, D.J. and Raghukumar, S. (2011). Four anamorphic fungi (with two new species) from forests of Western Ghats, India. Mycotaxon 117: 269-278.

Pratibha J, Nguyen HD, Mel'nik VA, Bhat DJ, White GP, Seifert KA 2015. Lectotypification, epitypification, and molecular phylogeny of the synnematous hyphomycete Pseudogliophragma indicum, the second genus in the Wiesneriomycetaceae. Mycoscience. Jul 31;56(4):387-95.

Pratibha J, Prabhugaonkar A, Hyde KD, Bhat DJ. 2014 Phylogenetic placement of Bahusandhika, Cancellidium and Pseudoepicoccum (asexual Ascomycota). Phytotaxa. Aug 20;176(1):68-80.

Pratibha J, Prabhugaonkar A. (2015) Multi-gene phylogeny of Pithomyces with the sexual morph of $P$. flavus Berk. \& Broome. Phytotaxa 218 (1):84-90

Pratibha J. 2013. Jayarambhatia rhizophorae gen. et sp. nov., an asexually reproducing fungus from Goa, India. Mycotaxon. 125:139-144

Pratibha J.; Amandeep, K.; Shenoy, B.D.; Bhat, D.J. (2010). Caliciopsis indica sp. nov. from India. Mycosphere 1(1): 65-72

Pratibha, J.; Raghukumar, S.; Bhat, D.J. (2009). New species of Digitoramispora and Spondylocladiopsis from the forests of Western Ghats, India. Mycotaxon 107: 383390.

Prelle, A., Spadaro, D., Garibaldi, A. and Gullino, M.L., 2013. A new method for detection of five Alternaria toxins in food matrices based on LC-APCI-MS. Food chemistry, 140(1), pp.161-167.

Prieto M, Aragon G, Martinez I (2010a) The genus Catapyrenium s. lat. (Verrucariaceae) in the Iberian Peninsula and the Balearic Islands. The Lichenologist 42(06):637-84.

Prieto M, Baloch E, Tehler M, Wedin M (2013) Mazaedium evolution in the Ascomycota (Fungi) and the classification of mazaediate groups of unclear relationship. Cladistics 29(3):296-308.

Prieto M, Martínez I, Aragón G, Gueidan C, Lutzoni F (2012) Molecular phylogeny of Heteroplacidium, Placidium, and related catapyrenioid genera (Verrucariaceae, lichen-forming Ascomycota). American Journal of Botany 99(1):23-35.

Prieto M, Martinez I, Aragón G, Otálora MA, Lutzoni F (2010b) Phylogenetic study of Catapyrenium s. str. (Verrucariaceae, lichen-forming Ascomycota) and related genus Placidiopsis. Mycologia 102(2):291-304.

Prieto M, Wedin M (2016) Phylogeny, taxonomy and diversification events in the Caliciaceae. Fungal Diversity doi:10.1007.s13225-016-0372-y

Prieto M, Westberg M, Schultz M (2015) New records of Lichinomycetes in Sweden and the Nordic countries. Herzogia 28(1):142-152

Prihatini R, Boonyuen N, Sivichai S (2010) Phylogenetic evidence that two submergedhabitat fungal species, Speiropsis pedatospora and Xylomyces chlamydosporus, belong to the order Jahnulales insertae sedis Dothideomycetes. Microbiology Indonesia 2 (3) 
Printzen C (2014) A molecular phylogeny of the lichen genus Biatora including some morphologically similar species. Lichenologist 46:441-453

Printzen C, Cezanne R, Eichler M, Lumbsch HT (2012) The genera Aphanopsis and Steinia represent basal lineages within Leotiomyceta. Biblioth Lichenol 108:177-186

Printzen, C., 2010. Lichen systematics: the role of morphological and molecular data to reconstruct phylogenetic relationships. In Progress in Botany 71 (pp. 233-275). Springer Berlin Heidelberg.

Printzen, C.; Spribille, T.; Tønsberg, T. (2008). Myochroidea, a new genus of corticolous, crustose lichens to accommodate the Lecidea leprosula group. Lichenologist 40(3): 195-207.

Proksa B. 2010. Talaromyces flavus and its metabolites. Chem Pap 64:696-714.

Puangsombat, P., Sangwanit, U. and Marod, D., 2010. Diversity of soil fungi in different land use types in Tha Kum-Huai Raeng Forest Reserve, Trat Province. Natural Sciences, 44, pp.1162-1175.

Pudhom K, Teerawatananond T. Rhytidenones A-F, spirobisnaphthalenes from rhytidhysteron sp. AS21B, an endophytic fungus. J Nat Prod. 2014;77(8):1962-6.

Pundhir, P., Tuda, C., Vincentelli, C., Morlote, D. and Rivera, C., 2016. Scolecobasidium granulomatous pneumonia and abscess-an emerging opportunistic fungal pathogen: a case report. International journal of STD \& AIDS, p.0956462416646688.

Punithalingam E, Spooner BM (2011b) Miricatena prunicola (Hyphomycetes), a new genus and species causing leaf spots of Prunus serotina in the UK. Kew Bulletin Vol. 66, No. 4 (2011), pp. 637-642.

Punithalingam E, Spooner BM 2011a A new fungicolous Scolecobasidium (hyphomycetes) and Caducirostrum gen. nov. (coelomycetes) from leaf litter in the UK and Italy. Kew Bulletin 66,(2) 309-324.

Purvis, W., 2012. Lichens. An Illustrated Guide to the British and Irish Species. by Frank S. Dobson. Slough: The Richmond Publishing Co., 2011. 496 pp. Paperback: ISBN: 978 0 85546, $3151 . £ 35.00$ plus postage ( 5 UK, $£ 10$ overseas). Hardback: ISBN: 9780 $85546,3168 . £ 50.00$ plus postage ( $£ 5$ UK, $£ 10$ overseas).

PYKÄLÄ J, Myllys L. 2016 Three new species of Atla from calcareous rocks (Verrucariaceae, lichenized Ascomycota). The Lichenologist. Mar 1;48(2):111-20.

Pykälä J, Stepanchikova IS, Himelbrant DE, Kuznetsova ES, Alexeeva NM. The lichen genera Thelidium and Verrucaria in the Leningrad Region (Russia). Folia Cryptogamica Estonica. 2012;49:45-57.

Qiao, M., Zhang, Y., Li, S.F., Baral, H.O., Weber, E., Su, H.Y., Xu, J.P., Zhang, K.Q. and Yu, Z.F., 2012. Orbilia blumenaviensis and its Arthrobotrys anamorph. Mycological progress, 11(1), pp.255-262.

Qin L, Qiao M, Yang Y, Yang GZ, Lu KP, Zhang KQ, Xu JP, Yu ZF. Dactylella pseudobrevistipitata, a new species from China. Annals of microbiology. 2011 Sep 1;61(3):591-5.

Qin Yang, Xin-Lei Fan, Pedro W. Crous, Ying-Mei Liang, Cheng-Ming Tian 2015 Cytospora from Ulmus pumila in Northern China. Mycological Progress 14: 74.

Qu, C.R., Yin, G.H., Zhao, G.Z, Cui B. K. \& Liu, X.Z. 2014.Three new species of Berkleasmium (hyphomycetes) from China. Nova Hedwigia 98(1-2):151-161

Quaedvlieg W, Groenewald JZ, de Jesús Yáñez-Morales M, Crous PW. (2012). DNA barcoding of Mycosphaerella species of quarantine importance to Europe. Persoonia 29: $101-115$.

Quaedvlieg W, Verkley GJM, Shin H-D, Barreto RW, Alfenas AC, et al (2013) Sizing up Septoria. Stud Mycol 75: 307-390. 
Quaedvlieg, W., Binder, M., Groenewald, J. Z., Summerell, B. A., Carnegie, A. J., Burgess, T. I., \& Crous, P. W. (2014). Introducing the Consolidated Species Concept to resolve species in the Teratosphaeriaceae. Persoonia 33, 1-40.

Quandt CA, Kepler RM, Gams W, Araújo JP, Ban S, Evans HC, Hughes D, Humber R, Hywel-Jones N, Li Z, Luangsa-Ard JJ. Phylogenetic-based nomenclatural proposals for Ophiocordycipitaceae (Hypocreales) with new combinations in Tolypocladium. IMA fungus. 2014 Jun 1;5(1):121-34.

Queloz V, Grünig CR, Berndt R, Kowalski T, Sieber TN, Holdenrieder O. Cryptic speciation in Hymenoscyphus albidus. Forest Pathology. 2011 Apr 1;41(2):133-42.

QUIJADA L, BARAL H.O., JAÉN-MOLINA R., WEISS M., CAUJAPÉ-CASTELLS, COOPER J., JOHNSTON P. \& BELTRÁN-TEJERA E. (2015) Exploring the phylogenetic and morphological relationships of disregarded genera in Helotiales s.l. XVII Congress of European Mycologist (21-25 September, Madeira, Portugal).

Quijada L, Baral HO, Beltrán-Tejera E. New species of Orbilia (Orbiliales) from arid ecosystems of the Canary Islands (Spain). Nova Hedwigia. 2013 Feb 1;96(1-2):23748.

Quilhot, W., Cuellar, M., Diaz, R., Riquelme, F. and Rubio, C., 2010. Preliminary study of the lichen flora of Isla Mocha, southern Chile. Gayana Botánica, 67(2), pp.206-212.

Raggio J, Green TGA, Crittenden PD, Pintado, A., Vivas, M., Pérez-Ortega, S., De los Ríos, A. and Sancho, L.G., 2012. Comparative ecophysiology of three Placopsis species, pioneer lichens in recently exposed Chilean glacial forelands. Symbiosis, 56(2), pp.55-66.

Raggio J, Pintado A, Ascaso C, De La Torre R, De Los Rios A, Wierzchos J, Horneck G, Sancho LG (2011) Whole lichen thalli survive exposure to space conditions: results of Lithopanspermia experiment with Aspicilia fruticulosa. Astrobiology 11(4):281-92.

Raitviir A (2008) The Helotiales of the Magadan and Chukotka areas of the Russian Arctic. Sommerfeltia 31: 179-190.

Raja H, Miller A, Shearer C (2010a) Freshwater Ascomycetes: Hyalorostratum brunneisporum, a new genus and species in the Diaporthales (Sordariomycetidae, Sordariomycetes) from North America. Mycosphere 1 (4):275-288

Raja HA, Carter A, Platt HW, Shearer CA (2008a) Freshwater ascomycetes: Jahnula apiospora (Jahnulales, Dothideomycetes), a new species from Prince Edward Island, Canada. Mycoscience 49 (5):326-328. doi:Doi 10.1007/S10267-008-0428-2

Raja HA, El-Elimat T, Oberlies NH, Shearer CA, Miller AN, Tanaka K, Hashimoto A, Fournier J (2015) Minutisphaerales (Dothideomycetes, Ascomycota): a new order of freshwater ascomycetes including a new family, Minutisphaeraceae, and two new species from North Carolina, USA. Mycologia 107 (4):845-862. doi:10.3852/15-013

Raja HA, Ferrer A, Shearer CA (2009a) Freshwater ascomycetes: a new genus, Ocala scalariformis gen. et sp nov, and two new species, Ayria nubispora sp nov and Rivulicola cygnea sp nov. Fungal Divers 34:79-86

Raja HA, Ferrer A, Shearer CA, Miller, A.N. (2010b). Freshwater ascomycetes: Wicklowia aquatica, a new genus and species in the Pleosporales from Florida and Costa Rica. Mycoscience 51(3): 208-214

Raja HA, Miller AN, Shearer CA (2008b) Freshwater ascomycetes: Aquapoterium pinicola, a new genus and species of Helotiales (Leotiomycetes) from Florida. Mycologia 100 (1):141-148 
Raja HA, Miller AN, Shearer CA (2012) Freshwater ascomycetes: Natipusillaceae, a new family of tropical fungi, including Natipusilla bellaspora sp. nov. from the Peruvian Amazon. Mycologia 104 (2):569-573. doi:Doi 10.3852/11-150

Raja HA, Oberlies NH, El-Elimat T, Miller AN, Zelski SE, Shearer CA (2013a) Lindgomyces angustiascus, (Lindgomycetaceae, Pleosporales, Dothideomycetes), a new lignicolous species from freshwater habitats in the USA. Mycoscience 54 (5):353-361. doi:10.1016/j.myc.2012.12.004

Raja HA, Oberlies NH, Figueroa M, Tanaka K, Hirayama K, Hashimoto A, Miller AN, Zelski SE, Shearer CA (2013b) Freshwater ascomycetes: Minutisphaera (Dothideomycetes) revisited, including one new species from Japan. Mycologia 105 (4):959-976. doi:10.3852/12-313

Raja HA, Oberlies NH, Tamam-El Elimat, Miller AN, Zelski SE, Shearer CA (2013c) Lindgomyces angustiascus, (Lindgomycetaceae, Pleosporales, Dothideomycetes), a new lignicolous species from freshwater habitats in the USA. Mycoscience 54:353361

Raja HA, Schmit JP, Shearer CA (2009b) Latitudinal, habitat and substrate distribution patterns of freshwater ascomycetes in the Florida Peninsula. Biodiversity and Conservation 18 (2):419-455. doi:Doi 10.1007/S10531-008-9500-7

Raja HA, Schoch C, Hustad V, Shearer C, Miller A (2011a) Testing the phylogenetic utility of MCM7 in the Ascomycota. MycoKeys 1, 63-94

Raja HA, Shearer CA (2008) Freshwater ascomycetes: new and noteworthy species from aquatic habitats in Florida. Mycologia 100 (3):467-489

Raja HA, Tanaka K, Hirayama K, Miller A, Shearer CA (2011b) Freshwater Ascomycetes: Two new species of Lindgomyces (Lindgomycetaceae, Pleosporales, Dothideomycetes) from Japan and USA. Mycologia 103: 1421-1432

Raja HA, Violi HA, Shearer CA (2010c) Freshwater ascomycetes: Alascospora evergladensis, a new genus and species from the Florida Everglades. Mycologia 102 (1):33-38. doi:10.3852/09-096

Rajakaruna, N., Knudsen, K., O'dell, R., Nathaniel, P., Olday, F.C. and Woolhouse, S., 2012. Investigation of the importance of rock chemistry for saxicolous lichen communities of the New Idria serpentinite mass, San Benito County, California, USA. The Lichenologist, 44(05), pp.695-714.

Rajeshkumar KC, Crous PW, Groenewald JZ, Seifert KA. 2016 Resolving the phylogenetic placement of Porobeltraniella and allied genera in the Beltraniaceae. Mycological Progress.:1-8.

Rajeshkumar, K. C., and A. Y. Rossman. (2013) Taiwanascus samuelsii sp. nov., an addition to Niessliaceae from the Western Ghats, Kerala, India." IMA fungus 4(1): 1-4.

Rajeshkumar, K.C. and Sharma, R., 2013. Tamhinispora a new genus belongs to family Tubeufiaceae from the Western Ghats, India based on morphology and phylogenetic analysis. Mycosphere, 4(2), pp.165-174.

Rajeshkumar, K.C. and Singh, S.K., 2012. Manoharachariella indica sp. nov. from the Western Ghats, India. Mycotaxon, 120(1), pp. 43-48.

Rajeshkumar, K.C., Kajale, S.C., Sutar, S.A. and Singh, S.K., 2013. Ellisembia karadkensis sp. nov. from southern Western Ghats, India. Mycotaxon, 121(1), pp. 181-186.

Ram, T.J., 2014. New species and new records in Roccellaceae (Arthoniales) from the Andaman Islands, India. Phytotaxa, 177(3), pp.155-162.

Rämä T, Mathiassen GH, Kauserud H (2014) Marine fungi new to Norway, with an outlook to the overall diversity. Agarica 34:35-54.

Rambelli, A., 2011. Some Dematiaceous Hyphomycetes from Mediterranean maquis litters. Flora Mediterranea, 21, pp.5-204. 
Ramos A.M., Cinto I.E., Tadic L.F. \& Ranalli M.E. (2011). AFLP molecular characterizations of some Saccobolus species (Ascomycota, Pezizales).

Randlane, T., Saag, A., Thell, A. and Ahti, T., 2013. Third world list of cetrarioid lichens - in a new databased form, with amended phylogenetic and type information. Cryptogamie, Mycologie, 34(1), pp.79-94.

Randriamanantany, Z.A., Annesi-Maesano, I., Moreau, D., Raherison, C., Charpin, D., Kopferschmitt, C., Lavaud, F., Taytard, A., De Blay, F. and Caillaud, D., 2010. Alternaria sensitization and allergic rhinitis with or without asthma in the French Six Cities study. Allergy, 65(3), pp.368-375.

Rangsiruji, A., Boonpragob, K., Mongkolsuk, P., Sodamuk, M., Buaruang, K., Binchai, S., Lumbsch, H.T. and Parnmen, S., 2016. Diversity and phylogenetic survey of cyanobacterial lichens (Collematineae, Ascomycota) in mangrove forests of eastern Thailand. The Bryologist, 119(2), pp.123-130.

Ranjbar-Bahadori, S., Razzaghi-Abyaneh, M., Bayat, M., Eslami, A., Pirali, K., ShamsGhahfarokhi, M. and Lotfollahzadeh, S., 2010. Studies on the effect of temperature, incubation time and in vivo gut passage on survival and nematophagous activity Arthrobotrys oligospora var. oligospora and A. cladodes var. macroides. Global Veterinaria, 4(2), pp.112-117.

Ranković BR, Kosanić MM, Stanojković TP. Antioxidant, antimicrobial and anticancer activity of the lichens Cladonia furcata, Lecanora atra and Lecanora muralis. BMC complementary and alternative medicine. 2011 Oct 20;11(1):97.

Ranković, B., Mišić, M. and Sukdolak, S., 2009. Antimicrobial activity of extracts of the lichens Cladonia furcata, Parmelia caperata, Parmelia pertusa, Hypogymnia physodes and Umbilicaria polyphylla. Biologia, 64(1), pp.53-58.

Ranković, B.V., Kosanić, M..A. and Stanojković, T..A.. 2014. Stereocaulon paschale lichen as antioxidant, antimicrobial and anticancer agent. Farmacia, 62, pp.306-317.

Rashmi, S. and Rajkumar, H.G., 2015. First Report of Foliicolous Lichen Biota in South Karnataka-India. Int. J. Curr. Microbiol. App. Sci, 4(6), pp.250-256.

Réblová M (2008) Bellojisia a new sordariaceous genus for Jobellisia rhynchostoma and a description of Jobellisiaceae fam. nov. Mycologia. Nov 1;100(6):893-901.

Réblová M (2011) New insights into the systematics and phylogeny of the genus Jattaea and similar fungi of the Calosphaeriales. Fungal Diversity. 49:167-198

Réblová M (2013) Two taxonomic novelties in the Sordariomycetidae: Ceratolenta caudata gen. et sp. nov. and Platytrachelon abietis gen. et comb. nov. for Ceratosphaeria abietis. Mycologia 105(2):462-75.

Réblová M (2014) Sporoschismopsis angustata sp. nov., a new holomorph species in the Retiulascaceae (Glomerellales), and a reappraisal of Sporoschismopsis. Mycol Prog 13:671-681.

Réblová M, Fournier J, Hyde KD (2010) Achroceratosphaeria, a new ascomycete genus in the Sordariomycetes, and re-evaluation of Ceratosphaeria incolorata. Fungal Diversity 43: 75-84.

Réblová M, Fournier J, Štěpánek V (2015a) Pisorisporiales, a new order of aquatic and terrestrial fungi for Achroceratosphaeria and Pisorisporium gen. nov. in the Sordariomycetes. Persoonia 34:40-49

Réblová M, Fournier J, Stepánek V. 2016a. Two new lineages of aquatic ascomycetes: Atractospora gen. nov. and Rubellisphaeria gen. et sp. nov., and a sexual morph of Myrmecridium montsegurinum sp. nov. Mycological Progress. 15:1-18

Réblová M, Gams W, Seifert KA (2011) Monilochaetes and allied genera of the Glomerellales, and a reconsideration of families in the Microascales. Studies in Mycology 68:163-191 
Réblová M, Gams W. 2011. The new hyphomycete genera Brachyalara and Infundichalara, the similar Exochalara and species of 'Phialophora sect. Catenulatae' (Leotiomycetes). Fungal Diversity. 46:67-86

Réblová M, Hubka V, Thureborn O, Lundberg J, Sallstedt T, et al. (2016b) From the tunnels into the treetops: new lineages of black yeasts from biofilm in the Stockholm metro system and their relatives among ant-associated fungi in the Chaetothyriales. PloS one. Oct 12;11(10):e0163396.

Réblová M, Jaklitsch W, Réblová K, Stepánek V. (2015b) Phylogenetic reconstruction of the Calosphaeriales and Togniniales using five genes and predicted RNA secondary structures of ITS, and Flabellascus tenuirostris gen. et sp. nov. PloS ONE. 10:1-46

Réblová M, Miller AN, Rossman AY, Seifert KA, Crous PW et al (2016c) Recommendations for competing sexual-asexually typified generic names in Sordariomycetes (except Diaporthales, Hypocreales, and Magnaporthales). IMA Fungus. 7, 131-153.

Réblová M, Réblová K, Štěpánek V. 2015c Molecular systematics of Barbatosphaeria (Sordariomycetes): multigene phylogeny and secondary ITS structure. Persoonia: Molecular Phylogeny and Evolution of Fungi. Dec;35:21.

Réblová M, Seifert KA (2011) Discovery of the teleomorph of the hyphomycete, Sterigmatobotrys macrocarpa, and epitypification of the genus to holomorphic status. Studies in Mycology 68:193-202.

Réblova M, Seifert KA (2012) Cirrosporium novae-zelandiae, an enigmatic coelomycete with meristem arthroconidia, with ancestors in the Eurotiomycetes. Mycologia 104(6):1315-1324

Réblová M, Seifert KA, Fournier J, Stepánek V (2012) Phylogenetic classification of Pleurothecium and Pleurotheciella gen. nov. and its dactylaria-like anamorph (Sordariomycetes) based on nuclear ribosomal and protein-coding genes. Mycologia 104(6):1299-1314.

Réblová M, Seifert KA, Fournier J, Štěpánek V. 2017 Newly recognised lineages of perithecial ascomycetes: the new orders Conioscyphales and Pleurotheciales. Persoonia.;37:57-81.

Réblová M, Štěpánek V (2009) New fungal genera, Tectonidula gen. nov. for Calosphaerialike fungi with holoblastic-denticulate conidiogenesis and Natantiella gen. nov. for three species segregated from Ceratostomella. Mycol. Res. 113(9): 991-1002.

Réblová M, Stěpánek V, Schumacher RK (2014) Xylochrysis lucidagen. et sp. nov., a new lignicolous ascomycete (Sordariomycetidae) with holoblastic conidiogenesis. Mycologia 106(3):564-572.

Réblová M, Untereiner WA, Réblová K (2013) Novel evolutionary lineages revealed in the Chaetothyriales (Fungi) based on multigene phylogenetic analyses and comparison of ITS secondary structures. PloS ONE 8:1-28.

Recio, M., del Mar Trigo, M., Docampo, S., Melgar, M., García-Sánchez, J., Bootello, L. and Cabezudo, B., 2012. Analysis of the predicting variables for daily and weekly fluctuations of two airborne fungal spores: Alternaria and Cladosporium. International journal of biometeorology, 56(6), pp.983-991.

Reddy, M.A., Nayaka, S., Shankar, P.C., Reddy, S.R. and Rao, B.R.P., 2011. New distributional records and checklist of lichens for Andhra Pradesh, India. Indian Forester, 137(12), pp.1371-1376.

Rehner, S.A.; Minnis, A.M.; Sung, G.H.; Luangsa-ard, J.J.; Devotto, L.; Humber, R.A. (2011). Phylogeny and systematics of the anamorphic, entomopathogenic genus Beauveria. Mycologia 103(5): 1055-1073. 
Ren F, Zhuang WY. A new species of the genus Chlorencoelia (Helotiales) from China. Mycoscience. 2014 May 31;55(3):227-30.

Ren J, Jie, C.Y., Zhou, Q.X., Li, X.H., Hyde, K.D., Jiang, Y.L., Zhang, T.Y. and Wang, Y., 2013a. Molecular and morphological data reveal two new species of Scolecobasidium. Mycoscience, 54(6), pp.420-425.

Ren J, Zeng C, Jiang YL, Hyde KD, Wang Y (2013b) A new Thai species of Astrosphaeriella (Dothideomycetes, Ascomycota) from submerged wood in freshwater. Sydowia $65: 33-43$

Ren SC, Ma J, Ma LG, Zhang YD, Zhang XG. Sativumoides and Cladosporiopsis, two new genera of hyphomycetes from China. Mycological progress. 2012a May 1;11(2):4438.

Ren SC, Ma J, Zhang XG 2012b. Two new Heteroconium species and two other forest microfungi newly recorded from China. Mycotaxon, 119(1), pp.361-367.

Ren SC, Ma, J. and Zhang, X.G., 2013c. Two new Ellisembia species from Hainan and Yunnan, China. Mycotaxon, 122(1), pp.83-87.

Ren, Q. and Li, S., 2013. New records of crustose lichens from China-1. Mycotaxon, 125(1), pp.65-67.

RESL P, MAYRHOFER H, CLAYDEN SR, SPRIBILLE T, THOR G, TØNSBERG T, SHEARD JW. Morphological, chemical and species delimitation analyses provide new taxonomic insights into two groups of Rinodina. The Lichenologist. 2016;48(5):469-88.

Resl P, Schneider K, Westberg M, Printzen C, Palice Z, Thor G, Fryday A, Mayrhofer H, Spribille T (2015) Diagnostics for a troubled backbone: testing topological hypotheses of trapelioid lichenized fungi in a large-scale phylogeny of Ostropomycetidae (Lecanoromycetes). Fungal Divers. 73(1): 239-258

Reynolds, D.R. (2010). Epifoliar fungi of Singapore. Gdns' Bull. Singapore, 61(2): 401-435.

Richardson M. J. (2008). Records of Coprophilous Fungi from the Lesser Antilles and Puerto Rico. Caribbean Journal of Science 44(2):206-214. 2008.

Riddell, J., Jovan, S.A.R.A.H., Padgett, P. and Sweat, K., 2011. Tracking lichen community composition changes due to declining air quality over the last century: the Nash legacy in Southern California.

Rifai, M.A. (2008). Another note on Podoconis megasperma Boedijn (Hyphomycetes). Reinwardtia 12(4): 277-279.

Rikkinen J, Tuovila H, Beimforde C, Seyfullah L, Perrichot V, Schmidt AR. Chaenothecopsis neocaledonica sp. nov.: The first resinicolous mycocalicioid fungus from an araucarian conifer. Phytotaxa. 2014 Jun 20;173(1):49-60.

Rincon-Espitia, A. and Mateus, N., 2013. Morphological and anatomical characterization of the genus Stereocaulon hoffmann (Lichenized ascomycetes) in Colombia. Caldasia, 35(2), pp.241-260.

Rivas Plata E, Kalb K, Frisch A (2010b) Wirthiotrema: a new genus for the Thelotrema glaucopallens group (Ascomycota: Ostropales: thelotremoid Graphidaceae). Lichenologist 42(2): 187-202.

Rivas Plata E, Lücking R (2012) High diversity of Graphidaceae (lichenized Ascomycota: Ostropales) in Amazonian Perú. Fungal Divers 58:13-32

Rivas Plata E, Lücking R, Lumbsch HT (2012a) A new classification for the family Graphidaceae (Ascomycota: Lecanoromycetes: Ostropales). Fungal Divers 52:107121

Rivas Plata E, Lücking R, Lumbsch HT (2012b) Molecular phylogeny and systematics of the Ocellularia clade (Ascomycota: Ostropales: Graphidaceae). Taxon 61(6): 1161-1179. 
Rivas Plata E, Lücking R, Sipman HJM, Mangold A, Kalb K, et al. (2010a) A world-wide key to the thelotremoid Graphidaceae, excluding the Ocellularia-MyriotremaStegobolus clade. Lichenologist 42: 139-185.

Rivas Plata E, Parnmen S, Staiger B, Mangold A, Frisch A, Weerakoon G, Hernández MJE, Cáceres MES, Kalb K, Sipman HJM, Common RS, Nelsen MP, Lücking R, Lumbsch HT (2013) A molecular phylogeny of Graphidaceae (Ascomycota, Lecanoromycetes, Ostropales) including 428 species. MycoKeys 6:55-94

Rivas Plata ET, Lücking R, Lümbsch HT, Chaves JL (2008) Gyrotrema wirthii, a new species of Gyrotrema (Ascomycota: Ostropales: Graphidaceae) from Costa Rica. Sauteria. 15:417-420.

Rivera-Orduña FN, Suarez-Sanchez RA, Flores-Bustamante ZR, Gracida-Rodriguez JN, Flores-Cotera LB. Diversity of endophytic fungi of Taxus globosa (Mexican yew). Fungal Diversity. 2011 Mar 1;47(1):65-74.

Rizzi, G. and Giordani, P., 2013. The ecology of the lichen genus Xanthoparmelia in Italy: an investigation throughout spatial scales. Plant Biosystems-An International Journal Dealing with all Aspects of Plant Biology, 147(1), pp.33-39.

Rizzi, G., Incerti, G., Ginaldi, F., Kodnik, D., Viglione, S. and Giordani, P., 2011. A contribution to the lichen flora of Sardinia. Mycotaxon, 115, p.535.

Rizzo L, Sutton DA, Wiederhold NP, Thompson EH, Friedman R, Wickes BL, Cano-Lira JF, Stchigel AM, Guarro J. Isolation and characterisation of the fungus Spiromastix asexualis sp. nov. from discospondylitis in a German Shepherd dog, and review of Spiromastix with the proposal of the new order Spiromastixales (Ascomycota). Mycoses. 2014 Jul 1;57(7):419-28.

Robène-Soustrade I, Jouen E, Pastou D, Payet-Hoarau M, Goble T, Linderme D, Lefeuvre P, Calmès C, Reynaud B, Nibouche S, Costet L. Description and phylogenetic placement of Beauveria hoplocheli sp. nov. used in the biological control of the sugarcane white grub, Hoplochelus marginalis, on Reunion Island. Mycologia. 2015 Nov 1;107(6):1221-32.

Rocha, F.B.; Barreto, R.W.; Bezerra, J.L.; Neto, J.A.A.M. (2010). Foliar mycobiota of Coussapoa floccosa, a highly threatened tree of the Brazilian Atlantic forest. Mycologia 102(6): 1240-1252.

Rodriguez Flakus PR, Printzen C (2014) Molecular evidence for the occurrence of the lichen genus Biatora (Lecanorales, Ascomycota) in the Southern Hemisphere. Phytotaxa 172:271-279

Rodríguez J, D; Kirschner, R; Piepenbring, M. 2015. New species and new records of Meliolaceae from Panama. Fungal Diversity. 70(1):73-84

Rogers JD, Ju YM. The Xylariaceae of the Hawaiian Islands. North American Fungi. 2012 Jul 27;7:1-35.

Rogers, P.C., Rogers, R.W., Hedrich, A.E. and Moss, P.T., 2015. Lichen Monitoring Delineates Biodiversity on a Great Barrier Reef Coral Cay. Forests, 6(5), pp.15571575.

Rojas EI, Herre EA, Mejía LC, Arnold AE, Chaverri P, et al. 2008 - Endomelanconiopsis, a new anamorph genus in the Botryosphaeriaeae. Mycologia 100, 760-775.

Romero AI, Robledo G, LoBuglio KF, Pfister DH. 2012 Rickiella edulis and its phylogenetic relationships within Sarcoscyphaceae. Kurtziana.;37:79-89.

Romón P, De Beer ZW, Fernández M, Diez J, Wingfield BD, Wingfield MJ. 2014 Ophiostomatoid fungi including two new fungal species associated with pine rootfeeding beetles in northern Spain. Antonie van Leeuwenhoek. Dec 1;106(6):1167-84. 
Root, H.T. and McCune, B., 2012. Regional patterns of biological soil crust lichen species composition related to vegetation, soils, and climate in Oregon, USA. Journal of Arid Environments, 79, pp.93-100.

Root, H.T., McCune, B. and Jovan, S., 2014. Lichen communities and species indicate climate thresholds in southeast and south-central Alaska, USA. The Bryologist, 117(3), pp.241-252.

Root, H.T., McCune, M. and McCune, B., 2013. Wind farm potential is higher in prime habitat for uncommon soil crust lichens. Ecological Processes, 2(1), p.1.

Root, H.T., Miller, J.E. and McCune, B., 2011. Biotic soil crust lichen diversity and conservation in shrub-steppe habitats of Oregon and Washington. The Bryologist, 114(4), pp.796-812.

Ropars J, Cruaud C, Lacoste S, Dupont J (2012) A taxonomic and ecological overview of cheese fungi. International journal of food microbiology. 155(3):199-210.

Rosentreter, R., Rai, H. and Upreti, D.K., 2014. Distribution ecology of soil crust lichens in India: a comparative assessment with global patterns. In Terricolous lichens in India (pp. 21-31). Springer New York.

Rosenzweig, N., Olaya, G., Atallah, Z.K., Cleere, S., Stanger, C. and Stevenson, W.R., 2008. Monitoring and tracking changes in sensitivity to azoxystrobin fungicide in Alternaria solani in Wisconsin. Plant Disease, 92(4), pp.555-560.

Rosling A, Cox F, Cruz-Martinez K, Ihrmark K, Grelet GA, Lindahl BD, Menkis A, James TY (2011) Archaeorhizomycetes: unearthing an ancient class of ubiquitous soil fungi. Science 333(6044):876-9.

Rosow, L., Jiang, J.X., Deuel, T., Lechpammer, M., Zamani, A.A., Milner, D.A., Folkerth, R., Marty, F.M. and Kesari, S., 2011. Cerebral phaeohyphomycosis caused by Bipolaris spicifera after heart transplantation. Transplant Infectious Disease, 13(4), pp.419-423.

Rossi W (2010). New Laboulbeniales (Ascomycota) parasitic on Staphylinidae from Ecuador. Mycol. Progr. 9(3): 407-415

Rossi W, Bergonzo, E. (2008): New and Interesting Laboulbeniales from Brazil. Aliso 26(1): $1-8$.

Rossi W, Bernardi M, Torres J.A. 2016a. New species of Laboulbenia parasitic on leaf beetles. Mycological Progress 15: 1-7. doi:10.1007/s11557-015-1146-8

Rossi W, Bernardi M, Torres JA. New species of Dimeromyces from Ecuador. Mycological progress. $2015 \mathrm{Feb}$ 1;14(2):5.

Rossi W, Haelewaters D., Pfister D.H. 2016b. Fireworks under the microscope: a spectacular new species of Zodiomyces from the Thaxter collection. Mycologia 108 (4): 709-715. doi:10.3852/15-148

Rossi W, Leonardi M. (2012). New species of Stigmatomyces (Laboulbeniomycetes) from Sierra Leone. Plant Biosystems iFirst article: 1-5.

Rossi W, Ponziani P.R. 2008. New Laboulbeniales (Ascomycotina) from French Guyana. Cryptogamie Mycologie. 29(1):3-9.

Rossi W, Proano Castro, A.C. (2009). New species of Rhachomyces from Ecuador, one of which is dimorphic. Mycologia 101(5): 674-680.

Rossi W, Santamaria S (2015) New species of Aporomyces. Turkish Journal of Botany 39(2):354-8.

Rossi W, Santamaría S. (2008a). New Laboulbeniales parasitic on endogean ground beetles. Mycologia 100(4): 636-641.

Rossi W, Santamaría S. (2012) Rodaucea, a new genus of the Laboulbeniales. Mycologia 104:785-788, doi:10.3852/11-337 
Rossi W, Santamaria, S. (2008b) Cesariella, a new genus of Laboulbeniales. Mycological Research 112(8): 917-920.

Rossi W, Santamaría, S. (2015) New species of Aporomyces. Turkish Journal of Botany 39: 354-358.

Rossi W, Santamaria, S. 2010. New species of Diphymyces (Laboulbeniales, Ascomycota). Mycological Progress. 9(4):597-601

Rossi W, Weir A (2008) New Species of Cucujomyces (Laboulbeniales) on Chilean Leiodidae. Aliso 26(1): 9-14.

Rossi W, Weir A. (2011). New species of Stigmatomyces from Asia. Mycologia 103(1): 131134.

Rossman A, Melgar J, Walker D., Gonzales,A., Ramirez,T. and Rivera,J. 2012 First Report of Dolabra nepheliae Associated with Corky Bark Disease of Rambutan and Pulasan in Honduras. Plant Dis. 96 (5), 765.

Rossman AY, Adams GC, Cannon PF, Castlebury LA, Crous PW, Gryzenhout M, Jaklitsch WM, Mejia LC, Stoykov D, Udayanga U, Voglmayr H, Walker DM (2015a) Recommendations of generic names in Diaporthales competing for protection or use. IMA Fungus 6: 145-154.

Rossman AY, Aime MC, Farr DF, Castlebury LA, Peterson KR, Leahy R. The coelomycetous genera Chaetomella and Pilidium represent a newly discovered lineage of inoperculate discomycetes. Mycological Progress. 2004 Nov 1;3(4):275-90.

Rossman AY, Allen WC, Braun U, Castlebury LA, Chaverri P, et al (2016a) Overlooked competing asexual and sexually typified generic names of Ascomycota with recommendations for their use or protection. IMA Fungus 7: 285-304.

Rossman AY, Allen WC, Castlebury LA. (2016b) New combinations of plant-associated fungi resulting from the change to one name for fungi. IMA Fungus 7(1): 1-7.

Rossman AY, Crous PW, Hyde KD, Hawksworth DL, Aptroot A, et al (2015b) Recommended names for pleomorphic genera in Dothideomycetes. IMA fungus. 6(2):507-23.

Rossman AY, Manamgoda DS, Hyde KD (2013a) (2233) Proposal to conserve the name Bipolaris against Cochliobolus (Ascomycota: Pleosporales: Pleosporaceae). Taxon, 62(6), pp.1331-1332.

Rossman AY, Schoch CL, Farr DF, Nishijima K, Keith L, Goenaga R (2010) Dolabra nepheliae on rambutan and lychee represents a novel lineage of phytopathogenic Eurotiomycetes. Mycoscience 51(4):300-309

Rossman AY, Seifert K.A., Samuels, G.J., Minnis, A.M., Schroers, H.J., Lombard, L., Crous, P.W., Põldmaa, K., Cannon, P.F., Summerbell, R.C. and Geiser, D.M., 2013b. Genera in Bionectriaceae, Hypocreaceae, and Nectriaceae (Hypocreales) proposed for acceptance or rejection. IMA fungus, 4(1), pp.41-51.

Rossmann B, Muller H, Smalla,K., Mpiira,S., Tumuhairwe,J.B., Staver,C. and Berg,G. 2012 Banana-associated microbial communities in Uganda are highly diverse but dominated by enterobacteriaceae. Appl. Environ. Microbiol. 78 (14), 4933-4941.

Rotter, M., 2010. A preliminary list of the lichen flora of the San Francisco Presidio. Bulletin of the California Lichen Society, 17(1-2), pp.23-26.

Rout, J., Singha, A.B. and Upreti, D.K., 2010. Pigment Profile and Chllorophyll Degradation of Pyxine cocoes lichen: A Comparative Study of the Different Degree of Disturbance in Cachar District, Assam. Assam University Journal of Science and Technology, 5(1), pp.85-88.

Roux C (2009) Naetrocymbe saxicola, likeno kun Trentepohlia. Bull. Soc. linn. Provence 60: $127-142$ 
Roux C, Gueidan C, Navarro-Rosinés P, Monnat JY. Encore Trimmatothelopsis!. Bull. Soc. linn. Provence. 2016;67:159.

Roux C, Gueidan C. Du novaj specioj de Verrucariaceae el Pyrénées-Orientales (Farncio): Placocarpus melanophthalmosus sp. nov. kaj Placopyrenium breussii sp. nov. Bulletin de la Société Linnéenne de Provence num. spec. 2011;14:163-76.

Rubini A, Belfiori B, Passeri V, Falini LB, Arcioni S, Riccioni C, Paolocci F. The AD-type ectomycorrhizas, one of the most common morphotypes present in truffle fields, result from fungi belonging to the Trichophaea woolhopeia species complex. Mycorrhiza. 2011 Jan 1;21(1):17-25.

Rubio, C., Saavedra, M., Cuéllar, M., Díaz, R. and Quilhot, W., 2013. Epiphytic lichens of Conguillío National Park, southern Chile/Líquenes epífitos en el Parque Nacional Conguillío, sur de Chile. Gayana. Botanica, 70(1), p.66.

Rubio, E.; Tabarés, M.; Martínez, M.A. 2011. Marcelleina parvispora (Ascomycota, Pezizales), a new Marcelleina species from Catalonia (Spain). Revista Catalana de Micologia. 32:31-35

Rubio, E.; Tena, R.; Ormad, J.; Suárez, A. 2010. Ruhlandiella reticulata comb. nov. y Ruhlandiella truncata comb. nov. (Ascomycota, Pezizales) Nuevas combinaciones para dos raras especies semihipogeas, eucaliptícolas y pirófilas de origen austral: Muciturbo reticulatus y Muciturbo truncatus. Revista Catalana de Micologia. 32:2330

Ruibal R, Millanes AM, Hawksworth DL (2011) Molecular phylogenetic studies on the lichenicolous Xanthoriicola physciae reveal Antarctic rock-inhabiting fungi and Piedraia species among closest relatives in the Teratosphaeriaceae. IMA Fungus 2: 97-103.

Ruibal, C., Gueidan, C., Selbmann, L., Gorbushina, A. A., Crous, P. W., Groenewald, J. Z., ... \& Staley, J. T. (2009). Phylogeny of rock-inhabiting fungi related to Dothideomycetes. Studies in Mycology 64, 123-133.

Ruibal, C., Platas, G., \& Bills, G. F. (2008). High diversity and morphological convergence among melanised fungi from rock formations in the Central Mountain System of Spain. Persoonia 21, 93-110.

Ruíz, R.F.C., Iturriaga, T., Abarca, G.H., Minter, D.W., Gené, J., Stadler, M., Saikawa, M. and Silvera-Simón, C., 2008. Notes on Heteroconium and a new species from Venezuela. Mycotaxon, 105, pp.175-184.

Ruiz-González, M.X., Lauth, J., Leroy, C., Jauneau, A., Gryta, H., Jargeat, P., Dejean, A. and Orivel, J., 2013. An efficient protocol for isolating melanised chaetothyrialean anamorphic fungi associated with plant-ants. Journal of basic microbiology, 53(1), pp.98-100.

Rungindamai N, Sakayaroj S, Somrithipol S, Plaingam N, Jones EBG (2012) Phylogeny of the appendaged coelomycete genera: Pseudorobillarda, Robillarda, and Xepiculopsis based on nuclear ribosomal DNA sequences. Cryptogamie Mycologie 33:319-332

Saag, A., Randlane, T., Saag, L., Thell, A. and Ahti, T., 2013. Third world list of cetrarioid lichens, a databased tool for documentation of nomenclatural data-lessons learned. Taxon, 62(3), pp.591-603.

Saag, L., Mark, K., Saag, A. and Randlane, T., 2014. Species delimitation in the lichenized fungal genus Vulpicida (Parmeliaceae, Ascomycota) using gene concatenation and coalescent-based species tree approaches. American journal of botany, 101(12), pp.2169-2182.

Sabirov, A., Hamilton, R.G., Jacobs, J.B., Hillman, D.E., Lebowitz, R.A. and Watts, J.D., 2008. Role of local immunoglobulin E specific for Alternaria alternata in the pathogenesis of nasal polyposis. The Laryngoscope, 118(1), pp.4-9. 
Saccente M, Woods GL. 2010. Clinical and laboratory update on Blastomycosis. Clin Microbiol Rev 23:367-381.

Saha, D., Fetzner, R., Burkhardt, B., Podlech, J., Metzler, M., Dang, H., Lawrence, C. and Fischer, R., 2012. Identification of a polyketide synthase required for alternariol $(\mathrm{AOH})$ and alternariol-9-methyl ether (AME) formation in Alternaria alternata. PLoS One, 7(7), p.e40564.

Saha, S., Sarkar, J., Chattopadhyay, D., Patra, S., Chakraborty, A. and Acharya, K., 2010. Production of silver nanoparticles by a phytopathogenic fungus Bipolaris nodulosa and its antimicrobial activity. Dig J Nanomater Biostruct, 5(4), pp.887-895.

Sakayaroj J, Pang KL, Jones EBG (2011a) Multi-gene phylogeny of the Halosphaeriaceae: its ordinal status, relationships between genera and morphological character evolution. Fungal Divers 46:87-109.

Sakayaroj J, Supaphon O, Jones EBG, Phongpaichit S (2011b) Diversity of higher marine fungi at Hat Khanom-Mu Ko Thale Tai National Park, Southern Thailand. Songklanakarin J. Sci. Technol. 33(1):15-22

Salgado-Salazar C, Rossman A, Samuels GJ, Capdet M, Chaverri P. Multigene phylogenetic analyses of the Thelonectria coronata and $\mathrm{T}$. veuillotiana species complexes. Mycologia. 2012 Nov 1;104(6):1325-50.

Salgado-Salazar, C; Rossman, A.M; Samuels, G.J; Hirooka, Y; Sanchez, R.M; Chaverri, P. 2014. Phylogeny and taxonomic revision of Thelonectria discophora (Ascomycota, Hypocreales, Nectriaceae) species complex. Fungal Diversity. 70(1):1-29.

Salgado-Salazar, C; Rossman, A.Y; Chaverri, P. 2016. The genus Thelonectria (Nectriaceae, Hypocreales, Ascomycota) and closely related species with cylindrocarpon-like asexual states. Fungal Diversity. 80:411-455

Salgüero, R., Borman, A.M., Herrtage, M., Benchekroun, G., Abbondati, E., Piola, V. and Vanhaesebrouck, A., 2013. Rasamsonia argillacea mycosis in a dog: first case in Europe. Veterinary Record Case Reports, 1(1), p.e101373.

Samerpitak K, van den Ende BH, Stielow JB, Menken SB, de Hoog GS. Barcoding and species recognition of opportunistic pathogens in Ochroconis and Verruconis. Fungal biology. 2016 Feb 29;120(2):219-30.

Samerpitak, K., Van der Linde, E., Choi, H.J., van den Ende, A.G., Machouart, M., Gueidan, C. and De Hoog, G.S., 2014. Taxonomy of Ochroconis, genus including opportunistic pathogens on humans and animals. Fungal Diversity, 65(1), pp.89-126.

Samerpitak, K; Gerrits van den Ende, A.H.G; Menken, S.B.J; de Hoog, G.S. 2015. Three new species of the genus Ochroconis. Mycopathologia. 180(1):7-17

Samón-Legrá E, Lavandera DE, González MC (2014) A Preliminary Checklist of Marine Fungi from Zapata Swamp Biosphere Reserve, South of Cuba. Middle-East Journal of Scientific Research 21:1771-1775

Samson RA, Visagie CM, Houbraken J, Hong S-B, Hubka V, Klaassen CHW, Perrone G, Seifert KA, Susca A, Tanney JB, Varga J, Kocsubé S, Szigeti G, Yaguchi T, Frisvad JC. 2014. Phylogeny, identification and nomenclature of the genus Aspergillus. Studies in Mycology 78:141-173.

Samson RA, Yilmaz N, Houbraken J, Spierenburg H, Seifert KA, Peterson SW, Varga J, Frisvad JC. Phylogeny and nomenclature of the genus Talaromyces and taxa accommodated in Penicillium subgenus Biverticillium. Studies in Mycology. 2011 Sep 30;70:159-83.

Samuels GJ, Lu BS, Chaverri P, Candoussau F, Fournier J, Rossman AY. Cyanonectria, a new genus for Nectria cyanostoma and its Fusarium anamorph. Mycological Progress. 2009 Mar 1;8(1):49-58. 
Sánchez FJ, Meeßen J, del Carmen Ruiz, M., Leopoldo, G., Ott, S., Vílchez, C., Horneck, G., Sadowsky, A. and de la Torre, R., 2014a. UV-C tolerance of symbiotic Trebouxia sp. in the space-tested lichen species Rhizocarpon geographicum and Circinaria gyrosa: role of the hydration state and cortex/screening substances. International Journal of Astrobiology, 13(01), pp.1-18.

Sánchez RM, Giordano L, Anderson FE, Bianchinotti M. A new species of Scopinella from pampas grass in Argentina. Mycotaxon. 2013 Mar 4;122(1):265-70.

Sánchez S, Gómez E, Martín M, De Miguel AM, Urban A, Barriuso J. Experiments on the life cycle and factors affecting reproduction of Sphaerosporella brunnea provide evidence for rapid asexual propagation by conidiospores and for homothallism in an ectomycorrhizal competitor of cultivated truffle species. Fungal Ecology. 2014b Apr 30;8:59-65.

Sanders, W.B. and de los Rios, A., 2016. Structure of foliicolous thalli of the Gomphillaceae in a south-western Florida lichen community. The Lichenologist, 48(04), pp.293-303.

Sanders, W.B. and Lücking, R., 2015. Three new species of foliicolous Gomphillaceae (lichen-forming ascomycetes) from southern Florida. The Bryologist, 118(2), pp.170177.

Sanders, W.B./ de los Ríos, A. 2016: Structure of foliicolous thalli of the Gomphillaceae in a south-western Florida lichen community. - The Lichenologist 48(4): 293-303.

Sanderson NA, Hawkswotrth DL, Aptroot A (2009) Melaspilea Nyl.. In: Smith CW, Aptroot A, Coppins BJ, Fletcher A, Gilbert OL, James PW, Wolseley PA (Eds).The lichens of Great Britain and Ireland. British Lichen Society, 576-579.

Sandoval-Denis M, Gené J, Sutton DA, Cano-Lira JF et al. (2016a) - Redefining Microascus, Scopulariopsis and allied genera. Persoonia 36,1-36.

Sandoval-Denis M, Gené J, Sutton DA, Wiederhold NP, Guarro J (2015a) Acrophialophora, a poorly known fungus with clinical significance. Journal of Clinical Microbiology 53:1549-1555.

Sandoval-Denis M, Guarro J, Cano-Lira JF, Sutton DA, Wiederhold NP, et al. (2016b) Phylogeny and taxonomic revision of Microascaceae with emphasis on synnematous fungi. Studies in Mycology 83:193-233.

Sandoval-Denis M, Sutton DA, Martin-Vicente A, Cano-Lira JF, Wiederhold N, Guarro J, Gené J. 2015b Cladosporium species recovered from clinical samples in the United States. Journal of clinical microbiology. Jul 15:JCM-01482.

SANDOVAL-LEIVA P., CARMARÁN C.C., PARK D., ROMERO A.I. \& P.R. JOHNSTON (2014) Vibrisseaceous fungi from the southern hemisphere, including Chlorovibrissea chilensis (Helotiales, incertae sedis) sp. nov. Mycologia 106(6): 1159-1167.

Sang H, An T, Kim CS, Shin GS, Sung GH, Yu SH. 2013. Two novel Talaromyces species isolated from medicinal crops in Korea. J Microbiol 51:704-708.

Sanjuan TI, Franco-Molano AE, Kepler RM, Spatafora JW, Tabima J, Vasco-Palacios AM, Restrepo S. Five new species of entomopathogenic fungi from the Amazon and evolution of neotropical Ophiocordyceps. Fungal Biology. 2015 Oct 31;119(10):90116.

SANOAMUANG N., JITJAK W., RODTONG S. \& WHALLEY A. (2013) Gelatinomyces siamensis gen. sp. nov. (Ascomycota, Leotiomycetes incertae sedis) on bamboo in Thailand. IMA FUNGUS 4(1): 71-87.

Santa Izabel TD, Almeida DA, Monteiro JS, Marques MF, Gusmão LF, Castañeda-Ruiz RF. Anaexserticlava caatingae, a new conidial fungus from the semi-arid Caatinga biome of Brazil. Mycotaxon. 2015 Jul 9;130(2):445-9. 
Santa-Izabel, T.S., Cruz, A.C.R. and Gusmão, L.F.P., 2013. Conidial fungi from the semiarid Caatinga biome of Brazil. Ellisembiopsis gen. nov., new variety of Sporidesmiella and some notes on Sporidesmium complex. Mycosphere, 4, pp.156163.

Santamaría S. 2008. Laboulbeniales on semiaquatic Heteroptera. A new species of Triceromyces (Ascomycota, Laboulbeniales) on Microvelia (Heteroptera, Veliidae) from Spain. Aliso 26: 15-21.

Santamaría S., Enghoff H., \& Reboleira A.S.P.S. (2014). Laboulbeniales on millipedes: Diplopodomyces and Troglomyces. Mycologia106 (5): 1027-1038

Santamaría S., Enghoff H., \& Reboleira A.S.P.S. (2016). Hidden biodiversity revealed by collections-based research-Laboulbeniales in millipedes: genus Rickia. Phytotaxa 243 (2): 101-127

Santamaría, S.; Faille, A. (2009). New species of Laboulbenia and Rhachomyces (Laboulbeniales, Ascomycota), some of them polymorphic, parasitic on termiticolous ground beetles from tropical Africa. Nova Hedwigia 89(1-2): 97-120.

Santos MD, Fonseca ME, Boiteux LS, Dianese JC. First approach to molecular phylogeny within the genus Phyllachora. InPHYTOPATHOLOGY 2012 Jul 1 (Vol. 102, No. 7, pp. 105-105). 3340 PILOT KNOB ROAD, ST PAUL, MN 55121 USA: AMER PHYTOPATHOLOGICAL SOC.

Sanz-Ros AV, Müller MM, San Martin R, Diez JJ. Fungal endophytic communities on twigs of fast and slow growing Scots pine (Pinus sylvestris L.) in northern Spain. Fungal Biology. 2015 Oct 31;119(10):870-83.

Saravanakumar, D., Ciavorella, A., Spadaro, D., Garibaldi, A. and Gullino, M.L., 2008. Metschnikowia pulcherrima strain MACH1 outcompetes Botrytis cinerea, Alternaria alternata and Penicillium expansum in apples through iron depletion. Postharvest Biology and Technology, 49(1), pp.121-128.

Sar1, A. and Tuzen, M., 2010. Biosorption of As (III) and As (V) from aqueous solution by lichen (Xanthoria parietina) biomass. Separation Science and Technology, 45(4), pp.463-471.

Sarkar, J., Ray, S., Chattopadhyay, D., Laskar, A. and Acharya, K., 2012. Mycogenesis of gold nanoparticles using a phytopathogen Alternaria alternata. Bioprocess and biosystems engineering, 35(4), pp.637-643.

Sarma (2015) A dichotomous key to genera of marine fungi recorded on Rhizophora spp. Indian Journal of Geo-Marine Sciences 44:1-7

Sarma VV, Raghukumar S (2013) Manglicolous fungi from Chorao mangroves, Goa, West coast of India: Diversity and frequency of occurrence. Nova Hedwigia 97:533-542

Sati, S.C.; Arya, P.; Belwal, M. (2009). Tetracladium nainitalense sp. nov., a root endophyte from Kumaun Himalaya, India. Mycologia 101(5): 692-695.

Sato H,. Ban, S.; Masuya, H.; Hosoya, T. (2010a). Reassessment of type specimens of Cordyceps and its allies described by Dr Yosio Kobayasi preserved in the mycological herbarium of the National Museum of Nature and Science (TNS). Part 1: The genus Torrubiella. Mycoscience 51(2): 154-161

Sato, H.; Ban, S.; Masuya, H.; Hosoya, T. (2010b). Reassessment of type specimens of Cordyceps and its allies described by Dr Yosio Kobayasi, preserved in the National Museum of Nature and Science. Part 2: Cordyceps (Elaphocordyceps) on Elaphomyces. Mycoscience 51(5): 387-390

Savić S, Tibell L (2008a) Atla, a new genus in the Verrucariaceae (Verrucariales). Lichenologist 40(4): 269-282. 
Savić S, Tibell L (2008b) The lichen genus Henrica (verrucariaceae, eurotiomycetes) in northern europe. Nordic Journal of Botany. Aug 1;26(3-4):237-47.

Savić S, Tibell L 2012 "Polyblastia in northern Europe and the adjacent Arctic." (2012): 1-69.

Savić S, Tibell L, Gueidan C, Lutzoni F. Molecular phylogeny and systematics of Polyblastia (Verrucariaceae, Eurotiomycetes) and allied genera. mycological research. 2008 Nov 30;112(11):1307-18.

Sbissi I, Neffati M, Boudabous A, Murat C, Gtari M. Phylogenetic affiliation of the desert truffles Picoa juniperi and Picoa lefebvrei. Antonie van Leeuwenhoek. 2010 Nov 1;98(4):429-36.

Schmechel D, Green, B.J., Blachere, F.M., Janotka, E. and Beezhold, D.H., 2008. Analytical bias of cross-reactive polyclonal antibodies for environmental immunoassays of Alternaria alternata. Journal of Allergy and Clinical Immunology, 121(3), pp.763768.

Schmidt LE, Deyrup,S.T., Baltrusaitis,J., Swenson,D.C., Wicklow,D.T. and Gloer,J.B. 2010a Hymenopsins A and B and a macrophorin analogue from a Fungicolous Hymenopsis sp. J. Nat. Prod. 73 (3), 404-408.

Schmidt V 2015 Fungal Infections in Reptiles-An Emerging Problem. Journal of Exotic Pet Medicine. Jul 31;24(3):267-75.

Schmidt V, Plenz B, Pfaff M, Pees M. Disseminated systemic mycosis in Veiled chameleons (Chamaeleo calyptratus) caused by Chamaeleomyces granulomatis. Veterinary microbiology. 2012 Dec 28;161(1):145-52.

Schmitt I, Fankhauser JD, Sweeney K, Spribille T, Kalb K, Lumbsch T (2010b) Gyalectoid Pertusaria species form a sister-clade to Coccotrema (Ostropomycetidae, Ascomycota) and comprise the new lichen genus Gyalectaria. Mycology 1(1): 75-83

Schmitt I, Otte J, Parnmen S, Sadowska-Deś, A., Luecking, R. and Lumbsch, T., 2012. A new circumscription of the genus Varicellaria (Pertusariales, Ascomycota). MycoKeys, 4, p.23.

Schmitt I, Partida-Martinez LP, Winkler,R., Voigt,K., Einax,E., Dolz,F., Telle,S., Wostemeyer,J. and Hertweck,C. 2008 Evolution of host resistance in a toxinproducing bacterial-fungal alliance. ISME J 2 (6), 632-641.

Schmull M, Miadlikowska J, Pelzer M, Stocker-Worgotter E, Hofstetter V, Fraker E, Hodkinson BP, Reeb V, Kukwa M, Lumbsch HT, Kauff F, Lutzoni F (2011) Phylogenetic affiliations of members of the heterogeneous lichen-forming fungi of the genus Lecidea sensu Zahlbruckner (Lecanoromycetes, Ascomycota). Mycologia 103(5): 983-1003

Schneider K, Resl P, Westberg M, Spribille T. A new, highly effective primer pair to exclude algae when amplifying nuclear large ribosomal subunit (LSU) DNA from lichens. The Lichenologist. 2015 Jul 1;47(04):269-75.

Schneider, K., Resl, P. and Spribille, T. 2016. Escape from the cryptic species trap: lichen evolution on both sides of a cyanobacterial acquisition event. Mol. Ecol. 25 (14), 3453-3468.

Schoch CL, Crous PW, Groenewald JZ, Boehm EWA, Burgess TI, Gruyter J, de Hoog GS, de Dixon LJ, Grube M, Gueidan C, Harada Y, Hatakeyama S, Hirayama K, Hosoya T, Huhndorf SM, Hyde KD, Jones EBG, Kohlmeyer J, Kruys A, Li YM, Lücking R, Lumbsch HT, Marvanová L, Mbatchou JS, McVay AH, Miller AN, Mugambi GK, Muggia L, Nelsen MP, Nelson P, Owensby CA, Phillips AJL, Phongpaichit S, Pointing SB, Pujade-Renaud V, Raja HA, Plata ER, Robbertse B, Ruibal C, Sakayaroj J, Sano T, Selbmann L, Shearer CA, Shirouzu T, Slippers B, Suetrong S, Tanaka K, Volkmann-Kohlmeyer B, Wingfield MJ, Wood AR, Woudenberg JHC, Yonezawa H, 
Zhang Y, Spatafora JW (2009) A class-wide phylogenetic assessment of Dothideomycetes. Studies in Mycology 64: 1-15

Schroers HJ, Gräfenhan T, Nirenberg HI, Seifert KA. A revision of Cyanonectria and Geejayessia gen. nov., and related species with Fusarium-like anamorphs. Studies in Mycology. 2011 Mar 31;68:115-38.

Schultz, M. and Moon, K.H., 2011. Notes on taxonomy and distribution of some critical cyanobacterial lichens from South Korea. Nova Hedwigia, 92(3-4), pp.479-486.

Schultz, M., Zedda, L. and Rambold, G. 2009. New records of lichen taxa from Namibia and South Africa. Bibliotheca Lichenologica, 99, pp.315-334.

Schumacher J., Reinbold J. \& Aikaterini D. (2015) The Lachnellula canker of Abies alba - a new disease phenomenon in the German Black Forest. Jahrbuch der Baumpflege/Yearbook of Arboriculture: 45-51.

Schutz, M., 2009. Home/All Titles/The Bryologist/Spring 2009/pg (s) 221-227. The Bryologist, 112(1), pp.221-227.

Scott JA, Ewaze JO, Summerbell RC, Arocha-Rosete Y, Maharaj A, Guardiola Y, Saleh M, Wong B, Bogale M, O'Hara MJ, Untereiner WA. Multilocus DNA sequencing of the whiskey fungus reveals a continental-scale speciation pattern. Persoonia. 2016;37:1320.

Seena S, Pascoal C, Marvanova L, Cassio F (2010) DNA barcoding of fungi: a case study using ITS sequences for identifying aquatic hyphomycete species. Fungal Diversity 44:77-87

Seena, S., Duarte, S., Pascoal, C. \& Cassio, F., 2012. Intraspecific variation of the aquatic fungus Articulospora tetracladia: an ubiquitous perspective. PLoS One 7(4). http://dx.doi.org/10.1371/journal.pone.0035884;

Seephueak P, Phongpaichit S, Hyde KD, Petcharat V. 2011a Diversity of saprobic fungi on decaying rubber logs (Hevea brasiliensis). Sydowia.;63(2):249-82.

Seephueak P, Phongpaichit S, Hyde KD, Petcharat V. 2011b Diversity of saprobic fungi on decaying branch litter of the rubber tree (Hevea brasiliensis). Mycosphere.; 2(4), 307330

Seifert KA, Morgan-Jones G, Gams W, Kendrick B. 2011. The genera of Hyphomycetes. CBS Biodiversity Series 9, CBS-KNAW Fungal Biodiversity Centre, Utrecht, The Netherlands.

Selbmann L, Hoog GS de, Zucconi L, Isola D, Ruisi S, et al. 2008. Drought meets acid: three new genera in a dothidealean clade of extremotolerant fungi. Studies in Mycology 61: $1-20$.

Selbmann L, Zucconi L, Isola D, Onofri S. 2015 Rock black fungi: excellence in the extremes, from the Antarctic to space. Current genetics. 61(3):335-45.

Selbmann, L., Isola, D., Egidi, E., Zucconi, L., Gueidan, C., de Hoog, G.S., \& Onofri, S. (2014). Mountain tips as reservoirs for new rock-fungal entities: Saxomyces gen. nov. and four new species from the Alps. Fungal Diversity 65, 167-182.

Selçuk F, Hüseyin E, Şahin A Cebeci CC 2014 -Hyphomycetous fungi in several forest ecosystems of Black sea provinces of Turkey. Mycosphere 5(2), 334-344.

Selçuk, F. and Ekici, K., 2014. A new species of Manoharachariella (hyphomycetes) from Central Anatolia, Turkey. Mycosphere, 5(3), pp. 419-423.

Selva SB. The calicioid lichens and fungi of the Acadian Forest Ecoregion of northeastern North America, I. New species and range extensions. The Bryologist. 2013 Aug 6;116(3):248-56.

Senanayake IC, Al-Sadi AM, Bhat DJ, Camporesi E, Dissanayake AJ, Lumyong S, Maharachchikumbura SSN, Hyde KD (2016) Phomatosporales ord. nov. and 
Phomatosporaceae fam. nov., to accommodate Lanspora, Phomatospora and Tenuimurus, gen. nov. Mycosphere, 7(5): 628-641.

Senanayake IC, Maharachchikumbura SS, Mortimer PE, Xu J, Bhat JD, Hyde KD. Phylogenetic studies on Vialaeaceae reveals a novel species, Vialaea mangiferae. Sydowia. 2014 Dec 19;66(2):203-16.

Senanayake IC, Maharachchikumbura SSN, Hyde KD, Bhat JD, Jones EBG, Mckenzie EHC, Dai DQ, Daranagama DA, Dayarathne MC, Goonasekara ID, Konta S, Li WJ, Shang QJ, Stadler M, Wijayawardene NN, Xiao YP, Norphanphoun C, Li QR, Liu XZ, Bahkali AH, Kang JC, Wang Y, Wen TC, Xu JC, Camporesi E. 2015 - Towards unraveling relationships in Xylariomycetidae (Sordariomycetes). Fungal Diversity 73, 73-144.

Şenkardeşler, A., Duman, D.C., Lökös, L. and Ahti, T., 2016. Cladonia trapezuntica (Cladoniaceae, lichenized Ascomycota): a robust morphotype of Pycnothelia papillaria, a taxonomic study with conservational survey. Turkish Journal of Botany, 40(1), pp.104-111.

Seo, C., Choi, Y.H., Ahn, J.S., Yim, J.H., Lee, H.K. and Oh, H., 2009a. PTP1B inhibitory effects of tridepside and related metabolites isolated from the Antarctic lichen Umbilicaria antarctica. Journal of enzyme inhibition and medicinal chemistry, 24(5), pp.1133-1137.

Seo, C., Sohn, J.H., Ahn, J.S., Yim, J.H., Lee, H.K. and Oh, H., 2009b. Protein tyrosine phosphatase 1B inhibitory effects of depsidone and pseudodepsidone metabolites from the Antarctic lichen Stereocaulon alpinum. Bioorganic \& medicinal chemistry letters, 19(10), pp.2801-2803.

Seo, M.Y., Matsuda, Y., Nakashima, C. and Ito, S.I., 2012. Taxonomic reevaluation of Raffaelea quercivora isolates collected from mass mortality of oak trees in Japan. Mycoscience, 53(3), pp.211-219.

Sepcic, K., Zalar, P. and Gunde-Cimerman, N., 2010. Low water activity induces the production of bioactive metabolites in halophilic and halotolerant fungi. Marine drugs, 9(1), pp.43-58.

Serrato-Diaz LM, Rivera-Vargas LI, Goenaga R, Verkley GJM, FrenchMonar RD (2011) First report of aLasmeniasp. causing rachis necrosis, flower abortion, fruit rot, and leaf spots on rambutan in Puerto Rico. Plant Dis 95(10):1313

Sert HB, Sümbül H, Sterflinger K. Two new species of Capnobotryella from historical monuments. Mycological Progress. 2011 Aug 1;10(3):333-9.

Sert HB, Wuczkowski M, Sterflinger K. Capnobotryella isiloglui, a new rock-inhabiting fungus from Austria. Turkish Journal of Botany. 2012 Jul 17;36(4):401-7.

Sérusiaux E, Brand A.M.; Fischer, E.; Killmann, D.; Boom, P.P.G. van den; Ertz, D. (2009a). A new species of Melanotopelia (Graphidaceae) from Africa. Lichenologist 41(3): 243-247.

Sérusiaux E, Goffinet B., Miadlikowska J. and Vitikainen O. 2009b. Taxonomy, phylogeny and biogeography of the lichen genus Peltigera in papua New Guinea. - Fungal Diversity 38: 185-224.

Sérusiaux, E., Van den Boom, P. and Ertz, D., 2010. A two-gene phylogeny shows the lichen genus Niebla (Lecanorales) is endemic to the New World and does not occur in Macaronesia nor in the Mediterranean basin. Fungal biology, 114(7), pp.528-537.

Sethy, P.P., Pandit, G.S. and Sharma, B.O., 2012. Lichens on mangrove plants in Andaman Islands, India. Mycosphere, 3(4), pp.476-484.

Severn-Ellis, A., Schoeman, M.H., Willemse, S., Sippel, A., Rees, J. and De Castro, M., 2012, April. Towards guava wilt disease resistance in South Africa. In III International Symposium on Guava and other Myrtaceae 959 (pp. 73-79). 
Seyedmousavi S, Guillot J, de Hoog GS. 2013. Phaeohyphomycoses, emerging opportunistic diseases in animals. Clinical Microbiology Reviews 26:19-34.

Seyedmousavi S, Samerpitak K, Rijs AJ, Melchers WJ, Mouton JW, Verweij PE, de Hoog GS. Antifungal susceptibility patterns of opportunistic fungi in the genera Verruconis and Ochroconis. Antimicrobial agents and chemotherapy. 2014 Jun 1;58(6):3285-92.

Sezer, O., Özgişi, K., Yaylaci, Ö.K., Öztürk, D., Koyuncu, O. and Savaroğlu, F., 2016. Contributions to Lichen Biota of Günyüzü (Eskişehir). Journal of Applied Biological Sciences, 10(1).

Shabana, Y.M., Abdel-Fattah, G.M., Ismail, A.E. and Rashad, Y.M., 2008. Control of brown spot pathogen of rice (Bipolaris oryzae) using some phenolic antioxidants. Brazilian Journal of Microbiology, 39(3), pp.438-444.

Shali, A., Ghasemi, S., Ahmadian, G., Ranjbar, G., Dehestani, A., Khalesi, N., Motallebi, E. and Vahed, M., 2010. Bacillus pumilus SG2 chitinases induced and regulated by chitin, show inhibitory activity against Fusarium graminearum and Bipolaris sorokiniana. Phytoparasitica, 38(2), pp.141-147.

Sharma BO, Khadilkar P (2011) Two additional new species of Carbacanthographis from India. Lichenologist 43:293-297

Sharma BO, Makhija U, Khadilkar P (2010) Two species of Carbacanthographis from India. Lichenologist 42:391-395

Sharma R, Gräser Y, Singh SK. Auxarthronopsis, a new genus of Onygenales isolated from the vicinity of Bandhavgarh National park, India. IMA fungus. 2011 4(1):89-102.

Sharma R, Sharma R, Crous PW (2015) Matsushimamyces, a new genus of keratinophilic fungi from soil in central India. IMA FUNGUS 6:337-343

Sheard, J.W., 2010. The Lichen Genus Rinodina (Ach.) Gray (Lecanoromycetidae, Physciaceae) in North America, North of Mexico. NRC Research Press.

Sheard, J.W., Knudsen, K., Mayrhofer, H. and Morse, C.A., 2011. Three new species of Rinodina (Physciaceae) and a new record from North America. The Bryologist, 114(3), pp.453-465.

Shearer BL and Crane CE (2014 Host range of the stem canker pathogen Luteocirrhus shearii mainly limited to Banksia. Australasian Plant Pathology Volume 43, Issue 3, pp 257266

Shearer CA, Pang KL, Suetrong S, Raja HA (2014) Phylogeny of the Dothideomycetes and other classes of freshwater fissitunicate Ascomycota. In: Jones EBG, Hyde KD and Pang KL (eds.) Freshwater fungi and Fungal-like Organisms. DE GRUYTER 25-45

Shearer CA, Raja HA, Miller AN, Nelson P, Tanaka K, Hirayama K, Marvanova L, Hyde KD, Zhang Y (2009) The molecular phylogeny of freshwater Dothideomycetes. Stud Mycol 64:145-153.

Sheik, M.A., Raina, A.K. and Upreti, D.K., 2009. Lichen flora of Surinsar-Mansar wildlife sanctuary, J \& K. J Appl Nat Sci, 1(1), pp.79-81.

Sheikh, M.A., Raina, A.K. and Upreti, D.K., 2016. Lichens-enshrouding the bare rocks in pappad area of Samba district, Jammu \& Kashmir. International Journal of Current Research and Review, 8(10), pp.29-32.

Shen W, Mao H, Huang Q, Dong J (2015) Benzenediol lactones: a class of fungal metabolites with diverse structural features and biological activities. European Journal of Medicinal Chemistry 97:747-777

Shenoy BD, Jeewon R, Wang H, Amandeep K, Ho WH, Bhat DJ, Crous PW, Hyde KD (2010) Sequence data reveals phylogenetic affinities of fungal anamorphs 
Bahusutrabeeja, Diplococcium, Natarajania, Paliphora, Polyschema, Rattania and Spadicoides. Fungal Diversity 44(1):161-9.

Shi H, Qian Z, Wang X, Liu D, Zhang Y, Ye X, Harada H, Wang L. The Genus Letrouitia (Letrouitiaceae: Lichenized Ascomycota) New to Cambodia. Mycobiology. 2015 Jun 1;43(2):163-5.

Shi, D., Lu, G., Mei, H., de Hoog, G.S., Samerpitak, K., Deng, S., Shen, Y. and Liu, W., 2016. Subcutaneous infection by Ochroconis mirabilis in an immunocompetent patient. Medical mycology case reports, 11, pp.44-47.

Shi, G.K.; Luo, J.T.; Hou, C.L. (2010). [Species of the Rhytismataceae on Pinus armandii]. Mycosystema 29(2): 159-163.

Shirouzu T, Hirose D, Tokumasu S, To-Anun C, Maekawa N. Host affinity and phylogenetic position of a new anamorphic fungus Beltraniella botryospora from living and fallen leaves of evergreen oaks. Fungal Diversity. 2010 Jul 1;43(1):85-92.

Shivarov VV, Stoykov DY. New records of pyrenocarpous lichenized fungi from Bulgaria. Mycotaxon. 2013 Jan 9;121(1):133-8.

Shivas RG, Marney TS, Tan YP, McTaggart AR. Novel species of Cercospora and Pseudocercospora (Capnodiales, Mycosphaerellaceae) from Australia. Fungal biology. 2015 May 31;119(5):362-9.

Shivas, R.G.; Grice, K.R.E.; Young, A.J. (2010) [2011]. Ramichloridium spp. on Musa in northern Queensland: introducing Ramichloridium ducassei sp. nov. on leaf streaks of Ducasse banana. Australas. Pl. Path. 40(1): 61-65

Shoemaker RA, Malloch D, Hambleton S, Liu M. A new Vestigium on Abies balsamea. North American Fungi. 2013 May 23;8:1-6.

Shrestha, G. and St. Clair, L.L., 2009. The lichen flora of southwestern Colorado. Evansia, 26(3), pp.102-123.

Shukla P, Upreti DK, Nayaka S, Tiwari P 2014a. Natural dyes from Himalayan lichens. Indian J Tradit Knowl, 13(1), pp.195-201.

Shukla V, Kumari R., Patel, D.K. and Upreti, D.K., 2016. Characterization of the diversity of mycosporine-like amino acids in lichens from high altitude region of Himalaya. Amino acids, 48(1), pp.129-136.

Shukla V, Patel D.K., Upreti, D.K., Yunus, M. and Prasad, S., 2013. A comparison of metallic contents in lichen Pyxine subcinerea, its substratum and soil. International Journal of Environmental Science and Technology, 10(1), pp.37-46.

Shukla V, Upreti D.K., 2009. Polycyclic aromatic hydrocarbon (PAH) accumulation in lichen, Phaeophyscia hispidula of DehraDun City, Garhwal Himalayas. Environmental monitoring and assessment, 149(1-4), pp.1-7.

Shukla V, Upreti DK, Bajpai R., 2014b. Lichen Diversity in Different Lichenogeographical Regions of India. In Lichens to Biomonitor the Environment (pp. 61-96). Springer India.

Shukla V, Upreti DK, Patel D.K., 2012. Physiological attributes of lichen, Phaeophyscia hispidula in heavy metal rich sites of Dehra Dun, India. Journal of Environmental Biology, 33(6), p.1051.

Siegel, D., Merkel, S., Koch, M. and Nehls, I., 2010. Quantification of the Alternaria mycotoxin tenuazonic acid in beer. Food chemistry, 120(3), pp.902-906.

Siegel, D., Rasenko, T., Koch, M. and Nehls, I., 2009. Determination of the Alternaria mycotoxin tenuazonic acid in cereals by high-performance liquid chromatographyelectrospray ionization ion-trap multistage mass spectrometry after derivatization with 2, 4-dinitrophenylhydrazine. Journal of Chromatography A, 1216(21), pp.4582-4588. 
Siemens JA, Zwiazek JJ. Root hydraulic properties and growth of balsam poplar (Populus balsamifera) mycorrhizal with Hebeloma crustuliniforme and Wilcoxina mikolae var. mikolae. Mycorrhiza. 2008 Oct 1;18(8):393-401.

Sigler L, Gibas CF, Kokotovic B, Bertelsen MF. 2010a Disseminated mycosis in veiled chameleons (Chamaeleo calyptratus) caused by Chamaeleomyces granulomatis, a new fungus related to Paecilomyces viridis. Journal of clinical microbiology. Sep 1;48(9):3182-92.

Sigler L, Hambleton S, Paré JA (2013) Molecular characterization of reptile pathogens currently known as members of the Chrysosporium anamorph of Nannizziopsis vriesii complex and relationship with some human-associated isolates. Journal of clinical microbiology 51(10): 3338-3357.

Sigler L, Sutton DA, Gibas CFC, Summerbell RC, Noel RK, Iwen PC. 2010b. Phialosimplex, a new anamorphic genus associated with infections in dogs and having phylogenetic affinity to the Trichocomaceae. Medical Mycology 48:335-345.

Silva BF, Carrijo-Mauad JR, Braga FR, Campos AK, Araújo JV, Amarante AF (2010) Efficacy of Duddingtonia flagrans and Arthrobotrys robusta in controlling sheep parasitic gastroenteritis. Parasitology research, 106(6), pp.1343-1350.

Silva CR, Castañeda-Ruiz RF, Gusmão P, Fernando L (2014) Anacraspedodidymum, a new genus from submerged wood in Brazil. Mycotaxon. Aug 21;128(1):11-5.

Silva CR, Gusmão LFP, Castañeda-Ruiz RF (2015) Two new conidial fungi from Chapada Diamantina, Brazil. Mycotaxon. 130(2):437-443

Silva GB, Lustosa DC, Nechet KL, Conceicao CS, Silva JF, Rego MJ, Pantoja MB (2011) Diversity of plant pathogenic fungi associated with native Amazon forest species. Phytopathology 101: S166-S167

Silva SS, Cruz AC, Gusmão LF, Castañeda-Ruiz RF. Diplococcium variegatum, a new conidial fungus from the semi-arid Caatinga biome of Brazil. Mycotaxon. 2014 May 29;127(1):59-62.

Silva SS, Gusmão LF (2013) Conidial fungi from the semi-arid Caatinga Biome of Brazil. A new species of Dictyochaeta. Mycosphere 4(4):701-705.

Silvansilva SS, Gusmão LFP, Castañeda-Ruiz RF (2015) Conidial fungi on Araucaria angustifolia: a new species of Trichoconis and new records from Brazil. Mycotaxon. 130:1051-1059

Silvera-Simón C, Mena-Portales J, Gene J, Cano JF, Guarro J (2009) Repetophragma calongeii [sic] sp. nov. and other interesting dematiaceous hyphomycetes from the north of Spain. An. Jard. bot. Madr. 66(S1): 33-39.

Silvera-Simón, C.; Mercado-Sierra, Á.; Mena Portales, J.; Gené, J.; Guarro, J. (2010). Two new species of Digitodesmium from Euskadi (Spain). Cryptog. Mycol. 31(2): 211218.

Silvério ML, Cavalcanti MA, Bezerra JL (2011) First record of Leptomeliola uvariae for South America. Mycotaxon 116(1):1-5.

Simmons, D.R; De Beer, Z.W; Huang, Y.T; Bateman, C; Campbell, A.S; Dreaden, T.J; Li, Y; Ploetz, R.C; Black, A; Li, H.F; Chen, C.Y; Wingfield, M.J; Hulcr, J. 2016. New Raffaelea species (Ophiostomatales) from the USA and Taiwan associated with ambrosia beetles and plant hosts. IMA Fungus. 7(2):265-273

Simon UK, Groenewald JZ, Crous PW. Cymadothea trifolii, an obligate biotrophic leaf parasite of Trifolium, belongs to Mycosphaerellaceae as shown by nuclear ribosomal DNA analyses. Persoonia-Molecular Phylogeny and Evolution of Fungi. 2009 Jun 30;22(1):49-55.

Singh G, Dal Grande, F., Divakar, P.K., Otte, J., Leavitt, S.D., Szczepanska, K., Crespo, A., Rico, V.J., Aptroot, A., Caceres, M.E., Lumbsch, H.T. and Schmitt, I. 2015. 
Coalescent-based species delimitation approach uncovers high cryptic diversity in the cosmopolitan lichen-forming fungal genus Protoparmelia (Lecanorales, Ascomycota. PLoS ONE 10 (5), E0124625

Singh G, Divakar PK, Dal Grande F, Otte, J., Parnmen, S., Wedin, M., Crespo, A., Lumbsch, H.T. \& Schmitt, I. (2013a). The sister-group relationships of the largest family of lichenized fungi, Parmeliaceae (Lecanorales, Ascomycota). Fungal Biology 117: 715721.

Singh KP, Swarnalatha G., 2011. A new species of Schistophoron from India. The Lichenologist, 43(03), pp.209-212.

Singh R, Ranjan S, Nayaka, S., Pathre, U.V. and Shirke, P.A., 2013b. Functional characteristics of a fruticose type of lichen, Stereocaulon foliolosum Nyl. in response to light and water stress. Acta physiologiae plantarum, 35(5), pp.1605-1615.

Singh SK, Singh PN 2012. A New species of Sarcinella from India. Indian Phytopathology, 58(3), pp.341-342.

Singh SM, and Ravindra, R., 2013. Impact of Climate Change on Lichen and Moss Communities in Ny-Ålesund, Arctic: Some Preliminary Observations. In Earth System Processes and Disaster Management (pp. 93-100). Springer Berlin Heidelberg.

Singh SM, Pereira N, Ravindra R 2010. Adaptive mechanisms for stress tolerance in Antarctic plants. Curr Sci, 99, pp.334-340.

Singh SM, Singh PN, Singh SK, Sharma PK. Pigment, fatty acid and extracellular enzyme analysis of a fungal strain Thelebolus microsporus from Larsemann Hills, Antarctica. Polar Record. 2014;50(01):31-6.

Singh UB, Sahu A, Sahu, N., Singh, B.P., Singh, R.K., Singh, D.P., Jaiswal, R.K., Sarma, B.K., Singh, H.B., Manna, M.C. and Rao, A.S., 2013c. Can endophytic Arthrobotrys oligospora modulate accumulation of defence related biomolecules and induced systemic resistance in tomato (Lycopersicon esculentum Mill.) against root knot disease caused by Meloidogyne incognita. Applied soil ecology, 63, pp.45-56.

Singh UB, Sahu A, Singh RK, Singh, D.P., Meena, K.K., Srivastava, J.S. and Manna, M.C., 2012. Evaluation of biocontrol potential of Arthrobotrys oligospora against Meloidogyne graminicola and Rhizoctonia solani in Rice (Oryza sativa L.). Biological Control, 60(3), pp.262-270.

Singh, S.K.; Gaikwad, V.P.; Waingankar, V.M. (2009). A new endophytic ascomycete from healthy leaves of Pongamia pinnata Merr.. Indian Phytopath. 62(1): 124-125.

Singtripop C, Camporesi E, Ariyawansa HA, Wanasinghe DN, Bahkall AH, Chomnunti, P, Boonmee S, Hyde KD. (2015) Keissleriella dactylidis, sp. nov., from Dactylis glomerata and its phylogenetic placement. Science Asia 41: 295-304

SINGTRIPOP C, HONGSANUN S, LI J, DE SILVA NI, PHILLIPS AJ, JONES GE, BAHKALI AH, HYDE KD. Chaetothyrina mangiferae sp. nov., a new species of Chaetothyrina. Phytotaxa. 2016 Apr 5;255(1):21-33.

Sinha, G.P. and Jagadeesh Ram, T.A.M., 2011. Lichen diversity in Sikkim. Biodiversity of Sikkim. Exploring and Conserving a Global Hotspot, pp.13-28.

Sinha, R. and Chattopadhyay, S., 2011. Changes in the leaf proteome profile of Mentha arvensis in response to Alternaria alternata infection. Journal of proteomics, 74(3), pp.327-336.

Sipiczki, M.; Pfliegler, W. P.; Safar, S. W. B.; Morais, P. B. \& Rosa, C. A. (2016) Metahyphopichia laotica gen. nov., sp. nov., a novel polymorphic yeast related to Hyphopichia. International Journal of Systematic and Evolutionary Microbiology 66(7): 2550-2557.

Sipman HJM 2014 New species of Graphidaceae from the Neotropics and Southeast Asia. Phytotaxa 189 (1): 289-311 
Sipman HJM, Lücking R, Aptroot A, Kalb K, Chaves JL, Umana L (2012) A first assessment of the Ticolichen biodiversity inventory in Costa Rica and adjacent areas: the thelotremoid Graphidaceae (Ascomycota: Ostropales). Phytotaxa 55:1-214

Sipman, H.J. and Raus, T., 2015. Lichens and lichenicolous fungi from the island of Chios (Aegean Sea, Greece). Herzogia, 28(2), pp.496-519.

Sir,E.B., Kuhnert,E., Lambert,C., Hladki,A.I., Romero,A.I. and Stadler,M. 2016 New species and reports of Hypoxylon from Argentina recognized by a polyphasic approach. Mycological Progress 15, 42

Sivakumar T (2013) A review on biodiversity of marine and mangrove fungi. Int. J. Curr. Res. Aca. Rev. 1:26-44

Sivichai S, Boonyuen N (2010) Jahnula morakotii sp. nov. and J. appendiculata from a peat swamp in Thailand. Mycotaxon 112 (1):475-481

Sivichai S, Sri-Indrasutdhi V, Jones E (2011) Jahnula aquatica and its anamorph Xylomyces chlamydosporus on submerged wood in Thailand. Mycotaxon 116 (1):137-142

Six DL, Stone WD, de Beer ZW, Woolfolk SW (2009) Ambrosiella beaveri sp. nov., associated with an exotic ambrosia beetle, Xylosandrus mutilatus (Coleoptera: Curculionidae, Scolytinae), in Mississippi, USA. Antonie van Leeuwenhoek 96:17-29

Skjøth, C.A., Sommer, J., Frederiksen, L. and Gosewinkel Karlson, U., 2012. Crop harvest in Denmark and Central Europe contributes to the local load of airborne Alternaria spore concentrations in Copenhagen. Atmos Chem Phys, 12(22), pp.11107-11123.

Slippers B, Boissin E, Phillips AJL, Groenewald JZ, Wingfield MJ et al (2013) Phylogenetic lineages in the Botryosphaeriales: A systematic and evolutionary framework. Stud Mycol 76:31-49

Small, K.W., Chan, C.K., Silva-Garcia, R. and Walsh, T.J., 2014. Onset of an outbreak of Bipolaris hawaiiensis fungal endophthalmitis after intravitreal injections of triamcinolone. Ophthalmology, 121(4), pp.952-958.

Smith ME, Henkel TW, Catherine Aime M, Fremier AK, Vilgalys R. Ectomycorrhizal fungal diversity and community structure on three co-occurring leguminous canopy tree species in a Neotropical rainforest. New Phytologist. 2011 Nov 1;192(3):699-712.

Smith, J.A., Mount, L., Mayfield III, A.E., Bates, C.A., Lamborn, W.A. and Fraedrich, S.W., 2009. First report of laurel wilt disease caused by Raffaelea lauricola on camphor in Florida and Georgia. Plant Disease, 93(2), pp.198-198.

Snelgrove, R.J., Gregory, L.G., Peiró, T., Akthar, S., Campbell, G.A., Walker, S.A. and Lloyd, C.M., 2014. Alternaria-derived serine protease activity drives IL-33-mediated asthma exacerbations. Journal of Allergy and Clinical Immunology, 134(3), pp.583592.

Soares, D.J.; Barreto, R.W. 2008. Fungal pathogens of the invasive riparian weed Hedychium coronarium from Brazil and their potential for biological control. Fungal Diversity. 28:85-96

Sobreira PN, Aptroot A, da Silva Cáceres ME 2015. A world key to species of the genus Bactrospora (Roccellaceae) with a new species from Brazil. The Lichenologist. 47(02):131-6.

Søchting, U, Garrido-Benavent I, Seppelt R, Castello M, Pérez-Ortega S, De los Ríos Murillo A, Sancho LG, Frödén P, Arup U (2014) Charcotiana and Amundsenia, two new genera in Teloschistaceae (lichenized Ascomycota, subfamily Xanthorioideae) hosting two new species from continental Antarctica, and Austroplaca frigida, a new name for a continental Antarctic species. The Lichenologist 46(6):763-782.

Sogonov MV, Castlebury LA, Rossman AY, Mejía LC, White JF, Jr (2008). Leaf-inhabiting genera of the Gnomoniaceae, Diaporthales. Studies in Mycology 62: 1-79. 
Sohrabi M, Leavitt, SD, Halici MG, Shrestha G, Stenroos S 2013a. Teuvoa, a new lichen genus in Megasporaceae (Ascomycota: Pertusariales), including Teuvoa junipericola sp. nov. The Lichenologist, 45(03), pp.347-360.

Sohrabi M, Myllys L, Stenroos S (2010) Successful DNA sequencing of a 75 year-old herbarium specimen of Aspicilia aschabadensis (J. Steiner) Mereschk. The Lichenologist 42(5): 626-628.

Sohrabi M, Stenroos S, Myllys L, Søchting U, Ahti T, Hyvönen J (2013b) Phylogeny and taxonomy of the "manna lichens". Mycol Progress 12:231-269.

Sohrabi, M., Sipman, H., Toghranegar, Z. and Nejadsattari, T., 2010. A contribution to the lichenized mycota of Zanjan province, Iran. Iranian Journal of Botany, 16, pp.125-129.

Solheim H, Torp TB, Hietala AM. Characterization of the ascomycetes Therrya fuckelii and T. pini fruiting on Scots pine branches in Nordic countries. Mycological progress. $2013 \mathrm{Feb} 1 ; 12(1): 37-44$.

Song, W., Ma, X., Tan, H. and Zhou, J., 2011. Abscisic acid enhances resistance to Alternaria solani in tomato seedlings. Plant Physiology and Biochemistry, 49(7), pp.693-700.

Soni, K., Pyasi, A., Tiwari, P. And Verma, R., 2011. Black Mildew of neem seedlings: a new disease record from India. Indian J. Trop. Biodiv, 19(1\&2), pp.133-136.

Sousa FM, Morais PB, Lachance MA, Rosa CA. Hagleromyces gen. nov., a yeast genus in the Saccharomycetaceae, and description of Hagleromyces aurorensis sp. nov., isolated from water tanks of bromeliads. International journal of systematic and evolutionary microbiology. 2014 Aug 1;64(8):2915-8.

Sousa, R.S., Rodrigues, F.Á., Schurt, D.A., Souza, N.F.A. and Cruz, M.F.A., 2013. Cytological aspects of the infection process of Pyricularia oryzae on leaves of wheat plants supplied with silicon. Tropical Plant Pathology, 38(6), pp.472-477.

Sparrius, L., J. A. Elix \& A. W. Archer. 2010. Austrographa, a new genus in the Roccellaceae with three species from Australia. Australasian Lichenology 67: 23-28.

Sparrius, L., J. A. Elix \& A.W. Archer. 2013. Index Fungorum 27: 1.

Sparrius, L.B. (2009). Synarthothelium, a new genus in the Arthoniaceae with a thalline exciple, similar to Synarthonia. Biblthca Lichenol. 99: 373-382.

Spatafora JW, Quandt CA, Kepler RM, Sung GH, Shrestha B, Hywel-Jones NL, Luangsa-ard JJ. New 1F1N species combinations in Ophiocordycipitaceae (Hypocreales). IMA fungus. 2015 Dec 1;6(2):357-62.

Spooren M. 2014 A new species of Bloxamia from freshwater in the Netherlands. Mycosphere 5(2): 346-9.

Spribille T, Goffinet B, Klug B, Muggia L, Obermayer W, Mayrhofer H (2011) Molecular support for the recognition of the Mycoblastus fucatus group as the new genus Violella (Tephromelataceae, Lecanorales). Lichenologist 43:445-466

Spribille T, Muggia L (2013) Expanded taxon sampling disentangles evolutionary relationships and reveals a new family in Peltigerales (Lecanoromycetidae, Ascomycota). Fungal Divers 58:171-184.

Spribille T, Resl P, Ahti T, Perez-Ortega S, Tonsberg T, Mayrhofer, H. and Lumbsch, H.T. 2014a. Molecular systematics of the wood-inhabiting, lichen-forming genus Xylographa (Baeomycetales, Ostropomycetidae) with eight new species Symb. Bot. Ups. 37 (1), 1-87.

Spribille T, Tønsberg T, Stabentheiner E, Muggia L., 2014b. Reassessing evolutionary relationships in the filamentous cyanolichen genus Spilonema (Peltigerales, Lecanoromycetes). The Lichenologist, 46(03), pp.373-388. 
Spribille, T., Björk, C.R., Ekman, S., Elix, J.A., Goward, T., Printzen, C., Tønsberg, T. and Wheeler, T., 2009. Contributions to an epiphytic lichen flora of northwest North America: I. Eight new species from British Columbia inland rain forests. The Bryologist, 112(1), pp.109-137.

Spribille, T.; Pérez-Ortega, S.; Tønsberg, T.; Schirokauer, D. 2010. Lichens and lichenicolous fungi of the Klondike Gold Rush National Historic Park, Alaska, in a global biodiversity context. The Bryologist. 113(3):439-515.

Sri-indrasutdhi V, Tsui CKM, Chuaseeharonnachai C, Yamaguchi K, Suetrong S, Okane I, Nakagiri A, Boonyuen N. Helicocentralis hyalina gen. et sp. nov., an aero-aquatic Helicosporous fungus (Leotiomycetes, ascomycota) in thailand. Mycol Prog. $2015 ; 14(10)$

Sri-Indrasutdhi, V., Boonyuen, N., Suetrong, S., Chuaseeharonnachai, C., Sivichai, S. \& Jones, E.B.G. 2010. Wood-Inhabiting Freshwater Fungi From Thailand: Ascothailandia grenadoidia gen. et sp. nov., Canalisporium grenadoidia sp. nov. with a key to Canalisporium species (Sordariomycetes, Ascomycota). Mycoscience 51: $411-420$

Stadler M, Fournier J, Gardt S, Peršoh D (2010a) The phylogenetic position of Rhopalostroma as inferred from a polythetic approach. Persoonia 25: 11-21.

Stadler M, Fournier J, Læssøe T, Chlebicki A, Lechat, C.; Flessa, F.; Rambold, G.; Peršoh, D. (2010b). Chemotaxonomic and phylogenetic studies of Thamnomyces (Xylariaceae). Mycoscience 51(3): 189-207

Stadler M, Fournier J, Læssøe T, Decock C, Peršoh, D.; Rambold, G. (2010c). Ruwenzoria, a new genus of the Xylariaceae from central Africa. Mycol. Progr. 9(2): 169-179.

Stadler M, Kuhnert E, Peršoh D, Fournier J (2013) The Xylariaceae as model example for a unified nomenclature following the "One fungus-one name" (1F1N) concept. Mycol Int J Fungal Biol 4:5-21

Stadler M, Læssøe T, Fournier J, Decock C, Schmieschek B, Tichy HV, Peršoh D. A polyphasic taxonomy of Daldinia (Xylariaceae). Studies in mycology. 2014 Mar 31;77:1-43.

Stamenković, S. and Cvijan, M., 2010. Determination of Airpolution Zones in Knjaževac (South Eastern Serbia) by using Epiphytic Lichens. Biotechnology \& Biotechnological Equipment, 24(sup1), pp.278-283.

Stamenković, S., Cvijan, M. and Arandjelović, M., 2010. Lichens as bioindicators of air quality in Dimitrovgrad (South-Eastern Serbia). Archives of Biological Sciences (Serbia).

Stehn, S.E., Walton, J.K., Nelson, P.R., Hampton-Miller, C.J. and Roland, C.A., 2015. A lichen species list for Denali National Park and Preserve, Alaska, with comments on several new and noteworthy records. Evansia, 32(4), pp.195-215.

Steiner U, Leibner S, Schardl CL, Leuchtmann A, Leistner E (2011) Periglandula, a new fungal genus within the Clavicipitaceae and its association with Convolvulaceae. Mycologia 103(5):1133-1145.

Steinmann, J., Dittmer, S., Houbraken, J., Buer, J. and Rath, P.M., 2016. In vitro activity of isavuconazole against Rasamsonia species. Antimicrobial Agents and Chemotherapy, 60(11), pp.6890-6891.

Steinmann, J., Giraud, S., Schmidt, D., Sedlacek, L., Hamprecht, A., Houbraken, J., Meis, J.F., Bouchara, J.P., Buer, J. and Rath, P.M., 2014. Validation of a novel real-time PCR for detecting Rasamsonia argillacea species complex in respiratory secretions from cystic fibrosis patients. New microbes and new infections, 2(3), pp.72-78. 
Stenroos S, Huhtinen S, Lesonen A, Palice Z, Printzen C (2009) Puttea, gen. nov., erected for the enigmatic lichen Lecidea margaritella. The Bryologist 112(3): 544-557.

Stenroos S, Laukka T, Huhtinen S, Döbbeler P, Myllys L, et al (2010) Multiple origins of symbioses between ascomycetes and bryophytes suggested by a five-gene phylogeny. Cladistics 26(3): 281-300.

Stępalska, D. and Wołek, J., 2009. Intradiurnal periodicity of fungal spore concentrations (Alternaria, Botrytis, Cladosporium, Didymella, Ganoderma) in Cracow, Poland. Aerobiologia, 25(4), pp.333-340.

Stepanchikova, I.S., Gagarina, L.V. and Kataeva, O.A., 2013. New and rare lichens and allied fungi from the Novgorod Region, Russia. Folia Cryptogamica Estonica, 50, pp.49-55.

Stepanchikova, I.S., Himelbrant, D.E., Kukwa, M. and Kuznetsova, E.S., 2011. New records of lichens and allied fungi from the Leningrad Region, Russia. II. Folia Cryptogamica Estonica, 48, pp.85-94.

Stielow B, Hensel G, Strobelt D, Makonde HM, Rohde M, Dijksterhuis J. Klenk H-P, Göker M (2013) Hoffmannoscypha, a novel genus of brightly coloured, cupulate Pyronemataceaeclosely related to Tricharina and Geopora. Mycol Progress 12:675686

Stocker-Wörgötter E, Hager A, Elix JA (2009) Intraspecific chemical variation within the crustose lichen genus Haematomma: anthraquinone production in selected cultured mycobionts as a response to stress and nutrient supply. Phytochemistry Reviews 8(3): $561-569$

Stordeur, R., Cezanne, R., Eichler, M., Heinrich, D., Kison, H.U., Schiefelbein, U., Schönbrodt, M., Seelemann, A., Sipman, H.J., Thiemann, R. and Ungethüm, K., 2015. First records and noteworthy lichens and lichenicolous fungi from Saxony-Anhalt and the western part of the Harz National Park (Lower Saxony). Herzogia, 28(2), pp.654678.

Su CM, Wang SW, Lee T.H., Tzeng, W.P., Hsiao, C.J., Liu, S.C. and Tang, C.H., 2013. Trichodermin induces cell apoptosis through mitochondrial dysfunction and endoplasmic reticulum stress in human chondrosarcoma cells. Toxicology and applied pharmacology, 272(2), pp.335-344.

Su H, Hyde KD, Maharachchikumbura SS, Ariyawansa HA, Luo Z, Promputtha I, Tian Q, Lin C, Shang Q, Zhao Y, Chai H. The families Distoseptisporaceae fam. nov., Kirschsteiniotheliaceae, Sporormiaceae and Torulaceae, with new species from freshwater in Yunnan Province, China. Fungal Diversity. 2016a Sep 1;80(1):375-409.

Su H, Liu S, Li Y, Cao Y, Chen M. and Yang, X., 2011a. Arthrobotrys latispora, a new nematode-trapping fungus from southwest China. Mycotaxon, 117(1), pp.29-36.

Su HY, Zhang, Y.; Baral, H.-O.; Yang, X.Y.; Mo, M.H.; Cao, Y.H.; Chen, M.H.; Yu, Z.F. (2011b). Four new species of Orbiliaceae from Yunnan, China. Mycol. Progr. 10(3): 373-381

Su KM, Xiong WP, Wang Y, Li SH, Xie R, Baima D. Tuber bomiense, a new truffle species from Tibet, China. Mycotaxon. 2014 Mar 14;126(1):127-32.

Su L, Deng H, Niu YC. Phialemoniopsis endophytica sp. nov., a new species of endophytic fungi from Luffa cylindrica in Henan, China. Mycological Progress. 2016b May $1 ; 15(5): 1-7$.

Su YY, Cai L (2012) Polyphasic characterisation of three new Phyllosticta spp. Persoonia 28:76-84

Su YY, Cai, L., 2013. Rasamsonia composticola, a new thermophilic species isolated from compost in Yunnan, China. Mycological progress, 12(2), pp.213-221. 
Suetrong S, Boonyuen N, Pang KL, Ueapattanakit J, Klaysuban A, Sri-Indrasutdhi V, Sivichai S, Jones EBG (2011a) A taxonomic revision and phylogenetic reconstruction of the Jahnulales (Dothideomycetes), and the new family Manglicolaceae. Fungal Divers 51:163-188

Suetrong S, Hyde KD, Zhang Y, Bahkali AB, Jones EBG (2011b) Trematosphaeriaceae fam. nov. (Dothideomycetes, Ascomycota). Cryptogamie, Mycologie 32: 343-358

Suetrong S, Klaysuban K, Sakayaroj J, Preedanon S, Ruang-Areerate P, Phongpaichi S, Pang KL, Jones EBG (2015) Tirisporellaceae, a new family in the order Diaporthales (Sordariomycetes, Ascomycota). Cryptogamie, Mycologie 36 (3):1-12

Suetrong S, Rungareerate P, Nor NABM, Alias SA, Jones EBG, Pang KL (2016) Bacusphaeria nypenthi gen. et sp. nov. from the mangrove palm Nypa fruticans. Botanica Marina (In Press)

Suetrong S, Rungjindamai N, Sommai S, Rung-Areerate P, Sommrithipol S, Jones EBG (2014) Wiesneriomyces a new lineage of Dothideomycetes (Ascomycota) basal to Tubeufiales. Phytotaxa 176:283-297

Suetrong S, Sakayaroj J, Phongpaichit S, Jones EBG (2010) Morphological and molecular characteristics of a poorly known marine ascomycete, Manglicola guatemalensis (Jahnulales: Pezizomycotina; Dothideomycetes, Incertae sedis): new lineage of marine ascomycetes. Mycologia 102:83-92

Suetrong S, Schoch CL, Spatafora JW, Kohlmeyer J, Volkmann-Kohlmeyer B, Sakayaroj J, Phongpaichit S, Tanaka K, Hirayama K, Jones EBG (2009) Molecular systematics of the marine Dothideomycetes. Stud Mycol 64:155-173

Sugui JA, Peterson SW, Figat A, Hansen B, Samson RA, Mellado E, Cuenca-Estrella M, Kwon-Chung KJ. 2014. Genetic relatedness versus biological compatibility between Aspergillus fumigatus and its sister species 52:3707-3721.

Suija A, de los Rios A, Pérez-Ortega S (2015a) A molecular reappraisal of Abrothallus species growing on lichens of the order Peltigerales. Phytotaxa 195: 201-226.

Suija A, Ertz D, Lawrey J D, Diederich P (2015b) Multiple origin of the lichenicolous life habit in Helotiales, based on nuclear ribosomal sequences. Fungal Diversity 70: 5572.

Suija A, Oja E, Suu, A. and Marmor, L., 2015c. New Estonian records: lichenized and lichenicolous fungi. Folia Cryptogamica Estonica, 52, pp.129-130.

Suija A, Suu A, Lõhmus P. Substrate specificity corresponds to distinct phylogenetic lineages: the case of Chaenotheca brunneola. Herzogia. 2016 Dec;29(2):355-63.

Sultan A, Johnston PR, Park D, Robertson AW. Two new pathogenic ascomycetes in Guignardia and Rosenscheldiella on New Zealand's pygmy mistletoes (Korthalsella: Viscaceae). Studies in Mycology. 2011 Mar 31;68:237-47.

Summerbell RC, Gueidan C, Schroers, H.-J.; Hoog, G.S. de; Starink, M.; Arocha Rosete, Y.; Guarro, J.; Scott, J.A. (2011). Acremonium phylogenetic overview and revision of Gliomastix, Sarocladium, and Trichothecium. Stud. Mycol. 68: 139-162.

Sun BD, Chen AJ, Gao WW, Zhou YG, Ghazanfar MU, Wakil W. A new endophytic ascomycete associated with the medicinal plant, Achyranthes bidentata Blume (Amaranthaceae). Pak. J. Bot. 2013 Feb 1;45(1):319-23.

Sun J-Z, Dong C-H, Liu X-Z, Liu J-K, Hyde KD (2016). Calcarisporium cordycipiticola sp. nov., an important fungal pathogen of Cordyceps militaris. Phytotaxa 268:135-144; doi: http://dx.doi.org/10.11646/phytotaxa.268.2.4

Sun,X. and Guo,L.-D. 2010 Micronematobotrys, a new genus and its phylogenetic placement based on rDNA sequence analyses. Mycological Progress 9, 567-574

Sundin R, Thor G, A. Frisch. 2012. A literature review of Arthonia s. lat. Bibliotheca Lichenologica 108: 257-290. 
Sung GH, Poinar GO, Spatafora JW. The oldest fossil evidence of animal parasitism by fungi supports a Cretaceous diversification of fungal-arthropod symbioses. Molecular phylogenetics and evolution. 2008 Nov 30;49(2):495-502.

Sung GH, Shrestha B, Park KB, Han SK, Sung JM. Enhancing Effect of Shimizuomyces paradoxus on Seed Germination and Seedling Growth of Canola, Plant Growth of Cucumber, and Harvest of Tomato. Mycobiology. 2011 Mar 1;39(1):7-11.

Sung GH, Shrestha B, Park KB, Sung JM. Cultural characteristics of Shimizuomyces paradoxus collected from Korea. Mycobiology. 2010 Sep 1;38(3):189-94.

Suresh Kumar, G.; Manoharachary, C.; Kunwar, I.K. (2009). Bhadradriomyces, a new dematiaceous hyphomycetous genus from India. Journal of Mycology and Plant Pathology 39(2): 238-240

Suto, Y. (2009). Three ascomycetes on leaves of evergreen Ilex trees from Japan: Rhytisma ilicis-integrae sp. nov., R. ilicis-latifoliae, and R. ilicis-pedunculosae sp. nov.. Mycoscience 50(5): 357-368

Sutton BC (1977) Coelomycetes VI. Nomenclature of generic names proposed for Coelomycetes. Mycol Pap 141:1-253

Sutton BC (1980) The Coelomycetes: Fungi imperfecti with pycnidia, acervuli, and stromata. Commonwealth Mycological Institute, Kew

Suzuki Y, Hatakeyama S, Harada Y, Tanaka K. Polystigma fulvum, a red leaf blotch pathogen on leaves of Prunus spp., has the Polystigmina pallescens anamorph/andromorph. Mycoscience. 2008 Dec 1;49(6):395-8.

Suzuki, F., Yamaguchi, J., Koba, A., Nakajima, T. and Arai, M., 2010. Changes in fungicide resistance frequency and population structure of Pyricularia oryzae after discontinuance of MBI-D fungicides. Plant Disease, 94(3), pp.329-334.

Svensson, M., 2013. Occurrence patterns of dead wood and wood-dependent lichens in managed boreal forest landscapes (Vol. 2013, No. 84).

Svensson, M., Dahlberg, A., Ranius, T. and Thor, G., 2013. Occurrence patterns of lichens on stumps in young managed forests. PloS one, 8(4), p.e62825.

Svensson, M., Johansson, V., Dahlberg, A., Frisch, A., Thor, G. and Ranius, T., 2016. The relative importance of stand and dead wood types for wood-dependent lichens in managed boreal forests. Fungal Ecology, 20, pp.166-174.

Swe A, Jeewon R, Pointing SB, Hyde KD (2008) Taxonomy and molecular phylogeny of Arthrobotrys mangrovispora, a new marine nematode-trapping fungal species. Botanica Marina 51(4): 331-338.

Sweet M, Bulling M, Cerrano C. A novel sponge disease caused by a consortium of microorganisms. Coral Reefs. 2015 Sep 1;34(3):871-83. 20;125(1):209-15.

Szczepańska K, Daniel Pruchniewicz, Justyna Sołtysiak \& Maria Kossowska 2015 LichenForming Fungi of the Genus Montanelia in Poland and Their Potential Distribution in Central Europe. Herzogia 28(2):697-712.

Szczepańska, K., 2015. New records of rare lichenicolous and lichen-forming fungi from volcanic rocks in SW Poland. Acta Mycologica, 50(1).

Tabar, A.I., Lizaso, M.T., García, B.E., Gómez, B., Echechipía, S., Aldunate, M.T., Madariaga, B. and Martínez, A., 2008. Double-blind, placebo-controlled study of Alternaria alternata immunotherapy: Clinical efficacy and safety. Pediatric Allergy and Immunology, 19(1), pp.67-75.

Taj-Aldeen SJ, Al-Ansari N, El Shafei S, Meis JF, Curfs-Breuker I, Theelen B, Boekhout T. Molecular Identification and Susceptibility of Trichosporon Species Isolated from Clinical Specimens in Qatar: Isolation of Trichosporon dohaense Taj-Aldeen, Meis \& Boekhout sp. nov. J. Clin. Microbiol. 2009; 47:1791-1799. doi:10.1128/JCM.0222208 
Takamatsu S (2013) Origin and evolution of the powdery mildews (Ascomycota, Erysiphales). Mycoscience 54: 75-86.

Takamatsu S (2014) Molecular phylogeny reveals phenotypic evolution of powdery mildews (Erysiphales, Ascomycota). Journal of General Plant Pathology 79: 218-226.

Takamatsu S, Havrylenko M, Wolcan SM, Matsuda S, Niinomi S (2008a). Molecular phylogeny and evolution of the genus Neoerysiphe (Erysiphaceae, Ascomycota). Mycological Research 112: 639-649.

Takamatsu S, Inagaki M, Niinomi S, Khodaparast SA, Shin HD, Grigaliūnaitè B, Havrylenko M (2008b). Comprehensive molecular phylogenetic analysis and evolution of the genus Phyllactinia (Ascomycota: Erysiphales) and its allied genera. Mycological Research 112: 299-315.

Takamatsu S, Ito (Arakawa) H, Shiroya Y, Kiss L, Heluta V (2015a). First comprehensive phylogenetic analysis of the genus Erysiphe (Erysiphales, Erysiphaceae) I. The Microsphaera lineage. Mycologia 107: 475-489.

Takamatsu S, Ito T, Yamamoto H, Braun U (2008c). Sawadaea nankinensis comb. nov.: a powdery mildew fungus of Acer buergeriana. Mycoscience 49: 161-167.

Takamatsu S, Kiss L, Heluta V (2015b). First comprehensive phylogenetic analysis of the genus Erysiphe (Erysiphales, Erysiphaceae) II: the Uncinula lineage. Mycologia 107: 903-914.

Takamatsu S, Matsuda S, Grigaliūnaitė B 2013. Comprehensive phylogenetic analysis of the genus Golovinomyces (Ascomycota: Erysiphales) reveals close evolutionary relationships with host plants. Mycologia 105: 1135-1152.

Takamatsu S, Niinomi S, Cabrera de Álvarez MG, Álvarez RE, Havrylenko M, Braun U (2005b). Caespitotheca gen. nov., an ancestral genus in the Erysiphales. Mycological Research 109: 903-911.

Takamatsu S, Niinomi S, Harada M, Havrylenko M (2010b). Molecular phylogenetic analyses reveal a close coevolutionary relationship between Podosphaera (Erysiphales: Erysiphaceae) and its rosaceous hosts. Persoonia 24: 38-48.

Takamatsu S, Siahaan SAS, Moreno-Rico O, Cabrera de Álvarez MG, Braun U (2016) Early evolution of endoparasitic group in powdery mildews: molecular phylogeny suggests missing link between Phyllactinia and Leveillula. Mycologia (http://www.mycologia.org/content/early/2016/06/13/16-010.full.pdf+html)

Takamatsu S. Molecular phylogeny reveals phenotypic evolution of powdery mildews (Erysiphales, Ascomycota). Journal of general plant pathology. 2013 Jul 1;79(4):21826.

Tan YP, Madrid H, Crous PW, Shivas RG (2014) Johnalcornia gen. et. comb. nov., and nine new combinations in Curvularia based on molecular phylogenetic analysis. Australasian Plant Pathology 43: 589-603.

Tan, X.M., Wang, C.L., Chen, J. and Guo, S.X., 2014. Chaetospermum malipoense sp. nov. from southwest China. Mycotaxon, 128(1), pp.159-164.

Tanaka E (2009) Specific in situ visualization of the pathogenic endophytic fungus Aciculosporium take, the cause of witches' broom in bamboo. Applied and environmental microbiology. 75(14): 4829-34.

Tanaka E, Ashizawa T, Sonoda R, Tanaka C. Villosiclava virens gen. nov., comb. nov., the teleomorph of Ustilaginoidea virens, the causal agent of rice false smut. Mycotaxon. 2008 Oct 1;106(1):491-501.

Tanaka K, Endo M, Hirayama K, Okane I, Hosoya T, Sato T (2011a) Phylogeny of Discosia and Seimatosporium, and introduction of Adisciso and Immersidiscosia genera nova. Persoonia 26:85-98. 
Tanaka K, Hirayama K, Yonezawa H, Hatakeyama S, Harada Y, Sano T, Shirouzu T, Hosoya T. (2009) Molecular taxonomy of bambusicolous fungi: Tetraplosphaeriaceae, a new pleosporalean family with Tetraploa-like anamorphs. Stud Mycol. 64: 175-209

Tanaka K, Hirayama K, Yonezawa H, Sato G, Toriyabe A, Kudo H, Hashimoto A, Matsumura M, Harada Y, Kurihara Y, Shirouzu T, Hosoya T (2015) Revision of the Massarineae (Pleosporales, Dothideomycetes). Studies in Mycology 82: 75-136.

Tanaka K, Mel'nik VA, Kamiyama M, Hirayama K, Shirouzu T. Molecular phylogeny of two coelomycetous fungal genera with stellate conidia, Prosthemium and Asterosporium, on Fagales trees. Botany. 2010 Dec 20;88(12):1057-71.

Tanaka, K.; Hirayama, K.; Iqbal, S.H. (2011b). Massariosphaeria websteri sp. nov. and several members of the Pleosporales noteworthy to Pakistan.

Tangthirasunun N, Philippe SP, Bhat DJ, Maharachchikumbura SSN, Hyde KD (2014a) Greeneria saprophytica sp. nov. on dead leaves of Syzygium cumini from Chiang Rai, Thailand. Phytotaxa 184(5):275-282

Tangthirasunun N, Philippe SP, Bhat DJ, Maharachchikumbura SSN, Wijayawardene NN, Bahkali AH, Hyde KD (2015) Morphology and phylogeny of two appendaged genera of coelomycetes: Ciliochorella and Discosia. Sydowia 67:217-226

Tangthirasunun N, Silar P, Bhat DJ, Chukeatirote E, Wijayawardene DNN, Maharachchikumbura SSN, Hyde KD (2014b) Morphology and phylogeny of Pseudorobillarda eucalypti sp. nov., from Thailand. Phytotaxa 176:251-259

Tanney JB, Douglas B, Seifert KA 2016 Sexual and asexual states of some endophytic Phialocephala species of Picea. Mycologia. 108(2):255-80

Tanney, J.B. and Seifert, K.A., 2013. Rasamsonia pulvericola sp. nov., isolated from house dust. IMA fungus, 4(2), pp.205-212.

Taole MM, Burgess TI, Gryzenhout M, Wingfield BD, Wingfield MJ. DNA sequence incongruence and inconsistent morphology obscure species boundaries in the Teratosphaeria suttonii species complex. Mycoscience. 2012 Jul 1;53(4):270-83.

Tapper, S.L., Byrne, M., Yates, C.J., Keppel, G., Hopper, S.D., Van Niel, K., Schut, A.G., Mucina, L. and Wardell-Johnson, G.W., 2014. Prolonged isolation and persistence of a common endemic on granite outcrops in both mesic and semi-arid environments in south-western Australia. Journal of Biogeography, 41(11), pp.2032-2044.

Tarasova, V., Androsova, V., Sonina, A. and Ahti, T., 2015. The lichens from the City of Petrozavodsk in the Herbarium of the Botanical Museum, University of Helsinki. Folia Cryptogamica Estonica, 52, pp.41-50.

Tarasova, V.N., Sonina, A.V., Androsova, V.I. and Stepanchikova, I.S., 2016. The lichens of forest rocky communities of the hill Muroigora (Arkhangelsk Region, Northwest Russia). Folia Cryptogamica Estonica, 53, pp.111-121.

Tarigan M, Roux J, Van Wyk M, Tjahjono B, Wingfield MJ. A new wilt and die-back disease of Acacia mangium associated with Ceratocystis manginecans and C. acaciivora sp. nov. in Indonesia. South African Journal of Botany. 2011 Apr 30;77(2):292-304.

Tarnowski, T.L.B., Palmateer, A.J. and Crane, J.H., 2013. First report of fruit rot on Hylocereus undatus caused by Bipolaris cactivora in South Florida. Australasian Plant Pathology, 42, pp.437-440.

Tasanathai K, Thanakitpipattana D, Noisripoom W, Khonsanit A, Kumsao J, Luangsa-ard JJ. Two new Cordyceps species from a community forest in Thailand. Mycological progress. 2016 Mar 1;15(3):1-8. 
Taylor K, Andjic V, Barber PA, Hardy GE, Burgess TI. New species of Teratosphaeria associated with leaf diseases on Corymbia calophylla (Marri). Mycological progress. 2012 Feb 1;11(1):159-69.

Tehler A (2011) Roccella, the Sonoran species reviewed. Bibliotheca Lichenologica, 106, pp.309-318.

Tehler A, Baloch E, Tibell L, Wedin M (2009a) The systematic position of Schistophoron. Bibliotheca Lichenologica, 99, pp.383-392.

Tehler A, Ertz D, Irestedt M (2013a) The genus Dirina (Roccellaceae, Arthoniales) revisited. The Lichenologist 45(4):427-476.

Tehler A, Irestedt M, Bungartz F, Wedin, M., (2009b). Evolution and reproduction modes in the Roccella galapagoensis aggregate (Roccellaceae, Arthoniales). Taxon, 58(2), pp.438-456.

Tehler A, Irestedt M, Ertz D (2013b) Austroroccella, a new fruticose genus in the family Roccellaceae. Bryologist 116 (2), 162-168.

Tehler, A., 2012. Fruticose Roccellaceae. The Bryologist, 115(1), pp.210-214.

Tehler, A., Irestedt, M., Wedin, M. and Ertz, D. 2010. The Old World Roccella species outside Europe and Macaronesia: taxonomy, evolution and phylogeny System. Biodivers. 8 (2), 223-246.

Telfer AC, Young MR, Quinn J, Perez K, Sobel CN, Sones JE, Levesque-Beaudin V, Derbyshire R, Fernandez-Triana J, Rougerie R, Thevanayagam A, Boskovic A, Borisenko AV, Cadel A, Brown A, Pages A, Castillo AH, Nicolai A, Glenn Mockford BM, Bukowski B, Wilson B, Trojahn B, Lacroix CA, Brimblecombe C, Hay C, Ho C, Steinke C, Warne CP, Garrido Cortes C, Engelking D, Wright D, Lijtmaer DA, Gascoigne D, Hernandez Martich D, Morningstar D, Neumann D, Steinke D, Marco DeBruin DD, Dobias D, Sears E, Richard E, Damstra E, Zakharov EV, Laberge F, Collins GE, Blagoev GA, Grainge G, Ansell G, Meredith G, Hogg I, McKeown J, Topan J, Bracey J, Guenther J, Sills-Gilligan J, Addesi J, Persi J, Layton KK, D'Souza K, Dorji K, Grundy K, Nghidinwa K, Ronnenberg K, Lee KM, Xie L, Lu L, Penev L, Gonzalez M, Rosati ME, Kekkonen M, Kuzmina M, Iskandar M, Mutanen M, Fatahi M, Pentinsaari M, Bauman M, Nikolova N, Ivanova NV, Jones N, Weerasuriya N, Monkhouse N, Lavinia PD, Jannetta P, Hanisch PE, McMullin RT, Ojeda Flores R, Mouttet R, Vender R, Labbee RN, Forsyth R, Lauder R, Dickson R, Kroft R, Miller SE, MacDonald S, Panthi S, Pedersen S, Sobek-Swant S, Naik S, Lipinskaya T, Eagalle T, Decaëns T, Kosuth T, Braukmann T, Woodcock T, Roslin T, Zammit T, Campbell V, Dinca V, Peneva V, Hebert PD, deWaard JR. 2015. Biodiversity inventories in high gear: DNA barcoding facilitates a rapid biotic survey of a temperate nature reserve. Biodivers Data J. 2015 Aug 30;(3):e6313. doi: 10.3897/BDJ.3.e6313. eCollection.

Templeton, G.E., 2016. Alternaria toxins related to pathogenesis in plants. Microbial toxins, 8, pp.169-192.

Tennakoon DS, Hyde KD, Wanasinghe DN, Bahkali AH, Camporesi E, Phookamsak R 2016 - Taxonomy and phylogenetic appraisal of Montagnula jonesii sp. nov. (Didymosphaeriaceae, Pleosporales) from Italy. Mycosphere 7(9): 1346-1356

Teran, C.G., Downes, K. and Medows, M., 2014. Fatal Bipolaris spicifera infection in an immunosuppressed child. BMJ case reports, 2014, p.bcr2013009703.

Thambugala KM, Ariyawansa HA, Li YM, Boonmee S et al. (2014a) Dothideales. Fungal Diversity 68, 105-158

Thambugala KM, Ariyawansa HA, Liu ZY, Chukeatirote E, Hyde KD (2014b) Towards a natural classification of dothideomycetes 6: the genera Dolabra, Placostromella, 
Pleosphaerellula, Polysporidiella and Pseudotrichia (Dothideomycetes incertae sedis). Phytotaxa 176(1):55-67.

Thambugala KM, Daranagama DA, Phillips AJ, Bulgakov TS, Bhat DJ, Camporesi E, Bahkali AH, Eungwanichayapant PD, Liu ZY, Hyde KD. 2016 Microfungi on Tamarix. Fungal Diversity.:1-68.

Thambugala KM, Fang YC, Camporesi E, Bahkali AH, Liu ZY, Hyde KD (2015a).

Pseudodidymosphaeria gen. nov. in Massarinaceae. Phytotaxa 231(3): 271-282

Thambugala KM, Hyde KD, Eungwanichayapant PD, Romero AI, Liu Z-. Additions to the genus rhytidhysteron in hysteriaceae. Cryptogam Mycol. 2016;37(1):99-116

Thambugala KM, Hyde KD, Tanaka K, Tian Q, Wanasinghe DN, Ariyawansa HA, Jayasiri SC, Boonmee S, Camporesi E, Hashimoto A, Hirayama K, Schumacher RK, Promputtha I, Liu Z-Y (2015b) Towards a natural classification and backbone tree for Lophiostomataceae, Floricolaceae, and Amorosiaceae fam. nov.. Fungal Diversity (2015) 74: 199-266.

Thambugala KM, Singtripop C, Chunfang Y, Mckenzie EHC, Liu ZY, Chukeatirote E, Hyde KD (2014c) Towards a natural classification of Dothideomycetes 7: The genera Allosoma, Austropleospora, Dangeardiella, Griggsia and Karschia (Dothideomycetes incertae sdis). Phytotaxa 181:34-46

Thell A, Crespo A, Divakar PK, Kärnefelt I, Leavitt SD, Lumbsch HT, Seaward MR. A review of the lichen family Parmeliaceae-history, phylogeny and current taxonomy. Nordic Journal of Botany. 2012 Dec 1;30(6):641-64.

Thell A, Högnabba F, Elix JA, Feuerer T, Kärnefelt I, Myllys L, Randlane T, Saag A, Stenroos S, Ahti T, Seaward MRD (2009) Phylogeny of the cetrarioid core (Parmeliaceae) based on five genetic markers. Lichenologist 41:489-511

Thongkantha S, Jeewon R, Vijaykrishna D, Lumyong S, McKenzie EH, Hyde KD. Molecular phylogeny of Magnaporthaceae (Sordariomycetes) with a new species Ophioceras chiangdaoense from Dracaena loureiroi in Thailand. Fungal Divers. 2009 Jan 31;34:157-73

Thüs H, Muggia L, Pérez-Ortega S, Favero-Longo SE, Joneson S, O’Brien H, Nelsen MP, Duque-Thüs R, Grube M, Friedl T, Brodie J. Revisiting photobiont diversity in the lichen family Verrucariaceae (Ascomycota). European Journal of Phycology. 2011 Nov 1;46(4):399-415.

Thynne E, McDonald MC, Evans M, Wallwork H, Neate S, Solomon PS. Re-classification of the causal agent of white grain disorder on wheat as three separate species of Eutiarosporella. Australasian Plant Pathology. 2015 Sep 1;44(5):527-39.

Tian Q, Chomnunti P, Bhat JD, Alias SA, Mortimer PE, Hyde KD. Towards a natural classification of Dothideomycetes 5: The genera Ascostratum, Chaetoscutula, Ceratocarpia, Cystocoleus, and Colensoniella (Dothideomycetes incertae sedis). Phytotaxa. 2014 Aug 20;176(1):42-54.

Tian Q, Liu JK, Hyde KD, Wanasinghe DN, Boonmee S, Jayasiri SC, Luo ZL, Taylor JE, Phillips AJ, Bhat DJ, Li WJ, Ariyawansa H, Thambugala KM, Jones EBG, Chomnunti P, Bahkali AH, Xu JC, Camporesi E (2015) Phylogenetic relationships and morphological reappraisal of Melanommataceae (Pleosporales). Fungal Divers 74:267-324

TIAN, H.Z.; YANG, Z.; WANG, S.; HOU, C.L.; PIEPENBRING, M. (2013). A new species and phylogenetic data for Nematococcomyces. Botany 91 (1), 592-596. 
Tibell L, Frisch A, Thor G. Additions to the calicioid flora of Japan and Korea, with the descriptions of two new species. InAnnales Botanici Fennici 2014 Jun 11 (Vol. 51, No. 3, pp. 189-194).

Tibell S, Tibell L. Two new species of Atla (Verrucariaceae). The Lichenologist. 2015 Mar 1;47(02):93-8.

Tibell, L. and Frisch, A., 2010. New data on crustose mazaediate lichens from tropical Africa. Bibliotheca Lichenologica, 104, pp.323-332.

Tibell, L., 2014. Umbilicaria crustulosa on the Swedish West Coast. Graphis Scripta, 26, pp.51-53.

Tibpromma S, BHAT J, Doilom M, Lumyong S, Nontachaiyapoom S, Yang JB, Hyde KD. Three new Hermatomyces species (Lophiotremataceae) on Pandanus odorifer from Southern Thailand. Phytotaxa. 2016a Sep 19;275(2):127-39.

Tibpromma S, Daranagama DA, Boonmee S, Promputtha I, Nontachaiyapoom S, Hyde KD. 2017a Anthostomelloides krabiensis gen. et sp. nov.(Xylariaceae) from Pandanus odorifer (Pandanaceae). Turkish Journal of Botany. Jan 17;41(1):107-16.

Tibpromma S, Hyde KD, Jeewon R, Maharachchikumbura SS, Liu JK, Bhat DJ, Jones EG, McKenzie EH, Camporesi E, Bulgakov TS, Doilom M. et al. (2017b) Fungal diversity notes 491-602: taxonomic and phylogenetic contributions to fungal taxa. Fungal Diversity $83:: 1-261$.

Tibpromma S, Wijayawardene NN, Manamgoda DS, Boonmee S, Wanasinghe DN, Camporesi E, Yang JB, Hyde KD. Camarosporium arezzoensis on Cytisus sp., an addition to sexual state of Camarosporium sensu stricto. Saudi journal of biological sciences. 2016b Jan 31;23(1):1-8.

Timdal, E. (2008). Studies on Eschatogonia (Ramalinaceae) in Peru. The Lichenologist 40: 31-38.

Timdal, E. (2010). Porpidinia (Porpidiaceae), a new genus for Toninia tumidula. Bibliotheca Lichenologica 104: 333-337.

Tiwari CK, Jagrati P, Verma RK. A new and rare species of Phlyctaeniella from central India. Mycosphere. 2012 Jan 1;3(4):450-3.

Tiwari, V. and Rai, A.N. (2009). New species of Megalodochium and Monochaetia from India. Indian Phytopathology 62 : 268-272.

To-anun, C., Hidayat, I. and Meeboon, J., 2010. Cercospora cristellae, a new cercosporoid fungus associated with weed Cristella parasitica from Northern Thailand. Journal of Agricultural Technology, 6(2), pp.331-339.

To-Anun, C., Hidayat, I. and Meeboon, J., 2011. Genus Cercospora in Thailand: taxonomy and phylogeny (with a dichotomous key to species). Plant Pathology \& Quarantine, 1(1), pp.11-87.

Tokizawa, M., Ohmura, Y., Moon, K. H. and Takeshita, S. 2015. Sarcogyne endopetrophila (Acarosporaceae, Lichenized Ascomycota), a New Species from Japan Shokubutsu Kenkyu Zasshi 90, 46-51.

Tomaso-Peterson, M. and Balbalian, C.J., 2010. First report of Bipolaris oryzae causing leaf spot of switchgrass in Mississippi. Plant Disease, 94(5), pp.643-643.

Tonouchi, A., 2010. Isolation and characterization of a novel facultative anaerobic filamentous fungus from Japanese rice field soil. International journal of microbiology, 2009.

Tønsberg, T., 2013. Xylographa soralifera (lichenized Ascomycetes) new to Switzerland. Opera Bot, 119, pp.1-61. 
Torriani SFF, Penselin D, Knogge W, Felder M, Taudion S, Platzer M, McDonald BA, Brunner PC 2014. Comparative analysis of mitochondrial genomes from closely related Rhynchosporium species reveals extensive intron invasion. Fungal Genetics and Biology 62: 34-42.

Torta,L., Lo Piccolo,S., Piazza,G., Tomasello,A., Burruano,S., Colombo, P. Ottonello,D.Maida G, Pirrotta M, TomaselloA Calvo,S., 2015 Lulwoana sp., a dark septate endophyte in roots of Posidonia oceanica (L.) Delile. Plant Biology Volume 17, Issue 2 505-511.

Toxopeus J, Kozera CJ, O’Leary SJ, Garbary DJ (2011) A reclassification of Mycophycias ascophylli (Ascomycota) based on nuclear large ribosomal subunit DNA sequences. Botanica Marina 54(3):325-34.

Traeger S, Altegoer F, Freitag M, Gabaldon T, Kempken F, Kumar A, Marcet-Houben M, Pöggeler S, Stajich JE, Nowrousian M. The genome and development-dependent transcriptomes of Pyronema confluens: a window into fungal evolution. PLoS Genet. 2013 Sep 19;9(9):e1003820.

Trakunyingcharoen T, Lombard L, Groenewald JZ, Cheewangkoon R, To-Anun C, Crous PW (2015) Caulicolous Botryosphaeriales from Thailand. Persoonia: Molecular Phylogeny and Evolution of Fungi. 34:87.

Trakunyingcharoen T, Lombard L, Groenewald JZ, Cheewangkoon R, To-anun C, Alfenas AC, Crous PW. Mycoparasitic species of Sphaerellopsis, and allied lichenicolous and other genera. IMA fungus. 2014 Dec 18;5(2):391-414.

Trappe MJ, Trappe JM, Bonito GM 2010 Kalapuya brunnea gen. \& sp. nov. and its relationship to the other sequestrate genera in Morchellaceae. Mycologia 102 no. 5 1058-1065.

Trappe, J. 2009 The hunted: commercially attractive truffles native to North A merica. In Les champignons forestiers comestibles à potentiel commercial. ÉDITEUR. Biopterre, ACCHF, Université Laval, CEF, RNC, 30 novembre et 1er décembre. pp. 1-5.

Trappe, J.M.; Kovács, G.M.; Claridge, A.W. (2010). Comparative taxonomy of desert truffles of the Australian outback and the African Kalahari. Mycol. Progr. 9(1): 131-143

Travadon R, Lawrence DP, Rooney-Latham S, Gubler WD, Wilcox WF, Rolshausen PE, Baumgartner K. Cadophora species associated with wood-decay of grapevine in North America. Fungal biology. 2015 Jan 31;119(1):53-66.

Tripp EA, Lendemer JC, Harris RC (2010) Resolving the genus Graphina Müll. Arg. in North America: new species, new combinations, and treatments for Acanthothecis, Carbacanthographis, and Diorgyma. Lichenologist 42:55-71

Tripp, E.A., 2015. Lichen Inventory of White Rocks Open Space (City of Boulder, Colorado). Western North American Naturalist, 75(3), pp.301-310.

Trouillas FP, Pitt WM, Sosnowski MR, Huang R, Peduto F, Loschiavo A, Savocchia S, Scott ES, Gubler WD (2011) Taxonomy and DNA phylogeny of Diatrypaceae associated with Vitis vinifera and other woody plants in Australia. Fungal Divers 49:203-223.

Trouillas, F.P.; Sosnowski, M.R.; Gubler, W.D. 2010. Two new species of Diatrypaceae from coastal wattle in Coorong National Park, South Australia. Mycosphere. 1(2):183-188.

Trouillas, F.P; Peduto-Hand, F.; Inderbitzin, P. and Gubler, W.D. 2015. The genus Cryptosphaeria in the western United States: taxonomy, multi-locus phylogeny and a new species, C. multicontinentalis. Mycologia. Mycologia 107 (6):1304-1313

Truong C, Divakar PK, Yahr R, Crespo A, Clerc P (2013) Testing the use of ITS rDNA and protein-coding genes in the generic and species delimitation of the lichen genus Usnea (Parmeliaceae, Ascomycota). Mol Phylogenet Evol 68:357-372. 
Tsang CC, Chan JF, Ip PP, Ngan AH, Chen JH, Lau SK, Woo PC. 2014a Subcutaneous phaeohyphomycotic nodule due to Phialemoniopsis hongkongensis sp. nov. Journal of clinical microbiology. Sep 1;52(9):3280-9.

Tsang CC, Hui TWS, Lee KC, Chen JHK, Ngan AHY, Tam EWT, Chan JFW, Wu AL, Cheung M, Tse BPH, Wu AKL, Lai CKC, Tsang DNC, Que TL, Lam CW, Yuen KY, Lau SKP, Woo PCY. 2016. Genetic diversity of Aspergillus species isolated from onychomycosis and Aspergillus hongkongensis sp. nov., with implications to antifungal susceptibility testing. Diagnostic Microbiology and Infectious Disease 84:125-134.

Tsang CH, Chan JFW, Trendell-Smith NJ, Ngan AHY, Ling IWH, Lau SKP, Woo PCY (2014b) Subcutaneous phaeohyphomycosis in a patient with Ig G4-related sclerosing disease caused by a novel ascomycete, Hongkongmyces pedis gen. et sp. nov.: first report of human infection associated with the family Lindgomycetaceae. Med Mycol 52:736-747

Tsuge, T., Harimoto, Y., Akimitsu, K., Ohtani, K., Kodama, M., Akagi, Y., Egusa, M., Yamamoto, M. and Otani, H., 2013. Host-selective toxins produced by the plant pathogenic fungus Alternaria alternata. FEMS Microbiology Reviews, 37(1), pp.4466.

Tsui CK, Berbee ML. Transfer of two Helicoma species to Troposporella based on molecular and morphological data. Mycoscience. 2010 Mar 1;51(2):144-8.

Tsuneda A, Davey ML, Tsuneda, I; Hudgins, A; Currah, R.S. 2011a. Endophoma, a new didymellaceous endoconidial genus from bat-cave soil. Mycologia. 103(5):1146-1155

Tsuneda A, Hambleton S, Currah RS. 2011b. The anamorph genus Knufia and its phylogenetically allied species in Coniosporium, Sarcinomyces and Phaeococcomyces. Botany 89:523-536.

Tsuneda, A.; Davey, M.L.; Tsuneda, I.; Currah, R.S. 2010. Two new dothideomycetous endoconidial genera from declining larch. Botany. 88:471-487

Tsurykau, A. and Khramchankova, V., 2011. Lichens From Gomel Region: A Provisional Checklist. Botanica Lithuanica, 17(4).

Tu, E.Y., 2009. Alternaria keratitis: clinical presentation and resolution with topical fluconazole or intrastromal voriconazole and topical caspofungin. Cornea, 28(1), pp.116-119.

Tufan-Çetin, Ö. and Sümbül, H. 2011. Lichens of the Köprülü Canyon National Park in Turkey. Mycotaxon, 115, p.536.

Tuovila H, Davey ML, Yan L, Huhtinen S, Rikkinen J. New resinicolous Chaenothecopsis species from China. Mycologia. 2014 Sep 1;106(5):989-1003.

Tuovila, H. A. N. N. A., and P. Larsson 2011. "Three resinicolous North American species of Mycocaliciales in Europe with a re-evaluation of Chaenothecopsis oregana Rikkinen." Karstenia 51 (): 37-49.

Tuovila, H.; Rikkinen, J.; Huhtinen, S. (2012). Nomenclatural corrections in calicioid fungi. Kastenia 52: 73-74.

Tuzen, M., Sari, A., Mendil, D. and Soylak, M., 2009. Biosorptive removal of mercury (II) from aqueous solution using lichen (Xanthoparmelia conspersa) biomass: kinetic and equilibrium studies. Journal of Hazardous Materials, 169(1), pp.263-270.

Twaroch, T.E., Focke, M., Fleischmann, K., Balic, N., Lupinek, C., Blatt, K., Ferrara, R., Mari, A., Ebner, C., Valent, P. and Spitzauer, S., 2012. Carrier-bound Alt a 1 peptides without allergenic activity for vaccination against Alternaria alternata allergy. Clinical \& Experimental Allergy, 42(6), pp.966-975. 
Udayanga D, Castlebury LA, Rossman A, Ekachai Chukeatirote, Hyde KD (2014a) Insights into the genus Diaporthe: Phylogenetic species delimitation in the D. eres species complex. Fungal Diversity 67:203-229.

Udayanga D, Castlebury LA, Rossman AY, Hyde KD. Species limits in Diaporthe: molecular re-assessment of D. citri, D. cytosporella, D. foeniculina and D. rudis. PersooniaMolecular Phylogeny and Evolution of Fungi. 2014b Jun 30;32(1):83-101.

Udayanga D, Liu X, Crous PW, McKenzie EH, Chukeatirote E, Hyde KD. A multi-locus phylogenetic evaluation of Diaporthe (Phomopsis). Fungal Diversity. 2012 Sep 1;56(1):157-71.

Untereiner W.A., Bogale M., Carter A. et al. 2013. Molecular phylogeny of Boliniales (Sordariomycetes) with an assessment of the systematics of Apiorhynchostoma, Endoxyla and Psseudovalsaria. Mycologia 105: 564-588.

Untereiner WA, Gueidan C, Orr M-J, Diederich P (2011) The phylogenetic position of the lichenicolous ascomycete Capronia peltigerae. Fungal Divers 49:225-233

Uppadhyay, V., Ingle, K.K., Trivedi, S. and Upreti, D.K.2016. Diversity and distribution of lichens from the monuments of Gwalior division, Madhya Pradesh with special reference to rock porosity and lichen growth. Tropical Plant Research 3(2): 384-389.

Upreti, D.K. and Patel, D.K., 2012. Rinodina sophodes (Ach.) Massal.: a bioaccumulator of polycyclic aromatic hydrocarbons (PAHs) in Kanpur City, India. Environmental monitoring and assessment, 184(1), pp.229-238.

Upreti, D.K., Nayaka, S. and Joshi, Y., 2009. Ramboldia amarkantakana (Lecanoraceae, Ascomycota), a new lichen species from India. Mycotaxon, 107(1), pp.239-242.

Urbanavichene, I., Urbanavichus, G., Mežaka, A. and Palice, Z., 2013. New records of lichens and lichenicolous fungi from the Southern Ural Mountains, Russia. II. Folia Cryptogamica Estonica, 50, pp.73-80.

Urbanavichene, I.N. and Zapovednik, B., 2015. New and rare findings of lignicolous lichen species for the Southern Siberia from the Baikal nature reserve. Turczaninowia.

Urbanavichus, G. and Ismailov, A., 2016. New records of lichens and lichenicolous fungi from Dagestan, Russia. Folia Cryptogamica Estonica, 53, pp.65-69.

Urbanavichus, G. and Urbanavichene, I., 2011. New records of lichens and lichenicolous fungi from the Ural Mountains, Russia. Folia Cryptogamica Estonica, 48, pp.119-124.

Urbanavichus, G. and Urbanavichene, I., 2015. New records of lichens and lichenicolous fungi from the NW Caucasus (Russia). Herzogia, 28(1), pp.185-192.

Urbanavichus, G., Gabibova, A. and Ismailov, A., 2011. New records of lichens and lichenicolous fungi for Russia and the Caucasus. Turkish Journal of Botany, 35(3), pp.291-297.

Usui E, Takashima Y, Narisawa K. 2016. Cladophialophora inabaensis sp. nov., a new species among the dark septate endophytes from a secondary forest in Tottori, Japan. Microbes and Environments 31:357-360.

Vaghefi N, Pethybridge SJ, Ford R, et al. (2012). Stagonosporopsis spp. associated with ray blight disease of Asteraceae. Australasian Plant Pathology 41: 675-686.

Valadbeigi T, Nordin A, Tibell L. 2011a Megaspora rimisorediata (Pertusariales, Megasporaceae), a new sorediate species from Iran and its affinities with Aspicilia sensu lato. The Lichenologist. Jul 1;43(04):285-91.

Valadbeigi T, Sipman HJ, Rambold G. 2011b The genus Immersaria (Lecideaceae) in Iran, including I. iranica sp. nov. The Lichenologist. May 1;43(03):203-8.

Valadbeigi, T. 2014. Lichen flora of the Ilam province, South West Iran. Mycotaxon, 128, pp.248-55. 
Valadbeigi, T. and Sipman, H.J., 2010. New records of lichens and lichenicolous fungi from Iran and their biogeographical significance. Mycotaxon, 113(1), pp.191-194.

Valadbeigi, T.; Brackel, W. von. 2011. Two new species of Lichenostigma (Lichenotheliaceae) from Iran. Willdenowia. 41:191-195.

Valadbeigi, Tahereh; Sipman, Harrie J. M. 2010 New records of lichens and lichenicolous fungi from Iran and their biogeographical significance. Mycotaxon, 113. 191-194.

van den Boom PI, Etayo JA. 2014 New records of lichenicolous fungi and lichenicolous lichens from the Iberian Peninsula, with the description of four new species and one new genus. Opuscula Philolichenum.;13:44-79.

van den Boom PP, Giralt M. 2012 Checklist and three new species of lichens and lichenicolous fungi of the Algarve (Portugal). Sydowia. Dec 31;64(2):149-207.

van den Boom PP. 2012 Additions and notes to the checklist of lichens and lichenicolous fungi of Cape Verde. Österreichische Zeitschrift für Pilzkunde.;21:5-16.

van den Boom PPG (2009) New Halecania species (Catillariaceae) from Europe and South America. The Bryologist 112(4): 827-832

van den Boom PPG (2010). New or interesting lichens and lichenicolous fungi of Gran Canaria (Canary Islands, Spain). Willdenowia 40(2):359-367

van den Boom PPG, Brand AM 2008 New records of lichens, lichenicolous and allied fungi from Belgium and The Netherlands. Sauteria 15, 95-101.

van den Boom, P.P. and Sipman, H.J., 2016. Foliicolous lichens from Suriname and Guyana: new records and three new species. Folia Cryptogamica Estonica, 53, pp.101-110.

Van den Boom, P.P.G. 2015. Lichens and lichenicolous fungi from graveyards of the area of Eindhoven (the Netherlands), with the description of two new species. Annalen des Naturhistorischen Museums Wien. serie B 117:245-276

van den Boom,P.P.G. 2016. Lichens and lichenicolous fungi of the azores (portugal), collected on são miguel and terceira with the descriptions of seven new species. Acta Botanica Hungarica. 58(1-2):199-222

van den Brink J, Facun K, De Vries M, Stielow JB. Thermophilic growth and enzymatic thermostability are polyphyletic traits within Chaetomiaceae. Fungal biology. 2015 Dec 31;119(12):1255-1266.

van den Brink J, Samson RA, Hagen F, Boekhout T, de Vries RP. 2012. Phylogeny of the industrial relevant, thermophilic genera Myceliopthora and Corynascus. Fungal Diversity 52:197-207.

van den Broeck D, Ertz D. Cryptophaea, a new genus of byssoid Arthoniaceae (lichenized Ascomycota) and its phylogenetic position. Phytotaxa. 2016 May 18;261(2):168-76.

van den Broeck D, Luecking R, Damien ER 2014. The foliicolous lichen biota of the Democratic Republic of the Congo, with the description of six new species. The Lichenologist. Mar 1;46(02):141-58.

van Vooren, N. (2009). Note sur Smardaea ovalispora comb. nov. (Pezizales). Bull. Mycol. Bot. Dauphiné-Savoie 49(no. 192): 23-38

van Vooren,N. 2014. Type-revision of Lachnea velenovskyi, a new species in the genus Spooneromyces (Pezizales). Ascomycete. 6(4):89-92

van Wyk M, Wingfield BD, Clegg PA, Wingfield MJ. Ceratocystis larium sp. nov., a new species from Styrax benzoin wounds associated with incense harvesting in Indonesia. Persoonia. 2009 Jun;22:75.

van Wyk M, Wingfield BD, Wingfield MJ. Four new Ceratocystis spp. associated with wounds on Eucalyptus, Schizolobium and Terminalia trees in Ecuador. Fungal Diversity. 2011 Jan 1;46(1):111-31. 
van Wyk, M.; Wingfield, B.D.; Marin, M.; Wingfield, M.J. (2010). New Ceratocystis species infecting coffee, cacao, citrus and native trees in Colombia. Fungal Diversity 40: 103117.

Vandeputte P, Ghamrawi S, Rechenmann M, Iltis A, Giraud S, Fleury M, Thornton C, Delhaès L, Meyer W, Papon N, Bouchara JP. Draft genome sequence of the pathogenic fungus Scedosporium apiospermum. Genome announcements. 2014 Oct 30;2(5):e00988-14.

Varga J, Frisvad JC, Samson RA. Two new aflatoxin producing species, and an overview of Aspergillus section Flavi. Studies in Mycology. 2011 Jun 30;69:57-80.

Varga J, Samson RA, Frisvad JC. 2010a. Polyphasic taxonomy of Aspergillus section Sparsi. IMA Fungus 1:187-195.

Varga J, Samson RA, Frisvad JC. 2010b. Aspergillus sect. Aeni sect. nov., a new section of the genus for A. karnatakaensis sp. nov. and some allied fungi. IMA Fungus 1:197205.

Vasilyeva L, Chernyshev A, Stephenson SL 2010 Pyrenomycetes of the Russian Far East 4: family Nitschkiaceae (Coronophorales, Ascomycota). Mycologia 102 no. 1 233-247

Vasilyeva Larissa; Li, Yu; Stephenson, Steven 2009 Some pyrenomycetous fungi new to China. Mycotaxon, Volume 109, July-September 2009, pp. 415-428

Vasilyeva LN 2010. New species of pyrenomycetes from eastern Russia: Endoxylina rufula (Diatrypaceae). Mycosphere. 1(2):163-166

Vasilyeva LN, Chernyshev AV, Stephenson, S.L. 2012. Neochaetosphaerella thaxteriospora gen. et sp. nov. and Tympanopsis texensis sp. nov. (Coronophorales, Ascomycota) from Texas, USA. Fungal Diversity. 52(1):191-196.

Vasilyeva LN, Ma, Hai-xia; Stephenson, Steven L. 2016 Biogeography and taxonomy of pyrenomycetous fungi 3. The area around the Sea of Japan. Mycotaxon, Volume 126, October-December 2013, pp. 1-14.

Vasilyeva LN, Rossman AY, Farr DF (2008) [2007]. New species of the Diaporthales from eastern Asia and eastern North America. Mycologia 99(6): 916-923

Vasilyeva LN, Stephenson SL (2010) Biogeographical patterns in pyrenomycetous fungi and their taxonomy. 1. The Grayan disjunction. Mycotaxon 114: 281-303.

Vasilyeva LN, Stephenson SL. 2014 Notes on pyrenomycetous fungi in the Mountain Lake area of southwestern Virginia. Mycosphere. Jan 1;5(1):218-27.

Vasylieva L.N., Chernyshev A.V., Stephenson S.L., Hyde K.D. 2013. Tortulomyces thailandicus gen. et sp. nov. and Nitschkia siamensis sp. nov. (Coronophorales, Ascomycota) from northern Thailand. Mycoscience 54: 110-115.

Vaupotič, T., Veranic, P., Petrovič, U., Gunde-Cimerman, N. and Plemenitaš, A., 2008. HMG-CoA reductase is regulated by environmental salinity and its activity is essential for halotolerance in halophilic fungi. Studies in mycology, 61, pp.61-66.

Vazquéz-Campos X, Kinsela AS, Waite TD, Collins RN Neilan BA (2014) Fodinomyces uranophilus gen. nov. sp. nov. and Coniochaeta fodinicola sp.nov., two uranium mine-inhabiting Ascomycota fungi from northern Australia. Mycologia 106(6):10731089

Vélëz, H., Glassbrook, N.J. and Daub, M.E., 2008. Mannitol biosynthesis is required for plant pathogenicity by Alternaria alternata. FEMS microbiology letters, 285(1), pp.122129.

Velmala S, Myllys L, Goward T, Holien H, Halonen P (2014) Taxonomy of Bryoria section Implexae (Parmeliaceae, Lecanoromycetes) in North America and Europe, based on chemical, morphological and molecular data. Annales Botanici Fennici 51: 345-371.

Verkley GJM, Dukik K, Renfurm R, et al. (2014). Novel genera and species of coniothyriumlike fungi in Montagnulaceae (Ascomycota). Persoonia 32: 25-51 
Verkley GJM, Quaedvlieg W, Shin HD, Crous PW (2013) A new approach to species delimitation in Septoria. Stud Mycol 75:213-305

Verkley, G.J.M.; Hofland-Zijlstra, J.D. 2010. Rhizodermea veluwensis gen. et sp. nov. Persoonia. 24:130-131

Verma, R.K.; Sharma, N.; Soni, K.K.; Jamaluddin (2008) Forest Fungi of Central India 418 pp.+ incl. colour plates Lucknow: International Book Distributing Co.

Verma,NK;Rai,AN. 2014. Distocercospora indica, a new dematiaceous hyphomycete from central India. Mycotaxon. 127:97-101.

Vermeulen M, Gryzenhout M, Wingfield MJ, Roux J. Species delineation in the tree pathogen genus Celoporthe (Cryphonectriaceae) in southern Africa. Mycologia. 2013 Mar 1;105(2):297-311.

Vicente VA, Attili-Angelis D, Pie MR, Queiroz-Telles F, Cruz LM, Najafzadeh MJ, de Hoog GS, Zhao J, Pizzirani-Kleiner A. 2008. Environmental isolation of black yeast-like fungi involved in human infection. Studies in Mycology 61:137-144.

Vicente VA, Orélis-Ribeiro R, Najafzadeh MJ, Sun J, Guerra RS, Miesch S, Ostrensky A, Meis JF, Klaassen CH, de Hoog GS, Boeger WA. 2012. Black yeast-like fungi associated with lethargic crab disease (LCD) in the mangrove-land crab, Ucides cordatus (Ocypodidae). Veterinary Microbiology 158:109-122.

Vicol, I., 2012. The sinstructure of epiphytic lichens within forests from the eastern part of Bucharest Municipality (Romania). Botanica Serbica (Serbia).

Videira SIR, Groenewald JZ, Braun U, Shin HD, Crous PW (2016). All that glitters is not Ramularia. Studies in Mycology 83: 49-163.

Videira SIR, Groenewald JZ, Nakashima C, Barreto R, Braun U, Crous PW (2017) Mycophaerellaceae - chaos or clarity? Studies in Mycology: in prep.

Villalta, C.F.; Jacobson, D.J.; Taylor, J.W. (2009). Three new phylogenetic and biological Neurospora species: N. hispaniola, N. metzenbergii and N. perkinsii. Mycologia 101(6): 777-789.

Visagie CM, Yilmaz N, Frisvad JC, Houbraken J, Seifert KA, Samson RA, Jacobs K. 2015. Five new Talaromyces species with ampulliform-like phialides and globose rough walled conidia resembling T. verruculosus. Mycoscience 56:486-502.

Visagie CM, Yilmaz N, Renaud JB, Sumarah MW, Hubka V, Frisvad JC, Chen AJ, Meijer M, Seifert KA. 2017. A survey of xerophilic Aspergillus from indoor environments, including descriptions of two new section Aspergillus species producing eurotiumlike sexual states. MycoKeys 19:1-30.

Visentin I, Gentile S, Valentino D, Gonthier P, Tamietti G, Cardinale F. Gnomoniopsis castanea sp. nov.(Gnomoniaceae, Diaporthales) as the causal agent of nut rot in sweet chestnut. Journal of Plant Pathology. 2012 Aug 1;94(2):411-9.

Vitoria NS, Cavalcanti MA, Hyde KD, Bezerra JL. (2012) Brunneiapiospora brasiliensis sp. nov.(Clypeosphaeriaceae) on palms from Brazil. Nova Hedwigia. Feb 1;94(1):245-50.

Vitoria NS, Cavalcanti MAQ, Hyde KD, Bezerra JL (2011) Arecomyces new to Brazil, including A. attaleae sp. nov. Cryptogamie. Mycologie 32:103-108.

Voglmayr H, Gardiennet A, Jaklitsch WM (2016) Asterodiscus and Stigmatodiscus, two new apothecial dothideomycete genera and the new order Stigmatodiscales. Fungal Divers DOI 10.1007/s13225-016-0356-y

Voglmayr H, Jaklitsch WM (2011) Molecular data reveal high host specificity in the phylogenetically isolated genus Massaria (Ascomycota, Massariaceae). Fungal Divers 46:133-170

Voglmayr H, Jaklitsch WM (2014) Stilbosporaceae resurrected: generic reclassification and speciation. Persoonia-Molecular Phylogeny and Evolution of Fungi 33(1): 61-82. 
Voglmayr H, Jaklitsch WM. Prosthecium species with Stegonsporium anamorphs on Acer. Mycological research. 2008 Aug 31;112(8):885-905.

Voglmayr H, Park MJ \& Shin HD. (2011) Spiroplana centripeta gen. \& sp. nov., a leaf parasite of Philadelphus and Deutzia with a remarkable aeroaquatic conidium morphology. Mycotaxon 116: 203-216.

Vondrák J, Frolov I, Davydov EA, Urbanavichene I, Chesnokov S, Zhdanov I, Muchnik E, Konoreva L, Himelbrant D, Tchabanenko S (2016) The extensive geographical range of several species of Teloschistaceae: evidence from Russia. The Lichenologist 48(3): 171-189

Vondrák J, Khodosovtsev A, Šoun J, Vondráková O (2012) Two new European species from the heterogeneous Caloplaca holocarpa group (Teloschistaceae). Lichenologist 44: 73-89

Vondrák, J. and Liška, J., 2013. Lichens and lichenicolous fungi from the Retezat Mts and overlooked records for the checklist of Romanian lichens. Herzogia, 26(2), pp.293305.

Voytsekhovich A, Dymytrova L, Nadyeina O. Photobiont composition of some taxa of the genera Micarea and Placynthiella (Lecanoromycetes, lichenized Ascomycota) from Ukraine. Folia Cryptogamica Estonica. 2011;48:135-48.

Vu, A.L., Dee, M.M., Gualandi Jr, R.J., Huff, S., Zale, J., Gwinn, K.D. and Ownley, B.H., 2015. First report of leaf spot caused by Bipolaris spicifera on switchgrass in the United States. Phytopathology, 105(8), pp.1146-1154.

Vu, A.L., Dee, M.M., Gwinn, K.D. and Ownley, B.H., 2011. First report of spot blotch and common root rot caused by Bipolaris sorokiniana on switchgrass in Tennessee. Plant Disease, 95(9), pp.1195-1195.

Vujanovic, V.; Goh, Y.K. (2009). Sphaerodes mycoparasitica sp. nov., a new biotrophic mycoparasite on Fusarium avenaceum, F. graminearum and F. oxysporum. Mycol. Res. 113(10): 1172-1180.

Vujanovic, V.; St-Arnaud, M.; Neumann, P.J.; Fortin, J.A. 1998. Diarimella laurentidae anam.: sp.nov. from Quebec. Canadian Journal of Botany. 76(12):2037-2041.

Walker DM, Castlebury LA, Rossman AY, Mejía LC, White JF. 2012 Phylogeny and taxonomy of Ophiognomonia (Gnomoniaceae, Diaporthales), including twenty-five new species in this highly diverse genus Fungal Diversity 57, (1) 85-147

Walker DM, Castlebury LA, Rossman AY, Sogonov MV, White JF. Systematics of genus Gnomoniopsis (Gnomoniaceae, Diaporthales) based on a three gene phylogeny, host associations and morphology. Mycologia. 2010 Nov 1;102(6):1479-96.

Walker DM, Lawrence BR, Wooten JA, Rossman AY, Castlebury LA. Five new species of the highly diverse genus Plagiostoma (Gnomoniaceae, Diaporthales) from Japan. Mycological Progress. 2014 Nov 1;13(4):1057-1067.

Walsh E, Luo J, Naik A, Preteroti T, Zhang N. (2015) Barrenia, a new genus associated with roots of switchgrass and pine in the oligotrophic pine barrens. Fungal biology. 119(12):1216-1225.

Walsh E, Luo J, Zhang N (2014) Acidomelania panicicola gen. et sp. nov. from switchgrass roots in acidic New Jersey pine barrens. Mycologia 106(4):856-864.

Wanasinghe DN, Jones EBG, Camporesi E, Dissanayake AJ, Kamolhan S, Mortimer PE, Xu J, Abd-Elsalam KA, Hyde KD. 2016 - Taxonomy and phylogeny of Laburnicola gen. nov. and Paramassariosphaeria gen. nov.(Didymosphaeriaceae, Massarineae, Pleosporales). Fungal Biology 120, 1354-1373

Wanasinghe DN, Jones EBG, Camporesi E, Mortimer PE, Xu J, Bahkali AH, Hyde KD (2015) The genus Murispora. Cryptogamie Mycologie 36:419-448 
Wanasinghe DN, Jones EBG, Camporesif E, Boonmee S, Karunarathna SC, Thines M, Mortimer PE, Xu J, Hyde KD (2014) Dematiopleospora mariae gen. sp. nov., from Ononis Spinosa in Italy. Cryptogamie Mycologie 35:105-117

Wang H, Luo H, Li J, Bai Y, Huang H, Shi P, Fan Y, Yao B (2010a) An alpha-galactosidase from an acidophilic Bispora sp. MEY-1 strain acts synergistically with betamannanase. Bioresource Technology 101: 8376-8382.

Wang HK, Hyde KD, Soytong K, Lin FC (2008a) Fungal diversity on fallen leaves of Ficus in northern Thailand. Journal of Zhejiang University SCIENCE B, 9(10), pp.835-841.

Wang J, Wang R, Yang XY (2013a) Efficacy of an Arthrobotrys oligospora N mutant in nematode-trapping larvae after passage through the digestive tract of sheep. Veterinary microbiology, 161(3), pp.359-361.

Wang J, Xu S, Strongman DB. (2010b) Two new Harpellales inhabiting the digestive tracts of midge larvae and other trichomycetes from Tianshan Mountains, China. Mycologia 102(1): 135-41.

Wang L, Groenewald M, Wang QM, Boekhout T. (2015a) Reclassification of Saccharomycodes sinensis, Proposal of Yueomyces sinensis gen. nov., comb. nov. within Saccharomycetaceae (Saccharomycetales, Saccharomycotina). PloS one. Sep 16;10(9):e0136987.

Wang LS, McCune B (2010) Contributions to the lichen flora of the Hengduan mountains, China 1. Genus Pseudephebe (lichenized Ascomycota, Parmeliaceae). Mycotaxon. Jul $1 ; 113(1): 431-7$.

Wang LS, Wang, X.Y. and Lumbsch, H.T., 2013b. Eight lecanoroid lichen species new to China. Cryptogamie, Mycologie, 34(4), pp.343-348.

Wang MM, Jin LT, Jiang CX, Hou CL (2009a). Rhytisma huangshanense sp. nov. described from morphological and molecular data. Mycotaxon 108: 73-82.

Wang QM, Zhang YH, Wang B, Wang L (2016a) Talaromyces neofusisporus and T. qii, two new species of section Talaromyces isolated from plant leaves in Tibet, China. Sci Rep 6:18622.

Wang QX, Yang JL, Qi QY, Bao L, Yang XL, Liu MM, Huang P, Zhang LX, Chen JL, Cai L, Liu HW (2013c) 3-Anhydro-6-hydroxy-ophiobolin A, a new sesterterpene inhibiting the growth of methicillin-resistant Staphylococcus aureus and inducing the cell death by apoptosis on K562, from the phytopathogenic fungus Bipolaris oryzae. Bioorganic \& medicinal chemistry letters, 23(12) : 3547-3550.

Wang R, Yang XY, Han HB (2008b). Influence of amino acids on traps forming of nematode-trapping fungus-Arthrobotrys oligospora [J]. Heilongjiang Animal Science and Veterinary Medicine 7: 3

Wang S, Cannon P, Li ZJ, Hou CL (2014a) Multigene phylogenetic analysis detects cryptic species of Tryblidiopsis in China. Mycologia 106(1): 95-104

Wang S, Kirschner R, Wang Y-W, Hou C-L (2014b) Hypohelion from China. Mycological Progress 13: 781-789

Wang S, Taylor J, Hou C-L (2013d) Species of Rhytismatales on Berberis from China. Mycological Progress 12 (4): 629-635

Wang TW, Haelewaters D, Pfister DH (2016b) Long-hidden in Thaxter's treasure trove: Laboulbenia camerunensis sp. nov. parasitic on African Curculionidae. Mycotaxon 131 (3): 613-619.

Wang W, McGhee D, Gibas CFC, Tsuneda A, Currah RS (2009b) Phialocephala urceolata, sp. nov., from a commercial, water-soluble heparin solution. Mycologia 101(1): 136141. 
Wang W, Wang Y, Tao H, Peng X, Liu P, Zhu W (2009c) Cerebrosides of the halotolerant fungus Alternaria raphani isolated from a sea salt field. Journal of natural products 72(9): 1695-1698

Wang X, Gao Q, Bao J (2015b) Transcriptional analysis of Amorphotheca resinae ZN1 on biological degradation of furfural and 5-hydroxymethylfurfural derived from lignocellulose pretreatment. Biotechnology for biofuels 8(1):1

Wang X, Huhtinen S, Hansen K. (2016c) Multilocus phylogenetic and coalescent-based methods reveal dilemma in generic limits, cryptic species, and a prevalent intercontinental disjunct distribution in Geopyxis (Pyronemataceae sl, Pezizomycetes). Mycologia 19:16-20.

Wang X-H, Xu L, Jia Z-F (2015c) The lichen genus Leiorreuma in China. Mycotaxon 130 (1): $247-251$

Wang XW, Houbraken J, Groenewald JZ, Meijer M, Andersen B, Nielsen KF, Crous PW, Samson RA (2016d) Diversity and taxonomy of Chaetomium and chaetomium-like fungi from indoor environments. Studies in Mycology 84: 145-224.

Wang XY, Goffinet B, Liu D, Liang MM, Shi HX, Zhang YY, Zhang J, Wang LS (2015d) Taxonomic study of the genus Anzia (Lecanorales, lichenized Ascomycota) from Hengduan Mountains, China. Lichenologist 47: 99-115

Wang XY, Gu HL, Li Q, Wang LH, LinYR (2014c) A new species of Coccomyces with dimorphic paraphyses. Mycotaxon 129(2): 297-302

Wang XY, Joshi Y, Hur JS, Oh SO, Wang LS (2010c) Taxonomic studies on the lichen flora of southwestern China (1). Pilophorus yunnanensis sp. nov. (Cladoniaceae). The Bryologist 113(2): 345-349

Wang XY, Joshi Y, Oh SO, Jae-Seoun HUR, Wang, LS (2011a) Pilophorus fruticosus (Cladoniaceae), a new species from south-western China. The Lichenologist 43(2): 137-140

Wang XY, Wang LS, Kawakami H, Hur SJ (2011b) The genus Pilophorus (Lichenized Ascomycota, Cladoniaceae) from China. 菌物学报 30(6): 889-894

Wang Y, Bao Y, Shen D, Feng W, Yu T, Zhang J, Zheng XD (2008c) Biocontrol of Alternaria alternata on cherry tomato fruit by use of marine yeast Rhodosporidium paludigenum Fell \& Tallman. International Journal of Food Microbiology 123(3): 234-239

Wang Y, Chen XR, Yang CD (2013e) A new Stigmella species associated with Lycium leaf spots in northwestern China. Mycotaxon 122(1):69-72

Wang Y, Hyde KD, McKenzie EH, Jiang YL, Li DW, Zhao DG (2015e) Overview of Stachybotrys (Memnoniella) and current species status. Fungal Diversity 71(1):17-83

Wang Y, Shao J, Yao S, Zhang S, Yan J, Wang H, Chen Y (2014d) Study on the antithrombotic activity of Umbilicaria esculenta polysaccharide. Carbohydrate polymers 105: 231-236

Wang Y, Yu T, Li Y, Cai D, Liu X, Lu H, Zheng XD (2009d) Postharvest biocontrol of Alternaria alternata in Chinese winter jujube by Rhodosporidium paludigenum. Journal of applied microbiology 107(5): 1492-1498

Wang Y-Z, Huang CL, Wei JL (2016e) Two new species of Sarcoscypha (Sarcosyphaceae, Pezizales) from Taiwan." Phytotaxa 245(2): 169-177

Wang YZ, Huang CL (2015) A new species of Urnula (Sarcosomataceae, Pezizales) from Taiwan. Nova Hedwigia 101(1-2): 49-55

Wanporn Khemmuk, Andrew D.W. Geering and Roger G. Shivas 2016 Wongia gen. nov. (Papulosaceae, Sordariomycetes), a new generic name for two root-infecting fungi from Australia. IMA Fungus 7(2): 247-252 
Waxman KD, Bergstrom GC (2015) First report of a leaf spot caused by Bipolaris oryzae on switchgrass in New York. Current Research on Fungal Pathogens Associated with Rice $8: 482-501$.

Wedén C, Larsson S, Burman R, Backlund A (2009) The edible truffle Choiromyces venosus and its use in Sweden. Acta Botanica Yunnanica 31(S16): 94-96.

Wedin M, Högnabba F, Goward T (2009a) A new species of Sphaerophorus, and a key to the family Sphaerophoraceae in western North America. The Bryologist 112(2): 368-374.

Wedin M, Jørgensen PM, Ekman S (2011) Vahliellaceae, a new family of cyanobacterial lichens (Peltigerales, Ascomycetes). The Lichenologist 43(01): 67-72

Wedin M, Wiklund E, Jørgensen PM, Ekman S (2009b) Slippery when wet: phylogeny and character evolution in the gelatinous cyanobacterial lichens (Peltigerales, Ascomycetes). Molecular Phylogenetics and Evolution 53:862-871

Weerakoon A, Aptroot HT, Lumbsch, P.A. Wolseley, S.C. Wijeyaratne \& C. Gueidan. (2012a) New molecular data on Pyrenulaceae from Sri Lanka reveal two wellsupported groups within this family. Lichenologist 44: 639-647

Weerakoon G, Aptroot A (2016) Nine new lichen species and 64 new records from Sri Lanka. Phytotaxa 280(2): 152-162

Weerakoon G, Jayalal U, Wijesundara S, Karunaratne V, Lücking R (2015) Six new Graphidaceae (lichenized Ascomycota: Ostropales) from Horton Plains National Park, Sri Lanka. Nova Hedwigia 101(1-2): 77-88

Weerakoon G, Wijeyaratne SC, Wolseley PA, Plata ER, Lücking R, Lumbsch HT (2012b) Six new species of Graphidaceae from Sri Lanka. The Bryologist 115(1): 74-83

Weerakoon G, Wolseley PA, Arachchige O, Eugenia da Silva Cáceres M, Jayalal U, Aptroot A (2016) Eight new lichen species and 88 new records from Sri Lanka. The Bryologist 119(2): 131-142

Węgrzyn M, Wietrzyk P, Adamska E, Nicia P (2015) New records of driftwood lichens in the Kaffiøyra Plain (NW Spitsbergen, Svalbard). Polish Polar Research 36(2): 189-195

Wei LX, Zhang HX, Tan JL, Chu YS, Li N, Xue HX, Wang YL, Niu XM, Zhang Y, Zhang KQ (2011) Arthrobotrisins A-C, oligosporons from the nematode-trapping fungus Arthrobotrys oligospora. Journal of natural products 74(6): 1526-1530

Weir A (2008) The g Prolixandromyces (Laboulbeniales) in the Old World. Aliso 26(1): 2935

Weir BS, Johnston PR, Damm U (2012) The Colletotrichum gloeosporioides species complex. Studies in mycology 73: 115-180

Wen TC, Xiao YP, Li WJ, Kang JC, Hyde KD (2014) Systematic analyses of Ophiocordyceps ramosissimum sp. nov., a new species from a larvae of Hepialidae in China. Phytotaxa 161(3): 227-234

Wendt L, Sir EB, Kuhnert E, Heitkämper S, Lambert C, Hladki AI, Romero AI, Luangsa-ard JJ, Srikitikulchai P, Peršoh D, Stadler M (2017) Resurrection and emendation of the Hypoxylaceae, recognised from a multigene phylogeny of the Xylariales. Mycol Progress: DOI 10.1007/s11557-017-1311-3

Westberg M, Frödén P, Wedin M (2009) A monograph of the genus Placomaronea (Ascomycota, Candelariales). The Lichenologist 41(05): 513-527

Westberg M, Millanes AM, Knudsen K, Wedin M (2015) Phylogeny of the Acarosporaceae (Lecanoromycetes, Ascomycota, Fungi) and the evolution of carbonized ascomata. Fungal Diversity 70:145-158

Westberg M, Sohrabi M (2012) A conspectus of the lichen genus Candelariella (Candelariaceae, Ascomycota) in Southwest Asia with emphasis on Iran. Nova Hedwigia 95(3-4): 531-546. 
Wetmore CM (2009) Lichens collected in the Big Horn Mountains, Wyoming. Evansia 26(1): $10-14$.

Whalley MA, Khalil AM, Wei TZ, Yao YJ, Whalley AJ (2010) A new species of Engleromyces from China, a second species in the genus. Mycotaxon 112: 317-323

Whitton SR, Mckenzie EHC, Hyde KD (2012a) Anamorphic fungi associated with Pandanaceae. In Whitton, S.R., E.H.C. Mckenzie \& K.D. Hyde: Fungi associated with Pandanaceae. Fungal Diversity Research Series (Hong Kong) 21: 125-353

Whitton SR, McKenzie EHC, Hyde KD (2012b) Teleomorphic microfungi associated with Pandanaceae. InFungi Associated with Pandanaceae (pp. 23-124). Springer Netherlands.

Wicklow DT, Rogers KD, Dowd PF, Gloer JB (2011) Bioactive metabolites from Stenocarpella maydis, a stalk and ear rot pathogen of maize. Fungal Biology 115(2): 133-142.

Wieczorek A, Łysko A (2012) Lichen biota of the Wolin Island (Poland). Biodiversity: Research and Conservation 25: 83-89.

Wieschollek D, Helleman S, Baral HO, Richter T (2011) Roseodiscus formosus spec. nov. ein Bryophiler Pionier mit falschem Namen. Zeitschrift für Mykologie 77(2): 161-174.

Wiewióra B (2012) The effect of seed health of perennial ryegrass (Lolium perenne L.) on germination capacity. Plant Breeding and Seed Science 65(1): 51-62.

Wight WD, Kim KH, Lawrence CB, Walton JD (2009) Biosynthesis and role in virulence of the histone deacetylase inhibitor depudecin from Alternaria brassicicola. Molecular plant-microbe Interactions 22(10): 1258-1267.

Wijayawardene DNN, McKenzie EHC \& Hyde KD (2012) Towards incorporating anamorphic fungi in a natural classification - checklist and notes for 2011. Mycosphere 3(2): 157-228.

Wijayawardene NN, Bhat DJ, Hyde KD, Camporesi E, Wikee S, Chethana KWT, Tangthirasunun N, Wang Y (2014a) Camarosporium sensu stricto in Pleosporinae, Pleosporales with two new species. Phytotaxa 183(1): 16-26.

Wijayawardene NN, Camporesi E, Bhat DJ, Song, Y, Chethana KWT, Chukeatirote E, Wang Y, Hyde KD (2014b) Macrodiplodiopsis in Lophiostomataceae, Pleosporales. Phytotaxa 176: 192-200.

Wijayawardene NN, Crous PW, Kirk PM, Hawksworth DL, Boonmee S, et al. (2014c) Naming and outline of Dothideomycetes-2014 including proposals for the protection or suppression of generic names. Fungal Diversity 69:1-55

Wijayawardene NN, Goonasekara ID, Camporesi E, Wang Y, An YL (2016a) Two new Seimatosporium species from Italy. Mycosphere 7(2): 204-213.

Wijayawardene NN, Hyde KD, Bhat DJ, Camporesi E, Schumacher RK, et al. (2014d) Camarosporium-like species are polyphyletic in Pleosporales; introducing Paracamarosporium and Pseudocamarosporium gen. nov. in Montagnulaceae. Cryptogamie Mycologie 35(2):177-19

Wijayawardene NN, Hyde KD, Bhat DJ, Goonasekara ID, Nadeeshan D, Camporesi E, Schumacher RK, Wang Y (2015) Additions to brown spored coelomycetous taxa in Massarinae, Pleosporales: Introducing Phragmocamarosporium gen. nov. and Suttonomyces gen. nov. Cryptogamie Mycologie 36(2):213-224.

Wijayawardene NN, Hyde KD, Wanasinghe DN, Papizadeh M, Goonasekara ID, et al. (2016b) Taxonomy and phylogeny of dematiaceous coelomycetes. Fungal Diversity 77: 1-316.

Wikee S, Lombard L, Crous PW, Nakashima C, Motohshi K, Chukeatirote E, Alias SA, McKenzie EHC, Hyde KD (2013a) Phyllosticta capitalensis, a widespread endophyte of plants. Fungal Diversity 60:91-105 
Wikee S, Lombard L, Nakashima C, Motohashi K, Chukeatirote E, Cheewangkoon R, McKenzie EHC, Hyde KD, Crous PW (2013b) A phylogenetic re-evaluation of Phyllosticta (Botryosphaeriales). Studies in Mycology 76:1-29

Wikee S, Udayanga D, Crous PW, Chukeatirote E, Mckenzie EHC, Bahkali AH, Dai DQ, Hyde KD (2011) Phyllosticta - an overview of current status of species recognition. Fungal Diversity 51:43-61

Williams ME, Rudolph ED, Schofield EA, Prasher DC (2012) The role of lichens in the structure, productivity, and mineral cycling of the wet coastal Alaskan tundra. InVegetation and production ecology of an Alaskan Arctic tundra 1978 (pp. 185-206). Springer New York.

Wirth V, Hauck M, Brackel WV, Cezanne R, de Bruyn U, Dürhammer O, Eichler M, Gnüchtel A, Litterski B, Otte V, Schiefelbein U (2011) Checklist of lichens and lichenicolous fungi in Germany. Georg August University of Göttingen 2: 19.

Wiseman MS, Kim YK, Dugan FM, Rogers JD, Xiao CL (2016) A new postharvest fruit rot in apple and pear caused by Phacidium lacerum. Plant Disease 100(1): 32-39.

Wolf J, O'Neill NR, Rogers CA, Muilenberg ML, Ziska LH (2010) Elevated atmospheric carbon dioxide concentrations amplify Alternaria alternata sporulation and total antigen production. Environmental health perspectives, 118(9): 1223.

Wong SS, Ngan AH, Riggs CM, Teng JL, Choi GK, Poon RW, Hui JJ, Low FJ, Luk A, Yuen KY (2011) Brittle tail syndrome is an emerging infection in horses caused by a keratinolytic fungus Equicapillimyces hongkongensis gen. nov., sp. nov. Veterinary Microbiology 155: 399-408

Wongsawas M, Wang HK, Hyde KD, Lin FC (2009) Two new hyphomycetes from submerged wood collected in China. Sydowia 61: 345-351

Wood AR, Damm U, van der Linde EJ, Groenewald JZ, Cheewangkoon R, Crous PW. 2016. Finding the missing link: Resolving the Coryneliomycetidae within Eurotiomycetes. Persoonia 37:37-56.

Woudenberg JH, Aveskamp MM, De Gruyter J, Spiers AG, Crous PW (2009) Multiple Didymella teleomorphs are linked to the Phoma clematidina morphotype. PersooniaMolecular Phylogeny and Evolution of Fungi 22(1): 56-62.

Woudenberg JHC, Groenewald JZ, Binder M, Crous PW (2013) Alternaria redefined. Studies in Mycology 75: 171-212.

Woudenberg JHC, Truter M, Groenewald JZ, Crous PW (2014) Large-spored Alternaria pathogens in section Porri disentangled. Studies in Mycology 79: 1-47.

Wrzosek M, Dubiel G, Gorczak M, Pawłowska J, Tischer M, Bałazy S (2016) New insights on the phylogeny and biology of the fungal ant pathogen Aegeritella. Journal of Invertebrate Pathology 133:1-7

Wu DK, Zhang CP, Zhu CY, Wang YL, Guo LL, Zhang KQ, Niu XM (2013a) Metabolites from carnivorous fungus Arthrobotrys entomopaga and their functional roles in fungal predatory ability. Journal of agricultural and food chemistry 61(17): 4108-4113.

Wu HX, Schoch CL, Boonmee S, Bahkali AH, Chomnunti P, Hyde KD (2011) A reappraisal of Microthyriaceae. Fungal Diversity 51:189-248

Wu HX, Tian Q, Li WJ, Hyde KD (2014) A reappraisal of Microthyriaceae. Phytotaxa 176 (1):201-212

Wu HY, Kim DG, Ryu YH, Zhou XB (2012a) Arthrobotrys koreensis, a new nematodetrapping species from Korea. Sydowia 64(1): 129-136.

Wu HY, Kim DG, Zhou XB (2012b) First report of an unrecorded nematode-trapping fungus species Dactylellina candidum in Korea. African Journal of Microbiology Research 6(1): 203-205. 
Wu Y, Wang SJ, Meng YQ, Tang YP, Lin YR (2015) Terriera fici sp. nov. on Ficus vasculosa from Hainan Province, China. Mycotaxon 130(4):1111-1116.

Wu Y-M, Xu J-J, Wang H-F, Zhang TY (2013b) Geosmithia tibetensis sp. nov. and new Gibellulopsis and Scopulariopsis records from Qinghai-Tibet. Mycotaxon 125: 59-64

Wu Y-M, Xu J-J, Wang H-F, Zhang T-Y (2013c) Radulidium xigazense sp. nov., Rhinocladiella tibetensis sp. nov., and three new records of Ramichloridium from China. Mycotaxon 125:123-130.

Wu YM, Zhang TY (2009) New species of Phialosporostilbe and Pleurothecium from soil. Mycotaxon 110: 1-4.

Wu YM, Zhang TY (2010) Three new species of Scytalidium from soil. Mycotaxon 114: 205210.

Wu YM, Zhang TY (2013) New species of Humicola and Endophragmiella from China. Mycotaxon 121(1):147-51.

Wulandari NF, To-Anun C, Hyde KD, Duong LM, De Gruyter J, Meffert JP, Groenewald JZ, Crous PW (2009) Phyllosticta citriasiana sp. nov., the cause of Citrus tan spot of Citrus maxima in Asia. Fungal Diversity 34(1): 23-39.

Wynns AA (2015) Convergent evolution of highly reduced fruiting bodies in Pezizomycotina suggests key adaptations to the bee habitat. BMC Evolutionary Biology 15: 145 .

Xia JW, Ma LG, Castañeda-Ruíz RF, Zhang XG (2014a) Minimelanolocus bicolorata sp. nov., Paradendryphiopsis elegans sp. nov. and Corynesporella bannaense sp. nov. from southern China. Mycoscience 55(4): 299-307.

Xia JW, Ma LG, Ma YR, Castañeda-Ruíz RF, Zhang XG (2013a) Corynesporopsis curvularioides sp. nov. and new records of microfungi from southern China. Cryptogamie Mycologie 34(3): 281-288.

Xia JW, Ma YR, Gao JM, Li Z, Zhang XG (2015a) Codinaea jianfenglingensis sp. nov. and new records from southern China. Mycotaxon 130(3):835-841.

Xia JW, Ma YR, Gao JM, Zhang XG, Li Z (2016) A new species of Blastophragma and three new records of other dematiaceous hyphomycetes from southern China. Nova Hedwigia 102(1-2):223-32.

Xia JW, Ma YR, Zhang XG (2014b) New species of Corynesporopsis and Lylea from China. Sydowia 66(2): 241-248.

Xia JW, Ma YR, Zhang XG (2015b) Anungitea guangxiensis and Ellisembia longchiensis, two new species from southern China. Mycotaxon 130(1): 41-46.

Xia JW, Ren SC, Ma LG, Zhang XG (2013b) Heteroconium bannaense sp. nov. and a new record of the genus from China. Mycotaxon 121(1): 413-417.

Xie J, Strobel GA, Mends MT, Hilmer J, Nigg J, Geary B. Collophora aceris, a novel antimycotic producing endophyte associated with douglas maple. Microbial ecology. 2013 Nov 1;66(4):784-95.

Xu D, Ondeyka J, Harris GH, Zink D, Kahn JN, Wang H, Bills G, Platas G, Wang W, Szewczak AA, Liberator P (2011) Isolation, structure, and biological activities of fellutamides C and D from an undescribed Metulocladosporiella (Chaetothyriales) using the genome-wide Candida albicans fitness test. Journal of natural products 74(8):1721-30.

Xu L, Ravnskov S, Larsen J, Nilsson RH, Nicolaisen M (2012) Soil fungal community structure along a soil health gradient in pea fields examined using deep amplicon sequencing. Soil Biology and Biochemistry 46: 26-32.

Xu X, Zhang Y, Meng Q, Meng K, Zhang W, Zhou X, et al. (2013) overexpression of a fungal $\beta$-mannanase from Bispora sp. MEY-1 in maize seeds and enzyme characterization. PLoS ONE 8(2): e56146. doi:10.1371/journal.pone.0056146 
Yacharoen S, Tian Q, Chomnunti P, Boonmee S, Chukeatirote E, Bhat JD, Hyde KD (2015) Patellariaceae revisited. Mycosphere 6(3): 290-326.

Yadav S, Bhat DJ (2009a) Dimastigosporium yanense, a new coprophilous fungus from the forests of Western Ghats in Karnataka State, India. Mycotaxon 107: 397-403

Yadav S, Bhat DJ (2009b) Lomachashaka gomaya, a new sporodochial hyphomycete from India. Mycotaxon 110: 357-361.

Yago JI, Lin CH, Chung KR (2011) The SLT2 mitogen-activated protein kinase-mediated signalling pathway governs conidiation, morphogenesis, fungal virulence and production of toxin and melanin in the tangerine pathotype of Alternaria alternata. Molecular plant pathology, 12(7): 653-665.

Yamazaki A, Kawasaki H (2014) Lipomyces chichibuensis sp. nov., isolated in Japan, and reidentification of the type strains of Lipomyces kononenkoae and Lipomyces spencermartinsiae. International journal of systematic and evolutionary microbiology 64(8):2566-2572.

Yamazaki A, Toyama K, Nakagiri A (2010) A new acidophilic fungus Teratosphaeria acidotherma (Capnodiales, Ascomycota) from a hot spring. Mycoscience Nov 1;51(6):443-455.

Yang GZ, Lu J, Yu Z, Zhang K, Qiao M (2011a) Uncispora sinensis, a new species from China. Mycotaxon 116(1):171-174.

Yang H, Ariyawansa HA, Wu HX, Hyde KD (2014) The genus Leptoxyphium (Capnodiaceae) from China. Phytotaxa 176(1):174-83.

Yang HL, Sun GY, Batzer JC, Crous PW, Groenewald JZ, Gleason ML (2010) Novel fungal genera and species associated with the sooty blotch and flyspeck complex on apple in China and the United States. Persoonia 24:29-37.

Yang J, Maharachchikumbura SS, Bhat DJ, Bahkali AH, Jones EG, Liu ZY (2015a) Aquapteridospora lignicola gen. et sp. nov., a new hyphomycetous taxon (Sordariomycetes) from wood submerged in a freshwater stream. Cryptogamie, Mycologie 36(4):469-478.

Yang J, Wang L, Ji X, Feng Y, Li X, Zou C, Xu J, Ren Y, Mi Q, Wu J, Liu S (2011b) Genomic and proteomic analyses of the fungus Arthrobotrys oligospora provide insights into nematode-trap formation. PLoS Pathogens 7(9) p.e1002179.

Yang J, Yu Y, Li J, Zhu W, Geng Z, Jiang D, Wang Y, Zhang KQ (2013) Characterization and functional analyses of the chitinase-encoding genes in the nematode-trapping fungus Arthrobotrys oligospora. Archives of microbiology 195(7): 453-462.

Yang Q, Fan XL, Crous PW, Liang YM, Tian CM (2015b) Cytospora from Ulmus pumila in Northern China. Mycological Progress 14(9):74.

Yang SL, Chung KR (2012) The NADPH oxidase-mediated production of hydrogen peroxide $\left(\mathrm{H}_{2} \mathrm{O}_{2}\right)$ and resistance to oxidative stress in the necrotrophic pathogen Alternaria alternata of citrus. Molecular plant pathology, 13(8): 900-914.

Yang SL, Lin CH, Chung KR (2009) Coordinate control of oxidative stress tolerance, vegetative growth, and fungal pathogenicity via the AP1 pathway in the rough lemon pathotype of Alternaria alternata. Physiological and Molecular Plant Pathology, 74(2): 100-110.

Yang T, Groenewald JZ, Cheewangkoon R, Jami F, Abdollahzadeh J, Lombard L, Crous PW (2016) Families, genera, and species of Botryosphaeriales. Fungal Biology 121(4):322-346 
Yang Y, Chai R, He Y (2012) Early detection of rice blast (Pyricularia) at seedling stage in Nipponbare rice variety using near-infrared hyper-spectral image. African Journal of Biotechnology 11(26): 6809-6817.

Yatsyna A (2011) The first contribution to lichens, lichenicolous and allied fungi from Braslav Lakes National Park (NW Belarus). Botanica Lithuanica 17(4): 177-184.

Yatsyna A (2014) Lichens from Manor Parks in Minsk Region (Belarus). Botanica Lithuanica 20(2): 159-168.

Yatsyna A, Motiejūnaite J (2015) New And Noteworthy Lichens To Belarus. Botanica Lithuanica 21(1): 57-63.

Yavuz Y, Özdemir Türk A, Böcük H (2015) Epiphytic lichen diversity of the Sündiken mountains (Eskisehir, Turkey). Herzogia 28(2): 753-761.

Yazawa T, Kawahigashi H, Matsumoto T, Mizuno H (2013) Simultaneous transcriptome analysis of Sorghum and Bipolaris sorghicola by using RNA-seq in combination with de novo transcriptome assembly. PLoS One, 8(4), p.e62460.

Yazici K, Aslan A (2016) Merismatium, Porpidia and Protoparmelia spp. new for Turkey and Asia. Mycotaxon 131(2): 337-343.

Yazici K, Elix JA, Aslan A (2010) Some parmelioid lichens new to Turkey and Asia. Mycotaxon 111(1): 489-494.

Yeshitela K, Fischer E, Killmann D, Serusiaux E (2009) Aspidothelium hirsutum (Thelenellaceae) and Caprettia goderei (Monoblastiaceae), two new species of foliicolous lichens from Ethiopia and Kenya. Bryologist 112(4): 850-855

Yilmaz N, Houbraken J, Hoekstra ES, Frisvad JC, Visagie CM, Samson RA (2012) delimitation and characterisation of Talaromyces purpurogenus and related species. Persoonia 29: 39-54.

Yilmaz N, López-Quintero CA, Vasco-Palacios AM, Frisvad JC, Theelen B, Boekhout T, Samson RA, Houbraken J (2016a) Four novel Talaromyces species isolated from leaf litter from Colombian Amazon rain forests. Mycological Progress 15: 1041-1056.

Yilmaz N, Visagie CM, Frisvad JC, Houbraken J, Jacobs K, Samson RA (2016b) Taxonomic re-evaluation of species in Talaromyces section Islandici, using a polyphasic approach. Persoonia 36:37-56.

Yilmaz N, Visagie CM, Houbraken J, Frisvad JC, Samson RA (2014) Polyphasic taxonomy of the genus Talaromyces. Studies in Mycology 78:175-341.

Yin M, Duong TA, Wingfield MJ, Zhou X, de Beer ZW (2015) Taxonomy and phylogeny of the Leptographium procerum complex, including Leptographium sinense sp. nov. and Leptographium longiconidiophorum sp. nov. Antonie van Leeuwenhoek 107(2):547563

Yonezawa H, Tanaka K (2008) A second species of Neoheteroceras and additional characters of the genus. Mycoscience 49(2): 152-154.

Yoshiaki KON, Ohmura Y (2014) Regeneration of Pseudocyphellaria aurata transplanted on a tree in Japan. The Lichenologist 46(06): 833-836.

Young CA, Charlton ND, Takach JE, Swoboda GA, Trammell MA, Huhman DV, Hopkins AA (2014) Characterization of Epichloë coenophiala within the US: are all tall fescue endophytes created equal? Frontiers in Chemistry 2: 95.

Yu H, Duan J, Wang B, Jiang X (2012) The function of snodprot in the cerato-platanin family from Dactylellina cionopaga in nematophagous fungi. Bioscience, biotechnology, and biochemistry 76(10):1835-42.

Yu ZF, Qiao M, Zhang Y, Qin L, Zhang KQ (2011) Pseudotripoconidium, a new anamorph genus connected to Orbilia. Mycologia 103(1):164-73. 
Yuan L, Zhao PJ, Ma J, Li GH, Shen YM (2008) Tricycloalternarenes A-E: five new mixed terpenoids from the endophytic fungal strain Alternaria alternata Ly83. Helvetica Chimica Acta 91(8): 1588-1594.

Yuan ZL, Lin FC, Zhang CL, Kubicek CP (2010) A new species of Harpophora (Magnaporthaceae) recovered from healthy wild rice (Oryza granulata) roots, representing a novel member of a beneficial dark septate endophyte. FEMS Microbiol Letters 307:94-101.

YueMing W, TianYu Z (2008) Soil dematiaceous hyphomycetes from Dahingganling Mountain Range, Inner Mongolia, China I. Mycosystema, 27(1): 5-15.

Yu-liang WA, Abdulla A, Abbas A. (2012) Anzina, a lichen genus new to China. Arid Zone Research.;1:029.

Yun HY, Rossman AY. Tubakia seoraksanensis, a new species from Korea. Mycotaxon. 2011 Jan 1;115(1):369-73.

Zainuddin N, Alias SA, Lee CW, Ebel N, Othman NA, Mukhtar MR, Awang K (2010) Antimicrobial activities of marine fungi from Malaysia. Botanica Marina 53:507-513.

Zambare VP, Christopher LP (2012) Biopharmaceutical potential of lichens. Pharmaceutical Biology 50(6): 778-798.

Zarabska D, Rosadzinski S (2011) New records of the lichen species Pycnothelia papillaria in Poland in the context of threats to species. Roczniki Akademii Rolniczej w Poznaniu. Botanika-Steciana 15: 149-152.

Zare R, Asgaria B, Gams W (2010) The species of Coniolariella (Xylariales). Mycologia 102(6):1383-1388.

Zare R, Gams W (2016) More white verticillium-like anamorphs with erect conidiophores. Mycological Progress 15(10-11): 993-1030.

Zelski SE, Raja HA, Miller AN, Bar bosa FR, Gusmão LFP, Shearer CA (2011a) Longicollum biappendiculatum gen. et sp. nov., a new freshwater ascomycete from the Neotropics. Mycosphere 2(5): 539-545.

Zelski SE, Raja HA, Miller AN, Shearer CA (2011b) Chaetorostrum quincemilensis, gen. et sp. nov., a new freshwater ascomycete and its Taeniolella-like anamorph from Peru. Mycosphaere 5(2): 593-600.

Zelski SE, Raja HA, Miller AN, Shearer CA (2104) Conioscypha peruviana sp. nov., its phylogenetic placement based on 28S rRNA gene, and a report of Conioscypha gracilis from Peru. Mycoscience 56: 319-325.

Zeng JS, de Hoog GS (2008) Exophiala spinifera and its allies: diagnostics from morphology to DNA barcoding. Medical Mycology 46: 193-208.

Zeng XY, Wen TC, Chomnunti P, Liu JK, Boonmee S, Hyde KD (2016) Ceramothyrium longivolcaniforme sp. nov., a new species of Chaetothyriaceae from northern Thailand. Phytotaxa 267(1): 51-60.

Zeng ZQ, Zhuang WY (2013a) A new combination of Allantonectria (Hypocreales). Mycosystema 32(2): 294

Zeng ZQ, Zhuang WY (2013b) Four new taxa of Ilyonectria and Thelonectria (Nectriaceae) revealed by morphology and combined ITS and $\beta$-tubulin sequence data. Phytotaxa $85(1): 15-25$

Zhang B-C, Minter DW. (2011) Elaphomyces spinoreticulatus sp. nov., with notes on Canadian species of Elaphomyces. Can J Bot 67:909-914.

Zhang H, Hyde KD, Abdel-Wahab MA, Abdel-Aziz FA, Ariyawansa HA, et al (2013a) A modern concept for Helicascus with a Pleurophomopsis-like asexual state. Sydowia 65:147-166.

Zhang H, Hyde KD, McKenzie EHC, Bahkali AH, Zhou D (2012a) Sequence data reveals phylogenetic affinities of Acrocalymma aquatica sp. nov., Aquasubmersa mircensis 
gen. et sp. nov. and Clohesyomyces aquaticus (Freshwater coelomycetes). Cryptogamie Mycologie 33: 333-346.

Zhang H, Hyde KD, Zhao Y, McKenzie EH, Zhou D (2014a) Freshwater ascomycetes: Lophiostoma vaginatispora comb. nov. (Dothideomycetes, Pleosporales, Lophiostomaceae) based on morphological and molecular data. Phytotaxa 176(1):184-191.

Zhang H, Jones GEB, Zhou D, Bahkalf AH, Hyde KD (2011a) Checklist of freshwater fungi in thailand. Cryptogamie Mycologie 32(2): 199-217.

Zhang H, Zhang X, Qi YX, Pu JJ, Lv YC et al (2010a) A New Leaf Spot Disease of Banana Caused by Pyricularia angulata. Journal of Tropical Organisms 2: 12.

Zhang HX, Tan JL, Wei LX, Wang YL, Zhang CP, et al (2012b) Morphology regulatory metabolites from Arthrobotrys oligospora. Journal of natural products 75(7): 14191423.

Zhang HX, Wang LS, Du ZZ, Hua Y (2012c) Comparative Analyses on Chemical Composition of Sulcaria sulcata and Sulcaria sulcata f. vulpinoides. Journal of Southwest Forestry University 2: 25.

Zhang J, Zhou Y, Dou Z, Fournier J, Zhang Y (2015a) Helicascus unilocularis sp. nov., a new freshwater pleosporalean ascomycete from the Caribbean area. Mycological Progress 14: 47.

Zhang JF, Liu JK, Hyde KD, Liu YX, Bahkali AH, et al (2016a) Ligninsphaeria jonesii gen. et. sp. nov., a remarkable bamboo inhabiting ascomycete. Phytotaxa 247: 109-117.

Zhang JZ, Li MJ (2009) A new species of Bipolaris from the halophyte Sesuvium portulacastrum in Guangdong Province, China. Mycotaxon 109(1): 289-300.

Zhang K, Ma J, Ma LG, Zhang XG (2009a) A new species of Berkleasmium from Chongqing, China. Mycotaxon 108: 5-7.

Zhang K, Ma LG, Ma J, Castañeda-Ruiz RF (2014b) Xiuguozhangia, a new genus of microfungi to accommodate five Piricaudiopsis species. Mycotaxon 128(1): 131-135.

Zhang L, Zhou Z, Guo Q, Fokkens L, Miskei M, et al. (2016c) Insights into adaptations to a near-obligate nematode endoparasitic lifestyle from the finished genome of Drechmeria coniospora. Scientific Reports 6: 23122

Zhang M, Koko TW, Hyde KD (2011b) Towards a monograph of Dothideomycetes: Studies on Diademaceae. Cryptogamie Mycologie 32: 115-126.

Zhang N, Luo J, Rossman AY, Aoki T, Chuma I, Crous PW, Dean R, De Vries RP, Donofrio $\mathrm{N}$, Hyde KD, Lebrun MH (2016b) Generic names in Magnaporthales. IMA fungus 7(1): 155-159.

Zhang N, Zhao S, Shen Q (2011c) A six-gene phylogeny reveals the evolution of mode of infection in the rice blast fungus and allied species. Mycologia 103(6): 1267-1276.

Zhang Q, Guo WJ, Fu CL, Ma S, Zhu MQ (2013b) Chemical Constituents from an Endophyte, Cercosporella sp. Chemistry of Natural Compounds, 49(1): 117-118.

Zhang R, Yang HL, Sun GY, Li HY, Zhuang JL, et al (2009b) Strelitziana mali, a new species causing sooty blotch on apple fruit. Mycotaxon 110: 477-485.

Zhang W, Liu BY, Wu, YM, Zhang TY (2012d) A preliminary report of dematiaceous hyphomycetes from soil in Liaoning Province, China. Mycosystema 31(1): 1-7.

Zhang X, Xu G, Tang H, Li Y, Liu C (2017) Development of Loop-Mediated Isothermal Amplification (LAMP) Assay for the Rapid Detection of Alternaria alternata. Journal of AOAC International, 100(1): 99-103. 
Zhang Y, Crous PW, Schoch CL, Bahkali AH, Guo LD, Hyde KD (2011d) A molecular, morphological and ecological re-appraisal of Venturiales - a new order of Dothideomycetes. Fungal Diversity 51: 249-277.

Zhang Y, Crous PW, Schoh CL, Hyde KD (2012e) Pleosporales. Fungal Diversity 53: 1-221.

Zhang Y, Fournier J, Bahkali AH, Hyde KD (2011e) Inflatispora, a novel lignicolous genus of Pleosporales from France. Sydowia 63(2): 287-295.

Zhang Y, Fournier J, Crous PW, Pointing SB, Hyde KD (2009c) Phylogenetic and morphological assessment of two new species of Amniculicola and their allies (Pleosporales). Persoonia 23: 48-54.

Zhang Y, Fournier J, Phookamsak R, Bahkali AH, Hyde KD (2013c). Halotthiaceae fam. nov (Pleosporales) accommodates the new genus Phaeoseptum and several other aquatic genera. Mycologia 105(3): 603-609.

Zhang Y, Fournier J, Pointing SB, Hyde KD (2008a) Are Melanomma pulvis-pyrius and

Trematosphaeria pertusa congeneric? Fungal Divers 33: 47-60.

Zhang Y, Jeewon R, Fournier J, Hyde KD (2008b) Multi-gene phylogeny and morphotaxonomy of Amniculicola lignicola: a novel freshwater fungus from France and its relationships to the Pleosporales. Mycoklogical Research 112: 1186-1194.

Zhang Y, Liu F, Wu W, Cai L (2015b) A phylogenetic assessment and taxonomic revision of the thermotolerant hyphomycete genera Acrophialophora and Taifanglania. Mycologia 107: 768-779.

Zhang Y, Qiao M, Weber E, Baral HO, Hagedorn G, et al (2010b) Arthrobotrys scaphoides from China and Europe with a phylogenetic analysis including the type strain. Mycotaxon 111(1): 291-300.

Zhang Y, Qiao M, Xu J, Cao Y, Zhang KQ, et al (2013d) Genetic diversity and recombination in natural populations of the nematode-trapping fungus Arthrobotrys oligospora from China. Ecology and Evolution 3(2): 312-325.

Zhang Y, Schoch CL, Fournier J, Crous PW, De Gruyter J, et al (2009d) Multi-locus phylogeny of Pleosporales: a taxonomic, ecological and evolutionary re-evaluation. Studies in Mycology 64: 85-102.

Zhang Y, Wang HK, Fournier J, Crous PW, Pointing SB, et al (2009e) Towards a phylogenetic clarification of Lophiostoma / Massarina and morphologically similar genera in the Pleosporales. Fungal Diversity 38: 225-251.

Zhang Y, Yang Y, Zhang XD, Cui BK, He SH, Fournier J (2014c) Helicascus gallicus sp. nov., a new freshwater pleosporalean ascomycete from France. Phytotaxa 183: 183192

Zhang Y, Yu ZF, Baral HO, Mo MH, Zhang KQ (2009f) New species and records of Orbilia (Orbiliaceae, Ascomycota) from China. Fungal Diversity 36: 141-153.

Zhang Y, Yu ZF, Xu J, Zhang KQ (2011f) Divergence and dispersal of the nematode-trapping fungus Arthrobotrys oligospora from China. Environmental microbiology reports 3(6): 763-773.

Zhang Y, Zhang J, Wang Z, Fournier J, Crous PW, Zhang X, Li W, Ariyawansa HA, Hyde KD (2014d) Neotypification and phylogeny of Kalmusia. Phytotaxa 176(1): 164-173.

Zhang Y, Zhang X, Fournier J, Chen J, Hyde KD (2014e) Lindgomyces griseosporus, a new aquatic ascomycete from Europe including new records. Mycoscience 55 (1): 43-48.

Zhang YD, Ma J, Ma LG, Castañeda-Ruíz RF, Zhang XG (2011g) New species andrecord of Pseudoacrodictys from China. Mycological Progress 10: 261-265.

Zhang YD, Ma J, Ma LG, Castañeda-Ruíz RF, Zhang XG (2011h) New species of Phaeodactylium and Neosporidesmium from China. Sydowia. 63(1): 125-130. 
Zhang YD, Ma J, Ma LG, Castañeda-Ruíz RF, Zhang XG (2012f) A new species of Corynesporella and two new records from southern China. Cryptogamie Mycologie 33(1): 99-104.

Zhang YD, Ma J, Ma LG, Castañeda-Ruíz RF, Zhang XG (2012i) A new species of Quadracaea and new records of other dematiaceous hyphomycetes from southern China. Nova Hedwigia 94(3-4):405-11.

Zhang YD, Ma J, Ma LG, Zhang XG (2010c) A new species of Heteroconium from Fujian, China. Mycotaxon, 114(1): 315-318.

Zhang YD, Ma J, Ma LG, Zhang XG (2010d) Taxonomic studies of Dactylella from Fujian, China. Mycotaxon 114: 259-261.

Zhang YD, Ma J, Ma LG, Zhang XG (2010e) Two new species of Kylindria from Fujian, China. Mycotaxon 114: 367-371.

Zhang YD, Ma J, Ma LG, Zhang XG. (2012g) Parablastocatena tetracerae gen. et sp. nov. and Corynesporella licualae sp. nov. from Hainan, China. Mycoscience 53(5): 381385.

Zhang YD, Ma J, Ma LG, Zhang XG. (2012h) Two new species of Taeniolina from southern China. Mycological Progress 11(1):71-74.

Zhang YL, Zhang TY (2014) Notes on soil dematiaceous hyphomycetes from Guangxi Province, China. Mycosystema 33: 793-799.

Zhang Z, Liu X, Wang X, Zhou M, Zhou X, et al (2012j) An R2R3 MYB transcription factor in wheat, TaPIMP1, mediates host resistance to Bipolaris sorokiniana and drought stresses through regulation of defense-and stress-related genes. New Phytologist 196(4): 1155-1170.

Zhao G, Liu X, Xie X, Cao A. (2009a) Saprobic dematiaceous hyphomycetes from shennongjia region, china. Nova Hedwigia 88(1-2):217-227.

Zhao G, Yu P, Liu X (2013a) Cancellidium and Canalisporium (hyphomycetes) from China. Nova Hedwigia 96(1-2): 221-36.

Zhao GC, Zhao RL (2012) The higher microfungi from forests of yunnan province, Yunnan Science and Technology Press, Kunming, 564pp

Zhao GZ, Cao AX, Zhang TY, Liu XZ (2011a) Acrodictys (Hyphomycetes) and allied genera from China. Mycological Progress 10: 67-83

Zhao KN, Yin GH, Zhao GZ, Cao AX (2014a) Embryonispora, a new genus of hyphomycetes from China. Mycotaxon 126(1): 77-81.

Zhao P, Luo J, Zhuang WY (2011b) Practice towards DNA barcoding of the nectriaceous fungi. Fungal Diversity 46(1): 183-191.

Zhao Q, Tolgor B, Zhao YC, Yang ZL, Hyde KD (2015) Species diversity within the Helvella crispa group (Ascomycota: Helvellaceae) in China. Phytotaxa 239(2):130142.

Zhao X, Leavitt SD, Zhao ZT, Zhang LL, Arup U, et al (2016) Towards a revised generic classification of lecanoroid lichens (Lecanoraceae, Ascomycota) based on molecular, morphological and chemical evidence. Fungal Diversity 78:293-304

Zhao X, Wang Y, Zhao Y, Huang Y, Zhang KQ et al. (2014b) Malate synthase gene AoMls in the nematode-trapping fungus Arthrobotrys oligospora contributes to conidiation, trap formation, and pathogenicity. Applied microbiology and biotechnology 98(6): 2555-2563.

Zhao Y-J, Hosoya T, Shirouzu T, Kakishima M, Yamaoka Y (2013b) Lambertella pyrolae (Rutstroemiaceae, Ascomycota), a new species from Japan. Phytotaxa 136:54-60. 
Zhdanov I (2009) Interesting records of lichens on the coast of Baydaratskaya Bay (YamalNenets Autonomous District, Russia). Folia Cryptogamica Estonica, 46: 79-82.

Zheng CJ, Shao CL, Guo ZY, Chen JF, Deng DS, Yang KL, Chen YY, Fu XM, She ZG, Lin YC, Wang CY (2012) Bioactive hydroanthraquinones and anthraquinone dimers from a soft coral-derived Alternaria sp. fungus. Journal of natural products 75(2): 189-197.

Zheng HD, Zhuang WY (2013) A new species of Roseodiscus (Ascomycota, Fungi) from tropical China. Phytotaxa 105(2): 51-57.

Zheng HD, Zhuang WY (2014) Hymenoscyphus albidoides sp. nov. and H. pseudoalbidus from China. Mycological Progress 13(3): 625-638.

Zhou F, Wang XY, Zhang L, Lin YR (2013) Terriera angularis sp. nov. on Illicium simonsii from China. Mycotaxon 122(1): 355-359.

Zhou XD, Jacobs K, Kirisits T, Chhetri DB, Wingfield MJ (2008) Leptographium bhutanense sp. nov., associated with the root collar weevil Hylobitelus chenkupdorjii on Pinus wallichiana in Bhutan. Persoonia 21:1-8.

Zhou Y, Gong G, Zhang S, Liu N, Wang J, Li P, Yu X (2014) A new species of the genus Trematosphaeria from China. Mycological Progress 13(1): 33-43

Zhu XF, Pan Y, Chen LJ, Duan YX, Wang YY (2012) First Report of Leaf Spot of Soybean Caused by Aristastoma guttulosum in China. Plant Disease 96(11):1694.

Zhu XQ, Niu CW, Chen XY, Guo LY (2016) Monilinia Species Associated with Brown Rot of Cultivated Apple and Pear Fruit in China. Plant Disease 100(11):2240-50.

Zhuang WY (2009) The genus Sowerbyella (Pezizales) in China. Mycotaxon 109: 233-237.

Zhuang WY (2010) Taxonomic assessment of some pyronemataceous fungi from China. Mycotaxon 112: 31-46.

Zhuang WY (2013) The genus Scutellinia (Pyronemataceae) from China with a key to the known species of the country. Mycosystema 32(3): 432.

Zhuang WY, Luo J, Zhao P. (2011) Two new species of Acervus (Pezizales) with a key to species of the genus. Mycologia 103(2): 400-406.

Zhuang WY, Yang ZL (2008) [2007] Some pezizalean fungi from alpine areas of southwestern China. Mycologia Montenegrina 10: 235-249.

Zhurbenko M, Dillman K (2010) Polycoccum hymeniicola comb. nov. (Dacampiaceae) and other interesting lichenicolous fungi from southeastern Alaska. The Bryologist 113(2):260-266.

Zhurbenko MP (2008) Lichenochora thorii (Phyllachorales), a new lichenicolous ascomycete from Europe. Nova Hedwigia 87(3-4): 509-512.

Zhurbenko MP (2009) Lichenicolous fungi and some lichens from the Holarctic. Opuscula Philolichenum 6: 87-120.

Zhurbenko MP (2010a) Lichenicolous fungi and lichens growing on Stereocaulon from the Holarctic, with a key to the known species. Opuscula Philolichenum 8: 9-39

Zhurbenko MP (2010b) New and interesting lichenicolous fungi from Eurasia. II. Mycosphere 1(3): 213-222.

Zhurbenko MP (2011) Lichenicolous fungi growing on Thamnolia, mainly from the Holarctic, with a worldwide key to the known species. The Lichenologist 44: 147-177

Zhurbenko MP (2013) Lichenicolous fungi and some allied lichens from the Canadian Arctic. Opuscula Philolichenum 12: 180-197

Zhurbenko MP, Braun (2012) Cecidiomyces, a new subantarctic lichenicolous hyphomycete genus. The Lichenologist 44(06): 801-806.

Zhurbenko MP, Braun U (2013) Ameroconium cladoniae gen. et sp. nov. and Phoma psoromatis sp. nov., new anamorphic lichenicolous fungi from the Holarctic. The Lichenologist 45(5): 583-591. 
Zhurbenko MP, Braun U, Heuchert B, Kobzeva AA (2015a) Three new lichenicolous hyphomycetes from Asia. Herzogia 28(2): 584-598

Zhurbenko MP, Etayo J, Fedrowitz K, Thor G (2015b) Miscellaneous reports of lichenicolous fungi from Argentina including the new species Didymellopsis nephromatis. Opuscula Philolichenum 14: 82-89

Zhurbenko MP, Heuchert B, Braun, U. (2015c) Talpapellis solorinae sp. nov. and an updated key to the species of Talpapellis and Verrucocladosporium. Phytotaxa 234(2): 191194.

Zhurbenko MP, Himelbrant DE, Kuznetsova ES, Stepanchikova IS (2012) Lichenicolous fungi from the Kamchatka Peninsula, Russia. The Bryologist 115(2):295-312.

Zhurbenko MP, Kukwa M, Oset M (2009) Roselliniella stereocaulorum (Sordariales, Ascomycota), a new lichenicolous fungus from the Holarctic. Mycotaxon 109(1):3238.

Zhurbenko MP, Otte V (2012) Lichenicolous fungi from the Caucasus: new records and a first synopsis. Herzogia 25: 235-244.

Zhurbenko MP, Pino-Bodas R (2015) New lichenicolous fungi growing on Cladia in New Zealand. The Lichenologist 47(6): 395-402.

Zhurbenko MP, Tugi EW (2013) Some noteworthy lichenicolous fungi from Khabarovsk Territory of Russia. Mycosphere 4(1), pp.46-51.

Zhurbenko MP, Zhdanov IS (2013) Melaspilea galligena sp. nov. and some other lichenicolous fungi from Russia. Folia Cryptog. Estonica, Fasc. 50: 89-99

Zitouni-Haouar FE, Alvarado P, Sbissi I, Boudabous A, Fortas Z, Moreno G, Manjón JL, Gtari M (2015) Contrasted genetic diversity, relevance of climate and host plants, and comments on the taxonomic problems of the genus Picoa (Pyronemataceae, Pezizales). PloS one 10(9):e0138513.

Zou S, Li Q, Kong L (2011) Additional gene data and increased sampling give new insights into the phylogenetic relationships of Neogastropoda, within the caenogastropod phylogenetic framework. Molecular Phylogenetics and Evolution 61(2):425-35.

Zupančič J, Novak Babič M, Zalar P, Gunde-Cimerman N (2016) The black yeast Exophiala dermatitidis and other selected opportunistic human pathogens spread from dishwashers to kitchens. PLoS One 11:e0148166. 